
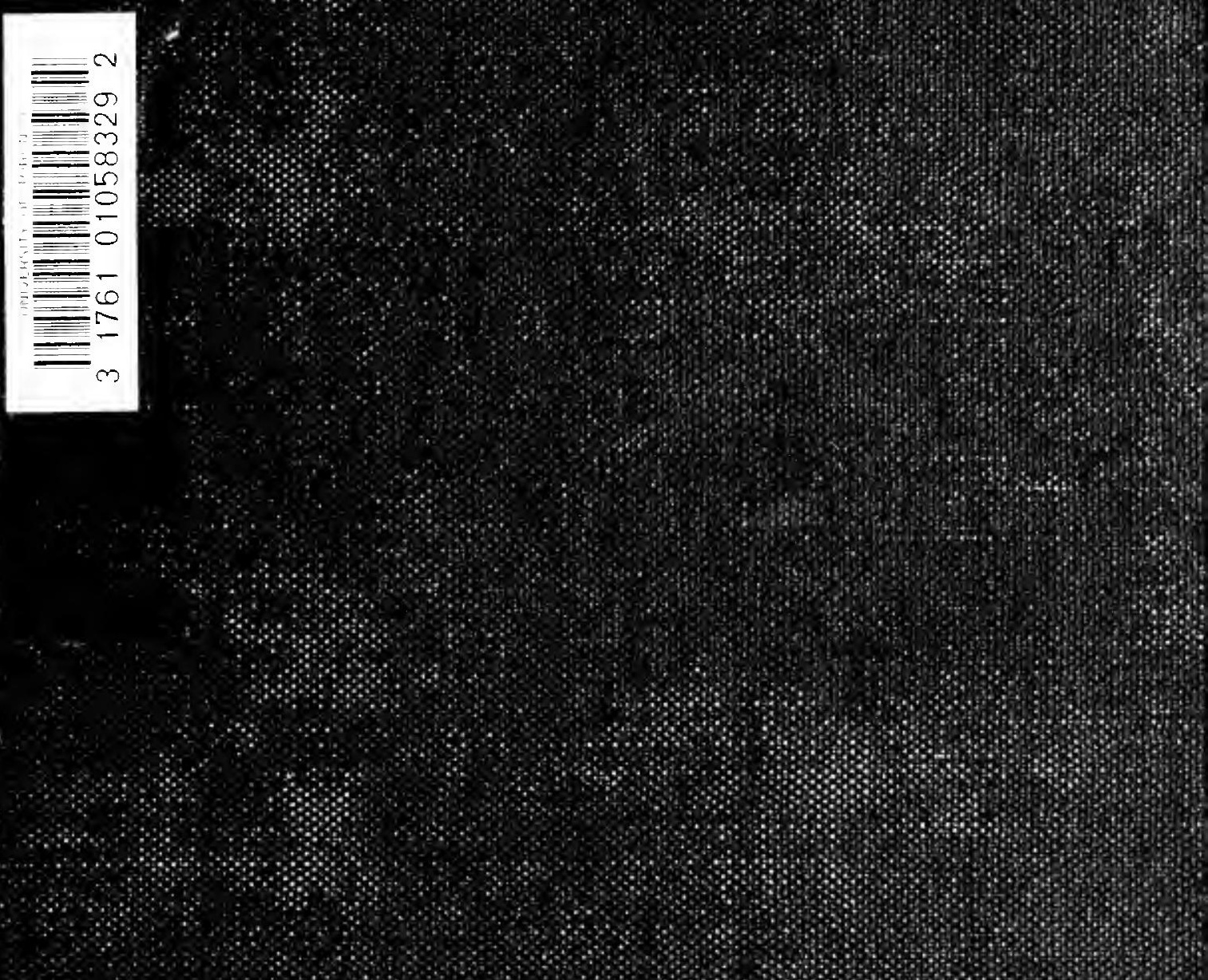

; \%

\title{
Uave of Toroirto IBRARY
}





\section{S}





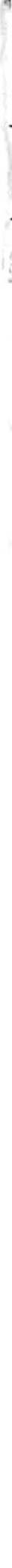


A CONCORDANCE

TO THE WORKS OF HORACE 


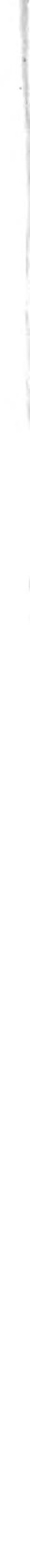




\section{A CONCORDANCE}

(i)

\section{THE WORKS OF HORACE}

COMPILED AND EDITED

BY

\section{LANE COOPER}

PROFESSOR OF THE ENGLISH LANGUAGE AND LITERATURE IN CORNELL UNIVERSITY

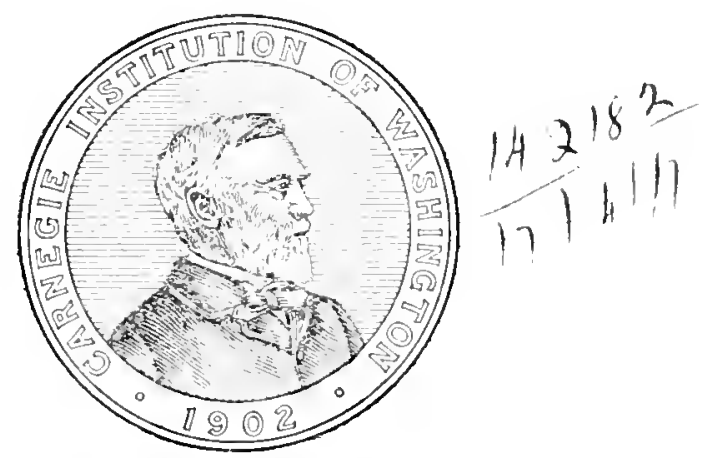

PubLishad By

The Cakneghe Institution of Wasmington

Washington, 1916 


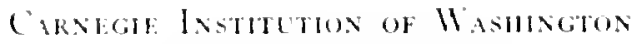

Persicatros No. 202

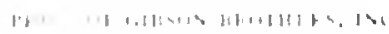

और 14101,110 


\section{PREFACE}

This Concordance of Horace was planned in May, I9I3; the quotations were recorded and collected in June and July of that year; the alphabetical ordering was carried on at intervals during the autumn, and finished early in the following spring; the work was accepted for publication by the Carnegie Institution on May 2I, I9I4. I had hoped to complete the proof-reading with dispatch, but various other demands upon my scanty leisure, and a threatening eye-strain which supervened, have delayed the progress of the volume through the press; for with all advantages and facilities the task of editing the 593 pages of a Latin concordance could not be a light one. Yet the aid that came from friends and pupils of mine at the outset made it possible to produce the work in a relatively brief time.

The labor was undertaken for more than one reason. First, it was my hope that a concordance of a Litin poet, emanating from a teacher of English, might tend to strengthen the bonds of sympathy between devotees of the ancient classics and students of modern literature; for unless such bonds are constantly renewed, the study of modem literature, at least, is prone to become one-sided or unduly sentimental, or to go entirely astray.

Secondly, I had found that no existing index of Horace was altogether adequate to the needs of modern scholarship-for example, in an attempt to determine the influence of this author upon the thought and language of the English poets - although the index in Zangemeister's edition of Bentley's Horace (Berlin, I 869), that in Hirschfelder and Mewes' edition of Orelli (Berlin, vol. 2, I892), and those in the edition of Keller and Holder (Leipzig, vol. I, second edition, I899; vol. 2, first edition, I 869) are of much assistance. Of these, the index by Zangemeister is the best for ordinary purposes; yet its general value is impaired by the inevitable subordination of traditional readings to the less happy among Bentley's conjectures; moreover, the work containing it is out of print. But even were the index obtainable, the inferior typography would justify supplanting it with a well-printed concordance which should take account of Horatian textual criticism since the year i 869 .

I must add that the indexes already existing not only suggested the desirability of a better typographical display for the language of Horace, but have also led to one feature of the present work which otherwise might raise a question. Since Zangeneister and the others take account of grammatical forms to the extent of listing eram, esse, and fui under sum, and laturus and tuli under fero, etc., it has been thought wise in this volume to maintain a purely alphabetical sequence, and thus to 
supplenent the indeses with an apparatus wherely the presence or Abence of am gisen form in llorace mal he instantly detected. More-

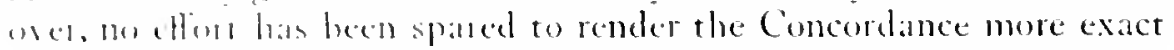
and more anmplete than any of the indexes.

This is mer the place on elaborare a defense of concordanes, whether of ancicut of medern anthers. Before the trihumal of scholarship steh works require no adverate: hut since their value sometimes is ewestioned by pesons whe might, il well-disposed, be influential in

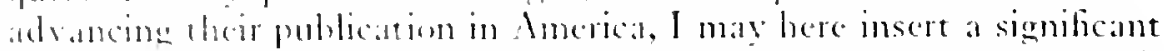
possige tomstated from the preface to livet's Lexique de la langue de Molite a work crowned by the Fench Academy) in onder to show the steem in which they are generally held by men of leaming:

fium an historical point of view, ans in the lighe of a decper anderstanding of the language. lexicons of on great writers in general, and a lexion of Molice in particulat. pussess a utility which here needs no demenstration.

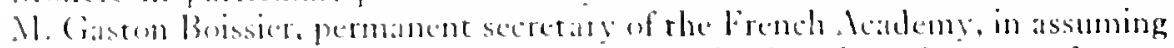
without difece actuatintance with the atulare the function of sponsor for my book; the Acoldeny, in aw arding one of its prizes to my work withour applica-

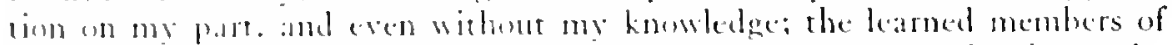
the commisson on endomed pullications, in proposing to print it at the apense of the State and. linally the Minister of Public Instruction, in accepting that propesal have sufliciently arinced the interest which attaches to works of this sort in the minds of the most competent and atuhoritative men in Framce.

Gencrally considered, the reasons for engaging in an enterprise like this must he somght for in the interests of the compiler and in the value, hoth intrinsic and histurical, of the poetry which thus becomes open (a) further sertuing ihrough a recombination of its elements. () the perennial worth of thorace als a master of phrase, and hence on the need of an exhatustive lloratian concordance, there is no call for a lone dispunition. The poet fully deserves the care and pains which have becen las ished upon him hy generation alter eneneration of scholars, as the difice of classical leaming has advanced rowad perfection. If the plescon work contributes its portion in the uphuilding of that still greater ideal fatrice, merer complete hut ever aspring. which is the mansion of scholdrship and the human house divine, the labor here represented will hase hen sweet amough.

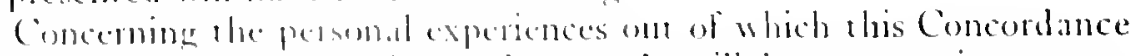
lats arisen, it is heped that of fiw words will have some interest or

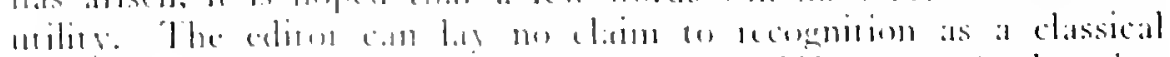

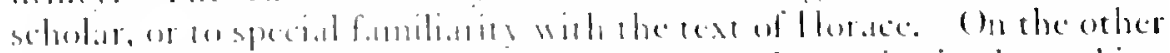

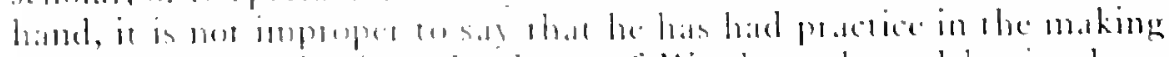

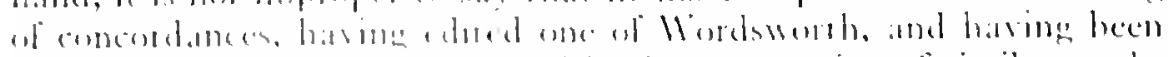

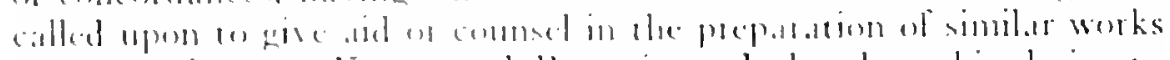

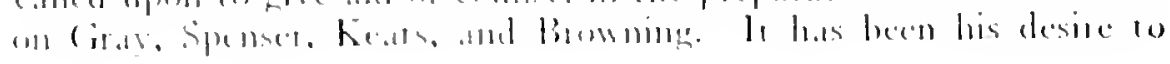


perfect and, as in the present case, to exemplify a method by which works of this description may be produced quickly and with a great saving of energy, through organization of effort, the collaboration of many hands, and the use of mechanical derices for the attainment of speed and accuracy in recording.

As for the method of compilation, a full account of it would serve to transmit some part of the acquired experience, whereas usually this kind of knowledge dies with the individual who gains it. A short explanation may assist the next compiler of a similar work, and in addition will throw light on the nature and use of the volume.

In brief, the method here enployed was substantially the same as that which was followed for my Concordance of Wordsworth. A standard text having been chosen (that of 'Tollmer's editio minor of Horace, Leipzig, I910), fourteen copies of this were taken to pieces, and the pages so combined again as to fumish each of the collaborators with seven copies of the odd and seven of the even pages of text that each of them was to excerpt. The eighteen collaborators were also provided with somewhat more than 2,500 slips of paper measuring three inches by five; with rubber stamps having movable types, for recording the book and number of a poem (as Carm.I.I); and with a set of typewritten instructions explaining with the utmost precision how to register each Latin word on a separate slip, how to cut and paste the printed metrical line containing that word, and how to stanip and write an exact reference to the place where that line occurs in the text.*

The result of this process was a body of about $+5,000$ slips representing every word in Vollmer's text, in the order of occurrence, with the metrical line in all cases, save for a small number of particles. While the slips were in this order, they were systematically examined with a view to improving the context in the quotations, since very often the metrical line, especially in the Odes and Epodes, does not well illustrate the use of an individual word. In a large proportion of all cases, however, the printed line sufficed; so that, aside from the quotations which were anended either then, or subsequently in the proofs, and aside from the quotations for variant readings, this Concordance is the printer's transcription of the basic text.

Meanwhile the editor had prepared slips for the variant readings noted by Vollmer in his editio maior of $\mathrm{Ig} / 2$, and for a few others included by E. C. Wickham in the well-known edition published at Oxford (Odes, Carmen Saculare, and Epodes, Igot; Satires, Epistles, and Ars Poetica, 1903). These variants have been compared with the readings in the edition of Keller and l lolder mentioned above, and the testimonia listed by Follmer have been rerified where the sources were

* These instructions have been printed, with slight alterations, and confes may bobtained from the editor at Ithaca. New Fork. 
acessible to me. In the Concondance, quet ations illustrative of variant readings and confeculues are generally longer than the other quotations. At one poine, lioweres, my alphabet could not include the variant reading of permit a quotitions, this is the case of the abbreviation ia in Serm.1.2.3 (Vollmer, eqhin maior, p. 174). Othenwise I have endeavored to list everreading offered hy Vollmer, whether important or not. The basic text once chosen, a concordance must be faithful to it, save in case of palpable aros; there is no other principle to follow, and no exceptions can safely be made. I may add that variations in the order of words within the line have been indicated, but not variations in the order of lines. Further, in an alphabetical list there seems to he mo satisfactory way of recording instances where the variation consists in the omission of a word or words; if in one or two cases (see, for example, under nemo, the quotations for Serm.1.1.109) I have tried to surmount the difficulty, the information supplied by the Concordance on this head is sporadic and gratuitous.

The order is strictly alphatetical, except that in a very few cases of unimportant orthographical variation l have given the same quotation twice, once with the catchword spelled at it oceurs, and again with orher, normal cases (see aequem and aequem). I had no thought of performing this work of supererogation throughout, since those who are likely to use the book will readily find their way in the Latin alphahet, remembering the ordinary equivalents (such as imm-inmand imp-inf-): and some of the variant readings, since they vield to no interpretation, would have made consistency of treatment impossible.

The separation of words spelled alike but of different meanings, and of the same grammatical forms with slightly different functions, was (especially as regards the latter) a similar work of supererogation; but here I hatie tried wo be more tiorough and consistent. A fresh catchword in bold-faced rope indicates a new meaning or a new grammatical function. ler, as a compatison of the lloratian indexes will show, the identification of grammatical forms is not always cettain: and in the case of variant readings I have sometimes repeated the catchword as the only way out of a dithiculty in classification.

The proofs of this work have been verified with Vollmer's editio maior of 1912, which repesents that selwolar's latest opinion on textual matters. Lnfortunately, that edition itsell was not so calcefully proofread as the editin mane of 11907 an the editin minor of 1910 . Obrious misprints in the bate we lave heen silently recrified in the Concordance; where decision was domblul, I ascenamed the intended reading

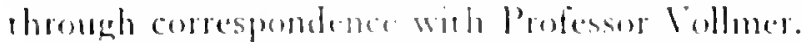

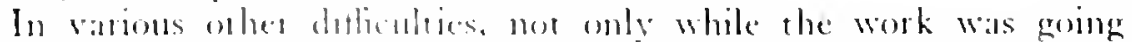
though the poses. hut hom the inception of the undertaking, I have had the henefir of hetp and conmel from my friend and colleague. Professos Clatrles E. Bemetr, an expert in the study of llorace. Without 
encouragement from him I should never have engaged in this task, labor of love though it has been.

It gives me pleasure also to record the names of those who generously assisted in preparing the slips:

Miss Evelyn M. Alspach

Professor Henry H. Armstrong

Mr. Dane L. Baldwin

Mr. Murray W. Bundy

Mr. Alexander M. Drummond

Miss Fannie H. Dudley

Miss Esther C. Dunn

Mrs. Laura C. Evans

Mliss Estella C. Fisher
Dr. Allan H. Gilbert

Miss Winifred Kirk

Miss Georgina Melville

Miss Mary A. Molloy

Miss Fay $H$. Newland

Miss Mation E. Potts

Miss Mand M. Sheldon

Miss Mary Rebecca Thayer

Miss Mildied Watt

A number of the same persons, with other friends and students of the editor, gave aid in the first stages of the alphabetical ordering of slips. To Miss Mary A. Ewer a word of thanks is due for her special efforts to make the record exact and complete. To the Camegie Institution of Washington there must come a tribute of gratitude, not only from the present writer, but from every scholar in America, for its interest in the class of works to which the Concordance of Horace belongs.

ITHACA, NEW YORK, 


\section{SIGNS AND ABBREVIATIONS \\ Irs Poct. = Ars Poetica \\ Corm. = Carmina \\ Epist. = Epistulac \\ Corm. Sace = Carmen Saeculare \\ Epod. = Epodi \\ Sirm. = Scrmones}

The abbrevation gar. is used to designate a variant reading listed hy Vollmer or hy Wickham, but not admitted into Vollmer's text (editio maiur, 1912): and coni. to designate a conjectural reading so listed, whether admitted or not. In the quotations, square brackets enclose manuscript and comiectural readings, and readings supplied by testimonia, immediately after the corresponding words as accepted by Vollner. A mark of interrogation sometimes precedes the word or words in brackess, and the sar. or coni. in the column of titles, when there is donte as to the nature of the reading-for example, when what passes for a conjecture may he decipherable in a manuseript, or when the case involies the validity of testimonia; hut the absente of this mark implies mothing as to the value of a bracketed reading or conjecture.

The dagere $\dagger$ and the open brackets have been retaned for the few doubtul expressions which they accompany in the basic text.

The asterisk * has been used to indicate guot at ions and line-numbers for the dousheful or spurious lines preceding Sirm.1.10.

The references to Carm.3.12 follow the arbitrary division of lines made by the printer in Vollmer's text. 
a. C"arm.1.27.18;2.17.5; Epedi.5.71 (i,is)

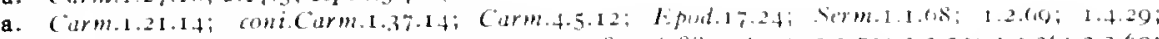
serm.1.4.37; 1.4.97; $1.4 .111 ; 1.5 .92 ; 1.0 .18 ; 1.0 .88 ; 1.0 .94 ; 2.1 .71 ; 2.2 .5372 .3 .30 ; 2.3 .69 ;$ itrm.2.3.320;2.5.52;2.5.83;2.0.50; Lpist.1.1.10.3; 2.2.4; 2.2 .13

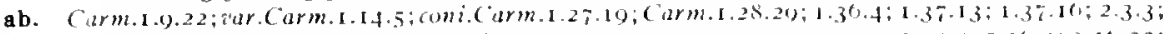

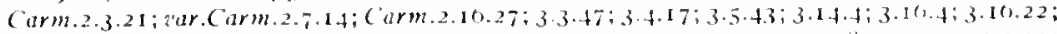
Carm.3.17.1; 3.17.5; 317.11; 3.10.1; 3.20.10;3.27.2; 3.27.12; 3.27.58; 4.4.14; 4.4.53: Corm.4.4.59; 4.5.18; 4.8.31; 4.15.10; Epol.5.23; S.19; cond.Epod.1.17; Epod.10.13;

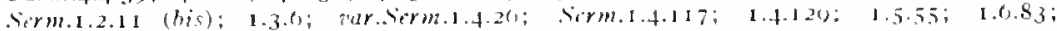
firm.1.7.22; $1.8 .5 ; 2.1 .42 ; 2.100 ; 2.2 .3 ; 2.2 .10 ;$ ar.tierm.2.3.4; 5 irm.2.3.10.3; 2.3-308;

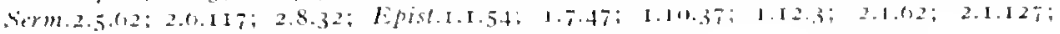

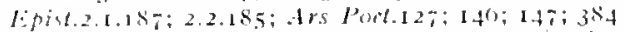

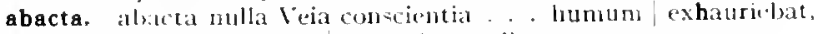
necolum ommis atbacta pauperies epulis regum:

abdioerint, utque lupi Jarban .. abdickerint furtim terric

abdidit. militiol simul fessas cohurtes abdidit oppidia.

abdita, indicis monstrare recentibus abolita rerum:

abditae. Acrisium virginis abditae custoxlen

abdito. nullus argento color et avaris abdito ter ris,

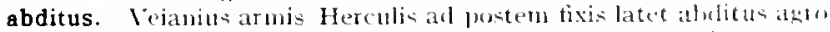

abeant. quorsum abeant? sani ut cretu. an carbone motati"

abeas. Ienia increlas abcasque parvis aequese alumni-

abeat. acl sanos abeat tutela propinquos.

ut releat miseris, abeat fortuma superbi=

abentis. plercm artio in te nil agentis labentis] exitus?

abeo. aben. "t revocas nono port mellne

abes. alr:iam nimium ditu;

abest, fonec virenti canitiss alest norows.

nec severus/uncus abest fituidumque plumbum;

inportuma tamen pauperies abest

curtae noscio quid semper abest ret.

-iquid abust, Italis adiudicat armis.

actor causarum mediocris abest virtute diserti Mecallin.

abeunte. sol . . anicum tempuc agens abeunte curru.

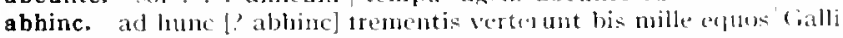
scriptor alhine annos centum qui decistit.

abi, abi. quo blandac iuvenum te revesant preces.

cadatier unctum oleo largo nudis umeria tulit heres, acilic at chbi [et abi] si possert mortua:

abi, quaere et refor, unde tomu, quis.

non es avarus: abi.

abibis. 'solventur risu tabulae, tu mi-cú abibis."

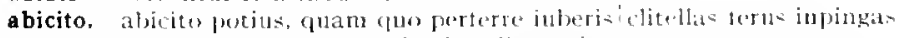

abiectis. nimirum salere est abicetis ntile mugis

abjecto, ommi aliecto instrunento artia clunaque taberna sutor terat

abigat. repuiso, (quou curas abigat,

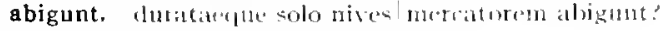

abii. ibill, umbe al bii, redeo:

abire. inssu abire domum

"misere cupice induit "abire.

tempuc alire tibi ('st,

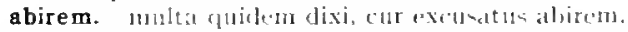

abit, dun aes exigitur, dun mula ligatur, tota abit fors.

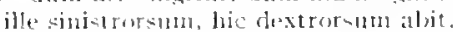

abito. s jer insicum mora ianitoren fiet, shito.

abludit. have a to nom multum alslurit images.

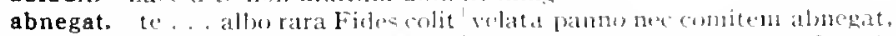

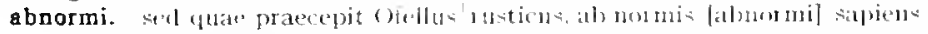

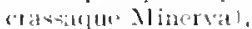

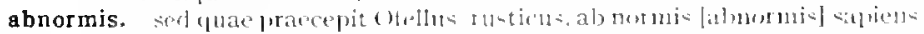
croculue Minterval.

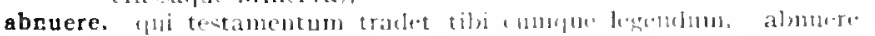
[I]:-1a]1atis. 1.pori.5.20)

strm.2.2..t4

Sirm.1.8.4.3

(imm.3.4.35

dis Pet.ti)

Cirm.3.10.5

(itrm.2.2 2

Lepit.1.1.5

ierm.2.3.24n

( $1 \mathrm{rm}^{\mathrm{m}} \cdot 3 . \mathrm{s} \cdot 3$

sirm.2.3 218

Ar $S^{3}(x) .201$

itur. Lowl.17.8 $\mathrm{I}$

irm.1.0.0.1

(arm.t.5.2

(iorm.1.1).17

(itmm.1.35.20

Carm.310.37

(arm.32.8.4

Epil.1.15.5\%

for Poxt 370

(arm.3.4.4.4

? coni.leporlog. 17

Lipist.2.1.36?

(amm.t.1.7

Erar..verm.2.5.87

EPint. 1.7.53

Esive.2.205

serm.2.1.so

fopt.1.1.3.7

Epist.2.2.141

irim.1.3.131

Epist.r.15.14)

(iorm.3.24.40)

sirm.1 1.108

Eport.1 1.20

Sirm.10.14

Eptit.2.2.215

Itpiv1.0.7

Term.1.5.1

Arm.2.3.51

riam.314.2.

arm.2.3.320

(amb.1.35.22

inte Sirm.2 33

"ar.trom 2.2.3

Sirm 2.5.52 


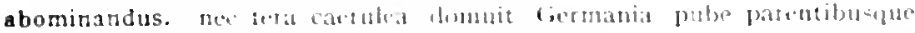

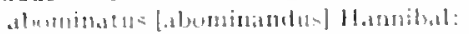

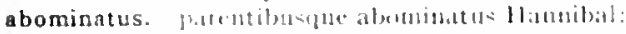

ine. I:poid 19.8

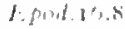

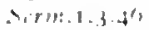

iar. I. Fist.2.1.11.

(armation

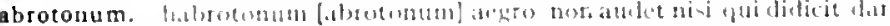

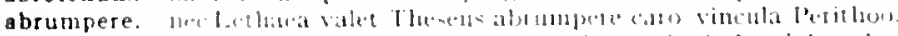

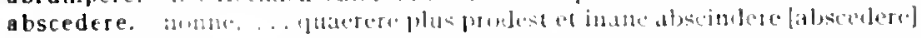
athles:

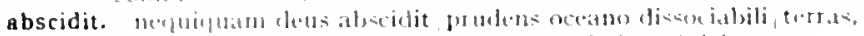

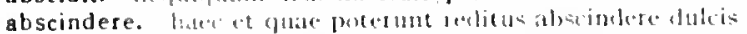

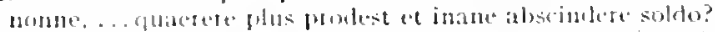

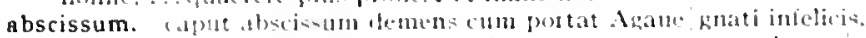

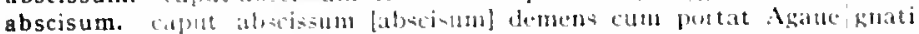
intlilins:

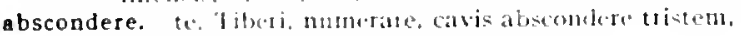

absens. "vilis lintope" pater utget absens:

illis aceodals socius: latudes butuleric ut absens.

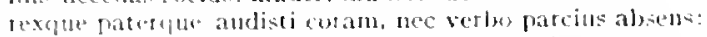

Ruma lavdetur Sitmos et (hios et Rhodos abstns.

absentem. Matrus absentw Xovium cum carpert.

‘ubentem g̨ui sertit, anicum qui mon defomlit alio culpaste,

abent(n ut cantat amicaul multa profutus vappa nata

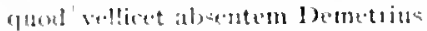

almenfom ructions V'rbeu|tollis ad atra levis.

absentis. alsentis ranate pullis vituli pede pressis

absentis. qui aniog alsentis liabet:

absint. absint inani fumere meniae

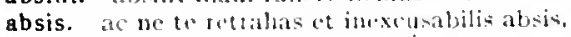

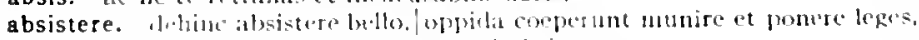

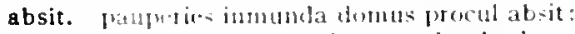

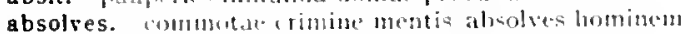

absona. i licinticerunt fortunis absema dicta.

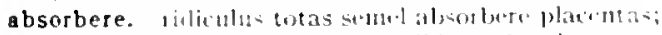

absorberet. silicet ut leciens solidum absobledet.

abstemius. alontumins herbis vivis ut urtical.

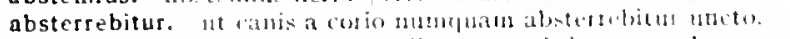

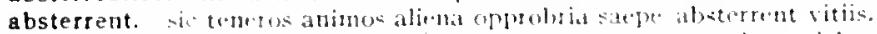

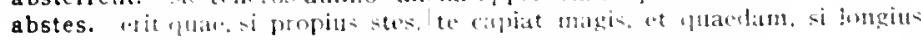
alseterin.

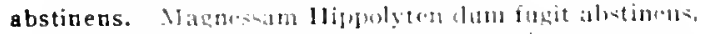

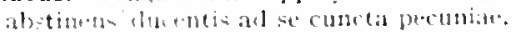

abstinet. foust quactit et inventis mised abind ac timat uti.

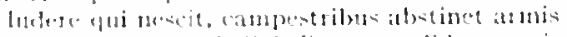

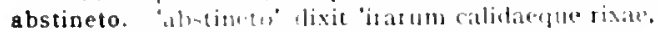

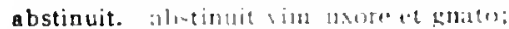

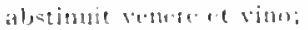

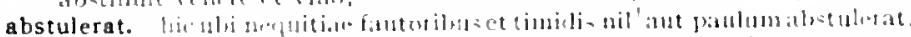

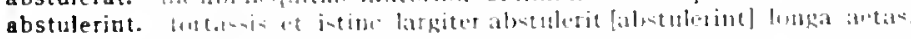

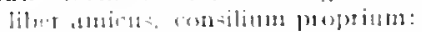

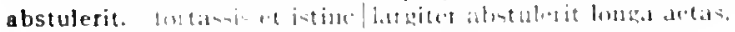

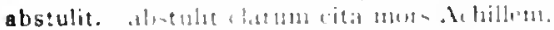

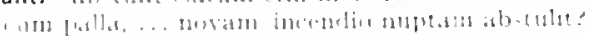

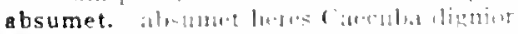

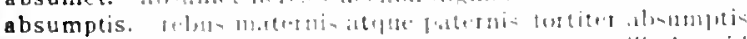

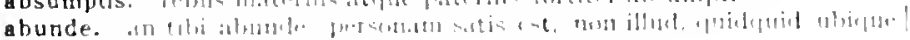
wht it "rit.tt"

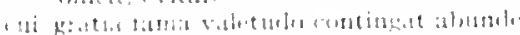

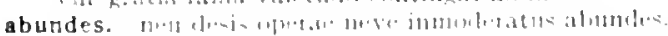

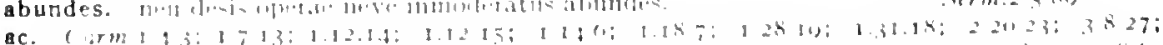

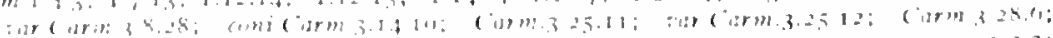

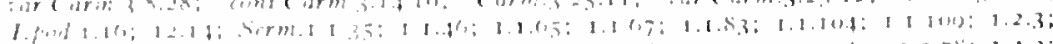

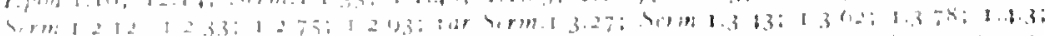

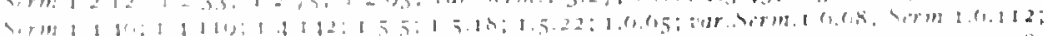

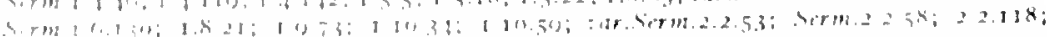

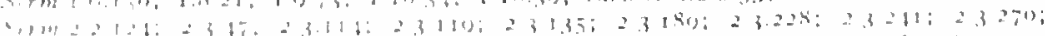

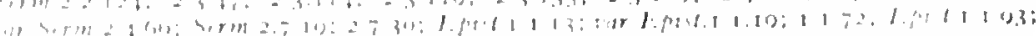

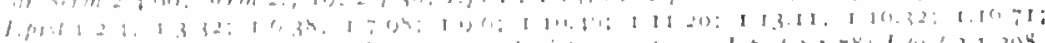

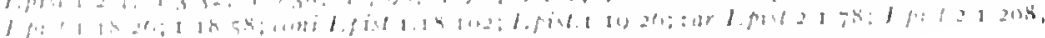

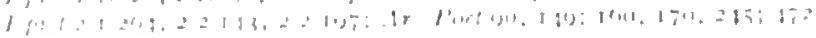


Academi. atque inter silvas Academi quaerere verum.

accedam. "nee unnc, cum me vocat ultro. accislan?

accedas. illi = aceedas socius: laurles, lauderis ut absens.

accedat. 'deficient inopem renaete, ni cibrs atclue ingens accedit [accedati stonacho fultura ruenti.

"o si angulus ille proximus accedat. qui nunc denormat agullum!" .

accedent, ubiquaccedent ami, tratari mollius atas imbecilla volet:

accedente. lenion et melior fis accedente sencta?

accedere. iubet. . accedere plures'ad numatam Ium:

unde etian trimetri= accescert [accedercl iusit nomen iambeis. .

accedes. accectes "pera agro nona Sabino."

accedes siccus ad unctum.

accedet. tum meate. . vocis acedet bona puse

tibi quidnam accedet ad intann. . . nollitic'n.

accedit. ni cibus atcue ingens aecedit stomacho fultura ruenti. tantum de" medio sumptis accedit honotis. .

accendis. 'accemlis quare cupiam magis illi jpoximuze esse.' .

accendit. quodsi mon pulerior ignis/accendit obsessam flion.

acceperis. tune insantus eris, si acceperis,

accepisse. rutiens urbanum murem mus panpere fertur/aecepise cavo.

accepit. egressun magna ne accepit Aricia Roma|hospitio modico.

hic simul accepit patrinoni mille talenta.

cun senrel accepit Solem furibundus acnitum?

ius imperinucue Phraates/ Causaris acecpit genibus minor;

accepta. !ibertasclue recurrentis accepta per annos! lusit amabiliter.

lex est accepta chorusque | turpiter obticuit

acceptos. rettulit acceptos, regale nominna, Philippos. .

acceptus. acefotuaque novem Camenis.

accersit. creditur, ex medio quia res accussit, habere, -udoris minimum... comoedia

accessit. ut senel icto accessit fervor capiti numerusque lucernis;

creditur, ex medio quia res accersit [accessit]. labere|sudoris mininum, . . crmoedia accessit numerisque modisque licentia maior.

Acci. nil comis tragici mutat Lucilius Acci?

hic et in Acci|nobilibus trimetris adparet rarus

accidit. quid accidit?

accidit ut cuidam testis caudanque salacen/demeterent ferro.

accipe. o quid agis? fortiter occupa [? accipe]/portum.

accipe. si ris, | accipiam tabulas; .

ecce/Crispinus minimo ne provocat accipr, si vis, faccipiam laccipe iam] tabulas:

agedum, pauca accipe contra.

accipe nunc, victus tenuis quae quantaque secum/adferat.

nunc accipe, quare/desipiant onnes aeçue ac tu.

"accipe quod numquam reddas mihi" si tibi dicam:

accipe quid contra haec iuvenis responderit aecuos.

accipe: primum|aedificas.

accipe qua ratione queas ditescere.

accipiam. "accipe. si vis, | accipiam tabulas;

accipiar. ut ego accipiar laute.

accipiss. nililo plus aceipras quam/qui nil portarit.

accipiebat. (puer hic non laeve iussa Philippi|accipicbat)

accipiens. haud ita pridem|Galloni praeconis erat acipensere [accipiens ere] mensa |infamiz.

accipiet. multum Nasica negutas/accipiet tandem et tacitus leget

certius accipit damnum propiusve medullis

accipio. Messius 'accipio.' caput et movet.

accipis, das nummos, aecipis uram./pullos, ova, cadum temeti: .

accipit accipit et bis dena super sestertia nummum.

accipiter, accipiter velut $\mid$ mollis columbas

metuit fovam lupus accipiterque/suspectos laqueos

accipiunt, aequis accipiunt animis donantre corona.

accisis. Ofellum integris opibus novi non latius usum|quam nune accisis.

Accius. aufert/l'acuvius docti faman senis. Aceius alti,

acclinis. eum acclinis falsis animus meliora recusat.

accrescere. unde etian trinetris acerescere jussit nomen iambcis.

accurrit. accurrit quidam notus milhi nomine tantum

acer. quen iuvat. . acer et Mlarsi peditis cruentum/voltus in lostem;
Epist 2.2.45

Sirm.2.3.203

Serm.2.5.72

iar. Serm.2.3.154

Sirm.2.0.9

$\operatorname{Sin} 2.2 .85$

Lpist.2.2.21 I

Serm.2.3. 149

var..trs Poet.232

Serm.2.7.IIS

lipivt.17.12

(arm. 2.46

Sirm.2.2.86,

Sirm.2.3.154

Lrs Poet.243

Sierm.1.0.53

I.Pol.14.14

serm.2.3.07

Sicrm.2.6.8I

Serm. [.5.I

ierm.2.3.226

lipist.1.10.1 7

Epist.1.12.28

fipist.2.I.I 47

Ars I'fet. 283

fipist.2.1.234

carmasacet)

Epist 2.1.10.8

Sirm.2.1.25

E'tr. Epist 2.1.108

Ars PoiltaII

Sirm.1.10.53

Ars Poil.258

Epod.5.6I

Serm.1.2.45

botar.Curm.I.14.2

Sirm.1.4.14

2ar.Sirm.1.4.15

Sirm.1.4.38

Serm.2.2.70

Sirm. 2.3.46

Sirm.2.3.06

Serm.2.3.233

serm.2.3.307

Serm.2.5.10

Serm. I.4.15

Sorm.2.8.67

Sirm.I.I.48

Epist.1.7.53

inr..Sim.2.2.47

Serm.2.5.68

I.Pist.i.io. 28

Sorm. I. $5.5 \mathrm{~S}$

Epist.2.2.162

I.pist.2.2.3.3

Carm.1.37.1 7

I.pist.1.10.50

Ars Poet 250

fierm.2.2.114

Iipist.2.1.50

Sirm.2.2.6

Ars Poet. 2.52

Sirm. 1.0.3

Carm.1.2.39 


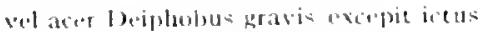
primu-

driecit acer plus vice singulici:

alle acet hosetis Bupdo.

quatr colus atcer ubi littrat sus.

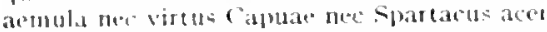

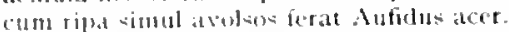

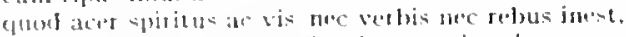

sulcius alcer ambulat et Caprius, rauci male cumbue libellis.

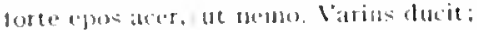

sunt punbus in satura videat nimis aces

"ut pations, ut anticis aptus. at aces?"

et plotent sibi, natura sublimis at atce:

ieviunis desteibus acer.

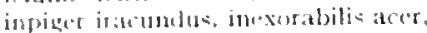

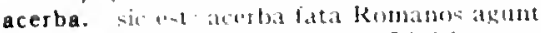

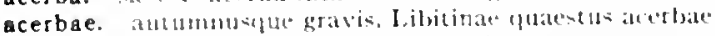

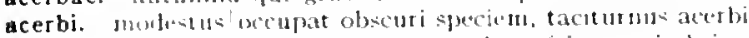

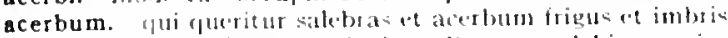

acerbus. and dus odisti et fugis ut Rusomem debitor aleris, ineiotum doxtumeque fugat tecitator actbus:

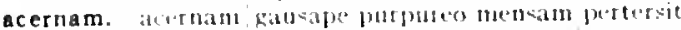

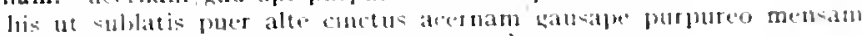

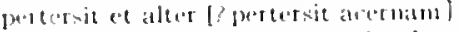

acerra. quit velint flotes et acersa turis/ plena

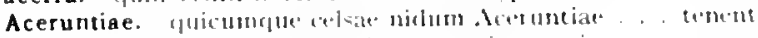

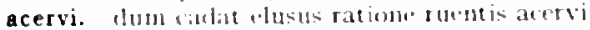

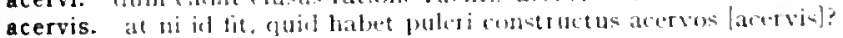

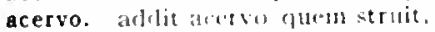

acervo. at hi inl fit. quall habet pulf ri constructus acervos lacervol?

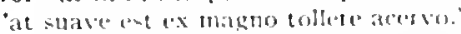

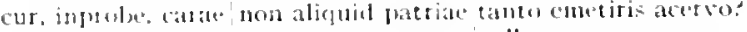

ex numbico, pluant um tes posect. acesso tollam

acervom. siquis at ingentem frumenti semper acerbon porrectus vigilet

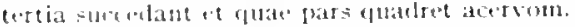

acervos. at hi itl fit, guid habet puleri constructus acerven?

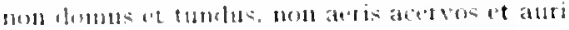

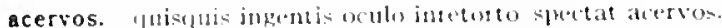

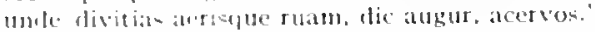

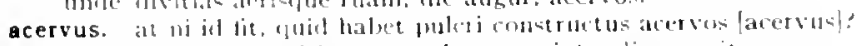

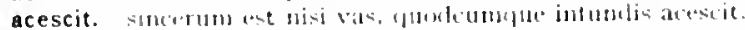

aceti. vetelis nem partolic ancti

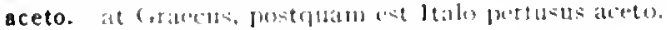

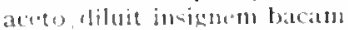

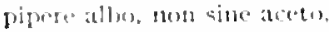

acetum. ato potet anctum;

Achaemenes. num th quae tumut dives Achatmenes

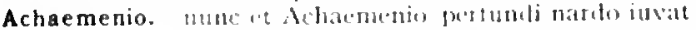

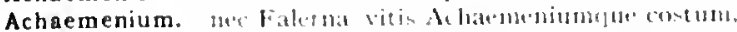

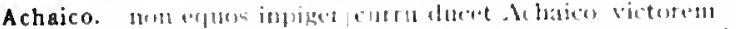

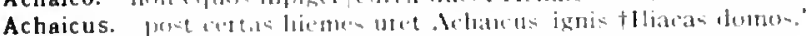

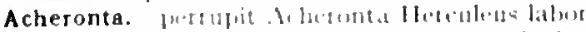

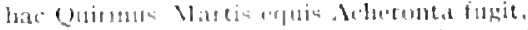

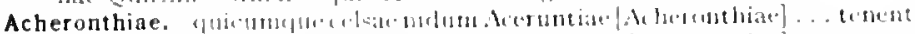

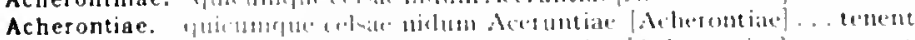

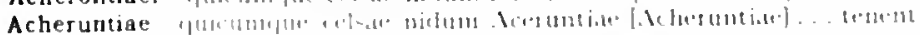

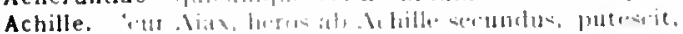

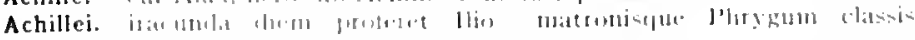
B. Hillen:

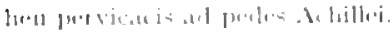

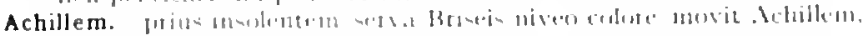

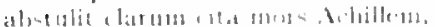

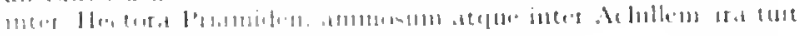

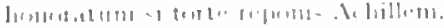

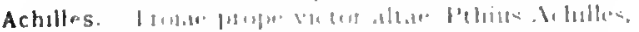

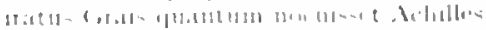

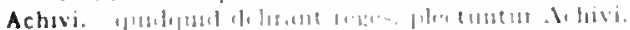

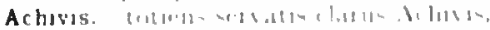

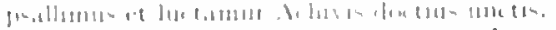

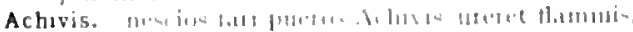

Cism.4.9.22

Carm.t.14.13

lipod.o.14

Eprol.12.0

lipod.10.5

Sorm.1.1.58

Sierm.1..t th

Serm. I the 5

Serm.1.10.43

Sirm.2.1.1

Serm.2.5.4.3

l.pist.2.1.105

Epist.2.2.20

Ars l'oct.t21

Epod.7.17

Sirm.2.0.10

Epist I. 18.05

1.pist.1.17.53

Sirm.1.3.85

Ars Pock.t74

Serm 2.8.10

If'dr.Serm.2.8.1 I

(idrm.3.82

encicarm.3.4.14

L.p.s6.2.1.47

sur.serm.1.1..44

cirm.1.1.34

sar.serm.1.1.4t

Serm.t.1.51

Sirm.2.2.10.5

Lipist.2.2.100

Serm.2.3.111

lipst.1.0.35

term.1.1.4t

I.pri.1.2.47

(i)m.2.2.24

Sirm.2.5.22

iar.sirm.1.1.4t

fipiat.1.2.5.t

Serm.2.2.12

sirm.1.7.32

Sierm.2.3.240

fierm.2.8.10

Sirm-2.3.117

(iir)m.2.12.21

lipod 1.3.8

Cirm-3.1.4.t

(c)

(arm.1.1535

(ism.1.3.3)

Carm.3.310

surciarm.3.14

iar.corm.3.4.14

aur Cism 3.+1 1.4

Sirm.2.3.103

cism.1.15.3.1

1. porld 17.1 .1

farm.2.t.8

('surm.2.14,20)

sirmitit:

Irs lint.1 20"

(armato. 1

I-pert.2.2.82

1.pret.1 2.14

urme $2+11) .4$

A:pert.z: 13

(a) 19.14 .18 
Achivos. nec Priani domus periura pugnacis delivos/ Jactoreis opilus refringit

acidas. cum rapula plenus! at que aciclas mavolt inulas.

acidum. quol petis, id sane est invisum acidunque duobus.

acies. non me Philippis versa acjes setro. . . extinxit

cum stupet insanis acies fulgoribus

acinaces. vino et lucernis Medus acinaces immane quantum discrepat:

acinacis. vino et lucernis Medus acinaces [acinacis], immane quantuu discrepat

acinum. aridum et ore terens acinum semesague lareli irusta devit.

acipensere. Galloni pracconis erat acipensere musa|infamis.

acre. acte potet acetum;

acrem. et acrem militiam paras

fugiens hic decidit acrem pratedonum in turban.

acreonta. non aliter Samio dicunt arsisse Batlyllo Anackonta [non acreonta] Teiuns.

acres. in ius acres concursunt.

acri. nam lactuca inmatat acri| post vinum stomacho;

acri. quem virum aut heroa lyra vel acri|tibia sumis celebrare.

paupuritom pati / robustus acri militia puer / condiscat

ridiculum acri|fortius et melius magnas plenumque secat res.

acria. acria circum rapula, lactucac, radices,

acria. seul quis capit acria fortis|pocula

acrior. fretis acrior Hadriae

auro repensus scilıet acrior miles redibit:

furorne caecos an rapit vis acrior an culpa?

ast ubi me fessum sol actior ire lavatum admomuit,

quanto constantior isdem | in vitis. tanto levius miste ae prior fmiset action| ille

acris. solvitur actis lik'ms grata vice veris et liavoni

ubi acris invidia atque vigent ubi crimina:

acris ubi me natura intendit.

acris. truclit acris hine et hinc nulta cane apros

11t pavet acris agna lupos

caldior est: acris intor numeretur:

actis I subicctat lasso stimulos

nil sic met uentis ut acris|potores,

Acrisium. Acrisium virginis abditate custodem

acriter. vele quod placet ut noulacriter elatrem,

acrium. proklia virginun | sectis in iuvenes ungubus acrium

acrius. atqueiquante perditior quisque est, tanto aerius urget: crevlicht ingens paupenien vitium et cavit nihil acrius,

Acroceraunia. qui sidit . . infamis scopulos Acroceraunia?

Acrocerauniae. infamis scopulos Acroceraunia [Acrocerauniae)?

acta. aut agitur ses in scaenis aut acta refertur.

actae. memor actae non alio rege puertiae

acti. laudator temporis actil se puero.

Actia. Actia pugna te duce per puesos hostili more retertur:

actor. quibus oblitus actor cum stetit in scaena. actor/causarum nediocris abest virtute diserti| Messallate

actoris. actoris partes chorus officimouc virile/defendat.

actu. neve minor neu sit quinto profuctior actu|fabula,

actum. ac non ante malis dementem actum loriis

actus. rectius Iliacum carmen deducis in actus neu quid melios intercinat actuc

actus. et malus celeri saucius [actus] Africo

ct malus celes i saucius [actus ab) Arico

ille Notis actus ad Oricum

ut nuper, actus cum treto Nejtunius/dux tugit

iracundior est paullo, ninus antus [actus] acutis / hasibus hormm homilin:m.

acuens. foruset rupilo semper ardentis acuens sagitas / conc cruenta. acuis. seu linguan causis acuis . responderc parti

acuisse. audiet civis acuisse ferrum,

acuit. haec dentis acuit timendos,

acumen. Empedocles an Stertinium dediret atum-n.

acumen. indicis argutum quae non formidat atcurn;

acumina. nota fefert meretricis acumina.

serus enim Graecis admovit antua chartis

(iarm.3.3.27

Sirm.2.2.14

Lisist.2.2.14.4

Cirm.3.1.2h

s.rm.2.2.5

(arm-1.27.5

zur. Curm. [. 27.5

Sirm.2.0.8.5

Sirm. 2.2.47

Serm.2.3110

(arm.1.20.2

Sirm.1.2.42

ivar. E.pol.1.10

Serm.1.7.2 I

Sirm.2.4.59

(arm.1.I2.I

Cirm.3.2.2

Serm.1.10.14

Serm.2.8.7

Serm.2.6.(n)

Carm.1.3.3.1.5

Curm.3.5.25

I.pod.7.I.3

sirm.1.6.125

sar.sirm.2.7.19

Curm.1.4.1

Sirm-1.3.013

Sirm.2.7.47

Epod.2.3 I

Lpod.12.25

sirm.1.3.53

Serm.27.93

Sirm.2.8. $3^{6}$

(arm.3.19.5

Epist.1.18.18

Carm.10.18

Sirm.1.2.15

Serm.2.3.92

Carm.1.3.20

tuar.Carm.1.3.20

Ars Poet. 179

Cism.I.3p.8

Ars Poct.173

Epist. I. I8.61

I.pist.2.1.204

Ars Poet. 300

Ars Pott.103

Ars Puet.189

Sirm.2.3.135

Ars Puet.129

Ars Potl-104

2ur. Corm.1.14.5

idar.Carm.1.14.5

Carm.3.7.5

Efold.y.7

sidr.s.rm.1.3.20

(urm.2.8.15

Jpist.1.3.2.3

Carm.1.2.2工

Carm.3.20.10

Epist.1.12.20

Ars I'oel.301

Epist.1.17.5.5

I.pist.2.I.IOI 
acuta. sell voce nuth mistia acuta

acuta. sive te tupos ct acula beto sa va dedectant.

acute. non acuta si geminant corbbutes acra. curas sagacen expediunt per acuea belli". in ruem tela acuta torserat.

acutas. vils.. aus is colpripolum Satyrorum acutas.

acutis. minus agens acutis nabibus horam hominum,

acuto. geluque pumina consticetint actuto?

hime apicem rapax fortuma cum striclore acuto/ sustulit,

quod latus aut remes norbo termptentur acuto. .

si batus ant renes morbo temptantur acuto.

lucbintis acuto me secer ungui.

acutum. cur in anicorms vitis sam cernis acutum/quam aut aquila at sogrens Evichautius?

umbrac cun sigand resomarint triste et acutum

acutum. cun semel accepit Solem furbundus acutum?

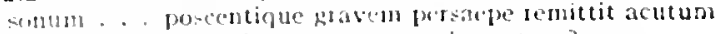

acutum. in matris iugulo tertum tepedecit acutum?

acutum roddere quac fersum valet
Carm.3.4.3

Corm.3 27.01

Carm.1.10.7

Carmitios

Lifod.17.10

Carm.2.19.4

Sirm.1.3.20

Corm.1.9.4

Corm.1.3.1.15

Serm.2.3.163

E.pist.1.0.28

J.pis!.1.19.40

Serm.1.3.26

Sirn.1.8.41

Epist.1.10.17

Ars Joct.3.40

Sirm.2.3.130

Ars l'oet.304

8d. Cirm.11.1; 1.1.22; 1.17.15; coni.Corm.1.23.6; Carm.1.29.8; 1.35.15 (1.is); 2.1 2.25; 3.4.75; Carm.3.9.40:3.7.5; 3.20.58:3.30.13:4.4.50; 4.5.30; 4.5.31; 4.8.34;4.9.2; 4.9.35; 4.12.21:

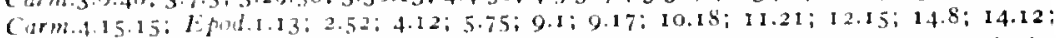
Epold19.49: 17.14: Sirm.1.1.43; 1.1.97; 1.2.26;1.2.12; 1.2.09; 1.3.7: 1.3.17; :ar.serm.1.3.27; Serm.1.3.177; 1.4.29; 1.5.32; 1.5.56: 1.5.65; 1.5.83; 1.5.96; 1.6.45;

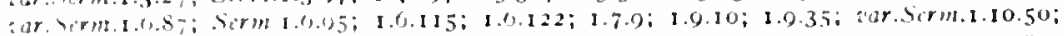
term.21.31; 2.2.27; 2.2.81; 2.2.82; 2.2.80; 2.2.105; 2.3.19; 2.3.111; 2.3.150; 2.3 .171 ; Serm.2.3.21:; 2.3.300; 2.5.70; 2.5.97; 20.31; 2.0.35; 2.6.42; rar.serm.2.6.54: form.2.6.72; $2.6 .75 ; 2.0 .00 ; 2.7 .22 ; 2.7 .24 ; 2.7 .29 ; 2.7 .30 ; 2.7 .32 ; 2.8 .25 ; 2.8 .32: 2.8 .75$; Epist.1.1.5; 1.1.9; 1.1.45; 1.1 108: 1.2.31; 1.5.17; itr.Epist.1.5.2S; Epist.1.6.12; 1.7.11:

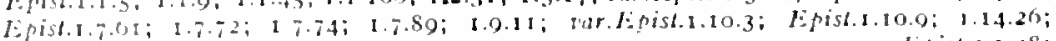

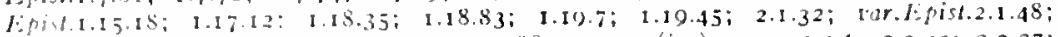

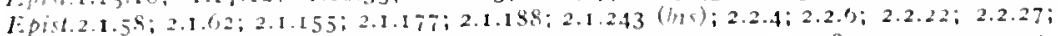
Epis 2.08; 2.2.138: 2.2.185: Ars lont 108; 109; 110; 120; 148; 254: 255; 294:

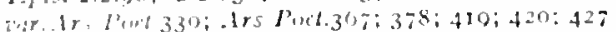

adamantina. ynis Martem tunica tectum adamantiualdisne senpserit adamantinos. ai tigit adamantimasummis verticibus dira Xecessitas clisuos.

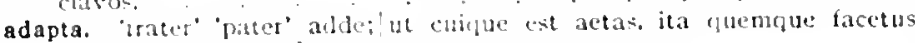
adepta ladipta?.

adbibe. nunc ajtsibe puto pertore vetbas, puer.

adcredere. scribere te nobiz, tibi nos adcredere par est

aderevit. invidia aherevt. pributs guae minor esset.

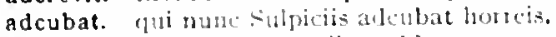

addam. reabum num amplius adlam.

nil verbi, percas quin fortitr. adılan -

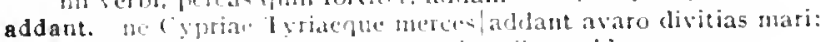

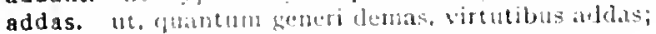

adde. adele gruat pulwes tibj crescis ommis.

alde guas lamana sibi dohat natuat negatis.

alde bue qubut mercesu sine fucis festat,

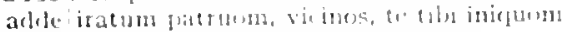

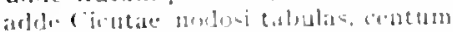

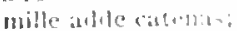

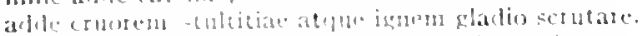

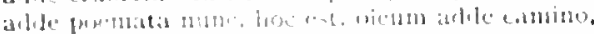

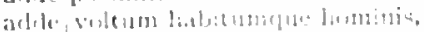

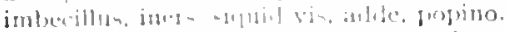

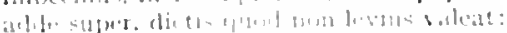

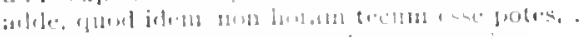

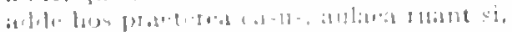

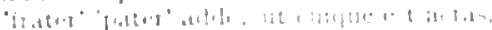

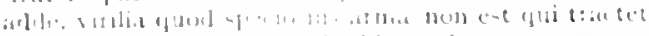

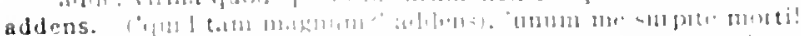

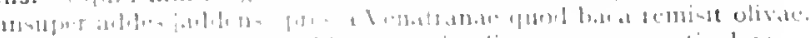

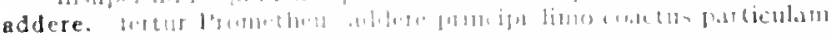

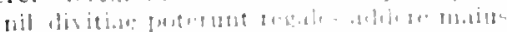

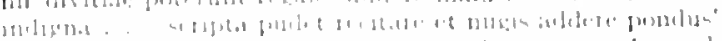

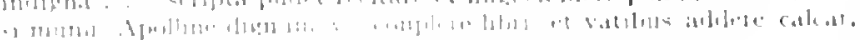

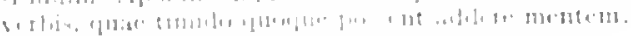

Corm.1.1.13

Carm.3.2+5

ar. Jipist.1.6.55

lipist.1.2.67

Epist.1.15.25

Serm.1.0.26

Cormed.12.18

Sorm.1.1.121

Sirm.2.3.42

Curm.3.20.10

Lpist.1.20.22

Carm.28.17

serma1.1.7.1

Serm.1.2.83

Serm.2.2.00

Serm.2.ing

Sermi.2.3.70

serm.2.3.275

tiorm.2.3.321

Sirmez.a.08

Serm.2.730

sorm.2.7.-5

sim.2.7.111

serm.2.5.7

f.pister c.54

1. pist.1.19.52

sermi.2.32h3

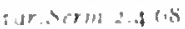

Cirm l Intas

Laper 1.8 ace

1. (185) 1.11$) .42$

f. ple $=1.217$

I post 22.31 
addes, insuper addes/pressa Venafranae quod baca icmisit olivac.

addicere. dic, ... gaudentem nummo te addicere.

addictus. nullius adductus [addictus] intrare in verba magistri,

addidit. saepe Diespiter/neglectus incesto addidit integrum,

militia simul fessas cobortes abdidit [addidit] opyidis.

sic priscae motumque et lixuriem addidit arti/tibicen

addis. addis cornua pauperi

addit. addit acervolquem struit.

hominem sic etigit; addit et illud:

dixeris: 'experiar', si vis, potes,' addit ct instat.

addit opus pigro rivos, si decidit imber.

additis. flagitio additis/damnum;

additum. Medumque flunen gentibus additum/victis

femur tumentibus|exile suris additum.

additum. beatae coniugis additum|stellis honorem

additum feris |alitibus atque canibus honicidam Ifectoren.

additus. ales, nequitiae additus/custos;

addocet. sollicitis animis onus cximit. addocet artis.

addubites. "an hoc inhonestun et inutile factu|necne sit addubites.

adducere, dens nom me vetat . . iambos/ad umbilicun adducere.

adducet. opella forcnsis/adducit [adducet] tebris et testamenta resiguat.

adducit. opella forensis/adducit febris

adductum. dicas adductum propius frondere Tarentum.

adductus. nullis adductus iurare in verba magistri.

addunt. ne Cyptiae Tyriaeque merces|addant [? addunt]avaro divitias mari: adduxerat, cum Servilio Balatrone/Vibidius quos Maecenas adduxerat umbras.

adduxere. adduxere sitim tempora, Vergili:

adempta. adempta rati reddidere lumina:

ademptum. senper urges fiebilibus modis|Mysten ademptum

ademptum. quid autem / Caecilio Plautoque dabit Romanus ademptum| Vergitio Varioque?

ademptus. ademptus Hector /tradidit fessis leviora tolli|Pergama Grais.

adeo. cetera de genere hoc, adeo sunt multa,

confidens tumidus, adeo sermonis amari.

nemo adeo ferus est, ut non mitescere possit,

adeo sanctum est vetus onne poema.

adeptum. quid auten | Caccilio Plautoque dabit Romanus ademptun ladeptun]||Vergilio Varioque?

aderat. aderat querentilperfidum ridens Venus

iamque dies aderat, nil cum procedere lintrem|scntimus.

ipse nihi custos incorruptissinus omnis/circum doctores aderat. .

aderit. si lacta aderit V'enus

ades. 'si me amas,' inquit. 'pauhum hic ades.' .

adesos. nunc lapides adesos/stirpisque raptas . . volventis una,

adesse. tibin . . adezse choris erat utilis

adesses. 'ante secundam, Roscius orabat sibi adeses ad I'uteal cras.'

adesset. cum mihi Cous adesset Amyntas.

adest. heu heu, guantus cquis, quantus adest viris/sudos.

quod adest memento conponere aequos;

cocto num adest honor idem?

si quod adest gratum iuvat (hac prece te oro): .

adeste. nunc, munc adeste.

adfatus. sic tristis adfatus amicos:

adfer. capaciores adfer huc, puer, scyplios

adferat. victus tenuis quae quantaque secum|adferat.

adferet. nec pietas nroram|rugis et instanti senectae/adferet

adfert. praelambens omne quod adiert.

adfertur. adfertur squillas inter murena natantis/in patina porrecta.

adfigit. atque adfigit humo divinae particulam aurae.

adfirmo. ipse cgo, qui nullos me adfirmo scribere versus.

adfixa. 'signa ego Punicis|adfixa delubris

adfixit. aut alius casus lecto te adfixit.

adflasset. velut illis/Canirlia adflassct, peior serpentibus Mfris.' .

gdflent. ut ridentibus adrident, ita flentibus adflent humani voltus.

adfirit. at si condoluit temptatum higore complas alius casus lecto te adfixit [adtixit].

adfluentis. ex hac/luce Maecenas neus adfuentis 'ordinat annos.

adfuit. si vocata partubus|Lucina veris adfuit.
Serm.2.4.68

Serm.2.5.109

tor.Epist.1.1.14

Carm.3.2.30

ar.Corm.3.4.38

Ars Poel. 214

Corm.3.21.18

Scrm.1.1.34

Serm.2.3.150

Serm.2.6.30

Epist. I.14.29

Corm.3.5.26

Carm.2.9.2I

Ispod.8.10

Corm.2.19.13

Epod.17.11

Carm.3.4.78

Epist.1.5.18

Serm.1.4.125

Erod.14.8

rar.Epist.1.7.

Epist.1.7.9

Epist.1.16.1 I

Epist.1.1.14

7'ar.Carm.3.29.6I

Serm.2.8.22

Corm.4.12.13

Epod.17.44

Carm.2.9.10

Ars Pocl.5.

Carm.2.4.10

Serm.1.1.13

Serm.1.7.7

Epist.1.1.30

Epist.2.1.54

tor.Ars Poel. 54

Carm.3.27.66

Serm.1.5.20

Serm.r.0.82

Corm.3.21.21

Sirm.1.9.38

Corm.3.29.36

Ars Pnel.204

Srm.2.6.35

Epod.12.18

Corm.1.15.9

Carm.3.29.32

Serm.2.2.28

Serm.2.6.13

Epod.5.53

Corm.1.7.24

Epod.9.33

Serm.2.2.71

Corm.2.I 4.4

Serm.26.109

Sirm.2.8.42

Serm.2.2.79

Epist.2.1.11

Carm.3.5.10

Scrm.I.I.8I

Serm.2.8.95

Ars I'otitior

iat.5erm.1.1.81

Carm.4.15.19

If pod. 5.0 
adfulsit. enim voltus ubi tuos/arfulsit ropulo.

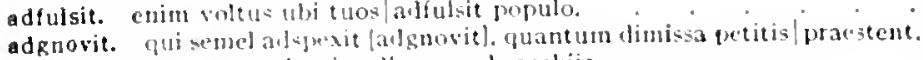

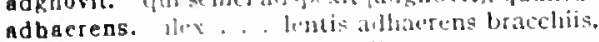

Carm.4.5.7

adbaeret. cui casis ex vero dictum cogsomen adhactet.

adbaesit. sibe pratis veteri craterat limus adhacsit.

adbibe. thuntachue adhibe vim saplentiae.

adhibebitur. no. puicumque deus, gurumque admbebitur heros.

adhibet. alteris te mensis adhibet deum;

adhuc, voces atudit adluc inseger.

nuptiarum expers el adhuc protervo' cruda narito.

dicam insigne, tecens, alluclindictum ore alio.

spirat allutuc amor

o crudelis athur it Venes is mucribus potens.

ad huc fadlucl frementis veterunt bis mille equos/Galli

nil parsom sajias el adbuc sublimia cures:

disce, docendus adhuc quae censet aniculus.

"Jixit adluce aliquid?" "ail sane." 'quid placet ergo?"

et versentur adhuc inura peretralia Vestae:

grammatici certant et adhuc sub iudice lis est

maturusne senex an adbue florente iuventa|forvidus.

adiciant. an adiciant hodiermac crastina summac/tempora di superi?

adiecere. adiecete bonac paulo plus artis Athenat.

adiecisse. adjecisse pracdam/torquil)us exiguis tenides.

adiecti. quidve Calabtis/saltibus adjectil Lucani,

adiectis. adiectis Britannis,imperio gravibusque l'ersis.

adimam. "adiman bona."

forum putcalque I,ibonis! mandabo siccis, adimam cantate severis"

adimat. interdicto huic omme adimat ius/practor.

adimis. ter vocata audis adimisque leto. diva trifomis,

'Iuppiter, ingentis qui das adinisque dolors.'.

adimunt. nec tibi somnos adimunt amatque ianua limes.

multa fermo anoi venientes commoda secum. multa recelentes adimunt:

adinunctum. si prodesse tuis paloque benignius ipsum/te tractare voles.

accedes siccus ad unctum [adinunctum].

adire. cura/non mediocris inest, fontes ut adire remotos

non cuivis lonini contingit adire Corinthum.

adite. hue jropius me, . . vos ordine adite.

aditis. non adytis [aditis] quatit mentem sacerdotum incola Pythius.

adito. cautus aditolnen desis operae neve inmoderatus abundes.

aditure. Serptimi, Gatlis aditure mecum

aditus. conuelditfictis aditus primos babet.'

adiudicat. sitguid abest, Italis adiudicat armis.

adiunctis. semper in adiunctis aevoque norabitur aptis.

adiungere. "atclificare casas, plostello adiungere muris,

adiutor. sun cro. abbilium scrijtornm auditor [adiutor] et ultor.

adiutorem. habues magnum aliutosem, .

adiutorem. Hat. adistat hor quogue, sed vincit longe prius ipsum lexpugnare caput. adlaborandum. ore allabotandum ese tibi.

adlabores. simplici myrto milhil anllabures

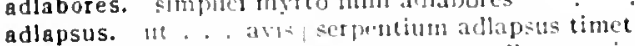

adlata. quacumque inmundis fervent adlata popinis.

adlinet. incomblitadlinet atrum/trunsverso calumo signum,

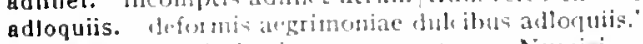

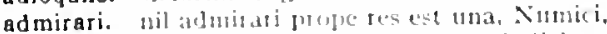

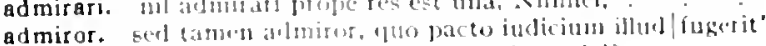

admissi. spectatum allntinci siculn trucatis, anici?

admissus. et lesis antanis Minos admisisus

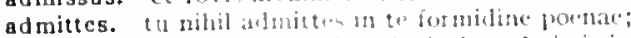

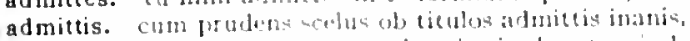

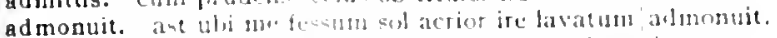

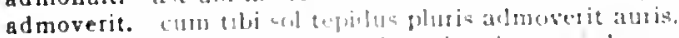

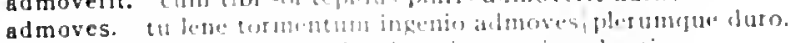

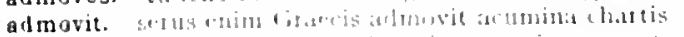

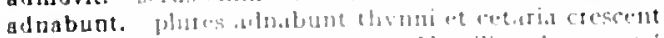

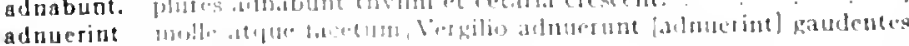

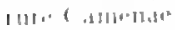

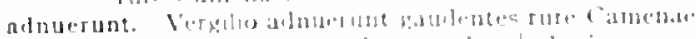

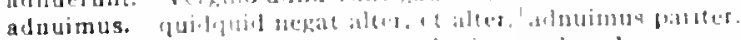

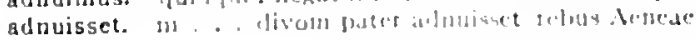

coni.Epist.1.7.96

Epod.15.6

Serm.2.2.56

Scrmi.2.4.80

Carm.3.28.4

Ars $\operatorname{loct.227}$

Carm.4.5.32

$\operatorname{Carm} \cdot 3 \cdot 7.22$

Carm.3.11.1t

Carm.3.25.7

Carm.t.9 10

Carmitito.i

tar.lipod.9.17

Esist.1.12.15

Epist.1.17.3

Epist.2.1 206

Eipist.2.2.11.4

Ars Poct.78

Ars l'oct. I 5

Carm.4.7.17

Lsist.2.2.43

Carm.3.0.11

Epist.2.2.178

Carm.3.5.3

Epist.1.16.75

Epist.1.19.9

Serm.2.3.217

Carm.3.22.3

Serm.2.3.258

Carm.1.25.3

Ars Podtigo

rar.ESist.1.17.12

Serm.2.49.

Epist.1.17.36

Serm.2.3.81

rar.Curm.1.10.5

Serm.2.5.88

Carm.2, 1 .

Serm.1 9.50

lipist 1.13.57

Ars l'oet.i78

Serm.2.3.2.47

rar.lepist.1.19.39

Serm.1.9.40

Serm.2.5.7.3

lepod.8.20

Carm.1.38.5

Epod.1.20

Scrm. 2.4.62

Ars Poct.4.46

Epod.13.18

If pist 10.1

sermit.4.09

itrs Poct. 5

(arm.1.28.9

f.jist.1.16.5.3

Serm.2.3.212

Serm.1.11.120

Epist.1 20.19

Carm.3.21 13

Epist.2.1.10

Serm 2.5.4.4

bar.sorm 1.1"45

sorm 11045

I.paxt 10 S

(curm.s.0.22 
adnumerunt. molle atque facetum | Vergilio adnuerunt [adnumernnt] gaudentes rure Camenae.

adoleverit. simul atque adoleverit aetas."

adopta. 'frater' 'pater' adde; ut cuique est aetas, ita quenque facetus adopta.

ador. esset ador loliumque, dapis meliona relinguens.

adorea. qui primus alna risit adorea.

adparatus. Persicos odi. puer, adparatus.

adpare. rebus angustis animosus atque/fortis adpare:

adpareat. nec sidus atra nocte amicum adpareat.

adparent. quam per vatis opus mores animique virorum/clatou um adparent.

adparere. plurima, quae invideant pure adparere tibi rem.

cum lamentamur non adparere labores/nostros

adparet. adparetque beata pleno/Copia cornu.

dapes inemptas adparet:

hic et in Acci|nobilibus trimetris adparet rarus

nec satis adparet. cur versus factitet:

adpelle. "luuc adpelle"; 'trecentos inseris": 'olke, iam satis est."

adpingit. delphinum silvis adpingit. fluctibus aprum.

adplicat. rotis puetorum amicas/adplicat auris:

adplicet. dic modos, Lyde quibus obstinatas/adplicet auris,

adplorans. querebar adplorans tibi.

adponatur. ne male conditum ius adponatur.

adpone. quem Fors dierum cumque dabit. lucroladpone

adponet. illi quod tibi dempserit /adponet annus).

adponit. cantat et adponit meus est amor huic sinilis:

adposcere, si plus adposcere visus, f fit Mimnermus

adpositis. "Albanum. .. sive Falernum/te magis adpositis delectat:

adposuisse. insani leonis $\mid$ rim stomacho adposuisse nostro.

adprecati. rite deos prius adprecati.

adquirere. ego cur, adquirere pauca/si possum, invideor.

adrasum. conspexit. . . adrasum quendam va ua tonsoris in umbra adrepe. leniter in spem/adrepe officiosus.

adrident. ut ridentibus adrident. ita flentibus adflent/humani voltus.

adridere. quibus haec, sint qualiacumque.|adridere velim.

adrogavit. optatum peractis/imperiis decus adrogavit. .

adsciscet. adsciscet nova, quae genitor produxerit usus.

adscribi. adscribi quiet is/ordinibus patiar deorum.

adscripsit. ut male sanos|adscripsit Liber Satyris Faunisque poetas, .

adsectaretur. cum adsectaretur. 'numquid vis?' occupo.

adsentatores. adsentatores iubet ad lucrum ire poeta

adsideat. habes quiladsideat, fomenta paret.

adsidens. ut adsidens inplumibus pullis aris .

et inquietis adsidens praceordiis

adsidet. parcus ob heredis curam nimiumque severus|adidet insano:

adsiduas. non feret adsiduas potiori te dare noctes

adsignant. dum . . . agros adsignant, oppida condunt.

adsis. utque soles, custos mihi maxinus adsis.

adsisto. pererrolsaepe forum, adsisto divinis.

adsit. avis . . non, ut adsit, auxili|latura plus praesentibus.

adsit | tegula, peccatis quae poenas inroget aequas.

uti mox nulla fides damnis verisque doloribus adsit.

adsita. qua populus adsita certis/limitibus vicina refugit iurgia;

adspectu. pallor utrasque|fecerat horrendas adspectu.

adspersus. qui Capua Romam petit. imbre lutoque/adspersus

adspexit. quem simul adspexit scabrum intonsumque Philippus.

qui semel adspexit. guantum dimissa petitis, praestent.

adspice. tamen adspice, siquid / et nos, quod cures proprism fecisse. loquamur.

adspice. Plautus|quo pacto partis tutetur amantis ephebi.

adspice primum.|quanto cum fastu.

adspicere. non satis est 1 thacam revehi patriosque Ptnates/adspicere?"

adspici. et voltus ninium lubricus adspici

adspiciam. o rus, quando ego te adspician

adspiciat. sed ut veniens dextrum latus arlspiciat sol.

adspicit. seu Libra seu me Scorpios adspicit

interque signa turpe nilitaria|sol adspicit conopium.

adspirare tibia. : adspirare et adesse chorin erat utilis

:ar.Serm.1.10..15

serm.1.9.34

Lpist.1.6.55

Serm. 2.6.89

Carm.1.4.4t

Carm.I.38.I

Carm.2.10.22

Epod.10.9

Epist.2.1.250

Serm.1.2.100

Epist.2.1.224

Carm.Saec.59

Epod.2.48

Ars Poet. 259

Ars Poet. 470

Serm.1.5.12

Ars Pocl.3o

Carm.Saec.72

Carm.3. I I.8

Epod.1 1.12

Serm.2.8.69

Carm.1.9.15

Carm.2.5.15

Serm.1.2.107

Epist.2.2.100

Serm.2.8.17

Carm.1.10.10

Carm.4.15.28

Ars Poet.55

Epist.I.7.50

Serm.2.5.48

Ars Pot.io I

Sermi.10.89

Carm.4.14.40

Epist.2.2.1 I9

Carm.3.3.35

Epist.1.19.4

Serm.1.9.6

Ars Poet.420

Serm.1.1.82

Epod.1.19

Epod.5.9.5

Epist.1.5.14

Epod.15.13

Epist.2.1.8

Serm.2.6.15

Serm.1.0.II

Epod.1.2I

Serm.1.3.117

Epist.1.1 7.57

Epist.2.2.170

Serm.1.8.20,

Epist.1.11.1 2

Epist.1.7.90

Epist.1.7.96

Epist.1.1 7.4

Epist.2.1.170

Epist.2.2.92

Scrm.2.5.5

Cirm.1.19.8

Serm.2.6.00

Epist.1.16.6

Cirm.2.17.17

Epod.g.10

Ars Poet.201

Sirm. 0.117 
adstricto. quam non ardetricto percutrat pulpita socco;

Epist.2.1.174

sdstrictum. corticen atstetum pice timowebit

adstringitur. artius atque betera proceral adstingitur ilex

adsuerit. Jis qui, lolubibs alsuctit mentem compusque superbum

arm.3.8.10

Efowit5.5

adsuctum. (si kumana fatigat /militia aslsuetum graccari)

adsuitur. puppuress, hale qui splendeat, nnus et aler/adsuitur pannus.

adsumam. nisi "ena prior potionque puella Sabinum/detinet atsumam;

Serm.2.2.109

Serm.2.2.11

irs Potion

List.1.5.28

adsumere. panestum coutum digoos adsumere ptibialambitione procul.

adsunt. Int identihus adrident. ita thentibus adlent ladsunt / humani veltus. adulta. adultio vis go|suspiret:

ndulta. adulta vitium propagine altas matitat poymbs

Serm.1.0.51

var.Ars Podtin

Carm.3.2.8

Epod.2.9

adulter. ne quin fur esset neu lato neu quis adulter.

Serm.1.3.10\%

odulterae. inn mec lacarnae splendet adultegat, famosus hospes

adulteretur. adult retur et columba miluo.

adulteri. non sola comptos arsie adulteri/crinis

ndulteris. municant satis/ boctunis ah adultesis.

adultero. dec nitilo filit adulteso;

adultero. guam turpi lhole pecet adultero. .

nec Damalis novol divelletur adultero

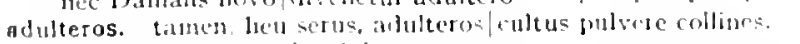

mov iuniures pluedit actulteros

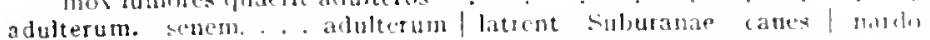

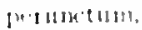

adunce. It platidue solent, naso suspendis aduaco'ignotos.

Carm.3.3.25

Efod.16.32

Carm.4.9.13

Carm.3.16.4

Carm.3.24.20

Corm.1.33.9

Carm.1.30.10

Carm.1.15 19

Carm.3.6.2.5

adurgens. (aesa al lialia volantem|reonis adurgens.

aduri. on a. Bantuis an!uti Colchicis.

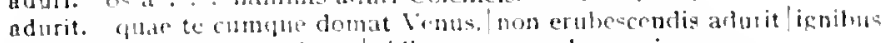

adusto. (t) precture adusto/vidinnus et merulas poni

adustus. ne panis adustus. ne male conditum ius ahlponatur.

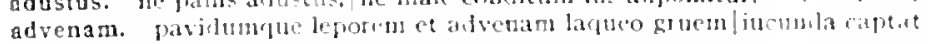
fircininias.

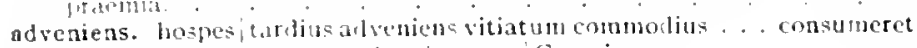

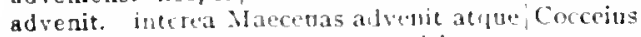

adventum. lassi sul, alventum viri

adventus. seu mobilibus veps is /veris] iobormiclat ventum [aventus] adversa. qui timet his adversia.

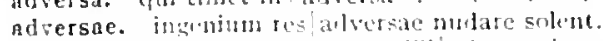

edversarius. Cabll venie obvilus illi|arlversarius

alfersarius rest fuater, laws lladria.

adversis. fortiacjuc adversis opponite pectora teluss."

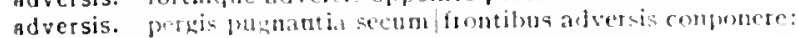

adrursis bulun innersabilis undis.

mon tamen inlversis actatrm thecimus austris.

Erod.5.57

Sirm.1.0.5

Carm.1.37.17

Frod 5.24

Carm.1.27.15

Sorm.2.8.20

Serm-2.8.8

Fpod.2.35

Serm.2.2.91

Serm.1.5.3I

Epod.2.14

iar.Carm.1.23

Epist.1.6.9

Serm.2.8.79

Sorm.1.9.75

Egist.1.18.0.3

Serm.2.2.13"

Serm 1.1.103

Epist.1.2.22

Epist.2.2.202

Serm 2.3.205

adverso. ut haverutis adverso litore navis eriperm.

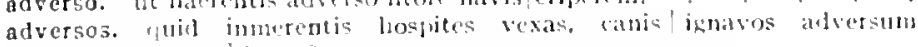
forlwescout dupos?

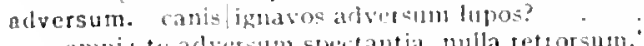

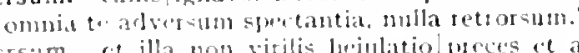

:ar.lepodt 2

Iisod.6.2

Epist 1.1.75 les.4m.

bु1

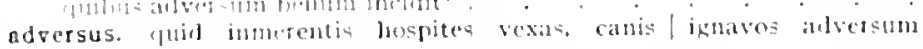

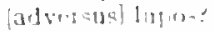

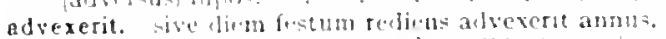

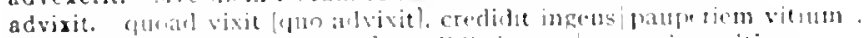

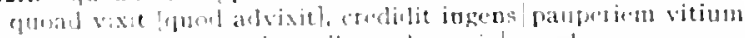

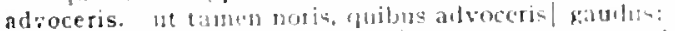

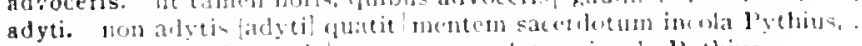

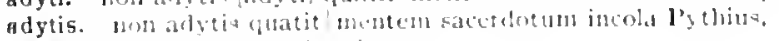

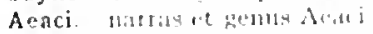

Aeacum. re iurlirantem vilinuma Aracums

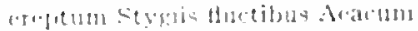

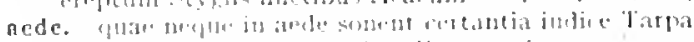

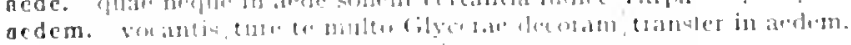

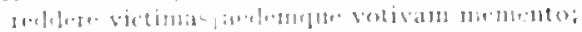

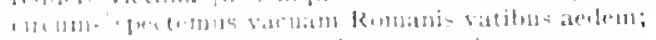

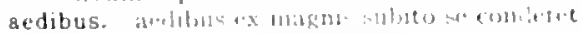

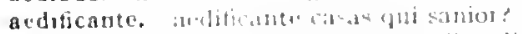

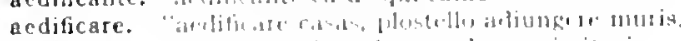

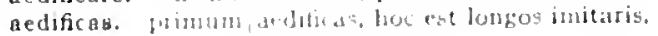

ar. Fpod.10.18

serm.7.71

tar.lipod.0.2

Serm.2.2.83

gar.serm.2.391

earserm.2.3.91

Carm.4.11.13

cont Curm.1.10.5

Carm.1.10.5

Carm3.19.3

Carm.2.13.22

Carm.4 825

Scrmilin 38

Carm. 1.30.4

(ame.17.3

Jeget 2.20 .4

siom $=7.11$

$\therefore$ crm 23.275

Sorm.2.32.47

serm.2.3.305 
aedificat. diruit, aedinicat, mutat quadrata rotundis?

Epist.1.1.100

aedilis. uter aedilis fueritve / vestrum praetor.

Serm.2.3.1 So

aedis. donec templa refeceris/aedisque labentis deorum

Carm.3.6.3

iratusque Philippi tendit ad aedis.

2edituos. qualis/aedituos habeat belli spectata domique/virtus, .

Aefulae. Aefulae/declive contempleris arvon

Aegaeo. otiun divos rogat in patenti/prensus Aegaeo. .

Aegaeas. me ... tutum per Aegaeos tumultus!aura feret

Aegaeum. idcirco navin trans Aegaeum mare vendas.

aeger. 'non est cardiacus . . hic aeger.'

aegida. iam galeam Pallas et aegida ... parat.

quid ... contra sonantem Palladis aegida/pussent

aegri. cuius, velut aegri somnia, vanae/fingentur species,

aegrimonia. fastidiosa tristis aegrimonia. .

aegrimoniae. deformis aegrimoniae dulcibus adloquiis."

aegris. vicus gemit. invidus aegris

isti tabulae fore librum persimilem, cuius, velut aegri [aegris] somnia.

ranael fingentur species.

aegro. quan mihi das aegro, dabis aegrotare timenti,|Maecenas, venian, habrotonum aegro non audet nisi ņui didicit dare.

Epist.1.7.80

Epist.2.1.230

Carm.3.29.6

(arm.2.16.2

Carm.3.29.63

Epist.1.15.16

Serm.2.3.I 62

(arm.1.15.1 I

Carm.3.4.57

Ars Poet.

Epod.17.73

Epod.13.IS

Enist.1.15.7

var. Ars Poet.7

Epist.1.7.4

Epist.2.1.II 4

aegros. avidos vicinum funus ut aegros/exanimat .

Sirm.1.4.126

aegrotare. quo me/aegrotare putes animi vitio.'

dabis aegrotare timenti.|Maecenas, veniam.

Serm.2.3.307

Epist.1.7.4

Serm.1.6.30

Epist.1.8.6

nec quia longinguis armentum aegrotet in agris;

aegrato. olin quod volpes aegroto cauta leoni|respondit.

aegrato. aegroto fomini deduxit corpore febris,

aegrum. mali copia quando|aegrum sollicitat stomachum.

casus medicisve levarit / aegrum ex praecipiti:

nil audire relim, nil discere, quod levet aegrum;

orientia tempora notis instruit exemplis, inopen solatur et acgrum.

Aeli. Aeli vetusto nobilis ab Lamo -..

Aemilium. Aemilium circa ludum faber imus

aemula. aemula nec virtus Capuae nec Spartacus acer.

rupit Iarbitan Timagens aemula lingua.

tibia non, ut nunc, orichalico vineta tubaeque acmula,

aemulari. Pindarum quizquis studet aemulari,

aemuli. quanderte potentior largi munetibus rinerit aemuli.

aemulos. subruit aemulos|reges mureribus;

aena. clavos trabalis et cuneos manu gestans aena

Aenea. ab alto, demissum genus Aenea.

aenea. Danaen turris aeneal robustaeque fores. . munierant.

aenea. inpares formas atque animos subiuga aenea/saevo mittere cum ion. nec magis expressi voltus per aenea signa

Aeneae. ri ... dirom pater adnuisset/rebus Aeneae.

Aeneas. nos ubi lecidinus|quo pius Aeneas, quo Tullus dives et Ancus. castus Aeneas patriae superstes

aeneo. diductosque iugo cogit aeneo?

aeneus. ter si resurgat murus aeneus

latus ut in circo spatiere et aeneus ut stes.

hic murus aeneus esto:

aenum. emptis|sub noctem gelidam lignis calefactat aenum;

Aeoliae. conmissi calores/Acoliae fidibus puellae.

Aeolides. damnatusque longi|Sisyphus Acolides laboris.

Aeoliis. vilimas. . Aeoliis fidibus quetentem /Sappho

quotiensnue educet in agros/Acto'is [Acoliis] onerata plagis iumenta canesque.

Aeolio. fingent icolio carmine nobilem.

Aeolium. princeps heolium carmen ad l talos/deduxisse modos.

aequa. aequa tellus, pauperi recluditur|regurnque pueri-

'pictoribus atque poetis quidlibet audendi semper fuit aequa potestas.'

aequa. aequa lege Necessitas / sortitur insignis et imos, .

coepit et in vitum fortuna labier aeçua:

aequale. nil acquale homini fuit illi:

aequali. aequali recreat sorte vicarius.

aequalis. cur nerue militaris/inter aequalis equitet. ne foret aequalis inter convisa.

aequam. aequam memento rebus $1 \mathrm{n}$ as duis, servate muntem, aequam: rem inperito

Epist.J.1.73

Epist.1.2.48

Scrm.2.2.43

Serm.2.3.293

Epist.1.S.S

Epist.2.1.131

Carm.3.17.I

Ars Poct.32

Epod.10.5

Epist.1.19.15

Ars T'ott.203

Carmulat

Carmat.1.18

Corm.3.16.1 4

Carm.1.35.19

Serm. 2.5.63

Corm.3.10.I

Carm.1.3.3.II

Epist.2.1.248

Carm.4-0.23

Corrat.4.7.15

Carmsace.42

Carm.3.0.1s

Carm.3.3.0.5

Serm.2.3.183

Epist.1.1.6n

Jipist.2.2. I0

Carm.4.9.12

Carm.2.14.20

Curm.2.13.24

far. Fpist.1.18.+6

Carm-4.3.12

Carm.3.30.13

Carmezs.3.32

- Irs Poit.10

Cerm-3.I If

Epist.2.1.94

Serm.13.9

(arm-3.2.14

Carmaser

Iopod.12.23

Carm.2.3.I

serm.2. Is 


\section{AEQVAM}

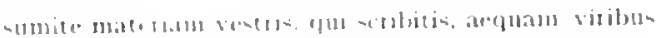

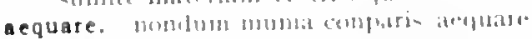

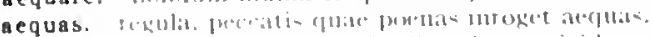

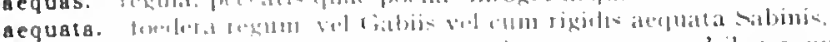

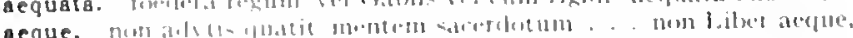

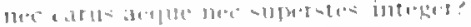

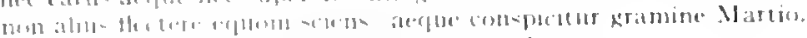

nete

munc ate

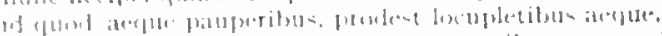

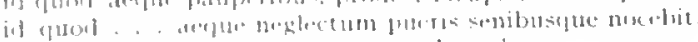

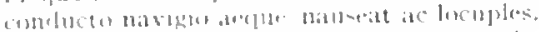

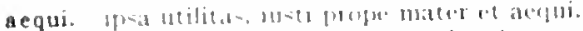

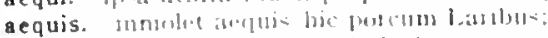

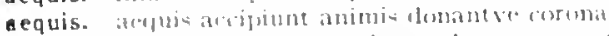

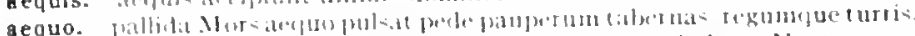

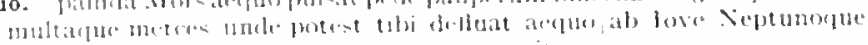

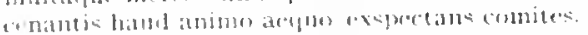

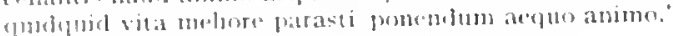

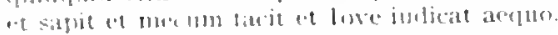

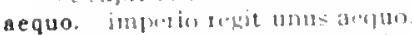

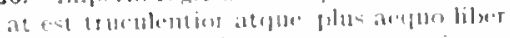

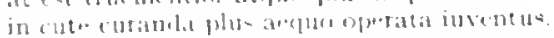

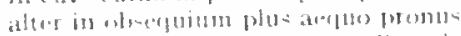

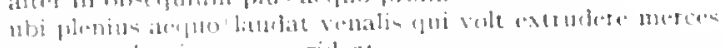

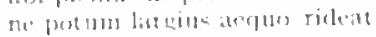

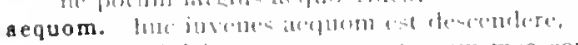

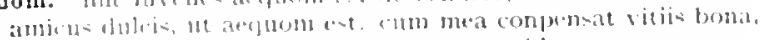

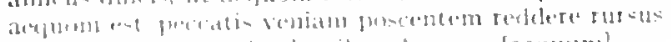

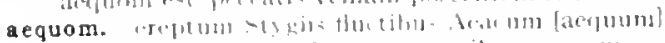

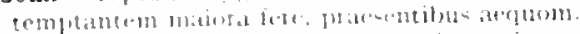

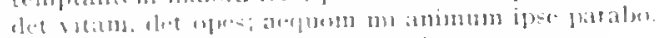

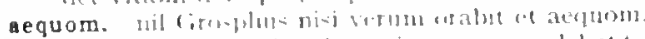

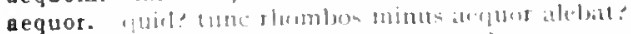

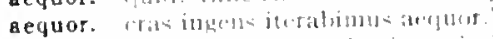

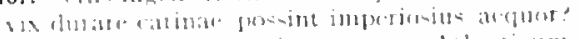

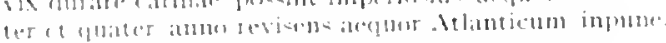

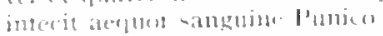

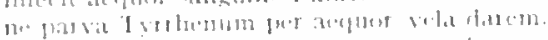

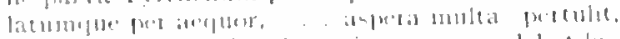

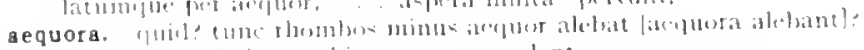

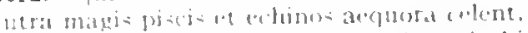

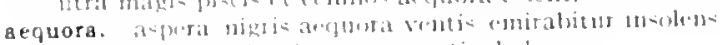

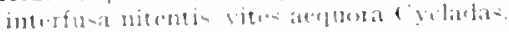

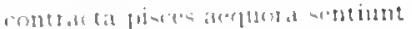

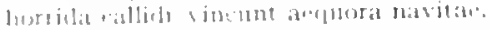

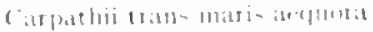

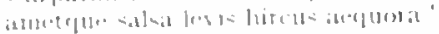

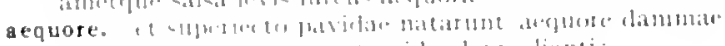

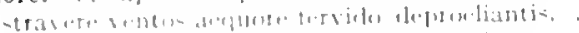

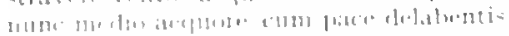

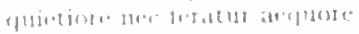

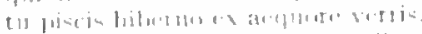

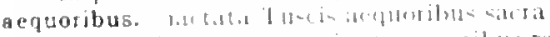

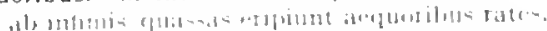

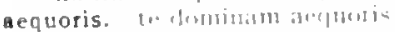

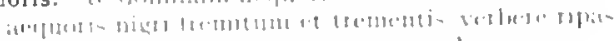

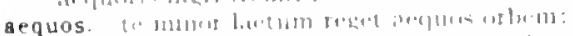

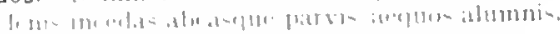

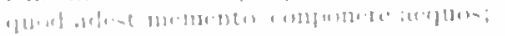

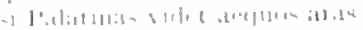

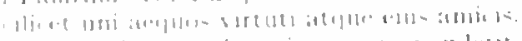

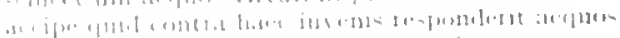

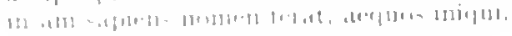

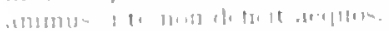

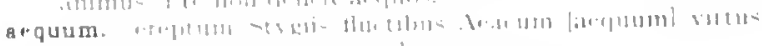

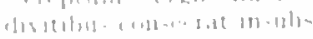

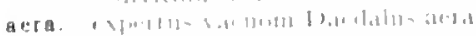

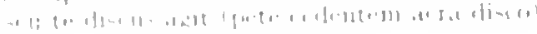

irs $\operatorname{lont} 38$

(ivrm.2.5.3

$\operatorname{sen} 1.3$ I 18

Lipt.t 2.1.25

(

(arm.2.1.7.7

(init $3 \cdot 7 \cdot 26$

(4)m.3.7.27

sim.23.75

I.pis.1.125

I.prat. I 20

1.pisl. I.1 02

Derni.1.3.0N

Serm $2,3.10,4$

Ir Jore.250

Corm.1 413

(arul. 1.25 .28

Serm.1.5.5

serm. 2.3 .16

lipist.2.1.0.8

(iorm $3 \cdot 4+48$

stm.1.3.52

I.pist. I.2.20

I:pist.1.18

I.pir.2.2.10

1.pill.2.2.21.5

Trrme 2.31

Sermat.3.0.0

Serm. [.3.7.

aser (armat 8.25

1.pist. I. 17.2.4

I.PII.1.JS.112

I.pint. I 12.23

Sirm 2.2.45

(iir). 1. .32

( IIM.J.J.

( inrm. 1.31.1.

(is m 3.e. 31

(a) at... 15.3

I.plat. I.2.21

at sirm 2.2.1k

f.pist. 1.15:3

( drots 1.5.7

(ism.t. 1.20)

(trm.3.1.3.3

(

(int) 15.10

t.prid. Ie. 38

(i) 1 .2.12

(arm.1.0.111

( afm: 3.20).31

I. pold I0.1 I

Sirm.2.3.2.35

( is rm. + 5 .t

(itron.t.8.32

(iz $\mathrm{rm} .1 .35 .1$ )

( atm.3 27.23

( t)m.1.12.57

( Ir) $318 . .1$

(aren-3.21) 3.3

(afwiset.tis

serns.: 1 - 715

s.rwi.2.32.33

Ipolio.15

I. MAl 1530

1.111431

i.

(arm. 13.34

sim 2213 
aera. nec tamen ignotat, quil distent aera lupinis.

aera. non acuta|si geminant Corybantes aera. donarem pateras grataque commodus, / Censorime, neis aera sudalibus, quid attinet tot ora laera] navium gravi|rostrata duci pondere/contra latrones

ibant octonos [octonis] referentes idibus aeris [aera],

argentun et marmor vetus aeraque et artis $\mid$ suspice.

aut aliss Lysippo duceret aera|fottis Alexandri voltum simulantia

hic meret aera liber Sosiis, hic et nare transit

aerata. decedit aerata trireni

aeratas. scaudit aeratas vitiosa navis/Cura

aere. me. . denso paventem sustulit aere.

Boeotum in crasso iurates aer. natum.

aere. exegi monumentum aere perennins:

ut inquinavit aere tempus aureum.

aere, dehinc ferro duravit saecula,

liunc capit argenti splemelor; stupet Nllus acre:

quaerere anaban. qun vater ille pedes laviset singphus acre.

servoste tllos, quos aere pararis.

res urget me nulla: neeo suin pauper in aere.

si proprium est, ruod quis libra metcatus et aere tst,

si iractis enatat exspes/ navibus, aere dato qui pingitu?

unguis exprimet et mollis initabitur aere capillos.

hic meret aera [aere] liber Sosiss hic et mare transit

aerea. ut inģuinavit aere tempus aureum, acte, [aerea] debinc furo duravit saecula,

aeri. ibant octonos [octenos] reletentes idibus acris [aeti],

aerias. nec quidquam til,i prodest acrias temptasse domos

aeris. acerbus odisti et fugis ut Rusonem debitor aetis.

ibant octonos referentes idibus artis,

unde divitias aerisque ruam, dic augur, acersos."

non domus et fundus. non aeris acervos et auri

mancupiis locuples eget acris Cappactocum rex:

marmoris aut eboris fabros aut aeris amavit,

utilium tardus provisor, prodigus aeris.

aerugo. hic nigrae sucus lolliginis, hace est aerugo mera;

haec animos aerugo et cura peculi, cum semel imbuerit.

aerumnis. Luculli uniles collecta viatica multis / acrumnis.

aes. illi robur et aes triplex/circa pectus crat.

dum aes exigitur, fun mula ligatur, tota abit hora.

Aeschinus. post hune personac pallatepe repertor honestae/ teschylus [Aeschinus]

Aeschylos. quid Sophocles et Thespis tet Aeshytos utile ferrent;

Aeschylus. post hunc petsonae pallaeque repertor honestae / Aeschylus

Aeschynus. post hunc personae pallaeque repertor honestae Aeschyllis [. leschynus]

aesculetis. necpe militaris Daunias latis alit aesculetis

aesculo. nec rigida mollior aesculo

Aesopi. filius Aesopi.. diluit insignen bacan:

Aesopus. quac gravis tesopus, quat doctus Roscius egit:

aestas. ver proterit aestas/interitura.

aestatem. ignean/defendit atstaten caldellis

aestates. ille salubrislaestates peraget

aestimat. ectera nequaquam simili ratione modorfu' aestimat

qui redit in fastos et virtutem aestinat annis

aestiva. ubi nulla campis arbor aestiva tecreatur anra.

aestivam. atstivam setuone benigno tenderenoctem.

aestuat. balbaras Sytis, ubi Matra semper aestuat unda: aestuat et vitae disconvenit ordine toto,

aestum. nume fluvis graven solantis atsum,

fabula. . . sultorum regun et populorum continet aestus [aestum].

aestuosa. nullius astril gregem aestursid torret inpotentia.

aestuosae. non atetuosac grata Calabrias armenta.

aestuosas. sive per siytis iter atentuosas. . lacturus

aestuosis. te... unda tretis tulit acstuosis.

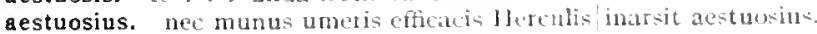

aestus. cum te neque fervilus aestus dinoveat lucro

oleamque momorderit aestus.

civilisque rulem bulli tulit aestus in arma
Ispist.1.7.23

Carm.1.10.\$

(itrm.-4.8.2

coni.Epod..4.17

var.Sirm.1.0.7.5

Epist.1.0.17

Epist.2.1.240

Ars Poel. 315

Curm.3.1.39

Carm.2.16.21

Carm.2.7.14

Fpist-2.1.24t

Curm.3.30.1

lipod.16.64

Iipoti.10.0.5

Serm.1.t.26

Sirm 2.3.2 I

sirm.2.3.129

Epist.2.2.I 2

lipist.2.2.158

Ars loct.2 I

Ars Pod.3;

tor. Irs Fot?.34.5

zar. Epod.16.65

7ur.sirm.1.0.7.5

Carm.1.28.5

serm.s.3.8\%

Sirm-1.0.75

sirm.2.5.22

Epist.1.247

Jist.1.0.30

I.pist.z.1.00

Ars Poet. TOA

Serm.1.A.IOI

lors Poe!.33"

l: pist.2.2.27

(arm.1.3.0

serm.1.5.1.3

"ar.trs Poet.270

lipisl.2.1.103

Irs l'Ot'.27)

iur Ars Pod!.370

Curm.1.22.14

Carm-3.10.17

Serm.2.3.230

tipist.2.I.8z

Carm-t.7.Q

Carm.1.17.3

Serm.2.7.22

Iipist.2.1.21

Jpistan. I.

Carm.1.22.1s

Epist. I.5.1 I

(armt.2.0.1

IEpist. I. I.90

(it)ml.2.5.7

Ear. lipind. 1.2 .6

I.pod.10.6?

Carm.

( irm.1.22.5

(ilrm.2.7.10

tipont.3. Is

Serm.1.1.38

Fist.1.8.5

I.pist.2.2.17 


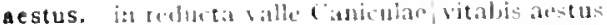

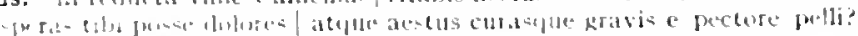
talini... stultorum tefun ce populorum contiuet aestus.

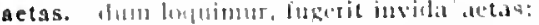

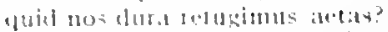

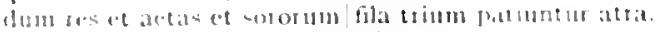

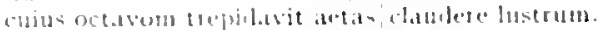

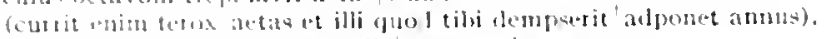

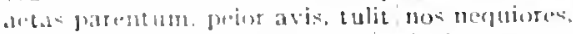

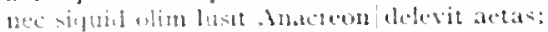

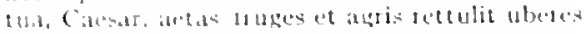

alleta i.nu enitur bellis civilibus actas,

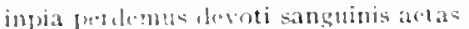

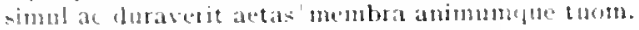

tothesis et jutine latgiter abstuleril longa aetas.

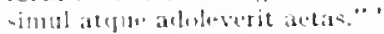

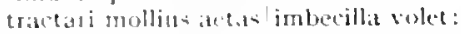

piscibuc atgue avibus guae natura et foret aetas.

Iinn eadem ext aletas. non mens.

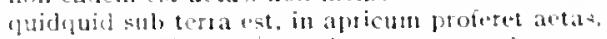

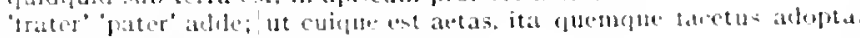
bretiust detis alteda sordet.'

cilltistio Romace, fonec te deserat actas:

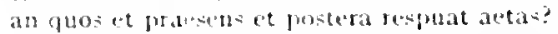

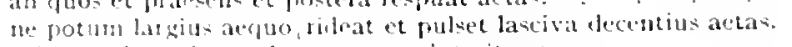

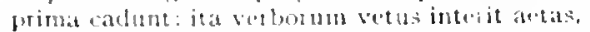

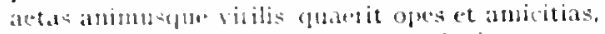

aetatem. non tatmon alvessis alotitem ducimus austris,

aetatis. actutis culdstue notandi sunt tibi mores.

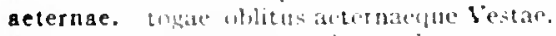

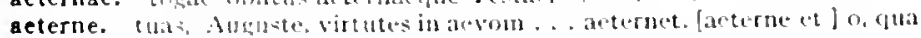
sol lablealujic mluatrat oras.

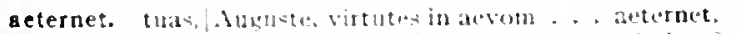

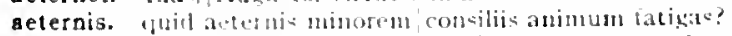

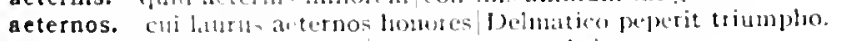

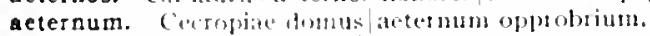

aeternum. nei in actermum/"silium injositura cymbar. aletormata nueditans dectus stullis inserere

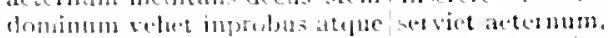

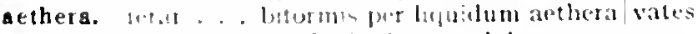

aetheria. Jest ifucu antheria domo subductum

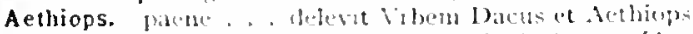

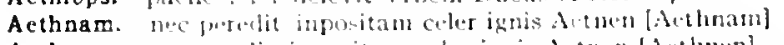

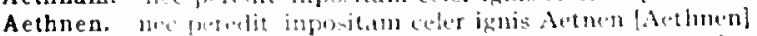

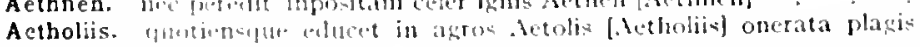

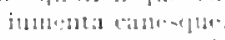

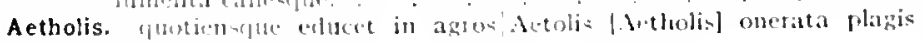

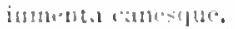

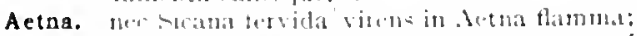

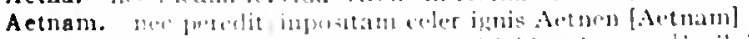

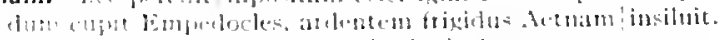

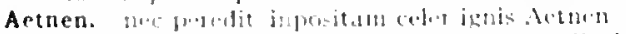

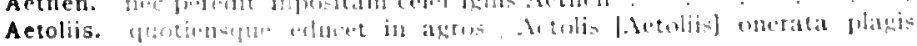

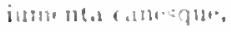

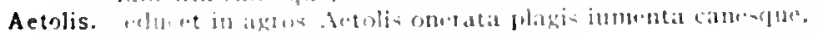

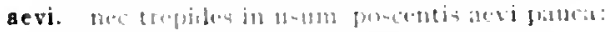

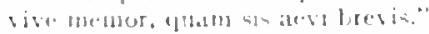

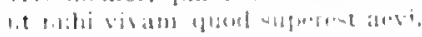

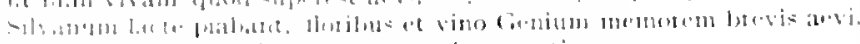

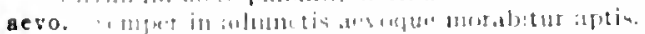

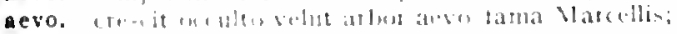

vinet p.

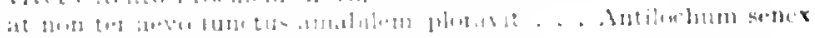

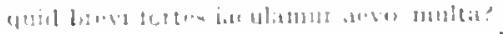

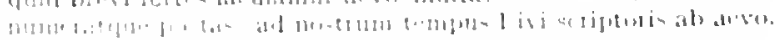

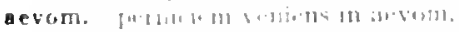

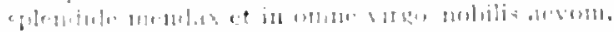

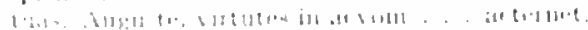

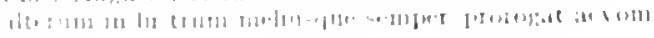

Term!.1.2.110

tist.1.2.8

(urm.1.11.8

Carme.1.35.35

(arm.2.3 15

Curnt.2.+23

(urm.2.5.1.1

Cism.3.(t.t)

(armatido

Cisrind.15.t

lipod.je I

tisollos $(0,0)$

Sirnid.t.t10

Serm.1.4. 132

serm.1.0.31

Sirnth.2.2.85

sirm.2.4.45

lipist.1.I.A

Iipist.1.0.24

lifist.1.0.55

Jpist.1.1S. Is

H.pist. 1.20.60

1.pist.2.t.42

l. pist. 2.2.216

- Irs l'oeldel

- Irs Iract. 100

Pist.2.2.202

Ars Poel. 15 \%

(urm.3.5. II

intr. Citrm.t. 14.5

ciorm.4.1.4.5

(iirm.2.11.11

Cirrm.2.1.15

(a) (u)..12.7

Curres.2.3.27

(itrm.3.25.5

Epist.1.10...1

(armt.2.20.2

(arm.1.3.29

(aris.3.1.14

:1r. (arm. 3.4 .70

int Carm.3.4.70

:ur.t.pist.1. Is.4t

itr.JPilt.1.18.40

Fond 17.33

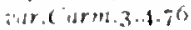

- Irs linet 4

(enrm.i.s.70

tour.Jpist.1.18.46

lipist I. 8.4 (

(tarm.2.11.5

sierm.2.11.17

JPI.1.1.1\$.108

J.fis 2.1.1.4

'les Jind.1\%8

Cam. I 12.45

(ist)..25

(itrm 2.1) 1.1

( I) H.2.10.17

l. figt: $=142$

(a)m.3 511 )

Carm.tillo

(iism 1 1.1.3

(istren tod c.es 
namque deos didici securum agere aerom a certis annis aevon temeare peractum si foret hoc nostrum fato delapsus in aevom, labitur et labetur in orne rolubilis aevon. bella quis et paces longum diffundit in aevon? qua ratione queas traducere leniter aevom. forte meum siquis te percontabitur aevom: sed in longum tamen aevom/manserunt

et longum noto scriptori prorogat aevom.

aevum. quod semel [simul] dictum est stabilisque rerum [est, stabilis per aevum], terminus servet [servat]. .

Afer. dirus per urbis Afer ut Ita! las

affert. praelambens omne quod adfert [affert].

afflat. nec non verniliter ipsis|fungitur oficiis. praelambens onne quod adiert [afflat].

affligit. atque adfigit [aftligic] humo divinae particulam aurae.

afore. quod vitium procul afore chartis/atque animo prius, .

Afra. non Afra avis descendat in ventrem meum.

tostis matcenten squillis recreabis et Afra|potorem corlea:

Afrani. dicitur Afrani toga convenisse Menandro.

Africa. trumenti quantum metit Africa.

Africa. columnas ultima recisas/Africa

"qui domita nonen ab Africa| lucracus rediit".

Africae. fulgentem imperio fertilis Africae

Africani. nec Iıgurthino parem/bello reportasti ducem|neque Africanum [Africani], cui super Karthaginem / virtus sepulcrum condidit.

Africano. nee Iugurthino parem|bello reportasti ducem/neque Africanum [Africano].

Africanum. neque Africanum, cui super Karthaginem/virtus sepulcrum condidit.

Africis. si mugiat Africis malus piocellis,

Africo. et malus celeri saucius Airico

Africum. luctanten Icariis fluctibus Africum.

nec timuit praeciptem Africum/decertantem Aquilonibus nec pestilentem sentiet Africum/fecunda vitis

Africus. si mugiat Afrieis [Africus]/malus procellis. Notus vocabit aut protersos Africus.

Afris. deorum quisquis anicior/Afris

Afris. velut illis|Canidia adflasset, peior serpentibus Afris.' .

Afro. te bis Afro murice tinctae restiunt lanae: qua medius liquor / secernit Europen ab Afro.

agam. Martiis caelebs quid agam kalendis.

nil habeo guod agan et non sum piger: usque sequar te."

si quaeret quid again.

agam. diris agam vos:

th agam per altas aure sublata nivis quaecuntulue praectedet fera;

Agamemnona. vizere fortes ante Agamennonal multi:

agaso. si patinam pede lapsus trangat agaso.

agat. vitamque sub divo et trepidis agat! in rebus.

$\therefore$ siquis ad illa clus subito te agat, usque recuses, tecum sic agat "hice candidus. . . fiet

Agaue. caput abscissum demens cum portat Agaulgnati infolicis.

age. quidquid habes, age, depone tuti= auribus:

age dic Latinum barbite, carmen.

eburna. dic age. cum lira' maturet.

descende caelo et dic age tibia

age te procellacicrede reloci.

age iam, meormm / finis amorum,

age, quaeso, tu nilail in magno doctus reprehendis Homero?

age, si et stranentis incubet unde. octoginta annos natus.

'nt vivas igitur vigila. hoc age.'

"nunc age, luxurian et tomentanum arripe mecum:

'age, libertate flecembri. quando ita maiores voluerunt, uterc:

"liber liber sunı." rlic age.

illa|redde, age, quae deinceps risi-ti." .

fortis omissis/ hoc age delicis.

nunc age. quirl nostrum concentum dividat, audi.

loc age, ne mutata retrorsum te ferat aura.

verum age et his, qui so lectori credere malunt.
Sirm.1.5.10I

Sirm.1.6.94

Sirm.1.10.68

Epist.1.2.43

Epist.1.3.8

Epist.1. I 8.07

Epist.1.20.26

Epist.2.1.159

drs Poet. 346

coni.Carm.Saec.26

Cum.t.4.42

zar.Serm.2.6.109

zar.Serm.2.6.109

v'ur.Serm.2.2.79

Sirm.1.4.10I

E.pod.2.53

S.rm.2.4.58

Epist.2.1.57

Serm.2.3.87

Carm.2.18.5

Carm.4.8. 8

cam.3.16.3 I

coni.Epod.9.25

zar.Lpod.9.25

I.pod.9.25

Carm.3.29.57

Corm.1.14.5

Curin.1.I.I5

Corm.1.3.12

Carm.3.23.5

ior.Carm.3.29.57

Epod 16.22

Carm 2.120

Serm.2.8.95

Corm.2.10.35

Carm.3.3.47

Carm.3.8. I

Scrm.1.0.19

lipist. I.8.3

Epod.5.89

Epod.5.7

Carm.4.9.25

Sirm.2.8.72

carm.3.2.5

Sirm.2.7.24

Epist.2.2.3

Sorm.2.3.303

Carm 1.27.17

Carm.1.32.3

Carm.2.I1.22

Carn-3.4.1

Corm.3.27.62

Corm.1.11.3 I

Serm.1.10.5I

Serm.2.3.1 I 7

Sirm.2.3.152

Sierm.2.3.224

Serm.2.7.4

Serm.2.7.92

serm.2.8.50

Epist.1.0.3 I

Epist.1.14.3I

lepict.1.18.88

Epist.2.1.21 1 


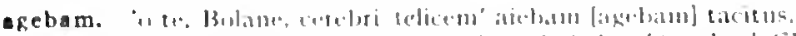

Sur.sions.1.0.12

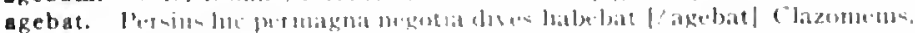

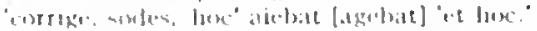

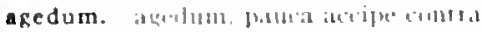

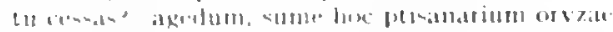

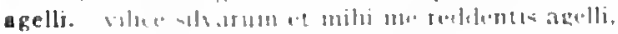

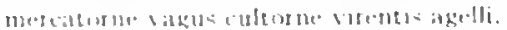

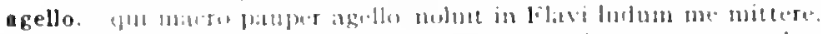

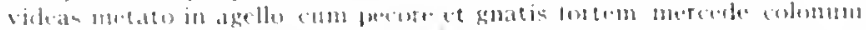

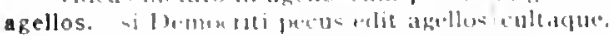

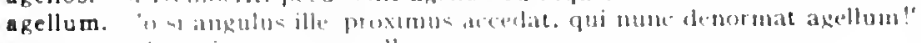

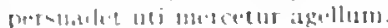

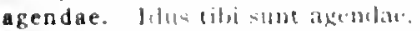

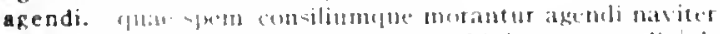

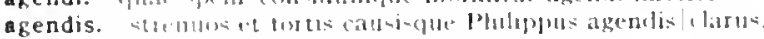

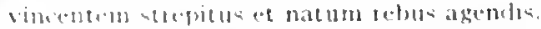

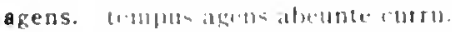

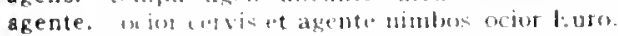

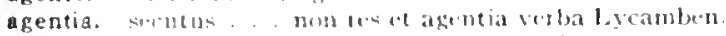

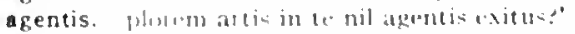

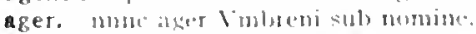

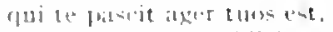

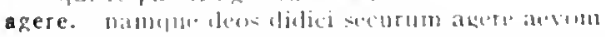
navelu abete montrus navis timer.

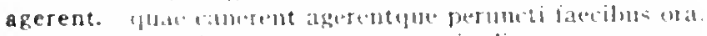

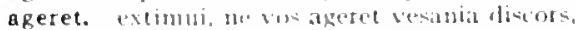

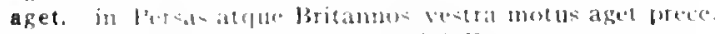

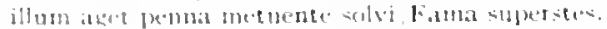

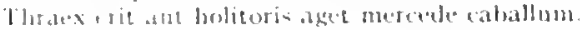

aggere. nus lart. agere in apros spatiati.

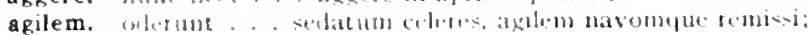

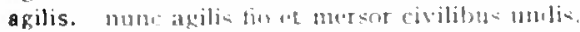
quate circumbolitats atgilis thyma?

arimur. nou agronur tumidis velis acpuilemes secundo:

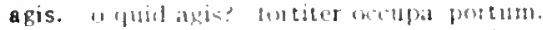

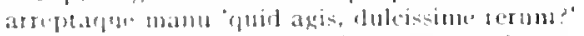

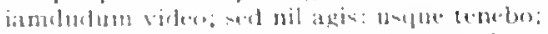

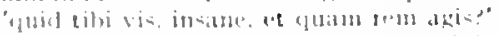

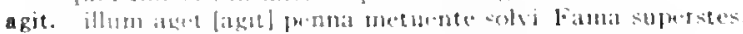

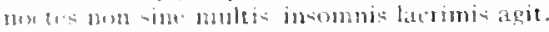

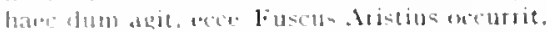

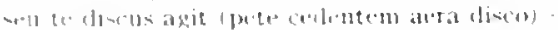

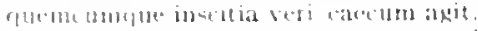

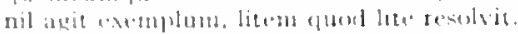

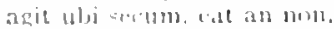

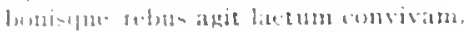

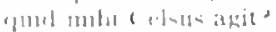

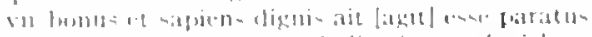

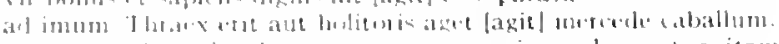

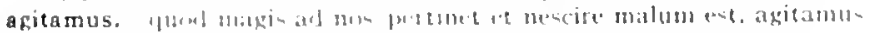

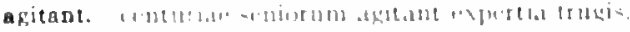

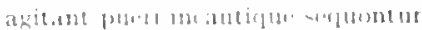

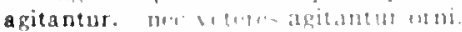

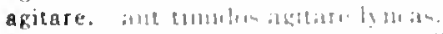

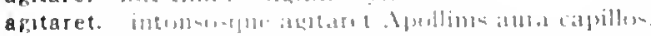

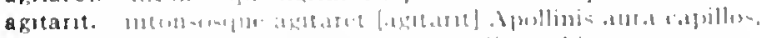

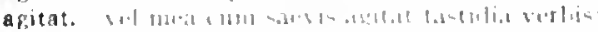

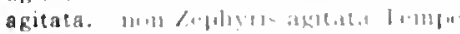

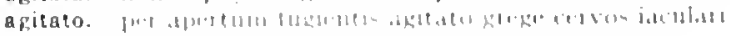

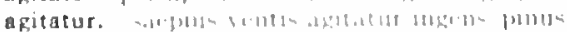

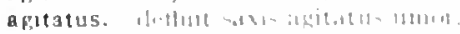

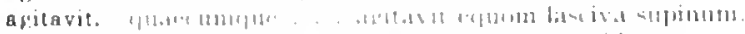

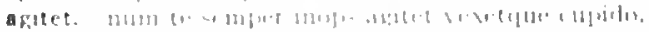

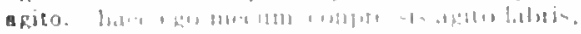

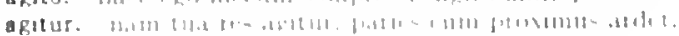

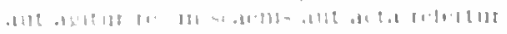

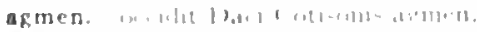

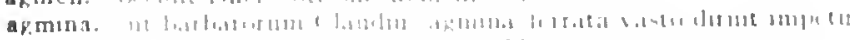

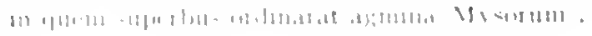

frat term. 1.7 .4

sor lirs l'oet t30

Sirm. 1.38

ierm. $2-3+155$

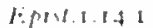

irs linititi

brom.t.6.7

trem.2.2.114

I.pist I.12.12

Sirm.2.6.9

Jipst. 1.7.8I

Curm.4.111

fipist 1.1.24

lipist. $7.4 \%$

irs Proctsz

(ism.3.1. 4

( arm.2.10.23

LPPS.1.20.25

I:pord.17.81

verm.2.2.133

lipert.2.2.160

yerm. 1.5101

lipist.2.1.114

Irs 1'udt.277

Serm. 2.3.17.

cirrm.1.21.10

(tom.2.2.7

lipist.1.18.3n

Surm.LAS 15

lepest 1.1heros

l.pista.1.1s

1.pist.1.321

I.pist.2.2.201

(iorm.1 1+2

Sirmido.

vern.1.0.15

Sirm 2.(1.20)

Fur Carm.2.2."

(arm.3.7.8

Serm.1.0.00

Serm.2.2.13

Therm.2.3.44

sirm.2.3.143

sirm.2.3.2(3)

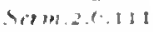

I.pret e 3.55

ialr. Jipist. 1.22

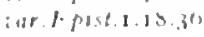

sirm 2.ts.t.

irs Pot $3+1$

Irs rint 450

(aromele 1)

(arm 2.13.14)

(poll.15.1)

inr lapillou

r. prot.12 I3

(a)m 3.12 .4

(isr) 12.111

(ism 2.11) e)

(itrm 1 12.21)

sirm 2.7.50

l.pole ax

som 1.4135

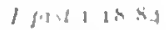

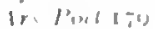

1 arm? 3 8. 18

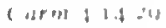

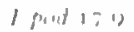


horrentia pi'islagmina . . describit .

agminum. rudis agminum|sponsus

agna, vel agna festis caesa Terminalibus. immolabitur caper/et agna Tenpestatibus. ut paret acris!agna lupos capreaeque leon-s!"

agna. seu poscat agna sive malit haedo. siquis gnatam pro muta devovet agna.

agnam. nos humilem feriemus agnam.

pullam divellere mordicus agnam jeceptrunt:

siquis lectica nitidam gestare amet agnam.

agni. non ut! serpentes avibus geminentur, tigribus agui.

agninae. patinas cenabat omasi vilis et agninae,

agnine. patinas cenabat omasi / vilis et agninae [agninte].

agnini. patinas cenabat omasi vilis at agninac [agninil, tribus ursis quod satis esset;

agnis. Jupis et agnis quanta sortito obtigit,

ggno. vincta verbenis avet immolatu|spargier agmo;

agnos. inter audacis lupus errat agnos,

Aixx cum imneritos occidit desipit agnos:

agnoscere. Augusti laudes agnoscere possis;

agnorit. munere cum fungi propioris censet amici: quid possini ridet ar novit [agnovit] ne valdius ipso.

ggnum. fasciculum portes librorum, ut rusticus agnum,

agor. quae nemora aut quos agor in specus,

egrestem. baec ubi dictilagrestem pepulere.

ergo ubi purpurea porrectum in veste locavit agrestem. .

qui, nunc Satyrum, nunc agresten Cyclopa novetur.

agresti. Graecia capta ferum victorem cepit et artes|intulit agresti latio.

agrestis. asperitas agrestis et inconcinua gravisque,

agrestis, spargit agrestís tibi silva frondes. mox etiam agrestis Satyros nudavit

agrestium, somnus agrestiun lenis virorum qua panper aquae Daunus agrestiuni|regnavit populorum,

ggri. usque proximos/revellis agri terminos hoc erat in votis: modus agri non ita magnus. scribetur tibi forma loquaciter et situs agri. 'dives agris [agi1], dives positis in faenore nummis."

agricolae, agricolae prisci, fortes parrofue beati,

agricolam. agricolam laudat iuris legumque peritus.

agricolis, Canem illum.|invisnm agricolis sidus,

Agrippa. scilicet ut plausus quos tert Agrippa feras tu.

Agrippa. nos. Agrippa, neque hace dicere

Agrippae. porticu= Agrippar, via te conspeverit Appi. fructibus Agrippae Siculis, quos colligis, Icci, si recte frueris,

Cantaber Agrippae, Claudi virtute Deronis|Armenius cecidit:

agris. horrendampue cultis|diluviem neditatur agris. fruges et agris rettulit uberes neglectis urenda filix innascitur agris.

quodsi bruma nives Albanis inlinet agris.

agris. capnt Autumnus agris extulit,

dives agris, dives positis in facnore nummis.

nudus agris, nudus numinis, insane, paternis:

caule suburbano qui siccis crevit in agris/rlukior,

pulveris atri|quantum non Aquilo Campants excitat agris.

ne plus irumenti dotalibus enetat aglis

nec quia longinumis armentum argmotet in agris:

"dives agris, dives positis in faenore numnis."

agro, acceles opera agro nona Sabino.'

agro. agro qui statuit meo|te, tijit. lignum.

ab agro rava decurrens luna Lanuvino

armis/lerculis ad postem fxis latet abditus agro,

spinas animone ego foutius an tu evellas agı.

agros. gaudentem patrios fudere sarculn'agtos

non semper iubres nubibus hispirlos manant in agros

nunc torrentia agros!sidera,

tendens Venatranos in agros

me vel cxtremos Numidarum in agrou/rlasion releget:

agros at que lares patrios habitanlactue fana, apris reliquit

laudaturque domus, longos quae prosjucit ingos:
Serm 2.1 .14

Citm.3.2.9

Lipol.2.59

Lipost.10.2.4

Iipol. 12.36

Cirm.1.4.12

Serm.2.3.219

Corm.2.17.32

Sirm.1.8.27

sirm.2.3.214

Irs l'oct. 13

Epist.t. 15.35

"ar. Ipist.1.1535

E'ar.Jipist.1.15.35

lipoll.t. I

cirm.1.1.8

Carm.3.18.13

Serm.2.3.2II

Ifpist.1.10.29

ior.Lipist.1.9.f

List.1.13.13

(arm.3.25.2

Serm.2.0.98

Serm.2.0.107

Epist.2.2.125

lipist.2.1.157

Epist.I.I8.0

Carm.3.I8.It

Ars Port.22I

Carm.3.I.2I

Carm.3.30.1 I

Carm.2.18.24

Serm.2.6. I

Epist.1.10.4

'ur.Ars Poct.+21

I.pist.2. I. 139

Yerm.1.I.9

Serm.1.7.26

Sirm.2.3.185

cirm.1.0.5

E.pist.1.0.26

Fipist.1.12.1

lipist.1.1 2.26

Carm+1.14.28

Carm.t. 5.5

sermi.1.3.37

Epist.1.7.10

Epod.2.18

Serm.1.2.13

ferm.2.3.184

xim.2.1.15

sirm.2.8.50

Epist.1.6.21

Epint.8.6

irs 10orf.42I

Serm.2.7.IS

(i) m.2.13.10

Corm.3.27.2

E.P.I.1.I.5

IDist.I. 4.5

(orm.1.1.12

Carm.2.9.2

( iurm.3.1.3 I

(arm.35.55

carm.3 +1.47

lipoldo. Io

Efisl.1.10.23 
quotsenutge educe in agros Artolis onerata plagis iumenta.

Fpist.1.18.45

luts. . . igros adsignant, oppida comdunt.

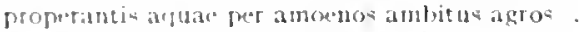

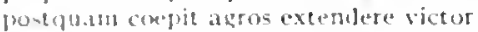

agrum. Lrecentos cinpus in agrumblic dabat.

albis informen enetabant osibus agrum: .

gui meterenarius agrum, illum ipsum mercutui aravit.

nempe modo icto palatim mercatis agtum.

sidestern flammis et ferres mitiget agrum,

agunt. Ste f"ut: acetba lata Romanos agunt

agunto. eq ifucumque volent animum auditoris agunto.

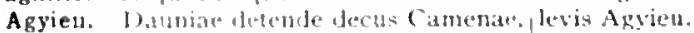

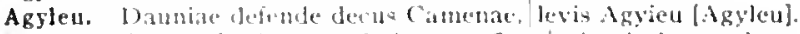
ab. a. .1. [ah. ah ] solutus ambulat vencficat ecientioris carmine.

Aiacem. movit Siacum Telanone natum forma captivae "nexpluis humate belit Alacem, Atrida, vetas cur?"

Aiacem. vitabis strepitumelue et celerem segui Xiacem:

Aiacis. in inpiam Aiacis ratem.

Aiax. Cur Aiax, heros ab Achille secundus. putescit, insantus quid enim Aiax fecit?

Alax "un immeritos occidit resipit agnos;

ajebam. "o te. Bohne cerebri folicem ajoban tacitus.

aiebas. "crte nescio quid secreto velle loqui te / a iebas necum."

aiebat. "deprensi non bulla est fana linenoni" aiebat.

ut aicbit conac pater:

Balatro. . "hatec est condicio vivendi" aitbat.

'non hercule miror,' aiebat, 'siqui comedunt bona,

Quintilio singud recitares, "contige. sodes, /hoc' aicbat et hoc."

aio. "ne fictiam, inguis. fomnino versus?" "aio."

103 sapue et solos aio bene vivere.

'habes pretum, lotis non ureris, aio.

ais. "non stun merehus" ais.

ait. Olortunati mercilore" gran'is armis miles ait.

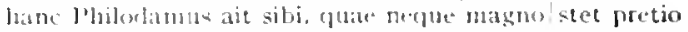

"heus, tu' quillum ate "ignotas qu

aie llarpgiic grula digna raprejbus.

mater ait pheri mensis ian eluingue cubantis.

tum rusticus: "hat milu rata, est opus hac" ait

uti mos rester ate.

nil ait esse prits, medius nil carlibe vita;

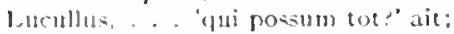

vir bonu et sapiens dignis ait esse parat

rui mu-telat porel "si vis" ait "effugere istinc,

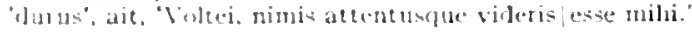

doves amictss. . ait prope vera:

"rifles" ait, "el Jovin aluribus juta servas

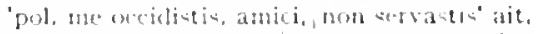

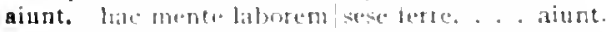

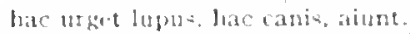

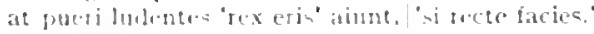

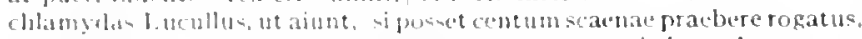

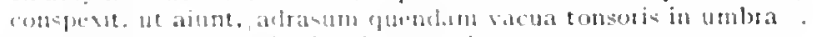

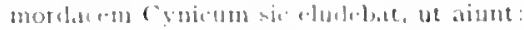

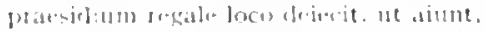

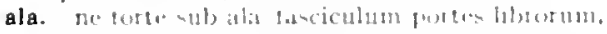

alas. Volucriorlue lati tardavit alis.

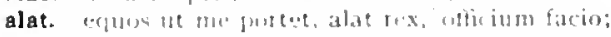

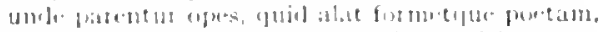

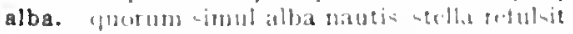

tmo pinu- ingerns albaque pupulus

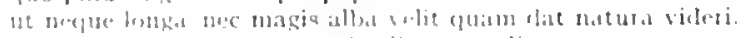

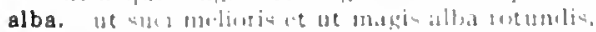

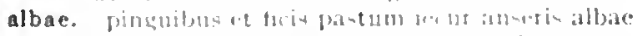

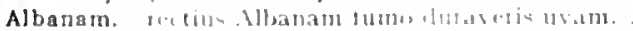

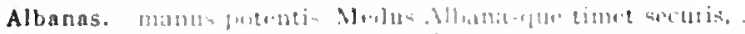

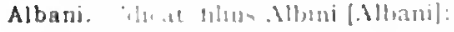

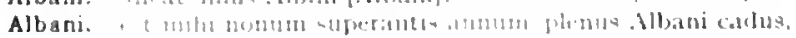

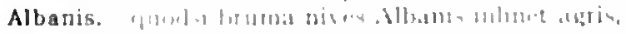

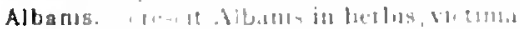

tepist 2.1 .8

Ars Pedit?

Ars linel 208

Seth. 1.8.12

serm 1.8.16,

Serm.2.18.11

Epist.2.2.16.4

Epist 2.2.180

tipol 7.17

Ars Poct.100

Curm.4 1.28

tor.cirm.4.0.26

Iar. Ifpod.5.71

Corm.2.4.5

Sorm.2.3.187

Corm.1.15.19

Eportio.14

Sirm.2.3.193

Serm.2.3.201

Serm.2.3.211

Sermit. 12

Serm.1.0.68

Sirm.1..1.115

Serm.2.8.7

Serm.2.8.05

Epist.1.15.42

Ars Joct.139

Serm.2.1.6

Epist 1.15.45

Epist.1.19.47

Sirm 2.7 .72

Sorm.1.1.5

Serm 1.2.121

Serm.1.3.22

Serm!2.2.10

serm.2.3.250

Serm.20.10

Serm 27.80

Epist.1.8.8

Epist. 1.0.\$2

Fist. 7.22

Epist.1.7.32

Eport. $7.9 \mathrm{I}$

E.pivi.1.18.28

Epist.1. 19.43

E.pist.2 2.1.31)

Serm.1 1.32

Sorm.2.2.14

Epist 1. 1.50

R.pititio

Spost 1.7.40

r.pist.1.17.88

fepist 2.2 .30

lopist 1.13.12

(iurm.217.25

L.pist 1.17.20

Ars boel.307

Cism.1.12.27

Curm 23.9

Sirm, 2.12 .4

Serme. 2.3

Sirm 28.88

Serm. 242

Carm, saecs.s

aj irs Fort.327

( alm 11.2

fopt.t 7.10

(ivron. 23 11 
Albano. dictitet Albano Musas in monte locutas.

lipist.2.1.27

Albanos. Albanos prope te lacus/ponet marmoream

Carm.4.1.10

Albanum. "Albanum. Maecenas, sive Falernum|te magis adpositis delectat:

Serm.2.8.16

albatus. natalis aliosve dierum / festos albatus celebret)

Serm.2.2.61

albescens. lenit albescens animos capillus

Albi. Albi. ne doleas plus nimio menor

Albi, nostrorum sermonum candide iudex.

Albi. nonne vides, Albi ut male vivat filius utque|Baius inops?

albi. 'nolim laudarier' inquit / sic me' mirator cunni Cupiennius albi. pinguibus et ficis pastum iecur anseris albae [albi]

albicant. nec prata canis albicant pruinis.

Albini. dicat filius Albini: si fe quincunce remota est/uncia.

Albinovano. Celso gaudere et bene rem gerere Albinovano

albis. quaeque vos bubus veneratur albis

Sisennas. Barros ut equis praecurreret albis.

albis informem spectabant ossibus agrum; .

merdis caput inquiner albis $\mid$ corvorum

Albius. hunc capit argenti splendor; stupet Albius aere:

albo, te Spes et albo rara Fides colit/velata panno non Chloris albo sic umero nitens dente si nigro fieres vel uno lalbol/turpior ungui,

albo. nisi causa morbi|fugerit venis et aquosus albo|corpore languor. non saxa nudis surdiora navitis/Neptunus alto [albo] tundit libernus salo. et lapathi brevis herba, sed albo non sine Coo. . pipere albo, non sine aceto.

Albuci. Canidia Albuci, quibus est inimica, venenum. servis | Albuci senis exemplo. dum munia didit, | sacvos crit.

album. album mutor in alitem|superne voveram duicis epulas et album|Libero caprum pinguem vitiis albumque neque ostrea . . invare piper album cum sale oigrolincretum .

Albuneae. quam comus Albuneae resonantis

albus. albus ut obscuro deterget nubila caelo! saepe Notus

quid albus $\mid$ peccet lapyx.

tacent et albus or a pallor inficit

tacent et albus ora pallor [ora pallor albus] inficit

$\mathrm{t}$ uis capil!us albus est odoribus.

lapis albus pocula cum cyatho dno sustinet.

sive elephans albus volgi converteret ora; .

Genius. . . voltu mutabilis, albus et ater.

Alcaee, te sonantem plenius aureo, Alcaee.

Alcaei. Pindaricae latent/Ceaeque et Alcaei minaces

Alcaeus. temperat Alcaeus, sed rebus et ordine dispar, discedo Alcaeus puncto illius;

Alciden. dicam et Alciden puerosque Ledae,

Alcido. quae nivali pascitur Algido [Alcido] devota duris ut ilex tonsa bipennibus / nigrae feraci frondis in Algido [Alcido].

Alcinoi. Alcinoique|in cute curanda plus aequo operata iuventus,

Alcon. Hydaspes|Caecuba vina ferens. Alcon Chium maris expers.

alea. perraro haec alea fallit.

quem damnosa venus, quem praeceps alea nudat.

alea. seu malis vetita legibus alea,

aleae. periculosae plenum opus aleae.

alebant. quid? tunc thombos minus atquor alebat [aequora alebant]?

alebat. quid? tunc rhombos ninus aequor alebat?

ales. mutata iuvenen figura ales in terris imitaris almae, filius Maiae. visan. . canorus/ales Hyperboreosque campos.

ales, nequitize additus/custos:

tibi qualum Cythereae puer ales, ... aufert,

purpureis ales oloribus comissabere

exemplum grave praebet ales/1'egasus

aletur. sicui practerea validus male filius in re/pracclaia sublatus aletur.

Alexandrea. portus Alexandrea supplex/et vacuam patefecit aulau,

Alexandri. aut alius Lysippo duceret aera fortis Alexandri voltun simulantia.

Alexandro. gratus Alexandro tegi magno fuit ille / Choerilus,
Alfenus. ut Alfenus vafer omni|abiecto instrumento ar tis clausaque tabena

Carm.3-14.25

Carm.1.33.I

Epist.1.4. I

Serm.1.4.109

Serm.1.2.36

var.Serm.2.8.88

Carm.1.4.4

Ars Poel.327

IEpist.I.8.1

Carm.bace.49

Serm.1.7.8

Serm.1.8.16

Serm.1.8.37

Serm. I. 4.28

Carm.1.35.2 I

Carm.2.5.1 8

coni.Carm.2.8.3

Carm.2.2.15

coni. Epod.I 7.55

Sirm.2.4.29

Serm.2.8.49

Serm.2.1.48

Sirm.2.2.07

Carm.2.20.10

Carm.3.8.6

Sirm.2.2.2I

Serm.2.4.7t

Carm.1.7.12

Carm.1.7.15

Carm.3.27.19

Epod.7.15

zar. Epod.7.Is

Epod.17.23

Serm.1.6.116

Epist.2.1.196

Epist.2.2.189

Carm.2.13.27

Carm.4.9.7

Epist.1.19.29

Epist.2.2.99

Carm.1.12.25

var.Carm.3.23.9

Far Corm.4.4.58

Epist.1.2.28

Serm.2.8. 5

Scrm.2.5.50

Epist.1.18.21

Carm.3.24.58

Curm.2.1.0

Sur. Serm.2.2.48

Serm.2.2. 48

Carm.1.2.42

Carm.2.20.1 6

Carm.3.+.78

Carm.3.12.t

Carm.4.1.10

(arm.4.11.26

Sirm.2.5.46

Carm.4.14.35

Epist.2.1.24I

Epist.2.1.232

Sirm.1.3.130 
Alfus. haee nbi lerutua fanerator Alfus,

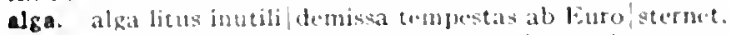

I:pod.2.67 et gerus et vistus, nisi cum re, vilior alga e.st."

Corm.3.17.10

Sorm.2.5.8

algere. cur mo tunesto properent arcere lalgerel veterma:

Algido. touacemente aus gelido prominat Algides nam quac mivali pascitur Algido devota

Iur.lipist. I.8.10

(corm.1.21.6 nigrale frrall $\mathrm{i}$ frondis in Algido.

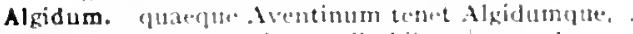

alia. cesent volumas? non alia biban/metcede. "donec mon alia magis arsisti (non "rim posthic alia calebo fenina) non alia quam qua Byzantia putuit orea.

alia. multame habes vicia?" inmo alia et furtase minora.

aliam. 'doneco non alia [alian! magis arsicti

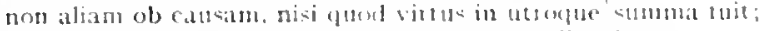

alias. consilio patres, formaret auctor mumquam alins dato

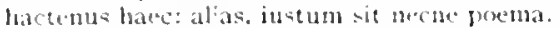
ignowees; alias locpliar." "qui species aline veris ecelerisque tumultu permixtas capiet. nil oriturum alias, nil ortum tafe totentes.

Aliatti. quam si Myglonis nognum Alyatci [Aliatil/campis continuen. .

Aliattici. quam si Myglonis regnum Alyttei Aliatticil/ampis continuem. aliena. quodque aliena capella gerat distentius uber. domb har noc putser ulla "st nec magis his aliena malis; te coniunx alicna capic, meretricula Davom:

aliena. sic temeros animos aliena opprobria saepelabscortent vitis. abiua negotia centum, per caput et circal saliunt latus. ne mox incutiant aliema tibi peceata pudorem.

aliena. alima negotia curolexcustus proputis. quatenus ima petit volvens alle na vicilus. nec tua laulabis studia aut aliema reprentes. mon aliena meo pressi pede.

alienas. non alicnas permolere wores.'

alieni. qui (a) meros caulis alieni iregertit horti

alienis. duceris ut norvis alienis mobile lismum.

alienis. 'nil fucrit mi' inquit 'cum axoribus umquan alituis.' cum rapies in ius malis ridentem alienis.

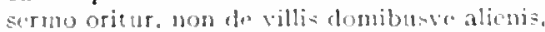

alieno. num sine sonsu / tempore mum faciant aliono.

alienos. scorto postpomet honetum, oncium, nummos alionos pascet.

alij. munc mihi nume alii benigna. sed cerlet in usum, nune milii, nume alii.

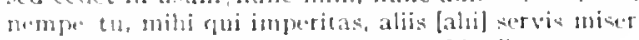

alii. laudabunt alii clatam Rhodon aut Mytilanen atque alii, ruorum comoedia pricta vinornm ext.

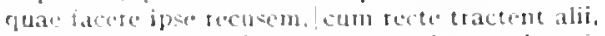

alii. "une (bisme alii ut) tegams spurco bamat latus?

alis. erit mulli proprina, fed cedes in usum| nunc mihi, nunc alii [aliis).

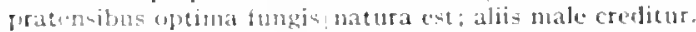
tu. mihi qui impertas, alifo setvis minet

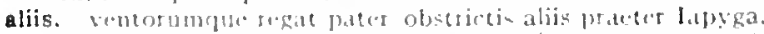

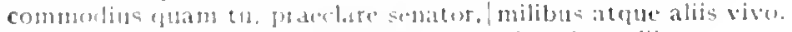

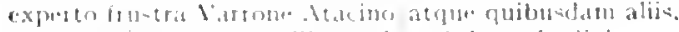

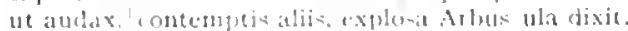

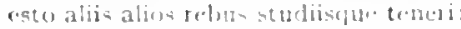

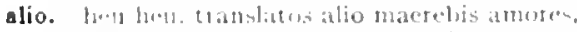

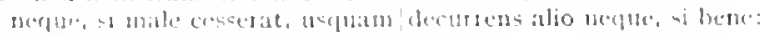

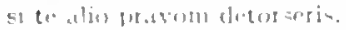

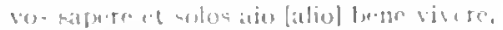

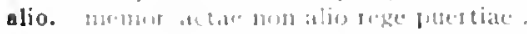

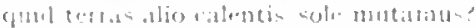

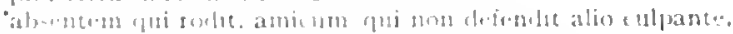

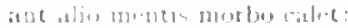

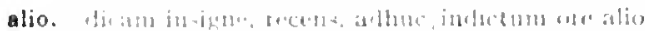

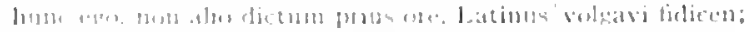

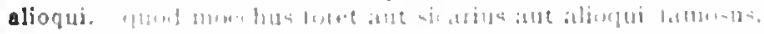

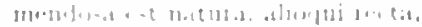

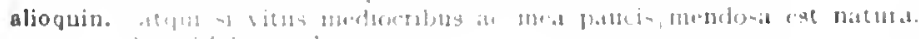

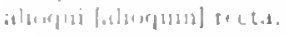


alios. dant alios Furiae torvo spectacula Marti.
atque alios legere, ad fastum quoscumque parentes $\mid$ optaret sibi quisque.

conpluris alios, doctos ego quos et amicos/prudens praetereo.

natalis aliosve dierum | festos albatus celebret)

esto aliis alios rebus studiisque teneri:

post effert animi [? alios] motus interprete lingua.

aliquid. quodsi interciderit tibi nunc aliquid repetes mox,
aliguid. ut siquid promittere de me / possum aliud [aliquid] vere. promitto.

das aliquid famae, quae carmine gratior aurem loccupet humanam? cur, inprobe. carae/non aliquid patriae tanto emetiris acervo? sobrius ergo' dic aliquid dignum promissis. "dixit adhuc aliquid?" "nil sane." "quid placet ergo?" .

aliquis. nunc aliquis dicat mihi quid tu? aliquir cubito stantem prope tangensfinquiet.

alis. polypus an gravis hirsutis cubet hireus in alis, sell mors atris circumvolat alis,

alit. neque militaris Damnias latis alit aesculetis vicinas ubes alit et grave sentit aratrum.

alite. Vario... Maeonii carminis alite,

Troiae renascens alite lugubri|fortuna

potiore ductos!alite muros -

strperte fugit alite.

mala soluta navis exit alite

secundil raten occupare quid moramur alite?

optat Prometheus obligatus aliti [alite].

alitem. album mutor in alitem $/$ superne

qualen ministrum fulminis ahtem.

aliter. mordaces aliter difiugiunt sollicitudines.

non aliter tamen/dinovit obstantis propinquos

non aliter Samio dicunt arsisse Bathyllo

emptum cenat holus, quamvis aliter putat:

alites. post insepulta nembra different Jupi|et Esquilinae alites.

aliti. scriberis Vario . . victor Naconii carminis alite [aliti]. optat Prometheus obligatus aliti,

alitibus. additum feris|alitibus atque canibus homicidam Hectorem. aliud, turdus! sive aliud privon dabitur tibi, (cocto Chium sic cunvenit, ut non hoc magis ullum aliud);

aliud. ut siquid promittere de mel possum aliud vere, promitto. . vocando hane Furiam, hune aliud. iussit quod splendida bilis.

alium. edit cicutis alium nocentius.

alium. neve putes alium sapiente bonoque beatum

aliunde. neque ultra/caeca timet aliunde fata.

alius. quamvis non alius flectere equon scien:

aliusque et idem / nasceris.

sed alius ardor aut puellae candidae laut teretis pueri

sed alius ardor [ardor alins] aut puellae candidaelaut teretis pueri

aut alius casus lecto te adfixit.

contra alius nullam nisi olenti in fornice stantem.

at est bonus, ut melior vir/non alius quisquam,

tut alius Lysippo duceret aera'fortis Alexandri voltum simulantia.

non alius faceret meliora poemata:

allec. ego faecem primuset hallec. primus et invenior piper album is ego primus face nec allec miscui]

allet. ctian stillabit amicis/ex oculis roren, salict [allet], tundet pede terram.

Allifanis. invertunt Allifanis vinaria tota/Vibidius Balatroque

Allobrox. novisque rebus infidelis Allobrox

alma, uutrit rura Ceres almaque Faustitas,

alma. cui primus alma risit adorea.

ut suci melioris et ut magis alba [alma] rotundi:

almae. mutata invenen figuralales in terris imitaris almalfilius Maiae,

almael progenien Veneris canenus.

almae. vos lene consilium et datis et datolgaudetis, almae.

alme. alme Sol, curru nitido diem qui pronis et celas

almum. almum|quae rapit hora diem.

Alpibus. arcis/Alpibus inpositas tremenclis/deiecit

Alpibus. Raetis bella sub Alpibus\} Drusum gertutem

Curm.1.28.17

Serm.t.6.05

firm. [.10.87

Sorm.2.2.6u

E.pist.1.1.8

Piar.Ars Poet.III

Sirm.2.4.6

zar.Serm.1.4.103

Sirm.2.2.94

Serm.2.2.105

$\operatorname{Sen} .2 .3 .6$

Epist.z.1.206

Serm.1.3.19

Serm.2.5.42

Epod.12.5

Sirm.2.1.58

Carm.1.22.1 4

Ars Poct.66

Carm.1.6.2

Carm.3.3.6I

Carm.4.6.24

Epod.3.1.7

Ispod.io.1

IEpod.10.24

zar. Epod. 17.67

Carm.2.20.10

Carm.4.4.5

Carm.1.18.4

Carm.3.5.50

Epod.14.9

Epist.2.2.168

Epod.5.100

coni.Carm 1.6.2

Epod.17.67

Epod.17.12

Serm.2.5.I1

Sirm.2.8.49

Sirm.1.4.503

Sirm.2.3.14I

Epod.3.3

IDist.1.16.20

Carm.2.13.16

Carm.3.7.25

Carm.Saecio

Epod.11.27

coni.Epod.1 1.27

Serm.1.1.81

Serm.1.2.30

Serm.1.3.33

Ispist.2.1.240

Ars Pot'.303

? qur.serm.2.4.73

tar. Ars Poet.430

Sirm.2.8.39

lipod. I0.0

Carm.4.5.1 8

Carm.4.4.41

conistirm.2.4.13

Carm.1.2.42

Ciarm.4.15.31

Carm.3.4.42

Cormotiateo

Carm.17.7

Curm.4.14.12

Carm.4.17 


\section{ALPINVS}

Alpinus. turgidus Alpinut iugulat dum Mennona

Alpis. Furius "hibermas cana nive conspuet Alpis."

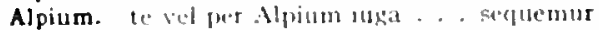

alsit. Inulta tulie teritque puer, suclavit et alsit,

alta. nec intunescit alta vijutis humus;

demus alta Mulocils personuit canibus.

alta. vides ut altan stet nive combielum soracte cus then sub ilta bel platano te'tum sub alta - sic lowi gratum - demo.

beporent venator ut alta in nive sectetur.

alta. ibis liburnis inter alta navium, ambe, propugnacula, .

altae. Froiale prope vietor altac I'thius Achilles.

altes. altas maticat populos agam per altis ature sublata nivis

alte. puer alt viutus acroman gausaje purpureo mensam pertersit.

alter. nil obstet tibi, dum ne sit te ditior alter.

Anconi, non ut magis alte's, amicus.

neque" quis me sit devinction alter.

ducendus et unus et comes aler.

alter. . vegetus proesterinta ad munia surgit.

si vare unus et alter in idiatosest prarroso fugerit hamo,

alter sublegit qundeumgue iaceret inutile

cave ne portus oeculuet alter.

quidelud negat alter, ct altet, adnuimus pariter.

alter purpuretum non expectabit amictum,

alter Mheti textan cane pebs et angui vitabit chlanidem.

clamat "victum date." sutcinit alter "it mih."

alter in obecpuinu plus aecuo pronus.

alter rivatur, de lana sape cafrina.

Ennius, et sajpens et tortis et 'alter liomerus'.

siverus paulo concinnior unuse et alter.

guid dem? quilt men flom? rentis yuol th, iubet alter;

ut alter aluerius sermone meros audiret homotes.

cur alter fratrum ce-sate et lublete et ungui pracferat

alter dives et inportunus ad umbram lucis ab ortu.

mur pureus. hate qui splendeat, unuk et alter|adsuitur pannus,

altera. to meste si partent animae tapit maturior vis, quid moror altera,

altra iam teritur bellis civilibus aetas.

altera, nil obstat: Cois tibi parene viclere est ut nudam. .

lanea et entipies erat, altera cerea:

llecaten vocot altirat.

lewater vocat altera. saevam altera Tesphonen:

sine nervic altora quidquirl conposui jas esse putat

pretium atetes alteras sordet.

altretius sic alterab puscit opem res

altera. cervos uti vallis in altrat vioum protte lupum

altera. mille talenta rotundentur, totielem altera.

altera. pormuted ilominos et cectat in altera inta.

alteram. sperat intestis, metuit stemelis alteram sortem

altercandente. metuens inducetic atcue | alterante [altercandente] libidinibus tremis nasa favore.

altercante. altercante libininibus tremis gana pavole

alteris. altoris te mencis allibe deum;

alterius. metuens altumas viri certo formere catitas.

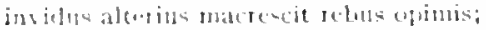

cui placet alertius, sha nimisume ent retio sors.

he alerer alterius sermone meros audiret homores,

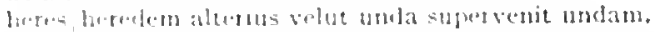

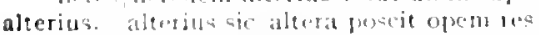

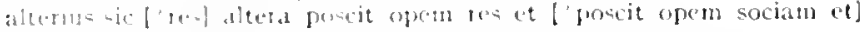
commised amice.

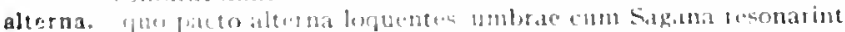

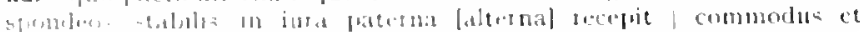
1.4t $11 \cdot 11$ -

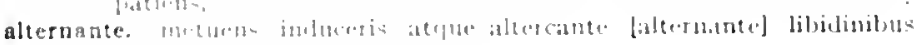

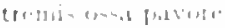

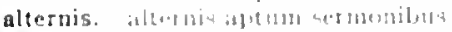

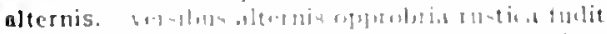

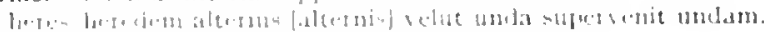

ALTERNIS

Serm.1.10.30

Sirm.2.5.4 I

I:Poil.1.11

Ars Pod.q13

Esod.10.52

Serm.2.0.11.4

Curm.1.0.1

Carm.2.11.13

lisodig. 3

Serm.1.2.105

Lepot.1.1

Carm.4.0.3

Eipod. 2.10

lipol.6.7

Sorm.2.8.10

Sirm.1.1. 90

Serm.1.5.33

Serm.1.5.42

Serm.1.6.102

Sirm.2.2.80

Sirm.2.5.24

Serm 2.8. I I

Espist 1.0.32

List.1.10.4

b pist.1.17.27

List.1.17.30

l.pist.1.17.48

epist.1 I8. Io

Ifpist.1.18.15

L.pist.2.1.50

Epist.2 1.74

Eipist.2.2.63

IEsist.2.2.87

Lipist.2.2.183

Epist.2.2.184

Ars l'od.15

(arm.2.17.6

spod.1\%.1

Scrm.1.2.10t

Sirm.1.8.30

Sirm.1.833

serm.t.s.34

Serm.2.1.2

Epist.1.18.18

Ars Poet.q1

Carm.1.15.20

1 pist 1.t.3.

Lifist 2.2.174

Corm.2.10.14

ior.serm.2.7.57

sem.27.57

cirm.4.5.

(arm.3.24.22

IEpist.1.2.57

LPist.1.14t

I. pist.2.2.88

1. pist.2.2.176

irs l'oet 410

3:ar Ars l'odt.qio

sorm.1.s.so

mar.Ars lode.250

*ur sirrn: 27.57

Ars lenetsi

I. Ptst.2 1.t.ge

(c)ust:pust.2 2.170 
alterno. iunctaeque Ximphis Gratiae decentes / alterno terram quatiunt pede.

altero. et Marte Poenos proteret altero; .

alterum. alterum et huic varum et nihilo sapientius

alterum. dices 'heu', quotiens te in speculo videris alterum.

alterum. alterum in lustrum meliusque semper|prorogat aevon,

alterutrum. donec alterutrum velox Victoria fronde coronet.

alti. aufert/Pacuvius docti faman senis, Accius alti,

att. ut unum|scilicet egregii mortalem altique silenti.

altilium. nec somnum plebis laudo satur altilium

altior. Carthago, probrosis/altior Italiae ruinis."

altis. altis urbibus ultimae stetere causae, cur perirent

altis. labuntur altis interim ripis aquae,

quantus altis montibus|frangit trementis ilices;

mont ibus altis! levis crepante lympba desilit pede.

voles modo altis desilire turribus,

altius. regalique situ pyramidum altius,

altius. altius ac nos praecinctis unum:

alto. reiecit alto dona nocentium/voltu.

tramsnanto Tiberim, somno quibus est opus alto,

ac venerata Ceres, ita culmo surgeret alto,

ab alto/demissum genus Aenea,

alto. et celer arto [alto] latitantem fruticeto excipere aprum.

Neptunus alto tundit hibernus salo.

deos id tristis ex alto caeli demittere tecto.

lupus hic Tiberinus an alto/captus hiet?

nec si te validus iactaverit Auster in alto.

dum tua jaris in alto est.

altos. omne cum Proteus pecus egit altos/visere montis.

tendit. Antoni, quotiens in altos/nubium tractus:

nun illius, num rerum dura negarit versiculos natura magis factos [altos] et euntis / mollius

altricis. nutricis [altricis] extra limina Pulliae

altum. vos Caesarem altum. ... finire quatentem labores

altum. exstructis in altum|divitis potietur heres.

neque altum $/$ semper urgendo

iactis in altum molibus: .

altum Saganae caliendrum exciclere

altus. latus [altus] ut in circo spatiere et acneus ut stes,

aluere. imbres/quem super notas aluere ripas.

alumni. an custos famulusque dei Silenus alumni.

alumni. aut dulces alumni|pomifero grave tempus anno.

alumnis. Jenis incedas abeasque parvis|acquos alumnis.

alumno. nobilis ut grandi cecinit Centaurus alumno:

quid roveat dulci nutricula maius alumno.

alveo. Tusco denatat alveo.

nunc nedio acquore [alveo] cum pace delabestis Etruscum ' in mare.

alvo. infirmo capiti fluit utilis, utilis alvo.

alro. ureret llammis, etiam latentem matris in alro.

neu pransae Lamiae vivom puerum extrahat alvo.

alros. si dura morabitur alvos.

Alyattei. si Mygdoniis regnum Alyattei/campis continuem.

amabam. olim nan quaerere amabam.

amabile. tu trigus anabile fessis vomere tauris praebes

seu condis amabile carmen.

amabilem. at non ter aevo functus anabilem/ploravit omnis Antilochum senexlannos

amabilem. te .. qui semper vacuam, semper anabilen/sperat,

amabilis. boлus sane vicinus, amabilis hospes.

amabilis. auditis? an me ludit amabilis|insania?

amabilis. inter amabilis / vatum ponere me choros

amabiliter. libertasque recurrentis accepta per annos,lusit amabiliter.

amabitur. exstinctus amabitur idem.

amabo. dulce ridentem Lalagen amabo, dulce loquentem.

mon .. dominantia nomina solum/verbaque, Pisones, Satyrorum scriptor amabo

amanda. modos, amanda/roce quos reddas:

amando. Sybarin cur properes amandolperdere.

amandus. quo sit amore parens, quo frater amandus et hospes.

Carm.1.4.7

Carm.3.5.34

Serm.2.3.56

Carm. 10.6

Carm.Saecor

Epist.1.18.64

Epist.2.1.56

Serm.2.6.58

Epist.1.7.35

Carm.3.5.40

Carm.1.16.18

Epod.2.25

Epod.10.7

Epod.10.47

Epod.17.70

Carm.3.30.2

Serm.1.5.5

Carm.9.9.42

Serm.2.1.8

Serm.2.2.I 24

Serm.2.5.62

var.Curm.3.12.1I

Epod.17.55

Serm.1.5.103

Serm.2.2.3I

Epist.I.II.I 5

Epist.1.15.87

Carm.1.2.7

Carm. $\$ 2.20$

2ur.Serm.I.J0.58

Far.Carm.3.4.10

Carm.3.4.37

Carm.2.3.19

Carm.2.10.1

Carm.3.1.3.

Serm.1.8.48

coni.Serm.2.3.183

Carm.2.6

Ars Pot'.239

Carm.3.23.7

Carm.3.18.4

Lpod.13.II

Epist.1.4.8

Carm.3.7.28

iar.Corm.3.29.34

Epist.1.J0.14

Carm.t.0.20

Ars l'oti. 340

Serm.2.4.27

conicarm.3.16.4I

Sirm.2.3.20

Carm-3.13.10

Epist.1.3.24

Carm.2.9.13

Carm.1.5.10

Epist.2.2.132

Carm-3.4.5

Carm+3.14

Lpist.2.I.I q5

Epist.z.I.14

Carm.1.22.23

Ars Poet. 235

Carm.t.1. 34

Carm.1.82

Ars 10.t.3I 
amant. qun pines ingens allaque populus/umbram hosplatem consocjare amant / ramsis?

glunl lilelli stoici inter setices iacere puls illos amant.

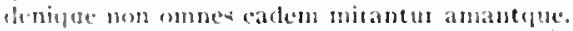

amantem. in puic amantem lansuot et silentium arguit

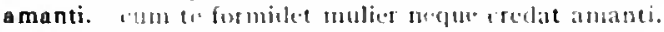

amantis. gun pacto partic tutcetur atmantic epluphi.

amantis. auc luerlou lapatli prata amantis

amantium. we tinctus siola pallor anatreium

amara. amilla lento/temperet risu: anturatue / curarum eluese eflicax.

amaras. amatas porrecto iugulo hiscorias cajtives ut audit.

erucas virilis, inmla e go primus amaras moustrati incogucre:

amste. si puctilius lic raltio esse evincet anture

amares. guin sine rivali tequ. et tua solus amates.

amari. pluribus lisce. . . inclinet, aniaj si volet:

amari. comtidena tumidus, adeo sermonis anari.

amaris. ac pertins foliis parcus vencatur anaris:

a marulenta. "e amara lento [amasulenta] temperet risu:

amas. "si me amas." incuit, 'paulum hic alles." annasclue, yood nusplatm tibi sit potammom.

amat. nec tilji somnos adimunt amatiue/ianma limu'n, aurum - frosumpere amit saxa potentius ictu fulminco: .

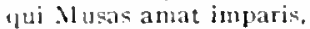

lot amat it laulat 'matronam nullam ego tango." inportunus amot latudari:

mens. . annat spatis ubstantia rumpere claustra.

versts amat. hec sthele unum:

scriptorum chotus unthis amat nemus et lugit Vrom.

havec amat obsemtum; volet hace sub lace videri.

amata. anatel nastis multum ce inscitosibus.

amata. sublinis cupiefusque et anata relinquere pernix.

amati. Irangete enitat molo muleum anati cornua monstri.

amator. Faltue, Ningharum fusicnetun amator.

ne quondam Matsineus, amator Originis ille.

amator relusus qui distat,

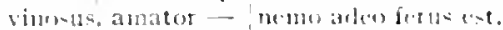

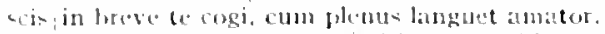

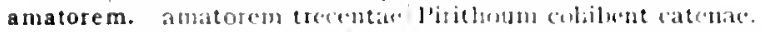

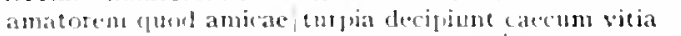

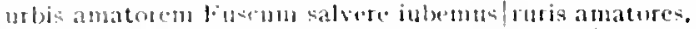

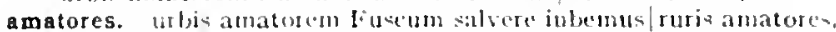

amavit. marmotis alle eburis fabous atut antis amavit.

Amazonia. Amozonia securi destras obarnet.

ambagibus. ifuando fatumeliem nissin ambagibus hotres.

ne te longis ambagibus ulta yuam satis est noter: .

ambas. met ito quin illis [uppiter ambas joatus buecas inflet

ambiat. ut we frigilior Fluatean ne puriot ambiat llebrus.

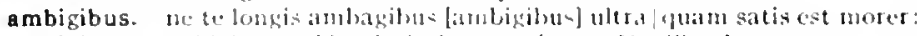

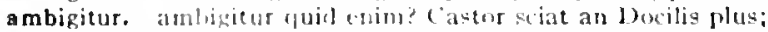

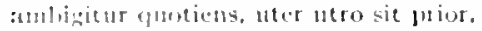

ambiguam. ambiguam trollute nova Salanina gutuan.

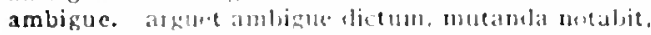

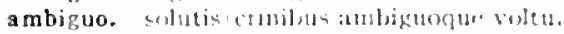

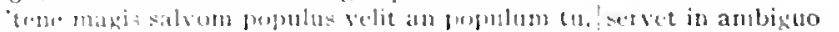

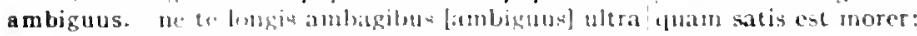

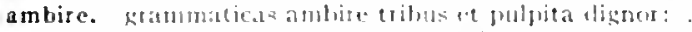

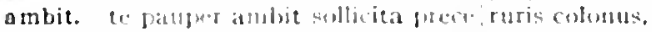

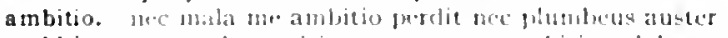

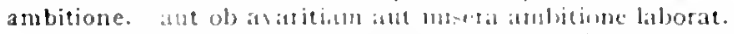

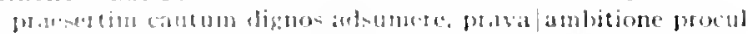

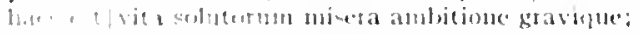

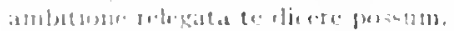

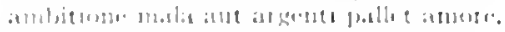

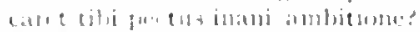

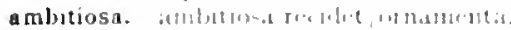

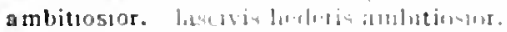

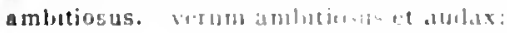

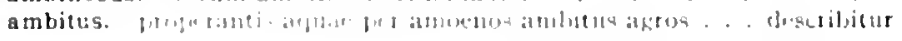

Carm.2.3.10

lipol.s.10

1.pist.2.2.5i

lipolliti.s

$\operatorname{serm.2.7.25}$

Iipist.2.1.1

lipoul.2.57

Cirm.3.10.14

(arm.2.16.26)

Corm..t.12.10

Serm.1.3.88

Sirm.2.8.51

ferm.2.3.25")

Ars Podittl

Sirm.1.3.7

Serm.1.7.

Sirm.2.3.114

roni.Curm.2.16.2\%

Serm.1.12.38

Serm.2.7.31

Carm.1.25.3

Carm.3.16.10

Curm.3.19.13

scrm.1.2.5t

sam.2.5.0h

lipist.1.1.1.0

Epist.2.1.120

Epist.2.2.77

Ars $\mathrm{POCl}_{303}$

Epod.17.20

Lrs l'oet.10.5

Carm.3.27.47

carm.3.28.t

vimil2 55

Sirm.2.3.250

Epist.1.1.38

Ifprst $1.20 \mathrm{~K}$

Carm.3.7.70

Serm.1.3.3s

l.pist.1.10.1

Jipist.1.10.2

I:Pist.2.1.9e

carm.4.20

Sirm.2.5.9

List.1.7.82

Sorm.1.1.20

Ispixt. I. 10.13

tar.I.pist.1.7.82

Jipist.1.18.10

Lfist.2.1.55

Carm. 7.29

Ars I'ort.dino

corm.2.5.2.

Ifpistide.28

tar.J.pist.1.7.82

Jipist.1.10.40

carm.1.35.5

Sirm2.0.14

sierm.1.o+ 20

sirms.1.1.52

sirmasion

serm.1.1081

harm 2.3.7k

1.pist 2 . 2.20\%

Ars.lined as?

(irm. 1.3 $3^{p}$.')

sorm.2.3.10

. Irs 1 iord 17 
ambo. inde/ambo propositum peragunt iter,

ambo. iure|iurando obstringam ambo:

estne marito matronae peccantis in ambo iusta potestas,

ambos. estne marito/matronae peceant is in ambo [ambos] iusta potestas.| in corruptorem vel instior?

ambubaiarum. ambubaiarun collegia, pharmacopolae, imendici, minae. balatrones.

ambulat. solutus anbulat venteficat scientioris carmine.

Maltinus tunicis denissis ambulat;

Sulcius acer ambulat et Caprius, rauci male cunque libellis,

ambules. licet superlus ambules pecuniat.

ambulet. marita. quac rotundioribus|onusta bacis anrbulet. ambulet ante|nocten cum facibus.'

ambustum. capsis quen fana este librisque ambustum propris.

ambustus. terret ambuttus l'hathon avaras|spes

amem. tecum vivere ancm, tecun obcam lubens.'

Romae Tibur amem, ventosus Tibure Roman.

amens. deliruset amens/ndique dicatur merito.

infectum volet esse, dolot quod suaserit et mens [amens].

amentia. siquem delectet barbatum: amentia verset.

ames. hic ames dici pater atque princeps

amet. ametque salsa levis hircus acquora."

e quibus nums avet [amet] quavis aspergere cunctos/praeter enm qui

pracbet aquam;

anet scripsisse ducentos ante cibum versus,

siquis lectica nitidam gestare amet agnam.

mea cur ingratus opuscula lector laudet ametque domi,

hoc anet. hoc spernat pronissi carminis auctor.

et regat iratos et amet pacare timenti:

amica. dum mihi fas recantatis amica oppobriis.

clamet anica, mater. honesta soror cum cognatis, pater, uxor:

ut nox longe quibus mentitur amica

amica. divitum mensis et anica templis.

anica vis pastoribus,

clamet anica, mater [clanet amicalmater,] honesta soror cum cognatis. pater, uxor:

vixisset canis inmundus rel amica luto sus.

amica. quorl meretrice nepos insanus anica/filius uxor.m. . recuseq. yomine te pratis an amicta [anica] vitibus ulmo:

amicae. amatorem quod anicae turpia deripinnt caccun vitia

amicae. Glind me Lucanae iuvenem commendet amicae);

amicam. absentem ut cantat anicam/nulta prolutus vappa nauta

amicas. rotis pucrorum amicas'adplicat auris:

amice. angustam anice pauperien pati.

ille bonis taveatque ct consilietur amice

alterius siclaltera poscit open res et coninat anice,

amice. amice Valgi, stat glacies iners

non. . . amice. places inlacrimabilem | Plutona tauris.

ibis Liburnis inter alta navitm.|amice, propugnacula,

rapianus, amici [anicel, occasionem de die

"dinice | praesupti nemoris pationtent vivere doran?

te, dukis amice, reviset cum Zephyri:

quid sentire putas, quid credis, anice. precari?

Flore, bono claroque fidelis amice Neroni,

amici. sume. Maecenar, cyathos amici|sospitis centum

amatorem quod anicae [amici] turpia decipiunt caecum vitia

sic nos debemus anici| siquod sit vitium non fasticlire:

de te pendentis, te respicientis anici?

nuncre cum fungi propiuris censet amici:

quodsi depositum laudas ob amici iussa pulorem.

tu cede potentis anici lenibus imperis.

intra marmoreun venesandi linen amici.

dulcis inexpertis cultura potentis anicı.

amici. ibi tu calentem delita sparges lacrima favillam vatis amici

quid plausus et amici dona Quiritis

amici. difugiunt cadis/eum laece siccatis mici,

mihi dules ignuscent, siquid peccaro stultus, amici

amici. angustam amice lamici] paupericm pati|robustus acri militia pueri condiacat.

Serm.2.0.00

Serm.2.3 I 80

Sirm.2.7.6.2

i'ar.Sirm.2.7.62

Scrm.1.2.1

Epod.5.7.1

Serm.1.2.25

term. I.t.60

Epod.4.5

Epod.8.I 4

Serm.I.4.5I

Serm.1.10.64

Ciom.t.11.25

Carm.3.9.24

Epist.1.8.12

Serm.2.3.107

iar.Epist.1.2.00

Serm.2.3.249

Corm.1.2.50

Epud.16.34

sodr.Serm.1.4.87

Serm.1.10.00

Sirm.2.3.214

Epist.1.19.36

Ars Poet 45

Ars Poet.ig7

Corm.1.10.27

Serm.2.3.57

Epist.I.1.20

Carm.3.11.6

Epod.0.6

äar.Serm.2.3.57

Epist.1.2.26

Serm. I.t.t9

sar.Lpist.1.16.3

Serm.1.3.38

Epist.I.I5.2 I

ferm 1.5.15

Carm.Sace.TI

Carm.32.I

Ars Poet.106

Ars loot..1II

Curm.2.0.5

Carm.2.14.6

Epol.1.2

coni.l.pod.13.3

vem.2.0.00

Epist.1.7.I2

Epist.1.18.zo6

IPist.2.2.I

Carm.3.5.13

iur.serm.1.338

Sirm. I. 3.43

Ifpist.1.1.105

I.pist.1.9.5

Epist.1.9.12

Epist.1.18.44

Epist.1.18.73

Epist.1.18.8\%

Carm 2.0.24

Epist 1.6.7

Carm.1.35.27

Scrm.I.3.I to

tar. ("orm.3.2. I 


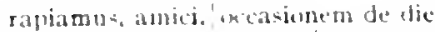

T:pod.13.3

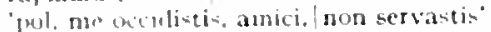

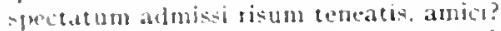

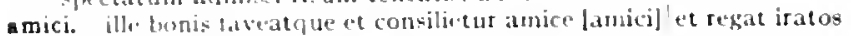

amicjor. I uno et deorum guinguis amiciot/Aris

amicis. mox retan pecus praeceptis format anicis.

jite bonis laveatque et consilietur anice [amicis] et regat iratos etian stillabie amicis, ex oculis rorem.

amicis. sic nos debetnus amici [andeis] siguod sit vitium non fastidire: concinus antici postulat ut videatur;

nee rejto enjuan nisi amicis idgue coactus.

sic duleis andicis occurran.

(ut sue collatudem). si et vivo carus amicis:

scilicet uni a.epus vircuti atque eius amicis.

"ut patiens. ut inmit is aptus, ut acer?"

fidis utfenchar medicis, irascat anicis.

ignosuts anticis?

gui didicit, patriae quid debeat et guist amicis.

amicis. non ille pro caris amicis aue patria timidus perite.

flentibus hine latius discedie maestus amicis.

amicitia. vellem in amicitia sic ersaremus

an sit andicitia dignus;

amicitiam. si petetet per amicitian patris atque suam.

doute Cati. per andiciam divosque togitus

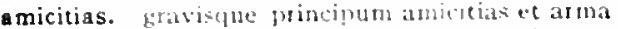
guidve ad annicitia, usus tetumbe, trahat nos quacrit opes et anticitiss, inservit honori.

amicitur. piper ele elidguid chatic anseitus ineptis.

amico. antico puace dlederis animo.

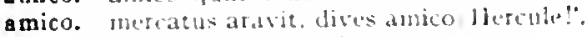

amico. incupi clase nolit ausicus.

dummedo tisum, excutiat sibi num. non cuipuam parcet anico nil ego contulerim iucundo sanu- amico.

hace mihi tertinus, sapientum octaros anicolarma dedit.

amico. reerne diule mili furere est antico.

ine Captolinus convictore usus amicuefue a puero est

a micorum. unde expedire non amicorum stuant libera consilia cur in andcorum vitio tam cernis acutum.

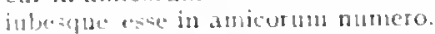

blis amiorum est anmona. bonis ubi quid deest.

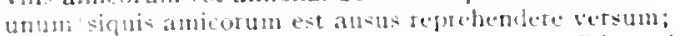

amicos. ferthat incerto fuete ad non amicos heu mibi postis

amicos. sin tristiu arllatus andicos:

interglate mas?entsa amicos

non alits tanded dimosit ob-tantis propinepes [amicos]

in si cogsatum. . . retinere velis struarertue amicos

inter amicos nt nunguam imelucant animum cantare rogati.

late. Ites et jumgit, imatos et servat amicos.

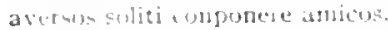

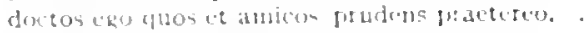

ne tidos infer asuess, st

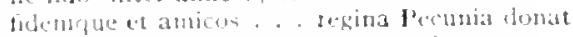

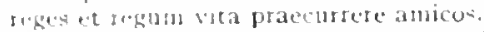

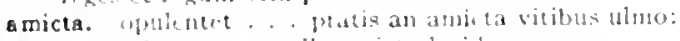

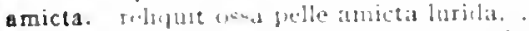

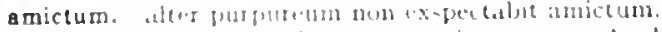

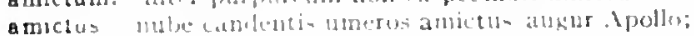

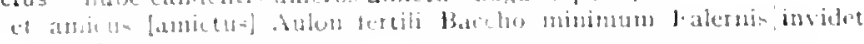
isi-:

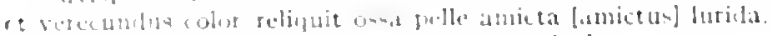

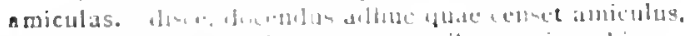

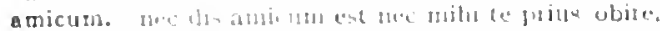

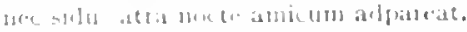

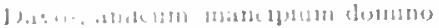

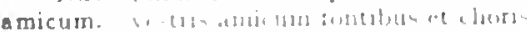

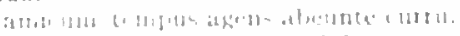

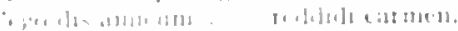

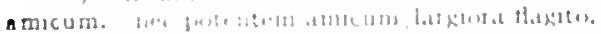

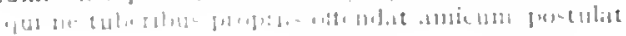

List.2.2 138
Ars l'oet.5

yar. Irs l'oet. 196

Carm.2.1.25

Ispist.2.1.128

rar.irs l'oet. 106

irs Poct.ot20

for.term. 1.3 .43

Serm.1.3.50

Sorm.1.473

Serm.1.\$13.5

serm. 1.0 .70

Sorm.2.1.70

Sirm.2.5.93

l.pist. 1.8 .9

Epist.2.2.210

Ars Poct. 312

Carm.4.9.5I

Sirm.1.5.93

serm.1.3.41

Ars Pocl. 930

sicm.1.3.5

Serm.2.4.88

Carm.2.1.4

Serm.2.6.75

dis l'octidit

Epist.2.1270

(orm.t.7.19)

Serm.2.0.12

serm 1.2.5

Sirm.1.4.35

Serm.1.5.4.

Serm.2.3.200

Carm.2.7.28

Serm. I.a.gh

Sipod.11.25

Serm.1.3.20

Serm.1.0.02

tipist.1.12.24

lipist.21.222

l.poit.11.21

Carm.1.7.24

Carm.3.5.17

rar.Carm.3.5 51

Serm.1.1.89

serm.1.3.1

Serm.1.3.54

Serm.1.5.20

sormi.1.10.87

Epist.1.5.24

1. pist.1.6.3n

1. pist.1.10.33

I.p).st.1.10.3

I. pod 17.22

l.pist.1.17.27

Carm.1.2.31

cum Ciarm 2.0.18

gur l.pol 17.22

Lpost.1.17.3

(a)m.2.17.2

l.pold 10.0

Serm $27 .$.

(arm $3+2.5$

(arm 30.03

( t)rmatis

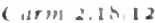

serm 1.37 
absentem qui rodit, amicum/qui uon defendit alio culpante. ita te quoque anicum. casu quod te sortitus amicum:

si bene me novi, non Viscum pluris amicm.

"tibi me virtus tua tecit amicum.

veterem vetus hospes anicum.

ni sapiens sic Nomentanus anicum|tolleret:

metues, liberrime Lolli. / scurrantis speciem pracbere, professus amicum. quid minuat curas, quid te tibi reddat amicum.

mirabor, si sciet inter-| noscere mendacem verumque beatus anicum. 'cur ego anicum offendam in nugis?'

amicus. Il usis anicus tristitiam et metus $\mid$ tradanı... ventis

amicus Aulon | fertili Baccho

réertque tenta grex amicus ubera

vix credere possis, / quam sibi non sit amicus.

at est bonus, ut nelior vir|non alius quisquam, at tibi amicus,

amicus. quae detraxerat / servis amicus perfidis.

amicus dulcis, ut aequom est. / cum nea conpensat vitiis bona,

paulum deliquit asnicus. I quod nisi concedas, habeare insuavis:

minus hoc iucundus amicus/sit mihi? .

longa aetas, liber amicus. |consilinm proprium: .

Antoni, non ut magis alter, amicus.

maiorum nequis anicus|frigore te feriat."

infido seurrae distabit amicus.

quen paupertatis pudor et fuga, dives anicus, . . . odit

amissas. quibu amissas reparare queam res/artibus atque modis.

amisso. sed tanen amoto (amisso] quaeranus seria ludo): .

amissos. neque amissos colores/lana refert

amite. aut anite levi rara tendit retia

amittit. neque vitam amittit in undis.

amne. Phocbe, qui Kantho lavis amne crinis.

amem. et Scythicum inviolatus amnem.

amni. vemens et liquidus puroque simillimus amni

amni. quale fuit Cassi rapido ferventius amni|ingenium.

amnis. vagus et sinistra labitur ripa Iove non probante u-l xorius anuis. quae Liris quicta! mordet aqua taciturnus amnis.

monte decurrens velut amnis.

rusticus exspectat, dum defluat amnis;

seu cursun mutavit iniquon frugibus ammis/doctus iter melius:

amnis. pontisne inter iactatus an amnis|ostia sub Tusci?

amnis. tu flectis amnis, tu mare barbarum.

cum fera diluvies quietos/irritat amnis.

amo. non ego: namque parabilem amo venerem facilemque.

amoena. amoena vocat mecum qui sentit,

amoenae. nimium brevis/flores amoenae ferre iube rosae,

amoenae. amoenae|quos et aquae subeunt et aurae.

hae latebrae dulces et, iam si credis, amoenae.

amoeni. ego laudo ruris amoeni $\mid$ rivos

amoenis. 'nullus in orbe sinus Bais praelucet amoenis'.

amoenos. properantis aquae per amoenos ambitus agros

amoenum. velox amoenum saepe Lucretilem 'mutat Lycaco Faumus

Brundisium comes ant Surrentunn ductus amoenum

Amor. quae subsequitur caecus Amor sui

amor. suprena citius solvet amor die.

cum tibi flagrans amor et libido.

insignem tenui fronte Ltcorida/Cyri torret amor.

ne sit ancillae tibi amor pudori,

illam cogit amor Nothi.

me lentus Glycerae torret amor meae.

egit amor dapis atque pugnae;

spirat arthuc amor

quis non malarum quas amor curas habet

amor Lycisci me tenet;

novaque monstra innerit libidine/mirus anor,

cantat et adponit 'meus est anor huic similis:

stultus et inprobus hic amor est dignusque notari.

aut si tantus amor scribendi te rapit.

hunc amor, ira quidem communiter urit utsunque.

amore. ingenuoque semper|amore peccas. ierm.1.4.8

Serm.1.6.50

Sirm.1.6.53

Sirm.1.0.22

Serm.2.5.33

Serm.2.0.8 I

Serm.2.8.60

Epist.1.18.2

Epist.I.I B.IOI

Ars P'oet.425

Ars Poet.450

Carm.1.26.1

Carm.2.0.18

Epol.10.50

Sirm.1.2.20

Serm. I.3.33

Epod.9.10

Sorm. 1.3 .69

Serm.1.3.84

Serm.1.3.93

Serm.1.4.132

Serm.1.5.33

Sirm.2.1.61

Epist.1.18.4

Epist.1 18.24

Serm.2.5.2

ior.Sirm.I.1.27

Carm-3.5.27

Enod.2.33

Sirm.I.I.00

Carm.40.20

Carm.3.4.35

Epist.2.2.120

Strm.1.10.62

Curm.1.2.20

Carm.1.3I.8

Corm.4.2.5

Epist.1.2.+2

Ars I Jel.67

Serm.2.2.32

Corm.2.19.17

Carm.3.20.4 I

Serm.1.2.1I9

Enist.1.1.20

Corm.2.3.14

Carm.3.4.7

Etist.1.16.15

Epist.1.10.6

Epist.1.T.S3

Ars Poet.i 7

Carm.I.I.I

Epist.1.17.52

Carm.I.IS.I4

Carm.1.13.20

Curm.1.25.I3

Carm.1.33.6

Carm.2.4. I

Carm.3.15.II

Carm.3.10.28

C.11 m.4.4.12

Carm.4.9.10

Ispol.2.37

Ispod.11.24

1.pod.10.31

Sirm.1.2.107

Sirm.1.3.24

Sermez.I.IO

Epist.1.2.13

Carm.1.27.17 
quam non ameste sic neo llagres.

l: pod.5.81

amore prestsom gravi,

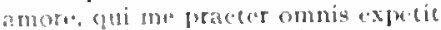

EPod.11.2

a turpi meletricis amotel cum decerteret:

ambitione mala ant argenti pallet anore.

requitia et nugis. fravorum et anore gemellum.

f pod.11.3

Sirm.1.1.111

Sirm. $2 \cdot 3 \cdot-7 \alpha$

serm.2.3.2.4.

an meretriejs amose $\mid$ sollicitus plores:

in amorth hace sumt mala.

laulis amote tumus:

invidia rel amore vigil torguebere.

$\therefore$. . sine amore iociefuc nil est incumdum,

vivas in amore ireisque.

inmoritur stuliis et amore senescit habendi.

Sirm.3.3.252

Serm.2.3.26\%

Jipist.1.1.36

Epist.1.2.37

Epist.1.6.05

List. 1.0 .00

EPist.1.7.85

oderunt peccare beni virtutis amote:

quo sit amure prarens. quo frater amandus et hospes.

Iipist 1.10 .52

Ars I'oel 313

Epoditit

Epod. I5.II)

fore hunc anorem mutuom,

si romo pracestet. quen mon increaris, amorem?

Serm.1.1.57

lacus et mare sconcit amorem/icstinantis eri

Epist.1.1.St

gua parilis fropter narratur amorem Graecia barbariae lento collia disclito

fiet lumo et ponet famo-ate noreis anorem.

amores. noc tibi besperoisurgente decedunt anores

amores. now dulets amores sperne puer

pullente lacison amotes

incestos andores de tionero meditatur ungui.

se.11 rixalm et imabnos amotes

ruate tyiraloat anores.

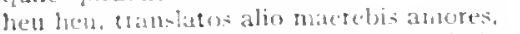

amori. mistartum ot neque amosi dare iudurs

amoribus. fini:ia animum realdere anorilus.

beup muthis thelum frectlo amoribus:

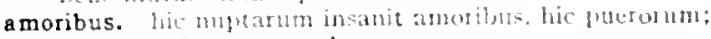

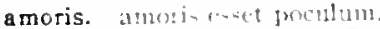

amorum. ikn: jam, thertum finis amorum.

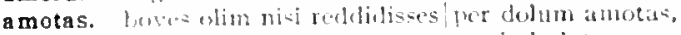

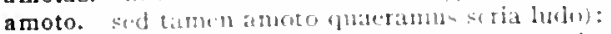

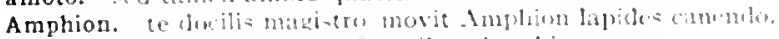

iraternis ansiste putatur, moribus Amphion:

Amplinon. Tlulanate conditor mbis. / saxa moxere

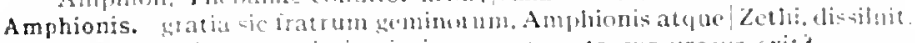

amphora. amphera nepit institui: currente rota cur urcens exic:

amphora. no: Latsergonia buclus in amphora|languecit mihi

amphorae. neu fromptiat mulus amplorac

amphoras inmum hibere institutae consule Tislo.

amphoram deripere horto olcesintem Bibuli comblis amphoran.

amphoris. ant flecan fouts mella comdit amploris

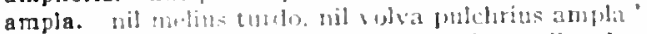

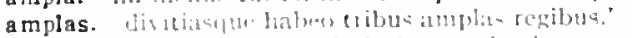

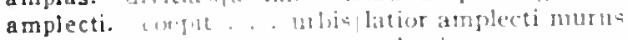

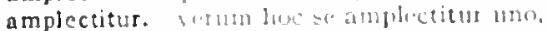

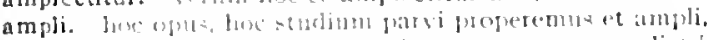

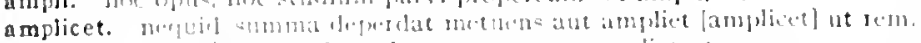

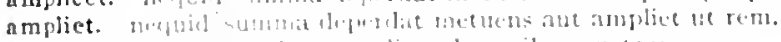

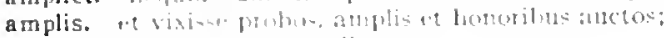

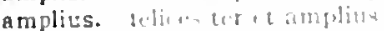

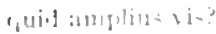

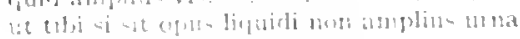

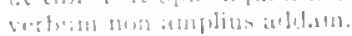

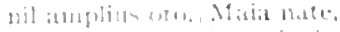

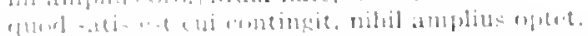

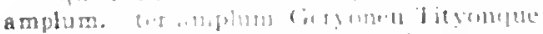

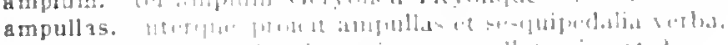

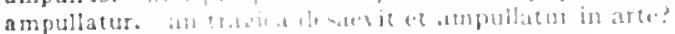

Iipist.1.2.6

Ars Poet.400

(arm.2.0.1 1

(armi.1.0.15

(arm.2.11.7

Carm.3.0.23

Carm.3.21.3

(iarm.t.13.15

L pod. 1523

(arm.3.12.1

(arm.1.10).

carm.2.12.10

sirm.1.1.27

J.pod.5.35

(arm.t. I3.32

(arm. b.10.10

term.1.1.27

Curm.3.11.2

IFist.I. I S.4t

Irs Iroel.30.1

fipist.1. Is. 1

Ars Putel I

Carm.3.10.34

Cirm. I $36.1 \mathrm{t}$

carm.3.8.1 1

(orm.3.28.8

Ispot.2.15

JPist. I. I 5.43

Serm.2.2.IuI

irs Pod 200

tirm. 2.2.53

1. pist. 1.3 .28

isr.sirm.1.432

virm.1.4.32

semplosi

("nTmi.1.1.17

l.pod. 17.30

virmid.1.54

STrm.1.I.I I

serm.2, 2,4

1.pist.1.2.1

(arm.2.1.7

Ars Jict.or

1. . is. 1.3 .1 .9

1. ponitis.13

I. prod.12.18

(a)m. 1.30 .14

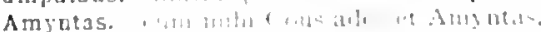

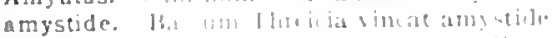

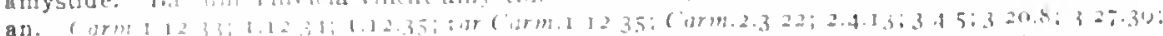

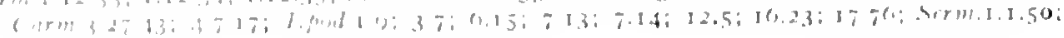


Serm.1.1.76; 1.1.88; 26r.Serm.1.1.101; Serm.1.2.59; 1.2.103; 1.3.22; 1.4.124; 1.9.41; Sirm.I.I0.25; I.10.74; 2.1.34; 2.2.31; 2.2.32; $2.2 .110 ; 2.3 .67 ; 2.3 .83 ; 2.3 .134 ; 2.3 .157$; Serm.2.3.167; 2.3.210; 2.3.246; sar.Serm.2.3.246; Serm.2.3.252; 2.3.200; 2.3.263; 2.3.278; Serm.2.3.312; 2.4.10;2.5.58;2.6.56;2.6.74; 2.7.59; 2.7.109; Epist.1.1.62; 1.1.08; 1.3.4: Epist.1.3.5; 1.3.14; 1.3.31; I.4.4; 1.0.12; 1.11.5; 1.11.6; 1.12.20; 1.14.4; I.14.5; 1.16.2; Epist. 1.16.3; tur.Epist.1.16.3; Epist.1.16.27;1.17.45; 1.18.19;1.18.20; tur. S.pist.1.18.102; Epist.1.18.103; 2.1.37; 2.1.42; 2.I.170; 2.2.106; 2.2.195; 2.2.200; Ars Pott.II4; II5; Ars Pot I16; I 8 (bis); :ar.Ars Pot.237; Ars Poet.239; 205; 330; 408; 436; 462; 471 Anacreon. nec siquid olim lusit Anacreon/delevit aetas;

Anacreonta. non aliter Samio dicunt arsisse Bathyllo! Anacreonta Teium. anceps. sequor hunc, Lucanus an Apulus anceps:

anceps. ius anceps novi, causas defendere possum;

Anchisae. clarus Anchisae Venerisque sanguis!inpetret.

Anchisen. Anchisen et almae/progeniem Veneris canemus.

anciliorum. anciliorm et nominis et togae $/$ oblitus

ancilla. si|ancilla aut verna est praesto puer.

non ancilla tuom iecur ulceret ulla puerve

ancilla. quid inter-|est in matrona, ancilla peccesne togata?

ancillae. ne sit ancillae tibi amor pudori.

ancillas. paret ancillas, paret aurum,

Ancus. quo pius Aencas, quo Tullus dives et Ancus,

ire tamen restat. Numa quo devenit et Ancus.

Andromedae. occultum Andromedae pater/ostendit ignem.

anellis. saepe notatus/cum tribus anellis.

Anerio. scribe decem a Nerio [Anerio]: non est satis;

angat. ne dominus . . munere te parvo beet aut incommodus angat.

angiportu. flebis in solo levis angiportu

angit. hac urget lupus, hac canis, aiunt [angit].

pudor" inquit "te malus angit,

meum qui pectus inaniter angit.

ant ael humum maerore gravi deducit et angit;

angue. alter Mileti textam cane peius et angui [angue]/vitabit chlanidem,

anguem. aut in avem Procne vortatur, Cadmus in anguem.

angues. intorti capillis Eumenidum recreantur angues?

furiale centum|mniant angues caput eius

angui. alter Mileti textam cane peius et angui/ritabit chlanidem,

anguibus. nee Mauris animum mitior anguibus:

angulo. intumo|gratus puellae risus ab angulo

angulus. ille terrarmm mihi praeter onnis|angulus ridet,

'o si angulus ille/ proximus accedat, qui nunc denormat agellum!"

angulus iste feret piper et tus ocius ura

angusta. reddes|forte latus, nigros angusta fronte capillos.

angustam. angustam amice pauperiem pati

forte per angustam tenuis volpecula rimam|repserat

angustis. rebus angustis aninosus atque fortis adpare:

huc prius angustis ciecta cadavera cellis

angusto. angustoque vagos piscis urgere catino.

anhelitu. sublini fugies mollis anhelitu,

Anici. rapianus, amici [Anici]. | occasionem de die.

anicla. clanet amica. [anicla]| mater, honesta soror cum cogmatis, pater. uxor:

anilis. Cervius hacc inter vicinus garrit anilis lex re fabellas.

animae. et serves animae dimidium meae. animaenue magnae|prodigum Paulum superante Poeno. a, te meae si partem animae rapit/maturior vis.

animae. si parcent animae fata superstiti.

animae. inpellunt animae lintea Thraciae. animat qualis neque candjdiores/terra tulit

animalia. cum prorepserunt primis animalia teris,

animantem. hic stilus haud petet ultro|quemoum animantem

animas. tu pias laetis animas reponis|sedibus tu pias laetis animas [animas laetis] reponis/sedibus manis elicerent animas responsa daturas. terrestria quando mortalis animas rivont sortica

animi. rotus in fratres animi paterni: iam nce spes animi credula mutui sordidus atque animi quod parvi nolit haberj, / respondet. inopis me quodque pusili finxerunt animi. rectum animi servas cursum?

Carm.4.9.9

IEpod.14.10

Sirm.2.1.34

Sirm.2.5.34

Carm.Sacc.50

Carm.4.15.31

Carm.3.5.10

Sirm.1.2.1I7

lipis!.1.18.72

Serm.1.2.03

Carm.2.4.

Serm.2.3.21 5

cism.7.7.15

Epist.1.0.27

Carm.3.29.17

virm.2.7.0

frar.serm.2.3.69

IEpist.1.18.75

Carm.1.25.10

I'ur.Sirm.2.2.64

Scm.2.3.39

Fpist.2.1.21 I

Ars Poet. I 10

Ear.EPist.1.17.30

. Ars Poct.187

Curm.2.13.36

Carm-3.11.I8

Epist.1.17.30

Carm.3.I0.18

Carm.1.9.22

Carm.2.6.It

Scrm.2.0.8

Epist.1.14.23

Fipist.7.20

(urm.3.2.1

Epist.1.7.20

Corm.2.I0.2I

Serm.T.8.8

Serm.2.4.77

Carm.I.I5.3I

comitipod.13.3

coni.serm.2.3.57

Serm.2.0.77

Carm.1.3.S

Carm.1.12.37

Carm.2.17.5

Carm.3.9.12

Carm.4.12.2

Sirm. I.5.11

Scrm.1.3.99

Serm.2.I.20

(armar.10.17

"irr.carm.s.10.17

Sirm.1.8.29

Serme2.0.04

Carm.2.2.

Carm+1.30

Sermidizo

Serm.t.4.18

s.rm.2.3.201 
intener ant anim? ne dixcris.

Serm. 2.3.220

quo mo argotate putes anini vitio."

quarto devites animi canitisque labore

post effert animi notus interprete lingua.

Sorm.2.3.307

Epist.1.1.4.4

Ars l'oelitit

animi. quam jer vatis opus mores animique sitosum/clarorum adparcut. sectantem levia nervi|deficiunt animigue:

ut cito dicta perciphant animi dociles tencantque fideles:

numquan te allent animi sub volpe latentes.

animis. vel cus his animia incolumes non redeunt genae?" sollicitis animis onus exmmit, addocet attis.

sic ananis hatwm inventumque porma invandis.

animis. at cetera paene genelli fraternis animis: ut partis aninis et parter corpore maitus; aequis accipiunt animis donantre corona.

animo. sumas animone go fortius an tu/eveflas agro.

animo. animogle rotundum! percurisse polum norituro. jhem ullete vis omne metis animo movent is. nec Mauris animum [animo] nutior angubus: amicolyuthe declogis animo. quod vitiun procul afore chart islatque anino stius. quod vitiun yocul afore chattis atque animo prits, ut siefuld [anino. prins ut, siquid] promittere de me possum aliuel vere, promitto. conantis haml animo acquo expectans conntes. quidquid vita meliore parasti ponendum aequo animo." stas animo et purun est vitio tibi, cum tumidun est cor?" deduxit . . non anisno curas; si. . Iefixis oculis animoque ct corpore torjet? iacinnt prope plura dolentibus ex animo.

animos. inpates homas atque anmos sub iuga acnea' saevo mittere. Ienit alluescenti animos captillus sic tenerei animos aljena ofptobria satepe /absterrent vitis. cambintus quat versant at que venenis lumanos animos. numeros animosque secutus Archilochi, segnius irritut animos demissa per aurem hase arimos aerugo et cura peculi $/$ cum senel imbucrit. mafes animos in .lantia bella versiluts exacuit:

animosum. aut versis animosum equis|l'arthum dicere intor|flectora priamilen. animosum atque inter Achillem is iut

animosus. rebus anguatis aninosus atque for tis adpare: nut sure dis animostu infans.

animum. fias reatutatis andeal oppobris animusuge redelas. firntis animum teddere amuribus. cuncta tetrarum subactis fracter atrocem animum Catomis. quiel aeternis nunotem ensilis animum tatigas?

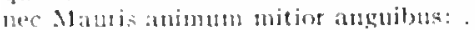

non animum meth, non motis faqueds cxpetless captut. viris animumselue morespe aureos nelucit per canlic als ifso ducit opes animuneque tero. ut numquall inducast ansusur cantare rogati.

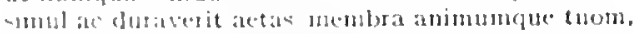

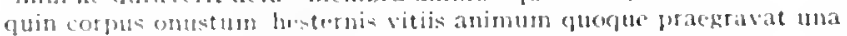

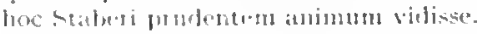

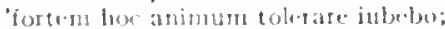

ut tamern altum|sobeset hospitis animum.

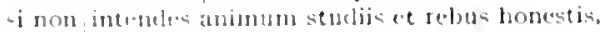

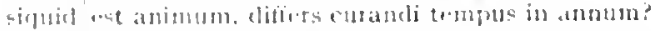

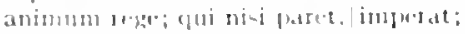

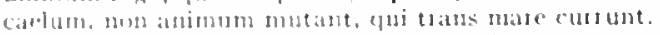

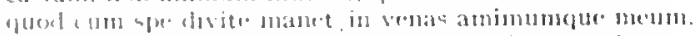

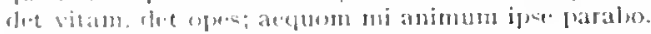

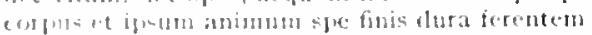

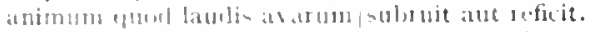

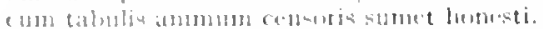

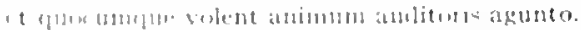

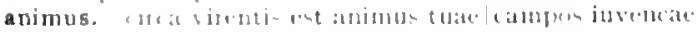

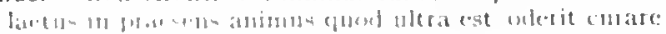

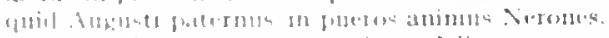

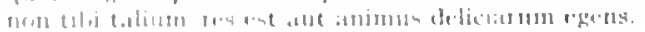

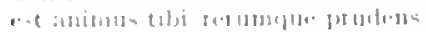

Eipist.2.1.2.49

Ars 1 od.27

Ars $\operatorname{loc} .336$

Ars 1 od 1.437

Corm.4.10.8

Lisist.5.5.18

Ars Poel.377

Ejpist.1.10.4

Epist.1.17.40

Irs loul.250

lepist.1.14.4

Carm.1.28.5

Curm 3.4 .08

sar.Carm.3.10.18

Carm.t7.20

Sorm.1.4 102

(1) ni.serm.1.4.102

Serm.1.5.8

Sorm.2.3.16

Sirm.2.3.213

lepisti.1.2.49

Iepist.1.0.14

tirs 1"ort.432

Carm.1.33.11

Carm.3.14.25

Sirm.1.4.128

Serm.18.20

l.pist.1.19.24

lirs Port.180

Ars l'od.330

Ars l'uet.qua

Corminig.II

cerm.1.7.12

(orm.2.10.21

Carm.3.4.20

Cism.1.10.28

Cirm.1.19.4

(iorm.2.1.24

('urm.2.J1.12

(ivm.3.10.18

( arm.3.24.7

Cirm. 2.22

Carm.t.t.60

Serm.1.3.2

Sorm.1.4. 20

Sirm.2.2.78

sirm.2.3.80

Sirm.2.5.20

Sirm.2.0.83

l:pist 1.2.30

LPist.1.2.39

1:pist.1.2.02

1.pist 1.11 .27

1.pisl 1.15.20

l:pist.1. I8.112

l.pist.2.1.1.1

I.psir 2.1 .170

l:fisst 2.2.110

Ars I"wel. 100

carm.2.5.5

(arm.2 10.25

(iarmat. 1.28

(arm.4 s.10

(i) m.to.34 
huic si mutonis verbis mala tanta videnti|diceret haec animus 'quid vis tibi?

cumlacclinis falsis animis meliora recusat.

tibi ingens/virtus atque animus cenis responsat opimis?"

est animus tibi, sunt mores et lingua fidesque,

animus si te non deficit aequos.

dum peregre est animus sine corpore velox?

tamen istuc mens animusque | fert

in culpa est animus. qui se non effugit umquam.

vatis avarus/non temere est animus;

aetas animisque virilis/quaerit opes et amicitias.

Anio, et praeceps Anio ac Tiburni lucus .

anni. consulque non unius anni.

anni. eheu fugaces. Postume. Postume, / labuntur anni

ubique |accedent anni, tractari mollius aetas/imbecilla volet:

singula de nobis anni praedantur euntes:

multa ferunt anni venientes commoda secum.

annis. mobilibusque decor naturis dandus et annis.

annis. 'o fortunati mercatores' gravis armis [atnis]|miles ait, a certis annis aevom remeare peractum

haec seges ingratos tulit et feret ommibus annis.

qui redit in fastos et virtutem aestimat annis

anno. ter et quater|anno revisens aeguor Atlanticum inpune.

hic dies anno redeunte festus

si tener pleno cadit haedus anno

pomifero grave tempus anno.

ut toto non quater anno| membranam poscas.

collegam Lepidum quo duxit Lollius anno.

qui deperit minor uno mense vel anno.

qui rel mense brevi vel toto est iunior anno."

annona. vilis amicorum est annona. bonis ubi quid deest.

annonae. annonae prosit, portet frumenta penusque.

annorum. innumerabilis|annorum series et fuga temporum.

annos. (currit cnim ferox|aetas et illi quod [quos] tibi dempserit|adponet annus [ammos]).

non... ploravit omnis Antilochum senex/annos. quam per exactos ego laetus annos

ex hac luce $\mathrm{M}$ aecenas meus adfuentis /ordinat anno.

Cinarae brevisjannos fata dederunt.

certus undenos deciens per annos/orbis

si et stramentis incubet unde-|octoginta annos natus.

cum tibi sol tepidus pluris admoverit auris [annos].

scriptor abhinc annos centum qui decidit.

"est vetus atque probus, centum qui perficit annos."

libertasque recurrentis accepta per annos, lusit amabiliter,

studis amos septem dedit insenuitquelibris et curis.

ut silvae foliis pronos mutantur in annos. .

annosa. aquae nisi fallit augur|annosa cornix.

annosa. pontificum libros, annosa volumina vatum/dictitet

annoso. quid? cum balba feris annoso verba palato.

annua. nec cultura placet longior annua

ennuerant. molle atque tacetum |Vergilio adnuerunt [amuerant] gaudentes ture Camenae.

annum. quod et hunc in annum/virat et plures.

est mihi nonum superantis amum| plenus Albani cadus.

quae. simul inversum contristat Aquarius annum.

differs curandi tempus in annum?

grata sume manu neu dulcia differ in annun,

quae mare compescant causae, quid temperet annum.

sit bona librorum et provisae frugis in annum|copia

inpetrat et pacem et locupleten. frugibus annum:

nonumoque prematur in anmm, membranis int us positis;

annuo. cunctantem spatio longius annuo

annus. (currit enim ferox/aetas ut illi guod tibi dempserit/adponet annus). inmortalia ne speres, monet annus

tonantis annus hibernus lovis

sive rliem festum rediens advexerit annus, .

septimus octavo propior iam fugerit annus,

ut piger annus|pupillis, quos dura premit custodia ntatu un:

Sirm.1.2.69

Serm.2.2.6

Sirm.2.7.103

Epist.1.1.58

Epist.1.II.30

Epist. I.I2.13

Epist.1.1.48

Epist.1.14.13

Epist.2.1.120

Ars Poel.160

Carm.1.7.13

Carm.4.9.39

Carm.2.14.2

Sirm.2.2.85

Epist.2.2.55

Ars Poel. 75

Ars Pote. 57

idr.Serm.I.I.4

Serm.1.6.94

Epist.1.7.21

Epist.2.1.48

Cam.1.3I.It

Carm.3.8.9

Carm.3.18.5

Carm.3.23.8

Serm.2.3.I

Epist.1.20.28

Epist.2.1.40

Epist.2.1.44

Epist.1.1 2.24

Epist.r. 6.72

Carm.3.30.5

2ur.Corm.2.5. 15

Curm.2.9.15

Curm.322.6

Carm-4i I.20

Corm.4.I 3.23

Carmbaec 21

Serm.2.3.I I 8

var. Epist. 1.20.19

IE pist.2.1.36

Epist.2.1.39

Esist.2.I.147

Epist.2.2.82

Ars Poet.oo

Carm.3 I7.I3

Epist.2.1.20

Serm.2.3.274

corm.3.24.14

v'ar.S.rm.1.10.45

Carm.1.32.2

Curmatil.I

Serm.1.1.30

I.pist.1.2.39

Epist.I.I I.23

Iipist.1.12.16

Epist.1.18.109

Epist.2.1.137

-trs Poet.388

Corm.4.5.1 I

coni.curm.2.5.I5

Corm.4.7.7

Itpolt.29

Sirm.2.2.53

Serm.2.6.40

Ippist.I.I.2 


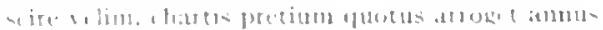

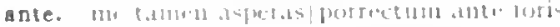

(arm 3.10$) .3$

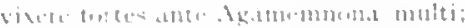

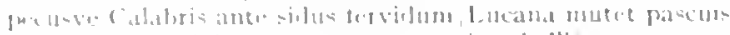

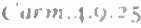

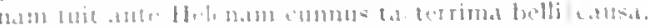

I poid.1.27

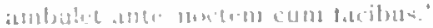

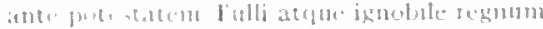

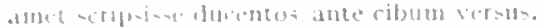

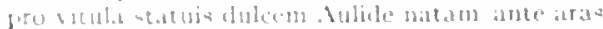

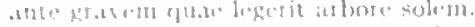

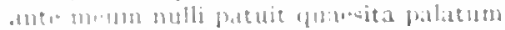

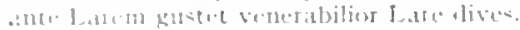

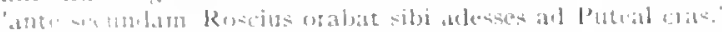

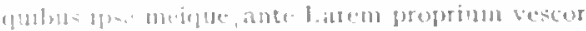

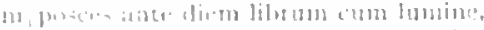

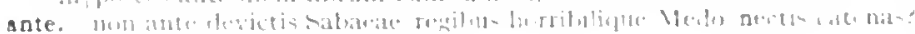

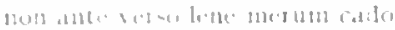

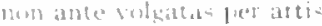

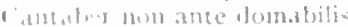

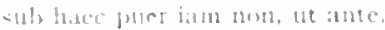

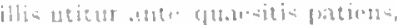

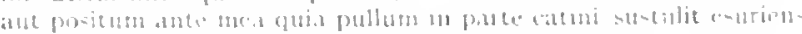

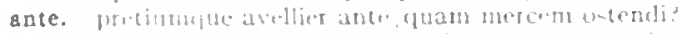

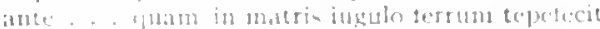

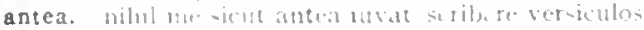

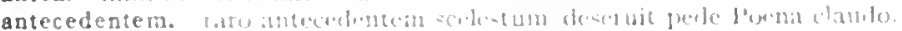

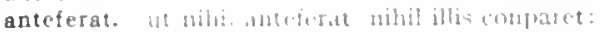

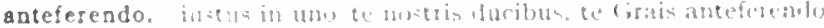

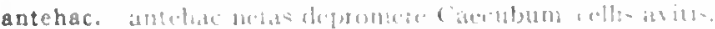

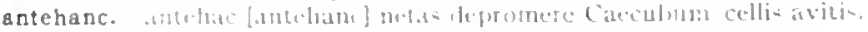

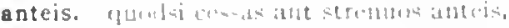

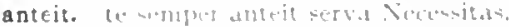

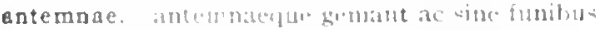

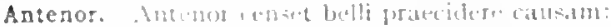

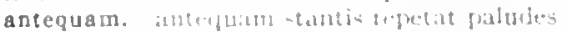

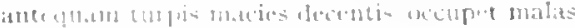

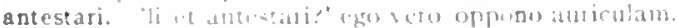

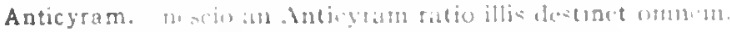

natriget intertams.

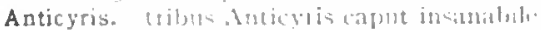

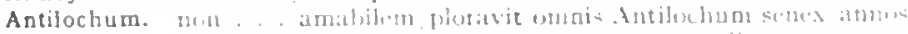

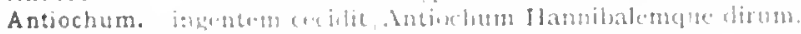

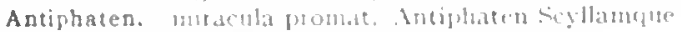

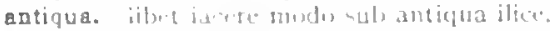

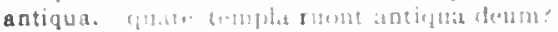

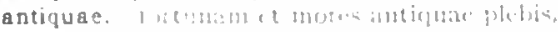

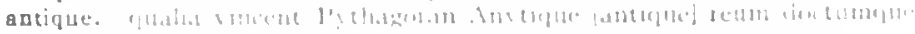

$$
1 \text { 1..1611, * }
$$

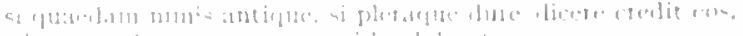

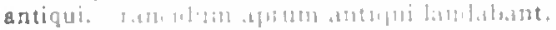

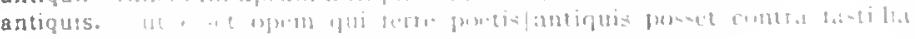
13., 28.1 "

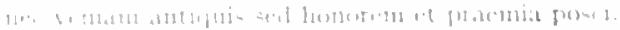

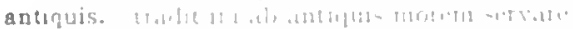

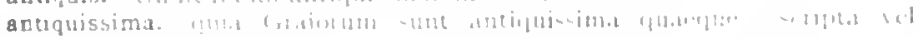
1.j० 1111.1 .

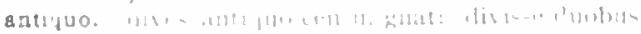

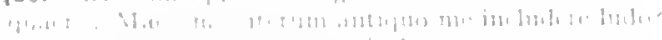

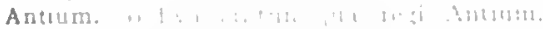

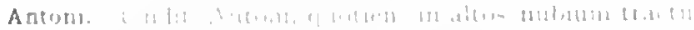

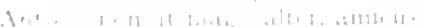

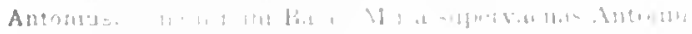

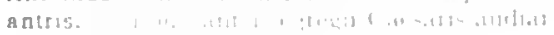

antro, ..., f $1: 1 \ldots$ il, $+1,21,1$

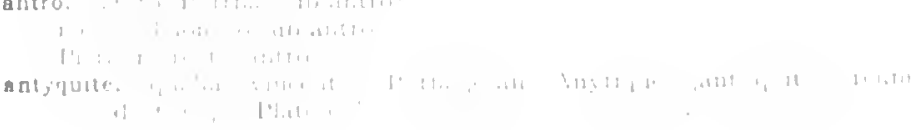

tirm: 3.107

s.rm.1.1.51

D.2m?.1.0.0

Sermilatid

Serm.2.5 200

viren 2.23

verill.2 $1.4^{11}$

verm.2.5.14

virm.2.11.3.1

serme, 2, (1, (, , )

I. pist 1.2.35

( ils $1 \%: 1.29 \cdot 3$

(iarm.3 20.2

(urm...9.3

(arm. $1+41$

firoi. $5 \times 3$

4.rm.1.1.37

verm.t.3.9=

Serm.1.2.10:

verm. 3.135

I: poid I 1.1

(arm.3.2.31

l.pise $=.1 .6 .5$

I.pid.2.1.10

( arm-1.37.5

icar ciurm. $13 \%$

I.jif 1.2.70

( urm.1.3.5.17

(itron 1 1:

1.PU1.1.2.?

(iarm:-3.2.7.0)

(arm.i.27.5j

verus. 1.0 .70

tron:2.3\$3

sermi.2.3.100

Irstioliono

(i.rmi.2.0. I 4

(iarm. 3. (1).31)

Irs lind 115

1. $p+4 t, 2.23$

rirmi $=2.10 .8$

$4+n=2.23$

ifr Sirpid $2 \therefore$

1 t.s.

Sen: $2,2.4$ )

$\therefore r m i 1110 \%$

$1.11 .4 .2 .1=5$

Sirn: $111:$

$1 p d+2=124$

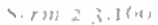

$1 \cdot \because 11.3$

( 1) $1+51$

( $112 m 1+21$

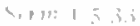

$1+1105$

t ant it

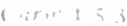

(.129): , , )

$(x+2)<1+4)$

idt tor th: : 
anulo. tu cum proiectis insignibus, anulo equestri

Sirm.2.7.53

snum. sed mala tollet anum vitiato melle cicuta.

Serm.2.1.50

anus. invicem moechos anus arrogantis

fis anus et tamen $\mid v$ is formosa videri

Carm.1.25.0

neque in sepuleris pauperum prudens anus | nov"endialis disipare" pulveres.

Sabella|quod puero cecinit divina mota anus urna:

anus inproba Thebis!ex testamento sic est elata:

Carm. 13.2

Eprod.17.47

Sirm. I 9.30

Sorm.2.5.84

Epod.5.98

Epol.17.t,o

quid proderat ditasse Paelignas anus

a furno redeuntis scire lacuque /et pueros et anus."

anxis. tu spem reducis mentibus anxiss

Anxur. subimus inpositum saxis late candentibus Anxur.

Anryr. subimus,inpositum saxis late candentibus Anxur [Anxy].

Anyti. Pythagoran Anytique reum doctunque Platona."

Apella. credat ludaeus Apella, non ego:

Apellen. nequis se praeter Apellen|pingeret

aper, seu rupit teretes Marsus aper plagas.

echinus aut Laurens aper.

putet aper rhombusque recens,

fiet aper, modo aris. modo saxum et, cum volet, arbor.

Vimber et iligna nutritus glande rotundas feurvat aper

in primis I, ucanus aper:

aperire. rite naturos aperire partus/lenis,

aperit. condita cum verax aperit praecordia Liber.

aperta. una|cum scriptore meo capsa porrectus operta [aperta]|deterar in vieum

apertam. donec iam saevos apertam|in rabiem coepit verti iocus

aperte. apertelquod venale habet ostendit

apertis. adde huc quod mercem sime fucis gestat, aperte [apertis]|quod renale habet ostendit

iustitiam legesque et apertis otia portis:

apertos. fastidire lacus et rivos ausus apertos.

apertum. per apertum fugientis agitato grege cervos iaculari

nullique malo latus obdit apertum.

apes, quamquan nec Calabrae mella terunt apes

apicem. Jine apicem rapax Fortuna cum stridore acuto|sustulit,

apices. neque iratos trementi regum apices

Apici. rapianus. anici. [Apici]|occasionem de die

spio. quis udo/deproperare apio coronas/curatie myto?

apis. ego apis Matinae/more modoque

apium. neu vivax apium neu breve lilium.

est in horto. Phylli, nectendis apiun coronis,

Apollinari. laurea donandus ipollinari.

Apolline, vel Baccho Thebas vel Apolline Delphos!insignic si munus Apolline dignum / vis complere libris

Apollinem. quid dedicatum poscit Apollinem vates?

Apollinis. natalemque, mares. Dulon Apollinis intonsosque agitaret Apollinis aura capillos.

A pollo. nube candentis uneros amictus/augur Apollo;

cettus enim promisit Apollo.

puerum minaci| voce dum tettet, viduos pharetra|risit Apollo. suscitat Musan neque semper arcum|tendit Apollo.

Delius et P'atareus Apollo.

sic me servavit Apollo.

divinare etenim magnus mihi donat ipollo."

scripta, Palatinus quaecumque recenit Apollo.

ne forte purfori, sit tibi Musa lyrae sollers et cantot Apollo.

Apollo. supplices audi pueros, Apollo:

'Iane pater' clare. clare cum dixit 'ipollo."

apotheca. neque illiclaut apotheca procis intacta est ant pecus:

appellat. strabonem appellat pactum pater. solem Asiae Brutum appellat

stellasque salubri- /appellat comitus

sppellet, ut forte legentem, aut tacitum inpellat [appellet] quovis sermone: siquis... Rufam aut Pusillam appellet

sppello. Catienis mille ducentis 'mater, te appello' clanantibus.

Appenninus. in mare seu celsus procurerit Appennimus

Appi. inde Fotum Appi differtum natuc catponibus atque malignis.

Carm.3.21.1

Sirrin. I.5.26

iar.tirm.1.5.26

Sirm.2.4.3

Sirm.1.5.100

Epist.2. I 23 ?

Carm.1.1.28

Ispod.5.28

Sirm.2.2.42

4rom.2.3.73

Sirm.2.4.41

Serm.2.8.6

Carm.Suec. 13

Serm I.4.89

zar. Epist.2.1.248

Ipist.2.1.1.48

Serm.I.2. $\$_{3}$

rat.Serm.1.2.83

Ars Poct.199

Epist.1.3.11

Carm.3.12.10

firm. 1.3 .59

Carm.3.16.33

Carm.1.34.IA

Carm.32I.20

coni.Lpod.1 3.3

Cirm.2.7.2.

Curm.4.2.27

(arm. I. 30.10

Curm.1 $1 \mathrm{I} \cdot 3$

Curm.t.2.9

Corm.1.7.3

Epist.2.1.216

Curm.1.31.1

Curm.1.21.In

Epod.15.9

ciam.1.2.32

Carm.1.7.2S

Carm.1.10.12

Carm.2.10.20

Carm.3.4.04

Sirmol.0.78

sirm.2.5.00

Epist.1.3.I7

Ars Poct.107

Carmistec.34

I.pit.1.10.59

Sirm.2.5.7

Sirm.1.3.45

Sirm-1.7.24

Sirm.1.7.25

rone.herm.13t5

sirm.2.3.210

serm.2.3.02

Lpodicieg

Cirm.1.5.3 


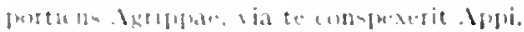

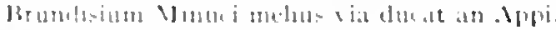

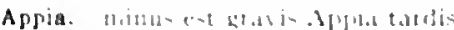

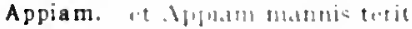

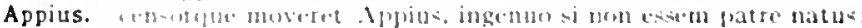

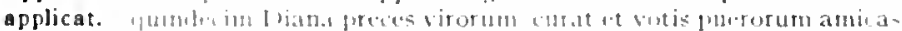

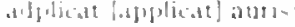

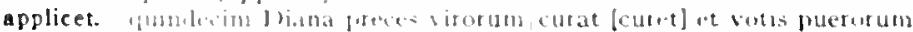

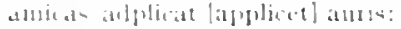

aprica. per meve thiss el aprice ruta

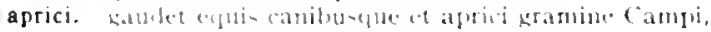

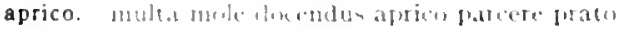

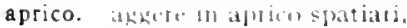

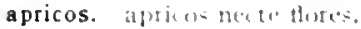

apricum. cur agrious enlesit campum pations pulveric atquesolis.

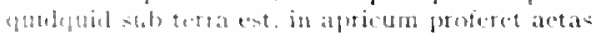

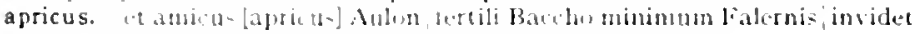
uiv:

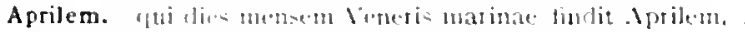

apris. apri-reliquit of rapacibus lupis.

apros. Lrudit alcis linc te libe multa cane apros

thatus uter pluris lepuses. Her aducet apros;

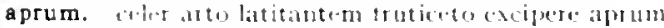

sanciloms aprum antigui latudabant.

nt agrom enemego;

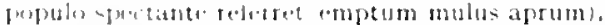

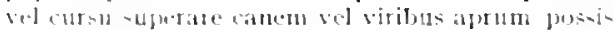

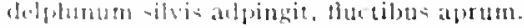

apta. Libi collit hingutum aptat quarlrigic equa,

stotili-ve diu palus aphardue remi-

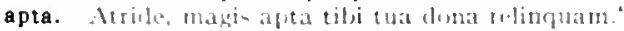

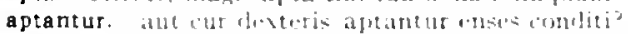

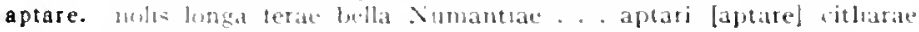
modi-

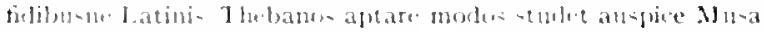

aptari. mollibus uptari citdattale modis

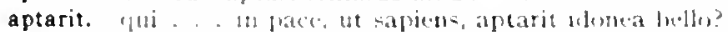

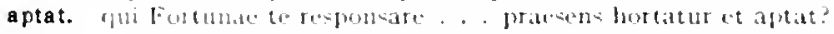

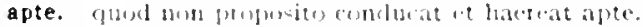

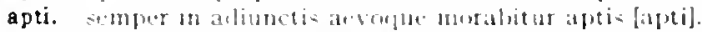

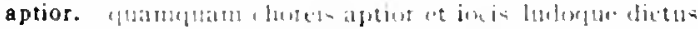

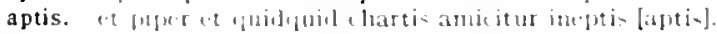

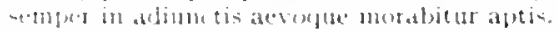

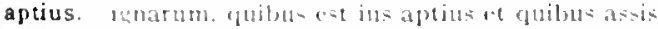

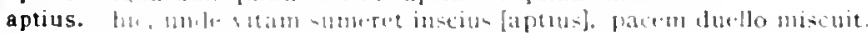

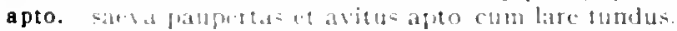

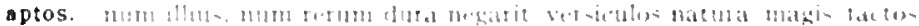

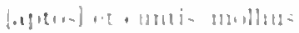

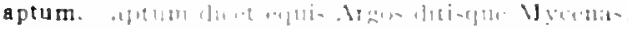

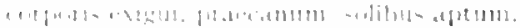

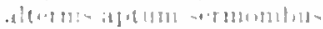

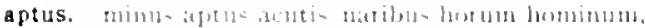

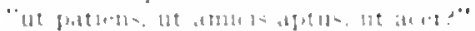

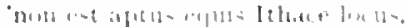

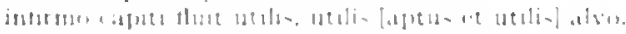

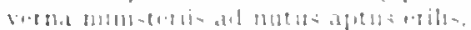

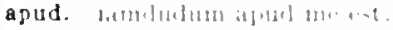

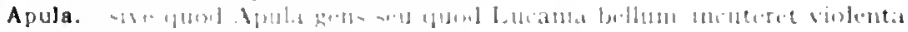

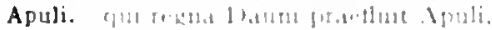

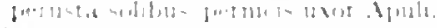

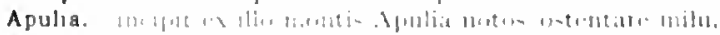

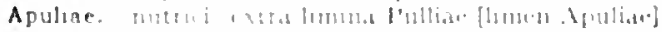

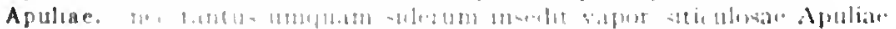

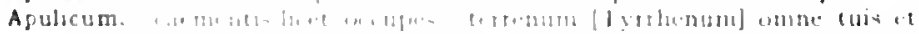

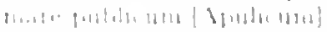

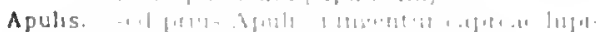

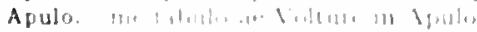

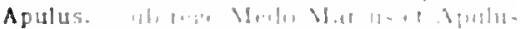

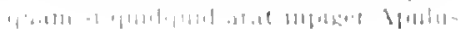

I.pist.t.e.26

fipist 1.18 .20

Serm.1.5.1"

Expotitit

Serm.1.1.21

I'ar.ciam Sisce. - ?

ior c armasec. 72

curm.3.18.2

Ars litidente

l.pise 1. B. 30

Sirm.18.15

(arm.1.20.7

Corm 1.8 .3

Epist.t.1.2.t

conicism.2.6.18

Curm.1.11.16

fipolt 10.20

Ifpod.2.32

Isist.1.15.22

Cirm.3.12.12

Serm.2.2.50

Sirm.2.3.23.4

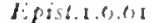

t.pist.1.18.51

Ars livel.zo

Carm.2.11.35

Ars Juens

tonist. 1.73

tipot 7.2

iur Ciarm.2.12.1

I. Mist.1.3.1.3

(i)rni.2.12.4

Jerm 2.2.111

Jipotig.t.tu

- Irs lived.10s

idir.etrs Povelis

(iirm.2.11).25

ist.tipist.2.1.2,0

- Irs lineldith

virm $2.43 \mathrm{~s}$

for ( iorm 3.5 .37

(idr) 1.12.43

$\therefore r, n+11,34$

(arni 1.-.

f.post $1=0.24$

Ir) Jinethi

Term.1.320

verm.2.5 43

I.pul 1.7.91

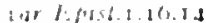

1.pist.2.2.0

cisem 3 an 5

siren $21.3 \mathrm{~s}$

(urm..t 1- al

1 pint 2 \&

serme 1577

inter ciarn $3: 10$

I. pent 3 ic

: atr ( o.

(and $133=$

(arm 3 :

(armis 5

a arm is ale 
sequor hunc, Lucanus an Apulus anceps:

Sirm.2.I.34

aqua. venit vilissiua rerum|hic aqua,

purior in vicis aqua tendit rumpere plumbun

aqua. quae Liris quieta!mordet aqua taciturnus amnis.

quantum exstant aqua|suspensa mento corpora;

aquae. Innc ad aquae lene caput sacrae.

non hoc semper erit linunis aut aquae, caelestis patiens latus.

purae rivos aquae silvaque iugerum paucorum

aquae nisi fallit augur annosa cornix.

qua pauper aquae Daunus agrestium | regnavit populorum.

nam Canusi lapidosus, aquae non ditior urna.

bortus ubi et tecto vicinus jugis aquae fons

collectosne bibant imbric puteosnt" peremais/iugis aquae.

quae scribuntur aquae potoribus.

properantis aquae per amonos ambitus agros

aquae. antoenaelquos et aquale subeunt et aurae.

sed quae Tibur aquae fertile praetiont

nutriant tetus et aquae salubres et Iovis aurae.

labuntur altis interim tipis aquae.

aquam. quis aquam temperet ignibus.

is neque limo turbatam haurit aruam

avet quavis aspergere cunctos, prater eum qui pratbet aquan;

hic ego propter aquam, quod erat deterrima.

nec sic 11 simplex Naevius unctam convivis praebebit aruan:

Aquarius. quae. simul inversum contristat Aquarius ammun.

aquas. arbore nunc aquas, culpante.

te per atuas, dure, volubilis.

spargens. Arernalis aquas,

caelestis implorat aquas docta prece blandus.

aquila. acutum quan aut aquila aut serpens. Epilauı in=?

aquilae. neque inbellem feroces/ pogenerant aquilat columbam.

Aquilo. insurgat Aquilo, quantus altis montibus/Irangit trementis ilices; pulveris atri|quantum non Aquilo Campanis excitat agris.

aquilo. non aquilo impotens possit dirut:te sive aquilo radit terras

Aquilone. nunc mate. nusc siluae/Threicio Aquilone somant.

aquilone. non agimur tunidis velis aquilone secundo:

Aquilonibus. praecipiten Airicum/decertanten Aquilonibus me... obicere incolis plorares Aquilonibus.

Aquilonibus. receptus, terra Neptunus clazsia Aquilonibus arcet. aquilonibus. aut aquilonibus querceta Crargani laborant

Aquinatem. Aquinatem potantia vellera fucum.

aquosa. qualis ant Nirens luit aut aquosa|raptus al, lda.

aquosus. nisi causa motbi tugerit venis et aquosis albo / corpore languor.

ut neque largis aquosus Eurus arva radat imbribus.

ara. vetus ara multo' tumat orlort. ara castis vincta serbenti= cum lucus tet ara Dianae. . describitur

Arabas. diffingas retusum in Massagetas Arabasque ferrun. quid mari extremos Arabas clitantis

Arabes. quid maris extrenos Arabas [Arabes] ditantis

Arabum. Icci. beatis nunc Arabum invides/gazis plenas aut Arabum domos.

thesauria Arabun et divitis Indiate

nec otia divitis Arabum libertima mute.

aram. inmuniz aran si tetigit manu:

arando. spem mentita seges. bos est enectus arando:

arare. optat ephippia bos, piger ontat arare caballu-

aras. si l'alatinas videt aeguó ata-

pro vitula statuis dulcem Aulide natam ante ara-

iurandasque tuon per numen ponimus aras.

arat. quam si quid 1 uid arat inpiger Apulus

arat follerni mille fundi iugerou

nam Venusinus arat fin"m sub utrumque colonus.

arator. ac neque han stabulis gaudet frecus aut alater igni

aratra. non ut iuvencis inligata pluribus|aratra nitantur meis

aratro. iam pauca aratro iugera regiae mules relinguent.

aratro. ille grasum duto terram rui vertit aratro.

irm.1.5.s9

Epist.1.10.20

Carm.1.31.8

Epod. 5.35

Carm.1.1.22

Carm.3.10.19

Carm.3.16.29

Carm.3.17.1 2

Carm.3.30.II

Serm. I.59 I

Serm.2.6.2

Epist.1.15.16

Epist.1.I9.3

Ars Pot. 7

Carm.3.4.8

Carm.t.3.10

Curm.5uec.3 I

Epod.2.25

curm.3.19.0

sirm.1.1.60

Sirm.1.4.88

Sirm.J.5.7

Serm.2.2.09

Sirm.1. I. 30

Carm.3.I.30

Carm.t.to

E.pod.5.20

Epist.2.1.135

Serm.1.3.27

Curm.4.4.32

Epod.10.7

Serm.2.8.50

Curm.3.30.3

serm.2.0.25

Ipot. 3.3

Epist.2.2.201

Carm.1.3.13

Carm.3.10.4

Ats Jost.ot

Carm.2.0.6

Epist.1.1027

Carm.3.20.I 5

Carm.2.2.15

I.pod.10.54

Curm.3.18.7

Carm. II. 6

Ars Potero

Carm.1-35-40

Epist.r.o.t

Sar. Epist. . 0.6

Carm.1.20.I

Carm.2.12.24

Curm.3.24.2

Epist.1.7.36

Carm.3.23.I7

Epist.1.7.87

Epist.1.14.43

Carm.sace.05

Sirm.2.3.2no

lifist.2.1.10

(arm.3.10.20)

Epol.1. 13

s.rm.2.1.35

Curm.1.4.3

Eperl. I. 20

(inm.2.15.t

Sirm.I.I.2S 


\section{ARATRVM}

aratsum. inprimesetque nuris hostile aratum exercitue insolens. vicinas urbes alit et grave sentit aratrum.

aravit. qui mercennatius agrum illum ipsum mercatus aravit.

arbiter. fluo non arbiter Hadriae, maior. arbiter pugnate posuisse nuclo/ sub pede palmam/fettur. non locus effusi late naris arbiter

arbitrae. 'o sebus nu.is non infileles arbitrat.

arbitria. de te. splemlide, Minos/tecerit aibitria.

arbitrio. semulesum| permissum arbierio sine sordibus exstrue:

arbitrio. nec stumit aut ponit securis/arbitrio popularis aurae. epulum arbitrio Arti.

arbitrium. natris ad arbitrium recisos portare fusti=, quem penes arbitrium est el ius et norna boquendi.

arbitrum. quem lenus arbitrum, dicet bibendi?

arbor. crescit occulto velut arbor aevo fama sIarcellis: ubi nulla campis/arbor aestiva recreatur aura. devota non extinxit arbor quam nova collibus arbor inbacret. fiec aper, modo avic, modo saxumet, cum rolet arbor.

arbore. arbore nume aquas culpaste. antes graven quate legerit asbote solem.

arborem. nullam, Sare, sacra vite prius severis arborem suamelue pulla ficus of nat arborem.

arbores. et vitem viluas ducit ad arbores;

arboribus. auditam moderete arboribus fiden. redeunt ian gramina campir arboribusque conac:

asboris. jrope funeratualarboris ictu.

arborum. harmul quas colis atburum

lecta de pinguisimis/oliva ramiz asborum

arbos. sacrilega manu produxit, arbos.

Arbuscula. It andax, contemptis alits, explua Arbuscula dixit.

arbusta. est ut viro vir latius ordinet arbusta sulcia.

arbusto. expressa arbusto regeril conviciat.

arbuto. nume virili membra sub arbuto seratus.

arbutos. injune tutum per nemus arbutos/quacrunt latentic

arca. simul ac nummos contemplor in arca."

coneerros vili portanda locabat in atca;

cui seragula vestic. . . puerescat in arca:

an turpi clamsus in arca,

Arcadiae. niggi colles Arcadiac placent.

arcana. arcana cum fiunt sacra.

nec te l'ythagotae fallane areana renati

arcana. arcanta promotat loco.

ille velut fidis arcana sodalibus olinl credebat libris

arcanee. cui Cereric sacrum volgarit alcanae.

arcani. arcanique Fides prodiga, perlucidior vitso.

arcanis. et Jovis arcanis Minos admirus

arcanum. arcantum iocoso/ consilum retegis l. vaco.

ercanum. arcanum neque tu scrutaberis illius umęuam,

arcem. eros ubi ma in montes et in arcens ex urbe nemovi-

arceo. odi frotatum volgus te arceo.

arcere. cur mo fumento proprent arcule suterno;

arces. ille te meeum locus tot beatate punculant arces:

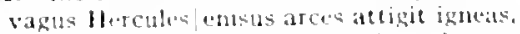

if [islastimas ride aequos aras [atces]

superbas invilate Karthagis Romanus arees ureger.

tluminat dicre ce atces montibus inpostas

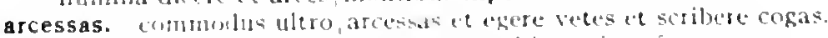

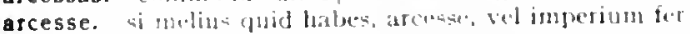

arcessitus. "puo reluturus etat hon arcesilus.

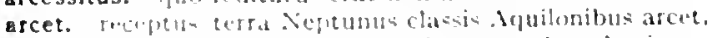

Archiacis. i phe Archicis convisab secmbere lectis

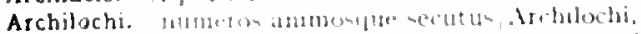

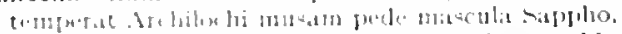

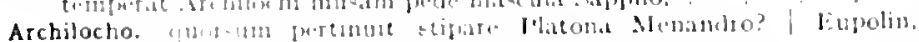

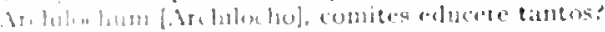

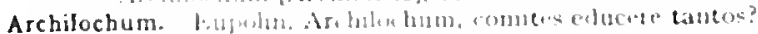

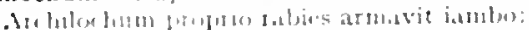

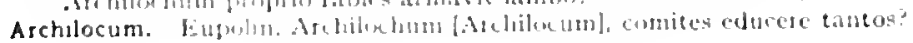

ARCHILOCVM

Carm.1.16.21

Ars Podters

Sorm.2.6.12

Carm.1.3.15

Carm.3.20.11

I.pist.1.11.26

I:poit 5.50

Carm.4 7.22

Sirm 2.5.105

Cirm.3.2.20

Sirm.2.3.8\%

Carm.3.6.40

Irs Port.72

Carm 2.7 .25

Carm.1.12.45

Carm.1.22.15

Carm.3.427

lipoll. 12.20

Serm.2.3.73

Carm.3.1.30

S.rm.2.4.23

carm.1.18.1

i.pod. $10.4^{6}$

(iorm.t.5.30

Carm.1 24.14

Corm.\$.7.2

Curm.3.8.8

Carm.2.1422

Iifol.2.5e

(ism m.2.13.3

verm.1.10.77

Carm.3.1.10

Sirm.1.7.29

Corm.1.1.21

Ciarm.1.17.5

Sermidetip

Serm. 1.8 .9

serm.2.3.119

sorm.2.7.50

(iarm.t 12.12

lepod.5.52

Jipotl.15.21

J.pod.11.1.4

Sirm.2.1.30

Carm.3.2.27

Curm.1.18.16

Carm.1.28.0

Carm.3.21.15

Jipist.1.18.37

serm.2.1.10

(iarm.3.1.1

lipist.s.50

carm.20.22

carm.3.3.10

fur.corm.siaec.05

J. pod. 7.0

ff pist 2.3 .252

1. pist.2.t 228

Fist 1.50

trerm. 2.3201

irs roctos

lipist 15.5

J.pist.1.1025

l.pist.1.12:8

iar Sirm 2.3.12

icrm.2.312

irs lot:o

idr term 2312 
Archyta. te maris et terrae numeroque carentis harenae/mensorem cohibent, Archyta.

arcis, dictus et Amphion, Thebanae conditor urbis [arcis], / saxa movere sono testudinis

arcis. rubente'dextera sacras iaculatus arcis/teruit libem, arcis|Alpibus inpositas tremendis/deiecit

Arcto. quis sub Arcto/rex gelidae metuatur orae.

arcton. nulla. - opacam|porticus excipiebat arcton

Arcturi. nec sacvos Arcturi cadentis|impetus .

arcu. non eget Mauris laculis neque arcu

doctus sagittas tendere Sericas/arcu paterno?

ian scythae laxo meditantur areul cedere campis.

perfidum ridens Venus et remisso|tilius arcu.

lyncas et cervos collibentis areu.

primusve Teucer tela Cydonio derexit arcu;

augur et fulgente decorus arcu $\mid$ Phoebus

arcum. suscitat $M$ usam neque semper arcum|tendit Apollo. numquam umeris positurus arcum

arcus. aut flumen Rhenum aut plovius describitur arcus; nec semper feriet quodcumque minabitur arcus.

arcus. hic ponite lucida funalia et vect is et tarcus / oppositis foribus minacis. ardens. lum gravis Cyclopum/Volcamus ardens visit officinas. at pater ardens saevit. .

ardentem. cui per ardentem sine fraude Troiam ardentem frigidus Aetnam/insiluit.

ardentis. quis puer ocius|restinguet ardentis Falerni|pocula

ardentis. semper ardentis achens sagit tas|cote cruenta.

ardeo. o mare et terra, ardeo.

arderet. rubro ubi coccol tincta super lectos canderet [arderet] vest is eburnos ardet. Fervet [? ardet] avaritia miseroque [? caecaque] cupisline pectus: nam tua res agitur, paries cum proximus ardet,

ardor. non civium ardor prava iubentium.

sed alius ardor aut puellae candidae |aut teret is pueri

sed alius ardor [ardor alius] ant puellae candidaelaut tetetis pueri

ardua. quod pulcrae clunes, breve quod caput, ardua cervix.

arduae. virtutisque viam deserit arduae.

ardui. nil mortalibus ardui est:

arduis. quis neget arduis/pronos relabi posse rivos|montibus nolem propinquan nubibus arduis.

arduis. aequam memento rebus in arduis|servare mentem.

arduom. cum larentis regna per arduom/cohors gigantum scanderet inpia, arduos. Fester, Camenae, vester in arduos/tollor Sabinos.

arduum. nil mortalibus ardui [arduum] est:

area. milia frumenti tua triverit area centum: ponendaeque domo quaerenda cst area primum:

areae. nunc et campus et areac... repetantur

areis. quidquid de Libycis verritur areis.

Arelli. siquis nam laudat Arelli|sollicitas ignarus opes. .

arente. arente fauce traxerim,

arentes. navita Bosporum / temptabo et urentis [arentes] harenas / litoris Assyrii viator,

arentis. navita Bosporum | temptaboet urentis [arentis] larenas / litoris Assyrii viator,

aret. ingera centum an mille aret? serviet utiliter; sine pascat clurus aretcue, .

argentea. ubi vasa praetereo sapiens argentea.

argenti. quid iuvat inmensum te argenti pondus tet auri hunc capit argenti splendor; stupet Albius aere; ambitione mala aut argenti pallet amore. pauper Opimius argenti positi intus et auri, o si urnam argenti fors quae mili monstret. quem tenet argenti sitis inportuna famesque,

argento. nullus argento color est araris|abdico teri is. miraris, cum tu argento post ommia ponas.

argento. ridet argento domus.

argentum. vilius argentun est auro, virtutibus aurum. quacritur argentum puerisque beata creandis|uxor

argentum. argentum et marmor vetus aeraque et artis/suspice. . "nempe pecus, rem, lector, argentunt tollas licet."

Carm.1.28.2

Fir.Ars Poel.394

(arm.1.2.3

Carm.4.14.1 I

Carm.1.26.3

Carm.2.15.16

Carm.3.1.27

Carm.I.22.2

Carm.1.29.10

Carm.3.8.23

Carm.3.27.08

Carm.4.6.34

Carm.4.9.18

Carm.Saecor

Carm.2.10.19

Carm.3.4.60

Ars Poel. 8

Ars I'oet.350

Carm.3.26.7

Carm.1.4.8

Sirm.1.4.45

Carm.Saec.4 I

Ars Poel.405

Carm.2.11.19

Carm.2.8.15

Ispod. 17.30

coni.serm.2.6.503

7ear.Epist.I. I.33

Epist.1.18.84

Carm.3.3.2

Lipod.11.27

coni.Epol.I $[.27$

Serm.1.2.89

Carm.3.24.44

Corm.1.3.37

Carm.1.29.10

Carm.3.20.10

Carm.2.3.1

Carm.2.19.2 I

Carm.3.4.2I

z'ar.Carm $\quad 1.3-37$

Serm.1.1.45

Epist.1.10.13

Carm.1.9.18

Carm.I.I.IO

Serm.2.6.78

Epod.14.4

var.Carm.3.4.3 I

tar.Carm.3.4.3 I

Serm.I.I.5I

Epist.1.16.70

Sirm.2.7.73

Serm.I.I.4I

Sorm.1.4.28

Serm.2.3.78

Serm.2.3.142

Serm.2.0.10

Epist.1.18.23

Cum.2.2.I

Serm.1.1.80

Carmatio

Epist.I. I.52

Eist.1.2.4.

lipist.1.6.17

Epist.1.10.70 


\section{ARGENTVM}

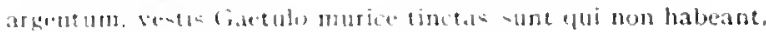

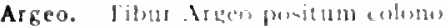

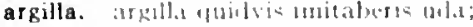

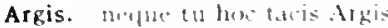

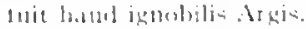

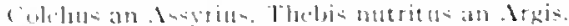

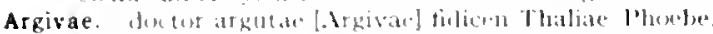

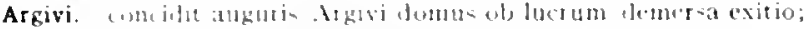

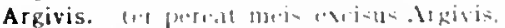

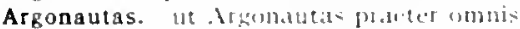

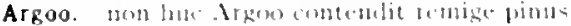

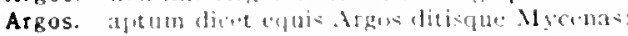

arguens. nomor et in gersia tution labitur arguens,

arguet. arklne andsigut dictum, mutatula mothbit.

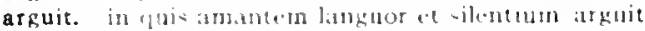

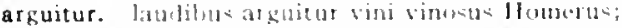

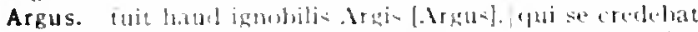

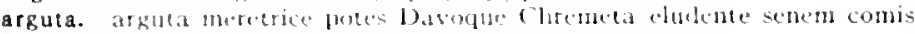
giatire libuthos

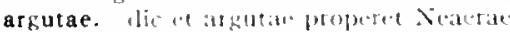

docetor argentace fielicen Thabiate

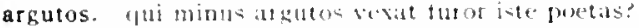

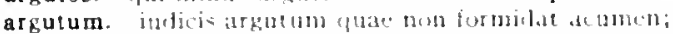

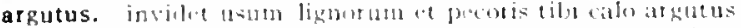

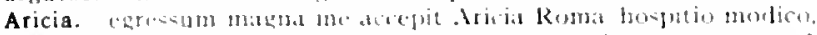

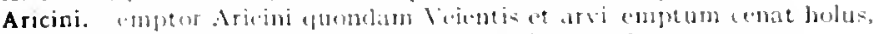

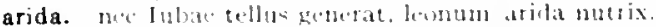

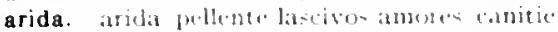

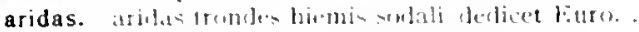

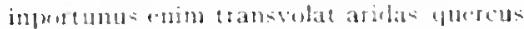

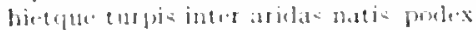

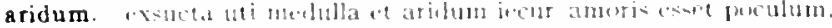

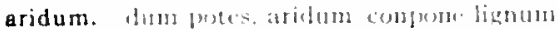

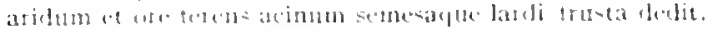

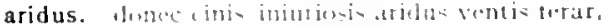

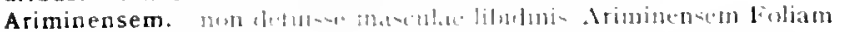

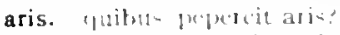

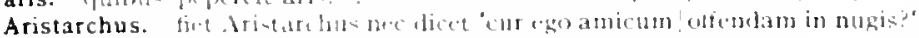

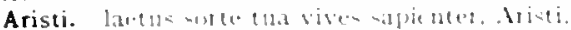

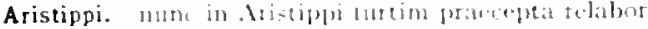

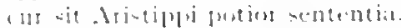

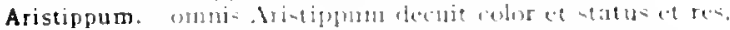

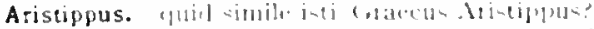

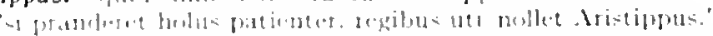

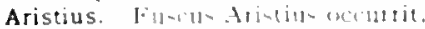

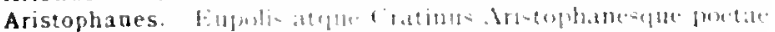

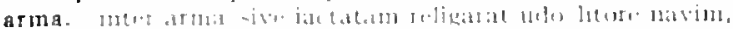

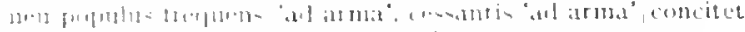

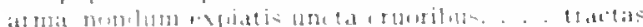

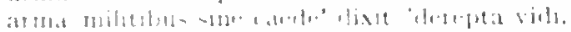

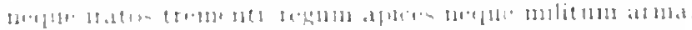

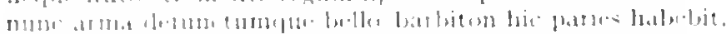

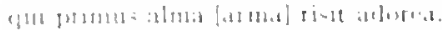

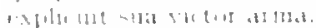

a.g

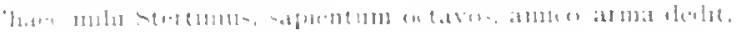

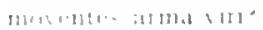

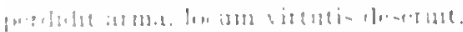

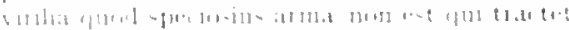

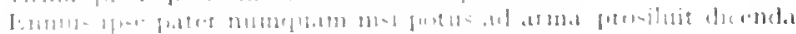

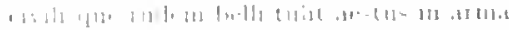

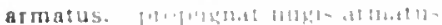

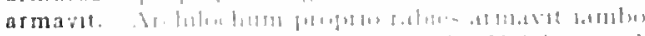

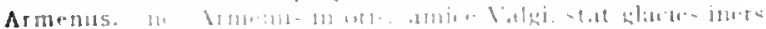

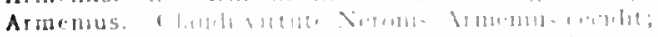

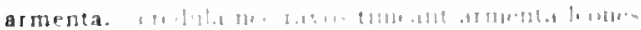

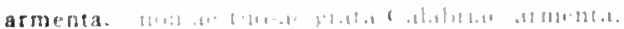

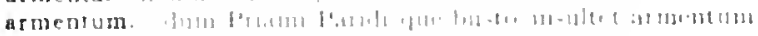

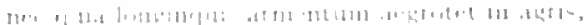

ARMENTVM

Fist.2 2.181

('arm.2.13.5

lipive.2.2.8

Sirm.2.3.132

I:pist 22.128

1re Petis is

:ar ciarm.to.25

Ciarm 3.je.12

(iarm.3.3.18

lipol 39

lepodere.57

(iorm.1.7.1)

(arm.1.13.7

Ars lortat9

lipod.11 10

lipist 1.19.8

iar. Ispist. 2.2 .128

Serm.1.10.10

Carm.3.14.21

Ciurm.t. 0.25

lipist.2.2.00

Ars l'oct.304

lipistilit 12

serm.1.5.1

lipise 2.2.105

(urm 1.22.10

(iarm.2.110

(arm.1.25.10

(iurm.1.13.0

l:plond 8.5

1:Pod.5.3.

(idrm 3.17 .13

tirm.20.45

l. perd.1 $1,3.4$

tipend $5.2_{2}$

(arm.1.35.3s

Airs lient.p5o

Epist.1014

lepten.ts

l.pive1.17. 7

lepist.1.1\%.2.

irm.2.3.10u

lipost.1.1.14

sermelader

Siples. I. I I

( $\mathrm{rarm} 13230$

(

(armizat

form 3.5. Iu

(iurme.3 2120

(iarm.3.20).3

orr cirm $+4+1$

(armati) it

fipiat o. 1.3

Serm 2 3 ant

Sirm.2.7. [111)

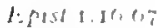

f.mos 1 185

lpul 10;

l.pul 2.2

1. Po: 1. 1 स te

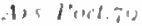

( a $\left.n^{2}: 1\right)$,

fond 1228

1. pord let is

(

(asmi.3 \& is

l.pest a s.e 
armis. siutuid abest, Italis adiudicat armis. jura nege't sibi nata, nihil non arroget anmis.

armis. neque iam livida gestat armis/brachia hunc tanget armis, visere gestiens. hostium . . consenuit socerorum in armis Nedus infestus sibi luctmosic' dissilet armis. te caede gaudentes Sygambri conpoxitis venerantur armis. 'o fortunati mercatores' gravis armis, miles ait, pugnabant armis quae post fabticaterat usus, rides $\mathrm{T} u r b o n i s$ in armis | spiritum et incessun: armis, Herculis ad postem fixis res Italan armis tuteris, moribus or nes, nec virtute foret clarisve potentius armis/quam lingua Latiun. lndere qui nescit, campestribus abstinet arnis

armorum. iam fulgor armorum fugacis terret equoz

armos, mantica cui lumbos onere uleeret atque eques armos: fecundae leporis sapiens stectabitur armos. et leporum avolsos, ut multo suavius, armos,

arrepta, arreptaque manu "quid agis, dulcissine rerum?"

Arri, epulum arbitujo Arri. Quinti progenies Arri, par nobile fratrum, .

arripe. "nunc age, luxurian et Nomentanum arripe meeum: lenter in spem adrepe farripe] oliciosus,

arripit, media de nocte caballum / arripit

arripuit. prinares populi arripuit populumque tributim. quem vero arripuit, tenet ocilitque legendo,

arrogantem. sublimi flagello tange Chloen semel arrogantem.

arrogantis. invicem moechos anuc arrogantis

arroget. nee sibi cenarum quivis temere arroget artem. scire velin, chartis pretium quotus arroget annus. iura neget sibi nata, nibil non arroget armis.

arserit. imagine cerea largior arserit ignis

arsisse, non aliter Samio dicunt arsisse Bathyllo Anacreonta Trium.

arsisti. 'donec non alia magis! arsisti

arsit, arsit Atrides medio in triunuplo|virgine rapta.

non sola comptos arsit adulteri, crinis

ubi sedulus hospes paene macros arsit

nunc athletarum studis, nunc arsit equorum,

arta. arta decet sanum comitem toga;

arta. neque me sub arta, vite bibentem.

arta. sed nimis arta premunt olidae convivia caprae.

arte. arte matema rapidos morantem thuminum lapsus

hac arte Pollux et vagus Hercules/enisus arces attigit igneas, qui salutari levat arte fessos corpotis artus. ut arte cmendaturus fortunam; an tragica desaevit et ampullatur in atte?

ujit enim fulgore suo qui praegravat artes [?artel / infra se positas ['positos]:

vincere Caecilius gravitate, Terentius arte.

praecipue cum se numeris commendat at arte.

in vitium ducit culpae fuga, si caret arte.

nova fictaçue nuper habebunt resba fidem, si Graeco tonte cadent parce [arte] detorta.

ingenium mistra quia fortunatius arte credit

fabula nullius veneris, sine pondere $t$ t arte.

natura fieret laudabile carmen an arte.

artem. mini Phobus arten/carminis nonenque dedit poetar.

nec sibi cenarum quivis temere arroget antem.

aut spem deponas aut artem inlusus omitas.

di tibi diritias dederunt artemque frurndi.

quam scit uterque, libens, censebo, exerceat artem.

quod timui mutare nodos et carminis artem:

artes, qui praegravat artes intra se positas:

Graecia capta lerum rictorem copt te artes intulit agresti $\mathrm{E}$ atio:

tanto cum strepitu ludi spectantur et attes diritiatpue peregrinae.

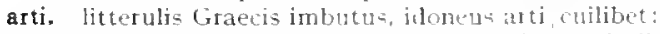
sic priscae motumque et luxurien aldidit atti, tibien

artibus. iudicium subtile vichedis artibus illud

artibus, motus doceri gandet Ionicos, matura rirgo et fingitur artibus

Lisist.1.18.57

Ars l'oet. 22

("arm.1.8.10

Carm $3 \cdot 3 \cdot 3.54$

(arm.3.5.8

(arm.3.8.20

Curm.1.1.52

(o) iskerm.1.1.1

serm.1.3.102

serm.2.3.310

Epist.1.1.t

Epist 2.1.2

Ars Poct.289

Ars Port.379

Cirm.2.1.19

Serm. [-1.10e

Serm.2.4.t

Serm.2.8.89

Serm. I.0.4

Sirm.2.3.sts

serm.2-3.243

serm.2.3.224

for..serm.2.5.18

Epist I.7.8y

sirm.2.1.0

Ars Inet.475

Carm.3.2t.12

Cirm.1.25.9

Sirm.2.+35

Epist.2.1.35

Ars Joet.122

Sirm.1.8.t

Ispod $1+9$

Carm-3.0.0

Carm.2.t.

Carm.4.9.13

serm.1.5.72

Epint.2. 95

Itpist.1.J.30

Carm.1.38.?

Epist. 5.29

Carm.1 2.9

Carm.3.3.9

Curm Sadects 3

sirm.2.58

Epist.1.3.14

3 nar. Fpist 2.I.I3

Epist.2.1.59

Epil.2.1.201

Ars loet.3 I

sar. Ar Pret. 53

Ars fluet. 295

Ars bot 320

Ars livet tos

(irm.t.0.20

rerm.2.4.35

serm.2.5.20

IPPint.A.7

I.pistatitit

EPR:I.T.27

LPin 2 I. I 3

I.pt: t.2.t.150

Epist.2.1.21.3

Epit2.2.7

Ars lot.21:

Jefiet 2. 242

(arm.31.2z 


\section{ARTIBVS}

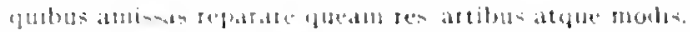

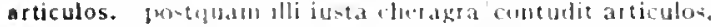

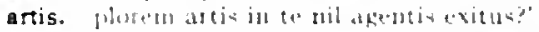

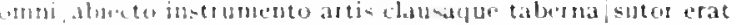

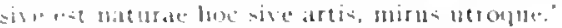

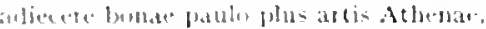

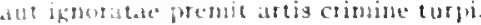

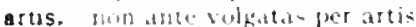

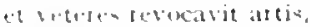

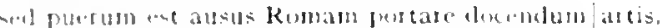

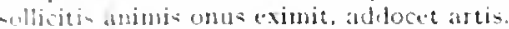

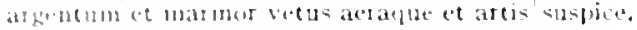

artis. erigute artin litibus implicitum.

artium. tet cetum puer artum

givite mue scilicet attium

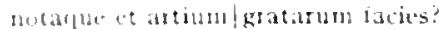

artius. artius alepe letera proceta ad-tingitur itex

arto. "Ner arto laticancen truticeto cxcipere aprum.

l.us irto -tipata theatro, spectat Roma potens.

artubus. nutus loceri gaudet [onicos. . et fingitus artibus [artubus]

artum. Ut taneds attum solveret hospitis animum.

macta caroun tepetes artum. gurm macta subint."

now de-plies imitator in artum.

artus. gui silutari levat ate dessus, corpori- artus.

arva. Fila tumidus rikit as va Xilun.

vili... arba Marte coli populata moseru

arva luextat petambs.

atra divituset insulas,

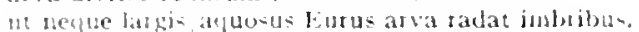

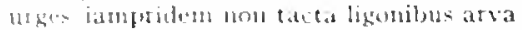

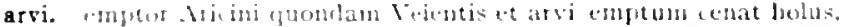

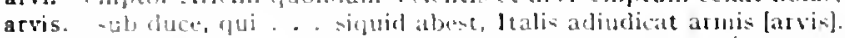

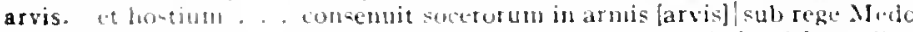

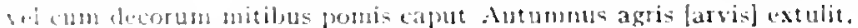

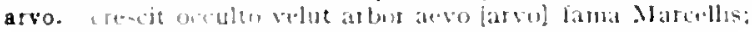

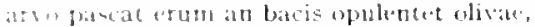

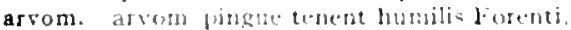

Befrlate drelibe contemplutsa atron

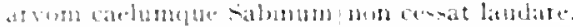

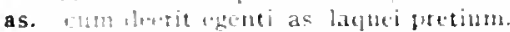

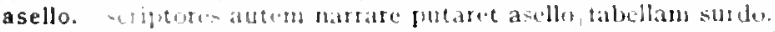

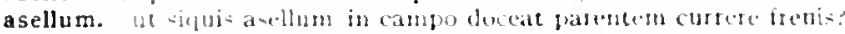

guj male jarouten in tupis potrusic asellum iratus:

asellus. demito auriculis, wt iniruae montis anellus,

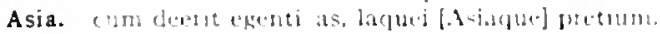

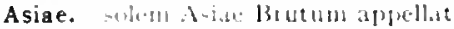

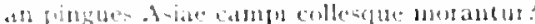

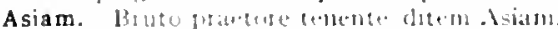

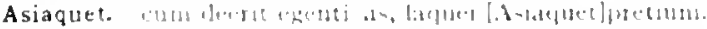

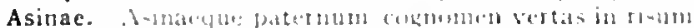

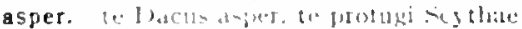

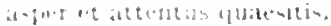

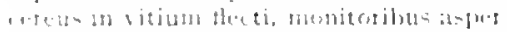

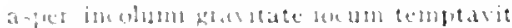

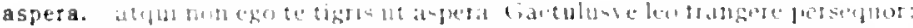

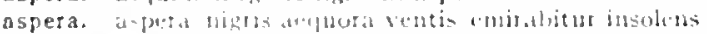

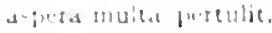

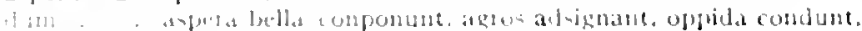

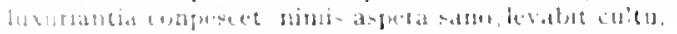

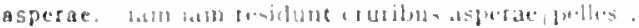

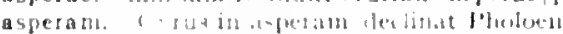

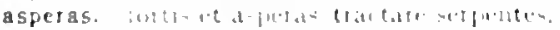

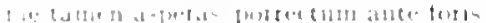

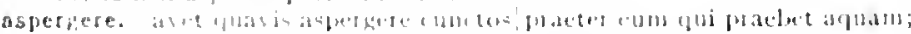

aspetoribus. Murabs a

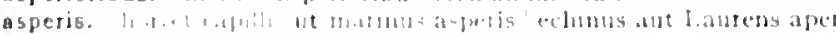

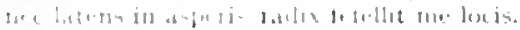

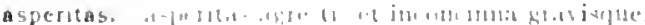

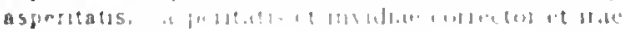

ASPERITATIS

Serm $2.5 \cdot 3$

Term.2.7.10

1.pod.17.81

Serm.1.3.131

cerm.2.4.7

i. pist. 2.2 .43

- Irs luet.2\%2

(arm.4.9.3

(idm.t.15.1:

Germ.1.0.7

L.fist.1. 5.18

Epist.1.0.17

Ars l'tect.d23

Carm.t1.15

Corm.4.8.5

Corm.4.13.21

lipod.15.5

Curm.3.12.1 I

Efist.2.1.60

:'ur.Curm.3.0.22

Serm.2.0.82

Epist. 1.7 .33

Ars loct.134

Carmsiaccos

Carm.3.3.48

(arm.3.5.23

lipod.10.41

lifordese.42

Fipod.10.54

lipish 1427

lipist.2.2.167

conitlopist. is.57

coni. Carmi.3.5.8

(a). I. pod.2. Is

contc arm.1.12.45

EDpsid.10.2

Ciurn.3.1.13

(arm.3.2us 7

1.pist.1.7.77

Striz2.20

I.pist.2.1.199

Sirm.s.1.00

lipisint.20.15

Sirm.1.9.20

acr.term.2.2.00

sorm.1.7.2.

l.pist.t.3.5

Sermit.7.19

atr.term.2.2.2u

Fipis.1.13.8

( arm.1.35.9

Sorm.2. 2.s?

Irs Pectedo.3

- Irs Jock.221

(iurm.1.239

Curm.t.5.s

l.pisl.1.2.2!

J.p151.2.1.7

IEstit2.2122

(iurm 2200

(arm.3.33.0

(urm.1.37..."

(arm.3.11, 2

firm. 1.4.5.

(4) $3: 3.2153$

1. pud.5.27

I. fort. 5.8.

I peses lse

1002121 
asperrimus. cave. cave, nanque in malos asperinut patiata tollo cormus. asperum. aspenun| tactu leonen.

aridun et ore [? asperum et oral ferens acinum semesagur lardi fiusta aspexit. qui semel adspexit [aspexit]. quantum dimissa petitis praestent, mature redeat

aspice. chalen commendes, etian atqut etian aspice.

Assaraci. te manet Assaraci tellus.

assem. 'quod. si conmintus. vilen redigatur al asten.'

iu trivio fixum cum se demittit ob assem,

lassus fum noctu stertit, ad assem/perdiderat: .

assen ldiscunt in partis centum diducere.

assibus, 'quanti emptae?" "parvo." "([manti ergo?" octusil)us [octo assibus]" assint. ut ridentibus adrident, ita flentibus adtent [assint]| liumani voltus. assis. unius assis/non umquam pretio pluris licuisse.

assis. ignarun, ... quibusasis languirlus incubitumianseconvisareponet. assis. simul assis miscueris elixa, simul conchylia turdis,

assos. siquis uunc mergos suavis elixerit assos.

assunt. ut rideutibus adrident, ita flentibus adtlent [assunt]|innani voltus.

Assyria. dum licet. Assyriaque nardo'potamus uncti?

Assyrii. wrentis harenas, litoris Assyrii viator,

Assyrio. Assyriaque [Assyioque] nardo potamus uncti?

Assyrius, Colchus an Assyius. Thebis nutritus an Argí.

ast. ast ego vicissin risero.

ast ubi me fessum sol acrior ire lavatumladmonuit,

ast importunas rolucris in vertice harumdo' terret fixa

Asterie. quid fles, Asterie, quen tibi, candida, / primo restituent vere Favonii

astra. dum rediens fugat astra Phoebus.

nocte sublustri nilil astra praeter|vidit et undas.

noresulue aureos educit in astra

"tu pudica, tu proba|perambulabis astra sidus aureun.."

absentem rusticus Viben|tollis ad astra levis.

astri. nullius astri gregem aestuosa torret inpotentia.

astrum. utrunique notrum incredibili modolconsentit astrum;

astrum. scit Genius, natale comes qui temperat astrun.

astuta. astuta ingenuon rolpes imitata leonem? -

astutum. pro bene sano ac non incanto fictun astutumque rocanus.

astutus. cantes astutus ibique testanenta senum.

Lipod.6.1 I

Carm.3.2. I0

? our.ser:n.3.t.85

var Hoist. I. T. gr

Epist. I. I 8.70

Epol.13.13

Sirm.1.1.43

Epist.1.10.04

Ifpist.2.2.27

Irs Poet.325

a ar. Serm.2.3.156

var..1rs Poel.10I

serm. I.6.13

sirm.2.4.38

Serm.2.2.73

Se'm.2.2.5I

rar. Ars Poeb. [OI

Cirm.2.11.16

Curm.3.4.32

fur. Curm.2.1 1.16

Ars l'oel. I 8

Ispod.15.24

Sirm.1.0.125

Strm.1.8.6

Carm.3.7.I

Carm.3.2I.24

Carm.3.27.31

Carm.t.2.23

lipod.17.4

Serm.2.7.29

Epod.10.01

Curm.2.17.22

lepist.2.2.187

Sirm.2.3.180

Serm. I.3.02

5 serm.2.5.23

at. Carm.1.28.23; tur.Carm.1.31.18; Carm.1.35.25;2.9.13; 2.18.9; 3.7.22;1.pot.2.29;3.19;5.1; lipod.5.25; cont.Epod.9.1;; Serm.1.1.44; I.I.51; I.I.59; zur.Serm.1.1.0I; Serm.1.1.66; Sirm.1.1.80; zar.Serm.1.1.88; Sirm.1.1.99; iar.Serm.1.1.109; Serm.1.2.18; 1.2.47; I.2.49; Serm.1.2.73; 1.3.27; $1.3 .32 ; 1.3 .33$ (bis); 7.1\%.Serm.1.3.43; Serm.1.3.51; 1.3.5.5; 1.4.19; Serm.1.4.48; 1.4.67; 1.5.60; tar.Serm.1.0.6; Serm.1.6.40; I.6.42; 1.0.47; 1.6 .87 ; zar..Serm.1.7.10; Serm.1.7.32;1.8.37; 1.8.47; I.9.6;1.9.7 I; 1.10.3; I.10.20; I.10.23; 1.10.50; Serm.2.1.44; 2.2.40;2.2.73; 2ur.Serm.2.2.1 10; Serm.2.3.4; 2ur.Serm.2.3.189; Serm.2.4.53; Serm.2.4.93; 2.6.32; 2.6.51; 2.7.100; Epist.1.1.59; 1.2.42; 1.7.16; :0r.Lsist.1.7.40; Epist.1.10.3; 2.1.245; 2.2.109;2.2.155; Ars Potl.270; zur.Ars Poet.3.30

Atabulus. quos tortet Atabulis ct quos numquam erepsenus,. $.5 \mathrm{p}^{2} .1 .5 .78$

Atacino. experto frustra Varrone Atacino . . . . . Sirm. . . . . . . . . . .

atavis. Maecenas atavis edite regibus,

ater. visendus ater flumine languido|Cocytos errans

Camm.1.I

ego quid sit ater Hadriac novi sinus

cum sit tihi flens ater

voltu mutabilis, albus et ater.

Athenae. adiecte bonae paulo plus at tis Athenae.

Athenas. ingenium, sibi quod racuas desumpsit Athenas

Athenis. ut quidam memoratur Athmis sordidus ac dives, -

iam mallet doctus Athenis/vivere.

ut nagus, et modo me. Thelis, modo ponit Athenis.

athletarum, nunc athletarum studis, nunc arsit equorum.

Atlanteus. Taenari!serles Atlanteusque finis/concutitur.

A:lanticum. ter et guater, anmo revisens aequor Atlanticum inpume. .

Carm.2.1.17

Carm.3.27.18

Epod.8.3

Epist.2.2.189

lopist.2.2.24.3

lipist.2.2.8 I

Serm. I. I.64

Sirm.2.7.13

Epist.2.1.213

Epist.2.1.95

Carm.I.34. I I

Carm.1.31.1.4

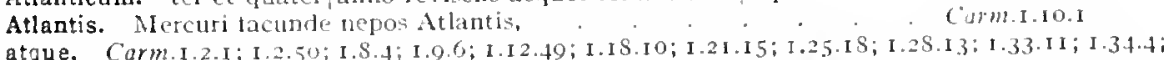

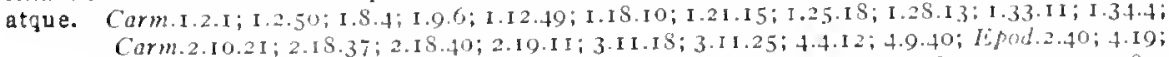

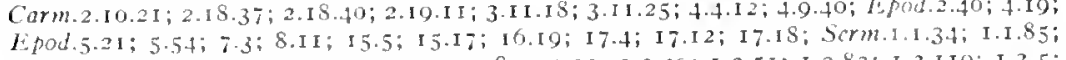
Sorm.1.I.I 2; 1.2.7; 1.2.10; 1.2.14; 1.2.18; I 2.22; 1.2.40; I.2.51; 1.2.82; 1.2.1 I0; I.3.5; Serm.1.3.12; I.3.51; I.3.55; I.3.6I; I.3.83; I.3.98; 1.3.I00; I.3.10I; I.3.1 29; 1.4.1 ; I.4.2; Serm.I.4.12; I.4.43; 1 4.102; 1.4.107; $.4 .126 ; 1.5 .4 ; 1.5 .16 ; 1.5 .25 ; 1.5 .27 ; 1.5 .31 ; 1.5 .76 ;$ 


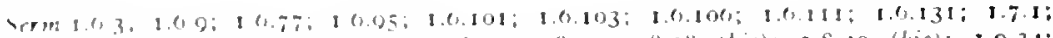

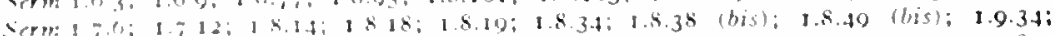

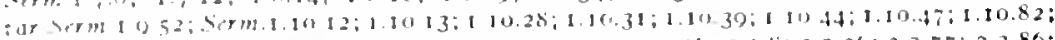

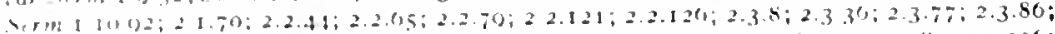

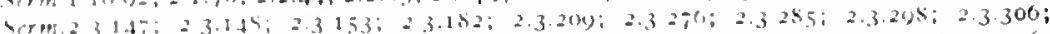

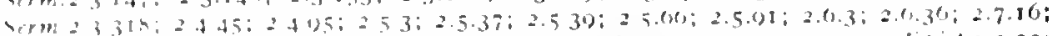

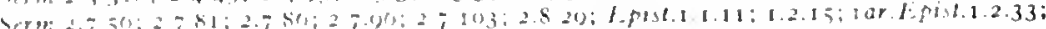

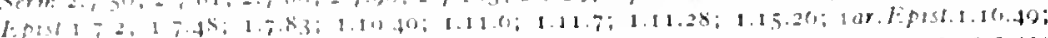

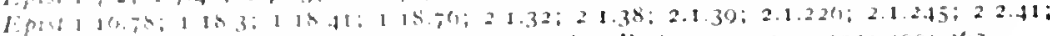

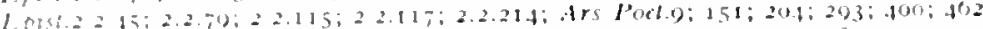

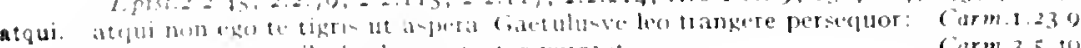

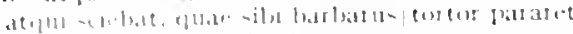

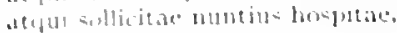

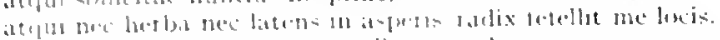

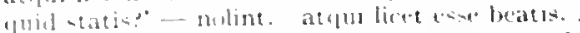

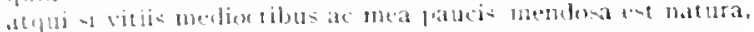

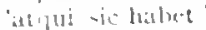
at)

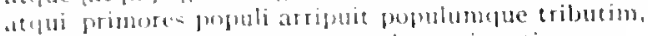

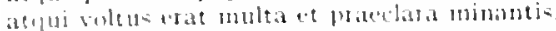

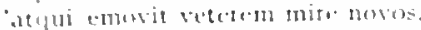

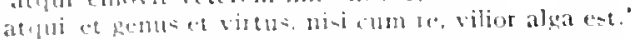

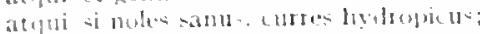

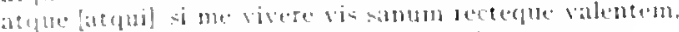

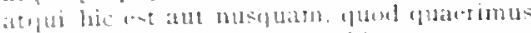

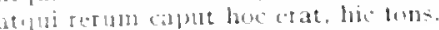

atra. vimul atra luber comdidit lithats

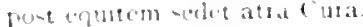

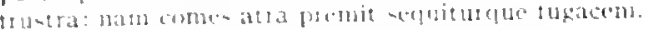

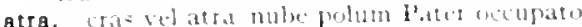

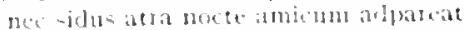

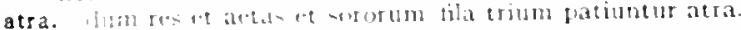

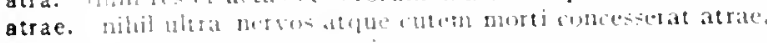

atrae. minlutut ats.l. carmint curat.

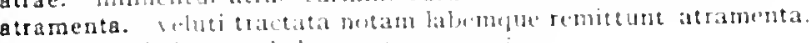

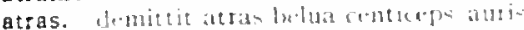

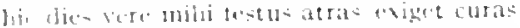

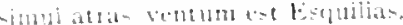

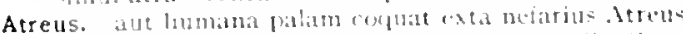

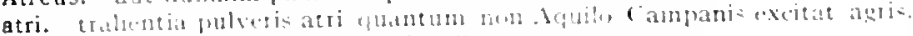

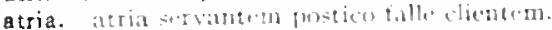

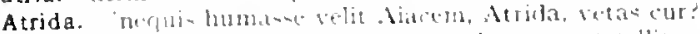

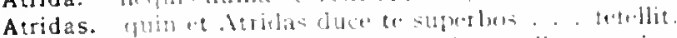

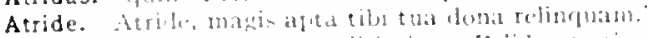

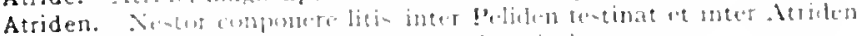

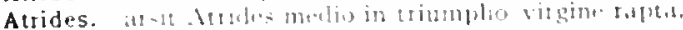

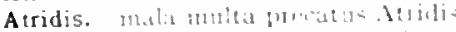

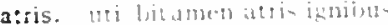

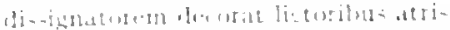

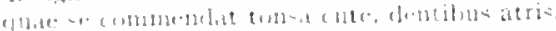

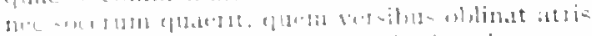

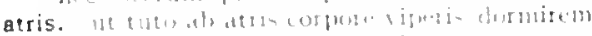

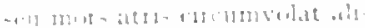

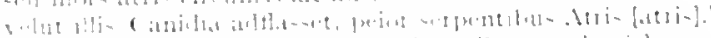

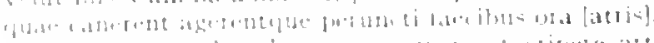

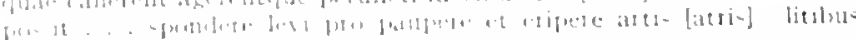

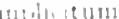

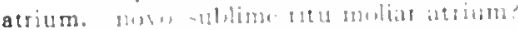

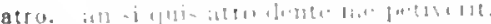

a.

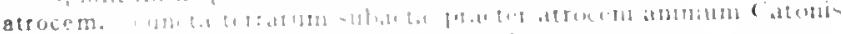

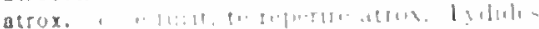

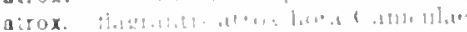

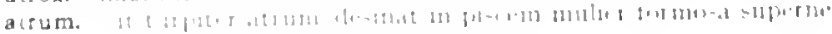

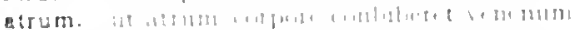

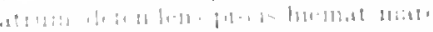

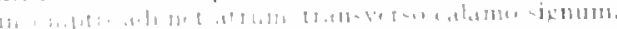

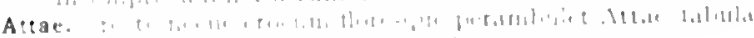

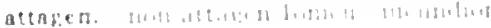

(arm.3.5.

Carm.3.7.0

trood.5.17

Serm.1 1.19

Sich 1.6 .05

serm.1.0.52

coni.ferm, I.10.31

Serm.2.1.0

Sirm.2.3.0

Sorm.2.3.27

Sirm.2.5.7

Epist.1.3.33

lar Ifpist.1.7.2

Ispist.1.17.3s

l:pis!.1.17.45

(a)m.z. 10.2

Carm.3.1.to

Serm.2.7.115

(arm.3.20.43

I. pud.10.9

(inrm.2.310

Carm, 1.2\$.13

Carm A. I 1.35

I. Pict.2.1.230

Carm.2.13-3.t

Carm.3 1.4 1.3

setn. 2.6.32

Ars Pont. 180

s.Yun.2.5.53

I.pose15.31

Sirti.3.15

Carml.1.14.13

f: 0101.17 .43

I.pist.2.1 =

("irmil. 2.7

serm 23.203

find $5 \times 2$

I:pivi.1.7.t

1 pirt.18.7

1.pist 1.10 .30

(i) 191.3 .17

serm.2.1.58

iar.scrm.2.8.05

int.elrs l'oet.277

idr Ars lime.423

(arm.31 fo

1:.1.4.1.10.15

f fectitis

(arti:- 12.8

(a)roti. 1, 15:7

( $13 \mathrm{ron}+130$

Irs I I ind 3

(a) $13 \%$

Selm: 210

Irstiul it?

fpol: 1 ;

l. pind = 5 : 
Attali. neque Attali/ignotus heres regian occupavi

Attalicis. Attalicis condicionibus numquam demoveas. . an venit in votum Attalicis ex urbibus una.

attamen. 'attanen et iustum poteras et scribere fortem, attemptas. mecum facientia iura|si tamen attemptas? . attentam. verba per attentam mon ibunt Caesaris aurem. attenti. ut patris attenti, lemonis ut insictiosi.

attentius. spectaret populum ludis attentius ipsis,

attentus. asper et attentus quaesitis.

'durus", ait, 'Voltei, nimis attentusque videris/esse mihi.'

attenuat. insignem at tenuat deus/obscura promens;

atterens. Curberms.. . leniter atterens/caudam

Attica. ut Attica virgo|cum sacris Cereris

Atticis. finibus Atticis reddas incolumem precor

attigit. hac arte Pollux et vagus Hercules/enisus arces attigit igneas,

attineat. tamquam ad rem attineat quidquam.

attinent. Parthum dicere nec quac nihil attinent.

attinet. nec quat niluil attinent [attinet].

te nihil attinet i temptare multa caede bidentium

quid attinet tot ora navium gravi|rostrata duci pondere

attingit. res gerere te captos ostendere civibus hostis/attingit solium lovis

attollens. et tollens [attollens] vacuom plus nimio Gloria verticem

attollere. nec semel inrisus trivis attollere curat 'fracto crure planum.

attonitus. ternos ter cyathos attonitus petet vates;

ternos ter cyathos attonitus [attonitus cyathos] petet|vates; .

auceps. pomarius, auceps. . . mane domum veniant. si veluti mermlis intentus decidit aucepsin puteum.

auctius. anctius atque/di melius fecere.

auctor. iudice te non sordidus auctor, naturae veripue.

donec labantis consilio patres firmaret auctor

est auctor quis denique corum, / vixi cum quibus?

quam rudia et Graecis intacti carminis auctor

donec vos auctor docuit practorius.

ipsa memor praecepta canam, celabitur auctor.

hoc amet, hoc spernat promisi carminis auctor.

quis tamen exiguos elegos emiserit auctor,

auctor. sive neglectum genus et nepotes/respicis, auctor

auctoratus. uri virgis ictroque necari|auctoratus eas.

auctore. ter si resurgat murus aenens|auctore Ptocho, auctore ab illo dicis originem.

actorem. "habes auctorem, quo facian hoc"

auctos. et vixisse probus, anplis et lonoribus auctos;

audacem. saepe etiam audacen fugat hoc teretque poutan,

audaces. nautaeque, per omnelaudaces mare qui currunt.

audacis. inter audaeis Iupus errat agnos,

seu per audacis nova dithyrambos, verba devolvit

audax. Enceladus iaculator audax

verum ambitiosus et audax:

ultro' qui meliorem audax rocet in ins.

ut nibil intersit. Davosne loquatur et audax Pythits.

audax. audax omnia perpeti gens humana

proximos illi tamen occupavit $\mid$ Pallas houtes $/$ proeliis autax

scatentem beluis pontum mediasfue fraudes palluit audax.

ut audax, contemptis aliis, explosi Arbuscula dixit.

paupertas inpulit audax / ut versus facerem.

audax. audax lapeti genus

aude. aude Caesaris invicti res dicere. dimidium tacti, qui coepit, habet: saperte aude,

audeat. indomitan audeat refrenare licentian. neque illine auteat esuriens doninus contingere granum

audebit. vir bonus et sapiens audelsit dicere: audebit. . verba movere loco.

audendi. pictorihn atque portis | quillibet audendi semper fuit aequa potesta:.'

audent. qui caput ct stomachun supponere fontibus audent, Clusini:

audes. "tume. . . audes deicere de saxo civis aut tratere Cadmo:" ipse quid azurles?

nulline faterier audes?

audes/personam formare novan,.
Carm.2.18.5

Carm.1.1.12

Epist.1.11.5

Sirm.2.I.I

Epist.2.2.24

Sirm.2.1.19

Epist.2.1.172

Epist.2.1.197

Serm.2.0.82

Epist. 1.7.91

Curm.1.34.13

Carm.2.19.30

S.rm.2.8.13

Carm.1.3.\%

Carm.3.3.10

Sirm.2.2.27

Carm.1.19.1 2

Far.Carm.1.19.12

Carm.3.23.13

Epoldte17

Efist.1.17.34

vir.carm.1.18.15

Epist.1.1\%.58

Carm.3.19.14

rear.Carm.3.19.I4

Serm.2.3.227

Ars Pott. 459

Serm.2.6.3

Carm.1.28.14

Carm-3.5.45

Serm.1.480

Serm.1.10.60

Serm.2.2.50

Serm.2.4. I I

Ars Poct. 45

Ars Puet.7

Carm+1.2.30

Serm.2.7.59

carm-3-3ress

Carms.5

sermet $12+$

Serm.1.0.11

Ipist.2.1.182

Sirm.1.1.30

Carm.3.18.13

Carmot.2.10

Curm.3.5

Serm.2.3.1\%5

Serm.2.5.20

Ars 1'uct.237

Carm.1.3.25

Carm.1.12.21

Cirm.3.27.28

S.rm.1. [0.70

Epist.2.2.5 I

cirm.1.3.27

Serm.2.1.10

Eprot.1.2.tu

Cirm.3.24.28

Sirm.2.3. 13

L.pist.1.16.73

I. fish.2.2. I 11

Ars Poel.io

Epist.1.15.S

Serm 1.0.3s

Epist.1.3.20

I.pist.2.2.14s

Ars l'oet. 25 
audet. Fratid. . audet dicere nuda choros:

Curm.4.7.5

neglecta redice birtus/audet

Carm.Suec.59

habrotonum aegto mon auket nisi çui didicit dare.

lipist.2.1.115

nam spirat tragion satis et telicier audet.

nec meds audet rem tomptare pudor quam vires ferte recusent.

Epist.2.1.160

nui nercit, versur tamen audet fingere.

audi. supplices audi puetos. Apollo;

-jderum regina bicornis, audi. Luna. puellas.

Epist.2.1.258

Ars Poet.3\$2

Curm.saec.34

Carm.tivec -35

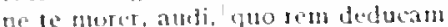

, ur ita crelidesius, nini quid te detinet, audi.

nunc age, quil moserum concentum dividat, audi.

Serm.1.1.14

E.pist.1.2.5

Epist.1.14.31

lipist.1.17.10

junior atudi, eur sit Aistippi potior sententia.

mux etian, i forte vacas, secfuere et ptocul audi.

EDist.2.2.95

t11. quid ego et populus mecum desideret, audi.

Ars P'oet.153

Carm.3.25.4

audiar. qubus antris egregii Caeraris audiat.

Carm.1.13.13

audias. mon, si me satis audias.

audiat. audiat lyde scelus atyue notas, virginum poenas

Carm.3.11.25

Carm.3.19.22 audint invidusidementem serepicum Lycus

audiendum. siquid lorpar audiendum.

audientem. prece qua fatigent/virgines sanctae minus audientem/carmina Vostam? - bo bili decedere pravan stultitiam;

audieras. audiefas, cui rem di donarent, illi decedere pravam stultitiam:

audieris. "quartar sit partis Vlixes" audieris "heres": . ruticl hoc intersit, ab ipsolaudieris tnelius.

Carm.t.2.45

audierit. non magis audierit, quam Fufius ebrius olin, .

audiet. audict civis acuisse fertum. andiet pugnas vitio parentus tara iuventus. dixet in insunum qui me, totirlem atudiet

audire. audite magnosian vileor duces. . audire et villoor pios errase per lucos. andire est operale pretium, procedere recte qui moedis num voltis. aludire atulle bogan juber conponere.

discere et aurdire et melion credere non vis?

nil audir solin, nil discere, quod levet aegrum:

Romar dule diu luit. . matores athire, minoti diceste nut se crelebat miros audise tragoedos

audiet. numpuid l'omponis istis, ambiret leviora. paler si vivetet? ut alcer alterius sermone me-sos auclicet honores.

audiri. labra movet motuens auchis: "iulchra Laverna.

audis. aludis minuset minda lan: at urlis. quo strejutu ianua.

ir vocata atuis arbmingue leto, diso triormis.

r) deormm sicutio hate autis.

Matusine panter, sen "laste" libentius audis.

subtilis vecterum iuclex et collidlus atubis.

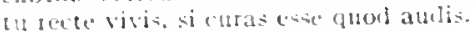

audist. muाnejuil de Dociz audisti?"

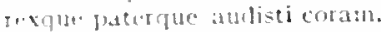

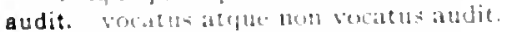

veces andit alluge integes.

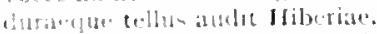

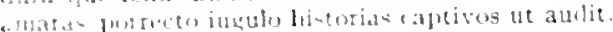

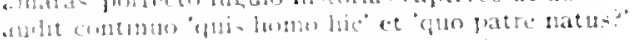

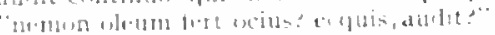

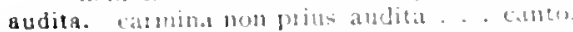

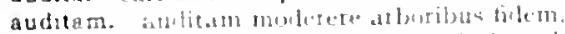

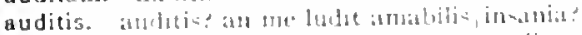

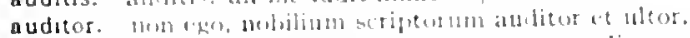

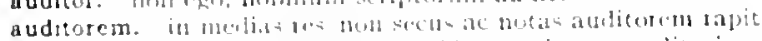

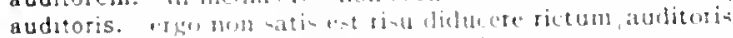

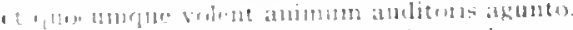

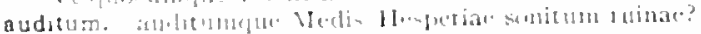

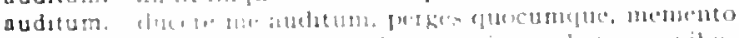

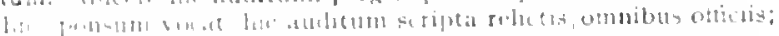

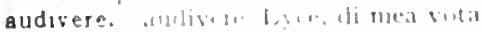

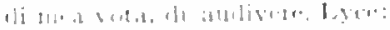

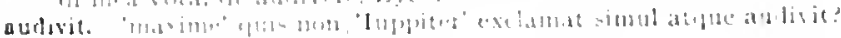

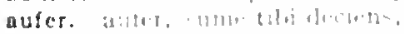

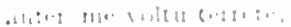

Carm.1.2.27

Eisist.2.2.151

Serm.2.5.101

Serm.2.8.33

Serm.2.3.00

Curm.t.2.21

Carm.1.2.23

Serm.2.3.203

Carm.2.1.21

Carm.3.4.0

Sirm.1.2.37

Serm.2.3.7\%

Lpist.1.1.45

Eist.1.8.8

Inist.2.1.106

ipist.2.2.1 $=9$

Serm.1.53

lipist.2.2.5s

fepist.1.10.60

Carm.2.25.6

Corm.3.10.5

Carm.3.22.3

Cirm.3.27.51

simm.2.0.20

Sorm.2.7.101

Epist.1.10.17

Sirm.2.0.53

Lepist.1.7.35

Curm.2.18.40

Carm.3.7.2.2

(arm.t. 1.50

Sirm.1.3.5o

Sirm.1.0.20

sermi.2.7.35

(arm.3.1.3

('urm.1.2414

Cirm.3.4.5

l. pist 1.10.30

Ars l'wet. 10

Sermitios

Ars I.1.t.800

Cirm 2.1.31

Sirm 2.+ kis

1.pis6.2.2.07

curm $11.3 \mathrm{I}$

(iarm.4.1.3.

Sorm.1.2.18

serm.2.32.30

Sirm. 2.7 .93 
auferam. pavore somnos auieram.

auferet. "hunc neque dira renena nec hosticus auferet ensis 'ni tua custodis, avidus iam haec auferet heres.' qui dedit hoc hodie, cras si volet aujeret.

aufers. quare, ... periuras, surripis, aufers/undique?

autert. nee levis somnos timor aut cupido! sordidus aufert. tibi telas operosaeque Minerve studium aujert. somnus tamen aufert/intentum vener: si ratio et prudentia curas, . . autert, sed satis est orare Iovem quae ponit et aufert. aufert Pacuvius docti iamam senis,

Aufidienus. Aufidienus, / cui Canis ex vero dictum cognomen adhaeret,

Aufidio. Fundos Aufidio Lusco praetore libenter'linquinus,

Aufidius. Aufidius forti miscebat mella Falerno,

Aufidum. longe sonantem natus ad Aufidum

Aufidus. qua violens obstrepit Aufidus sic tauriformis volvitur Aufidus, cum ripa simul avolsos ferat Aufidus acer.

aufugiens. saepe velut quilcurrebat fugiens [curtelct aufugiens] hostem. auge. nunc i, rem strenuos auge.

augenda. qui semper in augenda testinat et obruitur re.

augent. et iuvenum ritu florent modo nata vigentque [? et nova iuvenum ritu florent motat augentque].

augere. cur me funesto properent arcere [augerc] veterno;

augur. nube candentis umeros amictus/augur Apollo; . aquae nisi fallit augur|annosa cornix. augur et fulgente decorus arcu/ Phoebus unde 'divitias aerisque ruam, dic augur, acervos.' quodsi non odio peccantis desipit augur,

auguris. concidit anguris/Argivi domus ob luctum/demersa exitio; da, puer, auguris Murenae:

Auguste. tuas, f Auguste, virtutes in aevon . . acternet.

Augusti. potius nova/cantemus Auguti tropaea/Caesaris super inpetratol fortis Augusti redit u quid Auguati paternus in pueros animus Nerones. quibus terrarun militet oris/Clandius Augueti privignus. quis sibi res gestas Augusti scribere sumit?

Auginti laudes agnoscere possis;

Caesaris Augusti non responsura lacertis.

Augusto. Auguto reddes signata volumina, Vinni.

Augustus. quos inter Augustus recumbens praesens diros habebitur|Augustus

aula. nulla certior . . aula divitem manet erum.

aula. puer quis ex aula capillis |ad cyathum statuetur unctis caret invidenda $\mid$ sobrius aula. lectus genialis in aula est: ex quoltempore cervinam pellem latravit in aula,

aulae. cessit immanis tibi blandientianitor aulae

aulaea. interea suspensa gravis aulaea ruinas/in patinam fecere. adde hos praeterea casus, aulaca ruant si, quattuor aut plures aulaea premuntur in horas.

aulaea. si plosoris eges aulaea manentis

aulaeis. cenate sine aulaeis et ostro

aulam. Troas et laetam Priami choreis|falleret aulam, et vacuam ratefecit aulam.

Aule. te talos. Aule, nucesque/ferre sinu haxo,

Aulide. pro vitula statuis dulcem Aulide natan/ante ara:

Aulon. amicus Aulon fertili Baccho

Aulus. nec scit guantum Cascellius Aulus,

aura neve te nostris vitis iniquon /ocior aura|tollat; tua ne retardet/aura naritos. tutum per Aegaeos tumultus faura feret multa Dircaeum levat aura cycnum. intonsosque agitaret Apollinis aura capillos. mone, si increbruit aura, cantus uti velet carum caput; ubi gratior aura|leniat et rabiem Canis hoc age, ne mutata retrorsum te terat aura.

aura. ubi nulla campis/arbor aestiva recreatur aura. nocturna siquid crassi est tenuabitur aura.

Epod.5.96

Serm.1.9.3 I

Scrm.2.3.15I

Epist.1.16.33

Serm.2.3.127

Curm.2.16.16

Carm-3-12.5

Serm.1.5.83

Epist.1.11.26

Epist.I.I8.I I I

Epist.2.1.55

Serm.2.2.55

Serm.1.5.34

Serm.2.4.24

Carm.4.9.2

Carm.3.30.50

Carm.1.14.25

Serm.1.I.5S

comiscrm.I.3.10

Epist.1.7.71

Epist.1.10.68

7 mar.drs Poet.tiz

"ar. Epist.1.8. Io

Curm.1.2.32

Carm.3.17.12

Carm.Saéco

Serm.2.5.22

Epist. I 20.9

Carm-3.10.I I

Carm.3.19.10

Carm.4.14.3

Carm.2.9.10

Carm. 4.2 .13

Carm.t.4.27

Epist.1.3.2

IEpist.1.3.7

Ipist.1.16.29

Epist.2.2.48

Epist.1.13.2

Corm.3.3.1 I

Corm.3.5.3

Carm.2.18.3 I

Carm.1.29.7

Curm.2.10.8

Epist. I. I.87

Epistr.2.10

Carm.3.11.10

Serm.2.8.54

Serm.2.8.7I

Lpist.2.I.I 89

Ars 1'oct. 54

Curm.3.20.15

Cirm.t.6.10

Carm.4.1.4.30

Sirm.2.3.I I I

Sirm.2.3.199

( irm.2.0.18

Ars 1'oet.37 I

carm.1.2.48

Carm.2.8.24

Carm.3.29.04

carm. 2.25

lipod.15.9

Sierm.2.5.93

Epist.1.10.15

Ispist. I.I8.8.

Curm.1.22.15

Sorm.2.4.52 
aure. -perat, ratius ause iallacis

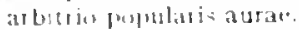

atpla" alligut humo divithat particulim autac.

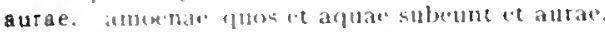

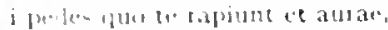

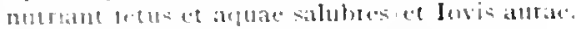

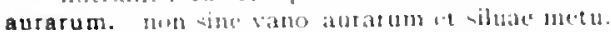

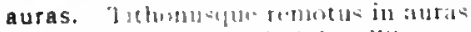

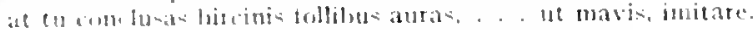

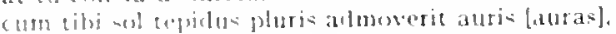

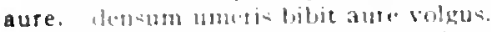

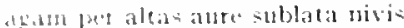

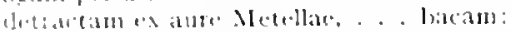

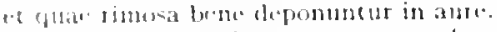

-

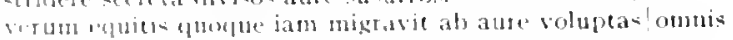

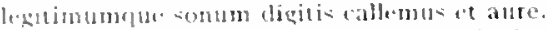

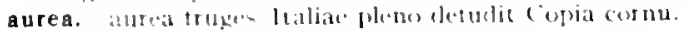

aurea. ghi numb a truitur credulus atreat.

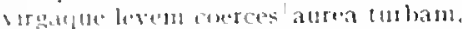

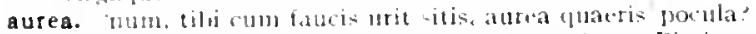

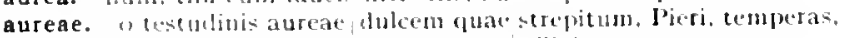

auream. aturum quisquis medioeritat.m diligit.

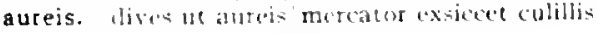

aurem. vetis ut prabluat aurem?

in aturem dicere nescio ruid puero.

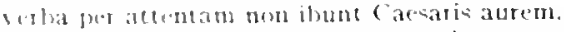

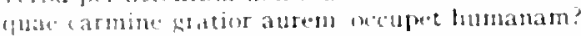

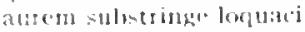

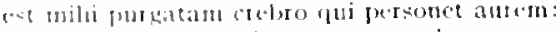

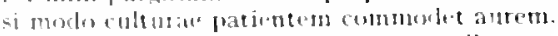

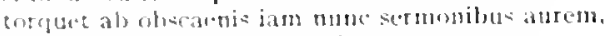

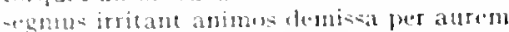

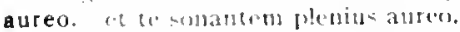

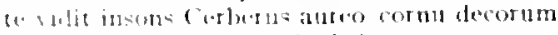

aureos. moresple anteos calucit in astra

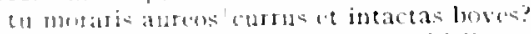

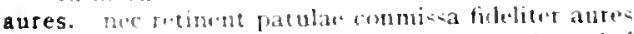

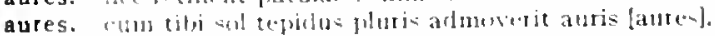

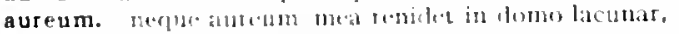
ut influinavit atere t*inpus aurtum.

"u pulica, tu proba peratubulabie actra sidus auteum."

auri. quid insat inmen=um te asgenti fondus ace anti

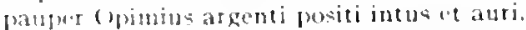

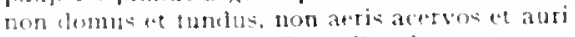

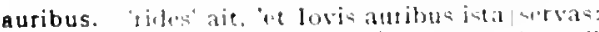

auribus. quilquirl habes, age. /eponge tutis auribus.

qual obmeratic auribus tumdis jorecos?

-anu- utriatu. anribus atpue onculis:

auriculae. (gitulent joanomitu* nolles anticulae)

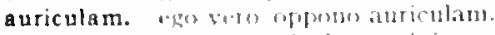

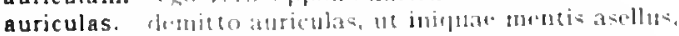

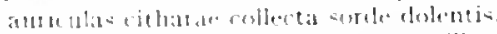

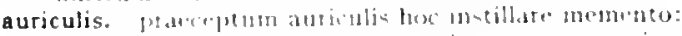

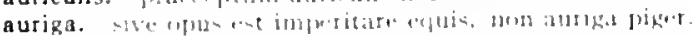

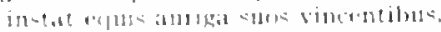

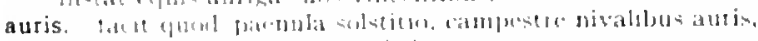

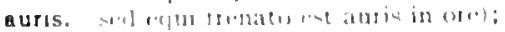

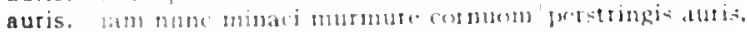

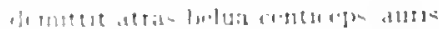

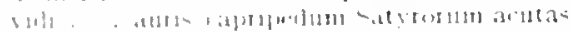

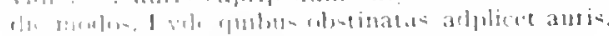

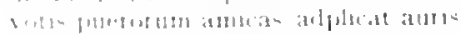

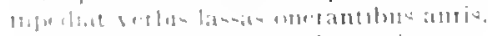

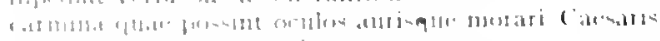

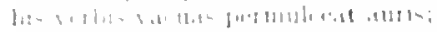

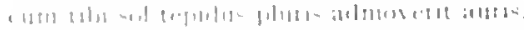

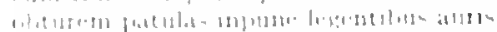

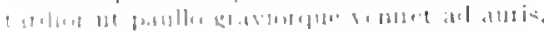

Corm.1.5.1:

Corm. 3.2.20

Sirm.2.2.79

Cirm.3 4.8

Curm.3.11.40

Cirm.silec. 32

Carm.1.23.4

Carm.1.28.8

Serm.1.1.10

:ur.lipull 1.20 Iu

Curm.2.13.32

lipoldo. 7

Serm.2.3.2.39

Sirm.211.20

Serm. $2: 78$

Ppost.2.1.187

Ars PoCt.274

fipist.1.12.28

Curm.1.5.0

Carm.1.10.19

Serm.12.114

Carm..1.3.17

Carm.2.19.5

(arm.1.31.10

Serme.1.22

Serm.t.0.9

Serm.2.1.19

Serm.2.2.94

serm.2.5.95

Fist.1.t.7

Epist. I.1..10

Epist.2.1.127

dirs l'mel. 180

cirm.2.13.20

(arm.2.10).29

carm.4.2.23

Epertis.21

tipis.3.18.70

far lepset. 20.19

carm.2.1s.?

tepodiciou

Epoditi...1

Sirm.1.1.41

Serm.2.3.1.42

Epist 1.2.17

I. pist.1.11)..43

Carm 1.27.18

fisul.17.5.3

berm. 2.3.285

Serm 2.5.33

Sirm 10.77

Sirm.1.0.20

Epist.1.2.53

Epistatses

("arm.1.15.20

Serme1.115

tipul.1.1 1.8

t.pos 1.15.13

(arm.2.1.

Cirm.213.35

(a)m. 2 [1) 3

Corm. 3198

cirmsierc.72

sermel 11] to

I. pots 1.3 .17

I.p1:61,191.20

fpesti.211 in

l:pou 22105

Aroluct.255 
in Maeci descendat iudicis aunis/et patris et nostras

auritas. blandum et auritas fidibus canoris ducere quercus.

auro. Grosphe, non gemmis neque purpura ve- nale nee auro. nec satelles Orci|callidum Promethea/revexit auro captus; auro repensus scilicet acrior miles redibit:

quia venut auro'rara avis

thesauro [tres aurol invento qui nercennarius agrum . . aravit

vilius argentum est auro, virtutibu= aurum.

si metit Orcus/grandia cum parvis, non exorabilis anro?

regali conspectus in auro nuper et ostro,

aurum. aurum per medios ire satellites . . amat

vilius argentum est auro. virtutibus aurun.

aurum. non aurum aut ebur Indicum.

aurum inrepertum et sic melius situm,. . . spernere

gemmas et lapides aurım et inutile.

nec dabunt, quanvis redeant in aurum tempora priscum.

autum vestibus illitum mirata

qui servos proicere aurum|in media iussit Libya,

qui nummos aurumque recondit,

paret ancillas, paret aurun,

ausa. ausa et iacentem visere regiam $\mid$ voltu sereno.

ausculto. 'iamdudum alusculto et cupiens tibi dicere servos/pauca tefor mido.'

ausi. merture decus vestigia Graca|ausi deserere

ausim. neque ego illi detrahere ausin. . cum multa laude coronam.

Ausonias, pertulit Ausonias ad urbis.

auspex. ego cui timebo, providus auspex,

auspicatos. iam bis $\mathrm{Ml}$ onaeses et Pacori manus/inauspicatos [non auspicatos] contudit impetus| nostros

auspice. nil desperandum Teucro duce et auspice:

fidibusne Latinis| Thebanos aptare morlos studet auspice Musa.

auspicis. Ronuli praescriptum et intonsi Catonis/auspicis

immanisque Raetos auspiciis pepulit secundis.

tuisque atuspicis totum confecta duella per orben

suspicium. cui si vitiosa libido tecerit auspicium,

Auster. Auster, dux inquieti turbidus Haclriae.

indomitas prope qualis undas exercet Auster

nec si te validus iactaverit Auster in alto.

Auster. ut horridis utrumque verberes latus, Auster, memento thetibus;

auster. nec mala me ambitio pertit nec plumbeus auster

austera. celsi practereunt austera poemata Ramnes:

austerum. molliter austerum studio fallente laborem,

Austri. sentiant notus orientis Austri

nulla nocent pecori contagia, nullius astri [Austri]/gregem aestuosa turret inpotintia.

Austri. praesentes, Austri, cuquite horum obsonia

Austris. contra nercator, navim iactantibus Austis,

austris. non tamen adversis aftatem ducinus austris,

Austro. leni fuit itustrolcaptus.

austrum. nocenten | corporibus metuemus austrum:

ausus. sed puetum est ausus Romam potare docendum|artis,

cum est 1,ucilits ausus prinus in hunc operis conponere camina morem. non Pyladen ferjo violare ansuste sororem/Electran,

fastidire lacus et rivos ausus apertos.

unum siquis amicorum est au-us reprehendere versun;

sudet multum irustrague laburct ausus idem:

nec scit quantum (ascelliu A Alus [atrus]. (sed tamen in pretio est);

Ars Poit.387

Carm.1.I2.I I

Carm.2.16.8

Carm.2.18.36

Carm.3.5.25

Serm.2.2.25

ier. Sorm.2.0. I I

Epist.1.1.52

liptst.2.3.179

Ars Poet.228

Carm.3.10.9

Epist.1.1.52

Carm.1.31.6

Carm.3.3.49

Carm.3.24.48

Carm.4.239

Carm.4.9.14

Serm.2.3.100

Serm.2.3.109

Sirm.2.3.215

Carm.1.37.25

serm.2.7.I

Ars Pot.287

Serm. I 10.48

Carm.4.7.56

corm.3.27.8

var.Carm.3.6. I0

Carm.1.7.27

Epist.1.3.13

carm.2.15.12

Carm.t.I4.nes

Epist.2.1.254

Epist.1. I.80,

Carm.3.3.4

Carm.4.I.2I

EPISt.I.IIIS

Efod.10.4

Serm.2.6.18

Ars Porl.342

Serm.2.2.12

Carm.3.27.22

i'ar. Epod.ro.6 t

Serm.2.2.41

Serm.I.IS

lipist.2.2.202

Serm.2.8.

Corm.2.14.16

sirm.1.0.010

Serm.2.1.1,2

Serm.2.3.130

Eptist.1.3.II

Epist.2.1.222

irs Poell.z+2

?'il. 1 rs Poet.37I

aut. Corm.1.4.3; 1.4.6; I.1.10; 1.6.3; 1.0.14; 1.6.15; 1.7.1; 1.7.2; 1.7.4; 1.0.24; 1.12.1; 1.12.5; Carm.1.12.6; fur.Carm.I I 2.I5; Carm.I.I2.IS; I.IS.5; ? coniCarm.1.Io.II; Carm.I.2I.0; Corm.1.21.7; 1.21.8; 1.21 1; 1.31.13;1.37.18;2.1.33;2.9.2;2.9.0;2.9.10;2.12.22; 2.12.2.4; Carm.2.12.26; 2.13.40; 2.I9.15; 3.1.2s; 3.2.19; 3.4.54; 7 ; Carm.3.10.19; 3.12.2; 3.19.11; 3.20.15 (his); 3.23.7; 3.23.11;3.24.24; tar.Corm.3.24.20;

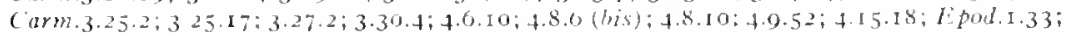

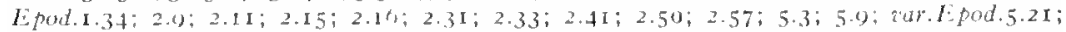
Epol.5.28; $5.40 ; 0.5$ (bis); 6.14; $7.1 ; 7.7 ; 0.20 ; 9.31 ; 9.32 ; 9.34 ; 11.4 ; 11.27 ;$ I I.28;

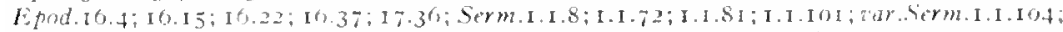
Serm.1.2.8 I; 1.2.1 I7; ar.Serm.1.2.1 I7; Serm.1.2.133 (his); 1.3.27 (his); 1.3.3e; 1.3.39; iar.serm.1.3.t.t; Serm.1.3.6.5; 1.3.88; 1.3.02; 1.3.94; 1.4.7 (his); 1.4.26 (his); 1.4.32;

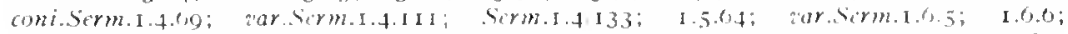

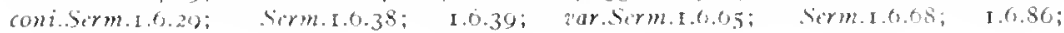




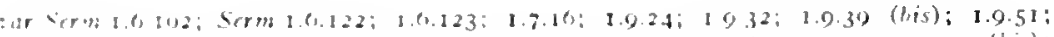

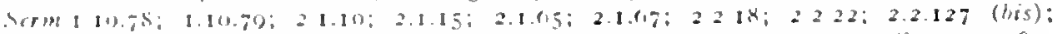

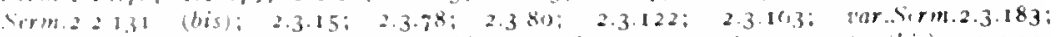

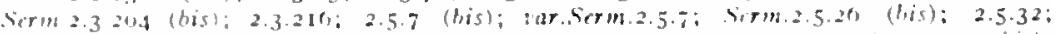

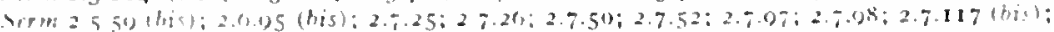

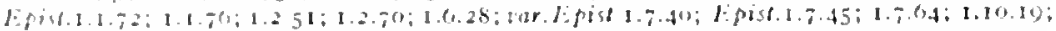

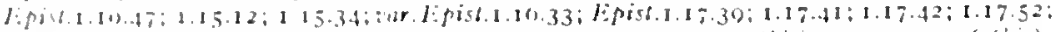

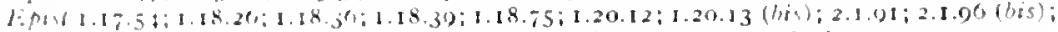

lipest.1.101: 2.1.1\$0; 2.1.186 (his):2.1.180; cont.Episf.2.1.200; L.pist.2.1 202; 2.1.221;

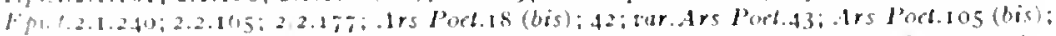

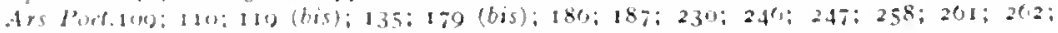

Ars Poet 333 (his): $33.4: 352 ; 353 ; 443: 453: 45.1$

autem. unde ditum [autciul sentis. Jupus lic Tibronts an alto captus biet?

scriptores atutum natrate putatet acello tabellam surdo.

scdulisas atberm stulte quesm diligit urget.

quiel atuten ('alecilio Plautogur dabit Romanus

autumat. ionutum Chysphi porticus et grex antumat.

autumnos. per antumnos nocentem/corporibus metuemus atustum:

Autumass. captht Autumnus agris extulit.

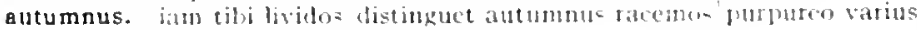
colene.

Domiter atumnus iruges effuderit.

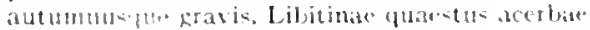

auxili. ausli latus ghus parsentibus.

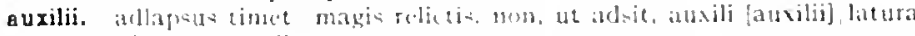
phus pratesentibus.

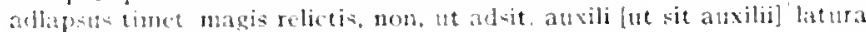
Dhu joratentibus.

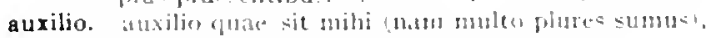

ararae. vinlex avanto maulis

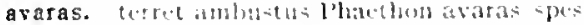

qui irutis et pomis viluas veruentut asaras

ovarior. viberte in tertis tre siquis ararior uno.

avaris. "datula ene ellebori multo pars maxima avaris:

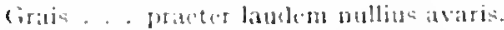

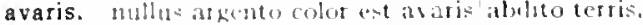

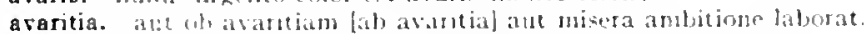

M-Ivet an artia miscroque cupidine pectus:

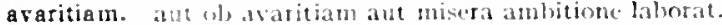

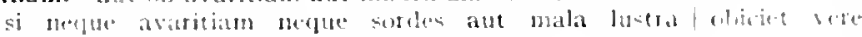

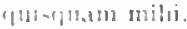

eraro. adelone astro clivitias mari

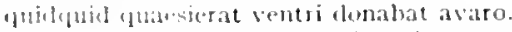

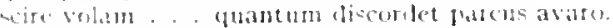

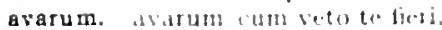

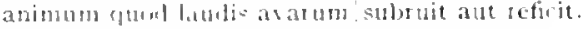

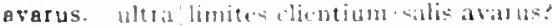

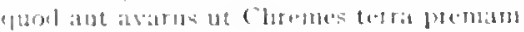

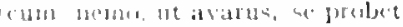

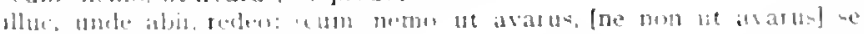
pullitet

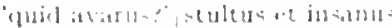

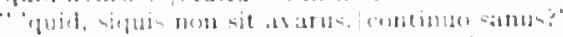

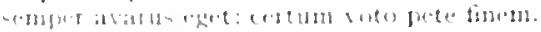

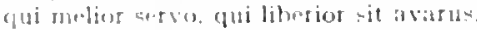

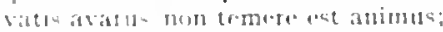

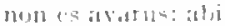

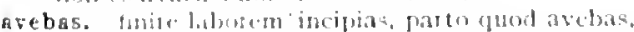

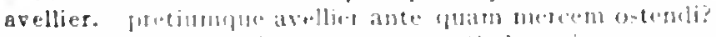

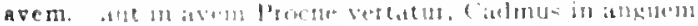

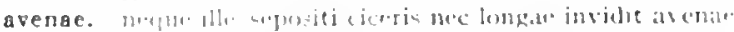

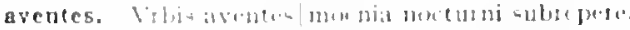

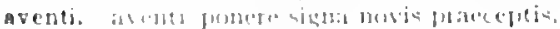

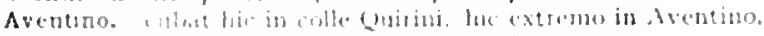

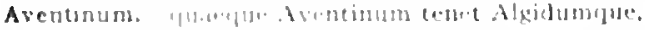

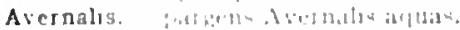

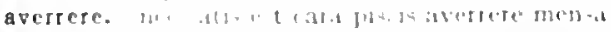

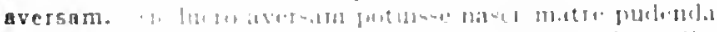

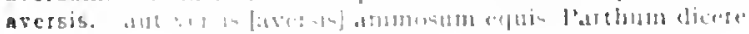

coni.Serm.2.2-31

Epist.2.1.190

lipist.2.1.200

Ars Poct. 53

Sirm.2.3.45

Carm.2.1.1.15

fisod.2.18

Carm 2.5.11

Carm.4.7.11

verm.2.0.19

If poul. I.2I

ier. lipod.1.21

D.y.lepod.1.2

Sirmilat 1 d

(arm.

Carm.t.11.25

Liptict.1.8

List.2.2.157

virm. $2-3.82$

Ars l'od.324

(arm.2.2.1

rear.serm.1.4.20

Epist.1.1.33

crom.1.420

Sermat.6.68

ciurm.3.29.61

liprst.1.15.32

lipist.2.2.104

Sirmid1.103

lipist.2.1.170

corm.2.152\%

f.pod. 1.33

sem.t.108

sur firrm.t.1.1 U8

Sierm. 2.3.158

herm.2.3.150

sepist 1.2.5t

Eipist. 10.03

Ferrer.2.119

Lipol 2.2 .205

cerm 1.1.94

seme! $2.10 \mathrm{~A}$

Ars livel. 187

irm.2.0.s.t

Sarm $=(x, 00)$

Sirrin 2.4

lopes 2210

(itrm suret

1. prids 20

verem a 837

cirm 2.4 .10

ide (arm.8.10.11 
aversos. mollivit aversos Penatis

Carm.3.23.19

aversos soliti conponere amicos.

Serm.1.5.29

Epod.10.1 8

aversum. preces et aversum ad Iovem.

aversus. einat... nautica velalaversus inercaturis:

Sirm.2.3.107

avertere. nec satis est cara piscis averrete [avertere] mensa'ignarun.

sar.sirm.2.4.37

ita commendate dicacis/ conveniet Satvros, ita vertere [Satyros avertere] seria ludo,

avertit. avertit morbos, metuenda pericula pellit,

avertunt. mali culices ranaeque palustres, avertunt somnos;

aves. quetuntur in silvis aves

avet. ara castis/vincta verbenis avet inmolato/spargier agno;

e quibus unus aret quavis aspergere cunctos/praeter eum qui praebet aquan;

istuc mens animusqueffert et amat [avet] spatis obstantia mimpere claustra.

avi. avi curatque parentis/praeclarani ingrata stringat nalus ingluvie rem, avi. "mala ducis avi domun

avibus. piscibus atque avibus quae natura et foret aetas,

avibus. non ut / serpentes avibus geminentur, tigribus agni.

avida. hornalfruge Laris avidaque porca:

avidas. cuncta manus avidas fugient heredis

avide. pransus non avide, quantum interpellet inani/ventre dienidurare,

avidi. cum fas atque nefas exiguo fine libidinum idiscernunt avidi.

Avidienus. Aufidienus [Aridiemus], /cui Canis ex vero dictum cognomen adharet.

avidis. exitio est avidum [avidis] mare nautis;

evidos. avidos vicinum funus ut aegros/exanimat

convivas avidos cenam servosque timentis, tum rapere. . velle

avidum. exitio est avidum mare nautis;

avidum. latius regnes avidun domardo!spiritum

avidus. hinc avidus stetit|Volcanus.

'ni tua custodis, avidus iam haec auferet heres.'

dilator, spe longus, iners avidusque futuri.

aviis. quaerenti pavidam montibus aviis/matrem

avis. imbriun divina avis imminentium,

Ityn flebiliter gemens, |infelix avis

ut adsidens inplumibus pullis avis

non Arra avis descendat in ventren meum.

quia veneat auro|rara avis

fiet aper, modo avis, modo saxun et, cum volet, arbor.

avis. ego apis [avis] Matinae/more modoque . . carmina fingo.

avis. cui rex deorum regnum in avis vagas|permisit

nos, inquam, cenanus avis, conchylia, piscis,

avis. aetas parentum, peior avis.

avita, avita ex re praeberi sumptus mihi crederet illos.

avitae. avitae/tecta relint reparare Troiae.

avitis. depromere Caecubum cellis avitis.

avitus. sacva paupertas et avitus apto cuin lare fundus.

avium. non avium citharaeque cantus|comnum reducent:

deus inde ego. furum aviumque/maxima formido:

si forte suas repetitum renerit olin /grex avium plunas,

arolsos. cum ripa sinul avolsos ferat Aufidus acer. et leporum avolsos, ut multo suavius, armos.

aros. nec quod avos tibi maternus fuit atque paternus.

survius ac s' quaestor avos pater atque meus patruosque fuissent.

ar.Ars Poet.226

Epist.2.I.I 36

Sirm.1.5.I5

Epod.2.20

Carm.4.11.7

Serm.1. 4.87

coni. Epist.1.14.9

Sermi.1.2.7

Carm.1.15.5

Serm.24.45

Ars Poet. 13

Carm.3.23.4

Carm.4.7.19

Sirm.1.0.127

Carm.I.I8.I I

g'ar..Serm.2.2.55

rar Curm.1.28.18

Serm.1.4.1 26

Sorm.1.5.75

Curm.1.28.18

Carm.2.2.9

Carm.3.4.58

Serm.2.3.I5I

Ars Pot.l.72

Carm.1.23.2

Corm.3.27.IO

Carm.4. 12.0

Epod.1.I9

Epod.2.5.3

Serm.2.2.26

Serm.2.3.73

yar.Carm.4.2.27

Carm. 4.2

Sirm.2.8.27

Carm.3.t..16

Serm.1.0.79

Carm.3-3.59

Carm.1.37.6

Carm.1.12.43

Carm.3.1.20

Sirm.1.8.3

Epist. [.3.19

Sirm.1.I.58

Serm.2.8.89

Serm.1.6.3

Serm.1.6.13]

B

Babylonios. Leuconoe, nec Babyonios temptaris numeros.

baca. viridique cestat baca lenafro.

pressa Venafranae quod baca lemisit olivate.

bacam. aceto'diluit insignem bacan:

bacchabor. non ego sanius/bacchabor Eulonis:

Bacchae. ab ovolusque ad mala citart "io Bacchae"

bacchante. Thracio bacchante magis sub inter-lunia vento,

Baccharum. O Naiadun potens, Baceharumque valentium

Bacche. quis non te potius, Bucche pater, teque, decens lenus?

euloe, parce Liber, [- heu hoe, Bacclre, precor.] 


\section{BACCHE}

liac te merentom. Bacche pater

quo me, liaclic, rapis tuilplenum?

a conlibuiset, ab ovo/usque al mala citaret io Bacchae [Bacche]'

Bacchi. Jlenoque Bacclí pectore tubidum/lactatur.

tiec cliens batehi somno gaudentis et umbra:

Bacchius. non a cupositum melius cum Bitho Bacehius.

Baccbo. vel Bacelio Thebas rel Apolline Delphos insignis

araicus Aulon fertili Baccho

Bacchum. verecundumque Bacchum|sanguneis prohibete rixis.

Bacelum in remotis carmina supibus vidi docenten.

Bacchus. nee Law.etrugonia Bacchus in amphora/languescit mihi

Bache. if conlibuisse. ab ovo, usque ad mala citaret 'io Bacchat [Bache]'

bacis. marta. quate rotundioribus|ontseta bacis anbulet.

atro jascat "rum an bacis opulentet olivac.

Bactra. quid Seres ce regnata Cyol Bactra parent

Baiae. seu liquiclat placuere Baiac.

Baiano. mutice Batano melior Luctina peloris.

Baianus. murire Batiano [murex Baians] melior I woma peloris.

Baias. nam mihi Baias/Musu supervacuas Antonius. non mihi cumbs|est iter aut Baias

Bais. matisque Bais obstrepentis urges/submovere litora. 'nullus in orbe sinus Bais praclucet amoenis"

Baius. nomme rides. Albi ut male rivat flius utque/Baius inops?

balanus. presea tuin balanus capillis

balathroces. nundici, mimae, balatrones [balathrones]. hoc genus onne] maestum ac sollicitum est

Balatro. Invertume . Hlifanis vinata tota/Vibidius Jalatroque Bulatrosturndens omnia naso

Balatrone. Fu sirvilio Balatrone/Vibidiua quos Maecenas adduxerat unbratis

dumbla ritletur fictis rerum Balatone secundo.

balatrones. ambubairum collagia. pharmacopolae./mendici. nimae. bistitrones.

Balatoni. quich "nisu differt batathone [Balatroni]/dones quidquid habes

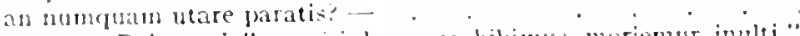

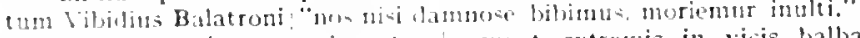

balba. ue putose elementia docentem/occupet extrenis in vicis balba sencetus.

balba. quid: cum lalla feris annoso verba palato.

Babinum. delectant, veluti Balbinum polypus Ilagnae.

balbum. os tenerum pteri babumpue poeta figutat.

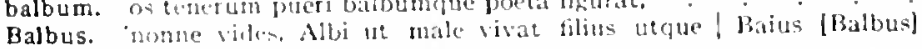
inops?

balbuti:. illum balbutit scaurum pravis fultum male talis.

balnea. mutat cenactula, lectos, balnea, tonsores, nec grit nigus collegit, futmos et balnua lauelat. nuace lébera et lidos et bulnea vilicus optas; -ecretat jetit loca. balnea vitat.

Bandusiae. of foth Bandustac splendiclior vitro.

Bantinos. altequr. Bantinos ct astom pingue tenent humilis Forenti,

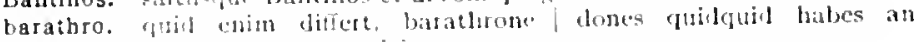
ntuhcluan uture paratis? -

Barathroni. quie! conim difice. barathone [Batathoni]lones guidquid labbes an mmmillam utabe potratio:-

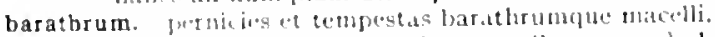

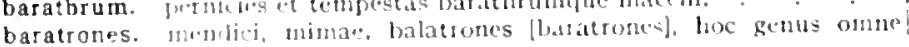

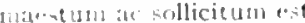

barba. milli latiol [lasba] aut tragicis opts esse cothumit.

barbam. vellunt tibi barbim lascivi pueri.

uerue lupi barbutu varite cum dente colubrae

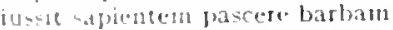

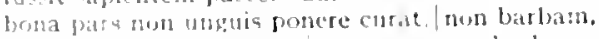

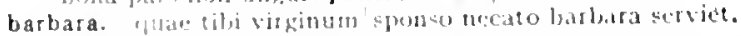

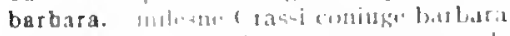

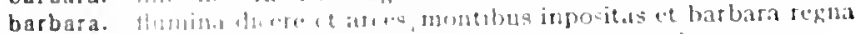

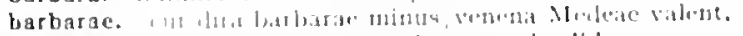

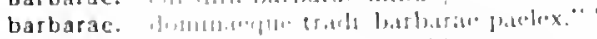

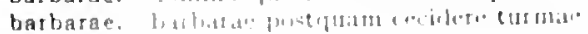

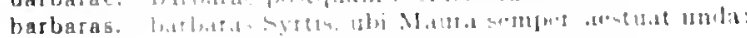

\section{BARBARAS}

$\operatorname{Carm} \cdot 3 \cdot 3 \cdot 13$

Carm.3.25.1

var.Serm.1.3.7

Carm.2.19.0

Lisisl.2.2.78

Serm.1.7.20

Carm.1 7.3

Carm.20.19

Carm.1.27.3

Corm.2.10.1

Corm.3.10.34

far.serm.1.3.7

Epod.8.t

Epist.1.10.2

Carm.3.29.28

Carm.3.4.24

Serm.2.4.32

coni.Serm.2.4.32

Eipt.1.15.2

Epist.I.15.1 2

Cirm.2.18.20

Epist.1.1.83

Sirm.1.4.110

Carm.3.29.4

iar.Serm.1.2.2

Sierm.2.8.40

Serm.2.8.6.4

Serm.28.21

siom.2.8.53

S.r.1.1.2.2

sur.serm.2.3.166

Serm.2.5.33

Epist.1.20.18

Serm.2.3.274

Serm.1.3.40

Epist.2.1.126

Par.serm.1.4.110

sirm.1.3.48

Epist.1.1.92

Epist.t.I. I.3

lipist 1.14.15

Ars Puct.208

corm.3.131

Carm.3.1.15

$56 r m .23106$

tur..5erm.2.3.106

Fpist.1.15.3I

asr.serm.t.2.2

:ar.siorm, $1.5 .6 \mathrm{~d}$

Serm.1.3.133

Serm.1.8.12

Serm 2.3 .35

Ars loet 209

Carm.1.290

corm. 355

1.p15t.2.1.253

I. pod s.pi

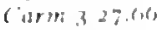

(urm: : 0

(ism.2. 3 
male barbaras|regum est uita libidines.

barbare. speres perpetuom dulcia barbare|laedentem oscula,

barbariae. Graecia barbariae lento collisa duello.

barbaro. pede barbaro|lustratam Rlodopen,

barbarorum. regumque matres barbarorum

nt barbarorum Claudius agnina|ferrata vasto diruit impetu .

barbarum. pugnare Thracum est: tollite barbarum/morem .

barbarum. tu flectis amnis, tu mare barbarum.

hac Dorium, illis barbarum?

barbarus. quae sibi barbarus|tortor pararet:

barbarus heu cineres insistet victor

ut siqui aegrotet quo morbo Barius [barbarus].

barbas, bona pars non unguis ponere curat, (non barbam [barbas],

barbatum. siquen delectet barbatum: amentia verset.

barbite, age dic Latinum, barbite, carmen,

barbiton. nec Polyhynnia Lesboum refugit tendere barbiton. arma defunctumque bello! barbiton hic paries habebit.

Bari. via peior ad usquel Bari moenia piscosi;

Barinae. ulla si iuris tibi peierati/ poena, Barine [Barinae], nocuisset unquam.

Barine, ulla si iuris tibi peieratil poena, Barine, nocuisset unnuam.

barris, quid tibi vis, mulier nigris dignissina barris?

Barros. Sisennas, Barros ut equis praecurteret albis.

Barrus. 'nonne vides, Albi ut male vivat filius utque/Baius [Barrus] inops? ut siqui aegrotet quo morbo Barrus.

Barus. 'nonne vides, Albi ut male vivat filius utque Baius [Barus] inops?

Bassareu. non ego te, candide Bassareu, invitum quatiam .

Bassum. Bassum Threicia vincat amystide

Bathyllo. non aliter Samio dicunt arsisse Bathyilo| Inacreonta Teium,

batillum. insani ridentes praemia scribae, | praetextam et latum clavom prunaeque vatillum [batillum].

beabit. fundet opes Latiumque beabit divite lingua:

bearis. bearis interiore nota Falerni.

beat. dignum laude virum Musa vetat mori, caelo Mlusa beat.

beata. adparetque beata pleno/Copia cornu. esto beata.

quaeritur argentum puerisque beata creandis uxor.

beata. arva beata petamus, arva divites et insulas.

beatae. beatae coniugis additum|stellis honorem omitte mirari beatae/fumum et opes strepitumque Romae. atque haurire queam vitae praecepta beatae.'

beatae. ille te mecum locus et beatae postulant arces: .

beatam. o quae beatam diva tenes Cyprum

beate. o beate Sesti, vitae summa brevis spem nos vetat incohare longan; quando ... beate Naecenas, bibam .

beati. rectius occupat|nomen beati qui deorum|muneribus sapienter uti . 'ut Nasidieni iuvit te cena beati?

beati. nescias an te generum beati Phyllidis flavae decorent parentes: qualibet exsules in parte regnanto beati; utrumne divitis bomines an sint virtute beati; agricolae prisci, fortes parroque beati. si taceas, laudant quidquid sctipsere beati.

beatior. Persarum vigui rege beatior." fallit sorte beatior.

beatis. lcci, beatis nunc Arabum invides gazis quid statis?" - nolint. atqui licet esse beatis.

beato. novistine locum potiorem rure beato?

beatorum. dissidenz plebi numero beatorum eximit Virtus.

beatum. nihil est ab omni|parte beatum.

beatum. quem tibi... . Himo restiquent vere Faronii| Thyna merce beatum.

non possiclenten multa vocaveris recte beatum;

inde fit, ut raro, qui se vixisse beatum' dicat

quae possit facere et servare beatum.

si res sola potest facere et servare beatum,

rure ego viventem, tu dicis in V'rbe beatum:

iactamus iam pridem omnis te Roma beatum; neve putes alium sapiente bonoque beatum

beatus. quo beatus|volnere, qua pereat sagitta. satis beatus unicis Sabinis.
Carm.4.12.7

Corm.1.13.1.4

Epist.1.2.7

Carm.3.25.1 I

Carm.1.35.I I

Curm.4.14.29

Carm.1.27.2

Carm.2.19.17

Epod.g.t,

Carm.3.5.49

Epod.16.1 I

zar.Serm. I.6.30

ior. Ars Poet.298

Serm.2.3.249

Corm.1.32.1

Carm.1.1.34

Carm.3.26.4

Sirm.1.5.97

gar.Carm.2.8.2

Curm.2.8.2

Epod. I 2. I

Serm.1.7.8

ar.Serm.1.4. 10

Strmico.30

zar.Serm.1.4. I I0

Carmi.1S.II

Carm.1.36.14

IEpod.14.9

var. Serm.1.5.36

Epist.2.2.12I

Carm.2.3.7

Carm.4.8.29

Carm.Saec.59

Erod.8.II

Epist.I.2.4t

Epod.10.4I

Corm.2.19.13

Curm.3.29.I I

Serm.2.4.95

Carm.2.6.21

Carm.3.26.9

Corm.1.4.14

Epod.9.4

Corm.4.9.47

Serm.2.S.1

Carm.2.4.1 3

Carm.3.3.39

Sermi2.0.74

Epist.2.1.139

Epist.2.2.108

Carm.3.9.4

Carm.3.10.32

Carm.1.29. I

Sermin.I.I9

Epist.1.10.14

Curm.2.2.IS

Carm.2.16.28

Carm.3.7.3

Curmit.9. $\$ 6$

Serm.I.I.I1

Epist.1.0.2

Epist.1.6.47

Epist.1.14.10

Epist.I.IU.I 8

EPpist.1.10.20

Carm.1.27.1 $\mathrm{I}$

Curin.2.18.14 
'beatus ille' qui procul negotis.

Epod 2.1

privatusulue mas vivam te rege beatus.

Serm.1.3.142

beatur Fannius ultro delatis capsis te imagine.

voltum habitumruc lominis, quem tu vidisse beatus, non magni pundis. dum licere, in rebus iucundis vive beatus,

ut salvos genget vivatgue beatus.

Serm.1.4.21

serm.2.4.92

Serm.20.00

lipist.1.2.10

beatus enim ian cum pulthris tunicis sumet nova consilia et spes.

mirnbor, si sciet inter-, noscere mendacem verumque beatus amicum.

beet. ne lominus. . munce te parvo betet ant incumodus angat.

bella. bellogur matribus detestata. trictia bellat quo scribi possent numero.

bella. nolis lonea ferac bella Nimmantine

et pugnata sacro bella sub llio:

intermised. lenus, diu rurms bella moves?

Ractis bella sub Alpibus Drusum girentem

betla cutis et paces longum difundit in aevom?

siquis by lla tibi terra pugnata marique dicat

saevam militian puer et Cantabrica bella tulisti

thm. acpera bellaj conponunt agros adsignant, oppida condunt.

et pust l'unica bella quietú quactefe coppit.

mares animos in Martia bella versibus exacuit;

bella. 'deprensi non bella est fama Treboni'

ut butos elementa docentem, occupet extremis in vicis balba [bella]

srlectus.

bellante. bellante priot, iacenten' lenis in hostem.

bellantis. matron bellantis tyanni frospicions

lipist.1.18.32

Irs livel. 425

Epist.1.18.7.5

Carm.1.1.24

Ars I'oct.73

Carm.2.12.1

Carm.3.19.4

Carmati.2

Cirm.4.47

Epist.1.3.8

Jpist.1.J0.25

Jist.1.18.55

Epist.2.1.7

Jipist.2.1.162

Ars 1'oel.402

serm.1.tit

belle. loc quiclam non belle: numguid egoilli inprudens olin lacian sinile?"

Bellerophontae. dalis inpulerit criminibus mimis| casto Bellerophonte

[Be]lerophostac] maturare aecent.

Bellerophonte. nimis casto Belleroplunte maturare necen.

Bellerophonte. eques ipso mulior Bullerophonte.

Bellerophontem. lega tus teremun equitern gravatus, Bellerophontem,

Bellerophonti. dalsis inpulerit criminibus nimis / "asto Bellerophonte

[3e-1lerephonti] maturare necem.

belli. hellique calsas ef vitia et modos

quare thumina lugubris ignara belli?

dura iugare mala. dura belli.

and ident pacis eras mediusque belli.

"ueat sakites expediunt per acuta belli".

pelli socumlos redidiclit exitus

nam fuit ante Jelenam cunnus tacterima bell causa,

ut si selvas pontquam Discosflia titetra, lebli ferratos postis portasque retregit,

Troini belli seriptorem. Maxine Lolli,

Antusur censet belli prifecidere causam:

me primis Vrlis belli placuise domique.

qualic aedituns habeat belli prectata domique , istus.

cirilisfue rudem belli tulit aestus in arma

idr. Sipist.1.20.18

Carm.Saec.5 I

Carm-3.2.7

sirm.1.4.130

iar Carm.3-7.1 5

Carm.3.7.15

Carm.3.12.8

Carm.4 11.28

var.corm.3.7.15

Carm.2.1.2

Curm.2.T.34

Corm.2.13.28

(arm.2.19.28

carm.4 4 7o

(ism.4 14.38

Serm.1.3.107

Serm.1.4.6I

Epist.1 2.1

Eptst.1.2.9

lipist.1.20.23

J.pist.2.1.230

lipist.2.2.47

Carm.4.3.0

carm.3.3.57

carm.2.11.1

Ispolito.I

a ar..serm. 1.0 .00

1. pist.2.I 93

Carm.1.12.42

Serm.2.2.11

Carm.1.32.0

Carm.2.10.5

Corm.3.2r.3

I.pol. 9.24

sarm.1.3.104

serm.2.3.223

carm: 3.330

I. pud.1.2.1

Serm.7.7.11

serm 1.7. 10

Sorm 23217

Cum.21.13

Carm. 27.15 
quis ferae/bellum curet Hiberiae?

hic ego propter aquam, quod erat deterrina, ventri indico bellum, seu quod Lucania bellum|incuteret violenta.

ir a truces inimicitias et funebre bellum.

fortunam Priami cantabo et nobile bellum."

nee gemino bellum Troianun orditur ab ovo;

quaelpartes in bellum missi dueis:

belua. demittit atras belua centiceps auriz

uti petita ferro belua?'

ut ingens/belua cognatos eliserit:

quae belua ruptis, |cum senel efigit, reddit prava catenis?

belua multorum es capitun.

beluis. saevis inimica virgo' lueluis.

beluis. seatentem beluis pontum

beluosus, beluosus qui remotis/obstrepit Oceanus Britannis.

bene. relicta non bente parmula.

sperat infestis, metuit secundis/alteram sortem bene praeparatum| pectus.

bene mutuis ndum pectus anoribus;

vivitur parvo bene cui paternum|splendet in mensa tenui salinum bene est cui deus obtulit | parca quod satis est manu.

scelerum si bene paenitet.

potes hac ab orno|pendulum zona bene te secuta e- lidere collum.

bene ferie magnam, disce fortunam;

indecorant bene nata culpat.

si chartae sileant quod bent feceris.

pro bene sano/ac non incauto fictum astutumque vocamus.

di bene fecerunt, inopis me quodque pusilli|finxerunt animi,

bene siquis/et vivat puris manibus.

si bene me novi, non Viscun pluris anicum,

hine repetit, paucorum homilium et mentis bene sanae;

memini bene, sed meliote tempore dican;

neque, si male cesserat, usquam|decurens alio neque, si bene:

cum sale panis|latrantem stomachum bene leniet.

in primis valeas bene:

bene erat non piscibus V lrbe petitis,

sed unde/tam bene me nosti?"

si male rem gerere insani est, contra bene sani:

columbino limum bene colligit ovo.

bene est. nil amplius ono, | N aia nate.

et quat rimosa bene deponuntur in aure.

quo bone, [bene] circa, dum licet, in rebus iucundis vive beatus. .

iurat bene solis esse maritis. .

si conportatis rebus bene coritat uti.

me pinguem et nitidum bene curata cute vises.

cum bene notum| porticus Agrippae, via te conspexerit Appi.

ae bene numnatum decorat Suadela Venusque.

si bene qui cenat bene vivit,
si bene qui cunat bene vivit [? vivit bene], lucet, eamus/quo ducit gula;

Celso gaudere et bane ren gerere Albinovano

navibus atque, quadrigis petimus bene vivere.

si ventri bene, si lateri est pedibusque tuis.

ros sapere et solos aio bene vivere.

si bene te novi, metues, liberrime Lolli |scurantis speciem praebere. ad bene dicendum delectandunque redacti.

clamabit enim 'pulchre, bene, recte.'

Beneventum. tendimus hinc recta Beneventum.

benigna. at fides et ingeni benigna vena est

nunc nihi nunc aiii benigna.

benigna, deus haec fortasse benigna/reduct in sedem vice.

benignae. egens bunignae Tantalus semper dapis.

benignae. quid si rubicunda benigni [benignae]/cona vepreset pruna ferant.

benigne. "at tu. quantum vis, tolle" "benigne"

quid multa? "benigne" respondet.

quid si rubicunda benigni [benigne] fcorna vepres et pruna ferant.

benigni. quid si rubicunda benigni|coma veptes et pruna ferant.

benignis. dabinusque divis|tuta benignis.

benignitas. satis superque me benignitas tua/ditavit.

bengnius. atque berignius, deprome quadimum Sabina.

Carm.4.5.28

Serm.1.5.8

Scrm.2.1.38

lipist. 1.19 .49

Irs Poit.137

Ars Poct.147

Ars Puct.3 I5

Carm.2.13.34

Epod.5. 10

serm.2.3.316

Sirm.2.7.70

Epist.1.1.76

Carm.1.12.23

Carm.3.27.27

Carm-4.I.47

Carm.2.7.10

Carm.2.IO.It

Carm.2.12.15

Carm.2.10.13

Curm.3.16.43

Carm.3.24.50

Cirm.3.27.59

Carm.3.27.74

Carm.t. 46

Carm.4.8.21

Sorm.1.3.61

Sirm.1.4.I 7

Sirm.1.t.07

Serm.1.9.22

sirm. I.9.44

Sirm.1.0.68

$5 \mathrm{erm} .2 .1 .32$

Sirm.2.2.1S

Serm.2.2.71

Sirm.2.2.120

Serm.2.3. I 8

Serm.2.3.74

sirm.2.4.56

Scrm.2.6.

Serm 2.6.46

iar.Serm.2.6.95

Epist.I.I. 89

lipist.r.2.50

Epist.1.4.15

Epist.1.6.25

Epist.1.6.38

Epist. 1.6.56

var. Epist.1.6.56

Epist.1.8.1

Epist.1.I. I.29

Epist.I.12.5

Epist.r. I5.45

Epist.1.I8.I

Epist.2.1.155

Ars Poet.tes

Serm. I.5.7 I

Carm.2.18.10

Curm.3.29.52

Epod.13.7

Epod.17.66

var. Epist. I. I 0.8

Epist.1.7.16

Epist.1.7.62

vur.Epist.1.16.8

Epist.1.16.8

Carm.t.2.52

lepod.1.3 I

Carm.1.9.6 


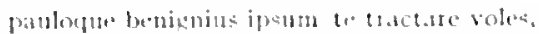

Epist.1.17.11

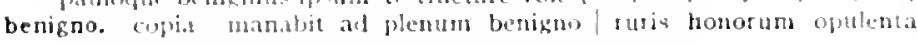
cormuls

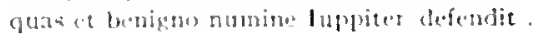

Carmiti7.15

(iarm.4.4.7.4

aestivan sermone fernigno tomdere noctem.

Epist. $1.5 \cdot 11$

Lisist.1.11.20

benignum. dum furet ac boltum

at hic i. . . Whet bonus atcue benignus lesse.

quon viui somnique benignus

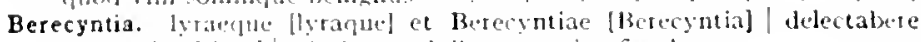
tibise [tibia] mixtic carminibus non sine fistula;

Berecyntiae. cut Borecrutiae cesam hamina tibiae?

Beterytiat delectabere tibiac

Berecyntio. Facva tenc cum berecymis cornu tympana.

Siern.1.2.t

Sirm.1.2.5I

$\operatorname{serm} \cdot 2 \cdot 3 \cdot 3$

Beselli. est inter lanain quidrlan socerumque V'i-elli [Beselli]:

Bestius. ut ventros lama camdente motum diceret urendos correctus Bisijua.

bibam. cessat volumtas? non alia bibam mercede.

quasde... beat" Maecena bibam.

bibant. collectome bibant imbris puteosne peremnis/iugis aquae

bibendi. grem benus arbitrum dicet bibendi?

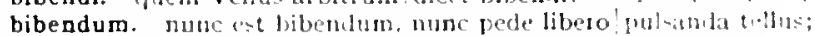

bibentem. neque me st:b arta vite bibentem.

bibenti. quin etian canct infoctum sed dulce bobenti.

bibere. amplorae fumum bibere intitutal consmle Tullo.

biberent. guor-i follesen cand biberent exsangut cuminum.

biberes. meremum $T$ atmain si bilueres, lyce.

biberis. mi llymetia mella falemo ne biberis diluta.

bibes. ptolu domitan ("al-ros th bibec uvar:

Cavelum et fitelo domitan caleno tu bibes [non bibes] uvam:

vima bibe* itertum Tauro diffusa paluctris inter Ninturnas

bibet Auzustus recuntros plupureo bibet ore metal.

bibimus. "nos nin dammose bilsintes, moriemur inulei,"

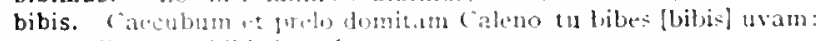

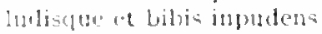

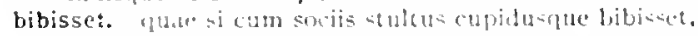

bibisti. Juai-ti sattin, relinti satis atque tillizti:

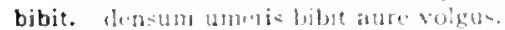

guos inter Auguatus tecumbus jurpureo bitset [bilit] ore nectar,

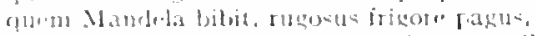

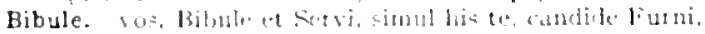

Bibuli. testantin Bibuli consulis amphoran.

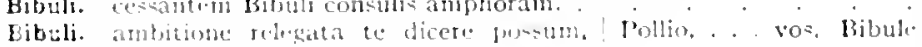

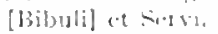

bibuli. [potores libuli media de noct. Jablernil

bibulum. quen fibulam liquili molis de lace traletni: .

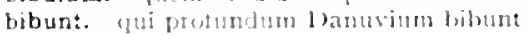

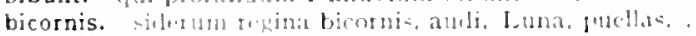

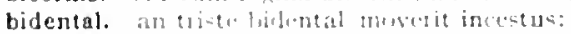

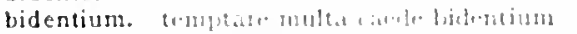

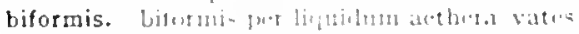

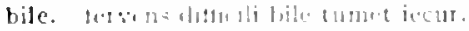

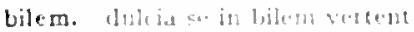

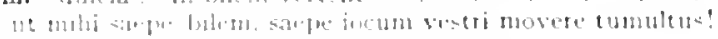

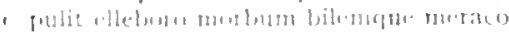

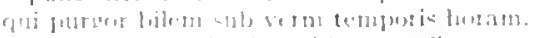

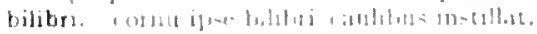

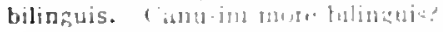

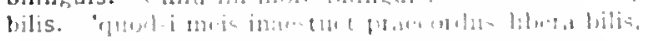

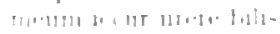

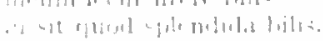

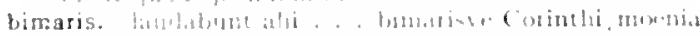

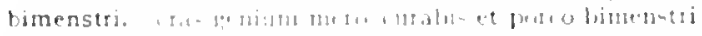

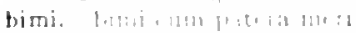

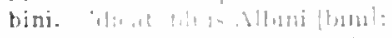

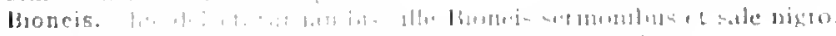

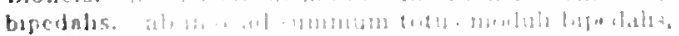

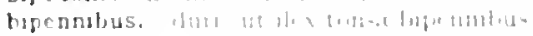

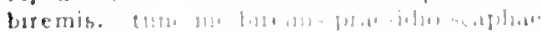

ar.Carm.4.1.22

Corm.3.19.1s

Carm.t.1.22

Carm.1.18.13

tar.Serm.1.1.105

Fpist.1.15.37

Carm.1.27.2.3

Epod.9.4

Epist.1.15.15

Carm.2.7.20

Carm.1.37.I

Carm.1.38.8

List. 2.9

Carm.3.8.11

lipist.1.19.18

Curm.3.10.1

Serm.2.2. If $^{2}$

carm.1.20.10

conicarm.1.20.10

1:pist.1.5.t

Carm.3.3.12

serm.2.8 3.4

:ar.Curm.1.20.10

Corm.4.13.4

tepist.1.2.24

Jipist.2.2.21.

Carm.2.13.32

2or.Carm.3.3.12

Jipist.1.18.105

conisiorm.1.10 86

Corm. 3.28 .8

iar.serme 1.0 .80

:ur. Lpist.t.15.91

Jifis 1.1.4.34

(ism 6.15 .21

Carmavarias

- irs Jinetatis

Cirm-3.2.3.

(iarmi.2.20.2

Cirm.1.13.4

Sirm.2 2.75

Iipist.1.10.20

1 pist.2.2.137

irs l"uet 302

sermi =2.11

termisingo

l.pod.1) 1".

sirmen ineco

som.2 3514

(arm.1.7.2

(uarm.317. 5

(armil 1i) 15

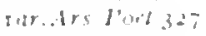

I pist 2.2011

term 2 ; 3100

(

(a)m. 3 की 
Birri. ut sis tu similis Caeli Birrique latronum.

bis. te bis Afro/nurice tinctae/vestinnt lanae: jam bis Monaeses et Pacori manus/inauspicatos contudit impetus pto quo bis patiar mori.

illic bis pueri die... ter quatient humum. cum bis trium ulnarum toga,

longo die bis terque mutatae dapis canis|ignavos adversum lupos [ignavus vel bis hostis lupos adversum]? ad hunc frementis verterunt bis mille equos

'solventur risu [solventur bis sex] tabulae, tu missus abibis.' . quas bis quinque viri sanxerunt. .

accipit et bis dena super sestertia nummum. quem bis terve bonum cum risu miror;

nelius te posse negares/bis terque expertum frustra:

Bistonidum. nodo coerces viperino/Bistonidum sine fraude crinis.

Bitho. non/conpositum melius cum Bitho Bacchius.

Bithyna. quicumque Bithyna lacessit/Carpathium pelagus carina:

Bithyna. ne Cibyratica, ne Bithyna negotia perdas;

bitumen. utifbitumen atris ignibus.'

blanda. saxa movere sono testudinis th prece blanda|ducere.

blandae. quo blandae iuvenum te revocant preces.

blandi. ut pueris olin dant crustula blandi|doctores.

blandienti. cessit immanis tibi blandienti|ianitor aulae

blandior. ron sumptuosa blandior hostia.

blandius. quid? si Threicio blandius Orpheo

blandos. catelestis inplorat aquas docta prece blandus, [blandos]|avertit morbos.

blandum. blandum et auritas fidibus canoris/ducere quercus.

blandus. caclestis inplorat aquas docta prece blandus. .

Blandusia. o fons Bandusiae [? Blandusia et] splendidior vitro,

Blandusiae. ofons Bandusiae [Blandusiae] splendidior vitro.

blateras. cum magno blateras clamore fugisque.

blattarum. stragula restis, blattarum ac tinearum epulae,

bobus. et iuga demeret bubus [bobus] fatigatis

quacque vos bubus [bobus] veneratur albis

beatus ille qui . . . paterna rura bubus [bobus] exercet suis

Boeotum. Boeotun in crasso iurares aere natum.

Boetum. Boeotum [Boetum] in ctasso iurares aere natum.

Bolane. 'o te. Bolare, cerebri|felicem'

bona. pluribus hisce, si modo plura mihi bona sunt, inclinet.

bona. cum nea conpensat vitiis bona.

dividit ut bona diversis, fugienda petendis:

in cicere atque faba bona tu perdasque lupinis,

'non hercule miror? | aiebat, 'siqui comedunt bona. 'adimam bona."

bona. tum meae, . . vocis accedet bona pars

ut bona pars hominum decepta cupidine falso

sit bona librorum et provisae frugis in annum/copia

bona pars non unguis ponere curat. non barbam,

bona. bona iam peractis/iungite fata.

sed bona siquis iudice condiderit laudatus Caesare?

bonae. non sum qualis eram bonae/ sub regno Cinarae.

bonae. hoc paces habuere bonae ventique secundi. adiccere bonae paulo plus artis Athenae.

bonam. spem bonan certanque domum reporto bonam deperdere famam. | ren patris oblimare malum est ubicumque.

bone. lucem redde tuae, dux bone. patriae:

'lorgas o utinam, dux bone, ferias|praestes lfesperiae!"

o bone, re te frustrere: insanis et tu stultique prope omnes.

o bone (nam telscire. . oportet).

quo, bone, circa, / dum licet, in rebus iucundis vive beatus,

'i boze. quo virtus tua te vocat, i pede fausto.

boni. et quae st natura boni summunque quid eius.

boni. nihil maius meliusve terris, fata chavere bonique divi oderunt peccare boni virtutis amore:

boni. quae virtus et quanta, boni, sit vivere parvo

bonis. multis ille bonis tlebilis occidit.

fortes creantur fortibus et bonis:

vita redit bonis! post morten ducibus,
Serm.1.4.69

Carm.2.16.35

Carm.3.6.9

Corm.3.9.1.5

Carm.t.1.25

Epod.4.8

Epod.5.33

iar.Epod.6.2

Epod.9.17

conti.sern.2.1.86

Epist.2.1.24

Epist.2.2.33

Ars Poet.35s

Ars Poel. 440

Cirm.2.19.20

Serm.1.7.20

Carm.r.35.7

Epist.1.6.33

Epod. 5.82

Ars Potl.395

Carm.t.1.8

Sirm.1.1.25

Carm.3.II. 5

Carm.3.23.18

Carm.1.24.13

"ur.Epist.2.1.I35

Carm I.I2.II

Epist.2.I.135

? inar.Carm.3.13.I

var.Carm.3.13.I

Serm.2.7.35

Sertit2.3.1 I9

rar.Carm.3.6.43

var.Carm.Saec.49

var. Epod.2.3

Epist.2.1.24t

Tur.Epist.2.1.24t

Serm.1.9.II

Serm.1.3.7 I

Serm.1.3.70

Serm.1.3.314

Sicrm 2.3.182

Epist.1.15.42

Epist.1.I0.75

Curm.4.2.40

Serm.1.1.5:

Enist.1.18.100

Ars Pot.297

Carm.Sace.27

Serm.2.I.83

Carm.4.1.3

Epist.2.1.102

Epist.2.2.43

Curmance.7t

serm. I z.6 I

Corm.t.5.5

Carm.4.5.37

Sierm.2.3.3 I

Serm.2.0.5 I

Serm.2.0.95

Epist.2.2.37

Sirm.2.6.75

Corm.4.2.38

Epist.1.10.52

Serm.a.z.I

Carm.1.24.9

Carm +29

carm.t.s.ts 


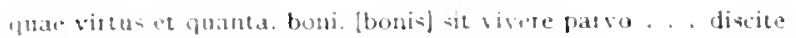
vilis amicoran tat annona, honis ubi quild dexest.

ille boni- buedatue et consilietur amice

bonis. non aen in bonic ab insolenti temperatam laetitia. divas tole buste, optume Romulate custos genti-

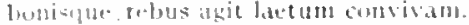

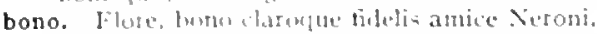

bono. moseri digna bortes die.

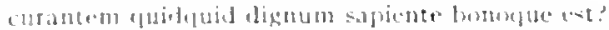

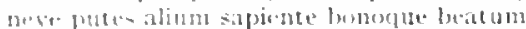

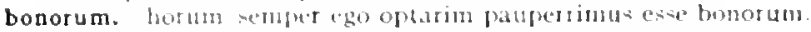

bonos. I.jher vota bonos ducit ad exitus. quinutue bonos sulitum Varian dimiltere patro.

bonum. "urantem quilquid dignum sipinte bonoque [bonunquel est?

bonum. st rhe tui gregis hunc et fortern crede bonumque. quem bis tere bonum cum rinu mitor;

bonus. quutiena bosms atque fidus iudex honestum praetulit utili. at hic si. . Fithet bonus atcue benignus/esse.

at est bombe, ut melior vir mon alius guisquam.

et sutur bonus et solus formosus et est rex.

secl des vemiam bonus, oto.

ita vir lumus es convivaque comis"

vir buntas et siphens dignis ajt esce paratse

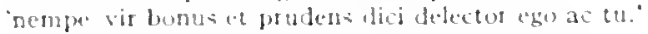

vir buinge est plias?

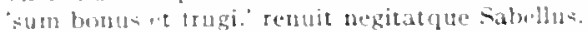

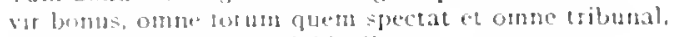

vir luntur et antiens audebit dicere:

absurita dius pupula bontes eruet

bonns sane bicinus, almabilis hosgess,

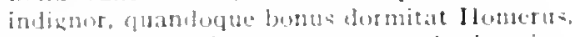

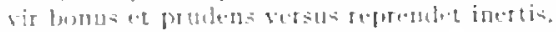

Boreae. noc Burar. finitimum latus

bos. tutus bos atenim rura perambulat.

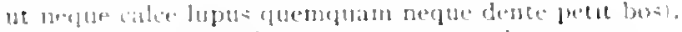

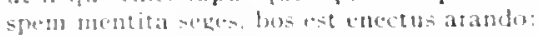

oftat ephippiat bos, piger optat atare calialles:

Bospori. vizan gesmentis litora buspori

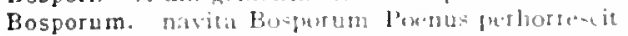

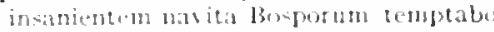

bove. fectus in protis vant otiono cumb bose masts.

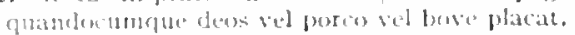

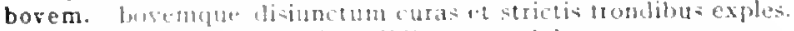

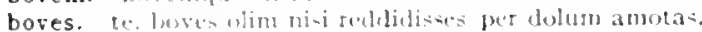

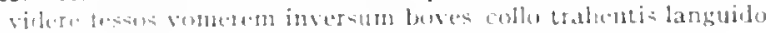

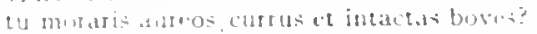

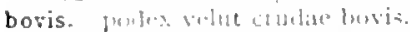

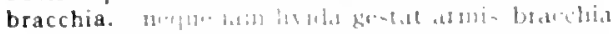

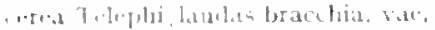

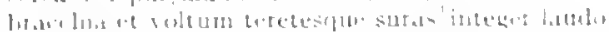

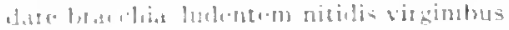

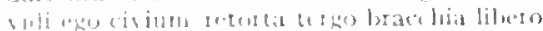

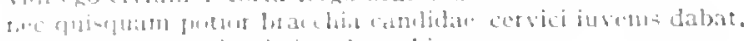

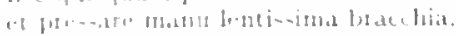

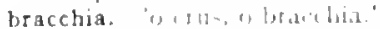

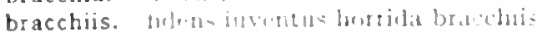

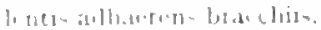

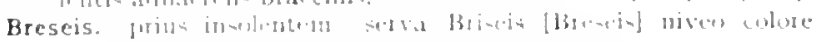
1. hillo.ll,

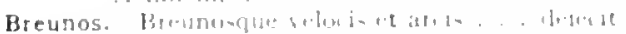

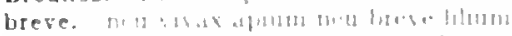

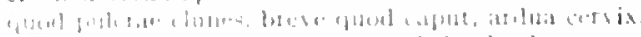

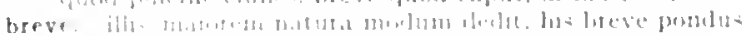

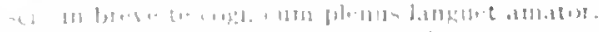

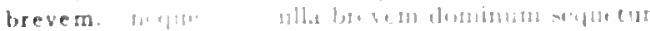

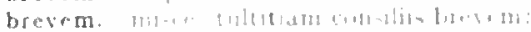

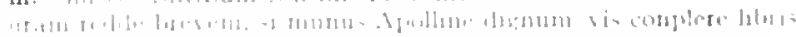

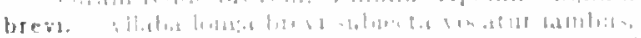

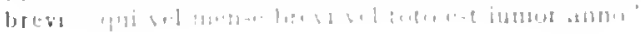

:ar Sermiz.2.I

Lpist 1.12 .24

ders Poct.19"

Carm.2.3.2

Cirm.et 5.1

stm.2.6.1119

I.pist.2.2. 1

(urm.3.21.)

l. pist I.45

Epist 1.10.20

Sorm.1. 1.90

Corm.4 8.34

Epist 1.14.3

tar.lipis\$1.4 5

lepisti.0.13

Ars Poet.358

Carm.4.9.40

Sirm.1.2.51

Serm. 1.3 .32

Serm.1.3.125

Serm.2.4.5

Serm.2.8. 0

Epist 1.7 .22

Lipist.1.10.32

Itpist I. 10.40

lipist.1.11.49

List.1.1\%.57

lipist.1.16.73

lipist 2.2.1 Is

L.sist.2.2.132

Ars l'ote. 350

Irs l'oet.ats

Curm-32:35

(armat5.17

Siem 2.1 .55

Epint 5.7 .87

lepist I $1 . \$ 3$

(urm.2.21).14

("irm.2 13.14

(ism.3.4.3n)

cirm.3. IS.I 2

Epistir. It. 58

Lepist.1.14.27

Cirm!1.10.9

lipod.2.03

lipol.0.22

Iipud.s.o

Curm.1 \$.11

carm.1.13-3

(orm.2.4.21

Cifrm 2.12.1s

(iorm.3.5.22

(iorm.3.1).2

Sirmis.0.0.4

serm.t. 2.92

(iarm.3 +.5t)

leped a 50

bir cirm.2 : b

cirmm.t II

carm. I 3 3 ' I I"

sermet and

Serm.2.37

f.pist.1.208

cirm.2.1 24

( 4 ) M..p 12.27

t:pet $21.21 \%$

in Mret $25 \mathrm{I}$

l.pest 2.1 in 
brevi. sapias, vina liques et spatio brevi|spen longam reseces.

Carm.1.II.6 quid brevi fortes iaculamut aevolmulta? verum ! depugis. nasuta. brevi latere ac pede longo est.

brevi. quid Titius? Romana brevi venturus in ora.

brevibus. brevibus illigata viperis/crinis

brevioribus. ac ne me foliis ideo brevioribus ornes.

brevis. privatus illis census erat brevis,

ira furor brevis est:

brevis esse laboro. /obscurus fio;

quidquid praecipies, esto brevis.

brevis. vitae summa brevis spem nos retat incohare longan; te lapathi brevis herba, sed albo non sine Coo. cena brevis iuvat et prope rivom sommus in herba;

brevis. ille dapes laudet mensae brevis.

brevis. vive memor, quam sis aevi brevis."

Silvanum lacte piabant, floribus et vino Genium nemorem brevis aevi

brevis. nimium brevis|flores amoenae ferre iube rosae, Cinatae brevis annos fata dederunt.

brevitate. est brevitate opus. ut currat sententia

Briseis. serva Briseis niveo colore/movit Achillem.

Britannis. qui remotis|obstrepit Oceanus Britannis,

Britannis. adiectis Britannis|imperio

Britannos. in | Persas atque Britannos'vestra motus ayet prece. serves iturum Caesaren in ultimos!orbis Britannos visam Britannos hospitibus feros

Britannus. intactus aut Britannus ut descenderet bruma. mox bruma recurtit iners. seu bruma nivalem interiore diem gyro trahit. quodsi bruma nives Albanis inlinet agris.

brumam. facit quod .. per brumam Tiberis, Sextili mense caminus.

brumas. ver mbi longun tepidasque praebet/luppiter brumas

Brundisium. Brundisium longate finis chartaeque viaeque est.

Brundisium. Brundisium comes aut Surtentum ductus amoenum Brundisium Minuei melius ria ducat an Appi.

bruta. quo bruta tellus et vaga flumina.

Brutam. Butram [3rutam] tibi Septiciumque . . adsumam;

Brute. per magnos, Brute, deos te/oro.

Bruto. deducte Bruto militiae duce.

Bruto praetore tenentelditem Asiam.

Brutum. laudat Brutum laudatque cohortem. solem Asiae Brutum appellat

bubus. et iuga demeret|bubus fatigatis quaeque vos bubus veneratur albis beatus ille qui . . paterna rura bubus exercet suis

buccas. merito quin illis I uppiter ambas/iratus buccas inflet

Buccillus. facetus/pastillos Rufillus [? Buccillus] olet,

Bullati. quid tibi visa Chios, Bullati, notaque Lesbos,

Bupalo. aut acer hostis Bupalo.

busto. dum Priani Paridisque busto' insultet armentum

Butram. Butram tibi Septiciunque . . adsumam;

Byzantia. non alia quan qua Byzantia putuit orca.

Carm.2.10.17

Sirm.1.2.93

Epist.1.3.9

Epod.5.15

Eipist.1.1920

C'arm.2.15.13

Ipist.1.2.1,2

Ars Poel.25

Ars Poet.335

Carm.1.4.15

Sirm.2.4.29

Epist.1.14.35

Ars Puet. 198

Serm.2.6.97

Epist.2.1.1.1.

Carm.2.3.13

Carm.4.13.22

Serm.1.10.9

Curm.2.4.3

Cirm.4.14.45

Carm.3.5.3

Carm.1.21.15

Carm. $1.35 \cdot 30$

Carm.3.4.33

Epod.7.7

Corm.4.7.12

Sirm.2.6.25

Epist.1.7.10

Epist.1.14.19

Curm.2.0.18

Serm.1.5.504

Epist.1.17.52

Epist.1.1\$.20

Carm.1.3.4.9

gror.Jpist.1.5.20

Sirm.1.7.33

Curm.2.7.2

Serm.1.7.18

Sirm.17.23

Serm.1.7.24

Carm.3.5.43

Carm.Saer.49

Epod.2.3

Scrm.1.1.21

? tar.Serm.1.2.27

Epist.1.II.I

I.pod.t. 14

(arm.3.3.4")

Epist.1.5.2\%

sirm.2.4.100

\section{C}

caballi. plutes calones atque caballi pascendi. ducenda petorrita.

caballo. non ego circum me Satuteiano vectari rura caballo.

caballum. nedia de nocte caballum arripit

Thrat $x$ erit aut holitoris aget mercede caballum

caballus. optat eplippia bus, piger optat arare caballus:

cacatum. in me veniat mictum atque cacatum

cachinnum. Romani tollent equites peditecque cachinnum.

cacumina. quando/Padus Matua laverit cacumina.

cadant. quo pronissa cadant et somnia Pythagorea;

nova fictaque nuper hafebunt verba fidem, si / Graeco fonte calent

[cadant] parce detorta.

cadat. atque haec rara carlat dura inter saepe peticla.

dun cadat elusus ratione ruentis acervi

cadat an recto stet fabula talo.

Serm. . 6.103

Serm. 1.0 .50

Epist. . 7.38

lipist.1.18.36

Epist.1.1.4. 43

Serm.1.8.38

Ars Poet. I 3

Expod.10.28

Ispist.2.1.52

zar.ars I'oet. 53

Sirm.1.2.40

Jpist.2.1.47

Jpisl.2.1.176 
cadaver. collaver unctuns cheo largo nudis umatis tulic heres.

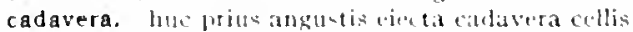

cadens. mofu+ ut superni villa cambus [cadens] Tusculi/circaea tangat moeniat:

cadent. si firleco fonte calent parce detortat.

callentege quan nute sunt in henose vorabula.

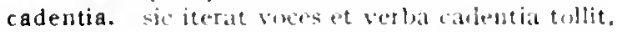

cadentis. nec saevers Arcturi callontis impetus

cadi. nee poti, vetulaul, faece tenus cads.

cadis. necipare callis tibi destinatis.

cadis. difupiunt catis lenm face sicat is amici.

of po-itis ineus ("hif veterisque falerni|mille cadjo.

cadit. si tenhet pleno caldit haerlus amus cur fanula parum decono inter vepba cadit lingua silentio? dith tristis criem carlit:

Cadmo. elciere de saxo civiz aut tratere (aelmo?"

Cadmus. aut in arm l'soche vertatur, Cadmus in anguen.

cado. non antevererses lene mellum cates

caduco. fulmine suatulerit carluco

caducum. triste lismum, te, carlucum in dontri capue inmerentis.

cadum. ct eadum Marsinemorem duelia,

quo (hium pretio calum mercenur.

mardi parsos onyx ellicict catum.

las mummos, accipis wram, pullos, ova, calum terneti: .

cadunt. pullus, ova cadum forbunt temeti: nempe moderisto prima collut: ita verbotmsn vetus intetit atetas.

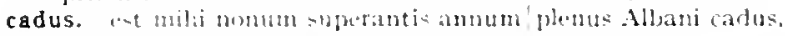

caeca. Cartathitamia sort.

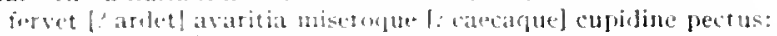

caeca. mentu. ultra carca timet aliumble tala.

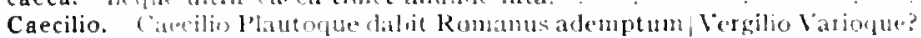

Caecilius. vincere Caecilius gevitate. Terentius arte.

caecior. Ilypara casedint illa. quat ublat sunt. spectes.

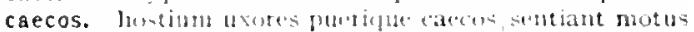

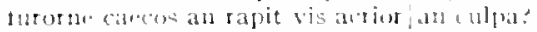

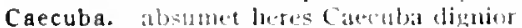

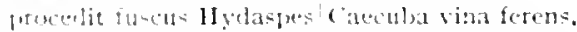

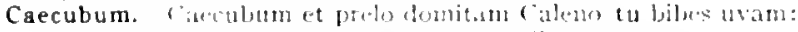

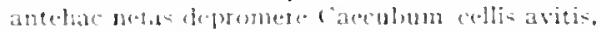

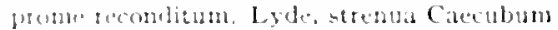
quasuln gepoutum Caecubum ad festas dapes.. Biban motite nobis ("ileculumins.

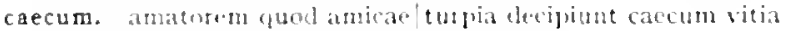

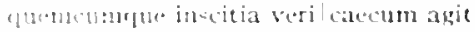

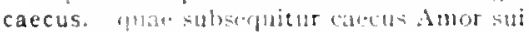

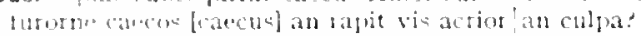

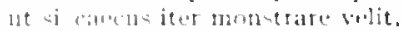

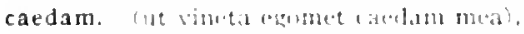

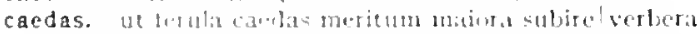

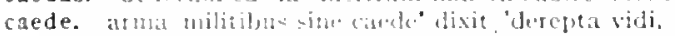

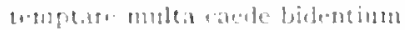

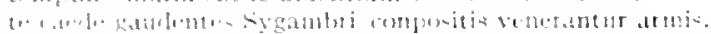

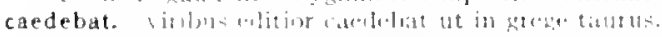

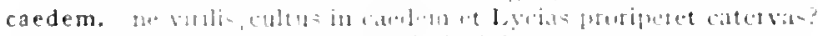

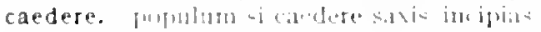

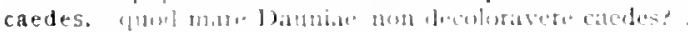

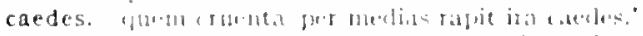

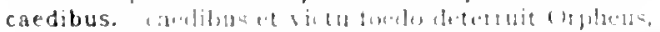

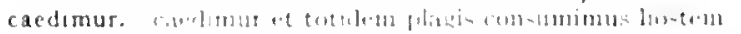

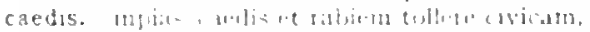

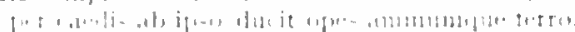

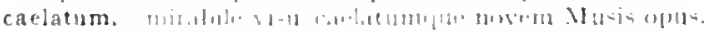

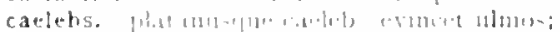

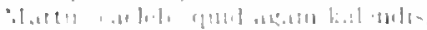

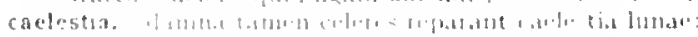

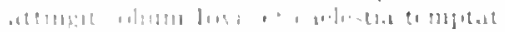

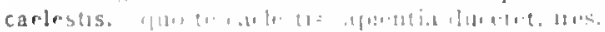

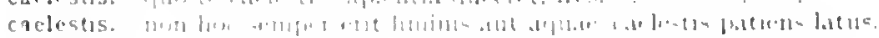

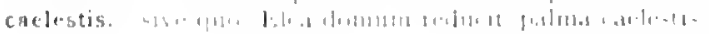

serm.2.5.85

Sirm.1.8.8

:ar.Lpod.1.29

Ars J'or't.53

irs Poet.7o

L.pirt.1.15.12

Curm.3.1.27

Corm.3.15.16

Carm.2.7.20

Carm.1.35.26

Sorm.2.3.11s

Carm.3.28.5

Carm-4.1.3'

Epodicio

Serm.1.0.30

Ars Pues.187

Carm-3.20.2

Carm.3.4.4.4

Carm.2.13.11

Carm.3.1.1.18

Carm.3.19-5

Carm.4.12.17

Epist.2.2.163

iar. Epist.2.2.163

Ars Iod.oI

Carm.4.11.2

Sirm.2.3.209

rtar. Efist.1.1.33

Carm.2.13.10

Ars Poet.it

Epist.2.1.59

Sorm.1 2.01

(iorm.3.27.21

L.pod.7.13

Cirm.2.1. $=5$

Sorm.2.8.15

Corm.1.20.1)

Carm.1.37.5

Cirm.3.2S.3

Lpodo. 1

1.80.1.9.30

Sorm.1.3.39

S.rm.2.3.44

Carm.1.1.14

ior.lipod.7.13

Lipiti.1...

Ipist.2.1.220

berm.1.3.120

ciurm.3.5.20

(ismi.3.23.14

(orm.t.1.5!

Serm.1.3110

Ciarmets.so

cerm.2.3.12s

(iarm.2.1.35

(ism.3.12

Ars Pont.jos

Lepiste2.87

(carms.32.420

(iarm.1.150

l.pest.2 2.2.2

(a)m.2 15.4

(arm) B. I

(arm 4 \%. 13

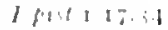

I. 18314327

(.) 110.3 .30 .21

(idr) 1218 
caelestis. caclestis inplorat aqua docta prece blandus,

Lipist.2.1. 135

Caeli. ut sis tu similis Caeli Birrique latronum,

caeli. Iucidum caeli decus. .

deos id tristis ex alto cacli demittere tecto.

Sirm.1.4.69

Carm.Sact. 2

Sirm.1.5.103

ianque tenebat $\mid$ nox nedium caeli spatium.

Serm.2.0.101

caelibe. nil ait esse prius, melius nil caelibe vita;

Epist.1.1.83

caelibis. ne manifestumfcatibis obsequium nudet te.

caelitum. utrumque tege temperante caclitum.

caelo. quem virum . . acri tibia sumis celcbrare, Clio [caclo]? quis te redonavit Quiritem | dis patriis Italoque caelo, caelo supinas si tuleris manus

Massica si caelo suppones vina sereno.

caelo, albus ut obscuro deterget nubila catlo| saepe jotus.

toto taciturna noctis signa cum caelo.

descende caelo et dic age tibia

caelo tonantem credidimus Iovem $\mid$ regnare;

dignum laude virum Musa vetat mori. / caelo Musa beat.

at o deorum quidquid in caelo regit

lunamque caclo deripit.

nox erat et caelo fulgebat Luna sereno

refixa caelo devocare sidera.

caelo diffundere signa parabat;

caelum. priusque caelum sidet inferius mari

quae sit hiems Veliae, quod caelun. Vala, Salerni,

caelum. serus in caclum redeas

caelum ipsum petimus stultitia

Virtus, tecludens inmeritis mori $\mid$ caelum,

horrida tempestas caelum contraxit

donee "ole iam" ad caelum manibus sublat is dixerit,

arron caelumque Sabinum | non cessat laudare.

quae vos ad cachm fertis rumore secundo.

caelum, non animum mutant, qui trans mate currunt.

caementa. huc frequens caementa demittit redemptor.

caementis. caementis licet occupes/terremum omme tuis et rare publicum:

caeno. haeres nequiquam caeno cupiens evellere plantam.

Serm.2.5.47

Epod. 10.56

Far.Carm.1.12.2

Carm.2.7.4

Carm.3.23.I

Serm.2.4.51

Carm.1.7.15

Comm.2.8.II

Carm-3.4.I

Carm.3.5.1

Carm.t.8.20

Epod.5.1

Epod.5.4t

Epod. I5.1

I.pod.17.5

Serm.1.5. I0

I.pod.5.79

Epist.1.15. I

Camm 12.45

Carmr. 3.38

Carm.3.2.22

F.pod.I3. I

Serm.2.5.97

Epist.1.7.77

Epist.1.10.9

Epist.1.II.27

Carm.3.1.35

Carm.3.24.3

Simm.2.7.27

Lpist.I.I2.2 I

Caerite. Caerite cera|digni, remigiun vitiosum Ithacensis Vixei, . . . Fist.t.0.02
caerula. nec mater domum caerula te reveluet. . . . . . Epol.13.10

caerula. nec mater domum caerula

caerulea. nec fera caerulea domuit Germania pube

caesa. Vel agna festis caesa Terminalibus

Caesar. Caesar ab Italia volantem remis adurgens.

Caesar Hispana repetit penatis|victor ab ora.

Caesar, qui cogere posset.

militibus promissa Triquetra praedia Caesar an est Itala tellure daturus?"

Caesar. neu siras Meus equitare inultos, te duce, Caesar. .

tua. Caesar, aetas firuges et agt is rettulit uberes

si longo setmone morer tua tempora. Caesar.

Caesare. tu secundol Caesare regnes.

pestemque a populo et principe Caesare

nec mori per vim metuam tenente, Caesare terras.

'o sol pulcer, o laudande!' canam recepto|Caesare felix. .

quis Parthum pareat. . . incolumi Caesare?.

custode retum Caesare

victore laetus Caesare

sed bona siquis indice condiderit laudatus Caesare?

cras nato Caesare festus, dat veniam somnumque dies:

Caesaren. serves iturum Caesarem in ultimos/orbis Britannos Caesarem altum,... finire quaerenten labores concines maiore poeta plectro Caesarem. quaerit patria caesarem.

Galli canente: Caesarem

caesariem. nequiquam Venet is praesidio ferox/pectes cateariem

Caesaris. filus Maise, paticns vocari Caesar is ultor: laudes cgregii Cacsaris et tuas orte Saturno, tibi cura magni. Caesaris fati data: potius nova, cantemus . Iugusti tropatal Causaris turue pedestribu, dices listeris protia Catsaris. quibus antris eguegii Cacsale audiar auternum meritans decus

I:Pod.10.-

Epod.2.50

Carm. 1.37 .10

Corm.3.143

Sorm.1.3.t

Sirm.2.6. $5^{\circ}$

Carm.1.2.52

Curm.4.15.4

Epist.2.I.4

Carm.I. 2.52

Camm.I.I.I4

Cum.3.14.10

Carm.a.2.4s

Carm.4.5.27

(urm.t.15.17

Epod.9.2

Sirm.2.1.S.

EPist.t.5

(a)m.I.35.20

Carm.3.4.37

Carm.4.2.34

Curm.1.5.10

Jipol.9. Is

Carm.I.I5.14

carm.T.2.t.

Camm.t.II

Carm.I, I2.5 I

Carm.2.90

Carmazz.In

Carm.3.25 i 


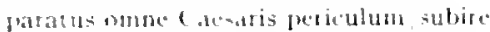

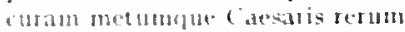

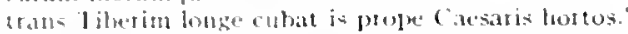

ande canearis invioti res dicere.

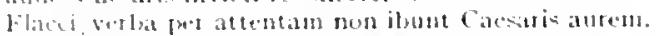

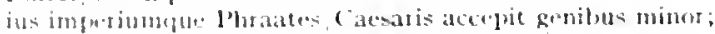

sarmina guat posint xulos ansigue motari Caesaris.

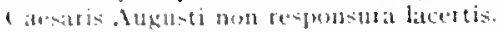

caespite. po-ituritu casbo in calspite rivo.

caespitem. hic vivum miht cate-nitem,

me. fortuitum spernete caespitcm

caesus. ille Hatgllis an moten carsus.

jugnis catesus fertorgue jetitus.

Calaber. non yluo mon pisis veci Calaber iubee hospes

Calabrae. yuanoruan nec Calabua medla forunt apes

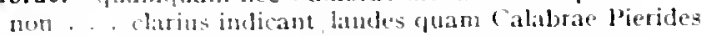

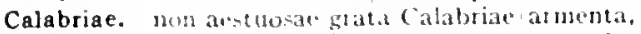

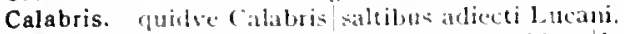

Calabris. pecuse Cabris ante siclus fetrielum L heana mucet pascuis

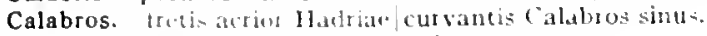

Calais. IJurini (alais filius ()rnyti.

calami. hastáce calatui spicula ('nesii vitabis.

calami. culpantus tuatra calami

calamo. incomptis allinet attum transverso calamo signum.

calamum. prius ortu sole vigil calamum et chat tas et scrinia posco.

calcanda. et calcandia semol siateti.

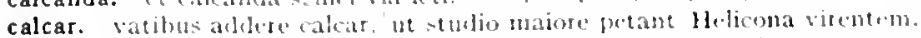

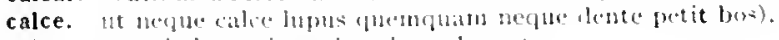

calceus. mal. lisxus in prede calcens hacret-

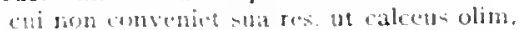

caldior. caldine eat : antis inter numberetor:

calebo. (mon crim gorthac alia calebol femina)

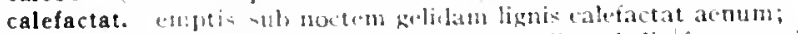

Calena. jreman Cahnam [Calenal tabe quitus dedie, fortma vitem.

Calenam. Jremant calenan Galce quibus dedit fortuna vitem.

Caleno. pils chomitam Calenu, tu bibes uram:

calentem. ibi tu calcotem lebita sparges lactima favillam vatis amici.

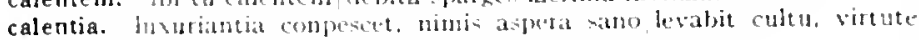
catential [ealentia] tollet:

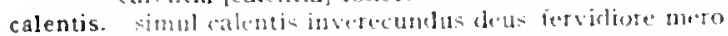

calentis. duid terras alio calumtis sule nutamus?

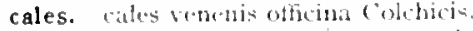

calet. quo salet iuscotus nume omnis ct mox virgines tepebunt. .

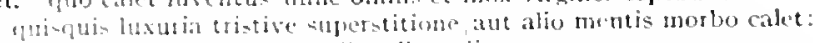

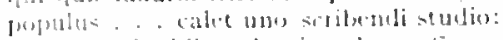

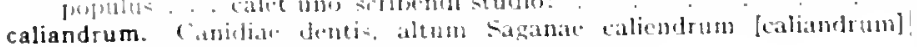

$$
\text { excinler. }
$$

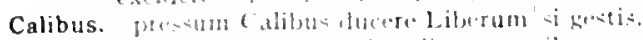

calicem. gum nuctio tratarit calicem manilus.

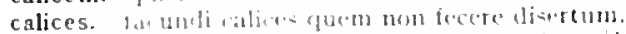

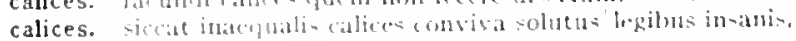

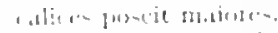

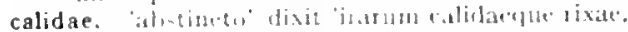

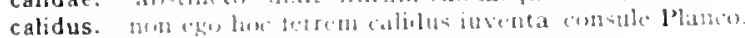

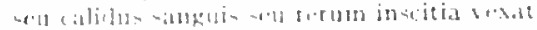

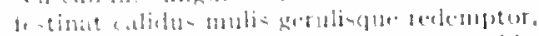

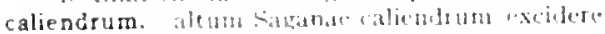

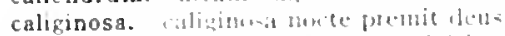

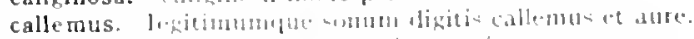

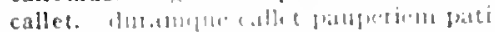

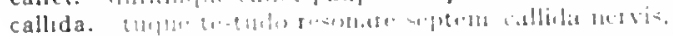

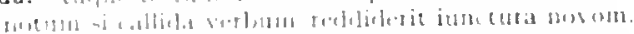

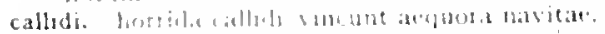

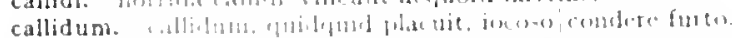

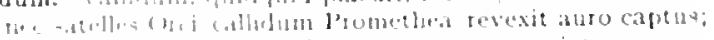

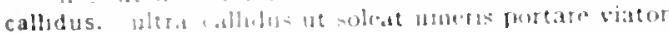

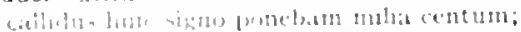

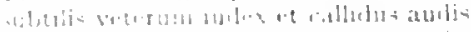

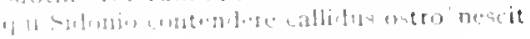

lepoll.1.3

Food.9.37

Sorm.1.918

Serm.2.1. II

Serm.2.1.19

tepist.1.12.28

IE pist.1. I 3.18

lipist.2.2.48

Cirm.3.8.4

Cirm.1.19.13

Carm.2.5 5.17

Serm.1.2.42

Sorm.1.2.6e

Fipt.1.7.14

Cirm.3.16.33

Curm.4.8.20

Curm.1.31.5

L.pist.2.2.177

Epod.I.27

Carm.1.33.16

Carm.3.9.14

Carm.1.15.1\%

Sirm.2.3.7

Ars 1)ot..147

Ifpist.2.1.13

carm.1.28.10

Epist.2.1.217

Serm.2.1.55

Serm.1.3.32

lipist.1.10.42

Sirm.1.3.53

Carm.4.11.33

Epist.2.2.100

ror. (iarm.1.31.9

Cirm.1.31.0

(irms. 20.1)

ciarm.2.0.22

:ar. FPist.2.2.123

L.pod.11.13

Curm.2.10.18

Epol.17.35

Carm.t.19

trom.2.3.50

Epict 2.1 .108

var.serm.1.8.45

Cirmin.12.14

Serm.2.4.79

lipist.1.5.19

viem.2.0.68

Sirm.2.8.35

(itrm.3.27.70

Cirm.3.14.27

lipist. 1.3 .33

lipist.2.2.72

Sirm.t.8.

(itrm.320.30

ders I'ortezid

(atmodido

Cismm.3.11..6

. Irs lint 47

citrm 32.4 .10

ciorm.1.jo.7

cirm.2 2 s. 35

Sorm.1.5 po

Serm. 2.3.2.3

sirm 27.101

lipust a 1020 
Callimachus. ille meo quis?|quis nisi Callimachus?

Calliope. dic age tibia/regina longum Calliope melos,

callosa. namque marem cohibent callosa vitellum.

calo. invidet usum|lignorum et pecoris tibi calo argutus

calones. hunc perminxerunt calones;

plures calones atque caballi|pascendi, ducenda petorrita.

calor. dum ficus prima calorque/dissignatorem decorat

calores. conmissi calores/ Aeoliae fidibus puellae.

caloribus. si neque fervidis pars inclusa caloribus $\mid$ mundi

caluisse. prisci Catonis/saepe mero caluisse virtus.

Calvom. nil praeter Calvom et doctus cantare Catullum.

camelo. divorsum confusa genus panthera camelo.. . converterct ora;

Camena. prima dicte mihi, summa dicende Camena.

camena. gratus insigni referam camena|Fabriciunque.

Camenae. spiritum Graiae tenuem Camenae

Dauniae defende decus Camenae.

surge et inhumanae senium depone Camenae.

ignotun tragicae genus invenisse Camenae

Camenae. Stesichorive graves Camenae

Vergilio adnuerunt gaudentes rure Camenae.

vina fere dulces oluerunt mane Camenae.

Camenae. vester, Camenae, vester in arduos'tollor Sabinos,

Camenis. acceptusque novem Camenis.

cameram. gaudes, si cameram percusti forte, penes te es?

per angustam tenuis volpecula rimam|repserat in cumeram [cameram] frumenti,

Camillis. et maribus Curifs et decantata Camillis?

Camillum. Curium. . bello tulit et Camillum/saeva paupertas

camino. arlde poemata nunc, hoc est, oleum adde camino, .

camino. udos cum foliis ramos urente camino.

caminus. facit quod . . per brumam Tiberis, Sextili mense caminus.

Campana. adstat echinus/vilis, cum patera guttus, Canpana supeltex.

Campana. festis potare diebus/Campana solitus trulla

Campanis. pulveris atri|quantum non Aquilo Campanis excitat agris.

Campano. proxima Campano ponti quae villula, tectum praebuit

Campanum. Campanum in morbum, in faciem permulta locatus,

campestre. facit quod/paenula solstitio. campestre nivalibus auris.

campestres. campestres melius Scythae. . . vivont

campestria. quo clamore coronae proelia sustineas campestria;

campestribus. Ludere qui nescit. campestribus abstinet armis

Campi. gaudet equis canibusque et aprici gramine Campi,

campi. per gramina Martii|campi.

campi. an pingues Asiae campi collesque morantur?

campis. si Mygdoniis regnum Alyattei/campis continuem. redeunt iam gramina campis

campis. pone me pigtis ubi nulla campis/arbor

leporem citus/venator in campis nivalis|Haemoniae.

exiguis equitare campis. .

iam Scythae laxo meditantur arcu' cedere campis.

quae velut latis equa trima campis / ludit exsultim

parumne campis atque Neptuno super/fusum est Latini sanguinis

Campo. gandentem. . ludis et post decisa negotia Campo. cunctane prae Campo et Tiberino fumine sordent?

campo. ludit herboso pecus omne campo .

ille gravem duro terram qui vertit aratro, | perfidus hic caupolfervidus hic campo].

ut siquis astllum in campo doceat parentem currere frenis?

ut rupes fluviosque in campo obstare queratur;

ludos spectaverat, una luserat in campo:

campos. circa virentis est animus tuae/campos iuvencae visam ... canorus/ales Hyperboreosque campos.

campum. cur apricum /oderit campum patiens pulveris atque solis. hic generosior ${ }^{\dagger}$ descendat in campum petitos. ut siquis asellum in campo [campum] doceat parentem currere frenis? fugio campum lusumque trigonem. servos|diftertum transire forum populumque [campumque] iubebat,

campus. nec tam Larisae percussit campus opimae nunc et campus et areae. . repetantur. quis non Latino sanguine pinguior / campus
Epist.2.2.100

Carm.3.4.2

Serm.2.4.14

Epist.1.14.42

Serm.1.2.44

Serm.1.6.103

Epist.1.7.5

Carm.t.9.I

Carm.3.24.37

Carm.3.2I.I 2

Serm.I.I0.10

Epist.2.I.195

Epist.I.I.I

Carm.1.12.39

Carm.2.16.38

Carm.t.6.27

Epist.1.18.47

Ars Poel.275

Carm.t.9.8

Serm.1.10.45

Epist.1.10.5

Carm.3.4.2I

Carm.5at".62

Serm.2.3.27.3

gar.Epist 1.7.30

Epist.1.1.04

Carm I.I2.42

Serm.2.3.321

Serm.1.5.8I

Epist.I.I1.Io

Serm.1.0.1Is

Serm.2.3.14t

Serm.2.8.56

Sirm.1.5.45

Serm.1.5.62

Epist.1.1 I.18

Carm.3.24.9

Epist.1.18.54

Ars Pot. 379

Ars Pot. 102

Carm.4.1.40

Epist.I.3.5

Carm.3.16.42

Carm.4.7.I

Carm.1.22.17

Carm.1.37.19

Carm.2.9.24

Carm.3.8.24

Carm.3.15.9

Epod.7.3

Epist.1.7.50

Epist.I.II.t

Curm.3.Is 9

sar..Serm.I.I.29

Serm.1.1.9I

Serm.2.3.55

Serm.2.3.49

Curm.2.5.6

Carm.2.20.1'

Carm.1.8.4

Carm.3.I.II

zar Serm.1.I.9I

Serm.5.0.120

coni.Epist.1 0.59

Carm.1.7.I

Carm.1.9.18

Carm.2.1.30 


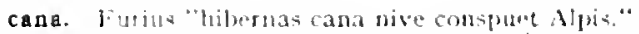

Srm.2.5.4I

canam. benan, magni fotis et deorum/numtinm

'osiol pulcer, o laudande!" canan recepto/Cacsare felix. -

Carm.1.10.5

ips numor pracepta canam. celdbitur auctor.

Corm. 2.47

Serm.2.4.11

tar. Carm.3.43

canas. sul ve nunc mavio [canas] acuta

ril ejgnum aetronne camas.

Serm.2.3.4

candens. nuelte ut superni vilh candens Tuaculi ('ircaea tangat moenis:

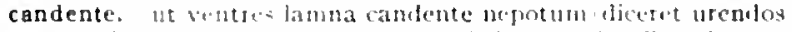

candentibus. subinus inposizum savia late candemtibus Auxut.

candentis. nulu catulentis uneros amictus iaugur Apollo:

canderet. rulbo ubi cuco tincta super lectos tanderet vestis ebutnos

candida. sombita rectaque sit, mumbla hactenus,

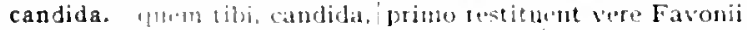

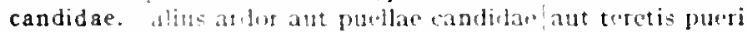

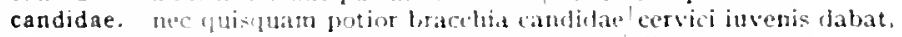

candidam. Blobun prospicienset nive candidan Thracen.

candide, num "go tr, candide Bussarem, invitum quatiam

comblide Mitecellatí, occirlis sacpe rogando:

fos. Bibule et Servi, simul his te, candicle jurat,

Alhi, motrorum setmonum cambide itulex.

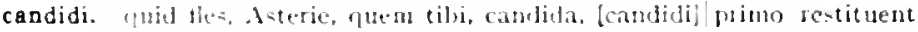
vere jasconii

iam net prata tigent nec fluvii strepunt hibernt nive turgidi ['candidi].

candidior. "fons Bandusiae splendirlior [eanditior] sitro.

candidiores. animate qualis nepte tandilines/terra tulit

candidis, et steilis nebulam spargere candidis.

candido. prete candido in morem Salitm ed quatient lumum.

candidos. sor tibi anditos turpartunt umeros in modicae mero' rixae

candidum. vite- ut altas stet nive candidum / Suracte

candidum. camelidum Mecoua mirata est ilucems,

candidum. "contrane lucrum nil valete candidun pauperis ingenium"

candidus. siugual novinti rectius istis, candidtus inperti;

'lue et conlintus et talos at vertice pulcher arl imos fiet

Epod.1.29

l. pist.1.15-30

Serm.1.5.26

Corm. $1.2 .3 \mathrm{r}$

Serm.2.8.103

Serm.1.2.123

Curm. $3 \div 1$

Epod.11.27

Corm.3.9.2

Carm.3.25.10

Curm.1.18.11

Ispod.1.5

Serm.1.10.8\%

Lipist.1.4.1

:ar.Curm.3.7.1

7 :ar.Carm.4.12.4

i'ar.Carm.3.13.1

Serm.1.5.4

Carm.3.15.6

Corm.t. 1,27

Carnatis.9

Curm.1.0.1

Liporl.3.0

Epoditi.1 I

Eipist.1.0.6s

Epist.2.2.4

Epoli.2.31

Eprit.1.17.30

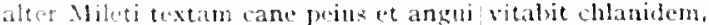

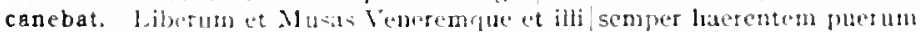
tanelsit

Canem. ('antun illum, invisun agicolis sijus.

casem. vel cursu supterare can vel viribus aprum, posis.

canemus. alma progeniem leneris tanemus.

canendo. te deciliz magistro novit Amphion bapides canendo,

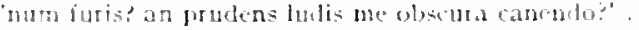

canentes. tite Latomae puerum canentes,

Gitil canentes Caesatem

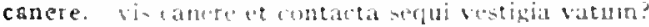

canerent. Tha. anerent agerentgute perunti fatcibus ora.

caneret. obrubt otio venton ut cancret fera dereus fata.

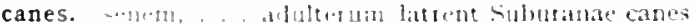

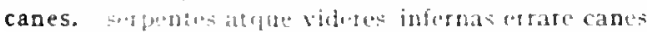

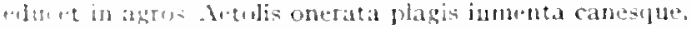

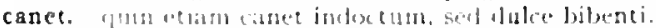

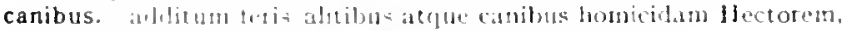

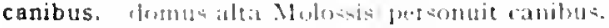

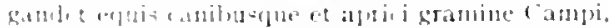

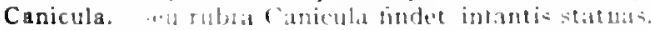

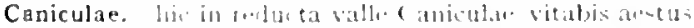

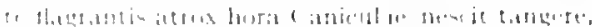

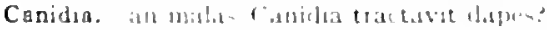

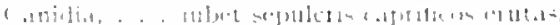

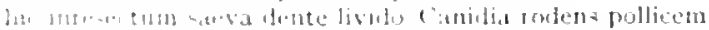

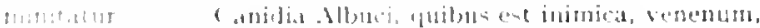

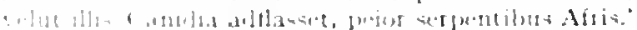

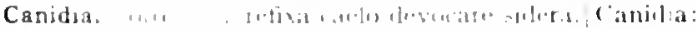

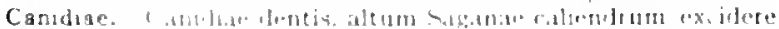

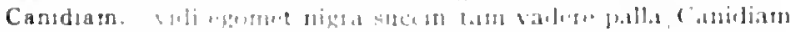

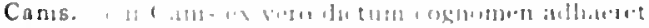

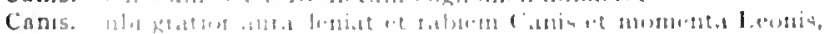

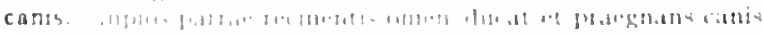

Carm 1.32.10

Serm.1.7.25

Epist.1.18.51

Corm.t.15.32

Curm.3.11.2

Serm.2.5.58

Carm.40.37

I. pod.0.1 is

1: pist 2.2 .80

its liont.277

Cirm 1.15 .4

I.pod.5.55

Germ.1.8.35

Epret.1.18.4\%

lipist.2.2.9

Ifpod.17.1.

S.rm.2.10.115

. Irs Jortic2

seren.2.5.30

Cismin:17.17

(iorm 3130

IApd 38

IDpol 7.15

Epod.5...8

Serm 21 . 18

Sicrm 2 s 05

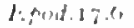

Sem 1 \& 8.48

Syem.18.2:

inm.2.2 $5^{\circ}$

I. pat t. I 10 10

(ii) 327.2

I fint? (1. I 
quam canis acer ubi lateat sus.

ianua frangatur. latret canis,

nec vercor, ne, dum futuo, vir rure recurrat, iania frangatur, latret canis [canis latret].

liac urget lupus, hac canis, aiunt.

ut canis a corio mumquam absterrebitur uncto.

vixisset canis innundus vel amica luto sus.

hac rabiosa fugit canis. hac lutulenta ruit sus:

canis. et ossa ab ore rapta ieiunae canis.

canis. nec prata canis albicant pruinis.

canistris. quae procul exstructis inerant hestema canistris.

canit. seu deos regesque canit, deorum/sanguinem,

Pollio regum|tacta canit pede ter percusso;

canitie. aridal pellente lascivos amores/canitie facilemque somntm.

canities. donec virenti canities abest/morosa.

canopium. interque signa turpe militaria/sol adspicit conopium [canopium].

canorae. quam versus inopes rerum nugavque canorae.

canoris. blandun et auritas fidibus canoris ducere quercus.

canoros. inunc et versus tecum meditare canoros.

canorus. visam. . litora Bopori Syrtisque Gaetulas canoruslales". canos. rosalcanos odorati capillos,

senem. [? senes] quod omnes rideant, adulterum|latient Suburanae canes

[? rideant cunctos canos]

Cantaber. quid bellicosus Cantaber et Scythes, . . cogitet

servit... Cantaber, sera domitus catena.

te Cantaber non ante domabilis . . miratur.

Cantaber Agrippae, Claudi virtute Neronis|Armenius cecidit;

cantabimus. nos cantabimus invicen/Neptunum

cantabitur. flebit et insignis tota cantabitur l'rbe.

cantabo. 'fortunam Priami cantabo et nobile bellum."

Caatabrica. saevam/militiam puer et Cantabrica bella tulisti

Cantabrum. Cantabrum indoctum iuga ferre nostra

cantamus. nos convivia, nos proelia virginum . . cantamus.

cantarat. 'fortunam Priami cantabo et [cantarat] nobile bellum'.

cantare. vinique fontem lactis et uberes/cantare rivos

ut numquam inducant animum cantare rogati. .

nil praeter Calvon et cloctus cantate Catullun.

forum putealque Libonis/nandabo siccis, adiman cantare severis"

cantat. solos lelicis viventis clamat [cantat] in V'rbe.

cantat et adponit 'meus est amor huic similis:

absentem ut cantat amicam multa prolutus vappa nauta

qui Pythia cantat tibicen, didicit ptius

centata. tu me inter strepitus nocturnos atque diurnos|vis canere et contacta [cantata] sequi vestigia vatum?

cantemus. potius nova/cantemus Augusti tropaea

cantent. ut numquam inducant animum cantare rogati [? rogati ut numquam cantent]. iniussi numquam desistant.

cantharis. vile potabis modicis Sabinum! cantharis.

cantharus. ne non et cantharus et lanx |ostendat tibi te,

canto. dum meam canto Lalagen

virginibus puerisque canto.

invideat quod et IJermogenes, ego canto."

cantor. cantor tamen atque, optimus est modulator;

sesstri, donec cantor "vos plaudite" dicat:

ne iorte pudori sit tibi M I sa lyat sollers eantor Apollo.

cantoribus. omnibus hoc vitium est cantoribus,

cantoris. hoe genus onne naestum ac sollicitum est cantoris norte $\mathbf{T}$ igelli.

cantu. neque in vias|sub cantu querulae respice tibiae

et cantu tremulo pota Cupidinem | lentum sollicitas.

illic onne malum vino cautuque levato.

cantum. prina nocte domum claude neque in viasisub cantu [cantum] querulae despice tibiae

sub galli cantum consultor ubi ostia pulsat.

cantus. non avium citharaeque cantu=, somnum reducent:

cantus. praecipe lugubris, cantus, Mtelpomene,

me dulis dominae Musa Licymniae/cantus. . . voluit dicere

orbis ut cantus reteratrue ludos

canum. inclusin Danatn turio achea.. et vigilum canum / tristes excubiae munic:ant
Epod.12.6

Sirm.1.2.128

2ar.serm.1.2.1 28

Serm 2.2 .64

Sicm.2.5.83

Epist.1.2.26

Epist.2.2.75

Ispolt.5.23

Carm.1.4.4

Sirm.2.6.105

Carm.4.2.13

Strm.I.10.43

Carm.2.II.8

Carm.1.9.17

var. Epod.9.10

Ars Poet.322

Corm.I.I2.I I

Epist.2.2.76

Carm.2.20.15

Carm.2.IIIS

? 7ur.Epod.5.58

Carm.2.II.I

Carm.3.8.22

Carm.4.14.4I

Epist.1.12.26

Carm.3.289

Serm.2.I.46

Ars Pot'. 37

Epist.1.18.55

Carm.2.6.2

Carm.1.6.19

zar.Ars Poet.Ij:

Carm.2.I9.II

Serm.1.3.2

Sirmirio.I9

Ipist.1.19.9

ar.berm.1.1.I

Serm.1.2.10T

Sierm.1.5.15

Ars Poet.ti 4

tar. Epist.2.2.80

Carm.2.9.19

? Tar.Serm.1.3.2

Cam.1.20.2

Epist. I.5.23

Carm.1.22.10

Carm.3.1.4

Serm.1.9.25

Serm.1.3.129

Ars Poet. 55

lirs roet.407

serm. I.3. I

Serm.1.2.3

Carm.3.7.30

Carm.4. 13.5

Epol.13.17

2ar.Carm.3.7.30

Serm.t.1.10

carm.3.1.20

(arm.1.24.3

cirm.2.12.14

Carm.Siatcoz

Carm.3.10.2 
CANVS!

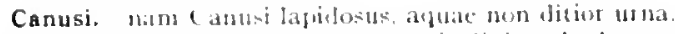

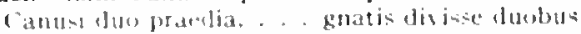

Canusini. (anurini nore bilinguis?

capacibus. Iume capacibus anguenta de conchis. .

capaciores. alvaciores adter huc, puet, scyphos

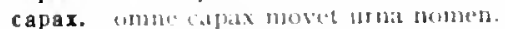

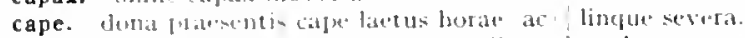

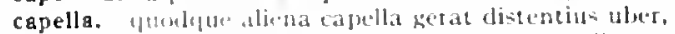

capellae. illir iniusae veniunt ad mulcera captllate

vesum uhi ures furto, morbo periere capellace.

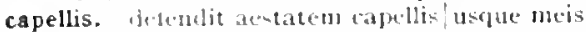

caper. libilinosus innolabitur taje"s

capescens. pitrs multa natat. modo recta capessens [capescens], interdum pravis obnuxia.

capessens. pars multa natat, modo recta capescens, interdum pravis (1) mosia.

capiat. si propulus stes, le capjiat magis.

capiet. men tus hoc caplet venter plus ac ments.

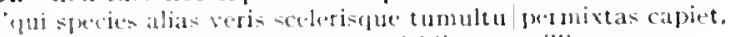

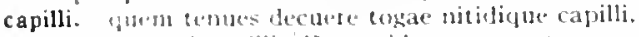

capillis. Interti tapillis Eumenielum receantur anguen?

presol tuis balanus captilis

capillis. Lunc et incomple ("urium captlie

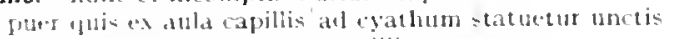

sparsum orlanatis untrum capillis.

longet copillis ut marinus aspetis, echinus

capillo. ytuali sit tacke, sua quali. perte dente, cajollo:

pedibua muli passogute caprillo,

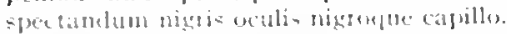

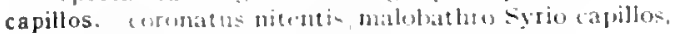

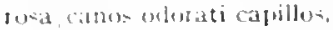

inton-mefue agitaset Aprollinic atura capillos.

si curatu-imarepuali toncors capillos vecurti.

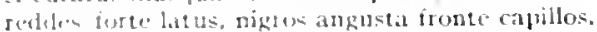

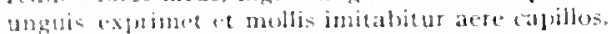

capillus. lenit allsescens animba capillus

tuic capillux alluse ent entoribus,

capit. hume capte agenti splendor; stupet Albius ater:

sen quik cagnit actia botls, pocula

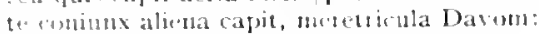

capitalis. ins tuit rapitalis, ut ultima divileret nots.

capite. misture eln'to me capice in tlumen.

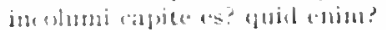

stes caprite obstijos, mulum similis metuenti

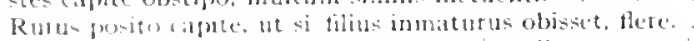

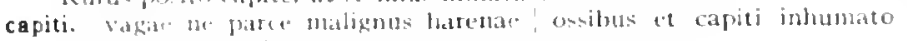
patrouhun dare.

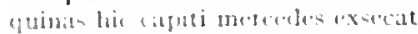

hetribre. Haerentem cignti cum multa latude coroman

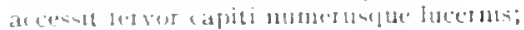

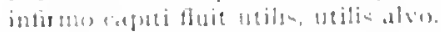

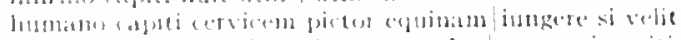

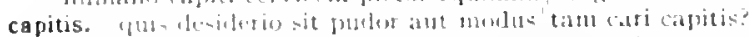

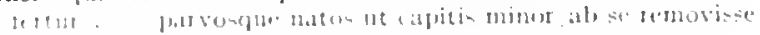

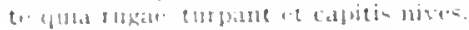

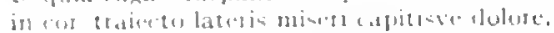

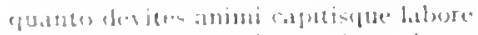

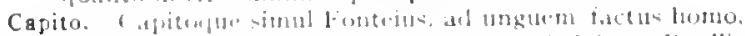

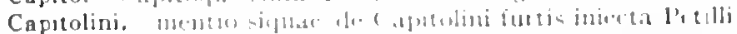

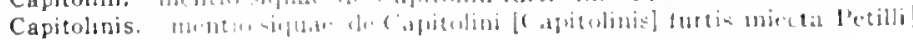

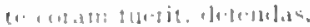

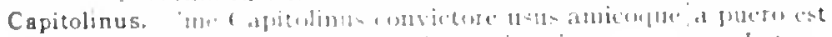

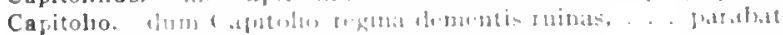

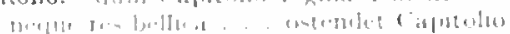

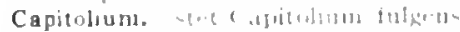

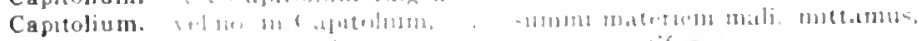

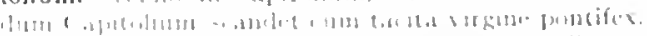

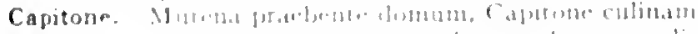

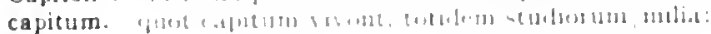

CAPITVM

Sirm.1.5.

Serm.2.3.168

Serm.1.10.30

Curm.2.7.22

I.pod.9.33

Curm.3.1.16

Corm.3.8.27

Sirm.1.110

Epod.16.49

I.pist. 1.7.80

Carm.1.17.3

Lpod. 10.23

gar.Scrm.2.7

Sorm. 2.7.7

lirs loot 362

Serm.1.1.po

Sirm.2.3.200

E.fist.1.1.32

(itrm.2.13.35

Carm.3.29.4

Carm.1.12.4I

Carm.1.29.7

Carm.3.20.14

Fipod.5.27

Sirm.10.33

Sirm. 3.8.24

Ars lod 3 ?

Curm.2.78

Curm.2.11.15

Iipol I5.Q

Lpist.1.1.04

List.1.20

Ars Poeb.3.3

Curm.3.1425

Epod.17.23

serm.1.2.28

Serm.2.0.00

Serm.2.7..ps)

Serm.1.7.13

Serm.2.3.38

herm.2.3.1.32

serm.2.5.02

Serm 2.5 .58

Carm.I.2S 24

Serm.1.2.1.4

serm.1 10.40

Serm.2.1.25

Fopstide.14

- Irs Poet.

Curm.1.2.2 2

cism.3.5.42

(izm $m+1312$

Sirm.2.3.20

E.pist.1.1.4.4

Sirm.1 5.32

Serm 1 1.9:

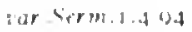

Serme1 i ges

cism 137.0

( $3 \mathrm{rm}^{4}+3 \mathrm{z}$

carm 3342

(arm 324.15

(inm? 3 31,

Sern: 1.5.3.

torm.2.12: 
belua multorum es capitum.

Cappadocum. mancupiis locuples eget aeris Capparlocum sex:

Caprae. post incana Caprae siclera

caprae. sed nimis arta prenunt olidae convivia caprate.

caprea. qualemve laetis caprea pascuis/intenta

capreae. illan cogit anor Nothi|lascivae similem ludetr aproat.

capreae. sed prius Apulis iungentur caprae lupis.

ut pavet acris/agna lupos capreatque leones!"

capreas. vinea submittit capreas non semper edulis.

Capri. non ego sim Capri neque Sulci : cur metuas me?

Capricornus. tyranmus, Hesperiac Capricornus undae:

caprificos. jubet sepuleris caprificos erutas,

caprina. alter rixatur, de lana saepe caprina.

capripedum. virli. . auris' capripedun Satyrorum acutas.

Caprius, sulcius acer ambulat et Capins, ratuci male cumque libellis,

caprum. voveram duleis epulas et abum Libero caprum

capsa. ne . . capsa porrectus operta deferar in vicun

capsis. beatus Fannius ultro/delatis capis et imagine,

capsis quem fama est esse librisque/ambustum propriis.

capta. ter uxor, capta virum puerosque ploret."

erus "hace gravida" inquit|"capta est.

Gracia capta ferum victoren cepit

capta. di tibi clent capta classem redfucce Troia.

naxime regum, di tibi dent capta classem [elassem capta] redducere Troia.

captae. captat post tempora Troiae.

captas. 'Tantalus a labris sitiens tugientiai captat [eaptas], Humina' - quid rides?

quat parvo sumi nequeunt, obsonia captas?

captat. incunda captat praenia.

"Tantalus a labris sitiens fugientia captat, tumina" -

nam | transvolat in medio posita et fugientia captat."

solutos qui captat risus honinum famamque dicacis.

captator. captatorcu dabit risus Kasica Corano." .

captes. cuptes astutus ubique/testamenta senum

captet. aut, Jum vitat humum, nubis inania cajtet.

captis. sed palan captis graris, hell netas, heu,

captiva. si non periset lam niserabilic, captiva pubes. captivom portatur ebur. captiva Corinthu:

captivae. unvit. . Forma captivae dominum Tecmeseae.

captivom. captirom portatur ebur, captiva Corinthus.

captivom. vendere cum possis captivon, occiclere noli:

captivos. antaraz, porrecto ingulo historias captivos ut audit.

capto. cum scribo et supplex populi suffragia capto;

captos. res gerere captos ostendere ciribus hostis

captum. jin captum terneo,

captus. nec satelles (Irci/callidum Promethea, revexit anro captus;

lupus hio Tiberinus an alto captua liet?

'in prinis Lituanus aper: leni fuit ductro captus.

Capua. qui Capua Romam petit, inbre lutoque adspersils

Capuae. armula nec virtus Capuae nee Spartacus acer. hine muli capuae clitellas tempore ponunt.

caput. quon pulcrae ilunes, breve quod caput, ardua cervix. atcui rerum caput how erat, hic foms.

ut nec pes nec caput uni rerldatur formac.

caput. stratuz. munc ad aquae lene caput sacrae.

num decet aut viridi nitidum capat imperlire nasto

nullum / saeva caput Proserpina fugit:

tu simul obligasti perfidum votis caput.

caducum in domini caput inmerentis.

furiale centum | muniant angues caput cius

non mortis laqueis expedics caput.

vel cum decorum nitibus pomis caput Autumus agris rotulit.

brevibus illigata viperis, crinis ct incomptun caput.

caputque Marsa dissilire nenia.

ac inulae nataeque caput lumborque sitimol fuste dolat

Messius accipis," caput et moxtet.

merdis caput inquiner albic onvorum

diffingit Rhoni luteum caput.
Epist.t.1.76

Epist.1.0.39

Carm.3.7.6

Epist.1.5.29

Corm.4.4.13

Carm.3.15.1 2

Corm. [.33.8

Epod.12.26

Serm.2.4.43

Sirm.1.+70

Carm.2.17.20

Ejod.5.17

Iipist. I.18.15

Carm.2.19.t

Sierm. I.ters

Cirm.3.8.7

Jipist.2.1.208

Term.1.4.22

Sirm. 1.10 .13

Carm.3.3.08

Sirm.2.8.4.4

Epist.2. I. 150

Sim.2.3.191

gar.serm.2.3.19

Irs loutita

romi.5erm.1.1.68

Sirm.2.7.100

Epod.2.30

Sirm.1.1.68

Sorm.1.2.108

Sirm.1.4.83

Serm.2.5.57

Serm.2.5.23

. Irs Poth.z3o

Curm.t.0.17

Carm.3.5.18

Lipis6.2.1.193

(arm.2.1.)

Epist.2.1.193

Epist.1.10.010

Germ.1.3.89

Epist.2.2.103

Epist.1.17.33

Carm.1.38

Corm.2.18.30

serm.2.2.32

sirm.2.8.7

Epist.1.IL.1 I

topod.10.5

Sirm.1.5.47

Srm. 1.2.84

lipist.1.17.+5

Irs Puet.s

Ciarm.1.I.22

Carm.1.4.0

Corm.1.28.20

Corm.2.8.

Carm.2.13.12

(arm.3.1 I.Is

(arm.3.2.4.

EPrul.2.17

1.pol 5.10

1. pol. 17.20

"rom. I.5.22

Sirm. I. 5.58

Sirm.1.8.37

sirm.1.10-37 
in versu facjerno saepe caput scaberet. capucefue coxperis inpexa focdum porrigine?

spargisque mola capue, inprobe, salsa.

apue absiswum demens cum portat Agaue gnati infelicis.

vincit longe prius ipsum/expugnare caput.

cautus uti velet carum caput:

allenal negotia contum per caput et circa sidiunt latus.

turpis offoratum caput obscurante lacerna.

contraczum geruilus tangas caput?

qui caput et sconachum supponere fontibus audent Clusinis

maturte deus lomanae, mortalis in unun' quodque caput,

si tribus Anticysis aput infubbile numpuan tonsori Licino conmiserit.

caput. O nulea fleturun caput.

cara. Jec satis est cara piscis averrere mensa

carae. dominus jueri pulchri caracre puellae

carse. cus. inprobe. carac non aliquicl patriae tanto emetiris acervo?

carbo. positurque carbo in cacopite vivo.

carbone. quorsum abeant? sani ut creta. an carbone notati?

proclia rubrica picta aut catbone.

carceribus. ut. cum catceribus missos rapit ungula currus.

cardiacus. "hon est carliacus . . Jic atger"

cardines. quile pius multum facilis movebat cardines.

care. Clare [care] Maccenas eques.

care. poena gui tam ridiculum tam care prodigus emit.

caream. "fuota Paclignis cascan frigotibus, taces.

careat. Cressa me careat pulcra dies nota

carebimus. irustrit cruento marte carebimus

carent. carent quia vate sacro.

quapque carent ventis et solibus ussa Quirini.

carentem. noc turpern senectans/degere nec cithara carentems.

Memplin carentem Siefondia nive.

vitiis cascutem, luelit insgo, vana,

carentia. sistute carentia tolleet:

carentibus. matre corcutibus frivignis nulier temperat

carentis. W matis et tertat numeropue cartutis hatemae / mensorem colibent,

itu operae celeris nimium curaque carentis

carentis. gelidaque divos, morte correntis.

carere. torte guir expediat communiter aut melor pars malis carere quatritis laboribus: .

caret. quae caret ora crusse nostro?

tutus cartet obsoleci sordibus tecti.

caret invidemela sobrius aula.

corceque ripa vagis taciturna ventis.

'molestus communi sem $\times$ plane caret' inquimus.

qui pauperion veritus potiore metallis/libertate caret.

Carct tili pectus mani ambitione?

carcet moreis furmidine et ira?

11 vitium ducit colpat fuga. -i calet arte.

ut scriptor si pecat ibern librarius meque, quansise est monitus, venia calte.t

cari. broklat. sornt tari lactil ducis

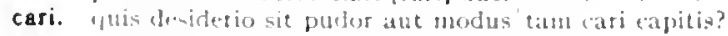

cari. nece curt lapides terupura.

si patriate volumus, si nobis vivere cari.

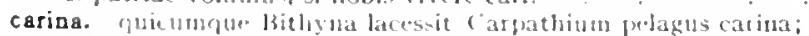

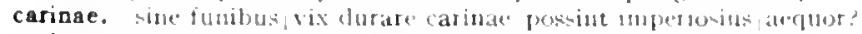

carinam. cum roumgiens sinus Doto catinan ruperit.

Carinas. fore nimiun dintate Carinas, jam gramelis natu queritur.

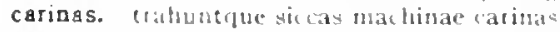

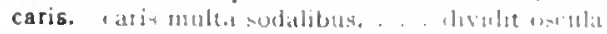

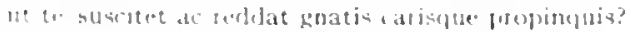

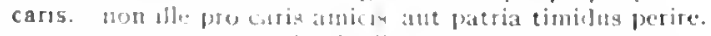

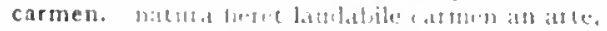

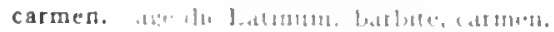

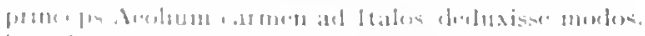

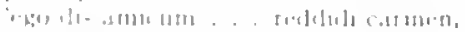

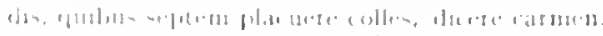

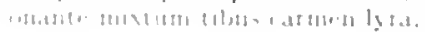

Serm.1.10.7 I

$\operatorname{Ser} m .2 \cdot 3 \cdot 125$

Serm.2.3.200

Serm.2.3.303

Sirm.2.5.7.

Serm.25.94

Serm.2.0.34

Serm.2.7.55

Serm.2.7.61

Lpist.1.15.8

Epist.2.2.189

Ars Port.300

Fpod.5.74

Sirm.2.4.37

Epist.1.18.74

Serm.2.2.104

Carm.3.8.3

Serm.2.3.240

Sorm.2.7.98

Serm.1.114

Serm.2.3.101

Corm.1.25.0

or.Carm.1.20.5

Epist.2.1.238

Carm.3.19.8

Corm.1.30.10

Carm.2.14.13

Carm.4.9.28

Ispod10.13

Carm.1.31.20

Carm.3.20.10

Cism-3.27.39

Ispist.2.2.123

Curm.3.24.17

Cism.1.28. I

Ars Poet.201

Corm.2.8.12

Epod.10.16

Carm.2.1.30

Corm.2.10.6

Carm.2.10.7

Corm.3.29.23

Serm.1.3.00

Epist.1.10.40

Fipist.2.2.200

Iipist.2.2.207

irs Pod.31

- Irs Pod 355

:ar. Carm.314.7

corm. I 24.2

(iom.4.13.14

lipist.1.3.20

Carm.1.35s

("arm.1.147

I.pod 10.20

I:Pist.1 7.48

(arm.1. 2

( arm.1.30.5

Acrmil.1.83

Corm 4.951

Ars linetas

(iarm. 32)

( iarmi.3 30.13

(iarm: 10.13

(urm sibcas

f poilles 
inceptos, olim promissum carmen, iambos.

seu condis amabile carmen.

iam Saliare Numae carmen qui laudat

neque parvom|carmen maiestas recipit tua

rectius lliacum carmen deducis in actus

ex noto fictum carmen sequar,

carmen reprehendite, quod non $\mid$ multa dies et nulta litura coercuit

carmina. nulla placere diu nec vivere carmina possunt, qquae scribuntur aquae potoribus.

carmina. prece qua fatigent|virgines sanctae minus audientem/carmina Vestan?

inbelli cithara carmina divides;

Bacclum in remotis carmina rupibus/vidi docentem.

carmina non prius|audita... canto.

operosa parvos/carmina fingo.

gaudes carminibus; carmina possumus/donare

dicunt in tenero granine pinguium|custodes oviun carmina fistula

Sabella pectus increpare carmina .

an tua demens/vilibus in ludis dictari carmina malis?

prinus in hunc operis conponere carmina morem.

si mala condiderit in quem quis carmina. .

scribet mala carmina vecors:| jaudato.

ferendo|carmina quae possint oculos aurisque morari|Caesatis.

non equidem insector delendave carmina Livi|esse reor.

fronde comas vincti cenant et carnina dictant.

media inter carmina poscunt aut ursum aut pugiles:

ut simul atque / carmina rescieris nos fingere.

expectata tibi non mittam carmina mendax.

carmina conpono, hic elegos:

ridentur mala qui conponunt carmina;

speremus carnina fingi|posse linenda cedro

dictae per carmina sortes

si carmina condes, | numquam te fallent animi sub volpe latentes. .

carmine. intactae lalladis urbem/carmine perpetuo celebrare

dum grato Danai puellas/carmine mulces. .

summo carmine quae Cnidon|fulgentisque tenet Cycladas

et spissae nemorum comae fingent Atolio carmine nobilem.

minuentur atrae/carmine curae.

Lydis remix to carmine tibiis .

solut us ambulat veneficae/scientioris carmine.

quae carmine gratior aurem|occupet humanam?

nec sponsae laqueum famoso carmine nectit.

carmine di superi placantur, carmine Manes.

malo quac nollet carmine quemquan /describi:

fere scriptores carmine toedo/splendida facta linunt.

carmine tu gaudes, hic delectatur iambis.

carmine qui tragico vilem certavit ob hircum.

verum ubi plura nitent in carmine.

carminibus. sic honor et nomen divinis vatibus atquejcarminibus renit.

carminibus. quid mirum, ubi illis carminibus stupens

tibiae / mixtis carminibus non sine fistula; .

gaudes carminibus; carmina possumus|donare

quantum carminibus quae versant atque venenis|humanos animos. privatis ac prope socco|dignis carminibus narrari cena Thyestae: .

carminis. Vario... Maeonii carminis alite. .

mili Phoebus artem/carminis nomenque dedit poetae.

quam rudis et Graecis intacti carminis auctor.

tu carminis estolprincipium.

quod timui mutare modos et carminis artem:

hoc anet, hoc spernat promissi carminis auctor.

carminum. per atque libros carminum valentium.

carne. carme tamen quamvis distat nil,

deterior post partum carne futura.

carnem. curvat aper lances carnem vitantis inertem:

caro. nec Lethaea valet Theseus abrumpere caro/vincula Perithoo.

caro. non in caro nidore voluptas' summa, sed in te ipso est.

Carpathii. Carpathii trans maris aequora

Carpathium. quicumque Bithyna lacessit/Carpathium pelagus carina;

carpe. carpe diem quan minimum credula postero.
Epod.14.7

Epist.1.3.24

Epist.2.1.86

Epist.2.1.258

Ars Poet.1 29

Ars Poel.240

Ars Podt.292

Epist.1.19.2

Carm.1.2.28

Carm.1.15.15

Carm.2.19.1

Carm.3.1.2

Carm.4.2.32

Carm.4.8.II

Carm.4.I2.IO

lipod.1 7.28

Serm.1.10.75

Serm.2.1.03

Serm.2.1.82

Sirm.2.5.74

Epist.1.13.17

Epist.2.1.69

Epist.2.I.I Io

Epist.2.1.185

Epist.2.1.227

Epist.2.2.25

Epist.2.2.9I

Epist.2.2.100

Ars Poet.33 I

Ars Poel. 403

Ars Pod. 436

Carm.1.7.0

Carm.3.11.24

Carm.3.28.13

Carm.4-3.12

Carm.4.11.36

Carm.4.15.3o

Epod.5.72

Serm.2.2.94

Epist.1.19.3I

Epist.2.1.138

Epist.2.1.153

Epist.2.1.236

Epist.2.2.59

Ars Pot't 220

Ars Poet. $35 \mathrm{I}$

Ars Potido I

Carm.2.13.33

Carm.4.I.24

Carm.4.8. I I

Serm.1.8.19

Ars Poet.gI

Carm.1.6.2

Carm.4.6.30

Serm.1. 10.66

Serm.2.0.22

Epist.1.19.27

dirs Poet.45

Epod.1 7.4

Sirm.2.2.29

Sirm.2.8.44

Serm.2.4.41

Cirm.4.7.27

Sirm.2.2.19

Carm.4.5. Io

Carm.1.35.8

Carm.I.II.8 


\section{CARPE}

carpe vism, milis cretle. commes.

carpentes. Hpute lumgum carpentes icer et factum cormptiu- inbri.

carpentis. gritit carpentis thyma per laburen pluriun

carpere. smpromum carpere iter comites parati.

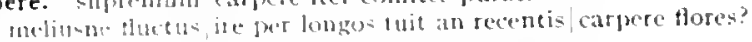

nisi erjhe mavic carpere prensum

patial hbores impune, Lolli, carpere lividat obliviones.

carperet. M.wnilá abentem Dovium enm carperet.

carpsisse. Hicitur ex exlle futim carpisece coronas.

Carthago. w malua Cirthago. probrocic altior Italiae ruinis:

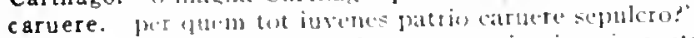

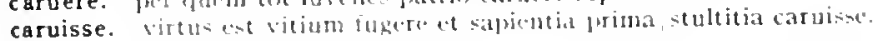

carum. caltus uti velet carum caput:

carus. mercator... dis cartas ipsis.

nex cortus arejue nec superstes integer?

molu- incons (ut me collatulem), si et wo carus amicis:

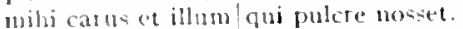

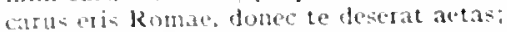

casas. "awelintare casas, plosedlo adiungere muris, acdificante cisils qui saniur?

Cascellius. nec -cit quantum Cascellius Aulus,

Caspium. alt marn ('aspium vaxan inaeguales procellate! usque

cassa. to contemptum cassa nuce pauperct:

Cassi. Ferusei quale fut Cassi rapido terventius ami ingeniun. scribere quod cassi Parmensis opusculat vincat.

casta. nullis pollutur casta domus stupris.

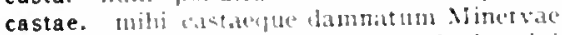

Castaliae. qui rosc pruso Cataliae latit arinis sulutos.

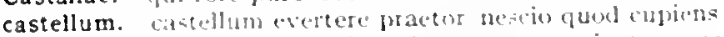

castigator. landator temporic acti, se pueso, cascigator censorene minorum.

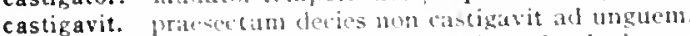

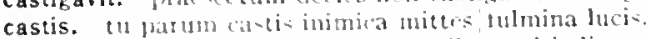

castis. calis cum luberis ignara juella thatiti disceret unde preces.

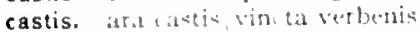

castitas. mletuence altelius visi certo forelere castitas.

casto, nimis cato Bollegophombe matutate necem.

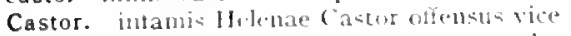

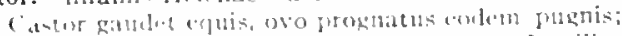

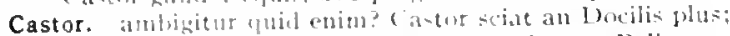

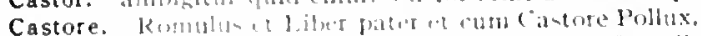

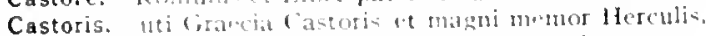

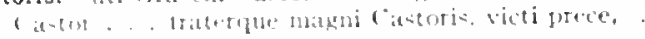

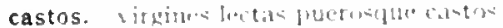

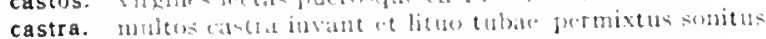

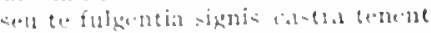

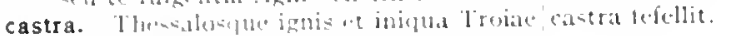
nil cupientium nurlu= castra juetu

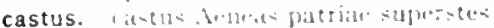

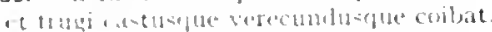

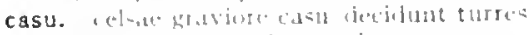

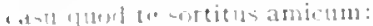

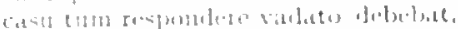

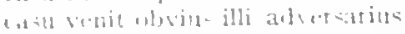

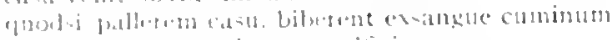

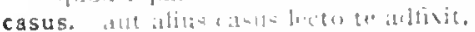

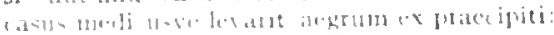

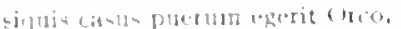

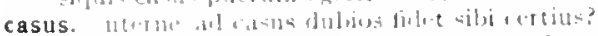

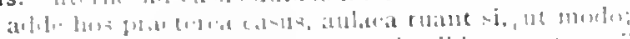

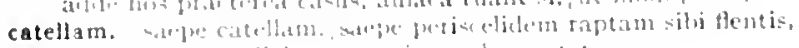

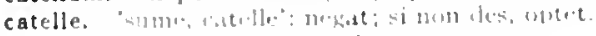

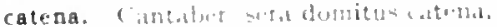

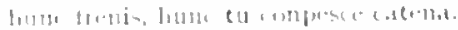

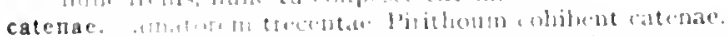

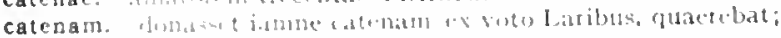

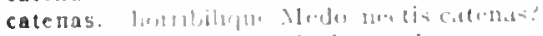

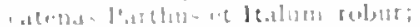

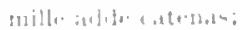

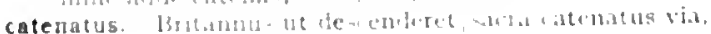

CATENATVS

Sorm.2.1.93

Sern.1.5.95

(arm.4.2.20

Carm.17.12

Curm.3.27.41

Cirm.3.27.64

Cirm.4.9.33

Serm.1.32I

Serm.2.3.250

Carm $-3 \cdot 5 \cdot 3$ ?

Serm.2.3.190

Epist.1.1.42

Serm.2.5 9.1

Carm.1.31.13

Carm.2.17.7

Serm.t.6.7o

Serm.1.0.01

Epist.1.20.10

Scrm.2.3.2.17

Serm.2.3.275

lis Poet.37

Curm.2.9.2

Serm.2.5.36

Serm. 1.10 .02

Fpist.1.4.3

Carm.4.5.21

Carm.3.3.23

Cirm:-3.4.11

Epist.2.2.34

Ars I'oet I74

irs lent.20:

Corm.t.12.59

fepist 2.1 .132

cormt.t1.0

Corm.3.2.1.23

(iorm.3.7.15

1. pord.17.12

Strm.2.1.21

I.pist.1.18.10

Itpist.2.1.5

carm.+.5.35

L.pol.17..13

ciomesisecos

Carm.1.1.23

Carm.1.7.20

Carm.1.10.10

Carm.3.10.23

( armedart 42

Ars l'oct.207

(i)rm.2.1010

serm. 1.0.53

Sicrll.1.0.36

Sirm.1.7.74

Jopist.1.10.1S

strll. 1.81

Sirm.2.3.292

Serm 25.49

serm.2.2.108

crmm.8.8.

l.pist.1.1755

Serm.2 3.250

Carm.3 822

l.pist.1.2.03

Cirm.3.tio

serm. 1.5 .65

(arm. 1.205

carm.2.13 is

sarm.2.370

1.pod.7.8 
catenis. daret ut catenis|fatale monstrum. cum semel effugit, redit se prava catenis?

Carm.1.37.20

Serm.2.7.7I

Carm.3.1 1.45

catenis. me pater saevis oneret catenis. hunc frenis, hunc tu conpesce catena [catenis]. .

tur. Epist.1.2.03

Corm.4.423

Epist.2.1.190 dum fugiunt equitum turmae peditumque catervae;

catervas. ne virilis/cultus in caedem et Lycias proriperet catervas? ducente victrices catervas/coninge me lovis et sorore. cum per obstantis invenum catervas|ibit per obstantis catervas |explicuit sua victor arma. magnas Graecorum malis inplere catervas.'

cathedras. discipularum inter iubeo plorare cathedras.

Cathilli. circa mite solum Tiburis et moenia Catili [Cathilli];

Cati. docte Cati. per amicitian divosque rogatus.

Catia. nil cemere possis'cetera, ui Catia est, demisa veste tegentis. .

Catienis. Catienis mille ducentis|'mater, te appello' clamantibus.

Catili. circa mite solum Tiburis et moenia Catili; .

catillis. puris circumposuisse catillis.

catilum. conminxit lectum potus mensave catilium | Euandri manibus tritum deiecit: .

catini. aut positum ante mea quia pullum in parte catini|sustulit esuriens. catina. porrectun magno magnum spectare catino/vellem" angustoque vagos piscis urgere catino.

catinum. ad porri et ciceris refero laganique catinun:; .

Catius. 'uncle et quo Catius?'

Catone. *Lucili, quam sis mendosus, teste Catone | defensore tuo pervincam,*

Catonem. siquis... pede nudo / exiguaeque togae simulet textore Catonem.

Catonibus. quae priscis menorata Catonibus atque Cethegis

Catonis. Ronuli|praeseriptum et intonsi Catonis|auspiciis . prisci Catonis| saepe mero caluisse virtus.

'macte/ virtute esto' inquit sententia dia Catonis; virtutemne repraesentet moresque Catonis? cum lingua Catonis et Enni|sermonem patrium ditaverit

Catonis. Tarquini tascis, dubito, an Catonis|nobile letum: cuncta terrarum subacta $\mid$ praeter atrocem animum Catonis.

catulis. seu visa est catulis cerva fidelibus

Catullum. nil praeter Calvom et doctus cantare Catullun.

catulos. catulos ferae celent inultae, quanto moveas periclo, Pyrrhe, Gaetulae catulos leaenae?

catulus. venaticus, ex quo tempore cervinam pellem [? ex quo/cervinam catulus pellem] latravit in aula. militat in silvis catulus.

catus. voce formasti catus et decorae!more palaestrae. catus idem per apertum fugientis agitato grege cerv"os iaculari post hace ille catus. quantumvis rusticus,

Caucasum. sive facturus per inhospitalen! Caucasum per Alpium iuga|inhospitalem et Caucasum . . sequemur .

cauda. picta pandat spectacula cauda:

caudae. quaecumque excepit turgentis verbera caudaelclunibus. caudaeque pilos ut equinae / paulatim vello

caudam. Cerberus.. . leniter atterens/caudam accidit ut cuidam testis caudamque salacem|deneterent ferro. nihilo ut sapientior ille / qui te deridet caudan trahat.

Caudi. villa, quae super est Caudi cauponas.

caule. caule subutbano qui siccis crevit in agris!dulcior.

caulibus. cornu ipse bilibri| caulibus instillat.

caulis. qui teneros caulis alieni fregerit hot ti ungtuere si caulis oleo meliore

caupo. perfidus hic caupo. miles nautaeque.

caupana. si laedit caupona. Ferentinum ire iubebo:

caupona. neque... volet in caupona vivere:

cauponas. villa, I quae super est Caudi cauponas.

cauponibus. inde Forum Appi!difertum nautis cauponibus atque malignis.

causa. nec sitim pellit, nisi causa morbi|fuget it venis

nam fuit ante Helenam cunnus taeterina belli|causa.

causa fuit pater his.

dura tibi peragenda rei sit causa Petilli?

causa. causaque mea permulta rogatus, fecit

Carm.1.8.16

$\operatorname{Corm} \cdot 3 \cdot 3 \cdot 63$

Carm.3.20.5

Carm.4.9.43

Sorm.1.10.35

Serm.1.10.91

var.Carm.1.18.2

Serm.2.4.88

Sirm.1.2.95

Serm.2.3.6I

Carm.1.18.2

Strm.2.4.75

Serm.1.3.90

Serm.1.3.92

Serm.2.2.39

Sirm.2.4.77

Serm.1.6.115

Serm.2.4.I

Serm.1.10.*1

Epist.1.19.13

Epist.2.2.117

Carm.2.15.11

Carm.3.21.1 I

Serm.1.2.32

Epist.1.19.14

Ars Pod. 56

Carm.1.12.35

Carm.2.1.24

Curm.1.1.27

Serm.1.10.19

Carm.3.3.41

Carm.3.20.2

? var.Epist.1.2.60

Epist.1.2.67

Carm.1.10.3

Carm.3.12.10

Epist.2.2.39

Carm.1.22.7

Epod.1.12

Serm.2.2.26

Serm.2.7.49

Epist.2.1.45

Carm.2.19.3I

Serm.1.2.45

Serm.2.3.53

Serm.1.5.51

Serm.2.4.15

Serm.2.2.62

Serm.1.3.116

Serm.2.3.125

Sarm.1.1.29

Epist.1.17.8

Epist.I.I1.I2

Serm.1.5.5I

Serm.1.5.4

Carm.2.2.14

Serm.1.3.108

Serm.1.0.7 I

Serm.1.10.26

Serm.1.4.97 
fama civem causacue priorem, sperne.

Sorm.2.5.30

ficta voluptatis causa sint proxima veris

causae. quid caukae est, metito quin illjs luppiter ambas iratus buccas inflet

causae. altis urbibus ultima" stetere cause, cur perirent

irs $\operatorname{Ioc} 6.3 .38$

quate mafe conpescant causae, quil tenperct annum.

Scrm.1.1.20

quo res sponborte et quo cassate teste tenentur.

Corm.1.10.19

Esist.1.12.16

causam. non alam ob causam. .

Persius expronit caucam:

Antenor consec belli praceidere causan:

miece levis speset certamina divitiarum|et Moschi causam: .

causarum. actor cansan un mediocris abest virtute diserti Messallae

causas. bedlique casas et vitia et modos.

sapiens. vitatu quitgue petitu' sit melius. causas reddet tibi:

cum fedius causas exsufec Poplicolat at que Corvinus.

ius anceps novi, causas defendere possum: .

si non causas narraret earum et naturas dominus;

causatur. stultus uterque locum inmeritum causatur inique:

causis. seru linguan causis acuis

causis. strenuos et fortis causiaque Philippus agendis/clarus.

cauta. olim guod volpes aegtoto cauta leoni|respondit,

cautius. Cur olizom! sanguine viperinolcautius vitat

cautos. "matutina parum cautos i.un frigora mordent";

cautos nominibus rectis expendere nummos.

I.jist. I. 10.43

Serm.1.7.14

Serm.1.7.22

fistist.2.9

Epist.1.5-9

Ars Pool.37o

Carm.2.1.2

Serm.1.4.116

Serm.1.10.28

Serm.2.5.34

Serm.2.8.92

Epist.1.14.12

Epist.1.3.23

Epist.1.7.46

Epist.1. 1.73

Corm.1.8.10

Serm.2.6.45

Egist.2.1.105

cautum. numpuam hounini satis/cautum est in horas:

cautum. praesertim cautum dignos adsumere, prava ambitione procul,

Carm, 2.13.1.

cautus. Jum procellas/cautus borrescis,

cautus adito nen desis operae neve jnmoderatus abundes.

caucus uti velet carum caput:

cautus enin metuit foream lupus

serpit humi tutus [cautus] nimium timidusque procellae:

in verbis ctiam tenuis cautusque serendis

tutus et intra spem veniae cautus?

cava. qui persaepte cava testudine flevit amorem mella casa matant ex ilice.

cave. tu, nisi ventis debes ludibium, cave.

ne vicinus Enipeus plus iusto placeat cave:

cave, ave, namque in malos asperrimus patata collo cornua.

"cave faxis!te quicquam indignum.

tu cave ne mimus, tu ne maius facias id

cave to roset; ultro Penelopam facilis potioti trade "

cave the portus occupet alter.

vale, cave ne titubes mandataque frangas.

caveae. obiectos cavear valuit si frangere clatros, .

caveant. silvis deducti caveant me iudice bauni.

caveas. serl tamen ut monitus caveas.

cavebis. evasti: credo, metues toctusque cavebis -

caverat. loc citherat mens provida Reguli

cavere. parce privatus nimiun cavere

cavet. conmisise cavet guod mox nutate labotet.

caveto. hic niget est, hune tu, Romant, caveto."

cavis. me dicente cavis ingositam ilicen' saxis.

cavis. truncis lapsal cavis jterare mollit;

cavis. te. libri. numberte, cavis abscondere tristern.

cavit. carit nihit acriss.

mallis, quas itut incuria fult aut humana parum cavit natura.

cavo. rancicus urbanum murem mus panpere fertus |accepisas cavo,

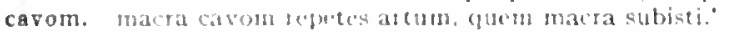

cavos. mat silro conosque tures ab insidns tenui solabitur ervo."

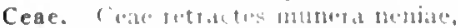

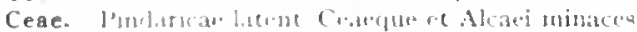

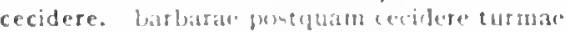

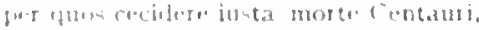

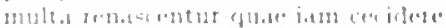

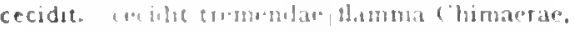

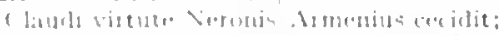

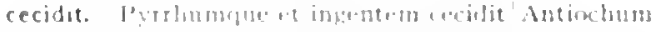

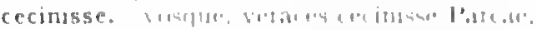

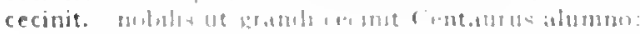

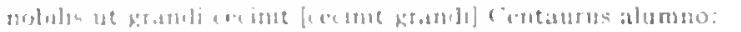

cermit.6.5

Corm.2.10.3

Serm.2.5.88

Sirm.2.5.94

Epist.1.10.50

coni.trs Poet.28

Ars Poet. 46

Ars Poel 207

IEpod.14.1I

Ifod.10.47

Curm.1.1416

Carm.3.7.24

Epod.c. I

Serm.2.3.38

Serm.2.3.177

Serm.2.5.75

Epist.1.6.32

Epist.1.13.19

Ars Poct.473

Ars Poe!.24.4

Sorm.2.1.80

Serm.2.7.68

Carm.3 5.13

Carm.3.8.20

Ars Poct.jo 8

Serm.1.4.85

Carm.3.13.14

Carm.2.1912

Serm.2.3.173

Sermi2.392

Ars Iort. 3.53

Serm.2.0.81

lipist.3.7.3.3

Sorm.2, (b.1 to

Carm 2.1.39

(arm 4.9.7

Cormz 49

carmis 214

Ars Porlio

(armat 215

Jepret 1.1227

(iarm.3 fi.3.5

(iorm viariezs

I: pol 1, 131

a Ir Jod.13 il 


\section{CECINIT}

quod puero cecinit divina mota anus urna:

Cecropiae. Cecropiae domus/aeternum opprobrium,

Cecropio. grande munus|Cecropio repetes cothurno.

cedat. grande certamen, tibi praeda cedat. | naior an illa.

cedat uti conviva satur. reperire queamus.

permutet dominos et cedat in altera iura.

cede. tu cede potentis amici|lenibus inperiis.

cedentem. seu te di-cus agit (pete cedentem aera disco) - .

cedere. gravem Pelidae stomachum cedere nescii

iam Scythae laxo meditantur arcu/cedere campis.

cederet. nitidus qua quisque per oralcederet.

non ut de sede secundalcederet aut quarta socialiter.

cedes. cedes coemptis saltibus et domo

cedes et exstructis in altum/divitiis potietur heres.

cedet. nec semel offensi cedet constantia formae.

meaeque terra cedet insolentiae.

sed cedet in usum |nunc mili, nunc alii.

tamquam|sit propriun quicquam, puncto quod mobilis horae/nunc prece, nunc pretio,... cedat [cedet] in altera iura.

cedit. volgus infidum et meretrix retro' periura cedit,

cedro. carmina fingi|posse linenda cedro .

cedunt. nec tibi vespero|surgente decedunt [cedunt] amores

Picenis cedunt pomis Tiburtia suco:

celabitur. 'ipsa memor praecepta canam, celabitur auctor.

celantia. piscis, / longe dissimilem noto celantia sucum, .

celare. est/gaudia prodenten voltum celare.

ingenium res|adversae nudare solent, celare secundae." "

celas. curru nitido diem qui|promis et celas

celat. sic melius situm. cum terra celat.

te fontium qui celat origines| $\mathrm{N}$ ilusque et Hister,

stultorum incurata pudor malus ulcera celat.

celata. paulum sepultae distat inertiae/celata virtus -

celeberrima. quidlibet indutus celeberrima per loca vadet

celebrabitur. "ipsa memor praecepta canam, celabitur [celebrabitur] auctor.

celebrare. intactae Palladis urbem|carmine perpetuo celebrare

quem virum aut heroa lyra vel acri|tibia sumis celebrare, Clio?

meruere decus restigia Graeca | ausi deserere et celebrare domestica facta

celebret. (licebit ille repotia, natalis aliosve dierum /festos albatus celebret)

celebris. sacro|Dianae celebris die.

celent. catulos ferae/celent inultae. utra magis piscis et echinos aequora celent,

celer. sed me per hostis Mercurius celer. . sustulit

nec peredit inpositam celer ignis Aetnen.

celer arto latitantem fruticeto exeipere aprum.

hunc medicus multum celer atque fidelis excitat

celeratus. effugiet tamen haec sceleratus [hic celeratus] vincula Proteus. .

celerem. nequiquam .. calami spicula Cnosis vitabis strepitumque et celerem sequi|Aiacem:

irasci celerem, tamen ut placabilis essem.

celerem. tecum Philippos et celerem fugam $\mid$ sensi.

miles sagittas et celerem fugam|Parthi.

prosperam frugum celeremque pronos/volvere mensis.

celeres. oderunt .. sedatum celeres, agilem navomque remissi;

celeres. damna tamen celeres reparant caelestia lunae:

"celeres fugae reiectaeque retrorsum Hannibalis minae".

celeres. rapidos morantem|fluminum lapsus celeresque ventos,

ingrato celeres obruit otio rentos

me... in celeres iambos $\mid$ misit furentem.

rivos celeres morari;

celeres. interim. dum tu celeres sagittas|promis.

si celeres quatit pennas.

celeri. et malus celeri saucius Africo.

celeris. non 'celeres fugae [celeris fuga] / rejectaeque retrorsun Hannibalis minae',

celeris. tu curva recines lyra|Latonam et celeris spicula Cynthiae; .

celeris. aut operae celeris nimium curaque carentis

aut operae celeris nimium [ninium celeris] curaque carentis

celeris. "qui species alias veris sceletisque [celerisque] tumultu | permixtas capiet, commotus habebitur,
Serm.1.9.30

Carm.4.12.0

Carm.2.1.12

Carm.3.20.7

Serm.1.I.IIg

Epist.2.2.1 7.4

Itpist.1.18.44

Serm.2.2.13

Carm.1.0.0

Carm.3.8.24

Serm.2.1.65

Ars Port.258

Carm.2.3.17

Carm.2.3.19

Epod.15.15

Epod.17.75

Serm.2.2.134

zar.Epist.2.2.174

Carm.1.35.26

Ars Port-332

gor.Carm.2.9.I I

Serm.2.4.70

Serm.2.4.I I

Serm.2.8.28

Sirm.2.5.104

Serm-2.8.74

Carm.Sace.Io

Carm.3.3.50

Carm.4.14.45

Epist.1.16.24

Carm.4.9.30

Epist.1.I7.28

iar.Serm.2.4.I I

Carm.1.7.6

Carm.1.12.2

Ars Poet.287

Sirm.2.2.6I

Carm.2.12.20

Corm.3.3.42

Epist.1.15.23

Corm.2.7.13

Carm.3.4.76

Carm.3.12.I I

Serm.2.3.147

var.Serm.2.3.7 I

Carm.1.15.18

Epist.1.20.25

Carm.2.7.9

Carm.2.13.17

Carm.4.6.39

Epist.1.1 8.90

Carm.4.7.13

Carm.4.8.15

Carm.1.12.10

Carm.I.I5.3

Carm.1.16.24

Carm.3.11.I4

Carm.3.20.9

Carm.3.29.53

Corm.1.14.5

sar.Carm. $\$ .15$

Carm.3.28.12

Ars Iod.20I

qar. Ars Poet.201

:ar.Serm.2.3.208 
celet. mer, sipuing hommti est. iactat habetque palam, ruacait, quo turpia extet

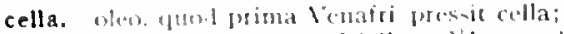

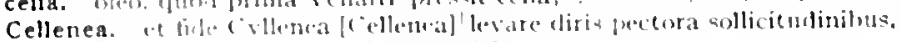

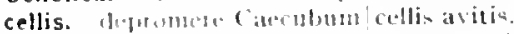

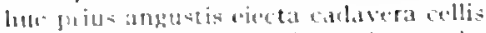

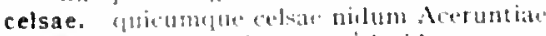

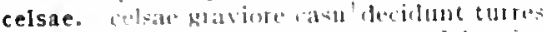

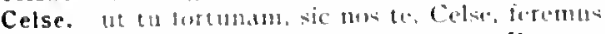

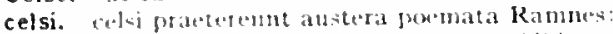

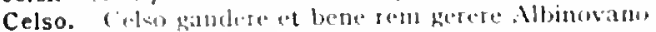

Celsus. puid milic Colmbs agit?

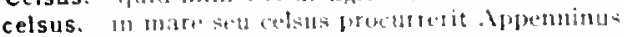

cena. cona mistotgatut pueris tribus

'ut Xusidienti invit te" atena beati?

nisi ena pris fotionque puella sabinum detinet adsumam;

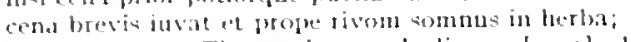

rupit Larbitam Timagenis aemulat lingua [cena], dum studet urbanus urditulue diactus haberi.

privati- ac moln" socoldignic carminibus narrari cena Thyestae: guterable linci guia cenat sine istis:

cena. ut pallidua munis dena desurgat dubia?

cupiens varia fastirlia cena vincere

multargur de magna supreressent forcula cona.

cenacula. guid paulper? ride: usutat conacula, lectos.

cenae. Itt aicbut cente pater:

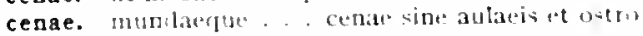

cenas. "moctes ienaingue deum.

cenam. prorsta iucumele enam producimus illan.

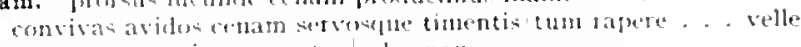

si nusquam tes forte sonatus ad cenam.

dire.' ad crnam ventat:"

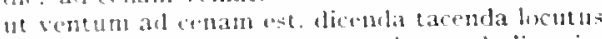

cenamus. nos, inquan, cemanus avis, comehylia, piscis.

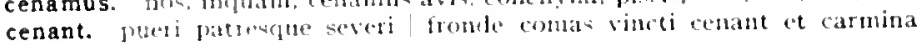
dictint.

cenantibus. sorl quis crountibus una, fundani, pulcre fueric tibi.

cenantis. cenantia haud animo aequo|exsyetans connites.

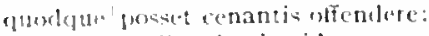

cenare. sarje tribus letis vileas cenare quaternos.

nec moticat crate times loduc omne patella,

cenarum. me shi conarum quivis temere arroget atcem,

infenzis collarum ret tritale munere vestis;

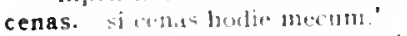

cenat. i lene gut cende beme vivit.

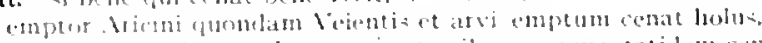

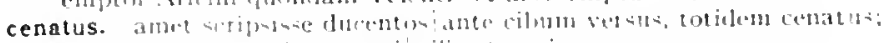

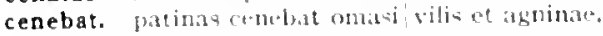

cenem. ut ajpunt anem erge:

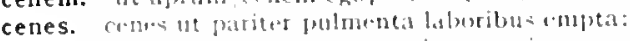

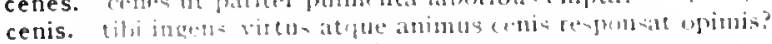

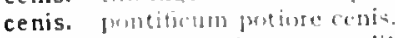

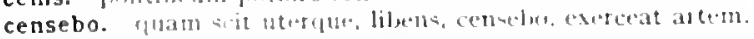

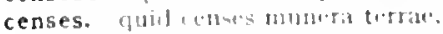

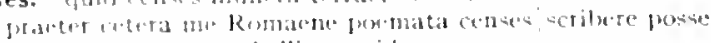

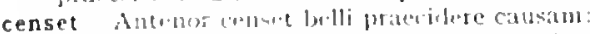

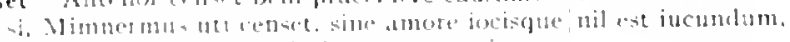

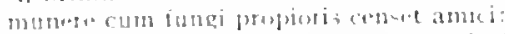

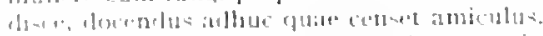

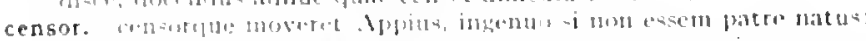

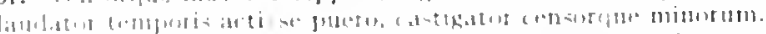

$\operatorname{serm} 1.2 .85$

Serm.2.s.gis

iar.lipol.139

carm.1.37.

Sirm. 1.8 .8

Carm. $3+14$

Carm.2.10.10

f.pist.1.8.17

irs 1'oct.3.42

Lipist.1.8.1

Lpist 1.3 .15

lipord.112.20

term tob.110

cierm.2.8. 1

Hepist.1.5.27

lipist.1.14.35

gar.lepist.1.19.15

Ars loclot

Ars Porl.376

sirm.2.2.77

Serm.2.0.86

Serm.20.10.4

Epist.t.t.ot

Serm.2.8.7

Curm.3.29.15

tiorm.2.0.05

Sirm.1.5.70

serm.1.5.75

Sirm.2.7.30

Eipist.1.7.01

lipist-1.7.72

Sorm.2.5.27

fopist.2.110

Sierm.2.8. 8

verm. 1.5.8

Sirm.2.8.13

Sirm. J...8\%,

IEpist.1.5.2

Sirm.2.1.35

Epist.1.19.38

1.pint.1.7.70

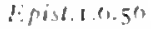

tipis 2.2.168

trorm 1.10101

J.pist.1.15.34

Serm.2.3.235

Lipist.1.28.48

Serm.2.7.103

(i) 271.28

Lisit.1.1.14

IFpist.t.0.5

L pist 2.2.15

repist 1.2 .9

r.pist. 10.65

I. pilt 1.05

f. pist 1.17-3

serm.t.0.20

Irs lioct.17

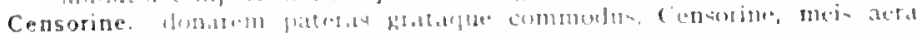
(2)1.13)

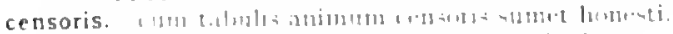

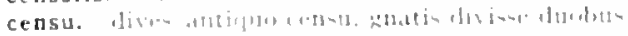

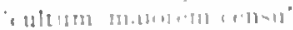

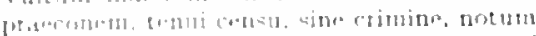

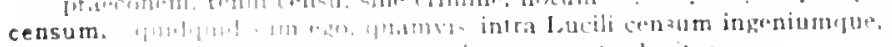
friguch +

(iarm. \& 8.2

1. prut.2.2.110

$\operatorname{trn} 2.310$

Serm. 23.32 .8

lisist 1.7 .50

Srrm.2.1.75

f.pist 1.13 
census. privatus illis census prat brevin.

praesertinı census equestrem|sunnam nummorum.

Centaurea. Centanrea monet cum Lapithis rixa super meroidebellata.

Centauri. per quos recidere iustal morte Centauri.

Centaurus. nobilis ut grandi cecinit Centausus alumno:

centena. deciens centena dedisses/huic parco, paucis contento:

centiceps. demittit atras belna centiceps/auris

centimanus. nec si resurgat centimanus gigas/divellet umquam:

testis mearun centimanus gigas/sententiarum.

centum. servata centum clavibus

te greges centum Siculaeque circum|mugiunt vaccae.

sume, Maecenas, cyathos amici|sospitis centum

quanivis turiale centum|muniant angues caput eius

quae simul centum tetigit potentem/oppidis Creten.

et centum puer artium

et centum potiore signis! unnere donat,

aut ille centum nobilem Cretann urbibus

seu poposceris'centum iuvencos.

milia frumenti tua triverit ares centum:

iugera centum an mille aret?

callidus buic signo poneban milia centum;

adele Cicutal nodo-i tabulas, centum.

gladiatorun dare centum damnati populo paria

aliena negotia centum ! per caput et circa saliunt latus.

chlamydas. . . si posset centum scaenae praebere rogatus.

seriptor abbinc annos centum qui decidit.

est vetus atque probus, centum qui perficit annos."

assen discumt in partis centum diducere.

centuriae. centuriae seniorum agitant expertia frugis.

centurionibus. magni quo pueri magnis e centurionibus orti,

cepere. lnuc sotci cepere pedem grandesque cothurni.

cepisset. si vacuom tepido cepissct villula tecto.

cepit. quem cepit vitrea fama.

Graecia capta fertm victorem cepit

cera. quid prima secundo/cera velit versu;

cera. Caerite cera digni, remigium vitiosum Ithacensis V'lixei,

ceratis. ceratis ope Daedalea! nititur pernnis

Ceraunia. qui vidit mare turgidum ef / infamis scopulos Acroceraunia [: Cerannia]?

Cerberus. te vidit insons Cuberus aureo/cornu decorum cessit imnanis tibi blandienti|ianitor aulae/Cerberus,

cerea. lanca et effigies erat, altera cerea: cerea suppliciter stabat.

cerea. inagine cerea largior arserit ignis

cerea. cervictm roseam, cerca Telephi|laudas bracchia,

cereas. an quate movtre cereas imagines.

cerebri. 'o te, Bolane, cercbri|felicem'

cerebro. me truncus inlapsus cerebro

cerebrosus. donec cerebrosus prosilit unus

cerebrum. putidius multo cerebrum est, mihi crede, Perelli

Cererem. fruges et Ccrerem ferunt spicea donet Cererem corona:

cererem. reddit ubi cererem tellus inarata quotannis

Cereris. qui Cereris sacrum/volgarit arcanae.

ut Attica virgo cum sacris Cereris

Ceres. nutrit rura Ceres almaque Fanstitas. ac venerata Ceres, ita culmosurgeret alto.

cereus. neque fictolin peins voltu proponi cereus usquan cerens in vitium llecti, monitoribus asper,

Cerinthe. nec magis. . Cerinthe, tuo tenerum est femur aut crus/rectius: nec magis.. Cerinthe. tuo tenerum est fenur [? femur. Cerinthe. tutum]

cernere. matrona prater facien nil etnert possis/cetera.

cernis. cur in amicorum vitiis tan cernis atutum

cerritus. Marius cum praecipitat se, cerritus fuit?

certa. segetis certa fides meat

certa. nec te. metuende certa' I'lioebe sagitta.

nec mens mihi nee color, certa sede nanent. insanire paret certa ratione nodoque.'

Carm.3.4.69

Carm.2.14.26

Carm.2.16.33

Carm.3.8.14

Carm.3.1].I 7

Carm.3.27.33

Carm.4.1.15

Carm.4.2.19

Lpod.9.29

Epod. 7.39

Serm.1.1.45

Sirm.1.1.50

Serm.2.3.23

Serm.2.3.70

Serm.2.3.85

Serm.2.0.33

Epist.1.6.4I

Epist.2.1.36

Epist.2.1.39

Ars Pot.326

Ars Poet.34I

Serm.1.0.73

Ars Port.80

Serm.2.3.10

Serm.2.3.222

Epist.2.I.I 56

Serm.2.5.54

Epist.1.6.02

Carm.4.2.2

7 tar.Carm.1.3.20

Carm.2.19.29

Carm.3.11.17

Serm.1.8.30

Serm.1.8.32

Serm.1.8.43

Carm.1.13.2

Epod.17.70

Serm.1.9.11

Carm.2.17.27

Serm.I.5.2I

Serm.2.3.75

Carm.3.24.13

Carm.Saec. 30

Epod.10.43

Carm.3.2.26

Sirm.2.8.14

Carm.4.5.18

Sirm.2.2.12.4

Lpist 2.1 .205

Ars Poet.jo3

Serm.1.2.81

7 uor.ticrm.I. 2.8 I

Serm.1.2.04

Sirm. T.3.26

Sirm.2.3.278

Carm.3.10.30

Carm.I.12.23

Carm.1.13.6

Serm.2.3.27I 


\section{CERTA}

certa. moplue custa fulgernt sidera nautis,

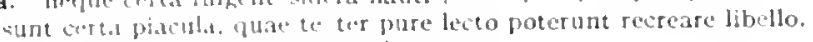

certa. nopips si compora corta modosque,

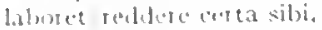

certabitur. makna minorve toro si res certabitur olim:

certam. sperlu bonirn certanque domum reposto

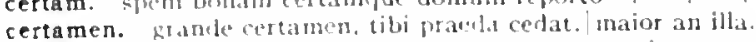

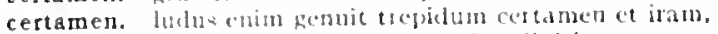

certamina. mite leveis spes et ceramina divitiarmm

certamine. suctulus in certamine Martio

donec minot in certamine longo inploravit opes

1.t pukilem sicturem et épuom certaminc primum

certans. Jiud ica Troiac|me gensi. centans semper nuclioribus."

certant. Krolumatiei cratat et adhuc sub iudice lis est.

certantem. cortantumec usam juifurac。

certantia. quar neque in aede sonent corcantia iudice Tarpa

certare. bec certar " ioco nce lare bracchia

nec centar"invat moro

desinet inparibus certare submotus „undor.'

tanto dissimil'm et tanto cercare minorem?

arta dece sannm comitem toga; desine mecumicertare."

non cessavere poetae mocturno certale mero, putere diurno.

certas. post certas hiemes uret Achaicus ingis thacas domos."

certat. si mobilum turba Quiritiun certet tergeminis tollere honoribus. viridirpe cescat baca lemafro.

certatim. absentem nt cantat anican multa prolutus vappa mata atque viatur certatim.

certavit. carminc dui tragico vilen certavie ob hircum.

certe. reginu corte henus, tet penatis macret iniquos.

certus nomeno: [certe sunt denow] deciens per annosforbis

"certu mecio quid secreto vell" loqui te aliebas mecunt."

postremum expellet certe vivacior lixtes.

corte furit ac vedut tisus.

certemus. extentis, spinat animone go forcius an tu evellas agro.

certes. grande malum Turius, siçuid se iudice certes.

certi. post rifut [post et cesti] animi motus interprete lingua.

certi. ese modna in tebus, sunt certi drnifue fines.

certior. nulla ertuor bincon rapacis ()rci sede destinatalaula

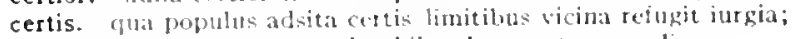

certis. cutis mediun et toluabile rebus recte concedi .

certis. a cercis anmis acom romeare peractum

certis. decodentia cutis tempora momentis

certius. cotius acipiet damnum propiusve medullis

certius. utrence ad casus dobios fidec situccreiss!

certo. nisi guat pente certo differt sermoni. scomo metus.

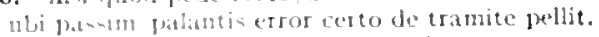

gamelentem porvieque sodialibus et lare corto

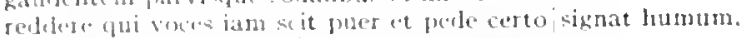

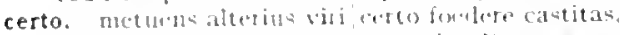

urale fibi reditulu certo cubcominc latrae rupere.

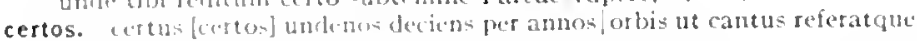
ludos

certum. semper avarus egret: cortum voto pete finem.

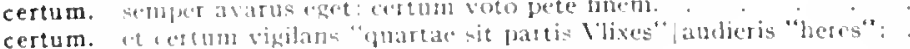

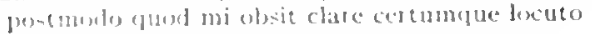

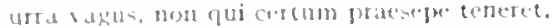

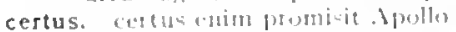

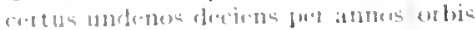

mi cortus intentit doles

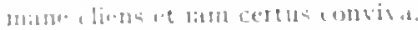

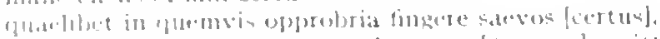

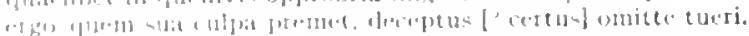

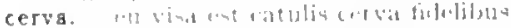

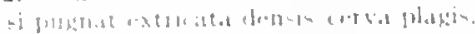

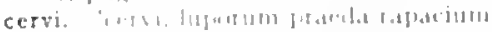

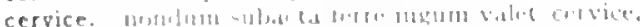

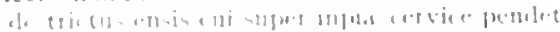

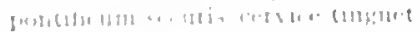

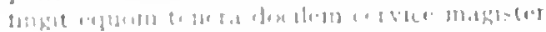

CER VICE

Carm.2.10.3

Epist.1.1.3

Sirm.1.4.58

Serm.2.3.270

Siem.2.5.27

Curm.Suec.74

$\operatorname{Cornt} 3 \cdot 20.7$

lipist.1.19.48

Fist.1.5.8

Curm.1.14.17

Lopist.1.10.35

.195 Poct.84

ierm.2.5.19

drs l'oet.78

lipud.2.20

Serm.1.10.38

Corm.2.12.18

Carm.4.1.31

Epold1.Is

Serm.2.3.313

Epist.1.18.31

Epist.1.19.1

Carm.1.15.35

Carm.1.1.8

Carm.2.6.15

Serm.1.5.17

dis boet.220

Corm.2.4.15

qur.Corm.Saec. 21

sirm.1.9.07

Serm.2.2.132

Ars l'oet.diz

IEpist.1.1.4.

Serm.2.1.49

iar.irs J'oct.111

Sorm.1.1.100

Cirm.2.18.29

Itpist.2.2.170

drs Joet.368

Serm.1.0.94

lipist.t.0.3

J.pist.1.10.2S

Sierm.2.2.108

sirm.1.4.47

Serm.2.3.49

Eipist.1.7.58

Ars l'oet. 158

Cism.3.24.23

E.pod.13.15

iar.cormsiace 21

IEpist 1.2.50

trm.2.100

sorm.2.0.27

Lipist.1.15.28

Carm.1.7.2s

(armatace 1

lepul.15.10

l.furt 7.75

ar Lepist i $\$ 530$

r:ar lipist.1.t. -0

(a)m.1.1.27

(urm.35.32

( $13 \mathrm{rm}+50$

(arm.2.5.2

( $13 \mathrm{rm} \cdot 3.1 .2 \mathrm{~s}$

("ism. 32.3 .13

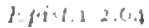


rerum inscitia vexat|indomita cervice feros?

cervicem. Telephi|cervicen roseam, cerea Telephi|laudas bracchia, cum thagrantia detorquet ad oscula/cervicem

illum et parentis crediderim sui|fregisse cervicem

humano capiti cervicem pictor equinam iungere si velit

cervici. nec quisquam potior bracchia candidae/cervici iuvenis dabat,

cervinam. ex quo|tempore cervinam pellem latravit in aula.

venaticus, ex quo] tempore cervinam pellem [? ex quo|cervinam catulus pellem] Jatravit in aula,

cervis. iuvet ut tigris subsidere cervis,

cervis. ocior cervis et agente nimbos/acior Euro.

Cervius. Cervius iratus leges minitatur et urnam.

Cervius haec inter vicinus garrit anilis|ex re fabellas.

cervix. quod pulcrae clunes, breve quod caput, ardua cervix.

cervos. cervos uti vallis in altera/visum parte lupun cervos equom pugna melior communibus herbis|pellebat,

cervos. per apertum fugientis agitato grege cervos iaculari. fugacis|lyncas et cervos colnibentis arcu.

cessant. cur Berecyntiac/cessant flamina tibiae?

cessantem. cui pulcrum fuit in medios dormire dies et / ad strepitum citharae cessatum [cessantem] ducere curam [somnum]. dictaque cessantem nervis elidere morbum

cessantem. parcis deripere horreo cessantem Bibuli consulis amphoram. cessantis. neu populus frequens ' ad arma'. cessantis 'ad arma'|concitet cessare. et properare loco et cessare et quaerere et uti. ubi plura|cogere quam satis est ac non cessare videbor. . cur alter fratrum cessare et ludere et ungui|praeferat

cessas. "quid mori cessas? tu cessas? agedum, sume hoc ptisanarium oryzae." quodsi cessas aut strenuos anters,

cessat. cessat voluntas? non alia bibam $/$ mercede. arrom caelumque Sabinum | non cessat laudare. sic mihi, qui multum cessat, fit Choerilus ille.

cessator. nequam et cessator Davos:

cessatum. ad strepitum citharae cessatum ducere curam.

cessavere. non cessavere poetae|nocturno certare mero, putere diurno.

cessavit. semel hic cessavit et, ut fit. in scalis latuit

cesserat. inulta cesserat inpotens/tellure.

neque, si male cesserat, usquam/decurrens alio neque, si bene:

cessisse. fraternis cessisse putatur|moribus Amphion: .

cessisset. cui saepe viator|cessisset magna conpellans voce cuculum.

cessit. cessit immanis tibi blandienti|ianitor aulae/Cerberus,

cetaria. plures adnabunt thynni et cetaria crescent.

cetera. nam cetera turba. / nos, inquam, cenamus avis.

cetera. cetera fluminis/ritu feruntur.

cetera de genere hoc, adeo sunt multa. loquacen | delassare valent Fabium.

cetera item nequeunt stult is haerentia.

cetera ian simul isto/cum ritio fugere?

cetera. permitte divis cetera.

qua notam duxit, niveus videri,|cetera fulvos. .

cetera mitte loqui:

matronae practer faciem nil cernere possis/cetera,

nec tamen hoc tribuens dederim quoque cetera:

pingue pecus domino facias et cetera praetur/ingenium,

nunc itaque et versus et cetera ludicra pono.

at cetera paene gemelli fraternis animis:

excepto quod non simul esses. cetera laetus.

cetera nequaquam simili ratione nodoquelaestimat

praeter cetera me Romaene poemata censestscribere possc

cetera qui vitae servaret munia recto/more.

ceteris. Pthius Achilles. ceteris maior, tibi miles inpar,

Cethegis. quae priscis memorata Catonibus atque Cethegis

fingere cinctutis non exaudita Cethegis/continget

ceu. ceu flamma per taedas

charta. charta laudatur eadem.

chartae. Brundisium longae finis chartacque viaeque cst.

si te forte meae gravis uret sarcina chartae.

chartae. si chartae sileant quod benc teceris.
Epist.1.3.3.4

Carm.1.13.2

Carm.2.12.26

Carm.2.13.6

Ars Poet. 1

Carm.3.9.3

Epist.1.2.66

7 zar.Epist.1.2.66

Epoll.10.31

Carm.2.16.23

Serm.2.1.47

Serm.2.6.77

Serm.1.2.89

Carm.1.15.29

Epist.1.10.34

Carm.3.12.1 I

Carm.4.6.34

Carm.3.19.19

tor.Epist.1.2.3 I

Epist.1.15.6

Carm.3.28.8

Carm.1.35.15

Epist.1.7.57

Epist.1.10.46

Epist.2.2. 183

Carm.3.27.58

Serm.2.3.155

Epist.1.2.70

Carm.1.27.13

Epist.1.7.78

Ars Poet.357

Sirm.2.7.100

Epist.1.2.31

Epist.1.19.10

Epist.2.2.14

Carm.2.1.26

Serm.2.1.31

Epist.I. 18.43

Serm.I.7.3I

Carm.3.II.15

Serm.2.5.44

Scrm.2.8.26

Carm.3.29.33

Sirm.1.1.13

Serm.1.3.77

Epist.2.2.205

Carm.1.9.9

Corm.t.2.60

Epod.13.7

Serm.1.2.95

Serm.1.10.5

Serm.2.6.1 4

Epist.1.1.10

Epist.1.10.3

Epist.1.10.50

Epist.2.I.20

Epist.2.2.05

Epist.2.2.13 I

Carm.4.0.5

Epist.2.2.II

Ars Poet.50

Carm.4.4.43

Serm.I.IO.4

Serm.1.5.10.

Epist.1.13.0

Carm.4-8.2I 


\section{CHARTAE}

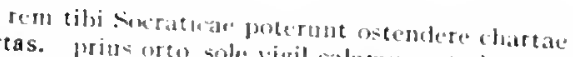

chartas. prits ofto sole vigil calatmom et clartase

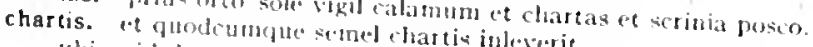

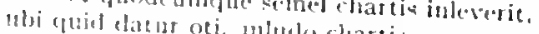

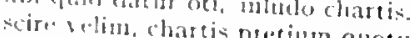

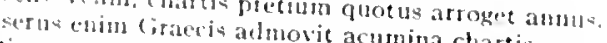

chartis. nou cours acumina chartis

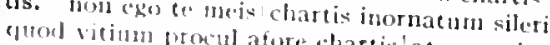

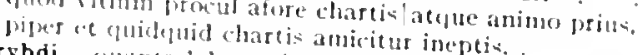

Charybdi. gutunta loboras in Chargh ineptis.

Charybdin. miracula promat harbli,

Chaybdin: promat. Antiphaten syllancue et cum crelope

cheragra. pestguam illi iusta cheragralconturlit articulos.

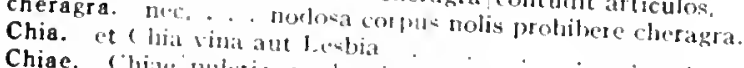

Chiae. Chiar muleris excubat in genia.

Chii. si puritis iutus Chii veterieglue Falerni mille eadis.

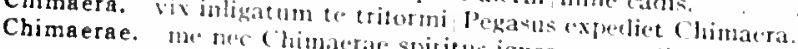

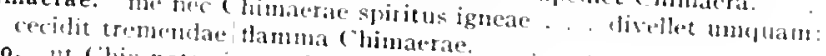

Chio. He (hio nota si conmixta Famater

Chios. chid tibis sico conmixta Falerni est."

Romate laudetur Chas, Bullati. aoticfue leshos,

chiragra. prostquam illi instat cheragra el Rhodos absens.

chiragra. Me. . . nodosa corpus nolishagta]/contudit artirulos.

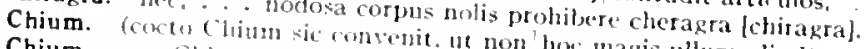

Chium. fluo Chium pretio calum meren hoe magis ullum aliudl:

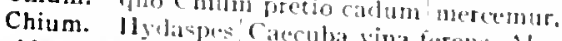

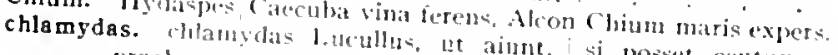
prablere logeths.

chlamydem. alter

[chlamycten].

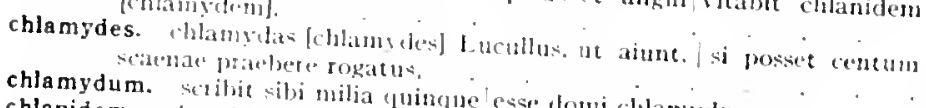

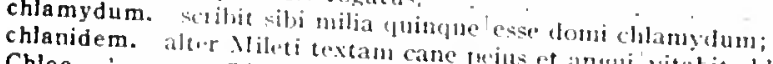
Chloe. nue nunc litessa Chloe regit.

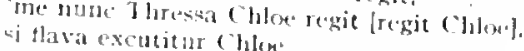

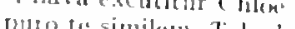

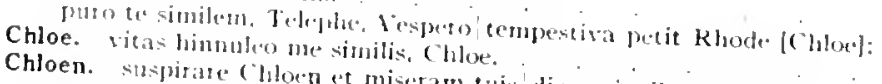

nergue erat lovelia post chloen.

sublimi flaguliat post Chlien.

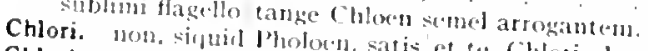

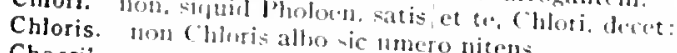

Choerilus. prabur dlexare ic umero nitens

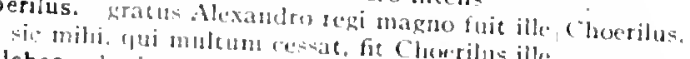

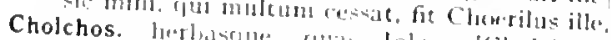

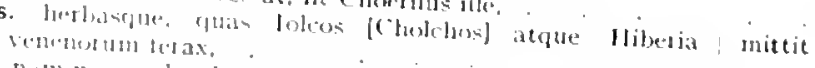

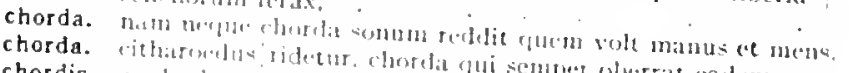

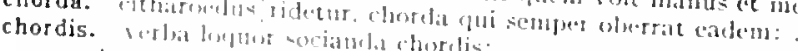

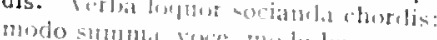

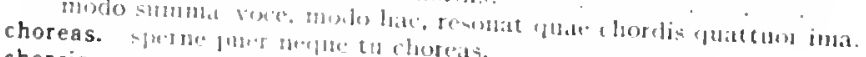

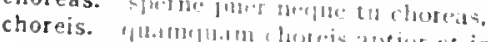

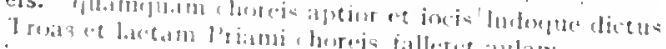

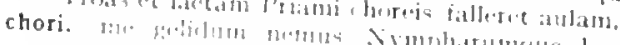

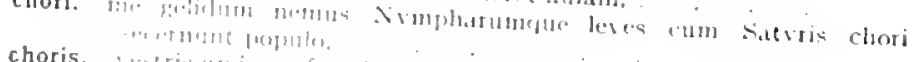

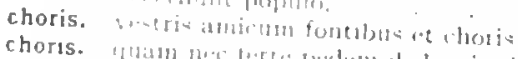

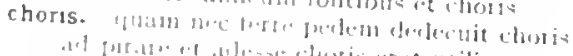

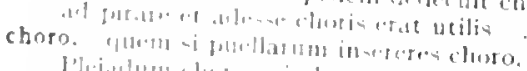

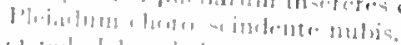

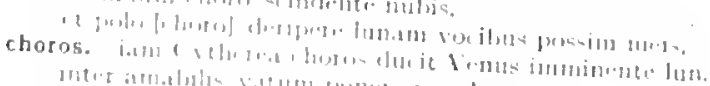

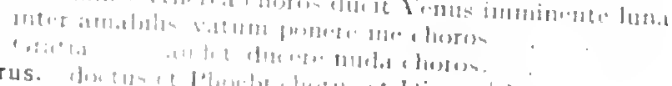

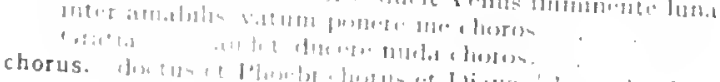

CHORVS

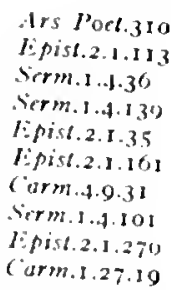

Ars I'oet.145

Simm.2.7.15

Epist.1.3.31

lipod.9.34

(iom.1.13.7

Sierm.2.3.115

Carm.1.27.2.1

Carm.2.17.13

Carm.1.2.10

Serm.1.10.24

Epist.1.11.1

Epist.I.II.2I

tur.term.2.7.15

ger.lepist.1.1.3t

Sirm.2.8.48

(arm. 3.19 .5

Serm.2.8.15

11)i. Esist.1.6.40

iur.Jipist.I.I.7.31

tar lopist.1.0.40

Esist. I.t.4t

Epist.1.17.31

Curm.3.9.9

coni.Carm.3.9.9

Carm.39.19

iar.Carm.3.19.27

Ciurm.1.23.1

(arm.3.7.10

Curm.3.9.6

(arm.3.20.12

cirm.3.15.8

('arm.2.5.18

lipist.2.1.233

irs 196.6.35"

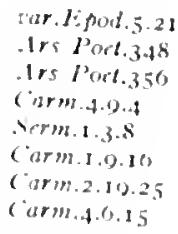

(iarm) I 1.31

cirm.3.2.25

(iurm.2.12.17

- Irs I"vel. 204

(istur.2.5.21

(isrm.t 1.4 .21

cus lepend $17 \%$

(urm.1.4.5

c arm.t.jo 5

(arm.at 7os

(arm. yate. 75 
poscit opem chorus et praesentia numina sentit.

Epist.2.1.134

scriptorum chor us omnis anut nemus et fugit libem.

Espist 2.2.77

actoris partes chorus officiumque virile|defendat.

Ars Potet. 103

chorusque|turpiter obticuit sublato iure nocendi.

Chremes. quod aut avarus ut Chremes terra premam,

Ars I'oet.283

Epod.1.33

iratusque Chremes tumido delitigat ore;

Ars I'Oet.94

Chremeta. arguta meretrice potes Davoque Clireneta / eludente senem comis garrire libellos

Chrysippi. insanum Chrysippi porticus et grex|autumat. clum, quae Crispini [Chrysippi] docuit me ianitor, edo.

Chrysippo. planius ac melius Chrysippo et Crantore dicit.

Chrysippus. 'non nosti, quid pater,' inquit,|'Chrysippus dicat:

loc qunque volgus/Chrysippus ponit fecunda in gente Meneni. -

chyragra. postquam illi iusta cleragra [chyragra]|contudit articulos.

nec. . . nodosa cotpus nolis prohibere clieragra [chyragra].

cibaria. cum sibi sint congesta cibaria:

cibaria. urbana diaria [cibaria] rodere mavis.

cibo. interminato cum semel fixae cibo

ciboria. obliviuso levia Massico/ciboria exple.

cibum. proiectum odoraris cibun.

anet scripsive ducentos ante cibum veran.

siccus. inanis|sperne cibum vilem;

cibus. ni cibus atque ingens accedit stomacho fultura ruenti.

Cibyratica. ne Cibyratica, ne Bitly'na negotia perdas; .

cicatricem. heu heu, cicatricum et sceleris pudet/fratrumque.

cicatrix. at illi foeda cicatrix/saetosan laevi fronten turpaverat oris.

Cicerci. nunc milui paucis/Samenti scurrae pugnam Messinue Cicirri [Cicerci].] inusa, velim memores

cicere. in cicre atque faba bona tu perdasque lupinis.

ciceris. ad porri et ciccris refero laganique catimum;

neque ille | sepositi ciceris nec longae invidit avenae.

neque ille/sepositi ciceris nec longae [? nec ciceris nec longate] invidit avenae,

nec, siquid fricti ciceris probat ct nucis emptor,

Cicerri. nunc nulji paucis / Sarmenti seurat pugnan Messiute Ciciri [Ciccri]. |nusa, velim menores

Cicerrus. nulta Cicirrus [Cicerrus] ad laec:

cichorea. me pascunt olivae, / me cichorea levesqute malvae.

Cicirri. Sarmenti scurrae pugnam Messique Cicirri.

Cicirrus. multa Cicirrus ad hae:

ciconia. tutus erat rhombus tutoque ciconia nido.

cicuta. sed nuala tollet anum vitiato melle cicuta.

Cicutae. adde Cicutae/nodosi tabulas, centum,

cicutae. quae poterunt umquan satis expurgare cicutae.

Cicutam. tu Xomentanum, tu ne sequerere Cicutam.

cicutis. edit cicutis alium nocentius.

cimex. men moreat cimex Pantilius

Cinarae. non sum qualis eram bonae sub regno Cinarae.

inter vina fugam Cinarae maerere protervae.

Cinarae. Cinarae brevis/annos fata dederunt.

quem scis inmunem Cinarae placuisse rapaci.

Cinaram. felix post Cinaran notautue et artim gratarum facies?

Cinare. resldes ridere decorum et inter vinis fugam Cinarae [Cinare] maerere protervae.

cinctos. iacentes sic tenere et rosalcanos [cinctos] orlorati capillos.

cinctus. puer alte cinctus acernan/gausape purpureo mensan purtrat

cinctutis. fingere cinctutis nom exaudita Cethegis continget

Cinerae. reddes ridere decorum et / inter vina fugan Cinarae [(inerae] maere protervae.

quen scis inmunem Cinarac [Cincrae] placuisse rapaci.

cinerem. vert rat in fumum et cineren.

cineres. expedit matris cineres opertos|fallere

dilapsan in cineres facen.

barbarus heu cineres insistet victor

utrum $\mid$ minxerit in patrios cincres

cineri. incedis per ignis|suppositos cincri duloso.

cinge. nuhi Deiphica|lauro cinge volens, Melpourene, conam

cingentem, deum/cingentem riridi tempora panpino.

ciniflones. custodes, lectica, ciniflones, parasitae.

Serm. I. I0.40

$\sin 2 \cdot 2 \cdot 3 \cdot 44$

"ar..Serm.2.7.45

Epist.1.2.4

Sorm.1.3.127

Serm.2.3.287

var.scrm.2.7.15

z'tr.epist.1.I.3 I

Sirm.1.1.32

7ar. Epist I. 14.40

Lipod.5.39

(arm.2.7.22

Epod.o.to

Serm.I.IU.6I

Serm.2.2.15

Serm.2.3.153

Lipist.1.0.33

Carm.1.35.33

sirm.1.5.

ar.sirm. I.5.32

Serm.2.3.182

Sirm.I.t. I I 5

cirm.20.84

? atur.tirm.2.6.84

Ars Poet 249

far.Serm.1.5.52

icionerm.1.5.65

Cirm. I.3I. [t)

irm.I.5.52

Serm. I.5.05

Serm.2.2.49

Serm.2.1.50

Serm.2.3.09

Fipist.2.2.53

Sirm.2.3.175

Lpod.3.3

Serm.t.10.7s

Cum.4.t.4

I:PisI.I.7.28

(at) 4.13 .22

Epist.I.14.33

Carm.4.13.21

Iur.Epist.1.7.28

coni.Cum.2.I I.I5

Serm.z.8. Io

Ars Poct.50

sar. Fpist.1.7.28

atr. IPpist. I. 4.33

lopist.15.41

Cirm.2.8.9

Carm-4.13.28

Ispot.10.11

Ars Poet.ti I

Carm.2.1.8

Carm.3.30.10

Carm.3.25.20

Serm.1.2.08 


\section{CINIRAE}

Cinirae. sedeles ridere decorun et | inter vina fugan Cinarae [Cinirae] matere potervae.

cinis. tu, donece cinis iniuriosts aridus ventiv ferar.

Cinyrae. redites ridere decosum et inter vira lugan Cinarae [Cinyrae] matreb protersae.

Cinyrae. quen scis inmunem Cinarac [Cinyrae] placuisse rapaci.

Cingre. Judes ridere deconum et / inter vina fugam Cinarac [Cingre] marerere protervae.

Cinyre. quen scis inmunem Cinarae [Cinyte] placuisse rapaci.

cippus. treentos cippus in atgrum/hic dabat,

ciprus. wille pedes in tronte, trecentos cippus [ciprus] in agtum/ bic diblot.

ciragra. postruan illi iusta cheragra (ciragralicontudit articulos.

Circa. Sabtosid duris cxuerc pellibus. . volente Circa nombra;

circa. illi tobur et ates triplex/circa pectus erat.

circa mite solum Tiburis et moenia Catili: .

saeviet circa jecur ulcerosum $\mid$ non sine questu.

cired vir.utis cest animus tuae $\mid$ campos iurencac

circa lustra decem tlectere nollibus iam durum imperiis:

circa ne'lus uvidique/ Tiburis ripas

aliena negotia centum | per caput ct circa saliunt latus.

Aemilium circa ludum faber inus

si non circa vilem patulumque motaberis orben

Circae. sactosa duris txuere pellibus/aboriosi remiges Vlixei volente Circa [Circat] membra;

Sirenum voces et Circue pocula nosti;

Circaea. ("ircaea tangat moenia:

Circe. saecosa duris "xuere pellibus/laboriosi ieniges vixei volente Circa [Curce] thembra:

Circeis. oxtlea Circeis, Miseno oriuntut chini.

Circen. dices laborantis in uno l'enelopen vitreamgue Circen;

circiter. ab oficis octaran circiter horam, dun redit

circo. latus ut in circo spatiere et aeneus ut stes.

circum. curas laqueata circum, tecta volantis.

circum renidentis Laris."

urgeris turba cicum te stante

ipse mila custos incorruptissimus onnis/circuni doctores aderat.

ian circum loculos et clavis laetus ovansque

qui circum compita siccus/lautis nane senex manibus currebat

et "lytias dare cirellm inluta toralia vestis.

quis circum pagos et circum compita pugnax

circum. quam Iocus circum volat et Cupido;

te greges centum Siculaeque circum mugiunt vaccae.

nos mant ( Keanus circun vagus:

circum $\mid$ me Satureiano vectari tura caballo.

actia cisenu rapula, lactucae, radices,

circum. fallacen circum vespertinumque perero, saepe forum.

circumagi. 'nit opus est te circumagi :

circumdata, all talos strala demica et circumdata palla.

circumdata. si interdicta setes. vallo circundata.

circumgemit. He sespertinus circumgenit ursus ovile.

circumlita. muaco rirumlita saxa nenusque.

circumposuisse. puria circumposuisse catillis.

circumroditur. qui dentc Theonino cun circumroditur.

circumspcctemus. quanto molimine circum-spectemus vacuam Romanis vatibus ardem.

circumtonuit. Imuc circumtonut gaudens Bellona cruentis.

circumveniunt. mult at semen circumveniunt incommoda.

circumvolat. seu mors atris circunbolitt alis.

circumrolitas. glae circumvolitas agilis thyma?

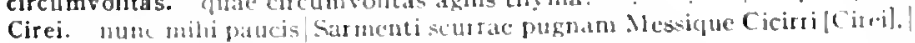
m11sis. Whm méno:

cistam. ant eintan efrractam ct subducta viatica plorat.

cita. alewtuht tazum cital mors Achillem,

hor ine, inom nto cita mors vent ant victoria laeta."

cita. Jue latentis tase cita reparavit ords.

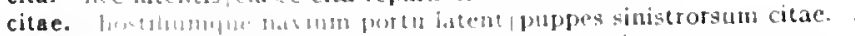

citaret. aboso 1 -efuce and mala citaret "io Barehate"

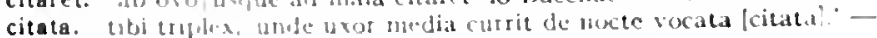

CITATA

var. Epist.1.7.28

Iepod.17.33

rar. Epist.1.7.28

tur. Epist.1.14.33

1.ar. Epist. 1.7 .28

tar.Lpist.1.14.33

Setm.1.8.12

: $3 r . S e r m .1 .8 .12$

Iur.Serm.2.7.15

Epod.17.17

Carm.1.3.10

Carm.I.IS.2

Carm.1.25.15

Carm.2.5.5

Carm.4.1.0

Curm.4.2.30

Serm.2.6.34

Ars Poet.32

Ars lott.132

1.ur. Lpod.17.17

Lipist.1.2.23

Epod.1.30

tar.lipod.17 17

Serm.2.4.33

Curm.1.17.20

Lipist.1.7.47

Serm.2.3.183

Carm.2.10.11

Epod.2.00

Serm.1.3.135

Sirm.r.6.82

Sorm.2.3.140

Serm.2.3.28t

Serm.2.4.84

Lipist.1.1.49

Carm.1.2.34

Curm.2.10.33

Epod.10.41

tierm.1.0.58

Serm.2.8.7

Serm.1.0.113

Serm. [.9.17

Serm.1.2.99

serm.1.2.90

I. pould $10.5 \mathrm{I}$

lifist.1.10.7

Serm.2.4.75

lipist.1.18.82

Epist.2.2.93.94

Sarm.2.3.223

der l'oel. 109

Serm.2.1.58

lipist.1.3.2I

tar.Serm.1.5.52

I.Pist.1.17.54

Cism.2.16.29

Sirm.1.1.8

Cism.1.37.2.t

L pod 920

Sermi.1.3.7

sur.sern. 2.3.238 
citbara, inbelli cithara carmina divides; cui liquidam pater/vocem cum cithara dedit. nec turpeur senectam/degere nec cithara carentem. . quondam cithara tacentem/suscitat Mlusam seu fidibus citharave Phoebi.

citharae. mollibus faptari citharae modis. non avium citharaeque cantus / somnum reducent: dulis docta modos et citharae sciens, nec studio citharae nec Musae deditus ulli, ad strepitum citharae cessatum ducere curam.

citharae. non citharae decent auriculas citharac collecta sorde dolentis.

citharas. siquis emat citharas, emptas conportet in unum.

citbaroedus. citharoedus'ridetur, chorda qui semper oberrat eadem: .

citius. suprema citius solvet amor die. nam quis me scribere plures|aut citius possit versus? ubi dicto citius curata sopori|mcmbra dedit. eripiet quivis oculos citius mihi quam te / contemptum cassa nuce pauperet; pingimus atque | psallimus et iuctamur Achivis doctius [citius] unctis. discit eniu citius meminitque libentius

cito. ut cito dicta| percipiant animi dociles

citra. quos ultra citraque nequit consistere rectum. atque ego cum graecos facerem, natus mare citra. / versiculos, vino quinquemni, verım citra mare nato, /dum coquitur.

citrea. Albanos prope te lacus/ponet marmoream sub trabe citrea. citum. citumque retro solve, solve turbinem.

citus. leporem citus |venator in campis nivalis nec quisquam citus aeque Tusco denatat alveo. i. puer, atque meo citus hace subscribe libello. syllaba longa brevi subiecta vocatur iambus, | pes citus: cirem. fama civem causaque priorem/sperne. inpransus non qui civem dignosceret hoste, cires. 'o cives. cives. quaerenda pecunia primum cst; licet 'succurrite' longum|clanet 'io cives,'

ciri. Lesbio primun. modulate civi,

civibus. res gerere et captos ostendere civibus host is cirica. seu civica iura|respondere paras

civicam. caedis et rabiem tollere civicam,

civicum. motuan ex Metello consule civicum civilia. si|aut valeo stare aut novi civilia iura: civilibus. nunc agilis fio et mersor civilibus undis, civilibus. altera iam teritur bellis civilibus aetas, civilis. non furor civilis aut vis exiget otium, civilis. civilisque rudem belli tulit aest us in arma. civilis. mitte civilis super V'rbe curas:

civis. audiet civis acuisse ferrum.

sic qui promittit civis. Trben sibi curae, imperium fore. deicere de saxo civis aut tradere Cadmo?" .

civitas. "io trumphe" | civitas omnis dabimusque divis/tura benignis. Phocaeorum/velut profugit exsecrata civitas eamus omnis exsecrata civitas

civitatem. tu civitatem quis deceat status/curas civium. non civium ardor prava iubentium, civiun retorta tergo bracchia libero superba civium/potentiorum linina.

clade. fortuna tristi clade iterabitur stravit humum sine clade victor.

clades. hoc fonte derivata clades/in patriam populumque fluxit.

clamabit. clamabit enim "pulchre, bene, recte,"

clamans. ct Menelaum una mecum se occidere clamans."

clamantibus. Catienis mille ducentis|'mater, te appello' clanantibus.

clamas. aut quia non sentis, quod clamas, rectius esse.

clamat. solos felicis viventis clamat in "rhe. qui dicit, clamat 'victum date.'

clament. insanum te omnes pueri clamentque puellae; clament periisse pudorem |cuncti paene patres.

clamet. desiliat mulicr, iniscram se conscia clamet, clamet amica, mater, honesta soror eum cognatis, pater, uxor:

Carm.1.15.15

Carm.1.24.4

Carm.1.31.20

Carm.2.I0.I 8

Carm.3.4. 4

Carm.2.I 2.4

Carm.3.r.20

Carm.3.9.ro

Serm.2.3.105

Epist.1.2.31

Carm.3.I5.It

Epist.1.2.53

Serm.2.3.104

Ars Poet.355

Carm.I.I3.20

Serm.I.9.24

Serm.2.2.80

Serm.2.5.35

var.Epist.2.1.33

Epist.2.1.262

Ars Poet.335

Serm.I.I.I07

Serm.1.10.31

Serm.2.8.47

Carm.4.1.20

Epod.17.7

Carm.1.37.18

Carm.3.7.27

Serm.1.10.92

Ars Poet.252

Serm.2.5.30

Epist.1.15.20

Epist.1.1.53

Ars Poet. 460

Carm.I.32.5

Epist.I.17.33

Epist.1.3.23

Carm.3.24.26

Carm.2.I.I

Serm.I.9.39

Epist.r.1.16

Epod.16.1

Carm.4.5. 8

Epist.2.2.47

Carm.3-8.17

Carm.1.2.2I

Serm.1.6.34

Sirm.1.6.39

Carm.4.2.5 I

Epod.10.Is

Epod.16.36

Carm.3.29.25

Carm.3.3.2

Carm.3.5.2I

Epod.2.7

Carm.3.3.62

(arm.4. It.32

Carm.3.6.19

Ars Poet.428

sirm.2.3.198

Sirm.2.3.02

Serm.2.7.25

Serm.I.I.I2

Epist.I.17.48

Serm.2.3.130

Epist.2.1.80

Serm.1.2.130

Serm.2.3.57 


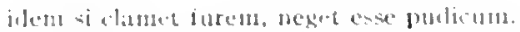

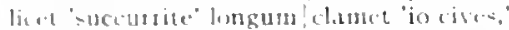

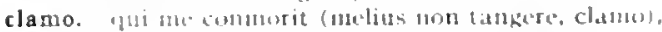

displite jate lon clamo et diludiat pusco.

irs l'oel. ploo

Serm.2.1.45

Epist.1.19.47

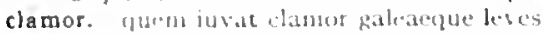

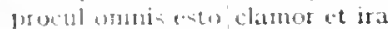

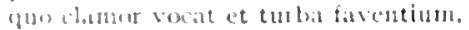

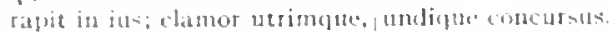

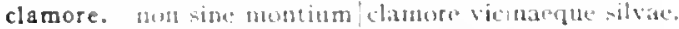
cunb hazm) blaturts dimore fugisque.

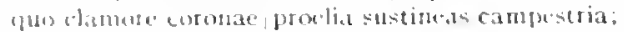

clamorem. impium, lenice chanonam sodaleg

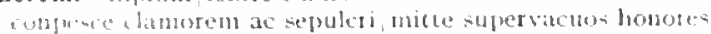

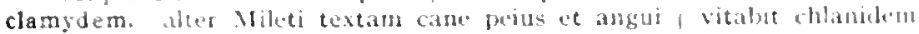

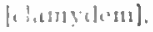

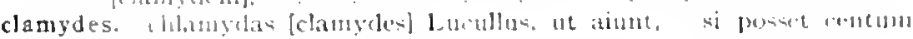

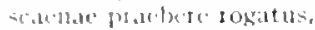

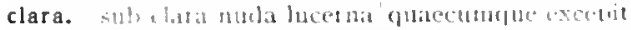

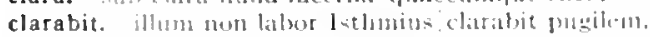

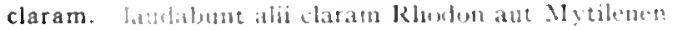

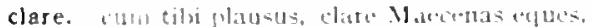

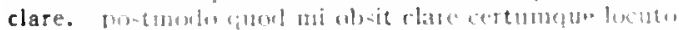

'lant pater" "late, clare cum rlixit "Apullo"

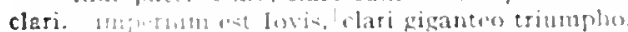

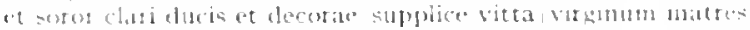

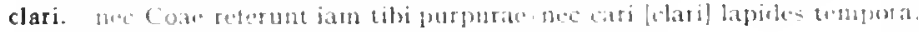

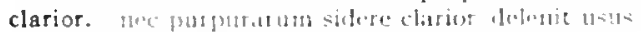

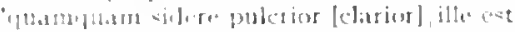

clarior. Rummilat vigui dajor llia."

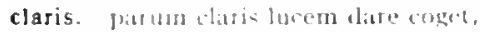

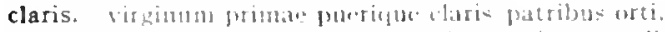

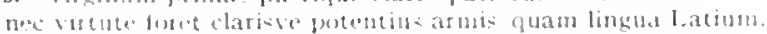

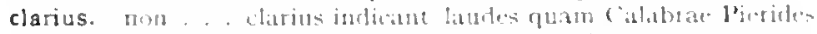

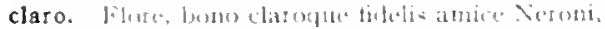

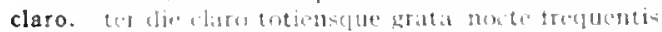

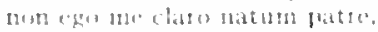

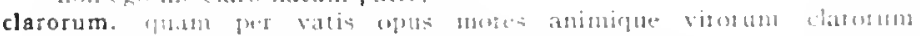
inlilisentit.

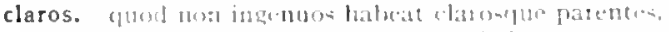

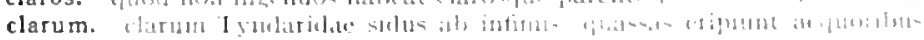
ritin.

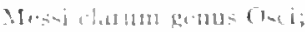

clarum. ab-tulit chorum ata mors on hillom,

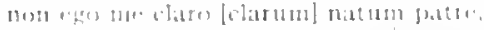

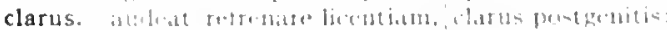

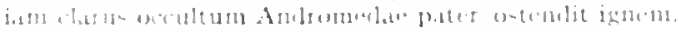

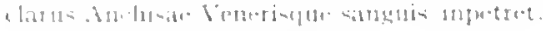

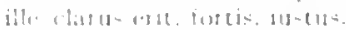

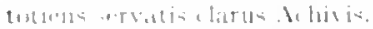

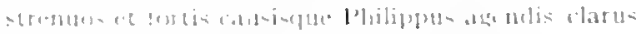

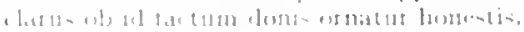

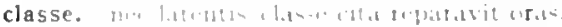

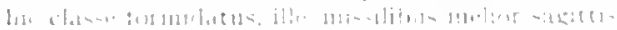

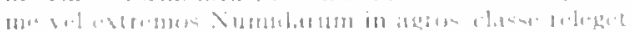

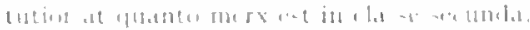

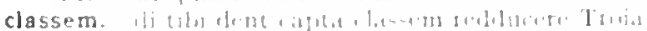

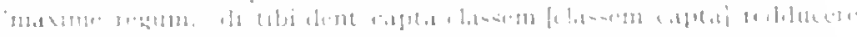
1:10101.

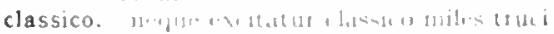

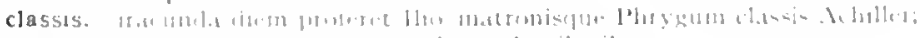

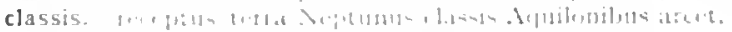

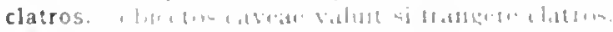

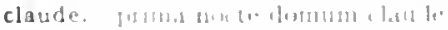

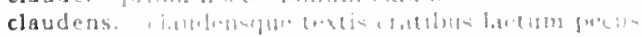

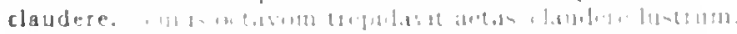

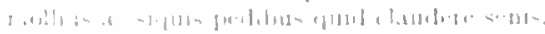

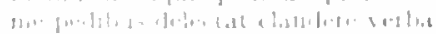

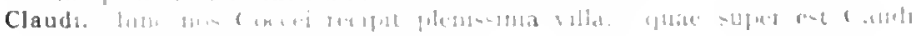

Cism.1.2.35

(arm.3.8.10

(iarm.3.24.40

Trem 19.78

(ism.3.29 39

Srom.2.7.35

1.pist.1.18. 53

(itrm. 1.27.7

Cism.2.20.23

:dr.l.pist.1.17.31

iur. Listist (1. fo

ierm.2.7.4s

(itrm.4.3.4

(iormi.1.7.

Cirm.1.20.5

serm.2.8.27

lepist. 10.59

Cism-3.1.7

(iarm.3.14

turecorm.t13.14

(arm? 1.92

ior.cirm.3.921

(is) 39.8

1) 1'mettes

(ism.4.0.31

Irs lint.2so

(iarm +sito)

lipelt 22.1

(arm asetic 23

serm 1.6.58

1.pist.21.250

virn:1.0.21

Cirme 1:31

s.rm, 1.5.54

(urm) $2.11 \% .20$

ielr hermen.t. 58

(irm 3.2.303)

(arma.3.2017

(iormo veloseso

S.rm. 3.07

sirm 2.3.10.4

1.pest.1.7.47

l:petzes 32

(iorm 1 37.24

(itrmis 12.15

(arm.11..4k

sim. 2.97

serom 23101

inr arm.23.101

I.puld 2.5

(arm 15.31

Irs linetela

las reit $\$ 73$

(arn: $; \pi .20$

1. puit 2.45

( arm 2.1 .21

hem 1 111.50

$\checkmark m=126$

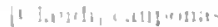

itr truts 55 


\section{CLAVDI}

Claudi virtute Neronis|Armenius cecidit:

Claudi. Septimius, Claudi, nimirum intellegit unus. fruanti me facias:

Claudiae. nil Claudiae non perficient manus.

Claudius. ut barbarorum Claudius agmina|ferrata vasto diruit impetu quibus terrarum militet oris $\mid$ Claudius

claudo. raro antecedentem scelestum|deseruit pede Poena claudo.

claudum. 'credite, non ludo; crudeles, tollite claudum.'

clausa. omni| abiecto instrumento artis clansaque taberna|sutor crat:

clausas. vidi.. portasque non clansas

clausit. vacuom tuellis| Tanum Quirini clausit

claustra. nec te feriam neque intra/claustra tenebo.

a mat spatiis obstantia rumpere claustra.

claustraque custodem pacis cohibentia lanum

clausus. an turpi clausus in arca.

clavibus. absumet heres Caecuba dignion / servata centum clavibus

clavis. It heres iam circum loculos et clavis laetus ovansque/curreret. odisti clavis et grata sigilla purlico;

clarom. praetextam et latum clavom prunaeque vatillum. sumere depositum clavom ficrique tribuno? latum demisit pectore clavom. clavom ut mutaret in horas,

claros. clavos trabalis et cuneos manu/gestans aena si figit adanantinos/ summis verticibus dira Necessitas/clavos,

Clazomenis. l'ersius hic pernagna negotia dives habebat|Clazonenis.

clemens. quod viro clemens misero peperci,

cliens. mane cliens et iam certus conviva.

rite cliens Bacchi somno gaudentis et unbra:

cliens. iuvenum nobilium cliens,

clientae, nec Laconicas mihi trahumt honestae purpuras clientae.

clientem. atria servantem postico falle clientem.

clientes. nce Laconicas mihi|trahunt honestae purpuras dientae [clientes]. clienti. Romae dulce diu fuit . . clienti promere iura,

clientiae. nec Laconicas mihi $\mid$ trabunt honestae purpuras clientac [clientiae].

clientium. ultra|limites clientium|salis avarus?

illi turba clientium|sit maior:

quam si clientum [clientium] longa negotia, dindicata lite relinqueret

clientum. quam si dientum longa negotia

Clio. quen virum aut heroa lyra vel acri tibia sumis celebrare. Clio?

clipeo. quanris clipeo Troiana refixoltempora testatus

clitellas. hine muli Capuae clitellas tempore ponunt.

quam quo perferre iuberis/clitellas ferus inpingas

clivom. per sacrum clivon merita decorus, fronde.

clivos. viribus uteris per clivos flumina lamas.

clivum. seu mihi frigidum | Prateste se'u Tibur supinum [? clivumque supinum]

cloacam. illud idem in rapidum flumen iaceretre cloacam? -

clune. vidinus et merulas poni et sine clune palumbis,

clunes. quod pulcrac clunes, breve quod capnt, ardua cervix.

clunibus. quiecunque excepit turgentis verbera caudae dunibus

Clusinis. qui caput et stomachum supponere fontibus audent/Clusinis

Clusinos. qui raprt et stomalnum suplenere fontibus audent/Clusinis [Clusinos] Crabiosque petunt et frigida rura.

Cnidi. o Venus rengina Cuidi Paplicjue.

Cnidius. Cnitiusve Grges, / guen si pullarm insereres choro,

Cnidon. quat Cuidon fulgentisque tenet 'ycladas

Crosii. hastas ct calami spicula Cnosii!vitabis

Coa. siser, hallec, taecula Coa.

coactor. si prapco parvas aut ut fuit ipse. conctor muedes superer;

coactus. fertur l'bonetheus addere frtincipi lino coactus particulam

nec recito ctiquam nisi amicis idque coactus.

Coae. nec Coan reterunt ian tibi purpurac

Coccei. hinc no: Coccei recipit plenissina villa.

Cocceius. buc venturus erat Maecenas optimus atque cuccuss.

interea Maecenas advenit atrue / Coceuls

cocco. rubro ubi coccoltincta super lectos canderet restis eburnos

coclea. tost is marcentem squillis recreabis et Airapotorem coclea:

cocto. cocto num adest honor idem?

(cocto Chim sic convenit. ut non) hoc magis ullum aliud);

Cocytia. inultus ut tu riseris Cotytia [Corytia] volgata,

\section{COCYTIA}

I.pist.1.12.20

Epist.1.0. I

Carm.4.4.73

Carm.4.14.29

Epist.1.3.2

Carm.3.2.32

Epist.1.17.01

Sirm.1.3.13I

Carm.3.5.23

Carm.4.15.9

Carm.3.II. 44

Epist.1.14.9

Epist.2.1.255

Serm.2.7.59

Carm.2.14.26

Serm.2.3.140

Epist. 1.20.3

Serm. I.5-3t

Serm.1.0.25

Serm.t.0. 28

Serm.2.7.10

Carm. [. 35.18

Carm.3.24.7

Sorm.1.7.5

Carm.3.1 1.t6

Epist.1.7.75

Epist.2.2.78

Corm.at I 2.15

Carm.2.18.8

Epist.1.5.3I

var.Curm.2.18.8

Eptist.2.I. IO4

Tur.carm.2. I8.8

Carm.2.18.25

carm.3.I.I 3

F'ar.cirm.3.5.53

Carm.3.5.53

Carmit12.2

Corm. I.28.I I

Serm. 1.5 .47

Epist.1.13.8

Carm.4.2.35

Ispist.1.13.10

? arr.carm.3.4.23

Serm.2.3.242

Sirm.2.5.01

Sirm.1.2.89

Sim.2.7.50

Enist.1.15.0

zur. Epist.I. 15.9

Carm-1.jo.1

(arm.2.5.20

Carm.3.2k.13

Curm.1.15.17

serm.28.9

sirm.1.8.S6

carm.1.1'1 4

Sirm.1.4.73

Carm.t 3.13

Sirm:. I.5.50

srrm.1.5.28

Serm.1.5.32

Serm.20.102

Serm.2.4.59

Serm.2.2.28

crom.2.8.

iar. L.Pud.17.56 
Cocytos. atur tumine languido/Contos errans

Codrus. colrus pur patria non timulus mor

coeant. sed nom ut placidis coeant inmitia.

coeat. Ut conat pus iungaturque pari:

coemens. ommia combetis contucts ubonin numbis:

coemptas. Iucinias soliti inpenso prandere conntas.

coemptis. Ades cocmptis saltibus et domo

coemptos. comptus undicue molibia! libos Panacti

coeperis. conutulu coeperis inpexa foedm portigine?

comerecatu ubi manbus sordescere volgi coneris.

coeperunt. oplislit cosperunt munire et potere leges. pullam divellese mordicus angun! conpertuse;

coepi. vellere conpi et pressare manu lentissina bracchia.

coepit. 'mon faciam" ille. et pracedere cocpit;

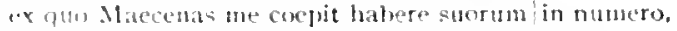

rlinidium facti. pui coepit, habet: sapere atule.

ut . urbanus coepit laberi.

ut prisum postis nugari Graecia bellis/conpit

Jonec fan saequs apestam in rabien conpit vesti iocus

donec insm sitevos ajpettam in rabien coepit verti [verti coepit] jocus

('t puet Punica bella quictus quaterere conple.

castellum evestere prator uescio quod cupicns hot tari coepit

anplust arepit|institui: currente rota cur urceus exit?

postquasn compit agros extender" victor

coesceat. vil guml huemem nauscan coerceat

coerces. vin saque levem coerces/atrea turbam.

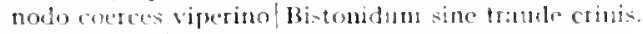

quos qu nisi huste coerees.

coercet. hic sujulwum|Tamtalum atque Tantali|genus corcet.

fes ue quatorue ent. ita supplicids delictat coercet?

mint tures dextra coercet

qual saltis thene putat pater et natura coercet.

coercuit. "flod mon multit dies et multa litura coercuic

coetus. Coethatu" volgaris et udam spernit hummo

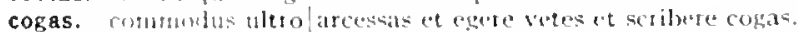

copat. illam cugit [cogat] amor Xothi lascivate similesu ludere capreae.

ormi- mortalis curase et fuaterese ongit !cogat].

cogat erans pondera dextram/porigere:

cogemus. veluti celudaci cogemus in hanc concedare turbam.

cogere. quasm cogere liumangs in mus

lilosir. qui cogere puscet.

ubi plura coget quam sat is at ae non cesare videbot.

cogeris. tammuam pallerte sion is cogeris.

coges. 'fuil] nue perferre patique indigunm coges?"

coget. osmis mortalis cularu et qua rese cogit [8 coget].

parunu clotsis ludern rlare coget.

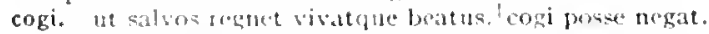

et acis in hreve te cogi. cum plenus langutet amatot.

cogimur. unnege perlem cogimur.

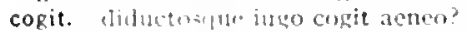

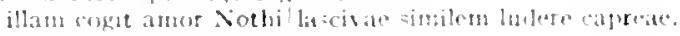

mertiorfun motu sibi jarcere cokit.

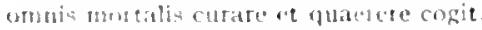

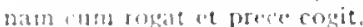

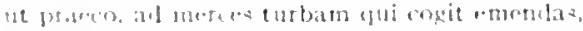

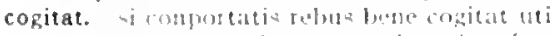

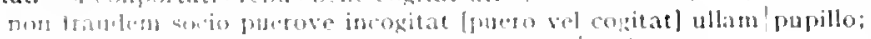

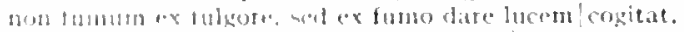

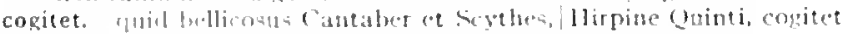

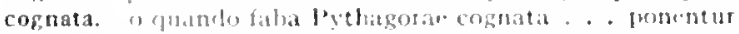

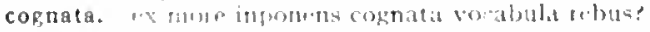

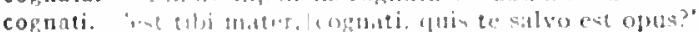

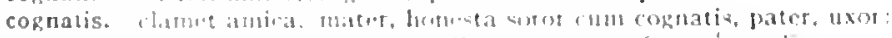

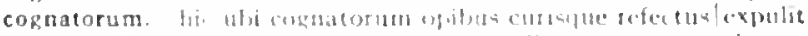

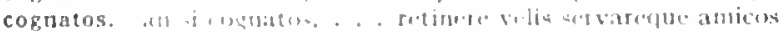

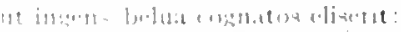

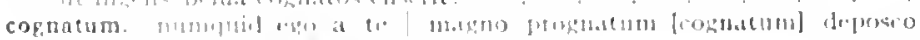

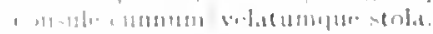

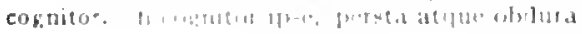

Carm.2.1.18

Carm.3.19.2

Ars Pod.12

Epist.1.5.25

Serm.1.2.9

Serm.2.3.245

Carm.3.17

Carm.1.20.13

Serm.2.3.12\%

Epist.1.20.12

Serm.1.3.105

Serm.t.s.28

Serm.1.9.03

Serm. 1.9 .42

Serm.20.4 I

Epist.1.2.40

I.pist.1.15.27

LPist.2.1.94

fepist 2.1.149

Far. Iipist.2.1. I 49

Jisist.2.1.102

lepist.2.2.35

Ars J'oct.2I

Ars l'oct.208

ENod. 9.35

Carm.1.10.18

Carm.2.19.19

Serm.1.3.134

Curm.2.18.38

Sirm.1 3.70

Sirm.1.8.4

Sirm.2.3.178

Ars Joel.293

Curm.3.2.23

Epist.2.1.228

conte inm-3.15.1 $\mathrm{J}$

var. Sirm.1.1.37

Epist.1.6.51

S.rm.1.4.43

Cirm.3.3.51

Sirm.1.3.4

Fipist.1.10.46

Sirm.1.1.2

Ejist.1.10.75

istar.tierm. 1.0.37

Ars Port.48

IEpist.1.2.11

Epist.1.20.8

Curm. 2.325

(ism.3.9.18

Corm.3.15.11

Sorm.1.4 127

Serm.1.6.37

lipirt.1.0.2

frs fod 110

Espist.1.2.50

lar lipist.2.1.122

Ars l'oet.14t

Cirm: 2.11 .2

Serm 2.0.13

Sirm 23250

Sirm 1.9.27

sirm.2.3.5B

l:pist 2.2.1.36

firm t.1.s.

Sit.2.3310

:ur Sirm 12.70

firm.2538 
cognomen. cui Canis ex vero dictum cognomen adhaeret.

cognomen, illi|'tardo' cognomen, 'pingui' damus. .

unde frequentia Mercuriale|inposuere miki cognomen compita."

cognomen vertas in risum et fabula fias.

cognomine. fit Mimnermus et optivo cognomine crescit.

cognoscere. sed tamen est operae pretium cognoscere. .

cogor. iterare cursus/ cogor relectos:

coberedum. siquis forte coheredum senior male tussiet.

coberes. solus multisne coheres, / veloci pereurre oculo.

cohibebot. nec Stygia cohibebor unda.

cohibent. te mariset terrae uumeroque carentis harenae! mensorem cohibent. amatorem trecentae/Pirithoum cohibent catenae.

namque maren cohibent callosa vitellum.

cohibente. dic et argutae properet Neaerae / murreim nodo cohibere [cohibente] crinem;

cohibentia. claustraque custodem pacis cohibentia Ianum

cohibentis. lyncas et cervos cohibentis arcu.

cohibere. murteum nodo cohibere crinem;

cohibet. si neque tibias|Euterpe colnibet

cohors. nova febriurnterris incubuit cohors

cum parentis regna per arduom/cohors gigantum scanderet inpia.

laboriosa nec cohors Vlixci.

quid studiosa cohors operum struit? hoc quoque curo.

cohortem. laudat Brutum laudatque cohortem,

cobortes. militia simul fessas cohortes abdidit oppidis,

cohorti. ut placeat iuveni, percontare utque cohorti.

cobortis. qui dissimulat netum| Mlarsae cohortis Dacus

coibat. populus . . . et frugi castusque verecundusque coibat.

Cois. Cois tibi paene videre est / ut nudam.

coit. an male sarta/gratia nequiquam coit et rescinditur

Colcha. ille venena Colcha ... tractavit.

Colchi. monstrumve submisere Colchi|maius .

Colchica. ille venena Colcha [Colchica] . . tractavit,

Colchicis, flammis aduri Colchicis.

cales venenis officina Colchicis.

Colchis. neque inpudica Colchis intulit pedem.

Colchos. herbasque, quas Iolcos [Colchos] atque Hiberia|mittit venenorum ferax.

Colchus, me Colchus et qui dissimulat metum| MIarsae cohortis Dacus

Colchus an Assyrius. Thebis nutritus an Argis.

Colcos. herbasque, quas lolcos [Colcos] atque Hiberia|mittit venenorum ferax.

cole. caule [cole] suburbano qui siccis crevit in agris/dulcior.

colendi, ocolendi semper et culti,

coli. arva|Marte coli populata nostro.

colis. harum quas colis arborum

colit. te Spes et albo rara Fides colit / velata panno

colla. regum colla minacium. eripe turpi |colla iugo.

collatis. varias inducere plumas, | undique collatis membris

collaudem. purus et insons|(nt me collaudens), si et vivo carus amicis:

colle. caule [colle] suburbano qui siccis crevit in agris|dulcior.

colle. cubat hic in colle Quirini, hic extremo in Aventino.

collecta, imperat aut servit collecta pecunia cuique,

collecta. auriculas citharae collecta sorde dolentis.

collecta. Luculli miles collecta viatica multis|aerumnis. . . perdiderat:

collectos. collectosne bibant imbris puteosne perennis|ingis aquae

collectus, fertur uti pulvis collectus turhine,

collega. 'at Novius collega gradu post me sedet uno:

collegam. collegan Lepidum quo duxit Lollius anno.

collegia. ambubaiarum collegia, pharmacopolat,|mendici, mimae, hala trones.

collegisse. quos curriculo pulverem Olympicum / collegisse iuvat .

collegit, nee qui|frigus collegit, furnos et balnea laudat

colles. mea nec Falernae temperant vites neque Formiani|pocula colles. cui peeus et nigrilcolles Arcadiae placent.

dis, quibus septem placuere colles. dicere carmen.

an pingues Asiae campi collesque morantur?

collibus. condit quisque diem collibus in suis .
Serm.2.2.56

Serm.1.3.58

Serm.2.3.26

Epist.1.13.9

Epist.2.2.101

Epist.2.1.229

Curm.1.34.5

Serm.2.5.107

Serm.2.5.54

Carm.2.20.8

Carm.1.28.2

Carm.3.4.80

Serm.2.1.14

coni.Carm.3.14.22

Epist.2.1.255

Carm.4.6.34

Carm.3.I4.22

Carm.1.1.33

Carm.1.3.3 I

Curm.2.19.22

Epod.16.60

Epist.1.3.6

Serm.1.7.23

Corm.3.4.38

Epist.1.8.14

Corm.2.20.18

Ars Pot.207

Sirm.1.2.101

Epist.1.332

Carm.2.13.8

Carm.4.4.03

'ar.Carm.2.13.8

Epod.5.24

Epod.17.35

Epod.16.58

Ior.Epod.5.2I

Carm.2.20.17

Ars Poet.118

iar. Epol.5.2I

iar.Serm.2.4.15

Carm.Saer. 2

Carm.3.5.24

Corm.2.14.22

Carm.1.35.21

Carm.2.12.12

Serm.2.7.92

Ars I'oet.3

Serm.1.6.70

var.Serm.2.4. 55

Epist.2.2.08

Epist.1.10.47

Epist.1.2.53

Epist.2.2.20

Epist.1.15.15

Serm.1.4.3 I

Serm.1.6.40

Epist.1.20.28

Serm.I.2.I

Carm.1.1.4

Epist.1.11.13

Cirm.1.20.1 2

Carm.4.12.12

Curm.Satc.7

Itpist.1.3.5

Carm.4.5.29 


\section{COLLIBVS}

quan muris collibus arbor inlineret.

collige. imperet boc naturat potens. wic collige mecum.

levis hatec imania guantas| virtutes habeat, sic colige

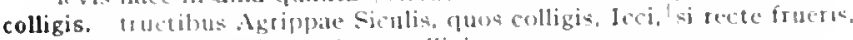

colligit. columbino limum bene colligit oro.

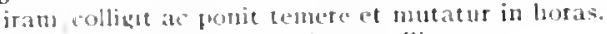

collines. achulermin cultur pulvere collines.

collisa. Gibera burbatriae lento collisa duelth.

collo. thite verere tigfes indorili ingum collo trabentes.

collo trabertis languido

dicitur "x collo furtim carpsiste cotomas.

collocare. (sptal supremo collocare sisplinus/in monte saxum:

collum. pestes hac ab otno pendulum zoma bene te secutat e- lidere collum. procidit he posuitque collum in pulvere lencto:

contendat lateues collum presisse patternum

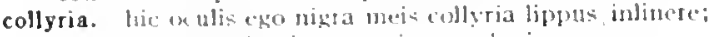

coloni. sir. roget ise inopese erimus coloni.

colono. Tibut Argero positum colono

colonum. cum perore et gratis fortem merede colonum

colonus. te puluper ambit sollicita prece ruris colenus.

natn Venusinus arat them sub utrumque colonus.

Colophon. Zmyrna guid et Colophom. maiora mimotane jama?

color. tunc nee mens mili nee color certa sede manent.

nullus argento color est avaris abdito ters is.

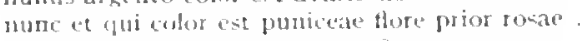

guose colot, decerss quo motus?

colorque stercote fucatus enocoliti

verecundus colut, seliquit ossa pelle amicta lutida.

quisquis erit vtale scribam color."

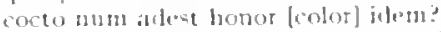

dum tie pse prma calorque [eolongue], discignatorem decorat lictoribus

$$
\text { atris, }
$$

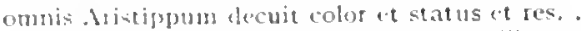

colore. servi Briseis niseo colofe movit Achillem.

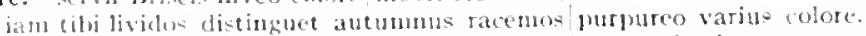

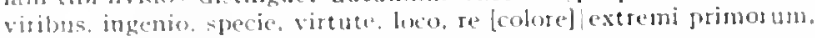

colores. merplue amiana colores lana retert cura gemmis l yrios mitafe colores;

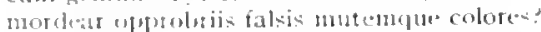

diseriptis servare vices opmtumplue colotes

colori. nee wic "nitat tragico ditieste coluri.

coloribus, hic suxu, liquidis ill, coloribus! sollers

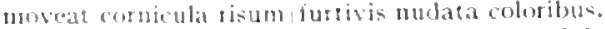

colubrae. Iterue lopi barban variae cum dente colubrataludiderat

colubras. me visidis metwont colubras

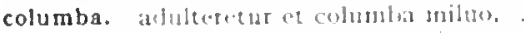

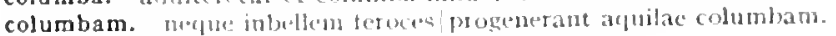

columbas. atoripter velut mollis columbas

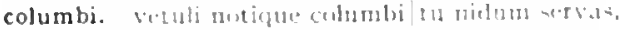

columbino. columbino limnum bence colligit oso.

columbis. metab plual secles duatat columbis.

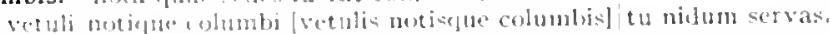

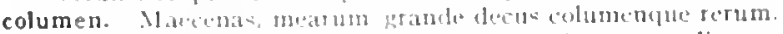

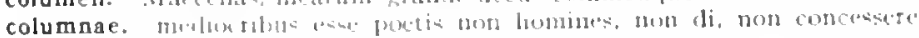
tellithrtite".

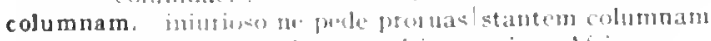

columnas. pretumut columbas ultimatecisat dficol

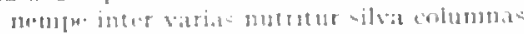

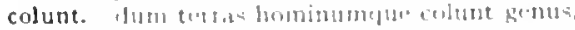

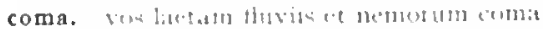

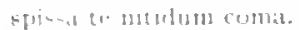

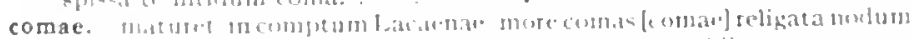

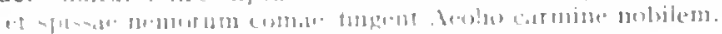

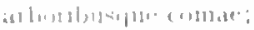

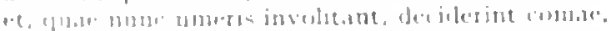

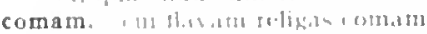

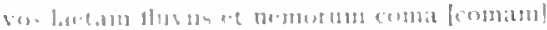

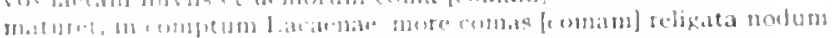

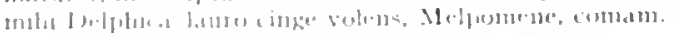

Serm.2.1.51

Iipist.2.1.10

Epist.I.I2.1

Sicrm.2.4.56

Ars Poct.16el

Carm.1.15.20

Lpist.1.2.7

(arm.3.3.15

fipod 2.0 .1

Scrm.2.3.250

tepod.17.08

Carm.3.27.60

cirm.t.0.11

fipist.1.10.37

Serm.1.5.30

Curm.2.14.12

(iarm.20.5

Serm.2.2.115

Carm.1.35.

Serm.2.1.35

Epist.1.11.3

(orm.1.13.5

Corm.2.2.1

Curm.4 10.4

Carm.4.13.17

Food.12.10

Ispod.17.2I

Serm.2.1.00

iur.Serm.2.2.25

ar. Epist.1.7.5

Lepist.1.17.23

Curm.2.4.3

Curm.2.5.12

Tar. Epist.2.2.203

Curm.3.5.27

Iipis1.1.0.18

EpIst-1 I0.38

Ars Poet so

dirs l'ort.230

Carm+4.8.7

E.post.1.3.20

Sirm.1.8.42

Curm.1.17.8

Jipol. I 3.32

Corm.1.32

Curm.1.37.18

I.sist.1.10.5

Serm.2.4.5

(arm.1.2.10

Pur. L.pist.1.jo.5

Carm $2.1 \%+4$

. Irs Pod 373

Carm.1.35.1.

(arm.2.18.4

Epist.1.10.22

I. pist.2.1.7

(urm.1.21.5

(arm.3.10).25

fear (arm.211.24

(iarmo..13 311

Curm.t? 72

(arm +10 ?

Carm I . 5..4

iur.cirm.1 21.5

: ar c (arm.2. I 24

Corm.3.30.18 
aut teretis pueri longam renodantis comam.

comas. in comptum Lacaenae/more comas religata nodum.

nos cantabimus invicem / Neptunum et viridis Nerejdum comas; .

fronde comas vincti cenant et carmina dictant.

comedenda. 'ut libet: haec porcis hodie comedenda relinques.'

comedunt. 'non hercule miror," aicbat. "siqui comedunt bona.

comes. me quoque devexi rapidus comes Orionis lllyricis Notus obruit undis.

culpam poena premit comes.

comes minore sum futurus in metw.

rhetor comes Heliodorus, | Graecorum longe doctissinus;

ducendus et unus/et comes alter.

ne tamen illi|tu comes exterior, si postulet, ite recuses.' .

frustra: nam comes atra premit sequiturque fugacem."

rura suburhana indictis comes ire Latinis.

Brundisium comes aut Surrentum ductus amoenum

scit Genius, natale comes qui temperat astrum,

comes. carpe viam, mihi crede, comes,

comica. versibus exponi tragicis res comica non volt;

comicus. Davos sis comicus atque/stes capite obstipo,

comis. et parum comis sine te Iuventas|Mercuriusque.

hic tibi comis et urbanus liberque videtur.

nil comis tragici mutat Lucilius Acci?

fuerit Lucilius. inquan, /comis et urbanus,

ita vir bonus es convivaque comis"

conis in uxorem, posset qui ignoscere servis

comis. comis garrire libellos

comisabere. tempestivius in domum / Pauli purpureis ales oloribus conissabere [comisabere] Maximi.

comissabere. purpureis ales oloribus $\mid$ comissabere

comitabere. tempestivius in domm | Jauli purpureis ales oloribus comissabere [comitabere] Maximi,

comitem. albo rara Fides colit|velata panno nec comitem abnegat. arta decet sanum comitem toga; .

comites. supremum|carpere iter comites parati.

iam veris comites, quae mare temperant,

comites. tu potes tigris comitesque silvas/ducere

regalisque cultus, et comites

cenantis haud anino aequo exspectans comites.

stellasque salubris/appellat comites

Eupolin, Archilochum, comites educere tantos?

comites. o socii comitesque.|nil desperandun Teucro duce et auspice:

comiti. musa rogata refer, comiti scribaeque Neronis.

commendare. it a commendare dicacis/conveniet Satyros.

commendat. quod me Lucanae iuvenem commendet [commendat] amicae); quae se commendat tonsa cute, dentibus atris. .

praecipue cum se numeris commendat et arte.

commendes. qualem commendes, etian atque etiam aspice.

commendet. quod me Lucanae iuvenem commendet amicae);

comminxit. conminxit [comminxit] lectum potus mensave catillum Euandri manibus tritum deiecit:

committis. cum prudens scelus ob titulos admittis [committis] inanis.

committit. cum prudens scelus ob titulos admittis [committit] inanis.

commixit. conminxit [commixit] lectum potus mensave catillum|Euandri manibus tritun dejecit:

commixti. conminxit [commixti] lectum potus mensave catilum|Euandri manibus tritum deiecit: .

commoda. "tibi di, quaecumque preceris/commoda dent:

non istic obliquo oculo mea commoda quisquam, limat.

in publica commoda peccen,

intervalla vides humane commorla.

multa ferunt anni venientes commoda secum,

commodet. si modo culturae patientim commodet aurem.

commodis. tribus aut novem miscentur cyathis pocula commodis.

donarem pateras grataque commodus [commodis]. | Censorine, meis aera sodalibus.

commodius. hoc ego commodius quam tu, praeclare senator, |milibus atque aliis vivo.

hospes/tardius adveniens vitiatum comnodius . . consuneret. .
Epod.1 1.28

Carm.2.11.24

Cirm.3.28.10

Epist.2.1.1 10

Epist.1.7.10

Epist.1.15.42

Carm.1.28.2 I

Carm.4.5.24

Epod.1.17

Serm.1.5.2

Serm.1.0.102

Sirm.2.5.I7

Serm.2.7.II5

Epist.1.7.76

Epist.1.17.52

Epist.2.2.187

Serm.2.6.93

Ars loct.89

Serm.2.5.91

Carm.1.30.7

Serm.1.4.90

Serm.I.IO.53

Serm.1.io.65

Serm.2.8.70

Epist.2.2.1 33

Serm I.IO.4I

tar.Carm.4.1.I I

Carm.t.I.II

zar.Carm.4.1.11

Carm.1.35.22

Epist.1. I 8.30

Carm.2.17.I2

Carm.4.12.1

Carm.3.11.13

Carm.4.9. 16

Serm.1.5.9

Serm.1.7.25

Serm.2.3.1 2

Carm.1.7.26

Epist.1.8.2

Ars Poet.225

zar.Epist.1.15.21

Epist.I.I 8.7

Epist.2.1.201

Epist.I.I 8.76

Epist.I.I5.2I

:ar.sorm.1.3.90

iar.Serm.2.3.212

var.serm.2.3.2 I 2

:ar.Serm.1.3.90

qar.Serm.1.3.90

Serm.2.8.70

Epist.1.1.4.37

Epist.2.1.3

Epist.2.2.70

Ars lott. 175

Epist.1.1.40

Corm.3.19.1 2

var.Carm.4.8.I

Serm.1.6.110

Sirm.2.2.91 


\section{COMMODVS}

commodus. domasem patera grataque commodus Censotine, meis acra sodalibu

dissimulator oris propriae, mihi commolus uni.

commolus ultrol arecsas et egere vetes et scribete cogas.

spondes stabilis in iura paterna recent comort. . . Hebit

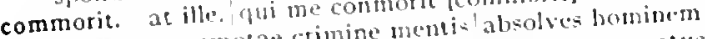

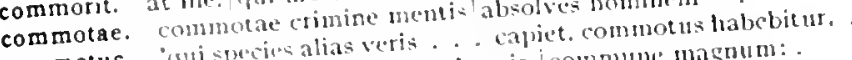

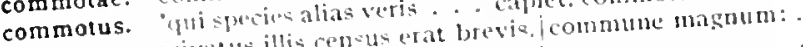

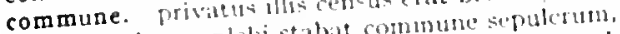

hor miserae plebi stabat comtmone caret inquimus.

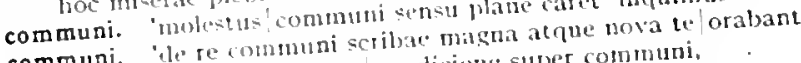

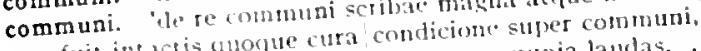

Curm.4.8.1

lipist.1.0.9

Episl.2.1.227

Ars I'oet.257

gor.Serm.2.1.45

Serm.2.3.278

Serm.2.3.209

Carm.2.15.14

Serm.1.8.10

serm.1.3.06

Serm.2.0.30

Epist.2.1.152

Episti.20.4

Ars I'Oct.128

Epist.1.10.34

Efoul.10.15

Epist.1.2.13

Serm.1.4.2

Sorm.1.4.45

Serm.1.10.10

Episl.2.1.169

Ars Poel.93

Ars Port.28 I

Carm.1.33.14

Carm.t.11.24

Eipod.4.4

Epist.1.3.3

Epist.1.16.77

wor.serm.1.7.31

rar.Serm.1.3.70

Epist.2.1.12

Serm.2.3.20

Sirm.2.3.25I

Serm.2.0.50

Lepist.1.1.49

Ars loed.205

Epod 0.9

Ars Ioct.76

quis circum pagos et circum compita pughax the;

complere. nonchun spisst ninus complentesti nemus.

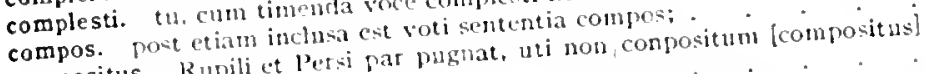
compositus. Rupili et Petsi nar pus

ut lius cun Bitho Bacehius. . ori comptique ministrent?

ur.scrm.1.7.20

Serm.2.8.70

Carmat.9.13 compti. ut onnes, praecincti recte
comptos. non sola comptos arsit alu!teri|crinis a num illius. num rtrotis mollius

[comptos] id euntis mollus acte comat religata nodum.

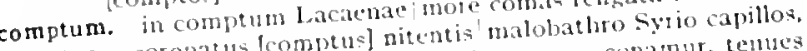

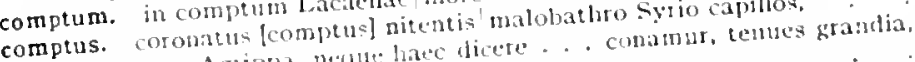
conamur. nos. Agipga, metat hec dicete.

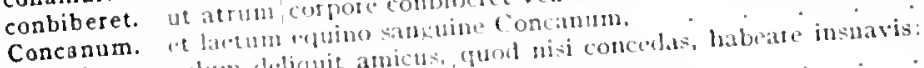

concedas. paulum deliquit amber.

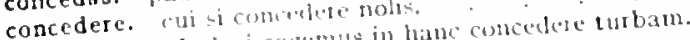

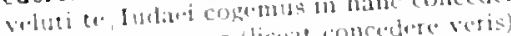

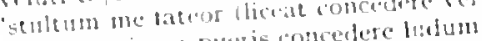

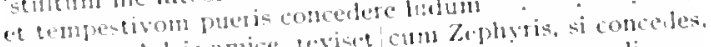

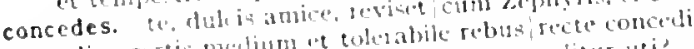

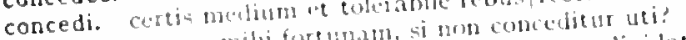

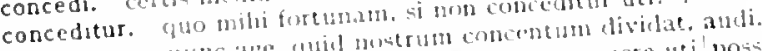

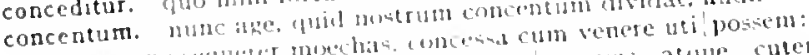

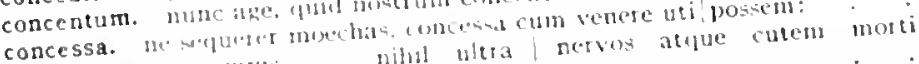
.

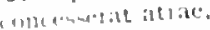

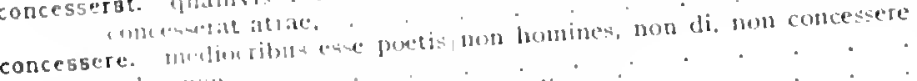

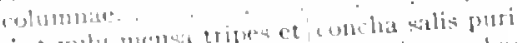

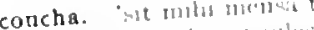

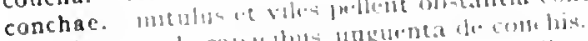

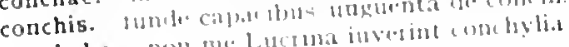

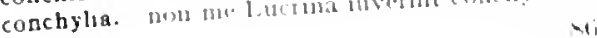




\section{CONCHYLIA}

conchylia. simul assis / niscueris elixa, simul conchy”lia turdis. lubrica nascentes inplent conchylia lunac; . nos, inquam, cenamus avis, conchylia, piscis.

concidit. concidit auguris /Argivi domus ob lucrum/demersa exitio;

concidunt. concidunt venti fugiuntque nubes

concilio. aeternum meditans decus|stellis inserere et consilio [concilio] Iovis? maturum reditum pollicitus patrum $\mid$ sancto concilio redi.

concines. concines maiore poeta plectro|Caesarem, concines lactosque dies

concinet. concines [concinet] maiore poeta plectro|Caesarem, concines [concinet] laetosque dies

concinna. quid concinna Samos, quid Croesi regia Sardis,

concinnior. si versus paulo concinnior unus et alter.

concinnus. concinnus amicis' postulat ut videatur;

"at sermo lingua concinnus utraque/suavior.

concipitur. quidquid usquam concipitur nefas.

concita. pulso Thyias uti concita tympano.

concitet. net populus frequens/"ad arma'. cessantis 'ad arma"|concitet

conclave. currere per totum pavidi conclave

concludere. neque enim concludere versum/dixeris esse satis

conclusas. at tu conclusas hircinis follibus auras.

conclusus. suave locus voci resonat conclusus.

concordia. quid velit et possit rerum concordia discors.

concredere. cui concredere nugas| hoc genus: 'hora quota est?"

concubitu. concubitu prohibere vago, dare iura maritis,

concupiveris. at siquid umquam tale concupiveris,

concurrant. si plostra ducenta/concurrantque foro tria funera,

concurrit. actor $/$ cum stetit in scaena, concurrit dextera lacvae.

concurritur. "militia est potior. quid enim? concurritur:

concurrunt. in ius/acres concurrunt.

concursus. rapit in ius; clamor utrimque. /undique concursus.

concussa. quone malo mentem concussa? timore deorum." .

concute. denique te ipsum|concute, numqua tibi vitiorum inscverit olim | natura

concutitur. quo Styx et invisi horrida Taenari|sedes Atlanteusque finis| concutitur.

condere. callidum. quidquid placuit, iocoso/condere furto. .

conderet. acdibus ex magnis subito se conderet

condes. si carmina condes, | numquam te fallent animi sub volpe latentes.

condet. in apricum proferet aetas, | detodiet condetque nitentia.

condicio. "hace est condicio rivendi" aiebat.

cui sit condicio dulcis sine pulvere palmae?

condicione. fuit intactis quoque curalcondicione super communi.

condicionibus. dissentientis condicionibus|focdis

condicionibus. Attalicis condicionibus/numquam demoveas.

condiderit. si mala condiderit in quem quis carmina, sed bona siquis| indice condiderit laudatus Caesare?

condidit. illum. si proprio condidit horreo

simul atra nubes |condidit lunan.

cui super Karthaginem/virtus sepulcrum condidit.

condis. seu condis amabile carmen.

condiscat. robustus acri militia puer|condiscat

condisce. condisce modos. amanda/voce quos reddas: .

condit. condit quisque diem collibus in suis

aut pressa puris mella condit anphoris

condita. quae semel/not is condita fastis/inclusit rolucris dies.

coudita cum verax aperit praecordia Liber.

condita post frumenta levantes tempore festo

conditi. aut cur dexteris/aptantur enses conditi?

condito. condito mitis placidusque telo

conditor. dictus et Amphion. Thebanac conditor urbis, isaxa movere

conditum. ne male conditum ius adponatur.

conditum. Gracca quod ego ipse testa|conditum levi,

conditus. qui locus a forti Diomede est conditus olim.

condo. condo et conpono quac mox depromere possim.

condoluit. at si condoluit temptatum frigore corpus

conducat. quod non proposito conducat et haereat apte.

conducere. pars hominum gestit conducere publica;

conductae. qui conducti [quae conductae] plorant in funcre

\section{CONDVCTAE}

Serm.2.2.7.1

Serm.2.4.30

Serm.2.8.27

Carm.3.10.11

Carm.1.12.30

zar.Carm.3.25.0

Curm.4.5.4

Corn.4.2.33

Carm.4.2.41

conti.Cirm.4.2.33

conti.Carm.4.2.4I

Epist.1.11.2

Epist.2.1.74

Serm.1.3.50

Serm.1.10.23

Carm.2.13.9

Carm.3.15.10

Carm.1.35.16

Scrm.2.0.113

Serm.1.4.40

Serm.1.4.19

Serm.1.4.76

Epist.1.12.19

Serm.2.6.43

Ars Poet.398

Epot.3.19

Serm.1.6.43

Epist.2.1.205

Serm.1.1.7

Sirm.1.7.21

Serm I.9.78

Serm.2.3.295

Serm.1.3.35

Carm.1.34.12

Curm.1.10.8

Serm.2.7.I I

Ars Poet.436

Esist.1.6.25

Serm.2.8.65

Epist.1.1.51

Epist.2.1.152

Carm 3 5.14

Carm.1.I.I?

Serm.2.1.82

Serm.2.1.84

Carm.1.1.9

Carn.2.16.3

Epod.9.26

Epist.1.3.24

Carm.3.2.3

Carm. 4 II. 34

Carm.4.5.29

Epod.2.15

Carm.4.13.15

Serm.1.4.89

Epist.2.I.140

Epod.7.2

Carm.Saé 33

Ars P'oet.394

Serm.2.8.69

Carm.1.20.3

Serm.1.5.92

Epist.1.1.12

Serm.1.1.80

Ars Port.195

Epist.1.1.77

coni.Ars Poct.43 I 
conducti. He qui conducti plorant in functe dicume

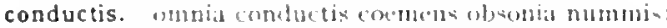
conducto. conducto navigies aecpuen natuat ac locuples. conductum. gui fro se tolleret stefle mitteret in phinum talos, mercerle liutmot condurtum pavit:

condunt. dum . a agros atsignant, oppida condune.

conectere. Wrba lyar motura somum conectere digner?

coner. qu.m an destingere comer

seilicet ut tibi se labufare et tratere coner.

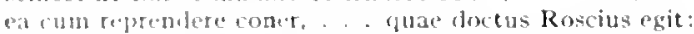

coneris. linment prosise purtorm/cuncti paene patres, ea cum reprendere nomer [/ responlere contis].

confecta. tuiscrue auspicios totum confucta duella per orbem

conferbuit. nea cum conferbut ita?"

confestim. ut teecomfotion linulutus liortunar rivos inauret.

confice. confice: nomegne instat fatum mihi triste.

confidens. contilens tumielus, arteo sermonis amati.

confundet. nec Stuleius cum Marte contundet Thoncus prosia

confusa. divorsm confusa gesus pantherd canclo . . converteret ora:

confusum. hoc ubi contusum soctis inferbut hetbis

confusus. cruor in fosim confusus.

Iusticus urbano confu<u<. turpis homesto?

congesta. cum sibi sint congesta cibariat:

congestis. congestis undique saceis indotmis inhians

coniuge. coniuge: nue Iovis ct sorme.

milesne ('rassi coniuge batbaraptutpis nutrit? vivit

cum socis opertum et pueris ie coniuge fida

coniugibus. proelia conimpibus loquendat.

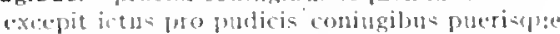

coniugis. vendon tomare coningis inmemor. bratae ronitgis additun: stulio hononem

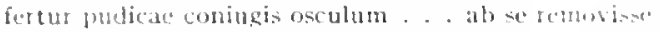

coniunx. nec docata regit virum coniunx.

demi gi gnatus erte focundare commx.

te ondun aliona capit, meretricula Davom:

coniurat. alterius sic altera pescit open tes ce confurat amice.

coniurata. coniurata enas rampere nuptias

coniux. domi si gnatus eric fecumbre coniux.

conlata. ut premetes sactal lauronue conlataque myrto

conlibuisset. si comblbiscet, ab ovolusque ald mala citalet "io Bacchace"

conludere. fatic paribus conlutere

conminuas. "quod, si conminuas, vitem troligatut ad assem."

conminxit. comminxit lectum potus menadle catilum Euandri nanibas tritum deiceit

conmiserit. si tribus Anticyris carut in anabile numquam tonsoni I icino commicult

conmisisse. comminisce calct rund mox mutare labort.

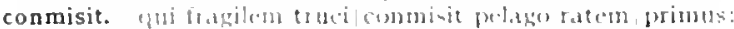

mator Xeronum mox grate provlium commicit

conmissa. if pordilerit conmisial fule sponsumb nogarit?

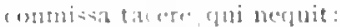

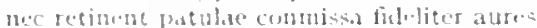

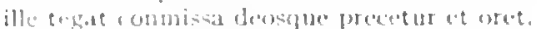

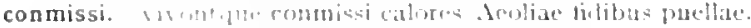

conmissum. vigilan-me floto tupe commistum

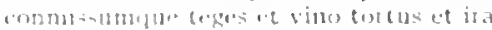

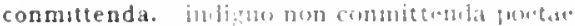

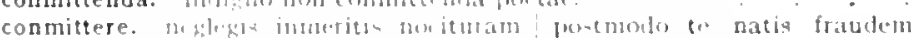

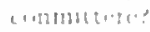

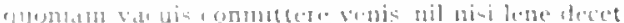

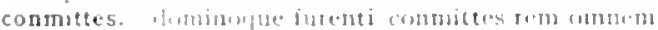

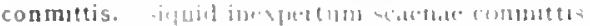

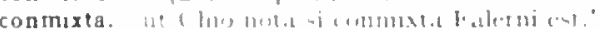

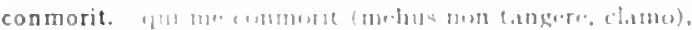

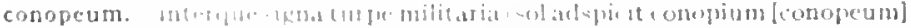

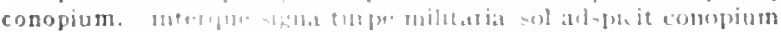

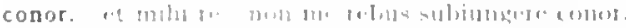

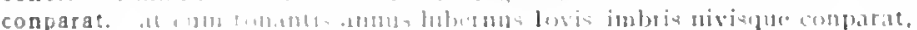

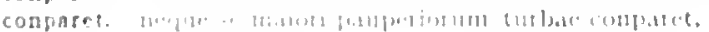

Ars Port +31

Serm I 20

Fipit.1 1.92

Serm.2.7.18

Epist.2.1.8

I.pist.2.2.86

Serm.2.1

Fopist 10.3

Epist.2.1 K1

7 int. Epist. $2.18 \mathrm{I}$

Lisisi 2.1.25.1

Sirm.1 2.7

List.1.12.0

Serm. 1020

serm. I.7.

Carm.1.17.23

lifist.2.1.195

Sem.2..4.67

Serm.18.28

Ars Jot. 213

Serm.1.t.32

Sermin. I . 7o

Carm.3.364

Carm.3.5.5

lipist.2.1.142

Corm.t.68

Carm. 9.24

Carm.1.1.20

Ciam.2.10.13

Carm.3.5.41

Corm.3.24.20

Sierm.2.5.31

Serm. 2.7..40

Ars lood.111

Carm.1.15.7

Serm.2.5.31

Corm.3.1.19

sirm.1.3.8

Ars Poet. 150

Sern.1.1.43

Serm.1.3.90

Ars Poet.301

Arj Prect. 168

(arm.1.3.11

Carmalt.15

Serm.1.3.05

Serm 1 ...8.

IEPist.1.18.70

- Irs l'oet 200

(iurm..1 0.11

ciam.327.30

Ipist 1.18.38

E.pist.2.1 23 I

Cirm. I. $283 \mathrm{I}$

Sirm 2.425

Serm.2.7.127

Ars Jixt 125

Serm I 102.4

rom. 21.45

adr lipodo a

I potopito

l. pist I 1.10

1. $\operatorname{sent} 230$

tirm I I II 
ut nihil anteferat, nihil illis comparet

conparis. nondun munia comparis/aequare

conpellans. cessisset magna compellans voce cuculum

Epist.2.1.65

Carm.2.5.2

Serm.1.7.3I

conpellarer. posthac ne compellarer inultus.

Serm.2.3.297

conpellor. liac ego si conpellor imagine, cuncta resigno:

Epist.1.7.34

conpensat. amicus dulcis. ut aequom est, / cum mea conpensat vitis bona,

conpescant. quae mare conpescant causae, quid temperet annum,

conisism. 1.3 .70

Epist.1.12.10

conpesce. conpesce nenten:

conpesce clamorem ac sepuleri mitte supervacuos honores.

hunc frenis, hunc tu conpesce catena.

conpescere. Varius mappa conpescere risum/vix poterat.

conpesceret. maior/lanea, quae poenis conpesceret inferiorem;

conpescet. luxuriantia conpescet, nimis aspera sanollevabit cultu.

conpescit. qui ter amplum|Geryonen Tityonque tristi|conpescit unda,

conpilasse. ne me Crispini scrinia lippi|conpilasse putes,

conpilent. ne te conpilent fugientes.

conplere. si munus Apolline dignum| vis conplere libris

undun spissa nimis complere sedilia flatu;

conplexus. o qui conplexus et gaudia quanta fuerunt.

conplures. conpluris [conplures] alios, doctos ego quos et amicos|prudens praetereo.

conpluris [conpluresque] alios, doctos ego quos et amicos|prudens praetereo.

conoluris. conpluris alios. doctos ego quos et amicos|prudens praetereo,

conpone. lum potes, aridum/conpone lignum:

cooponere. quod adest menento/conponere aequos;

pergis pugnantia secum |frontibus adversis conponere:

tacetus, / emunctac naris, durus conponere versus.

aversos soliti conponere anicos.

cum est Luciliusausus | primus in hunc operis conponere carmina morem, audire atque togam iubeo conponere.

Nestor conponere litis|inter Peliden festinat et inter Atriden. . .

nec sermones ego mallem|repentis per humum quam res conponere gestas

hunc ego me, siquid conponere curem,|non magis esse velim . . .

conpono. condo et conpono quae mox depromere possim.

carmina conpono, hic elegos:

conponunt. dum ... aspera bella | conponunt, agros adsignant, oppida condunt,

ridentur mala qui conponunt carmina;

conportatis. si conportatis rebus bene cogitat uti.

conportet. sicuis emat citharas, emptas conportet in unum,

conposita. conposita repetantur hora,

conpositis. te caede gaudentes Sygambrilconpositis venerantur amis. nescius uti conpositis

conpositum. uti non/conpositum melius cum Bitho Bacclius. non quia crassel conpositum inlepideve putetur.

conposui. "haud mitai quisquam.| omnis conposui."

sine nervis altera quidquid/composui pars esse putat

conpressis. haec ego mecum/conpressis agito labris:

conpulerit. nigro conpulerit Mercurius gregi? .

conscia. desiliat mulier. miseran se conscia clanet.

quo te demisit peccati conscia erilis,

conscientia. abacta nulla Veia conscientia

conscio. sed inssa coram non sine conscio'surgit marito,

conscire. nil conscire sibi, nulla pallescere culpa.

conscripti. quod sit coneripti, quod iudicis officium,

consecrat. lingua potentium|vatum divitibus consecrat insulis.

consentire. consentite suis studis qui crediderit telfautor.

consentit. utrumque nostrum incredibili modo/consentit astrum;

consenuit. hostium . . consenuit socerorum in armis

conservos. conservos vili portanda locabat in arca;

sive vicarius est. qui servo paret. . . seu conservos.

considere. retatque novis considere in hortis.

consili. vis consili expers mole ruit sua,

consilia. non anicorum queant libera consilia nec contuneliac graves,

consilia. beatus enim iam/cum pulchris tunicis sumet nova consilia et spes, consiliantibus. glatum elocuta consiliantibus|I unone divis: .

consilietur. ille bonis faveatrue et consilietur amice

Carm.1.16.22

Carm.2.20.23

Epist.1.2.03

Sirm.2.8.03

Serm.1.8.31

Epist.2.2.122

Carm. 2.1.9.9

Serm.1.1.121

Serm.1.1.78

Epist.2.1.217

Ars l'oe't.205

Sirm.I.5.43

zar.Serm.1.10.87

gar.Serm.1, 10.87

Serm.1.10.87

Curm.3.17.14

Carm.3.29.33

Sirm.1.1. $\mathrm{IO}_{3}$

Serm.1.4.8

Serm. 1.5.29

Serm.2.1.03

Serm.2.3.77

Epist.I.2.I I

Epist.2.1.25I

Ars Pott.35

Epist.1.1.12

Epist.2.2.9 I

Epist.2.1.8

Epist.2.2.100

Epist.1.2.50

Serm.2.3.104

Carm.1.9.20

Carm. 14.52

Serm.2.3.110

Serm.1.7.2n

Epist.2.1.77

Serm. I.9.28

Serm.2.1.3

Serm.1.1.138

Carm.1.24.18

Serm.1.2.130

Serm.2.7.60

Epod.5-29

Carm.3.0.29

Epist.J.I.6I

Ars Poet.314

Carm.4.8.27

Epist.1. 18.05

Carm.2.17.22

carm.3.5.8

Serm.1.8.9

Serm.2.7.80

Serm.1.8.7

carm.3.t.65

Epod.11.20

Epist.1.18.33

Carm.3.3. 7

Irs Poct.196 
consilis. misce stultitiun com-ilig breven:

Curm.4.12.27

consilis. quid aeternic minom/comsilis animum fatigas? .

Cirm.2.11.12

anbjlita iubenis revitate

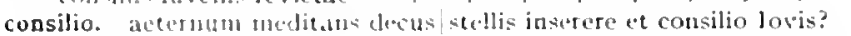

Curm.4.4.24

maturan reditum pollicisus patrum / saneto concilio [consilio| redi.

Carm.3.25.0

i'ar. Cirm. $4 \cdot 5 \cdot 4$

consilio. donce labantis consilio patres/frmatet auctor numquam alias disto

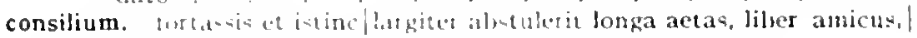
constiun proprium

consilium vos lence consilium et datis et dato/gandetis, almate.

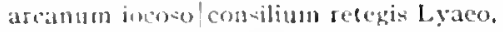

te eossilium et tuos prábertu duvos.

di te. Bama-ippe. deateque/verm ob consitium elonent tonsore. .

quate tes nee modem habet necque consiliusm.

quate spem combiliumque norantur agendi naviter

consistere. §uos ultra citraque nequit consistere rectum.

ire modu ocius. interdum concistere.

consistimus. con istimus. "unde venss' et |quo tendis?' rogat et respondet. consistit. vilibus in scopis, in mappis. in scobe quantus/consistit sumptus? consociare. unbram hospital'm consociare anant ramis?

consolor. hic me consolor victurum suavius

consortem. consortem socium fallat re hospites

conspectus. regali conspectus in anro nuper et ostro.

conspexerit. cum bene notum/porticus Agtippac, via te conspexerit Appi. conspexit. consuexit, ut aiunt, adrasum quendam sacua tonsoris in umbra conspicitur. quamvis non alus thectere equom sciens; aeque conspicitur cuorum / conspicitur uitidis fundata pecunia villis.

conspicuom. late conspicuom tollere verticen.

conspuet. Furins "thibernas cana nive conspuet Alpis."

constanter. "pars hominum vitiis gaudet constanter

constantia. nec sentel otiensi cedet constantia format.

constantior. cuius in iulomito constantior inguine nervos

quanto constantior isdem in vitis.

constantis. contantis iuvenem fule/(;gen?

constare. me constare mihi scis et discedere tristem

constat. siniplex e dulci constat olivo.

constet. servetur al imun qualis ab incepto processerit et sibi constet.

constiterint. getuque| Ilumina constiterint acuto?

constitit. conseitic intignibus raptis puer.

constrictos. sed tulgente trillit constrictos Gloria curru

constructus. at ni id lit. quid habet pulcti constructus acervos?

construxerit. puas qui construserit. ille, clarus erit.

consueris. qui regen consueris tollege.

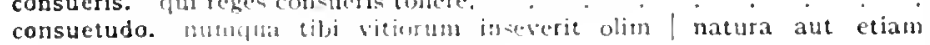
corbueturlo mali;

consul. consulfute non unius anmi.

consularis. mon enim gazum nefue consularis submovet lictor

consule. motun t'x Metello consule civicum

anphotd fumam bibese inctitutal consule Tullo.

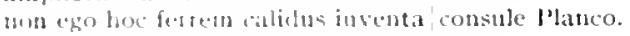

6) natio mecturb consute Manlio.

ta vina larguato nove consule pressa meo.

numequid "ges at t. magno prognatum deposco consule cunnum

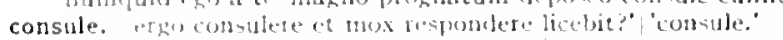

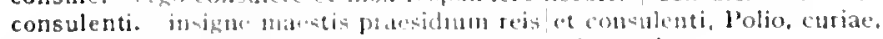

consulere. "rgo consulere et mox responblene licebit?"

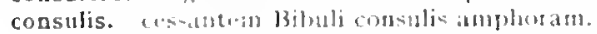

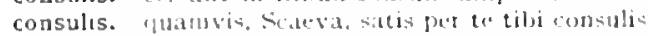

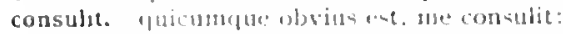

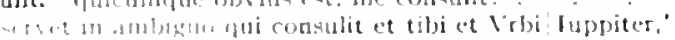

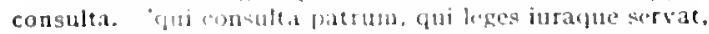

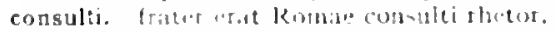

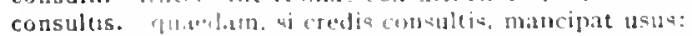

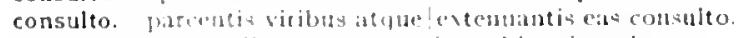

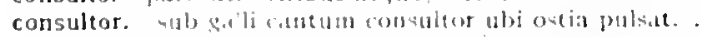

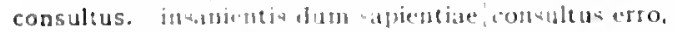

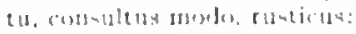

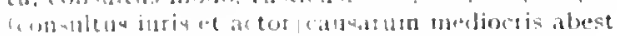

Carm.3.5.45

Sirm.1.4.133

Carm.3.4.41

Carm.3.21.16

Curm.4.14.33

Sirm.2.3 7

Serm.2.3.266

Eipist.1.1.24

Serm.t.t.107

Serm.1.90

Serm, 1.9 .62

Sirm.2.4.82

corm.2.3.10

Serm.1.0.130

Corm.3.24.00

Ars Poet.228

IEpist.1.6.26

E.pist.1.7.49

Carm.3.7.26

Epist.1. 15.40

Carm.3.16.19

Serm.2.5.41

Serm. 2.7 .6

I.pod.15.15

Lipod.12 19

Serm.2.7.18

Carm. 3.7.4

Ijpist.1.14.16

Serm. 2.464

Ars Pot.127

Carm.1.9.4

Lipod.5.11

Sirm. 1.0 .23

Sirm.1.1.44

Serm.2.3.90

firm. 1.7.34

Serm.1.3.36

Carm.4.9.39

Carm.2.10.9

Carm.2.1.I

Carm.3.8.12

Carm.3 14.28

Corm: 3.21 .1

lipoli.13.6

Serm.1.2.70

Serm.2.3.19.3

Carm.2.1.1.1

Strm.2.3192

carm.328.8

Epist.17.1

Sorm. 2 4.51

Epist.1.10.2s

Iipist. 10..1

Epist.2.2.87

Epist.2.2.159

Sermil 10.14

Sirm.1.10

Cinm.1-34-3

Sirmol 8.17

Ars l'oel zoo

Serm.2 4.48 
nos nunerus sumus ct fruges consumere nati.

consumeret. quam|integrum edax dominus consumeret. consumet. garrulus hunc quando consumet cumqte: consumimus. cacdimur et totidem plagis consuminus hostem contacta. vis canere et contacta sequi vestigia vatum? . contagia. nulla nocent pecori contagia. contagia. cum tu inter scabiem tantam et contagia lucri|uil parvom sapias contaminato. contaminato cum grege turpium /morbo virorum contemnas. non tamen idcirco contemnas lippus inungui;

contemnat. at bene siquis|et vivat puris manibus, contemnat utrumque. . quis . . pugnax/magna coronari contemnat Olympia. .

contemnere. populi contennere voces'sic solitus contennere miser. responsare cupidinibus, contemnere honores/fortis, . contemni. sulpura contemni vicus genit. . contemplare. ne corporis optima Lyncei contemplere [contemplare] oculis, contemplere. ne corporis optina lyncei contemplere oculis.

contempleris. Acfulae declive contempleris arvom

contemplor. simul ac nummos contemplor in arca.'

contemptae. contemptae dominus splendidior rei. contemptis. ut audax./contemptis aliis, explosa Arbuscula dixit. contempto. Othone contempto sedet.

contemptum. te/contemptum cassa nuce pauperet;

contendat. moribus lic meliorque fana|contendat. contendat laqueo collum pressisse paternum:

contendere. ut contendere durum $\langle$ est $\rangle \mid$ cum victore, non possis oculo quant $u$ m contendere Lynceus: qui Sidonio contendere callidus ostro/nescit meae (contendere noli) | stultitiam patiuntur opes;

contendit. non huc Argoo contendit remige pinus contenta. me libertina, nec unol contenta, Phryne macerat. . contento. deciens centena dedisses/huic parco, paucis contento: contento. qui iam contento, iam laxo fune laborat.' Pacideiani contento poplite niror/proclia rubrica picta . contentus. ut nemo, ... illa/contentus vivat, exacto contentus tempore vita|cedat uti conviva satur. . viverem uti contentus eo quod ni ipse parasset: meis contentus honestos/fascibus et sellis nollen mihi sumere. siquis pedibus quid claudere senis, / hoc tantum contentus, contentus pancis lectoribus. an qui contentus parvo metuensque futuri

conticuit. donec suspecta severo/ conticuit ly.ra.

contigerit. quod satis est cui contingit [contigerit], nibil amplius optet. contigit. Rhodio quod Pitholeonti/contigit? non magni pendis, quia contigit; quod satis est cui contingit [contigit]. nihil amplius optet. Romae nutriri milui contigit atque doceri,

continente. parum locuples continente ripa; continet. stultorum regum et populorum continet aestus. contingat. cuilgratia fama valetudo contingat abunde contingere. metuensque velut contingere sacrum? audeat esuriens dominus contingere granum quae nisi divitibus nequeant contingere mensis?" qui studet optatan cursu contingere metam.

continget. fingere cinctutis non exaudita Cethegis continget contingis. (nam te/scire, deos quoniam propius contingis, oportet), contingit. quod sat is est cui contingit, nihil amplius optet. verum ubi quid nelius contingit et unctius. non cuivis homini contingit adire Corinthum contingunt. nam neque flivitibus contingunt gatudia solis continuat. continuatque dapes nec non verniliter ipsis|fungitur officiis. continuem. si Mygdoniis regnum Alyattei! campis continuem. continui. continui montes. ni dissocientur opaca|valle. continuit. grata detinuit [? continuit] compede Myrtale| libertina, unde manum iuventus|metu deorum continuit?

continuo. impetus in quem | continuo fiat. audit continuo "quis homo hic' et "quo patre natus?" nam mili continuo maior quaerenda foret res " quid, siquis non sit avarus, / continuo sanus?"
Epist. 5.2 .27

Serm.2.2.92

Serm. 1.9.33

Epist.2.2.97

Epist.2.2.80

Epod.16.01

Epist.I.12.14

Carm.1.37.9

Epist.1.1.20

Scrm.1.4.68

Epist.1 1.50

Serm.1.1.05

Serm.2.3.14

Serm.2.7.85

Epist.1.15.7

idr.Sirm.1.2.0I

Sirm.1.2.91

Ca."m.3.29.7

Serm.1.1.67

Carm.3.16.25

Serm.1.10.77

Epod.4.16

Sirm.2.5.36

Carm.3.1.13

Epist.1.16.37

Sirm.1.9.42

Epist.1.1.28

Epist.r.10.26

Epist.1.18.28

Epod.16.57

Epod.14.16

Serm.1.3.16

Serm.2.7.20

Serm.2.7.97

Serm.1.1.3

Serm.1.1.I8

Serm.1.4.108

Serm.1.6.96

Serm. I. ro.60

Serm.1.10.74

Serm.2.2.110

Epist.1.18.43

coni.Epist.1.2.46

Serm.r.J 0.23

Serm-2.4.93

Far. Epist.1.2.46

Epist.2.2.41

Carm.2.I8.22

Epist.1.2.8

Epist.1.4.10

Scrm.2.3.15o

Sirm.2.3.I 13

Serm.2.4.87

Ars Poct.4 I 2

Ars Poet.5t

Serm.2.6.52

Epist.1.2.46

Epist.1.15.40

Epist.1.1.36

Episi.1.17.9

Sirm.2.0.10S

Carm.3.10.42

Epist.1.I\%.5

? qur.Carm.1.33.14

Carm.1.35.37

Serm.1.2.118

Serm.1.6.29

Serm.1.0.100

Sim.2.3.100 
ut w.] continuo patut.

Sierm.2.8.20

contra. contra sonantern Palldulis ategida

centria latumes atefue servilem manum

contrane luesum nif valere camlislum, pauperis ingeniums

carm.3.4.57

Lipod.4.19

* ut cusct ogmem qui ferre poetic antiguis posset contra fastidia nostra.*

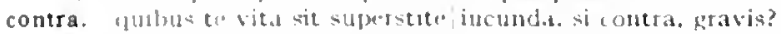

Fipod.11.II

contra mercatos. Mastun dactantibus Austris, |'militia est potior.

contra hic. He pordigun cese dicatur meturns.

contra alius nullam nisiolenti in fornices stantem.

at tibi costsa evenit, inquitallt vitia ut that tutsus et illi.

aperlunt, pauca accipe contra.

contial haevinum, linlers genus,

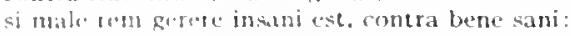

arcipe quid contia hawe iuvenis tesponderit aecplos.

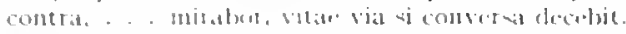

contracta. contractia quem non in paupertate solutum?

contracta. contractal pisces atequorat semtiunt

tu ne inter strepitus nocturnos atque diunos/sis canere et contacta

[contrata] sidui vestigia vatum?

contractae. explicult vino contractile seria frontis.

contracto. contracto melius parvat cupidine vectigalia porrigam.

contractu. an turgi clatusus in arca. . contactum lcontractuj genibus tallkits caput?

contractum. contractungersibus tanges caput?

contractus. sibi parcet contractusejue leget;

contrahes. contrabes vento nimium secundolturgida velat.

contraria, rlum vitant stult vita, in contraria currunt.

contrarerit. quas qui construxerit [contraxerit], illelclarus erit fortis. instus:"

contraxit. horrida tompestas carlum contraxit

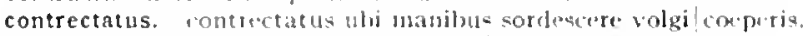

contremuit. fulgrat contrenuit domus/ Satuni veteris:

contristat. "flaw. simu! inversum contristat Aquarius annum.

contuderit. flus trgum tumidas contudesit minas,

lasud giua grando contuderit vitis

contudit. Pacori manus/inauspicatos contudic impetus/nostros.

postruam ill ibsta cheragra|contudit articulos.

duan qui contwlit bydram.

contulerim. nil ego contulerm iucundo sanus amico.

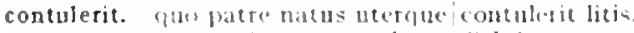

contulit. diram qui contudit [costulit] hydranı.. comperit invidiam supremo fine domari.

contumeliae, non amicorunt queant / libera concilia nec contumeliae grases. contundat. bo turlat vicatim hinc et hinc saxia petensiconturiet lconturialat obscatnas anus;

contundet. vos tubl vicatim hinc et hinc saxis petens/contundet

contundit. ditam qui contudit [contundit] lydram . . comperit invidiam ataprestors fine domiati.

conveniat. ste tibi cura quantac conveniat Munatius.

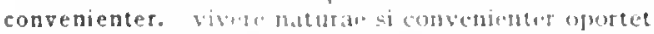

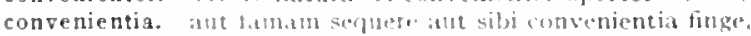

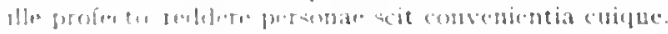

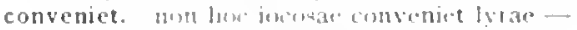

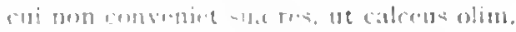

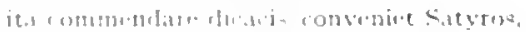

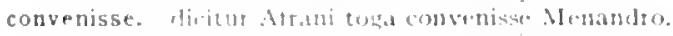

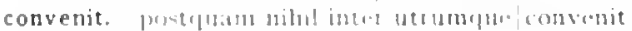

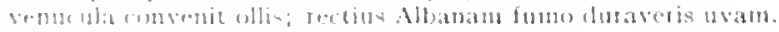

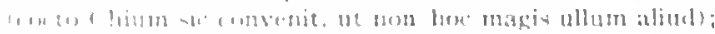

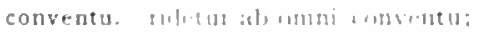

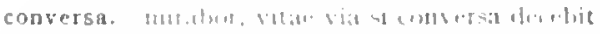

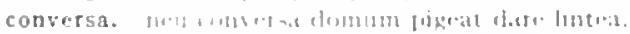

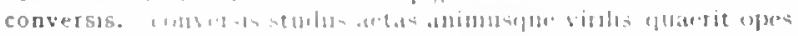

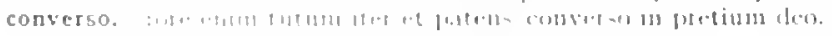

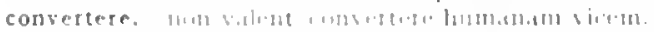

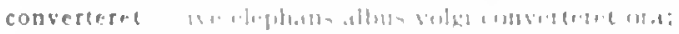

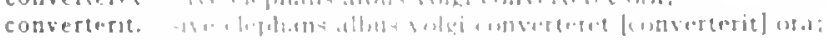

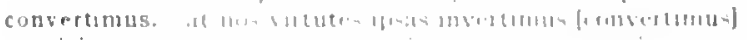

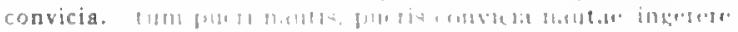

Serm.1.10.*7

Epol.1.0

Sorm.1.1.

Serm.1.2.4

Serm 1.2 .30

Serm.1.1.27

Serm.1.4.38

Serm.10.12

Serm. 2.3.74

Sirm.2.3.233

Jipist.1.17.25

Epist. 1.5.20

Carm.3.1.33

sar.t.pist.2.2.80

Serm.2.2.125

Carm.3.16.30

var.Sirm.2.7.61

Serm.2.7.61

Epist.1.7.12

Carm.2.10.23

Serm.1.2.24

$\because \operatorname{or.Serm} .2 .3 .96$

Ispot.13.1

Lpist 1.20 .11

Curm.2.12.8

serm.1.1.36

Carm.4 3.8

Epist. 1.8 .5

Carm.3.0.10

Sorm. 27.16

Epist 2.1.10

serm.1.5.44

Serm.1.5.54

iur. Epist.2.1.10

Epol.11.20

iar Itpod.5.08

lipod.5.08

Eur Epist.2.1.10

Epist 1.3.31

Epist 1.10 .12

Ars linet. I 10

Ars l'oet.zin

Carm.3.3.to

Epista.10.12

Ars loel 220

I.pest.2 1.57

Serm.7.7.

Siem.2.7. I

Serm.2.8.98

Serm.1 7.2.3

1. 90.1.1.17.20

lipol 10.27

Ars lool leve

(arm $3: 0.8$

difind 588

I. pist 2.1 . I1,

tar liast 2.1100

tar . Term 1.55

sem.1.511 
expressa arbusto regerit convicia.

Sirm.I.7.20

convictor. nunc, quia sim tibi, Maecenas, convictor.

convictore. 'me Capitolinus convictore usus amicoque / puero est

Serm.1.0.47

Serm.1.4.96

conviva. occidit et Pelopis genitor, conviva deorum.

Carm.1.28.7

ne foret aequalis inter conviva.

exacto contentus tempore vital cedat uti conviva satur.

quod ineptus|Fannius Hermogenis laedat conviva Tigelli?

Epod.12.23

Serm.T.I.II9

sive operum vacuo gratus conviva per imbrem! vicinus.

languidus in cubitum iam se conviva reponet.

Serm.I.10.SO

Serm.2.2.119

Serm.2.4.30

Serm.2.0.08

Serm.2.8.70

ita vir bon us es convivaque comis"

si potes Archiacis conviva recumbere lect is

mane cliens et lam certus conviva.

ut cum pileolo soleas conviva tribulis.

convivae. ini convivae lecti nihilum nocuere lagoenis. tres mihi convivae prope dizaentire videntur

convivam. bonisque rebus agit laetum convivam. iusselit ad se/ Haecenas. . venire/convivam:

nam milui quaerenti convivam dictus here illic/de medio potare die."

nam mihi quaerenti convivam [? convivam quaerenti] dictus here illic/de medio potare die."

convivas. convivas avidos cenam servosque timentis/tum rapere. . velle

convivatoris. convivatoris, uti ducis, ingenium

convivia. nos convivia, nos proelia virginum . . cantamus.

sed nimis arta premunt olidae convivia caprae.

eripucre iocos, veneren. convivia, ludum;

Epist.1.5.I

Epist.1.7.75

Epist.1.13.15

Serm.2.8.41

Epist.2.2.0I

Serm.20.0.1II

Sirm.2.7.34

Serm.2.8.2

3 tar.Sirm.2.8.2

Serm. I.5.75

Sirm.2.8.73

Curm.1.6.1 7

Epist.1.5.29

Epist.2.2.50

conviviorum. leu ne, per Irbem . . tabula quanta fui, conviviorum et paenitet.

convivis. nee sic ut simplex Naevius unctam convivis praebebit aquam:

Coo. et lapathi brevis herba, sed albo non sine Coo.

cooperto. famosisque Lupo cooperto versibus?

Copia. adparetque beata pleno/Copia cornu.

autea Iruges|Italiae pleno defudit Copia cornu.

copia. hinc tibi copia| nanabit ad plenum

myrtus et omnis copia narium

plenior ut siquos delectet copia iusto.

nil cernere possis/cetera. ni Catia [copial est, denissa veste tegentis.

mala copia quando|aegrum sollicitat stomachum.

non est ut copia maior/ab Iove donari possit tibi.

maior utrum populum frumenti copia pascat.

sit bona librorum et provisae frugis in annum / copia

si tibi nulla sitim finiret copia lymphae.

copiam. fastidiosam desere copiam

copias. te copias, te consilium et tuos / praebente divos.

copula. quos ir.-upta tenet copula

coquat. aut humana palam coquat exta nefarius Atreus

coquite. at vos, praesentes. Austri. conuite horum obsonia.

coquitur. vino quinquenni, verum citra mare nato./dum coquitur

cor. stas animo et purum est vitio tibi. cum tumidum est cor?"

cor. in cor traiecto lateris miseri capitisve dolore. si curat cor spectantis tetigisse querella.

coram. sed iussa coram non sine conscio surgit marito.

ut veni coran, singultim pauca locutus

rexque paterque audisti coram, nec verbo parcius absens:

coram. non ubivis coramve quibuslibet.

mentio siquae de Capitolisi furtis iniecta Petilli / te coram fuerit. coram rege suo de paupertate tacentes|plus poscente ferent: ne pueroe coram populo Medea trucidet

Corano. captatorque dabit risus Nasica Corano.

forti nubet procera Corano' filia Nasicae.

corde. et corde et genibus tremit.

cordi. dis pietas mea let musa cordi est.

Corinthi. laudabunt alii claram khodon ... bimarisve Corinthi moenia

Corinthum. non cuivis homini contingit adire Corinthum.

Corinthus. captivom portatur ebur. captiva Corinthus.

corio. ut canis a corio numquam absterrebitur uncto.

corna. quinquennis oleas est et silvestria corna

quid si rubicunda benigni corna vepres et pruna ferant,

Ispod.1 1.8

Serm.2.2.69

Serm.2.4.29

Serm.2.1.08

Curm.Saec.oo

Epist.1.12.29

Curm.1.17.14

Carm.2.15.6

Sorm.1.1.57

sor.serm.1.2.95

Serm.2.2.42

Epist.1.12.2

Epist.I.I5.I4

Epist.1.18.110

Epist.2.2.140

Corm.3.29.9

Carm.14.33

Carm.1.13.1 8

Ars Poe'l.186

Serm.2.2.4 I

Serm.2.8.48

Serm.2.3.213

Serm.2.3.28

Ars Poit.98

Carm.3.0.29

Sirm.1.6.50

Lisist.1.7.38

Serm.1.4.74

Sirm.1.4.95

Epist.1.1 7.43

Ars Pot'.185

Serm.2.5.57

Serm.2.5.04

Carm.1.23.8

Carm.1.I.14

Carm.1.7.2

Epist.1.17.36

Epist.2.1.193

sirm.2.5.83

Serm.2.2.57

Epist.1.10.0

cornibus. cui frons turgida cornibus primis

Carm.3.13..1 
comicis. servatua diu paten/cornicis vetulae temporibus lycen.

Carm.4.13.25

cornicula. moveat cornicula risum/furtivis nudata coloribus.

cornix. aruae nisi fallit augur/annosa cornix. .

tr.juc nec lacvos vetet ire picus/nec vaga comix.

cornu. copia.. benigno ruis honorum opulenta cotnu. .

sacivitue cum B.recrntiol cornu tympana.

te vidit insons fetberus aureof cornu decorum .

adparentue beata pleno/Copia cornu.

"farnum habet in comu. longe fuge:

"o, tha cornu ni forct exsecto frons."

dente lupus, cornu taurus petit:

cornu ipse bilibrilcaulibus instillat.

aura fruges|ltaliae pleno defudit Copia cornu.

cornua. atdis cornua pauperi

frangere enitar modo mult um amati cornua monstri.

cum tibi imvisus laceranda reddel cornua taurus.

parata tollo cormua.

non luc sifonii torserunt cornua nautae. .

magna sonabit / comua quod vincatque tubas: .

cornuom. iam nunc minaci murmure cornuom/perstringis auris.

corona. uch Lyeo/tempora populea fertur vinxisse corona .

spicea donet Cererem corona;

acquis accipiunt animis donantve coroua.

coronae. debitat Nymphis opifex coronat

quo climore cot onae/proelia sustineas campestria;

coronae. displicent nexae pliblya coronae.

ne spiscite ti-um tollant inpune coronac:

coronam. et scindat haerentem coronam, crinibus.

necte meo landian coronatn.

neque ego illi detrahere ausim liaerentern capitj cum multa laude coromam.

quid ferat et quare sibi nectat uterque cotonam.

coronantem. parvos coronantem marino tore deos

coronari. magna coronari contemnat Olympia.

coronas. 'puis ulo/ leproperare apio coronas curatie inyrto?

i peec unguentum, puer, et coromas

dicitur ex collo furtim carpsisse coronas.

coronatus. corenatus nitentis! malobathro Syrio capillos.

coronet. donec alterutrum velox Victoria fronde coronet.

coronis. est in horto.|Pbylli. nectendis apium coronis,

corpora. quantum exstant aqua/suspensa mento corpora:

corpore. ut atrum/corpore conbiberet venenum.

nisi causa motbi fugerit venjs et aquosus albo/corpore languor.

ut tuto al, attis corpore viperis dormirem

non byelta secto corpore firmior

dedit hic pro cotpore nummos.

at ingenium ingens inculto latet hoc sul, corpore.

exregio inspertos reprendas corpore naevos,

corpore maiorem rides Turbonis in armic spiritums.

1) ominoulu. futenei|commiuses rem onnem et vitam et cum corpore bitmitm.

aeksote demini deduxit cotpore feloris.

ui. . Alefixis reculis animogue "t corpore corpet? .

ire foras folesos tondebat corpore frustra

serl quia menti. minus validus quam corpore toto

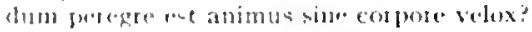

ut fiat vis animis et parvo corgore majus;

corpori. Rravi|mitrite salulutes corpori

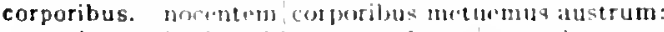

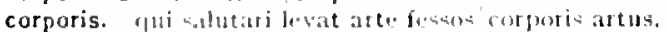

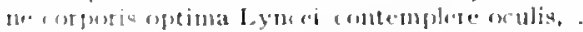

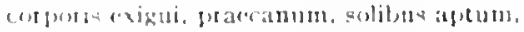

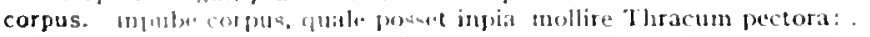

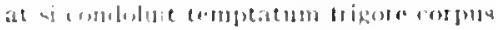

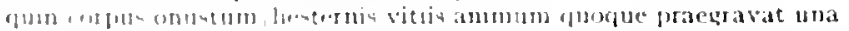

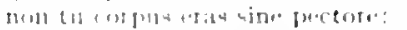

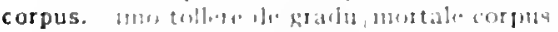

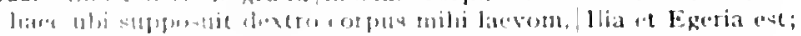

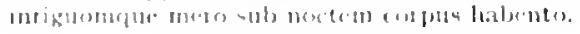

Epist.1.3.19
Carm.3.17.13
Carm.3.27.16
Carm.1.17.16
Carm.1.18.14
Carm.2.19.30
Carm.Satc.00
Sorm.1.4.34
Sarm.1.5.58
Sarm.2.1.52
Sarm.2.2.61
Epist.1.12.29
Carm.3.21.18
Carm.3.27.48
Carm.3.27.72
Epod.0.12
Epod.:6.59
Sarm.1.6.44
Carm.2.1.17
Carm.1.7.23
Carm..Saec.30
Ars Pot.250
Carm.3.27.30
Epist.1.18.53
Carm.1.38.2
Ars Poct.381
Carm.1.17.27
Carm.1.20.8

Stm.1.10.49

Epist.2.2.96

Carm.3.23.15

List.1.1.50

Carm.2.7.24

Carm.3.14.17

Serm.2.3.250

Carm.2.7.7

Epist.1.18.6.

Carm.4.11.3

Epod.5.36

Carm.1.37.28

Carm.2.2.16

Carm.3.4.17

Carm.4.4.0I

Sorm.1.2.43

Serm.1.3.34

Sicrn.1.0.07

Serm.2.3.310

Serm.2.7.07

Epist1.2.48

IFpist.to.t.t

E.pist.1.7.3 1

Epist.1.8.7

IEpist.1.12.13

Epist.1 17.40

Epod.2.58

(arm) $214.1 \%$

Carm.sisecos

Sirm.1.2.00

Epist. 20.24

Fpold 5.13

Corm.1.1.80

sirm.2.2.75

I.pist.1.4.0

Carm 1.35.3

Serm 12.325

Serm 2.1.9 
seu recreare volet tenuatum corpus

hic qui|pluribus adsuerit mentem corpusque superbum

inlusique pedes vitiosum ferre recusant / corpus.

nec. . . nodosa corpus nolis prohibere cheragra.

levantes tcinpore testo/corpus et ipsum animum

corrector. scilicet ut ventres lamna candente nepotum/diceret urendos correctus [corrector] Bestius.

asperitatis et invidiae corrector et irac;

correctus. scilicet ut ventres lamma candente nepotum/dicerct urendos correctus Bestius.

correptos. scilicet ut ventres lamna candente nepotum/diceret urendos correctus [correptos] Bestius.

correptus. postquan est inpransi correptus voce magistri?

scilicet ut ventres lamna candente nepotum/diceret urendos correctus [correptus] Bestius.

corrige. 'corrige. sodes, / hoc' aiebat "et hoc.'

corrigere. sed levius fit patientia|quidquid corrigere est nefas.

corripuit. necessitas Leti corripuit gradum;

corruget. ne sordida mappa|corruget naris,

corrumpam. muneribus servos corrumpan;

corrupta. utque illis multo corrupta dolore voluptas

corruptius. utpote longum|carpentes iter et factum corruptius imbri.

corruptorem. in corruptorem vel iustior?

corruptus, male verum examinat onnis/corruptus iudex.

corruptus vanis rerum, quia veneat auro|rara avis.

postquam est inpransi correptus [? corruptus] voce magistri?

cortice. tu levior cortice et inprobo iracundior Hadria:

simul ac duraverit aetas/membra animumque tuom, nabis sine cortice.

corticem. corticem adstrictum pice dimovebit

corusco. Diespiter.|igni corusco nubila dividens|plerumque,

ut inpios | Titanas immanemque turbam | fulmine sustulerit caduco [corusco]

Corvino. descende Corrino iubente

Corvinus, cum Pediu= causas exsudet Poplicola atque/Corvinus.

corrom. oscinen corvon prece suscitabolsolis ab ortu.

plerumque recoctus / scriba ex quinqueviro corvom deludet hiantem

corvorum. merdis caput inquiner albisl corvorum

corvos. sed tacitus pasci si posset corvos.

corvos. "non hominem occidi." non pasces in cruce corvos.'

Corybantes. non acuta|si geminant Corybantes aera.

Corycio. Corycionue croco sparsum stetit.

costum. nec ialerna vitis Achaeneniumque costum.

cote. semper ardentis acuens sagittas|cote cruenta.

cothurni. hunc socci cepere pedem grandesyue cothurni.

cothurnis. nil illi larva aut tragicis opus esse cothurnis.

cothurno. grande munus|Cecropio repetes cothurno,

et docuit magnumque loqui nitique cothurno.

cotis. ergo fungar vice cotis.

Cotisonis. occidit Daci Cotisonis agmen. .

Cotytia. inultus ut tu riseris Cotytialvolgata.

Cous. cum milhi Cous adesset Amyntas,

Cragi. nigris aut Erymanthi $\mid$ silvis aut viridis Cragi;

Crantore. planius ac melius Chrysipjo et Crantort dicit

cras. cras ingens iterabimus aequor."

quid sit futurum cras. inge quaerere

cras donaberis haedo,

cras foliis nemus . . tempestas ab Euro/sternet. .

cras genium mero/curabis et porco bimenstri

cras vel atra|nube polum Pater occupato/vel sole puro:

non sollicitus mihi quod cras/surgendum sit mane. .

id crede thom et vel nunc pete vel cras.'

'ante secundam | Roscius orabat sibi adesses ad Puteal cras.'

cras ferranenta Teanum|tolletis, fabri.

cras nato Caesare festus! dat veniam somnumque dies;

qui dedit hoc hodie. cras si volet auferet.

crassa. toga. quae defendere frigus / quanvis crassa queat.' .

crassa. Ofellus rusticus, ab normis sapiens crassaque $M$ inerva).

crasse. non quia crassel conpositum inlepideve putetur.

Crassi. milesne Crassi coniuge barbara
Serm.2.2.84

Serm.2.2. 109

Serm.2.7.109

Epist.1.1.31

Episl.2.I.I +I

qar. Epist. I.15.37

Epint.2.1.129

Epist.1.15.37

var. Epist.1.15.37

Serm.2.3.257

iar.1Episl.1.15.37

Ars Poet. 438

Corm.1.24.20

Carm.1.3.33

Epist.1.5-23

Serm.1.9.57

Serm.1.2.39

Sirm. I.5.95

Serm.2.7.03

Sirm.2.2.9

Serm.2.2.25

3 ar.Serm.2.3.257

Carm.3.9.22

Serm.1.4.120

Carm.3.8. Io

Carm.1.3.6

coni.Carm.3.4.44

Carm.3.21.7

Serm.1.10.29

Carm.3.27.I 1

Serm.2.5.50

Serm.1.8.38

Epist.1.17.50

Epist.1.10.48

Carm.1.10.8

Serm.2.7.68

Carm.3.1.44

Corm.2.8.16

Ars Poet.80

Serm.1.5.64

Carm.2.1.12

Ars Ioel. 280

Ars Poet.304

Carm.3.8.18

Epod. 7.56

E.pod.12.18

Carm.1.21.8

Epist.1.2.4

Carm.1.7.32

Carm.1.0.13

Carm.3.13.3

Carm.3.17.9

Carm.3.17.14

Carm.3.29.43

Serm.1.6.119

Serm.2.3.232

Serm.20.35

Fipist.1.1.80

Epist.1 5.9

Epist.1.50.33

Serm.1.3.1 5

Sirm.2.2.3

Epist.2.1.76

Corm. 3.3 
crassi. momeuna silfuief crasaj est tenubbitur auta

crasso. jocrolum in crasso iuraros atre natum.

crassum. crascum unguentum at Sarlo cum nelle papaver/offendunt.

crastina. (pun a dit an atliciant forliermac crastina summatempora di

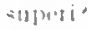

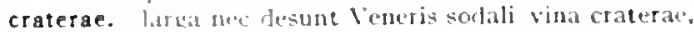
sive gravia veteri craterac limus allacsit.

Craterum. (traterum dixisere putato)

cratibus. Gumlensque textis cratibus laetum pecus

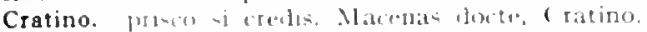

Cratinus. Lupolis atque Cratinus Aristoplanesque poetae

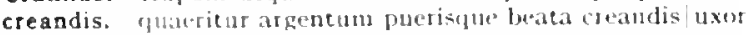

creantur. tortes creantur fortibus et bonis

crebris. Ifuablate tenostras iactibus crebris iubenes protervi

crebro. ent mibi furgatam crebro gui personct aturem:

credam. preo getgatum vincor ut credam nises.

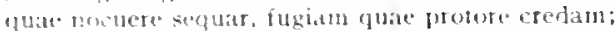

credas. the forte credits interitura quae. . . verba loguer

nam variage tes ut noceatut homini, ctedits.

(1)u thatgis his rerelats.

exal seteor. no cui de te plus quam tibi crealas

ut puerum saveno credas dickata magistro reddere

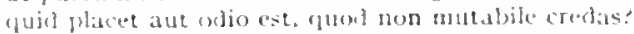

credat. crendat ludatels Afmella non ego:

cum te tormidet mulier netue credat anturti.

crede. creple non illan tibi de ecelesta plebe dilectam

ages te procellate erete veloci.

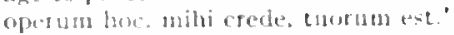

Siande vivasem cretp nepoti matrem

hoc te crefle molo insanums.

putifium muleo cerebrum est. mili creale, Perelli

id crede tuon et rel nunc pete rel cras.

carpe viam, mihi crede, comes.

ommente crede diem tibi diluxision supremum:

scrube tui gregis hunc et turtem creds bonumque.

credebat. ille volut filis arcana solalibus dim credobat libris yui secterbebatt mitos audire tragoedos

credere. vix urdere possis, quatn sibi nou sit andons,

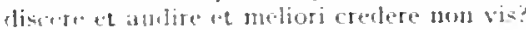

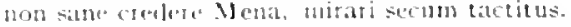

vesum age et lis, qui so lectori creciere matunt

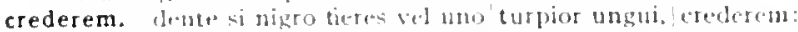

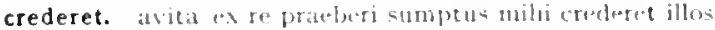

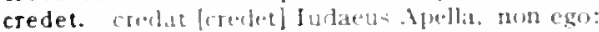

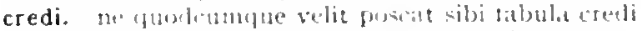

credjbile. 'magnum nartas, vix croblibile."

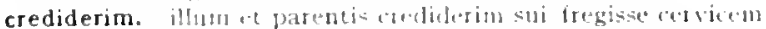

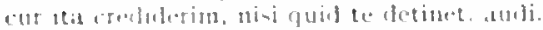

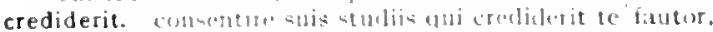

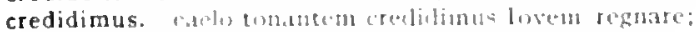

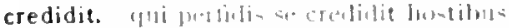

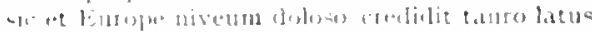

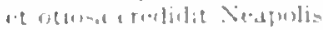

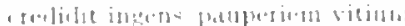

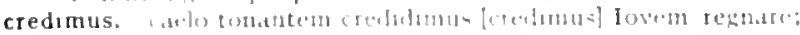

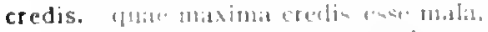

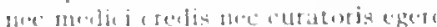

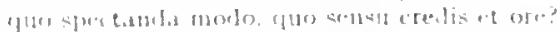

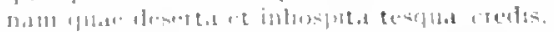

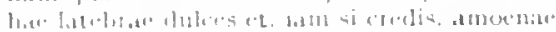

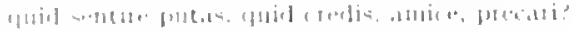

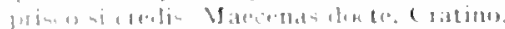

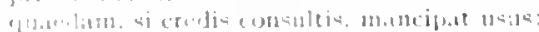

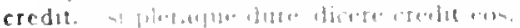

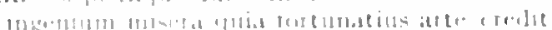

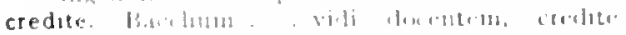

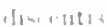

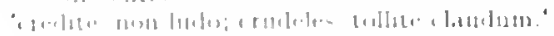

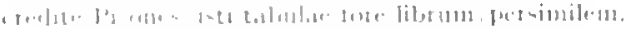

Serm.2.4.52

Lipisl 2.1 .2 .44

Ars P'oct.375

Cirm.4.7.17

Corm.3.18.7

verm.2.4.80

serm.2.3.101

lipord.2.45

1:- $\operatorname{tis} 1.10 .1$

Sirm.1.4.1

lipist.1.2.4.4

Corm.

Curs. 25.2

Epistis.1.7

J pod.17.27

I.pist.1.8.11

Carm [1] 1 1

Serm.2.2.72

Serm.2.2.112

Epist.1.10.19

IEpist. I. I8.13

Epirt.2.1.101

Serm.1.5.100

Serm 2.7.05

Cirm.2.4.17

carm.3.27.03

Serm.1.7.35

Serm.2.1.53

Sirm.2.3.52

serm.2.3.75

sirm.2.3.232

SiTm.2.00.3

Lpist.1.4.13

lipist 1.9.13

Sirm.2.1.3 I

Jipist 2.2.129

Scrma1.210

Epist.1.1.48

finist.1.7.0.1

Epost.2.1.2I

(ium,2.8.5

Serme 1 d.so

1uer Sirmot.5 100

Ars P'ret.330

termit.0.52

(iarm.2.13.5

l.pist t.2.5

J.pold 1. 18.15

Corms 31

( Irm.3.533

(itrm.3.27.20

J. podt.5.4.3

birm 2 ; 121

iar ciam 3.5. I

f.pist. 1 \&

lepist 1.1.102

J pist a 6.8

J.p.1.1.1.420

I.pol.1.111.25

J.prtat.1.10e

l:pold 10.1

I.P.1.2.: 159

t.pute 21.07

irs lined zurt

(iaren: 2.11)?

1 pold 1.17 .01

ire louks 
creditor. integer est mentis Damasippi creditor? esto.

creditum. mavis, quae tibi creditum| debes Vergiliun;

heu non ita creditum / poseis Quintiliun deos.

creditur. pratensibus optima fungis/natura est; alis male creditur.

creditur, ex medio quia res accersit, habere/suloris minimum, comonlia

credo. non quia masus illis nullus erat. sed. credo. hac mente, credo. hoc staberi prudenten aninum vidisse.

eredo, quod nimium institerat riventi.

evasti: credo. metues doctusque cavebis -

credula. carpe dien quatm minimum credula postero.

ian nee spes animi credula mutui

credula. credula nec ravos timeant annenta leones

credulum. ut I'roetum mulier perfida credulum falsis inpulerit criminibus

credulus. qui nunc te fruitur credulus aurea, .

cremato. gens, quae cremato fortis ab llio

crematos. possinr crematos excitare mortuos

Creontis. magni Creontis filiam.

crepante. montibus aitis levis crepante lymplua drilit pede.

crepat. quis post vina gravem militim aut pauperiem crepat?

siquid Stertinius veri crepat,

sulcos t vineta crepat mera, pracparat ulmos.

crepent. aut inmunda crepernt ignominiosaque dicta.

crepet. quis prost vina gravem militiam aut pauperiem crepat [? crepet]? .

crepidas. sapiens crepidas sibi nunquam nec soleas fecit;

crepuit. cum populus frequens/laetum theati is ter crepuit sonum;

crescam. usque ego postera|crescam laude recens.

crescat. qui sudor vietis et quam malus undique membris/crescit [crescat] odor,

crescent. plures aslnabunt thymi et cetaria riescent.

crescentem. crescentem tumidis infla sermonibus utrem.

crescentem. crescentem sequitur cura pecuniam

rite Latona puerum canent $=$, | tite crescentem face Nutilucam.

crescere. per quae/crescere res posset, minui damnosa libido.

crescit. crescit occulto velut arbor aevo/fama Marcellis;

crescit indugens sibi dirus hydrops

adde quod puben tibi crescit omnis.

serviture crescit nova

crescit Albanis in herbis / victima,

quam malus undique membris/creacit odor.

multi= oceulto crescit res faenore.

fit 11 immernus et optivo cognomine erescit

crescunt. nec pinguia Gallicislerescunt vellera frasuis: scilicet inprobae crescunt divitiae.

Cressa. Cressa ne careat pulcra dies nota

creta. neçlle illi' ium manet umida crota

q110rsum abeant? sani ut creta, an carbone notati?

Cretam. aut ille centun nobilem Cretam urbibus... ituruk

Creten. quae simul centum tetigit potentem oppidis Creten.

creterrae. larga ner desunt Veneris sodali|vina craterae [cretirae], sive gravis veturi craterae [ereterrac] limus adhasit.

Creticum. tistitiam et metus tradam protervis in mate Creticum portale bentis,

crevere. per quas Latinum nomen et Italae crevere vires

(sic atian filloum voces crevere severis)

crevit. Romana pubes crevit

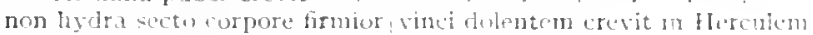
caule suburbano enti siccis crevit in ayris dulcior.

crimina. libi acris invidia atılıe virent ubi crimina: ut penitus notum, si temptent crimina, serves

crimine. commotae crimine ment is alsolves hominem praeconen. tonui censu, sine crimine, notum

aut igmorata" prenit artis crimine turpi

criminibus. ut l'ruetum mulier perfida credubum falsis inpulerit criminibus criminosis. qtem crininozis cumgute voles mondum pones iambis,

crine. et Lycum nigris oculis nigrofue crines decorum.

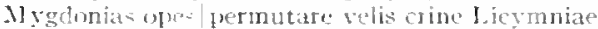

crinem. mutrum nodo cohibere cimen:

crines. tamen. leu serus aduteros cultus [crines] puldere collines.
Sirm.2.3.05

('irm.1.3.5

(arm.1.24.II

Serm.2.4.2I

Jpist.2.1.108

Sirm.2.2.00

Sirm.2.3.88

Serm.2.5.57

Sirm.2.7.68

Cirm. I 11.8

Cirm.4.1.30

Irpold 10.33

Carm.3.7.13

Carm. I. 5.9

Carm.4.4.53

Epol.17.79

Epol.5.64

Epod $11+.+8$

Cirm.t.I8.

Sirm.2.3.3.3

Epist.i.7.84

Ars Porl.247

? car.Carm.1. I 8.5

Sirm.1.3127

Carm.2.17.26

Carm.3.30.s

ati. Epot I 2.8

Serm.2.5.4.

Serm.2 5.98

Carm-3.1\% 7

Carm.4.6.38

Ispist.2.1.107

Carm.1.I 2.45

Cam.2.2.13

Carm.2.8.17

(arm 2.8. I 8

Carm 323 . I

Eppod.128

Fipist 1.1 80

Epist.2.2. I0I

Carm.3.16.30

Curm.3.24.63

Carm.1.3r.10

Epod.12.10

Sirm.2.3.240

Lpoldo 29

Curm.3.27.34

fur.Carm.3 I8.7

sar.serm.24.80

Carm, I. 201.2

(irmat 15.14

ars Pont-210

Cirm. $+44^{6}$

Cirmed +1.

Serm. $3 .+15$

Sirm. I 3.6.

Ifpist 1 Is 80

Sirm 2-3.278

Fipist. 1.7.51"

Ars Port.202

(armi37.14

(ium.1.16.2

(iorm.1.32.1 2

Cimm.2.12.23

Curm.3 1.1 .22

sur Corm.1 15.20 


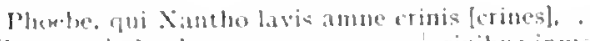

crinibus. seinhat haterenton cotonan crimbus inmeritamgute vestem

crinibus. solutic crinbue ambigumque volus.

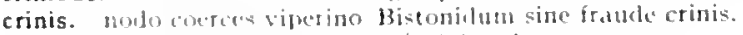

qui fure putu ("antolliat lavit crinis solutos.

Phode. pui Xintlu lavis amme crintis.

mom rolat comptos arsit arlulteri crinis

elua rerinis religata fulges.

loverihus illigata viperge crinis

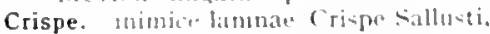

Crispini. ne ne Crispini serinia lippi compilaste putes.

ham, quate crispini doctut me iantor. edo.

Crispinum. neptue te luiketuan stipator ineptum prater Crispinum sectalitur

Crispinus. Crispinus minimo me proworat

critici. Jisniu. . alto Homerus", ut critici dieunt.

croco. Corbelefue atho sparam stetit.

crocodili. colotefuce - trefore fucatus coocodili

crocum. reet. nene acocum floresque perambulet Atac fabula

Croesi. quirl concinna silnow. quid Croesi regia Sarclis.

cruce. siquic enum servom. . . in cruce suffigat.

pecalt uter nowtrum ertece dignius?

"non bominem serifi." "ron pasces in cruce corvos."

cruciatibus. mosis ut isque suppetas laboribus [n ruciatibus)

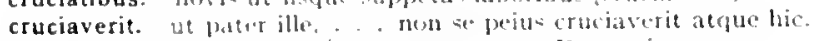

cruciet. aut eruejet quot vellicet absentrom Demetrius

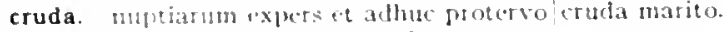

crudae. podex vilut crubae bovis.

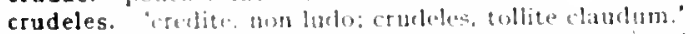

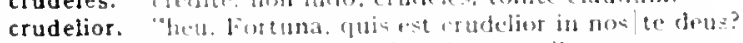

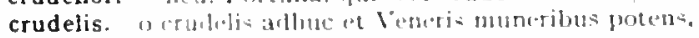

crudi. ermbi tumirlintute lavemur.

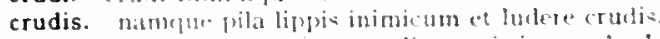

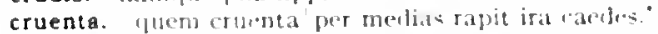

cruenta. smper arelentis acterns sagiteds cote crupnta

cruentis. hume circumtonuit gatultene Bellonat ctuentis.

cruento. Irustra crumen marle cart)imus

buluere atuento dente lacessiti.

cruentum. acer et Marsi pedicis cruptum volus in hostem;

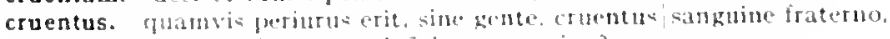

crumina. mundus victus non rleficiente crumitua?

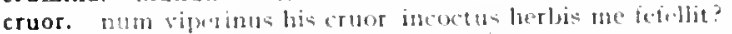

ut inmerontis fluvit in tertam R+mi! satcet mepotibus cruos.

eruts in fimiant confusus.

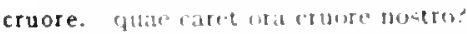

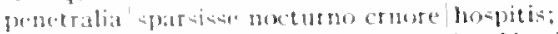

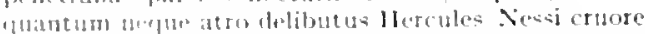

(ui) ermore subros obsetrix pannos latsit.

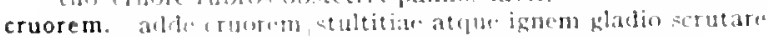

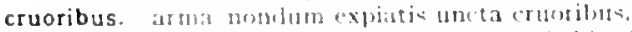

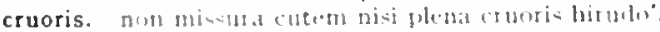

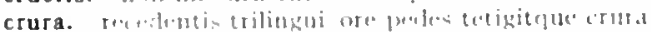

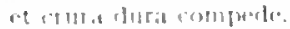

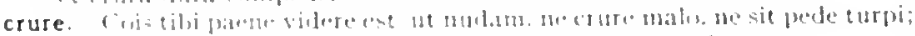

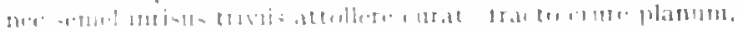

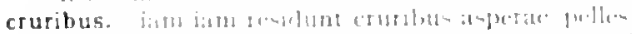

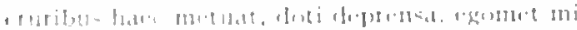

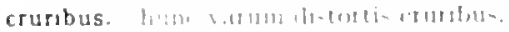

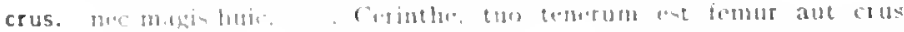

$$
\text { ind tils-: }
$$

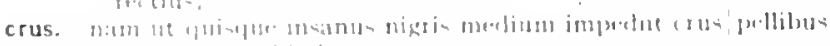

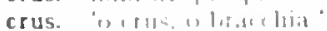

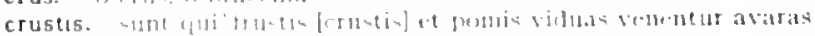

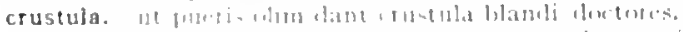

-nnt +14)

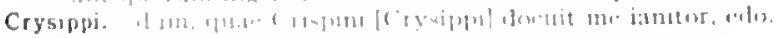

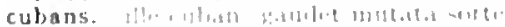

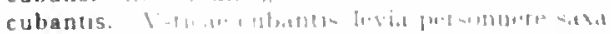

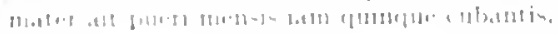

Iar.Carm.4.6.26

Carm.1.1728

Carm.2.5.24

Curm.2.19.20

(arm.3+62

(arm.

Carm.t.9.14

Carm.t.11.5

I: pod.5.16,

Corm.2.2.3

Serm.1.1.120

Sirm 2.7 .45

Serm.1.3.139

Serm.1.4 1.4

Lisit.2.1.5 I

Sorm.2.4. 8

lipod.12.11

IEpist.2.1.79

lipist.1.1 I. 2

Sirm.1.3.82

Serm.2.7.47

Epist.1 16.48

sur. Ifpod 17.04

Serm.1.2.22

Sirm.1.1078

Carm.3.11.12

Epod.s.6

Epist.t. $17.0 \mathrm{I}$

form.2801

(arm. 10.1

lipist 1.6 .01

Serm 1.5.40

Corm.32.11

("arm 2.8. If

Sirm.2.3.22.3

Curm 2.1413

Epist.2.1.150

Carm.1.2.30

Sirm.2.5.15

lepist.1.4.11

lepoid.3.6

Iipud. 7.20

Serm.1.828

(urm.2.1.3"s

Carm.2.137

lipod. 17.32

I.pod.17.51

sirm.2.3.275

Corm.2.5

dis loel.tió

( irm 2.10).32

I: proded 1

Sirm 1.2.102

Fpol 1.1.50

(ism 19.2 20.1)

Sirm 1.21 .31

sim.1.3.17

Sirm 1.2 si

Serm 11,27

Sorm 12132

isr. A.sist 1.1.78

Sirm.125

srme 117

tur lerm 27.45

verm.210.110

farm 17.15

herm.2. $32 \mathrm{sg}$ 
cubat. trans Tiberim longe cubat is prope Caesaris hortos.' cubat hic in colle Quirini, hic extrcmo in Aventino,

cubet. extrema et in sponda cubet.

polypus an gravis hirsutis cubet hircus in alis,

cubili. ad ortus/solis ab Hesperio cubili. .

cubilia. iamque subando|tenta cubilia tectaque rumpit. mollis et exspes/inominata perpremat cubilia. glandem atque cubilia propter/unguibus et pugnis, . . . pugnabant cubilibus. indormit unctis omnium cubilibus|oblivione paelicum? cubital. ponas insignia morbi, fasciolas, cubital. focalia,

cubitale. ponas insignia norbi. fasciolas, cubital [cubitale], focalia, cubito. et cubito remanete presso.

aliquis cubito stantem prope tangens|inquiet.

cubitum. languidus in cubitum ham se conviva reponet.

cuculum. cessisset magna conpellans voce cuculum.

cuderet. nequis... alius Lysippo duceret [cuderet] aera/fortis Alexandri voltum simulantia.

cui. cui Pudor et lustitiae soror .. quando ullum inveniet parem? cui laurus aeternos honores Delmatico peperit triumpho.

cui paternum|splendet in mensa tenui salinum.

cum [cui] populus frequens\}laetım theatris ter crepuit sonun;

destrictus ensis cui super inpia/cervice pendet. .

cui frons turgida cornibus/primis

bene est cui dens obtulit | parca quod satis est nanu.

cui licet in diem dixisse "vixi:

cui rex deorum regnum in avis vagas|permisit .

cui pecus et nigri|colles Arcadiae placent.

cui super harthagineni virtus sepulcrun condidit.

ingenium cui sit, cui mens divinior atque os/magna sonaturum,

cui satis una|farris libra foret.

mantica cui lumbos onere ulceret atque eques armos:

cui saepe viator $\mid$ cessisset magna conpellans voce cuculum.

cui male si palpere, recalcitrat undique tutus.'

cui Canis ex vero dictum cognomen adhaeret.

cui stragula vestis. . . putrescat in arca:

cui concredere nugas hoc genus: "hora quota est?"

cui spes. I cui sit condicio dulcis sine pulvere palmae?

cui sit condicio dulcis sine pulvere palmae?

cui si vitiosa libido/fecerit auspicium.

quod satis est cui contingit, nihil amplius optet.

cuilgratia fama valetudo contingat abunde

cui libet hic fascis dabit

eripietque curule/cui volet inportunus ebur.

cui non conveniet sua res, ut calceus olim.

pauper enim non est, cui rerum suppetit usus.

cui placet alterius. sua ninirum est odio sors.

cui sic extorta voluptas et demptus per vim

cui|rem di donarent, illi decedere pravam|stultitiam:

cui lecta potenter erit res.

cui. Melpomene, cui liquidam pater/vocen cum cithara dedit.

cui placet inpares | formas atque animos sub iuga aenea . . mittere ego cui tinebo. i providus auspex,

cui per ardentem sine fraude Troiam

iuventus, | cui pulcrum fuit in medios dormire dies

cui mustela procul 'si vis' ait 'efíngere istinc,

cui. cui si concedere nolis.

cui potior patria fuit interdicta voluptas.

cui, cui dabit partis scelus expiandi|Iuppiter?

cui flavam religas comam

cui donet inpermissa raptim/gaudia

muricibus Tyriis iteratae vellera lanae/cui properabantur?

quid de quoque viro et cui licas, saepe videto.

cui. sed vereor, ne cui de te plus quam tibi credas

tu seu donaris seu quid donare roles cui.

cui. dives ut aureis/mereator exsiccet culillis [cui illis]|rina Sya reparata merce.

cuicumque. Eutrapeius cuicumque nocere volebat|vestimenta dabat pretiosa:

cuidam. accidit ut cuidam testis caudanque salacem / demeterent ferro.
Serm.1.9.18

Ifpist.2.2.08

Epod.3.22

Epod.12.5

Curm.4.15.16

Epod.I2.12

Epol.10.38

Serm.1.3. 100

Epod.5.09

Serm.2.3.255

var.serm.2.3.255

Carm.1.27.8

Serm.2.5.42

Serm.2.4.39

Serm.1.7.3I

conit.Epist.2.1.240

Carm.1.24.6

Carm.2.r.15

Carm.2.10.13

coni.Carm.2.17.25

Carm.3.1.17

Carm.3.13.4

Carm.3.10.43

Carm.3.20.42

Carm.4.4.2

Carm.t.I2.II

Epod.9.25

Serm.1.4.43

Serm.1.5.08

Serm.1.0.106

Serm.1.7.30

Serm.2.1.20

Serm.2.2.56

Serm.2.3.11 8

Serm.2.0.43

Epist.1.r.50

Epist.I.I.5I

Epist.1.1.85

Epist.1.2.40

Epist.1.4.9

Epist.1.0.53

Epist.1.6.54

Epist.r.10.42

Epist.1.12.4

Epist.I.I f.I I

Epist.2.2.139

Epist.2.2.I5 I

Ars Poetifo

Carm.1.24.3

Carm.1.33.10

Carm.3.27.7

Carm.Saec. 4

Epist.1.2.30

Epist.1.7.32

Serm.I.4. 40

Epist.1.0.04

Carm.1.2.29

Carm.1.5.4

Curm.3.0.27

Epod.12.22

Epist.1.18.68

Epist.1.10.10

Ars Poet 426

iur.Cirm.1.31.II

Epist.1.18.3 I

Serm.1.2.45 


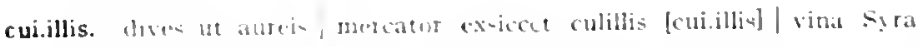

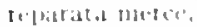

roges dicuntur multis ugere culilia [cui illis] let torquere nero.

cuilibet. liturulis Graecis imbutus, idoneus artilcuilibet:

cü illis. reges aticuntur multis utgere culi]lis [ci] illial let torquere meto.

cuiquam. Jummolo ricum excutín sibi non, non cuiquam pareet amico

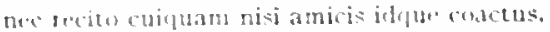

cuique. "bithorm dulce lenimen tmilicumque [mihi, cuiquel salvel rite vininti

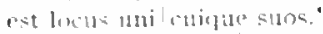

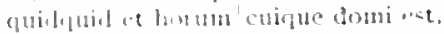

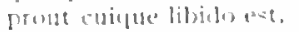

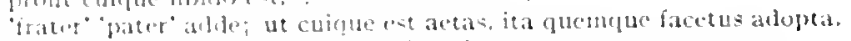

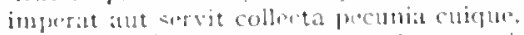

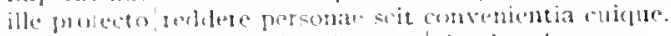

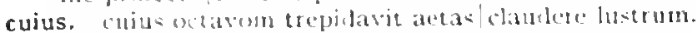

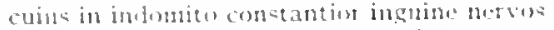

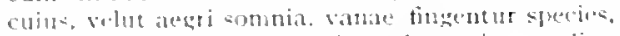

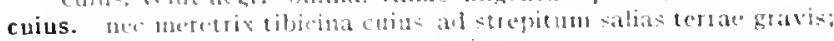

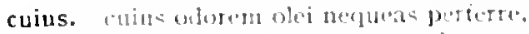

cuius. Anins recimet iocosia nomen imast?

cuius. cuins fortunite. yuo sit patre puone patrono."

cuiusque. artatic culdegue notandi sunt tibi mores.

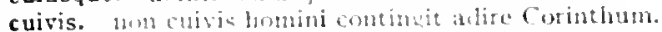

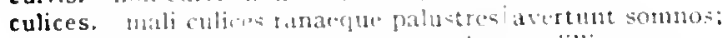

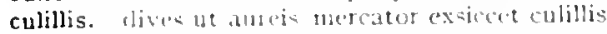

regus dicuntur multis urgere culillis

culinae. mec tontum veneris quantum sulioes culinac.

culinam. Burpa prisplente domum, Caphone culinam.

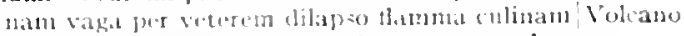

culmo. ac vemerated (ivera ital culmo surgeret alto.

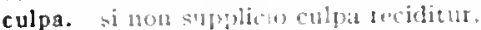

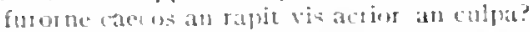

qurotu sha culpa prenet, leceptus omitte tueti.

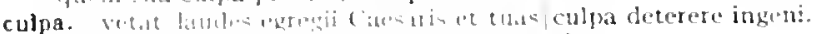

levis una mus est virginum culpar [culpa].

fout loc hulds enat telubit potare magistra

nue sun fircturus vitio culpare minomem:

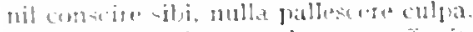

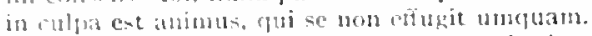

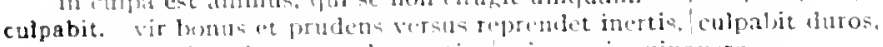

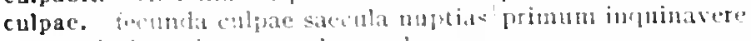

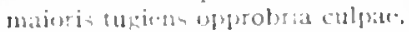

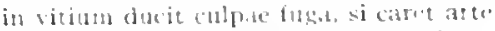

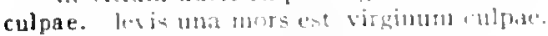

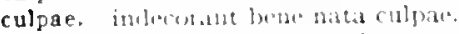

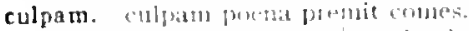

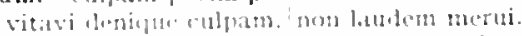

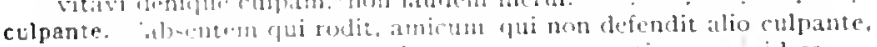

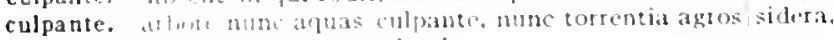

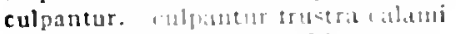

culpari. (miluari metuit findas,

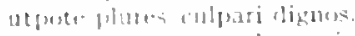

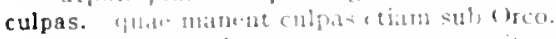

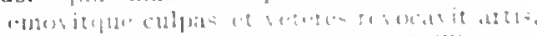

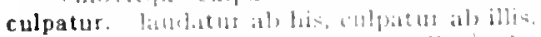

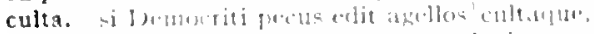

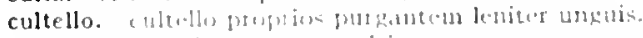

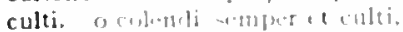

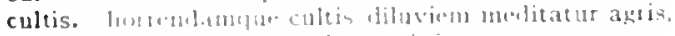

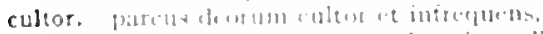

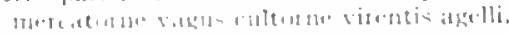

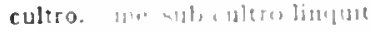

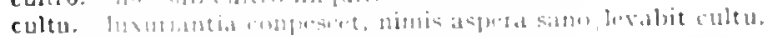

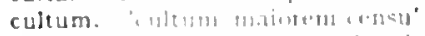

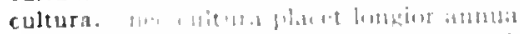

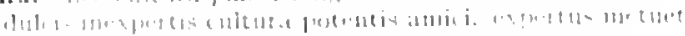

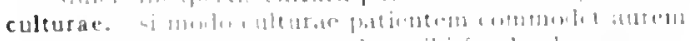

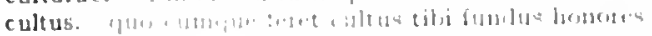

far Carn.t.3 i :

rar..ters loet. 434

Epist.2.2.8

sar.Ars P'od.434

Serm.1.435

Scrm.1...73

conti.Carm.1.32.15

Serm. 0.52

Serm.2.3.232

Sirm.z.6.07

Lipist. 1.6 .55

Espirt 1.10 .47

Ars foet.zie

Carm.2.4.23

Lpod.1 2.10

Ars Pode 7

I:pist.1.14.25

Serm.2.2.59

Corm.1.12.3

I.pist 1.7.5.

Ars Pod. 50

I.pist.1.17.3ी

Serm.1.5.1.4

C'arm.1.31.11

Ars Poct.134

Serm.2.5.80

serm.1.5.38

Serm.1.5.73

Sirm.2.2.12.8

ciarm.3.24.34

Irpod.7.1.4

Espirt.1.18.70

Cirm.1 0.82

sar.Carm.3.27.38

Sirm.2.2.123

Sirm.2.0.7

Epistid.tit

Epist.1.:-13

irs Inertite

carm.3etit?

Epist 0.10

Irs Pot.3 I

Cirm.3.27.38

(itrm.4.4.3')

(i) 1 m. 4.5.24

Ars Pitherä

Sirmet.4.82

Cirm.3.1.31

Sirm.2.3.7

Corm +5.20

Serm.1.4.25

Carm.3.11.29

carmat is. II

Sirm.1.2 II

fiptst.1.12.13

Epist. 7.51

('itrph.sisec.3

(arm?1. 27

citrm 1. 3.4.1

Ars Poetiaz

Serme1.974

l: filst 2.22 123

Term.2.3.323

(ism) 32414

tivil I I . .

Lest I T. 40

Sirmi.2.5.1.3 


\section{CVLTVS}

\section{CVNCTA}

cultus. ne virilis/cultus in caedem et Lycias proriperet catervas?

cultus. in neutram partem cultus miser.

cultus. rectique cultus pectora roborant;

cultus. qui feros eultus hominum recentum/voce formasti catus .

adulteros $\mid$ cultus pulvere collines.

aurum vestibu= illitum ' mirata regalisque cultus|et comites

cululis. dives ut aurcis | mercator exsiccet culillis [culuits] | vina syra reparata merce.

reges dicuntur multis urgere culillis [cululis]|et torquere mero.

culullis. dives ut atureis | mercator exsiccet culillis [culullis] vina Syra reparata merce,

reges dicuntur multis urgere culillis [eulullis] et torquere mero.

Curm.1.8.16

Sirm.2.2.66

Corm.4.4.34

Carm.I.IO.2

Carm.1.15.20

Carm.1.9.15

F'trr. Carm.1.31.II

irir.trs Poet. 434

2ar.Carm.1.3I.11 wer.tis Poel.434

cum. Carm.1.1.31; 1.12.44; 1.17.23; 1.18.8; 1.18.13; 1.19.15;1.24.4; 1.31.19; 1.33.12; 1.34.15;

Carm.1.35.27; 1.37.9;2.5.8; 2.7.0;2.8.11; 2.11.22; 3.1.36;3.3.24; 3.17.10; 3.18.12: Carm.3.19.20;3.29.3; 3.29.21; 3.29.35; 3.30.9;4.1.26;4.4.67;4.7.5; 4.12.21; 4.15.27; Epod.4.8; 1 7.37; Serm.1.1.58; 1.2.57; 1.2.58 (bis); I.3.70; 1.4.5; 1.4.50; 1.4.52; 1.4.66; Serm.1.4.81; 1.4.105; :.5.81; 1.6.117; 1 6.118; 1.7.5; 1.7.17;1.7.20;1.8.25; 1.8 +1 ; 1.8.42; Serm.1.8.50; 1.9.43; 1.10.49; 1.10.85; 2.1.73;2.1.76;2.2.17; 2.2.96, 2.2.1I5; 2.2 II 7; Strm.2.2.122; 2.3.25;2.3 $58 ; 2.3 .112 ; 2.3 .229$ (bis); 2.4.73; 2.4.7.4; 2.5.8; 2.7.9; 2.7.35; Sirm.2.7.67; 2 8.14; 2.8.21; 2.8.90; zur.Serm.2.8.90; Epist.1.2.24; 1.2 35; 1.6.18; 1.6.36; Epist.1 7.13; 1.10.21; 1.1315; 1.14.40; 1.15.19; 1.18.33; 2.r.5; 2.1.25; 2.1.132; Epist.2.1.142; 2.1.203;2.1.246; 2.1.208;2.2.93; 2.2.110; 2.2.179; 2.2.2u6; Ars I'opt.145; Ars I'ot $200 ; 358 ; 375$

cum. Carm.1.7.3I; I.30.5; $1.32 .2 ; 2.1 .39 ; 2.0 .1 ; 2.6 .21 ; 2.7 .1 ; 2.7 .9 ; 3.2 .2 S ; 3.429 ; 3.9 .24($ bis $)$; Carm.3.21.1; Epod I 8; 4.2; 9.3; Serm.1.1.102; 1.3.57; 1.4.137; 1.9.43; 1 9.1.8; 2.I.51; Serm.2.27; $2270 ; 2.3 .198 ; 23224 ; 2.3 .260 ; 25.82 ; 2.7 .112 ;$ Epist.1.1.97; 1.6.68; Epist.1.7.02; 1.7.70; 1.14.20; 1.18.30; 2.1.68; 2.1.87; 2.2.3; 2.2.23; 2.2.70; 2.2.1.5; Ars Poct.153; 175

cum. Carm.1.2.7; 1.13.1; 1.18.10; I.25.13; I.29.13; 2.7.11; 2.12.25; 2.17.25; 3.3.50; 3.5.29; Carm.3 IS 10; $320.5 ; 327.71 ; 329$ 40; zar.Carm.4 2.6; ? 2ar.Carm.4 2.10; Carm.4.5.40; Carm 4.7.21; +10.2; 4.14.27; Epod.2.17; 2.29; 5.52; 5.55; 5.65; 6.9; 9.7; 10.13; Epod 10.19; 12.8; 12.13; 15.3; Serm 1.1.104; I.1.I14; 1.2.71; 1.2.114; 1.2.1 10; 1.2.122; Serm.1.3.87; I.3.97; I 3.99; I.4.89; I.4.133; 1.5.20; 1.6.7; 1.6.108; 1.8.2; 1.8.17; 1.9.2I; Serm.1.10.55; 2.1.IS; 2.1.23; 2.1.62;2.2.5 (bis);2.2.14;2.2.43;22.98; 2.3.30; 2.3.6I; Serm.2.3.72; 2.3.73; 2.3.90; 2.3.131; 2.3.199;2.3.202; 2.3.211; 2.3.212; 23213 ; iar.Serm.2 3230; Serm.2.3.258; 2.3.262; 2.3272; 2.3274; 2.3.277; 2.3.303; 2.5.99; zar.Serm.2.6.67; Serm.2.6.101; 2.6.111;2.7.53;2.7.71;2.795; 2.796;2.8.29; Episl.1.1.97; Epist I.1.108; 1.4.16; I $92 ; 1.9 .5 ; 1.10 .17$; 1.154; I.15 18; 1.15.42; 1.16.30; 1.16.55; Epist.1.16.59; 1.10.64; 1.I8.40; I.IS.S2; 1.18.84; 1.20.8; 1.20.19; 2.1.205; 2.1.220; Epist.2.1 221; 2.1 223; 2.1.224; 2.1.226; 2.1.261; 2.2.10.3; 2.2.161; Ars Poet.16; 96

cum. Carm I.7.22; I.15 I; 1.33.13; 2.19.21; 3.24.59; Epod.5.35; 5 39; 8.3; 1 2.18; Serm.1.1.32;

Serm.1.1 38; 1.1.86; 1.1.92; coni.Serm.1.1.108; Serm.1.2.31; 1.2.07; 1.3.21; 1.3.25; 1.3.60;

Serm.I.3.12I; 1.4.II; 1.4.22; I.4 107; 1.4.II2; 1.4.113; 1.4.125; 1.5.59; :ar.Serm.1.6.31; Serm.1.96; 1.9 I0; 1.9.12; 1.10.25 (bis); I.10.28; I.10.3I; 2.3.37; 2.3286; 2.3.318; Serm.2.4.7; 2.6.88; 2.7.40; 2.7.65; Epist.1.1.104; 1.6.25; 1.12.1.7 1.15.39; 1.16.69; Epist.1.18.50; 2.1.1;2.1.81; coni.Epist.2.1.174; Epist.2.1.209; 2.2.153; Ars Pot.56; 253 ; Ars Pot.33I

cum. Carm.1.20.4; Serm.1.10.33

Cumas. non mihi Cumas est iter aut Baias"

cumeram. tenuis volpecula . . repserat in cumeram frumenti,

cumeris. cur tua plus laudes cumeris granaria nostris?

cuminum. quodsi pallerem casu, biberent exsangue cumiunm.

cumque. quam rem cumque ferox navibus aut equis

'quo nos cumque feret melior fortuna parente. .

quem Fors dierum cumque dabit.

quem criminosis cumque voles modum|pones iambis.

quae te cumque domat lienus.

o laborum |duke [quale] lenimen mihi cumque salve] rite vocanti.

garrulus hunc quando consumet cumque:

qui testamentum tradet tibi cumque legendum.

quo me cumque rapit tempestas, deferor hospes.

cuncta. cuncta testinat manus.

cuncta. cuncta manns avidas fugient heredis

cunctane prac Campo et Tiberino flumine sordent?

cuncta. audire. . cuncta terrarum subacta

cuncta supercilio noventis.

abstinens/ducentis ad se cuncta pecuniae,

huic ego volgusfertori sinilem cunctum [sinilis cuncta] insanire docebo. quo pacto cuncta tenerem

E.pist.1.15.II

Epist. I.7.30

Serm.1.1.53

Epist.I.19.18

Carm.1.6.3

Carm.1.7.25

Carm.1.9.14

Carm.1.10.2

Corm.1.27.14

coni.Carm.I.32.I5

Serm. ?.9.33

sirm.2.5.5 I

Epist.1.1.15

Carm.4.11.0

Carm.4.7.10

Epist.1.II.t

Carm.2.1.23

Carm.3.1.s

Carm.4.9.38

7'elr.Serm.2.3.63

Serm.2.4.8 
nom puanvis memor reforas mili pectore cuncta,

hace ego i conprllor tmagine. cunctat tesigno:

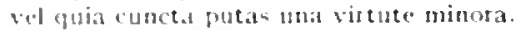

inter cumctas lest"s et pereontaber. dectos.

cunctantem. cunclantem spatio longius annuo

cunctata. tu me inter strepitus nocturnos atque diurnos / vis canete et contuta lemetata] serpui vertigia vatum?

cunctetur. neque cunctutur, cum est illswa, venire.

cuncti. danesut periess pudorem cuncti paente patres.

cunctos. hare lovem sentire deosque cunctos.

senem. [/ somes] quod ommes rideant, arblterum|latrent Suburanae cantes ] rideant cunctos canos!

avet quivis aspergere cunctos prator eum qui praebet aquan:

cunctum. Huic ego volgus errori smblem eunctum insanire docebo.

cuneos. clavos trabalis et cuneos manu'gestans aena

cunni. 'nolim laudarier' inquit / sic me" mirator cunni Cupiennius albi.

cunnum. numquid ego a te magno prognatum deposco consule cunnum

cunnus. nam fuit ante Helenam cunnus taeterrima belli/causa. .

cupa. post hoc ludus erat tculpa [cupa] potare magistra

Cupennius. mirator cunni Cupiennius [Cupennius] albi.

cuperem. si quantun cuperem possem quoque:

cupiam. 'accendis quare cupiam magis illi| proximus esse."

cupias. com pateris [cupias] sapiens emendatusque vocari, respondesne tuo. dic, solles, nomine?

cupiat. haberi et cupiat formosus.

utrum gaudeat an doleat, cupiat metuatne.

cupide. quol cupide petiit, mature plena reliquit.

cupidine. contracto melius parva cupidine/vectigalia portigam

ut bona pars lominum decepta cupidine falso.

ferve araricia miseroque cupidine pectus:

Cupidinem. et cantu tremulo pora Cupidinem|lentum sollicitas.

cupidinem. colle cupidin'm! inmitis urae:

cupidinibus. nonne, cupidinibus statuat natura modun quem. responsate upidinibus, conemunce honores/fortis.

Cupidinis. sacrum liberi Cupidinis.

cupidinis. cradenda cupidinis pravi sunt elenenta

Cupidinum. nater saeva Cupielinum

desine, clulcium mater saeva Cupidinum,

Cupido. quam locus circun volat et Cupido;

ferce cupido semper ardentis acuens sagitas

cupido. cum tibi thagrans amor el libido [cupido]. . . saeviet circa iecur nicerositm

nec lovis sommos timor aut cupirlo' sorditus aufert.

nec quisquam noceat cupido mihi pacis!

num te semper inops agited vexeque cupielo.

cupidos. Ienit albescens aninos cafillus, lisum et rixae cusidos protersac;

cupidum. cuplelum, pater optime. vires dificiunt:

t. tibi iniquem it frustra mortiu cupidum.

si cuprifum timidumbute minus te:

cupidus. Ifute si cum arcio stultua supiduspue bibisset.

sublindis rupidusfue ct amaca relinefuere pernix.

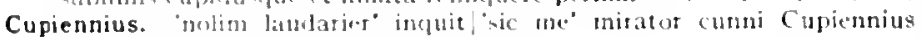
altis

cupiens. cupienc vasia factidia roma vincere

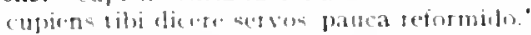

haten moguiguant cacno enpiens evellete plantans.

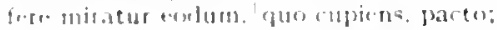

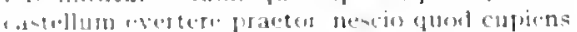

cupientium, nil cupiontium mulus ristta beto

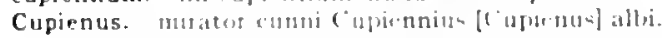

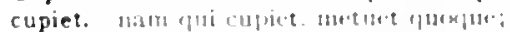

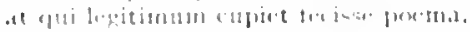

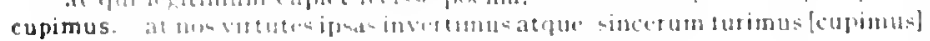

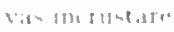

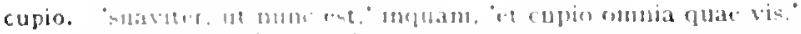

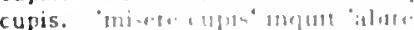

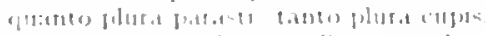

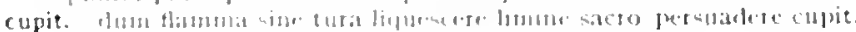

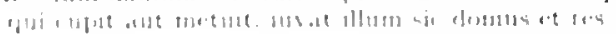

Serm. 4.90

Epist.1.7.34

Epist.1.12.11

Epist.1.18.96

Corm..4.5.1 I

gur. Epist. 2.2.80

Serm.1.2.122

Lfpist.2.1.81

Carm.Saec. 73

7 :ar. Epod.5.57

Sorm.1.4.87

Sirm.2.3.03

Carm.1.35.18

Serm.1.2.36

Sirm.1.2.70

Sorm.1.3.107

vor.Serm.2.2.123

tar.Serm.1.2.30

Eisist 2.1 .257

Sorm.t.9.53

tar. Epist.1.16.30

Serm.1.6.31

Epist.1.0.12

Ispist.2.1.100

Carm.3.16.39

Serm.1.1.61

Epist.1.1.33

Carm.4.13.5

Carm.2.5.9

Sorm.1.2.111

Sorm.2.7.85

Epod.17.57

Carm.3.2.4.51

Carm.1.19.1

Curm.4.5

Carm.1.2.34

Carm.2.8.14

far.Carm.1.25.13

Carm.2.10.15

Serm.2.1.4.

Fist 1.18.98

Carm.3.4.20

Scrm.2.12

Serm.2.2.98

I.pist 2.2.150

IEpist.1.2.2.4

Ars l'oet.105

Sorm.1 $2.3^{0}$

Serm.2.0.80

Srm.2.7.1

Sirm.2727

Fipist 10.10

I.pist 2.2.35

(arm.3.10.22

iar.sirm.1.2.30

lepst a.10.0.5

I. pist 2.2 .100

ar.5em.1.3.50

sern.to 5

Serm.1.0.1.1

J-puse $22+18$

sirm 15.100

1.pot 1.251 
qui variare cupit rem prodigialiter nnam.

tdeus inmortalis haberi|dum cupit Empedocles.

cupressi. nec cupressi|nec veteres agitantur orni.

cupresso. carmina fingi|posse linenda cedro et levi servanda cupresso?

cupressos. praeter invisas curressos

iubet cupressos funebris. . aduri

cupressum. neque harum quas colis arborum|te [? nec te] praeter invisas cupressos [? invisan cupressum]|ulla . . sequetur.

et fortasse cupressum|scis simulare:

cupressus. icta ferro|pinus aut inpulsa cupressus Euro,

iubet cupressos [cupressus] . . aduri

cur. Carm.1.8.2; 1.8.3; 1.8.5; 1.8.8 (bis); 1.16.19;1.33.3; 2.11.13;2.17.1; 3.1.45; 3.1.47; 3.19.18; Carm.3.10.20; zar.Carm.3 27.7; Carm.4.1.33 (bis):4.1.35; 4.10.7; 4.10.8; Epod.5.61; 7.I; f'ar.Epod.12.2(bis); Epod.14.1; Serm.1.1.53; coni.Serm.1.1.108; Serm.1.2.7; 1.3.20; 1.3.77; Sirm.1.3.120; 1.4.70; 1.5.08; 1.7.34; 2.1.41; 2.2.7; 2.2.103; 2.2.10.4; 2.3.160; 2.3.187; Sirm.2.3.193;2.7.104; Epist.1.1.70;1.2.5;1.2.37;1.8.10;1.9.7;1.17.17; 1.19.3.5; 2.2.183; Ars Poet.22; $55 ; 87 ; 88 ; 450 ; 470$

Cura. scandit aeratas vitiosa navis/Cura post equitem sedet atra Cura.

cura. tibi cura magni Caesaris fat is data: nunc desiderium curaque non levis. iuvenumque prodis|publica cura. crescentem sequitur cura pecuniam quae cura patrum quaeve Quiritium at mihi cura|non mediocris inest. haec mea cura est, | nequid tu perdas. est ubi divellat somnos minus invida cura? me quamvis Lamiae pietas et cura moratur|fratrem maerentis. fuit intactis quoque cura|condicione super communi, haec animos aerugo et cura peculi cum semel imbuerit,

cura. cum te servitio longo curaque levarit. aut operae celeris nimium curaque carent is

cura. simplici myrto nihil adlabores/sedulus curo [cura] "inprimat his cura Maecenas signa tabellis."

curabis. cras genium mero/curabis et porco bimenstri nec verbo verbum curabis reddere fidus interpres

curae. sic qui promittit civis. V'rbem sibi curae, imperium fore curae sunt atque labori.

'quin id erat curae.

sit tibi curae / quantae conveniat Munatius.

curae. curae sagaces expediunt per acuta belli." minuentur atrae/carmine curae.

curam. curam metumque Caesaris rerum iuvat dulci Lyaeo solvere. . puellis iniciat curam quaerendi singula.

nequaquam satis in re una consumere curam.

quanto curam sumptumque minorem|haec habeant.

iam vino quaerens, iam somno fallere curam;

ad strepitun citharae cessatum ducere curam.

inter spem curamque, timores inter et iras

parcus ob heredis curam nimiumque severus/adsidet insano:

curam redde brevem, si munus Apolline dignum/ris conplere libris

curanda. in cute curanda plus aequo operata iuventus,

curandi. differs curandi tempus in annum?

curantem. curantem quidquid dignum sapiente bonoque est?

curare. latus in praesens animus quod ultra est oderit curare omnis mortalis curare et quaerere cogit.

ire domum atque $\mid$ peliculam curare iube;

'alter Honerus,' . . . leviter curare videtur. |quo pronissa cadant

curarier. fugeres radice vel herba' ptoficiente nihil curaricr:

curarum. amaraque curarum eluere efficax.

quodsi frigida curarum fomenta relinquere posses, .

curas. nunc vino pellite curas;

dissipat Enhius |curas edacis.

neque consularisisubmovet lictor...curas laqueata circum / tecta volantis.

mitte civilis super Vrbe curas:

hic dies vere mihi festus atras/exiget curas:

sapientium / curas et arcanum iocoso|consiliun retegis $L$ yaco,

quis non malarum quas amor curas habet .
Ars Poet.20

Ars Poet. 405

Carm.1.0.1I

Ars $10 \mathrm{~d} \cdot 332$

Carm.2.1 +23

Epod.5.18

I iur.Carm.2.14.23

Ars Poet.io

Carm.4.0.10

iar. Epod.5.18
Carm.3.1.40

Carm.1.I2.50

Carm.1.14.18

Carm.2.8.8

Carm.3.16.17

Carm.4.14.1

Serm.2.4.93

Serm.2.5.36

Epist.1.10.18

Epist.1.14.0

Epist.2.1.15I

Ars Poit. $33^{\circ}$

Serm.2.5.99

Ars Pott.26r

coni.Carm.1.38.6

Serm.2.6.38

Carm.3.17.15

Lirs Pott.133

Serm.1.6.34

Serm.1.8.18

Serm.2.4.8

Epist.1.3.30

Carm.4.4.75

carm.4.1 1.36

Epod.9.37

Serm. 1.6.32

Serm.2.4.48

Serm.2.4.85

Serm.2.7.114

Epist.1.2.31

Epist.1.4.12

Epist.1.5.13

Epist.2.1.210

Epist.1.2.29

Epist.1.2.39

Epist.t.t 5

Serm.1.0.37

Serm.2.5.38

Epist.2.I.5 I

Epist.2.2.151

Carm.4.12.20

Epist. [.3.20

Carm.1.7.31

Curm.2.11.18

Carm.2.10.1 I

Carm.3.s.17

Carm.3.14.t4

Carm.3.21.15

Epod.2.37
Carm.2.16.22

Corm.2.10.20 


\section{CVRAS}

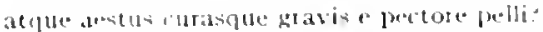

Atedust num animo cutas:

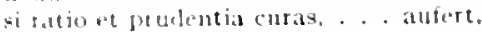

pequero. gquol curat abigat.

guil minuate curas. quid te tibi redlut amicum,

stribere preser inter tot curas totque libores?

et iusenum curas et libera sina retetre - -

curas. tu cisitatem quis deceat status/curas

bos.monut distumetum curas et strictis trondibus explas.

(1) recte visis, si curas "sve quod audis.

quamvis nil extra numertm fecisse nolumque curas:

si curat [ouras] cor spectantis tetigisse querella.

curat. quis udo deptoperare apio coromas curatue myrto?

nec curat Gron leones aut timidos agitare ly nas.

nec verat virtus, cun senel excidie, curat reponi deterionibus.

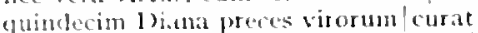

nec seme! inrisus trivis atollere curat fracto crure planum,

sunt qui nom habeant, est qui non curat habert.

si cutat cor spectantis tetigisse querclla.

bona pars non unguic ponere curat, [ non barbam.

curata. me pinguem et nithlum bene curata cute vises,

curata. ubi dicto citios cusata sopori membra declit.

curatoris, nee buedici ctedis nec curatoris efore a practore clati.

curatus. si curatus inaequali tonsore capillos occurri, riles;

cure. lum ego me siquid conpontere curem [curs]. mon magis esse velim

curem. hunc ego me, siquid conponere curem, non magis esse velim

cures. no cures cal quate stulte miraris et optas.

atqui si noles sums, curres [eures] hydropicus;

nil parrom sapias et adhuc sublinia cures:

siguid et now quod cures proprium fecisse, loquamur.

curet. quis ferat bellum curet lliberiate?

quindecim Diana preces viorum curat [curet] et votis puerormu anicas arplicat (ap)licet) auris:

non sit qui tollare chret.

si curet quis open ferre cot domittere iunem:

curia. (procutia inversigue mores)

curiae. insigne matestis praesilinm reis "'consulenti, Polio, curiae.

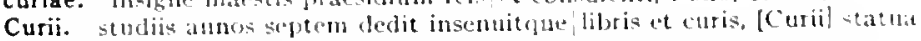
taciturnins exit

Curiis. et maribus Curiis et decantati Camillis?

curiosus. ut jpse nosti curiosus.

ut ijse nosti cut losus [curiosus novi i].

curis. studis annos septem dedit inamulape libris et curis.

curis. ulera terminum curis vagor expeclicis.

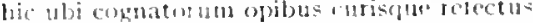

Curium. bunc et imcomptis Curium capillis ucilesn bello tulit. . saeva vanperatas

curo. simplici miveo nibil adlabores, solulu= como:

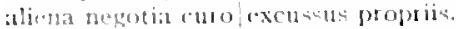

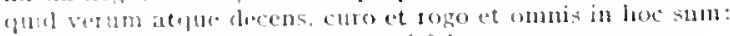

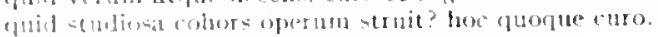

curras. licetie inimeto ter pulverecutras.

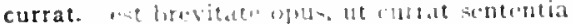

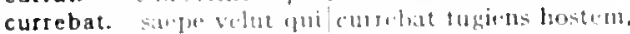

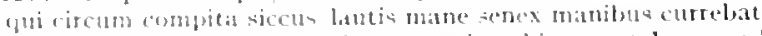

currens. horme abilliw ut mabinus a a)

currente. ne asronte folro tumi- rat sotat:

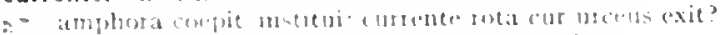

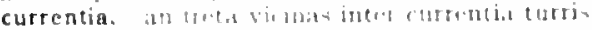

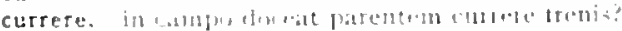

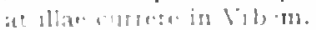

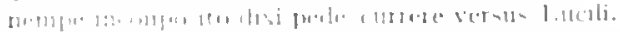

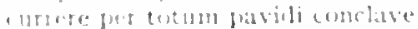

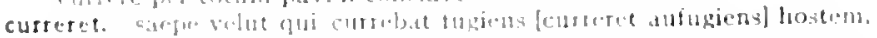

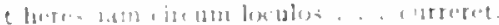

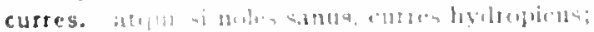

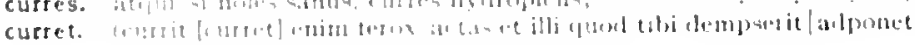
iा $11111+1$,
Serm 12,150

Epist. 1.2.19

I.pist.1.11.25

lepist I. I 19

Epist.1.18.141

I.pist.2.2.60

drs Pod.85

Curm.3.29.2\%

fipist.1.14.28

Epist.1.13.17

Epist.1.18.60

:ur. Ars Port.g8

Carm.2.7.25

Carm.2.13.39

Corm.3.5.30

Carmsare. 7

Epist.1.17.58

Fist.2.2.182

Ars Poet.98

irs l'oe't.297

Epist.1.4. I 5

Sirm.2.2.80

Epist.1.1.102

Epist.1.1.94

Jar.A1rs Podt.35

Ars loet. 35

Epist.1.1.47

iur.Epist 1.2.3.4

Ispist.1.12.15

Epist.1.17.5

Carm.t. 5.28

iur. Cirm.Suec.7

irs Poct.ato

Ars linet.poI

Corm.3.5.7

Curm.2.1.

zur. Epist.2.2.83

Epist.1.r.6.t

Epod.17.77

var Epod 17.77

Epist.2.2.8.3

carm.1.22.1 I

Epist.2.13

Carm.1.12.41

Curm.1.38.6

Sirm.2.3.10

IEpist.1.1.11

Epist.1.3.6

(itrm.1.28.36

Sirm.1.10.9

sirm.1.3.10

Sierm. 2.3252

Iur.lipud 5.28

(arm.3.10.10

irs Jint.22

lepist $1,3 . .1$

sirm.t.1.01

Sirm.1.84

Sirm 1.111 .1

serm.20.113

conisern 1.3.10

sirm.2.3 1.47

Fipist. 2.3 .4

tar.Curm.25.13 


\section{CVRRICVLO}

curriculo, sunt quos curriculo pulverem Olympicum|collegisse iuvat curris. (inpiger extremos curris mercator ad Indos.

currit. (currit enim ferox laetas

unde uxor media currit de nocte vocata." -

caelum. non animum mutant [? mutat]. qui trans mare currunt [? currit].

curru. tu gravi curru quaties Olympum,

pone sub curru nimium propinqui|solis

tempus agens abeunte curru.

non equos inpiger|curru ducet Achaico! victorem

alme Sol, curru nitido diem qui|promis et celas

sed fulgente trahit constrictos Gloria curru

laevom discedens curru fugiente vaporet.

quem tulit ad scaenam ventoso Gloria curru.

currum. per purum tonantis|egit equos rolteremque currum,

currunt. per omne audaces mare qui currunt.

dum vitant stulti vitia, in contraria currunt.

caelum, non animum mutant, qui trans nare currunt.

currus. jam gulestu Pallas et aegida currusque et rabiem parat.

tu moraris aureos|currus et intactas boves?

ut, cum carceribus missos rapit ungula currus.

cursitant. Inc et illuc/cursitant mixtae pueris puellae,

cursitat. veluti succinctus cursitat hospes

cursu. iussa pars mutare Lares et urbem|sospite cursu.

quam neculitre proci recto deptllere cursu?'

arlspiciat sol, | laevom discedens curru [cursu] fugiente vaporet.

vel cursu superare canem vel viribus aprum possis.

qui studet optatam cursul contingere metam.

cursum. rectum animi servas cursum?

seu cursum mutavit iniquom frugibus amnis|doctus iter melius:

cursus. nec cursus duplicis per mare Vlixei

iterare cursus/cogor relectos:

curtabit. quantulum enim summae curtabit quisque dierum.

curtae. curtae nescio quid semper abest rei.

Curti. an superhos Tarquini fascis, dubito, an Catonis [anne Curti]| nobile letum:

Curtillus, inulas. . monstravi incofuere; inlutos Curtillus echinos,

curtis. vin tu curtis I udaeis oppedere?"

curto. nume milic curto ire licet mulo

gaudentem parvisque sodalibus et lare certo [curto]

curto. unde tibi reditum certo [curto] subtemine Parcael rupere.

curule, eripietque curule fcui volet inportunus ebur."

curva. tu curva recines lyra Latonam

curvae, deorum nuntium curvaeque lyrae parentem,

curvantis. fretis acrior Hadriae curvantis Calabros sinus.

curvat. nec vir Pieria paelice saucius curvat.

Vinber . . curvat aper lances

curvatos. fronte curvatos imitatus ignis

curvis. petamque voltus umbra curvis unguibus.

Curvius. Cervius [Curvius] haec inter vicinus gatrit anilis!ex re fabellas.

curvo, curvo nec faciem litore dimovet:

opima quodsi praeda curvo litore|perrecta mergos iuverit,

curvo. scilicet ut vellen curvo dignoscere rectum

cuspide. Dardanas turris quateret trennenda cuspide pugnax nec fracta perenntis cuspide Gallos

custode. ab Iove Septunoque sacri custode Tarenti.

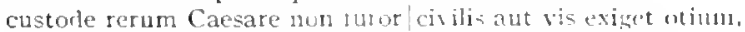

'in manicis et compedibus saevo te sub custode tenebo."

inberbis juvenis, tandem custole remoto.

custodem. Acrisium virginis abditae/custolem pavidum

claustrautu custorlem pacis cohibentia Janum

custodes. dicunt in tenero granine pinguium |cu-todes oviun carmina custodes, lectica, ciniflones, parasitae,

detur nobis locus, hora. |custodes;

custodes. et ture et fubus invat plucare . . custodes Numidae deos.

custodia. ut piger annu- pupillis, quos dura premit custodia matrum:

custodiet. me veluti custodiet ensis|vagina tectus:

custodis. tuanque.|dum custodis eges, vitam famamque tueri|incolumem

custodis. dis inimice senex, custodis? ne tibj desit?

\section{CVSTODIS}

Carm.1.1.3

Epist.J.I.45

Carm.2.5.13

Serm.2.3.238

7 iar Epist.I.11.27

Carm.1.12.58

Carm.1.22.21

Carm.3.0.44

Carm.4.3.5

Carm-Sat'c.9

Serm.1.6.23

Epist.1.16.7

Epist.2.1.177

Carm.1.34.8

Sorm. I. I.30

Sirm.1.2.24

Epist.1.11.27

Carm.1.15.12

Epod.9.22

Serm.I.I.IIA

Carm.4.11.10

Serm.2.6.107

Carm.Saec. 40

Serm.2.5.78

ior Epist.1.16.7

Epist.1.I8.5I

Ars Poct.qI 2

coni.Serm.2.3.20I

Ars Poet.67

Carm.1.6.7

Carm.1.34 4

Serm.2.3.124

Carm.3.2464

coni.Carm.I.12.35

Serm.2.8.52

Serm.1.9.70

Serm.to.104

var. Epist.1.7.58

coni.Epod.13.15

Epist.1.0.53

Carm.3.28. I I

Carm.1.10.6

Carm.1.33.16

Carm.3.10.16

Serm.2.4.4I

Carm.1.257

Epod.5.93

var.Serm.2.6.77

Carm.4.5.14

Epod.10.2I

Epist.2.2.14

Carm.t. 8

Serm.2.I.I

Carm.1.28.20

Carm.t.15.17

Epist.1.10.77

Ars Poetigi

Carm.3.16.6

Epist.2.1.255

Carm.4.12.10

Serm.1.2.98

Serm $\mathrm{x} .4 .10$

Carm.1.36.3

Epist.1.1.22

Serm.2.1.po

Serm.1.4.118

Serm.2.3.123 
"nj tua chsturlis, avidus iam hate auferet heres."

custodit. Latvom matsinat qui leneris latus custodit.

custos. Faunus. . Mercurialium|erustos virorum.

alex. neyutiae ahtitur custos;

ipre mila cutes incuraptissimus omnis/circum doctores aderat

utrue serles. elutos mihi maximus arlsis.

vitutis verace su-tos rigiduscjuce satelles;

an custor fantulusque din silenus alumni.

custos. geent is humanate pater atene custos.

montium cusbus n'surumgue. virko.

optume: Romulat custos gentis.

cute. in cule euranta plus arejuo operata iuventus.

me pinguern el nitidum betu curata cute vises.

quat s. commendat tonsa cute, derstilus atris.

cutem. nihil ultra nervos aldue cutem moti concesserat atrac. .

non missura cutem nisi plena cruoris hirudo'.

cyathis. tribus aut novem miscentur cyathis pocula commodis. .

cyatho. ut tibi si st opus liquirli non amplius urna'vel cyatho

poeula cum cyatho duo sustinet.

cyathos. sume, Matcenas, cyathos amici|sospitis centum

ternos ter cyathos attonitus petet vates:

ternos t.T cyathos atconitus [actonit us cyathos] petet | vates;

cyathum. puer quis "x aula capillis ad cyathum statuetur unctis

Cycladas. interfusa nitentis|vites aequora Cycladas.

fulgentisque tenet Cycladas

cyclicus. nec sic intipies. ut scriptor cyclicus olim:

cyclius. nec sic incipies, ut scriptor cyclicus [cyclius] olim:

Cyclopa. pastorem saltaret uti Cyclopa rogabat:

qui nunc Satymum. nunc agrestem Cyclopa novetur.

Cyclope. miracula promat. | Antiphaten Scyllamque el cum Cyclope Charybdin:

Cyclopum. dum gravis Cyelopum Voleanus ardens visit officinas.

cycni. donatura cycni. si libeat, sonum,

cycnum. multa Dircaeum levat aura eycnun.

Cydonio. primuses Teucer tela Cyelonio/derexit arcu;

Cyllena. fide Cyllenea [Cyllenal hevare diris pectora sollicitudinibus.

Cyllenea. et fick cyllenea/levare diris pectora sollicitudinibus.

Cyllenia. et fide Collenea [Cyllenia] levare diris pectora sollicitudinibus. cymbae. nos in aetornum exilium inpositura cymbae.

Cynicum. mordacem Cynicum sic elurlebat, ut aiunt:

Cynthiae. In enrat tecine Iyra Latonam et celeris spicula Cynthiae:

Cynthium. intonsum pueri dicice Cynthium

Cyprea. Nhanos prope te lacus / ponet mamoteam sub trabe citrea

$$
\text { [cyproad. }
$$

Cypri. sic te diva potens Cypri. . . regat

Cypria. ut thabe Cymia Myrtoum pavidus nanta secet mare.

Cypriae. nu" (ynae Tyriateque metces aeliant avaro divitias mari:

Cypron. o Verus. . sperne diletam Cypron

Cyprum. in ne tota tuens lenus ("yotum aleseruit

o quac beatim diva tenes Cyprum

cyragra. ponteusm jlli iustat cheragra [eyragtal contudit articulos.

Cyri. redliturn Cyri selio Phratan

Cyri. insignem tenui ironte Jycotida/Cyri torret amor.

Cyro. ruid tres et regnata Cyro Bactiol parent

Cyrum. mo nutues protervom|sispecta Cyrum.

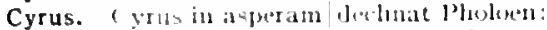

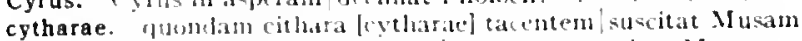

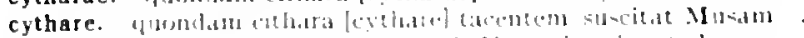
Cytherea. iam (vitherea choros ducit linus imuinente luna

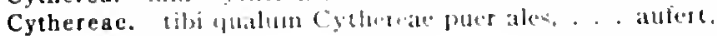

Sirm.2.3.151

Carm.3.26.6

Carm.2.17.30

Carm.3.4.79

Sirm.1.6.81

Serm.2.6.15

lipist.1.1.17

Ars Poel.239

Corm.1.12.49

Corm.3.22.1

Corm.4.5.2

Epist.1.2.29

Epist.1.4.15

Epist.1.18.7

Carm.1.28.13

Ars l'oet.47o

Curm.3.19.12

Serm.1.1.55

Sirm.1.0.117

Carm.3.8.13

Carm.3.19.14

i ar.Carm.3.19.14

Carm.1.20.8

Carm.1.14.20

Carit.3.28.14

Ars Poel.13o

far.atrs Poct.1 36

Serm.1.5.63

lipist.2.2.125

Ars Pod.145

("arm.1.4.7

Carm.4.3.20

Corm.4.2.25

Carmat9.17

iar Epod. 13.9

lipod.13.9

:ar. Epod.13.9

Corm.2.3.28

Epist.1.17.18

Carm.3.28.12

Carm.1.21.2

sar.Corm.4.1.20

Carm.1.3.1

Carm.1.1.13

Carm.3.29.00

Carm.1.30.2

Curm.1.19.10

Carm.3.20.9

gar.Serm 2.7.15

Corm.2.2.17

(arm.t.33.e)

Carm.3.29.27

Carm.1.17.25

Curm.1.330

far.carm.2.10.18

iar. (iamom.2. I11.18

Corm.t. 5

Corm.3.12.4

D)

da. Jit Lunige propuse nevale.

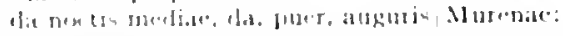

did, a

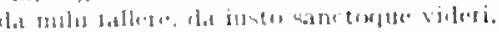

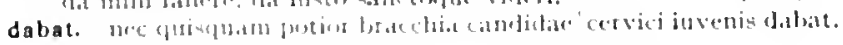

(arm.3.10.1)

Carm.3.loso

Serm.2.8.4

l.pist.t.10.61

(13m:30).3 
trecentos cippus in agrum hic dabat.

Eutrapelus cuicumque nocere volebat/vestimenta dabat pretiosa: dabimus. civitas omnis dabinusque divis/tura benignis.

dabis. hoc mibi iuris/cum venia dabis:

dabis aegrotare timenti.|Maecenas, veniam.

dabit. cui dabit partis scelus expiandi/fuppiter?

quem Fors dierum cumque dabit.

captatorque dabit risus Nasica Corano."

tabulas socero dabit atque| int legat orabit;

cui libet hic fascis dabit.

ludentis speciem dabit et torquebitur.

Caecilio Plautoque dabit Romanus ademptum/Vergilio Varioque?

dabitur. turdus| sive aliud privon dabitur tibi.

dabiturque licentia sumpta pudenter.

dabunt. nee dabunt, quamvis redeant in aurum / tempora priscum.

Daci. occidit Daci Cotisonis agmen.

Dacis. numquid de Dacis auditi?"

Dacus. te Dacus asper, te profugi Scythae . . . metuont qui dissimulat metum| Marsae cohortis Dacus paene. . . delevit Vibem Dacus et Aethiops.

Daedalea. ceratis ope Daedalea/nititur pennis

Daedaleo. iam Daedaleo notior Icaro|visam gementis litora Bospori

Daedalus. expertus vacuon Daedalus aera

Dalmatico. cui laurus aeternos honores | Delmatico [Dalmatico] peperit triunpho.

Dama. "ergo nunc Dana sodalis|nusquan est? prodis ex iudice Dama.

Damae. "tune, Syri, Damae aut Dionysi filius, andes 'utne tegam spurco Damae latus?

Damalin. omnes in Damalin putris/deponent oculos

Damalis. neu multi Damalis meri| Bassum Threicia vincat amystide nec Damalis novo| divelletur adultero

Damasippe. "di te. Damasippe, deaeque/verum ob consilium donent tonsore.

teneas. Damasippe, tuis te' -

Damasippi. integer est mentis Damasippi creditor? esto.

Damasippus. insanit veteres statuas Danasippus emendo:

dammae. et superiecto pavidae natarunt/aequore dammae.

damna. per damna, per caedis ab ipso/ducit opes animumque ferro. . damna tamen celeres reparant caelestia lunae:

damnabis. sceleris damnabis eundern

damnatam. mihi|castaeque damnatum [damnatam] Minervae/cum populo et duce fraudulento.

damnati. ni sic fecissent, gladiatorum dare centum|damnati populo paria.

damnatum. mihi|castaeque damnatum Minervae.

damnatus. damnatusque longi|Sisyphus Aeolides laboris.

damnis, uti mox nulla fides damnis verisque doloribus adsit.

damnis. offensus damnis media de nocte caballum|arripit

damno. daret quantum satis esset nec sibi damno/dedecorique foret.

damno. grandes rhombi patinaeque grande ferunt una cum damno dedecus.

damnosa. damnosa quid non inminuit dies?

quem damnosa venus, quem praeceps alea nudat.

per quae crescere res posset. minui damnosa libido.

damnose. "nos nisi damnose bibimus, morienur inulti,"

damnum. dannum est, non facinus, nihi pacto lenius isto. .

damnum. flagitio additis damnum:

'Stoice, post damnum sic vendas omnia pluris.

certius accipiet damnum propiusve medullis

damus. illi "tardo" cognomen, "pingui' damus.

cum tibi librum! sollicito danus aut fesso;

scimus, et hanc veniam petinusque danusque vicissim;

Danaen. inclusam Danaen turris aeneal rubustaerue fores. . munierant satis

Danai. Cocytos errans et Danai genus'infame dum grato Danai puellas carmine nulces.

danda. "danda est ellebori multo pars maxima av"aris:

dandus. mobilibusque decor naturis dandus et annis.

dant. dant alios Furiae torvo spectacula Marti. ut puetis olin dant crustula blandi doctores.
Sirm.1.8.13

Epist.1.18.32

Corm.4.2.5I

Serm.I.4.105

Epist.1.7.4

Carm.1.2.29

Carm.1.9.14

Serm.2.5.57

Sirm.2.5.06

Epist.1.6.53

Epist.2.2.124

Ars Port.54

Serm.2.5.II

Ars Poet.51

Carm.4.2.39

Carm.3.8.1 8

Serm.2.6.53

Carm.1.35.9

Carm.2.20.18

Carm.3.6.1.4

Carm.4.2.2

Carm.2.20.13

Carm-1.3.34

sar.Carm.2.1.I6

Serm.2.5.101

Serm.2.7.54

Sirm.1.6.38

Serm.2.5.1 8

Carm.1.36.17

Carm.1.36.13

Carm.1.36.18

Sirm.2.3.16

Sirm.2.3.324

Serm.2.3.65

Serm.2.3.6.4

Carm.1.2.12

Carm.4.4.59

Carm.4.7.13

Serm.2.3.279

coni.Carm.3.3.23

Serm.2.3.86

Carm.3.3.23

Corm.2.14.19

Epist.1.17.57

Epist.I.7.88

Serm.1.2.52

Serm.2.2.96

Carm.3.0.45

Epist.1.18.21

Epist.2.1.107

Serm.2.8.34

Epist.1.16.56

Carm.3.5.27

Sirm.2.3.300

Epist.1.10.28

Sirm.1.3.58

Epist.2.1.221

Ars l'oet. I I

Carm.3.I6.I

Carm.2.I.4.18

Carm.3.11.23

Serm.2.3.82

Ars Poet.15\%

Carm.1.28.I7

Serm.1.I.25 


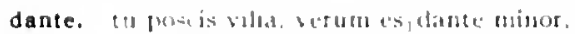

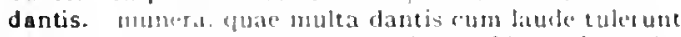

lipist.1.17.22

dantur. fluent ilipescenti non dentur [dantut] pocula.

Lpist.2.1.2.16

sir.serm.2.8.82

Danuvium. "fui profumum Danuvium bibunt

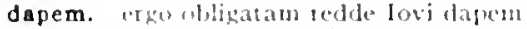

dapes. non siculae dajes dulcen elabonabunt suporem.

dapes. dapes intomptis adparet:

an malles' (andia tractavit dopere?

reprositum caecubum ad festian diapes

continuatque dapes nec non verniliter ipsisifungitur officiis.

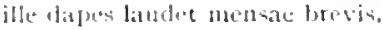

dapibus. "decus thothi de dapibus supremi graca testudo lovia.

dapibus. Saliublus or nare pulvinar leorum/tempus erat dapibus, vermacye procacis pasco libatis dapibus.

dapis. egit amor dapis alefue pugrae;

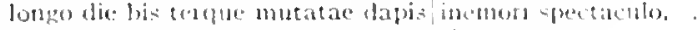
engena renignae Tantalus senuper dapis.

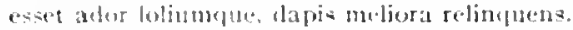

haberet plus dapis ot rixale multo ninus inviliaeque.

Dardanae, fuintia moves fumcra l)ardanae|genti. .

Dardanas. Dartanats tursis quaterce tremenda / cuspide pugnax-

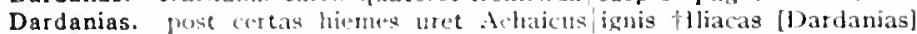
domes.:

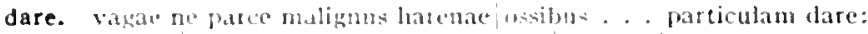

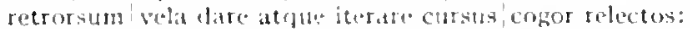

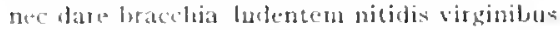

timplatieruce pessit Roma ferox date iura Medis.

miserarunt rest nupue amori dare Jutum

nec. si plura velim, tu clate deneges.

non feret alsifuas potiorj te dare noctues

net conver a fomum pigeat date lintea.

inopi dare nolit atuico.

an ut igrutum dare nobis verba putas?"

gladiatorum dare centum/damati populo paria

inmane est vitium ditre milia terma macello

et Tyrias date dircum inluta toralia vestis.

si vitus hoc una putest dare.

fons etian tho dare nomen idonews.

habrotomum aegro' non audet nisi qui didicit date.

non fumum ex fulgore, sed ex fumo date lucem/cogitat.

concubitu prohiberte vago, dare iura maritis.

parum clati-lucem dare coget,

darem. ne parva Tyertenum per atequor vela darem.

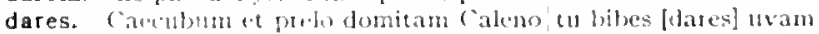

daret. Haret ut catris fittile momstram.

datet quantum satis esect nec sibi damno dedecorlune foret.

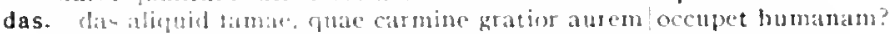

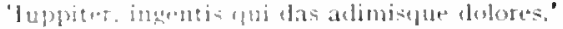

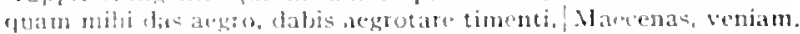

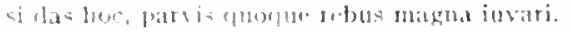

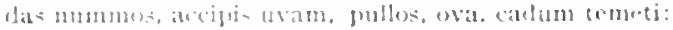

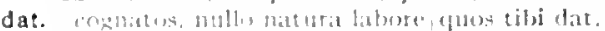

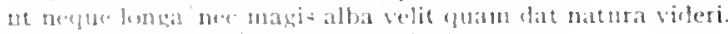

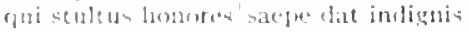

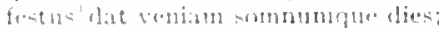

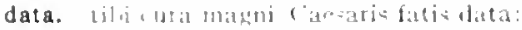

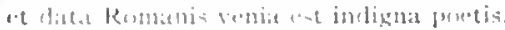

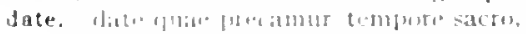

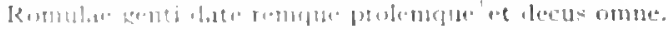

go-pmen-18me etater.

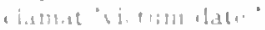

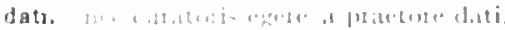

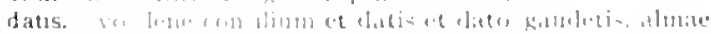

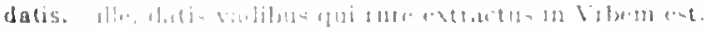

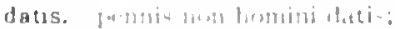

dats. glaud :

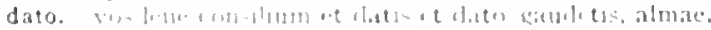

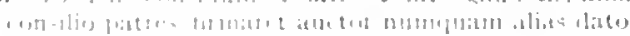

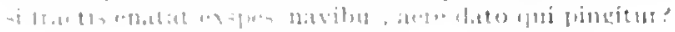

Cirm.1 15.21

Curm.2.7.17

Carm.3.1.19

lipod.2..48

lipori.3.8

Epod.9.1

firm.2.0.108

Ars l'oct. 108

Carm.1.32.13

Corm.1.37..4

Serm.2.0.07

Curm.4.412

Esod.5.33

Ispod. 17.00

tierm.2.6.89

Lisist.1 I 7.51

Citrm.1.15.80

Carm.6.7

tar.Curm.1.15.36

Cirrt.1.28.25

Curm.1.34.4

Corm.2,12,18

Cism-3.3.4.4

Curm. 3.12 .1

Carm.3.10.38

lipol.15.1.3

lisold 10.27

Sierm.1.2.5

Serm 1.3 .22

Serm.2.3.85

Serm.2.4.70

Serm.2..1.8.1

Eipist.1.6.30

lipist.1.16.12

Epist.2.2115

Ars Pnct.143

Ars loet 398

Ars Poct.4.49

Carm..4.15..4

coni. Cirm. I.20.10

C"irm.1.37.20

Sorm.1.2.52

Serm.2.2.0.1

Sirm. 2.3288

leptid.1.7.4

lipist.2.1.125

F.pist.2.2.112

Sirm.1.80

ferm.1.2.124

serm.1.10

Lipist.t.5.80

Cism.1.12.51

Ars P'ort. 29,4

Cirm siber 3

(iormataredi

l.pel. 7.1 .1

Epist.1.17..48

fepiot 1.1.10'3

(atrmatid 19

hirm. 1. I I

corm 8.3.35

I. pisil 2.2.102

(iarm.3.1.14

(ivm 3.5.2p)

irs lod al 


\section{DATVM}

datum. narrat paene datum Pelea Tartaro.

datum. unile datum sentis, lupus lic Tiberinus an altolcaptus biet?

datur. quorum piis secunda vate me datur fuga. ubi quid datur oti,|inludo chartis. est quadam prodire tenus, si non datur ultra. si (c) quia perpetuos nulli datur usus

daturas. ut indel manis elicerent animas responsa daturas. cum segetes occat tibi mox frumenta daturus [daturas].

daturos. tulit hos nequiores, mox daturos|progeniem vitiosiorem.

daturus. nititur pennis vitreo daturus nomina ponto. liberum munivit iter. daturus|plura relictis: militibus promissa Triquetra| praedia Caesaran est 1 tala tellure daturus?" cum segetes oceat tibi mox frumenta daturus,

datus. datus in theatrolcum tibi plausus.

Dauni. qui regna Dauni praefuit Apuli.

Dauniae. Dauniae defende decus Camenae.

Dauniae. quod mare Dauniae/ non decoloravere caedes?

Daunias. neque militaris/Daunias latis alit aesculetis

Daunus. qua pauper aquae Daunus agrestium/regnavit populorum.

Davo. arglla meretrice potes Davoque Chremetaleludente sentem comis garrire libellos

Davom. te coniunx aliena capit, meretricula Davom:

Davos. 1).17os sis comicus atque/stes capite obstipo,

'Davosne?" 'ita: Davoz, anucum|mancipium domino nequam et cessator Davos;

ut nihil intersit. Darosne loquatur et audax Pythias.

Davus. intererit multum, divosne [Davusne] loquatur an heros.

\section{DECEDENS}

Carm.3.7.17

Sirm.2.2.31

lipod. 10.00

Serm.s.4. 33

Epist.1.1.32

Epist.2.2.175

Som.1.8.20

zar.Epist.2.2.161

Carm.3.0.47

Corm.4.2.3

Carm.Saer.43

Serm.2.0.50

Epist.2.2.10I

Corm.1.20.3

Cirm.4.14.26

Curm.4.6.27

Carm.2.1.3.

Carm.1.22.14

Corm.3 30.11

Sirmit.10.4n

Sirm:2.7.40

Sirm.2.5.91

Serm.2.7.2

Serm.2.7.100

Ars Joet.237

ver. Ars Pest.114

de. Carm.I.I.10; 1 I.20;1.31.2; 1.35.2;2.3.23;2.4.17;2.7.23;2.13.25;3.0.24; 3.1 1.33; 4.7.21; Epod.2.55; 13.4; Serm.1.1.13; 1.1.55; 1.1.69; 1.4.94; 1.4.102; 1.5.28; 1.6.30; 1.10.55; yar.Serm.2.2.116; Sirm.2.3.49; 2.3.238; 2.5.82; 2.6.36; 2.6.53; 2.0.71; 2.6.10.4; 2.8.3; Simm.2.8.40; 2.8.81; Epist.1.1.105; 1.2.32; 1.4.16; 1.7.88; 1.14.7; 1.14.34; 1.10.19; Epist.1.10.55; 1.17.43; 1.I8.15; 1.18.68; zor.Epist.1.18.91;Epist.2.1.245; 2.2.55; 2.2.191; Epist.2.2.212; Ars Port.243;257;327;337

dea. "invicte, nortalis dea nate puer Thetide.

deae. Deliae tutela deae.

deae. indicat uvida|suspendisse potenti/vestinenta maris deo [deat].

deae. "di te, Damasippe, deacque/verum ob consilinm donent tonsore.

debacchentur, qua parte debacebentur ignes. .

debeas. quirl debeas, o Roma, Neronibus,

debeat. qui dilicit, patriae quid debeat et quid amicis,

debebat. casu tum respondere vadato/debebat.

debellata. Centaurea monet cum lapithis rixa super nero/debellata,

debemur. debemur morti nos nostraque:

debemus. sic nos debemus amici|siquod sit vitium non fastidire: debemur [debemus] morti nos nostraque:

debent. tectum/praebuit et parochi, quae debent, ligna salemqut.

debentia. ut iam nunc dicat iam nume debentia dici.

debentibus. diesque longa videtur opus debentibus.

debes. navis. quae tibi creditum|debes Vergilium;

tu. nisi ventis debes ludibrium. cave.

debes hoc etiam rescribere.

debet. scriptor... inter|perfectos veteresque referti debct

debetur. laus illi debetur et a me gratia maior.

debilitat. quae nunc oppositis debilitat pumicibus mare/Tyrrhenum:

debita. ibi tu calentem/debita sparges lacrima favillam vat is amici.

debita. fors et debita iura vicesque superbae/te maneant ipsum:

debitae. debitae Nymphis opifex coronat

debito. fidibus iuvat|placare et vituli sanguine debito

debitor. acerbus olisti et fugis ut Rusonem debitor ateris.

decantata. nenia. . . et maribus Curiis et decantata Camillis:

decantes. neu miserabilis! decantes elegos.

deceat. tu civitatem quis deceat status/curas quid deceat, quid non, obliti.

quo tandem pacto deceat naioribus uti,

quid deceat, quid non, nuo vittus, quo ferat crror.

decebit. quod pingui miscare mero muriaque decelsit mirabor, vitac via si conversa decehit.

decede, vivere si recte nescis, decede puritis.

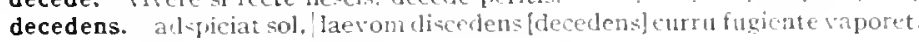

Epod.13.12

Cirm.4.6.33

comi.Carm.1.5.16

Sierm.2.3. In

Corm.3.3.55

Carm.7.4.37

Ars I'sel. 3 I 2

Strm.1.9.37

(armi.1.15.9

- Los Pod.03

Serm.1.3.43

velr.Ars Potdo3

Sermil 5.40

Ars Poet. 43

Epist.1.1.2工

Corm.1.3.6

Carm.1.14

Inpist.1.3.30

Epist.2.1.37

Serm.1.0.88

Carm.t.11.5

Cirm.2.6.23

(itrm.1.28.32

cinm.3.27.30

Carm.1.30.2

virm.I.3.so

Epist.1.0.

(iarm.1.33.3

("a)m.3.29.25

Ispist. 1.6.02

Epist 1.17.2

1rs 1'oct.308

Sirm.2.4.t.5

Epist.1.17.26

lipist 2.2.213

comi.Jpirt.I.I0.7 


\section{DECEDENTIA}

decedentia. Aroulentia certis empora momencis

decedere. cui'rem di lonarent, illi decedere pravam/stultitiam:

decedet. el decedet odor nervis inimicus:

decedit. neque decodit aerata triremi . . atra Cura.

decedite. hine vos t vos hinc mutatis discedite [decerlite] partibus.

decedunt. ubi non llymetto mellat decedunt

nec tibi vespero surgente decedunt amolea

decem. circa lustra efecem flectere mollibus ian durum imperiis:

te decem tallsi totidemque vaccae,

gundecim [unin decem] Diana preces virorum/curat

habebat saeje ducentos, f saepe decem servos:

scribu drem a Nerio: non est sati-;

dives amichs, sinpe decen vitis instructior, odit et horret.

December. Hic tertius Decenber, ex quo destiti|juachia furere.

Decembres. cum tibi nonae redenut Decembres.

decembri. libertate tecembri. quando ita maiores voluerunt, utere:

decembris, mr quater undenos sciat inplevisse decembris.

decempedis. nullia thecempedis/metata privatis opacam/porticus cxcipiehat arctorn

decens. nampute et mobilis et decens. . linte signa letet

quove color, decens quo motus?

decens. quis non te potius, Bacthe pater, tequa, decens lenus?

decens. quil verum atque decens, curoet rogo et omnis in hoc sum:

decent. non citłarae decent

parvom parva decent

tristia maestun voltum verba decent.

decentem. singula gurbelue locum teneant sortita decenter [decenteni].

decenter. singula quateque locum teneant sortita decenter.

decentes. Ciatiae decentes alternoteram quatiunt pede.

decentis. anter[uan turpis mates decentisiocupet malas

decentius. It' potum latgius atquo rideat et pulset lasciva decentius aetas.

decepta. ut buna pars hominum decepta cupidine falso

deceptum. hat magi illan inparibus tormis deceptum be petere esto:

deceptus. Villins in Fatusta syllae gener. boc miser uno nomine deceptus. juenas dedit

quem sua culpa premet, decoptus omitte tueri.

decerpens. ut gaudet insitiva decerpens pira

decerpere. Hodalaris plus hantire mali est quam ox re decerpere fructus. decerptae. undique decerptan fronti [decerjtae fsondi] praeponere olivam: decerptam. undique decerptam tronti praxponere olivam;

decertantem. nec timuit pracipitem Afticum decertantem Aquilonibus

decessit. si paulum summo deressit, vergit ad imum

decet. nume decet ant virili nitidum caput impedire mysto.

nuncet in umbrosis jiauno decet immolate lucis.

terjut thasplue ricect sorotes.

non. siquirs Pholoen, satis'et te. Chori. decert: .

decet qual firste non mollis viros?

dunifue sirent gatmulal et decet.

quoniam varuis committere venis, nil nisi lene decet:

arta doct sanum comitom toga;

deciderint. et, "fuat" nunc uneris involitant, deciderint comae.

decidimus. nos 11 lo deridimus quo pills Armeas,

decidit. fugiens lic: decistic actern pratonum in turbam.

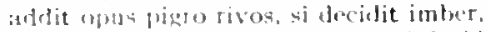

scriptor ablume innos centun qui decidit.

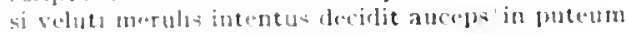

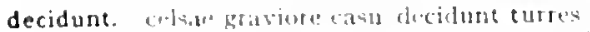

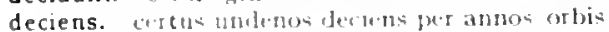

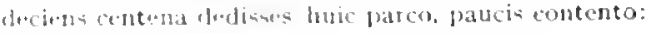

sman tibs rlowns;

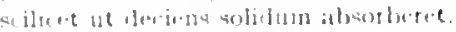

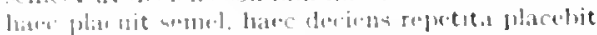

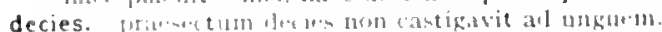

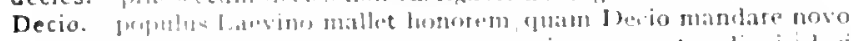

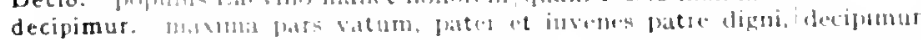

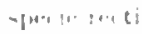

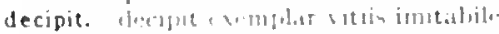

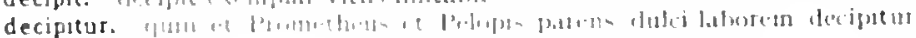
tinlas
DECIPIT VR

Epist.1.6.3

Epist.2.2.152

Serm. 2.+53

Carm.3.1.39

coni.Serm.1.1.18

Corm.2.6.15

Carm.2.9.11

Curm.4.1.6

Carm.4.2.53

tar.Carm.Saec.70

Serm.1.3.12

Serm.2.3.69

lipist.1.18.25

I.pod.1 1.5

Cirm.3.18.10

Serm.2.7.4

Itpist.1.20.27

Cirm.2.15.14

Carm.4.1.13

Corm.1.13.17

Corm.1.18.6

Epist.1.1.1 I

Carm.3.15.14

I.pist. T.7. +4

Ars Pod. 106

tar.Ars Poot.92

Ars Poct. 92

Corm.1.4.8

Curm.3.27.53

Iipist 2.2.216

Sirm.1.1.61

Sirm.2.2.3

Serm.1.2.65

I:pist.1.18.79

Epod. 2.19

Serm.1.2.79

coniciarm.1.7.7

Curm.1.7.7

Carm.1.3.13

Ars Poet. 378

Corm.1.49

Corm.1.4.11

Carm.1.26.1 2

Curm.3.15.8

Epoll.

IEpod.13.5

Sirm.2.420

Epist.1.18.30

Carm.t.10.3

Corm.4.7.14

Sorm.1.2.42

Epist.1.1+20

Epist.2.1.36

Ars Poet. 458

(arm.2.10.1)

Carm.suci.21

Serm.3.3.15

Serm.2.32.37

Serm 2.3.240

Ars Ponel.zes

. Irs lood 291

Serm 1020

Ars Poed 25

lipist 10.17

(iurm 2.13.38 
decipiunt. amatoren quod anicac|turpia decipiunt caecum vitia

decisa. ludis et post decisa negotia Campo.

decisis. decisis humilem pennis inopemque paterni/et laris et fundi,

declamas. dum tu declamas Romae. Praeneste relegi;

declinat. Cyrus in asperam/declinat Pholoen:

declive. nec semper . Aefulac/declive contempleris arvom

decoloravere. quod mare Dauniae|non decoloravere caedes?

decoqueretur. donec/ decoqueretur holus.

decor. fugit retro levis iuventas et decor

mobilibusque decor naturis dandus et annis.

decora. ne si facies, ut saepe, decora $\mid$ molli fulta pede est, emptorem inducat hiantem.

decora. introrsum turpem, speciosum pelle decora.

decorae. voce formast i catus et decorae/more palaestrae,

decorae. et soror clari ducis et decorae/supplice vitta/virginum matres

decoram. vocantis/ture te multo Glycerae decoram transier in acdem.

decorare. deorum templa novo decorare saxo.

decorari. nec prave factis decorari versibus opto, .

decorat. ac bene nummatum decorat Suadela Venusque.

dum ficus prima calorque dissignatorem decorat lictoribus atris.

decorent. an te generum beati|Phyllidis flavac decorent parentes:

decori. otium Medi pharetra decori.

decoris. verbisque decoris obvolvas vitium?" .

decoro. cur facunda parum decorolinter verbacadit lingua silentio?

decoros. quandoque trahet ferocis per sacrum clivom merita decorus [decorus]'fronde Sygambros;

decorum. dulce et decorum est pro patria mori:

inter quae verbum emicuit si forte decorum

decorum. te lycum nigris oculis nigroque/crine decorum.

te vidit insons Cerberus aureo cornu decorum

decorum. vel cum decorum mitihus pomis caput / Autumnus agris extulit, vaga Luna decorum / protulit os.

decorum. reddes dulce loqui, reddes ridere decornm

decorus. per sacrum clivom merita decorus|fronde augur et fulgente decorus arcu Phoebus

decrescentia. decrescentia ripas flumina praetereunt;

decreta. patrumque|prosperes decreta super iugandis|feminis

decuere. quem tenues decuere togae nitidique capilli,

decuit. omnis Aristippum decuit color et status et res. .

decurrens. monte decurrens velut amnis.

neque, si male cesserat, usfuan decurrens alio neque, si bene:

decurrens. ab agro rava decurrens lupa Lanuvino

decurrere. at miseras preces/decurrere

bic ubi saepe occultum visus decurtere piscis ad hamum,

decus. virtus, fama, decus, divina humanaque pulcris / divitis parent ; ac bene nummatum decorat [? decus] Suadela V'enusque.

decus. egregii Caesaris audiar|aeternum meditans decus/stellis inserere

Danniat defende decus Camenae.

optatum peractis/imperiis decus adrogavit.

Romulae genti date remque prolemgauelet decus omne.

per hoc inane purpurae das precor.

aut decus et pretinm recte petit experiens vir.

nec minimum mefuere decus vestigia Cracca' ausi descrere

decus. o et praesidium th inlee decus meum:

o decus Mhoebi et dapibus suptemi grata testudo Iovis.

Maecenaz, mearum grande decus columemule rerum.

Maecenas, equnitum decus.

Phoebe silvarumque potens Diana, / heidum cacli decus.

decutit. his tertim Jocember. silvis honorem decutit.

dedat. siquis infamem mibi num iuvencum? dedat iratae.

dedecet. neque te ministrum, dedecet ingrtus

dedecorant. ntcumque defecere mores, inclecorant [dedecorant] bene nata culpac

at neque dedrcorant tua de se iudicia.

dedecori. nec sibi damno'dedecorique foret.

dedecorum. dedecorum pretiosus emptor.

dedecuit. quam nec ferre pedem dedecuit choris

dedecus. ebrius et. magnum quad dedecus, ambulet antel noctem cum facibus.
Serm.1.3.39

Epist.1.7.59

Epist.2.2.50

Expist.1.2.2

Carm.1.33.7

Carm.3.29.7

Carm.2.1.35

Serm.2.1.74

Carm.2.I I 6

Ars Poit.157

Serm.1.2.87

Epist.1.16.45

Carm.1.IO.3

Carm.3.1.7.7

Carm.1.30.3

Carm.2.15.20

Epist.2.1.200

Epist.1.6.38

Epist.1.7.6

Carm.2.4.14

Carm.2.10.6

Serm.2.7.4I

Carm.4.I.35

var.Carm.4.2.35

Carm.3.2.13

Epist.2.I.73

Carm.1.32.12

Carm.2.19.30

Epod.2.I 7

Serm. I.8.21

Epist.1.7.27

Carm.4.2.35

Carm.tidecon

Curm.4.7.3

Carm.Saec. Is

Epist.t.I4.32

Epist.I.I7.23

Curm.4.2.5

Serm.2.1.32

Carm.3.27.3

Carm.3.29.59

Epist.1.7.7.

Serm.2.3.95

7 zar. Epist. I.6.38

Carm.3.25.5

Cirm.4.6.27

Carm.4.17.40

Carm.Soéc.48

E.pod.5.7

Epist.I.I 7.42

Ars Poet.286

Carm.I.1.2

Carm.1.32.13

Carm.2.17.4

Carm.3.10.20

Carmsace.

liporl I I.6

Carm.3.27.46

Carm.1.38.7

Frar. Carm.4.4.36

Epist.2.I.2.45

Sirm.1.2.53

Carm.3.n.32

Carm.2.12.17

Serm.1.4.51 


\section{DEDECVS}

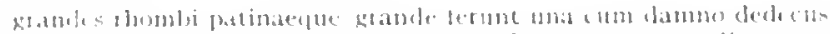

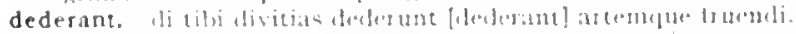

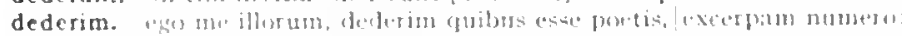

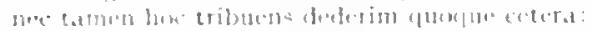

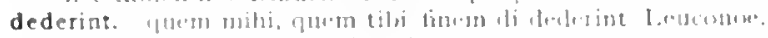

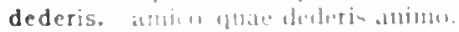

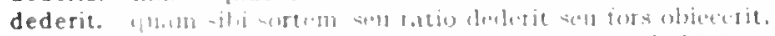

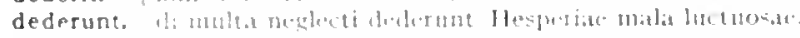

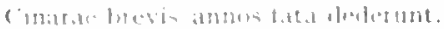

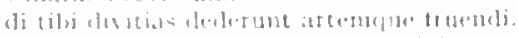

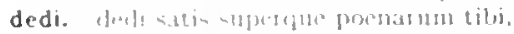

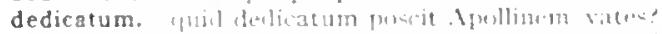

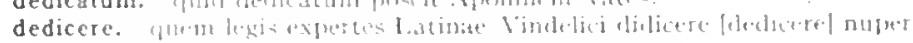

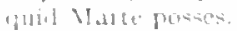

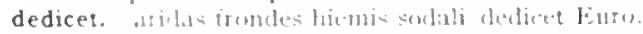

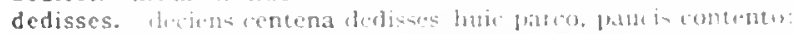

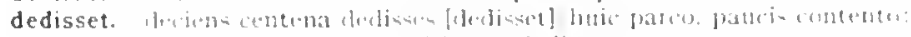

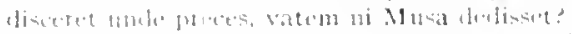

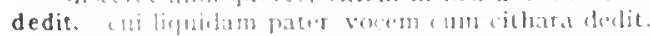

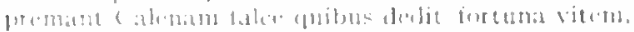

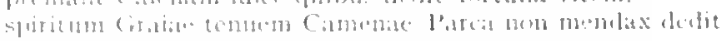

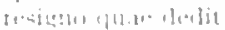

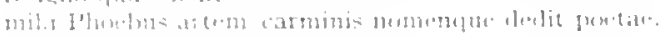

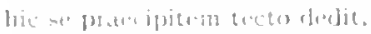

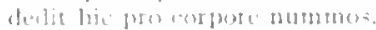

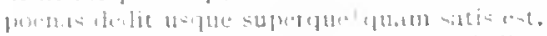

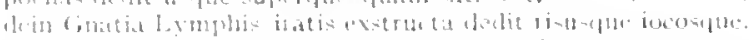

nil sige magnos vita Iabore detlit mentalibus."

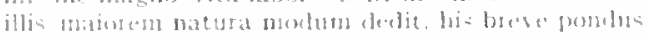

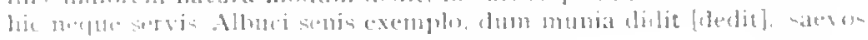
$1 \mathrm{int}$

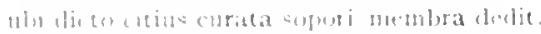

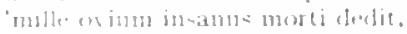

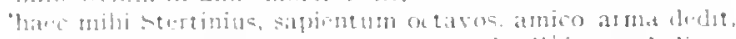

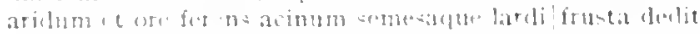

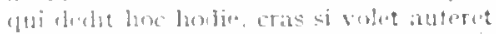

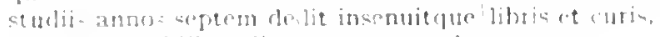

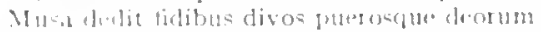

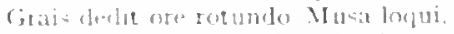

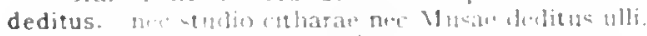

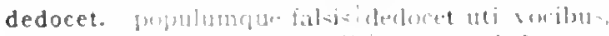

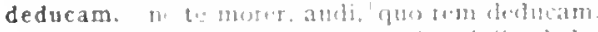

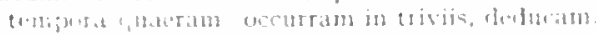

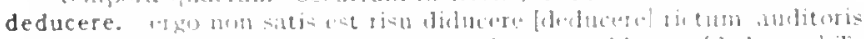

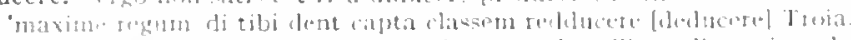

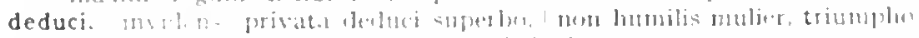

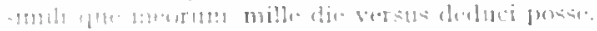

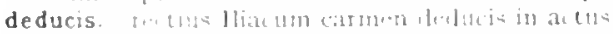

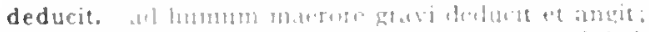

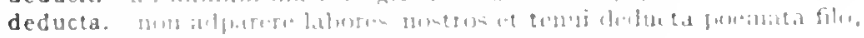

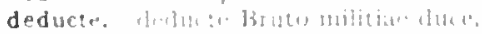

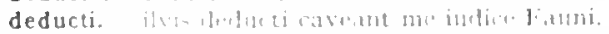

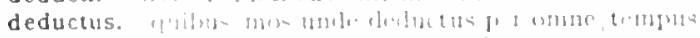

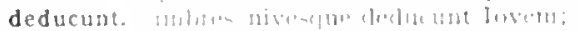

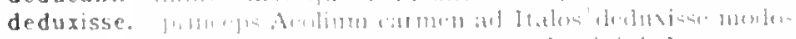

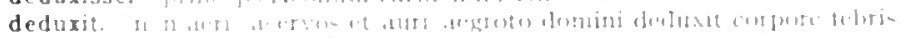

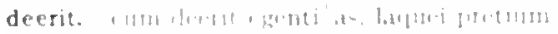

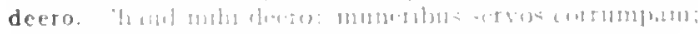

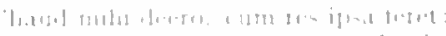

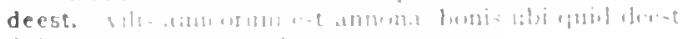

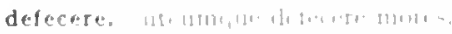

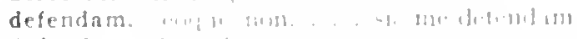

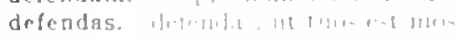

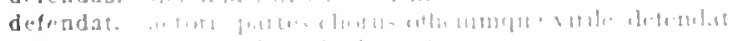

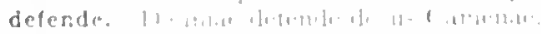

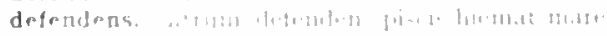

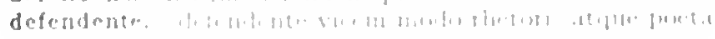

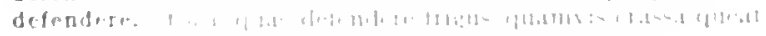

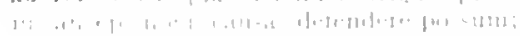

\section{DEFENDERE}

$\operatorname{Serm} 2.2 .96$

ist Jist.1.

S.rm.1.4.39

Serm.1.10.5

(eirm,1.11.2

(urm 4720

trom 1.1.2

(iorm. 30.7

(ism.9 1.3.23

l.pixt.1.t.7

Epolel it. I0)

(irm. J.3

iar (idrm. 14.8

cirm 1.25 .20

sirm.1.3.15

iedr.cerm.1.3.15

l.pist.2.1.133

(c)m 1.2.14

(armatis)

(ustr. $=2(1.31)$

(itrm.3.21).5.

(iurmeter. on

Sirm : 2.41

herm. 1.2.43

trm: 20.5

serm.1.5.08

Germis 1 g.eno

serm:2 237

in S.rm:2, 2,

Gits $22 \mathrm{SI}$

Serm 2.3.107

Serm 23207

Sirm. 2 tose

Ipite.1.14.3.3

tepid $2.2 \times 2$

irs Fivet 83

irs llore sz?

tirui.2 3.105

(itrm.2220

virmidis

verm.1 1).51)

iir vermi. 10.7

ar Sirm 23 101

(a)m 137.31

serm.2.1.4

is lint(20)

1, Pirt.110

$1 ; 3121.225$

(i) m. 2. . 2

Ar: Mot.24t

(ivr): \$ +10)

ifoll $3=$

(is) 3430.1 :

l.pil 1 a. an

sermez zas

virmi.1.0.5

s,re: $=115$

1 pret.12:

cillm: 4 s

Trm: 10.00

S,en: 1805

1, Inint in:

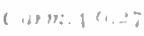

$\checkmark m: 21=$

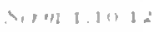

>n+mis 13

Trn: $=$ is 
si defendere delictum quam vertere malles.

defendis. aut quia non firmus rectun defendis

defendit. Lucretilem|mutat Lycaeo Fanms et igneam/defendit aestatem capellis

quas et benigno numine Iuppiter|defendit

absentem qui rodit. anicum qui non defendit alio culpante.

defensor. illius esto defensor;

defensore. *Lucili, quam sis mendosus, teste Catone | defensore tuo

defer. siquid petet, ultroldefer:

deferar. ne... deferar in vicum vendentem tus et odures

deferens. regnum et diadema tutum/deferens uni propriamque laurum

deferor. quo me cumque rapit tempestas, deferor bospes.

deficiant. 'deficient [deficiant] inopem venae te, ni cibus atque ingens accedit stomacho fultura ruenti.

deficient. 'deficient inopem venae te.

deficiente. et mundus victus non deficiente crumina?

deficit. animus si te non deficit aequos.

deficiunt. 'cupidum, pater optime, vires/deficiunt:

cum res deficiunt, satis inter vilia fortis:

sectantem levia nervi|deficiunt animique;

defindit. turgidus Alpinus iugulat dum Nemnona dunrue | diffingit [defindit] Rheni luteum caput,

defingas. o utinam nova incude diffingas [defingas] retusum in Massagetas Arabasque ferrum.

defingit. turgidus Alpinus iugulat dum Nemnona dumque diffingit [defingit] Rheni luteum caput.

defit. sed quod non desit [defit] habentem/quae poterunt unquam satis expurgare cicutae.

defixa. per atque libros carminum valentium refixa [defixa] caelo devocare sidera.

defixis. si. . . defixis oculis animoque et corpore torpet? .

defluat. multaque merces/unde potest tibi detiuat aequo|ah, love

antequan turpis macies decentif | occupet malas teneraeque sucus detluat praedae.

Iusticus expeetat, dum detluat amnis;

defluet. antequan turpis macies decentis occupet malas temeraeque sucus detiuat [detuet] praedae,

defluit. defluit saxis agitatus umor.

teneraeque sucus|dethuat [defluit] praedae.

rideri possit eo quod rusticius tonso toga defluit

defluxit. sic horridus illeldefluxit nunerus Saturnius

defodiet. in apricun. proferet aetas, deforiet condetque nitentia.

deformis. deformis aegrimoniae duleibus adloquiis."

defossa. furtim defosta timidum deponere terra?

defricuit. quod sale multo V'rbem defricuit.

defudit. aurea fruges I taliae pleno defudit Copia cornu.

defuisse. non defuisse masculae libidinis Ariminensen Foliam

defuncta. quae terris semota suisquel temporibus defuncta videt.

defunctum. defunctumque laboribus aequali recreat sorte vicarius. nunc arma defunctumque bello barbiton hic paries habebit,

defundere. ac nisi mutatum parcit defundere vimum

defundit. aurea frugus/Italiae pleno defudit [defundit] Copia cornu.

defuso. te pros quitur mero/detuso pateris

degere. nec turpem senectam degere nee cithara carentem.

deget. ille potens sui|laetusque deget

dehinc. aere. delninc ferro duravit saecula,

donec verla. ... nominarte inverere; dehine absistere bello.

dein [dehine] Gnatia Lymphis iratis txstructa dedit risusque iocosfute.

ut speciosa deline miracula promat.

dei. dein [dei] Grutia Lymphis iratis exstructa dedit risusque jocosque. an custos famulusque dei Silenus alumni.

deicere. andes deicere de saxo civis aut tralere Cadmo?"

deiecerit. 'qui scis, an prudens huc s. leiecerit

deiecit. Drusus. . arcis|Alpibus inporitas trentendis/defecit

conminxit lectum potus mensare tatilum Euandri manibus tricum deiecit :

praesidium regale loco dejecit, ut aiunt,

deiectum. ire deiectum monumenta regis umplaque lestae.
Ars Tot.142

Serm.2.7.26

Carm.1.17.3

Carm.4.4.75

Serm.1.4.82

Serm.2.5.30

Serm.1.10.*2

Epist.1.12.23

Epist.2.1.260

Carm.2.2.22

Epist.I.1.15

fur.Serm.2.3. I 53

Serm.2.3.153

Epist.1.t.II

Epist.1.11.30

Serm.2.1.13

Epist.1.15.39

Lis Poit.27

2*1 . Serm.1.10.37

far. Carm.1.35.39

:ar.Serm.1.10.37

(1) II.Lpist.2.2.52

Aar. Epod.17.5

Apist.1.1. 1

Carm.r.28.28

Carm.3.27.55

Epist.1.2.42

2ar.Carm.3.27.55

Carm.I.I 2.29

vur.Carm-3.27.55

Serm.1.3.31

Epist.2.1.15s

Epist.10.25

Epod.13.Is

Serm.I.I. 12

Sirmido.t

Epist.1.12.29

Epod.5.4I

Epist.2.1.22

Carm.3.24.I5

Carm.3.20.3

Sirm.2.2.58

Far.Epist 1.12 .29

Carm.4.5.3.t

Carm.1.31.20

Carm.3.29.42

Epod.10.05

firm.1.3.104

iar.term. 1.5.97

Ars Puellat

Ftor sirm.1.5.97

Ars Perl.230

Serm.1.t.30

Ars Ioritos

Carmat-1.1.3

Serm.1.3.01

Epist.2.2.30

(iorm.1.2.15 


\section{DEIN}

dein. umguibus et pugnis, dein fustims atgue is potrol pugmabant armis

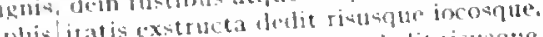

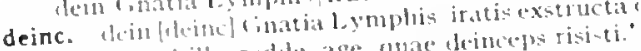

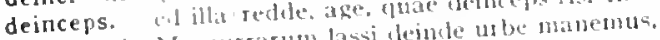

deinde. in Mamurfarum

d. inde (o) dormitum.

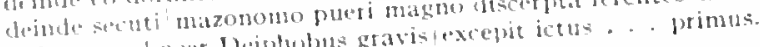

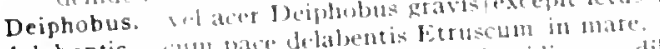

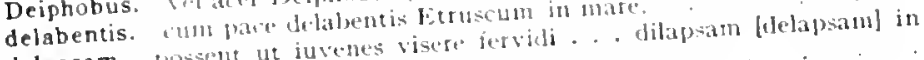

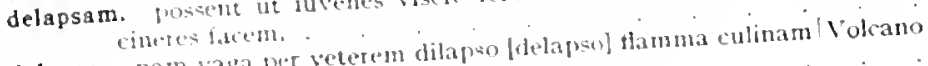

delapso. nam vaga per veterem dilapioldelaps smmmum poperabat lanbere tectunt

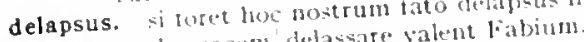

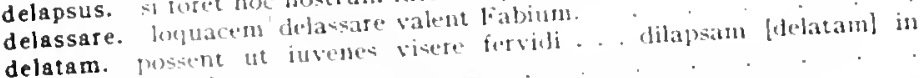$$
\text { cincres bacent. }
$$

delatis. beistus lamius ulto delatio capsen ad lunam delecta.

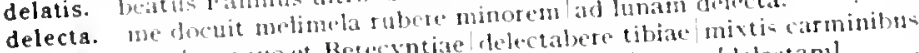
delectabere. Is raeplue at Besecrntise hele plebe dilectam [delectan].

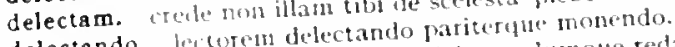

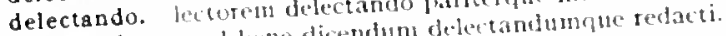

delectandum. ald lene dicendum detol saxa dolectant.

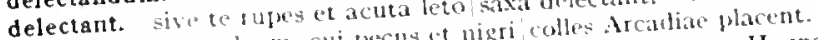

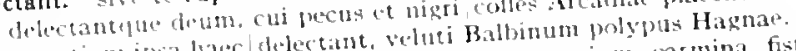

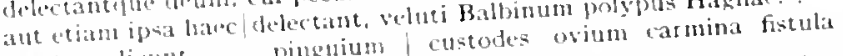

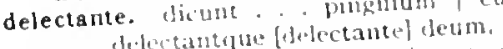

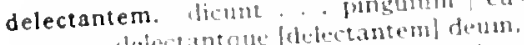

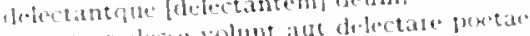

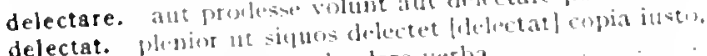

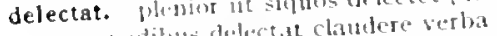

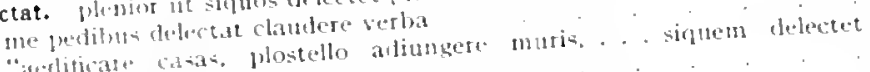

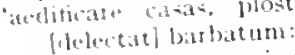

sive folernum to magis atperitis delectat:

(n)

delectatur. carmin. tu gatudes, hic dedectatur iambis.

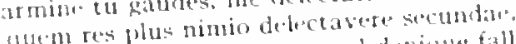

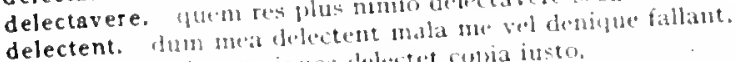

delectet. plention $11 \mathrm{t}$ siguos delectet consia iusto.

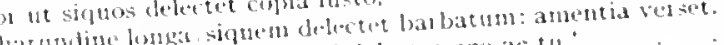

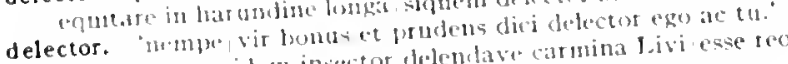

equilen insector telendave carmina l,ivi esse teor.

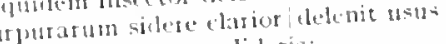

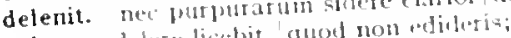

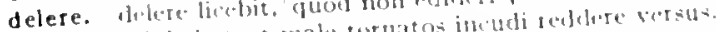

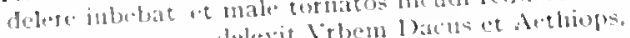

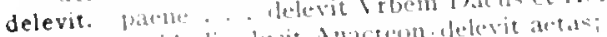

nece squnil olim lusit Amb

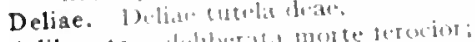

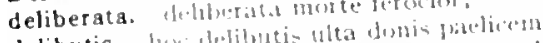

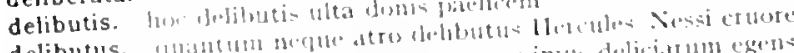

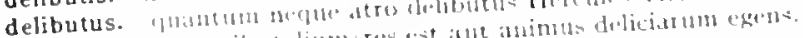

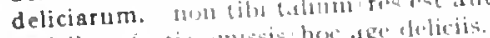

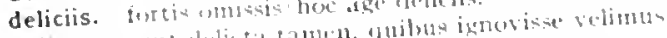

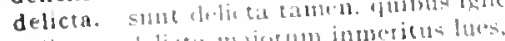

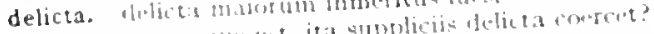

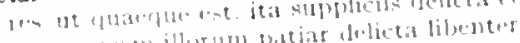

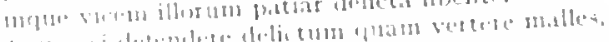

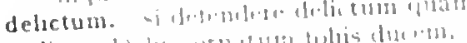

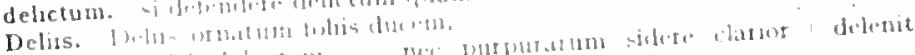

dehnte phent-i dedentem .

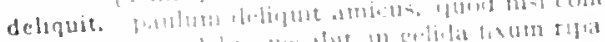

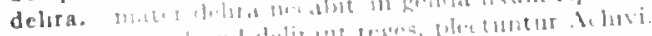

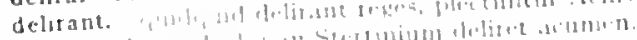

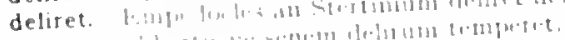

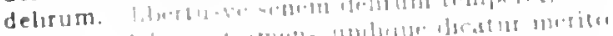

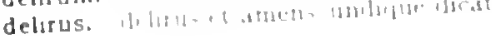

Serm.1.3.101

Serm. I. 5.07

:119.5ermi.1.5.97

sorm.2.8.80

serm.1.5.37

Sorm.1.6.119

Sicrm.2.8.85

Carm. 10.22

Carm.3.29.35

pur.Curm.t.13.28

a.s. Serm.1.5.73

Siem.1.10.08

serm.1.1.14

iur. Corm $\div 13.28$

Serm.1..4.22

Sirm.2.8.32

Cirm. 1.23

ar Corm.2.+18

Ars Joed.3.4

Epist.2.1.155

Carm.3.27.02

Carm.t.12.1

Serm.1.3.49

fus (orm +12.11

:ur.cism.4.12.18

Ars Poet 333

[1] Y. Serm 1.1 .57

serm.2.1.25

?187.5.4m.2.3.2.49

Serm.2.s.17

I.pist.1.17.7

Epist.2.2.59

Epist.t.10.30

Epist.2 2.127

S.TH.1.1.57

sierm.2.3.2.49

Eptst.1 10.32

Epist.2.100

Carm.3.1.43

Ars Puel. 380

irs Pottat"

Corm.3 0.14

Curm +0.10

(is rmat 0.3 .3

(arm 1.37 .29

lipond 3.1.3

I.pet.17.31

Carmats

Feptes.0.31

des Ieirb.3.t7

(a)m.3. 3

serm.1.3.70

serm.1.11 11

lers line 442

(itriti. I 3.1

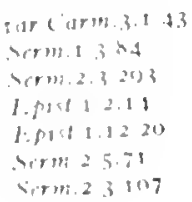


praetulerim scriptor delirus inersque videri.

Epist.2.2.126

delitigat. iratusque Chremes tumido delitigat ore;

Ars Poet.94

Delius. Delius et Patareus Apollo.

Delli. moriture Delli.|seu maestus omni tempore vixeris

Cirm.3.4.0.4

Delmatico. cui laurus aeternos honores/Delmatico peperit triumpho

Curm.2.3.4

Carm.2.1.16

Delon. ros Tempe totidem tollite laudibus | natalemque, mares, Delon Apollinis

Delphica. mihi Delphica/lauro cinge volens, Melponene, comam.

delphinum. delphinum silvis adpingit, fuctibus aprum.

Delphis. sortilegis non discrepuit sententia Delphis.

Delphos. vel Baccho Thebas vel Apolline Delplios insignis .

delubra. Vibem sibi curae.|imperium fore et Italiam, delubra deorum,

delubris. 'signa ego Punicis/adfixa delubris

deludet. plerumque recoctus|scriba ex quinqueviro corvom deludet hiantem dem. quid dem? quid non dem? renuis quod tu. iubet alter;

demas. ut, quantum generi denas, virtutibus addas;

deme. deme supercilio nubem:

demens. demens iudicio volgi, sanus fortasse tuo,

an tua demens/vilibus in ludis dictari carmina malis?

nec ferro ut demens genetricem occidis Orestes.

demens. caput abscissum demens cum portat Agaue/gnati infelicis,

dementem. audiat invidus|dementem strepitum Lycus ac non ante malis dementem actum Furis

dementia. et tu, potes nam, solve me dementia.

dementis. dun Capitolio|regina dementis ruinas.

demere. nec partem solido demere de die/spernit.

nam cur/quae laedunt oculum. festinas demere:

demeret. ilga demeret bubus fatigatis

demersa. concidit auguris/Argiw domus ob lucrum/demersa exitio; .

demeterent. accidit ut cuidam test is caudamque salacem demeterent ferro.

demeteret. accidit ut cuidam [quidam] testis caudamque salacem| demeterent [demeteret] ferro.

Demetri. Demetri, teque, Tigelli, | discipularum inter iubeo plorare cathedras.

'Demetri,' . . . 'abi, quaere et refer,

Demetrius. quod/vellicet absentem Demetrius

demisit. demisit hostem vividus impetus.

latum demisit pectore clavom.

quo te demisit peccati conscia erilis.

quo te demisit peccati conscia erilis [peccati conscia erilis demisit],

demissa. demissa tempestas ab Euro

ad talos stola demissa et circumdata palla,

demissa. nil cernere possis/cetera, ni Catia est, demissa veste tegentis.

demissa. segnius irritant animos demissa per aurem

demissis. Maltinus tunicis demissis ambulat;

demissum. iuvens Parthis horrendus, ab altoldemissum genus Aenea.

demissum. habentque Tartara Panthoiden iterum Orco|demissum.

demissus. probus quis nobiscum vivit, nultum demissus homo:

demittere. deos id/tristis ex alto caeli demittere tecto.

gestit enim nummum in loculos demittere.

si curet quis opem ferre et demittere funem:

demittit. demittit atras belua centiceps auris.

hue frequens caementa demittit redemptor

in triviis fixum cum se demittit ob assen.

demitto. demitto auriculas, ut iniquae mentis asıllus,

demo. pilos ut . . parlatin vello et demo unum, demo etiam unum.

Democriti. si Democriti pecus edit agellos/cultaque.

Democritus. si foret in terris, rideret Democritus, excludit sanos I Helicone poetas Democritus.

demoveas. Attalicis condicionibus numquan demoveas,

demaveat. cum te neque fervidus aestus/demoveat lucro

demovebit. hic dies anno redeunte festus | corticem adstricturn pice dimurebit [demovebit]|amphorae

demovet. curvo nec faciem litore dimovet [demovet]:

dempserit. illi quod tibi dempserit /adponet annus).

demptus. el demptus per vim mentis gratissinus error."

demum. quarta vix demum exponinur hora.

dena. accipit et bis dena super sestertia nummum.

Carm.1.21.10

Carm.3 30. 15

Ars Poet.30

Ars Poel.219

Carm.1.7.3

Serm.1.6.35

Corm.3.5.19

Serm.2.5.56

Epist.2.2.63

Epist.1.20.22

Epist.1.18.94

Serm.1.0.97

Serm.1.10.74

Sirm.2.3.133

Serm.2.3.303

Corm.3.19.23

Serm.2.3.135

Epod.17.45

Carm.1.37.7

Carm.1.1.20

Epist.1.2.38

Carm.3.0.42

Carm.3.16.13

Sorm. 1.2.46

gar..5orm.1.2.46

Serm.1.10.90

Epist.1.7.52

Serm.1.10.79

Carm.4.4.10

Serm.1.6.28

Serm.2.7.60

zar.serm.2.7.60

Carm.3.I7.II

Serm.1.2.99

Serm.1.2.95

Ars Pot. 180

Serm.1.2.25

Serm.2.5.63

Carm.1.28.I I

Serm.1.3.57

Serm.1.5.103

Epist.2.1.175

Ars Port 401

Corm.2.13.34

Carm.3.1.35

Epist.1.10.04

Serm.1.9.20

Epist.2.1.46

Epist.1.12.12

Epist.2.1.294

Ars Poel.297

Carm.1.1.13

Serm.1.1.39

qur. Carm.3.8.10

tar. Carm.4.5.14

Carm.2.5.14

Epist.2.2.140

Serm.1.5.23

Epist.2.2.33

Serm.2.3.315 


\section{DENATAT}

denatat. nuc quisquan citus aeque, Tusco denatat alveo.

deneges. nec, si plura velim. tu dare deneges.

denique. Jenique sit finis quacromit

met molus in rebus, sunt certi denique fines.

ne nummi questert aut pugal aut denique fama.

deniche (" ipsum concule.

denifute, quatenus excili penitus vitium irae.

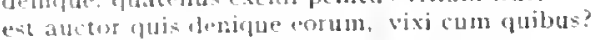

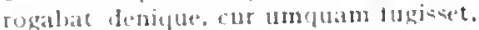

sopitns. . liber, honoralus, pulcer. ox denique regum,

deniclue quod non, frovidistet entr.

si valibus, si betus arte, si dernique posect:

denique sitvam militiam puer et Cantabrica bella tulisti

[enique non ommes eadem nirantur amanteve.

dun moi delectemt mala me vel denique fallant.

denipur -it guted vis, simplex dumtaxat et unum.

vitavi denifute culpan. non lauderus merui.

denominatos, quadelo eq prores line labias ferune denominatos

denormat. "os angulus ille proximus atcelat, qui nunc denormat agellusn?"

dens. cum sut tibi dens ater

densa. sell flonsa tentbit Tiburis umbrit tui.

densentur. mixtal serum ac burenum dencentur funera,

densis. ai pugnat extricata lensis cerva plagis,

denso, nue.. denso fraventem sustulit aere.

densum. Jensum umeris bibit ause volgus.

dent. di tibi dent wijta classem redducere Troia.

"tibi di, quatecunsque preceris, commola dent:

dente. inpressit mumorem dente labis notan.

dente i nigso fictus vel uno turpior ungui.

te jam dento ninus mordeor invido.

caprea... (ente nuvo perizua

hic infecetuns sava dente livido, Canidia rodens pollicen

an in fluiz atros lunte ne petiverit.

guali wit tack. sura quali. polde, dente, catiollo

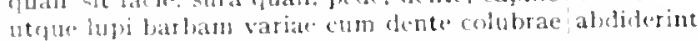

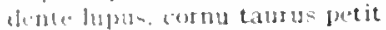

(misum. ut neque rale lupus guempuam neque dente petit bons.

tangentis mal. -ingula dente supetbo:

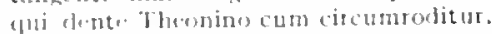

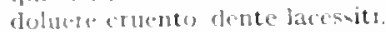

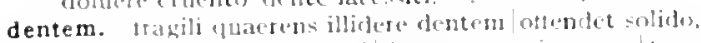

dentes. Jefugit to quia lurvil dentes. te qua rugae/turpant

dentibus. "quar stommendat toma cute", dontibus attis.

iolutis deotibus actr.

dentis. hate dentis acuit timendos.

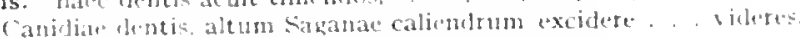

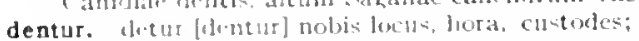
ryure sild pumart mon dentus puxulas.

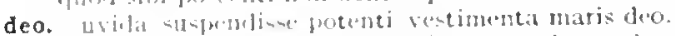

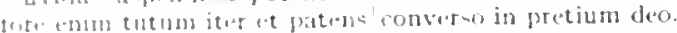

deorum. Q.e lonast, magni lovis at decorum, muntiuss

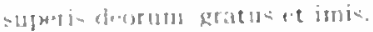

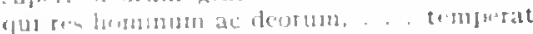

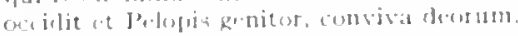

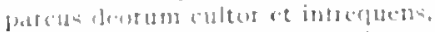

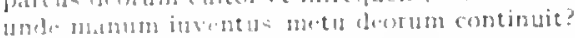

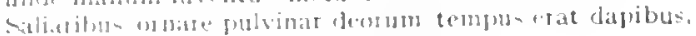

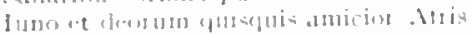

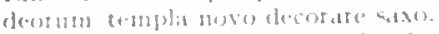

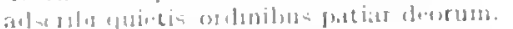

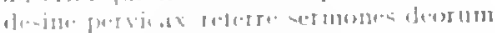

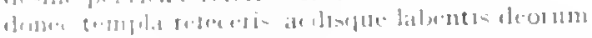

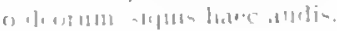

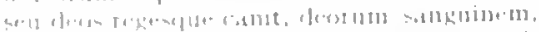

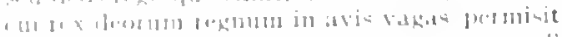

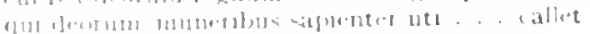

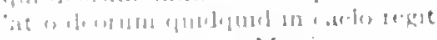

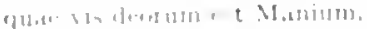

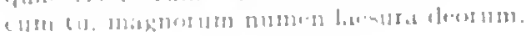

\section{DEORVM}

Curm.3.7.28

Carm.3.16.38

Serm.1.1.92

Serm.j I 100

Sorm.1.2.133

Serm.1.3.3.1

Serm.1.3.70

Sierm 1.4 80

Serm.1 5.08

Jipist 1.1.107

Jepist.1.7.08

Jisist.1.13.3

Lepist.1.18.54

lefist.2.2.58

Efist.2.2.127

Ars J'oel. 23

Ars loel 207

Carm.3.17.3

Serm.2.6.9

Jipod 8.3

Curm.1.7.20

(armi.1.28.19

Carm 3.5.31

Carm: 2.7.1.t

Carm.2.13.32

Sirm.23 191

Sirm 2.8.76

Carm 13.12

Carm.2.8.3

Carm.s.3.10

Carm.4.18,

Fipod.5.47

Epol 0.15

Sorm.1.0.33

serm 1842

Sicm.2.1.52

Siorm 21.55

Sermas 0.57

Epist.1.18.82

Ejist.2.1.151

Sirth.2.1.77

Carm.t13.11

Lipist.1.18.7

Lpist.2.229

Carm.3.20.10

Sirm.1.8.48

a ar.serm.1.4. 15

Serm.2.S 52

Cormel-5.10

Corm.3.16.8

carm.1.10.5

Cormitio.19

(arm.1.1214

Ciarm. 28.7

(iarm 1.341

carm.1 35.37

(arm.1.37 3

(arm.2.1.25

(arn:2.15.10)

(armi.3.3.36

(arm.3 3.71

(iarm 34.3

(arm-3.2750

carmat 213

curm.d.d 2

Curm.4 13.47

Jipot.5.1

I:poils 0.4

F.pond is 3 
Vrben sibi curae, Imperium tore et Italiam. delubra deorum. quone malo menten concussa? timore deorum." post ingentia facta deorum in templa recepti. Musa dedit fidibus divos puerosque deorum sacer interpresque deorum|caedibus et victu foedo deterruit Orpheus.

deos. terrarum dominos evehit ad deos/hunc. heu quotiens fidem $\mid$ mutatosque deos flebit dic per omnis|hoc deos vere. non ita creditum poscis Quintilium deos. iuvat placare... custodes Nunidae deos, nihil supra/deos lacesso paternos $\mid$ in sinu ferens deos. ex quo destituit deos|mercede pacta Laomedon, parvos cororantem marino/rore deos seu deos regesque canit, deorum |sanguinem. fana deos habuere rectos. rite deos prius adprecati. haec Iovem sentire deosque cunctos namque deos didici securum agere aevom nec. . . deos id $/$ tristis ex alto caeli demittere tecto. 'per magnos, Brute, deos te|oro, (nam te/scire, deos quoniam propius contingis, oportet). quod te per Genium dextramque deosque Penatis|obsecro quandocumque deos vel porco vel bove placat. .

ille tegat conmissa deosque precetur et oret.

depellat. est ubi divellat [depellat] somnos minus invida cura?

depellere. frigus quo duranque famem propellere [depellere] possit. . quam nequiere proci recto depellere cursu?'

deperdat. nequid/summa deperdat metuens aut ampliet ut rem.

deperdere. bonam deperdere famam, | rem patris oblimare malum est ubicumque.

deperiit. qui deperiit minor uno mense vel anno,

depetere, hac magis illam/inparibus formis deceptum te petere [depetere] esto:

depigis, verum/depugis [depigis], nasuta, brevi latere ac pede longo est. . deponas. aut spem deponas aut artem inlusus omittas.

depone. deprome [depone] quadrimum Sabina. . . merum diota. quidquid habes. age, / depone tutis auribus. fessum militia latus/depone sub lauru mea surge et inhumanae senium depone Camenae,

deponent. omnes in Damalin putris/deponent oculos

deponere. argenti pondus et auri|furtim defossa timidum deponere terra? lenire dolorem|possis et magnam morbi deponere partem.

deponuntur. et quae rimosa bene deponuntur in aure.

deposco. numquid ego a tel magno prognatum deposco consule cunnum depositum. sumere depositum clavom fierique tribuno? quodsi|depositum laudas ob anici iussa pudorem.

deprenderis. si me stultior ipso/quingentis empto drachmis deprenderis? deprendi. deprendi miserum est: Fabio vel iudice vincam.

deprensa, cruribus haec metuat, doti deprensa, egomet mi.

deprensi. 'deprensi non bella est fama Treboni'

deproeliantis. ventos aequore fervido/deproeliantis.

deprome. teprome quadrimum Sabina, . . merum diota.

depromere. antehac nefas depromere Caecubum

condo et conpono quae mox depromere possim.

deproperare, qujs udo/deproperare apio coronas/curatve myrto?

depugis. verum|depugis, nasuta, brevi latere ac pede longo est. .

depugnare. depugnare parati.|si discordet eques.

depulit. non equitem dorso, non frenum depulit ore.

depulsum. matris ab ubere iam lacte depulsum leonem

depygis. verum/depugis [depy.gis], nasuta, brevi latere ac pede longo est. derepta. arma|militibus sine caede" dixit|"derepta vicli.

signa ... derepta Parthorum superbis|postibus

dereptum. pignusque dereptum lacertis

derexit, primusve Teucer tela Cydonio/derexit arcu;

deridet. nihilo ut sapientior ille/qui te deridet caudam trahat.

meminitque libentius illud / quod quis deridet quam quod probat et veneratur.

deripere. parcis deripere horreo ... amphoram.
Serm.1.6.35

Serm.2.3.295

Epist.2.1.0

Ars Poet.83

Ars Poet.391

Corm.1. 10

Carm.1.5.6

Carm.1.8.2

Curm.1.24.12

Carm.1.36.3

Carm.2.18.1 2

Carm.2.18.27

Carm.3.3.2I

Carm.3.23.16

Carm.4.2.13

Carm.4.4.48

Carm.4. 5.28

Carm.Saec.73

Serm.1.5.10I

Serm.1.5.102

Serm.1.7.33

Serm.2.0.52

Epist.7.7-94

Epist.1.16.58

Ars I'oet. 200

:ar,Epist.1.10.18

t'ar. Serm.1.2.6

Sorm.2.5.78

Serm.1.4.32

Serm.1.2.6I

Epist.2.1.40

zar.Serm.2.2.30

var.Serm.1.2.93

Serm.2.5.26

var.Carm.1.9.7

Carm.1.27.18

Carm.2.7.19

Epist.1. 18.47

Carm.1.36.18

Serm.I.I.42

Epist.1.1.35

Serm.2.6.46

Serm.1.2.70

Serm.I.6.25

Episi.1.9.12

Serm.2.7.43

Serm.1.2.134

Serm.1.2.131

Serm.1.4.114

Carm.1.9.11

Carm.1.9.7

Carm.1.37.5

Epist.1.1.12

Carm.2.7.24

Serm.1.2.93

Epist.2.I.184

Epist.I.I o. 38

Carm.4.4.I5

var.Serm.1.2.93

Carm.3.5.21

Carm.4.15.7

Carm.1.9.23

Carm.49.18

Serm.2.3.53

Epist.2.1.263

Carm.3.28.7 


\section{DERIPERE}

polo deripere lunam vocibus possin meis.

Lipod.1 7.78

deripit. Innamqu' caelo deripit.

derisor. 'ut tu semper eris derisor.'

ini' (lerisor lacti sic nutum divitis horret.

Epod.5.40

Serm.2.6.54

Epist.1.18.11

sic derisor vero plus laudatore movetur.

Ars Poct. 433

derisum. in mala terisum semel exceptumque sinistre

Ars Pot. 452

Cinm.3.6.19

Serm.1.4.4.8

des. des nominis huius lonotem.

"sume, catclle' negat; si non des, optet.

sed des verniam bonus, oro.

cles nummos, exceptit nihil te si iuga laedat:

desaeviet. intoglum tamen et vocem cumordia tollie iratusque Chremes tumido delitigat [desaeviet] ore:

desaevit. an tragica desacvit et ampullatur in arte?

descendat. hie generosion/descendat in campun petitor. non Afra avis descestat in ventrem meum,

in Marei efescendat indicis aurislet patis et nostras

descende. desconde caclo et dic age tibia

descende Corvino iubente/promese languidiora vina.

descendens. adspiciat sol. | lacvom discedens [descendens] curru fugiente vapotet.

descendere. huc iuvenes aequom est descendere.

fuge quo descendere gestis: non erit emisso reditus tibi. . . .

descenderet. intactus aut Britannus ut descenderet sacra catematus via.

descendet. ad mare descendet vates tuos

descendi. frontis af urbanae descendi praemia.

describat. aut labentis equo describit [describat) volnera Parthi."

describet. aut labentis equo describit [describet] volnera Parthi."

describi. sicuis erat dignus describi, quod malus ac fur.

malo quat nollet carmine quemquam/describi: .

describit. aut labentis equo deseribit volnera Partli."

describitur. aut tumen Rhenum aut plovius deseribitur arcus; .

descripsi. unde exo mira/descripsi docilis praecepta baec.

descripta. votiva pateat veluti descripta tabella

descriptas. quam patene.. vilimus Aeacum / sedesque discriptas [descriptas] piormu .

discriptas [dencriptas] servare vices operumque colores/eur ego si nequeo ignororive. prota salutor?

desectam. tertur l'rometheus aldere principi/limo coactus particulam undique / desectam

deserat. carms eris Romae, donec te deserat aetas;

desere. fastiliosam descre copiam

deserere, magnum paupries opprobrium iubet /puilvis et facere et pati vitutisque vian destrit [ursercrel arduac.

meruere decus vestigia Gracea ausi deserere

deseret. carus "ris Romae, donec te deserat [deseret] aetas;

nec facundia destrot bune nec lucidus ordo.

deserit. virtutiofuc vian desesit arduae.

deserta. nunc situs informis promit el deserta vetustas;

deserta. nam qukte lleserta it inbospita tesqualcredis.

desertior. Gabiis descrtiot atque Fidrnis vicus:

deseruit. in me tota ruens lenusl Cyprum deseruit

raro anteredentem secelestum | dretuit pede Poena claudo.

pererlidit arma. lorum vireutis deseruit,

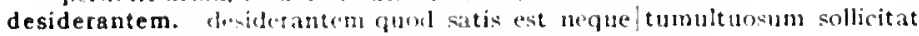
nilat. .

desideret. tu, quir egn ot populus mecum desideret. audi.

desideri. deciclericulue temprerate pocula.

desideriis. sic decirferiis icta follolibuse

desiderio. eluis desidesio sit purler aut morlus/tan cari capitin? .

desiderium. nume teaiderium curaque non levis,

desiderium. fornix tibi at uncta popinalincutiunt Vibis desjoderium,

desideror. Sextilem totum mendax desicleror. .

desidia, vitamela est improba siton/desistia

designat. guid non rotutay disnignat [rlesigmat]?

designatorem. dum ficus prina calorque / dissignatorem [designatorem] Hecutat lictoribus atria,

desiliat. vapallinla lectoidesiliat mulios,

desilies. necc druilies imititor in attum,

Serm.2.3.259

Serm.2.4.5

Epist.2.2.16

1ar. Ars Port.94

Epist.1.3.14

Carn.3.1.1 I

Iipod. 2.53

Ars Poel.387

Carm.3.4.

Carm.3.21.7

sar.Epist.x.16.7

Serm.1.2.34

Epist.1.20.5

Epod.7.7

Epist.1.7.1

Epist.1.9.11

var.Serm.2.1.15

tar.Serm.2.1.15

Serm.1.4.3

Epist.2.1.154

Serm.2.15

Ars Poct. 8

Serm 2.3.34

Serm.2.1.33

Ear.Carm.2.13.23

sor.Ars Poct.86

Carm.1.16.15

Epist.1.20.10

Carm.3 29.9

coni.Carm.3.2.4.44

Ars Poct.287

gar Épist. I.20.10

Ars Poet.4I

Carm.3.24.44

Epist.2.2.118

Epist.1.149

Epist.1.1.7

Carm.1.19.10

Carm.3.2.32

Epist.1.10.67

Corm.3.1.25

Ars Iowl.t 53

Epod.17.80

Carm.t515

Carm.1.2.8.

Carm.1.14.18

Epist.1.14.22

Epist.t.7.2

Serm.2.3.15

rar.Epist.1.5.16

rar.Epist.1.7.0

Serm.1.2.130

Ars Poct.134 
desilire. voles modo altis desilire turribus,

Epod.1 7.70

deailit. montibus altis |levis crepante lympha desilit pede.

desiliunt. unde loquaces lymphae desiliunt tuae. .

desinat. ut turpiter atrum|desinat in piscem mulier formosa superne:

desine. tanden desine matrem/tempestiva sequi viro.

desine mollium/tandem quereliarum

desine pervicax/ referre sermones deorum

maturo propior desine funeri| inter ludere virgines

desine, dulcium $\mid$ mater saeva Cupidinum.

quare, ne paeniteat te, / desine sectari matronas,

'iam desine" -

arta decet sanum comitem toga; desine mecum|certare.'

desinet. desinet inparibus certare submotus pudor."

desint. neu desint epulis rosae

sed quadringentis sex septem nilia desunt [desint]: plebs eris.

desipere. dulce est desipere in loco. .

desipiant. nune accipe, quare/desipiant omnes aeque ac tu.

desipit. Aiax cum inmeritos occidit desipit agnos; .

quodsi non odio peccantis desipit augur,

desis. neu desis operae neve inmoderatus abundes.

desistam. non, hodie si exclusus fuero, desistam;

desistant. iniussi numquam desistant.

desit. paulum severae musa tragoediae/desit theatris:

dis inimice senex. custodis? ne tibi desit?

quod non desit habentem

desperandum. nil desperandum Teucro duce et auspice:

desperat. quae/desperat tractata nitescere posse, relinquit

desperes. quia desperes invicti membra Glyconis. .

despice. neque in vias / sub cantu querulae despice tibiae

destinat. cui frons turgida cornibus/primis et venerem et proelia destinat.

destinata. rapacis Orci sede destinata

destinatis. nec parce cadis tibi destiuatis.

destinet. nescio an Anticyram ratio illis destinet omnem.

siquis lectica nitidam gestare amet agnam,... fortique marito destinet uxorem:

cur ita crediderim, nisi quid te detinet [destinet], audi.

destiti. ex quo destiti|Inachia furere.

destituit. ex quo destituit deos/mercede pacta Laomedon.

destrictus. destrictus ensis cui super inpia/cervice pendet.

destringere. quem cur destringere coner

desum. neque enim, cum lectulus aut melporticus excepit, desum mihi.

desumpsit. ingenium, sibi quod vacuas desumpsit Athenas

desunt. multa petentibus| desunt multa:

larga nec desunt V'eneris soda!i|vina craterae.

sed quadringentis sex septem milia desunt:

desurgat. ut pallidus omnis|cena desurgat dubia?

det. nt neque longa $\mid$ nec magis alba velit quam dat [det] natura videri. det vitam, det opes; aequon mi animum ipse parabo.

deterere. landes egregii Caesaris et tuas/culpa deterere ingeni.

detereret. detereret sibi multa.

deterget. albus nt obscuro deterget nubila caelo|saepe Notus

deterior. deterior post partum carne futura.

deterioribus. nec vera virtus, . . . curat reponi deterioribus.

deterius, nilo deterius dominae ius esse:

deterius. dolituru, si placeant spe/deterius nostra.

deterius Libycis olet aut nitet herba lapillis?

deterreret. a turpi meretricis amore|cun deterreret:

deterret. quas neque Noricus|deterret ensis nec mare naufragum

deterrima. nam fuit ante Helenam cunnus taeterrima [deterrima] belli causa.

hic ego propter aquam, quod erat deterrima, ventri|indico bellum.

deterruit. silvestris homines.. . caedibus et victu foedo deterruit Orpheus.

detestanda. bellaque matribusidetestata [detestanda].

detestata. bellaque matribus|detestata.

detestatio. dira detestatio/nulla expiatur victima. .

detinet. cur ita crediderim, nisi quid te detinet, audi.

nisi cena prior potiorque puelia Sabinum/detinet adsumam;

detinuit. ipsum. . grata detinuit compede Myrtale|libertina,

Epod.10.48

Corm.3.1.3.16

Ars Poet.q

Carm.I.23.II

Carm.2.9.17

Cerm.3.3.70

Carm.3.15.4

Carm.4.1.4

Serm.1.2.78

Serm.2.3.323

Epist.1.18.30

Epod.1 I. 18

Carm.1.36.I 5

zar. Epist.1.1.57

Carm.4.1 2.28

Sirm.2.3.47

Serm.2.3.2II

Epist.1.20.0

Serm.2 5.89

Serm. 0.58

Serm.1.3.3

Carm.2.I. Io

Serm.2.3.1 23

Enist.2.2.52

Corm.1.7.27

Ars Poet.i 50

Epist.1.1.30

Cerm.3.7.30

Carm.3.13.5

Carm.2.18.30

Carm.2.7.20

Serm.2.3.83

Serm.2.3.217

lar. Epist.1.2.5

Epod.II.5

Carm.3.3.21

Carm.3.1.17

Serm.2.1.4I

Serm.1.4.134

Epist.2.2.81

Carm.3.16.43

Carm.3.18.6

Epist.1.1.57

Serm.2.2.77

iar.Serm.1.2.124

Epist.1.18.112

Carm.1.6.I 2

Serm.1.10.69

Carm.1.7.1 5

Serm.2.8.44

Corm.3.5.30

Serm.1.5.67

Serm. I. 10.90

Epist.1.10.19

Serm.I.4.II 2

Carm.1.16.10

Ear.Sirm.1.3.107

Serm.1.5.7

Ars Poot.392

?ar.Carni.1.I.25

Carm.1.1.25

Epod.5.89

Epist.1.2.5

Epist.1.5.28

Carm.1.33.14 


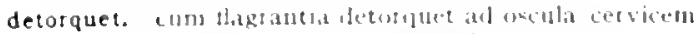

Carm.2.12.25

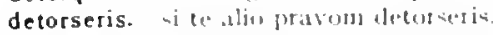

detorta. si cintere fonte cadent patree dectortal.

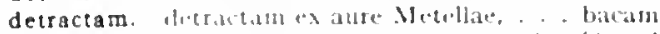

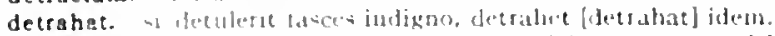

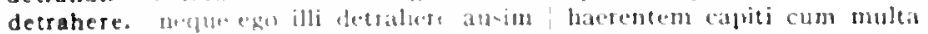
lander sogonatu

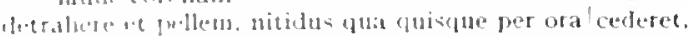

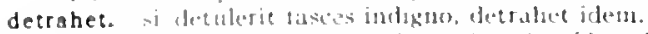

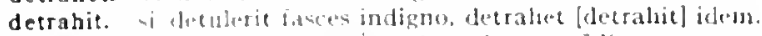

detraxerat. latale detraxiorat segvis amicus perfidis.

detriments. Actrimenta, fugas sospotum, incendia rjet.

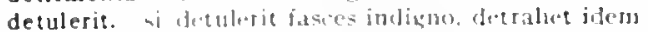

detur. me longus tibl somnas mult. non times detur:

detur molis locus. hola. custodus:

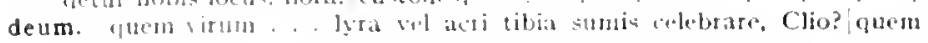
dentmo

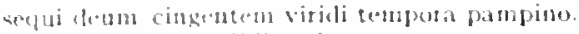

alteris te mencis atllibet derum:

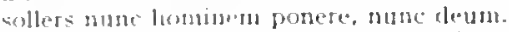

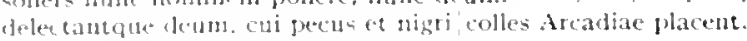

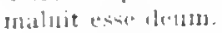

deum. quate temapla ruont antiģua deumé

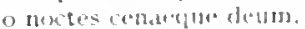

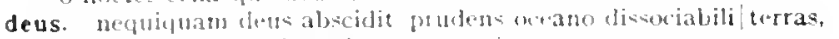

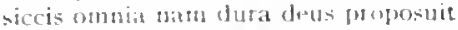

quis te sulvers Thescalis makus venenis, quis poterit deus?

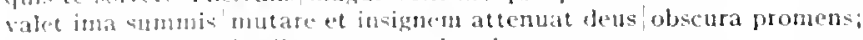

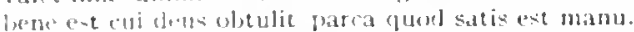

prodentuturi temporis exicumicaliginsa nocte urenit deus

simul calentis inverecumba deds fervidiote meto atcana promorat loco.

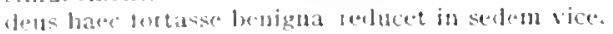

Serm.2.2.55

Ars 7 'oef. 53

Sierm.2.3 239

ror.lipist.1.16.34

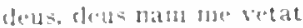

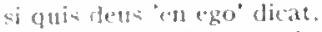

delas inclo ego, furum aviumelue maxima formirlo:

sicpis ad illa derat subito te apat. usque recuses.

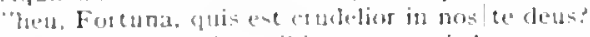

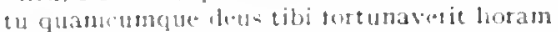

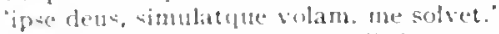

naturate deus humatse, mortitlis in unum quodgue caput.

neC dels intornit, ni-i dignus vindice nodus inciderit;

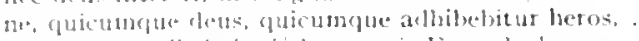

deus inmortalis latberi lust cuprit Jimpredocles.

devenit. ife tamell testat. Numa quo desenit et Ancus.

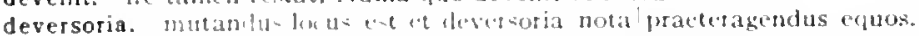

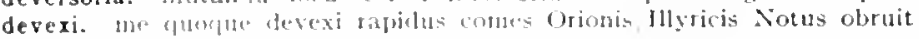
undis.

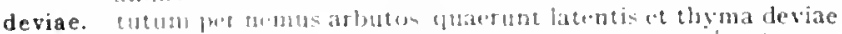

Sirm 1.10.48

Serm.2.1.0.4

lipist.1.10.3.4

tor.Jipist.1.10.34

lipot.o.9

lipist.2.1.121

Epist.1.10.37

Carm.3.11.39

Serm.1.1.15

Carm.1.12.3

Corm.3.25.19

Corm.1.5.32

Corm. 8.8

Carm.t.12.II

Sirm. 1.8.3

Serm.2.2.104

Serm.2.6.65

Carm.1.3.2I

Curm.1.18.3

(arm.1.27.22

(ism.1.34.13

Carm.3.10.43

Carm.3.29.30

Fpeld.1.13

Ifpol 13.7

Iipositato

Serm.1.1.15

Serm. 1.8.3

Sierm.2.7.24

Serm.2.8.02

lipust.1. 11.22

l.pist.1.10.78

lipist.2.2.188

Ars J'oit.191

Ars loct.227

Ars Poif.404

lipist.1.0.27

lipist.1.15.10

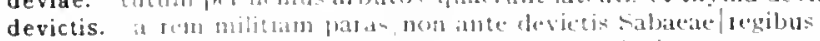

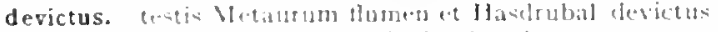

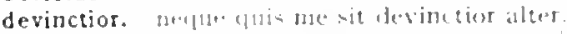

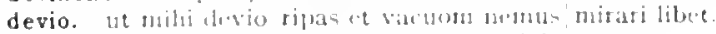

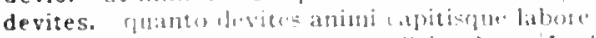

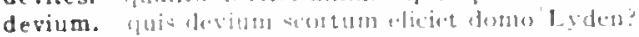

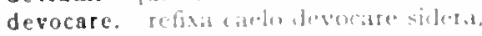

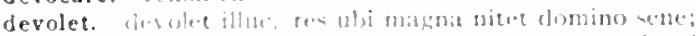

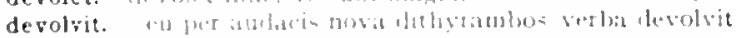

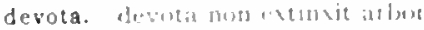

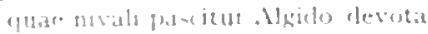

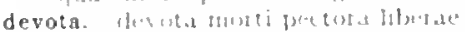

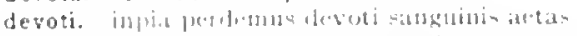

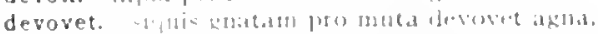

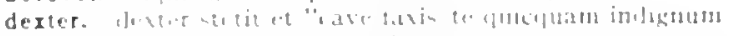

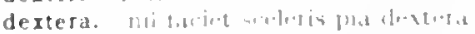

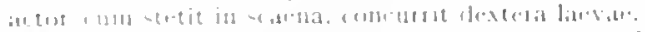

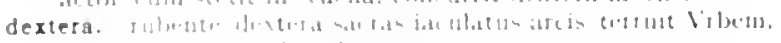

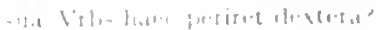

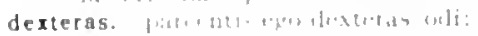

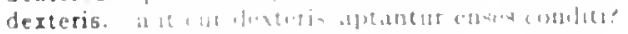

Cirm.1.28.21

(arm 1.17 .6

(iorm.1.29.3

(iorm.4.43)

sirm.1.5.42

(arm.3.25.12

lipist.1.1.int

(arm.2.11.21

1 pold. 7.5

term.25.11

Carm \$2.1I

Carm-3.427

Carm.323 10

(arm.ti 18

lipod teres

Serm.2.3.210

serm.2.3.3.

Serm.21.54

fipist.2 12115

(ium.1 2.3

I. pod. .10

(i)rm.3.10.21

I: $p(x) \div$ 
derterius. nemo dexterius fortuna est uans.

Serm. $1.9 \cdot 45$

dextra. nam fures dextra coercet

dextra. nisi faunus ictum/dextra levasset.

omne sacrum rapiente dextra.

dextram. cogat trans pondera dextram porrigere:

quod te per Genium dextramque deosque Penatis|obsecro

Sterm.1.8.4

Carm.2.17.29

Carm.3.3.52

Epist.1.6.5I

Epist.1.7.94

Carm.4.4.21

dextras. Amazonia securi dextras obarmet.

dextris. aut cur dexteris [dextris]/aptantur enses conditi?

yar.Epod.7.I

dextro. haec ubi supposuit dextro corpus mihi laevom, / Ilia et Egeria est ;

dextro. nisi dextro tempore, Flacci|verba per attentam non ibunt Caesaris aurem,

dextrorsum. ille sinistrorsum, hic dextrorsum abit.

dextrum. haec ubi supposuit dextro [dextrum] corpus milii laevon [laevol, i Ilia et Egeria est; sed ut veniens dextrum latus adspiciat sol.

di. quem mihi. quem tibi fintem di dederint. Leuconoe,

non di, quos iterum pressa voces malo.

di me tuentur, dis pietas mea/et musa cordiest.

vim temperatam di quoque provehunt in maius;

di multa neglecti dederunt| Hesperiae mala luctuosae.

an adiciant hodiernae crastina summae/tempora di superi?

audivere. Lyce, di mea vota, di|audivere, Lyce:

di bene fecerunt, inopis me quodque pusilli|finxerunt animi.

'di te. Damasippe, deacque/verum oh consilium donent tonsore.

di tibi dent capta classen redincere Troia.

auctius atque/di melius fecere.

at omnes di exagitent me.|si quicquan."

"tibi di, quaecumque preceris, / commoda dent:

di tibi formam, |di tibi divitias dederunt

di tibi divitias dederunt artemque fruendi.

quod superest aevi. siquid superesse volunt di; .

carmine di superi placantur, carmine Manes.

cui|rem di donarent, illi decedere pravan|stultitiam;

mediocribus esse poetis/non homines, non di, non concessere columnae.

di. di, probos mores docili iuventae, . . date

di, senectuti placidae quietem. ... date

dia. 'macte/virtute esto' inquit sententia dia Catonis; .

diadema. regnum et diadema tutum|deferens uni

Diana. inferni neque enim tenebris Diana pudicum|liberat Hlippolytum . quindecim Diana preces virorum / curat

aut morbus regius urget |aut fanaticus error et iracunda Diana,

Diana. Phoebe silvarumque potens Diana,

Nox et Diana, quae silentium regis.

Dianae. sacro Dianae celebris die.

notus et integrae temptator Orion Dianae

doctus et Ploebi chorus et Dianae/dicere laudes.

per et Dianae non movenda numina,

cun lucus et ara Dianae. . a aut plosius describitur arcus; .

Dianam. Dianam tenerae dicite virgines,

diaria. urban diaria rodere mavis.

dic. Lydia, dic per omnis|hos deos vere, .

age dic Latinum, | barbite, carmen.

eburna, dic age, cum lyra/maturet,

descende caelo et dic age tibia

dic modos. Lyde quibus ohstinatas/adplicet auris,

dic et argutae properet Neaerae murreum nodo cohibere crinem;

vel dic, quid referat intra|naturae finis viventi,

sobrius ergo dic aliquid dignum promissis.

unde | divitias aerisque ruam, dic augur, acervos."

huic tu dic. . . gaudentem num te addicere.

"liber liber sum," dic age.

'da [dic], si grave non est. \{quae prima iratum ventrem pacaverit esca.'

Roscia, dic sodes, melior lex an pterorum est / nenia,

dic, lad cenan veniat."

dic multa et pulcra minantem/vivere nec recte nec suaviter. respondesne tuo, dic, sodes, nomine? .

dic mili, Musa, virum.

dicacis. qui captat risus hominum famamque dicacis. ita commendare dicatis, conveniet satyros.

Serm.1.2.125

Serm.2.I.I 8

Serm.2.3.50

i'ar.Serm.1.2.125

Epist.1.16.6

Carm.1.11.2

Carm.1.I4.Io

Carm.1.17.13

Carm.3.4.60

Carm.3.0.7

Corm.4.7.18

Carm.4.I3.I

Serm.1.4. 7

Serm.2.3.16

Serm.2.3.19I

Serm.2.0.4

Serm.2.6.5.4

Serm.2.8.75

Episí.1.4.6

Epist.1.4.7

Epist.1.38.108

Epist.2.1.138

Epist.2.2.152

Ars Poet. 373

Carm.Saciot 5

Carm.Saec. 15

Serm.1.2.32

Carm.2.2.2I

Carm.4.7.25

Carm.Sace.70

Ars Poet.454

Carm.Saec. I

Epod.5.5I

Corm.2.12.20

Carm.3.4.7

Carm.Suec. 75

Epod.17.3

Ars Poet.Io

Carm.I.2I.I

Epist.1.1.4.40

Carm.1.8.I

Carm. 1.32 .3

Carm.2.II.22

Carm.3.4.1

Carm.3.11.7

Carm.3.1.4.2I

Serm.1.1.49

Serm.2.3.6

Serm. 2.5.22

Serm.2.5.108

Serm.2.7.92

var.Serm.2.8.4

Epist.1.1.62

Iipist.1.7.60

Epist.1.8.3

Epist.I.10.3I

Ars Poel.id I

Serm. I.4.83

Ars Muel.225 
dicam. quid prius dicam solitis parentis/audibus.

Carm.1.12.13 quill num te elicam racere in regione Perlana? niming patienter utrumęue ne alicam stulte. mirati.

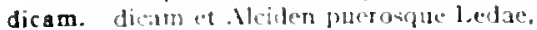

dican incigne, recens, adluc inelictum ore alio.

'memin leru., sed meliore tempore dicam;

eur hoc"? diean, si potero.

"acipe quol numquam redos mihi' si tibi dican:

"iur, stover" diken

nun dico [licam] horrendam rabiem' -

"Laertiale, quidquid dicam, aut erit aut non:

me sene quod dicam lactum e'st.

'ini scis, an pruk'n : huce ce leie erit atque/servari nolit?' dican

dicar. licar,... princeps Aeolium carmen ad Italos/deduxisse modos.

dicas. dicas magno de flumine malim

cum dieas esse paris res/turta latrociniis

ut quocumque loco fueris vixise libenter te dicas:

dicas adductum propius irondere Tarentum.

tu quill de quoque viso et cui dicas. saepe videto.

dicat. dicat Opuntiae, fratur Megillac. . . qua pereat sagitta.

si quis deus "en ego" dicat.

neque se fore posthac tam facilem dicat.

inde fit. ut taro. qui se vixisse beatum/dicat

nunc aliquis dicat mihi "quid tu? .

'non nosti, quid pater.' inquit.|'Chrysippus dicat:

sicuis bella titi terra pugnata marique dicat

'nee furtum feci nec fugi.' si mihi dicat / servos:

per sanctum iuratus dicat Osirim:

annosa voluminat vatum / dictitet [dicat et] Abano Musas in monte locutas.

ut ian nume dicat iam nunc debentia dici.

sessuri. donec cantor 'ros plaudite' dicat:

dicat fulius Albini: si de quincunce remota est/uncia.

dicatur. ne prodigus esse dicatur metuens.

parcius hic vivit : frugi dicatur:

Labeone insanior inter | sanos dicatur.

delirus et amens undique dicatur merito.

dicemus. "in triutuphe" non semel dicemus.

dicenda. diuencla Musis procin;

ue ventum all cenam est. dicenda tacenda locutus

Ennius ipse pater numquam nisi potus ad arma/prosiluit dicenda.

dicende. prima ticte mili. summa dicendo (amena.

dicendum. ad ben diendum delectamlumque redacti

dicens. subirare (hloen et miseram tuis licens ignibus uri.

dicente. we Hicente cavis inpositam ilicem/saxis,

dicentis. si dicontis prunt fortunis absona dicta.

dicere. nos. Agrippa, neque haec dicere . . . conanur.

Patclung diugre noc quae nilit attinent.

me volut dicrese lucidun fulgentis oculos

utrumqu" sacro digna silentio mirantur umbrac dicere.

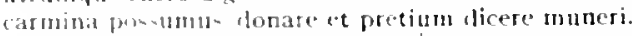

his, quibus sotem phaterere colles. dicute carnen.

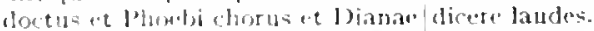

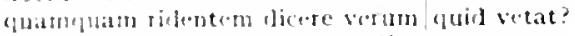

mansirti opjululo, guod versu dicure non est.

felicen elicere non lox me possim.

in allrem dicere nescio puid phero.

ambitune telogita te dicers joisum.

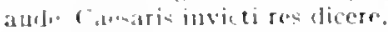

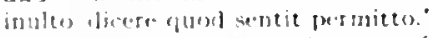

chriens tibi dicere servos panca reformido.

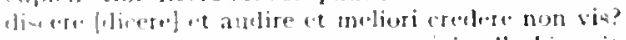

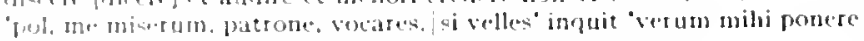

[alicere.] nomisent.

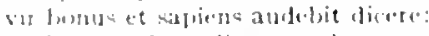

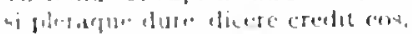

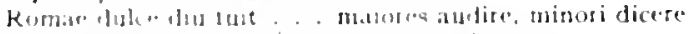

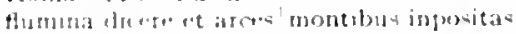

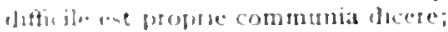

Epist.1.4.2

Ars Poet.272

Carm.1.12.25

Carm.3.25.7

Sermit.0.00

Sorm.2.2.8

term 2.3 .00

Serm.2.3.10

iur.serm.2.3.323

Sirm.2.5.59

Sirm.2.5.84

Lrs l'oell 4 's

Cism.3.30.10

Serm.1.1.55

Sirm.1.3.121

Epist.1.11.25

IEpist. : I 0.11

Fist.1.18.68

Curm.1.27.10

Sierm.1.1.15

Serm.1.1.22

Serm.1.1.118

Serm.1.3.19

Scrm.1.3.127

Epist.1.16.26

Epist.1.16.46

Epist.1.17.60

tur. Epist.2.1.27

Ars Poct.43

Ars Poel 155

Ars Poct.326

Sirm.I. 2.5

Serm. 1.3.40

Serm.1.3.83

Serm.2.3.108

Carm.42.50

Carm.4.9.21

Epist.1.7.72

Fost.1.108

lEpist 1.1.1

Epist 2.1.155

Carm 3.7 11

Carm 3.1314

Ars Poet.112

Carm.1.6.5

Carm.1.19.12

Carm.2.12.14

Carm.2.13.30

Carm.48.12

Carmovaces

Curmsiaec io

Serm 1.1.2.4

Serm.1.5.87

Scrm.1.1.52

Sermal 0.10

Sirmilo.k.

Serm 2.1.II

Sirm.2.3.100

Sirm.2.7. 1

rar liprel. I 8

rar. LPist. 1.793

lipist $1.1 \% .73$

Epjst.2.1.0.7

tepist 2.1 .100

Epist.2.1.252

Ars Poet 128 
aut prodesse volunt aut delectare poetaelaut simul et iucunda et idonea dicere vitac.

dicerer. occultare meis dicerer horreis.

Ars Poet.334

Curm.3.16.27

diceret. huic si nutonis verbis mala tanta videntildiceret laee animus 'quid vis tibi?

scilicet ut ventres lamna candente nepotum|diceret urendos correctus Bestius.

dices. fide Teia/dices laborantis in uno

tuque pedestribus/dices historiis proelia Caesaris,

nupta iam dices 'ego dis amicum . . reddidi carmen.

dices 'heu', quoticns te in speculo virleris alterum,

'non dices hodie, quorsum haec tam putida tendant.

'quid miser egi? quid volui?' dices.

tu nihil invita dices faciesve Minerva:

dicet. aptum dicet equis Argos ditisque My'cenas:

quem Venus arbitrum/dicet bibendi?

si dicet 'recte.' primum gaudere.

laeva stonachosus habena/dicet eques;

nec dicet 'cur ego asnicum, offendam in nugis?"

dicetur. quae... kaphon | iunctis visit nloribus | dicetur, merita Nox quoque nenia.

dici. hic anes dici pater atque princeps

'nempe|vir bonus et prudens dici delector ego ac tu.'

dum volt libertas dici mera veraque virtus.

ut iam nunc dicat iam nunc debentia dici, .

dicimus. dicimus integro/sicci mane die. dicimus uvidi.|cum sol Oceano subest.

dicis. ita te felicem dicis rure ego viventem. tu dicis in Vrbe beatum:

dicit. plurimus . . . aptum dicet [dicit] equis Argos quos Elea domum reducit/palma caclestis . . . dicit forte epos acer, /ut nemo. Varius ducit [? dicit]; edicit [et dicit]. piscator uti, pomatius, auceps.... mane domum veniant.

planius ac melius Chrysippo et Crantore dicit.

"nec furtum feci nec fugi," si mihi dicat [dicit]|servos:

"indotata mihi soror est. . . . qui dicit, clamat "victum date"

$$
\text { Sirm.1.2.69 }
$$

Epist.1.15.37

Carm I 719

Carm.2.12.10

Cam.4.6.4 I

Carm.4.ro.6

Sirm.2.7.2I

Epist.1.20.7

Ars Poet.385

Carm.1.7.9

Carm.2.7.20

Epist.1.8.15

Epist.I. 15.13

Ars Poet.450

Carm 3.28.16

Carm.1.2.50

Epist.1.16.32

Epist.I.I 8.8

Ars Poet.43

Curm.4.5.38

Carm.4.5.39

Serm.2.7.3I

Epist.1.14.ro

var.Carm.1.7.9

Carm.4.2.19

8 zar.Serm.1.10.44

2'ar.Serm.2.3.227

Epist.I.2.4

zar.Epist.I. [6.46

Epist.1.1 7.48

zar.Epist.2.1.27

Cum.t.2I.I

Carm.1.21.2

Carm.3.1 7.6

Sirm.2.3.256

Epist.2.1.57

Ars Pofl.276

Carm.3.3.58

Sorm.1.2.45

Serm.1.5.57

Serm.2.3.323

Serm.2.5.23

Epist.2.2.18

var.Epist.2.2.I 8

var.Epist.2.2. 8

var.Epist.2.2.I8

Epist.1.15.6

Ars Poel.335

Sirm.2.6.97

Ars Port.I 2

Epist.I.5.25

Ars Poel.247

Epist.I.10.49

Serm.1.4.10

Ars Poet. 403

dictae. dictae per carmina sortes

dictant. pueri patresque severi|fronde comas vincti cenant et carmina dictant.

dictantis. cerebrum . Perelli|dictantis, quod tu numquam rescribere possis.

dictare. memini quac plagosum mihi parvolOrbilium dictare;

dictari. an tua demens/vilibus in ludis dictari carmina malis?

Epist.2.1.1 Io

Serm.2.3.76

Epist.2.1.7I

Serm.1.10.75

Episl.1.1.55 
us puenum survordas dictata magistro reddere

lipist.1.18.13

dicte. primat dicte mihi. summat dicende Camena.

Epist.1.1.1

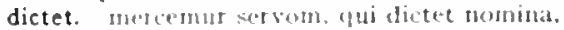

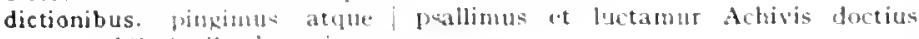
[ilin tionibus! unctis.

dictis. sic no tor mabat puesum dictis adde syper, dictis quod non levius valeat

dictitet. si te pupulas samum recterfue valentern dictitet. dictiter Albano Musas in munte locutas.

dicto. Uhi dieto citish curasta sopori membra declie. scimus jnurbanum lepido seponere dicto

dictu. tristia manstum voleum verba decent. . severum seria dictu.

dictum. yuod semel dictum iest cui canis "x wo dictum cogmonen althacet.

dictum. Hune ego, mon :tlo lictum prius ore, Jatinus/volgavi fadicen;

dictum. hoc tibielicturn tolle nemor. arguet antsigue dictum, mutanda nutabit.

dictus. quampuatu choteis aptiot et jocis ludoque dictus I I.reulis titu moto dictus. . Caesar quod semel dictum [dictus] est stabilisque terum terminus setset. nume ager Vubreni sub monime, nupet obell / dictus.

nam nuhi quarenti convivan dictus here illic de medio potare die.' dictus ob ho denire cigres rabidoscue leones; dictus et Amphion. Thebanate conditor untis. Sana movere

dicunt. ut marina filium dicunt Thethis sub lacrimosa Troiatef functa.

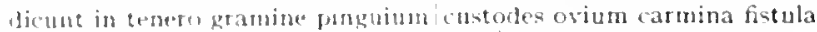

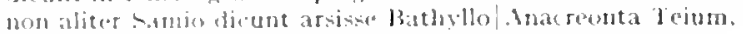

Ennius. . "aleer Homerus", ut eritice dicunt. vel quia nil tentum, nisi quod platcust sibs, ducune [dicunt] ut qui cendut ti jorant in tunere dicunt

dicuntur. poges dicuntur mult is urgere culillis

didicere. Vindelici didicete mupet quitl barte pobses.

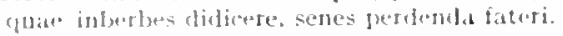

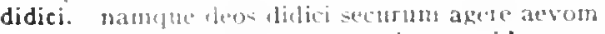

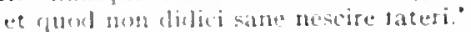

didicit. habretonuna aegrol non audet nisi qui didicit das". qui dulcit. patriae quid dubeat et quid amicis. .

rui I"y hia cantat tubion. didicit ptius extimuitque magistrum.

didit. Mlinuci sens anemplo. dem munia didic.

diducere. ago mon antis est risu diducere rictum auditoris at:an discunt in partis centum diducere.

diduci. similicelue menum ntille die setsus deduci fdiduci\} posse.

diductos. diductospue iugo cogit aemeo?

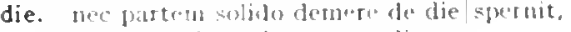

sujurema citius solvet amor diet.

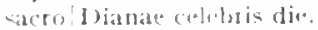

ille ret andinto the pusuit alje*

ermentur diens dian

mosued digna bunn die.

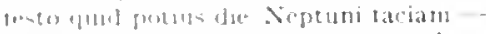

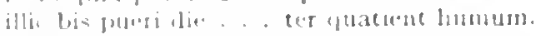

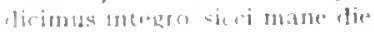

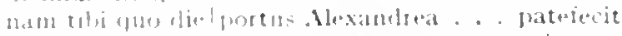

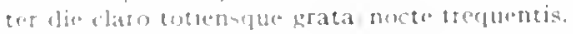

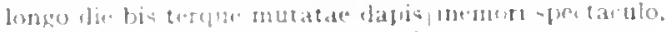

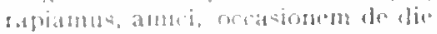

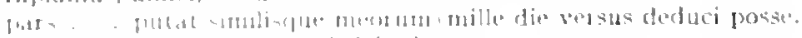

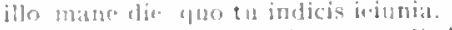

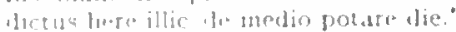

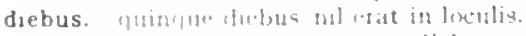

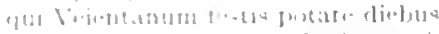

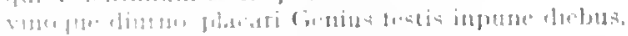

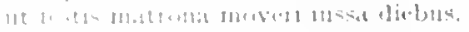

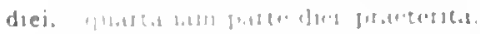

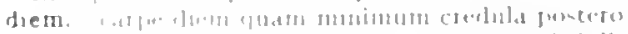

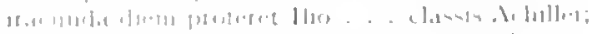

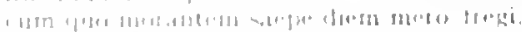

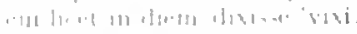

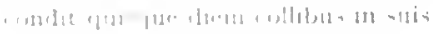

Epist.1.0.50

:ar. Lapist 2.3.33

Sorm.1.1.121

Serm.2.7.78

Epist.1.16.22

lipist.2 1.27

Serm.2.2.80

irs 1 loet.273

Ars Poct 107

Carm.sace.zo

Sorm.2.2.5e

lipist.1.19.32

Ars Poet.307

Ars Poet. 49

Carm.2.19.26

Carm.3.14.

iar.Carm.Sace. 26

Serm.2.2.134

Sotm.2.8.2

Ars Poit.393

- Ars Pot 39.1

Carm.1.8.14

Cismot 129

lipod 14.9

Lipist 2.1.51

:ir tepist.2.1.83

- Irs l'oct.431

- Irs Poet.t3a

Carm..t.1.8.8

Eptst.2.185

Serm 1.5 .101

Ars l'od.t18

Fipist.21.145

Ars l'vel-312

Ars Poct.415

Sirm 2.2 .07

Sierm 1.10.7

irs l"oes. 320

vis fierm.2.1.4

(arm-3-9.18

Cium.1.1.20

(iurm.1.33.20

Carm.2.12.20

(arm.2.13.1

Curm.2.18.15

Carm-3.21.0

Carm.328.1

Carm.4.1.25

(arm.1.5.39

Curm.4 1.3. 3

Carm.Suci.23

ISpod 533

lifod 13.1

Serm.2.1.1

Serm.2.3.201

Sicrm.2.8.3

Sirm.1.3 to

serm. 231.43

Ars Jined 210

Ars Juel 2.32

term.1 135

(itrm 1.118

(iorm.1.15.33

(arm 2.70

( arm 3 and

(arm +5.20 
monet annus et almum $\mid$ quae rapit hora diem. curru nitido diem quilpromis et celas . urget diem nox et dies noctem noctis vigilabat ad ipsum/mane, diem totum stertebat. quantum interpellet inani/ventre djem durare, . sive diem festum rediens advexerit annus, . sen bruma nivalem/interiore diem gyro trahit. per totum hoc tempus subiectior in diem et horam/invidiae noster. ni|posces ante dien librum cum lumine, omnem crede diem tibi diluxisse supremun:

dierum. quem Fors dierum cumque dabit, natalis aliosve dierum (festos albatus celebret) quantulum enim summae curtabit quisque dierum. .

dies. Cressa ne careat pulcra dies nota ille dies utramque ducet ruinam. . truditur dies rie damnosa quid non inminuit dies? hic dies anno redeuste fest us

hic dies vere mihi festus atras / exiget curas: reluti stet volucris dies. pulcher fugatis ille dies Latio tenebris. gratior it dies qui dies mensem Veneris marinae findit Aprilem, quae semel ... inclusit voluctis dies. urget diem nox et dies noctem iamque dies aderat, nil cum procedere lintrem|sentinus, diesque longa videtur opus debentibus. cras nato Caesare festus|dat veniam somnumque dies; si meliora dies, ut vina, poemata reddit, quod non multa dies et multa litura coercuit

dies. non, si trecenis quotquot cunt dies, . . tauris,

dies. seu te in remoto gramine per dies! festos sole dies referente siccos; concines laetosque dies noctesque diesque formidare malos fures, incendia, cui pulcrum fuit in medios dormire dies quinque dies tibi pollicitus me rure futurum

Diespiter. namque Diespiter, igni corusco nubila dividens/plerumque. saepe Diespiter neglectus incesto addidit integrum.

differ. grata sume manu neu dulcia differ in annum,

differat. iractosque remos differat; pleraque differat et praesens in tempus omittat.

different. poit insepulta membra different lupi

differre. si puerilitu his ratio esse evincet amare/nec quicquam differre. nec sic enitar tragico differre colori.

differs. differs curandi tempus in annum?

differt. nisi quod pede certo/differt sermnni, sermo merus. quid enim differt, barathrone dones quidquid habes an numquam utare paratis? -

differtum. inde Forum Appi|differtum nautis cauponibus atque malignis.. servosidiffertum transire forum populumque iubebat.

difficile. difticile est proprie communia dicere:

difficile. quine putetis/difficile et mirum.

difficilem. difficilem 0 t morosum offendet garrulus:

difficilem. non te l'enelopen difticilem procis/Ty menus genuit parens. difficili. meum/fervens difficili bile tumet iecur.

diffilis. difficilis, cuerulus, laudator temporis actilse puero.

difficilis. te saepe vocanti duram difficilis mane.

difficilis. eque difficilis aditus primos habet.'

diffidere. equidem nihil hinc diffindere [diffidere] possum.

diffidit. diffidit urbium portas vir Macedo

diffigas. o utinam nova|incude diffingas [dliftigas] retusum in/Massagetas Arabasque ferrum.

diffindas. o utinam nova|incude diffingas [diftindas] retusum in | Massagetas Arabasque ferrum.

diffindere. 'equidem nihil hinc diffindere possum. . . . . . . diffindit. turgidus Alpinus iugulat dun Memnona dumquelelifingit [diffindit] kheni luteum caput.

diffingas. utinam novalincude diffingas retusum . . ferrum.
Carm.4.7.8

Carm.Sacc.9

Epod.17.25

Serm.1.3.18

Serm.1.6.1 28

Serm.2.2.83

Serm.2.6.26

Serm.2.6.47

Espist.1.2.35

Epist.1.4.13

Carm.1 9.1 4

Serm.2.2.60

Sirm.2.3.1 2.4

Carm.1.36.10

Carm.2.17.8

Carm.2.18.15

Carm.3.6.45

Carm.3.8.9

Carm.3.14.13

Carm.3.28.6

Carm.4.4.40

Carm.t.5.7

Carm.4.11.15

Carm.t.T3.Io

Epod.17.25

Serm.1.5.20

Epist.1.1.20

Epist.1.5.10

Epist.2.T.34

Ars Poet.293

Carm.2.14.5

Carm.2.3.6

Corm.3.29.20

Carm.4.2.4I

Sirm.I.I.70

Epist.1.2.30

Epist.T.7.I

Curm.I.345

Carm.3.2.29

Epist.I.J 23

Epod.10.6

Ars I'oct.4t

Epod.5.99

Sirm.2.3.25I

Ars Poet. $23^{6}$

Epist.1.2.39

Serm. I 4.48

Serm.2.3. 160

Sirm.1.5.4

Epist. I. 0.59

Ars Port.1 28

Serm.1.10.22

Serm.2.5.90

Carm.3.1O.II

Carm.1.13.t

Ars Poet. 173

Carm.3.7.32

Serm.t.9.56

zar.serm.2.1.79

Corm.3.16.13

tar.Cnrm.1.35.39

tar.Carm.1.35.39

Sorm.2.I.79

coni.Serm. I I I O.37

Carm.1.35.39 


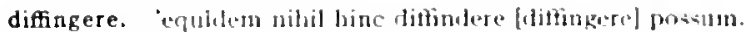

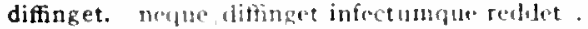

diffingit. Anmulue diffingit Rheni hoteum qubut.

diffisss. pundi dittisea nate ficus:

difuderit. mollis inertia cur tantam difuderit imisloblivionem sensibus.

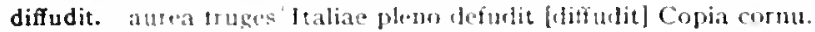

difugere. distngere nives.

diffugiunt. mordinces aliter dintugiunt sollicitudines. litimginat callis cum farce siccatis amici.

diffundere. salo ditumlere signa parabat; induiderm oibil binc ilifindere |diffumderel possun

diffundit. bella guis et paces longum diffundit in aevon??

diffusa. vina bibes itıum Tauro difusa palustris inter Minturnas Simuesinumbute Petrinum.

diffuso. to phosaputur meroldeluso [alifuso]

difigit. turgidus Alphu iugulat dum $\mathrm{H}$ (emnona dumqueldifingit [difigit] Khorul luteurti caput.

Digellus. Sardus babebat iltr Tigellius [Digethe] hoc:

Digentia. me (lustions reficit geli(las l)igentia rivos.

digitis. legitimumeque sonum digitis callemus et aure.

digito. pignusute dereptum lacertis ant digito male pertinaci.

guod monstor digito practeteuntium

siquid forte lateret, indice monstraret digito:

digitos. nascunturefue laves per digitos umetosfue plumase.

digna. una de multis face nuptiali|digna.

moresi digna bono dire.

ait Jlan prife gula digna rapacibus.

tortum digna segui potius quam ducere funem.

digna. iterum quan digna legi siot scripturus,

digna. uerumelu sisco digna silentio mirantur umbrac dicere, semper ut to digna cepuare

non tanen intws digna geri fromes in scacham

dignam. on in vitum libertas cxeblit et vim dignam lege regi:

dignatur. Romat principis urbium dignatur suboles

digne. digm. pues meliore flamma.

(andei digne meto non sine thoribus.

digne. quis Matem tunica tectum adamantina digne seripserit .

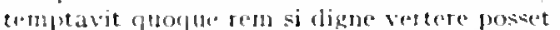

digner. verbat lvac motura somusu conectere digner?

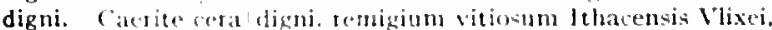

maxima pare vatum, pater et iuvenes patre digni. decipimur specie recti.

dignior. aldemet lutes Caecuba dignior

dignis. vir bonus ret sapions dignis ait esse paratus

dignis. mivatis a prope socoo dignis caminibus marari

dignissima. quirl tils vis, mulict nigr is dignissima barris?

dignius. peecat uter mostrum cruce dignilss?

dignor. Erammations ambire tribus et pulpita dignor:

dignos. utunte blures culpari diknow.

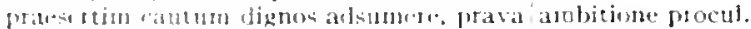

dignoscere, silinet at vellem curvo dignosere tectum

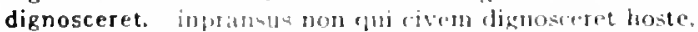

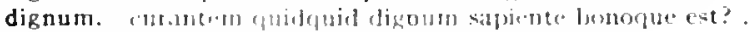

dignum. dignem lintele virums Masil vetate mos.

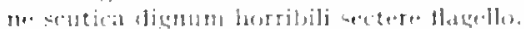

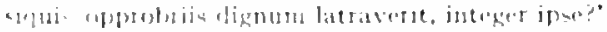

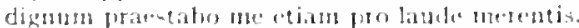

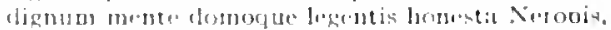

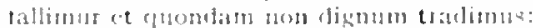

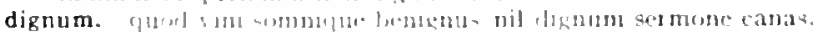

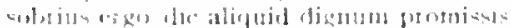

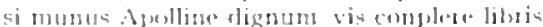

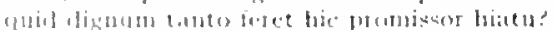

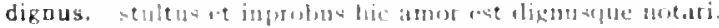

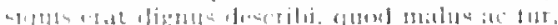

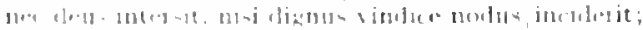

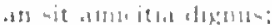

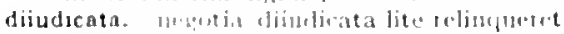

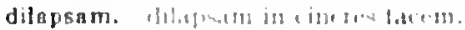

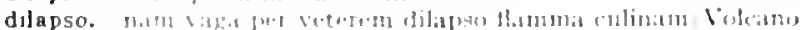

ar.Scrm 2.1 .79

Curm.3.29.47

Siorm.1.10.37

Sirm. r 8.47

Epod.14.1

var. Epist.1.12.29

Carm.4.7.1

Carm.1.18.4

Carm.1.3.5.26,

Sirm.1.5.10

tur.tirm.2. 70

Epist.1.38

Epist.1.5.4

atr.Carm.4.5.34

: ar. Sorm.1.10.37

var.serm.1.3.4

Episti.18.104

Ars l'od 274

Corm.1.0.24

(arm.1.3.22

Sirm.2.8.26

Carn.2.20.12

Carm.3.11.34

Carm 3.21 .6

Serm.2.2.40

I.pist.1.10.48

Sirm 1.10 .72

Carm.2.13.29

(arm.4 11.29

.1rs Joet.183

Ars I'odt.283

Carm.4.3 14

Carm.1.27.20

Carm.3.13.2

Carm 1.0.1.4

Epist.2.1.104

Epirt 2.2.86

Fitist. 1.0 .03

Ars Poct.24

Carm.2.14.25

Enist.1.7.22

Ars l'oetior

Food.12.1

Sirm.2 7.47

Epist.1.19.40

serm.1.4.25

Sierm.1.0.51

Epist.2.2.44

lipist.15.29

Epist 1.45

(iarm.ds.28

serm.1.3.110

serm 21.85

lepiet 1.7.2.4

lipint: 8.9

Epiti.ts.

Sirm.2 31

sorm. 2 is

Ipivz:210

Irs I'DAl $1,3 \mathrm{~K}^{\circ}$

Serm.1.3.2:

serm.1:3

irtiosios

les l'ors. 1.30

(ii) m 3.5 .5 .4

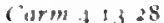

virm.573 


\section{DILAPSVS}

dilapsus, sed ille. |si foret boc nostrum fato delapsus [dilapsus] in aevom, | detereret sibi multa.

dilatar. dilator, spe longus, iners avidusque futuri,

dilatus. sed ille, |si foret hoc nostrum fato delapsus [dilatus] in aevom.| detereret sibi nulta,

dilecta. iam proterva|fronte petet Lalage maritum/dilecta,

dilectam. Latonamque supremo/dilectam penitus Iovi.

o Venus . . sperne dilectan Cypron

crede non illam tibi de scelesta/plebe dilectani

dilecte. ego, quem vocas, / dilecte Maecenas,

dilecti. dilecti tibi Vergilius Variusque poetae.

diligeret. magis quem/diligeret mulier sua quan te.

diligit. auream quisquis nediocritatem|diligit,

nec sequar aut fugiam quae diligit ipse vel odit:

sedulitas autem stulte quem diligit urget.

disudia. 'displicet iste locus' clamo et diludia posco.

diluit, aceto' diluit insignem bacam: .

diluta. nisi Hymettia mella Falerno/ne biberis diluta.

diluviem. horrendamque cultis'diluviem meditatur agris,

diluvies. cum fera diluvies quietos/irritat amnis.

diluxisse. omnem crede diem tibi diluxisse supremun:

dimidio. 'maior dimidio'. 'num tanto?' .

dimidium. et serves auinae dimidium meae.

dimidium facti, qui coepit. habet: sapere aude.

dimisere. unde simul primum ne dimisere Philippi

dimisit. nam ut quisque insanus... latum demisit [dimisit] pectore clavom.

quo te demisit [dimisit] peecati conscia erilis.

dimissa. quantum dimissa petitis/praestent.

dimittar. 'tam teneor lono, quam si dimittar onustus'

dimittere. nec, siquid miri faciat natura, deos id/tristis ex alto caeli demittere [dimittere] tecto.

quingue bonos solitum Variam dimittere patres.

gestit enim nummum in loculos demittere [dimittere].

si curet quis opem ferse et demittere [dimittere] funem:

dimittes. nec me dimittes incastigatum,
dimittis. nec me dimittes [dinittis] incastigatum. ubi pluralcogere quam satis est

dimittit. hue frequens, caementa demittit [dimittit] redemptor

dimittit neque famosum neque sollicitum

in trivis fixum cum se denittit [dimittit] ob assem.

dimittitur. tanrlem dornitun dimittitur.

dimoveas. gaudentem . . numquam demoveas [dimoveas].

dimoveat. cum te neque fervidus aestus/demoveat [dimoveat] lucro neque hiemps.

dimovebit. corticem adstıictum pice dimovebit

dimovere. selu virides rubum | dimovere lacertae.

dimovet. curvo nee facim litore dimovet:

dimovit. num aliter tamen llimovit obstantis propinquos

emovitque [rlimovitque] culpas, et veteres revocavit artis.

Dindymene. non Dindynene, non adytis quatit | menten saccrdotum incola l'ythius.

Diomede. qui lotus a forti Diomede est conditus olim. .

Diomedi. ut Dionedi eum Lycio Glauco.

Diomedis, nec reditum Diomedis ab interitu Meleagri. . orditur .

Dionaeo. mecum I ionaeo sub antro.

Dionysi. 'tune, Syi, Damae aut Dionysi filius, audes .

diota, deprone quadrimum Sabina, /o Thaliarche. merum diota.

dira. si figit adamantinos|summis verticibus dira Necessitas/clasos, . dira detestatio/nulla expiatur victima.

dira. cur dira barbarae minus, venena Medeae valent. "hune neque dira venena nec hosticus anferct ensis

dirae. iam satis tertis niris atque dirae/grandinis misit Pater

diram. diran qui contudit hydram

Dircaeum. multa Dircaeum levat aura cyenum.

Dircaeus. post hos insignis llomerus|Tyrtaeusque [Dircaeusque] mares animos in Martia bella versibus exacuit;

Dirceus. post hos insignis Ilonerus/Tytaeusque [Dirceusque] mares animos in Martia bella versibus exacuit;

\section{DIRCEVS}

2ur.Serm.1.10.68

Ars Poil.i 72

var.Serm.1.10.68

Carm.2.5.17

Carm.1.21.4

Carm.1.30.2

Carm.2.4.I8

Carm.2.20.7

Epist.2.1.247

Epod.12.24

Carm.2.10.0

Epist.1.1.72

Epist.2.1.260

Epist.1.19.47

Serm.2.3.24I

Serm.2.2.16

Carm.4.14.28

Carm.3.29.40

Epist.1.4.I3

Serm.2.3.318

Carm.1.3.8

Epist.1.2.40

Epist.2.2.49

q'ar.Serm. I .6 .28

iar.Scrm.2.7.60

Epist.1.7.96

Epist.1.7.1 8

g'ar.Serm.1.5. 103

Epist.1.14.3

tar.Epist.2. E.1 75

var. Ars Poet.46I

Epist.I.10.45

2ar.Epist.I.10.45

2ar.Carm.3.1.35

Sirm.2.7.5 I

tar.Ispist.1.16.64

Epist.1.7.73

var, Carm.1.1.I3

Far.serm.1.1.39

Carm.3.8.10

Carm.1.23.7

Carm.4.5.14

Carm.3.5.5t

var.Carm.4.I 5 . I I

Carm.1.10.5

Serm.1.5.92

Sirm.1.7.I0

Ars Poet.146

Carm.2.1.39

Sierm.1.6.38

Carm.1.9.8

Carm.3.2+6

Epoll.5.89

Epod.5 6I

Serm. I.g.3I

Curm.1.2.1

Epist.2.1.10

Curm.t.2.25

sar.Ars Poet.402

s'ur.ifrs Poet.to2 


\section{DIREPTA}

direpta. derepta [ojiepta] vidi, visj ego civium / retorta tergo bracchia libero

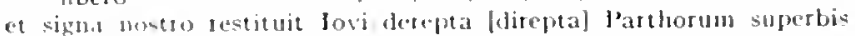
pectibus

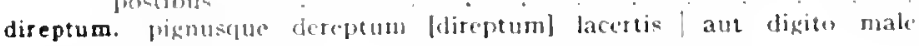
juertincti.

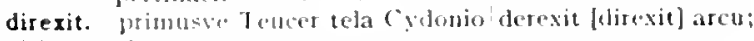

diris. diris atgent vos:

diris. levite diris pectora sollicitudinibus.

diruere. non atuifo impotens, posit diruere

diruit. Clamblus agmina ferrata vasto disut imjetu

diruit. indificat, nutat quadrata roundis?

dirum. Hec durum [dirum] Hannibalem nec Siculum mare. . aptari cirlazane mollis

cecidil Antiochum Ilannibalemence dirnu.

dirus. crescit jululgens sibi diras hydrops

ditus pet utbis Ater ut Jalas. . efuntavit

dis. tre doctarum berlerae pratmia fromtiuml fis noscent superis.

dis pietals mea ot musa cordi est.

mercator. . discaras ipsis.

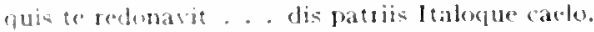

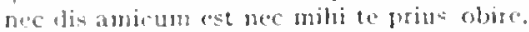

ego dis amicum . . reddicti armen.

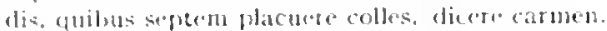

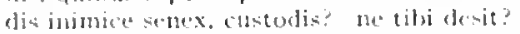

lis ctonim titeite ast

(sic dis placitumb)

dis. not rime div andmosus intans.

dis te minurem quevel getian inperas:

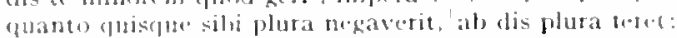

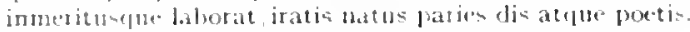

disce. bebe terte mannam disce fortunam;

disce, dormelue adlute quate conset amiculus.

discedat. discedat - pulcrior, udro|mumeribus nissing:

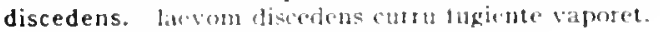

discedere. miscre discodere guacions

guotsi me nolds usquan discetere.

me com-bate mili scis et discedere tistem

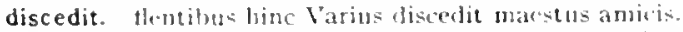

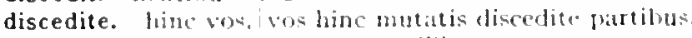

discedo. disccedo Alcan puncto illius:

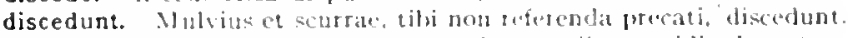

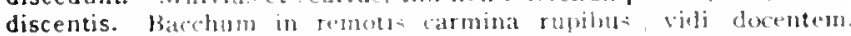
Dymphlateque alicentis

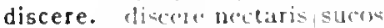

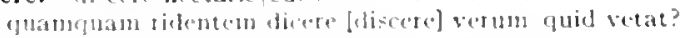

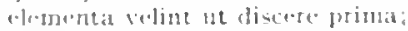

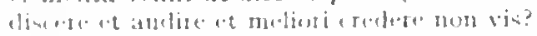

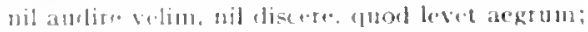

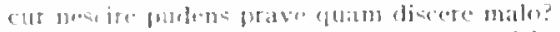

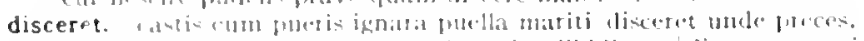

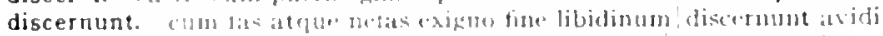

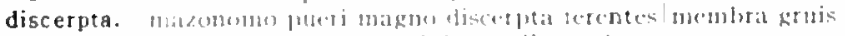

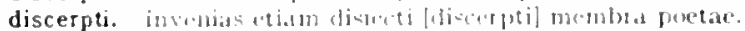

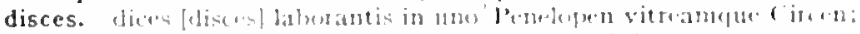

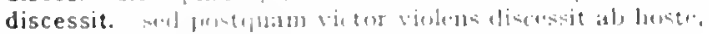

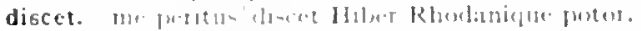

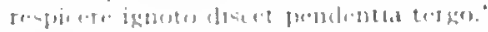

dincit [4]

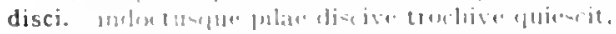

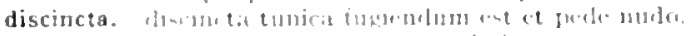

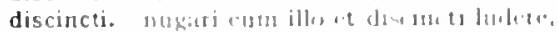

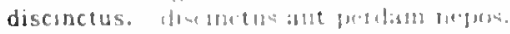

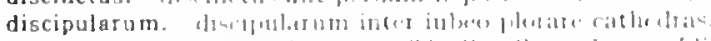

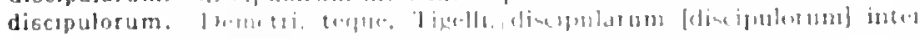

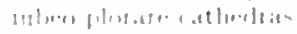

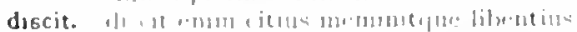

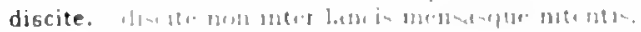

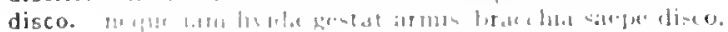

iar. Curm.3.5.21

iar. Curm.4 15.7

gar.Corm.1.9.23

iar.c "arm.4.9. 18

lipol.5.89

fipres. 3.10

Carm.3 30..4

(ismm.t. 30

J.sist.1.1.100

ilr.Carm.2.12.2

Curm.3.0.36

Curm.2.2.1.3

Carm.4.42

Carm.1.1.30

Cirm.1.17.13

Curm.1.31.23

Curm.2.7.4

Carm.2.17.2

(arm.t.0.4I

(arm.sisec.7

Sirm. 2.3 .123

Serm.2.3.284

Serm.2.0.22

Carm. 3.4 .20

Carm.3.6.5

(arm.3.16.22

Sirm.2.3.5

corm.3.27.75

depist 1.17 .3

Sirm.1.7.17

IEpist.j.1e.

Sorm 1.0.8

1.pist 1.7.25

Epist.1.t.

Serm 1.5 .93

Serm.1.18

Epist.2.2.09

Serm.2.7.37

('arm. 2.10 .3

(istm.3.3.3.4

iar.serm.1.1.24

viem.1 1.20

1.p.t.1.1.4k

I.poy a 8.8

Ars lood ho

1.pist.2.4. $\$ 33$

( wrm.t.18.1

Serm.s.ses

iur.oterm $1 . .+42$

aur. (arm. 1 17.10

1.put.1.1037

("1rm.2 20.20

sim. $2.3 .2(x)$

atr $1 \cdot$ prat.2.1.2f:2

Ars lorel ises

serm12.132

serm.2 1.73

1. pod. I.3.

sirmelined

Jipit. 2.1202

sin? $23 . .4$

( a) I A. I I 
seu te discus agit (pete cedentem aera disco) --

discolor. ut matrona meretrici dispar erit at fue/ discolon.

disconvenit. aestuat et vitae disconvenit ordine tota. eo disconvenit inter/meque et te:

discordet. depugnare parati,|si discordet cutues, quantum discordet parcus avaro.

Discordia. ut si solvas "postquam Discordia tactral bolli balluen potis portasque refregit.' .

discordia. tecum mihi discordia est. duo si discordia vexet inertis

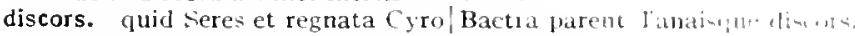

discors. extimui, ne vos ageret vesania discors, quid velit et possit rerum concordia discors. ut gratas inter mensas symplionia discors

discrepat. vino et lucernis Medus acinaces/immane quantum din depat: longe mea discrepat istis let vox et ratio: qui discrepat istis|qui nummos aurumque recondit.

discrepet. vino et lucernis Medus acinaces inmane fuantum discrepat [discrepet]:

quantum simplex hilarisque nepoti|diserepet primo ne medium, medio ne discrepet imum.

discrepuit. sortilegis non discrepuit sententia Delphis.

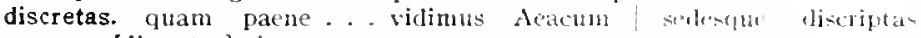
[discretas] piorum

discrimen. mire sagacis falleret hospites/discrimen olycumun

discriptas. vidimus Aeacum $\mid$ sedesque discriptas piorum

discriptas servare vices operumque colores

discunt. Romani pueri longis rationibus assem/discunt in putis orntum diducere.

discus. seu te discus agit (pete cerlentem aera discon) -

diserti. actor/causarum mediocris abest virtute diserti, Masallate

disertum. facundi calices quem non fecere disertum.

disertus. dum studet urbanus tenditque divertus habei

disiecta. tectaque Penthei/disiecta non leni ruina

disiecti. invenias etian disiecti menbra poetae.

disiunctum. bovemque/disiunctum curas et strictis frondilus aples.

dispar. temperat Alcaeus, sed rebus et ordine dispar.

dispar. ut matrona meretrici dispar erit atque/diseolor.

dispar. nec fuit leonibus/umquam nisi in dispar feris.

disparem. ultra|quam licet sperare nefas putando|dispant.n vit...

dispari. ne male dispari|incontinentis iniciat nanus

disparibus. aut si disparibus bellum incidat.

dispensare. tu si modo recte/dispensare velis

dispeream. dispeream, ni|sumnosses onnis."

displicent. displicent nexae philyra coronae.

displicet. 'displicet iste locus' clamo et diludia posco.

displosa. displosa sonat quantum vesica.

disponuntur. 't quae rimosa bene deponuntur fdisponumur| in allse.

disquirite. verum lic inpransi mecum disquirite.

dissentientis. Reguli|dissentientis condicionibus focdis

dissentire. tres mibi convivae prope dissentire videntur

dissentis. nisi quid tu, docte Trebati, /dissentis.'

dissidens. Ihraaten/dissidens plebi numero beatorum eximit lin

dissidet. Nedus infestus sibi luctuosis $\mid$ disillet armis, si toga dissidet inpar.

dissignat. quid non ebrietas dissignat?

dissignatorem. dissignatorem decorat lictonibus atric,

dissiliat. repallida lecto/desiliat [dissiliat] nulier.

dissilire. caputque Marsa dissilire nenia.

dissilit. montibus altis|levis crepante [? sonante] lympha dwilit [/ disilit] pede. .

dissiluit. gratia sic fratrum geminorum. Amphionis atque \% (hi, eliswiluit. dissimile. dissimile hoc illi est.

dissimilem. tanto dissimilem et tanto certare minorem?

cenamus avi $=$ concbylia, piscis, | longe rissimilem noto culnutia suellm.

dissimiles. hac in re scilicet una|multum dissimilea.

dissimilis. 'Scetani dissimilis sis."

dissimulare. nale salsus|ridens dissimulare;

dissimulat. qui dissimulat metum/Marsae cohortic Datus
Sirm.2.2.13

lipist a.1.

lipist.1 I.99

lipist.1.1.1.8

Epist.2.1.185

lipist.2.2.10.4

Sirm.1 f.6,

Eisti. 7.2

Sirm.1.7.15

Corm.3.29.2s

rerm.2.3.1.4

Fpist.1.12.19

lis lout.374

(arm.1.27.0

Sirm.1.0.92

serm.2.3.108

iar.curm.1.27.6

Lipist.2.2.194

Irs Poet.I52

Irs Pont zin

iar.corm.2.13.23

Carm.2.5.23

( arm.2.13.2.3

conister Poetso

Irs Pull. 320

ierm.2.2.13

Ars Pext.37\%

Epist.1.5.60

Iipist.1.19.10

Curm.2.10.15

Strm.1.4.62

Ifpist.1.1.4.25

Epist.1.1020

Epist.1.18.3

Epol.7.12

camal.11.31

Curm.1.17.25

Serm.t.7.10)

Sirmt1.2.75

Serm. J.9.47

carm.1.3k.

Epist 1-10.4?

Serm.1.8.at?

var.serm.2. 4

Sermo.2.

carm.3.5.14

lipist.2.2.11

Sirm.2.1.79

Carm.2.2.18

(corm.3.8.20

EFist.1.1.gr

Epist.1.5.b"

Epist. a 7 es

iersirmes 2134

Ispot.17.2.

Sar.Lpod.solt

Epist.t.18.t2

Serm.1. I. 49

remm.2., 431,3

serm.2 $8.2 \mathrm{~s}$

lepist.1.10.3

Serm.1.421

Serm.1.9.1,

corm.2.24. 17 
dissimulstor, dissimulator opis propriac. mibi commodus uni. dissinules. Hell. . . ccultam febrim sub tempus edendi|dissimules, dissipsbit. osea (uirini. (nefas videre) dissipabit insolens. dissipse. prudens anus/novendialis dissipare pulveres.

dissipat. disupat Eulius|curas edacis.

dissocisbiles. nequicjuam deus abscidit/prudens oceano dissociabili (dissnciabiles)|tertas.

dissociabili. u॰quiquan deus abscidit prudens oceano dissociabili|terras, .

dissocientur. continui montes, ni diseocientur opaca/valle,

dissolvss. quem si dissolvas, quivis stomachetur eodem/quo personatus pacto pater.

dissolve. dissolve frigus ligna super focollarge reponens

distabst. cordidus a tenui victu rlistabat ()tello iudice:

distabit. sordidus a tenui victu distabat [distabit] Ofello|iudice:

stultitiane erret nihilun distabit an ira.

infido scurrae distabit annicus.

distantia. emendala videri|pulchraque ex exactis minimun diatantia miror.

distsre. loto niminu distare Carinas iam grandis natu queritur.

distat. quantum dintet [distat] ab Inacho|Codruy

paulum repultae distat incrtiac colata virtus-

carese samen quamsis distat nil.

amator!exclunus qui distat.

distit, sumatse pudenter|an rapias.

distat enim. spargise tua prodigus, an neque sumptum invitus facias

distenet. cur ita (rodiderim, nisi guid te detinet [distenet], audi

distent. nec tumen ignorat, quid distent aera bupinis.

distenta. distenta siccet ubera

distentius. quomlue aliena capella gerat discentius uber,

distet. quantum distet ab Juachol Codrus

distinet. "fuem Notus... dulci distinet a rlomo.

cur ita crediderim, nisi quid te detinet [distinet], audi

distinguere. fuann (fui non poterit vero distingure falsum.

distinguet. iam tibi lividos/distinguct autumnus racenos/purpureo varius colore.

distorquens. distorpuens oculos. ut me eriperet.

distortis. I,13ne varum distortis cruribus.

districtum. tene, ut ego accipiar laute, torqueries onni sollicitudine districtum,

districtus. dentrictus [districtual areis cui super inpia cervice pendet. distringere. quen ent destringere [distringere] coner / tutus ab infertio litbonibus?

distuli. fluturere (listuli) nec scire fas est omnia.

ditsntis. nuid mari- toxtemos drabas ditantio

ditssse. "luicl profletat ditasse l'aelignas anus

ditaverit. cum lingus Catonis et Enni sermonem pattinm dituverit

ditovit. satis supreque me benignitas tualditavit.

ditem. Bruto practore tenente/ditem Asiam.

ditescere. ifcejpe tua ristione queas ditescere.

dithyrsmbos. seu per audacis nova dithytambos verbit fovolvit

ditior. nil alsutet tibi, duth se sit te ditior altert.

nam Camus laphlosu- aquae non rition urda.

ditior hic alut est quia doctior:

litior ant tormake melioris neiat eolem.

ditis. positostuke vernas, disis examen domus,

ditis. antun dicet erpuis Argos ditisque Mycenas:

diu. dinçut lactus intersin populo Quirini

interming. Jenus, diu rursua Jella noves?

diulaterale victices catervar.

alsero iall nimium diu:

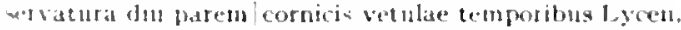

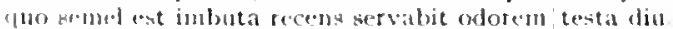

te proficiventing docui te sacpe diugue.

null. ylow"re liu nec vivere carmina possunt,

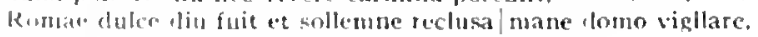

1) bucusatil diu jerpulo bonus eruet

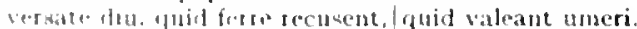

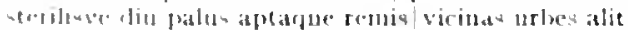

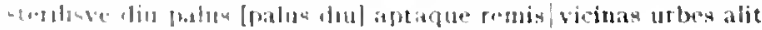

Epist.1.9.9

Epist.1.16.23

I.pod.16.14

Epod.17.48

Carm.2.11.17

coni.Curm.1.3.22

Carm.1.3.22

IEpist.1.16.5

Serm.1.4.55

Carm.1.9.5

Serm.2.2.53

for.Serm 2.2.53

Serm.2.3.210

I.pist.1.18.4

Jifist.2.1.72

lipist.1.7.48

yar.Carm.3.19.1

Carm.4.9.29

Serm.2.2.20

Serm.2.3.260

Lpisl.1.1 7.44

Epist.2.2.195

rar. Eipist 1.2.5

Epist.1.7.23

IEpod.2.46

Serm.1.IIO

Carm.3.19.1

Carm.4.5.12

Iur. Epist.1.2.5

Jipist.1.10.20

(arm.2.5.1

Serm.1.0.65

sern.1.3.47

Derm.z.8.

sor.Curm.3.1.17

tibr. herm.2.1.41

Carm.4.4.21

tipist.1.0.6

lipod I 7.00

Ars Jeret. 57

lipoul. I. 32

Sirm.1.70

Serm.2.5.10

Carmit 2.10

Sirm. I. I. 40

serm.1.5.01

Sermi.1.9.5

Scrm. 2.7 .52

fipod.265

Carm.1.7.0

Corm.1.2.45

Carm.4.I.I

Carm.4 122

(arm.4.5.2

(arm.1.13.24

I.pist.1.2.7n

lipit. 1.13 .1

lipist 1.10.2

IEpirt.2.1.103

Iipist.2.2.115

Ars Joet.39

Irs Joel.65

romi Ars Joet.os 
diurna. qui prose tolleret atque/mitteret in phimum talos, nercede diuma conductum pavit:

vos exemplaria Graeca/nocturna versate manu, versate diurna.

diurno. nocturno certare mero, putere diurno.

vinoque diurnolplacari Genius fest is inpune diebus.

diurnos. tu me inter strepitus nocturnos atque diurnos/vis canere

diva, sic te diva potens Cypri. . . . regat

diva, o diva, gratum quae regis Antium,

ter vocata audis adimisque leto, / diva triformis.

o quae beatam diva tenes Cyprum

diva, producas subolem

dive, dive, quem proles Niobea magnae/vindicem linguae... sensit

divellat. est ubi divellat somnos minus invida cura?

divellere. pullam divellere mordicus agnam / coeperunt;

divellet. me ... nec si resurgat centimanus gigas/divellet unquam:

divelletur. nec Damalis novo/divelletur adultero

diversa. laudet diversa sequentis?

potius laudet diversa sequentis

poscentes vario multum diversa palato.

diversis. dividit ut bona diversis, fugienda petendis;

diversoris. mutandus locus est et deversoria [diversoria) nota] praeteragend us equos.

diversum, est huic diversum vitio vitium prope maius,

dives. Ilio dives Priamus relicto . . castra fefellit.

dives ut aureis|mercator exsiceet culillis

divesne prisco natus ab Inacho/nil interest

num tu quae tenuit dives Achaemenes

pauperemque dives|me petit:

quo pius Aeneas, quo Tullus dives et Ancus,

nos ubi decidimus|quo... Tullus dives [dives Tullus] et Ancus, pulvis et umbra sumus. .

plena dives ut in domo. .

sis pecore et multa dives tellure licebit

ut quidam menoratur Athenis|sordidus ac dives,

dives|ut metiretur nummos. .

dives agis, dives positis in faenore nummis.

at quanto meliora monet pugnantiaque istis|dives opis natura suae.

si dives, qui sapiens est.

Persius hic permagna negotia dives habebat/Clazomenis.

dives, inops, Romae seu fors ita iusserit exsul.

dives|antiquo censu. gnatis divisse duobus|fertur

ante Larem gustet venerabilior Lare dives.

mercatus aravit, dives amico| llercule!".

'nullus in orbe sinus Bais praelucet amoenis'|si dixit dives,

sapiens uno minor est Iove, dives.

quein paupertatis pudor et fuga, dives amicus, . . odit

alter dives et inportunus ad umbram lucis ab ortu . . mitiget ayrum.

"dives agris, dives positis in faenore nummis."

dives. puella/dives et lasciva

divi. nihil maius meliusve terris / fata donavere bonique divi

dividat. ut haec ingrata ventis dividat |fomenta nunc age, quid nostrum concentum dividat, audi.

dividens. Diespiter, |igni corusco nubila dividens/plerumqut.

divideret. ira fuit capitalis, ut ultima divideret mors,

divides. inbelli cithara carmina divides:

dividit. nulli plura tamen dividit oscula dividit ut bona diversis, fugienda petendis;

dividuo. dividuo findetur munere quadra.

divina. imbrium divina avis imminentiun, quod puero cecinit divina mota anus urna: utiliumque sagax rerum et divina futuri

divina. divina humanaque pulcris/divitiis parent; .

divinae. atque adfigit liumo divinae particulam aurae.

divinare. divinare etenim magnus mihi donat Apollo."

divinior. cui mens divinior atque os/magna sonaturum,

divinis. pererro|saepe forum, adsisto divinis, sic honor et nomen divinis vatibus atque carminibus venit.

divis. permitte divis cetera. gratum elocuta consiliantihus| I unone divis:

Serm.2.7.17

Ars Poet.260

Epist.1.19.I I

Ars Poet.200

Epist.2.2.79

Carm.1.3.I

Carm.1.35.1

Carm.3.22.4

Carm.3.26.9

Carm.Saec.I 7

Carm.46.1

Epist.I.I0.18

Serm.1.8.27

Carm.2.17.15

Carm.1.36.19

Serm.1.1.3

Sirm.1.i.rog

Epist.2.2.62

Serm.r.3.114

var.Epist.1.15. I0

Epist.1.18.5

Carm.1.10.I 4

Carmi. 31.10

Carm.2.3.2I

Carm.2.12.21

Carm.2.18.10

Carm.4.7.15

I'ar.Carm.4.7.I 5

Carm.4.I2.24

Epod.15.19

Serm.1.1.65

Serm.1.1.95

Sirm.1.2.13

Sirm.1.2.74

Serm.1.3.127

Serm.1.7.4

Sirm.2.I.59

Serm.2.3. 168

Serm.2.5.I4

Serm.2.6.1 2

Epist.1.1.84

Epist.1.1.rob

Epist.1.18.24

Epist.2.2.1 85

Ars Poct.t2 I

Carm.4.11.23

Carm.4.2.38

Epod.1 I.I6

Epist.1.14.31

Carm.1.34.6

Serm.1.7.13

Carm.1.I5.I5

Carm.1.36.6

Serm.1.3.114

Epist.1.17.49

Carm.3.27.10

Sirm.1.9.30

Ars l'oet. 218

Serm.2.3.95

Serm.2.2.79

Serm.2.5.6ro

Serm.1.4.43

Sirm.1.6.1 14

Ars Poct.too

Carm.1.9.9

Carm.3.3.18 


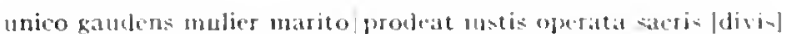

'in triumphe" civitas onmis dabinustule divis! tua benignis.

divis. Sivis orte bonis, optume Rommlae/cuctos gentis,

divisimus. hoc iter ighavi divisimus.

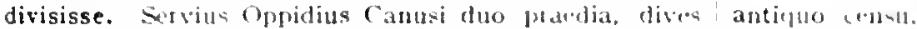
gnatis divisse [divisisse] duobus|fertur

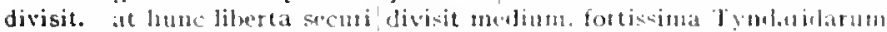

disisos. stridere seceta divisos aute sustrmas."

divisse. gnatis divised duobus fertur

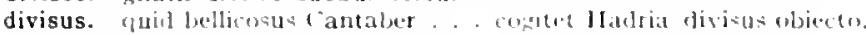

divite. divife me scilicet antium

cut exet indignus quisquan to divite?

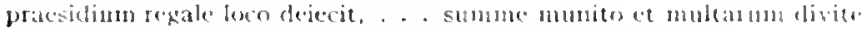
rerume

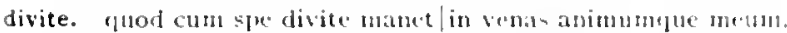

fundet opes Latumine beabit divite lingud:

nec studiun sime divite vena nec rude ptuid prosit viefero ingenium

divitem. aula divitem manet erum.

divites. arvin beata!petamus, arva divites 4 insular.

divitise. scilicet inptobae/crescunt divitiat.

nil/divitiae poterunt regales attlere maius.

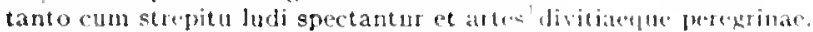

at si "livitiae prodenten rerluer" pussent.

divitiarum. mitte levis spes et certamina divitiarmm

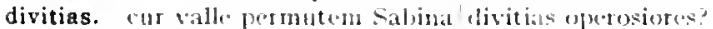

adclane aturo livitias mari:

rlivitiasence habeo tobus anglas regibur."

tu protuns, unde divitias actisque ruath, bie aupur, andian."

divitias miscras!

di tibi divitias dederunt antemqu. truemuli.

divitibus. plesumatue gratae divitibus vice

nam neque divitibus contingunt gatudiat $<$ olis:

divitibus. lingua potentium / vatum divitihus consersat inkulis.

quat" nisi divitibus nequeant continger. macheis"

divitis. 'omnis enim res, . . divitiis pale 11 ;

divitiis. exstructis in altum divitis protictur heres. nermme / livitis homines an sint virtute beati: nec otiat divitio Arabum libertina mute.

divatis. ini ferisur lecti sic nutun livitis horret.

divitis. thosantis Arabum et divitis Indian.

divitum. divitum mensis et amicot templis,

transfuga divitum purtis lincuere gestio,

divo. an paujue et infimale gente sub dive mosulit.

vitamque sub divo et tuendis agat in mobns.

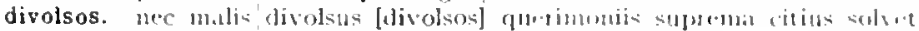
antuer die.

divolsus. nuc malis divelsus efucrinonits. . athen

divom. Mec vastio obsiti frondibus/sub divom ripian

divom. fuend veret divom populus ruentis impori telust?

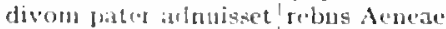

1.t qui metermug sicra divom legertit.

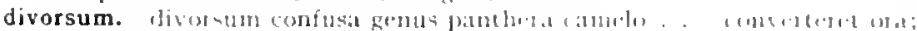

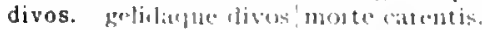

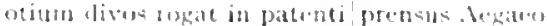

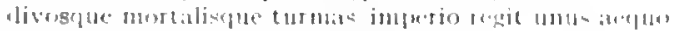

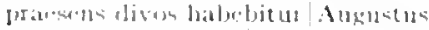

teconsilian e"t thes pracluente dives.

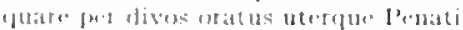

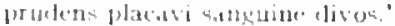

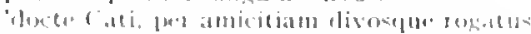

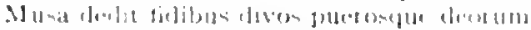

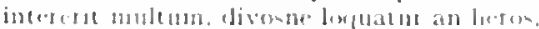

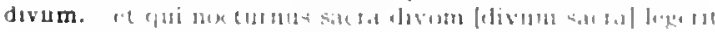

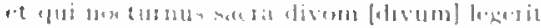

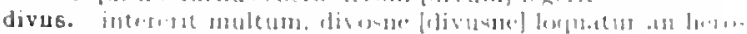

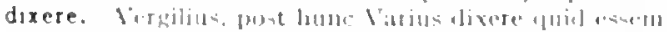

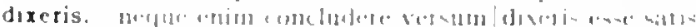

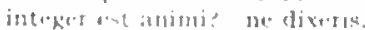

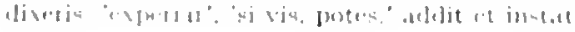

isir $(\operatorname{arm} 3.3 .140$

( arm. 4.2 .51

firm.4.5.t

Yrm.1.5.

- we term: $2.31 \mathrm{lin}$

sirmaj.j.

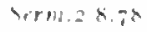

term.2.3 1eir)

(i) ind.: $=11.3$

(inmot. 5.5

S.rmi.2.2.103

1.p:3 $=231$

Fised I5.10

Jist 2.2.1 21

Ars tentefupo

(arm.2.18.31

Iiport.ut 42

Corm.3.2.1.3

Epistas.t2.0

Epist.2.1.204

t. pist 2.2.155

I.pist.1.5.t

(arm-3.1..4s

(inr):3.20.11

sirm.2.2.101

Sirm.2.5.22

torm.2.

1. $f: 11.1 \%$

(arm 3.2913

l.pist.1 170

(a)m-2.25

term.2 is

verm.2.39

( ormi $=3.20)$

term.2.11.7.t

lid.1.7.

t.pitio 1.15.11

(armi.3.2.4.2

(ar)in. 11.4

(arin.3.16.23

(arm. $\therefore .3$

( itrliti.2.5

coni (trin.t. J3 10

f urm.1.13.10

(i) rm.1.18.13

(ism.1.2.25

(arm. (1).2?

sermat:11:

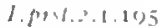

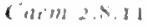

( iir $11, .210,1$

(armi.t.: $4=$

(arli.3.5.

(a)m. 11.831 .1

Sorm 2 3170

urem 2.3 ente

vermi it ha

lis I cirdis?

Irs lint 11!

. Ar Sol: 13.11 ;

alr Sirm 1311 ;

ior I, Herl 11.1

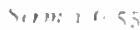

4ers. 1.1 .11

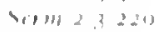

vell: 1 रेग 


\section{DIXERIS}

dixeris cgregie, notum si callida verbum|reddiderit imeturit novnn.

dixerit. dixerit insanum qui ıe, totidem aurliet

Jonec "ohe iam" ad caelun manibus sublat is dixerit.

"etenim fateor me" dixerit ille|"duci ventre levem.

dixeris [dixerit] egregie, notum si callida rebum'rellithit inmetuat novom.

dixero. liberius si|dixero quid, si fotte jocosilus.

dixi. non cgo perfidum dixi sacramentum:

nenpe inconposito dixi pede currere versus Lucili.

at dixi fluse hunc lutulentum,

"dixi equidem et dico:

Inulta quidem dixi, cur excusatus abirem.

cripta pudet recitare et nugis addere pondus' i ilini

dixi me pigrum proficiscenti tibi, dixi|talibus otficiis propm mancum.

dixisse. eni licet in diem/dixisse 'vixi:

(Craterum rixisse putato)

clivisse. . fertur et hoc moriens pueris dixise vocatis' al lectum:

-i de quincunce remota est / uncia, quid superat? potoraz dixise."

nune satis tut dixisse ego mira poenata pango:

dixit. arma/militibus sine caede" dixit|"derenta virli.

surge" quat" dixit iuveni matito.

pietasque" fixit| "ricta furore.

"abstineto'/dixit 'irarun calidaeque rixae.

lixitque tanden Imerfidus Ilannibal:

ıuid dixit aut quid tacuit?

ut audax ' contemptis alis, explosa Arbusula dixit.

wim quod volpes [? quod dixit volpes] acgroto canta leoni| respondit, referam:

"nullus in orbe sinus Bais praelucet amoenis" si dixit dives,

"lane pater" clare, clare cum dixit "Apollo,"

collegam Lepidum quo duxit [dixit] Lollius amo.

'dixit adhuc aliquid?' "nil sane." 'quid placet ergo?"

do. iam iam efficaci do manus scientiae.

llia et Egeria est; do nomen quodlibet illi.

doce. utrius horum/verba probes et facta, doce

doceat. in campo roceat parentem currere frenis:

quas doreat quivis eques atque senator semet prognatos.

rocebo: . . quid alat formetque poetan, 'quil decrat [doceat], quid non.

docebo, huic ego volgus errorí similen cunctum insaniro docebo. munus et officium, nil scribens ipse, docebo:

docendum. sed puerum est ausus Roman portare docemlum artis.

docendus. multa mole docendus aprico parcere prato. disce, docendus adhuc quae censet amiculus,

docentem. Bacchun in remotis carmina rupibus!vidi docentem.

ut pueros elementa docentem | occupet extremis in vicis lalba senectus.

docentis, et peccare docentis|fallax bistorias monet.

doceo. dum doceo insanire onunis,

doceri. motus doceri gaudet Ionicos.

Romae nutriri mihi contigit atque doceri.

docilem. fingit equom tenera docilem cervice tnagister

dociles. ut cito dicta/percipiant animi dociles tencanteque ficleles;

docili. di. probos mores docili iuventae.

Docilis. ambigitur quid enim? Castor sciat an Docilis plus;

docilis. te docilis nagistro movit Amphion lapides canenro. reddidi carmen, docilis modorum/vatis Horati." narebit pravi docilis Romana iuventus. unde egn mira| descripsi docilis praccepta haec.

docta. Sabellis docta ligonibus, versare glaebas dulcis doeta nodos et citharae sciens.

docta. caelestis inplorat aquas docta prece blandus.

doctae. doctae psallere Chiae

doctarum. me doctarum hederae praemia frontium ris miscut superis.

docte. docte sermones utriusque linguae?

nisi quirl tu, docte Trebati, dissentis.'

docte Cati, jer amicitiam divosque rogatus

prisco si credis, Naecenas docte. Cratino.

docti. autert Pacurius docti famam senis,

docti. 'noris ms' inquit; 'docti sumus.'

\section{DOCTI}

1.5 Pod.t7

T.rm.2.3.2.,8

Sirm.2.5.95

s.rm.2.7.3.

ing los loiphti

Girm: $1+104$

(itrm.2.17.14)

sirm.1.10.1

serm.1.10.50

Sirm.2.5.23

Eipist.1 0.7

lipist.1.10 43

lipist.2.2.20

Carm.3.21).4.3

Tirm.2.3.101

ciem. 2.3.17\%

lirs I'urt.328

Irs Poet.jig

curm.3.5.20

curm.3.1 137

Carm.3 27.35

Carm.3 $27.7^{\circ}$

Carm.t.t9

Epod.5.40

sirm.1.ro.7

? Far. Epist.1.1.73

Epist.1.R.

Epist.1.16.59

tar.Epist.1.20.28

Epist.2.1.200,

Epod 17. I

Serm.1.2.I26

Epist.1.17.16,

Serm.s.e I

Serm.1.0.77

i ar. Lrs Poet $30 \mathrm{~s}$

Serm.2.3.1.3

- Ars Poel.zor

herm. 1.0.70

Iipist. I.1.30

Epist.1.17.3

Curm.2.10.2

Epist.1.20.17

Carm.3.7.19

sirm.2.3.8I

Camm.3.6.2 I

IEpist.2.2.+1

Epist.t.2.tot

Ars $T^{\prime} 0 \mathrm{et} .3 .30$

Carm.sate.t5

Ispist.I.IS. ID

Carm.3.Is [

Carm.te.43

Sirm.2.2.52

Ser.n 2.3.3.1

Corm.3.n.34

Ciam!3.0.10

Epist.2.1.135

Carm 4137

Carm.1.1.22

Carm.3.8.5

Sirn.2.1.78

Serm.2.1.88

Epist.1.19.1

Eifist.2.1.5ी

Sirm.1.0 - 
scthlinus indocti docticfue poentrata jassim.

doctior. venarique timet. Judere doctior.

ilitior lic atut est quin doctior:

doctissimus. Iletor comes lleliodorms, Graceorum longe doctissimus: * iammaticorum e'guitum doetisinus.

doctilet. annus volumina vatum dictitet [doctitet] Albano Mlusas in monte locutas.

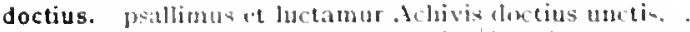

doctor. cloctor argutae fidiecn Thaliae l'hoebes. ian moechus Romac, iam mallet ductus [doctor] Athenis|vivere.

doctores. nt pueris olim dant crustula blandi|doctores. ipre mili custos incorruptissinus ommis circum loctores aderat.

doctos. doctos ego quos et amicos/prudens practerno. inter cumcta leges et percontabere doctos.

doctrina. doctrina sed vim promovet insitam viscutem doctrina paret naturane donet.

doctum. blandum [doctum] el auritas fidibus canoris/ducere quercus. pythingran Anvtique reum doctumque Platona." respiccre exumplar vitae morumque jubebo/doctun imitatosem indoctum doctumque fugat recitator accrbus;

doctus. Joctus sagittas tendere Sericas/arcu paterno?

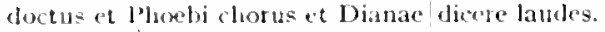
simius iste nil proter Calvom et doctus cantare Catullum. (1) nihil in magno doctus epreluendis Honero? deren eris vivam musto mersare lialerno: iam mallet doctus Athenis/vivere. pasti: credo, metues doctusqua (avebis quae gravis . tesopus, quate doctus Rosedus egit:

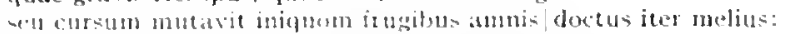

docuere. insolitos focuero nisus venti paventem. vel qui praviextati vel qui fochere togata:

docui. we proficiacentem docui te satepe diuque.

docuit. dowec vos anctor docuit practoris. dum. guar Crispini docuit me ianitor, edo. me docuit melinela ruber minosem/ad lunand delecta. et docuit magnumgur loqui nitique cothurno.

documentum. magnun documentum, ne patriam reti perdere quis velit." dolat. nulae natlar"fuc caput lumbosque saligme fuste dolat:

doleas. Albi, ne doleag plus nimio menor imnitis Glycetive.

doleat. (quis humana sibi cloleat natura negitis. utrum/gatudeat an doleat. cupiat nuetuatme.

dolendum. si vis m. Jere, Jolendum cot primum ipit tibi:

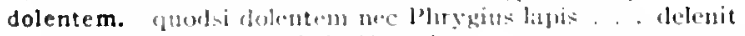

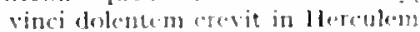

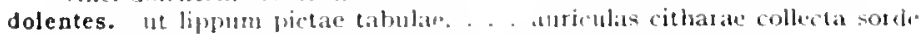
drientic ferdenters].

dolentibus. faciunt pow pluta dolentibus a $x$ animo.

dolentis. atritulas ithata collecta sorde dolentis.

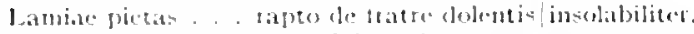

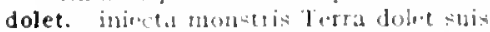

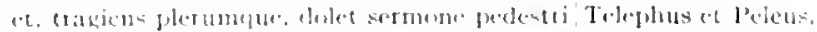

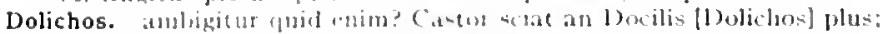

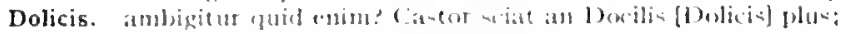

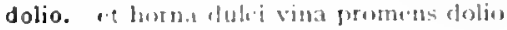

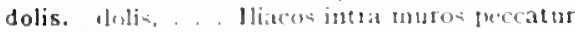

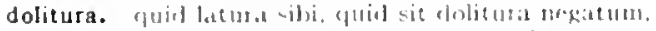

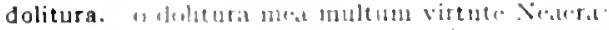

doliturus. efolitus

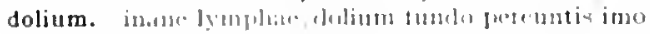

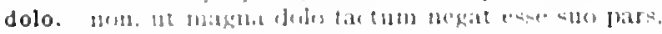

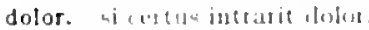

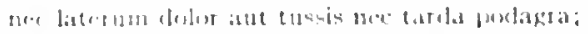

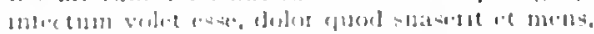

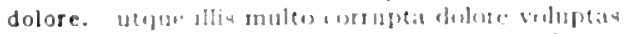

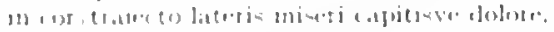

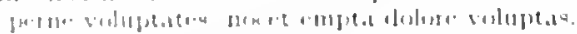

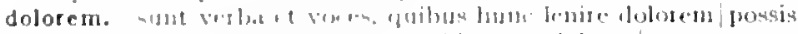

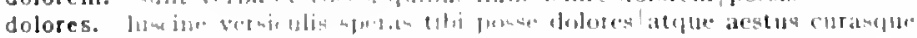

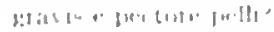

Carm.3.24.50

$\operatorname{Serm} 1 \cdot 9.51$

Serm.1.5.3

Sicrm.1.10.*8

:ar.l:pist.2.127

1. pist.2.1.33

Curm.t.0.25

var.. Firm.2.7.13

firm.1.1.20

Sorm.1.6.82

Serm.1.10.87

Jipist.1.18.90

Carm.4.4.33

Epist.1.1S.100

تar.Carm.1.12.11

Sirm.2.4.3

Ars Pod' 38

Ars Poct.474

Carm.1.20.9

Carm.suen.75

Sirm.1.10.19

Sirm.1.10.52

Sirm.2.4.19

Sirm.2.7.13

sirm.2.7.08

Fisist.2.1.82

Irs I'od.os

Curm......8

Irs 196mess

fisid.1.13.1

Sirm.2.2.50

Sirm.2.7.45

serm.2.8.31

- Irs Poet.zon

Serm.1.4.110

cirmi.1.5.23

ciurm.1.33.1

Serm.1.1.75

Lipist.1.6.12

Irs lenditoz

Cirm 31.41

carm.4.4.12

a'cur. Lipist.1 $2 \cdot 5.3$

Ars 10et.e132

LPist.1.2.53

J.pist.1.14.7

('a) m.3.4.73

Irs Port.0.5

ar. Lpist.1.18.14

iwr.Jpist.1.18.19

1.pod. 3.47

Lpist.1.2.15

Sirm.1.2.112

1. pod.15.11

cirm.1.10.80

cism.3.11.27

Girin.1.0.00

l.poli.15.10

Sirm. 1.y.32

ligind a $=10$

toren 1.2.31)

Sirm.23.20

l.pist. 2.55

1. Polt 1.1.3t

Sirit:2 2 fores 
an potius mediter finire dolores?

'Iuppiter, ingentis qui das adinisque dolores,"

doloribus. novis ut usque suppetas laboribus [doloribus].

uti mox nulla fides damnis verisque doloribus adsit.

dolos. turdis edacibus dolos

dolosa. mulier si forte dolosa|libertusve senem delirum temperet.

dolosi. ferre iugum pariter dolosi:

doloso. incedis per ignis|suppositos cineri doloso.

Europe niveum doloso|credidit tauro latus

'iamne doloso/non satis est Ithacam revehi

dolosos. 'iamne doloso [dolosos] | non satis est lthacam reveli patıiosque Penates|adspicere?"

doluere. ingenio ofiensi aut laeso doluere Metello.

dolucte cruento|dente lacessiti.

dolum. boves olim nisi reddidisses/per dolum amotas,

domabilis. Cantaber non ante domabilis

domando. latius regnes avidum domando|spiritum

domari. comperit invidiam supremo fine domari.

domat. quae te cumcue domat Venus,

domestica. vestigia Graecalausi deserere et celebrare donestica fucta

domesticus. pransus non avide. ... domesticus otior.

domi. 'populus me sibilat, at mihi plaudolipse domi.

quidquid et horum|cuique domi est.

domi si gnatus erit fecundave coniux. .

supremo te sole domi, Torquate, manebo.

post paulo seribit sibi milia quinque/esse domi chlamydum;

mea cur ingratus opuscula lector/laudet ametque domi,

me primis Vrbis belli placuisse domique.

qualis/aedituos habeat belli spectata domique/virtus,

domibus. in terra domibus negata:

domibus. sermo oritur, non de villis domibusve alienis,

domina. Sarmenti donina exstat:

domina. sub domina meretrice fuisset turpis et excors,

dominae. nec priores inpiae tectum dominae relinquont,

me dulcis dominae Musa Licymniae | eantus, . . voluit ricere

o tutela praesens|Italiae dominaeque Romae.

nilo deterius dominae ius esse:

dominae. dominaeque tradi|barbarat paelex.,

dominam. te dominam aequoris

dominantia. inornata et dominantia nomina solum|verbaque,

domini. caducum in domini caput immerentis.

scriba quod esset, |nilo deterius dominae [domini] ins esse:

non aeris acersos et aurilacgroto domini deduxit corpore felris,

domino. fertilibus donino priori,

pingue pecus domino facias et cetera praeter/ingenium, .

Davos, anicum, mancipium domino

dominoque furenti conmittes rem omnem

domino. res ubi magna nitet domino sene;

dominos. terrarum dominos evehit ad deos/hune, permutet dominos et cedat in altera iura.

dominum. Inovit Aiacem Telanone natum | forma captiva* doninum Tecmessac,

neque . . ulla brevem dominum sequetur.

et dominum fallunt et prosunt furibus.

dominum vehet inprobus atque/serviet aeternum.

$\langle$ si quercus et ilex/multa fruge pecus, nulta dominum iuvet umbra?

vilicus Orbi,... te dominum serstit.

dominus. dominusque terael fastidiosus:

Timor et Minae/scandunt eodem, quo dominus,

contemptae dominus splendidior rei.

integrum edax dominus consumeret.

audeat esuriens dominus contingere granum

mentem, nisi litigiosus, |exciperet dominus, cum venderet.

ture mihi dominus,

urget enim dominus mentem non lenis

si non causas narraret earum et/naturas dominus;

ne dominus pueri pulchri caraeve puellae/munere te parvo beet

ne dominus pueri [pueri dominus] pulchri . . . munete te parvo beet aut incommodus angat.
Sirm.2.3.203

Sirm.2.3.288

sar.lepod.17.04

Epist.1.17.57

Epod.2.3.1

Sirm.2.5-70

Carm, 1.35.28

Carm.2.I.8

Carm.3.27.25

Sicrm.2.5.3

far.sirm.2.5.3

Serm.2.1.67

Epist.2.1.150

Curm.t.10.10

Carm.4.14.41

Carm.2.2.9

Epist.2.1.1 2

Carm.1.27.14

Ars Poet.287

Serm.1.0.1 28

Sermit.te7

Sirm.2.3.232

Sirm.2.5.31

Epist.1.5.3

Epist.r.0.44

Epist.1.19.3

Epist.1.20.23

Epist.2.1.230

Carm.1.22.22

Serm.2.6.71

Serm.1.5.55

Episl.1.2.25

Carm.2.8.19

Carm.2.12.13

Carm-4.14.44

Serm.1.5.07

Carm.3.27.05

Carm.1.35.6

Ars Port.234

Carm.2.13.12

car.serm. 1.5 .07

Ipist.1.2.48

Carm.2.15.8

Serm.26.14

Serm.2.7.3

Sermi2.7.00

Sirm.2.5.12

Carm.1.1.0

Epist.2.2.174

Carm.2.4.6

Carm.2.14.24

Epist.1.0.40

Epist.1.10.40

Epist.1.10.10

Epist.2.2.102

Carm.3.1.30

Carm.3.1.38

Carm.3.16.25

Sirm.2.2.02

Sirm.2.3.113

Serm.2.3.280,

Serm.2.7.75

Serm.2.7.93

Sirm.2.8.93

Epist.1.18.74

iar. Ipist. 1.18.74 


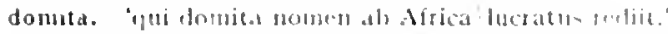

domitem. pteder homitans ("aleno tu bibes ubaln:

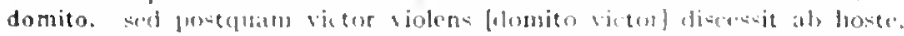
non teernum dejumlit are.

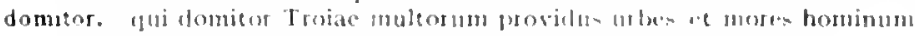
insperit

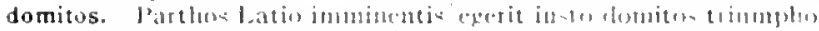
elomitosflue llerculea manu| l'elluris imeans.

domitus. virgimea domitum signtta

1"intaber, soral domicus catena.

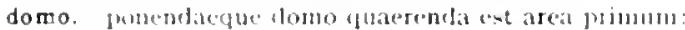

domo. poit igutu atheria demol subductum

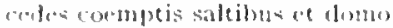

y:as devium scortum eliciet domolt yoden?

neque itureum! mea renidet in tomo hatnar.

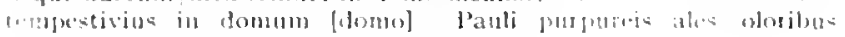
comisestrert Maximi.

Hulci diecimee a dermo.

Hatha disere ut in domo.

(..um -ub) alta - sic lovi aratum - dosmo.

antestem pepulesen, domo le vis exsilit;

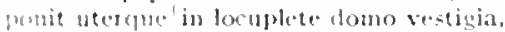

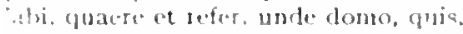

lisnum mente domorne legentia homesta Xiponis.

Romac dulce diu fuit et sollemne rechas mane domo vigilare.

domos. uret Achatens ignis tlliacas domos."

nee quilequm tibi prolest ace jas temptasse flomm

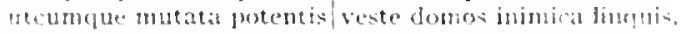

plenas aus Arabum domon.

-rouleti iamemor strais domos

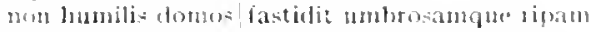

muptias primum inguinavere et genus et elomes:

filis rectius/esmenat iuvenum domos.

fuotum platustra vagas tite trahunt domo*,

arpisefue raptas et pecus et domos! volventis ana.

in hostilis domos/iram atque numen vertite.

hortos egregiaspue domes mercatier unes' cum fusere not an:

por lonestas! ir. domus inpume minax.

domuit. nec fera carrultal domuit Germania fuble

domum. nec silevam Pelopis domum

imala dueis avi domum

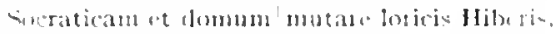

fima nocte domum claucle

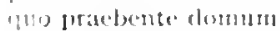

+enguestrius in domom pauli . Maximi,

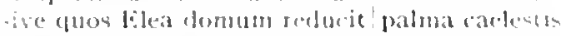

4pan lonam certanque loman reporto

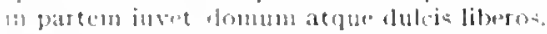

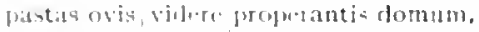

per totam domum elutgens Awernalis arpua.

infand abire domman

me mates domum carrula to seveluet.

"1. 11 conserea donum pigeat lare lintea.

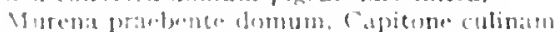

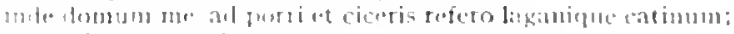

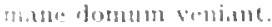

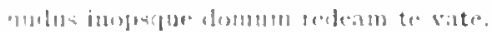

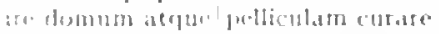

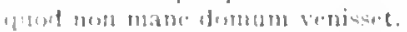

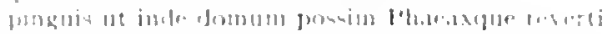

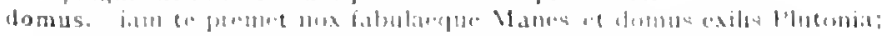

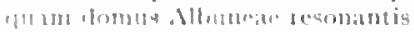

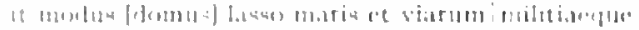

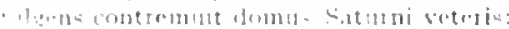

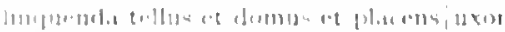

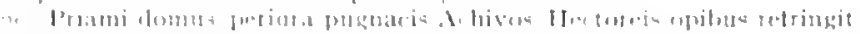

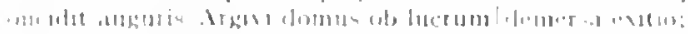

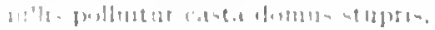

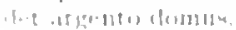

(arm..p. s.t8

(iom.1.20.0)

wni lipist in 37

Fist.t 2.80

( itrm 1 12.54

(iirm. $12.12 \%$

(ibrm-3 +72

(arm:-3.8.2=

Iipits 10.13

(irm. 1.3.21)

Cirm.2.3.17

Cium. 2.11.21

Cism.2 182

iur (inrmat to

Carm+5.12

(irm.1.12.24

fordes 3

Serm.2.6.08

sermizo.joz

fipist 1.7 .53

Fipivi.1.9.4

I.pist.2.1.10.7

Cirm.1.15.36

Carin.1.28.5

Cirm.1.35.2.4

(arm.2.12.24

(ivrm.2.15.10

Corm 3.1.22

(iorm 3.4.1S

(itrm.3150

(ivm?3.24 Jo)

(iorm3.29.37

lipod.5 53

Serin 2.32 .9

Fist.21.150

fipoldr.t

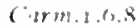

('arm. 155

(itmi.1.201.8

(arm.37.29

(iurm 319.7

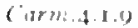

Cirm 12.17

Ciarm siser.t?

I. poul a.to

Iipol 2.02

Ef pod 5.25

1 pod it zos

Fool 1,3.te

Epodloz:

com 1.5.3.

Serm: 1.0144

virer: $23 \cdot 230$

serm = 5.

arm 25.35

f pist a - 18

f pist I 1.524

( is? 1318

(isens $1=12$

wnic arm.2.7

(iorm $212 \mathrm{~b}$

(iarm: $: 1921$

(iarm $3321 \%$

(iorm 311 12

(uis: 1521

firms \&110 


\section{DOMVS}

Indique magno|pulsa domus strepitu reionet.

domus hac nec purior tlla est

lomus alta Molossis/personuit canibus.

non domus et fundus, non aeris acervos ct anti

qui cupit aut metuit, iuvat illum sic domus et res

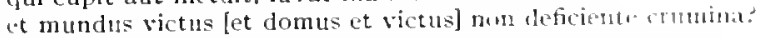

'xilis domus est, ubi non et inulta supersunt

landaturque domus, longos quae prospicit afros

sed videt hunc omnis domus et vicinia totia intros allu turpent

domus. Cecropiae domuslaeternum opprobritum,

positosque vernas, ditis examen domus.

ex parte tua seu fundi sive domus sit emptort.

cuin pater ipse domus palea porrectus in hornit

pauperies innunda donus procul absit:

dona. dona praesentis cape laetus horie (ac in lut -

reiecit alto dona nocentium| roltu,

censes. . quid plausus et anici dona Quiritis.

Atride, magis apta tibi tua dona relinquan."

ad libros et ad haec Musarum dona vocares.

donabat. quidquid quaesierat ventri donabat avaro

donaberis. cras donaberis haedo.

donandi. venit enim magnum donandi parca iuventus:

donandus. laurea donandus Apollinari,

donant. aecuis accipiunt animis donantre corona.

donarat. quidquid quaesierat ventri donabat [donaral] arano.

donare. carmina possumus'donare et pretium dicere nuneri.

spes donare novas largus

te talos, Anle, nucesque ferre sinu laxo, donare et lurbte vidi.

tu seu donaris seu quid donare voles cui,

donarem. donarem pateras grataque commodus, Censorine, muts aera sodalibus, .

donarem tripodas, praemia fortium|Graiorum.

donarent. cui|ren di donarent, illi decedere pravann|stultitian;

donaret. quidquid quaesierat ventri donabat [donaret] avaro.

donari. ut copia maior|ab Iove donari possit tibi.

donarint. cuilrem di donarent [donarint],

donaris. tu seu donaris seu quid donare roles cui.

donasset. donasset jamne catenam $\mid e x$ voto Laribus, quaprehat:

donat. dicit et centun potiore signis|munere donat.

qui patrium minke donat fundumque Larenqu".

divinare etenim magnus mihi donat Apollo:

et genus et formam regina Pecunia donat

prodigus et stultus donat quae spernit et odit: .

dum septem donat sestertia, mutua septen!'promittit.

ced satis est orare Iovem quae ponit [donat] et aufert.

donata. si melpalma negata macrum. donata reducit opinum.

donata. inspice, si possum donata reponere laetus.

donatum. spectatum satis et donatum iam rude

donatura. donatura cycni, si libeat, sonum,

donatus. ne rubeam pingui donatus inunere

donavere. nihil mains meliusve terris fata donavere

donec. donec virenti canities abest / morosa.

donec labantis consilio patres|firmaret aurtor

donec templa refeceris

'donec gratus eram tibi

-donec non alia magis' arsisti

tu, donec cinis iniuriosis aridus ventis ferar.

donec verba, quibus voces sensusque notarnt, nominaque imventu;

donec cerebrosus prosilit unus

donec/decoqueretur holus,

donec vos auctor docuit practorius.

fonec "obe ian" |ad caelum manibus sublatis dixerit.

lonec nunot in certamine longo inploravit opes

donec manihus tremor incidat unctis.

donec suspecta severo/conticuit lyra.

donec/alterntrum velox Victoria fronde coronet.

carus eris Romae, donec te deserat aetas;

donec iam saevos apertam|in rabiem coefit velti inchs

sessuri, donec cantor "vos plaudite" disat:
DONEC

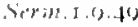

Serm 2.1.114

Epist.1.2.47

ISpit 1.2 .51

comitipist.1 1.1 I

Epither.t.5

Ispist.1.10.23

tepist.1.10.44

carm +2.6

Fipodizens

Siom-2.5.10

पidem.2.1.88

Jipist.2.2.100

(anth 3.8.2.

(atrm.4.0.12

Epist.1.6.?

l.pis.1.7.83

L.tist.2.1.243

Epist.1.1.5.32

Curm-3.13.3

Strm.2.5.79

("arm-1.20

lors lent.250

futr. Jepist r. 15.32

carm.t.8.12

(arm.t 12.19

Serm.2.3.172

Irs Iort.tan

Curm t.s.

Carm.4.8.3

Epist.2.2.152

conitepist.1.15.32

Epist.1.12.3

conitipist 2.2.152

tre Prot.dents

Sirtid. I. 5.105

(क)

sirm.1.2.5'

Sirm.2.5.10

lipist.1.0.37

lisist.1.7.20

Lipist I 7.811

rar. Epist.I.18.1 II

Epist.2.1.181

Epist.1.7.30

Epist.1.1.2

(arm? 3.20

Lisist.2.1.267

Carm.1.2.38

Carm.1.9.17

Carm.3.5.45

Corman.6.2

Carm.30.1

Cormi-3.0.5

Iipul.17.33

Serm.1.3 10.3

Sem-1.5.21

Sirm.2.1.73

Girma 25 si

Sirm 250

Epist 11035

L.piat.1.1\%3.23

Jopist.1.18.42

Epist 1.1 s.t.3

Epist.1.20.10

Ifte 2.1 .148

1. Pinet.155 
donem. vertis obliefuon neditantis ictum/sanguine donem.

donent. ili tr. Banasipre, deaeque/ vesum ob consilium donent tonsore.

dones. Irui paratin et valido mihi. latoe, dones ac precor integra barathone / fomes quidquid habes

donet. cui donet inpermissa raptim|gaudia spicea donet Certerm corona; virtutem doctina paret naturane donet.

donis. hoc elelibutis ulta donis paelicent clarus ob iel factum donis ornatur honestis.

dono. 'tam teneor dono, guam si dimittat onustus'

Dorium. hat l)orium, illis barbarum?

dormiet. dormict in lucem. scorto postponet bonestum officium.

dormire. tanclem fessus lormire viator|incipit

verum nequen domire."

cui pulcrum fuit in medios dormire dies

ni melius dormire putem quan scribute versus?

dormirem. ut tuto ab atris corpore viperis/dormirem et ursis.

dormis. 'nuc tuo longas pereunte noctes, Lydia, dormis?"

tu nive lucana dormis ocreatur.

dormitabo. nale si mandata loqueris. aut dormitabo aut ridebo.

dormitat. guamelonue bonus dormitat llonerus.

dormitum. lysum it Maceenas. formitum rgo Vetgiliusque;

deinde (x) dormitum.

tandem tormicum timittitur.

dorso. fun gravill dorso subiit onus.

praesupti nemosis patientem vivere dorso?

non equitem forso, non frenum rlepulit ore.

dos. dos est magna parentium/virtus

Dossennus. puantus st Jusemus edacibus in parasitis.

dotalibus. 116 plus trunchti dotislibus tometat agr is

dotata. nee destata regit virun $\mid$ comiunx

dote. probancue pauperiem sine dote quatero.

filius uxorem grandi cum dote resucet.

scilicet uxotem com dote. . regina l'ecunia donat

doti. crusibue bure netuat, doti deprensa. egomet mi.

drachmis. sine stultior ipso guingentis empto drachmis deprenteris?

dracones. num in reluctantis dracones

Drusum. vitlete Raeti- bella sub Alpibus/Drusum gerentem Vindelici.

Drusus. Drusus Genannos. . . dejecit acer plus vice simplici; .

duarum. Inormetim voces Furiatum et facta duarum.

dubia. ut pallidis omnis/cena desurgat dubia?

dubiae. neth tluitrm dubiae spe pendillus horac.'

dubiis. recundis tomporibus dubistue roctus.

dubios. utrate anl casus dubios firlet sibi ecitius?

dubitem. recte necre crocum floreselue jerambulet Attac / fabula si dubitem.

dubito. an suprom Tarquini tascis, dubito. an Catonis/nobile letum:

dubius. ad dubiuk unde rumperet silantium, ¿lubius sum, quid taciam, inquit.

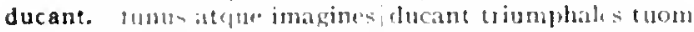

ducat. inples partate recinentis omen, durat

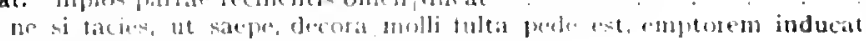
[rlarit) hiantem.

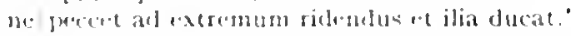

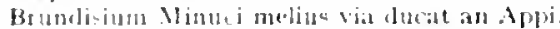

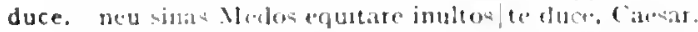

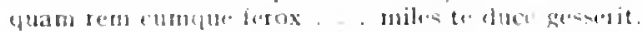

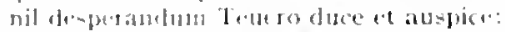

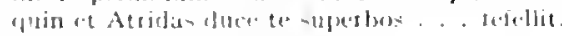

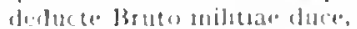

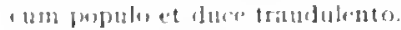

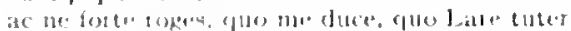

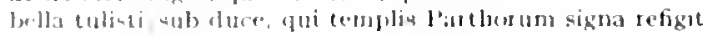

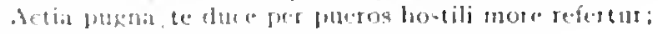

ducem. J B.lit: or natum tolias derem.

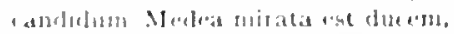

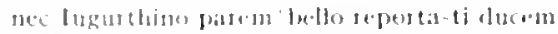

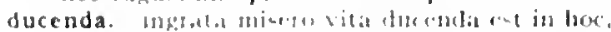

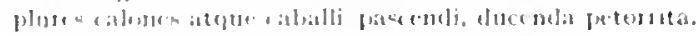

(arm.3.22.8

Sirm.2.3.17

Carm.1.31.18

ferm.2.3.167

Carm.3.6.27

Carm.Sarc.30

Epist 1.18 .100

I.pod.3.I 3

Epist.2.2.32

I.pist.1.7.18

Epod.9.0

lepist.1.18.34

Serm.1.5.17

Serm.2.1.7

IEpisl.1.2.3o

Jipist.2.2.54

Carm.3.4.18

Curn.1.25.8

Sirm.2.3.23.

dis l'oct.105

A.5 I'Od.359

Serm.1.5.48

Serm 1.0 .119

Efist.1.7.73

Serm.1.0.21

Serm.2.0.01

List.1.10.35

(arm.3.24.21

LPist.2.1.173

E.pist.1.0.21

Curm.3.24.19

Curm.3.29.50

cirm.1.t.50

Epist.1.6.36

Serm.1.2.131

Sirm.2.7.43

(arm.4.4.1

( arm.4.4.18

Curm.14.10

Scrm.1.8.45

serm.2.2.77

lepist.1.18.110

(arm.4.9.30

Sirm.2.2.108

Ljest.2.1.80

Curm.1.12.35

tipod. 5.85

Sermi.1.9.40

Lpod 8.12

(a)m.3.27.2

coni.serm.1.2.85

Iipist 1.1.0

Ifist.1.18,20

Curmi.1.2.52

(urits 1.0.4

Carm.1.7.27

(ismi 1.10.13

Carm.2.7.2

Corm:3.324

I.pisl.1.1.13

Jipirt 1.15.5\%

Jjpis 1.18.0.2

(arm 43.7

1. poil. 3.10

I: fuil o. 2.4

I. foll 17.0 .3

soren is 100 . 


\section{DVCENDVS}

ducendus. ducendus et unus $\mid$ et comes alter,

ducent. lave nugae seria ducent.

ducenta, si plostra ducenta/concurrantque foro tria funera,

ducente, ducente victrices catervas/coniuge me Iovis et sorore.

ducenter, singula quaeque locum teneant sortita decenter [ducenter].

ducentia. pocula Lethaeos ut si ducentia somnos.

ducentis. abstinensiducentis ad se cuncta pecuniae.

ducentis. Catienis inille ducentis/'mater, te appello' clamantibus.

ducentos, habebat saepe ducentos, saepe decen servos; in hora saepe ducentos, | ut magnum, versus dictabat amet scripsisse ducentos/ante cibun versus,

ducere. blandum et auritas fidibus canoris/ducere quercus. .

illum ego lucidas linire sedes, discere [ducere] nectaris|sucos . . . patiar tu potes tigris comitesque silvas/ducere

audet/ducere nuda cboros:

pressun Calibus ducere Liberum | si gest is.

ducere ne auditum, perges quocumque, menento.

quandoque licebit . . . ducere sollicitae iucunda oblivia vitae?

ad strepitum citharae cessatum ducere curam.

tortum digna sequi potius quam ducere funem.

respicere .. iubebo|doctum imitatorem et vivas hinc ducere vocus. . dictus et Amphion, Thebanae conditor urbis, | saxa ... ducere, quo vellet. nolito ad versus tibi facton ducere plenum|laetitiae;

duceret. quo te caelestis sapientia duceret. ires.

nequis... alius Lysippo duceret aera | fortis Alexandri voltum simulantia.

duceris, duceris ut nervis alienis mobile lignum.

duces. innocentis pocula Lesbii|duces sub umbra. illic plurima naribus/duces tura.

duces. audire magnos iam videor duces.

munera navium|saevos inlaqueant duces.

virtute functos more patrum duces . . canemus.

ducet, ille dies utramquel ducet ruinam.

tua sectus orbis nomina ducet."

non equos impiger curru ducet Achaicolvictorem

quotiensque educet [quotiens quoque ducet] in agros/Aetolis onerata plagis iumenta canesque.

duci. quid attinet tot ora navium gravi|rostrata duci pondere "etenim fateor me"dixerit ille|"duci ventre leven. poterat duci quia cena sine istis:

ducibus. vita redit bonis|post mortem ducibus. te nostris ducibus, te Grais anteferendo

ducimus. non tamen arhersis aetatem ducimus austris.

ducis. mala ducis avi domm quam nulto repetet Graecia auctore ab illo ducis originem,

ducis. et soror clari ducis et decorae 'supplice vitta|virginum matres convivatoris, uti ducis, ingtnium res/adversae nudare solent, celar secundae."

quat partes in bellum missi ducis:

ducit. ian Cytherea choros ducit Venus inminente luni

auctore ab illo ducis [ducit] originem,

quae porta fugiens eburna|somnium ducit?

per caedis ab ipso/ducit opes animumpue ferro.

et ritem viduas ducit ad atbores;

Liber vota bonos ducit ad exitus.

forte epos acer, /ut nemo. Varius ducit;

ducit te species, video:

locuples, quem ducit priva triremis.

Jucet, eamus quo ducit gula;

quotienzque educet [quotiens quoque ducit] in agros, Aetolis onerata plagis iumenta canesque.

iniuste totun ducit venditque poema.

in vitiun ducit culpae fuga, sj caret arte.

duco. magnum hoc ego dnco, quod placui tibi,

ducor. nil ego, si ducor libo fumante:

ducta. ductaque per vias regum colla minacium.

ductore. luctere [ductore], multa proruet integrum icum lande victorem

ductos. potiore ductos alite muros -
DVCTOS

Serm.1.6. I0I

Ars l'oet.45 I

Serm.1.0.42

Carm.3.3.63

iar.A's Pont.92

Epod.1.4.3

Carm.4.9.38

Serm.2.3.0I

Serm.1.3.1 I

Serm.1.4.9

Serm.1.10.60

Curm.1.12.12

zor.Corm.3.3.34

Carm.3.1I.14

Corm.4.7.0

Carm.4.12.14

Sirm.2.4.80

Serm.2.0.62

Epist.I.2.31

Epist.1.10.48

Ars Poet.318

Ars Poct.396

Ars Poet.427

Epist.1.3.27

Epist.2.1.240

Serm.2.7.82

Carm.1.17.22

Carm.4.1.22

Carm.2.I.2I

Corm.3.16.16

Carm.4.15.29

Carm.2.17.9

Carm.3.27.76

Carm.4.3.5

iur. Epist.1.18.45

Epod.4.18

Serm.2.7.38

Ars Poel. 370

Carm.4.8.15

Epist.2.1.19

Epist.2.2.202

Carm.1.15.5

Carm.3.17.5

Carm.3.14.7

Serm.2.8.73

Ars Pol.31.5

Carm.1.4.5

coni.Carm.3.17.5

Carm.3.27.42

Carmatico

Carm.t.5.30

Carm.1.8.34

Serm.1.10.44

Sirm.2.2.35

Epist.r. I.93

Epist.1.6.57

qar.Lpist.1. I $\$ .45$

Epist.2.1.75

Ars Poit.3

Serm. 1.0.02

Serm.2.7.102

Carm.2.I2.II

var.Corm.4.4.60

Carm.-1.0.23 
duces. forte enos acer, at neno. Varius ducit [dutul:

ductum. nostrisque ductum seditionibus bellum resedic:

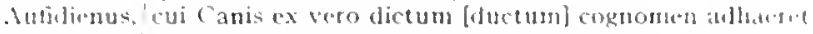

ductus. Hrumdisiun coness aut sirnentum ducturamoenum

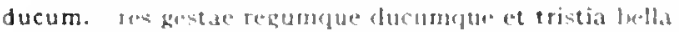

ducunt. vel quia nil recturs, nisi quod phatut sibi. ducunt

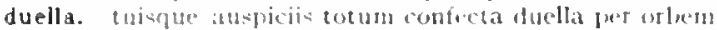

duelli. "t calurn Marsi mamorem durlli.

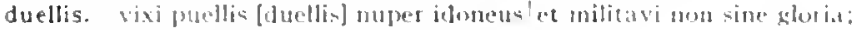
viturom dutllis lanum Quirini clausit

duello. pretem duello miscuit.

Grifua bathariae lento collisi ducllo.

lento Samnites ad lumina prima duello.

dulce. becepto dule mihi turere est amico.

lutere de dincormu est pro patria mori:

dulce periculum est, o fenaec.

Julie est desiprese in loco.

4hill pure tranquillet, honos ac dulce lucellum

Romato dulce diu fuit et sollemne reclusa mano domo vigilast.

dulce. otium! non dulce, ni tecm simul.

dulce. Julce riftentem lalagen amabo.

dulce loquenterm.

dulc" pellitis ovibus Galaesi thumen

feides dulce loqui, reddes ridere decorum

quin retiam canct infoctum, sed dulce bibrnti

dulce. o th presilium et dulce decus neum:

o luburum/dulce lenimen tmihicanque salve rige veanei.

dulcem. non Siculae dapes/dulcem elaborabunt saporem.

Iulcem quae strepitum, l'ieri, temperas.

dulcem. provitula statuis duleen Aulide natam inte atris

dulces. ant dulces alumni pomifero grave tempus antho

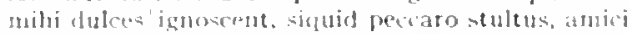

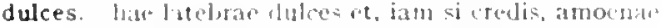
vint tore dulees wherunt mane (amenac.

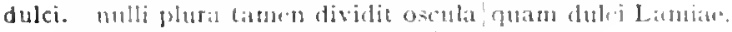
ynda vowat dulci nutricula maius alumno,

dulci. lulci labotem decipitur somo

dulri sopor" languidae.

dukei logen solvere.

dulci. empavie in tulei iusenta fervor utemmon dutci. Tymdari. fistula

yudlibet ingotens speraro iortumatue duhi|ebria

dulei distinet a romo

dulci. neque Jutci mala vino lavere

dulei digne mero non sine toribus.

-t horna dulci vina promens dolio

aimple.x e dulci ronctat olivo.

cmun. Inlit punctum. qui miscuit utile duke

dulcia. dulcial se in bilem vertent

mon satis est pukbra esoo poemata: dulcia sumbs

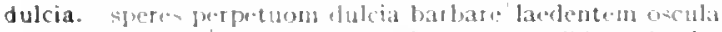

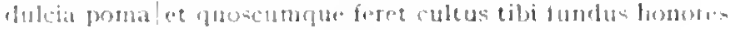

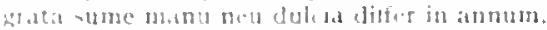

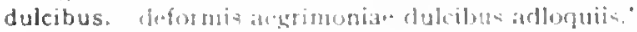

dulcior. Aula suburbano qui sicois crevit in agris duheior.

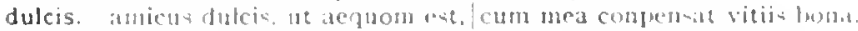
sice dulcis amicis occurtints.

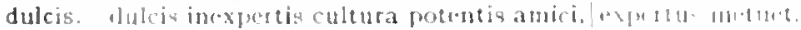

dulcis. "ri sit indicio dulcio sine pulvere palmate?

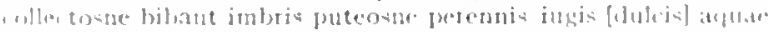

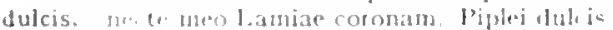

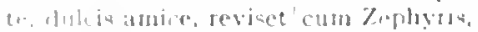

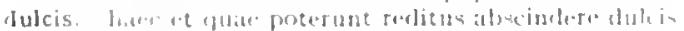

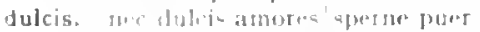

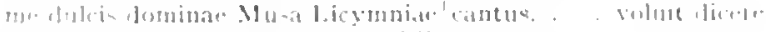

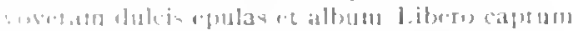

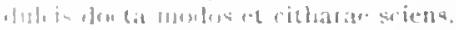

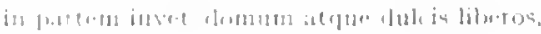

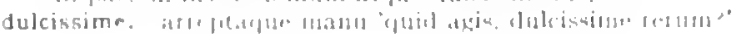

sar.firm.1.10.4t

Ciurm.3.320

rar Serm.2.2. $2 f_{1}$

Peist I 17.5 ?

Irs l'oet.73

Epist 2.183

5)

(atron 3.1.8. 18

imi.corm.3 $2 \%, 1$

cormat 15s

Carm. 35.38

Epint i 27

Epist 2.2.t)

Curm.2.7.28

Cism.3.2.13

Corm.3 25.

Curm. 12.28

Episti.18.10\%

Frist. 21.103

lipod.1.8

Carm.1.22.23

Curm 1.22.24

Ciurm.2.0.10

Ejist.1.7.27

Sepist 2.2 .9

Carmiti?

Corm.1.32.15

Corm 3 i.l')

Carm +318

Serm.2310y

carm 323.

Serm 1.3 I.3\%

1.po: 1.:10.15

Lpist 1 105

(armis 1.3p.7

lepist 4.48

Carm.2.1.35

E.rud.5.5

Jipude.s.

(arm. 10.2.;

(corm.1.17.19

(itrm. 13.14

(arm. 5.12

Ciurm 3.12.1

(arm.313.2

Japol 2.47

cirm.2 \&

Ars Poul 31.3

Sith.2.275

Ars livelors

Curm.1.13.14

Sirm.2.5.12

lepied 1 11.23

fipod 13.18

Citula 2410

sirems. 1 (no

trom 1.4 .135

fisist 1.18 .80

Jifict 1 1 5t

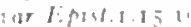

(iarmis 1 :pos)

finet.1 12

l. poldete.35

( isth.1 015

ciurm 2.12 13

(i) , 3.....

(ism:914)

rpol: y

Sirm | 1 


\section{DVLCIVM}

dulcium. desine, dulcium / mater saeva Cupidinum.

(arm.4.5.4

dum. Carm.1.2.17; 1.4.7; 1.6.9; 1.10.11; 1.11.7; 1.10.26; 1.2 2.10; 1.3.1.2; 1.37.0; 2.3.1.5; 2.10.2;

Carm.2.11.16; var.Carm.2.12.25; Carm.3.3.37; 3.3.40; 3.7.18; 3.11.23; 3.11.50; 3.17.13; Carm.3.20.9; 3.21.24; 3.30.8; 4.2.49; 4.12.26; Epod.13.4; 15.7; Sirm.1.1.40; 1.1.52; Serm.1.2.24; var.Serm.1.2.97; Serm.1.2.127; 1.3.137; 1.4.20; 1.4.1 I8; 1.5.13(bis); 1.5.72; Serm.1.5.90; 1.6.8; 1.9.60; 1.10.36 (bis); vur.serm.2.1.18; Serm.2.2.67; 2.3.31; 2.3 .81 ; zar.Serm.2.3.230; Serm.2.4.79; 2.6.90; 2.7.45; far.Serm.2.7.105; Serm.2.8.45; 2.8.80; Serm.2.8.82; Epist.1.2.2; 1.2.21 (bis); 1.2.42; 1.2.61; 1.7.5; 1.7.7; 1.7.48; 1.7.79 (bis): Epist.1.7.So; 1.11.20; 1.12.13; 1.18.8; Epist.1.18.87; 1.19 I6; 2.1.7; 2.1.17; 2.1.190: List.2.2.27; 2.2.127; irs Poct.230; $457 ; .705$

dumeta. qui I yciae tenet/dumeta natalemque silvan quaerit et horridi|dumeta Silvani

dummodo. dummodo risum | excutiat sibi non, non cuiquam parcet anico dumtarat. dumtaxat ad hoc, quen tollere racda'vellet iter facions

denique sit quod vis, simplex dumtaxat et unum.

Corm $3 \cdot 4 \cdot 6 \cdot 3$

(imm.3.20.23

Serm.1.4.34

Sirm.2.0.42

Ars Poet.2.3

Sirm.1.7.15

Serm.1.6.117

duo. pocula cum cyatho duo sustinet,

Canusi duo praedia. . . gnatis divisse duobus duobus. gnatis divisse duobus|fertur

quod petis, id sane est invisum aciduntue duobus.

duplice. tum pensilis uva secundas let nux ornabat mensas cum duplice ficu. dupliceis. nec cursus duplicis [dupliceis] per nare Vlixei

duplices. nee cursus duplicis [duplices] per mare Vlixti

duplici. contra, quem duplici panno patientia velat.

duplicis. nec cursus duplicis per mare Vlixei

duplicis. est operae pretium duplicis pernoscere iuris naturam.

dura. quid nos dura refugimus|aetas?

dura tibi peragenda rei sit causa Petilli?

num rerum dura negarit/versiculos natura

clura valetudo inciderit seu tarda senectus?

ne gallina malum responset dura palato.

si dura morabitur alvos.

pupillis, quos dura premit custodia matrum:

dura. et crura dura conpede.

dura. dura sed emovere loco me tempora grato

dura. siccis omnia nam dura deus proposuit

plectro dura navis,

dura fugae mala, dura belli.

dura post paulo fugies inaudax/proelia raptor.

limina dura, quibus lumbos et infregi latus.

atque haec rara cadat dura inter saepe pericla.

corpus et ipsum animum spe finis dura ferentem

dura. o dura messorum ilia.

durae. duraeque tellus atudit Hiberiae,

duram. te saepe vocanti|duram difficilis mane.

duramque callet pauperiem pati

frigus quo duramque famem propellere possit. .

durare. sine funibus|vix durare carinae | possint imperiosius atequor?

quantum interpellet inani|ventre diem durare. .

idem eadem possunt horam durare probantes?

duratae. durataeque solo nives|mercatorem abigunt?

duraveris. rectius Albanam fumo duraveris uvam.

duraverit. simul ac duraverit aetas / membra animumute tum.

duravit. aere, deline ferro duravit saecula.

dure. te per aquas, dure, volubilis.

si pleraque dure/dicere credit eos,

duri. nil intra est olea. nil extra est in nuce aluri;

duris. ligonibus duris humum|exhauriebat. nomina sectatur modo sumpta veste virili, sub patıibus lubin tironum.

duris. duris ut ilex tonsa bipennibus

saetosa duris exuere pellibus . . membra;

durius. quid sculptum infabre, quid fusum durius esset.

duro. tu lene tormentum ingenio admoves plerumque duro.

duro. ut glaciet nives/puro [duro] numine ]uprit.r?

inpiae sponsos potuere duro/perdere ferro.

ille gravem duro terram qui vertit aratro.

duros. versus reprendet inertis, / culpabit duros,

durum. durum: sed levius fit patientia ut contendere durum $\langle$ est $\rangle \mid$ cum victore.

Sirm.2.3.168

Sirm.2.3.169

Epist.2.2.04

Serm.2.2.122

mar.Carm.1.6.7

aur. Curm. I.o.

Epist.1.17.25

Carm.1.6.7

Serm.2.4.03

Carm.1.35.34

Serm.1.10.20

Serm.1.10.57

Serm.2.2.88

Serm.2.4.18

Serm.2.4.27

Epist.1.I.22

Epod.4.4

Epist.2.2.46

Carm.1.18.3

(arm.2.13.27

Cirm.2.13.28

Carm.3.20.3

Lpod.1 1.22

Sirm.1.2.40

Episi.2.1.14

IFpod.3.4

carm.4.14.50

Carm.3.7.32

carm.49.49

Serm.1.2.0

Carm.1.14.7

Serm.t.(1.128

Epist.1.1.82

cirm.3.24.30

cierm.2.4.72

sirm.1.4.119

Epodtolos

(a)m.4.1.40

lipist.2.1.60

Iipist.2.1.31

Ifod.5.30

hirm.1.2.

(arm.4.4.5:

Lopod.17.15

Sirm.2.3.22

Carm.3.2I.14

ani.Carm.3-10.5

carm.3.1 1.31

verm.1.1.28

dirs livet. 440

(arm.1.24.10

Sirm. 1.92 


\section{DVRVM}

durum. nec durum IIannibalem nec Siculum mane

et ingentem ceciclit Antiochum Hannibalemque dilum [disum]. thectere mollibus|iam durum imperis:

durus, dirus [durus] per urbia Afer ut Italas. . equitavit facetus, | emunctae naris, durus conponere versus: dutus homo atque odio qui posset vincere kegem. durus, / vindemiator et invictus.

"durus", ait, "oltei, nimis attentusque videris/esac milii." serviet utiliter; sine pascat durus atetque,

dur. dux inquieti turbidus lladriate. Neptunius/dux fugit ustis navibus: qui sibi fidet. / lux reget examen.

dux. lucen redule tuae. dux bone, patriae: "longas o utinam, dux bone, ferias|pracestes llesperian!"

duxit. qua notam duxit, nivens videri.|cetera fulvos. Liber vota bonos ducit [duxit] ad exitus. guilduxit ab oppressa meritum Karthagine nomen. collegam l,epirlum quo duxit I ollius anno.

Dyrteus. Ilenterus. Tyrtaeusque [Dytrosque] mares animos in 11 artia trellat verubus (xacuit:
ECHINOS

Carm.2.12.2

gar. $\operatorname{Corm} \cdot 3 \cdot 6 \cdot 36$

Carm.1.1.7

Iar. Corm.4.4.42

Sorm.1.4.8

Serm.1.7.6

Serm.1.7.29

Epist.1.7.91

Lpist.1.16.70

Carm.3.3.5

Epod.g.8

Epist.1.19.23

Carm.4.5.5

Carm.1.5.37

Corm.t.2.59

far.Carm.4.8.3.

Sirm.2.1.66

lipist. I.20.28

I

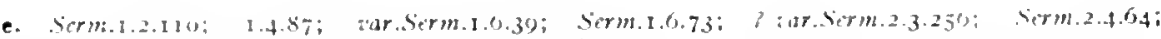
conf.term.2.5.103; Epist.1.0.60; :ar.J.pist.1.11.10

ea. id tibi iurlicium e-s. ea mens.

ea. ne cures ea quac stulte miraris et optas. ea cum rejuendere coner. . . (luae doctus Roscius egit:

idr.olrs Pod.402

Eacum, ereptum stygis fluctibus Aeacum [Eacum] / virtus.. - vatum divitibs consecrat insulis.

eadem. "juac mens est hodie, cur eadem non puero fuit non eafem est aetas. non mens.

eadem. hac lese in trutina ponetur eadem. chasta laudatur eadem. si. . . Romani pensantur eadem/scriptores trutina. cithuresus rifletur, chorla qui semper obertat eadem:

eadem. irlem eaclen jossunt horam durare probantes? non eadeun miramus: devique non onnes eadem mirantur amantque.

eamus. eamus omnis rexecratil civitas luret. camus' (nuo dincit gula:

earum, stuavis res, si non causas narraret earum et naturas dominus;

eas. pascentis visibus atgue extenuantis eas consulto.

eas. velut usquam vinctus eas. uri virgis forromue mecari auctoratus eas.

eat. ne curregte retro iunis eat rota: rat quacumelue, Juellis | iniciat curam quactendi singula. agit ubi secun. vat an non.

ebibat. filits ant "tian ha"c libettus ut cbibat heres.

eboris. matmoris atut eburis labros aut aetis amavit.

ebria. fortumatue dulu i chulat.

ebrietas. equid non e.t) ictas discignat?

ebrius. "brius ct, manum guod dedecus, ambulet ante | noctem cum tacibus." non magis atulivit. quam liufus ebrius olins.

ebur. Hon chur nexpe ancum, mea renidet in dono lacumar. calptivom pertatur ebur, captiva cosinthus.

ebur. non aurum aut efurr Indicum, eripietpue rutule ecui volet inportunus ebur." Remmas, marnot, ebur, . . sunt qui non habesnt.

eburna. eburnil, dic age, cum lyra maturct. ruave postat fugicus reburna somnium ducit?

eburnos. rubro uhi cek coltincta sujer lectos candetet vevtis eburnos

ecce. ence tuste experise atrox. Tydides

-ece. ("rimpinas minimo me provorat

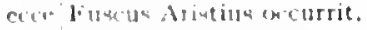

cece setwos, num joalus sippiontion

echini. untroa Iteeju. Minemo oriunter exdini.

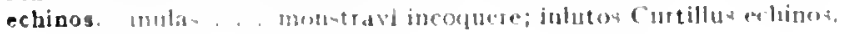

\author{
Ars Joel 380 \\ Jpist.1.1.47 \\ lipist.2.1.8I
}

$\because$ ar.Carm.4.8.25

Carmat 10.7

lepist.1.1.4

Serm.1.3.72

Serm.1.10.4

Lipist 2. 1.29

its Jot.35'

Pepist.1.1.82

List.1.1.18

Jipist.2.2.58

Ifpod.16.30

Prist.1.0.5

Sirm.2.8.92

Sicrm.1.10.14

Sirm.2.7.31

Sirm.2.7.59

Curm.3.10.10

Scrm.1.6.31

Serm.2.3.200

Seth.2.3.122

Epist.2.1.96

Corm.1.37.12

lipist 1.5. It

Sirm.1.4.51

Sirm.2.3.0n

(eirm.2.I8.

Lipist.2.1.193

(arm.1.31.1

lipist t.0.54

lipter.2.2.18u

Carm.2.11.22

Carm.3.27.41

Sorm.2.0.103

(arm.1.15.27

Sorm.1..13

ierm.1.0.60

sarm. 2.3.201

virem $2+3.3$

virm? $=5$ = 


\section{ECHIN OS}

utra magis piscis et echinos aequora celent.

echinus. ut marinus asperis/echinus aut Laurens aper.

adstat echinus/vilis, cum patera guttus,

Echioniae. monstrunve submisere Colchi|maius Echioniaeve Thebae

ecqui. ecquid [ecqui]lad te post paulo ventura pericula sentis?

ecquic. ecquid [ecquicllad te post paulo ventura pericula sentis?

ecquid. ecquidlad te post paulo ventura pericula sentis?

ecquis. "nemon oleum fert ocius? ecquis|audit?"

edacibus. turrlis edacibus dolos.

edacibus. quantus sit Dossentus edacibus in parasitis,

edacis. dissipat Euhius|curas edacis.

edat. edit [edat] cicutis alium nocentius.

et leporum avolsos, ut multo suavius, armos, / quam si cum lumbis quis edit [edat].

edax. quod nou imber edax, non aquilo impotens/possit diruere

integrum edax dominus consumeret.

ede. 'ede hominti nomen, simul et, Romanus an hospes."

"quid tamen ista velit sibi fabula. si licet, ede."

edendi. neu,... occultam febrim sub tempus edendi|dissinules,

edi. 'non ego' narrantem "temere edi luce profesta|quicquam praeter holus

edicit. edicit, piscator uti, pomarius, . . mane domum veniant.

hos ediscit [edicit] et hos arto stipata theatrolspectat Roma potens,

edicta. non qui mofundum Danuvium bibunt/edicta rumprnt Iulia,

edicto. edicto vetuit, nequis se prater Apellen!pingeret

edideris. delere licebit, / quod non edideris;

ediscere. sed verae numerosque modosque ediscere vitat.

ediscet. hos ediscit [ediscet] et bos arto stipata theatro/ spectat Roma potens.

ediscit. hos ediscit ot hos atto stipata theatro|spectat Roma potens,

edissere. tantun hoc edissere, quo me! aegrotare putes animi vitio.' .

edisti. Jusisti satis, cojisti satis atque bibisti:

edit. edit cicutis alium nocentius.

avolsos, ut multo suavius, armos, / quam si cum lumbis quis edit.

edit. si Democriti pecus edit agellos/cultaque,

edite. Maccenas atavis edite regibus,

editior. viribus editior caedebat ut in grege taurus.

edixerit. siquis nunc mergos suavis edixerit assos.

edixi. adiman cantare severis' hoc simul edixi.

edirit. "for um putealque Libonis/nandabo siccis, adindm cantare severis" hoc simul edixi [edixit],

edo. dum, quat Crispini docuit me ianitor, edo.

edomuit. mos et lex maculosum edomuit nefas,

Edoniis. non ego sanius bacchabor Edonis [Erlonits]:

Edonis. non rgo sanius/bacchabor Edonis:

non secus in iugis|ErIonis stupet Euhias

edormit. Fufius cbrius olim, / cum Hlionam edormit,

educere. Euprolin. Archilochum, comites educere tantos?

educet. tractu: uter pluris lepores, uter educet apros;

educet. quotiensque educet in agros|Aetolis onerata plagis iumenta

educit. moresfluc|aureos educit in astra

edulce. 'non ego' narrantem 'temere edi luce [et edulcel profestil] çnicquam praetel loolus

edulis. vinea submittit capreas non semper edulis.

effare. efiare; iussas cum fide poenas luam.

efferet. natura... post effert [efferet] animi motus interprete lingua.

effert. natura.. post effert animi motus interprete lingua.

effertis. simul ista teliqui, | quae vos ad caelum fertis [effertis] rumore secundo,

efficaci. "iam lan eficaci do nanus scientiae,

efficacis. nec munu uneris efficacis Ilerculis|inarsit aestuosius.

efficax. anaraque/curarum eluere efficax.

efficiet. non tamen irritum|quodcumque retro est efficiet

effigies. lanea $k$ 't rffigies erat, altera cerea:

effuat. quanvi furiale centum | muniant angues caput eius atque [effluatque]|spiritus tacter saniesque manet $\mid$ ore trilingui;

efractam. aut cistam effractan et subducta viatica plorat.

effuderit. simul|pomifer autumnus fruges effuderit.

efugere fallere et efiugere est triumphus.

eui musteld procul 'si vis' ait 'effugere istinc.

\section{EFFVGERE}

Episl.1. I5.23

Epod.5.28

Serm+1.6.117

Carm.4.4.64

irar.Epist.x.18.82

tor.Lpist.1.18.82

Epist.1. 18.82

Serm.2.7.34

Epod.2.34

Epist.2.1.173

Carm.2.11.18

zar. Fpod.3.3

var.Serm.2.8.90

Curm.3.30.3

Serm.2.2.92

Serm.2.4.10

Serm.2.5.til

Epist.1.16.22

Sim.2.2.116

Serm.2.3.227

z'ar.Epist.2.1.60

Carm.4.15.22

Epist.2.1.239

Ars Poct.390

Epist.2.2.144

tar. Epist.2.1.60

Epist.2.1.60

Serm.2.3.306

Epist.2.2.2I4

Epod.3.3

Serm.2.8.00

Epist.1.12.1?

Carmi.1.I

Serm.1.3.110

Serm.2.2.51

Epist.1.19.10

rar.Lpist 1.10 .10

Sirm.2.7.45

Carm.4.5.22

var.Carm.2.7.27

Carm.2.7.27

coni.Carm.3.25.9

Serm.2.3.6I

Serm.2.3.12

Epist.1.15.22

Epist.1.18.45

Cirm.4.2.23

2ar.Serm.2.2.110

Sirm.2.4.43

Epod.17.37

ar. Ars Poct. I I

Ars Poet. I 11

qar. Lipist.1.10.0

Epod.I;.1

Epod.3.17

Corm.t. 2.20

Carm.3.20.46

serm.1.8.30

coni.Carm.3.1 [.18

Epist.1.17.54

Carm.4.7.1 I

Corm.4.4.52

IEpist.1.7.32 


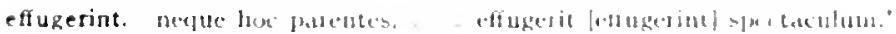

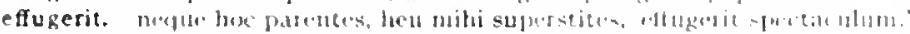

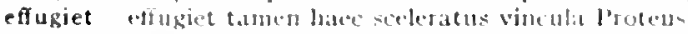

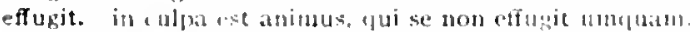

effugit. unus ubi efthgit, matei denarrat.

cum somsel ellugit, reldit se pava catenis:

effundi. mensam poni iubet atque effundi sacers nummonum.

effusi. mon locus edf usi litte matio abbiter.

effutire. effucire levis indigna trighedia versus,

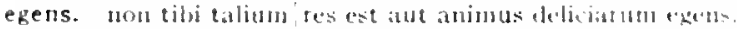

"gens berbignate Tantalus semper dapis.

egentem. efuamvis fers t. nullius egentem."

egenti. cum deerit egenti as, laquei pretius.

egeo. pam egro iam inellitis potiote placentis

egere. nec nuedici credis mec 'uratoris egere

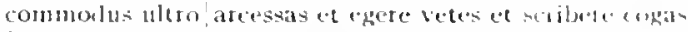

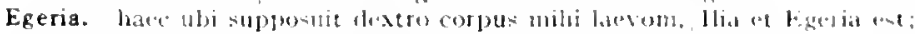

egerit. Parthos latio imminentis egerit iunto domitos triumplor sieguis casus pueram egereit theo.

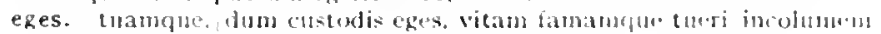
protinus ut monean (sipuid montoris eges

si plosor is extes anlaca mancotis.

eqet, non enet Vauris iaculis negue arou

at fui tintuli ceret quanto est opus.

cur exet indignus quiacuam te divite?

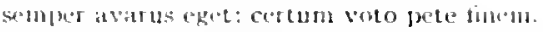

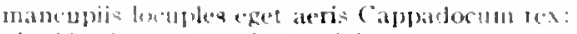

egi. "fuill minet eki? quid volui?" dices.

egit. otmue cum l'sotens pecus egit altos/viser. nonti-

mer purum tonantis egit equos volucremrue eurrum.

egit amor dapis atc gue pugnate;

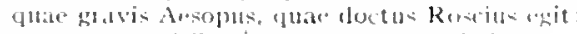

ego. Junc rog mitibus|mutate qualeto tristia.

non ego te, candiele Bassared. finvitum cutatian

Grava quol rou ipace terta|combitum levi.

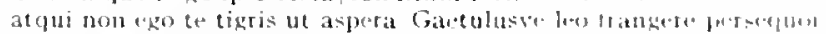

non ego sunita bacchabor Eifonis:

non ego pertidum dixi sucramentum:

ego. patugretum kanguis parentum,

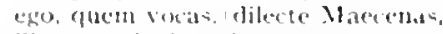

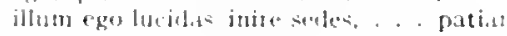

cigna can Punicis adfixa Jelubris. . villi,

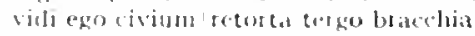

egu illis' mellios nete to teriam

ogo nex tumultum| nee mori per vim me.tim

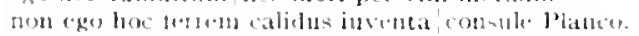

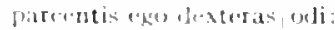

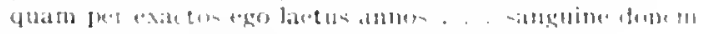

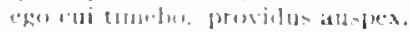

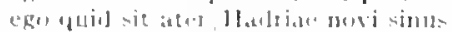

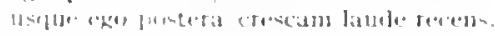

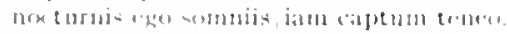

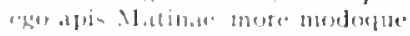

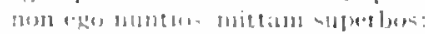

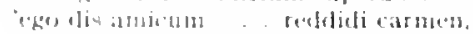

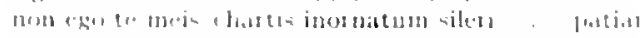

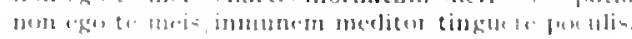

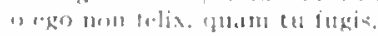

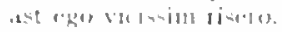

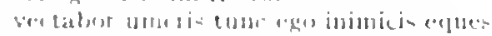

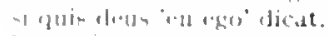

hos

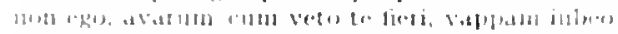

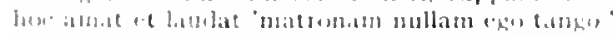

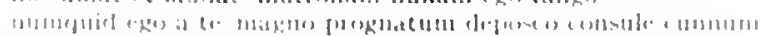

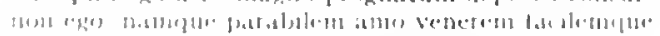

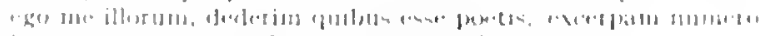

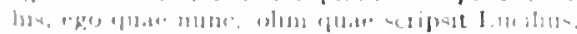

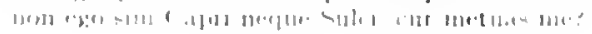

(a) I: ped.5.102

lifind.5.102

serper $2.3 .7 \mathrm{I}$

1.pist.1.14.13

cerst. 2.3315

herm.2.7.7

Sirm 2.3.140

Liviti.11.20

Lors lort.231

(iarriats.10)

lipued.17.6e

1.pist.1.17.2.?

Sirm1.2.2.98

l.tist.1.10.11

lipist.1.1.102

I.ppt.2.1.22K

serm.t.2.12t,

(arm.1.12.5.4

sirm.2.5. Al

rerm.1.f.11s

Epistuldeng

Ira Prit.l.

(inrmot.22.2

(rm.1.1.50

virm.2.2.103

l. pist.i.2.5\%

Jpist.1.17.30

lapist.1.20.1

(iarm 1.2.7

Corm-1.3.4.8

(iormat ald

Jipist 2.1.8?

(ismm.1.10.25

(armitisti!

(isrin.1.20.2

(iormt.1.231)

(ivmi.2.7.26

Cirm.2.17.0

(iarm.2.20.5

(iurnti.2.20.r

(iirm) 3-3.3.3

(ismm 5.5.18

( torm.3.5.2I

( $110 m 3.15 .42$

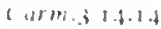

ciorm.3 1125

(iirm. 3 10.2:

(iarm, 3.226

(iurm. 3.27.

(1) 1010.327 .18

corm.3.30:

(4) 1 1. 3

(iorm.1.2.27

(iormistales

(arm-let.)

( $4 r m+9.30$

( irmatit222

1. pod.12.25

1 pod 1521

101.17 .7

veren-1.1.15

som.1.iog

irm.1.1.110.3

virm.3.2.5.1

vorn 1.2.tip

Sirm.1 2.110

berm $1+80$

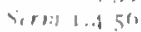

s.m 1.4.71 
ego si risi, quod ineptus|'pastillos Rufillus olet. Gargonius hircum,' ex hoc ego sanus ab illis|perniciem quaecumque ferunt. numquid ego illi|inprudens olim faciam simile?"

haec ego meeum|conpressis agito labris;

hic ego propter aquam, quod erat deterrina, ventri|indico bellum.

hic oculis ego nigra meis collyria lippus!inlinere;

nil ego contulerim iucundo sanus anico.

lusum it Maecenas, dormitum ego Vergiliusque:

hie ego mendacem stultissimus usque puellan | arl mediam noctem exspecto;

credat Iudaeus Apella, / non ego:

non ego me elaro natum patre, non ego circum| me Satureiano vectari rura caballo. ... narro.

magnum hoc ego duco. /quod placui tibi.

neque ego essem questus.

hoc ego commodius quam tu, pracelare senator. I milibus atque aliis vivo. ego, leetolatut seripto quod me tacitum iuvet, unguor olivo.

deus inde ego, furum aviumque / maxima formido:

hic ego 'pluris|hoe' inquam 'mili eris.'

invideat quod et Hermogenes, ego canto."

felices. nunc ego resto.

ego, ut contendere durum 〈est $\rangle \mid c n m$ victore, sequor.

ego vero oppono aurieulam.

atque eyo cum graecos facerem, natus mare citra, / versiculos.

dunque diffingit Rheni luteun caput, haee ego ludo.

neque ego illi detrahere ausin | haerentem eapiti cum multa laude coronam.

non ego: nam 'satis est equitem mihi plaudere",

doctos ego ruos et amicos|prudens praetereo.

quidquid sum ego, quamvis|infra Lucili censum ingeniumque.

ego vectigalia magna/divitiasqut habeo

puer hune ego parvos Ofellum|integris opibus novi

'won ego' narrantem 'temere edi luce profesta

quanto aut ego parcius aut vos, $/ 0$ pueri, nituistis,

unde ego mira|deseripsi docilis praeeepta haec.

huic ego volgus/errori similem cunctum insanite docebo.

sive ego prave! seu reete hoc volui,

'verum ego. . . prudens placavi sanguine divos.'

ut aprum|cenem ego;

segnis ego. indignus qui tantum possideam:

ego nam videor mihi sanus."

hanc ego cum malis, ego faecem primus et hallec.

o rus, quando ego te adspiciam

tu cum sis quod ego et fortassis nequior,

neque ego, hercule, fur, ubi vasa/praetereo sapiens argentea

tibi quid sum ego?

qui peccas minus atque ego,

nil ego. si ducor libo fumante:

'summus ego et prope me Viseus Thurinus

erucas viridis, inulas ego primus amaras|monstravi ineoquere:

ut ego accipiar laute.

restat ut his ego me ipse regam solerque elementis.

haee ego procurare et idoneus inperor

hac ego si conpellor imagine, cuncta resigno:

sic ego, . . frontis ad urbanae descendi praemia.

ego laudo ruris amoeni|rivos

spinas animone ego fortius an tu levellas agro.

rure ego viventem, tu dicis in Vrbe beatum:

nimirum hic ego sum; nam tuta et parvola laudo,

'nempe/vir bonus et prudens diei delector ego ac tu.'

scurror ego ipse mili., populo tu:

Parios cgo primus iambos|ostendi Latio,

hunc ego, non alio dictum prius ore, Latinus/volgavi fidicen:

non ego ventosae plebis suffragia venor

non ego, nobilium scriptorum auditor et ultor.

ad haec ego naribus uti|formido.

ipse ego. . . invenior Parthis mendacior

nec sermones ego mallem / repentis per liumum

hic ego rerum fuluctibus in meliis
Serm.1.4.01

Serm.1.4.1 29

Serm.1.4.130

Serm.1.4.137

Serm.1.5.7

Serm.1.5.30

Serm.1.5.4.4

Serm.1.5.48

Sirm.1.5.82

Serm.1.5.101

Serm.1.6.58

Serm.1.6.62

Serm. I.6.87

Serm.1.6.110

Sirm.1.6.122

Serm.1.8.3

Serm.1.0.7

Serm.1.9.25

Serm.1.9-28

Serm.1.9.42

Serm.1.9.76

Serm.1.10.3I

Serm.I. 10.37

Serm.1.10.48

Serm.1. 10.76

Serm.1.10.87

Serm.2.1.74

Serm.2.2.100

Serm.2.2.112

Serm.2.2.110

Sirm.2.2.127

Serm.2.3.33

Serm.2.3.02

Serm.2.387

Sirm.2.3.205

Serm.2.3.235

Serm.2.3.230

Serm.2.3.302

Serm.2.4.73

Serm.2.6.60

Serm.2.7.40

Serm.2.7.72

Serm.2.7.80

Serm.2.7.96

Serm.2.7.102

Serm.2.8.20

Serm.2.8.51

Serm.2.8.07

Epist.1.1.27

Epist.1.5.21

Epist.1.7.34

Epist.1.0.10

Epist.1.10.0

Epist.1.14.4

Epist.1.14.10

Epist.1.15.44

Epist.1.16.32

Epist.1.17.19

Epist. I.Ig. 23

Epist.1.19.32

Epist.1.19.37

Epist.1.19.39

Epist.1.10.45

Epist.2.1.III

Epist.2.J.250

Epist.2.2.84 


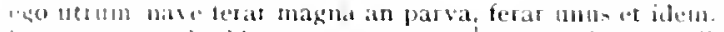

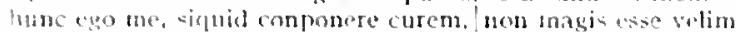

usdinis hase vistuse erit et venus, aut ego fallos.

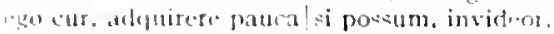

ir egir si nedpleo inguroque, poeta saluto:?

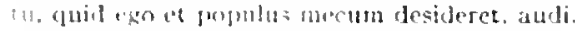

ton ege inornatia et dominantia nomina solum

- i modo engo at vosiscimas

1) ego laeves, 'qui putgor bilem sub verni temporis lonam

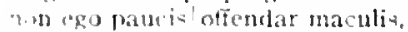

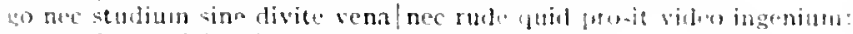

thutue sitis est dixisse "ego mira poemata pango;

"ur ego amicum offendain in nugis?"

egomet. cruribus haec metuat, doti deprensa, egonet mi.

iegomet ni ignosco" Maenius inejuit.

vidi esomet rigra succinctam vadere palla/Casidiam

It vineta egnmet edam mea).

hunc ego me [e gomet]. siqutl conponere curen., non magis ese velim

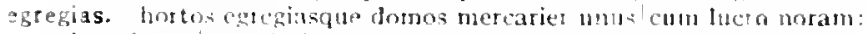

egregie. tumus engegic factum lauclet vicina

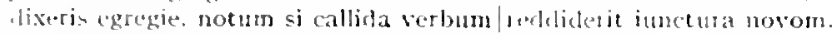

egregii. Jaurles egregii Cassaris et tuas

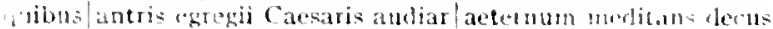

t unum. scilicet egregii mortalkm altique silenti.

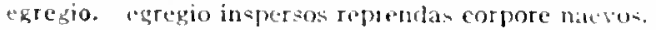

egregius. egregius properaret exul.

egressum. egresum magna me accepit Aricia Roma' lompitio inodico.

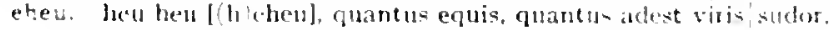

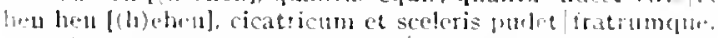

- helu fugares. Jostume. Postume, Jabuntur and

'heu, ne rubivagminum' eponsus hacessa: leyius

-ingulos chen lacerame:

Romatus olust . . Fert vallum et arma mijes

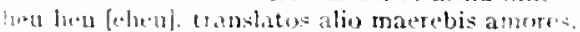

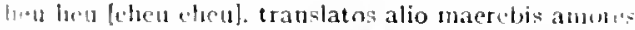

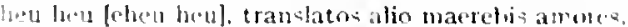

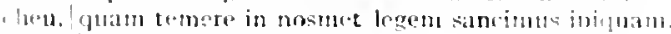

he'll, iquict redert.

eia. cit. quid stitlis?" - nolint.

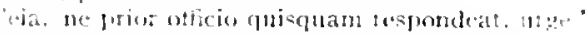

eiecta. huc puius ansuctis ejecta cadavera crlli-

eius. fur iale centum muniant angure caput eju-

+\$1s. . . elarios inlicant iavdes

rilicet uni arguns vituti atque eius atmi. :

' 1 quate sit natura boni summumque quill (ill.

elabi. scilicet elabi -i pouset mortua:

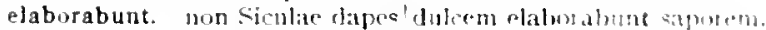

elaboratum. nur. elabontatum arl pedem.

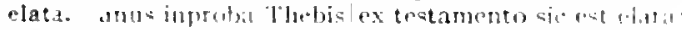

platrem. vere quol places ut non acriter elatrent

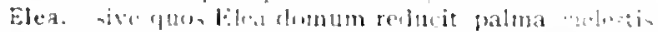

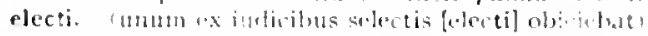

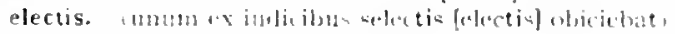

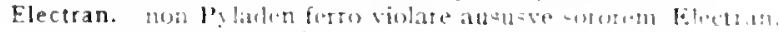

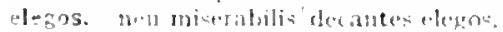

atmins tonjunn, hir thoges

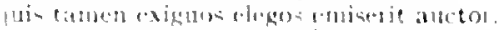

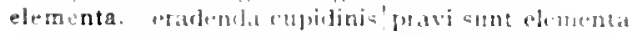

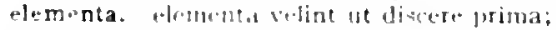

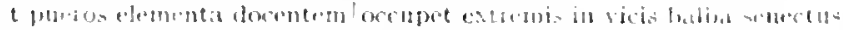

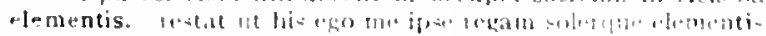

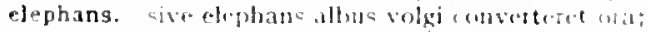

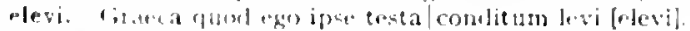

-liccrent. manis elicrent animag seaponat diatuis.

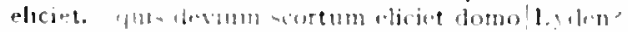

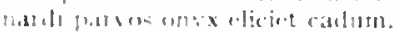

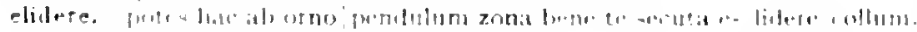

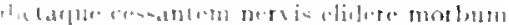

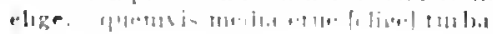

Epist.2.2.199

Ars Porl.35

Irs Pocl. 42

Ars Juel.55

. Irs Poids7

lirs Pivel.153

Ars Pi)el.234

Ars Portiziz

Ars Pool.zol

Ars Poet.35 I

Ars Pirtidog

Ars Poct.4io

irs Pist.450

Serm.1.2.131

Sirm.1.3.23

Sim.1.8.23

JPist.2.1.220

iver.trs Poit.35

Sern:2.3.24

Sirn: 2.5.106

. Irs Pocl.48

Curm.t.o.It

Cirm.3.25.4

siom. 2.1 .58

Sith 1.0 .017

Cirmi.3.5.18

Sirm.3.5.1

ius. Corm.1.15.9

- ar Carmi.1.35.33

Comit. 3.14.1

(itrm.3.2.9

(itrm.i.11.92

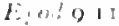

ator. L.pent.15.2.

atr. J.Podd. 15.23

sor.tiph 15.23

sirm-1 3.140

sirm.2.3.15"

(r) 1.1.is

'yrm. 20,23

Srm.1.R.8

Cirr. 3.31 .14

(iurm \& 818

Nerm $2.1 \%$

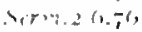

Sirme2.5.87

(iom.3.10)

Fipod 1.4.

sirm. 2.3 .85

Epit.1.18.18

(itren: 1.2.17

atrowh t.4.12;

ar serm. 19.123

ares. 2.1 .70

citm.1.33.

1 pist. 2.2.31

irs I'sestaz

(iarmo 3.21.5.

s.yos 1820

IEPtol.20.1

l.jid.t.1.27

l.pel 2.1.10\%

iar (arm) 1203

Jermi.1.R.20)

(arm.211.2)

(arm.12.17

aniciarm.3.2750.80)

lipetidiso

arraven I : 25 
eligit. neque eligit / cui donet inpermissa raptim/gauli.

eliminet. qui dicta foras eliminet.

elirant. cruor in fossam confusus, ut inde/manis elicertut [thrant] animas responsa daturas.

thent. cruor in fossam confusus, ut inde/ nuanis elicerent [elirent] animas responsa daturas.

eliserit. ingens|belua cognatos eliserit:

elixa. simul assis/miscueris elixa, simul conchylia turdix.

cllebori. "danda est ellebori multo pars naxina avaris:

elleboro. expulit elleboro morbum bilemque meraco

elocuta. gratum elocuta consiliantibus|I unone divis:

eloquium. et tulit eloquium insolitum facundia praeceps

eludebat. mordacem Cynicum sic eludebat, ut aiunt:

eludente. arguta neretrice potes Davoque Chranta / elingente senem conis garrire libellos

eluere. amaraque/curarum eluere efficax.

elusus. dum cadat elusus ratione ruentis acervi

elutius. inriguo nihil est elutius horto.

emancipatus. emancipatus feminae|fert vallum et arma miles

emat. siquis cunat citharas, emptas conportet in 111111.

ematur. panis ematur, holus, vini sextarins.

emendare. * Catone.. qui male factos emendare parat vifin:

emendas. nt praeco, ad merces turbam qui cogit emendas.

emendata. enendata videri|pulchragne et evactis minimum distantia mitor. emendaturus. Nasidiene, ... ut artelemendaturus fortunam:

emendatus. cum pateris sapiens emendatusque vocari.

emendes. noribus ornes.|legibus emendes:

emendo. insanit veteres statuas Damasippus emendo:

emetat. ne plus frumenti dotalibus emetat agris / Mutus

emetiris. cur, inprobe, carae/non aliquid patriae tanto emetiris acerso?

emicuit. inter quae verbum emicuit si forte decorum

emirabitur. aspera|nigris aequora ventis|emirabitur insolens

emiserit. quis tamen exiguos elegos emiserit auctor.

emisso. fuge quo descendere gestis:| mon erit emisso reditus tibi.

emissum. et senel emissum volat inrevocabile verbum.

emisti. prudens emisti vitiosum, dicta tibi est lex:

emit. poema'qui tam ridiculum tam care prodigus init.

emovere. dura sed enovere loco me tempora grato

emovit. emovitque culpas/et veteres revocavit artic.

emovit veterem mire novos,

Empedocles. Empedocles an Stertinium deliret acumen.

"deus immortalis haberi dum cupit Enperloclez, arrenten frigidus Aetmam insiluit.

empta. sperne voluptates: nocet empta dolore voluptas.

empta. cenes ut pariter pulmenta laboribus empta:

emptae. 'quanti enptae?' 'parvo.' 'quanti ergo?' 'octuscibus

emptas. siruis emat citharas, emptas conportiot in unum.

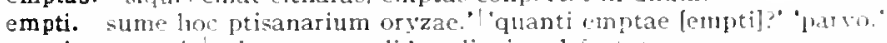

emotis. emtis sub noctem gelidam lignis calefactat aunum;

empto. si me stultior ipso|quingentis empto frachmis diptenderic?

emptor. dedecorum pretiosus emptor.

ex parte tua se'l fundi sive domus sit/cmptor.

emptor Aricini quondam V'eientis et arvilemptum cenat holıs.

nec, sicuid fricti ciceris probat et nucis emptor.

emptorem. emptorem inducat hiantem.

emptum. populo spectante referret emptum nulus aprum?

fortasse trecentis aut etiam supra nummorm milibus tmptum.

emptum. emptor Aricini quondam V'eienti-et arsi enptun renat holu:

emunctae. facetus, /emunctae naris, durus conponere ver $* 11 *$

emuncto. Pythias, emuncto lifcrata Simone talentum.

en. si quis dets 'en ego' dicat.

enatat. si fractis enatat exspes f navibus, acre dato "fui pingitut

enaviganda. unda. scilicet ommibus. . .naviganda.

Enceladus. Enceladus iaculator andax

enectus. spem mentita seges. bos est enectus arandn:

enervet. viris quid entret meas.

enim. certus enim promisit Apollo

iam te sequetur (currit enim ferox/aetas

non enim gazae neque consularis/submoset lictor

L.P.St.I.5.25

ther.sirm.1.8.29

iur.sern.1.8.20

Serm.2.3.310

serm. 2.2.74

Sirm.2.3.82

Epist.2.2.137

(imm.3.17

Ars Piotit.217

Epist.1.17.18

Serm.t.10.45

Cism.t. [2.20

I.Pist.2.1.4:

xirm.2-2.1\%

l: poul.o I 2

sirm.2.3.104

Serm.1.74

Serm. [ - Io.*3

dis Poet.tug

Epist.2.1.7

Serm.2.8.85

Epist. I.10.30

Epist.2. I.3

Serm.2-3.is

Epist.r.t.2I

Serm.2.2.105

Epist.2.1.73

Cirm.1.5.8

1) Poet.75

Epist.1.20.0

Epist.1.18.7I

Fpist.2.2.18

Fist.2.2.238

Lepist.2 $2.4^{\circ}$

inm.1.15.1

sem.2.3.28

lipist. I. 1 2."

Les linet.tos

Epist.1.255

listat. 18.48

cirm.2.3.15

Sirm.2.3.104

tar.serm.2.3.5.

Epist.2.2. its

Sirm.2.7.4.3

Carm.3.1).32

tierm.2.510u

Epistandist

lirs lolt.249

Shrow. $1.28 \mathrm{~S}$

Erist.j.6.ti

Fotict.2.165

Epist 2.2.108

Serm.1. 1

Irstrot.23

tirm.t.1 15

irs lonet.20

carmil. I.t.

Cormeztis

Epivt.5.8.

TPod.8.2

Carm.1.7.24

(iom.2.5.13

( $(\mathrm{r}) \cdot 2 \mathrm{D}(\mathrm{s})$ 
fore enim tutum iter et paterns

Cism.3.16.7

instar veris crim voltus uhi tuos

Carm. 4.6

infernis necplse enim tenebris.

(non enim posthac alia calebo/tenuna)

Cirm.4.7.25

inprortunus enim transwolat aridasfquercus

Carm.4.11.33

inilitia est potior. (fuid enim? concurritur:

(arm.4.13.9)

Sirm.1.1.7

neeple enim concludere versum/dixoris esse satis

necue enim an lectulus aut nef porticus excepit, desum mihi.

Serm.1.4.40

Sicrm.1.4.133

mosue enim quivis . . deseribit volnera Parthi."

Serm.2.1.13

Sirm.2.3.9.4

quantulum enim summae entabit quisque dierum.

Serm.2.3.124

incolumi capite es? quid euim?

quid anim differt harathrome/ dones quidquid habes an numquan utat parati-? -

insanus (puld enin Aiax fecit?

vincet enim stultos ratio in anire nepotes. .

guid tum [enim]? renere fumuentes, verba facit leno:

venit enim magnum donandi parea inventus

Serm.2.3.132

urget enim dominus mentam non lenik

tergo plector enim.

pauper enim non est. cui rerum supuetit usus. .

cautus enim metnit foveam lupus

ambigitur quid inim? Castor sciat an Docilis plus;

beatus enim iam/cum pulchris tunicis sumee nern consilia et spes.

fidis enim manare poctica mella te solum.

fudus enin gromuit trepirlum certamen et iran.

quis enim invitum servare laboret?

urit roum fulgore suo qui praegravat artes intra se positas:

serus enim Graecis admovit acumina chartis

gestit enim nummum in loculos demittere.

discit enim ritus meminitgus libentius

Jistat enim. spargas tua prodigus. an neque sumptum invits iacias

format enim natura priss no: intus ad onnem fortumarum habitum:

indoctus quid enim saperet liberquo laborum / rusticts

offenduntur enim. quibus est cquos at pater et ress

nanciscetur enim pretiun nomengue protac.

clamabit enim "pulchre, bene, secte,"

Enipens. ne sicinus Enipeus plus justo placéát

enisus. vagus llovenles enisus arces attigit igneas.

enitar. frangere enitar modo multum amatil cornua monstri.

nee sic anitat tragicon differre colori.

enitescis. thitucis pulcrior multe

Enni. non ridet versu Enni graviate minores.

cum lingua fatonis et Enni|sermon patrium difaverit

Funi in seandum missos cum magno pondere versus

Ennius. dinuiu- |par pater numfluam nisi potus at at ma prosihuit dicendi.

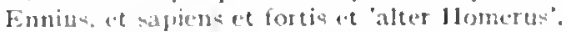

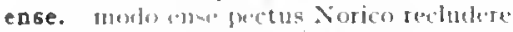

ensem. nex muliobriter expatit ensem

eases. allt cour clovericlaptantur anses conditi?

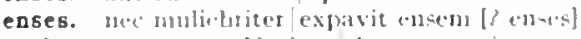

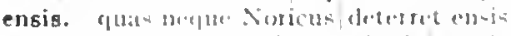

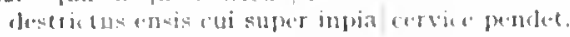

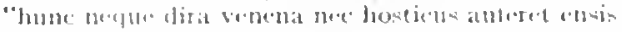

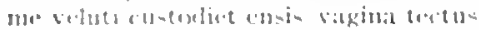

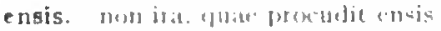

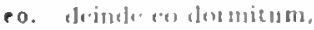

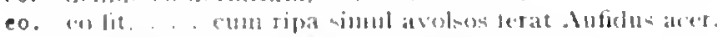

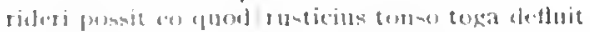

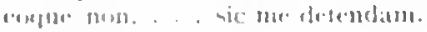

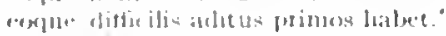

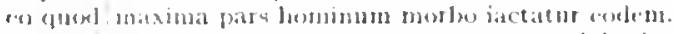

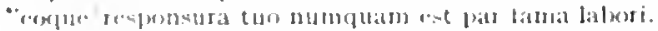

сен

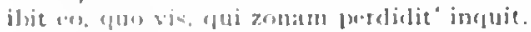

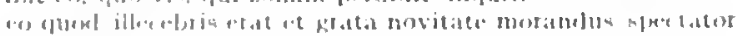

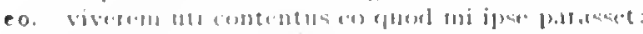

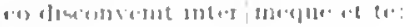

Serm.2.3.10\%

Serm.2.3.201

Serm.2.3.225

coni.Serm.2.3.230

Serm.2.5.70

Sorm.2.7.93

Serm.2.7.105

Epist.1.12.4

Iipist.1.10.50

Epist.1.18.19

Ifpist.1.18.32

lipist.1.19.44

lipist.1.19.48

lipist.1.20.10

Eipist.2.1.13

lipist.2.1.101

IEpist.2.1.175

I.pist.2.1.202

L.pisl.2.2.195

Ars Puet. 10 s

frs Joel.212

Ars J'oet. 248

Irs l'oel.299

dis lodt.42s

corm.3.7.23

(arm.3.3.10

(arm.3.27.47

Ars Joel.236.

(urm 2.8.6

Serm.1.10.54

Ars Pool. 57

Ars Poel.250

EPst.1.19.7

IEpist.2.1.50

tipold 7.71

(arm.1.37.23

1:pod.7.2

1:ar.Carm.1.3\%.2.3

(ism.1.Jo.1)

( armo3.1.17

Sirm.1.0.31

Siem.2.1.40)

("arm..t 15.10)

Serm.1.0.110

trem.1.1.5r

Sermt 1.3 .30

ierm1.0.80

sorm.1.9.5.5

Serm.2.3.120

ferm.2.8.0.5

1.pist.2.1.220

1.p.st.2.2.40

. Ir Jivel.222

ierm.1.4.108

fipul.1.1.

( arm 2.325 
Timor et Minae/scandunt eodem, quo dominus.

Carni.3.1.38

ditior aut formae melioris meiat eodem.

Serm.2.7.52

eodem. eo quod / maxima pars hominum morbn iactatur eodem.

Serm.2.3.121

eodem. quem si dissolvas. quivis stomachetur eodem /quo personatus pacto pater.

Castor gaudet equis, ovo prognat us eodem |pugnis; .

Serm.1.4.55

Serm.2.1.26

fere miratur eodem, quo cupiens, pacto;

Eois. examen Eois timendum| partibus Oceanoque rubro.

Eois intonata fuctibus|hiems

eorum. est auct or quis denique eorum, | vixi cum quibus?

Epist.1.6.9

Carm.1.35.3I

Epod.2.51

Serm.1.4.80

Epist.2.1.67

eos. si pleraque dure/dicere credit eos,

ephebi. quo pacto partis tutetur amantis ephebi.

Epheson. laudabunt alii claram Rhodon aut Mytilenenlaut Epheson

ephippia. optat ephippia bos. piger optat arare caballus:

Epicharmi. Plautus ad exemplar Siculi properare Epicharmi.

Epicuri. cum ridere voles. Epicuri de grege porcum.

Epidaurius. acutum/quam aut aquila aut serpens Epidaurius?

epistula. ne mea saevos|iurgares ad te quod epistula nulla rediret.

epos. forte epos acer, / ut nemo. Varius ducit; .

epulae. stragula vestis, blattarum ac tinearum epulae,

nempe inamarescunt epulae sine fine petitae

epulas. voveram dulcis epulas et album /Libero caprum

has inter epulas ut iuvat pastas ovis/videre

eputis. neu desint epulis rosae

sic lovis interest optatis epulis inpiger Hercules.

epulis. necdum omnis abacta/ pauperies epulis regum: .

epulum. dare.. epulum arbitrio Arri.

equa. tibi tollit hinnitum/apta quadrigis equa,

quae velut latis equa trima campis

eque. cineres insistet victor et Vrbem | eques [eque] sonante verberabit ungula,

eques. Parthos ferocis|vexet eques metuendus hasta

eques ipso melior Bellerophonte.

sedilibusque magnus in primis eques.

Vrbem |eques sonante verberabit. ungula.

vectabor umeris tunc ego inimicis eques

quas doceat quivis eques atque senator'semet prognatos.

mantica cui lumbos onere ulceret atque eques armos:

ire viam qua monstret eques;

laeva stomachosus habena|dicet eques;

depugnare parati,|si discordet eques,

eques. datus in thearo/ cum tibi plausus. I clare Maecenas eques,

equestrem. praesertim census equestrem / summam nummorum .

equestri. tu cum proiectis insignibus, anulo equestri \begin{tabular}{l} 
equestri. tu cum proiectis insignibus, anulo equestri \\
equi. cineres insistet victor et Vrbem | eques [equi] sonante verberabit \\
ungula. \\
\hline
\end{tabular}

equi te esse feri similem dico.'

sed equi irenato est auris in ore);

equidem. equidem nihil hine diffindere possum.

'dixi equidem et dico:

numquid de Dacis audisti?" 'nil equidem.'

non equidem insector delendave carmina $\mathrm{Livi}$ esse reor.

equina. mammae putres/equina quales ubera.

equinae. caudaeque pilos ut equitrae/paulatim vello

equinam. humano capiti cervicem pictor equinam /iungere si velit

equino. et laetum equino sanguine Concanum.

equis. aptum dicet equis Argos ditisque 11 yeenas:

heu lieu. quantus equis, quantus adest viris/sudor, .

sive opus est imperitare equis. I non auriga piger.

instat equis auriga suos vincentibus,

inon est aptur equis I thace locus,

sed equi [equis] frenato est auris in ore);

equis. quam rem cumque ferox navibus aut equis.

hune equis, illum superare pugnis| nobilem;

aut versis animosum equis! Parthum dicere

hac Quirinus|Martis equis Acheronta fugit,

est in equis patrum / virtus

Sisennas, Barros ut equis praecurretet albis.

Castor gaudet equis, ovo prognatus eodem|pugnis; .

Epist.2.1.I 7 I

Carm.1.7.2

Epist.1.1 4.43

Epist.2.1.58

Epist.1.4.16

Serm.1.3.27

Epist.2.2.22

Serm.1.10.43

Serm.2.3.119

Serm.2.7.107

Corm.3.8.6

Epod.2.6I

Carm.1.36.15

Carm.4.8.30

Serm.2.2.45

Serm.2.3.86

Carm.2.16.35

Carm.3.I I.9

var.Epod.I6.I 2

Carm.3.2.4

Carm.3.I2.7

Epod.4.15

Epod.16.12

Epod.17.74

Serm.1.6.77

Serm. I.6. 106

Epist.r.2.65

Epist.1.15.13

Epist.2.1.185

Carm.1.20.5

Ars Poal.383

Serm.2.7.53

qar.Epod.I6.I2

Serm.1.5.56

Epist.1.15.13

Serm.2.1.79

Sirm.2.5.23

Serm.2.6.53

Epist.2.1.69

Epod.8.8

Episl.2.1.45

Ars Poet.1

Carm.3.4.34

Carm.1.7.9

Carm.1.15.9

Carm.1.I 5.25

Serm.I.I.I 5

Epist.1.7.4I

var.Epist.1.I 5.13

Carm.1.6.3

Carm.1.12.26

Carm.I.19.I I

Carm.3.3.16

Carm.4.4.30

Serm.1.7.8

Sirm.2.1.26 


\section{EQVIS}

Raurfet equia canibusque et aprici gramine Campi.

equitare. neu sinas Medos equitare inultos te duce. Caesar.

Ars P'ort.162

exiguis equitar" campis.

lukete par inpar, equitare in hasundine longa

equitat. cur noque nilhtaris'inter aequalis equitet [equicat].

equitavit. vel Eurug per Siculas equitavit undas.

equitem. port equiterusedet atra Cura.

Petgasua terrenum equiten gravatus $\mid$ Bellerophontem.

non ego: nas satis the equitem mihi plaudere".

non equitem dorso, non frenum depuit ore.

equites. Romani tollont equitrs preditesque cachinnum.

equitet. cur neque militaris'inter aequalis equitet.

equitis. venum equitis quoque iam migravit ab aure voluptas/omnis

equitum. teret échos equit umegue voltus.

nec turmas orluitum retincluit

Naccenas, equitum decus.

- grammaticorm equitum doctissimus.*

dum fugione equitum tumae peditumeque caterve;

equo. mescil aguo rudis hatere ingenuos puer

itle non inclusus equo Minetrael acra shertito

aut labentis ertuo describit volue' a Parthi."

leporem stectat us expove lassus ab indomito

equom. quanvis nom alius flectere equom sciens pugilenve explumve! dicit

irementem 'nittere equam nedios per ignis.

anitavit equom lasciva supinum.

solve renescentem mature sanus equom.

fingit equom teftera tocilen cervice naghinter

crovo equon pugnat melior communibus herbis|pellebat,

et pukilent victorem et equom certanine primum

equorum. quae solet mattes furiare equorum.

nute athletarum stulis, nunc arsit equorum,

equos. non equos iajpiges curru ducet Achaicolvictorem

deversotia nota pratetagendus entuos.

equos ut me portet. alat rex. officiun facio;

offenduntur enim, qubisus ast equos et pater et tes.

equos. per purum tomantis erit echuos voluctengue cursum.

iam fulgot armormm fugaris terter equos

ad hane fermertis verterune bis mille equos

regibus hic mos eat, ubi cofluos metcantur:

eradenda. eradenta cuphlinis pravi sumt elementa

eram. ilonec gratus cram tibi

non sum qualin teram bonat/sub regno Cinarae.

seat quord etam nasto.

olim trumens cram ticulnas, inutile dignum.

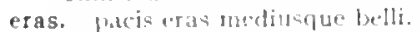

non tu iorpus etas sine percure:

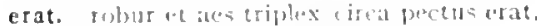

Saliatibus onate fulvinar deotum tempus erat dapibus.

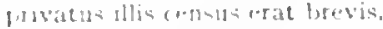

mogue etal Ly lia post chlon.

nox erat et cislofo fulget)at L.una sereno

cuppe batrigne erat.

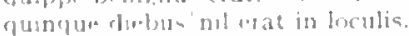

11t Alfous vafte comi abiecto instrumento atis clausague taberna

sazersin orat:

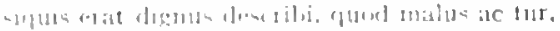

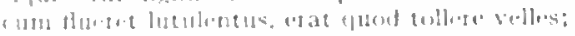

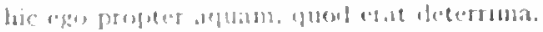

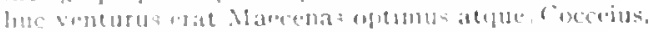

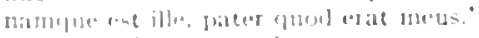

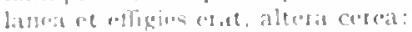

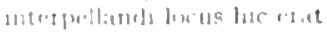

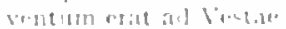

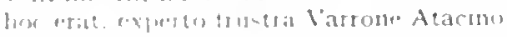

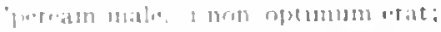

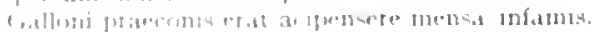

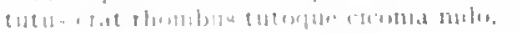

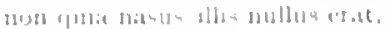

Carm.1.2.51

Carm.2.9.24

Serm.2.3.248

1ar.Corm.1.8.6

Carm. 4.4 .44

Carm.3.1.40

Carm.4.11.27

Serm.1.10.76

Epist.1.10.38

Ars Poet 113

Carm.1.8.6

Epist.2.1.187

Carm.2.1.20

Corm.2.16.22

Carm.3.10.20

Serm.1.10.*8

Fist 2.1.190

Corm.3.24.54

Carm.4.0.13

Serm.2.1.15

Serm.2.2.9

Carm.3.7.25

Carm.4.2.18

Carm.4.14.2.1

Serm.27.50

Epist.1.1.8

Etist.1.2.0.1

Epist.1.10.34

Ars Paet. 84

Carm.1.25 1.4

Epist.2.1.05

Carm.4 3.4

Epist.I.15. I I

Epist.1.17.20

Ars Poet. 248

Corm.1.3. 4.8

Curm.21.20

lipolig.17

Sirm.1.2.86

Curm.3.2.2.51

Carm.3.9.1

Carm.4.1.3

Sirm.1.0.00

S.rm.1.8.

Corm.2.19.28

Epist.1.4.6

Carm.1.3.10

Curm.1.37.4

Corm.2.15.13

Corm.39.6

fipod.15.J

Serm.1.2.1

Sirm.1.3.17

Sirm.1.3.132

Serm. I.t.3

sirm.1..1 11

siom 1.5.7

Sorm. 1.5.27

serm. 1 .to 41

Serm.1.830

Serm.1.0.20

Serm.1035

term 1.10..po

Serm 2.1.7

tirm.2 2.47

Serm.2 240

Serm.2. 2.00 
bene erat non piscibus V'rbe petitis,

post hoc ludus erat tculpa potase magistra

atqui voltus erat multa et praeclara minantis.

Serm.2.2.120

Serm.2.2.12.5

serm....3 34

Sierm.2.3.201

quo rediturus erat non arcessitus.

"libertinus erat, qui . . . eurrebat

'quin id erat curae. .

tion.2.3.2s:

sirm.2.4.8

ierm.2.c.s

xirm.3...23

hoe erat in votis: modus agri non ita magnus

Vomentanus erat super ipsum. Porcius infra

rluidquid erat nactus praedae maioris.

I.fivis. $1.1 .5 \cdot 3$

Jpist.1.17.45

lepist. $22.8 \%$

irater erat Romae consulti rlietor.

sed nunc non crat his locus.

tibia. . . adspirare et adesse choris crat utilis

co quod illecebris erat et grata novitate morandus/spectalor

ere. 'o ere, quae res| nec modum habet neque consilium.

ere. hic meret aera [ere] liber Sosiis, hic et nare transit

ere. haud ita pridem / Galloni praeconis erat acipensere [aceipiens ut] mensa|infamis.

erectum. Fortunae te responsale superbae / liberum et erectin

erepsemus. quos torret Atabuius et quos|nunquan repsenus.

ereptum. ereptun Stygiis fluctibus Aear'um

ereptus. vel haedus ereptus lupo.

ergo. ergo Quintilium perpetuos sopor|urget?

ergo obligatam redde lovi dapem

ergo aut adulta vitium propagine

ergo negatum vincor ut credam miser,

ergolnon satis est puris versum perscribere verbis.

ergo non satis est risu diducere rictum | anditoris

quo pertinet ergo|proceros odisse lupos?

ergo... parebit pravi docilis Romana iuventus. -

ergolquod superat non est melius quo insumere possis:

sobrius ergo/dic aliquid dignum promissis.

"quid ergol sensit.

'quanti emptae?' 'parvo.' 'quanti ergo?' 'octuasibus..

ergo consulere et mox respondere licebit?"

ergo ubi pravalstultitia, hic summa est insania;

'ergolpauper eris.' .

"ergo nunc Dama sodalis|nusquam est?

ergo ubi me in montes et in arcem ex urbe remori

ergo/sermo oritur, non de villis domibusve alienis,

ergo ubi purpura porrectum in veste lowit agestem.

ergo... hoc primus repetas opus.

ergo/post nonam venies;

ergo|quem sua culpa premet, deceptus mitue tueri.

'dixit adhuc aliquid?" 'nil sane.' 'quid placet ergo?" .

ergo fungar vice cotis.

quid ergo est?

eri. lacus et mare sentit amorem/festinants cri;

erigimur. postquam niluil esse pericli|sensinus, eriginu ;

erigit. hominem sic erigit; addit et illud:

erile. nisi erile mavis/carpere pensum

erilis. quo te demisit peccati conscia erilis,

quo te demisit peccati conscia erilis [pecati conscia erilis deminit).

erilis. verna ministeriis ad nutus aptus erilis.

erimus. sive inopes erinus coloni.

eripe. eripe te morae

quemvis media erue leripe] turba:

eripe turpi|colla iugo.

eripere. possit ... eripere artis! litibus inplicitum,

eriperem. ut haerentis adverso litore navis eriperem,

eriperet. distorquens oculos, ut me eriperet.

eripi. quae poscente magis gaudcat eripi,

eripiam. vix tamen eripiam, posito pavone velis

eripias. eripias si|tempora certa modosọuc,

eripiet. eripiet quivis oculos citius milni

eripietque curule / cui volet inportunus ebur."

eripiunt. clarum Tyndaridae sidus ab infmis/quassas erintunt arumoribus rates, .

Ais Porit. 19

.105 I'thel.204

Jis Pot.223

Sirme.2-3.205

ar.etrstoet. 345

ar.term.2.2.4:

Epist I (at)

Serm.1.5.79

carm.4.8.25

J.poll.z.rou

('orm.1.2+5

G 'urlit.2.7.17

i.poll.2.9

Epoll.1.2.

5 sm.1.4.53

Sim.10.1

STm.2.2.3.5

Cirm:2.2. 31

Sirm.2.2.111

'rm.2.3.5

Sim.2.3.8u

timm.2.3.1 5 h

sirm.2.3.10)

sirm.2.3.220

Titm.2.5.19

remi2-5.ret

sim.2.

4orm.2.0.70

sirm.20, 100

Ispitente.t"

tepist.1.7.74

Epist. 18.78

Epist.2.1.2urt

Ars l'ort.3ut

ir. Prot. 353

1:Pist.1.1.8.

Sorm.2.s. 58

rerm.2.3.15"

cinm.3.27.43

som.2.7.94

fall. Sirm.2.7.06

Ispist.2.2.0

('is).2.14.12

Carm.3.30.5

ver.tierm.1.425

Serm.2.7.01

Ars 1'Det +2.3

Sirmidis.zoc

sermalon

( urm.2.12 =7

Sirm.2.2.23

Sermat.57

Serm.2.5.35

Epist.t.5. 


\section{ERIPVIT}

oripuit. to lovie inpio|tutela saturno refulgens/eripuit .

Curnt 2.17 .24

eris. cris tu. qui molo miles., mercator;

"pluristhoc" inquam 'milis eris.'

tune in waus esis, si acceperis.

'non, ki (1. tuperis.' inquit. | par eris."

doctus eris vivam musto merware paalerno:

'irgo, pauper etis."

ut t11 semper eris elericot.

plebs urs, at pueriludentes 'rex eris' ainut, si recte facies."

non tu corpus cras [eris] sine pectore:

carus eris Romae, donec te deserat aetas;

erit. ut melius, quidquid erit. pati.

non, si male nunc, et olim sic erit:

erat ille fortis qui perfidis se credidie hostibus

nou hoc hemprer etit liminis aut aquae/caelestis patiens latus.

'juisquis erit vitae scriban color.'

mundus erit. cruat non offendat sordibus

lic nerfle servis. . sarvos erit.

erit nulli proprius, sed cedet in usum/nume mihi, nunc alii.

hoc si erit in te $\mid$ solo.

ille clarus erit, fostis. iustus."

fui sceleratus, fet furiosus erit;

long:t quibus facies ovis erit, illa memento.

quamvis feriurus erit, sine gente.

domi si gratus erit fecundave coniux.

'o Laertiade. quidquid dican, aut erit aut non:

iuvenis Parthis horrendus. . . tellure marique/magnus erit.

scortator erit: cave te roget: .

si pede maior erit, subvertet, si minor, uret.

si valiclus, si lartus erit, si denique poscet;

qui metuend vivet. liber milii non erit umquan.

ut matrona meretrici dispar erit atque/eliscolor.

ad inun. Tliraex erit aut holitoris aget mercede caballum.

fuge quo descrndere gestis: | non erit emiseo reditus tibi.

inter quos referendus erit?

eritque tuos nummorum milibus octo.

cui lecta potenter erit rea.

ordinis latec virtus erit et venus. aut ego fallor.

publica materies privati iuris erit.

erit quare. si propius stes. / te capiat magis.

nec semel hoc fecit, nec si retractus erit.

eritis. utcumque mecum vos critis.

errans. ater flumine languido/Cocytos errans

errantis. Inugientium | prospectat errantis greges

orrare. audire et vieleor pios/errare per lucos.

serpentes atque videres infernas errare canes

erraremus. vellem in anicitia sic erraremus

errat, inter alldacis lupus esrat agnos.

si vecters ita miratur laudatque poetas. I ut nihil anteferat, nihil illis conparet : errat;

hic, dum sublimis versus ructatur et errat.

errem. utinam inturerem muda leones.

errent. stellac sponte sua illssacne vagentur et errent.

erret. stultitiane erret nihilum distabit an ira.

erro. insanientis dum sapientiac / consultus erro.

erro. teque ipsum vitas fugitivos ret erro.

error. "rror cresto ile tramite pellit.

unus utrifue/ertor, sed varis inludit partibus:

hic eror tamen ret levis haec insania fuantas/virtutes habeat.

dernptus jer vim mentis gratisainus error."

guild rlaceat, quill nom, que virtus, quo ferat ersot.

urget aut fandicus error et itacunda Diana.

errori. iqti|urrori nom.n virtus posuiset lonestum.

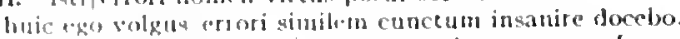

eruam. tu motians. unde / divitias atrigque ruam [eruam], dic augur. inerose.

erubescendis. mon mubracendis adurit ignibus

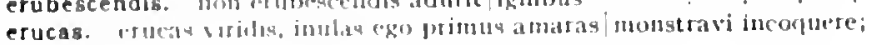

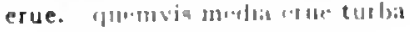

Serm.1.1.10

Serm.1.9.8

Serm.2.3.67

Sirm.2.3.32u

Sern1.2.4.19

Tierm.2.5.20

Sern1.2.6.54

Iipist.1.1.59

coni.l.pist.1.4.6

Eisist.1.20.10

Carm.1.11.3

Carm.2.10.18

Carm.3.5.32

Corm.3.10.19

Serm.2.1.60

Sirrn.2.2.65

Sirm.2.2.68

Sorm.2.2.134

Serm.2.3.41

Serm.2.3.97

Serm.2.3.222

Sierm.2.4.12

Sorm.2.5.15

Serm.2.5.31

Serm.2.5.59

Serm.2.5.64

Serm.2.5.75

Epist.1.10.43

Epist.1.13.3

Epist.t.16.66

Epist.1.18.3

Epist.1.18.36

Epist 1.20 .6

Epist.2.1.4t

Epist.2.2.5

Ars Poet.4o

Ars J'ort.42

Ars Port.131

Ars Port.361

Ars Poet. 468

Carm.3.1.29

Carm.2.14.18

Epod.2.12

Carm.3.4.7

Serm.18.35

icrm.1.3.41

Carm.3.18.13

Epist.2.1.65

Ars Port.457

Carm.3.27.5I

Epist.1.12.17

Serm.2.3.210

Carm.1.34.3

Serm.2.7.113

Serm.2.3.49

Serm.2.3.5t

Epist.2.1.118

Epist.2.2.140

Ars loet. 308

Ars I'ort.454

Serm.1.3.12

Sorm. $2 \cdot 3 \cdot 63$

rar.sirm.2.5.22

Corm 1.27.15

Sorm.2.8.51

tierm.t.t.25 
eruet. obscurata diu populo bonus truet.

Lipit.2.2.115

erum. aula divitem inanet/erum.

Carm.2.18.32

nan propriae telluris erum natura neque illun $\mid$ nee me nec quemquam statuit:

arvo pascat crum an bacis opulentet olivat,

erunt. uni nimirum recte tibi senper erunt res.

quatumqu". . sine pondere erunt et lonos" indigna ferentur, verbat

si dicentis erunt fortunis absona dicta.

erus. hic erus "Allanum. Maecenas. sive Falernim/te magis adpositis delectat:

sub hoc erus "haec gravida" inguit|"capta est.

erutas. iubet sepulcris caprificos erutas.

ervo. me silva cavosque|tutus ab insidis tunui solabitur ervo." :

Erycins. sive $t 11$ mavis. Erycina ridens,

Erymanthi. nigris aut Erymanthi silvis

Sirm.2.2.129

Epist.1.16.2

Sirm.2.2.100

IEpistz.2.I 12

Ars Poet.1 12

Serm.2.8.16,

Serm.2.8.43

Epod.5.17

Serm.2.6.117

Carm.1.2.33

Curm.1.21.7

Epod.15.17

es. et tu, quicumque es felicior

incoluni capite es? quid enin?

gaudes, si cameram percusti forte, penes te es?

si nusquatn es forte vocatus/arl cenam.

non es quod simulas?

ita vir bonus es convivaque comis"

belua inultorum es capitum.

tu poscis vilia, verum es/dante minor.

cum sis nihilo sapientior ex quo/plenior es.

non es avarus: abi.

escs. quae prima iratum ventrem pacaverit esca."

escae. memor illius escae, / quae simplex olim tibi sederit.

Esquilias. simul atras/ventum est Esquilias,

Esquiliis. nunc licet Esquiliis habitare salubribus.

Esquilinae. post insepulta nembra different lupi]et Esquilinae alites

Esquilini. et Esquilini pontifex venefici

esse. uxor invicti lovis esse nescis.

quid statis?" - nolint. atqui licet esse beat is.

iubeas mistrum esse. libenter/quatenus id facit.

horum | semper ego optarim pauperrimus esse bonorum.

ne prodigus esse dicatur metuens,

quaque morleste munifico esse licet.

at hic si. . . vellet bonus atque benignus $\mid$ esse,

quis paria esse fere placuit peccata.

cum dicas esse paris res|furta latrociniis

ego me illorum, dederim quibus esse poetis, | excerpam numero:

Serm.2.3.132

Serm.2.3.273

Serm.2.7.29

Serm.2.7.56

Sirm.2.8.76

Epist.1.1.76

Epist.1.17.21

Epist.2.2.154

Epist.2.2.205

Serm.2.8.5

Serm.2.2.72

Sorm.2.0.33

Serm.1.8.14

Epod.5.100

Epod.17.58

Carm.3.27.73

Sermitirg

Serm.1.1.03

Serm.1.1.79

Sorm.1.2.4

Serm.1.2.5 I

Serm.1.2.52

Serm. I.3.06

Serm.1.3.12I

Sirm.1.4.39

Serm.1.4.41

neque enim concludere versum | dixeris esse satis

neque, siqui scribat uti nos|sermoni proplora, putes hunc esse poetam.

"equi te lesse feri similem dico."

nil illi larva aut tragicis opus esse cothurnis.

nilo deterius dominae ius esse:

iubesque | esse in amicorum numero.

non, ut magna dolo factum negat esse suo pars.

opinor omnibus et lippis notum et tonsoribus esse.

maluit esse deum.

accendis quare cupiam magis illi proximus esse."

capsis quem fama est esse librisque / ambustum propris.

sine nervis altera quidquid/conposui pars esse putat

quod satis esse putat pater et natura coercet.

si puerilius his ratio esse evincet amare

aut quia non sentis, quod clamas, rectius esse,

non horam tecum esse potes.

postquam nihil esse pericli|sensimus.

quae maxima credis|esse mala.

nil ait esse prius, melius nil caelibe vita;

iurat bene solis esse maritis.

infectum volet esse, dolor quod suaserit et inens,

spes iubet esse ratas, ad proelia trudit inertem.

tu quotus esse velis rescribe

sibi milia quinque esse domi chlamydum; .

vir bonus et sapiens dignis ait esse paratus

'durus, ait, 'Voltei, ninis attentusque videris/esse mihi.'

Serm.1.4.42

Serm.1.5.57

Serm.1.5.64

Serm.1.5.67

Serm.1.6.62

Serm.1.6.90

Serm.1.7.3

Serm.1.8.3

Serm.1.9.54

Serm.1.10.63

Sorm.2.1.3

Serm.2.3.178

Serm.2.3.250

Serm.2.7.25

Serm.2.7.112

Serm.2.8.57

Epist.1.1.43

Epist.I.1.88

Epist.1.1.89

Epist.1.2.60

Epist.1.5.17

Epist.1.5.30

Epist.1.0.44

Epist.1.7.22

Epist.1.7.92

Epist.1.16.17 
irlem si tiance furem, neget esse purjicum,

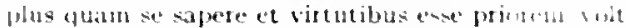

non equidem insector dedendive carmina 1 ivi tente reor.

brevis esu laboro. obscurus fro:

lume ego me, siyuid componere curem, non magis aste velim

non satis est pulchra esse poemata; duleja sunto

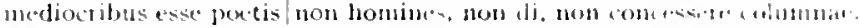

esseda. csicula festimant, pilenta, petonita, noves.

essem. ingertuo si non esiem patre natus:

Vispilits, post hunc larius dixtere quid asemoll.

meque ego essem questus.

ansci colerem. tamen ut placabilis esam.

esses. excupto quod non simul eses. cotera larous.

esset. aridum ieculamoris esinet poculam.

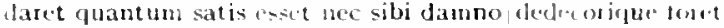

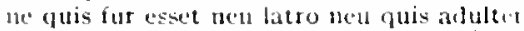

ielcirco quidan comoedia necte pontalesset quatesivent.

-criba yuod esset, inilo deterius fominae ins "use":

invidia aderevil. privato quac minot esset.

"ut esset opem qui ferre poetis|antiquis pusset contrat fatidial noun at,

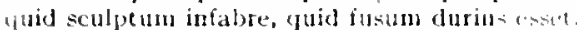

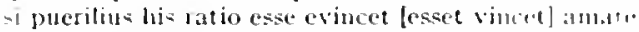

'ilis ester furis, ni sapiens. . tolletet:

tribus ursis quot sut is enset;

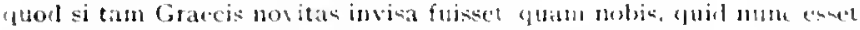
retus?

esset. cum pater ipse domus. . esset atdor blimmenu.

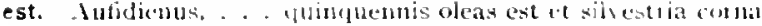

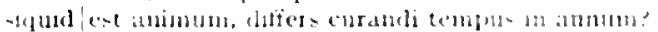

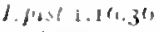

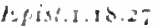

f.pisteg.t.7o

irs Pexel.25

ter Poet.3i

irs fiseticen

lis livet.372

fisist.2.J.102

verm.1.1.21

Trmitid. 55

Term: 1.6.8,

lipist.1.20.25

lipist.1.10.50

tipod.5.3h

sern: 1.2 .52

serm.1.3.10

serm.1.4.4"

serm.s.5.te

serm.1.0.21"

Serm.1.10.*f

term.2.3.22

. ar.sorms... 3.250

icrm.2.8.59

1. pist.1 15.35

\section{Eipist.2.1.y.}

irm.2.(3.si)

Sirn.2.2.2.57

(:.).1.1.2.3i

est. Corm.1.1.10;1.1.27;1.3.37; 1.7.5; 1.15.25;1.17.14;1.24.20; 1.27.2; 1.28.1s; 1.28.35; 1.37.1; Corm.2.2. $2.5 .5 ; 2.7 .28 ; 2.11 .9 ; 2.13 .14 ; 2.10 .25 ; 2.10 .27 ; 2.17 .225 .18 .10 ; 2.10 .9 ;$

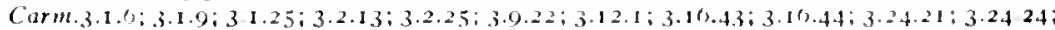
Corm.3.25.15: $3.27 .37 ; 3.20 .5 ; 3.20 .4 \%: 3.20 .57 ; 4.3 .21 ; 4.3 .2 .4: 4.4 .2: 4.4 .30$ (bis):

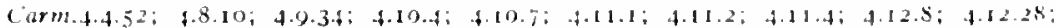

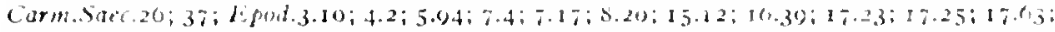
Serm.1.1.7:1.1.11; 1.1.20;1.1.33;1.1.51;1.1.50; 1.1.12; 1.1.95;1.1.105;1.1.1041.1.120; Serm.1.2.3; 1.2.13; 1.2.25; 1.2.28; 1.2.3.4; 4.2.37; 1.2.47; 1.2.5i ini ; 1.2.e.13; 1.2.12;

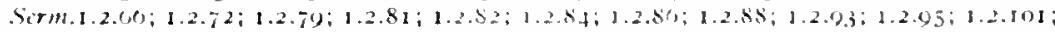
Sorm.1.2.107; 1.2.177; 1.2.122; 1.2.120) 1.2.1.32; 1.2.1.34; 1.3.1; 1.3.24; 1.3.29; 1.3.32:

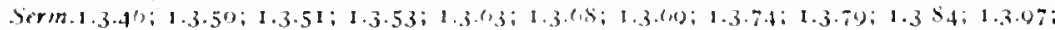
Serm.1.3.111; 1.3.124; 1.3.125; 1.3.1.25; 1.3.1311; 1.3.333; 1.4.22 1.4.54; :.4.55; 1.4.80;

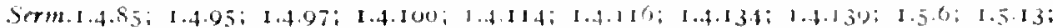

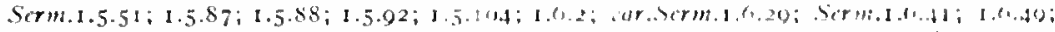

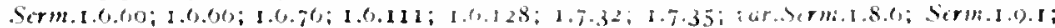

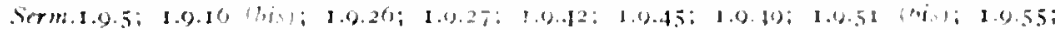
Serm.1.0.71: 1.10*4, coni.Serm.1.10.45; Serm.1.10.2; 1.14.7; 1.10.8; 1.10.6; 1.10.1 I; Serm.1 10.10; 1.10.24; 1.10.93; 1.19.50; 2 1.S; 2.123; 2.1.30; 2.1.45: 2.4.02: 2.1.82;

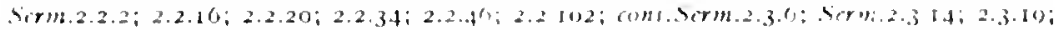

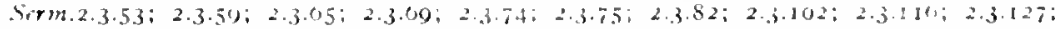

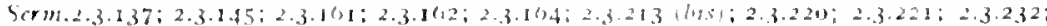

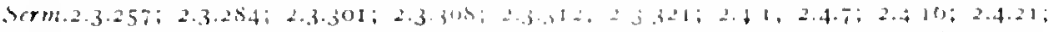

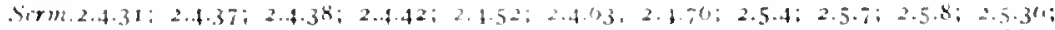

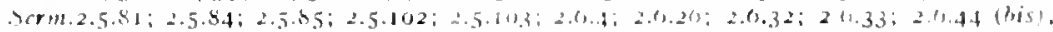

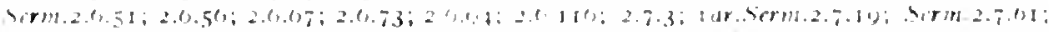

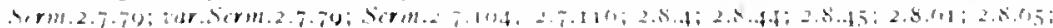

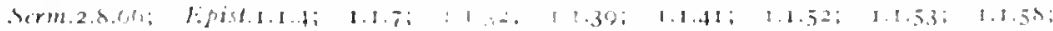

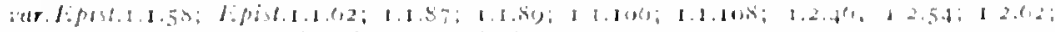

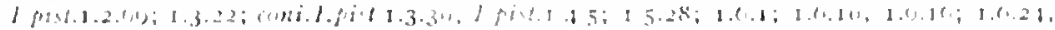

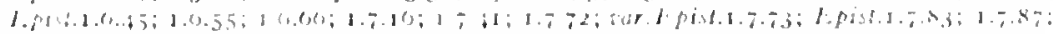

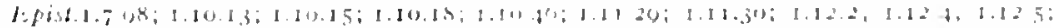

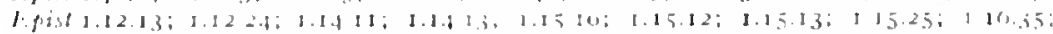

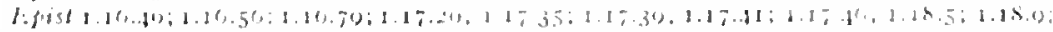

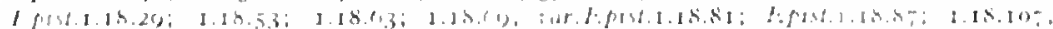

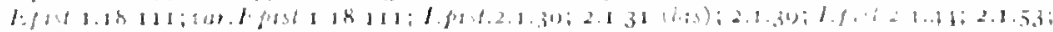

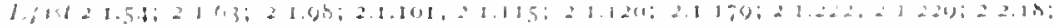

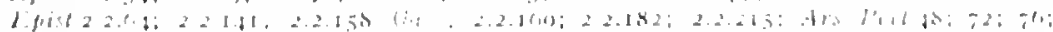

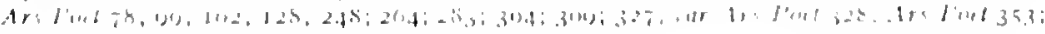

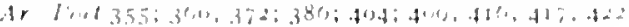


procul onnis esto! clamor et ira.

Carm.3.8.15

inminens villae tua pinus esto,

Carm.3.22.5

esto beata.

"nacte /ritute esto" inquit sententia dia Catonis;

namque esto: populus Laevino mallet honorem /quan Decio mandare novo

'esto, siquis mala; sed bona siquis | iudice condiderit laudatus Caesare?

inparibus formis deceptum te petere esto:

"dum nequid simile huic, esto ut libet."

integer est mentis Damasippi creditor? esto.

is intestabilis et sacer esto."

illius esto / defensor;

tu carminis esto/principium.

hic murus aenelys esto:

esto aliis alios rebus studisçue teneri:

sedit qui timuit, ne non succederet. 'esto.

quidquid praecipies, esto brevis.

id tibi iudicium est [esto\}. ea mens.

esuriens. num esuriens fastidis omnia praeter pavonem rhombumque? positum ante mea quia pullum in parte catini|sustulit esuriens.

neque illinc/audeat esuriens dominus contingere granum

Epod.8.1 I

Serm.1.2.32

Sirm.1.6.10

Serm.2.1.83

Serm.2.2.30

Sirm.2.3.31

Serm.2.3.65

Serm.2.3.Is!

Serm.2.5.29

Serm.2.6.22

Epist.r. 10

Epist.1.1.81

Epist.I.17.37

Ars Poet.335

cont.Ars Pot. 386

Serm.I.2.115

Serm.1.3.93

Serm $2.3 \mathrm{II}_{3}$

et. Carm.1.1.16; 1.1.23;1.2.2; 1.2.9; 1.2.11;1.2.18;1.2.34; 1.2.3.5; 1.2.39;1.3.8; 1.3.9; I.3.19; Carm.1.3.30; 1.4.1; 1.4.17; 1.4.20; 1.5.6; 1.6.1; 1.6.1 I; 1.7.6: 1.7.27; 1.8.I0; I 9.13: Carm.1.IO.3; I.10.5; I.10.15; 1.10.20; I.I I.6; tar Comm.1.12.I5; Camm.1.12.22; 1.12.3 I: Corm.1.12.37; 1.12.41; I.12.42; 1.12.43; I.12.56; I.I3.0; I.I3.I7; I.I.4.5; I.I5.8; I.I5.II; Carm.1.15.I2; 1.I5.I7; I.I5.I8; var.Carm.1.15.24: Cam.1.I6.15; 1.I\%.I8; 1.16.24; Carm.1.17.2; 1.17.6; 1.17.11; 1.17.14; 1.57.18; 1.17.27; 1.18.2; 1.18.15; 1.10.3; 1.10.8; rar.Carm.1.19.11; Carm.1.20.6; I.20.9; 1.21.5; 1.21.14; 1.22.10; 1.23.4; 1.24.6; coni.Carm.1.24.6; Carm.1.25.0; 1.25.13; 1.20.1; 1.27.5; 1.27.8; 1.28.1; 1.28.9; 1.28.16; zar.Carm.1.28.19; Carm.1.28.24; I.29.2; 1.29.12; 1.30.2; I.30.5; 1.30.7; 1.31.13; 1.31.17; Carm.1.32.2; 1.32.3; 1.32.11; 1.32.13; 1.34.1; 1.34.9; " tar.Carm.1.34.0; Carm.I.34.10; Corm.1.34.13; 1.35.10; I.35.I1; I.35.I8; I.35.2I; I.35.25; 1.35.30; I.35.33; I.36.2; 1.37.25; Corm.1.37.26; 2.1.2 (bis); 2.1.4; 2.1.7; 2.1.14; 2.1.23; 2.1.25; 2.2.11; 2.2.15; 2.2.2I; Carm.2.3.13 (bis); 2.3.17;2.3.19;2.3.22;2.3.27;2.4.10;2.4.15;2.4.21;2.5.14; 2.6.1 : 2.0.2: Carm.2.0.7; 2.6.11; 2.6.18; 2.6.21; 2.7.9; 2.7.11; 2.5.10; 2.S.14; 2.0.8; 2.0.I8; 2.0.20; Carm.2.10.10; 2.11.I； 2.II.6; 2.I1.14; 2.12.5; 2.12.15;2.13.1; 2.13.2; 2.13.5; 2.13.6; Carm.2.13.9;2.13.17;2.13.18;2.13.22;2.13.23;2.13.26;2.13.31;2.13.35;2.13.37;2.14.3: Carm.2.14.18; 2.14.2I (bis); 2.14.26; 2.15.5; 2.15.6; 2.I5.II; 2.15.19; 2.I (1.II; 2.16.23: Carm.2.10.20; 2.16.31; 2.10.37; 2.10.39; 2.IS.9; 2.IS.IS; 2.18.24; 2.18.28 (bis); 2.19.3: Carm.2.19.10; 2.19.16; 2.19.25;2.19.31; 2.20.10;2.20.17;2.20.18;2.20.23; 3.1.1; 3.1.15; Carm.3.1.37:? Carm.3.1.39; Carm.3.1.45; 3.2.3; 3.2.5:3.2.8; 3.2.13; 3.2.23; 3.3.1; 3.3.9: Carm.3.3.20;3.3.24; 3.3.30; 3.3.3I; 3.3.35; 3.3.1 I; 3.3.49; 3.3.6.4; 3.3.7 I; 3.4. I; 3.4.6; Carm.3.4.15;3.4.18;3.4.25;3.4.31; 3.4.34; 3.4.30;3.4.4\%; 3.4.53; 3.4.50; 3.4. $4 ; 3.5 .0$ : Carm.3.5.9; 3.5.12; 3.5.15; 3.5.19; 3.5.23; 3.5.3.4; 3.5.43; 3.5.52; 3.6.3; 3.6.0; 3.6.II; Carm.3.6.14;3.6.22;3.6.23;3.0.35;3.6.39;3.0.42;3.7.10;3.7.19;3.7.31;3.8.2; 3.8.6; 3.8. I.t; Carm.3.8.10; 3.8.26; var.Carm-3.8.27; Carm.3.9.10; 39.22; 3 107: ? 7ar.Carm.3.10.1.7: Carm.3.II.II; 3.II.I4: 3.II.20; 3.II.35; 3.II.39; 3.II..10; 3.II.5O; 3.II.5I: 3.I2.II;

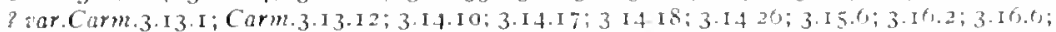
Carm.3.10.7; 3.16.10; 3.10.14:3.10.23; 3.16.30; 3.17.7; 3.17.10; 3.17.1.5:3.18.2; 3.10.3; Carm.3.19.4; 3.19.7; 3.19.24:3.20.13; 3.21.3; 3.21.I5; 3.2I.I8; 3.2I.2I; 3.3.3.3; 3.23.I0; Carm.3.23.20; 3.24.2; 3.24 4; 3.24.11; 3.24.13; 3.24.22; 3.24.24; 3.24.26; 3.24.41; Carm.3.24.48 (? bis); 3.24.52; 3.24.60; rar.Carm.3.25.2; Carm.3.25.0; 3.25.10; 3.25.13; Carm.3.20.2; 3.26.7 (bis); 3.26.9; 3.27.2; 3.27.14; 3.27.10; 3.27.22; 3.27.23; 327.26 ; Carm.3.27.29;3.27.32; 3.27.45;3.27.61;3.27.67; 4 r.Carm.3 28.3; Carm.3.28. In; 3.28.12; Carm.3.28.14; 3.29.3; 3.29.6; 3.29.7; 3.29.9:3.20.12:3.20.15; 3.29.I9: 3.20.22: 3.20.21;

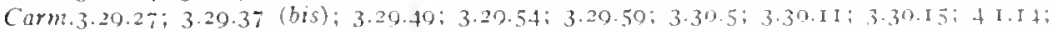

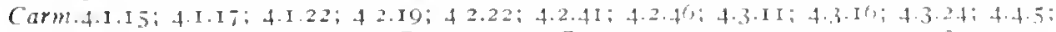

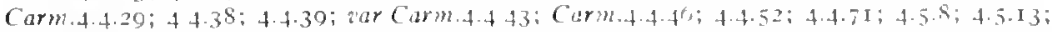
Carm.4.5.22; 4.5.30; 4.5.31; 4.5.34:4.5.36; 4.0.3; 4.1.15:4.6.34; 4.7.3; 4.7.7; 4.7.11: Carm.4.7.10; $4.7 .21 ; 45.12 ; 4.8 .14 ; 4.8 .26$ (bis); 49.7; 4.0.1.4; 4.9.10;40.35; 40.37 ; Carm.t10.1; 4.10.3; 4.10.4; 4.1 1.9; 4.1 I.23; 4.1 1.26; 4.1 1.20; 4.12.0; 4 I2.1 I; +12.25; Carm.1.13.2; 4.13.4; 4.13.5; 4.13.6; 4.13.10; 4.13.12; 4.13.21; tar Carm.4.14.5:

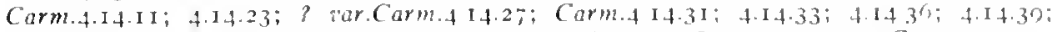
Corm.1.42: 4.14.46; 4.15.2: 4.15.5: 4.15.6: 4.158; 4.15.9: itr.Carm.4.15.10:

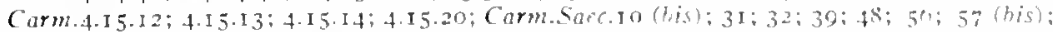

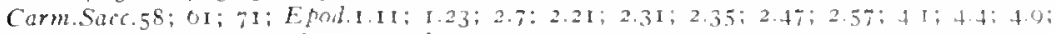
Epod.4. I : 5.2; zar.Epod.5.3: Epot.5.10; 5.19:5.23:5.37:5.43: 5.44; 5.51; $5.95 ; 5.07$; Epod.5.100;6.4; 7.15; $5.3 ; 8.7 ; 8.9 ; 9.13$ (bis); 9.22; 9.34; 10.17; 10.2.1; 11.21; 11.22; 
Epod.12.7: 13.1; 13.5; 138; 139; 13.14; 15.1; 15.7; I5.14; 15.17; 15.19; I6.11:

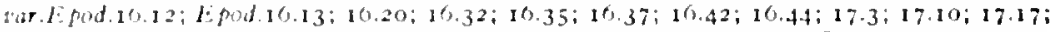
Jipod.17.20; 17.21; 17.25; 17.30; 17.45; 17.49; 17.50; 17.58; 17.77; Serm.1.1.37; 1.1.41; ferm.1.1.53; I.1.71; 1.1.93; 1.1.1 18; 1.2.54; 1.2.99; 1.2.197; 1.2.108; 1.2.1 13; 1.2.120; Sirm.1.2.1.32; $1.3 .13 ; 1.3 .14 ; 1.3 .20 ; 1.3 .24 ; 1.3 .31 ; 1.3 .11 ; 1.3 .45 ; 1.3 .50 ; 1.3 .63 ; 1.3 .86 ;$ Serm 1.3.08; 1.3.100; 1.3.101; $1.3 .105 ; 1.3 .117 ; 1.3 .122 ; 1.3 .125(\mathrm{tcr}): 1.3 .130 ; 1.3 .139 ;$ herm.1 .+ $18 ; 1.422 ; 1.4 .30 ; 1.458 ; 1.4 .60 ; 1.4 .68 ; 1.770 ; 1.04 .90 ; 1.4 .03 ; 1.4 .98 ; 1.4 .121 ;$ Arm. I.4.124; 1.4.130; 1.5.10; 1.5.30; 1.5.40; 1.5.43:1.5.410; 1.5.40; 1.5.53; 1.5.57: 1.5.78; Serm.1.5.95; 1.6.16; 1.0.17; 1.1.28; 1.0.20; I.1.31; 1.0.35; 1.0.37; 1.0.42; 1.6.61; I.0.04;

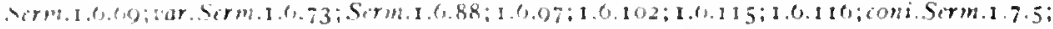
sorm.1.7.10; 1.7.30; 1.8.3; 1.830; 1.8.39; 1.8.41; 1.8.43; 1.8.4.7 1.8.45; 1.9.5; 1.9.19;

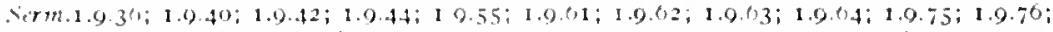

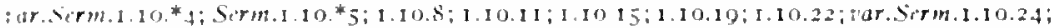
iar.serm.1.10.50; Sirm.1.10.58; 1.10.05; 1.10.013; 1.1070; 1.10.81; 1.10.82; 1.10.83;

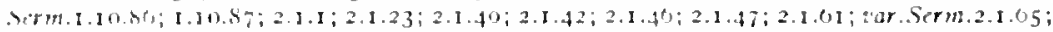
Serm.2.1.71; 2.1.72; 2.1.73; 2.1.77; 2.2.1; 2.2.5; 2.2.10;2.2.26; 2.2.57; 2.2.58; 2.2.63;

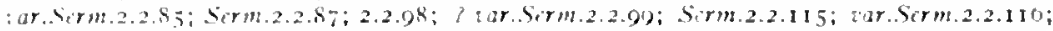
Serm 2.2.1 22; $2.3 .9 ; 2.3 .27 ; 2.3 .30 ; 2.3 .38 ; 2.34 .3 ; 2.3 .44 ; 2.3 .50$ (his); $2.3 .73 ; 2.3 .92 ;$ Sorm.2.3.07; 2.3.98: 2.3.106: 2.3.107; 2.3.1.42; 2.3.1.40; 2.3.150;2.3.165; 2.3.170; 2.3.172; Sirm.2.3 I $78 ; 2.3 .151 ; 2.3 .183 ; 2.3 .188 ; 2.3 .102 ; 2.3 .108 ; 2.3 .203 ; 2.3 .213 ; 7$ ar..5irm.2.3.216; Serm.2.3.21s; 2.3.22.4; :ar.jerm.2.3.227; Sirm.2.3.232: 2.3.2.41; 2.3.261; $2.3 .260 ; 2.3 .279$; sirm.2.3.282;2.3.300;2.3.311;2.3.313;2.4.1; 2.4.13;2.4.28;2.4.29;2.4.38; $2.4 .40 ; 2.4 .12 ;$ Sirm.2.4 $45 ; 2.4 .53 ; 2.4 .55 ; 2.4 .60 ; 2.4 .73 ; 2.484 ; 2.5 .13 ; 2.5 .21 ; 2.5 .23 ; 2.5 .24 ; 2.5 .44$; Serm.2.5.52; 2.5.08; 2.5.90; :ar.serm.2.5.07; Serm.2.5.100; 2.5.103; 2.0.2; 2.6.3; 2.1).14;

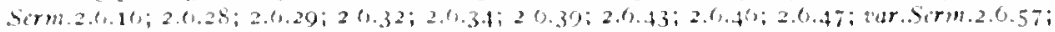

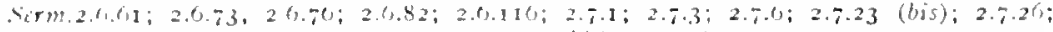
Far.serm.2.7.3.4; Som.2.7.30; 2.7.40; 2.7.1. (bis); 2.7.86; 2.7.93; 2.7.100; 2.7.101; Scrm.2.7113; 2.8.11; 2.8.20 (bis); $2.835 ; 2.8 .77 ; 2.8 .80 ; 2.8 .12 ;$ Epist.1.1.2; 1.1.9;

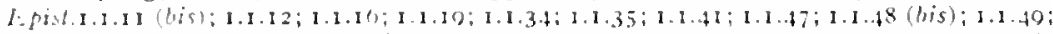

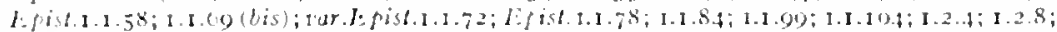
1. pist.1.2.12; 1.2.15; 1.2.10; 1.2.17;1.2.20; 1.2.2.3; 1.2.25; 1.2.27; 1.2.30; 1.2.34; 1.2.30; E.pist.1.2.43; 1.2.45; 1.2.47 (bis); 1.2.51; 1.2.60; 1.3.8; 1.3.11; 1.3.1.4; 1.3.10; 1.322;

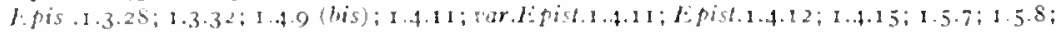

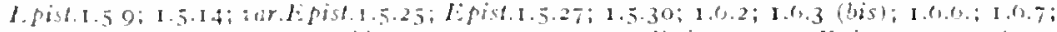

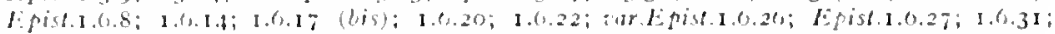
Epist.1.1.3\%; 1.6.37 (his); 1.6.47: 1.6.40; 1.6.51; 1.7.7; 1.7.8; 1.7.9; 1.7.11; 1.7.13; Jpit.1.7.20 (bis); 1.7.21; 1.7.22; 1.7.27; 1.7.40; 1.7.53i 1.7.55: sar.Lpist.1.7.55: f.pist.1.7.58; 1.7.50 (bis); 1.7.03; 1.7.66; 1.7.67; 1.7.75; 1.7.79; 1.7.8.4; 1.7.8.5; 1.7.95; 1.pist.1.5.1; 1.8.3;1.8.13:1.9.2; 1.9.3; 1.9.13:1.10.7:1.30.8:1.10.25:1.10.33; 1.11.3:1.11.1:

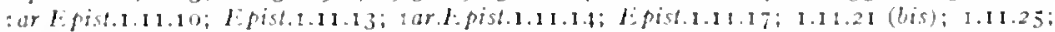
1.pist.1.12.8; 1.12.1.4; 1.12.15; 1.12.17; 1.12.10; 1.12.21;1.12.22;1.12.23; 1.13.9; 1.1.1.1;

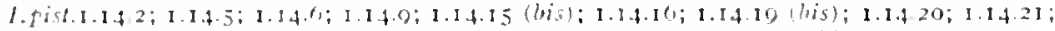

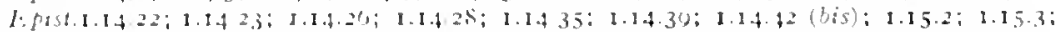

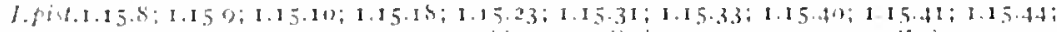

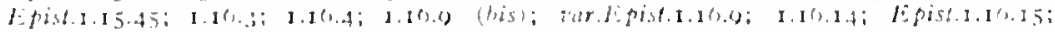

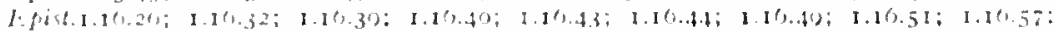

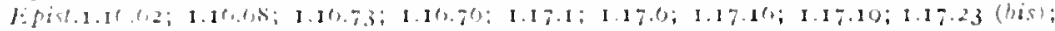

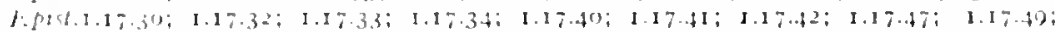

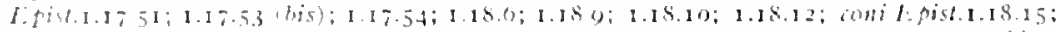

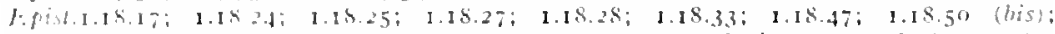

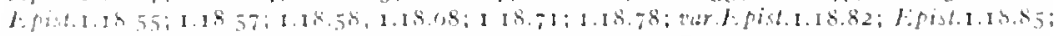

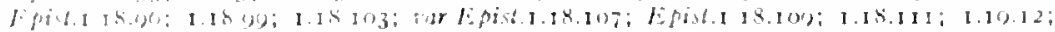

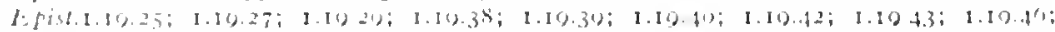

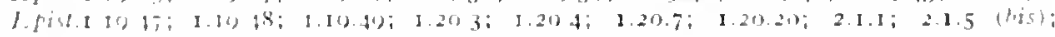

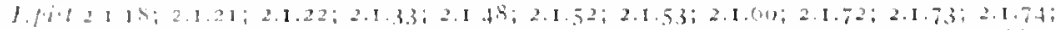

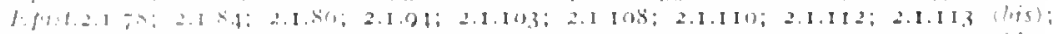

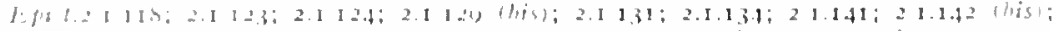

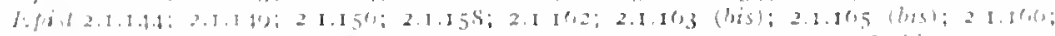

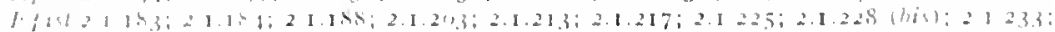

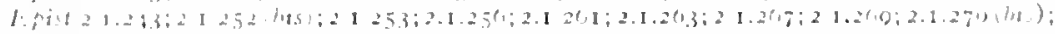

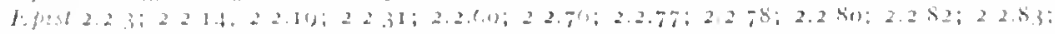

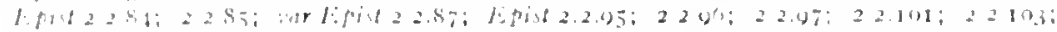

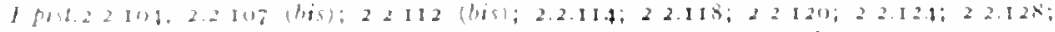

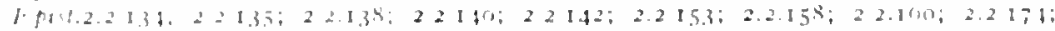

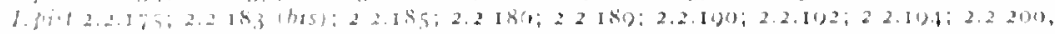

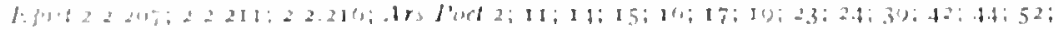

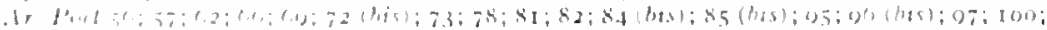

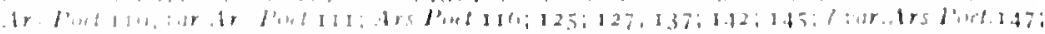

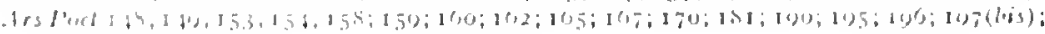


Ars Poct.199; 200; 204; 207; 208; 214; 217; 218; 221;223; 224 (bis); 228; 230; 234; 237 ; Ars Poct.248 (bis); 249;257; 264; 266;272; 274; 276;282;287;291;293; 296;306;312; Ars Poet.313; $318 ; 320 ; 330 ; 332 ; 348 ; 355 ; 358 ; 362 ; 368 ; 360 ; 375$ (bis); $383 ; 388$ (bis); Ars Poct.392; 395; 400; 40.4 (bis); 406; 407; 411;413;414;418;423 (bis); 432; 435; 439; Ars Poit.447; $44 ; 445 ; 454 ; 457 ; 461 ; 469$

et. Carm.1.12.1 I; 1.20.14; var.Carm.1.31.10; Carm.1.37.8; 3.4.70; 3.24.48; 3.27.5; 4.7.15; Corm.Saec.3; Epod.1.1 $2 ; 2.20 ; 3.22 ; 10.18 ; 11.8 ; 10.2 ; 16.40 ; 17.2 ;$ Serm.1.4.51; 1.5.58; Serm.1.5.86; I.6.70; 1.6.10I; I.10.71; 2.1.6.4; 2.3.23I; 2.3.244; 2.4.74; $2.6 .85 ; 2.8 .88$; Epist.1.1 .0; 1.15.35; 2.1.46; var.Epist.2.1.46;2.2.33; 2.2.167; Ars Poet.157; 394

et. Carm.1.1.2 (bis); 1.7.13 (bis); 1.9.18 (bis); 1.14.13 (bis); 1.23.8 (bis); 1.32.9 (bis); 1.30.1 (bis); Carm.2.3.15 (bis); 3.4.8 (bis); 3.4.4 I (bis); 3.5.10 (bis); 3.6.18 (bis); 3.11.5; 3.11.6; Carm.3.13.5 (bis); 3.14.7 (bis); 3.17.2;3.17.3; 3.24.43 (bis); 4.1.13 (bis); 4.4.74; 4.4.75; var.Carm.4.5.7; Carm.4.15.25 (bis); 4.15.31 (bis); Carn.Saec.75 (bis); Epod.11.9; I1.10; Serm.1.3.54 (bis); 1.4.38 (bis); 1.0.1 I (bis); 1.6.93 (bis); 1.7.3 (bis); 2ar.Serm.1.10.*5; Scrm.2.1.16 (bis); 2.5.8 (bis); 2.5.48; 2.5.49; 2.8.91 (bis);Epist.1.1.10 (bis); 1.1.6.4 (bis); Epist.1.5.2 I (bis); 1.5 .23 (bis); I.6.34; 1.6.35; 1.6 .42 (bis); 1.6.45; 1.6.40 (bis); Epist.1.7.57 (qualer); 1.10 .16 (bis); 1.16.28 (bis); 1.18 .22 (bis); 1.18.38 (bis); 2.1 .42 (bis); Epist.2.1.50 (ter); 2.1.68 (ter); 2.1 .137 (bis); 2.2.3; 2.2.4; 2.2.25 (bis); 2.2.5 (bis): Ars Poat.32; 33; 258; 259; 270 (bis); 279; 280; 309 (bis); 334 (bis); \}arar.Ars Poet.334; Ars Pot. $345 ; 346 ; 306 ; 307$

et. Carm.1.4.11; 1.9.2I: I.10.13; I.12.25; 1.28.7;1.28.31;2.10.17;2.13.37;2.19.13; 3.2.14;3.2.25; Carm.3.I1.21; 3.14.2I; 3.15.8; 3.2I.II; 3.27.25; var.Carm.4.4.18; var.Epod.5.11; Epod.16.45; Serm.1.3.28; Far.Serm.1.4.69; 1.4.116; Serm.1.4.1.31; iar.Serm.1.6.6; Serm.1.0.25; 1.10.6; 1.10.25; 1.10.56; zar.Serm.2.1.68; Serm.2.3.32; 2.3.117; 2.3.150; Serm.2.3.222; 2.3.322; 2.4.10; var.Serm.2.5.87; Epist.1.5.28; 1.10.4; iar.Epist.1.10.42; Epist.1.17.5; car. Epist.2.1.27; Epist.2.1.214; Ars Poet.49; ?'ar.Ars Poet.61; Ars Poet.93; var.Ars Poit $\$ 16$

etenim. tutus bes etenim rura perambulat.

nulla etenim mihi te fors obtulit;

(hoc etenim sunt omnes iure molesti|quo fortes,

dis etenim facile est.

divinare etenim magnus mihi donat Apollo.'

"etenim fateor me" dixerit ille!"duci ventre leven,

etiam. quae manent culpas etiam sub Orco. ureret flammis, etian latertem/matris in alvo.

quin etiam illud | accidit ut cuidan tectis caudamque salacen demeterent ferro.

atque etian melius persaepe togatac (est)

natura aut etian consuetudo mala:

turpia decipiunt caecum ritia aut etiam ipsa haecldelectant.

invenias etiam disiecti memhra poctat.

etiam litis cum Rege molestas.

'etiam et rex|et quidquid volet."

filius aut etiam haec libertus ut ebibat beres,

'stultum me fateor . . atque etiam insanum;

ultra|"non" "etian" sileas:

debes hoc etiam reseribere.

dignum praestabo me etiam pro laude nerentis.

mane cliens et iam [etian] certus conviva,

fons etiam rivo dare nomen idoneus. .

qualem commendes, etiam atque etian aspice. .

'sit mihi, quod nunc est, etiam minus.

demo unum, deno etiam unum,

mox etian pectus praeceptis format amicis.

quin etian lex / poenaque lata.

saepe etian audacen fugat hoc terretque poetam.

quin ctiam canet indoctum, sed clulee bibenti.

quereris super hoc etian,

mox etiam, si forte vacas, sequere et proeul audi.

fortasse trecentis|aut etiam supra numnonn milibus cmptum.

in verbis etiam tenuis cautusque serendis

post etiam inclusa est voti sententia compos;

(sic etiam fidibus voces crevere severis)

mox etiam agrestis Satyros nudavit

unde etiam trimetris accrescere iussit | nonen ianther.

etiam stillahit amicis $\mid \mathrm{ex}$ oeulis rorem.

Etrusca. minacis aut Etrusca Porsenae manus.

Etrusca. Etrusca praeter et volate litora.

Etrusci. Etrusci quale fuit Cassi rapido ferventius anui|ingenium,
Carm.4.5.17

Serm.1.6.54

Serm.1.7.10

Serm.2.3.28.4

Serm.2.5.60

Serm.2.7.37

Carm.3.11.29

Carm.4.6.19

Serm.1.2.44

Sirm.1.2.82

Serm.1.3.30

Serm.1.3.39

Sirm.1.4.62

Serm.1.7.5

Serm.2.3.97

Serm.2.3.122

Serm.2.3.306

Serm.2.5.9I

Epist.1.3.30

Epist.1.7.24

t'ar.Epist.1.7.75

Epist.r.I0.12

Epist.1.18.76

Epist.1.18.107

Epist.2.1.46

lipist.2.1.I 28

Epist.2.1.152

Epist.2.1.182

Epist.2.2.9

Epist.2.2.24

Epist.2.2.95

Epist.2.2.105

Ars Poet.46

Ars Poet.7o

Ars Poet.210

Ars Poet.22I

Ars Poet.252

Ars Poel. 429

Epod.1 6.4

Epod.16.40

Sirm. I. I0.6I 
Etrusco. retortis/litore Etrusco violenter undis

Etruscos. Lydorum quidquid Etruscos|incoluit tinis.

Carm.1.2.1.

Sirm.1.6.1

Cirm.3.29.35

Etruscum. cum pace delabentis Etruscum in mare.

J liaeque litus Etruscum tenuere turmar.

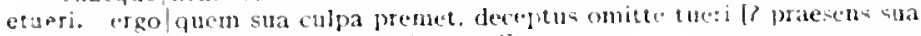
culpa ire deceptus omittit etueri].

eu. au! ren poteris s.rvare tuam.

Euandri. conminvit lectum potus mensave catullum Enandi nanibus tritum deiceit

euhantes. condita post frumenta levantes [enhantes] tempore festo corpus

Euhias. non secus in iugis/Edonis stupet tuhias

Euhius. monet Sithonis non levis Euhius.

lissipat Euhius!curas edacis.

eukoe. iuloe, recenti mens trepidat metu.

"uboe, parce l, iber.

eun. siguis eun servoli, . . . in eruce sulfigat.

- Irgente a sole ad eum. quo vespertina tepet rogio

- 4 tet quavis aspergere cunctos' prater eum qui prabet aquan;

. in tu reris eum ocisa insanisip parente

is nizque quod non providisect enm.

Eumenidum. intorti capillis/Eumenidum recreantur angues?

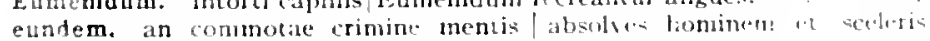
dammabis eundem

hortari coepit cundem/verbis.

eunt. non, si treceniz quotquot eunt dies. . . taturis.

euntem. illum practeritum temnens extremos inter runtem: -

euntes. singula de nobis anni praclantur euntes:

eunis. versiculo natura magis factos et cuntis mollus

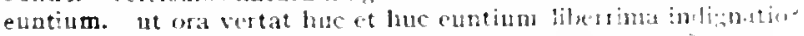

Eupolin. Eupolin. Arbilochum, consites educrice tantus?

Eupolis. Eupolis atrue Ciatinus Aristophanespue putave

Euso. aridas fromes hiemis sodalifaded furo.

Euro, orior (revis et agente nimbos/neior liuro.

iemissa tempestas ab Ëuro

. ut inpulsa cupressus Euro.

Europe. linroge niveum doloso exclidit tauro butus

Europe. "vilis Europe" patri urget absens:

Ev:co en. qua medius liquos | secernit Eurojen al, Atro.

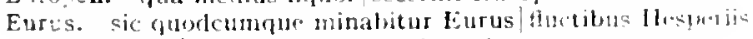

vel Eurus/per Siculas equitavit undas

atiger rudentis Eurus inverso mari

:t neque largis aquosus Eurus arva rablt imbribus.

Eutcipe. si neofle tibia liuterpe cohbibet

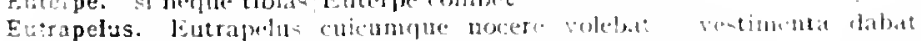
pretiosa:

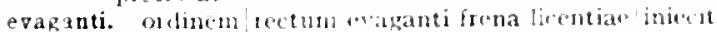

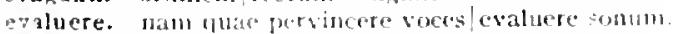

evasti. r.acti: molo. motues loctusque cavbin

evehit. terramindominos redist ad deos hum.

eqellas. spinat animone rge foltius an tul cvellits :iseto.

evellere. hacres/nequiquan caeno cupiens evellere phontinn

eqenit. merstes proundo. puldorior evenit;

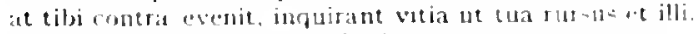

coeatum. semjur aul eventum fertinat

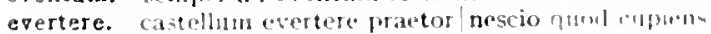

evincet. platimustjue cacolobe evincet ulmos:

-1 ple rilins hiv ratio esse revincet andre

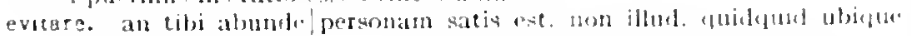
nfticit, revitare?

evitata. motarue fervidis evitata rotis palnutum molviliu

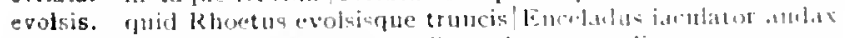

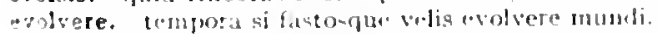

Corm.tive. $3 x$

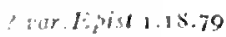

ars lact 328

Serm.t.3.91

coni.l.pist.2.1.140

(arm.3.25.9

(iorm.1.18.9

(arm.2.1 I.

Corm.2.10) 5

(urm.2.10.7

Sermi.3.3.8n

Sirm.1.1.20)

Sirmitidiss

Serm.2.3.1.54

lipist.t.7.9

(irm.2.13.3"

Sirm.2.3.270

Fopist.2.2.35

Curme145

Sorme1.1.1\%

Jipist.2.2.5.

Serm.1.10 58

lipod a. ?

STm.2.3.

sermet.1

curm 1.25.2)

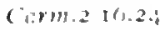

carm 3.17.11

(carm fecto)

c isrin.3.27.25

( urm.joz-5;

Cirm.3.3...t5

(urm.1.28.25

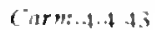

lopolio.s

EProl [r.s)

(iorn 1.1.3:

f.pist.1.1S.31

(arm t I 5 . I0

tipist 2.1 .201

verme 7 ess

cirmblato

E.pist I. I 1 S

ferm.2.7.27

(arm.1.1.15

cerm 1.3 .28

Ars Put.tish

E.pict 2.2.3.4

iirm.2.15.5

srm. 2.3.2511

Sirm.l 2,1

ciurm.t.r.s

cirmatis

sermatilat

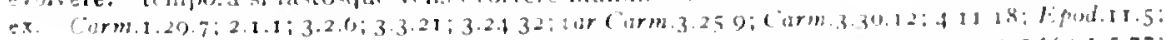

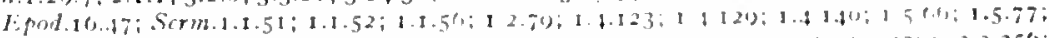

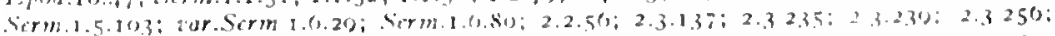

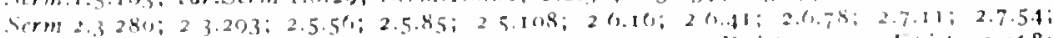

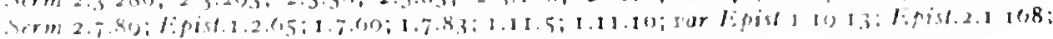

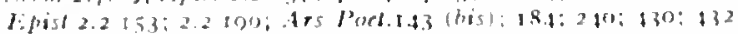

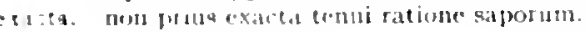




\section{EXACTIS}

exactis. emendata videri|pulchraque et exactis minimum distantia mior. exacto. exacto contentus tempore vita

exactos. pugnas et exactos tyrannos/densum uneris bibit aute voligus. quam per exactos ego laetus annos

exacuit. post hos insignis Homerus . . versibus exacuit;

exagitant. "at omnes di exagitent [exagitant] me. | si quiçuam."

exagitas. cur [? quid] me querclis exaninas [? Pxagitas] tuis?

exagitent. "at omnes di exagitent me.!si quicquam."

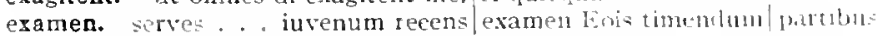
positosque vernas, ditis examen domus.

qui sibi fidet, dux reget examen.

examinat. male verum examinat ommis/com uptus iudex.

exanimari. exanimari metuentis patruac verbera linguzt.

exanimas. cur me querelis exaninas tuis?

exanimat. avidos vicinum funus ut aegros/exanimat

cxanimat lentus spectator, sedulus inflat:

exanimem. an vigilare metu exanimem.

exanimes. magisutuelexanimes trepidare,

exaret. rugis vetis frontem senectus exaret

exaudita. fingere cinetutis non exaudita Cethegis/continget

exauditus. ridtbit monitor non exauditus,

excantata. quae sidera xcantata voce Thessala

excepit. non ferox/lfector vel acer Deiphobus gravis! excepit ictus: . prinus.

cum lectulus aut mel porticus excepit.

egressum magna me accepit [excepit] Aricia Roma|lospitio modico. quaecumque excepit turgentis verbera caudae / clunibus.

excepta. des mummos, excepta nihil te si fuga laedat:

excepto. stellasque salubris/appellat comites excepto Rege:

haec populos, haec magnos formula reges, / excepto sapiente tenet.

excepto. excepto quod non simul esses. cetera laetils.

exceptum. in mala derisum semel exceptumque sinistre

excerpam. ego me illorum. dederim quibus es-e poetis, /xcerpan numero:

excerpens. quirl? cum Picenis excerpens semina pomis

excidere. altum Saganac caliendrum / excidere

excidi. denique, quatenus excidi penitus vitinn irap.

excidit. nec vera virtus, cum semul exeidit.

in vitum libertas excirlit et rim

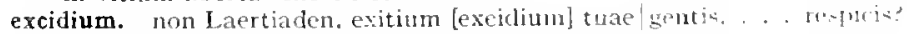

excipere. ceier arto latitantem fruticeto excipere aprum

exciperet. mentem, nisi litigiosus. lexciperet dominnc, cun venderet.

excipient. cxcipiantque senes, quos in vivaria mittant:

excipiebat. mulla.. porticus excipiebat aretun

excipit. egresian magna ne accepit [excipit] Aricia Roma Muspino muliou.

excisus. tet pereat nucis excisus Argivis,

excitare. possin crematos excitare mortuos

exeitat. hunc nodicus multum celer atque fuldis excitat

pulveris atril quantum non Aquilo Campanis excitat agris.

excitatur. neque excitatur classico miles truci

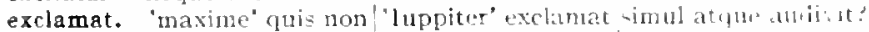

Persill exclamat: "per magnos, Brute, deos te: oro.

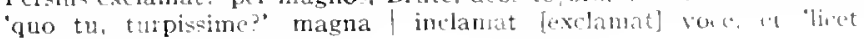
antestari?"

excludat. excludat inrgia finis.

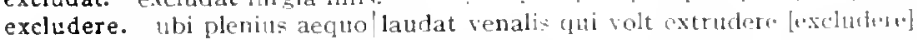
merces:

excludet. spissa ramis laurea fervidos'exelul ictus.

excludit. excludit sanos Helicone poetas|Democritus.

exclusit. exclusit; revocat: redeam? non, si obsecret."

exclusus. exclusus fore, eum Longarenus foret intur.

non, hodie silexclusus fucro, desistan;

antator|exclusus qui distat,

excors. an magis excors/reiecta praeda,

sub domina meretrice fuisset turpis et extor

excubat. pulcris exeubat in genis.

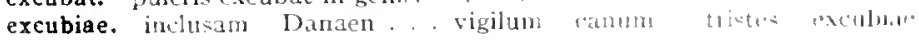
munierant

excusare. excusare laboren et mercennaria vincli.

excusatus. nulta quirlen dixi. cur excusatus abirem.
EXCVSATVS

lisist.ing. $7^{2}$

Sirm.1.I.IS

earm.2. 3.3 .31

(arm.3220

los Pots.

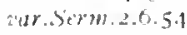

iar.carm.2.17.

Sermi.2.6.5t

Carm. 1.35.31

Epod.2.0.5

Epist.r.10.23

Sorm.2 2.3

Corm.3.12.2

(arm.2.17.1

Serm.1.127

LAive.1.178

Serm.1 1 5

Sirm.s.t. I1

Epolst

Ars lite $\%$

IEpist.1.20.1 1

litod. 5.15

Cirmit, 23

Sernt.1.1.31

Fir.sithit.5.t

Sorra.2.7. 49

Eppis!.2.2.10

Serm.1.7.25

sirm.2.3.4"

Epist.1.10 50

Ars Pot.452

Sirm.1.4. 40

imm.2.3.272

Sirme1.8.40

sem.1.3.70

(arm.3.5.20

Ars Porf.282

inr Cirm.1.15.2I

carm.3.12.12

(rin 3280

I.nial. I. T.70)

Cirm 2.15 10

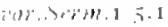

citaliz.3.3.4.

Epest.17.-1)

Term.2.3. $\$ 8$

Serm.zists

fipot.2.5

5.4.1.2.15

rim.1.7.3.i

[ur.senth.t.g

tapist : : 1 .35

भin. 1.5ist.2.2.1

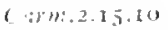

tis l'ot:.20fo

Sirm.2.3.201

Germ.1.2.1.5

Sirm 1.0 .58

Serint.2.3.2(10)

s.m.2.3. 37

Fipit.1 3.25

(ior)t.1.3.

cismm.3.16.,

Epist.1.7.87

l.pilan? 
excussit. Cum subito ingens| valvarum strepitus locis excussit utrumutue". excussus. aliena megotia curo|exeussus propriis.

excutial. dumnodo risum lexcutiat sibi non, non euiquan parcet anico excutitur. si Hava excutitur Chlos

ereat. (fuamois furiale centum | muniant angues caput eius atgut [exentque]| spiritus taetor saniesque manet /ore trilingui;

execta. "xsuctal [execta] uti medulla et aridum iecur/amorisesset poculum,

exegi. exegi monumentum aere perennius

exemplar. Iecipil exemplar vitiis imitabile:

exemplar. utile proposuit nobis exemplar Vlixen. Plautur ad t'xemplar Siculi properare Epicharmi. respicente vemplar vitae morumque

eremplaria. vos exemplaria Graeca| nocturna versate manu. versate durna.

exempli. Rigulil lissentientis condicionibus fordis et exemplo [exempli] trahentis/perniciem

eremplis. It rugerem exemplis vitiorum quaterue notando. orientia trmpota notis instruit exemplis, inopen solatur et acgrusu.

eremplo. ex"mplo trahentis/perniciem veniens in acvom. parvola. nan exemplo est, magni formica laboris

exemplo. hic mefue servis thluci senis exemplo, lum munia diclit, saevo erit.

eremplum. nil agit exemplum, litem quod lite resolvit.

exemplum. iximplum grave praebet ales/Pegilsus

exempta. quid te exempla iuvat spinis de pluribus una:

exerceat. quam scit uterque, libens, comsebo, exerceat artem.

exercet. indomitas proje qualis undaspexeret Auster paterna tura bubus exercet suis stronua now exescet inertia:

exercitatas. extercitatas aut petit Syrtis noto

exercitus. injrimeretque muris/hostile arattum exereitus insolens. pattitur lintres exercitus.

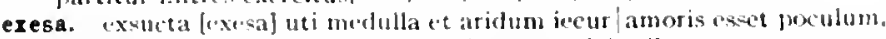

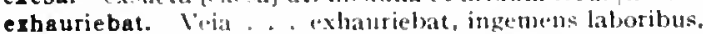

exhortatus. "jui multum pherum lonis ot funibus ussit exoratus [exhen tatus].*

exierit. illam "post paulo" 'sced pluris' 'si cxierit vir'jGallis.

eriget. hic dies vere mili fescus atrastexiget curas: nen futor civilis aut vis exiget otium,

exigit. hie dies vete mibi featus atras/exiget [exigit] curas: custole retum (acsare nou furor/civilis aut vis exiget lexight otiun.

erigitur. dum ates exigitur, dum mula ligatur, tota abit hora.

exiguae. kiquis. . pede nurlo exiguaeque togae simulet textote ("atomem. exigui. pulveris exigui prop* hatum parva Matinum|munera

exigui. corporio cxigui, prateanum, solibus aptum, . . essem.

exiguis. adiecisue pracdam|torguilus exiguis tenidet.

exiguis. exiguis erptutare campis.

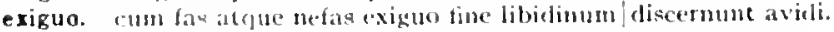

exiguo. rxiguo gaturfue fluarin tempore raptim.

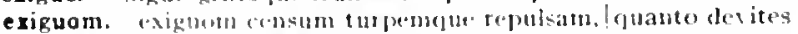

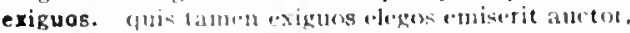

exile. formur tumentibus exile surse atditum,

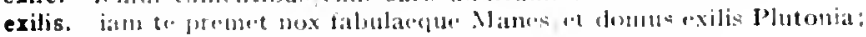
cxilis doumbs a.et, ubi non tet multal supersunt

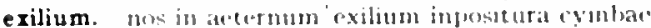

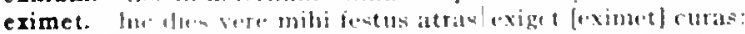

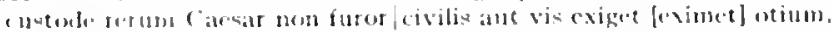

eximit. fhriatun... numero beatorumleximit Vistus sollicitis anmas emuse eximite aldocet artis.

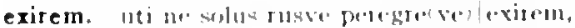

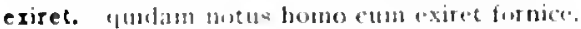

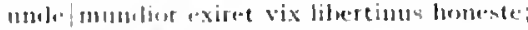

exit. mala solusten navis exit alite

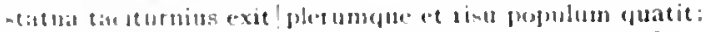

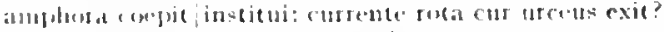

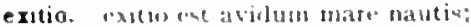

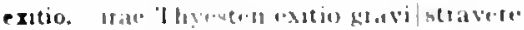

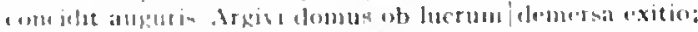

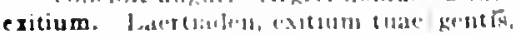

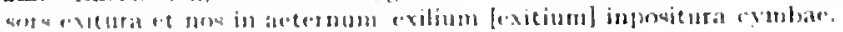

Strm.2.6.1 I 2

Serm.2.3.20

verm.1.4.35

Carm.3.9.19

coni.Carm.3.11.18

ar.t.pod.5.37

Carm.3.30.1

Etpist.1.19.17

Epist.1.2.18

Epist.2.1.58

Ars Poct.317

- Irs Poct.208

coni.Carm.3.5.15

Serm.1.4.100

Epist.2.1.131

Carm.3.5.15

Sermr.1.1.33

Serm.2.2.07

Sirm.2.3.103

Carm.4.11.26

Epist.2.2.212

Epist.1.14.44

Carm.4.14.21

Epod.2.3

Epist.1.11.28

Epod.9.31

Carm.1.16.21

l.pist.1.18.61

comi.tepod.5.37

lipod 5.3!

:ar.Serm.1.10.*i,

Serm.1.2.120

Corm.3.J.14

Carm.t.15.18

Iar.Corm.3.1.1.14

sar.Carm.4.15.18

Serm. J.5.13

Lepist.1.19.13

Corm.t.28.3

Epist.1.20 24

(itrme.3.6.12

Carm.2.9.24

(armit.18.10

Fist.2.2.198

Lpist.1.2.13

As Put.77

Food.10

(arm:1.4.17

List.1.0.45

(arm.2.3.2

Sur.Carm.3.14.14

ine. (orm.d.15.18

Curm.2.2.19

Hist.1.5.18

Cermb1.1.103

Sermi.1.2.31

Sirm 2.7 .12

Eipod. 10.1

I.pist. 2.2.83

drs Podt.2?

Carm.1.28.18

(orm.t 10.17

farm.3.10.13

("irm.1.15.21

Ear Curm.2.3.28 


\section{EXITIVM}

Thracis et exitium Lycurgi.

exitum. tectaque Penthei|disiecta non leni ruina/Thracis t exitim [exitum] Lycurgi.

hinc omne principium, huc refer exitum:

prudens futuri temporis exitum / caliginosa nocte premit rions plorem artis in te nil agentis exitus [exitum]?*

exitura. omnium |versatur urna serius ocius|sors exiturat

eritus. Liber vota bonos ducit ad exitus.

belli secundos reddidit exitus plorem artis in te nil agentis exitus?'

exlex. spectator functusque sacris et potus et exlex.

exmens. infectum volet esse, dolor quod suaserit et mens [exm-ns],

exomnis. non secus in iugis|Edonis [exomnis] stupet Euhias

exorabilis. si metit Orcus/grandia cum parvis, non exorabilis auro?

exoratus. *qui multum puerum loris et funibus ussit iexoratus,*

exorberet. scilicet ut deciens solidum absorberet [exorberet], acetoldiluit insignem bacam:

exoret. ne populum extrema totiens exoret harena.

exornet. ne populum extrema totiens exoret [exornet] harena.

exors. ergo fungar vice cotis, acutum/reddere quae fermm valet exsors [exors] ipsa secandi;

exortita. ergo fungar vice cotis, acutum|reddere quae ferrum valet exsors ipsa [exortita] secandi;

expalluit. Pindarici fontis qui non expalluit haustus

expavit. nec muliebriter/expavit ensem

expectant. opueriet puellae / iam virum fexpertae, [? (ian vis um expectant)] male nominatis| parcite verbis.

expectate. iam virum texpertae, male nominatis [expectate male ominatis] parcite verbis.

expediat. forte quid expediat communiter aut melior pars/malis carere quaeritis laboribus;

expedies. non nortis laqueis expedies caput.

expediet. vix inligatum te triformi|Pegasus expediet Chimaera.

expedire. unde expecire non amicorum queant / libera consilia

expedit. expedit matris cineres opertos/fallere

expedita. at expedita Sagana, per totam domum spargens Avernalis aquas,

expeditis. ultra/terminum curis vagor expeditis.

expedito. saepe trans finem iaculo nobilis expedito?

expeditus. et ultralterminum curis vagor expeditis lexpeditus].

expediunt. curae sagaces/expediunt per acuta belli'.

expellas. naturam expelles [expellas] furea, tamen usque recuret

expelles. naturam expelles furca, tamen usque recurtet

expellet. postremum expellet certe vivacior heres. .

expendere. Romae dulce diu fuit . . cautos nominibus rectis espuntere nummos.

expergisceris. ut te ipsum serves, non expergisceris?

experiar. dixeris: 'experiar,' 'si vis, potes,' addit et instat.

experiens. aut decus et pretium recte petit experiens vir.

expers. mollis et exspes [expers]/inominata perpremat cubilia.

si fract is cnatat exspes [expers]| navibus, aere dato qui pingitur?

expers. vis consili expers mole ruit sua,

nuptiarum expers et adhuc proterro/erida marito.

expers. Hydaspes/Caecuba vina ferens, Alcon Chim maris expers.

expertae. o pueri et puellae liam virum texpertae.

expertes. quem legis expertes Latinae/Vindelici

expertia. centuriae senionum agitant expertia frugis,

experto. experto frustra Varrone Atacino

expertum. melius te posse negares/bis terque expertum iru-tia:

expertus. expertus vacuom Daedalus acra

expertus filetem / Iuppiter in Ganymede flavo. .

dulcis inexpertis cultura potentis amici. expertus metuet.

expes, mollis et exspes [expes] inominata perpremat cubilia.

quid hoc, si fractis enatat exspes [expes] navibus, aere dato qui pingitu?

expetit. amore, qui me praeter omnis expetit

expiandi. cui dabit partis scelus expiandi/Iuppiter?

expiare. paratus expiare, seu poposceris/centum iuvencos

expiatis. arma/nondum expiatis uncta cruoribus.

expiatur. dira detestatio/nulla expiatur victima.

\section{EXPIATVR}

Carm.2.10.10

far.carm.2.19.10

Carm.3.c.,

ciarm.3.29 29

iur.Epod.17.8 I

Carm.2.3.27

Carm. 18.34

Curm.1.14.38

lipod.17.81

Ars Pott.224

iur. Epist.1.2.60

fur.Carm.3.259

Epist.2.2.179

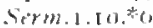

nu. sirm.2.3.240

Epist.1.1.0

zar Episl.1.I."

iar..ters Pod.305

gar.ars Iovel.305

Epist I.3.10

Carm. 1.37 .23

boniciarm-3. I4.I I

comicarm.3.14.II

Epod.10.1.5

Carm.3.24.8

Carm.1.27.21

Epod.1 1.25

Curm.2.8.9

Epod.5.25

Carm.1.22.II

Carm.1.8.12

zar.Curm. I, 22.1 I

Carm.4.7.70

lar.Epist.1.10.24

Epist.1.10.24

Sirm.2.2.132

Epist.2.1.105

Epist.1.2.33

Sirm.2.6.39

Epist.1.17.42

itar. Epod.1 6.37

ver. Ars Pot?.20

Carm.3.4.05

Curm.3.II.II

Sorm.2.8.15

Corm.3.1.1.II

Carm.4.14.7

Ars Potl.34 I

Serm.1.10.te)

Ars I'oel.44's

Carm.r.3.34

Curm.4.4.3

Epist.1.18.87

far. It pod I 0.37

sar.etrs Pirt.2o

Epod. I I.3

Carm.1.2.29)

Epoterg.zs

Corm.2.1.5

trod $500^{\circ}$ 
exple. oblivioen fevia Massico ciboria explen.

exples. busmilu" Jisinctum curas et strictis frondibus exples.

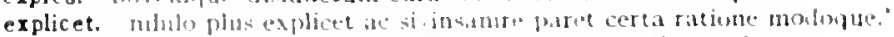

Corm.2.7.22

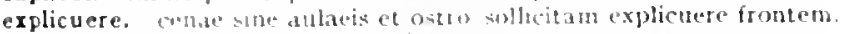

Epist.1.1.4.28

Serm.2.3.270

Carm.3.29.1\%

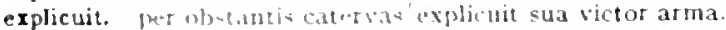

Carm.1.9.44

peplicut vinu contractae seria frontis.

explosa. 11 andix. contemptin alis, "xplosa Arbuscula dixit.

Serm.2.2.125

exponi. versthus prponi tr.ugicis res comica non vole;

exponimur, quartab vivemum exponimur hora

exponit. Prtella exponit causam;

expressa. expresis ubusto regerit comvioia.

expressi. nee magis expresi voltus por aenea signa

exprimet. biber ims et unguistexprimet et mollis mitabitur aere capillow.

expugnabis. 'velis tant ummolo: quac tua virtus, lexpugnabi:;

expugnare. vincit longe prius ipsum expugnare caput.

expugnat. tilia rectius expugnat invenum domos.

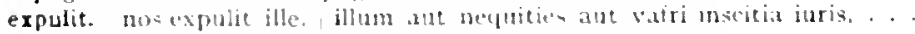
expelleet

*xpulit elleboto morbum bilenque inetaco

expurgare. quat poterunt unquan sutic expurgare cicutace,

exsangue. quodai palleren casu, bibetent exsugur cuminum

exsecat. quinis hic capiti nercedes exsocat

exsecrata. Phocatorum | velut profugit extecrata civitas

amus onnis exrectata civitas

exsecta. costrtis lexecta] uti medulla ot aridum iecur amoris esset moct:1แm,

exsecto. 'o. tha cormu' ni foret exisecto frons,"

exsiccet. dives ur aureis mercator exsiccet culills

exsilis. utcumcum fortis exsilis puerperd.

exsilit. agrestem pepulere, domo beris exsilit;

exsomnis. non secus in iugis|Edonis [oxiomnis] stupet Fuhias

exsors. cotis, acutum reddere quae fermu valut exsors ipsa secandi:

exsortita. etgo fungir vice cotia, acutum reblere quae fermm valet exsors ipas [exortita] sccandi;

exspectabit. alter purpuretum non expectabit amictum,

exspectanda. tibbula, quae posci volt et spectanda [exapectandal repori:

exspectans. comants haud animo aerino exsectans conbites.

exspectat. seu nuc tranquilla senectus exspectat

mitus exspetat. dum detuat anmis;

exsectata. exprectata tibi non mitham camina mentix.

expecto. metulacen stultisimus naque puellam ad median noctem exspercto:

exspes. molli-e exepes inominata perptemat cubiliat.

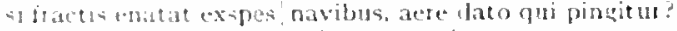

exspiravero. Iltin, uhi perite insus exspiravero.

exstant. quantum exstant atua suspensa mento corporil;

exstat. Sit monte tomina exstat:

exstinctus. "xatmetus amabitur infem.

exstrual. sacrun vetustis exstrat lignis focum

exstrue. sepulcrum permisium arbitrio sine soralibus cxatrue:

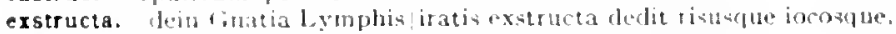

exstructis. flut" procul exstructio inerant hestexna caniatrin.

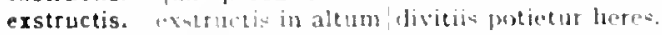

exsucta. f.ribu.tob utu medulla et aridun lecur

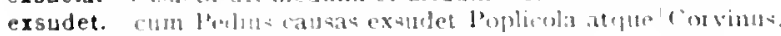

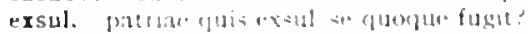

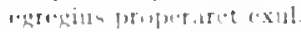

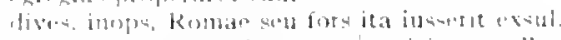

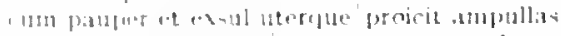

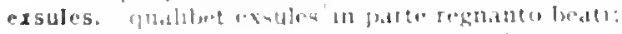

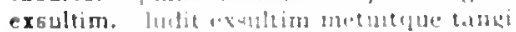

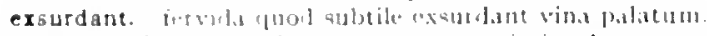

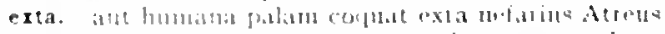

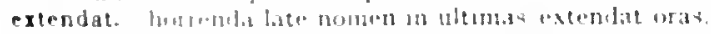

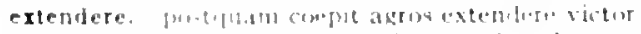

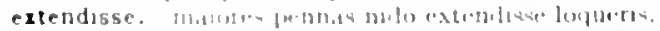

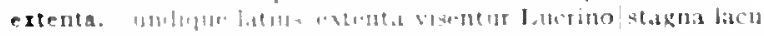

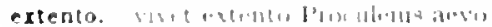

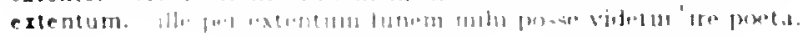

Serm.1.10.77

Ars Poct.89

Serm.1.5.23

Serm.1.7.22

Serm.1.7.29

Epist.2.1.2.18

- Irs Poct.33

Serm.1.0.55

Serm.2.5 7.4

Carm.3.15.9

Serm.2.2.130

Epis!.2.2.137

Fist.2.2.53

Epist.1.19.18

Sitm.1.2.1

Epodide is

Ispod.10.36

iur. E.pod.5.37

Serm.1.5.59

Curm.1.31.II

Epod.17.52

Serm.2.6.98

Far.Carm.3.25.0

. Irs Puet.305

nur Irs Poet 305

Epist.1.17.27

fide.tes Poet ion

Serm. 1.5 .9

scrm.2.1.58

Epist.1.2. 2

Espist 2.2 .25

Serm.1.5.8.3

fepod 10.37

los Pod.20

Jipod 5.01

lipol.5.35

serm. 5.55

Epist.2.1.1

Epol 2.43

Serm.2.5.105

Sirm.1.5.08

Serm.2.0.105

Carm.2.3.10

tipod.5.37

Sermid.10 28

Carm.210.10

( ${ }^{4} 1 \mathrm{rm} .3 .5 .9 \mathrm{~s}$

Serm.2.1.50

les linel $9^{\prime}$

(i) rmb.3.3.38

carm.3 1 t. I

Sirm $=8.3^{R}$

ies Portongen

Carm.3.3. 80

tos live 2018

Eapti.1 20.2?

Carm 2.15.3

Curm 225

lopist = 1.211 
extenuantis. urbani, parcentis viribus atque/extenuantis eas consulto. exterior. ne tamen illi|tu comes exterior, si postulet, ire recuses."

externat. inprovisa simul species exterruit. utrum [externat utrumque.] gaudeat an doleat,

externi. externi nequid valeat per leve morari,

exterret. inprovisa simul species exterruit. utrum [exterret utrumque.] gaudeat an doleat. . . . . . . . . . .

exterrit. inprovisa simul species exterruit. utrum [exterrit utrumque.]| gaudeat an doleat. .

exterruit. inprovisa simul species exterruit.

extimui. extimui, ne ros ageret vesania discors,

extimuit. qui Pythia cantat|tibicen, didicit prius extimuitque magistrum.

extinxit. devota non extinxit arbor

extiterat. credo lquod nimium institerat [extiterat] viventi.

extollens. et tollens [extollens] vacuom plus nimio Gloria verticem

extore. siquis... pede rudo/exiguaeque togae simulet textore [extore] Catonem.

extorquere. tendunt extorquere poemata: quid faciam vis? .

extorta. "cui sic extorta voluptas/et demptus per vim.

extra. nutricis extra limina Pulliae

liacos intra muros peccatur et extra.

quamvis nil extra numerum fecisse modumque/curas:

laudet ametque domi, premat extra limen iniquos.

extra. nil intra est olea, nil extra est in nuce duri;

extractus. ille. datis vadibus qui rure extractus in Vrbem est.

extrahat. neu pransae Lamiae vivom puerum extrahat alvo.

extrahe. extrahe turbaloppositis uneris; .

extrema. extrema et in sponda cubet.

ne populum extrema totiens exoret harena.

extremi. extremi primorum, extremis usque priores.

extremis. ut pueros elementa docentem/occupet extrenis in vicis balba senectus. extremi primorum, extremis usque priores.

extremo. cubat hic in colle Quirini, / hic extremo in Aventino,

extremos. me vel extremos Numidarum in agros/classe releget:

primosque et extremos metendo

illum | practeritum temnens extremos inter euntem:-

(inpiger extremos curris mercator ad Indos,

quid maris extremos Arabas ditantis

extremum. extremum Tanain si biberes, Lyce,

cum senos redderet ictus/primus ad extremum similis sibi:

occupet extremum scabies; mihi turpe relinqui est

extremum. ne|peccet ad extremum ridendus et ilia ducat.'

extricat. mercedem aut nummos unde unde extricat,

extricata. si pugnat extricata densis/cerva plagis,

extrudere. ubi plenius aequo|laudat venalis qui volt extrudere merces:

extuderit. cum labor extuderit fastidia:

extulit. cun decorum mitibus pomis caput $\mid$ Autumnus agris extulit,

exucta. exsucta [exucta] uti medulla et aridum iecur/amoris esset poculuni, exuere. saetosa duris exuere pellibus|laboriosi remiges . . . membra;

exul. interque maerentis amicos/egregius properaret exul.

Sirm.I.IO.I 4

Serm.2.5.17

coni.Epist.1.6.I I

Serm.2.7.87

var.Epist.r.6.II

7ar. Epist. I.6.I I

Epist.r.6.I I

Sirm.2.3.I 74

Ars Poet.4I 5

Carm.3.4.27

2rar.Serm.2.5.88

tar.Carm.1.18.15

2ar.Epist.1.19.13

Epist.2.2.57

Epist.2.2.I39

Carm.3-4. 10

Epist.1.2.10

Epist.1.18.59

Epist.1.19.36

Epist.2.I.3 I

Serm.I.I.I I

Ars Poet.340

Serm.2.5.94

Epod.3.22

Epist.1.1.6

Epist.2.2.204

Epist.1.20.1 8

Epist.2.2.204

Epist.2.2.69

Carm.3.1 1.47

Carm.4.14.3I

Serm. I. I. I 6

Epist.1.I.45

Epist.1.6.6

Carm.3.IO.I

Ars Poet.254

Ars Poet.4I 7

Epist.1.r.9

Serm.1.3.88

Carm.3.5.3I

Epist.2.2.I I

Serm.2.2.14

Epod 2.I 8

var. Epod.5.37

Epod.17.1 5

Carm.3.5.48

\section{F}

faba. o quando faba Pythagorae cognata . . ponentur

faba. in cicere atque faba bona tu perdasque lupinis.

fabae. nam de mille fabae modis cum surripis unum,

fabellam. scriptores autem narrare putaret asello|fabellam surdo.

fabellas. Cervius haec inter vicinus garrit anilis/ex re fabellas.

faber. cum faber, incertus scamnum faceretne Priapum,

quo vafer [faber] ille pedes lavisset Sisy phus aere, |quid sculptum infabre. .. esset.

Aemilium circa luduen faber imus

Fabia. 'hic multum in Fabia valet, ille Velina;

Fabio. deprendi miserum est: Fabio vel iudice vincan.

deprendi miserum est: Fabio vel [Fabio hoc vel] indice vincan.

Fabium. loquacem delassare valent Fabium.

fabri. quod medicorum est f promittunt medici, tractant fahrilia fabri:

Serm.2.6.03

Serm.2.3.182

Epist.1.16.55

Epist.2.1.200

Serm.2.6.78

Serm.1.8.2

var.Serm.2.3.2 I

Ars Poct.32

Epist.1.6.52

Serm.I.2.I34

coni.Serm.I.2.1 34

Serm.1.1.14

Epist.2.1.ro 
fabri. cras ferrameuta Teanun/tolletis, fabui.

lipist.1.1.87

fabricaverat. pugnabant armis quae post fabricaverat w-us,

Serm.1.3.102

Fabricio. atque a liabricio non tristem ponte reverti.

Fabricium. gratus insigni teferam camena/Fabriciunque.

Serm. $2 \cdot 3 \cdot 3^{\circ}$

fabrilia. quod medicorm est promittumt medici. tractant fabrilia falsti:

fabros. nutmoric aut cboris fabros aut aet is amavit.

fabula. per Vibem. . fabula quanta fui.

inutato nonine de te/fabula narratur:

non lonja est fabula.

resenti fabula quem miserum gnato vixisse fugato inducit.

'quid tament ista velit sibi fabula, si licet, ede." .

fabula, qua Paridis propter narratur amorem

cognomen vertas in risum et fabula fias.

recte necne crocum foresque perambulet Attae fabula

tadat ant recto stet fabula talo.

neve minos neu sit quinto productior actu/fabula.

fabula nullus veneris, sine poudere et arte, |vidius oblectat pupulum

ne quodiumque relit poscat sibi fabula credi

fabulae. iam te premet nox tabulacque Manes

fabulosae. me fabulosie lolume in ipulo

fabulosus. quae loca fabulosts/lambit IIydasjes.

face. me torset face mutua|Thurini Calais filistornyti.

una de multis face nuptiali/digna

nite crescrntem face foctilucam.

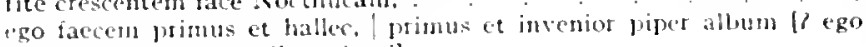

primus face nec allec miscui]

facem. dilapsam in cineres faccm.

facere. iubet quibris et facere ct pati

quid oportet/nos facere a volgo longe longeque remotos?

tuid nunc te dicam facese in regione Pedana?

ruac possit facere et servire beatum. .

si res sola potent facete et servare beatum.

quae facore: ipse recusem. |cum recte tractent alii.

facerem. sive iubebat $/$ ut facrem quid.

atque ego cum graecos facerem, natus mare cita, versiculos, paupertas inpulit audax ut versus facerem.

faceres. 'o, tua cornul mi foret exsecto frons.' inquit. 'quid faceres,

faceret. ium laber, incertus scamnum faceretne Priapum. nemo hoc mangonum faceret tibi; non alius faceset meliora poemata:

facetum. molle atcue facetum Vergilio adnuctunt gaudentes 1 ure Camenac.

facetus. factus pastillos Rufillus olet, Gargonius hircum:

facetus. emunctite naris, durus componere vetsus.

"frater" "patcr" adde;|ut cuique est aetas, ita quemque facetus adopta.

faciam. festo quin potius dic/ Jeptuni faciam -

puid fichast, si furtum fecerit

ne lospun facian: dum to quadrante lavatum, an ibis

'Hubiun sum, quill faciam, incuit.

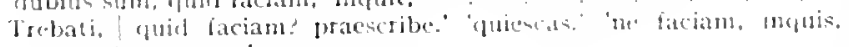
omminu verstas:"

'puicl hariant: "antat Milonius.

ne lonturn :erciant:

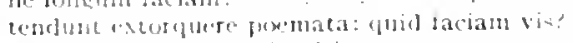

facian. "b.111 laciam quad voltis:

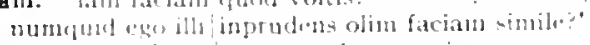

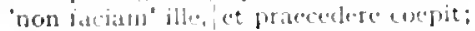

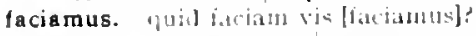

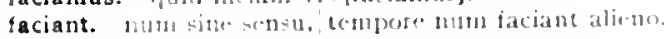

facias. qual fardat illi? iubeds misedunt esse.

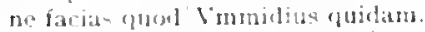

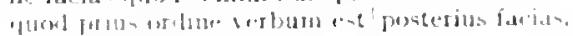

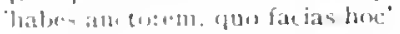

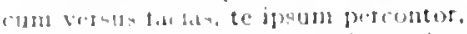

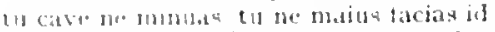

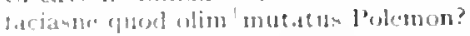

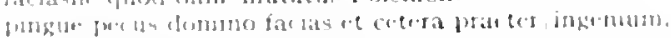

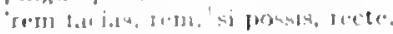

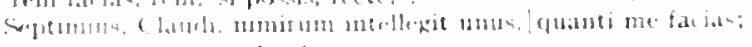

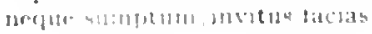

lipist.2.1.12

List.2.1.96

Epod.1 1.8

Sirmi.1.1.70

Scrm.1.1.95

Serm.1.2.21

Sicm.2.5. PI

lipist.1.2.?

Fist.1.13.9

lipist.2.1.So

l.jist.2.1.170

Ars l'oet.100

irs Pot 320

Ars l'oet. 339

Cormetio

Carm.3.4.9

Carm. 1.22 .7

Carm.3.9.13

Carm.3.11.33

Curm.4.6.38

3 Irsm.serm 2.4.73

Carm.4.13.28

Carm.3.24.43

Sorm.1.0.18

lipist.t.t2

Itpist.10.2

IEpislate.t7

Epist.2.1.20s

Sirn.1.1.122

Sermid10 31

IEpist.2.2.52

Serm.1.5.59

Serrit 1.8.2

lepist.2.2.13

Ars l'ort 303

Siemi.1.10.4t

Serm. 1.2.26

Sormi.t.4.7

Jepist.1.6.55

corm.3.25.2

Serm. 3.94

Sirm.3.3.137

Sirm.1040

Sirm.2.1.5

Serm.2.1.2.

Serm.2 153

Lepist.2.2.57

Sirm. 1 ir

Serm.141.37

forms 10..t?

sur. Lpist.2.2.57

Sirm.1. 48

Sirmet l 1.3

fermes 144

bermi 1.450

Sermid 122

Serm.1 10.25

Sorm.2.3.17\%

Sierm 2.3.2.5.3

comb.2.19

1.prot. I i.e.5

I.pist.t.o:

l: fist $2: 10 \mathrm{p}$ 
faciat. siquid miri faciat natura.

facibus. ambulet ante|noctem cum facibus."

facie. quali|sit facie, sura quali, pede, dente, capillo:

Picenis cedunt pomis Tiburtia suco: nam facie praestant.

Serm.1.5.102

Serm.1.4.52

Serm.1.6.33

Serm.2.4.71

Carin.4.5.Ia

faciem. curvo nec faciem litore dimovet:

mutatus, Ligurine, in faciem verterit hispidan,

mutatus, Ligurine, in faciem verterit [verterit in faciem] hispidam,

matronae praeter faciem nil cernere possis/cetera.

Campanum in motbum, in faciem permulta iocatus,

vertere pallor/tum parochi faciem

ut turpiter atrum | desinat in piscem inulier [? faciem] formosa superne:

facienda. luctandum in turba et racienda iniuria tardia.

faciendo. in versu faciendo/saepe caput scaberet.

faciens. hoc faciens vivam melius.

quem tollere raeda|vellet iter faciens

facientia. mecum facientia iura|si tamen attemptas?

facientibus. nenia, quae regnum recte facientibus offert.

facies. notaque et artium/gratarum facies?

nt* si facies. nt saepe, decora/molli fulta pede est, enptorem inducat hiantem. longa quibus facies ovis erit, illa memento,

facies. non Viscum piuris amicum, / non Varium facies: quae siquis sanus fecit, sanus facis et tu [sanus facit, et sanus facies $t u$ ]. at pueri ludentes 'rex erig' aiunt. | 'si recte facies.' tu nihil invita dices faciesve Minerva:

faciet. nil faciet sceleris pia dextera. hoc teneran faciet. tum gener hoc faciet :

facile. dis etenim facile est'

facilem. arida/pellente lascivos amores/canitie facilemque sommum. seu facilem, pia testa, somnum,

neque se fore posthac|tam facilem dicat, votis ut praebeat aurem?

facilem. non ego: namque parabilem amo venerem facilemque.

faciles. quae prius multum facilis [faciles] movebat/cardines.

facili. aut facili saevitia negat

facilis. quae prius multum facilis movebat/cardines. ultro/ Penelopam facilis potiori trade.'

facimus. multa quidem nobis facinus mala saepe poetae.

facinus. damnum est, non facinus, mihi pacto lenius isto.

facio. equos ut me portet, alat rex, fofficium facio;

facis. 'laedere gaudes,'|inquit, 'et hoc studio pravos facis.' neque tu hoc facis Argis quae siquis sanus fecit, sanus facis et $t u$

fscit. inbeas miserum esse, libenter/quatenus id facit. at in se pro quaestu sumptum facit hic."

si interdicta petes, vallo circumdata (nam te/hoc facit insanum), verba facit leno:

an. quodcumque facit Maecenas, te quoque verum est. .

quae siquis sanus fecit, sanus facis et tu [sanus facit, et sanus facies $t u$ ]. 'aut insanit homo aut versus facit."

incolumi Rhodos et Mytilene pulcra facit

illis / me facit invisum.

et sapit et mecura facit et love iudicat aequo.

invitum gui servat, idem facit occidenti.

faciunt. qui conducti plorant in funere dicunt / rt faciunt prope plura dolentibus ex animo.

facta. doctus iter melius: mortalia facta peribunt.

facta. nova fictaque [factaque] nuper habebunt verba ficlem,

facta. recte facta refert, orientia tempora notis instruit exemplis,

facta. horruerim voces Furiarum et facta duarum.

Pollio regum|facta canit pede ter pereusso;

utrius horum verba probes et facta, doce.

post ingentia facta deorum in templa recepti,

fere scriptores carmine foedo/splendida facta linuıt.

vestigia Graecalausi deserere et celebrare domestica facta

facti. dimidiun facti, qui coepit, habet: sapere aude.

factis. nee prave factis decorari versibus opto,

factitet. nec satis adparet, cur ver 11 . factitet;

Carm.4.10.5

z'ar.Carm.4.10.5

Sirm.t.2.94

Serm. 1.5.62

sirm.2.8.36

fiar..trs Poet.t

Serm.2.6.28

Germ.1.10.70

Sierm.1.4.I 35

Sirm.2.6.43

Enist.2.2.23

Epist.1.1.63

Corm 4.13 .22

Serm.1.2.87

Scrm.2.4.12

Serm. 1.9 .23

"ar.Sirm.2.3.322

Epist.1.1.60

Ars Poel. 385

Sirm.2.1.54

Serm.2.4.20

Sirm. 2.5.60

Serm.2.3.284

Carm.2.1 I.8

Carm.3.21.4

Sirm.1.1.22

Serm.1.2.II9

Far.Carm. I.25.5

Carm.2.12.26

Carmi.1.25.5

Sicrm.2.5.76

Epist.2.1.219

Epist.1.16.56

Epist.1.17.21

Serm.1.4.79

Serm.2.3.132

Serm.2.3.322

Serm.1.1.64

Serm.1.2.10

Serm.1.2.97

Serm.2.3.231

Serm.2.3.312

var.Serm.2.3.322

Sirn.2.7.117

Epist.I.II.I7

Epist.1.15.4

Epist.2.1.68

Ars Port.467

. Irs Poct. 432

irs Poct.os

vur.Ars Poct.52

Epist.2.1.130

Serm-1.8.45

Sirm.1.10.43

Epist.1.17.16

Epist.2.1.6

Epist.2.1.237

Ars Pot.287

Epist.1.2.40

Epist.2.1.266

Ars loet.47\% 
facto. servave ab onm non solun facto. versn opprobrio quoque turpi.

factos. "Catone. qui nule factoslemendare parat versus."

num rebum dura negarit|vesiculos natura magis factos.

nolie ad versus tubi factos ducere plenum/lactitiae:

lactu. 'an hoc anhonestum et inutile factul necue sit addubites.

Iactum. me setie quod dicam factum est.

lactum. an hoc inhonestum et inutile factu [factun]/necne sit addubites. utpe longun citpertites iter et factum corruptius imbri. non. ut magna dobo factum negat esce suo pars. lunus egregie hactum hadet vicinis.

lactum. clatus ob id factum donis of natur honestis.

facturus. sive facturu- per inhospitalem / Caucasum nec sum facturua vitio culpave ninorem:

factus. Capitoque sinul Fonteius, ad unguen'factus homo.

facunda. cur facunda parun decorolinter verba cadit lingua silentio?

facunde. Mercuri facunde nepos Alantis,

facundi. facundi calices quem non fecere disertum.

facundia. non te facundia. mon te/restituet pietas; nec lacundia desefet liunc nec lucidus ordo. quac mox narset facundia praesens: et tulit eloguium insolitum facundia praeceps

face. difugiunt cadis/cum face sicatis amici. nec poti, vetulam, fatec tenus cadi. Surtentina valer qui miscet iace Falerna/vina.

la ecem. hanc ego cum malis, ego fatecem primus et labllec,

laecibus. quac can'rent aperentque jeruncti fícecibus ora.

Iaecula. siset, hallec, facculia Coa.

faenerator. hace ubi locutus fisenerator Alfus.

faenore. solutus ommi fatere

dives agris, dives positis in faenote mummin.

multis occulto crescit res tacmore.

"dives agria, duves positis in faenore numamis."

Iaenum. "facnum habet in comu, longe fuge;

falce. prenant Calesan falce equbus dedit fortuna vitem. inutilisque falcr ratuos atmputans magnis parva mincris falce uecinusum simbli te.

Falema. תec balet ma|vitis Achaemeniuncue costum.

Falerna. Surtentina vater qui misect fatece lialesma|vina,

Falernae, nea nec Falemaelemperane vites nec purpurarum ... delenit usus nec lealerna [Falemae] | vitis Achatuentumque costum,

Falerni. voltis severi me quorjue sumere partem lolerni? bearis interiore mota Falemi. guis puet ocius restinguet ardentse Faledni pocula arae Falem mille fundi iugera ut Chio nota si eonmixta Falerni est." si positic intus Clii veterisque balerni/mille cadis, quen bibulum liequidi media de luce Fater ni: [potores bibuli media de nocte lialet ni]

Falernis. mimmum lalen mistinvidet uvis;

Falemo. nisi Hymettia mella fales no ne biberis duluta.

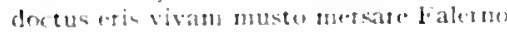
Aufdise torti nuncebat mella falerno.

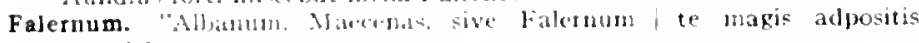
de.lectat

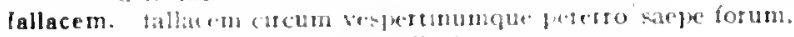

fallacis. sperat, nesesus allar fillacis

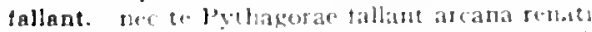

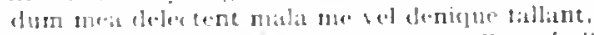

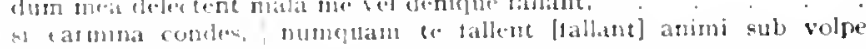
latesto.s.

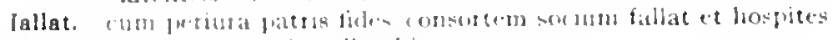

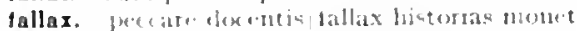

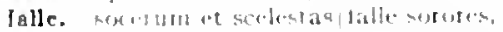

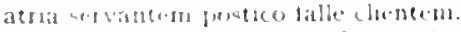

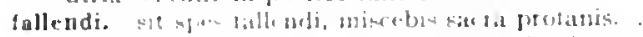

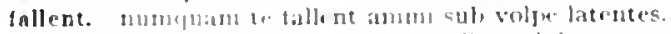

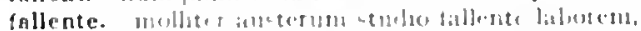

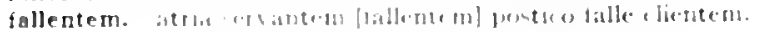

Serm.1.6.84

Sorm.1.10*2

Serm.1.10.58

Ars l'oct. 427

Serm.1.4.124

Serm.2.5.84

var.Serm.1.4.12.4

Serm.1.5.95

Serm.1.0.90

Sorm.2.5.100

Ejist.2.2.32

Carm.1.22.6

Serm.2.6.7

Serm.1.5.33

Carm.4.1.35

Carm.1.10.1

Epist.1.5.19

Carm.4.7.23

Ars Poct.4I

Ars Poct.184

Ars Ioct.217

Carm.1.35.27

Corm.3.15.10

Serm.2.4.55

Sorm.2.4.73

Ars Joet.277

Serm.2.8.9

Fpod.2.67

Isod.2.4

Serm.1.2.13

Epist.1.1.80

Ats IoctidzI

Serm.1.4.3.4

Carm 1.31.9

Fpod 2.13

Sorm.1.3.123

Carm.3.1.43

Serm.2.4.55

Carm.1.20.10

far.Carm.3.1.43

Carm. I.27.10

Carm.2.3.8

Carm.2.15.19

lipedat 13

Serm.1.10.24

Sorm.2.3 II 5

List.1.14 34

tur. Epist.1.18.91

Carm:2.1.19

Scrm.2 2.I 5

Sirm. 24.10

Scrm.2.424

Serm.2.8.10

Serm.1.6.113

Carm 1.5.12

L pod.15.21

I. pist.2.2.127

: ar. Ars Ined.437

Carm.3 240

Carm.3.7.20

Carm.3.11.80

l.pist. 2.5.31

fipist.1.10.54

Ars l'od 437

Serm.2.212

iar. Ifost $1,5,3$ 
FALLENTIS

fallentis. germinat et numquam fallentis termes olivae quid pure tranquillet. . . . secretum iter et fallentis semita vitae.

fallere. expedit matris cineres opertos | fallere.

Spartacum siqua potuit vagantem / fallere testa. fallere et effugere est triumphus. iam vino quaerens, iam somno fallere curam; da mihi fallere, da iusto sanctoque videri, .

falleret. mire sagacis falleret hospites/discrimen obscurum ille non... Troas et laetam Priami choreis/falleret aulam.

fallimur. fallimur et quondam non dignum tradimus:

fallit. segetis certa fides meae |fulgentem imperio fertilis Africae|fallit sorte beatior.

aquae nisi fallit augur|annosa cornix. . perraro haec alea fallit.

fallor. ordinis haec virtus erit et venus, aut ego fallor.

fallunt. nec te Pythagorae fallant [fallunt] arcana renati et dominum fallunt et prosunt furibus.

falsa. atque ita mentitur, sic veris falsa remiscet.

falsis. acclinis falsis animus meliora recusat,

falsis. irritat, mulcet, falsis terroribus inplet

falsis. populumque falsis/dedocet uti|vocibus, falsis|dedocet uti|vocibus [? dedocet uti falsis vocibus].

falsis. ut Proetum mulier perfida credulum|falsis inpulerit crininibus mordear opprobriis falsis mutenıque colores?

falso. ut hona pars hominum decepta cupidine falso

falsum. quam qui non poterit vero distinguere falsum.

falsus. falsus honor iuvat et mendax infamia terret

Fama. illum aget penna metuente solvi|Fama superstes.

fama. crescit occulto velut arbor aevo|fama, Marcellis; famaque et imperi|porrecta maiestas ad ortus/solis unde/fama malum gravius quam res trahit. ne nummi pereant aut puga aut denique fama.

'deprensi non bella est fama Treboni'.

capsis quem fama est esse librisque ambustum propriis.

missus ad hoc pulsis, vetus est ut fama. Sabellis.

fama, decus divina humanaque pulcris/divitis parent; quern cepit vitrea fama.

"eoque/responsura tuo numquam est par fama labori.

cui|gratia fama valetudo contingat abunde

fama. moribus hic meliorque fama|contendat, fama civem causaque priorem! sperne.

Zmyrna quid et Colophon, maiora minorane fama?

famae. qui stultus honores/saepe dat indignis et famae servit ineptus, das aliquid famae, quae carmine gratior auren loccupet humanam? Romanis sollemne viris opus, utile famae

famam. Fufidius vappae famam timet ac nebulonis. bonam deperdere famam, |rem patris oblimare maltum est ubicumque. qui captat tisus hominum famamque dicacis, tuamque. /dum custodis eges, vitam famamque tueri|incolumem . conmittes rem omnem et vitam et cum corpore famam. aufert | Pacuvius docti famam senis. aut famam sequere aut sibi convenientia finge,

famem. haec bellum lacrimosum, hic miseram famem / pestemque frigus quo duramque famem propeliere possit.

fames. crescentem sequitur cura pecuniam/maiorumque fames. quem tenet argenti sitis inportuna famesque,

famosae. fiet homo et ponet famosae mort is amorem.

famosis. nequitiae fige modum tuac|famosisque laboribus;

famosis. famosisque lupo cooperto versibus?

famoso. nec sponsae laqueum famoso carmine nectit.

famosum. dimittit reque famosum neque sollicitum

famosus. nee Lacaenae splendet adulterae! famosus hospes. quod moechus foret aut sicarius aut alioquilfamosus,

famulis. redemptor/cum famulis dominusque terrae|fastirliosus: cum famulis operum solutis.

famulus. an custos famulusque dei silenus alumni

fana. fana deos habuete rectos.

fana. agros atque lares patrios habitandaque fana lapris reliquit

fanaticus. urgetlaut fanaticus error et iracunda Diana.
FANATICVS

Epod.1 6.45

Epist.1. I 8. 103

Carm.2.8.10

Carm.3.14.20

Carm.4.4.52

Serm.2.7.11t

Epist.1.16.ti

Carm.2.5.22

Carm.4.0.16

Epist.1.18.78

Carm.3 I 6.32

Carm.3.17.12

Serm.2.5.50

Ars Poct. 42

zar. Epod.I.5.2 I

Epist.1.6.40

Ars Port.I5 I

Serm.2.2.6

Epist.2.I.2I 2

Carm.2.2.19

? zar.Curm.2.2.2I

Carm.3.7.I4

Epist.1.10.38

Serm.1.1.6I

Epist.1.10.20

Epist.1.16.39

Carm.2.2.8

Carm.1.12.40

Carm.4.I5.I4

Serm.1.2.59

Serm.1.2.133

Serm.1.4.1 4

Serm.1.jo.ti3

Serm.2.1.3n

Serm.2.3.95

Serm.2.3.222

Serm.2.8.66

Epist.1.4.IO

Carm.3.1.12

Serm.2.5.30

Epist.1.11.3

Serm.1.6.I6

Sirm.2.2.94

Epist.1.18.49

Sirm.1.2.12

Serm.1.2.0́1

Serm.I.4.83

Serm.I.t.118

Serm.2.7.67

Epist.2.1.56

Ars Poet. I 19

Carm.1.2I.13

Serm.1.2.6

Carm.3.10.1s

Epist.1.18.23

Ars Pott.tog

Carm.3.15.3

Serm.2.1.08

Epist.I.19.3 I

Serm.2.7.5I

Carm.3.3.26

Sirm.1.4.5

Carm-3.1.30

Carm.3.17.10

Ars Poet.239

Carm.4.4.48

Epod.16. Io

Ars Poct. 454 
Fannius. beatua loanniuz ultroldelatis capais et magine,

"fuml mepus|liannus Hermogenis laedat comviva Tigelli?

fanum. laaec tibi dictabant post ianum putre l'acunac.

far. prefcuntor puanti holus ac far.

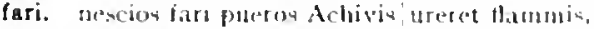
qut sifere et fari possit puace sentiat

farra. nulbit rura [farral Ceres almague lianstitan,

farre. farre pio et saliente nuica.

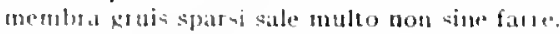

farris. cui sitis unat farris libra foret.

fartor. (um scurris fartor. cum l'elabro onme macellum

fas. das pervicacis est mihi Thyiadats cantar". . fas et beatac coniugis adelitum/stellis honotem hec scire fas est onnin.

'veruena magit non fas netaseflae.

verum operi longo f.ls est obregere somnum.

fas. cum tis atque nefas exiguo fine libidinum

ridnque, si mortalis ultra|fas trepidat

fasces. sildetulerit fasces indigno. detrahet idenu.

fascibus. lhonestos fascibus et sellis nollem mihi sumere.

fasciculum. He forbe sub ala fasciculum portes librorum.

fascinum. minusve languet fascinum?

fasciolas. ponas incignia morbi,|fasciolas, cubital, focalia.

fascis. an superbos/Tarquini fascis, dubito, an Catonis/nobile detum: cui libet hic fascis dabit

fastidia. vel med cum suevis agitat fantidat verlos:

*ut (sset open qui ferre portis antiquis posset contra lastidia nostra." cum tabor extudenit fastidia:

magna movet stomble fastidia

Varia tastidia cena vincere tangentis male singula dente superbo:

et thila futrumpet turtim fastidia victro

quasu spectators tastidia ferre superbi.

fastidienti. mains infundam tibi|fastirlienti poculum

fastidiosa. fastidfosa teistis acerimonia.

fastidiosam. fastidiosam desere copiam

fastidiosus. dominusefue terract lastidiosus:

fastidire. sic no: debenus anci|siquol sit vitim non tastidire" fastidire lacus et rivos ausus apertos.

fastidiret. 'si sciret regibus uti,|fatidiret holus, qui ne notat.'

fastidis. num esuriens fastidis omnia prarter/pavonem thombumque? quem tu fastirlic, habitatum quinclue focis

fastidit. somnus. . non lumilis domos/fastidit umbrosamque ripam. . nisi quate tertis semota suisque/temporibus defuncta videt. fastidit et olit.

fastidium. praeconis ad fastidium

fastigia. naturam expelles furca, tamen uspue recurtet, et mala perrumpet furtion fistidia [fastigia] victrix.

fastis. notis conditia lastis

fastos. nejotum| jeer menores genus omme fancon per titulos mernosesque fastos temprora al fatoseque velis evolvere munds

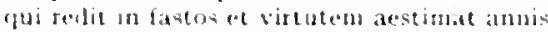

fastu. "fuanto cum fistu. quanto molimine ciscum- spectemus

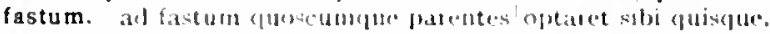

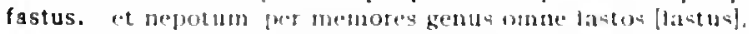

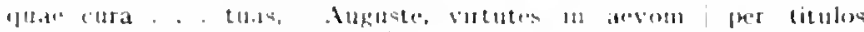

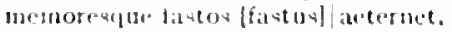

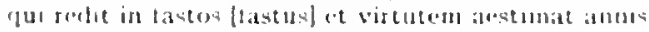

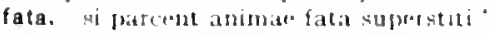

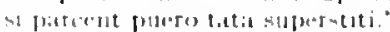

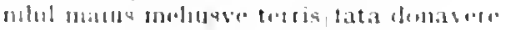

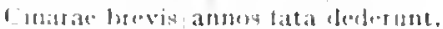

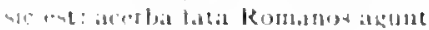

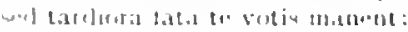

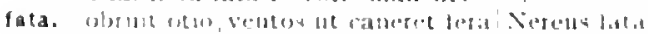

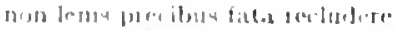

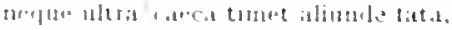

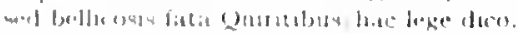

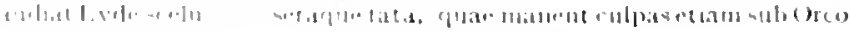

Serm.1.21

Serm.1.10.80

tipist 1.10 .40

Sirm.1.1.112

Carm 4.0 .18

I.pist.1.4.0

coniclurm.4.5. 18

Curm.3.23.20

Sirm.2.8.87

Serm. 1.5. (20)

fierm.2.3.220

(iurm.2.19.0)

Carm.2.19.13

(arm .4 .22

I.pod. 5.87

Ars floel.36o

Carm.1.18.10

C'urm.3.29.32

Epist.1.10.34

Sierm.1.0.97

Epist 1.13.13

Epol.8. 18

Serm.2.3.255

Corm1.12.35

Epist. 1.6 .53

tipod.12.13

Serm.1.10.7

Sirm.2.2.14

Serm.2.4.78

Sirm.2.0.80

Epist.1.10.25

fiptst.2.1.2:5

Iipod.5.78

Epod.17.73

Curm.3.20.9

Carm.3.1.37

Sirm.1.3.44

Fipisl.1.3.1

frpist.1.17.15

ferm.1.2.115

Eipist 1.14.2

(iurm.3.1.23

tepist.2.1.22

I. poit.1.12

gar. Spist.1.10.25

(iarm.4.13.15

(arm.3.17.4

(arm.t.1.1.)

Serms. 3.112

lipist $2.1 .4 \mathrm{~s}$

lepist.2.2.9.3

serm.1.0.95

sar.curm.317.4

tar. Curm.4 14.1

edr.l:pist 2.1.48

Carm-9.12

(arm.3.9.11"

Carm.1.2.8

Carma1323

fipod 7.17

fipod.17.1,2

Cium-15.5

Ciarm.1.2.47

Ciurm.2.13.16

Curm.3.3.57

(atrit? I 28 
bona iam peractis|inngite fata.

Pollio regum | facta [fata] canit pede ter percusso;

(arm.siacc. 28

fatale. daret ut catenis| fatale monstrum.

fatali. notaque fatali portenta laborc subegit,

fatalis. fatalis incestusque iudex

fateare. iura inventa metu iniusti fateare nccesse est.

fateatur. quis tam Lucili fautor inepte est, / ut non hoc fateatur?

fatebitur. me/cum magnis vixisse invita fatebitur usque/invidia

fatentes. nil oriturum alias, nil ortum tale fatentes.

fateor. 'stultum me lateor (liceat concedere veris)

peccat um fateor, cum te sic tempore laevo interp.llirim;

"etenim tateor me" dixurit ille|"duci ventre levem.

fateri. quaelinberbes didicere, senes perdenda fateri.

et quod non didici sane nescire fateri."

faterier. nulline faterier audes?

fatetur. i pieraque dure|dicere credit cos, ignave multa fatetur:

Fati. volucrisque Fati/tardavit alas.

fatigarat. devota morti pectora liberae / quantis fatigaret [fatigarat] ruinis. fatigaret. quantis fatigaret ruinis.

fatigas. quid aeternis minorem/consiliis animum fatigas?

fatigat. (si Romana fatigat/militia adsuetum graecari).

fatigatis. iuga demeret/bubus fatigatis

fatigatum. Iudo fatigatumque somno

fatigent. prece qua fatigent / virgines sauctae mims audientem | carmina Vestam?

fatiget. (si Romana tatigat [iatiget]| militia ardsuetum graecari).

tatis. tibi cura magni|Caesaris fatis data:

fato. si foret hoc rostrum fato delapsus in aevom.

fatum. namque instat fatum mihi triste, .

fauce. arente fauce traxerim,

faucis. num, tibi cum faucis urit sitis, aurea quaeris poula?

Faune. Faune, Nympharum fugientum amator,

Fauni. silvis deducti caveant me iudice Fauni,

Faunis. ut male sanos/adscripsit Liber Satyris Faunisque poetas,

Fauno. nunc et in umbrosis Fauno decet immolare lucis.

Faunus. velox amoenum saepe Lucretilem |mutat Lycaeo Faunus

nisi Faunus ictum|dextra levasset. Mercurialium|custos virorum.

Fausta. Villius in Fausta Syllae gener, . . poenas dedit

faustis. quid indoles/nutrita faustis sub penetralibus/poset.

Faustitas, nutrit rura Ceres almaque Faustitas,

fausto. "i bone, quo virtus tua te vocat, i pede fausto,

fautor. quis tam Lucili fautor inepte est.

consentire suis studiis qui crediderit telfautor.

sic fautor veterum, ut tabulas peccare vetantis.

frater [fattor] erat Romae consulti rhetor,

fautoribus. hic ubi nequitiae fautoribus et timidis nil aut paulum abstulerat.

faveat. ille bonis faveatque et consilietur amice

faventium. quo clamor vocat et turba faventiun.

favet. dum favet Nox et Venus.

ingeniis non ille favet plauditque sepultis. .

favete. favete linguis: carmina non prius|audita

favillam. ibi tu calentem|debita sparges lacrima favillam/vatis amici.

Favoni. solvitur acris hiems grata vice veris et Favoni

Favonii. candida, primo restituent vere Favonii

favor. virtus et favor et lingua potentium |vatum.

favorem. plotavere suis non respondere farorem/speratim metitis.

faxis. "cave faxis|te quicquam indignum.

nisi ut propria haec mihi munera faxis.

febrem. mater delira necabit|in gelida fixum ripa tebrimque [febremque] reducet.

non aeris acervos et auri|aegroto domini deduxit corpore febris [tebren!].

febres. non aeris acervos et auri|aegroto domini deduxit corpore febris [febres].

febrim. mater delira necabit/in gelida fixum ripa febrimque reducet. neu. . . occultam febrim sub tempus edendi|discimules.

febris, aegroto domini deduxit corpore febris. opella forensis adducit febris

febrium. nova tebrium|terris incubuit cohors

gar.Serm. 1.10 .43

Cirm.1.37.21

Epist.2.1.I I

Carm.3.3.19

Serm. I. 3. I I

Serm. I. 10.3

Serm.2.1.76

Epist.2.1.17

Serm.2.3.305

Serm.2.4.4

Serm.2.7.37

Epist.2.1.85

Ars Pot.tis

Epist.2.2.1 48

Iipist.2.1.67

Carm.2.17.24

íur.Carm.4.14.19

Carm.4.149

Carm.2.1.12

Serm.2.2.10

Carm.3.6.43

Carm.3.4.1 I

Cism.1.2.26

var.serm.2.2.10

Carm.1.12.5 I

Sirm.1.10.68

Sirm.I.0.20

Epot.I4.4

Sirm.1.2.It4

Carm.3.18.1

Ars Poth.24t

Epist.t.10.4

Carm.1.4.I

Carm.1.17.2

Carm.2.17.28

Scrm.1.2.64

Carm.4.4.20

Carm.4.5.18

Epist.2.2.37

Sirm.1. 10.2

Epist.1. 8.66

List.2.1.23

coni.Epist.2.2.87

I.pist. I. I 5.33

Ars Poet. 196

Carm.3.24.4t

Carm.3.11.50

Epist.2.1.88

Carm.3.1.2

Carm.20.23

Carm.I.4.I

Cism 3.7.2

Carm.4.8.20

Epist.2.1.9

Sirm.2.3.38

Sirm.2.6.5

3/sr.term.2.3.207

zar. Epist.1.2.48

var.lipist.1.2.48

Sirm.2.3.294

Epist.1.16.22

Epist.1.2.48

Epist.1.7.9

(arm.1.3.3o 
fecerat. pallor utrasque, fecerat horrendas adsprectu.

Serm.1.8.2\%

fecere. auctius atque/di melius fecerte.

interea sucpenat gravis aulaca ruinas!in patinam fecere,

Serm.2.6.4

facundi calices quem non fecere disertum.

feceris. si chartae sileant quod bene foceris.

tecerit. de te, splendide, Minosffecerit arbitria.

quid faciam, si furtum fecerit

cui si vitiosa libido tecerit auspicium.

fecerunt. di bene fecerunt, inopis me quodque pusilli finxerunt animi.

feci. si neque maiorem feci ratione mala ren. "nec furtum feci nec fugi." si mili dicat|sctos:

fecisse. siquid et nos. quod cures proprium fecisse, loquanur. guamvis nil extra numerum fecisse modumque/curas:

at unuj lcgitimum cupiet fecisse poema.

fecissent. fecissent. gladiatorum dare centum damnati populo paria

fecisset. debebat, guod ni fecisset, perdere litem.

fecisti. tu ne fecisti locupletem:

fecit. sapiens crepidas sibi numquam/nec soleas fecit; . causaque mea petmulta togatus/fecit

"at magnum focit, quod resbis gracca latinis/miscuit." nil sane fecit quod tu reprebendere possis:

insanus quid "nim Aiax fecit?

quale siquik sanus fecit. samus facis et tu

"tibi me" virtus tua fecit anjicum.

qui provenit fecitne vijiliter?"

mult a tulit focitque pur.r, stulavit et alsit.

nec semel lex focit, nec si retractus erit.

fecunda. nec jestilentem stutiet Airicun fecunda vitis domi si guatus erit fecundate coniux.

fecunda. Chrysippus fionit fecunda in gente Meneni. -

fecunda. fecume culpae sacula nuptias/prinum inguinavere

fecundae. fecundac leporis sapicns sectabitur armos.

fecundi. fectumelate [fecundi] lepotis sapiens sectabitur armos.

fecundi. fiacundi [iecundi] calices quem non fecere disertum.

fefellit. l'iamus.. Thesealosque ignis ct iniqua Troiae/castra fefellit. num viferinus life cruos / incoctus hetbis me fefellit? nec latens in appos radix fofellit me locis. noc vixit male, qui natus moriengegle fefolit.

felicem. felicem dicere non boe me possin.

ote, Bolanc, cetebri felicem" ita urelicen dicis

felices. fedices ter et amplius

plutaque felices mirabiun

Celitecen. nune ego resto

felicior. et th. efurcumqua eselicior

felicioses. famoc amputans/feliciores insarit

felicis. relow folicis viventis clamat in Vibe.

feliciter. nam eprat tragicum satis et foliciter atuder.

felix. sis licep bolix. ubicumgue mavis,

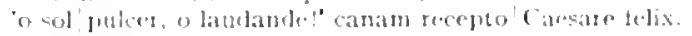

telix puse cinaram notaque et attiun gratarm tacies?

o (2gu) non dellix. quan to fugis.

felix. Fomege Romianam l.atimugue folix

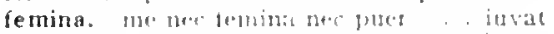

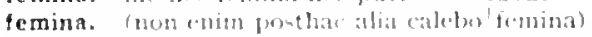

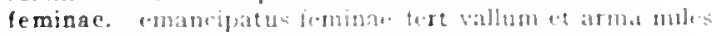

feminis. orathefue forbinis, inbelli cithara carmina

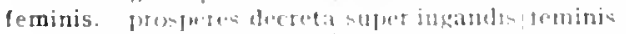

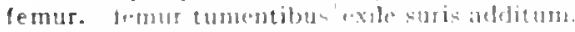

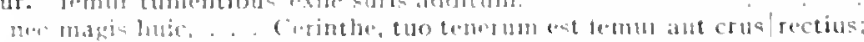

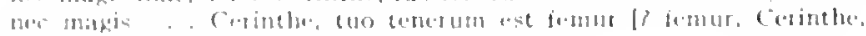
[1111:11]

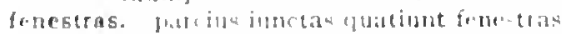

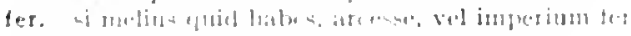

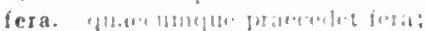

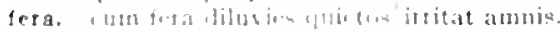

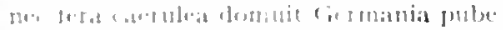

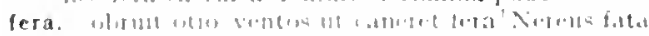

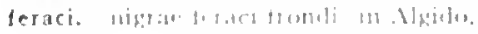

Sorm.2.8.55

Epist.1.5.19

Carm.4.8.21

Carm.4.7.22

Serm.1.3.9.4

Eptist.1.1.81

Sermil.4.17

Serm.20.0

Epist.1.10.40

Fpist.1.17.5

List.1.18.50

Epist.2.2.I09

Serm.2.3.85

Scrm.1.9.37

Epist.1.7.15

Sermit.3.128

Serm.1.4.98

Serm.1.10.20

Serm.2.3.138

Serm.2.3.202

Serm.2.3.322

Serm.2.5.33

Epist.1.17.38

Ars Poct.4 13

Ars Pod.qos

Carm.3.23.6

Serm. 2.5.3 I

Serm.2.3.287

Carm.3.6.17

Serm.2.4.44

sur.Ferm.2.4.44

sar.Epist.1.5.19

Carm.I.IO.Is

lipod.3.7

s.pod.5.68

EPist.1.17.10

Sorm. 1.0.52

Serm.1.9.12

sorm.2.7.31

Carm.1.13.1:

Efod 10.53

Scrm.1.9.28

lipod.15.17

Fpod.2.14

Serm.1.1.12

Sepist.2.1.100

Carm.3.27.13

Carm. 2.48

Carm.1.13.2t

Epod. 12.25

Curnstacelo

Carmati.zo

Carm.4.11.34

Epodo.12

(arm.1.15.14

Curmbace.11)

lipod 8.9

siom.1.2.81

7 rur.som.1 28 :

(arm.1.25.1

fiprol.1 s.e

l. prodecis

carm.3.29.80

fipud ine.

Carm.1.15.4

Cismos $4.5 x$ 
prolisque novae feraci|lege marita.

Carm.Saec.19

feracis. non opinae/Sardiniae segetes feraeis,

Carm.1.31.4

Carm.3.3.41

Epod.5.55

formidulosis cum latent silvis ferae

feraeque suetae/hune vexare locum

Serm.1.8.17

ferae. nolis longa ferae bella Numantiae.

quis ferae/bellum curet Hiberiae?

ferant. quid si rubicunda benigni|corna vepres et pruna ferant. .

ferar. non usitata nee tenui ferar penna

donec cinis|imiuriosis aridus ventis ferar.

ego utrum|nave ferar magna an parva, ferar unus et idem.

ferarum. quos venerem incertam rapientis more ferarum

feras. "in silvam non ligna feras insanius.

scilicet ut plausus quos fert Agrippa feras tu,

ferat. cum ripa simul avolsos ferat Aufidus acer. insani sapiens nomen ferat, aequos iniqui, hoc age, ne mutata retrorsum te ferat aura.

ille terat pretium poenae securus, opinor.

quid ferat et quare sibi nectat uterque coronam.

quid deceat, quid non, quo virtus, quo ferat error.

Corm.2.12.I

Corm.4.5.27

Epist.1.16.9

Carm.2.20.I

Epod.1 7.34

Epist.2.2.200

Serm.1.3.109

Serm.I.10.34

Serm.2.3.185

Serm.1.1.58

Epist.1.6.15

Epist.1.18.88

Epist.2.2.17

Epist.2.2.96

Ars Pot.308

Epod.jo.1I

Epod.5.22

var.Serm.1.2.7 1

Sern.2.6.104

Serm.1.3.96

Epist.1.6.9

Epist.1.17.24

Epist.1.19.5

Epist.2.1.230

Epod.11.20

Carm.2.19.27

Epod.1.I1

Epist.1.8.17

Epist.1.13.16

Carm.2.18.27

Epod.10.2

Sorm.2.6.85

Serm.2.8.15

Epod.16.21

Epist.1.17.44

Serm.1.10.50

Epist.1.19.33

Epist.2.1.141

Serm.2.8.86

tar.Carm-3.4.10

Epist.1.17.8

sar.Corm.3.29.34

Epist.2.2.112

Epist.1.3.25

Epist.1.7.17

Cism.1.7.25

Carm.3.10.22

Carm.3.29.64

Corm 4.1 .10

Epod.15.13

Serm.2.1.18

Serm.2.2.70

Serm.2.5.13

var.Serm.2.7.34

Epist.1.7.21

Epist.1.1.4.23

Epist.1.17.20

Ars Puet. 138

Sirm.1.5.57

Carm.1.1.36

Carm.3. I I.43

Serm.2.7.99

Corm.4.5.37

Serm.2.162 
feriatos. male feriatos, Troas.. falletet

Carm.4.6.1.

feriemus. nos hunulem ferienus agnam.

ferient. inpavidum ferjent ruinae.

feriet. nec semper feriet quodcumque minabitur ascus.

Carm.2.17.32

Carm.3.3.8

Ars Pod 350

feris. quitel? cum baltu feris annoso verba palato.

feris. unquam nisi in dispar feris.

afelitum feris alitibus atque conilos homicidan lfectorem,

vis tu honine V'rbemqua feris praeponere silvis?

feris. serisque rursus occupabitur solum:

feriunt. feriuntulue summos|fulgura montis.

fero. multa fero, it placem genus irritabile vatum.

feroces. neque inbellem feroces progenerant aquilae columbam.

ferocior. duburatis morte ferocior:

ferocis. Parthos ferocis/vexet eques metuendus hasta yuandoque trahet ferocis| pr sacrum clivom . . . Sygambros:

Feronia, ora manusque tua lavimus, Feronia, lympha;

feros. qui feros cultus hominum recentum voce formasti catus visam Britannos hospitibus fetos rerum inscitia vexat indonita cervice feros?

ferox. quam rem cumque ferox navibus aut equis|mites. . gescerit. nequiguam Venctis praesidio ferox qui ferox bello tamen, inter arma non ferox ffector... primus.

ferox. iam te sequetur (curric enin ferox aetas triumphatisflue possit Roma ferox dare iura Medis

sit Merlea ferox invictarue. flebilis Ino.

ferox. urbesume gentesqui et fatium ferox

ferramenta. cras furtanenta Teanum/tolletis, fabri.

ferrata. batbarorum Claudius agmina ferrata vasto dirit impetu

ferratos. ut si solvas postquam Discordia taetral belli ferratos fustis portasulue refregic,"

ferre. ferte iugum pariter dolosi:

ninium brevis thes anowae ferre inhe rosae nondum subatia ferte iugum valet cervice,

cantabrum indoctum iuga ferte nostra

quam nec ferre predem dedecuit cloris

bene ferte magnam disce forcunam;

lecet qua firre non mollis viros?

hat mente Jaborem/ sese ferte. . . aiunt.

garrulus atcue piger scribendi fette labotem.

qui se Voltum fette negat Novionm posse minot is.

magnum adiutorem, posset qui ferte secundas.

* ut esect ofertin rui forte poetis lantiquis posset contra fastidia nostra.* L. taloz, Aule, nucesque ferre sinu laxo, donate et ludere vidi.

inlusique perles vitiosum ferre recusant corpus.

Ifum spectatoris fastidia ferre supesbi.

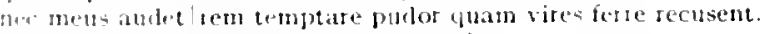

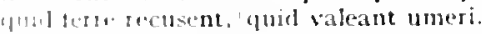

-1 cuset quic opem ferre in denithere funem:

ferrem. non ego hoc ferrem calidus iurenta consule Planco.

ferrent. quit Sophorles at Thespls at Aeschylos utile ferrent;

ferres. natplue tu pasuma moner um, ferres.

ferret. persapto belut gui hunonis sacra fenct;

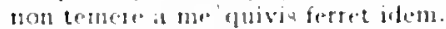

ferro. audnet civis acuisic ferrum [iacuisse ferro]. impiat sponsoa potvere duro pudete ferro.

laterite ferso et/frangere enitar. . comma

per caedis ab ipso'ducit opes animumque berto.

morataci relut ieta fersolpons

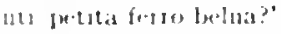

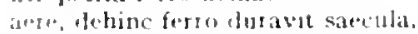

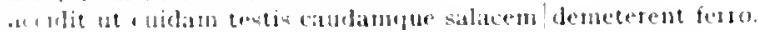

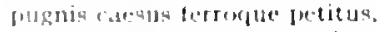

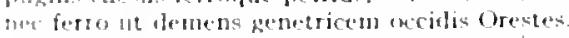

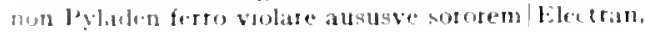

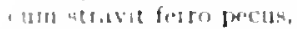

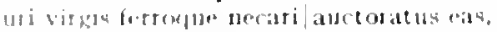

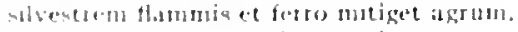

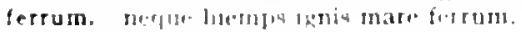

Epod.7.12

I.pod.17.I I

Sirm.2.0.92

Iipodi.16.10

Curm.2.10.11

Epist.2.2.102

Carm.4.41

Carm+1.37.29

Cirm.3.2.3

Cirm.2.34

Serm.1.5.24

Corm.1.10.2

Carm.3.4.33

Lipist.1.3.34

Carm.16.3

Curm.1.15.13

Carm.1.32.0

Curm.4.9.21

Cirm.2.5.13

Carm.3.3.44

Ars l'oet.123

Carm.1.35.10

Lipist.1.1.86

Cism.1.14.30

Serm.1.4.01

Carm.1.35.28

Corm.2.3.14

Curm.2.5. I

Corm.2.6.2

Carm.2.12.17

Corm.3.27.7.1

Ipodi 10

Sirm.1.1.31

Sirm.1.4.12

Sirm.1.6.121

Sirm.1.9.40

Serm.1.10.*0

Serm.2.3.172

Serm.2.7.108

Epist.2.1.21.5

IFist.2.1.250

Ars Pod 30

- Irs Poct.dos

Curm.3.14.27

Epist.21.10.3

Cirm.4.8.5

sirm.1.3 11

Epist 2.2 .14

conicorm.1.2.21

Carm.3.11.32

Corm.3.27.40

Carm.4.4.00

curmalos

I.ped.5.10

tipod lo.ps

Sierm 1.2..."

Sirm.1.2.00

Sorm.2.3.133

torm 2 3.130

Serm 2.3202

Serm.2.7.58

lep13t 2.2 .180

siom 1.1.39 


\section{FERRVM}

o pater et rex|Iuppiter, ut pereat positum robigine telum [? ferrum]

ferrum. audiet civis acuisse ferrum.

diffingas retusum in | Massagetas Arabasque ferrum.

usque laborantis, dun ferrum molliat ignis.

in matris iugulo ferrum tepefecit acutum?

acutum |reddere quae ferrum valet

fers. quamvis fers te nullius egentem.'

fert. quid iste fert tumultus

fert vallum et arma miles

quam pracsens Mercurius fert?

scilicet ut plausus quos fert Agrippa feras tu.

"nemon oleum fert ocius?

tamen istuc mens animusque | fert

tertile. sed non on ne mare est generosae fertile testat:

fertile. sed quae Tibur aquae fertile praefluont

fertili, anicus Aulon/fertili Bacclio

fertilibus. spargent olivetis odorem/fertilibus domino priori,

fertilis. et amicus Aulon|fertili [fertilis] Baccho minimun Falernis/invidet uvis;

fertilis. fertilis frugum pecorisque tellus

fertilis. fulgentem inperio fertilis Africae

fertis. quae vos ad caelum fertis rumore secundo.

fertur. uda Lyaeol tempora populea fertur vinxisse corona fertur Prometheus addere principi|limo coactus

fertur pudicae coniugis osculum . . ab se removisse arbiter pugnae posuisse nudo|sub pede palmam|fertur verba devolvit numerisque fertur|lege solutis,

aut fertur incerto mari.

quin per mala praeceps/fertur uti pulvis collectus turbine,

fertur quo rara securis.

Servius Oppidius . . gnatis divisse duobus/fertur

rusticus urbanum nuren mus paupere fertur/accepisse cavo,

ferula. ferula caedas meritum maiora subire/verbera

ferum. Graecia capta ferum victorem cepit

ferunt. flore, terrae quem ferunt solutac.

quamquam nec Calabrae mella ferunt apes

quando et priores hinc Lamias ferunt |denominatos

fruges et Cererem jerunt

ex hoc cgo sanus ab illis|pernicien quaecumque ferunt

grandes i hombi patinaeque grande ferunt una cum damno dedecus.

coram rege suo de paupertate tacentes/plus poscente ferent [ferunt]:

multa ferme anni venientes commoda secum

feruntur. cetera fluminis/ritu feruntur.

audebit. quaecumque... honore indigna ferentur [feruntur].|verba movere loco.

ferus. ferus et Cupido/semper ardentis acuens sagittas nemo adeo ferus est, ut non mitescere possit.

quam quo perterte iuberis/clitellas ferus inpingas

quid? siquis voltu torvo ferus et pede nudo

fervens. fervens difficili bile tumet iecur.

fervent. quaecumqne inmundis fervent adlata popinis.

ferventius. quale fuit Cassi rapido ferventius amni|ingeniun,

fervet. fervet inmensusque ruit profundo| I'indarus ore.

fervet avaritia miseroque cupidine pectus:

fervida. nec Sicana fervida|virens in Actna flamma:

fervida. fervida cluod subtilc exsurdant vina palatum.

fervidi. possent ut iuvenes visere fervidi .

fervidiore. simul calentis inverecundus deus/tervidiore nero

fervidis. si ncque fervidis/pars inclusa caloribus/ mundi

fervidis metactue fervidis/evitata rotis

fervido. stravere ventos aequore fervidoldeproeliantis.

fervidos. tum spissa ramis laurea fruidos |excludet ictus.

fervidum. pecusve Calabris ante sidus fervidum|Lucana mutet pascuis

fervidus, fervidus tecum puer et solutis|Gratiae zonis properentque.

ille graven duro terram qui vertit aratro. | perfidus hic caupo [fervidus hic campol,

cum te neque fervidus aestus|demoveat lucro

maturusne senex an adhuc florente iuventalfervidus,

fervit. fervet [fervit] inmensusque ruit profundo|Pindarus ore.
FERVIT

? var. Serm.2.1.1.3

r arm.1.2.2I

(iorm.1.35.40

Serm.1.4.20

Sierm.2.3.130

Ars l'ort.395

Lpist.1.17.22

Epod.5.3

lipod.9.13

Sirm.2.3.68

Sirm.2.3.185

Sirm.2.7.34

Epist.1.14.9

Serm.2.4.31

Curm.4.3.10

(arm.2.0.10

Carm.2.15.8

2'ar.Carm.2.6.19

Carm.Sacc.29

Carm.3.16.3I

Epist.1.10.9

Carm.1.7.23

Carm.t.10.13

Carm.3.5.41

Curm.3.20.13

Carm.t.2.J I

Epod.9.32

Serm.1.4.31

Sirm.1.7.27

Serm.2.3.I 70

Serm.2.6.80

Serm.1.3.120

Epist.2.1.15'

Carm.1.4.10

Carm.3.16.33

Carm.3.17.2

Carm.3.24.13

Sirm.1.4.130

Serm.2.2.96

int. Epist.I.I7.44

Ars Poet. 75

Carm.3.29.34

var. Rist.2.2.112

Carm.2.8.14

Epist.1.1.39

Epist.1.13.8

Epist.1.10.1 2

Carm.1.13-4

Strm.2.1.0.2

Serm.t.jo.

carm.4.2.7

Epist.1.1.3.3

Epod. 17.32

Sirm.2.8.38

Carm.4.13 213

Stpodidita

Carm.3.24.3')

Cirm 1.1.4

Carm,1.9.11)

Carm.15.)

Epod.1.27

Carm.1.30.5

sur.ticm! 1-1.29

Sirm. 1.1 .38

Ars Poel. II

2ar.c arm.t.2.7 
fervor. emplavit in dulci iuventa/fesvor

ut armel ictolaccessit fervor capiti numerusque lucernis;

Curm.1.16.24

Fescennina. Fescennina per lunc inventa licentia morem

fessas. nillitia sinul festas cohortes abdidit oppidis.

fessi. in le Ruboi fessi pervenimus,

fessis. traldilt fusis leviora tolli|Pergama Grais. frigus anabile hesis vomere tauris/pracbes

fesso. cum thbi horum sollicito damus aut fesso:

fessos. qui sulutari leqat alte fessos/corporis artus. lecsus vonnem inversum boves/collo trahentis languido

fessum. ast ubi me fessum sol acrior ire lavatum $\mid$ admonuit.

fessum. longanun frssum militia latus

fessus. pator umbras cum grege languido/rivomque fessus quaerit tandem teest ilormise viator/incipit.

festas. saeculo festas referente luces repositum Caccubum ad festas dapes

festinant. "sucla festinant, pilenta. petorrita, naves,

festinanti. (sic festinanti semper locupletior obstat).

festinantis. lacus et mare sentit amorem/festinantis en;

festinas. quamquam festinas, non est mora longa: quae laedunt oculum. festinas demere:

festinat. cuncta festinat manus. Nestor conponere litis/inter Peliden festinat et inter Atriden. lum pornas odio per vim festinat inulto. quil semper in augenda festinat ret obruitur re. irstiuat calings mulis gerulisque redrmptor. semper anl ceventum festinat

festis. qui Veitentanum festis potare diebus puret ut festis Quinquatribus olim.

vinoque diurno, placari Genius festis inpune diebua, ut festis matrona moveri iussa liebus.

festis. vel anna fertis caesa Terminalibus

festivam. inpune licebit / aestivam [festiram] sermone benigno tendere noctem.

festo. festo cuinl potius die $/$ Neptuni faciam -

festo. condita post frumenta levantes tempore festo

festos. in remoto gramine pet diea!fostos reclinatum natalis aliosbe dierum iestos albatus celebret)

festum. sive diten festum rediens advextrit annus,

festus. hic dies anno redeunte festus

hic dies vere mihi fest us atraslexipet curas:

fiotus in prati- vacat otiozolcum bove pagus.

pretur' dat beniam sommumque dies:

feta. ab atgro, raves decurrens lupa banuvinolfecaque volpes;

fetus. Fermania quos horrida parturit/fetu nutrint fot un elt altac salubres/et lovis aurat.

fi. in connitor ipse. / persta atque obdura:

6as. dum mihi thes recantatia andica opprobris

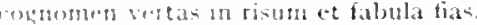

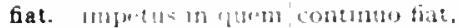

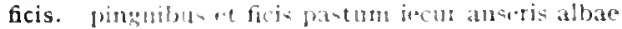

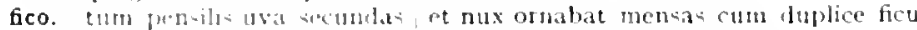
[tices]

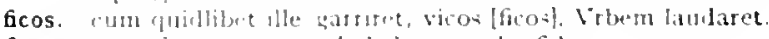

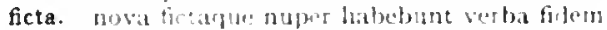

ficta voluptatis causa sint proxima bris

fictis. ribethe fictis rerum Balatsune sectumb.

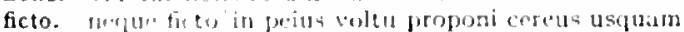

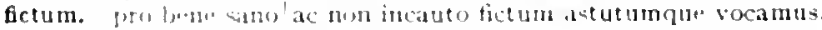

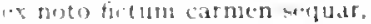

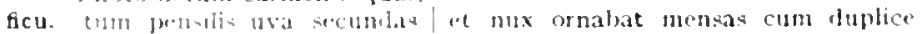
dicis

ficulnus. shith trameld cram ficulnus, indtife lignum.

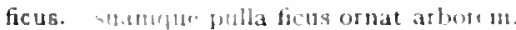

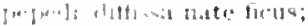

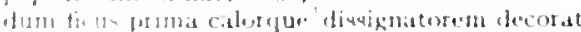

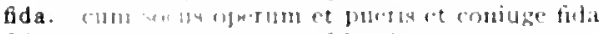

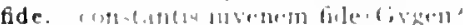

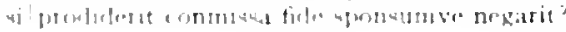

Serm.2.1.25

Epist.2.1.1.45

Curm.3-4.38

Serm.1.5.94

Carm.2.4.11

Curm.3.13.11

Epist.2.1.221

Carm.Sacc.03

Epod.2.03

Sirm.1.0.125

Carm.2.7.18

Carm.3 29.22

Serm.1.5.17

Corm.4.0.42

Epod.9.1

Epist.2.1.192

Serm.1.1.113

Epist.1.1.85

Carm.1.28.35

Epist.1.2.38

Carm.t.I1.0

Epist.1.2.12

Epist.1.2.61

Epist.1.16.08

Epist.2.2.72

Ars Poet. 18

Serm.2.3.143

F.pist.2.2.197

Ars Poet.210

Ars Poct.232

Epod.2.50

E'ar.Epist.1.5.1]

Carm.3.28. I

Esisf.2.1.1.g1

Carm.2.3.7

Serm.2.2.01

Serm.2.2.83

Curm.3.8.9

Carm.3.14.13

Carm.3.18.11

Epist.1.5.9

Curm.3.27.4

Carm.4.5.27

Carm.Suec.3!

Sorm.2.5.38

Curm.1.10.27

Epist.1.13.9

Scrm.1.2.11s

Sicrm. 2.8 .88

:'ar.Serm.2.2.122

gar.Serm.1.913

Ars Poet. 52

Ars Puet 335

Sorm. 2.8 .83

Epist.2.1.2114

Serm.1.3.1.2

irs Pore 2.41)

Scrm.2.2.122

Serint 1.8.2

lipod.1pi.te

serm 1.8.17

Esset t.7.5

fipist 2.1.14

( arm 3.7.4

serm 1305 
fide. cur tibi iunior/laesa praeniteat fide.

Carm. I.33.4 effare; iussas cum fide poenas luam.

Epod.17.37

Carm.1.I7.I 8

fide Cyllenea levare diris pectora sollicitudinibus.

fidei. quid fles,... constantis iuvenem fide [fidei]|Gygen?

fidelem. expertus fidelem|I uppiter in Ganymede flavo. unde mihi tam fortem tamque fidelem?"

fidelem. neque sic fidelem, / sic lucro aversam

fideles. ut cito dicta/percipiant animi dociles teneantque fideles;

fideli. est et fideli tuta silentio|merces:

fidelibus. seu visa est catulis cerva fidelibus quam quae sunt oculis subiecta fidelibus

fidelibus. sie desideriis icta fidelibus

fidelis. hunc medicus multum celer atque fidelis/excitat

fidelis. Flore, bono claroque fidelis amice Neroni,

fideliter. nec retinent patulae conmissa fideliter aures

fidem. heu quotiens fidem $\mid$ mutatosque deos flebit fidemque et amicos . . . regina Pecunia donat multa fidem promissa levant. nova fictaque nuper habebunt verba fidem.

fidem. auditam moderete asboribus fidem,

Fidenis. Gabiis desertior atque/Fidenis vicus;

fidens. fidens iuventus horrida bracchijs

fidens. ut penitus notum, si temptent crimina, serves | tuterisque tuo fidentem [fidens est] praesidio:

fidentem. serves/tuterisque tuo fidentem praesidio:

fidenter. It penitus notum, si temptent crimina, serves/tuterisque tuo fidentem [fidenter] praesidio:

fidentes. ne nimium pii rebusque fidentes

Fides. arcanique Fides prodiga, perlucidior vitro. incorrupta Fides nudaque Veritas te Spes et albo rara Fides colit / velata panno iam Fides et Pax et Honor Pudorque.

fides. at fides et ingeni|benigna vena est segetis certa fides meae. cum periura patris fides. culpari metuit fides. est animus tibi, sunt mores et lingua fidesque, uti mox/nulla fides damnis verisque doloribus adsit. scilicet, ut non/sit mihi prima fides

fidet. uterne/ad casus dubios fidet sibi certius? qui sibi fidet, / dux reget examen. .

fidibus. conmissi calores|Aeoliae firlibus puellae. fidibusne Latinis| Thebanos aptare modos studet auspice Musa, ac non verba sequi fidibus modulanda Latinis. Musa dedit fidibus divos puerosque deorum (sic etiam fidibus voces crevere severis)

fidibus. blandum et auritas fidibus canoris/ducere quercus. hune fidibus novis, hunc Lesbio sacrare plectro et ture et fidibus iuvat Aeoliis fidibus querentem|Sappho seu fidibus citharave Ploebi.

fidicen. quod montror digito prateremutium| Romanae fidicen lyrae: doctor argutae fidicen Thaliae hunc ego. non alio dictum prius ore, Latinus|rolgavi fidicen;

fidis. fidis enim manare poetica mella|te solum.

fidis. ille velut fidis arcana sodalibus olin' 'credebat libris

fidis. fidis oftendar medicis, irascar amicis.

fidit. nil pietis timidus navita puppibus|fidit. nec nitido fidit adultero: qui sibi fidet [fidit]. |dux reget examen.

fidos. ne fidos inter amicos $\mid$ sit

fidum. bene mutuis/fidum pectus amoribus:

fidus. quotiens bonus atque fidus|iudex honestum prartulit intili, nec verbo verbum curabis reddere fidus interpres

feres. dente si nigro fieres vel uno turpior ungui,

fieret. si volnus tibi monstrata radice vel herba|non fieret levius. natura fieret laudabile carmen an arte.

fieri. avarum 'um reto te firi.

Epod.13.9

sar Carm.3.7.4

Corm.4.4.3

Serm.2.5.102

Carm.2.4.18

irs Poct.336

Carm.3.2.25

Carm.I.I.27

Ars Poet. I 8 I

Carm.4.5.15

Serm.2.3.147

Epist.2.2.1

Epist.I.I8.70

Carm.I.5.5

Epist.I.6.36

Epist.2.2. Io

Ars Poet.52

Carm.1.24.1 4

Epist.1.11.8

Curm.3.4.50

Far. Epist.I.I 8.8 I

Epist.I.IS.8 I

var.Epist.1.18.8 I

Carm.3.3.59

Curm.1.18.16

Carm.1.24.7

Carm.1.35.21

Carm.Saec. 57

Carm.2.18.9

Carm 3.16.30

Curm 3.2459

Carm.4.5.20

Epist I. I.58

Epist.1.17.57

Epist.I.I8.1 7

Serm.2.2.108

Epist.1.19-22

Carm.4.9.I 2

Epist.1.3.12

Epist.2.2.1 43

Ars Poel.83

Ars Podt. 210

Carm.I.I 2 I

Carm.1.26.10

Carm.1.36.1

Carm.2.13.24

Curm.3.4.4

Carm 4.3 .23

Carm.40.25

Epist.1.19-33

Epist.1.19.44

Sirm 2 I. 30

Epist.I.S.9

Curm.1.4.15

Carm.324.20

arr. Epist.1 I0.22

Epist.r.524

Carm.2 2.10

Carm.4.9.40

Ars Poet.13:

Carm.2 8.3

Epist.2.2.150

lrs Poet.fos

Serm.I. I. IO4 


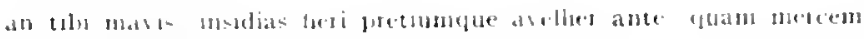
antemili?

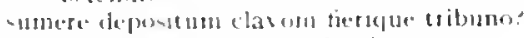

fies. tius notidiun tu quogure fontium

fiet. si fuer montum mora ianitorem fiet. abito.

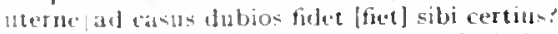

[un] fi.e: at ifwis Saturnalibus hue fugisti.

tiec aper. mulo avis. nodo saxunet, cum volet. arbor.

hic el candiclus et talos a sertice pulcher ad imos fiet

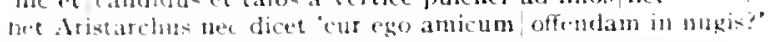

firet bonler et pronet famosar mortis amotem.

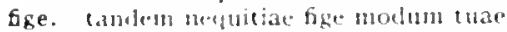

figit. si figit adamantinos summin verticibus duat Decestas davos.

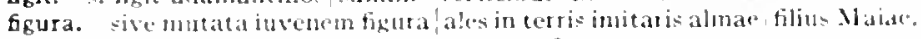

figurat. on cemertum pleri balbumque poeta figutal.

fila. dum ges el aetas et sororum hila trium patiuntur atra.

fiex. mancule neglectis urenda filix [files] innascitur agujs.

flia. Pontua pinus. silvae filia nolvilis.

filia rectiss, expugnat iuvenum domos.

terte nubet precra Coramo filia Nasicare.

flia. o mase puleta filia puleriot.

filiae. "pater. "relictum/ filiae nomen

fliam. magni ('ocentis fliam,

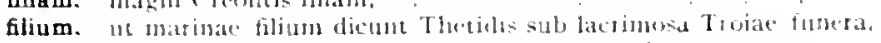

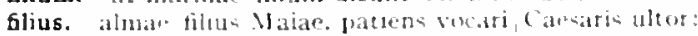

1 hurini Calaie dilias Ormyti.

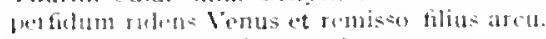

filius cuamois thetidis matimae.

non usor salvom te volt, non filius;

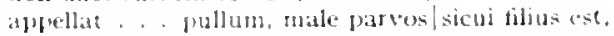

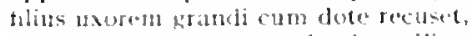

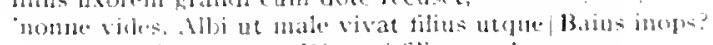

tune, Syr. I).male ant Dionysi filius, audes

fillus aut etian hace libertus ut ebibat lietes.

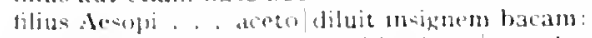

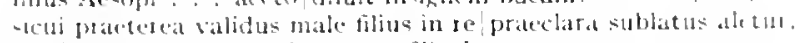

mas lusesat in campo: 'fortunave fitius' ommes.

ut siliue inmaturuz obisent.

"dienat tilius . Mlthini: si de quincunce remota cost, moncial.

flix. neglecese menda filix innation agris.

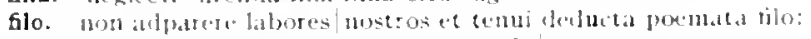

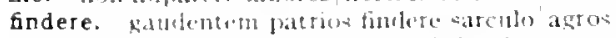

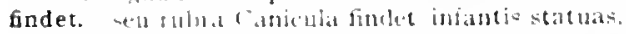

findetur. dumluo findetur mumede quadra.

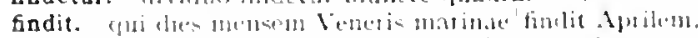

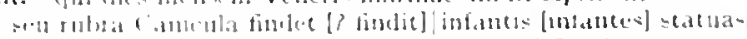

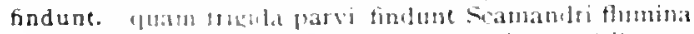

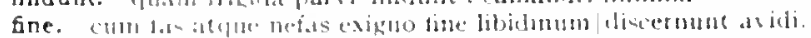

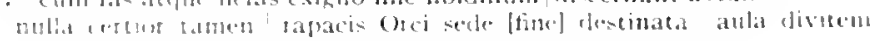

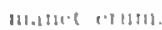

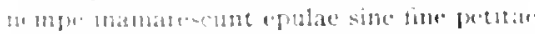

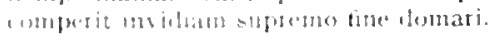

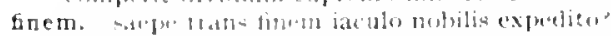

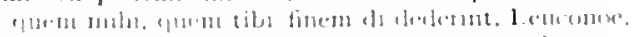

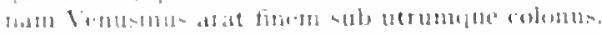

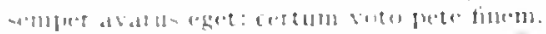

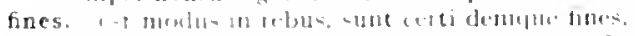

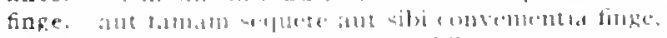

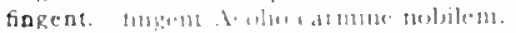

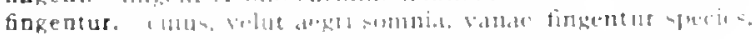

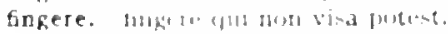

"flateldy

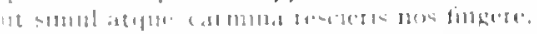

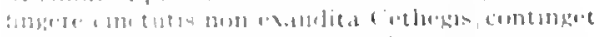

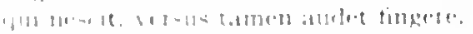

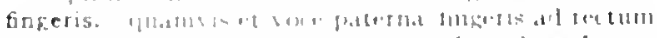

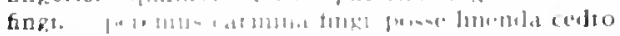

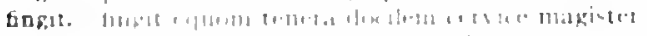

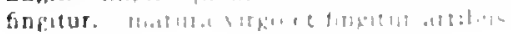

term.1.2.104

term.1.0.25

carm. 3.13.13

cium.3.1. 1.24

idr.term.2.2. Ius

Sirm.2.3.4

tierm.2.3.73

lipist.2.2.5

- Ire Poet.

les Poet.jog

(irm.3.15.2

(isrm.3.24.5

Curm.1.2.41

lipist.2.1.120

Cirm.2.3.10

iar.siom.1.3.37

carm.1.It.I?

Carm.3.15.8

sirm.2.5.65

carm. I.IO.I

Curm.3.27.35

tipod.5.6.:

Carm.1.8.1

Curm.1.2.43

(arm-3.9.14

(arm.3.27.0s

curmat.o.t)

verm.1.1.8.

serm. 1.3.4"

verm.1.4.51

Sermid.a. IOu

Serm.t.0.3k

4.Till.2.3.122

Sirm.2.3.230

Sirm.2.5.45

verm.2.(1. 10

verm.2.8.50

les Port.327

serm. 1.3 .37

lipist.2-1.225

(urm.1.1.1I

trom 2.5 .30

1.pist.1.1\%.40

cimmet t1.1\%

1 iar Sicrm. 2.5 .31

l. peat 1319

(irm.IIS II)

icer carm.z.18.30

virm.2.11\%

l. pist 2.1.1 2

(arm. 1.812

(arm.1.11:

serm.2.1.35

l. pestit.z 50

serm. I. I.I int

Irs loce i in

curm.at312

- Ir liseto

vern.ta

l.pos 1.15.5.1

1.pult.2.2.7.

Irs linet 50 "

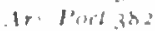

Irs l'erlatis

1.) Ninet.3.31

1 pist.1.2\%

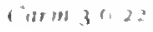


fingo. operosa parvos/carmina fingo.

finibus. finibus Atticis reddas incolumen precor

finiet. qui nigris prandia moris/finiet.

finire. sic tu sapiens finire memento/tristitiam vitacque labores

finire quaerentem labores

finire laborem /incipias, parto quod avebas,

an potius mediter finire dolores?

finiret. si tibi nulla sitim finiret copia lyniphae,

finis. Taenari/sedes Atlanteusque finis/concutitur.

quae frnis ant quod me manet stipendium?

denique sit finis quaerendi

Brundisium longae finis chartacque viaeque est.

quis esset / finis, ni sapiens . . . tolleret

excludat iurgia fuis.

Indusque repertua et longorum operum finis:

finis. corpus et ipsum animum spe finis dura ferentem

finis. age iam, meorum finis amorum.

finis. per meos finis et aprica tura/lenis incedas

quid referat intra|naturae finis viventi,

Lydorun quidquid Etruscos/incoluit finis.

finitimi. quan neche finitimi valuerunt perdere Marsi

finitimum. nec Boreae finitimum latus

finitis. finitis animum reddere amoribus.

finitis. idem finitis studis et mente recepta

finium. pater Silvane, tutor finium.

finxerunt. inopis me quodque pusilli|finxerunt anini,

finxisse. sed timui, mea ne finxisse minora putarer.

fo. nunc agilis fio et mersor civilibus undis.

brevis esse laboro, lobscurus fio;

firmandae. et tenerae nimis | mentes asperioribus iomamlae [frmandae] studiis

firmaret. donec labant is consilio patres $\mid$ firmaret auctor

firmior. non hydra secto corpore firmior.

firmo. nec firmo inveni neque naris obesae?

firmus. inbellis ac firmus parum? aut quia non firmus rectum defendis et fundus nec vendibilis nec pascere firmus.

fis. fis anus et tamen/ris formosa videri lenior ct melior fis accedente senecta?

fistula. cur pendet tacita fistula cum lya?

fistula. utcumqle dulci, Tyndari, fistula tibiae mixt is carninibus non sine fistula;

dicunt in tenero gramine pinguium/custodes ovinm carmina fistula

fit. durum: sed levius fit patientia

qui fit, Maecenas, ut nemo, . . contentus vivat.

at ni id fit, quid habet pulcri constructus acervos?

eo fit, . . cun ripa sinul avolsos ferat Anfidus acer.

inde fit, l1t raro, qui se vixisse beat $11 \mathrm{~m} /$ dicat

quo fit ut omnis | votiva pateat veluti descripta tabella sita -nis.

ut lethargicus hic cum fit pugil et medicum urget.

ex nitido fit rusticus

semel hic cessavit et, ut fit. in scalis latuit

fit Nimnermus et optivo cognomine crescit.

redit uncia, quid fit?' "semis."

sic mihi, qui multum cessat, fit Choerilus ille.

fiunt. arcana cum fiunt sacra.

fixa. ast inportunas volucris in vertice harundo terret fixa

fixae. interminato cum semel fixae cibo

fixis. armis! Herculis ad postem fixis

fixum. mater delira necabit in gelida fixum ripa febrimque reducet. in trivis fixum cum se demittit ob assen,

Flacci. Flacci|verba per attentam non ibunt Caesaris and m.

Flacco. nam siquid in Flacco viri est.

flagellis. "scetus flagellis lic triumviralibus

ille flagellis/ad mortem caesus,

flagello. Sirblimi flagello tange Chloer

ne scutica dignum horribili sectere flagello.

flagitat. perna magis et magis hillis/flagitat inmoisus refici.

flagitio. flagitio additic/damnum

Corm..42.32

Carm.1.3.0

Serm.2.4.23

(arm.1.7.J?

Carm.3.4.39

Serm.1.1.93

Serm.2.3.20.3

Fpist.2.2.1 4 h

Carm.1.34.1

Epod.17.36

Serm.1.1.92

virm.1.5.104

fierm.2.8.60

Epist.2.1.38

Ars Poet.400

Epist.2.1.1.t.

Carm.4.11.32

Carm.3.18.2

Sirm.t.1.50

Serm.1.6.2

Epod.16.3

Carm.3.2.4.38

Cirm.r.19.4

Epist.2.2.J04

lepod.2.22

Sirm.1.4.18

H.pist.1.9.8

Epist.1.1.10

Ars l'ot.26

conticurm.3.24.54

Carm.3.5.th

Carm.4.4.0 I

Expot.12.3

tipod.I.It

Serm.2.7.20

Epist.1.17.47

Cam +3.2

Epist.2.2.2II

Carm.3.19.20

Carm.I.17.I0)

Carm.t.24

Corm.t.12.10

Carm.1.24.10

Serm.1.I.I

Sirm.1.1.47

Serm.1.1.50

ierm.1.1.117

sirm.2.1.32

Sirm.2.3.30

Epist.1.7.83

Ispist.2.2.14

Epist.2.2.101

dirs loet.329

Ars Poct.357

Iipod 5.52

Sirm.1.8.7

I: pod.5.39

l. hist.I.I. 5

Serm.2.3.294

Epist.1.10.en

Sermat.is

lepod. 1512

Epod.4. I I

Sirm.1.2.4

corm.3.20.1

Sirm.1.3.110

Serm.2.+1 1

(irm.3 5.20 
flagitium. peiusque leto flagitium timet.

fagrans. cum tıbi tlagrans amor et libido.

flagrantia. Em tlagrantia detorquet ad oscula/cervicen

flagrantis. H.Igrantis atrox hora Caniculae

Carm.2.12.25

flagres. quam non amore sic meo tlagres

flagret. Jagret rumore malo cum/ hic atque ille?"

flamina. cut Berecyntiae/cessant flamina tibiae?

t?amma. cejolit tremendae/tlamma Chimacrae.

ceu flamma per taedas

nec Sicuna fervida/virens in Aetna flamma:

nam vaya per veterem dilapso flanma culinam Jolcano

Carm.3.13.9

Epod.5.8I

Serm.1.4.125

Carm.3.19.19

Carm.4.2.16

Corm.4.4.43

Epod.17.3.3

Serm.1.5.73

Carm.1.16.3

flamma. portes iambis, sive flamma|sive mari libet Hadriano. digne puer meliore tlamma.

dum flamma sine tura liquescere limine sacro/persuadere cupit.

Carm.1.27.20

Serm.1.5.99

Carm.4.11.11

flammae. sordidum flammae trepidant rotantes/vertice fumum.

flammis. nescios fari pueros Achivis|ureret thammis.

Hammis aduri Colchicis.

vilvestrem tlammis ef ferro mitiget agrum.

flatu. quem Notus invido/ thatu .. . dulci distinet a domo. nondun spissa nimis complere sedilia llatu:

flava. si flava excutitut Chloe

favae. an te genetum beati Phyllidis flavae decorne parentes:

flavam. cui thitan teligas coman

Flavi. noluit in lilavi ludum me mittere,

favo. cxperens fidelem! Iuppiter in Ganymede llavo.

favom. vidimus flarom Tiberin retortis|litore Etrusco violenter undis|ire cur timet harom Tiberim tangere?

flavos. villaque, tlavos quam Tiberis lavit.

credula nec ravos [flavos] timeant armenta leones

flebili. Hebili sponace ituenemve raptum plorat

flebilibus. tu semper urges tlebilibus modis

flebilior. nulli febilior guam tibi. Vergili.

flebilis. mult is ille bonis Rebilis occidis.

sit Medea ferox invictaque, flebilis Ino.

febiliter. Ityn bobiliter genens. Infelix avis

flebis. Hebis in solo levis angiportu

flebit. heu quotiens fiden mutatoque deos thebit t]e-bit et insigni- tota cancabitur V'rbe.

flebo. inulets ut tlebo puer?

flectantur. benusinac plectantur [tlectantur] silvac te sospite

flectere. quambis nom alius tlectere equom sciens flectere mollibus ian durum imperis:

flecti. oreus in vitum Hecti, monitoribus asper.

flectis. tu flectis amnis. tu mare barbarum.

flentibus, \#!ntibu hine Varius discedit maestus anicis.

ut ridentibus adrident, ita flentibus adtent humani voltus.

flentis. sacp potiscelidem raptam sibi tlentix.

flere. Kufu- prito capite, ut si|filin inmaturus obiaset, there.

s vis the there, dolendum est/primum ipsi tibi:

fles. quid Hew, Butiotic, quen tibi, candida. / primo restutuent vere Favonii

fleturum. ornultat He.turum caput.

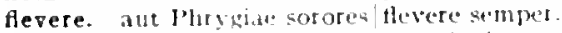

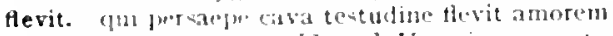

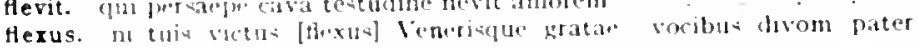
abubisinet

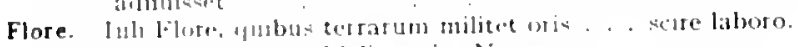

Carm.4.6.19

Epod.5.24

Epist.2.2.186

Carm.4.5.10

Ars Pocl.205

Carm.3.9.19

Carm.2.4.1.4

Carm.1.5.4

Siom. 1.72

Carm.4.4.4

Carm.1.2.13

Carm.1.8.8

Carm.2.3.18

Sar. Epod.16.3.3

Carm.4.2.21

Carm.2.99

Carm.1.24.10

Carm.t.24.9

Ars Poet.1 23

Carm.t.t2.5

Carm.1.25.10

Carm.1.5.6

Serm.2.1.46

Lipod.6.16

far.Carm.1.28.27

Cirm.3.7.25

Carm.4.1.6

Ars Poct.163

Carm.2.19.17

Serm.1.5.93

Ars loetion

IEpist.1.17.5"

term.2.8.59

irs Poct. I02

Carm.3.7.1

lipod.5.74

Carm.2.9.17

IEpot.14.11

iar Corm.4.621

Fiprel.1.3.1

IEpist 2.2.1

(carm.1.4.10

(arm.3.20.3

(arm 4.10..

irs l'oel.oz

Ars l'ued il 5

(arm.1.20.7

(iurm.2.3.1.4

Carm.38.2

carm.3.27.4

l.pist.1.5 th 
recte necne crocum floresque perambulet Attae | fabula

ut silvae foliis [? flores] pronos mutantur in annos, prima [? et prima] cadunt:

floret. et inputata floret usque vinea.

foribus. non semper idem floribus est honot/vernis

floribus. dulci digne mero non sine floribus,

nec vincire novis tempora floribus

piabant.|floribus et vino Genium memorem brevis aevi.

forum. nuper in pratis studiosa florum

flos. nec flos purpureus rosae

fluat. tibique Pactolus fluat

fluctibus. Inctantem Icariis fluctibus Africum

sic quodcumque minabitur Eurus|fluctibus Hesperiis ereptum Stygiis fluctibus Aeacun

Eois intonata fluctibus|hiems

delphinum silvis adpingit, fluctibus aprum

fluctibus. fractisque rauci fluctibus Hadriae. ut horridis utrumque verberes latus, |Auster, memento fluctibus; . rerum|fluctibus in mediis et tempestatibus Vtbis

fuctus. o navis, referent in mare te novi|fluctus.

fluctus. meliusne fluctus|ire per longos fuit

fluentem. vel quod fluentem nauseam coerceat

fluenti. tum Praenestinus salso multoque fluenti

fluere. at dixi fluere hunc lutulentum.

flueret. cum flueret lutulentus, erat quod tollere velles;

fluit. infirno capiti fluit utilis, utilis alvo.

fluitantia. siquis... caeca fluitantia sorte laboret reddere certa sibi.

fluitem. neu fluitem dubiae spe pendulus horae.'

flumen. testis Metaurum flumen et Hasdrubal|devictus ruebat|flumen ut hibernum.

aut flumen Rhenum aut plovius describitur arcus; .

flumen. dulce pellitis ovibus Galaesi|flumen . . petan

Medumque flumen gentibus additum/victis

non Tanain prope flumen orti.

mittere operto/me capite in flumen,

illud idem in rapidum flumen iaceretve cloacam? -

flumina. geluque/flumina constiterint acuto?

quo bruta tellus et vaga flumina.

qui gurges aut quae flumina lugubris/ignara belii?

decrescentia ripas|flumina praetereunt;

quan frigida parvi|findunt Scamandri fumina

flumina. 'Tantalus a labris sitiens fugientia captat /flumina'viribus uteris per clivos flumina lamas.

Humina dicere et arces/montibus inpositas

flumine. visendus ater flumine languido|Cocytos etrans

dicas imagno de flumine malim

dum flamma sine tura liquescere linine [flumine] sacro / persuadere cupit.

cunctane prae Campo et Tiberino flumine sordent?

fluminis. ut paterni|fluminis ripae simul et iocosa|redderet laudes cetera fluminis/ritu feruncur.

fluminum. rapidos morantem | fluminum lapsus celeresque ventos,

fluont. sic mihi tarda fluont ingrataque tempora

fluvii. nec fluvii strepunt|hiberna nive turgidi.

fluvis. vos laetam fluviis et nemorum cona. nunc fluviis gravem/solantis aestum.

fluvios. ut rupes fluviosque in campo obstare queratur;

ignis|per medios fluviosque ruentis:

fluvius. aut flumen Rhenum aut plovius [fluvius] describitur arcus;

fuxit. clades/in patriam populumque fluxit. ut inmerentis fluxit in terram Reni|sacer nepotibus cruor.

focalia. ponas insignia morbi.|fasciolas, cubital, focalia.

focis. quem tu fastidis, habitatum quinque focis

foco. dissolve frigus ligna super focol large reponens

focum. sacrum vetustis exstruat lignis focum .

focus. iamludum splendet focus tet tibi nunda supellex.

fodicet. laevom qui fodicet latus

foeda. at illi focda cicatrix/saetosam laevi fronten turpaverat oris.

foeda. foeda nigto simulacra fumo.
I.pist.2.1.79

3 arar.Ars Poet.6o

Epod.16.44

Carm.2.II.9

Carm.3.13.2

Carm.4.1.32

Epist.2.1.1.44

Carm.3.27.29

Carm.3.15.15

lipod. 15.20

Carm.1.1.15

Carm.1.28.26

Carm.4.8.25

Epod.2.5I

Ars Poct.zo

Carm.2.14.14

Epod.10.4

Epist.2.2.85

Carm.1.14.2

Carm.3.27.42

Epod.9.35

Serm.1.7.28

Serm.1.10.50

Serm.1.4.11

Epist.1.16.I 4

Serm.2.3.269

Epist.1.18.1 10

Carm.4.4.38

Serm, 1.7.27

Ars Poet.1 8

Carm.2.6.I I

Carm.2.9.2 $\mathrm{r}$

Carm.4.15.24

Serm.2.3. $3^{8}$

Serm.2.3.242

Carm, 1.9.4

Carm.1.34.9

Carm.2.1.33

Carm.4.7.4

Epod.13.14

Serm.1.1.69

Epist.1.13.10

Epist.2.1.252

Carm.2.14.17

Sermt1.t.55

zar.Serm. 1.5 .99

Epist.1.r.4

Carm.1.20.6

Carm.3.29.33

Carm.1.12.10

Epist.1.1.23

Carm.4.12.3

Carm.1.21.5

Carm.2.5.6

Serm.2.3.55

Serm.2.3.57

tar. Ars l'oet. 18

Carm.3.6.20

Ispod.7.19

Serm.2.3.255

Epist.1.14.2

Carm.1.0.5

IPpod.2.43

Epist.1.5.7

Epist.1.6.5 I

Serm.1.5.60

Curm.3.i.t 


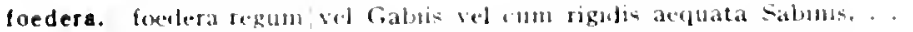
dictitet

foedere. metwens alterius viri certo fordere castitas.

foedis. disentient is condicionibus foedis

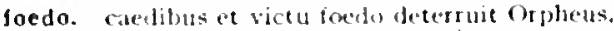

foedo. fere seriptores carmine foedol splendida facta liumet.

goedum. caputgue coeperis impexa foelum porrigime?

foedus. indigni fraternum rumpete fondas.

folia. we sivise folis [ $]$ ut folia in silvis] pronos mutantur in annos, prima catlunt :

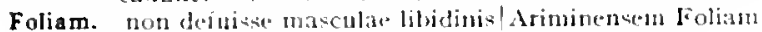

foliis. sas mobilibus repris inbourut ad rentum folis

et foliis viduaneur orni:

coliis nomus multis . . tempestas ab Eurolsternet.

Delits ormatum foliis ducem.

udos cum folis ramos urente camino. .

ac potius folits parcus vescatur amaris;

ac ne me folis ideo brevioribus ornes,

ut silva" folis pronos mutantur in annos.

folis. Ut silvate folis [silve folis] pronos mutantur in annos, prima callunt:

follibus. at tu conclusas hircinis follibus auras.

fomenta. ut lipjum pictite tabulae, fomenta podagrum.

fomenta. ut hace ingrata ventis fividat fomenta.

habes quil adsicleat. fomenta paret.

guodsi figida curatum fomenta rolinquere posses.

fons. hortus ubi et tecto vicinus iugia autrar fons

tons etiam tivo dare nomen idoneus.

atqui tetum caput loc etat. lic fons.

scribendi recte sapere est et principiuna fons.

fons. Ofons Bandusiae splentidior vitro.

fonte. hoc fonte derivatit clades

si' Graeco font e calent patce detorta.

Fonteius. Capitoque simul fontcils, ad unguem tactus bomo.

fontem. vinique tontem lactis ret ubeses/cantare tiros

fontes. fromlesque [fontesque] lymphis obstrepunt manantibus. fontes ut alliti remotos

fontibus. vest is anticum tontibus et chotis gui carut at stomachum supponete fontibus andent clusinis

fontibus. ofuate fontibus integris gaudes.

fonticulo. utum ox hoc fonticulo tantundem sumere."

fontis. pindatici fontis qui non expalluit hatsatus

fontium. fies nobilium tu guoque fontium fontium qui colat origines/ Nibusque

foramine. tibia. tenuis simplexque foramine pouch

foras. gui dicta foras pliminet.

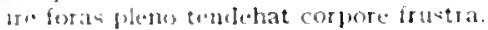

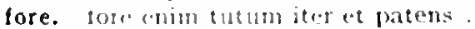

fore hutw a:moresm muthom,

Heque se fore pusthac tan ficilend alcat,

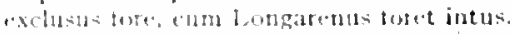

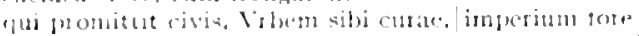

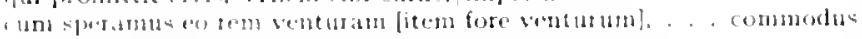

$$
\text { Hol(w) ationatis }
$$

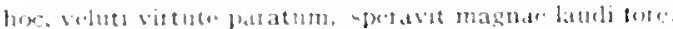

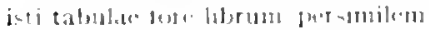

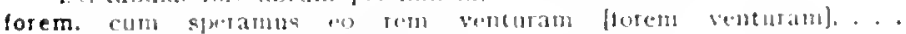

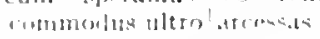

forenses. ne velut innati trivits ac pateme forenses

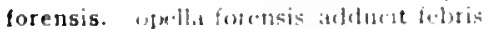

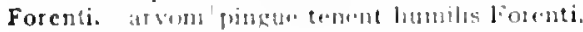

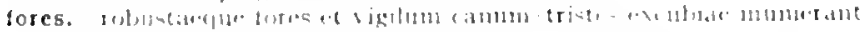

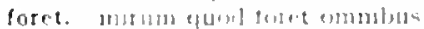

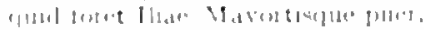

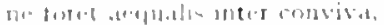

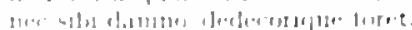

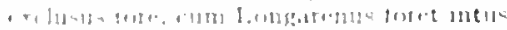

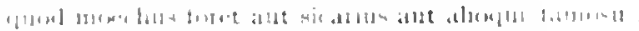

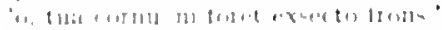

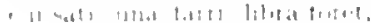

Epist.2.1.24

Carm.3.24.23

Carm.3.5.15

Ars Poet. 392

I:pist.2.1.23t

Serm.2.3.120

Esist.1.3.3.5

ifrar.Ars loetepe

1.pod.5-42

Curm.1.230

Carm.2.9.8

Corm.3.17.0

Carm.4.3.7

Sirm.1.5.81

Sirm.2.3.114

Fipist.1.19.2\%

Ars Pod luo

atar. irs Portoo

firm.1.4.10

lipist.1.2.52

lipod.15.I7

Sitm.1.1.82

Epist 1.3 .20

Serm.2.0.2

Iipist.1.16.12

Epist.1.17.45

Ars Port.3oo

Curm.3.13.1

(irm.3.0.19

Ars Por 6.53

Sirm.1.5.32

Carm.2.19.10

iur. Esod.2.27

Serm.2.1.94

Corm.3.4.25

Epist.1. 5.8

Carm.1.20.n

Serm.1.1.50

Epist.1.3.10

Carm.3 13.13

Carm.4.14.45

Irs l'oet 20.3

Lipist.1.5.25

Epist.1.7.31

Carm.3.16.7

Fpol.15.10

Serm 1-1.21

term.1.2.17

Sierm.1.0.35

odr.Epist 2 : 22"

sirm.2.3.20

irs l'ocs.

sur.lefist.2.1 221

Ars l'oet. 2.45

fisist.t.

Carm 3.4 lio

(arm.310.-

Carm.3...3 3

('armot.? 2

Lpod 12.23

Sirm.1.253

Sormen.2u;

trom $1+1$

serm 1.5.50

sorm $15 .(4)$ 
nam mihi continuo naior quaerenda foret ses ne foret his testis, post magna latere sepulcra. si foret hoc nostrum fato delapsus in aevom. piscibus atque avibus quae natura et foret actas.

t't paulum silvae super his foret.

si foret in terris, rideret Democritus,

Gracchus ut hic illi, foret huic ut Mucius ille.

nec virtute foret clarisve potentius armis|quam Iingua Latiun,

foribus. vect is et farcus oppositis foribus minacis.

haeret/invisis foribus?

foribusque repulsum |perfundit gelida.

foris. me tamen asperas|porrectum ante for is

faris. patriis interniscere petita/verba foris malis,

foris est promus, et atrum/defendens piscis hiemat mare:

forma. novit . . forma captivae doninum Tecnessae,

scribetur tibi forma loquaciter et situs agri.

forma. formaque vincas Nirea,

formabat. sic me/formabat puerun dictis

formae. ditior aut formae melioris neiat codem.

formae. nec semel offensi cedet constantia formae. ut nec pes nec caput uni/reddatur formae.

formam. di tibi formam,|di tibi divitias dederunt et genus et formam regina Pecunia donat

formandae. mentes asperioribus|formandae studiis.

formare. audes personam formare novam.

formas. inpares formas atque animos sub iuga aenea/saevo mittere emat . . si scalpra et formas non sutor,

pictor . . si velit et varias inducere plumas [formas], / undique collatis nembris

formasti. voce formasti catus et decorae/more palaestrae.

format. mox etiam pectus praeceptis format anicis, format enim natura prius nos intus ad omnem/fortunarum habitum:

formet. unde parentur opes, quid alat formetque poetam.

Formiani. mea nec Falernae / temperant vites neque Formiani / pocula colles.

Formiarum. qui Formiarum moenia dicitur/princeps ... tenuisse

formica. magni formica laboris lore trahit quodcumque potest

formidare. formidare malos fures, incendia. quamvis|nocturnos iures te formidare tepores.

formidat. iudicis argutum quae non formidat acumen: .

formidatam. et formidatam Parthis te principe Roman.

formidatus. hic classe formidatus.

formidet. cum te formidet mulier neque credat amanti

formidine. haud umquam nisera formidine privet?

sunt qui formidine nulla|imbuti spectent:

tu nihil admittes in te formidine poenae:

vertere modum formidine fustis ad bene dicendum delectandumque redacti.

caret mortis formidine et ira?

formido. deus inde ego. furum aviumque maxima formido:

formido. ad haec ego naribis uti|formido

formidolosae. formidulosis [formidolosae] cum latent silvis terae | dulci sopore languidae.

formidolosis. formidulosis [formidolosis] cum latent silvis ferae / dulci sopore languidae.

formidolosus. seu me Scorpios adspicit formidolosu:

formidulosis. formidulosis cum latent silvis terae

formis. inparibus formis deceptum te petere esto: .

formosa. vis tormosa videri

ut turpiter atrum / desinat in piscem mulier formosa superne:

formasus. et sutor bonus et solus formosus et est rex,

haberi et cupiat formosus,

formula. haec populos, haec magnos formula reges, fexcepto sapiente, tenet.

fornice. contra alius nullam nisj olenti in fornice stantem.

quidarn notus homo cum exiret fornice.

fornix. fornix tibi et uncta popina incutiunt Vrbis desideriun.

foro. in medio qui scripta foro recitest.

si plostra ducenta|concurrantque foro tria funera,

magna minorve foro si res certabicur olim:

toro niminm distare Carinas'iam grandis natu queritur.

Sorm I fresou

Serm.1.8.30

Sirm.1.10.68

Serm.2.4.45

Serm. 2.0.3

Epist.2.1.194

I.pist.2.2.80

Ars Poet. 289

Carm.3.26.8

Serm.2.3.262

Serm.2.7.90

Carm.3.10.3

serm. I Io.3o

Sirm.2.2.10

Carm 2.4.0

Epist.1.10.4

Epod. 15.22

Serm.1.4.12I

Serm.2.7.52

Epod.15.15

Ars Poel.

IEpist.1.4.0

Epist.1.0.37

Carm.3.24.54

Ars Poet. I 20

Carm.1.33.11

Sermi2.3.106

conidess Poet. 2

Carm.1.10.3

Epist.2.I.128

Ars Poet. 108

Ars Poet.307

Carm. I.zo.I I

Carm.3.17.6

Serm.1.1.33

Serm.1.1.77

Epist.1.18.93

- Ars l'oel.3ot

Epist.2 1.256

Carm.3.0.15

Serm.2.7.05

Scrm.2.7.77

Epist 1.0.4

Epist 1.10.5.3

Epist.2.1.I54

Epist 2.2.207

Serm.1.S.4

Epist.1.19.40

zar. Enod 5.55

zar Epod. 5.55

Cirm.2.17.18

Ipod.5.55

Sirm.2.2.30

Carm.1.13.3

- Irs I'oet.t

Serm. I.3.1 25

Serm.1.0.31

Sirm 2.3.45

Sirm.1.2.30

Sirm.1.2.31

List.1.19.21

Sirm.1.4.75

Serm. [.6.43

Serm.2.5.27

lipist. I. . . +18 
Fors. quem liors dicrum cumque dabit.

fors. fots et/debita iura vicesque superbite te maneant ipsun:

Corm.1.28.31 seu ratio dederit seu fors obiecerit. nulla etenim mih te fors obtulit;

Serm.1.1.2 dives, inops, Romae seu fors ita iusseril cxsul. 'o si urnam argenti fors quae mibi monstret.

Serm.1.6.5.

Serm.2.1.59

Serm.2.6.10

tar.Corm.1.28.31

Carm.2.10.3t

tar.Carm.2.16.31

rar.Carm.1.28.31

lorset. et mihi forsan [torset] tibi quod negarit potriget hora.
tarsit. fors et [fot:it] lebita iura vicesque superbae/ te maneant ipsum: ut forsit honotem/iure mihi invideat quivis,

fortasse. deus laec tortasse benigna/reducet in sedem vice. nullane habes vitia?" immo alia et fortasse minora. demens iulleio solgi. sanus fortasse tuo. fortasce trecentis/aut etian supra nummorum milibus emptum. 't fortasse cupressum|scis simulare:

fortassis. fortassis et istinclargiter abstulerit longa actas. til cum sis quod ego et fortassis nequior.

forte. ne furte credas interitura quae. . verba loquor forte quill expediat communiter aut melior pars / malis catere quaerit is laboribus; si reticulum panis venalis inter onusto/forte vehas unero, ut fosfe legentem / aut tacitum inpellat quovis sermone: liberius si/dixero quid. si forte iocosius. iban forte via sacta, sicut theus est mos. ne forte negoti incutiat tibi quid sanctarum inscitia legum: forte minus locuples uno quadrante perisiet. gaudes, si cameram percusti forte, penes te es? mulier si forte dolosa libertusve senem delirum temperet. siquis: lonte coheredum seniot nate tussiet, si nusfuam es forte vocatus ad cenam. siquid forte lateret. indice monstraret digito: ac ne forte roges. quo nue duce, quo Lare tuter: quodsi me populus Romanus foste toget. si forte subucula pexaeltrita subest tunicae i forte suas tepetitum venerit olim/grex avium plumas, forte per angustam tenuis volpecula rimam, repserat si forte in medio positornm si te forte meac gravis unet rarcima chat tae. ne forte sub ala fasciculum portes librorum, ut rusticus agnum. forte meum siquis te petcontabicur aevon: inter quae verbum emicuic si forte decorum ne forte putes une. . . Iaudare maligne: siquis forte velit puerum tibi venclese. forte sub hoc tompus castellum arestere practor/nescio quod cupiens mox ectiam, si forte vacas, sequere ec precul aurli.

if force necesse est indicio monstrate recentibus abdita rerum: henoratum si borte teponis Achillem, ne forte sorula mantentut iureni partes

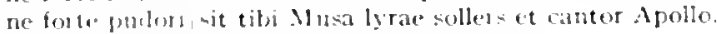

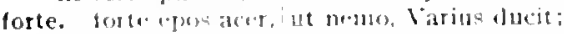

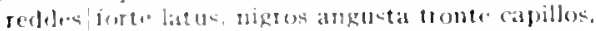

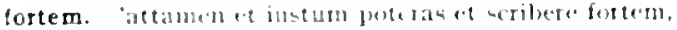

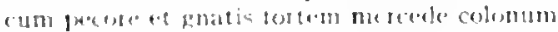

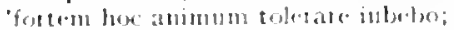

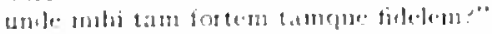

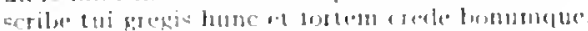

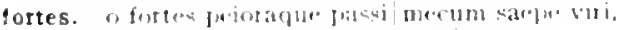

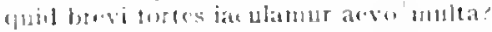

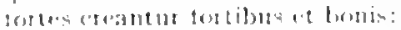

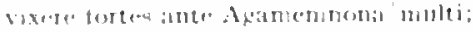

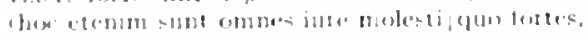

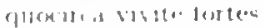

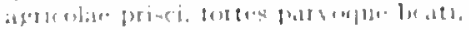

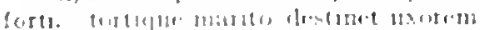

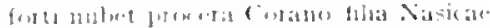

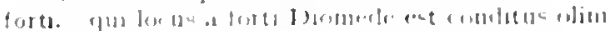

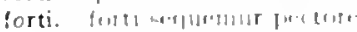

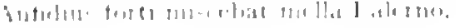

Scrm.1.6.40

ISpod 13.7

Scrm.1.3.20

Serm.1.6.9s

Epist.2.2.16.1

Ars Pod.19

Scrm.1.4.131

Serm.2.7.40

Carm.4.9.1

Epod.16.15

Serm.1.1. 48

Serm.1.3.04

Sorm.1.4.10.1

Serm.1.9.1

Serm.2.1.80

Sirm.2.3.93

Sorm.2.3.273

Serm.2.5.70

Serm.2.5.107

Serm.2.7.20

Serm.2.8.25

Epist.1.1.J3

Epist.1.1.70

l.pist.1.1.05

lipist.1.3.18

Epist.1.7.20

Epist.1.12.7

Epist.1.13.0

Epist.1.13.12

Epist.1.20.26

Epist.2.1.73

Epist.2.1.208

Epist.2.2.2

IEpist.2.2.3.1

Epist.2.2.95

Ars Poet.4S

Ars Pot.l20

Ars Poetion

Ars Port.40\%

Sirm.1.10..13

lepist 1.7.20

Serm.2.110

Sierm.2.2.115

sirm.2.5.20

Serm.2.5.102

Itpist. 1013

Carms.1. . 3.1

Corm.2.10).

Carm. 420

carm.14.25

Cerm.1

STr.2 2.135

I:pst.21.1.30

Sicm $23=10$

Sorm.25ind

Sorm. 1.5\%?

leped 1.14

arm.2.121 
fortia. fortiaque adversis opponite pectora rebus." .

Serm.2.2.136

fortibus. fortes creantur fortibus et bonis:

Carm.4.4.29

fortior, spernere fortior/quam cogere humanos in usus .

Carm.3.350

fortis. scriberis Vario fortis et hostium/victor rebus angustis animosus atque |fortis adpare: erit ille fortis|qui perfidis se credidit hostibus plus aequo liber: simplex fortisque habeatur: ille | clarus erit, fortis, iustus.'

seu quis capit acria fortis|pocula .

responsare cupidinibus, contemnere honores/tortis, . fortis omissis/hoc age deliciis.

strenuos et fortis causisque Philippus agendis/claruc. cum res deficiunt, satis inter vilia fortis:

Ennius, et sapiens et fortis et alter Homerus". .

fortis. fortis et asperas/tractare serpentes, gens, quae eremato fortis ab llio. utcumque fortis exsilis fuerpera."

fortis. super inpetrato|fortis Augusti reditu nequis... alius Lysippo duceret aera | fortis Alexandri roltum simulantia.

fortissima. at hunc liberta securi|divisit medium, fortissima Tyndaridarum.

fortiter. oquid agis? fortiter occupa|portum. nil verbi, pereas quin fortiter, addam. rebus maternis atque paternis|fortiter absumptis

fortium. tripodas praemia fortiun/Graiorum.

fortius, fortius et melius magnas plerumque secat res. spinas animone ego fortius an tulevellas agro, .

fortuitum. nec fortuitum spernere caespitem

Fortuna. hine apicem rapax|Fortuna cum stridore acuto|sustulit, Fortuna saevo laeta negotio.

Fortuna lustro prospera tertio

saeviat atque novos moveat Fortuna tumultus: dum licet ac voltum servat Fortuma benignum. ut redeat miseris, abeat Fortuna superbis.

Fortuna. "heu. Fortuna, quis est crudelior in nos te deus? "

fortuna. "quo nos cumque feret melior fortuna parente. premant Calenam falce quibus dedit|fortuna viten, Troiae renascens alite lugubri|fortuna tristi clade iterabitur occidit|spes omnis et fortuna nostri|nominis fortuna non mutat genus. in quem manca ruit semper fortuna. mox trahitur manibus regum fortuna retortis,

fortuna. quidlibet inpotens|sperare fortunaque dulci|ebria. nemo dexterius fortuna est usus. quo nihi fortunam [fortuna], si non conceditur uti? is vitium fortuna labier aequa :

Fortunae. ludumque Fortunae gravisquelprincipum amicitias ut te confestim liquidus Fortunae rivos inauret,

Fortunae. Fortunae te responsare superbae/liberum et erectum

fortunae. una|luserat in campo: 'fortunze filius" omne's. cuius fortunae, quo sit patre quove patrono." venimus ad summum fortunae,

fortunam. bene ferre magnam|disce fortunam; "laudas|fortunam et mores antiquae plebis. ut arte emendaturus fortunan; quo mihi fortunam, si non conceditur uti? ut tu fortunam, sic nos te, Celse, feremus. 'tortunan Priami cantabo et nobile bellum."

fortunarum. format enim natura prius nos intus ad omnen | fortunarum habitum:

fortunas. quo mihi fortunam [fortunas], si non conceditur uti?

fortunatam. ut fortunatam plene praestantia vitam;

fortunati. 'o fortunati mercatores' gravis armis|miles ait.

fortunatius, ingenium misera quia fortunatius arte|credic

fortunatum. si fortunatum species et gratia praestat,

fortunaverit. tu quamcumque deus tibi fortunaverit horam

fortunis. si dicentis erunt fortunis absona dicta.

Forum. inde Forum Appi|differtum nautis cauponibus atque malignis.

forum. vir bonus. omne forum quem spectat et olnne tribunal,

Carm.1.6.1

Carm.2.10.22

Carm.3.5.32

Serm.1.3.52

Serm.2.3.97

Serm.2.6. 10

Sterm.2.7.86

Epist. I.6.30

Epist.1.7.40

Epist. I. 15.39

Epist.2.1.50

Carm.1.37.26

Corm.4.4.53

Epod.I 7.52

Carm.4.2.43

Epist.2.1.24I

Serm.1.1.100

Carm.1.14.2

Serm.2.3.42

Epist.1.15.27

Carm.4.8.3

Strm.r.ro.I5

Epist.1.14.4

Carm.2.15.17

Carm.1.34.15

Carm.3.29.40

Corm.4.14.37

Serm.2.2.126

Epist.Y.I1.20

Ars Poel.20I

Serm.2.8.61

Carm.1.7.25

Curm.1.3 I.IO

Carm.3.3.02

Corm.4.4.7I

Epod.4.0

Sirm.2.7.88

Epist.2.1.191

Carm.1.37.11

Serm.1.9.45

zar. Epist. I 5.12

Episl.2.1.94

Carm.2.1.3

Epist.1.12.9

Epist. I.1.08

Serm.2.6.49

Epist.1.7.54

Epist.2.1.32

Curm.3.27.75

Sirm.2.7.23

Serm.2.8.85

Epist.1.5.12

Epist.1.8.17

Ars Poet.137

Ars Poet. 100

zar. Epist. I.5. I 2

Lpist.1.1.14

Serm.1.I. 4

Ars Poet.295

Iipist.1.0.19

Epist.1.11.22

Ars Poet.II 2

Sirm.1.5.3

Epist.1. 10 57 
forum. iurtis dugusti reditu formmege licibus orbma.

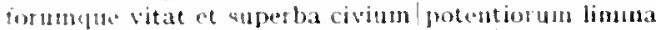

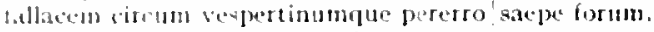
navos mane forture ef vespertinus prete tectusm.

sprom Jiffertun transire for um populumque iubebat.

form putealepe libonis mandabo siccis.

fossa. "lic foxea est infess, lic rupes maxima: segva!"

lossam. truor in fosian confusus,

fossor. gaulet invisan pepulise fosion ter perte tersam.

foveam. cautus enim metuit foveam lupus

si voluci merulis intentus decidt ancepe' in putenm foveanve.

fracta. relicta non bine parmula, cum fricta virtus.

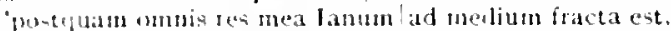

num sit quoque fracta litgoena.

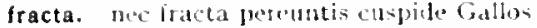

fracti. siquitl fricti [fracti] ciceris probat et nucis emptor.

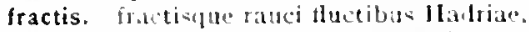

fractis. si fractis anatat exspes nuvblls, acre dato gui pingitur?

fracto. ne semel inrisus triviis atcollere curat fracts crure planum.

fractos. fratosgue remos differat;

fractus. si fratus inlabatur orbis.

miles atit. muleo ian fractus membra lidbore.

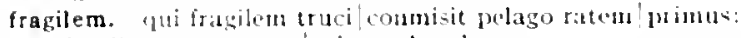
iragitemulue mecum / solvat phaselon:

fragili. irapili quactent illidere dentem

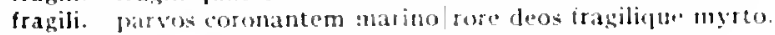

fragilis. lulius et fratgilis Pediatia furque Voranus.

fraglet. Magret [fraglet] rumere malo cum hic atclue ille?"

frangas. vale, cave ne titubes mandatadue frangas.

frangat. neth populus irefuens... improiumplle trangat;

si patinam perde litpist trangat agaso.

frangatur. iannlat trankatur, littet canis,

frangere. non egute tigris ut asperal Crateculuste leo frangere persequor: irangere enitar molo muleum amatif comua monstri.

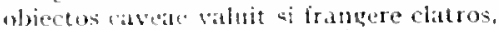

frangit. guantus altis montibus/frangit trementis ilices:

frater. dicat ()puntial frater Megillar, fuo beatus! volnere, qua pereat siagitta.

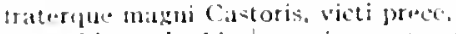

'frater" "pater' alde;| ut cuique est arotas,

whessarits cest frater. lacus Iladria.

frateg erat Ronae consulei rhetor.

quo wit amore parens, quo frater amatodus et lospes.

fraterna. incignemulue phatera fraternaque uncerm lya

fraternae. scolusguc fratermike aecis.

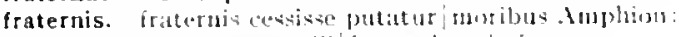

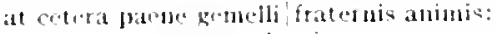

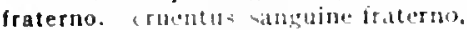

fraternum. imlight iraternum rumpere foufus

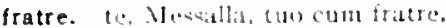

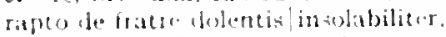

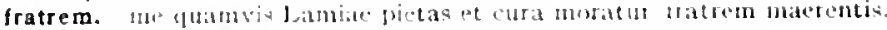

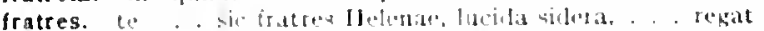

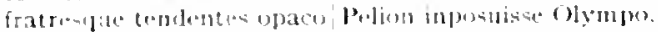

fratres. notue an isattos animi polterni:

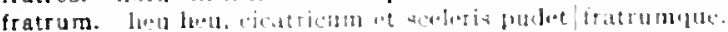

Quintu progenime Ari. par mobilo frotemm.

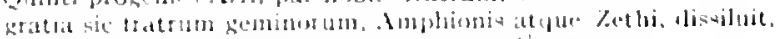

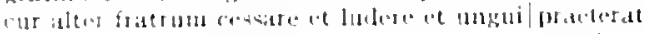

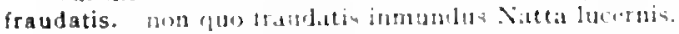

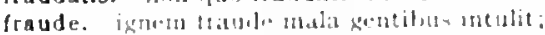

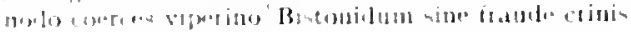

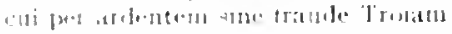

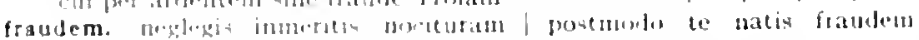

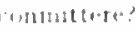

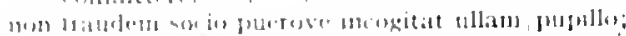

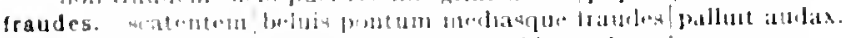

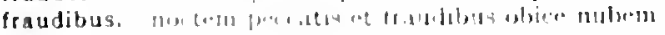

fraudis. vmlux
Carm.4.2.43

Fipod.2.7

Sorm.t.e.14t

Fipist.1.0.210

Epist.1.0.50

Epist.1.10.8

Serm.2.3.50

term.1.8.28

Carm.3.18.15

Epist.1 10.50

Irs Port.159

Carm.1.7.1

Serm.2.3.19

Serm.2.8.81

S.rm.2.1.14

irar.Ars Pocl.zal

Carm.2.14.14

Irs Pad 20

Epist.1.17.59

Epol.10.?

( $\operatorname{arm} 3.3 .7$

Sirm.1.1.5

C.urm.1.3.10

Carm 3.2.28

Sirm.2.1.77

carm.3.3.10

serm.1.5.39

sur.Serm.1.4.125

Epist.1.13.19

Carm.1.35.10

Serm.2.8.72

Serm.1.2.128

Carm.1.23.11)

Curm.3.27.47

Ars PDet 773

Epodito.s

Corm.1.27.11

Epodit7.43

Epist.1 0.54

Epist.1.18.03

Epist.2.2.87

Irs Pevel.31 3

Carm.3.21.12

Epod $7.1 \%$

Epist.1.18.4.

Epist.1 |lo.es

Sirm.2.5.10

fipist.1.3.35

Sirm 1.10.85

Epist.1.14.7

Epist.1.14.7

(ism.1.3.2

cirm.3.4.51

(i)m.2.2.13

Carm.1.35.3.1

Sirm.2.3.24;

Epist.1.18.4

I.pist 2.2.183

Serm.1.0.12.4

Carm.1.328

Carm.2.19.21"

ciormatare 41

Cifrm.t 28,31

lipest.21.122

Carm.3.27.27

Bepistit lionz

(iorm tas 


\section{FRAVDVLENTO}

fraudulento. cum populo tuce fraudulento.

fraxinos. valentium $\mid$ proceras manibus vertere fraxinos.

fraxinus. o Naiadum potens|Baccharumque valentium|proceras manibus vertere fraxinos [fraxinus].

fregerit. parentis olim siquis inpia manu|senile guttur tregerit. qui teneros caulis alieni fregerit horti

fregi. cum quo morantem saepe diem nero|fregi.

fregisse. ilium et parentis crediderim sui|fregisse corvicen

frementem. frementem| mittere equom medios per ignis.

frementis. ad hunc frementis verterunt bis mille equos

fremitum. aequoris nigri fremitum et trement is rerbere tipas.

frena. ordinesn/ rectum evaganti frena licentiae iniecit

frenato. sed equi frenato est auris in ore);

frenis. in campo doceat parenten currere irenis?

frenis. Gallica nec lupatis temperet ora frenis? iam vaga prosiliet frenis natura remotis.

hunc irenis, hunc tu conpesce catena.

frenum. inploravit opes honinis irenumique recepir. non equitem dorso, non frenum depulit ore.

frequens. neu populus frequens|'ad arma.' cessantis 'ad arma' concitet cum populus frequens laetum theatris ter crepuit sonum;

huc irequens/caementa demitit redemptor

frequentes. quid tum? venere irequentes.

frequentia. unde frequentia Mercuriale/inposuere nili cognomen compita. "

frequentis. ter die claro totiensque grata| nocte frequentis.

freta. cum fracta [freta] virtus, et minaces'turpe solum tetigere mento;

freta. an freta vicinas inter currentia turris

freta. tollere seu ponere volt freta;

pastor cum traberet per ireta navibus, Idaeis Helenen

fretis. fretis acrior Hadriae curvantis Calabros sinus. unda fretis tulit aestuosis.

freto. ut nuper, actus cum freto Neptunius

fricti. nec, siquid fricti ciceris probat et nucis emptor.

frigida. 'frigida si puerum quartana reliquerit.

frigida. Guam frigida parvi|findunt Scamandri flumina

frigida. quodsi frigida curarum fomenta relinquere posses. Gabiosque petunt et frigida rura.

frigidas. fricidas/noctes non sine multis|insomnis lacrimis

frigidior. ut nec trigidior Thraecam nec purior ambiat Hebrus.

frigido. manet sub Iove srigido

frigidum, seu mini frigidum Praeneste sen Tibur supinum

frigidus. irigidus a rostris manat per compita rumor: Empedoeles, ardentem frigidus Aetnam 'insiluit.

frigora. trigora mitescunt Zephyris. 'matutina parum cautos iam frigora mordent":

frigore. at si condoluit temptatum frigore corpus maiorum nequis amicus|frigore te feriat." . morietur trigore. si non|rettuleris pannum. quem Mandela bibit, rugosus frigore pagus,

trigoribus. quota Paeliguis caream frigoribus, taces.

frigus. dissolve frigus ligna super foco|large reponens tu frigus amabile lessis vomere tauris/pracbes. frigus quo duramque famem propellere possit. toga, quae defendere trigus|quanvis crassa queat." nec quifrigus collegit, furnos et balnea budat. gelida cum perluor unda per medium frigus. qui queritur salebras et acerbum frigus et inbris

fronde. fronde nova puerum palumbes|texere. per sacrum clivon merita decorus/tronde donec/alterutrum velox Victoria ironde coronet. fronde comas vincti cenant et carmina dictant.

frondere. dicas adductum propius frondere Tarentum.

frondes. frondesque lymplis obstrepunt manantibus,

frondes. aridas frondes hiemis sodali/dedicet Euro. spargit agrestis tibi silva frondes.

frondi. undique decerptam fronti [decerptae frondi] pratenere olivam:

frondibus. nec varis obsita frondibus sub divom rapian. bovemque disiunctum curas et strictis frondibus exples.
FRONDIS

(arm.3.3.24

Curm.3.25.16

var.Carm.3.25.15

Epod.3.2

Serm.1.3.1 I6

Carm.2.7.7

Carm.2.13.6

Carm.4.14.23

Epod.9.I 7

Curm.3.27.23

Carm.4.15.10

Epist.1.1.5. I.3

Serm.I.I.91

Carm. I.8.7

Sirm.2.7.74

lepitt. 2.03

Epist.1.10.3i

Eppist.1.10.38

Carm.1.35.14

Carm.2.17.25

Corm.3.1.34

Sirm.2.3.230

Sierm.2.3.25

Carm.Sact.24

iur.Curm.2.7.I I

Epist.1.3.4

Carm.1.3.10

Carm 1.15.1

Corm.1.33.15

Carm.2.7.10

Epod.0.7

Ars Pott.249

Serm.2.3.290

Epod.13.I3

Epist.1.3.20

Ëpist. I. I 5.9

Cirm.3.7.0

Epist. I.to. 13

Curm.1.I.25

Carm.3.+.22

Serm.2.6.50

Ars Pold.tos

Carm.4.7.9

Sirm.2.0.45

sirm.1.1.80

Serm.2.1.02

Epist.1.17.31

Epist.1.18.105

Curm.3.19.8

carm.1.9.5

Carm.3.13.10

serm. I.2.0

Sorm.1.3.14

Epist.1.11.13

Epist.1.15.5

Epist.1.17.53

Curm.3.4.I 2

Carm.4.2.30

Epist.1.18.04

Epist.2.1.110

Epist.1.10.II

coni. Epod.2.27

Carm.1.25.19

Carm-3.18.14

conicarm.1.7.7

Carm.1.18.12

Epist.I.I 4.28

Carm.t.4.58

frondis. nigrae feraci frondis in Aigito 


\section{FRONS}

frons. cuj froms turkida cormbus/primis 'o. tua cornu mioret exacto frons."

fronte. insignem tenui fronte Lycorida

iam protersa! fronte petet Lalage maritumidilecta.

fronte curvatos initatus ignis

obducta solvatur fronte senectus.

mille pedes in fronte.

reddes|forte lacus, nigros angusta fronte capillos.

frontem. sollicitam explicuere frontem.

rugis vecus/frontem senectus exaret

at slli focda cicatrix/saetosam laevi fronten turpaverat oris.

fronti. undique decerptan fronti pracponere olivam;

frontibus. pergis pugnantia secum|frontibus adversis conponete:

frontis. explicuit vino contractae seria frontis.

Nacidicue. ledis mutatac frontis.

frontis ad urbanae descendi praenia

frontium. me doctarum hederae praemia frontium:

fruar. ut porticibus sic indicijs fruar.

fruaris. exiguo gratoque fruaris tempore raptim.

fructibus. fructibus Agrippae Siculjs, quos colligis, lcci, / si recte frueris.

fructus. unde laboris/plus haurire mali est quam ax re decerpere fructus.

fruendi. di tibi divitias dederunt artemque fruendi.

frueris. fructibus Agrippae Siculis, quos colligis, Jcci, lsi recte irueris.

frugaliter. cum sne hortaretur, parce frugaliter atque/vivesem uti contentus co

fruge. si ture placaris et hornalfruge Laris

(si quercus ct ilex multa fruge pecus. multa dominum iuvet umbra? .

fruges. liberas in pomifer autuninus fruges effuclerit.

fruges et agris rettulit nbetrs

nos numerus sunus et truges consumere nat

aurea fruges|italiae pleno dofudit Cupia cormu.

frugi. parcius hic vivit: frugi dicatur:

perduci poterit tam frugi tameque pudica.

sic tibi l'enelope frugi ese:

trugi quod sit satis, hoc est. |ut vitale putes."

"ita: Davos, amicum/mancipinm lonino et frugi quod [donino? et frugi?" "quod] sit satis. hoc est, [ut vitale putes."

sum bonus et frugi.' senuit negitatque Sabellus.

et trugi castusque verecunejusque coibat.

frugibus. seu cursum mutavit inguon irugibus annis/foctus iter melus:

frugibus. infetrac et pacem et locupletern frugibus annum:

frugis. sit bona librorum et provisac trugis in annum|copia centuriac senorum agitant expertia frugis.

Irugum. prosperam frugum celegemente ponos volvere anedsis. fegtilis frugum jecorisque teilus

Irui. frui pratis ce valido mihi, / Latoe, dones

fruitur. qut nunc te puitur creflulus aurea.

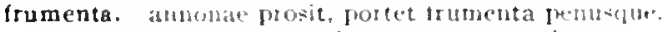
conelita post irumenta livantes temprose iesten cum segetus oceat tobj mox frumentat daturus.

frumenti. Hila is unenti en:a triverit ared centum: frumenci fuantum mett Arjea.

sifuts ard ingertem frumenti semper acervom posectus vigilet ne plus frumenti rolabbus emetat agris

repsesat in cumetam frumenti.

major utrum populum Inum"sti copia pascat.

Irusta. ariflum et ote fortus acimmin stmesaque lardiffusta dedit,

frustis. qui grantis at pomis viduas venestur avaras

frustrs. th, fruatra pius, luten non ita credutum

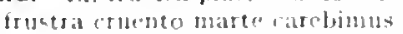

trustia per ant umnea nexentern corporibus meturnus aust tum:

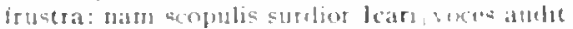

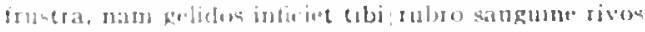

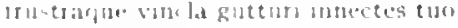

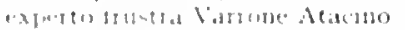

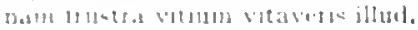

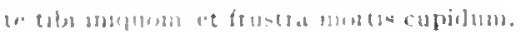

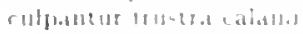

FRVSTRA

Carm.3.13.4

Serm.1.5.59

Corm.1.33.5

Carm.2.5.14

Carm.4.2.57

Epod.13.5

Serm.1.8.12

Epist.1.7.21

Carm.3.29.IP

Epod.8.4

Serm.1.5.0:

Corm.1.7.7

Serm.1.1.103

Serm.2.2.125

Scrm.2.8.s.4

Epist.1.9.I I

Corm.1.1 20

Epist.1.1.7

Epist.2.2.19.

Epist.1.12.1

Serm.1.2.79

Epist. 1.4 .7

Ispist.1.12.2

Serm.1.4.107

Carm.3.23.4

Epist.1.10.10

Corm.3.24.13

Corm.4.7.11

Corm.4.15.5

Epist.t.2.27

Epist.1.12.28

Serm.t.3.40

Setm.2.5.77

Sorm.2.5.8I

Sirm.2.7.3

coni.Serm.2.7.3

Epist.1.10.49

Ars l'oetzoz

Ars I'odel:

Epist.2.1.137

Ejist.I.18.Ino

Ars I'oet.341

Carm.4.0.30

Corm.saec.20

Carm.1.31.1;

Corm.1.5.9

Epist.1.10.72

Efist.2.1.1.40

Ejisf.2.2.101

Serm, 1.1 .45

Serm.2.3.87

Serm.2.3.11?

Epist.1.0.21

Epist. 1.7.30

Epist.1.15.1.

Serm.20.80

Epist.1.1.78

Carm.1.2.11

Carm 2.141:

Carm.2.145

Corm.3.7.21

corm 3.83.

lipod.17.72

term.1.10.96

herm.2.2.54

Sirm.2.2.04

som 23.7 


\section{FRVSTRA}

aridum et ore ferens acinum semesaque lardi|frusta [frustra] dedit. frustra: nam comes atra premit sequiturque fugacem.' ire foras pleno tendebat corpore frustra.

sudet multum frustraque laboret/ausus idem:

melius te posse negares|bis terque expertum frustra:

frustrere. 'o bone, ne te/frustrere: insanis et tu stultique prope omnes, fruticeto. celer arto latitantem fruticeto excipere aprum.

fucatus. colorque/stercore fucatus crocodili

fucis. adde huc quod mercem sine fucis gestat,

fuco. neque amissos colores/lana refert medicata fuco.

fucum. nescit Aquinatem potantia vellera fucum.

fudit, versibus alternis opprobria rustica fudit maculis, quas aut incuria fudit

tuerat. nota quae sedes fuerat columbis.

fueris. ut quocumque loco fueris vixisse libenter/te dicas:

fueris. ne fueris hic tu.

fuerit. uter aedilis fueritve/vestrum praetor,

fuerit. 'nil fuerit mi' inquit 'cum uxoribus umquam alienis.' mentio siquae|de Capitolini furtis iniecta Petilli|te coram fuerit. . fuerit Lucilius, inquam. |comis et urbanus,

fuerit limatior idem

'sic, ut mihi numquam / in vita fuerit melius.'

sed quis cenantibus una, |Fundani, pulere fuerit tibi,

fuero. non, hodie si exclusus fuero, desistam;

fuerunt. o qui conplexus et gaudia quanta fuerunt.

Fufidius. Fufidius vappae famam timet ac nebulonis,

Fufius. non magis audierit, quam Fufius ebrius olim.

fuga. innumerabilis|annorum series et fuga temporum.

non 'celeres fugae [celeris fuga] | reiectaeque retrorsum Hannibalis minae,"

quorum|piis secunda vate me datur fuga.

neque ulla est/aut magno aut parvo leti fuga:

quem paupertatis pudor et fuga, dives amicus, . . odit

des nummos, excepta nilil te si fuga laedat:

in vitium ducit culpae fuga, si caret arte.

fuga. ne nummi pereant aut puga [fuga] aut denique fama.

fugacem. nors et fugacem perseguitur virum

frustra: nan comes atra premit sequiturque fugacem.'

fugaces. eheu fugaces, Postume. Postume,/labuntur anni

fugacis. iam fulgor armorum fugacis/terret equos

fugacis/yncas et cervos cohibentis arcu.

fugae. dura fugae mala, dura belli.

fugae. 'celeres fugae/reictaeque retrorsum Hamibalis minae',

fugam. tecum Philippos et celerem fugam/sensi

miles sagittas et celerem fugam |Parthi,

quaere fugan morbi. vis recte vivere (quis non?): .

inter vina fugam Cinarae maerere protervae.

fugas. detrimenta. fugas servorum, incendia ridet,

fugat. dum rediens fugat astra Phoebus.

saepe etiam audacem fugat hoc terretque poetam.

indoctum doctumque fugat recitator acerbus; .

fugatis. pulcher fugatis|ille dies Latio tenebris.

fugato. Terenti|fabula quem miserum gnato vixisse fugato|inducit.

fugax. quid obliquo laborat|lympha fugax trepidare rivo? quantum non Plioloe fugax,

fuge. quid sit futurum cras, fuge quaerere

fuge suspicari|cuius octavom trepidavit aetas|claudere lustrum.

'faenum habet in cornu, longe fuge;

fuge magna: licet sub paupere tecto

fuge quo descenfere gestis: | non erit emisso reditus tibi.

cetera iam simul isto/cum vitjo fugere [fuge rite]?

fugere. cetera iam simul isto|cum vitio fugere?

fugere. virtus est vitium fugere et sapientia pumalstultitia caruisse.

fugerem. ut fugerem exemplis vitiorum quaeque notando.

fugeres. fugeres radice vel herba|proficiente nihil curarier: .

fugeret. Teucer Salamina patremque/cum fugeret.

fugerit. dum loquimur, fugerit invidalaetas:

nisi calsa morbi|fugerit venis et aquosus albo/corpore languor. sed tamen admiror, quo pacto iudicium illud/fugerit':

\section{FVGERIT}

war.Serm.2.6.86

Serm.2.7.II 5

Epist.1.7.31

Ars Pot.241

Ars Poel.440

Serm.2.3.32

Carm.3.I2.II

Epod.12.I1

Serm.1.2.83

Carm.3.5.28

Epist.1.10.27

Epist.2.1.146

Ars Poet $35^{2}$

Carm.1.2.10

Epist.1.11.24

Epist.1.6.40

Serm.2.3.I80

Serm.1.2.57

Sermi.1.4.95

Serm.1.10.64

Serm.1.10.65

Serm.2.8.4

Serm.2.8.19

Serm. I.9.58

Serm.I.5.43

Serm.1.2.I2

Serm.2.3.60

Carm.3.30.5

nar.Carm.4.8.15

Épod. 10.60

Sirm.2.6.95

Epist.1.18.24

Epist.2.2.10

Ars l'oel.31

gor.Serm.1.2.133

Carm.3.2.14

Serm.2.7.115

Carm.2.14.I

Carm.2.1.19

Carm.4.0.33

Carm.2.13.28

Carm.4.8.15

Carm.2.7.9

Carm.2.13.17

Epist.1.6.29

Epist.1.7.28

Epist.2.1.12 I

Carm.3.21.24

Epist.2.1.182

Ars Poct.474

Carm.4.4.39

Serm.1.2.2I

Carm.2.3.12

Carm.2.5.17

Carm.1.9.13

Carm.2.4.22

Serm.1.4.34

Epist.1.10.32

Epist.1.20.5

iar. Epist.2.2.20t

Epist.2.2.200

Epist.1.1.41

Serm.1.4.100

Epist.2.2.150

Carm.1.7.22

Carm.I.II.7

Carm.2.2.15

Serm.I.4.100 


\section{FVGERIT}

i vafor unus et alter insibatorem praeroso fugerit bamo.

serptimus octavo propior ian fugerit annus,

fugi. "nee furcum feci nec fugi," si milii dicat/servos:

fugiam. nec sequar aut fugiam quac tiligit ipse vel odit:

quac nocucre sequar, fugiam quae profore credam;

fugienda. tu si molo recte dispensise velis ac non fugienda peendis | inmiscre.

divielit ut bumas diversio, lugienda petendis;

fugiendum. discincta tunica fugiendum est et pedte nudo.

fugiens. fugiens hic decidit acten praedonum jn turbam.

satep velut quilcurrebat fugiens hostem.

mer mart pauperien fugiens, per saxa. per igniki:

sic "go, matoris fugiens opprobria culpae.

fugiens. quate porta fugiens eburna|somnium dur it? quot fugiens semel hora vexit.

fugient. cuncta manus avidas tugient heredis

vesamun tetigisse tinent fuginnque [fugientutue] poetam qui sapiunt;

fugiente. nec rapidum fugiente solem. linevon bucolen= curru fugiente rapotet.

fugienie. spernit humum fugiente penna.

fugientes. arvos, ne te conpilant fugientes.

fugientia. "Tatutalus a labris sitiens fugientia captat/fumina" กam transvolut in medio posita et lugientia captat."

fugientis. per aluertum fugientis agitato g'rege cervos iaculari

fugientum. latum, Xympharum fugientum anator,

fugies. sublimi fugies mollis andelitu. dura post paulo fugies inatudax/proclia raptor. ant fugies licam aut vinctus mitteris lerdam

fugimus. at nos virtutes ipaso invertimus atque, smontum furimus [fuginus] bas incrustate.

quem now sic luginus ulti.

fugio. fagio canpum lusumque trigonem.

fugis. o ego non tolix, quam tu fugis.

aterbus, oflisti et fugis ut Rusonum debitor aeris.

cum nagno hlateras clamore fugiselue.

fugisset. togrtbat denique, cur umquan fugisset.

fugisti. at igsis Siturnalubus huc fugisti.

fugit. fugit fetro levis imentas

Jagnesam Ilipgolyten dum fugit abstinens.

hic tugit onnja insidiats

unde Superbus Tarquiniss regno puisus tugut.

fugit inprobus ac me, sub culcto linquit

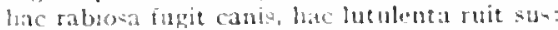

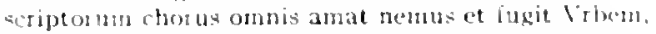

decreta petit [tugit] loca, balnea sitiat.

fugit. me silva lupus in Sabina. . . fogit inconemi

mullum satevat captat Proserpina fugit:

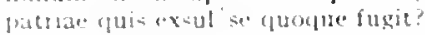

huc Guirints, Marti-cefuis Acheronta tugit.

reno fuglt vornt, hed.

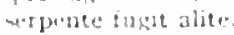

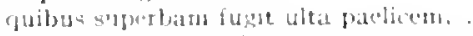

dux fuget untes masiblas

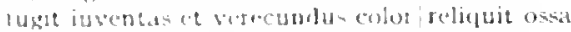

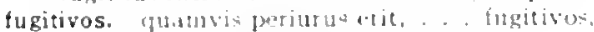

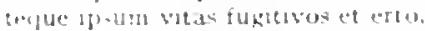

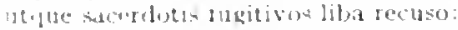

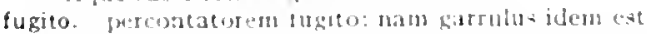

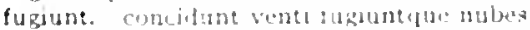

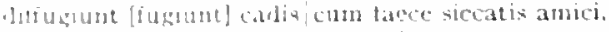

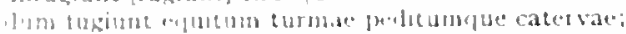

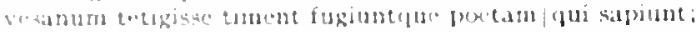

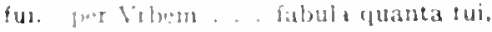

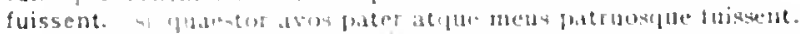

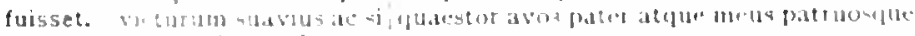

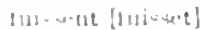

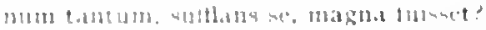

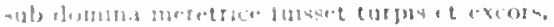

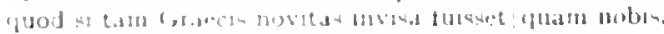

FVISSET

Serm.2.5.25

iorm 2.t. 40

IEpist.1.16.46

I.pist.1.1.72

Epist.1.8.1]

Serm.1.2.75

Serm.1.3.114

Sirm.1.2.132

irrm.1.2.\$2

Sorm.1.3.10

Iipist.1.1.40

lepist 1.0.10

('arm.3.27.41

Carm.3.29.48

(arm.t.7.19

iar.Ars Poet. 455

Cirm.2.9.12

fipist.1.10.7

Curm.3.2.2.

Sorm. 1. 18

Sirm.1.1.68

Serm.1.2.108

cirm.3.12.1u

Carm.3.18.1

(itrm.1.15.3 I

Curm.3.20.3

Ifpist. 20.13

: ar.Sorm.1.350

herm.2.8.93

sirm.1.0.120

I.pold.12.25

Sorm.1.3.se

serm.2.7.35

sermi.5.06

Sirm.2.3.5

Corm.2.I1.5

Carm.3.7.1s

Sorm 1.3.5s

ferm.10.13

Sirm.1.9.73

Rpist.2.2.75

Epist.2.2.77

par. Ars Port.zos

(arm.1 22.12

(")rm.I.2S.24

(arm.2.10.211

(arm-3.3.14)

(is) $11.13 .1 \%$

IProd.3.1.

lipod.5.1.3

I:Pud.o.8

lipod.17.21

Seren 2.5 .10

Serm.2.7.113

Epist a 10.J"

lipist.1.18.00

(irm. I. I 230

of Corm.1.35.20)

l.plas. I 1 . Ion

fos I'ued. 155

lopod.u 1.8

Sirm 10.131

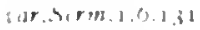

sirm.2.3.317

lifist.1.2.25

l.p.5. 1.1$) 1$ 
fuit. periurum fuit in parentem / splendide mendax qualis aut Nireus fuit aut aquosa|raptis ab Ida. melinsne tuctus|ire per longos fuit "quae mens est hodic, cur eadem non puero fuit neque hic lupis mos nec fuit leonibus nil acquale homini fuit illi: nil tuit unquam/sic inpar sibi. ut abortivos fuit olim/Sisyphus; nam fuit ante Helenam cunnus taeterima belli|causa. nam fuit hoc vitiosus: nec quod avos tibi maternus fuit atque paternus

Laevinum. Valeri genus, unde Superbus, Tarquinius regno pulsus fugit [finit], causa fuit pater his. si praeco parvas aut, ut tuit ipse, coactor/mercedes sequerer; ira fuit capitalis, ut ultima divideret mors. quod virtus in utroque] summa fuit; quale fuit Cassi rapido ferventius ammi|ingenium. Marius cum praecipitat se, /cerritus fuit? leni fuit Austro/captus,

cui pulcrum fuit in medios dormire dies

cui potior patria fuit interdicta voluptas.

Romae dulce diu fuit et sollemne reclusa|mane domo vigilare.

fuit intactis quoque cura|condicione super communi. gratus. Nlexandro regi nagno fuit ille|Choerilus.

fuit hatd ignobilis Argis,

"pictoribus atque poetis /quidlibet audendi semper fuit aequa potestas." fuit haec sapientia quondam | publica privatis secernere.

fulgebat. nox erat et caelo fulgebat Luna sereno

fulgens. fulgens contremuit domus | Saturni veteris:

fulgens. stet Capitolium|fulgens

fulgent. neque certa fulgent/sidera nautis,

fulgente. augur et fulgente decorus arcu|Phoebus sed fulgente trahit constrictos Glotia curru

fulgentem. Eulgentem imperio fertilis Africae|fallit

fulgentia. molli, Plance. mero, scu te fulgentia signis|castra tenent

fulgentis. dicere lucidum|fulgentis oculos

fulgentis. fulgentisque tenet Cycladas

fulges. qua crinis religata fulges.

fulget. Virtus, repulsae nescia sordidac, intaninatis fulget honoribur

fulgor. iam fulgor armorum fugacis/terret equos

fulgore. urit enim fulgore suo qui praegtawat artes/infra se positas: non fumun ex fulgore, sed ex fumo dare lucen/cogitat, .

fulgoribus. cum stupet insanis acies fulgoribus

fulgura. feriuntque summos/fulgura mont is.

fulmina. per nostrum patimur scelus/iracunda loven ponere sulmina. tu parum castis inimica mittes/fulmina lucis. spectandus in certamine Martio [inter fulmina Martia]

fulminantis. nec fulminantis magna manus lovis:

fulmine. fulmine sustulerit caduco maeretque partus fulmine luridum|missos ad Orcum;

fulmineo. permmpere amat saxa potentius|ictu fulninco:

fulminis. qualem ministrum fulminis alitem,

fulta. ne si facies, ut saepe. rlecora|molli fulta pede est, emptoren inducat hiantern,

fultum. illum| balbutit scaurum pravis fultum male talis.

fultura. ni cibus atque ingens accedit stomacho fultura ruenti.

fulvae. fulvae matris ab ubere/iam lacte depulsum

Fulvi. cum Fulvi Rutubaequc . . miror|proelia rubrica picta

fulvos. 'qua notan duxit, niveus videri, /cetera fulvos. nam qualis aut Molossus aut fulyos Lacon,

fumante. nil ego, si ducor libo fumante:

fumat. vetus ara multolfumat odore.

fumo. Foeda nigro simulacra fumo.

lactimoso non sine fumo,

rectius Albanam fumo duraveris uvam.

non fumum ex fulgore. sed ex fumo dare lucem /cogitat.

fumosae. quicquam practer holus fumosac cum pede pernae.

fumum. amphorae fumum bibere institutac|consule Tullo.

Carm.3.11.34

Carm.3.20.15

Curm.3.27.43

Carm.4.10.7

Fpod.7.11

Serm. I.3.9

Sirm.1.3.18

Serm.1.3.10

Serm.1.3.107

Sirm. I.4.0

Sirm. I.6.3

var.Serm. 1.0 .13

Serm.1.6.7 I

Serm. I.0.86

Sirm.1.7.13

Sirm.1.7.15

Serm.1.10.62

Serm.2.3.278

Serm-2.8.0

Epist.1.2.30

Epist.1.0.04

Eipist.2.1.103

Epist.2.1.151

Epist.2.1.232

Epist.2.2.128

Ars Poet.ro

Ars Port. 396

Epod.15.I

Carm.2.12.8

Carm.3.3.43

Carm.2.16.3

Carm.Satcol

Sirm. 10.03

Carm.3.16.31

Carm.1.7.19

Carm.2.12.15

Carm.3.28.14

Carm.1.11.5

Carm.3.2.18

Carm.2.1.19

Epist.2.1.13

Ars Poet. 43

Sirm.2.2.5

Carm.2.10.I 2

Carm.1.3.40

Carm.1.12.60

coni.Carm.4.14.17

Corm.3.3.6

Carm.3.4.44

Carm.3.4.74

cram-3.I6.I I

Carm.4.4.I

Serm.t.2.85

Sirm.1.3.48

S.rm.2.3 I54

Cirm.4.4.14

Sirm.2.7.90

Carm.t. 2.00

ispoll.0.5

Serm.2.7.102

Curm.3.1s.s

Carm-3.0.4

Sirm.t.5.80

Serm.2.4.72

lors Pel. 43

Serm.2.2.11?

Carm.3.8. I I 


\section{FVM VM}

mirari beatae/fumum et opes strepitumgale Ronae. sordicum Hammat trepidant totantes/vertice fumtum. verterat in fumum et cincrem.

non funum ex fulgore, sed ex fumo dare lucem/cogitat,

funalia. hic, hic ponite lucidalfunalia

functoa. virtute functos more patrum duces.. cancinus.

functum. hic levare functum pauperen laboribus

functus. at non ter aevo functus... senex.

spectator functusque sacris et potus et exlex.

Fundani. comis garrire libeljos/unus vivorum, Fundani: sed quis cenantibus una. Fundani, julcre fuerit tibi,

fundata. guorum|conspicitur niticlis fundata pecunia villis.

funde. funde capacibus lugguenta de conchis.

fundens. quid orat de patera novom!fundens liquorem?

fundere. ac nisi mutatum parcit defundere [fundere] vinum

fundet. fundet opes Latiunque beabit divite lingua:

fundi. arat Falerni mille furdi iugera

ex parke tua seu fundi sive domus sit emptor.

decisis humilem pennis inopemulue paternilet laris et fundi.

fundis. "quid obseratis auribus fundis preces?

funditus. causae, cur perirent | funditus

fundo. inane lymphac|dolium fundo pereunt is imo

Fundos. Fundos Aufidio Lusco practore libencer|linquimus,

fundum. qui patrium mimae donat fundumque Larenque.

fundus. sacsa patupertas et avitus aptoleum lare fundus. non verberatae grandine vincal fundusque mendax quascumclue feret cultus tibi fundus honorey non donus et fundus, non acris acervos et auri ne perconteris, fundus meus, optine Quinti.|arvo pascat erum et fundus nec vendibilis nec pascete firmus"

fune. qui iam contento, iam laxo func laborat."

funebre. ira truces inimicitias et funcbre bellun.

funebris. iubet cupressos funcbris . . aturi

funem. tortun digna sequi potius quam ducere funem. ille per extrntum futen mihi posse videtur]ire poeta, si curet ruis opentu ferre et demitere funem:

funera. nixta senum ac iuvenum densentur furera. si plocera riscenta|concurrantelte toro tria funera, uristia robustis iuctantur funcra plaustris. .

funera. sub lacrimosa Troiaeffunera. cuanta moves funera Dardana / genti son parentes funera falliae

funeratus. prope funcratus arboris ictu.

funere. aboint inani funere veniae

ut qui conducti plorant in funere dicunt

funeri. maturo propior desine funcri|inter ludere virginew

funeribus. sujerlos!vertere funeribus trumphos:

funesto. cur mo funesto properent arcere veterno:

fungar. crge fungar vice cotis.

fungi. Inumete clutu fungi propioris crosel anici:

fungis. fratconilus optima fungis/natura est;

fungitur. noc fum verniliter ipsis fungitur officis,

funibus. ac sinc tunibus|vix clurare carinae| possnt impriosius|aequor? Jubericis perduste funibus latus

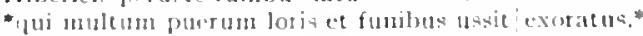

funis. ne curtente retro funis eat iota

funus. avidos vicionu funns 12 aegros/exanituat

funus. tuntes ci inpertio liatabat

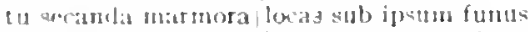

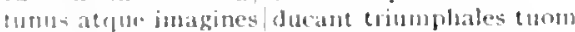

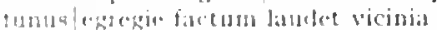

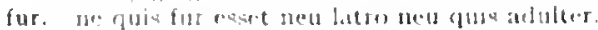

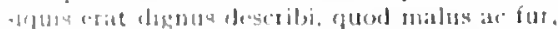

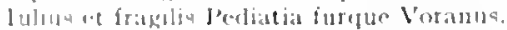

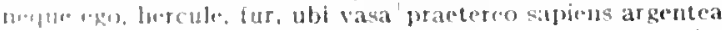

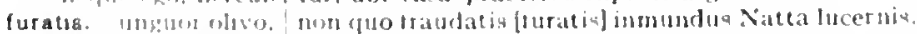

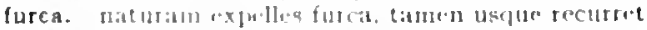

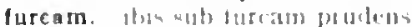

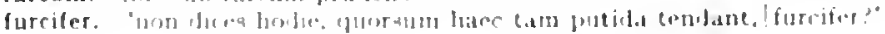

FVRCIFER

Corm.3.20.12

Corm.4.11.52

Epist.1.15.4I

Ars J'ort. 43

Carm.3.26.7

Corm.4.15.20

Carm.2.18.38

Corm.2.9.13

Ars roel.224

Serm.1.10.42

Serm.2.8.19

Epist.1.15.4t

Carm.2.7.22

Carm.1.31.3

rar.Sirm.2.2.5s

lipist.2.2.12I

Epod.4.13

Serm.2.5.ro8

Epist.2.2.51

Epod. 7.53

Carm.1.16.20

Carm.3.11.27

Sirm.1.5.34

Serm.1.2.50

Carm.1.12.44

Carm.3.1.30

Serm.2 5.13

Epist.1.2.47

Epist.1.10.1

Epist.1.17.47

Sirm.2.7.20

Epist.1.19.49

Epod.5.13

Epist.1.10.48

Epist.2.1.210

Ars Pod.401

Curm.1.28.19

Sorm. 1.6.43

Epist.2.2.74

Carm.1.8.15

Corm.1.15.10

Carm.4.14.49

Carm.3.8.7

Carm.2.20.21

Ars I'oct.43I

Cirm.3.15.4

Carm.1.35.4

Epist.1.8.10

drs Port.3os

Epist.1.9.5

Sirm.2.4.20

Sicrm.2.0.100

Carm.1.14.6

Lipod.4.3

Serm.1.10."5

Carm.310.10

Serm.1.1.120

Carm.1.37.8

Carm.2.18.18

lipod 8.1 I

Serm.2 5.105

ierm.1.310\%

Serm.1.4.3

Serm.1.8.39

Serm 2.7 .72

1ur.cerm. J 012 ?

I.pist 1, 10.2.1

sirm.2.7.06

Serm 27.22 
furem. idem si clamet furem, neget esse pudicum.

furens. sive puer furens|inpressit memorem dente labris notam.

furens. nec Sicana fervida|virens [furens] in Aetna flamma;

furentem. me... in celeres iambos/misit furentem.

Neptunum procul ex terra spectare furentem.' .

furenti. dominoque furenti|conmittes rem omnem

furere. recepto/dulce mihi furere est amico.

ex quo destiti|Inachia furere

primum nam inquiram, quid sit furere:

fures. furesque feraeque suetae/hunc rexare locum

fures. formidare malos fures, incendia, servos. nam fures dextra coercet

Furiae. dant alios Furiae torvo spectacula Marti.

furiale. furiale centum $\mid$ muniant angues caput eius

Furiam. socando/hanc Furiam, hunc aliud,

furiare. quae solet matres furiare equorum,

Furiarum. hotruerim roces Furiarum et facta duarum

furibundus. cum semel accepit Solem furibundus acutum?

furibus. et dominum fallunt et prosunt furibus.

Furiis. ac non ante malis dementem actum Furis

furimus. sincerum furimus vas incrustare.

furiosa. otium bello furiosa Thrace,

sibi tunc furiosa videtur?"

furiose. 'nempe tuo, furiose?' 'meo, sed non furiosus.'

furiosius. quanto hoc furiosius atque/maius peccatum est:

furiosus. 'nempe tuo, furiose?' "meo, sed non furiosus.' qui sceleratus, et furiosus erit:

furis. 'num furis? an prudens ludis me obscura canendo?' cum magno blateras clamore fugisque [furisque]

furit, ecce furit, te reperire atrox, |Tydides

iam Procyon furit

hac rabiosa fugit [furit] canis, hac lutulenta ruit sus:

certe furit ac velut ursi's,

Furius. pingui tentus omaso|Furius "hibernas cana nive conspuet Alpis."

Furni. ras, Bibule et Servi, simul his te, candide Furni,

furno. omn: /gestiet a furno redeuntis scire lacuque

furnos. nec quilfrigus collegit, furnos et balnea laudat.

Furor. nocturnus occurram Furor

furor. non furor civilis aut vis exiget otium,

furorne caecos an rapit vis acrior

ira furor brevis est:

qui minus argutos vexat furor iste potas?

furore. pietasque' dixit | victa furore.

furorem. sed minuit furorem/vix una sospes navis ab ignibus

furores. "mille puellarum, puerorum nille furores" -

furta. cum dicas esse paris res/furta latrociniis

puer unctis/tractavit calicem manibus, dum furta ligurrit.

furtim. umor et in genas furtim labitur arguens,

furtin defossa timidum deponere terra?

abdiderint furtim terris

dicitur ex collo furtim carpsisse coronas.

nunc in Aristippi furtim praecepta relabor

et mala perrumpet furtim fastidia victrix.

furtis. mentio siquae/de Capitolini furtis iniecta Petilli quid refert, morbo an furtis pereamque rapinis?"

furtiva. sub notem qui puer uvam/furtiva mutat strigili:

furtivae. ut vinosa glomus furtivae $\dagger$ Pirria lanae.

furtivis. moveat conicula risum furtivis nudata coloribus,

furto. callidum. quidquid placuit, iocosolcondere furto.

verum ubi oves furto, morbo periere capeliae,

furtum. quid taciam, si furtum fecerit

'nec furtum feci nec fugi,' si mili dicat/servos:

furum. deus inde ego, furum aviumque maxima fol tuido:

furvae. quam paene furvae regna Proserpinae

Fusce. nec venenatis gravida sagittis, / Fusce, pharecra,

Fuscum. urbis anatorem Fuscum salvere iubemus|ruris amatores.

Fuscus. ecce/Fuscus Aristius occurrit,

Fuscus et haec utinam Viscorum laudet nterque

fuscus. propedit fuscus Hydaspecl Caccuha vina ferens.
Epist.1.16.36

Carm.1.13.11

var.Epod.17.33

Carm.1.16.25

Epist.1.11.10

Serm.2.7.66

Carm.2 7.28

Epod.1 1.6

Serm.2.3.4I

Serm.1.8.17

Serm.1.1.77

Serm.1.8.4

Carm.1.28.17

Carm.3.11.17

Serm.2.3.14I

Carm.1.25.14

Serm.1.8.45

Epis!.1.10.17

Epist.1.6.46

Serm.2.3.135

Serm.1.3.56

Carm.2.16.5

Serm.2.3.304

Strm.2.3.207

Serm.1.3.83

Scrm.2.3.207

Serm.2.3.222

Serm.2.5.58

var.Serm.2.7.35

Carm.1.15.27

Carm.3.29.18

var.Epist.2.2.75

Ars Poel. 472

Serm.2.5.41

Serm.1.10.86

Serm.1.4.37

Epist.1.11.13

Epod.5.92

Carm.4.15.17

Epod.7.13

Epist.1.2.62

Enist.2.2.00

Carm.3.27.30

Carm.1.37.12

Sirm.2.3.325

Serm.I.3.I 22

Serm.2.4.79

Carm.1.13.7

Sirm.1.1.42

Serm.1.8.43

Serm.2.3.25"

Epist.I.I.18

Epist.1.10.25

Serm. I.4.94

Serm.2.3.157

serm.2.7.110

fipist.I.13.14

Epist.1.3.20

Carm.1. I0.S

Epist.1.7.80

Sirm.1.3.94

Epist.1.16.96

Serm.1.8.3

Carm.2.13.2I

Carm.1.22.t

Epist.1.10.1

term.1.9.6 J

Sirm.1.10.8.3

Serm.2.8. I 
Fusidius. Fufidiu-[Fusidus] vappare famam timet ac nebulonia.

fuste. quos tu nisi iuste corces.

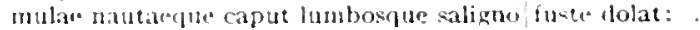

tirm. I-3.1.3.t

porrectus vigiled cum longo fuste.

fustibus. unguilus ot pugnis, dein fustimas atque ita porro pugnabant irmis

fustis. vedere mofum formidine fustis ad bere dicendun delectandumque redarti.

fustis. matris ad arbitriun recisos/portare fustis,

fusum. harunde campis atque Xeptuno super|tusum est Latini sanguinis. quid sculpum infabre, quid fusum elurius esset.

Futidius. Fufictue [lutidius] vappae famam tincet ae mebulenis.

futuo. nec vertert, me, dun futmo, vir rure recurat.

futura. leterior post partum carne futura.

futuram. ambiguan tellure nova Salamina futuran.

futuri. putens tuturi tomporis exitum/caliginosa moth fomit deus laud ignara ac non incauta futuri.

an qui contentus parvo metuensque futuri

dilator, spe longus, iners avidusque futuri.

utiliumejue sagas rerum et divina futuri

luturum. guid sit futurum cras. fuge quaerere

futurum. quinclue dies tibi pollicitus me nue futurum

futurus. contes minore sum futurus in metu. ian jam fucurus rusticus.

Sirm.1.5.23

Sirn. $2 \cdot 3 \cdot 112$

Serm: 1.3 IOI

Epist.2.1.15.

Curm.3.0 11

Fpoil. 7.4

virm.2.3.22

sar.Serm.1.2.12

serm.1 2.127

Siem. 28.44

Carm.1.7.29

Carm.3.2920

Serm.1.1.35

Sierm.2.2.110

Ars loet. Ti2

Irs loet. 218

Carm.1.0.13

Ejest.1.7.1

Epol.1.17

Fipod. 2.68

\section{( ;}

Gabis. Cabain freseltior atque Fidenis vicus:

foxdera regum vel Gabiis vel cum tigidis aeduata Sabinis. puerum tibi verdere natum| Tibure vel cabii

Gabios. Gabionciues petunt et frigida ruta.

Gadibus. quan - libyam remotis Gallous inngas

Gadis. Septimi. Cadis aditure mecum

Gaetulae. Gaetulae catulos harnate?

Gaetulas. visan . . litura kbonori Syrtisque Gaetulas canorus ales

Gaetulo. argerstum, vectis Gideto murice tinctas|sunt qui non labeant.

Gaetulus. non ego de tigris ut aspera/Gaetulusve leo frangere persecpuon:

Galaesi. Aulo pultitis ovibus Galaesi thumen

Gslatea. "t menor nostri, Galatea, vivas

Galba. 'itu'" onne; Cialba negabat

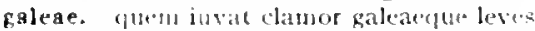

galeam. Tam kaleam Pallas ct aegida. patal.

Galli. Galli cammene Canearentu

salli. sub hath cantum collather ula oxt ial pulate.

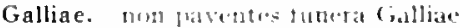

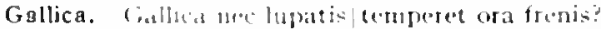

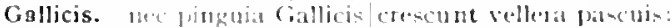

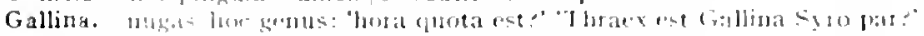

fallira. We sollinat malum respenset dura babato.

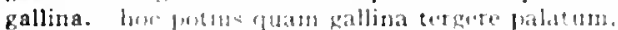

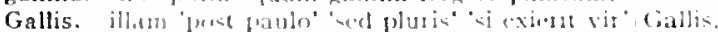

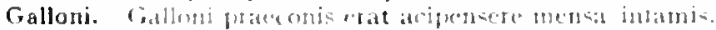

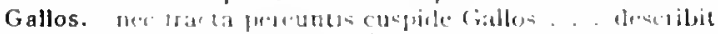

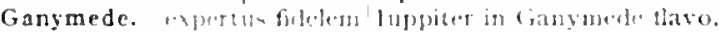

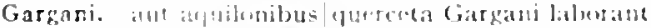

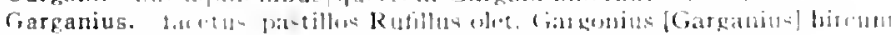

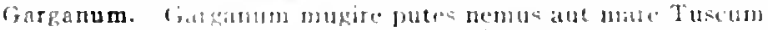

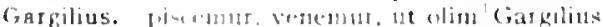

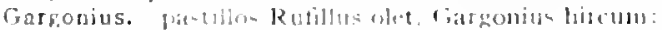

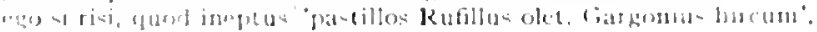

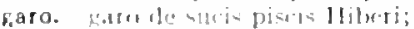

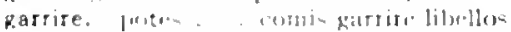

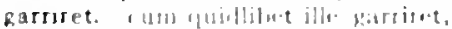

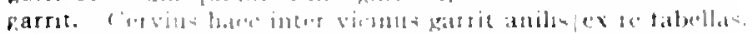

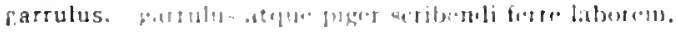

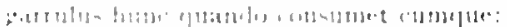

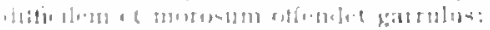

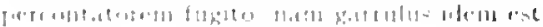

Evist.1.11\%

F.pist.2.1 2.5

Efist.2.2.3

Frist 1.15 .0

(iom.2.2.11

(arm.20.1

(itm. 3.20?

(iirm,2.20.15

L.pid.2.2181

crom.1.23.1"

(urm. 2.0.Ju)

(ithm-3.27.8.

cirm.1.2.4n

(iurm.1.2.38

firm.1.15.11

bpeides is

Sirmi.1.1.11

(iormetata be)

('irm.t.s.en

(arm.3.11).35

Sirm 2."1.9.

Sirmid.2.4.15

Sirm.2.2.2.

Sirm.1.2121

Sirm:2.2.15

virme.t.1.

I ism.4.4.4

(arm.2.0)

istr sorm.1.2 2i

lipice 2.1 ?"

l. prot 1.6.5s

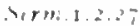

sermidies

Serniza 8

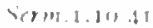

(2)

Sirn 2.0 .75

Sirm 1:2

symel,u3

Term.25 (j)

I:ptos is in 
gaude. gaude sorte tua: gaude quod spectant oculi te mille loquentem;

gaudeat. laeta quod pubes hedera virenti|gaudeat pulla magis atcue mystu. quae poscente magis gaucleat eripi. gaudeat ut populus Priami Prianusque inhumato. . utrum gaudeat an doleat.

gaudens. ut gaudet [gaudens] insitiva decerpens pira

gaudens. unico gaudens mulier marito hunc circumtonuit gaudens Bellona cruentis.

gaudent. (gaudent praenomine molles/auriculat) verum gaudent scribentes et se venerantur

gaudentem. gaudentem patrios findere sareulo|agros dic. . . gaudentem nummo te addicere. gaudentem parvisque solahbus et lare certo

gaudentes. te caede gaudentes sygambri conpositis ventantur amis.

gaudentes. V'ergilio adnuerunt gaudentes rure Cannat.

gaudentis. rite cliens Bacchi somno gaudentis et umbra:

gaudere. aut pictis tamquam gaudere tabellis.

Celso gaudere et bene rem gerere Albinovano

si dicet 'recte," primum gaudere. .

gaudes. o quae fontibus integris gaudes.

gaudes carmintbus; carmina possumus|donart

'laedere gandes." inquit, et hoc studio pravos facis."

gaudes, si cameram percusti forte, penes te es?

ut semper gaudes inludere rebus lumanis!"

carnine tu gaudes, hic delectatur ianbis.

gaudet. ac neque iam stabulis gaudet pecus aut arator igni.

hic posuisse gitudet

nrotus doceri gaudet Ionicos matura virgo

gaudet invisam pepulisse fossor|ter pede terram.

ut gaudet insitiva decerpens pira.

Castor gaudet equis, ovo prognatus eodem/pugnis: .

ille cubans gaudet mutata sorte

pars honinum vitiis gaudet constant

aut ursun aut pugiles: his nam plebecula gaudet.

gaturet cruis canibusque et atrici gramine Campi.

gaudetis. vos lene consilium et datis et datolgaudetis, almat.

gaudia. o qui conplexus et gaudia quanta fuerunt.

nam neque diritibus contingunt gaudia solis

gaudia. donet inpermissa raptin/gandia luminibus remotis, ad quate si properas gaudia.

est gaudia prodentem voltum celare.

migtavit ab aure voluptas omnis al incertos oculos tet gaulia vana.

gaudiis. ut tamen noris, quibus advocens $/$ gaudis:

gausape. acernam gausape purpureo mensan pertersit

gavisa. nunc tibicinibus, nume test gavisa tragoedis;

gazae. non enim gazae neque consularis/submovet lictor

gazis. beat is nune Arabum invides/gazis

gelida. gelidaque diros morte carentis.

mater lifira necabit in gelida fixm ripa febringue inducet.

foribusque tepulsum $\mid$ perfundit gelida,

gelida cum perluor unda per medium frigus.

gelidae. quis sub Areco, rex gelidac metuatur orar.

gelidam. emptis|sub nocten gelidam lignis calefuctat anum,

gelide. vel gutul tus onnis tinicle gelideque ministrat.

gelido. aut super Pindo gelidove in Haemo?

quafcumalue aut gelido prominet Algido

gelidos. gelidos inficiet tibi rubro sanguine rivos

gelidum. geliedun nenual Nympharumque leversum Satyis chos

gelidum. quis l'arthum paveat, quis gelidum scythen.

gelidus. me quotiens reficit gelidus Digentia rivos.

Gelli. non secus in bonis/ab insolenti temperatan|lactutia, monture Delli [indi],

Geloni. me - . ultimi/noscent Geloni,

Gelonos. intraque praescriptum (relonos/ exisuis equitare campis.

visan pharetratos Gelonos

gelu. geluque/ Hlusina constiterint acuto?

gemant. antennatque gemant ac sine tunibus

gemelli. at cetera paene gemelli traternis animis:

Effod.14.15

liptstorito. Io

(arm.1.25.18

(ivm.2.12.27

Sirm.2.3.195

lipist. I P.I 2

ver. Epod.2. Io

(arm.3.14.5

Serm. 2.3.223

Sirm.2.5.32

lipist.2.2.107

("arm.I.I.I I

Sierm.2.5.109

Lifist.1.7.58

Carm.t.14.51

Sirm.J.J0.45

Epist.2.2.75

Trm.1.1.72

Epist. I. 8. I

Epist.1. 15

Curm.1.26.7

Carm.4.8. I

Sirm.1.4.78

Sirm.2.3.273

cirm.2.8.62

Epist.2.2.59

Carm.1.4.3

Cirm.1.3.1.16

Carm.30.21

Carm.3.15.15

Ispod.2.10

Serm.2.1.26,

Sirm.2.0.1 I0

Serm.2.7.0

lipist.2.1.180

Ars Poet. It:2

Cism.3.4.42

sirm. I. 5.4.3

Epist.1.17.9

Curm.3.t.28

(dir)m.12.2I

Serm.2.5.104

Lpist.2.1.188

carmat.II.It

Serm.28. II

Iifist.2.1.98

Curm,z.I0.0

(iarm.1.29.2

(am.2.8.1

sim.2.3.204

Sorm.2.7.91

Epist.J.15.4

Carm.1.20.4

Ifpist.2.2.1to

Irs loet.17I

Carm. I 200

Carm.1.21.0

(arm.3.13.0

(armit. [.30

(arm.t.5.25

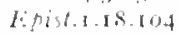

coni.Carm.2.3.4

(iorm.2.20.50)

curm.2.0.23

(arm.3.4.35

(armes.0.3

(arm]14.0

Epist. 10.3 
gemellum. nequitia et nugis, pravorum et anore gemellum.

gemens. Ityn flebiliter gemens. |infelix avis

gementis. visam gementis litora Bospori.

geminant. hon acuta|si geminant Corybantes aera.

geminentur. non ut serpentes avibus geminentur, tigribus agni.

geminis. Gratia cum Xymphis geminisque sororibus

gemino. nee gentino bellum Troianum orditur ab ovo: .

gemiarum. gratia sic fratrum geminorum. Amphionis atque | Zethi. dissilutit.

geminus. aura feret geminusque Pollux:

gemis. pancis ostendi gemis et communia laudas.

gemit. sulpura contemni vicus gemit.

gemmas. gemmas et lapides aurum et inutile,

gemma: marmor, ebur, . . . sunt qui non habeant,

gemmis. Grosphe, non gemmis neque purpura ve-|nale nec auro.

cum gemmis Trrios mirare colores;

genae. vel cur his animis incolumes non redeunt genae?'

genas. umor et in genas|furtim labitur arguens.

cur|manat tara meas lacrima per genas?

Genaunos. Drusus Genaunos, inplacidum genus,. . . deiecit acer

gener. qualis lycambae spretus infido gener.

Villus in liauta Syllae gener. . . poenas dedit

tum gener hoc faciet:

generat. nec lubae tellus generat. leonum/arida nutrix.

generatur. urule nil maius gemeratur ipso

genere. cetera de genere hoc, adeo suut inulta,

Villius in Fatustit Sylae gener [genere], hoc miser uno| nomine deceptus,

generi. ut, quantum generi demas, virtutibus addas;

genero. Villifi in fiausta Syllate gener [genero]. hoc miser uno/ nomine deceptus,

generosae. sed non omne mare est generosae fertile sestae: .

generasior. lic generosior/descendat in campum petitor.

nesno senctosior est te

generosis. non minus ignotos generosis.

gecerosius. quae generosius/perire quaerens

generosum. id mare cum veni, kencrosum et lene requiro.

generum. nescias an te generum beati|Phyllidis flave decorene parentes:

genetricem. nec ferto ut denens genetricen occidis Orestes.

Genetyllis. sive tu Lucina probas vocari|seu Gunitalis [Genetyllis]:

genialis. lectus gemialis in aula est:

genibus. "t corde et genibus tremit.

contractum genibus tangas caput?

ius imperiumelue I'hraates/Caesaris accepit genibus minor:

genis. pulcris excubat in genis.

Genitalis. sive tu bucina probas vocari|seu Genitalis:

genitar. occiclit et lelopis genitor, conviva deorum. adsciscet nov"a, quae genitor produxerit usus.

Genium. ruol t. per Genium lextramque deosque penatis|obsecro. piabant. Horibus et vino Genium memorem brevit acri.

genium. cras genium mero|curabis et porco binemstri

Genius. scit Grutu, matale comes qui temperat astrum, vinonue diurno placari Genius festis inpune diebus,

geas. gens loumana tuit fer vetitum nefas: geens. quile eremato fortis ab llio.

ut prisca gens mortalium.

sive quem. Dpula gens seu quod l.ucania bellum incuteret violenta

gente. an pauper et infimalde sente sub divo moreris:

Chryippus pontt fecund.s in gente Meneni. -

qualmis periurum erit, sine gente.

gentes. wrbesclue gremtesque et Liblium ferox

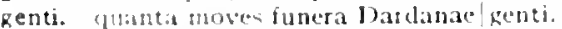

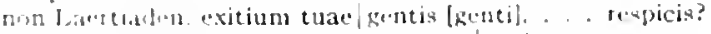

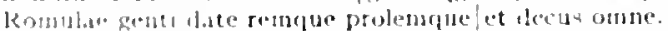

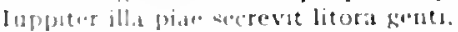

gentubus. grasm itaude mala gentibus sutulit;

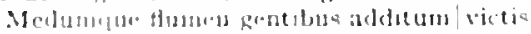

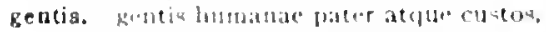

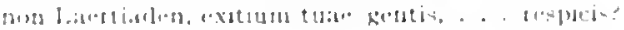

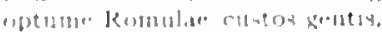

Serm.2.3.2.4.

Carm.4.12.5

Carm.2.20.14

Corm.1.10.8

Ars Poel. 3

Carm.4.7.5

Ars Poel.147

Epist.1.18.41

Carm.3.20.64

Epist.1.20.4

Epist.1.15.7

Corm.3.24.48

Epist.2.2.180

Corm.2.16.7

Epist.1.6.1 8

Cormt.10.8

Carm.1.13.6

Carm.4.1.34

Carm.4.14.10

Epod.6.13

Serm.1.2.64

Sirm.2.5.60

Carm.1.22.15

Carm.1.12.17

Sirm.1.I.I3

coni.Serm.1.2.64

Epist.1.20.22

coni Serm.1.2.64

Serm.2.4.31

Carm.3.10

Serm.1.0.2

Serm.1.6.24

Carm.1.37.21

Epist.1.15.18

Carmi.2.4.13

Serm.2.3.133

coni.Carm.Sacc.16

Epist.1.1.87

Carm.1.23.8

Serm 2.7 .61

Epist.1.5 2.28

Corm.4.13.8

Carm.Sicc.16

Corm.1.28.7

Epist.2.2.119

Epist.1.7.94

Epist.2.1.144

Carm.3.17.14

Epist.2.2.187

Ars Poct.210

Carm 1.3 .26

Carm.4.4.5.3

Epod.z.2

$5 \mathrm{crm} .2 .1 .33$

Carm.2.3.23

Serm.2.3.287

Sicrm.2.5.15

Ciarm.1.35.10

Carm.1.1511

:ar.Curm.1.15.22

Carm Sirec.ot 7

lipolatopos

ciurm.1.3.28

Carm.2.9.21

carm.1.12.40

(arm.1.15.22

c arm? +5 
gentis. terruit gentis, grave ne rediret/saeculum Pyrrhae inprovisa leti|vis rapuit rapietque gentis.

genua. dumque virent genualet decet.

genuit. non te Penelopen difficilem procis|Tyrrhenus genuit parens. ludus enim genuit trepidum certamen et iram,

genus. piscium et summa genus haesit ulmo, . audax Iapeti genus|ignem fraude mala gentibus intulit; : Cocytos errans et Danai genus!infame non, Torquate, genus, non te facundia, non tel restituet pietas; hoc genus omne/maestum ac sollicitum est cantoris morte Tigelli. quod sunt quos genus hoc ininime iuvat. meritone tibi sit/suspectum genus hoc seribendi. Messi clarum genus Osci;

"est genus unum|stultitiae nihilum metuenda timentis, . qua me stultitia, quoniam non est genus unum,|insanire putas? et genus et virtus, nisi cum re, vilior alga est." . iuvenis Parthis horrendus, ab altoldemissum genus Aenea, divorsum confusa genus panthera camelo . . . converteret ora;

genus. sive neglectum genus et nepotes/respicis, auctor iactes et genus et nomen inutile: . regium certe genus, et penatis /maeret iniquos. hic superbum $\mid$ Tantalum atque Tantali|genus coercet. nuptias|primum inquinavere et genus et domos: nepotum! per memores genus omne fastos, nartas et genus Aeaci Drusus Genaunos, inplacidum genus, . . deiecit acer. fortuna non mutat genus. regit/terras et humanum genus. cum genus hoc inter vitae versetur, contra Laevinun, Valeri genus. nugas|hoc genus: 'hora quota est?' et genus et formam regina Pecunia donat dum terras hominumque colunt genus, multa fero, ut placem genus irritabile vatum, ignotum tragicae genus invenisse Camenae gerat. quodque aliena capella gerat distentius uber. post haec, ut valeat, quo pacto rem gerat et se. gerentem. Raetis bella sub Alpibus|Drusum gerentem gerere. si male rem gerere insani est, contra bene sani: Celso gaudere et bene rem gerere Albinovano res gerere et captos ostendere civibus hostis

geret. geretque|proelia coniugibus loquenda. geri. non tamen intus!digna geri ptomes in scaenam geris. dis te minotem quod geris, imperas: seu tu querelas sive geris iocos

gerit. geretque [geritque]|proelia coniugibus loquenda . Germania. Germania quos horrida parturit|fetus. nec fera caerulea domuit Germania pube germinat. germinat et numquam fallentis termes olivae gerulis. festinat calidus mulis gerulisque redemptor, Geryonem. qui ter amplum | Geryonen [Geryonem] Tityonque tristi conpescit unda,

Geryonen. ter amplum|Geryonen Tityonque.

gesserat. arcana... credebat libris neque. si male cesserat [gesserat], usquam/decurrens alio neque, si bene:

gesserit. quan rem cumque ferox . . miles te duce gesserit.

gessi. haud ita Troiae/me gessi, certans semper nelioribus.'

gesta. nam male te gesta cum vellem mittere operto/me capite in flumen. . gestae. res gestae regumque ducumque et tristia bella. gestans. clavos trabalis et cuneos manu/gestans aena. gestare. siquis lectica nitidam gestare amet agnam, gestas. quis sibi res gestas Augusti scribere sumit? quain res conponere gestas|terrarumque situs gestat. neque lam livida gestat armis|bracchia adde hue quod mercem sine lucis gestat.

gestiens. hunc tanget armis, visere gestiens. gestiet. omnis|gestiet a furno redeuntis scire lacuque gestio. transfuga divitum/partis linquere gestio, gestis. pressum Calibus ducere I, iberum/si gestis,
Carm.1.2.5

Carm.2.I3.20

Epod.13.4

Carm.3.IO.I 2

Epist.r.I9.48

Carm.1.2.9

Carn.1.3.27

Carm.2.I4.I 8

Carm.4.7.23

Serm.1.2.2

Serm. I.4.24

Serm.1.4.65

Serm.I.5.54

Serm.2.3.53

Serm.2.3.30I

Sirm.2.5.8

Serm.2.5.63

Epist.2.I.195

Carm.1.2.35

Carm.1.14.1 3

Carm.2.4.I 5

Carm.2.18.38

Carm.3.6.I 8

Carm.3.17.4

Carm.3.19.3

Carm.4.14.10

Epod.4.6

Epod.5.2

Serm.1.3.60

Scrm.r.6.1 2

Serm.2.6.44

Epist.1.6.37

Epist.2.1.7

Epist.2.2.102

Ars Pott.275

Serm.I.I.IIO

Epist.r.8.13

Carm.4.4. 8

Serm.2.3.74

Epist.I.8.I

Epist.1. 7.33

Carm.4.4.67

Ars Port. 83

Carm.3.6.5

Carm.3.2 I.2

var.Carm.4.4.67

Carm.4.5.26

Epod.16.7

Ispod.16 45

Epist.2.2.72

var.Carm.2.14.8

Cirm.2.I 4.8

:'ir.Serm.2.I.3 I

Carm.r.6.t

Serm.2.5.19

Sirm.2.3.37

Ars Poct.73

Carm.1.35.19

Sirm.2.3.21 4

Epist.1.3.7

Epist.2.I.25 I

Carm.1.8.Io

Sern.1 2.83

Carm.3.3.54

Serm.1.4.37

Carm.3.16.24

Carm.4.12.I 5 


\section{GESTIS}

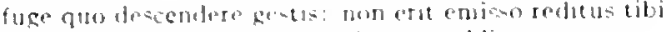

gestit. part hommum gestit conducese pullica;

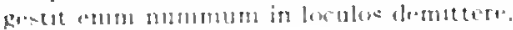

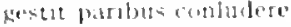

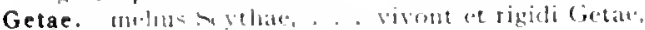

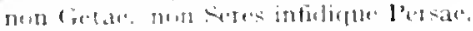

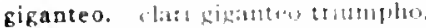

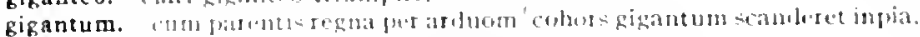

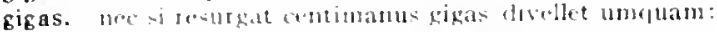

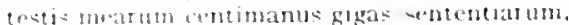

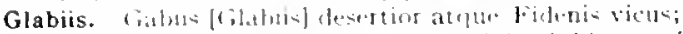

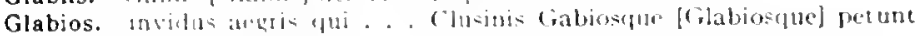
tot thirlit thra.

glacies. stat phlacies iners mensic mer ommis

glaciet. glibie't nites puro numinne Juppiter?

gladiatorum. gladiatorum dise centum, damnati populo paria

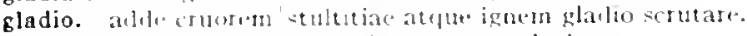

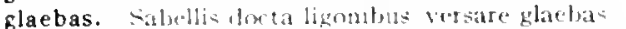

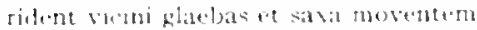

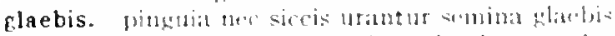

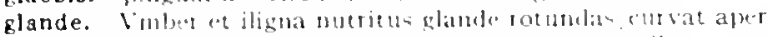

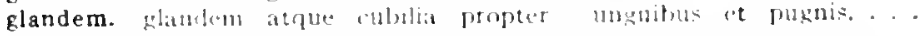
juseriabant

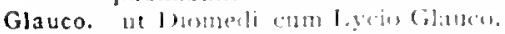

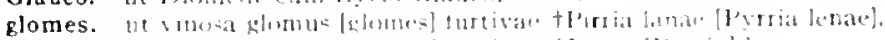

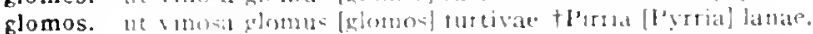

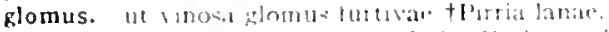

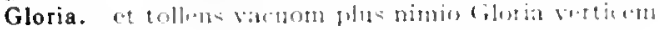

sed thl

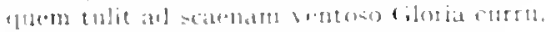

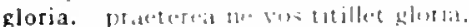

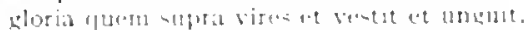

gloria. et militut mon cime klatia;

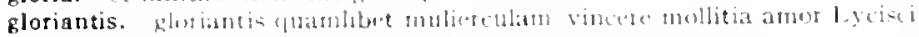

Glycerae. note mo inverate nitus

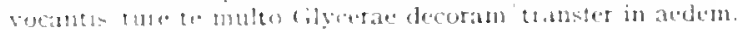

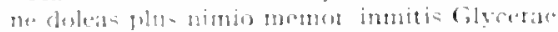

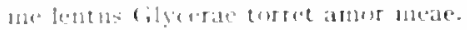

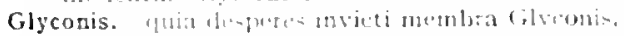

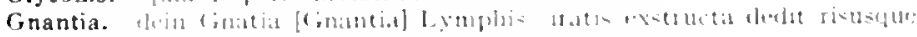
$14,12011100$.

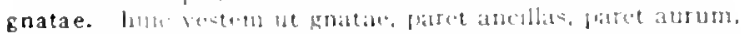

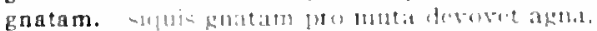

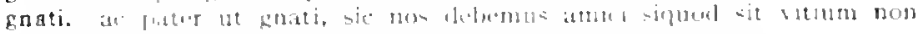
$\operatorname{lis}+\{11190$ :

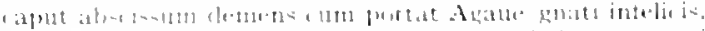

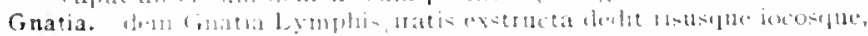

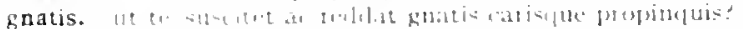

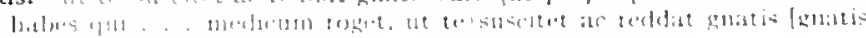
$1+1+1,1 t$

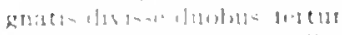

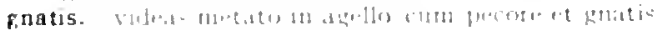

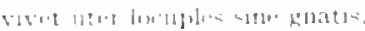

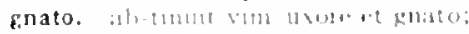

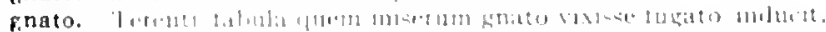

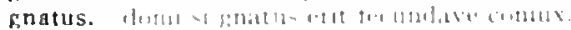

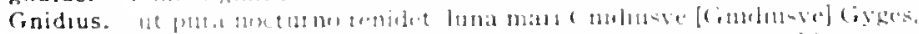

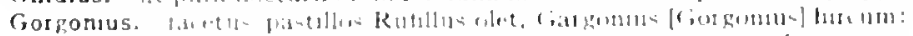

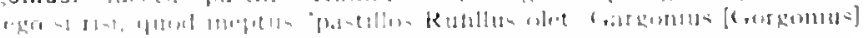
BII 11111 .

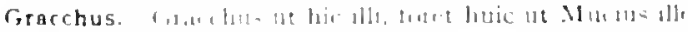

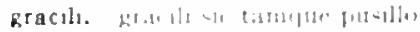

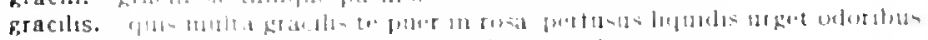

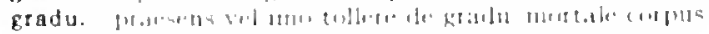

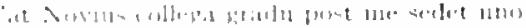

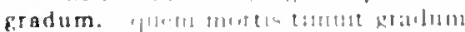

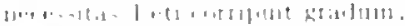

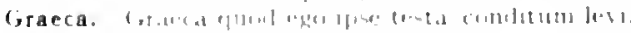

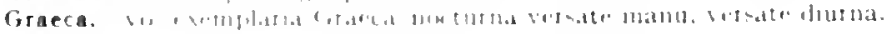

\section{GRAECA}

Lpist I.205

Epivil.1.7

lipist 2.1.175

ars I'orl 159

Cirm-3.2.11 I

(arm...4 15.22

(arm.3.1.

(iurm.2.10).22

Carm.2.17.14

ciarm.3.ting

:ar. lipist.r.11.2

sar lipivil1.15.0

Corm.2.05

(arm 3.101.7

serm.2.3.8.5

sirme 2 3.2-r

(arm.3 1.39

Eptst I I 30

lipod.16.55

serme..t to

Sirm.t.3.100

sermet.7.17

arr.lepist.1.13.14

a tor Estet $13 \mathrm{ta}$

I pist. 1.1314

(urm.1.18 5

serm.1.1.23

LPst.2.1.17

Sirm 23170

I) $1,1,1 \leq 22$

(arm $32 \mathrm{2n} 2$

I.pold.11.23

(ormaldos

(iilmes 318 ?

(arm.t.3.3.2

(arm.3.10.28

I.test. 1. in

6or. Yorm.1.5.07

Serm.23.215

$\therefore$ rm.23.210

Serm I.3.8

Sirm.z.3.3.?

Sermit 50 -

$\therefore r m+1 \mathrm{~s}_{3}$

inr Germer 1 r. 83

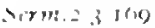

remez=1:3

sermi.z. 525

serm. 3203

Sermil = 1

srm.25.31

sid Curm. 520

pur verm I 287

arsara $1: 02$

1 prot 22 is

cirms 1.50

(a)m 15.1

("iarm 2.35 :

sormal 1 (1)

cares.

(arme 1.3 .3

( arm I in 2

irs liert 2pen 
meruere decus vestigia Graeca ausi deserere

irs Poit.280

graeca. quod verbis graeca latinis|mistuit."

serm.1. [0.20

graecari. (si Romana fatigat militia adsuetum graecari)

Graecia. quam multo repetet Graecia nilite.

uti Graecia Castoris, thagni memor Iferculis.

Graecia barbariae lento collisa ducllo.

ut primum positis nugari iraecia bellis/coepit

Graecia capta formm victoren cepit

Graecis. quam rudis et Graecis intacti carminis auctor

quod si tan Graecis novitas invisa fuisset quam nobjs.

Graecis. serus enin Graecis admotit acumina chartis

Graecis. litterulis Graecis imbutus, idoneus at i cuilibet:

Graeco. seu Graeco iubeas trocho

si Grateco fonte carlent parce detorta.

Graecorum. rhetor cones Ilelindor us. Graecorum longe doctissimus; magnas Graecorum malis inplere catervas." quia Graionu [Graecorum\} sunt antiquissina quacque / seripta rel optima.

graecos, atque ego cun graecos facerem, natus mare citra, / versiculos.

Graecus. at Gratcus, postquam est Italo periusus aceto. quid sinile isti|Graecus Aristippus?

Gragilius. piscemur, venemur, ut olim/Gargilius [Gragilius]

Graia. quan Graia victorum manus,

Graiae. spiritum Graiae tenuem Camenat

Graiorum. Graiorum, neque tu pessuma munerum ferros. quia Graiorum sunt antiquissina quaeque scripta vel optima,

Grais. tradidit tessis leviora tolli| Pergama Grais. te nostris ducibus, te Grais anteferendo iratus Grais quantum nocuisset Achilles. Grais ingenium, Grais dedit ore rotundo' Musa loqui,

gramina. per gramina Martii, campi, redeunt ian gramina campis

gramine. seu te in remoto gramine per dies/festos leclinatum aeque conspicitur gramine Martio,

in tenero gramine pinguim |custodes ovium modo in tenaci gramine: gaudet touis canibusque et aprici gramine Campi,

graminis. cervos uti vallis in alteral visum parte lupum graninis inmemor, grammaticas. grammaticas anbire tribus et pulpita rlignor:

grammatici. grammatici certant et achue sub iudice lisest.

grammaticorum. *grammaticurum equitum doctissimus.**

granaria. cur tua plus laudes cumeris granaria noztris?

grande. grande certamen, tibi pracda cedat, maior an illa.

grande. grande munus|Cecropio repetes cothurus.

graude malum Turius, siquid se iudico certes.

grandes rlombi patinatque grande ferunt una cum lamno dedecus.

grande. nearum grande decuz columenclue rerum.

grandem. saevit, quod meretrice nepos insanus [inkanit) amica | filitu uxorem grandi [grandem] cum dote recuset.

grandes. grandes rhombi patinaeque grande ferunt una cum damno dedectla.

hunc soci cepere peden srandusque cothurn.

grandi. nobilis ut grandi cecinit (entaurni alumno:

nobilis ut grandi cecinit [cecinit grandi] Centaurus alumno:

grandi fuondau lethargo grandi est oppressus,

grandi. filius uxoren granuli cun dote recuset,

grandia. nos,. . conamur. tenues grandia,

grandia latus meritorum praemia. quid stas?"

si metit Orcus! grandia cum parvis.

protessus srandia turget;

grandine. non verberatac grandine vineae

grandinis. iam satis terris nivis atrue dirae/grandinis misit Pater

grandis. foro nimium distare Carinas iam grandis natu queritur.

grando. haud quia grando contuderit vitis

granum. audcat esurien doninus contingere granum

grassare. obsequio grassare; mone, si increbruit aura.

grata. urit grata protervitas

nec loquax olim neque grata,

grata supervenite quae non sperabitur hora.

Serm.2.2.II

Carm.1.5.6

(imm.4.5.35

LPist.1.2.7

E.pist.2, I.9.3

lipist.2.1.15t

sem.1.10.tots

Epist.2.1.00

Jipist.2.1.101

IEpist.2.2.7

Carm.3.24.57

Als Plot. 53

virm. 1.5 .3

1.rm.1.10.35

Atr.lepist.2.1.28

sirm.1.10.31

Sirm.1.7.32

Serm.2.3. 100

I(d). E pist. 1.6.58

Epod.10.I 2

Carm.2.10.38

Carm.1.8.4

Iepist.2.1.28

(arm.2.4.12

Fist.2.1.19

EPist.2.2.+2

Ars Pot. 323

Carm.4. 19

cism.4.7.

Curme.2.3.0

Corm.3.-3.2n

Carm.t.120

lipol.2.2.

Ars Itart. 102

Cism. I 15.30

Epist. 1.10.40

Ars Pext.7S

sirm.1.10.*8

birm. I. I.5.3

('irm.3.20.7

Carm.zIII

Sirm.2.1.49

Sirm-2.2.96

(itrm.2.17.4

sur.firm.1.4.50

Sirm.2.2.05

Ars Pesteso

fipod I.3. I I

arr. EPoldz.II

Serm.2.3.145

Serm+1.50

Corm.t.e.9

Epist.2.2.38

Epist.2.2.179

. Ars Pot. 27

(ism.3.1.29

Carm.1.2.2

Iipist.1.7.4"

Fpist.1.8.t

Sirm.2.3.11;

Sirm.2.5.93

Curm.1.10.7

Carm.3.11.5

Epist.t.1.1 
si te grata quies et pimam somms in horam/delectat.

Epist.1.17.6

grata. o Herus the bi et dapibus supremi|grata testudo Iovis.

Carm.1.32.14

Carm.1.4.1

grata. solvitur actis hiems grata vice veriset Favoni

grata detimute compede Myrtale|libertina.

tenetgue gratalcompede vinctum.

ies die claro totienstulue grata nocte frequentis.

grata sume manu neu dulcia differ in annum.

co guod illccebris etat et grata novitate morandus/spectator

grata. gratarue teminis/inbelli cithasa carmina divides;

non acesuoate grata Calabriae/armenta,

prata carpentis thyma per laborem lplurimum.

donarem patcras grataque comnodus, /Censorine, meis acra sodalibus.

odisti clivis l.t grata sigilla pudico;

gratae. tuis victus Venctisque gratae/vocibus

gratae. plerumque gratae divitibus sices.

gratarum. notaque et artium /gratarum facies?

gratas. It gratas inter mensas symphonia discors.

grate. natalis grate numeras?

Gratia. Ciratia nudis imeta sororibus.

Gratia cum Nymphis geminisque sororibus

dein Gnatia [Gratia] Iymphis|iratis exstructa dedit risusque iocosque.

gratia. laus illi debetur et a me gratia maior.

an male satta/gratia nequiquan coit et sescinditur.

cui/pratia huma valetudo contingat abunde

si fortunatum species et gratia praestat,

gratia sie frat rum geminorum. Amphionis atque|Zethi, dissiluit. .

nedun sermomm stet lones et glatia wivax.

gratia regum| Ireris temptata modis.

Gratiae. inncarque Ximphis Gratiae decentes / alterno terram quatiunt perle.

solutis/Gratiae zonis propesentque Nymplat.

aegnesque nodun solvere Gratiae

gratiae. militabitur beilum in tuae spen gratiac,

gratior. gatior it dies

quae camme gratior aurem loccupet humanam?

ubi gratior aura|leniat et rabiem Canis

gratissima. pustera lux oritur nulto gratiscima:

gratissimus. demptus per vim mentis gratissimus error."

grato. dura sed einovere loco ne tempora grato

grato. grato, Pyrrhis, sub antro?

dun giato Danici puellas/carmine mulees. .

"xigho gratorne is harse tompore dajtim.

gratum. tecum sub alta - cic losi gratum - domo,

si guod adest gratum iuvat (bac prece te oro):

gratum. o disa, gratum quae regia Antiun.

gratum -locuta consiliantibus / I unene divis:

gratus. gratus purllae risus al angulo

superis tewam / gratus et imis.

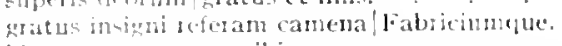

rlonece peritlus itam tibi

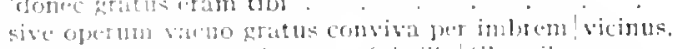

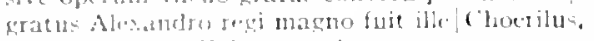

gravat. IH! mesor whiciun guod me diasat

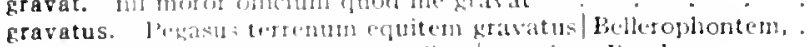

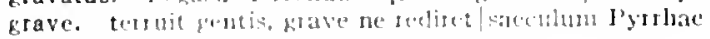

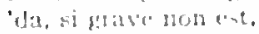

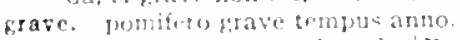

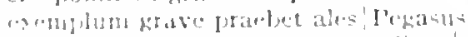

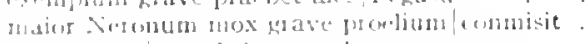

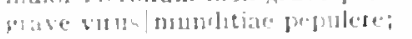

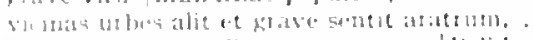

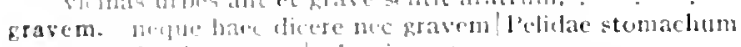

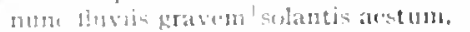

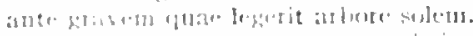

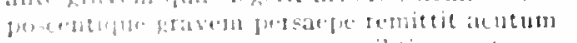

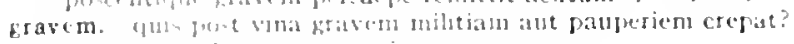

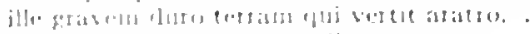

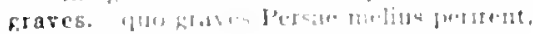

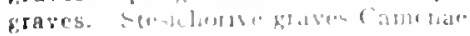

Carm.1.33.14

Corm.4.11.23

Carm..Sacc.23

Ispist.1 I1.23

Ars loet.223

Curm.1.15.14

Carm.1.31.5

Carm.4.2.29

Carm.4.8.1

Epist.1.20.3

Corm.4.6.2I

Carm.3.29.13

Carm..4.13.22

Ars Pod.374

Jpist.2.2.210

Carm.3.19.16

Carm.4.7.5

tor.Serm.1.5.97

Serm.1.6.88

Epist 1.3 .32

Epist.1.4.10

1.pist.1.0.49

Epist.1.18.41

Ars Pocteco

Ars Poct.40.4

Carm.1...6

Carm.1.30.1

Curm.3.21.22

J.pod.1.24

Curm.4.5.7

Serm.2 2.04

Jpist.1.10.15

Serm.1.5.39

Epist.2.2.140

Jipist.2.2.40

Carm.1.5.3

Carm.3.11.23

Jipt.2.2.198

Epod.9.3

Serm.2.0.13

Carm.1.3.5.1

Carm.3.3.1 7

Corm.I.9.22

Corm.1.10.20

Corm.1 12.39

(i)m.3.9. I

sirmi2.2.19

J.pist.2.1.232

f.pist.2.1.20.d

Curm.4.11.27

Carm.1.2.5

Serm.2.8.4

Corm.3.23.s

Corm.4.11.20

Corm \&1: 14

tepist $2.1 .155^{\circ}$

ars leneted

Corm. I. 1.5

Corm 2.5.0

Serm 2.4.23

Ars 1'0 (1.3.11)

Corm.1.18.5

Sorm.1.1.26

Corm.1.2.22

carmas 
non amicorum queant|libera consilia nec contumeliae graves,

Epod.II.26,

gravi. gravi|malvae salubres corpori

gravi. tu gravi curru quaties Olympum. .

parce gravi metuende thyrso.

amore percussum gravi, .

aut ad humum maerore gravi deducit et angit;

gravi. vita solutorum misera ambitione gravique; .

gravi. irae Thyesten exitio gravi|stravere

tot ora navium gravi|rostrata duci pondere

gravibus. inceptis gravibus plerumque et magna professis|purpureus. . .

adsuitur pannus,

gravibus. adiectis Britannis|imperio gravibusque Persis.

gravida. erus "haec gravida" inquit|"capta est.

gravida. nec venenatis gravida sagittis, |Fusce, pharetra,

gravior. tardior ut paullo graviorque veniret ad auris.

graviore. celsae graviore casu|decidunt turres

gravis. sed palam captis gravis, heu nefas, heu.

polypus an gravis hirsutis cubet hircus in alis,

'o fortunati mercatores' gravis armis/miles ait,

sive gravis veteri craterae limus adhaesit.

autumnusque gravis, Libitinae quaestus acerbae.

nec meretrix tibicina cuius|ad strepitum salias terrae gravis; . quae gravis Aesopus, quac doctus Roscius egit:

gravis. quibus te vita sit superstite/iucunda, si contra, gravis? minus est gravis Appia tardis.

si te forte meae gravis uret sarcina chartae.

asperitas agrestis et inconcinna gravisque, .

gravis. vel acer Deiphobus gravis/excepit ictus

gravis. dum gravis Cyclopum|Volcanus ardens visit officinas.

nequiquan thalamo gravis|hastas ... vitabis

ludumque Fortunae gravisque/principum amicitias .

gravis|iras et invisum nepotem,

atque aestus curasque gravis e pectore pelli?

interea suspensa gravis aulaea ruinas/in patinam fecere.

gravitate. non ridet versus Enni gravitate minores.

vincere Caecilius gravitate. Terentius arte.

asper|incolumi gravitate jocum temptavit .

gravius. unde|fama malum gravius quam res trahit. cum gravius dorso subiit onus.

gravos. credula nec ravos [gravos] timeant armenta leones

grege. contaminato cum grege turpium $/$ morbo virorum per apertum fugientis agitato grege cervos iaculari. pastor umbras cum grege languido|riromque fessus quaerit aut pars indocili melior grege;

viribus editior caedebat ut in grege taurus.

cum ridere voles, Epicuri de grege porcum.

gregem. nullius astri $\mid$ gregem aestuosa torret inpotentia.

greges. te greges centum Siculaeque circum $\mid$ mugiunt vaccae,

greges. regum timendorum in proprios greges.

rougientium | prospectat errantis greges

gregi. nigro conpulerit Mercurius gregi?

gregis. lascivi suboles gregis.

scribe tui gregis lunc et fortem crede bonunque.

grex. refertque tenta grex amicus ubera.

insanum Chrysippi porticus et grex/autumat.

si forte suas repetitum venerit olim grex avium plumas,

Grosphe. Grosphe, non gemmis neque purpura ve-|nale nec auro.

Grospho. utere Pompeio Grospho et, siquid petet, ultroldefer:

Grosphus. nil Grosphus nisi verum orabit et aequom. .

gruem. pavidumque leporem et advenam laqueo gruem / iucunda captat praemia.

gruis. mazonomo pueri magno discerpta ferentes|membra gruis.

gula. ait Harpyiis gula digna rapacibus.

lucet, earnus/quo ducit gula;

gulae. nil servile gulae parens habet?

gurges. qui gurges aut quae flumina lugubris|ignara belli?

gustaremus. ut nihil omnino gustaremus,

gustarit. quae si semel uno/de sene gustarit tecum partita licellum.

gustet. ante Larem gustet venerabilior Lare dives.

Epod.2.57

Carm.1.12.58

Carm.2.19.8

Epod.1 I.2

Ars Poet.IIo

Serm.1.0.1 29

Carm.1.I6.I7

Epod.1.17

Ars Pot.i.

Carm.3.5.4

Serm.2.8.43

Carm.1.22.3

Ars Poel.255

Carm.2.10.10

Carm.1.6.I 7

Epod.12.5

Serm.I.I.t

Serm.2.4.80

Serm.2.6.19

Epist.1.14.26

Epist.2.1.82

Epod.1.6

Serm.1.5.0

Epist.1.13.0

Epist.1.18.0

Carm.4.9.22

Carm.1.4.7

Carm.1.15.16

Carm.2.I.3

Carm.3.3.30

Serm.1.2.110

Serm.2.8.5t

Serm.I.I0.54

Epist.2.I.59

Ars Poot.222

Serm.1.2.59

Serm.I.9.2 I

sar. Epod.r6.33

Carm.1.37.9

Carm.3.12.10

Carm.3.29.2 I

Epod.16.37

Serm.I.3.IIO

Epist.1.4.10

Epod.16.62

Carm.2.16.33

Carm.3.I.5

Epod.2.I 2

Carm.I.24.18

Carm.3.13.8

Epist.1.9.13

Epod.16.50

Serm.2.3.4.

Epist.1.3.19

Carm.2.16.7

Epist.1.12.22

Epist.I.12.23

Epod.2.35

Serm.2.8.87

Serm.2.2.40

Epist.1.6.57

Serm.2.7.III

Carm.2.1.33

Serm.2.8.9-1

Sirm.2.5.82

Serm.2.5.14 
guttur. Jratrentso olum supus mpia manu sembe guttur foegerit.

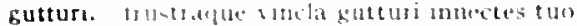

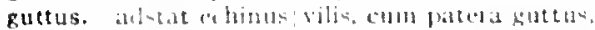

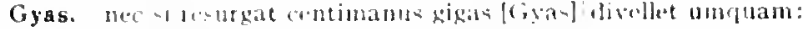

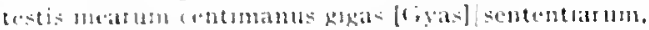

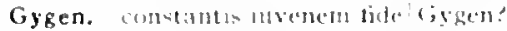

Gyges. Cnidiunte (inges, quem si puellanum insereres choro.

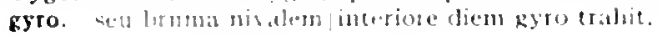

1. pod $3 \cdot 2$

t:pod.17.72

ferm 10.118

coniciorm.2.17.14

coniciom-3.4.6.

Corm.3.7.5

(arm.2520

seror 20,20

\section{H}

babeant. Gubuto curam sumptungue mustem hace habeant. sume qua non habeant est qui non curat habere.

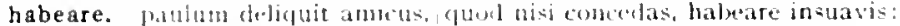

habeas. 'nil satte at. 'inguit. 'qual tant quantum babeis sis':

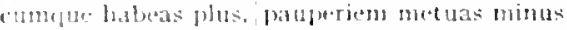

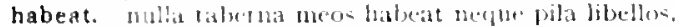

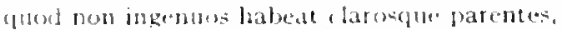

levis have insanit quantas virtutes hitbeat, se collige:

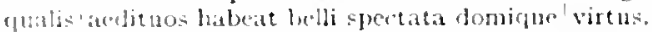

habeatur. plus acepuo !iber: sumplex lontinque habeatur;

habebas. "thinelihorem incipias. justo ryor] avebas [babebas], ne facias fruod Inmudius quidam.

habebat. Sitdlus habetat fille Tigelliun lue:

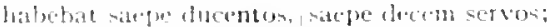

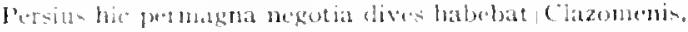

habebit. barbiton hir paries habelit.

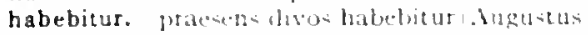

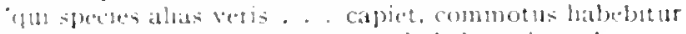

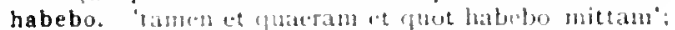

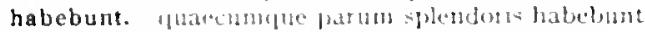

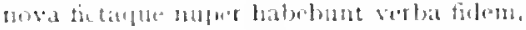

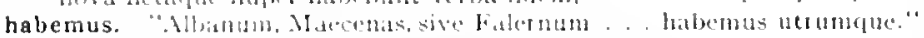

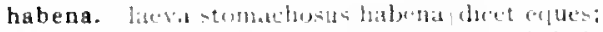

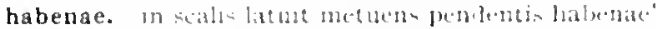

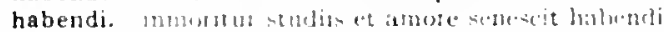

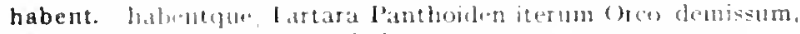

habentem. clusi nun desit habentem

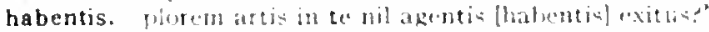

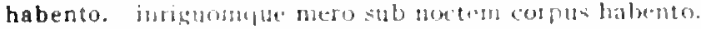

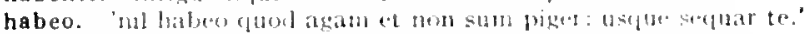

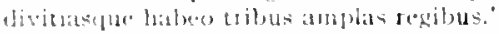

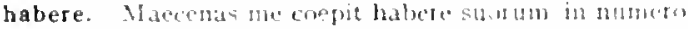

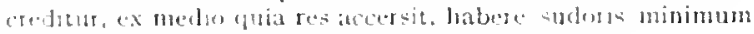

$$
\text { qumenedia }
$$

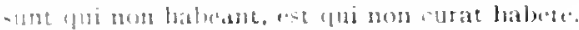

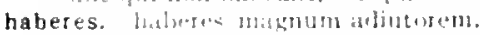

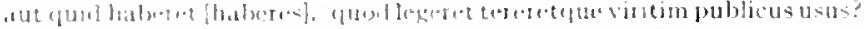

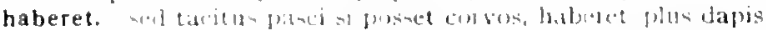

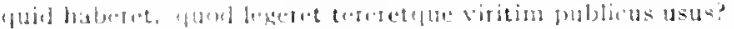

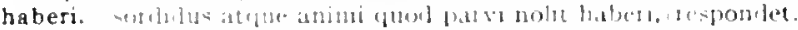

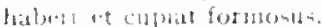

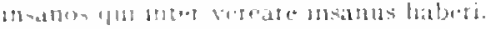

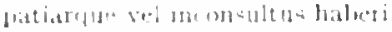

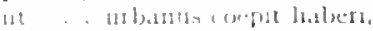

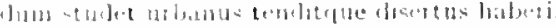

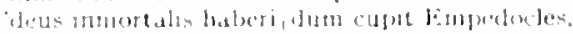

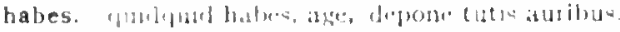

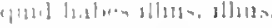

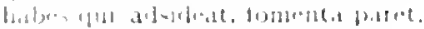

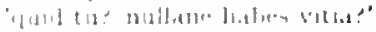

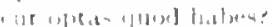

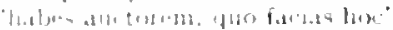

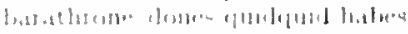

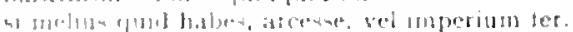

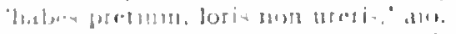

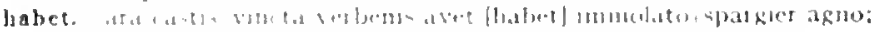

(y) Biallut ab-11th hallet

Sientit 2.480

I.posit.2.2.152

serm 13.85

Serm.1.1.1.2

Serm.1.1 02

Sermideti

Serm.1.6.0 $\mathrm{I}$

Epist 2.1.110

1.pist : 1.230

herm.1.3.52

: ar.serm.1.1.04

serm.1-3.3

Sirm.1.3.11

serm. 1.7.4

(corm.3.20..

Curm 3.5.2

Serm. 2.3.200

f.pist 1.0.42

Pepist.2.2.1 II

.1rs Pesets:2

cirm.2.8.17

fipist.1.1512

Jepist 2.2.15

Esist.7.85

Curm.1.28.9

Lipist.2.2.52

gur. I. pod.1.81

serm.2.1.

Serm.J.0.19

Serm.2.2101

s'm 2.13.4

lipid 2 I. Icos

I:pirt.2.2.15:

Serm. 0.45

iur. Jpist.2.1.ot

f.pist.1.17.50

tapuld.2. 1

herm-12.10

Sermis 1.30

Serms 2.3.40

t.pist o.5.15

1. pust 1.15.27

f.postitido bo

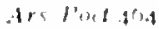

(is)m 1.27.17

Corm.t. 3.18

sermitist

serm. I 3.21)

Sirmat $312 \%$

sernel 9.122

sermi.2.3.107

Jipule 50

I:Pist.s.19.47

tar carm 11.7

I poids. 
quis non malarum quas amor curas habet

sic placet? an melius quis labet suadere?

at ni id fit, quid habet pulcri constructus acersos?

aperteluuod venale habet ostentit

nec. siquid honesti est. | iactat habetque palam.

faenum habet in cornu, longe fuge;

'atrui sic labet.'

eoque difficilis adit $u=$ primos habet.'

quar res' nec nodum habet neque consilium.

gui prafdia vendit. nil servile gulate parens habet?

dimilium lacti, qui coepit, habet: sapere aude. in ipe.

habet hos numeratque poetas

habet comedia tanto plis oneris, quation veniae minus.

habeto. inriguomqute mero sub nocten corpus hatrento [habeto].

habili. atudiat insidus dementem atrepitum lycus et vicina sen non habilis [habili! l, jeo.

habilis et vieina seni non habilis lyco.

habitabilis. qua sol habitabilis inlustrat oras.

habitanda. agros atque lares patrios habitandaque tana apris reliquit

habitare. nume licet Esquilis habitare salubribus

habitatum. futem tu fastidis, labitat um quinque tocis

habitu. tu cum poiectic insignibus, anulo equestri| Ronanoque habitu.

illa tanter se non habitu mutatre loco peccatve superne.

habitum. atcle soltum habitunelue hominis,

format chin natura prius nos intus ad onnem | fortunarum habitum:

habitus. aum. ex quo est habitu= male tutae mentis orestes.

habrotonum. habrotonum aegro| non aurlet nisi qu didicat dare.

babuere. tana deos liabuere rectos.

hoc pace habere bonae renticlue secumeli.

hac. sub aita vel platano vel hatelpinu iacentes

hac arte Pollux ct ragus Hercules/enisus arces attigit igneas.

hac te merentem. Bacche pater.

hac Qurinus Martis equis Aeheronta fugit.

bellicosis fata (unitibus hac lege dico.

potes bas ab orno pendulum

quod $x$ hac luce Maecenas meus adfuentis ordinat annos.

comante mixtum tibis carmen lyri.| hac Dorium, ullis babarum?

nulla sit hac potior sententia:

hac mente laboren' sese lerre, . . aiunt.

huc [hac) iurenes aequom est descendere.

modo summa foce, modo hac, resonat quae chordis quatuor ina.

hac lege in to utina ponetur eadem.

domus hac nec purior wha est

hac magi ithm, inparibus formis deceptum te peter:

hac urget lupus, hac canis, aiunt.

mon quia nacuz jilis nullus erat, ced, credo. hac mente,

-1 purd adest gratum iuvat hac prece te orol.

"Jand mihi vita est opma bac"

lac ego si conpellor imagine. cuncta resigno:

liac in t'e scilicet una multum dissimiles.

hac rabiona fugit canis. hac lutulenta ruit sus:

hactenus. candida rectaque sit, munda hactenus. hactenus hace: alias. Justum sit necne poema.

Hadria. adversariuz est frater, lacus Hadria.

Hadria. quict bellicosus Cantaber $t \cdot t$ scythes, Hinpine (yuinti. cogitet Haclria divisus obiecto inprobo iracundior Hadria:

Hadriae. quo non arbiter fladriae maior.

iretis acrior Hadiae curvantis Calabros sintli.

fractispue rauci fluctibus Hadriae.

dux inquieti turbidus Hadriae.

quid sit ater Hadriae novi sinus

Hadriano. sive fammal sive mari libet Hadriano.

hae. hae latebrae dulces et, iam si credis, amoenap hae nugae scria ducent 1.pol. 2.37

Iipod.10.23

S.rm.1.1.44

serm.1.2.s.

Sirm.1.2.85

Sirm.1.13.4

Sorm.1.0.53

Sirm. I 0.5'

sirm.2.3.260

serm 2.7.11

Epist. 1.2..to

Epist.2.161

l.pive. I.Jo

zor term.2. I.9

5ar (arm.3. I0.24

Carm.3 10.24

(arm.t. 14.5

ifpoldene

Sim.1.8. It

Epist.1.1.2

Sirm.2.7.5.1

Sirm.2.7.64

sim.2.4.2

Ars lert. Ioo

Sirm.2.3.137

If pist.2.I.ISt

Comm. 4.48

Etist.2.1.102

(arm.2.JII3

(arm.3.3.9

Carm 3.3.13

Carm:33.15

Carm.3.3.58

Corm.3.27.58

carm-1.] I.18

Iiposelo.",

IPpoliti.17

Serm 1.1.30

retr.serm. 1.2.3.4

virm.1.3.s

Serm.1.3.72

Sirm.1.0.49

strm.2.2.29

serm.2.2.0.4

serm.2.2.0r

Sirm.2.tr.13

sirm.20110

Epist.1.7.34

Fist.1.16.2

lipist.2.2.75

Sirm.I.2.123

xirmot.to3

Epist.1.18.13

(arm.2.15.2

Citm.3.923

Curm.1.3.15

Curm.1.33.15

Corm.2.14 It

( arm.3 3.5

('arm.3.27.19

carm.1.10.4

lipist. Ino. I5

irs loet.45 I

haec. coni.Curm.1.21.I3; Carm.3.20.10; 4.8.9; Epod.7.10; Serm.1.2.23; I.2.40; 1 2.125: I.2.I3I;

Serm.1.3.54; I.4.100; 1.6.128; 2.345 (his); 2.3.320; 2.5.30; 2.5.50; 2.4.43; 2.8 .05 ;

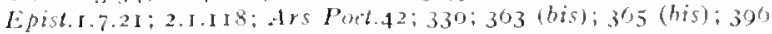

haec. Serm.1.3.39;1.4.03;2.3267;2.4.80; 2.6.97;2.7.21 
haec. Carm.1.0.5; 3.27.51; Carm.Sact.73; Lpod.2.38; 2.67; 5.8; 5.11; 5.83; 11.10; 11.19; 13.7; Ifpod.10.25; 10.35; Sorm.1.2.09; 1.4 137; 1.5.65; far.Serm.1.6.87; Serm.1.9.60; 1.10.37; herm 1.10 $82 ; 1.10 .83 ; 1.10 .88 ; 1.10 .92 ; 2.3 .34 ; 2.3 .71 ; 2.3 .122 ; 2.3 .151$; tar.Serm.2 3.170; Scrm.2.3.233; $2.3 .208 ; 2.3 .200 ; 2.5 .70 ; 2.0 .5 ; 2.0 .51 ; 2.6 .77 ; 2.8 .75 ;$ Epist.1.1.54; I.I.55; LPsist.1.5.21; 1.7.19;1.8.13;1.10.49; 1.19.45;2.1.2.43;2.2.39;2.2.145

Haedi. nec sunsos Arcturi cadentis impetus aut ofientis Haedi. .

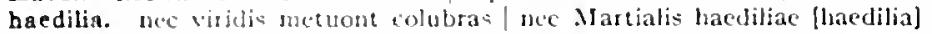
liput.

baediliae. Men Martialis labediliae lupos.

haedo. seu poscat agma sive nualit hacelo. cris demateris hacelo.

bethe erat non piscibus libe petitis./sod pullo atque haedo;

haedus. si tener jleno radit hacdus anno vin baedus eroptus lupo.

Haemo. aut supre l'indo gelidove in llacmo?

Ha moniae. renator in campis niralis|llacmoniae.

haereat. efuod non proposito conducat et hacreat apte.

haerentem. Venesempue et illi|semper hactentem puesum cancbat

haerentem. et scindat haetentem coronamferinibus laverentem cajiti cum multa laude cotonan.

haerentia. cotera iten nefucum stultis hacentia. .

haerentis. ut hacentis adverso litore navis/eripesent.

haerere. mescit equo rudis/harere ingenuos puer.

baeres. hacres requiquan caeno cupivens "vellere plantam.

baeret. suale daxus/in prede caleeus lateret-

haretetinvisis foribus?

Nimvits in manibus non est eq mentibus laterce

haesit. piscium t't summa gerutus hat sit ulwo.

Hagnae. defceant. velutu ballinum polypus llagnae.

hallec. siser, hallec, laceula coa.

hallec. laus ego cum malis, ego facen primus et hallec, . . inventor

hallece. pipere albo [? lallece], non sint atcto.

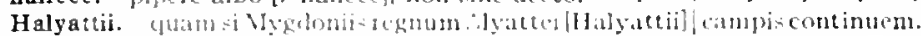

hamo. si vater unue el alter insidiatorem pracroso fugerit hamo,

hamum. occultum bisus docurrete piscis al hamum. metuit foveam lupua. . . et opertum miluos lamum.

hanc. hanc l'bilolidmus iat shi, (1) hanc ton, aut prostum anse mes quia pultum in parte catini|sustulic

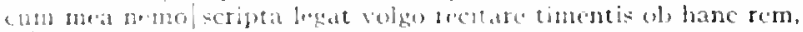

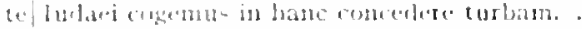
prot hase batger atut go. . . unguer ohso,

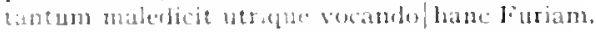

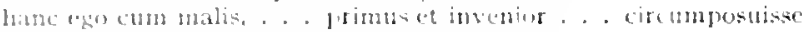
ft banc vetaba petimusque landusque vicissima;

Hanubal. dixitgus tandem perfolus llannibal:

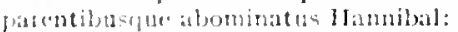

Hannibalem. nee form Hanilatem me Siculum mare

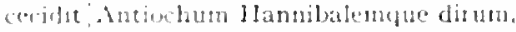

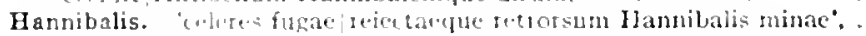

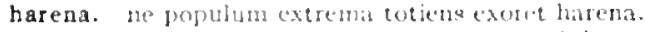

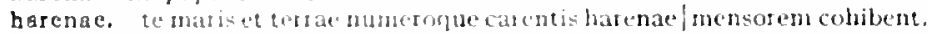
at tu, natutu, vage ne parce malisuls hatlenae. . particulam dare:

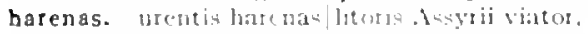

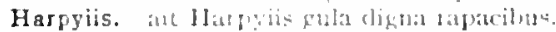

harum. baruma ribat cols abborum

harundine. lomene par inpat, erputate in has undine longa

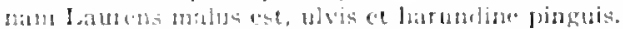

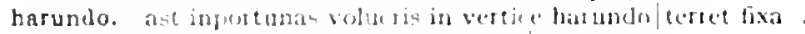

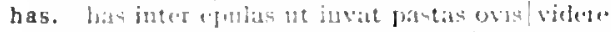

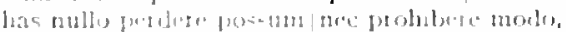

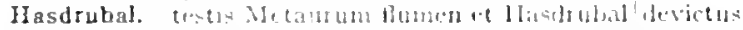

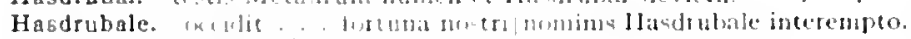

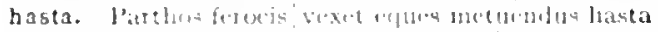

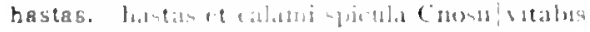

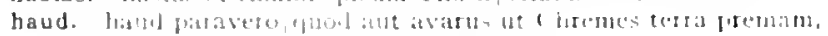

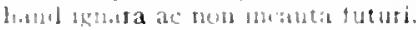

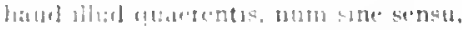

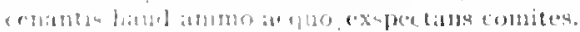

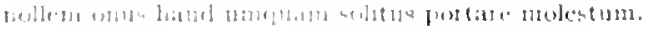

Carm.3.1.28

t'ar.Carm.1.17.9

Carm.1.17.9

Carm.1.4.12

Carm.3.13.3

Serm.2.2.121

Carm.3.18.5

Epod.2.60

Carm.1.12.t

Carm.1.37.20

Ars Poct.105

Carm.1.32.10

Carm.1.17.27

Serm.1.10.49

Serm.1.3.77

Sirm.2.3.205

Carm.3.24.55

Sirm.2.7.26

Sirm.1.3.32

Sirm.2.3.26I

Epist.2.1.53

Carm.1.2.9

Serm.1.3.40

Serm.2.8.9

Sirm.2.4.73

7 1 ar.Serm.2.8.49

sar.Carm.3.10.4 I

Scrm.2.5.25

Fpist.1.7.74

Efrist.t.1 1.5 !

Serm.1.2.121

Sorm. 1.3.1)

Serm.1..4.2.3

Sorm.1.4.1.13

Sirm.1.0.122

Serm.2.3.1.4

Serm.2.4.73

Ars l'vel.1

Carm.4.4.49

Fopd.10.8

Curm.2.12.2

Carm.3-0.30

Carm.4.8.10

Epist.1.1.

Carm, 1.2S.I

Carm.1.28.23

Carm.3.4.31

Sirm.2.240

Carm.2.1.4.22

Sicrm.2.3.2.15

Sorm.2.4.42

Sirm 1.8 .0

lipod.2.01

Sicrm 1.8.20

Carm.4.4.38

Curm.4 4.72

Cism.3.2.1

carm.1.15.1?

lifold.1.

Sorm. I. I.35

Serm.1...77

Sirrm. 1.5.8

Sorm 1. (1.,2) 
'haud mihi quisquam.|omnis conposui.'

'haud mihi deero:|muneribus servos corrumpam;

Serm.1.9.27

haud mihi deero. cum res ipsa feret:

sed hic stilus haud petet ultro/quemquam animantem

haud ita pridem |Galloni praeconis erat acipensere mensa|infamis.

haud ita Troiae/me gessi, certans semper melioribus.'

"haud milri vitalest opus hac"

haud umquam misera formidine privet?

haud male Telemachus, proles patientis Vijei:

haud quia grando|contuderit vitis

intervalla vides humane [haud sare] commoda.

fuit haud ignobilis Argis,

ordinis haee virtus erit et venus, aut [haud] ego fallor,

baurire. dum ex parvo nobis tantundem baurire relinquas,

unde laboris |plus haurire mali est quam ex re decerpere fructus.

cura . . . atque haurire queam vitae praecepta beatae.'

haurit. is neque limo/ turbatam haurit aquam

haustu. Pindarici fontis qui non expalluit haustus [? haustu]

haustus. Pindarici fontis qui non expalluit haustus

haut. 'quid tu? | nullane habes vitia?' immo alia et [alia baut] fortasse minora.

ut [haut] forte legentem laut tacitum inpellat quovis sermone:

ordinis laece virtus erit et venus. aut [haut] ego fallor.

Hebri. studium auiert, Neobule, Liparaei nitor Hehri.

Hebro. aridas frondes hiemis sodali] dedicet Euro [Hebro].

Hebrum. Hebrum prospiciens et nive candidam/Thracen

Hebrus. I lebrusque nivali compede vinctus

ut nec/frigidior Thraecam nec purior ambiat Hebrus.

Hecaten. Ifecaten vocat altera, saevam/altera Tesiphonen:

Hector. ademptus Hector/tradidit fessis leviora tolli\}Pergama Grais. non ferox Hector .... primus.

Hectora. inter/Hectora Priamiden, animosum atque inter Achillem/ira fuit

Hectoreis. pugnacis Achivos|Hectoreis opibus refringit

Hectorem. unxere matres Iliae additum feris | alitibus atque canibus homicidam Hectorem.

bedera. laeta quod pubes hedera virenti|gaudeat

artius atque hedera procera adstringitur ilex

hederae. est hederae vis/multa.

prima feres hederae victricis praemia.

bederae. me doctarum hederae praemia frontium $/$ dis miscent superis.

hederis. nec Damalis novo/divelletur adultero/lascivis hederis ambitiosior.

heheu. heu heu [heheu], quantus equis, quantus adest viris|sudor.

heu heu [heheu], cicatricum et sceleris pudet f fratrumque.

heiulatio. et illa non virilis heiulatio

Helenae. te ... sic fratres Helenae, lucida sidera, . . . regat . infamis Helenae Castor offensus vice.

Helenam. nam fuit ante Helenam cunnus tacterrima belli|causa.

Helene. non sola comptos arsit adulteri|crinis . . Helene Lacaena

Helenen. pastor cum traheret per freta navibus $\mid$ Idaeis Helenen perfidus hospitam,

Helicona. ut studio maiore petant Helicona virentem.

Helicone. excludit sanos Helicone poetas/Democritus, .

Heliconis. aut in umbrosis Heliconis oris

Heliodorus. thetor comes Heliodor us./Graecorum longe doctissimus;

Hellade. Hellade percussa Marius cum praecipitat se,

herba. aut herba lapathi prata amantis

nec herba nec latens in asperis/radix fefellit me locis.

pellent obstantia conchae et lapathi brevis herba, sed alto non sine Coo. deterius Libycis olet aut nitet herba lapillis?

berba. cena brevis iurat et prope rivom somms in herba;

si volnus tibi monstrata radice vel herba/non fieret levius,

fugeres radice vel herba|proficiente nihil curarier:

herbae. locus, ... nee multae prodigus herbae;

herbas. herbasque, quas Iolcos atque Hiberia|mit tit quin ossa legant herbasque nocentis. herbas atcue incantata lacertis/vineula

berbis. num viperinus his cruor incoctus herbis me fefellit?

herbis. crescit Albanis in herbis/victima, relicta matre qui largis iuvenescit herbis

Serm.1.9.56

Serm.2.1.1 7

Serm.2.I.39

Serm.2.2.46

Serm.2.5. 18

Sirm.2.6.115

Serm.2.7.77

Epist.1.7.40

Epist.1.8.4

coni.Epist.2.2.70

Epist.2.2.1 28

iar.Ars Poet.42

Serm.1.1.52

Serm.1.2.79

Sirm.2.4.95

Sirm. I. I.6o

7 var.Epist.1.3.10

Epist.1.3.10

qar.Serm.1.3.20

inr.Serm.1.3.64

var.Ars Poel.42

Carm.3.12.6

var.Carm.1.25.20

Carm.3.25.10

Epist.1.3.3

Epist.I.IG.I3

Serm.1.8.33

Carm.2.4.10

Carm.4.9.22

Serm.1.7.1 2

Corm.3.3.28

Epod.17.12

Carm.1.25.I 7

Epod.15.5

Carm.4.11.4

Epist.1.3.25

Carm.1.1.29

Carm.1.30.20

var.Carm.1.15.9

var.Carm. 1.35 .33

Epod.10.17

Carm.1.3.2

Epod. 17.42

Serm.1.3.107

Carm.49.16

Carm.1.15.2

Epist.2.I.2I8

Ars Poet.296

Carm.1.12.5

Serm.1.5.2

Serm.2.3.277

Epod.2.57

Epod.5.67

Serm.2.4.29

Epist.1.10.19

Epist.1. 14.35

Epist.2.2.149

Epist.2.2.150

Esist. 1.7.42

Epod.5.21

Serm.1.8.22

Serm.r.8.49

Itpod.3.7

Carm.3.23.I I

Corm.4.2.55 


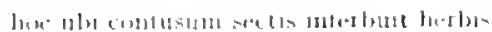

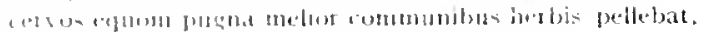

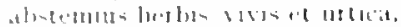

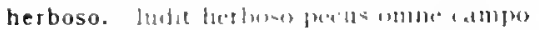

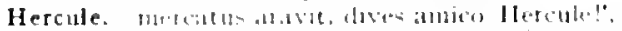

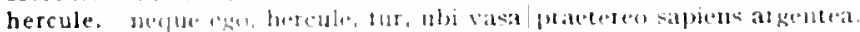

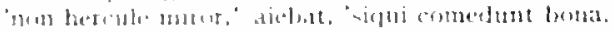

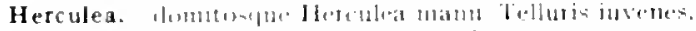

Herculem. sinci follentem ereve in Heroulem

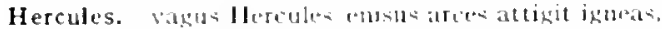

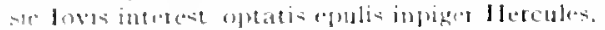

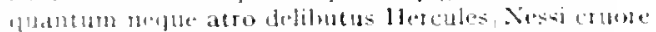

Hesculeus. Jertupie Achesomat liesculeus labor -

Herculis. IJerollic ntu modo alictus,

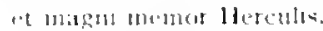

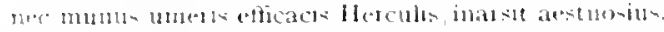

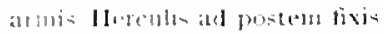

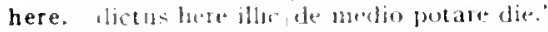

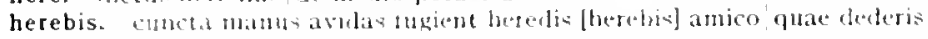
animus.

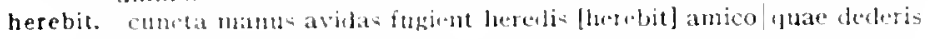
an)เm!n.

heredem. Jura heredem alterius velut unda supervenit undam,

heredes. luereles staberi summam meiclose sepuloso.

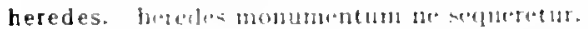

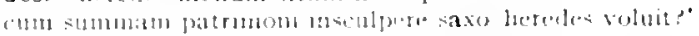

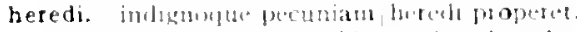

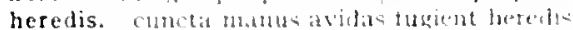

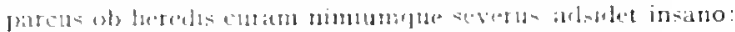

heres. (loveris putietur beres.

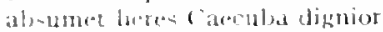

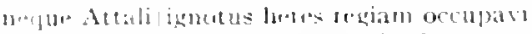

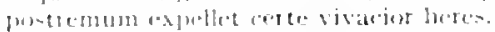

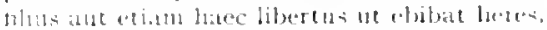

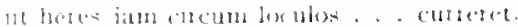

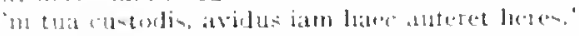

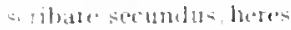

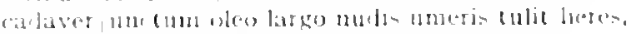

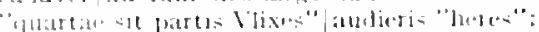

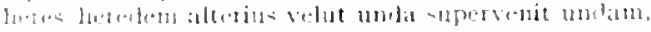

mor metrim, qual de me indicet heres.

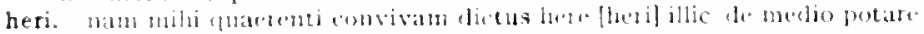
(और:

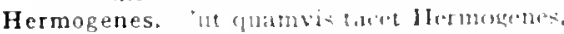

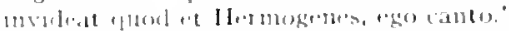

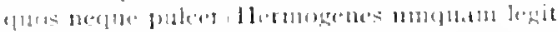

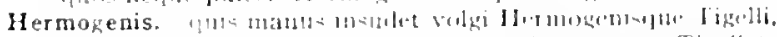

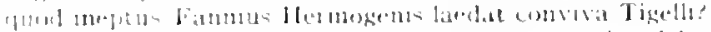

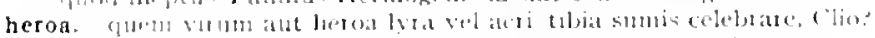

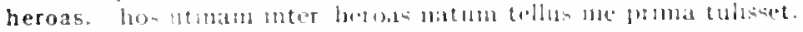

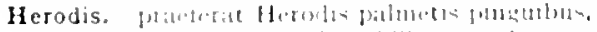

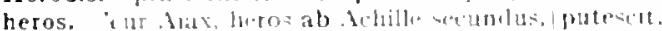

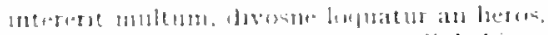

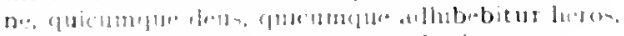

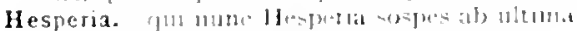

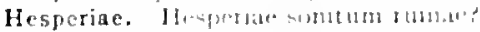

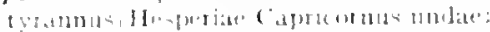

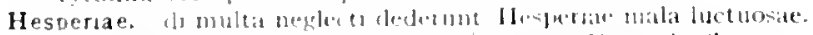

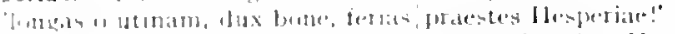

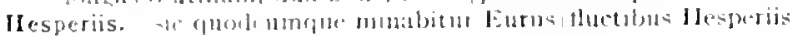

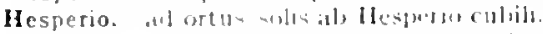

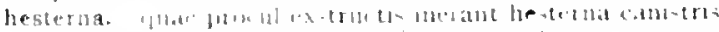

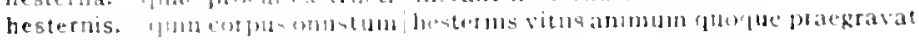
inthit

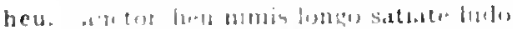

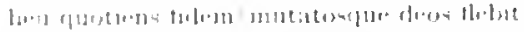

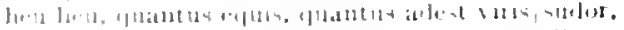

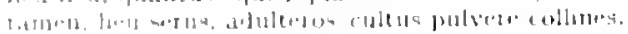

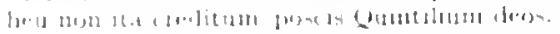

sorm $2+107$

I.p.s.t.1.10.34

Foptit.12.7

(arm.3180)

sirm.24.13

Sorm 2.7.72

lipist.1.15.4t

(iirm.2.12.4

(earn.t.4.t.

( ism 3.3.

cism..ts.30

L. port. 17.31

(itrm.1.3.3t)

(arm.3.14 I

(armats.3e

1.juitioly

1.p.st.1.5.

virm.2.8.2

firr.ciom.4.7.19

Fith Cirm.1.7.19

Eptst.2.2.17\%

Sirm.2.3.84

Girm.1.8.13

virm 23.01

(ivm.3.24.12

(iirm. 7.10

Lipt.8.1.5.13

(iorm.2.3.20

(iorm. 2.1.425

(iurm 2.180

sirm.2.2.132

sirma3.1.32

Serm.2.3.145

Sirm 2.3.15t

itim. 2.5 .40

virm.2.5.80

Sirme.5.101

lipiv.2.2175

I.pest.2.210

:'th.siren. 2.8.2

serm.13.120

Sirmis. 13.25

termis.10.18

som.1.12

1) 19.1 .10 .80

( arm.1.12,1

Virmin2.293

L.pis 2.2.184

जyid2.3.103

Ars lintili

- Irs livit.zy

(arm 1.36it

(ivrm.2.1.32

(ivm.2.17.20

(armases

(iurm.i.5.35

( 1 rom 1.28 20

(a)m +15.10

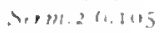

Sirm.2.2.75

(arm.1.2.37

(itrm.15.5

( a) 1.1509

(ivm 1.15.19

(arm) 2.4 .11 
heu heu. cicatricum et sceleris pudet |fratrumque. eheu [? heu heu] fugaces, Postume, Postume, labuntur anni eheu [? heu] fugaces, Postume, Postume, labuntur anni . euhoe. parce Liber, [? heu hoe, Bacche, precor.] quatenus, heu nefas.|virtutem incolumem odimus, sed cur heu, Ligurine.

sed palam captis gravis, heu nefas, heu,

dices 'heu.' quotiens te in speculo videris alterum. quo fugit venus, heu,

neque hoc parentes, heu milii superstites.

heu me, per Vibem . . fabula quanta fui,

ad non amicos heu mini postis et heu/limina dura. .

heu heu, translatos alio naerebis amores.

barbarus heu cinetes insistet victor

heu pervicacis ad pedes Achillei.

o [heu] si urnam argenti fors quae mihi monstret.

"heu. Fortuna. quis est crudelior in nos te deus?

seu [hell] linguam causis acuis seu [heu] civica iura' respondere paras ac vos! seu [heu] catidus sanguis seu [heu] rerum inscitia rexat indomita cervice feros?

"triens." 'eu [heu]! rem poteris servate tuan.

heus. 'heus, tu' quidam ait 'ignoras te

hi. omnes hi metuont versus, odere poetas.

hiantem. pmptorem inducat hantem.

plerumqut recoctus|scriba ex quinqueviro corvom deludet hiantem

hiatu. quid dignum tanto feret hic pronissor hiatu?

Hiber. me meritus discet Hiber Rhodanique potor.

Hiberi. garo de sucis piscis Hiber:

Hiberia. herbasque, quas I olcos atque Hiberia|mit it

Hiberiae. quis ferae bellum curet IJiberiae?

duraeque tollu- audit Hiberiae.

Hibericis. Hibericis peruste funibus latus

Hiberis. libro Panati socraticam et domum mutare loricis Hiberis.

hiberna. nec Huvii strepunt hiberna nive turgidi.

hibernas. Irurius "hiberna = cana nive conspuet Alpis.,"

hiberno. tu piscis hiberno ex aequore verris.

hibernum. ruebat Humen ut Jibermum.

hibernum. turbaret hihernum mare

hibernus. tonantis annus bibernus Iovis

Deptumus alto tundit hibernuc salo.
Carm.1.35.33

ivar.Carm.2.14. I

7 var.Corm.2.14.I

inar.Carm.2.19.7

Curm.3.2. $33^{\circ}$

Carm.4.1.33

Carm.t.0.17

Carm.t.10.6

Carm+4.13.17

Epod.5.101

lepod.II.7

Lpod II.2 I

Epod. 15.23

Epod.16.1 I

Fpod.17-1

cer serm.2.6.10

Sirm.2.8.t I

s.tir. Epist.1.3.23

F'ar. Epist.1 3.33

zer..trs Poet. 328

Serm.1.3.2I

sirm.1.4.33

Sirm.1.2.85

sirm.2.5.50

Ars Puit.izs

Carm.2.20.20

Sirm.2.8.10

Epod 5.21

Carm +.5.28

Carm 4.1450

Fond.4.3

Carm.1.20.15

Curmt. 2.4

Serm.2.5.4 1

Serm. 2.3-235

serm.1.7.27

Epod I 5

Fpod.2.20

lipod.17.55

fierm.1.7.2

hibrida. librila quo pacto sit Persils ultus.

hic. Carm.1.21.13; Far.Carm.1.21.13; Carm.2.19.30; 2.18.38: 3.1.10; 3.1.12; 3.5-37; $31.15 ;$ Curm.3.8.0; 3.14.13: 3.20.4; 4.8.7; Epod.4.11; 7.11; 11 5; Serm.1.1.20) 1 2.4; 1.2.14; Strm.1.2.19; 1.2.22; 1.2.41:1.2.42; 1.2.43;1.2.49;1.2.80; 1.3.24; 1.3.49; 1.3.50; 1.3.58; Serm.1.4.27 (bis); 1.4.20; Fur.werm.1.4.35; Sorm.1.4.85: 1.4.90; 1.4.100; 1.4.126; 1.0.29; temm 1.0.42; 1.7.t; $1.9 .51 ; 2.1 .39 ; 2.2 .2 ; 2.2 .31 ; 2.2 .040 ; 2.2 .82 ; 2.2108 ; 23.30 ; 2.3 .50 ;$ ior.term.2.3.71; Sorm.2.3.162; 2.3.105; 2.3.220; 2.7.109; Epist.1.1.61, 1.0.23; 1.6.40;

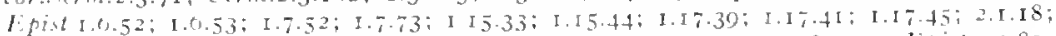
Epist.2.1.1 [8; 2.2.3; 2.2.14;2.2.59; 2.2.07 (bis); 2.2.08; 2.2.09; 2.2.89; :ur.t.pist.2.2.89; Lipit.2.2.91; 2.2.130; Ars Podt $138 ; 1+0 ; 258 ; 345$ (his); 457

hic. Corm 1.2.49; 1.2.50; 7ar.Carm.1.17.14; Carm.1.17.17; 1.17.21; 1.19.1.3 (his); 1.34.16; Carm.3.26, (bis); coni.Carm.3.29.6; Lfod.5.47; Torm.1.5.7; 1.5.30; 1.5.42: 1.5.89;

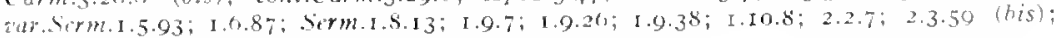
Serm.2.3.221;2.8.16; Epist.1.1 1.29; I. I7.39;2.2.84

hiemat. atrum defendens piscis hiemat mare:

hiemes. est ubi plua tepeant hiemes.

hiemes. sell pluris hiemes seu tribuit Iuppiter ultimam. post certas hiemes uree Achaicus ignis fliacas fomos." intormis hiemes reducit, Iuppitro culpante. . . munc hiemes iniqua-.

hiemet. naviget ac medis hiemet mercator in undis.

hiemis. aridas frondes hiemis sodali dedicet Euro.

hiemps. neque hiemps ignis mate fertum.

hiems. solvitur acris hiems grata vice veris et Favoni Eois intonata t]uctibus hiens quae sit hiems Veliae, quod caelum. Vala, Salerni.

hiet. hietcue turpis inter atidas natis porlex lupus hic Tiberinus an alto captus hiet?

hilarem. oderunt hilarem trictes tristemque iocosi,

Serm.2.2.17 EPTSt.10.I5 Carm.1.11.4 ("urm. I. I.5.35 Cirm.2.10.15 (arm.3.1.32

Epist.1.10.7 I Carm.1.25.19

Scrm. I. I. 39

Carm.I.4. I

Spod 2.52

Epist. I. I.5. I

Fpod.8.5

ferm.2.2.32

Fpist. I 18.80 
hilaris. quantum simplex hilarisque nepoti/discrepet

hillis. magis hillis/flagitat innorsus refici.

hine. hine tibi copialmanabit ad plenum

hate [hinc] bellum lacrimosun... . aget .

hinc apicem rapax|fortuna cum stridore acutolsustulit.

hinc avilus stetit / Volcanus.

hinc matrona Iuno.

hinc oune principium, huc refer exitum:

quando et priores hinc Lamias ferunt/denominatos.

bine ad vina redit laetus

trudit acris hinc et hine multa cane/apros.

vos turba vicatim hine et hinc saxis petens

ad bunc [at linc] frementis verterunt bis mille equos/Galli

hinc vos. vos hine nutatis discedite partibus.

vos hine mutatis discedite partibus.

hinc ommis prondet Lucilius, hosce secutus.

hinc muli Capuae clitellas tempore ponunt.

hine nos Coccei recipit plenissima villa.

truflimus hinc recta Beneventum.

quattuor hinc rapiun viginei et milia raedis.

flentibus hine Varius disceelit maestus amicis.

persequar hinc quo nunc iter est tibi."

hinc r.petit. 'paucorum hominum et mentis berse sanae:

equidem nihil hinc diffindere possum.

guantum hinc inminuet?

'ocius line te ni rapis.

hic fhincl ubi saepeloccultun visus decurere piscis ad hamum. . iubetur

hinc illate lacrimae.

vivas hinc ducere voces.

hinnitum. tubi tollit hinnitum /apea guadrigis equa.

hinnuleo, vitas hinnuleo me similis, Chlor.

Hiolcos. herbusfuce quas Jolcos [1Jiolcos] atque Hiberia|mittit vencnorum ferax.

Hippolyten. Magnessam Hippolyten dum fugit abstinens.

Hippolytum. neque enim tenebris Diana pudicum/Jiberal Hippolytum

hircinis. at $t$ conciusas hircinis follibus auras,

hircum. pistilloa Kuffllns olet, Gargonius hircum: .

"go sifi, ruol ineptus| pastillos Rufillus olet. Gargonins hircum"

colrmine qui tragico vilem certavit ob hircun.

hircus. polypu an gravis hirsutis cubet hircus in alis, . ancepuse salsa levis hircus aequora."

Hirpine. quil bellicous Cantaber et Scythes. | Hirpine Quinti, cogitet

hirsutis. polypus an gravis litsutis culret hircus in alis.

hirtum. non thbi parvom/ing (niam, non incultum est et turpiter hirtum:

hirudo. non miscura cutem nisi plena cruoris hirudo.

hirundine. te, dulcis amice. reviset/cum Zephyris, si concedes, et hirundine joirna.

his. ve! "ur his in incolumes non redeunt genae?"

alis maborm natura modum dedit, his breve pondus: cbut.

verum aget his, guiselectoricrelere malunt . . curam reddebrevem. successit vetus his conochia, non sine multa/bande;

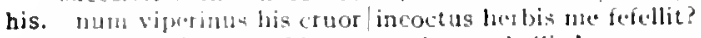
ingrimat lis cura $\mathbf{M a c c e n a s}$ signa tabellis.'

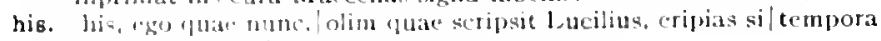
calla fuic patr.t lis.

ne foret his teatis, post magna littere sepulera.

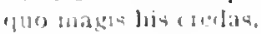

equi tumet lis ahereat.

aeel nume jeen erat his locus.

his. non has inventus orta porentibus

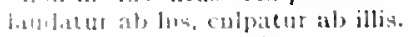

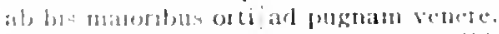

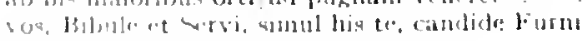

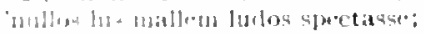

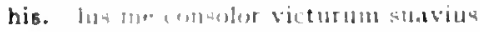

nac matgin has allimbles maht;

Epist.2.2.193

Sirm.2.4.60

Carm.1.17.14

var.Carm.1.21.13

Corm.1.34.14

Carm.3.4.58

Corm.3.4.59

Corm.3.6.6

Curm.3.17.2

Corm.4.5.31

lipod.2.3 I

IPpod.5.97

cons.lipod.9.I 7

Sermi.1.17

Serm.t.I.18

Serm.j.4.6

Serm.1.5.47

Sorm.5.5.50

Serm.1.5.7I

Serm.1.5.86

Serm.1.5.93

Serm.1.0.16

Sirm.1.9.44

Serm.2.1.79

Serm.2.2.127

Scrm.2.7.117

rar.Epist.1.7.73

Epist.1.19.4I

Ars Podt.318

Corm.2.16.34

Carm.1.23.1

tar.I.pod.5.2 I

Carm.3.7.1 8

Corm.4.7.26

Serm.1.4.19

Serm.1.2.27

Serm.1.4.92

Ars Port.220

Epod.12.5

Epod.16.34

Corm.2.11.2

Epod.1 2.5

Epist.t.3.22

Irs I'oct.476

Epist. I. 7.13

Carm.4.10.8

Serm.2.2.37

var Epist.1.6.53

fipist.2.1.21 4

Ars Ploct.28I

Epod.3.6

Serm.20.38

ficrm.1.4.50

Serm.1.0.7

Serm.1.8.36

Sirm 2.2.112

lipist.t.t.e

liss Podtag

Ciarm.30.33

ierm.1.2.1 I

Serm.1.5.55

siorm. 1.10 .80

Sierm.2.8.79

Sicrin.r.t.130

sorm. 19.50 
si puerilius his ratio esse evincet amare

et paulum silvae super his foret.

potesnelex his ut proprium quid noscere?

his ut sublatis puer alte cinctus

his mixtum ius est: .

restat ut his ego me ipse regain solerque elementis. .

his utere mecum.

his verbis vacuas permulceat auris;

aut ursum aut pugiles: his nam plebecula gaudet.

pallescet super his, etiam stillabit amicis/ex oculis rorem,

hisce. pluribus hisce, / si modo plura mihi bona sunt, inclinet,

hiscine. hiscine versiculis speras tibi posse dolores/atque aestus curasque gravis e pectore pelli?

Hispana. Caesar Hispana repetit penatis/victor ab ora.

Hispanae. seu navis Hispanae magister. servit Hispanae vetus hostis orae

hispidam. Ligurine, in faciem verterit hispidam,

hispidos. non semper imbres nubibus hispidos|manant in agros .

Hister. Nilusque et Hister, . . a audit

historias. peccare docentis|fallax historias monet.

amaras|porrecto iugulo historias captivos ut audit.

historiis. dices historiis proelia Caesaris.

boc. Carm.3.3.69; 3.10.19; 4.3.21; Epod.1.23; 3.5; 5. 501; Serm.x.1.78; 1.2.2; 1.2.81; 1.2.97; Serm.1.3.1; 1.3.83; I.4.24; 1.4.65; 1.4.77; I.4.124; 1.4.134; I.4.139; 1.6.44; 1.6.49; Serm.1.7.35; I.8.I0; I.I0.46; $2.1 .21 ; 2.2 .69 ; 2.3 .41 ; 2.3 .308 ; 2.3 .32$ I; $2.4 .7 ; 2.4 .20 ; 2.4 .67$; Serm.2.5.73; 2.6.I; 2.6.32; 2.7.3; 2.8.32; Epist.I.I7.I9; I.I7.45; I.20.I7; 2.I.I82; Ars Poet.20

hoc. Carm.I.8.2; 1.15.32; 2.8.13; 3.5.13; 3.14.27; 4.4.45; Epod.2.52; 5.7; coni.Epod.9.17; Epod.17.63; rur.Serm.1.2.19; Serm.1.2.54; 1.2.90; 1.3.4; 1.3.60; 1.3.115; 1.4.79; 1.4.80; Serm.1.4.104; 1.4.105; 1.4.122; I.4.135; I.4.136; I.5.5; 1.6.8; 1.6.02; I.10.3; I.10.5; Serm.I.I0.68; 2.I.36; 2.I.5I; 2.2.7; 2.2.1 $23 ; 2.3 .88 ; 2.3 .89 ; 2.3 .98 ; 2.3 .132 ; 2.3 .152$; Serm.2.3.155; 2.3.170; 2.3.286; 2.3.306; 2.4.49; 2.5.1; 2.5.20; 2.5.66; 2.6.42; 2.6.44; Serm.2.6.47; 2.8.25; 2.8.3 I; 2.8.43; Epist.1.3.6; 1.3.28 (bis); 1.3.30; 1.6.30; 1.6.31; Epist.1.6.48 (bis); I.8.16; 1.16.33; I.16.79; 1.18.88; 1.19.10; 2.1.102; 2.I.120; 2.1.125; Epist.2.1.175; 2.2.13; 2.2.24; 2.2.23; 2.2.34; Ars Poet.45 (bis); 367; 393; 439 (bis); Ars Poet.468

hoc. Corm.3.0.19; Ipod.4.20 (bis); Serm.1.1.56;2.2.24; 2.3.5I

hoc. Epod.3.12; 3.13; Serm.1.1.I3; I.I.46; 1.2.53; 1.2.64; coni.Serm.1.2.134; 1.3.34; 1.3.93; Serm.1.4 9; 1.4.129; 1.6.41; 1.6.52; 1.6.87; 1.6.110; 1.7.10; 1.9.8; 1.10.*3; 1.10.17(bis); Serm.1.10.60; 2.3.148; 2.8.49; Epist.I.I.I I; var.Epist.2.1.I 8

hoccupat. das aliquid famae, quae carmine gratior anrem / occupet [loccupat] humanam?

hodie. quae mens est hodie, cur eadem non puero fuit non, hodie silexclusus fuero, desistan;

hodie tricesima sabbata:

nigrisque est oleis hodie locus.

orabant hodie meminisses, Quinte, reverti.

'non dices hodie. quorsum haec tam putida tendant,

'ut libet: haec porcis hodie comedenda relinques."

si cenas hodic necum.'

qui dedit hoc hodie, cras si volet auferet,

manserunt hodieque manent vestigia ruris.

hodiernae. an adiciant hodiernac crastina summae/tempora

hoe. euhoe, parce Liber, [? heu hoe, Bacche, precor,]

halitoris. Thraex erit aut holitoris aget mercede caballum.

holus. panis ematur, holus, vini sextarius.

percontor quanti holus ac far,

donec|decocueretur holus.

bolus. quicquam praeter liolus fumosae cum pede pernae. laudas securum holus

nec modica cenare tines holus omne patella.

'si pranderet holus patienter, regibus uti|nollet Aristippus.'

'si sciret regibus uti, fastidiret holus, qui me notat."

emptor Aricini quondam Veientis et arvi emptum cenat holus,

holuscula. uncta satis pingui ponentur boluscula lardo?

homaso. infantis statuas, seu pingui tentus omaso [homaso]

Homereum. honoratum [Homereum] si forte reponis Aclillem,

Homeriacum. honoratum [Homeriacum] si forte reponis Achillem,

Homero. tu nihil in magno doctus reprehendis Homero? 7or.serm.2.2.93

Carm.t.10.7

Serm.1.9.57

Sirm. I.9.69

Sirm.2.2.46

Sirm.2.6.37

Serm.2.7.2I

Epist.1.7.19

Epist.1.7.70

Epist. I 10.33

Epist.2.1.160

Carm.4.7I7

7 var.Carm.2.19.7

Epist.I.18.30

Serm.1.I.74

Serm.1.6. I 2

Sirm.2.1.74

Serm.2.2.II

Serm.2.7.30

JEpist.1.5.2

Epist.1.17.13

Epist.1.17.15

Epist.2.2.I65

Serm.2.6.64

"ur. Sirm.2.5.40

coni.Ars Poet. 20

coni.drs Poet. 20

Serm.t.10.5= 


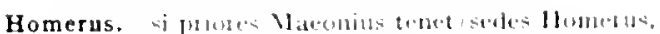

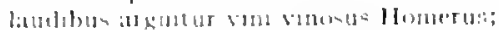

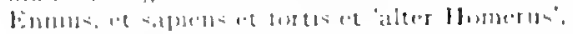

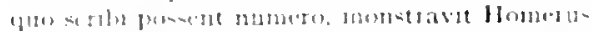

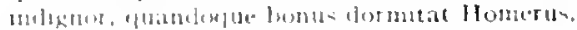

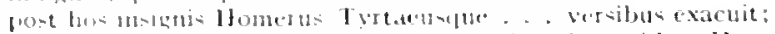

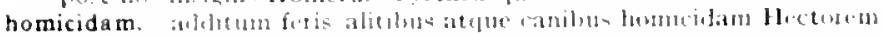

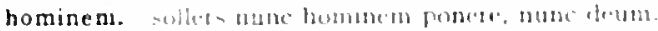

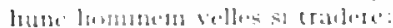

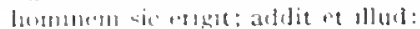

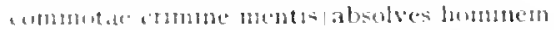

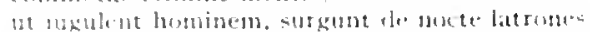

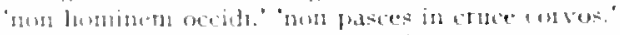

homines. :- thb regnum petuictant bommes. unde humats operum primos vateque lalugen m-tituont

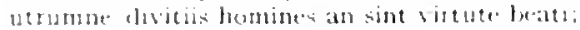

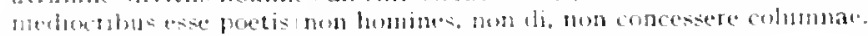

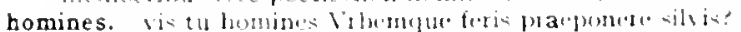

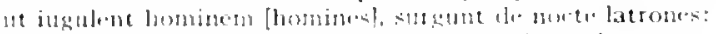

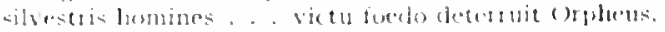

homint. jurnis nom homini date:

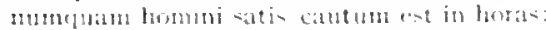

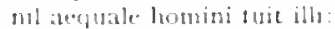

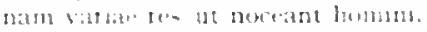

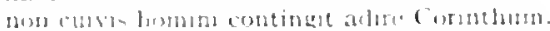

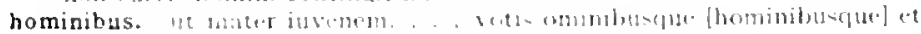

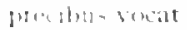

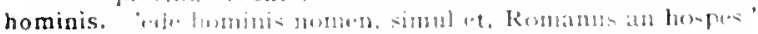

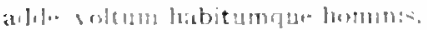

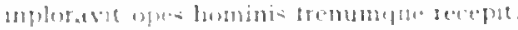

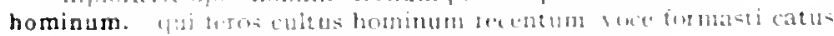

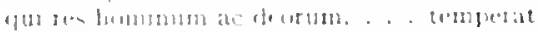

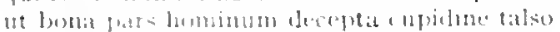

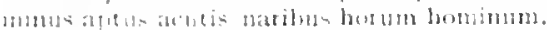

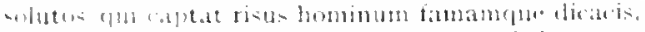

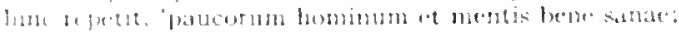

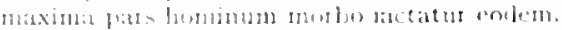

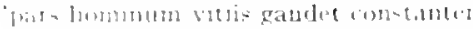

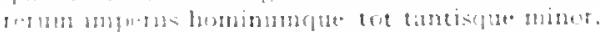

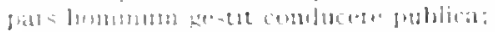

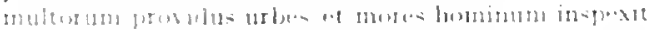

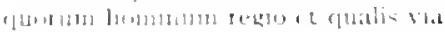

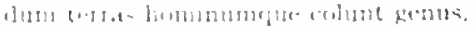

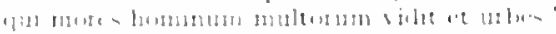

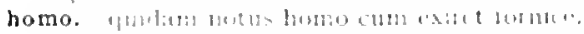

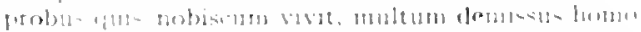

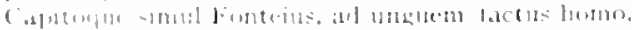

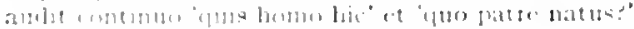

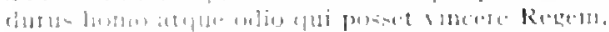

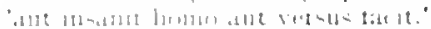

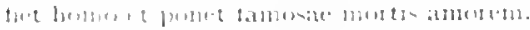

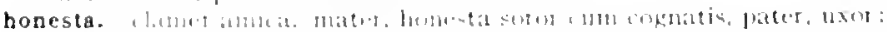

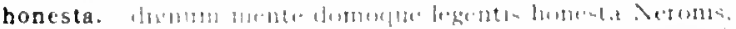

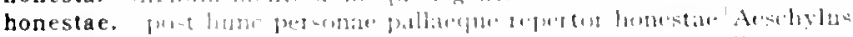

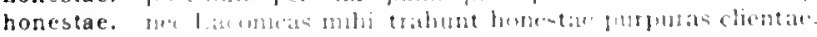

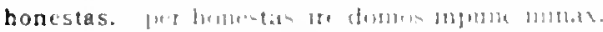

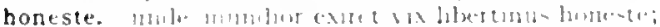

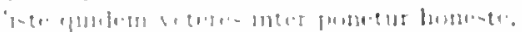

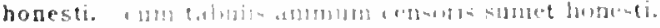

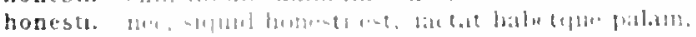

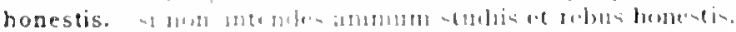

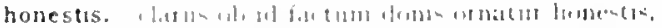

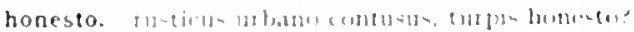

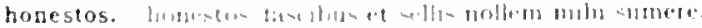

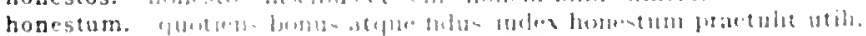

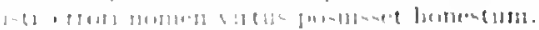

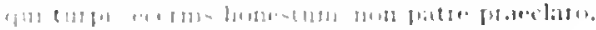

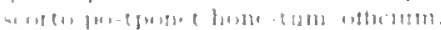

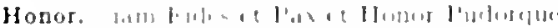

(arm.4.0.(1)

lisistitiog

List.2.1.51"

Ars Mort.its

Ars $120+1.350$

irs linet.and

inpolitiot

(arm...4.8.

Tirm.1.9.47

Sirm.2.3. $55^{\circ}$

sirm.2.3.270

Lisist.1.2.32

fipist.1.10.48

srm.1.3.124

Dirm.201.21

Term.201.7.1

Ars flut:37.3

Sirm.2.1.0)2

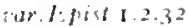

Lrs 1111.301

ciom.t.3.35

(arm.2.13.13

Serm.1.3.

Sermi.2.2.72

l.pit t.

asr.cirm.: $: 53$

cormanile

Serm.2.1.12

l:pret.1.11).36

(i.rmel.tor.

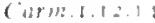

Sermal.1.1.1

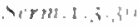

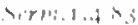

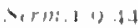

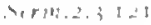

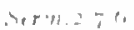

romezos

l.fited.1.;

1 pid.1.2.211

l.pist.1.15.2

tifit.z.t.

Ir) fix: :12

S.r⿲丿丨.

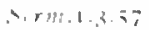

s.rmt.1.5.3.3

Dirme (1.20)

serm.t.7.4

serm.2. 717

ir 1000 , f(1)

sirm.2.3.58

1.pantal a)

Irs Jard zog

( iarm.2.14s

l.pit.2.1 J.fo)

sermiz.7.12

1 pon. 2.1 .13

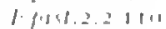

hermet.2.n.t

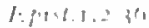

1. put $2 \div 32$

1rilled 213

iermet.cine

(ism : 40.11

Sirm 1.3 .82

serm 1 pepes

I pold as at

(armalat 5i 
honor. non semper idem floribus est honor/vernis. notus in voltus honor. cocto num adest honor iden? falsus honor iuvat et mendax infania terret sic honor et nomen divinis vatibus atque/carminibus venit.

honoratum. honoratum si forte reponis Achillem.

honoratus. sapiens. . liber, honoratus, pulcer, rex denique regum,

honore. plurimus in Iunonis honorem [honore] aptum dicet equis Argos

hinc tibi copia / manabit ad plenum benigno / ruris honorun [honore] opulenta cornu.

quod numero plures, virtute et honore minores,

sine pondere erunt et honore indigna ferentur. .

cadentquelquae nunc sunt in honore vocabula.

honorem. plurimus in Iunonis honorem|aptum dicet equis Argos beatae coniugis additum / stellis honorem

silvis honorem decutit.

des nominis huius honorem. .

populus Laevino mallet honorem/quam Decio mandave novo

ut forsit honorem /ure mihi invideat quivis.

nec veniam antiquis sed honorem et praemia posci. .

honores. nil sine te mei prosunt honores:

honores. proximos illi tamen occupavit Pallas honores cui laurus aeternos honores|Delmatico peperit triumpho. sepulcri|mitte supervacuos honores. transmutat incertos honores, qui stultus honores/ saepe dat indignis quoscumque feret cultus tibi fundus honores responsare cupidinibus, contemnere honores/fortis. praesenti tibi maturos larginur honores ut alter|alterius sermone neros audiret honores.

honori. quaerit opes et amicitias, inservit honori.

honoribus. certat tergeminis tollere honoribus, intaminatis fulget honoribus

et vixisse probos, amplis et honoribus auctos;

honoris. tantum de medio sumpt is accedit honoris.

honorum. copia.. benigno|ruris honorum opulenta cornu. plenis honorum muneribus

Honos. Ifonor [Honos] Pudorque |priscus neglecta redire Virtus/audet

honos. pudicum.|qui primus virtutis honos, quid pure tranquillet, honos ac dulce lucellum nedum sermonum stet honos et gratia vivax. sic honor [honos] et nomen divinis vatibus atque/carminibus venit.

honustos. meis contentus honestos [honustos] fascibus et sellis nollem mihi sumere,

hora. et mihi forsan tibi quod negarit ! porriget hora. Hagrantis atrox hora Caniculae quod fugiens semel hora vexit. a)mun! quac rapit hora diem. detur nobis locus, hora, / custodes; dum aes exigitur, dum mula ligatur, / tota abit hora. nugas /hoc genus: 'hora quota est?" grata supervenet, quae non sperabitur hora.

hora. conposita repetantur hora, in hora saepe ducentos, /ut magnum, versus dictabat quarta vix deunu exponimur hora.

horae. pars violentior natalis horae. dona praesentis cape laetus horae $\langle$ ac $\rangle$ |linque severa. horae momento cita mors venit aut victoria lacta.' neu fluiten dubiae spe pendulus horae.' puncto quorl nobilis horae. . permutet dominos

horam. per totum hoc tempus subiectior in diem et how am invidiac noster. non horam tecum esse potes.

idem eadem possunt horam durare probantes?

qui recte vivendi prorogat horam.

ab officis octavam circiter horam /dum redit

tu quamcumque deus tibi fortunaverit horam

si te grata quifs et primam sommus in horam / delectat,

qui purgor bilenı sub verni temporis horam.

horas. numouam homini satis/cautum est in horas: (arm.2. I I.

Epod.17.I 8

Sirm.2.2.28

Iipist.1.10.39

Ars Pott.too

Ars Poet.1 20

Epist.I.1.T07

conti.Carm.1.7.8

mar. Curm.1.17, I6

Epist.2.1.183

Epist.2.2.112

Ars Podt.7I

Carm.1.7.8

Corm.2.19.I4

Epod. I I

Sirm.1.4.4t

Sermi.6.19

Serm.1.0.49

Epist.2.1.78

Carm.1.26.10

Carm.1.12.20

Curm.2.1.15

Carm.2.20.24

Carm.3.29.51

Sirm.1.10.I 5

Sirm.2.5.13

Sirm.2.7.85

Epist.2.1.15

Epist.2.2.85

Ars Poet.167

Carm.1.I.8

Carm.3.2.18

Serm.1.6.II

Ars Poes.24.3

Corm.1.IT.20

Carm.1.1.2

qar.Carm.Sacc.57

Serm.1.0.83

Iipist.I.IS.102

irs Poet.6o

s'ar.Ars Pott.400

rar. Serm, I . 0.06

('irm.2.10.32

Carm.3.13.9

Carm.3.29.48

Carm.4.7.8

Serm.1.4.15

Sorm. T.5.14

Sirm.2.6.44

Epist.I.4.14

Carm.1.9 20

Serm.1.4.9

Sirm, 1.5.23

(iurm.2.17.19

carm.3.8.27

Sirm.I.I.7

Ipint.18.110

Epist.2.2.172

firm.2.t.47

Sirm.2.7.112

Epist.1.1.t2

Epist 1.2.41

Epist.1.7.47

Epist.1.11.22

Ipist.1.17.0

Ars Poet.302

("arm.2.13.1. 
clavom ut mutaret in horas.

quattuor aut plures anlaea premuntur in horas,

Iram $/$ colligit ac ponit temere et mutatur in horas.

Horati. ibi tu calenten | debita sparges lacrima favillam / vatis amici [Ilorati].

reddidi carmen. docilis modorum/vatis Horati."

Horatius. inclior sit Horatius an res.

horis. qui mare ac terras varisque inundum/temperat horis? nunc veterum libris, nunc somno et inertibus horis. uncoluncu tibi me praestant septembribue horis.

horoa. si cure placaris et horna/fruge Laris

cum pater ipse domus palea porrectus in horna

horna. et horna flulci vina promens dolio

horrea. quid vici prosunt aut horrea?

horreis. qui nunc Sulpicis adcubat horreis.

horreis. occultare meis dicerer horreis.

horrenda. horrenda late nomen in ultimas/extendat oras.

horrendam. Jorrendamque cultis/diluviem ineditatur agris. non dico horrendam rabiem' -

horrendas. pallor titrasquelfecerat horrendas adspectu.

horreodus. Juvenis Parthis horrendus, ab altoldemissum genus Aenea.

borrentia. horrentia pilis/agmina

horreo. ilium. si proprio condidit horreo

parcis deripere horreo/cessantem Bibuli consulis amploram.

horres. 'quando pauperiem missis ambagibus horres.

horrescis. dum procellas/cautus horrescis, nimium premendo/litus iniquom. horret. neque liorret iratum mare

horret capillis ut marinus asperis/echinus

'negat inprobus et te|neglegit aut horret."

hic onus horret. | ut parvis animis et parvo corpore inaius;

imi|derisor lecti sic nutum divitis horret.

quem paupertatis pudor et fuga, dives amicus, . . odit et horret.

horribilem. Rhoetum retorsisti leonis/unguibus horribilemque mala; .

horribili. horribilique Medo/nectis catenas?

horribili. Rhoetum retorsisti leonis/ungubus horribilemque [horribilique] inala:

horribili. ne scutica dignum horribili sectere flagello.

horribilis. Rloetum retorsisti leonis|unguibus horribilemque [horribilisque] inalia:

horrida. quo Sty $x$ et invigi horrida Taenarilsedes

filens iuventus horrida bracchiis.

Germania quoq horrida parturit / fetus

lorricla cumpestas caelum contraxit

horrida. quam virga semel horrida

horrida. horridit callidi/vincunt aequora navitae.

horridam. horrendamque [? et horridam] cultis diluviern meditatur agris, . horridi. horridilatumeta Silvani

horridis. ut horidia utrumque verberes latus.|Auster. menento fluctibus;

horridus. non ille... . te neglegit horridus:

sic hortilus alle/delluxit numerus Saturnius

horruerim. looruerim voces Furiarum et facta duarum.

hortaretur. cum ne hortaretur. parce frugaliter atque | viverem uti contentia eo

hortari. castellum ivertere praetor/nescio quod cupiens hortari coepit

hortatur. fibj lostunae te responsare. . pracsens hortatur et aptat?

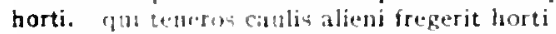
unvilve เusum|lignorum et pecoris tibi calo argutus et horti.

hortis. vetatque movis considere in hortis.

nunc sonuo et inrtibus horis (hortis)/ducere solicicae iucunda oblivia vilar:"

horto. Pris horto. Phylli, nectendis apium coronis. unrugus nihil at elutius horto.

bortos. truna Tibreirs longe cubat is prope Caesaris hortoy.' horcos expesiandue doisos mercarier unus/cum lucro noram: .

bortus. burtus nbu et tecto vicinus iugis ą̧uae fons

horum. minua astus acutis|naribus hortsm hominum.

prapunties. Austri, contuite horum ohsonia.

fu.li tgltur betu apiens utecur et hortun |ucrum imitabitur?

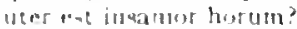

Serm.2.7.10

Epist.2.1.189

Ars Poct.160

rar.Carm.2.6.24

Carm.4.6.44

Epist.1.J4.5

Carm.1.12.16

Serm.2.6.6I

Epist.1.16.16

Carm.3.23.3

Serm.2.6.88

Epod.2.47

Epist.2.2.177

Carm.4.12.18

Corm.3.16.27

Carm.3.3.45

Carm.4.14.27

Serm.2.3.323

Serm.1.8.26

Serm.2.5.62

Serm.2.1.13

Carm.1.1.9

Carm.3.28.7

Serm.2.5.9

Carm.2.10.3

Epod.2.6

Iipod.5.27

Epist.1.7.6.4

Epist.1.17.39

Epist.1.18.1I

Epist.1.18.25

coni.Carm.2.19.24

Carm.1.29.4

var.Carm.2.19.24

Serm.1.3.119

iar.Carm.2.19.24

Carm.1.34.10

Carm.3.4.50

Carm.4.5.26

Epod.13.1

Carm.1.24.16

Carm.3.2.4.40

8 irar.Curm.4.14.27

Corm.3.29.22

Epod.10.3

Corm.3.21.10

Epjist2.1.157

Serm.1.8.45

Serm.1.4.107

Epist.2.2.35

Epist.1.1.60

Serm.1.3.116

Epist.1.14.42

Serm.1.8.7

ar.Serm.2.6.6I

Carm.4.11.2

Serm.2.4.1"

Serm.1.0.1 8

Serm.2 3.2 .4

Sorm. 2.0.2

Serm 1.330

Sierm.2.2.41

Serm.2.2.63

Serm.2.3.102 
quidquid et horum/cuique domi est.

Sirm.2.3.23I

horum tu in numerum voto ruis; .

utrius horum verba probes et facta, doce.

horum. horum|semper ego optarim pauperrimus csse bonorum. . si veneror stultus nihil horum

hos. Romulum post hos prius . . dubito,

hos utinam inter/heroas natum tellus me prinu tulisset.

adde hos praeterea casus, aulaea ruant si, .

hos ediscit et hos arto stipata theatro|spectat Roma potens.

habet hos numeratque poctas

post hos insignis Homerus|Tyrtaeusque . . versibus exacuit;

hosce. hinc onmis pendet Lucilius, hosce secutus.

hospes. nec Lacaenae splendet adulterae|famosus hospes

ubi sedulus hospes|paene macros arsit

quod hospes / tardius adveniens vitiatum commodius . . consuneret.

ac mihi seu longum post tempus venerat hospes

"ede hominis nomen, simul et, Romanus an hospes."

si vespertinus subito te oppresserit hospes.

veterem vetus hospes amicum,

veluti succinctus cursitat hospes.

quo ne cumque rapit tempestas, deferor hospes.

non quo nore piris vesci Calaber iubet hospes.

bonus sane vicinus, amabilis hospes.

quo sit amore parens, quo frater amandus et hospes.

hospitae. atqui sollicitae nuntius hospitae,

hospitale. tibi hospitale pectus et purae manus

hospitalem. umbram hospitalem consociare amant|ramis?

hospitam. cum traheret per freta navibus/Idaeis Helenen perfidus hospitam. .

hospitem. cum periura patris fides|consortem socium fallat et hospites [hospitem]

hospites. mire sagacis falleret hospites consortem socium fallat et hospites quid inmerentis hospites vexas.

hospitibus. visam Britannos hospitibus feros

hospitiis. ut tamen artum/solveret hospitis animum.

hospitio. egressum magna me accepit Aricia Roma/Lospitio nodico.

hospitis. penetralia|sparsisse nocturno cruore/hospitis; sume, Maccenas, cyathos amici|sospitis [hospitis] centum

hoste. sed postquam victor violens discessit ab hoste. inpransus non qui civem dignosceret boste,

hostem. acer et Marsi peditis cruentum/voltus in hostem; demisit hostem vividus impetus.

bellante prior. iacentem|lenis in hostem.

saepe velut qui|currebat fugiens hostem.

caedimur et totidem plagis consumimus hostem

hosti. vehemens lupus et sibi et hosti|iratus pariter.

hostia. mactata veniet lenior hostia. . non sunptuosa blandior hostia.

hostibus. qui perfidis se credidit hostibus

hosticis. Illum ex moenibus hosticis.

hosticus. "hunc neque dira venena nec hosticus auferet ensis

hostile. inprimeretque muris|hostile aratrum exercitus insolens.

hostili. Actia pugna'te duce per pueros hostili more refertur;

hostilis, in hostilis domos|iram atque numen vertite.

hostilium. hostiliumque navium portu latent $\mid$ puppes

hostis. servit Hispanae vetus hostis orae

aut acer hostis Bupalo.

terra marique victus hostis

quo ne per vacuom Romano incurreret hostis.

hostis. sed me per hostis Mercurius celer

res gerere et captos ostendere civibus hostis

hostis. canis | ignavos adversum lupos lignavus vel bis hostis iupos adversum]?

hostium. scriberis Vario fortis et hostium/victor hostium ... consenuit socerorum in armis hostium uxores puerique caecos/sentiant motus inpiger hostium | vexare turmas

huc. huc vina et unguenta et nimium brevis/flores

Epist.1.14.41

Epist.1.17.15

Serm.1.1.78

Sirm.2.0.8

Carm.1.12.33

Sirm.2.2.92

Serm.2.8.7I

Epist.2.1.60

Epist.2.1.6I

Ars Poet.401

Serm.1.4.6

Carm.3.3.26

Serm.1.5.7 I

Serm.2.2.90

Serm.2.2.118

Serm.2.4.10

Serm.2.4.17

Serm.2.6.8I

Serm.2.6.107

Epist.1.I.15

Epist.1.7.14

Epist.2.2.132

Ars Foet.313

Carm.3.7.9

Epod.17.49

Carm.2.3.10

Carm.1.15.2

var.Carm.3.24.60

Carm.2.5.22

Carm.3.24.60

Epod.6.I

Corm.3.4.33

Serm.2.6.83

Serm.1.5.2

Carm.2.13.8

var.Carm.3.8.14

Epist.1.10.37

Epist.1.15.29

Curm.1.2.40

Carm.4.4.10

Carm.Saec.52

Serm.1.3.10

Epist.2.2.97

Epist.2.2.28

Carm.1.19.16

Carm.3.23.18

Curm.3.5.33

Carm.3.2.6

Sirm.1.9.3 I

Carm.1.16.2 I

Epist.1.18.62

Epod.5.53

Epod.9.19

Carm.3.8.2I

Epod.0.14

Ispod.9.27

Serm.2.1.37

Carm.2.7.13

Epist.1.1 7.33

var. Epod.6.2

Carm.1.6.I

Carm.3.5.6

Carm.3.27.21

Carm.4.14.22

Curm.2.3.13 
huc trequens camenta demutit indemptor

finc omme prencipum. Juc seler exitum:

huc et illuc iursitant mixtac puesis purllae.

ut ora vertat lue et huc euntium

quin luc inank, si potes, vertis minas

ad hunc lat luec fromentis verterunt bis mille cous cialli

capaciores adter hus, pure, seyphos

non hise Argon contendit remige pinus

non lud sidonit torserunt cornua nautac.

huc juvents acguom est descendere.

add " huc quod mercem sine fucis gestat,

"lue allyelle"; 'trecentos imseris"; ohe, iam satis est."

huc venturus trat Maecenas optimus atque Cocceins.

huc prius angustis e.jecta cadavera cellis

ut hue novos incola venit?

at ipsis / saturnalibus huc fugisti.

hue propins mo. . . vos ordine adite.

"qui scis, an jrudens huc ste deiecerit

bui. at hun [at hui] frementis verterum bis mille equos calli

huic. huic si mutonis verbis mala tanta videnti diceret baec animus nec magus lusic. . . tuo tenetum est femur

cantat et alponit meus t'st amor huic similis:

decens contena dedisese huic parco, paucis contento:

dum neculd simile huic, esto ut libet."

huic ego volgus errori sinitem cunctum insante docebo.

interdito huic onme adimat ius prator

huic tu/dic. . gaudentem numbo te addecte.

Gracchus ut hilli, foret huic ut Mucius ille.

huic. luic vestem ut gnater, paret ancillas, parct anrum.

huic. Vagate ne pase nalignte harenac| oseibus tec conti inhunato fonpiti lute inhunatoli particulam elase:

callidus thic signo poneban milia centum;

alterun ct hus varum et mihilo sapientins

est lutic duetsun vitio vitum prope maius.

huius. nil me paeniteat sanum patris huius,

huius. des molling hujus homotern.

humana. gens humathat rut per vetitum netas: quis lumana Mbi doleat natura megtis.

macculia, (quas ant incuria furlit aut humanat pasm cavit natura

humana. Jwma immanaque puctis|diveis parthe;

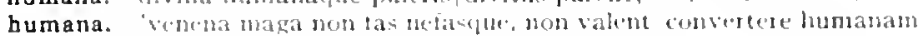
vicend [humana invircen].

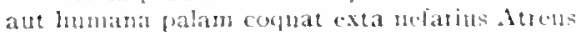

humanae. gentis humanare pater atgue "rstos,

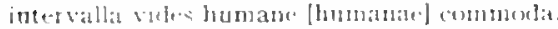

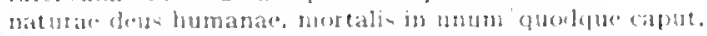

humanam. comertere humantan sitem.

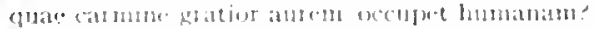

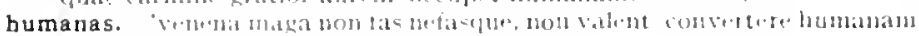
[humbnat vickn [? vires].

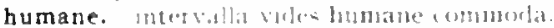

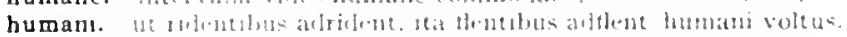

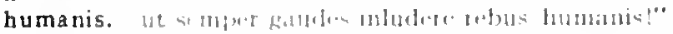

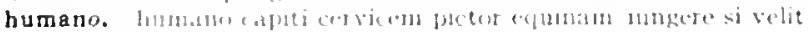

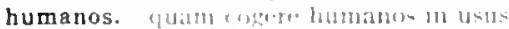

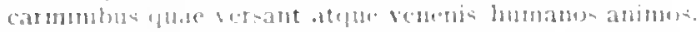

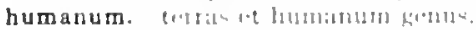

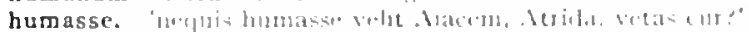

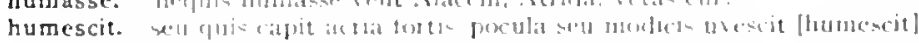
latetilus.

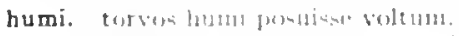

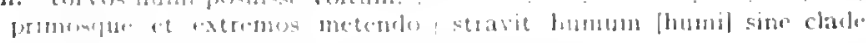
iाt tor.

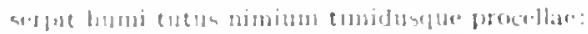

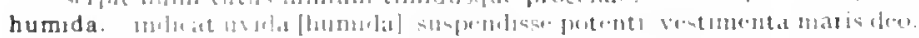

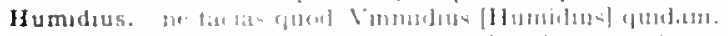

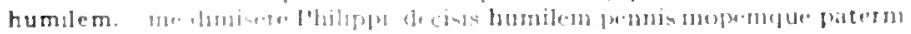

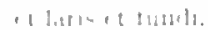

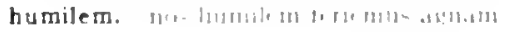

Carm.3.1.3.1

Carm.3.0.0

Carm.4.11.9

lipod.4.9

lipod 0.3

:ar. Epod.9.17

lisodi.0.3.3

I.podirti.57

Lipod.10.59

Serm.1.2.34

sirm.1.2.83

Sirm.1.5.12

Serm.1.5.27

Sicrm. 1.8

Serm.2.2.128

Serm.2.3.5

Sirm.23.80

Ars Joct.402

coni.l:pod.9.17

Serm.1.2.08

Serm.1.2.80

Sirm.1.2.107

Serm.1.3.16

Sirm.2.3.31

Serm.2.3.62

term.23.217

sim.2.5.107

List. 2.80

Serm.2.3.215

Gomic (arm.1.28.24

sirm.2.3.2.3

Sierm. 2.3.50

Epost.1.18.5

Sirm.1.0.80

Serm.1.4.4t

Carm.1.3.20

Sorm.1.1.75

irs 10et.353

Serm.2.3.95

conitipod.5.8s

Ars l'oeltatio

(urmis 12.40

iar. Jipist.2.2.70

lopist 2.2.185

I.pind 5.88

hrm.2.205

comilepod. 5.88

Itpist.2.200

Irs lintlo 102

Sirm.2.0.3 3

irs Piet.

ciorm.3.3.5

ferm.1.2.213

I. poit 5.2

s.rm.2.3.157

var hirm 2.0.70

(arm.3.5.44

coni ( iarm 4.14.32

Ars lemt.za

:itr a arm.1.5.14

as Sirmi.1 1.05

I.PNA 2.2 .50

(iirm $=17.32$ 
bumili. nil parvom aut humili modo,

ex humili potens. | princeps Aeolium carmen ad italoi/derluxisse modos. migret in obscuras humili sermone tabernas

humilis. privata deduci superbo. non humilis mulier, triumpho. .

humilis. arvom pingue tenent humilis Forenti.

humilis. non humilis domos fastidit umbrosamque ripam,

bumo. atque adfigit humo divinat particulam aurae.

humum. udam|spernit lumum fugiente penna.

in morem Salium ter quatient humum.

stravit humum sine clade victor, .

ligonibus duris humum |exhauriebat.

nec sermones ego mallem/repentis per humum.

aut ad humum maerore gravi deducit et angit;

reddere qui voces iam scit puer et pede certol signat humum,

aut, dum vitat lumum, nubis et inania captet.

humus. nec intumescit alta viperis humus;

Carm.3.25.17

Cirm.3.30.1 2

Ars Port. 229

Carm. I. $37-32$

Carm.3.4.16

Carm.3.1.22

Serm.2.2.79

Carm-3.2.24

(arm.4.1.28

cirm.4.14.32

Ispd.5.30

Epist.2.1.25I

Ars Pottil

Ars Poet.159

Ars roel.zzo

Epod.10.52

bunc. Carm.1.1.7; I.I2.26; I.I2.41; 1.20.10; 1.20.11; 1.32.2; 3.3.5.7; Epod.1.1); 9.17; 15.10; Serm.1.1.99; I.1.112 (bis): 1.2.7; 1.2.44; 1.3.47; 1.4.28; 1.4.42; 1.4.85; 1.4.88; 1.6.55;

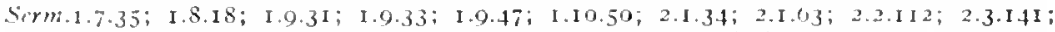

Strm.2.3.147; 2.3.223; 2.6.90; Epist.1.1.34; 1.2.13; 1.2.1.3 (bis); 1.t.3; 1.1).13; 1.16.44: iar.Epist.I.I0.45; Epist.1.I0.32; 2.I.145; 2.2.19;.1rs Pott.35; 4 ; 80; 278

huncine. Iuncine solem/tam nigrum surrexe mihi!

Sirm. $1.9 \cdot 72$

Hyadas. timuit . nec tristis Hyadas nec rabien Noti.

Hydaspes. quae loca fabulosus|lambit Hydaspes.

Hydaspes. procedit fuscus $H y^{\circ}$ daspes/Caecuba vina ferens,

hydra. non hydra secto corpore firmior

hydram. diram qui contudit hỹdran

hydropicus. si noles sanus, curres hydropicus;

hydrops. crescit indulgens sibi dirus hydrops

Hylaeum. nimium mero Hylaeum domitosque I Herculea manu

Hymettia. nisi Hymettia nella Falerno! ne biberis diluta.

Hymettiae. non trabes Hymettiae premunt columnas.

Hymetto. ubi non Hymetto mella decedunt

Hyperboreos. visam gementis litora Bospori|sytisque Gaetulas canoru= ales Hyperboreosque campos.

Hypsaea. Hypsaea caecior illa, quae mala sunt. spectes.

Carm.1.3.14

Carm.1.22.8

Serm.2.8.1 4

Carm.4.4.61

Epist.2.1.10

Epist.t.2.34

Carm.2.2.13

Carm.2.12.6

Serm.2.2.15

Curm.2.18.3

Corm.20.14

Carm.2.20.16

Serm.1.2.91

\section{I (rocal.)}

i. i pertes quo te rapiunt et aurae.

dum favet Nox et V'enus, i secundo onine

i pete unguentum, puer, let coronas

i, puer atque meo citus haec subacribe libello.

i nunc. argentum et marmor vetus atraue et artis suspice. numc i. rem strenuos auge.'

i bone. quo virtus tua te bocat, i perbe iausto. .

i nune et versus tecum meditare canoros.

iambeis. unde etian trimetris accrescere iussit nomen iambeis.

iambis. quem criminosis cumque voles modum pones iambis,

iambis. hic relectatur iambis. ille IBoneis sermonibus

iambo. Archilochum proprio rabies armavit iambo:

iambos. fervor et in celeres iambos misit furentem.

inceptos, olim promissum carmen, ianbos

Patios ego primus iambos/ostendi latio.

iambus. svllaba longa brevi subiecta vocatur iamlvis.

lapeti. audax Iapeti genus

Iapgga. ventorumque regat pater obstrictis alis praeter Iapsga.

Iapyx. quid albus|peccet Iapyx.

Iarbitam. rupit Iarbitam Timagenis aemula lingua.

lasonem. perunxit boc Jasonem.

ibam. ibam forte ria sacra, sicut mens est mos,

ibant. ibant octonos referentes idibus atris.

ibi. ibi tu calentem/debita sparges lacrima favillan! vatis anici.

ibimus. 'quo nos cumque feret melior fortuna parenta. |ibimusibimus, ibimus, futcumque praecedes.

ibis. ibis libumis inter alta navium, anice, propugnacta. dum tu quadrante lavatum rex ibis

ibis sub furcam prudens

Carm.3.11.49

Carm.3.11.50

Carm.3.14.17

Serm.1.10.92

Epist.1.0.J 7

Epist.1.7.71

Epist.2.2.37

Epist.2.2.70

Ars Podt.253

Carm.1.10.3

Lipist.2.2.59

Ars Poet.79

Carm.16.24

Epod.14.7

Epist.1.19.23

Ars Poct.25 I

Carm.1.3.27

cirm.1.3.4

Cirm.2.27.20

tipist.1.19.15

Epol.3.12

sirm.1.0. I

Serm.1.0.75

(iorm.2.6.22

Carm.1.7.29)

Carm.2.IT.IO

lepol. I. I

Serm.1.3.138

serm.2.7.60 
ibit. cum per obstant is iuvenum catervas ibit "ibit, ibit co, quo vis, qui zonam perdidit" . ibit eo, quo vis. qui zonam perdidit' inquit.

ibunt. verba pet at entam non jbunt Caesaris aurem.

Ibyci. wxor palupes is lbyci. .

Icareis. Iuctantem leariis [1 [carejs] fluctibus Airicum

Icarj. frustra: nam scopulic surdior Icari.

Icariis. Iutantem icaris tluctibus Africum

Icaro. ian Datedaleo notior lcaro

Icci. Icci, beatis nunc Arabum invides/gazis iructibus Agrippar Siculis, quos colligis, Icci, / si recte frueris.

icta. sic desideriis ictal fidelibus. nordaci velut icta ferrolpinus

icto. ut senuel icto accessit fervor capiti

ictu. prope funcratus/arboris ictu. perrumpre amat saxa potentius|ictu fulmineo:

ictum. nisj Faunts ictum|dextra levasset. verris obliquon meditantis ictum/sanguine donem. lesbitu servate perlem meique|pollicis ictum.

ictus. spissa ranis latuea fervidos/excludet ictus. Deiplsolus gravis/excepit ictus cum senos teddefet ictus'prinus ad extrenum similis sibi:

id. at ni id fit, quid habet pulcri constructus acervos? ijuin id erat curae. quod petis, id sane est invisum acidumque duobus. id tibj iudicium est, ea mens.

id. iubeas miscrum esse, libenter/quatenus id facit. nec recito cuiquan nisi amicis idque coactus. deos id tristis ex alto caeli demittere tecto. tu cave ne minuas, tu ne maius facias id id crede tuom et vel nunc pete vel cras." agendi naviter id quod aeque pauperibus, prodest locupietibus aerpe, clarus ob id factum donis ornatur lonestis.

Ida. qualis aut Nisens fuit ant aquosa|raptus ab Ida.

Idaeis. cum traluret per freta navibus I lacis Helenen

idcirco. idcirco quiplan comordia necme poemaleset quaesivere, non tanen jefirco contenfas lippus inungui; idcisco navim trans Acgaenu mare vendas. incircome vager scribangue dicenter?

idem. informis hirmes seducit|iuppitr. idem/submovet. sapienter idem/contrahes vento nimium secundo/turgida vela. non semper idem toribus est lonor/vernised idem| vacus eras mediuscue brelli. catus idem per ajertum tugientis agitato glege cervos iaculari nliusque et idem nascertis. at idem, quod su!e multo Vibem defricut. chat la ladatur eadem. fuerit limation idem/ quam rudis et Gracis intacti caminis auctor cocto num rislext honor jolem? jrem corpere maionem rides Turbonis in armis|spintum quanto cometumtion isden [irleme]|in vitija.

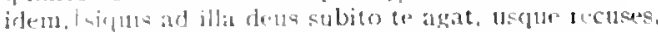

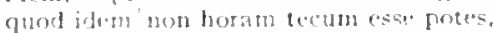
ut ponticalus sic iudicus fruat istem [aden]

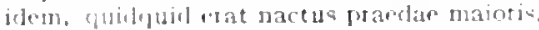

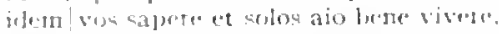
a deculetit lasera andigno, detratut idem.

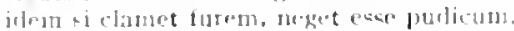

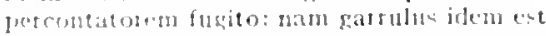

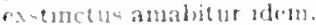

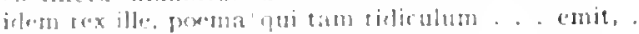

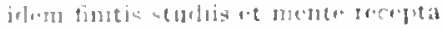
tamen refent sare volam.

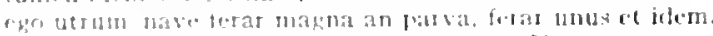

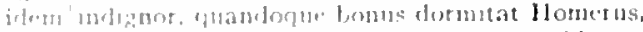

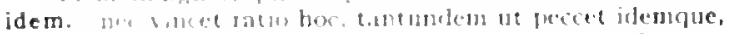

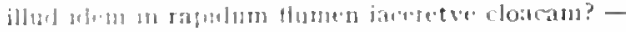

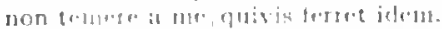

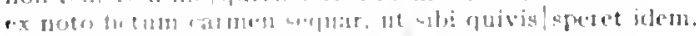

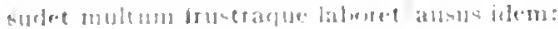

Carm.3.20.6

Epist.2.2.39

Lepist 2.2 .40

Serm.2.1.19

Carm.3.15.1

tar.Corm.1.1.15

Carm.3.7.21

Carm.1.1.15

Carm.2.20.13

Corm.1.29.1

I.pist.1.12.1

Corm.4.5.15

Carm.4.6.9

Scrm.2.1.2.

Carm.3.8.8

Carm.3.10.11

Carm.2.17.28

Carm.3.22.7

Carm.4.0.36

Carm.2.15.10

Carm.4.9.23

Ars Poet.253

Serm.1.1..14

Serm.2.4.8

Epist.2.2.64

Ars I'oet. 380

Serm.1.1.6.

Serm.1.4.73

Sern. I. 5.102

Serm.2.3.177

Scrm.2.3.232

Epist.1.1.2.

IEpist.2.2.32

Carm.3.20.10

Carm.1.15. 2

Serm.1.4..\$5

Epist.1.1.29

Jpist.1.11.10

Ars Poct.zos

Carm.2.10.10

Carm.2.10.22

Carm.2.11.9

Carm.2.19.27

Carm.3.12.10

Carmsisec. 10

Sermiso.3

siom.1.10.05

Serm.2.2.28

Sorm.2.3.309

:ar.Sorm.2.7.18

sorm.2.7.23

Sorm.2.7.111

rar.Jpist.1.1.71

1.pist.5.15.37

EPISt.1. I 5.40

Eprst.1.10 3.4

Lpist.1.10.30

Epist.1. Is 10

Epist.2.1.1.1

1:pisf.2.1.237

lipist.2 2.104

Ispirt.2.2.192

Efist.2.2.200

Ars Juet 358

Serm 1.3.IIS

Serm.2.3.242

Efist.2.1.9

Ars loct 2.11

Ars Jod 2.12 


\section{IDEM}

ut scriptor si peccat idem librarius usque. . invitum qui servat, idem facit occidenti.

idem. idem odere viris/omne nefas animo moventis.

idem eadem possunt horam durare probanteg?

idem. panlatim vello et demo unum, demo etiam [et idem] unum,

ideo. ac ne me foliis ideo brevioribus ornes,

idibus. omnem redegit idibus pecuniam, ibant octonos referentes idibus aeris,

Idomeneus. non pugnavit ingens|Idomeneus Sthenelusve solus .

idonea. in pace, ut sapiens, aptarit idonea belio? aut simul et iucunda et idonea dicere vitae.

Idoneum. si torrere iecur quaeris idoneum;

idoneus. non sat idoneus|pugnae ferebaris; vixi puellis nuper idoneus

haec ego procurare et idoneus imperor

fons etiam rivo dare nomen idoneus.

litterulis Graecis imbutus, idoneus arti|cuilibet:

Idus. Jdus tibi sunt agendae,

igitur. "quid mi igitur suades?

quali igitur victu sapiens utetur

'ut vivas igitur, vigila. hoc age.'

'quisnam igitur sanus?' qui non stultus.

recte est igitur, surgetque?

quisnann igitur liber? sapiens, sibi qui imperiosus,

ignara. haud ignara ac non incauta futuri.

castis cum puetis ignara puella mariti disceret unde preces,

ignara. quae tlumina lugubris/ignara belli?

ignarum. ignarum, quibus est ius aptius et quibus assis

ignarus. siquis nam laudat Arelli|sollicitas ignarus opes.

navem agere ignarus navis timet.

Ignave. si pleraque dure|dicere credit eos, ignave multa fatetur:

ignavi, hoc iter ignavi divisinus,

ignavis. et piper et quidquid [? piperve/et si quid] chartis amicitur ineptis [? ignavis].

ignavos. canis/ignavos adversum lupos? .

ignavus. canis/ignavos adversum lupos lignavus vel bis hostis lupos adversum]?

igneae. me nec Chimaerae spiritus igneae

igneam. igneam|defendit aestatem capellis! usque meis

Igneas. vagus Hercules/enisus arces attigit igneas,

ignem. ignem fraude mala gentibus intulit;

post ignem aetheria domo|subductum

occultum Andronedae pater/ostendit ignem.

adde cruorem/stultitiae atque ignem gladio scrutare.

lgnes. qua parte debacchentur ignes,

igni. ac neque iam stabulis gaudet pecus aut arator igni Diespiter, | igni corusco nubila dividens/plerumque. . dum turdos versat in igni:

lgnibus. quam lentis penitus macerer ignibus. non erubescendis adurit/ignibus

vix una sospes navis ab ignibus

miseram tuis|dicens ignibus uri,

quis aquam temperet ignibus.

uti| bit umen atris ignibus.'

ignis. uret Achaicus/iguis †lliacas domos.'

quas ncque Noticus | deterret cnsis . . nec saevos ignis

nec peredit inpositam celer ignis Aetnen

quodsi non pulcrior ignis|accendit obsessam Ilion,

cum te neque fervidus aestus/demoveat lucro neque hiemps ignis mare ferrum,

usque laborantis, dum fermm molliat ignis,

imagine cerea|largior arserit ignis

ignis. Thessalosque ignis et iniqua Troiae/castra fefellit.

Iulium sidus velut inter ignis|luma minores.

incedis per ignis|suppositos cineri doloso.

curvatos imitatus ignis|tertium lunac referentis ortum, frementem $\mid$ mittere equom medios per ignis.

ut ignis. |ut rupes fluviosque in campo obstare queratur:

ignis|per medios fluviosque ruentis:
$1 G N 1 S$

Ars Poet. 354

Ars Poet.407

Carm.3.4.07

Epist.1.1.82

tar. Epist.2.I.46

Epist.1.19.20

Epod.2.09

Serm.1.6.75

Carm.4.9.20

Serm.2.2.III

Ars Poet.334

Carm.4.1.12

Carm.2.19.26

Carm.3.26.1

Epist.1.5.2I

Epist.1.16.12

Epist.2.2.7

Carm.4.II.I4

Serm.I.I.IOI

Serm.2.2.03

Serm.2.3. 52

Serm.2-3.158

Serm.2.3.162

Serm.2.7.83

Serm.1.1.35

Epist.2.1.132

Carm.2.1.34

Serm.2.4.38

Serm.2.0.79

Epist.2.1.114

Episl.2.1.07

Serm.1.5.5

7 var.Epist.2.1.270

Epod.0.2

ar. Epod.0.2

Carm.2.17.13

Carm.1.17.2

Carm.3.3.10

Carm.1.3.28

Carm.1.3.29

Carm.3.29.18

Serm.2.3.270

Carm.3.3.55

Carm.1.4.3

Carm.1.34.6

Serm.1.5.72

Carm.1.13.8

Corm.1.27.16

Carm.1.37.13

Carm.3.7.II

Carm.3.19.0

Epod.5.82

Carm.1.15.30

Carm.1.I0.I I

Carm.3.4.70

Epod.14.13

Serm.I.I.39

Sirm.I.4.20

Serm.1.8.44

Corm.1.10.15

Carm.1.12.47

Corm.2.1.7

Corm.4.2.57

Carm.4.14.24

Serm.2.3.54

Serm.2.3.5" 


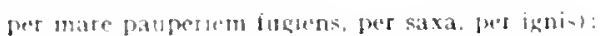

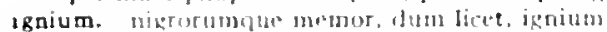

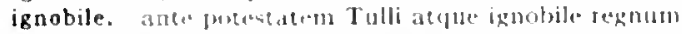

ignobilis. Iut haturl ignobilis . Irgis.

ignominiosa. alse mmunda efement ignominiosague dieta.

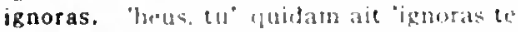

ignorat. nee tanem ignorat, guid dietent aera lupinis.

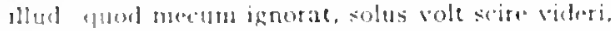

ignoratae. ant inmoratate promit artiscrimint turpi.

ignores. ne tanuen ignores, quo slt komana loco res:

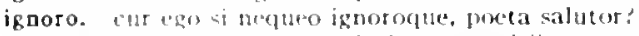

ignoscas. muliocrabus et quis igntweas vitiis teneor;

ignoscat. cul m tubesbus propris ollendat amicum postulat, igmosect [ignoscat] vertucis illius:

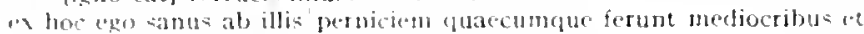
quis ignencas [ignoscat) vitis tentor;

ignoscent. ignosent. siquid peccato stultus, anici

ignoscere. combis in uxorem. posidet qui ignoscereservis

ignosces. ignoscer: alias loguar:

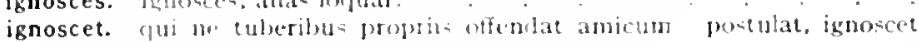
verrmeis illius:

ignoscis. nutaliverate numeras? ignotcis amicis?

ignosco. "t"gomot mi ignoseo" Marmitu inquit. .

ignota. quo patre sie natus, num igmota matre inhonestas.

ignota. jencuta tauris andigaturmm iuga

m11ami -i profertes igmota indictafun primus.

ignoti. ommes inlacimabiles atgentul ighoticlue longat nocte,

ignotis. Ged icmotis jorjerune mortibus illi.

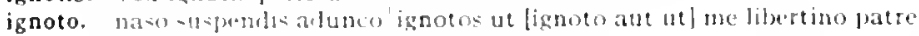
nat 1131 .

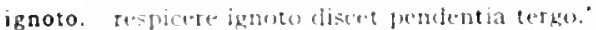

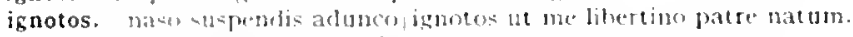

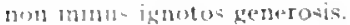

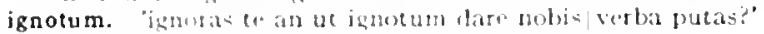

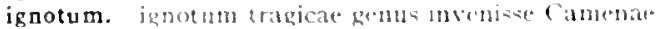

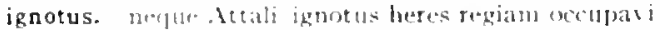

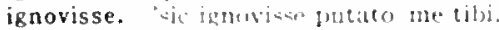

unt delic tat tamen, quibus ignovisto velimus:

llerdam. aut fugies vicam aut vinetur mitteris Jlegdasm.

ilex. aluris ut ales tonsia bipounibus

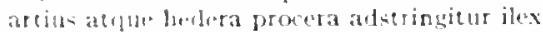

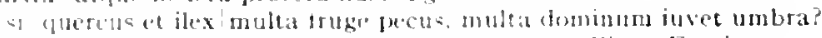

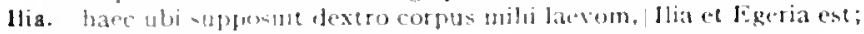

llia. Romana vigui latior Jlia.'

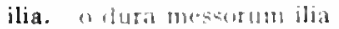

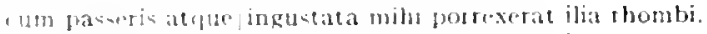

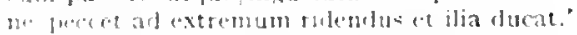

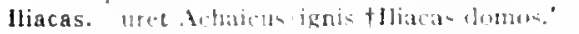

lliacos. Jlaterse intra muros peceatur et extra.

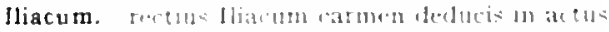

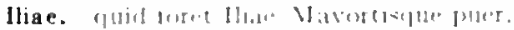

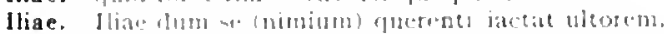

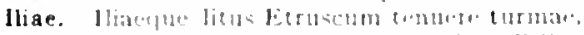

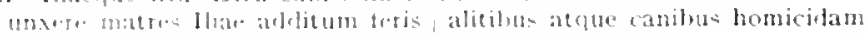

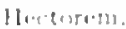

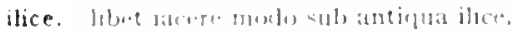

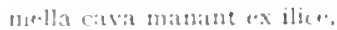

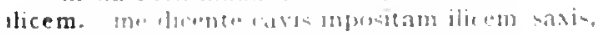

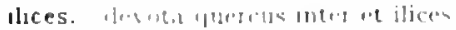

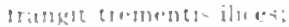

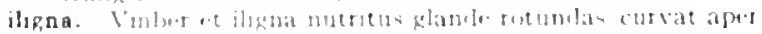

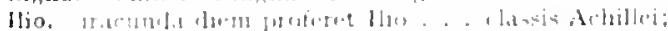

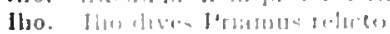

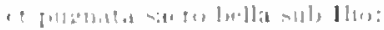

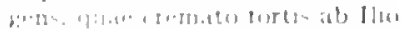

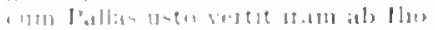

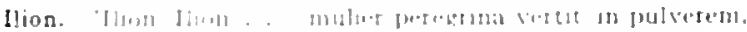

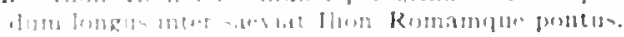

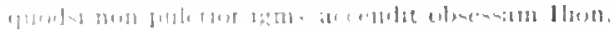

I.pist 1.1 .40

Corm. 4.12 .20

fierm.1.1,.0

lipist 2.2 .128

Ars Poet.24\%

Sirm.1.3.22

lipist.1.7.23

IEpist 2.1 .87

Ars lort 202

Epist.1.12.25

Ars Port.8-

Strm.1.13 I

isr Sirm.1.3.74

:Ar..sorm.1.4.13t

serm.1.3.140

Epist.2.2.133

term.1.0.72

Serm.1.3.7.4

lipist 2.2.2 Io

Serm.1.3.23

serm.1.0.30

Iipol 3.11

- Irs lonelizo

(iorm.t9).27

serm.1.3.108

conisirem.1.0.0

Nerm.2.3. 209

Germata.6

serm. 1.1). 2.4

Serm 1.322

Ars 1'uti.275

Cism.2.Is.a

I.pist.1.7.6o

Ars 1.net.347

I.pist.1.20.13

(arm.4.4.57

I.pod.15.5

lipist I. I 6.0

Sirm.1.2.126

(arm.3.9.8

I.polit 3.4

Serm.2.8.311

lipist.1.1.9

(arm.1.15.30

lipal 1.2 .10

$-1,5$ I Oot 129

(itrm 4.5 .22

Curm.1 2.17

(armisuec. 37

I.pod.17.1 1

I.pord.2.2,3

lipod ici.d7

(irm 3.13.14

(a)m. 32.310

I. poul io.s

Scrm 2..1 +

Cirm 19.5 .3 .3

('arm.1.10.1.t

( orm 310.4

Carm 4.53

l.pont 1013

(arm.3.318

(curm.3.37

fipol 1.81 .8 
Ilionam. Fufius ebrius olim, / cum llionam edonnt,

Ilios. non semel Ilios vexata;

Ilithyia. rite maturos aperire partus/lenis, Ilithyia, tutere matres.

illa. nagnum illa terrorem intulerat lovi.

grande certamen, tibi praeda cedat, maior an illa.

et illa non virilis heiulatio

illa rogare. quantane? .

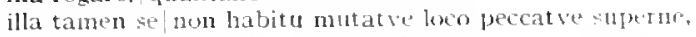

illa. ut neno. . . illa|contentus vivat.

Ijypaea caecior illa.

hac nagis illam [illa]. . te petere esto:

illa. at illa integrum perfunt lino vitiata saporem.

illa. Inppiter illa piat secrevit litora genti,

longa rubus facies ovis erit, illa menento,

siquis ad illa deus subito te agat. usque recuses.

qui tu inpunitior illa. . obsonia captas?

sed illa 'redde, anet, quat deincepr risisti."

illa. illan [illa] 'post panlo' sed pluris" si exierit vir" fidlia

illae. at illate currere in libem.

hinc illike lacrimae.

illam. crede non illam tibi de scelesta|plebe dilectam

illan cogit anor Nothi|lascivae similem ludere capreite:

illam 'post paulo' sed pluris' 'si exierit vir'|Gallis.

prorsus ilucunde cenam producimus illam.

hac nagis illan | inparibus formis deceptum te petertesto:

illas. sunt qui nolint tetigisse nisi jllas|quarum subsuta talos tegat instita veste.

ille. Corm.1.12.53; 1.24.9; 2.6.13; 2.0.2I; 2.13.1; 2.13.8; 2.17.8; 3.5.32; 3.6.15; 3.7.5; 3.9.22; Curm.3.21.9; 3.29.4I; 4.4.40; 4.0.9; 4.0.13; 4.8.7; 4.9.51; 4.13.6; Epod.2.1; 9.29; Serm.1.1.11; 1.1.28; 1.2.20; 1.2.41; 1.2.55; 1.3.4; zar.Serm.1.3.57; Serm.1.3.68; 1.4.126; S.rm.1.6.11; 1.9.6; 1.9.12;1.9.21; 1.9.4I; 1.10.*3; 1.10.67;2.1.30;2.1.4.1; 2.2.60; 2.2.130; Sorm.2.3.21; 2.3.50; 2.3.52; 2.3.96;2.3.20.4; 2.3.255; 2.4.21; 2.6.8; tur.hirm.2.6.10; Serm.2.0.83; 2.6.1 10; 2.7.19; 2.7.37; Epist.1.2.42; 1.6.52; 1.7.03; 1.7.66; 1.18.40; 7ar.Epist.1.19.47; Epist.1.20.14; 2.1.88; 2.1.157; 2.1.210; 2.1.232;2.1.237; 2.2.17; 2.2.39; Epist.2.2.00; 2.2.89; 2.2.99; Ars Pott.190; 198 (his); 200; 315:357

lllecebris. to quod illecebris erat et grata novitate morandus/spectator.

illi. illi robur et aes triplex/circa pectus erat.

proximos illi tamen occupavit Pallas honores

illi turba clientium / sit maior:

quid facias illi? iubeas miserum esse.

nil aequale homini fuit illi:

illi| 'tardo' cognomen. 'pingui' damus.

numquid ego illi inprudens olim faciam simile?"

at illi foeda cicatrix saetosam lacsi frontem turpaverat oris.

nil illi larva aut tragicis opls esse cothurnis.

laus illi debetur et a me gratia maior.

ut illi nil respondebam.

accendis quare cupiam nagic illi| proximus esse."

casu venit obvius illi adversarius

neque ego illi detrahere ausim haerentem capiti cum urulta laude coronain. ne tamen illi|tu comes exterior, si postulet, ire recuses.' . .
ut illi, | thf sauro invento qui mercentarius agrum illum ipsum mercatus aravit.

postquam illi justa cheragra/cont tid articulos.

hic tibi sit potius quam tu mirabilis illi.

licet illi plurima manet/Lacrima.

Gracchus ut hic illi, foret huic ut Mlucius ille.

Gracchus ut hic ill, foret huic [lic] ut Mucius iłle lilli].

cui rem di donarent, illi decedere pravam stultitian;

illi. Veneremque et illi / semper hacrentem puerum canebat

illi quod tibi dempserit/adponet annus).

grande certamen, tibi praeda cedat. | maior an illa [illi].

neque illi|iam manet umida creta

Ilia et Egeria est; do nomen quodlibet illi.

illi. dissimile hoc illi est.

1111. hoc illi recte; ne corporis optima Lyncei, contemplere oculis. inquirant vitia ut tua rursus te illi. sed ignotis perierunt nortibus illi,
Sierm.2.3.61

(iorm.4.9.1 8

Carm.Sace I 1

(itrm.3.4.44

comiciarm-3.20.8

Epod.10.17

Serm.2.3.31\%

Serm.2.7.13

Serm.1.1.2

serm.1.2.01

t'ar.sirm.2.2.29

Sirm.2.4.5.3

E.poldo.o.

Girm.2.1.12

Sirm.2.7.24

Sirm.2.7.105

Sirm.2.8.79

fur.Sirm.1.2.120

firm.1.8.47

I.pist. I. ID.tI

carm.2.4.17

Carm.3.15.1 I

Sirm.1.2.120

Serm.1.5.70

Sirm.2.2.20
Ars Petit.223

Carm.1.3.9

Carm.1.12.19

Cirm.3.1.13

Serm.1.1.03

Serm. I.3.9

Sirm.1.3.57

Serm.1.4.130

serm. 1.5.00

Sirm. I.5.64

Serm. I.0.88

lierm. I.O.I 3

Sirm.1.9.5.3

Sirm. I.9.74

Serm.1.10.48

Serm.2.5.16

$5 \mathrm{crm} .2 .6 .10$

Epist.1.0.23

Epist.1.17.59

Epist.2.2.S9

Far. Epist 2.2 .89

Enti.2.2.152

Carm.1.32.9

Curm.2 5.14

gier Carm-3.20.8

lipol. 12.9

Sirm.1.2.126

Serm.1.0.40

Sirm.1.2.00

S.rm. I. 3.28

Serm.1.3.108
Sirm.2.7.15 
illi. scripta quibua comoedia prisca viris est.

llic. illic nutre carentibus/privignis nulier temperat

illic plurina nasibus|duces tura

illic bis pueri die. . ter quatient humum.

illic omne malum vino cant uque levato.

illic iniusage veniunt ad inulctra capelhe

'non isto vivinuts illic, quo tu rere, nodo;

neque illiclaut apothera procis intacta est aut pecus:

dictus here lllic/de nedio potare die."

tanem illic vivere vellem

illidere. fragili quacrens illidere dentem

illigata. brevilus illigata viperis/crinis

llinc. neque illinc audeat esuriens dominus contingere granum

illis. privatus illis census erat brevis.

merito quin illis luppiter ambas/iratus buccas inflet

litque illis multo corrupta dolore voluptas.

illis/maioren natura modum dedit, his breve pondus:

non quia nasus, illis nullus erat.

trescio an Anticuran ratio illis destinet omnem.

illis / accodas socius: laudes, lauder is ut absens.

oblitusque meorum, obliviscendus et illis

ut nihil anteferat, nihil illis conparet: .

illis. velut illis/Canidia adflasset, peior serpentibus Afris.'

tamen illial ne facit invisum,

illis. laudatu ab his, culpatur ab illis.

illis. ego illis! mollior nec te feriam

sonante mistm tibii= carmen lyes, hac lotium, jllis barbatum?

nescio (fuid meditans nugarum, totus in illis:

illis. quid mirum, ubi illis carminibus stupeng

illis utitur ame:quaesit is patiens.

ex hoe ego sanus ab illis perniciem quaecumque ferunt

loc est madioctibus illisiex vitiis unum;

tanto reprelicondi iustius illis.

illis. dives ut aureis/mercator exiccet culills [cui.illis]|vina syra reparata merce.

perna nagis et magis hilis [illis]| tagitat inmorsus tefei.

illitum. aurum setibus illitum| mitata

lllus. qui ne tuberibu propriji offendat anicum postulat, ignoscet verrucis illitı:

num jllius. num refurm dura negarit / versiculos natura

ct miror norbi jurgatum te illius."

illius esto/defensor;

atcanum nerge tu serutaberis illius uniguam.

discrdo Alcaeus puncto illius:

llius. quid habes illius, illius, / quaespirabat anores.

memor illiss escar, 'quae simplex olim tibi sederit.

(nam vina nilil noror illius orae.

illo. auctor" ab illo ducis originem.

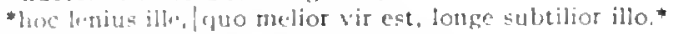

nugari enu illo et diecincti ludere.

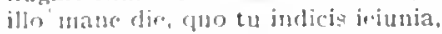

cui ridiculua minus illo?

tanto leves mise ac prior ille [illollqui am contento, iam laxo fune laborit."

illo. inciput c $x$ ille mont is Apulia notos/ontentare milui

illorum. inçu" vicem illorum patiat delicta libenter

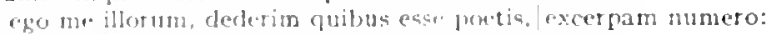

illos. avita ex re pracberi sismptua mihi crealeret illog.

illuc. huc et illuc curatant mixtae purres puellae.

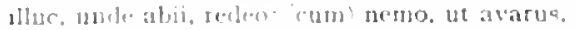

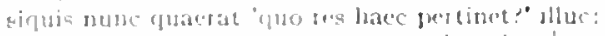

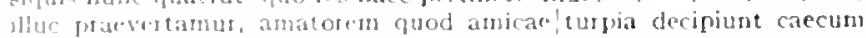
viliat

* en releatan illare *

durolet illuc, rea ubi magna nitet domino aene;

vis tor puromiti simul ac perveneris illus.

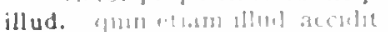

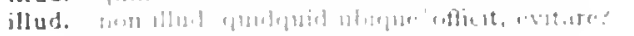

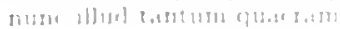

Sorm.1.10.10

Carm.3.24.17

Carm.4.1.21

Carm.4.1.25

Epod.13.1\%

Epod.16.49

Serm.1.9.4S

Serm.2.5.0

Sorm.2.8.2

Epist.1.11.8

Sorm.2.1.77

Epod.5.15

Serm.2.3.112

Carm.2.15.13

Sorm.1.1.20

Serm.1.2.39

Serm.2.2.36)

Serm.2.2.90

Serm.2.3.83

Serm.2.5.7 I

Efist.1.11.9

Epist.2.1.05

Serm.2.8.94

Epist.1.15.3

Serm.1.2.1I

Corm.3.11.42

Epod.o.o

Sorm.1.9.2

Cirm.2.13.33

Sorm.1.1.37

Serm.1.4.129

Serm.1.4.139

Serm.2.4.81

rar.Carm.1.31.1:

sar.jerm.z.dino

Corm-4.9.4

Scrm.1.3.74

Sorm.1.10.57

Serm.2.3.27

Serm.2.5.29

Fist.1.18.37

Epist.2.2.99

Carm.4.13.18

Strm.2.2.72

Epist.1.15.16

Carm.3.17.5

Serm.1.10.*

Serm.2.1.73

Serm.2.3.290

Serm.2.3.31

rar.sem.2.7.19

Serm.1.5.77

Sorm. I.3.1. I

serm. 1.4.39

Sirm.1.0.80

Corm.tis.o

Scrmil I.ros

Serm.1.2.23

Serm.1.3.35

Sirm.1.to.

Serm.2.5.11

l:Pist.8.13.11

Serm.1.2..11

irrm 1.2.80

Sirm.t.ing 
inanis!hoc iuvat, haud illud quaerentis,

Serm.1.4.77

adniror, quo pacto iudicium illud|fugerit':

Serm.1.4.99

nam frustra vitium vitaveris illud.

Serm.2.2.54

nos expulit ille, |illum fillud] aut nequitics aut vafri inscitia iuris,...

expellet

addit et illud:

qui sanior ac si illud idem in rapidum flumen iaceretve cloacam? -

il)ud ad haec iubeo:

et illud. ... solus volt scire videri,

quodsi|iudicium ... illud|ad libros . . vocares,

meminitque libentius illud | qoud quis deridet

illum. iuvat . . illum, si proprio condidit horreo / quidquid de Libycis verritur areis.

dicam . . illum superare pugnis|nobilem;

illum aget penna metuente solvi|Fama superstes.

illum et parentis crediderim sui|fregisse cervicen

illum ex moenibus hosticis|matrona bellantis tyranni|prospiciens.

illum ego lucidas inire sedes. . . patiar.

illum non labor Isthmius/clarabit pugilem.

illum | praeteritum temnens extremos inter euntem:-

illum balbutit scaurum pravis fultum male talis.

Canem illum, |invisum agricolis sidus, venisse:

et illum $\mid$ qui pulcre nosset.

nam propriae telluris erum natura neque illum | nec me nec quemquam statuit:

nos expulit ille. illum aut nequities aut vafri inscitia iuris,

qui mercennarius agrum|illum ipsum mercatus aravit.

iuvat illum sic domus et res.

IHyricis. me quoque devexi rapidus comes Orionis | Illyricis Notus obruit undis.

ima. modo sunma | voce, modo hac, resonat quae chordis quattuor ima.

ima. valet ina summis|inutare... deus quatenus ima petit volvens aliena vitellus.

imagine. beatus Fannius uitro/delatis capsis et imagine, imagine cerea|largior arserit ignis

hac ego si conpellor imagine, cuncta resigno:

imagines. funus atque imagines/ducant triumphales tuom

imagines. an quae movere cereas imagines,

imagini. num vanae redeat sanguis imagini,

imaginibus. qui stupet in titulis et imaginibus.

imago. cuius rerinet iocosa|nomen imago

iocosa!redderet laudes tibi Vaticani|montis imago. .

vitiis carentem / ludit imago/vana,

haec a te non multum abludit imago. .

imbecilla. tractari mollius aetas/imbecilla volet:

imbecillus. "etenim fateor me" .. imbecilius, iners,

imber. quod non imber edax, non aquito impotens|possit diruere

ut te confestim liquidus Fortunae rivos [? confestim jargus imber] inauret,

addit opus pigro rivos, si decidit imber,

imberbus. inberbis [imberbus] iuvenis, tandem custode renoto. | gaudet equis

imbre. qui Capua Romam petit, imbre lutoque/adspersus

imbrem. sive operum vacuo gratus conviva per inbrem/vicinus,

imbres. non senper imbres nubibus hispidos/manant in agros

imbres quem super notas aluere ripas.

imbres nivesque deducunt Iovem;

imbri. utpote longum/carpentes iter et factum corruptius imbri.

imbribus. ut neque largis/aquosus Eurns arva radat imbribus.

imbris. Notus neque parturit imbris|perpetuos,

at cum tonantis annus hibernus lovis/imbris nivisque conparat,

collectosne bibant imbris puteosne perennis/iugis aquae

qui queritur salebras et acerbum frigus et imbris

imbrium. imbrium divina avis imminentium,

imbuerit. haec animos aerugo et cura peculi|cum semel imbuerit,

imbuit. quae Venus/quinta parte sui nectaris imbuit.

imbuta. quo semel est imbuta recens servabit odorem/testa diu.

imbuti. sunt qui formidine nulla|imbuti spectent:

imbutum. cum palla, tabo munus imbutum,

var..Serm.2.2.131

Serm.2.3.150

Serm.2.3.242

Sirm.2.5.70

Epist.2.1.86

Epist.2.1.242

Epist.2.1.262

Carm.1.I.9

Carm.1.12.26

Carm.2.2.7

Carm.2.13.5

Carm.3.2.0

Carm.3.3.33

Carm.4.3.3

Serm.I.I.I 15

Serm.1.3.47

Serm.1.7.25

Serm.1.9.6I

Serm.2.2. 129

Serm.2.2.I31

Serm.2.6.1 2

Epist.1.2.5 I

Carm.1.28.22

Serm.1.3.8

Carm.1.34.12

Serm.2.4.57

Serm.1.4.22

Serm.1.8.43

Epist.1.7.34

Epod.8.I I

Epod.17.76

Carm.1.24.I 5

Serm.1.6.17

Carm.1.12.4

Carm.1.20.8

Carm.3.27.40

Serm.2.3.320

Serm.2.2.86

Serm.2.7.39

Carm.3.30.3

7 var. Episl.1.1 2.9

Epist.1.14.29

var.Ars Poot.16I

Epist.I.II.II

Serm.2.2.119

Carm.2.9.1

Carm.4.2.5

Epod.I3.I

Serm.I.5.95

Epod.16.54

Carm.1.7.16

Epod.2.30

Epist.1.15.15

Epist.1.17.53

Carm.3.27.10

Ars Poct.33I

Carm.1.13.16

Epist.1.2.09

Epist.1.6.5

Epod.5.65 


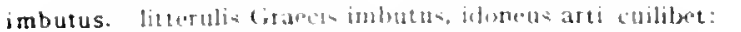

lipist.2.7.7

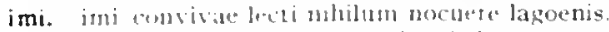

Sierm.2.8.40

imi dericor lactl ac numbun davitis horret.

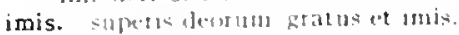

nollis inntia cut lantam diffulerit nowioblivionem stnsibus.

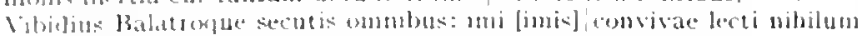

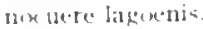

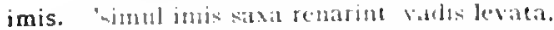

imitaberis. atgill. quidvis imataberis nda;

imitabile. Akeipit enuplat vitiis imitabile:

imitabimur. argilla guit) is imbaberis [imitabimur] alda:

imitabitur, quali igttur victu sapiens utetur et horum utrum imitabitur? ar aillat guidsic imbtaberis [imitabinat una:

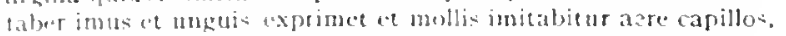

imitandi. hox stabant. hoc sumt imitandi;

imitare. tu conclusitu hircinis follibus ansas. . . ut mavis, imitare.

"lama latentino violas imitata [imitare] renems."

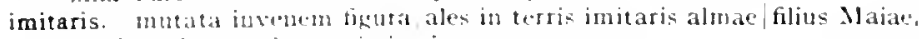
ar-dincas. henc ent hongos imitarin.

imitata. antuta ingunnom volfees instata leonem? -

"lana latemeint violas imitata vemeno."

imitator. ntec desilies imitator in .1rtum,

imstatorem. respicere templar vitac norumque inbebo doctum imitat orem imitatores. o) imitatores, iervom pects.

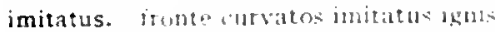

immane. vino et hecernis Nlerles acinare imman" quantum discrepat:

immanem. inpics Tiknas mmanemege turbam

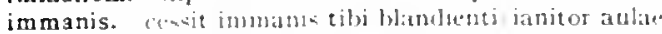

immanis. immansque Ractos auspicis pepulit secumbis,

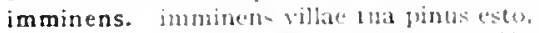

imminente. Sam Cyeluea choros duest bense imminente luma

imminentis. ille wold lathos l.atso imbunemtis

imminentium. imbrium divina avis imminentium.

immo. nullam habe vitia" inmo alia ct fortase minora

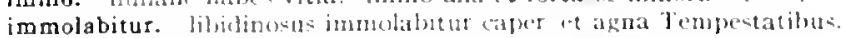

immolare. nume et in umbrosis fiamo decet immolare lucis.

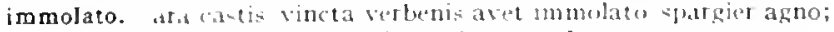

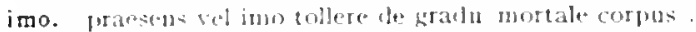

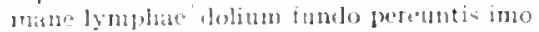

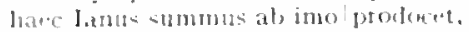

imo. latere peticus mo spiritns.

ab ignc at sumanum totum notuli lipedalis.

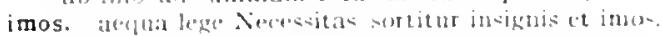

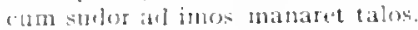

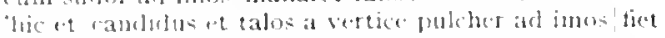

imparis. flli Mu-as amat jmparis.

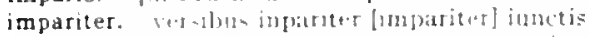

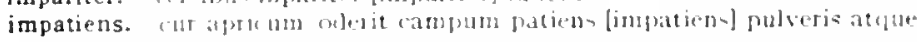
$s$ lin.

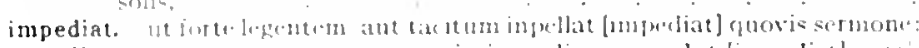

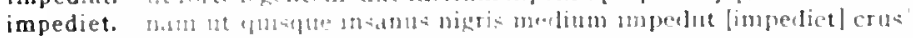
[m. Inbu-

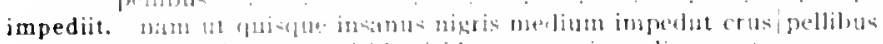

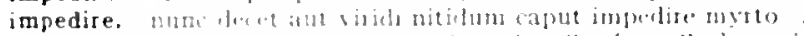

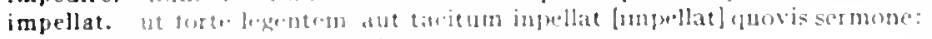

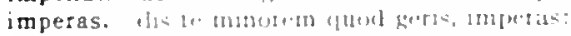

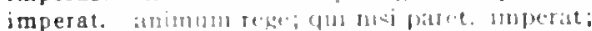

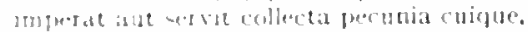

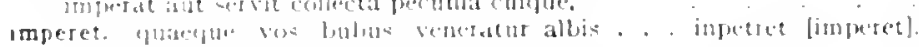
b)

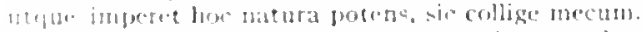

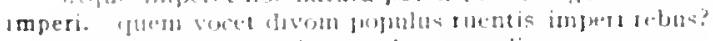

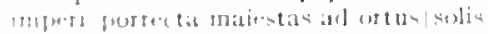

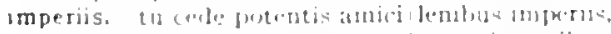

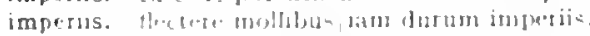

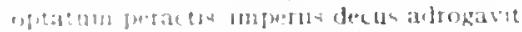

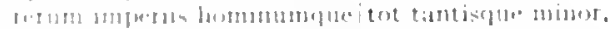

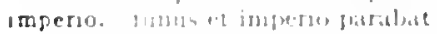

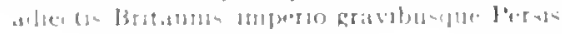

Corm.1.10.20

lipol.1.1

sar.sirm.2.8.10

Jipoll.10.25

Epist.2.2.8

Epist.1.19.17

iur Jisist 2.2.8

Serm.2.2.6.4

idar. Itsist.2.2.8

irs 10.1 .33

Serm.1.10.17

berm.1.4.2r

ill. Esist.2.J.207

(iorm.1.2.\$2

Serm.2.3.308

Sirm.2.3.150

Esist 2.1.207

Ars Port.134

- Irs Poet.318

fisist. I I 19

("arm.4.2.57

Carm.1.27.6

(itrm.3.4.43

Carm.3.1I.I5

Cinm.4.145

ciom.3.22.5

(urm.1.4.5

(arm.1.12.53

Carm.3.27.10

sirm. 1.3.20

EPot.10.23

(arm.1.1 1

Corm.t11.7

(is)m.1.35.2

(ism.3.I1.27

Efist 1.1.54

IEpol.11.10

Sirm.2.3-308

(iom.3.1.15

Sirm.t. 0

lifist.2.2.4

(arm 3.10 .13

:ar.ars lool.25

ecmic arm.t.8.4

comiserm.1.3.15

:12r. Sierm.1.0.27

cermalo 27

(arm 1. 1.2

rar.sorm.1.3.05

( inme3.3.5

f.pol.1.2.03

lisist 1.10.47

inerarm Soce 51

sirm.2 I.51

Curm.1.20

(arm..\$5.1!

List.1.15.45

(ivron.t 1.7

("arm+14.

Serm.2.7.75

(ians 1.37 .0

(a) 35 . 
imperio. imperio regit unus aequo.

fulgentem inperio fertilis Africae

imperiosa. sed melimperiosa trahit Proserpina:

imperiosius. vix durate carinae /possint imperiosius|aequor?

imperiosus. seu vocat institor | seu navis Hispanae magister, / dedecorum pretiosus [imperiosus] emptor.

quissam igitur liber? sapiens, sibi qui imperiosus.

imperitare. sive opus est imperitare equis.|non auriga piger.

imperitarent. nec quod avos tibi maternus fuit atque paternus | olim qui magnis legionibus imperitarint [imperitarent].

imperitarint. olim qui magnis legionibus imperitarint,

imperitas. tu, mihi qui imperitas, aliis servis miser

imperito. 'tex sum.". . 'et aequan/rem imperito

imperium. reges in ipsos imperium est Iovis, .

imperium. neu populus frequens... imperiumque trangat;

qui promittit civis, Irbem sibi curae.|imperium fore

si melius quid habes, arcesse, vel imperium fer.

ius imperiumque Phraates/Caesaris accepit genibus minor;

imperor. haec ego procurare et idoneus imperor

impetu. agmina|ferrata vasto diruit impetu

impetus. nec saevos Arcturi cadentis|impetus aut orientis Haedi.

demisit hostem vividus impetus.

impetus in quem/continuo fiat.

impetus. inauspicatos contudit impetus / nostros

impingas. quan quo perferre iuberis/clitellas ferus inpingas [inpingas]

impium. inpium [impium]/fenite clamorem sodales

implicata. Canidia. brevibus illigata [implicata] viperis|crinis

impotens. non aquilo impotens|possit diruere

impransi. postquam est inpransi [impransi] correptus voce magistri?

imum. primo ne medium, medio ne discrepet imum.

imum. ad imum | Thraex erit aut holitoris aget mercede caballum. servetur ad inum qualis ab incepto processerit

si paulum sumno decessit, vergit ad imum.

imus. e quibus unus [imus] avet quavis aspergere cunctos/practer enm qui praebet aquam;

Aemilium circa ludum taber imus
Carm.3.4.48

Carm.3.16.3 I

serm.2.5.110

Cirm.1.14.8

coni.Carm.3.6.32

Sirm.2.7.83

Carm.I.I5.25

var.Serm. I.6.4

Serm. I.6.4

Sirm.2.7.8 I

sirm.2.3. 89

Carm.3.1.6

Carm.1.35.16

Sirm.1.0.35

Fipt.1.5.6

I pist.1.12.27

Epist.1.5.2I

Carm.4.14.30

Carm.3.1.28

Carm.t.4. Io

Serm.I.2.117

carm.3.to. 0

i'ar. IE pist. I. 13.8

zar.Carm.1.27.6

var. Epod.5.15

Carm.3.303

qar.Sirm.2.3.257

Ars Poct.152

Epist.1.18.35

Ars Poet.1 26

Ars Poet. 378

i'ur.Serm.1.4.87

Ars Poet.32

in. Carm.1.2.40; 1.2.45; 1.6.18; I.7.8; I.8.10; 1.13.0; I.141; I.16.24; 1.19.9; 1.21.14; 2ar.Carm.1.21.15; Carm.1.26.2; 1.27.1; I.28.8; 1.30.4; I.32.2; 1.33.6; 1.35.29; I.35.39; Carm.1.30.12; 1.30.17; $1.37 .15 ; 2.2 .6 ; 2.3 .19 ; 2.3 .27 ; 2.5 .4 ; 2.7 .1 ; 2.7 .15 ; 2.9 .2 ; 2.11 .4$; Curm.2.11.23; 2.13.3; 2.13.12; 2.13.14; 2.16.25;2.20.10;3.1.5; 3.1.0; 3.1.1. ; 3.1.34; Carm.3.3.21; 3.3.45; 3.3.51; 3.4.21; 3.4.67; 3.5.10; 3.5.55; 3.6.20; 3.7.20; 3.8.15; Corm.3.11.34; 3.11.35; 3.1 1.47; 3.10.8; 3.24.45; 3.24.47; 3.25.2; vir.cirm.3.28.9; Cirm.3.20.30; $329.42 ; 4.1 .9 ; 4.1 .28 ; 4.2 .23 ; 4.2 .20 ; 4.2 .39 ; 4.2 .56 ; 4.4 .2 ; 4.4 .9 ; 4.4 .11$; Carm.4.4.28; 4.4.02; 4.10.5; 4.13.28; 4.14.3; Carm.Sace.52; 67; Epod.1.24; 2.32; 2.39; 1.pud.2.53;5.4; 5.53;0.11;7.12;7.19;10.14; 13.8; 15.4;10.25; 10.20:17.0; 17.10; 17.18; Epod.17.8I; Serm.1.1.11; I.I.31; 1.2.18; 1.2.24; 1.2.43; 1.2.48; 1.2.1 I 7; I.3.67; I.3.1.41: Serm.1.4.80; 1.4.1.43; 1.5.02 (his): I.0.72; 1.7.20; 1.8.1 2; 1.8.28; 1.4.38; 1.8.47; 1.9.9; Sirm.1.0.77; I.10.34; 1.10.08; 2.1.03; 2.1.71; 2.1.82;2.2.34; 2.2.00; 2.2.75; 2.2.134; Sirm.2.3.28; 2.3.38; 2.3.72; 2.3.104; 2.3.242; coni.serm.2.3.270; Serm.2.4.39; *or.Serm.2.4.01; Sirm.2.5.29; 2.5.47; 2.5.50; 2.0.16 (bis); 2.0.47; 2.7.10; 2.7.17; 2.7.62; Sirm.2.7.03; 2.7.88; 2.8.55; 2.8.01; Epist.1.1.14; 1.1.18; 1.1.79; 1.2.311; 1.2.30; 1.2.43; Eptst.1.3.8; 1.3.9; 1.3.36; 1.0.24; 1.7.30; I.11.5; 1.11.23; 1.13.0; 1.14.41; 1.15.20; Epist.1.15.30; 1.15.41; 1.I6.53; I.17.6; I.I8.I0; I.18.34; 1.18.45; I.IS I00; I.20.8; Epist.1.20.15; 2.1.3; 2.1.0; 2.1.48; 2.1.94;2.1.149;2.1.159;2.1.175; 2.1.180;2.1.205: Epist.2.1.260; 2.2.47; 2.2.110; 2.2.133; 2.2.I74; 2.2.188; Ars Pott.4; 31; 44; $00 ; 129$; Ars Poel.134; 148; I00; I $13 ; 183 ; 187$ (his); 229:250; 200;282; 315; 326; 387; 388; Ars Poet.402; $452 ; 450 ; 471$

1n. Carm.1.2.42; 1.4.11; 1.5.1; 1.12.5; 1.12.0; 1.15.20; I.10.23; 1.17.17; I.I7.I1); 1.20.3; 1.22.9; Carm.3.22.22; 1.25.10; 1.27.10; 1.37.19; 2.3.1; 2.3.2; 2.3.6; 2.1.7; 2.5.7; 2.9.4; Carm.2.16.1: 2.10.14; 2.15.2; 2.18.27; 2.19.1; 2.19.18; 2.20.3; 3.3.6; 3.3.30; 3.4 .9 ; Carm.3.5.8; 3.8.3; zar.Carm.3.8.4; Carm.3.12.7; 3.10.34; 3.18.1 I; 3.23.1 1; 3.25.8:3.27.29; Carm.4.4.4; 4.4.30 (bis); 4.4.58;4.5.29; 4.0.11; 4.0.20; 4.10.6; 4.1 1.2; 4.12.0; 4.12.24: Carm.t.12.28; 4 13.8; 4.1.17; Epod.1.17; 2.1 I; 2 24; 2.20; 3.5; 3.22; 4.15; $5.1 ; 5.67$; Epod.11.4 (bis); I1.9; I 2.5; 12.19; 15.12; 17.33; I 7.47; 17.43; 17.09; sirm.1.1.12;

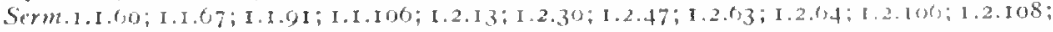
Serm.I.3.17; I.3.26; I.3.32; I.3.41; I.3.72; I.3.82; 1.3.02; 1.3.110; 1.49; I.4.10; I.4.34; Serm.1.4.74; 1.4.98; 1.5.37; 1.5.72; 1.0.17; 1.6.22; 1.6.62; 1.6.79; 1.7.1.1; 1.8.0; 1.8.7; Serm.I.S.9; 1.S.12; I.8.I5; 1.0.2; 1.9.59; I.10.38; 1.10.52; 1.10.70;1.10.75; 2.1.1 ; 2.2.19;

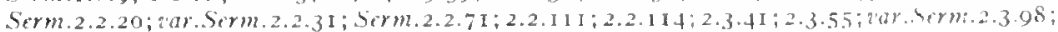


Serm.2.3.101; 2.3.119; 2.3.1.30; 2.3.162; 2.3.183; trar.Serm.2.3.23.; Serm.2.3.248; Serm.2.3.251; 2.3.267; 2.3.287; 2.3.292; 2.3.294; 2.3.310; 2.4.15; 2.4.48; 2.4.81 (ber); Serm. 2.5.45; 20.1; 2.0.28; 2.0.42;2.6.46;2.6.49;2.6.88;2.6.96;2.6.102;2.0.106;2.7.19; Sorm.2.7.59; 2.7.80; 2.8.4; 2.8.0; 2.8.43; var.Sorm.2.8.52; Serm.2.8.77; Ifpist.1.1.I1; Épisl.1.r.R3; I.1.87; 1.2.29; 1.2.00; 1 $2.67 ; 1.3 .14 ; 1.4 .2 ; 1.5 .20 ; 1.6 .52 ; 1.6 .60 ; 1.7 .50 ;$ EPist.1.8 0;1.10.2; 1.10.20; 1.10.35; 1.11.12; I.II.15; 1.12.7; 1.14.10; 1.14.13;1.14.35; List.1.15.13; 1.16.28; 1.16.48; 1.16.64; 1.16.68; 1.16.71; 1.16.76; rar.Lpist.1.16.76; lapist.1.18.87; 1.20.18; 1.20.20; 2.1.18; 2.1.27; 2.1.31; 2.1.53; 2.1.173; 2.1.194; 2.1.205; I.pist.2.1.24.4; 2.2.12; 2.2.15; 2.2.18; 2.2.09; 2.2.85; 2.2.130; 2.2.157; Ars Poet.46; I sar.Ars Poet.60; Ars Poct.71; 1 78; 179; 228; 258; 351; var.Ars Poet.300; Ars Poct.372; Ars 1 ot $121 ; 431 ; 451$

Inachia. ex quo destiti|Inachia furere.

"Inachia langues minus ac me;

Iaachiam. Inachiam ter nocte potes, milsi semper ad unum |inollis opus. Inacho. divesne prisco natus ab lnacho|nil interest

quantum distet ab J nacho| (oxlrus.

inaequales. aut mare Caspium|vexant inaequales procellae |usque iaaequali. si curatus inaequali tonsore capillos loceurri.

inaequalis. sacpe notatus / cum tribus anellis, modo lacw Priscus inani vixit inaefualis, clavom ut intaret in boras.

inaequalis. siccat inaequalis calices conviva solutus|legibus insanis. . inaestuet. 'quodsi meis inaestuet praceorlis/libera bilis.

inamarescunt. nompe inamarescunt epulac sine fine petitae

Fif 10 d. I I.0

L.pod.12.14 Epod.12.15

Carm.2.321

Carm.3.19.I

Carmi.2.9.3

Iipist.I.1.94

Serm.2.7.10

Serm.2.0.08

Epod.11.1.5

Serm.2.7.107

Epist.1.17.4

Carm.3.11.26

bipod.5.7

Serm.1.2.113

Ars Peel.443

Serm.10.127

Serm.2.7.9

Lpist.2.2.206

Curn.2.20.2I

Ars Joet.230

Sicrm.2.2.14

Serm.1.4.70

Serm.2.3.2 2

Epod.0.3

Epist.2.1.2 I

Lpot 10.43

lipot.3.15

Carm.3.20.3

List.1.12.9

Carm.3.0.10

Epist.1.7.45

Carm.4.4.31

Carm.1.15.15

lepod.a. I

Corm. I.6.10

Corm.3.2.15

Lipist.2.1.85

coni.lepist.2.I.85

Ars Podines?

qur.Curm.3.21 I I

Sermil.8.49

lepist.1.10.45

Srrm 1.1.35

Ars Proll 150

Serm.1.3.02

cidm.3 15.3

7 gur Serm.2.1.6.4. 05

carm.2.6.7

A.pol.1518

sorm.1.1.112

suar Ars Pued 223

cirm.s.817

Jepist r.1.8.85

serm. I J.77 
detrimcnta, fugas servorum. incendia ridet,

Epist.2.1.12

incendio. novam incendio nuptam abstulit?

Epod. 5.66

incendit. acris ubi me/natura intendit [incendit]

inceptis. inceptis gravibus plerumque et magna professis/purpureus. . . . adsuitur pannus,

incepto. scrvetur ad imum/qualis ab incepto processerit

inceptos. inceptos, olim pronissum carmen, iambos

var.serm. 2.7.48

incertam. quos venerem incertam rapientis more ferarum

incerto. ferebar incerto pedelad non amicos heu mihi postis

incerto. aut fertur incerto mari.

incertos. transmutat incertos honores,

migravit ab aure voluptas/omnis ad incertos oculos et gaudia vana.

incertus. cum faber, incertus scamnum faceretne Priapum. .

incessum. rides Turbonis in armis/spiritum et incessum:

incesto. saepe Diespiter/neglectus incesto addidit integrum.

incestos. incestos amores|de tenero meditat ur ungui.

migravit ab aure voluptas /omnis ad incertos [incestos] oculos et gaudia vana.

incestus. fatalis incestusque iudex

an tristc bidental moverit incestus:

incidat. aut si disparibus bellum incidat,

doncc manibus tremor incidat unctis.

incidere. heredes Staberi summam incidere sepulcro.

incidere. nec lusisse pudet, sed non incidere ludum. oppida moliri, leges incidere ligno.

inciderit. dura valetudo inciderit seu tarda senectus? nisi dignus vindice nodus/inciderit;

incidit. quibus adversum bellum incidit:

incipe. dic aliquid dignum promissis. incipe. nil est? sapere aude, |incipe.

incipiam. potarc et spargere flores/incipiam

incipias. finire laborem/incipias, parto quod avebas, populum si caedere saxis|incipias

incipies. nec sic incipies, ut scriptor cyclicus olim:

incipit. tandem fessus dormire viator/incipit.

incipit ex illo montis Apulia notos/ostentare mihi.

incipit ille: 'si bene me novi.

sic incipit: "olim ... fertur.

incisa. non incisa notis marmora publicis.

incitat. sed incitat me pectus

inclamat. 'quo tu. turpissime?" magna|inclamat voce. .

inclinare. inclinarc meridiem/sentis

inclinet. pluribus hisce. / si modo plura mihi bona sunt, inclinet,

inclitum. inclitum Vlixen/et Menelaum una necum se occidcre clamans.'

includere. quaeris. Maecenas, iterum antiquo me includcre ludo?

includo. ubi quid datur oti,|inludo [includo] chartis.

inclusa. si neque fervidis|pars inclusa caloribus $\mid$ mundi post etiam inclusa est voti sententia compos;

inclusam. inclusam Danaen turris aenea|robustaeque fores . . nunierant satis

Inclusit. quae semel . . . inclusit volucris dies.

inclusus. ille non inclusus equo Minervae/sacra mentito

incoctus. num viperinus his cruor|incoctus herbis me fefellit?

incogitat. non fraudem socio puerove incogitat ullam|pupillo;

incohare. vitae summa brevis spem nos vetat incohare longam; ,

incola. non adytis quatit/mentem sacerdotum incola Pythius.

ut huc novos incola venit?

incolis. me... obicere incolis|plorares Aquilonibus.

incoluit. Lydorum quidquid Etruscos $\mid$ incoluit finis.

incolumem. finibus Atticis/reddas incolumem precor incolumem tibi me praestant septembribus horis.

incolumem. virtutem incolumem odimus,

si .. . vitam famamque tueri|incolumem possum;

lncolumes. vel cur his animis incolumes non redeunt genae?"

Incolumi incolumi Rhodos et Mytilene pulcra facit

incolumi. incolumi Iove et urbe Roma?

quis Parthum paveat. . . . incolumi Caesare?

incolumi. asper|incolumi gravitate iocum temptavit

incolumi. incolumi capite es? quid enim?

Ars Poel. 4

Ars Poet. 127

Epod.14.7

Serm.1.3.109

Epod.1 1.20

Epod.9.32

Carm.3.29.5I

Epist.2.1.1 88

Serm.1.8.2

Serm.2.3.31 I

Carm.3.2.30

Carm.3.6.23

coni.Epist.2.1.I 83

Carm.3.3.19

Ars Poel.472

Sermin.7.16

Epist.1.16.23

Serm.2.3.84

Epist.1.14.36

Ars Poet.399

Serm.2.2.88

Ars Poel.193

Serm.1.7.I I

Serm.2.3.6

Epist.1.2.4I

Epist.1.5.15

Serm.1.1.94

Sermi.2.3.129

Ars Poet.1 36

Serm.1.5.18

Serm.1.5.77

Scrm.1.9.21

Serm.2.6.79

Carm.4.3. 3

Epodi.8.7

Serm.1.9.76

Carm.3.28.5

Serm.1.3.7I

Serm.2.3.197

Epist.1.1.3

coni.Serm.I.4.I39

Carm.3.24.37

Ars Porl.76

Carm.3.16.I

Carm.4.13.16

Carm.4.6.13

Epod.3.7

Epist.2.1.122

Carm.1.4.I 5

Carm.1.16.6

Serm.2.2.128

Carm.3.10.3

Serm. 1.6 .2

Carm.1.3.7

Epist.1.16.Io

Carm.3.2.4.3I

Sirm.1.4.110

Carm.4.10.8

Epist.1.I1.17

Carm.3.512

Carm-4.5 27

irs Poet.222

Serm.2.3.132 


\section{IN COLVMIS}

incolumis. incolumis laetor quod surit in libe:

incommoda. multil senent cireunveniunt incommoda.

incommodus. munere te barvo beret aut incommodus angat.

incomptam. maturet, in comptum lincomptan] lacaenat more comas [comam! religatea nodum [nodo].

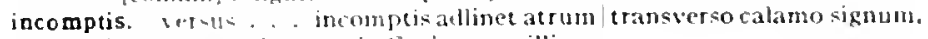

incomptis. Inue et incomptis Curium capillis

incomptum. brevibus illigata vipetis/criniset incomptun capul.

inconcinna. aspeticas agtestis et inconcinna gravisque.

inconcinnus. perconamque feret mon suconeinnus utratnque:

inconposito. nempe inconposito dixi pede curere versus ledeili.

inconsultus. patiatque vel ineonsultus haberi.

incontinertis. ne male dispar incontinensis inciat manus

intonunentic nece Tityi iecur reliquit ales.

incoquere. "rucas viridis, imula ego primus amaras monstravi incoquere: incorrupta. incorrupta Fides nudiugue Viritas

incorruptissimus. ipse mihi custos incorruptissims omnis circum doctores aderat.

increbruit. mowe, increbrut atura, cautus uti velet carm caput;

increbuit. mene, si increbruic [increbuit] aura. [ cautus uti velet carum: сарн1t:

incredibili. utrumque nostum incredibili molo consentit astrun:

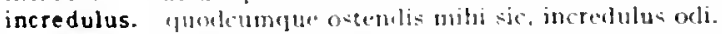

increpare. Sabella pertus inctepare cam

increpat. quis puse vina grasum militiam aus paperiem crepat lincrepat!?

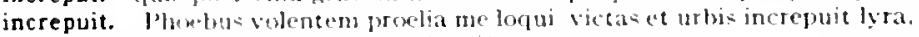

incretum. piper allum cum sale nige inerecoum

incrustare. sibcerum iurimus vas incruatare.

incubet. si et stramentis inculyes unde- octogunta annos natus.

incubuit. nova tehrum, terris incubust cohot:

incude. ueiman mova incurle diftugas retusum . . dertunt.

incudj. male entmatsincudi reildre veresse.

incultae. incultae patantur somere silvae:

incultis. incultis qui versibus et male natis restulst. . Mhilippre.

inculto. at ingenium ingens inculeo latet bre sub corpore.

incultum. mon tiln patrom ingeniun. non incultum est et turpites histum

incumbo. uhi quid datut ori. unludo [incumbo] chartis.

incurata. sultorum incurata puder malu- ulectal delat.

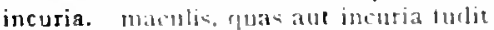

incurreret. (fue su. per vachon Rotrano incurreret hosts.

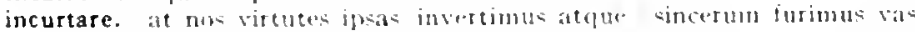
hut rustate [noturtar. $]$.

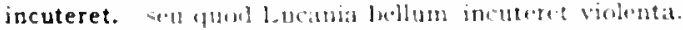

incutiant. ne nux incutiant aliema tibi peceatit puxtentem.

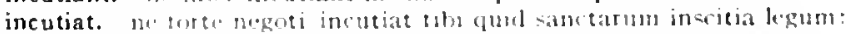

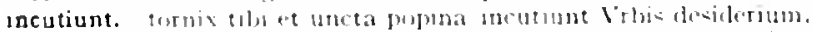

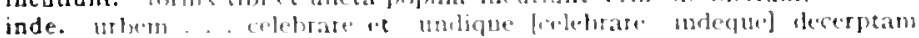
atenth frawernete olisam:

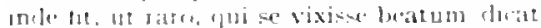

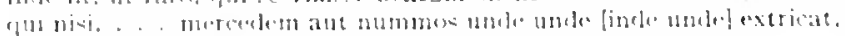

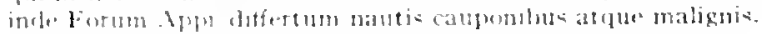

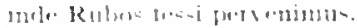

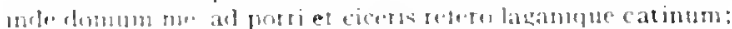

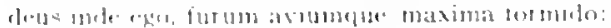

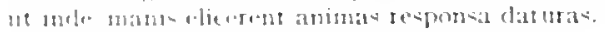

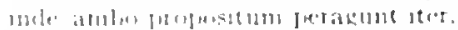

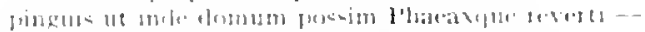

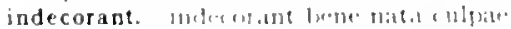

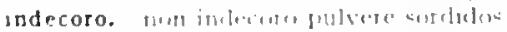

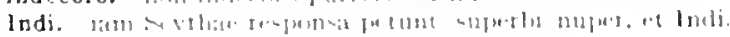

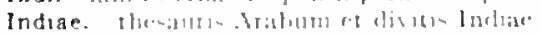

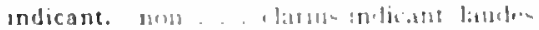

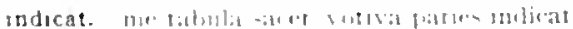

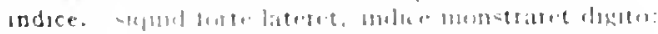

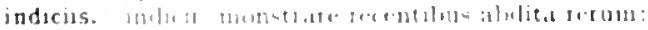

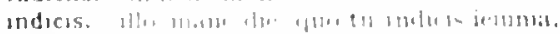

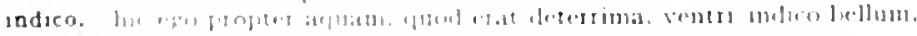

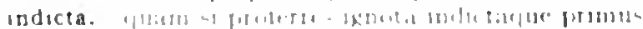

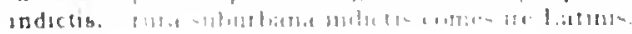

INDICTIS

Serm.1.408

Ars Poct.ico

Epist.1.18.75

coniciarm.2.11.23

Ars loet 400

Carm.1.12.41

Epod.5.1\%

Epist.1.180

Fipist.1.17.20

Serm.1.10.1

L.pist.1.5.15

Carm.1.17.26

Carm.3.4.77

Sorm.2.8.52

Carm.1.24.7

Serm.1.0.81

S.TH.2.5.93

:ar.Scrm 2.5 .93

Carm.2.17.21

Ars Poct. 188

lipod. $17.2 \mathrm{~S}$

iur.curm, 1.18.5

Carm.t.15.2

Serm.2.4.75

Sirm. T.3.5r

Serm.2.3.117

Carm.i.3.31

Corm.1.35.30

irs Poet. 11

IEste.t.2.45

I.pist.2.1.2.33

Siems.1.3.34

Epst.1.3.22

sur Serm.1.1.139

fipust.t.18.2.1

Ars lised.3.32

Arrm.2.1.37

iar...erm.1 $3.5^{6}$

Siem 2.130

lopistas.7.7

Sormas. I si

l.p.t.1.1.t.22

comicarm.1.7.7

sirnidiat

:ur.sorm.1.3.8s

Serm. I.5.3

Strm.1.504

Sirmes.colt

serm. 1.8 .3

serm 1.8. 28

sermi.2.0.0.

f.jukt.1524

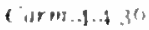

(arm. I I 23

Carm tare 50

(iurm. 3242

(arm: \& a 10)

(arm 1.5.3!

arm: $x_{20}$

lis lient ife

aren: $: 3201$

serm 158

Are Jeirt.130

1. pist. $1.7 .7^{11}$ 
indictum. dicam insigne, recens, adhuc/indictum ore alio.

Indicum. ton aurum aut ebur Indicum,

indigna. effutire levis indigna tragoedia versus,

et data Romanis venia est indigna poetis.

indigna. sine pondere erunt et lonore indigna ferentur,

indigna. ispissis indigna theatris/scripta pudet recitare

indignatio. ut ora vertat huc et huc euntium|liberrima indignatio?

indignatur. indignatur iten privatis ac prope socco / dignis carminibus narrari cena Thyestae:

indigni. indigni fraternum rumpere foedus.

indignis. qui stultus honores/saepe dat indignis

indigno. indignoque pecuniam/heredi properet.

si|detulerit fasces indigno, detrahet idem.

indigno non conmittenda poetae.

indignor. indignor quicquam reprendi, non quia crasse connositum. idem |indignor, quandoque bonus dornitat Homerus.

indignum. (indignum, quod sit peioribus ortus)

indignum. quid me perferre patique|indignum coges?"

indignum. "cave faxis/te quicquam indignum.

indignus. cur eget indignus quisquam te divite? segnis ego, indignus qui tantum possideam:

(indignum [indignus], quod sit peioribus ortus) | hic tibi sit potius quam tu mirabilis illi.

indiguus. cur eget indignus [indiguus] quisquam te divite?

indocili. aut pars indocili melior grege;

indocili. tuae|vexere tigres indocili iugum |collo trahentes.

indocilis. quassas indocilis pauperiem pati.

indocti. scribimus indocti doctique poemata passim. indocti stolidique et depugnare parati.

indoctum. Cantabrum indoctum iuga ferre nostra. indoctum doctumque fugat recitator acerbus;

indoctum. quin etiam canet indoctum, sed dulce bibenti.

indoctus. indoctus quid enim saperet liberque labormm|rusticis indoctusque pilae discive trochive quiescit,

Indoles. quid indoles/nutrita faust is sub penetralibus prosset,

indomita. rerum inscitia vexat /indomita cervice feros?

indomitae. nec pietas moram|rugis . . adferet indomitaeque morti,

indomitam. indomitan audeat refrenare licentiam. cum pene soluto|iudomitan properat rabiem sedare.

indomitas. indomitas prope qualis undas/exercet Auster

indomito. leporem sectatus equove lassus ab indomito.

indomito. cuius in indomito constantior inguine norvos

indomitus. indomitas [indomitus] prope qualis undas/exercet Auster

indormis. congestis undique saceis/indormis inllians

indormit. indormit unctis omnium cubilibus/oblivione paelicum?

Indos. sive subiectos Orientis orae/ Seras et Indos.

(inpiger extremos curris mercator ad Indos,

censes . . quid maris extremos Arabas ditantis et lndos/ludicra.

indotata. "indotata mihi soror est, paupercula mater,

inducant. ut numquam inducant aninum cantate rogati,

inducat. emptorem inducat hiantem,

inducere. iam nox inducere terris/umbras et caelo diffundere signa paralat; varias inducere plumas, | undique collat is membris

Induceris. metuens induceris atque / altercante libidinibus tremis ossa pavore.

inducit. Terentil fabula quem miserum gnato vixise fugatolinducit.

indulgens. crescit indulgens sibi dirus hydrops

Indus. Medusque et Indus, te profugus Scythes/miratur,

indutus. quidlibet indutus celeberrima per loca vadet

inemori. posset.. dapis/inemori spectaculo.

inemptas. dapes inemptas adparet:

inemptis. et piper et quidquid clartis anicitur ineptis [inemptis]

inepte. quis tam Lucili fautor inepte est.

quanto rectius hic, qui nil molitur inepte:

inepti. quis tam Lucili fautor inepte [inepti] est, ut non hoc fateatur?

ineptis. piper et quidquid chartis amicitur ineptis.

ineptum. neque te quisquan stipator ineptum|praeter Crispinum sectabitur.

ineptus. ineptuslet iactantior hic paullo est: ego si risi, quod ineptus|'pastillos Rufilus olet, Gargonius hircun,,
Curm.3.25.8

Carm.1.31.0

Ars I'OR'. 231

Ars l've'son

Lisist.2.2.1 12

IEpist.1.19.4I

Epod.t.ro

1rs Poet.00

Epist.1.3.35

Serm.10.10

Carm.3.24.0I

E.pist.J.J 6.34

Epist.2.1.231

Epist.2.1.70

Ars Poet.359

Iipist.10.22

Epist.1.16.75

Sirm.2.3.30

Sermi.2.2.103

Serm.2.3.230

tar. Eptst.1.1.22

toni.Serm.2.2.103

Epod. 16.37

Carm.3.3.14

Carmi.J.18

Epist.2.1.17

IEpist.2.1.I8.t

Carm.2.0.2

Ars 1'oet. 474

Epist.2.2.9

Ars l'oel.aI2

Ars Iod. 380

Carm.4.4.25

Epist.1.3.3+

Carm.2.1.4.t

Carm.3.24.28

Epol.12.9

Carm.4.14.20

Scrm.2.2.10

Epod.12.I0

2ar.Curm.4. I 4.20

Serm.1.1.71

Epod.5.c9

Carm.1.13.50

Epist.r.1.45

Epist.1.0.6

Epist.1.17.40

Sirm.1.3.2

Sim.1.2.88

Serm.1.5.9

Ars Jout.2

Sirm.2.7.5

Sirm.1.2.22

Curm.2.2.13

Curm.4.1.42

I.pist.1.17.28

lipod.5.3.t

ispod.2.18

iar.IPist.2.1.270

fiom.1.16.2

dirs I'eret. 10

'ur..term.I.10.2

1.pist.2.1.270

Serm.1.3.138

Serm.1.3.49

Serm.1.4. I 


\section{INEPTVS}

711. f.nmze servit ineptus.

int quol incptia|liannius II eronogenis laedat couviva Tigelli?

moretur frigore, si non/rettuleris pannum. refer et sine vivat ineptus. inerant. qua procul exstructis ineraut hesterna caniatris.

inert. ina [/ ita et] verborum vetus interit [? inerit] antas.

inermem. in silsa lupht in Sabina. . I tusit inersnom;

: gu: I non ebriecas disignat? . . al proslia trudit instem [inermem], iners. qui lora restrietis lacertis/sensit iners

(enim iubes: ma" . . imbecillus, iners,

mers, vinosus, amator - nemo adeo ferts est. .

praetulerim scriptor delirus intersque videri.

dhator, spe longus, iners avidusque futuri.

inera. stat slaciea iners/mensis per omuis

mox bruma recurrit iners.

inertein. yuae te|Lesbia quaerenti taurum monstravit inertem,

epes iubet csice ratas, ad proelia trudit inertenn.

inertem. qui toun inerten. qui mare temperat

cur:at aper lances carnem vitantis inertern:

inertia. molliw inertia cur tantam difuderit inis/oblivionem sensibus.

strenua nos cxercet inertia:

inertiae. paulum sepultae distat inertiaelcalata virtus-

inertibus. nunc vecerum libris, nune somno et inereibus horis

Inertis. duo si discordia vexet inertis

vit bonus at prulen; versus reprendet inertis.

inertis. aut tinsar maces taciturnus incrtis

inest. fyo 1 a sper spitus ac vis!nee verbis nee rebas inest. at milai cura' non mediocris incst.

inexcusabilis. ac n: ce retraha - et inexcusabilis absis.

inexorabilis. Achillem. Inpiger iracundu*, inexorabilis acer.

inexpertis. dulci: inexpertis cultura potentis amici.

inexpertum. siquid inerpertum scaenae conmittis

infabre. quid sculptun infabre, guid fusuru duriug esset.

infame. Costoicrans et Danai genus|infame

infamem. siquis iniamem mihi nunc iuveneum/dedat iratae.

infamia. faliug honor iuvat et mendax infamia terret

infamis. Galloni pracconis erat acipensere mensalinfamis.

infamis. intanis IJenae Castor offensus vice

infamis. qui vidit . . infamis scopulos Acroceramia?

infamis. seu rubra Canicula fudet/infantis [infamid statuas.

infans. nou sine div animosus infans.

infans namque pulor prohibebat plura profari)

- 1 b nutrece puella velut si luderet infans.

infantes. s:u rubra Canicula findet) infantis [infantes] statuas.

infantis sen rubsa Canicula findet/infantis statuas.

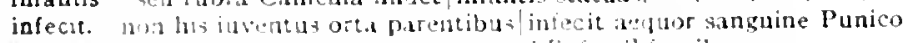

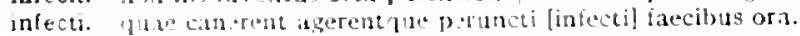

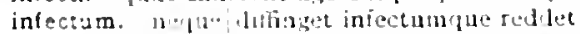

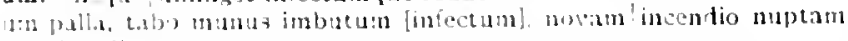

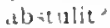

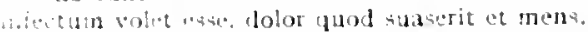

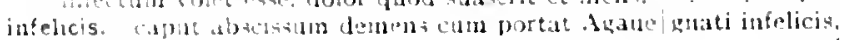

infelix. "1 ego non felix, quan [? infelix, quem] tu fugia, ut pavet arris/agna lupos

inteilix, apeitum perdas.

melax operis smmma. quia ponere totum/neaciet:

infelix. Ityu Hebiluter gemens. Infelix avis

inferbus. ho ubi conlusum sectia inferbut herbs

inferias. vicoram nepotes/rettulit inferias Iugurthat.

inferiorem. "flu. proms conpesceret inferiorem:

inferius. maldfe calum sidel inforius mati

infernas. serpento atgue videres/inferma errats camed

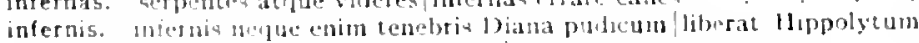

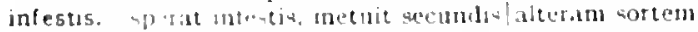

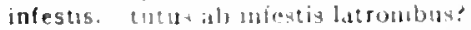

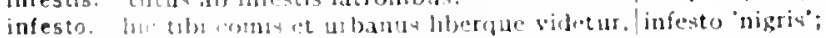

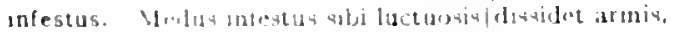

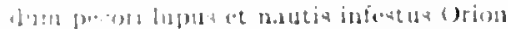

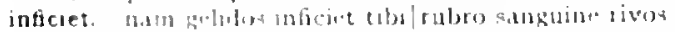

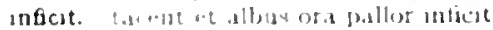

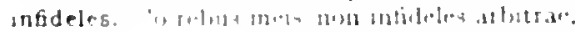

INFIDELES

Serm.1.6.15

Serm.1.10.79

Epist.1.17.32

Serin.2.6.105

r.ir.Ars Poet.61

Carm.I.22.12

Ear.Epist.1.5.17

Carm.3.5.35

Serm.2.7.39

Epist.1.1.38

Epist.2.2.126

Ars Poet.171

Corm.2.9.5

Carm.4.7.12

Epod.12.I 7

Epist.1.5.17

Carm.3 4.45

Serm.2.4.41

Epod.14.1

Epist.1.1 1.28

Carm.4.9.29

Serm.2.6.61

Serin.1.7.1 5

Ars Pact.445

Epist.1.20.12

Serm.1.4.47

Serm.2.4.94

Epist.1.18.58

Ars Poet.i 2 I

Epist.1. I 8.86

Ars Poet. 25

Serm.2.3.22

Carm.2.14.19

Carm.3.27.45

Espist. 5. 16.39

Serm.2.2.48

lipol.17.42

Carm.1.3.20

coni.Serm.2.5.40

Cirm.3.4.20

Serm.1.6.57

Epist.2.1.99

j'ar.Serm. 2.5.40

Serm. 2.5.40

Cism.3.0.34

inat.ars Poct.27z

Carm.3.29.47

var.Epod.5.65

List. 1.2 .00

Scrm.2.3.304

7 rar.Epod.12.25

Serm.1.1.90

Ars loet.3.t

Carm.4.12.0

Sorm.2.to7

Carm.2.1.28

Sirm.1.8.31

lipod.5.70

Serm.1.8.35

Carm.t.725

(arm 2.10.13

Serm.2.1.42

Serm.1.4 ot

Carm.3.8.19

Lipod 15.7

Cism .3 .13 .6

I:pol.7.15

I.pol. 5.50 


\section{INFIDELIS}

infidelis. novisque rebus infidelis Allobrox

infldi. optat quietem Pelopis infidi pater,

infidi. non Seres infidique Persae,

infido. qualis Lycambae spretus infido gener infido scurrae distabit amicus.

infidum. at volgus infidum et meretrix retro|periura cedit, . infima. an pauper et infinalde gente sub divo moreris:

infimis. ab infigis|quassas eripiunt aequoribus rates,

infirmas. aut tondet infirnias ovis.

infirmior. sum paulo infirmior, unus |nultorum.

infirmo. infirmo capiti fluit utilis, utilis alvo.

infla. crescenten tumidis infla sermonibus utrem.

inflaret. cun magis atque/se magis inflaret,

inflat. exanimat lentus spectator, sedulus inflat:

inflavit. 'nam simul ac venas inflavit taetra libido,

inflet. merito quin illis I uppiter anbas|iratus buccas inflet

informem. albis informem spectabant ossibus agrum;

informis. nunc situs informis premit el deserta vetustas;

informis. informis hiemes reducit|Iuppiter,

infortunia. tum tua me infortunia laedent.

infossus. quo posset infossus plier

infra. infra Lucili censum ingeniumque,

infra, |si nemini, Varius:

Nomentanus erat super ipsum, Porcius infra.

qui praegravat artes|infra se positas:

infregi. limina dura, quibus lumbos et infregi latus.

infrequens. parcus deorum cultor et infrequens.

infundam. maius infundam tibi|fastidienti poculum

infundis. sincerum est nisi vas, quodcumque infundis acescit.

ingemens. exhauriebat, ingemens laboribus,

ingeni. culpa deterere ingeni.

at fides et ingeni|benigna vena est

ingeniis. ingeniis non ille favet plauditque sepultis

ingeniis. invat inmemorata ferentem ingenuis [ingeniis] oculisque legi manibusque teneri. .

ingenio. tu lene tormentum ingenio admoves/plerumque duro.

ingenio. ingenio offensi aut laeso doluere Metello. ingenio, specie, virtute, loco, relextremi primorum, .

ingenium. at ingenium ingens inculto latet hoc sub corpore. ingenium cui sit, cui mens divinior atque os/magna sonaturum, quale fuit Cassi rapido ferventius amni|ingenium. sunt quorum ingenium nova tantum crustula promit. non tibi parvom|ingenium. ingenium, sibi quod vacuas desumpsit Athenas nec rude quid prosit video ingenium:

ingenium. 'contrane lucrum nil valere candidum|pauperis ingenium' infra Lucili censum ingeniumque, pingue pecus domino tacias et cetera practer/ingenium, sed convivatoris, uti dueis, ingenium res/adversae nudare solent. ingenium misera quia fortunatius arte|credit

Grais ingenium, Grais dedit ore rotundo|Musa loqui.

ingens. non pugnavit ingens|Idomeneus Sthenelusve solus . subito ingens | valvarum strepitus lectis excussit utrumque.

ingens. quo pinus ingens albaque populus saepius ventis agitatur ingens/pinus

'hic fossa est ingens, hic rupes maxima: serva!'

ni cibus atque ingens accedit stomacho fultura rnenti.

ingens | belua cognatos eliserit.

tibi ingens | virtus atque animus cenis responsat opimis?

ingens, at ingenium ingens|inculto latet hoc aub corpore. neglectis flagitium ingens.

ingens. cras ingens iterabimus aequor."

credidit ingens/pauperiem vitium

torquet nunc lapidem, nune ingens machina tignum,

Ingentem. Pyrrhumque et ingentem cecidit $\mid$ Antiochum siquis ad ingentem frumenti semper acervom|porrectus vigilet

ingentia. post ingentia facta deorum in templa recepti.

ingentis. quisquis ingentis oculo inretorto spectat acervos. . "Iuppiter, ingentis qui das adimisque dolores."

\section{INGENTIS}

Epod.16.0

Epod.17.65

Carm.4. 55.23

Epod.6.13

Epist.1.18.4

Carm.1.35.25

Carm.2.3.22

Carm.4.8.3 I

Epod.2.I 6

Serm.I.9.7I

Epist.1.16.14

Serm.2.5.98

Serm.2.3.319

Epist.2.1.178

Serm.1.2.33

Serm.1.1.21

Serm.1.8.16

Epist.2.2.118

Carm.2.10.15

Ars Poet.103

Epod.5.32

Serm.2.1.75

Serm.2.8.20

Serm.2.8.23

Epist.2.1.14

Epod.II.22

Carm.1.34.1

Epod.5.77

Epist.1.2.54

Epod.5.3I

Carm.1.6.I 2

Carm.2.18.9

Epist.2.1.88

:or.Epist.1.19.34

Carm.3.21.13

Serm.2.1.67

Epist.2.2.203

Serm.1.3.33

Serm.1.4.43

Serm.1.10.63

Serm.2.4.47

Epist.1.3.22

Epist.2.2.81

Ars Poet.410

Epod.II.1 2

Serm.2.I.75

Serm.2.6.15

Serm.2.8.73

Ars Poet.295

Ars Poet.323

Carm.4.9.19

Serm.2.6.III

Carm.2.3.9

Corm.2.10.9

Serm.2.3.59

Serm.2.3.154

Serm.2.3.315

Serm.2.7.102

Serm.1.3.33

Sorm.2.4.82

Carm. 1.7 .32

Serm.2.3.9I

Epist.2.2.73

Carm.3.6.35

Serm.2.3.III

Epist.2.1.6

Carm.2.2.23

Serm.2.3.288 
ingenuis. jubat inmemorata ferentumlingenuis onlisque legi manibusque tenett.

ingenuo. ingenuoguse semper |amose pecas.

ingenuo si non essem paste natus:

ingenuom. astutia ingenuom volges imitata leonem? -

ingenuos. nescit equo tudis/haerere ingenuos puer

cum tefore negas, quali sit quisque parente/matus, dum ingenuos,

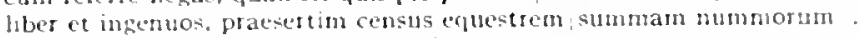

ingenuos. quol non ingenuos habeat clasosque patentes.

ingerere. tum putsi matis. puetis convicia natue/ingerere

ingluvie. avi cus atque patege is praedaram ingratat stringat malus ingiuvie rem.

ingrata. ingrata misero vita ducendia cest in hoe:

ingrata. avi cur atque patentis practaram ingtatis strigat malis inghue tem.

ingrata. sic nihi tatda fluont ingratidgue tempora

ingrata. ut hatec ingrata ventis dividat bonenta

ingratam. ingratam Veneri pone superbiam.

ingratis. haec seges ingratos [ungtatis] tulit et leset onubus anris.

ingrato. ingtato celeres obruit otio'motor

ingrato. haec sege inglatos lingiatol twit ex inet emmilus andis.

ingratos. lave seges ingtatos tulit et leset ommibus anni-

ingratus. meca cus ingratus opuscula lecor|lauket andetque domi,

inguen. est guilinguen ad obscanum subductic uspue;

inguina. cument tibi cumi imguima.

inguine. guod at superbo provoces ab inguine.

cuius in indomito constantiot inguine norvon

obscachogue suber portectus ab imguine plitus.

ingustata. cum paseris atque ingustata milsi porrextat ilia rhombi.

inbaeret. gham nova collibes arbor inharet.

inhians. congestis undique saccictindomis in!hans

inhonestum. "an hoc inhone sum "e instile factu necue sit addubires.

inhonestus. q1:0 patre sit natıs, num ignota matue inhonestus.

inhorrute. nam stu mobilibus vepris inhorut ae! rentem folis

inhospita. nam quae deserta et inhospita tesqu.1 (ctedis.

inhospitalem. sive facturus per inhospitalem/Caucasum [rer Alpitm isga inhospitalem et Caucasum . . sequenur

inhumanae. suge el irhumanac soism degone Camenae.

inhumato. vagae ne parce maligmus hatchae/osilus et capiti inbumato Daticuburare:

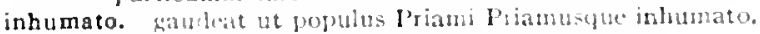

inciat. me male dispartincontinentis iniciat manus mellis inicial curan quaetendi singula. 1.

iniecit. ordinem rectum evanti frenat licentibe, inircit

iniecta. iniecta monistris Terra dolet suis

mentio siquac/de Capitolini furtis infueta Petill

iniecto. licebri insecto ter pulvere curras.

inimica.

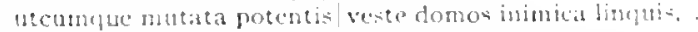

Canidal Albuci, quibus est insmbica, ventonum,

inimica. tu patum cartis inimica mites fulmina lucis.

inimicat. "th matrats inimicat urlis.

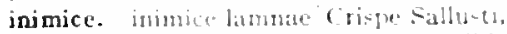

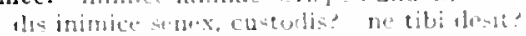

inimicis. o maknus porethe ininicis gicula

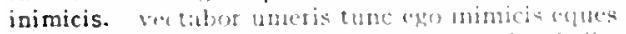

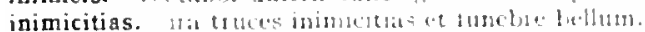

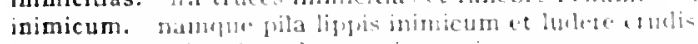

inimicus. et deredet odor nesvis manicus;

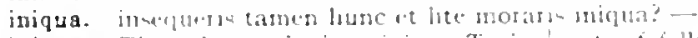

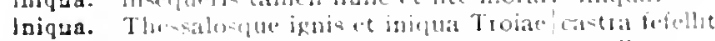

uniquae. demito atriculas, ut miguae mentis andlus.

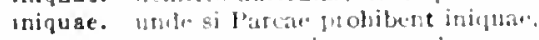

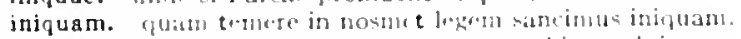

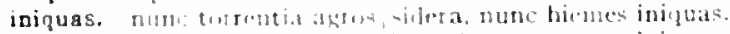

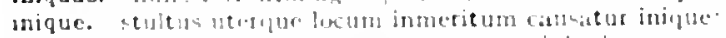

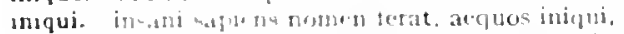

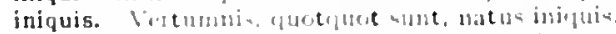

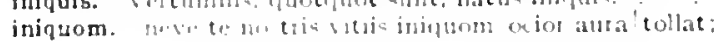

1. pist.1.19.3.

Cirm:1.27.10

Sirm.1.0.21

Serm.2.3.1 80

Carm.3.2.55

Serm.1.r.s

Ars Poct. $3 s_{3}$

Sirm.1.0.91

Sirm.1.5.12

Sirm.1.2.8

1.pond.1 7.03

Vierm.I.z\&

Fist.1.1.23

Fpod.11.10

Curm.3 I0.9

iar.tsist.1.7.21

Carm.1.15.3

ar. Lfist.j.7.2I

I.pet.1.7.21

Fist.1.19.35

sam.1.2.20

Serm.1.2.116

lipol.s. 10

Efod.12.10

serm.1.8.5

serm.2.8.30

lipod.12.20

Sermiti.7!

serm.1..1.124

Sermito. 3e)

Carm.1.23.5

Epist 1.14.19

Carm1.22.0

Erod.1.12

Efist.1.18.47

(urm.1.2S.24

Serm.2.3.195

Corm.1.17.26

Sorm.1.6.32

Carm.t. I5.I I

Carm.3.4.73

Serm.1.4.

Carm. 2536

Curm.1.12.22

Carm.1 35.24

Sorm.2.1.4s

Carm.1.12.59

Carmot.15.20

(arm.2.2.2

Sirm.2.3.123

Scrm.z.107

1. povt.17.74

lepist 1.1049

Sirm.1.5.49

Sormi.2. 4.53

firist.2.20

(arm.1.1015

Sirmiso 00

Corm.ze 9

Sermes.3.t.

(arm.3.1.32

1.pos] 1.12

f.jist d t. 5

srom.z.74

iorm 1.2..97 


\section{INI QVOM}

te tibi iniquom et frustra mortis cupidum.

seu cursum mutavit iniquon frugibus amnis|doct us iter melius:

iniquom. nimium premendo|litus iniquom.

nec natura potest iusto secernere iniquom,

iniquos. Jaudet ametque domi, premat cxtra limen iniquos.

iniquos. regium certe genus, et penatis|macret iniquos.

inire. illun ego lucidas|inire sedes,

iniuria. luctandum in turba et facicnda iniuria tardis.

iniuriosis. donec cinis iniuriosis aridus ventis ferar,

iniurioso. iniurioso ne pede proruas|stantem columnam

iniussae. illic iniussae veniunt ad mulctra capellae

iniussi. mumquam inducant animum cantare rogati, iniussi numquam desistant.

iniuste. iniuste totum ducit venditque poema.

iniusti. iura inventa metu iniusti fateare necesse est.

inlabatur. si fractus inlabatur orbis.

inlabetur. si fractus inlabatur [inlabetur] orbis,

inlacrima. sparge subinde et, si paullum potes inlacrimare, est [inlacrima:c re est]|gaudia prodentem voltum celare.

inlacrimabilem. amice, places inlacrimabilem|Plutona tauris,

inlacrimabiles. omnes inlacrimabiles|urgentur ignotique longa|nocte,

inlacrimare. sparge subinde et, si paullum potes inlacrinare.

inlapsus. me truncus inlapsus cerebro

inlaqueant. munera navium | sacros inlaqueant duces.

inlecebris. co quad/illecebris [inlecebris] crat et grata novitate morandus spectator

inlectos. migravit ab aure voluptas/omnis ad incertos [inlectos] oculos et gaudia vana.

inlepide. non quia crassc|conpositum inlepideve putetur,

inleverit. et quodcumque semel chartis inleverit.

inliciat. puellis iniciat [inliciat] curam quaerendi singula,

inligata. non ut irvencis inligata plutibus/aratra nitantur meis

inligatum. vix inligatum te triforni|Pegasus cxpediet Chimaera.

inligaturum. ignota tauris inligaturum iuga

inlinere. hic oculis ego nigra meis collyria lippus|inlinere;

inlinet. quodsi bruma nives Albanis inlinet agris,

inlitterati. inlitterati num minus nervi rigent.

inlota. et Tyrias dare circum inluta [inlota] toralia restis,

inlotos. in]utos [inlotos] Curtillus echinos, ut melius muria quor testa marina remittat."

inludens, sed postquan victor violens [ricto in]udens] discessit ab hoste, .. non frenum depulit ore.

inludere. ut semper gaudes inludere rebus | humanis!"

inludit. unus utricue error, sed varis inludit partibus:

inludo. ubi quid datur oti. |inludo chartis.

inlusi. inlusique pedes vitiosum ferre recusant corpus.

inlustrat. qua sol habitabilis inlustrat oras.

injustrem. (quid prius inlustrem saturis musaque pedestri)

inlusus. aut spen deponas aut artem inlusus omittas.

inluta. et Tyrias darc circum inluta toralia vestis,

inlutos. inulas. . monstravi incoquere; inlutos Curtillus echinos, .

inmane. inmane est pitium dare milia terna macello

inmaturus. ut si,filius inmaturus obisset.

inmemor. venator tenerae coniugis inmemor. .

cervos uti vallis in alteralvisum parte lupum graminis inmemor.

sepulcri|inunemor struis domos

inmemorata. iuvat inmemorata ferentem i ingenuis oculisque legi manibusque teneri.

inmemori. quo posset infossus puer/longo dic bis terque mutatae dapis inemori [inmemori] spectaculo.

inmensum. quid iuvat inmensum te argenti pondus ct auri .

inmensus. fervet inmensusque ruit proimdo/Pindarıs ore,

inmerentis. caducum $/$ in domini caput inmerentis.

ut inmerentis fuxit in terram Remi|sacer nepotibus cruor.

inmerentis. quid inmerentis hospites vexas,

inmeritam. scindat haerentem coronam/crinibus injeritamque vestcm. . inmeritis. neglegis inmeritis nocituram | postmorlo te natis fraudem conmittere?

Virtus, recludens inmeritis morilcaclum,
I NMERITIS

Sirm.2.2.07

Ars 10.6 .67

Carm.2.10.4

Serm.I.3.II3

Epist.1.19.30

Carm.2.4.16

Carm.3.3.34

Serm.2.6.28

Lipod.1 7.34

Carm.1.35.13

Epod.1 0.49

Sirm.1.3.3

Epist.2.I.75

Serm.I.3.III

Carm-3.3.7

var.Curm.3.3.7

(o) 1.5 smm.2.5.103

Carm.2.14.6

Carm.4.9.20

S.rm.2.5.103

Carm.2. 17.27

Carm.3. 16.16

2'ar. Ars Poet.223

(o)i.Epist.2.1.188

Epist.2.1.77

Serm. T.4.36

var.Srm.1.6.32

Epod.1.25

Carm.1.27.23

lipod.3.I I

Serm. [.5.3 $\mathrm{L}$

Epist.1.7.10

Epod.8.17

tar..Serm.2.4.84

s'ar.Serm.2.8.52

coni.Epist.1.10.37

Serm.2.8.62

Serm.2.3 $5 \mathrm{I}$

Serm.1.4.139

Serm.2.7.108

Carm.4.14.6

Serm.2.6.17

serm.2.5.20

Sirm.2.4.84

Sirm.2.8.52

Serm.2.4.76

Serm.2.8.59

Carm.1.1.26

Carm.1.15.30

Carm.2.18.19

Epist. I.19.33

qar. Epod. 5-34

Serm.t.I.4I

Carm.1.2.7

Curm.2.13.12

lepod.7.19

Iipod.o. I

Corm.1.17.2S

Carm.1.28.30

Carm.32.21 


\section{INMERITOS}

inmeritos. Aiax cum inmeritos occidit desipit agnos:

Aiax cum in nustos [inmeritos cum] occidit desipit agnos;

inmeritum. stultus uterque locun inmeritum catusatur inique:

inmeritus. dedican maiorum inmeritus lues.

inmentusque laborat |iratis natus paries dis atque poetis.

inmersabilis. antrersis rerum inmersabilis undis.

inmetata. innetata quibus iugera liberas frugeget Cererem ferunt

inminentiun. anlequam stantis repetat paludes / imbrium divina avis muinentium [inninentium). .

inminentum. anteruan stantis regetat paludes imbrium divina avis immisentium [inminentum].

inminuet. quantum hinc inninuet?

inminuit. dammosa quid non inminuit dies?

inmiscere. tu si molo recte | dispensare velis ac non fugienda petendis inmiscere.

inmiserabilis. si non periret ian miserabilis [inniserabilis]/captiva pubes.

inmitia. sed non ut placidis corant inmitia.

inmitis. ne doleas plus nimio memor/inmitis Glycerae .

tolle cupidinem inmitis uvae:

inmoderatus. neu desis operae nev inmoderatus abundes. .

inmodicae. turparunt umeros inmodicae merolrixae

inmodulata. non guivis videt inmodulata poemata iudex

inmolet. innolet aequis/hic norcum laribus;

inmoritur. immoritur studis et amore senescit habendi.

inmorsus. perna magis et magis hillis|flagitat inmorsus refici.

inmortalia. insnot talia ne speres, nonet annus

inmortalis. eleus innortalis haberi/dum cupit Enpedocles.

inmunda. pauperies inmunda donus jrocul absit: .

inmunda. aut inmunda crejnent ignominiosaqute dicta.

inmundis. quaecumelue innundis fercent adlata popinis.

inmundo. tun inmmo somnin visu/nocturman vestem naculant

inmundus. unguor olvo, 'non quo raudatis inmundus Natta lucernis.

vixisect canis insundus vel ansica luto sus.

inmunem. non ego te mejs| inmuncm meditor tinguere poculis,

quem ecis inmunem Cinarae placuisse rapaci.

inmunis. inmunis aram si tetigit manus.

innantem. Jrincegs et innastem Maticet litorbus tenuise Lirim.

innascitur. meglectis urenda filix innascitur agtis.

innatat. nam lactuca innatat acri| post vinum stomacho;

innati. ne velut innati trivils alc pilene forenses

innectes. frustrante vincla guttui imectes tuo

innisus. Jic antel'ollux et sigu llorules/enisus [it istus] arcesattigit igneat, innocens. matw carentibus privignis nulier tomperat innocens.

innocentis. hic innocentis proula l,eshii

innominete. mollis et expes inominata [innoninata] perpremat cubitia. insumerabilis. innumerahilislannorun series et fuga tcmporm.

Ino. sit Medea terox invetaque, flebilis lno.

inominata. nollis ex expec inominata perprenat cubilia.

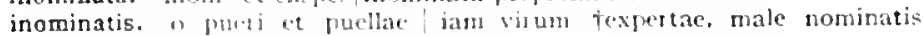
[mominatis] parcite vithis.

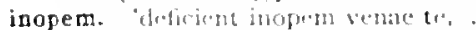

ofutia trmpora notis|inctuit a xumplis, inopem solatur et aegum.

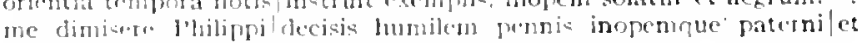
latis a.t fameli,

inopes. hre ane sive inofres rimus coloni.

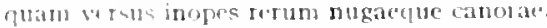

inopi. inofis dase nolit amico.

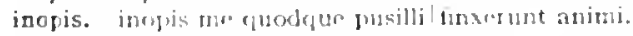

inops. maknas inter orse inops.

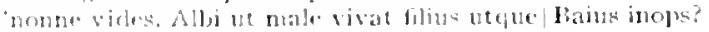

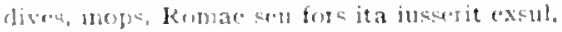

nudge inopsolue domum Iredeam to vate.

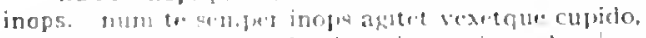

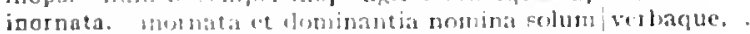

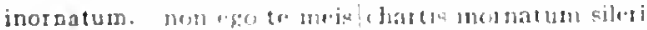

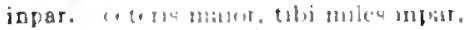

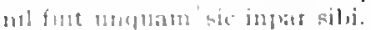

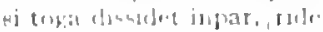

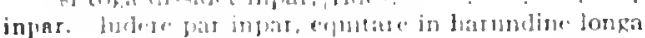

Sorm.2.3.211

1 ar. Serm.2.3.211

Epist.1.14.12

Carm.3.0.1

Sinm.2 3.7

E.pist.1.2.22

Carm.3.24.12

:ar.Carm.3.27.10

Jar.Carm.3.27.10

Serm.2.2.127

Curm.3.6.45

Serm.1.2.70

tar.Carm.3.5.17

Ars Pochiz 2

Carm.1.33.2

Carm.2.5.10

Sorm.2.5.89

Corm.1.13.10

Ars Pod.203

Sorm.2.3.164

Epist.1.7.85

Sorm 2.1.01

Carm.a.7.7

Ars Pool.464

Epist.2.2.109

Ars Pod.2.47

serm.2.1.2

Serm.1.5.8.4

sirmidizas

F.pist.1.2.20

Carmot 12.23

Ejist.I.I 3.3

Corm.3.23.17

Corm.3 17.7

Sorm 1.3.37

Sirm.2..4.59

Ars l'ocil.2.45

Fpod.17.72

ior.Carm.3.3.10

Curm.324.18

Carm.1.17.21

iar. Ffed.I6.38

Corm $3 \cdot 39.4$

Ars Pot. 123

lipod.1:-3s

conicomis.14.1]

Sorm.2.3.153

lepist.2.1.131

1.fist.2.2.50

Corm.2.14.12

Ars IOCH.322

Serm.t.2.5

Sormor thit

Carm.3.10.es

Sirmolatio

Srm.2.t.50

verm.2.50

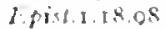

Ars Iorli.2.7

Corm.t $0.3 \mathrm{~s}$

Carmet 1.5

sorm.1.3.10

Lisistig.on

srom.2.3.24s 
inpares, inpares|formas atque animos sub iuga . . mittere

Carm.1.33.10

inparibus. desinet inparibus certare submotus pudor.'

inparibus. inparibus formis deceptum te petere esto:

inpariter. versibus inpariter iunctis querimonia prinum,

inpavidi. urgent inpavidi te Salaminius|Teucer, te Sthenelus,

inpavidum. inpavidum ferient ruinae.

inpediat. inpediat verbis lassas onerantibus auris, .

inpellat. ut forte legentem | aut tacitum inpellat quovis scrmone:

inpellit. natura ... iuvat aut inpellit ad iram

inpellunt. inpellunt animae lintea Thraciae.

inpensis. inpensis cenarum et tritae munere vestis;

inpenso. Iuscinias soliti inpenso prandere coemptas,

inpermissa. cui donet inpermissa raptim/gaudia

inperti. siquid novisti rectius istis, / candidus inperti;

inpetrat. inpetrat et pacen et locupletem frugibus annum:

inpetrato. super inpetratolfortis Augusti reditu

inpetret. clarus Anchisae Venerisque sanguislinpetret,

inpexa. caputquelcoeperis inpexa foedun porrigine?

inpia. cum parentis regna per ardnom/cohors gigantum scanderet inpia.

inpia perdemus devoti sanguinis aetas

unguentarius ac Tusci turba inpia vici.

inpia. destrictus ensis cui super inpia|cervice pendet. parentis olim siquis inpia manu|senile guttur fregerit,

inpia. campus sepulcris inpia proelia/testatur quale poscet inpia/mollire Thracum pectora:

inpiae. nec priores inpiae tectum dominae relinquont, non 'incendia Karthaginis inpiae'

inpiae. si tamen inpiael non tangenda rates transiliunt rada. inpiae nam (quid potuere maius?), inpiae sponsos potuere durolperdere ferro.

inpiam. in inpiam Aiacis ratem.

inpias. inpias/caedis et rabien tollere civicam, nollibus lenire verbis inpias.

inpiger. quam si quidquid arat inpiger Apulus non equos inpiger |curru ducet Achaico | victoren sic Iovis interest optatis epulis inpiger Hercules. inpiger hostium / vexare turmas

(inpiget extremos curris mercator ad Indos.

Achillem. Inpiger iracundus, incxorabilis acer,

inpingas. quan quo perfere iuberis|clitellas ferus inpingas .

inpio. te Ioris inpio|tutela Saturno refulgens eripuit

inpio. inpio/vastata Poenorum tumultu|fana

inpios. inpios! Titanas imnanemque turbam

inpios parrae recinentis omen|ducat

inpium. inpium|lenite clamorcm sodales

inplacidum. Genaunos, inplacidum genus,

inplent. lubrica nascentes inplent conchylia lunae;

inplere. magnas Graecorum nalis inplere catervas."

inpleris. inpune ut Vrbem nomine inpleris mco?

inplet. poeta, meum qui pectus . . irritat, mulcet, falsis terroribus inplet

inplevisse, me quater undenos sciat inplevisse decenbris,

inplicitum. cripere artis|litibus inplicitum.

inplorat. caelestis inplorat aquas docta prece blandus,

inploravit. donec ninor in certamine longo inploravit opes.

inplumibus. ut adsidens inplumibus pullis avis

inponens. ex more inponens cognata vocabula rebus?

inportes. odiumque libellis!sedulus inportes opera velinente minister.

inportuna. inportuna tamen pauperies abest

quem tenet argenti sitis inportuna fanesque.

inportunas. ast inportunas volucris in vertice larundolterret fixa

inportunus. inportunus enim uansvolat aridas/quercus inportunus amat laudari:

eripietque curule|cui volet inportunus cbur."

dives et inportunus ad umbram lucis ab ortu

inposita. quem ter vindicta guatesque inposita

inpositam. nec peredit inpositan celer ignis Aetnen me dicente cavis irpositam ilicem/saxis,

inpositas. arcis/Alpibus inpositas tremendis.. . deiecit fumina dicere et arces | montibus inpositas

Epod.11.1.

Sirm.2.2.30

Ars Pod.75

Carm.1.15.23

Carm.3.3.8

Serm.1.10.10

Sorm.1.3.65

Ars Poeliog

Carm.4.12.2

Epist.I.19.38

Sorm.2.3.245

Carm.3.6.27

Epist.1.0.68

Epist.2.I.137

Carm.4.2.42

Carm.Sate.5I

Serm.2.3.120

Corm.2.19.22

Epod.16.9

Sirm.2.3.228

Carm.3.1.17

Epod.3.I

Carm.2 1.30

Epod.5.I3

Carm.2.8. I9

Carm.4.8. I

Carm.1.3.23

Carm.3.I1.30

Carm-31I.3I

Epod.10.14

Carm.3.24.25

Epod.5.84

Carm.3.It).20

Carm.4.3.4

Carm.4.8.30

Carm.4.14.22

Epist.I.I.45

Ars Pod.I 2 I

Epist.1.13.8

Carm.2.17.23

Carm.4.4.4t

Carm.3.4.12

Carm.3.27.I

Carm.1.27.0

Carm.4.I4.Io

Serm.2.4.30

Serm.I.I0.35

Epod.17.59

Epist.2.1.2I 2

Epist.1.20.27

Ars Poel.424

Epist.2.1.135

Epist.1.10.3e

Ffod.I.IO

Serm.2.3.280

ENist.1.13.5

Carm.3.16.37

I.pist.1.18.23

Sermir.8.6

Carm.4.13.9

Serm.2.5.co

Lfist.1. (1.54

Epist.2.2.IB5

Sirm2.7.77

Carm.3.4.70

Carm.3 I3.I.t

Camititin 2

Epist.2.1.253 


\section{INPOSITVM}

inpositum. subimus/upost

impositura. nos in aeternum|exilium inpositura cymbat.

inpositus. Inpositus mannis arrom calumque Sabinum|non cessat laudare.

inposuere. unle frepuentia Mercuriale mpostere mihi cognomen compita."

inposuisse. temdentes opaco|l'telion inposuisse Olympo.

inpotens. quidlibet inpotens sperare fortumaque dubi' sbria.

inulta cessercut inpotens / tellure

num aluih impotens poisit diruere

inpotentia. nullius atri gregeun aestuosa torret inpotentia.

inpransi. postquan est injmanis correptus voce magiatri?

inpransi. vorum lic inpransi mecum disquirite.

inpransus. injransus non quj civem dignegceret hoste.

inpressa. mordaci velut icta ferro, pisus aut inpulsa [inpressal cupressus Euro.

inpressit. sive puer furen inpressit menorem dente labris notan.

inprimat. 'mprinat his cura Mapcenas signa tabellis."

inprimeret. iuprimeretque muris|hostile aratrum excrcitus insolens.

inprimet. Imprineretgue [? inprimetque] muris/hostile aratum .

iaproba. vitanda est inproba siren/desidia

ama inpreba Thobisiex testamento sic est elata:

inprobae. scilicet ingrobat crescunt divitiae.

inprobaturum. per inprobaturum hace loven.

inprobe. cur, inprobe, carae hou aliguid patriac tanto emetiris accrvo?

spargistue mola capue, improbe, salsa

inprobo. inprobo iracundior Hadria:

inprobus. Fultu- et nuprobus lac atmer eat lignusqu." nutars.

iaste inprobus atc me sub eulto linquit.

improbus, ultrolqui meliotem audax vocet in its.

iuprobus urget iratis precibus:

'inegat inprobus ot tolueglegit aut hotred.

dominuth velue inprobus atque | sem vet abeterum,

inprorsim. sel viden linte omnis domus... introssum [improrsum] turpen. speciosum poble decora

inprovisa. inprovial leti vis repat rapiefue genti:

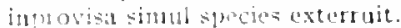

inprudens. numprise exo illi inprudens olim facian simile:"

inpube. inpule corpus, quale posset inpia nollite Thucum pectora:

inpubem. nec impubem parentes Troilon atle Pjorggiae sorores / flevert samper.

inpudens. inpulens liqui patrios Penates.

inpurd:n Oreum moror.

Judieque et bibis inpudena

inpudica. nedue inputica Colchis ineudit pedem.

inpugna:- noetra sed iupugrat, noa nostraque lividus odit.

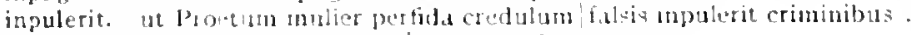

inpulie. pupertaz inpulit andax! ut versus facerem.

inpulsa. int inpula cupressus biro.

inpune. impunw tutum ger nemus arbutos quarerunt

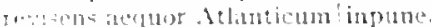

totwe tuse lateias laborezlinpunc, Lolli, carpere

impuge ut Vilecu mentine iupleris meo?

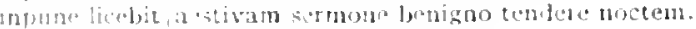

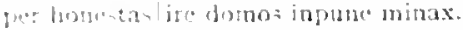

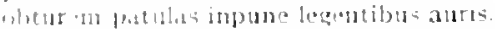

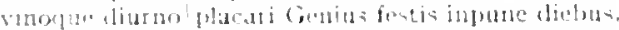

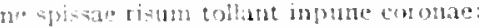

inpunitior. gui tu iupunitiot illa. . oljonia captas?

inputata. eq inputata thotet weque vineas.

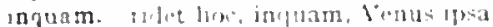

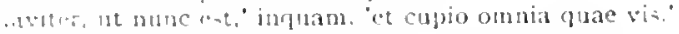

"mhitie ho." inquan 'mihi eris."

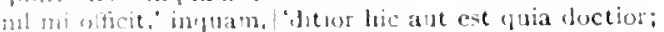

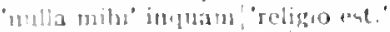

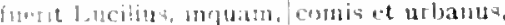

moln, minam, Heblate fercussa Marius

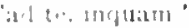

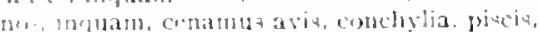

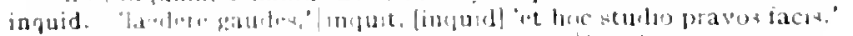

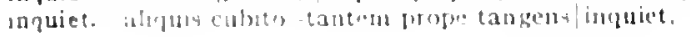

INQVIET

Sirm.1.5.2\%

Carm.2.3.28

Epist.1.7.77

Serm.2.3.20

Carm.3.4.52

Carm.1.37.10

Carm.2.1.20

Cism.3.30.3

Epod.10.62

Serm.2.3.257

Serm.2.2.7

lipist.1.15.29

:ur.Curm.1.6.10

Carm.1.13.12

Tierm.2.6.38

(arm.1.10.20

7.ur.Carm.1.10.20

Serm.2.3.14

Sirm.2.5.5.4

Curm.3.24.02

lipol. 5.8

sirm.3.2.104

Sirm.2.3.200

Cirm.3.9.22

$5 r m \cdot 1.3 .24$

Serm. I.0.73

Sirm.2.3.28

Serm 2.6.29

I.pist.1.7.03

Epist.1.10.40

Ear.Jpist.1.16.45

Carma.13.10

lipist.t.6 I

Serm.1.4.1.37

Erod.5. 13

Carm.2.9. I5

C.sm.3.27.49

Carm.3.27.50

Carm.4 13.4

Epoldo.5s

Fpist.2.1.8?

Cium.3.7.14

E.pist.2.2.51

citrm.t.10.10

Cirm.1.17.5

Corm.1.31.15

ciarn 4.933

lepotit7.50

Expst. 5.10

Lpist.2.1.151)

lepest.2.2.105

Ars Puct.210

Ars Pvil.381

Serm. $=7.105$

Epodio. 14

Cirm. 2.313

serm.1.0.5

sirm.1.9.8

Serm.1.0.50

serm.1.0.70

Sorm.1.10.19

Serm 2.3.27\%

Siדm.2.7.22

Serm. 2.8.27

fur..term 1.470

tierm.2.5.13 


\section{INQVIETI}

inquieti. dux inquieti turbidus Hadriae. inquietis. et inquietis adsidens praecordiis inquimus. 'molestus/communi sensu plane caret' inquimus.

inquinavere. fecunda culpae saecula nuptias|primum inquinavere inquinavit. ut inquinavit acre tempus aureum,

inquiner. merdis caput inquiner albis|corvorum

inquiram. primum nam inquiram, quid sit furere: .

inquirant. inquirant vitia ut tua rursus et illi.

inquis. 'lacdere gaudes,' inquit [inquisl, 'et hoc studio pravos facis." 'ne faciam, inquis, / omnino versus?"

inquit. 'nil satis est', inquit, 'quia tanti quantum habeas sis': 'nacte/virtute esto' inquit sententia dia Catonis;

'nolim landarier' inquit |sic me' mirator cunni Cupiennius albi.

'nil fuerit mi' inquit 'cum uxoribus umquam alienis.'

'egomet mi ignosco" Maenius inquit.

'non nosti, quid pater,' inquit, |'Chrysippus dicat:

'laedere gaudes,' 'inquit, 'et hoc studio pravos facis.

'o. tua cornu ni foret exsecto frons." inquit.

'noris nos' inquit; 'docti sumus.' .

'misere cupis' inquit 'abire.

'si me antas,' inquit. 'paulum hic ades.'

'dubius sum, quid faciam,' inquit,

'iure' inquit 'Trausius istis|iurgatur verbis:

pudor" inquit "te malus angit,

'non, si te ruperis, inquit. 'par eris.' .

tandem urbanus ad hunc "quid te iuvat" inquit. "amice,

erus "haec gravida" inquit|"capta est.

si velles' inquit 'verum mihi ponere nomen.

'pone, meum est,' inquit: pono tristisque recedo.

ibit eo. quo vis, qui zonam perdidit' inquit.

inrepertum. aurum inrepertum et sic melius situm.

inresectum. hic inresectum saeva dente livido|Canidia rodens pollicem

inretorto. quisquis ingentis oculo intetorto/spectat acervos.

inrevocabile. et semel cmissum volat inrevocabile verbum.

inrevocati. cum loca iam recitata revolvinus inrevocati;

inriguo. inriguo nihil cat elutius horto.

inriguom. inrignonque mero sub noctem corpus habento.

inrisus. nec semel inrisus trivits attollere curat/fracto crute planum.

inroget. regula, peccatis quae poenas inroget aequas,

inrupta. felices ter et amplius /quos inrupta tenet copula

insana. post insana Caprae sideta

insanabile. tribus Anticyris caput insanabile

insane. laudas, insane, trilibrem mullum.

nudus agris, nudus nummis, insane, paternis;

'o maior tandem parcas, insane, minori.'

"quid tibi vis, insane, et quan rem agis?"

vel cum Pausiaca torpes, insane, tabella.

insani. in ani leonis/vim stomacho adposuisse nostro.

insani ridentes praemia scribae.

si male rem gerere insani est, contra bene sani:

insani sapiens nomen ferat, aequos iniqui,

insani. insanus [insani] guid crim Aiax|fecit?

insania. auditis? an me ludit amabilis insania?

ne vos ageret resania [insania] discors.

ubi prava stultitia, hic summa est insania;

levis haec insania quantas/virtutes habeat.

insanientem. insanientem navita Bosporum/temptabo

insanientis. insanientis dum sapientiae/ consultus erro,

insanior. Labeone insanior inter|sanos dicatur. uter est insanior horum?

insanire. insanite iuvat:

huic eso volgus|errori similem cunctum insanire docebo.

dum doceo insanire omnis,

vincet enim stultos ratio insanire nepotes.

insanire paret certa ratione modoque."

qua me stultitia, quoniam non est genus unum, |insanire putas?

insanire putas sollemnia me neque rides

et signo laeso non insanire lagoenae.

insanis. insanis et tu stultique prope omnes.

\section{INSANIS}

Carm.3.3.5

Epod.5.93

Sirm.1.3.60

Carm.3.6.18

Epod.16.64

Sorm.1.8.37

Sirm-2.3.41

Sirm.1.3.28

zar.Serm. 1..4.79

Serm.2.1.5

Serm.1.1.02

Sirm.1.2.32

Sirm1.1.2.35

Sirm.1.2.57

$\sin \cdot 1 \cdot 3 \cdot 23$

Serm.1.3. 120

Ferm 1.4.79

Sorm.1 5.50

Sirm.5.9.7

Serm.1.0.1

Sirm.1.9.38

Sirm.1.0.40

Sirm 2.2.99

Sirm.2.3.39

Sirm.2.3.319

Sirm.2.0.90

Sirm.2.8.43

Epist.1.7.93

Jpist.1.16.35

I.pist.2.240

Carm.3.3.49

Epod.5.47

Carm.2.2.23

Epist.I.I8.7 I

Epist.2.1.223

Serm.2..1.10

Sirm 2.1 .9

Epist.1.17.58

Serm.1.j.118

Curm.1.13.1S

Carm.3.7.0

Ars lot.300

Sirm.2.2.3.3

sirm.2.3.184

Serm. 2.3.320

Siring.2.0.20

Serm.2.7.95

Curm.t.10.15

form. 1.5.35

Sirm.2.3.74

Epist.1.6.15

cont.serm.2.3.201

Carm.3.4.6

tar.sirm.2.3.174

serm.2.3.221

Epist.2.I.IIS

Cirm.3.4.30

Carm.1.34.2

Sirm.1.3.82

Sirm.2.3.102

Carm.3.19.1 8

Sirm.2.3.63

Sirm.2.3.8I

Sirm.2.3225

Serm.2.3.27I

Serm.2.3.302

Epist.1.1.101

Epist.2.2.134

Sirm.2.3.32 
INSANIS

Insanis. cum stupet insanic acios fulgoribus

insanis. siccat inaegualis caliccs conviva solutus|legibus insanis.

insanisse. an tu reris cun accisa insanisse parente

issanit, Sallustius in quas/non minus insanit quam qui moechatur.

hic nuntarum incanit amoribus, hic puerorum; .

saevit. quor meretrice nepos incanus [insanit] amica | filius uxorem gramli cum dote recuset.

insanic veterea statuas Danasippus cmendo:

'aut: incanit homo aut versus facit.'

insanius. in silvam non ligna feras insarius

insano. qui tibi nomen| insano posucte.

parcus ob hordis curam nimiumclue sever us adsidet insano:

insasos. sucu rixan et insanos amores

insonos guti inter vereare jnsanus haberi.

insanum. si interdicta petes, vallo circumdata (nan te hoc facit insanum). incanus: Chrysippi porticus et grex|autumat.

hoc tel redr modo insanum.

insanum te ommes pueri clamentque puclae:

dixerit insanum qui me, totidem audiet

scultum me fateor. . atque etiam insanum

insanus. quor mefetrice negos insanus amica/filius uxorem. . recuset. nam ut quiqque insanus nigric medium impedit crus/pelibus insanos qui inter vereare insanus habeli.

tune insanus eris, si acceperis.

nimirm insanus paucis videatur,

quare, |si quilvis satis est, periuras. surripis, aufers! undique? tun sanus [tu insanแa]?

'quid avarus? stultus et insanus.

'mille orium jnsamms motti dedit.

insauus quil enim siax|forit?

inscitae. sed tur furm putat inscite [inscitae] metuitque lituram.

inscite. sod turpern putat inscite metuitque lituram.

inscitia. incutiat tibi guid sanctarum inscitia legun.

illuns aut mequities aut vafri inscitia iusis.

quemeumelue inceitia veri! caecum agit.

scu calidus sanguis seu perum inscitia vexat

inscitiae. sed turgen putat inscitc linscitiae] metuitque lituran..

inscium. nido laborum protulit inscium

inscius. bic, umle vitam sumeret incius.

inscriptis. serl turpern putat incite [inscrintis] mequitgue lituram.

insculpere. cum summan patrimoni insculpers saxo'heredes voluit?"

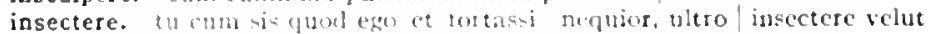
melior

insectot, ton erpudem insector dedendare comina Livilesse reor.

insecutae. unde vocalen truere insecutalo/orplea silvac.

insederit. nunusua tibi viciorum inscerit [insederit] olim/natura aut etiam crisucuctiolo mala:

insedit. nec tantus umguam siderun isaedit vapor

insenuit. studis anos septem eledt ineenuitque libris ot curis.

insepula. prok insepulta membra cifierent lupi

insequeris. invepuris tamen lunce lite monas inigua? -

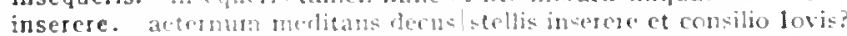

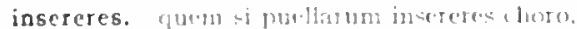

inseres. ctuold me lyticis vabus inser es.

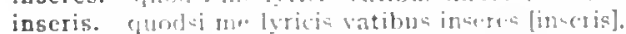

"Huc aldpelle"; 'trecenton instis"; "whe, lian satis est."

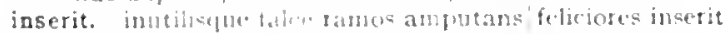

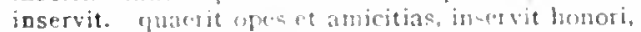

insererit. mumqta thi witionm inserert olim natura

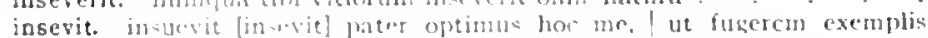
viciorum gravegue motanclo.

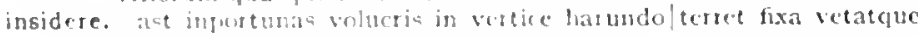

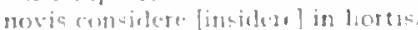

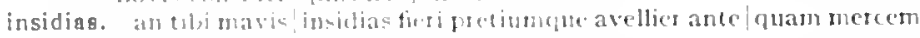
antrult?

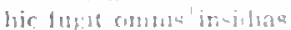

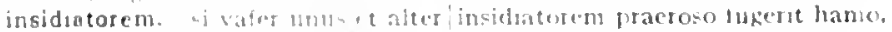

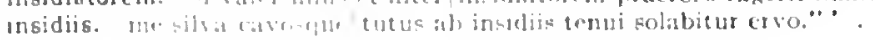

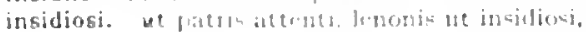

INSIDIOSI

$\operatorname{sinm} \cdot 2 \cdot 2 \cdot 5$

$\operatorname{Serm} .2 .0 .00$

$\operatorname{Sorm} \cdot 2 \cdot 3.134$

Serm.1.2.49

Sorm.1.4.27

ar.Som.1. 4.49

Scrm.2.3.04

Sorm.2.7.117

Serm.1.10.34

Sorm.2.3.48

Epist.1.5.14

Carm.3.21.3

Serm.2.3 40

Sorm.1.2.07

Sorm.2.3.44

Serm.2.3. 52

Sirm.2.3. 130

Serm.2.3.298

Sirm.2.3.306

Scrm.1.4.49

Serm.1.0.27

Sorm.2.3.40

Sormi2.3.07

Serm.2.3.120

:ar.serm.2.3.128

Sorm: 2.3 .159

Serm.23.197

Sorm.2.3.20I

yar. Eppist.2.1.167

Egist.2.1.107

Serm.2.I.81

Serm.2.2.13I

Serm. 23.43

Efist. I. 3.33

"ar. Epist.2.1.167

Corm.4.4.6

Corm.3.5.37

tar. Epist.2.1.107

Serm 2.300

Sorm.2.7.41

Fistist.1.09

Carm.1.I2.7

zur.Som. I. 3.35

fopod.3.15

Ifpist.2.2.82

Eport.5.99

E.pist.2.2.19

Carm.3.25.0

Carm.2.5.21

Carm.1.1.35

sar Carm.1.1.35

Serm.1.5.1 2

Epotizat

Ars Podsion

Sitm. 335

:ar.seres 1.4.105

$10 x .50 \% 1.8 .7$

Scrm.1.2 I0.1

Strm.1.350

sorm.2.5.25

serm.2.1.117

liptst 2.1172 
insigne. insigne maestis praesidium reis

insigne. valet ima summis | nutare et insignem [insigne] attenuat deus j obscura promens;

dicam insigne, recens, adhuclindictun ore alio.

insignem. insignemque pharetra|fraternaque umerun lyra.

insignem tenui fronte Lycorida|Cyri torret amor.

insignem attenuat deus/obscura promens; .

ibit insignem repetens Nicarchum:

insignem. aceto|diluit insignem bacam:

insigni. gratus insigni referam cancna|Fabriciumque.

insignia. ponas insignia morbi, |fasciolas, cubital, focalia,

insignibus, ut haec trementi questus ore constitit | insignibus raptis puer, tu cum proiectis insignibus, . . prodis

insignis. flebit et insignis tota cantabitur Vrbe. post hos insignis Homerus|Tyrtaeusque . . versibus exacuit;

insignis. vel Baccho Thebas vel Apolline Delphos/insignis aequa lege Necessitas|sortitur insignis et imos,

insiluit. Empedocles, ardentem frigidus Aetnam Insiluit.

insistet. barbarus heu cineres insistet victor

insitam. doctrina sed vim promovet insitam

insitiva. ut gaudet insitiva decerpens pira

insolabiliter. rapto de fratre dolentis|insolabiliter.

insolens, aspera|nigris aequora ventis|emirabitur insolens inprimeretque muris|hostile aratrum exercitus insolens. ossa Quirini.|(nefas videre) dissipabit insolens.

insolentem. prius insolentem $/$ serva Briscis niveo colore $\mid$ movit Achillem, ludum insolentem ludere pertinax

insolenti. non secus in bonis|ab insolenti temperatam|laetitia,

insolentiae. meaeque terra cedet insolentiac.

insolitos. insolitos docuere nisus/venti paventem,

insolitum. et tulit eloquium insolitum facundia praeceps

insomnis. noctes non sine multis/insomnis lacrimis

insons. te vidit insons Cerberus aureo/cornu decorum. purus et insons|(ut me collaudens), si et vivo

insonuit. studiis annos septem dedit insenutque [insonnitque] / libris et curis,

insperata. irsperata tune cum reniet pluma superbiae.

inspersos. egregio inspersos reprendas corpore nacvos,

inspexit. qui domitor Troiae multorum providus urbes/et mores hominum inspexit

inspice. inspice, si possum donata reponere laetus.

inspiciunt. opertos inspiciunt,

instanti. nec pietas moram|rugis et instanti senectae/adferet

instantis. non voltus instantis tyranni

instar. instar veris enim voltus ubi tuos

instat. o quantus instat navitis sudor tuis

instat equis auriga suos vincentibus,

namque instat fatum mihi triste.

dixeris: "experiar", 'si vis. potes," addit et instat.

instillare. pracceptum auriculis hoc instillare menento:

instillat. cornu ipse bilibri|caulibus instillat.

instita. nisj illas|quarum subsuta talos tegat instita veste,

institerat. quod nimium institerat viventi.

institor. non sine conscio|surgit marito. sew vocat institor .

institoribus. amata nautis multum et institoribus.

institui. amphora coepit institui: currente rota cur urceus exit? .

instituistis. quanto aut ego parcius aut vos, o pueri, nituistis [instituistis], instituont. unde homines operum primos vitaeque labores/instituont institutae. amphorae fumum bibere institutac|consule Tullo.

institutum. rumpit et serpens iter institutum.

insto. nec tardum opperior nec praecedentihus insto.

instravit. Aeschylus et modicis instravit pulpita tignis.

instructior. dives amicus, saefe decem vitis instructior.

instruit. orientia tempora notis / instruit exemplis, inopem solatur et aegrum.

instrumento. onni|abiecto instrumento artis clausaque tabernal sutor erat: insuavis. paulum deliquit amicus. / guod nisi concedas, habeare insuavis: . insudet, quis manus insudet volgi Hemogenisque Tigelli. insuevit. insuevit pater optimus hoc me.

Carm.2.1.13

coni.Corm.1 $34 \cdot 13$

Carm.3.25.7

Carm.I.2I.II

Corm.1.33.5

Carm.1.34.13

Carm.3.20.6

Serm.2.3.24I

Carm.1.12.39

Serm.2.3.254

Epad.5.12

Serm.2.7.53

Serm.2.1.46

Ars Poet.joI

Carm.1.7.4

Carm.3.1.15

Ars Poct. 466

Epod.I6.II

Carm.4.4.33

Epod.2.19

Epist.1.14.8

Corm.1.5.8

Carm.1.10.21

Epod.16.14

Carm.2.4.2

Corm.3.29.50

Carm.2.3.3

Epod.17.75

Corm.4.4.8

Ars Pott.217

Carm.3.7.8

Carm.2.19.29

Serm.1.0.69

var. Epist.2.2.82

Carm.4.10.2

Serm-1.0.67

Epist.1.2.20

Epist.1.7.39

Serm+1.2.87

Carm.2.14.3

Carm.3.3 3

Carm.4.5.6

Fpod.10.15

Serm.I.1.115

Serm.I.9.29

Serm.2.0.39

Epist.1.8.IE

Serm.2.2.62

Serm.1.2.29

Serm.2.5.88

Corm.3.6.30

Epoed.1\%.20

Ars l'oe:.22

qar.5erm.2.2.1 28

Serm.2.0.22

Carmi3.8.I I

Carm.3.27.5

Epist.r.2.71

Ars Poit.279

Epist.1.18.25

Epist.2.1.13I

Sirm.1.3.131

Sirm.1.3.85

Serm.1.4.72

Serm.1.4.105 
insules. arva beata| retanus, arva divites et insubs, insulis. lingua potentium / vatum divitibus consecrat insulis. insultet. Jum l'riani Paridisque busto|insultet armentum insumebat. mullum ultra vetbutu aut operam insumebat inanem. insumere. quod sujerat non est melius quo insumere possis? insuper. insiljer addes/pressa lenafranae quod baca remisit olivae. insurgat. insurgat Aquilo, quantus altis montibus/frangit trementis ilices: intabuissent. intermnato cum semel tixae cibo/intabuisent pupulae. intacta. neque illic aut apotheca procis intacta est aut pecus: intectre. intactic Palladis urbern|cat mine perjetuo celebrare intactas. II morian atuteos/currue el intactas boves? intacti. guam rutlis et Graccis intacti carminis auctor intactis. fuit intacsis quoque cura|condicione super communi. intactis. intactis opulentior/thesauris Arabum intactum. guid intactum nefasti|liquimus? intactus. intactus aut Britanus ut descenderet cum sbi quisfue timet, quamquam est intactus, et olit." intaminatis. intaminatis fulget honoribus integer. integer vitae sceletisque purus

iracchia et voltum terctesque suras integer laudo: noc car us aeque nec superstes/integer? sou audit alluc integer. : "1 uiz opprobrige dignum latraverit, integer ipse?" integet est mentis Damasippi crelitor? esto. 113:eger wst animi? ne dixurtis.

integra. Latot, dones ac precor integral cum memte integra. non this sunt integra lintea. integrae. Hotus et integrac/ Lemptator Orion Diande integris. o quae fontibus integris/ gaudes. integris. Ofelfun integris oprbus novi non latius usum integro. dicinus integro/sicci mane die.

integrum. stope luteiter neglectus incesto addidit integtum. inule proruet integrum|cum laude victorem

intorgum ediax fominus consumeret.

ustegran perdunt lino vitiata saporem.

intellegit. septomis. Claudi, nimisum intellegie nnus, fuanti me facias: intemptata. miseri, (juibus intemptata nites. .

intemptatum. nil intemptatum nostu liquere poetate

intendens. s nots intendes [intendens] animun studiis ce rebus honestis.] inviriz rel amore vigil torquebere

intendere. "unt qubus in sutura videar minis acer et ultra|legen tendere [untenlere) opu-;

intendes. ai non interdes animum studis et rebus honestis,

intendit. acric ubi me natura incemelat.

intenta. iatio cojpera pascuis/incenta

intentun. Somnus tamen ilutert intentum vionesi:

intentus. si velut merulis intentus decirlit auceps m puteum

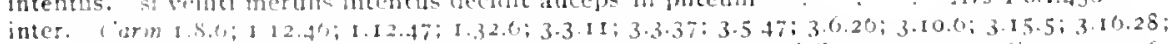

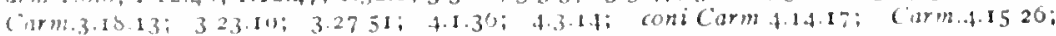
Epel I I; $238 ; 2$ f1; X.5; S.15; $9.15 ; 12.23 ; 152 ;$ Sim.1.1.47; I.1.105; 1.1.110; 1.2.40; terve.1.2.80; 1.3.1; $1.353 ; 1.360 ; 1.3 .82 ; 1.7 .9 ; 1.7 .11 ; 1.712 ; 1.10 .91 ; 2.2 .4 ; 2.2 .32$;

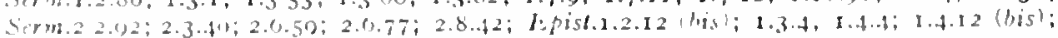

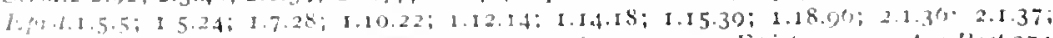

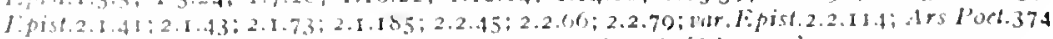

interat. ut silvas tolis [? llotes] . . ita verbormm vetus interit [? interat] atctas.

interciderit. guodsi interciderit tibi nunc aliquid, sepetes mox, intercunat. nea quid medins intetcinat actus interdicta. cui potor patria tuit interdicta voluptas. interdicta. si interrjicta petes. vallo circumelata interdicto. interdicto huic omse alimat ius/practor interdum. incerlum rajucte ocenpet" 15. molo octus. intertum consistate merefum 11 bans, parentiq viribus

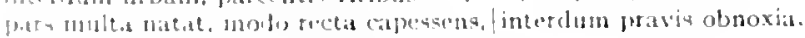
interdian nugaria smat paterno

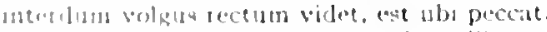

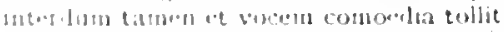

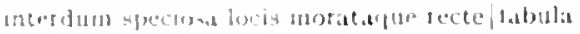

lipod.16.42

Carm.48.27

(

Ars Poet. 943

Sirm.2.2.102

Serm.2.4.88

Epod.10.7

lipod.5.40

Serm.2.5.7

Carm.1.7.5

Epod.9.22

Serm. I. 10.06

Epist.2.1.151

Corm.3 2.4.I

Cirm.1.35.35

Epold.7.7

Carm.32.18

Curm.1.22.I

Corm.2.4.22

Carm.2.17.8

Corm.3.7.22

Serm.2.1.85

Sirm.2.3.05

Serm.2.3.220

Carm.1.31.18

Carm.1.t.9

Corm.34.70

Carm.1.26.6

Sirm.2.2.153

Curm.t.3.38

Carm.3.2.30

Carm.1.q.es)

Strm.2.2.92

Serm.2.4.5.1

Epist.1.2.I

Cirm.1.5.13

Ars Poct.285

iur.LPist.1.2.3'

coni.tiorm.2.1.2

Espist.1 2.36

Sirm. 2.7 .48

Carm 4.414

sirm. 1.5.8.4

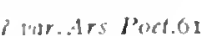

Serm.2.t.

Ars Joot.19.4

Eprist.1.0.0.t

vern.1.2.90

Sierm 2.3.217

Carm 2.12.28

Sierm. I.0.9

serm.1.10.13

Serm. 2.7 .8

tipist.1.18.00

E.pist.2. I 03

.1er loctos

dirs Poct.310
Sirm 2.1.23 
quandoque bonus [ $\beta$ interdum magnus] dormitat IHomerus,

7 rar.Ars Puet. 359

interes. interea Maecenas advenit atque Cocceius interea suspensa gravis aulaea ruinas / in patinam fecere,

inteream. 'inteream, silaut valeo stare

interempto. Hasdrubale interempto. .

intererit. intererit multum, divosne loquatur an heros, intererit Satyris paulum pudibunda protervis.

interest. divesne prisco natus ab Inacho/nil interest an pauper sic Iovis interest optatis epulis inpiger Hercules. quid inter-|est in matrona, ancilla peccesne togata?

interfusa. interfusa nitentis/vites aequora $\mathrm{Cy}$ cladas.

interim. interin, dum tu celeres sagittas|promis,

labuntut altis interim ripis açuae,

interimis. cum laqueo uxorem interimis matremque veneno,

interiore. seu bruma nivalem/interiore diem gyro trahit.

interiore. bearis interiore nota Falerni.

interire. nowaeque pergunt interire lunae:

interit. prima cadunt: ita verborum vetus interit aetas,

interitu. nec reditum Dionedis ab interitu Meleagri

interitum. dicam Siculique poetae/narrabo interitum.

interitura. aestas|interitura, simul|pomifer autumnus iruges effuderit,

interitura, ne forte credas interitura quae. . verba loquor

interlunia. Thracio bacchante magis sub inter-|lunia vento.

interminato. interminato cum semel fixae cibo

intermiscere. patris interniscere petitalverba foris malis.

intermissa. cui donet inpermissa [intermissa] raptim / gaudia luminibus remotis,

intermissa, Venus, diu|rursus bella mores?

intermori. quo posset infossus puer / longo die bis terque mutatae dapis | inemiori [intermori] spectaculo.

internoscere. mirabor, si sciet inter-" noscere mendacen verumque beatus amicum.

interpellandi. interpellandi locus hic erat est tibi mater.

interpellarem. "peccatum fateor, cum te sic tempore laevo / interpellarim [interpellarem]:

interpellarim. cun te sic tempote laevolinterpellarim;

interpellet. quantum interpellet inani|ventre diem durare,

interpres. non tamen interpres tantundem iuveris.

nec verbo verbum curabis reddere fidus|interpres

sacer interpresque deorum|caedibus et victu foedo detenruit Orpheus.

interprete. post effert anini notus interprete lingua.

intersis. diuque laetus intersis populo Quirini

intersit. quid hoc intersit, ab ipsolaudieris melius.

nec deus intersit, nisi dignus vindice nodus|inciderit;

ut nihil intersit, Darosne loquatur et audas/Pythias,

intervalla. intervalla vides humane commoda.

intestabilis. is intestabilis et sacer esto.'

intimo. latentis proditor intumo [intimo] gratus puellae risus ab angulo

intonata. Eois intonata fluctibus hiens

intonsi. Romuli|praescriptum et intonsi Catonis anspicis

intonsis. incomptis [intonsis] Curium capillis/utilem bello

intonsas. intonsosque agitaret Apollinis aura capillos,

intonsum. intonsum pueri dicite Cynthium

quem simul adspexit scabrum intonsumque Philippus,

intorti. intorti capillis|Eumenidum recreantur angues?

intra. intraque praescriptum Gelonos

nec te feriam neque intra|claustra tenebo.

quid referat intra|naturae finis viventi.

lliacos intra muros peccatur et extra.

intra marmoreum venerandi limen anici.

nil intra est olea, nil extra est in nuce duri;

et versentur adhue intra penetralia Vestae;

tutus et intra/spem veniae cautus?

intrarit. si certus intrarit dolor.

introrsum. nitidus qua quisque per ora|cederet. introrsum turpis:

introrsun turpen, speciosum pelle fecora.

introrsus. sed videt hune omnis domus . . introrsum [intiorsus] turpem, speciosum pelle decora.

intueris. quid tit noverca me intureris

Serm.I.5.3 I

Scrm.2.8.5

Serm.1.9.38

Carm.4.4.72

Ars Poet. 14

Ars Port.233

Carm.2.3.22

Carm.4.8.29

Serm.1.2.02,63

Carm.1.14.19

Carm.3.20.9

lipod.2.25

Serm.2.3.I3I

Serm.2.6.26

Carm.2.3.8

Carm.2.I8.IU

Ars Poitor

Ars Toet.intio

Ars loctitit

Carm.1.7.10

Carm.t. I

Carm.1.25.11.12

Efod.5-39

Sormitio 29

var.Carm.3.6.27

Carm.4.I.I

coni.Ipod.5.34

Ars Poet.424.425

Sirm.t.o.zis

E'ar.Sorm.2.4.5

Serm.2.4.5

Serm.1.t. 27

Serm.2.4.9I

Ars Poet. 34

Irs Poet.39I

Ars Poel. II

Carm.1.2.4\%

Serm.2.8.32

Ars Ioction

Ars lotel.237

Epista.2.70

Serm.2.3.ISI

sar.Carm.I.9.21

Epod. 2 . I

Corm.2.15.11

"ur.Carm.I.I2., I

I.pod.1 5.9

Carm.1.2I 2

Epist.1.7.90

Carm.2.13.3.5

Curm.2.9.23

Carm.3.11.43

Serm.1.1.49

Ippist.1.2.If

Efrist.I.IS.7.3

Epist.2.1.3 I

Epist.2.2.t14

Ars Portant

Epod.15.10

Serm.2.1.05

J.pist.I.10.45

zar. Eptst.3.10.45

Epod.5.0 
intulerat. magnum illa terrorem intulerat lovi | fidens iuventus horrida braceliis

intulit. audas lapeti genus|ignem fraude nala gentibus intulit; . neque inpudiea Colchis intulit pedent.

Graecial capta ferum victorem cepit et artes|intulit agresti Latio:

intumescit. nec intumescit alta viperis humus;

intumo. nunc et latentis prodicor intumo|gratus puellac risus ab angulo

intumulato. ossibus et capiti inhumato [intumulato]/particulam dare:

intus. exclusus fore, cum Jongarenus foret intus.

in ius [intus]] acres concurrunt, magnum spectaculum uterque.

cornu taurus petit: unde nisi intus monstratum?

si positjs intus Chii veterisque Falerni|mille cadis.

pauper Opimius argenti positi intus et auri.

format cuim natura prius nos intus ad onsnem/fortunarum labitum:

non tanen intus/digna geri promes in scacnam

nonumque prematur in annum| membranis ditus positis:

inulas. cum rapula plenus|atque acidas mavolt inulas.

erucas viridis, inulas ego primus amaras/monstravi incoquere:

inulta. inulta cesserat inpotens/tellute

inultae. caculus ferac|celent inultae.

inulti. "nos nisi damnose bibimus, moriemur imulti."

inultis. precibus non linquar inultis

inulto. inultoldicere quod sentit permitto."

inulto. dum poenas odio per vim festinat inulto.

inultos. neu sinas Medos equitare inultos/te duce. Caesar.

inultus. inultus ut flebo puer?

inulus ut tu riseris Cotytia|volgata.

ut non testis inultus

posthac ne conpellarer inultus.

Inunctis. cum tua pervideas oculis mala lippus inunctis.

inunctum. si prodisse tuis pauloque benignius ipsum/ te tractare voles. accedes siccus ad unctum [inunctum] .

inungui. non tamen idcirco contemnas lippus imngui; .

inurbanum. scimus inutbanum lepido seponere dicto

inutile. 'an loc inhonestum et inutile factu| necne sit addubites.

olim trumcus eram ficulnus, inutile liguum.

sublegit quodcumque iaceret inutile

inutile. iactes et genus ct nomen inutile:

gemmas et lapides aurum et inutile.

inutili. algit litus inutili|demissa tempestas ab Eurolsternet.

inutilis. inutilisque falce ramos amputans

invecta. Fescennina per hunc inventa [invecta] licentia morem/versibus alturnis opprobria rustica fudit

invenere. donec verba, quibus voces sensusque notarent, I nominaque inv'enere":

invidia siculi non invenere tyranni|maius tormentum.

Invenerit. yuod non plura datis invenerit;

inveni. primus et invenior [inveni] piper album cum sale nigrolineretum

invenias. invernias etiam disiecti mersbra poetae.

invenict. rui. . quando ullun inverniet parem?

invenicetut: nil sibi legatum practer plorare suisque.

invenior. prisula et invenior piper albun cum sale nigrolincretum

ipse "go. . . invenior Patthis mendacior

invenisse. ignotum tragican genus invenisse Camenaeldicitur . . Thespis. invenit. minns ee invenior finvenit) piper album cum sale nigrolincretum

inventa. Feucennina per hunc inventa licentia moreu

inventa. iura inventa motu iniusti fateare necesse est.

inventis. guod'guarrit et isventis miser abstinet ac timet uti.

invento. thesituro invento qui mercennarius agrum| 1llum ipsum snercatus

inveator. irimus el inventor [inventorl piper albun cum sale nigtol 1110 2utum

inventore. (furd acribere possem, |inventore minor;

inventum. uis animiq natum inventumgar poens iusandia,

inverecundum. collat bablosm | morem verecundumpe linverecundumquel

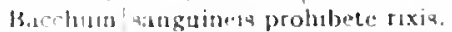

Inverecundus. smon! calentis inverecundus dewa/fervidiote mero

inversi. (

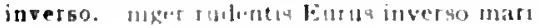

Corm.3.4.49

Corm.1.3.28

Epod.16.58

Epist.2.1.157

Epod.10.52

Corm.1.9.21

coni.Corm.1.28.24

Srrm.1.2.67

:ar.Serm.1.7.20

Sorm.2.1.52

Serm.2.3.115

Serm.2.3.1.42

Ars Port.108

Ars l'oet.1 82

Ars Poet.389

Sirm.2.2.44

Serm.2.8.51

Carm.2.1.26

Carm.3.3.42

Strm.2.8.34

Carm.1.28.33

Serm.2.3.189

Epist.1.2.6I

Corm.1 2.51

Epod.6.16

Lipod.17.56

Serm.1.8.44

Serm.2.3.297

Sirm. 3.25

tur.Epist.1.17.12

Lipist.1.1.29

Ars Pott.273

ferm.1.4.124

Sirm.1.8.1

Sicrm.2.8.12

Carm.1.14.13

Carm.3.24.48

Carm.3.17.10

Lpod.2. 3

coni.Epist.2.1.145

Serm.1.3.104

Epist.1.2.58

Epist.2.2.192

zur.Scrm.2.4.74

Serm.1.4.62

Curm.1.24.8

Serm. 2.568

Serm.2.4.74

Epist 2.1.112

Ars l'odt.275

var.Serm.2.4.74

Epist.2.1.145

Serm.1.3.111

Ars l'oelitio

$5 \mathrm{srm} 2.0 .11$

ror.sirm.2.4.74

Serm.1.10.48

Ars Poet. 377

contCarm.1 27.3

lipod It.13

Carm. 5.7

lipod.105 
inversum. fessos vomerem inversum boves/collo trahentis languido quae, simul inversum contristat Aquarius annum,

invertimus, at nos virtutes ipsas invertimus

invertunt. invertunt Allifanis vinaria tota/Vibidius Balatroque.

invicem. invicem moechos anus arrogantis/flebis

nos cantabimus invicem | Neptunum

venena maga non fas nefasque, non valent convertere humanam vicem

[humana invicem].

Invicta. sit Medea ferox invictaque, flebilis Ino.

invicte. "invicte, mortalis dea nate puer Thetide.

invicti. uxor invicti lovis esse nescis.

aude|Caesaris invicti res dicere.

quia desperes invicti membra Glyconis.

invictus, durus,|vindemiator et invictus, .

invida. dum loquimur, fugerit invida|actas: si taciturnitas |obstaret meritis invida Romuli? est ubi divellat somnos minus invida cura?

invidae. superbas invidae Karthaginis|Romanus arces ureret.

invideant. plurima, quae invideant pure adparere tibi rem. .

invideat. ut forsit honoren|iure mihi invideat quivis, invideat quod et Hermogenes, ego canto." .

invidenda. caret invidenda|sobrius aula.

invidendis. cur invidendis postibus et novo|sublime ritu moliar atrium?

invidens. saevis Liburnis scilicet invidens/privata deduci

invideor. ego cur, adquirere pauca/si possum, invideor.

invides. Icci, beatis nunc Arabum invides/gazis

invidet. amicus Aulon|fertili Baccho ninimum Falernis|invidet uvis; moresque /aureos educit in astra nigroque/invidet Orco invidet usum|lignorum et pecoris tibi calo argutus.

invidi. sublatam ex oculis quaerimus invidi.

invidia. ubi acris|invidia atque vigent ubi crimina: invidia adcrevit, privato quae minor esset. me|cum magnis vixisse invita fatebitur usque/invidia

invidia. invidiaque naior/urbis relinquam. invidia vel amore vigil torquebere. invidia Siculi non invenere tyranni maius tormentum.

invidiae. haberet/plus dapis et rixae multo minus invidiaeque. asperitatis et invidiae corrector et irae;

invidiae, per totum hoc tempus subiectior in diem et horam i invidiae noster.

invidiam. invidiam placare paras virtute relicta?

$\therefore$ comperit invidiam supremo fine domari.

invidit. neque ille / sepositi ciceris nec longae invidit avenae.

invido. et iam dente minus mordeor invido.

quein Notus invido flatu. . dulci distinet a domo.

invidus. audiat invidus/dementem strepitum Lycus

invidus, iracundus, iners, vinosus, amator - nemo adeo ferus est.

invidus alterius macrescit rebus opimis;

sulpura contemni vicus gemit, invidus aegris

inviolatus. visam .. Scythicum inviolatus amnem.

invisa. quod si tain Graecis novitas invisa fuisset quam nobis.

invisa. quandocumque trahunt invisa negotia Romam.

invisa. 'non invisa feres pueris inunuscula parvis'

invisam. neque harum quas colis arborum|te [? nec te] praeter invisas cupressos [? invisam cupressum] |ulla . . sequetur.

gaudet invisam pepulisse fossor|ter pede terram.

invisas. praeter invisas cupressos

invisi. quo Styx et invisi horrida Taenari|sedes

invisis. haeret invisis foribus?

invisum. quod petis, id sane est invisum acidumqu* duobua

invisum. gravis iras et invisum nepotem,

si per invisum mora ianitorem/fiet, abito.

illis/me facit invisum.

invisum. Canem illum.| invisum agricolis sidus,

invisus. cum tibi invisus laceranda reddet cornua taurus.

invita. ne/cum magnis vixisse invita latebitur usquel invilia

invita. tu nihil invita dices faciesve Minterva:

invita. verba movere loco, quamsis invita recedanc verbaque provisam rem non invita sequentur.
Epod.2.63

Serm.1.1.36

Serm.1.3.55

Serm.2.8.39

Curm.1.25.9

Carm.3.23.9

coni.Epod. 5.88

Ars Poet. 123

Epod.13.12

Carm.3.27.73

Serm.2.1.11

Epist.1.1.30

Serm.1.7.30

Carm.1.11.7

Carm.4.8.24

Epist.1.IO.I8

Epod.7.5

Serm.1.2.100

Serm.t.6.50

Serm.1.9.25

Carm.2.10.7

Carm.3.1.45

Carm.1.37.30

Ars Poet.56

Carm.I.29.I

Carm.2.6.20

Carm.4.2.24

Epist.1.14.41

Carm.3.24.32

Serm.1.3.6I

Serm.1.6.26

Serm.2.1.77

Carm.2.20.4

Epist.5.2.37

Epist.1.2.58

Epist.1.17.51

Epist.2.1.129

Sirm.2.6.48

Serm.2.3.I 3

Epist.2.1.12

Serm.2.6.84

Carm.4.3.16

Carm.4.5.9

Carm.3.19.22

Epist.1.1.38

Epist.1.2.57

Epist.1.15.7

Carm.3.4.36

Epist.2.1.90

Epist.1.14.17

Epist.1.7.17

3:ar.Carm.2.14.23

Carm.3.18.15

Corm.2.14.23

(arm.1.34.10

Serm:2.3.262

I.pist.2.2.64

Carm.3.3.31

(arm.3.14.23

lepist.1.15.4

Serm. 1.7 .26

Carm.3.27.7I

Serm.2.1.76

Ars Poet. 385

Epist.2.2.113

Ars Poct.3II 
invitet. somnos guod invitet levis.

invito. quin .e lxion Tityosque voltu/risit insito.

invitum. non coo te. candice Bassarea. |invitum quatiam quis enim invitum servare laboret?

imvitum yui servat, idem facit occidenti.

invitus. Ia ece procurare et idoneus inperor ct non'invitus, sicpuid nirabere, pones'invitus.

seque sumptum |invitus facias

involitant. et, fuac nunc umeris involitant, decielesint comae.

involvo. malvintute me involvo

10. perfilus lxion. Io vaga. tristis Orestes.

io. terpue, elum procedis, io triumphe"

treque [ioque]. dum procedis, "io trimple $\mid$ non semel dicenus,

non semel dicemus, io triumphe'

io Trinulute. tu moratic aureos/curus

in Triumphe" nec lugut hino parem bello repontasti ducem

ab ovo ustue ad mala citaret io Bacehac"

licet succurtite longun |clamet io cives:"

lolcos. quas lolcos atque Hiberia mitcit.

lonicos. motus doceri gaudet lonicos

lonicus. non attagen Ionicua/iucunclion

lonius. lonius udo cum remugiens sinu- foto rabom rupesit. .

insa. riclec loo, inquam, Vernú ipea.

suls et ipkit Roma viribus ruit.

srosus moresque repugnant atque ipsat utilitis.

haud milit derero. cum resipal teret:

cotis. actum reddere quite ferrum ralet exsos ipsa secandi;

ipsa. turbit decipunt caccun vitia aut etiam ipsa hate/delectant.

ipse. 'ipsa memor praccepta canam, celabitur auctor.

ipsam. ultra fuan atis est vitutum si petat ifsam.

ipsas. at nos viscutes ipsas invertimus

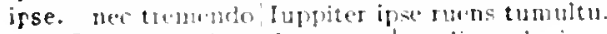

Gracea yuol cgo ipse testa' conditum bevi.

ureris ipsec micer:

ut ipse nouti curbosus,

populus me citilat, at mui plaudolipse clomi,

viverem uti contentus co quod mi ipse parased:

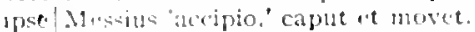

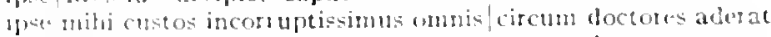

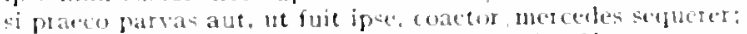

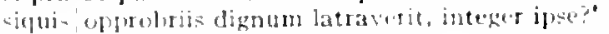

consu ifse bilibul caulibus instillat.

ipese videretur sibi nequior:

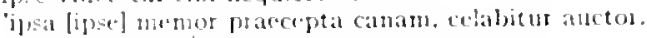

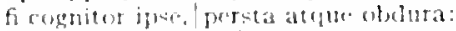

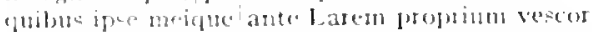

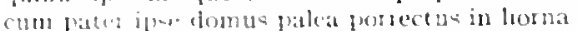

continuateque dapes ne nom versiliter ipsis [igel fungitur offucis.

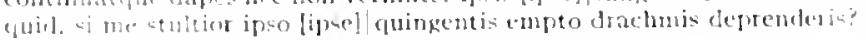

at ifue untulia vetertm iudes

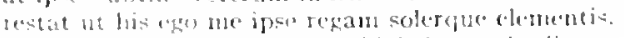

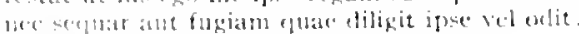

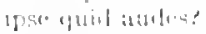

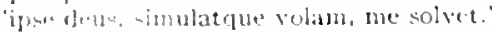

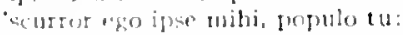

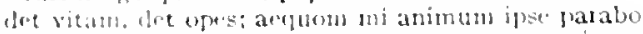

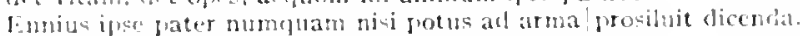

ipue. rgo. . - invenior l'ar this mentacios

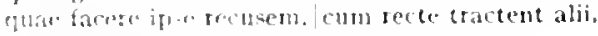

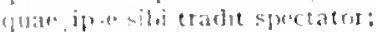

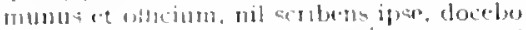

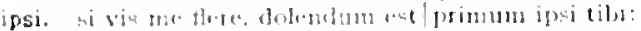

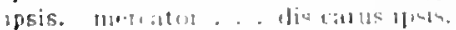

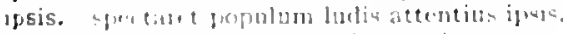

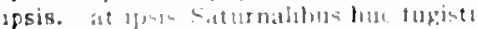

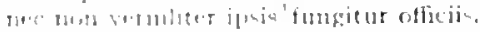

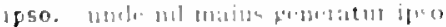

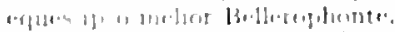

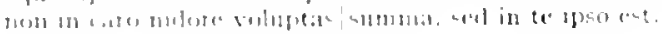

Lipod.2.28

Corm.3.11.22

Curm.1.18.12

Lipist.1.20.10

Irs Poct.407

lipist.1.5.22

lepist.1.10.32

l:pist.2.2.190

Carm.4.10.3

Corm.3.29.55

drs Poet.124

Carm. 2.49

coni.Cerm.4.2.49

Carm. 2.50

lipoll.g.21

lipod.0.23

Sirm.1.3.7

A.s I'oct.400

lipod.5.21

Corm-3.21

lipod.2.5.1

Efod.10.19

Curm.2.8.13

I. pol 10.2

Serm. 3.08

sorm.2.1.18

irs Poct.305

Serm. 1.3 .39

serm.....11

Epist.t.1.1\%

serm.t.3.5.5

(iorm. I 1 H. I 2

Curm.s.20.2

Ifod.1.13

I.pul.t.77

Sirmet.s.c.7

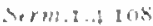

sermi.2.5.57

$4, r m+1,8,81$

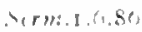

Sirni.2.1.85

sirm.2.2.0:

Serm.2.3.0.1

acr.serm.2.4. I

sirmin. 2.38

Sirmezens

crme.zess

conicistm.20.100

pur.cem.2.7.42

Sirm. 7.100

lepivi.1.27

PNoti.1.72

lepist 1.3.20

lipist.10.7s

Jist.1.1. I0

I.fist:.18.112

1. ist. 1.10 .7

L pist.2.1.11

I. pist.z. 1.20s

- Irs Put 182

. $19 \mathrm{~s}$ Jind 300

Ars In:? 103

(arm. I. 3 I 1.3

I. fist 2.1107

Sirm: 23.4

somi.z.11.10.

Carm 1.12.15

(a)m.3.1 $2 \mathrm{x}$

Sirm.2 221 
si me stultior ipso/quingentis empto drachmis deprenderis? $t$ in se ipso totus, teres atque rotundus, quid hoe intersit, ab ipso/audieris melius. 'scitari libet ex ipso quodcunique refers: quid possim videt ac novit me valdius ipso.

ipso. per caedis ab ipso/ducit opes animumque ferro.

ipsos. reges in ipsos imperium est lovis.

ipsum, tors et|debita iura vicesque superbae/te maneant ijsum: ipsum ne... grata detinuit compede Nyrtale/libestina. denique te ipsum $\mid$ concute.

cum rersus facias, te ipsum percontor.

non ille aut Teucrum aut ipsum violavit Vlixen."

qui mercennarius agrum |illum ipsum mercatus aravit.

tecue ipsum vitas fugitivos et erro,

Nomentanus erat super ipsum, Porcius infra,

ut te ipsum serves, non expergisceris?

pauloque benignius ipsum/te tractare voles.

corpus et ipsum animum spe finis dura ferentem

ipsum. caelum ipsum petimus stultitia

tu secanda marmora|locas sub ipsum funus

noctis vigilabat ad ipsum/nane, diem totum stertebat.

vincit longe prius ipsum / expugnare caput.

ira. quem cruenta|per medias rapit ira caedes.'

procul omnis esto clamor et ira.

non ira, quae jrocudit ensis

mea cum conferbuit ira?"

ira [uit capitalis, ut ultinia divideret mors,

hunc amor, isa quiden communiter urit utrumque. .

ira turor brevis est:

ira truces inimicitias et funcbre bellum.

ira. stultitiane erret nibilum distabit an ira.

ira| Iliacos intra muros peccatur

conmissumque teges et vino tortus et ira.

caret mortis formidine et ira?

iracunda. iracunda dien proferel llio/matronisque Phrsun classis Achillei; urget aut ianaticus error et iracunda Diana,

iracunda. per nostrum patimur scelus iracunda lovem ponere inlmina.

iracundior. inprobo iracundior Hadria: iracundior est paullo, minus aptus acutis | naribus horum hominum.

iracundus. iracundus, iners, vinosus, anat or - nemo adeo ferus est,

Achillem, inpiger iracundus, inexorabilis acer,

irae. denique, quatenus exeidi penitus vitium irae. asperitatis et invidiae corrector et irae;

irae. qui non moderabitur irae, infectum volet esse.

irae. tristes ut rae, quas neque Corticus deterret ensis irae Thyesten exitio gravi|stravere

iram. nunc in hoctilic domos fram atque numen vertite. cum Pallas usto vertit iram ab llio

qui non moderabitur irae [iram], I infectun volet esee, flolor quod suaserit et mens.

Judus enim genuit trepidum certamen et iran. .

ituat aut inpellit ad iram

iram colligit ac ponit temere et mutatur in horas.

irarum. "abstineto' drit 'irarum calidaeque rixae.

iras. gravis|iras et invisum nepotem.

inter spem curanque, timores inter et iras

irascar. fidis offendar medicis, irascar amicis,

irasci. irasci culerm, tamen ut placabilis essen.

iratae. siquis infamem mihi nunc iuvencum/dedat iratate

iratis. inueritusque laborat|iratis natus paries dis atque poetis.

iratis. dein Gnatia Lymphis|iratis exstructa dedit risusque iocosque, inprobus urget iratis precibus:

irato. porrigis irato puero cun poma, recusat;

iratos. neque iratos trementilregum apices et regat iratos et amet pacare timentis;

iratum, adde/iratum patruon, vicinos.

quae prima iratum ventrem pacaverit esca."

tristia maestum /voltum verba decent, iratum plena minarum,

iratum. neque lorret iratum mare serm.2.7.42

Sirm.2.7.80

cerm.2.8.32

Epist.1.7.00

Epist. I.9.6

Carm.4.4.59

Carm 3.10

Carm.1.28.33

Curm.1.33+13

Sterm.1.3.34

Serm.1.10.25

Sirm.2.3.20.4

Sirm.2.6.12

Sirm.2.7.II 3

Sirm.2.8.23

Epist.1.2.33

Epist-1.17.11

Epist.2.1.ItI

Carm.1.3.38

(

cirm.1.3. I

Sirm.2.5.73

Corm.3.2 I 2

Carm.3.8.

Carm+15.19)

Sirm.I.2.7 I

serm.I T.I3

Epist.1.2.13

Epist.1.2.t2

Epist.1.19.49

Sirm.2.3.2I0

List.1.2.I 5

Epist.1.18.38

Epist.2 2.20\%

Carm.1.15.33

Ars Poel 454

Carm.1-3 to

Carm.3.9.23

firm.1.3.29

Epist. I, I. 38

Ars Poet. I 2 I

5 som.1.3.76

lipist.2. I. 129

Epist.1.2.50

Corm.I, In.?

Corm.I.Itri-

Epod.5.5.4

Epod.10.13

a ar. Epist. I, 2.50

Epist.1.19.48

Ars Poel.100

Ars Poet. 159

Carm.3.27.70

carm.3.3.3 I

Epist.1.4.12

Epist.x.8.9

Epist 1.20.25

Carm.3.27.40

serm. 2.3 .6

Serm.1.5.0s

Sirm.2.0.30

serm.2.3.25s

Carm.3.21.19

Ars Poel.19:

Serm.2.2.97

$5 \mathrm{rm} .2 .8 .5$

Ars l'oct. nots

Epout.2.0 
iratus. et ifuaceret iratus pareme

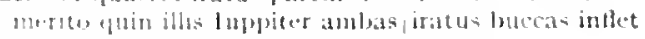

Epad.15.14

f ersille iratus leges mistatur et urmam.

wriptorum quacopue retexegs, iratus tibi.

dathlsque P'lulippi tendit ad audis.

lob mate parentem in rupis protusit asellum iratus:

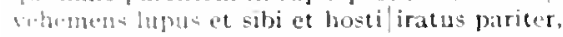

is atu f ;rais quantum nocuisset Achilles.

iratusifure Chromes tumido delitigat ore:

ire. vidnus 1 latom riberim ... ire deicoum monumenta regis|templaque bestian.

Virt心, . . menatit temptat iter [ire] sia

intum pus merlios ire satellites

tegrie nce larvos vetet ire picus nec vaga comix.

meliusne fluctus ire per longos fuit

ire. pedes quocumque ferent.

nume milii custolire licet mulo

act ubi me festun sol acrior ire lavatum admonuit,

ire modo ocius, interdun consistere.

ne tamen illi tu comes exterior, si postulet, ire recuses.

ire domum atque pelliculan curare iube:

ire mecesse tost.

tingit equom . . . ire viam qua monstret eques:

ire tamels restat. Numa quo devenit et Ancus.

int foras plene tendebat corpore frutera.

iateen rusa cuburbana indictis comes ire latinic.

-1 lavelic camoma. Ferentinum ire iubebo:

"Igu fluem sua culpa premet drocetus omitte taeri l? praesens sua culpa ire deceptus omittit "theri).

pal homestatir domos inpune minax.

lle per extentum funem mihi posse vicletur ire poeta.

shlentatore jubet ael luerum ire prota

irent. ylua tardius irent propter onu- segnes.

ires. gar to cablestis sapientia duceret, iros.

irritabile. multa toro, nt placem genus irritabile satum,

irritant. "tgnius irritant animos demisca per aurem

irritat. andera elilusies quictoz, irritat alusuis.

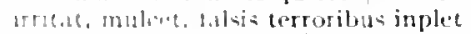

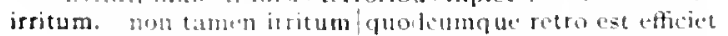

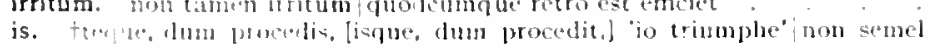
$1 \mathrm{l}+\mathrm{m} m \mathrm{~m}$.

de nerue lins turbatam haurit aquam

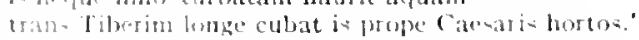

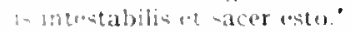

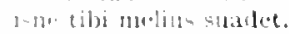

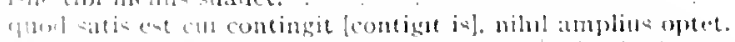

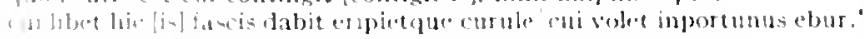

is dem. tarnen uter monitoribus isclem?

isdem. -ub [4ling साt trabibua

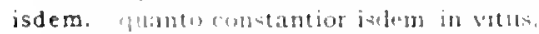

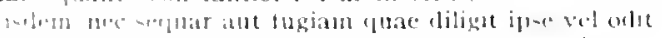

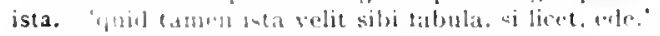

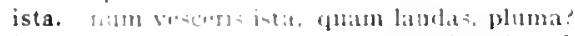

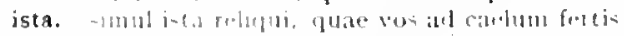

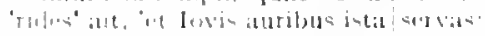

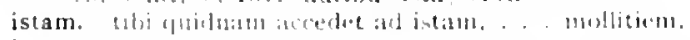

iste. Hoid ato tort tumbltus

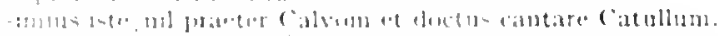

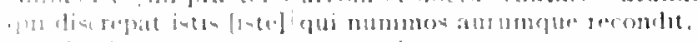

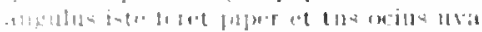

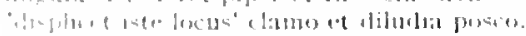

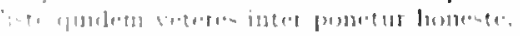

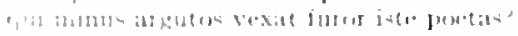

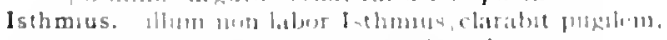

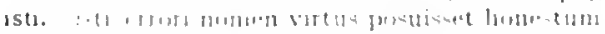

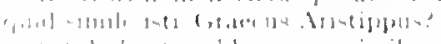

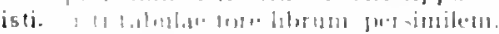

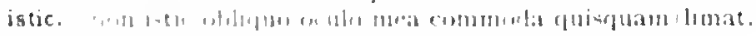

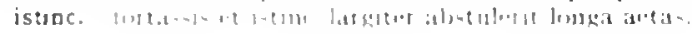

Serm.1.1.21

Serm.2.1.47

Serm.2.3.3

Epist.1.7.89

Epist.1.20.16

Epist.2.2.29

Epist.2.2.42

Ars Poet.94

Curm.1.2.15

:ar.Curm.3.2.22

Carm.3.16.9

Curm 3.27.15

Corm.3.27.43

Lipod.16.21

Scrm.1.6.105

Serm.1.6.125

Serm.1.9.9

Serm.2.5.17

Serm.2.5.37

Serm.2.0.26

Eifist.1.2.65

Epist.1.6.27

Epist.1.7.31

Epist.1.7.76

List.1.17.8

?ur.Epist.1.18.79

Eipist.2.1.150

IEpist.2.1.211

Irs Poet.420

serm.2.3.101

IEpist.1.3.27

Eofist.2.2.102

Ars Jot. 180

Cirm.3.29..4 I

Lipist.2.1.212

Curm.3.29.45

conic(urm.4.2.4?

Serm.1.1.59

Sirm.1.0.18

sirm.2.3.181

Lepist.1.1.05

ine. Epist.1.2.46

idr. I. pist 1.0.53

IEpist.2.2.15.4

Cium.3.2.27

Serm.2.7.15

Epist.1.7.

Serm.2.5.(1)

Sirm.2.2.27

Epist.1.10.8

lipist.1.10.43

Sirm.2.2.80

lipod 5.3

Serm 1.10 .15

:itr Sirm.2.3. 108

I.pist.1.1.23

IEpive. 10..87

I.pint $2.1 . .43$

l. pist.2.2.00

(ism. 3.3

trom.1.3.4t

torm 2.3.00

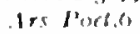

Iifist 1.1.437

Sirm.1 +1.31 
cui nustela procul 'si vis' ait 'effugere istinc,

istis. at quanto meliora monet pugnantiaque istis/dives opis natura suae. longe meil discrepat istis/et vox et ratio:

qui discrepat istis|qui nummos aurumque recondit.

istis. numquid Pomponius istis/audiret leviora, pater si viveret? iortassis et istinc [istis] | largiter abstulerit longa aetas, liber aricus consilium proprium:

'inre' inquit 'Trausius istis/iurgatur verbis;

siquid novisti rectius istis, candidus inperti; poterat duci quia cena sine istis:

isto. 'non isto vivimus illic, |quo tu rere, modo; nempe modo isto| paulatim mercaris agrum,

isto. damsum est, non facinus, mili pacto lenius isto. cetera iam simul isto/cum vitio fugere?

istuc. tamen istuc mens aninusque fert

it. gratior it dies

Jusum it Maecenas, dormitum ego Vergiliusqute;

it. redit et narrat.

ita. tu. frustra pius, heu non ita creditum / poscis Quintilium deos. non ita Romuli|praescriptum et intonsi Catonis auspiciis

ita sordidus ut se non umquam servo melius vestiret,

ita, ut pater ille, Terenti fabula quen miserum gnato vixisse fugato inducit.

res ut quaeque st. ita suppliciis delicta coercet?

ita porro pugnabant armis quae post fabricarerat usus. .

ita te quoque amicum.

dives, inops. Romae seu fors ita insserit exsul. .

haud ita pridem|Galloni praeconis erat acipensere nensa infamis.

ac venerata Ceres, ita culmo surgeret alto,

haud ita Troial me gessi, certans semper melioribus.'

hoc erat in votis: modus agri non ita naguus,

'Davosne?' 'ita; Davos, amicum mancipium domino

libertate decembri, 'quando ita maiores voluerunt, utere:

ita te felicem dicis

ita vit bonus es convivaque comis"

cur ita crediderim. nisi quid te detinet, audi

'frater' 'pater' adde; | ut cuique est aetas, ita quemque facetus adopta.

paucis ostendi gernis et communia laudas, / non ita nutritus.

si veteres ita miratur laudatque poetas.

prima cadunt: ita verborum vetus interit aetas.

ut ridentibus adrident, ita flentibus adflent humani voltus.

atıue ita mentitur, sic veris falsa remiscet.

verum ita risores, ita commendare dicacis conveniet Satyros,

ita vertere seria ludo.

non ita pridem, tardior ut paullo graviorque veniret ad auris.

Itacae. 'non est aptus equis I thace [Itacae] locus.

Itace. 'non e-t aptus equis I thace [Itace] locus,

Itala. militibus pronissa Triquetra, praedia Caesar an est ltala tellure daturus?"

Italae. per quas Latinum nomen ct l talae: crevere vires

Italas. dirus per urbis Afer ut Italas

res 1 talas armin tuteris. motibus ornes.

Italia. Caesar ab Italia volantem|remis arjurgens.

Italiae. probrotis, altior Italiae ruinis:"

o tutela praesens Italiae dominaeque Romae.

aurea fruges Italiae pleno defurlit Copia cornu.

Italiam. Yrbem stbi curae. imperiun tore t.t Italian. delubra deorum,

Italis. siquil abest. Italis adiuricat armis.

Italo. ris patriis Italoque caelo.

Italo. at Graecus. postquam est Italo pertusus aceto,

Italos. princeps Aeolium carmen ad Italos $\mid$ deduxisse modos.

Italum. catenas I'arthus et Italum robur;

itaque. nunc itaque et versus et cetera ludicra pono.

item. cetera item nequeunt stultis haerentia.

paulatim rello et demo unum, demo etiam \{et item\} unun.

paulatim vello et demo unum, demo vtiam [demo fian item] unum.

cum speramus eo ren venturam [item fore venturum]. . . commolus ultro|arcessas

indignatur item privatis ac prope succoldignis carminibus natrati
Epist.1.7.32

Serm. 1.2 .73

Serm.1.0.92

Serm.2.3.108

Sirm.I.4. 52

5'ar Serm.1.4.13 I

Serm.2.2.99

Epist.1.0.67

Ars Poet.376

Serm.1.9.48

Epist.2.2.163

Epist.1.16.56

Epist.2.2.205

Epist.1.I4.8

Carm.4.5.7

Serm.I.5.48

Epist.1.7.55

Carm.1.24.1 I

Carm.2.15.10

Serm. I. I.96

Sirm.1.2.20

Serm.1.3.79

Serm.1.3.IOI

Serm.1.6.50

Serm.2.1.59

Serm.2.2.46

Sirm.2.2.12.4

Serm.2.5.I 8

Serm.2.6.I

Serm.2.7.2

Sirm.2.7.5

Serm.2.7.31

Serm.2.8.70

Epist.1.2.5

Epist.1.0.55

Epist.1.20.5

Epist.2.1.64

Ars Poitol I

Ars Poet. Ion

Ars Pott. 151

Ars Poet.225

Ars I'ot'.226

-1rs Poet.254

iar. Epist. I.7.t

for. Epist.1.7.t 1

Serm.2.0.50

Carm.4.15.13

Carm.4.4.42

Epist.2.1.2

Carm.1.37.16

Carm.3.5.40

Carm.4.14.4t

Epist. I.1 2.29

Serm.1.6.35

Epist.1.18.57

Curm 2.7.4

Sirm.1.7.32

Curm.3.30.13

Curm.2.13.18

Epist.1.1.10

sirm.1.3.77

iar. Epist.2.1.46

atar. Epist.2.1.40

Iur.tepist.2.1.226

- Irs Poet.go 


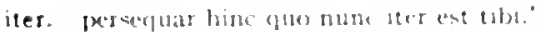
non mili cumas erst iter aut Baias"

quid pure trancpullet. . . secretum iter et fallentic somita vitat

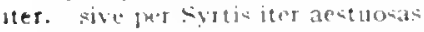

supremum cotprete iter comites parati.

Virtuc. Merata templat iter via

fore "nim elltum iter et paters

rumput et cerpense jter institut um.

liberum mumive ster, clatusus plura relictis

loc iter gnavi divicinua.

utpose hongum lorpenter iter et factum corruptiuc imbri.

gutum tollere fanda velllet iter faciens

inde annbo fropositum peragunt iter.

ut si caecus ites monetrace velit.

rea cusum mutalit iniguom arugabus ammis doctus jter melius:

iterabimus. cras mgens itrabimus aequor."

iterabitur. tosturab tristi clade strabitur

iterare, ireane oursus cogot reletos:

truncis lapsa cavis iterato mella;

iterat. sic itcrat voces et verba callentia tollit.

jteratae. muricibus Tyris iteratae "ellera lanae cui poperahantur?

iterum. non di. quos iterum presca voces malo.

habentedu| Tartara Pantholen iqdum Orco demisann.

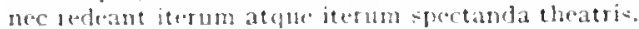

terum gatae digna legi sint scriptutus,

quando iterum pareas iterumque jusire poseis.

quaeris, Maccenas, iteruna antiguo mo includere ludo?

vina bibe iferum Tauro diffusa pahstris|inter Minturnas

Ithacae. 'non e.et aptug equis lihace [lethacal locus.

Ithacam. non satis est litham reveli

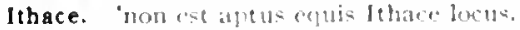

lthacensis. femiglum vitinsum lthacencis llixej.

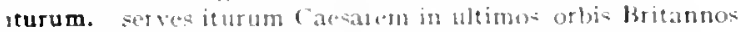

turus. ventis iturus non suis

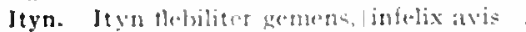

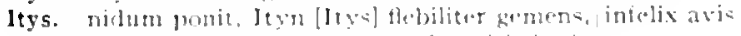

Irion. ptum tet lxion Tityospuce voltu risit imbito.

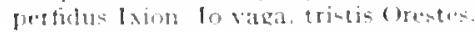

Serm.1.0 a

Esist.1.15.12

Lepist 1.18.10.3

Carm.t 22.5

Carm 2.17 .12

Cirm.3.2.22

Carm.3.10.7

Carm.3275

Carm.saec.43

Serm. 1.5 .5

Serm.1.5.05

Serm.201.043

Serm. $=0.00$

Epist.1.17.4

Ars Pocles

Carm.1.7.32

Cism-3.3.112

Corm.1.3.4.

(arm.2.10).12

IEpist.1.1S.12

I.pod.12.21

Carm.1.14.10

Carm.1.28.10

Sermirin.30

Sorm.1.10.72

Sirm.2.7.(10)

Jipist.1.1.3

I.pist.1.5.4

or. Fosist 1.7.41

Serm.2.5.1

Dipise. 1.11

l.pist.1 epe.3

Carm.1.35.20

tipol 0.30

Carm.t25

far.Carm.42.

Corm.3.11.21

Irs I'sed. I 2.4

\section{I (cons.)}

iacertem. bellange pror, iacentem letuis in hostem.

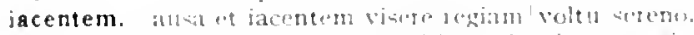

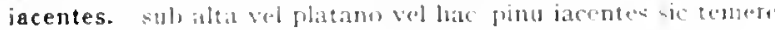

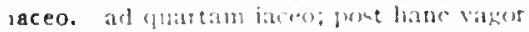

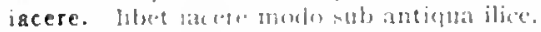

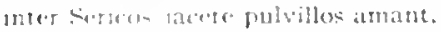

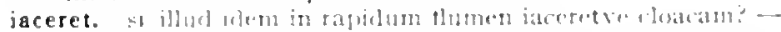

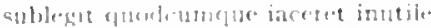

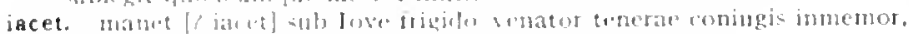

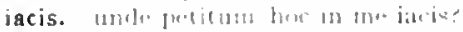

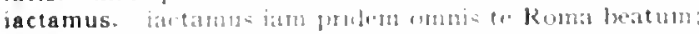

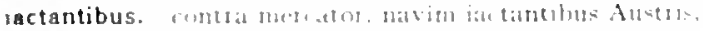

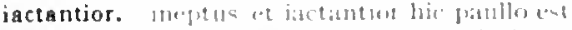

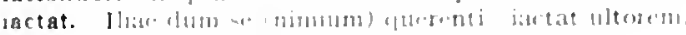

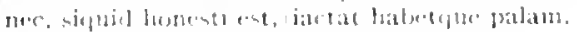

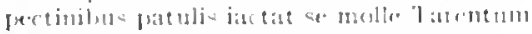

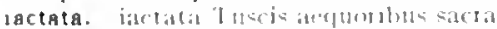

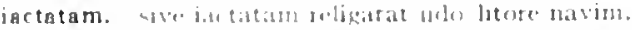

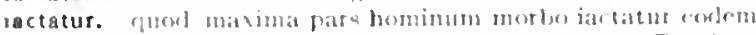

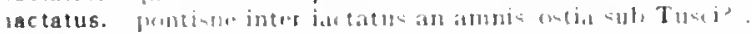

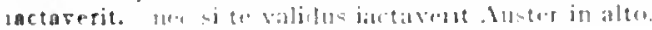

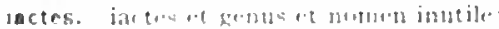

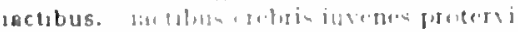

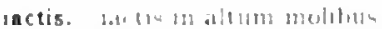

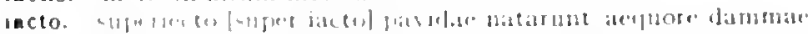

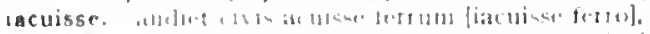

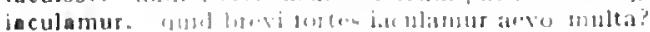

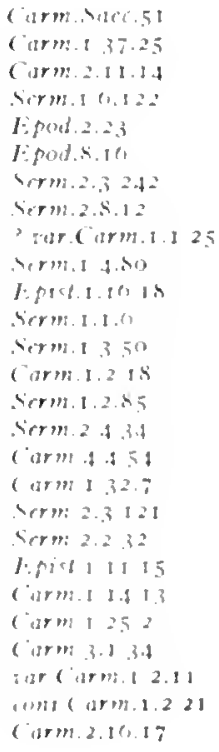




\section{IACVLARI}

iaculari. catusidem per apertum fugientis agitato grege cervos iaculari

iaculator. Enceladus iaculator audax

iaculatus. rubente/dextera sacras iaculatus arcis/terruit Vrben.

iaculis. non eget Mauris iaculis neque arcu

iaculo. saepe trans finem iaculo nobilis expedito?

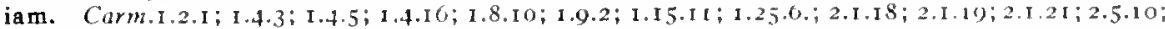

Carm.2.5.13; 2.5.15; 2.I5.1; 2.20.9 (bis); 2.20.13; 3.3.25; coni.Carm.3.5.17; Carm.3.6.9;

Carm.3.8.23;3.14.11;3.29.17;3.29.18;3.29.21;4.1.7; 4.1.30;4.1.38 (bis); 4.3.16; 4.4.7;

Carm.4.4.15;4.4.69;4.5.2;4.6.41;4.7.1; 4.11.31; 4.12.1; 4.12.3;4.13.13;Carm.Saec.27;

Carm.Sacc.53; 55; 57; Epod.2.68 (bis); 5.83; 12.10;12.11; 16.1; 17.1 (bis); Serm.1.1.5;

Serm.I.I.I0; I.1.120; aur.Sirm.1.4.15; Serm.1.5.9; I.5.13; 1.5.20; 1.5.65; coni.Serm.1.7.5;

Serm.1.8.33; 1.9.35; 2.3.146; 2.3.15I; 2.3.289; 2.3.323; 2.4.39; 2.5.3; 2.5.06; 2.6.40;

Serm.2.6.45; 2.0.100; 2.7.13 (bis); 2.7.20 (bis); 2.7.74; 2.7.1It (bis); Epist.1.I.2;

I.pist.1.7.16; 1.7.44; I.7.49; 1.7.75; I.10.11; I.I0.15; 1.18.32;2.1.86; 21.148; 2.1.187;

Enist.2.1.223; 2.2.205; iar.4ts Poet.38; Ars Pott.70; 158; 468

iam. Carm.2.1.17; 3.0.23; Epist.2.1.127; Ars Poet.43 (bis)

iam. Epist.I.10.18

iamdudum. iandudum apud me est:

iamdudum video; sed nil agis: usque tenebo;

'iandudum ausculto et cupiens tibi dicere servos|pauca teformido.

iamdudum splendet focus et tibi munda supellex.

iampridem. urges|iampridem non tacta ligonibus arva

Iane. Matutine pater, seu 'Iane' libentius audis.

'Iane pater' clare, clare cum dixit 'Apollo,'

ianitor. cessit immanis tibi blandienti|ianitor aulae/Cerberus,

dum, quae Crispini docuit me ianitor, edo.

ianitorem. si per invisum mora ianitorem|fiet, abito.

ianua. nec tibi somnos adinunt amatque ianua limen.

reiectaeque patct ianua Lydiae?' .

audis, quo strepitu ianua. . . remugiat

ianua frangatur, latret canis.

Ianum. vacuom duellis I Inun Quirini clansit

postruam omnis res mea Ianum/ad medium fracta sst.

Vortumnum lanumque, liber, spectare videris,

claustraque custodem pacis cohibentia Ianum

Ianus. haec Ianus suminus ab imo|prodocet.

iecur. ferv'ns difficili bile tumet iecur.

exsucta uti medulla et aridum iecur

iecur. libido, . . saeviet circa iecur ulcerosum / non sine questu.

incontinentis nec Tityi iecur

si torme iecur quaeris idonemm;

meum iecur urere bilis.

pinguibus et ficis pastum iecur anseris albae

non ancilla tuom iecur ulceret ulla puerve

iejunae. tossa ab ore rapta iciunat canis

ieiunia. illo mane die, quo tu indicis ieiuna.

ieiunis. ieinnis dentibus acer.

jeiunus. ieiunus raro stomachus volgaria temnit.

ioca. quid]ibet indutus celeberrima per loca [ioca] vadet

jocatus. Campanum in morbum, in faciem permulta iocatıs.

iocis. quamquam choreis aptior et iocis|!ndoque dictus

iocis. sed ne relictis, Musa procax, iocis

si, . . sine amore iocisque $\mid$ nil est incundum,

vivas in amore iocisque.

interdum speciosa locis [iocis] morataque recte/fabula

ioco, sub iuga aenea'saevo mittere cum ioco.

nec certare ioco nec dare bracchia

cum magno risurute iocoque videres.

iocos. seu tu quereliz sive geris iocos

dein Gnatia Lymphis iratis exstructa dedit risusque iocosque.

eripuere iocos, venerem, convivia, ludunt;

iocosa. cuius recinet iocosa nomen inago

iocosa|redderet laudes tibi Vaticani montis imago.

iocose [iocosal Maecenas, precor, / manum puella savio opponat tuo.

iocosae. non hoc iocosae conveniet lytae -

iocose. iocose Maecenas, precor,

iocosi. incer iocosi munera Liberi

iocosi. oderunt hilarem tristes tristenque iocosi.

iocosius. liberius si|dixero quid, si forte iocosius,
Curm.3.29.5

Sirm.1.9.15

Sirm.2.7.I

Epist. [.5.7

Epist.1.14.27

Serm.2.6.20

Epist. I. 6.59

Carm.3.11.10

Serm.2.7.45

Carm.3.14.23

Carm.1.25.4

Carm.3.9.20

Carm.3.10.5

Serm.1.2.1 28

Carm.4.15.9

Serm.2.3.18

Epist.1.20. I

Epist.2.1.255

Epist.1.1.54

Carm.1.13.4

IEpoll.5.37

Carm.1.25.15

Carm.3.4.77

Carm.4.1.1 2

Sirm.1.0.0is

Serm.2.8.88

Epist.I.I8.72

Epod.5.23

Serm.2.3.29I

Epist.2.2.29

Serm.2.2.38

gur. Epist.1.17.28

Sirm.1.5.02

Carm.2.19.25

Carm.2.1.37

Epist.1.0.05

Epist.1.0.00

var. Los Potl.zig

Carm.1.33.12

Carm.2.12.18

Serm-1.8.50

Carm-3.21.2

Serm.1.5.98

Enist.2.2.56

Carm.1.12.3

Carm.1.20.0

coni.lipod.3.2n

Carm.3.3.60

Epod.3.20

Carm.4.15.20

Epist.1.18.89

Serm.1.t.10.4 


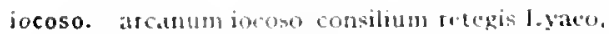

et sermunte opula est modo tristl, sarege iocoso.

(arm.3.21.15

iocoso. callidum. quidefujil placuit, joccese icondese

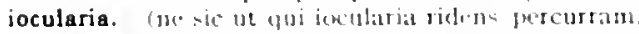

iocum. It mihi sacpe bilen, sacpe iocuns vestri movere tumultus! asper fuchluni gustate jucum temptasit

locus. quan locu circum rolat et cupido;

locus. nequill tu merlas neu sis jocus." doner ban sacvos apertan un rabien coepit veru bous

Iove. mance sub love figido bagunet sinstra labitut rija love non probante u- xorius annis. detluat ale gum ab Jove Neptunoque sacricustode Tarenti. ncolumi lose et urbe Roma? sapiens lno minot est love, dives. ut copia maios ab love domati possit tibi. et silpit et mecun facit et love iudicat alequo.

lovem. [et nostrum patimut seclus iracumda Jovent ponere fuluinat. cato tonanten credidimus lovem|regnare; hace Jovem semtire deosque cunctos per inprobaturum baec loven. preces et aressum all lovem. imbres nivesque deducunt lovem: sed satis est orare Joben quac pronit et auftett.

lovi. Jatonangue supremo, dilectam protus Iori.

"Tgo obligatam tedde Iovi daperm maxntum illa ceroretu intuletat lovitidens inventus horrida bracchis: signa notro sestituit Jori tecum sul, altil - sic lowi gratum - domo.

lovis. te canams. magni Iovis et dootum| numtum -t Iovis aroans Minos admissus dapibus suphems grata testudes Iosis.

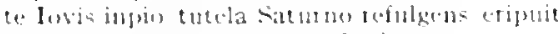
regus in ipsos intjurium ent lovis.

nec fuluimants magna manus Joris:

coniuge the lowis et sorore.

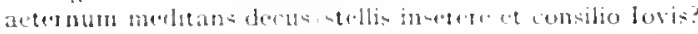
uxor invicti lovis ense moscts.

sic lovic intretest optatis epulis impiget llercules.

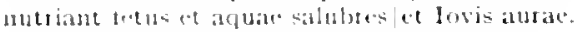
tonatis annus hiferoms bovis

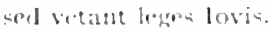

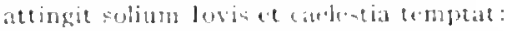

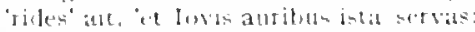

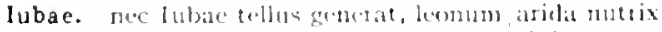

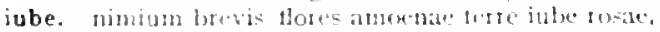
in donum attrue pelliculan curate inbe;

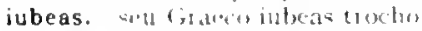

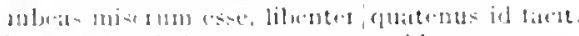

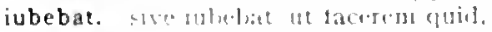

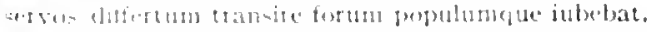

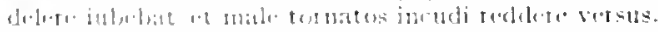

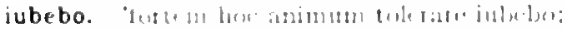

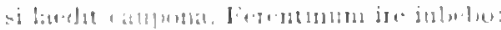

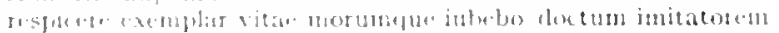

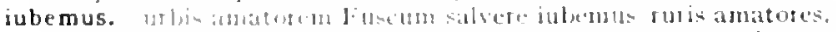

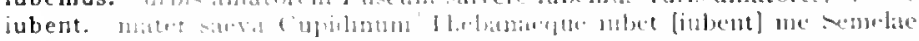
[1110.1

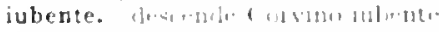

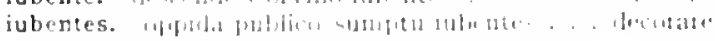

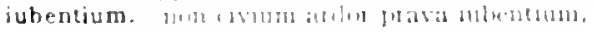

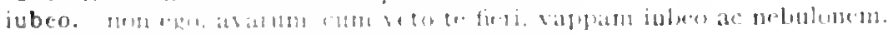

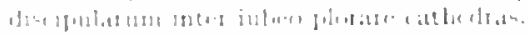

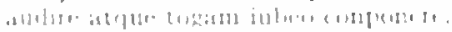

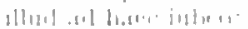

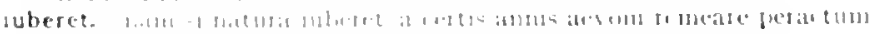

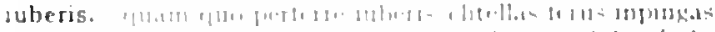

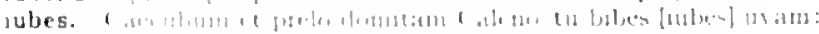

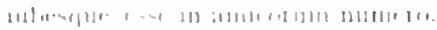

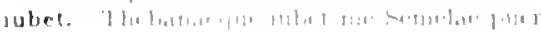

Sorm.I.IO.I

Corm.1.10.7

Serm.1.1.23

Lipist.1.19.21)

Ars $\operatorname{lod} 222$

Cirm.1.2.3.4

Sirm.2.5.37

Epist.2.1.140

Carm.1.1.25

(arm.1.2.19)

Carm.1.28.29

Carm.35.12

Jpist.1.1.100

Epist.1.12.3

Epist.2.1.8

Carm.1.3.4"

Carm.3.5.1

Carm.saec.73

Lipod.5.8

lipod.10.18

Epod.132

Epist.I.18.1 I 1

Carm.1.21.4

Carm.2.7.

Carm.3.4.49

(arm+15.0

Lsod.?.3

carm.I.10.5

carm.1.28.

(arm.1.32.1.t

(iurm.2.17.2

(arm-3.1.

(arm.3.3.s

(arm.3.34.4

carm.3.25.

Carm-3.27.73

Cormats.20

(armsided 32

I:pod.2 20

Spod.17.eng

I.pist. I. I7.34

lipist. 1. [1]. +3

(arm.1.22.15

Curm.2.14

serm.2.5.38

(arm.3.2.5.57

Serm.1.1.ts

torm.1.121

List (. (1).51)

Irs Puelatio

herm.2.5.20

J.pist.1.t.s

- Irs leethit

l.pistituen

or (arm.1.11).2

(arm.3.21.7

(arm.2.15.lus

(arm.3.32

serm. 1. 1.10.4

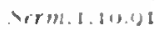

som.2378

Sorma 5.71

srrm $1 .(1,1) 3$

1.5014 1. 1.3.7

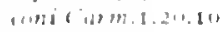

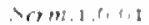

( Ir) I.11): 
magnum pauperies opprobrium iubet .

iubet sepulcris caprificos erutas,

iubet cupressos funebris . . Hanimis aduri Colchicis. mensam poni iubet

ebrietas. . . spes iubet esse ratas, ad proelia trudit inerten, non quo more piris vesci Calaber iubet hospes.

Volteium mane Ihilippus. . . occupat et salvere iubet prior; quid dem? quid non den? renuis quod tu, iubet alter; adsentatores iubet ad lucrum ire poeta adsentatores iubet ad lucrum [ad lucrum iubet] ire poeta

iubetur. iubetur/rura suburbana indict is comes ire latinis. .

iucunds. quibus te vita sit superstite/iucunda,

iucunda, iucunda captat praemia.

ducere sollicitae iucunda oblivia vitae?

aut simul et iucuada et idonea dicere vitae.

iucunde. prorsus iucunde cenam producimus illam.

iucundior. non Atra avis descendat in ventren melum, . . itucundior

iucundis. dum licet. in rebus iucundis vive beatus,

iucundo. nil ego contuletin iucundo sanus amico.

iucundum. si,... sine amore iocisque $\mid$ nil est iucundum,

iucundus. minus hoc iucundus amicus / sit mihi?

Iudaei. veluti te|ludaei cogemus in hanc concedere turbam.

Iudaeis. vin tulcurtis Iudaeis oppedere?'

Iudaeus. credat Iudaeus A pella, non ego:

iudex. fatalis incestusque iudex.

quotiens bonus atque fidus |iudex honestum praetulit utili,

male verum examinat omnis/corruptus iudex.

subtilis veterum iudex et callidus audis.

non quivis videt inmodulata poemata iudex

iudex. Albi, nostrorum sermonum caudide iudex.

iudicantem. et iudicantem vidimus Aeacum

iudicat. et sapit et mecum facit et love judicat aequo.

iudice. iudice te non sordidus auctor/naturae verique.

deprendi miserum est: Fabio vel iudice vincam.

notante iudice ouo nosti populo.

quae neque in aede sonent certantia iudice Tarpa

grande malun Turius, siquid se iudice cestes.

sed bona siquis iudice condiderit laudatus Caesare?

sordidus a tenui victu distabat Ofello|iudice:

prodis ex iudice Dama.

quo multae magnaeque secantur iudice lites,

grammatici certant et adhuc sub iudice lis est.

silvis deducti caveant me iudice Fauni.

ludicet. nec metuam, quid de me iudicet heres,

iudicia. at neque dedecorant tua de se iudicia

iudicibus. (unum ex iudicibus selectis obiciebat)

iudiciis. ut porticibus sic iudiciis fruar

iudicio. demens/iudicio volgi, sanus fortasse tuo,

iudicis, quod sit conscripti, quod iudicis officiun,

iudicis argutum quae non formidat acumen;

in Maeci descendat iudicis auris et patris et nostras

iudicium. si mala condiderit in quem quis carmina, ius est|iudiciumque.' . id tibi iudicium est, ea mens.

iudicium. sed tamen admiror, quo pacto itticium illud/fugerit': quodsi' iudicium subtile videndis artibus illud|. . . vocares,

iuga. inpares formas atque animos sub iuga aenea/satro mittere

Cantabrum indoctum illga rerre nostra

iuga demeret| bubus fatigatis

nec seinper... contempleris arvom et Telegoni inga parricilae.

te vel per Alpium iuga... sequemur

ignota tauris inligaturum iuga

iugandis. prosperes decteta super iugandis/feninis

iugera. inmetata quibus iugera liberas/fruges et Cerenen ferunt

iugera. ian pauca aratro iugera regiat| moles relinguent,

arat Falerni mille fundi iugera

iugera centum an $\mid$ mille aret?

iugerum. purae rivos aquae silvaque iugerum | paticorm

iugis. hortus ubi et tecto vicinus iugis aquae fons

collectosne bibant imbris puteosne perennis|iugis ađuae (arm.3.2.4.42

Iepol.5.17

Epod.5. I

Serm.2.3.1.48

Epist.1.5.17

Epist.1.7.I.

Epist.1.7.0\%

Epist.2.2.03

Ars Porl.t20

var. Ars Poit. 420

Epist.1.7.7.5

Epod.1. (e)

Epod.2.36

Serm.2.0.02

Ars Poet.334

Sirm.1.5.70

Epod.2.5.5

Sirm.2.(1.0t,

hirm. 1.5.+1

Epist.r.0.06

Sirm.1.3.93

Serm. 1.4 .143

cierm. 1.9.70

sirm.1.5.100

(arm-3-3.10

Carm.4.9.t

Serm.2.2.0

sirm.2.7.101

Ars Porl. 243

Ipisl.1.t.l

Curm.2.13.22

Epist.2.1.08

Corm.r.zsit

Sorm.1.2.134

Sirm.1.1).15

serm.1.10.35

Serm.2.1.to

Serm.2.1.84

Serm.2.2.54

Serm.2.7.54

Lpist 1.10 .92

Ars Poct. 8

Ars l'otl.244

Epist.2.2.191

Ipist.2.I.245

Sirm.1.f.I23

Lpist.1.1.7

Sirmoros

Ars Toit.314

- irs Pocl. $3^{1-i}$

Ars Poit. 387

Sirm.2.1.83

Ars Pool.zs

Sirm.1.1.90

Epist.2.1.2+2

Curm.1-3,3.I I

Carm.2.t).2

Carm.3.0.12

Carm.3.20.5

Epol.I. I

Ispol.3. I I

Carm.sesters

curm.3.24.12

cism.2.15. I

lipod.ot. 3

Sirm.1.1.50

Carm.3.In.20

Serm.2.0.2

lipist.1.15.10 
iugis. tu sepuratis uvidus in ingis

run sectas in iugis/ Edonis stupet Eubiat

Corm.2.19.18

jogo. Juluctosifue iugo cogit aeners?

t Ifme tuspilcolla iugu,

iugulas. cur mon hume Regens iugulas?

iugulat. turgidas Alpitus iugulat dum Nemnona

iugulent ut iugulent hominem, surgunt de nocte latrons:

lugulo. amatals frotecto iugulo historias captivos us atudit

in matrin ingulo ferr un tepefecit acutum?

lugum. forle ingin patritur dolosi:

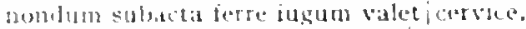

that" ware tigres indocili ingum / collo tralu'ntes.

Iugorthae. vicurum nepotes rectulit inferiac lugurthae.

logurthino. nec lugutthino parem bello reportisti ducem

Iule. l'indarmm quíacuis studet aemulari.|lulle [I ule].

luli. Lufi folere, quibus terrarum nilited oris.. scire laboro.

Iulia. mon qui profundum Danuvium bibunt edicta rumpent lulia.

Iulium. Iulatu sidus velut inter ignis|luna minores.

Iulus. Iulius et tragilis lediatia furque Voranus.

Iulle. Pandatum quisquis stulet aemulari.|Julle.

Julus. nus ubi decidimus quo... Tullus dives [dives lulus] et Ancus.

pulvis et umbra sumus.

iumenta. educet in agros Actolis oneratit plagis iumenta canesque.

iuncta. [itatia, mulis iunctd sororibus.

ts bis nu, ut nune, orichateo vincta [iuncta] tubaeque aenula.

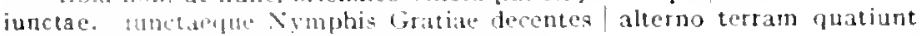
perile.

iunctas. parcius iunctid quatiunt fenestra-

iunctis. Prophon, innetis visit olonbus

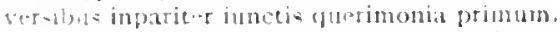

vasbu- ingariter iunctis guerimonia primum, post etian inclusa est

[utiam inmetis] voti sententia compos;

iunctos. bate reset inngit, innctoa el servat arsicos.

iunctura. notum si callida verbum reddiderte innctura novom.

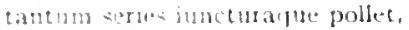

iunc:us. bertha = mparter iunceis querimonia primum. post etian incluas wat [ethan innctna] roti sentencia compou:

iungas. ytatm i libyam remotio Goublus iungas

iungatur. Ht cont mar iungaturque pari:

iungentur. sed prius Apulis|iungentur capreste lupis

iungere. humano capiti cervicem pictor equinam|iungere si velit

iungi:. hare seos iungit. iunctos et servat amicos.

iungite. bonis im peracts iungite fata.

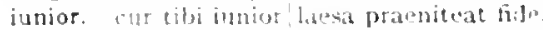

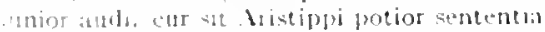

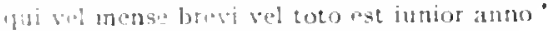

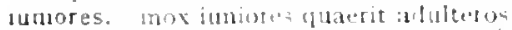

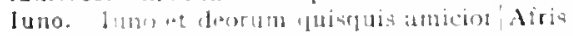

bur mitronal lune

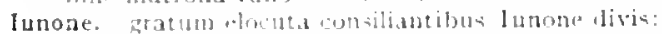

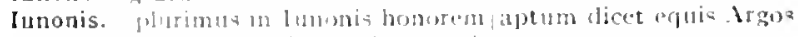

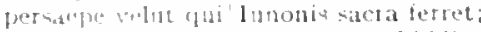

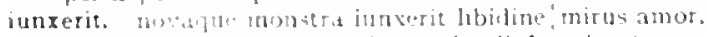

luppiser. cur thane frartis scedus explandi I upprites?

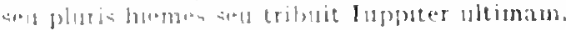

nea: Le.

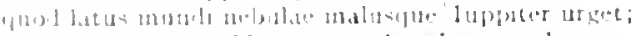

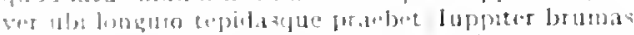

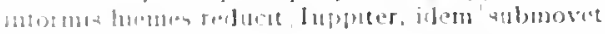

ander nower puras numbure luppiter?

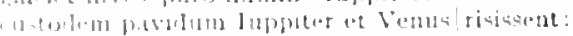

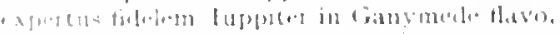

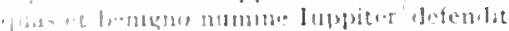

J

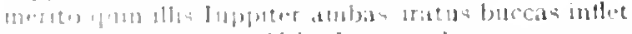

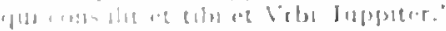

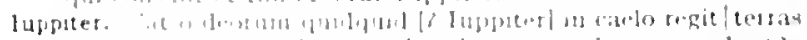

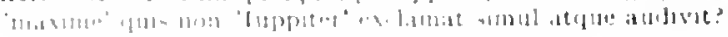

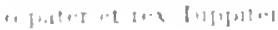

Carm.3.25.8

Carm.3.9.18

Serm 2.7.92

Sirm.1.7.35

Serm.1.10.3"

Lisist.1.2.32

Serm 1.3.89

serm.2.3.13"

Carm.1.35.28

Carm.2.5.1

Carm.3.3.1

Carm.2.1,2s

lipod. 0.23

ior.Corm. 1.2 .2

lipist 1.3. I

Corm.1.15.22

Carm.1.12.47

Serm.1.8.39

(arm.t.2.2

inar.Corm 4.7 .15

Epist.1.18.40

Curnt.3.19.7

vir.tr.s Poet.202

(iam.1.4.e

Ciam-1.25.1

carm.3.28.15

.1rs Piset.75

:ar. Irs Poet.70

siem.1.3.54

Ars Poel.t.

.1rs 1001.242

Eur. Irs Poet.jo

Cirm.2.2.11

Lisive. 5.20

Cism.1.33.8

Irs Port.2

Sirm.1.3.5.4

Carm.succ.28

Cirm.1.33.3

Epist.1.17.10

Epist 2.1.4t

Carm-3.?.25

cism.2.1.25

carm.3.4.59

Ciurm.3.3.18

(itrm.t. 5.8

Serm.1.3.11

Liporit 10.30

(iurm.1.2.30

cirm.r.15.t

Curm.t.16.12

Cisrm.1.22.20

Corm.2.(b.ss

(arm.2.10.16)

(isrm.3.10.8

Corm.3.10.0

Corm.t. 4 .

Curm.4 4.7

lipuld 11.0.3

Sierm.1.1.20

Epist 1.10.20

inar li poid 5.1

Serm 1.2.18

Serm 2.1.13 
"Iuppiter, ingentis qui das adimisque dolores,"

iura. fors et debita iura vicesque superbae/te maneant ipsum:

iura. iriumphatisque possit / Roma terox dare iura Medis. nec semper udum Tibur et Aefulat declive contempleris arvon ot

Telegoni iuga [iura] parricidat.

iura inventa metu iniurti fateare necesse est.

si aut valeo stare aut novi civilia iura;

cum rapies in ius [iura] malis ridentem alienis, fiet aper, modo avis, modo saxum

seu civica iura/respondete paras

'qui consulta patrum, qui leges iuraque servat.

Romae tulce diu fuit. . clienti promere iuta.

mecun facientia iura|si tamen attenptas?

permutet dominos et cedat in altera iura.

Ihra neget sibi nata. nilhil non arroget arnis.

smondeos stabilis in iura paterna recepit

concubitu prohibere vago, dare iura maritis.

iurabas. in virba iurabas mea.

iurandas. iurandasque tuom per mumen ponimus aras,

iurando. luse iurando obstringam ambo: .

iurantem. lurantem me scire nihil mirantur

iurare. unllis adductus iurare in verba magistri.

iurares. Botutum in crasso iurares aere natum.

iurat. Imat bene solis esse maritic.

iuratus. per sanctum iuratus dicat osirim:

iure. iure perhorruilate conspicuom tollere verticem.

ime collemnis mihi sanctiorque

"iure" onnes; Galba negabat.

ut forst honorem iure mini invideat quivis,

(boc etenim sunt omnes iure molesti|quo fortes,

'iure' inquit "Trausius istis iurgatur verbis;

chorusque / turpiter obticuit sublato inre nocendi.

iure. iure iurando obstringam ambo:

iuremus. sed iurenus in haec:

jures. quamilis, nocturmos inres te formidare tepores.

iurgares. ne nea saevos iurgares ad te quod epistula nulla rediret.

iurgatur. 'iure' inquit 'Traucius istis'iutgatur verbis;

iurgia. excludat iurgia finis.

qua populus adsita certis/limitibus vicina refugit iurgia;

iuris. ext operat pretium duplicis pernosere iuris naturam.

iuris. nlla i iuria tibi peierati/poena.

agricolarn laudat iuris legunque peritus.

hoc nihi iuristcum venia dabis:

illum aut nequities ant vafri inscitia iuris.

publica materies privati iuris erit.

fcom-ultus iuris et actot 'causarum medtocris abest

ius. ignarum, quilus est ms ajtius pt quibuc arsis

his mixtur ius rst:

ne male conditum ius adponatur,

ius. si mala condiderit in quem ruis carmina, ius est / iudiciumque." quem penes arbitrium est et ius et norma loquendi.

sit ius liceatque perite poetis:

ius. semeson priscis tepidumque ligurierit ius.

ius. nilo deteriua dominae ius esse:

in ius $\mid$ acres concurrunt.

rapit in ius; clamor utrimque. /undique concursus.

cum rapies in ius malis sidentem alienis.

interdicto luic onme adimat ius praetor

ultro qui meliorem audax vocet in ius.

ius anceps novi. causas defendere possum;

ius imperiumque Phraates| Caevaris accept genibus minor;

iussa. sed iussa coram non sine conscio|surgit marito.

iussa pars mutare Lares et urbem|sospite cursu.

neque cunctetur, cum est iussa, venire.

ut festis matrona moveri iussa diebus.

iussa. (puer hic non laeve iussa Philippi accipiebat) quodsi|depositum laudas ob amici iussa pudorem.

jussae. stellac sponte sua iussaene vagtntur et errent,

iussas. iuscar rum fide poenas linam.
Sirm.2.3.288

Corm.1.28.32

Ciarm.3.3.4.4

?tur.Carm.3.29.8

Serm. I.3 I I I

Serm.1.0.39

v'ar.sterm.2.3.72

Ifict. I. 3-23

Ifpist. I. [0.7 I

IfPist.2.1.104

LPist 2.2 .23

Epist.2.2.174

drs Pint. 122

Ars l'vet. $25^{\circ}$

Ars I'vel. 398

Epol.15.4

Epist.2.1.16

Serm.2.3.150

Serm.2.0.57

Epist.1.1,1 4

Enist.2.1.2.4.

Epist.1.1.89

Epist.1.17.00

Carm.3.16.18

Carm.1.11.17

serm.1.2.4t

serm.1.6.50

Serm.1.7.10

Serm.2.2.09

drs Port.28.4

Serm.2.3.179

Epod.16.25

Epist.1.18.0.3

Iitist.2.2.22

Sirm. 2.2.100

Epist.2.1.38

Lfist.2.2. 71

Sorm.2.4.03

Carm.2.8 I

SirmIJI, 0

Serm.t.4.104

Serm.2.2.13 I

Ars Poet.13

Irs l'mel.300

serm.2.35

Serm.2.8.15

Siem.2.8.09

Sirm.2.1.82

Ars loct.72

Ars Pothoton

Serm.1.3.8 I

Serm.1.5.07

Sirm.1.7.20

Serm.1.9.77

Serm.2.3.72

Serm.2.3.217

Sirm.2.5.20

Sirm.2.5.34

Epist.1.12.27

Carm.3.6.20

Carm.siaec 39

Sicrm.1.2.1 22

1rs P'ot.232

Epist.1.7.52

Epist.1.9.12

Epist.I.12.17

Epot 17.37 
iusserit. dme, inoph, Romat seu fors ita imsergif exsul.

Scrm.2.1.59

insererit and se/ Malectors of rum

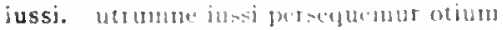

jussit. insit mpinentern pascere basban

qui servos polcere aurum, m media iussit libya.

iusit qund splemdida bilis

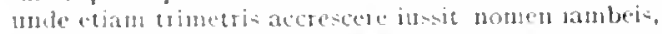

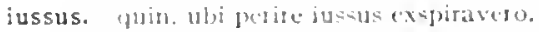

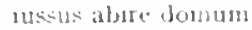

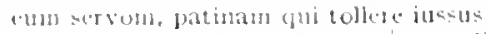

iusta. postejum illi iusta cheragra, contudit articulos.

estre marito/matronae pecantis in ambo iusta potestas,

iusta. per yuos cecidere iusta morle centauri.

tusti. ipsa utilitas insti prope mater et acepui.

iustior. In amlue inta potestas.jin corruperen ved iustior?

iustis. prodeat iustis operita sacris

lustitia. Vui Pulor et Iustibiae [lustitia et] solor]incorrapta Fides

lustitiae. I'befer et lustitia suror/incortupta lides

Iustitiae. sic potenti Inctutide placitumetue l'arcis.

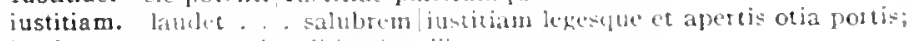

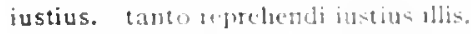

iusto. da milit billere, da insto sancturlue viduri.

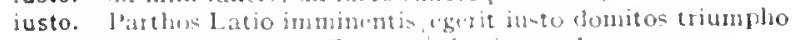

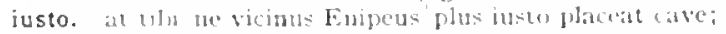

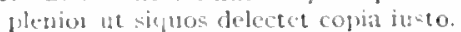

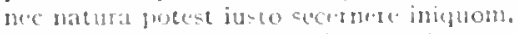

iustum. Hatemus hate: alias, inktum sil nectur poema.

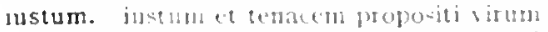

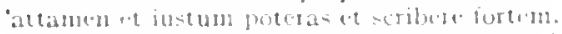

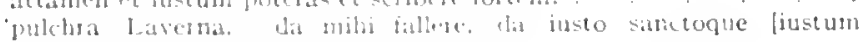
samctunuguc] vin].ri.

iustus. ille chasu=erit, forke, itu-tu-"

sicui vinlecer non iustus.

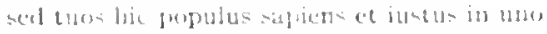

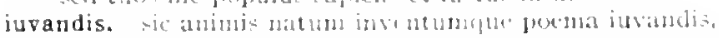

iuvant. Hultes catha invane et lituo tubae permixtus sonitus

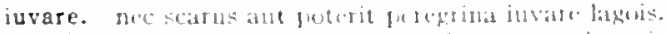

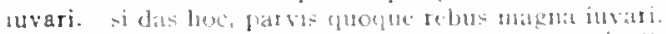

iuvat. sunt quos curiculo puls lem Olymplemirolleginse insat

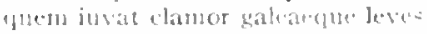

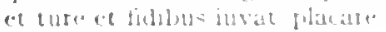

in-anise* jubat:

necentabe intat nero

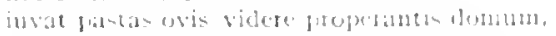

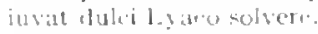

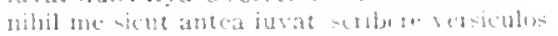

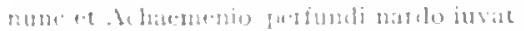

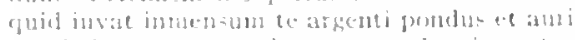

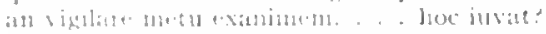

j!luod -

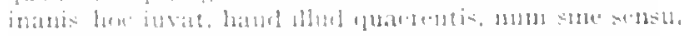

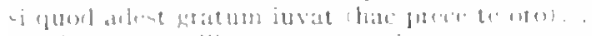

lox: insat it matli e-t, mon mentiat.

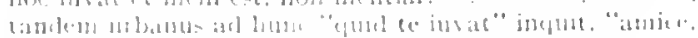

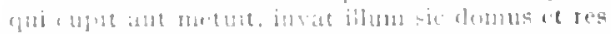

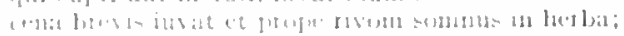

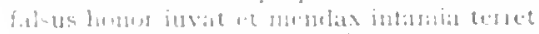

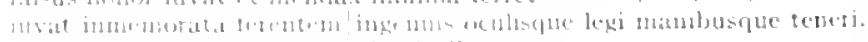

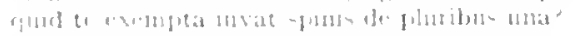

maturas . Juvat ant :minellit all iram

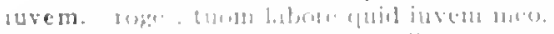

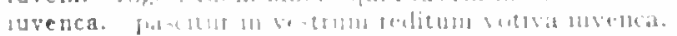

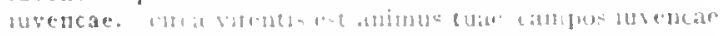

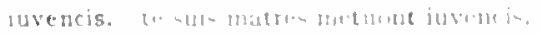

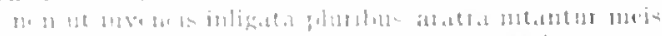

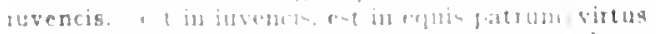

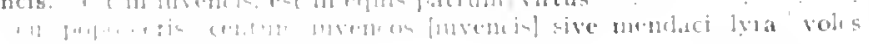

tim. 2.7 .32

Eipod.1.7

Serm.2.3.35

Serm.2.3.101

Serm.2.3.1. 11

Ars Pod.252

I.pod.5.01

Lpod.11.20

Sirm.1.3.80

Sirm.2.7.15

Sirm.2.7.0.2

Corm.4.2.14

sirm.1.3.9k

siorm.2.7.63

(arm.3.1.1.)

conichm.1.24.0

(arm.1.24.6)

Carm.2.17.10

Ars Port.109

scrm.2.4 sio

lipist 1.10.01

Carm.1.12.54

Curm.3.7.24

Serm.1.1.57

Sirm.1.3.113

Sirm.1.4.63

Carm.3.3.1

serm.2.1.10

: ar. I.pst.1.Ju.c1

Sirm.23.07

serm.2.3.180

I.pist.2.1.18

Ars 1'061.377

Carm.1.1.23

Serm.2.2.22

frpist.2.1.125

Curm.1.1.4

Corm.1.2.38

Carm.1.301

(arm.3.10.18

(arm.i. I. 31

l: pod.2.sil

I: pold.9.37

Epold I. 1

fisoul.1.3.0

sirmint...1

Serm.1.1.78

Sorm.1.4.2.

Serm, L.at o

serm.2.t.13

Serm.2, 4.32

Serm.2.to.co

I.pist.1.2.5 1

J.prst.1.1.4 3.5

f: pist. I. 1(1..31)

I.fist.1.10).33

t.post.2.2.212

Ars fuel $1 \mathrm{Wr}$

I. pord.1.15

l.pistit is an

carmiz. 5 .

Gorm.2.2 21

1. piod 1.2.5

(i)

iar 1.pend.17.39 
iuvencos. seu poposceris/centum iuvencos

Eod.17.39

iuvencum. siquis infamen mihi nunc iuvencum|dedat iratae.

iuvenem. sive mutata inveneru figuralales in terris imitaris almae/filius Maiae.

constantis iuvenem fide/Gygen?

flebili sponsae iuvenenve rapum/plorat

ut mater iuvenem,. . . precibus voeat

non tuae sortis iuvenem

quod me Lucanae iuvenem commendet amicae);

iuvenentur. aut nimium teneris iuvenentur versibus umquam

iuvenes. quatiunt fenestras | iactibus crebris iuvenes protervi possent ut iuvenes visere fervidi.

per quem tot iuvenes patrio caruere sepulcro?" .

haec recinunt iuvenes dictata senesque

iuvenes. proclia virginum|sectis in iuvenes yaguibus acrium

domitosque Herculea manu|Telluris iuvenes.

huc iuvenes aequon est descendere.

iurenes. maxima pars vatum, pater et iuvenes patre digni, / decipimur specie recti.

iuvenescit. relicta|matre qui largis iuvenescit herbis

iuveni. 'surge' quae dixit iureni marito.

nec frno iweni neque naris obesae?

ut placeat inveni, percontare utque cohorti.

ne forte seniles mandentur iuveni partes pueroque ririles:

iuvenis. nec quisquam potior bracchia candidae/cervici iuvenis dabat. accipe quid contra haec iuvenis responderit aequos.

iuvenis Parthis horrendus, ab alto|demissum geaus Aenea, inberbis invenis, tandem eustode remoto, gaudet equis

iurenis. consilis iurenis revictae

iuventa. temptavit in dulci imventa|fervor non ego hoc ferrem calidus iuventa|consule Planco. maturusne senex an adhuc florente iuventa|fervidus,

iuventae. nee parcit inbellis iuventae/poplitibus timidove tergo. di, probos mores docili iuventae. . . date

Iuventas. et parum comis sine te Iuventas|Mercuriusque.

iuventas. fugit retrolevis iurentas et decor olim iuventas et patrius vigor

fugit iuventas et verecundus color reliquit ossa

iuventus. audiet pugnas vitio parentum|rara iuventus.

quo calet iuventus! nunc onnis et mox virgines tepebunt.

uade manum inentus/metu deorum continuit?

fidens iuventus horrida bracchiis.

non his iuventus orta parentibus.

parebit pravi docilis Romana iuventus.

venit enim magnum donandi parca iuventus

Alcinoique in cute curanda plus aequo operata iu ventus,

juvenum. mixta senum ac iuvenum densentur funera.

iuvenum recens examen

iurenumque prodis ipublica cura.

virginum matres iuvenumque nuper/sospitum;

filia rectius/expugnat invenum domos.

cum per obstantis iuvenum catervas

quo blandae iuvenum te revocant preces.

iuvenum nobilium cliens,

et iuvenum ritu florent modo nata vigentque.

et iuvenum curas th libera vina reierre - -

o makor iuvenum, quamvis et voce paterna/fingeris ad rectum

iuverint. non me Lucrina iuverint concliylia

iuveris. opina quodsi praeda curvo litore porrecta mergos iuverit [iuveris], non tamen interpres tantunlem itureris.

iuverit. porrecta mergos iuverit,

iuvet. quodsi pudica mulier in partem iuvet/domum iuvet ut tigris subsidere cervis,

lectolaut scripto quod me tacitum iuvet.

(si) quercus et ilex multa fruge pecus, nultil dominum iuret umbra?

iuvit. 'ut Nasideni itut te con beati?

Carm.1.2.ti

Carm.3.7.4

Carm.4.2.21

Carm.4.5.9

Carm.4.11.22

List.I.I5.2I

Ars Poet.2 $4^{6}$

Carm.1.25.2

Carm.4.13.26

Serm.2.3.196

Epist.1.I.55

Carm.1.6.18

Carm.2.12.7

Serm.1.2.34

Ars Poct. 24

Carm.4.2.55

Carm.3.1 1.37

Epod.12.3

Epist-1.8.1

Ars loetili

Carm.3.9.3

Serm.2.3.233

Serm.2.5.62

Ars Poet. I0I

Carm.4.4.24

Corm.1.10.23

Carm.3.1.27

Ars I'oet.I I 5

Carm.3.2.15

Carm.Saec.t5

Carm.1.30.7

Carm.2.II.6

Carm.4.4.5

Epod.17.2I

Cirm.1.2.24

Carm.1.t.19

Carm.1.3.5.3\%

Carm.3.4.50

Carm.3.0.33

Serm.2.2.53

Serm.2.5.:9

Epist-1.2.29

Curm.1.28.19

Carm.1.35-30

Carm.2.8.7

Carm.3. 14.9

Carm.3.15.9

Carm.3.20.5

Curm.4.1.8

Carm.4.12.15

Ars Poetion

Ars Puet.85

Ars Poet.300

Epod.2.49

var. Iipod. I 0.22

serm.2.4.9I

Epod.10.22

Epol.2.30

Epod.10.3I

Serm.1.0.123

Ifpist. I. IU. IO

Serm.2.8.I 


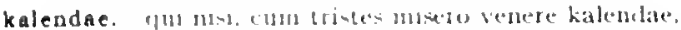

Torm.1.3.87

kalendis. Mattus calelon quid agam halendis.

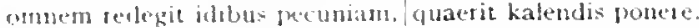

Curmi.3.8.1

Lipod.2.70

Serm.2.1.00

Karthagine. duxit ab opyresa mexitum harthagine nomen

Karthaginem. cui super Karthaginem vitus sepulerum condidit.

L.pod.2.25

Karthagini. Karthagui iam non ego numtos|mittan superbos

Karthaginis. non incendia Karthiginis inpiace"

murethas invidate hat chaginis Komamus arces ureret.

\section{I.}

labantis, efonec labantis consilio patres formarce anclor

labem. veluti tractata uotan labencue rembtunt atranunta.

labentis. aut labentis equo deseribit volnera lanthi"

labentis. beteceris aedisfue babentis deorum

Labeone. Labeone insanior inte' / sames dicatur.

Laberi. et Laberi mimos ut pulcra poenata mires.

labetur. at hile labitur et labetur in onue volubilis atevon.

labi. calaver unctum oleo hago nuds uneris tulit beres, / scilicet edabi [r.t labi] si posset mortua:

labier. m vitum tortuna labier aequa:

labitur. vague et sinictra labitur ripa love non probante a- xorius amenis. nmor et in genat furtim labicur argunens.

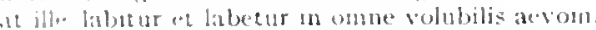

labor. metropit Achotoma Herculeus lablus -

slom non laber lothmidu clarabit pugilem.

(1) labor exenderis iastidia

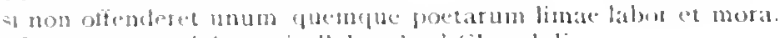

laborabas, quinta labora in |laborabast charydi.

laborant. aut aquilonibus quereteta Gagani laboran

l.tbotant, cism ventum ad vermu ent

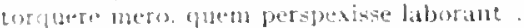

laborantes. nec intn suetineant onus silwe labotantes

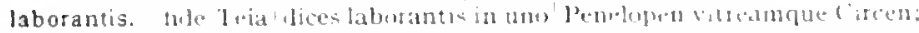

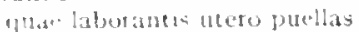

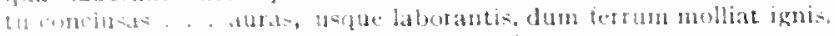

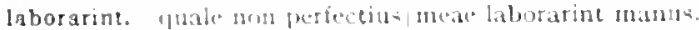

laborazunt. narlo perunturs, quale non perfectits meate haborant [laborizunt] mrants:

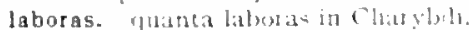

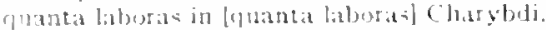

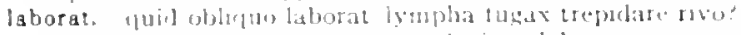

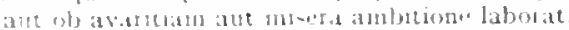

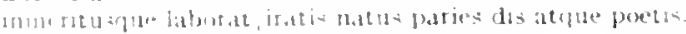

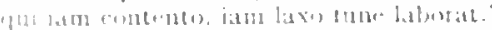

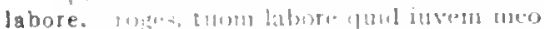

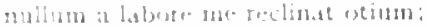

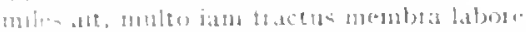

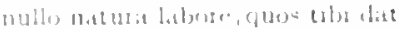

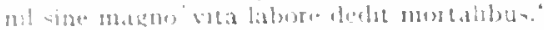

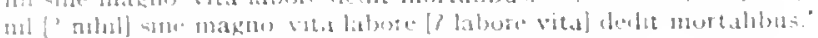

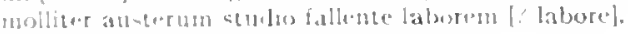

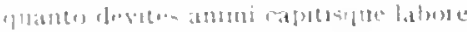

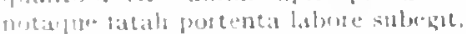

laborem. Hake laburem decipatur - wan

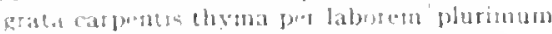

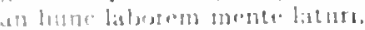

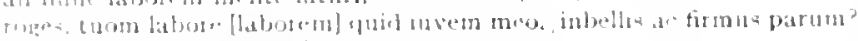

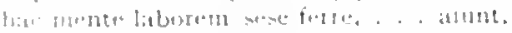

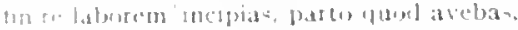

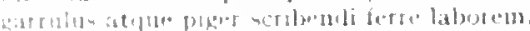

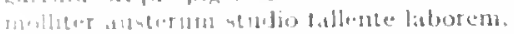

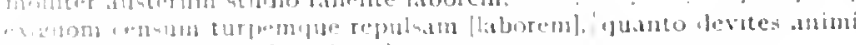

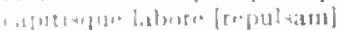

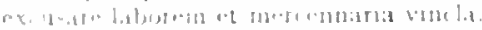

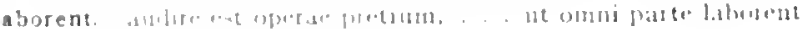

Curm.3.5.45

L. pust.2.1.23,

term.2.1.15

Cirm.3.1.3

Serm.1.3.82

Term.1.10.0

Epist 1.2.4.3

:ur..serm.2.5.57

Epist.2.1.0.t

Carm.1.2.19

(ur).1.13.7

finist.1.2.43

(iorm.1.3 30

Cism.a.3.3

cirm.2.2.14

- Irs loet.201

"ar.Carm.1.27.10

(ism 2.0.7

Sirm. I. 3.04

des liaed.4.35

(arm.J.4.3

Carm.1.17.Ju

(ivm.3.22.2

Serm.1.420

Epod selio

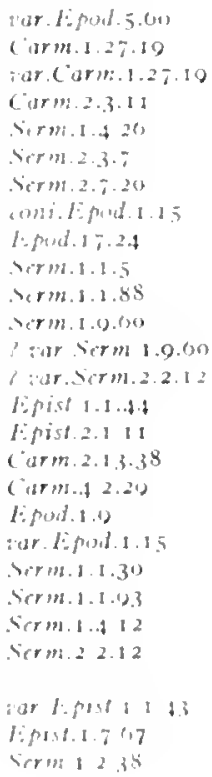




\section{LABOREN T}

quem perspexisse laborant [laborent] lan sit amicitia dignus: .

labores. tu sapiens finire mementoltristitiam vitafyue labores

finire quaerentem labores

totve tuos patiar labores inpune. Lolli, carpere

unde homines operun primos vitaeque labores/instituont

cum lamentamur non adparere labores / nosttos

scribere posse inter tot curas totque labores?

labores. tuo vitio rerumne labores, | nil referre putas?

neque te it miretur turba labores.

neque plura parare labores

laboret. neglegens, ne qua populus laboret,

bunc atcue hunc superare laboret

siquis. . caeca fluitantia sorte laboret/reddere certa sibi, ut siquis solum hoc, mala ne sint vina, laboret.

quis enim invitum servare laboret?

conmisisse cavet quod mox mutare laboret.

nec quarta loqui persona laboret.

sudet multum frustraque laboret $\mid$ ausus idem:

labori. curae sunt atque labori.

"eoque reponsura tuo numquan est par fama laboni.

laboribus. tanden nequitiae fige modum tnae/famosisque laboribus; novis ut usque suppetas laboribus.

laboribus. hic levire functum| pauperem laboribus defunctumque laboribus | aequali recreat sorte vicarius. post hoc secundis usque laboribus exhauriebat, ingenens laboribus. malis carere quaeritis laboribus; cenes ut pariter pulmenta laboribus empta:

laboriosa. laboriosa nec cohors Vlixei.

laboriosi. laboriosi remiges Vlixei

laboris. damnatusque longi/Sisyphus Aeolides laboris. magni formica laboris'ore trahit quodcumque potest unde laboris plus haurire mali est quam ex re decerpere iructus.

laboro. sed quis cenantibus una, Fundani. pulcre fuctit tibi, nosse laboro. quibus terram militet oris/Claudiue Augusti privignus, scire laboro. brevis rose laboro. lobscurus fio;

laborum. olaborun |dulce leninen quin et Prometheus et Pelopis parens|dulci laborem [laborum] decipitur sono

nido laborum protulit insciun

multa laborun praemia laturus.'

indoctus quid enin saperet liberque laborum |rusticus

labra. labra novet metnens autliri: "pulchra Laverna.

labris. inpresit memorem dente labris notam.

labris. "Tantalus a labris sitiens fugientia captat|flumina"laec ego mecun |conpressis agito labris:

jabuntur. ehen fugaces, Postume, Postume, labuntur anni labuntur altis interim tipis aquae.

Lacaena. non sola comptos arsit aruluteri|crinis . . Helene Lacaena

Lacaenae. in comptum Lacaenae/more comas religata nodum. iam nec I acaenae splendet adulterae famosus hospes

Lacedaemon. me nec tam patiens lacedaemon . . percussit

Lacedaemonium. aut Lacedaemonium Tarentum.

laceranda. cun tibi invisus laceranda reddet / cornua taurus.

lacerant. quae velut nactae vitulos leaenae, singulos cheu lacerant:

lacerare. lacerare ferro et frangere enitar . . cornua

laceraverit. sicuis opmobriis dignum latraverit [laceraverit], integer ipse?"

laceravit. venaticus, $\mathrm{x}$ quoltempore cervinam pellem latravit [laceravit] in aula.

lacerna. tuspis ocloratum caput obccurante lacernal.

lacertae. seu virides rubum idimovere lacertae.

lacertis. pignusque dereptum lacertis

Caesaris Augusti non responsura lacertis.

lacertis. qui lora restrictis lacertisisenvit iners herbas atque incantata lacestis|vincula

lacerto. laevo suspensi loculos tabulamque lacerto. 'laevo suspensi loculos tabulanuue lacerto.'

lacessat. ne rudis agminum sponsus lacessat regins as perun | tactu leonen,

lacessit. quicumque Bithyna lacessit/Carpathium pelagus carina:
LACESSIT

¿ar. Ars Port. 435

Curm.1.7.1 8

Carm.3.+.39

Carm.1.9.32

Serm.2.6. $2 \mathrm{I}$

Epist.2.1.224

Epist.2.2.66

Sirm.1.2.70

Serm.1.10.73

Epist.2.2.196

Cirm.3.8.25

Sierm. I. I.JI2

Sierm.2.3.269

Sierm.2.4.49

Lipist.1.20.16

Ars Poet.ros

Ars Poct.192

Ars Poet.2.t1

firm.

Serm.2.8.60

Corm.3.15.3

Lpod.17.04

Cirm.2.18.39

Carm-3.24.15

Carm.t.4.45

Epod.5.3I

Epod.16.16

Epist.1.18.48

repod.10.to

Epod.17.10

Corm.2.14.20

serm.1.I.33

Sirm.1.2.58

Sirm.2.8.19

Epist.1.3.2

Ars l'oet.25

Carm.1.32.14

'tur.Carm.2.13.38

Corm.4.t.t)

Serm.2.I.II

Ars loot.2I 2

Epist.teleon

Carm.1.13.12

Serm.1.1.58

serm.1.4.133

Cirm.2.14.2

Epoll.2.25

Carm.t.9. 10

Corm.2.11.23

Carm.3.3.25

carmes.7. I0

Carm.3.5.5\%

Carm.3.27.71

Carm-3.II.12

Cirm.3.27.40

inesterm.2. 1.85

Ear. Hipist. 1.2.00

serm.2.7.5.5

(arm.1.33\%

Corm.1.0.23

Lipist.2.2.45

Carm.3.5.35

Serm.1.8.10

cierm.1.0.74

lipist.1.1.5t

Carm.3.2.10)

Cirm.1.35.7 
lacessiti. doluese cruentoldente lacessici.

Epist.2.1.15!

lacesso. nibul supral deos lacesso

Laco. masn qualis aut Molossus aut fulvos Lacon [Laco],

Lacon. nasne funlis aue Molossus aut fulvos Lacon.

Laconi. Eegnaten petam Laconilrura Phalantho.

Laconicas. noc l. foconicas mihi|trahunt honestae purpuras clientae.

lacrima. cor manat rara meas lacrima per genas? . luet ill purima manet | lacrima.

lactima. fol tu calenten/debita sparges lacrima favillam/ratis amici.

lacrimge. Linc illat lacrimae.

lacrimis. nowes non sine multis/incommia lacrimis

lacrimosa, tilium dicunt Thecidis sub lacrimosa Troiatefunera. ut poopius apectes lacrimosa poemata Pupi;

lacrimaso. lactimbso non sine fumo.

lacrimosum. hec bellum lacrimosum, hic miseram famem

lacte. Lulvae natris ab ubere iam la te depulsum.

Tillurem porco, Silvanum lacte piahant.

lactea. cerma (lactea) Telephi laudas bracchia.

lactis. inique fontem lactis et uberes cantare tivos

lactuca. lactuca innatat acri post vinum stomacho:

lactucae. acria citcum rapula, lactucae, raclices,

lacu. undique latus extenta visentut lucino stagna lacu omnis gestiet a turno redeuntis scire lacucue

lacunar. necpte atroum mea renidet in domo lacunar,

lacus. fatun th mare sentit amorem festinantiseri; alderarills cel irater, lacus lladria.

lacus. Albanos prope te lacus ponct marmoream 1a:?ilste lacus el rivos ansis apertos.

laedat. quod tneptua Fannius llermogenis laedat conviva Tigelli? des num:noz. excopta nihit te si fuga faedat:

laedent. tum tua me infortunia laedent.

laedeniem. spres perpetuom dutia batbare laedentem oscula.

laedere. Jotes hac ab orno pendulum zona bente te secuta te- liciere liecuta hiselestis collum.

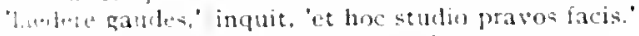

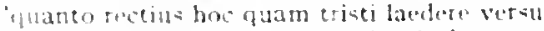

laedet. - to pulvis. . s laedit [lacdeol cuppona, Ferentinum ite iubebo:

laedimur. cum lablimur. unum siquin amicortum est ausus teprehendere verstums:

laedit. al laertit caupona, Ferentinum ire iuluebo:

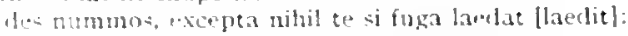

laedunt. (quar lachunt oedlum, festinas domere:

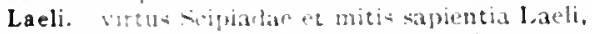

Laelius. num ladeliu: . . Ingentio ottensi

Laertiade. "o I.acrtiade. quidquid dicam, aut erit aut non:

Laertialen. Lastialen. exitim tuar gentis. . Tespicin.

laesa. ald tibi iunior latsa pracniteat fule.

laeserit. quid folui?" dices, ubi quid te laseserit:

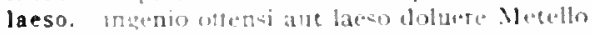

laeso. et ismo han non insanure lagoemac.

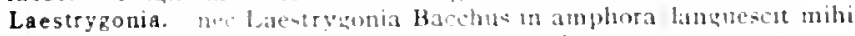

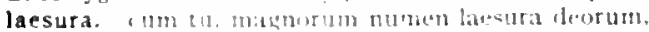

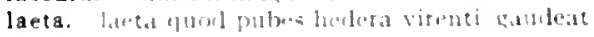

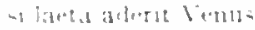

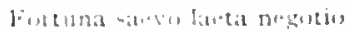

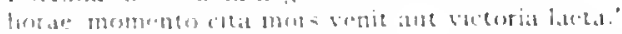

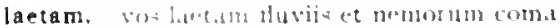

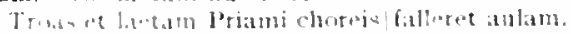

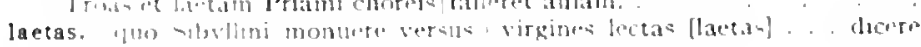
armisu.

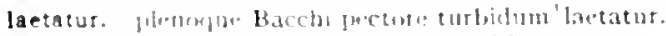

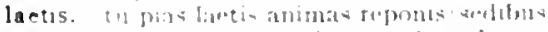

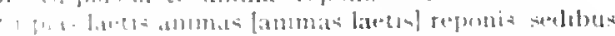

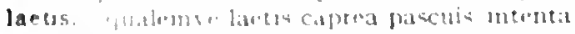

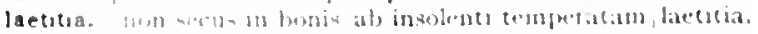

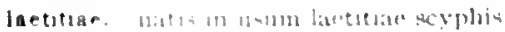

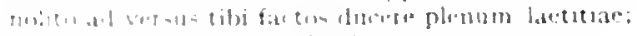

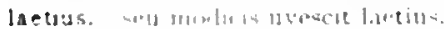

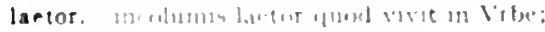

Carm.2.18.12

sar. Epod.6 5

lipodio. 5

Curm.2.t.II

Curm.2.18.7

Curm.t.1.34

Epist.1.17.00

Carm.2.0.23

Fist.1.19.41

Carm.3.7.8

Curm.1.8.14

Epist.1.t.

Sim.1.5.80

Corm.1.21.13

Carm.4.4.15

Epist.2.1.13

I'ar.Curm.1.13.2

Carm.2.19 ro

Serm.2.4.59

Serm.2.8.8

Carm.2.15.4

Serm.1.4.37

Curnt.2.18.2

I.pist.1.1.84

E.pist.1. \$8.63

Curm.t.1.19

E.pist.1.3.11

Serm.t.10.80

Epist 2.2.10

- Irs Poel 103

Curm.1.13.15

fur.Curm.3.27.90

Serma.4. is

Siern.2.1.2

iar. Lipist.1.17.8

Fpist.2.1.221

Epist.1.17.8

for.l.pist.2.2.16

Epist.1.2.38

Serm.2.1.72

Sirm.2.1.05

Sirm.2.5.59

Carm.1.15.21

Carm.1.33.4

I.pist.1.20.7

Sitm.2 1.07

LPist.2.2.134

Carm 3.10 .34

bipod. 15.3

Carm.1.25.17

Cirm.3.21.21

Carm.3 20.40

Sirm.1. I

(irm.l 21.5

(iurm.to.15

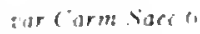

Corm 2.30.7

cisrm. I to.17

sar (arm.1.101?

cirm $4+13$

(istm. 234

(i) 1.27 .1

irs loophas

Serm 2. P. 70

Sermel 128 
laetos. concines laetosque dies

laetum. te minor laetum reget aequos orben:

cum populus frequens|laetum theatris ter crepuit sonmm;

et laetum equino sanguine Concanum.

bonisque rebus agit laetum convivam,

laetum. claudensque textis cratibus laetum pecus

laetus. diuquel laetus intersis populo Quirini .

laetus in praesens animus

dona praesentis cape laetus horae (ac)/linque severa.

quam per exactos ego laetus annos. . . sanguine donen.

ille potens sui| lictusque deget

hinc ad rina redit laetus

Dauniae defende decus Camenae, levis [laetus] Agyieu.

victore laetus Caesare

heres iam circum loculos et clavis laetus ovansque/curreret. .

inspice, si possum donata reponere laetus.

laetus sorte tua vives sapienter. Aristi.

excepto quod mon simul esses, cetera laetus.

si validus. si laetus erit, si denique poscet;

in vacuo laetus sessor plausorque theatro.

laeva. saepe notatus|cum tribus anellis, modo taeva Priscus inani

laera stomachosus lrabena/dicet eques;

cum stetit in scaena, concurrit dextera laevae [laeva].

laevae. actor cum stetit in scaena, concurrit dextera laevae.

laeve. (puer hic non laeve iussa Plilippi|accipiebat)

Laevi. non equidem insector delendave carnina Livi [Laevillesse reor.

laevi. at illi foeda cicatrix|saetosam laevi frontem turpaverat oris.

Laevino. populus Laevino mallet honorem|quam Decio mandare novo

Laevinum. contra Laevinum. Valeri genus.

laevo. laevo suspensi loculos tabulamque lacerto,

'laevo suspensi loculos tabulamque lacerto.'

laero. haec ubi supposut dextro [dextrum] corpus mihi laevon [laevo], | 1 ia

et Egeria est;

cum te sic tempore laevolinterpellarim:

laevom. laevom marinae qui Veneris latus/custodit.

haee ubi supposuit dextro corpus mihi laevom,| llia et Egeria est:

mercemur servom, qui dietet nomina, laevon|qui fodicet latu-

adspiciat sol, |laevom discedens curru fugiente vaporet.

laevos. teque nec luevos retet ire pieus/nec vaga cornix.

o ego laevos, / qui purgor bilem sub verni temporis horam.

laevum. mercemur servom, qui dictet nomina, laevons [laerum] qui fodicet latus

lagani. ad porri et ciceris refero laganique catinum;

lagoena. num sit quoque fracta lagoena.

lagoenae. et signo laeso non insanire lagoenae.

lagoenis, inil convivae lecti nihilum nocuete lagoenis.

lagois. nec scarus aut poterit peregrina iurare lagois.

lagonis. pinguem vitiis albunque neque ostrea | nec searus aut poterit peregrina iuvare lagois [lagonis].

Lalage. iam proterva fronte petet Lalage maritum/dilecta.

Lalagen. dum mean canto l_alagen

dulce ridentem Lalagen amabo. I dulce loquentem.

lamae. inimice lamnae [lamael|Crispe Sallusti.

lamas. viribus uteris per clivos flumina lanas.

lambere. summum properabat lambere tectunı.

lambit. quae loca fabulosus lambit Hydaspes.

lamentamur. cum lamentamur non adparere labores nostros

Lamiae. me quamvis Lamiae pietas et cura noratur fratrem naerentis.

Lamiae. necte neo Lamiae coronam,

nulli plura tamen dividit oscula|quam dulci Laniae.

Lamiae. neu pransae Lamiae virom puerum extraliat alvo.

Lamias. quando et priores hinc I amias ferınt|denominato:

lammae. inimice lamnae [lammae]|Crispe Sallusti.

lamna. ut ventres lamna candente nepotum|dicret urendos

lamnae. inimice lamnae/Crispe Sallusti.

Lamo. Aeli vetusto nobilis ab Lamo-

lana. neque amissos colores' lana refert medicata iuco

"lana Tarentino violas imitata venemo."

lana. alter rixatur. de lana saepe caprina.

Carm.4.2.4I

Carm 1.12.57

Cirm.2.17.20

Carm.3.4.3.4

Sirm.2.6.1II

I pod.2.45

Carm.1.2.40

Carm.2.16.25

Carm.3.8.27

c "arm.3.22.0

Carm.3.29.42

Carm-4.5.31

ar.Carm.4.6.28

Epod.9.2

Sirm.2.3.140

Epist.1.7.39

Epist.I.I0.44

Epist.1.10.50

Epist.1.13.3

Epist.2.2. I3o

Serm.2.7.9

Epist.1.15.12

var.Epist.2.1.205

Epist.2.I.205

Epist.1.7.52

Idr.lipist.2.1.69

Serm. I.5.6 I

Serm.1.0.19

Serm.1.0.12

Sierm.1.6.74

Epist.1.1.50

fur.strm.1.2.125

Serm.2.4.4

Carm.3.20.5

Sirm.1.2.125

Epist.1.1.50

Epist.1.16.7

Carm-3.27.15

- los Poet.301

s'ar. Epist.1.6.50

Serm.1.0.I 15

Scrm.2.8.8 [

lipist.2.2.134

herm.2.8.4

Sirm.2.2.22

"ar..Serm.2.2.22

Carm.2.5.16

Carm.1.22.10

Carm.1.22.23

ior.c (arm.2.2.2

Ispist.1.13.10

Sirm. [.5.74

Cirm.1.22.8

Epitl.2.1.224

Fipist.1.1.to

(itrm. I.26.8

(itrm.1.35.7

. Irs Inet.340

(itrm.3.17.2

int. (urm.2.2.2

lipist.1.15.36"

Cirm.2.2.2

Cism.3.17.1

Corm.3.5.28

Iipist.z. I.207

EDist 1.IS15 


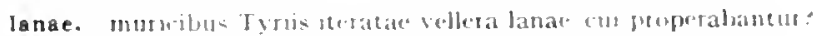

L.ped.12.21

ut vinuse klonus furtirac †l'stia lanac.

lanae. te bjo Aso murice tim tace $\mid$ vestiunt lande

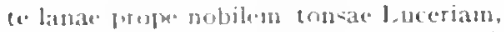

lances. curvat apet lances carment vantis inertem

lancis. Heste neos inter laneis mensasque nitentis.

lenea. lamea et refigies erat, altura cerea:

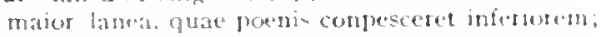

langues. "Inatula langues minus ac me";

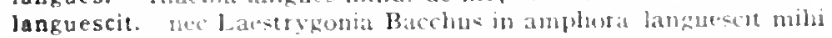

languet. minume languct tascinum?

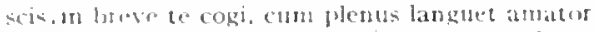

languidae. "um Jatent silvi- lerac' dulci sopore languidate.

languidiora. fromere languidiora sina.

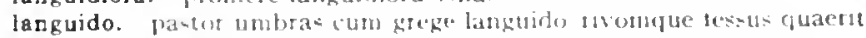

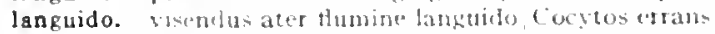

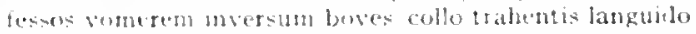

languidus. langudus in cubitum latm xe combiva teponer.

languor. Catus morti fugerit venis el aquosus albo, corpote lansuor. in guis amantem languor et silentiust arguat

Lanuvino. al agro lara decturens lura Lanturino

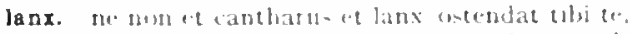

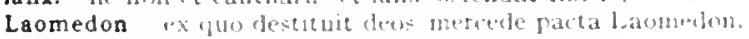

lapathi. ant lurbalapathi juata amantin

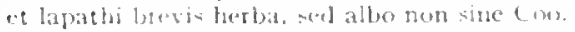

lapiden. "unde wihi lapideme"

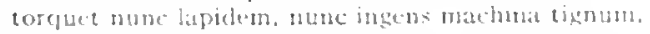

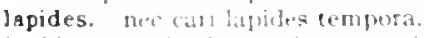

lapides. te doculi- magiver movit Implion lapides cantendo.

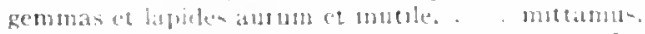

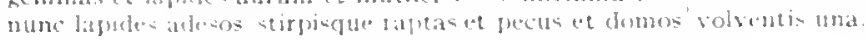
cen lapulde varus lutulenta ralete palma

lapidosus. manı . . nam Canus laptosus, aruae non ditiot und

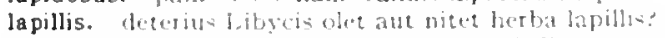

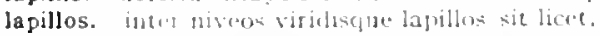

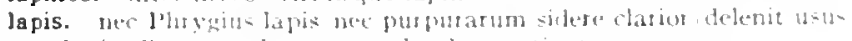
lapis albus perela cum cyatho duo sirisze?.

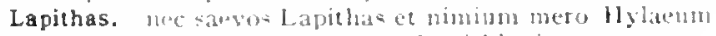

Lapithis. Centautea monet cum lapithis rixa sujuer meto

lapsa. tom is lapso caris itcrare mella:

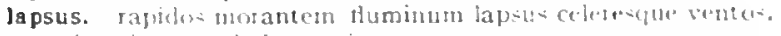

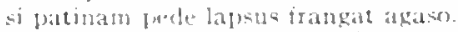

Jaqueata. chan- landerata cirenm, tenca volants.

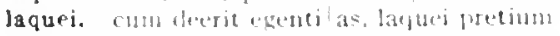

laqueis. mon morta laqueis expediec caput.

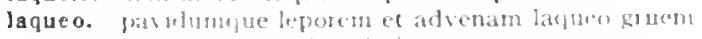

9um lisflen thosem interimis matremque verseno.

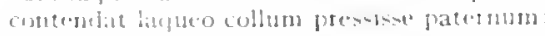

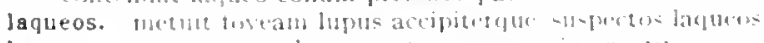

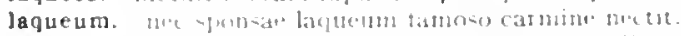

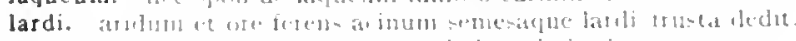

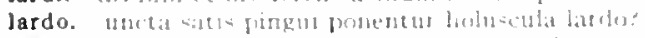

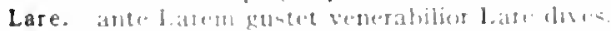

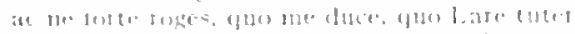

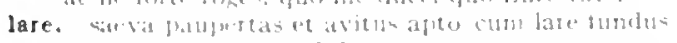

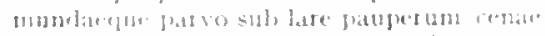

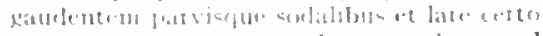

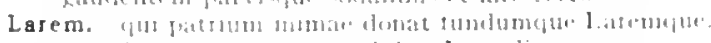

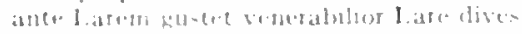

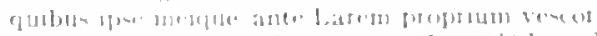

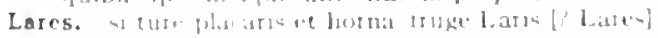

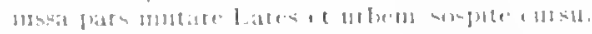

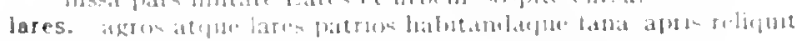

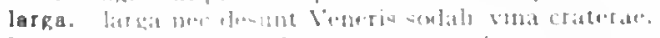

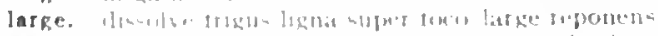

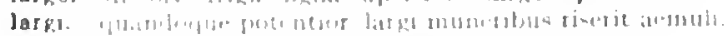

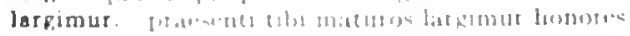

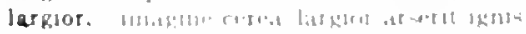

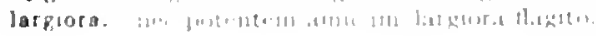

List: 13.14

(arm.2.16.37

(arm 3.1513

Serm.2.4.4

Sirm.2.2.1

torm.1.8.30

serm.1.831

Jipod.12.1.4

Corm.3.10.35

lipod.8. is

f.pist 1.208

Epod 5.50

(crm. 321.8

(arm.3.20.2I

Curm.2.14.17

t.pod 2.64

scrm.2.430

carm.2.11)

tipod I I.9

Carm.3.27.3

l.pist.1.5.23

(arm.3.3.22

Epot 2.5\%

Trom.24.20

Sirm.2.710

Epist.2.2.3

Cormat 13.14

(iarm is:2

carm.3.24.9s

( ism 3.24.36)

term $2+13$

sermit 5.01

Fpal.1.10.10

irm.1.2 80

(a)m? 1 \&

cern: 19,11"

(iorm.2125

(arm.1.1s.s

(arm.2.10.12

(arm.1.12.10

serial. 2.5 72

(arm.2.161.1 I

serm.2.2.00

( arm.3.2.8.

lifoll 2.35

$\therefore$ rem.2.3.131

Jpratel 17.3?

l:prstid to. 1

lipistionaj

vermete.5.5

vime pos

Serm.25.14

I.pisted I 1.3

(upmis +2..44

(iv) 201.1

I.pold 758

serm.t $=50$

sirm 2511

verm.2 in per

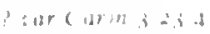

1 arm 4aie 30

1 pod.1.10

sarm is

(a) (a) : 12)

(am 14

I pien.2 1.15

trom t a 11

(.1 0 m) $=18.13$ 


\section{LARGIRI}

largiri. dissolve frigus ligna super focollarge teponens [largiri potis]

largis. relicta| matre qui largis iuvenescit herbis ut neque largis |aquosus Eurus atva radat imbribus,

largis. quandoque potentior|largi [largis] muneribus tiserit aemuli,

largiter. fortassis et istinc/largiter abstulerit longa aetas.

largius. ne potum largius aequo|rideat

largo. cadaver/unctum oleo largo nudis uneris tulit heres, .

largus. spes donare novas largus

ut te $/$ confestim liquidus [? largus] Fort unae rivos inauret,

Laribus. Laribus tuom /miscet numen,

donasset iamne catenam $\mid$ ex voto Laribus, quaerebat;

inmolet aequis hic porcum Laribus;

Laris. si ture placaris et horna|fruge Laris circum renidentis Laris.'

laris. decisis humilem pennis inopemque paternilet laris et fundi,

Larisae. nec tam Larisae percussit campus opimae

larva. nil illi larva aut tragicis opus esse cothurnis.

lasanum. pueri, lasanum portantes oenophorumque.

lasciva. jubet me Semelae puer|et lasciva Licentia

puella |dives et lasciva

agitavit equom lasciva supinum.

ne potum largius aequo|rideat et pulset lasciva decentius aetas.

lasciva. tristia naestum|roltum verba decent. . . ludentem lasciva.

lascivae. lascivae similem ludere capreae,

lascivi. lasciri suboles gregis.

lascivi. vellunt tibi barbam |lascivi pueri.

lascivis. lascivis hederis ambitiosior.

lascivos. pellente lasciros amores

lassas. inpediat verbis lassas onerantibus auris,

lassi. lassi sub adventum viri

lassi. in Mamurrarum lassi deinde urbe manemus,

lasso. sit modus lasso maris et viarum|militiaeque acris | subiectat lasso stimulos

lassum. qualia lassum|pervellunt stomachum,

lassus. leporem sectatus equove / lassus ab indomito lassus dum noctu stertit, ad assem | perdiderat:

lata. quin etiam lex|poenaque lata.

late. horrenda late nomen in ultimas/extendat oras, late conspicuom tollere verticem. tenuisse Lirim. |late tyrannus -

late signa feret militiae tuae.

diullateque victrices catervae

procidit late posuitque collum in|pulvere Teucro:

subimus inpositum saxis late candentibus Anxur.

atque subimus|inpositum saxis late [late saxis] candentibus Anxur. quid oportet nos facere a volgo longe longeque [lateque] remotos? non locus effusi late maris arbiter

purpureus, late qui splendeat, unus et alter/adsuitur pannus,

lateat. quam canis acer ubi lateat sus.

latebrae. hae latebrae dulces et, iam si credis, amoenae

latens. nec latens in asper is / radix fefellit me locis.

latent. non.... Pindaricae latent

formidulosis cum latent silvis ferae

hostiliumque navium portu latent/puppes.

latentem. ureret flammis, etiam latentem|matris in alvo,

latentes. numquam te fallent animi sub volpe latentes.

latentis. nunc et latentis proditot intumo/gratus puellae tisus ab angulo.

latentis. tutum per nemus arbutos|quaerunt latentis et thyma deviae nec fatentis|classe cita reparavit oras.

latere. latere petitus imo spiritus.

verum/depugis, nasuta, brevi latere ac pede longo est.

latere. Lunamque rubenten, | ne foret his testis, post magna latere sepulcra.

lateret. siquid forte lateret,|indice monstratet digito:

lateri. si ventri bene. si lateri est pedibusque tuis. .

lateris. in cor/traiecto lateris niseri capitisve dolore.

laterum. nec laterum dolor aut tussis nec tarda podagra;

latet. quid latet. ut marinae|filium dicunt Thetidis

at ingenium ingens|inculto latet hoc sub corpore.

Veianius armis|Herculis ad postem fixis latet abditus agto.
LATET

sar Carma logo

Carm.t.2.55

Epod.10.53

:ar.Curm.4.1.18

Serm.1.4.132

Eipist.2.2.215

Sorm.2.5.86

Carm.t.12.19

i sar.Epist.1.12.9

Carm.4.5.34

Serm.1.5.60

Serm.2.3.105

Carm.3.23.4

Epod.2.60

Epist.2.2.5 I

Carm.1.7.1I

serm.1.5.04

Serm.1.0.100

Carm.1.19.3

Carm.4.11.23

Serm.2.7.50

Epist.2.2.210

Ars Poet.107

Carm.3.15.12

Carm-3 13.8

Serm.1.3.134

Carm.1.30.20

Carm.2.II.

Serm.1.10.10

Epod.2.4t

Serm.1.5.37

Carm.2.6.7

Serm.2.7.9.

Serm.2.8.8

$5 \mathrm{crm} 2.2 .10$

Epist.2.2.27

Epist.2.1.153

Carm.3.3.45

Corm.3.10.19

Carm.3.I.9.9

Cormitiots

Carm.4.4.23

Carm.4.0.11

Serm.1.5.2\%

6ar.serm.1.5.26

[']r.Serm.1.0.18

Epist.1.11.20

Ars 1'oel.15

Epod.12.6

Epist.I.10.15

Epod.5.07

Carm.4.9.C

Epcd.5.55

Epod.9.I9

Carm.t.e.19

Ars Poet. 37

Corm.1.9.2I

Carm.1.170

Corm.1.37.23

Epod.11.10

Serm.1.203

serm.1.s.3p

Serm.2.8.25

1. pist.1.125

Serm.2.3.20

Strm.1.0.32

(arm.1.8.13

Sirm.1.3.34

Epist.I. 5 
Latinae. quem legis expertes Latinae/Vindelici didicere sclicet oblitos patriaedue pitrisque Latini [Latinael.

Latine. sclicet oblitos patriaeque patrisque Latini [Latine].

Latini. parumue campis atque Neptuno super|fusum est Latini sanguinis. scilicut oblitos jatriaeque patrisque Latini.

Latinis. Lidibusne Latinis/Thebanos aptare modos studet auspice Musa. .

Latinis. tura suburbana indictis comes ire Latinis. ac non verba sequi fidibus modulanda Latinis.

Latinis. hutuc cogo, non alio dictum prius ore. Latinus [Latinis] / volgavi fidicen:

latinis. quod verbis graeca latinis|miscuit.'

Latino. guis non Lattino sanguine pinguior/campus

Latinum. ape dic latinum, barbite, canmen.

per quas batinum nomen et Italae/ctevere vires

Latinus. lume egu, non alio dictun prius ore. Latims/rolgari fidicen;

Latio. ille sell Pastios Latio imminentis

i’arios ego primus iambos|ostendi Latio.

Graccia capta ferum victoren cepit et artes intulit agresti Latio: .

Latio. pulcher fugatis|ille dies Latio temebris.

latior. urbis latior amplecti murus

latis. quae selut latis equa trima campis

Jatis. necule militaris|Daunias latis alit aesculetis.

Jatitantem. caler al to latitantem fruticeto excipere api uns.

Latium. urbesque kentesque et Latiun forox. nec virtute foret clarisse potentius armis quan lingua Latium,

Latium. rempue Romanam Latinmenue folix . . prorogat . tundet ores Latiumque beabit divite lingua:

latius. latios regnes avidum domando'spititum undique latiug extenta visentur J,uctiuo stagna lacu ( - t ut viso vir latiss ordinct/arlusta sutcis.

Ofellum integris opibus novi non latius usum/quam nunc accisis.

Latoe. frui parati* cl valido mihi, Latot, dones ac precor integra .

Latonae. rite Jatonae puerum canentes

Latonam. Latonanque sujpemo/dilectam penitus iovi. en curva reeines lyra|Latonam

latrantem. cum sale panis|latrantem stomachum bese leniet.

latras. Iumperis ct latras, nagnorum maxime regum.

latraverit. siquis' opprobriis dignum lattaverit, integer ipse?"

latravit. ex quo tempore cervinam pellem latrasit in aula.

latrent. litrent suburanae canes

latret. Ianua irangatur, latret canis, .

nee vereor. n*. dum futuo, vir rute recurrat, ianua frangatur, hatret Catinis [canis latret].

latro. we quis fur esset neu latro neu quis adulter.

jatrociniis. cum dieas esse paris restfurta latrocinicu

latrones. ut ingulent hominem, surgunt de nocte latrones:

latrones. contu iatrones atque servilem manum

latronibus. magnus uterque timor beronibus:

latronibus. tutu: ab infestis latrombus?

latronum. ut uis tu similis Cacli Birtique latronum.

latuit. in scalis bituit metuens pendentis habenae"-

Jatum. to minor laetum [latum] reget aequos orben:

pulveris rexigu prope latum parva Matinum ! munera

Discextan et latum clavon prunaeque vatillum

latum demiat fectore clatom,

iatum. latemelu" fer aecjuor. dem sibi, dum socis redicum parat.

Jatura. man, ut anlat, auxili latura plus pratesentubus. guind latura sho. quad site dolicusa negatum,

laturi. an hume laboten mente laturi.

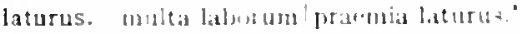

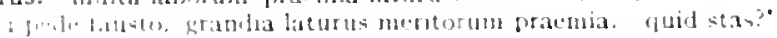

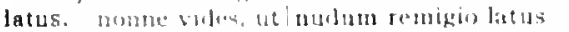

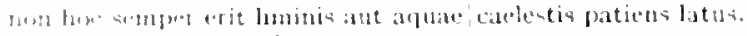

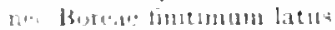

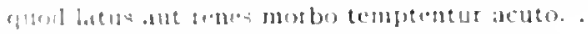

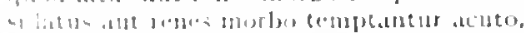

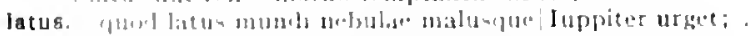

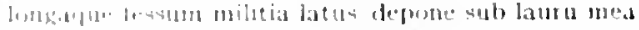

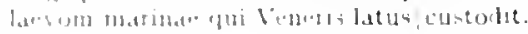

Carm 4.14 .7

tor.Serm.1.10.27

tar.Serm.1.10.27

Ejod.7.4

Serm.1.10.27

Epist.1.3.1 2

Epist.1.7.76

Epist.2.2.143

3 vor.Etist.1.19.32

Serm.1.10.20

Carm.2.1.29

Carm.1.32.3

Carm.4.15.13

Epist.1.19.32

Carm.1.12.53

lipist.1.19.2.4

Epist.2.1.157

Carm-4.4.40

Ars Poct.209

Carm.3.11.9

Carm.1.22.14

Carm.3.12.11

Carm.1.35.10

Ars Poct.290

Carm.Saec.66

Epist.2.2.121

Corm.2.2.9

Carm.2.15.2

Carm.3.1.9

Serm.2.2.1 13

Carm.1.31.18

Carmato.37

Carm.1.21.3

Carm.3.28.12

Sirm.2.2.18

Sirm.1.3.1 $3^{\mathrm{t}}$

Srm.z.1.85

Epist.1.2.66

lipod 5.55

Sirm.1.2.128

:ar.Serm.1.2.128

Serm.1.3.100

Sierm.1.3.122

IDpist.1.2.32

Epolato

Sermet.4.07

Sirm.2.1.42

Sirm.1.4.09

I.pist 2.2.15

ior.Corm.1.12.5"

Carm.1.23.3

Sirm.1.5.30

Serm.1.6.28

Epista.2.20

Fpod. 1.22

firm.1.2.112

lipodi.9

Scrm.2.1.12

lipist 2.2 .38

(arm 1.14.4

(arm.3.10.20

(arm 3.2+35

Serm.2.3.103

lepst.1.28

(urm.1.22.19

(iarm.2.7.18

carm.320.5 
Europe niveum doloso|credidit tauro latus Hibericis peruste funibus latus utrumque verberes latus.|Auster, memento limina dura, quibus lumbos et infregi latus. metiri possis oculo latus.

nullique malo latus obdit apertum.

'utne tegam spurco Damae latus?

aliena negotia centum| per caput et circa saliunt latus.

laevom |qui fodicet latus

reddes|forte latus, nigros angusta fronte capillos,

sed ut veniens dextrum latus adspiciat sol,

latus. pulveris exigui prope latum [latus] parva Matinum|munera

latus. latus ut in circo spatiere et aeneus ut stes.

laudabant, rancidum aprum antiqui laudabant.

laudabile. natura fieret laudabile carmen an arte,

laudabis. nec tua laudabis studia aut aliena reprendes.

laudabit. utroque tuom laudabit pollice ludum.

laudabunt. laudabunt alii claram Rhodon aut Mytilenen

laudande. 'o sol|pulcer, o laudande!"

laudant. si taceas, laudant quidquid scripsere beati.

laudantes. bis pueri die|numen cun teneris virginibus tuom|laudantes

laudantur. laudantur simili prole puerperae.

laudare. arvom caelumque Sabinum/non cessat laudare. scilicet ut tibi se laudare et tradere coner. . ne forte putes me,... laudare maligne:

laudaret. garriret, vicos, V'rbem laudaret.

laudari. inportunus amat laudari:

laudarier. 'nolim laudarier' inquit|'sic me' mirator cunni Cupiennius albi.

laudas. cerea Telephi|laudas bracchia, vae,

num vesceris ista. quam laudas, pluma?

laudas, insane, trilibrem|mullum,

laudas | fortunam et mores antiquae plebis,

laudas securum holus

quodsi / depositum laudas ob amici iussa pudorem.

Lebedum laudas odio maris atque viarum?

paucis ostendi gemis et communia laudas,

laudasti. saepe verecundum laudasti,

laudat. mercator metuens otium et oppidi|laudat rura sui; agricolam laudat iuris legumque peritus. hoc amat et laudat "matronam nullam ego tango."

laudat Brutum laudatque cohortem. siquis nam laudat Arelli|sollicitas ignarus opes, nec qui tigus collegit, furnos et balnea laudat. si veteres ita miratur laudatque poetas, iam Saliare Numac carmen qui laudat ubi plenius aequollaudat venalis qui volt extrudere merces:

laudato. scribet mala carmina vecors: laudato.

laudator. laudator temporis acti|se puero,

laudatore. derisor vero plus laudatore movetur.

laudatur. laudatur ab his, culpatur ab illis. at idem, quod sale multol Vrbem defricuit, charta laudatur eaden. laudaturque domus, longos quae prospicit agros:

laudatus. sed bona siquis|iudice condiderit laudatus Caesare?

laudaveram. ubi haec severus te palam laudaveram.

laudavere, at vestri proavi Plautinos et numeros et laudavere sales.

laude. usque ego postera/crescam laude recens. multa proruet integrum|cum laude victorem dignum laude virum Musa vetat mori, haerentem capiti cum multa laude coronam. dignum pracstabo me etian pro laude merentis. munera. quae multa dantis cum laude tulerunt successit vetus his comoedia. non sine multallaude;

laudem. laudemque et optatum peractis/imperis decus adrogavit. vitavi denique culpam. Inon laudem nerui. praeter laudem nullius avaris.

lauderis, illis/accedas socius: laudes, lauderis ut absens.

laudes. cur tua plus laudes cumeris granaria nostris? illis |accedas socius: laudes, lauderis ut absens.

quo pacto, pessime?" laudas [latules]| fortunam et mores antiquac plebis.
Carm.3.27.26

Epod.4.3

Epot.10.3

Epod.1 1.22

Serm.1.2.103

Serm.1.3.59

Sirm.2.5.18

Serm.2.6.34

Epist.1.0.51

Epist.1.7.26

Epist.1.16.6

var.Carm.1.28.3

Serm.2.3.183

Serm.2.2.89

Ars Poet. 408

Epist.1.18.39

Epist.1.18.06

Carm.1.7.I

Carm.4.2.47

Epist.2.2.108

Curm.4.1.27

Carm.4.5.23

Epist.1.7.78

Epist.1.9.3

Epist.2.1.209

Serm.1.9.13

Serm.2.5.90

Serm.1.2.35

Carm.1.13.3

Serm.2.2.28

Sirm.2.2.33

Serm.2.7.22

Serm.2.7.30

Epist.1.9.1 2

Epist.I.II.0

Epist.1.20.4

Epist.1.7.37

Carm.I.I.I

Serm.1.1.9

Sierm.1.2.54

Serm.1.7.23

Sirm.2.0.78

Epist.1.11.13

Epist.2.1.6.t

Epist.2.1.So

Epist.2.2.I I

Serm.2.5.75

Ars Poct. 173

Ars Pott.433

Serm.I.2.II

Sirm.I.I 0.4

Epist.1.10.23

Serm.2.1.8.

Epod.11.10

Ars Poet.275

Corm.3.30.8

Carm.4.4.67

Cirm.4.8.28

Serm.1.10.49

Epist.1.7.24

Eipist.2.1.2.40

Ars Poel.282

Cirm.4. 14.39

Ars I'oet.208

Ars Pod.324

Sirm.2.5.72

Sierm. I. I.53

Sirm.2.5.72

Iar.Serm.2.7.22 
temperiem laudes.

laudes. laudes egregii Cacsaris ct tuas

redderet laudes tibi Vaticani|montis imago.

non... clarius indicant|laudes.

doctus et lho bi chorus et Dianac/dicere laudes.

Augusti luudes agnoscere possis;

laudet. laudet diversa sequentis?

potius laudet diversa sequentis

Fuscus et hace utinam Viscorum laudet uterque.

funus egregie factum laudet vicinia.

mea cur ingratus opuscula lector|laudet ametque domi.

ille dapes laudet mensac brevis.

laudetur. Romac laudetur Samos et Chios et Rhodos absens.

laudi. speravit magnac laudi fore.

laudibus. quid prius dicam solitis parentis/laudibus.

tos Tempe totidem tollite laudibus

laudibus arguitur vini vinosus Ilomerus;

laudis. laudis amore tumes:

aninum quod laudis avarum|subruit aut reficit.

laudo. bracchia et voltum teretesque suras/integer laudo: laudo manentem:

nec somnum plebis laudo satur altilium

cgo laudo ruris amoeri|rivos

nimirum hic ego sum; nam tuta et farvola laıdo,

laurea, tum spissa ramis lawea fervidos/excludet ictus.

laurea. lassea donandus Apollinari. .

Laurena. echinus aut Laurens aper.

aper. . nam Laurens malus est, ulvis et harundine pinguis.

laura. longaque fessum militia latus/depone sub lauru [lauro] mea ut premerer sacta|lauroque conlataque myrto mibi Jelphica / lauro cinge volens. Melpomene. comam. .

lauru. latus depone sub lauru mea

laurum. diadena tutum/deferens uni proprianugue laurum. morte venalem petiisse laurum

laurus. cui laurus aeternos honores/Delmatico peperit triumpho.

laus. laus illi debetur et a me gratia naior. principibut placuisse viris non ultima laus est.

laute. "it. ego accipiar laute.

lautis. lautia nauc senex manibus currebat

lavantes, sunt multi quique lavantes:

lavat. villacue. flavos quam Tiberis lavit [lavat,

lavatum. dum tu quadrante lavatum/rex ibis . ast ubi me fessm sol acrior ire lavatum/admonuit.

lavemur. crudi tumidique lavemur.

lavere. Heque dulci mala vino lavere

laverit. quando' Padus Matina laverit cacumina.

Laverna. labra novet metuens atuliri: "pulchra laverna.

lavimus. ore manueque tua lavinus. Feronia, lympla;

lavis. Phoebe, yuj Xantho lavis anne crinis.

lavisset. quo vifor ille peeles lavisset sisyphus aere.

lavit. villatgu, thavos quam libers is lavit.

yui tore" puro Castaliar lavel crinis solutos.

Photer. qui Xantho bvis // lavit] amne crinis [crines],

tuo'cruse rubroa obatetrix pannos lavit.

larit. simul unctos Tiberinis uneros laves in undis.

laro. Dims soltae laxo meditantur arculcedere campis.

te talos, Aille. mucesejuelfeise subu haxo.

"fui ian contento. iam laxo fune laborat."

laxus. male laxus in perle taberus hacret -

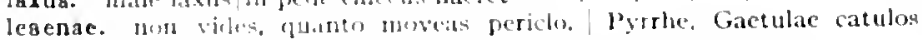
landine?

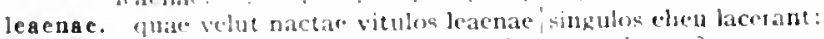

Lebedum. an l. rbelum lamdas odio maria atque viarum?

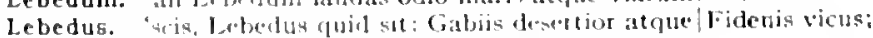

lecta. Jecta do pinguissinic/oliva tamis atborum

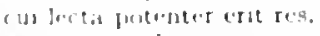

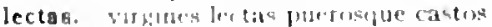

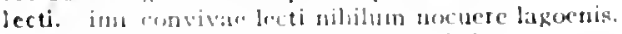
milolergast dosti sic nueum divitis horret.

Fpist.1.10.8

Carm.1.6.1 I

Carm.1.20.7

Carm.4.8.20

Carm.Sace.7e

Epist.1.16.29

Scrm.1.1.3

Serm.1.1.109

Serm.1.10.83

Serm.2.5.100

Epist.1.19.36

Ars Poet. 198

Fjist.1.11.21

Serm.2.3.99

Corm.1.12.14

Corm.1.21.9

Epist.t.19.0

Epist.1.1.36

Epist 2.1.179

Carm.2.4.22

Carm.3.29.53

I.pist.1.7.35

Epist.1.10.6

Epist.1.15.4.4

Carm.2.15.9

Carm.4.2.9

coni.Epod.5.28

Sorm.2.4.42

rar.Carm.2.7.10

Carm.3.4.19

Corm.3.30 10

Curm.2.7.19

Corm.2.2.22

Corm.3.1.4.2

Carm.2.1.15

Serm.1.0.88

Epist.1.17.35

Serm.2.5.67

Serm.2.3.282

Serm.1.7.75

sor.Carm.2.3.1s

Serm.1.3.137

Serm.1.0.125

Lepist.1.0.01

Curm?.122

Epod.10.28

Epist I. I 10.00

Scrm.1.5.2.4

Carm.t (1.26)

Serm.2.3.21

Corm.2.3.1s

Carm.3.4.0!

var.Carm.t. 1.20

Epod.17.51

Corm.312.7

Carm.3.8.23

Sorm.2.3.172

Sirm. 27.20

Serm. 1.3.31

Carm.3.202

Carm.3 11..1

Epistitato

EFit.I 11.7

Epoti.2.55

lest lecel to

Carmstiarion

Scrm.2.

1.pove1.18.15 


\section{LECTICA}

lectica. custodes, lectica, ciniflones, parasitae,

lectica. siquis lectica nitidam gestare amet agnam.

lectis. saepe tribus lectis videas cenare quaternos, . valvarum strepitus lectis excussit utrunque.

si potes Archiacis conviva recumbere lectis

lecto. aut alius casus lecto te adfixit,

lecto. vepallida lecto/desiliat mulier.

tum in lecto quoque videres

lecto. sunt cesta piacula, quae te/ter pure lecto poterunt recreare libello.

lecto. Jectolaut scripto quod me tacitum iuvet.

lector. inea cur ingratus opuscula lector/laudet ametque domi,

lectorem. lectorem delectando pariterque monendo.

lectori. verum age et his, qui se lectori credere malunt

lectoribus. contentus paucis lectoribus.

lectos. rubro ubi cocco/tincta super lectos canderet vestis cburnos

quid pauper? ride: mutat cenacula, lectos,

'nempe pecus, rem,| lectos, argentum : tollas licet.'

lectulus. cum lectulus aut me/porticus excepit,

lectum. conminxit lectum potus mensave catilum|Euandri manibus tritun deiecit:

hoc moriens pueris dixisse vocatis/ad lectum:

lectum. quocumque lectum nomine Massicum/servas,

lectum. an Catonis'nobile letum [lectum]:

lectus. lectus genialis in aula est:

Ledae. dicam et Alciden puerosque Ledae,

ledit. si te pulvis ... si laedit [ledit] caupona, Ferentinum ire jubebo:

legant. quin ossa legant herbasque nocentis.

legat. cum mea nemo|scripta legat

tabulas socero dabit atque/ut legat orabit;

legati. missi magnis de rebus uterque/legati,

legatum. nil sibi legatum praeter plorare suisque. .

lege. aequa lege Necessitas|sortitur insignis et imos.

beliicosis fata Quiritibus hac lege dico,

verba devolvit numerisque fertur|lege solutis.

prolisque novae feraci|lege marita.

hac lege in trutina ponetur eadem.

in vitium libertas excidit et vin/dignam lege regi: .

legem. quam temere in nosmet legem sancimus iniquan.

witra legem tendere opus:

legendo. quem vero arripuit, tenet occiditque legendo,

legendum. qui testamentum tradet tibi cumque legendum,

legentem. ut forte legentem laut tacitum inpellat quovis sermone:

legentibus. obturem patulas iupune legentibus auris.

legentis. dignum mente domoque legentis honesta Neronis,

legentis. quid vetat et nosmet Lucili scripta legentis

legere. atque alios legere, ad fastum quoscumque parentes / optaret sibi quisque.

legeret. quod legeret tereretque viritim publicus usus?

legerit. et qui nocturaus sacra divom legerit. ante gravem quae legerit arbore solem.

leges. inter cuncta leges et percontabere doctos,

leges. nec fortuitum spernere caespitem leges sinebant. quid leges sine moribus/vanae proficiunt. sed vetant leges Jovis.

leges. oppila coeperunt munire et ponere leges. Cervius iratus leges minitatur et urnam,

'qui consulta patrum, qui leges juraque servat.

laudet... iustitiam legesque et apertis otia portis; oppida moliri, leges incidere ligno.

leget. at qui tantuli eget [tanto leget] quanto est opus. multum Nasica negatas|accipiet tanden et tacitus leget sibi parcet / contractusque leget;

legi. iterum quae digna legi sint|scripturus, invat inmemorata ferentem |ingenuis oculisque legi manibusque teneri.

legibus. seu nalis vetita legibus alea.

siccat inaequalis calices conviva solutus|legibus insanis, . moribus ornes. |legibus emendes:

legio. quod mihi pareret legio Romana tribuno.

legionibus. olin qui magnis legionibus imperitarint,

\section{LEGIONIBVS}

Serm.1.2.98

Serm.2.3.214

Serm.1.4.86

Serm.2.0.112

Epist.1.5.r

Serm.1.1.8 I

Serm.1.2.129

Serm.2.8.77

Epist.1.1.37

Serm.1.6.122

Epist.1.19.35

Ars Poet.344

Epist.2.1.214

Serm.1.10.74

Serm.2.6.103

Epist.1.1.91

Epist.1.16.76

Serm.1.4.I33

Sirm.1.3.90

Strm.2.3.17I

Carm.3.21.5

var.Carm. 1.12.36

Epist.1.1.87

Carm.1.12.25

var. Epist.1.17.8

Serm.1.8.22

Serm.1.4.23

Serm.2.5.67

Serm.1.5.29

Serm.2.5.69

Carm.3.1.14

Carm 3.3.58

Carm.4.2.12

Carm.Salec.zo

Serm.I.3.72

Ars Poet.283

Sern.1.3.67

Sirm.2.1.2

Ars I'oel.475

Scrm.2.5.5I

Serm.1.3.0.4

Epist.2.2.105

Epist.1.9.1

Serm.1.10.56

Serm.1.0.95

Epist.2.1.92

Serm.1.3.117

Serm.2..1.23

Epist.1.18.06

Carm.2.I5.IS

Carm.3.2.4.35

Epod.17.69

Serm.1.3.105

Serm.2.1.47

Epist.1.10.41

Ars Pot'. 199

Ars Poct.390

qar.Sirm.1.1.5

Serm.2.5.68

Epist.1.7.12

Serm.1.10.72

Epist.1.19.34

Carm.3.24.58

Serm.2.6.69

Epist.2.1.3

Serm.1.0.19

Sirm.1.6.4 


\section{LEGIS}

legis. quem legis expertes Latinat Vimblici didicere

legit. quos neque pulcer|llermogenes umquam legit

legitimum. at pui legitimum cupiet fecisse poema,

legitimumque sonum digitis callenus et aure.

legum. agticolan laudat jutis legumque juritus,

incutiat tibi quit sanctarum inscitia legum:

lemures. nocturnoc lemures portentaque Thessala rides?

Learee. dulce periculum est. o Lenate.

lene. hon ante verso lene merum cado

lene. nume ad aquat lene caput sacrae.

vos lene consilium et datis ct dato/gaidetis, almae. zu lene tormentum ingenio armoves plerumque duro, quoniam vacuis conmittere venis|nil nisi lene decet: ad mate cum veni. generosum et lene rexuiro.

lene. nec male necne l,epos [nec male nec lene post] saltet:

lenes. lenesilue sub noctem susurti

leni. leni recreare vento

leni init Austrol captus,

leni. lliciecta non leni ruina

leni. leni pracordia mulso prolueris molius.

lenia. sectantem levia [lental nervi detutunt animinue;

leniat. ubi gratior aura leniat et rabiem Canis et momenta Leonis.

lenibus. til cede potentis amici beribus isuperits.

leniet. cum sale panis/latranten stomachum bene leniet.

lenimen. o bahorum dulce lenimen fmihicumpue salve|rite vocanti. .

lenior. Hatchta venict lenior hostia. Ienior et melior bis accelente senceta?

lenire. nollobus lenise verbis inpias. sunt vesta at reces, quibus lume lenire folotem possis

dictus ob hix lenire thres rabiblosque leones:

lenis. non lenis jrecibus rata recluelere

somnus agrestium letzis virurum

lenis incela abeasflue parvis|acruos alummis.

belbate prior, jacenten/bersis in howem.

urget enim dominus mentem non lenis

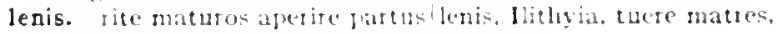

lenit. lenit albesectos animos a a jillus

lenite. inpium lenite clamormatales

leniter. Corberts. . Jenter atqerens caudarn

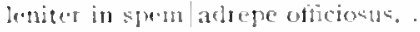

(u)ello preprotios putgantem leniter uneuis.

quá ratbone queas traducere lenter aevoum.

tenius. dammun ers, non farmas, mili pacto lenius isto.

lenius. Floc lenius ille, que meliot vit ist, longe subtilior illo,

leno. verba facit leno:

lenonis. llt patris attenti, lenonis ut insidioni.

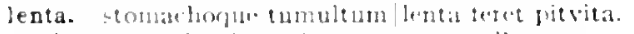

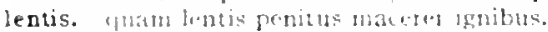

lentis. lubtu athaerens brachitio

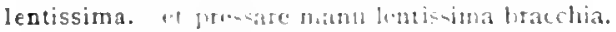

lento. atmataliesto temperet risu:

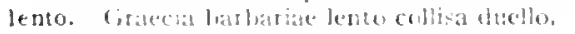

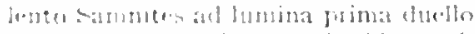

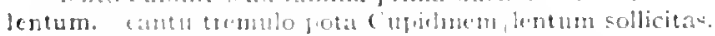

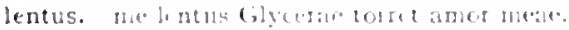

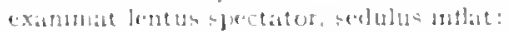

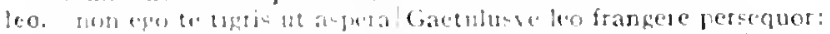

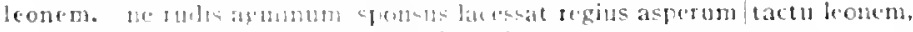

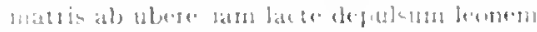

a)

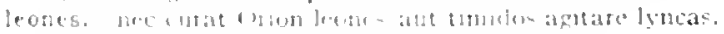

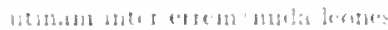

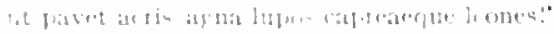

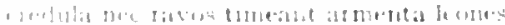

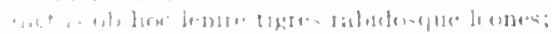

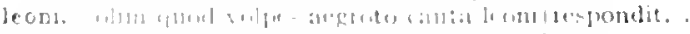

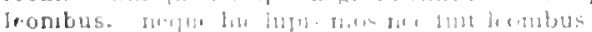

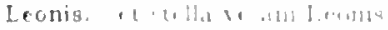

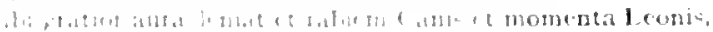

Carm.4.14.7

Serm.1.10.18

Epist.2.2.100

Ars l'oct.274

Scrm.1.1.0

Serm.2.1.81

Epist.2.2.209

Carm.3.25.19

Carm.3.29.2

Corm.1.1.22

Carm.3.4.41

Carm.3.21.13

Scrm.2.4.21

Epist.1.15.18

zor.Serth. 2.6.72

Carm.1.0.10

Carm.3.20.13

Serm.2.8.6

Carm.2.19.15

Serm.2.4.20

tar.dirs Poet.26

Epist.1.10.10

Epist.1.18.45

Serm.2.2.18

Carm.1.32.15

Corm.1.10.10

Epist.2.2.211

Epod.5.84

Epist.1.1.34

Ars Poil.zo3

Curm.1.2417

Carm,3.1 ?2

Carm.3.15.3

Carm.. sesec.52

Serm.2.7.03

Carmsariat

Carm.3.1425

Corm.1.27.7

Carm.2.19.30

Sorn.2.5.47

Epist.7.5!

Fopst.t.9.97

Epist.1.10.50

Serm.1.10.*3

Serm.2.3.231

Pfist.2.1.172

serm.2.2.70

Corm.3.13.8

Lfod. 15.4

Serm. 1.6.14

Carm.2.10.20

Epist.: 27

I. pist.2.2.08

Carm.1330

Carm.3.10.2S

Ifpist.2.1.8

Curmes 23.t口

Cormi 3.2 .14

Corm. 4.15

Serm.zis tse

(arm 2.1330

(i)rus.32752

Ifoutlaz

I. Arot. 10.3.3

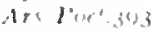

I. Port $1: 83$

1:pel 71

Carm $3=250$

I. prot thete 
leonis. insani leonis| vim stomacho adposuisse nostro.

Rhoetum retorsisti leonis|unguibus

leonum. nec I ubae tellus generat, leonum |arida nutrix,

lepido. scimus inurbanum lepido seponere dicto

Lepidum. collegam Lepidum quo duxit Lollius anno.

leporem. leporem citus|venator in campis nivalis

pavidumque leporem et advenam laqueo gruem / iucunda captat praemia.

leporem venator ut alta|in nive sectetur. .

leporem sectatus equove lassus ab indomito

lepores. tractus uter pluris lepores, uter educet apros;

leporis. fecundae leporis sapiens sectabitur armos.

leporum. et leporum avolsos, ut multo suavius, armos,

Lepos. nee male necne Lepos saltet; .

Lesbia. quae telLesbia quaerenti taurum monstravit inertem.

Lesbia. et Chia vina aut Lesbia

Lesbii. hic innocertis pocula Lesbii .

Lesbio. Lesbio primum modulate civi.

Lesbio. hunc Lesbio sacrare plectro.

Lesbium. Lesbium servate pedem meique|pollicis ictun

Lesbos. quid tibi visa Chios, Bullati, notaque Lesbos, .

Lesboum. nec Polyhymnia|Lesboum refugit tendere barbiton.

letas. quo Sibyllini monuere versus | virgines lectas [letas]... dicere carmen.

Lethaea. nec Lethaea valet Theseus abrumpere caro|vincula Perithoo.

Letbaeos. pocula Lethaeos ut si ducentia somnos

lethargicus. ut lethargicus hic cum fit pugil et medicun urget.'

letbargo. quondam lethargo grandi est oppressus. .

Leti. necessitas|Leti corripuit gradum:

leti. sed onnis una manet nox et calcanda semel via leti. inprovisa leti|vis rapuit rapietque gentis.

neque ulla est /aut magno aut parvo leti fuga:

leto. ter vocata audis adimisque leto./diva triformis. sive te rupes et acuta leto|saxa delectant. .

leto. peiusque leto flagitium timet.

letum. an superbos/Tarquini fascis, dubito, an Catonis| nobile letum:

Leuconoe. quem mili, quem tibi|ñem di dederint, Leuconoe.

leva. quibus oblitus actor | cum stetit in scaena, concurrit dextera laevae [leva].

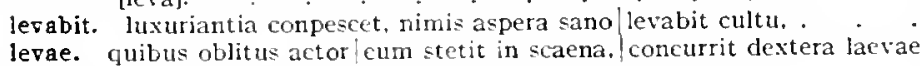
[levae].

levant. multa fidem promissa levant.

lerantes. condita post frumenta levantes tempore festo/corpus

levantia. volnus nil malum levantia,

levare. hic levare functum | pauperem laboribus levare diris pectora sollicitudinibus, neque est|levare tenta spiritu praccordia. .

levarit. casus medicusve levarit/aegrum ex praecipiti: cum te servitio longo curaque levarit.

lerasset. nisi Faunus ictum|dextra levasset.

levat. multa Dircaeum levat aura cycnum.

qui salutari levat arte fessos/corporis artus.

cuid te exempta iuvat [levat] spinis de pluribus una?

levata. Simul imis saxa renarint valis levata.

levato. illic omme malum vino cantuque levato,

leve. (puer hic non laere [leve] iussa Philippi|accipiebat)

lere. sic leve, sic parrom est, animn quod laudis avarum|subruit .

leve. externi nequid valeat per leve morari.

levem. "etenim fateor me" dixerit ill." "luci ventre leven.

levem. virgaque levem coerces aurea turbam.

leres. Aympharumeue leves cum Satyriz chori non praeter solitum leves.

leves. me pascunt olivae! me cichorca levesque malvae. quem iuvat clamor galeaeque leves

nascunturque leves| per digitos umerosque plumae.

levet. nil audire velim, nil discere, quod levet aegrum;

Levi. non equiden insector drlendave catmina Livi [Levi] iesse reor. .

levi. et spondere levi pro paupere

leri. seu fidibus citharare Phoebi [levi]. .
Carm.1.16.I 5

Carm.2.19.23

Carm.1.22.15

Ars Poct.273

Epist.1.20.28

Carm.1.37.18

Epod.2.35

Serm.1.2.105

Sirm.2.2.9

Epist.I.15.22

Serm.2.4.4.4

Serm.2.8.89

Sorm.2.0.72

Epod.I2.I 7

Epod.9.34

Carm.1.I7.2 I

Carm.1.32.5

Carm.1.20.1 I

Carm.4.6.35

Epist.I.II.I

Carm.1.1.3.

sar.Carm.Saec.6

Carm.4.7.27

Epod.1.4.3

Sirm.2.3.30

Serm.2.3.1. 95

Carm.1.3.33

Carm.1.28. In

Carm.2.13.19

Serm.2.0.95

Carm.3.22.3

Carm.3.27.0I

Carm.4.9.50

Carm.1.12.36

Carm.I.II.2

2ar.Epist.2. 1.205

Epist.2.2.123

zar.Epist.2.1.205

Epist.2.2.10

Epist.2.1.I.to

Epod.I I.IT

Carm.2.18.38

Etod.13.10

Epod.17.2\%

Serm.2.3 292

Serm.2.5.99

Corm.2.17.20

Carm.4.2.25

Carm.Sac6.03

var.Epist.2.2.2I 2

Epod.10.20

Epol.13.17

qar.Epist.1.7.52

Epist.2.1.179

Serm.2.7.87

Sirm.2.7.38

Carm.t.I0.Is

Carm.1.1.3I

Corm.1.0.20

Cirm.1.31.Io

Carm.1.2.35

Carm.2.20.II

Epist.r.8.s

i'ar. ISpist.2.1.09

Ars 1'oct.123

iar. Carm.3.4.4 
aut anite levi rara tendit retia

levi. (puer hic non laeve [levi] iussa thilippi laccipiebat)

levi. Carmina fingil posse linenda cedro et levi servanda cupresso?

leri. Fracka qual ego ipse testalconditum levi,

levia. Visicae cubantis levia personuere saxa.

ublivioso levia Massico/ciboria exple.

aectantem levia nervi|deficiunt animique;

levior. tu levior contice et inprobolitacundior Hadria:

leviota. tralidit fessin leviora tolli|lergama Grais. num ud l'omponius istis! audiret leviora, pater si viveret?

leviore. guare modos leviore plectro.

leris. :monet Sithoniis non levis Euhius. agrostm pepulere, domo levis exsilit:

Romar Ius optas; absentem rusticus V'rbem/tollis ad astra levis matarat mentem populus levis.

levis. nurn desiderium euraque non levis,

:Hbls in solo levis angiportu

lewis una mors est! virginum eulpae.

nontibus altialevis crepante lympla desilit pede.

Jenis hato insania quantas' virtutes habeat.

levis. $a^{*}$ levis somnos timor aut eupido/sordidus aufert

colriso: guod invitet levis.

ctontre levis indigna tragerdia versus,

leris. mathe levis spes et certamina divitiarum

levis. "metque alsa levis bircus aequora."

levis. Matitro levis inventas et decor

levis. Hangia defurle decus Camenae, levis Agyien.

leviter. Inviter curar viletur, iquo promisat cadont

levius. durn" sed levius fit patientia

tan:o bovius mizer ac ptior ille

alle super, dictis yuod non levius viteat:

I soltus tibi monstrata radice vel herba' non fieret levius.

lex. mo- et lex maculosim edomuit nefas.

Rocia, dic sorfes, meliot lex an puerorum est |nenia.

ginn eeiam lex/poenague lata.

fruten emisti viosum, dicta tibi est lex:

1:-dens emisti vitiosun, dicta tibi est hex [est dicta tibi lex]:

prulfone emiati vitionum, dicta tibi est Jex [dicta tibi lex est]:

fort lens emtati vitiosum, dicta tibi eat les [dicta es: tibi lex]:

infule prodem proterre pudor vetet aut operis lex.

lex es: accepta chorusque turpiter obticuit

liba. "Lif10 sacerdotis fugitivo liba recuso

libatis. vernarne frocacis/pasco libatis dapibus.

libeat. lomatura croni, si lib.at, sonum.

libelli. sund libelli Stoici inter Suricos iacere pubillos amant.

libellis. ortumque libullis selulu inportes opura vehemente minister.

libellis. Gildus acet ambulat et Cuprus, ratei male cumque libellis.

libelio. i. muer. at que meo citua hase subacribe libello.

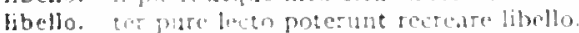

libellos. nuthe taberna meos trabeat neque pila litullos. conde gatrite libullos

libens. Jihenc inanientem navita Bosporum'engutabo

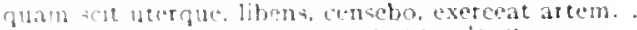

libenter. libenter hoc ot omne inilitabitur 'bellum

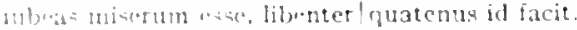

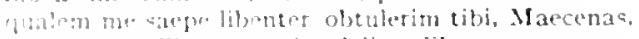

18 jig vom illorum patiar relicta libenter

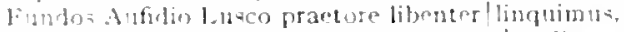

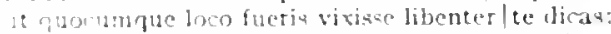

libentius. Matutino patco, seu lan" libentius audia.

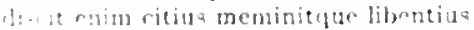

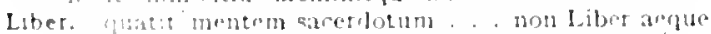

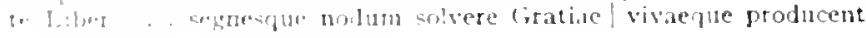
Ihringian,

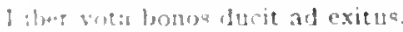

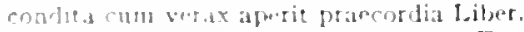

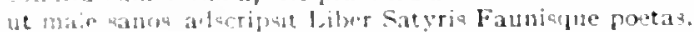

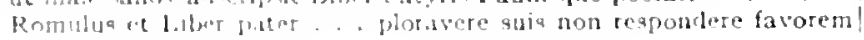
erintulum moritlo
Epod.2.33

iar. EPist.1.7.5:

Ars Poll.332

Carm.1.20.3

Carm.1.17.12

Carm.2.7.2I

Ars l'o(t.26)

Curm.30.22

Corm.2.1.11

Serm.1. +53

Carm.2.1.10

Carm.1.18.9

Serm.2.6.08

Serm.2.7.29

Epist.2.1 IOS

Carm.1.I.1 8

Corm.t.25 I0

Carm.3.27.37

I.pod.16.48

Epist.2. I. I 8

Corm.2.16.15

Epod. 2.28

lirs loot.23I

Epist.1.5.8

Fpod.10.34

Carm.2.11.0

Corm.4.0.28

IEpist.2.1.5 I

Carm.1.24.19

Serm.2.7.10

Serm.2.7.78

Epist.2.2.150

Curn.4.5.22

Epist.1.1.02

Epist.2.1.152

Epist.2.2.1s

lar. Epist.2.2.18

ar.lepist.2.2.18

ar.lipist.2.2.18

Ars Poct.135

Ars Poet.283

IPtist.1.10.I0

Sirm.2.0.67

Carm.4.3.2)

Ispolis.15

Iipist 1.13.4

sermetaton

Sornil1.10.92

Epist.1.1.37

Cermitit I

storm.1.10.4I

Carm.3.4.29

Epist.1.144t

Epol. 1.23

Serm.1 1.03

Serm.1.3.13

Serm 1 3.14:

Serm 1.5.34

I.pist.1.1.2:

Sirme 2.t.20

Epist.2.1.2†2

Carmint?

Curm 3.21.21

Cism.4.8.34

Serm.t.4 So

IEpist.1.10.4

Ipist. 21.5 
Liber. neque te sitebo, |Liber enhoe, parce Liber, .

liber. at est truculentior atque / plus aequo liber:

Carm. [.12.22

Carm.2.19.7

Sirm.1.3.52

lic tibi comis et urbanus liberque videtur.

longa aetas, liber anicus, /consilium proprium:

quisnam igitur liber? sapiens, sibi qui imperiosus.

Serm.1.4.90

Serm.1.4.132

Sirm.2.7.8.3

"liber liber sum," dic age.

sapiens . . liber, honoratus, pulcer, rex denique regum,

qui metuens vivet, liber mihi non erit umquam.

Serm.2.7.92

Epist.1.1.107

Epist.1.16.06

Ars I'oet.2 I 2

indoctus quid enim saperet liberque laborum |rusticus " nimorim

Ars $P^{3}$ oet. 383

liber. hic meret aera liber Sosiis, hic et mare transit

liber. Vortumaum lanumque, liber, spectare videris.

libera. 'quodsi meis inaestuet praecordis/libera bilis.

libera. non amicorum queant|libera consilia nec contumeliae graves.

libera per vacuom posui vestigia princeps.

et iuvenum curas et libera vina referre - -

liberae. devota morti pectora liberae

liberas. liberas|frugez et Cererem ferunt

liberat. neque enim temebris Diana pudicum/liberat Hippolytum

Liberi. ac ne quis modici transiliat munera Liberi. inter iocosi munera Liberi

liberi. sarrum liberi Cupidinis.

liberior. qui melior servo qui liberior sit al"arus,

liberius. liberiu\& si|dixero quid, si forte jocosius,

vel quod maledicunt liberius

Libero. voveram dulcis epulas et album | I ibero caprun

libero. munc pede liberolpulsanda tellus;

libero. retorta tergo bracchia libern.

liberas. puodsi pudica mulier in partem ilvet $\mid$ domum atcue dulcis liberos.

per liberos te. si vocata partubus|Lucina veris adfuit.

liberrima. ut ora vertat huc et huc euntium/liberrima indignatio?

liberrima. neclotia divitis Arabum liberrima muto.

liberrime. tnetues, liberrime Lolli, / scurrantis speciem prabere.

liberta. at hunc liberta securi|divisit medium, fortissima Tyndaridarum. .

libertas. dum volt libertas dici mera veraque virtus.

libertasque recurrentis accepta per amos|lusit amabiliter, in vitium libertas excidit et vim|dignam lege regi:

Ars Poit. 345

Epist.1.20. I

Epot II.IÓ

Epod.1 I.26

Epist.1.19.2I

Ars Poel.s.5

Curm.t.I4.18

Carm.3.2.1.12

Citrm.4.7.26

Carm 1.18 .7

Carm.4.15.20

Epol. 7.57

Epist.1.10.03

Serm.1.4.103

Serm.2.8.37

Carm-3.8.7

Carm.1.37.I

Carm.3.5.22

Epod.2.to

Epod.5.5

Epod.1.10

Efrist.1.7.30

Epin!.I.IS.I

Serm.1.1.99

Epist.1. I 8.8

Epist.2.1.147

Ars 'oet.282

Serm 1.4 .5

Serm.2.7.4

Epist.1.10.40 qui pauperiem veritus potiore metallis/libertate caret.

libertiaa. grata detinuit compede Myrtale/libertina. me libertina, nee uno contenta. Phryne macerat.

libertinarum. in classe secunda.|libertinarum dico.

libertino. ignotos ut me libertino patre natum. nunc ad me redeo libertino patre natum. quem rodunt omnes libertino patre natum. me libertino natum patre et in tenui re. . loqueris,

libertinus. "libertinus erat, qui ... currebat unde mundior exiret vix libertinus honeste;

libertus. filius aut etiam haec libertus ut ebibat heres. . libertusve senem delirum temperet.

Liberum. Liberum et MI Sas Venerenque. . . canebat pressum Calibus ducere Liberum/si gestis.

liberum. Fortunae te responsare superbae/liberum et erectum

liberum. liberum munivit iter, daturus/plura relictis:

libet. sive flamma sive mari libet Hadriano. ut mihi devio|ripas et vacuom nemus|mirari libet. libet iacere modo sub antiqua ilice. nunc mihi eurto|ire licet mulo vel si libet usque Tarentum. "dum nequid simile huic, esto ut libet." cui libet hic fascis dabit "ut libet: hace porcis hodie comedends relinques." scitari libet ex ipso quadcunque reters:

"sic ignovisse putato me tibi, si cenas hodie mecum." "ut libet."

Carm.2.33.15

Epod.1.1. 5

Serm. [.2.45

Serm. I.0.0

Sermation.45

Serm.t.190

Epist.1.20.20

Sirm.2.3.28 I

Sirm.2.7.12

Serm.2.3.122

Sirm.2.5.7 I

Carm.1.32.0

Carm.4.12.14

Epist.1.1.09

Carm.Saec.43

Carm.1.10.4

Carm.3.25.14

Iepord.2.23

Serm.1.6.105

Serm.2.3.3 I

Epist.1.6.53

Epist.1.7.19

Epist.1.7.60

Epist.1.7.70

Epod.10.30

Epist. I.2.15 libidine... Iliacos intra muros peccatur .

libidines. male barbaras/regum est ulta libidines.

Carm.4.I 2.8 
libidinibus. altercante libidinibus temis osta javore.

libidinis. non de fuisse masculate hbidinis.

libidinosus. libjelinosus immolabitur caper

libidinum. cun fas atque nefas exiguo tine libidinum/discernunt avidi.

libido. cun tibi tlagrans amor et libiclo.

nam simul ac venas intlavit tactra libido.

quacumplue libido est. fincedo solus;

frout cuique libido est.

cui si vtios libidolfecerit auspicium,

fret quae isescete res posset, minui dannosa libido.

Libitina. miraturque nihil nisi quod I ibitina sacravit.

Libitinae. antumnusque gravis. libitinac quaestus acerbae.

Libitinam. Inultacue pars mei|vitabit I.ibitinam;

libo. ni] ego, si ducot libo fumante:

Libonis. formm putealque Libonis/mandabo siccis.

Libra. seu libna seu ne Scorpios adspicit

libra. cui satis una/tarris libra loret.

libra. si froptium e.st, quod quis libra nercatus et aese est.

librarius. He seriptor si peccat idem hbrarius usque.

libris. jle vilut firtis arcana sodalibus olim crodebat libris -tudiis annos sefutem dedit insenuitgue libris et curis.

libris. apuis fuem fama est exe librisque ambustum promis. nunc veterum libris, nune somno de inertibus horis .

si munus Apolline dignum vis complere libtis

librorum. tre forte sub ala faciculum portes librorum. -it bona librorum et provisac frugis in anmum copia

labros. coempros undic|ue nobili libros Panact $i$

per atque libses carminum valentiom.

fentiticum hbros, anmosa volumina vatum dictice.

ruodsi iudiu iun . . . illud, ad libros et ad hace Musarum dona vocares

librum. ni poses ante dien librum cum lumine.

cum tibi librum|sollicito damus ant fesso:

sti tabulae tore librum, persinilem.

Liburnis. saevis J iburnis scificet invidens prisata deduei

Liburnis. ibis libunis inter ata navium. antice, mopugnacula.

Libya. qui servos proicere aurmm in media iussit Libya.

Libyam. quan si l.dbyan renotis|Cadibu- inngas

Libycis. deterins Libycis olet aut nitet hesba lapillis?

Libycis. guirleudel de Libyein vertitur areis.

liceat. 'tultum me fateor (lichat concedere veris) sit ins licuatque perite poctis:

licebit. licebut injecto ter pulvere curras.

sis pecore ct multa dives tellute licebit

(licebit ille sepotia. . . chlebset)

- iso consuluse et mox respondere licebie?"

quandnfue licebit . . Alucere sollicine iucundas oblivia vitac?

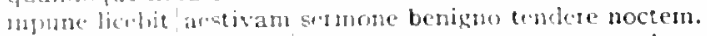

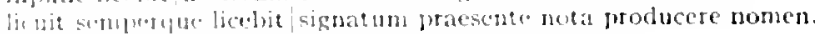

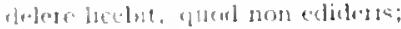

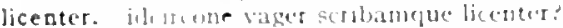

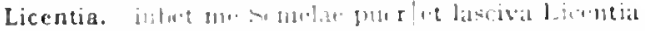

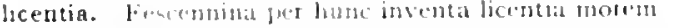

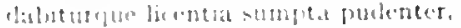

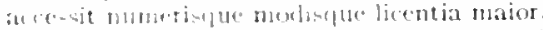

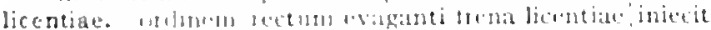

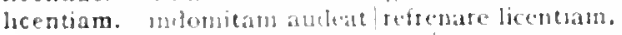

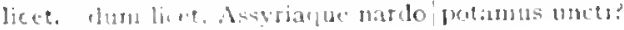

ranilentin liciet occupes

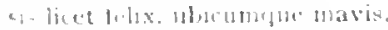

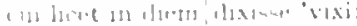

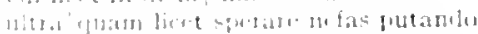

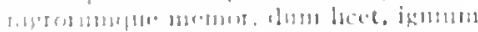

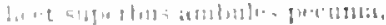

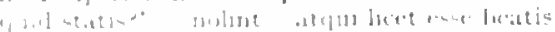

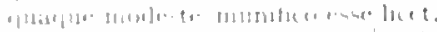

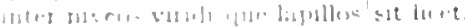

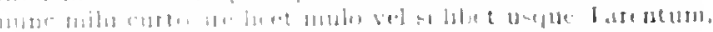

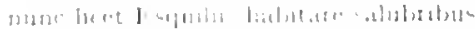

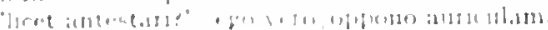

Serm.2.7.57

Epod.5.4I

lipod.10.23

Corm.1.18.10

Carm.1.25.13

Serm.1.2.33

Serm.1.0.111

Serm.2.0.07

Episf.1.1.85

Epist.2.1.107

Epist.2.1.49

Serm.2.0.19

Carm.3.30.7

Sorm.2.7.102

Epist.1.19.8

Carm.2.17.17

Setm.1.5.69

Lpist.2.2.158

Ars Pod.354

Serm.2.1.3I

Efist.2.2.83

Serm.1.10.63

Scrm.2.6.01

Lepist.2.1.217

Epist.1.13.13

Epist.1.18.100

Carm.1.29.14

Epod.17.4

List.2.1.26

Epist.2.1.243

IEpist.1.2.35

Epist.2.1.220

Ars loces

Carm.1.37 30

Epodi.1

Sorm.2.3.101

Ciarm.2.2.10

Lepist.1.10.19

Carmit.1.10

Serm.2.3.305

dirs loeldou

Carm.1.28.35

IEpod.15.19

Serm 2.2.50

Serm.2.3.192

Serm.2.0.00

Epist.1.5.I0

Ars loet 58

Ars l'oct.3so

Ars lod 205

Carm.1.19.3

Leis!.2.1. 145

Ars Podts 1

Ars l'vet.211

Carm.u.15.10

Carm.3.2.120

(arm.2.11.10

Carm.324.3

Corm.3.27.8.3

Corm. $3=942$

Curm.4.11.31

Carm..12120

L pold. 45

crmit 1.10

herm.1.2.5l

serm.t.2.s1

Serm b.1.10

Sermi : S.1.4

sorma 9 ju 
"quid tamen ista velit sibi fabula, si licet, ede." .

dum licet, in rebus iucundis vive beatus.

licet sub paupere tecto/reges et regum vita praecurrere amicos.

dum licet ac voltum servat Fortuna benignum,

nempe pecus, rem, lectos, argentum: tollas licet."

licet illi plurima manet / lacrima.

licet 'succurrite" longum/clamet "io cives,"

Licini. tectius vives, Licini, neque altum/semper urgendo

Licino. si tribus Anticyris caput insamabile numquam / tonsori Licino conmiserit.

lictor. neque consularis $\mid$ submovet lictor miseros tumultus $\mid$ mentis

lictoribus. dissignatorem decorat lictoribus atris,

licuisse. unius assis|non umquam pretio pluris licuisse.

licuit. licuit semperque licebit|signatum praesente nota producere nomen.

Licymniae. me dulcis dominae Musa Licymriae/cantus, . . . voluit dicere permutare velis crine Licymniae

ligatur. dun aes exigitur, dum mula ligatur. / tota abit lora.

ligna. dissolve frigus ligna super focollatge teponens

tectum / praebuit et parochi, quae debent, ligna salenque.

in silvain non ligna feras insarius

virtutem verba putas et|lucum ligna:

lignis. sacrum vetustis exstruat lignis focum

emptis/sub noctem gelidam lignis calefactat atnum;

ligno. oppida moliri, leges incidere ligno.

lignorum. invidet usum|lignorum et pecoris tibi calo argutus

lignum. olim truncus eram ficulnus, inutile lignum,

duceris ut nervis alienis mobile lignum.

lignum. dum potes, aridum / conpone lignum:

lignum. agto qui statuit meo|te, triste lignum,

ligonibus. Sabellis docta ligonibus/versare glaebas

ligonibus duris humum |exhauriebat,

urges iampridem non tacta ligonibus arva

Ligurine. sed cur heu, Ligurine, cur|manat rara . . lacrima Ligurine, in faciem verterit hispidam,

Ligurinum. mutatus, Ligurine, [mutatus Ligurinum] in faciem verterit hispidam,

ligurrierat. patinam qui tollere iussus|senesos piscis tepidunque ligurrierit [? ligurtierat] ius,

ligurrierit. semesos piscis tepidunque ligurrierit ius,

ligurrit. puer unctis/tractavit calicem manibus, dun furta ligurrit.

lilium. neu desint epulis rosae neu vivax apium neu breve liliun.

limae. si non offenderet unum quemque poetarum limae labor et mora.

limat. non istic obliquo oculo mea commoda quisquan|limat,

limatior. fuerit limatior idem ! quam rudiset Graecis intacticarminis auctor

limen. nec tibi somnos adimunt amatque/ianua linen,

nutricis extra limina Pulliae [linen Apuliae]

intra marmoreum venerandi limen amici,

laudet ametque domi, premat extra limen iniquos.

limina. nutricis extra limina Pulliae.

forumque vitat et superba civium|potentiorum linina. .

linina dura, quibus lumbos et infregi latus.

limine. dun flamna sine tura liquescere limine sacrolpersuadere cupit.

liminis. non hoc semper erit liminis aut aquae/caelestis patiens latus.

limis. ut limis rapias, quid prima secusdo/cera velit versu;

limitem. Et ultra limites [linitem] clientium|salis avarus? .

limites. ultra linites clientium/salis avarus?

limitibus. qua populus adsita certis|lintitibus vicina refugit iurgia;

limo. Prometleus addere principi|limo coactus particulan.

limo. is neque limo turbatam laurit aquan

limum. columbino limum bene colligit ovo.

limus. sive gravis veteri craterac linus adhacit.

linea. mors ultima linea rerun est.

linenda. carmina fingi|pose linenda celro

lingua. inter ver ba cadit lingua silentio!

virtus et favor et lingua potentium] vatum

est aninus tibi, sunt mores tet lingua fidesque.

rupit Iarbitam Timagenis aemula lingun.

cum lingua Catonis et Enni|sermonem patrium ditaverit

lingua. at sermo lingua concinnus utraque/suavior.
Serm.2.5.6 I

Serm.2.6.96

Epist. 1.10 .32

Epist.1.11.20

Epist.1.10.70

Epist.I.17.59

Ars Poit. 459

Carm.2.10.1

Ars Poel.30I

Carm.2.16.10

Epist.1.7.0

Serm.1.6.17

Ars Poct. 58

Carm.2.12.13

Carm.2.12.23

Serm.1.5.13

Carm.1.9.5

Serm.1.5.46

Serm.1.10.34

Epist.1.6.32

Epod.2.43

Epist.2.2.169

Ars Poit. 399

Episl.I.I $4.4^{2}$

Serm.I.S.I

Serm.2.7.82

Carm.3.17.14

Carm.2.13.11

Carm.3.0.38

Epod.5.30

Epist.1.14.27

Carm.4.1.33

coni.Carm.4.10.5

2ar.Carm.4.10.5

? zar.Serm.1.3.8 I

Serm.1.3.81

Serm.2.4.79

Carm.1.30.16

Ars Poet.29I

Epist.1.14.38

Sirm.1.10.05

Carm.1.25.4

F'ar.Carm.3.4. Io

Epist.1.18.73

Epist.1.19.30

Carm.3.4.10

Epod.2.8

Epod.11.22

Sirm.1.5.90

Carm.3.10.19

Serm.2.5.53

tar.Carm.2.18.25

Carm.2.18.25

Epist.2.2.171

Carm.r.Iont

Serm.1.1.59

Serm.2.4.50

Sirm.2..1.80

Epist.1.10.79

Ars I'vel. 332

Curm.4.1.30

Carm.4.8.20

Epist.1.1.58

Epist.1.10.15

Ars Poet.50

Serm.1.10.23 
fundet opes l.atimuge beabit divite lingua: poit elfert animi motus interprece lingua. nec virtute foret clarisve potentius armis/quam lingua Latium.

linguae. docte sermones utriusque linguae?

'xanimari metuentis patruae verbera linguae. proles X゙́obea nagnae|vindicen linguae Tityosque raptor|sensit rluctor connes fieliodorus, / Graecorum longe [linguae] doctissimus;

linguam. seu linguan causis acuis

linguis. forete linguis: carmina non priuslaudita

lino. integrum perdunt lino vitiata saporen.

linquar. precibus non linquar inultis.

linque. dona prasentis cape laetus horae ac)/linque severa.

linquenda. linquenda tellus et domus et placens/uxor

linquere. transfuga divitum/partis linquere gestio.

linquimus. quid intactum nefasti/liquimus [linquimus]?

I.umlos Aufidio l.ueco practore libenter linquimus.

linquis. utcumque mutata potentis/veste domos inimica linquis.

linquit. fugit inprobus ac me/sub cultro linquit.

lintea. non tibi sunt integra lintea.

impellunt animae lintea Thraciae.

linsea. neu conversa domum pigeat dase lintea.

lintrem. nil cum procedere lintrem/sentimus, .

lintres. partitur lintres exercitus.

linum. columbino limum [linum] bene colligit ovo.

linunt. fere seriptores carminc foedo/ splendida facta linunt.

Liparaei. studium autert. Neobute, Liparaei nitor Jlebri.

lippi. ne me Crispini sctinia lippilconpilasse putes.

lippis. namque pila lippis inimicum et ludere crudis.

omaibus et hppis notum et consoribus este.

lippum. we me Crispini serinia lippi [lippun]/ conpilasse putes. verbum non amplius addinn.

ut lippun pictae tabulae, fomenta podagrum.

lippus. cum twa pervideas oculis mala lippus inumetis

lic oculis ego nigra meis collyria lippus! inlinere:

mon ramen illitco contommas lippus inungui;

liquere. nil intemptatum nostri liquere poetat:

liques. appias, vina liques et spatio brevi spem longam reseces.

Caccubun ef prelo domitam Calenoltu bibes [liques] uram:

liquescere. Aum flammat sine turat liquescere limine sacrolpersuadere cupit.

liqui. impuden liqui patrios Penates.

liquidae. reu rour supinum seu lirpidae placuere Baiae.

liquidam. Melpomene, cui liquidam pater/vocem cum cithara dedit.

liquidi. ue tibi si sit opus liquidi non amplius urma

quem bibulum linuidi media de luce Falerni:

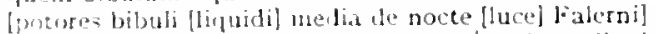

jiquidis. quis andeta gracilis te puer in rosal perfusus liquidis urget odoribus

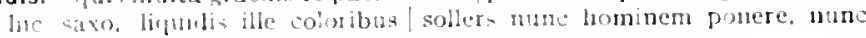
1. 11 iाt

liquidum. necerorus/uncus abest liquidumque plambum;

liquidum. biformis per liquirjum acthera vates

liquidus. ut te confestin liquidus Fottunate rivos inauret.

venenget liquirlus puroque similtimus amni

verums et licpilus [et vehemeni liquidus] puroque simillimus ammi

liquimus. geil intactum nofantiliquinus?

liquor. qua melioliquor|secernit Europen ab Afro.

liquorem. risid orat de" patera novon fundens liquorem?

Lirim. mincepi et inmantem Marbar!litoribus tenuise Lirim.

Liris. non rura, quae Liris queta! mordet aqua taciturnus amnis.

lis. Hitumatici certant et alluc sub iudice lis est.

lite. nogetial hiudicata lite selingucret

nil agrt excmplum, litem quod lite resolvit.

marperis tamen hunc et hte mosaris iniqua? -

litem. delwebat, guol ni fecisect, purblere liten.

ni , agt examplum, litem quod lite resolvit.

Ltes. (fur) multin* magnaeque secantur iudice lites.

litubus. ioreiv Augurer reditu forumpelitibus orbum

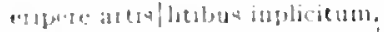

hegiosus. montens. nivi htırosus. |exciperet dominua,

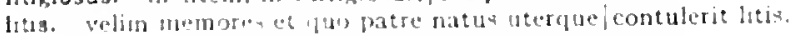

Epist.2.2.12 I

Ars Pod.tII

Ars Poct. 290

Carm.3.8.5

Carm.3.12.3

Cism.4.6.2

sur Serm.1.5.3

lipist.1.3.23

Carm.3.1.2

Serm.2.4.54

Carm.1.28.33

Curm.3.8.28

Corm.2.1.2.2I

Curm.3.16.24

gar.Carm. $1.35 \cdot 36$

Serm.1.5.35

Carm.1.35.2.4

Serm.1.9.74

Carm.1.14.0

Curm.1.12.2

Epod.10.27

Serm.1.5.20

Epist.1.18.01

iur.Sirm.2.4.56

Epist.2.1.237

Carm.3.12.0

Serm.1.1.120

Serm.1.5.49

Serm.1.7.3

coniserm.1.1.120

Lpist.1.2.52

Sirm.1.3.25

Serm.1.5.30

Epist.1.1.20

-Irs Poet.285

Carm.1.11.6

coni.Carm.1.20.I?

Serm.1.5.99

Ciarm.3.27.49

Carm.3.4.24

Carm.1.24.3

Serm.1.1.54

Epist.1.1434

coni.Epist.1.19.9:

(arm.1.5.2

Carm.t.8.7

Carm.1.35.20

(iarm.2.20.2

Epist.1.12.0

Epist.2.2. 20

var. Epist.2.2.120

Curvi.1.35.3"

Curm.3.3.4"

Carm.1.313

Curm.3.17.8

Carm.1.31.7

ars loct.7s

Carm.3.5.54

Serm.2.3.103

LPist 2.219

Sirm.1.0.37

ficrm.2.3.103

EDist.1.10.42

Corm.t.2.4.

Ars l'ort.d2.4

fierm. 2.3.285

Sorm.1.5.54 
etiam litis cum Rege molestas.

Nestor conponere litis/inter Peliden festinat et inter Atriden.

Serm.1.7.5

Epist.1.2.I I

Carm.3.1.4.26

Carm.2.18.21

Carm.2.20.14

Epod.16.40

Epod.16.63

Carm.1.2.14

Carm.1.32.8

Carm.4.5.14

Epod.10.2I

Serm.2.3.205

Carm.3.17.8

Carm.3.4.32

Epist.2.2.7

Carm.2.1.18

Carm.1.1.23

Ars Poet.293

Epist.2.1.167

zar.Carm.1.28.3

Carm.2.10.4

Carm.3.17.10

Carm.Saec. 38

Epist.2.1.62

Epist.2.1.69

Carm.1.8.10

Carm-4.9.33

Epod.5.47

Carm.2.5.10

Serm.I.4.93

Epist.2.1.89

iar. Epist.2.1.60

Carm.1.22.7

Epist.1.17.28

Epist.2.1.223

Ars Poct.298

Serm. I.8.9

Carm.2.I8. I8

Serm.2.6.100

Epod. 5.68

Ars Pott.3I9

Carm.4.12.28

Epod.11.1t

Scrm.2.7.64

Epist.1.7.57

Epist.I.II 24

Epist.I.12.25

Epist.2.2.30

Epist.2.2.46

Epist.2.2.113

Epist.2.2.203

Carm.1.3\$.3

Epist.1.3.34

Sorm.I.3.I7

Serm.1.0.74

Serm.2.3 It

Epist.1.1.56

Epist.2.I.I.5

Serm.1.8.I8

var.Epist.1.7.57

Epist.I.IO.I4

Epist. I.I4.I2

Epist.1.10.67

Ars Poet.92

ar. Ars Poct.222

Carm.2.I8.22

Serm.2.3.03

locuples. parum locuples continente ripa; forte ninus locuples uno quadrante perisset. 
vivet uner locuples sine gnatis.

Serm.2.5.28

locuplea, quesn ducit priva triremis.

Epist.1.1.03

mancuptiv locuples eget aeris Cappadocur tex:

Epist.1.0.39

Serm.2.6.102

Fpist.1.7.15

locupletem. tu me fecisti locupletem:

infu-trat "t pacern et locupletem frugibus annum:

Epist.2.1.137

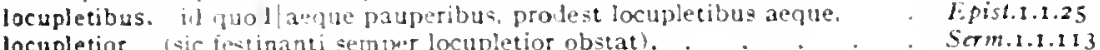

locupletior (sic fextinanti semjuer locupletior obstat).

Carm. 2.6.21

locus. ille te mecum locus et beatae postulant arces:

Sorm.1.4.15

detur nubis locua, hora icustoles:

- Hitre locus voci reionat conclusus.

yu locus a torti Diomede eat conditua olim.

interfullandi locus hic erat

est locus unil enique suos."

nigrtiflue ext oleis hodie locu:

locus ent et pluribus umbris:

ron ent aptus equis J thace locus.

non locns effuci late maris atbiter

nutandus locus est et deversoria notal praeteragendus equos.

"displicet iste locua' clamo et diludia posco.

sed nunc non crat bis locus.

locutas. dinttitet Albano Musas in monte locutas.

locuti. po-tmodo quor! mi obsit clare certumque locuto [ locuti]/luctandum in turbat facienda iniuria tatdis.

locuto. pustanodo puod mi obsit clare certumque locuto

locutus. hame ubi locutu= faenerator Mlfus.

ut ven coran, singultim pauca locutus

fi vertum all cenam e-t, dicenda tacenda locutus

loetalis. - qu ne sorphos adspicil formidolosus, pars violentiot natalis [loetalis] horae.

lolium. cont arfor loliumque, dapis noliota relinquens.

Lolli. totre thos patiar labores inpune. l.olli. carpere

Trobni bulli scriptorem. Maxime Lolli.

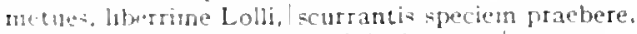

lalliginis. hir nigtae suctas lohiginis, hace est/aerugo mera:

Lollius. collegan Lepidum quo duxit Lolliua anno.

longa. guampuam lestinas. non est mora longa:

Jonkid Tuthonum minuit senectus

notr longa e.s. fabula.

ut n*o̧te longa nec magis alba velit quam dat natura videri.

furtatint tot intinc largiter abstulerit longa aetas,

lonkis qubus facis ovi- erit, illa mememto.

ut nox longa quibus mentitur amica

dwropur longa videcur opus debentibus.

* wilaba longa brevi cubiecta vocatur iambus.

longa. bongatque besum militia latus.

omnes inlacrimabiles urgentur ignotique longa' nocte.

lurlet. par inpar, equitare in hatundine longa

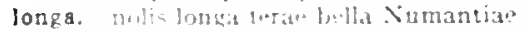

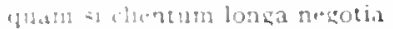

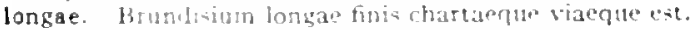

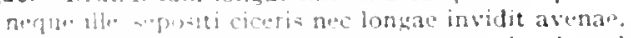

longam. vit. -umpra brevi= spem nos vetat incohare longan:

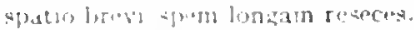

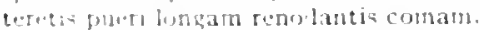

Longarenus. "rhll-hatose, cum Longarmus foret intus.

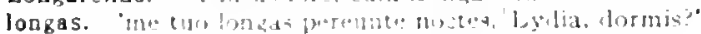

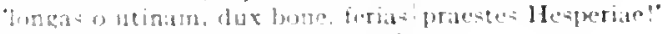

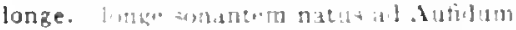

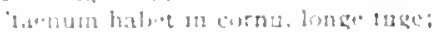

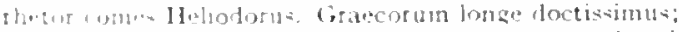

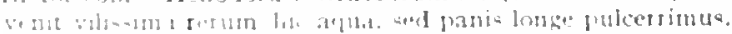

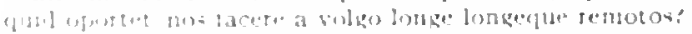

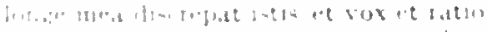

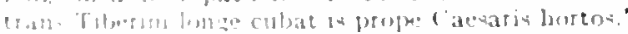

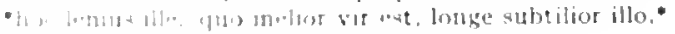

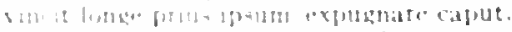

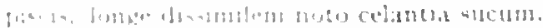

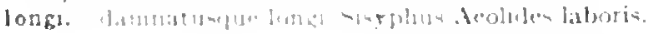

Serm.1.1.70

Sorm.1.5.92

Sirm.1.9.20

Serm.1.9.51

Serm.2.2.46

Epist.1.5.28

Epist.1.7.41

Epist.1.11.26

Epist.1.15.10

Epist.1.19.47

Ars Poct.10

Epist.2.1.27

7 I'ar..Scrm.2.0.27

serm.2.0.27

Epod.2.07

Serm.1.6.56

Epist 1.7.72

5or.Corm.2.17.19

Sirm.2.t.89

Curm.4.0.33

Epist.1.2.1

Epist.1.18.I

Sirm.1.t.100

Lipist.1.20.28

Carm.1.28.35

Carm.2.10.30

Serm.1.1.95

Sern.1.2.123

Sermat.1.132

Serm.2 +12

I.pist.1.1.20

Epist.1.1.21

Ars Poct.251

Curm.2.7.1 8

Corm.t.0.27

serm 2.3 .248

Corm.2.12.1

Corm. 3.553

serm 1.5.104

Serm.2.0.84

Curm.1.4.15

Carm.1.11.7

Epoll11.28

Sirm.! 2.17

Carm.1.25.7

Curm. +5.37

Carm +0.2

serm.1.43

tiem 15.3

serm 1580

ternesis.1s

Serm $1,0.02$

sern.1 0.18

tern. 10.4

serm.2.573

Serm. 28

Corm 21410 


\section{LONGIN QVIS}

longinquis. nec quia longinquis armentum aegrotet in agris;

longior. nec cultura placet longior annua

longis. ne te longis ambagibus ultra|quam satis est morer:

longis rationibus assem/discunt in partis centum diducere.

longius. neque in terris morabor/longius .

cunctantem spatio longius annuo

erit quae, si propius stes, / te capiat magis, et quaedam, si longius abstes.

longo. verum operi longo fas est obrepere somnum.

longo. auctor heu nimis longo satiate ludo.

longo die bis terque mutatae dapis

verum/depugis, nasuta, brevi latere ac pede longo est.

porrectus vigilet cum longo fuste.

si longo sermone morer tua tempora. Caesar.

longo. rogare longo putidam te sacculo.

cum te servitio longo curaque levarit.

donec minor in certamine longo|inploravit opes

longorum. ludusque repertus|et longorum operum finis:

longos. meliusne fluctus|ire per longos fuit aedificas, hoc est longos imitaris.

laudaturque domus, longos quae prospicit agros:

longum. ver ubi longum tepidasque praebet|Iuppiter brumas dic age tibia / regina longum Calliope melos,

ne longum faciam: dum tu quadrante lavatum |rex ibis ut pote longum / carpentes iter et factum corruptius imbri. ne longum faciam:

ac mihi seu longum post tempus venerat hospes

bella quis et paces longum diffundit in aevom?

sed in longum tamen aevom/manserunt

et longum noto scriptori prorogat aevom.

licet 'succurrite' longum / clamet "io cives,' .

longus. dum longus inter saeviat Ilion|Romamque pontus, . ne longus tibi somnus unde/non times detur;

dilator, spe longus, iners avidusque futuri,

loquacem. loquacem|delassare valent Fabium. extrabe turba| oppositis umeris; aurem substringe loquaci [loquacem].

loquaces. unde loquaces lymphae desiliunt tuae.

joquaci. aurem substringe loquaci.

loquacis. loquacis, /si sapiat. vitet.

loquaciter. seribetur tibi forma loquaciter et situs agri.

loquamur. siquid et nos, quod cures proprium fecisse, loquamur. non est quod multa loquamur:

Joquar. nil mortale loquar.

siquid loquar audiendum.

verba loquor [loquar] socianda chordis:

ignosces; alias loquar.'

loquatur. intererit multum, divosne loquatur an heros. ut nibil intersit. Davosne loquatur et audax $\mid$ Pythias.

Joquax. nec loquax olim neque grata.

loquenda. geretque proelia coniugibus loquenda.

loquendi. quem penes arbitrium est et ius et norma loquendi.

Jex est accepta chorusque | turpiter obticuit sublato iure nocend [loquendi].

loquens. modoreges at que tetrarchas, | omnia magna loquens.

loquentem. dulce ridentem Lalagen amabo, dulce loquentem.

di bene fecerunt. inopis me quodque pusilli finxerunt animi, raro et perpauca loquentis [loquentem]; gaude quod spectant oculi te mille loquentem;

loquentes. quo pacto alterna loquentes/umbrae cum Sagana resonatint

loquentis. fincerunt animi, raro et perpauca loquentis; .

loqueris. maiores pennas nido extendisse loqueris. male si mandata loqueris. /aut dormitabo aut ridebo.

loqui. volentem proelia me loqui

cetera mitte lofui:

"certe nescio quid secreto velle loqui te aiebas natum."

reddes dulce loqui, reddes ridere decorum

nec quarta loqui persona laboret.

et docuit magnumque loqui nitique cothurno.

Grais dedit ore rotundo Musa loqui.

loquimur. dum lofuimur. fugerit invida aetas:

\section{LOQVIMVR}

Epist.1.8.6

Corm.3.2.4.14

Epist.1.7.82

Ars Poel.325

Carm.2.20.4

Carm.4.5.11

Ars Poel.362

Ars Poet.360

Carm.1.2.37

Eppod.5.3.3

Serm.1.2.93

Serm.2.3.112

Episl.2.1.4

Epod.8.I

Sorm.2.5.99

Epist.1.I0.35

Ars Poet.106

Carm.3.27.43

Serm.2.3.308

Episl.1.10.23

Carm.2.6.17

Carm.3.4.2

Serm.1.3-137

Serm.1.5.9.4

Serm.2.1.57

Sirm.2.2.1 18

Epist.1.3.8

Epist.2.I.I 59

Ars Porl. 3.6

Ars Pot. 459

Carm.3.3.37

Carm.3.11.38

Ars Poit.1 72

Serm.I.I.13

a'ur.Serm.2.5.95

Carm.3.13.15

Serm.2.5.95

Serm.1.9.33

Epist.1.10.4

Epist.I.I7.5

Epist.2.1.3o

Curm.3.25.18

Carm.4.2.45

var.Carm.4.9.4

Serm.1.9.72

Ars I'oel.1 I4

Ars Potl.237

Carm.3.11.5

Carm.4.4.68

Ars Poet.72

iur.Ars Poet.284

Serm.1.3.13

Carm.1.22.24

coni.serm.1.4.18

Epist.1.6.19

Sirm.1.8.40

Serm.I.4.I8

Epist.1.20.2 I

Irs Poet.104

Carm.15. I

Lepod.13.7

Serm.1.9.67

Ispist.1.7.27

Ars loct.102

Ars Poet.281)

Ars l'oet.32.

Carm.1.11.7 
loquitur. cum de se loquitur non ut maiore reprensis?

loovor. turs mear, siquid loguar [loquor] audiondum,| socis accedet bonat pars

verba lorjor socianda chordis:

quocira inecum loquor haec. tacieusque recordor: .

lora, qui lora testrictis lacertis/sensit iners

loricis. libros Panacti Socraticam et domum/inutare loricis Hiberis.

loris. "qui multum puerum loris et funibus ussit |exoratus.*

"habes pretium, loris non ureris," aio.

luam. ilusis cum fide pornas luam.

Jubens. tecum vivere amem, tecum obean lubens.'

lubrica. lubrica nascentes inplent conchylia lunar:

lubricus. et voltus nimium lubricus adspici.

findunt Sianandri flumina lubricus et Simois.

Lucana. 'unive Lucana dormis ocreatus,

Lucana. pecusse Calabris ante sidus ferdium/Lucana mutet pascuis

Lucanac. quod me Lucanae iuvenem commendet amicae);

Lucani. quidve Calabris|saltibus adiecti Lucani,

Lucania. seu guod Lucaria bellum incuteret violenea

Lucanus. sequor hunc, Lucanus an Apulus anceps: 'in primis L.ucanus aper:

luce. cx hat luce Maecenas meus adfuentis/ordinat annos.

'non ego' narantem 'temere edi luce profesta

4uem bibulum liquidi media de lue Falerni:

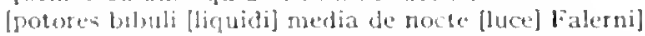

bate amat obscurum, solet haec sub hee videri,

lucellum. quid pule trancuillet, honos ac dulce Jucellum as scctetum iter

lucellum. ghite si semel uno/ de sene gustarit tecum partita lucellun.

lucem. vigiles lucernas perfer in lucem:

lucem redite tuae, dux bone, patriat

rite Latonae Juerum canentes./rite crescentem face N゙otilucam [nocte lisem].

dormiet in lucem, scorto postponet honestum ofticiun.

proferet in liferm speciosa vocabulis resum,

non fumum ex fulgore, sed ex fumo dare lucem / cogitat.

parum clatus lucem date coget.

Luceriam. lanat prope nobilem tonsan Luceriam.

lucerna. sub clata nuda lucerna quaccuncuc.

sub clara nuda lucerna [lucerna nuda]| quaccumque excepit turgentis verberat callulat / clunibus

cunt . polis ex iudice Dama. ' turpis odoratum coput obscurante lacutra [lucerna], non es quod simulas?

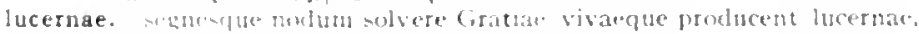

lucernas. vagles lucernas perfer in lucesu:

lucernis. arensit tervor cajti numerusqut lucesnis;

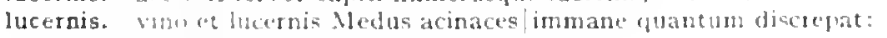
non guo traudatis inmundus Satta lucermis.

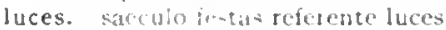

lucet. luict, camus quo ducit gula:

lucibus. nosifte ct profestis lucibus et sacris

lucida. sic Hatre- llelenae, luciáa sidera.

lucida. his, its ponite lucirlalfumalia

lucidas. illum ege lucidat inire sedes.

lucidum. an vilut dicere lucidum tulgentis oculos

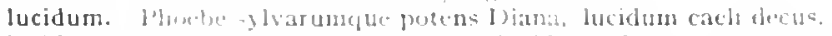

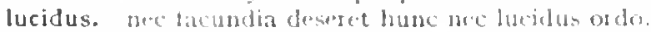

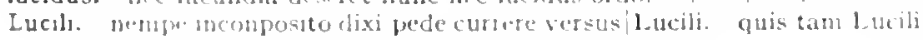

fautur arrepte est.

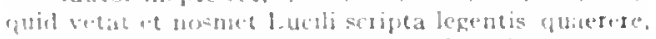

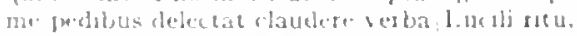

y

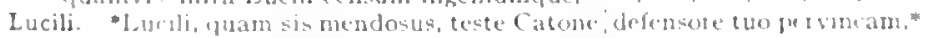

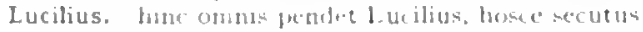

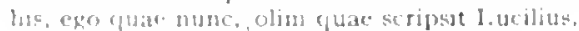

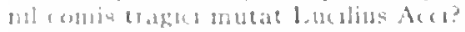

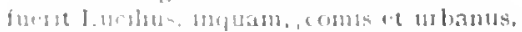

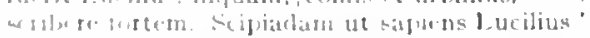

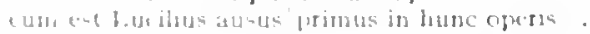

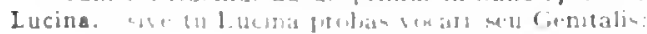

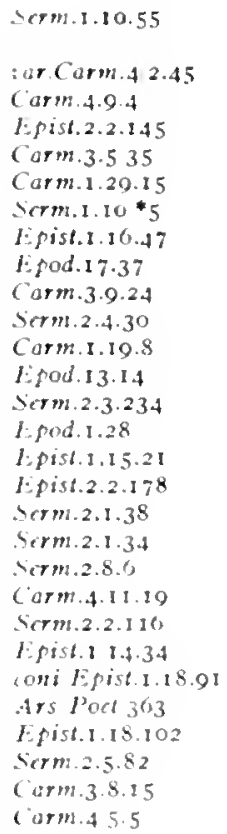

Serm.1.10.55

: ar. Carm.4 2.45

Corm.4.9.4

I.pist.2.2.145

Corm.3.535

Corm.1.29.15

sorm.1.10*5

Lspist.1.16.47

lifod.17.37

Corm.3.9.24

Serm.2.4.30

Corm.1.19.8

Lifod.13.14

Serm.2.3.234

l. pod. 1.28

1.pist.1.15.2 I

Lpist.2.2.178

Scrm.2.1.38

Serm.2.1.3.4

Sirm.2.8.

Corm.4.11.19

Serm.2.2.I10

F.pist.1 1.\$.34

coni Epist 1.18.91

Ars I'od 363

Epist.1.18.102

Scrm.2.5.82

Corm.3.8.15

curm.4.5.5

Dur Corm 4.0 .38

l.jist.1.1.34

1.pist.2.2.110

Ars lonet.143

Ars Portid4s

carm.3 15.14

serm.2.7.48

:ar.s.9m.2.748

iar.sorm:.2.7.55

( armi-3.21.23

(arm.3.5.14

serm.2. 25

(arm. 1.27 .5

Serm 1.0.124

(arm.4.t).12

Epist.1 0.5 h

(iirm.4.15.25

(iumb.3.2

(arm.3.211.0)

(orm.3.3.3.3

(a)m2.12 14

carmisiace?

Ars loet

Srm.t. I0

sirm. 3.10.50

Scrm.2.1.20

Strm.2.1.75

sermato.1

sermot.ate

term. 455

serm. 3.10.53

serm.10.104

sormel 17

Sorm.2.1.12

(om idet. 5 
si vocata partubus|Lucina veris adfuit,

Lucinam. sive tu [? te] Lucina [? Lucinam] probas vocari .

lucinias. luscinias [lucinias] soliti inpenso prandere coemptas,

lucis. tu parum castis inimica mittes/fulmina lucis.

lucis. nunc et in umbrosis Fauno decet immolare lucis,

Jucis. dives et inportunus ad umbram lucis ab ortu

Jucos. audire et videor pios/errare per lucos.

jucrata. Pythias, emuncto lucrata Simone talentum.

Jucratus. 'qui domita nomen ab Africa|fucratus rediit.'

Lucretilem. velox amoenum saepe Lucretilem $\mid$ mutat Lycaco Faunus

lucri. verum pone moras et studiun lucri

at $n \mathrm{i}$ id fit, quid habet pulcri [lucri] constructus acervos?

cum tu inter scabiem tantam et contagia lucri .

Lucrina. murice Baiano melior Lucrina peloris,

Lucrina. non me Lucrina iuverint conchylia

Lucrino. undique latius/extenta visentur Lucrino/stagna lacu

lucro. quen Fors dierum cumque dabit, lucroladpone

sic lucro aversam potuisse nasci|matre pudenda.

lucro. cum te neque fervidus aestus|demoveat lucro domos mercarier unus|cum lucro noram:

lucrum. concidit auguris|Argivi domus ob lucrum demersa cxitio; 'contrane lucrum nil valere candidum | pauperis ingenium' adsentatores iubet ad lucrum ire poeta adsentatores iubet ad lucrum lad lucrum iubeti ire poeta

luctamur. psallinus et luctamur Achivis doctius unctis.

luctandum. luctandum in turba et facienda iniuria tardis.

luctantem. luctantem Icariis fluctibus Africum

luctantis. luctantis acuto ne secer ungui, .

Juctantur. tristia robustis luctantur funera plaustris.

luctere. luctere, multa proruet integrum/cum laude victorem

iuctum. vos, quibus est virtus, muliebrem tollite luctum,

luctuosae. di multa neglecti dederunt|Hesperiae mala luctuosac.

luctuosis. Medus infestus sibi luctuosis|dissidet armis

luctus. luctusque turpes et querimoniae; .

luculenta. ten lapides varioz lutulenta [luculenta] radere palma.

Luculli. Luculli miles collecta viatica multis/aerumnis,

Lucullus. chlamyrdas Lucullus, ut aiunt. | si posset centum scaenae praebere rogatus,

lucum. virtutem verba putas et/lucum ligna:

lucus. et praeceps Anio ac Tiburni lucus cum lucus et ara Dianae. . . describitur.

ludas. in pulvere, trimus|quale prius, ludas opus,

ludentem. dare bracchia/ludentem nitidis virginibus

tristia maestum|voltum verba decent, ... ludentern lasciva,

ludentes. at pueri ludentes 'rex eris' aiunt, | "si recte facies."

ludentis. ludentis speciem dabit et torquebitur,

ludere. in udo|ludere cum vitulis salicto/praegesticntis

inter ludere virgines

lascivae sinilem ludere capreae,

venarique timet, ludere doctior,

ludun insolentem ludere pertinax

namque pila lippis inimicum et ludere crudis.

nugari cum illo et discincti ludere. . . soliti.

te talos, Aule, nucesquel ferre sina laxo, donate et ludere vidi.

ludere par inpar, equitare in harundine longa

cur aiter fratrum cessare et ludere et ungui|praeferat

ludere qui nescit, campestribus abstinet armis

luderet. sub nutrice puella velut si luderet infans,

ludi. tanto cum strepitu ludi spectantur.

ludibrium. nisi ventis/debes ludibriun, cave. .

Judicra. valeat res ludicra, si me / palma negata nacrim, donata reducit opimum.

Iudicra. nunc itaque et versus et cetera ludicra pono, quid maris extremos Arabas ditantis et lindos/ludicia.

ludis. ludisque et bibis inpudens

"num furis? an prudens ludis me obscura canendo?"

ludis. an tua demens|vilibus in ludis dictari carmina nials? gaudentem . . ludis et post decisa negotia Campo. spectaret populun ludis attentius ipsis.
Epod.5.6

iar.Carm.Sué. I 5

i'ar.Sirm.2.3-2.45

Carm.1.12.00

Carm.1.4.11

Iipist.2.2.185

Carm.3.4.7

Ars Poet.238

carm.4.8.19

Carm.r.17.1

Carm.4.12.25

contiserm.r.I.44

Epist.I.12.14

serm.2.4.32

Epod.2.49

Carm.2.15.3

Carm.1.9.14

Carm.2.4.10

Serm.1.1.39

Sirm.2.3.25

Curm.3.10.12

Epod.II I I

Ars Poel. 420

idr.tirs Poet.q2o

Epist.2.1.33

firm.2.0.28

Carm.1.1.15

Epist.1.19.4"

Epist.2.2.74

Carm.4.40

Epod. 10.39

Carm.3.6.8

Carm.3.5.19

Curm.2.20.22

a'ar.Serm.2.4.83

Lipist.2.2.21

Epist.I.ta..p

Epist.1.1.32

Carm.1.7.13

Ars I'oet.io

Serm.2.3.252

Carm.2.12.19

Ars l'oet.1ut

Epist.1.1.59

Epist.2.2.I24

Curm.2.5.8

Carm.3.15.5

Carm.3.15.12

(c)m.3.24.50

(arm.3.20.50

Serm.1.5.49

Sorm.2.I.73

Sernt.2.3.172

Serm.2.3.24s

Lpist.2.2.183

Irs Poet.3.9

Lpist.2.I.99

I.pist.2 1.203

(arm.1.1420

Iipist.2.1.180

Jepist.1.10

Epist.t. (8)

Carm.1.13.4

Serm.2.5.5s

Serm.1.10.75

Jpist.1.7.50

Epist.2.1.19: 
ludit. athditia? an me ludit amabilislinsania?

Carm.3.4.5 ludit exsultim metuitgue tangi

lurit herboso pecus omne campo .

vitis carestem / ludit imago/vana.

ludo. dunguel difngit Rheni luteum caput, haec ego ludo. iredite, non ludo: crudeles. tollite clandum.'

Iudo. guaminam choreis aptior et iocis/ludoque dictus

Iudo. altctor heu nimis longo satiate ludo.

lulo fatigatumçue somno

sed tamen amoto quaeramus seria ludo):

"yuaeris. Macconas, iterum antiquo me inciudere ludo?

it a vertere seria ludo.

ludos. orbin ut cantus reteratque ludos

ludos spectaverat, una|luserat in campo:

inullos his mallem ludos spectasse;

nunc l'rbem ret ludos et bainea vilicus optas;

ludum. ludumque Fortunae gravisque/principum amicitias miseratum est neque amori dare ludum

ludum insolentem ludere pertinax

concimes lactosque dies et Vrbis|publicum ludum

noluit in Flavi ludum me mittere.

mec lusisee pudet, sed non incidere ludum.

utroque tuom landabit pollice ludum

cripuere iocos, veneren, convivia, ludum; .

et umpestivom pueris concedere ludum

Acomilinn circa ludum faber imus

ludus. poit loc ludus erat tculpa potare magistra

luda enim genuit trepidum certamen et iram.

fudusfiue repertus/et longorum operum finis:

lues. Gelicta maiorun inmeritus lues.

Jugubre. hoitis Punicollugubre mutavit sagum.

Jugubri. Troiac renascens alite lugubri|fortuna

lugubris. gui gurges aut quae llumina lugubris|ignara belli?

Jugubris. praecipe lugubris|cantus, Melponene.

lumbis. avolsos, ut multo suavius, armos, /quam si cum lumbis quis edir.

lumbos. limina dura. quibus lumbos et infregi latus. ac intale nataeque caput Iumboscfue saligno|fuste dolat: mantica cui lumbos onere ulceret atque eques armos:

Jumina. adempta rati reddidere lunina: cerum sub lumina prima venire/convivan: lento Samnites ad lumina prina duello.

lumine. nacrntem placido iumine videris.

ni poeces ante diem librum cum lumine,

luminibus. cui clonct inpermissa raptim / gaudia luminibus remotis,

Luna. nox crat et caelo fulgebat l, ma sereno vand Juma decorum|protulit os.

Luna. illerum regina bicornis, audi. Luna. puellas.

Juna. I utimm sidus velut inter ignis/luna minores. ut pura hocturno renidet/luna mari neque uno luna rubens nitet/voltu:

luna. Lath Creherea choro ducit Venua imminente luna rach supistas si tuleris manua| nascente luna.

luna. diasolve ifigus ligna [lunal auper foco/large reponens

Junge. curvatos mitatus ignis/tertium fumae referentis ortum, quid premat olycurum lunae, quid proferat orbem.

lunae. dil Innif ptopere novac.

Iunae. nowanflu pergunt interire lumae: dasmn tamen celeres reparant cacleatiat lunae: .

hidron hascentea inplent conchylia lunae:

Lunam. l.mbnugue rubentem, / He foret his testis, post magna latere Hepulatit.

lunam. vimnl atra nubmifondidit lunam

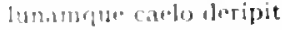

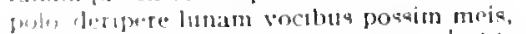

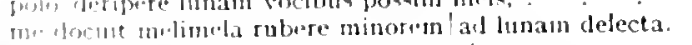

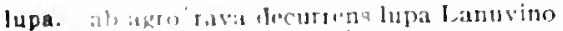

Jupatis. Gallu nu lupatia lemperet ora trenis?

lupi. "Heflue lujpi biubam varia cum dente colubra"

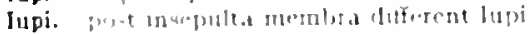

Carm.3.II.t

Carm.3. 18.9

Carm.3.27.40

Sam.t.10.37

Epist.1.17.61

Carm.2.19.26

Carm.1.2.37

Carm.3.4.11

Serm.1.1.27

Epist.1.1.3

Ars Poct.225

Carm.Saec.22

Serm.2.6.48

Serm.2.8.79

Episti.14 15

Carm.2.1.3

Carm.3.12.1

Carm.3.29.50

Carm.4.2.42

Serm 1.6.72

Epist.1.14.36

Epist.1.18.66

E.pist.2.2.56

Epist.2.2.142

Ars Poel. 32

Serm.2.2.123

Epist.1. 19.48

Ats Poct.405

Carm.3.6.I

Epod.9.28

Carm.3.3.6I

Carm.2.1.33

Carm.1.242

Serm.2.8.90

IEpod.1 1.22

Serm.1.5.22

serm.1.6.106

Epod.17.44

Sorm.2.7.33

Epist.2.2.98

Carm-4.3.2

Fpist.1.2.35

Carm-3.0.28

Epod.15.I

Scrm.t.8.21

Curm.Sacc.36

Carm.1.12.48

Carm.2.5.20

Carm.2.11.10

Carm.1.4.5

Carm.3.23.2

rar Carm.1.9.5

Curm.4.2.58

Epist.1.12.18

Curm.3.19.9

Curm.2.18.10

Corm.-47.13

Serm.2.4.30

Serm.1.8.35

Carm.2.16.3

I.pod.5.46

Epod 17.78

Serm.2.8.32

Corn.3.27.3

Corm.1.8.6

Sorm.1.8.12

Epol.500 


\section{LVPINIS}

lupinis. in cicere atque faba bona tu perdasque lupinis,

nec tamen ignorat, quid distent aera lupinis.

lupis. sed prius Apulis|iungentur capreae lupis

lupis et agnis quanta sortito obtigit.

neque hic lupis mos nec fuit leonibus

apris reliquit et rapacibus lupis.

Lupo. famosisque Lupo cooperto versibus?

lupo. vel haedus ereptus lupo.

luporum. 'cervi, luporum praeda rapacium,

lapos. nec viridis metuont colubras / nec Martialis haediliae lupos, canis|ignavos adversum lupos?

ut pavet acris|agna lupos capreaeque leones!"

lupos. quo pertinet ergo| proceros odisse lupos?

lupum. cervos uti vallis in altera|visum parte lupum graminis inmemor.

lupus. namque me silva lupus in Sabina, . . . fugit inermem;

inter audacis lupus errat agnos.

dum pecori lupus et nautis infestus Orion

dente lupus, cotnu taurus petit:

ut neque calce lupus quemquam neque dente petit bos),

hac urget lupus, hac canis, aiunt.

cautus enim metuit foveam lupus

vehemens lupus et sibi et hosti iratus pariter.

lupus. lupus hic Tiberinus an alto captus hiet?

Jurids. reliquit ossa pelle amicta lurida,

luridi. refugit te quia luridi|dentes,

luridum. maeretque partus fulmine luridum/missos ad Orcum;

luscinias. luscinias soliti inpenso prandere coemptas,

Lusco. Fundos Aufidio Lusco praetore libenter|linquimus.

luserat. ludos spectaverat. una|luserat in campo:

luserit. ludos spectaverat [spectaverit], una|luserat [luserit] in campo:

Jusimus. si quid vacui sub umbra|lusimus tecum. .

lusisse. nec lusisse pudet, sed non incidere ludum.

lusisti. lusisti satis, edisti satis atque bibisti:

lusit. mox ubi lusit satis, "abstineto"|dixit

nec siquid olim lusit Anacreon/delevit aetas;

ast ubi me fessum sol acrior ire lavatum | admonuit, fugio campum lusumque [lusitque] trigonem.

libertasque recurrentis accepta per annos|lusit amabiliter.

lustra. circa lustra decem flectere mollibus/iam durum imperiis:

lustra. si neque avaritiam neque sordes aut mala lustra | obiciet vere quisquam mihi.

lustratam. pede barbarol lustratam Rhodopen,

Justro. Fortuna lustro prospera tertio

lustrum. cuins octavom trepidavit aetas/claudere lustrum.

alterum in lustrum meliusque semper/prorogat aevon. .

lusum. lusum it Naecenas, dormitum ego Vergiliusque;

lusum. fugio campum lusumque trigonem.

luteum. diffingit Rheni luteum caput.

luteus. tibique pallor luteus

luto. vixisset canis inmundus vel amica luto sus.

luto. erucas viridis, inulas ego primus amaras i monstravi incoquere inlutos Curtillus [incoquere in luto Scurtillus] eclinos,

qui Capua Romam petit, imbre lutoque/adspersus.

Iutulenta. hac rabiosa fugit canis, hac lutulenta ruit sus:

lutulenta. ten lapides varios lutulenta radere palma

Jutulentum. at dixi fluere hunc lutulentum.

lutulentus. cum flueret lutulentus, erat quod tollere velles;

lux. o, qua sol [lux] habitabilis/inlustrat oras.

postera lux oritur multo gratissima:

perditur haec inter misero lux non sine votis:

luxere. unxere [iuxere] matres Iliae additum feris|alitibus . . Hectorem,

Inxuria. quisquis luxuria tristive superstitione / aut alio mentis morbo calet:

Juxuriam. "nunc age, luxuriam et Nomentanum arripe mecum: . sic priscae motumque et luxuriem [luxuriam] addidit arti|tibicen .

luxuriantia. luxuriantia conpescet, nimis aspera sano/levahit cultu.

Juxuriem. sic priscae motumque et luxuriem addidit arti|tibicen

Lyaeo. tamen uda Lyaeo/tempora populea fertur vinxise corona arcanum iocoso|consilium retegis Lyaco. dulci Lyaeo solvere.
LYAEO

Serm.2.3.1 82

Epist.1.7.23

Carm.1.33.8

Epod.4.1

Epod.7.II

Epod.r6.20

Serm.2.1.68

Epod.2.60

Carm.4.4.50

Carm.1. 7.9

Epod.6.2

Epod.1 2.26

Serm.2.2.36

Carm.r.15.30

Carm.1.22.9

Carm.3.18.13

Epod.1 5.7

Serm.2.1.52

Serm.2.r.55

Sorm.2.2.64

Epist.r.16.50

Epist.2.2.28

Serm.2.2.3I

Epod.17.22

Carm.4.13.10

Corm.3.4.74

Serm.2.3.245

Serm.1.5.34

Serm.2.6.49

lar.Serm.2.6.49

Carm.1.32.2

Epist.1.14-36

Epist.2.2.2 I4

Carm.3.27.69

Carm.4.9.9

var.Serm.1.6.1 26

Epist.2.I.I 48

Carm.4.1.6

Serm.1.6.68

Carm.3.25.12

Carm.4.14.37

Carm.2.4.24

Carm.Saec.67

Serm.1.5.48

Serm.1.0.126

Serm.I.I0.37

Epod.ro.r6

Epist.1.2.26

var.Serm.2.8.52

Epist.I.II.I

Epist.2.2.75

Serm.2.4.83

Serm.1.10.50

Serm.I.4.I I

sur.Carm.4.14.5

Serm.1.5.39

. ierm.2.6.59

iar.lepod.r7.I I

Serm.2.3.79

Sirm.2.3.224

tar.Ars Poel.214

Epist.2.2.I22

Ars l'oel.2I 4

Carm.1.7.22

Carm.3.21.16

Epol. 9.38 
Lycaeo. amocnum saepe Lucretilem|mutat Lycaeo Faunus

Lycambae. qualis I ycambac spretus infido gener

Igcamben. secutus. . non res et agentia verba lycamben.

Lyce. extremum Tanain si biberes, Ly"ce.

audivere, I.yce, di mea vota, dilandivete, Lyce:

anelivere, lyce, di mea vota, di audivere, lyce:

Lycen. servatura diu pasen! cornicis vetulae temporibus Lycen.

Lyciae. qui Iyciac tenct/dumeta natalemque silvam

Lycias. ne virilis/cultus in caedem et Lycias proriperet catervas?

Lycidan. quo simul mearis, . . Inec tenerum lycidan mirabere,

Lycio. aut si clisparibus bellum incidat, ut Diomedi|cum Lycio Glauco.

Lycisci. anor Lycieci me tenet; .

Ifcius. qui Iyciae tenet/dumeta natalemque silvam/Delius [/ Lycius] et Patareus Apollo.

Iyco. et vicina seni non habilis $\mathbf{l}, \mathbf{y c o}$.

Lycorida. insignem tenui fronte Lycoriela|Cyri torret amor.

Lycum. et lycum nigtis oculis nigtoque/crine decorum.

Lycurgi. Thracis et exitium Lycurgi.

Lycus. audiat invidus/dementem strepitum Lycus

Lyde. dic modos, Lyde quibus obstinatas/adplicet auris, audiat Lyde scelus atque notas/virginum poenas

Lyde. prome reconditum. Lyde, strenua Caecubum

Lyden. quis devium scortum eliciet domo|Lyden?

Iydia. neque erat Iydia post Chloen. multi lydia nominis. / Romana vigui clarior llia."

Lydia. 1.ydia, dic jer omnis/hoc deos vere. cum tu, I.ydia, Telephi|cervicem roseam. . . laudas 'me tuo longas pereunte noctes, I L tia, dormis?"

Lydiae. rejectaeque patet ianua Lydiae?"

Lydis. Lydis remixto carmine tibiis

Lydorum. Iydorum quidquid litruscos/incoluit finis.

jymphs. quid obliquo laborat/ÿmpha fugax trepidare rivo? montibus altis|levis crepante lympha desilit pede.

Iympha. restinguet ardentis Falerni|pocula practereunte lympha? ora manusque tua lavimus, Feronia, Jympha;

lymphae. inane iynoluae|dolium fundo pereuntis ino. si tibi nulla sitim finiret copia lymphae.

Iymphae. unde loquaces/lynphac desiliune tuac.

lymphatam. niencemque lymphatam Mareotico redegic in veros timores. Iymphis. dein Gnatia Lymphis|iratis exstructa dedit risusque iocosque. lymphis. frondesque fymphis obstrepunt manantibus,

yncas. att timidos agitare lyncas.

fugacis/lyncas et cervos cohibentis arcu.

Lyncei, ne corporis optima Lyncei/contemplere oculis.

Lynceis. ne corpotis optima lyncei [Lynceis]|contemplere oculis.

Lynceus. non possis oculo quantum contendere Lynceus:

ynx. cur in anicosum vitis tam conis acutum quan aut aquila aut

$$
\text { [1] } 1 \text { t lynx vel] sespens Epielaurins? }
$$

lyra. donec sucpecta severo|conticuit lyta.

lysa. quem vism aut heroa lyra vel acri|tibia sumis celebrate.

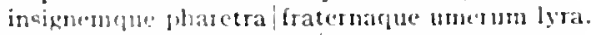

cburma, elic ape, cum lyas | maturet.

cus pences tircted fistula cum lyra?

tu curvit recines lyral Latonat

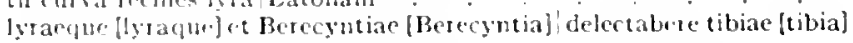
mixts carminibus non sine fistula;

l'hochus volentem proelia me loqui|victas et ubis incuevuit lya.

conante mixtum tibils carmuct lyra.

sive numelaci lytal voles conare:

lyrse. pudor mbellisfue lyta. Musa potens betat

loorum nuntium curvedue lyrac parentem.

lyracence et Berecyntiac| delectabere tibiac|mixtis caminilus

Konnua fdicen fyrae:

vellatial motura sonum conectre digner?

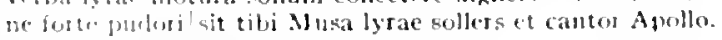

lyrae. non lirm ionosae comoniet lyrae -

lyricis. fumb-1 sub ly ticis vatibus inceres.

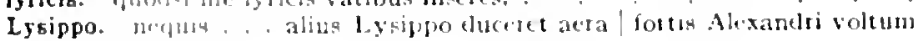
Homblantia.
Carm.1.17.2

Epod.6.13

Epist.1.19.25

Carm.3.10.1

Carm.4.13.1

Carm.4.13.2

Carm.4.13.25

Carm.3.4.62

Carm.1.8.10

Carm.1.4.19

Serm.1.7.17

Epod II.24

7 far.Carm.3.4.64

Corm.3.19.24

Carm.1.33.5

Cormi.1.32.11

Carm.2.19.10

Carm.3.19.23

Carm.3.11.7

Carm.3.11.25

Carm.3.28.3

Carm.2.11.22

Cerm.3.9.0

Carm.3.9.7

Carm.t.8.I

Carm.1.13.1

Curm.1.25.8

Carm.3.9.20

Carm.4.15.30

Serm.1.0.1

Carm.2.3.12

Fpod.10.48

Corm.2.11:=0

Serm.1.5.2.4

Carm.3.11.20

Epist.2.2.140

Carm.3.13.10

Corm.1.37.14

Sorm.1.5.97

Epod.2.27

Curm.2.13.40

Curm.4.6.34

Serm. 2.90

iar..sirm. 2.90

Epist.1.1.28

7 a ar.serm:1.3.27

Lpist.1.18.43

Carm.1.12.1

Carm.1.21.12

Carm 2.11.22

Carm.3.19.20

Carm-328.11

ar Curm.4.1 22

Carm.4 15.2

I:pod.o.5

Epod.17.32

(arm I. (1).10)

ciurm.1.100

Carm.4.1.22

Carm.+.3.23

Epist 2280

Ars boet.fot

Carm.3ro

Corm.1.3.3.5

J jist 2.12 .40 
Macedo. diffidit urbium/portas vir Macedo macelli. pernicies et temptestas barathrumque macelli. macello. inmane est vitium dare milia terna macello macellum. cum scurris fartor, cum Velabro onne macellum macerat. me libertina, nec uno/contenta, Phryne nacerat. . macerer. quam lentis penitus macerer ignibus. machina. torquet nunc lapidem, nunc ingens machina tignum, machinae. trahuntque siccas machinae carinas

Machinus. Maltinus [Machinus] tunicis demissis ambulat: . macies. macies et nova febrium|terris incubuit cohors . antequam turpis nacies decentis]occupet malas macra. nacra carom repetes artum, quem macra subisti." . macrescit. invidus alterius macrescit rebus opimis; macro. qui macro pauper agello|noluit in Flavi ludum me nittere. macros. vibi sedulus hospes/paene macros arsit macrum. si ne | palma negata macrum, donata reducit opinum. mactat3. mactata veniet lenior hostia. macte. "mactelvirtute esto" inquit sententia dia Catonis; maculant. tum inmundo somnia visu | nocturnam restem maculant ventremque supinum.

maculis, non ego paucis|offendar maculis,

maculosum. mos et lex maculosum edomuit nefas.

madet. quamquam Socraticis madet/sernonibus,

Haecenas. ex hac luce Maecenas meus adfuentis fordinat annos.

luc venturus erat $\mathrm{M}$ aecenas optimus atque/Cocceius.

interea Maecenas advenit atque/Cocceius .

lusum it Maecenas, dormitum ego Vergiliusque;

'Maecenas quomodo tecum?'

Plotius et Varius, Maecenas Vergiliusque,

an, quodcumque facit Maecenas, te quoque verum est,

'inprimat his cura Maecenas signa tabellis.'

Maecenas me coepit babere suorum | in numero.

iusserit ad se/Maecenas serum . . Venire/convivam:

cum Servilio Balatrone/Vibidius quos Maecenas adduxerat umbras.

Maecenas. Maecenas atavis edite regibus.

cum tibi plausus, / clare Maecenas eques.

dices historis proelia Caesaris./Maecenas.

Maecenas, mearum /grande decus columenque rerum.

ego, quem vocas, / dilecte Maecenas, obibo .

sune, Maecenas, cyathos amici|sospit is centum

Maecenas, equitum decus.

Tyrrhena regum progenies, . . Maecenas,

paratus omne Caesaris periculum|subire, Maecenas, tuo:

iocose Maecenas, precor.

quando... beate Maecenas, bibam.

candide Maecenas, occidis saepe rogando: .

qui fit, Maecenas, ut nemo, . . . contentus vivat.

cualem me saepe libenter|obtulerim tibi, Maecenas.

non quia, Maecenas, . . nemo generosior est te

nunc, quia sim tibi, Maecenas, convictor.

"Albanum. Maecenas, sive Falernum/te magis adpositis delectat:

quaetis. / Maccenas, iterum antiquo me includere ludo?

dabis aegrotare timenti.| Maecenas, reniam,

prisco si credis, Maecenas docte, Cratino,

Maecenatem. ad Maecenatem memori si mente recurras.'

Maeci. in Maeci descendat iudicis auris|et patris et nostras

Maenius. ut vivam Naevius [Maenius] aut sic/ut Nomentamus?"

Maenius absentem Novium cum carperet.

"egontet mi ignosco" Maenius inquit.

Maenius. . . urbanus coepit haberi, / scurra,

Maeonii. Vario ... Maeonii carminis alite.

Maeonius. si priores Maeonius tenet/sedes Homerus,

maerebis. heu heu, transiatos alio maerebis amores.

maerentis. me quamvis Lamiae pietas et cura moratur|fratrem merentis, maerentis. interque maerentis amicos

matrere. reddes... inter vina fugam Cinarae maerere protervae. maeret. regium certe genus, et penatis|maeret iniquos.
Carm.3.16.14

Epist.1.15.31

Sirm.2.4.76

Sorm.2.3.229

Eforl.14.16

Carm.1.13.8

Efist.2.2.73

Carm.1..4.2

rar.Serm.1.2.25

Carm.1.3.30

Corm.3.27.53

Epist. 1.7 .33

Epist.1.2.57

Serm.1.6.7 I

Sirm. I.5.72

Epist.2 I.I8I

Carm.1.19.16

Serm.1.2.3 I

Serm. I.5.85

Ars Poct. 352

Carm.4.5.22

Carm.3.2 r.9

Carm.4.11.19

Serm.1.5.27

Sorm.1.5.3 I

Serm.1.5.48

Serm.1.9.43

Serm.1.10.81

Serm.2.3.31 2

Serm.2.6.38

Sirm.2.6.1I

Serm.2.7.33

Serm.2.8.22

Carm.1.1.I

Curm. I.20.5

Curm.2.12.II

Carm.2.17.3

Cirm.2.20.7

Carm.3.8.13

Carm.3.16.20

Carm.3.29.3

Epod.r.4

Epod.3.20

Epod.9.4

Epod.14.5

Sirm.I.I.I

Sirm.1.3.64

Serm.1.6.I

Serm.1.0.47

Serm.2.8.16

Epist.1.1.3

Epist.1 7.5

Epist.1.19. I

Serm.2.6.3I

Ars Poit.387

cont.Serm.I.I.IOI

Serm.1.3.2I

Serm.1.3.23

Epist.1.15.26

Carm.1.0.2

Carm.4.9.5

Epod.15.23

List.I.1.7

Carm.3.5.47

Esist.1.7.28

Carm.2.4 16 


\section{MAERET}

macretguc partus fulmine lurichu'missos ad Orcum;

maerore. aut ad humum maesore gravi deducit et angit;

maestis. msigne matestis praesidium reis.

maestum. hoc genus onne maestum ac sollicitum est cantoris morte Tigelli.

maestum. tristia macstum/voltum verba decent,

maestus. seu macstus omni tempote vixeris

tlentibus hinc Parius discedit maestus amicis.

Maevium. mala soluta navis exit alite/ferens olenten Mevium [Maevium].

maga. rencha maga non fas nefasque, non valent/convertese humanam vincm.

magicos. somnia. terrores magicos, . . rides?

magis. Thracio bacchante magis sub inter-|lunia vento.

laeta quod pubes hedera virenti! gaudeat pulla magis atque myto.

quae poscente magis gaudeat eripi,

magis pugnas et exactos tyrannos

donec non alia magis/arsisti

ut adsilens inplumibus pulis avis serpentium adlapsus timet/magis relictis.

ragisve rlombus aut scari.

inliterati num minus [magis] nervi rigent / minusve languet fascinum? magis quem|diligeret nulier suat quam te. .

nec mayis huic. . . Lo tencoum est femur

ut nẹtue longa/nec magis alba velit quan dat matura videri.

privatuspue magis vivan te tege beatus.

Antoni, hon ut magis alter, anicus.

nec magis his aliena malis;

'accends guarc cupiam magis illi proximus esse."

tum retum dura negatit versiculos natura magis factos.

hac maxis illam imparibus formis deceptum te petere

quo magis his credas.

non magis audierit. quan Fufus ebrius olim.

tune insanus rois. si accereris, an magis excors/reiecta praeda.

cum magis atque se magis inflatet.

cum magis atcue se magis inflatet.

ut suci meliotis et ut magis albu rotundis.

perna magic ct magis hillis flagitat inmorsus refici.

quod magis ad nos/pertinet.

magisque exanimes trepielare.

"Abanum, Matcras, sive Falernum te nagis adpositis delectat:

(cocto (lijum :ic convenit, ut non hoc magis ullum aliud);

Atride, magis apta tibi tua doma selinquan.'

utra magis jiseis et echinos atequora celent.

tene magis salrom populus velit an populum $t u$,

nce magis axpressi voltus per aenca signa.

lutuc ego m\%, siquid conponete curem, non magis esse velim

si puphes stes, te capiat magis,

magister. seu havis His bande magister,

fingit erpum tencra docilem cervice magiste

magistra. juet hor lutus clat feulpa potare nagistra

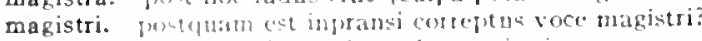

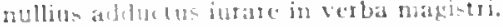

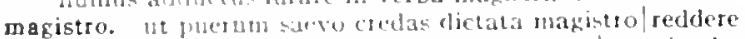

magistro. Mercuri, nam to docilis magistro| movit Amphion lapides (antontor,

magistrum. Aldicit frius estimuterue magistrum.

magna. we fulninantis magn namus lovis:

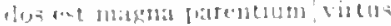

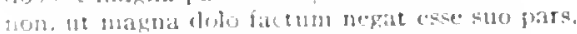

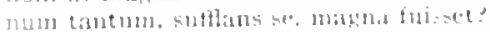

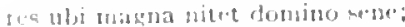

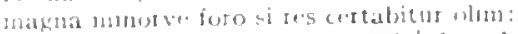

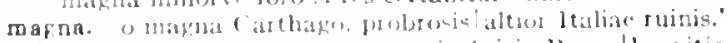

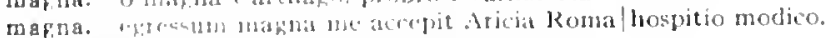

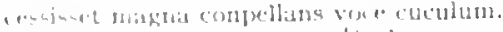

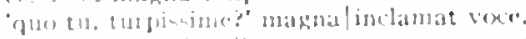

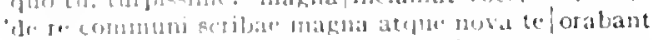

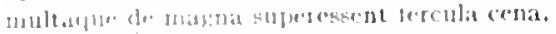

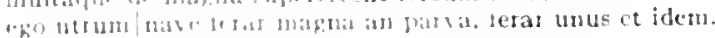

MAGNA

Carm.3.4.74

Ars l'oetino

Carm.2.1.13

Serm.1.2.3

Ars l'oel.105

Corm.2.3.5

Serm.1.5.93

tor.Lpod.10.2

coni.lipod.5.87

Epist.2.2.208

Carm.1.25.11

Carm.1.25.18

Carm.2.12.27

Carm.2.13.30

Car:m.3.9.5

Epod.1.2I

ipod.2.50

coni.lepod.8.17

Epod.12.23

Serm.1.2.80

Serm.1.2.124

Serm.1.3.1.42

Serm.1.5.33

Sirm.1.9.50

Sitm.1.9.53

Sirm-1.10.58

Serm.2.2.29

Sirm.2.2.112

Sirm.2.3.00

Sirm.2.3.07

Sirm.2.3.318

Sirm.2.3.319

Sermi.2.4.13

Serm.2.4.00

Serm.2.0.72

Serm.20.113

Serm.2.8.17

Serm.2.8.49

Epist.1.7.43

List.1.15.23

Epist.1.10.27

List.2.1.2.48

Ars Pocl.zo

Ars l'oet.302

Corm.3.(1.3 I

Eisist.1.2.04

Sirm.2.2.123

scrm.2.3.257

Epist 1.1.14

Evist.1.18.13

Carm.3.11.1

Ars lorl.4I5

Curm.3.3.0

Carm.3.24.21

Serm.1.6.00

serm.2.3.317

Sorm.2.5.12

Serm.2.5.27

Cirm.3.5.39

Sierm. 1.5.1

Sorm.1.7.31

Serm 2.0.75

Sirm.2.10.3p

serm.2.81.10.7

lipist.2.2 200 
magna. magna modis tenuare parvis.

modo reges atque tetrarchas, /omnia magna loquens,

Carm.3.3.72

cui mens divinior atque os/magna sonaturum, .

magna sonabit / cornua quod vincatque tubas:

ne foret his testis, post magna latere sepulcra.

Sirm.1.3.13

Serm.1.4.4.

Serm.1.0.43

Serm.1.8.30

ego vectigalia magna|divitiasque habeo

Serm.2.2.100

magna novet stomacho fastidia

Serm.2.4.78

magna coronari contemnat Olympia,

fuge magna: licet sub paupere tecto | reges et regum vita praecurrere amicos.

si das hoc, parvis quoque rebus magna iuvari.
inceptis gravibus plerumque et magna professis | purpureus. ... adsuitur pannus.

magnae. animaeque magnac|prodigum Paulum superante Poeno proles Niobea magnae/vindicem linguae . . . sensit

magnae. speravit magnae laudi fore.

magnae. quo nultae magnaeque secantur iudice lites.

magnam. bene ferre magnam|disce fortunam; magnam morbi deponere partem.

magnas. magnas inter opes inops.

ridiculum acri|fortius et melius magnas plerumque secat res.

Epist.1.1.5

Epist.1. I 0.32

Epist.2.1.125

Ars Poetid

Carm.I. 2.37

Carm.4.6.I

Sirm.2.3.99

Epist.1.16.42

Carm.3.27.74

Epist.I.I.35

Carm.3.16.28

Serm.I.io. 5 magnas Graecorum malis inplere catervas.'

Serm.I.I0.35

magne. illo | mane [magne] die, quo tu indicis ieiunia, nudus $\mid$ in Tiberi stabit.'

Magnessam. Magnessam Hippolyten dum fugit abstinens.

magni. te canam, magni Iovis et deorum ' nuntium

tibi cura magni|Caesaris fatis data:

et magni memor Herculis.

magni Creontis filiam,

fraterque magni Castoris, victi prece.

magni formica laboris/ore trahit quodcumque potest

magai. non magni pendis, quia contigit; .

magni. magnilquo pueri magnis e centurionibus orti,

magnis. olim qui magnis legionibus imperitarint.

magnis. magnis parva mineris|falce recisurum simili te,

magnis. magni|quo pueri magnis e centurionibus orti, me fcum magnis vixisse invita latebitur usquelinvidia

magnis. missi magnis de rebus uterque|legati. aedibus ex magnis subito se conderet

magno. neque ulla est laut niagno aut parvo leti fuga: . gratus Alexandro regi magno fuit ille|Choerilus,

magno. 'at suave est ex magno tollere acervo.'

numquid ego a te/magno prognatum deposco consule cunnum quid responderet? 'magno patre nata puelia est.' undique magno|pulsa domus strepitu resonet,

in magno ut populo, siqui vidisset,

cum nagno risuque iocoque videres.

nil sine magno vita labore dedit mortalibus.

tu nihil in magno doctus reprehendis Homero?

'porrectum magno magnum spectare catino/vellem'

illo|mane [magno] die, quo tu indicis ieiunia, nudus|in 'Tiberi stabit." cum magno blateras clamore fugisque.

nazonomo pueri magno discerpta ferentes/membra gruis

magno. dicas magno de flumine malim lquam ex hoc fonticulo tantuiden. sumere.'

quac neque magno|stet pretio

Enni|in scaenam missos cum magno pondere versus

magnorum. cum tu, magnorum numen laesura deorum.

rumperis et latras, magnorum maxime regun.

magnos. hic magnos potius triumphos, | hic ames dici pater. audire magnos ian videor duces,

per magnos, Brutc, deos teloro.

haec populos, haec magnos formula reges, lexcepto sapiente, tenet.

magnum. privatus illis census erat brevis, / commune magnum: magnum pauperies opprobriun iubet

venena maga non [magnum] fas nefasque. non valent/convertere humanam vicem. ebrius et, magnum quod dedecus, ambulet ante|noctem cun facibus.' magnum documentum, ne patrian rem|perdere quis velit.'

var.Serm.2.3.291

Carm.3.7.18

Carm.1.10.5

Carm.1.12.50

Carm.4.5.30

Epod.5.4.

Epod.17.43

Serm.1.1.33

Serm.2.4.93

Serm.1.0.72

Sirm.1.t.t

Serm.1.3.122

Sirm.1.0.73

Serm.2.1.76

Sirm.1.5.28

Serm.2.7.II

Serm.2.t.95

Epist.2.1.232

Scrmili.5I

Serm.1.2.70

Sirm.1.2.72

Serm.1.2.128

Serm.1.0.79

Serm.1.8.50

Sirm.1.9.59

Serm.1.10.5z

Serm.2.2.39

var.Serm.2.3.29I

Sirm.2.7.35

Sirm.2.8.80

Serm.1.1.5.5

Serm.1.2.12I

Ars Polt.260

Epod.15.3

Serm.1.3.136

Carm.1.2.49

Corm.2.1.2I

Serm.1.7.33

Serm.2.3.45

Corm.2.15.14

Carm.3.24..12

ior.Epad.5.8;

Sermin.t.5I

Sirm.1... II O 
magnum spectaculum uterque.

Sim.1.7.2I

vitim hoc quoque magnum.

Serm.2.2.69

'(quid t.an magnum?" addens). 'unum me surpite mottil

magnum. Inagnum illa terorem intulerat lovi fidens iuventus lorrida bracchits

haberes magnum adiutorem.

'porrectum magno magnum spectate catino/ wllem"

magnum. in hora satpe ducentos, |ut magnum, vetus dictabat

masnum hoc ago duco. / quod placui tihi.

"mignum namas, vis credibile.'

"ut magnum tecit, quod verbis graeca latinis! miscuit."

'vont enim uagnum donandi parca iuventus

et Incuit magnumque loqui nitique cothurno.

magnus. sedilibusque magnus in primis eques

maguns utereque timor latronibus;

o magnus posthac inimicis risus.

divinaro ctenim magnus mili ronat Apollo.'

iuvonis larthis horrendus. . . tellure marique|magnus erit.

lw trat in sotis: modus agri non ita magnus,

"luandoque bonus [? interdum mignus] dormitat llomerus,

magus. quis te solver Thessalis/magus ven'nis, quis poterit dens?

116 magus, et modo me Thebis, modo ponit Athenis.

Maia. mil amglius oro. Maia nate.

Maiae. what filus Maiae, paticns vocat Caceatis ultor:

maiestas. inperi, jorrecta maicstas ad ortes! solis ab llesperio cubili.

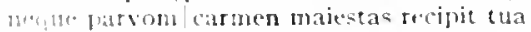

maior. quo non atbiter Haclriae maios.

frigge invidiane maior | urbis relinguam.

a loris maion. tubi miles inpar.

mator Xefomum mox grave provlium lonmisit

flit maior absentis habet:

a peto maior crit. subvertet, si minor, wet.

maior. illi utla clientum|sit maior:

prable certamen, tibi praeda cedat, mator an illa.

latss illi debetur "t a me gratia maior.

nam mibi continuo maiot quaerenda foret res

harra ex cligies erat, altera cerea: maior/lanea.

"mater distilio." "num tanto?"

and at ut copia maior/ab Iove donari josit tibi.

mator utrum jopulum frumenti copia pascat.

acerest nune isque modisque licentia maior.

major. 'o maior tandem parcas, insane, minori.'

D matur iuvenum, quamvis et voce paternal fugeris ad rectum

maiora. Zmyrna guil et Colophon. maioris minorane fama?

majora. Ut fortala carlas meritum maioza subire/vetbra non vereot.

12 tuondam smaiora tuli $t$ ).

winptantem maiora fere, pritesentilus acquom

maiore. chm ro se lorpitur non ut maiore regerensis?

maiore. Cum Sagnatuatore nlulantem:

maiore. concines maiure prota plectro Cacsitrum.

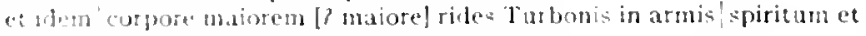

$$
\text { irlite-istin: }
$$

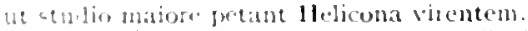

maiorem. jlla mator.ar natuta modum dedit, his breve pondus:

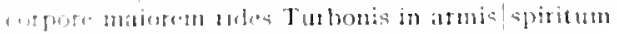

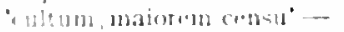

majorem. aj nerue matorem teci ratione mala tem

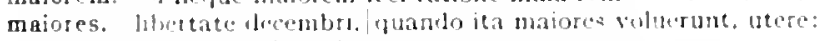

maiores. Callicea powit maioses.

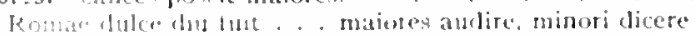

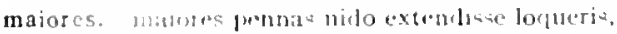

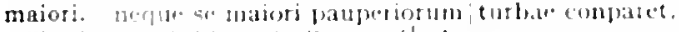

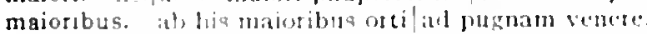

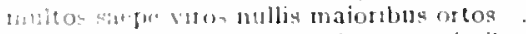

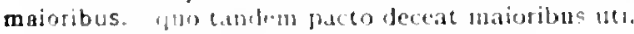

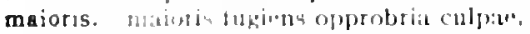

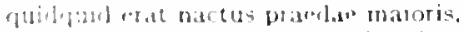

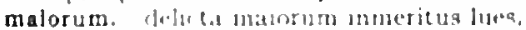

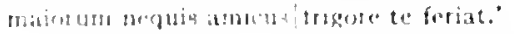

Serm.2.3.283

Carm.3.4.40

Sictm.1.0.4f

Sirm.2.2.39

Sirm.1.4.10

Sicrm.1.0.02

Serm.1.9.52

Serm.1.10.20

Serm.2.5.79

Ars $\operatorname{Poct.280}$

Ipod.1-15

Sermoletet

Serm.2.2.107

Sirm.2.5.60

Sirm.2.5.6.4

Serm.20.I

? quar.Ars Poet.3j)

Carm.1.27.22

Epist.2.1.213

Serm.2.6.5

Carm.1.2.43

Carm.4.15.15

Ifpist.2.1.258

Carm.1.3.10

Carm.2.20.4

Carm.t. 1.5

Carm.t.14 14

I:pod.1. 18

IEpist.I 10.43

Carm.3.14

Curm.3.20.s

Sirm.1.0.88

Sirm.1.6.100

Sirm.1.8.30

Sirm.2.3.318

lepist.1.12.2

IFpist. I. I 5.14

Ars loet.z I

Sirm.2.3.326

Ars Pot.366

Epist.1.11.3

Sirm.1.3.120

Serm.2.5.21

Ifpist.1.7.24:

firm. I.10.55

Serm.1.8.25

Cism.4.2.33

? tar.sorm.2.3.310

1.pist.2.1.2Is

S.rm.2.2.37

Vierm.2.3.310

Serm.2.3.32.4

sorm.20.0

Serm.2.7.5

Sierm.2.8.35

lipiti.2.1 10 ,

I.jict.20.21

S.rm.1.1.1II

Serm.1.5.5.5

sermatio

Epist.1.17.2

Epist.0.10

Jpist.1.15.35

Corm.311

Sirmet.1.1 
maiorum. crescentem sequitur cura pecuniam| maiormmgue fames.

maius. unde nil maius generatur ipso

quanto hoc furiosius atque maius peccatum est:

Carm.1.12.17

Sirm.1.3.8.4

Epist.1.18.5

est huic diversum vitio vitium prope maius,

maius. vim temperatam di quoque provehunt|in maius;

(quid potuere maius?)

quo nibil maius meliusve terris/iata donavere.

monstrumve submisere Colchi|maius.

possis nihil urbe Roma/visere naius.

maius parabo, maius infundan tibi|fastidienti poculutu

tu cave ne minuas, tu ne maius facias id

nos maius veriti, postquam nihil esse pericli|sensinus, crigimur;

invidia Siculi non invenere tyranui|maius tormentum.

quid roveat dulci nutricula maius alumno.

nil divitiae poterunt regales adicre maius.

hic onus horret, ut parris animis et parvo corpore maius;

mala. Rhoetum retorsisti leonis|unguibus horribilemque mala;

mala. in amore haec sunt mala. belium. 'pax sursum:

dum mea delectent mala me vel denique fallant.

mala. rura fugae nala, dura belli.

di multa neglecti dederunt/Hesperiae mala luctuosac.

neque dulci mala vino lavere

huic si nutonis verbis mala tanta videnti diceret haec animus

curn tua pervideas oculis mala lippus inunctis.

quin per mala praeceps|fertur uti pulvis collectus turbine.

mala multa precatus Atridis .

quae maxima credis|esse mala.

multa quidem nobis facimus mala saepe poetae.

hae nugae seria ducent / in mala derisum semel exceptumque sinistre.

mala. ab ovolusque ad mala citaret 'io Bacchae'

mala. natura aut etiam consuetudo mala;

sed mala tollet anum vitiato melle cicuta. .

mala copia quando/aegrunı sollicitat stomacium,

"quem mala stuititia et quemcumque inscitia veri caecum agit. nec mala me ambitio perdit nec phumbeus auster ut mala quem scabies ant morbus regius urget

mala. audax lapeti genus ignem fraude mala gentibus intulit:

inala ducis avi domum /quam inulto repetet Gratcia milite mala soluta navis exit alite|ferens olentem Meriun.

ambitione mala aut argenti pallet amore. .

si neque maiorem feci ratione mala rem

mala. Hypsaea caecior illa.|quae mala sunt, spectes.

ut siquis solum hoc, mala ne sint vina, laboret.

mala. si neque avaritiam neque sordes aut mala lustralobiciet

si mala condiderit in quem quis carmina.

esto, siquis mala;

scribet mala carmina vecors: laudato.

et mala perrumpet furtim fastidia victrix.

ridentur mala qui conponunt carmina;

malarum. quis non malarum quas anor curas habet | liaec inter obliviscitur?

malas. antequam turpis macies decentis/occupet tnalas

malas. an malas/Canidia tractavit dapes?

Malchinus, Maltinus [Malchinus] tunicis demissis ambulat;

male. pignusque dereptum lacertis/aut digito male pertinaci.

ne male dispari incontinentis iniciat manus

non, si male nune, et olim|sic erit:

male nominatis $\mid$ parcite verbis.

male feriatos|Troas . . . falleret

male barbaras|regum est ulta libidines.

pereat male quae te|Lesbia quaerenti taurum monstravit inertem. toga defuit et male laxuslin pede calceus liaeret -

pullum, male parvos/sicui filius est.

illum |balbutit scaurum pravis fultum male talis.

Sulcius acer/ambulat et Caprius, rauci male cumque libellis.

'nonne vides. Albi ut male vivat filius utque Baius inops?

male salsus|ridens dissimulare:

*Catone. . qui male factos iemendare parat versus,* .

peream male, si non|optimum erat:

Sirm.2.0.0

serm.1.2.92

Serm.2.4.49

tierm. 1.0 .68

Sorm.2.1.8z

Serm.2.1.83

Sitm.2.5.74

Epist.1.10.25

Ipist.2.2.100

Epod.2.37

Carm.3.27.54

ispod. 3.7

ziar.serm.1.2.25

("arm.t.9.24

Carm.I.17.25

Carm.2.10.17

Carm.3.14.1 I

Carm.46.14

Carm.4.12.7

Lpod.12.10

Serm.1.3.3I

Sirmi.1.3.45

Serm.1.3.48

Sirm.1.4.60

Siem.1.4.109

Serm.1.9.65

Sermt.1.10.*2

Serm.2.1.6 
cui male si palpere, recalcitrat undique tutus."

Serm.2.1.20

neque, si male cesserat, usquan|decurrens alio neque, si bene:

Serm.2.1.31 sed mala [nale] tollet anum vitiato melle cicuta.

male verum examinat omnis/contuptus iudex.

ram male te gesta cum vellem mittere opertolme capite in Piumen.

si male rem gerere insani est, contra bene sani:

quin, ex quo est habitus male tutae mentis Orestes.

pratensibus oftima fungis|natura est; aliis male creditur.

sicui practerea validus male filius in re/praeclara sublatus alctur.

siquis|forte coheredum senior male tussiet.

nec male necne Lepos saltet;

tangentis male singula dente superbo;

ne male conditum ius adponatur.

an male sarta/gratia nequiquan coit et rescinditur.

liand male Tolemachus, proles patientis V'lixei:

nec vixit male. qui natus noriensque fefellit.

ut male samos adsctipsit Liber Satyris Faunisque poetas.

qui male parentem in rupis protrusit ascilum iratus:

incultis qui versibus et male natis rettulit . . Hhilippos.

male si mandata loqueris, aut dormitabo aut riclebo.

delere iubebst et nale tormatos incudi reddere versus.

maledicit. tantum maledicit utrique.

maledicunt. vel quod maledicunt liberius

mali. Remmas et lapides aurum et inutile. summi materiem mak.

(nam pudet tanti maji)

mali. unde labos plus litusire mali est quam ex re decerpere fructus.

mali. nali culices ranaeque palustres/avertunt somnos;

maligne. ne fort putes me, . . laudare maligne:

malignis. mele for Appiliffertum nantis cauporibus atque malignis.

malignum. P'arca non mendax dedit et malignum | spernere volgus.

malignus. at tu, nauta. vagae ne parce malignus harenae. . particulam diac:

malim. dicas magno de thume malim|quam ex boe fonticulo tasturdem sunwere."

malis. seu malis vetita legibus alea.

malis tentigise rumpi?

patris intermiscere petitalverba foris malis.

i) magnas Graecorum malis inplere catervas."

an tua demens/vilibus in ludis dictati camina malis?

malis. cum rapies in ius malis ridentem aliersis.

malis. hane ego cum malis, ego faccem prinus et liallec.

malis. nee magis lis alicna malis;

malis. malis cascte quatritis liboribus;

malis. néc malis divolsus guerimoniis

ac non ante malis dementem actum Furib quam

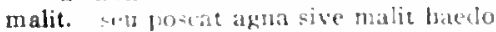

guin omnia nalit / quaccumpe inmundis fervat adlata popinis.

malle. 'matgo te flumine malim [malle]'quan ex hoc fonticulo tantundem

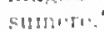

mallem. "makso de flumine malim [mallem] / quan ex hoc fonticulo tartunden sumere.'

'nullow his mallem luelos spectasse;

nec sermones "go mallem, repentis per human.

malles. si rbofrube delictum quan vertere malles,

mallet. popnlus Jaseving mallet homorem/quam becio mandare novo

ian muechas Konar. iam mallet doctus Acheris/vivere.

Mallio. "I mata nuecurn consule Minlio [Mallio].

malo. Cur noscirc pullens prave guam discore malo?

malo. mullichu. malo latua obdit apertum,

malo. non di. quan itorim firesea veres malo.

meo nume sumbus unedis malo.

quone malo mentern concusera timote deorum."

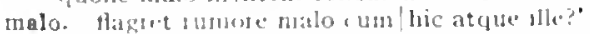

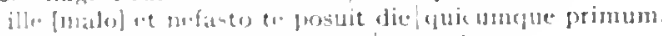

malo. Con thl patene videre est/ut nudars, ne coure malo, ne sit pede

$$
\text { tispi: }
$$

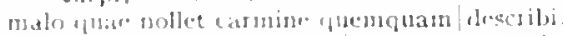

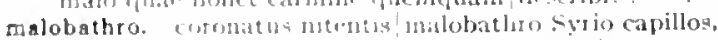

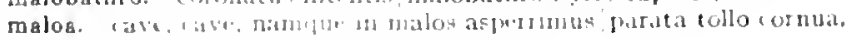

Serm.2.2.8

Scrm.2.3.37

Serm.2.3.74

Serm.2.3.137

Serm.2.4.21

Sorm.2.5.45

Serm.2.5.107

Sorm.2.0.72

Serm.2.0.87

Serm.2.8.09

Epist.1.3.31

Epist.1.7.40

Epist.1.17.10

Epist.1.19.3

l.pist.I.20.15

Epist.2.1.233

Ars Poct.104

Ars Pocl.4.4

Scrm.2.3.140

Sitm.2.8.37

Carm.3.24.49

Epodil1. 7

Serm.1.2.79

Scrm.1.5.14

Epist.2.1.209

Sorm.1.5.4

Carm.2.10.39

Curm.1.2S.23

Serm.1.1.55

Carm.3.24.58

Scrm.1.2.118

Serm.1.10.30

Serm.1.10.35

Serm.1.10.75

Serm.2.3.72

Serm.2.4 73

Serm.1.9.50

Epod.10.10

Carm.1.13.18

Sorm.2.3.135

Curm.t.4.12

Serm.2.4.61

lar.Serm.1.1.55

var.Serm.1.1.55

Sirm.2.8.79

Lpist.2.1.250

Ars Poct.442

Sorm.1.6.10

Scrm.2.7.13

Iur.Curm.3.21.

Ars Poed 88

Serm.1.3.59

Carm.1.110

Epod.15.28

Serm.2.3.295

Sirm.1.4.125

iur.Carm.2.13. J

Sorm.1.2.102

Esist.2.1 53

Curm.2.7.s

l.pod.o. I 


\section{MALOS}

formidare malos fures, incendia.

Malthinus. Maltinus [Malthinus] tunicis demissis ambulat;

Maltinus. Maltinus tunicis demissis ambulat;

maluit. cum faber. . . maluit esse deum.

malum. bonam deperdere famam, I rem patris oblimare malum est ubicumque.

quod magis ad nos/pertinet et nescire malum est,

malum. illic omne malum vino cantuque levato,

unde fama malum gravius quam res trahit.

grande malum Turius, siquid se iudice certes.

malum. volnus nil malum levantia,

malum. ne gallina malum responset dura palato.

malunt. verum age et his, qui se lectori credere malunt

malus. quod latus mundi nebulae malusque|l uppiter urget;

quam malus undique membris!crescit odor.

avi cur atque parentis/praeclaram ingrata stringat malus ingluvie rem. siquis erat dignus describi, quod malus ac fur,

pudor" inquit "te malus angit.

nam Laurens malus est, ulvis et harundine pinguis.

stultorum incurata pudor nalus ulcera celat.

militiae quamquam piger et malus, utilis V'rbi.

malus. et malus celeri sancius Africo

si mugiat Africis|malus procellis,

malvae. me pascunt olivae, me cichorea levesque malvae. gravi|malvae salubres corpori

mammae. mammae putres|equina quales ubera

Mamurrarum. in Mamurrarum lassi deinde urbe manemus.

manabit. tibi copialmanabit ad plenum

manant. non semper imbres nubibus hispidos/manant in agros mella cava manant ex ilice.

manantibus. frondesque lymphis obstrepunt manantibus.

manare. fidis enim manare poetica mella/te solum.

manaret. cum sudor ad imos $\mid$ manaret talos.

manat. cur/manat rara meas lacrima per genas?

frigidus a rostris manat per compita rumor:

omne supervacuon pleno de pectore manat.

manca. in quem manca ruit semper fortuna.

mancipat. Quaedam, si credis consult is, mancipat usus:

mancipium. Davos. amicum' mancipium donino

mancum. me ... dixi|talibus officis prope mancum, .

mancupiis. mancupiis locuples eget aeris Cappadocum rex:

mandabo. forum putealque Libonis/mandabo siccis,

mandare. populus Lacvino mallet honorem quam Decio mandare novo

mandata. vale, cave ne titubes mandataque frangas.

male si mandata loqueris, | aut dormitabo aut ridebo.

Mandela. quen Mandela bibit, rugosus frigore pagus, .

mandentur. ne forte seniles/mandentur iuveni partes pueroque viriles:

mane. noctis vigilabat ad ipsum|nane, diem totum stertebat.

mane. dicimus integrof sicci mane die, dicimus uvidi,

non sollicitus mihi quod cras/surgendum sit mane.

niane donum veniant.

latis mane senex manibus currebat

illo| mane die, quo tu indicis ieiunia, nudus in Tiberi stabit."

navos inane forum et vespertinus pete tectum. .

(qui mane plagas. . . transire forum populumque iubebat.

Volteium mane Philippus . . occupat

quod non mane domum venisset,

mante cliens et iam certus conviva.

vina fere dulces oluerunt mane Camenae.

Romae dulce diu fuit et solleme reclusa mane domo vigilase.

mane. te saepe vocanti|duran difficilis mane.

maneant. fors ct|debita iura vicesque superbae/ te maneant ipsum:

manebo. supremo te sole domi. Torquate, mantbo.

manemus. in Mamurrarum lasci deinde urbe manemus.

manent. nec mens mihi nec colot certa secte manent.

quae manent culpas etian sub Orco.

sed taidiora fata te votis manent:

manserunt hodieque manent vestigia ruris.

manentem. laudo manentem;
MANENTEM

Serm.1.1.77

var.Serm.1.2.25

Serm.1.2.25

Serm.1.8.3

Serm. 1.2 .62

Serm.2.6.73

Epod.13.17

Serm.1.2.59

Serm.2.1.49

Epod.1 I.I

Sorm.2.4.18

Epist.2.1.2I4

Carm.1.22.19

Epod.12.7

Sirm.1.2.8

Serm. I.4.3

Serm.2.3.39

Sirm.2.4-42

Epist.1.10.24

Epist.2.1.124

Carm.1.14.5

Carm.3.29.58

Carmi.1.31.16

Epod.2.58

Epod.8.7

Serm.1.5.37

Carm.1.17.15

Carm.2.9.2

Epod.10.47

Epod.2.27

Epist.1.19.44

Serm.1.9.I 1

Carm.4.1.34

Serm.2.t.50

Ars Poel. 337

Serm.2.7.88

Epist.2.2.159

Serm.2.7.3

Epist.2.2.21

Epist.1.6.39

Epist.1.19.9

Serm.1.6.20

Epist.1.13.19

Ars Poet. 104

Epist.1.IS.105

Ars Poet.rit7

Sirm.1.3.18

Carm.4.5.39

Sirm.1.0.120

Serm.2.3.230

Serm.2.3.282

Serm.2.3.20 I

Epist.1.0.20

Epist.1.6.58

Epist.1.7.t.

Epist.1.7.08

Epist.1.7.75

Epist.1.19.5

Epist.2.1.104

Carm.3.7.32

Carm.1.28.33

I.pist.1.5.3

Serm.1.5.37

Carm.1.I3.

Carm.3.11.29

Fpod.17.02

Epist.2.1.160

Carm.3.29.53 
manentis. si plosoris eges aulaca manentis

Ars Poet. 15 t

Manes. iam te prenet nox labulacque Manes carmine di superi placantur, carmine Manes.

Carm.t.4.10

Epist.2.1.1.38

Carm.1.1.25

2usr.Carm.1.13.6

Curm. 1.28 .15

Corm.2.18.3I sted onnis una manct nox

nulla certior . . aula disitem manet/erum.

neque illi|iam manct umida creta

tc manet Assaraci tellus.

no: manet Oceanus circum vagus:

qu+de finis aut quod me manet stipendium?

ho yuopue te manet.

manet. sfiritus tacter saniesque manet /ore trilingui;

fuod cum spe divite manet in venas animumrue meum,

lipod.12.10

E.pot.13.13

Ispod.16.41

1.poil. 17.30

lipist 1.20 .17

Carm.3.11.10

List.1.15.19

lipist 1.17 .59

lipist.2.2.13

mangonum. nemo hoc nangonum faceret tibi;

manibus. auor in fossan confusus, ut inde / manis [manibus] elicerent animas responsa daturas

manibus. donce manibus tremor incidat unctis.

manibus. valentium proceras manibus vertere fraxinos,

conumxit lectum potus nensave catilum | Euandri manibus tritum deiecit:

bene siquislet vivat puris manibus,

lautis mane senex manibu= currebat

ifud, caput abscissum demens [manibus] cum portat Agane / gnati infelucis.

Guirl. caput abscissum demens cum po: tat [abscissum manibus portavit]

Agauel gnati infelicis.

puer untis/tractarit calicem manibus.

donec "ole jam" ad caelum manibus sublatis dixerit.

sur.serm.1.8.20

Epist.1.10.23

Carm.3.25.10

Sirm.1.3.01

Serm.1.4.08

Serm.2.3.2.2

qar.s.m.2.3.303

:ur. Sirm.2.3.303

Sirm.2.4.70

Sirm 2.5 .97

Lipist.1.19.3.t

iuvat inmenorata ferentem|ingenuis oculisque legi manibusque teneri. contrectatus ubi manibus sordescere volgi/coeperis.

Caevius in manibus non est et mentibus haeret paene recens?

lipist.1.20.1 I

Lipist.2.1.53

Epist.2.1.10 mox trahitur manibus regum fortma retortis,

manic:s. "in manicis et compedibus saevo te sub custode terebo." manifestum. ne manifestum |caclibis obsequium nudet te.

Manilio. o nata necum consule Manlio [Manilio].

manis. nt imle nanis elicerent amimas responsa daturas.

manium. "luate vis deorum est Manium.

Manio. o nata mecum consule Manlio.

mannis. inpositus mannis arvom cachuque Sabinum/non cessat laudare.

mannis. it Afpian mannis terit

mannos. si per obliquom similis sagittae/terruit mannos:

manserunt. nanterunt bodreque mancut vestigia ruris.

mansuri. mancuri opfidulo, quod versu dicese non est.

mantica. mantica cuj lumbos onete ulectet atque eques armos:

manu. I lavos trabulis et cuneos manulgestans atena

romituarpe llerculea manu| Telluris invenes.

sischexis mont produxit. arbos.

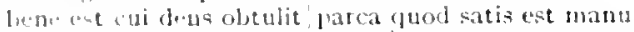

farentis olin siguis injia manu/senile guttur fregerit.

artentalue manu "quid agis, dulcissime rerum?"

et presate manu lentissima bracchia.

gratit sumu numu neu rlulcia difter in ammun.

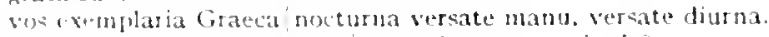

manum. unde manum iuventus/netu deorum contimut?

nunum purlla savio opponat t(u).

centsa latrones atque serwilem manum

mantus stonachumqua teneto,

manus. Heo fulminantis magua mams lovis:

1.6m bia Mondoses et Pacori mams

munnis aram si tetiglt manus.

- uruta festinat manus.

fuan Giala victorum manus,

murticis int listuscal Possenac unanus.

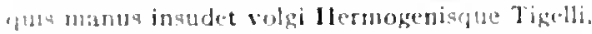

multa butarum veniat manus.

nasm noplue a borta sonum reddit quen volt manua et mens.

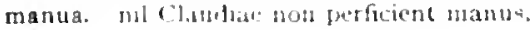

Ejist.1.10.7P

Sirm.2.5.46

[rur.Carm.3.21.:

Sirm.1.8.29

Fipod.5.94

Corm.3.21.1

lepist.t.7.7

fipod..t.1.

carm.3.27.7

I.pist.2.1.10

Sirmi. 1.8.

Sirm.1.0.100

(ism.1.35.1.

(orm.2.12.0

(isrm.2.13.2

Carm.3 10.44

lipod.3.1

Serm.1.0.4

S.rm.1.0.0.4

l. pist.1, 11.23

irs foet.200

Carm.1.35.39

Eped.3 $=1$

fipollat 19

Serm.2.7.44

(arm.3.3.0)

Cism.3.0.9

(arm.3.2.3.17

(iorm.g.1 1.9

Fond co.t2

Ifpellok.4

Serme172

term.1.1.11

Ars l'uet.34\%

carm.4.4.3 
quale non perfectius/meae laborarint manus..

tibi hospitale pectus et purae manus

manus. ne nale dispari|incontinentis iniciat manus

caelo supinas si tuleris manus

cuncta manus avidas fugient heredis

manus potentis|Medus Albanasque timet securis,

'iam iam efficaci do manus scientiae,

ora manusque tua lavimus, Feronia, Jympha;

mappa. ne sordida mappa|corruget naris,

mappa. Varius mappa conpescere risum / vix poterat.

mappis. vilibus in scopis, in mappis, in scobe quantus|consistit sumptus?

Marcelli. crescit occulto velut arbor aevo/fama Marcellis [Marcelli];

Marcellis. crescit occulto velut atbor aevo|fama Marcellis;

marcentem. tost is marcentem squillis recreabis et Afralpotorem coclea:

mare. deterret ensis nec mare naufragum

exitio est avidum mare nautis;

tumultuosum sollicitat mare.

nunc mare, nunc siluae/Threicio Aquilone sonant.

cum te neque fervidus aestus | demoveat lucro neque hiemps ignis mare ferrum,

atrum|defendens piscis hiemat mare:

sed non omne mare est generosae fertile testae:

lacus et mare sentit amorem/festinantis eri;

mare. Myrtoum pavidus nanta secet mare.

qui vidit mare turgidum

nec cursus duplicis per mare Vlixei

quae nunc oppositis debilitat pumicibus mare|Tyrrhenum:

qui mare ac terras variisque mundum|temperat horis?

o navis, referent in mare te novilfuctus.

tristitiam et metus/tradam protervis in mare Creticum/portare ventis, quod mare Dauniae/non decoloravere caedes?

aut mare Caspium / vexant inaequales procellae|usque

Siculum mare|Poeno purpureum sanguine

tu flectis annis, tu mare barbarum,

qui terram inertem, qui mare temperat / ventostun.

caementis licet occupes|terrenum omne tuis et nare publicum:

vel nos in mare proximum/gemmas . . . mittamus.

cum pace delabentis Etruscum/in mare.

pacatum volitant per mare navitae:

lam veris comites, quae mare temperant,

neque horret iratum mare

hiems ad hoc vertat mare.

nautis infestus Orion/turbaret hibernum mare.

in mare seu celsus procurrerit Appenninus

per omnelaudaces mare qui currunt.

atque ego cum graecos facerem, natus mare citra.|versiculos.

vino quinquenni, verum citra mare nato. dum coquitur .

per mare pauperiem fugiens, per saxa, per ignis):

ad mare descendet vates tuos

idcirco navim trans Aegaeum mare vendas.

caelum. non animum mutant, qui trans mare currunt.

quae mare compescant causae. quid temperet annum,

ad mare cum veni, generosum et licne requiro.

Garganum nugire putes nemus aut mare Tuscum: .

hic meret acra liber Sosiis, hic et mare transit

mare. o mare et terra, ardeo,

nare. priusque caelum sidet inferius mari [mare] tellure porrecta super

marem. namque marem cohibent callosa vitellum.

Mareotico. mentemque ly mphatam Mareotico'redegit in veros timores'Cacsar

mares. mares animos in Martia bella/versibus exacuit;

rares. natalemque, mares, Delon Apollinis

mari. addant avaro divitias mari:

mari. sive flammalsive mari libet Hadriano.

ut pura nocturno renidet/luna mari

iam mari terraque manus potentis|Medus Albanasque timet securis. priusque caelum sidet inferius mari | tellure portecta super

terra marique victus hostis

aut fertur incerto mari.

niger rudentis Eurus inverso nari
I.pod.5.60

Epod.17.49

Corm.1.17.26

Carm.3.23. I

Carm.4.7.19

Carm.Sate.53

Epod.I7.I

Serm.1.5.24

Epist.1.5.22

Sirm.2.8.63

Serm.2.4.8 I

iar.Carm.1.I 2.46

cont.Carm.1.12.46

Sirm.2.4.53

Carm.1.16.10

Carm.1.25.18

Carm.3.1.26

IEpod.13.2

Serm.1.1.39

Sirm.2.2.1 7

Scrm.2.4.3 $\mathrm{I}$

Epist.1.1.8.4

Carm.I.I.I

Carm.1.3.19

Carm.1.6.7

Carm.1.1I.5

Carm.I.I2.I5

Carm.I.I. I

Carmi.20.2

Carm.2.1.34

Carm.2.9.2

Carm.2.12.2

Carm.2.19.27

Carm.3.4.45

Carm.3.24.4

Carm.3.24.47

Carm.3.29.30

Carm.4.5.19

Cormutiz.I

Epod.2.6

E.pod.2.52

Epod.1 5.8

Epod.10.29

Serm.t.1.30

Serm. I.10.3 I

Serm.2.8.47

Epist.1.r.4t

Epist.1.7.II

Epist.1.11.16

Epist.1.I1.27

Epist.1.12.16

Epist.1.15.18

Epist.2.1.202

Ars Pet. 345

Epod.1.30

iar. Epod.5.79

Serm.2.4.1

Corm.1.37.14

Ars Poet.poz

Carm.1.21.IO

Carm.3.29.0I

Carm.1.1 4.4

Carm.2.5.20

Carm.Sale. 53

Epod.5.79

Fpod.9.27

Epod.9.32

Epod.10.5 
tellure marique/ magnus erit.

siquis bella tibi terra pugnata marique/dicat

maribus. et maribus Curiis et decantata Camillis?

Maricae. princeps et innantem Maricaellitoribus tenuisse Lirim.

marina. ut melius muria quod testa marina remittat."

marinae. quid latet, ut marinae|flium dicunt Thetidis

laevom marimae qui V'eneris latus|custodit.

filus quamsis Thetidis marinae

qui di.s mensem Veneris marinae / findit Aprilem.

marino. parvos coronantem marino|rore deos

marinus. ut marinus asperis|echinus aut Laurens aper.

maris. uvida/suspendisse potenti|vestimenta maris deo.

te maris et terrae aumeroque carentis harenae/mensorem cohibent.

sit inolus lasso maris et viarum|militiacque.

marisque Bais obstrepentis urges/submovere litora.

Carpathii trans maris aequora

1) vospes/Caecuba vina fereng, Alcon Chium maris expers.

c'nses mutsera terrae. quid maris extremos Arabas ditantis

an Lebedum laudas odio maris atque viarum?

non locus effusi late maris arbiter

marita. nec sit marita. quae rotundioribus/onusta bacis ambulet.

marita. prolisque novae feracil lege marita.

maritat. ergo aut adulta vitium propagine/altas maritat populos

mariti. clentis uxores mariti

iuniores quaerit aduleros inter mariti vina

catis cum puctis ignara puella matiti|disceret unde preces.

maritis. iurat bene solis esse maritis.

ronculbitu probibere vago, dare iura maritis.

marito. nuptiarum expers et adluc protervolcruda marito. .

"surgec" quae dixit iuveni marito.

fortique maritoldestinet uxorem:

est me marito matronac pecantis in ambo iusta potestas.

marito. non sine conscio surgit marito.

unico gaudens mulier marıto

maritos. tua ne retardet/aura maritos.

maritum. iam protervalfronte petet Lalage maritum/dilecta,

maritus. mil"sne Crassi coniuge barbara/turpis maritus vixit

Marius. IJellade percussa Marius curn praecipitat se.

marmor. argentum et marmor vetus aeraque et artis/suspice.

gemmas, marmor, ebur. . . . sunt qui non habeant.

marmora. non incisa notis marmora publicis.

marmora. tu secanda marmora|locas sub ipsum funus.

marmore. splendentis Pario marmore purius. .

marmoream. Abanos prope te lacus/ponet narmoream sub trabe citrea.

marmoreum. intra marmoreum venerandi limen amici.

marmoris. narmoris aut eboris fabros aut aeris amavit.

Marsa. caputque Marsa dissilire nenia.

Marsae. fui dissimulat metum/Marsae cohortis Dacus

Marsaeus. ut quondam Marsaens, amator Originis ille.

Marsi. acer et Marsi peditis cruent 1 m / voltus in hostem:

Marsi. et carlum Marsi memorem duelli.

Marsi. quam nerpue finitimi valuerunt perdere Marai

Marsis. nec vorata mens tual Marsis redibit vocibus.

Marsus. seu rupit tretes Vargut aper plagas.

sub rege Medo Marsus et Apulus.

Maraya. Marsyit. qui se/voltum terre negat Noviorum posse minoris.

Marte. nec semeleius' cum Marte confundet Thyoneus/proclia. arval Marte coli populata nostro

i.t Marte Promos proteret altero:

guidd Morte possers.

marte. Irutra cruento matte carcbimus

Martern. quia Martem tunica tectum adimantinaldiene seripserit

Marti. dame alion Juriae torvo spectacula Mart.

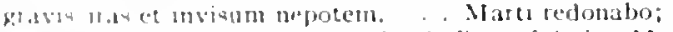

Marta. agroctudut in certamine Martio [inter fulmina Nartial. 111.tra animos in Martia bella/ versibus exacuit;

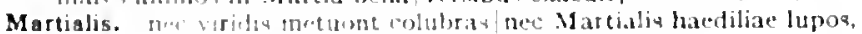

Martii. jur keramena Martui|campi.

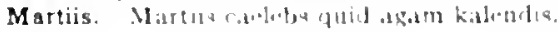

Serm.2.5.63

Epist.1.16.25

Epist.1.1.64

Carm.3.17.7

Serm.2.8.53

Carm.1.8.13

Carm.3.20.5

Carm.1.6.6

Carm.4.11.15

Carm.3.23.1 5

Epod.5.27

Carm.1.5.16

Carm.1.28. I

Carm.2.6.7

Carm.2.18.20

Carm.4.5.10

Sorn.2.8.1 5

Epist.1.0.6

Epist.1.1 10

Lisist.1.1.20

Fpod.8.13

Carm.Sace.20

I pod.2.10

Carm.1.17.7

( $a r m .3 .0 .26$

Epist.2.1.132

Epist.1.t.89

Ars Poet.398

Carm.3.11.12

Carm.3.11.37

Serm.2.3.210

Serm.2.7.01

Carm.3.0.30

Carm 3.14 .5

Carm.2.8.24

Carm.2.5.10

Curm.3.5.6

Serm.2.3.277

Epist.1.6.17

Epist.2.2.180

(iar).4.8.13

Carm.2.18.17

Carm.1.19.6

Cirm.4.1.20

Epist.1.18.73

Epist.2.1.96

Epod.17.20

Carm.2.20.18

Sorm.1.2.55

coni.Carm.1.2.39

Cirm.3.14.18

I.pol. I0.3

Epod.5.70

Corm.1.1.28

Carm.3 5.9

Serm.1.0.120

Corm.1.17.23

Cirm.3.5.24

Corm.3.5.34

Cirm.t. is 9

Curm.2.1.13

Corm.1.0.13

Garm.t.28.17

Curm.3.3.33

conicarmA.tA.t?

Ars Ioct.qoz

Cormelat7.9

Cirm.4.1.39

Corm $3 \mathrm{~s}$ 


\section{MARTIO}

Martio. aeque conspicitur gramine Martio, spectandus in certamine Martio

Martis. hac Quirinus| Martis equis Acheronta fugit,

mascula. sed rusticorum mascula militum/proles, temperat Archilochi musam pede mascula Sapplio.

masculae. non defuisse masculae libidinis

Massagetas. diffingas retusum in/Massagetas Arabasque ferrum.

Massica. Massica si caelo suppones vina sereno,

Massici. est qui nec veteris pocula Massici . . spernit.

Massica. oblivioso levia Massicolciboria exple,

Massicum. quocumque lectum nomine Massicum |servas,

mater. mater saeva Cupidinum .

ut mater iuvenem. . . precibus vocat

nec mater domum caerula te revehet. .

ipsa utilitas, iusti prope mater et aequi.

est tibi mater.|cognati, quis te salvo est opus?"

clamet amica, mater, honesta soror cum cognatis, pater, uxor:

clamet amica. mater. [clamet amica / mater,] honesta soror cum cognatis, pater, uxor:

nater ait pueri mensis iam quinque cubantis. mater delira necabit |in gelida fixum ripa.

"indotata mihi soror est, paupercula mater.

veluti pia mater/plus quam se sapere . . volt

mater. desine, dulcium|mater saeva Cupidinum,

Catienis mille ducentis/ 'mater, te appello' clamantibus. .

mater. sunite materiam [iam mater] vestris, qui scribitis, aequam |viribus

matercula. dum pueris omnis pater et matercula pallet

materiam. sumite materiam vestris, qui scribitis, aequam/viribus

materiem. gemmas et lapides aurum et inutile,/summi materiem mali.

materies. publica materies privati iuris erit.

materna. arte materna rapidos morantem|fluminum lapsus

maternis. rebus maternis atque paternis/fortiter absumptis

maternus. nec quod avos tibi maternus fuit atque paternus

Matina. quando| Padus Matina laverit cacumina, .

Matinae. ego apis Matinae/more modoque

Matinum. pulveris exigui prope latum parva Matinum|munera .

matre. o matre pulcra filia pulcrior.

sic lucro aversam potuisse rasci|matre pudenda.

matre carentibus/privignis mulier temperat

relicta|matre qui largis iuvenescit herbis

quo patre sit natus, num ignota matre inhonestus,

matrem. quaerenti pavidam montibus aviis!matrem

tandem desine matrem/tempestiva sequi viro.

Scaevae vivacem crede nepoti|matrem:

cum laqueo uxorem interimis matremque veneno.

matres. te Dacus asper. . . regumque matres barbarorum et | purpurei metuont tyranni.

te suis matres metuont iuvencis.

virginum matres iuvenumque nuper / sospitum;

unxere matres Iliae additum feris / alitibus atque canibus homicidam Hectorem.

matres. quae solet matres furiare equorum,

Ilithyia. tuere matres.

matri. matri denarrat, ut ingens/belua cognatos eliserit:

matribus. bellaque matribus|detestata.

matris. expedit matris cineres opertos|fallere severae matris ad arbitrium .

fulvae matris ab ubere iam lacte depulsum

ureret flammis, etiam latentem / matris in alvo,

in matris iugulo ferrum tepefecit acutum?

matrona. matrona bellantis tyranni|prospiciens

hine avidus stetit/Volcanus, hinc matrona Juno

ut matrona meretrici dispar erit atque/discolor.

matrona potens an sedula nutrix.

ut festis matrona moveri iussa diebus.

matrona. quid inter- est in matrona, ancilla peccesne togata?

matronae. matronae praeter faciem nil cernere possis/cetera,

estne marito|matronae peccantis in ambo iusta potestas.

matronam. hoc amat et laudat 'matronam nullam ego tango.'

\section{MATRONAM}

Carm.3.7.26

Carm.4.14.17

Carm.3.3.16

Carm.3.6.37

Epist.1.19.28

Epod.5.41

Carm.I.35.40

Sim.2.4.51

Carm.1.1.19

Carm.2.7.2I

Carm.3.21.5

Carm.I.I9.I

Carm.4.5.9

Epod.13.16

Serm.1.3.98

Serm.1.9.26

Serm.2.3.58

rar.Serm.2.3.58

Serm.2.3.289

Serm.2.3.293

Epist.1.17.46

Epist.1.18.26

Carm.4.1.5

Serm.2.3.62

var.Ars Poet.38

Epist. 1.7

Ars Poet. 38

Carm.3.2.4.49

Ars Poet.1 $3 \mathrm{I}$

Carm.1. I 2.9

Epist.1. I 5.26

Sirm.1.6.3

Epod.16.28

Carm.4.2.27

Carm.1.28.3

Carm.1.16.1

Carm.2.4.20

Curm.3.24.17

Carm.4.2.55

Serm.1.6.36

Carm.1.23.3

Carm.1.23.1I

Serm.2.1.54

Serm.2.3.131

Carm.1.35.11

Carm.2.8.21

Curm.3.14.9

Epod.17.11

Carm.1.25.14

Carm.Saec.14

Serm.2.3.315

Carm.1.I.2.

Carm.2.8.9

Curm.3.0.4n

Carm.9.1.14

Carm.46.20

sirm.2.3.136

Carm.3.2.7

Carm.3.4.59

Fist.1.18.3

Ars Poet.1 16

Ars Poet.232

Sierm.1.2.63

Sirm.1.2.9.4

Serm.2.7.62

Serm.1.2.54 
matronas. quate, ne paeniteat te./desine sectari matronas,

Sirm.1.2.78

matronis. Iracunda diem poteret hlio/matronisque Phrygun classis Achillei; Corm.1.15.34

matronis. cun prole matronisque nostris.

matrum. pupills, quos dura premit custodia matrum: .

Carm.4.15.27

matura. notus doceri gaudet lonicos/matura virgo

maturare. nimis/casto Bellerophonte/maturare neceu.

mature. solve senescentem mature sanus equom.

mature redeat repetatque relicta.

quod cupide petiit, mature plena reliquit.

maturet. eburna, dic age, cum lyra/maturet.

maturior. te meat si partem animae rapit|maturior vis,

maturis. nobilibusque decor naturis [maturis] dandus et annis.

maturo. maturo propior desine funeri|inter ludere virgines

maturos. natosplue natuosque patres/pertulit susonias ad urbis.

rite maturos aperire partus|lenis,

praesenti tibi naturos largimur honores

maturum. maturum reditum pollicitus patrum | sancto concilio

maturus. maturusne senex an adluc florente iuventa|fervidus.

matutina. 'matutina parum cautos iam frigora mordent';

Matutine. Matutine pater. seu 'lane' libentius audis.

Maura. barbaras Syrtis, ubi Naura semper|acstuat unda:

Mauri. acer ef Marsi [Mauri] peditis eruentum 'roltus in lostem: non eget Mauris [Mlauri) iaculis

Mauris. nec Matris animun mitior ankubus:

Mauris. non eget Mauris iaculis neque arcu

mavis. sive $t u$ mavis. Erycina ridens.

seu voce nume mavis acuta! seu fidbus cillatave phoeb.

sis licet felix, ubicumque navis.

nisi erite mavis/carnere pensum

an eibi mavis insidias feri petinmque avellier ante quam meocm ostemdi?

tu contusa liteinis follibus auras, . . He mavis, initare.

urbana liaria rodere mavis.

mavolt. cun rapula plenus atque acidas mavole inulas.

Mavortis. quid toret lliae/Mavortisque puer,

maxima. deus inde ego, furum aviumque maxima formido:

'hic fossa est ingens, hic rupes maxima: serva!"

"danda est ellebori multo pars maxima avaris: .

maxima pass hominum norbo iactatur eoden.

maxima pars vatum, pater et iuvenes patre digni, decipinur specie secti.

maxima. quac maxima credis/esse mala.

Maxime. "roiani belli scriptorem. Maxime J.olli.

maxime. Augute. . . maxime principum.

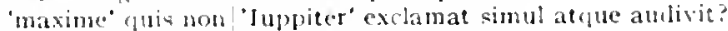

rumpris ce latsas, nagnormm maxime regum.

'maxime: ftum, di tibi dent

Maximi. tempentivus in clomum l'auli . Maximi.

maximus. ut fuc" soless, custos mihi maximus adsis.

mazononio. nakomomo purri magno discerpta letentes mentora gruic

me. me dextanum lederae praemia frontium/dis miscent superis.

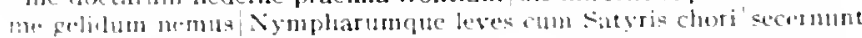
joppulo

quodsi me lÿlicis vatibue inseres.

me tabula swet/votiva paries indicat

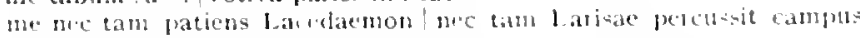
upinitiv.

mo ne. [/ ne me tam patiens Lacodacmon. . percusst

non. si mon satla audian.

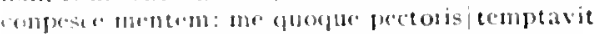

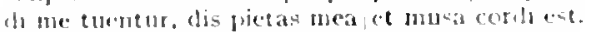

"Thebana*due iubet me somelase purt.

uis mu cilyertae meor

m ne totit suens Venus

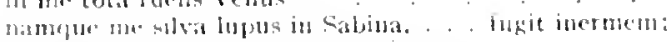

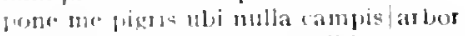

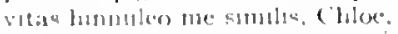

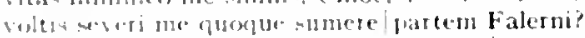

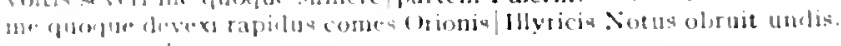

Ejist.1.1.22

Carm.3.6.22

Carm.3.7.16

lipist.1.1.8

Fipist.1.7.97

Sipist.2.1.100

Carm.2.11.23

(urm.2.17.0

iar.Ars Poet.157

Carm.3.15.4

Carm.4.45

corm.sace.1 3

Epist.2.1.15

Corm.4.5.3

Ars Pod. 15

Serm 2.0.45

Serm. 2.6.20

Carm.2.0.3

:ar.Carm 1.2.39

:ar.Curm.1.22.2

Carm-3.10.IS

(arm.1.22.2

Carm.1.2.33

Carm.3.7.3

Carm. 327.13

Carm.3.27.03

Sirpm 1.2103

crom.1.21

Spist.1.1.4.

form 2.2.+1

(corm.4.8.23

sorm.8.8.4

Serm.2.350

Srm.2.3.32

sirm.2.3.121

Ars Poites

Epist.1.42

Iptst.1.2.t

(armet. 140

Trmititis

serment.3.130

sirm. 23.100

carm.1.1. I

Cerm 2.0.15

Srrm 2.s.5n

(arm. 1.20

Cirm.1.1.30

cirm.1.1.35

cirm.1.5.1.3

Cirme1.7. 10

7 :ar Carm. 1.7 .10

(arm.1 13.13

(iurm.1.10.22

(arm.1.17.13

(arm.1 19.2

(arm.10.5

corm.1.109

( arm 1.22 .9

(arm.1.22.17

(arm.1.23.1

(arm.t 27.9

(arm.1.2521

firm.t.31.15 
me pascunt olivae, ine cichorea levesque malvae.

(arm.1.31.16

me melior cum peteret lenus,

neque me sub arta| vite bibentem.

sed me per hostis Mercurius celer/denso paventem sustulit aere.

Carm.1.33.13

(arm.1.35.7

me duleis dominae Musa Licymniae/cantus, . . . voluit dicere

Carm.2.7.13

me voluit dicere lucidun fulgentis oculos

cur me querelis exanimas tuis?

me nee Chimacrae spiritus igneae . . divellet uncuam:

seu Libra seu me Scorpios adspicit/formidolosis,

me truncus inlapsus cerebro|sustulerat.

pauperemque dives/me petit:

me Colchus . . et ultimi noscent Geloni,

me peritus/discet Hiber Rhodanique potor.

auditis? an me ludit amabilis|insania?

me fabulosae Volture in Apulo

non nue Philippis versa acjes tetro,

tme nunc Thressa Chloe regit.

'me torret face mutua|Thurini Calais filius Ormyti, .

ne tamen asperas|porrectum ante foris obicere

me pater saevis oneret catenis.

ne vel extremos Numidarum in agros/classe releget:

me lentus Glycerae tortet amor meae.

quo me, Bacche, rapis tui|plenum?

pressa tuis balanus capilis/iandudum apud me est:

mea| virtute me involvo

tunc me biremis praesidio scaphae . . aura fetet

me nec remina nec puer. . iuvat

me tener solvet vitulus. .

inter amabilis / vatum ponere me choros

quac me surpuerat mih:

volentem proelia me loqui

satis superque me benignitas tualditavit,

non me Lucrina iuverint conelylia

num viperinus his cruor|incoctus herbis me fefellit?

quid omnium / voltus in unun me truces?

quid ut noverca me intueris.

nec latens in aspetis/radix fefellit me locis.

o multa fleturum caput, iad me recurres

et me remorsurum petis?

an si quis atro dente me petiverit.

sed incitat me pectus

nihil me sicut antea iuvat|scribere versiculos

amore, qui ine praeter omnis expetit

heu me, per Viben . . fabula quanta fui,

amor Lycisci me tenet; .

deus. deus nam me retat

me libertina, nec uno|contenta, Phryne macerat.

nullum a labore ne reclinat otium;

quae finis aut quod me manet stipendium?

tet tu. potes nam. solve me dementia.

'populus me sibilat, at mihi plaudolipse domi.

ne nue Crispini scrinia lippi|conpilasse putes.

'nolim laudarier' inquit|"sic me" mirator cunni Cupiennius albi.

qualem ne sacpe libenter 'obtulerim tibi, Naccenas.

Carm.2.12.13
Carm.2.12.14

Carm.2.17.1

Carm.2.17.13

Carm.2.17.17

Carm.2.17.27

Carmi.z.IS.I I

Carm.2.20.1 7

Carm.2.20.19

Carm.3.4.5

Carm.3.4.9

Carm-3.4.26)

carm.3.0.9

Carm.3.9.13

Carm.3.10.2

Carm.3.11.45

Carm.3.II.47

Carm.3.19.28

Carm.3.25. I

Carm.3.29.5

(arm.3.29.55

Carm.3.29.62

Carm.4.1.29

Corm.4.2.5t

Carm.t.3.15

Corm.1.13.20

Carm.4.15.1

Epod.1.31

Epod.2.49

Epod.3.7

Epol.5.4

Epod.5.9

Epod.5.68

Epod.5.7.5

Epod.6.4

Eporto.15

Epod.8.7

Lpod.II I

Epod. I I.3

Epot.11.7

Epod I 24

Epod.140

Epod.14.15

Epod.17.24

Epod.17.3'

Epod.17.45

Sirmatiog

Serme1.1.120

Serm.1.2.30

Serm.1.3.03

far.serm.1.3.92

serm.1.4.14

Crispinus minimo me provocat

inopis ne quodque pusilli finxerunt animi.

ego me illorum, dederim quibus esse poctis. / excerpani numero:

non ego sim Capri neque Sulci: cur metuas me?

unde petitum hoc in me iacis?

insuevit pater optinus hoe me.

cum me hortaretur, parce frugaliter atque vivesem uti contentus co

sic me formabat puerum dictis

cum lectulus aut me porticus excepit.

egressum magna me accepit Aricia Roma lospitio nodico.

Sirm.1.4.I7

sirm. 1.4 .30

Serm.1.4.20

fierm.1.a 80

Sirm.1.4.105

Sirm.J.p.107

Serm.1.4.120

Sirm.1.4. 133

simm. 5.1

Serm.tote

serm. 10.4n

Serm.1.0.45

Serm. I 0.53 
non toge me clare natum patre.

circum, me Satureiano vectati rura caballo.

purus et insonstut me collaudemi), si et vivo carus amicis:

moluit in lavi ludum ne mittere.

nid me prenteat sanum patris huius.

roque mon. . . sic me defendam.

inde domun melad porri et ciceris refero laganigue catinum;

lecto aut seripto quod me tacitum iuver. .

ast ubj stle tessum sol acrior ire lavatum/admonuit.

his me consolor victurum suavius

in me verat mictum atque cacatum

"si bene me novi, non Viscum pluris amicum.

"si me amas, inquit. "paulum bic ades."

"tene relinquam an rem.' 'me, sodes."

distorquens oculoz. ut me eriperet.

lugic inprobus ac me sub cultro linguit.

sic ne servibit Apollo.

vetuit me tali voce Quirims.

men moveat cimex Pantilius

we jedibus relectat claudere verba

we veluti custodiet ensis bagina tectus:

qui me commorit (nclius non tangere, clamo).

stu ne tranquilla senectus | xspectat.

tamen mo cum magnis vixisge invita fatebitur usque invidia hos utinam inter/heroas natum tellus ine prima tulisset.

propare telluriserum natura nec illum/nec ne nec guemquan statuit: unde tam bene me nosti?"

tempore quo me : solatus iussit sapientem pascere barbam mittere operto me capite in tlumen.

lauc propius me, / luni duces insanire omnia, vos ordine adite.

"nec nutc, cum ne vocat ultro. laccedam?

('quid tim magnum?' addens). 'unum me surpite morti!

dixerit insanun qui me, totidem audict

qua me stultitia, quoniam non est genus unum. |insanire putas?

stultum ne fateor (liceat concedere veris)

quo me acgrotare putes animi vitio."

divere me auditum. perges quocungue, memento.

haud iti Troial me gessi. certans scmper molioribus."

"tibi me virtus tua fecit amicum.

'num furis:' an prudens ludis me obscura canendo?" .

sed mo inspesiosa trahit Proserpina:

ergo ubi me in montes et in arcem ex urbe removi nec mala me aubitio perdit nec plumbeus auster

Konac sponcorem me rapis.

Naecenas nue coepit habere suorum/in numero.

quicumejue oluvius est, we consulit:

"at onmes rli "xagitent me. / ai quicquam."

imrantem $1311^{\circ}$ srise aihil mirantur

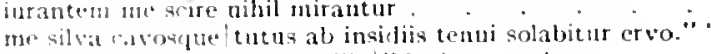

"etenim tatues me" dixerit ille "duci ventre levem.

anter nue voltu torrete:

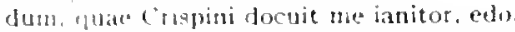

acria 11 Hs 32 natura intendit.

summas eger it prope ne V'iscus Thurinus

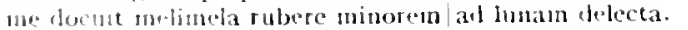

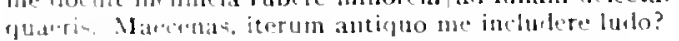

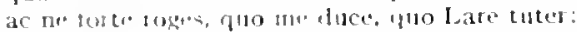

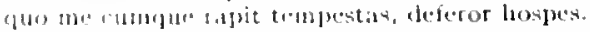

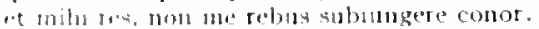

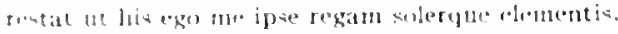

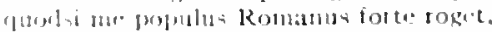

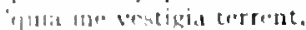

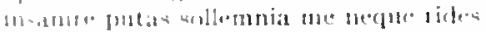

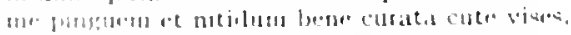

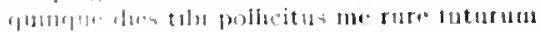

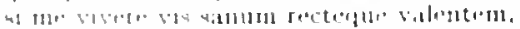

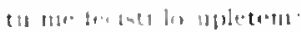

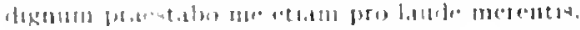

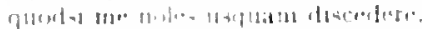

Serm.1.6.58

Serm.1.6.59

Serm.1.0.70

Serm.1.6.72

Serm.1.6.89

Serm.1.6.92

Serm.1.0.1 I4

Serm.1.6.123

Serm.1.6.125

Serm.1.6.130

Serm.1.8.38

Serm.1.0.22

Sarm.1.9.38

Serm.1.9.41

Serm.1.0.05

Serm.1.9.73

Serm.1.9.78

Serm.1.10.32

Serm.1.10.78

Serm.2.1.28

Serm.2.1.40

Serm.2.1.45

Serm.2.1.57

Serm.2.1.75

Serm.2.2.93

Serm.2.2.130

Serm.2.3.18

Serm.2.3.34

Serm.2.3.38

Serm.2.3.80

Sirm.2.3.202

Serm.2.3.283

Sirm.2.3.298

Serm.2.3.301

Serm.2.3.305

Serm.2.3.300

Sien.2.4.89

Serm.2.5.19

Serm.2.5.33

Serm.2.5.58

Serm.2.5.100

Serm.2.1.10

Sorm.2.6.18

Serm.2.0.23

Serm.2, 10.41

Serm.2.6.5I

Serm.2.0.54

Sirm.2.0.57

Serm.2.0.110

Sirm.2.7.37

Serm.2.7.44

Serm.2.7.45

Sornt.2 7.47

Serm. 2.8.20

Serm.2.8.3

Epist.1.1.3

Epist.1.1.13

Fipist.1.15

Epist.1.1.10

Epist 1.1.27

Epist.1.1.70

fist.1.1.74

Epist.t.t.lol

Eprest 1.4 .15

Epist.t.7

Epist 1.7.3

Epist.1.7.15

fopest 1.7 .24

I.pot.1.7.25 
'sic ignovisse putato| me tibi.

Lipist. I. $7 \cdot 70$

'pol, me miserum, patrone, vocares.

List.1.7.92

obsecro et obtestor, vitae me redde priori."

cur me funesto properent arcere veterno;

Septimius. Claudi, nimirum intellegit unus,|quanti me facias;

nec me dimittes incastigatum,

vilice silvarum et mihi me reddentis agelli.

me quamvis Lamiae pietas et cura moratur|fratrem maerentis.

me constare mihi scis et discedere tristem.

eo disconvenit inter meque et te:

illis me facit invisum.

quod me Lucanae iuvenen commendet amicae);

incolumem tibi ne praestant septembribus horis.

quid me perferre patique/indignum coges?"

'ipse deus, simulatque volam, me solvet.'

'si sciret regibus uti, | fastidiret holus, qui me notat.'

equos ut me portet, alat rex, lofficium facio;

me quotiens reficit gelidus Digentia rivos,

ac ne me folitis ideo brevioribus ornes.

me libertino natum patre et in tenui re . . loqueris,

me primis Vibis belli placuisse domique.

me quater undenos sciat inplevisse decembris,

ipse ego. qui nullos me adfirmo scribere versus,

si melpalma negata macrum, donata reducit opimum.

ne forte putes me, . . . laudare maligne:

ut magus, et nodo me Thebis, modo ponit Athenis.

nil moror officiun quod me gravat

res urget me nulla: meo sum pauper in aere.

dixi me pigrum proficiscenti tibi.

dura sed emovere loco me tempora grato

unde simul primum me dimisere Philippi

praeter cetera me Romaene poemata censes|scribere posse

tu me inter strepitus nocturnos atque diurnos/vis canere

dum mea delectent mala me vel denique tallant.

'pol, me occidistis, amici. | non servastis'

hunc ego me. siquid conponere curem.|non magis esse velim

si vis me flere, dolendum est $/$ primum ipsi tibi:

tum tua me infortunia laedent.

me. o fortes peioraque passi|mecum saepe viri.

"me tuo longas pereunte noctes, | Lydia, dormis?"

mecum Dionaeo sub antro

Septimi, Gadis aditure necum

ille te mecum locus et beatael postulant arces:

o saepe mecum tempus in ultimum

fragilemque mecum solvat phaselon; .

coniuge me Iovis et sorore.

utcumque mecum vos eritis.

me dicente cavis inpositam ilicem / saxis,

o nata mecum consule Manlio.

divite me scilicet artium

Inachia langues minus ac me;

quorum | piis secunda vate me datur fuga.

me Capitolinus convictore usus amicoque/a puero est

ut siquid promittere de me' possum aliud vere, promit to.

haec ego mecum ' conpresis agito labris:

neque quis me sit devinctior alter.

laus illi dehetur et a me gratia maior.

nam quis me scribere pluresl aut citius possit versus?

'certe nescio quid secreto velle loqui telaiehas nuecum.' .

imperet hoc natura potens, sic collige mecum.

verum hic inpransi necum disquitite. .

'men vivo?' 'ut vivas igitur, vigila. hoc age.'

et Menelaum una mecum se occidere clamans.'

"munc age. Inxuriam et Nomentanum arripe mecum:

me sene quorl ricam factum est.

si me stultior ipso quingentis empto drachmis deprenderis?

mea cum pugnat sententia secum (mecum).

his utere mecum.

si cenas hodie mecum.' .

Epist.r.7.95

Epist.1.8.10

Epist.1.0.2

Epist.1.10.45

IEpist.1.14.I

Epist.1.14.6

Epist.1.14.16

Epist.1.14.19

Epist.1.15.4

Epist.1.15.2I

Epist.I.I6.I6

Epist.r.16.74

Epist.1.16.78

Epist.r.I7.15

Epist.1.17.20

Epist.r.18.104

Epist.1.19.26

Epist.1.20.20

Epist.1.20.23

Epist.r.20.27

Epist.2.I.III

Epist.2.1.180

Epist.2.I.208

Epist.2.1.213

Epist.2.1.264

Epist.2.2.12

Epist.2.2.20

Epist.2.2.40

Epist.2.2.49

Epist.2.2.65

Epist.2.2.79

Epist.2.2.127

Epist.2.2.138

Ars Poet.35

Ars Pott.102

Ars Pott.103

Carm.1.7.3I

Carm.1.25.7

Cirm.2.1.39

Carm.2.6.1

Carm.2.0.2I

Carm.2.7.1

Curm.3.2.28

Carm.3.3.64

Carm.3.4.29

Carm.3.13.14

Carm.3.21.I

Carm.4.8.5

Epod.r2.14

Epod.16.66

Serm.1.4.96

Serm.1.4.102

Serm. 1..1. 137

Serm.1.5.42

Serm.1.6.88

Sermit.0.23

Serm.1.9.68

Serm.2.1.5I

Serm.2.2.7

Sirm.2.3152

Serm.2.3.198

Serm.2.3.224

Serm.2.5.84

Serm.2.7.42

var.Epist.r.I.97

Epist. T.6.68

Fpist. 1.70 
fuid possin videt ac novit ne validus ipso.

amoena vocat mecum qui sentit. .

arta lecet sanum comitcm toga: desine mccum/certare.

ec saput et mecum facit et love iudicat acouo.

illuel. / quod meeum ignorat. solus volt scire videri.

non tumere a mel quivis ferret iden.

mecum facientia iura/si tamen attemptas?

quocirca mecum loquor haec. tacitusque recordor: .

nec metham, quid de me indicet heres.

tu. quil ego et populus necum desilerct, audi.

slvis deducti caveant me iudice Fauni.

mea. dis pictas mealet musa cordiest.

mea cum conferbuit ira?"

atqui si vitis mediocribus ac mea pancis/mendosa est natura.

longe mea discrepat istis/et rox et ratio:

"postquan omnis res mea lanum/ad medium fracta est.

haec nea cura est.| nequid tu pesdas.

mea cum pugnat sententia secum.

me mea saevos/ingares arl te quod epistula nulla rediret.

mea. latus/alepone sub lauru mea

neque auteum / mea renidet in clomo lacunar.

mea virtute me involvo

o dolitura mea multum virtute Xeaera:

aut positum ante mea quia pullum in parte catini|sustulit esuriens. causacue nue permulta rogatus fecit.

mea. non ut iuvencis inligata pluribus/aratra nitantur neis [mea] dum mea delectont mala me vel denique fallant.

mea. mea nec jalernac/temperant vites nequ' Formiani, pocula colles. me tener solvet vitulus, . . in unea rota. audibere, lyce, di meat vota, dilaudivere, lyce: vel mea cum socris agitat fastidia verbis: in ves ba iurabas mea.

cum urea confensat vitis bona.

cum mea nemolscripta legat

sed timui, ma ne fimxisse minora putarer.

non istic obliquo oculo mea comnoda quiscuam/limat. . mea cur ingratus opuscula lector | laudet ametque domi.

(ut vineta egomet caedam mea).

an omuis | visuros peccata putem mea.

meae. et serves animae dimidium meas.

st mene seves utinam sernectae.

a. te meat si partem animate rapit | maturior vis.

regctis certa fulms meae

me lentus (ilycuac torret amor meate.

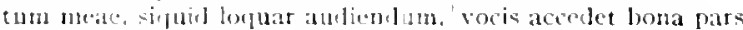

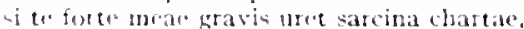

meae. meroplae torta cerlet insolentiae.

meae. quali non reglectus meat laborarint manus.

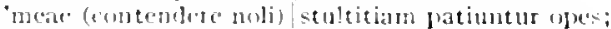

meam. Ifum nuean canto balagen

mearis. puo cimul mearis. nec regna vini sortiere tallis

mearum. meatum gratule deas columernque rerum.

testic mentum entimants gigitif sententurum.

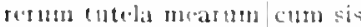

meas. Cur manat raral meds lactima pet punas?

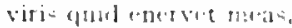

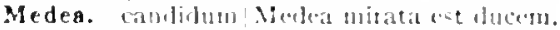

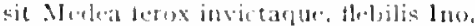

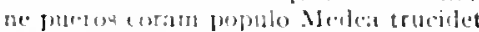

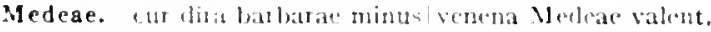

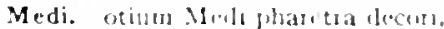

media. gunduvis malia erue turba:

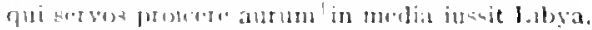

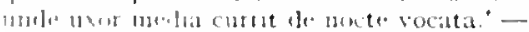

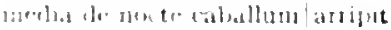

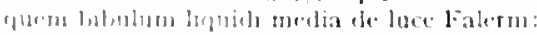

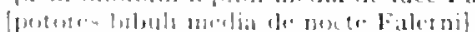

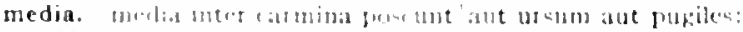

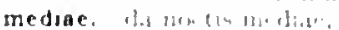

E.pist. I.0.6

Epist.1.14.20

Esist.1.18.30

lipist.2.1.08

Jepist.2.1.87

l. pist.2.2.13

Jisist.2.2.23

Epist.2.2.145

IFist.2.2.191

Ars Poct. 153

Ars Poet.24:

Carm.1.17.13

Serm.1.2.71

Serm.1.0.65

Serm.1.0.02

Serm.2.3.1 8

Serm.2.5.36

lipist.1.1.97

Epist.2.2.21

Carm.2.7.10

Carm.2.18.2

Carm.3.29.54

Epol.15.1 I

Serm.1.3.02

Serm.1.1.97

tar. Epod.1.20

Epist.2.2.127

Carm.1.20.10

Carm.4.2.50

Carm.t.13.1

lipod.12.13

lipod.15.4

sirm.1.3.70

Serm.1.4.22

Epist.1.0.8

Epist.1.14.37

Epist.1.10.35

Fpist 2.1.220

Ars Port.200

Corm: 1.3 .8

Carm.2.6.6

Carm. 2.17.5

Carm.3.10.30

Carm.3.19.2s

Carm.4.2.45

l.pist.t.13.e?

IEpodis 7.75

lisod.5.10

EFist.1.18.28

Carm.1.22.10

Carm.1.1.17

Corm 2.17.3

Carm-3.4.to

Epist.1.1.303

Carmit 1.3 .4

lipods. 2

lipul 3.10

Ars livel.123

its level.185

IPpol.5.1.2

Ciarmi.2.100

Sirm.1.125

Sirm.2.3.101

Sirm. $323 k$

Epive 78.8

l.pict 1.1 .43 .4

inr.l.fert.1.180 I

fipil 2.1185

(Gorm.3.10.10 
mediam. mendacem stultissimus usque puellam i ad mediam noctem exspecto:

post niediam noctem visus, cum soninia vera:

medias. quem cruenta/per medias rapit ira caedes.' scatentem |beluis pontum mediasque fraudes|palluit audax. in medias res!non secus ac notas auditorem rapit

mediastinus. tu mediastinus tacita prece rura petebas,

medicandum. quem nisi mendosum et medicandum?

medicata. nę̧ue anissos colores/lana refert medicata fuco.

medici. nec medici credis nee curatoris egerela praetore lati,

medici. quod medicorum est/promittunt medici,

medicis. folis offendar medicis, irascar amicis,

si tibi nulla sitim finiret copia lymphae, narrares medicis:

medicorum. quod medicorum est/promittunt medici,

medicum. o laborum, dulce lenimen †mihicumque [medicumque] salve/rite vocanti.

medicum roget, ut te/suscitet ac reddat gnat is carisque propinquis? ut lethargicus hic cum fit pugil et medicum urget.'

medicus. Lunc medicus multum celer atque fidelis/excitat casus medicusve levarit /aegrum ex praecipiti:

mediis. terum|tluctibus in medis et tempestatibus Vrbis

mediis. naviget ac medis thiemet mercator in undis,

medio. dictus here illic/de medio potare die.'

medio, arsit Atrides medio in triumpho|virgine rapta. nune medio aequore /cum pace delabentis

medio. nam !transvolat in medio posita et fugientia captat."

in medio qui|scripta foro recitent.

si forte in nedio positorum

creditur, ex medio quia res accersit, habere / sudoris minimum. . . comoedia

primo ne nedium, medio ne discrepet imum.

tantum de medio sumptis accedit honoris.

mediocribus. mediocribus et quis/ignoscas vitiis teneor; hoc est mediocribus illis ex vitiis unum;

atqui i vitis mediocribus ac mea paucis/mendosa est natura,

mediocribus esse poetis, non homines, non di, non concessere columnae.

mediocris. actor/cansarum mediocris abest virtute diserti / Messallae

mediocris. at nihi cura|non mediocris inest.

mediocritatem. auream quisquis mediocritatem diligit.

mediocriter. num pavor et rerum meliocriter utilium spes.

medios. aurum per medios ire satellites

frementem mittere equom medios per ignis.

ignis pet medios turiosque ruentis:

cui pulerum fuit in medios dormire dies

nell quid medios intercinat actus.

Medis. anditumque Medis' Hesperiae sonitun tuinae?

triumphatisque possit Roma ferox dare iura Merlis.

meditans. aeternum meditans decus stellis inserere nescio quid meditans nugarum, totus in illis:

meditantibus. purae sunt plateae, nihil ut meditantibus obstet."

meditantis. verris obliquon meditantis ictum / sanguine donem.

meditantur. iam Scythae laxo meditantur arcu/cedere campis.

meditare. i nunc et versus tecum meditare aunos.

meditatur. incestos amores/de tenero meditatur ungui. horrendamoue cultis diluviem nredititur agris,

mediter. an potius mediter finire dolores?

meditor. non ego te neis inmunem neditor tinguere poculis.

medium. pastillos Rufillus olet, Gargonius hircum: ail medium est. virtus est medium vitiorum et utrimque reductum. primo ne medium. medio ne discrepet imum.

medium. at hunc liberta fecuri|divisit nudium, "postquam omnis res mea lanum|ad medium fracta ext.

medium. nam ut quisque insanus nigris medium impedit crus|pelibus iamcue tenebat|nox medium caeli spatium. gelida cum perluor unda|per mediun frigus. certis medium et tolerabile rebus recte concedi

medius. sed ilem! pacis eras mediusque belli. qua medius liquor $/$ secernit Europen ab Afro.

Medo. horribilique Nedo|nectis catenas?

Serm. I. 5.83

Sirm.1.10.33

Carm-3.2.12

Carm.3.27.27

Ars Pot.its

Epist.I.I.t.I

Epist.1.16.40

Carm.3.5.28

l.pist.1.1.102

Epist.2.1.116

Epist.1.8.9

L.pist.2.2.1.7

Epist.2.1.II5

coni.Carm.1.32.15

Serm.1.1.82

Sierm.2.3.30

Sorm.2.3.147

Serm.2.3.202

Epist.2.2.85

Epist.1.16.7t

Sorm.2.8.3

Carm.2.7.7

Corm.3.29.34

Serm.1.2.108

Serm.1.4.74

Epist.1.12.7

Epist.2.1.I 68

Ars Poet. 52

Ars Poet.2\$3

Serm. 1. 1.130

Serm.1. 130

Serm. I it.65

Ars Pote.372

irs Int?.37o

Serm.2.+4.94

Carm.2.10.5

Epist.1.18.99

Cirm.3.10.9

Corm.t $1+24$

Serm.2.3.57

Epist.1.2.30

Ars Port.19t

Carm.2.1.31

(arm.3.3..44

Carm.3.25.5

Sirm.1.0.2

Epist.2.2.7:

Corm.3.22.7

(arm.3.8.23

IEpist.2.2.70

Carm.3.0.2.

Carmot.1.28

Sirm?.2.3.203

Curm.t.12.23

Sirm.1.2.28

Fpistrass.o

Ars Poct.152

Sirm.1.1.100

Serm.2.3.10

Sermin.0.27

Serm.2.6.10I

Epist.1.15.5

Ars 10at.36s

Carm.2.19.29

Carm.3.3.ts

Carm.1.29.4 
Medo. sub lege Medo Marsus et Apulus.

Medos. neta sinas Medos equitare intultos/te tuce, Cacsar.

Carm.3.5.9

medulla. exelucta uti medulla el aridum iceur.

Corm.1.2.51

Lipod.5.37

medullis. certur accipiet damnum propinsve medullis

Medum. Medumque tlumen gentibus additum/victis

Lipist.1.10.28

Carm.2.9.21

Medus. vino "t lucernis Medus acinaces|immane quantum discrepat:

Medus infestus sibi luctuosis/dissiclet armis.

Medusque et Indus, te profugus Scythes/miratur.

Corm.1.27.5

Corm.3.8.19

Carm.4.14.42

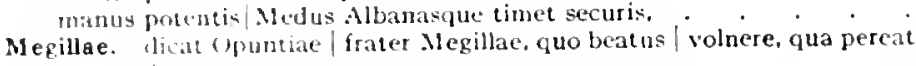
sigitlat

Megille. dicat Opuntiac/irater Megillae [Negille].

Megyllae. dicat Opuntiaelfrater Megillac [Megyllae].

Megylle. dicat Opuntiae/ frater Negillae [Megylle],

mei. multalue pars mei | vitabit Libitinam;

mei. L.esbium servate peden meique/pollicis ictum

mei. nil sine te mei/prosunt honores:

quibus ipse meiquelante larem proprium vescor

Carm.Saer. 54

meiat. ne/ditior aut formae melioris meiat coden.
meis. donatem pateras grataque commodus. Censorine, meis aera sodalibus. hic onlis eno nigra neis collyria lippus/inlinese;

meis. defendit acktatem capellis|usque meis pluviosque ventos. . o rebus meis, non infideles arturtat.

meis. ter pereat meis/excisus Argivis. meis contentus honestos/taseibus et sellis nollem mihi sumere.

meis. non ego te meis|chantis inornatum sileri polo' derignele lunam vocibus possin meis, .

meis. coculate neis dicerer hotreis, .

non ego te neis inmunem nexditor tinguere poculis.

non ut iuvencis inligata pluribus aratra nitaneur meis

"quodsi meis inaestuet praceordiw/libera bilis.

mel. hoc invat et melli [mel] est, non mentiar.

Meleagri. nec rellitum Diomedis ab interitu Meleagri

melici. quod medicorum [melicon um] et promittunt medici [melici],

melicorum. quod medicorum [melicot um] est pronitunt nedici [nelici].

melimela. me docuit melimela subere minorem ?ad lunam defecta.

melior. Tydides melior patre:

moribus hic neliorque famis, conterutat.

ille |nissilibus melior sagit tis.

ropes ipso nuclior Br.llerophonte.

al $"-t$ brouls, ut melior vir non aliue quisquan.

* Her lenias ille, quo melior vir est. longe subtilior illo,"

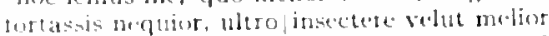

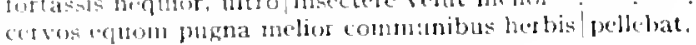

nuelior sit llotatius an rex.

gui nuliot serwe qui liberier sit avatus.

Jonios et melines fis arcedente senecta:

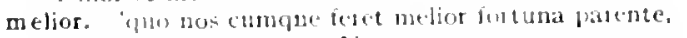

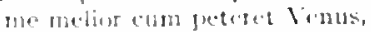

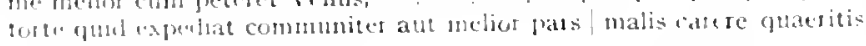

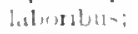

aut prots indocili melior grege:

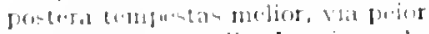

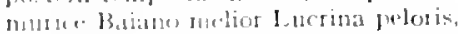

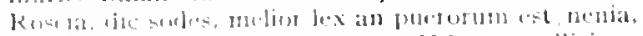

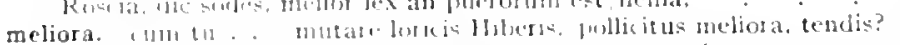

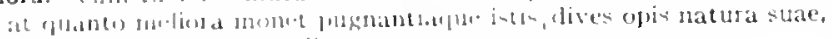

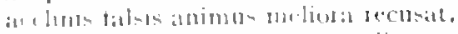

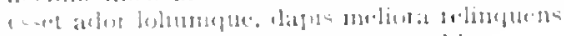

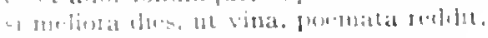

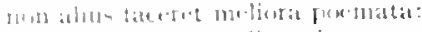

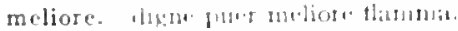

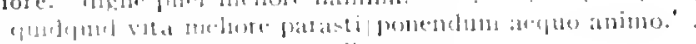

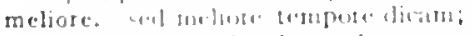

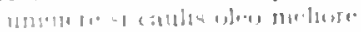

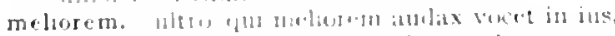

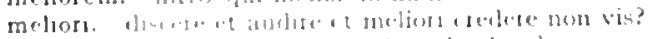

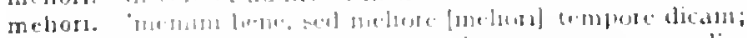

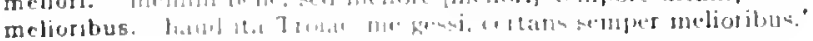

Carm.1.27.1 I

ior.Carm.1.27.11

sar Carm.1.27.1I

:ar.Carm.1.27.II

Carm.3.30.6

Carm.4.0.35

Carm.1.20.9

Serm.2.0.65

Serm.2.7.52

Carm.4.8.2

Serm.1.5.30

Corm.1.17.4

Iipod. 5.49

Carm.3.3.00

Serm.1.6.90

Carm.4.9.30

Lpod.17.7s

Carm.3.16.27

Carm.4.12.22

Ifpol.1.20

lipoll.1 1.15

iur.serm.2.0.32

Ars l'oet.140

comi.tipist.2.1.1 I6

coni. Jipist.2.1.11.5

Serm.2.8.3 I

Carm.1.15.28

Carm.3.1.12

Carm.3.0.10

Carm.3 12.8

Sorm 1.3 .32

Serm.1.10.*4

Sorm.2.7.4 1

I.pist.1.10.34

I.pist 1. I 4.5

l.pist.t.10.03

l.pist.2.2.21 I

Carm.1.7.25

Carm.1.33.13

Epodilo. 15

lopol.16.37

sivm.1.5.90

Sirm.2.4.32

Epistar. 1.02

(iom.1.20.16

Sormen.2.7.3

serm.2.2.1

Serm.zef Sos

lipist.2.1.34

Ars Int.343

(iorm. I.27.20

Serm.2.3.15

Sermiliceses

sem. 2.3125

serm 2.5.20

1.fors.1.atis

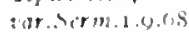

Serm.2.5.19 
nunc adbibe purolpectore verba, puer, nunc te melioribus offer.

melioris. Lucili ritu, nostrun melioris utroque.

ut suci melioris et ut magis alba rotundis.

melioris. ditior aut formae melioris meiat eodem.

melius. ut melius, quidquid erit, pati.

meliusne fluctus ire per longos fuit an recentis/carpere flores? atque etian melius persaepe togatae (est).

sapiens, vitatu quidque pet itu/sit melius, causas reddet tibi;

qui me conmorit (melius non tangere, clamo),

hoc iuvat et melli [melius] est, non mentiar.

quanto constantior isdem | in vitiis, tanto levius [tanto est melius] nused ac prior ille

verum ubi quid melius contingit et unctius.

cum sit obeso| nil melius turdo,

melius. quo nihil maius meliusve terris | fata donavere .

alterum in lustrum meliusque semper|prorogat aevom,

sic placet? an melius quis habet suadere?

hic tamen ad melius poterit transcurrere quondam,

ut melius nuria quod testa marina remittat."

nil ait esse prius, melius nil caelibe vita;

si melius quid habes, arcesse, vel imperiun fer.

quidquid vidit melius peiusve sua spe.

ni melius dormire putem quam scribere versus?

seu cursum mutavit iniquom frugibus amnis/doctus iter melius:

melius, quo graves Persae melius perirent.

dices historiis proelia Caesaris / Maecenas, melius

aurum inrepertum et sic melius situm. / cum terra celat.

contracto melius parva cupidine/vectigalia porrigam

campestres melius Scythae, . . . vivont

gratior it dieslet soles melius nitent.

ut se|non umquam servo melius vestiret.

hoc faciens vivam melius.

non | conpositum melius cum Bitho Bacchius.

ridiculum acri| fortius et melius magnas plerumque secat res.

melius quod scribere possem,

quod superat non est melius quo insumere possis?

leni praecordia mulso/prolueris melius.

auctius atque di melius fecere.

sic, ut mihi numquam|in vita fuerit melius.

quid hoc intersit, ab ipsolaudieris melius.

isne tibi melius suadet.

planius ac melius Chrysippo et Crantore dicit.

Brundisium Minuci melius via ducat an Appi.

valdius oblectat populum meliusque moratur

melius te posse negares bis terque expertum frustra:

mella, ubi non $\mathrm{Hy}$ mettolmella decedunt .

mella cava manant ex ilice.

mella. truncis lapsa cavis iterate mella;

quamquam nec Calabrae mella ferunt apes

aut pressa puris mella condit amphoris

nisi Hymettia mella Falerno| ne biberis diluta.

Aufidius forti miscebat mella Falerno.

fidis enim manare poetica mella| te solum. .

melle, sed mala tollet anum vitia to melle cicuta.

crassum unguentum et Sardo cum nelle papaver offendunt,

melli. hoc iuvat et nelli est, non mentiar.

mellitis. pane egeo iam mellitis potiore placentis.

melos. dic age tibia /regina longum Calliope melos.

Melpomene, praecipe lugubris cantus, Melpomene, cui liquidam pater vocem cum cithara dedit.

mihi Delphica|latro cinge volens, Melpomene, comam.

quem tu, Melpomene, semel nascentem placido lumine videris.

membra, nunc viridi membra sub arbuto|stratus.

post insepulta membra different lupi

saetosa duris exvere pellibus . . membra;

miles ait, multo iam fractus membra labore.

invenias etian disiecti membra poetae.

simul ac duraverit actas/membra animumque tuom.

quis membra moveres mollius?
Epist.1.2.018

Serm.2.1.29

Sirm.2..t. 13

Serm.2.7.52

Carm.I.II.3

Carm.3.27.42

Serm.1.2.82

Serm.1.4.116

Serm.2.1.45

s'ar.Serm.2.6.32

2ar.serm.2.7.19

Epist.I.15.40

Epist.I.I 5.43

Carm.4.2.37

Carm.saec.67

Fpod.10.23

Serm.2.2.82

Serm.2.8.53

Epist.t.1.88

Epist.1.5.0

Epist.1.6.13

Epist.2.2.54

Ars Pod.os

Carm.I.2.22

Corm.2.12.II

Carm.3.3.49

Carm.3.10.39

Carm.3.24.9

Carm.4.5.8

Scrm.I.I.97

Serm.1.4.135

Serm.1.7.20

Serm.1.10.15

Serm.1.ro.t7

Serm.2.2.102

Serm.2.1.27

Serm.2.6.4

Serm.2.8.4

Serm.2.8.33

Epist.1.1.65

Epist.1.2.4

Epist.1.18.20

Ars Pott.32I

Ars Poct. 439

Carm.26.15

Epod.16.47

Carm.2.19.1 2

Carm.3.10.33

Epol.2.15

Scrm.2.2.15

Serm.2.24

Ipist.1.19.44

Serm.2.1.50

Ars Potl.375

Serm.2.6.32

Epistil.10.11

Carm.3.4.2

Carm.1.24.3

Carm-3.30.56

Carm.4.3.I

Carm.1.1.2I

Epod.5.09

Epod.17.17

Serm.I.I 5

Serm.1.t.8

Serm.1.2.120

Serm.1.9.24 
ubi dicto citius curata sopori/nembra dedit.

Serm.2.2.8I

ma zonomo pueri magno discerpta ferentes/membra gruis

Sorm.2.8.87

guia deoperes invicti membra Glyennis.

membranam. ut toto non quater anno membranam poscas,

membranis. nonumque prenat ur in annm membranis intus positis:

membris. quam malu: undique membrisicreacit odor.

utile bama / vatacque et membria. praesertim cum valeas

varias inlucere plunas. | undique collatis membris

memento. sic tu sapiens finire memento tristiciam vitaeque labores.

at quam menento rebus in arduis|servare mentem.

redile: victimus ; aedemque votivam menenco:

yuol allost memento componere aequos;

nt insmis utrumque verberes latus. Auster, memento Huctibus:

hor ae mumento [memento] cita mors senit [vehit] aut victoria laeta."

Ining qubus facies ovis erit, illa memento. . . ponere:

ducere me aucitum. perges quocumque. memento. .

abnuere et tabulis a te removere memento.

praceptum aurieulis hoc instillare memento:

memini. mcmini bene. sed meliore/tempore dicam:

prop me Viscu Thurinu- et infra si menini, Vatus:

menini quae plagosum mihi parvo Orbilium dictare:

meminisses. orabant hodie meminisses, Quinte, reserti."

meminit. ut valet? ut meminit nostri?

discit enim citius meminitque libentius

Memnona. curgidus Alpinus iggulat dum Memnoma

memor. Albi, ne rloha plus nimio anemor/inmitis Glycerate

memor actar non alio rege: puertiac

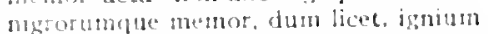

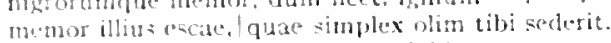

"ipea memor praperepta cantul celabitur anctos.

rive memor, glatm -is and brevis."

boc tibi dictum tolle memor.

memor. et meinor notri, Gidatea, vivas

uti Graceda Catoris et magni memor Ilerculis.

memornta. pua priscis nemorata Catonibus atque Cethegis

memoratur. at quidam menoratur Athesistsorlitus ac dises.

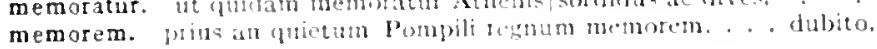

singulat ruml momorem.

néthlum Marsi menorem durli.

memorem. inprentit menorem dente habris notam.

metri memorem sepulcro scalpe gueralam.'

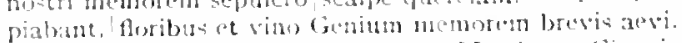

memores. Sarmonti scurra pugnam Xestque cicari. Imas. velim no:mores

memores. nepotum per numores genus oma iasto:

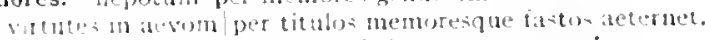

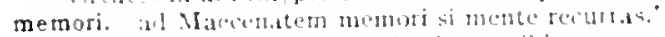

memori. man quansis memori reberas mili poetone runcta.

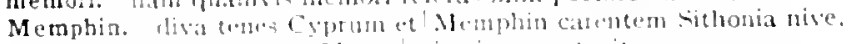

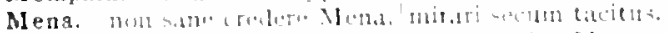

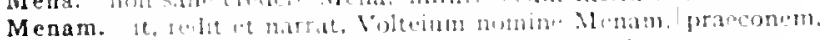

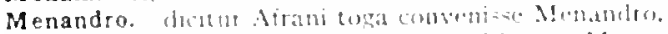

Menandro. guotsum jertinutit scipate Platomat Manamirn?

mendacem. talsus honor fuvit of mendax infama tertet / quem niaj

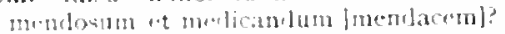

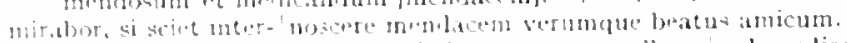

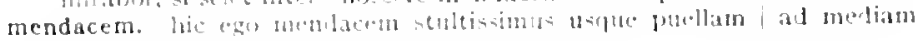
metema

mendaci. Hise momlaci lyra voles somare:

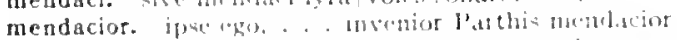

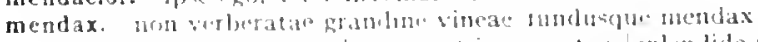

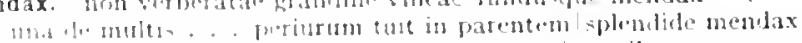

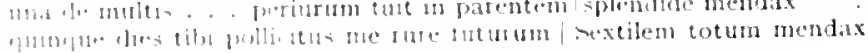

$$
\text { 1.?--inloners. }
$$

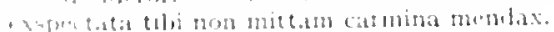

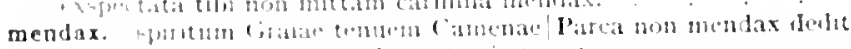

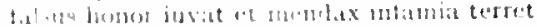

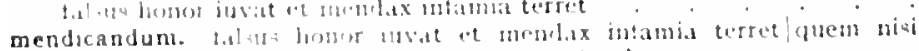

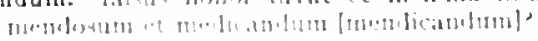

Epist.1.1.30

Serm.2.3.2

Ars Pot 1.390

fipod.12.7

Epist. I. I 50

Ars Poet. 3

Carm.1.7.17

Carm.2.3.1

Carm.2.17.31

Carm.3.29.32

Epot.lo.t

gror.serm.1.1.8

Serm.2.4.12

Sirm.2.4.89

Sirm:.2.5.52

Epist.1.8.1\%

Serm.1.0.08

Serm.2.8.2\%

lipist.2.1.70

Serm.2.0.37

Epist.1.3.12

lipist.2.1.262

Serin.1.10.3/s

(carm.1.33.1

Carm.1.3 $3^{10.7}$

Carm.12.2's

Serm.2.2.72

Sirnt 2.4.1 I

Serm 2.0 .97

Ars Joet.zos

Carm.3.27.14

Carm.4.5.30

Epist.2 2.117

sirm I.1.t)

Carm.1.12.34

Sirm.1.8.10

Carm.3.14 is

Carm.1.13.12

Carm.3.11.5I

tipist.2.1.14

Sicrm.1.5.53

Carm.3.17.4

Carmatitat

Sirm.2n.31

sirm.2.qun

Carm.3.2\%.10

Epist.1.7.e.

Epist.1.7.5.

lepist.2.1.5i

Sierm.2.3.1I

idr.tipist.1.1(1.q1)

Ars l'oet.az

serm. 1.5:

lipod 17.30

lipist.2.1.112

Carm.3.I 30

Carm.3.11.35

Epist.1.7.2

I.pssi.2.2.25

Carm.2.1\%.3.

J.pist.1.1.3)

sar lipist talus? 
mendici. ambubaiarum collegia. pharmacopolae. | mendici. mimae. balatrones.

mendicum. talsus honor iuvat et mendax infamia terret / quem nisi mendosum et medicandum [mendicum]?

mendosa. si vitis mediocribus ac me pancis/mendosa est natura.

mendose. Aufidius forti miscebat mella Falerno, |nendose.

mendosum. quen nisi mendosmm et medicandum?

mendosus. *Lucili, quan sis mendosus, teste Catone / deiensore tuo pervincam.*

Menelaun. et Menelaum una mecum se occidere clamans." . .

Meneni. hoc quoque volgus | Chrysippus ponit fecunda in gente Meneni. -

mens. tunc nec mens mihi nec color certa sede manunt.

euhoe, recenti mens trepidat metu

hoc caverat mens provida Reguli

sensere. quid mens rite. . . posset. .

'quae mens est hodie, cur eadem non puero fuit

nec vocata mens tua| .Iarsis redibit vocibus.

tune mens et sonus! relapsus.

cui men s divinior atque os / magna sonaturum.

non eaclem est aetas, non mens.

infectum volet esse, dolor quod suaserit et mens.

tamen istuc mens animusque fert

nam neque cliorda sonum reddit quem volt manus et mens.

id tibi iudicium est, ea mens.

mensa. "sit mihi mensa tripes et/concha salis puri

Galloni praeconis erat acipensere mensa|infamic.

mensa. splendet in mensa tenui salinum.

conninxit lectum potus nensave catillum | Euandri nanibus tritum deiecit:

nec satis est cara piscis averrere mensa

mensae. ille dapes laudet mensae brevis.

mensam. mensam poni iubet atque/effundi sacos numnorum. acernam | gausape purpureo mensam pertersit

mensas. diccite non inter lancis mensasque nitentis. tum pensilis uva secundas |et nux ornabat mensas ut gratas inter mensas symphonia discors.

mense. abeo, et revocas nono post mense

facit quod . . per bruman Tiberis, Sextili mense caminus. qui deperiit minor uno mense vel anno. qui vel mense brevi vel toto est iunior anno."

mensem. qui dies mensem Veneris marinae/findit Aprilem.

mensis. divitum mensis et amica templis.

alteris te mensis adhibet deum;

quae nisi divitibus nequeant contingere mensis?"

mensis. stat glacies iners/mensis per omnis prosperan frugum celeremque pronos/volvere mensis. mater ait pueri mensis iam quinque cubantis.

mensorem. te maris et terrae numeroque carentis harenae | mensorem colibent.

mente. dones ac precor integra|cum mente mente quatic solida neque Auster.

quae nemora aut quos agor in specus, / velox mente nova? an hunc laborem mente laturi, decet qua ferre non mollis viros? hac mente laborem / sese ferre. . . aiunt,

non quia nasus fillis nullus erat, sed, credo. hac mente. ad Matenatem memori si mente recurras."

sed quia mente minus validus quam corpore toto

dignum mente domoque legentis lonesta Neronis.

idem finitis studiis et mente recepta

menteis. hortari coepit eunden! verbis, quae timido quoque possent addere mentem [menteis]:

mentem. mentemque lymphatain Mareotico redegit in veros timores Caesar

non adytis quatit /mentem sacerdotum incola Pythius,

conpesce menten: me quoque pectoris/temptavit . . turvor aequam memento rebus in arduis|servare mentem. pluribus adsuerit mentem corpusque superbum mentem, nisi litigiosus, /exciperet dominus.

Serm.1.2.2

"ar.lipist.1 I 6.40

Sirm.t.0.00

Sierm.2.4.25

Ispist. I. 10.40

Sirm.1.10.*I

Serm.2.3.108

Serm.2.3.287

Cirm.1.13.5

Cism.2.19.5

Cinm.3.5.13

(arm.4. 25

Carm.1.10.7

Epod.5.75

Epod.17.17

Serm. 1.4 .43

Epist.1.I.4

Epist. 1.2.60

inist.1.14.8

.1rs Poet.34s

Ars $\mathrm{Poet}_{3} \mathrm{So}$

Serm.1.3.13

Serm.2.2.47

Carm.2.16.14

Sirm.1.3.90

. irm.2.4.37

irs Porl. 199

cirm.2.3.1.48

Sirm.2.S.11

Sirm.2.2.4

Serm.2.2.122

Ars Poel.374

Serm.1.0.6I

Epist.I.I1.19

Epist.2.1.40

Epist.2.1.t.

Cirm.t.IIJ

(inm-3 II d)

Carm.4.5.32

cierm.2.4.87

(irm.2.0.6)

(iarm. $0 . .10$

serm.2.3 280

(ism.1.28.2

carm.I.3r.19

(arm.3.3.4

Carm.3.25.3

Iipoti.

virm.1.1.30

Sierm.2.2.00

Sirm.2.(1).3 I

Iipist.1.8.7

Iipist I.9.4

Epist.2.2.104

inr. Lpist.2.2.3t

Carm.1.37.14

Cirm.1.10.6

Carm.1.16.22

Cirm.2.3.2

Sirm.z.z.100

Serm 23.285 


\section{MENTEM}

quonc malo micaten concussa? timore deorum." unget emindominus nustem non lenis su-pendit peta voltum mentemgue tabella. mutivit mentem populus bives.

verbis, guac timido quoque posient addere mentem:

mentes. tenerat nimis mentes noperioribus formandae studife. mentesque perpolac stupent.

mentiar. hux insit et melli est, non nuntiar.

mentibus. $\{u$ fle qu funcis mentibus anxiis

mentibus. Darvis in manibut non est ot mestibus hace / paene recens?

mentio. Junciu -icuae $/$ de Capitolini furtis iniecta Petilli

mentior. mestlor at siquid.

mentis. Hequ consllaris isubmove lictor miseros tumultus/mentis

de anito auriculas, ut iniquae mentis asellus.

hime sepetit. 'paucorum hominum et mentis bene sanae;

integer est mentia Damasippi creditor? csto.

ant alio nentis motbo calet:

guin, ex quo est habitus male tutae mentis Orestes.

commotac crimine mentis $\mid$ absolves hominem

demptus per vim mentis gratissinus error."

mentita. :f Mon mentita seges bos est enectus arando:

mentite. On nulli quicquam mentite.

mentito. ille non inclusu epuo Minervalsacta mentito

mentitur. nt nox longa quibus nentitut amica atgue ila mantitur, sic veris falsa temiscet.

mento. minaces/eurfe solum tetigere mento;

quantum extint aqua - us $x$ nea mento corpora:

meo. nutemol andiac consan.

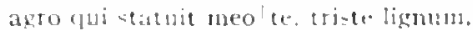

i. Jur atche suro citus hace subactibe libello.

meo. soges, twom labore quirl iusem neo.

cuant non ansere sic nuto thang

tu vina loncluato nowe ounsule pressa neo.

placavi sangune divos." 'Hempe two, turiose?" 'neo. sed non furiosus.

non aliena meos pressi perde.

una cums seriptore meo... deferar in vicum

meo. nue nunc|sulerbus incedis malo.

mpunce ut libem nomine inpleris meo?

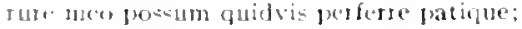

me uspet mor mulla; neo sum pauper in aere.

ille meo cluic: quis nisi Callimachus?

seorum. Pontei, merum fume sodalium?

ag. iant, nueorum finis anormm.

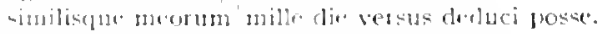

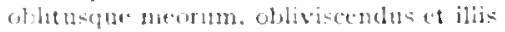

meos. joet moces finis et apritia suta

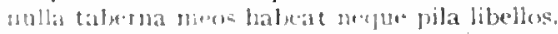

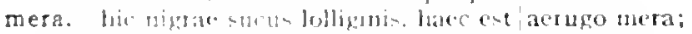

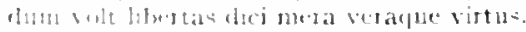

mera. -uhcert vineta crepat mera. macparat uhos.

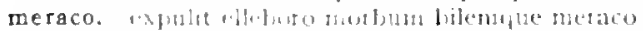

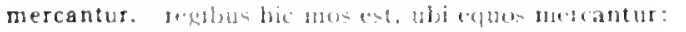

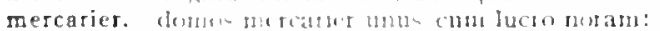

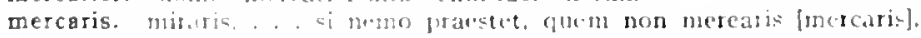
in moldent:

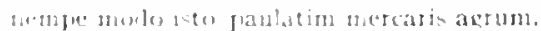

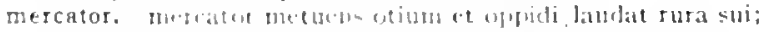

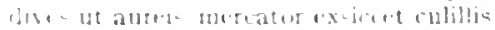

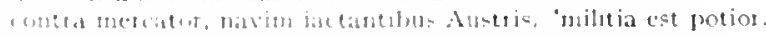

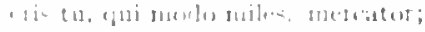

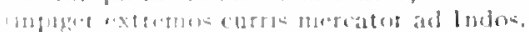

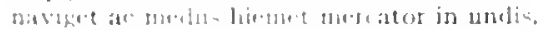

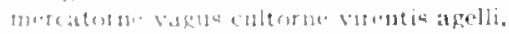

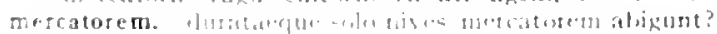

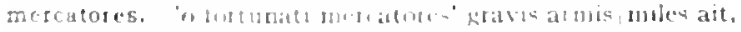

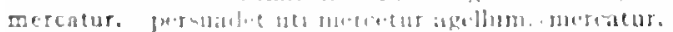

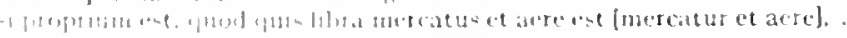

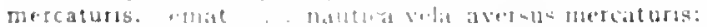

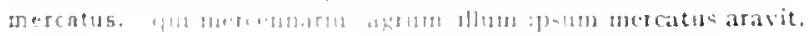

MERCATVS

Sorm.2.3.295

Serm.2.7.93

Epist.2.1.97

lipist.2.1. 108

Iipist.2.2.3t)

Carm.3.24.53

lipod.7.10

Sorm.2.0.32

Carm.3.21.17

Epist.2.1.53

Sirm.1.4.93

Serm.18.37

Carm.2.10.1 I

Sirm.1.9.20

Serm.1.9.44

Serm.2.3.05

Serm.2.3.80

icrm.2.3.137

Sorm.2.3.278

Epist.2.2.140

Epist.1.7.87

Serm.2.5.5

Corm.4.0.14

I.pist.1.1.20

Ars I'oct.1 5 I

Carm.2.7.12

E.poil. 5.36

C'arm.1.26.8

Curm.2.13.10

serm.1.10.92

I.pend.1.15

I.pod.5.8 I

J pod. 3.0

Serm.2.3.207

lipist.1.19.22

Epist.2.1.21.8

l.pod.15.17

Epod.17.59

List.1.15.17

Epist.2.2.12

Epist.2.2.99

Carm.2.7.5

Carm.4.11.31

Sirm.2.1.3

Iifist.1.11.9

Carm.3.18.2

Sorm.1.4.7 I

Serm.1.4.101

If pist.1. I 8.8

IEpist.1.7.8.

IfPst.2.2.1.37

sterm.1.2.80

Sorm.2.3.24

tar.sierm.1 1.87

fipust.z.2.104

Curmitate

Carmt.31.J1

sirmitio

Serm 1.1 .17

l. pisfill.t.

bepistesto.j

Ars loet.II 7

curn.324 An

Sirm 1.1 .4

IEpest 17.82

ist.l.pist.2.2.158

Sirm.2.3.107

ierm 2.13.12 
si proprium est, quod quis libra mercatus et aere est.

Lipist.2.2.1 58

merce. vina Syra reparata merce.

Thyna nerce beatum.

cuni tua|velox nerce veni:

mercede. cessat voluntas? non alia bibam/mercede.

ex quo destituit deos $\mid$ mercede pacta Laomedon.

cun pecore et gnatis fortem mercede colonum.

qui pro se tolleret atque / mitteret in phimuni talos, mercede diurna conductum pavit:

Thraex erit aut holitoris aget mercede caballum.

mercedem. neque, / si chastae sileant quod bene feceris, / mercedem tuleris. mercedem aut nummos unde unde extricat.

mercedes. quinas hic capiti mercedes exsecat. si praeco parvas aut, ut fuit ipse, coactor/mercedes sequerer;

mercem. adde huc quod mercem sine fucis gestat. pretiumque avellier ante/quam mercem ostendi?

mercemur. quo Chium pretio cadum|mercemur. mercemur servom, qui dictet nomina,

mercennaria. excusare laborem et mercennaria vincla,

mercennarius. qui mercennarius agrum|illum ipsum mercatus aravit,

merces. multaque merces|unde potest tibi defluat est et fideli tuta silentio/merces: .

merces. ne Cypriae Tyriaeque merces/addant avaro divitias mari:

merces. hic nutat merces surgente a sole

ubi plenius aequo|laudat venalis qui volt extrudere nerces:

ut praeco, ad nerces turbam qui cogit emendas.

mercetur. persuadet uti mercetur agellum.

Mercuri. Mercuri facunde nepos Atlantis.

Nercuri, nam te docilis magistro/movit Amphion lapides canendo

Mercuriale. unde frequentia Mercuriale inposuere mihi cognonen compita."

Mercurialem. unde frequentia Mercuriale [Mercurialem]|inposuere mihi cognomen compita."

Mercuriali. unde frequentia Mercuriale [Mercuriali] | inposuere mihi cognomen compita.'

Mercurialium. Mercurialium /custos virorum.

Mercurius. nigro conpulerit Jercurius gregi?

et parum comis sine te Iuventas|Nercuriusque.

sed me per hostis Mercurius celer/denso paventem sustulit aere, . quam praesens Nercurius fert?

merdis. merdis caput inquiner albis/corvorum

merearis. si nemo praestet, quem non merearis, amorem?

merebere. nardo vina merebere.

mereberis. sed pressum Calibus ducere Liberum $\mid$ si gestis, . . . nardo vina merebere [mereberis].

merentem. hac te merentem. Bacche pater.

merentis. dignum praestabo me etiam pro laude nerentis. .

meret. hic meret aera liber Sosiis, hic et mare transit

meretrice. quod neretrice nepos insanus amica filius uxoten . . recuset, arguta meretrice potes Daroque Chremeta|eludente senem conis garrire libellos

sub domina meretrice fuisset turpis et excors.

meretrici. ut matrona meretrici dispar erit atque/discolor.

meretricibus. verum est cun minis, est cum neretricibus.

meretricis. a turpi neretricis amore/cum deterreret: an meretricis anore sollicitus plores: .

nota refert ineretricis acumina.

meretricula. te coniunx aliena capit, meretricula Davom:

meretrix. at volgus intidum et netetrix retro|periura cedit. nec neretrix thicina cuiuslad strepitum salias terrae gravis;

mergitur. perditur [mergitur] hacc inter misero lux non sine votis:

mergos. opma quodsi pracela curvolitore|porrecta mergos iuverit. siquis nunc nergos suavis edixerit assos.

meri. bimi cun patera meri: neu multi Damalis meri

meridiem. inclinare meridiem gentis

Merionen. pulvere Troico nigrum Merionen Merionen quoque nosces.

merita. dicetur, merita Nox quoque nenia. per sacrum clivom merita decorus'fronde

Carm.r.3r.12

Carm.3.7.3

Carm.4.12.22

Carm.1.27.14

Carm.3.3.22

Serm.2.2.I I 5

Sirm.2.7.17

Epist.1.18.36

Corm.4.8.22

Serm.1.3.88

Sirm.1.2.I

Serm to6.87

Sirm.1.2.83

Serm.r.2.105

Carm.3.19.6

Epist.1.6.50

Epist.1.7.67

Serm.2.6.II

Carm.1.28.27

Corm.3.2.26

Carm.3.29.60

Sirm.1.4.29

Epist.2.2.I 1

Ars Poet.419

Epist.1.7.8 I

Carm.1.10.I

Carm.3.1I.I

Serm.2.3.25

iar.Serm.2.3.25

iar.Sirm.2.3.25

Carm.2.17.29

Carm.I.24.Is

Carm.1.30.8

Carm.2.7.13

Serm.2.3.68

Serm.1.8.37

Serm.1.1.87

Corm.4.12.16

ear.Carm..4.12.16

Carm.3.3.13

Epist.1.7.24

Ars Poet. 345

Serm.1.4.49

Serm. I.I0.40

Epist.1.2.25

Epist.I.I8.3

Sirm.I.2.58

Sirm.I.4.III

Serm.2.3.252

Epist.1.17.55

Serm.2.7.40

Carm.1.35.25

Eist.1.J. 7.25

coni.serm.2.0.59

lipod.10.22

Strm.2.2.5I

Carm.1.I0.I5

Carm. 1.36 .13

Carm.3.28.5

Carm.t.6. 55

Carm.1.15.20

Corm.3.28.16

Carm.4.2.35 
meritis. si taciturnitas ob-tares meritio invida Romuli? floranere suie non respondere faverem / speratum meritis.

meritis. sume supelisum quaesitam meritis

merito. matitus quin illis l luppiter ambas iratus buccas intlet nunc illud tantum yuatran. meritone tibi sit

rel unerito, queniam in propria non pelle quiessem.

feliruse th anemalmulique dicat ur merito.

meritorum. gramlia laturus meritorum pracmia. ifuid stas?"

meritum. He forta cachas mestum matora subire/verbera non vereor.

meritum. duif duxit ab oppessa meritum harthagin nomen

meritum. "baborm|dulce lenimen tmihicumgue |meritumquel salve/rite vocanti.

mero. finte menento cristitian vitaedue labores' molli, Plance, mero.

turpar nut umetos inmodieate mero|rixac

fentaurea monct cum lapithis rixa supee mero

1'tm quo morantem sitepe diem mero fregi.

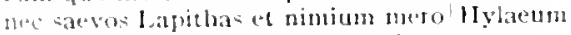

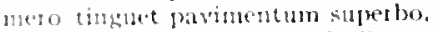

dulej digne mero mon sine toribus.

crat genium mero curabis at porco bimenstri

prisci catonis satepe mero calluise virtus.

nece crotale illat mero

(1. poseguitur meroldefuso pateris

-mmul calentis inverecundus deu teridiore meso

imiguomylue mero sub noctem cor pus habento.

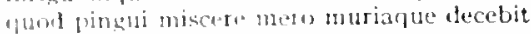

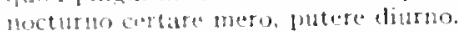

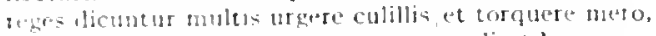

meros. at altor alceras sermone metes audiret homores.

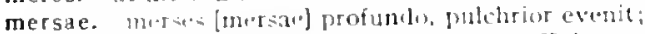

mersare. ducture eris vivam musto mesare Falerm.

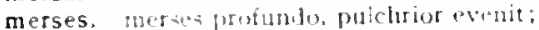

mersor, mulc agili- no ret mersor civilibu a undis.

mersus. merses [mosus] protundo, pulchrior evenit;

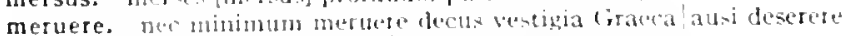

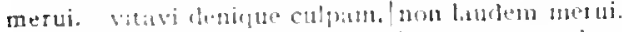

merulas. tum pectore aducto, vidimus et merula possi

merulis. i veluti marulis intentus deciub aucepa in putom

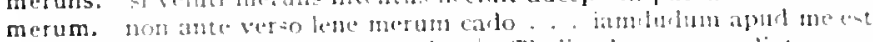

merum. Jeorome quatrimum Sabina, o Thaliarche merum diota

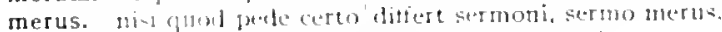

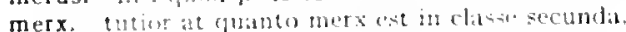

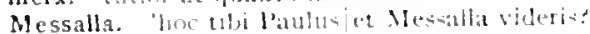

Messalla. [1., M1.4atlat, tho cumb fratre,

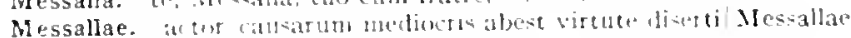

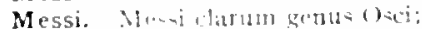

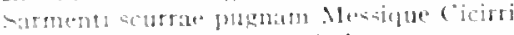

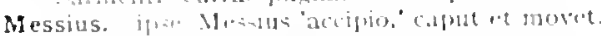

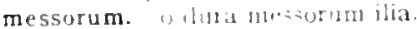

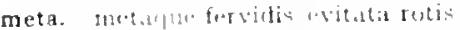

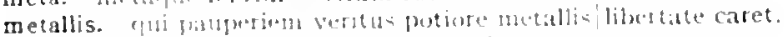

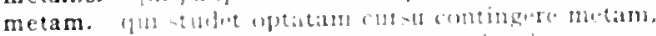

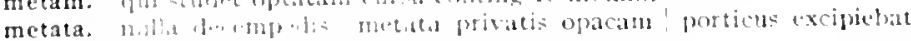

$$
\text { anto }
$$

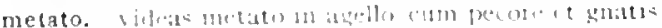

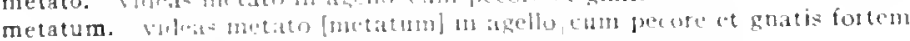

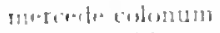

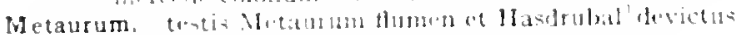

Metellae. detratam in aute Metellar. . Dacam:

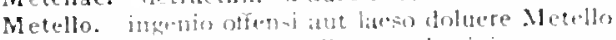

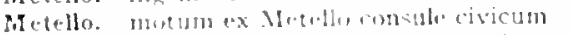

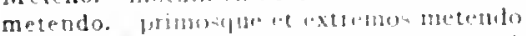

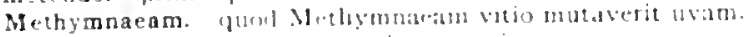

metiente. viluene, sat tam metiente te vians

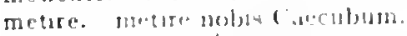

meturetur, elives! me meturetur mummos.

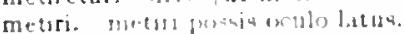

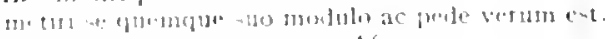

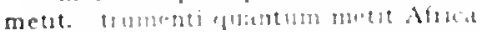

Carm 4.8 .24

Epist.2.1.10

Cirm.3.30.15

Strm.1.1.20

Serm.1.4.4

Serm.1.0.22

Serm.2.3.108

Epist.2.2.35

Serm.1.3.120

Serm.2.t.es

coni.Carm.1.32.15

Carma.i.19

Corm.1.13.10

Carm.1.18.8

Carm.2.7.0

Carm.2.12.5

Cirm.2.1.20

Carm.3.13.2

Corm.3.17.14

Carm 321.12

Carmi.4.1.31

Carm.1.5.33

Epod.15.14

Sirm.2.1.0

Sorm.2.4.15

EPist.1.10.1 I

Irs loct.435

lipist 2.288

iar.Carm.4.415

Sierm.2.19

cirm.t.1.5

EPist.1.1.19

iar. Carm.tat (5

Ars Pilet.28\%

drs Port.2ess

Sierm.2.8.0I

dos roct.t.5

Carm.3.20.2

Carm.1.0.s

Serm.1.1.48

Serm.1.2.47

Serm.1.0.42

serm.1.10.85

Ars Port.371

Sermb.1.5.5.1

serm.1.5.52

Serm. I.5.5\%

1: pold.3.1

cirmo1.1.4

linist 1.10 .30

Ars Prital =

Carm. 2.15.1

Sirm.2.2.11.4

4ur.serm.2.2.11:

Carmat 48

serm. $2.3231 \%$

serm.2.1.07

(i)m.2.1

carmatitat

horm.2.8.50

lepollt 7

I.pod.0.30

Sion. 1. $1.9^{\prime \prime}$

Serm 1.2.103

1. pist.1 $7.0 \mathrm{~s}$

torm.2.3.87 
si metit Orcus|grandia cum parvis,

metu. non sine vanolaurarum et siluae metu.

unde manum iuventus| netu deorum continuit?

euhoe, recenti mens trepidat metu

non animum metu.| non mortis laqueis expedies caput.

comes minore sum futurus in metu.

an vigilare metu exanimem, noctesque diesque formidare malos fures.

iura inventa metu iniusti fateare necesse est.

mortisque metu sibi parcere cogit.

metuam. pro qua non metuam mori, nec mori per vin metuam tenente/Caesare terras. nec metuan, quid de me iudicet heres.

metuas. cumque habeas plus, | pauperiem metuas minus non ego sim Capri neque Sulci: cur metuas me?

metuat. cruribus hace metuat, doti deprensa, egomet mi. utrum / gaudeat an doleat, cupiat metuatne,

metuatur. quis sub Arcto/rex gelidae metuatur orae.

metuebat. ne se penuria victus|opprimeret metuebat.

metuemus. nocentem ' corporibus metuenus austrum:

metuenda. "est genus unum |stultitiae nihilum metuenda timentis, avertit morbos, metuenda pericula pellit.

metuende. nec te, metuende certa|Phoebe sagitta. parce gravi metuende tliyrso.

metuendus. Parthos ferocis|vexet eques metuendus hasta

metuens. luctantem Icariis fluctibus Africum/mercator metuens ne prodigus esse / dicatur netuens,

nequid \$sumna deperdat metuens aut ampliet ut rem.

an qui contertus parro metuensque futuri

metuensque velut contingere sacrum?

metuens induceris atque altercante libidinibus tremis ossa pavore.

credo, metucs [metuens] doctusque cavebis -

labra movet metuens audiri: 'pulchra Laverna.

qui metuens vivet. liber mihi non erit umquam.

in scalis latuit metuens pendentis habenae'-

metuens. tris prohibet supra/rixarum metuens tangere Gratia metuens alterius viri|certo foedere castitas.

metuente. illum aget penna metuente solvi|Fama superstes.

metuenti. stes capite obstipo, multum similis metuenti.

metuentis. filia Nasicae. metuentis reddere soldum. vertere pallor/tum parochi faciem nil sic metuentis ut acris/potores.

metuentis. exanimari metuentis patruae verbera linguae.

metues. nec metues protervom/suspecta Cyrum, . credo, metues doctusque cavebis metues, liberrime Lolli, | scurrant is speciem praebere.

metuet. nam qui cupiet, metuet quoque; dulcis inexpertis cultura potentis amici. / expettus metuet.

metuit. sprat infestis, metuit secundis/alteram sortem ludit exsultim metuitque tangi culpari metuit fides. qui cupit aut metuit, iuvat illum sic domus et res cautus enim metuit foream lupus dulcis inexpertis cultura potentis anici, /expertus metuet [metuit]. sed turpem putat inscite metuitque lituram.

metum. qui dissimulat metum| Marsac cohortis Dacus curam metumque Caesaris rerum iuvat|dulci Lyaeo solvere.

metuo. nec vereor [metuo], ne, dum futuo, vir rure recurrat, 'o puer. ut sis vitalis metuo.

metuont. nec viridis metuont colubras te. . purpurei metuont tyranni, te suis matres metuont iusencis. . omnes hi metuont versus, odere poetas.

metus. tristitian et metus | tradam protervis in mare Creticum | portare ventis.

metum. o laborum/duice leninen imihicunque [metumque] sahe rite vocanti.

meum. vae, meum fervens difficili bile tumet iecur. non est neum. . . acl miseras preces/decurrere 'pone, meum est.' inquit: pono tristisque recedo.

meum. non Afra avis descenclat in ventrem meun,

Epist.2.2.1 78

Carm.1.23.4

Carm.1.35.37

Carm.2.19.5

Carm.3.24.7

Epod.1.17

Sirm.1.1.76

Sirm.1.3.III

sicm.1.4.127

Carm 3.9.I I

Carm.3.14.15

Epist.2.2.19I

Serm.1.t.93

Serm.1.4.70

Serm.1.2.13I

Epist.1.0.12

Curm.1.26.4

Sirm.1.1.99

Carm.2.14.16

Sirm.2.3.54

Efist.2.1.136

Carm.1.12.23

Carm.2.19.8

Carm.3.2.4

Carm.1.1.16

Serm.1.2.5

Serm.1.4.32

Serm.2.2.110

Sirm.2.3.150

Serm.2.7.56

rar.5erm.2.7.68

Epist.1.I0.00

Epist.1. 10.00

Epist.2.2.15

Carm.3.10.16

Carm.3.24.22

Corm.2.2.7

Serm.2.5.92

Scrm.2.5.65

Serm.2.8.36

Carm.3.12.2

Carm.I.17.24

Serm.2.7.68

Epist.t.18.1

Epist. I. I 6.65

Epist.1.18.87

Cirm.2.10.1 3

Carm.3.11.10

Carm.4.5.20

Epist.1.2.51

Epist.1.10.50

iar. Epist.1.18.87

Epist.2.1.167

Carm.2.20.17

Epod.9.37

sur.serm.1.2.127

Sirm.2.I.01

(arm.1.17.8

Carm.1.35.12

Carm.2.8.2t

Sirm.I.4.33

Curm.1.20.I

coni.Carm.1.32.15

Cism.1.13.3

Curm.3.29.57

Ispist.1.10.35

Hpol.2.53 
quorl cum spe divite manet | in venas animumpue meum.

meum. nuenun jecur urete bilis.

ante meum nulli patuit quacsita patatum.

forle meum siguis te percontabitur aevom:

incum cul pectus inaniter angit,

meum. ort paesillum et dulce decus meum:

meus. \& $x$ lac luce Macenas meus adtuentis/ordinat annos.

bon $\mathrm{tun}$ loc capict venter plus ac meus.

calltat tet alponit "neus est amor huic similis:

namelue tait ille, pater quod erat meus.'

quacscor avoos pater atque neus patruosque fuissent.

iban forte via sacra. sicut meus est mos,

(1ice meth hic serno est, sed quae praecepit Ofellus

ne perconteris, fundus melas. optime Quinti.larvo pascat erum

nec mous andet rem temptare pudor guam vires ferre recusent.

Mevium. mala soluta navisexil alitelferens olentem Mevium.

mi. 'quid mi igitur suades?.

'nil fuesit mi' juquit 'cun uxoribus umquan alienis.'

cruribus hace metuat, doti deprensa, egomet mi.

'egonet mi ignosco' Maenius inquit.

viverem uti contentus co quod mi ipse parasset:

mi satis est si traditum ab antiquis morem servare. . . possum;

nil tul officit, incluam. | ditior hic aut est quia doctior;

'at mi: s11m paulo infirmior, unus/multorum.

postmorto quod mi obsit clare certumque locuto

det vitam. det opes; aequom mi animum ipse parabo.

mica. tatre fro et saliente mica.

micat. macat inter omnis|lulium sidus velut inter ignis/luna minores.

mictum. in m.* viniat mictum atque cacatum

migravit. vorum equitis quoque iam migravit ab aure voluptas/onnis

migret. migret in obscuras humili sermone tabernas

mihi. quem silhi, quem tibi|finem di dederint.

tune sec uesus uihi nee color $/$ certa sede manent,

nufer sollicitun quae mithi taedium,

dum mibil fias recantatis amica/opprobris

hic vivon mihi caspitem, hic/vorbenas, puter, ponit.

fru paratis et valido mili,|/,atoe, dowes

o laborum/dulce lonimen tmilicumque salve/rite rocanti.

ille torratum milai practer omnis|amgulus ridet.

receptosidulce milui furete est amico.

et mbi forsan tibi quod negarit|portiges hora.

mihi parva rura et spiritum Graiae tenuem Camonae... dedit

nec dis anicum os nec mihi te prius/obire.

nec laconicas mili| trahunt honestae purpuras clicntae.

fas pervicacis ont mihi Thyiadas

milu caltaenue damnatum Minerve.

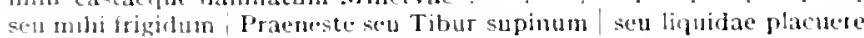

$$
\text { Bitilice. }
$$

hic dues vere mili ientus atras exiget curas:

nel dawetroma Bacchus in amphora|languescit mihi

ue mol dever ripas et vachom newus | marari libet.

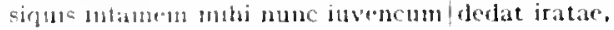

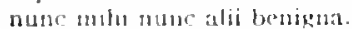

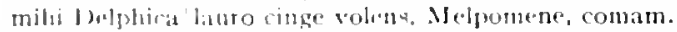

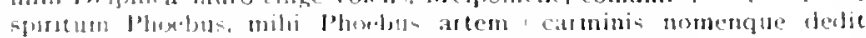

$$
[1+1+1.3 \cdot 4 .
$$

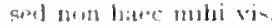

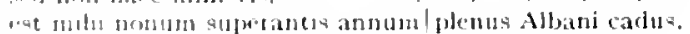

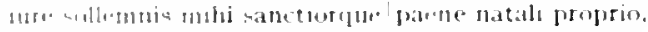

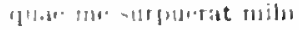

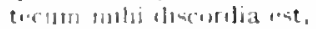

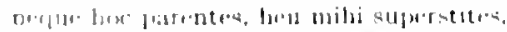

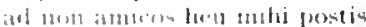

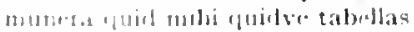

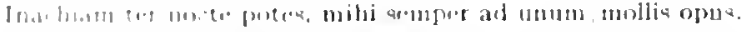

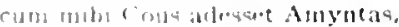

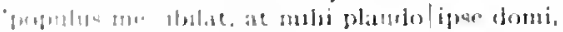

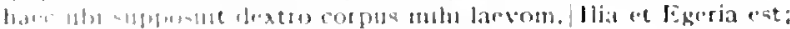

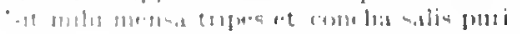

Epist.1.15.20

Strm.1.9.0\%

Serm.2.4.40

Epist.1.20.20

lipist.2.1.21

Carm.1.1.2

Carm.t.11.19

Serm.1.1.46

Serm 1.2.107

Serm.1.0.41

Serm.I.0.13I

Serm.1.0.1

Sorm.2.2.2

Epist.t.10.1

Epist.2.1.258

Epod.10.2

Serm.1.1.101

Serm.1.2.57

Serm.1.2.13I

Serm.1.3.23

Serm.t.4.108

Serm.1.4.116

Serm.1.9.50

Serm.1.0.71

Sirm.2.0.27

Epist.1.18.1 2

Carm.3.23.20

Curm.1.12.46

Serm.1.8.38

Epist.2.1.187

Ars Ioet.220

Carm.1.II.I

Cirm.1.13.5

Carm.t.14.17

Carm.1.16.20,

Carm.1.19.13

Carm.1.31.17

Carm.1.32.15

Carm.2.0.13

Cirm.2.7.28

Carm.2.16.31

Carm.2.10.37

Carm.2.17.2

Cirm.2.18.7

Carm.2.19.9

Carm.3.3.22

Curm.3.4.22

Carm.3.14.13

Corm.3.10.35

C"arm.3.25.12

Carm.3.27.45

C"arm.3.29.52

Cism.3.30.15

Corm.t.0.29

Curm.4.8.9

Carm.t.11.I

Carmat.11.17

Cism.1.13.20

lipind..2 2

lipod.5.10!

Iipod.u I. 2 I

IEpol.1 22

lipod.12.15

lipod.12.18

term.1.1.00

Sicrn.1.2.125

ferm. 1.313 
nunc aliquis dicat mihi 'quid tu? .

pluribus hisce. / si modo plura mili bona sunt, inclinet.

minus hoc iucundus amicus |sit mihi?

mihi dulces /ignoscent, siquid pecearo stultus, amici

hoe mihi iuris/cum venia dabis:

mi [mihi] satis est si|traditum ab antiquis morem servare . . possum; mi satis est [sed mihi sat] si|traditum ab antiquis morem servare. . possum;

neque enim, cum lectukus aut me|porticus excepit, desum mihi. auxilio quae/sit mihi (nam multo plures sumus),

nunc tnihi patcis | Sarmenti scurrae pugnam Messique Cicirri. | musa. velim memores

incipit ex illo montis Apulia notos ostentare mihi,

quod mihi pareret legio Romana tribuno. .

ut forsit honorem/iure mihi invideat quivis.

nulla etenin mihi te fors obtulit;

obiciet vere quisquam mihi.

avita/ex re praeberi sumptus mihi crederet illos.

ipse mihi custos incorruptissimus omnis/circum doctores aderat.

honestos|fascibus et sellis nollem mihi sumere. .

nam mihi continuo maior quaerenda foret res.

nune mihi curtolire licet mulo

obiciet nemo sordis mihi, quas tibi, Tilli.

non sollicitus mihi quod cras/surgendum sit mane.

operum hoe, mihi crede, tuorum est.' .

mihi non tantum furesque feraeque suetae |hunc vexare locum curae sunt accurrit quidam notus mihi nomine tantum

"pluris/hoc' inquam 'mihi eris.'

"haud mili quisquam. | omnis conposui."

namque instat fatum mihi triste. .

'nil mi [mihi] officit,' inquam, |'ditior hic aut est quia doctior;

'haud mihi deero: muneribus servos corrumpam;

mihi carus et illum|qui pulcre nosset.

'nulla nihi' inquam|'religio est.' .

huncine solem lam nigrum surrexe mihi! .

non ego: nam "satis est equitem mihi plaudere".

'haud mihi deero. / cum res ipsa feret: .

nec quisquam noceat eupido mihi pacis!

ac mihi seu longum post tempus venerat hospes

sed cedet in usum / nunc mihi, nunc alii.

inposuere mili cognomen compita."

'accipe quod numquam reddas mihi' si tibi dicam:

putidius multo cerebrum est, mihi crede. Perelli

"sive ego prave|seu recte hoc volui. ne sis patruos mihi":

'quidquid mihi, quidquid et horum 'euique domi est, id crede tuo:t

"haee mihi Stertinius, sapientum octavos, amico arma dedit.

ego nam videor mihi sanus." .

non est mihi tempus

nam quanvis memori referas mihi pectore cuncta.

at mihi cura| non mediocris inest.

eripiet quivis oculos citius mihi

divinare etenim magnus mihi donat Apollo."

unde mihi tam fortem tamque fidelem?"

nisi ut propria haec mihi munera faxis.

o si urnam argenti fors quae miki monstret.

utque soles, custos mihi maximus adsis.

carpe viam, nihi crede, comes.

"haud mihi vita est opus hac"

tune mihi dominus.

tu, mihi qui imperitas, aliis servis miser

obsequium ventriz mihi perniciosius est cur?

'unde mihi lapidem?"

mihi quaerenti convivam dictus here illic/de medio potare die."

sic, ut mihi numquam! in vita fuerit melius."

cum passeris atque ingustata mihi porrexerat ilia rfombi.

prima dicte mihi. summa dicende Camena.

est mihi purgatam crebro gui personet aurem:

ct mihi res, non me relus subiungere conor.

sic mihi tarda Huont ingratalue tempora
Serm.1.3.1 9

Serm.1.3.71

Sirm.1.3.94

Serm.1.3.139

Serm.I.A. 104

"ar.Serm.I.4.IIt

2'ar.Serm.I.4.I I6

Serm.1.4.134

Scrm.1.4.1 42

Serm.1.5.51

Serm.1.5.78

Serm.1.0.48

Serm.1.0.50

Serm.1.0.54

vierm.1.0.09

Serm.1.6.80

Serm.1.0.81

Sirm. I.0.97

Serm.1.6.100

Serm.1.6.104

Serm.1.0.107

Serm.1.6.1 10

Serm.1.7.35

Serm.1.8.17

Serm.1.9.3

Serm.1.9.8

Serm.1.9.27

Serm.1.9.20

zar.Serm.1.9.50

Sirm.1.9.56

Serm.1.9.61

Serm. I.9.7o

Sirm.1.9.73

Serm.1.10.76

Scrm.2.1.17

$5 \mathrm{crm} .2 .1 .44$

Serm.2.2.11 8

Sirm.2.2.135

Serm.2.3.20

Sorm.2.3.06

Serm.2.3.75

Serm.2.3.88

Serm.2.3.23 I

Serm.2.3.290

Serm.2.3.302

Serm.2.4.1

Serm.2.4.90

Serm.2.4.93

Sierm.2.5.35

Serm.2.5.60

Serm.2.5.102

Serm.2.0.5

Sirm.2.0.10

Sirm.2.0.15

Serm.2.0.93

Sirm.2.0.115

Sirm.2.7.75

firm.2.7.8I

Serm.2.7.10.1

Sirm.2.7.110

Serm.2.8.2

Serm.2.8.3

Serm 2.8.30

f:pist.I.I.I

Epist.1.1.7

I.pist.1.1.10

Is pist. 1.1.2.3 
duid milu Celsus agit?

guo milu fotmam, si mon conceditur uti?

yuam mihi dit aegro, dabis aegrotare timenti. Maecenas, veniam, mlif hum non regia Roma, fret vacuon Tibur placet

"nexect ille mihis"

"Mutus, ait. 'Viltei, nimis attentusque videris/essu mihi,

-1 velles" inulut verum mili ponere nomen.

discimulator ofis proptiae, mihi commodus uni.

vilice silvirntu et mili me redelent is agelli.

me constur mulis scis et discedere tristem

(nan mobi lhara/ Musa sujervacuas Antonius.

nom mili (umatest iter aut Baias"

'nec lurtum teci nee tugi,' si mihi dicat/setvos:

dammun at. mon facinus, mili pacto lenius isto.

da mili fallete, da iusto sanctoque videri,

gui metuenc vivet, liber mihi non erit umquan.

scutrot ego ipse mihi, populo tu:

indotiat a nilis sor or est, paupercula mater.

chmat "vicum date." succinit alter 'et milsi."

"ilice"t, ut mo ? sit mili prima fudes

st milsi, quod nuncest, ctian minus, ut mihi vivam l guod superest arvi,

ut mili sarpe bilem, sacpe iocum vestri movere tumultus!

memini quac plagosum mitu parso () biliun dictare;

ille pers extentum funem mihi posste videtur ise porta.

Roman mutis mihi contigit atque docesi,

tes mili convivae prope dissentice videntur

औhe mati. Mutia, virum,

ghodrumelue ostendis milui sic, inctedulus odi.

se nitit. gui multum censat. fit choctibs ille,

se mihi, qui multum [multum mihi (gui] ecesat, fit Chorilus ille, occupet extemum sealsus: mihi turpe relingui cat

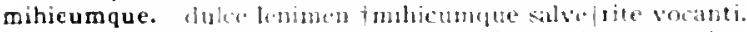

miles. quan rem cumque ferox . . miles te duce gessest.

miles sagitatio celerem fugam | Iarthi,

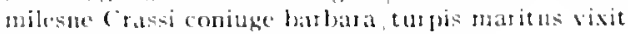

auto reporsus seilicet acrior $\mid$ miles redibit:

ceteris mater. tibi milos ingar.

megue excitatur clasico miles thuci

Romanus ehe"u. . fent vallum et arma sniles

o fortunati mercatores' gravis arsuis miles at.

tris tu, qui movlo miles, mercator;

peotidus duc caupo, miles matalecule.

j. laculli miles collecta viaticat multic aerumnis.

Mileti. alter Malet lextan canc preius et anguil vitabit clalanden.

milia. quot cupitum visont, totic!m studiotm|milia: .

sef ptladrmpentis sex septem milia desumt:

milia. mulin humenti thas trivedit atea centum:

milis tum panai tria repimua

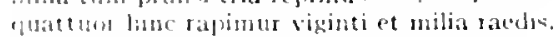

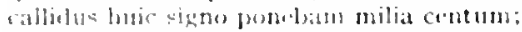

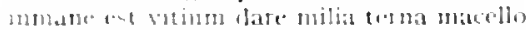

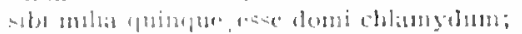

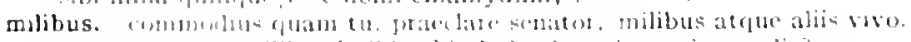

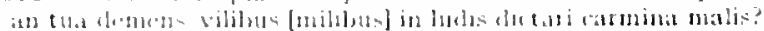

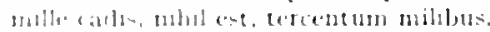

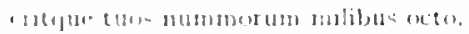

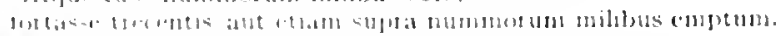

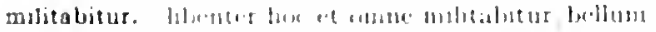

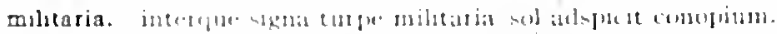

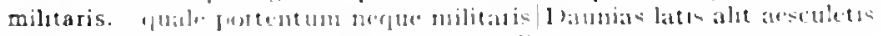

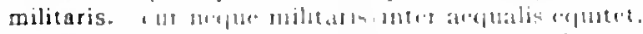

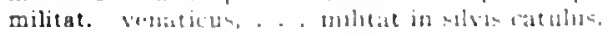

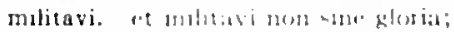

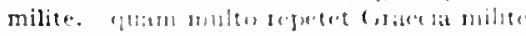

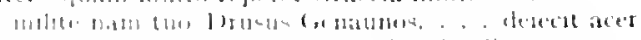

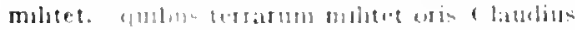

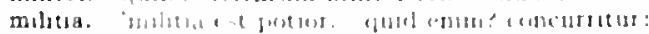

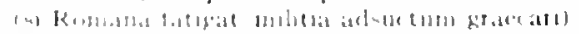

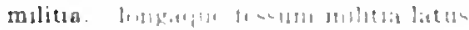

lipist 1.3.15

Lipist.1.5.12

List.1.7.4

Eisist.1.7.44

Epist.1.7.03

Eist.1.7.92

Epist. 1.7 .93

Epist.1.0.9

Jipist.J.1. I

fipist.1.14.16

lipist.t.15.2

lipist.t.15.1 I

IEpist.1.16.46

IEpist. 1 de $5^{6}$

lEpist.l.17.0I

IEpist.1.10.06

Epist.1.17.19

ISpist.1.17.4\%

Epist.1.17.49

Epist.1.18.17

Epist.1.18.10\%

Lpist.1. I 9.19

Epist.2.1.70

Epist.2.1.210

List.2.2.4I

Epist 2.2.0 I

Ars Poel. It

-lers l'odt. IS8

Ars l'ue: $35 \%$

tar.jes J'ont 357

Ars livel 117

('ilm.1.32.15

curmido.s

Corm.2.13.17

c arm.3.5.5

corm. 3.520

(i)rmide. 5

I.poul.z. 5

I.podio. 13

sirm.1.1.5

S.rm.1.10

Sirm.1.20

IPist.2.2.20

I.pist.1.17.30

Serm.2.1.28

lipist.1.1.57

sermit.1. 5

Serm 1.5.25

Sirmet t.jipt

arm 2.3.2.3

$\therefore r m=4.70$

L. pist.t 1.43

Serm. J o.1 II

iarsomer.10.75

acth.2.3110

I.post.2 2.5

I. pist.2.211.5

I. poul 1.23

f.penilo 15

(iorm.1.22.1.3

c (irm 1.⿻一

lifiuter 2.87

ciorm.3.210.2

( iarm.1.15.t)

(arm. 4190

l. fist.1.31

scond 1.7

Strm.2.2.11

( arm 2.7 .18 
robustus acti militia puer/condiscat

militia simul|fessas cohortes abdidit oppidis.

militiae. sit modus lasso maris et viarum militiaeque.

o saepe mecum tempus in ultimum/deducte Bruto militiae duce.

late signa feret militiae tuae .

militiae quanıuam piger et malus, utilus Vrbi, ji das hoc.

militiam. quis post vina gravem militiam aut pauperien crepat?

et acrem militiam paras

saevam militiam puer et Cantabrica bella tulisti

militibus. arma|militibus sine caede' dixit |'derepta vidi.

militibus promissa Triquetra / praedia Caesar an est Itala tellure daturus?'

militum. sed rusticorum mascula militum/proles.

neque iratos trementi|regum apices neque militum arma.

hoc, hoc tribuno militum?"

mille. temptat mille vafer modis.

arat Falerni mille fundi iugera

ad hunc frementis verterunt bis mille equos

iugera centum an |nille aret?

mille pedes in fronte, trecentos cippus in agrum|luic dabat.

mille die versus deduci posse.

Catienis mille ducentis!'mater, te appello' clamantibus.

mille adde catenas;

si positis intus Chii veterisque Falemi $\mid$ mille cadis,

hic simul accepit patrimoni mille talenta.

'mille puellarum, puerorum mille furores' -

gaude quod spectant oculi te mille loquentem; .

mille talenta rotundentur, totidem altera,

nam de mille fabae modiis cum surripis unum. .

mille. 'mille ovium insanus morti dedit.

Millonius. saltat Milonius [M illonius], ut semel ictolaccessit ferror capiti numerusque lucernis;

Milonis. quia desperes invicti membra Glyconis [Milonis],

Milonius. saltat Milonius, ut semel icto/accessit fervor capiti

miluo. adulteretur et columba miluo,

miluos. metuit foveam lupus . . et opertum miluos hamum.

mimae. qui patrium mimae donat fundumque Laremque.

mimae. ambubaiarum collegia, plarmacopolae, | mendici, mimae. balatrones.

Mimas. sed quid Typhoeus et validus Minas . . possent

mimis. verum est cum mimis, est cum meretricibus,

Mimnermus. si, Mimnermus uti censet, sise amore iocisque / nil est iucundum.

fit Mimnermus et optivo cognomine crescit.

mimo. ut sibi praebentem mimo spectacula plura.

mimos. et Laberi minos ut pulcra poemata mirer.

mimum. partis mimum tractare secundas;

minabitur. sic quodcumque minabitur Eurus|fluctibus Hesperis:

nec semper feriet quodcumque minabitur arcus.

minaces. minaces! turpe solum tetigere mento;

Pindaricae latent|Ceaeque et Alcaei minaces

minaci. aut quid minaci Porphyrion statu.

minaci. puetum minaci! voce dum terret,

minaci. lam nunc minaci murmure comuom perstringis auris.

minacis. minacis aut Etrusca Porsenae manus,

minacis. vectis et farcus/oppositis foribus minacis.

minacium. regun colla minacium.

Minae. sed Timor et Minae/scandunt eodem, quo dominus,

minae. 'celeres fugae |reiectaeque retrorsum Hannibalis minae'

minantem. dic multa et pulcra ninantem | vivere nec recte nec suaviter.

minantis. atqui voltus erat multa et praeclara minantis.

minarum. tristia maestum/voltum verba decent, iratum plena minarun.

minas. quod regum tumidas contuderit minas.

quin huc inanis, si potes, vertis minas

minati. nec priores inpiae tectum dominae relinquont. I sepe ninati.

Minatius. sit tibi curae/quantae conveniat Munatius [Minatius].

minatur. horrendamque cultis'diluviem neditatur [? minatur] agris, .

minatus. dux fugit ustis navibus|minatus V"rbi vincla.

minar. et minax, tquia sic voluere, pontolunda recumbit.
Carm.3.2.2

Carm.3.+. 37

Carm.2.0.8

Carm.2.7.2

Carm.4.1.10

Esist.2.1.12.4

Carm.1.18.5

Carm.1.29.2

Epist.1.18.55

Curm.3.5.20

Serm.2.6.55

Carm.3.6.37

Carm.3.21.20

Epod.4.20

Carm.3.7.12

Epod.4.13

Epod.9.17

Sirm.I.I.5I

Serm.1.8.12

Serm.2.1.4

Serm.2.3.01

serm.2.3.70

Serm.2.3.110

Serm.2.3.226

Serm.2.3.325

Epist.1.0.19

Epist.1.0.34

Epist.1.10.55

Serm.2.3.197

Far.Serm.2.1.24

var. Epist.I.I.30

Serm.2.1.24

Epod.10.32

Epist.1.10.5I

Serm.1.2.56

Scrm.1.2.2

Carm.3.4.53

Serm, 1. 2.58

Epist.r.0.05

Epist.2.2.10I

Lipist.2.1.108

Sirm.1.10.0

Epist.1.18.14

Carm.1.28.25

Ars Puet. 350

Corm.2.7.11

Carm.4.9.7

Carm.3.4.5.1

Carm.I.10.10

Carm.2.1.17

Epod.Ifia

Cirm.3.20.8

Carm.2.12.12

Carm.3.1.37

Carm.4.8.

Lipist.1.8.3

Sirm.2.3.9

Ars Puet.100

Carm.a.3.s

Epode. 3

Carm.2.8.20

zar.Lpist.1.3.3 I

? qar.Carm.1.14.28

lipod.g.s

Carm.I I2.3I 


\section{MINAX}

per hornestas ire domos inpune minax.

mineris. magnis parva mineria|fale recisurum simili te,

Minerra. Ofellua/ruaticus. ab normis sapiena crasaque Minerva).

(u) niluil in s'tal lices faciesve Minerva:

Minerrae. mihileastaeque damnatun Minervae

Minervae. tibi telas operozaeque Minervae studium aufert. ille non inclusus equo Minervae/sacra mentito

minime. quol sunt quos genus hoc minime iuvat.

"'quil. siquis non sit avarus. / continuo sanus?" minime.

minimis. vitus nomo sime nascitur; optimus ille est.|qui minimis urgetur.

minimo. Crispinua minimo me provocat.

minimarn. creditur, ex medio quia res accersit, habere/sudoris minimum. ... comoedia.

nec minimum meruere decus vestigia Graecalausi deserere

minimum. Carpe diem quam minimum credula postero.

amicus Aubn|tertili Baccho mininum Falernis|invidet uvis

emendatia videri|pulchraque et exactis minimum distantia miror. .

minister. olium que libellis|sedulus inportes opera vehemente minister.

ministeriis. vernd ministeriis ad nutus aptus erilis.

ministrat. ve! quod res omnis timide gelideque ministrat.

ministratur. cena ministratur pueris tribus

ministrent. ut omnes/praecincti recte pueri comptique ministrent?

ministret. requiro. . quad verba ministret.

ministrum. neque te ministrum|dedecet myrtus

Zquale:n ministrum fulminis alitem.

minitaris. cum sic mutilus minitaris?'

minitatur. horrenlamque cultis|diluviem meditatur [minitatur] agris,

Cervius iratus loges minitatur et urnam,

miniteris. 'quid faceres, cum sic mutilus minitaris [miniteris]?"

minor. te minor lactum reget aequos orbum:

parvosque natos ut capitis minor/ab se removisse.

quod scribere possem. |inventore minor;

rerum imperiis hominumque/tot tantisque minor.

sapiens uno minor est love, dives.| liber. honoratus.

donec minor in certamine longolinploravit opes

si pede maior erit, subvertet, ai minor, uret.

jus imperinmque Phraates/Caesaris accepit genibus minor:

t 1 potris vilia. verum es/dante minor.

quis deperiit minor uno mense vel anno.

cur alter [8 curque minos] fratrum cessare et ladere et ungui praeferat

Hlorodia palmetis pinguibus.

neve minor neu sit quinto productior actu|fabula.

minor. invillia aflcrevit, privato quae minor esset.

magna muorse foro si res certabitur olim:

minora. Zny'rna guid et Colophon, maiora minorane fama?

minora. caelo fulgebat Luna serenolinter minora sidera. nullane babon vitia?" immo alia et for tasse minora.

sed timus. mea ne finxisse minora putarer.

vel quia curncia putas una virtute minora.

minore. comes mirore sum futurus in metu.

minorem. ciur! anternis minorem/consilizic animum fatigas?

dis te minotorn quod geris, imperas:

tanto diesisuikm et tanto certare minorem?

quanto curam sumptumque minoren/haec habeant.

minorem. r.m $\mathrm{m} \cdot \mathrm{C}$ 4um facturus vitio culpare minorem: me fox uit melimela rubere minorem ad lunam delecta.

minores. fund numbo plured, vistute et honore minoses.

minores. lulinm sillus wolut inter ignis|luna minotes.

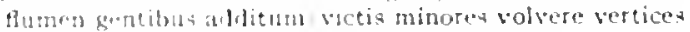

Mon rilut viols tenni gravitate minores

minori. 'o maior tandem pareas, insane, minori."

Remar duler diul fust. . maiores audire, minori diceres

minoribus. w. l quia turpe pueane paresr minoribus

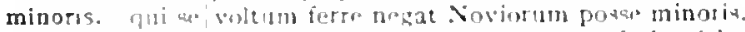

minorss. nold ridet versua Fon gravitate minores [minoris].

minorum. Jablitor termotizacilse puero. Cartigator censorque minorush.

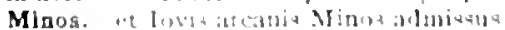

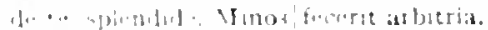

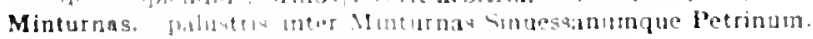

MINTVRNAS

Epist.2.I.I50

Serm.1.3.122

Serm.2.2.3

Ars Pott.385

Carm.3.3.23

Carm.3.12.5

Carm.4.6.13

Serm.1.4.24

Serm.2.3.160

Serm.1.3.69

Serm.1.4.14

Epist.2.1.160

Ars Poct.286

Carm.I.II.8

Corm.2.6.19

Epist.2.1.72

Epist.5.13.5

Epist.2.2.6

Ars Poet. 75

Serm.1.6.1 I6

Serm.2.8.70

IEpist.1.15.20

Carm.1.39.6

Carm.4.4.I

Serm.1.5.60

var.Carm.4.54.23

Serm.2.1.47

itar.Serm.1.5.60

Carm.1.12.57

Carm.3.5.42

Serm.1.10.45

Serm.2.7.76

Epist.1.1.106

Epist.1.10.35

Epist.1.10.43

Epist.1.12.28

Iipist.1.17.22

Epis?.2.1.40

7 rar.Epist.2.2.183

Ars l'oet.iso

S.rm.1.6.26

Serm.2.5.27

List.1.1 I.3

Epol.15.2

Serin. 1.3 .20

Epist.r.9.8

Rpist.1.12.11

lipot.1.17

Carm.2.11.1I

Carm.3.6.5

Serm 2.3.313

Serm 2.1 .85

Serm.2.0.7

Serm.2.8.31

lipist.2.1.18.3

Carm.1.12.49

Carm.2.9.22

Sorm.1.10.54

Serm.2.3.32\%

Ippist.2.1.10\%

Epist.2.1.84

Serm.10.121

par firren.1.1059

Ars linetizat

Carm 1.280

Cirm.4.7.21

lipist 1.5.5 
minuas. in singula quem minuas pulmenta necesse est.

Serm.2.2.34

tu cave ne minuas, tu ne mains facias id

Serm.2.3.177

Epist.r.18.101

Epist.1.18.20

Minuci. Brundisium Minuci melius via ducat an Appi.

Carm.4.1 I.35

minuentur. minuentur atrae / carmine curae.
minuere. at nos virtutes ipsas invertimus atque $\mid$ sincerum furimus vas incrustare [minuere].

minui. per quae/crescere res posset, minui damnosa libido. .

iar.Serm.1.3.56

Epist.2.1.107

Carn.1.37.12

Carm.2.16.30

longa Tithonum minuit senectus.

minus. 'sit mihi, quod nunc est, etiam minus,

minus. haberet|plus dapis et rixae multo minus invidiaeque.

habet comoedia tanto/plus oneris, quanto veniae minus:

Epist. I.18.107

Epist.1.17.5 I

Epist.2.1.1 70

minus. prece qua fatigent | virgines sanctae minus audientem | carmina

Vestam?

audis minus et minus iam:

et iam dente ninus mordeor invido.

cur dira barbarae minus / venena Medeae valent,

inlitterati num minus nervi rigent

minusve languet fascinum?

Inachia langues minus ac me;

cumque habeas plus, | pauperiem metuas minus

Sallustius in quas/non minus insanit quam qui moechatur.

minus aptus acutis/naribus horum hominum.

minus hoc iucundus amicus|sit mihi? .

minus est gravis Appia tardis.

sed fulgente trahit constrictos Gloria curru / non minus ignotos generosis. .

quid? tunc rhombos minus aequor alebat?

forte minus locuples uno quadrante perisset,

qui ridiculus minus illo?

qui peccas minus atque ego.

sed quia mente minus validus quam corpore toto

est ubi divellat somnos minus invida cura?

qui minus argutos vexat furor iste poetas?

si cupidum timidumque minus te:

minxerit. utrum $\mid$ minxerit in patrios cineres

mira. unde ego mira|descripsi docilis praecepta haec. nunc satis est dixisse ego mira poemata pango;

mirabere. quo simul mearis, . . nec tenerum Lycidan mirabere siquid mirabere, pones|invitus.

mirabile. mirabile visu/caelatumque novem Musis opus.

Carm.1.2.27

Curm.1.25.6

Carm.4.3.16

Epod.5.61

Epod.8.17

Epod.8.I 8

Epod.12.14

Serm.1.1.93

Serm.1.2.49

Serm.1.3.29

Serm.1.3.93

Serm.1.5.6

Serm.I.6.24

Serm.2.2.48

Serm.2.3.93

Serm.2.3.311

Serm.2.7.96

Epist.1.8.7

Epist.1.10.18

Epist.2.2.90

Epist.2.2.156

Ars Poet.47 I

Serm.2.3.33

Ars Poet.4I6

Carm.1.4.19

Epist.I.I0.3I

Epist.2.2.9 I

Epist.1.6.23

Epod.16.53

Epist.1.17.26

Ars Poet.42.4

Iipist.2.2.208

Ars Poet.144

Epist.1.12.12

Epist.1.14.18

Carm.2.13.3o

Sirm.2.6.57

Epist.2.2.58

Epist.1.6. 8

Carm.3.25.14

Carm.3.29-1I

Fipist.1.7.62

Carm.3.8.3

Serm.1.1.86

Eipist.1.1.47

miras. 'divitias miseras (miras)! sed quis cenantibus una,|Fundani, pulcre fuerit tibi, nosse laboro.'

mirata. aurum vestibus illitum/mirata

candidum | Medea mirata est ducem.

mirati. nimium patienter utrumque, / ne dicam stulte mirati. ${ }^{\circ} \cdot{ }^{\circ}$

mirator. 'nolim laudarier' inquit / sic me' mirator cunni Cupiennius albi. .

miratur. te profugus Scsthes|miratur.

iurantem me scire nihil mirantur [miratur] ut usum/scilicet egregii mortalem altique silenti.

coni.Serm.2.8.18

Carm.4.9.15

Fipol.3.10

Ars I'oet. 272

Serm.1.2.36

Carm.4.1 4.43

tar.Serm.2.6.57 
qui timet his anlyersa, fere minatur codem. fquo cupleas, pacto; . miraturque nihil risi quod L.ibitina sacravit.

si veteres ita miratur laudatque poetas.

mire. Inire sagacis falleret hospites

emovit vecterem mire novos.

miret. et Laberi mimos ut pulcra poemata nirer.

miretur. ncepue te ut miretur turba labores.

miri. sicjuid miri faciat natura.

miror. "t niror morbi purgatum te illius."

cum. . miror/proelia rubrica picta

non hescule miror, aiebat, "siqui comedunt bona.

sed emendata videri|pulchraque et exactis minimum distantia miror.

quem bis teme bonum cum risu miror;

miros. qui se credebat niros audire tragoedos

mirum. quid mirum, ubi illis carminibus stupens.

mirum quod foret omnibus.

(mirum. ut neque calce lupus quenquam neque dente petit bos),

mirum. oscri studiorum, quine putetis/dificile et mirum, .

mirus. novaque monstra iunxerit libidine /mirus amor.

sive est naturae hoc sive artis, mirus utroque." .

misce. misce stultitiam consiliis brevem:

miscebat. Aufidius forti miscebat mella Falerno.

miscebis. sit spes fallendi, niscebis sacra profanis.

miscent. me doctarum hederac praemia frontium $/$ dis miscent superis,

miscentor. tribus aut novem miscentur [miscentor] cyathis pocula commodis.

miscentur. tribus aut novem / miscrntur cyathis pocula commodis.

miscere. quod pingui miscere mero muriaque decebit

miscet. Laribus tuom | miscet numen.

Surrentina vafer qui miscet faece Falema' rina.

miscueris. simul assis miscueris elixa, simul conchylia turdis.

miscui. cgo facem prinus et hallec, / primus et invenior piper album [? ego primus face nec allec miscui]

miscuisse. quid ptoderat ditasse laelignas anus/velociusve miscuisse toxicun?

miscuit. hic, unde vitan sumeret inscius, pacem duello miscuit. quod verbis graeca latinis/miscuit."

omne tulit punctum, qui miscuit utile dulci

Miseno. ostrea Circeis. Miseno oriuntur echini.

miser. Heris ipat miser

ergo negatum vincor ut credam miser.

Villius in fausta Syllae gener, hoc miser uno'nomine decetus. miserqu" | mupuis et latras, magnorum maxime regum. aut ob aturitiam aut misera [niser] ambitione laborat. in neneran parten cultus micr.

tanto levino miater ac prior ille

(u. moli "qui inperitas, alis servis miset

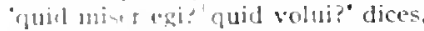

fluol cuacrit anventis miser abstinet ac thmet uti,

miser. it min. roluanta laboras in Charybdi.

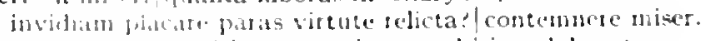

misera. atut ol, atyritian aut misera ambitione labotat. vita soluturum miscra ambitione gravique"; baud unguan misera formidine privet? ingesulum mi-tal guia lortunatius aste/credit

miserabilis. in moriret bim niserabilis/captiva pubes.

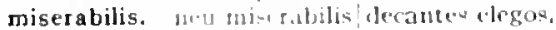

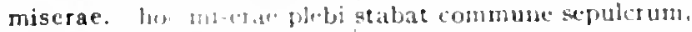

miserac, mistangue nujeer virgines nuptac.

miseram. Jarc leflum licrinoum, hic nimesam famem miseram tuis'duens igrubus uri.

nubean miser Joniluat mulicr. muceram se conscia clanect.

miserantik. vistuns nil miterantis (uci

miserarum. muvarum ion nectue anori dare bulum

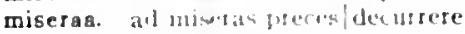

at mindits atlanicat urbis.

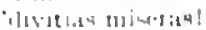

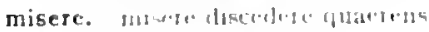

Epist.2.1.49

Epist.2.1.64

Carm.2.5.22

Serm.2.3.28

Serm.1.10.6

Serm.1.10.:3

Serm.1.5.102

Serm.2.3.27

Serm.2.7.97

Epist.1.15.41

Epist.2.1.72

Ars Poit.358

Epist.2.2.129

Corm.2.13.33

Carm.3.4.13

Sern.2.1.5.4

Serm.1.10.22

Epod.10.31

Serm.2.4.7

Carm.4.12.27

Serm.2.4.24

Epist.1.16.54

Carm.1.1.30

coni.Carm.3.19.12

Carm.3.19.12

Serm.2.4.05

Corm.4.5.35

Serm.2.4.5.5

SeTm.2.2.74

7 gar.Serm.2.4.74

Ispod.17.01

Carm.3.5.38

Sirm.1.10.21

Ars Poct.343

Sirm.2.4.33

Efod 1.1 .13

Epod.17.27

Sermidi.2.64

Sorm.1.3.135

tar.5rm.1.4.26

Serm.2.2.10

Serm.7.19

Serm. 2.81

lipist.1.20.6

Ars l'oet 150

Carm.1.27.18

Serm.2.3.14

Serm.1.4.20

Sorm 1.1120

Sirm.2.7.77

Ars l'or'.205

coniciarm.3.5.17

Carm.1.33.2

Sorm.1. 10

Cirm.2.8.22

Curm.1.21 13

Carm.3.7.80

sor..4rtm.1. b. 3

Serma 1130

Carm.2.324

Carm.3.12.1

Cami3 29.58

Cinm.t 15.20

term.2.tis

Sorm.1.8.8 
'misere cupis' inquit 'abire.

miseri. in cor|traiecto lateris miseri capitisve dolore.

Serm.1.9.14

miseri. miseri, quibus/intemptata nites.

miseris. ut redeat miseris, abeat Fortuna superbis.

misero. quod viro clemens misero peperci.

ingrata misero vita ducenda est in hoc.

qui nisi. cum tristes misero venere kalendae,

perditur haec inter misero lux non sine votis:

fervet avaritia miseroque cupidine pectus:

miseros. neque consularis|submovet lictor miseros tumultus|ment is

miserum. deprendi tniserum est: Fabio vel iudice vincam.

miserum. iubeas miserum esse, libenter/quatenus id facit.

Terenti|fabula quem miserum gnato vixisse fugato|inducit.

pol, me miserum, patrone, vocares,

misisset. si non Acrisium . . I I uppiter et Venus/risissent [? misisset]:

misit. satis terris nivis atque dirae|grandinis misit Pater

in celeres iambos/misit furentem.

misit Thyesteas preces: .

missa. delere licebit. /quod non edideris; nescit vox missa reverti.

missae. missae pastum retinacula mulae/nauta piger saxo religat

missi. quae/partes in bellum missi ducis:

missi. nissi magnis de rebus uterque/legati,

spectatum admissi [missi] risum teneatis, amici?

missilibus. ille! missilibus melior sagittis.

missis. 'quando pauperiem missis ambagibus horres.

missis. pulcrior, ultro/muneribus missis):

missas. partus fulmine luridum ! missos ad Orcum;

ut, cum carceribus missos rapit ungula currus,

Enni|in scaenam missos cum magno pondere versus

missura. non missura cutem nisi plena cruoris hirudo".

missus. missus ad hoc pulsis, vetus est ut fama, Sabellis,

'solventur risu tabulae, tu missus abibis.'

mite. circa mite solum Tiburis et moenia Catili;

mitescere. nemo adeo ferus est. ut non initescere possit,

mitescunt. frigora mitescunt Zephyris.

mitibus. nunc ego mitibus|mutare quaero tristia.

decorum mitibus pornis caput

mitiget. silvestrem flammis et ferro mitiget agrum.

mitior. nec Mauris animum mitior anguibus:

mitis. condito mitis placidusque telo... Apollo:

mitis. virtus Scipiadae et mitis sapientia Laeli,

mittam. non ego nuntios | mittam superbos:

'tamen et quacram et quot habebolmittam';

exspectata tibi non mittam carmina mendax.

mittamus. in mare proximum/gemmas . . mittanus,

mittant. excipiant?̧ue senes, quos in vivaria mittant;

mitte. mitte sectari, rosa quo locorum/sera moretur.

sepulcri $\mid$ mitte supervacuos honores.

mitte civilis super Vrbe curas:

mitte singultus, bene ferre magnam/disce fortunam;

cutera mitte loqui:

mitte levis spes et certamina divitiarum

mittere. cui placet inpares/formas atque animos sub iuga aenealsaevo mittere

frementem/mittere equom medios per ignis.

noluit in Flavi ludum me mittere.

cum vellem mittere operto| me capite in flumen,

mitteret. qui prose tolleret atque/mitteret in phimum talos.

mitteris. aut fugies Vticam aut vinctus mitteris Ilerdam.

mittes. tu parum castis inimica mittes fulmina lucis.

munera quid mihi ... mittis [mittes] nec firmo iuveni neque naris obesac?

mittis. munera quid mihi quidve tabellas / mittis

mittit. Hiberia|mittit venenorum ferax.

mitulus. mitulus et viles pellent obstantia conchae

mixta. mixta senum ac iuvenum densentur funera.

mixtae. cursitant mixtae pueris puellae.

mixtis. tibiae/mixtis carminibus non sine fistula;

mirto. doctus eris vivam musto [mixto] mersare Falerno:

Serm.2.3.29

Carm.1.5.1 2

Ars Poet.2ar

Carm.3.11.46

Epod.17.63

Serm.1.3.87

Sirm.2.0.59

Epist.1.1.33

Carm.2.16.10

Serm.1.2.134

Sirm.1.1.63

Serm.j.2.2 I

Epist.1.7.92

? war.Carm.3. 6.7

Carm.r.2.2

Curm.1.16.25

Epod.5.86

Ars Poet. 390

Serm.1.5. 18

Ars Poet.315

Sirm. I.5.28

var.Ars Poet.s

Corm.3.6.16

Serm.2.5.9

Serm.1.7.1 8

Carm.3.4.75

Serm.I.I.II

Ars Poet.260

Ars Poet.476

Serm.2.1.36

Serm.2.1.86

Carm.1.18.2

Epist.1.1.39

Carm.4.7.9

Carm.1.10.25

lepod.2.17

Epist.2.2.186

Carm.3.ro.1 8

Carm.Saec. 33

Sirm.2.1.72

Curm.4.4.70

Epist.1.6.43

Epist.2.2.25

Carm.3.24.50

Epist.1.1.79

Carm.1.38.3

Carm.2.20.2.4

Carm.3.8.1 7

Carm.3.27.74

Epod.1 3.7

Epist.1.5.8

Carm.r.33.12

Curm.4.14.24

Serm.1.0.72

Sirm.2.3.37

Serm.2.7.17

Epist.1.20.13

Carm.1.12.59

var. Epod. 12.3

Epod.12.3

Epod.5.22

Serm.2.4.28

Carm.1.28.10

Carm.4.1.10

Carm.4.1.24

tar.Serm.2.4.19 
mirtum. his mixtum ius est:

mixtum. sonunce mixtum tibis carmen lyra.

Serm.2.8.45

mobile, lucetis ut nervis alienis mobile lignum. • • • • •

mobilia. hatc siquis tempestatis prope ritujuobilia . . laboret/reddere certa sibi.

mobilibus. nobilibusque decor naturis dandus et annis.

mobilibus. nam sen mobilibus vepris inlorroit/ad ventum folis

mobilibus. ucla|mobilibue pomariá rivis.

mobilis. puncto quod mobilis hotae . . permutet dominos

mobilium. hunc, si nobilium turba Quiritium | certat tergeminis tollcre lomoribus.

moderabitur. qui non moderabicur irae, infectum volet esse. . . .

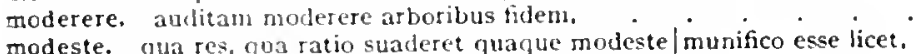
modeste. qua res. qoa ratio suaderet quaque modeste/munifico esse lice modestus. 'molestus [modestus] / communi sensu plane care
modestus occupat obscuri speciem, taciturnus acerbi.

modica. nec modica cenare times holus omne patella.

modici. ac ne quis modici transiliat munera Liberi.

modicis. Aesclyylos et modicis instravit pulpita tignis.

modicis. vile potabis modicis Sabinum/cantharis.

modicis. seu molicis uvescit laetios.

modico. ex moelico, quantum res poscet, acervoltollan

modico. egressum nagna me accepit Aricia Rona|hospitio modico, .

Serm.2.7.82

modicom, at lethargicus hic com fit pugil et medicum [modicum] urget. .

modicus. qua uredius [modicus] liquor] secernit Europen ab Afro.

modis. nam de mille fabae mudis cum surripis unum.

modis. mullibus/aptari cithatae modis

accesst numerisque modistue licentia maior.

modis. to semper utges flebilibus modis

makna modis tenuare parvis.

temptat mille vafer modis.

servilibus ut quaeliam peritura modis.

quibus amiscas reparare queam res/artibus atque modis.

gratia regum/Pieris temptata modis.

modo. Herculis ritu modo dietur.

irangere cnitar modo moltum amati' cornua monstri.

libet iacere modo sub anticua ilice.

nodo in tenaci gramine:

voles modo altis desilire turribus,

modo anso pectus Norico iceludere

eris $\mathrm{tu}$, qui moto miles. mercator;

tu. consulews modo, rusticus:

nonina sertatur modo somuta veste virili|sub patribus duris tironum.

tus morlo recte dispensiue velis.

molo summal roce.

modo hac. Irsonat quae chordis quattuor ima.

hribbit. . modo teges atgue tetrarchas, /umnia magna loquens.

molo sit mbi mensa tripes et/concha salis puri

phrobur hince. 'si modo jura mili bona sunt. inclinet.

guat mod" taista nltis informen spectabant osibus agrum;

ire morlo orins, interdun consietere.

'velip tantummalo [moto velis]: quae tua vistus, |expugnabis:

et sermone opus thet modo tristi. saepe iocono.

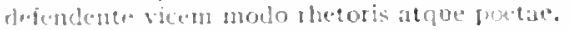

fict apm, moto avis. mordo saxom et, chm solet, arbor.

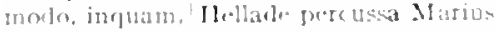

pars multa matat, moflo recha cafresene, interdum pravis obnoxia.

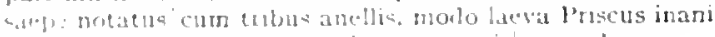

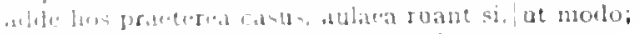

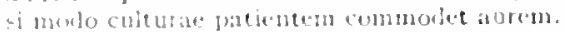

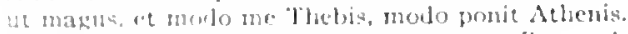

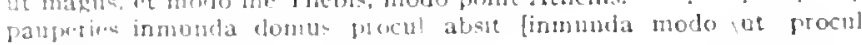
al, -1 ! ! :

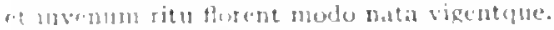

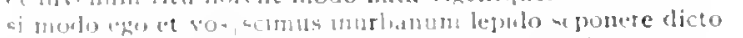

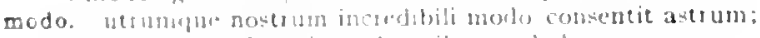

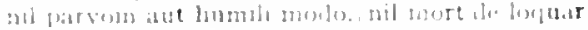

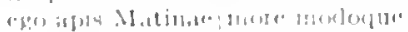

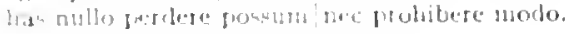

Serm.2.3.209

Ars Poct. 157

Corm.1.23.5

Corm.1.7.14

Epist.2.2.172

Carm.1.1.7

Epist.1.2.59

Carm.1.24.14

Sorm.1.2.50

gar.Serm. I.3.65

Epist.1.1 8.9 .4

Epist.1.5.2

Carm.1.18.7

Ars Poet.279

Carm.1.20.1

Serm.2.0.70

Epist.2.2.190

Scrm. 1.5 .2

:ar.Sirm.2.3.30

coni.Carm 3.3.46

Epist.1.16.55

Carm.2.12.4

Ars Poct.21I

Carm.29.9

Curm.3.3.72

Carm.3.7.12

Serm.1.8.33

Serm.2.5.3

Ars loes.asos

Carm.3.1

Carm.3.27.47

Epod.2.23

Ispod.2.24

Epod.17.70

Epod.17.71

Serm.1.10

Serm.1.1.17

Serm.1.2.16

scrm.1.2.74

Sern.1.3.7

$5 \mathrm{~cm} .1 .3 .8$

Scrm.1.3.12

Serm.1.3.13

Sorm.1.3.7 I

Serm.1.8.15

Sictin.1.9.9

tar.Serm.t.0.54

Sirm.1.10 11

Sirm.1.10.12

Sirn.2.3.73

Serm.2.3.27)

Serm.2.7.7

Serm.2.7.12

Serm.2.8.72

I.pist.1.1.40

Epist 2.1.213

coni. Fpist.2.2.190

Ars Poedic:

Ars l'oet 272

Carm.217:1

Curm.32517

Camb.2 28

Sirm.1.8.21 
'non isto vivimus illic, / quo tu rere, modo; hoc te/crede modo insanum,

ratione modoque|tractari non volt.

insanire paret certa ratione modoque.'

'rem facias, rem, / si possis, recte, si non, quocumque modo, rem," quo spectanda modo, quo sensu credis et ore?

cetera nequaquam simili ratione modoquelaestimat

nempe modo isto/paulatim nercaris agrum,

modorum. reddidi carmen, docilis modorum|vatis Horati.' .

modos. bellique causas et vitia et modos.

quaere modos leviore plectro.

dulcis docta modos et citharae sciens,

dic nodos, Lyde quibus obstinatas/adplicet auris,

princeps Aeolium carmen ad lalos deduxisse modos.

condisce modos, amanda/voce quos reddas:

eripias si|tempora certa modosque,

fidibusne Latinis/Thebanos aptare modos studet auspice Musa, quod timui mutare modos et carminis artem:

sed verae numerosque modosque ediscere vitae.

modulanda. ac non verba sequi fidibus modulanda Latinis, .

modulate. Lesbio primum modulate civi,

modulator. cantor tamen atqueloptimus est modulator:

moduli. ab imolad summum totus moduli bipedalis,

modulis. cur non|ponderibus modulisque suis ratio utitur

modulo. metiri se quemque suo modulo ac pede verum est.

modum. quem criminosis cumque voles modum /pones iambis,

tandem nequitiae fige modum tuae

nonne, cupidinibus statuat natura modum quem.

illis | maiorem natura modum dedit, his breve pondus:

quae res/nec modum habet neque consilium.

quamvis nil extra numerum fecisse modumque/curas: vertere modum formidine fustis | ad bene dicendum delectandumque
redacti.

madus. quis desiderio sit pudor aut modus|tam cari capitis?

neu promptae modus amphorae

sit modus lasso maris et viarum / militiaeque.

est modus in rebus, sunt certi denique fines,

hoc erat in votis: modus agri non ita magnus,

et mundus victus let modus et victus] non deficicnte crumina?

moechas. ne sequerer moechas, concessa cum venere uti|possem:

moechatur. Sallustius in quas/non minus insanit quam qui moechatur.

moechis. procedere recte|qui moechis non voltis,

moechos. invicem moechos anus arrogantis|fiebis .

audire est operae pretium, procedere rectelqui mocchis [moechos] non voltis,

moechus. quod moechus foret aut sicarius aut alioqui|famosus, iam moechus Romae, iam mallet doctus Athenis|vivere, "non sum moechus" ais.

moenia. laudabunt alii . . bimarisve Corinthi|moenia circa mite solum Tiburis et moenia Catili; qui Formiarum moenia dicitur|princeps . . . tenuisse Tusculi|Circaea tangat moenia:

via peior ad usque! Bari mocnia piscosi;

Vrbis aventes/moenia nocturni subrepere.

virum, captae post tempora [moenia] Troiae/qui mores hominum multorum vidit et urbes.'

moenibus. ex moenibus hosticis matrona bellantis tyanni|prospiciens postquam relictis moenibus rex procidit

mola. spargisque mola caput, inprobe, salsa,

mole. $v$ is consili expers mole ruit sua,

multa mole docendus aprico parcere prato.

Actia pugnalte duce per pueros hostili more [mole] refertur; .

molem. molem propinquam nubibus arduis,

moles. iam pauca aratro iugera regiae/moles relinquent.

molesta. praecipue sanus, nisi cum pitvita molesta est.

molestas. etiam litis cum Rege molestas,

molesti. (hoc etenim sunt omnes iure molesti|quo fortes,

molestum. no!lem onus baud umquam solitus portare molestum.

molestus. 'molestus|communi sensu plane caret'
Serm.I.9.49

Serm.2.3.52

Serm.2.3.266

Serm.2.3.271

Epist.1.1.60

Epist.1.6.8

Epist.2.1.20

Epist.2.2.1 63

Carm.4.6.43

Carm.2.I.2

Carm.2.1.40

Carm-3.9.10

Curm.3.11.7

Carm.3.30.14

Carm.4.1r.34

Serm.1.4.58

Epist.1.3.13

Epist.1.19.27

Epist.2.2.1 44

Epist.2.2.143

Carm.1.32.5

Serm.1.3.130

Serm.2.3.309

Serm.I.3.78

Epist.1.7.98

Carm.1.16.2

Carm.3.15.2

Serm.I.2.I I

Serm.2.2.37

Serm.2.3.266

Epist.I.I 8.59

Epist.2.I.154

Carm.1.24.I

Carm.1.30.II

Carm.2.6.7

Serm.1.I.I06

Serm.2.6. I

var.Epist.I.4.II

Serm.1.4.113

Serm.1.2.49

Serm.1.2.38

Carm.1.25.9

var.Serm.I.2.38

Serm.1.4-4

Serm.2.7.13

Serm.2.7.72

Carm.1.7.3

Carm.1.18.2

Carm.3.17.6

Epod.1.30

Serm.1.5.97

Sirm.2.6.100

var.Ars Poet.I4I

Carm.3.2.6

Epod.17.13

Serm.2.3.200

Carm.3.4.65

Epist.I.14.30

var.Epist.1. 18.62

Carm.3.29.10

Carm.2.15.2

Epist.I.I.108

Serm.1.7.5

Serm.1.7.10

Serm.1.6.99

Serm.1.3.65 
pavor est ntrubique molestus.

moliar. "wr invidends postibus ce novo, sublime ritu moliar atrium? molibus. contractis pisces aequora sentiunc iactis in altum molibus: . molimine. (Inanto cum fastu, quanto molimine circum.| spectemus moliri. eppisla moluri. leges incidere linno.

molitur. guanto rectius hic, qui nil molitur inepte:

molle. fretumbus patulis iactat se molle Tarentun.

molle. molde atclue tacetum/ Vergilio adnuerunt gandentes rure Camenae. molles. Gutulent praenomine molles/auriculac)

molli. ne si tiscies, ue saepe. decoral nolli fulta pede est, emptorem inducat molli. finue memento/ tristitiam vitaeque labores / molli, Plance, mero, molliat. usigue laborantis, dum ferrum molliat ignis.

mollibit. molluit [mollibit) aversos l'enatis/farre pio et saliente mica. mollibus. mollibue aptari citharae molis

mollibus. mollibus in pueris atut in puellis

mollibus. Acctere mollibus /iam durum imperiis: nollibus lenire vetbis inpias.

mollior. nee rigida mullior aesculo

.go dllis mollior nec te feriant neque intra flaustra tenebo.

mollire. "juale posat inpialmollice Thracum pectora:

mollis. sublimi fugies mollis anlelitu.

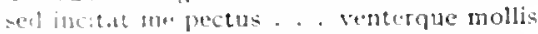

inolliam ter nucte potes. mili remper ad unum/mollis opus.

mullis et expes/inominata perpremat cubilia.

mollis. mollis neptia cut tantam diffuders ind oblivionem sensibus.

mollis. dew.t yua terre non mollis viros?

unguis exprimet et mollis initabitur aete capillos.

molbs. arcepitur belut mollis columbas

molliter. molluct austerum studio fallente laboren.

mollitia. fiornantis quambibet mulierculam 'vincere mollitia.

mollitie. nune klos iantis quanlibet mulierculim| vincere mollitia [molnitie] anos bycici mo tenet;

mollitiem. quis post vinz gravem militian (f mollitiem aut pauperiem croplite

ubi guilnam abectet ad istan. . . mollituen.

mollium. dentue mollium haden querellarum

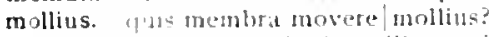

•runtic mollius ac siquis perlibus quid clitulere senis.

tractari mollius aetas|imbecilla volet:

mollivit. mollivit aversos Penitis

Molossis. fomus alta Molossis/personuit canibus.

Molossus. nam clualis aut Moloss aut iulvos Lacon.

momen. ume etian trimetris accrescere iussit/nomen [momen] iambeis,

momenta. ubi sratior aura leniat et rabiem Canis et nomenta Leonis.

momentis. decedentia certis tempord momentis

momento. horae monento cita mots venit aut victoria laeta.' .

momorderit. weanulue momorelerit acsus.

Monaeses. ian bis Wonaeses ct Pacori manus

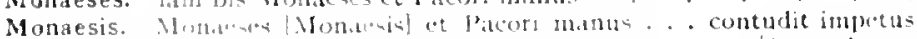

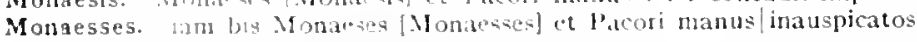
coneulit impetus, moitros

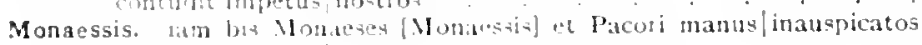
contulit impetua noveron

mone. mont, st incrobrut aura. |cautus utu velet castum capur;

moneam. protinus 14 monam (signul moniturio cyes).

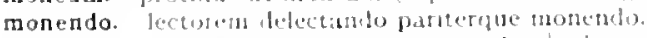

monendus. montum multumq̨u monendus. privatis ut quaerat opes

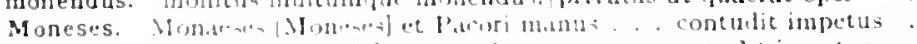

Monesis. Wonareser [Monevis] et l'acori manus. . contudut impetus

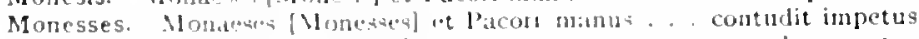

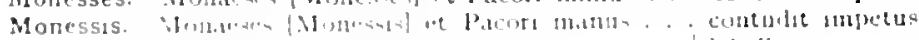

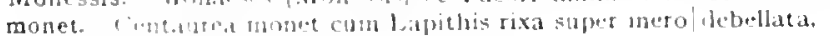

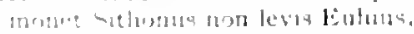

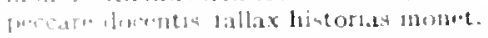

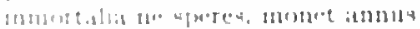

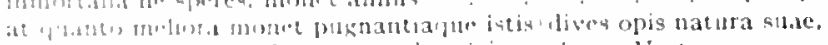

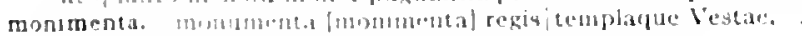

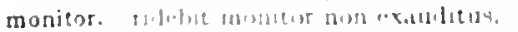

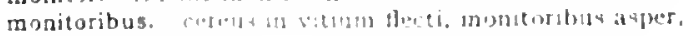

Epist.1.0.10

Corm.3.1.40

Carm.3.5.3.

Epist.2.2.93

Ars P'ot'.399

Ars l'odi. 140

Serm.2.9.34

Serm.1.10.49

Serm.2.5.32

Serm.1.2.85

Corm.1.7.19

Serin.1.4.20

Itur.Cirm.3.23.89

Curm.2.12-3

Epols.jed

Curm.1.6

I.pod. 5.83

Cirm.3.10.17

Corm.3.11.43

I.porl.5.14

Carm.1.15.31

Epolds.o

Efod.12.10

lipod 16.37

Epod.14.I

lipod.1.10

Ars Poct.33

Corm.137.19

Serm.2.2.12

If pod.t1.24

:or. Epod.11.24

7 fur.Corn.1.18.5

Serm.2.2.87

Cirm.2.9.17

SiTm.1.9.25

Serm.1.10.59

Sirm.2.2.85

Carm.3.23.19

Serm.2.0.114

lipod.6.5

ani.AYs Poct.253

Epist.1.10.10

Epist.t.0.4

Serm.1.1.S

Epist.1.s.

Carm.3.0.9

iar.curm. 3.0.9

2.1r.Curm.3.0.9

nur.Curm.3.0.9

serm.2.5.93

L.pist.1.18.07

Irs Poot.34t

Epist.1.3.15

in corm.3.0.9

iar.Curm. 3.0 .9

tar.cirm.3.0.9

lar carm zecios

(i)rm.1.18.8

Curm.1.18.0

Corm.3.7.20

Carm.9.7.7

Serm.1.2.73

var.Curm.1.2.15

I.pist.1.20.14

Irs l'od 103 
monitoribus. tamen uteris monitoribus isdem?

Epist.2.2.154

monitoris. protinus ut monean (siquid monitoris eges).

Epist.1.18.07

monitus. sed tamen ut monitus caveas. monitus multumque monendus, privatas ut quaerat opes ut scriptor si peccat idem librarius usque./quamvis est monitus.

Serm.2.1.80

Epist.1.3.15

Ars Poet.355

Curm.1.2.6

Cirm.1.3.18

Epod.10.30

qui siccis oculis monstra natantia. . . vidit

novaque monstra iunxerit libidine/mirus amor.

monstrare. ut si/caecus iter monstrare velit.

si forte necesse est indicits monstrare recentibus abdita rerum:

Epist.1.17.4

Ars Pot. 49

Sirm.2.8.20

Ars Pocl.to.t

monstrata. dictac per carmima sortes let vitae monstrata via est

monstrats. si volnus tibi monstrata radice vel herba|non fieret levius,

Epist.2.2.1.19

monstratam. dente lupus. cornu taurus petit: unde nisi intus/monstratum [inonstratam]? .

monstratum. dente lupus, cornu taurus petit: unde nisi intus|monstratum?

monstravi. erucas viridis, inulas ego primus amaras/nonstravi incoquere;

monstravit. quae te|Lesbia quaerenti taurum monstravit inertem. quo seribi possent numero. monstravit Homerus.

monstret. 'o si urnam argenti fors quae mili monstret. equom. ... ire viam qua monstret eques;

monstri. frangere enitar modo multum amati|cornua monstri.

monstris. iniecta monstris Terra dolet suis

monstror. quod monstror digito praetereuntium

monstrum. daret ut catenis/fatale monstrum. monstrunve submisere Colchi| maits.

monte. monte decurrens velut amnis. optat supreno collocare Sisyphus|in monte saxum; dictitet Albano Musas in monte locutas.

montes. continui montes, ni dissocientur opaca/valle. . parturient montes, nascetur ridiculus mus.

montes. omme cum Protcus pecus egit altos|visere montis [montes], . ergo ubi me in montes et in arcem ex urbe removi-

montibus. quis neget arduis/pronos relabi posse rivos/montibus flumina dicere et arces/montibus inpositas

montibus. quacrenti pavidam montibus aviis|matrem quantus alt is montibus|frangit trementis ilices; montibus altis' levis crepante lympha desilit pede.

montis. redderet laudes tibi Vaticani|montis imago.

montis. omme cum Proteus pecus egit altos/visere montis. feriuntque summos|fulgura montis.

incipit ex illo montis Apulia notos/ostentare mihi.

montium. sol ubi montium|mutaret umbras montium custos nemorumque, virgo, non sine montium/clanore vicinaeque silvae.

monuere. quo Sibyllini monuere versus

monumenta. ire deiectum monumenta regis/templaque Vestae.

monumentum. heredes monumentum ne sequeretur.

monumentum. exegi monumentum aere perennius

mora. quamquam festinas, non est mora longa;

si per invisum mora ianitorem/fiet, abito. .

si non offenderet unum |quemque poctarum limae labor et mora. .

moraberis. si|non circa vilem patulumque moraberis orbem

morabimur. semper in adiunctis acvoque norabitur [norabimur] aptis.

morabitur. si dura morabitur alvos.

semper in adiunctis aevoque morabitur aptis.

morabor. neque in terris morabor|longius

morae. eripe te morae .

moram. nec pietas moram|rugis et instanti senectaeladieret

moramur. secunda|ratem occupare quid moramur alite?

morandus. eo quod|illecebris erat et grata novitate norandus/spectator.

morantem. arte materna rapidos morantem|fluminum lapsus cum quo morantem saepe diem mero|fregi. et populum reditus morantem

morantur. tempora quae spem/consiliumque morantur an pingues Asiae campi collesque morantur?

morari. tu potes.. . rivos celeres morari; externi nequid valeat per leve morari, carmina quae possint oculos aurisque moraril Caesaris.

Ars Pott.74

Serm.2.0.10

Epist.1.2.65

Carm.3.27.48

Carm.3.4.73

Carm.4.3.22

Carm.1.37.2I

Carm.4.4.03

Carmat 2.5

Epod.17.69

Epist.2.1.27

Epist.1.10.5

Ars Potl. 139

iar.Carm.1.2.8

Serm.2.0.10

Carm.1.29.12

Epist.2.1.253

Carm.1.23.2

Epod.10.7

Epod.10.47

Corm.r.20.8

Cirm. I.z.S

Carm.2.10.1 2

Sirm.1.5.77

Carm.3.6.4I

Curm.3.22.1

Carm.3.20.38

Carmestace 5

Corm.1.2.1 5

Serm.1.8.13

Carm.3-30.1

Carm.1.28.35

Cirm.3.14.23

Ars Potl.291

Ars Porl.132

var. Ars Poel. $7 \mathrm{~S}$

Serm.2.4.27

Ars Pote. -

Carm.2.20.3

Carm.3.29.5

Carm.2.14.2

Epod.16.24

Ars Poet.223

Curm.1.12.9

Carm.2.7.6

Carm.3.5.52

Epist.r.1.24

Epist.1.3.5

Curm.3.11.14

Serm.2.7.87

Epist.1.13.17 
moraris. tu moras aureos/curruset intactas boves? insequeris tanen liunc et lite mosais iniqua? -

moras. verum pone motas et studium lucri

morata. interdum speciosa locis motataque recte|fabula

moratur. me quanvis Lamiae pietas et cura moratur/fratrem maerentis, fabula . . valdius oblectat populum meliusque moratur

morbi. nee sitim pellut, nisj causa trosbi|fugerit venis ct miror morbi purgatum te illius.'

pona insigria morbi. / facciolas, cubital, focalia. magram nurbi deponere partem.

quaere fugan morbi. vis rocte vivere (quis non?):

morbo. contaminato cum grege turpium|mos bo virorum

ut siqui aegrotet quo morbo Bartus.

aut alio meneis morbo calet:

maxima pars honisum morbo iactatur eodem.

guid refert, motbo an furtis pereamque rapinis?"

quod latus aut renes morbo temptentur acuto.

ci latus aut renes morbo temptantur acuto.

verum ubi oves furto. mos bo periere capellae.

morbos. avertit mobos, metuenda pesicula pellit.

morbum. Campanum in motbm, in facim pernulta iocatus.

dictaque cessantem nervis elidere morbun

expulit clicboro morbum bilentque meraco

morbus. ut mala quem scables aut morlus regius urget

mordacem. nordacen Cyricum sic elurlebat, ut aiunt:

mordaces, monlaces alizer difugiunt sollicitudises.

mordaci. motdaci selut inta ferso pinu:

mordax. lividu=et mordax videos tibi?

mordear. morluar opjolinic falcis mutemque colores?

mordent. "matutua parum catuos iam trigora mordent";

mordeor. "t iam deste minus nerderer invido.

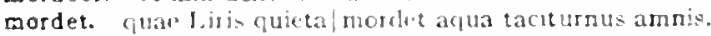

mordicus. pullan divelicer morticus agnath

more. vore formacti catus et decorac|more palaestrae.

in comptum Lacaenat|more comas seligata nodum.

ego apis Matimatmore modociue

virtute functos more patrum duces. . castsmus.

ques venerem incentam sapientiv nore ferarum

putais hotrmisce petich verba foris mals. Canusini more bilinguis?

(.x more inponene cograta vocabula rebus?

non puo mote piris vesci Calaber inbet hospes

Artia pugna'te duce per frebos hostili nore reictur:

cetera gui vicae servaret munia recto' nore.

moren. pugnare Thacum ent: tollitu barbarum|motem

neld morem in Salium sit seques pedum

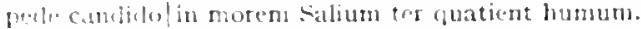

trablutum ab anticuis mosem servate

primus in hunc operis conponcte carmina morem.

feremana per lunc imema licentia morem

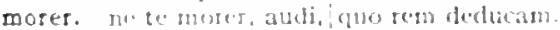

n" te iongis anbagitus ulera' quans satis ast morer:

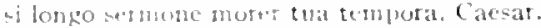

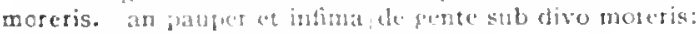

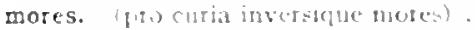

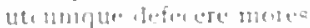

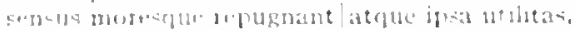

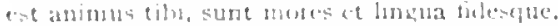

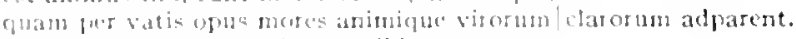

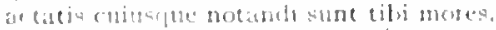

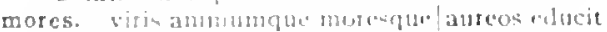

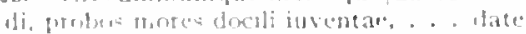

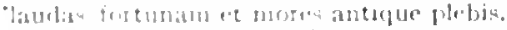

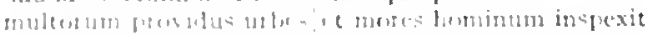

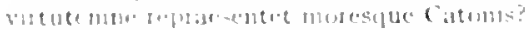

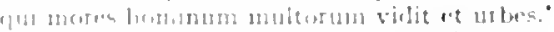

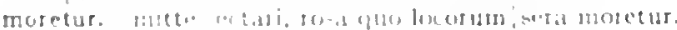

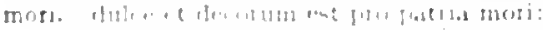

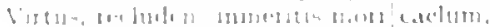

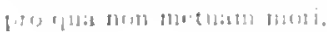

Epod.9.2 I

Erist.2.2.19

Carm.4.12.25

Ars Poet.3in

Epist.1.14."

Ars PoCh.32I

Carm.2.2.14

Serm.2.3.27

Serm.2.3.254

Epist.1.1.35

Epist.1.0.29

Carm.1.37.10

Srrm.1.6.30

Serm.2.380

Serm.2.3.12:

Sorm.2.3.157

Serm.2.3.103

Epist.1.0.28

Epist.1.7.80

Epist.2.1.136

Serm.1.5.02

Epist.1.15.6

Epist.2.2.137

Ars Poet. 453

Epist.1.17.18

Carm.1.18.4

Carm.4.6.9

Serm. J.4.9.3

Epist.1.16.38

Serm.2.6.45

Corm.4.3.10

Carm.1.31.8

Sirm.1.8.27

Corm.1.IO.4

Corm.2.11.24

Corm.4.2.28

Carmid I5.29

Serm.1.3.109

Sorm.1.10.30

Serm.2.3.280

Efist.1.7.14

Epist.1.18.02

Epist.2.2.132

Carm.1.27.3

Carm.1.30.12

Carm 41.28

Somm.1.4117

Serm.2 1.63

Efist.2.1.1.45

Serm-1.1.

Lfist.1.7.83

Epis?.2.I.4

Carm.2.3.23

Carm.3.5.7

Carm.4.4.35

Sorm.1 397

Epist. [.1.58

lifist.2.1.240

Ars Foct. 50

Carm 42.22

Carmisace.45

Serm. 2.7 .23

I.pist.1.2.20

Epost. I. 10.19

Ars l'ort. I. 2

Corm 1.38 .4

Carm.32.13

Carm. $32.2 \mathrm{I}$

Carm.301 
pro quo bis patiar mori.

Carm.3.9.15

nec mori per vim metuam tenente/Caesare terras.

Carm.3.14.15

Codrus pro patria non timidus mori

Carm.3.19.2

et peccare nefas aut pretium est mori.

"quid mori cessas? .

dignum laude virum Musa vetat mori,

Carm.3.24.24

Carm.3.27.58

Carm.4.8.28

var.Serm.2.8.34

moriamur. "nos nisi damnose bibimus, morienur [moriamur] inulti,"

moriar. non omnis moriar multaque pars mei|vitabit Libitinam;

opinor, /hoc sentit 'moriar.'

moribus. fraternis cessisse putatur|moribus Amphion:

moribus. moribus bic meliorque fama|contendat. .

quid leges sine moribus|vanae proficiunt,

tes ltalas armis tuteris, moribus ornes.

moriemur. "nos nisi damnose bibimus, moriemur inulti,"

moriens. hoc moriens pueris dixisse vocatis|ad lectum:

nec vixit male, qui natus moriensque fefellit.

morientes. velut si|re vera pugnent, feriant vitentque moventes [morientes]| arma viri?

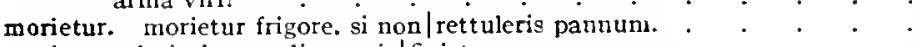

moris. qui nigris prandia moris|finiet.

moriture. moriture Delli, |seu maestus omni tempore vixeris . . .

morituro. nec quidquam tibi prodest . . . animoque rotundum | percurrisse polum morituro.

moror. te meae si partem animae rapit/maturior vis, quid moror altera.

inpudens liqui patrios Penates, |inpudens Orcum moror.

scribendi recte: nam ut multum, nil moror.

(nam vina nihil moror illius orae.

nil mozor officiun quod me gravat

morosa. donec virenti canities abest|morosa.

Carm.3.30.6

Epist.r.16.79

Epist.r.18.44

Carm.3.1.1 2

Carm.3.24.35

Epist.2.1.2

Serm.2.8.34

Serm.2.3.170

Epist.1.17.10

var.Serm.2.7.99

Epist.1.17.31

Serm.2.4.22

Carm.2.3.4

Carm.1.28.6

Carm.2.17.6

Carm.3.27.50

Serm.1.4.13

Epist.1.15.16

Epist.2.1.264

Carm.1.9. 8

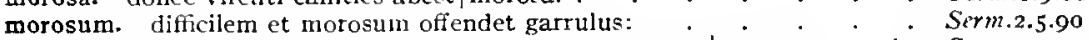

Mors. pallida Mors aequo pulsat pede pauperum tabernas/regumque turris. Carm.I.4.I3

mors. sed omnis una manet nox [mors]

abstirlit clarum cita mors Achillem.

mors et fugacem persequitur virum

levis una mors est/virginum culpae.

horael momento cita mors venit aut victoria laeta.".

ira fuit capitalis, ut ultima divideret mots,

seu mors atris circumvolat alis.

quem neque pauperies neque mors neque vincula terrent.

mors ultina linea rerum est.

morsu. non odio obscuro morsuque venenat:

morsus. perna magis et magis hillis|flagitat inmorsus [in morsus] refici,

mortale. ino tollere de gradu $\mid$ mortale corpus

nil parvom aut humili modo. I nil mortale loquar.

mortalem. ut unum|scilicet egregii mortalem altique silenti.

mortalia. mortalia facta peribunt. I nedum sermonum stet honos et gratia vivax.

mortalibus. nil mortalibus ardui est:

nil sine magno! vita labore dedit mortalibus.'

mortalis. ridetque, si mortalis ultralfas trepidat.

naturae deus humanae, mortalis in unum|quodque caput.

mortalis. "invicte, mortalis dea nate puer Thetide,

mortalis. omnis nortalis curare et quaerere cogit.

mortalis. mortalisque turmas|imperio regit unus aequo.

terrestria quando/mortalis animas vivont sortita

mortalium. ut prisca gens mortalium, | paterna rura bubus exercet suis

morte. deliberata morte ferocior;

gelidaque divos|morte carentis.

morte venalem petiisse laurum

per quos cecidere iusta|morte Centauri.

hoc genus omne|matstum ac sollicitum est cantoris morte Tigelli. nunc norte supremal permutet dominos

var.Carm.1.28.15

Carm.2.16.29

Carm.3.2.14

Carm.3.27.37

Serm.1.1.8

Serm.1.7.I3

Serm.2.I.58

Serm.2.7.84

Epist.1.16.79

Epist.1.1 4.38

var.Serm.2.4.6I

Carm.1.35.3

Carm.3.25.18

Serm.2.6.58

Ars Poet.68

Carm.1.3.37

Serm.1.9.60

Carm.3.29.3 I

Epist.2.2.1\$8

Epod.I3.I 2

Serm.1.6.37

Carm.3.4.47

Serm.2.6.94

Epod.2.2

Carm.1.37.29

Carm.2.8.12

Carm.3.14.2

Carm.4.2.I 5

Serm.1.2.3

Epist.2.2.173

Carm.3.5.36

Carm.4.8.1 5

Serm.1.2.42

vita redit bonis/post morten ducibus.

ille flagellis / ad mortem caesus.

morti. nihil ultra|nervos atque cutem morti concesserat atrae. nec pietas motam/rugis . . adferet indomitaeque morti,

devota morti pectora liberae

Carm.1.28.13

Carm.2.14.4

Carm.4.14.1 8

mille ovium insanus morti dedit.

Serm.2.3.197 
("quad t.un magnum?" addens), "unum me surpice mortil

Serm.2.3.283

debermur moti nok nostranue:

mortibus. sed ignotia perierunt mortibus illi.

mortis. guturn motia timut gradum .

non mortin hintueis expedies caput.

mortialfur metu sibi parcere cogit.

te tibl ingluom ce frustra mortis cupidum.

caret morto formidine ce ira?

111 lome tet ponct famosac mortiq anorem.

mortua. silicet clabi si posset mortua;

mortuos. pxisim crematos excitare mortuos

morum. respore exemplar vitae morumque

mos. yudbus mos unde deductus per omne/tempus

mos et lex maculosum edomuit nefas. .

neque hic lupis mos nec fuit leonibus.

whibus hic mos est, ubi equos mercantur:

debendas. us thos est mos:

responder, ut tuos est mos. parea:

barn forte via sacra, sicut meus est mos.

uti mos seiter ait.

Moschi. mitte levis speset certamina divitiarum/et Moschi causam:

mota. duod buero cecinit divina mota anus urna: .

motat. et invoum ritu horent morlo nata vigentque $/ \gamma$ et nova iuvenum th ritu tionent motat augentguel.

motaverit. pupere albo, non sine accio, quod Nethymaean vitio mutaverit [motaverit] uvam.

motionis. hur a mutonis (motionis) verbit mala tanta videnti|diceret baec anmus

motum. mostum ex Metello consule civicum

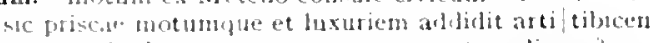

motura. verba lorae motura sonum conectere digner?

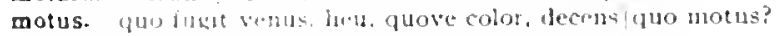

motus. mutua deceri gaudet Ionicot

"alecolatentiant motus urientis Autri.

pout rifert animi motus interprete lingua.

motus. in lersac atque Britannos westrat motus anget prea.

move. tu vinit Torquato move consulc pressa nuco.

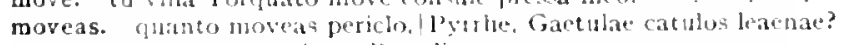

moveat. men mowat cimex Pantiliua

alevid atgue novos moveat liortuna tumultus:

in... moveat cornicula sinum / fustivis nudata roloribus.

movebat. quat prius nuleum facilis novebat cardines.

movends. fur et lojuse non movendat mumina.

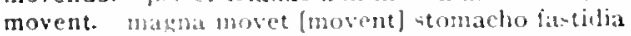

moventem. fiedent vicini glaebas et kaxa moventem

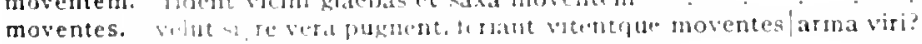

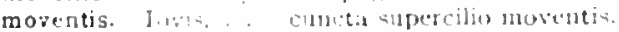

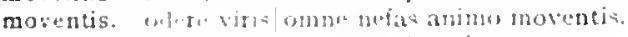

movere. an quate movere cerras imagimes.

yuts ment,ta movere mollits?

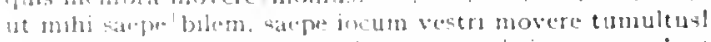

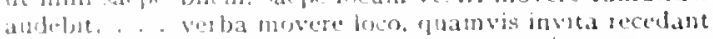

dectur Amphion. Thebande confleor urbis, saxa movere

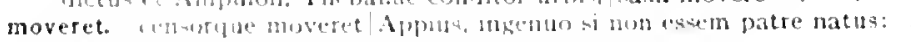

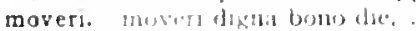

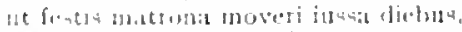

moverit. ant tinte biskentil moverne incestua:

moves. guantas movica funera l).trdanate ponti.

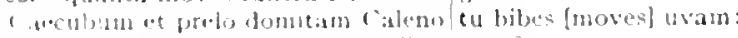

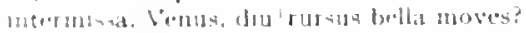

movet. andme depax movet urma nomen.

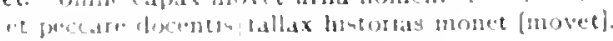

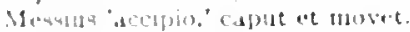

magria movet stemacho tagtudiat

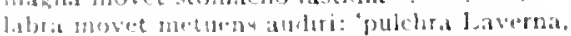

movetur. "qui nun: Salverm. nunc agreatem Cyclopa movetur.

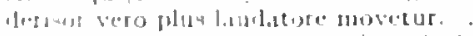

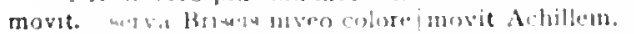

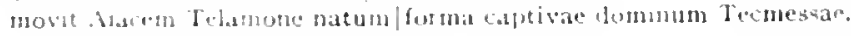

Ars loortoz

Serm.1.3.108

Carm.t.3.17

Curm.3.24.8

Serm.1 4.127

Serm.2.2.08

Epst.2.2.207

Ars l'oet.pes

Serm.2.5.87

Epod 17.79

Ars Pert.317

Carm+4.10

Corm.t 5.22

fipid.7.1I

Serm.1.2.56

Sicrm. 4.95

Serm.1.0.00

Serm.1.9.1

Sierm.2.7.70

lipst. 1.5 .9

Sorm.1.9.30

7 ar.otrs Poel.62

rar.5erm.2.8.50

atr.serm.1 2.08

Carm-2.1.1

Ars Poet.214

Epot.2.2.80

Carm.4.13.1S

Corm.3.0.21

Carm.3.27.22

irs lodil11

(irm.1.t.l')

Jipoll:3.1

Carm.3.201

Serm: 1.10 .78

Sirm.2 2.120

l.pist.1.3.10

Carm.1.25.5

Lipod.17.3

:ar.term.2.4.75

Ifpist.1.19.39

Sorm.2.7.09

Cirm-3-1.s

(arm.3.8.08

I:pod 17.70

Sirm.1.9.24

Jipust. 19.20

lep1.1.2.2.113

. Irs J'inel.395

Serm t (1).20

Ciurm.3.24.0

Ars Iind.2.32

irs fiod 472

(iorm.1.85.10

cumliarm. 1.20 .10

(iorm.4.1.2

Carm3.1.13

sar (arm.37.20)

term.1.5.58

Sirm.2.4.78

Expet 1 . I0 (1)

IEpost.2.2.125

ars Joet 133

ciorm.2.d.d

c arm 2.4.5 
te docilis magistrolmovit Amphion lapides canendo. novit nepotem Telephus Nereium.

mox. mox reficit rates/quassas indocilis pauperiem pati. quo calet iuventus/nune omnis et mox virgines tepebunt. nox ubi publicas|res ordinaris. mox iuniores quaerit adulteros mox daturos|progeniem vitiosiorem. mox ubi lusit satis, 'abstineto'| dixit mox in ovilia/demisit lostem vividus impetus, mox |bruma recurrit iners.

maior Neronum mox grave proelium/conmisit ergo consulere et mox respondere licebit?" . quodsi intercider it tibi nune aliquid, repetes mox, condo et conpono quae mox depromere possim. uti nox/nulla fides damnis verisque doloribus adsit. ne nox/incutiant aliena tibi pecata pudorem. . mox etian pectus praeceptis format amicis. mox trahitur nanibus regum fortuna retortis, mox etiam, si forte vacas, sequere et pıocul audi, cum segetes occat tibi nox frumenta daturus, conmisisse cavet quod mox mutare laboret. quat mox narret facundia praesens: nox etian agrestis Satyros nudavit

Mucius. Gracchus ut hic illi, foret huic ut Mucius ille. . mugiat. si mugiat Africis! malus procellis. mugientium. mugientium | prospectat errantis greges mugire. Garganum mugire putes nemus aut mare Tuscum: mugiunt. te greges centum Siculaeque circum|mugiunt vaceae, mula. dum aes exigitur, dun mula ligatur, / tota abit hora. mulae. retinacula mulae/nauta piger saxo religat ac mulae nautacque caput lumbosque saligno/fuste dolat: mulae. Line muli [nulac] Capuae clitellas tempore ponunt. mulces. dum grato Danai puellas/carmine mulces. mulcet. irritat, mulcet, falsis terroribus inplet mulctra. illic iniussae veniunt ad mulctra capellae muli. hine nuli Capuae clitellas tempore ponunt. muliebrem. vos, quibus est virtus. muliebrem tollitc luctum, muliebriter. nee muliebriter /expavit ensem mulier. privata deduci superbo. I non hunilis nulier, triumplio. llion . . . mulier peregrina vertit/in pulverem, ut Proetun mulier perfida credulum | falsis inpulerit crininibus unico gaudens mulier marito matre carentibus / privignis mulier temperat innocens quodsi pudica mulier in patem iuvet/donum . quid tibi vis, mulier nigris dignissima barris? magis quen/diligeret mulier sua quam te. . vepallidia lecto/desiliat mulier, miseram se consciu clanet. mulior si forte dolosa|libertusve senem delirum temperet, cum te formidet mulier neque credat amanti. quincue talenta| poscit te mulier, ut tupiter atrum/desinat in piscen mulier formosa superne: mulierculam. gloriantis quamlibet mulierculam/vincere mollitia mulis. festinat calidus mulis gerulisque redesuptor. mullum. laudas, insane, trilibrem|nullum, mulo. nunc mini custo|ire licet mulo

mulso. leni praecordia mulso/prolueris melins.

multa. multaque merces/unde potest tibi defluat inultaque pars mei|vitabit Libitinam; multa Dircaeum levat aura cycnum. est hederae vis|multa. multa poetarum veniat manus. pars multa natat, modo recta capessens, /interdum pravis obnoxia. quod non| nulta dies et nulta litura cocreuit

multa. quis nulta gracilis te puer in rosa/perfusus liquidis urget odoribus temptare multa caede bidentium. multa proluet integrum|cum laude victorem te multa prece, te prosequitur meto trudit acris hinc et hinc nulta cane /apros. sis pecore et multa dives tollure licebit
Carm.3.r. 1.2

Eipod.17.8

Carm.1.1.17

Carm.1.4.20

Carm.2.1.10

Carm.3.6.25

Carm.3.6.47

Carm.3.27.09

Corm.4.4.9

Carm.4.7.II

Carm.4.14.14

Sirm.2.3.192

serm.2.4.6

Iepist.1.1.1 2

Epist.1.17.56

Epist. I. 8.76

Epist.2.1.128

Epist.2.1.191

Epist.2.2.95

Epist.2.2.101

Ars Poel. 68

Ars Poet.184

Ars Porl.22I

List.2.2.89

Carm.3.29.57

Epol.2.I I

Epist.2.1.202

Curm.2.16.34

Sirm.1.5.13

Sirm.1.5.18

Scrm.1.5.22

var.Sorm.1.5.47

Carm.3.11.2.4

Epist.2.1.21 2

Epod.10.49

Sirm.1.5.47

Epod.10-39

Carm. [.37.22

Carm.1.37.32

Carm.3.3.20

Carm.3.7.13

Carm.3.14.5

Carm.3.24.18

Epod.2.39

Epod.12.1

Epod. I2.24

Serm.1.2.130

firm.2.5.70

Sirm.2.7.05

Sirm.2.7.90

Ars Poet. 4

Ifpod.1 23

Epist.2.2.72

Serm.2.2.34

Sirm.t.0.105

Sirm.2.4.26

Carm. 1.28 .27

Carm-3.30.6

Carm.t.2.25

Carm.4.11.5

Sirm.1.4.I4I

Sirm.2.7.7

Ars l'oet.293

Carm.I.5.I

Carm.3.23.14

Carm.4.4.60

Carm.4.5.33

I.pod.2.31

Ipod.15.19 
Imulta curn libestate notabant.

Sorm.1.4.5

absentem ut cantat amicam|multa prolutus vapja nauta

Serm.1.5.16

haerenem capiti cum multa laude coronasn.

Serm.1.10.49

oratus multa prece nitere, porrolvade;

Esist.1.13.18

multa mole docendus aprico parcete prato.

Ejist.1.14.30

(si) guercus at ilex|multa fruge pecus, multa dominun iuvet umbra?

Iipist.1.16.10

munera, (fuae multa dantis cum laude tulerunt

Epist.2.1.246

succesit vetus his comocdia, non sine multa|laude; . . . . Ars Poct.281

multa. nulta petentibus|desunt multa:

cetera de genere hoc, adeo sunt nulta.

inuleacue de magna superessene fercula cena.

exilis donus est, ubi non et multa supersune

multa fulem promisca levant.

urulea senascentur quac iam cecidere

multa cenern circumveniunt incommoda.

multa. caris multa sodalibus.| null plura tamen dividit oscula|quam dutci

1. amiat.

guid brevi fortes iaculamur acvo'multa?

di nulta neglecti dederunt|Hesperiac mala fuctuosae.

multa jeentibus|desunt multa:

non posidentem multa vocaveris/recte beatum;

o multa detutum caput.

mulea Cicirrus ad haec: .

ģuid multa?

detereret sibi multa.

mule laborum praemia laturus."

at pui voltus erat inulta et pracclara minantis.

mala multa precatus Atridis.

quid multa ${ }^{2}$

dun cili. dun cociis reditum parat, aspera multa/pertulit,

quid multa? 'benigne'|respondet.

dic multa et pulcra minantem|vivere nec recte nec suaviter,

nulta quilem dixi, cut excusatus abirem

non est quod multa loquamur:

si pletaque lurel dicere credit eos, ignave multa fatetur:

multa puidem nobis facimus mala saepe poetae.

multa furo, ut placen genus irritabile vatum,

multa ferunt anni venientes commoda secum.

mulia recolentes adimunt:

multafun tollos ex oculis.

multa tulit fecitque puer, sudavit et alsit.

multae. locus... nec nultae prodigus herbac:

multae. mulfac tibi tum offeicnt res:

fus multir magnaeque secantur indice litcs.

multarum. summe munito et multarum divite rerum.

multi. nem mult i Danalio meri mitlei l.ylia nominis.

multi. vixte fortes ante Agamennona/multi: cunt multi quique lavantes:

muleis. muleis ille bonia flebilis occidit.

fuil Juma secmolo/cera velit versu; solus multisne coheres, muleis acculeo crescit res facnore.

Carm.3.16.43

Sorm.1.1.13

Serm.2.6.104

Epist.t.6. 45

IEpist.2.2.10

Ars lodizo

Ars I'oet.169

Carm.1.36.5

Carm.2.16.18

Carm.3.6.7

Carm.3.16.42

Carm.4.9.45

Epod.5.7.4

Serm.1.5.05

Serm.1.0.82

serm. 10.09

Sirm.2.1.11

Serm. 2.3.9

Serm.2.3.203

Serm.2.6.83

Epist.1.2.21

Epist.1.7.62

Eipist.1.8.3

Fist.1.0.7

Epist.2.1.30

Epist 2.1.07

Efist.2.1.219

Ifist.2.2.102

irs l'od.175

Ars Portizo

Ars loct. 183

Ars Poct $\{13$

Epist.t.7.\$2

sirm.1.2.97

Epist.1.16.42

Jipist.2.2.31

Carm.1.3"1.13

Corm.3.9.7

Carm.4.0.26

Sirm.1.75

Curm.1.24.9

Serm.2.5.54

I.pist.1.1.80

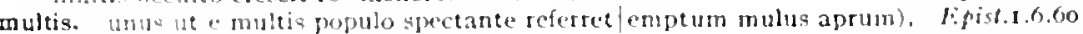
regea dicustur multis urgere culilliw

multis. mocens non sine multia' incomnis lacrimis

una d. mu!tis face nuptiali|digna

J.uculli miber crillecta viatica multia|aerumnis,

multis. folis monuslinultiz... tempestas ab buto'sternet.

multo. tum l'sumetinus salso multonue fuenti

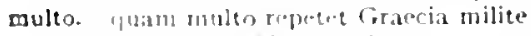

vet the itsis mules fumat odore.

mulers nors -ine timis

muse alt, multo iam fractus inembra labor".

necue llitis mulen corruptat folore voluptas.

'fund wath multo' 'rbem defricuit,

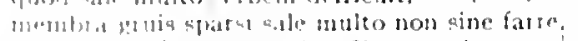

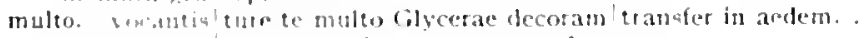

multo. Antus is malesior multo.

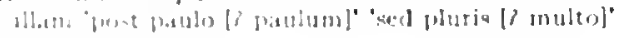

Ars Poet. 434

Carm.3.7.7

(i)m.3.11.33

I.pist.2.2.20

Carm.3.17.10

Sich 1.7 .28

Carm.1 is.t)

Carm.3.18.7

Carm.t13.27

Sirm.1.5

Sorm.1.2.32

Sirm.1.10.3

Sicrm.2.8.87

Corm. 303

(igrm.2.8.7

P iar firm.1.2.120 
auxilio quae/sit mihi (nam multo plures sumus),

Serm.1.4.142

postera lux oritur multo gratissima:

putidius multo cerebrum est. mihi crede, Perelli

Serm.1.5.39

"danda est ellebori multo pars maxima avaris: .

Serm.2.3.75

avolsos, ut multo suavius, armos, /quam si cum lun

Serm.2.3.82

rectius hoc et/splendidius multo est.

haberet | plus dapis et rixae multo minus invidiaeque.

Serm.2.8.89

Epist.1.17.20

Epist.1.17.51

Serm.1.9.72

multorum. sum paulo infirmior, unus multorum.

qui domitor Troiae multorum providus urbes $\mid$ et mores hominum

inspexit

qui mores hominum multorum vidit et urbes." .

Epist.I.2.I9

Ars Poct.142

Epist.I.I.76

Carm.1.1.23

Serm.1.6.10

Ars Poet.1 14

Carm.1.25.5

Carm.3.27.47

Epod.I 5.II

Epod.17.20

Serm.1.3.57

Serm.1.4.1 3

probus quis/nobiscum vivit, multum demissus homo:

scribendi recte: nam ut multum, nil moror.

tum Praenestinus salso multoque [multumque] Huenti i expressa arbusto regerit convicia,

*qui multum puerum loris et funibus ussit|exoratus,*

hunc medicus multum celer atque fidelis / excitat

haec a te non multum abludit imago. .

nultum Nasica negatas/accipiet tandem et tacitus leget

stes capite obstipo, multum similis metuenti.

si paullum potes inlacrimare, est/gaudia prodentem voltum [multum] celare.

postmodo quod mi obsit clare certumque [multumque] locuto luctandum in turba et facienda iniuria tardis.

monitus multumque monendus, | privatas ut quaerat opes

"hic multum in Fabia valet, ille Velina:

hac in re scilicet una|multum dissimiles,

poscentes vario multum diversa palato.

sudet multum frustraque laboret |ausus idem:

sic mihi, qui multum cessat, fit Choerilus ille,

sic mihi, qui multum [multum mihi qui] cessat, fit Choerilus ille,

mulus. unus ut e multis populo spectante referret (emptum mulus aprum),

Mulvius. Mulvius et scurrae, tibi non referenda precati, | discedunt.

Munatius. sit tibi curae/quantac conveniat Munatius.

munda. candida rectaque sit, munda hactenus,

iamdudum splendet focus et tibi munda supellex.

mundae. nundaeque parvo sub lare pauperum/cenae

mundi. quod latus mundi nebulae malusque|Iuppiter urget;

si neque fervidis/pars inclusa caloribus|mundi .

tempora si fastosque velis evolvere mundi.

mundior. unde/mundior exiret vix libertinus honeste; * * * *

munditiis. cui flavam religas comam/simplex munditiis? . . .

mundo. quicumque mundo terminus obstitit. .

mundum. qui mare ac terras variisque mundum / temperat horis?

mundus. mundus erit, qua non offendat sordibus. mundus victus non deficiente crumina?

scilicet ut prostes Sosiorum pumice mundus.

munera. pulveris exigui prope latum parva Matinum $\mid$ munera

o quamvis neque te munera nec preces

munera navium|saevos inlaqueant duces.

munera. ac ne quis modici transiliat munera Liberi.

Ceae retractes munera neniae.

inter jocosi munera Liberi

munera quid mihi quidve tabellas $\mid$ mitt is

nisi ut propria haec mihi munera faxis.

quid censes munera terrae.

at neque dedecorant tua de se iurlicia atquel munera

munere. quicumque terrae munere vescimur

da, puer. auguris| Murenae [munere]: .

dicit et centum potiore signis|munere donat.

var.Serm. I.7.28

Serm.1.10.*5

Serm.2.3.147

Serm.2.3.320

Serm.2.5.67

Serm.2.5.92

var.Serm.2.5.104

yar.Serm.2.6.27

Epist.1.3.15

Epist.1.6.52

Episl.1.10.3

Epist.2.2.62

Ars Poet.241

Ars Poet.357

vur.Ars Poet.357

Epist.1.6.61

Serm.2.7.36

Epist.1.3.3I

Serm.1.2.1 23

Epist.I.5.7

Carm.3.29.1 4

Carm.r.22.19

Carm.3.24.38

Serm.1.3.II 2

Serm.2.7.1 2

Epist.2.1.I 59

Carm.1.5.5

Carm.3.3.53

Carm.I.I2.I 5

Serm.2.2.65

Epist.1.4.II

Epist.1.20.2

Carm.1.28.4

Carm.3.I0.I 3

Carm.3.I6.I 5

Carm.1.18.7

Carm.2.1.38

Carm.4.15.26

Epod.1 2.2

Serm.2.6.5

Epist.1.6.5

Epist.2.1.246

Carm.2.14.10

"'ar.Carm.3.I. I I

Curm.4.2.20 
munere cum tungi propiotis censet anzici:

Epist 1.95

dividuo fudetur munere quadra.

Epist.1.1 7.49

muncre te fitro beet atut incommodus angat.

l.pist.1.18.75

mpensis comarum et thac munere vestis; .

ni" suberam pingui donatus munere

muneret. qua muresctus [muneret] te, Priape, et te, pater silvane. muneretur. qua muncretur tu. Priape.

muneri. carmust possumu- donare et pretium dicere muneri.

muneribus. subruit aemulos/rexes muncribus;

(jwanderpe poucentior/largi muneribus riserit aemuli.

(jui derorui muneribus sapienter nti.

o crudelis adhuc et Veneris mueribus potens,

pleris henorumi muneribus

bilerios, ultro| muneribus missis):

muncribus servos corrumpam;

muneris. totum muneris hoc tui est.

carmina persumus/donare et pretium dicere nuneri (muneris).

munerum. neque tu pessuma munerum ferres,

munia. nondum munia comparis/aequate

me mequ servis Albuci senis exemplo, dum muna didit.jevoserit.

segetus praescripta ad nunia surgit.

cetera qui vitac servaret in unia sectolmore,

muniant. quamsis furiale contum/musiant angues caput cius

munierant. munierant satis nocturnis ab adulteris,

lipist.1.19.38

lipist 2.1.20?

1.r. I pod.2.21

lipod.2.2I

Carm.4.8.12

Curm.3.10.15

Carm.1.1.18

Carm.4.9.48

Carmato.1

Carm.t.14.2

Serm.1.7. 8

Serm.1.9.57

Carm.4 3.21

Iar.Carm.4.8.12

Cism.48.4

Carm.2.5.2

Sirm.2.2.67

Serm.2.2.81

Lfist.2.2.131

Corm.3.11.18

Carm.3.10.3

munifica. quatue modeste munifico esse licet.

munificum. "fua res. qua ratio suaderet quaque modeste | munifico [mumblicum] esse Jickot.

munire. uppidil conperunt munite ponere leges, .

munitae. Huntuclec adhibe vin sapientiae.

munito. summo masito et multarum divite retum.

munivit. castus deneas patriae superstes/liberun munivit iter,

munus. nec munus umeris efficacis llerculis inarsit aestmosius.

cum palla, tabo munus imbutum, nowan|incendio nuptan ab-ublt?

munus. gramb inums Cecropio repetes cothurno.

it nunus Apolline dignum/ vis conplere libris

mumus et othojur, nil sombens ipse. docebo:

munuscula. 'mon mosa feres meris nunuscula parvis'.

murem. Iuticus urbanum mutem mus pupere fertur/accepisse cavo.

Murena. Murena pracbente domum. Capsitone culinam.

murena. idfortur squillas inter murena natanis in patina portecta.

Murenae. da. puer, auguris|Muremae:

murex. murice Baino [muex Baianss] molior Lucrina pelotis.

muria. ghes pingui miscere nero muriaque decebit

ut melius nusia quod testa matina renittat."

murice. te bis Afolmusce tisctac vestiunt lanae:

marice Batiano metion Lactina pelotis.

argentum. veress Galetulo murice timetasisunt qui non habeant.

muricibus. muricibus I yis iteratate vellera lame, cui properabuntur?

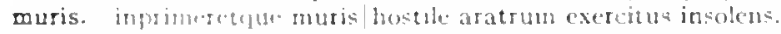

muris. "athducase casas. plostello adiungere murs.

murnure. lam nume minaci murmuse cornuons ferstringis ausis.

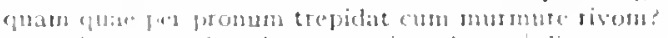

muros. adnumet fobus dencate potione ductos alite musus -

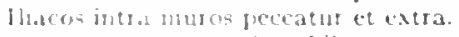

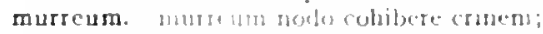

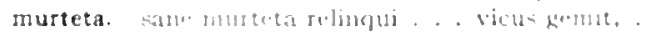

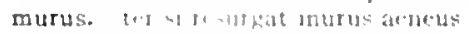

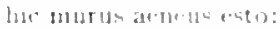

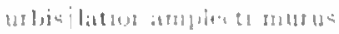

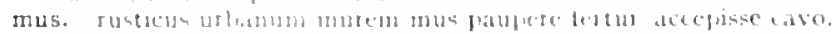

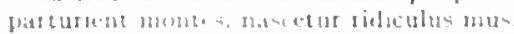

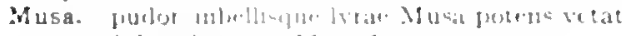

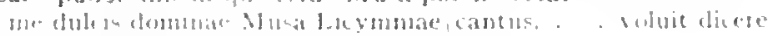

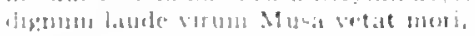

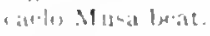

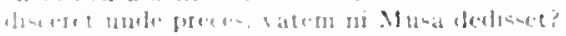

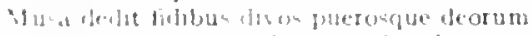

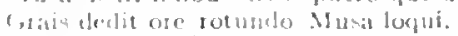

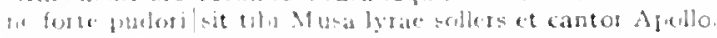

Serm.t.2.51

sar.serm.1.2.51

Serm.1.3.105

Carm. 3.28 .4

List.2.2.3I

Carm.tiace. 43

Epod.3. I

I. poi.5.05

Curm.2.1 11

Epist.2.1.210

Ars loot 300

Episti.7.87

Serm.2.1.80

Sormi.1.5.38

Sirm 28.42

Corm3.19.11

combitierm.2.4.32

Sirm.2.4.05

Sim.2.8.53

(itm.2.10.30

Sierm.2.4.32

E.pist.2.2.18

l.pod.12.21

(ia) 1.31 .20

Sirm.2.3.247

Carmit2.1.17

I.pist.1.14.2I

Curm.t.?.24

lisiti.210

Carm.3 14.22

lipist.1.15.5

(a)m.3.3.?5

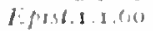

Ars l'ort. zum

scom 20 so

Ars Jient 1.30

(iim) 1.610

('term 2.12 1.3

(armls.ts

cirm a 4.20

foret $=113.3$

Ars f'ortis.s

Ars Pueb-324

Ars fort.407 
Musa. sed ne relictis, Musa procax, bocis

yuo. Musa, tendis? .

dic mihi, Musa, virum.

Musa. fidibusne Latinis Thebanos aptare modos studet alfuice Musa.

Epist.1.3.13

Musa. (nam mibi Baias/Musa supervacuas Antonius,

musa. dis pietas mealet musa cordi est. . paulum severae musa tragoediae desit theatris:

musa. Sarmenti scurrae pugnam Messique Cicirri, musa. vim mumoms muza rogata refer, comiti scribaeque Neronis.

musa. (quid prius inlustrem saturis musaque pedestri)

Musae. nee studio citharae nec Musae deditus ulli,

Musam. quondam cithara tacentem / suscitat Musam

musam. temperat Arehilochi musam pede mascula Sappho,

Musarum. Musarum sacerdos/virginibus puerisque canto. ad libros et ad haec Musarum dona vocares.

Musas. Liberum et Musas Veneremque . . canebat . qui Musas amat imparis.

dictitet Albano Musas in monte locutas.

Epist.1.15.3

Carm.1.17.14

Carm.2.1.9

Sirm.1.5.53

Epist.1.8.2

Serm.2.6.17

Sirm.2.3.105

(urm.2.10.19

Epist I.19.28

Cilm?.3.1.3

Lpist.2.1.243

Carm.1.32.9

Curm.3.19.13

Epist.2.1.27

Epist.1.10.7

carm.1.26.1

Carm.4 9.21

lepist 2.2.02

lipist.1.7.32

rerm.2.4.19

Sirm.2.3.210

Epist.2.1.101

Epist.2.2.189

coni.Epod.9.28

Carm.2.10.19

- irs Poel.ta

Epist.I. I5.10

Epist. I. I1.27

E.pist.1.I.00

Ars Poelono

Carm.1.16.20,

Carm.1.29.15

Carm.1.34.13

Carm.5aec.39

Epist.1.12.10

Epist.1.19.27

Ars Poet.168

Carm.3.0.12

hirm.2.7.10

Carm.1.17.2

(arm.t.7.3

Epod.4.6

Sermid.20

Serm.1.10.53

Serm.2.7.04

Sirm.2.7.1111

Epist.1.1.9 I

Inist.1.1.100

diruit, aedificat, mutat quadrata rotundis?

catlum, non animum mutant [? mutat], qui trans nare curume [? currit].

mutata. loo age, ne nutata retrorsum te ferat aura.

mutata. sive mutata invenem figura/ales in terris imitaris almae filius Maiae.

utcunçue mutata potenticisese dones ininica linquis.

ille cubans gaudet nutata sorte

mutatae. Intmo! actae non alio rege purciae mutateque simul tugde.

longo die bis terque mutatae dapis

Nasidiene, redis inutatae frontis.

mutatae. quem res plus nimio delectarese secundae, mutatac quationt

mutatis. hosce secutus mutatis tantum pedibus numerisque.

mutatis. luine bos, res hime mutatis dincerfite partibus.

mutato. Hatito nomine de te fabula narratur:

mutatos. beu quotiens fidem |mutatosque deos thibit

mutatum. ac nisi mutatun parcit dufudere vinum

mutatur. iramicolligit ae ponit temere et mutatur in horas.

For List.1.I I.27

J.pist.1.18.88

(iirm: 1.2.41

Curm. I-35.23

sinm.2.6.110

(1) 1 m. 1.36 .9

S.poit.5.3.3

firm.2.8.8.4

Epist.1.10.31

termer. 7

Serm.t.r.18

Sirm.1.1.69

(itrm. I. 5.6

serm.2.2.58

irs Toition

mutatus. qui color est punicear fore prior rosae| mutitus. 


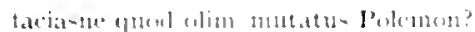

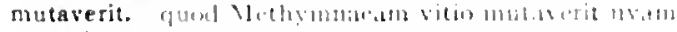

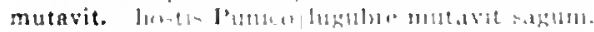

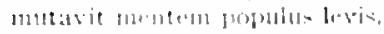

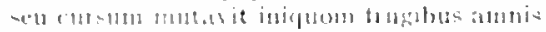

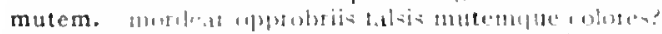

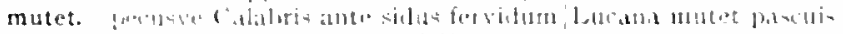

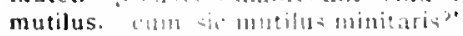

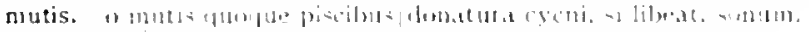

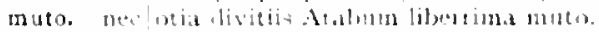

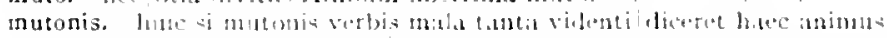

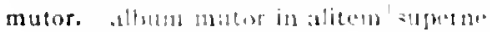

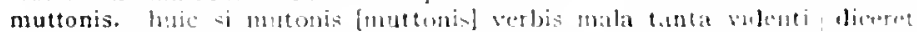

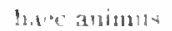

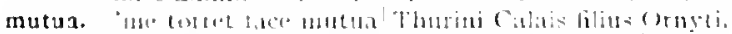

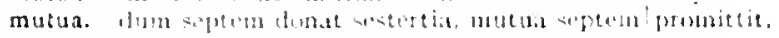

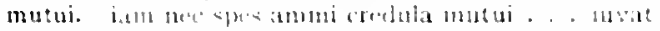

mutuis. bene mutuic blum pectus athotibus;

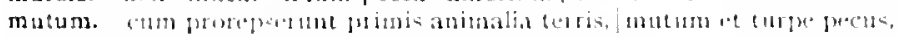

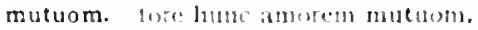

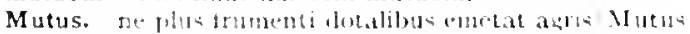

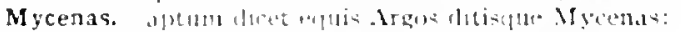

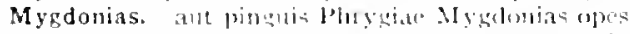

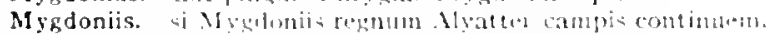

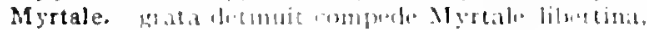

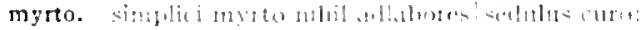

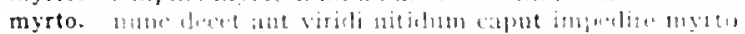

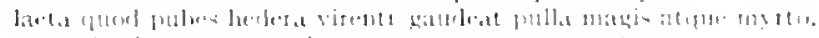

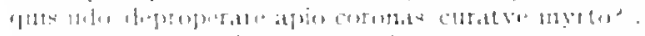

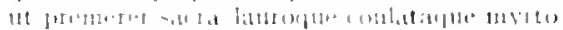

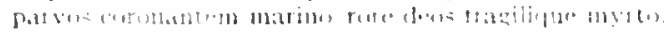

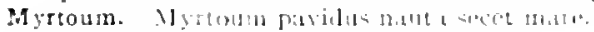

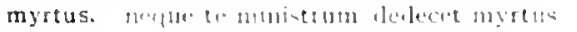

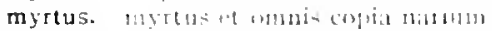

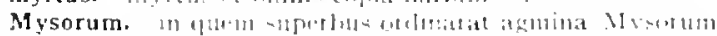

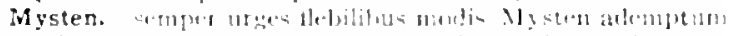

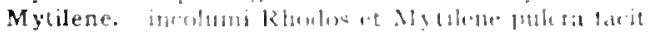

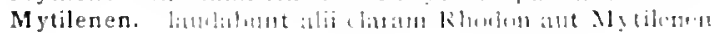

Sirm 2.3.25.4

Sierm. 2 S.50

Jipil 0.28

Iipixt.2.1.10N

Ars Port 7

EPle 1.1038

Epoll 1.28

Sirmb. 1.5.610

(arm-1.10)

liping 1.i.ip

sirm. 1 zik

(i)rm. 2 2011)

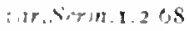

rirm.3013

f.pist.1. . So

(arm +1.30

("arn 2.12 .15

herm 1.3.1010

fipill 15.20

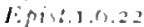

(itrm.1.7.)

(iarm.2.12.22

Cirm.3.20.41

ciarm. 1.33.8.4

(iarm.t.3.s.5

(isml 1)

(iurn. $25.1 \mathrm{~s}$

(iorm.2.7.25

(armitis)

cisen is ? Ir

(

C':rm: 1-3.8.

(itrm.2.35\%

f.potitis

(itrm. 2.01) 10

i.peld 1117

(imm. $1 \div 1$

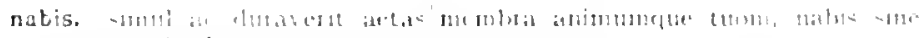
(1)! ti.

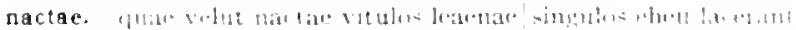

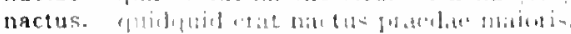

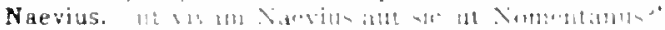

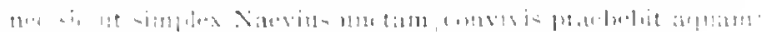

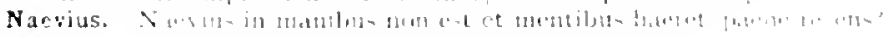

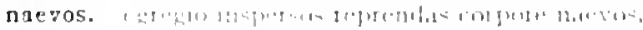

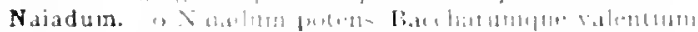

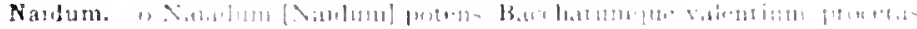

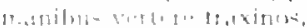

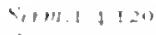

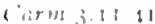

$\lim 1.15,38$

४.1.1.1.11

arm 201 .

fin: a 15 ;

Derm 1.e 1.

(4)

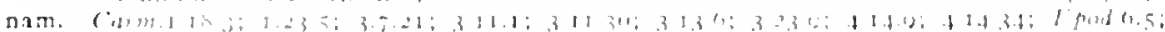

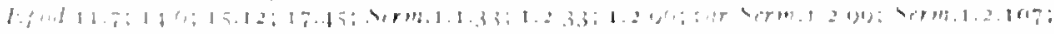

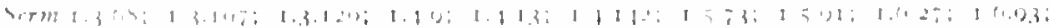

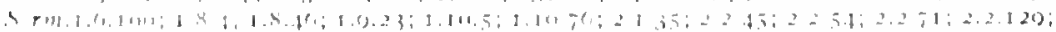

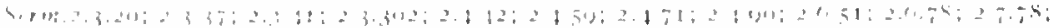

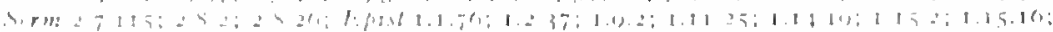

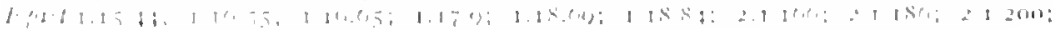

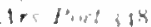

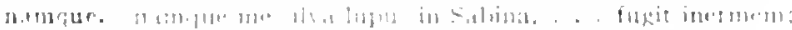

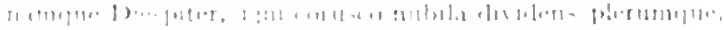

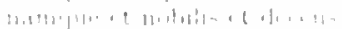

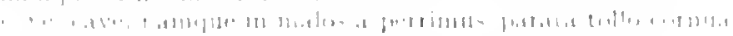

:

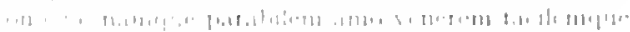

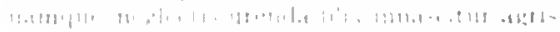

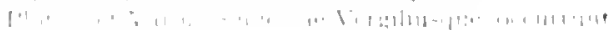

(ier)t. 1 (e)

( irtid a

a in \& 1 i

| find | I

f. Pint a :

sine ! I [1]

birm. 1 ; in

NA! ; i 
namque pila lippis inimicun et ludere crudis.

namque deos didici securum agere aevom.

namque esto: populus Laevino mallet honorem| ruan idecio mandate novo.

namque est ille. pater quod rat meus.'

(inians namque pudor prohibebat plura profari)

namque instat fatum mihi triste.

namque marem cohibent callosa ritellum.

nam quae [namque] deserta et inhospita tesqua credis.

namque/mordacem Cynicum sic eludebat, ut aiunt:

nanciscetur. nanciscetur enim pretium nomenque poetae.

nardi. nardi parvos onyx eliciet cadum.

nardo. dum licet, Assyriaque nardo! potamus uncti?

nardo vina nerebere.

nasdo perunctum, quale non perfectius/meae labor.unin manua.

nunc et Achaemenio perfundi nardo iuvat .

naribus. minus aptus acutis naribus hormm hominum. .

naribus. Illic plurima raribus/duces tura

ad hace ego naribus uti|formido.

naris. nec fimo iuveni meque naris obesae?

facetus, | emunctae naris, durus conponere versus.

naris. ne sordida mappa/corruget naris,

narium. myttus et omnis copia narium

narra. libertate decembri, fquando ita majores voluerunt, utere: marra."

narrabo. dicam Siculique poetae narrabo interitum.

narrantem. "non ego" narrantem "temere edi luce proficsta

narrare. scriptores autem narrare putaret asello fabellam surdo.

narrares. si tibi nulla sitin fuiret copia lymphae. narrares medicis:

narraret. si non causas narraret carun et naturas dominus;

narrari. indignatur item privatis ac prope soceo/ dignic carminibu= natrari cena Thyestae:

narras. quantum distet ab Inacho|Codns... natras

"magnum narras, vix credibile."

narrat. narrat paene datum Pelea Tastaso.

it, sedit et narrat. Volteiun nonine Menam. | prarcomem.

narrata. 'hoc quoque. Teresia, prater nariata petenti' remponde.

narratur. narratur et priaci Catonis|saepu mero calusie virtur.

mutato nomine de te fabula narratur:

qua Paridis propter narratur anorem Graecia barbaria knte whisa duello,

narres. ne volgo narres, te sudavisse ferendolcarmina

narret. quae mox narret facundia praesens:

narro. num ego ne claro natum patre. . . sed quod tham narso.

nascente. catlo supinas si tuleris manus'nascente lumil,

nascentem. quem tu, Melpomene, semel|mascentem pladolumine vinteris. nascentes. lubrica mascentes inplent conchylia lunae;

nasceris. aliusque et idem| nasceris.

nascetur. parturient montes, nascetur ridiculus mus.

nasci. sic luero asersam potuicie nasci|matre pudenda.

nascitur. nam vitis nemo sine nascitur;

nascuntur. nascunturque leves | per higitos umerosque plinar.

Nasica. captatorque dabit risus Nasica Corano.

multum Nasica negatas|accipiet tandem et tacitus hest

Nasicae. filia Nasicae, metuentis reddere soldum.

Nasice. forti nubet procera Corano filia Nasicae [Nasici:].

Nasidiene. Xasiolien, redis nutatae frontis, ut arte cmonlaturus for tunam:

Nasidieni. 'ut Nasidieni iuvit te cena beati?'

Nasidienus. Nasidienus ad haec "tibi di, quaecumque prepsiz. commola degit:

naso. ut plerique solent. naso suspendis aduncolignotos

Balatro suspendens omnia naso

naso vivere pravo|spectandam nigris oculis

nasum. "tetenim fateor nee" . . nitsum nidore supimot.

nasus. non quia nasus illis nullue crat,

nasuta. verum|depugis, nasuta, brevi latere ac perle longo ext.

nata. quid responderet?" "magno patre nata puclla ust."

quin ctiam lex | poenaque lata [natal, nalo quate mollet cambu quemquan describi:

nata. O nata mecum consule Manifo.
Se'm $1+5.40$

Serin. I.5. I OI

S.rm.i.6.jo

Sirm.t.o.ti

Sierm.1.0.57

Sirm. 1.0 .20

Sirm.2.21.1.t

itur. Esist I.IA.IO

lipist.1.17. 7

Ars l'oet. 299

Cirm.4.12.17

(itrm.2.15.16

(iorm.1.12.16

Epod.5.59

Epol.1.3.9

Serm.1.3.30

Carm.t.1.2 I

I.sist.1.19.45

Epod.1 2.3

Sermer.t.8

Epist. 1.5 .23

Cirm.2.15.0

Serm 2.7.5

Ars Pott. tht $^{6}$

Serm.2.2.116

Epist.2.199

Epist.2.2.147

Serme.2.8.92

Ars PothoI

Cirm.3.19.3

sirm. I.9.52

Cirm.3.7.17

Epist.1.7.55

Serm.2.5. I

Carm.32I.II

Serm.t.7.

Efist.I. 2.6

Epist.1.13.10

Ars loter is.t

Sierm. 1.6 .00

Cirm.3.23.2

Cirm.4.3.2

Serm.2.430

(imm.saec.II

Ars Pot t. 39

Curm.2.4.I9

Sirtin, I.3.0.8

Carm.2.20.1I

Sirm.2.5.57

Sirm.2.5.67

Serm.2.5.15

ater.sernt.2.5.05

Serm.2.8.8.7

sermiz.s.

Serm.2.9.75

Se'y 12.11 .5

Dirmazisont

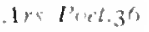

Sierm.2.7.35

Sirm-2.2.80

Strm.1.2.93

serm.1.2.72

ind.lipist.2.I.I 53

rarmi-3.1.i 


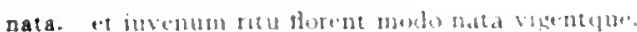

nata. indecorane bere nata culpate

tura meges shi nata, tahil mon atroget armi

natale. sitt fenius, mulde comes qui terupetat atrum,

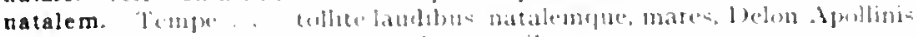

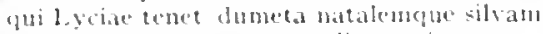

natali. sametionclue paesue uatali proptio.

natalis. patrs vichentior ratalis horat,

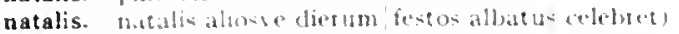

matales grate mutheras?

natam. pro vitula statuic duferm Aulick natam ante aras

natamia. qui siccie oculis monctra natantia. . . vidit

natantis. adfestur squillas incer murena natantis in patina portectat

natarunt. et superfeces pavidace natarunt aecuore dammate

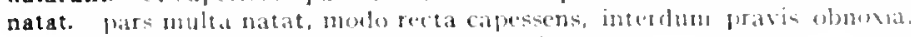

nate. 'mucte, mortalis dea nate puer Thetide.

nil amplius tho, Maia tatt.

nate. frefredi deftion nate fiets:

nati. hos numerus sumus et th

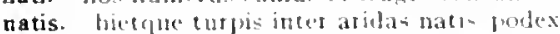

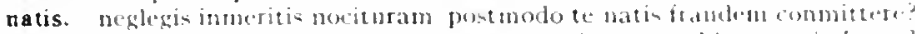

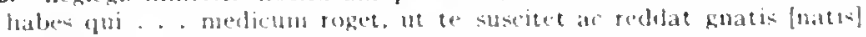
carisque propinquas?

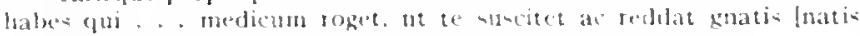
[erlutat catringue propinguis!

incultis qui seg eibus et male natis reetulst. . Jhilipure.

natis. Mattis in usum latetiale seyphis

nato. crat nato (")

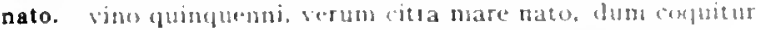

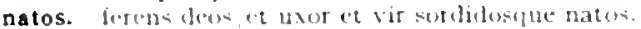

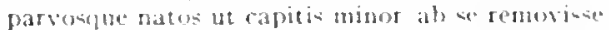

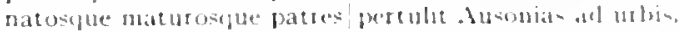

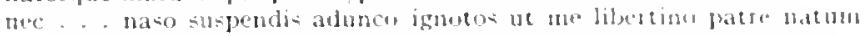
[natou].

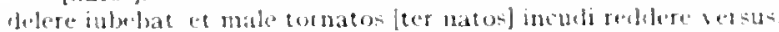

Natta. mon quo iraudatis inmundus Xitla lucerni-

natu. Lofo nomium dictare Carinas iam grandis natu queclitur.

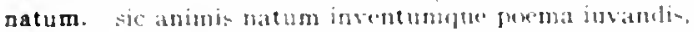

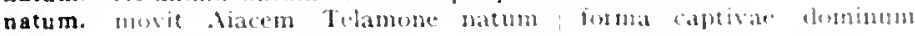
1 exminate.

agnotos ut me libertino patte natum

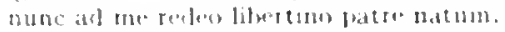

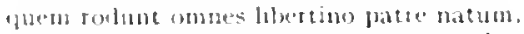

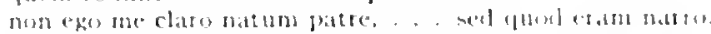

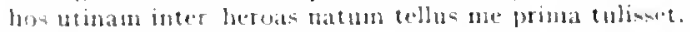

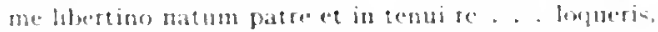

Buxutum in craseo iurares acere natum.

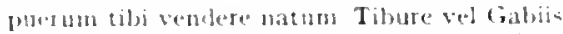

bucentem strepitus et nattum rejus agendis,

natura. quis husmana sibi doleat natura negath.

nulls natura labore quen tibi dat

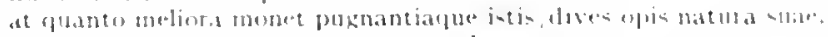

nomme, copmbinbus - tatuat naturat modum quetr.

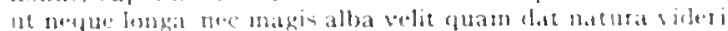

numequa (1), vitierum inneserit olim natua

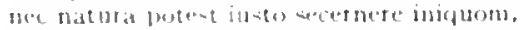

-

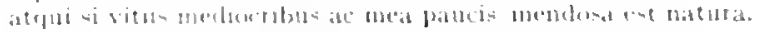

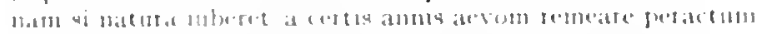

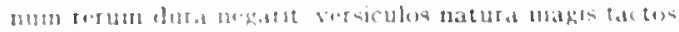

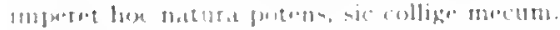

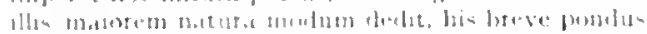

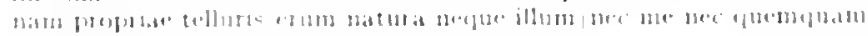
4 t. 1 tist

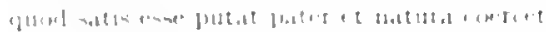

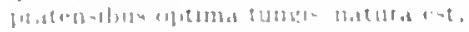

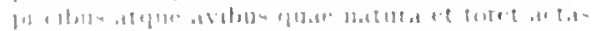

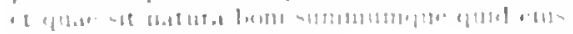

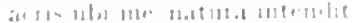

- Irs Poet.o2

iarm.4.4.313

Irs Port.122

lipist.2.2.15\%

(iom.1.23.10)

Carm.3.t.3

torm.t.]1.15

tarm.2.17.19

torm.2.2.(2)

l.pist.22.210

Sirm.2.3.199

(iurm.1.3. 18

Serm.2.8.42

(arm.1.2.11

Term. 2.7.7

1.pod.1.3.12

$\sin 2.1 .5$

corn. 18.47

1.pist.1.2.27

fipod.8.5

Cirm.1.2S.31

: $a r .50 m .1 .1 .83$

a ear.serm.2. 1.83

f.pist.2.1.233

(irm.1.27.1

Sipist.1.5.9

Gem.28.47

(irm.2.18.28

(arm.3 5.42

(urm.4 455

a or sorm 1 copel

and.Ars loet.at

virm.t.f. 24

L.pist 1.7.40

irs l'ort $37 \%$

(a)m.245

arm. 1.0 .0

virm.1.e \$5

serm.t.t.ap

serm.1.1.58

Sirm.2.2.9.3

lipis! 1.20 .20

I.pist.2. 24.4

Lpist.2.2.2

Ir laded 2

corm.1.1.75

Serm.1.1.88

sorm.1.2.74

sim.1.2.111

serm.1.2.12.4

s.rm. $13.3^{\prime 3}$

verm. 1.3.113

verm.15.10\%

sorm tolepen

serm. 1.4.0.i

Trm 1.10 .58

rerm. 2 I 51

sim.2.23\%

irrm.22120

stm. 3158

Sorm $2+21$

srmed 45

verm. a 10

orm 2.7. 
iam vaga prosiliet trenis natura remotis.

virtutem doctrina paret naturane donet.

format enim natura prius nos intus ad onnem fortunarum habitum: maculis, quas ant incuria furlit / aut humana parum carit natura.

natura, et placuit sibi, natura sublimis et acer:

natura fieret laudabile carnen an arte.

naturae. iudice te non sordidus auctor/naturae verique.

quid referat intra|naturae fuis viventi.

sive est naturae hoc sive artis, mirus utroque.'

naturae deus humanae. mortalis in unum / quodque caput,

naturae. vivere naturae si convenienter oportet

naturam. est operae pretium duplicis pernoscere inis/naturam.. naturam expelles furca, tamen usque recurret vel quia naturam mutare pecunia nescit

naturas. si non causas narraret earum et naturas dominus:

naturis. mobilibusque decor naturis dandus et antin.

natus. divesne prisco natus ab Inacho|nil interest

longe sonantem natus ad Aufidum

velin menores et quo patre natus nterque / contulerit litis.

nec. . naso suspendis adunco / ignotos ut me libertino patre natum [natus].

cum referre negas, quali sit quisque parente|natus. .

ingeniro si non essem patre natus:

audit continuo "quis homo hic' et "quo patre natus?"

quo patre sit natus, num ignota matre inhonestus,

quem rodunt omnes libertino patre natum [natus].

atque ego cun graecos facerem, natus mare citra. / versiculo-

inneritusque laborat |iratis natus paries dis atque poetis.

si et stramentis incubet unde-foctoginta annos natus.

Vertumnis, quotquot sunt, natıs iniquis.

nec vixit male, qui natus moritensque fefellit.

naufragum. quas neque Noricus/detertet ensis nec mare naufragum

nauseam. vel quod fluentem nauseam coerceat

nauseat. conducto navigio aeque/nauseat ac locuples,

nausiam. vel quod fluentem nauseam [nausiam] coerceat metire nobis Caecubum.

nauta. Myrtoum pavidus nauta secet mare.

absentem ut cantat amicam | multa prolutus vappa nauta

retinacula mulaelnauta piger saxo religat stertitque supinus.

nauta. at tu, nauta, vagae ne parce malignus harenae. . particulam dare:

nautae. ac mulae nautaeque caput lumbosque saligno fuste dalat:

nautae. non huc Sidonii torserunt cornua nautae,

nautaeque, per omnelaudaces mare qui currunt.

tun pueri nautis, pueris convicia natae ingerere

nautica. emat.. nautica velalaversus mercaturis:

nautis. quorum simul alba nautis/stella refulsit.

exitio est aridum mare nautis;

neque certa fulgent/sidera nautis.

dum pecori lupus et nautis infestus Orion.

tum pueri nautis, pueris convicia nautae/ingerese

nautis. amata nautis multum et institoribus.

inde Forum Appi|differtum nautis cauponibus atque malignis.

nave. ego utrum nave ferar magna an parva, ferar mus et ifem.

navem. ravem agere ignarus navis timet.

naves. esseda festinant, pilenta, petorrita, naves,

navibus. quam rem cumque ferox navibus aut equis mules. . gesserit. pastor cum traheret per freta navibus|Idaeis Helenen

dux fugit ustis navibus

navibus atque quadrigis petimus bene vivere.

si fractis enatat exspes | navibus, aere dato yui pingitu!?

naviget. rerum anbitiosus et audax:| naviget Anticyam. naviget ac medis hiemet mercator in undis,

navigio. conducto navigio aeque | nauseat ae locuples,

navim. sive lactatam teligarat udo'fitore navim,

contra mercator, navim iactantibus Austris,

idcirco navim trans Aegaeum mare vendas.

navis. Sted minuit furorem / vix una sospes navis ab ignibus

mala soluta navis exit alite

dum tua navis in alto est.
Serm.2.7.74

Epist.1.18.100

Ars Poit.108

Ars Poet.353

Epist.2.1.155

Ars Poit.fos

Cinm.1.28.15

Serm.I. I 50

Sirm.2.4.7

Epist.2.2.188

Epist.1.10.12

Serm.2.t.64

Epist.1.10.24

Epist.I.I2.10

Serm.2.8.93

. 1 rs Poct. 157

Carm.2.3.2I

Carm.t.9.2

Serm. T.5.53

7'ar.Serm. I.0.6

Sierm. I.0.8

firm.1.6.21

Serm.1.0.29

Serm.1.0.30

rar.Serm, 1.0.46

Sermi I. I0.3 I

Serm.2.3.8

Serm.2.3.1 I8

Serm.2.7.14

Epist.I. I7. I0

Curm.tolo

IEpod.9.35

Epist.1.1.93

zar. Epod.9.35

Corm.1.1.14

Serm.1.5.16

Serm.1.5.19

Carm.I.28.23

Serm.1.5.22

lipod.10.59

Sirm.1.1.29

Serm.1.5.1 I

Sirm.2.3.106

Curm.1.12.27

Carm.1.28.18

Carm.2.10.1

Epod. 15.7

Serm.1.5.I I

Epod. 17.20

Serm.1.5.4

Epist.2.2.200

Epist.2. I.IIt

Epist.2.1.192

Carm+1.0.3

Corm.I.I5.I

Epod. 0.8

IEpist.T.I I.28

Ars l'oet. 2 I

Serm.2.3.106

I.pist. I.16.7f

Epist.1.1.92

Carm. I-32.8

Sirm.1.1.6

Epist.1.11.10

Carm.1.37.13

Epod.10. I

Epist.1.18.87 


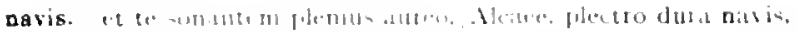

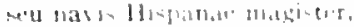

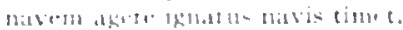

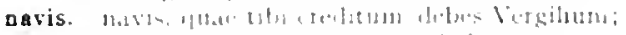

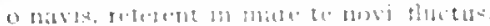

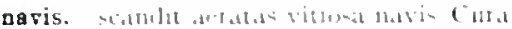

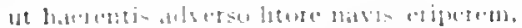

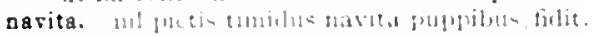

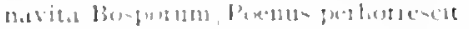

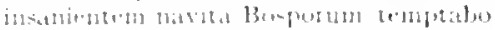

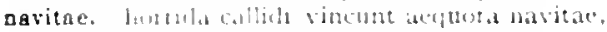
fitcat

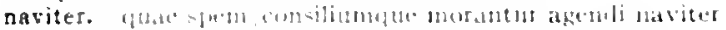

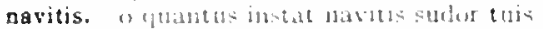

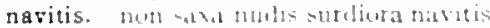

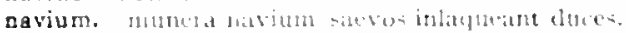

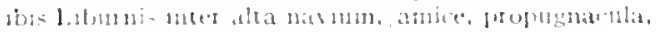

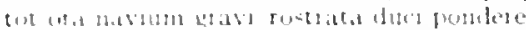

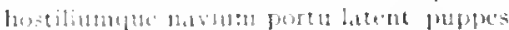

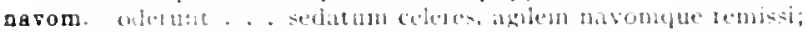

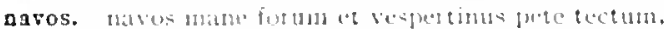

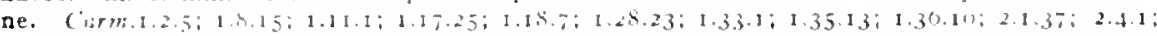

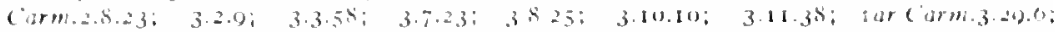

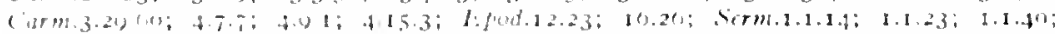

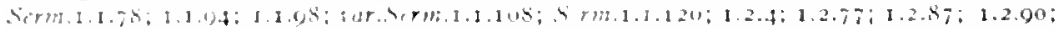

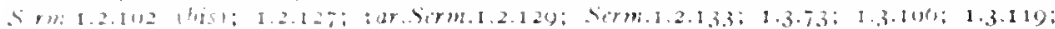

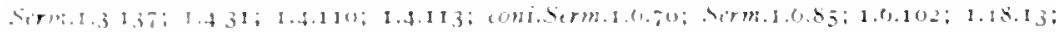

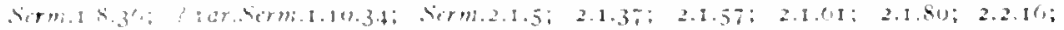

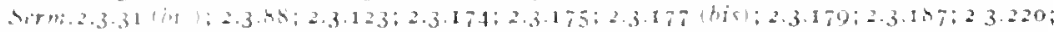

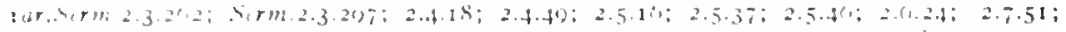

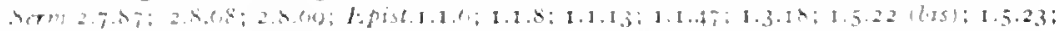

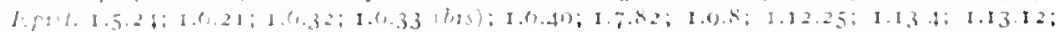

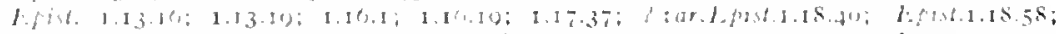

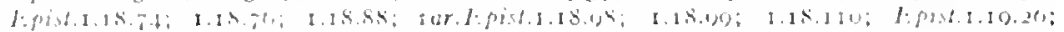

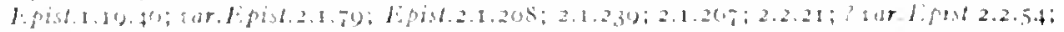

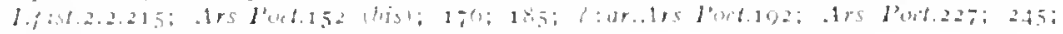

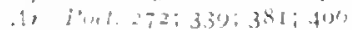

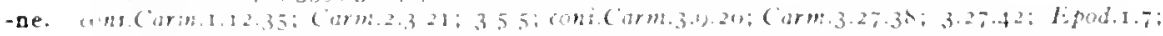

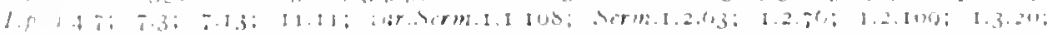

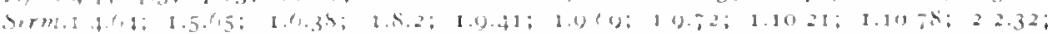

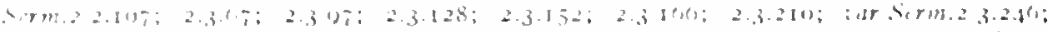

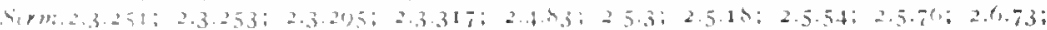

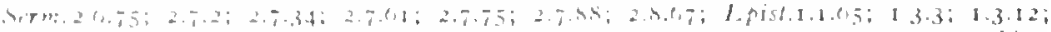

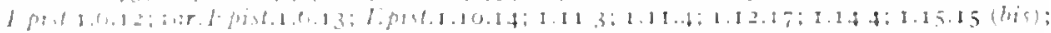

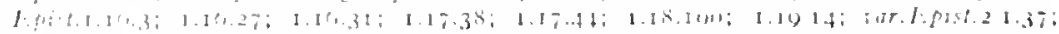

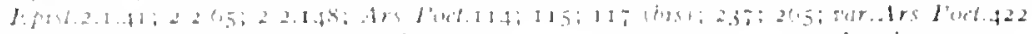

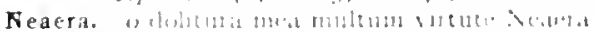

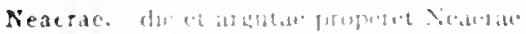

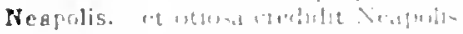

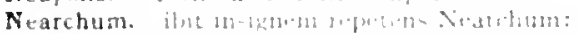

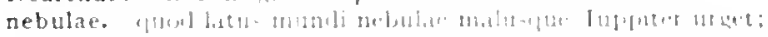

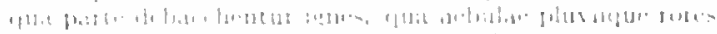

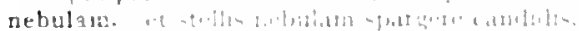

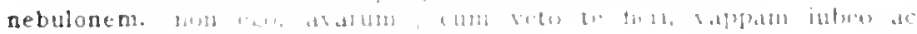
$13 \cdot 1,1] d_{1+10+111}$

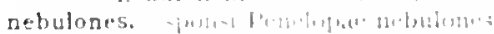

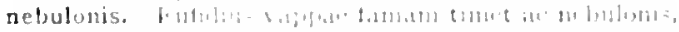

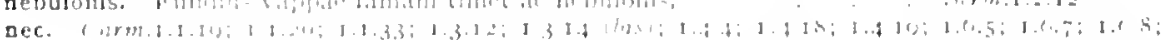

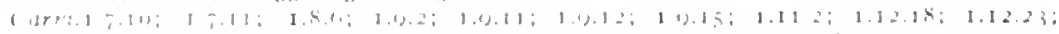
f (4)

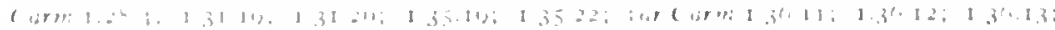

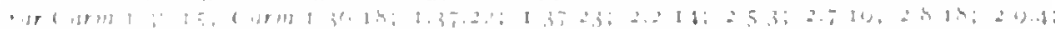
(

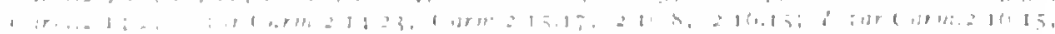

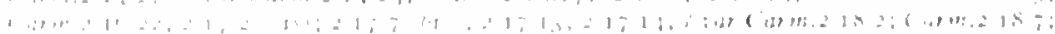
1..

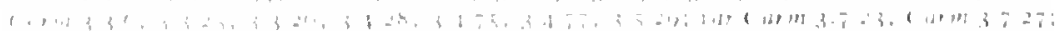
( 
Carm.3.15.15; 3.15.16;3.15.33:3.16.34; 3.16.35;3.16.38; 3.18.0;3 23.5:3.23.6; 3.24.14; Carm.3.24.19; 3.24.20; 3.24.38; 3.27.15; 3.27.16; 3.29.0; 4.1.20 (6.3); 4.1.30; 4.1.3I; Carm.4.1.32; 4.2.39; 4.4.22; 4.5.14;4.7.27; tar.Carm.4.8.9; Carm.4.9.9; :ar.Carm.4.9.19; Carm.4.12.3 (bis); 4.I3.13; 4.13.I4; Epod.3.15; 3.17; 5.07 (bis); 5.75; 7.11; 8.1.3; 9.23; Epod.10.9; I0.II; I 1.26; 12.3; 13.10; 14.15; 15.15; 15.21; 10.5 (his); 14.7; I0.33; 10.51; Epod.10.52; 16.55; 16.60; I7.32; I 7.40; zar.Serm.1.1.2.3; 1.I.78; Serm.1.2.52; 1.2.80; Sirm.1.2.84; 1.2.124; 1.2.127; 1.3.113; I.3.115; 1.3.128; 1.4.47 (bis); 1.4.73; 1.5.102; Serm.1.6.3; zor.Serm.1.6.68; Serm.1.0.85; 1.8.21; 1.9.31; 1.9.32 (bis); 1.9.19; 1.9.50; 1.10.5; Sirm.1.10.39; 2.I.14; 2.I.47; 2.2.2; 2.2.22; 2.2.6S; 2.2.130 (bis); 2.3.I05 (bis); Serm.2.3.133; 2.3.251; 2.3.262; 2.3.206; 2.4.35; 2.4.37; rar.Serm.2.4.73; Serm.2.5.80; Serm.2.0.7; 2.6.I8 (bis); 2.6.72; var.Serm.2.6.72; Serm.2.6.84; 2.6.108; Itist.1.1.30; Epist.1.1.72;1.I.IO2 (bis); I.2.7 I (bis); adr.Epist.1.3.22; Efist.1.5.2; 1.7.23; 1.7.35 (bis); Epist.1.7.38; 1.7.12; 2ar.Epist.1.7.82; Epist.1.8.4 (bis); 1.8.6; 1.10.45; 1.1 1.12; 1.1 1.15; var.Epist.1.13.16; Epist.1.14.24; 1.14.25; I.I4.36; I.It.12; 1.16.13; 1.16.40 (bis); Epist.1.17.10; 1.17.47 (bis); I.17.58; I.I 8.30; 1.18.40; I.18.70; 1.19.2; 1.19.30; 1.19.31; Epist.2.1.78; var.Epist.2.1.79; Epist.2.1.248; 2.1.250; 2.1.258; 2.1.260; 2.2.101; Ars Poet.8 (bis); 41 (bis); 133; 134; I36; 146; 147; 191; 192; 231; 249; 286; 289; i'ar.Ars Poet.339; Ars Poel.350; 371; 400; 4 I0; var. Ars Poe' $416 ;$ Ars Poet.450; 408 (bis); Ars Poet.tio

necabit. mater delira necabit in gelida finm ripa febrinque reduct. necari. uri virgis ferroque necari|aucioratus eas.

necato. quae tibi virginum |sponso necato barbara servict,

necdum. necdum omnis abacta|pauperies epulis regum:

necem. nimis/casto Bellerophonte! maturare necem,

necesse. iura inventa metu iniusti fateare necesse est, .

in singula quem minuas pulmenta necesse est. .

ire necesse est.

si forte necesse est|indicis monstrare recentibus abdita renum:

$\boldsymbol{N e c e s s i t a s . ~ t e ~ s e m p e r ~ a n t e i t ~ s e r v a ~ N e c e s s i t a s . ~}$

aequa lege Necessitas|sortitur insignis et imos.

si figit adanantinos!summis verticibus dira Necessitas|clavos,

necessitas. semotigue prius tarda necessitas/Leti corripuit gradum;

necis. acerba fata Romanos agunt | scelusque fraternae necis,

necne. idcirco quidam comoedia necne poenalesset quaesivere,

hactenus haec: alias, iustum sit necne poema.

an hoc inhorestum et inutile factu'necre sit addubites,

nec male necne Lepos saltet;

recte necue crocum floreque perambutut Attae fabula

necrepos. ergo/sermo oritur, non de villis domibusve alienis, nee malc necne Lepos [necnepos] saltet;

nectar. purpureo bibet ore nectar

nectaris. oscula, quae Venus|ruinta parte sui ncctar is imbuit.

discere nectaris|sucos... patiar

nectat. quid ferat et quare sibi nectat uterque coronam.

necte. apricos necte Hores.

necte neo Laniae coronam, .

nectendis. ent in horto. Plyylli, nectendis apium coronis,

rectes. frustraque vincla gutturi innectes [nectes] tuo.

nectis. horribilique Medo nectis catenas?

nectit. nec sponsae laqueum famoso catmine nectit.

nedum. nedum sermonum stet honos et gratia vivax.

nefarius. aut humana palam coquat exta nofarius Atreus

nefas. tu ne quaesietis, scire netas, quem mili, quem tibi|fincm di dederine, quidquid corrigere est nefas.

antehac nefas depromere Caecubun

quidquid usquan concipitur nefas

et peccare nefas aut pretium est mori.

quatenus, heu nelas, virtutem incolumen odinus,

sed palan captis gravis, heu nefas, heu nocios tar putors Achis

ureret thammis,

ossa Quirini, (nefas videre) dissipabit insolens.

ne redire sit wefas;

nefas. gens lumana ruit per rutitum nefas:

cum fas atque nefas exiguo fine libilimm/ discennmt ivint

omne nefas animo nurentis.

mos et lex maculosum elonut nefas.

ultralquan licet sperare nefis putando

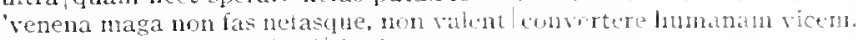
nefasti. quid intactum nefazti| liquimus?

Sirm.2.3.293

Sirm.2.7.58

(arm, $1.29 \cdot 6$

Sirm_2.2.44

Corm.3.7.16

Serm.1.3.I I I

Sirm.2.2.34

Sirm.2.1.20

Ars Pocl.18

Carm.1.35.17

Carm.3.1.I4

Carm.3.2.4.

Carm.1.3.32

Epod.7. Is

Sirmit.4.45

5 sm.s.4.63

sirmititi 25

Sirn 2.6.72

Epist.2.1.79

*nr. Serme.2.0.72

Carm.3.3.12

Carm.1.13.1t

Carm.3.3.34

E Pist.2.2.90

Carm.1.26.7

Carm.1.26.S

Carm.4.11.3

iur.lepod.1 7.72

Carm.1.20.5

Epist.1.19.3I

Ais Poelen

Ars Pod.1S6

Cirm.I.II.I

Cirm.1.24.20

carm.1.37.5

(arm.2.13.9

Carm.3.24.24

(iirma.3.24.30

Carm.4.6.I7

Eporl I s. It

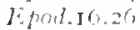

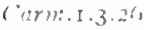

(iorm.I.IS.10)

cerm.3.t.c.s

cirm.t 5.22

Citm.t.11.30

Iipol.5.87

Corm.1.35.35 
nefasto. ille at netante te postut dice

("arm.2.131

negabat. "Iurt" unthes; Cralba negabat.

negabit. Jetr ant igitur. surgetqua? negabit.

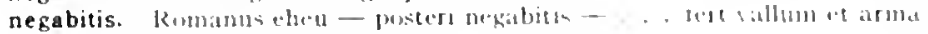
uniles:

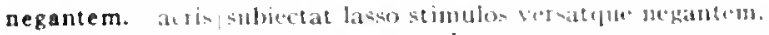

werunt portecta mexantern pecula.

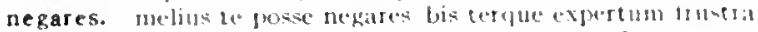

negarit. ot muli torsan tibi quod negarit for

si prodiderte commissa ficle sponsmmse negatrit:

num terum dura negat it versiculos natura

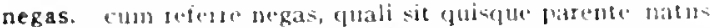

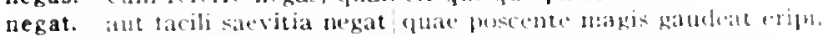

Inon, ut maguit dolo tactum negat esse sub jats.

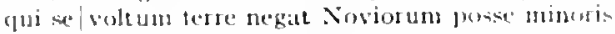

"untue, catelle*" thegat; si non des, optet.

ut salvos regnet vivatque beatus, copi posse negat

"negat injubus et te neglegit aut horret."

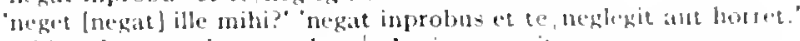

yuiblyud negat alter, et alter, /adnumus pariter.

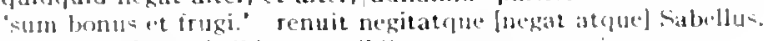

iura neget [negat] sibi nata, nibil non ar roget attuis.

negata. si me paluna negata macrusu, donata felucie ppinum.

negata. in terta lomibus negatal

nerata temptat itco via

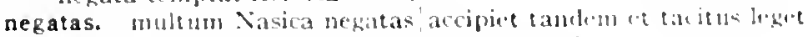

negatis. guis humani sibi doleat natura negatis.

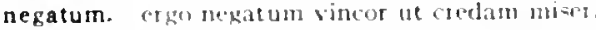

yuid latura sibi, quid ste dolitura negitum.

negaverit. cuanto quisque sibi phuta negaverit.

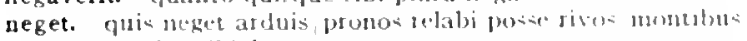

"negret ille" milij."

jelom si chandet turem, neget esse pudiomm.

iura neget sibi nata, mihil non artoget atmis.

negit. "sum bonuset trugi.' renuit negitatque [negit atcuel sabellus.

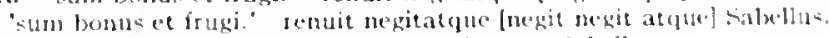

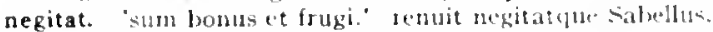

neglecta. neglecta redite l'irtus|audre

neglecta. "treglecta solent incerdia sumere vitus.

neglecti. di multa nerlecti dod.runt flesporiae malia luetuosit".

neglectis. neglectis uenda filix mmascutut agrim.

neglectis. moglectis thagitium ingens.

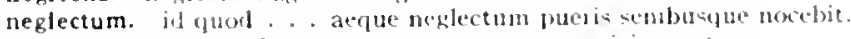

neglectum. sise noglectum genuset nepoles respicis. anetom

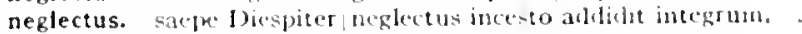

neglegens. neglegurs. ne qua populus laboret.

negleget. non ill., quamquam socraticis malet sermonilsus. to neglegit [negleget] loortidus: .

neglegis. moglegis inmericiz nouturam, postumblo to natis iraudem committere?

neglegit. non ille. . te neglegit horrialus:

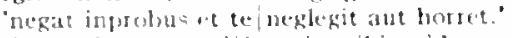

negoti. me forte negoti incutiat tibi quid sanctinmm inscitia le gum:

negotia. aliena megotia centum ject cabut et cheat sahunt hatus.

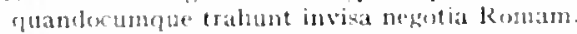

negotia. negotialdiudicata lite relinejuedet

Jerwiua hic pormagna negotia dives habelat, " lacomenis.

aliena mogotia curo'excussus juopma.

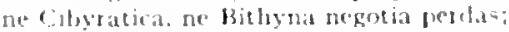

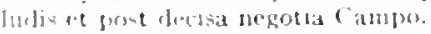

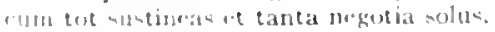

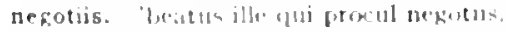

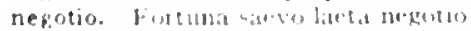

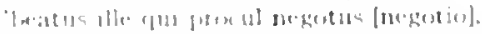

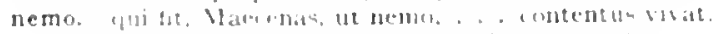

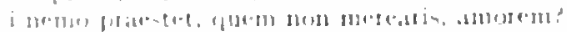

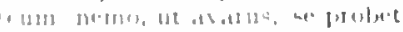

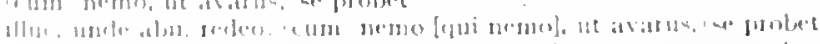

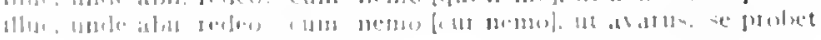

Serm. 1.2 .40

serm.2.3.102

I pod.9. I1

Sierm 2.7 .94

Epist.1.18.02

Irs Pod.430

(arm.2.19.3.

Serm.1.3.05

Serm.3.10.5\%

Sorm.1. (1.

(arm.2.12.26,

Serm.1.0.0)

Serm.1.0.121

verm.2.3.250)

Epist.1.2.11

Epist.1.7.63

tor. Ispist.1.7.6.3

Epist. I.J0.4

rar.fipist.1.16.40

idr.Ars l'ort.j?2

fipist.2.1.181

("ism.1.22.22

("urmi.3 2.22

Sirm.2.5.07

sirm.1.1

Epod.17.2\%

Sirm.1.2 II

(istm.3.10.21

(urm.1.2010

Liptst.1.7.113

toist 1.16 .316

Irs Poel.122

Jur lipist.1.11.40

iver lipist.1.1 (3..40)

tipist.1.10..p

Corm.tidec.58

Epist. I. 885

(isrus 3.6.7

sirm. $1.3 .3 \%$

Sirm.2.482

t.pist.1.20

Curm.1 2.35

('urm.3.2.30

(urm.3.8.25

iur (item.3.21.10

Curm.1.28.30

(idrm 3.21.10

lipist 1.7.0.1

Serm.2. I.80

5 trm.2.0.33

lipist.1.14.17

Curm. 35.53

Sicrm. 1.7 .4

sirm.2.3.10

f.pist, 1, (t. 3.3

t.pist 1.7.50

l.pist 2.1 .1

l: $P(\mathrm{~N}) .2 .1$

(iarm.3 20) W4

iar $t: p i s|z|$

serm 1.1

Som 1.1 ถ⿻

ama serm.1.1 Bus

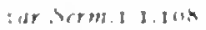

and hen: 11104 
illuc, unde abii, redeo: (cum) nemo. [redeo: nemon] ut avarus, / se probet illuc, unde abii, redeo: (cum) nemo [si nemo], ut avarus, / se probet nam vitits nemo sine nascitur; cum mea nemo|scripta legat neno generosior est te obiciet neno sordis mihi, quas tibi. Tilli, nerno dexterius fortuna est usus. forte epos acer.|ut nemo, Varius ducit; "nemon oleum fert ocius? nemo adeo ferus est, ut non mitescete possit, nemo hoc mangonum faceret tibi;

nemora. quac nemora aut quos agor in specus. nemoris. praerupti nemoris patientem vivere dorso? nemorum. vos laetam fluvis et nemorum cona montium custos nemorumque, virgo, . et spissae nemorum comac

nempe. cui properabantur? tibi nempe. nempe inconposito dixi pede currere versus lucili. 'nempe tuo, furiose?' 'meo, sed non furiosus.' nempe $\mid$ tu, mihi qui imperitas, aliis servis miser nempe inamarescunt epulae sine fine petitae nempe inter varias nutritur silva columnas nempe | vir bonus et prudens dici delector ega ac tu." 'nempe peeus, rem. / lectos, argentum: tollas licet.' nempe ruberes. viveret in terris te siquis avarior uno. nempe modo isto|paulatim mercaris agrum.

nemus. gelidum nenus| Nympharumque leves cum Satyris chori quo nemus|inter pulcra satum tecta remugiat.

nemus. inpune tutum per nemus arbutos|quaerunt folis nemus $\mid$ multis. . tempestas ab Euro|sternet. ut mihi deviolripas et vacuon nemus|mirari libet. circa nenus uvidique | Tiburis ripas tu. cum timenda voce complesti nemus. ego laudo ruris amoeni|rivos et museo circumlita saxa nemusque. Garganum nugire putes nemus aut mare Tuscum: . scriptorum chorus omnis amat nemus et fugit libem.

nenia. nenia, quae regnum recte facientibus offert,

nenia. dicetur, metita Nox quoque nenia. caputque Marsa dissilire nenia.

neniae. Ceac retractes munera neniac,

neniae. absint inani funere neniac

Neobule. tibi telas operosaeque Minervae studium aufert. Neobule. nepos. discinctus aut perdam nepos.

quod aut avarus ut Chrenes terra premam. I discinetus aut perdam nepos [perdam ut nepos].

quod metrice ncpos insanus anica|filius uxorem . . recuset. nec male necne Lepos [nepos] saltet; nec male necre Lepos [nec nepos] saltet:

nepos. Mercuri facunde nepos Atlantis.

nepotem. invisum nepotem. | Troica quem peperit sacerdos, | Marti redonabo; movit nepotem Telephus Nereium,

Pantolabum scurram Nonentanumque nepoten,

nepotes. sive neglectum genus et nepotes $\mid$ rcspicis, auctor victorum nepotes/rettulit inferias Iugurthae. vincet enim stultos ratio insanire nepotes. .

nepoti. I'antolabo scurrac Nomentanoque nepoti. Scaevae vivacem crede nepoti|matrem: quantum simplex hilarisque nupoti|discrepet

nepotibus. ut inmerentis tluxit in terram Reni $\mid$ sacer nepotibus cruor nepotum. in nepotum! perniciem opprobriumque pagi; nepotum | per memores genus onme fastos. ut ventres lamna candente nepotum/diceret urendos

Neptuni. festo quid potius die/ Teptuni facian-

Neptunius. ut nuper, actus cum ireto Neptunius

Neptuno. ab love Septunoque sacri custode Tarenti. parumnc campis atque Neptuno super fusum est Latini sanguinis,

Neptunum. nos cantabinus invicem/ Veptunum Xeptunum procul ex terra sjectare furentem."
Frar. Serm.1.1.108

coni.sirm 1.1.IOS

Sirm.1.3.68

Sirm.1.4 22

Serm. 1.0.2

Serm.1.0.107

Sierm. I.0.45

Serm. I 10 .t.

Sierm.2.7.3.4

Epist.1.1.39

Fpist.2.2.13

Curm.3.25.2

Serm 2.6.91

Carm.I.2I.5

Curm.3.22.I

Carm.4-3.1

Lipod. I 2.22

Serm.I.JO.I

Sirm.2.3.207

Sirm.2.7.80

Sierm.2.7.107

Epist.1.10.22

Epist.t.16.3 I

Epist.1 16.75

Epist.2.2.156

Epist.2.2.103

Carm.1.1.30

Carm.3.10.5

Carm.1.17.5

Carm 3.17 .9

Carm.3.25.13

Carm.4.2.30

Epod.0.9

Epist.1.10.7

Epist.2.1.202

Epist.2.2.77

Epist.1.1.03

Carm.3.28.16

Ispod.17.29

Carm.2.1.38

Carm.2.20.21

Carm.3.12.5

Epod.1.34

tar. Epod.1.31

Serm. 4.49

zur..Serm.2.6.72

s'ar.Serm.2.6.72

Curm.1.IO.I

Carm.3.3.3I

Epod. 7.8

Serm.2.1.22

Carm-1.2.35

Carm.2.1.27

Sirm 2.3.225

Serm.1.8.I I

Serm.2.1.53

Epist.2.2.193

Ipod.7. 20

Carm.2.1.3.3

Carm.3.17.3

Epist.1.15.30

Curm 3.28.2

lipod.9.7

Curm.1-28.29

lipod.7.3

Carm-3.28.10

Ispit. I.IIIO 


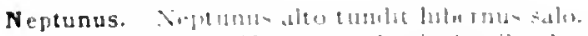

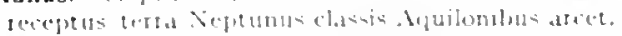

gequam. mond

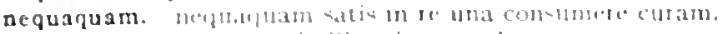

Sirm.2.7.100

serm. $2+48$

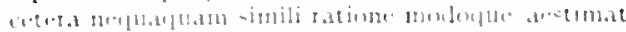

l.pist $=1.20$

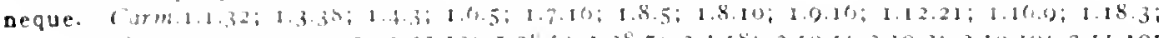

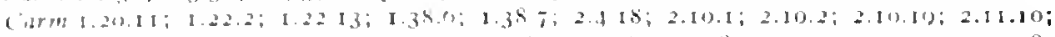

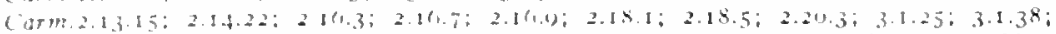

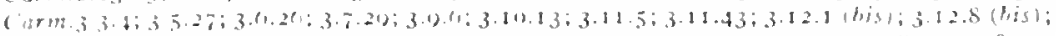

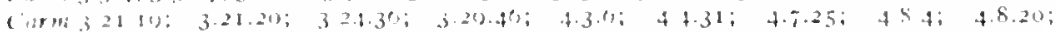

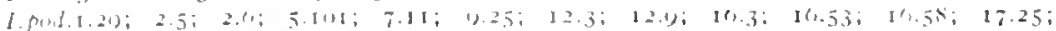

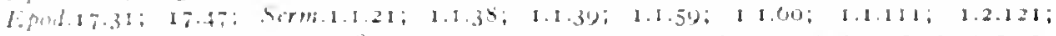

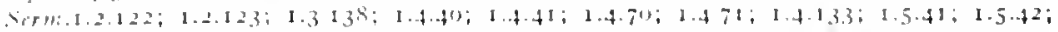

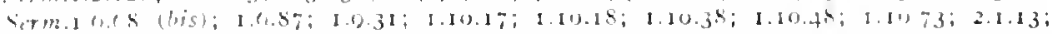

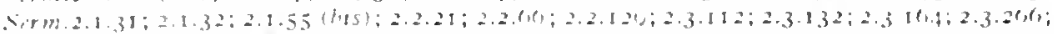

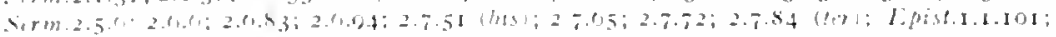

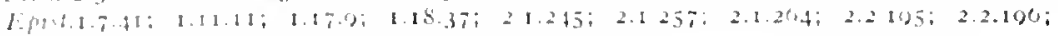
Ars $\operatorname{lnt}^{2}+3$ :

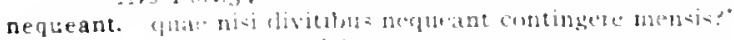

Shm.2.4.8\%

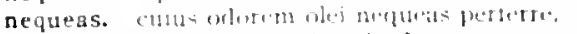

nequeo. virum nerplue dentuire."

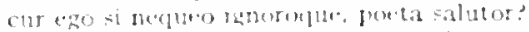

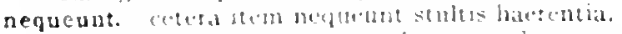

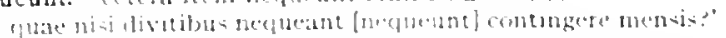

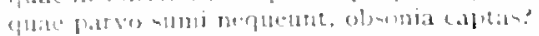

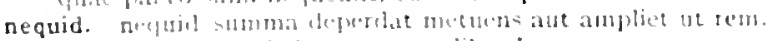

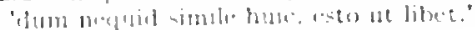

non

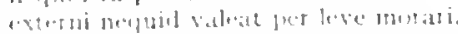

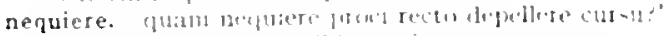

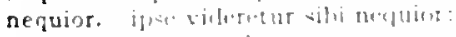

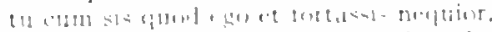

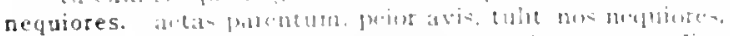

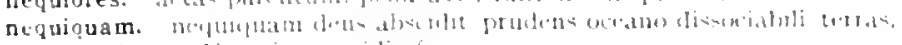

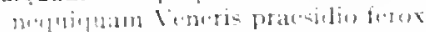

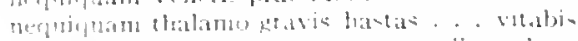

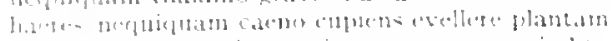

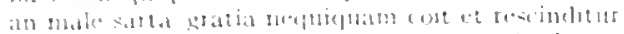

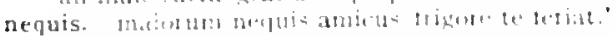

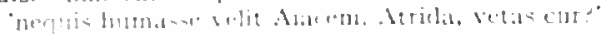

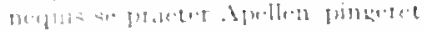

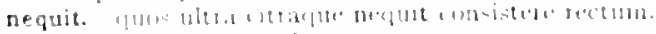

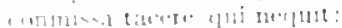

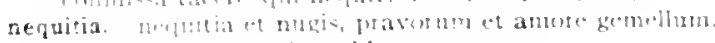

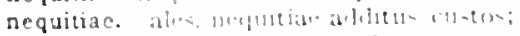

\{am?

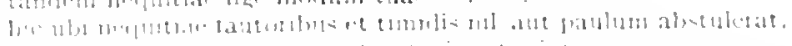

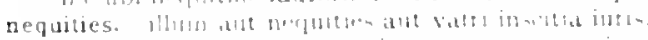

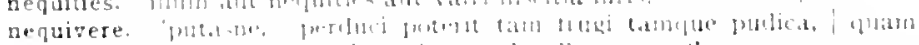

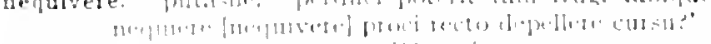

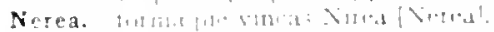

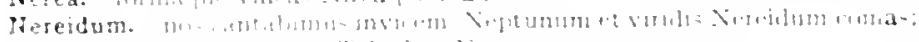

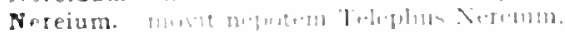

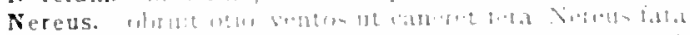

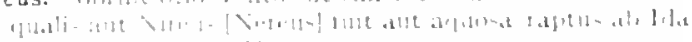

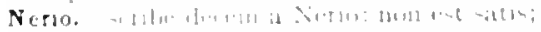

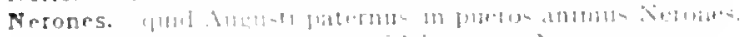

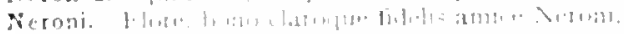

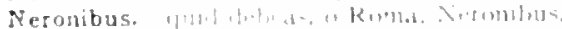

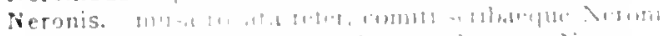

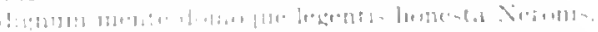

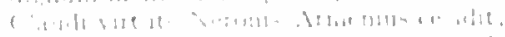

Nefosum. Bhent)

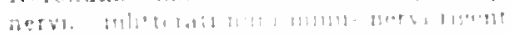

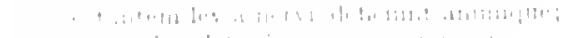

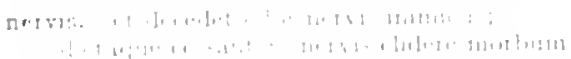

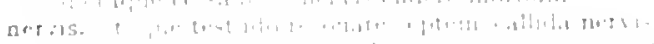

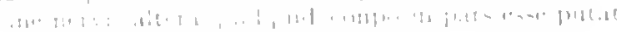

Sirm.2.2.50

Sirm.2.1.7

firs I'orts:

Serm.3.3.7.

itor.sorm.2.4.8.

sirmezitoe

sient-1..4.31

sirme.2.31

Sirm.2.5.37

Sirm-2.7.57

Serm 2-5.78

sermis z.3.0.1

Trem-2.74

Corta.3.11. :

citrm-1.321

(itrm. 1.15 .13

(iurm 1.15.10

Sorw.2.7.27

l. 1.93 .1 .3 .32

Termazicit

arme3 3 is

1.pist.2.2.230

Sirme1.1.117

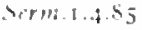

Sirm.2.3244

Cirm.jo.ts

ciarvi.3.15.2

lifist.1.15.3.3

s.rm.2.2.131

:ur.sim.

iar. Leprod $15=2$

(a)m.3 28.10

l.p.hlt 7 . S

cism.1.15.5

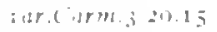

sermezesus

(iorm.: : $:$ s

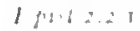

firm of is 37

fitidis

1 (11:11):

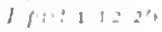

(arm: 1 : 14

f p i 17

irs $1:+1,1 .+$

aren: $2: 53$

$13+4105$

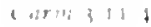

$4,108 \div 1=$ 
duceris ut nervis alienis mobile lignum.

nervos. nihil ultra nervos atque cutem morti concesserat atrae.

Gim.2.7.82

cuius in indonito constantior inguine nervos

nescia. J'irtus, repulsae nescia sordidae.

nescias. nescias an te generum beati Phyllidis flavade decontent parentes:

nesciet. quia parro nesciet uti.

infelix operis summa. quia ponere totum 'nesciet:

nescii. gravem $\mid$ Pelidae stomachum cedere nescii

nescio. curtae nescio quid semper abest rei.

nescio quid meditans nugarum, totus in illis:

in aurem/dicere nescio quid puero.

"certe nescio quid secreto velle loqui te laiebas necum."

nescio an Anticytam ratio illis destinet omnem.

castellum evertere praetor|nescio quod cupiens

nescios. nescios fari puetos Achivis/ureret flammis,

nescire. nec scire [nescire] tas est ommia.

quod magis ad nos pertinet et nescire malum est.

cur nescire pudens prave quam discere malo?

et quod non didici sane nescire fateri.'

nescis. uxor invicti Iovis esse nescis.

nescis quo valeat nummus, quem praebeat usum?

vivere si recte nescis, decede peritis.

nescit. te flagrantis atrox hora Caniculae nescit tangere,

nescit equo rudis haerere ingenuos puer

ut siquis solum hoc, mala ne sint [mala nescit] vina, laboret. iquali perfundat piscis securus olivo.

qui Sidonio contendere callidus ostrol nescit

vel quia naturam nutare pecunia mescit

actor causarum mediocris... nec scit [nescit] quantum Cascellius Aulus,

ludere qui nescit, campestribus abstinet armis

qui nescit. versus tamen audet fingere.

delere licebit, quod non edideris; nescit rox missa reverti.

nescius. sperat, nescius auraeffallacis.

qui nunmos aurumque recondit, nescius uti/compositis

Nessi. quantum neque atro delibutus I Hercules Nesi cruore

Nestor. Nestor conponete litis inter Peliden festinat et inter Atriden.

Nestora. non Pylium Jestora respicis?

non Pylium Nestora [? Nestora Pylium] respicis?

neu. nel sinas Medos equitare inultos/te duce, Caesat.

neu miscrabilis| decantes elegos.

neu populus frequens|'ad arma.' cessantis 'ad arma'|concitet

neu promptae modus amphorac

neu morem in salium sit requies pedum

neu multi Damalis meri

neu desint epuis rosae

neu vivax apium neu breve lilium.

nec [neu] Damalis nusoldivellitur adultero

neu conversa domum pigeat dare lintea.

ne quis fur esset nexu latro neu quis ardulter.

neu se inpediat verbis lassas onerantibus auti.,

neu, . . aut spem deponas aut artem inlusus omitas.

nequid tu perdas neu sis iocus."

cautus arlitul nen desis operae neve innoderatus abundes.

grata sune manu neu dulcia differ in annum,

ne [neu] rolgo narres, te sudavisae ferendo carmina

net. . . occultan febrim sub tempus edendi discinules,

neu fluitem dubiae spe pundulu= lorae."

neve minor neu sit quinto productior actu|fabula.

ne'u quitl merlios intercinat actus

neu pranaa. lamiae vivom puerum extrahat also.

neutram. in neutram partem cultur miser.

neve. newe to notris vitis iniquon ucion aura tollat;

cautus aduch neu desis operate neve inmoderatus abundes.

neve putes alium sapiente bunoure beatum

neve minor neu sit quinto proulutior actu fabulat.

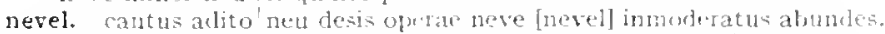

Nevi. non equidem insector delendare carmina Livi [xevi] tsere ment

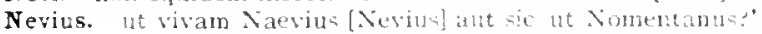

('irm.1.28 13

Jipod.12.19

Cam 3.2.17

Carm.2.+1 3

Jipist.I. I0.4 I

Ars Pott.35

Carmaties)

(intor.3.24.0.1

Serm.1 1.2

Sirm.1.90

Serm 1.9.0\%

Sirm.2.3.83

Evist.2.2.35

(arm.t.1). Is

surecmot +.22

sirm 2.0.73

Irs Joctso

Ars Jaent 118

Cirm.3.27.73

serm.1.1.73

Enist.2.2 213

Corm.3.13.10

Carm.3.24.54

7ar. Sorm. 24.49

ispist.1.10.27

Jpist.1.12.10

adar..Ars Pot.37 I

Ars Port.379

Ars Prit.382

Ars Pret 300

Carm.1.5.11

Serm.2.3.109

Epord.17.32

Epist.I.2.I I

Cirm.1.15.22

isur.Carm.1.15.22

Carm.1.2.51

Carm.1.33.2

carm.1.35.J4

(irm. I.30.1 I

Carm.1.35).12

(arm.1.36.1.3

C(u) 12.315 .15

Carm.1.3p. [r)

zar.Corm. I 3u, IS

Esod.16.27

sirm.1.3.10is

Sirm.1.10.9

Sirm.2.5.24

Sirm.2.5.37

Sirm.2.5.tis

jpist.1.1 23

atr.tist.t. I 3.10

Ipistr.16.21

lpist.1.13110

Ars Jibet. 80

- lers Intejot

Ars Libl. $3 \neq 0$

stmenesir

(")pm-1.2.17

strmenses

A. pis 1.14.20

Ar) Jisel 1 Sog

iter.erm 2.5.kig

rar. Jepist.2 1.60

जor.tern.1.1.101 


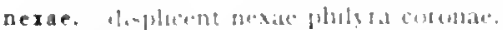

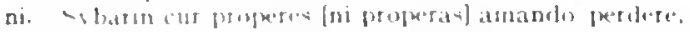

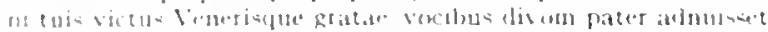

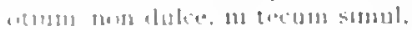

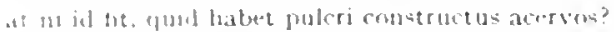

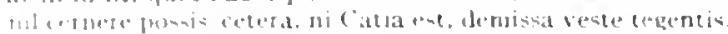

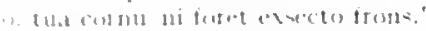

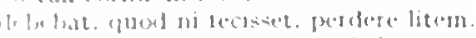

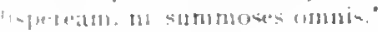

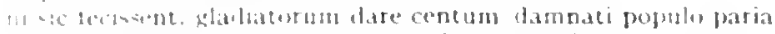

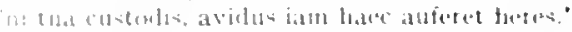

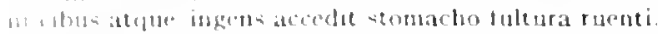

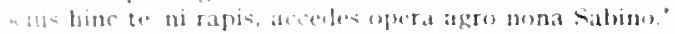

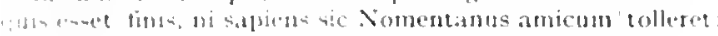

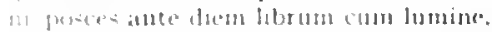

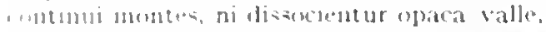

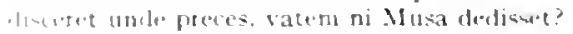

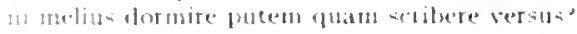

nido. malu labersum protulic inccium

cutas erat rhombus tuturge siconia nido.

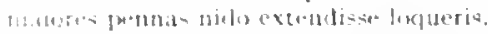

nodore. mon in caro nidote voluptat sumbat sed in te ipres eve.

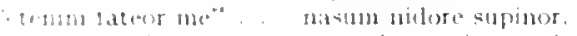

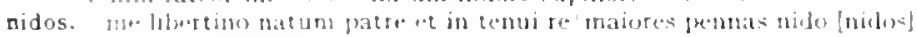

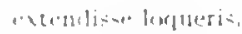

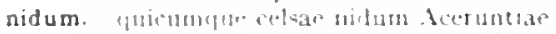

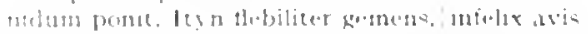

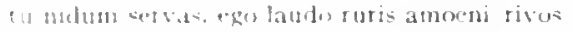

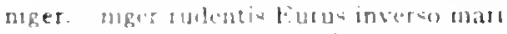

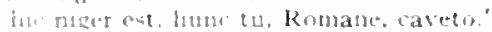

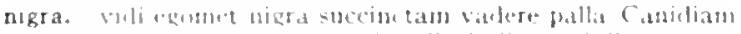

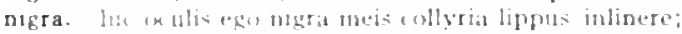

nigrae. nigrate forate trombla in Agrido,

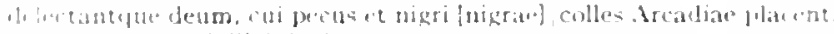

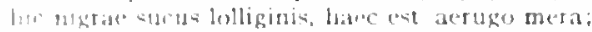

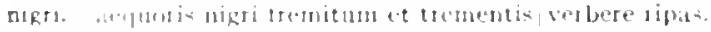

nigrs. math enlles Arcalliae Jlacent.

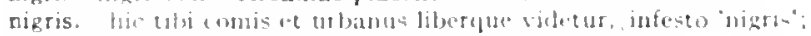

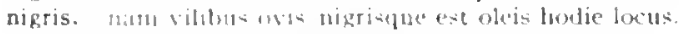

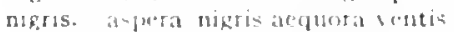

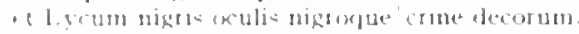

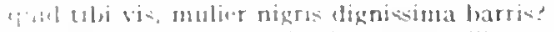

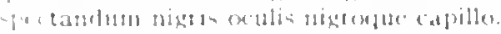

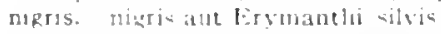

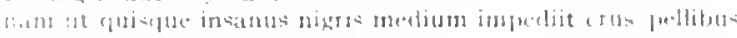

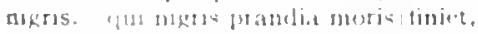

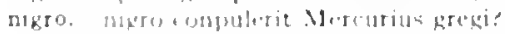

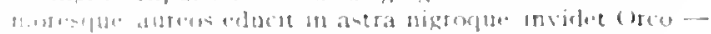

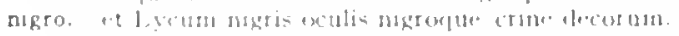

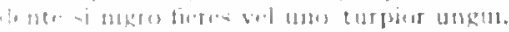

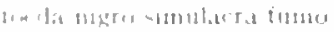

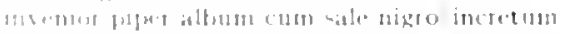

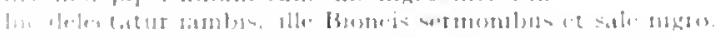

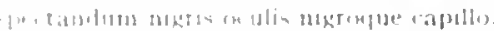

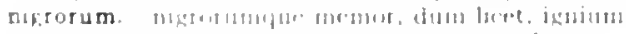

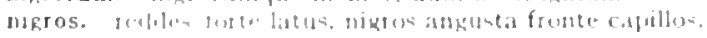

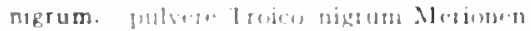

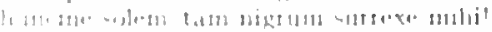

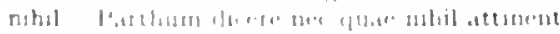

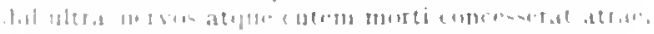

(1) What a

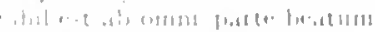

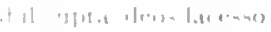

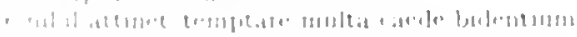

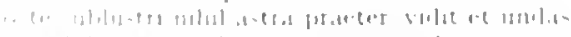

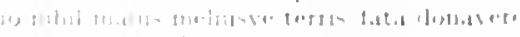

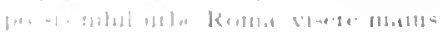

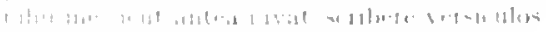

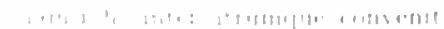

Carm.1.38.2

cons.cirm.1.8.2

Carmato21

lipolis

firm.1 1.44

Sictm 1.2 .95

Sirm. 1.5.59

Sirm 1.1) 37

ferm 1.9.47

Serm.2.385

serm. 23151

Serm 2.3.153

ferm.2.7.118

Sirm $2.8 \mathrm{eO}$

Eptst. 23.4

Epost t. In.5

J.pist.2.1.133

fopird 2.2 .54

Carm it?

Serm 2.2.4?

Ifpist 1.20.2 【

Serm 2.210

firm 2.7.38

sar. I pist. 1.20 .21

Carm 34.14

cirm:12.5

Epiot 1.10.i

liped 10.5

Sirmes.t.5

Sirm I 8.23

virm 1.530

Carm 15 - 5 i

iar Corm t 12.11

Serm-1 1 ito

Curm.32\%.23

Corm+12.11

Sitm.1.9.

term 2240

(arm.1.5.7

(arm.1.32.11

lipod 121

. Irs l'ort 37

(arm.1 217

serm.18.27

term 2.422

(arm. 1.24 is

(arm+2.23

(urm 1.32 I1

(arm.2.83

Curm.3.0.4

strm 2.4 id

lipest : 2 inl

.trs loort.37

(arm i 1220

1. post 1.7 .26

Cisme-1 P. 5

sermit 0.73

(arm 1.1012

(arm 1.25.12

(ij) 1 . 3h 5

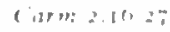

cism: Is 11

(arm.32313

(irm 32\% 3

(ism: 237

ciam sare 11

I. pint 11.1

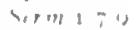


nil [? nihil] sine magno/vita labore [? labore vita] dedit nortalibus." tu nihil in magno doctus reprehendis Homero?

'equidem nihil hinc diffindere possum.

credidit ingens | pauperien vitium et cavit nihil acrias,

mille cadis, nihil est, tercentum milibus,

inriguo nihil est clutius horto.

si veneror stultus nihil horum

iurantem me scire nihil mirantur.

postquam nibil esse pericli|sensimus.

ut nihil omnino gustaremus, .

quod satis est cui contingit, nihil amplius optet.

(nam vina nihil moror illius orae.

tu nihil admittes in te formidine pocnae:

miraturque nihil nisi quod Libitina sacravit.

ut nibil anteferat, nihil illis comparet:

des nummos, excepta nihil te si fuga laedat:

purae sunt plateae, nihil ut meditantibus obstet.'

fugeres radice vel herba|proficiente nihil curarier:

iura neget sibi nata. nihil non arroget armis.

ut nihil intersit. Davosne loquatur et audax|Pythias.

tu nihil invita dices faciesve Minerva:

nihilo. nihilo plus accipias quam |qui nil portarit.

niluilo ut sapientior ille qui te deridet caudan trahat. alterım et huic varum et nihilo sapientius nihito plus explicet cum sis nihilo sapientior ex quolplenior es.

nihilum. "est genus unum|stultitiae nihilum metuenda timentis, stultitiane erret nihilum distabit an ira. imi|convirae lecti nihilum nocuere lagoenis.

nil. nil nortalibus ardui est:

nil desperandum Teucro duce et auspice: unde nil maius generatur ipso nil pictis tinidus navita puppibus / fidit.

nil sine te mei|prosunt honores:

divesne prisco natus ab Inacho| nil interest

victima nil miserantis Orci.

nihil [? nil] est ab onni parte beatum.

nil cupientium | nudus castra peto

nil parvom aut humili modo,

nil mortale loquar.

nil Claudiae non perficient manus,

'contrane lucrum nil valere candidum pauperis ingenium"

volnus nil malum levantia,

plorem artis in te nil agentis exitus?"

nil obstet tihi, dum ne sit te ditior alter.

nihilo plus accipias quam/qui nil portarit. .

'nil satic est', inquit, 'quia tanti quantum habeas sis"

pastillos Rufillus olet, Gargonius hircum:| nil medium est.

nil fuerit mi' inquit 'cum uxoribus umquam alienis.'

tuo vitio retumne labores, | nil referre putas?

matronae praeter faciem nil cernere possis/cetera,

altera, nil obstat: Cois tibi paene videre est/ut nudam,

nil aequale homini fuit illi:

quinque diebus!nil erat in loculis.

nil fuit unquam|sic inpar sibi.

scribendi recte: nam ut multum, nil moror.

nil cum procedere lintrem/sentimus.

nil ego contulerim iucundo sanus amico.

nil illi larva aut tragicis opus esse cothurnis.

nil me paeniteat sanum patris huius,

ut illi nil respondebain.

iamdudum video; sed nil agis: usque tenebo;

nil opus est telcircumagi:

'nil habeo quod agam et non sum piger: usque sequar te.'

nil mi officit,' inquam. | ditior hic aut est quia doctior;

nil sine magno| vita labore dedit mortalibus.'

neque simius iste| nil praeter Calvom et doctus cantare Catullum. nil comis tragici mutat Lucilius Acci?

nil faciet sceleris pia dextera
7 our. Simm. I.9.50

Sirm.1.10.52

Sirm.2.1.78

Sirm.2.3.92

Sirm.2.3.IIt

serm 2.4.11

ferm.2.0.8

50 sm.2.0.57

Serm.2.8.57

Serm.2.8.9t

Epist.I.2.t"

Ispist.I.I5.10

Epist.1.10.53

Epist.2.1.t)

Epist.2.1.0.5

Iipist.2.2.1"

Epist.2.2.7 I

Kpist.2.2.5I

Ars Poel.1 22

Ars Poet.237

. 1 rs Poit.3b5

Serm.I.I. 15

Serm.2.3.52

Serm.2.3.50

Sierm.2.3.274

Epist.2.2.153

Serm.2.3.5t

serm.2.3.210

Som.2.3.41

carm.1.3.37

(arm.1.7.27

Carm.1.12.17

Carm.1.It.It

Carm.1.20.0

(arm.2.3.22

(arm.2.3.24

3 iar.Carm.2.I6.27

Carm.3 I6.2.

carm.3.25.1 ;

Carm.3.25.18

Carmat.73

Epod.12.1 I

Epod.IIIT

Ispod.17.81

Sirm.1.1.t"

Serm.I.I.t?

Germ.1.1.0

serm.1.2.2s

Serm.1.2.57

Serm.1.2.7\%

Serm.1.2.14.4

serm.1.2.101

Serm.1.3.9

Serm.1.3.17

Serm.1.3. Is

Sirm.1.t.I3

Serm. I.5.211

serm. I.5.4t

Serm.1.5.0.t

fierm.1.0.sis

Serm.1.0.1

Sirm.1.0.1.

Sirm. I.0.1"

Sorm.1.g.I

Sirm-1.0.5

Sirm-1.0.5)

Sorme1.10.10

Sirm.1.10.53

rimm.2.1.5t 


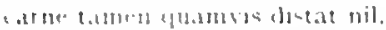
nu! d:

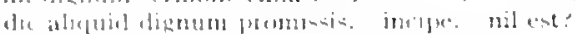

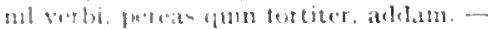

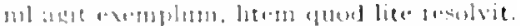

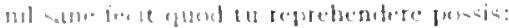

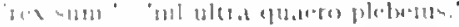

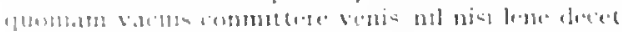

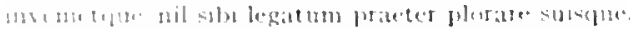

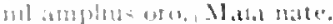

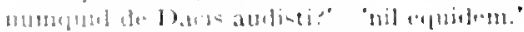
mul e'pos, si dueur libo tumantu: Imbl m.5 sul ic mothemele ut acric potorn.

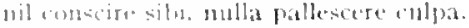

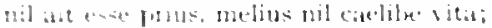

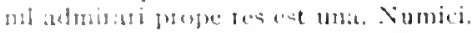

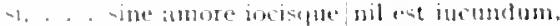

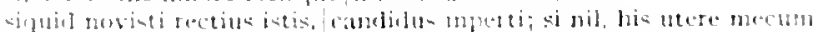

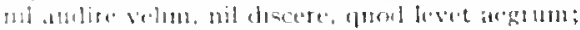

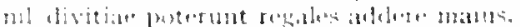

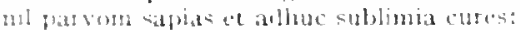

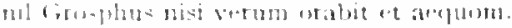

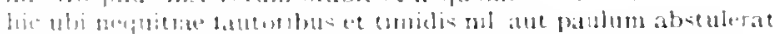

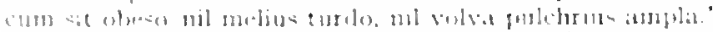

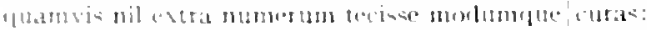

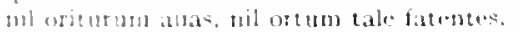

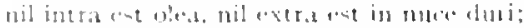

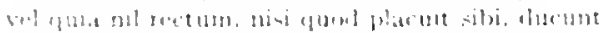

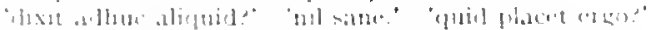

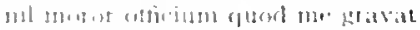

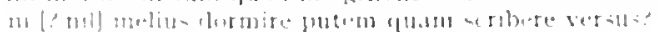

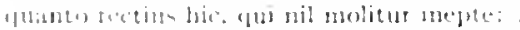

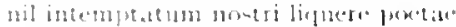

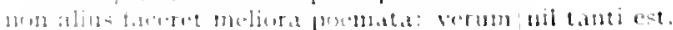

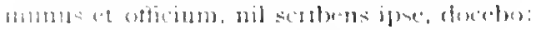

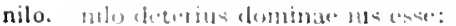

Nilus. sua tomilue rigat anva Xifus.

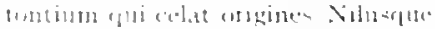

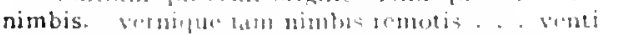

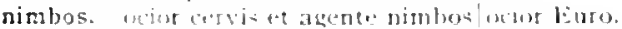

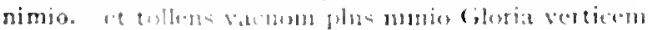

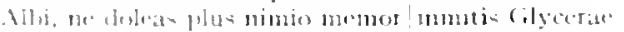

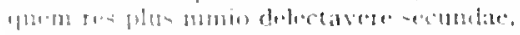

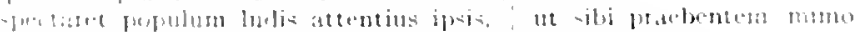

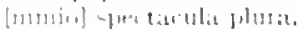

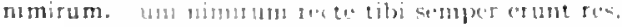

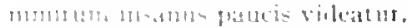

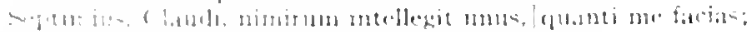

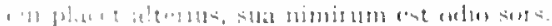

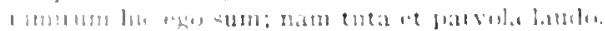

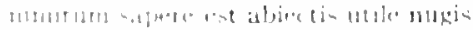

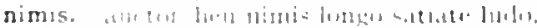

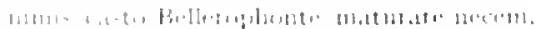

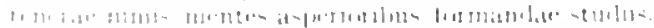

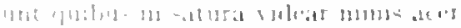

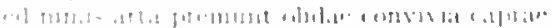

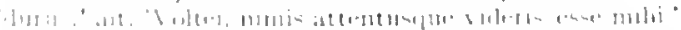

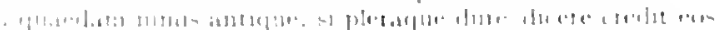

G.

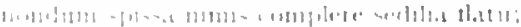

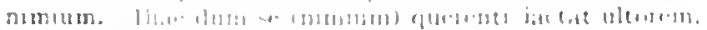

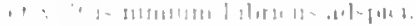

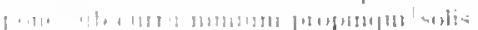

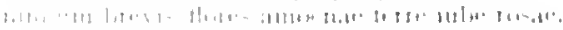

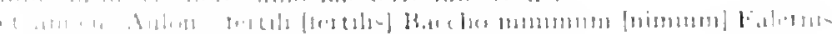
$111:+1,1131$,

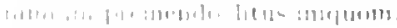

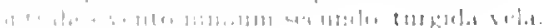

$\operatorname{cirm} 22.20$

term $=3.1$

ani herm $23 \%$

Crom.2.3.

Serm.2.3 103

Sirm.2.3.8.35

Sirm 2.31.8

Sermi.2.1 20

sirm. 2.5.(11)

sirm 2 ro..d

Sirm 29,53

Sirthi.2.7.102

Sirm 2.7.111

Serm 2.tise

Lipet I. I PI

liptor.s.8s

Epist 1.0.1

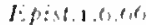

lifist a repes

Epist.1 8.8

Ifpist 1.125

EPtst.1.12.15

lipis/1.12.23

Epro.1.15.3.3

lipst 1.15.4.3

lipiel 1.18.59

lipist.21.17

Ep: : 2.1 .31

I.pis 2.1.83

I:piat 2.1 2ut

I.pis $=1.2 p 1$

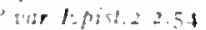

ies l'oit 1 .qu

irs lomedses

lers lintezus

irs leert zon

tirom 1.5.1\%

Cizm 3.3 .45

("arm.1. 14

(arm 1.47

(iirm 2.111.23

(umm 1 18.15

(arm.t.33.1

Jist 1.1031$)$

:3r lifist 2. I 119

rern.2: lam

Yrm 2.3120

tipivt a 1

l. pout 11.411

1 pid $1.15:$ :

l: 13022.2111

(i)m.1.23

(i3) 3714

(itrm:3.2.430

serm: 11

1.pist 1.520

H. खो का

1 pul 1 pit

f.pouz $212=2$

ire lowe? Ins

( a

(iorn: 1 10) 5

( $137 \mathrm{~m})+231$

1 14012313

or cism arm 10

(.)

(.1, n $111 ?$ 
ne nimium pii rebusque fidentes. parce privatus nimium cavere abes iam nimium diu; quod nimium institerat viventi.

parcus ob heredis curam nimiumque severus $\mid$ adsidet insano foro nimium clistare Carinas/iam grandis natu queritur. serpit humi tutus nimiun timidusque procellae: aut nimium teneris iuvenentur versibus umquam aut operae celeris ninium curaque carentis aut operae celeris nimium [nimium celeris] curaqu anentio | ant ignoratae premit artis crimine turpi.

nimium patienter utrumque.|ne dicam stulte, mirati. nimium. nec saevos Lapithas et nimium mero|Hylaem

Niobea. proles Niobea magnaelvindicem linguae. . sunit

Niphaten. nova|cantemus Augusti tropaea|Caesaris et rigidum Niphaten Nirea. formaque vincas Nirea.

Nireus. qualis aut Nireus fuit aut aquosa raptus ab Iia. (it)m.3.3.5s

carm.3.8.20

(arm $\cos +4.5 .2$

S.rm.2.5.88

Efist 1.5 .13

Epist.t.7.48

Irstroct.28

Irs I'oet.2s'

los Port.201

aller.trs Poet.zor

los Poet.27I

Cirm.2.12.5

(itrm t.0.1

(in rm.2.0.20

Iford.15.22

Citm.3.20.15

nisi. Carm.1.10.9; 1.I 4.15; 2.2.3; 2.2.14; 2.17.28; 3.17.I2; 3.27.63; Efmd.7.12; Som.1.2.28;

Serm.1.2.30; 1.3.85; 1.3.87; 1.3.134; 1.7.47; 1.4.73; 1.5.70; 1.7.14;2.1.18; 2.1.52; 2.1.78;

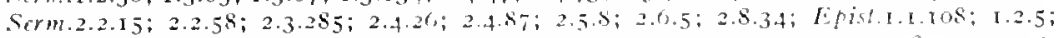

Epist.1.2.54; 1.2.62; I.5.27; 1.12.23; 1.16..40; I.19.7; 2.1.21; 2.1.44) ? 1.83; 2.1.115;

Epist 2.2.100; Ars Port.191; 476

nisu. carmina conpono, hic elegos: mirabile risu [nisu] caelatumque novem Musis opus.

nisus. insolitos doctere nisus/venti paventem.

(nilitist.2.2.0T

('arm.4.4.8

nitantur. non ut iuvencis inligata pluribus aratıa nitantur meis.

nitedula. per angustan tenais volpecula [nitedula] rimam rejustat in cumeram irumenti.

nitens. non Chloris albn sic unero nitens

nitent. gratior it dies et soles melius nitent.

verum ubi plura nitent in carmine.

nitentia. aetas, defodict condetque nitentia.

nitentis. coronatus nitentis/malobathro Syrio capillo:

nitentis. interfusa nitrntis/vites aequora Cycladas.

discite non inter lancis mensasque nitentis.

nitere. oratus multa piece nitere, porro/vade;

nites. miseri, cuibus intenptata nites.

nitescere. quae/desperat tractata nitescere posse, relingut

nitet. neque uno luna rubens nitet/roltu:

res ubi magna nitet domino sene:

deterius Libycis olet aut nitet herba lapillis?

niti. et docuit magnumalue loqui nitique cothurno.

nitidem. siquis lectica nitidam gestare amet agnam.

nitidi. quem tenutes devere togae nitidique capilli.

nitidis, dare bracchia|ludentem nitidis virginibus .

nitidis. quorum conspicitur nitidis fundata pecunia rilli-

nitido. nee nitido filit alliliuro:

nitido. curru nitido diem quil pronis cet celas

ex nitido fit rustirus

nitidum. -pissa te ntichum coma.

m. pinsuem et nitichm bune curata cute viun.

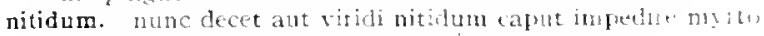

nitidus. nitidus qua guisque per ora'cederet.

nititur. coratis ope Daedalea nititur pennis

nitor. urit me Glycerae nitor

stulium aufert. Neobule, Liparaei nitor Hebri,

nituistis. quanto aut ego parcius aut vos. 10 pueri. nitui-t:-

nivalen. stu bruma nivalem interiore diem gyo thahit.

nivali. nam quae nivali pascitur Algido/derota

nivali. Hebrusque nivali compede viuctus

nivalibus. facit quod prenula solstitio campestre nivalibu- wuth.

nivalis. leporen citus, venator in campis nivalis, Haenonian.

nive. vides ut alta strit nive candidum / Soracte

Hebrum prospiciens et nive candidam / Thracen

Memplin carenten Sitlonia nive.

nee flurii strepunt hibrrna nive turgidi.

"leporem venator ut altalin nive sectetur.

'tu nive Lucana dormis ocreatu.

I.poli, [.20)

(unilfrivt.7.20

(ammis $5.1 \mathrm{~s}$

(a)mat.s

los Poth is I

lipist 1.13 .25

Carm.2.7.7

(irm.1 19

smm.2.4

Fpi:t 1.I3.18

Cirm.15.13

los lout. I50

(Urmi.2.I1.ID)

Sirm.2.5. 2

Histito.to

Irs Iot 280

serin 23217

I PA. I 1432

(i)rmaI2.1Y

I.pist. I 5 th

(urrin 32420

(urm.ciario

Epist. 783

(vim.3.10.25

Epist. +15

(armato

riem.2.1.4

(a) 253

('1)m.1.10.5

(irm.3.12.t?

srm 2.2.128

Sirpez:2.6.25

(iirm.3.230

l. pist.1.3.3

Epist.11.1.

(rirm.x.3.10)

(izrmber 9.1

(i:ym-2.25.20

(

(aris) $+1=4$

sermer.z.10"

งirm 2.3.234

rem:zit 


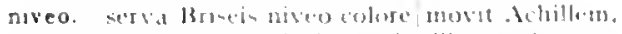

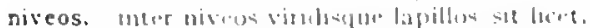

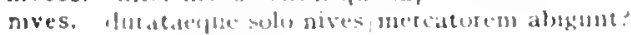

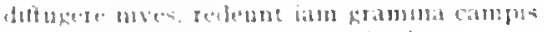

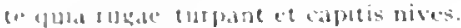

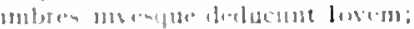

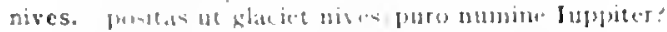

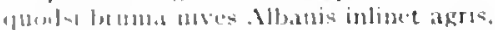

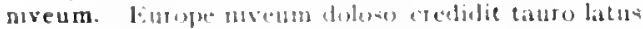

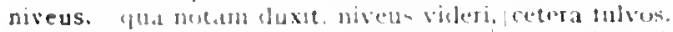

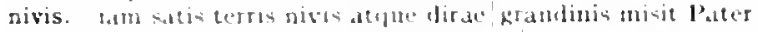

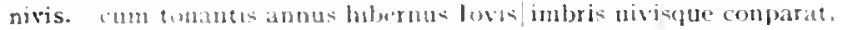

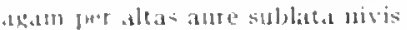

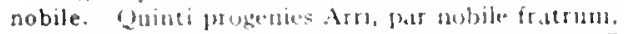

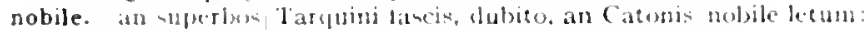

fortuan ['riami cantabe en mole bellum."

nobilem. bunce equis, illum sujurate pugnistnobilem;

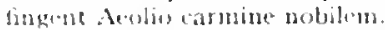

nobilem. te lamse prope nobilen tuncill Lucesiam.

aut illя requtun nobilem Cretam trbibus

nobiles. nob!ls [nobiles] libros $1^{2}$ anatet focratican et dormum mutum loticts Hiberis.

nobilibus. hice ee in Acci nobilibus tmmetris astparet sarus

nobilis. nimmene et nobilicet decens.

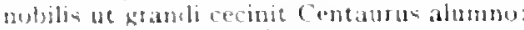

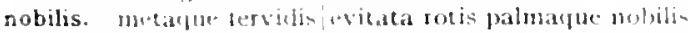

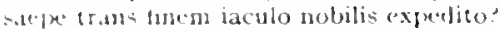

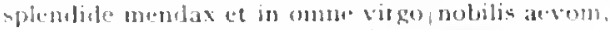

nobilis. coxnuptur usdique nobilis librow Panaed

nobilis. 1'ontica pronts, cilbate filial mobilis.

nobslis. Aeli retunte mobilis ab I, atmo -

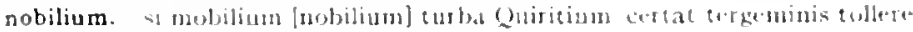
hasuribus:

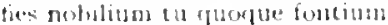

inveruntm nobilium clems.

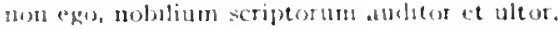

nobis. metire nobis ('acenbum.

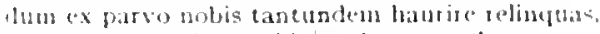

an ut igmotum lare nubis, verba putas?"

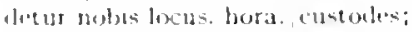

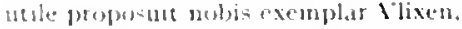

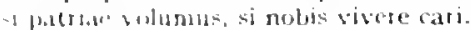

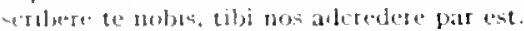

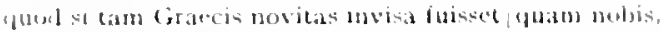

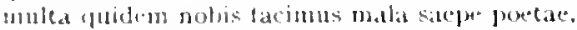

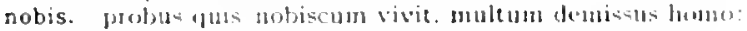

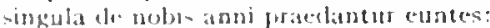

noceant. nam vartale res ut nxcant hommi, credas,

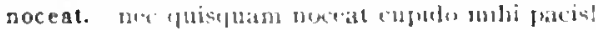

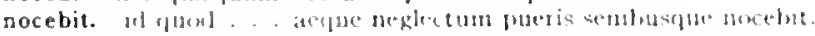

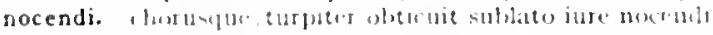

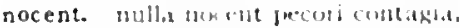

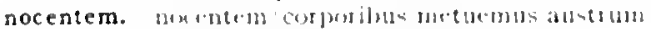

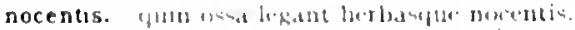

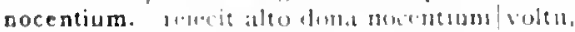

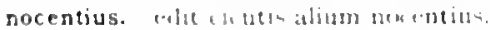

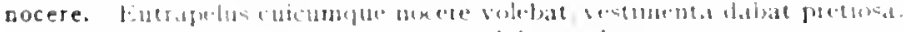

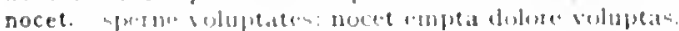

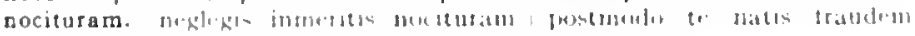

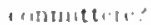

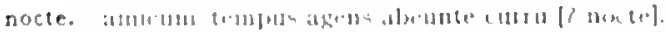

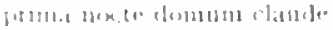

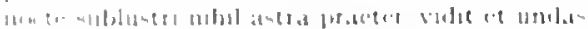

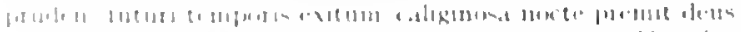

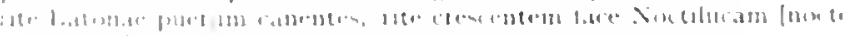
l11.?.11!

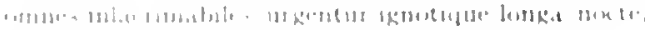

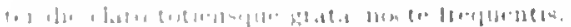

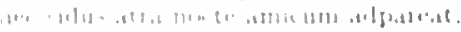

( is?m.2.+4.3

Serm.1 $2 . \mathrm{K}_{11}$

(ism.3.2. 34

(arm.tit 71

Cism.4.13.12

lipol.132

corm 3.10 .7

lipist.1 7.10

(asm.3.27.25

(isrm.t.2.5s)

Cism 1.2.1

fopol.2.30

1:perd.1.7.7

serm.2.3.243

Corm.1.12.36

Ars $104 t .37$

(arm.1.1227

(arm.4.3.12

(arm.3.15.1.3

1. pod.1).24

Itur. (arm.1.20.1.3

Irs loct.250

(armatil 13

f.poll.13.11

( iurm.1.1.5

("arm.1.8.12

Corm.3.11.3e

(is rm. 1.29 .13

(is)m.1.1412

carm.3.17.1

Fur (itrm 1.1.7

(a)m 3.1313

(urnt+12.15

Lipist.1.10.30

fiperd 0.36

sirm 1.1 .52

Sirm. 3.22

sorm 1.4.15

Epest.1.2.18

fipd 1.3 .29

Iipost.t.15.25

Ispost.2.1.01

Iffot.2.1 210

sirm.1.3.57

I.pist 2.2 .55

Sirm.2.2.72

sirm 2.1.44

fopst 1 1.20

. Irs l'set.28.

l.poldenenter

(iarm.21.15

Sirm.1.822

(ist) 10.92

lipind 3.3

lipes its

f:put 2.55

(i) 12430

Past Cism 3 P. 4.1

(arm. 37 2u

( 1.17).3.27.31

( 1117,3 21) 311

:ur ( arm $m, 0.34$

(at). a 28

(a) in tidec.2.t

1 pin! 1no 


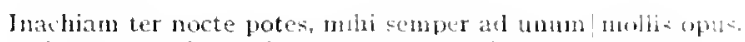
mule usor media currit de nocte vocata." ut iugulent hominem, surgunt de nocte latrones: media le nocte caballum arripit [rovores bibuli media de note lialerni]

noctem. lenesque sub noctem susurri urget diem nox et dies noctem ambulet ante noctern cum facibus.'

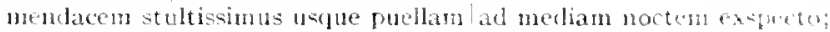
post mediam noctem risus, cum somnia vera: iniguonque mero sub nocten corpus habento. sub) nocteru qui puer uvan|furtiva mutat strigili: inpure licent/aestivan sermone benigno tenkese nocten. noten pecatis et fraudibus obice nuben.' emptis sub noctem gelidan lignis calefactat atenum;

noctes. "me tuo longas pereme noctes, Lyedia, dormis?" frigrlas noctes non sine multisl insomnis lacrimis agit. won teret adsieluas potiori te dare noctes noteritue diesque formidure malos huses, incentia,

noctes. "noctes renaeque deum.

Noctiluca. rite Latonae puerum canentes, rite creacentem face foctilusm [Nuctiluca].

Noctilucam. rite crescentern face Soctilucam.

noctis. toto taciturna noctis/signa cum caejo. lia nocis mediae.

noctis. noctis vigilabat ad ipsum mane, dietn totun stertebat.

noctu. hrsus dum noctu stentit, ad asen perdiderat:

nocturna. nucturna siquid crassi enst tenuabitur aura ros extmplaria Graeca nocturna versate manu, versate diurna.

nocturnas. plumamque nocturnae strigis . . aduri plomamoque nocturnae stigis [strigia nucturmae] . a aduti

nocturnam. tum inmundo somnia vish | nocturnam vestem matritom ventremque supinum.

nocturni. Vibis aventes moena nocturni subrepere.

nocturnis. munierant satis nocturnis ab adulteris.

noctirnis. nocturnis ego somnis, iasu captum tenco.

nocturno. penetralia sparsise noturno cruore huspitis;

nocturao. ut pura nocturno reniclet luna mati

nocturno certare mero, putere cliurno.

nocturnos. quamia nocturnos iures te formidare tumes.

tu mo inter strepitus noctarnos at qua diurnos vis canore

nocturnos lemures portentanuc lihessald rirlis?

nocturnus. nocturnus occurram Firmer

et gui nocturntis sicta chom legetit.

nocuere, ind convivae lecti nitilum mocuere lagoenis.

quac nowlere sceluar, fugian cluate protore credan;

nocuisset. ulla si iuris tibi peicrat poena. Barine, nocuistet umbuam, itatus Grais quantum nocuisset lehills.

nodo. whatust, in comptun [inconptam] Lacaenae/more comas [comats relizata nolum [nodo].

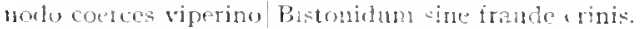
murteun nodo colnbere rinem;

quo ten'an voltus mutantem loretea nodo?

nodosa. nec, . nolowa corpus nols prohibere cheragra.

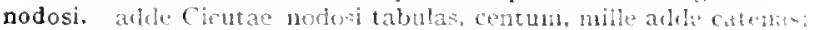

nodum. in conptum Lakenat mor comas religata mown.

segresclue nodum solvere Giatine

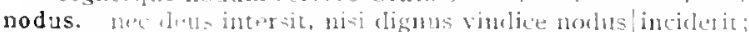

nolent. ceia. quid statis?" - nolim [noient].

noles. si noluzsanus, curres hydruticits;

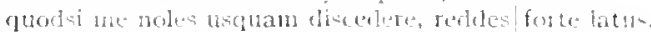

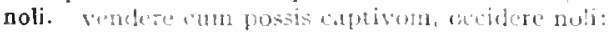

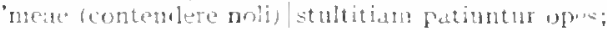

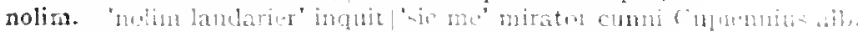

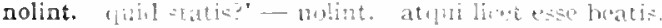
sunt qui molint tatigise nini illis

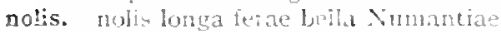

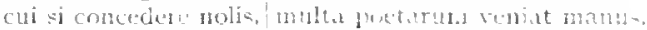

nee, . . norlosa corpus nolis fundube theragra.
I.poti.t2.15

s.rm.2-3.238

J:Pi.t. 1.2 .32

1.sin 1.7 .88

iar Eitist 1.1S.g.

(erm-1.0.11)

L.pod. 57.25

Sim.1.4.52

S.rm.1.5.8.3

s.rm.1.10.33

Sirm.2.1.0

(1)m.2.7. I0y

loist. $5.1 \mathrm{I}$

E.P.st.1.16.02

lipis a 2.1 rog

Cimm.1.25.7

carin 3.7.7

t.pul. 15.13

Sormines 1.70

4rom.2. 2.05

ar.comate 38

(a)m.4. (a.3)

Commes.no

(urma.jonto

Sim. I.3.i i

Spist.2.2.27

Serm.2. 9.52

- be Poct. 200

Epoti.5.20

W.I.POA. $5=0$

serm.1.5.85

Sirm.2. 1001

(ii) $\mathrm{m.3} \cdot 10.4$

(am). 1.3)

(iorm.2.13.)

(c)m.2.5.19

l. pist.1.19.1

Znivi.1. $\$ .93$

Ifpis. 2.2.70

1.pi:1.2 2.200

l. 1.016 .5 .912

Simis.3117

S.7.2.2.8.4i

J.pis.t.k.1 t

('trm.2.8.2

1.t.2. $2.2 .4^{2}$

iunt Corm.2.11.24

('irm.2.10.10

(tam.3.1.4.22

fopict togo

1.pist.1.1.3 I

(rrmaz-7o

(

(itr) 3.21.22

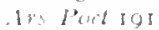

(i) Strmaldis

I.f. 1.1 .1 .2 .3 .7

lipint 1.2.25

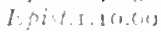

I pint 1.19.23

S.rni.1.2.35

(C) I.I. II)

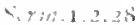

(i) (i)

(5.).r.1.1.1.40

f.'Pl.1.1.3. 


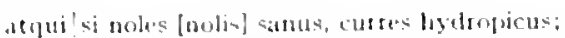

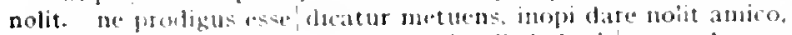

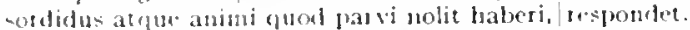

"leporens inatur ut alta in nive sectetur, positum sic tangere molle"

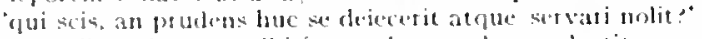

nolite. nolito arl vetsus tibi factos ducete plenum lactitas:

nollem. Imustus fascibus et sellis mollem mihi sumere.

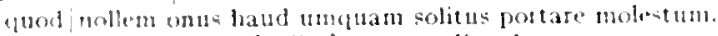

nolles. quorlat me moles [nolles] usquam disceder.

nollet. "si prambetet holus patienter, regibus uti' nollet Aristipus."

malo gua" nollet carmine quenquam/describi: .

noluit. noluit in Flavi ludum me mittere.

nolunt. sunt qui molint [nolunt] tetigisse nisi illas/ quarum subusa tahs tegat instita veste.

nomen. 'pater. o relictum f fliae nomen

per quas latinum nomen et Italac icrevere virs's

alut viths nomu'n inane est.

sic homot "t noma divinis vatibus atque /caminibus venit.

nomen. cuius recinet iocosa! nomen imago

iactes et genus et nomen inutile: .

anne capix movet urna nomen.

horrenda late nomen in ultimas execndat oras,

mihi l'hoebus artem!carminis nomenque dedit poetac.

'qui donita nomen ab Árica/lucratus redit.'

sectus occupat nomen beati qui deorum/numeribus sapieneer uti

llia et Fereria est; do nomen quodlibet illi.

istilertori nomen virtus posuisset homestum.

qui duvit ab oppressa meritum Kathagine nomen .

qui thi nomun insano posuere.

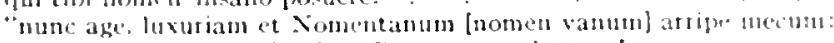

"ede hominis nomen, simulet, Romannk an hospes"

insani sıpicme nomen ferat, aeguos imqui,

i velles" isfquit serum mili ponete nomesu.

fons etiam tivo date nomen idonens,

surandatume tuom per numen [momes] ponimus aras,

signat um prasente nota procudise nomen.

unde etian trimetris accrescese iussit nomen iambeis,

manciscet ut enim pretium nomerulue poetae.

Nomentano. l'antolibo seurrae Nonentanoque nepoti.

Nomentanum. Pantolabum scurram Nomentanumque nepotem. tu Xom.ntanum. tu ne sequerere Cicutam.

"nunc age, luxuriaun et Xomentanum arripe mecum:

Nomentanus. Ht vivan Naevius aut sic/ut Nometutanus?"

Nomentanus rat super ipanm, l'orcius infra.

Conentants ad hoc, qui, siquid forte lateret. indice monstrate dienitu: ni sapirnu sic Xomentanus amicum, tolleret:

nomina. Cua sect us or bis / nomina ducet."

nititur pennis vitreo daturucl nomina ponen.

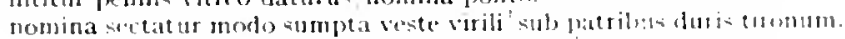

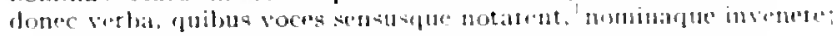

mercomur servom, qui dictet nomina.

nova rentum mosnisa ptotulerit?

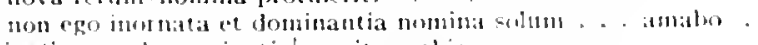

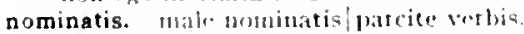

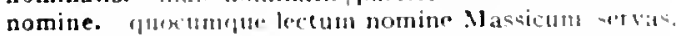

inpun ut bilwan nomine inpleris neo?

nututes nomine de te [abu\}a nam ratur:

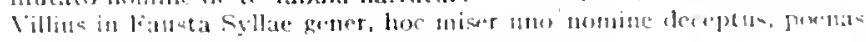
ateilst

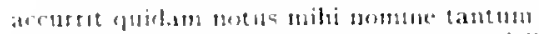

munc a

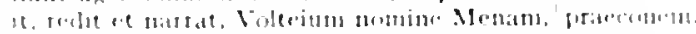

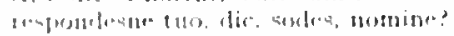

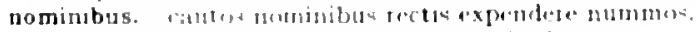

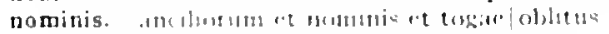

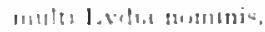

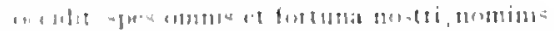

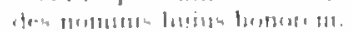

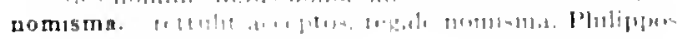

sor. Fpist.1.2.34

Serm.1.2.5

Sirm.1.2.Ju

Serm.1.2.10\%

Ars Pod at 3

Irs $\operatorname{loct} 127$

Serm.1.0.07

serm I trov

sar. Epist.t.7.25

Epist.1.17.14

Lipist.2.1.153

Sirm. I.6.72

3ar.Serm.1.2.28

Carm.3.27.35

Carm.4.15.13

L.pist 1.17 11

Ars l'ocl.too

(iurm.1.12.4

(arm.1.1 13

(arm.3.1.16)

Carm.3.3.45

Carm.4.6.30

Carm+18.18

Curm.1.9.47

ferm.1.2.126

Serm.1.3.12

serm.2 1 (in)

Term 2.3.47

inr.serm. 2.3.221

sirm.2 + 10

Epist 0.15

Epist. 1.7 .93

1.pist 1.10 .12

sur tist.2.1.10

irs Poot.59

lirs Poit 2.53

- Irs Poel zos

Serm.1.8.11

Sirm.2.1.22

Sirm.2.3.175

Serm.2.3.224

Serm.3.1.102

Sierm.2.8.23

Serm.28.25

serm.28.60

Cirm.3.27.71

(ivem.t 2.4

Sirm.1.2.11

term. 1.31 las

Epist.1.1.50

- Irs Poet 5 s

Irs I'od.23.4

Carm.31.11

ciorm.321.5

I. pod 17.50

strm.1 1.80

Norm.1.2.15

Sorm.1.9. 3

serm.2.2.13.3

I:pid1.755

IEprots 10 31

lipted.21 115

( arm 3.5.14

(.10m.307

(armatis

sim 14.14

l.pistav1.23 
non. Carm.1.2.19; I.3.15; 1.3.24; 1.3.35; 1.6.20; 1.13.13; 1.14.0; 1.14.10; 1.14.18; I.15.21; Carm.I.I5.22; I.15.26; I.I5.32; I.I6.5 (bis); I.I6.7 (bis); I, I8.6; I.I8.9; I.I8.II; coni.Carm.1.20.10; Carm.1.22.2; 1.23.3; 1.23.9; I.24.11; 1.24.17; 1.25.16; 1.27.13; Carm.1.27.1.5; 1.28.14; $128.33 ;$ I.28.35; 1.29.3; I.31.3; 1.31.5; 1.31.1; 1.31.7; 1.36.8; Carm.1.37.32; 2.1.22; 2.1.29;2.1.35; 2.3.2;2.4.I7:2.5.17:2.5.18; 2.6.14; 2.7.10; 2.7.26: Carm.2.9.1; 2.9.13; 2.10.17; 2.II.9; 2.II.13; 2.I4.5; 2.I5.10; 2.16.7; 2.16.9; 2.16.39; Carm.2.I7.9; 2.IS.I; 2.I8.3; 2.I8.40; 2.I9.I5; 2.I9.20;2.20.1; 2.20.5; 2.20.0; 3.1.2; Carm.3.1.18; 3.1.20; 3.1.22; 3.1.24; 3.1.29;3.3.2; 3.3.3; 3.3.60;3.4.20; 3.4.26; 3.4.27; Carm.3.5.17; coni.Carm 3.5.17; Carm.3 5.23; 35.50; iar.Carm.3.6.10; Carm.3.6.29; Carm.3.6.33; 3.6.45; 3.7.7; 3.7.25; 3.9.5; 3.9.1I; 3.10.1 I 3.10.19; 3.1 I.39; 3.13.2; coni.Carm.3.I4.II; Carm.3.14.27; 3.15.7; 3.15.14; 3.16.5; 3.19.2:3.19.24; $320.1 ; 3.21 .9$; Carm.3.23.Is; 3.24.7; 3.24.8; 3.24.34; 3.25.8; 3.26.2;3.29.2; 3.29.38; 3.29.45; 3.29.57; Carm.3.30.3 (his); $3 \cdot 30.6 ; 4.1 \cdot 3 ; 4 \cdot 1.1 .4 ; 4.1 .24 ; 4.2 .50 ; 4.3 \cdot 3: 4.3 .4 ; 4.4 .01 ; 4.4 .69 ; 4.4 \cdot 73 ;$ Carm.t.6.13; 4.7.23 (tor); 4.8.9 (bis); 4.8.13; 4.8.15; 4.8.17; 49.3; 4.9.5; 4.9.13; Carm.4.9.18;4.9.19;4.9.21;4.9.30;4.0.39;4.9.45;4.9.51;4.10.7; 4.10.8;4.11.22:4.I1.33; Corm.4.12.22;4.13.27;4.14.41; 4.14.49;4.15.17; 4.15.19; 4.15.21; 4.15.22; 4.15.23; Carm.4.15.24; Epod.1.8; 1.10; I.21; I.25; $2.37 ; 2.49 ; 2.53 ; 2.54 ; 4.0 ; 5.41 ; 5.50 ; 5.59$; Epod.5.73; 5.81; 5.83; 5.87; coni.Epod.5.87: Epod.7.5; $9.30 ;$ I0.I 7; I I.21; I I.25; I 2.25: Epod.14.9:20ar.Epod.14-10;Epod.14.12;14.13;15.13;10.57;16.59.173; 7.54;Serm.1.1.35; Serm.1.1.37; 1.1.40; 1.1.54; 1.1.84 (bis); 1.1.87; 1 1.95; 1.1.97; 1.1.103; var.Serm.1.1.108; Scrm.1.1.121; 1.2.17; 1.2.20;1.2.22;1.2.34;1.2.38;1.2.49;1.2.60; 1.2.75; 1.2.119; 1.3.5; var.Serm.1.3.25; Serm.1.3.33; 1.3.44; 1.3.62; 1.3.77; 1.3.121; 1.3.126; 1.4.35 (bis); Serm.1.4.54; 1.4.60; 1.4.70; 2ar.Serm.1.4.73; Serm.1.4.7.; 1.4.82; 1.4.84; 1.4.1 1.4; 1.4.136; Serm.1.5.33; 1.5.80; 1.5.87; 1.5.91; 1.5.101; 1.6.1; 1.6.14; $1.0 .21 ; 1.0 .22 ; 1.6 .24 ; 1.0 .49 ;$ Serm.1.6.52; 1.6.58 (bis); 1.6.64; 1.6.84; 1.6.90; 1.6.01; 1.6.1 19; 1.0.124; 1.0.127; 1.7.14; Serm.1.7.19; 1.7.34; 1.8.17; 1.8.44; 1.9.17; I.9.19; 1.9.22; 1.9.23; I.9.41; 1.9.48; I.9.57; Serm.1.10.3; 1.10.7; I.10.34; 1.10.54; I-10.55; 1.10.76; I. I.0; 2.1.19; 2.I.45;2.2.4; 2.2.19; Serm.2.2.62; 2.2.65; 2.2.89; 2.2.102; 2.2.105; 2.2.1 I3; 2.2.1 $16 ; 2.2 .120 ; 2.3 .1 ; 2.3 .36$; Serm.2.3.60;2.3.69;2.3.106; 2.3.135;2 3.139;2 3.1 $58 ; 2.3 .159 ; 2.3 .161 ; 2.3 .164 ; 2.3 .189 ;$ Serm.2.3.204; 2.3.207; 2.3.259; 2.3.260; 2.3.261; : ar.Serm.2.3.202; Serm.2.3.204; 2.3.265; Serm.2.3.267; 2.3.301; 2.3.319; 2.3.320; 2.3.323; 2.4.1; 2.4.29; 2.4.31; 2.4.36; 2.4.43; Serm.2.4.66; 2.4.91; 2.4.93; 2.4.94; 2.5.4; $2.559 ; 2.5 .91 ; 2.6 .1 ; 2.6 .32 ; 2.0 .59 ; 2.6 .71$; Serm.2.6.108; 2.7.21;2.7.25;2.7.26; 2.7.36;2.7.50;2.7.04; $2.772 ; 2.7 .78 ; 2.7 .92 ; 2.7 .93$; Serm.2.7.1 12 (bis); 2.8.4; 2.8.48; $2.8 .49 ; 2.8 .56 ; 2.8 .82 ; 2.8 .87 ; 2.8 .92 ;$ Fpist.1.1.4 (bis); Epist.I.I.19; I.1.28; I.I.29; I.I.32; I.I.39; I.I.48; I.I.66; I.I.7I； I.I.80; I.2.3; 1.2.33; Epist.1.2.35; 1.2.47 (bis); 1.2.49; 1.2.58; 1.2.59; 1.3.10; I.3.21; 1.3.22; 1.4.0; 1.4.11; Epist.1.4.14; 1.5.12; 1.5.16; 1.5.19; 1.5.20; 1.5.2I; 1.5.23; 1.0.29; 1.0.45; 1.6.62; var.Epist.1.6.68;Epist.1.7.14; 1.7.17; 1.7.41; 1.7.44; 1.7.52; 1.7.01; 1.7.08 (bis); 1.7.78; zar.Epist.1.9.8; Epist.1.10.26; 1.10.29; 1.10.3S (his); 1.I0.42; I.10.40; I.I0.50; 1.1 1.26; Epist.1.11.27; 1.11.30; I.I2.2; I.12.4; 1.14.13; I.I4.I8; I.I4.27; I.14.36; I.I.4.37; I.I4.38; Epist.1.15.11: 1.15.28; 1.15.29; 1.15.41; I.16.47; 1.16.48 (his); I.I6.56; 1.16.65; I.10.66; Epist.1.17.27; 1.17.29; 1.17.31; 1.17.35; 1.17.36; 1.17.37; 1.I7.61; 1.I8.16; 1.18.17; Epist.1.18.26; 1.18.53; 1.18.72; 1.18.78; 1.10.10; 1.19.22; 1.19.25; 1.19.32; I.I9.37; Epist.1.19.39: 1.20.5; 1.20.6; 1.20.9; 1.20.1 4; 2.1.0; 2 I.30; 2.1.53; 2.1.69; 2.1.76; 2.1.88; Epist.2.1.10I；2.I.II5; 2.1.1 20;2.I.122;2.1.I74;2.1.224;2.1.231;2.2.13;2.2.25;2.2.48; Epist.2.2.52; 2.2.58; 2.2.63; coni.Epist.2.2.80; Epist.2.2.13.; 2.2.139; 2.2.143; 2.2.150; Epist.2.2 179; 2.2.182 (bis); 2.2.192; 2.2.201; 2.2.202; 2.2.205; Ars Poet.I2 (bis); 19; Ars Pott.36; 50; 89; 99; 122; 132; I 43; 149; 182; 195; 202; 219;234; 254; 257; 263; Ars Poet.268; 281; 290; 292; 294; 297; 208; 303; 308; 3II; 351; 304; 373 (ter); Ars Poet.390; 4 I8; var. Ars Poet.450; Ars Poet.460; 470

nona. accedes opera agro nona Sabino."

nonae. cum tibi nonae redeunt Decembres,

nonam. 'ergo/post nonam venies;

nondum. arma|nondum expiatis uncta cruoribus. nondun subacta ferre iugum valet /cervice. nondum munia conparis/aequare nondum spissa nimis complere sedilia flatu:

nonne. nonne vides, ut'nudum remigio latus nonne. . . quaerere plus prodest

nonne vides. Abi ut male vivat filius atque Baius inom-

"nonne vides" .. "ut patiens, ut anicis aptus.

nono. abeo. et revocas nono post mense

nonum. nonum superantis annm plenus Albani cadus. nonumque prematur in annum membranis intus positis;

noram. domos mercarier unus/cum luero noram:

Norico. modo ense pectus Norico recludere

Noricus. tristes ut irae, quas neque Noricus deterret en-ic

noris, ut tamen noris, quibus advoceris|gaudis: 'noris nos' inquit: 'docti sumus.'
Serm.2.7.1 I 8 Carm.3.18.10 Epist.1.7.7 Cirm.2.1.5 Carm.2.5.1 Carm.2.5.2 Ars Pot.205 Carm.1.14.3 Sirm.1.2.III Serm.I.4. I09 Sirm.2.5 42 Sirm. I.0.61 Carm 4.II.I Ars Poel. 389 Serm.2.325 Epod. I 7.7 I Carm-1.10.9 Curm.4.III 3 Serm.1.9.7 


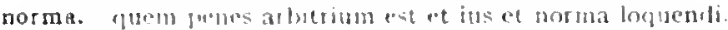

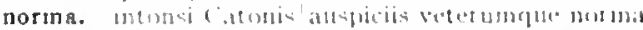

normis. (Hellus, Haticts, ab normis sapions cassigue Minetsa).

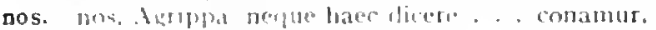

nus (n)

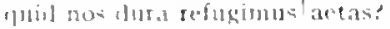

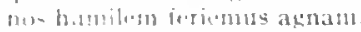

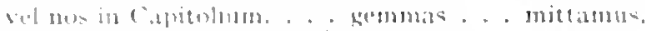

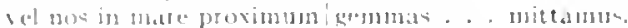

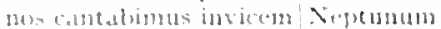

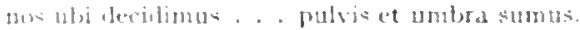

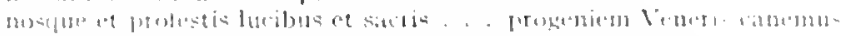

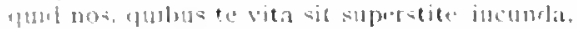

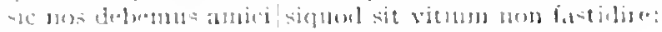

at mos valute" jpstas invertinus

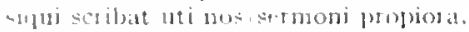

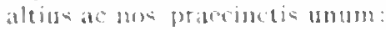

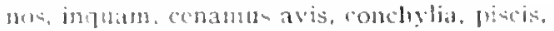

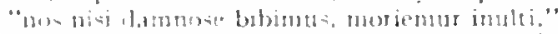

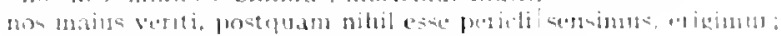

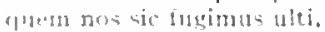

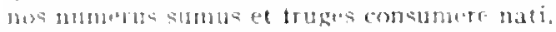

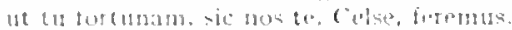

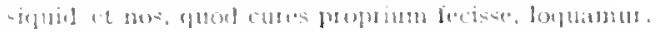

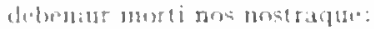

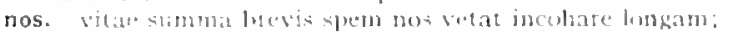

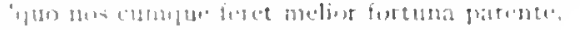

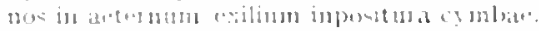

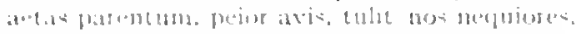

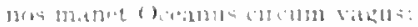

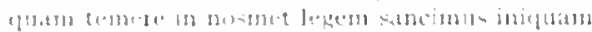

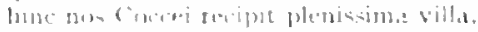

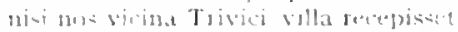

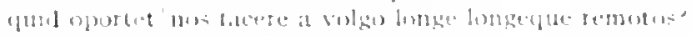

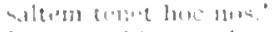

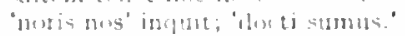

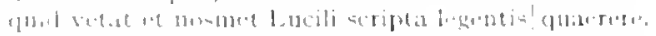

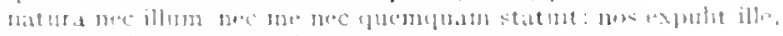

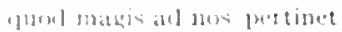

(11)! \&

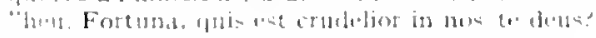

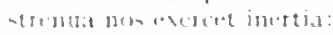

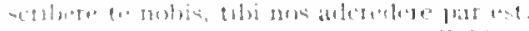

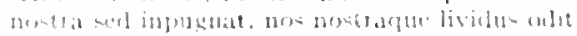

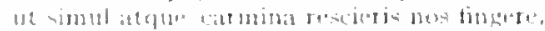

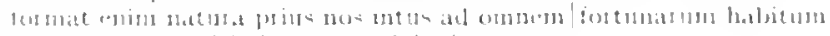

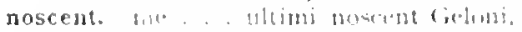

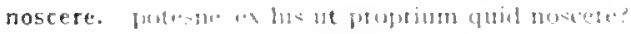

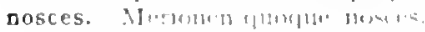

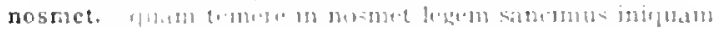

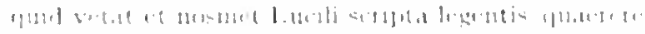

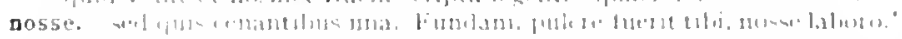

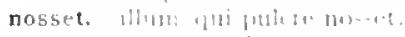

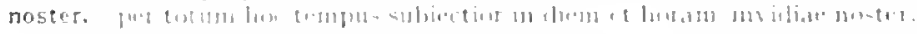

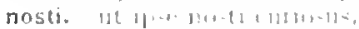

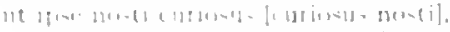

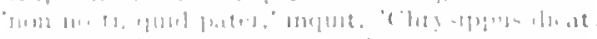

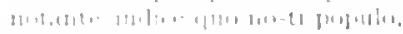

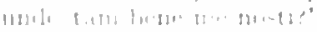

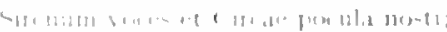

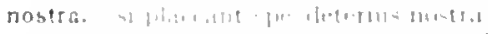

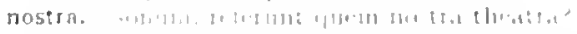

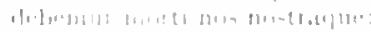

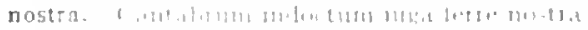

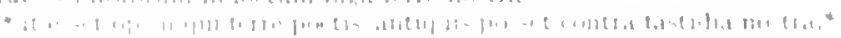

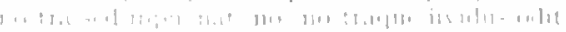

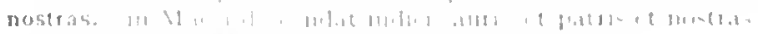

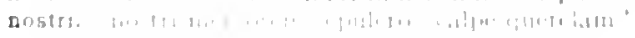

Serm $2 \geq 3$

cirm.1.1.5

(itrma.1.6.

(ierns. 135.34

(itrm.2 1732

(itrm 3.24.15

(itrm. 32.4 .47

(itrm 3.28.1)

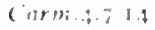

cirm 115.25

f pend 1.5

sirm 1.3 .13

vro 13.55

serest $4+1$

sermi.1.5.5

siren 2.8 .27

serm.2.S.31

Serm. 28.57

- termiz \$.0.3

1.post 12.27

IPAN 1.83

d.pist 1.17.5

irs Pedeces

(atrm.1.15

Curm. 1.7.25

(izrm.2.3 $=7$

rigrm:30.47

t. pout to. 11

- rim.1.3.1\%

s.rent. 1.5.51"

4. F I. I. $5 ; 1)$

Sirn: 1.e.1S

sermi.1. \&

S.r.m.t.0.

Jin. 1.1450

S.TH:.2.2.1301

Sermon. 72

sim 2. 2.5

virm 2.xil

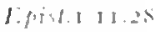

1.7.21 1.1525

$1 f+6=1.81)$

Ifist.2.2.27

Irs Ioldas

(arm.2 2010

sirm 2.7.sis

(arm 1. I5 -7

seron.1.3\%

4, 112.1.11.5\%

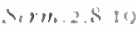

rem 100.0

s.rit. $2.1 .4^{4}$

l- gerdet 17.7

in. I.fow $17.7 \%$

Sirm: \& $1:=$

sirm: 15

1.rm:315

Ifoit $2=3$

sim I 11, 1, 10

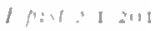

(1) $1: .1 \% 3$

( )

$1,+, 1,11$,

if. 1 : 1 , sis

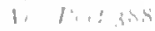

1 $4 m$ क 11 ।

( ख) 
ut valet? ut meminit nostri?

ne studio nostri pecees

nostri. oecidit|spes omnis et fortuma nostri|nominis

nostri. nil intemptatum nostri liquere poetae.

nostris. inauspicatos [non auspicatos] contudit impetus/nostros [? nost is] te nostris ducibus, te Grais anteftrento

nostris. neve te nostris vitis iniquom focior aura|tollat;

nostris. nostrisque ductum seditionibus bellum resedit;

cum prole matronisque nostris.

cur tua plus landes cumeris granaria nostris?

nostro. insani leonis/vim stomaclo adposuisse nostro. signa nostro restituit Iovi

nostro. quae carte ora cruore nostro: arva Marte coli populata nostro.

nostrorum. Albi, nostrorum sermonum candide iulex. .

nostros. inauspicatos contudit impetus nostros cum lamentamut non adparere labores |nostros

nostrum. utrunque nostrum incredibili modo/consentit astrum;

Lucili ritu, nostrum melioris utrofue.

peccat uter nostrum cruce dignius?

nostrum. nunc age, quid nostrum concentum diviclat, andi.

nostrum. per nostiun patimur scelus iracunda Jovem ponere fulmina. si foret hoc nostrum fato delapsus in aevom,

al nostrum tempus Livi scriptoris ab aevo.

Nota. Ionius ndo cum remugiens sinus, Nuto [Nota] carinam ruperit.

nota. Lt Chio nota si commixta Falerti est."

nota. Cressa ne careat pulcra dies nota

bearis|interiore nota Falerni.

signatum praesente nota procudere nomen.

nota. nota quae sedes fuerat columbis.

notaque et artium ! gratarum facies?

quid tibi visa Chios, Bullati, nutaque Lesbos.

nota. deversoria notalpraeteragendus equos.

nota refert neretricis acumina,

notaque fatali portenta labore subegit.

notabant. multa cum libertate notabant.

notabit. arguet ambigue dictum, mutanda notabit.

notam. inpressit nemorem dente labris notan.

qua notam duxit, niveus videri.|cetera fulvos. .

veluti tractata notam labemque remittunt atramenta,

notandi. aetatis cuitsque notandi sunt tibi mores.

notando, ut fugerem exemplis vitiorum quaeque notando.

notante. notante iudice quo nosti populo.

notarent. donec verba, quibus voces sensusque notarent.

notari. stultus tet inprobus hic anor est dignusque notari.

notas. audiat J yde scelus atque notas virginum poenas

imbres/ quem super notas aluere tipas.

in medias res/non secus ac notas auditorem rapit

notat. "si sciret regibus uti. fastidiret holus, qui me notat."

notati. quorsum abeant? sani ut creta. an carbone notati?

notatus. saepe notatus/cum tribus anellis, modo laewa Priscus inani .

Nothi. illam cogit amor Nothi

Noti. timuit .. nec trist is Hyadas nec rabiem Toti. .

noti. onnes/vicini oderunt, noti, pueti atque puellae.

vetuli notique columbi|tu nidum servac,

notior. iam Daedaleo notior Icaro

Notis. ille Notis actus ad Oricum

notis. non incisa not is marnora publicis,

notis. vetuli notique columbi [? vetuli= notisque columbin/tu nidum servas.

notis. tempura. quae seme-l| notis condita fastis|inclusit volucris dies.

notis. orientia tempora notis/instruit exemplis, inopen solatur ot atogrum.

Noto. Ionius udo cum renuglens sinus/ Noto carinam ruperit.

noto. exercitata: aut petit Syrtis notolat fertur incertu mari.

noto. piscis,/longe dissinilem noto culantia sucum,

et longum note scriptori prorogat arvom.

noto. ex noto fictum carmen sequar.

notos. incipit t'x illo montis Apulia notos, ostentate mihi.

notum. quendam rolo visere non tibi notun;

cum bene notum porticus Igrippae, via te consperetit Ippis.

Lipist.1.3.12

Epist.1.13.4

Carm.t.4.7

Ars Poit.285

?íar.Carm.3.6. I I

Fpisl.2.1.19

Carm.1.2.47

(arm.3.3.29

cirm.4. 5.27

sirm.I.I.53

carm.1.10.10

Carm.4.15.6

Carm.2.1.3ts

Carm 3.5.24

Epist.1.4.I

Carm 3.0.1 1

Epist 2.1.225

cirm.21\%.2

cirm.2.1.29

Sim.2.7.47

IEpist.1.14.31

(cirm.1.3.39

Sierm.1.10.68

Epist.2.1.02

far. I.pod.10.20

Sirm. I. 10.21

Carmi.35.10

Carm.2.3.8

Ars l'oet.59

Carm.1.2.10

Carm.t. 3.21

lipist.1.11.1

Epestir.15.10

Epist.1.17.55

Epist.2.I.II

Serm.1.4.5

Ars 100\%.49

Corm.1.13.12

Carm.4.2.59

Epist.2.1.235

Ars loet. 150

sirm.t.t. $10 \%$

Serm. I I t

Sirm.13.103

Serm-1.3.24

Corm.3.111.25

Carm.4.2.t)

Ars Poetil $\$ 9$

Epist.1.17.15

Sirm.2.3.2.40

Serm.2.7.8

Carm.3 I5.1 I

Carm.1.3.14

Serm.1.1.85

Epist.1.10.5

Carm.2.20.13

Carm-3.7.5

Carm.4.8.13

zar. Epist.1.10.5

Carm.4.13.15

Epist.2.1.130

Fpod. 10.20

Iipol.9.31

Sirm.2.8.28

Ars Poit.34t5

Ars livet 240

Serm.1.5.77

Sirm.1.0.17

Epist.1.0.25 
mateconem

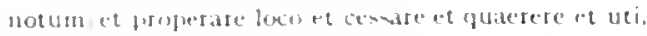

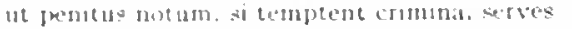

notum. ornubur ec lippis notum et tomsoribus essed.

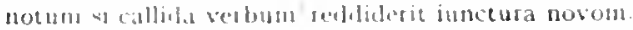

Notus. eleterget nubsla carlo sicere Notus neque parturit imbris

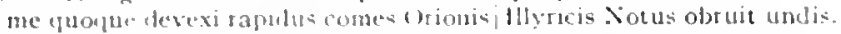
quesu Xintus invieto thatu. . dulci distinet a dumo.

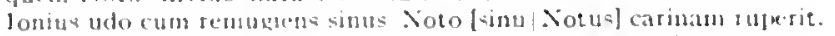

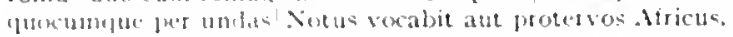

notus. noths in frates allimi paterns:

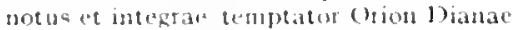

notue in volt us homor.

quidam notus homo sum exiret for nice.

accurrit eludam notus milui momine tantum

nova. Hova febrium tetris incubut cohors

servitus crescit nova

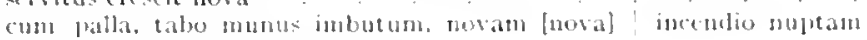
abstulit?

gram nosa collibus athor inhactet.

nova, ambiguam tellure nova Salamina futurans.

o utinam nova|incucte difingas retucuun. . fertun.

fromele nova puesum palumberserese.

quac nemori aut ques agot in slecus. velox mente nova?

novaque monstra immerst labiline mirus amor.

nova. nova fietalue nuper lablebunt resbat fidem.

et juvenum ritu florent modo nata vigentque 7 et nova iurenum ritu florent motat augentiuel.

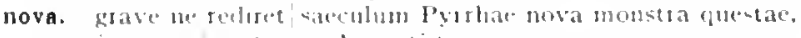

potius nowal camternus Augueti tropiteas

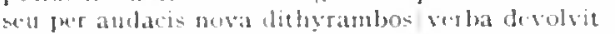

sunt guosum ingerium nesat tantum crustula ptome

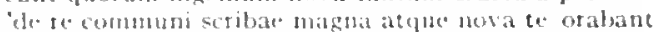

beatus enim ian cum pule has turicis sumet nova consilia et spees.

adscisect nova. quate guntor proluxesit asus.

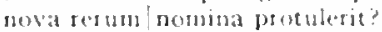

novae. joolicque movar teracil lege mallit.

novae. dal lunte progure novar.

novae. novaedue pergunt interir lunda :

novam. novin, atreendio suptam abutulit?

audes foremam bomare novan.

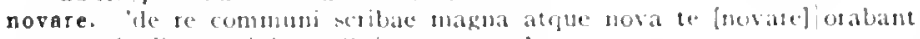

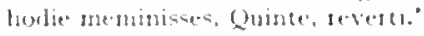

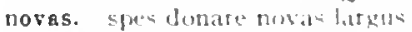

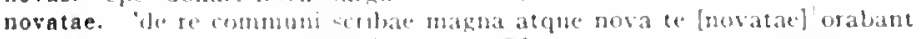

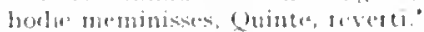

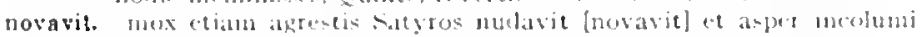
gravitate iocum templatit

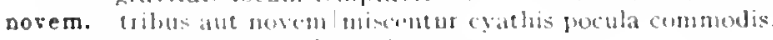

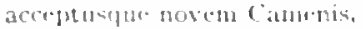

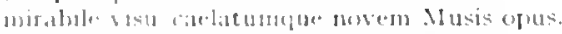

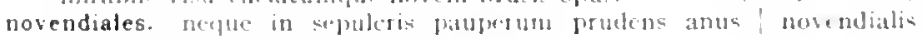

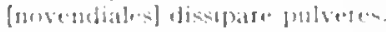

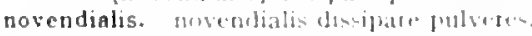

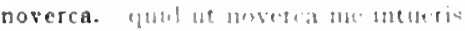

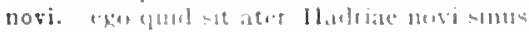

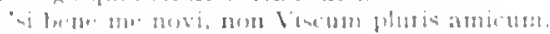

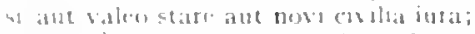

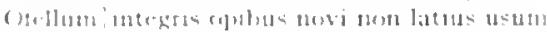

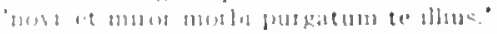

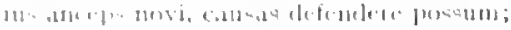

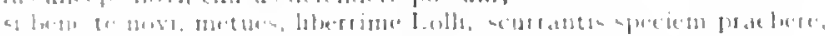

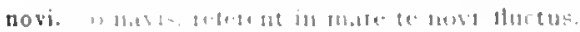

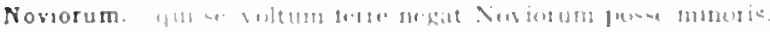

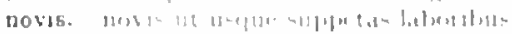

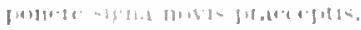

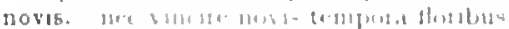

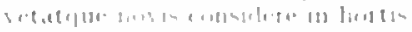

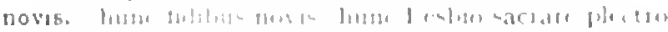

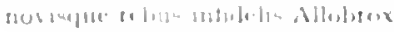

l.pist.1.7.56

lipirt.18.80

Sirm.1.7.3

Ars lintiti

Carm.1.7.10

Carm.1.28.22

Carm.4.5

:ur.lipod: 10.20

Ispod. 10.22

Carm.2.2.t

Carm.34.70

Epod.17.18

Serm.1.2.31

Serm.19.3

Carm.1.3.30

Carm.28.18

var.l.pod.5.05

Ifod.12.20

Corm.1.7.29

Carm.1.35.38

Carm.3 \&: 2

Carm.3.25.3

Epod.10.30

Ars I'ort.52

I tar..Irs l'oet.62

Carm.1.2.0

Corm.2.9.18

(arm.t.10)

Serm.2.4.47

Serm.2.0.3"

Epiut.1.18.33

Lipist.2.2.110

Ars lert.57

(arm.sace.10)

Curm.3.10?

(arm.18.10)

lipol s.es

Ars Port.120

a ar.sirm.2.0.36

(iorm.12.19

ar.serm.2.13.3

:ar. Ars Port.221

Carm.310.11

(arm.sisecenz

leptst 2.2 .92

:ar. Lperd.17..48

I. pould $7 . .6 \mathrm{~s}$

lepoil.5.2.

Carm.327.10

serm.1.0.22

Serm. 1 y. 39

Serm.2.2.113

serm.2.3.26

Sirm 25.34

I pivitis.

Cirm. 141

sometelat

I. poul : i col

sorm.2.12

(armis I .32

termis 87

( amm. 1 efou

l. peed sepe. 
novisti. siquid novisti rectius istis, / candidus inperti;

Iipist.1.6.67

novistine locum potiorem rure beato?

novit. quid possim videt ac novit me valdius ipso.

novitas. quod si tam Graecis novitas invisa fuisset /quan nobis.

novitate. eo quod|illecebris crat et grata novitate norandus|spectator

Novium. Maenius absentem Novium cum carperet.

Novius. 'at Novius collega gradu post me sedet uno:

novo. populus Laevino mallet honorem quam Decio mandare noro

novo. nec Damalis novo|divelletur adultero

novo|sublime ritu moliar atrimm?

caprea . . leonem/dente novo peritura vidit:

novo. deorum templa novo decorare saxo.

novom. quid orat de patera novom/tundens liquorem?

novom. notum si callida verbum |reddiderit iunctura novom.

novos. ut huc novos incola venit? atqui|emovit veterem mire novos.

novos. sacriat atque novos moveat Fortuna tumultus: referri debet an inter|vilis atque novos?

novum. notum si callida verbum|reddiderit iunctura novom [novum].

Nox. dum favet Nox et Venus. dicetur, merita Nox quoque nenia.

Nox erat et caelo fulgebat Luna sereno

Nox. Nox et Diana, quae silentium regis.

nox. iam te premet nox fabulaeque Manes sed omnis una manet nox urget diem nox et dies nocten iam nox inducere terris|umbras iamque tenebat nox medium cacli spatium, ut nox longa quibus mentitur amica

nube. nube candent is umeros amictus/augur Apollo; cras vel atra|nube polum Pater occupato|vel sole puro;

nubem. noctem peccatis et fraudibus obice nubem.' deme supercilio nubem:

nubes. simul atra nubes/condidit lunam.

nubes. concidunt venti fugiuntque nubes

nubet. forti nubet procera Corano/filia Nasicae.

aubibus. non semper imbres nubibus hispidos/manant in agros desere copiam et $\mid$ molem propinquam nubibus arduis.

nubila. albus ut obscuro deterget nubila caelo|saepe Notus Diespiter. / igni corısco nubila dividens f plerumque,

nubis. Pleiadum chorolscindente nubis,

aut, dum vitat humum, nubis et inania captet.

nubium. tendit. Antoni, quotiens in altos|nubium tractus:

nuce. te contemptum cassa nuce pauperet:

nil intra est olea, nil extra est in nuce duri;

nuces. te talos. Aule, nucesque|ferre sinu laxo,

nucis. siquid fricti ciceris probat et nucis emptor.

nuda. incorrupta Fides nudaque Veritas.

utinam inter errem / nuda leones. .

Gratia . . audet/ducere nuda choros:

sub clara nuda lucerna'quaecumque

sub clara nuda lucerna [lucerna nuda]|quaecumque excepit turgentis verbera caudae clunibus

nudam. Cois tibi paene videre est/ut nudam, ne crute malo, ne sit pede turpi;

nudare. ingenium res/adiersae nudare solent.

nudat. quem damnosa venus, quem praeceps alea nudat.

nudata. moveat cornicula risum |furtivis nudata coloribus.

nudavit. mox etiam agrestis Satyros nudavit

nudet. ne manifestum|caelibis obsequium nudet $t t^{\prime}$,

nudis. non saxa nudis surdiora navitis

gudis. Gratia/nudis iuncta sororibus.

nudis. Canidiam pedibus nudis passoque capilio. cadaver/unctum oleo largo nudis umeris tulit her"s.

nudo. arbiter pugnae posuisse nudo!sub pede palmam discincta tunica fugiendur est et pede nudo. quid? siquis voltu torvo ferus et perle nurlo

nudum. nonne vides, ut nudum remigio latus

audus. nil cupientium nudus castra peto

Epist.I.10.14

Epist.1.9.6

Epist.2.1.90

Ars Poet.223

Serm.1.3.2I

Serm.1.0.40

Serm.1.0.20

Carm.1.36.18

Carm.3.1.45

Carm.4.4.16

Carm.2.15.20

Carm.1.31.2

Ars Poet. 8

Sirm.2.2.128

Strm.2.3.28

Serm.2.2.126

Epist.2.1.38

var.Ars Poet.48

Carm.3.I I.50

Carm.3.28.16

Epod.15.1

Epod.5.5I

Carm.1.4.16

Carm.I.28.J5

Epod.17.25

Serm.1.5.9

Sirm.2.6.10I

Epist.1.1.20

Carm.1.2.3I

Carm.3.29.44

IEpist.1. 10.62

Epist.1.18.94

Carm.2.16.2

Carm.1.12.30

Serm.2.5.64

Carm.2.9. I

Carm-3.29.10

Carm.1.7.15

Carm.1.3.6.0

Carm.1.14.22

Ars Poct.23o

Carm.4.2.27

Sirm.2.5.30

Epist.2.I.3I

Sirm.2.3.17I

Ars I'vet. 249

Carm.1.24.7

Carm.3.27.52

Carm.4 7.6

Sirm.2.7.48

iar.Serm.2.7.48

Sirm.1.2.102

Srm.2.8.74

Epist.I.IS.2I

Epist.1.3.20

Ars lott.22I

Sirm.2.5.47

Epod.1 7.54

Carm.3.I9.I7

Sirm.1.8.24

Sirm.2.5.86

Carm.3.20.I I

sirm.1.2.132

IEpist.1.19.I2

Carm.1.1.4.4

Carm.3.16.23 


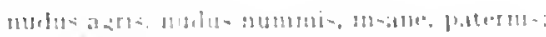

Serm 2.3 .184

nullus in liberts atellit.

serm. $2,3.201$

nuld

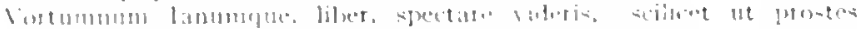
(⿻)

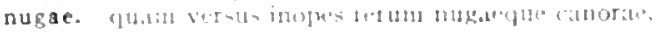

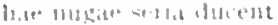

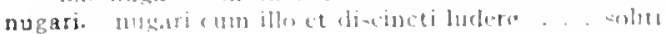

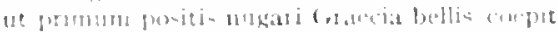

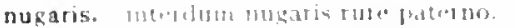

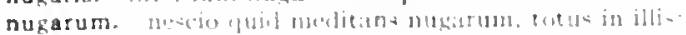

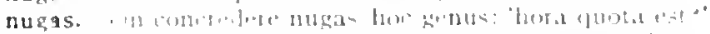

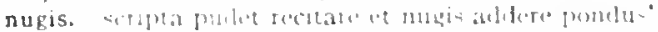

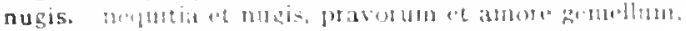

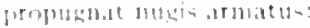

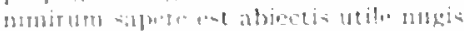

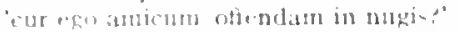

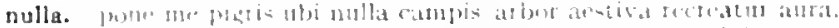

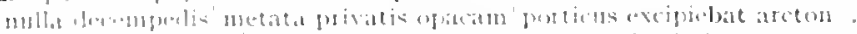

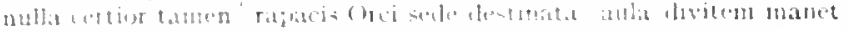

$$
\text { 1: :1111. }
$$

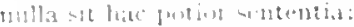

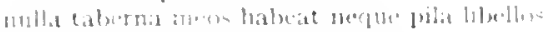

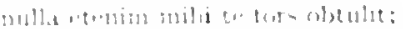

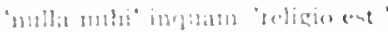

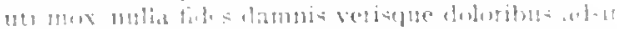

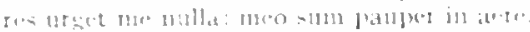

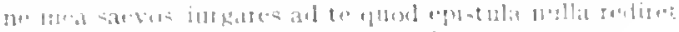

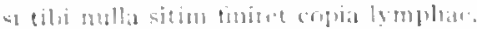

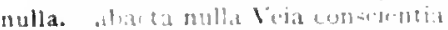

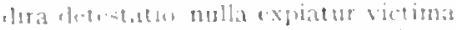

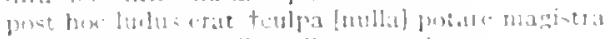

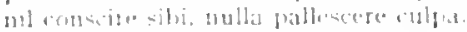

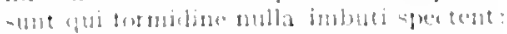

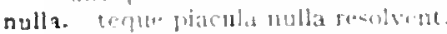

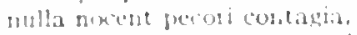

combla to actrey

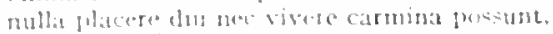

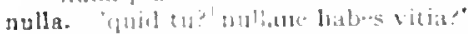

nullam. nublam, Vare, cacts lite prius seresis arlorem

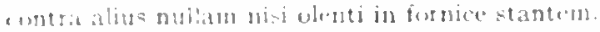

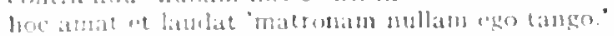

nulli. nulli trobilior quant thi, Vergili.

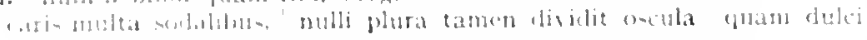

1.intibili:

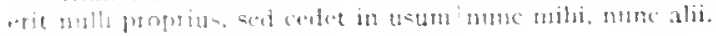

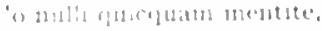

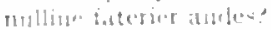

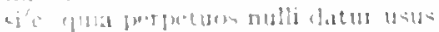

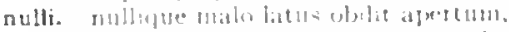

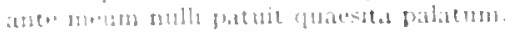

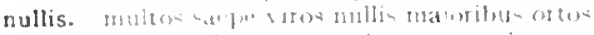

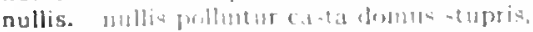

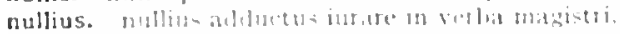

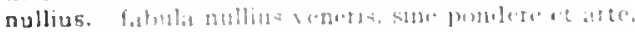

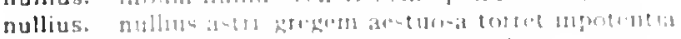

nullus. "f1]

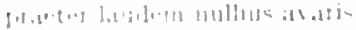

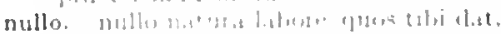

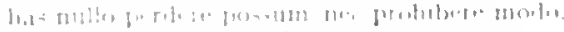

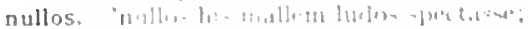

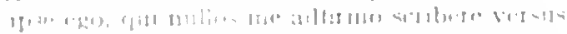

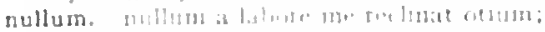

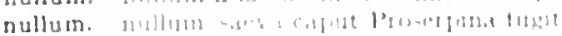

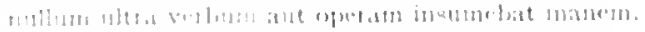

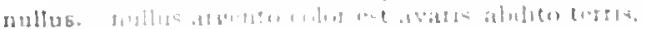

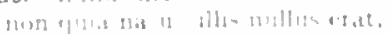

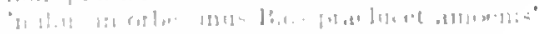

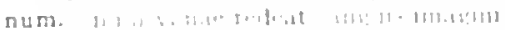

inter fopist 120.2

irs loct 322

irstoctint

Sirem 2.1 .73

lipist.2.1.93

lipos! \& isions

Sitmi.02

Serm:2.0.43

Litel 10 4:

irem 2.3.2.14

lipisi.1.18.10

lipist.2.2.14t

Ars lonet 451

cisme.1.22.17

Curm.2.5.14

Curm. 2.18.29

1:pot.10.17

hermidit

sermetic.5.

cirmation

fpist t. 5.57

J. Pist 2.2.12

lipal 2.2 .22

Jipis $2.2 .1 . j$

I. prille.t)

I. Pol 5013

tums verm 2.2123

J. prst.1.1 c.t

Esicter i

carm 1.2834

lined 10.81

lipist 1.1 .75

I.pist.1.10.2

s.rm. 1.320

(istem 1.18.1

Nirm.1.2.30

sermid.25

(Ir) 1.2110

Cisprs, $1,3^{p+10}$

Stom 2.2.13.4

herot.25.5

f.p

l.post.2.2.175

Q.rm. 1350

s.rm $=1.1 \%$

Sirm.1.1010

cism 1521

lipint 1.1.14

lis Juet 320

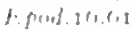

1 pise 1.1722

Irs linet 321

S r

S.9m.1 8.20

Themsing

$1.1 .12 .1 .1) 1$

lipol 1; 24

1 Hrm 15810

108 Jiarl 193

( III $=21$

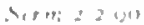

1 eis 113

cirms $1: 1=$ 


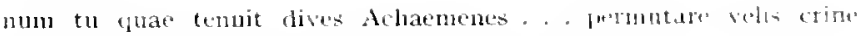

Licymian

num viperinus his eruor incoctus herbis me fefellit?

inlitterati num minus nervi rigent

num, tibi cum faucis urit sitis, aurea çuaeris/pocula?

mu esuriens fastidis omma practer/pavonen rhombunque?

num, . . malis tentigine rumpi?

hatud illud quartentis, num sine sensu,

tempore num faciant alieno.

cuo patre sit matus, num ignota matre inhonestus,

nam [num] sic et Labesi mimos ut pulcra poematia mires.

num illius, num rerum dura negarit / versiculos natura

num Iacelius. . . ingenio offensi

nnm vesceris ista. quam landas, pluma?

cocto num adest honor idem?

num tantum, sufflans se, magna fuisset?

"Inaior dimidio." 'num tanto?"

"num furis? an prudens ludis me obscura canendo?"

num sit quoque iracta lagoena.

num te semper inops agitet vexetque cupido,

num pavor et rerum mediocriter utilium spes.

ne,.. . dum [num] sitat humum, nubis et inania captet.

Numa. ire tamen testat, Numa quo devenit et Ancus.

Numae. Jam Saliare Numae carmen qui laudat

Numantiae. nolis longa ferae bella Ninmantiat

numen. numen cum teneris virkinibus tuom | laudantes

Laribus tuom | miscet numen,

nune in lrostilis domos/iram atque numen vertite.

cum tu. magnotum numen lasesira deorum.

iutandasque tuom per numen ponimus aras,

mumerabilis. quo sane populus numerabilis, utpote parvos,

numerandum. eff undi saccos nummorum, accerepeplures/ad numerandum:

numerare. vidi.|te. Tiberi, numerare, cavis abscondere triatem,

numeras. natalis grate numeras:

numerat. habet lum numeratcue poetas.

numerato. quid refert, vivas numerato nuper an olim?

numeretur. caldior est: acris inter numeretur:

numeris. accessit mumerisque modisque licentia maicr.

numeris. verba devolvit numerisque fertur|lege solutia,

mutatis tantum pedibus numerisque,

sic horridus ille / defuxit numerus [nuneris] Saturnius praecipue cum se numeris commendat et arte.

numero. temaris et terrae numeroque carentis harenat menandem cohbent. dissidens plebi nume to beatorum|eximit lirtus

ego me illorum, deterin quibus esse poetis, / excerpan mumen:

iubesque/tuse in amicorum numero.

Maecenas me coepit labere suorum in numero.

quod numero plutes, virtute et honore minores,

quo seribi possent numero. monstravit Homerus.

numeros. I.euconox, nee Babylonios temptaris numero:

unmetos animosque secutus|Archilochi.

sed petae numerosque modosque ediscere vitae.

at vestri proavi Plautinos et numeros et laudavere sales.

numerum. hotum tu in numerum voto rus: (juameris nil extra numerum fecisse modinquelcuras:

numerus. accessit fervor capiti numerusube lucernis; nos numerus sumus et fruges consunere mati, sic horridus ille deftuit numerus saturnius

Numici. nil ithmari prope res est una, Ninuici,

Numidae. custorles Numidae doos,

Numidarum. me vel extremos Numidarum in agros/chate leheget:

numina. per ct Dianae non movenda numina.

poseit opem chorus et praesentia numina sentit.

numine. glaciet nives/puro fumine Imppiter?

quocumque lectum nomine [numine] Masicunt servas,

quen tu, Nelpomene, sonel / nascenten placido lumine [numine] videris,

quas et benigno numine luppiter defendit

nummatum. ac bene nummatum decorat suarlela lemusque.

(arm.2.12,21

Epod.3.0

Iipot.s 17

Serm.1.2.II

verm.t.2.1 I5

Serm.1.2. I10

siom.1.7.77

Serm.1.7.8

Simes.0.3n

rup.Serm.1.10.5

Serm.1.10 57

Sirm.z.t.5

virm.2.2.27

sim.2.2.28

term.2.3.317

Serm.3.3.318

firm 2.5.58

Serm.2.8.S1

Epist T. 18.08

Epist.1.I8.99

iar. Ars Iott.230

Ispist.1.6.27

Epist 2.r.80

Cam.2.12.I

Curm.1.1.20

Carm.4.5.35

Eprul. 5.54

Epot.1 5.3

Epist.2.1.10

Ars Port.2063

Sirm.2.3.150

firm.2.3173

F.pivt.2.2.2 to

Epist.z.to

Epist.2.2.100

Sirm. I. 3.53

Ars PotleII

Carm.1.2.I 1

Serm.1.4.7

rar. Epist.2.1.1 58

Epist.2.1.26:

Carm.I.28 I

Corm 2.2.18

serm.t. 4 .

cirm. I. (1.0)2

Sirm.2.0.42

Epist.2.1.183

Irs Poel.74

Carm.I.II.3

Epist.1.1924

Epist.2.2.14.4

Ars Pret.270

Epirt.1.14.4I

Epist.1.18.59

Sirm.2.1.25

Epist.1.2.27

Epist.2.I.15\%

Epist.1.0.I

Carm.1.36.3

Carm.3.11.47

lipoti. 7.3

Epivt.2.I. 34

(arm.3.10.5

ar. (arm.3.2 I.5

(1) Carm 1.3.2

Curnot +7.4

Lpist.e. 0.3S 


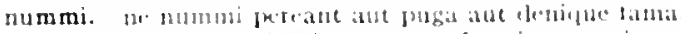

nummis. ommia combluctis cocmens obsonia numbuic:

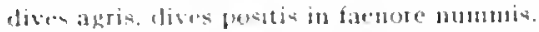

mudus akts. nudus nummis, mane, paternis:

"Jives agre, diqes positis in tarnore numbrs."

nummo. dic. . . kaudenten nummo te adtlicere. scmiper avarus enget // eget numbuo):

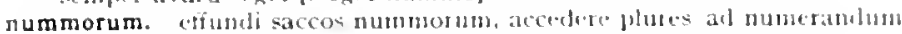
reriteque tuos nusumornm milibus orto.

soltase trecentis aut ctian supla hummorum milibus emptum. pracsertim census enuestrem|-ummam nummorum.

rummos. simul ac nummos contemplor in area

dives ut metiretur numbur.

dedit hic pro corpore numanos.

macelem aut nummos unde unde extricat.

qui numbus aurumune recondit.

gluacrenda frecunia primum est; virtus post nummos":

scorto postponet homestum /ofticium, nummes alicnos pascet.

cibtos nonimbus rectis cxpentere nummos.

des nummos. excegtat nihil te si fuga lacdat:

das nummos, accipis uram, pullos, ova, cadum tencti:

nummum. gestit cnim nummum in loculos demictere,

ficuit somperque licebit signatum praesente nota procultere nomen [nแmกนm].

nummum. accijit et bis dena sujer esotial numbum.

nummus. nescis quo valeat nummus, quem pracbeat usum?

numqua. nunqua tibi vitiorum insererit olim|natura

numquam. Attalicis conficionibur numpam demoveas.

mumçuan homini satis cautum ext in horas:

numblam umeris positurus arcum

consilio patres firmaret auctor numquam alias dato

neque hic lupis nos nec tuit leonibus, umquam [numquan] ni-i in chingar feris.

germinat et numguan tallentiv termes ulivae

ut numuluam inducant animum contare sogats.

ut Inunuam inducant animum cantare regati [? rogati ut numepant cantent]. iniussi numçuam desistant.

iniussi numepuam desistant.

capirne crepirlas sibi numguam noc suleas docit;

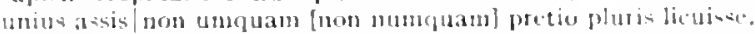

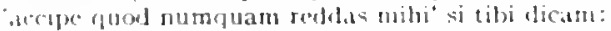

yuod th numglualu rescribere positis.

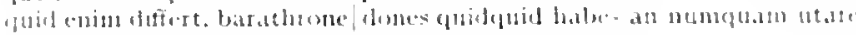
parativ? -

ut comis a coron numequan absterrebitur uncto.

"ic. ut miht numpuam in sita buerit melius:"

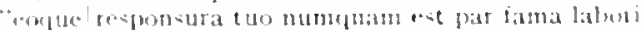

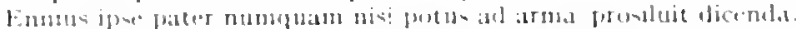

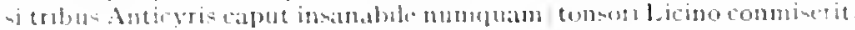

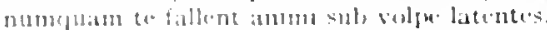

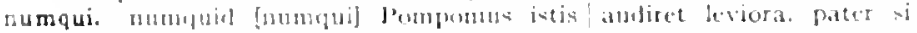

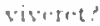

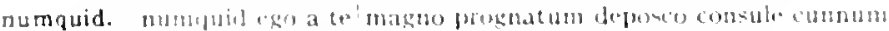

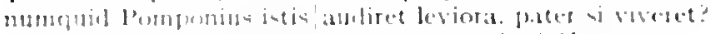

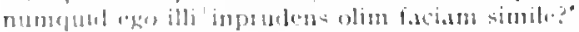

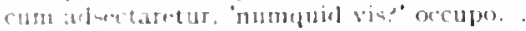

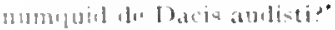

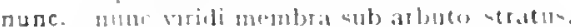

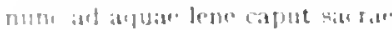

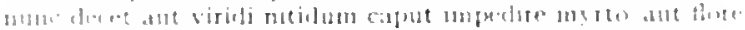

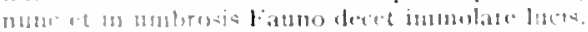

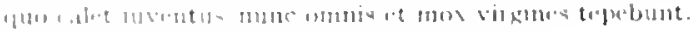

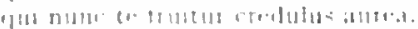

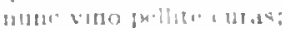

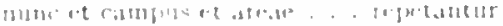

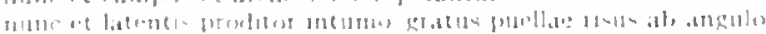

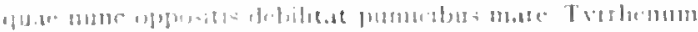

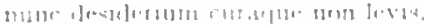

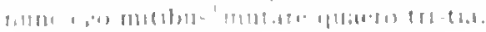

Sern. 1.2 .133

Serm.1.2.9

Sirm. 1.2 .13

Sierm.2.3.15.

Ars Poct.itzi

Sorm.2.5.109

P: at. Jipist.1.2.5\%

ierm.2.3.149

Iipist.2.2.5

I.pist 2.2.105

Ars loes 3 tht

Sorm.1.1.07

Serm.1 1.90

Sorm.1.2.43

Sirm. $1.38 \mathrm{~s}$

Serm.2.3.100

lipist 1.1.54

Epist.1.18.35

Epist.2.1.105

EDist.2.2.10

Epist.2.2.162

Epist.2.1.175

coni.Ars Port.59

Epist.2.2.33

Sorm.1.1.73

Serm.1.3.35

Corm.1.1.13

Corm.2.13.13

Carm.3.4.00

Curm.3.5.46

iar. Epod. 7.12

Epod 10.45

Sorm.1.32

1 aur.Sorm.1.32

Serm.1.3.3

serm.1.3.127

sur Serm.1.0.1.1

Serm. 23.00

Serm.2.3.7\%

Serm.2.3.107

serm.2.5.83

corm.2.8.3

serm. $2 . s(2)$

f.pist 197

Ars loct.3011

irs Pottist

tar.serm.1.452

Sirm.1.2(ic)

Serm.1.452

sorm.1.1 13 r

Serm.1 20

$\therefore c m .28 .53$

Cirma I 21

(iorm 1122

(iorm 1.40

(itrm. 1.411

(iirm.1. 2011

ciurm 1.5.0

(iarm.1 7 . 1

(iarmin? is

( istm.1 1) 21

(iarm.l 11.5

(iorm.1.1.18

Citrm.110.25 
Icci, beatis nunc Arabum invides/gazis nunc retrorsum / vela dare... cogor. qui nune Hesperia sospes ab ultima nunc est bibendum, nunc pede libero| pulsanda tellas; nunc Saliaribus ornare pulvinar deorum|tempus erat dapibus. iam nunc minaci murmure cornuom|perstringis auris. nunc fluviis gravem/solantis aestum, nunc in udo|ludere cum vitulis salicto|praegestientis. non, si male nunc, et olim|sic erit:

arbore nunc aquas/culpante.

nunc torrentia agros sidera.

nunc hiemes iniquas.

seu roce nunc mavis acuta

iam nunc et incestos amores/de tenero meditatur ungui.

'me nunc Thressa Chloe regit,

nunc et/divitum mensis et amica templis.

nunc arma defunctumque bello'barbiton hic paries habebit.

siquis infamem mihi nunc iuvencum|dedat iratae,

nunc nedio aequore / cum pace delabentis.

nunc lapides adesos/stirpisque raptas et pecus et domos volventis una.

nunc mihi nunc alii benigna.

nunc in reluctantis dracones/egit amor dapis atque pugnae: .

sollers nunc hominem ponere. nunc deum.

et, quae nunc umeris involitant, deciderint comae.

nunc et qui color est puniceae flore prior rosae

qui nunc Sulpiciis adcubat horreis,

nunc, nunc adeste. nunc in hostilis domos iram atque numen vertite.

nunc gloriantis quamlibet mulierculam/vincere mollitia amor Lycisci

$$
\text { me tenet; }
$$

nunc mare, nunc siluae/ Threicio Aquilone sonant.

nunc et Achaemenio| perfundi nardo iuvat

meo nunc/superbus incedis malo,

siquis nunc quaerat 'quo res haec pertinet?" illuc:

nunc aliquis dicat mihi 'quid tu?

his, ego quae nunc, olim quae scripsit Lucilius.

nunc illud tantum quaeram, meritone tibi sit

nunc mihi paucis | Sarmenti scurrae pugnan Messique Cicirri,

nunc ad me redeo libertino patre natum.

nunc, quia sim tibi, Maecenas, convictor.

at hoc nunc/laus illi debetur et a me gratia maior.

nunc mihi curtolire licet mulo

nunc licet Esquilits habitare salubribus

'suaviter, ut nunc est." inquam, 'et cupio ommia ruae vis." persequar hinc quo nunc iter est tibi."

omnis conposui.' 'felices. nunc ego resto.

siquis nunc mergos suavis edixerit assos,

accipe nunc, victus tenuis quae quantaque secum ladierat.

Ofellum integris opibus novi non latius usum |quam nunc accisis.

nunc ager Vmbreni sub nomine, nuper Ofelli dictis,

rrit nulli proprius, sed cedet in $ı$ sum nunc mihi, nunc alii.

nunc accipe, quare/desipiant omnes aeque ac tu,

"nunc age, luxuriam et Nomentanum arripe mecum:

id crede tuom et vel nunc pete vel cras.'

'nec nunc, cum me vocat ultro. accedam?

adde poemata nunc, hoc est, oleum adde caminu.

quodsi interciderit tibi nunc aliquid, repetes nox.

"ergo nunc Dama sodalis|nusquam est?

o si angulus ille proximus accedat, qui nunc denoumat agellum!"

nunc veterm libris, nunc somno et inertibus horis

nunc itaque et versus et cetera ludicra pono.

nunc agilis fio et mersor civilibus undis,

nunc in Aristippi furtim pratcepta relabor

hunc [nunc] amos, ira quirlem communiter urit utrungut.

nunc adbibe puro'pectore verha, pier.

nunc te melioribus offer.

quid nunc te dicam facere in regione Pedana?

i nunc, argentum et marmor vetus aeraque et artis|su pice.

"trgol post nonam venies; nunc i, rem strenuos auge."

nunc V'rbem et ludos et balnea vilicus optas;
(irm.1.20I

Carm.1.34.3

Carm.1.36.4

( $\operatorname{arm}, 1.37 .1$

Carm.1-37.2

Carm.2.1.17

Carm.2.5.6

Carm.2.5.7

Carm.2.10.17

Carm.3.1.30

Carm.3.3.31

Carm.3.1.32

Carm.3.4.3

Carm.3.6.23

Carm.3.9.9

Carm.3.11.5

Carm.3.26.3

Carm-3.27.45

Carm.3.29.34

Carm.3.29.3"

Carm.3.29.52

Carm.t.4.I

Carm.4.8.8

Carm.4.10.3

Carm.4.10.4

Carm.t.52.18

Epod.5.53

Epod.1 1.23

Epod.13.2

Epod.13.8

Epod.15.17

Serm.1.2.23

Serm 1.3.10

Serm.1.4.50

Serm.1.4.64

Serm. 1.5.5I

Serm.1.6.45

Serm. 1.6.47

Serm.1.6.87

Serm.1.6.104

Serm.1.8.14

Serm.1.9.5

Serm.1.0.16

Sirm.1.9.28

serm.2.2.51

Sierm.2.2.70

Serm. 2 2.II?

Serm.2.2.133

Serm.2.2.135

Serm.2.3.10

Sirm.2.3.224

$5 . r m .23 .232$

Sirm.2.3.2f=

Sirm.2.3.32I

Sirm.2.4.6

verm.2.5.InI

Serm.2.6.9

Serm.2.0.6I

Epist.1. f. Io

Epist.I.I.Io

Epist.j.I.Is

iar. Epist.1.2. 3

Epist.1.2.07

lipist.1.2.08

Epist.1.4 2

Epistoto.r

Epist.1.7.7

Epist.r.I4 Is 


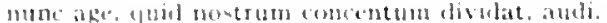

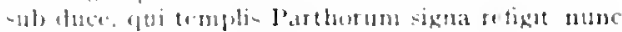

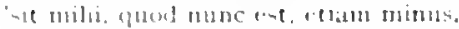

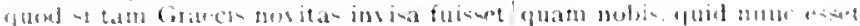
vetus?

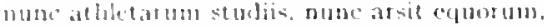

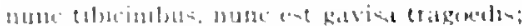

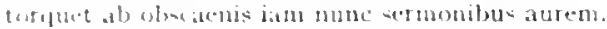

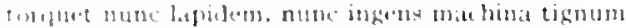

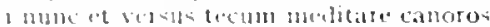

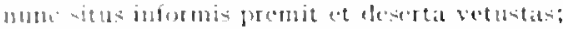

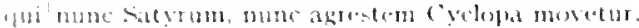

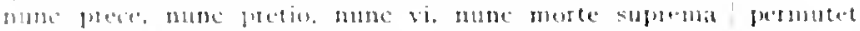
demimes

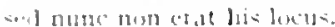

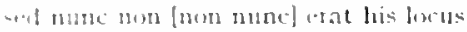

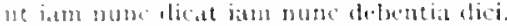

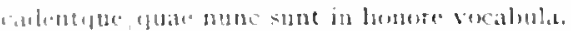

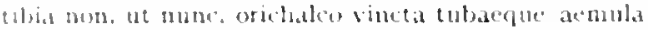

mume ot is ent dusisa "ego mira poemat a pango;

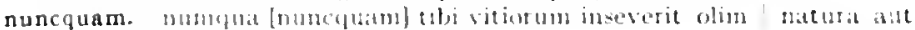
retian constuetule mala:

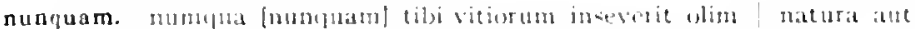
etiand comsine melos mala:

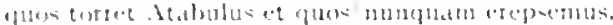

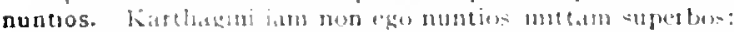

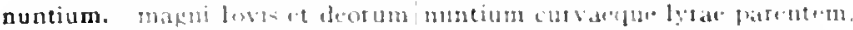

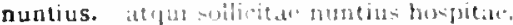

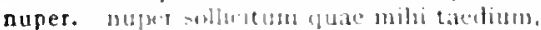

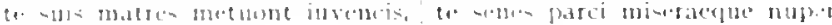

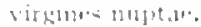

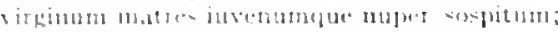

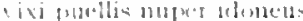

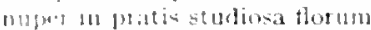

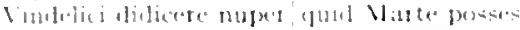

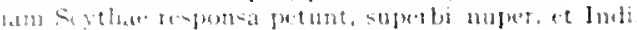

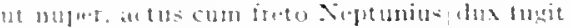

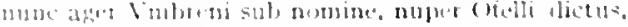

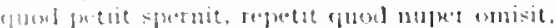

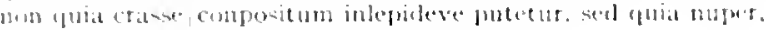

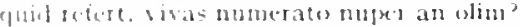

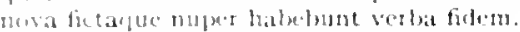

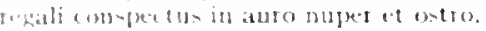

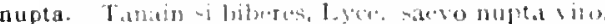

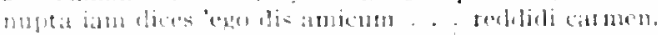

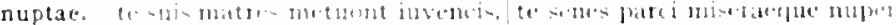

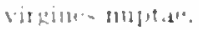

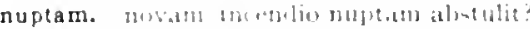

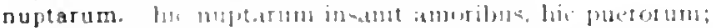

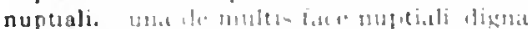

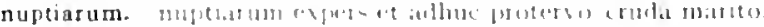

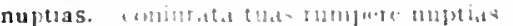

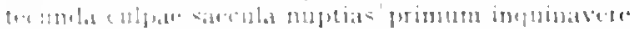

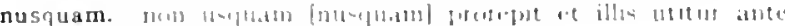

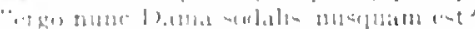

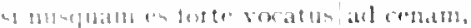

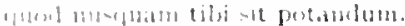

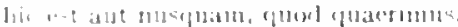

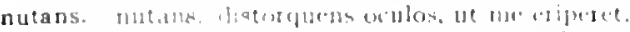

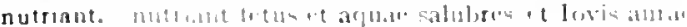

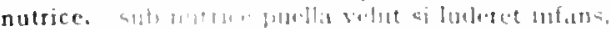

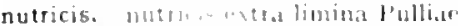

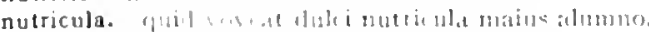

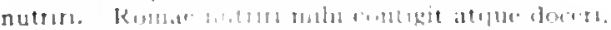

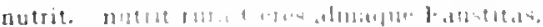

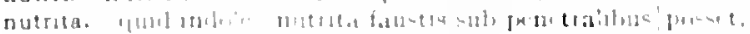

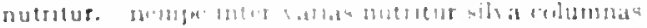

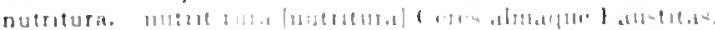

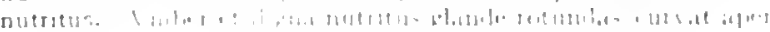

Fifist.1.31

lipres.1 $1 \$ .57$

lipist 1 18.107

l.pint 2 i.gt

Esist.2.1.05

Epist 2.1.08

L.pist.2.1.127

lepist. 2.73

Epist.2 2.7\%

lipist.2.2.118

J.pit.2.2.125

Ifpit. 22.173

lors I'vet. (1)

iur Irs levet.to

les livel.t3

. Irs Pued it

Ars Poel. 20 :

1rs Pinet.ato

:ur.verm.1.33 35

for firm 1.335

cirm.1.5.70

Carm.l pop

Cism.1.80.0

cioni-3io

(arm114.17

Cidrm: 2.8.22

Curm.3.14.0

(urm.3.20.1

(iarm.3.25.29

(iorm.1.18

Cirmsisest)

lipoles?

Serm 2.2.133

Jpitt 1.05

Fist.2.177

Epist.2 2.100

trs Iivet.52

1rs l'oet 228

Cirm 3.10.2

Corm. 0.41

(istm.2.5 23

I poul seres

iorm, $1: 27$

(issm.3. I 1.33

(4)m.11.11

(i) 1 it 15.7

(itrm 3.0.t7

: 18 . Sirm 1.1.37

Sirm.25.102

Sirm.2.20

ferm 2.7 .32

Jipst.1.17.30

sermel 001

carm.sace $3 \mathrm{I}$

lepist.2 I 20

Carm $3+10$

dipioted as

l. ist 2 2.91

(itrm 5.15

cianch a 20

1 firfol 10:2

int 1 irm: 1518

simz 2 i : 
pancis ostendi genis et communia laudas, I non ita nutuitus.

Colehus an Assytius. Thebis nutritus an Argis.

nutrix. nec lubae tellus generat, leomum|arida nutrix.

loquatur . . matrona potens an sedula nutrix,

nutum. imi dtrisor lecti sic nutum divitis horret,

nutus. verna ministeris ad nutus aptus erilis.

nux. tum pencilis uva secundas/et nux ornabat mensas

nympha. montibus altis/levis crepante lympha [nymplat] desilit pede.

Nymphae. solutis/Gratiae zonis propesentque Nymphat

rident |simplices Xymphae,

nymphae. unde loquaces/lymphae [nymphae] desiliunt tuae.

Nympharum. Nympharumque leves cum Satyris clori

Faune, Nymplarum fugientum amator.

Nympbas. Baccium . . vidi docentem. . Nimpláafue diacenti

Nymphis. innctaeque Nymphis Gratiae decentes alterno teram quatint peeles,

debitate Xymphis opifex coronae

Nymphis. Gratia cum Ximphis geminisque sotoribus
I.pist.1.20.5

Ars lititis

(iarm.1.22.10

Ars lort.110

tepit.1.18.I1

Iipinta.2.0

Serm.2.2.122

Fav. Epod.10.4s

Cirm.1-30.6

Carm.2.8.54

2n: Carm.3.13.10

Carm.t.I.3I

Corm.3.1s.1

Cum.2.19.3

Cormentes

(a)m.3.27.30

cismot.t.5

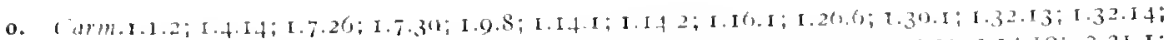

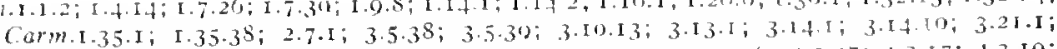

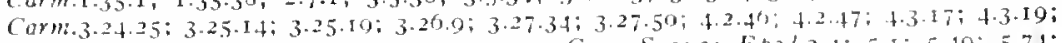
Carn.t.4.37; .1.5.37; 4.10.1; 4.145; 4 1.4.43; Cam.Satc.2; Epot.3.4; 5.1; 5.49; 5.74; Ipod.10.15; 12.25; 15.11; 17.30; zar.Epod.17.31); Epod 17.to: S.rm.1.1.4; 1.2.92 (bis); Sirm.1.5.43; 1.5.58; I.9.1 I; I. I0.21; 2.I 42; 2.1.60; 2.2.107; 2.2.125; 2.3.31; 2.3.205; Strm.2.3.320; 2.5.5; 2.5.59; 2.6.5; 2.0.10; 2.0.51; 2.6.t); 2.0.13; 2.0.1.5; $2.7 .70 ;$ IE pist.1.t.53; 1.19.19; Ar.5 Poct.291;301; $3^{60}$

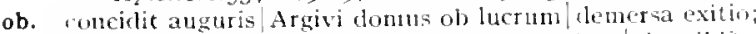
ob hane rent. . . minus hoc incundus anicus| sit mili??

(') volgo recitart timentis ob hanc rem. at ob avaritian aut misera ambitione laborat. non aliam ob causam, idi te, Damasippe. deaeque verum ob consilium donent tonsore cum prudens scelus ob titulos admittis inanis. prave seetum stomacheris ob ngguem varcus ob horedis euran nimimmque severbs arlid.t insano: yuodsi depositum latudas ob amici iussa pudoren. in trivis fixum cum se demittit ob asseth. clarns ob id factum donis ornatur hosestis, carmine gui tragico vilen certasit ob hircum. dictur ob hot lenire tigres rabidosque leones,

obarmet, Amazonia securi|dextras obarmet,

obdit. nullique malo latus obdit apertum.

abducta. obducta solvatur fronte senectus.

obdura. fi cognitor ipse. persta atcue obdura:

obeam. tecum vivere amen, tecin obeam lubens."

oberrat, citharoedus ridetur, chorda qui semper oberrat eadem:

obesae. nec firmo iuveni neque naris obesae?

obeso. cu:n sit obeso|nil melius turdo.

obeundus. non sollicios nihi quarl cras surgenelum sit mane, obenndus Mityan.

obibo. vbibolnec stygia cohibebor unta.

obice. nuten peccatis et fraudibus obice subem.'

obicere. mie.. . obicese incolis/plorares Aquilonibus.

obiciebat. (unim ex iudicilsts selectis obicicbat)

obiciet. si nerpe avaritiam neque sordes. . obiciet vere guisquam mili, obiciot memo sot dis mihi, quas tibi, Tilli,

obiecerit. suratio dederit seu fors obiecerit.

obiecta. quid hellicosus Cantaber et Scythes. . cogitet Hadria / divisus obick to [obreta],

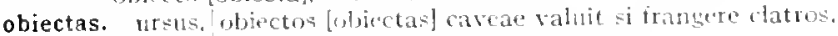

obiecto. Hadria divisus obiecto.

obiectos. ubictos caveae valuit si frangere clatios.

obire. nec dis amiem est new nili te prinsiobire.

obisset. ut silfius inmatum abisset,

oblectat. fabula. . valdins oljectat populum meliusdar moratur

Sirmid. 3.01

S.rm.1.4.23

Serm 1.4.20

Sirm.1.7. 1

Sirm.2.3 I

herm.2.3.21 2

Epist.1.1.104

Ipisi. 1.5.13

Lpist.1.0.12

Ivpist. I. I 1.0.t

Ipist.2.2.32

- 1 rs I0rt.2.20

- Ars F'orl.393

Carm.t.4.2I

Sirm.1.3.59

lipol.13.5

Sirm.2.530

Curm.3.9.2t

dos $100+6.350$

lipinl.12.3

epist. I 15.42

Serms 5.0 .120

(arm 220.7

LEt:t.1.10.1.2

Cirm. 3.10.3

Serm.1.1. I 23

Sierm. I. S. 9

Sith 1 (1.107

Serm.1.1.2

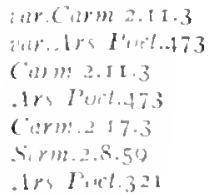


obligasti. sed tu simul obligastí petfidum rotis caput.

obligatam. rigo obligatam redde bovi dapent.

obligatus. optitt l'ometheus obligatus aliti.

oblimare. bunam deperdere tamam. Fem flatis olulimare malum ant ubicum?tun.

oblinat. nee somerum quatrit, quem versibus oblinat atris,

obluqua. quid ollifuo labor at Jympha fugax trepielare rivo?

non istic asliquo oculo mea commoda quiseuam "limat.

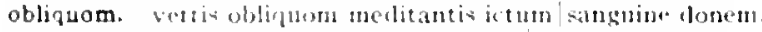

obliquom. si fuer obliguom similis sagittac|terruit mannos: -

obliti. yuid leceat. quid non, obliti.

oblitis. acilicet oblitos [oblitis] patriaeque patrisque Latini.

oblitos. scilicet oblitos patriaterue patristue Latini.

oblitum. oblitum. . . tanto reprelsendi instius illis.

oblitus. ancilintum et nominis et togae, oblitus [? anciliorum ublitus nombinga cet tokatel

thyae oblitui acternaeque Vestace,

- ilieret oblitos [oblitus] patriacque patrisque d,atini.

bhlutusque meorum, obliviscendus et illis

gubu oblitus actor/cum stetit in scacua.

ablivia. dure sollicitae incunda oblivia vitae?

oblivione. unctis omnium cubilibus oblivione paelicum?

ablivionem. mullis inertia cur tantam diffuderit imis oblivionem senubus.

obliviones. patiar labores'inpunc, 1.olli, carpere lividas obliviones.

oblivioso. obliviono levia Massico'ciboria exple,

obliviscendus. oblitusque meorum, obliviscendus allis

obliviscitur. quis non malarum quas amor curas habet hatec inter obliviscitur?

obnoxia. pars multa natat, modo reca cafesuens, intersum pravis obnoxia.

obpedere. vintuleurtic Judacis oppedere [olppedere]?"

obrepere. vrum operi longo fas rest obreperc somnum.

obrut. ingrato celeres obruit ot io/ventos

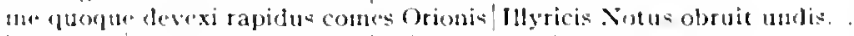

obruitur. quil semper in augenda festinat et obruiqur re.

obscaenas. vos turba viatim line et hine saxis petens / contundet obscacnas anus;

obscrenis. torquet ab obicaenis iam nunc sermonilus aurem.

obseaeno. obreacnorue ruber porrectus ab inguine palus,

obscaenum. est qui inguen ad obscaconm subductis usque;

obscenis. totequet ab obscatnis lobacenis] iam nume semonibus aurem.

obsrura. insignetu attenuat deus/obscura promens:

"num fuis? an prudens ludis me obscura canendo?"

obscurante. turpis offotatum caput obscurante lacerna.

obscuras. migret in obscuris lunuili sermone tabernas

obscurata. vilba . . obscurata diu polulo bonus cruet

obscuri. modentu- accupat obscuri specicm. taciturnus acerbi.

obscuro. albus ut obscuro deterget nubila caelol saepe Notus mon oflio abicuro mor wluque venenat:

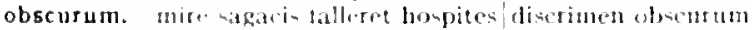

obscurum. quil premat obscurum lunac, quid proferat ofben. Jisec amate obscusum; volet hatec sub luce vileri.

obscurus. Previc ene laboto. obscurus fio;

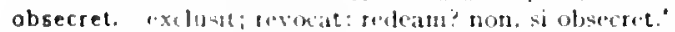

obsecro. te. . Abacto et obtestor, vitace me relale priosi."

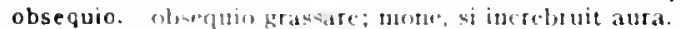

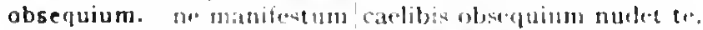

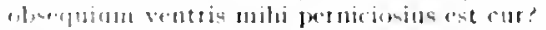

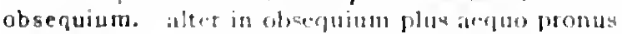

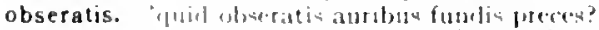

absessam. qubeta non fulcrior ignis accendet obsesuan llion.

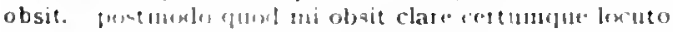

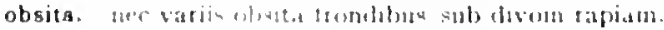

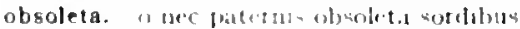

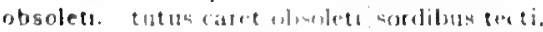

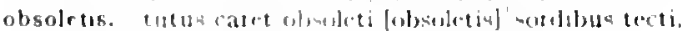

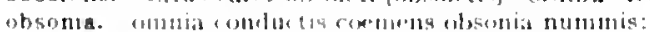

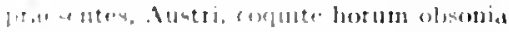

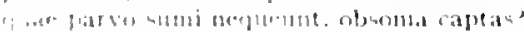

Carm.2.85

Carm.2.7.17

fipod.17.6\%

Sirm.1.2.1.2

Ispist.1.10.30

Corm.2.311

Epist.1.1.37

(arm 3.22.7

Carm.3.27.6

Epistit.0.02

coni.tierm.1.10.27

coni.sirm.1.10.27

Sirm! $2 .+85$

? ear.Curm.3.5.10

Corm 3.5.11

tar. Serm.1.10.27

lipist.1. I 1.9

IEpist. 2.1 .204

Serm.2.0.02

tipod.5.70

Ispoll.1.2

Curm.4.9.34

Cirm.2.7.21

fipist.1.11.9

lipod.2.38

Sirm.2.7.8

iur. Serm.1.0.70

. Irs Port.360

Curm.1.15.3

Curm.1.28.22

Espist.1.10.688

lipod. 5.08

lipist.2.1.127

Sirm.1.8.5

Sirm.1.2.26

"ur. Epist.2.1.127

(arm.1.3.1.14

Sirm.2.5.58

Sirm.2.7.55

Ars Poel.220

lisist.2.2.115

Epist.1. I 8.95

(urm.1.7.15

Lepist.1.14.38

(iurm.2.5.23

lisist.1.12.18

Ars Port.303

Ars Porl.20

Sirm.2.3.204

Epist.1 7.05

Trrm.2503

Serm.2.5.47

Sirm 2710.1

Epist 1.18 .10

t.pent 17.53

Epold.t.

Sorm 2.0.27

(i) $119+2$

1. post.17..16

carm.2 Io.f

for carm.2.106

serm. 2.0

Sorm 22.11

srom 27100 
obsorbere. Porcins infra, | ridiculus totas semel absorbere [obsorbere] placentas;
obsorberet. scilicet ut deciens solidum absorberet [obsorberet]. acetoldiluit insignem bacan:

obstantia. mitulus et viles pellent obstantia conchac amat spatiis obstantia rumpere claustra

obstantis, dimovit obstantis propinquos.

obstantis. cum per obstantis iuvenum catervas per obstantis catervas/explicuit sua victor arma. apros in obstantis plagas

obstare. ut rupes fluviosque in campo obstare queratur;

obstaret. si taciturnitas|obstaret meritis invida Romuli?

obstat. (sic festinanti semper locupletior obstat).

altera. nil obstat: Cois tibi paene videre est/ut nudam.

'tu pulses omne quod obstat,

obstet. nil obstet tibi. dum ne sit te ditior alter.

hunc atque hunc superare laboret / (sic festinanti semper locupletior obstat [obstet])

'verum purae sunt plateae, niliil ut meditantibus obstet'.

obstetrix. tuo|cruore rubros obstettix pannos lavit,

obstinatas. clic modos, Lyde quibus obstinatas/adplicet aurin,

obstipo. stes capite obstipo, multum similis metuenti.

obstitit. quicumque mundo terminus obstitit.

obstrepentis. marisque Bais obstrepentis urges |submovere litora.

obstrepit. qua violens obstrepit Aufidus

qui remotis/obstrepit Oceanus Britanns.

obstrepunt. frondesque lymphis obstrepunt manantibus.

obstrictis. ventorumque regat pater|obstrictis alis nraeter lapyga.

obstringam. iure iurando obstringam ambo:

obtestor. te . . obsecro et obtestor, vitae me redde priori.'

obticuit. chotusque/turpiter obticnit sublato iure nocendi.

obtigit. lupis et agnis quanta sortito obtigit.

obtinet. nec socerum quaerit, quem versibus oblinat [obtinet] atris

obtulerim. qualem me saepe libenter/obtulerim tibi, Maecenas.

obtulit. cui deus obtulit/parca quod satis est manu. nulla etenim mihi te fors obtulit;

abturem. obturem patulas inpune legentibus auris.

obvius. casu venit obvius illi|adversarius

quicumque obvius est, me consulit:

obvolvas. verbisque decoris] obvolvas vitium?"

occasionem. rapiamus, amici, /occasionem de die

occat. cum segetes occat tibi mox frumenta daturus,

occidenti. invitum qui servat. iden facit occidenti.

occidentis. vel occidentis usque ad ultimum sinumiforti sequemur pectore

occidere. et Nenelaum una necum se occidere clamans."

vendere cum possis captivom, occidere noli:

occideris. cum semel occideris et de te. splendide, Minos/fecerit arbitria.

occidi. 'non lominem occidi." 'non pasces in cruce corvos.'

occidis. candide Nlaecenas, occidis saepe rogando:

nec ferro ut demens genetricem occidis Orestes.

occidistis. "pol, me occidiatis, anici.|non servastis"

occidit. multis ille bonis Hebilis occidit,

occidit et Pelopis genitor, conviva deorum.

occidit Daci Cotisonis agmen,

occidit, occidit/spes omnis et fortuna nostri| nominis

occidit. Aiax cum inmeritos occidit desipit agnos;

quem vero arripuit, tenet occiditque legendo,

occisa. an tu reris eum occisa insanisse parente

occultam. neu. . . occultam febrim sub tempus edendi|dissimules.

occultare. arat inpiger Apulus foccultare meis dicerer horreis.

occulto. crescit occulto velut arbor aevo|fama Marcellis;

multis occulto crescit res faenore.

occultum. occultum Andromedae pater/ostendit ignem.

occultum visus decurrere piscis ad hainur.,

occupa. o quid agis? fortiter occupa| portum.

occupabit. proximos illi tamen occupavit [occupabit]/Pallas honores.

occupabitur. ferisque rursus occupabitur solum:

occupare. secunda|ratem occupare quid moramur alite?

tar. $5 \mathrm{erm} .2 .8 .24$

tor.serm.2.3 2.40

Serm.2.4.28

Epist.1.14.9

Carm.3 5.5I

Carm.3.20.5

Corm.4.9.43

Epod.2.32

Strm 2.3.55

Carm.t.8.24

Sermit1.113

Serm.1.2.10 I

Serm.2.0.30

Serm.1.1.to

zar.Serm.1. I. I 13

Espist.2.2.71

lepod.17.5I

Carm.3.11.7

Sirm.2.5.92

Carm.3.3.53

Carm.2.18.20

Carm.3.30.10

Carm.t. 148

Epod.2.27

Carm.1.3.t

Serm.2.3.180

Epist.1.7.95

Ars I'ot'.284

Ispod.4. I

ent. Epist. I. I 9.30

serm.1.3 to.

Carm.3.10.43

Serm.1.0.54

Epist.2.2.105

Sirm.1.9.74

Serm.2.0.5 I

Serm.2.7.42

Epod.13.t

Epist.2.2.16]

Ars Poet. 467

If pod. I I 3

Serm.2.3.198

Epist.1.16.09

Carm.4.7.2I

Epist.1.10.48

Epod.1 4.5

Serm.2.3.133

Epist.2.2.138

Corm.1.24.9

Carm.1.28.7

Carm.3.8.18

Carm.4.4.70

Sirm.2.3.21 I

Ars Poed.475

ierm.2.3.134

IEpist.1.10.22

(arm.3.10.27

Carm.1.12.45

Epist.j. 1.80

Carm.3.29.17

Lpis!1.7.74

Curm.1.142

conicurm.I.I2.I9

fopd.16 10

Fpod 16.24 


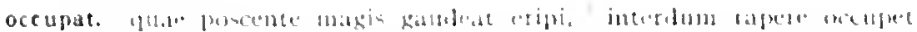
$[1 \mathrm{~m}, 4 \mathrm{j}) \mathrm{at}]$ :

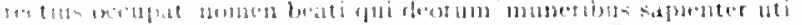

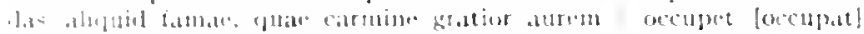

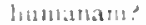

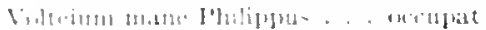

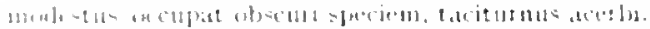

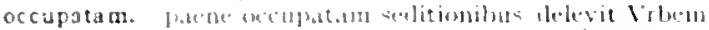

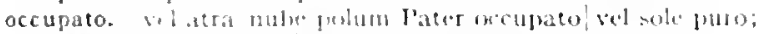

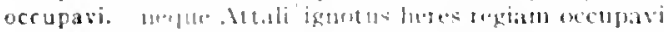

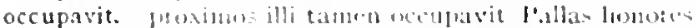

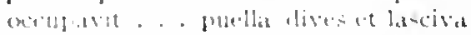

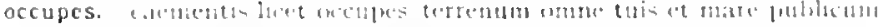

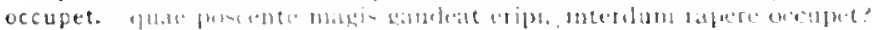

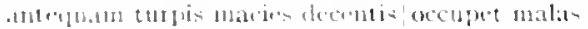

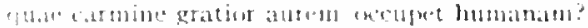

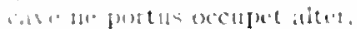

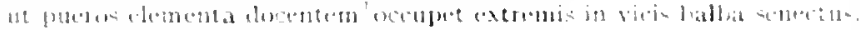

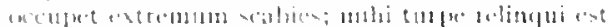

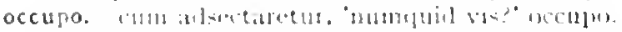

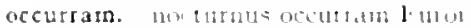

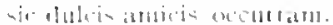

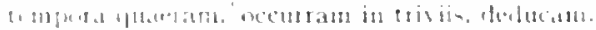

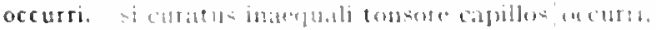

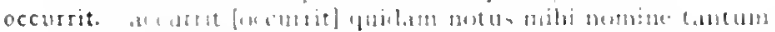

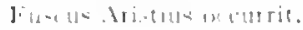

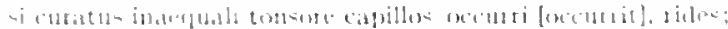

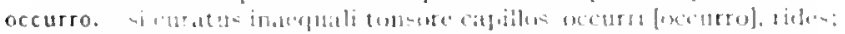

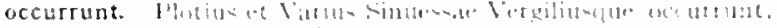

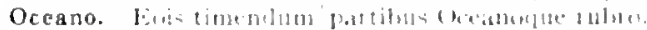

Oceano. 1 1401 -

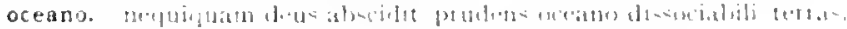

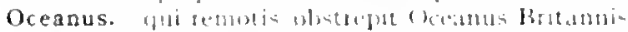

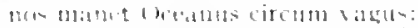

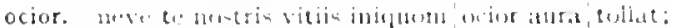

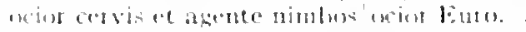

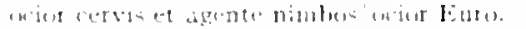

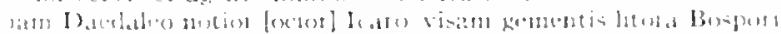

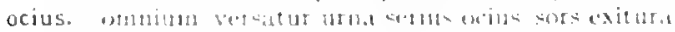

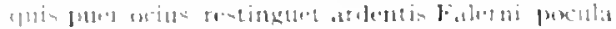

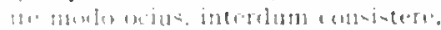

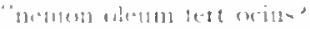

in illa bille le ni retis.

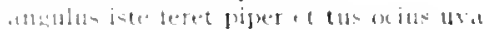

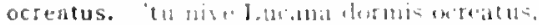

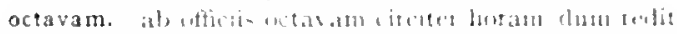

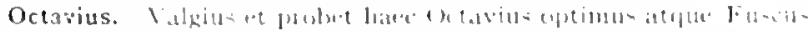

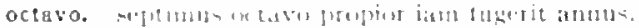

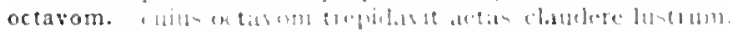

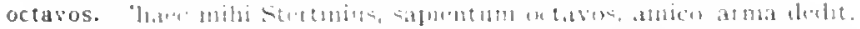

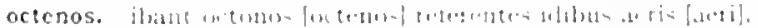

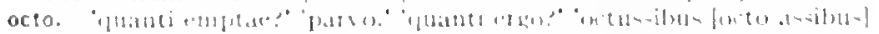

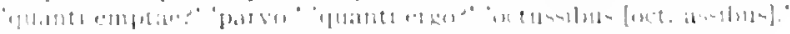

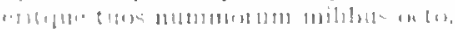

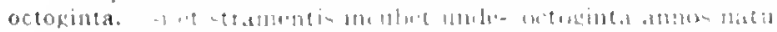

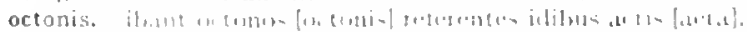

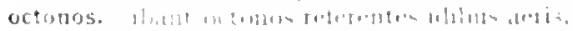

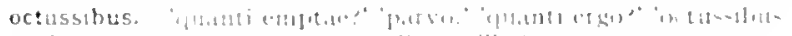

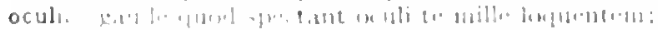

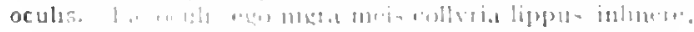

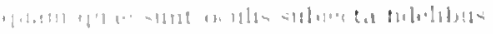

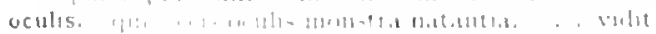

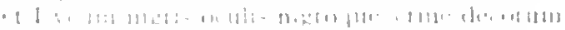

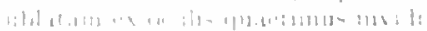

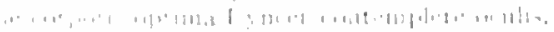

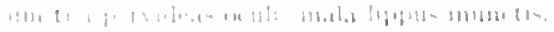

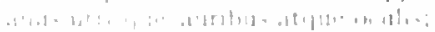

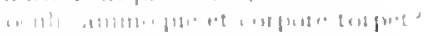

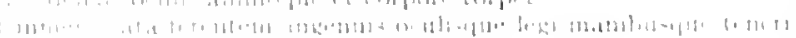

iar (arm: 22 is

(avm+o..t)

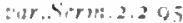

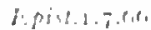

fopister Is o.s

(iorm. 3.113

(urm.3.20.+4

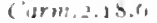

(itrm:1.12.10

(i)

(itrm. 32.8 .3

(irm.2.12.28

( $125 m \cdot .3 \cdot 27.5 .4$

Sirm 22.05

1. 14.61 .1 .32

J.f.5. $1.20 \mathrm{IN}$

Ars Putedt?

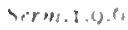

loperis 502

crm.1.1.131

cermidio50

lopis! 1 1.0.5

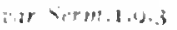

Sirmel.0.01

ar. Jiphl.1.1.45

inr.l.pinel.1.15

Sirm.1 5.d1

(arme1.35.3.

(armets so

('in).1.3.2.

(atm.t. 1: 8x

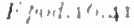

(irmed I is

corm. 2.810.23

(iarm, 2.1\%124

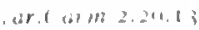

(a)m.2 32 ?h

(arm.211.18

Sirm : (1)

Sirms 2.7 .34

sicme.2-117

f.p.t.8 1.9 .23

verm.2, 3.2.3.1

1 pint 1.7.t.

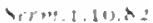

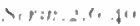

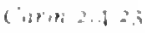

verm. \& 3.2upr

atr serm a ide.j

iar sorm a is

ir 4 - rni.2.3.15\%

l.pict: 25

arin?

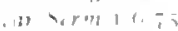

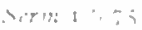

irren: 315

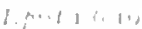

S.ron 1 ; 10

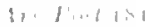

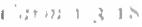

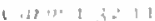

(4) यद: 2 ,

$1, t: 1 \geqslant 1$

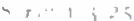

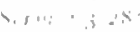

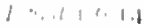

13110319 
spectandum nigris oculis nigroque capillo. .

Ars Poet. 37

multaque tolles/ex oculis,

etian stillabit amicis|ex oculis rorem.

oculo. quisquis ingentis oculo inretorto/spectat acervos.

metiri possis oculo latus.

solus multisne coheres, / veloci percurre oculo.

non possis oculo quantum contendere Lynceus:

Ars Poet.184

Ars Poet.430

Carm.2.2.23

Serm.1.2.103

Serm.2.5.55

Epist.1.1.28

Epist.1.14.37

Carm.1.36.18

Carm.2.12.15

Serm.1.9.65

Serm.2.5.35

iar.Epist.1.1.28

Iar.Epist.1.2.38

Epist.1.13.17

Epist.2.I.I 88

Epist.1.2.38

Carm.3.4.67

Serm.1.4.33

Carm.1.8.4

Carm.2.16.26

Serm.I.I.85

Epist.1.16.52

Epist.1.18.89

Epist.1.18.92

Carm.1.38.I

Carm.3.].I

Carm.3.19.22

Ars Poel. 88

Carm.3.24.31

Epist.1.I4.I I

Epist.2.1.101

Serm.1.7.6

Epist.1.2.6I

Epist.I.I I.6

Epist.I.I 4.38

Epist.1.20.9

Serm.2.2.36

Serm.1.3.86

Epist.1.20.3

Serm.2.1.23

Episl.1.1.72

Epist.1.7.20

Epist.1.14.20

Epist.1.18.25

Epist.1.18.26

aut, si non odit, regit

nisi quae terris semota suisque/temporibus defuncta videt, fastidit et odit.

nostra sed inpugnat, nos nostraque lividus odit.

odium. odiumque libellis|sedulus inportes opera vehemente minister.

odor. quam malus undique membris|crescit odor,

et decedet odor nervis inimicus;

odoraris. proiectum odoraris cibum. .

odorati. rosa|canos odorati capillos.

odoratis. sparsum odoratis umerum capillis,

odoratum. turpis odoratum caput obscurante lacerna.

odore. vetus ara multolfumat odore.

odorem. spargent olivetis odorem

cuius odorem olei nequeas perferre,

quo semel est imbuta recens servabit odorem | testa diu. .

Epist.2.1.22

Epist.2.1.89

Epist.I.I 3.4

Epod.1 2.8

Serm.2.4.53

Epod.6.10

Carm.2.11.15

Carm.3.20.14

Serm.2.7.55

Corm.3.18.8

Carm.2.15.7

Serm.2.2.59

Epist.1.2.69

Epist.2. I.269

edoribus. quis multa gracilis te puer in rosa | perfusus liquidis urget odoribus

tuis capillus albus est odoribus.

odoror. namque sagacius unus odoror,

oenophorum. pueri, lasanum portantes oenophorumque.

Ofelli. nunc ager Timbreni sub nomine, nuper Ofelli|dictus,

Ofello. sordidus a tenui victu distabat Ofello|iudice:

Ofellum. puer hunc ego parvos Ofellum|integris opibus novi

Carm.I.5.2

Epod.17.23

Epod.1 2.4

Serm.1.6.109

Serm.2.2.133

Sierm.2.2.53

Serm.2.2.II2 
Ofellus. Inec mant hic sermo mit. aed quate praecepit Otellus|rusticus. offendam. "ins ego amicum / offendam in nugis?"

offendar. fidis ontendar nedicia, iratcar amicis, nun e.go parteis offendar maculis.

offendat. gui ne tuberibus propriis offendat amicum|postulat. mundur utit, yua non offendat sordibu:

offendere. fuollute| posset cenantis of endere:

off enderet. si non offenderet unum / quemque poctarum limae labor et mora.

offendes. difficikn et morowim offendet [offendes] garrulus:

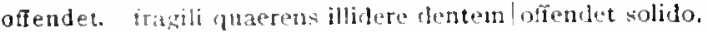
diticilen et morosum offendet garrulus:

offendit. duticilem et morosum offendist [offendit] garrulaz:

affend unt. ut gratis inter mensas symphonia discors/et crassum unguentum - offendiune.

affenduntur. offonluntur enim. quibus est equos et pater et res.

offensae. nee semel offensi [ohensae] cedet comstantia formae,

affensi. nec semel offensi cedet constantia formae.

offensi. ingenio offensi aut latso doluere Metelio

offensus. infami Helenae Cator offensus vice/raterque magni Castoris. off ("nsus dammin media de nocte cabalJum /arripit

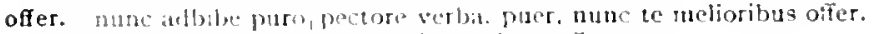

offert. nenia. quat resnum recte facientibus offert.

offcient. multat tibi tum offcient res:

officis. nec non verniliter ipsis/fungitur olficis.

ab ontiis octabam circiter horam!dum tedut

ne. . Aixi|talbus obticis prop* mancum

hic sponsun vocat, hic auditum scripta relictis/omnibus oncis:

afficina. caltes verueniu officina Colchicis.

officinas. kravis Cyclopum/Volcanus ardens viuit offeinas.

officio. "uich me prior olficio quisquan respondeat. urie."

officiosa. mticiosulue selulitas et opella forensisladfucit febris

officiosus. Jeniter in sperm|adrepe ofticiosus.

afficit. an tibi abunde | personam satis e-t, non illud. quidquid ubique | nfticit, evitare?

nit mi onleit, inquam. ! 'elitior hic inte est quia doctior;

afficium. fluol sit conscripti, quod iudicis officium,

afficium. "letos ut me portet, alat rex, lofticium fucio:

1h sumet in lucern, scorto postponet honestum $\mid$ othicium.

nil moros ofticium quod me gravat

a.toris partea chorus officiumque virile lefendat.

munu et officin, nil seribens ipse, focebo:

afficint. sinterlicta petes. . . multae tibi cum officient [officiunt] res: ohe. ingerere 'fuc alpelle'; 'trecentos inseris"; 'ohe./ian satis est."

dome "ohe i.tu" al caelum manibus sublitis dixerit.

oherequires. 'o er., quate res [olyerequires] ! nec modum habed neque consiliunu.

olea. nil intra ext olua, nil extra est in nuce duri:

oleam. undifue lecerptam ironti praeponere olivam [oleam]:

olenmelue momorderit aestus.

nil intrit at wea [oleam], ni] extra est in nuce duri;

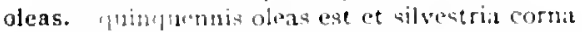

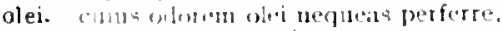

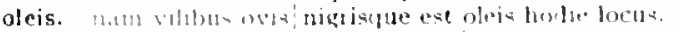

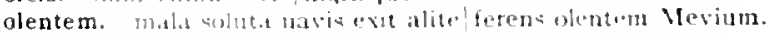

alenti. rontal aluz nullam niaj olenti in formice stantem.

glentis. "hrute 11 rores mariti

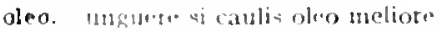

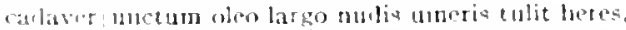

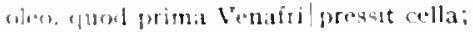

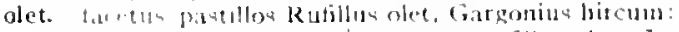

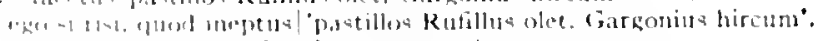

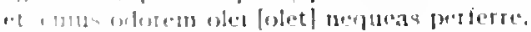

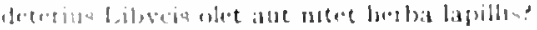

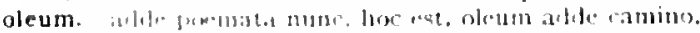

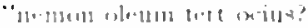

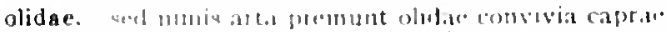

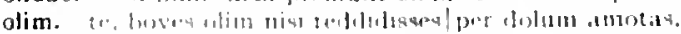

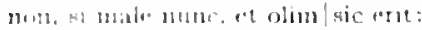

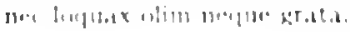

Serm.2.2.2

Ars Poet.45I

Epist.1.8.9

Ars Poet.352

Serm.1.3.73

Serm.2.2. 5

Serm.2.8. 13

Ars Poet.290

coni.Serm.2.5.90

Serm.2.1.78

Serm.2.5.90

gur.Serm.2.5.90

Ars Poet.37"

Ars Poet.2.48

iar.Epod.15.15

Epod.15.15

Serm.2.1.67

Epod.17.42

Spist.I.7.88

Epist.1.2.0.8

Esist.1.1.03

Serm.1.2.97

Serm.2.6.1 0

Epist.1.7.47

Epist.2.2.21

Epist.2.2.08

Epod. 17.35

Carm.1.4.8

Sirm.2.0.24

Epist.1.7.8

Sierm.2.5.49

Serm.1.2.6I

sirm.1.0.50

Ars Poet.314

Epist.1.17.21

Epist.1.18.35

Epist.2.1.264

Ars Poet.193

Ars Poet. $30^{\prime}$

iar.serm. 1.2.97

Sorm.1.5.12

Serm.2.5.26

Tar.serm.2.3.205

Epist.2.1.3!

sar.Curm.1.7.7

Epist.1.8.5

I'ar. Epist.2.1.3I

Serm.2.2.57

Serm.2.2.50

Serm.2.2.40

lipoll.10.2

Serm.1.2.30

Corm.t.17.7

Serm 2.3.125

Simm.2.5.80)

Siern.2.8.45

Serm.1.2.27

Serm.1.1.02

:ar. Yerm. 25 ?

Epist.1.10.10

Norm.2.3.321

Sictin.2.7.3.4

Efist 1.5.21

Carm 1.10 .0

Cirm.2.10.17

Cirm 3.11.5 
olim inventas et patrius vigor|nido laborum protulit inscium nec siquid olim lusit Anacreon/delevit aetas; parentis olim siquis inpia manu|senile guttur fregerit. inceptos, olin promissum carmen. iambos . ut pueris ofim dant crustula blandi|doctores, numqua tibi vitiorum inseverit olim/natura male parvos|sicui filius est, ut abortivos fuit olim/Sisyphus; his. ego quae nunc, folim quae scripsit Lucilius. numquid ego illi | inprudens olim faciam simile?' qui locus a forti Diomede est conditus olim. olinı qui magnis legionibus imperitarint. at olim. Iquod mihi pareret legio Romana tribuno. optimus olim | Vergilius, post hunc Varius dixere quid essem. olim|si praeco parvas... mercedes sequeret; olim truncus eram ficulnus, inutile lignum. ille velut fidis arcana sodalibus olim/credebat libris quae simplex olim tibi sederit.

olim nan quaerere amabam. . . aere. non magis audierit, quam Fufins ebrius olin, faciasne quod olim |mutatus Polemon? magna minorve foro si res certabitur olim:

olin! rusticus urbanum murem mus paupere fertur|accepisse caro, olim quod volpes aegroto cauta leoni|respondit, si forte suas repetitum venerit olim/grex avium plumas. piscemur, venemur, ut olin' 'Gargilius ut calceus olim. | si pede maior erit. subvertet. quid refert, vivas numerato nuper an olim? puer ut festis Quinquatribus olim. sterilisve diu palus [palus olim] aptaque remis/vicinas urbes alit et grave sentit aratrum, nec sic incipies, ut scriptor cyclicus olim: siquid tamen olim|scripseris.

oliva. lecta de pinguissimis / oliva ramis arborum .

olivae. gerninat et numquam fallentis termes olivae pressa Venafranae quod baca remisit olivae. arvo pascat erum an bacis opulentet olivae.

olivae. me pascunt olivae. me cichorea levesque malvae.

olivam. undique decerptam fronti praeponere olivam;

olivetis. spargent olivetis odorem

olivo. lecto laut scripto quod me tacitum iuvet, unguor olivo. quali perfundat piscis securus olivo. simplex e dulci constat olivo,

olivom. cur olivom |sanguine viperino/cantins vitat ollis. venucula convenit ollis; | rectius Albanam fumo duraveris uvam. aloribus. Paphon|innct is visit oloribus purpureis ales oloribus $/$ comissabere

oluerunt. vina fere dulces oluerunt mane Camenae.

Olympia. magna coronari contemnat Olympia,

Olympicum. sunt quos curriculo pulverem Olympicum|collegisse iuvat Olympo. opaco|Pelion inposuisse Olympo.

Olympum. tu gravi curru quaties Olympum. .

omasi. patinas cenabat omasi|vilis ct agninae,

omaso. pingui tentus omaso|Furins

omen. inpios parrae recinentis omen/ducat

ominatis. o pueri et puellae | iam virum texpertae, male nominatis [ominatis]| parcite verbis.

omine. dum favet Fox et Venus, i secundo|omine

ominibus. votis ominibusque et precibus vocat

omisit. quod petiit spernit, repetit quod nuper omisit.

omissis. rebus omissis/atria servantem postico falle clientem. fortis omissis|hoc age deliciis.

omittas. aut spem deponas aut artem inlusus omittas. hoc primus repetas opus, hoc postremns omittas.

omittat. pleraque differat et praesens in tempus omittat.

omitte. omitte mirari beatae/fumum et opes strepitumque Romae. quem sua culpa premet. deceptus omitte tueri.

omittit. ergo/quem sua culpa premet, deceptus omitte tueri [? praesens sua culpa ire deceptus omittit etueri].

omne. nepotum | per memores genus oinne fastos, .
Carm. $4 \cdot 4 \cdot 5$
Carm.4.9.9
Epod.3.I
Epod.I4.7
Serm.1.I.25
Serm.1.3.35
Serm.1.3.46
Strm.1.4.57
Serm.1.4.137
Serm.I.5.92
Serm.1.6.4
Serm.x.6.47
Sirm.1.6.54
Serm.1.6.85
Serm. I.8.I
Serm.2.1.30
Serm.2.2.73
Serm.2.3.20
Serm.2.3.60
Serm.2.3.253
Serm.2.5.27
Serm.2.6.79
Epist.I.1.73
Epist.1.3.18
Epist.1.6.57
Epist.1.10.42
Epist.2.2.I 66
Episl.2.2.197

coni.Ars Poet.65

Ars Poel. 136

Ars Poet.386

Epod.2.56

Epod.10.45

Serm.2.4.60

Epist.1.16.2

Carm.1.31.15

Carm.1.7.7

Carm.2.I5.7

Serm.1.6.I 23

Serm.2.4.50

Serm.2.4.64

Carm.1.8.8

Serm.2.4.7I

Carm.3.28.15

Carm.4.I.ro

Epist.r.ro.5

Epist.1.r.5o

Carm.1.1.3

Carm.3.4.52

Carm.1.12.58

Epist.1.15.34

Serm.2.5.40

Carm.3.27.I

2ar.Carm.3.14.I:

Carm.3.I I.5 I

Carm.4.5.13

Epist.1.1.98

Epist.1.5.30

Etpisl.1.6.30

Sirm.2.5.26

Epist.1. 6.48

Ars Poet.44

Carm.3.29.1 I

Epist.1.18.79

8 var.Epist.I.I 3.79

Carm.3.I7.4 
ludit hetboso pecus omne campo libenter hoc et omne militabitur bellum et omne vicinum oppidum. hoc genus omne/matesu ac sollicitum est cantoris mote Tigelli. cum scurris fartor, cum V(clabro omne macellum ced non onne mare est genesosae fertile testac: vit honus, omne forum quem spectat et omne tribunal, adeo sanctum est vetus omne poema. . omne superiacuom pleno de pectote manat.

omne. omne cum Proteus pecus egit altos/visere montic. omne capax movet urna nomen. omne sacrum rapiente dextra. omne nefas animo moventis. binc onne principium, huc refer exitum: splendide mendax et in omne virgo/nobilis atevom. caementis licet occupes/tersenum onne tuis et mare publicum: guibus | mos unde deductus per omne/tempus Romulae genti date remque prolempuelet decus omne. paratus omne Caesaris periculum / subire. illic onne malum vino cantuque levato. natuegue, pes omnelaudaces mare qui curunt. reciferet omne, quod ultra! perfectum traheretur. interdicto buic onne adimat ius'practor 'tu pulses omne quod obstat. praclambens omne quod aclfest. labitur et labetur in omne volubilis aevom. nec modica cenate times lolus omme patella. ubi onne/verterat in fumum et cinerem, omne tulit punctum, qui miscuit utile dutci

ornem. omnem crede diem tibi diluxisse suprenum: format enim natura prius nos intus ad omnem/fortunarum habitum:

omnem. omnem redegit idibus pecuniam. nescio an Anticyram ratio illis clestinet omnem. connittes f'm omnen et vitam et cum corpore famam.

omnes. omnis in Damalin putris/deponent oculos omnes eoden cogimur. ommes inlacrimabiles/urgentur ignotique longa|nocte. schem, quod ommes rideant, adulterum hate et guac poterunt reditus abscindere dulcis leamus omnis [omnes] exsectata civitas onnes/vicini oderunt, noti. pueri atque pueblae. "jure" onnes; Galba negabat.

omnes hi metuont versus, odere poetas.

quem rodunt onnes libertino patre natum.

(hoc etenim sunt omnes iure molesti|guro fortes. insanis ee to stultique proje omnes. munc arcipe, quare desipiant omues anque ac $t u$. insanum to ommes puci clamentque purllae: 11mat|flgesat in campo: 'fortunat filius' omnes. 'at omnes di easgitent mé. |si quicquam.'

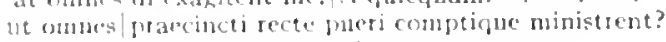
desidge notu dunes vadem mirantur anantedue.

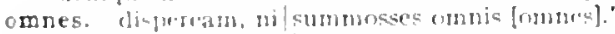

omni. rirlecur ab onani conventu:

omni. mhil ent ab) omni|parte beaturn.

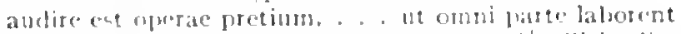

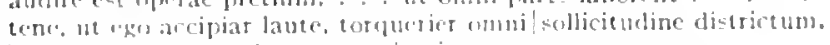

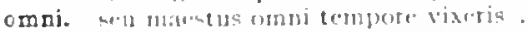

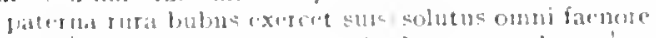

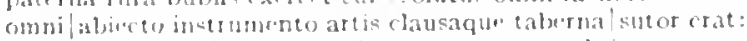

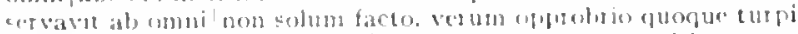

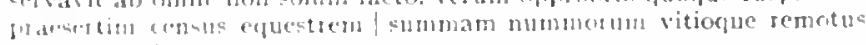
a) omni,

omsia. cmmb te adveraum sfectantia. nulla tetrotsm."

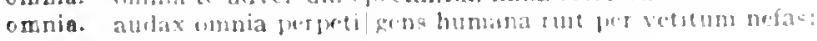

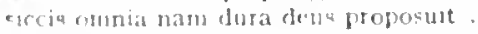

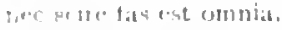

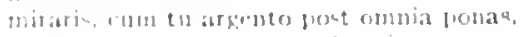

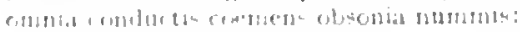

$\operatorname{Carm} 3.18 .9$

Ispod.1.23

Epod.5.44

Strm.1.2.2

Serm.2.3.229

Serm.2.4.31

Epist.1.10.57

Epist.2.1.5.4

Ars 1'oet.3.37

Carm.1.2.7

Carm.3.1.16

Carm.3.3.52

Carm.3.4.08

Carm-3.0.0

Corm.3.11.35

Carm.3.24.4

Corm.4.4.19

Carm.Saec. 48

Epod.1.3

I.pod.1317

Serm.1.1.29

Serm.1.10.69

Serm.2.3.217

Serm.2.6.30

Scrm.2.6.309

Epist 1.2.43

Epist.1.5.2

Epist.1.15-38

Ars I'od: 3.43

Epist.1.4.13

Ars Poet. 108

Epod.2.60

Srm.2.3.83

Serm.2.7.07

Carm.1.30.17

Carm.2.3.25

Corm.4.9.20

Ispod.5.57

iar.Epod.10.30

Sorm.1.1.84

Serm. 1.2.46

Serm.1.4.33

Serm.t.6.4\%

Serm.1.70

Serm.2.3.32

Sirm.2.3.47

sirm.2.3130

Serm.2.1.40

Scrm.2.11.54

Scrm.zeg

lipist.2.2.58

: ir.serm. 0.18

serm.1.722

Carm 210.27

Serm.1.2.3s

Serm.2.847

Cism.2 is

lipod 24

scrm. 2.31.30

Serm 1.0.83

Ars loed $3 x_{4}$

Fpist 1175

Carm.1 325

(armat.183

(1)ry +1 22

Sermitise

Scrm. 120 
num esuriens fastidis omnia praeter|pavonem rhombumque?

Serm.1.2.1 15

modo reges atque tetrarchas, |omnia magna loquens,

'suaviter, ut nunc est. 'inquam. 'et cupio omnia quae vis.'

Serm.1.3.13

Serm.1.9.5

'Stoice, post damnum sic vendas omnia pluris,

Serm.2.3.300

Sirm.2.4.61

quin omnia malit quaecumque inmundis fervent adlata popinis.

Serm.2.8.64

Carm.2.14.9

Carm.3.4.13

Serm.1.3.I

omnibus hoc vitium est cantoribus.

omnibus et lippis notum et tonsoribus esse.

Serm.1.7.3

omnibus. invertunt Allifanis vinaria tota /iVibidius Balatroque secutis omnibus:

haec seges ingratos tulit et feret omnibus annis.

omnibus. ut mater iuvenem... votis ominibusque [omnibusque] et precibus vocat

hic sponsum vocat hic auditum scripta relictis iomnibus officis:

omnino. 'ne faciam, inquis.|omnino versus?' .

ut nilil omnino gustaremus. .

omnis. procul omnis esto/clamor et ira.

non omnis moriar multaque pars mei|vitabit Libitinam;

hinc omnis pendet Lucilius, hosce secutus .

male verum examinat omnis/corruptus iudex.

ut pallidus omnis/cena desurgat dubia?

quid verum atque decens, curo et rogo et omnis in hoc sum: .

dum pueris omnis pater et matercula pallet

omnis Aristippum decuit color et status et res.

scriptorum chorus omnis amat nemus et fugit Vibem.

omnis. quo calet iuventus/nunc omnis et mox virgines tepebunt.

adde quod pubes tibi crescit omnis.

myrtus et omnis copia narium

civitas omnis dabimusque divis/tura benignis.

occidit|spes omnis et fortuna nostri|nominis

eamus omnis exsecrata civitas

omnis | votiva pateat veluti descripta tabella|vita senis.

necdum omnis abacta/pauperies epulis regum: .

postquam omnis res mea Ianum /ad medium fracta est.

omnis enim res. . . . divina humanaque puleris|divitiis parent;

iactamus iam pridem omnis te Roma beatum;

sed videt hunc omnis domus et vicinia tota/introrsum turpem.

migravit ab aure voluptas onnis ad incertos oculos ct gaudia vana.

Serm.2.8.40

Epist.1.7.2I

2ar.Carm.4-5.13

Epist.2.2.08

Serm.2.1.6

Sirm.2.8.94

Carm.3.8.15

Carm.3.30.6

Serm.1.4.6

Serm.2.2.8

Serm.2.2.76

Epist.r.r.I I

Epist.1.7.7

Epist.1.17.23

Epist.2.2.77

Carm.1.4.20

Carm.2.8.17

Carm.2.15.6

Carm.4.2.5 I

Carm.4.4.7

Epod.16.36

Serm.2.I.32

Serm.2.2.44

Serm.2.3.Is

Serm.2.3.94

Epist.1.16.18

Epist.r.10.44

Epist.2.1.188

Serm.1.3.132

Carm.1.8.r

Carm.1.12.46

Carm.1.28.15

Carm.2.6.13

Carm.2.9.6

Curm.2.9.1 4

Epod.3.9

Epod.11.3

Serm.5.4.36

Serm.I.5.76

Serm.1.6.37

Serm.r.0.8I

Sirm.1.9.28

Serm.1.9.48

Serm.2.3.8I

Ars Poet.265

Serm.I.3.58

Epist.1.6.44

Ars Poet. I I

Carm.2.3.25

Epod.5.3

Epod.5.69

Serm.I.IO.Io

Episl.1.18.46

Srm.1.6.106

Carm.3.I I.45

Epist.2.I.I7o

oneris. habet comoedia tanto|plus oneris, quanto veniae minus:

onus. nec iam sustineant onus/silvae laborantes

Carm.1.9.2 
nollen onus haud unguam solitus portate molestum.

Serm.1.0.00

cum graviug dorso subijt onus.

quia tardius isent gropter onus segues.

sollicits animis onus eximit. adducet artis.

sic positum servabis onus.

hic onuthoret. I ut partis animis et parvo corpore maius;

Serm.1.9.2I

Serm.2.3.102

Epist.1.5.18

Epist.1.13.12

E.pist.1.17.39

Epod.8.14

onusta. Martit. 1] tuat rotundioribus/onusta bacis ambulet.

Serm.1.1.47

onusto. gilmoticulum panis venalis inter onusto|forte vehas umero.

onustos. meis contentus bonestos [onustos]|fascibus el sellis nollem mihi sumerc.

onustum. quin corpus onustum / hesternis vitiis animum quoque pracgravat una

onustus. 'tan teneor dono, quan si dimittar onust us'

onyx. nardi parvos onyx ticict cadum.

opaca. continui montes, ni dissocientur opaca/valle.

opacam. nulla.. metata prisatis opacam|porticus excipiebat arcton

opaco. opaco|Pelion inposuisse Olympo.

ope. one lalladia/Tydiden superis parem

ceratic ope Daedalealnititur pennis

opells. opelia torencic|adducit febri

$0 p \in \mathrm{m}$. *ut cset opem qui lerse pertis | antiquis posset contra fastidia nosita.*

poscit open clorus et prackentia numina sentit.

alterius sic|altera poscit open res

si curet quis open terte det demitcese fumem:

opera. accedes opera agro nomal Sabino.'

opera. cautus alito|neu desis operae [operal neve inmoderatus abundes. ofiungue libellis: sedulus inportes opera velemente minister.

operae. abdire ret operae pretium, frocedere recklqui moechis non voltis.

ist operae pretum duplicis pernoscere iuris naturam.

sed tamen est operae fretium cognoscere.

aut ofmat celeris nimiun curaque carent is

operae. mou desis operae neve inmodtratus abundes.

operam. infelix, operan perdis.

nullum ulta verbum aut operam insumebat inanem.

operata. prodeat iustis operata sacris

in cute cutanda plus aequo operata iurentus.

opere. veran opesi [opere] longo fas est obs (pere sommus.

operi. verum ofneri longo fas est obripere sonmum.

oferis. saphon operis atc optimus omnis/ect upilex.

frimes in hunc operis conponete carnima morem.

mielix operis stmma, quia ponere totum/mesciet:

undc joden proletre pudor veter ant aperis lex.

operosa. (I)

operosac. tubi telas operosacenc Minervae studium anfert.

operosiores. cur valle permutcm Sabina/divitias operosiores?

eperta. n!. . . capsa porrectus opertal décar in vicum

operta. quid now elgrietas dissignat? apesta recludit.

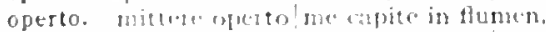

opertos. experdit matis cineres ogertociallete

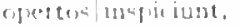

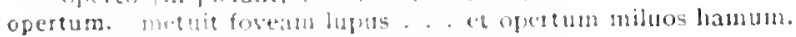

operum. Tum banulis of sum solutio.

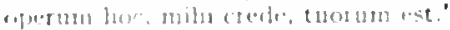

esce of

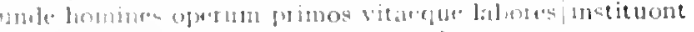

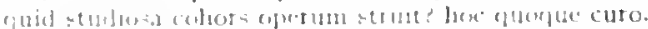

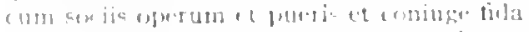

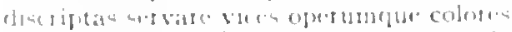

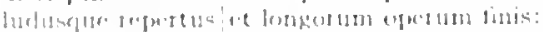

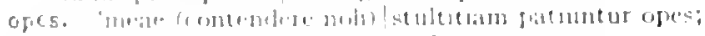

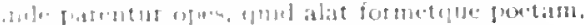

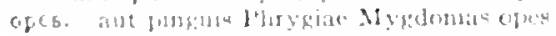

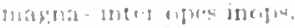

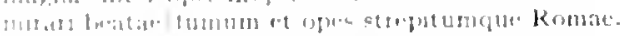

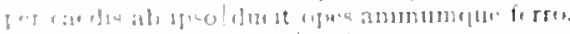

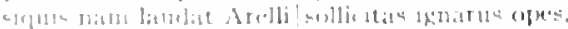

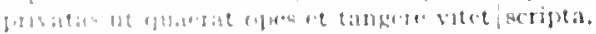

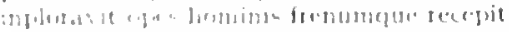

:ar.sorm.1.6.90

Serm.2.2.77

Epist.1 7.18

Carm.4.12.17

Epist.1.16.5

Carm.2.15.15

Corm.3.4.51

Carm.1.6.15

Carm.4.2.2

Efist.1.7.8

Sorm.1.10.*6

Epist.2.1.134

Ars Pod.4II

Ars Poel.4hI

Sorm.2.7.118

coni.Serm.2.5.89

Lif ist.1.1.3.5

Soth.1.2.37

Serm.2.4.63

Epist.2.1.229

Ars POCl. 201

Serm.2.5.8Q

Serm.1.1.00

Ars Puet.4.13

Carm.3.1."

Epist.1.2 20

vir.sirs I'oct.360

Ars Pies.zo

Serm.1.3.132

Serm.2.1.3

Ars Poit.34

Ars Poct.135

Carm.4.2.31

Carm.3.12.5

Carm.3.1..15

Epist.2.1.20s

Fist.1.5.1\%

Sirm.23.37

Carm.2.8.

sirm.1 2.81

f.pist 1.10.51

Carm.3.17.10

Sirm.1.7.35

Sorm.2.2.119

Sirm.20.21

Lpist.1.3p

lipest.2.1.42

Ars foredso

Ars Inet quot

1.pist.1.15.20

Ars $I$ bet.307

Carm.2.12.22

Carm 3.112 28

Carm $3=0.12$

Carmet is ou

Sorni-2, po

lepresta.30

l.pist $1319.3^{13}$ 
det vitam, det opes; aequom mi animum ipse parabo. fundet opes Latiumque beabit divite lingua: quaerit opes et amicitias. inservit honori.

opibus. pugnacis Achivos|Hectoreis opibus refringit Ofellum |integris opibus novi non latius usum hic ubi cognatorum opibus curisque refectus|expulit opifex. debitae Nymphis opifex coronae sapiens operis sic optimus omnis|est opifex,

opima. opima quodsi praeda curvo litore.

opimae. nec tam Larisae percussit campus opimae non opimae | Sardiniae segetes feracis, .

opimis. virtus atque animus cenis responsat opimis?

opimis. invidus alterius macrescit rebus opimis;

opimis. clarus ob id factum donis ornatur honestis [opimis].

Opimius. pauper Opimius argenti positi intus et auri,

opimum. si melpalma negata macrum. donata reducit opimum.

opimus. quos opimus|fallere et effugere est triunphus. pauper Opimius [opimus] argenti positi intus et auri.

opinor. opinor. | haec res et iungit, iunctos et servat amicos. opinor|omnibus et lippis notum et tonsoribus csse. . opinor, |hoc sentit 'moriar.'

ille ferat pretium poenae securus, opinor.

opis. at quanto meliora monet pugnantiaque istis/dives opis natura suae. dissimulator opis propriae, mihi commodus uni.

oportet. quid oportet|nos facere a volgo longe longeque remotos? (nam telscire, deos quoniam propius contingis, oportet).

valeat possessor oportet.

vivere naturae si convenienter oportet

oppedere. vin tu/custis ludaeis oppedere?

opperior. nec tardum opperior nec praecedentibus insto.

oppetiverit. an si quis atro dente me petiverit loppetiverit], | inultus ut flebo puer?

oppida. oppida publico|sumptu iubentes . . decorare

oppida coeperunt munire et ponere leges.

dum . . . agros adsignant, oppida condunt,

oppida moliri, leges incidere ligno.

oppidi. mercator metuens otium et oppidi|laudat rura sui; .

oppidis. militia simul|fessas colıortes abdidit oppidis. quae simul centum tetigit potentem oppidis Creten.

Oppidius. Servius Oppidius Canusi duo praedia. . . gnatis divisse duobus fertur

oppidulo. mansuri oppidulo, quod versu dicere non est,

oppidum. et omne vicinum oppidum,

opponat. manum puella savio opponat tuo.

opponite. fortiaque adversis opponite pectora rebus."

oppono. ego veroloppono auriculam.

oppositis. vectis et tarcus/oppositis foribus minacis.

oppositis. quac nunc oppositis debilitat pumicibus mare| Tyrrhenum:

extrahe turbaloppositis umeris; .

oppressa. duxit ab oppressa meritum Karthagine nomen

oppresserit. si vespertinus subito te oppresserit hospes.

oppressus. quondam letlargo grandi est oppressus,

opprimeret. ne se penuria victus/opprineret metuebat.

opprabria. sic teneros animos aliena opprobria saepelabsterrent vitiis.

opprobria. maioris fugiens opprobria culpae,

quaelibet in quemvis opprobria fingere saevos.

versibus alternis opprobria rustica fudit

opprobriis. dum mihil fias recantatis amicalopprobriis .

siquis|opprobriis dignum latraverit, integer ipse?"

mordear opprobriis falsis mutemque colores?

opprobrio. servavit ab omni| non solum facto, verum opprobrio quoque turpi

opprobrium. magnum pauperies opprobrium iubet

Cecropiae domus|aeternum opprobrium.

opprobrium. in nepotum|pernicicm opprobriumque pagi;

optarem. horum |semper ego optarim [optarem] paupcrimus esse bonorum. optaret. ad fastum quoscumque parcntes|optaret sibi quisque,

optarim. horum|semper ego optarim pauperrimus esse bonoru $\mathbf{n}$. optas. cur optas quod habes?
Epist.1.I8.II2

Epist.2.2.1 21

Ars Poct.10\%

Carm.3.3.28

Serm.2.2.113

Epist.2.2.136

Carm.3.27.30

Serm.1.3.133

Epod.10.21

Carm.1.7.1 I

Carm.1.3I.3

Serm.2.7.103

Epist.1.2.57

zar.Epist 2.2.32

Scrm.2.3.1 42

Epist.2.I.I 8 I

Carm.4.4.5I

zar.Serm.2.3.142

Serm.1.3.53

Serm.1.7.2

Epist.1.16.78

Epist.2.2.I 7

Serm.1.2.74

Epist.I.9.9

Serm.1.6.I 7

Sirm.2.6.52

Epist.1.2.49

Epist.1.10.12

Scrm.I.9.70

Epist.I.2.7I

var.Epod.6.I 5

Carm.2.15.18

Serm.1.3.105

Epist.2.1.8

Ars Poet.399

Corm.1.1.16

Carm.3.1.38

Carm.3.27.34

Serm.2.3.108

Serm.1.5.87

Epod.5.4.4

Epod.3.2I

Serm.2.2.136

Serm.I.9.77

Carm.3.26.8

Corm.I.II.5

Serm.2.5.95

Serm.2.1.66

Serm.2.4.I 7

Serm.2.3.145

Serm.1.1.99

Serm.1.4.I28

Epist.r.9.10

Epist.1.15.30

Epist.2.1.1.46

Carm.1.j6.28

Serm.2.1.85

Epist.1.10.38

Serm.1.6.84

Carm.3.24.42

Carm.4.12.7

Carm.2.13.4

ver.Serm.I.I.79

Serm.1.6.g6

Serm.1.1.79

Serm.1.3.I 26 
Romae rus optas:

ne cures ea quae stulte miraris et optas.

Sorm.2.7.28

nunc liben et ludos et balnea vilicus optas:

Epist.1.1.47

Epist.1.14.15

optat. optat quietem pelopis infidi pater.

optat l'rometheus obligatus aliti.

Epod.17.65

Epod.17.67

optat supremo collocare Sisyphus! in monte saxum;

qui firtunis" te responsare superbae / liberum et erectum praesens luttitur et aptat [optat]?

optat ephippia bos, piger optat arare caballus:

optatam. qui studet optatam cursu contingere metam.

optatis. sic lovis interest/optatis epulis inpiger llercules.

optatum. latudemque et optatum peractis/imperis decus adrogavit.

optet. Iunc atque liunc superare laboret)(sic festinanti semper locupletior obstat [optet]).

'sume, caltelle': negat; si non des. optet.

quod satis est cui contingit, nihil amplius optet.

optima. pratensibus optima fungis /natura est;

optima. tuia Graiorum sunt antiquissima quaeque/scripta vel optima.

optima. ne corporis optima I,yncei contemplere oculis.

optime. cupidum, pater optine, vires/deficiunt:

ne petconteris, fundus meus, optime Quinti.

optimum. 'peream male, si non optimum esat;

optimus. nam vitis nemo sine nascitur; optinus ille est, | qui minimis urgetur.

cantor tamen atque optimus est modulator;

sallenc uperis sic optimus ummis|est opifex,

insurvit pater optimus hoc me.

hue volurus erat Maccena optimus atquel Cocceius,

optimu olim | Verpilius, post hunc Varius dixere quid essem.

lalgius et probet haec Octavius optimus atque| Fuscus

optivo. fit Vimnermus et optivo cognomine creacit.

opto. nec prave fictis decorari versibus opto, .

optume. optume Romulaelcustos gentis.

opulenta. copia .. benigno' ruris honorum opulenta cornu.

opulentet. irvo pascat crum an bacis opulentet olivac.

opulentior. intactis opulentior/thesauris Arabum.

Opuntiae. dicat Opuntiae/1rater Megillat.

opus. sunt quibus unum opus est intactae ['alladis urbem/carmine perpetuo

$$
\text { celebrare }
$$

Roma si vestrum rest opts

Rominis sollemne viris opus, utile famue

clascis Aquilonibus arcet, regis opus.

opus. vericulosac plenum opus aleae.

lnathian ter nocte potes, min somper ad unump inollis opus.

ulera|legem tenderc opus;

in pulvere, trimus quale prits ludaz opus.

diesquellonga videttr opus debentibus.

hoc opus, loc studium parvi properemus et ampli.

hec primus repetas opus, hoc postremu omittas.

adelit opms pigro rivos, si decidit inber.

quam per vatis opu nores animique virom liclarorum adparent.

mirabile viculcalatumue novem Mutis opus.

opus. Five opua "st imperitare equis, / mon auriga piger.

ut tubi ai sit ofus lapudi won anplius uma

at qui tantoli enet quante rout opus.

nil illi larva aut trapers opus esse cothurnis.

nil opus est te' citcumasi:

iat tibi matror. cognati, quis te salvo est opus?"

ari brovitate opus, ut currite sententia

at anernone opus eat modo triati, supe iocoso.

tran-riante Tiberim, somno guble cest opus alto.

"hatul mhli vitalent opus hac"

"unde mihi lapiding?" 'quoraum cat opus?"

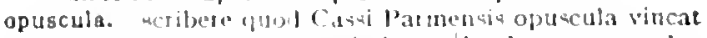

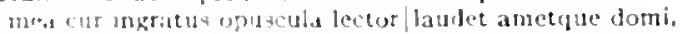

ara. quin caret ord cruorp noatro?

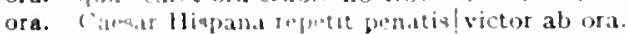

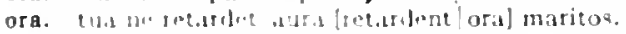

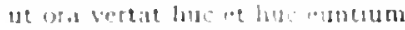

Epod.17.68

tar.l.pist.1.1.69

Epist. I. I 4.43

Ars Podt.t12

Carm.4.8.30

Corm.4.1.39

sar.Serm.1.1.113

Serin.2.3.259

lipist.1.2.40

Sorn.2.4.20

Epist.2.1.29

Serm.1.2.90

Serm.2.1.12

Lepist. I. $16 . \mathrm{I}$

Sterm.2.1.7

Serm. 3.3 .68

Sierm.1.3.130

Sorm.1.3.132

Sirm.t.4.105

Serm.1.5.27

Serm.1.0.54

Sirm.1.10.82

Epist.2.2.10I

Epist.2.1.200

Curm.4.5.I

Carm.1.17.15

Epist.1.10.2

Carm.3.24.I

Carm.1.27.10

Carm.1.7-5

Carm.Saec.37

Jipist.1.18.49

Ars l'out.05

Carm.2.1.6

Epod.12.16

Serm.2.1.2

Serm.2.3.252

Episti.1.21

Lipist.1.3.28

Eipist.1.0.48

Epist.1.14.29

Epist.2.1.24?

Lipist.2.2.92

Carm.1.15.25

Serm.1.1.54

Serm.1.1.50

Sorm.1.5.64

Serm.1.9.1"

Serm.1.0.27

Serm.1.10.9

Serm.t.IO.I

Serm.2.1.8

Serm.2.0.11"

Srm.2.7.110

Epist.1.4.3

Epist.1.19.35

Carm.2.1.3

Carm.3.I.4

coni.Carm.28.2

lipol.to 
ora. Gallica nec lupatis/temperet ora frenis? tot ora navium gravi/rostrata duci pondere tacent ct albus ora pallor inficit tacent et albus ora pallor [ora pallor albus] inficit ora manusque tua lavimus, Feronia, lympha; nitidus qua quisque per ora/cederet, quid Titius? Romana brevi venturus in ora, sive elephans albus volgi converteret ora; quae canerent agerentque peruncti faecibus ora.

ora. aridum et ore [? asperum et ora] ferens acinum semesaque lardi orabant. scribae . . . te|orahant hodie meminisses, Quinte, reverti." orabat. 'unum me surpite mortil|dis etenim facile est' orabat. 'ante secundam |Roscius orabat sibi adesses ad Puteal cras." .

orabit. tabulas socero dabit atque/ut legat orabit; nil Grosphus nisi verum orabit et acquom.

orae. quis sub Arctolrex gelidac metuatur orae. servit Hispanae vetus hostis orae (nam vina nihil moror illius orae.

orae. sive subiectos Orientis orae/Seras et Indos, .

orare. sed satis est orare Iovem quae ponit et aufert,

oras. nec latentis/classe cita reparavit oras.

horrenda late nomen in ultimas/extendat oras, qua sol habitabilis inlustrat oras,

orat. quid orat de patera novom/fundens liquorem?

oratus. quare per divos oratus uterque Penat is oratus multa prece nitere, porro/vade;

orbe. 'nullus in orbe sinus Bais praelucet amoenis'

orbem. te minor laetum reget aequos orbem: fronte curvatos imitatus ignis|tertium lunae referentis ortum [orbem]. quid premat obscurum lunae, quid proferat orbem. . tuisque |auspicis totum confecta duella per orbem. si|non circa vilem patulumque moraberis orbem

Orbi. vilicus Orbi, ... te dominum sentit.

Orbilium. memini quae plagosum mihi parvolOrbilium dictare;

orbis. si fractus inlabatur orbis,

tua sectus orbis|nomina ducet.

certus undenos deciens per annos/orbis

orbis. serves iturum Caesarem in ultimos/orbis Britannos

orbum. fortis Augusti reditu forumque|litibus orbum.

orca. non alia quam qua Byzantia putuit orca.

Orci. victima nil miserantis Orci. rapacis Orci sede destinata

nec satelles Orci / callidum Promethea/revexit auro captus;

Orco. habentque/Tartara Panthoiden iterum Orco/demissum. moresque aureos educit in astra nigroquelinvidet Orco siquis casus puerum egerit Orco.

Orco. quae manent culpas etiain sub Orco.

Orcum. partus fulmine luridum | missos ad Orcunı; inpudens Orcum moror.

Orcus. si metit Orcus|grandia cum parvis,

ordinarat. in quem superbus ordinarat agmina|Mysorum ordinaris. mox ubi publicas|res ordinaris,

ordinat. cx hac|luce Maecenas meus adfluentis ordinat annos.

ordine. quod prius ordine verbum est |posterius facias.

huc propius me. . . vos ordine adite.

aestuat et vitae disconvenit ordine toto.

temperat Alcaeus, sed rebus et ordine dispar,

ordinem. ordinem/rectum evaganti frena licentiae|iniecit

ordinet. est ut viro vir latius ordinet /arbusta sulcis,

ordinibus. adscribi quietis/ordinibus patiar deorum.

ordinis. ordinis haec virtus erit et venus, aut ego fallor.

orditur. nec gemino bellum Troianum orditur ab ovo;

ordo. nec facundia deseret hunc nec lucidus ordo.

ore. recedentis trilingui|ore pedes tetigitque crura.

purpurco bibet ore nectar.

spiritus taeter saniesque manet /ore trilingui;

dicam insigne, recens, adhucl indictum ore alio.

fervet inmensusque ruit profundo| Pindarus ore.

ut haec trementi questus ore
Carm.1.8.7

Epod.4.1 7

Epod.7.1 5

"ar. Epod.7.15

Serm.1.5.24

Serm.2.1.64

Epist. I.3.9

Epist 2.1.196

Ars Poet.277

? iar.Serm.2.6.35

Sirm.2.6.37

Serm.2.3.284

Serm.2.6.35

Strm.2.5.07

Epist.1.12.23

Carm.1.26.4

Curm.3.8.21

Epist.1.15.16

Carm.I.I2.55

Epist.1.18.1 I I

Curm.1.37.24

Carm.3.3.46

Curm.4.14.0

Carm.1.31.2

Serm.2.3.176

Epist.1.13.18

Epist.r.1.83

Curm.I.I2.57

zur.Curm.4.2.55

Epist.I.I 2.18

Epist.2.1.254

Ars Poet.I32

Epist.2.2.160

Epist.2.I.7I

Cirm.3.3.7

Carm.3.27.75

Carm.saec.22

Curm.1.35.30

Carm.4.2.44

Serm.2.4.60

Cirm.2.3.24

Carm.2.15.30

Carm.2.18.34

Curm.5.28.50

Curm.4.2.24

Serm.2.5.49

Carm.3.15.29

Corm.3.4.75

Curm.3.27.50

Epist.2.2.178

Epod.1 7.9

Carm.2.I.I I

Carm.t.11.20

Serm.1.4.58

Serm.2.3.8I

Epist.I.I.99

Epist.I.I9.29

Carm.4. 5.9

Carm.3.1.9

Carm.3.3.36

Ars Poet.42

Ars Poet. 147

Ars Poet.4I

Carm.2.19.32

Carm.3.3.12

Carm.3.I I.20

Carm.3.25.8

Carm.4.2.8

Epod.5.1 I 
et ossa ab ore rapta teinac canis cum promineres ore.

ore adluboramdun tost tibi.

magni formic labonsiore trahit quodcunque potes

aridum et ore ferens acinusu senesaque lardi frusta dedit.

quo spectanda nodo. quo sensu credis et ore?

nun ecpustern dorso. non frenum depulit ore.

seal equi ftenato est autis in ore);

squis. . pede nudo / exiguaeque togae simulet textore lex ore

Catoncm,

Inncego, non alio dictum prius ore, Latinus/volgavi fidicen;

iratusauce ("hrenes tumido delitigat ore;

Grais de'dit one rotundo/ Musa locui. .

orerequeres. 'o ere, quae res lorerequeres] i nec modum habet neque consiliun,

orerequires. o ere, quae res [orerequires] / nec modum habet neque consilium, .

Orestes. He' lerro ut denens genetricem occidis Orestes.

quin, ex quo est habitus nale tutae mont is Orestes,

furfidus Ixion, Io saga, tristis Orestes.

oret. ille tegat commissa deosque precetur ct oret. .

orichalco. tibia non, ut numc, orichalco sincta tubaequelaemula,

Oricum. ille Notis actus ad Oticum

orientia. ot ientia tempota notis instruit exemplis, inopen solatur et aegrum.

Orientis. sive subiectos Orientis orae Setas ct Indos.

orientis. Hec sacvos Arcturi cadentis/impetus aut orientis Haedi.

soutiant motus orientis Austri

originem. anctorc ab illo ducis originum. .

origines, fontum qui celat origines|Nilusque.

Originis. lit quondam Mascacus, amator Utiginis ille.

Orion. nec curat (tion leones/aut timidos agitare lyncas.

notus et integrat"|temptator Orion Dianat

guanto trepidet tumuleu, prons Orion

qua tristis Orion cadit;

dum pecori lupus et nautis infestus orion

Orionis. He quodue deveri rajidus cones Orionis/llysicis Notus obruit undis.

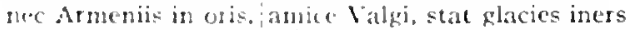

trabentia pulvers atri |quantum non Aquilo Campanis excitat agris [ori-].

quibus termam militet oris/Claudius

oris. at illi foedil cicatrix suctuan laevi frontem turpaserat oris.

oris. si plosors [plus oris] eges aulaca manentis et usque sessuri,

oritur. posteria lux otitut multo gratissima:

sermo oritur, non de vills clombusve alienis,

oriturum. Hl ut itum alias, nil oftum tale fatentes

oriuntur. ontrot ("isceis, Minno oriuntur cohini,

orize. agedum. sume hoc fticathium |tysanarium] oryzac [otize]."

ornabat. tum ferdins uvis secundas / nux ornabat mensas

ornamenta. ambitiosed tecidet on namenta.

ornare. Suliaribus ornate fulvmat dextum|tempus esat dapibus.

ornat. shaturge pulla ficus urmat asbotens.

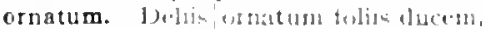

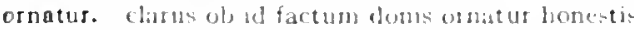

ornatus. ormatus viridi tompora pampino

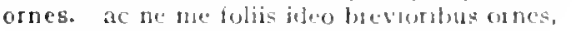

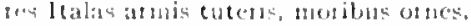

orni. nec relteges agitantur on ni.

- t folit viluantur orni:

orno. potas lat als orme jumblum

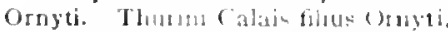

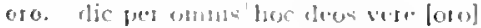

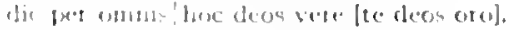

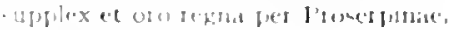

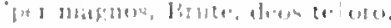

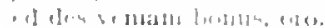

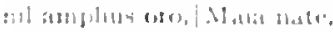

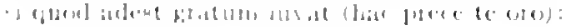

I.pod.5.23

Epod.5.35

Epod.8.20

Serm.1.1.34

Serm.2.0.65

Epist. 1.0 .8

Epist.1.10.38

Epist.1.15.13

sar. Epist.1.19.13

Epist.1.29.32

Ars Poel.9.

Ars Ioct.323

1ar.Serm.2.3.265

tar.Serm.2.3.265

Setm.2.3.133

Sorm.2.3.137

Ars Joet. 24

Ars Joel.200

Ars Pool.202

Carm.3.7.5

Epist.2.1.130

Carm.1.12.55

Carm.3.1.28

Carm.3.27.22

Corm.3.17.5

Carm.4.14.45

Serm.1.2.55

Carm.2.13.39

Carm.3.4.71

Carm.3.27.18

Epod.10.10

Epod.15.7

Corm.1.28.21

Carm.1.12.5

Carm.2.9.4

1.or.Serm.2.8.50

Efist.1.3.1

Scrm.1.5.1)

sar.Ars l'oel. 154

Serm.1.5.39

Scrmi2.0.71

Epist.2.1.17

Sorm.2.4.33

tor.scrm.2.3.155

strm.2.2.122

Ars J'act.4.45

Carm.1.37.3

Epod 10.ape

Carm.4.3.7

J.pist.2.2.32

Corm.t.8.33

Jpist.1.19.20

Epist.2.1 2

Carm.1.0.12

Corm.2.0.8

Corm 3.27.58

Corm 301.9

iar.Carma1.8.2

: ardarm.1 8.2

Jipol.17.2

Sorm.1.7.34

torm 2..t5

sermazenti.t

serm.2.0.13 
Orphea. unde vocalem temere insecutae/Orphea silvae,

Carm.I.12.8

Orpheo. quid? si Threicio blandius Orpheo.

Carm.1.24.13

Orpheus. sacer interpresque deorum | caedibus et victu foedo deterruit Orpheus,

orta. non his iuventus orta parentibus

orte. gentis humanae pater atque custos, forte Saturno.

divis orte bonis, optune Romulae/custos gentis,

orti. non Tanain prope flumen orti.

ab his maioribus orti|ad pugnam venere.

magni|quo pueri magnis e centurionibus orti, . . . ibant

orti. virginum primae puerique claris|patribus orti,

or to. prius orto|sole vigil calamum et chartas et scrinia posco.

ortos. multos saepe viros nullis maioribus ortos

ortu. oscinem corvom prece suscitabo|solis ab ortu.

dives et inportunus ad umbram lucis ab ortu

ortum. nil oriturum alias, nil ortum tale fatentes. .

ortum. tertium lunae referentis ortum.

famaque et imperi| porrecta maiestas ad ortus [ortumilsolis ab Hesperio cubili.

ortus. ad ortus|solis ab Hesperio cubili.

ortus. (indignum, quod sit peioribus ortus)

oryzae. tu cessas? agedum, sume hoc ptisanarium oryzae." .

os. cui mens divinior atque os/magna sonaturum.

os. vaga Luna decorum protulit 0 s. .

os tenerum pueri balbumque poeta figurat,

Osci. Messi clarum genus Osci; .

oscinem. oscinem corvom prece suscitabo/solis ab ortu.

oscula. speres perpetuom dulcia barbare/laedentem oscula,

caris multa sodalibus, | nulli plura tamen dividit oscula | quam dulci

Lamiae,

cum flagrantia detorquet ad oscula|cervicem

osculum. fertur pudicae coniugis osculum... ab se removisse.

Osirim. per sanctum iuratus dicat Osirim:

ossa. quaeque carent ventis et solibus ossa Quirini.

ossa. et ossa ab ore rapta leiunae canis

reliquit ossa pelle amicta lurida.

quin ossa legant herbasque nocentis.

altercante libidinibus tremis ossa pavore.
ossibus. vagae ne parce malignus harenae | ossibus et capiti inbumato particulam dare:

ossibus. albis informem spectabant ossibus agrum;

ostendat. ne non et cantharus et lanx |ostendat tibi te.

ostendere. res gerere et captos ostendere civibus hostis

rem tibi Socraticae poterunt ostendere chartae.

ostendet. neque res bellica... ostendet Capitolio:

ostendi. Parios ego primus iambos/ostendi Latio,

ostendi. pretiumque avellier ante / quam mercem ostendi?

paucis ostendi gemis et communia laudas.

ostendis. quodcumque ostendis mini sic, incredulus odi.

ostendit. Andromedae pater|ostendit ignem.

aperte|quod venale habet ostendit

ostentare. incipit ex illo montis Apulia notos|ostentare mihi,

ostia. sub galli cantum consultor ubi ostia pulsat. .

pontisne inter iactatus an amnis|ostia sub Tusci?

ostrea. neque ostrea/nec scarus aut poterit peregrina iuvare lagois.

ostrea. ostrea Circeis, Miseno oriuntur echini,

ostro. cenae sine aulaeis et ostro

qui Sidonio contendere callidus ostro' nescit

regali conspectus in auro nuper et ostro.

Othone. nagnus in prims eques/Othone contempto sedet.

oti. ubi quid datur oti,|inludo chartis.

otia. senes ut in otia tuta recedant.

non otia recte/ponere

neclotia divitis Arabum liberrima muto.

iustitiam legesque et apertis otia portis;

otio. ingrato celeres obruit otio/ventos

otior. pransus non avide. .. domesticus otior.

otiosa. et otiosa credidit Neapolis

otjoso. festus in pratis vacat otioso 'cum bove pagus,

Ars Poel. 392

Carm.3.6.33

Carm.1.12.50

Carm.4.5.I

Carm.4.15.24

Serm.1.5.55

Serm.1.6.73

Carm.4.6.32

Epist.2.1.I12

Serm. i.6.10

Carm.3.27.12

Epist.2.2.185

Epist.2.1.17

Carm.4.2.58

2ar.Carm.4.I 5. I 5

Carm.4.15.15

Epist.1.6.22

Serm.2.3.1 55

Serm.1.4.43

Serm.1.8.22

Epist.2.1.126

Serm.1.5.54

Carm.3.27.1 I

Carm.1.13.1 5

Carm.1.36.6

Carm.2.12.25

Carm.3.5.4I

Epist.1.17.60

Epod.I6.I3

Epod. 5.23

Epod.I 7.22

Serm.I.8.22

Serm.2.7.57

Carm.1.28.24

Serm.1.8.16

Epist.1.5.24

Epist.1.17.33

Ars Poel.3 10

Carm.4.3.9

Epist.1.19.24

Serm.1.2.I05

Epist.1.20.4

Ars Poel. 188

Carm.3.29.18

Serm.1.2.84

Serm.1.5.78

Serm.I.I.IO

Serm.2.2.33

Serm.2.2.2I

Serm.2.4.33

Carm.3.29.15

Epist.1.10.26

Ars Poet.228

Epod.4.16

Serm.1.4.138

Serm.I.I.3 I

Sirm.2.7.II 2

Epist.1.7.36

Ars Poct.199

Carm.1.15.3

Sirm.1.6.128

Epod.5.43

Carm.3.18.1 I 
atium. nullum a labore ne reclinat otium:

otium. mercator metuens otium et oppidi|laudat rura sui; .

Epod.17.24

otiun divos rogat in patenti|prensus Aegaco.

otium bello furiosa Thrace.

utium Medi pluatetra decori.

non furor/civilis aut vis exiget otium.

utrumne iussi persequemur otium/non dulce.

ora. et uncta turpis ova ranae sanguine. . aduri

daq mumos, accipis uvam. | pullos, ova. cadum temeti: .

ovans. heres/ian circum loculoz et clavis lactus ovansque/curreret.

oves. verum ubi oves furto, motbo periere capellac.

ovibus. dulce pellitis ovibus Galaesi|flumen

ovile. nec vespertinus circungenit ursus ovile

ovili. nec vespertinus circumgenit ursus ovile [ovili]

ovilia. mox in ovilia/demisit hostem vividus impetus.

ovis. ant tondet infirmas oris.

pastas ovis/videre properantis domum.

ovis. nam vilibus ovis nigrisque est oleis hodie locus.

longa quibus facies ovis erit, illa memento.

ovium. in tenero gramine pinguium|custodes ovium 'nille ovium insanus morti dedit.

ovo. ab ovo/usque ad mala citaret "io Bacchae"

Cistor saudet equis, ovo prognatus codem/pugnis;

columbino limum bene colligit ovo.

nec gemino bellum Troianum ordiur ab ovo;

pacantur. incultae pacantur vomere silvat:

pacare. et regat iratos et amet pacare timentis;

pacatum. pacatum volitant per mare navitae;

pacaverit. quae prima iratum ventrem pacaverit eca."

pace. nunc inedio dequore|cum pace delabentis Etruscum in mare.

in pace. ut sapiens, aptarit idonea bello?

pacem. pacem duello miscuit.

infetrat et pacen et locupletum irugibus annum:

paces. hoc paces habuere bonae ventique sccundi.

paces. bella quis paces longum diffundit in acvom?

Pacideiani. Pacideiani contento poplite nirot/proelia rubrica pica

pacis. intem| pacis eras mediuscue belli.

n.*C quistuam noceat cupido mili pacisl

claustraque custodem pacis cohibentia Ianum.

pacisci. mon cut mentm. . . ad miseras preces/decurrere et votis pacisci

Pacori. ian bis Wonaeses et Pacorimanusfinauspicatos contudit impetus!

$\therefore=$ nustros

pacta. ex quo rlectituit deos/mercede pacta Laomedon.

pacto. tfuivis stomachetur eolem |quo personatus pacto pater.

seeb tansen aldmiror. quo pacto iudicium illud |fugerit':

hibrirla guo pacto sit Persius ultus.

guo pacto alterna loquentes|umbrate cum Sagana resonarint.

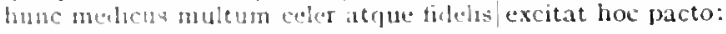

quo parto cuncta tenerem

"iluo pacto. pesime

fere muratur rolem, quo cupiens, pacto:

pout bacc. ut videat, quo pucts rem gerat et se.

damum est, non facinus, mibi pacto leuius isto.

fiac tiundem pacto deceat maioribus uti,

yuo pacto partia tutetur inumtis coluebi.

Pactolus. tibiruce l'actoilus thuat

Pactumeius. tuosqua venter Pactuneiss et tuo/ cruore rubros obstetrix bismou lavit.

Pacuvius. sufert|l'acuvius docti faman senis.

Padus. quamo|Paslus Matiba laverit cacumina.

paelex. dominitrue tradi|barbarae paelex."

paelice. noc vir l'urtia parlice saucius

paelicem. bue dulbutis ulta doniq puelicem

qubbu aupertsen fugit ulta paclicem.

paelicum. uncta omsian cublabug|ublivione parelicum?

Epist.1.2.45

Ars Poct.197

Corm.t.5.19

Serm.2.8.5

Corm.3.29.35

Serm.2.2.111

Cirm.3.5.38

Epist.2.1.137

lipist.2.1.102

Epist.1.3.s

Sirm.2.7.97

Curm.2.19.28

Sirm.2.1.4t

Epist.2.1.255

Carm.3.29.59

Carm.3.6.9

Carm.3.3.22

Serm.1.456

Serm. I. 190

Serm.1.7.2

Serm.1.8.40

Sorm.2.3.1.45

Serm.2.4.8

Serm.2.7.22

Epist. 1 . 1.10

Epist.1.8. 3

Epist.1.10.50

Epist.1.17.2

Epist.2.1.17

Epod.15.20

I.pod.17.50

Epist 2.1.50

Epoul 10.28

Carm.3.27.60

Carm.3.10.15

Iipol.3. 3

Epold.5.103

Epol.5.71 
Paelignas. quid proderat ditasse Paelignas anus

Paelignis. quota|Paelignis caream frigoribus, taces.

paene. quam paene furvae regna Proserpinae .

paene occupatam seditionibus|delevit Vrben

narrat paene datum Pelea Tartaro.

sanctiorque/ paene natali proprio.

Cois tibi paene videre est|ut nudam,

ubi sedulus hospes|paene mactos arsit

at cetera paene gemelli|fraternis animis:

Naevius in manibus non est et mentibus haeret $\mid$ paene recens?

clament periisse pudorem/cuncti paene patres,

ne velut innati triviis ac paene forenses

paeniteat. quare, ne paeniteat te.|desine sectari matronas, .

nil me paeniteat sanum patris huius.

paenitet. scelerum si bene paenitet.

conviviorum et paenitet,

paenula. facit quod paenula solstitio, campestre nivalibus auris.

paetum. strabonem appellat paetum pater.

pagi. in nepotum|perniciem opprobriumque pagi;

pagos. quis circum pagos et circum compita pugnax

pagus. festus in pratis vacat otioso|cum bove pagus,

quem Mandela bibit, rugosus frigore pagus.

palaestrae. voce formasti catus et decorae|more palaestrac.

palam. sed palan captis gravis, heu nefas, heu.

nec, siquia honesti est. | iactat habetque palam.

aut humana palam coquat exta nefarius Atreus

palam. ubi haec severus te palam laudaveram.

palantis. ubi passim/palantis error certo de tramite pellit,

Palatinas. si Palatinas videt aequos aras .

Palatinus. scripta. Palatinus quaecumque recepit Apollo.

palato. quid? cum balba feris annoso verba palato,

ne gallina malnm tesponset dura palato.

poscentes vario multum diversa palato.

palatum. hoc potius quam gallina tergere palatum,

ante menm nulli patuit quaesita palatum.

fervida quod subtile exsurdant vina palatum.

palea. cum pater ipse domus palea porrectus in horna

Palinurus. me ... devota non extinxit arbor|nec Sicula Palinurus unda.

palla. cum palla, .. novam/incendio nuptam abstulit? ad talos stola demissa et circumdata palla.

palla. vidi egomet nigra succinctam vadere palla|Canidiam

Palladis. ope Palladis|Tydiden superis parem?

intactae Palladis urbem/ carmine perpetuo celebrare

quid . . . contra sonantem Palladis aegidalpossent ruentes?

pallae. post hunc personae pallaeque repertor honestae/Aeschylus

Pallas. proximos illi tamen occupavit|Pallas honores|proeliis audax.

iam galeam Pallas et aegida|currusque et rabiem parat.

cum Pallas usto vertit iram ab llio/ in inpiam Aiacis ratem.

pallerem. quodsi|pallerem casu, biberent exsangue cuminum.

pallerent. quodsi pallerem [pallerent] casu, biberent exsangue cuminum

palleret. quodsi|pallerem [palleret] casu, biberent exsangue cuminum.

pallescere. nil conseire sibi, nulla pallescere culpa.

pallescet. pallescet super his, etiam stillabit amicis|ex oculis rorem,

pallet. quisquis/ambitione mala aut argenti pallet amore.

dum pueris omnis pater et matercula pallet

pallida. pallida Mors aequo pulsat pede panperum tabernas | regumque turris.

repallida [vae pallida] lecto / desiliat mulier.

vepallida [ve pallida] lectol desiliat mulier.

pallidus. ut pallidus omnis/cena desurgat dubia?

pallar. nec tinctus viola pallor amantium

tacent et albus ora pallor inficit

tacent et albus ora pallor [ora pallor albus] inficit

o quantus instat navitis sudor tuis| tibique pallor luteus

pallor utrasque | fecerat hortendas adspectu.

vertere pallor tum parochi faciem

palluit. scatentem | beluis pontum mediasque fraudes|palluit audax. .

jalma. metaque fervidis|evitata rotis palmaque nobilis.

sive quos Elea domum reducit $\mid$ palma caelestis .

Epod.1 7.60

Carm.3.19.8

Carm.2.13.21

Carm.3.6.13

Carm.3.7.17

Carm.4.II.I 8

Serm.I.2.10I

Serm.1.5.72

Epist.I.I0.3

Epist.2.1.54

Epist.2.1.8I

Ars Poet.245

Serm.I.2.77

Serm.1.6.89

Carm.3.24.50

Epod.II.8

Epist.1.I1.1 8

Serm.1.3.45

Carm.2.13.4

Epist.I.1.49

Carm.3.18.12

Epist.I I8.105

Carm.1.10.4

Carm.4.6.I 7

Serm.1.2.85

Ars Poet. 186

Epod.II.I9

Scrm.2.3.49

Carm.Saec.65

Epist.1.3.I7

Serm.2.3.274

Serm.2.4.I8

Epist.2.2.62

Strm.2.2.24

Sirm.2.4.46

Serm.2.8.38

Serm.2.6.88

Carm.3.4.28

Epod.5.65

Serm.1.2.99

Serm.I.8.23

Carm.1.6.15

Carm.1.7.5

Carm.3.4.57

Ars Poet. 278

Corm.I.I2.20

Carm.I.I5.I I

Epod.Io.I 3

Epist.I.19.18

var.Epist.I.Ig.I8

coni.Epist.1.19.18

Epist.1.1.6I

Ars Poet.u29

Serm.2.3.78

Epist.I.7.7

Carm.1.4.13

:ar.Serm.1.2.129

sur.Serm.1.2.I 29

Serm.2.2.76

Carm.3.IO.I 4

Epod.7.15

iar. Epod.7.I5

Epodino.16

Serm. I.8.25

Serm.2.8.35

Carm.3.27.28

Curm.1.1.5

Corm.4.2.18 


\section{PALMA}

si nu. palua negata macrum. donata reducit opinum.

palma. ten lapules varios lutulenta radere palma

palmae. cui sit conflicio dulcis sine pulvere palmae?

palmam. arbiter pugnate posuisse nudo/sub pede palmam

palmetis. pracferat IIerodis palmetis pinguibus.

palpere. cui male si palpere, tecalcitrat undique tutus.'

paludes. antequan stantis repetat paludes

palumbes. tonte nova puerum palumbes texere.

palumhis. non quae sedes fuerat columbis [pahumbis].

palumbis. vilinus et mesulas poni et sine clune palumbis,

palus. obscaenoque ruber porrectus ab ingune palıs.

palus. sterilisve cliu palus aptaque remis|vicinas utbes alit

sterilisve diu palus [palus diu] aptaque remis/vicinas urbes alit

palustres. mali culices ranaeque palustres/avertunt somnos;

palustri. ma bibes iterum Tauro diflusa palustris [palustri] | incer

Minturnas Sinuessanumque Petrinum.

palustris. pulustricl inter Mlinturnas Sinuessanumque Petrinum.

pampiso. leum/cingentem viridi tempora pampino.

omatus viridi tempora pampino|l Liber

Panaeti. co. ruptos undique nobilis/libros Panacti.

pandat. pictia pindat spectacula cauda:

pane. foune ereo iam arlitis potiore placentis.

vivit siliquis et pane secundo:

vivie siliquis et pane secundo [/ secundo pane]:

pangas. me, cum venari volet ille, poemata panges (pangas].

panges. Hec, cum venari volet ille, poemata panges.

panga. nunc satis est dixisse "ego misa pormata pango;

panjs. pingis ematur. holus, vint sextarius

secl panis longe pulcerrimus. .

cum sal* pang latranten stomachum bene leniet.

ne pinis adustus. ne male conditum ius adponatur.

panis. si teticulum panis venalis intes onusta|lotte vehas unero.

panno. albo sara Fides colit/relata panmo

contri, quem duplici panno patientia velat.

pannas. tho/cruore tubros obstetrix pannos lavit.

pannum. morietur frigore, si non/rettuleris pannum.

pannus. purpureus, late qui splendeat. unus et alter/adsuitur pannus.

panthera. divorsum confusa genus panthera camelo . . converteret ora;

Panthoidae. nec te l'ythagorae [1'antloidae] fallant arcana renati

Panthoiden. habentque/Tartara Panthoiden iterum Orco/denissum.

Pantilius. men moveat cimex Pantilius

Pantalabo. buc micerate piebi stabat commune sepulcrum, | Pantolabo scurrat: Vomentamoque nepoti.

Pantalabum. Pantolabum scurram Nomentanumque nepoten. . .

papaver. crassum unguentum et Sasdo cum melle papaver/offendunt.

Paphi. D Vinus regina Cnidi Paplique.

Paphon. 1'aphon iunctia visit oloribus

par. Rupili ut Petri par pugnat.

fuinti progenies Arri. par nobile fratrum.

par. "mon. si te ruperis, "incuit.l par eris."

mugas lioc genus: 'hora quota est?" 'Thraex est Gallina syro par?"

ut corist phir|iungaturque pari:

par. "cojue/responsura tuo numquain est par fama labori.

pat. scribere to nobis, tibi nos adcredere par est.

par. luders par inpar, equitare in harundine longa

parabat. dum ("sfotolio/regina dementis ruinas funus et inperio parabat jam mox unlucere terris umbras et caelo difundere signa parabat;

parabilem. mon ego: namque parabilom amo venesem facilemque.

parabo. Jualus jarabo, maius infundam tibi|fatiflenti poculum

flet vian, det opea; arequom m animum ipse parabo.

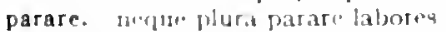

pararet. "fua" subu lut batus, tortor pararet:

pararie. eserovie thes quoq arere pasaria.

paras. it arpom militian paras.

suveliam placare butaq vistute selicta?

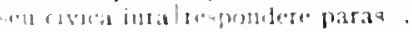

parasitac. cuveudow do tica. cinuthones. parasitac.

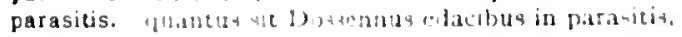

\section{PARASITIS}

Epist.2.1.18I

Serm.2.4.83

Epist.1.1.51

Curm.3.20.12

Epist.2.2.184

Serm.2.1.20

Carm.3.27.9

Corm.3.4.12

iar.Carm.1.2 10

Serm.2.8.91

Sirm.1.8.5

Ars Poot 05

coniders Poctos

Serm.1.5.14

itbr. Ejpist.1.5.4

Lpist.1.5.4

Carm.3.25.20

Curm. 8.33

Carm.1.29.14

Serm.2.2.2\%

Epist.1.10.11

Epist.2.1.123

7 :ur.Epist.2.1.123

iur.Epist.1.18.40

Epirt.r. I 8.49

los Poctaplo

Serm.1.1.4

Serm.1.5.89

Sirm.2.2.17

Serm.2.8.68

Sirmiti.47

Cirm.1.35.22

Fpist.1.17.25

Epol.17.5I

Pist.1.17.32

Ars Poct.10

Epist.2.1.195

coni.Fpod.15.21

Curm.1.28.10

Serm.1.10.78

Sirm.1.8.11

Serm.2.t. 22

Ars l'oct.375

Carm.1.30.I

Carm.3.28.14

Sirm.1.7.19

Serm.2.3.243

Serm.2.3.320

Serm.2.6.44

Epist.1.5.25

Serm.2.8.00

Epist.1.15.25

Serm.2.3.2.48

Carm 1.37.8

Serm.1.5.10

serm.1.2.19

Epod.5.77

Epist.1 18.112

Epist 2.2.19"

Carm.3.5.50

Scrm 2.3.120

Curm.1.29.2

Serm.2.3.13

Epist.1.3.2.4

tierm.1.2.98

Epist 2.1.173 
parassem. parce frugaliter atque/vivere $n$ uti contcatus eo quod mi ipse parasset [parassem]:

parasset. viverem uti contentus eo quod mi ipse parasset:

parasti. quidquid vita meliore parasti|ponendum acquo animo.' quanto plura parasti, | tanto plura cupis,

parat. iam galeam Pallas et aegida/currusque et rabiem parat. *Catone... qui male factoslemendare parat versus,* .

dum sibi, dum sociis reditum parat.

parata. cave, namque in malos asperrimus|parata tollo cornua, .

parati. supremum|carpere iter comites parati. depugnare parati,|si discordet eques, .

paratis. frui paratis et valido mihi, / Latoe, dones

harathrone / dones quidquid habes an numquam utare paratis? -

paratum. hoc, veluti virtute paratum, | speravit magnae laudi fore.

paratus. paratus omne Caesaris periculum/subire, Maecenas, tuo:

paratus expiare, scu poposceris/centum iuvencos

vir bonus et sapiens dignis ait esse paratus

paravero. haud paraverolquod aut avarus ut Chremes terra premam. Parca. spiritum Graiae tenuem Camenae/Parca non mendax dedit

parca. venit enim magnum donandi parca iuventus

parca. cui deus obtulit/parca quod satis est manu.

Parcae. unde si Parcae prohibent iniquae, unde tibi reditum certo subtemine Parcae/rupere.

Parcae. vosque, veraces cecinisse Parcae.

parcas. supplicibus tuis| parcas, . 'o maior tandem parcas, insane, minori.'

parce. at tu, nauta. vagae ne parce malignus harenae . . particulam dare: nec/parce cadis tibi destinatis. euhoe, parce Liber, parce gravi metuende thyrso. parce privatus nimium cavere parce, precor, precor.

Canidia: parce vocibus tandem sacris

parce. cum me hortaretur. parce frugaliter atque | vivereu uti contentus eo si|Graeco fonte cadent parce detorta.

parcent. si parcent animae fata superstiti.' si parcent puero fata superstiti.'

parcentis. urbani, parcentis viribus atquelextenuantis eas consuito.

parcentis. parcentis ego dexteras/odi:

parcere. tamquam parcere sacris/cogeris. mortisque metu sibi patcerc cogit. multa mole docendus aprico parcerc prato.

parcet. dummodo risum | excutiat sibi non, non cuiquam parcet amico sibi parcet $\mid$ contractusque leget;

parci. te suis matres metuont invencis, / te senes parci

Parcis. sic potenti|Iustitiac placitumque Parcis.

parcis. parcis deripere horreol cessantem . . amphoram.

parcit. mors.. nec parcit inbellis iuventae/poplitibus timidove tergo. ac nisi mutatum parcit defundere vinum

parcite. male nominatis| parcite verbis.

parcius. parcius iunctas quatiunt fencstras parcius hic vivit: frugi dicatur;

quanto aut ego parcius aut vos, $\rho_{0}$ pueri, nituistis,

rexque paterquelaudisti coram, nec verbo parcius absens:

parco. deciens centena dedisses/huic parco. paucis contento:

parcus. parcus deorum cultor et infrequens. veteris non parcus aceti. ac potius foliis parcus vescatur amaris; parcus ob heredis curam nimiumque severus|adsidet insano: quantum discordet parcus avaro.

pardus. festus in pratis vacat otioso|cum bove pagus [pardus],

parebit. parebit pravi docilis Romana iuventus. -

parem. ope Palladis/Tydiden superis parem?

cui . . quando ullum inveniet parem?

nec Iugurthino parem | bello reportasti ducem

et quaeret iratus parem

parem. servatura diu parem/cornicis vetulae temporibus Lycen,

parens. quin et Prometheus et Pelopis parens

non te Penelopen difficilem procis| Tyrrhenus genuit parens.

var.Serm.I.4.108

Serm.1.4.108

Serm. 2 3.15

Esist.2.2.1.7

Carm.1.I5.I 2

Sirm.1.10.*3

Epist.1.2.2 I

Epod.6.1 2

Carm.2.17.12

Epist.2.I.I 84

Carm.1.31.t7

Serm.2.3.167

Sirm.2.3.98

Epod.1.3

Epod.17.38

Epist.1.7.22

Epod.I.32

Carm.2.16.39

Serm.2.5.79

Carm.3.16.4t

Carm.2.6.9

Epod.13.1 5

Carm.Saec.25

Carm.3.10.I 7

Serm.2.3.325

Carm.1.28.23

Carm.2.7.20

Carm.2.19.7

Carm.2.19.8

Carm.3.8.26

Carm.4.1.2

Epod.17.6

Serm.1.4.107

.1rs Poet.53

Carm.3.9.I2

Curm.3.9.16

Serm-I.IO.I 3

Carm.3.19.2I

Serm.1.I.7 I

Serm.I.4.127

Epist.I.I4.30

Serm.I.4.35

Epist.I 7.I I

Carm.2.8.22

Carm.2.17.16

Carm.3.28.7

Carm.3.2.1 5

Serm.2.2.58

Carm.3.14.1 2

Carm.1.25.I

Serm.I.3.49

Serm.2.2.127

Epist.1.7.38

Serm.1.3.I6

Carm.1.3.1.

Serm.2.2.02

Serm.2.3.IIt

Epist.1.5.13

Epist.2.2.19.4

var.Carm.3.18.1 2

Serm.2.2.52

Carm.1.6.16

Carm.1.24.8

Epod.9.23

Epod.15.14

Curm.4.13.24

Carm.2.13.37

Carm.3.10.1 2 
quo sit amore patens, quo frater amandus et hospes.

garens. nif servile gulac parms labet?

parent. quid Sieset regnata Cyrol Bactra parent

onne conim tes./virtus, tama, decus. . . divitio parent;

porente. "que nos cumque ferct melior fortuna parente.

cum referte negas. quali sit quisque parente/natus. . an tu reris cum occisa insanisse parente

parentem. dworum|nuntium curvaeque lyrae parenteri. periurm luit in parentem | splendide mendax

parentem. posset qui rupem et puteum vitare patentem [parenten].

parentem. in campo doceat parentem cutrefe frenis? qui mali parentem in rupis protusit asellum|iratus:

parentes. an te generum beatil Phyllidis flavae decorent parentes: nec inpubem parentes|Troilon aut Plirygiae sorores/flevere semper.

parentes. neque hoc parentes, beu mihi superstites. / (effugerit spectaculum." yuod non ingenuos habeat clarosque parentes. ad fastun quoscumque parentes/optaret sibi quisque.

parentes. illum et parentis [parentes] crediderim sui|fregisse cervicem

parentibus. non his iuventus orta parentibus. pasentibusque abominatus IIannibal:

porentis. guid prius dicam solit is parentis/laudibus.

illum et parentis crediderim sui|fregisse cervicen cum parentis regna per arduon cohots gigantuns scanderet inpia. parentis olim siquis inpia manu sonile guttur fregerit. avi cur atqu parentis/praecham ingma stringat malus ingluvie rem. parentium. dos magna parentium/virtus

parentum. audiet pugnas vitio parentum/rata iurentus. quid prius dicam solitis parentis [parentum]/laudibus. . 6go, pamprum/sanguis parentum. aetas parentum. peior avis, tulit/nos neptuores. dos est magna parcntium [parentum]| virtus

parentur. mole parentur opes. quid alat formetque yoctam, parere. vel quia turpe putant parere minotilus pareret. quod mihi pareset legio Romana tribuno. paret. labes quil adsideat, fomenta paret. siquis. paret ancillas, paret aurum. s1 insanire parce certa ratione moloque." sive vicarins est qui setvo patet. . . seu conservos. animun rege; qui nisi paret, |imperat; wetuten doctrina paret naturane donet.

pari. Ut cosat par fiungaturque pari:

faria. sladiatorum dare centum|damnati populo paria

paria. puic futia esse fere placuit peceata.

faribus. gistjt paribus conludere

Paridis. Jum Jrami Pardicgue busto insultet armentum

yHa laridis progter narratur amorem ("ratecia barbariac lento collisa 1] [1+110.

;aries. Ho tabula sacer/votiva paries inclicat

barbiton lu paries habebit.

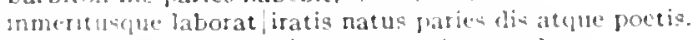

nam twil res aktur. paries cum froximus arelet.

Pario, splemelentia Pario marmore purius.

Parios. larien "ge primus iambos lonterdi I ation.

Paris. Antegur cencet belli praceidere cam-an: fonid Jaris?

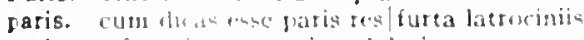

pariter. ferse ingum patiter dolosi:

ruidruid nowst alcer. et alter. |adnuimus parter.

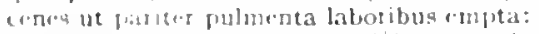

Whemen- lughe et sibi et hosti|iratus pariter.

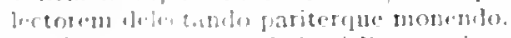

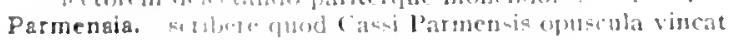

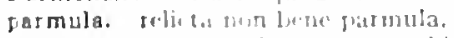

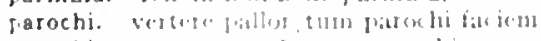

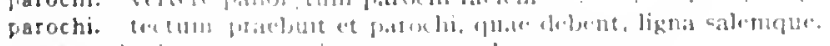

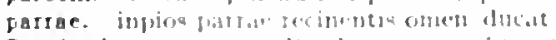

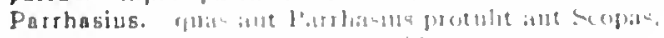

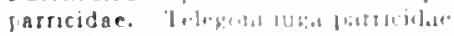

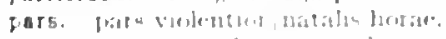

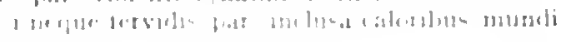

Serm.2.7.111

Carm.3.29.28

Serm.2.3.90

Carm.1.7.25

Serm.1 0.7

Serm.2.3.134

Carm.1.10.6

Corm.3.11.3.

rar.lipist.2.2.135

Sormi.1.91

Lpist 1.20.15

Carm.2.4.14

Carm.2.9.15

Iipod.5.101

Serm.1.6.91

Serm.1.6.95

tar.Carm.2.13.5

Corm.3.6.33

Epod.10.8

Carm.1.12.13

Corm.2.13.5

Carm.2.19.2I

Epod.3.1

Serm.1.2.7

Corm.3.24.21

Carm.1.2.23

rar.Corm.1.12.13

Carm.2.20.0

Carm.3.0.10

Iar.Carm.3.2421

Ars Joel.zoz

Epist 2.1.84

Serthesects

Serm.1.1.82

Serm.2.3.215

Serm.2.3.27I

Serm 2.7.70

Efist.t.2.112

Epist.1.18.100

Epist 1.5 .20

Serm.2.3.86

arm.1.300

Ars I"int. 150

Carm.3.3.t)

Lpist.1.2.0

(arm.1.5.14

Carm.3.20.4

firm.2.3s

I.p.st.1.18.8.1

(arm.1.10.0)

Lipist.1.19.23

Ifpist.1.2.10

Sirm.1.3.121

Corm.1 35.28

d. fill.1.10.5

Hoist 1.18 .95

lepist 2.2.20

Ars lued 3.11

1.pist 1.43

Curm 27 in

som. 2 औ 30

sorm. 1.5.4p

(i)rm? 27.1

c arm s 8 s.

(corm.3208

( tirm 217.18

(arm 32.43 
non omnis moriar multaque pars mei/vitabit Libitinam;

Carm.3.30.6

tum meae. . . vocis accedet bona pars

Carm.4.2.40

iussa pars nutare Lares et urbem|sospite cursu,

forte quid expediat communiter aut melior pars

aut pars indocili melior grege;

ut bona pars hominum decepta cupidine falso.

non, ut magna dolo factum negat esse suo pars,

sine nervis altera quidquid/conposui pars esse putat

"danda est ellebori multo pars maxima avaris: .

maxina pars hominum morbo iactatur eodem. .

'pars hominum vitiis gaudet constanter

pars multa natat. modo recta capessens. |interdum pravis obnoxia.

pars hominum gestit conducere publica;

tertia succedant et quae pars quadret acervom.

maxima pars vatum, pater et iuvenes patre digni. / decipimur specie recti. bona pars non unguis ponere curat, / non barbam,

Darte. quae Venus|quinta parte sui nectaris imbuit.

cervos uti vallis in altera|visum parte lupun graminis inmenor.

nihil est ab omni| parte beaturn.

qualibet exsules|in parte regnanto beati;

qua parte debacchentur ignes.

audire est operae pretium. ... ut omni parte laborent .

aut positum ante mea quia pullum in parte catini|sustulit esuriens,

quarta lam parte diei|praeterita. .

ex parte tua seu fundi sive domus sit|emptor.

partem. nec partem solido demere de die|spernit.

voltis severi me quoque sumere/partem Falerni?

a, te meae si partem animae rapit|maturior vis,

quodsi pudica mulier in partem iuvet/domum.

in neutram parten cultus miser.

aut spem deponas aut artem [partem] inlusus omittas.

magnam morbi deponere partem.

partem vel tolleret omnis.

partes. ne forte seniles | mandentur iuveni partes pueroque viriles:

quae partes in bellum missi ducis:

partes. actoris partes chorus officiumque virileldefendat.

Parthi. miles sagittas et celerem fugam|Parthi.

aut labentis equo describit volnera Parthi.'

Parthis. iuvenis Parthis horrendus, ab alto/demissum genus Aenea. et formidatan Parthis te principe Romam.

Parthis. ipse ego. . . invenior Parthis mendacior

Parthorum. derepta Parthorum superbis|postibus. sed ut secundum vota Parthorum sub duce, qui templis Parthorum signa refigit

Parthos. ille seu Parthos Latio imminentis legerit. Parthos ferocis/vexet eques metuendus hasta

Parthum. Parthum dicere nec quae nihil attinent. quis Parthum paveat, quis gelidum Scythen.

Parthus. catenas Parthus et Italum|robur;

partibus. Eois timendum|partibus Oceanogue rubro. hinc vos. vos hinc mutatis discedite partibus. unus utrique/error, sed variis inludit partibus: .

particulam. Prometheus addere. . coactus particulam undique $\mid$ desectam vagae ne parce malignus harenae . . particulam dare: atque adfigit humo divinae particulam aurae.

partis. "quartae sit partis Vlixes"|audieris "heres":

partis. cui dabit partis scelus expiandi|Iuppiter? transfuga divitumlpartis linquere gestio. partis mimum tractare secundas; quo pacto partis tutetur amantis ephehi. actoris partes chorus officiumque virile/detendat. assem/discunt in partis centum diducere.

partita. quae si semel uno/de sene gustarit tecum partita lucellum. partitur. partitur lintres exercitus.

parto. finire lahorem/incipias, parto quod avebas, partubus. si vocata partubus Lucina veris adfuit,

partum. unde putas aut/qui partum?

partum. deterior post partum carne futura

parturient. parturient montes, nascetur ridiculus mus.

Carm.Sate.39
Epod.16.15

Epod.10.37

Serm.1.I.0I

Serm.1.6.90

Serm.2.1.3

Serm.2.3.82

Serm.2.3.1 21

Serm.2.7.0

Serm.2.7.7

Epist.1.1.77

Epist.1.0.35

Ars Poet.24

Ars Poet. 297

Carm.1.13.16

Carm.1.15.30

Carm.2.10.28

Carm.3.3.39

Carm.3.3.55

Serm.1.2.38

Serm.1.3.92

Serm.1.9.35

Strm.2.5.108

Carm.1.I.20

Carm.1.27.10

Carm.2.17.5

Epod.2.39

Serm.2.2.00

iar.Serm.2.5.26

Epist.1.1.35

Epist.1.0.41

Ars Poet.r77

Ars Poet.315

Ars Poel. I93

Carm.2.13.18

Serm.2.1.I 5

Serm.2.5.62

Epist.2.1.250

Epist.2.I.II 2

Carm.1.15.7

Epod.7.9

Epist.I.I 8.56

Corm.I.12.53

Carm.3.2.3

Corm.1.I9.12

Carm.4.5.25

Corm.2.13.18

Carm.1.35.32

Serm.1.I.I8

Serm.2.3.5I

Carm.I.I6.14

Carm.1.28.25

Serm.2.2.79

Serm.2.5.100

Carm.1.2.29

Carm.3.10.24

Epist.1.IB.I 4

Epist.2.I.I7I

Ars Poet. 103

Ars Poet.326

Serm.2.5.82

Epist.1.I8.01

Serm.1.I.94

Epod.5.5

Serm.2.2.19

Serm.2.8.44

Ars Poet. 139 


\section{PARTVRIT}

parturit. Nortus neque parturit imbris| perpethos.

Germania quos horbida parturit fetus

parturiunt. p.erturient [parturiunt] montea, nascetur ridiculus mus.

partus. mancetque partus fulmine luridum/missos ad Orcum:

ritio maturos aperife partus|lenia.

parum. tu prorum catis inimica mittes/fulmina lucis.

et parum comis sine ce Iuventan|Mercuriusque.

parum locuples contisente ripa;

parum decoro inter verba cadit lingua silentio?

inbellis ate firtinti parum?

parume campiq atque Neptuno super|iusum est Latini sanguinis.

"matutina parum cautos iam frigora mordent"; .

quaecumine pasum splendoris habebunt

maculis. quaq aut incuria fudit / aut lumana parum cavit natura. .

parum clarie lucem dare coget.

parva. ego utrum| nave ferar magna an parva, ferar unus et idem.

parva. puberiv exigui prope latum parva .1latinum/munera parvom parva decent:

parva. mihi parva rura et/spiritum Graiae tenuem Camenae

contracto melius parva cupidine/vectigalia porrigans

ne jarba Tyrthenum per acpuor/ rela darem.

magnis parra mineris falce recisurum simili te.

parvas. si friwco parvas aut. ut fuit ipase coactor/mercedes sequerer:

parvi. fuan irigida parvi tindunt Scamandri flumina

sordidus atglar aniari quod parvi nolit haberi, peapondet.

parvi. hoc ofus, hoe studium parvi properemus et ampli.

parvis. Temis incedac abeasque parvislanequo* alumnis.

"non anvicat fere"s fuetiz mumuscula parvis".

parvis. magnia modju temuare parbis.

gaidentem parriague sodalibus et late certo

ut parvis animis et parvo corpore mains:

parvis. th th hoc, parbis quoque rebus masna iusuri.

parvis. - im tie Oreus grandia cum parsis.

parvo. neroun ulla $e^{2}+t_{\text {at }}$ angno aut parvo leti fuga: menini quae plagosum mihi parvolOrbilium dictars:

parvo. mumdaeque garvo sub lare pauperum / cenar dun a jarvo nobis tantundem haurire relinquas.

nato viver" pravo (parro) spectandum nigris oculis nigroque capillo

parvo. vivitur bato bene cui paternum | splentet in mensit tenui salinum ruar virtus et quanta. boni, sit vivere parso

an sui contentu= parvo metuensque futuri

"quant cmpta?" "parvo:" "quanti ergo?" octusubus."

guap parvo sumi nequeunt, obsonia cantas?

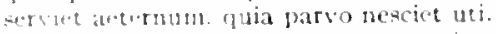

ut fliss sis animin et parvo corpore mains:

mumese gr fruto beet aut incommodua angat.

agricolat prised. bottes parvogue beati.

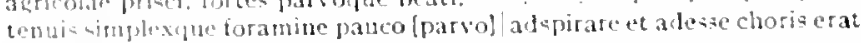
utilik

parvola. parsola nam exemplo ent, magni formica laboris

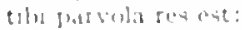

parvola. numirum lie ego sum; nam tuta et parvola laudo.

parvom. mo the parromlingrnium.

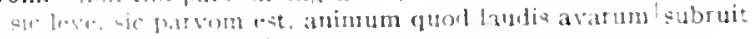

parvom. parsom bistra deremt:

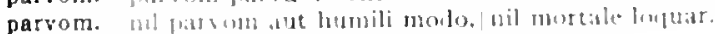

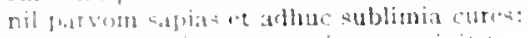

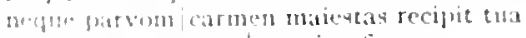

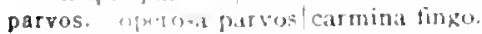

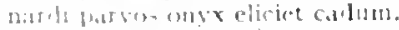

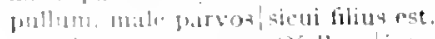

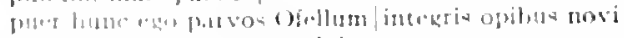

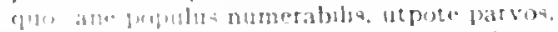

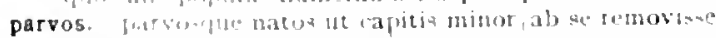

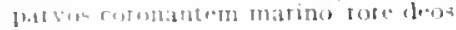

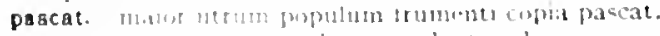

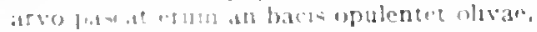

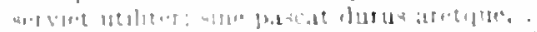

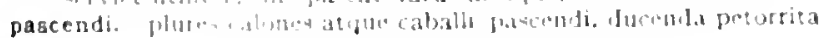

PASCENDI

Carm.1.7.10

Corm.4.5.26

rar.Ars Poel. 39

Carm.3.4.74

Carm.Saec.13

Carm.1.12.59

Carm.1.30.7

Carm.2.18.22

Curm.4.1.35

Epat.1.16

F.pod.7.3

Sirm.2.0.45

Fist.2.2.111

Ars Port.353

Ars Poet.4.48

Epist.2.2.200

Carm.1.28.3

Epist.1.7.44

Carm.2.16.37

Cirm.3.16.39

Cirm.4.15.3

Serm.1.3.122

Sirm.1.0.80

Epod.13.13

Sirm.1.2.10

Epist.1.3.29

Carm.3.18.3

Epist.1.7.17

Carm.3.3.72

L.pist 1.7 .58

l: pist.1.1.7.40

lipist.2.1.125

lipist.2.2.1 9

Sirm.2.6.95

Lipist.2.1.70

Corm.3.29 It

serm.1.1.52

"ar.etrs Poed.z'

Carm.2.10.13

Sirm.2.2.1

Serm.2.2.II0

Sirm.2.3.15"

Sirm.2.7100

1:Pist.1.10.4!

Epist.1.17.40

Eptot.1. I.75

F.pist.2.1.13?

1ar..1rs Poet.203

Setm.1.1.33

Lipt5t.1.18.20

IEpita.15.41

Lipist.3.3.21

Epist.2.I.IT

1.pist.1.7.4

Carm.3.25.17

lipist.1.12.15

lipust 2.1.25?

Citm. 2.36

cirm 4.12.17

sorm. 1.315

Sirm2 2.112

ars leace 20 "

Carm. $\$ 5.42$

Carm 3.2315

list.1.5.1

l.pist.1.80.2

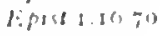

Sermit.0.104 
pascere. speciosa quaero|pascere tigris.

Carm.3.27.56

iussit sapientem pascere batbam .

Serm.2.3.35

et fundus nec vendibilis nec pascere firmus.

Epist.1.17.47

pasces. 'non hominem occidi.' "non pasces in cruce corvos."

Epist.r.16.48

aut tineas pasces taciturnus inertis

pascet. scorto post ponet honestum/officium, nummos alienos pascet.

pasci. sed tacitus pasci si posset corvos.

pascit. qui te pascit ager tuos est.

pascitur. nam quae nivali pascitur Algido/devota.

pascitur in vestrum reditum votiva iuvenca.

Epist.1.20.12

Epist.1.18.35

Epist.1.17.50

Epist.2.2.160

Curm.3.23.9

Epist.1.3.35

pasco. vernasque procacis|pasco libatis dapibus. . . . . . . . Serm.2.6.67

pascua. pecusve Calabris ante sidus fervidum / Lucana mutet pascuis [pascua]

pascuis. qualemve laetis caprea pascuis/intenta

pascuis. nec pingula Gallicis/crescunt vellera pascuis:

pecusve Calabris ante sidus fervidum | Lucana mutet pascuis

pascula. pecusve Calabris ante sidus fervidum / Lucana nutet pascuis [pascula]

pascunt. me pascunt olivae, me cichorea levesque malvae.

passeris. cum passeris atque|ingustata mihi porrexerat ilia rhombi.

passi. o fortes peioraque passi|mecum saepe viri. .

passim. ubi passim|palantis error certo de tramite pellit.

scribimus indocti doctique poemata passim.

passo. pedibus nudis passoque capillo.

pasta. pastaque rursus/ire foras pleno tendebat corpore trustra. .

pastas. pastas ovis, videre properantis domum.

pastillos. facetus|pastillos Rufillus olet, Gargonius hircum: .

ego si risi, quod ineptus|"pastillos Rufillus olet, Gargonius hircum",

pastor. pastor cum traheret per freta navibus | Idaeis Helenen perfidus hospitam. .

pastor umbras cum grege languido|rivomque fessus quaerit

gar.Epod.1.28

Carm.4.4.13

Curm.3.16.36

Epod.r.28

var.Epod.1.28

Carm.1.31.15

Serm.2.8.29

Carm.1.7.30

Scrm.2.3.4s

Epist.2.I.II

Sirm.1.8.24

Epist.1.7.30

Epod.2.61

Serm.1.2.27

Sirm.1.4.92

Carm.I.I5.I

Carm.3.29.2I

Serm.1.5.63

pastorem. pastorem saltaret uti Cy+clopa rogabat: .

pastoribus. amica vis pastoribus.

pastum. pinguibus et ficis pastum iecur anseris albae

pastum. missae pastum retinacula mulae/nauta piger saxo religat

Epod.0.6

Serm.2.8.88

Serm.1.5.18

Carm.3.4.64

pateat. omnis/votiva pateat veluti descripta tabella/vita senis. .

Serm.2.1.33

Carm.4.14.36

patefecit. portus Alexandrea supplex/et vacuam patefecit aulam.

patella. nec modica cenare times holus omne patella.

Epist.1.5.2

Carm.3.16.7

Epist.2.2.135

patentem. posset qui rupem et puteum vitare patentem.

patenti. otium divos rogat in patenti|prensus Aegaeo.

Pater. satis terris nivis atque dirae/grandinis misit Pater si quaeret Pater urbium|subscribi statuis. . vel atra|nube polum Pater occupato/vel sole puro; .

pater. hic ames dici pater atque princeps

te... ventorumque regat pater

Melpomene, cui liquidam pater/vocem cum cithara dedit.

me pater saevis oneret catenis,

"vilis Europe" pater urget absens:

clarus occultum Andromedae pater/ostendit ignem.

divom pater adnuisset/rebus Aeneae

Carm.2.I6.I

Carm.1.2.2

Carm.3.24.27

Carm.3.29.44

Carm.1.2.50

Carm.1.3-3

Cerm.1.2.4.3

Carm.3.I 1.43

Carm.3.27.57

Carm.3.29.17

Carm.4.6.22

iar.Curm.4.7.15

Epod.17.05

optat quieten l'elopis infidi pater.

ut pater ille. Terenti fabula quem niscrum gnato vixisse fugato inducit, ac pater ut gnati, sic nos debemus amici|siquod sit vitium non fastidire: strabonem lappellat paetum pater.

'non nosti, quid pater," inquit,|'Chrysippus dicat:

'at pater ardens|saevit.

numquid Pomponius istis/audiret leviora, pater si viveret?

quivis stomachetur eodem |quo personatus pacto pater.

insuevit pater optinus hoc me.

namque est ille, pater quod erat meus.'

causa fuit pater his.

quaestor avos pater atque meus patruosque fuissent.

clamet amica. | mater, honesta soror cum cognatis, pater, uxor:

quod satis esse putat pater et natura coercet.

cum pater ipse domus palea porrectus in horna

Serm.1.2.20

Serm.1.3.43

Serm.1.3.45

Serm.1.3.126

Serm.1.4.48

Serm.1.4.53

Sorm.1.4.56

Serm.1.4.105

Serm.1.6.4I

Serm.1.6.7 I

Serm.1.6.13I

Serm.2.3.58

Sim.2.3.178

Serm.2.6.88

ut aiebat cenae pater:

Serm.2.8.7 
dum pueris oninis pater et matercula pallet

Ennius ipse pater numquan nisi potus ad arma/prosiluit dicenda.

Romulus ef liber pater... plotavere suis non respondere favoren! speratum meritis.

offenduntur enim, quibus est equos et pater et res

fater. Lentis humanac pater atgue custos,

quis non te potius, Bacche pater, teque, decens lenus?

hac se merentem, Bacclie pates.

polter, o relictum| filiae nomen

te, pater Silvane, tutor finium.

"cupielum, pater optime, vireslefeficiunt:

- palro el rex luppicer.

Matutine pater, seu 'Iane' libentius audis.

"frater' pater' adde; ut cuique est aetas.

rexque paterque audisti coram.

"lane pater" clare, clate cum dixit 'Apollo."

maxina pars vatum, pater et iuvenes patre digni, / decipimur specie recti.

fatera. turaque bimi cum patera meri:

quid orat de patera novorn fundens liquoren?

adstat echinus|vilis, cum patera guttus.

pateras. donarem pateras grataque conmodus, | Censotine, meis aera sodalibus,

rateris. te proseluitur mero defuso pateris

pateris. cum vateris sapiens enendatusque vocari.

paterna. (juamis et voce paterna fingeris ad rectum

paterna. paterna rura bubus exercet suis

sponeleus stabilis in iura paterna recepit

paterni. notus in fratres animi naterni:

decisis lumbilem pennis inopenque paterni' "t hris et fundi.

paterni. ue paterni fluninis ripae simul et jocosa redeleret laudes

paternis. nudus agris, uudus nummis, insane, paternis;

paternis. o nec paternis obsoleta sordibus

rebus maternis atque praternis iortiter absumpeis

paterno. doctus sagit tas tendere sericas/arcu paterno?

paterno. interdum nugaris ture paterno.

paterno. vwitur harvo bene cui paternun [paterno] splendet in mensa tenui salinum

Daternos. paturnosin sinu icrens deos

paternum. cui paternum splendet in mensa tenui salinum

faternum. binatguc paternum|cognonen vestas in risum. contendat haveo collum pressisse paternum:

paternus. guid. posse, quid Augusti paternus in pueros animus Sirsones,

nec gurod avos tubi maternus fuit atque patronus

fotet. renctacene patet ianua lydiae?"

hic mutat merces surgente al sole ad cum, quo/vespertina tepet [patet] regpics.

hac magis illam inparibus formis decotum te petere [te patet] esto:

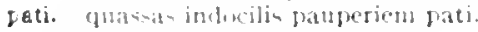

ut ma-lius, quirlquid erte, pati.

angulam athice paurerien pati

unbet qualsise elacere et pati

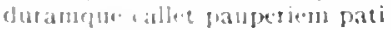

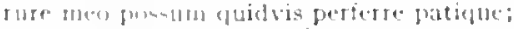

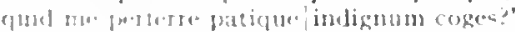

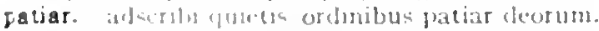

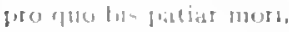

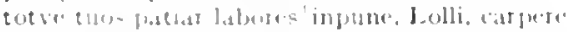

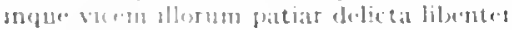

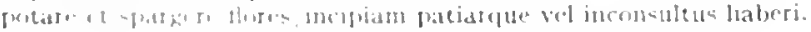

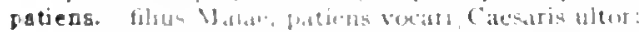

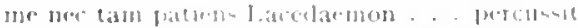

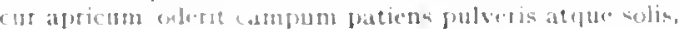

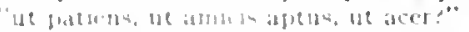

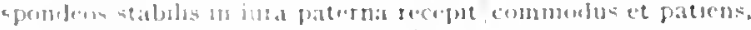

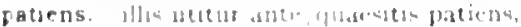

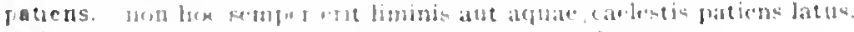

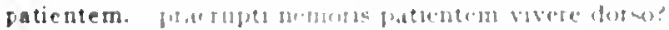

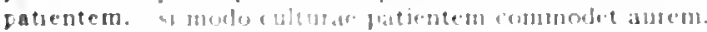

IEpist.1.7.7

Lipist.1.19.7

Epist. 2 I.5

Ars Poet. 248

Carm.1.12.49

Cormitis.0

Carm.3.3.13

Carm.3.27.34

Lpod.2.21

Serm.2.1.12

Serm.2.1. 2

Sorm.2.1.20

Lisist.1.0.54

I.pist.1.7.37

Epist 1.10 .59

Ars Poot. 24

Carm.1.19.15

Carm.1.31.2

Serm.1.0.118

Carm.4.8.I

Corm.4.5.34

Epist.1. I 30

Ars Poet. 300

Epod 2.3

Ars Poet.250

Carm.2.2.t

Epist.2.2.50

Carm.1.20.5

Serm.2.3.184

I.pod.17.4\%

Lpist.1.15.20

(arm.1.29.10

Lpist.1.18.60

iar.Carm.2.16.13

Carm.2.I8.20

Curm.2.10.13

List.1.13.8

lepist.1.10.37

Carm.4 4.27

sorm.1.0.3

Carm.3.9.20

:ar.sern. 1.430

iar.sorm.2.2.30

Carm.1.1 18

(arm.1.1) 3

carm.3.2.1

Corm $3.24+3$

carm 19.40

Epts I 15.17

l:pist.1.10.74

carm.3.3.3

carm.30.15

carm + o. 32

arm. 3.141

Lepist 1.5.5.5

Corm.1 2.83

Corm. i 10

carmis 1

torm.2.5.3

Ars lont 259

strm I 1.38

(arm 3 In 20

Sorm 2 (b.0)

I. pist 1 i .10 
patienter. 'si pranderet holus patienter, regibus uti|nollet Aristippus.' nimium patienter utrumque, / ne dicam stulte, mirati,

Epist.1.17.13

patientia. contra, quem duplici panno patientia velat.

patientia. durum: sed levius fit patientia .

patientis. haud male Telemachus, proles patientis Vlixei: . .

patimur. per nostrum patimur scelus/iracunda Iovem ponere fulmina.

patina. adfertur squillas inter murena natantis/in patina porrecta.

patinae. grandes thombi patinaeque | grande ferunt una cum damno dedecus.

patinam. eum servom, patinam qui tollere iussus.

interea suspensa gravis aulaea ruinas|in patinam fecere.

si patinam pede lapsus frangat agaso.

patinas. patinas cenabat omasi|vilis et agninae.

patitur. Venus|Cyprum deseruit nec patitur Scythas . . dicere

patiuntur. dum res et aetas et sororum|fila trium patiuntur atra. 'meae (contendere noli)!stultitiam patiuntur opes; .

patre. Tydides melior patre:

quid responderet? "magno patre nata puella est."

velim memores et quo patre natus uterque/contulerit litis.

ignotos ut me libertino patre natum.

ingenuo si non essem patre natus:

audit continuo "quis homo hic' et 'quo patre natus?"

quo patre sit natus, num ignota matre inhonestus.

nunc ad me redeo libertino patre natum.

quem rodunt omncs libertino patre natım.

non ego me claro natum patre. . . sed quod eram narro.

qui turpi secernis honestum|non patre praeclaro.

cuius fortunae. quo sit patre quove patrono."

me libertino natum patre et in tenui re.. loqueris,

maxima pars vatum, pater et iuvenes patre digni, | decipinur specie recti.

patrem. Teucer Salamina patremque/cum fugeret,

patres. clament periisse pudorem/cuncti paene patres,

pueri patresque severi|fronde comas vincti cenant

patres. donec labantis consilio patres|firmaret auctor natosque maturosque patres|pertulit Ausonias ad urbis. quinque bonos solitum Variam dimittcre patres.

patria. quaerit patria Caesarem.

patria. dulce et decorum est pro patria mori:

Codrus pro patria non timidus mori

Codrus pro patria non timidus [non timidus pro patria] mori

non ille procaris anicis/aut patria timidus perire.

cui potior patria fuit interdicta voluptas.

patriae. patriac quis exsul|se quoqtue fugit?

scilicet oblitos patriaeque patrisque Latini,

cui potior patria [patriae] fuit interdicta voluptas.

patriae. lucem redde tuae, dux bone. patriae:

castus Aeneas patriae superstes

cur, inprobe, carac| non aliquid patriae tanto cmetiris acervo?

si patriae volumus, si nobis vivere cari.

qui didicit, patriac quid debeat et quid amicis,

patriam. in patrian populumque fluxit.

patriam. magnum documentum, ne patriam rem / perdere quis velit." .

patribus. virginum primae puerique claris|patribus orti. nomina sectatur modo sumpta veste virili|sub patribus duris tironum. .

patriis. quis te redonavit Quiritem/dis patriis Italoque caelo,

patriis. patris intermiscere petita/verba foris malis.

patrimoni. cum summam patrimoni insculpere saxo|heredes voluit?" hic simul accepit patrimoni mille talenta,

patrio. per quem tot iuvenes patrio caruer scpulcro?"

patrios. gaudentem patrios findere sarculo/agros inpudens liqui patrios Penates.

agros atque lares patrios habitandaque fana|apris reliquit

non satis est Ithacam revehi patriosque Penates! ad spicere?"

Parios [patrios] ego primus iambos/ostendi Latio.

utrum $\mid$ minxerit in patrios cineres

patris. illum et parentis [patris] crediderin sui|fregisse ccrvicem cum periura patris fides/consortem sociun fallat et hospites bonan deperdere famam.| rem patris oblimare malum est ubicumque. si peteret per amicitiam patris atque suam.

Ars Poet.27 I

Epist.1.17.25

Curm.1.24.19

Epist.I.7.40

Carm.r.3.39

Serm.2.8.43

Serm.2.2.95

Serm.1.3.80

Serm.2.8.55

Serm.2.8.72

Epist.I.I 5.34

Carm.I.Ig.Io

Carm.2.3.16

Epist.1.18.29

Curm.I.I5.28

Serm.I.2.72

Serm.1.5.53

Serm.1.6.6

Serm.1.6.2I

Serm.1.6.29

Serm.1.6.35

S.rm. I.6.t5

Sirm. I.6. 46

Serm. I.6.58

Serm.1.6.64

Epist.1.7.54

Epist.1.20.20

Ars Poet.24

Carm.1.7.2I

Epist.2.1.8I

Epist.2.1.109

Carm.3.5.45

Cumm.4.4.55

Epist.1.T.1.3

Carmat.5. I6

Carm.3.2.13

Carm.3.19.2

vur.Curm.3.19.2

Carm.4.9.52

Epist.1.6.64

Curm.2.16.19

Serm.t.10.27

vor. Epist.1.6.64

Carm. +5.5

Carm.Saec.t2

Serm.2.2.105

Epist.1.3.29

Ars Poct.31 2

Carm-3.0.20

Serm.1.tido

Carm.4.6.32

Serm.1.2.I 7

Carm.2.7.t

Serm.1.I0.29

Sirm.2.3.90

Serm.2.3.226

Serm.2.3.196

Cirm.I.I.II

Curm.3.27.49

Epod.10.19

Serm.2.5.4

zar. Epist.I.I9.23

Ars Poet.47I

zar.Carm.2.t3.5

Carm.3.24.59

Serm.1.2.62

Serm.1.3.5 
nil me pacniteat sanum patris huius.

Serm.1.6.89

scilicet oblitos patriaceute patrisque Latini.

Serm.1.10.27

quo pacto partis tutetur amantis ephebi, | ut patris attenti.

in Maeci descendat judicis auris ot patris et nostras

fatrium. qui patrium mimae donat fundurnque Laremque.

cum lingua Catonis et Enni|sermonem patrium ditaverit

patrius. olim iuventas et patrius vigor' nielo laborum protulit inscium

patrone. "pol. me uniserum, patrone. vocares.

patrono. cuius fortunae, quo sit patre quove patrono.'. . . .

Epist.2.1.172

Ars Poel. 388

Serm.1.2.56

Ars Poct.57

Carm.4.4.5

E.pist.1.7.92

patruse. exanimari metuentis patruae verbera linguac.

patruis. victurum suavius ac si, quacstor abos pater atque meus patruosque [patruisque] iuisent.

patrum. est in equis patrum/virtue

maturum reditum pollicitus patrun' sancto concilio

quae cura patrum quaeve Quiritium

virtute functos more patrum duces . . . canemus.

natrumqu* prosperes decteta

'qui consulta patrum, qui leges iutaque servat.

potruom. adde iratum patruom, vicinos.

patruos. quaestor avos pater atque meus patruosque fuissent.

"sive ego prave|seu rect. hoc volui, ne sis fatruos mihi":

Epist.1.7.54

Carm.3.12.2

patruus. victurum suavius ac si guacstor avos pater atque meus patrosque [patrunsque] fuissent.

patuit. ante netum nulli patuit quacsita palatum. .

ut vel continuo patust.

patulae. nec retinent patulace conmissa fideliter aures

patulas. obturem patulas insune legentibus auris. .

patulis. pectinibus patulis iactat se molle Tarentum.

patulum. sifnon circa vilem patulumque notaberis orbem

pauca. nec treprides in usun poscentis aevi pauca:

iam pauca aratro iugera regiae moles telinquent.

apedum, pauca accige contra.

ut veni coram. singultin pauca locutus

respondes, ut tuos est mos, / pauca:

cupiens tibi dicere servos pauca reformido:

egocur. asjuigere buca| si posum, insideor,

paucis. nimirum insanus paucis videatur.

paucis ostendi gemis et communia laudas.

paucis. contentus paucis lectoribus. .

paucis. non exo paucis offendar maculis.

paucis. deciens centena dedises huic parco paucis contento:

mili paucis Sarmenti surrau puknam Messique Cicirri, . . nemores atqui si vitis nediocribus ac mea paucis, mentosa cot natura.

pauco. tibia. . tenuis simplexque foramine pauco

paucorum. hine repetit. "parcotum hominum et mentis benc sanae:

paucorum. purate rivos arjua silvarue iupermin/paucorum

paulatim. caulaeque pilos ut equinel paulatin vello nemfe morlo isto paulatim mercaris agrum.

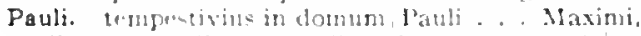

paullo. is armulior est paullo, nimus agtu- icutis, naribus borum lominum, inejus tot iactantios life patilo ent:

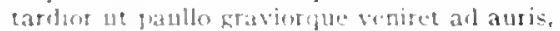

faullum. sparke cubmele et, sidullum pote inlactimate.

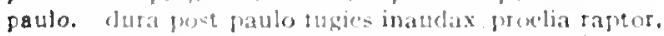

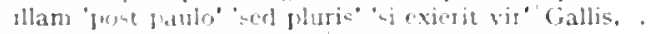

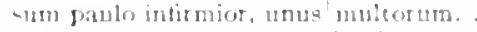

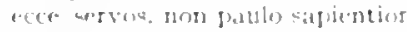

pow paulo scribit slif milia puindue esse tomi chlanydum;

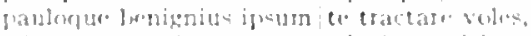

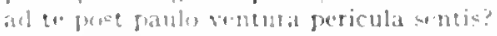

ci ver -

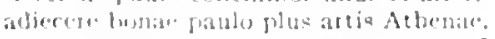

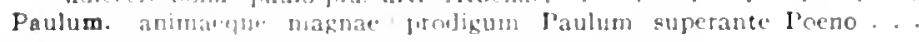

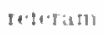

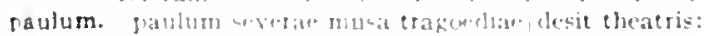

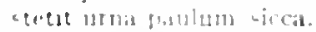

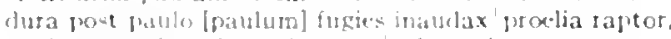

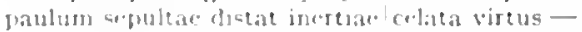

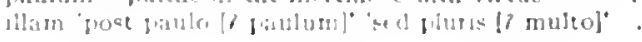

tar.Serm.1.6.131

Carm.4.4.30

Carm.4.5.3

Carm.4.I.I

Carm.4. 15.29

Carm.Saec.I 7

Epist.1.10.4I

Serm.2.2.97

Sorm.1.0.13I

Sorm.2.3.88

:ar.Serm.1.6.131

Serm.2.4.46

Serm.2.8.29

Espist.1.18.70

Epist.2.2.105

Serm.2.4.34

Ars I'oct. 132

Corm.2.11.5

Carm.2.15.1

Scrm.1.4.3s

Serm.1.0.50

sorm.1.0.01

Serm.2.7.

Ars loct. 55

Serm.2.3.120

Epist.1.20.4

Sirm.1.10.74

Ars loet.351

Serm.1.3.10

Sitm.1.5.5I

SeTm.1.0.05

Ars loed.203

Serm.1.9.44

Carm.3.10.30

IEfist.2.1..40

Epist.2.2.104

Carm.4.10

Scrm.1.3.20

Serm.1.3.50

Ars l'odt.255

cerm.2.5.103

Corm. $3 \cdot 20.3$

Sermitizizo

Serm.1.0.7

$\operatorname{ser} 2.3 .205$

Lisist. 10.43

EPist.1.17.11

lipist. I IS.83

tepist.2.1.74

1. pist.2.2.43

Com $12.3^{8}$

(arm 2.1 .0

Carm.3.1 1.22

for c irm.3.20.3

Cism 9.0 .20

Pror.serm.1.2.120 
paulum deliquit amicus, / quod nisi concedas, habeare insuavis:

Serm.1.3.84

"si me amas,' inquit, 'paulum hic ades.'

intererit Satyris paulum pudibunda proter $v$ is.

si paulum summo decessit, vergit ad imun.

paulum. et paulum silvae super his foret.

paulum. hic ubi nequitiae fautoribus et timidis nil $\dot{\mid}_{\text {aut }}$ paulum abstulerat,

Paulua. 'loc tibi Paulus|et Messalla videris? .

pauper. te pauper ambit sollicita prece/ruris colonus,

an pauper et infima/de gente sub divo moreris:

qua pauper aquae Daunus agrestium|regnavit populorum,

qui macro pauper agello|noluit in Flavi ludun me mittere.

pauper Opimius argenti positi intus et auri.

'ergo|pauper eris."

quid pauper? ride: mutat cenacula, lectos,

pauper enim non est, cui rerun suppetit usus.

res urget me nulla: meo sum pauper in aere.

cum pauper et exsul uterque|proicit ampullas

paupercula. 'indotata mihi soror est, paupercula mater.

paupere. rusticus urbanum murem mus paupere fertur|accepisse cavo,

licet sub paupere tecto|reges et regum vita praecurrere amicos. et spondere levi pro paupere

pauperem. pauperemque dives|me petit:

hic levare functum| pauperem laboribus

pauperet. quam te|contemptum cassa nuce pauperet;

pauperi. aequa tellus|pauperi recluditur|regumque pueris addis cornua pauperi

pauperibus. id quod/aeque pauperibus, prodest locupletibus aeque,

pauperiem. quassas indocilis pauperiem pati.

quis post vina gravem militiam aut pauperien crepat?

angustam amice pauperiem pati.

probamque|pauperiem sine dote quaero. .

duramque callet pauperiem pati .

cumque habeas plus. | pauperiem metuas minus

credidit ingens/pauperiem vitium

'quando pauperiem missis ambagibus horres,

per mare pauperiem fugiens, per saxa, per ignis):

qui pauperiem veritus potiore metallis|libertate caret.

pauperies. inportuna tamen pauperies abest.

magnum pauperies opprobrium jubet .

necdum omnis abacta|pauperies epulis regum: .

quem neque pauperies neque mors neque vincula terrent.

pauperies inmunda domus procul absit:

pauperiorum. neque se maiori pauperiorum|turbae conparet,

pauperis. uxor pauperis Ibyci,

'contrane lucrum nil valere candidum | pauperis ingenium"

pauperrimus. horum|semper ego optarim pauperrimus esse bonorum.

paupertas. tulit et Camillum | saeva paupertas et avitus apto/cum lare fundus.

paupertas inpulit audax $\mid$ ut versus facerem.

paupertate. contracta quen non in paupertate solutum?

sio de paupertate tacentes/plus poscente ferent:

paupertatis. quem paupertatis pudor et fuga, dives amicus, . . . odit

pauperum. pallida Mors aequo pulsat pede pauperum tabernas|regumque turris.

ego, pauperum|sanguis parentum,

mundaeque parvo sub lare pauperum |cenae

neque in sepulcris pauperum prudens anus|novendialis dissipare pulveres.

Pausiaca. vel cum Pausiaca torpes, insane, tabella,

paveas. quaeris, quando iterum paveas iterumque perire|possis,

paveat. quis Parthum paveat, quis gelidum Scythen,

paventem. denso paventem sustulit aere,

insolitos docuere nisus|venti paventem,

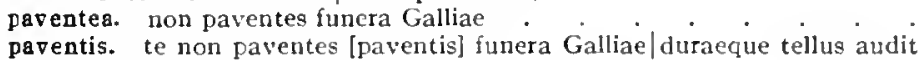
Hiberiae,

pavet. ut pavet acris/agna lupos

pavidae. et superiecto pavidae natarunt|aequore dammae. .

pavidam. quaerenti pavidam montibus aviis/matren

Serm. $1.9 \cdot 38$

Ars Pott. 233

Ars Poel. 378

Serm.2.0.3

Epist.1.I 5.34

Serm.1.6.41

Carm.1.35.5

Carm.2.3.22

Carm.3.30.I I

Serm.1.0.7 I

Serm.2.3.142

Serm.2.5.20

Epist.I.I.9I

Epist.1. I 2.4

Epist.2.2.12

Ars Poet.g6

Epist.1.I 7.46

Serm.2.6.80

Epist.1.10.32

Ars Port. 423

Carm.2.18.10

Carm.2.I8.39

Serm.2.5.36

Carm.2.I 8.33

Carm.3.21.I8

Epist.1.1.25

Carm.1.I.I8

Carm.1.18.5

Carm.3.2.I

Carm.3.29.56

Carm.4.9.49

Serm.1.I.93

Strm.2.3.92

Serm.2.5.9

Epist.1.1.46

Epist.1.10.39

Carm.3.10.37

Carm.3.24.42

Serm.2.2.45

Serm.2.7.84

Epist.2.2.199

Sermiti.iII

Carm.3.I 5.I

Epod.II.I 2

Serm.I.1.79

Carm.1.12.43

Episl.2.2.5I

Epist.1.5.20

Epist.1.17.43

Epist.1.18.24

Carm.1.4.13

Carm.2.20.5

Carm.3.29.14

Epod.1 7.47

Serm.2.7.95

Serm.2.7.69

Carm.4.5.25

Carm.2.7.14

Carm.4.4.9

Carm.4.14.49

var.Carm.4.I 4.49

Epod.I 2.25

Carm.1.2.II

Carm.1.23.2 
pavidi. currere per totum pavidi conclase

pavidum. Acrsium vitginis abelatae/custodem pavidum pavidunque leporem el adienam laqueo gruem

pavidus. Mytoum pavulus nauta secet mare.

spc. longus, iners avidusque [paviduspue] futuri.jdifficilis, querulus.

pavimentum. meroltinglet pavimentum superbo.

parit. gm fro ne tollere at que mitteret in phinum talos, mercede diurnal conductum partit:

parone. posico pavone velis quin hoc potius quam gallina tergere palatum. paronem. num esuriens fastidis omnia practer/pavonem thombumque? pavor. patror est ucrubique molestus.

num pavor "e reutum mediocsiter utilium spes. .

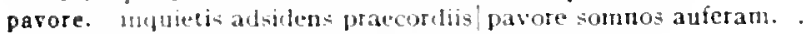

altercantc libidinibus tremis ossa pavore.

Pax. ham fides ut l'ax et Honor l'udorque

pax. in anore haec sunt mala, bellum, pax rursism:

peccabo. et nuihi dulces/ignosent. siquid pecaro [peccabol stultus, . peccantis. quodsi non otlio peccantis lesipit augur.

peccantis. estne marito/matronae peccantis in ambo iusta potestas.

peccare. pecore docentis/fallax historias monet.

et prectare nefas aut pretinth est moti.

on.runt peccare boni virtutis anore:

sil libulu veterum. ut tabulas peccare retantis.

en regat iratos et anet pacare [peccare] tmentis:

peccaro. ignoscent, siguid pecaro stultus, amici

peccas. ingenuopue semper'amore preccas.

fui juccis minus atque ego.

peccat. Meccat ueer nostrun ctuce dignius?

illa tamen se, non habicu nutatve loco peccatve superme.

an hic pecat, sub nocten qui puet uvam/turtiva mutat serigiti:

interdusn volgus tectum videt. est ubi pecat.

ue scriptor sl pecat idem librarius usque.

peccata. ne mox incutiane aliena tibi pectalta pudorens.

peccata. unis paria ense fere placuit pecata.

an omnistrisurow precatil putem thea.

peccati. quo te femisit peccati conscia crilis.

peccatis. pecatis vesian poscentem reddere rursus.

regula. peccatis quae poenas inroget aequas.

nocem pecatis et raudibus obice nubem."

peccatum. quanto hec tujosius atque matus pecatum est:

peccatum. "pecatum fateor. cum te sic tempore laevolintelpellarim;

peccatur. lliacos intrat mutos peccatur et extra.

peccaverit. 'dat, si stave non ét.|quae prima iracum ventren pacaverit [peccaverit] enca."

peccavit. an lic peccile [/ peccavit], sub noctem qui puer uvam/furtiva mutat atrigili

peccem. in publica commoda peccem.

pecces. 'fulil intio- ent in matrona, ancilla pecesne togata?

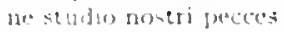

peccet. quan eut l'boloc pecect adulero.

quald albus patecel lapyx.

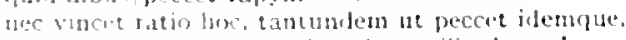

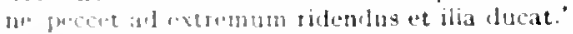

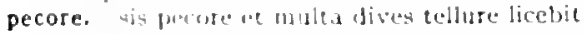

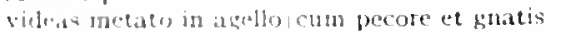

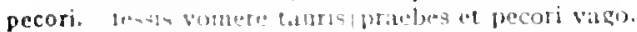

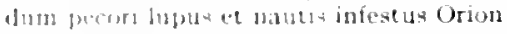

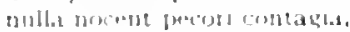

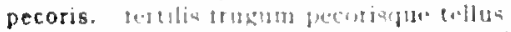

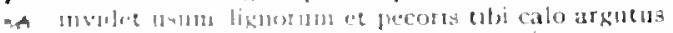

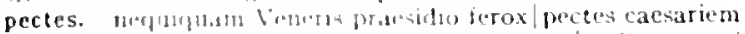

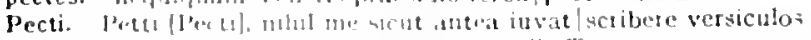

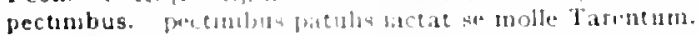

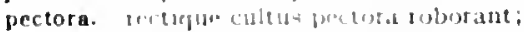

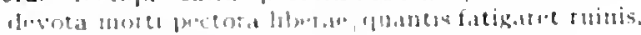

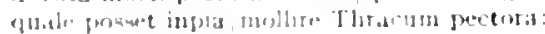

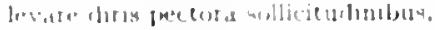

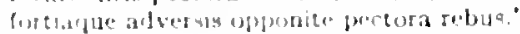

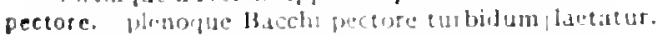

Serm.2.6.1 13

Corm.3.10.6

Lipod.2.35

Corm.1.1.14

cont.Ars P'oet.172

Carm.2.1.2.27

Serm.2.7.18

Sorm.2.2.23

Serm.1.2.110

Epist.1.0.10

Epist.t. 18.99

I.pod.5.90

Sirm.2.7.57

Carm.Saec.57

Sirm.2.3.208

iur.Serm.1.3.140

Epist.1.20.9

Sirm.2.7.62

C.sm.3.7.19

Curm.3.2.2.24

lipist.1.16.52

Epist.2.1.23

tur.ars Poet.197

Sirm.1.3.140

Carm.1.27.I

Serm.2.7.90

Sirm.2.7.47

Serm.2.7.0.4

Sirm.2.7.109

Epist.2.1.63

Ars l'oct.35t

Lpist.1.15.77

Serm.1.3.90

Ars 1'oct.200

Sirm.2.7.00

Serm.1.3.75

Serm.1.3.115

Epirt.1.10.02

Serm.1.3.84

Serm.2.4.4

Epist.1.2.16

rar.sirm.2.8.5

? :ur.Serm.2.7.502

Epist.2.1.3

Serm.1.2.03

tipist.1.13.4

Carm.1.33.9

Cirm.3.27.20

Serm.1.3.115

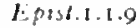

Epodi 15.19

Serm.2.2.115

Cirm.3.13.12

Epod.15.7

Iipod.10.01

Curm.saccizo

Epiv1.1.1.4.

Carmil.15.14

car.lipod.11.

Serm.2.4.34

Corm.t.4.3.4

Carm.t.1.18

lipod 5.14

Epod.13.tu

Sorm.2.2.13'

Curm.2.190 
forti sequemur pectore.

atque aest us curasque gravis e pectore pelli?

at ingenium ingens inculto latet hoc sub corpore [pectore].

latum demisit pectcre clavom.

secernis honestum | non patre praeclaro, sed vita et pectore puro.

nam quamvs memori referas mihi pectore cuncta.

tum pectore adusto vidinius et merulas poni

nunc adbibe puro|pectore verba, puer, nunc te melioribus ofter.

non tu corpus eras sine pectore:

omne supervacuon pleno de pectore manat.

pectoris. conpesce mentem: me quoque pectoris|temptavit

pectus. sperat infestis, metuit secundis|alteram sortem bene praeparatum | pectus.

sed incitat me pectus

tibi hospitale pectus et purae manus

fervet avaritia miseroque cupidine pectus:

caret tibi pectus inanilambitione?

pectus. illi robur et aes triplex/circa pectus erat.

me voluit dicere... bene mntuis | fidum pectus amoribus;

Sabella pectus increpare carmina.

modo ense pectus Norico recludere

occultam febrim sub tenpus [pectus] edendi|dissimules,

mox etiam pectus praeceptis format amicis.

meum qui pectus inaniter angit,

peculi. haec animos aerugo et cura peculi $/$ cum semel inbuerit.

Pecunia. et genus et formam regina Pecunia donat

pecunia. 'o cives, cives, quaerenda pecunia primum est;

imperat aut servit collecta pecunia cuique,

vel quia naturam mutare pecunia nescit

quorum / conspicitur nitidis fundata pecunia villis.

pecunia. licet superbus ambules pecunia,

pecuniae. abstinens $\mid$ ducentis ad se cuncta pecuniae,

pecuniam. crescenten sequitur cura pecuniam indignoque pecuniam | heredi properet. omnem redegit idibus pecuniam,

pecus. ac neque iam stabulis gaudet pecus aut arator igni ludit herboso pecus omne campo

cui pecus et nigri colles Arcarliae placent.

pecusve Calabris ante sidus fervidum/Lucana mutet pascuis.

cum prorepserunt primis animalia terris. $/$ mutum et turpe pecus,

neque illic |aut apotheca procis intacta est aut pecus:

si Democriti pecus edit agellos|cultaque.

pecus. omne cum Proteus pecus egit altos|visere montis.

stirpisque raptas et pecus et domos/rolventis una. .

claudensque textis cratibus laetum pecus

cum stravit ferro pecus.

pingue pecus domino facias et cetera praeter/ingenium.

(si) quercus et ilex | multa fruge pecus, multa dominum iuvet umbra?

'nempe pecus, rem, |lectos, argentum: tollas licet.'

pecus. o imitatores, servom pecus.

Pedana. quid nunc te dicam facere in regione Pedana?

pede. innctaeque Nymphis Gratiae decentes/alterno terram quatiunt pede. pallida Mors aequo pulsat pede pauperum tabernas|regumque turris. . iniurioso ne pede proruas|stantem columnam nunc pede libero|pulsanda tellus;

raro antecedentem scelestum|deseruit pede Poena claudo.

neque pugno neque segni pede victus,

gaudet invisam pepulisse fossor/ter pede terran.

arbiter pugnae posuisse nudo|sub pede palmam

pede barbaro|lustratam Rhodopen.

pede candido in morem Salium ter quatient hunum.

ferebar incerto pedelad non amicos heu mihi postis

montibus altis/levis crepante lympha desilit pede.

ne si facies, ut saepe, decoralmolli fulta pede est, emptorem inducat

hiantem.

verum |depugis, nasuta, brevi latere ac pede longo est.

Cois tibi paene videre est / ut nudam, ne crure malo, ne sit pede tuipi;

discincta tunica fugiendum est et pede nudo,

male laxus|in pede calceus haeret -
Lpod.1.14

Sirm.1.2.110

nar.Serm. I.3.34

Serm.1.6.28

Serm.1.0.64

Serm.2.4.90

Sirm.2.8.90

Epist.1.2.08

Epist. 1.4 .6

Ars Poct.337

Carm.1.16.22

Carm.2.10.15

Epod.8.7

Ipod.17.49

Epist.1.1.33

Epist.2.2.206

Carm.1.3.10

Carm.2.12.16

Epod.17.28

Epod.17.7I

z'ar. Epist.r.I6.22

Epist.2.1.128

Episl.2.1.2II

Ars Poet.330

Epist.1.0.37

Epist.1.1.53

Epist.1.10.47

Epist.I. I 2.10

Epist.I.I $5 .+6$

Epod.4.5

Carm.4.9.38

Carm.3.I0.I 7

Carm.3.24.6I

Epod.2.09

Carm.1.4.3

Carm.3.18.9

Carm.t.12.II

Epod.1.27

Serm.1.3.100

Serm.2.5.7

Epist.I.I2.12

Carm.1.2.7

Corm.3.20.37

Epod.2.45

Serm.2.3.202

Serm.2.0.14

Epist.1.16.10

Epist.I.I0.75

Epist.I.I0.I9

Epist.1.4.2

Carm.I.4.7

Carm.1.4.13

Corm.1.35.13

Carm.1.37.1

Carm.3.2.32

Carm.3.12.9

Carm.3.18.16

Carm.3.20.12

Carm.3.25.1 I

Carm.4.1.27

Epod.11.20

Epod.56.48

Serm.t.2.88

Serm.1.2.93

Serm.1.2.102

Serm.1.2.132

Strm.1.3.32 
versus dictabat stans pede in uno.

S(Tm.1.1.10

nisi quod pede certo differt enmoni. sermo merus.

Scrm.1.4.47

quali!sit facie, sura quali, pede, dente, capillo: .

nempe inconposito dixi pede currere versus|Lucili.

Pollio resum facta canit pede ter percusso;

Serm.1.0.33

Sorm.1.10.1

quicquam practer holus fumosae cum pede pernae.

absentis tanae pullis vituli pede pressis

si patinam pede lapsus trangat agaso.

metifi se quemque suo modulo ac pede verum est.

ut calceus olim.|si pede maior erit, subvertet, si minor, uret.

quid? siunis voltu corvo ferus et pede nudo

non alina neo pressi pede.

temperat Archilochi inusam pede nascula Sappho.

Serm.1.10.43

Sern1.2.2.117

Stm.2.3.31.4

Scrm.2.8.72

Epist.t.7.98

Epist.1.10.43

Epist.1.19.12

Epist.1.19.22

Epist.1.19.28

Epist.2.2.37

i bone. quo virtus tua te vocat. i perle fausto.

reddere qui voces ian scit puer et pede certolsignat humum.

saliet, tundet pede terran.

pedem. yuam nec ferte pedem dedecuit chotis

Ltubium servate peden neique|pollicis ictum

non eliboratum ad pedem.

neque inpulica Colchis intulit pedem.

une socci cepete pedem grandesque cothurni.

unde freden profete pulor betet aut operis fex,

pedes. i pedes guo te rapiunt et aurat.

ire. pedes quocumque ferent.

inlusique perles vitiosum ferre recusant, con pus.

pedes. recedencis trilinguilore jedes tetigitque crura.

heru pervicacis ad pedes Achillei.

mille gredes in tronte, trecentos cinpus in atgum / hic dabat.

quo vater ille podes lavisue sisynhus arere.

pedestri. trapicus plerumque, dolet sotmone pedestri Telephus

pedestri. (quid prims inlustrem saturis musuque pedestri)

Ars Poct.158

Ars Poct. 430

Carn.2.12.17

Carm.4.6.35

Lpod.14.12

Epod. 16.58

Ars Port.80

Ars Poct.135

Carm.3.11.49

Epod.16.21

Serm.2.7.108

Carm.2.19.32

Epod.17.1.4

Serm.1.8.12

Serm.2.3.21

Ars Pocl.95

Sorm.2.6.17

Corm.2.12.9

Serm.1.8.30

pediatia. in me veniat. . Iulins et fragilis l'odiatia furque loranus.

Epist.1.12.5

SeTm.I.A.T

Serm.1.824

Sorm.1.10.59

Sam.2.1.28

prodibus guid claudere sents. . contesutu.

me pelibus delectat claudere verba/ 1 ucali tutu.

pedites. Romani tollent coultes peditesque cachinnum.

peditis. acet et Warai freditis cruentum/voltus in hostem;

peditum. Hum fugiun "guitum turmae peditumpue catervae;

pedius. curn l'ulius causas exsudet I'oplicola atque/Corvinus.

pedum. nen morm in Salinm sit requies pedum

Pegasus. vix inligatum te triom mi|Prgasus "xpediet Chimaera.

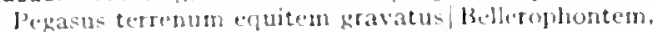

peierati. ullat si iuris tibi peietati pona.

peior. areas fratentum. peior avis, tulit| nos noepuintes,

via peint art usque / Barj noenia piscosi;

velut iflis, Canidia ablasset, peiot serpentibus Afris."

peiara. o forte peioraque pasci mecum saep viri.

peiaribus. (meliknum, quod sit pejoribus ortus)

peius. quidgud vidnt meliss friusve sua spe.

neque ficto in jurisa voltu groponi cerens usquan

peius. powitum lacto tlagitum timet,

non se pusua crucias it atque hic.

alter Mileti erextan cane peing et angui| vitnbit chlandem.

pelago. qui hatgilen truci conmicit pulgo ratmiftimus:

pelapus. guis umelue Bithyma lacescit Carpathuna [rolagus carina;

Pelea. natrate parne flatum lelea Tartito.

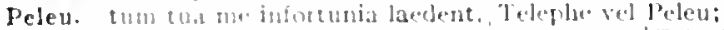

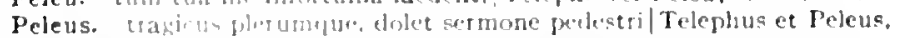

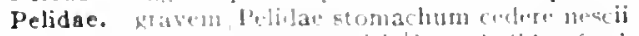

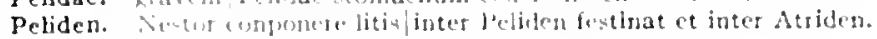

pelion. J lion inposulave rilympo.

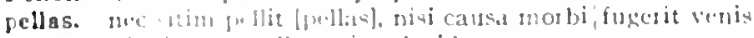

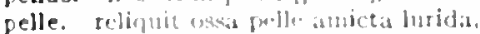

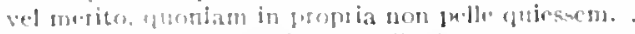

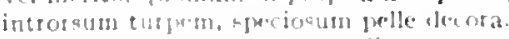

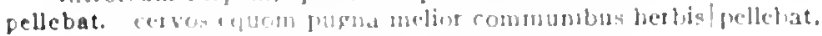

Ars Poct.1 I3

Carm.1.2.39

Epist.2.1.190

Sotm.1.10.28

Carm.1.30.12

Corm.1.27.24

Carm.4.11.27

Carm.2.8.1

Carm.3.0.40

Sorm.1.5.9p

Serm.2.8.95

Carm.1.7.30

E.pist.1.1.22

Epist.1.0.13

Epist.2.1.265

Carm.4.9.50

Serm.1.2.22

Jpist.1.7.30

Carm.1.3.11

Carm.1.35.8

Carm.3.7. 7

Ars loed.109

Ars Portog

Carm.1.0.1)

Epist.1.2.12

Carm.3.4.52

roni.Carm.2.2.14

I:poll.17.22

Scrm.1.0.22

Inist.1.16.45

Tpist.1.10.35 


\section{PELLEM}

pellem. detrahere et pellem, nitidus qua quisque per ora/cederet. ex quo|tempore cervinam pellem latravit in aula, venaticus. ex quoltempore cervinam pellem [ 8 ex quo cervinam catulus pellem] latravit in aula.

pellent. mitulus et viles pellent obstantia conchae

pellente. arida|pellente lascivos amores|canitie

pellere. has nullo perdere [pellere] possum / nec prohibere modo, .

pelles. iam residunt cruribus asperae/pelles

pelli. atque aestus curasque gravis e pectore pelli?

pellibus. saetosa duris exuere pellibus . . . membra;

nam ut quisque insanus nigris medium impedit crus/pellibus

pelliculam. ire domum atque pelliculam curare iube;

pellis. nec sitim pellit [pellis], nisi causa morbi|fugerit venis

pellit. nec sitim pellit. nisi causa morbi|fugerit venis error certo de tramite pellit,

avertit morbos, metuenda pericula pellit,

pellite. nunc vino pellite curas;

pellitis. dulce pellitis ovibus Galaesi / flumen

pellitur. pellitur paternos/in sinu ferens deos/et uxor et vir

pellunt. si dura morabitus alvos, mitulus et viles pellent ir peliunt] obstantia conchae

Pelopis. nec saeram Pelopis domum occidit et Pelopis genitor, conviva deorum, quin et Prometheus et Pelopis parens . optat quietem Pelopis infidi pater.

peloris. murice Baiano melior Lucrina peloris,

Penates. impudens liqui patrios Penates. non satis est Ithacam revehi patriosque Penates/adspicere?"

Penatis. mollivit aversos Penatis|farre pio et saliente mica. quare per divos oratus uterque Penatis quod te per Genium dextramque deosque Penatis|obsecro

penatis. regium certe genus, et penatis|maeret iniquos.

Caesar Hispana repetit penatis/victor ab ora.

pendentia. respicere ignoto discet pendentia tergo."

pendentis. de te pendentis, te respicientis amici?

pendentis. in scalis latuit metuens pendent is habenae"-

pendet. destrictus ensis cui super inpia|cervice pendet, cur pendet tacita fistula cum lyra?

hinc ommis pendet Lucilius, hosce secutus

pendis. quem tu vidisse beatus/non magni pendis, quia contigit;

pendulum. potes hac ab orno|pendulum zona bene te secuta e-llidere collum.

pendulus. neu fluitem dubiae spe pendulus horae.'

pene. cum pene soluto|indomitam properat rabiem sedare.

Penelopa. sic tibi Penelope [? Penelopa] frugi esi; .

Penelopae. sponsi Penelopae nebulones

Penelopam. ultro|Penelopam facilis potiori trade."

Penelope. sic tibi Penelope frugi est;

Penelopen. dices laborantis in uno/Penelopen vitreamque Circen, non te Penelopen difficilem procis| Tyrrhemus genuit parens. .

penes. gaudes, si cameram percusti forte, penes te es? . quem penes arbitrium est et ius et norma loquendi.

penetralia. penetralia|sparsisse nocturno ctuore/ hospitis; et versentur adhuc intra penetralia Vestae;

penetralibus. quid indoles |nutrita faustis sub penetralibus|posset penetravit. nec latentis/classe cita reparavit [penetravit] oras.

penitus. quam lentis penitus macerer ignibus.

Latonamque supremo/dilectam penitus lovi.

denique, quaterus excidi penitus vitium irae.

ut penitus notum, si temptent crimina, serves .

penna. illum aget penna metuente solvi|Fama superstes. non usitata nec tenui ferar/penna

coetusque volgaris et udam|spernit humum fugiente penna.

pennas. si celeres quatit | pennas,

maiores pennas nido extendisse loqueris.

pennis. pennis non homini datis:

ceratis ope Daedalea/nititur pennis

decisis humilem pennis inopemque paternilet laris et fundi,

pensantur. si, . . Romani pensantur eadem|scriptores trutina,
PENSANTVR

Serm.2.1.64

Epist.1.2.66

? zar.Epist.I.2.66

Serm.2.4.28

Carm.2.11.7

coni.Serm.1.8.20

Carm.2.20.10

Serm.1.2.110

Epod.I7.I 5

Serm.1.6.28

Serm.2.5.38

coni.Carm.2.2.14

Carm.2.2.1 4

Serm.2.3.49

Epist.2.1.136

Carm.1.7.31

Carm.2.6.5o

Carm.2.18.26

3 var.Serm.2.4.28

Carm.1.6.8

Carm.1.28.7

Carm.2.13.37

Epod.1 7.65

Serm.2.4.32

Carm.3.27.49

Serm.2.5.4

Carm.3.23.19

Serm.2.3.176

Epist.1.7.94

Carm.2.4.I 5

Carm.3.14.3

Serm.2.3.299

Epist.1.1.105

Epist.2.2.I5

Carm.3.1.I 8

Carm.3.19.20

Serm.1.4.6

Serm.2.4.93

Carm.3.27.59

Epist.1.I8.I Io

Epod.1 2.8

7 zar.Serm.2.5.8I

Epist.1.2.28

Serm.2.5.76

Serm.2.5.8I

Carm.1.17.20

Carm.3.10.1I

Serm.2.3.273

Ars Poet.72

Curm.2.13.6

Epist.2.2.I14

Carm.4.4.26

coni.Carm.1.37.24

Carm.1.13.8

Carm.1.21.4

Serm.1.3.70

Epist.1.18.80

Carm.2.2.7

Carm.2.20.2

Carm.3.2.24

Carm.3.29.54

Epist.1.20.21

Carm.1.3.35

Carm.4.2.3

Epist.2.2.50

Epist.2.1.29 
pensare. vellere cospi/ct pressare [pensarel manu lentissina bracchia. pensilis. Cum pensilis uva recundas/et nux ormabat mensas .

2ar.Serm.1.9.04

pensum.

nioi irife mavis/carpere pensum

Serm.2.2.121

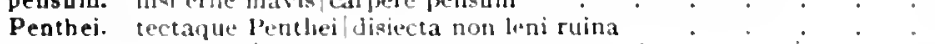

pentheu. 'Pencheu|rector Thebarun, quid me perferre patique/indignum coges?"

penuria. ne se penuria rictus, opprimeret netuebat.

penus. annonac prosit, portet frumenta penusque.

pepedi. nom, displosa sonat guantum vesica, pepedi/ditissa nate fieus;

Curm.3.27.64

Curm.2.19.1.4

peperci. quod viro clemens misceto peperci.

pepercit. quibus perereit aris?

peperere. sic horsidus ille defluxit numerus Saturnius et grave virus | munditiae jepulere [peperesel:

peperit. cui harus aeternos honores|Delnatico peperit triumpho.

Troica quem peperit sacerdos.

pepulere. haec ubi dictalagrestem pepulere.

grave virus/munditiae pepulere;

pepulisse. gaudet invisan pepulisae fossor ter pede terram.

pepulit. immanisque Ractos/auspiciis pepulit secundis,

Epist.1.10.73

Serm.1.1.98

Epist.1.10.72

Serm.1.8.40

Carm.3.11..40

Carm. I. $35 \cdot 38$

per. Carm.1.3.20;1.3.39; 1.6.7; 1.8.1; 1.10.10; 1.15.1; 1.17.5;1.22.5; 1.22.0;1.3.4.7;2.1.7;2.3.6; Corm.2.7.13; 2.9.6; 2.12.11; 2.14.15; 2.19.21; 2.20.2; 2.20.12; 3.2.12; 3.4.7; 3.12.10; Carm.3.1415; 3.14.23; 3.16.9; 3.17.4; 3.18.2; 3.20.5; 3.22.6; 3.27.0; 3.27.43; 3.29.63; Corm.4 I.34: 4.1.39; 4.1.40; 4.2.10: 4.2.1.4: 4.2.29: 4.2.35: 4.4.19; 4.4.42; 4.4.43: : ar.C.rm.4.4.43; Carm.4.4.4.4; 4.4.59 (bis); 4.4.70; 4.5.19; 4.8.1.4; 4.9.3; 4.9.43; 4.14.4; Carm.4.14.24;4.15.3:4 15.13; Carm.Sacc.21: coni.Carm.Saec.20; Carm.Suec.d1;:pod.1.11; Epod.5.5; 5.7; 5.8; 5.25; 6.7; 11.7: 10.21; 17.2; 17.3; 1 7.4; Sorm.1.1.29; 1.3.5; 1.4-30; Serm.1.5.73; 1.7.33; 2.1.19; 2.1.37; 2.1.6.4; $2.2 .119 ; 2.3 .57 ; 2.3 .170 ; 2.3 .190 ; 2.4 .88$; Serm 2.0.34; 2.6.47; 2.0.50; 2.6.113; 2.7.87; Epist.1.1.40 (6Cr); 1.2.20; 1.2.01; 1.7.29; lipist 1.7.94; 1.10.21; 1.11.19;1.1310;1.15.5; 1.17.1; 1.17.28; 1.17.00; 1.15.02; 1.19.21; Lpist.2.1.10; 2.1.100; 2.1.145; 2.1.147; 2.1.1.49; 2.1.210; 2.1.248; 2.1.249; 2.1.251; Epist.2.1.25. 2.2.140, Ars Poct.17; 180;215:307:403

peractas. utpote res tenuis, tenui sermone peractas."

peractis. optatum peractis imperiia decus adrogavit.

Jona iam peractis|iungite fata.

peracturn. a certis annis aevon remeare peractum

peragenda. dura tibi peragenda rei sit causa Petilli?

peraget. ille salubris aestates peraget

peragit. ille salubris | aestates peraget [peragit) qui nigris mandia monisi finject.

peragunt. indelambo propositum peragunt iter,

perambulabig. "tu pudica, tu probal prambulabis astra sidus aureum."

perambulat. tutue bos ctenim ruea perambulat,

recte necme crocum thotesqu" perambulet [peranbulat ittae fabula si dubir.m.

perambulet. recte necre crocum forearue perambulet Atcac labula si rubstrin.

percipiant. ut cite dicta preipiant animi dociles comeantque fideles;

percontabere. infer euncta loges et percontabese doctos.

percontabitur. forte molum siguis te percontabitur alevom:

percontare. ut phasat iuveni, fercontare utque cohorti.

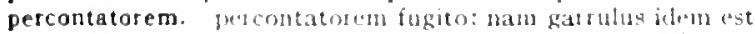

perconteris. Huth i ipconteris, avi cui atque patentis/paeclaram ingrata

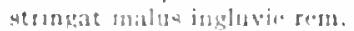

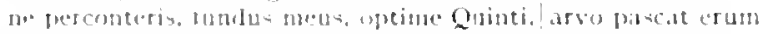

percontor. percontur guanti holus ac far.

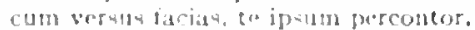

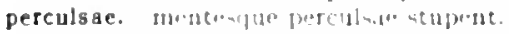

perculsum. levei, nilil me sout antea juvat scribere versiculos amore

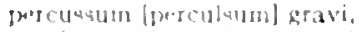

percurram. (no stc ut qui iocularat sidens/percurram.

pescurrat. guam non adsericte pereurat pidpita socico;

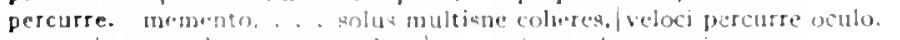

percurrisse. animoflue sotumlum / percurrise polum morituso.

percussa. Ilelladre purchasi Mariut cum pranciplat se,

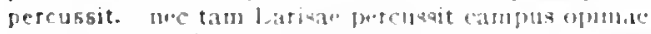

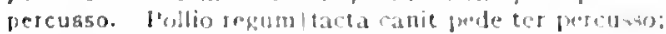

percussum. anore porcussum gravi.

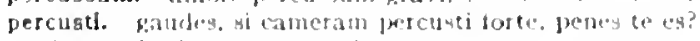

perdsm. discinctus aut gerelum no"jus.

Serm.2.4.9

Cirn.4.14.39

Carm.Saec. 27

Serm.1.0.94

Serm.1.10.20

Sirm. 2.4.22

tar.Serm.2.. 22

5 som. 2.090

Epod.17.4t

carm.4517

Iur. Epist.2. 1.79

Eipist.2.1.79

Ars Porb.330

Jipist. I 18.90

Jipist.1.20.20

Jipisl.1.8.14

Spist1.18.20

Sitm.1.2.7

Epist.1.10.1

Sirm.1.0.112

Sirm.1.10.25

lipod.7.1\%

lar.tipod.18.2

Sirm.1.1.2.1

Jpist.21.174

Serm.2.5.55

Carm.1.28.0

Scrm.2.3.277

( iarm.1.7.11

Serm.t 10.43

lipoditi.2

Sierm. 2.3.273

IEpod. 1.3 .4 
perdas. infelix, operam perdas, .

in cicere atque faba bona tu perdasque lupinis, nequid tu perdas neu sis iocus." ne Cibyratica, ne Bithyna negotia perdas;

perdemus. inpia perdenus devoti sanguinis aetas . perdenda. quaelinberbes didicere, senes perdenda fateri. perdere. Sybarin cur properes amando|perdere. inpiae sponsos potuere durolperdere ferro. quam neque finitimi valuerunt perdere Marsi magnum documentum, ne patriam rem|perdere quis velit." has nullo perdere possum|nec prohibere modo, debebat, quod ni fecisset, perdere litem.

perdiderat. lassus dum noctu stertit, ad assem/perdiderat: perdidit. perdidit arma, locum virtutis deseruit, ibit eo, quo vis, qui zonam perdidit' inquit.

perdit, nec mala me ambitio perdit nec plumbeus auster perditior. atque/quanto perditior quisque est, tanto acrius urget : perditur. perditur haec inter misero lux non sine votis: perduci. perduci poterit tam frugi tamque pudica, perdunt. integrum perdunt lino vitiata saporem.

peream. 'peream male, si non'optimum erat; quid refert. morbo an furtis pereamque rapinis?' pereant. ne nummi pereant aut puga aut denique fama. pereas. nil verbi, pereas quin fortiter. addam. pereat. quo beatus|volnere, qua pereat sagitta. ter pereat meis|excisus Argivis. pereat male quae te Lesbia quaerenti taurum monstravit inertem. o pater et rex Iuppiter, ut pereat positum robigine telum

peredit. nec peredit/inpositam celer ignis Aetren.

peregre. uti ne solus risve peregre〈ve $\rangle \mid$ exirem, uti ne solus rusve peregre (ve) [ne rus solusve peregre] lexirem. uti ne solus rusve peregre〈ve [rusve aut peregre]|exirem, dum peregre est animus sine corpore velox?

peregrina. Ilion . . mulier peregrina vertit|in pulverem, nec scarus aut poterit peregrina iuvare lagois.

peregrinae. tanto cum strepitu ludi spectantur et artes | divitiaeque peregrinae.

peregrinum. 'quaete peregrinum' vicinia rauca reclamat.

Perelli. putidius multo cerebrum est, mihi crede, Perelli|dictantis. perennis. collectosne bibant imbris puteosne perennis|iugis aquae perennius. exegi monumentum aere perennius

pererro. fallacem circum vespertinumque perersolsacpe forum, . pereunte. 'me tuo longas pereunte noctes,|Lydia, dormis?' . pereuntis. inane lymphae/dolium fundo pereuntis imo. pereuntis. nec fracta pereuntis cuspide Gallos perfacile. signis perfacile est: venit vilissima rerum/hic aqua. perfectius. quale non perfectius'meae laborarint manus. perfectos. inter/perfectos veteresque referri debet.

perfectum. quod ultralperfectum traheretur, praesectum [perfectum] decies non castigavit ad unguem.

perfer. vigiles lucernas|perfer in Jucem:

perferre. cuius odorem olei nequeas perferre. quam quo perferre iuberis/clitellas ferus inpingas rure meo possum quidvis perferre patique: quid me perferre patique/indignum coges?"

perfert. onus . . hic subit et perfert.

perficiant. nil Claudiae non perficient [perficiant] manus,

perficient. nil Claudiae non perficient manus,

perficit. "est vetus atque probus, centum qui perficit annos."

perficiunt. nil Claudiae non perficient [perficiunt] manus,

perfida. ut Proetum mulier perfida credulum|falsis inpulerit criminibus

perfidis. qui perfidis se credidit hostibus. quae detraxerat servis amicus perfidis.

perfidum. tu simul obligasti|perfidum votis caput. non ego perfidum / dixi sacramentum: . aderat querenti' perfidum ridens Venus

perfidus. pastor cum traheret per freta navibus|Idacis Helenen perfidus hospitam. dixitque tanden perfidus Iannibal:

Serm.1.1.90

Serm.2.3.182

Serm.2.5.37

Epist.1.6.33

Epod.16.9

Epist.2.1.85

Carm.I.8.3

Carm.3.11.32

Epod.16.3

Serm.I.4.11I

Serm.1.8.20

Serm.1.9.37

Epist.2.2.28

Epist.1.16.67

Epist.2.2.40

Serm.2.6.I8

Serm.1.2.15

Serm.2.6.59

Serm.2.5.77

Serm.2.4.54

Serm.2.1.6

Serm.2.3.157

Serm.1.2.133

Serm.2.3.42

Carm.1.27.12

Carm.3.3.66

Epod.12.16

Serm.2.1.43

Carm.3.4.75

Serm.1.6.1 22

coni.Serm.1.6.102

var.Serm.1.6.102

Epist.1.12.13

Carm.3.3.20

Serm.2.2.22

Epist.2.1.204

Epist.1.17.62

Serm.2.3.75

Epist.1.15.15

Carm.3.30.1

Serm.1.6.113

Carm.1.25.7

Carm.3.11.27

Serm.2.I.I 4

Serm.1.5.88

Epod.5.59

Epist.2.1.37

Serm.1.10.70

var.Ars Poet.294

Carm.3.8.15

Serm.2.2.59

Epist.1.13.7

Epist.1.15.17

Epist.1.10.74

Epist.1.17.41

'ar.Carm.4.4.73

Corm.4.4.73

Epist.2.1.39

var.Carm.4.4.73

Carm.3.7.13

Carm.3.5-33

Epod.9.10

Carm.2.8.6

Carm.2.17.9

Carm.3.27.67

Carm.1.I5.2

Carm.4.4.49 
perfidus hic caupo. miles nautaeque.

sit . perfudus Ixion, lo vaka, tristis Orestes.

perfundat. quali perfundat piscis securus olivo.

perfundi. nunc et Acluemeniolperfundi nardo iuvat

períundit. te mulier. . . perfundit gelida, rursus vocat:

perfusus. quis multa gracilis te pucr in rosa | perfusus liquidis urget oloribus

at Gratecus. postquam est Italo perfusus aceto,

Pergama. tradidit fessis leviora tolli| Pergama Grais.

Pergameas. post certas hicmes uret Achaicus | ignis tlliacas [Pergameas] lomo:.

perses. lucere me auditum perges quocumque, memento.

pergis. pergis pugnantia secum/frontibus adversis conponere: . .

pergit. poema. . . si paulum summo decessit, vergit [pergit] ad inum.

pergunt. novaeque pergunt interite lurat:

perhorrescit. navita Bosporum|Poenus perhorrescit

perhorrui. iure peshorruilate conspicuom tollere verticen,

peribit. non ille pro caris anicis/aut patria timidus perire [peribit].

peribunt. mortalia facta peribunt, nedum sermonum stet honos et gratia vivix.

pericla. atque liaec rara cadat dura inter saepe pericla.

pericli. postquam nilil esse perich| sensimus,

periclo. quatton moveas periclo, Pyrthe, Gaetulae catulos leaenae?

periclum. tolle periclum:|iam vaga prosiliet frenis natura remotis.

pericula. equid ad post paulo ventura pericula sentis?

avertit morbui, metuenda pericula pellit.

periculo. non vides, quanto moveas periclo [periculo], Pyrthe. Gaetulac catulos learuac?

periculosae. sericulosae plenum opus aleate,

periculum. dulct periculum est.| o lenate.

periculum. unde periculum! fulgens contremuit domus.

paratus onne Cuesaris periculum subire.

periere. verum ubi obes furto, morbo periuge capellae.

perierust. sed ignotis perierunt mortibus illi.

periisse. clasnent perijse pudotem/cuncti paene patres.

Perilli. Ineidins multo cerebum est, mili crede, lerelli [Perilli\}l dictantis.

perire. nuace generosius|perite quactena

tun ille pro carts amicis aut patria timidus perirt.

guin. ubs persire iusaus exspiravero.

quando iterum paveas iterumgue perire' possis,

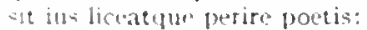

perirent. quo grawes Persae meliug perirent.

stetert" causate, cur perirent iunditus

si non periret ian miserabilis [perifent inmiserabilislieaptiva pubes.

perires. si non jeriret iam micrabilis [perires inmizerabilis] captiva pubes.

periret. st non poriset ian miserabilis/captiva pubes.

sua libs haec periret dextera?

s. inte wimus locuples uno quadrante periset [periret].

periscelidem. saepe periccelidern raptam sibi plentis.

perisset. si forte minus locuples uno quadrante perisset.

Perithoo. net luthatea valet "lheseus abrumpere carol vincula Perithoo.

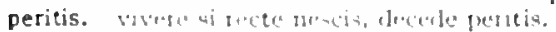

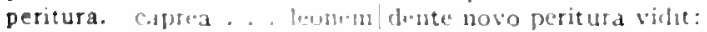
servilibme ue quat iam proritura mosio.

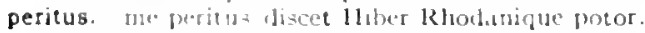

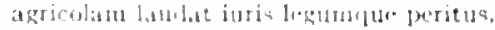

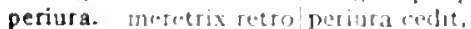

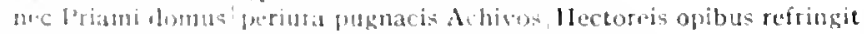

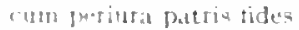

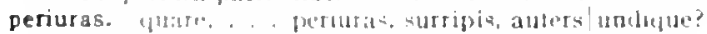

periurum. proruram iust in parentem|spl*ardide mendax

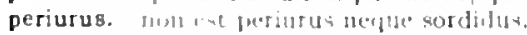

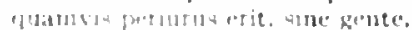

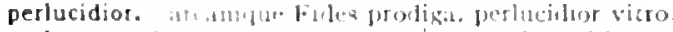

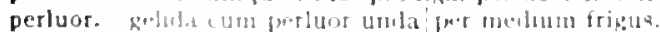

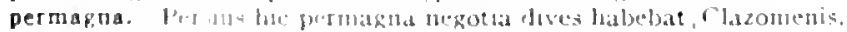

perminxerunt. Inse perminxutunt calones:

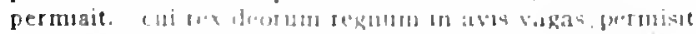

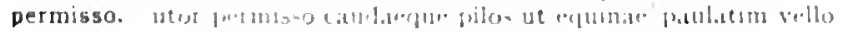

Sorm.1.1.20

Ars Poet. 124

Serm.2.4.50

Epod.13.9

Serm.2.7.9t

Carm.1.5.2

Serm.1.7.32

Carm.2.4.12

coni.Carm.1.15.36

Sernt.2.4.89

Serm.1.1.102

sar. Ars Poet.37s

Carm.2.18.16

Carm.2.13.15

Carm.3.10.1 8

iar.Carm.4.9.52

Ars Pott.68

Serm.1.2.40

Sirm.2.5.57

Curm.3.20.1

Serm.2.7.73

Epist.I.18.83

Epist.2.1.135

rar.Carm.3.20.1

Carm.2.

Carm.3.25.18

Carm.2.12.7

Epod 1.3

Epist. 1.7 .80

Serm.t.3.108

Epist.2.1.80

Idor.Serm.2.3.75

Corm.1.37.22

Curm.4.0.52

Epod.5.91

Serm.2.7.69

Ars Poct. 100

Carm.1.2.22

Carm.1.10.19

conic Curm.3.5.17

coni.Carm-3.5.I 7

(arm.3.5.17

Epod.7.10

sar..serm.2.3.93

1.pist.1.17.50

Serm.2.3.03

Corm.4.7.28

Epist 2.2 .213

Carm.4.4.10

Sorm.1.8.33

Curm.2.20.10

Serm.1.1.9

Carm.1.35.26

Cirm.3.3.27

(iurns.324.59

Serm.2.3.127

Carm.3.11.3.

Sorm.2.3.104

term 25.15

Carm.1.18.1\%

lipist.1.15.4

Strm. 1.4

Serm.1.2.4

Carm.t.4. 3

EPest.2.1 45 
PERMISSVM

permissum. sepulcrum/permissum arbitrio sine sordibus exstrue: permittant. si tibi regnum/pernittant homines.

permitte. pernitte divis cetera.

permitto. inulto/dicere quod sentit permitto."

permixerunt. dedit hic pro corpore nummos. | hune perminxerunt [permixerunt] calones;

permixtas. "qui species alia veris scelerisque tumultu|permixtas capiet. . permixtus. lituo tubae/permixtus sonitus bellaque matribus/detestata.

permolere. non alienas|permolere uxores."

permulceat. siquis... his verbis vacuas perumlceat auris;

permulta. causaque mea permulta rogatus/fecit

Campanum in morbum, in faciem permulta iocatus.

permutare. permutare velis crine licymniae

connisicse cavet quod mox mutare [permutare] laboret.

permutat. tanquam sit proprium quicquan, puncto quod mobilis liorae

. . morte supremalpermutet [permutat] dominos

permutem. cur valle permutem Sabinalelivitias operosiores?

permutet. per mutet dominos et cedat in altera inra.

perna. perma magis et magis hillis/ Hagitat inmorsus refici,

pernae. quiçuam practer holus fumosac cum pede pernac.

perniciem. in nepotum/pernicien opptobrimone pagi;

exemplo trabentis|perniciem veniens in aevom,

ex hoc ego sanus ab illis|pernicien quaecumque ferunt

pernicies. pernicies et tempestas barathumque macelli.

perniciosius. obsequium ventris mili perniciosius est cur?

pernicis. perusta solibus|pernicis uxor Apuli,

pernix. sublimis cupidusque et amata relinquere pernix.

pernoscere. est operae pretium duplicis pernoscere iuris|naturam.

perpauca. fuxerunt animi, raro et perpanca loquentis; .

perpeti. audax onnia perpeti|gens lumana ruit per vecitum nefas;

perpetuo. intactae Palladis urbem/carmine perpetno celebrare

perpetuo. neque parturit imbris/perpetuos [perpetno],

perpetuom. speres perpetuom dulcia barbare/laedentem oscula. .

perpetuos. crgo Quintilium perpetnos sopor/urget?.

si c) ruia perpetuos nulli datur usus

perpetuos. Notus neque parturit imbris/perpetuos.

perpremat. mollis et exspes' inominata ferpremat cubilia.

perprimat. nollis et exspes/inominata perpremat [perprimat]cubilia. .

perraro. perrato haec alea fallit.

perrivor. gelida cum perluor [pertivor] undalper medium frigus.

percumpere. perrumpere anat saxa potentius/ictu fulmineo:

perrumpet. et mala perrumpet furtim fastiblia victrix.

perrupit. perrupit Acheronta llerculeus labor -

persae. guo graves Persac melius perirent.

non seres intitlicue Persac.

persaepe. gui persaepe cava testuche flevit amorem

atrue etiam melius persacpe togatae sest.

persae pe velut qui| I unonis sacra ferret;

joscentigue gravem persacpe remittit acutum

persarum. Persarum vigui rege beatior.'

Persas. in|lersas atque Britannos/vestra motus aget prece.

perscribere. non satis est puris versum perscribere verbis.

persequar. perso'fuar hinc quo nume iter est tibi."

persequemur. utrumne inssi perseftuemur otium

persequitur. mors et fugacem persequitur virum

persequor. non ego te tigris ut aspera|Gaetulusve leo frangere persectuot:

Persi. Rupili et Persi par pugnat.

Persicos. I'ersicos odi, puer, adparatus.

persimilem. isti tabulas fore librum|persimilem.

Persis. arliectis Britannis/imperio gravibusçue Persis.

Persius. hibrida quo pacto sit lersius ultus,

Persius hic permagna negotia rlives habebat/Clazonienis.

Persiug exponit cansan;

Persius exclamat: "per magnoa, 13rute, deos teloro,

persona. nec ruarta lociui persona laboret.

personae. post hunc personae pallacfue repertor honestae/ issolylus

personae. ille profectol reddere peranae seit convenientia cuigue.

personam. an tibi abunde personam satis est. non illud, quidquid ubique| officit. coitate?

\section{PERSONAM}

Serm.2.5.105

Sirm.1.3.124

Carm.1.9.9

Serm.2.3.190

vor.Sorm.1.2.4t

Serm.2.3.209

Carm.1.1.24

Serm.1.2.35

lipist.1.10.26

Sirm.1.4.97

Serm.1.5.02

Carm.2.12.23

vir. Ars Pott. 608

qur.lEpist.2.2.17t

Carm.3.1.47

lipist.2.2.174

Serm.2.t.0n

Sirm.2.2.1 I7

Carm.2.13.4

Carm.3.5.10

sirm.1.4.130

Epist. [.15.3 1

Serm.2.7.104

Fpod.2.12

Ars l'oit. 65

Sirm.2.4.63

Sirm.1.4.18

carm.t.3.25

Curm.1.7.0

var.Curm.1.7.17

(arm.1.13.14

Carm.1.24.5

Epist.2.2.175

(idrm.1.7.17

lepol.16.38

भH.I:pod.16.38

Sirm.2.5.50

var.lepist.1.15.4

Carm.3.10.10

I.pist.1.10.25

(arm.1.3.30

Carm.1.2.22

Carm.4.15.23

Epol.r.4. I

Sierm.1.2.82

Serm.1.3.10

Ars Poct.340

Carm.3.9.4

(arm.1.21.15

Sirm.1.4.5.4

Serm.t.9.16

lipod.1.7

Carm.3.2.14

Cirm.1.23.10

Sirmi1.7.19

carm.1.38.

irs 1'oct.7

(arm.3.5.4

Sirm.1.7.2

Sirm.1.7.4

Sirm.1.7.22

Sirm.1.7.3.3

Irs I'ort.192

Irs loel.278

Ars Poet.310

S.rm.1.2.60 
personamque seret non inconcinnus utramgue; .

Epist.1.17.29

audesigersonam formare novam.

A.s Poet. 126

personatus. fulvis stomachetur todern tuo personatus pacto pater.

Serm.1.4.53

personet. est mihi purgatam crebro qui personet aurem:

personuere. Viticae cubantis/levia personuce saxa.

personuit. simnl dornus altat Molossis/personuit canjbus.

List.1.1.7

Carm.1.17.12

Serm.2.0.115

persperisse. torfuere nero, quem perspexisse laborant

Ars Poct.435

persta. fi cognitor ipse jersta atque obdura: .

Srm.2.5.39

perstringis. iam nunc minaci numure comuon/perstringis auris.

Carm.2.1.18

persuadere. dum Hamma sine tura liquescere limine sacrolpersuadere cupit. persuades. persuades hoc tibi vere,

persuadet. Prsuadet uti isercetur agellum.

pertersit. juer alte cinctus acernam/gausape purpurco nuensam pertersit.

pertinaci. pignusque defeptum lacertis/aut digito male pertinaci.

pertinax. Julum insolentem iudere pertinax

pertinet. simuis munc quaerat "quo res haec pertinet?" iliuc: .

quo rertinet ergo/proceros odisse lupos?

quod magis ad nos, pertinet

pertinuit. quorsum pertisuit stipare Jlatona Menandro?

pertulit. pertilit Ausonias ad urbis. aspreta multa pertulit.

peruncti. quac canerent agerestque peruncti fateibus ora. - . perunxit. perminxit hoc lasonem.

perusta. perusta solibus/pernicis uxor Apuli.

peruste. Hibericis peruste fumibus hat

pervellunt. "fualia lassum| pervellunt stomachum. .

perveneris. sictor propositi simul ac perveners illuc.

pervenerit. "ssto.! quid? qui pervenit [perventit] fecitne viriliter?"

pervenimus. inte Rubos tessi pervenimus.

pervenit. qui pervenit fecitne viriliter:"

pervicaces. tas pervicacis [jervicaces] est mibi Thyindas... cantare

pervicaci. fas pervicacis est [pervicaci sit] mihi Thyiadas . . cantare

pervicacis. hell pervicacis ad pedes dillillei.

Serm.1.5.100

Serm.1.6.8

Epist.1.7.81

Serm.2.8.11

Corm.1.9.24

Corm.3.29.50

Serm.1.2.23

Sorm.2.2.35

Sorm.2.6.73

Sorm.2.3.11

Corm.4.4.56

Epist.1.2.22

Ars Pod 277

Epod.5.59

Iipod.3.12

Epod.2.41

Ispod.4.3

Serm 2.8 .9

Lpist.1.13.1!

ar.I.pist.1.17.38

Serm.1.5.94

Lpist.1.17.38

gar.Carm.2.19.9

roni.Carn.2.19.9

lopod.17.14

pervicacis. fas pervicacis est mihi Thyiadas... cantate . . . . Corm.2.109

pervicax. desine pervicax referre sermones deorum

pervideas. cum tua porideas oculis mala lippus inunctis.

pervincam. *Jucili. quam sis mendosus, teste Catone / defonsore tuo persincam。*

pervincere. nam quae pervincest soces tovalucte somum.

pes. ut nec pes nec caput uni rechlatur formae.

syllaba longa brevi subiecta vocatur iambus, pes citus:

pessime. "yuo pacto, pessinte?" .

pessuma. neruc tu pessuma munerum/fertes.

pestem. his miseram fanem. pestemque a populo et pincipe Caesare

pestilentem. nec petilentern sentiet Africum fecuntia vitis .

petam. regrata frotan Laconif I uta Phalantho.

petamalue voleus unbra curvis unguibus.

petamus. arsa teeatal petamus, arva disites et insulas.

petant. Ut sturlio matore petant jelicona virentem.

petat. (inirım. ut ueque calce Inpus quemquam neque dente pefit fjetat) bos).

ultra yuan mition quat virtutem si petat ipsam.

Dete. 1 fetw unguentuas, juet, et coronas

fum huc mana, ai potes, vitis [verted minas et me remorsurum petis (necele):

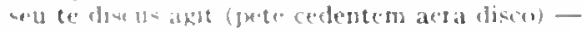

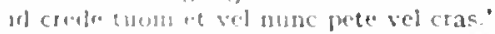

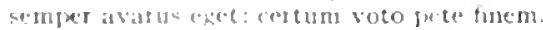

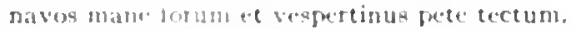

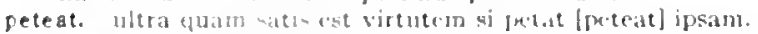

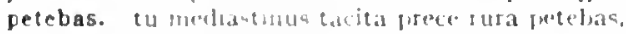

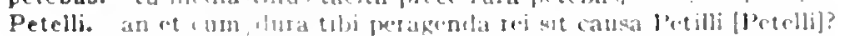

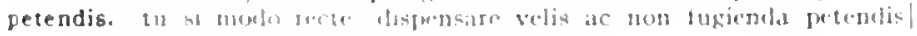
III IIII

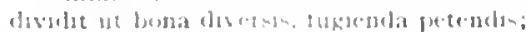

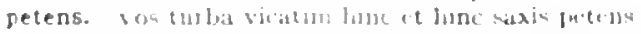

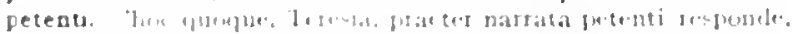

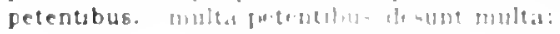

(arm.3.3.70

scrm. 1.3 .25

Sirm.1.10.2

I.pist.2.1.200

Ars linet.s

Ars Tod 252

Sirm.2.7.22

Carm.4.8.4

(orm.1.21.14

ciarm.3.23.5

carm.2.0.1t

l.pod. 5.93

Epod.10.42

I.pist.2.1.218

a ar.serm.2.1.55

Epist.t.1.10

corm.3.14.17

Tar. Epod.0.4

Serm.2.2.13

Sirm.2.3.232

l. pist.1.2.50

J.pist.1. 0

ar Lpist.1.0.10

lipist. I 49

:ar.sirm.1.10.20

Sormt 275

serm.1.3.11

1 podi.5.1)7

acrm 251

( $6 \mathrm{rm} \cdot 3.10 .42$ 
petere. inparibus formis deceptum te petere esto: .

Serm.2.2.30

peteret. me nelior cum peteret Venus.

si peteret per amicitiam patris atque suam.

petes. quin huc inanis, si potes, vertis ninas | et me remorsurum petis [petes]?

si interdicta petes, vallo circumdata

petet. iam proterva|fronte petet Lalage maritum|dilecta, ternos ter cyatlios attonitus petet /vates;

teque nec laevos vetet [petet] ire picus/nec vaga cornix. sed hic stilus haud petet ultro|quemquam animantem ultra quam satis est virtutem si petat [petet] ipsam. siquid petet, ultro|defer:

Peti. Petti [? Peti], nihil me sicut antea iuvat/scribere versiculos petiisse. dictus, . . morte venalem petiisse laurum

petiit. quod petiit spernit, repetit quod nuper omisit. quod cupide petiit, mature plena reliquit. .

Petilli. mentio siquae/de Capitolini furtis iniecta Petilli dura tibi peragenda rei sit causa Petilli?

petimus, caelum ipsum petimus stultitia . mavibus atque |quadrigis petimus bene vivere. scimus, et hanc veniam petimusque damusque vicissim; .

petis. Telephun. quem tu petis, et me remorsurum petis? quod petis, hic est, lest Vlubris. quod petis, id sane est invisum acidumque duobus.

petit. ian proterva|fronte petet [petit] Lalage maritum/dilecta, pauperemque dives|me petit:

tempestiva petit Rhode; exercitatas aut petit Syrtis noto dente lupus, cornu taurus petit: ut neque calce lupus quemquam neque dente petit bos). quatenus ima petit volvens aliena vitellus.

qui Capua Romam petit. imbre lutoque/adspersus aut decus et pretium recte petit experiens vir. secreta petit loca, balnea vitat.

petita. uti/petita ferro belua?"

petita. patris intermiscere petita/ verba foris malis.

petitae. nempe inamarescunt epulae sine fine petitae

petitis, bene erat non piscibus Vrbe petitis,

petitis. quantum dimissa petitis|praestent,

petitor. hic generosior/descendat in campum petitor.

petitu. "sapiens, vitatu quidque petitu|sit melius, causas reddet tibi;

petitum. unde petitum/hoc in me iacis?

petitus. latere petitus imo spiritus.

pugnis caesus ferroque petitus.

petiverit. an si quis atro dente me petiverit.

peto. nil cupientium|nudus castra peto

petorrita. plures calones atque caballi|pascendi, ducenda petorita. esseda festinant, pilenta, petorrita, naves,

Petrinum. palustris/inter Minturnas Sinuessanumque Petrinum.

Petti, Petti, nihil me sicut antea iuvat|scribere versiculos

petunt. iam Scythae responsa petunt, superbi|nuper, et Indi.

quatenus ima petit [petunt] volvens aliena vitellus. .

Gabiosque petunt et frigida rura.

pexae. si forte subucula pexae/trita subest tunicae

Phaeax, pinguis ut inde domum possim Pliaeaxque reverti -

Phaethon. terret ambustus Phacthon avaras $\mid$ spes .

Phalantho, regnata petam Laconi|rura Phalantho.

pharetra. puerum minaci|voce dum terret, viduos phatetra/risit Apollo insignemque pharetra|fraternaque umerum lyra. nec renenatis gravida sagittis,|Fusce, phatetra. otium Medi pharetra decori,

pharetratos. visam pharetratos Gelonos/et Scythicun inviulatus ammem. . pharmacopolae. ambubaiarum collegia, pharmacopolae, | mendici, mimae, balatrones.

phaselon. fragilemque necum | solvat phaselon;

Phidyle. rustica Plidyle, |si ture placaris

Phidyli. caelo supinas si tuleris manus / nascente luna, rustica Phidỹe [Phidy]i]. si ture placaris

Carm.1.33.13

Serm.1.3.5

iar. Epod.6.4

Sirm.1.2.96

Carm.2.5.16

Carm.3.19.14

var.Carm.3.27.15

Serm.2.1.39

gar.Epist.1.6.16

Epist.1.12.22

iar.Epod.II.I

Carm.3.14.2

Epist.1.1.98

Epist.2.I.I 00

Serm.1.4.94

Serm.1.10.26

Corm.r.3.38

Epist.I.IJ.29

Ars Poet.II

Carm.4.II.2I

Epod.6.4

Epist.I.I 1.29

Epist.2.2.64

i'ar.Carm.2.5.16

Carm.2.18.11

Carm.3.19.27

Epod.9.3I

Serm.2.1.52

Sirm.2.1.55

Serm.2.4.57

Epist.I.I1.1 I

Epist.1.17.42

Ars Poct.298

Epod.5.10

Serm.I.10.20

Serm.2.7.107

Serm.2.2.120

Epist.1.7.90

Carm.3.I.I I

Serm.1.4.15

Serm.1.4.79

Epod.I1. Io

Srm.1.2.60

Epod.6.1 5

Carm.3.16.23

Serm.1.6.104

Epist.2.1.192

Epist.1.5.5

Epod.II.I

Carm-Saec. 55

gor.Sirm.2.4.57

Epist.1.15.9

Epist.r.1.95

Epist.1.15.24

Carm.4.11.25

Corm.2o.s 2

Carm.r.10.I I

Carm.1.21.18

Carm.1.22.4

Carm.2.16.6

Carm.3.4.35

Serm.1.2.1

Carm.3.2.29

Cirm.3.23.2

coni.Curm.3 23.2 
Phalippi. (purer hic non l.eve iusar l'hilippilaccipiebat)

Epist.1.7.52

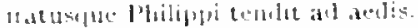

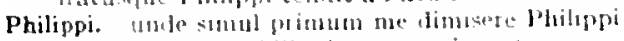

Philippis. nou nue Philiphis versa acies retro.

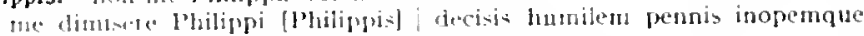
putterui at larin et fusedi.

Philippo ille isulippolexcusare haborem et mercennaria vincla.

Philippos. veum Philippos at celierem Ingam aensi retculit accotos. Fegale nomisma. Philippos.

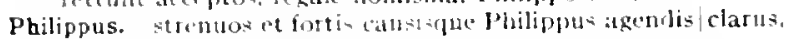
Volteitut mane l'hilippus. . oretupat villet ridetque lhilippus. yuen sinul adspexit seabrum intonsumqu. Philippus.

Philodamus. han. Philodamus at sibi, quace neque magno stet pretio

Philodemus. halle Philodamus [Jhilodemus] ait sibi. quae neque magno stot putetio

philyra. displicent nexae philyra coronate.

phimum. flui pro se tolleret atque|miteret in phimum tabs.

Phocaeorum. l'hoestorum vilut profugit essectata civitas

Phoceu. me sit an illae tibi amor pudori,| Xanthia l'hoceu:

Phoebe. nec to, metuende certa Phoebe sagitta.

Phorbe. "qui Kintho lavis amue crinis.

illerebe silvarumblue potens Diana.

Phoebi. o decus l'buebi et rapibus supremi gratia testudo lovis.

spu ficubus cutharave Phorbi.

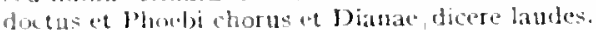

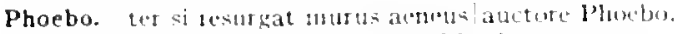

Phoebus. dest reofiens fugat a-trat Phoebus.

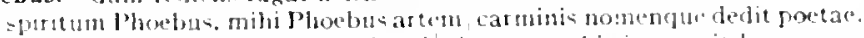

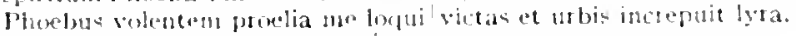
augur "t fulgertito decotus aren' l'hoebus

Pholoe. fuam turpi Pholox juccet adultero. dilet.t. yuantum non Pholse fusax.

Pholoen. "grus in asperatn declinat tholou: non. sicjusi Pholoen, satis cet te. Chlowi, decet:

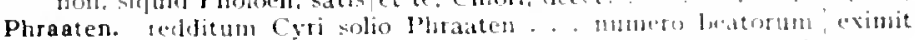

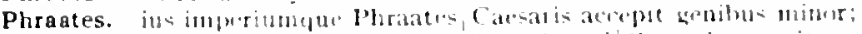

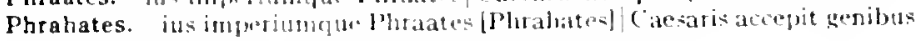
minor:

Phrygiae. atue pinguis Phrygiac Mygdonias ogen

Phrygiae. aut Phugriae sorotesiflevere semples

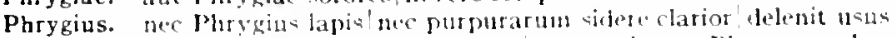

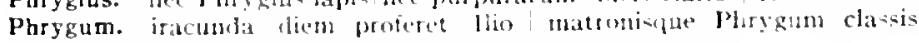
Achillei:

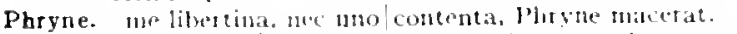

Phylli. "st in hotes. Phylli, nectumis apiust cotonis.

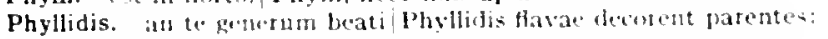

pia. nil taveje sceletis pist dextera

viluti pha matter plu- quam se sapere. . volt

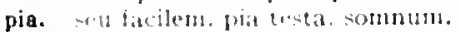

piabant. Telluredt fmerts, Silvanum lacte piabant.

piacula. terfue fhacula nulia resoblvent.

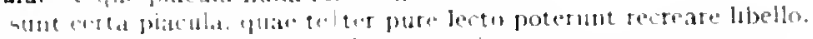

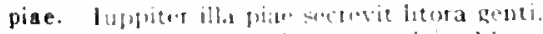

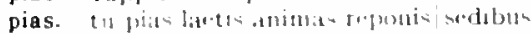

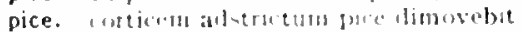

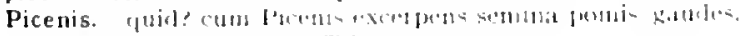

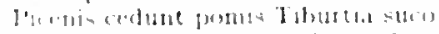

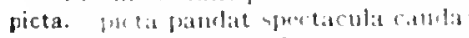

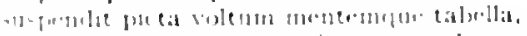

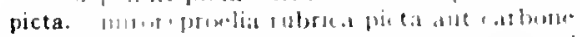

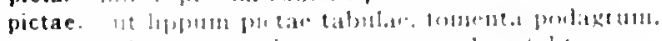

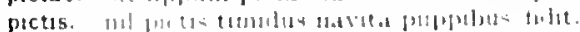

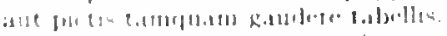

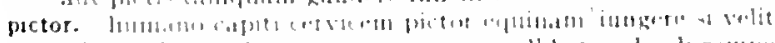

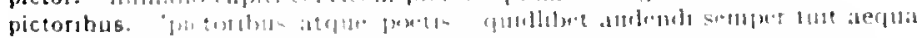
(in) $(10+1+1+\infty$

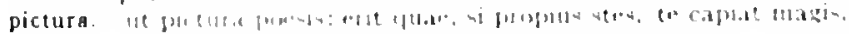

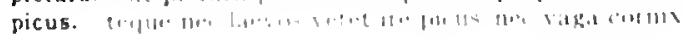

F.pist.t.7.89

I:pist.2.2.49

carm.3.4.20

ror. Pfist.2.2.44

IEpist.1.7.00

Carm.2.7.0

lipist.2.1.234

lepist.1.7..t?

Epist.1.7.04

l.pist.1.7.78

Jisist.1.7.90

Sirm.1.2.121

iis. Serm.1.2.12

Carm.1.38.2

Sierm.2.7.17

Epod.15.17

Carm 2.4.2

Corm.1.12.24

Carm. 4.0 .20

Corm.Suec.t

Curm.1.32.13

Carm.3.4.4

Curm.Sacc.75

Carm.3.3.06

Carm.3.21.2.4

(imm. 4.0 .29

(arm.4.15.1

Carm.Sacc.6z

Carm.1.33.9

(iam.2.5.17

(iz) $1 \cdot 33 \cdot 7$

Carm.3.15.7

(itrm.2.2.17

l.pist.1.12.27

ior Epist.1.12.27

Carm.2.12.22

Carm.2.0.10

(arm.3.1.41

(arm.t.15.34

lipod.14.10

(armatil1.3

Carm.2.14

herm.2.1.54

ispist.1. 820

(arm.321.4

E.pist 2.1 .1 .3

(arm.1.28.34

Epist 1.1.3n

I:Pixl.10.e 3

Cirm.10.17

(izm.3.8.10

Sierm. 2.3.272

serm.2.4.70

Sirm.2.20 20

I.post 2.1 .27

Sorm.2.7.0k

l:Post.1.252

(iurm.1114

Sorm.1.1.7

Ars liset.

Ars liveto

ars liost 301

cismb 3215 
Pieri. dulcem quae strepitum, Pieri, temperas.

Carm.4.3.18

Pieria. nec vir Pieria paelice saucius

Pierides. non .. . clarius indicant|laudes quam Calabrae Pierides.

Carm.3.I0.I 5

Carm.4.8.20

Pieriis. gratia regum/Pieriis temptata modis

Pierio. Pierio recreatis antro.

pietas. dis pietas mealet musa cordi est.

nee pietas moram |rugis et instanti senectae/adferet

pietasque" dixit|'victa furore.

non te restituet pietas;

me quamvis Lamiae pietas et cura moratur/fratrem maerentis.

piga. ne nummi pereant aut puga [piga] aut denique tama.

pigeat. neu conversa domun pigeat dare lintea,

piger. sive opus est imperitare equis, | non auriga piger.

garrulus atque piger seribendi ferre laborem.

retinacula mulae nauta piger saxo religat stertitque supinus.

'nil habeo quod agam et non sum piger: usque sequar te.'

ut piger annus pupillis, quos dura premit custodia matrum:

optat ephippia bos, piger optat arare caballus: .

militiae quamquam piger et malus, utilis Trbi.

pignus. pignusque dereptum lacertis

pigrior. discedat - pulcrior [pigrior]. ultro'muneribus missis):

pigris. pone me pigris ubi nulla campis|arbor

pigro. addit opus pigro rivos, si decidit inber,

pigrum. dixi me pigrum proficiscenti tibi.

pii. ne nimium pii|rebusque fidentes

piis. quorum piis secunda vate me datur fuga.

pila. nulla taberna meos habeat neque pila libellos,

pila. seu pila velox/moiliter austerum studio fallente laborem,

pila. namque pila lippis inimicum et ludere crudis.

pilae. indoctusque pilae discive trochive quiescit.

pilenta. esseda festinant, pilenta, petorrita, naves,

pileolo. ut cum pileolo soleas conviva tribulis.

pilis. horrentia pilis $\mid$ agmina

pilos. caudaeque pilos ut equinaelpaulatim vello

Pindaricae. non,... Pindaricae latent

Pindarici. Pindarici fontis qui non expalluit haustus

Pindarum. Pindarum quisquis studet aemulari,

Pindarus. fervet inmensusque ruit profundo|Pindarus ore, .

Pindo. aut super Pindo gelidove in Haemo?

pingeret. nequis se praeter Apellen/pingeret.

pingimus. pingimus atque $\mid$ psalimus et luctamur Achivis doctius unctis.

pingitur. si fractis enatat exspes|navibus, aere dato qui pingitur?

pingue. arvom/pingue tenent humilis Forenti.

pingue pecus domino facias et cetera praeter/ingenium. .

pinguem. pinguem vitiis albumque neque ostrea. . . iuvare

me pinguem et nitidum bene curata cute vises,

pingues. an pingues Asiae campi collesque morantur?

pingues. aut pinguis [pingues] Phrygiae Mygdonias opes/permutare velis crine Licymniae

pingui. illif'tardo' cognomen, 'pingui' damus.

pingui. quod pingui miscere mero muriaque decebit pingui tentus omaso|Furius

uncta satis pingui ponentur holuscula lardo?

ne rubeam pingui donatus munere

pinguia. nec pinguia Gallicis crescunt vellera pascuis: pinguia nec siccis urantur semina glaebis.

pinguibus. pinguibus te ficis pastum iecur anseris albae

pinguibus. praeferat Herodis palmetis pinguibus.

pinguior. quis non Latino sanguine pinguior f campus

pinguis. nam Laurens malus est. ulvis et harundine pinguis.

pinguis ut inde domum possin Phaeaxque revert $\hat{i}$ -

pinguis. aut pinguis Phrygiae Mygdonias opes

pinguissimis. leeta de pinguissimis/oliva ramis arborum

pinguium. in tenero gramine pinguium custodes ovium

pinu. sub... haclpinu iacentes sic temere

pinus. quamwis Pontica pinus, / silvae filia nobilis, .

quo pinus ingens albaque populus | umbram hospitalem consociart amant ramis!

saepius ventis agitatur ingens pinus

Ars Poel.405

Carm.3.4.40

Carm.1.17.13

Carm.2.14.2

Carm.3.27.35

Carm.4.7.24

Epist.1.14.6

z'or.Serm.I.2.1 33

Epod.10.27

Carm.1.15.26

Serm.1.4.12

Serm.1.5.19

Serm.1.9.19

Epist.I.I.2I

Epist.I. 4.43

Epist.2.I.I2.4

Carm.1.9.23

var.Serm.t.7.17

Carm.1.22.17

Epist.1.14.29

Epist.2.2.20

Carm.3.3.58

Epod. 16.66

Serm.1.4.7 I

Sirm.2.2.I I

Serm.1.5.49

Ars Poet.380

Epist.2.1.192

Epist.1.13.15

Serm.2.1.I3

Epist.2.1.45

Carm.4.9.6

Epist.1.3.10

Carm.4.2.I

Carm.4.2.8

Carm.I.1 2.6

Epist.2.1.240

Epist.2.1.32

Ars Poct.2I

Carm.3.4.10

Serm.2.6.It

Serm.2.2.2I

Epist.1.4.I 5

Epist.1.3.5

var.Carm.2.1 2.22

Serm.1.3.53

Serm.2.4.65

Strm.2.5.40

Sirm.2.0.64

Epist.2.1.267

Carm.3.16.35

Epod.16.55

Sirm.2.8.88

Epist.2.2.184

Carm.2.1.29

Serm.2.4.42

Fpist.1. I 5.24

Carm.2.1 2.22

Epod.2.55

Carm.4.12.9

Carm.2.I I.I4

Carm.1.I4.II

Carm.2.3.9

Carm.2.10.10 
inminens villac tua pinus esto. mordaci velut icta ferro pinus

non liue Argoo contendit remige pinus

pio. mollibit areros lenacis/farre pio et saliente mica.

piorum. iudicantem vidimus Acacum/sedesque discriptas piorum

pios. audice et videor piosferrare per lucos.

pipes. piper album cum sale nigro|incretum

angulus istr. foret piper et tus ocius uva

in vicum vendenten. . . piper et quidquid chartis amicitur ineptis.

pipere. pipere albo, non sine aceto.

Piplea. necte meo Lamiae coronam. | Piplei [Piplea] dulcis.

Piplei. necte meo l.amiat coronam, | Piplei dulcis.

pira. ut gaudet insitiva decerpens pira

piris. non quo more piris vesci Calaber iubet hospes

Piritboo. nee Lethaea valu Theseus abrumpere caro| vincula lerithoo [1'irithoo]. .

Pirithoum. amatorem trecentae / Pirithoum cohibent catenae.

Pirria. ut vinosa glomus furtivae t'irria lanae.

piscstor. elicit, piscat or uti, pomarits,. . . mane domum veniant.

piscem. ut turpiter atrum/desinat in piscen nulier formosa superne:

piscemur. piscemur, venemur, ut olim|Gargilius

pisces. contracta pisces aequora sentiunt

piscibus. o mutis quoque piscubus/donatura cyeni, si libeat, sonum.

piscibus atque avibus quae natura et foret aetas.

piscibus. bene erat non piscibus V'rbe petitis.

piscis. accultum visus decurtere piscis atl hamum,

piscis. garo le sucis piscis lliberi;

piscis. semeos piscis tepidumque ligurterit ius.

atrun | defonciens piscis biemat mare:

tu piscis liberno ex aceluore verris.

nec satis est cara piscis avertete mensa

ধuali perfundat piscis securus olivo.

angustoque vitgos piscis urget catino.

nos, inquam, cenamus avis, conchylia. piscis.

verum setu piacis seu porrum ot caepe trucidas.

ntra magis piscis et echinos aequora celent.

piscium. piscium et summa genus haesit ulmo.

piscosi. via prior ad usque/Bari moenia piscosi:

Pisones. creditte Pisones, isti tabulat fore librum/persimilem.

non... dominantia nonina solum / verbaque. Pisones. Satyrorum setipt or amabo

Pisonis. crelite Pisones [Pisonic], isti tabulac fore librum/persimilem. non ego inornata et dominantia nomina solum | verbaque. Pisones [lisonis]. Satyrorum seriptor amabo

Pitholeanti. Rhodio quod Pitholeonti|contigit?

pitvita, scomacliogue tumultum / Jentit feret pitvita.

proferpue sanus, nisi cum pitvita mokesta est.

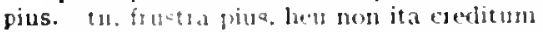

quo prus deneas, quo Tullus dives et Ancus.

placabilis. iracei collorent, tamen nt placabili teacm.

placantur. Carmine di superi flaciulur, camine Manca.

placare. et ture et folibus iuvat placare. . cuatodes Xumine deos.

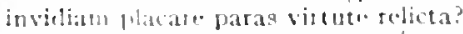

placari. compe. . vinogure diun no placari lienius fentis inpune diebus.

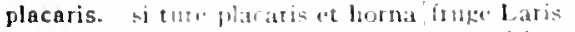

placse. quantin murgue deos vel pores vel bove placat.

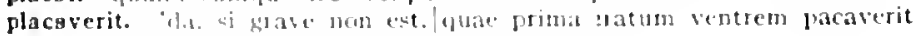

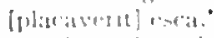

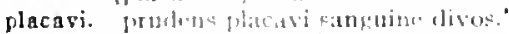

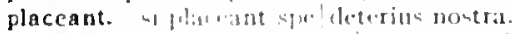

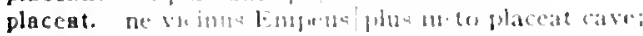

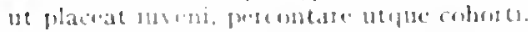

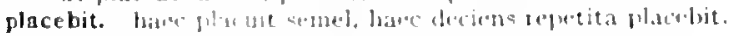

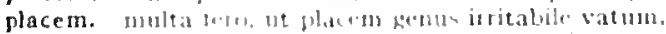

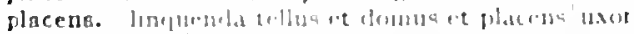

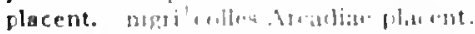

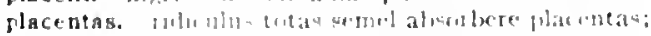

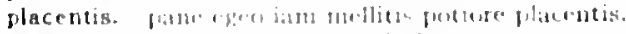

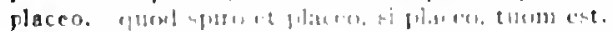

Carm 3.22 .5

Carm.4.0.10

Epod.16.57

Carm.3.23.20

Carm.2.13.23

Curm.3.4\%

Sorm.2.4.74

Epist.1.14.23

Epist.2.1.270

Sci m.2.8. 49

rar.Carm.1.26.9

Carm.1.26.9

Epod.2.10

Epist.1.7.14

var.Carm.4.7.28

Carm.3.4.80

Epist.1.13.14

Scrm.2.3.227

Ars I'octid

Epist.1.6.57

Carm.3.1.3.3

Carm.4.3.10

Serm.2.4.45

Serm.2.2.1 =0

Epist.1.7.74

Serm.2.8.4h

Serm.1.381

Sorm.2.2.17

Sorm.2.3.235

Serm.2.4.37

Sorm.2.t50

Sirm.2.4.77

Sorm.2.8.27

Lisist.1.12.21

Epist.1.15.23

Carm.1.2.9

Serm.1.5.07

Ars J'onto,

Ars Poet. 235

var.Ars I'ori.6

Far.Ars Port.235

Serm.1.10.22

Serm.2.2.70

Epis! 1.1.ro8

Carm.1.24.1I

Carm.t 7.15

Epist.1.20,25

Epist.2.1.13s

Corm.1.30.2

Serm.2.3.13

Ars lewt.210

Corm.32.3

Epist.1.10.5s

tar.sirm.2 8.5

Serm 2.32010

Sermates

Curm $3: 2.4$

I pist 1 \& 1.9

Ars lione 315

lepisf 2.2 IOI2

Corm: 1.821

( iorm 1 $121:$

irrm. 2821

J.for 1 101 I1

ciom 4 . 32.4 
placere. nulla placere diu nec vivere carmina possunt,

places. non. . . amice, places inlacrimabilem|Plutona tauris.

placet. cui placet inpares/formas atque animos sub iuga . . . mittere nec cultura placet longior annua. sie placet? an melius quis habet suadere? sed vacuom Tibur placet aut inbelle Tarentum. cui placet alterius, sua nimirum est odio sors. vere quod placet ut non / acriter elatrem. quid placet aut odio est. quod non mutabile credas? "dixit adhuc aliquid?" "nil sane." "quid placet ergo?" .

placidae. di. senectuti placidae quictem.

Placideiani. cum ... Pacideiani [Placideiani] contento poplite miror] proelia rubrica picta

placidis. sed non ut placidis coeant inmitia.

placido. nascentem placido lumine videris.

placidus. condito mitis placidusque telo

placitum. sic potenti| Iustitiae placitumque Parcis. (sic dis placitum),

placuere. seu liquidae placuere Baiae. dis, quibus septem placuere colles, |dicere carmen.

placui. magnitm hoc ego duco, quod placui tibi.

placuisse. quem scis inmunem Cinarae placuisse rapaci, principibus placuisse viris non ultima laus est. me primis Vrbis belli placuisse domique,

placuit. callidum, quidquid placuit, iocoso/condere furto. quis paria esse fere placuit peccata. vel quia nil rectum, nisi quod placuit sibi, ducunt et placuit sibi, natura sublimis et acer:

haec placuit semel, haee deciens repetita placebit.

plagas. seu rupit teretes Marsus aper plagas. apros in obstantis plagas

(qui mane plagas. . . . transire forum populumque iubebat.

plagis. caedimur et totidem plagis consuminus hostem

plagis. si pugnat extricata densis/cerva plagis.

educet in agros / Aetolis onerata plagis iumenta canesque.

plagosum. memini quae plagosum mihi parvo|Orbilium dictare

Plance. finire memento|tristitiam vitaeque labores/molli, Plance, mero. Planco. non ego hoc ferrem calidus iuventa|consule Planco.

plane. 'molestus fommuni sensu plane caret' inquimus.

plangas. nec, cum venari volet ille, poemata panges [plangas].

planges. nec, cum venari volet ille, poemata panges [planges].

planis. locus, ut neque planis|porrectus spatiis

planius. planius ac melius Chrysippo et Crantore dicit.

plantam. haeres/nequiquam caeno cupiens evellere plantam.

planum. nec semel inrisus trivis attollere curat/fracto crure planum.

platano. cur non sub alta vel platano vel hac|pinu iacentes

platanus. platanusque caelebslevincet ulmos;

plateae. 'verum|purae sunt plateae, nihil ut meditantibus obstet."

Platona. quorsum pertinuit stipare Platona Menandro?

qualia vincent| Pythagoran Anytique reum doctumque Platona.' .

plaudere. mon ego: nam "satis est equitem mihi plaudere".

plaudet. aut ursum aut pugiles: his nam plebecula gaudet [plaudet].

plaudit. ingeniis non ille favet plauditque sepultis,

plaudite. sessuri, donec cantor 'vos plaudite' dicat:

plaudo. 'populus me sibilat, at mihi plaudo|ipse domi.

plausis. dicitur et plaustris [plausis] vexisse poemata Thespis.

plausor. in vacuo laetus sessor plausorque theatro.

plausoris. si plosoris [plausoris] eges aulaea manentis et usque / sessuri, plaustra. quorum plaustra vagas rite trahunt domos.

plaustris. tristia robustis luctantur funera plaustris.

plaustris. dicitur et plaustris vexisse poemata Thespis,

plausus. datus in tbeatro/cum tibi plausus,

plausus. scilicet ut plausus quos fert Agrippa feras tu,

quid censes.. plausus et amici dona Quiritis.

Plautinos. at vestri proavi Plautinos et numeros et/laudavere sales.

Plauto. Caecilio Plautoque dabit Romanus ademptum/Vergiho Varioque?

Plautus. Plautus ad exemplar Siculi properare Epicharmi.

Plautus|quo pacto partis tutetur amantis ephebi.

plebe. crede non illam tibi de scelestal plebe dilectam
Epist.1.19.2

Carm.2.14.6

Carm.1.33.Io

Carm.3.24.14

Epod.16.23

Epist.r.7.45

Epist.1.14.II

Epist.1.18.17

Epist.2.1.IOI

Epist.2.1.206

Carm.Saec.46

zar.Serm.2.7.97

Ars Poct.1 2

Carm.4.3.2

Carm.Suec.33

Carm.2.17.16

Sirm.2.6.22

Carm.3.4.24

Carm-Saec.7

Serm.1.6.63

Epist.1.14.33

Epist.1.1 7.35

Epist.1.20.23

Carm.1.10.7

Serm.1.3.96

Epist.2.1.83

Epist.2.1.165

Ars Poet.365

Carm.1.1.28

Epod.2.32

Epist.1.6.58

Epist.2.2.97

Corm.3.5.32

Epist.1.1 8.46

Epist.2.1.70

Carm.1.7.19

Corm.3.14.28

Serm.1.3.66

zar.Epist.1.18.40

var.Epist.I.I 8.40

Epist.1.7.4I

Epist.1.2.4

Serm.2.7.27

Epist.1.17.59

Carm.2.II.I 3

Corm.2.I5.4

Epist.2.2.7 1

Serm.2.3.II

Serm.2.4.3

Serm.1.10.76

qar. Epist.2.1.186

Epist.2.I.88

Ars Poif.I 55

Serm.r.1.66

1ar. Ars Poet.276

Epist.2.2.130

iar.Ars Poet. 54

Carm.3.24.10

Epist.2.2.74

Ars Poet. 276

Carm.1.20 4

Serm.2.3.185

Epist.1.6.7

Ars Poct. $27^{\circ}$

Ars Poet.54

Epist.2.I.58

Epist.2.I.I70

Carm.2.4.1 8 
plebecula. aut ursum aut pugiles: his nam plebecula gaudet.

Epist.2.1.186

plebeius. velas cur?" "rox sum." "nil ultra quaeso plebejus."

plebi. l'hratent deseden: plebi numero beato um|eximit Virtua

Serm.2.3.188

hoc niserace plebi stabat commune: sepulcrum.

plebis. Plraaten discidens plebl [plebis] numesobeatorum/eximit Virtus.

fortunam et mores antiquae plebis.

nect somnum plebis laurlo satur altulium

non ego ventosae plebis suffragia renor

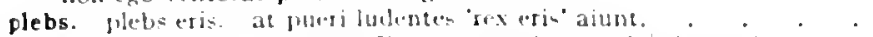

plebs. o plebs. . . Cacsar lispana repretie penatis/victor ab ora.

plectantur. Venusinat plectantur silvae se sospite.

plector. tergo plector enim.

plectro. hunc letsio sacrare plectro

quacre modos leviore plectro.

ho sonantem plenius auteo, / Alate, plectro dura navis,

concines masore poeta plectroi Caesarem.

plectuntur. quidquid delirant reges, plectuntur Achivi.

Pleiadum. l'lejarlum choro scindente nubis.

plena. (quid velint flores et acerta turis, plena miraris

quod cupide jetiit, mature plena reliquit.

non missura cutem nisi plena cruoric hirudo.'

plena. plena dives ut in dono.

plena. Histia maestum, voltum vesba decut, iratum plena minarum.

plenas. plenas aut Arshum domos.

plene. ut fortunatans plene praces antia vitam;

plenior. cum sis nihilo sapientios ex quo plenjor es.

plenior. plenior ut siquos delectet cervia iusto.

plenis. plenis honorum muneribirs

plenissims. linc nos ("oced recipit plenicsina villa.

plenius. et to sonantem plenius aureo.

planius [p]cnios] ac nulius Chrysippo et Crantorn dicit.

ubi plenius acruo laudat venalis qui volt extrudere merces:

pleno. si tener pleno cadic hacdus anno

pleno. plenoque Bacchi pectore turbidum lactatur.

adparctque beata pleno/Copia cornu. .

ire foras pleno tendebat corpore irustra.

aurea fruges/lealiae pleno defudit Copia connu.

omne supervacuom pleno de pectore manat.

plenum. quo me. Bacche. rapis tui plenum?

plerumque [? plenumque] recoctus scriba ex quinqueviro corvom dehulet hiantem

molto ad versus tibi factos ducese plenum, lactitiac;

plenum. tibi copias manabit a plenum

periculosac plenum opus aleace,

plenus. nonum superantis annum plenus Albani calus.

eum rapula plenus/atrue acidas mavolt inulas.

scis in breve be cogj, cum flenus languec amator.

pleraque. si pietique dure dicere cuedit eos.

pleraque differat et fracens in tempus omitat.

plerique. ut plesuue solent, naso susperdis adunco ignotos

plerumque. linspiter. joni corusco mubila dwidens plerumque.

tu beme losmentum ingenio arlmoves plerumplue duro.

plesumeque poratill divitibus vices

ridis whom it 11 fortiug et melius magnas flerumegue secat ros.

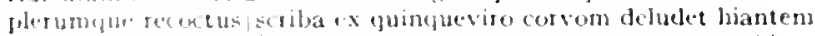

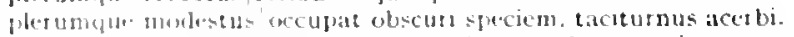

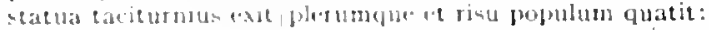

merotis grabus pletumgue et makna professis / purpureus. atcustur pannuc.

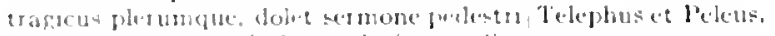

plorant. ut pul conducti jhy ant in tunere dicunt

plorare. Iheneetri, lectse. I uge!ll, discipularum inter iubeo plorate cathedras.

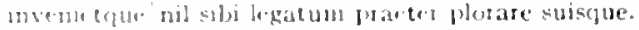

plorares. ma. . absecte incellis plorasen squilombus.

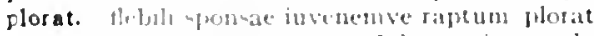

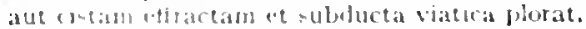

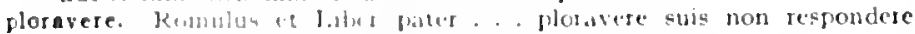

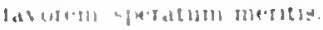

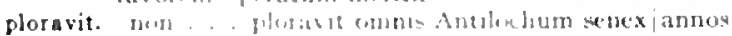

Carm 2.218

Serm.1.8.10

Iar.Carm.2.2.18

Serm.2.7.23

Epist.1.7.35

Epist.1.19.37

List.1.1.59

Carm.3.14.1

Corm.1.28.27

Serm.2.7.105

Carm.1.20.11

Carm.2.1.40

Corm.2.13.27

Carm.4.2.33

Epist.1.2.14

Carm.4.14.21

Carm.3.8.3

Epist.2.1. 100

Ars Poct.476

Carm.4.12.24

Ars Podtao

Carm.2.12.24

Epist.1.11.14

Epist.2.2.154

Sirm.1.1.57

Carm.14.2

Serm.1.5.50

Carm.2.13.26

sar.Jipist.1.2.4

IE pist 22.10

Carm.3.18.5

Carm.2.19.0

Carm.saec.59

Epist.1.7.31

Epist.1.12.29

Ars Poel 337

Carm.3.25.2

I tor.Serm.2.5.55

irs Poct.427

Carm.1.17.15

Carm.2.1.0

Corm.4.11.2

Sorm.2.2.43

Epist.1.20.8

Epist.2.1.60

Ars Pod.at 4

Serm.1.0.5

Carm.1.34.7

Carm.3.21.14

Carm.3.29.13

Serm.1.10.1 5

Scrm.2 5.55

Epist.1.18.99

E. pist 2.2.84

Ars Pues. 14

Ars Podes

Ars Puil 43 ?

Serm.1.10-91

Sorm.2.5.89

Carm.3.10.4

Corm \$.2.22

Epist I.17.54

Lipist 2.1.9

Carm.2.214 
plorem. plorem artis in te nil agentis exitus?"

plores. an meretricis amore/sollicitus plores:

ploret. ter uxor/capta virum puerosque ploret."

ploro. vigilansne ploro|turpe connissum .

plosoris. si plosoris eges aulaea manentis.

plostello. "aedificare casas, plostello adiungere muris.

plostra. si plostra ducenta|concurrantque foro tria funera,

Plotius. Plotius et Varius Sinuessae Vergiliusque occurrunt,

Plotius et Varius, Maecenas Vergiliusque,

plovius. aut flumen Rhenum aut plovius desctibitur arcus;

pluma. insperata tuae cum veniet pluma superbiae

pluma. num vesceris ista, quam landas, pluma?

plumae. nascunturque leves|per digitos umerosque pluniae.

plumam. plumamque nocturnae strigis

plumas. si forte suas repetitum venerit olim |grex aviun plumas. varias inducere plumas, undique collat is nembris

plumbeus. nec mala me ambitio perdit nec plumbeus auster

plumbum. nec severus /uncus abest liquidumque plumbum;

plumbum. purior in vicis aqua tendit rumpere plumbum .

plura. pluribus hisce. Isi modo plura milit bona sunt, inclinet. verun ubi plura nitent in carmine.

plura. nulli plura tamen dividit oscula| quam dulci Lamiae,

quanto quisque sibi plura negarerit,

ab dis plura feret:

nec, si plura velim, tu dare deneges.

liberum munivit iter, daturus / plura relictis:

pluraque felices mirabinur,

(infans namque pudor prohibebat plura profari)

saepe ferentem | plura quidem tollenda relinquendis.

ubi plura|cogere quam satis est ac non cessare videbor.

ut sibi praebentem mimo spectacula plura,

quanto plura parasti,

tanto plura cupis.

quod non plura datis invenerit;

neque plura parare labores

faciunt prope plura dolentibus ex animo,

plurae. 'verum | purae [plurae] sunt plateae, nihil ut meditantibus obstet.'

plures. auxilio quae sit mihi (nam multo plures sumus).

atque salutandi plures, ducendus et unus/et comes alter,

plures calones atque caballi $\mid$ pascendi, ducenda petorrita.

plures adnabunt thynni et cetaria crescent.

quod numero plures, virtute et honore minotes.

plures. 'verum | purae [plures] sunt plateae, nihil ut meditantibus obstet.'

plures. quod et hunc in annum/rivat et plures. utpote plures/culpari dignos.

nam quis me scribere plures|aut citius possit versus?

effundi saccos nummorum, accedere plures |ad numerandum:

plures. quattuor aut plures aulaea premuntur in horas,

pluribus. non ut iuvencis inligata pluribus|aratra nitantur meis locus est et pluribus umbris;

pluribus. pluribus hisce.|si modo plura milhi bona sunt, inclinet, pluribus adsuerit mentem corpusque superbum

pluribus. guid te exempta iuvat spinis de pluribus una?

plurima. licet illi plurima manet lacrima,

plurima. plurima, quae invideant pure adparere tibi rem.

plurima. illic plurima naribus/duces tura

plurimum. grata carpentis thyma per laboren/plurimum

plurimus. plurinus in Iunonis honorem|aptum dicet equis Argos

pluris. illam 'nost paulo' 'sed phuris' 'si exierit vir"|Gallis.

unius assis non nmquam pretio pluris licuisse.

'pluris|hoc' inquam 'mili esis.'

'si bene me novi. non Viscum pluris anicum,

'Stoice, post dannum sic rendas omnia pluris. .

pluris. tractus uter pluris lepores, uter educet apros;

pluris. seu pluris hiemes seu tribuit Iuppiter ultinam.

cum tibi sol tepidus pluris admoverit auris.

plus. unde laboris/plus haurie mali est quam ex se decerpere íructus.

plus. auxili|latura plus praesentibus.

non tuos hoc capiet venter plus ac neus.

Epod.1 7.81

Serm.2.3.253

Carm.3.3.68

Carm.3.27.38

Ars Poct. 154

Serm.2.3.247

Serm.1.0.12

Serm. 1.5.40

Sirm. I. I0.8 I

coni.Ars Poet. 18

Carm.4.10.2

Serm.2.2.28

Carm.2.20.1 2

Epod.5.20

Epist.1.3.19

Ars Poet. 2

Serm.2.6.I 8

Carm.1.35.20

Epist.1.10.20

Serm.1.3.7 I

Ars Poet.35I

Carm.1.30.6

Carm.3.16.2I

Carm.3.10.22

Carm.3.16.3s

Carm.Saec. 4

Epod.10.53

Serm.1.0.57

Serm.1.10.5I

Epist.1.10.45

Epist.2.1.198

Epist.2.2.1 77

Epist.2.2.1. $\$ 8$

Epist.2.2.192

Epist.2.2.196

Ars Poet.432

iar.Epist.2.2.7 I

Serm.I.t.I 42

Serm.t.o.iol

Serm.1.0.103

Serm.2.5.44

Epist.2.1.183

var.Epist.2.2.7 I

Carm.1.32.3

Sorm.I.t.2.7

Serm.1.9.23

Serm.2.3.149

Epist.2.1.189

Epod.1.25

Epist.1.5.28

Serm.1.3.70

Serm.2.2.109

Epist.2.2.212

Epist.I.17.59

Serm.1.2.100

Carm.t.1.2I

Carm.4.2.3o

Carm.1.7.8

Sirm.1.2.120

Serm.1.6.1.t

Sirm.1.9.7

Sirm.1.9.22

Serm.2.3.300

Epist.I.15.22

Corm.r.II.t

Epist.1.20.19

Sirm.1.2.79

Epod.1.22

Serm.1.1.t6 
nihibo plus accipas quam qui nil portarit.

cumcune habeaw plus, | pauperiem metuas minus

videamus uter plus seribere possit."

ne phus frumenti dotalibus emetat agris

suo de pauprertale tacentes|plus poscente ferent:

habercet plus dapin et rixae onulto minus invidiaeque.

itmbigitur quid enim? Castor seiat an Docilis plus;

haber conordia tanto/plus oneris, quanto veniae minus:

andiccerc bonace patulo plus artis Achenae.

si plus a fposcete visus, fit Mimmermus

plus. if tollens vacuon plus nimio Gloria verticem

Abi, ne doleas plus nimio memor|inmitis Glycerae.

ne vicinus Enipeus/ plua insto placeat cave:

Genaumes. . deiecit acer plus vice -implici;

cut lla plus laudes cumeris granaria nostris?

quactere plus prodest et inane abscindere soldo?

at est truculentior atque /plus aenuo liber:

nilalo plus explicet ac si|in wanire puret certa ratione modoque."

in cute curanda plus aequo operata iuventus.

est ubi plus tepeant biemes. .

qu.m res plus nimio delectavere sereundac.

sed vereor, ne cui de te plus quam tibi credas

alter in obsequium plus aequo pronuz

plus quam se sapere et virtutibus esse priorem/volt

si plosoris [plus oris] eges aubea mane atis et usquelsessuri.

deriane vero plus laudatore novetur.

Plutona. non . . places inlacrimabilem|Plutona tauris,

Plutonia. ian te prenet nox fabulaeque Manes/et domus exilis Plutonia; pluvii. qua nebulate pirviique tores.

pluvios. defondit aestatem capellis/usque meis pluviosque ventos.

pluvius. aut thmen Rhenum aut plovius [pluvius] describitur arcus;

pocula. tribus aut noven miscentur cythis pocula commodis. quol sibi poscenti non dentur pocula.

pocula. est qui nec veteris pocula Massici . . spernit,

hic innocentis poctala Lesbii|duces

mea nec lialernae'temperant vites neque liomianilpocula colles.

restinguec ardentis Falernil pocula practereute lympha?

pocula lethaeos ut si ducentia somnos/arente fauce traxerim.

desiderique temperare pocula.

num. tibi cum faucis urit sitis, aurea quacris/pocula?

pocula cum cyatho duo sustinet. .

seu ruis capit acria fortis/pocula.

Sirenum voces et Circae pocula nosti;

oderunt porrecta negantem pocula.

poculis. non ego te meis/inmunem meditor tinguere poculis.

poculum. amoris esset poculum.

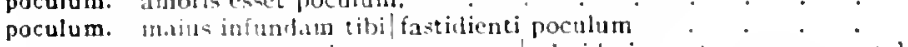
posim ctematos excitare mortuos | desiderigue temperare pocula [1rixulum].

podagra. nec laterum lolor aut tussia nec tarda podagra: .
podagram. qui cupit aut meturt. iuvat illum sic domus et res $\mid$ ut... fomenta pougrum [podagram!.

podagrum. ut lippum pictac tabulae, fomenta podagrum,

podex. podex vilut crudue bovis.

poema. illeirco quilan comoedia necne poema/esset quaesivere.

hactenus baec: aliag, iustum sil necne poena.

adeo sinctum eat verus omme poema. .

sic animis natum inveutumque poema juvandis.

poema. iniuste totum ducit venditque poema. porma' qui tam ridiculum am care prodigus emit. at quj leogitimum cupiet fecisse porma.

poemata. "t Iaberi minos ut pulera pormata mirer.

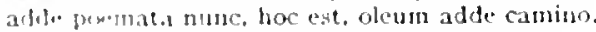

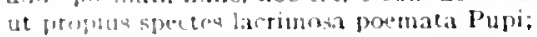

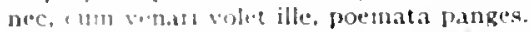
4i mofiord diva, ut vinat pormata reditt.

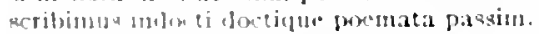

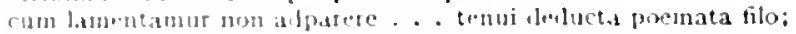

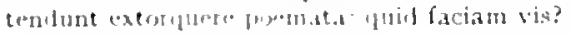

Serm.1.1.43

Serm.1.1.92

Serm.1.t.10

Epist1.0.21

Epist.1.17.44

Epist.1.17.51

Jpist.1.18.19

I:pist.2.1.170

Epist.2.2.43

Epist.2.2.100

Carm.1.18.15

Carm.1.33.1

Carm.3.7.24

Carm.t.14.13

Serm.1.1.53

Serm.1.2.113

Serm.1.3.52

Serm.2.3.270

Epist.1.2.29

Epist.1.10.15

Epist.1.10.30

Epist.1.16.19

Ëpist.1.18.10

Epist.I.I8.27

sur.Ars Poel.151

Ars Poel. 433

Carm.2.14.7

Carm.1.1.17

Carm.3.3.56

Carm.1.17.4

rar.its Poelis

Carm.3.ro.r 2

Serm.2.8.82

Carm.1.1.19

Carm.1.17.21

Carm.1.20.12

Carm.2.1 1.20

Epod.14.3

Epod.17.8o

Scrm.t.2.115

Serm.1.6.117

Serm.2.6.70

Jisist.t.2.23

Epist.1.18.92

Corm.4.12.23

lisolt.5.3

tepod. 5.78

rar. Epod 17.80

Serm.1.9.32

rar.lEpist.1.2.52

Epist.1.2.52

lipod.8.0

Serm.1.4.45

Serm.1.4.03

Epist.2.1.54

Ars loot.377

Epis1.2.1.75

Ifpist.2.1.237

Epist.2.2.100

Scrm.1.10.0

Serm.2.3.321

Epist.1.1.07

Epis1.1.18.40

Jpist.2.1.34

Fisi.2.1.17

IEpist.2.1.225

Epist 2.57 
praeter cetera me Romaene poemata censes|seribere posse non satis est pulchra esse poemata; dulcia sunto non quivis videt inmodulata poemata iudex dicitur et plaustriz vexisse poemata Thespis. non alius faceret meliora poemata: celsi praetereunt austera poemata Ramnes: nunc satis est dixisse ego mira poemata pango;

Poena. raro antecedentem scelestum/deseruit pede Poena claudo. poena. ulla si iuris tibi peierati|poena. Barine, nocuisset umquam. culpan poena premit comes. quin etiam lex poenaque lata.

poenae. tu nihil admittes in te formidine poenae; ille ferat pretium poenae securus, opinor.

poenarum. dedi satis superque poenarum tibi.

poenas. audiat Lyde scelus atque notas/virginum poenas

effare; iussas cum fide poenas luam,

poenas dedit usque superque |quam satis est.

regula, peccatis quae poenas inroget aequas.

faciasne quod olim |mutatus Polemon? ponas [? poenas] insignia morbi, dum poenas odio per virn festinat inulto.

poenis. quae poenis conpesceret inferiorem;

Poeno. Siculum mare/Poeno purpureum sanguine

Poeno. animaeque magnael prodigum Paulum superante Poeno

Poenorum. inpio|vastata Poenorum tumultu|fana

Poenos. et Marte Poenos proteret altero;

Poenus. navita Bosporum/Poenus perhorrescit

Poenus. quam si ... uterque Poenus|serviat uni.

poesis. ut pictura poesis: erit quae, si propius stes, | te capiat magis,

poeta. concines maiore poeta plectro|Caesarem.

os tenerum pueri balbumque poeta figurat.

ille per extentum funem mihi posse videtur/ire poeta.

cur ego si nequeo ignoroque, poeta salutor?

adsentatores iubet ad lucrum ire poeta

poetae. mihi Phoebus artem / carminis nomenque dedit poetae.

invenias etiam disiecti membra poetae.

defendente vicem modo rhetoris atque poetae,

nanciscetur enim pretium nomenque poetae.

dicam Siculique poetae/ narrabo interitum.

poetae. indigno non conmittenda poetae.

poetae. Eupolis atque Cratinus Aristophanesque poetae

non cessavere poetae/nocturno certare mero, putere diutno.

multa quidem nobis facinus mala saepe poetae,

dilecti tibi Vergilius Variusque poetae.

nil intemptatum nostri liquere poetae

aut prodesse volunt aut delectare poetae

poetam. omnes lii metuont versus, odere poetas [poetami].

neque, siqui scribat uti nos / sermoni propiora, putes hunc esse poetan. saepe etian. audacem fugat hoc terretque poetam,

unde parentur opes. quid alat formetque poetam,

vesanum tetigisse timent fugiuntque poetam|qui sapiunt;

poetarum. multa poetarum veniat manus, quamque poetarum seniorum turba;

si non offenderet unum |quemque poetarum linae labor et mora.

poetas. omnes hi metuont versus, odere poetas.

primum ego me illorum, dederim quibus esse poetis [poetas]. fexcerpan

$$
\text { numero: }
$$

ut nule sanos|adscripsit Liber Satyris Faunisque poetas.

veteresne poetas|an quos et praesens et postera respuat aetas?

habet hos numeratque poetas

si veteres ita miratur laudatque poetas.

qui minus argutos vexat furor iste poetas?

excludit sanos Helicone poetas|Democritus,

poetica. fidis enim manare poetica nrella|te solum,

poetis. ego me illorum, dederim quibus esse poetis, excerpam numero

*ut esset opem qui ferre poetis / antiquis posset contra fastidia nostra.*

'pictoribus atque poetis/quidibet audendi semper fuit aequa potestas.' et data Romanis venia est indigna poetis.

mediocribus esse poetis|non homines, non di, non concessere columnae.
Epist.2.2.65

Ars Poet.99

Ars Poet. 263

Ars Poet. 276

Ars Poet. 303

Ars Poel. 342

Ars Poet.t10

Carm.3.2.32

Carm.2.8.2

Carm.4.5.24

Epist.2.1.153

Epist.1.16.53

Epist.2.2.1 7

Epod.17.19

Carm.3.11.26

Epod.17.37

Strm.1.2.05

Serm.1.3.11 8

? arer.Serm.2.3.254

Fipist.1.2.61

Serm.1.8.3 I

Carm.2.12.3

Carm.1.12.38

Curm.4.4.47

Carm.3.5.34

Carm.2.13.I5

Carm.2.2.1 I

Ars Poet. 361

Carm.4.2.33

Epist.2.1.1 26

Epist.2.1.21 I

Ars Poet.87

Ars Poel.420

Carm.4.6.30

Serm.1.4.62

Sirm.I.IO. 12

Ars Poel. 299

Ars Poet.463

Epist.2.1.231

Sirm.I.4.I

Epist.1.19.10

Epist.2.1.219

Epist.2.1.247

Ars Pot. 285

Ars P'oet.333

? coni.Serm.1.4.33

Serm.1.4.42

Epist.2.I.I82

Ars Poet.307

Ars Poet.455

Serm.I.4.14 I

Serm.1.10.67

Ars Poet.29 I

Serm. I.4.33

vir. Strm. I. 4.39

Epist.1.I9.4

Epist.2.1.4 I

Epist.2.1.6I

Epist.2.1.64

Epist.2.2.90

Ars Poet.296

Epist.1.19.44

Serm.1.4.39

Serm.1.10.*6

Ars Poet.9

Ars Poet.264

Ars Poet.372 


\section{POETIS}

-

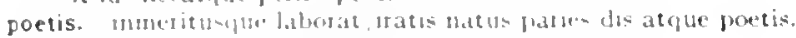

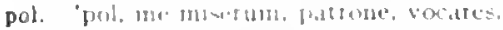

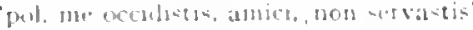

Polemon. laciantue yaod olim, mutatus l'olemon?

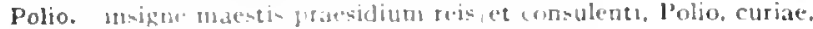

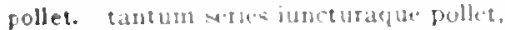

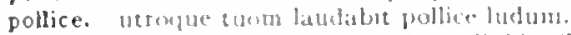

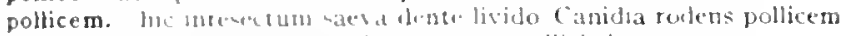

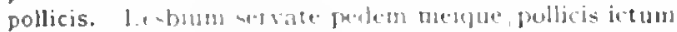

pollicitus. mon box fmlls itus tua".

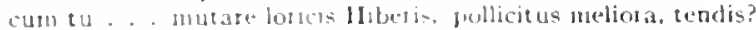

naturutm redutum pollicutus patrum, sancen concilio

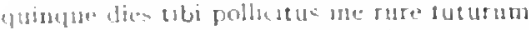

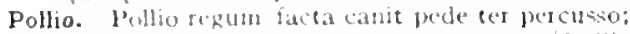

pollio. entutione telegata te dicere posinm. Pollio.

polluitur. rablic polluitut cata domus stupris,

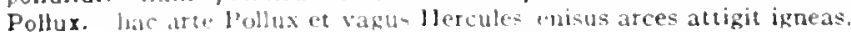

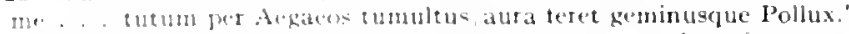

tum Castore Pollux - plotavere suis mon respondere favorem

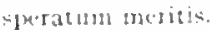

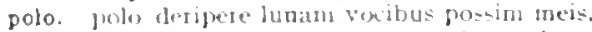

polum. animoque rotundurn percurtise polum noticuto.

ral atrit dube polum l'ater occupato vel sole puro;

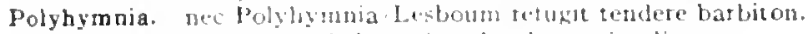

polspus. pelypus ath gravis lursueis culuet hems in aljs.

dejectane, veluti Balbisume polypus llaknas.

poma. portigi- irabe purep cush potma, teclsat:

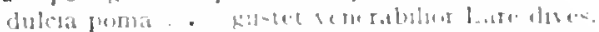

pomaria. loda moblobut inmaria rivis.

pomarius. pomardus, auceps. . . mane domum veniant.

pomifer. pornter autumbus truge- cofudets.

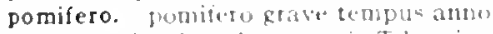

pomis. Jicenis eedunt jombis Tubrtia sue:

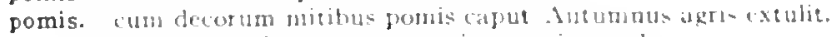

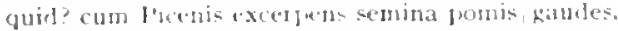

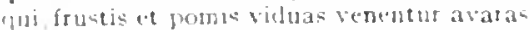

an bacis opulentet olisas., gutnisne

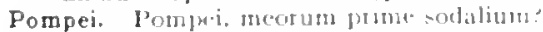

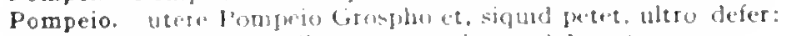

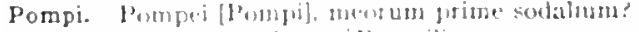

Pompili. prins als guitum l'ompili regnum menorem. . cubito.

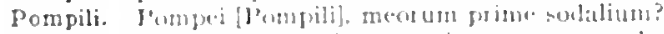

Pompilius. Vos, o Jompilium sanguis, atmen aptehendate.

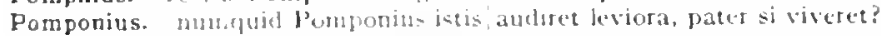

ponas. miratis. cutm cu argente post monia ponas. poras m-iknis morlu, fasciolas, cubbal, tocalia.

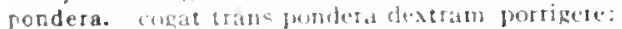

pondere. lot ora mabium gavi sostatia duct pondere

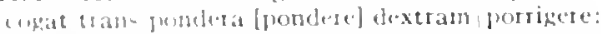

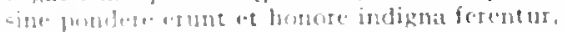

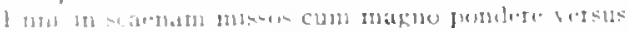

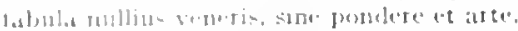

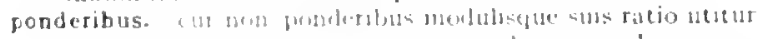

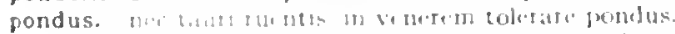

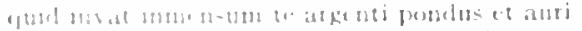

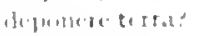

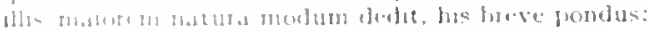

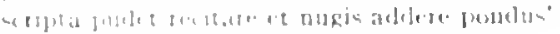

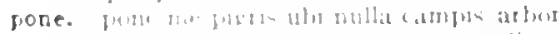

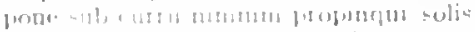

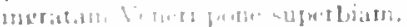

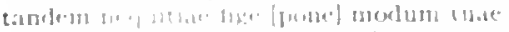

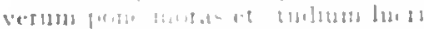

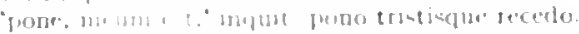

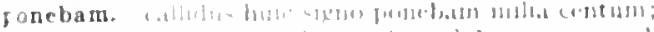

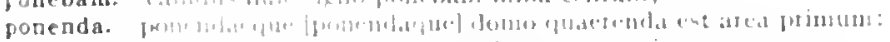

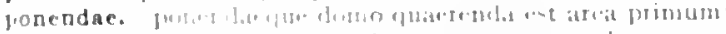

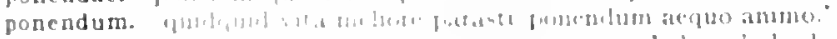

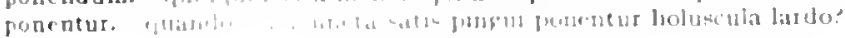

PONENTVR

Ars POCA $4^{(10)}$

Sictm.2 3.8

I.pist. I. . . 92

LPist.2 2.138

Scrm.2.3 25.4

Curm.2.1.1.

Ars Joel. 242

I.pist.1.18.00

Epod.5.48

Curm.4.0.3p

Carm.1.1532

Corm.1.2011

Curm 4.5 .3

Epist.1.7.1

ScTm.I.I0.42

Serm.1.10.85

Carm 4.5.2I

Curm.3.3.9

Can.3.20.0.4

Epist.2.1.5

Epod.17.77

Carm.1.28.0

Carm.3.29.44

Carm.1.1.33

Lpod.12.5

Serm.1.3.40

Serm.2.3.25s

arm.2.5.12

Carm.1.7.14

Serm.2.3.227

Carm 4.7 .11

Carm.3.23.8

Sicrm.2.470

lipod.2.17

Serm.2.3.272

Epist.1.1.78

Epist.1.14.3

Corm.2.7.5

Lpist.1.12.22

ior.Corm.2.7.5

Carm.1.12.34

a ar.Carm.2.7.5

Ars l'uel.292

Scrm.1.4.52

Sorm.1.1.80

scrm.2.3.254

lipist 1.7.51

lipod.4. Is

var.lisist.1.0.51

Eipist.2 2.112

Ars loot $2(\mathrm{~m}$

Ars 1'ot. 320

sorm.1.3.78

Curm.2.5.4

Serm.1.1.+1

Sorm 2.2.37

leprst.1 10.42

Carm.1 22.17

Carm.1 22.21

carm. 3.100

ior canm 315.2

(a)m.t12.25

t.pos? 1.10 .35

sermi.2.323

sar.t.piet 1.10.13

disperd 10.13

sermi.2.3.10

xem 2.0149 
ponere. tollere seu ponere volt ireta;

per nostrum patimur scelus/iracunda Jovem ponere fulmina.

inter amabilis|vatum ponere me clioros

sollers nunc hominen ponere, nunc deum.

omnem redegit idibus pecunianı, |quaerit kalendis ponere.

oppida coepernnt munire et ponere leges.

aventi|ponere signa novis praeceptis,

longa quibus facies ovis erit, illa memento, ... ponere:

potes, non otia recte $\mid$ ponere .

si velles' inquit 'verum mihi ponere nomen.

infelix operis summa, quia ponere totum/nesciet:

bona pars non unguis ponere curat. | non barbam.

si vero est, unctum qui recte ponere possit

pones. quem criminosis cumque voles modum $\mid$ pones iambis. siquid mirabere, pones/invitus.

ponet. Albanos prope te lacus|ponet marmorean fiet homo et ponet famosae mortis amorem.

ponetur. hac lege in trutina ponetur eadem.

'iste quidem vetcres inter ponetur honeste.

poni. mensam poni iubet atque/effundi saccos nummorum, vidimus et merulas poni et sine clune palumbis,

fabula, quae posci [poni] volt et spectanda [spectata] reponi [reposci];

ponimus. iurandasque tuom per numen ponimus aras,

ponis. quem criminosis cumque voles modum /pones [ponis] ianbis, .

ponit. nec sumit aut ponit securis/arbitrio popularis aurae. .

nidum ponit, Ityn flebiliter gemens, infelix avis

Chrysippus ponit fecunda in gente Meneni. -

cum ponit uterque in locuplete domo vestigia,

sed satis est orare loven quae ponit et aufert.

ut magus, et modo me Thebis, modo ponit Athenis.

iram | colligit ac ponit temere et mutatur in horas.

ponite. hic/verbenas, pueri, ponite turaque

hic, hic ponite lucida|funalia

pono. nunc itaque et versus et cetera ludicra pono,

'pone, meum est," inquit: pono tristisque recedo.

ponte. atque a Fabricio non tristcm ponte reverti.

ponti. proxima Campano ponti quae villula, tectum/praebuit

Pontica. quanvis Pontica pinus, |silvae filia nobilis.

Ponticum. cacmentis licet oecupes / terrenum [Tyrrhcnum] omne tuis et mare publicum [Ponticum]:

pontifex. dum Capitolium/scandet cum tacita virgine pontifex.

et Esquilini pontifex venefici|inpune ut V'rbem nomine inpleris meo?

pontificum. pontificum potiore cenis.

pontificum securis/cervice tinguet:

pontificum libros, annosa volumina vatum $\mid$ dictitet

pontis. pontisnc inter iactatus an amnis/ostia sub Tusci?

ponto. nititur pennis vitreo daturus|nomina ponto.

ponto. et minax, tquia sic voluere, ponto/unda recumbit.

hostiliumque navium portu [ponto] latent |puppes sinistrorsum citae.

pontum. scatentem / beluis pontum mediasque fraudes/palluit audax.

pontus. dum longus inter saeviat Jlion | Romamque pontus.

ponunt. hinc muli Capuae clitellas tempore ponunt.

popello. vilia vendentem tunicato scruta popello

popina. fornix tibi et uncta popina|incutiunt Vrbis desiderium, .

popinis. quaecumque inmundis fervent adlata popinis. .

popino. inbecillus, iners, siquid vis, adde, popino.

Poplicola. cum Pedius causas exsudet Poplicola atque/Corvinus.

poplite. Pacideiani contento poplite miror/proelia rubrica picta.

poplitibus. nec parcit inbellis iuventae/poplitibus timidove tergo.

poposceris. seu poposceris/centum iuvencos

popularibus. querentem/Sappho puellis de popularibus

popularis. nec sumit aut ponit securis/arbitrio popularis aurae. .

popularis. popularis/vincentem strepitus et natum rebus agendis.

populata. arva| Mlarte coli populata nostro.

populea. uda Lyaeo/tempora populea fertur vinxisse corona

populi. propuli contemnere voces/sic solitus

primores populi arripuit populungue tsibutim,

cum scribo et supplex populi suffragia capto;

populo. diugue/laetus intersis Iropulo Quirini

Sirm.1.3.72

Epist.2.1.43

Serm.2.3.1 48

Sirm.2.8.9I

coni.Ars Poet. 190

Epist.z.1.16

var.Carm.1.16.3

Carm-3.2.19

Carm.4.12.5

Serm.2.3.287

Serm.2.6.IOI

Epist.I.I 8. I I I

Epist.2.1.213

Ars Poet. 160

Carm.1.19.14

Carm.3.20.6

Epist.1.1.10

Epist.1.16.35

Serm.2.3.30

Serm.1.5.45

Carm.1.14.II

zar.Carm.3.24.4

Carm.3.30.9

Epod.1 7.58

Carm.2.14.28

Carm.3.23.1 2

Epist.2.1.20

Sirm.2.2.32

Carm.4.2.4

Carm.I.I2.3I

coni.Epod.9.19

Carm.3.27.27

Carm.3.3.38

Serm.1.5.47

Epist.1.7.05

Epist.I.I4.2I

Serm.2.4.02

Serm.2 7.39

Serm.1.10.28

Serm.2.7.97

Carm.3.2.16

Epod.17.38

Carm.2.13.25

Curm.3.2.20

Ars Port.8 I

Carm.3.5.24

Carm.1.7.23

Sirm.1.1.65

Sirm.2.1.60

Epist.2.2.103

Carm.1.2.40 
enin voltus ubi tuosiadfulsit populo.

gladiatorum dare centum|damnati populo paria

scurror ego ipse mihi. populo tu:

olsecurata diu populo bonus eruet

populo. me gelidum nemus / Xvmpharumque leves cum Satyris chori secernunt populo.

mestemque a populo et principe Cacsare. . a and

cum propulo et duce frandulento.

notante|judice quo nosti porulo.

in magno ut populo. siqui vidisset.

populo spectante refertel lemptum mulas apruml.

11" pueros ioram populo Medea trucidet

populorum. qua pauper aquae Daunus agrestium/regnavit populorum.

stultorum regum et populorum continct aestus.

populos. ha*c populos, have magnos formula reges.|cxcepto sapiente, tenet.

populos. antultit vieitum propagine/altas maritat populos

populum. popuhmque falsis|dedocet uti|vocibus, .

et populum reditus morantem

how fonce lerivata cladm/in patriam populumque fuxit.

primores populi arripuit populunque tributim.

populum si cacdere saxis/incipias

ne populum extrena totiens exoret harena.

servos differtum transire forum populumque iubebat.

maior utrum populum frumenti copia pascat.

tene magis salvon populus velit an populum tu.

spectaret populum ludis attentius ipsis.

statua taciturnius cxit/plerunque et risu populum quatic:

valdius oblectat populum meliusque moratur

populus. guem voce divom populus ruentis/imperi rebus?

neu populus frequens/ ad arma', cessantis 'ad arma'|concitet

cum populus irequens laetum theatris ter crepuit sonum;

nuglegens, ne qua populus laboret.

populus me sibilat. at mithi plaulo|ipse domi.

jopulus Lacvino mallet honorem / quam Decio mandare novo

gauleat ut populus Priami Priamusque inhumato.

yuodsi me populus Romanus forte roget,

si te populus sanum recteque valentem/dictitet.

cene magis salvom populus velit an populum tu.

sed two hic populus sapiens et iustus in uno

untarit mentem populus levis.

t18. quid ego et populus mecun desideret, andi.

fuo sane populus numerabilis, utpote parvos.

populus. quo pinus ingens ablique populus

qua populus alsita certis/limitibus vicina refugit iurgia;

porca. cras genium merolcurabis et porco [porea] bimenstrilcum famulis oprorum solutis.

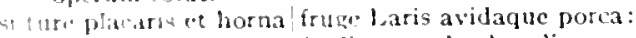

porcis. "ut litnet: hate porcis hodic comedenda relinques."

Porcius. Nomentanus erat super ipsum. Porcius infra.

porco. ctas genium merol curabis ee porco bimenstr!

quandocumque droa vel porco vel bove placat.

Tellutem porco. Silvanum lacte piabant.

porcum. inmolet acpluja/hic porcum laribus;

cum ridere volu., Epicuri de grege porcum.

porgitur. [merditur [porgitur] haec inter misero lux non sine votis:

Porphyreis. tempertivius in domum | Pauli purpureis [Porphycis] ales oloribus/comissabere Maximi.

Porphyrion. aut quirl minaci Porphyrion statu.

porrecta. imperi|porrecta maiestas ad ortus|solis ab llesperio cubili.

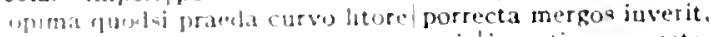

inlfectur srubllas inter nurena natantis|in patina porrecta.

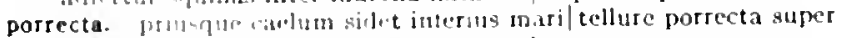

porrecta. olerust porrecta negantem pocula.

porrecto. asminal por recto iugulo historias captivos ut audit.

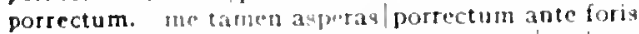

tu. cum tim*mo voce complesti nemus. proiectum [porrectum] odoraris cibusis.

"porrectum masno magnum apectare catino vellem"

ergo ubi purpurea porrentum in soute locavit/agrestem.
Curm.4.5.7

Serm.2.3.86

Fisist.1.17.19

I.pist.2.2.115

Carm.1.1.32

Carn.1.21.14

Carm.3.3.24

Serm.1.0.15

Serm.1.6.79

Epist.1.6.60

Ars PoCl. 185

Carm.3.30.12

Epist.1.2.8

Sirm. $2.3 \cdot 45$

Sipod. 2.10

Curm.2.2.19

Carm.3.5.52

Carm-3.6.20

Serm.2.1.69

Serm.2.3.128

Epist.1.1.6

Epist.1.6.59

Sist.t.15.14

Epist.1.16.27

frist.2.1.197

Epist.2.2.84

Ars l'oct.32I

Curm.1.2.25

Carm.1.35.14

Carm.2.17.25

Corm.3.8.25

Serm.1.1.60

Serm.1.0.19

Sarm.2.3.195

Espist.1.1.70

Epist.1.10.21

Epist.1.16.27

Episl.2.1.18

Epist.2.1.108

Ars Poct. 53

Ars Port.20'

Carm.2.3.9

Epist.2.2.170

*ar.Carm.3.17.15

Carm.3.23.4

lipist.1.7.19

Serm.2.8.23

Carm.3.17.15

Epist.1.10.58

I.pist.2.1.143

Serm.2.3.165

Lisist.1.4.16

cont Serm.2.6.59

conicorm.t.1.

Curm.3.4.54

Carm.t.15-15

Epot. 10.22

Serm.2.8.43

Fod.5.8o

fipist 1.18 .92

Scrm.1.3.89

Carm.3.10.3

civi Epod.6.10

Sierm. 2.2.39

Sirm. 20.100 
PORRECTVS

porrectus. obscaenoque ruber porrectus ab inguine palus, porrectus vigilet cum longo fuste .

cum pater ipse domus palea porrectus in horna

locus, ut neque planis/porrectus spatiis

ne... capsa portectus operta|deferar in vicum

porrexerat. cum passeris atque|ingustata mihi porrexerat ilia rhombi.

porrexerit. cum passeris atquelingustata mihi porrexerat [porrexerit] ilia rhombi.

porri. ad porri et ciceris refero laganique catinum;

porrigam. contracto melius parva cupidine/vectigalia porrigam :

porrigere. cogat trans pondera dextram/porrigere:

porriget. et mihi forsan tibi quod negarit | porriget hora.

porrigine. caputque/coeperis inpexa foedum porrigine?

porrigis. porrigis irato puero cum poma, recusat; .

porro. ita porrolpugnabant armis quae post fabricaverat usus,

porro et/tertia succedant

oratus multa prece nitere, porro/vade;

porro|qui metuens vivet, liber mili non erit umquam.

porrum. verum seu piscis seu porrum et caepe trucidas.

Porsenae. minacis aut Etrusca Porsenae manus,

Porsennae. quam neque finitimi valuerunt perdere $M$ arsi $\mid$ minacis aut

Etrusca Porsenae [Porsennae] manus, .

Porsinae. quam neque finitimi valuerunt perdere Narsi $i$ minacis aut

Etrusca Porsenae [Porsinac] manus.

porta. quae porta fugiens ebuma|somnium ducit? .

portanda. conservos vili portanda locabat in arca;

portantes. pueri, lasanum portantes oenophorumque.

portare. tristitiam et metus|tradan protervis in mare Creticum|portare ventis.

matris ad arbitrium recisos/portare fustis.

ultra|callidus ut soleat umeris portare viator.

sed puerum est ausus Romam portare docendum $/$ artis,

nollen onus haud umquam solitus portare molestum.

portarit. nihilo plus accipias quam/qui nil portarit.

portas. vidi ... portasque non clausas.

diffidit urbium portas vir Macedo

ut si solvas "postquam Discordia tactra|belli ferratos postis portasque refregit."

portat. caput abscissum demens cum portat Agaue|gnati infelicis.

portatur. captivom portatur ebur, captiva Corinthus.

portavit. 'quid, caput abscissum demens cum portat labscissum manibus pertavit] Agaue /gnati infelicis.

portenta. notaque fatali portenta labore subegit,

nocturnos lemures portentaque Thessala rides?

portentum. quale portentum neque militaris|Daunias latis alit aesculetis .

portes. ne forte sub ala|fasciculum portes librorum,

portet. annonae prosit, portet frumenta penusque.

equos ut me portet, alat rex, | officium facio;

porticibus. ut porticibus sic iudicis fruar

porticus. nulla decempedis / metata privatis opacam | porticus excipiebat arcton

cum lectulus aut me porticus excepit.

insanum Chrysippi porticus et grex|autunat.

porticus Agrippae, via te conspexerit Appi,

portis. laudet ... iustitiam legesque et apertis otia portis:

portu. hostiliumque navium portu latent $\mid$ puppes

portum. o quid agis? fortiter occupa|portum. .

portus. portus Alexandrea supplex/et vacuam patefecit aulam,

cave ne portus occupet alter,

poscas. ut toto non quater anno/membranam poscas.

poscat. seu poscat agna sive malit haedo.

ne quodcumque velit poscat sibi fabula credi

poscente. quae poscente magis gaudeat eripi.

suo de paupertate tacentes | plus poscente ferent:

poscentem. peccatis veniam poscentem reddere rursus.

poscentes. poscenteg vario multum diversa palato.

poscenti. quod sibi poscenti non dentur pocula.

poscentique gravem persacpe remittit acutum.

poscentis. nec trepides in usum poscentis aevi pauca:

\section{POSCENTIS}

Serm.1.8.5

Sirm.2.3.112

Serm.2.6.88

Epist.1.7.42

Epist.2.1.268

Serm.2.8.30

var.Serm.2.8.30

Serm.1.6.115

Carm.3.16.40

Epist.1.6.52

Carm.2.16.32

Serm.2.3.126

Serm.2.3.258

Serm.1.3.101

Epist.1.6.34

Epist.1.13-18

Epist.1.16.65

Epist.1.12.21

Epod.16.4

var. Epod.16.4

2ur.Epod.16.4

Carm.3.27.41

Serm.1.8.9

Serm.1.6.109

Carm.1.26.3

Carm.3.6.41

Serm.1.5.90

Serm.1.0.76

Serm.1.6.99

Serm. I. I.49

Carm.3.5.23

Carm.3.16.I4

Sorm.1.4.6I

Serm.2.3.303

Epist.2.1.193

itur. Sirm.2.3.303

Epist.2.1.I 1

Epist.2.2.209

Carm.1.22.13

Epist.1.13.13

Epist.1.16.72

Epist.1.17.20

Epist.r.1.7 I

Carm.2.15.I6

Serm.1.4.134

Sirm.2.3.44

Epist.1.6.26

Ars Poet. 199

Epod.9.19

Carm.1.14.3

Carm.4.14.35

Epist.1.6.32

Serm.2.3.2

Carm.1.4.1 2

Ars Poet.339

Carm.2.12.27

Epist.1.17.44

Sirm. I.3.75

Epist.2.2.62

Serm.2.8.82

Ars Poet.349

Carm.2.II.5 
posces. ni/ poucer ante dien librum cum lumine.

E.pist.1.2.35

poscet. of validus, w lactus erit. si demique poscet:

Epist.1.13.3

ex molico, yuntut um res poscet, acervo tollam

posci. hes verniam antiquis sed honotem et pracmia posci.

fabula. quate posci rolt et spectanda reponi;

poscimur. pessinur. si quid vacui sub umbra lusumu tecum.

poscimus. jrocimut [poscimus].

poscis. men tha creditum| poscis Ouintilium deos. tu puncis vilia, verum es dante numor

poscit. yuid dedicatum poscit Apollinen vates?

et *:L qui vinci posit [poscit] eoque lifficilis aditus primos habet.

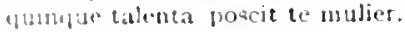

rabces posicit matores.

snleas poicit.

pocill oprem chorus et pracsentia numina sentit.

alecrius sic, altera poscit openu res

posco. "dimplicet iste locus" clamo el diludia posco.

priv orto sole vigil calanum et chartas et scrmia posco.

poscunt. media inter carmina poscunt/aut ursun aut pugiles:

Posillam. Rufam aue l'usillam [1'o-illam] appellet fortique maritoldestinet axerem:

posita. Han, transbulat in medio posita rt fugientiat captat."

positas. pu-this ut hlaciet nive's puro numine Iuppiter?

qui pracgravat artes! infra se positas:

positi. pauper Opunuc argenti positi intus et auri.

positis. dues agris, dives positis in faenore nummis. posit is me Chii seterisque Falcini mille cadis.

duven abin, dives positis in laenore numuis."

positis. somumqu" prematus in annum/membtanis ind prositic;

positis, ut pinum positis nugari Graccia bellis coepit

posito. pusito pason velis gun loc pouus quam sallina tergese palatum.

posito. Rutus pusitu capite, $1 \mathrm{t}$ if filus immaturus obisset, flere.

positorum. si horke in medin positorum

positos. pusitoifuce vernas, ditis cxamen domas.

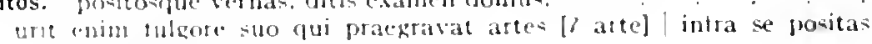
[1 ponitos]:

positum. liluer Argeo positum colono

luppiter, ut pereat posstum robigine tedum

positum. "leposen venator nt alta in nure accetur, positum sic tangere nuelit'

aut fortum ante mea quia pullum in parte catini sustulit esuriens.

positum. vic joutum servabin onus.

positurus. numkinam umeris poiturus arcum

positus. pontuspue carbes in caespite viser.

posse. gus nexol arduis, promos relabi posse rivos, montibus

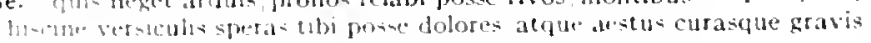

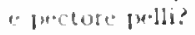

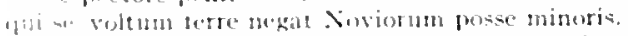

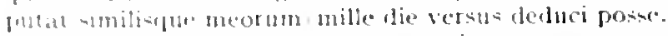

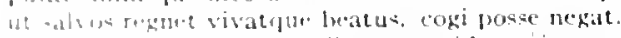

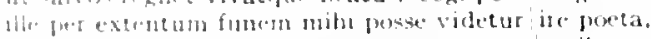

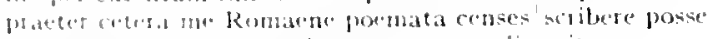

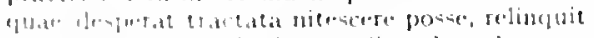

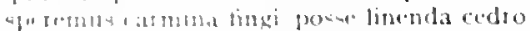

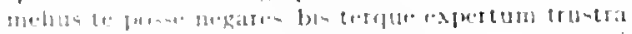

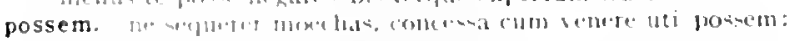

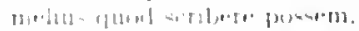

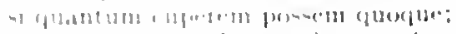

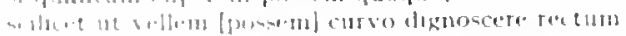

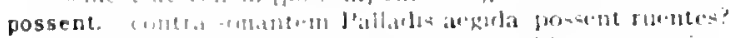

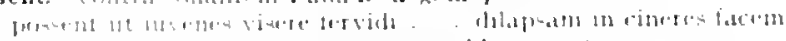

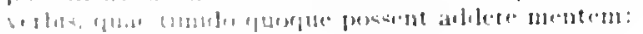

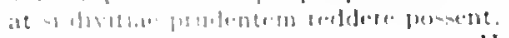

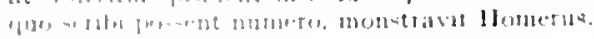

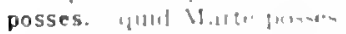

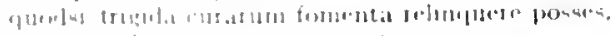

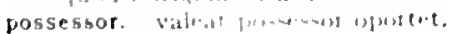

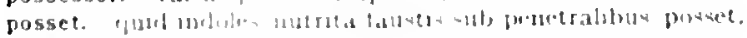

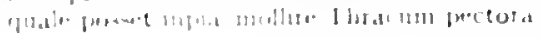

Epist.2.2.190

Epist.2.1.78

Ars Poct. 190

Carm.1.32.1

tor.Curm.1.32.1

Carm.1.24.12

Epist.1.17.21

Carm.1.31 t

coni.Serm.1.9.55

Serm.2.7.90

Serm.2.8.35

Serm.2.8.77

Epist.2.1.134

Ars Poet.aII

Epist. 19.47

Epist.2.1.113

Esist.2.1.185

Ior.Serm.2.3.216

Sirm.1.2.108

Carm.3.10.7

Epist.2.1.1.

Serm.2.3.1 $\$ 2$

serm.1.2.13

serm.2.3.115

Ars Loct.12I

irs Poet.389

l.pist.2.1.93

Serm.2.2.23

Sermi. 2.8 .58

Lisist.1.12.7

f. pod.2.65

7 gar Epist.z.1.14

Carm.2.6.5

5 crm.2.1.43

Sirm.1.2.500

Sirm.1.3.92

tipist.1.13.12

Carm.3.4.60

Carm.3.8.3

Carm.1.29.11

Serm.3.2.100)

Sirm. I. I. 21

Sirm.2.1.t

Epist I $2.1 \mathrm{I}$

Epist.2.1.210

Epist.2.2.06

Irs Port. 150

Ars P'oet. 332

Ars Poct. $\$ 39$

serm.1.4.119

Serm.1.10.47

I.pist.2.1.257

isr.t.pist.2.2.14

Cirm.3.4.58

(urm.t 1.3.20

Ifpist.2.2.3"

d.pt.t.2.2.155

ies Port 74

(iarm.4 149

f. post a 3.20

tepist 0.2 .42

Carm+427

I pil 5 I. 
quo posset intossus puer

Caesar, qui cogere posset.

durus homo atque odio qui posset vincere Regen?,

magnum adiutorem, posset qui ferre secundas.

*ut esset opem qui ferre poetis/antiquis posset contra fastidia nostra.* .

scilicet elabi si posset mortua;

quodque posset cenantis offendere:

chlamydas . . si posset centum scaenae praebere rogatus.

nec vicina subest virum praebere tabernalquae possit [posset] tibi

sed tacitus pasci si posset corvos.

per quae |crescere res posset, minui damnosa libido.

temptavit quoque rem si digne vertere posset

conis in uxorem. posset qui ignoscere servis

posset qui rupem et puteum vitare patenten.

possideam. segnis ego, indignus qui tantum possideam :

possidentem. non possidentem multa vocaveris/recte beatum;

possim. polo|deripere lunam rocibus possim meis.

possim crematos excitare mortuos

mi satisest si . . vitam famamque tueri|incolumem possum [possim];

felicen dicere non hoe/me possim.

loc erat. . . melius quod scribere possem [possim], inventore minor conda et compono quae mox depromere possim.

quid possim videt ac novit me valdius ipso.

pinguis ut inde domum possim Phaeaxque reverti -

scilict ut vellem [possim] curvo dignoscere rectum

possint. vix durare carinae|possint imperiosius|aequor?

possent [possint] ut iuvenes visere fervidi... dilapsam in cineres facers

carmina quae possint oeulos aurisque morari|Caesaris.

possis. possis nihil urbe Romal visere maius.

vix credere possis. /quam sibi non sit amicus.

matronae praeter facien nil cernere possis/cetera.

metiri possis oculo latus.

cum flueret lutulentus, erat quod tollere velles [? posis];

quod superat non est melius quo insumere possis?

dictantis, quod tu numquam rescribere possis.

nil sane fecit quod tu reprehendere possis:

quando iterum paveas iterumque perire|possis.

non possis oculo quantum contendere Lynceus:

lenire dolorem possis et magnam norbi deponere partem.

'rem facias, ren. / si possis, recte, si non, quocumque modo, rem.'

Augusti laudes agnoscere possis;

vendere cum possis captivon. occidere noli:

cum raleas et |vel cursu superare canem vel viribus aprum| possis.

possit. triumphatisque possit Roma feros dare iura Ifedis.

non aquilo impotens possit diruere

irigus quo duranuqu famem propellere possit. .

raesar, qui [quod] cogere posset [possit].

rideri possit eo quod 'rusticius tonso toga defluit

videamus uter plus scribere possit.'

nan quis me scribere plures aut citius possit versus?

et est qui vinci possit

nemo adeo ferus est, ut non mitesce possit.

rursus, quirl virtus et quid sapientia posait.

qui sapere et fari possit quae sentiat

quae possit facere et servare beatum.

ut copia nuajor ab Iove donari possit tibi.

quid velit et possit rerum concordia discors.

nec vicina subest vinum praebere tabernalquae possit tibi

nec rude quid prosit [possit] video ingenium:

si vero est, unctum qui recte ponere possit

possum. ut siquid promittere de me|possum aliud vert, promitto.

si . . vitam famamque tueri incolumem possum:

felicen dicere non hoc ne possim [possum]. casu quod te sortitus anicun:

has nullo perdere possum I nec prolibere modo.

ambitione relegata te dicere posium.

'equidem nihil hinc diftindere possum.

ius anceps novi. causa defendert possum; lipod.5.3.2

Serm. I. 3.4

Serm.1.7.6

serm.1.0.4h

Serm.I.10.*7

Serm.2.5.87

Serm.2.8.13

Epist.1.6.4I

zar.Epist.1.14.25

Epist.I.17.50

Epist.2.1.107

I.pist.2.1.164

Epist.2.2.133

Efist.2.2.135

Sirm.2.3.236

Curm.4.9.45

Epod.17.78

Epol.17.79

?ar. Serm. 1.4.II

Serm.1.6.53

zur.Serm.1.10.47

Epist.1.I.I2

Epist.1.9.t)

Epist.I.15.24

tur.Epist.2.2.44

Curm.1.1 4.8

?ar.Curm.4.13.26

Epist.1.13.17

Carm.Saec. I I

Serm.1.2.19

Serm.1.2.94

Strm.I.2.IO3

f ior.Serm. I.4.II

Serm.2.2.JO2

Serm.2.3.76

Serm.2.3.135

5 .rm.2.7.70

Epist.1.1.28

Epist.1.1.35

Epist.1.1.60

Epist.1.16.29

Epist.1.ro.69

Epist.t.18.52

Carm.3.3.43

Carm.3.30.4

serm.1.2.0

atur.serm.1.3.4

Serm.1.3.30

Sirm.1.4.16

Serm.1.9.24

Serm.I.9.55

Epist.1.1.39

Epist.I.2.I

Epist.1.4.9

Epist.1.6.2

Epist.1.12.3

Epist.1.12.10

lipist.1.14.25

tar. Ars Poet.qIo

Ars Poet.422

Sirm.1.4.103

cerm.I.4.IIo

2ar.Serm.1.6.53

Germ.1.8.20

Sierm.1.10.84

Serm.2.1.79

serm.2.5.34 
"qui possum tot?" ait:

Epist.1.6.42

unspice. st possum donata reponere laetus.

Epist. I.7.39

rure now possurn quidvis perferte patique:

rure meo possun quidvis [? quidvis possum] perferre patique:

Epist.1.15.17

ego cur, arlquirere paucal si possum, invideor.

7 iar.FPist.1.15.17

Ars l'ocl. 56

Corm.t.8.1 I

7 sar.Carm.1.14.8

possunt. vix durare carinat, possine [? possunt imperiosius aceluor?

gar.Carm.1.20.10

nil sine te mej' prosunt [possunt] honores:

felicun dece non loc | ne posim [possunt]. casu quod te sortitus anterum:

dem radem possunt horam dusare probantes?

:ar.serm.1.0.53

Espist.1.1.82

nullat platere diu nec vivere carmina possunt.

Fisist.1.19.2

post. Carm.1.3.20:1.12.33; 1.15.35; 1.18.5; 3.1.40;3.7.0;3.9.6;3.21.19;4.4.45; 4.8.15;4.13.21; Sern 1.0.40; 1.0.55; 1.0.122; 1.8.36; 1.10.33; 2.2.118; 2.2.123; 2.3.300; 2.4.60; 2.8.31;

Serm.2.8.44; Efist.1.1.54;1.7.59;1.7.71; 1.8.13; 1.10.49;2.1.6;2.1.1.40;2.1.162;2.1.175; List.2.2.28; 2.2.39; Ars I'ort.141; 275; 401

post. Carm.3.20.3; Epod.5.99; Scrm.1.1.86; 1.2.120; 1.3.102: 1.4.88; 1.0.61; Iar.Serm.2.6.72; Fpist.1.0.43; 1.18.83; Ars Poct.70; 11 I

postella. "acditicare casas. plostello [postella] adiungere muris. . . siquem delectu barbatum:

postello. "atditure casas, flostello [josteblol adjungere muris. . . siquem delecte't barbatum:

postem. armisllerculis at postem fixis

postera. po-tura bux oritur uulto gratissima:

posterat tendrestas mrolior, via prejor

in quoa ex pransonset postera tespuat atetas?

postera. usfu. "go postera crescam laude reerns.

posteri. Baclum, vidi docentem. credite posteri. Sinjulasque discentis

Romanus aneu - posteti negabitis - enancipatusteminate. . posterius. quod prius ordine verbun est posterius facias.

postero. carjw diem quam minimusn credula postero.

postgenitis. audeat refrenare licentiam.|clarus poitgesutis: .

posthac. (non enim posthac alia calebolfemina)

necue se fore postbac/tam facilem dicat.

o magnus frostlac iniuicis risus.

posehac a" conpellarer inultus.

postibus. Jeregta Parthorum superbis postibus

postibus. "us invidendis postibus et novo subline ritu moliar atrinm?

postico. atria servanten postico falle clientem.

postis. al non andicos he"u mihi postis

ut si solvas "postquam Discordiat tietra belli ferdatus postis poltasque tritregre.

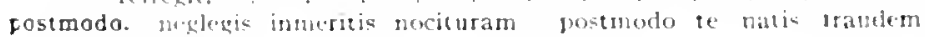
commitcerces

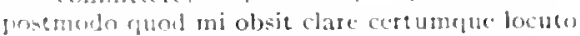

postponet. Gertongetponce honestum ofticium.

postquam. barbaraw postquan cecidere turmae

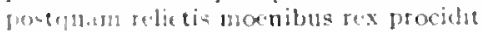

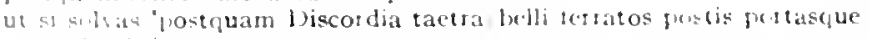
revinent.

poseruams mbil inter utrumplue / convenit

at (j)

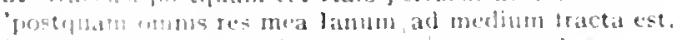

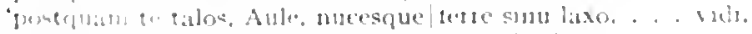

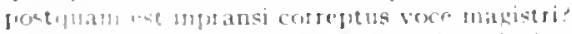

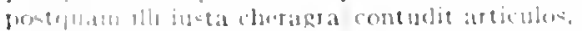

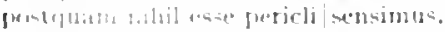

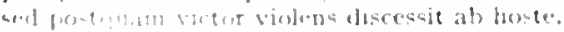

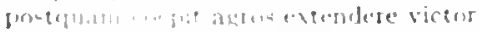

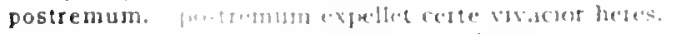

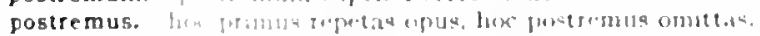

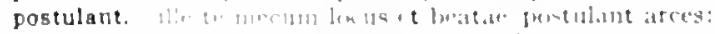

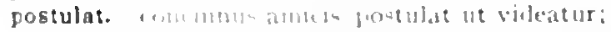

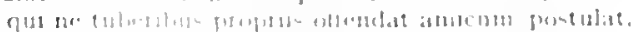

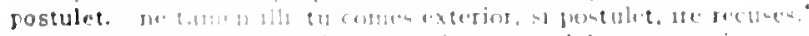

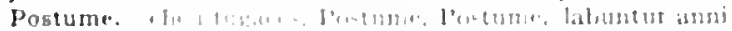

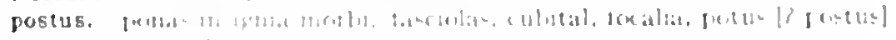

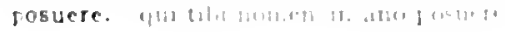

tar.Serm.2.3.247

:ar.Serm.2.3.2.47

E.pist.1.1.5

Sirm.1.5.39

Serm.1.5.90

Epist.2.1.42

Carm.3.30.7

Corm.2.19.2

Epod.o.11

Sirm.1.4.50

Cirm.1.11.8

Carm.3.2430

Carm.4. 11.33

sermiti.t.21

Serm.2.2.107

Sicrm.2.3.207

Carm.4.15.8

C"arm.3.1.45

If pist.1.5.3I

Ifpod.11.21

serm.t.at

Ciom.1.2S.31

sirm.2.0.27

L.fist.1.18.34

Carm.2.4.9

I. pod.17.13

Sirm. 1.4.eo

serm. 1.7.9

Sirm.1.7.32

Serm.2.3.18

serm.2.3.171

scrm.2.325i

verm.2.7.15

term.2.8.57

I: pist.1.80.37

irs l'uel 21 h

verm. $2=1.32$

fipest i t...8

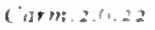

serma 151

serm.1.3.7.

sarm.2.5.17

(i) 2.10 :

1 teir.surm 23.255

sermas. 34 
posui. libera per vacuon posui restigia princeps,

posuisse. hinc apicem rapax / Fortuna cum stridore acuto/sustulit, hic posuisse gaudet.

torvos lumi posuisse voltum,

arbiter pugnae posuisse nudo|sub pede palmam

posuisset. isti|errori nomen virtus posuisset honestum.

posuit. ille et nefasto te posuit die

procidit late posuitque collum in |pulvere Teucro;

pota. et cantu tremulo pota Cupidinem|lentum sollicitas.

potabis. vile potabis modicis Sabinum|cantharis,

potamus. cur non ... dum licet. Assyriaque nardofpotanus uncti?

potandum. quod nusquam tibi sit potandum.

potantia. Aquinatem potantia vellera fucum.

potare. post hoc ludus erat fculpa potare magistra

qui Veientanum festis potare dicbus|Campana solitus trulla

dictus here illic/de medio potare die."

potare et spargere flores incipiam

potavi. vile potabis [potavi] modicis Sabinum|cantharis.

potens. ille potens sui|laetusque deget dicar. . . ex humili potens.

potens. sic te diva potens Cypri. . . regat

pudor|inbellisque lyrae Musa potens vetat

imperet hoc natura potens, sic collige mecun.

hos arto stipata theatro|spectat Roma potens,

loquatur... matrona potens an sedula nutrix.

potens. o Naiadum potens|Baccharumque valentium

potens. a crudelis adhuc et Veneris muneribus potens,

Phoebe silvarumque potens Diana,

potentem. nec potentem anicum|largiora flagito.

quae simul centum tetigit potentem |oppidis Creten,

potenter. cui lecta potenter erit res.

potenti. uvida|suspendisse potenti|vestimenta maris deo.

potenti. sic potenti|Iustitiae placitumque Parcis.

potentior. quandoque potentior|largi muneribus riserit aemuli,

potentiorum. superba civium | potentiorum limina.

potentis. tu cede potentis anici|lenibus imperiis.

dulcis inexpertis cultura potentis amici.

potentis. utcumque mutata potentis|veste domos inimica linquis, manus potentis/Medus Albanasque timet securis.

potentium. virtus et favor et lingua potentium / vatum

potentius. et perrumpere amat saxa potentius|ictu fulmineo: nec virtute foret clarisve potentius armis|quam lingua Latiun.

poteras. "attamen et iustum poteras et scribere fortem. si de quincunce remota est/uncia, quid superat? poteras dixisse." .

poterat. Varius mappa conpescere risum/vix poterat.

si de quincunce remota est | uncia, quid superat? poteras [poterat] dixisse." poterat duci quia cena sine istis:

poteris. quin id erat curae. quo pacto cuncta tenerem / utpote res [ut poteris] tenuis, tenui sermone peractas.'

cum pateris [poteris] sapiens emendatusque vocari, | respondesne tuo, dic, sodes, nomine?

rem poteris servare tuam.

poterit. quis te solvere Thessalis/magus venenis, quis poterit deus? . nec scarus aut poterit peregrina iuvare lagois.

hic tamen ad melius poterit transcurrere quondam.

"putasne. / perduci poterit tam frugi tamque pudica. quam qui non poterit vero distinguere falsum.

potero. 'cur hoc'? dicam, si potero.

poterunt. liaec et quae poterunt reditus abscindere dulcis piacula. quae te/ter pure lecto poterunt recreare libello. nil|divitiae poterunt regales addere maius. quae poterunt unquam satis expurgare cicutae. rem tibi Socraticae poterunt ostendere chartae.

potes. tu potes tigris comitesque silvas/ducere dum potes, aridum/conpone lignum:

potes hac ab ornol pendulum zona bene te secuta e- lidere collun. quin huc inanis, si potes, vertis minas

Inachiam ter nocte potes, mihi semper ad unum mollis opus.

Carm.1.34.10

carm.3.5.47

carm.3.20.15

Serm.1.3.42

Carm.2.13.5

Carm+46.I I

Corm.4.13.5

Carm.I.2O.I

Carm.2.11.17

Serm.2.7.32

Epist.1.10.27

Serm.2.2.123

Sorm.2.3.143

Serm.2.8.3

Epist.1.5.1 4

coni.Carm.1.20.I

Carm.3.29.41

Carm.3.30.12

Carm.1.3.I

Carm.1.0.10

Sirm.2.1.5I

Epist.2.1.ti

Ars Poet.1 16

Carm.3.25.14

Carm.t.10.I

Carm.sarco.

Carm.2.18.12

Carm.3.27.33

Ars Poet.4o

Carm.15.15

Carm.2.17.15

Carm.4 1.17

Epod.2.8

Epist.1.18.44

Epist.t. I 8.80

Carm. I 35.23

Corm.Saec.53

Carm.4.26)

Carm.3.10.10

Ars Pott. 289

Serm.2.1.10

Ars Port. 328

Serm.2.8.64

:ar.Ars Poet.328

Ars Poet.376

idur. Serm.2.4.9

zar. Epist.1.10.30

Ars Poet. 329

Carm.1.27.22

Serm.2.2.22

Sirm.2.2.82

Serm.2.5.7.

Epist.1.10.29

Serm.2.2.8

Epod.10.35

Epist.1.1.37

Epist.1.12,6

Epist.2.2.53

Ars Poet. 310

Carm.3.11.13

Carm.3.1\%.13

Carm.3.27.58

Epod.0.3

Lpod.12.15 


\section{POTES}

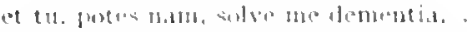

Spod.1 7.45

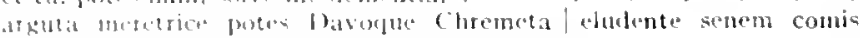

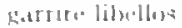

sbutge sulumb. et. a pallum potes inlacrimare.

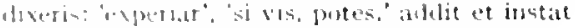

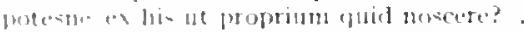

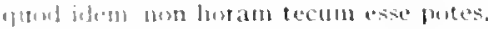

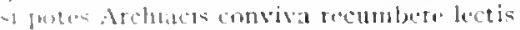

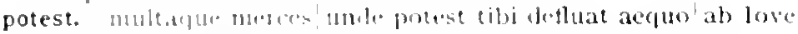

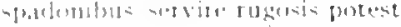

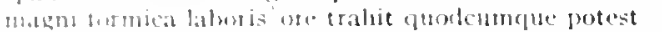

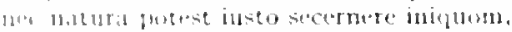

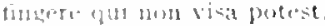

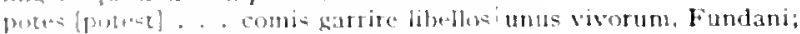

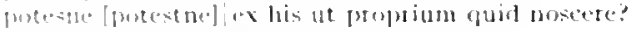

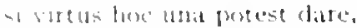

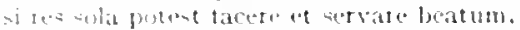

potestas. "itme marto matronic percantis in ambo insta potestas.

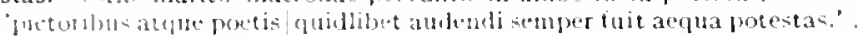

potestatem. alate putentaten Tulli atque ignobile regnum

potet. si... atcte protet acetum;

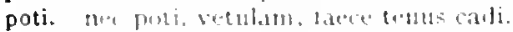

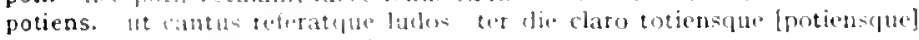

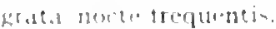

potietur. "x-trum un in allam divitic poticetur heres.

potionibus, non unitatiz. Vatee, putimibus.

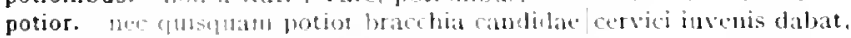

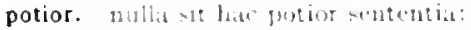

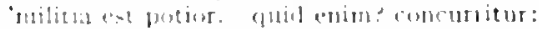

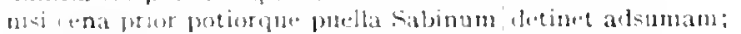

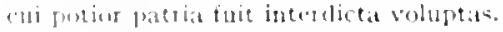

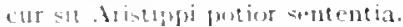

potiore. ban" rano bum mollitis potioge placentis.

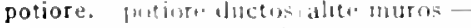

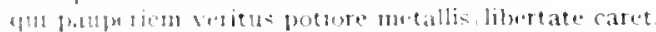

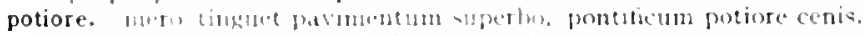

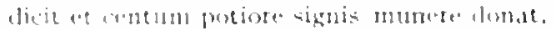

potiorem. Herietine hecum pustorem ruse beater?

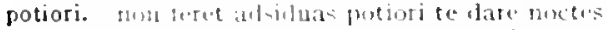

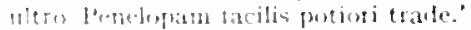

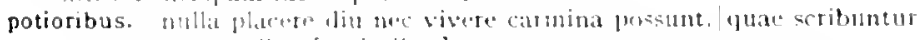

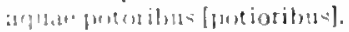

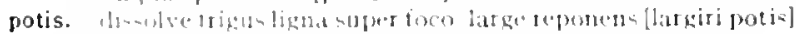
dum poene [portis]. arblum | conpone lignum:

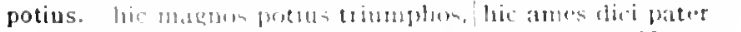

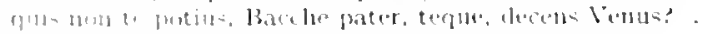

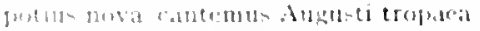

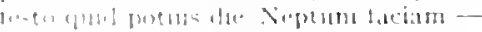

; w

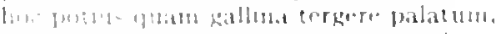

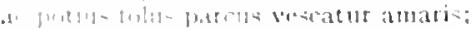

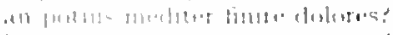

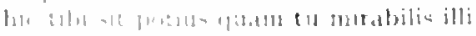

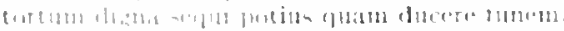

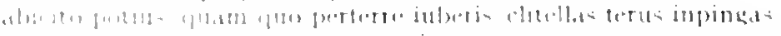

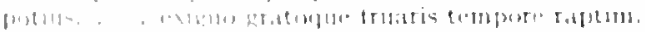

potor. 116 | A H

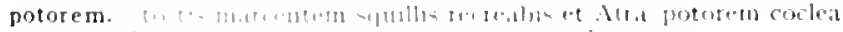

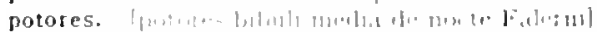

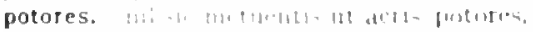

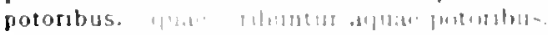

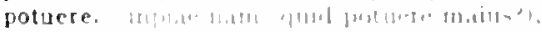

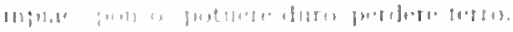

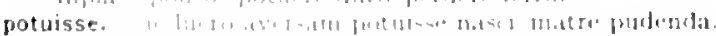

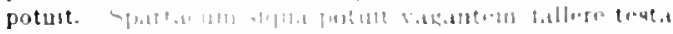

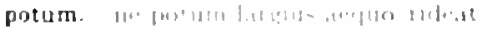

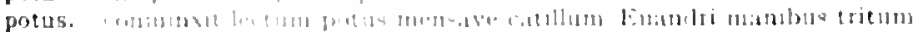

$$
\text { 1. } 1.111
$$

Serm.1.10.80

Sirm.2.5.103

Sirm.2.1.30

$\sin 2.7 .83$

Serm.2.7.112

Epist.1.5.1

Curm.J.28.28

Fipod.9.14

Serm.1.1.34

Serm.1.3.113

Sern.1.4.8.4

rar..Serm.1.10.40

far..serm.2.7.83

Jisist.r.0.30

Epist.2.8.47

Serm.2.7.62

Ars Potio

Sirm. 1.0 .9

Verm.2.3.117

carm.3.15.10

Sar.Carm.Sace.23

(armi.2.3.20

Epod.5.73

Carm.3.0.2

lipod.10.17

Serm.j.1.7

Epist. 5.27

I:pist.1.61,04

fipit.1.17.17

Lipistiso.jt

(arm.19.23

Lipist. in. 30

(iarm.2.14.28

(iorm? 2.10

J.pist.1.11). It

1.pod.1.5.13

Sicm.2.5. 56

:ur. Itpist.1.19.3

iar. Carm.1.0.6

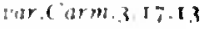

Cirm.1.2 to

(iorm.1 18.6

Cirm.2.0.18

(istm.3.28.1

Sorm.1.1.100

Sirm.2.2.24

Sorm.2.314

Sirm.2.3.203

Jipist 1.023

Epot.1.11.48

IEpist 1 13.7

liptst.22.127

Cism.2 20.20

Torm.2.450

ast L prof $1.38 .0 \mathrm{t}$

cern.2.8.37

I.pis! 1. (1) .3

Ciarm 311.30

ciorm $\{11,31$

(ium.2..410

(iirm 31410

fipt. 22215

Semi 3.00 
aspergere cunctos|praeter eum qui praebet aquam; post hunc quoque potus,

potus ut ille/dicitur ex collo furtin carpsisse coronas,

Ennius ipse pater numquam nisi potus ad arma|prosiluit dicenda.

spectator functusque sacris et potus et exlex.

Praates, ius imperiumque Phraates [Praates] / Caesatis accepit genibus ininor; prae. cunctane prae Campo et Tiberino flumine sordent?
praebeat. neque se fore posthac | tam facilem dicat, votis ut praebeat aurem?

nescis quo valeat nummus, quem praebeat usum?

praebebit. nec sic ut simplex Naevius unctam|convivis praebebit aquam:

praebente. quo praebente domum . . . taces.

te consilium et tuos praebente divos.

Murena praebente domun, Capitone culinan.

praebentem. ut sibi praebenten mimo spectacula plura.

praebere. chlanydas . . si posset centum scaenae praebere rogatus, nec vicina subest vinum praebere taberna|quae possit tibi

metues, liberrime Lolli, | scurrantis specien praebere, professus amicum.

praeberi. avitalex re praeberi sumptus mihi crederet illos.

praebes. fessis vomere tauris/praebes et pecori vago.

praebet. ver ubi longum tepidasque praebet Iuppiter brumas exemplun grave pracbet ales|Pegasus

avet quavis aspergere cunctos/praeter eum qui praebet aquam;

praebuit. proxima Campano ponti quac villula, tectum|praebuit

praecanum. corporis exigui, praecanum, solibus apturn. . . . essem.

praecedentibus. nec tardum opperior nec praecedentibus insto.

praecedere. 'non faciam'ille, |et praecedere coepit;

praecedes. ibimus.|utcumque praecedes. .

praecedet. quaecumque praecedet fera;

praecepit. (nec meus hic sermo est. sed quac praecepit Oiellus/rusticus.

praeceps. et pracceps Anio ac Tiburni lucus

quin per mala praeceps|iertur

praeceps. quem damnosa venus, quem praeceps alea nudat.

et tulit eloquium insolitum facundia pracceps

praecepta. unde ego miral descripsi docilis praecepta haec.

ipsa memor praecepta canam, celabitur auctor.

atque haurire queam vitae praecepta beatae.'

nunc in Aristippi furtim praecepta relabor

praeceptis. ponere signa novis praeceptis.

mox etiam pectus praeceptis format amicis.

praeceptum. praeceptum auriculis hoc instillare menento: .

praecidere. Antenor censet belli praecidere causam:

praecincti. ut omnes/praecincti recte pueri comptique ministrent?

praecinctis. altius ac nos/praecinct is unum:

praecipe. praccipe lugubris/cant us, Melpomene,

praecipies. quidquid praecipies, esto brevis.

praecipitat. Hellade percussa Marius cum praecipitat se.

praecipitem. nec timuit praecipitem Atricum/decertanten Aquilonibus hic se praecipiten tecto dedit.

praecipiti. casus medicusve levarit aegrum ex praecipiti:

praecipue. sapiens... praecipue sanus, nisi cum pitvita molesta est. praecipue cum se numeris commentat et arte.

praeclara. sicui praeterea validus male filius in re/praeclara sublatus aletur.

praeclara. atqui voltus erat multa et praeclara minantis,

praeclaram. avi cur atque parentis / praeclaram ingrata stringat malus ingluvie rem.

praeclare. hoc ego commodius quam tu, praeclare serator, . . vivo.

praeclaro. qui turpi secernis honestuni non patre praeclaro.

praeco. si praeco parvas aut, ut fuit ipse, coactor/mercedes sequerer: ut pracco. ad merces turbam qui cogit emendas

praeconem. praeconem, tenui censu, sine crimine, notum

praeconis. praeconis ad fastidiun

Galloni praeconis erat acipunsere mensa/infanis.

praecordia. neque est levare tenta spiritu praecordia. condita cum verax aperit praecordia Liber.

leni praecordia mulso prolueris melius.

praecordiis. et inquietis adsilen praecordiis quodsi meis inaestuet praecordiis libera biliz.

Serm.5.4.88

Serm.2.3.255

Epist.1.19.7

Ars Poet.22.

zar.Epist.1.12.27

Epist.1.11.4

Serm. I. I.22

Serm.I.I.73

Serm.2.2.69

Carm.3.19.7

Carm..4. 1.34

Sirm.1.5.38

List.2. I.198

Epist.1.6.41

Epist.1.1 4.24

Iipist.1.1 3.2

Serm.1.0.S0

Cerm.3.13.I2

Carm.2.0.1 7

Carm..t.1 1.26

Sirm.1.4.88

Serm.1.5.46

Epist.1.20.24

Epist.1.2.71

Serm.I.9.42

Carm.2.17.1 I

Epod.0.8

Serm.2.2.2

Carm.1.7.13

Sirm.1.4.30

Epist.1.18.2 I

Ars Port. 217

Strm.2.3.34

Serm.2.4. I I

Sirm.2.4.95

Epist.t.t.1 8

Serm.2.4. 2

Epist.2.1.128

Epist.1.8.1 6

Epist.1.2.9

Sirm.2.8.70

Sirm. I.5.6

Carm.1.24.2

Ars POAt.335

Serm.2.3.277

Carm.1.3.1 2

Sirm.1.2.4 I

Sirm.2.3.293

Epist.r.1.108

Epist.2.1.26I

Sirm.2.5.46

S.rm.2.3.9

Serm.1.2.8

Sermero.tro

S'erm.1.0.04

Sirm.1.0.86

Ars J'ot't. 49

Epist.1.7.56

Epod.1.I2

Serm.2.2.47

I.pod. 7.26

Serm.1.t.89

Serm.2.4.26

Epod. 5.95

ISpol.11.5.5 


\section{PRAECORDIIS}

praecordis. quid hoc venconi silevet in praecordiis?

praecurrere. licet. , seges et regum vita praccurrert amicos.

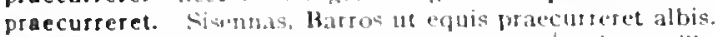

praeda. gratule certamen, tibi praeda cedat. maiot an illa. .

cervi. luporum praeda rapacium.

opima tuodei praeda curso litorel porrecta mesgros iuverit

praeda. an magis excots|rejecta pracda, quan praesens Mercurius fert"

praedae. quictiuld erat metus pracdae maioris.

praedae. teneracque sucus|detuat praedae.

praedam. adicisse pracdam torquibus exinuts renidet.

praedantur. singula de nobis anni praedantur cuntes:

praedia. Canusi luo praeclia. . . gnatis divisse duobus

nulicibus promissa Triquetra| pracdia Cacsar an est Itala tellure daturus?"

qui pracdia vendit, I nil sersile gula" parens habet?

praedonum. fugiens hic decidit actem, praedonum in turbam.

pracferat. cur alter iratrum cesare et ludere et ungui|pracferat llerodic valmetis pinguibus.

praefluent. sed quae Tibur acuae fertile praetluont [praefuent]

praefluit. qui rogna Dauni praefluit Apuli.

praefluont. sed quae Tibur aquae fersile practluont

praefluunt. sed quate Tibur aquae tertile [raeffuont [praefuunt].

praegestientis. in udo'ludere cum vitulis salicto fraegestientis.

praegnans. Impon parrat reventis onnetr ducat et praegnans canis

praegravat. quin corpus onustum | hesternis vitis animum quoque prategrat una

qui pratgravat artes/intra se positas

praelambens. patambens omne quod alliet

praelucet. "nullus in of be sinus bais praclucet andents"

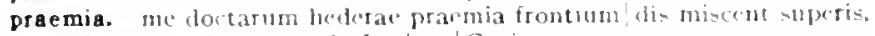

praemia. tripodas, pracmia fortium/Graiorum,

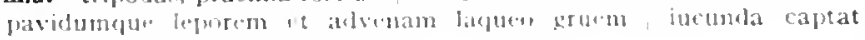
praximia

issani ridentes praemia scribar.

multa laborum praemia laturus.'

prima feres hederat victricis praemia

irones ad uslyanace elescendi praemia.

nec seniam antiquis sed honorem et prannia frosi.

prandua laturus merstorum praemia. quid stas?"

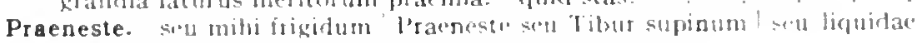

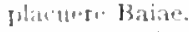

Praeneste. dum tu doclanas komae, l'sarmese relegi:

Praenestinus. tum l'racosestinus salso multogue thensi

praeniteat. cus tibi innior lawa praeniteat tid.

praenomine. (gaudent pracnomine molles'auriculae)

praeparat. sule os eq vincta crepat mosa. prateparat ulmus.

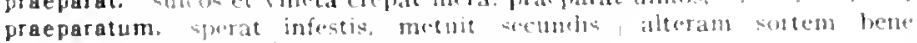

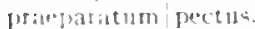

praeponens. praeponena ultima primis.

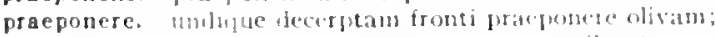

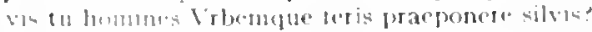

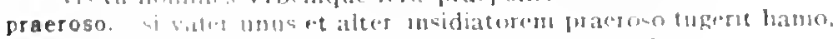

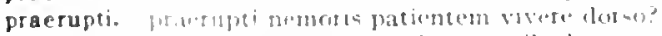

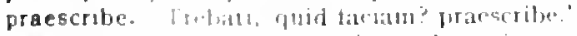

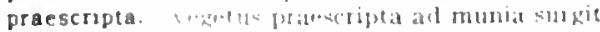

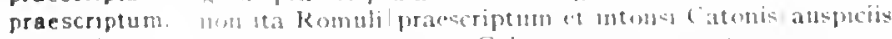

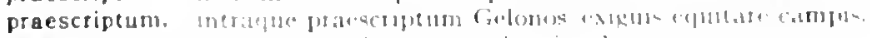

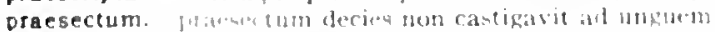

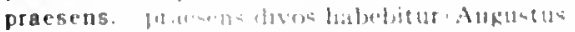

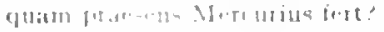

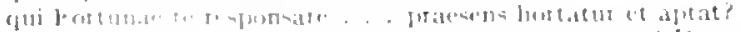

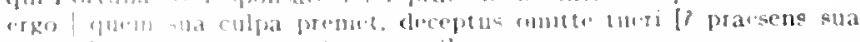
(a)

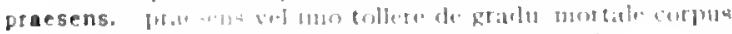

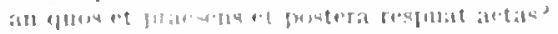

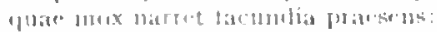

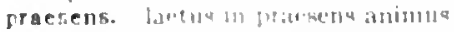

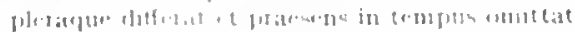

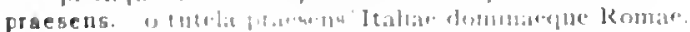

PRAESENS

Iipod.3.5

Lisist.1.10.3.3

Serm.1.7.8

Carm.3.20.7

Carm.t. 50

lepod.in.2I

Serm.2.3.1.

Epist.1.15.38

Corm.3.27.5.5

Carm.3.11

Epist.2.2.55

Serm.2.3.14.8

Serm 2 p. 50

Serm.2.7.110

Serm. 2.43

Fist.2 2184

iar. Carm.4.3.10

carm.t420

Carm-4.10

:ar.Carm 43 10

Carm.2.5.9

Carm 3.27.2

Sorm 2.2.78

Spist.2.1.13

Sirm.2.0.100

Epist.1.8 83

Cirm.1.1 20

Carm \& 83

1. pod $2.3^{\circ}$

serm.15.35

Serm 2.112

I.pist.1.3.25

Epost. 1.0.11

Epist.2.1.7s

Evist 2.2-3k

Corm.3.23

I.pist 1.2.2

Sorm. 1.7.28

Carm.1.33.1

Sorm 2.5.32

1.pist.1.7.84

(arm.2.10.14

virm 1.513

(arm 17.7

Serm.20.02

Shm.25.25

Sorm.2eul

Srm.21.5

trem.22 21

(arm: 2 15 11

(arm.2.223

Ars Jinel.212.

carm. 35.2

serm 2 a is

lpost i 1 (1)

I war liport.1.18.79

( a)m 1 352

fipot 21.92

Ats 140 it 18.4

(arin. 210.25

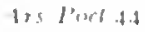

cartat 14.8 : 
praesente. signatum praesente nota procudere nomen. .

Ars Poet.59

praesentes. praesentes. Austri, coquite horum obsonia.

Serm.2.2.4I

praesenti. praesenti tibi maturos largimur honores

Epist.2 I.I 5

praesentia. poscit opem chorus et praesentia numina sentit.

praesentibus. non. it adsit. auxili|latura plus praesentibus.

Epist.2.1.134

Epod.1.22

praesentibus. temptantem maiora fere, praesentibus aequom.

praesentis. dona praesentis cape laetus horae (ac)|inque severa.

praesepe. scurra vagus, non qui certum praesepe teneret.

Epist.1.17.24

Carm.3.8.27

Epist.1.15.28

praesertim. praesertim cautum dignos adsumere, prava|ambitione procul.

utile famae/vitaeque et menbris, praesertim cum valeas

Sirm.1.6.5I

praesertim census equestrem | summam nummorum .

praesidio. nequiquam Veneris praesidio ferox

tunc me biremis praesidio scaphae|tutum . . auta teret

serves tutcrisque tuo fidentem praesidio:

praesidium. praesidium regale loco deiecit, ut aiunt.

praesidium. o et praesidium et dulce decus meum:

insigne maestis praesidium reis

praestabo. dignum praestabo me etiam pro laude merentis.

praestant. Picenis cedunt pomis Tiburtia suco:| nam facie praestant. incolumem tibi me pracstant septembribus horis.

praestantia. ut fortunatam plene praestantia vitam;

praestat. si fortunatum species et gratia praestat.

praestent. quantum dimissa petitis|praestent.

praestes. "longas o utinam, dux bone. ferias| praestes Hesperiae!"

praestet. si nemo praestet, quem non merearis, amoren?

praesto. si ancilla aut rema est praesto puer.

praesumis. quam puer et validus praesumis, mollitiem.

praeter. ventorumque regat pater obstrictis aliis praeter lapyga

non praeter solitum leves.

cuncta terrarum subactal praeter atrocem animum Catonis.

ille terrarum mini praeter omnis|angulus ridet.

praeter invisas cupressos

nocte sublustri nihil as ra praeter vidit et undas.

ut A:gonautas praeter omnis

amore, qui me praeter omnis expetit

Etrusca practer et volate litora.

matronae praeter faciem nil cernere possis/cetera.

num esuriens fastidis omnia praeter|pavonem rhonbunque?

neque te quisquam stipator ineptum|praeter Crispinum sectabitur.

avet quavis aspergere cunctos, praeter enm qui praebet aquam:

nil praeter Calvom et doctus cantare Catullum.

quicquam praeter holus fumosac cum pede pernae.

Epist.1. I 8.50

Ars loet. 383

Carm.1.15.13

Cerm.3.29.62

Epist.1.18.8 I

Epist.2.2.30

Carm.1.1.2

Carm.2.1.13

Epist.1.7.24

Serm.2.4.71

Epist.1.16.16

Epist.I.I I I

Epist.1.6.49

Epist. I.7.97

Corm.4.5.38

Serm.1.1.87

Serm.1.2.1 I7

Serm.2.2.87

Carm.1.3.4

Carm.1.6.20

Carm.2.1.24

Corm.2.6.13

Carm.2.14.23

Carm.3.27.3I

Epod.3.9

Epod.1 1.3

Epod.16.40

Serm.1.2.94

Serm.1.2.115

Serm.1.3.139

Serm.1.4.88

Serm.1.10.19

Serm.2.2 117

Serm.2.5.1

Serm.2.5.60

nil sibi legatum praeter plorare suisque.

pingue pecus domino facias et cetera praeter/ingenium.

nequis se praeter Apellen/pingeret

praeter cetera me Romaene poemata censes/scribere posse

Serm.2.6.14

Epist.2.1.239

Epist.2.2.65

Ars Poet.324

Epist.I.T5.II

Serm.1.1.23

Serm.2.3.179

Serm.2.5.45

Serm.2.8.7 1

coni.Serm.1.3.25

Serm.I.I0.88

Serm.2.7.73

Carm.4.7.4

Ars Podt.342

Carm.2.I 1.20

Carm.4.3.22

Serm.r.9.36

Serm.1.1.116

Serm. I.5.36

Ars Poet. 288

praetextas. vel qui praetextas vel qui docuere togatas. . . . . .
praetor. victurum suavius ac si quaestor avos pater atque mens patruosque $^{\text {. }}$ praetor. victurum suavius ac sil
[praetorque] fuissent.

uter aedilis fueritve / vestrum praetor.

interdicto huic omne adimat ius! praetor

castellum evertere praetor/nescio quod cupiens

coni.Serm.1.6.131

Serm.2.3.181

Sorm.2.3.21 8

Epist.2.2.34 
praetore. Fundes Aufielio I-usco prateor libenter|linquimus,

Serm.1.5.34

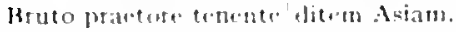

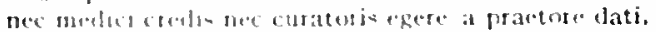

Serm.1.7.18

lipist.1.1.103

Sorm.1.0.108

Serm.2.2.50

praetorius. Honce ves auc or alocuit praetorius.

praetulerim. nil ego contulutim [praetulerim] incundo sanus anico.

iwr.Serm.1.5.tt

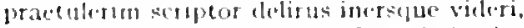

Epist.2.2.120

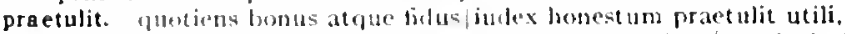

praevertamur. Jlluc pracvertamut, amatorem guodamicat/turpia decipiunt caceuth vitia

Carm.4.9.4I

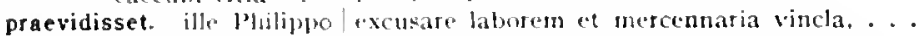
quol mon providicset [patevidiciet] e.um.

Prahaten. redditum Cyj solio l'hraten [l'rabaten]. . eximit Virtus

Prahates. ius imperiumegue Lhtadtes [l'rahates]| Cacsaris accepit genibus minest:

prandere. lumcinias soliti injenso prandete coemptas.

pranderet. "i prandetet holus patienter, togibus uti nollet Aristippus."

prandia. qui nigtis prandia moris funct.

pransae. men pansac lamiae vivon puerum extrabat alvo.

pransi. milia tum pransi tria repmus

pransus. |ramsu non avide, quantum interpellet inani|vented dem durare,

prata. nec prata canis albicant pruinis.

jann wec prata tigent nec thvij stepunt

prata. aut lerba lapathi mata amantis

pratensibus. pratensibus ontima tungis/natura est:

pratis. festus in pratis vacat otiosolcum bose pagus.

nuper in pratis studiosa florum

an bacis opulentet olivac. pomisne et pratis

prato. multa mole tecrudus aprico parcete prato.

prava. ubi prava! stulticia, hic summa est insania;

cum semel reffugit, redilie se prava caterus:

prava. pracartim cautum digmos adsumere. prava ambitione procul.

prava. non civiun ardor prava iubentium,

pravam. cui rem di donarent, illi decedere pravam stultitian;

prave. "sive ege pravel seu recte here volui.

prave sectum stomacheris ob unguests

nec prave lactis decorari versibus opto.

cut nescise puclens prave yuam discere malo?

pravi. eradenta cupidinis jravi sunt clementa

pravi. parelit pravi docilis Romana iuventus. -

pravis. prots multa matat, mete recta capesens, interdum pravis obnoxia.

pravis. illum balbutit staurmu pravis fultum male talis.

pravo. naso virete pravolspectandum niptis oxulis

pravom. si t" alis pravom detorsesis.

pravorum. nequitia et nugis, pravorum et anose gemellum.

pravos. cierlula nec ravos [maves] timeant arnenta leones

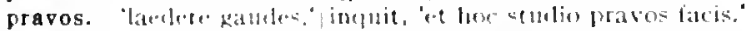

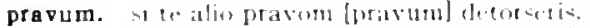

pravus. nam frotert vitium vitaveris illud. si te alio pravom [pravus]

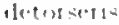

precamur. camlem veruiag precamur. a augur Apollo:

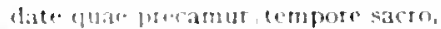

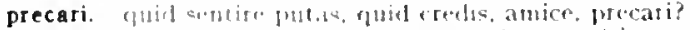

precaris. "thth fl, fuaccumque freceriv [prearis]./commoda dent:

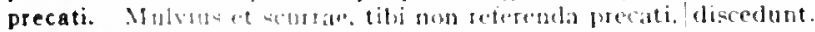

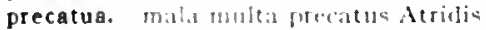

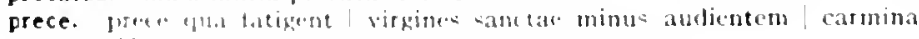

$$
1 \cdots+1,1916 ?
$$

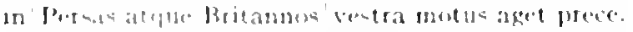

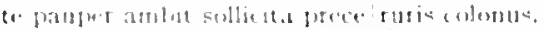

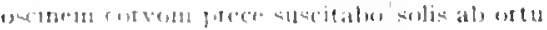

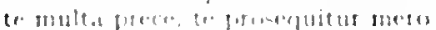

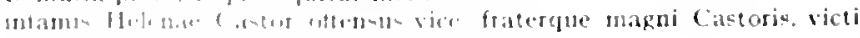
pre.ce.

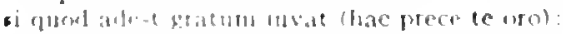

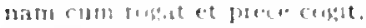

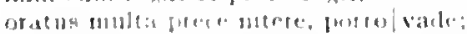

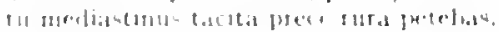

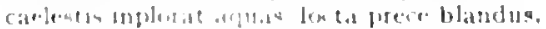

Serm.1.3.38

var. Epist.1.7.09

var.Carm.2.2.17

iar. Epist.1.12.27

Sorm.2.3.2.45

Epist.1.17.13

Serm. 2.4 .22

Ars Poel. 340

Serm.1.5.25

Serm.1.6.127

Carm.1.4.4

Corm.1.12.3

I.pod.2.57

Serm $2 .+20$

Carm.3.18.1I

Carm.3.27.29

Lipist.1.IC1.3

Ejist.1.14.30

Serm.2.3.220

Serm.2.7.71

Sorm.1.0.5 I

Carm. 3.3.2

Lipist.2.2.152

Sorm.2.3.87

Epist.1.1.104

Epist.2.1.20its

Ars Porlss

Corm.3.24.52

Sirm.2.2.52

Sierm.2.7.8

Serm. 1.3 .48

Ars Poet. 30

Sorm.2.2.55

Serm.2.3.2.14

rar. Epod. In.33

som.1.4.70

iar..5erm.2.2.55

:ar Serm.2.2.55

Cirm.1.2.30

Carmsate 3

Lepist.1.18.10\%

br.form. 2.8.75

serm 2.7.30

Serm.2.3.20.3

Cirm 1.220

Corm 1.2110

Carm.1.355

Carm.3 27.11

Ca) $m$. 5.33

Epodi it 13

Serm.2.1.13

I:pist 1.0 .2

Eprst.t.1318

lepist r.1. It

Ifpist.2 $\$ 135$ 
nunc prece, nunc pretio, nunc vi, nunc morte suprema | pernutet doninos

saxa movere sono testudinis et prece blandalducere,

preceris. "tibi di, quaecumque preceris. / commoda dent:

preces. o quamvis neque te munera nec preces/nec tinctus viola pallor . - curvat.

quo blandae iuvenum te revocant preces.

preces et aversun ad lovem.

preces. ad miseras preces/decuriere.

quindecim Diana preces virorun / curat

misit Thyesteas preces:

'quid obseratis auribus fundis preces?

castis cum pueris ignara puella mariti|disceret unde preces.

precetur, ille tegat conmissa deosque precetur et oret,

precibus. non lenis precibus fata recludere

precibus non linquar inultis.

votis ominibusque et precibus vocat

inprobus urget |iratis precibus:

precor. finibus Atticis|reddas incolumem precor

Latoe, dones ac precor integra|cum mente

euhoe, parce Liber, [/ lieu hoe, Bacche, precor,]

parce, precor, precor.

iocose Maecenas, precor,

per hoc inane purpurae decus precor, .

pauperies inmunda domus procul [inmunda procul, precer, absit:

prelo. prelo domitam Calenol tu bibes uvam:

premam. quod aut avarus ut Chremes terra premam.

premant. premant Calenam falce quibus dedit|fortuna vitem,

premat. quid premat obscurum lunae, quid proferat orbem.

nea cur ingratus opuscula lector/laudet anetque domi, premat extra limen iniquos.

prematur. nonumque prematur in annum|membranis intus positis;

premendo. nimium premendo|litus iniquom.

premerer. ut premerer sacra|lauroque conlataque myrto

premet. iam te premet nox fabulaeque Manes

quem sua culpa premet, deceptus omitte tueri.

premit. prudens futuri temporis exitum |caliginosa nocte prenit deus culpam poena premit comes.

frustra: nam comes atra premit sequiturque fugacem." . . pupillis, quos dura premit custodia matrum: nunc situs informis premit et deserta vetustas; aut ignoratae premit artis crimine turpi.

premunt. non trabes Hymettiae/premunt columnas acerba fata Romanos agunt [? prenunt]|scelusque fraternae necis. sed nimis arta premunt olidae convivia caprae.

premuntur. quattuor aut plures aulaea premuntur in horas.

prensare. vellere coepi et pressare [prensare] manu lentissima bracchia.

prensus. otiun divos rogat in patenti|prensus Aegaeo,

prerogat. Latiumque felix|alterum in lustrum meliusque semper|prorogat [prerogat] aevon.

pressa. non di, quos iterum pressa voces malo. pressa tuis balanus capillis

pressa Venafranae quod baca remisit olivae.

pressa, aut pressa puris mella condit amphoris

tu vina Torquato move consule pressa meo.

pressare. vellere coepilet pressare manu lentissima bracchia,

pressi. non aliena meo pressi pede.

pressis, absentis ranae pullis vituli pede pressis

pressisse. contendat laqueo collum pressisse paternum:

pressit. oleo, quod prima Venafri|pressit cella;

presso. et cubito remanete presso.

pressum. pressum Calibus ducere Liberum|si gestis,

presta. fi cognitor ipse.|persta [presta] at que obdura:

pretio. quo Chium pretio cadum |mercemur.

quae neque magno| stet pretio neque cunctetur, cum est iussa, venire.

unius assis/non umquam pretio pluris licuisse.

nunc pretio, nunc vi, nune morte supremalpernutet dominos

sed tamen in pretio est);

pretiosa. Eutrapelus cuicumque nocere volebat/vestimenta dabat pretiosa:

Epist.2.2.173

Ars Pod. 395

Serm.2.8.75

Carm.3.10.13

Carm.4.1.8

Epod.10.18

Carm.3.20.58

Carm.Sacic.70

Epod.5.80

Epod. 17.53

Epist.2.I. 133

Ars Poct. 200

Carm.1.24.17

Carm.1.28.33

Carm.4.5.13

Serm.2.0.30

Carm.1.3.7

Carm.1.31.18

? var.Carm.2.19.7

Carm.4.1.2

Epod.3.20

Epod.5.7

coni.Epist.2.2.190

Carm.1.20.9

Epod.1.33

Carm.I.3 I.9

Epist.1.12.18

Epist.r.19.36

Ars Poet. 388

Carm.2.10.3

Carm.3.4.18

Carm.1.1.16

Epist.1.18.79

Carm.3.29.30

Carm.4.5.24

Serm.2.7.115

Epist.1.1.22

Epist.2.2.I 8

Ars Poel. 202

Carm.2.18.4

l var.Epod.7.I

Epist.1.5.29

Epist.2.1.189

var.Serm.1.9.64

Carm.2.16.2

zar.Carm.Saec.68

Carm.1.I4.10

Carm.3.29.4

Serm.2.4.09

Epod.2.I 5

Epod.13.6

Serm.1.9.04

Epist.1.19.22

Serm.2.3.314

Epist.1.16.37

Serm.2.8.46

Carm.1.27.8

Carm.s.I2.I4

I'ar.Serm.2.5.39

Carm.3-19-5

Serm.1.2.122

Serm.1.6.14

Epist.2.2.173

Ars Port. 372

Epist.1.18.32 
pretiosus. dinecorum pretiosut emptor

Carm.3.6.32

pretium. "t peccase nefas atut pretium ent moll.

alublue est operat pretium, procelete recte qui moechis non voltis.

("t) is ustra mustin cupidum. cusn deerit egenti, as, laquei pretium.

est operate pretum duplicis pernosere iuris, naturam.

pretium actas alcera sordec."

well tamen est operae pretum cognoscere.

pretium. Hof engatutum iter "t patens converso in pretium deo

armand postumus, donare et pretsum dacere muneri.

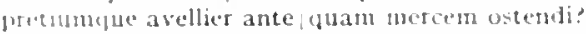

'bubes pretium. loris non ureris." aio

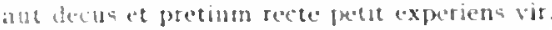

scife velim, chartis pretium quotus arroget annus

illet tat pretium poenae securus, opinos.

nancincetur enim pretium romengue poxtac.

pretore. al pratecore [pretore] date, rerum tutela mearum

Priami. tuan rumger nuptuas, et regum Priami vetus.

nec Prianu clomus| periura pugnacis Achivos/Vectoreis opibus refringit dum Priami laridisque busto insultet armentum

J'roan et litetam l'riami choreis, falleret atum.

sisule.st ut populus Priami Prianueque inhumato.

"intunam Priani cantabu ee nobile bellum."

priamiden. inter' II ectora Prianiden. animosum atque inter Achiblem / ira I.11

Priamus. Jho daved Priamus redicto

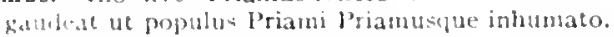

Priape. qua muneretur te, l'riape.

Priapum. cum laber, incereus seannum laceretnc l'riapum,

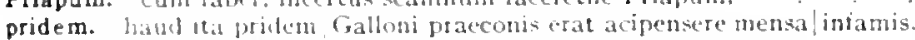

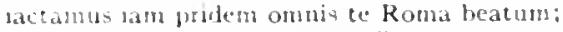

furn tea pridern, tardior ut paullo grabureue veniret ad auris.

prima. Jos utinam inter heroas natum teltue me prima tulisset.

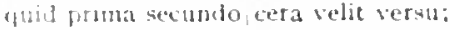

qual proma isatum ventrem pacatrerit esea "

deo. gluod prima Venatri|pressit cella;

butu- ent vamu fugete et saphentia prima tultitia cartasse.

dum ficus prima calorque / dissignatorem decorat

scilicet, ut non sic mith prima fides

rersilus inpariter iunctis querimonia primum lprimal. I post etiam incliba cost voti sententia compos:

prima. jorigna nocte domum clatude

prima dicte milsi, summa dicente Cannema.

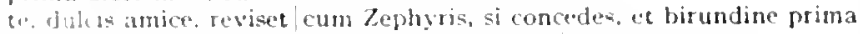

prima. Ut silsale folis pronos mutantur in annos. prima cadunt:

prima. etementa velint ut discere prima:

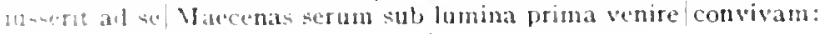

proma feres herlerae victricis praemia.

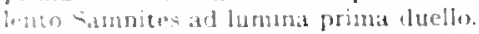

primae. varguman proma puerique daris patribus ofts.

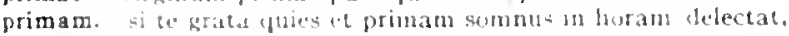

prime. Jompxi. morerm prime sodalium?

primis. me mimia litblebelli placuines domirgue.

primis. pratenoncons wienta primis,

primss. cusn proreguetunt primis animalia terris,

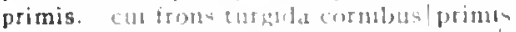

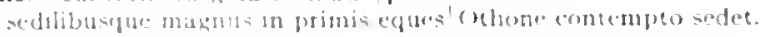

in primie valeitithene

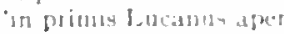

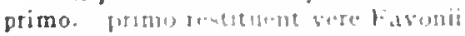

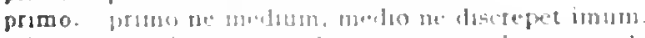

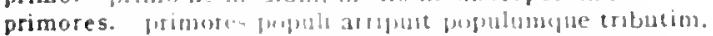

primorum. extrem prunorum, extrems usque priores.

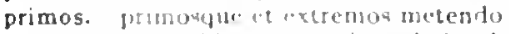

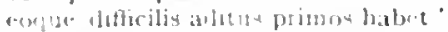

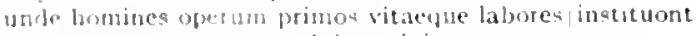

primum. I.4ubu promum moluliate civi.

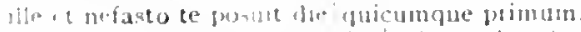

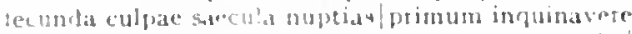

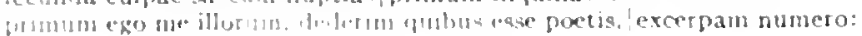

Carm.3.2.4.2.4

Sorm.1.2.37

Serm.2.2.99

Serm.2.4.03

E.pist.1.18.18

Epish.2.1.229

Carm. 310.8

Corm.4.8.12

Serm.1.2.104

Epist.1.10.47

Epist.1.17.42

Epist 2.1.35

Epist.2.2.17

Ars Poct.299

tar. Epist.r.t.to3

Carm.t.15.8

Carm.3.3.26

Carm.3.3.40

Carm.4.0.I 5

Sirm.2.3.195

Ars Poc\$.137

Serm.1.7.12

Carm.1.10.14

Serm.2.3.195

Epod 2.2I

Sirm.1.8.2

Sierm. 2.46

I.pist.1.16.18

Ars Poet.254

Serm.2.2.93

Serm.2.5.53

Serm.2.5.5

Serm.2.8.45

Epist.1.8.41

Epist.3.7.5

Epist.18.17

:ar.des loet.75

Corm.3.7.29

Epist.1.t.t

Ejpist.1.7.13

Ars Poitos

Serm.1.1.20

Serm. 27.33

Epist 1.325

Epist.2.2.08

Carm.t. 31

Epist.1.17.0

Corm.2.7.5

I. pist. 1.20 .23

STrm. J.4.59

Strm.1.3.90

Carn. $3 \cdot 13 \cdot 5$

Ispod..1 is

Serm.2.2.71

Serm. 2.8.6

Carm.3.7.2

. 1 rs liod.t.52

serm.2.1.(w)

Lipist 2.2.201

Carm+14.31

Serm. 1.9.50

Serm. 2.0.21

Carm 1.32.5

Corm.2.1.

Corm.3.8.1.

Serm.1.t in 
primum nam inquiram. quid sit furere:

Sirm.2.3.4 I

primum/aedificas, hoc est longos imitaris.

Serm.2.3-307

turdus/sive aliud privon [primum] dabitur tibi.

o cives, cives, quaerenda pecunia primum est; .

qur. Serm.2.5.I I

si dicet 'recte,' primum gaudere,

ponendaeque domo quaerenda est area primum:

ut primum posisis nugari Graecia bellis/coepit

Eipist.1.1.53

Epist.1.8.15

Fist.I.IO.13

Epist.2.1.93

unde simul primum me dirisere Philippi

adspice primum. quanto cum fastu.

versibus inpariter iunctis querimonia primum, .

si ris ne flere, dolendum est/primum ipsi tibi:

primum. et pugilem victorem et equom certamine primum

primum. hoc primus [primum] repetas opus, hoc postremus onittas.

primus. qui fragilem truci/connicit pelago ratemilprimus:

qui primus alma risit adorea,

primusve Teucer tela Cydonio' derexit arcu;

non terox/Hector . . excepit ictus pro pudicis / coniugibus puerisque primus.

pudicum. $\mid q u i$ primus virtutis honos,

primus in hunc operis conponere carmina motem.

utrumne in pulvere. trimus [primus] | quale prius, ludas opus, an meretricis amore sollicitus plores:

Epist.2.2.49

Epist.2.2.92

Ars Poet.75

Ars Poet. $\mathrm{IO}_{3}$

Ars Poet.8.4

I'ter. List.1.6.48

Carm.1.3.12

Curm.4.4.41

Carm.49.17

Carm.4.92.4

Serm.1.0.83

Serm.2.1.63

2ar.serm.2.3.25I

hanc ego cum malis, ego faecem primus et hallec.

ego faecem primus et hallec, /primus et invenior piper album [ 8 ego primus face nec allec miscui]

primus et invenior piper album cum sale nigro'incretum

erucas viridis, inulas ego primus amaras!monstravi incoquere;

hoc primus repetas opus, hoc postremus omittas.

Parios ego primus iambos/ostendi Latio.

quam si proferres ignota indictaque primus.

cum senos redderet ictus / primus ad extremum similis sibi:

princeps. hic ames dici pater atque princeps

princeps et innantem Maricaellitoribus tenuisse Lirim.

princeps Aeolium carmen ad Italos|deduxisse modos.

libera per vacuom posui vestigia princeps.

principe. pestemque a populo et principe Caesare .

et formidatam Parthis te principe Romam.

principi. fertur Prometheus addere principi| limo coact la $_{3}$

principibus. principibus placuisse viris non ultima laus est.

principis. Romae principis urbium|dignatur suboles

principium. tu carminis esto principium. scribendi recte sapere est et principium et fons.

principium. hinc omne principium. huc refer exitum:

principum. gravisque/principum amicitias et arma Auguste. . . maxime principum.

prior. nunc et qui color est puniceae flore prior rosae

bellante prior, iacentem|lenis in hostem.

prior Sarmentus equi telesse feri similem dico.'

ne prior officio quisquam respondeat, urge."

tanto levius miser ac prior ille

occupat et salvere iubet prior:

ambigitur quotiens, uter utro sit prior,

prior. nisi cena prior potiorque puella Sabinum/detinet adsumam;

priorem. fama cirem causaque priorem/sperne.

plus quam se sapere et virtutibus esse priorem/volt

priores. priores/inpiae tectum dominae relinquont.

extremi primorum, extrenis usque priores.

priores. quando et priores hinc Lamias ferunt/denominatos

priores. si priores Maeonius tenet/sedes Homerus.

priori. spargent olivetis oforem/fertilibus domino priori.

priori. obsecro et obtestor, vitae ne redde priori.'

prisca. 'quid si prisca redit Venus

ut prisca gens mortalium.

atque alii. quorum comoedia prisca virorum est,

illi, scripta quibus comoedia prisca viris est,

priscae. sic priscae motumque et luxuriem addidit arti tibicen

prisci. prisci Catonis/saepe mero caluisse virtus.

prisci. agricolae prisci, fortes parvoque beati. .

priscis. quae priscis memorata Catonibus atque Cethegis

Serm.2 +73

?:ar. Serm.2.4.73

Serm.2.4.74

Serm.2.8.5I

Epist.1.0.18

Epist.1.19.23

Irs Poel.j 30

- Irs Poet.254

Carm.1.2.50

Carm.3.17.7

Carm.3-30.13

Epist.1.I9.2I

Carm.I.2I.I 4

Epist.2.1.25to

Carm.1.10.13

Epist.1.17.35

Carm.4.3.13

Serm.2.0.23

Ars Poel.309

Carm.3,6.6)

Carm.2.1.4

Carm.4.14.6

Carm.t I0.4

Carm.Saec.5 I

Serm.1.5.56

Serm.2.6.2.7

Serm.2.7.19

Epist.I.7.66

Epist.2.1.55

Epist.1.5.27

Serm.2.5.30

Epist.1.18.27

Carm.2.8.18

Epist.2.2.204

Carm.3.17.2

Carm.at.9.5

Carm.2.15.8

Epist. 4.7 .95

Carm.3.9.I7

Epod.2.2

Serm.r.t.2

Serm.I.jo.16

Ars Poet.2 I 4

Carm.3.21.1 I

Fpist.2.1.139

Lpist.2.2.II7 


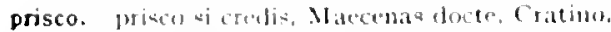

prisco. divesne priceo natte ab lnache nil intesest

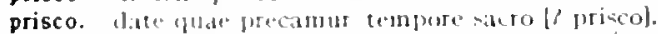

priscum. nec delbunt, qusmbis tedeant in antum tempora priscum.

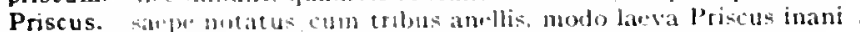

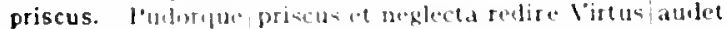

prius. eftenl funtas ordine verbesm est posterius facias.

prius. nil alt ceste prin<: moliua nul caclibe vitat:

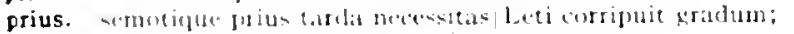
gud prius dicam solitis patential baudibua.

Romulan peret lose prius. . dubito.

gullatu. Var", sacra vile prius aneris aborem.

quite priu- multum tacilis movebat cardines.

acd praus . Ipulis iungentur capreate lupic

mitu inablemtem arta Briseis nive colore! movit Achillem.

nue gis amicum est nece mathi te ptius obire. Maenenas.

carmina non prius/audita

rite deos prith alpreciti.

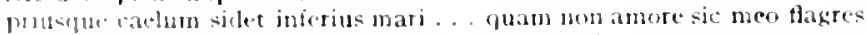

quod wetum preseul alore chartic atque anino prius.

foud sitim procul atere chartis atque animo prius, ut siquid lanimo

prits ut, siquibl] promittere de me pessum aliud vere promitto.

bu prius anguntio ereetal cadareta cellis

in pulvere, qrimute qualu prius, ludac opus.

non mus exacta tenus rations sapurum.

vincul longe phols ipsum expugnare caput.

(quid) priu= inlustfem saturic mu-aque fuedestri)

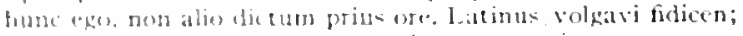

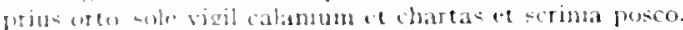

-

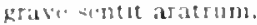

fotmate erim natura prose nos intus art ommen fortunarum habitum:

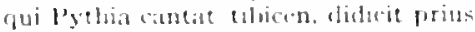

priva. Locuples, gusetud duest privat triremis.

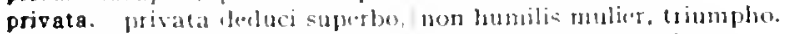

privatas. privatis 4 quacrat ofees et tankere vitet|scripta.

privati. publica meteries proveti iuris relst.

privatim. privatuaque [privatimgure] magis visam te rege beatus.

privatis. nulla. . metata privatic opacam porticus excipicbat arcton

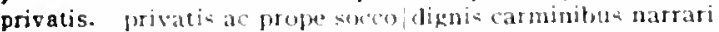

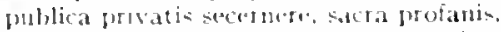

prisato. invidia aderevit, privato guat minor escet

privatus. privatus illis census enat brevis fommume maknum:

Jutce privistus minium eavere

privatustur magi- vivam te rege beatus

privet. fuen tor vindicta quaterque, inposita haud umquam misera dormolige fusiset?

privignis. matre arentulus privignis mulier tamperat innocens.

privignus. (guhus torarum militet oris Claudus Aupusti privignus.

privom. curifu-ive aliud furom dabicus cibi.

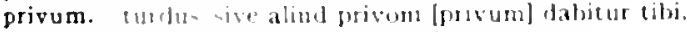

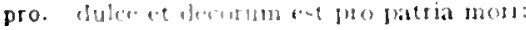

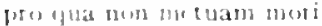

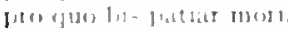

Colrus fors fatra non timblum mort

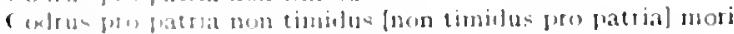

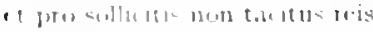

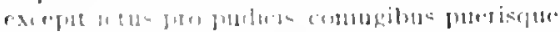

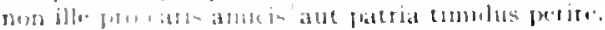

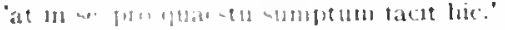

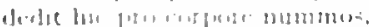

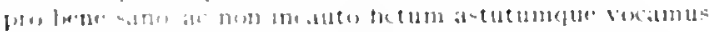

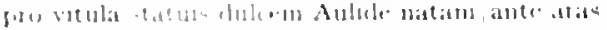

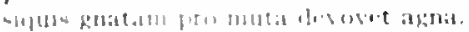

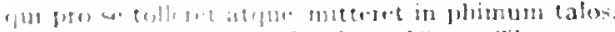

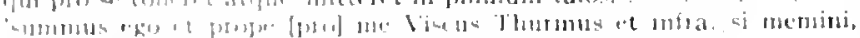
Si:11110;

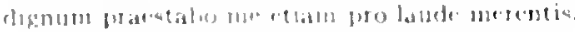

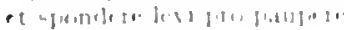

Epist.1.19.1

Carm.2.3.21

Piur Carm.saec.4

Carm.4 2.40

Sorm.2.7.9

Carm..Sarc. 58

Sorm.1. 158

Epist.1.1.88

Carm.1.3.32

Carm.1.12.13

Carm.1.12.33

Carm.1.18.1

Carm.1.25.5

Carm.1.35.7

Carm.2.4.2

Carm.2.17.2

Carm.3.1 2

Carm.t. 15.28

Epod.5.79

Sern.I.4.102

coni.Scrm.1.4.102

Serm.1.8.8

Serm.2.3.252

Sorm.2.4.30

Sorm.2.5.73

Serm.2.0.17

Epist 1.19.32

Epist.2.1.12

coni.ters Poct.o5

Ars Poit. 108

Ars Port.415

Eprst.1.1.9.3

Corm.1.37.31

Epist.1.3 10

Ars Poct.13I

tor $9 \mathrm{erm}, 1.3 .142$

Carm.2.15.15

Ars Poctigo

Ars Porl.307

Serm.1.0.20

Corm.2.15.13

Carm.3.8.20

Scrm.3.3.142

Serm.2.7.77

Carm.3.2.18

Epist.1.3.2

Serm.2.5.11

:ur.tiorm.2.5.11

Carm.3.2.13

Carm.3.9.1 I

Carm.3.9.15

Carm.3.19.2

var. Cirm-3.10.2

Carmat 1.1.4

(arm 4.9.23

(armat 0.5!

Sermin 1.2.10)

sorm : 2.1.3

serm. : 301

Serm.2.3.110

Serm.2 3.210

Serm. 2.; 10

war.sirm.2.8.20

l:port 1.7.2.

Ars Inet at 3 
pro. (pro curia inversique mores)

proavi. at vestri proavi Plautinos et numeros et / laudavere sales.

proba. "tu pudica, tu proba|perambulabis astra sidus aureum."

probam. probamque | pauperiem sine dote quaero.

probante. vagus et sinistra|labitur ripa Iove non probante $u$-|xorius amnis.

probantes. idem eadem possunt horam durare probantes?

probas. sive tu Lucina probas vocari|seu Genitalis:

probat. meninitque libentius illud/quod quis deridet quam quod probat et veneratur.

nee, siquid fricti ciceris probat et nucis emptor.

probes. utrius hornm/verba probes et facta, doce

probet. (cum) nemo. ut avarus, ise probet

Valgins et probet haec Octavius optimus atque| Fuscus

probos. di, probos mores docili iuventae.

et vixisse probos. amplis et honoribus auctos:

reteresne poetas [veteresne probosque] / an quos et praesens et postera respuat aetas?

probrosis. o magna Carthago. probrosis/altior Italiae ruinis."

probus. probus quis!nobiseum vivit. multum denissus homo: 'est vetus atque probus, centum qui perficit annos."

procacis. vernasque procacis' pasco libatis dapibus.

procax. sed ne relictis. Mnsa procax, iocis

procedere. procedere recte/qui moechis non voltis,

nil cum procedere lintrem|sentimus,

procedis. treque, dum procedis, "io triumphe'| non semel dicemus,

procedit. tteque. dum procedis [procedit], "io triumphe" non senel dicemus. procedit fuscus Hydaspes/Caecuba vina ferens.

procedunt. in ius /acres concurrunt [? procedunt].

procellae. serpit humi tutus nimium timidusque procellae:

procellae. age te procellae/crede veloei.

procellae. aut mare Caspium|vexant inaequales procellae/usque

procellas. dum procellas|cautus horreseis.

procellis. si mugiat Africis/malus procellis,

procera. artius atque hedera procera adstringitur ilex

forti nubet procera Corano|filia Nasicae.

proceras. valentium proceras manibus vertere fravinos.

proceros. quo pertinet ergo|proceros odisse lupos?

processerit. servetur ad imum /qualis ab incepto processerit

proci. quam neqniere proci recto depellere cursu?' .

procidit. procidit late posuitque collum in/pulvere Teucro;

postquam relictis moenibus rex procidit

procis. non te Penelopen difficilen procis|Tyrrhenus genuit parens.

procis. neque illic/ant apotheca procis intacta est aut pecus:

Procne. aut in avem Procne vertatur. Cadmus in anguen.

procudere. licuit semperque licebit | signatum praesente nota procudere nomen.

procudit. non ira, quae procudit ensis

procul. proeul omnis esto|clamor et ira.

'beatus ille qui procul negotiis, . . . paterna rura bubus exercet suis. quod vitium procul afore chartis|atque animo prius.

praesertim cautum dignos adsumere, pravalambitione procul.

quae procul exstructis inerant hesterna canistris.

cui mustela procul 'si vis' ait 'effugere istine,

Neptunum procul ex terra spectare furentem.' .

mox etiam, si forte vacas, sequere et procul audi.

pauperies inmunda domus procul absit:

pauperies inmunda domus procul [inmunda procul procul] absit: .

Proculeius. vivet extento Proculeius aevo.

procurare. haec ego procurare et idoneus imperor

procurrerit. in mare set celsus procurrerit Appenninus

procurrunt. in ius actes concurrunt [procurrunt, magnum spectaculum uterque.

Procyon. iam Procyon furit

prodeat. unico gaudens mulier maritolprodeat instis operata sactis

prodentem. est/gaudia prodentem voltum celare.

proderat. cuid proderat ditasse Paelignas anus

proderis. quid proderat [proderis] ditasse Paelignas anus / velociusve misenisse toxicum?

proderit. quid proderat [proderit] ditasse Paelignas anus
Carm.3.5.7

Ars Poét. 270

Epod.17.40

Carm.3.29.55

Carm.1.2.I9

Epist.1.1.82

Carm.Sace. 5

Epist.2.1.203

Ars Poet.249

Epist.1.17.16

Sorm.1.I.I09

Sirm.1.10.82

Carm.Sacc. 45

Serm.1.6.I I

coni.Epist.2.1.4 I

Carm.3.5.39

Serm.1.3.50

Epist.2.1.39

Serm.2.6.06

Carm.2.1.37

Serm.1.2.37

Serm.1.5.20

Carm.4.2.19

var.Carm.4.2.+19

Serm.2.8.1 4

7 :ur.Serm.1.7.2 I

Ars Poet.28

Carm.3.27.62

Carm.2.9.3

Carm.2.10.2

Carm.3.29.58

Epod.15.5

Serm.2.5.6.4

Carm.3.25.16

Serm.2.2.36

Ars Poet.1 27

Serm.2.5.78

Carm.t.6.1 1

Epod.17.13

Carm.3.IO.I I

Serm.2.5.7

Ars Poet. 187

Ars Poet.59

Carm.4.15.19

Carm.3.8 15

Epod.2.I

Serm. I.4.10I

Serm.1.6.52

Serm.2.0.105

Epist.1.7.32

Epist.1.t1.Io

Epist.2.2.95

Epist.2.2.199

Z'ar. Epist.2.2.199

Carm.2.2.5

Epist.1.5.2 I

Epod.10.29

var.Serm.1.7.2 I

Carm.3.29.18

Carm.3.1.6

Serm.2.5.104

Epod. 17.00

var.Epod. 7.60

var. Epod. 7.00 


\section{PRODESSE}

prodesse. si prodesse tuis pauloque bengnius ipsum/te tractare voles. aut prodesce volunt aut delectare poetae

prodest. nec quidguam tibi prodest/aerias temptasse domos quaerte plus prodest et inane abscindere soldo?

it quollaeque paperibus, prodest locupletibus aeque.

prodiderit, silprodiderit conmikea lide sponsumve negarit?

prodidit. quas atut [? qualis] Parrloasius protulit [prodidit] aut Scopas, prodiga. ascasique Fides prodiga. perlucidior vitro.

prodigialiter. qui variare cupit tem prodigialiter unam.

prodigum. animaeque magnae/prodigun Paulum superante Poeno

prodigus. ne prodigus esse|dicatur metuens.

irodigue et stultus donat quae spernit et odit:

low... nec mulae prodigus herbae;

ponama qui tam ridiculusu tam care prodigus enit.

elintat enim, spargas tua prodigus.

uthlium tardus provisor, prodigus aeris,

prodire. quadam prodire tenus, si non tatur uitra.

prodis. iuvenumque prodis/publica cura.

(1) cum prouctis insignibus. . . prodis ex iudice Dama.

proditor. numc et latentis proditor intumo/gratus puellae risus ab angulo. proditur. perditur [proditur] liaec inter misero lux non sine votis:

prodocet. hace lanus summus ab imolprodocet.

producas. diva, producas subolem patrumque prosperes decreta super iugandislfeminis producent. t*. *ivaeque producent lucernae,
producere. licuit semperque licebit / signatum praesente nota procudere [producere] nomen.

producimus. prorsus iucunde cenam producimus illam.

productior. neve minor neu sit quinto productior actu'fabula.

produrerit, adsciscet nova, quae genitor produxerit usus.

produrit. sacrilega manu|produxit, arbos,

proelis. nos convivia, nos proelia virginum... cantamus.

nee Semeleius/cum Narte confundet Thyoneus proelia

campus sepulcris inpia proclia|testatur

dices historiis proclia Caesaris.

et veneren et proelia destinat.

dura post paulo fugies inaudax| proelia raptor.

geretque! proelia coniugibus loquenda.

nun pugnavit ingtns||Wmeneus... dicenda Musis proelia:

volentem prodia ne loqui

miror proelia rubrica picta aut carbone

spes iubet esse razas, ad proelia trudit inertem.

quo clamore coronae/proclia sustineas campestria;

proeliis. proximos illi tamen occupavit|Pallas honotes/procliis audax.

proelium. maiur Neronum mox grave proclium|conmisit

Proetum. "It Prortum mulier perfida credulum/falsis inpulerit criminibus

profgnis. sic spes fallendi, micedbis sacra profanis.

puthica privatis secernere, sacra protanis.

profsnum. nili probanum volgus et arceo.

profsri. (anians nanque pudor prohibebat plura profari)

profeci. quid tum profeci. mecum tacientia iura|si tamen at temptas?

profecto. He prolesoledere personae scit convenientia cuique.

proter. et vipules lucernalperfer [profer] in lucem:

proferat. qujodquid utb turna est, in apricum proferet [proferat] aetas,

quef premat obacurum lunae, guial proferat orbem.

proferet. irarumdia diem pofofet lio... classis Achillei:

guafrubl sub tersaest. in apricum proferet aetaq.

proferet in hucren speciona vocabula terum.

proferre. innele perlen proferre pudor vetet aut operis lex,

proferres. quan si protertes ignota inelictaque primus.

professis. inceptiq grabibua plerumque et magna profossis purpureus. . .

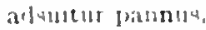

professus. mrturs, liberrim Lolli.|scurrantis speciem praebere, professus anicum.

frofesque grimbla turget:

prolesta. 'mon ego" marrancen 'temere enti lace profesta

profestis. potare. . Campana solitus trulla vappanque profestis.

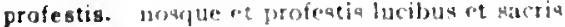

proficeret. Caras.... monlquicquam proficeret:

\section{PROFICERET}

Epist.1.17.11

Ars loet.333

Carm.1.28.4

Serm.1.2.113

Ĺpist.1.1.25

Serm.1.3.95

sar.Carm.t.8.6

Carm.1.18.10

Ars Poel.29

Carm.1.12.35

Sorm.1.2.4

Lipist.1.7.20

L. fist. 1.7 .42

E.pist.2.1.238

Epist.2.2.195

its Poct.104

Epist.1.1.32

Carm.2.8.7

Serm.2.7.54

Carm.1.9.21

coni.serm.2.6.59

Epist.1.1.55

Carm.Sace.17

Carm.3.21.23

:ar. Ars Pocl.59

Sermi 1.5.70

Ars loct. I 89

Epist.2.2.119

Carm.2.13.3

Carm.1.0.17

Carm.1.17.2.

Carm.2.1.30

Carm.2.12.10

Carm.3.13.5

Cirm.3.20.4

Cirm.t.t.68

Corm-4.9.2I

Carm.t. 5 .

Serm.2.7.98

Epist.1.5.17

Epist.I. 8.54

Carm.1.12.21

Corm.4.1.4.14

Cirm.3.7.13

Epist.t.15.5t

Ars Port.397

Carm.3.1.1

Serm.1.0.57

Epist.2.2.23

Ars Puet.315

rar.Carm.3.8.15

var. Inpist.1.0.24

Epist.1.12.18

Carm.1.15.33

Lepist.1.6.24

Epist.2.2.110

Ars P'od. 135

Ars Portizo

Ars Poetit

Epist.1.18.2

dis loet. 27

Serm.2.2.150

icrn.2.3.14.2

Carm.1525

Serm.t.3.0 
proficiente. fugeres radice vel herba|proficiente nihil curarier:

proficiscentem. ut proficiscentem docui te saepe diuque.

proficiscenti. dixi me pigrum proficiscenti tibi,

proficiunt. quid leges sine moribus/vanae proficiunt.

profluunt. sed quae Tibur aquae fertile praefluont [profluunt]

profore. quae nocuere sequar, fugian quae profore credam;

profugi. te Dacus asper, te profugi Scythae

profugit. Phocaeorum/velut profugit exsecrata civitas

profugus, te profugus Scythes/miratur,

profundat. quali perfundat [profundat] piscis securus olivo.

profundo. fervet inmensusque ruit profundo|Pindarus ore, . merses profundo, pulchrior evenit;

profundum. qui protundum Danuvium bibunt

progenerant. neque inbellem feroces progenerant aquilae columbam.

progeniem. mox daturos/progeniem vitiosiorem.

almae progeniem Veneris canenus.

progenies. Quinti progenies Arri, par nobile fratrum,

progenies. Tyrrhena regum progenies,

prognatos. quas doceat quivis eques atque senator|semet prognatos.

prognatum. numquid ego a te/magno prognatum deposco consule cunnum

prognatus. Castor gaudet equis, ovo prognatus eodem/pugnis;

prohibebat. (infans namque pudor prohibebat plura profari)

prohibent. unde si Parcae prohibent iniquae.

namque marem cohibent [prohibent] callosa vitellum.

prohibere. has nullo perdere possum|nec prohibere modo,

nec, . . . nodosa corpus nolis prohibere cheragra.

concubitu prohibere vago. lare iura maritis.

prohibet, tris prohibet supra|rixarum metuens tangere Gratia

probibete. verecundumque Bacchum| sanguineis prohibete rixis.

proicere, qui servos proicere aurum|in media iussit Libya,

proicit. uterque/proicit ampullas et sesquipedalia verba,

proiecerit. qui scis, an prudens huc se deiecerit [proiecerit] atque ! servari nolit?"

proiecit. conminxit lectum potus mensave catillum | Euandri manibus tritum delecit [proiecit]:

proiectis. tu cum proiectis insignibus. . . prodis ex iudice Dama,

proiectum. proiectun. odoraris cibum.

proiectus. siquis ad ingentem trumenti semper acervom | porrectus [proiectus] vigilet cum longo fuste

prole. laudantur simili prole puerperae, cum prole matronisque nostris,

prolem. Romulae genti date remque prolemquelet decus omne.

proles. sed rusticorum mascula militum proles,

quem proles Niobea magnae/vindicem linguae Tityosque raptor|sensit haud male Telemachus, proles patientis V'lixei:

prolis. prolisque novae feraci lege marita.

prolueris. leni praecordia mulso prolueris melius.

prolutus. absenten ut cantat amicam|multa prolutus vappa nauta

promat. ut speciosa dehinc miracula promat.

prome. prome reconditum, Lyde, strenua Caecubum

promens. insignem attenuat deus|obscura promens;

promens. et horna dulci vina promens dolio

promere. promere languidiora vina.

Romae dulce diu fuit . . clienti promere iura.

promes. non tamen intus/digna geri promes in scaenan

promethea. nec satelles Orci callidum Promethea|revexit auro captus;

prometheus. fertur Prometheus addere principillimo coactus quin et I'rometheus et Pelopis parens.

optat Prometheus obligatus aliti.

promineret. cum promineret ore,

prominet. quaecumque aut gelido prominet Algido

promis. dum tu celeres sagittas|promis,

curru nitido diem qui|promis et celas.

promisit. certus enim promisit Apollo

promissa. quo promissa cadant et sonnia Pythagorea;

multa fidem promissa levant.

promissa. militibus promissa Triquetra praedia Caesar an fost Itala tellure daturus:"

promissi. hoc anet, hoc spernat promissi carminis auctor.
Epist.2.2.I5 I

Epist.1.13.1

Epist.2.2.20

Carm.3.24.36

tar.Carm.4.3.10

Epist I.8.I I

Carm.1.35.9

Epod.16. 18

Carm.4.14.42

var.Serm.2.4.50

Carm.4.2.7

Carm.4.4.65

Carm.4.15.21

Carm.4.4.32

Carm.3.6.48

Carm.4. I 5.32

Serm.2.3.2.43

Carm.3.29.1

Serm.1.6.78

Serm.1.2.70

Serm.2.1.26

Serm.1.6.57

Carm.2.6.9

var.Serm.2.4.14

Serm.1.8.2I

Epist.1.I.3I

Ars Poet.398

Carm.3.19.15

Carm.1.27.4

Serm.2.3.100

Ars Poet.97

2ar. Ars Poet. 462

var.Serm.1.3.9 I

Serm.2.7.53

Epod.6.10

7ar.Serm.2.3. I I 2

Carm.4.523

Carm.4.15.27

Carm.Sack.47

Carm.3.6.38

Carm.4.0.1

Epist.1.7.20

Carm.Suec.19

Serm.2.1.27

Serm.1.5.10

Ars Poct.144

Carm.3.28.2

Carm.T.34.1 4

Epod.2.47

Carm.3.2I.8

Epist.2.I.IO4

Ars Poet. I 33

Carm.2.18.35

Carm.I.16.13

Carm.2.13.37

Epod.17.67

Epod.5.35

Carm.I.21.6

Carm.3.20.10

Carm.sace. Io

Carm.1.7.28

Epist.2.1.52

Epist.2.2 IO

Serm.2.6.55

Ars Poet.45 


\section{PROMISSIS}

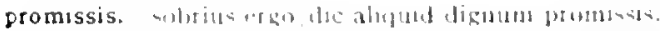

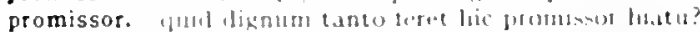

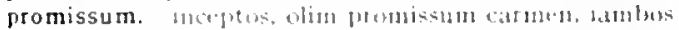

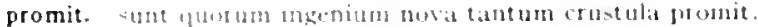

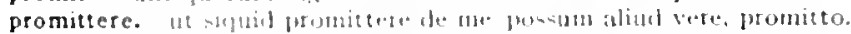

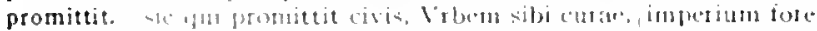

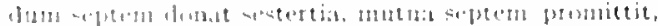

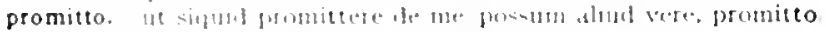

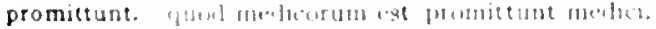

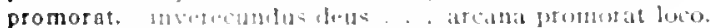

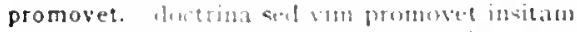

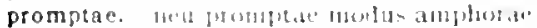

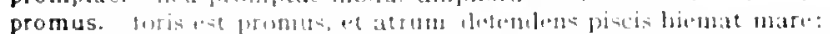

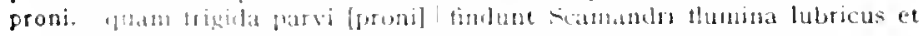
Pincis.

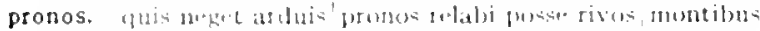

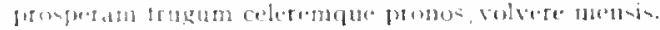

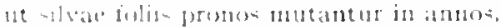

pronum. athan quac per prenum trepirlat cun murmate rivon?

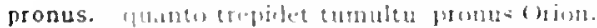

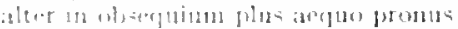

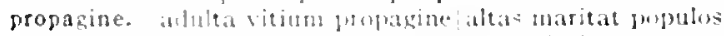

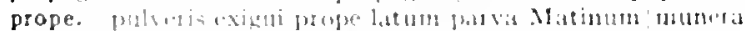

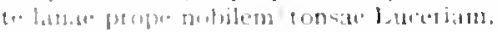

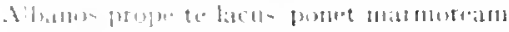

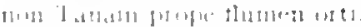

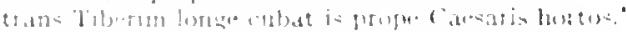

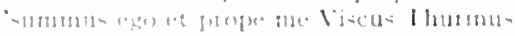

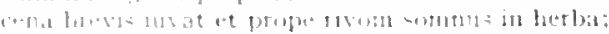

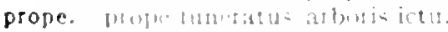

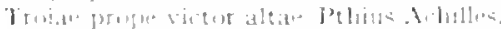

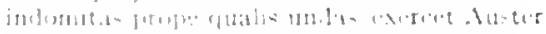

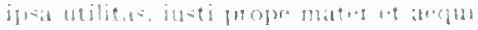

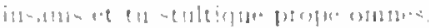

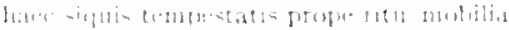

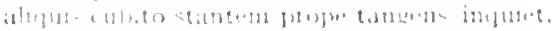

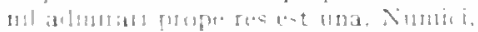

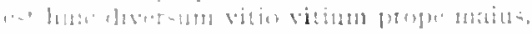

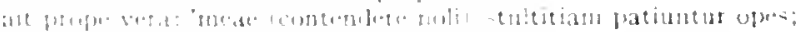

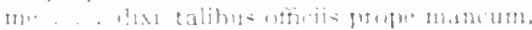

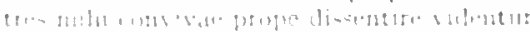

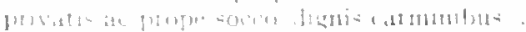

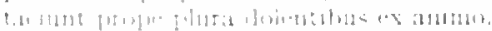

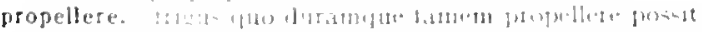

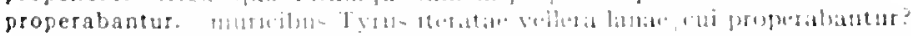

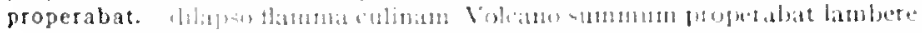
$\{0,\{11\} 1\}$.

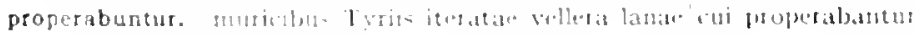

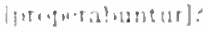

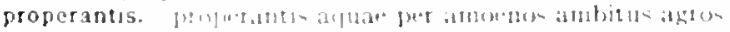

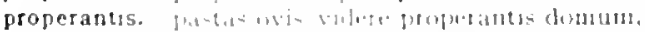

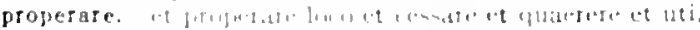

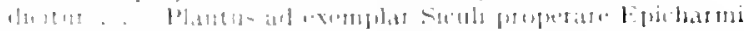

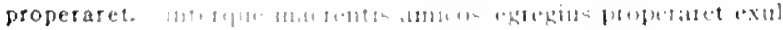

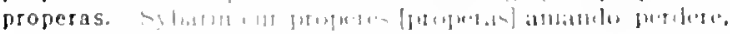

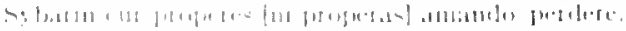

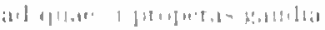

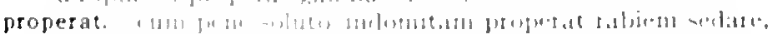

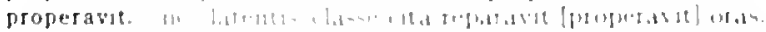

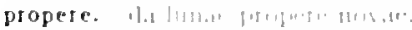

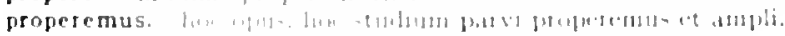

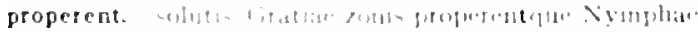

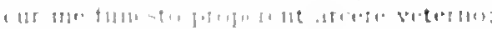

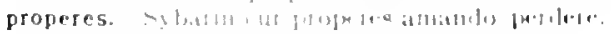

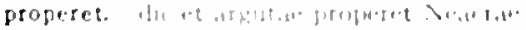

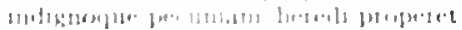

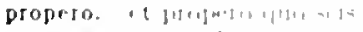

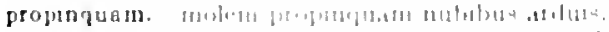

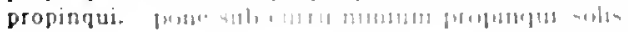

PROPINQVI

Serm 2.3.9

irstion. 138

lipolditition

Serm.2.1.47

Sirm.1.1.102

Sirm.1.1.34

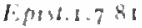

Sermat.103

Epist.2.1 1 16

Vipoliti.1!

carm... +33

(a)m 1.3\%.1.

Serm.2.2.1t

conilipol.1.3 13

(arm.1.20.11

(iarm.4. (1).39)

trs Pilet.(10)

Epise I. [10.2 I

Carm.327.18

Eprst I. I8.ro

lipol.2.9

Carm.1 28.3

Carm.3.15.1.3

Carm.1.19)

(itrm. 1 15.2.4

sermands

Sirm.2.8.20

Fipl.t.1.3.5.5

(iormis 3.7

ciarmat (x.3

(arm 1.1.8.20

srem. 309

vermat 33:

Sirm.2.320s

Niris.2.5.12

tapis a.c. I

Eprot.1.145

JPist.1.18.2R

I.p.st.2.2.21

bist.2.201

Lers liation

. Irs lidé.132

virm. 1 ack

Epond 12:2

Somp 1.5.7.9

ind f poidt 2.22

Ars literd 17

I.penl.z 12

1. 916.7 .57

J. pout $=8.58$

(iirm 35.18

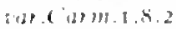

ron) ( iarm 1 . S 2

(iormat a 1 2 21

1. peit 1 21)

rom (iarm. 1.37 2.1

(itm 3.10)

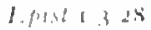

(arentalinc"

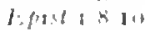

(arm.1 82

(iarm.311 21

(iarma 321 itz

term.1 0.911

(ism 3 20) 11,

(w) 1 221 
PROPINQVIS

propinquis. suscitet ac reddat gnatis carisque propinquis? propinquas. dimovit obstantis propinquos ad sanos abeat tutela propinquos.

propior. septimus octavo propior iam fugerit annus.

propior. maturo propior desine funeri|inter ludere virgines

propiora. siqui scribat uti nos sermoni propiora.

propioris. munere cum fungi propioris censet annici:

propius. certius accipiet damnum propiusve medullis

propius. hue propius me. . . vos ordine adite.

(nam te $\mid$ scire, deos quoniam propius contingis, oportet),

ut propius spectes lacrimosa poemata Pupi;

dicas adductum propius frondere Tarentum.

si propius stes, te capiat magis.

proponi. neque fictolin peius voltu proponi cereus usquan?

propositi. iustun et tenacen propositi virum.

victor propositi simul ac perveneris illuc.

proposito. quod non proposito conducat et haereat apte.

propositum. indelambo propositum peragunt iter.

propositum. "pars hominum vitiis gaudet constanter et urget/propositum;

proposuit. siceis ommia nan dura deus proposuit

utile proposuit nobis exemplar Vlixen.

propria. vel merito. quoniam in propria non pelle quiessem.

propria. nisi ut propria haec mihi munera faxis.

propriae. nam propriae telluris erum natura neque illum / nee me nec quemquam statuit: .

disimulator opis propriae, mihi commodus uni.

propriam. diadema tutumldeferens uni propriamque laurum

proprie. difficile est proprie communia dicere;

propriis. capsis quen fama est esse librisque lambustum proptiis.

propriis. qui ne tuberibus propriis offendat amicum | postulat.

aliena negotia curolexcussus propriis.

proprio. sanctiorquel paene natali proptio.

cultelio proprios [propriol purganten leniter unguis.

Archiloclum proprio rabies armavit iambo:

proprio. illum, si proprio condidit horreo.

proprior. septimus octavo propior [proprior] iam fugerit annus.

proprios. regum timendornm in proprios greges,

cultello proprios purgantem leniter unguis.

proprium. longa aetas, liber amicus, consilium proprium:

si proprium est, quod quis libra mercatus et aere est.

tamquam ! sit proprium quicquam.

proprium. quibus ipse meique ante Larem proprium vescot

proprium. potesnelex his ut proprium quirl noscere?

siquid et nos. quod cures proprium lecisse. loquamur.

praprius. erit nulli proprius, sed cedet in usum nunc mihi, nunc alii.

(nam telscire, deos quoniam propius [proprius] contingis, oportet),

propter. hic ego propter aquam, quod erat deterrima.

quia tardiu irent propter on se segres.

qua Paridis propter narratur amorem/Graecia barbariae lento collisa duello.

propter. glandem atque cubilia propter unguibus pugnis. . . pugnabant

propugnacula. ibis Liburnis inter alta navium. |amice, propugnacula.

propugnat. propugnat nugis armatus:

propulit. olim iuventas et patrius vigor nido... protulit [propulit]

prorepit. non usguam prorepit et ills utitur ante quacsitis patiens,

prorepserunt. cum prorepserunt prinis animalia terric.

proriperet. ne virilis/cultus in eardem et Lycias proriperet catervas?

prorogat. alterun in lustrum meliusque semper protogat aevom.

qui recte vivendi prorogat horam.

et longum noto scriptori prorogat aevom.

proroget. latiumque telix alterum in luterum meliusque semper|prorogat [proroget] aterom.

prorsus. prorsus iucunde cenam producimus illam.

sed videt hunc omnis domus . . introrsum [hunc prorsusl turpem. speciosum pelle decora.

proruas. iniurioso ne pede proruas / stantem columnam.

proruet. multa proruet integrum cum latule victorem

proruit. luctert. multa protuet [proruit] integrum 'cun laude victorem

proscripti. proscripti Ragis Rupiti pus atque venenum
PROSCRIPTI

Serm.1.1.83

Carm.3.5.51

Serm.2.3.218

Serm.2.0.40

Carm.3.15.4

Serm.1.4.42

Epist.r.9.5

Epist.1.10.28

Serm.2.3.80

Serm.2.6.52

Epist.1.1.67

Epist.I.I6.I I

Ars Poet. 36 I

Epist.2.1.205

Carm.3.3.I

Ipist.1.13.I I

Ars Poet. 195

Se'rm.2.0.99

Serm.2.7.7

Carm.1.18.3

Epist.1.2.18

Serth.10.22

Serm.2.6.5

Serm.2.2.1 29

Epist.1.9.9

Carm?.2.2.22

Ars Poet. 128

Serm.1.10.04

Serm.1.3.73

Serm.2.3.20

Carm.t.I1.1 8

"ar. Enist.1.7.51

Ars l'ott.79

Curm.1. I.9

car.serm.2.6.40

Corm.3.1.5

Epist.1.7.5I

Serm.1.7.133

Epist.2.2.158

Epist.2.2.172

Serm.2.t.tor)

Serm.2.7.89

Epist.1.17.5

Sirn.2.2.134

:ar.serm.2.0.52

serm. 1.5.7

Serm.2.3.102

Epist.1.2.6

Sirm.I.3.100

Epod.1.2

Epist.1.18.16

z'ar.Carm.4.4.to

ciermit1.1.37

Sirm. I-3.00

(iarm.1.s.10

Curmabecis

Iipist.1.2.41

drs l'set.3te

qur.cirm.sace.68

Sim.1.5.70

var. Epist.1.10.45

(itrm.1.35.13

Carm.tit.to

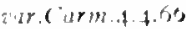

firm.!.7. 1 


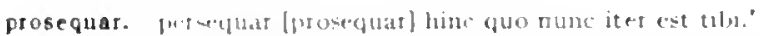

iar.Sirm.1.9.10

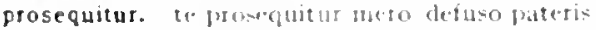

Proserpina. Jullur sacra capue I'foserguma iugit:

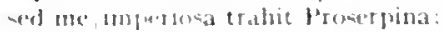

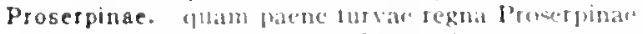

carm...5.5.33

(arm.1.28.20

Serm.2.5.110

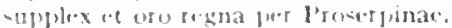

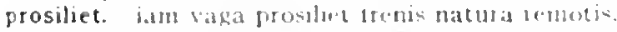

prosilit. Jonue combrosus mosilie untes

prosiluit. binmus ipse pater mumquam wini potus ad arma prosiluit dicenda.

prosit. anmonat" josit, postet frumenta penusgue".

nec rule yuid prosit video ingeruiurn:

prospectat. mugientium prospectat corantic gereges

prospera. Fontuna lustro prospera tertic

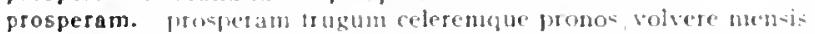

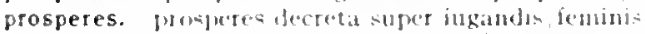

prospiciens. matsona brllantis tyannj|propicions et adulta virgo

buha*' Juhum frospicienset nive candidam| Thracen

prospicit. laudaturque derulus, Jongos gud" prospicit agros:

prostes. seilicet ut prostra sosiotun pumice mundus.

prosunt. nil sinc te mei prosunt honores:

('t forninum fallunt et prosunt furibis:

cpuid vici prosunt atut hurreat

Protea. quo teneam voltus mutantem Protea modo?

proteret. it Matto Ponos protarct altero:

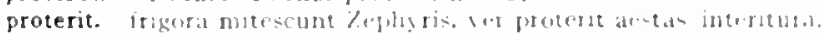

proterva. ham preverval tronte petet 1.alage maritum dilecta.

protervae. latium et rixae cupidos protervar";

inter vina lukin cinatat waerele protertar.

protervi. hetibus crebris ascenes protervi

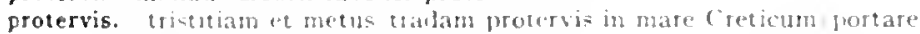
veritlis,

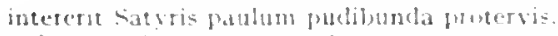

protervitas. wric grata ptotervitas

protervo. muptiatume expets athuc putervo cruda marito.

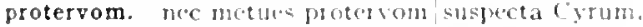

protervos. Sotus vecabit aut protervos Atricus.

Protens. omme anm l'ureus juche egit altos visete montis.

ut cannet fora Neteus [1'roten-] fatat.

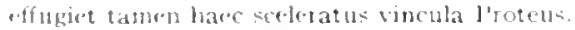

protinus. protuluset gravic iraset invisum nefotem. . Marticlonabo:

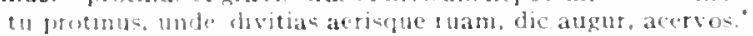

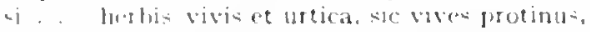

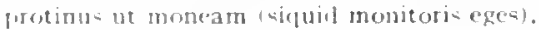

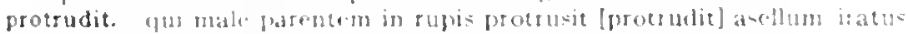

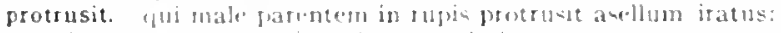

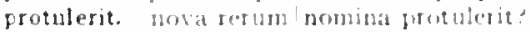

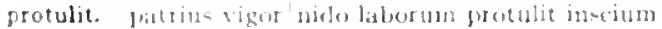

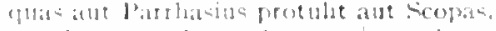

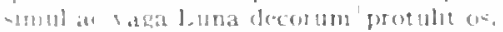

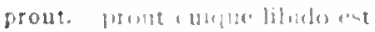

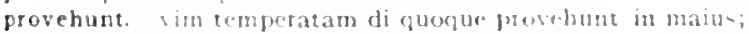

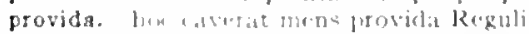

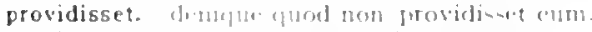

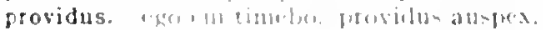

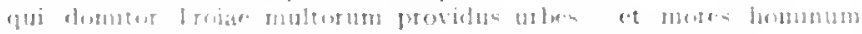

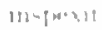

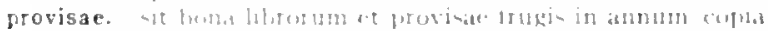

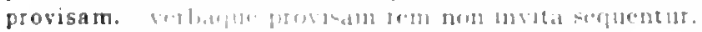

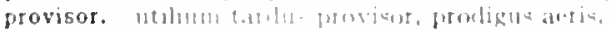

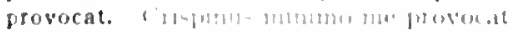

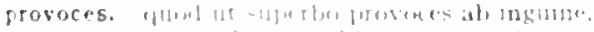

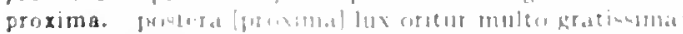

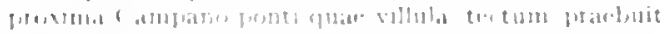

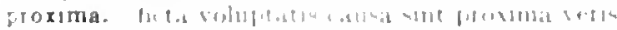

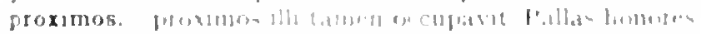

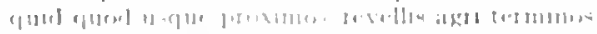

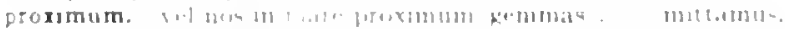

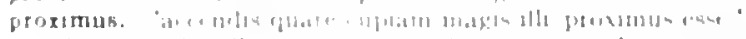

(arm.2. 3.21

Lpod.17.2

Serm. 27.74

serm.1.5.21

Epist.1.198

Ispist.1.14.72

irs l'oth 110

Epod.2.12

Carm.14.37

Carm.4.0.30)

(arm.siac. Is

( $\mathrm{arm} \cdot 3.2 .8$

Carm.3 25.10

F.pist.1.10.23

Epist 1.20.2

Carm. 1.20.10

l.pist. .0.4t

Lisi.2.2.177

Epist.1.1.00

(orm.3.5.3.

(arm.4.7.)

Corm. 2.5. 15

Corm.3.14.20

I.pist.1.7.25

Carm.1.25.2

Carmi.1.20.2

Irs toet. 23.3

(armi in) 7

Carm.3.1.11

(arm.1.17.24

Epod.11.22

Carm 1.2.7

itr.c Carm. I 15.5

sirum.2.3.71

Carm $3 \cdot 3 \cdot 30$

torm. 2.5.21

1.pist I. 12.8

risist as.07

iar ripist. 1.20 .15

I.pist 1.20.15

Irs I'Hed SS

(arm 4.t.

(armasis)

term.1.822

arth 2.c. (1)

(atm. 3 asece

Carm. 3.5.13

1.pist 1.7.m

(arm $32 \pi 8$

IEpist 1210

Jpisl a I I IOU

her Jiand bI

irs lieen leat

verm.t. 1.1

f. pinds is

a ar serm 1.5 .30

sermi.

- iver foul isó

( armi 1 1

( arm. : 18.23

(4) 32.17

sem 105.1

sem 2lu 
nam tua res agitur, paries cum proximus ardet.

prudens. nequiquam deus abscidit/prudens oceano dissociabili|terras, prudens futuri temporis exitum|caliginosa nocte premit deus est animus tibi|rerumque prudens

doctos ego quos et amicos/prudens praetereo. prudens placavi sanguine divos."

cum prudens scelus ob titulos admittis inanis.

'num furis? an prudens ludis me obscura canendo?'

ibis sub furcam prudens

neque ego, hercule, fur, ubi vasa| praetereo sapiens [? prudens] argentea. 'nempe/vir bonus et prudens dici delector ego ac tu."

prudens emisti vitiosum, dicta tibi est lex:

vir bonus et prudens versus reprendet inertis.

'qui scis, an prudens huc se deiecerit

prudens. neque in sepulcris pauperum prudens anus/novendialis dissipare pulveres.

prudens. aeque pauperibus, prodest [? prudens] locupletibus aeque,

prudentem. hoc Staberi prudentem animum vidisse.

si paullum potes inlacrimare, est/gaudia prodentem [prudentem] voltum celare.

at si divitiae prudentem reddere possent.

prudentia. si ratio et prudentia curas, . . aufert.

pruinis. nec prata canis albicant pruinis.

pruna. quid si rubicunda benigni|corna vepres et pruna ferant, .

prunae. praetextam et latum clavom prunaeque vatillum.

psallere. ille virent is et/doctae psallere Chiae/pulcris excubat in genis.

psallimus. psallimus et luctamur Achivis doctius unctis.

Pthius. Troiae prope victor altae/Pthius Achilles. .

ptisanarium. tu cessas? agedum, sume hoc ptisanariuni oryzae."

pube. nec fera caerulea domuit Germania pube

pubes. laeta quod pubes hedera virentilgaudeat

adde quod pubes tibi crescit omnis,

si non periret iam miserabilis captiva pubes.

post hoc secundis usque laboribus|Romana pubes crevit

Publi. "Quinte" puta aut "Publi" (gaudent praenomine nolles|auriculae)

publica. iuvenumque prodis/publica cura.

publica materies privati iutis erit.

publica. pars hominum gestit conducere publica;

in publica commoda peccem.

publica grivatis secernere, sacra profanis.

publicas. mox ubi publicas|res ordinatis.

publicis. non incisa notis marmora publicis,

publico. oppida publicolsumptt iubentes... decorare

publicum. concines laetosque dies et V'rbis|publicum ludum

publicum. caementis licet occupes/terrenum omne tuis et mate publicum:

publicus. quod legeret tereretque viritim publicus usus?

pudenda. sic lucro aversam potuisse nasci|matre pudenda.

pudens. cur nescire pudens prave quam discere malo?

pudenter. distat, sumasne pudenter|an rapias.

dabiturque licentia sumpta pudenter.

pudet. heu heu, cicatricum et sceleris pudet/fratrumque.

(nam pudet tanti mali)

nec lusisse pudet, sed non incidere ludum.

'spissis indigna theatris | scripta pudet recitare et nugis addere 'nondus'

pudibunda. intererit Satyris paulum pudibunda protervis.

pudica. quodsi pudica mulier in partem iuvet domum

"tu pudica, tu proba| perambulabis astra sidus aureum."

'putasne. | perduci poterit tam frugi tamque pudica,

pudicae. fertur pudicae coningis osculum . . ab se remorisse. .

pudicis. excepit ictus pro pudicis|coningibus puerisque

pudico. odisti clavis et grata sigilla pudico;

pudicum. neque enim tenebris Diana pudicum liberat Hippolytum pudicum. qui prinus virtutis honos, idem si clamet furem, neget esse pudicum,

Pudor. cui Pudor et Iustitiae soror . . quando ullum invenict parem? iam Fides et Pax et Honor Pudorquelpriscus et neglecta redire lirtus audet

pudor. dum pudor|inbellisque Iyrae Musa potens vetat quis desiderio sit pudor aut modus/tan cari capitis?
lipist.I.18.8.4

Carm.1.3.22

Carm.3.29.20

Carm.4.9.35

fierm.1.10.83

Sirm.2.3.20t

Serm.2.3.212

Serm.2.5.58

Serm.2.7.60

7 zar.Serm.2.7.73

Epist.1.16.32

Epist.r.2.I8

Ars Poct.4t5

Ars Poel.tio

Epod.17.47

? ar.Epist.1.1.25

Sirm.2.3.89

var.Sorm.2.5.104

Epist 2.2.155

Epist.I.I I.25

Carm.1.4 4

Epist.1.16.9

Sermi.1.5.3t

Carm.4.13.7

Epist.2.1.33

Carm.to.t

Sirm.2.3.155

Epod.16.7

Carm.1.25.17

Carm.2.8.17

Carm.3.5.18

Carm.t.t.ti

Serm.2.5.32

Carm.2.8.8

Ars Poet.131

Epist.1.1.7

Epist.2.1.3

trs Poet.3y7

Carm.2.1.10

Carm.4.8. 3

Carm.2.I5.I8

Carm.t.2.42

Carm.3.24.4

Epist.2.T.g=

Carm.2.1.20

Ars Port.88

Epist.I.I7.4

Ars Poct.5

Carm.1.35.33

Epod.1 I.7

Epist.1.14.3"

Epist.1.19.92

Ars Poet.233

Epod.2.39

Epol.17.40

Serm.2.5.7.

Carm.3-5.t1

Carm.4.9.23

Epist.1.20..3

Carm.4.7.25

Sorm.1.6.82

Epist.1.10.3ts

Carm.1.24.()

Corm.sobsts

Carm.1.6.9

Curm.1.24.1 
Aevine inpuribus certabe abbuntus putor."

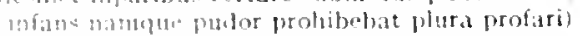

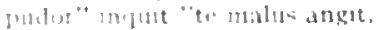

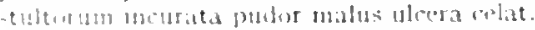

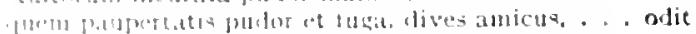

noc mals: andet tem temptar" purlor guam vires ferte tecusent.

unde fmelem proferse publor vetet aut operis lex.

pudor. o pulur, o magna Carthago.

pudorem. furofsilelepositum laudas ob anici iusea pudorem,

$n=$ mox in miant aliena tibi pecata pudorem.

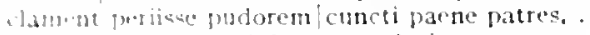

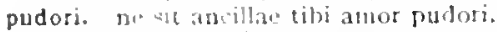

ne furte puloti sit tibi Múa tyrate sollers et cantor Apollo.

puella. purlla dises et laseiva

manum juclla savio opponat tuo.

"ibis repombere? 'magno patre nata puella est."

nisi cena prior potiorque puella Sabinum/detinet adsumam;

alo nutrice purblla velut si luderet infans.

ca-bi- cum pueris ignard puclla mariti/risceret unde preces.

puellae. hatertis proditor intumo gratus puellae rista ab angulo conrsicici calofes Aeolian fidibus puellac.

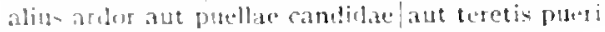

dominua purgi pulchi caraeve purblae

puellae. Gurstant mixtae pueris puellac.

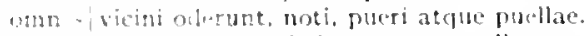

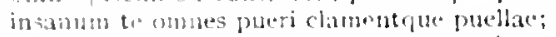

puellae. vos, n pueri et puellut iam virum texpertae.

puellam. He ego mendacem stultisimus u=que pucllatn ad mediam noctem imsineto;

puellarum. querm ai prellarum inserereg choro.

maile piellasum, puerotum mille furores' -

fuellas. Clum rrato Danai puellaal carmine mulces.

quede lathonatis utero putellas/ter vocata audis

sillerusn regiua bicornis, audi,| L,una, puellas.

puellis. vixi porellis nuper iefoneus

puchis/iniciat curam quaerendi singula.

puellis. fuerencon/Sapplo puelliz de popularibu:

libllibus in pueris aut in puellis urere.

puer. yuis multa gracilis te puer in rosalperfusus liquidis urgut odoritus nec inliz amorealaperne puer neque tu choreas.

sive puer turens inpressit memorem dente labris notam.

Thebanaelue iubet me Somelac puer.

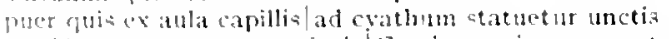

forsidus tecum puer et solutis Gratiae zonis properentque Nymplace

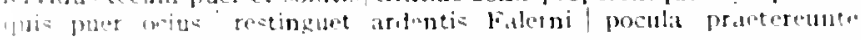

$$
\text { lymblo }
$$

Fbutu- acri militia muricondiscat

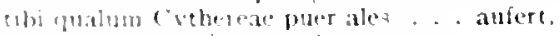

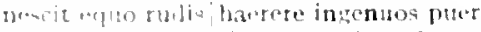

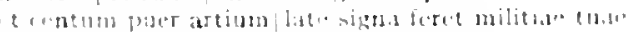

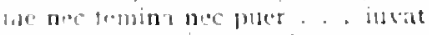

iglid foret llize Mavortiaque puer.

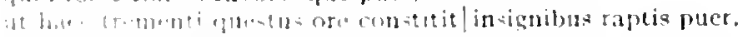

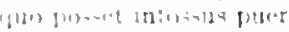

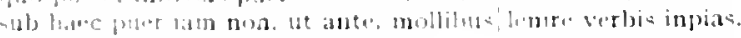

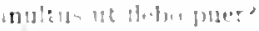

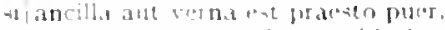

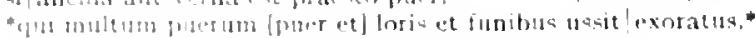

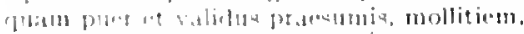

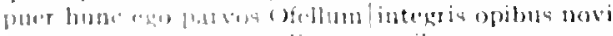

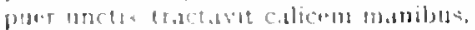

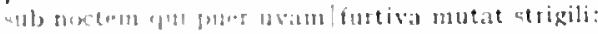

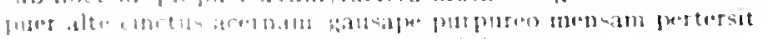

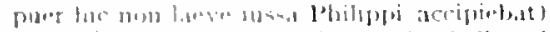

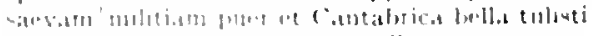

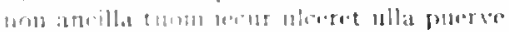

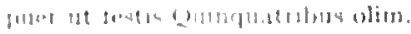

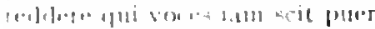

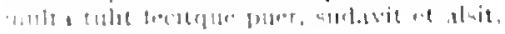

Epod.11.18

Serm.1.1.57

Serm.2.3.39

Epist.1.10.24

Epist.1.1824

Epist. 2 I. 259

Ars Poet. I35

Carm. $3 \cdot 5 \cdot 3^{8}$

Epist.1.9 I 2

IEpist.1.18.77

Epist 2.1 .80

Carm.2.4.I

Ars Porlotpor,

Carm.4.11.22

Epod.3.2 I

Serm.1.2.72

Epist.1.5.27

Epist.2.1.90

Epist.2.1.132

Carm.1.9.22

Carm.4.6.1 2

Epod.11.27

Epist.1.18.74

Corm.t11.10

Serm.1.1.85

Sirm.2.3.130

Carm.3.19.10

Serm.1.5.82

Carm.2.5.2 I

Serm.2.3.325

Corm.3.11.23

Carm.3.22.2

Carm. Sace. $3^{\circ}$

Cirm 3.20.1

Serm.1.10.31

Carm.2.13.25

Inod.11.4

Curm.t.5.I

Cirm.1.9.16

Corm.13.11

Carm.1.10.2

Corm 1.20.7

Carm.1.30.5

Carm.2.II I 8

Cirmi.32.2

Carm.3.12.4

Carm.3.2455

Cirm.t.15

Curm.4 1.29

Carm.4.8.3

I.pod.5.12

Epod.5.32

I.pold.5.83

Epodtu.to

Serme1.2.117

far. Serm.1.10."5

Serm.2.2.17

Sierm.2.2.112

Serm. 2.478

Serm $271 \mathrm{CH}$

Serm.2 8.11)

1:pirl 1. $\$ .52$

Epist.1.ts 55

Epist I.IK 72

Epist 2.2107

Ars lovel 158

Ars l'oet $\$ 13$ 
puer. digne puer meliore flamma.

Persicos odi. puer, adparatus.

i pete uaguentum, puer, et coronas

da, puer, auguris|Murenae:

capaciores adfer huc, puer, scyplos

invicte, mortalis dea nate puer Thetide.

i, purr, atque meo citus hace subscribe libello.

o puer, ut sis/vitalis metuo.

unnc adbibe puro|pectore verba, puer.

pueri. alius ardor aut puellae candidae/aut teretis pueri mater ait pueri mensis iam quinque cubantis.

dominus pueri pulchri caraeve puellae

ne cominus pueri [pueri dominus] pulchri ... munere te parvo beet aut incommodus angat.

os tenerum pueri balbumque poeta figurat,

pueri. hostium uxores puerique caecos/sentiant motus orientis Austri illic bis pueri die... ter quatient humum.

vicini oderunt, noti, pueri atque puellae.

vellunt tibi barbam|lascivi pueri.

tum pueri nautis, pueris convicia nautae|ingerere

magni quo pueri magnis e centurionibus orti,

cum Tiburte via praetorem quinque sequontur|te pueri.

insanum te onnes pueri clamentque puellae;

ut omnes praecincti recte pueri comptique ministrent?

ut ombes praecincti recte pueri [pueri recte] comptique ministrent?

mazonomo pueri magno discerpta ferentes/membra gruis

at pueri ludentes 'rex eris' aiunt.|'si recte facies."

pueri patresque severi|fronde comas vincti cenant

Romani pueti longis rationibus assem | discunt in partis centum diducere.

agitant pueri incautique sequontur.

pueri. lic/verbenas, pueri, ponite turaque

intonsum pueri dicite Cynthium

vos, o pueri et puellae /iam virum texpertae.

virginum primae puerique claris | patribus orti.

quanto aut ego parcius aut vos, $\mid$ o pueri, nituistis.

puerilius. si puerilius his ratio esse evincet amare.

pueris. aequa tellus| pauperi recluditur|regumque pueris

carminia non prius/audita . . virginibus puerisque canto.

ut pueris olim dant crustula blandi|doctores.

ergolnon satis est puris [pueris] versum perscribere verbis.

tum pueri nautis, pueris convicia nautae/ingerere

hoc moricus pueris dixisse vocatis/ad lectum:

id quod . . . aeque neglectum pueris senibusque nocebit.

quaeritur argentum puerisque beata creandis/uxor.

dum pueris omnis pater et matercula pallet

'non invisa feres pueris munuscula parvis' .

et tempestivom pueris concedere ludum

pueris. excepit ictus pro pudicis/coniugibus puerisque .

lue et illuc|cursitant mixtae pueris puellae,

mollibus in pueris aut in puellis urere.

cena ministratur pueris tribus

'Vibidius dum/quaerit de pueris, num sit quoque fracta lagoena. .

cast is cum pueris iguara puella mariti|disceret unde preces,

cum sociis opcrum et pueris et coniuge fida

pueritiae. memor | actae non alio rege puertiae [pueritiae] / mutataeque simul togae.

puero. si parcent puero fata superstiti."

"quae mens est hodie, cur eaden non puero fuit

in aurem / dicere nescio quirl puero.

quod puero cecinit divina mota anus urna:

porrigis irato puero cumn poma, recusat;

non fraudem socio puerove incogitat ullam/pupillo;

non fraudem socio puerove incogitat [puero vel cogitat] ullam |pupillo; ne forte seviles|mandentur juveni partes pueroque viriles:

puero. me Capitolinus convictore usus amicoquela puero est laudator temporis actilse puero.

puerorum. votis puerorum amicas/adplicat auris: hic nuptarum insanit amoribus, hic puerorum; .
Carm.1.27.20

Carm.1.38.1

Curm.3.14.17

Carm.3 19.10

Epod.9 33

Epod I3.12

Serm.1.t0.92

Sirm.2.1.to

Epist.1.2.68

Epod.1 1.28

Sirm.2.3.289

Epist.1.18.74

arar.Epist.I.1 8.74

Epist.2.1.126

Carm-3.27.21

Curm.4.1.25

Sirm.1 1.85

Serm.1.3.134

Sorm.1.5.11

Sirm.1.6.73

Serm.1.6.109

Serm.2.3.1 30

Sirm.2.8.70

zar.Serm.2.8.70

Serm.2.8.86

Epist.1.1.59

Epist.2.1.109

Ars Poet.325

Ars Poet.456

Carm.1.19.14

Carm.1.21.2

Carm.3.14.10

Carm.4.6.31

Serm.2.2.128

Serm.2.3.250

Carm.2.1 8.34

Carm.3.I.4

Serm.1.1.25

var.Serm.1.4.54

Serm.1.5.II

Serm.2.3.170

Epist.1.1.26

Epist.1.2.44

Epist.1.7.7

Epist.1.7.17

Epist.2.2.142

Carm-4.9.24

Carm.4.11.10

Epod. I I.4

Serm.1.6.116

Serm.2.8.8I

Epist.2.1.132

Epist.2.1.142

rar.Carm.1.36.8

Carm.3.9.16

Carm.4.10.7

Serm.1.0.10

Serm.1.9.30

Serm.2.3.258

Epist.2.I.1 22

tar.Epist.2.1.122

Ars Poel.177

Serm. I. 4.97

Ars Poet. 174

Carm.Saec.7 I

Serm.1.4.27 
mille puellatum, puctormm mille furores' -

Serm.2.3.325

Roseia. dic sodes, melior lex an puerorum est/nenia.

Epist.1.1.62

pueros. dicam et Aciden puerosque l.edae.

ter uxor|capta virun juerosplue ploret."

quil] Aukuti jatternus in pueros animus Nerones.

nescios fari pueros Achivis/uteret thammis.

virgines lectas puerosque castos

supplices audi pueros. Apollo;

a furme redcunt is scire lacuquelet pueros et anus."

Carm.1.12.25

Carm.3.3.08

Carm. 4.4 .25

Carm.4.6.1s

Carm.Saci.s

Actia pugnalte duce per pucros hostili more refertur:

Carm.Saec.34

Serm.1.4.38

ut puros elementa docentem/occupet extrenis in vicis balba senectus.

Musa dedit fidibus divos puerosque deorum

ne bueros coram populo Medea trucidet

puerpera. utcumque fort is exsilis jucrpera."

puerperae. laudantur sissili prole puesperac,

puertiae. memor/actae non alio rege puertiae|mutilatque simul togate.

puerum. puesun minacilvoce dun tertet.

Veneremque et illi|seruper haerentem puesum casebat

fronde nova puerum palumbes|texere,

rite latonac puerum canentes.

sic me| formabat puerum dictis

sed pucrum est ausus Romam portare docendum|artis.

Epist.1.18.12

IEpist.1.20.17

Ars Poet.83

Ars poet.is 5

Epod.17.52

Carm.4.5.2.3

Carm.1.30.s

Carm.l.10.10

Carm.132.10

Carm.3.4.12

Carm.4.6.37

Serm.1.4.121

Serm.1.6.76

* qui multum puerum loris et funibus ussit |exoratus. . . . .

puer [pucrum] hunc ego parvos Ofellun! integris opibus novi non latius usum |quam nunc accisis.

Irigide si puerum quartana reliquerit.

ciquis casus puerum egetit Orco.

ut puerum saevo crelas dictata magistro, reoldere

siquis forte velie puerum tibi vendere

neu pransite lamiac vivon puerum extrahat alvo.

Serm.1.10.*5

var.Serm.2.2.112

Serm.2.3.290

Serm.2.5.40

Epist.1.18.13

Epist.2.2.2

Ars Port.34"

Serm.1.2.133

Serm.2.3.30

Corm.t.2.18

Cirm.4.3.4

Ars f'ort.8.4

Epist 2.1.18\%

Spist.1.18.01

Jisist.1.10.34

Sirm.1.3.102

pugnabant. ita froro|pugnabant armis quae post horicaverat usus.

pugnacis. Jriami domus/periura pugnacis dehivos/llectorejs opibus refringit

pugnae. hrgent... te Stluenelua, scienslougnae.

arbites nugnac posuisse nudo|sub pecte palmatm

exyit anus dipis atque pugnae:

purnae. non sat ironeus, pugnae fercbaris:

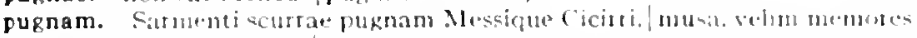
ab) his mainrilus orti at pugnam veruere.

pugnastia, pupis pugnantia secum frontibus alversis conponere:

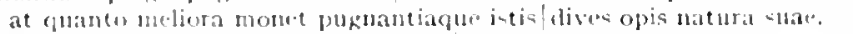

purnare. natju th uaum lactitiate scyplos puknase Thuacum est:

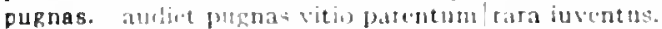

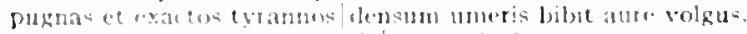

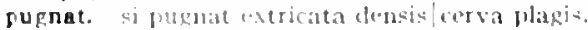

Rapili et loes-i pur puknat.

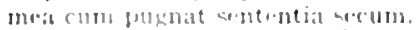

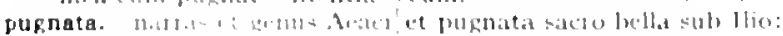

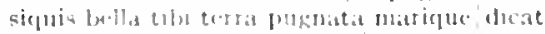

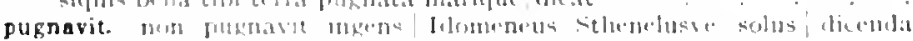

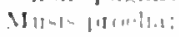

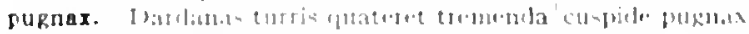

Carm.3.3.2\%

Carm.1.15.25

Cirm.3.20.1 I

Cirm.4.4.12

Corm.2.10.27

Sirm.1.5.52

Sirm.1.5.5\%

serm.1.1.102

Sirn 1.2.7.3

(urm.t.27.2

Curm.t.2.z3

Cirm.2.13.35

Carm.3.5.31

Sirmatio

fipt.1.1.17

Curm.3.10.4

Epist 1.14. 25

(arm... (4) 8.)

Cirmatis

Epivel. fo

sirmaza

1 119m.1.12 2h

serm l zepe

trrm.1.3

Srm.2.1.27

Giarni.312s

Serm.1 110.17

f. fort. 1.110: 
pulcer. 'o sol|pulcer, o laudande!'

Carm.4.2.47

pulcerrimus. venit vilissima rerum| hic aqua, sed panis longe pulcerrimus. pulcher. pulcher fugatis|ille dies Latio tenebris.

fidis enim manare poetica mella| te solum, tibi pulcher.'

'hic et / candidus et talos a vertice pulcher ad imos fiet.

pulchra. labra movet metuens audiri: 'pulchra Laverna,

pulchra, odit/quae tu pulchra putas.

emendata videri|pulchraque et exactis minimum distantia miror.

non satis est pulchra esse poemata; dulcia sunto

pulchre. clamabit enim 'pulchre, bene, recte,'

pulchri. dominus pueti pulchri caraeve puellae

pulchri. at ni id fit, quid habet pulcri [pulchri] constructus acervos? .

pulchrior. merses profundo, pulchrior evenit;

discedat - pulcrior [pulchrior], ultro|muneribus missis):

pulchris, beatus enim iam/cum pulchris tunicis sumet nova consilia et spes. pulchrius, nil melius turdo, ni] volva pulclirius ampla'

pulcra. Cressa ne careat pulcra dies nota

incolumi Rhodos ct Mytilene pulcra facit

pulcra. o matre pulcra filia pulcrior.

pulcra. quo nemus|inter pulcra satum tecta remugiat .

et Laberi mimos ut pulcra poemata mirer.

dic multa et pulcra minantem/vivere nec recte nec suaviter,

pulcrae. quod pulcrae clunes, breve quod caput, ardua cervix.

pulcre. illum/qui pulcre nosset.

sed quis cenantibus una,|Fundani, pulcre fuerit tibi, nosse laboro.

pulcri. at ni id fit, quid habet pulcri constructus acervos?

pulcrioz. 'quamquam sidere pulcrior /ille est.

quodsi non pulcrior ignis |accendit obsessam llion,

discedat - pulcrior, ultro|muneribus missis):

pulcrior. enitescis|pulcrior multo

pulcrior. o matre pulcra filia pulcrior.

pulcris. divina humanaque pulcris/divitiis parent;

pulcris. ille virentis et|doctae psallere Chiae|pulcris excubat in genis.

pulcrum. quid sit pulcrum. quid turpe, quid utile, quid non.

cui pulcrum fuit in medios dormire dies

pulla. suamque pulla ficus ornat arborem.

pulla. laeta quod pubes hedera virenti|gaudeat pulla magis atque myrto,

pullam. pullam divellere mordicus agnam/coeperunt;

Pulliae. nutricis extra limina Pulliae

pullis. ut adsidens inplumibus pullis avis

pullis. absentis ranae pullis vituli pede pressis

pullo. bene erat non piscibus Vrbe petitis, / sed pullo atque haedo;

pullos. das nummos, accipis uram.|pullos, ova, cadum temeti:

pullum. appellat . . pullum, male parvos|sicui filius est.

aut positum ante mea quia pullum in parte catini|sustulit esuriens,

pulmenta. in singula quem trimuas pulmenta necesse est.

cenes ut pariter pulmenta laboribus empta:

pulmentaria, tu pulmentaria quaere/sudando:

pulmenti. per angustam tenuis volpecula rimam | repserat in cumeram irumenti [pulmenti].

pulpa. post hoc ludus erat Tculpa [pulpa] potare magistra ....

pulpita. grammaticas ambire tribus et pulpita dignor:

quam non adstricto percurrat pulpita socco;

traxitque vagus per pulpita vestem

Aeschylus et modicis instravit pulpita tignis

pulsa. undique magno|pulsa domus strepitu resonet.

pulsanda. nunc pede libero|pulsanda tellus;

pulsat. pallida Nors aequo pulsat pede pauperum tabernas I 'regumqué turris.

sub galli canturu consultor ubi ostia pulsat.

pulses. 'tu pulses onne quod obstat.

pulset. ne potum largius aequo|rideat et pulset lasciva decentius aetas.

pulsis. missus ad hoc pulsis, vetus est ut fama, Sabellis,

pulso. pulso Thyias uti concita tympano.

pulsus. unde Superbus|Tarquinius regno pulsus fugit. unde Superbus|Tarquinius regno pulsus [pulsus regno] fugit, .

pulvere, digne sctipserit aut pulvere Troico|nigrum Merionen. adulteros/cultus pulvere collines.

licebit |iniecto ter pulvere curras.

Serm.1.5.89

Carm-4-4-39

Epist.1.19.45

Epist.2.2.4

Epist.r.16.60

Epist.1.14.21

Epist.2.1.72

Ars Poet.99

Ars Poet.428

Epist.1.18.74

zar.Serm.1.1.4t

Carm.4.4.65

war.serm.1.7.17

Epist.1.18.33

Epist.1.15.43

Carm.1.36.10

Episl.1.11.17

Carm.1.16.I

Carm.3.10.6

Serm.1.10.6

Epist.r.8.3

Serm.1.2.89

Serm.1.9.62

Serm.2.8.19

Serm.1.I.44

Carm.3.9.2 I

Epod.14.13

Serm.x.7.17

Carm.2.8.7

Carm.1.16.1

Serm.2.3.95

Curm.4.13.8

Epist.1.2.3

Epist.1.2.30

Epod.10.46

Curm.1.25.18

Serm.1.8.27

Carm.3.4. 10

Epod.1.19

Serm.2.3.314

Serm.2.2.12I

Epist.2.2.163

Serm.1.3.45

Serm.1.3.92

Serm.2.2.34

Epist.1.18.48

Scrm.2.2.20

coni Epist.1.7.30

coni.Serm.2.2.123

Epist.1.19.40

Epist.2.1.174

Ars Poet.2I 5

Ars Poet. 279

Sirm.1.2.129

Carm.1.37.2

Carm.I.+ 13

Sirm.1.r.10

Serm.2.6.30

Epist.2.2.216

Serm.2.1.36

Carm.3.15.10

Serm.1.6.13

var.Serm.1.6.13

Corm.1.6.1 4

Carm.1.15.20

Carm.1.28.36 
non indecoro pulsere urrdidos

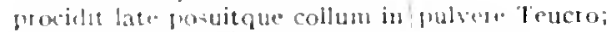

in pulvere, trimum! quale prius, ludas opus.

cul st combias dulcis sine pulvere palmae?

pulverem. sunt atuos curriculo pulverem Mtympicun/collegisse iuvat

lin $n$... multer peregrina vertit in pulverem.

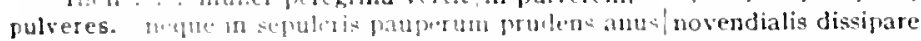
puldines.

pulveris. cur apricunfou.pit campun patiens pulveris atque solis,

pulvesis caigui frope latum parva Matintalmunera

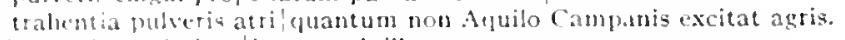

pulvillos. inter sericos/iacere pulvillos amant.

pulvinar. Salingbus'ornate pulvinar deotum tempun erat dapibus.

pulvis. pulvic et umbra sumus.

iertur uti nulvis collectus turbine.

si to pulvis strepitusque rotatum, | si laedit caupona.

pumice. scilicet ut prostes Sosionum pumice mundus.

pumicibus. quae nunc oppositis dehilitat pumicibus mare/Tyrhenum:

puncto. desedo Alcacus puncto illius:

puncto quod mobilis horac. . permutet fominos

puncturs. cmnte tulit punctum, qui miecuit utile dulci

Punica. et jost l'mica bellat quetus quactere coepit.

puniceae. munc at qui color est puniceae tlose prior rosae

Punicis. signa e.go Punicis!anfixa delubris

Punico. intrecit ar-ciuor singuine P'unico

latia l'unicol lugubre mutasit sagum.

Pupi. ut popius epectes lacrimosa poematal Puji;

pupillis. It figer annug| pupillis quos clua pemit custodia inatrum:

pupillo. non frauden socio puterove incogitas ullam / pupillo;

puppes. hostilinurgue nasium portu latent puppes

puppibus. nil pictis timidus navita puppibua| frdit.

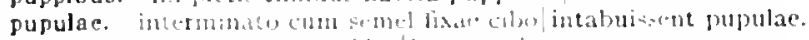

pusa. ue pura nocturno renidet/luna mari

purae. purae rivos aquar silvarue ingerum/patcorum .

purae. tabi hospitale froctua et jurae manus

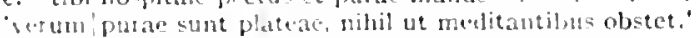

pure. plarima quas invideant pure adpatere tibi rem. .

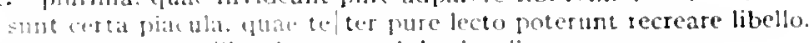

glidel pure trangullitet, honos ae dules lucellum

purgantem. cultallo poprios purgantem benitot unguis.

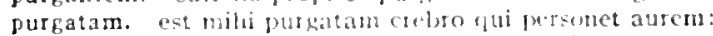

purgatum. et misor morbi purgatum te illius:"

purgor. "qui purgor bilem sul, vesn temporis horan.

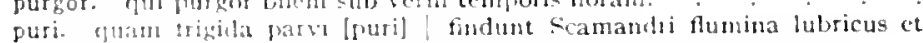

$$
\text { Sinuri: }
$$

puri. : it milis menta tripes et eroncha salic mui

purios. ut moc frigidior Thatecan mec puston ambiat Itebrus,

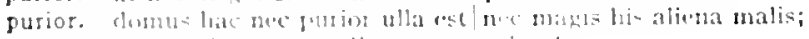

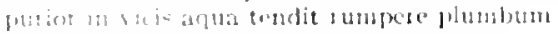

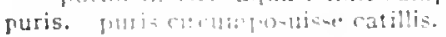

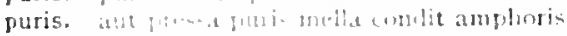

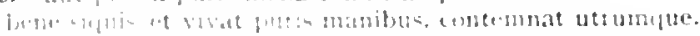

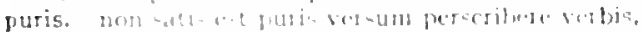

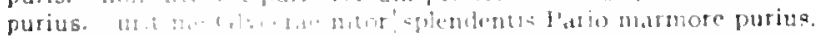

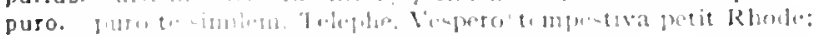

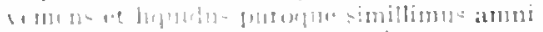

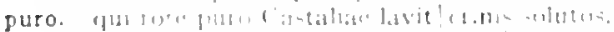

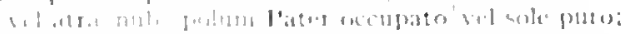

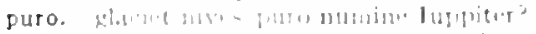

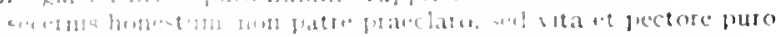

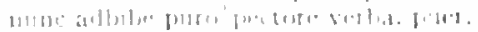

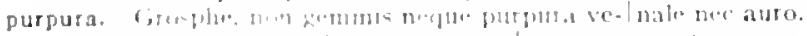

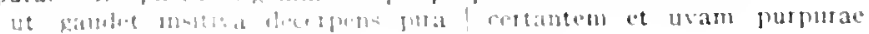
[phrmistis].

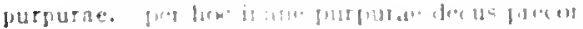

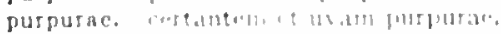

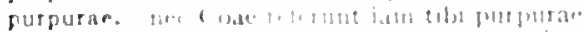

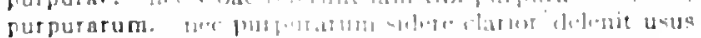

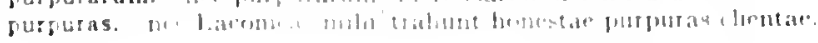

Carm.2.1.22

Carm.4.0.12

Serm.2.3.251

Fpist.1.1.51

Carm.1.1.3

Carm.3.3.21

Lipod.17.48

Curm.1.8.1

Carm.1.28.

Sirm.2.8.5.5

lipod.s.17)

Carm.1.37.3

Carm.4.7.10

Serm.1.31

lipist.1.17.7

lipist.1.20.2

Carm.111.5

Epist.2.2.90

Lpist.2.2.172

Ars Poet. 34.3

Epist.2.1.162

Curm 4.10.4

Curms.3.5.18

Corm.3.1.31

Epod 9.27

Epistid.1.67

lepist.1.1.22

Efist.2.1.123

Epod 0.20

Carm 1 1. 1.9

I. pod 5..po

Corm. 2.5.10

Carm.3.10.20

Ispod.17.40

IEpist 2.2.71

Sirmo1.2.100

Fipist.1.1.37

List.1.1S 102

l-pist. 7.51

lipistatit

Serm.2-3.27

Ars Pod.302

conilit fond.1313

Germe1-3.1.4

Lepstit.10.8

Sormet.9. 10

Epist 1.10 .20

serm 2.475

1. poid2.15

serme1.th

sirm-1.4.54

Corm.1 10,

Corm 310.24

lipilit2.2120

Carm.3.4.8

Carm-320.:5

Carm-3 10 to

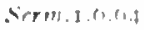

Egrive 20 :

Curmale?

कor. I prut 2.2.

Expis 5

Fifule $2 \geq 0$

Cormat313

Carm-3 1.4?

Ciarm.2 18.8 
purpurea. ergo ubi purpurea porrectun in veste locavit /agrestem. purpurei. te... purpurei netuont tyranni,

purpureis. purpureis ales oloribus|comissabere

purpureo. tibi lividos | distinguet autumnus racemos | purpureo varius colore.

purpureo. purpureo bibet ore nectar.

acernam |gausape purpureo mensam pertersit

purpureos. regumque matres barbarorum et | purpurei metuont tyranni [? purpureos tyrannos].

purpureum. alter purpureum non exspectabit anictum,

purpureum. Siculum mare/Poeno purpureum sanguine

purpureus. nec flos purpureus rosae.

purpureus, late qui splendeat, unus et alter|adsuitur pannus.

Purria. ut vinosa glomus furtivae †Pirria [Purria] lanae.

purum. stas animo et purum est vitio tibi, cum tumidum est cor?'

purum. per purum tonantis/egit equos

purus. integer vitae scelerisque purus

purus et insons| (ut me collaudem), si et vivo carus amicis:

pus. proscripti Regis Rupili pus atque venenum

Pusillam. Rufam aut Pusilam appellet fortique narito/destinet uxorem: pusilli. inopis me quodque pusilli|finxerunt animi,

pusillo. cui satis una|farris libra foret, gracili sic tamque pusillo.

puta. "Quinte" puta aut "Publi" (gaudent praenomine molles/auriculae)

putando. ultralquam licet sperare nefas putando

putant. vel quia turpe putant parere minoribus

putarer. sed timui, mea ne finxisse minora putarer.

putaret. Democritus... scriptores autem narrare putaret asello fabellam surdo.

putas. ne me Crispini scrinia lippi|conpilasse putes [putas], verbum non a mplius addam.

tuo vitio rerumne labores. / nil referre putas?

an ut ignotum dare nobis / verba putas?'

unde putas aut|qui partum?

qua me stultitia. quoniam non est genus unum, insanire putas?

putasne./perduci poterit tam frugi tamque pudica,

insanire putas sollemnia me neque rides

virtutem verba putas et|lucum ligna:

vel quia cuncta putas una virtute minora.

odit|quae tu pulchra putas.

quid sentire putas, quid credis, amice, precari?

putat. sine nervis altera quidquid|conposui pars esse putat .

quod satis esse putat pater et natura coercet.

insanire putas [putat] sollemnia me neque ides/nec medici credis . . egere

sed turpem putat inscite metuitque lituran.

emptum cenat holus, quamvis aliter putat:

putato. 'non est cardiacus (Craterum dixisse putato) / hic aeger.'

'sic ignorisse putato|me tibi, si cenas hodic mecum."

putatur. fraternis cessisse putatur|moribus Anphion:

Puteal. 'ante secundam/Roscius orabat sibi adesses ad Puteal cras.' .

puteal. 'fornm putealque Libonis/mandabo siccis,

putem. ni melius dormire putem quam scribere versus?

an omnis|risuros peccata putem mea.

puteos. collectosne bibant imbris puteosne permis/iugis aquae

putere. non cessavere poetae/nocturno certare mero, putere diurno.

putes. ne me Crispini scrinia lippi|conpilasse putes.

neque, siqui scribat uti nos|sermoni propiora, putes hunc esse poetam. quo melaegrotare putes animi vitio.'

frugi quod sit satis, hoc est, | ut vitale putes."

virtuten verba putas [putes] et |lucum ligna:

neve putes alium sapiente bonoque beatum

Garganum mugire putes nemus aut mare Tuscum:

ne forte putes me. . . lat dare naligne:

putescit. 'cur Alax, heros ab Achille secundus, |putescit,

putet. quamquam|putet aper rhombusque recens. .

putetis. quine putetis/difficile et mirum.

putetur. non quia crasse/conpositum inlepideve putetur.

puteum. posset qui rupem et puteum vitare patentem.

si veluti merulis intentus decidit auceps/in puteum foveanve,
Serm.2.6.I0',

Carm.1.35.12

Carm.4.1.10

Carm.2.5.12

Carm-3-3.12

Serm.2.8.1 I

7 var.Carm.1.35.12

Epist.1.17.27

Carm.2.12.3

Carm.3.15.15

Ars Poclis

:ar. Epist.1.13.14

Sirm.2.3.213

Carm.I.34.7

Carm.1.22.I

Serm.1.6.69

Serm.1.7.I

Serm.2.3.211

Serm.1.4.17

Sorm.1.5 00

Serm.2.5.32

Carm.4. I 1.30

Epist.2.I.84

Epist.1.9.8

Epist.2.I.I99

var.Serm. I.1.I2I

Serm. 2.77

Serm.1.3.2.3

Serm.2.2.I 8

Serm.2.3.302

Serm.2.5.70

Epist. I.I.10I

Epist.5.6.31

Epist.I.I2.I I

Epist.I.T4.2I

Epist. I. I . Io

Serm.2.I.3

Serm.2.3.178

zar.Epist.1.I.IOI

Epist.2.1.167

Epist.2.2.108

Sirm.2.3.10I

Epist.1.7.69

Epist.1.18.43

Serm.2.6.35

Epist.1.19.8

Epist.2.2.54

Ars Poet.260

Epist.1.15.15

Epist.I.19.1 I

Sorm.I.I.I2I

Serm.1.4.42

Sirm.2.3.307

Serm.2.7.4

var. Eptist.1.0.31

Epist.I.IU.zo

Jifist.2.1.202

Epist.2.1.208

Serm 2.3.194

Serm.2.2.42

Sirm.1.10.2 I

F.pist.2.1.77

Epist.2.2.135

Ars l'oet. 459 


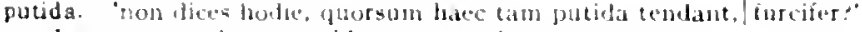
putuam. toparto longo putidam te saeculo.

putidius. jutulus multo cerebrum rest, milit crede, Derelli

putre. hatec tobidictaban pot fantum putre lacunae.

putres. manmule putresferpuina quales if bera

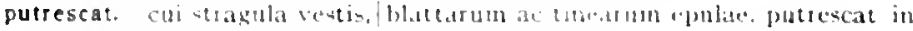
afla:

putris. ammes an lianalin putrisfleposent veulos

putust. non aliat quam (quat Byzantia putut of áa

nyga. ne summi pereant aut puga [pyga) aut denigue fama.

pygae. Ise nummi pertant aut puga [nygate] aut denique famis

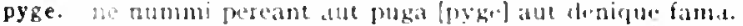

Pyladen. non Pyladen ferio violare ausleve sotorem|Electran.

Pylium. non l'ytim Nestors respicis:

nom l’yum Nestora [? Nestora l’ylium] respicis!

pyramidum. regaligute situ pyranidum aleius.

Pyrcaeus. pose how insignis llomerus Tyrtaensque [1"reatusque] mares antmos in Nartia bella versibus exacuit:

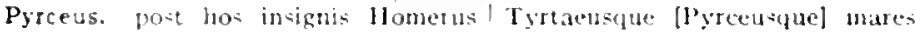
anduro in Martia bella versibus exacuit:

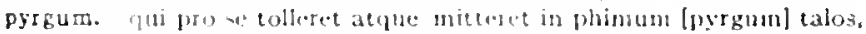

Pyrrha. siato. lyotha. sub antro?

Pyrrhae. -anculum Pyrthae nova monstra quentar.

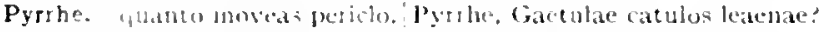

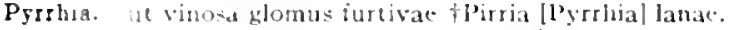

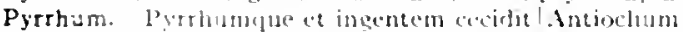

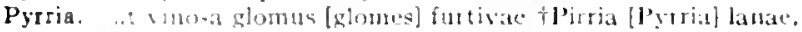

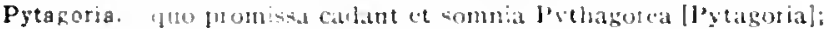

Pythagorae. nect te lythagorac tallant arcand remati

o thidelo taba ['ytlugorae cognata. . ponentus

Pythagoran. qualia vincent | Pythagoran Anvigue renu dostumque J'latona."

Pythagozca. diso promisos cadant et smmia lythagorea:

Pythia. qui l'ithia cantat/tibicen, didicit prus

Pythias. Ht nihil interst, Davosne boqutur et audax Pythias.

Pythius. mon arvetis quatic mentem sacardotum incola pythis.
Serm.2.7.21

Fipod.8.1

Serm 2.375

lipist.1.10.49

lipod 8.7

Serm.2.3.119

Carm.1.3 3.17

Serm.2.t.e日

tar.Sorm.1.2.133

iar..ferm. 1.2 .133

s'sr.Sirm.1.2.133

Serm.2.3.139

Carm.1.15.22

? iar.Carm.1.15.22

curm.3.30.2

fer.ters lod.gaz

var.ters loct.goz

iar. Serm. 2.7.17

Cirm.1.5.3

Cism.1.2.0

Carm.3.20.2

comi.Epist.1.13.14

Carm.3.6.35

Tar. Epist.1.13.14

rar. E. Pist.2.1.52

Esod.15.21

Serm.2.tion

Serm.2.4.3

Ejist.2.1.52

irs l'oct.int

Ars Poct.235

Carm.1.10."

\section{Q}

Qua. nhax. Tquia [qual sic voluere, ponto, unda recumbit.

1pua medius liquor|secernit Europen ab tro.

7ua tumirlus tigat arva Nilus.

steghegens, ne gua populua laboret.

Tua violens obatrepit Aufidus

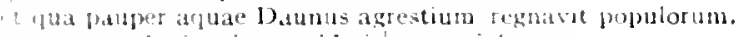

lua notam duxit. niveus videri, cetera fulvos.

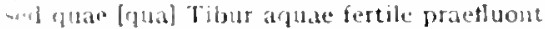

'juat col habitabria|inhustrat oris.

fua re. qua tatio sualeret quaque modeste, munifico esso licet.

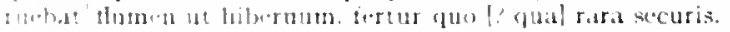

']ua molo tristis atbic informen spectabant ossibus agrum;

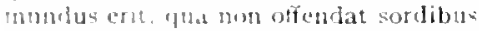

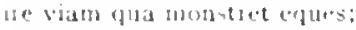

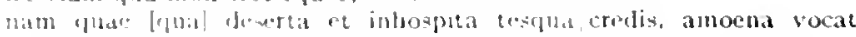
mecun gul sestit.

sed matis "ut orare lovem gnae (qual ponit et aufert.

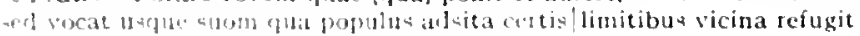
Iustiat:

qua. fro qua nos me mam mori.

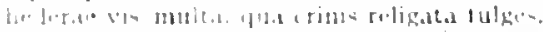

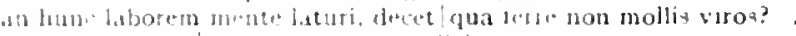

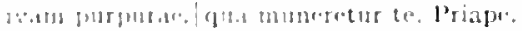

'guatristat orion callut:

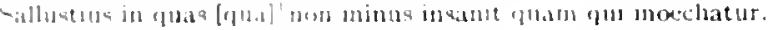

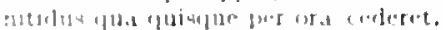

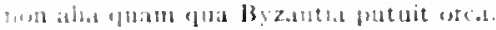

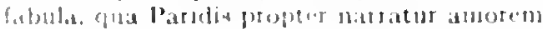

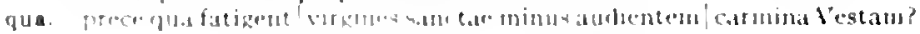

comi.Carm.1.12.31

Carm.3.3.4n

Corm.3.3.48

Carm 3.8.25

Carm.3.30.10

Carm.3.30.11

Curm.4.2.59

:ur.Curm.4.3.10

Carmatid.5

Scrm.t.2.50

I Idar.Sorm 1.7 .27

coni.term.1.8.15

Serm.2.2.05

List.1.2.05

Eur. Lpist.1.14.19

rar.l.pist.1.18.111

Lpist.2.27\%o

(arm.3.0.11

Carm.s.19.5

Fod.t.10

lipoil 2.21

Lpodido.to

1'ar.Serm.1.2.43

Scrm.2.1.pit

Serm.2.s.in

Efist. 1.2.13

Carm.1.2.20 
qua. quo beatus $\mid$ volnere, qua pereat sagitta.

Curm.1.27.1 2 qua parte debacchentur ignes.

qua nebulae pluviique rores. .

qua me stultitia, quonian non est genus unum. insuniro putas?

Carm.3.3.55

Carm.3.3.50

Serm.2.3.301

accipe qua ratione queas ditescere.

qua ratione queas traducere leniter aevom.

qua. Spartacum siqua potuit vagantem|fallere test i.

Sirm.2.5.10

Epist.I.18.97

Carm.3.14.19

mentio siquae [siqua] / de Capitolini turtis iniecta letilli|te coram fuerit, defendas.

quacumque. quan [qua] rem cumque.. miles te duce gesserit

eat quacumque, puellis iniciat curan quaerendi singula,

quacumque libido est, |incedo solus;

quadam. est quadam prodire tenus, si non datur witra.

quadra. dividuo findetur inunere quadra

quadrante. dum tu quadrante lavatum|rex ibis

forte minus locuples uno quadrante perisset.

quadrat. porro et tertia succedant et quae pars quadret [quidrat] acervom.

quadrata. diruit, aedificat, mutat quadrata rotuludis?

quadret. tertia succedant et quae pars quadret acervom.

quadrigis. tibi tollit linnitum|apta quadrigis equa,

quadrigis. navibus atque/quadrigis petimus bene vivere.

quadrimum. deprome quadrimum Sabina,

quadringentis. sed quadringentis sex septem milia desunt:

var. Serm.1.4.93

2ur.Carm.1.6.3

irm.1.6.31

Serm. I.6.I I I

Epist.1.1.32

Epist.1.17.49

Sirm.1.3.137

Sierm-2.3.93

vor. Fipist.1.0.35

Epist.1.1.100

Epist.1.0.35

Carm.2.16.35

Epist.1. I I.29

Corm.1.9.7

Epist.r.I.57

quae. Carm.1.2.10; I.3.5; I.II.5; I.I 4.1 7; I.25.5; I.25.14; 1.26.6; 1.35.1; I.37.21;3. I 1.9; 3.I I.37; Carm.3.22.2; 3.23.9;3.26.9;3.27.33; 3.27.4I; 3.28.13;4.3.18;4.4.53;4.7.8; 4. 10.7; Carm.4.13.19; 4.13.20; 4.15.19; Carm.Saéc.69; Epod.5.45; 5.51; 5.94;8.1 3; I 2. I6; 1 7.76; Serm.I.I.36; I.2.1 2I；1.3.8; I.3.I4, I.3.1I8; I.4.1.4I; I.5.45; I.5.5I; 1.6.26; I.8.3I; Serm.1.8.32; 1.9.54; 2.2.73; 2.2.94; 2.3.205; var.Serm.2.4.56; Serm.2.5.81; Lpist.1.1.63i Epist.I.4.I4; I.6.2; I.6.35; I.10.2I；1.10.23; I.I4.25; I.I8.7; 2.I.I53; Irs Pot'190; 305; Ars Poet.361; 364

quae. Carm.3.I I.4I; 4.3.10; 4.10.3; 4.12.1; Serm.1.8.19; coni.Ars Poet.43I

quae. Carm.1.19.12;3.11.29; Epod.16.13; 16.35; Serm.1.2.92; 1.2.100; 1.10.38; 1.10.72; 2.4.87; Serin.2.6.46;2.6.105; 2.7.106; Epist.1.1.23;1.1.30;1.2.38; I.8.I I (his); 1.13.17; 1.19.3; Epist.2.2.36; Ars Po:t.70; 7 I; 181

quae. Carm.1.13.15; I.I8.14; 1.22.7; 1.31.7; 2.I2.21；2.12.27; $329.54 ; 4.7 .20 ; 4.8 .14 ; 4.9 .1$; Carm.4.1 2.21; 4.13.14; Carm.Saec.3４99;Epod.9.9; Serm.1.3.102; 1.4.56; 1.4.57; 1.5.46; Serm.1.9.5; 2.2.2; var.Serm.2.3.190; Serm.2.3.322, 2.4.23; 2.7.45; 2.8.80; Epist.1.1.12; Epist.1.1.42; I.1.47; 1.1.72; I.2.24; I.4.9; 1.7.20; I.10.9; I.I4.I9;1.I4.21; I.I7.3; I.I8 III; Epist.2.1.21; 2.1.70; 2.1.73; 2.1.82 (bis); 2.1.S4; 2.1.208; 2.1.240; 2.2.117; 2.2.119; Ars Poet.149; 181; $184 ; 277$

quae. Corm.1.29.5; 2.1.36; 4.14.I (bis); Epod.17.36; serm.2.7.79

quae. Epist.2.1.200;2.2.53

quae. Corm.2.1.33

quae. Carm.3.25.2; Epist.1.3.2t

quae. var.Serm.1.2.50 (ter); Sirm.2.2.I; 2.9.45; 2.0.7t; 2.8.5; Epist.I.I5.I

quae. Epist.1.12.16; Ars Poet.314

quae. Corm.3.5.49; Serm.2.2.70; Epist 2.1.106

quae. $\operatorname{Carm}+1.27 .21$

quae. var. Epist.1.1.76

quae. Sirm.1.4.93;2.0.10

quaecumque. quaecumque aut gelido prominet Algide quae te cumque domat Venus,

quaecumque praecedet fera;

quaecumque excepit turgentis verbera caudae/clunibus

quaecumque. ex hoc ego sanus ab illis/perniciem quaecumque ferunt quaecumque inmundis fervent adlata popinis.

quaecumque parum splendoris habebunt . . . verba

quaecumque. "tibi di, quaecumque preceris, / commoda dent. scripta, Palatinus quaecumque recepit Apollo.

quaedam. (et est quaedam tamen hic quoque virtus): erit quae, si propius stes. / te capiat magis, et quaedam, si longius abstes.

quaedam. si quaedam nimis antique, si pleraque dure/dicere credit eos. quaedam, si credis consultis, nancipat usus:

Carm.1.21.6

Carm.1.27.14

lipod.6.8

Serm.2.7.49

Serm.1.4.130

Serm.2.4.62

Epist.2.2.II I

Serm.2.8.75

Ispist.1.3.17

Serm.1.I0.8

Ars Poet.362

Epist.2.1.66

Epist.2.2.159

Epist.I. I 5.30

quaelibet. quaelibet in quemvis opprobria fingere sacvos,
pictoribus atque poetis |quidibet [quaelibet] audendi semper fuit aequa potestas."

quaeque. res/ut quaeque est, ita suppliciis delicta coercet? . . .

quaeque. quia Graiorum sunt antiquissima quaeque |scripta vel optima. singula quaeque locum teneant sortita decenter.

?ar. Ars Poel. Io

Sirm.1.3.79

Epist.2.1.28

Irs Pot. 92 


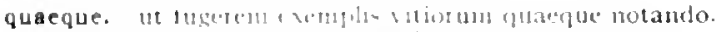

Sarm.1.4.100

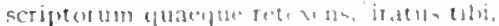

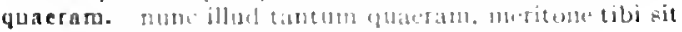

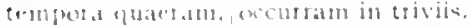

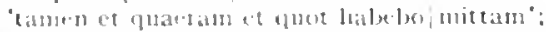

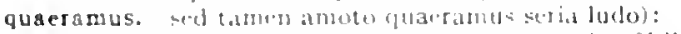

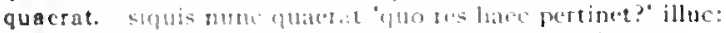

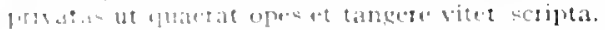

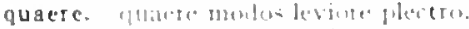

(1) pultuentatia quacte sublando

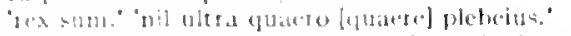

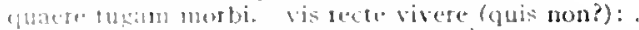

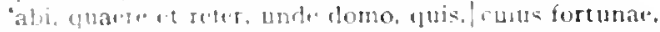

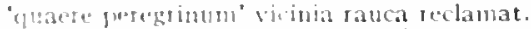

quaerebat. Jonasset iamn catenam ex roto Labus, quaerebat;

quacsenda. nam mili continuo nlitot quaesenda foret res

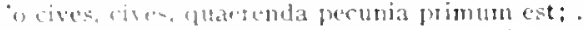

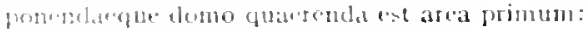

quaerendi. meniglue st finis quatendi

puedis, maciat curam quarounli singulit.

quaerens. micese discedeje guatertas

ian vino glaterens, iam sommo fillere curam;

quacrens. "pua" genetodus perate quaterens

tragili atracreas illidere dentem

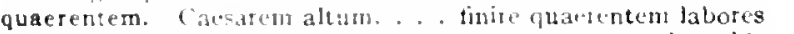

quaerenti. vitas linumlico me smilis, Cluloe, quaerenti pavidam montibus athis natretu

quare te l.osbia quacterti taurum monutravit jnetem.

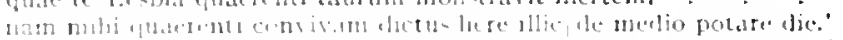

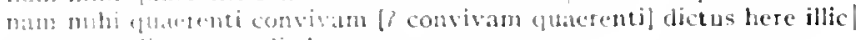

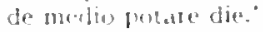

quacrentis. hath illud guarentis. num sine sencu,

quaerere. guitl sit futurum cras, tuge quame

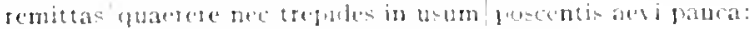

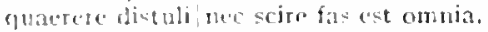

quartere plu frodest et inane abscindere soldo?

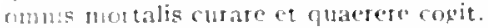

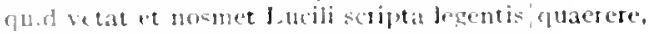

nlam nam quaxtere amabam, . . aces.

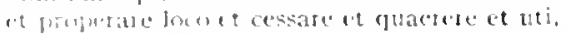

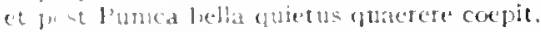

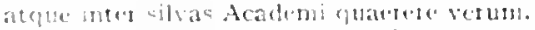

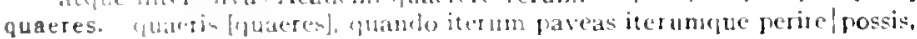

$$
\text { otetione-risin. }
$$

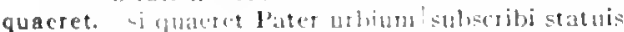

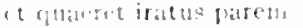

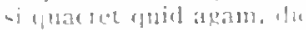

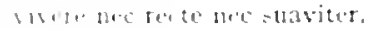

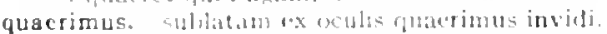

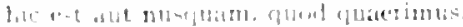

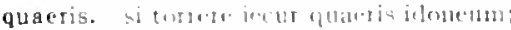

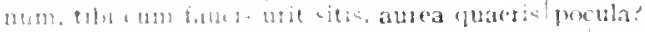

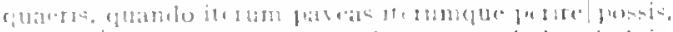

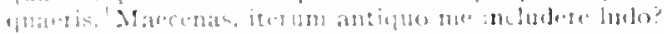

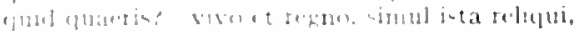

quacrit. mon Bumiries qualert ardelteros

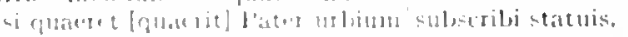

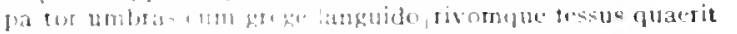

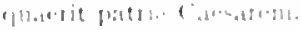

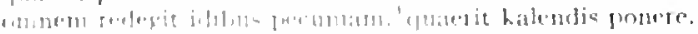

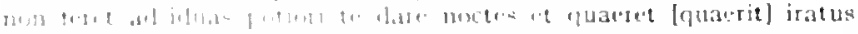

$$
\text { 1.item }
$$

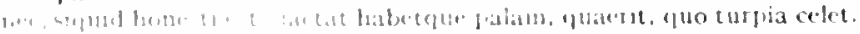

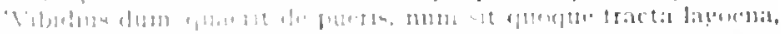

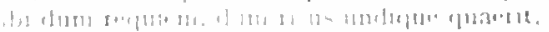

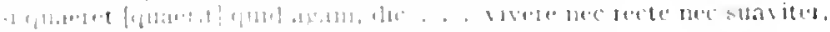

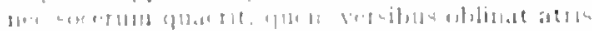

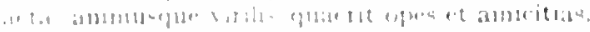

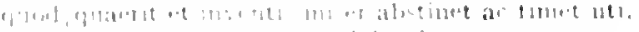

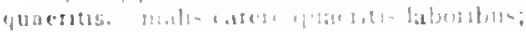

Serm.2.3.2

Serm.1.4.

Serm.1.9.5s

Epist. 1.42

Sorm.1.1.27

Serm.1.2.23

Lipist.1.3.1e

Carm.2.1.40

Sorm.2.2.20

f'ar.serm.2.3.188

Esist.1.6.20

Epist.1.7.53

Epist.1.17.02

Serm.1.5.06

Serm,1.0.100

Efist.1.1.53

Efist.1.10.13

Serm.1.1.92

Sirm.1.6.32

Serm.1.9.8

Serm.2.7.114

Carm.1.37.22

Serm.2.1.77

Carm.3.4.39

Corm.1.23.2

Epod.12.17

Scr, 2.8 .2

7 :ar.serm.2.8.2

Serme1.4.77

Carm.1.9.13

Corm.2.11.4

Corm.4.21

Sirm.1.2.113

Serm.1.1.37

Serm.1.10.57

Serm.2.3.20

Efist.1.7.57

Efist.2.1.162

Efist.2.2.45

Tar.serm.2.7.09

Carm.3.24.27

Efoul. 5.14

EFist.1.8 3

Corm.32.4.32

Efrist.1.17.30

Carm-1.1 2

Sorm.1 2.114

sermizas 209

Epst.1.1.2

Epist.10.8

Carm 3.10.25

a ar. Carm.3.24.27

Corm.3.2022

Carm.4.5.10

bipol.zon

gor. Epold.1.5.t

torm. $1.2 \$ 5$

Srm.s.s.

IPpes I 70

tar. Iipis 1.\$3

I.pisi 1.10 .30

Ars bief ling

Ars lint. 1 7o

I.pod 10.10, 


\section{QVAERITVR}

quaeritur. quaeritur argentum puerisque beata creandis/uxor

quaero. nunc ego mitibus|mutare quaero tristia.

speciosa quaero|pascere tigris.

probanque / pauperiem sine dote quaero.

age, quaeso [quaero], | tu nihil in magno doctus reprehendis Homero?

'rex sum.' 'nil ultra quaero plebeius.'

quaero, faciasne quod olim $\mid$ mutatus Polemon? .

quaerunt. tutum per nemus arbutos|quaerunt latentis et thyma deviae

quaesierat. quidquid quaesierat ventii domabat avaro.

quaesieris. tu ne quaesieris, scire nefas, quem mihi, quem tibi finem di dederint,

quaesita, ante meum nulli patuit quaesita palatum.

quaesitam. sume superbiam/quaesitam meritis

quaesitis. asper et attentus quaesitis,

quaesitis. illis utitur ante|quaesitis patiens.

quaesitum. natura fieret laudabile carmen an arte, iquaesitum est:

quaesivere. idcirco quidam comoedia neene poema|esset quaesivere.

quaeso. age, quaeso, tu nihil in magno doctus reprehendis Homero?

quaestor. quaestor avos pater atque meus patruosque fuissent.

quaestu. ' 'at in se/pro quaestu sumptum facit hic.'

quaestus. autumnusque gravis, Libitinae quaestus acerbae.

quale. quale posset inpia mollire Thracum pectora:

quale fuit Cassi rapido ferventius amni|ingenium.

quale. quale portentum neque militaris|Daunias latis alit aesculetis. nardo perunctum, quale non perfectius/meae laborariut manus.

in pulvere, trimus/quale prius, ludas opus,

qualecumque. olabornm/dulce [quale] lenimen †mihicumque [mihi eumque] salve / rite vocanti.

qualem. qualem ministrum fulminis alitem,

qualemve laetis caprea pascuis|intenta . . . leonem . . . vidit :

qualem me saepe libenter obtulerim tibi. Maecenas.

qualem commendes, etiam atque etiam aspice,

quales. mammae putres/equina quales ubera .

quali. quali igitur victu sapiens utetur

quali. cum referre negas, quali sit quisque parente/natus, quali / sit facie, sura quali, pede, dente, capillo: .

quali / sit facie, sura quali, pede, dente, capillo: .

quali. quali perfundat piscis securus olivo.

qualia. praeceptis, qualia vincent Pythagoran Anytique reum qualia lassum / pervellunt stomachum.

qualiacumque. quibus haec, sint qualiacumque.|adridere velim,

qualibet. qualibet exsules in parte regnanto beati;

qualis. qualis aut Nireus fuit aut aquosa|raptus ab Ida.

non sum qualis eram bonae; sub regno Cinarae.

nam qualis aut Nolossus aut fulvos Lacon.

Qualis Lyeambae spretus infido gener

qualis. Sabina qualis aut perusta solibus|pernicis uxor Apuli,

quorum hominum regio et qualis via

servetur ad inum|qualis ab incepto processerit

qualis. sed incitat me pectus et mammae putres/equina quales [qualis] ubera

qualis. qualis|aedituos habeat belli spectata domiquelvirtus.

qualis. quas aut [? qualis] Parrhasius protulit aut Scopas.

indomitas prope qualis undas|exercet Auster

animae qualis neque candidiores/terra tulit

qualum. tibi qualum Cythereae puer ales. ... aufert,

quam. Carm.1.7.12; 1.11.8; 1.13.8; 1.24.10; 1.33.9; 1.36.7; 2.2.10; 2.13.21; $3.3 .51 ; 3.5 .53 ; 3.16 .26$;

Curm.3.16.41; :ar.Curm.3.25.12; Carm.4.8.20; 4.11.30; Epod.2.55; $5.81 ; 10.12 ; 12.6$;

Epod.12.7; 12.20; 12.2.4; zar.Serm.1.1.46; Serm.1.1.48; 1.1.56; 1.2.20; 1.2.49; 1.2.59;

Sirm.1.2.66; 1.2.79; 1.2.105; 1.2.124; 1.3.27; 1.3.67; 1.6.20; 1.6.1 10; 1.10.*?; 1.10.66;

Serm.I.IO.C7; 2.I.2I; 2.2.24; $2.2 .91 ; 2.2 .114 ; 2.3 .60 ; 2.3 .135 ; 2.4 .60 ; 2.5 .35 ; 2.6 .97 ;$

E'ar.Serm.2.7.20; Serm.2.8.90; Epist.1.6.16; 1.6.23; 1.7.18; 1.7 83; 1.8.7; 1.10.21; 1.10.29;

Epist.1.50.4t; 1.10.48; 1.13.7; I.I0.19; 1.18.27; 2.1.91; 2.1.174; 2.1.215; 2.1.2.49; 2.1.251;

F.pist.2.1.2t,3; 2.2.5.; 2.2.128; Ars Pot.36;88; 130; $81 ; 290 ; 322 ; 4.42$

quam. Corm.1.2.34; 1.15.6; I.24.1t; 2.3.18; 2.12.17; 3.22.6; coni.Carm.3.27.4I; Epod.12.25;

Epod.13.13; It).3; Serm.1.I.I; 2.2.28; 2.2.87; 2.3.68; 2.5.78; cont.Serm.2.6.29;

2ar.Som.2.8.53; car.Lpist.1.2.65; 1.4.9; Epist.1.7.4; 1.14.44; 2.1.259; var.Ars Poet.72

quamcumque. tu quamcumque deus tibi fortunaverit horam

quam rem cumque . . . miles th riuce gesserit.

quamlibet. gloriantis quamlibet mulierculam/vincere mollitia
Epist.I.I1.22

Carm. I. 0.3

Epol.1 1.23 
quamquam. quamquam festinas, non est mora longa; quamquam choreis aptior et iocis/ludoque dictus quampluam sidere pulcrior|ille est. quamquam m.c Calabrae mella ferunt apes fiuancutum Socraticis malet|sermonibus.

quanquam tidentem dicere verum|quid vetat? cum sibi quisque timet. quamquam est intactus, et odjat." 1) uanuluam / putet aper rhombustule secens. milutul quamquam piger et malts, utilis Vrbi,

quamvis. quamvis l'untica pinus, /silvae filia noblis, quamsis. . nihil ultra| nervos atque cutem norti concesserat atrae. "fuamvis non alius tjectere equon sciens/aeque conspicitur quamquam [quamvis] sidere pulcrior/ille est. 1) Ifuamis neque te munera nec preces. . . curvat. guanvis luriale centum| muniant angues caput eius uec dubunt, quamis redeant in aurum/tempora priscum. filius quamvis Thetidis marinae toga. quat defendere frigus|quamsis crassa queat." "ut quanvis tacet Hermogenes, cantor tanch atque modulator;

fuamvis infra Lucili censum ingeniumque.

carne tamen quams is distat nil,

quatuquam [quamvicl| putet aper thombusque recens. nam quamsis memori referas milhi pectore cuncta, juamvis periurui erit. sine gente. me quanvis lamiae pietas et cura moratur/fratrem maerentis. quamris, seaeva, satis per te tibi consulis. quamsis fors te nullius egentem." quamvis ril extra numerum fecisse modumque" cutas: fuamvis | nocturnos iures te formidare tepores. . verba novere loco, quamvis invita recedant tomptum cenat holus, quamvis aliter putat: ut scriptor si peccat idem librarins usque. / quamvis est monitus. yuamvis et voce paterma fingeris ad rectum

quando. cui. . quando ullum imsenict parem?

quanclo et priores hinc Lamias ferunt/denominatos quando repositum Caecubum ad festas dapes... bibam quando' ladus Matina laverit cacumina mala copia quando/aegrum sollicitat stomachum. quanto pauperiem missia ambagibus horres.

orus, quando "go to adspiciam quandoque licebit... ducere sollicitac jucuncla oblivia vicac?

o quando faba Pythagorac cosnata . . ponentur. terrestria quando|mortalis animas vivont sortita librrtate decembri, /quando ita maiores voluerunt. utere: fluando iterum paveas iterusucque perire possis.

quandocumque. quandocumclue trabunt insisa negotia Romam. suantocumque deos bel porco vel bove placat.

quandocumque. Ratrulus hunc quando consunet cumque: quandoque. quandoque potentior/largi muncribus riserit aemuli. quandonue trahet ferocis per sacrum clivon . . Sygambros; indignor. quandonue bonus dormitat llomerus.

quanta. Lupis at agnis guanta sortito obtigit, per l'tbron. . fabula quanta fui, quat virtus et quanta, boni, ast visise pasto Illa ropare, quantane? num tantum, suftans se, matha fuistet?

quanta. qua. Venusfyuinta [quanta] parte sui nectaris imbuit. quanta laborat in Charybrti. .

quanta. o qui conflexus ce saudia quanta fuerunt.

quanta. quantia Inover funera bardande/genti victus trnuju quac quantaque secum/ariforat.

quantac. se tibi curac|quantae conveniat Munatius. quantas. lovis hace incanal quantalvirtutes habeat. quanti. percontor quanti holus ar far.

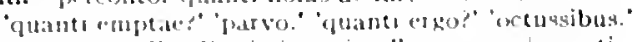

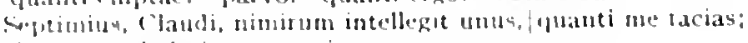
quantis. phantis !atigaret runis,

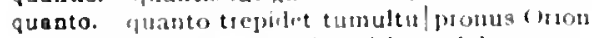
quanto revites intsni mpitiague labore
Carm.1.28.35

Carm.2.19.25

Carm.3.9.21

Carm. 3.16 .33

Carm.3.21.9

Serm.1.1.2.4

Serm.2.1.23

Serm.2.2.41

Ispist.2.1.124

Carm.1.I4.II

Carm.1.28.11

Carm.3.7.25

Tur.Carm.3.9.21

Carm.3.10.13

Carm.3.11.17

Carm.4.2.39

Corm.4.6.6

Serm.1.3.15

Serm.1-3129

Serm.2.1.74

Serm.2.2.29

Iar.Serm.2.2.4 I

Serm.2.4.90

Scrm.2.5.15

lepist.1.14.0

Epist.1.17.1

lisist.1.17.22

Epist.1.18.59

Epist.1.18.92

Epist.2.2.113

Epist.2.2.148

- Ars Poct.355

Ars Poct.300

Carm.1.24.8

Curm.3.17.2

Epod.9.1

Epod.10.27

Serm.2.2.42

Sorm.2.5.9

Sorm 2.000

Serm.2.0.03

Sirm.2.0.93

Serm.2.7.5

Serm.2.7.6

I.pist.1.14.17

Jistititi.58

Sorm.1.9.33

Carm.4.1.17

Carm.42.34

Ars loet 350

Iipintat 1

Epod.21.8

Serm 2.2 .1

Serm.2.3.317

conicarmi.13 10

Carm.1.27.19

Sorm.1.5.43

Cormis. 15.10

Sirm.2 2.70

Eipist.1.3.31

Ispist.2.118

Sirm.1.6112

irrm.2.3.150

Epist 92

Carm.4.1.4 19

Corm.3.27.17

Epist.1.1.t 
adspice primum, |quanto cum fast $u$. . . circum- | spectemus vacuam

Romanis vatibus aedem;

quanto. quanto quisque sibi plura negaverit.

quanto moveas periclo.|Pyrrhe, Gaetulae catulos leaenae?

at qui tantuli eget quanto est opus.

atque quanto perditior quisque est. tanto acrius urget;

tutior at quanto merx est in classe secunda.

at quanto meliora monet pugnantiaque istis/dives opis natura suae.

quanto hoc furiosius atque/ maius peccatum est:

quanto rectius hoc quan tristi laedere versu

quanto aut ego parcius aut vos. /o pueri, nituistis,

tanto dissimilem et tanto [tan te dissimilem quantol cettare minorem? quanto curam sumptumque minorem/haec habeant.

quanto constantior isdem / in vitiis.

habet comoedia tanto/plus oneris, quanto veniae minus:

arlspice primum. . quanto molimine circum- / spectemus vacuam

Romanis vatibus aedem;

quanto plura parasti. | tanto plura cupis,

quanto rectius hic, qui nil molitur inepte: .

quantulum. quantulum enim summae curtabit quisque dierum.

qnantum. vino et lucernis Medus acinaces fimmane quantum discrepat: dilecta, quantum non Pholoe fugax.

quantum distet $\mathrm{ab}$ Inacho| Codrus

quantum exstant aqua|suspensa mento corpora;

quantum neque atro delihutus Hercules|Nessi cruor

quantum carminibus quae versant atque venenis|humanos animos.

disp!osa sonat quantum vesica.

nec tantum veneris quantum studiosa culinae.

non possis oculo quantum contendere Lynceus:

qui semel adspexit. quantum dimissa petitis/praestent.

si quantum cuperem possem quoque;

iratus Grais quantum nocuisset Achilles.

quantum simplex hilarisque nepoti|discrepet

et quantım discordet parcus avaro.

nec scit quantum Cascellius Aulus,

quantum. daret quantum satis esset nec sibi damno| dedecorique foret. quantum interpellet inani/ventre diem durare. .

quantum. 'nil sat is est', inquit, 'quia tanti quantum habeas sis': quantum hinc inminuet?

quanto [quantum] aut ego parcius aut vos, $\mid$ o pueri, nituistis,

dare... frumenti quantum metit Africa.

pulveris atri|quantun non Aquilo Campanis excitat agris.

'at tu. quantum vis, tolle' 'benigne' .

ut, quantum generi demas, virtutibus addas;

ex modico, quantum res poscet, acervo|tollam

quantumvis. post haec ille catus, quantumvis rusticus.

quantus. heu heu. quantus equis, quantus adest viris/sudor.

quantus altis montibus|frangit trementis ilices;

o quantus instat navitis sudor tuis|tibique pallor luteus

vilibus in scopis, in mappis, in scobe quantus|consistit sumptus? quantus sit Dossennus edacibus in parasitis.

quare. quare, ne paeniteat te, /desine sectari matronas,

'accendis quare cupiam magis illi|proximus esse.'

quare|templa ruont antiqua deum?

nunc accipe, quare/desipiant omnes aeque ac tu.

quare, / si quidvis satis est, periuras, surripis, aufers/undique?

quare per divos oratus uterque Penatis

quid ferat et quare sibi nectat uterque coronam.

Quarta. nec quarta loqui persona laboret.

qnarta. quarta vix demum exponimur hora.

quarta iam parte diei|praeterita. .

non ut de sede secunda|cederet aut quarta socialiter.

quartae. "quartae sit partis Vlixes"|audieris "heres": .

quartam. ad quartam iaceo; post hanc vagor

quartana. "frigida si puerum quartana reliquerit,

quarum. nisi illas!quarum subsuta talos tegat instita veste,

quas. tristes ut irae, quas neque Noricus|deterret ensis

neque harum quas colis arborm / te praeter invisas cupressos...

Epist.2.2.93

Carm.3.16.21

Carm.3.20.1

Sirm.1.1.59

Serm.1.2.I5

Serm.1.2.47

Serm.1.2.73

Serm. I-3.83

Serm.2.1.2 I

Sirm.2.2.1 27

conti.Serm.2.3.313

Serm.2.4.85

Serm.2.7.I 8

Epist.2.I.I70

Epist.2.2.93

Epist.2.2.1 47

Ars Poet.1 40

Sirm.2.3.I 24

Carm.1.27.6

Carm.2.5.1 7

Carm.3 19.I

Epod.5.35

Epod.17.31

Serm.1.8.I9

Serm.I. 8.46

Serm.2.5.80

Epist.1.1.28

Epist.1 7.96

Episí.2.1.257

Epist.2.2.42

Epist.2.2.193

Epist.2.2.194

Ars Ioct.37I

Serm.1.2.52

Serm.1.6.1 27

Serm.1.1.62

Serm.2.2.127

zor.Serm.2.2.1 27

Serm.2.3.87

Serm.2.8.56

Epist.1.7.16

Epist. 1.2022

Epist.2.2.190

Epist.2.2.39

Corm.1.15.9

Epod.10.7

Epod.10.15

Serm.2.4.81

Epist.2.1.173

Serm.1.2.77

Sirm.1.9.53

Serm.2.2.103

Serm.2.3.40

Serm.2.3.12r)

Serm.2.3.170

Epist.2.2.96

Ars Poet. 192

Serm. I.5.23

Serm.1.9.35

Ars Poet. 258

Serm.2.5.100

Serm.1.0.122

Serm.2.3.290

Serm.1.2.29

Carm.1.16.9

Carm.2.14.22 
quas at bernizno numine luppiter/defendit quas aue learrhasius protulit ant sopan.

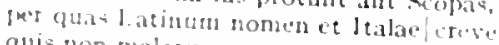

quis non malarum quas amor curas labet

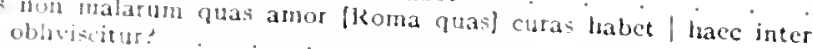

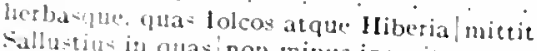

atlutius in quasinon minus insanit quam qui moechatur.

attis quas doceat quivis teques atque senator/semet prognatos.

obletet nemo sortis mihi, quas tibi, Tilli

quide parent; quas qui cometruxerit, ille clasus erit.

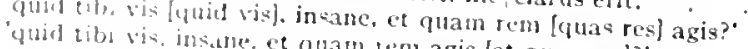

com sepvilo Balatrone" fibidius agis [et quas res]?' umbrax.

yua bis quinque viti sanxerunt. . . dictitet

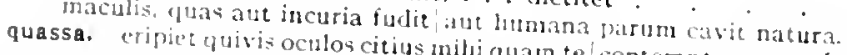

nuce parporet;

quassas. mox rencit rates quassas indocilis pauperien pati.

ab infonic' quasas cripiune aequoribus rates.

quatenus. quatenus, heu netas. / vistutem incolumen odimus.

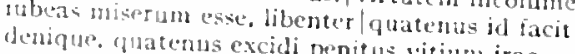

duatents duatenus excidi pentus vitium irac.

quater. guipoua petit volvens aliema vitellus.

ut toto non quater annolanembranam acquor Atlanticum linpune.

quen ter bindicta annolnembranam poscas.

the guater undengs aciat inplevisus in

quateret. Dardania turris quateret to decembris,

quaternos. sapre tribus lectis videas cenare quaperde pugnax -

quatiam. non erote, cundide Bars cenare quaternos. .

quatient. in morem Saliun ter quateu. insitum quatiain quem tes plut nimion ter quatient humum.

quaties. tu grabi curru quaties Olympum.
quatinus.

quatinus. quatenus lquatinus] excidi penitus vitium itat.

non.. mon adytis quatit mentem sacerdotum incola Pythius.

si celeres quate quatit solida neque Auster.

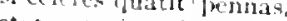

quatiunt. iunctarout exit/plerumguc et risu populum quatit : peale.

patcius iunctas quatiunt fenestras

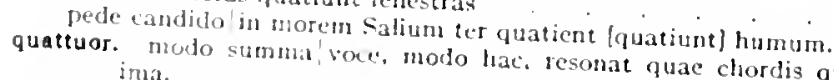

quattuor. modo summa! bou, modo fac, resonat quae chordis qua
ima.

quateror hinc rapunur viginti et inilia raedis.

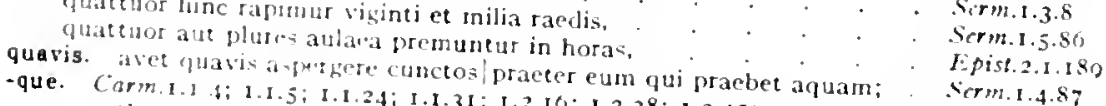

Cirm.1.4.1.1.5.6; 1.6.10; coni.Corm.1.7.7; Corm 1.45 1.3.3; 1.3.32; 1.4.2; 1.4.0; 1.4.14;

Curn.1.0.3; 1.1.10; 1.023; 1.10.0; 1.10.15; 1.10.18; 1.12.10.18; 1.7.21; 1.7.20; 1.7.30;

Carm.1.12.37; 1.12.40; I.14.0; 1.14.18; 1 1.10.18; 1.12.10; 1.1215; 1.12.25; 1.12.30;

Carm.J.Je.28; 1.17.4; 1.17.20;1.17.28; 1.181.12; 1.15.14; 1 15.1S; 1.15.34; 1.10.20;

Curn 1.21.11: 1.21.12; 1.21.1.1; 1.22.1; 1.22.10; 1.24; 1.19.2; I.19.14; 1.21.3: 1.21.10:

Curm 1.25.5; 1.24.8; 1.28.0; 1.28.15; 1.28.22; 1.24.7; 1.25.3; 1.27.3; 1.27.11; 1.28.1:

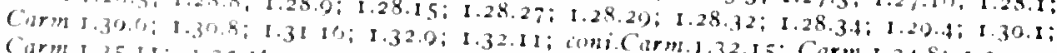

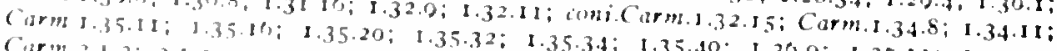

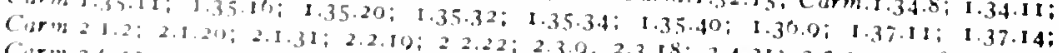

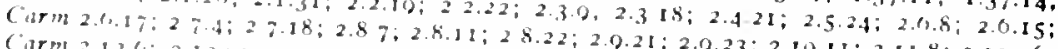

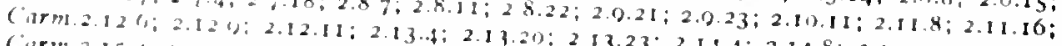

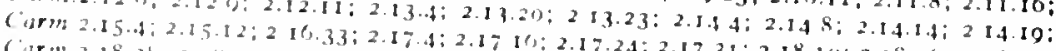

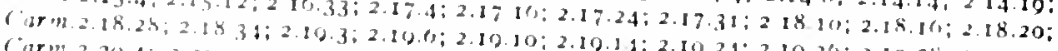

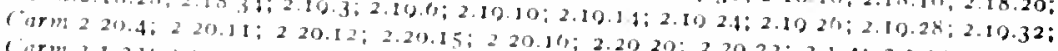

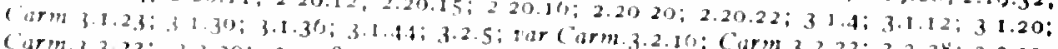

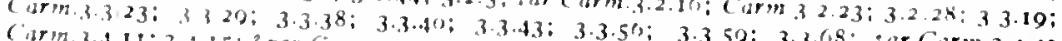

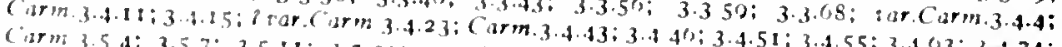

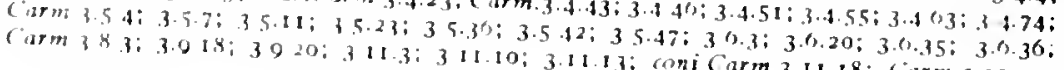


Carm.3.11.21; 3.11.28; 3.12.5; 3.14.9;3.15.3; 3.16.2; 3.16.18; 3.16.29; 3.18.3; 3.21.18; Carm.3.21.22; 3.21.23; 3.22.1; 3.22.3; 3.23.4; 3.23.16; 3.24.15; 3.24.39; 3.24.44; 3.24 .56 ; Carm.3.24.61; 3.25.1 5; 3.26.3; coni.Carm.3.26.7; Carm.3.27.4; 3.27.15; 3.27.21; 3.27.27; Carm.3.27.35; 3.27.54; 3.27.65; 3.27.70; 3.28.4; 3.2S.I4; 3.29.12; 3.29.14; 3.29.22; Carm.3.29.23; 3.29.28; 3.29.31; 329.37 ; 3.29.39; 3.29.42; 3.29.47; 3.29.55; 3.29.60; Carm.3.29.64; 3.30.2; 3.30.6; $4.1 .22 ; 4.2 .7 ; 4.2 .11 ; 4.2 .13 ; 4.2 .23 ; 4.2 .28 ; 4.2 .30 ; 4.2 .3^{8}$; Carm.4.2.41; 4.2.43; 4.2.49; 4.2.51; 4.2.53;4.4.7; 4.4.23;4.4.34; 4.4.49; 4.4.60;4.4.67; Carm.4.5.13;4.5.18;4.6.2; 4.6.11; 4.6.21; 4.6.30;4.6.31;4.6.3.5;4.6.39;4.7.2; 4.7.5; Carm.4.8 I; 4.8.16; $4.8 .23 ; 4.9 .7$; var.Carm.4.9.8; Carm.4.9.1 I; 4.9.15; var.Carm.4.9.17; var.Carm.4.9.20; Carm.4.9.24; 4.9.27; 4.9.35; 4.9.36; 4.9.39;4.9.49;4.9.50; 4.11.17; Carm.4.II.23;4.12.1 I; 4.12.19;4.I2.26;4.I3.4; 4.13.21;4.14.4; 4.14.I I; 4.I4.15; 4.14.27; Carm 4.I.4.3I; 4.14.39;4.14.42; 4.14.44; 4.14.46; 4.14.50;4.15.11; 4.1.5.14; 4.15.23; Carm.4.15.25; 4.I 5.27; 4.I 5.3 I; Carm.Sacc.I；6; 10; I 7; I9;22; 23; 25; 26; 29; 33; 37; Carm.Saic.49; 50; 53; 54; 57; 59; 62; 67; 73; 74; Epod.I.31; 2.7; 2.I.3; 2.27; Epod.2.3o; 2.35; 2.45; 2.65; 4.15; $5.20 ; 5.21 ; 5.33 ; 5.46 ; 5.79 ; 5.87 ; 5.93 ; 7.16 ; 7.18$; Epod.8.5; 8.9; 9.15; $9.19 ; 9.27$; 9.37 ; I0.6; I0.16; ar.Epod.11.11; Epod.12.10; I2.11; Epod.1 2.1 2; 1 2.26; I3.2; I3.4; I3.17; I 5.9; 15.20; I5.22; 16.6; I6.8; 16.10; 16.13; 16.19; Epod.16.30; I6.34; 16.46; 16.50; 16.53; 17.7; 17.19; 17.29; 17.43; I 7.50; 1 7.71; 17.75; Epod.I 7.So; Serm.1.1.9; 1.1.29; I.1.83; I.1.89; 1.1.92; 1.1.105; I.1.107; 1.1.I I0; 1.2.6; Serm.1.2.39; 1.2.45; 1.2.50; 1.2.53; 1.2.65; 1.2.66; 1.2.7 I ; 1.2.73; 1.2.80; 1.2.85; 1.2.504; Serm.1.2.1 I0; I.2.1 I6; 1.2.I I9; 1.2.1 23; I.3.24; 1.3.52; I.3.59; 1.3.62; 1.3.78; 1.3.8 I; 1.3.97; Serm.I.3.103;1.3.104; I.3.112; I.3.I15; I.3.13I; I.3.135;1.3.141; 1.3.142; 1.4.1; .4.7; 1.4.17; Scrm.1.4.37; 1.4.58; 1.4.61; 1.4.66; 1.4.69; 1.4.72; 1.4.73; 1.4.75; 1.4.83; 1.4.90; 1.4.96; Serm.1.4.97; I.4.109; 1.4.I I5; 1.4.120; 1.4.127; 1.5.14; 1.5.19; 1.5.20; 1.5.22 (bis); I.5.24; Serm.1.5.32; 1.5.36; 1.5.40; 1.5.46; 1.5.48; I.5.52; I.5.69; I.5.75; I.5.85; I.6.18; I.6.20; Serm.1.6.25; 1.6.43; 1.6.44; 1.6.61; 1.6.74; 1.0.78; 1.6.89; 1.6.91; 1.6.109; 1.6.I13; Serm.1.6.115; 1.6.126; 1.6.129; 1.6.131; var.Serm.1.7.7; 1.7.23; $1.7 .24 ; 1.7 .28 ; 1.8 .3$; Serm.1.8.5; 1.8.7; 1.8.11; 1.8.22; 1.8.24; var.Serm.1.8.32; Serm.1.8.35; 1.8.39; 1.8.42; Sorm.1.9.4; 1.9.55; 1.10.36; 1.10.40; 1.10.63; 1.10.67; 1.10.81; 1.10.85; tar.Serm.1.10.87; Serm.I.10.90; 2.1.3; 2.1.9; 2.1.22; 2.1.25; 2.1.50; 2.1.68; 2.1.69; 2.1.75; 2.1.83; 2.2.3; Serm.2.2.4; 2.2.21; 2.2.42; 2.2.46; 2.2.49; 2.2.70; $2.2 .75 ; 2.2 .84 ; 2.2 .95$; var.Serm.2.2.99; Strm.2.2.101; 2.2.109; 2.2.110; 2.2.136; 2.3.3; 2.3.7; 2.3.16; 2.3.24; var.Serm.2.3.29; Serm.2.3.32; 2.3.55; 2.3.57; 2.3.95; var.Serm.2.3.97; Serm.2.3.109; 2.3.110; 2.3.I15; Serm 2.3.125; 2.3.130; 2.3.131; 2.3.144; 2.3.146; 2.3.157; 2.3.162;2.3.171; 2.3.182; Serm.2.3.195; 2.3.200; 2.3.208; 2.3.2 I6; 2.3.266; 2.3.271; 2.3.288; var.Serm.2.3.292; Scrm.2.3.294; 2.4.65; 2.4.68; $2.4 .77 ; 2.485 ; 2.4 .88 ; 2.4 .92 ; 2.5 .4 ; 2.5 .6 ; 2.5 .22 ; 2.5 .30$; Serm.2.5.57; 2.5.63; 2.5.68; 2.5.69; 2.5.77; 2.5.99; 2.5.102; 2.5.110; var.Serm.2.6.7; Sirm.2.6.15; 2.6.17; 2.6.19; 2.6.21; 2.6.27; 2.6.58; 2.6.60; 2.6.63; 2.6.66; 2.6.76; Serm.2.6.85; 2.6.89; 2.6.92; 2.6.100; 2.6.104; 2.6.108; 2.6.110;2.0.113; 2.6.II6; Serm.2.7.31; 2.7.35; 2.7.41; 2.7.44; $2.7 .54 ; 2.7 .58 ;$ var.Serm.2.7.64; Serm.2.7.66; 2.7 .68 ; Serm.2.7.69; 2.7.75; 2.7.76 (bis); zar.Serm.2.7.83; Serm.2.7.90; 2.7.9.4; 2.7.96; 2.7.99; Serm.2.7.108; 2.7.113; 2.7.II5; 2.8.12; 2.8.40;2.8.65;2.8.70;2.8.76;2.8.82; Epist.I.I.17; Epist.1.1.20; 1.1.23; I.I.24; I.I.26; 1.I.27; I.I.33;1.I.43; I.I.44; 1.1.55; 1.1.56; I.1.58; Epist.1.1.79; 1.1.81; 1.2.10; 1.2.20; 1.2.24; 1.2.28; 1.2.44; 1.3.3; 1.3.5; 1.3.15; I.4.5; Epis..1.4.7;1.4.12; 1.5.5; 1.5.10; 1.5.13; 1.5.15; 1.5.26 (bis); 1.5.27; 1.6.2; 1.6.14; 1.6.17; Epist.1.0.25; 1.6.36; 1.6.38; 1.6.53; I.6.59; I.6.6I; I.6.65; I.6.06; 1.7.3; 1.7.5; 1.7.8; I.7.12; Epist.1.7.30; 1.7.46; 1.7.58; 1.7.77; 1.7.78; 1.7.89; 1.7.90; 1.7.91; 1.7.97; 1.8.2; 1.8.5; Epist.1.8.14; 1.9.4; 1.9.13; 1.10.5; 1.10.7; 1.10.10; 1.10.13; 1.10.23; “ar.Lpist.1.10.28; Epist.1.10.36; I.11.I; var.Epist.I.I1.3; I.II.4; Eptst.1.11.9; 1.I1.II; 1.12.5; 1.12.13; Epist.1.12.27; 1.13.1; I.13.4; 1.13.8; I.13.17; 1.13.19; I.14.S; 1.14.I9; 1.14.27; 1.14.32; Epist.I.14.38; I.15.6; I.I5.9; I.15.17; 1.15.20; 1.15.24; 1.I5.31; 1.10.20; I.16.21; 1.16.25; Epist.I.I6.30; I.I6.35; I.16.38; I.16.4I；I.16.42；I.I6.49; 1.16.50; I.16.6I; I.I6.70;

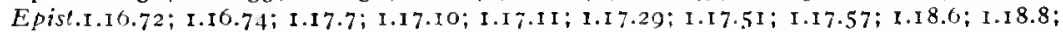
Epist.1.18.23; I.I8.38; I.18.45; I.I8.46; I.18.50; I.18.59; I.18.68; 1.18.81; 1.18.89; Epist.1.18.90; 1.18.98; 1.19.4; I.19.8; I.19.13; 1.19.14; I.19.16; 1.19.24; I.19.36; I.20.1; Epist.1.20.23;2.1.7; 2.1.11; 2.1.16;2.1.20;2.1.21; 2.1.37; coni.Epist.2.1.41; Epist.2.1.45; Epist.2.1.49; 2.1.6I; 2.I.64; var.Epist.2.1.69; Epist.2.1.72; 2.I.75; var.Epist.2.1.77; Epist.2.1.79; 2.1.88; 2.1.89; 2.1.92; 2.1.97; 2.1.102; 2.1.109; iar.lipist.2.1.109; Epist.2.1.117; zar.Epist.2.1.122; Epist.2.1.126; 2.1.139; 2.1.147; 2.1.153; 2.1.I55; Epist.2.1.160; 2.1.167; 2.1.182; 2.1.184; 2.1.190；2.1.204; 2.1.230; 2.1.2.35; 2.1.247; Epist.2.1.249; 2.1.252; 2.1.253; 2.1.255; 2.1.262; 2.2.I; 2.2.5; 2.2.47; 2.2.50; 2.2.58; Epist.2.2.64; 2.2.66; 2.2.72; 2.2.82; 2.2.92; 2.2.120; 2.2.121; 2.2.126;2.2.130; $2.2 .13^{6}$; Epist.2.2.137; 2.2.145; 2.2.156; ? :ar.Epist.2.2.183; Epist.2.2.193; 2.2.198; 2.2.209; Ars Poct.27; 28; 37; 46; 51; 52; 54; 55; 58; 02;03;65; var.Ars Pot.05; Ars Poct.70; 80; Ars Poet.S3; 86; 87; 94; 113; 123; I 28 ; 130; 132; 145; 157; 102; 105; 166; 171 ; 172; Ars Poct.174; 177; 178; I83; I93; 196; 199;200;202;203;209;212;214; 215;218;224; Ars Poet.235; 239; 241; 242; 247; zar.Ars Poct.250; Ars Poct.255; 261; 265; 274; 277 ; Ars Poet.278; 283; "'ar.Ars Poet.289; Ars Pact.299; 307; 31 I; 317; 310; 321; 322; 336: 


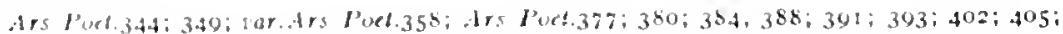
Ars Poet.413:415:425;440;444; $452 ; 455 ; 45^{\prime \prime} ; 403 ; 400 ; 474 ; 475$

-que. (orm.1 20.12(bis);1.35.10(bis);2.1.3(bis);3.4.19(bis);3.4.47(bis);4.2.22(bis);4.455(bis):

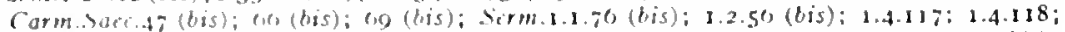

som.1.508 (bis); 1.5.104 (b.s); 1.8.17 (bis); 1.8.50 (bis); 1.10 .27 (bis); 2.43 (bis);

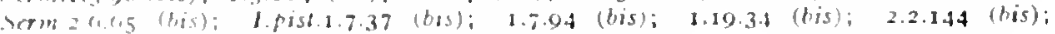

Ar: I'orf.11 (bis); 73 (bis); 207 (bis); 211 (bis); 280 (bis)

queam. astue liausire quedull vitae praccepta beatac."

qujbur anissas reparase quean 1 ces|artibus atque modis.

S.Tm.2.4.95

$\operatorname{serm.2.5.2}$

queamus. cediat nt conviva sutur, reperire qulamus.

queant. unde expedire non amicormm queant/libera consilia

Sicm.1.1.IIs

Queas. aceipe gua ratione queas ditescere.

quat satione queas traclucere leniter aevom,

queat. Loga, quite defendere frigus quanvis crasid queat."

quem. itucus. . quem iuvat clamor galeategue leve's

Hore, tertal 4l134m ferunt solutace.

Gigne, f quem si puellatum inserseres choro.

cho. gutem voug./dilecte Macenas.

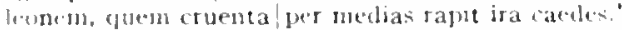

mbisum nepetesu. Troica quen nejerit sacerdos.

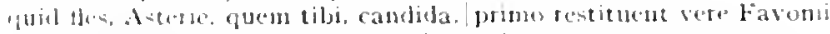

andir, imbres quen super notas aluere ripas.

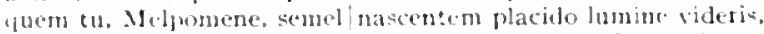

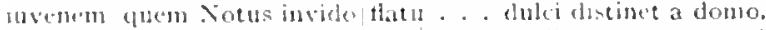

Hice, quem poles Niobea magnaw| vindicem binguar. . sensit

Toleplum, guem tu petis,

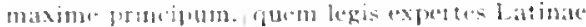

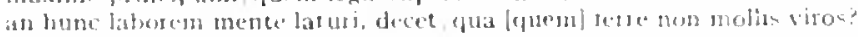

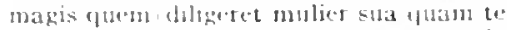

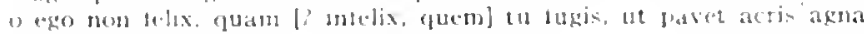
li1pos

an puem supenbus ordinarat annina' Mssotum.

in quentritid aculat tormerat.

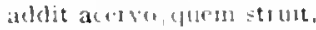

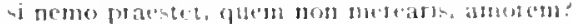

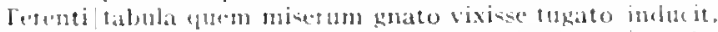

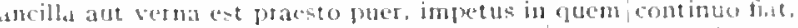

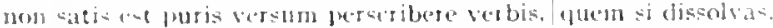

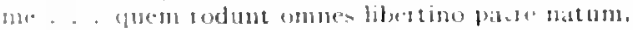

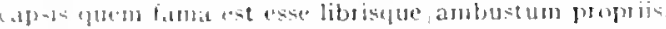

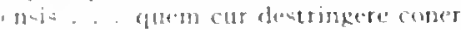

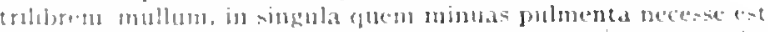

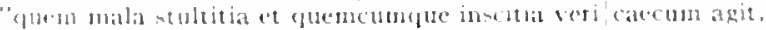

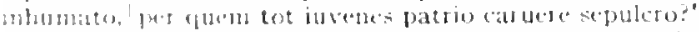

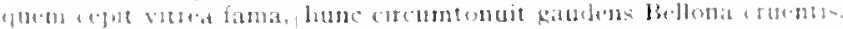

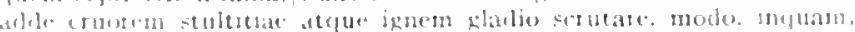

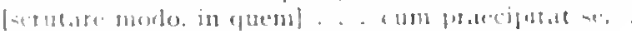

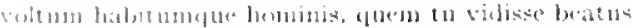

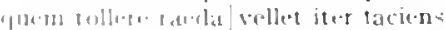

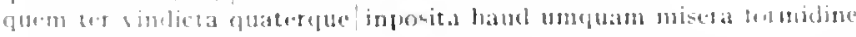
fit 1 inet:

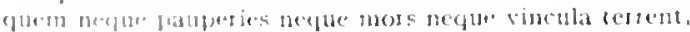

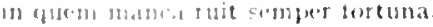

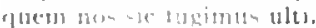

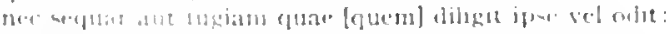

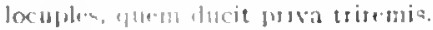

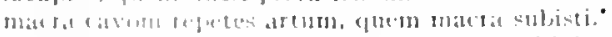

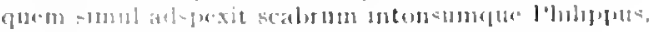

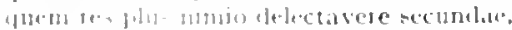

ag.

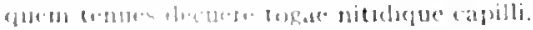

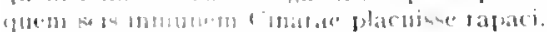

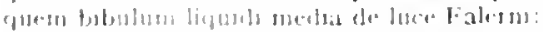

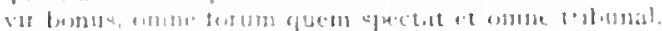

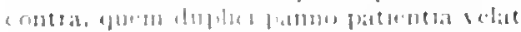

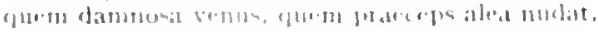

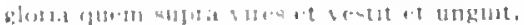

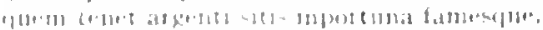

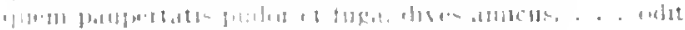

Lifod. 11.25

Sorm.2.5.10

lipist.1.18.97

Sitm.1.3.15

(arm.1.2.38

Corm.1.4.10

(arm.2.5.21

(arm+2.20\%

Curm.3.2.11

Carm.3.3.32

Carm.3.7

(arm.t.2.

(armi.4.3.1

Corm.4.5.9

carm.4.0.1

carma.1121

Cirm.4.ta.-

i ar lipod.t.du

I.pod.122.3

iar.t.pous.12.25

I:pod.17.9

lipod.17.10

corm.1.1.35

verm.1.1.85-

Serm.1.221

Sirm.1 2.112

Sim.1.t.55

sirm. I (1)..p(s)

virm.1.10.103

s.rm.2.1.21

serm.2.2.3.6

s.rm.2.3.43

serm.2.3.100

s.tm.2.3.222

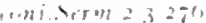

s.rnt.2 4.42

virm. $2 \cdot 1 .+2$

Diem.2.7.

serm.2.7.4.

Serm.2.7.8.8

serm.2.8.03

ate JPIS1.1.72

I.pist.1,1.03

J.pis:.1.7.1.3

li. $1.5,1,7.400$

I. pist.1.1030

I PJA.J.1. 2

I.pist.1.1.1.32

l.pot.1.1.3.3.

1.put. IA.34

1 post 1.10.57

19151.1725

I 10.1.1.1t.21

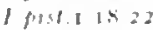

I.p151 5.182.3

1. PIst I. I 8.2. 
quem sua culpa premet, deceptus omitte tueri,

quem Mandela bibit, rugosus frigore pagus,

Epist.1.18.105

nec socerum quaerit, quem versibus oblinat atris,

Epist.1.19 30

quem tulit ad scaenam ventoso Gloria curru,

Lipist.2.I.I77

sonum, referunt quem nostra theatra?

sedulitas autem stulte quem diligit urget,

si volet usus. /quem penes arbitrium est et ius et noma loquendi.

nam neque chorda sonum reddit quem volt manus et mens,

quem bis terve bonum cum risu miror;

torquere mero. quem perspexisse laborant

ut mala quem scabies ant morbus regius urget

quem vero arripuit, tenet occiditque legendo.

quem. quem vocet divom populus ruentis|imperi rebus?

quem mortis timuit gradum

quem virum aut heroa lyra vel acri|tibia

lyra vel acri|tibia sumis celebrare, Clio?/quem deum?

quem Venus arbitrum/dicet bibendi?

nam quid sequar aut quem?

facundi calices quem non fecere disertum,

contracta quem non in paupertate solutum?

falsus honor iuvat et mendax infania terret/quem nisi nendosum th nuedicandum?

quem. quen mihi, quem tibi|finem di dederint.

nescis quo valeat nummus, quem praebeat usum?

nonne, cupidinibus statuat natura modum quen,

quem. si mala condiderit in quem quis carmina, equitare in harundine Jonga | siquem delectet barbatum:

quemcumque. quem Fors dierum cumque dabit. quem tu, cervos uti vallis in alteralvisum parte lupum . . fugies quem criminosis cumque voles modum/pones lambis. quemcumque inscitia veri|caecum agit,

quemquam. lic stilus haud petet ultro|quemquam animantem (mirum, ut neque calce lupus quemquam neque dente petit bos). erum natura neque illum | nec me nec quemquam statuit: malo quae nollet carmine quenquam/describi:

quemque. 'frater" "pater' adde; ut cuique est aetas. ita quenque facetus adopta.

metiri se quenque suo modulo ae pede verum est.

si non offenderet unum /quemque poetarum linae labor et mora.

quemvis. quemvis media erue turba: quaelibet in quemris opprobria fingere saeros.

quendam. quendam volo visere non tibi notum;

conspexit, ut aiunt, adrasum quendam vacua tonsoris in unhra

queratur. ut rupes fluviosque in campo obstare queratu;

querceta. aut aquilonibus/querceta Gargani laborant

quercus. Ssi quercus et ilex | multa fruge pecus, multa dominum invet unbra?

quercus. blandum et auritas fidibus canoris|ducere quercus.

devota quercus inter et ilices . . victima,

inportunus enim transvolat aridas|quercus

querebar. querebar adplorans tibi.

querelam. nostri nemorem sepulcro/scalpe querelan."

querelas. seu tu querelas sive ger is iocos

querelis. cur me querelis exanimas tuis?

querella. si curat cor spectantis tetigisse querella.

querellarum. desine mollium|tandem querellaı un

querellas. tolle querellas;

querentem. Aeolis fibus querenten |Sappho pucllis de popularibus

querenti. lliae dum se (nimium) querenti iactat ultorem.

aderat querenti|perfidum ridens lenus

quereris. quereris super hoc etian.

querimonia. versibus inpariter junctis querimonja primun. .

querimoniae. luctusque turpes et querimoniae; quid tristes querimoniae. .. proficiunt.

querimonis. nec malis/divolsus querimonis

querit. si quaeret [querit] Tater urbium|subscrili statuis.

queritur. foro nimium distare Carinas|iam grandis natı queritur. qui queritur salebras et acerbum frigus et imbris

querqueta. aut aquilonibus|querceta [querqueta] Gargani laborant

Epist.2.1.201

Ars Poet.72

Ars I"oet. 348

Ars Poet. 358

Ars Poct.435

Ars Poch. 453

Ars Poet.475

Carm.1.2.25

Carm.1.3.17

Carm.1.I2.1

Carm.1.12.3

Carm.2.7.25

Epist.1.I.

Epist.1.5.10

Epist.1.5.21

Epist.1.10.40

Carm.I.III

Serm.1.I. 3

Serm.1.2.II

Sirm.2.1.82

Serm.2.3.249

Carm.1.n.14

Carm.1.15.29

Carm.1.10.2

Sirm.2.3.43

Serm.2.1. do

Serm.2.I 55

Serm.2.2.130

Epist.2.1. 53

Epist.1.0.55

Epist.1.7.08

Ars Poet 20I

Serm.1.4.25

Epist.1.15.30

Sermal.9.17

Epist.1.7.5n

Serm.2.3.55

Carm.2.9.7

Epist.I.I0.0

Corm.1.12.12

Carm.3.23.10

Carm.4.13.10

Lpod.II.1 2

Carm.3.II.52

Carm.3.21.2

Carm.2.1.I

Ars Potegs

Carm.2.9.I8

Epist.1.12.3

Carm.2.13.24

(imm.1.2.17

carm.3.27.04

Litist.2.224

drs Poet. 5

Carm.2.20.22

(arm.3.2433

(arm.I.I3.19

tar.Carm.3.24.27

1:pist.I.7.49

I:pist. I. . 7.5.3

far.Carm 2.0.7 
querulae. neque an viaq + ub cantu querulae deapice tibiae querulus. difticilia, querulus, laudator temporis acti|se puero.

\section{queruntur. gueruntur in silvis aves}

questae. saeculum Pyrthe nova monstra questae.

questu. salviet circa iccur ulcerosum/non sine questu. .

questus. ut haec trementi questus ore constitit! insignibus raptia puer.

neque ego cracm questus.

Ars Poct.173

Epod.2.26

Carm.r.2.6,

Carm.1.25.16

Epod.5.11

Serm.1.6.87

qui. Cum.1.1.10; 1.3.10; 1.3.18; 1.3.10; 1.5.9; 1.5.10; 1.10.2; 1ar.Carm.1.1 1.5; Carm.1.12.14; Carm.1.12.15; 1.32.11; 1.36.4; 2.13.10; 2.14.7; 2.20.17; 3.2.26;3.4.45 (bis); 3.4.61; 3.4.62: Corm.3.5.33:3.5.35; 3.17.0;3.10.13:3.26.5; 4.2.55;4.4.41; 4.6.26; 4.5.18; 4.9.47; 4.10.4; Carm.4.18.15;4.12.18; $4.14 .20 ; 4.14 .45 ; 4.14 .47$; Carm.5arc.9;63; Epod.1.18; 2.1; 11.3;

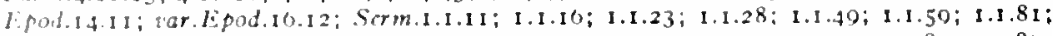
Sirm.1.1.117; 1.2.25; 1.2.49;1.2.50; 1.3.4; 1.3.9;1.3.10; 1.3.09; 1.3.73; 1.3.80; 1.3.87; serm.1.3.1 6 ; $1.3 .117 ; 1.3 .124 ; 1.4 .81 ; 1.4 .82 ; 1.4 .83 ; 1.4 .84 ; 1.4 .85 ; 1.4 .88 ; 1.5 .92 ;$ Serm.1.0.15; 1.6.17; 1.0.34; 1.6.13; 1.0.71; 1.6.83; 1.6.120; 1.7.0; 1.7.3.4; 1.9.46; Serm.1.0.5.7 1.0.62; 1.10.*2; 1.10.*5; 1.10.*6; 2.1.45; 2.1.65; :ar.Sern.2.1.68; 2.2.65; Serm.2.2.10S; 2.2.110;2.3.40;2.3.53;2.3.06;2.3.100;2.3.109;2.3.143; 2.3.158; 2.3.208; Sirm.2.3.22I; 2.3.236; 2.3.281; 2.3.258; 2.3.298; 2.4.15;2.422; 2.4.55; 2.5.15; 2.5.29; Scrm.2.0.9; 2.6.11; 2.7.10; 2.7.20; 2.7.79; 2.7.81; 2.7.83; 2.7.109; 2.7.110; 2.8.25; Jpist.1.1.7; 1.1.05; 1.1.68; 1.2.3; 1.2.10; 1.2.40; 1.2.41; 1.2.51; 1.2.59; 1.2.02; 1.3.10; l. pitt.1.4.0; 1.5.25; 1.0.9; 1.6.50; 1.6.51; 1.6.50; 1.6.58; 1.7.90; 1.10.26; 1.10.29: Fpist.1.10.39; 1.11.11; 1.11.12;1.14.13; 1.14.20; 1.15.28; 1.15.29; 1.16.28; 1.16.33; Epist.1.10.4t (bis); 1.16.05; 1.16.60; 1.16.07; 1.17.10;1.17.15; $1.17 .37 ; 1.17 .38 ; 1.17 .48 ;$ Epist.1.17.53; 1.18.53; I.18.5t; 1.18.e5; 1.18.81; 2ar.Epist.1.18.111; Fpist.1.19.22; Lpist.1.20.15; 2.1.10; 2.1.13; 2.1.30; 2.1.39; 2.1.40; 2.1.4.4; 2.1.45; 2.1.56; 2.1.111; Epist.2.1.115;2.1.211; 2.1.233;2.1.238; 2.2.11;2.2.40;2.2.100;2.2.12.4; 2.2.129;2.2.13I; Lipist.2.133; 2.2.135; 2.2.100; 2.2.182; 2.2.187; Ars Pact.15; 21; 29; 140; 142; 158;

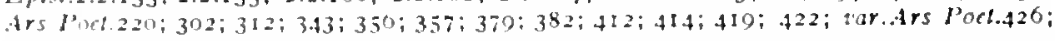
Ars f'ort.4'0: $4^{\prime \prime}, 7$

qui. Crm.1.0.9; zar.Carm.1.12.31; 4.3.10; Carm.115.21; Serm.1.1.30: 1.2.28; 1.2.38: 1.4.74; Serm.1.4.75; 1.6.4; coni.Serm.1.S.15; Sirm.2.3.47; for.Serm.2.3.230; Fsist.1.1.77: I.fist.1.6.4; 1.11.27: I 15.8; 2.1.21 4; 2.2.10\%: 2.2.182; Ars Poct.3s: coni.trs Pod.277; Irs Poet.288 (bis): $431 ; .150$

qui. Corm.2.1.33: Food.12.7

qui. Sirma.1. $5 \ldots+3$

qui. :or Carm.4.7.1; Sern.1.1.1; ar.erm.t.1.108; Serm.1.3.12S; 1.10.21; 2.2.19; 2.3.108; ferm.2.3.21; 2.32e; tar.Serm.2.3.272: Serm.2.3.275; 2.3.311; :ar.serm 2.5.7: Sirm.2 ;.1); 2.7.105; Epist.1.0.42; 1.10.63 (bis); Epist.2.2.00; Ars Poct.46z

qui. vir.1.1.1 1 1. $30 ; 1.0 .79$

qui. E.ptst.1.15.42

quia. ce minav, tquia sic voluere. pontolumda recumbut.

isent quiat vatr sacro.

frugit te quia luridi|dentes.

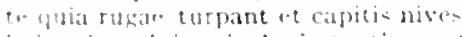

:11] *ation. imquit. "quia tanti quantum habmas sis":

dat po-itum ane thea quia pullum in parte catinil suatulit esuriens.

gon quia. Yd'denai. . . nemo genetosior at te

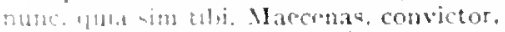

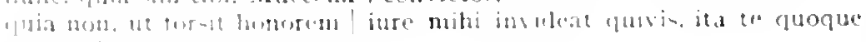
amirาm

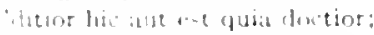

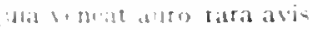

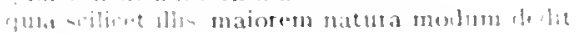

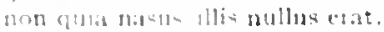

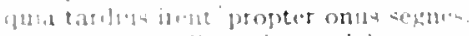

non makn gondis. quita contigit:

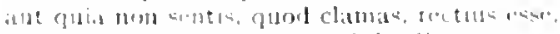

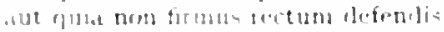

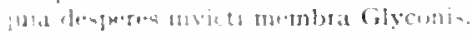

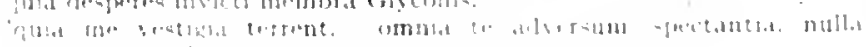

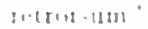

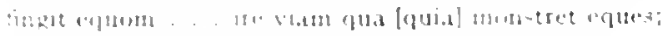

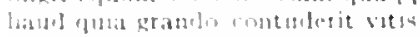

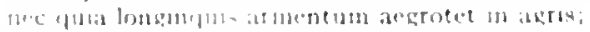

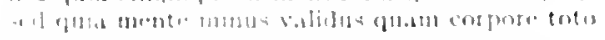

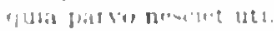

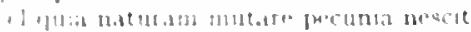

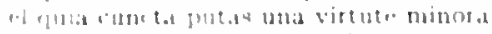

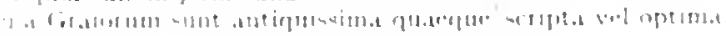

Carm.1.12.31

Carm.4.9.28

Corm.4.13.10

Carm.4.13.11

Sicrm.1.1.02

Sirm. 1.3 .02

Sierm 1.6 .1

Serm.t.4.47

Sirm.1.0.40

Sierm.1.0.51

Sirm.2.2.25

serm.2.2.30

serm.2.80

Sicrm.2.3.101

Serm. 2.903

verm.2.7 25

term $2.7 .2{ }^{\circ}$

IEpist.1 1.30

Epist.1.1.7.t

7 iar IPista.205

J.pist. 1.S.

Esuper s.e

IPpist 1.8.7

Thist.1.10 4

lipist.1 1210

I:pist.1.12.I I

fipin 2128 
non quia crasse conpositum inlepideve putetur.

non quia crasse conpositum inlepideve putetur, sed quia nuper.

vel quia nil rectum, nisi quod placuit sibi, ducunt

vel quia turpe putant parcre minoribus

creditur, ex medio quia res accersit, habere / sudoris nininum... comoedia.

sed roca, usque suom qua [quia] populus adsita certis/limitibus vicina refugit iurgia;

si $\langle$ c) quia perpetuos nulli datur usus

inielix operis summa, quia ponere totum/nescict:

ingenium misera quia fortunatius arte|credit

poterat duci quia cena sine istis:

quibus. miseri, quibus'intemptata nites.

sunt quibus unum opus est intactae Palladis urbem/carmine perpetuo celebrare

premant Calcnam falce quibus dedit / fortuna vitern.

dic modos. Lyde quibus obstinatas/adplicet auris,

inmetata quibus ingera liberas|fruges et Cererem ferunt

quibus | mos unde deductus

dis, quibus septem placuere colles / dicere carmen.

quibus te vita sit superstite|iucunda.

ros, quibus est virtus, muliebrem tollite luctum.

ego me illorum, dederim quibus esse poetis, excerpam numero:

quibus adversum bellum incidit:

illi. scripta quibus comoedia prisca viris est,

quibus haec, sint oualiacumque, / adridere velim.

sunt quibus in satura videar nimis acer

ter uncti|transnanto Tiberim. somno quibus est opus alto.

Canilia Albuci, quibus est inimica, venenum,

ignarum, quibus est ius aptius et quibus assis

ut nox longa quibus mentitur amica

offenduntur cnim, quibus est equos et pater et res

quibus. longa quibus facies ovis erit, illa memento, . . ponere:

sunt delicta tamen, quibus ignovisse velimus:

quibus. est auctor quis denique eorum.|vixi cum quibus?

e cuibus unus aret quavis aspergere cunctos|praeter cum qui praebet aquam;

quibus. quibus amissas reparare queam res/artibus atque modis.

o noctes cenaeque deum, quibus ipse meique / ante Larem proprium rescor

sunt verba et voces, quibus hunc lenire doloremi possis

divitiatque peregrinae, quibus oblitus actor ... concurrit dextera laevae.

quibus. qubus superbam fugit ulta paelicem.

heu|limina dura, quibus lumbos et infregi latus.

donec verba. quibus voces sensusque notarent, | nominaque invenere;

quibus. cuibus|pepercit aris?

quibus. quibus tertarum militct oris $\mid$ Claudius

quibus. quibus antris egregii Caesaris audiar

quibus. ut tamen noris, quibus adroceris/gaudiis: .

quibusdam. experto frustra Varrone Atacino|atque quibusdam alis.

quibuslibet. recito ... non ubivis coramve quibuslibet.

quicquam. tamquam/sit proprium quicquam,

quicquam. si peteret per anicitiam patris atque suam, non / quicquam proficeret;

non... edi luce profestalquicquam praeter holus

"care faxis/te quicquam indignum.

si puerilius his ratio esse evincet amare/nec quichuam differre,

o nulli quicquam mentite,

"at omnes di exagitent me, / si quicquam."

quicquam reprendi, non quia crasse / conpositum

quicumque. quicumque Bithyna lacessit|Carpathium pelagus carina;

ille et nefasto te posuit die $\mid$ quicumque primum,

quicumque mundo terminus obstitit.

et $t u$, quicumque es felicior

qui testamentum tradet tibi cumque legendum.

quicumque obvius est, me consulit:

ne, quicumque deus, quicumque adhibebitur heros. .

quicumque. quicumque terrae munere vescimur quicumque celsae nidum Aceruntiae . . tenent
Epist.2.1.76

Epist.2.1.77

Epist.2.1.83

Epist.2.1.84

Epist.2.1.I 68

tar.Epist.2.2.170

Epist.2.2.175

Ars Poet.34

Ars Poet.295

Ars Poet. 376

Carm.1.5.12

Carm.1.7.5

Carm.r.3 I.9

Carm.3.11.7

Carm.3.24.12

Carm.4.4. 8

Carm.Saec.7

Epod I.5

Epod. 16.39

Serm.1.4.39

Serm.1.7.I I

Serm.I.I0.16

Serm.1.10.88

Serm.2.1.1

Serm.2.1.8

Sirm.2.1.48

Serm.2.4.38

Epist.I.I.20

Ars Poet.248

Serm.2.4. 12

Ars Poct.347

Serm.1.4.81

Serm.I.4.87

Serm.2.5.2

Serm.2.6.65

Epist.1.1.34

Epist.2.1.204

Epod.5.63

Epod.II.22

Serm.1.3 IO3

Carm.1.35.37

Epist.1.3. I

Curm.3.25.3

Carm.4.11.13

Serm.1.10.47

Serm.1.4.74

Epist.2.2.1 72

Serm.1.3.6

Serm.2.2.II 7

Serm.2.3.39

Sirm.2.3.251

Serm.2.5.5

Serm.2.6.55

Epist.2.1.76

Carm.1.35.7

Carm.2.13.2

Carm.3.3.53

Epod.15.17

Serm.2.5.5I

Serm.2.6.5I

Ars l'oet.227

Carm.2.14.10

Carm.3.4.14 
quild. Carm.1.8.13; 1.913; 1.26.5; $2.11 .11 ; 2.13 .33 ; 2.18 .23 ; 2.18 .32 ; 3.27 .18 ; 3.27 .58 ; 4.8 .23 ;$ Fod 5.61; 6.1; 8.2; Scrm.1.1.20; 1.1.25; 1.2.62; 1.3.19; 1.4.115; 1.0.55; 1.10.56; tar.Serm.2.2.35; Serm.2.3.4; 2.322 (bis); 2.3.41; sar.Serm.2.3.108; Serm.2.3.157; Serm.2.3.160; 2.3.283; 2.6.75; 2.6.76; 2.6.90; 2.7.58; 2.7.80; 2.8.32; Ffist.1.1.11; lipist 1.2.3 (graler); 1.6.62 (bis); $1.11 .1 ; 1.11 .2$ (bis); 1.11.3; 1.11.7; 1.12.16; 1.12.18 (bis); Fist.1.1.4.31; 1.18.19; 1.18.101 (bis); 1.18.102; 2.1.101; 2.1.20t; 2.2.166; 2.212; Ars l'oet.307; 308 (bis); 328; 329; 353

quid. Iror Carm.1.8.2; Carm.1.12.13; 1.14.2; 1.24.13; 1.31.1; $1.31 .2 ; 1.35 .34 ; 1.35 .35 ; 2.3 .11$; Carn.2.11.1; 2.13.13; 2.10.17; 2.16.18; 8vor.Corm 2.17.1; Corm.2.17.0; 3.4.53; 3.4.54; Corm $3.4 .55 ; 3.6 .45 ; 3.7 .1 ; 3.8 .1 ; 3.8 .2 ; 3.9 .17 ; 3.11 .30 ; 3.24 .33 ; 3.24 .35 ; 3.27 .10 ; 3.28 .1$; Cirm.3.29.27; 4.4.25 (bis); 4.4.27; 4.4.37; 4.13.18; 4.14.9; Epod.1.5; 1.15; 35; 4.17: Epod.5.3 (his); 5.9; 5.49 (bis); 8.15; 12.1; 12.2 (bis); 16.24; 17.30; 17.53; 17.60; Scrm.1.1.7: 1.1.19; 1.1.41; 1.1.44; 1.1.49; 1.1.63; 1.1.69; 1.1.101; 1.2.69; 1.2.72; Scrm.1.2.112 (bis); 1.3.94; 1.3.126; 1.5.59; 1.6.17; 1.6.82; 1.8.40; 1.9.4; 1.9.40; 2.1.5; Sorm.2.1.24; 2.1.62; $2.2 .48 ; 2.3 .89 ; 23.99 ; 2.3 .132 ; 2.3 .152 ; 2.3 .158 ; 23.159 ; 2.3 .201$; Scrm.2.3.219;2 3.230;2.3233; 2.3.272; 2.3.274; $2.3 .303 ; 2.5 \cdot 3 ; 2.5 .53 ; 2.5 .61 ; 2.6 .17$; Serm.2.6.20; 2.6.55; 2.6.83; 2.7.42; 1'0r.Sern.2.7.105; Epist.1.1.76; 1.1.91; 1.1.97; 1.2.10: Epist 1.2.17 (bis); $1.3 .0 ; 1.3 .9 ; 1.3 .15 ; 1.3 .20 ; 1.4 .2 ; 1.4 .8 ; 1.5 .16 ; 1.0 .5 ; 1.6 .8 ; 1.6 .7 ;$ Epist.1.0.12; 1.7.23;1.7.02;1.8.3; 1.9.6; 1.10.8; 1.12.19; 1.16.8; 1.10.74; 1.17.38; 1.18.68; Ior.Epist.1.18.82; Epist.1.18.106 (bis); 1.19.12; 1.20.6; 1.20.7; 2.1.40; 2.1 oI (bis); Epist.2.1.103; 2.2.23; 2.2.38; 2.2.57; 2.2.03 (bis); 2.2.96; 2.2.177 (bis); 2.2.191; 2.2.205; Ars P'vel.20;30; 40; 53 ; $138 ;$ I $53 ; 212 ; 312$ (bis); 410

quid. Corm.3.15.7; 3.24.64; Epod.15.12; Serm.1.2.84; 1.4.135; 2.3.31; 2.4.52; 2.7.87; 28.25 ; Epist.1.2.5; 1.2.38; 1.12.24; 1.15.40: $1.18 .57 ; 1.20 .7$.

quid. Corm.1.6.19;1.32.1; var.Carm.3.27.7; Carm.4.2.45;4.9.9; Lood.3.19;10.15; Scrm 1.3.140; Serm 1.4.31; 1.4.102: coni.Sorm.1.4.102; Som.1.4.104; 1.4.122; 1.5.102; 1.8.37; 1.9.2; Serm.1.0.10; 1.9.67; 1.10.59; 2.1.49; 2.1.78; 2.1.81; 2.3.33; 2.5.37; 2.7.39; 2.7.89; Efist.1.5.0; 1.6.67; 1.10.31; 1.12.22; 1.17.4: 1.18.67; 1.18.108; Ars Poet.35; 125; 194; Ars Poet. $249 ; 386 ; 426 ; 438$

quidam. quod aut avarus ut Chremes .era preman. idscinctus aut perdam [? quidam! nepos.

ut quidam menoratur Athenis/sordidus ac dives.

ne facias guod imnidius quidam.

quidam notus homo cum exiret fornice.

accidit ut cuidam [quidam] testis caudanque alacem | demeterent [demeteret] ferro.

'heus. tu'| grailam ait 'ignoras te.

hoc quidan non belle: numquid ego illi infrudens olim faciam simile?" accurtic fuiclam wotus nuhi nomine tantum

quidam. idcirco quidam comoedia necne porma esset quaesivere

quiddam. "st ine"t Tanain quiddan socerumctue Viselli:

et 'unusi', ? ("quid tam [qujddan] magnum?" addens), "unum me surpite mot ti!

quidem, saepe ferentem / plura quiden tollenda relinquendis.

bune amor, ira quidem communiter urit nerungue.

multa quidem dixi, cur excueatus abirem.

jetro quidemb vetetes inter ponctur honesti".

multa quillem mobis facionts mala saepe pentate.

quidlibet. qualibe inposens/sperare fortunaque dulci, ebria

cum quillibut ille garriset.

quidjibue indueus celelertima per loca vadee

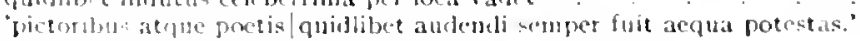

quidnam. ufi puldnam incetet at istam. . . mollitem.

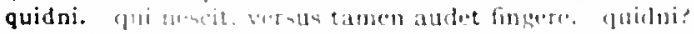

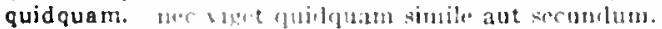

quidquam. nue quidquam ulu prodest arerias temptrane fomos

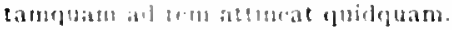

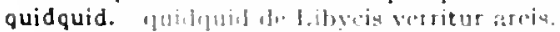

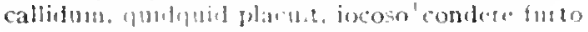

ut melius. equsliguid ent, pati.

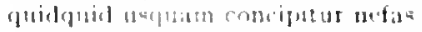

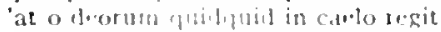

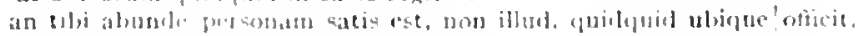
i-vitarn!

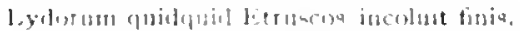

f)

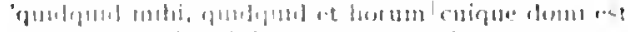

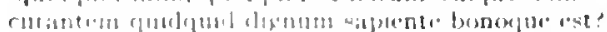

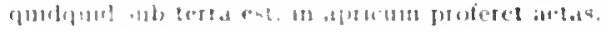

7 tar. Epod:34

Sirm.1.1.1.t

Sorm.1.1.05

Serm.1.231

tur.Serm.1.245

Sirm.1.3.22

Serm.1.4 $13^{\prime \prime}$

Serm.1.9.3

Serm.145

Sern. 11105

tor.Serm.2.3.283

iterm.t.10.5I

Epist. 2.13

Fpist.1.9.7

Efist.2.1.43

Eprist.2.1.210

(iam. I.37 10

form.1.0.12

I pist.1.17.28

Ars finel 10

Sirm:2 2.80

firs linel.382

(arm. I 2.18

(irm. I 25

Sirm.2 227

Corm.1.10

Carm I.lu?

Citmm.1.1.;

(iorm 2130

tipods 1

Serm. 2. in

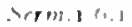

Sormez 1 :

urm. 23231

1 pist.1. 5

1 pirt.t p.z.l 


\section{QVIDQVID}

in vicum vendentem . . piper et quidquid chartis amicitur ineptis. .

quidquid. quidquid corrigere est nefas.

quidquid habes, age, depone tutis auribus.

quam si quidquid arat inpiger Apulus

sine nervis altera quidquid|conposui pars esse putat

quidquid vita meliore parasti|ponendum aequo animo."

"etiam et rex/et quidquid volet."

barathrone / dones quidquid habes

'o Laertiade, quidquid dicam, aut erit aut non:

qudquid delirant reges, plectuntur Achivi.

quidquid vidit melius peiusve sua spe.

quidquid negat alter, et alter, \}adnuimus pariter.

quidquid quaesierat ventri donabat avaro.

quidquid erat nactus praedae maioris,

si taceas, laudant quidquid scripsere beati.

quidquid praecipies, esto brevis.

quidvis. si quidvis satis est.

denique sit quod vis [quidvis], simplex dumtaxat et unum.

quidvis. iubet $\mid$ quidvis et facere et pati

rure neo possum quidvis perferre patique:

rure neo possum quidvis [? quidvis possum] perferre patique; argilla quidvis imitaberis uda;

quies. si te grata quies et primam somnus in horam|delectat.

quiescas. 'quiescas." 'ne faciam, inquis, omnino versus?"

quiescit. indociusque pilae discive trochive quiescit,

quiessem. rel merito. quoniam in propria non pelle quiessem.

quieta. non rura, quae Liris quieta|mordet aqua taciturnus amnis.

quietem. di, senectuti placidae quietem. . . . date

optat quietem Pelopis infidi pater.

quietiore. quietiore nec feratur aequore

quietis. adscribi quietis/ordinibus patiar deorum. .

quietos. cum fera diluvies quietos irritat amnis.

quietum. prius an quietum |Pompili regnum memorem. . . dubito.

quietus. et post Punica bella quietus quaerere coepit.

quin. quin et Atridas duce te superbos . . . fefellit.

quin et Prometheus et Pelopis parens|dulci laborem decipitur sono

quin et Ixion Tityosque voltu|risit invito,

quindecim [quin decem] Diana preces virorum/curat

quin, ubi perire iussus exspiravero. nocturnus occurran Furor

quin huc inanis, si potes, vertis minas

quin etiam illud |accidit ut cuidam testis caudamque salacem | demeterent ferro.

quin per mala praeceps|fertur

quin ubi se a volgo et scaena in secreta remorant

quin corpus onustum / hesternis vitiis animum quoque praegravat una

invidiam [? quin tu invidiam] placare paras virtute relicta? |contemnere niser.

quin. ex quo est habitus male tutae mentis Orestes.

"quin id erat curae,

quin omnia malit|quaecumçue inmundis fervent adlata popinis.

quin etiam lex poenaque lata.

quin etiam canet indoctum, sed dulce bibenti.

quin. merito quin illis Iuppiter ambas! iratus buccas inflet

quin ossa legant herbasque nocentis.

posito pavone velis quin hoc potius quam gallina tergere palatum.

nil verbi, pereas quin fortiter, addam. -

qui [quin] sapere et fari possit quae sentiat

quin sine rivali teque et tua solus amares.

quinas. quinas hic capiti mercedes exsecat

Quincti. quid bellicosus Cantaber et Scythes. | Hirpine Quinti [Quincti]. cogitet

quincunce. si de quincunce remota est/uncia, quid superat?

quindecim. quindecim Diana preces virorum/curat

quingentis. Si me stultior ipsolquingentis empto drachmis deprenderis?

Quinquatribus. puer ut festis Quinquatribus olim.

qninque. quinque diebus|nil erat in loculis.

cum Tiburte via praetorem quinque sequontur|te pucri,

mater ait pueri mensis iam quinque cubantis.

quinque talenta|poscit te mulier.
QVINQVE

Epist.2.1.270

Carm.1.24.20

Carm.1.27.17

Carm.3.16.26

Serm.2.1.2

Serm.2.3.15

Serm.2.3.98

Serm.2.3.167

Serm.2.5.59

Epist.1.2.14

Epist.1.6.13

Epist.1.10.4

Epist.1.15.32

Epist.1.15.38

Epist.2.2. 108

Ars Poel. 335

Serm.2.3.127

zor.Ars Poet.23

Carm-3.24.43

Epist.1.I5.I 7

? var.Epist.I.15.17

Epist.2.2.8

Epist.1.17.6

Sirm.2.1.5

Ars Poet. 380

Serm.1.6.22

Carm.1.31.7

Carm.Saec. 46

Epod.17.65

Epod.I0.I I

Carm.3.3.35

Carm.3.29.40

Carm.1.12.33

Epist.2.1.162

Carm.1.10.13

Carm.2.13.37

Carm.3.11.2I

var.Carm.Sace 70

Epod.5.9I

Epod.6.3

Serm.I.2.44

Serm.1.4.30

Serm.2.I.7I

Serm.2.2.77

? var.Serm.2.3.13

Serm.2.3.137

Serm.2.4.8

Strm.2.4.6I

Epist.2.I.I52

Epist.2.2.9

Serm.1.1.20

Serm.1.8.22

Serm.2.2.23

Serm.2.3.42

:ar. Epist.1. 4.9

Ars Poet.444

Serm.1.2.I4

var.Carm.2.1 I.2

Ars Poel. 327

Carm.Saec.70

Serm.2.7.413

Epist.2.2.197

Serm.1.3.16

Serm.1.6.108

Serm.2.3.289

Serm.2.7.80 
post patulo scrubu sibi milia quinque/esse domi chlamydum; quinque dies tibi pollicitus me rure futurum agelli. / quem tu fastidis. babitatum quingue focis quinque bonos solitum Varian dimittere patres. quas bis quigutue viri sanxerunt.

quinquenni. vino quinquenni, verum citra mare nato, / dum coquitut quinquennis. quinquennis oleas est et silvestria corna quinqueviro. plerumque recoctus / scriba ex quinquevito corvom deludet hiantem

quinta. quae Venus/quinta parte sui nectaris imbuit.

Quinte. quid belliconus Cautaber et Sesthes, | Hirpine Quinti [Quinte]. cogitet

"Quinte" puta aut "Publi" (gaudent praenonine molles|auriculae) orabant hodie meninisses, Quinte. reverti."

Quinti. quid bellicosus Cantaber et Scythes.|Jirpine Quinti, cogitet . ne perconteris, fundus meus, optime Quinti.

Quinti. Quinti progenies Arri, par nobile fratrum,

Quintilio. Quintilio siquid recitares, "corrige, sodes, /hoc' aiebat "et hoc."

Quintilium. ergo Quintilium perpetuos sopor/urget? non ita creditum | poscis Quintilium deos.

quinto. neve minot neu sit quinto productior actu|fabula.

quippe. quiple ter et quater |anno revisens atquot Atlanticum /inpune. quippe benignus erat.

Quirini. diuq̨ue/laetus intersis populo Quirini vacuom duellis|lanum Quirini clausit quaeque carent ventis et solibus ossa Quirini. cubat hic in colle Quirini, hic extremo in Aventino.

Quirinum. et vacuon duellis lanum Quirini [Quirinum] clausit

Quirinus. hac Quirinus|Martis equis Achetonta fugit. vetuit me tali voce Quirinus

Quiritem. quis te redonavir Quiritem/dis patris lialoque caelo,

Quiritibus. sod bellicosis fata Quiritibus/hac lege dico.

Quiritis. quid plansus et amici dona Quiritis,

Quiritium. Iunc, si mobilium turba Quiritium|cestat tergeminis tollere honotibus, quae cura patrum quaeve Quiritium . a aternet.

Quiritum. aut quid haberet./quod legeret tortetque viritim [Quiritum] publicus usus?

quis. Carm.1.5.1; 1.6.13; 1.18.5; 1.18.6;1.24.1; 1.27.21; 1.27.22;1.29.7; 1.29.10; 2.1.29; 2.7.3; Carm.2.7.23; 2.11.18; 2.11.21; 2.16.19; 3.19.6; 3.29.25; 4.5.25 (bis); 4.5.26; 4.5.27; Carm.7.7.17; Esod.2.37; Serm.1.2.17; 1.6.29; 1.9.23; 1.9.24; 1.10.2; tar.Serm.2.7.34; Sirm.2.8.50; 2.5.01; Fpist.1.1.49; 1.3.7; 1.3.8; 1.6.29; 1.7.53; 1.16.40; 1.20.10; 2.2.99; Epist.2.2.100; Ars I'oct.77

quis. Carm.1.18.7; Ior.Carm.3.24.25 (bis); Carm.3.27.45; 3.27.51; Epod.3.1; 6.15; 10.23; Germ.1.1.15; 1.1.90; 1.2.23; 1.3.56: 1.3.63; 1.3.80; 1.3.100 (bis); 1.4.3; 1.4.67: 1.4.80; Serm.1.4 111; var.Sirm.1.0.79; Serm.1.6.85; 1.10.59; $2.1 .01 ; 2.1 .82 ; 2.1 .83$ (bis): 2.1.8.4; Sorm.2.2.51; 2.3.10.7; 2.3.111; 2.3.159;2.3.187; 2.3.214; 2.3.210; 2.3.208; 23.322; Serm 2.4.49; 2.5 4); 2.5.100; 2.0.60; 2.6.78; 2.7.24; 2.8.90; Epist.1.16.25; 1.19.12; ilr.lipist.1.20.7; Epist.1.20.26; 2.1.222; 2.1.239; 2.1.263; 2 2.2; 2.2.157; 2.2.158; Ars l'set.afis

quis. Carm.1.26.3; :ar.Epod.12.7; Sorm.1.3.0\%; 1.4.72; 1.4.130; 1.5.42

quis. Food.11.0; Serm.1.1.75; tar.Serm.1.2.48; Serm.1.0.27:2.8.18

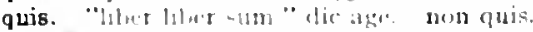

quínam. 'rphi-tlan igitus sanus?' qui non stuleus.

quenam igneut liluer? sapiens, sibi qui inumetosus.

quisquam. me quinglam, itus aequel Tunce dethatat alver.

nec fliseplatul potior bracehia candidael cervici iuvenis dabat.

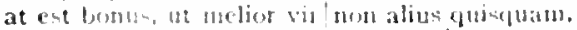

nectue to fluspham stipator ineptum / prater Crispinum sectabitur.

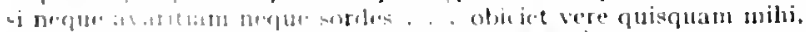

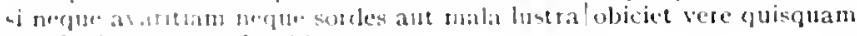

[quim

"haud mili quiseguam. | omnis conposui."

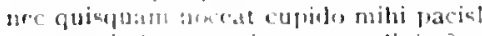

cur eget igrdighus quidequan te divite?

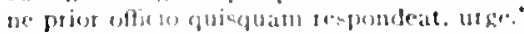

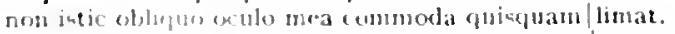

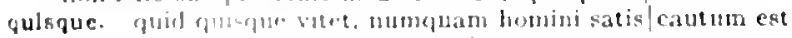

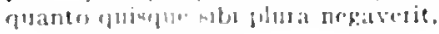

E.pist.1.6.43

Epist.1.7.I

Epist.1.14.2

Serm.2.8.47

Scrm.2.2.57

Serm.2.5.50

tar.Carm.2.11.2

Serm.2.5.32

Serm.2.6.37

(2.11.2

Serm.2.3.243

Ars Poet. $43^{8}$

Carm.1.245

Ars $P$ oel.

Serm.I.2.4

Carm.1.2.46

Carm.4.15.9

Epist 2.08

coni.Carm. 4.15 .9

Carm.3.3.15

crm. 1. 10.32

Carm. 3.3

Epist.1.6.7

Carm.1.1.7

Corm.t.t.

coni.Epist.2.1.92
Carm.1.31.13 
condit quisque diem collibus in suis

atque quanto perditior quisque est, tanıo acrius urget; cum referre negas, quali sit quisque parente| natus.

nan ut quisque insanus nigris medium impediit crus|pellibus

ad fastum quoscumque parentes|optaret sibi quisque,

cum sibi quisque timet, quamquam est intactus, et odit.'

ut quo quisque valet suspectos terreat

nitidus qua quisque per ora/cederet.

quantulum enim summae curtabit quisque dierum.

quisquis. Iuno et deorum quisquis amicior Afris

quisquis ingentis oculo inretorto/ spectat acervos.

auream quisquis mediocritatem/diligit,

o quisquis volet inpias/caedis et rabiem tollere civicam. .

Pindarum quisquis studet aemulari.

quisquis erit vitae scribam color.'

quisquis/ambitione mala aut argenti pallet amore.

quisquis luxuria tristive superstitione /aut alio mentis morbo calet:

quivis. quem si dissolvas, quivis stomachetur eodem|quo personatus pacto pater.

ut forsit honorem|iure mihi invideat quivis.

quas doceat quivis eques atque senator|semet prognatos.

neque enim quivis . . describit volnera Parthi."

nec sibi cenarum quivis temere arroget artem.

eripiet quivis oculos citius mihi

non temere a melquivis ferret idem.

ex noto fictum carmen sequar, ut sibi quivis/speret idem,

non quivis videt inmodulata poemata iudex

\author{
('arm.4.5.20) \\ Sirm.1.2.1.5 \\ Serm.1.0.7 \\ Sirm.1.6.27 \\ Serm.1.6.9) \\ Serm.2.1.23 \\ Serm.2.1.50 \\ Serm.2.1.6.t \\ Serm.2-3.124 \\ Carm.2.1.25 \\ Carm.2.2.23 \\ Carm.2.10.5 \\ Carm.3.24.23 \\ Carm.4.2.I \\ Serm.2.1.60 \\ Serm.2.3.7\% \\ Sirm.2.3.79
}

Serm.1.4.55

Serm.1.6.50

Serm.1.6.77

Serm.2.1.13

Serm.2.4.35

Serm.2.5.35

Epist.2.2.14

Ars Poet.240

Ars Poet.263

quo. Carm.1.3.15; I.4.19; 1.34.9; 1.34.10; 2.7.6; 3.9.15; 4.2.37; 4.1 4.3.4; Serm.1.4.29; 1.4.1 22; Serm.1.6.15; I.6.30; v'ar.Serm.1.8. 5; Serm.1.9.49; 2.3.29 i coni.Serm.2.7.88; Epis!.1.?60. Epist.1.7.14; 1.16.42; I.16.43 (bis); 1.20 .28

quo. Carm.1.2.22; 3.3.21; Carm.Saec.5; Epod.11.5; Strm.1.2.6; 1.2.85; 1.4.56; 1.6.1 2.4; 4.7 .11 ; Serm.1.10.*4;2.1.50; $23.34 ; 2.3 .137 ; 2.5 .62 ; 2.6 .41 ; 2$ ar.Serm.2.8.53; Epist.1.2.65; 1.6.10; var.Epist.1.16.63 (bis); Epist.2.2.153

quo. Serm.1.6.29; Epist.1.1.90; 1.6.8 (lis)

quo. Serm.2.3.295;2.7.22

quo. Carm.1.38.3; 3.10.5 (bis); Serm.1.5.53; 1.6.36; Epist.I.1.13 (bis); 1.7.54 (bis); 1.I2.25: Epist.1.18.53; Ars Pott.74; 313 (bis)

quo. Carm.1.27.11; 3.19.5; Serm.1.4.99; 1.7.2; 1.840; 2.3.21; 2.3.306; 2.4.8; Epist.5.13; Epist.1.17.2; 2.1.I7I

quo. Carm.3.19.7

quo. Carm.1.4.17; 2.3.9; var.Carm.2.3.11; Carm.3.1.38; 3.3.70; 3.11.49; 3.24.46; 3.25.1; 3.27.37; Carm.4.1.8; 4.7.I5 (bis); 4.13.17 (bis); 4.13.18; Epod.5.32; 7.I (bis); Serm.I.I.15; I.I.73; Serm.1.2.23; var.Sirm.1.3.12S; Serm.1.6.24; 1.6.73; I.7.27; 1.9.16; 1.9.40; 1.9.63; 1.9.75; Serm.2.1.37; 2.2.35; 2.2.102; tar.Serm.2.3.91; Serm.2.3.261; 2.4.1; 2.7.60; Epist.1.3.27; Epist.1.5.12; 1.6.27; 1.6.57; 1.13.7; I.I5.1 I; 1.20.5; 2.1.52; 2.2.37; 2.2.40; Ars Poel.206; Ars Poet.308 (bis); 396

quo. Serm.2.1.32;2.2.I1 2

quoad. quoad vixit, credidit ingens|pauperiem vitium : amicum|mancipium domino et frugi quod [quoad] sit satis, hoc est, | ut vitale putes."

quocirca. quocirca vivite fortes/fortiaque adversis opponite pectora rebus.' quo, bone, circa, / dum licet, in rebus iucundis vive beatus.

quocirca mecum loquor haec. tacitusque recordor:

quocumque. 'rem facias, rem, |si possis, recte, si non, quocumque modo. rem,"

ut quocumque loco fueris vixisse libenter/te dicas:

quocumque. quocumque lectum nomine Massicum|servas,

quocumque. ire, pedes quocumque ferent, quocumque per undas $\mid$ 广otus vocabit

ducere me auditum, perges quocumque, memento.

et quocumque volent animum auditoris agunto.

quocumque. 'quo nos cumque feret melior fortuna parente, |ibimus quo me cumque rapit tempestas, deferor hospes.

Serm.2.3.91

var.Serm.2.7.3

Serm.2.2.135

Sirm.2.6.95

Epist.2.2.145

Epist.1.1.66

Epist.1.11.24

Carm.3.21.5

Epod.16.2I

Serm.2.4.89

Ars Pot'. I 00

Carm.1.7.25

Epist.I.I.I5

quad. Carm.1.32.2; 2.10.25; 3.1.25; 3.4.13; 3.16.44; 3.29.32; Carm.Saec.26; Epod.2.2S; 9.35 ; zar.Epod.16.I5; Serm.I.1.43; I.4.51; 1.4.58; 1.6.41; 1.6.44; 1.6.60; I.0.123; 1.I0.22; Scrm.1.10.69; 2.2.102; 2.3.103; 2.6.13; 2.6.27; 2.6.30;2.6.72; 2.7.3; 2.7.40; 2.7.78; Serm.2.8.12; 2.8.50; Epist.1.1.24; 1.2.46; I.4.3; I.8.8; 1.15 19 (bis); I.15.20; I.I5.2I; Epist.1.15.35; I.18.17; 1.18.107; I.I8.I08; 2.1.83;2.1.115;2.1.179; 2.1.264; 2.2.52; Epist.2.2.S1: 2.2.172; Ars Pott.195 


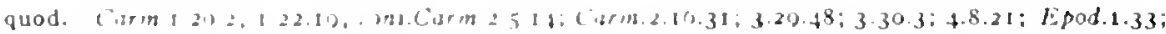

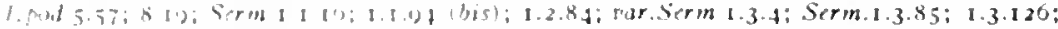
Serm 1 i I1; $1 .+101 ; 1.104 ; 1.5 .87 ; 1.0 .10 ; 1.0 .25 ; 1.0 .30 ; 1.9 .37 ; 1.10 .47 ; 2.3 .60 ;$

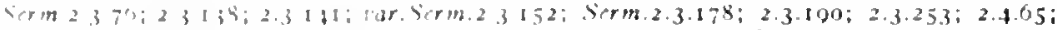

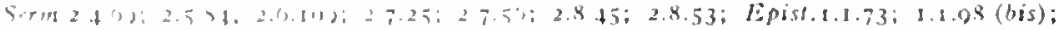

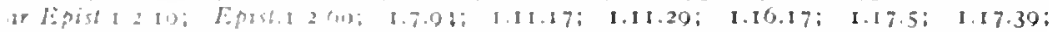

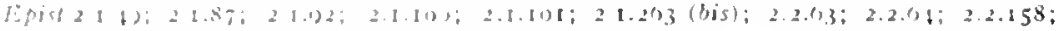

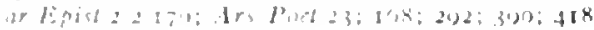

quod. $1: p+1,1 ; \cdot 3 \%$

quod. C.arm 2.1.34

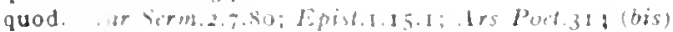

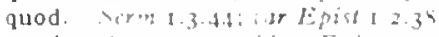

quod virn 2.1.34 (his); Epist.2.1.4n: 2.2.35

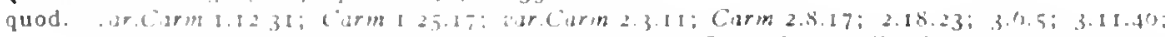

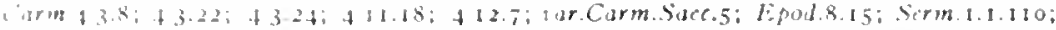

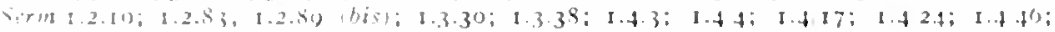

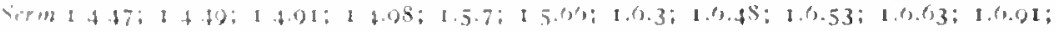

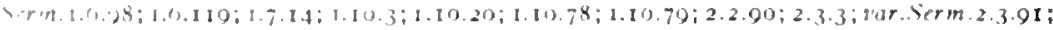

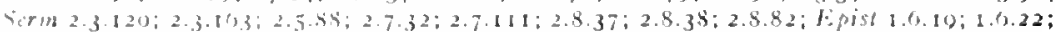

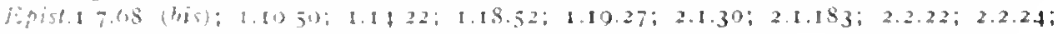

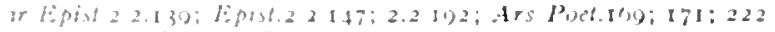

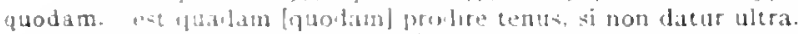

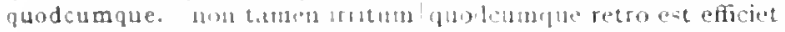

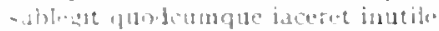

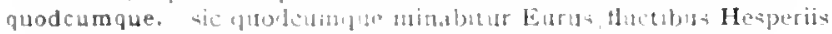

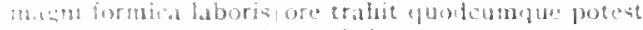

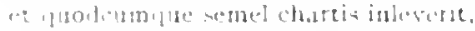

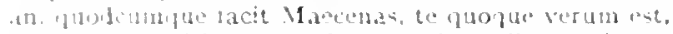

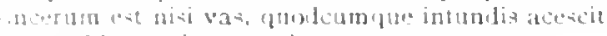

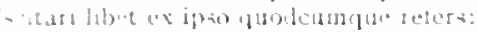

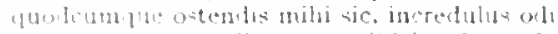

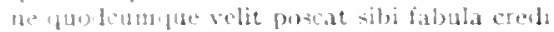

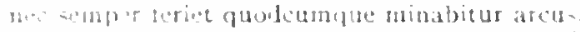

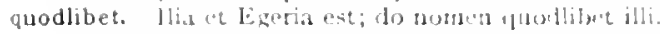

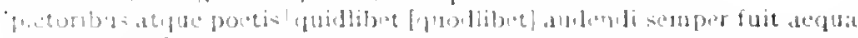
bustentatis,

quodque. Hatarde deus humande, morkds in unam guolque caput,

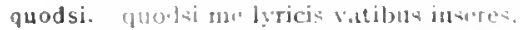

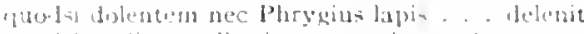

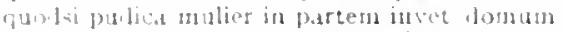

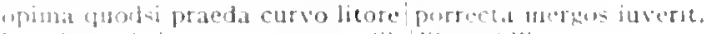

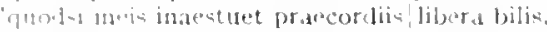

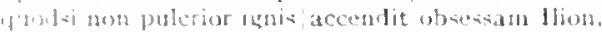

"fuolsi intertulerit tibi nune aliquid, repetes mox.

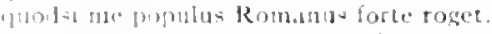

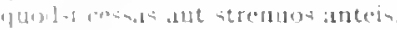

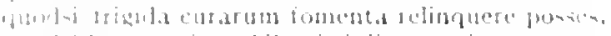

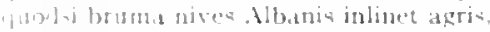

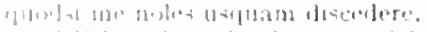

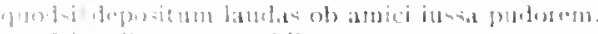

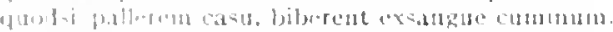

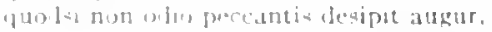

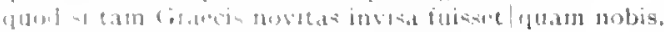

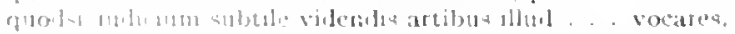

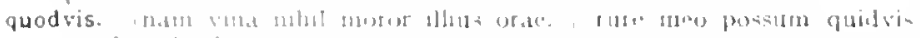

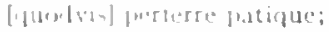

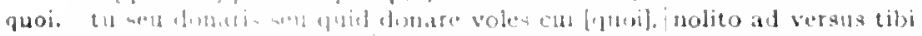

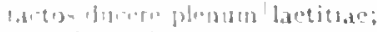

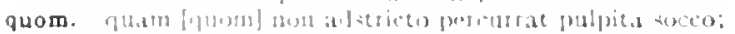

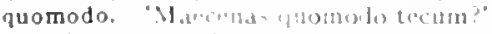

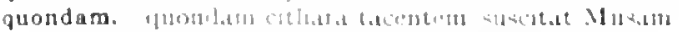

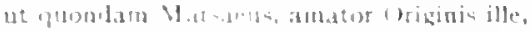

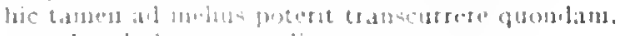

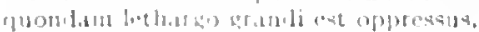

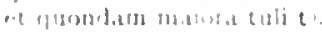

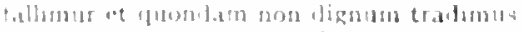

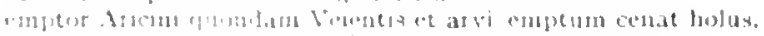

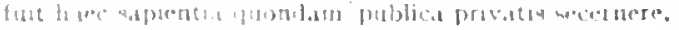

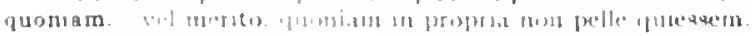

2ur.l:pist.1.1.32

Carm.3.29.40

verm.2.S.I2

Carm.1.28.25

Serm.1.1.3.1

$\operatorname{serm} 1 \cdot 4 \cdot 3 \sin$

Sorm 2.3312

Eprol. 2.54

Epist 1.7 .90

Ars Puet. $18 \mathrm{~s}$

Ars l'oe' 3312

Ars Poe?.350

Serm 1.2.12\%

izar. Ars Poet lo

Epist.2.2.180

Carm.1.1.35

Carm.3.1.41

Epoud.2.30

Epod 10.21

Epod.11.15

Epodita 13

Serm. 2 in

Epist.1.7.70

Epost. 1.2.71

Epist 1.3.25

Epict. 1.7. In

lepist.1.7.25

Lpisted.0.11

fopust.112.17

Epost.1.2010

Lipist.2.1.00

Epest 2.1.2.21

copilipret 1.15 .17
iur Ars Pord.t26
coni.lipist.2.1.174
Serm.1.9. 13
Cinem 2.81).18
Serm.1.255
Serm 2.2.tiz
Serm.2.3.15
Sirm.t.2.5.21
fepist.1. I 6.78
Epost 2.2.147
Ars I0, 1.301
Sierm.1.11.22 
qua me stultitia, quonian non est genus unum,|insanire putas? quoniam vacuis conmittere venis/nil nisi lene decet:

(nam te|seire, deos quoniam propius contingis, oportet).

emptor Aricini quondam [quoniam] Veientis et arvi $\mid$ emptum cenat holus,

quoque. tum in lecto quoque videres|stridere secreta divisos aure susurros." tur quid de quoge viro et cui dicas, saepe videto.

quoque. Merionen quoque|nosces.

conpesce mentem: me quoque pectoris/temptavit in fulci iuventa voltis severi me quoque sumere|partem Falerni?

me quoque devexi rapidus comes Orionis|Illyricis Notus obruit undis. . patriae quis exsul /se quoque fugit?

vim temperatam di quoque provehunt $\mid$ in maius:

fies nobiliun tu quoque fontium

dicetur, merita Nox quoque nenia.

o nutis quoque piscibus donatura cyoni. si libeat, somum.

aspergere cunctos/praeter eum qui praebet aquam; post hunc quoque potus.

quia non, ut forsit honorem / iure mihi invirleat quivis, ita te quoque amicum.

servavit ab omni|non solum facto, verum opprobrio quoque turpi

nec tamen hoc tribuens dederim quoque cetera:

(et est quaedam tamen hic quoque virtus):

vitium hoc quoque magnum.

quin corpus onustum |hesternis vitiis animum quoque praegravat una

hoc quoque volgus/Chrysippus ponit fecunda in gente Meneni. -

an, quoricumque facit Maccenas, te quoque verum est.

hoc quoque, Teresia, praeter narrata petenti|responde,

adiuvat hoc quoque, sed vincit longe prius ipsum|expugnare caput.

num sit quoque fracta lagoena.

quid studiosa cohors operum struit? hoc quoque curo.

nam qui cupiet, metuet quoque; .

quotiensque educet [quoticns quoque ducit] in agros | Actolis onerata plagis iumenta canesque.

hoc quoque te manet.

si das hoc, parvis quoque rebus magna iuvari

fuit intactis quoque cura|condicione super communi.

temptarit quoque rem si digne vertere posset

verum equitis quoque iam migravit ab aute voluptas/onmis.

si quantum cuperem possem quoque;

verbis, quae timido quoque possent addere mentem

quorsum. quorsum pertinuit stipare Platona Menandro?

rectum animi servas cursum? [servas?" "quorsum?'] 'insanus quid enim

Aiax|fecit?

quorsum abeant? sani ut creta, an carbone notati?

"non dices hodie, quorsum haec tam putida tendant. | furcifer?"

"unde mibi lapidem?" 'quorsum est opus?" .

quorum. puerosque Ledae. . . quorum simul alba nautis istella refulsit. Scythae. |quorum plaustra vagas rite trahunt domos.

atque alii, quorum comoedia prisca virorum est,

sunt quorum ingenium nova tantum crustula promit. quorum|conspicitur nitidis fundata pecunia villis.

quorum. quorum | piis secunda vate me datur fuga.

rectum animi servas cursum? [quorum] insanus quid enim Aiax / fecit?

quorum. quorum hominum regio et qualis via

quos. sunt quos curriculo pulverem Olympicum/collegisse iuvat

felices ter et amplius|quos inrupta tenet copula

non di, quos iterum pressa voces malo.

(currit enim ferox/aetas et illi quod [quos] tibi dempserit|adponet annus

[annos]).

quos inter Augustus recumbens

amoenae /quos et aquae subeunt ct aurae.

per quos cecidere iustal morte Centauri.

sive quos Elea domum reducit / palma caclestis .

quos opimus|fallere et effugere est triumphus. .

Germania quos horrida parturit | fetus

modos, amanda/voce quos reddas:

quo [quos] Sibyllini monucte versus | virgines lectas puerosque castos .. dicere carmen.

cognatos, nullo natura labore|quos tibi dat.
Sirm.2.3.30I

Serm.2.4.25

Sirm.2.0.52

Iar. Epist.2.2.107

Sirm.2.8.77

Epist.I. I 8.08

Carm.1.15.26

Cirm.1.10.22

Cirm.1.27.9

Carm.1.28.21

Carm.z.10.20

Carm.3.4.60

Carm.3.13.13

Carm.3.28.10

Carm.4.3.19

Serm.1.4.88

Sirm.1.0.50

Sirm.1.6.8.4

Serm.1.10.5

Sirm.1.10.8

Serm.2.2.to

Sirm.2.2.78

Serm.2.3.286

serm.2.3.3 I 2

Serm.2.5.I

Serm.2.5.73

Sirm.2.8.81

Epist.1.3.6

Epist.1.16.65

arar.Epist.I.18.45

Epist.1.20.1 7

IEpist.2.1.1 25

Epist.2.I.I 51

Epist.2.1.164

Epist.2.I.I87

Lpist.2.1.257

Epist.2.2.36

Sirm.2.3.II

itr. Serm.2.3.20I

serm.2.3.240

Serm.2.7.21

Serm.2.7.116

Curm.1.12.27

Cirm.3.24.10

Serm. I.4.2

Serm.2.4.47

Epist.I.15.45

Epod.10.65

var.Serm.2.3.20I

Epist.1.15.2

Carm.I.I-3

Carm.1.13.18

Carm.I.I4IO

tar.Carm.2.5. I4

C.rm.3.3.11

Carm.3.4.8

Carm.4.2.14

Carm.4.2.17

Carm.4.4.51

Carm.4.5.26

Carm.4.I I.35

ver.Carm.Saec.5

Sorm.1.1.89 
quos ultra citraque neeput consistere rectum.

Serm.t.1.107

quos venerem inceltan rapientis more ferarum / viribus editior caedebat

puedr, gluos tu nisi fuste coerces.

quod sumb guos finus hoc minime iuvat.

monsis. . guos torret Atabulus ct quos/nunquam erepsenus.

quos nexpe pulce / Ilermogenes umplam legit

docto: cgo quos et amicos|prudens practereo.

servosve tuos, quos aere pararis.

scilicet nt plausus quos fert Agrippa feras tu.

cun servilio Balatrone/Vibidius quos Macenas adduxerat umbras.

u jiger annus| pupillis, quos dura premit custodia matrum: .

excipiantque semes, quos in vivaria inictant:

fructibus Agrippae Siculis, quos colligis, lcci.|si recte frueris.

vetiresne buetislan quos ct pracsens et postera respuat aetas?

quos. guae renora aut quos agor in specus.

inter quos referendus erit?

quos. siquos Eois intonata fluctibus/firms at hoc vertat mare,

eo tit. pleniri ut sqquos delectct copia iusto.

quoscumque. all tastum quoscumque parentes|optart sibi quisque. quoscumque feret cultus tibi fundus honores

quot. quot capitum vivont, totidem studiorum| nilia:

'tamen et quaeram et quot habebolmittam';

quota. nugas hoc genus: 'liura quota est?"

quata. quotal'aclignis caream frigoribus.

quotannis. reddit ubi cererem tellus inarata quotannis

quatiens. heu quotiens fidem /mutatosque deos flebit

sendit. Antoni, yuotiens in altos|nubium tractus:

quotiens bonus atque fidus iudex honestum pratulit util.

dices 'heu', quotiens te in speculo videris altermm,

quotiensque educet in agros Aetolis onerata plagis iumenta canesque,

me quotiens reficit gelidu: Digntia rivos.

ambigitur quotiens, uter utro sit prior.

quotquot. non, si trecenis quotguot cunt dies. . - tauris.

v'ertumnis, quotquot sunt, natus iniquis.

quotus. tu quotus esse velis rescribe.

scire velim, chartis pretium quotus atroget anmus.

quovis. ut forte legentem |aut tacitum inpellat quovis sermone:

Serm.1.3.109

Serm.1.3.134

Serm.1.4.24

Serm.1.5.78

Serm.1.10.17

Serm.1.10.87

Scrm.2.3.129

Sorm.2.3.185

Serm.2.8.22

Epist. 1.22

Epist.1.1.79

Epist.1.12.I

Epist.2.1.42

Corm.3.25.2

Epist.2.1.41

Epod.2.5I

Serm.1.1.57

Serm.1.6.95

Serm.2.5.13

Serm.2.1.27

Epist.1.6.42

Serm.2.6.44

Carm.3.19.7

IEpod.16.43

Corm.1.5.5

Corm.4.2.26

Corm.4.9.40

Corm.4.10.6

Epist.1.18.45

Efist.1 18.10 .4

Epist.2.1.55

Corm.2.14.5

Sorm.2.7.14

Epist.1.5.30

Epist.2.1.35

Scrm.1.3.65

\section{R}

rabidos. dictus ob hoc lenire tigres rabilosque leones;

rabidus. me quonue derexi rapidus [rabidus] comes Orionis|lllyricis Notus obruit undis.

rabiem. tinuit. . rec tristis 11 yadas nec rabiem Noti,

Palla- ct argidal currusque et rabiem parat.

o qum quis velee inpiasl caedia et sabien tollere civicam.

cum jerre sesutolindomitam properat rabien sedare.

non dico horsendiam rabiem -

ubi gratest atua leniat et rabiem Canis et monenta Leonis.

donec iam saevos apertam / in rabiem coepit verti iocus

rabies. Archilechusi poprio tabies armavit iambo

rabiosa. hac sabiosil fugit canju. hac lutulenta ruit sus:

rabjosi. fugio canpum lusumgue trigon m [fugio rabiosi tempora signi].

racemos. iam tubi hvidos/fintinguet autumas racenos/pusputeo varius colore.

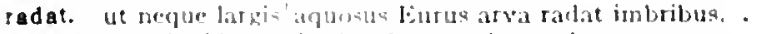

radere. ton laficlus varios lutulenta radere palma

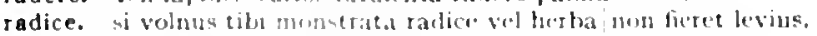

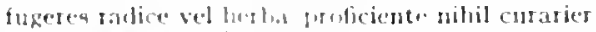

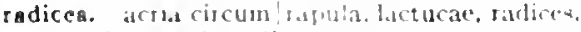

radit. sive arpulo tald tertins

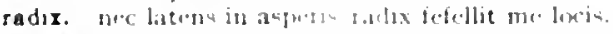

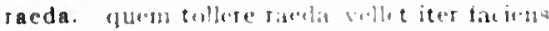

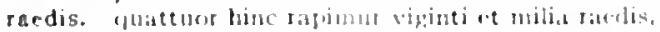

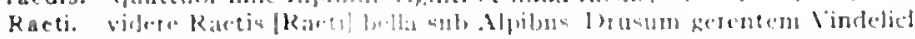

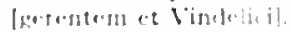

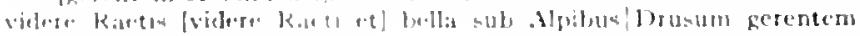
Visulelici.

Irs Poet.393

tar.Carm.1.28 21

Corm.1.3.14

Corm.1.15.12

Corm 3.24 .26

Epod 12.9

Serm.2.3.323

Jipist.1. I0.10

Jepist.2.1.140

Ars Poet. 79

I.pist.2.2.7.5

rar.Serm.1 0.126

Carm.2.5.1I

Ispod.10.54

Sirm.2.1.83

Epist.2.2.140

Epist.2.2.150

Srm. 2.8.8

Serm.2.0.25

Eporl.5.18

Serm.2.01.42

Sorm.1.5.8\%

sar.Carm..4.4.17

arcorm $4+17$ 
Raetii. videre Raetis [Raetii] bella sub Alpibus|Drusum gerentem Vindelici [gerentem et Vindelici].

Raetis. Raetis bella sub Alpibus/Drusum gerentem

Raetos. inunanisque Raetos |auspiciis pepulit secundis.

ramis. umbram hospitalem consociare amant|ramis? tum spissa ramis laurea fervidos/excludet ictus.

lecta de pinguissimus|oliva ramis arborum

Ramnes. celsi praetereunt austera poemata Ramnes:

ramos. inutilisque falce ramos amputans.

udos cum foliis ramos utente camino.

ranae. et uncta turpis ova ranae sanguine

absentis ranae pullis vituli pede pressis

ranae. mali culices ranaeque palustres/avertunt somnos;

rancidum. rancidum aprum antiqui laudabant.

rapaci. quem scis inmunem Cinarae placuisse rapaci,

rapacibus. apris reliquit et rapacibus lupis,

rapacibus. ait Harpyiis gula digna rapacibus. .

rapacis. rapacis Orci sede destinata

rapacium. 'cervi, luporum praeda rapacium,

rapax. hinc apicem rapax |Fortuna cum stridore acuto|sustulit. .

rape. dona praesentis cape [rape] laetus horae

rapere. quae poscente magis gaudeat eripi,|interdum rapere occupet? convivas avidos cenam servosque timentis|tum rapere . . velle.

rapiam. nec variis obsita frondibus/sub divom rapiam.

rapiamus. rapiamus, amici,|occasionem de dic

rapias. ut limis rapias, quid prima secundo/cera velit versu;

distat, sumasne pudenter an rapias.

rapido. quale fuit Cassi rapido ferventius amni|ingenium.

rapidos. arte materna rapidos morantem |fluminum lapsus

Orpheus, / dictus ob hoc lenire tigres rabidosque [rapidosque] leones;

rapidum. nec rapidum fugiente solem.

rapidum. illud idem in rapidum flumen iaceretve cloacam? $-{ }^{\circ} \cdot{ }^{*} \quad$.

rapidus. me quoque devexi rapidus comes Orionis|Illyticis Notus obruit undis.

te rapidus Tigris, ... audit

rapiente. omne sacrum rapiente dextra,

rapientis. quos venerem incertam rapientis more ferarum

rapies. cum rapies in ius malis ridentem alienis,

rapiet. inprovisa leti|vis rapuit rapietque gentis.

rapimur. quattuor hinc rapimur viginti et milia raedis,

rapinis. quid refert, morbo an furtis pereamque rapinis?'

rapis. quo me, Bacche, rapis tui|plenum?

Romae sponsorem me rapis.

ocius hinc te|ni rapis.

rapit. a, te meae si parten animae rapit|maturior vis.

quem cruenta|per medias rapit ira caedes.'

almun/quae rapit hora diem.

furorne caecos an rapit vis acrior|an culpa?

ut, cum carceribus missos rapit ungula currus,

rapit in ius; clamor utrimque, |undique concursus.

aut si tantus amor scribendi te rapit,

quo me cumque rapit tempestas, deferor hospes.

in medias res|non secus ac notas auditorem rapit

rapiunt. i pedes quo te rapiunt et aurac.

rapta. arsit Atrides medio in triumpho/virgine rapta,

rapta. et ossa ab ore rapta ieiunae canis.

raptam. saepe periscelidem raptam sibi flentis,

raptantur. aut cur dexteris loptantur [taptantur] enses conditi?

raptas. stirpisque raptas et pecus et domos/volventis una,

raptim. cui donet inpermissa raptim /gaudia luminibus remotis,

exiguo gratoque fruaris tempore raptim.

raptis. insignibus raptis puer.

rapto. rapto de fratre dolentis/insolabiliter.

raptor. dura post paulo fugies inaudax/proelia raptor.

proles Niobea nagnae vindicem linguae Tityosque raptor/sensit .

raptum. flebili sponsae iuvenenve raptum/plorat

raptus. qualis aut Nireus fuit aut aquosa|raptus ab Ida.

rapuisse. audiet civis acuisse [rapuisse] ferrum,

rapuit. inprovisa leti|ris rapuit rapietque gentis.

tar.Carm.4.4.17

Carm-4.4.1 7

Carm.4.14.15

Carm.2.3.II

Carm.2.15.9

Epod 2.56

Ars Poet. 342

Epod.2.13

Sirm.1.5.8I

Epod.5.19

Serm.2.3.314

Serm.1.5. 4

Serm.2.2.89

Epist.1.14.33

Epod.16.20

Serm.2.2.40

Carm.2.18.30

Carm.4.4.50

Carmi.1.34.IA

var.Carm.3.8.27

Carm.2.12.28

Serm. 1.5 .76

Carm.1.18.13

Epod.13.3

Serm.2.5.5.3

Epist.1.17.45

Serm.1.50.62

Carm.1.r2.9

var.Ars Poet.393

Carm.2.9.12

Serm.2.3.242

Carm.1.28.2I

Carm.4.14.46

Carm.3.3.52

Serm.1.3.109

Serm.2.3.72

Carm.2.13.20

Sirm.t.5.86

Sirm.2.3.157

Carm.3.25. I

Serm.2.6.23

Serm.2.7.II 8

Carm.2.17.5

Carm.3.2.I 2

Carm.4.7.8

Epod.7.13

Serm.1.I.IIt

Serm.1.9.77

Serm.2.1.10

Epist.1.1.15

Ars Poet. 49

Carm.3. II.49

Carm.2.4.8

Epod.5.23

Epist.1.17.50

coni.Epod.7.2

Carm.3.29.37

Corm.3.6.27

Epist.2.2.198

Epod.5.12

Epist.1.14.7

Corm.3.20.4

Carm.t.6.2

Corm.4.2.2I

Carm.3.20.16

coni.Corm.I.2.2 I

Carm.2.13.20 
rapula. acria circun /rapula, lactucae, radices,

rapula. cum rapula plenus/atque acidas mavolt inulas.

rara. auliet pugnas vitio parentum/rara iuventus. te Spes et albo rara Fitjes colit/velata panno cur manat rara meas lacrima per genas? atpue baec ralla cadat dura inter saepe pericla. rutbat flumen ut hbernum. fertur quo rara securia. quia vencest auro|rara avis

rara. aut anite levi rara tendit retia

rare. iciunus raro [rare] stomachus volgaria tenunit.

raris. jevinnus raro [raris] stomachus volgaria temnit.

raro. taro antecedenten scelestum / deseruit perle Poena claudo. inde tit. ut raro, gui se vixisze beatum|dicat fincerunt animi. raro et perpanca loquentis; ie-innu= raro stomachus bolgaria temnit.

sic raro seribis, ut toto non quater anno/ membranam poscas.

rarus. hic et in Accilnobilibus trimetris adparet rarus.

rata. atque hate rara [rata] calat lura inter saepe pericla.

ratas. upec iuluet cese ratas, al proclia trudit inertem.

ratem. qui fragilem trucil conmisit pelago ratem|primus:

in inpian diacio ratem.

secunda ratem occupare quit moramur alite?

rates. a tanun inpiae mon tangenda rates transiliunt vada.

rates. mox reicit rates' quasas indocilis pauperium pati.

ab infimia|quassa eripiunt aequoribus rates.

ratio. seu ratio decterit seu fors obiecerit.

qua ses. qua ratio suaderet quaque modeste munifico esse licet.

cur nonlponderibus modulisque suia racio utitur

noc vincet ratio hoc, tantundem ut pecect idemque.

long" nea fiscrepat istialet rox et ratio:

nescio an Anticyram ratio illis destinet onstrem.

sincet rnim stultos ratio insanire nepotes. .

si purilius hia ratio esse evincet amare

si ratio et prudentia curas, . . autert.

ratione. ratione modoque/tractari non s"olt.

insanire paret certa ratione modoque."

non priss exacta tenui ratione saporum.

accipe qua ratione queas ditescere.

si neque maiorem feci ratione mala rem

qua ratione queas traflucele legiter aevom,

cetera nequaluam sinili ratione nodoque/acstimat

dum carlit $"$ lu\&us ratione ruentis acervi

rationibus. Iongis rationibus asem/ediacunt in partis centum diducere.

rauca. "quarre peregrimus vicinia ranca reclamat.

rauci. fracticque rauci huctibus Ilatriae.

rauci. Sulcius acer/ambulat et Caprina, rauci male cumque libelis.

raucis. irutra cruento mate carebinus fractisyue rauci [raucis] fluctibus

$$
\text { Hidria.. }
$$

rava. at) ugrolrava decusrona lupa Lanuvino

ravos. crejula nec ravoz timcant arimenta leones

re. und. laboriz' pluq lawrire mali eat quam ex re decerpere fructus. .

avitalex a parloni sumptus mihi crederet illos.

nam male re sata cum vellem mittere operto' me capite in fumen,

nequaquam atio in re una consumere curam.

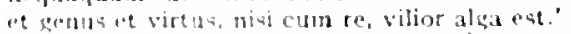

sicu pracerea validus male filis in relpracelara sublatus aletur.

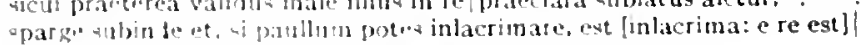
gandia prodertasu voltum colare.

re re communi seriba" masna atque nova te forabant

corvias bare inter vicinas siarrit anilis/ex re fabellas.

velut wilre vera plegnent.

har in se arilicen nal multum dissimilea.

ruifumpor in augenda feationt et obruitur re.

ine libartino natum putre et in tenui re. . loqueris.

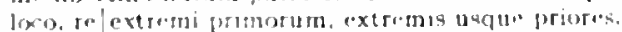

rebus. glan voret livom populua tuentia|imperi rebus?

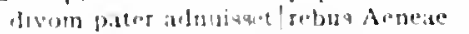

or rebus mejul nom infuleles arbicrar.

juent acer apritu4 ac vialuec verbig nec rebua inest.
Serin.2.8.8

Serm.2.2.43

Carm.1.2.2.4

Carm.1.35.21

Carm.4.1.34

Scrm.1.2.40

Serm.1.7.27

Sictm.2.220

Epod.2.33

rar.Serm.2.2.38

var.Serm.2.2.38

Carm.3.2.31

Serm.1.1.117

Serm.1.4.18

Scrm.2.2.38

Sorm.2.3.1

Ars Pott.259

y'r.Serm.i.2.40

Epist.1.5.17

Carm.1.3.11

I.pod.10.14

Epod.16.24

Carm.1 3.24

Carm.1.1.17

Carm.48.32

Scrin.1.1.2

Scrm.1.2.50

Serm.1.3.78

Serm.1.3.115

Serm.1.6.03

Sorm.2.3.83

Serm.2.3.225

Serm.2.3.250

Epist.1.11 25

Scrm.2.3.260

Serm.2.3.27t

Serm.2.4.30

Serm.2.5.10

Serm.2.0.6

Epis:1.18.97

Epist.2.t.20

Epist.2.1.47

Ars Poet. 325

Epist.1.17.02

Corm.2.1.4 14

Serm.1.t.06

far.Carm 2.14 .14

$\operatorname{Corm} 3 \cdot 27 \cdot 3$

Fopod 10.33

Sorm.1.2.70

Serm 1.0.80

Sorm.2.337

Serm.2.4.43

Scrm.2.5.8

Serm. $2 \cdot 5 \cdot 45$

coni.Sorm 2.5 .103

Serm.2.0.30

Serm. 20.78

Serm.2.7.09

Epist.1.to.2

Enist.1.16.0.8

Epist 1.20 .20

Epist. 2203

Carm.1.2.26

Carm 4.6.23

Epod 5.40

Sern.1.1.47 
fortiaque adversis opponite pectora rebus."

Serm.2.2.136

ex more inponens cognata vocabula rebus?

Serm.2.3.280

ut semper gaudes inludere rebus/humanisl"

Serm.2.8.62

et mihi res, non me rebus subiungere conor.

Epist.1.1.19

si non/intendes animum studiis et rebus honestis,

Epist.1.2.36

vincentem strepitus et natum rebus agendis.

certis medium et tolerabile rebus|recte concedi

rebos. aequam memento rebus in arduis|servare mentem.

rebus angustis animosus atque/fortis adpare:

vitamque sub divo et trepidis agat /in rebus.

ne nimium pii|rebusque fidentes avitae|tecta velint reparare Troiae.

novisque rebus infidelis Allobrox

est modus in rebus, sunt certi denique fines.

missi magnis de rebus uterque|legati,

dum licet, in rebus iucundis vive beatus.

bonisque rebus agit laetum convivam,

esto aliis alios rebus studisque teneri:

si conportatis rebus bene cogitat uti.

invidus alterius macrescit rebus opimis;

rebus onissis|atria servantem postico falle clientem.

rebus maternis atque paternis|fortiter absumptis

temperat Alcaeus, sed rebus et ordine dispar.

si das hoc, parvis quoque rebus magna iuvari.

recalcitrat. cui male si palpere, recalcitrat undique tutus."

recalcitret, cui male si palpere, recalcitrat [recalcitret] undique tutus."

recantatis. dum mihi|fias recantatis amicalopprobriis .

recedant. senes $u t$ in otia $t u t a$ recedant.

verba movere loco. quamvis invita recedant

recedentes, multa ferunt annivenientes commoda secum. ! multa recedentes adimunt:

recedentis. recedentis trilingui|ore pedes tetigitque crura.

Ars Poet.82

Ars Pot .368

Carm.2.3.1

Carm.2.10.21

Carm.3.2.6

Carm.3.3.59

Epod. 16.6

Simm.1.1.106

Serm.1.5.28

Sorm.2.6.96

Stm.2.6.1 II

Epist.1.1.81

Epist.1.2.50

Lipist.1.2.57

Epist.1.5.30

Epist.1.15.26

Epist.I 19.29

Epist.2.1.125

Serm.2.1.20

var.Serm.2.1.20

Carm.1.16.27

Serm.1.1.3I

Epist.2.2.113

Ars Poet.1 76

Carm.2.19.31

Epist.1.16.35

recedo. 'pone, meum est,' inquit: pono tristisque recedo. . . . .
recens. non. si trecenis [sit recens] quotquot eunt dies. . . places inlacrinabilem |Plutona tauris.

usquc ego postera|crescam laude recens,

putet aper rhombusque recens.

Naevius in manibus non est et mentibus haeret/paene recens?

recens. quo semel est imbuta recens servabit odorem | testa diu.

recens. iusenun recens/examen Eois timendum

dicam insigne, recens, adhuc|indictum ore alio.

recenti. euhoe, recenti mens trepidat metu

recentibus. indicis monstrare recentibus abdita rerum:

recentis. recentis/carpere flores?

recentum. qui feros cultus hominum recentum $\mid$ voce formasti catus

recepisset. nisi nos vicina Trivici|villa recepisset

recepit. scripta. Palatinus quaerumque recepit Apollo. .

inploravit opes hominis frenumque recepit.

spordeos stabilis in iura paterna recepit

recepta. idem finitis studiis et mente recepta.

recepti. point ingentia facta deorum in templa recepti.

recepto. recepto|dulce mihi furere esc amico.

'o sol|pulcer, o laudandel" canam recepto|Caesare felix.

receptus. sive receptus/terra Neptunus classis Aquilonibus arcet.

recideret. recideret omne, qund ultra|perfectum trahetetur,

recidet. ambitiosa recidet / or namenta.

reciditur. si non supplicio culpa reciditur.

recinentis. impios parrae recinentis omen/ducat

recines. tu curva recines lyra Latonam

recinet. cuius tecinet iocosa/nomen inago

recinit. cuius recinet [tecinit] iocosa] nomen imago

recinunt. haec recinunt iuvenes dictata senesque

recipit. hinc nos Coccei recipit plenissima villa.

neque parvom/carmen maiestas recipit tua

recisas. columnas ultima recisas/Africa.

recisos. matris ad arbitrium tecisos| portare fustis,

recisurum. magnis parva mineris|falce recisurun sinili te.

recitare. volgo recitare timentis ob hanc rem.

spissis indigna theatris|scripta pudet recitare

recitares. Quintilio siquid recitares, "corrige, sodes, /hoc' aiebat 'et hoc."

zar.Carm.2.14.5

Carm.3-30.8

Serm.2.2.42

Epist.2.1.54

Epist.1.2.69

Carm. 1.35-30

Carm.3.25.7

Carm.2.19.5

Ars Peet.q9

Carm.3.27.43

Camm.10.2

Serm. I. 5.80

Eipist.1.3.17

Etist.1.10.36

Ars Poet.256

Epist.2.2.104

Epist.2.1.0

Carm.2.7.27

Carm.4.2.47

Ars Poel.63

Serm. I. 10.69

Ars Poet 447

Carm.3.24.34

Corm.3.27.1

Com.3.28.I I

Carm.1.12.3

rar.Carm.1.12.3

Epist.1.t.55

Serm: 15.50

ENist.2.1.258

Curm.2.18.4

Carm. 3.0 .40

Serm.1.3123

Serm I.4. 23

Epist. I. 19.42

Ars Poet 438 
recitata. cum locil ian recitata revolvimus inrevoati;

Epist.2.1.223

recitator. indoctum doctumque fugat recitator acerbus

Irs Poel.474

recitent. In nedio quilacripta foro recitent,

tecito. nee recito cuiquam nisi amicis idque coact us,

Serm.1.4.75

reclamat. inacte peregrinum vicinia rauca reclanat.

Serm.1.4.73

reclinat. mu!lum a labore me reclinat otium;

reclinatum. In remoto gramine per dies/festos reclinatum

Epist.1.17.62

Epod.17.2.

recludens. Vituls, recludens inmerit is morilcaclum.

Carm.2.3.7

recludere. non lenis precibus lata recludere nigro conpulerit Mercurius gregis

modo ense portis Notico recludere

recludit. yuid non cbrietas dissignat? operta recludit.

recluditur. aequa tellus'paupri recluditur regumque pueris

Carm.3.2.2t

reclusa. Romac dulce diu fuit et sollemne reclusa mane domo vigilare.

recoctus. pleminque recoctus / scriba ex quincueviro corvom deludet hiantem

recondit. yui mummos aurumque recondit.

reconditum. prome reconditum. Iy de, strentia Caccubum

recordor. guocisca mecum loquor haec. tacitusplue recordor:

recreabis. tostis marcentem squillis recreabis et Afral potorem coclea:

recreantur. incorti capillis, Eumenidum recreantur angues?

recreare. heni recreare vento

seu recrears solet tenuatum corpus

tir pure lecto poterunt recreare libello.

recreat. arquali ricreat sorte vicatius.

recreatis. Caestem altum. . Pierio recreatis antro.

Curm.1.2.4.17

fipod.17.71

Epist.1.5.19

Carm.2.18.33

IDist.2.1.103

Sorm.2.5.55

Serm 2.3.109

Carm.3.28.2

Epist.2.2.1.45

Serm.2.4.58

Carm.2.13.36

Curm. 320.13

Serm.2.2.8.4

Epist.1.1.37

Curm.3.24.16

Carm.3.4.40

Curm.1.22.IS

recreatur. ubi nulla campis/arbor acstiva recreatur aura. .
recreetur. pon me pigris ubi nulla campis / arbor aestiva recreatur aura 18 recrectur umbra].

recta. cardish tectaque sit. munda hactenus.

mendosa est natura, alioqui recta.

recta. tendius hinc reca Beneventum.

recta. pars nulta natat, nodo recta rapessens. interdun pravis obnoxia.

rectae. uni nimirum recte [rectac] tibi semper erunt res, ! magnus prosthac inimicis risu4.

recte. non possidutem multa vocaveris|recte beatum; procedere recle! qui muechis non voltis.

tu i unglo recte' dispensare vilis .

ho illi recte; ne corporis optima Lyncil contemplere oculis.

scribendi reoto: nam ut multum, nil noror.

tondimus linc recta [recte] Beneventum.

uni nifustum recte thi senper erunt res.

uni nimusm lecte tibi [tibi recte] semper erunt res, fo magnus posthac inimiojis lisus.

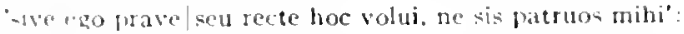

rectevent igitur, subgetque?

non ous two ponere

ut onu prave proti recte funi comptique ministrent?

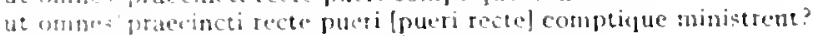

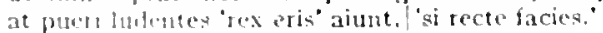

nenis. "luate rentam recte facintibus otfert.

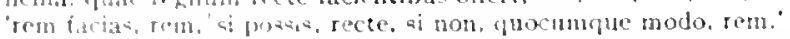

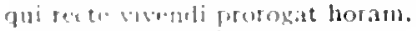

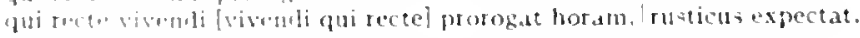

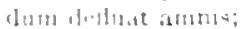

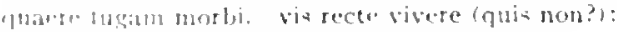

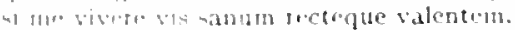

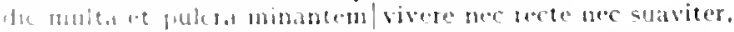

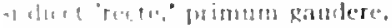

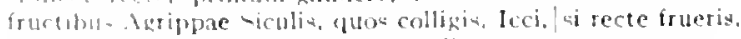

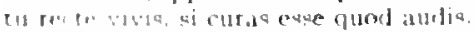

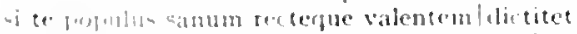

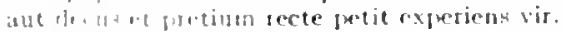

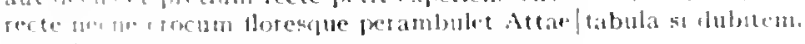

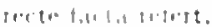

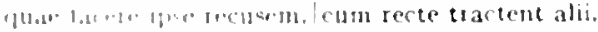

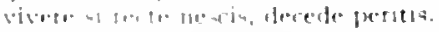

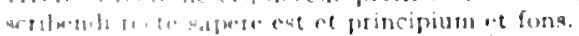

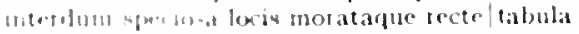

7 :ar Corm.1.22.18

Serm.1.2.123

Sirm.1.6.06

Sorm.1.5.71

Serm.2.7.7

gur.. Serm.2.2.100

Curm.9.9.4t"

Serm.1.2.37

Serm.1.2.74

Serm.1.2.00

Sirm.1.13

iur.sernis 5.71

S.rm.2.2.100

:ar.Sorm.2.2.100

Serm.2.3 S8

Sermi2.3.102

Serm.2.7.112

Sirm.2.8.70

I'tr. Serm 2.8.70

Epist.t.1.co

Epist. I.1.6?

lipist I. I th

Epist.t $2 . .4$

aur. Epist 12 \&t

I. pelt 1.0.20)

lipist 1.7 .3

IEpis 1.8.

Epist. I.S.15

lipist.1.12.2

fopter.16.17

Eprst.1.30.21

lopist.1.1.42

I.pist.2.1.70

Iipist.2.1.130

lipis 2.1 .200

Ifpist.2.2213

Ars Povet 300

les Port.31" 
certis madium et tolerabile rebus/ recte concedi si vero est, unctum qui recte ponere possit clamabit enitn 'pulchre, bene, recte,"

recti. maxima pars vatum, pater et iuvenes patre digni, decipimur specie recti.

recti. retique cult us pectora roborant;

rectis. qui siccis [rectis] oculis monstra natantia. . . vidit

rectis. cautos nominibus rectis expendere nunmos,

rectius. nec magis huic, . . Cerinthe, tuo tenerum est fernur aut cus rectius:

'rectius hoc est. hoc faciens vivam melius.

quanto rectius hoc quam tristi laedere versu

rectius hoc et $\mid$ splendidius multo est.

rectius. aut quia non sentis, quod clamas, rectius esse, siquid novisti rectius istis, | candidus inperti;

rectius. rectius vives, Licini, neque altum |semper urgendo.

filia rectius/expugnat iuvenum domos,

rectius occupat $\mid$ nomen beati qui deorum $\mid$ muneribus sapienter uti

rectius Albanam fumo duraveris uvam.

rectius lliacum carmen deducis in actus

quanto rectius hic, qui nil molitur inepte:

recto. quam nequiere proci recto depellere cursu?"

cadat an recto stet fabula talo.

cetera qui vitae servaret munia recto/more.

rector. 'Pentheu| rector Thebarum, quid me perferre patique | indignum coges?'

rectos. fana deos habuere rectos.

rectum. quos ultra citraque nequit consistere rectum.

quidve ad amicitias, usus rectumne, trahat nos

rectum. ordinem/rectum evaganti frena licentiae/iniecit rectum animi servas cursum?

rectum. aut quia non firmus rectum defendis .

interdum volgus rectum videt, est ubi peccat.

vel quia nil rectum, nisi quod placuit sibi, ducunt

scilicet ut vellem curvo dignoscere rectum

quamvis et voce paterna| fingeris ad rectum

rectus. sccundis|temporibus dubiisque rectus,

recumbens. quos inter Augustus recumbens|purpureo bibet ore nectar,

recumbere. si potes Archiacis conviva recumbere lectis

recumbit. et minax, tquia sic volucre, ponto|unda recumbit.

recurras. ad Maecenatem memori si mente recurras."

recurrat. nec vereor, ne, dum futuo, vir rure recurrat,

recurrentis. libertasque recurrentia acepta per annos|lusit anabiliter.

recurres. o muita fletırum caput. ad me recurres

recurret. naturam expelles furca, tamen usque recurret

recurrit. mox|bruma recurrit iners.

recusant. inlusique pedes vitiosum ferre recusant|corpun.

recusat. cumlacclinis falsis animus meliora recusat.

porrigis irato puero cum poma, recusat:

recusem. quae facere ipse recusem.|cum recte tractent alii.

recusent. nec mexs audet|rem temptare pudor quam vires ferre recusent. quid ferre recusent. quid valeant umeri.

recuses. ne tamen illi|tu comes exterior, si postulet, ire recuses.'

siquis ad illa deus subito te agat, usque recuses.

recuset. fiius uxorem grandi cum dote recuset,

recuso. utque sacerdot is fugitiros liba recuso:

redacti. ar bene dicendum delectandumque redacti.

reddas. finibus Atticis|reddas incolumen precor

fias recantatis a mica opprobriis animumque reddas.

modos amandal voce quos reddas:

'accipe quod numquam reddas milit' si tibi dicam:

Augusto redides [reddas] signata volumina, Vinni.

reddat. medicum roget, ut te $\mid$ suscitet ac reddat gnatis carisque propinguis? habes qui . . medicum roget. ut te / suscitet ac reddat gnatis Ignati. reddatl carisque propinquis?

quid minuat curas, quid te tibi reddat anicum.

reddatur. ut nec pes nec caput uni|reddatur formae

redde. ergo obligatan redile Iovi rlapern.

lucem redde twae, dux bonr, patrice:
Ars Poet.360

Ars Poet.422

Ars Poet.428

Ars Poct. 25

Carm.4.4.34

coni.Curm.1.3.18

Epist.2.r.105

Sirm.1.2.82

Sirm.1.4.134

Serm.2.1.21

Epist.1.17.19

Serm.2.7.25

Epist.1.6.67

Carm.2.10.I

Carm.3.15.8

Carm.4.9.46

Serm.2.4.72

Ars Poet.r 29

Ars Poet.r 40

Serm.2.5.78

Epish.2.1.176,

Epist.2.2.13I

Epist.r.16.74

Carm.4.4.48

Serm.I.I.107

Serm.z.6.75

Carm.4.15.10

Serm.2.3.201

Serm.2.7.26

Epist.2.x.63

Epist.2.1.83

Epist.2.2.44

Ars Poet.307

Carm.4.9.36

Carm.3.3.I I

Epist.1.5.I

Carm.I.12.32

Serm.2.0.3I

Sirm.1 2.127

Epist.2.1.1 47

Epod.5.75

Epist.1.10.24

Carm.t 7.12

Serm.2.7.108

Sirm.2.2.0

Strm.2.3.258

Epist.2.1.208

Epist.2.1.259

Ars Poe!.30

Serm.2.5.17

Serm.2.7.24

Serm.1.4.50

Epist. I. 1010

Epist.2.1.15.5

Carm.1.3.7

Carm.1.16.28

Carm.4.11.35

Serm.2.3.60

var.Epist.1.I3.2

Serm.1.I 8.3

rar.serm.1.1.8.3

Epist.1 I8.101

Ars Poct.o

Corm.2.7.17

rarm.4.5.5 


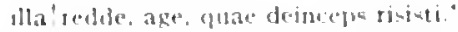

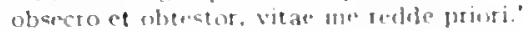

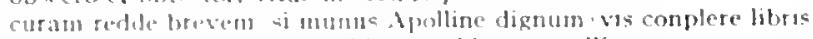

ceddentis. vilace sharum et mihi na tedlents agelli.

reddere. mblet mo. . dintic animum reddere ituoribus.

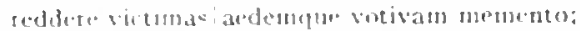

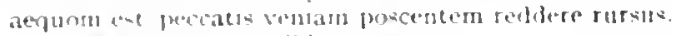

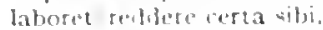

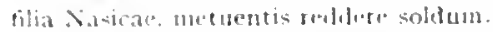

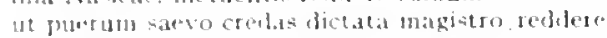

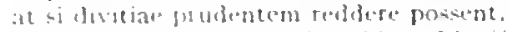

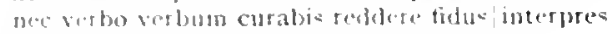

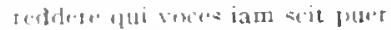

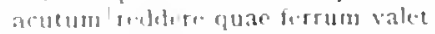

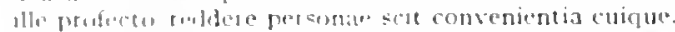

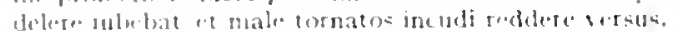

redderet. Fodderet lander tibi Vaticant montis mago.

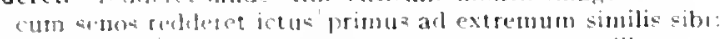

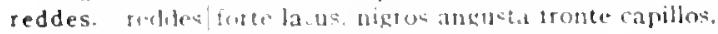

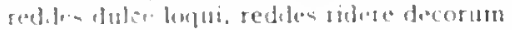

Alupuato redide signata volumishat. V'mni.

reddet. "um tibi invisus lacerandis redet, cotnua caurus.

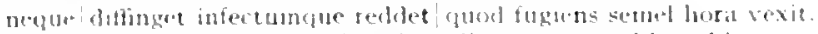

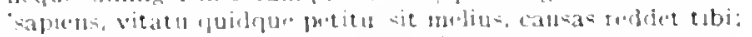

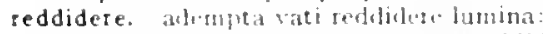

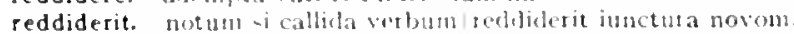

reddidi. redisle carmun, docilis molorm vatis llorati."

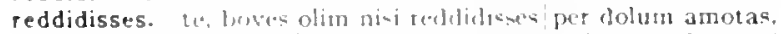

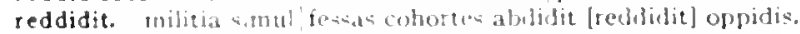
lortunat. . . melli secundoe sumblit exitus

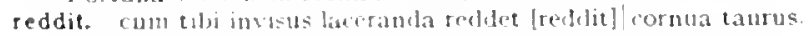

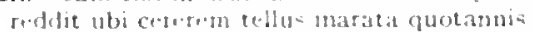

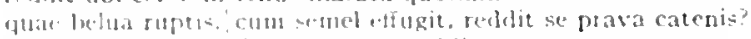

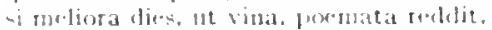

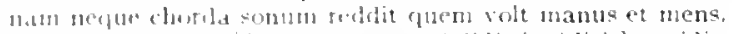

redditis. malitia cimul fests cohortes abolidit [redditis] oppris.

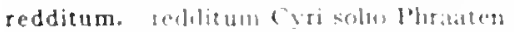

redducere. Gi uhi hlout capta clascons reshlucese Troia

redeam. *ut reteram illue*

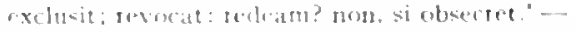

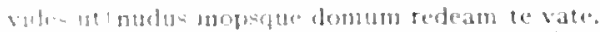

redeant. Hec dabunt. quansic redeatst in aurum tempora prisum.

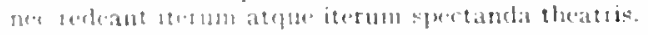

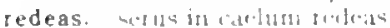

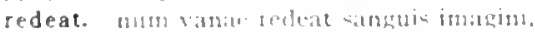

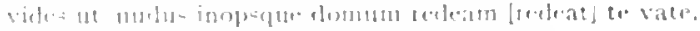

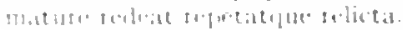

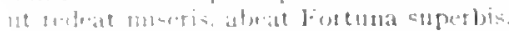

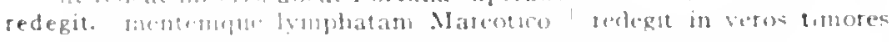

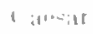

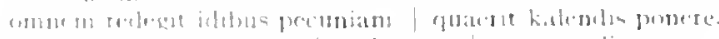

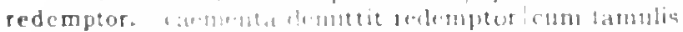

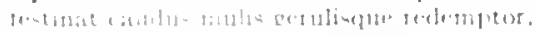

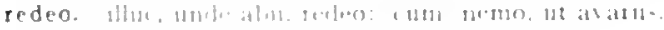

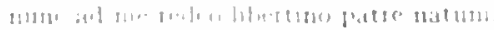

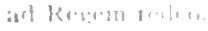

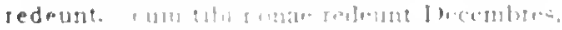

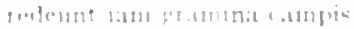

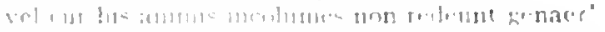

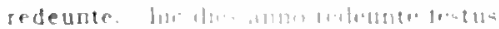

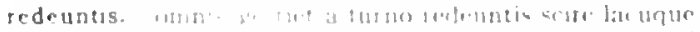

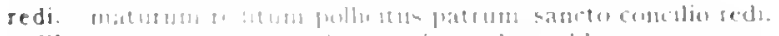

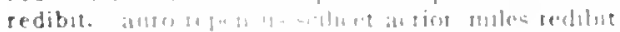

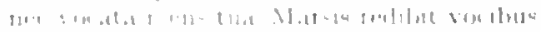

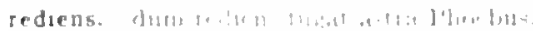

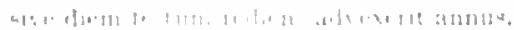

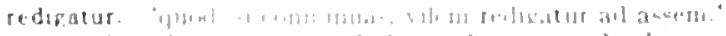

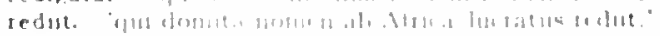

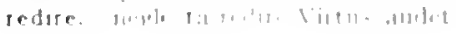

Serm.2.8.80

Epist.1.7.05

Epist.2.1.216

Epist.1.14.1

Carm.1.19.4

Carm.2.1730

Serm.1.3.5

Sirm.2.3.270

Serm.2.5.5

lepisi.1.18.14

Ipist.2.2.155

Ars l'oet. 133

Ars levet 158

Ars l'odt.305

Ars Pods 310

Ars Poet.44I

Corm.120.7

Ars l'oet.253

E.pist.1.7.25

Epist 1.7.27

Eipist 1.13.2

Carm.3.27.71

Corm.3.29.47

Sorm.1.4.110

lipolicitat

Ars Poot. 48

Carm.4.0.43

Carm.1.10.0

sar $\operatorname{Corm} 3.4 .38$

Corm.4.1438

ar $\operatorname{Corm} 3.27 .7 \mathrm{I}$

tipod re.4.3

Sorm.27:7

lipist 2.1 .34

A.s l'uel. 3.48

Far Corm. 3.438

(arm.2.1\%

ferm 23.101

serm 1 in:8

serm.23.26.4

serm.2.5.

Corm. 2.39

sitm 1.10 .39

Corm. 2.45

Carm.1.2.15

iar.sirm. 2.5.e

1 pist. 1.9.97

Arstivel.zol

Carm. 37.15

Find a (ic)

Carm 3135

lipol 2.2.2.2

sirm.1.1 108

Sem 1 \& 45

Serm 170

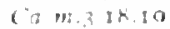

("arns 471

(ormases

Carm 380

scrm.1.8.37

(a)

(iarm is 20$)$

J. poud 570

(a) ini 21.24

sim 2 $2 \mathrm{k}_{3}$

serm : 1.13

(iorm a 810

Curm.tare 5 k 
ne redire sit nefas:

tediret. grave ne rediret/saeculum Pyrrhae

ne mea saevosidurgares ad te quod epistula mulla rediret.

sedis, Nasidiene, redis mutatae frontis, ut arte/ cmendaturus futunan;

sedit. "quid si prisca redit Venus

hinc ad vina redit laetus

per quae spiritus et vita redit

ab ofhicis octavam circiter horam dum redit

it, redit et narrat. Volteium nomine Menam,

qui redit in fastos et virtutem aestimat annis

et redit ad sese. "pol, me occidistis, anici, non servastis"

redit uncia, quid fit?"| "semis."

reditu. super inpetrato fortis Augusti reditu

reditum. naturum reditum pollicitus patrum|sancto concilio

unde tibi reditum certo subtemine Parcae|rupere.

dun sibi, dum socis reditun parat,

pascitur in vestrum reditum votiva iuvenca.

nec reditum Dionedis ab interitu Meleagri . . orditur

rediturus. quo rediturus erat non arcessitus,

reditus. fuge quo descendere gestis: non erit emisso reditus tibi.

reditus. et populum reditus morantem

haec et quae poterunt reditus abscindere dulcis

redonabo. gravis iras et invisum nepotem. . . Narti redonabo;

sedonavit. quis te redonavit Quiriten |dis patris Italnque caeh

reducent. non avium citharaeque cantus|somnum reducent:

reducere. 'naxime regum.|di tibi dent capta classem redducere [reducerie) Troia.

seducet. deur haec fortasse benigna|reducet in sedem vice.

nrater lelira necabit / in gelida fixum ripa febrimque reducet.

seducis. tu spem reducis mentibus anxiis

reducit. informis hicmes reducit/1 uppiter.

sive quos Elea domum reducit!palma caelestis

et viris aninumque moresque / aureos educit [reducit] in astra nigroque invidet Orco-

si me palma negata macrum, donata reducit opinum.

secucta. hic in reducta valle Caniculae/vitabis aestus.

aut in reducta valle mugientium prospectat ersantis greges

reductae. sed diu / lateque victrices catervat consilis invenis revictar [reductae] sensere.

seductum. virtus est medium vitios um et utrinque reductum.

:efeceris. donec templa refeceris | atedisque lab ntis deorum

refectus. hic ubi cognatorum opibus curisque refectus/expulit

refer. linc onne principium, huc refer exitum:

abi, quaere et reter, unde domo, yuis,

musa rogata refer, comiti scribaeque Neronis.

norietur frigore, si non / rettuleris pannum. refor st sine vivat ineptus.

referam. gratus insigni referan camena labriciumque.

olin quorl volpes aegroto cauta leoni'respondit. referam:

referas. nam quamis memori referas mihi pecter cuncta.

referat. orbis ut cantus referatque luclos.

quid referat intra| naturae finis viventi.

referenda. Nulvius et scurrae, tibi non releremela precatid/disculunt.

seferendus. inter quos referendus erit?

referent. o navis, reforent in mare te novi Huctus.

referente. sole dies referente siccos;

referente. saeculo festas referente luces

referentes. ibant octonos referentes idibuk aetis.

referentis. tertium lunae referentis ortum,

refero. ad porri ct ciceris refiro laganique catinum:

referre. desine perticax reterse sermones doorum

tuo vitio rerumne labores, | nil referte putas?

cum referre negas, spuali sit quisque parente! natus,

ct iuvenum curas et libera vina referte - -

refercet. unus ut e inultis populo spectantererret emptum mulus aprumi).

referri. inter perfectos veteresque referri debet

refers. scitari libet ex spso quodeumque refers:

refert. neque amisos colores/lana retert medicata fuco

ut Proetum mulier petfida credulum | fakis inpulerit criminibus... refert;

Epod.10.2e)

Carm.1.2.5

Epist.2.2.22

Srm.2.8.81

Carm.3.9.17

Carm.4.5.3I

Carm.4.8.

Itpist.1.7.48

Epist.1.7.5.5

Epist.2.5.48

Epist 2.2.138

Ars Poet.320

Carm. 2.43

Corm.4.5.3

Eperd.13.15

Fipist.t.2.2.

Epist.t.3.30

Ars Pot.14"

sirm.2.3.23I

Epist.1.20.0

Carm.3.5.52

Epot.10.35

Carm 3.3 .33

Carm.2.7.3

Carm.3.1.2I

i'th.serm. 2.3. I9

Epod.13.8

Serm.2.3.294

Cirm.3.2I.I 7

Carm.2.10.15

Carm.t2.17

var.Carm.4.2.23

Epist.2 1.181

Corm.1.IT.17

Epod.2 I I

far.carmit 4.24

Epist.I.Iso

Carm.3.t.2

Epist 2.2 .130

(arm.3.0.1)

Ispist. I. 7.53

Epist.1.8.2

List.1.17.32

Corm.1.12.39

Epist.1.1.7-

Serm.2.4.90

(arm.siner.22

Serm. I. I. 49

Serm.2.7.36

IEpist.2.I.tI

Carm.1.14.1

Corm.3.20.20

ciarm.4.6.12

sirm. I th. 75

(arm.4.2.5s

sirm.t.teI15

Cimm.3.3.7

Sirm.1.2.77

Sirmido.t

Ars IJodess

Epist.1.0.10)

Epist.2.1.37

Epist.d.7.

Carm.3.5.28

Curm.3.7.1P 


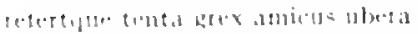

Epol.16.50

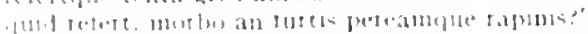

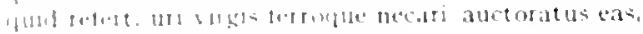

Serm.2.3.157

Serm.2.7.58

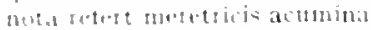

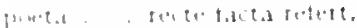

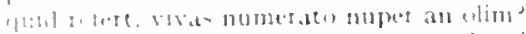

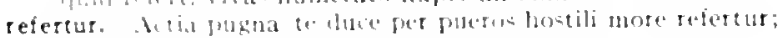

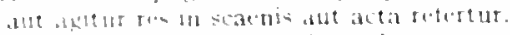

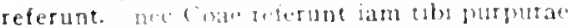

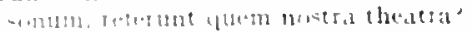

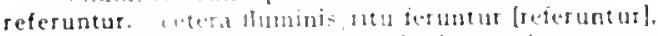

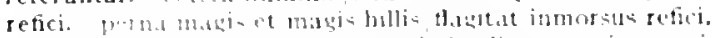

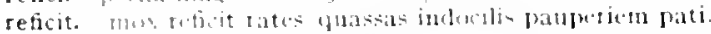

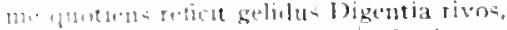

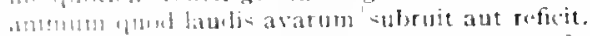

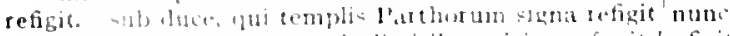

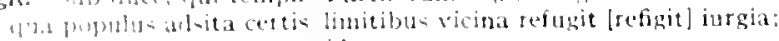

Fist.1.17.55

Epist 2.1.130

Epist.2.2. 1006

Epist 1.18 .62

Ars Poct.170

curm.+13.13

Fpist.2.1.201

aur.Curm.3.2034

Serm.2.tid

Carm.1.1.7

Eist.1.18.10.

Fpist.2.180

Enist 1.18.50

Ear. Epist.2.2.17

Jipod.17.5

Curm.t.28.1

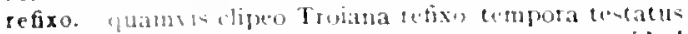

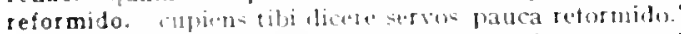

refregit. ut if solvas "po-tyuam biacodia tactsa, bolli ferratos postio

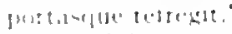

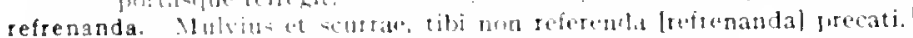
1:cislunt

refrenare, mbmitam andeat ichonate licentiam.

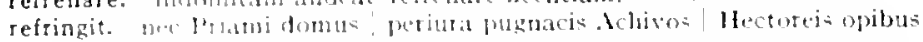

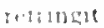

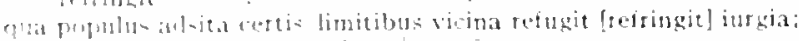

refugimus. "fuicl nos dura rotugimus aretas?

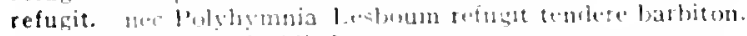

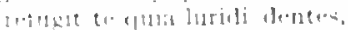

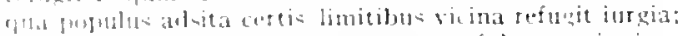

refulgens. t. lovis inpio tutela satumo reftugens tripuit

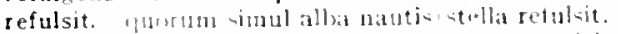

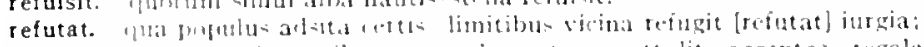

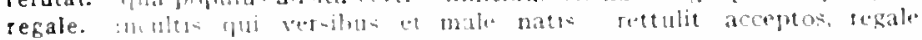
musionsa lhilipus

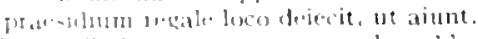

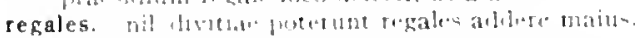

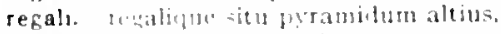

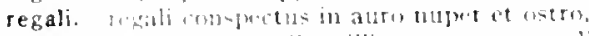

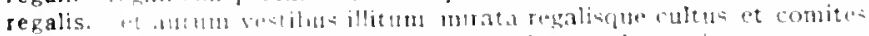

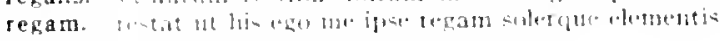

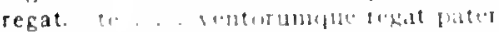

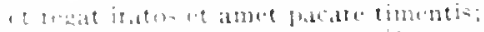

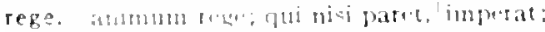

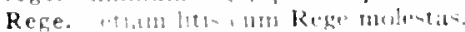

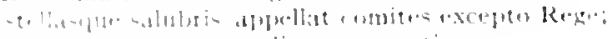

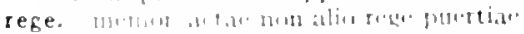

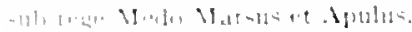

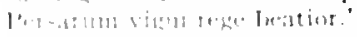

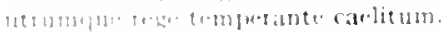

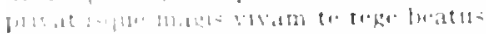

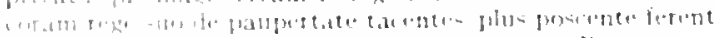

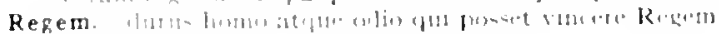

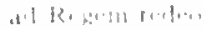

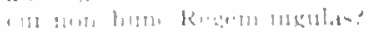

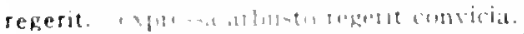

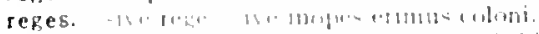

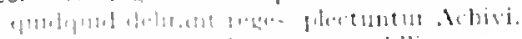

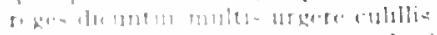

reges. Th

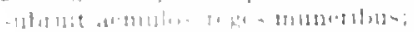

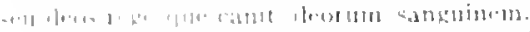

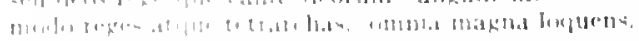

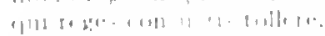

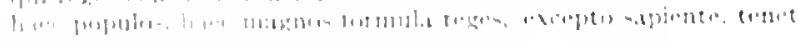

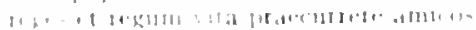

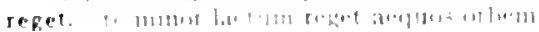

Sorm.2.7.2

Sim.1.t.

iar.serm 27.35

(iarm.3.2. 29

Ciarm. $3 \cdot 328$

conitipist.2 $217 \mathrm{I}$

(iorm.t.3534

Carm t. I. B.

Cirmat 13. In

lifict.2.17:

(iarm.21723

Curm.1.12.28

comi.lipist 2.2.1:1

Epist 2.123 .6

Fist.2 = 30

E) ist $1.12 \%$

Carm.330.2

Ars Jide.22s

(itrm.ti) 15

Evist 1.1 .27

(i) $1 \cdot 3 \cdot 3$

irs Piets 10?

Fise1 202

Serm.t.7.

Germe i 25

Cirm 1, 3ps

(arm.350

Cirm 3 9.4

Espidiciso

Sorm 1 3132

fipistes 178

sema $: \mathrm{p}$

sirm $1 ; 0$

Serm $17.3=$

trem. 720

Curm 214 11

lipesta 2 is

Ars Pitit .134

Carm 3 : 1

Cinm 310 is

(arm $4=13$

Serm 1312

serm.1 : 34

Sorm $23: 5$

fiput in te?

Curm, 125 
qui sibi fidet, / dux reget examen.

Epist.1.19.23

regi. in vitiun libertas excidit et vim/dignam lege regi:

Ars Pol. 283

regi. gratus Alexandro regi magno fuit ille/Choerilus.

Epist.2.1.232

regia. mihi iam non regia Roma. sted vacuom Tibur placet

Iipist.1.7.+1

quid concinna Sanos. quicl Croses regia Sardis.

regiae. iam pauca aratro iugera regiat moles relinquent.

regiam. ausa et iacentem visere regian voltu sereno.

neque . Ittali ignotus heres regiam occupari

Epist.1.11.2

Carm.2.15.1

Carm.1.37.25

Carm.2.18.0

regibus. militiam paras / non ante devictis Sabaeae / regibu horribilique Medo nectis catenas?

regibus hic mos est, ubi equos mercantur:

divitiasue habeo tribus anplas regibus.'

regibus. Maecenas atavis dite regibus.

'si pranderet holus patienter, regibus uti nollet Aristippus.'

"si sciret regibus uti. fastirliret holus. qui me notat.'

'scurror ego ipse mihi. poptlo tu: rectius [regibus] hoc et splendidiu= inulto est.

segina. dum Capitolio regina dementis runas. . . Parabat

Carm.1.20.4

Serm.1.2.80

Serm.2.2.101

(arm.I.I.I

Epist.I.17.13

Epist.I I T.1.

et genus et formam regina Pecunia donat

regina. ol knus regina Cnidi Paphique,

resina longum Calliope melos.

regina, sublimi flagello tange Choen semel arrogantem.

ciderum regina bicornis, audi. | Luna, puellas.

regio. surgente a sole ad eun, quol tespertina tepet regio. quorum hominum regio et qualis via

regione. quid nunc te dicam facere in regione Pedana?

Regis. proscripti Regis Rupili pus atque venenum

regis. ire deiectum monumenta regis|templaque Vestae. classis Aquilonibus arcet, | regis opus.

regis. o diva, gratum quae regis Antium.

o quae beatan dira tenes [regis] Cyprum

at o deorum quidquid in caelo regit [regis] terras

Nox et loiana, quae silentium regis,

regit. te minor laetum reget [regit] aequos orben:

divosque mortalisque turmas imperio regit unus aequo

ne nunc Thressa Cliloe regit.

me nunc Thressa Chloe regit [regit Chloe].

ne dotata regit virumiconiunx

at o deorum quidquid in catelo regit, terras

aut, si non odit, regit

qui sibi fidet, / dux reget [regit/ examen.

regium. regium certe genus. et penatis! maeret iniquos.

regius. ne $\mathrm{rudis}$ agminum|sponsus lacessat regius asperum $\mid$ tactu leonem. regiu = sangus dominaeque tradi barbarae paelex.".

ut mala cuem scabies aut norbus regius urget

regna. quo sinul mearis, nec regna vini sortiere talis

quani paene iurvae regna Proserpinae . . vidumus

cum parentis regna per arduom cohors gigantum scanderet inpia.

qui mare temperat, rentosum et urbis regnaque tristia

yui regna Dauni praefluit Apuli.

supplex et oro regna per l'roserpinae.

Humina dicere et arces muntibus inpositas et barbara regna

regnanto. qualibet exisules in parte regnanto beati;

regnare. calo tonantem credilimus lovem regnare;

regnata. quid sereset regnata Cyro Bactra parent

regnata. regnata petam Laconi rura Phalantho.

regnator. qua violens obstrepit Autidus ct qua.. Daunus agrestiun regnarit [regnator] populorum.

regnavit. qua pauper aquae Daunus agrestiun regnavit populorum.

regnes. tu secundo Caesate regites.

latius rognes aridum domando spiritum

regnet. ut silvoz regnet vivatque beatus. cogi posse negat.

regno. vivo et resno, simul ista reliqui.

regno. num sum qualis eram bonat|sub regno Cinarae.

uncle Superhus Tarquirius tegro pulsus fugit.

uncle Superbu- Tarquinius regno pulsus [pulsus regno] tingit.

regnum. prius an quicoum lonpli regnum memorem. . dubito. coniurata tuas rumpere nuptias et regnum P'itani vetus.

2ar.Epist.1.17.10

Carm.1.37.7

Epist.1.0.37

Corm.1.30. I

Carm.3.t.2

Carm-3.20.II

Carm.tace.35

serm.1.4.30

Epist.1.15.2

Epist.1.4.2

Sirm.t.7.I

Carm.1.2.15

Ars Poct.us

Carm.1.35.I

Far.Carm.3.26.9

tur. Epod.5. I

Epod.5.51

ine Cirm.1.12.57

Carm.3.4.4s

Carm.3.9.9)

comicarm.3.9.9

Carm.3.24.19

Epod.5.I

Itpist. I. 8.26

"ielr. Epist. 1.19 .23

Carm.2.1.5 5

Carm.3.10

Corm.3.27.65

Lrs Poil. 453

Corm.1.t.18

Carm.2.13.21

Carm.2.19.2!

Carm.3.4.4to

Curm.4.1.26

lipod.17.2

I.pist.2.1.253

Carm.3.3.39

Carm.3.5.2

(arm.3.29.27

(arm.2.0.1 I

Fur.Carm.3.30.12

(i)m.3.30.12

(arm.1.12.52

(arm.2.2.)

Eipisi.1.2.10

Fist.1.10.8

carm.t.1.t

sirm.1.6.13

cor..serm.1.6.13

(a)m.1.12.34

(arm.1.15.8

(arm.2.2.2t 


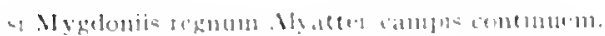

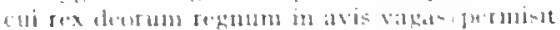

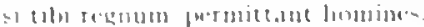

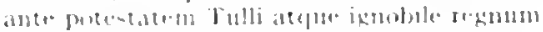

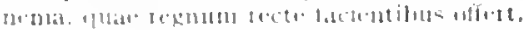

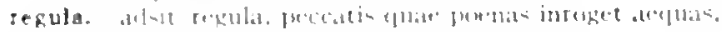

Reguli. hin antrat mems porvida keguli

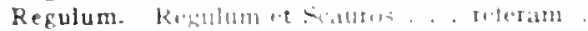

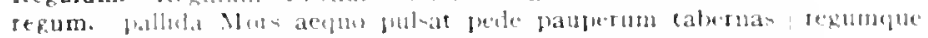
thistis,

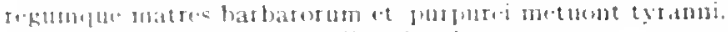

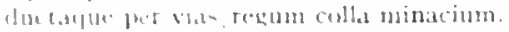

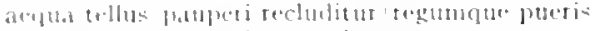

regum timendorum in proprios ereges,

mejue trateos eresuenti regram apices

Tyrutua rogum progenies.

quou regum enmidas contulerit minas.

male barlaras tegum ext ulta hbidines.

rumpetse latras, makmotum maxine regum.

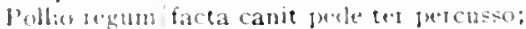

neclum onnis abaces pauperium copulis regum:

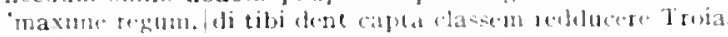

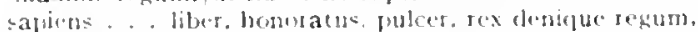

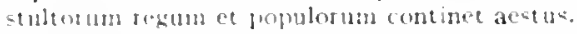

ze.ges et regum vita pracentere amicos.

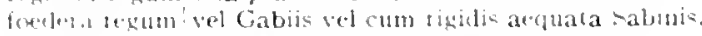

mox trahutut manibus tegun fortuna retortis.

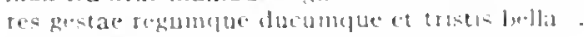

Heatia regum l'ieris temptata moli

rei. contempreate domimus splendidior mi.

tei. curtar nescio quid semfert abest roi.

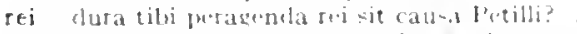

reiecit. reiprit alto doma nocrntium volu.

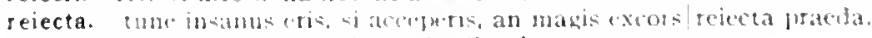

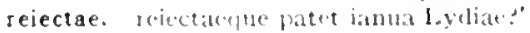

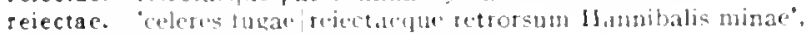

reis. insugm mantis prandium reis.

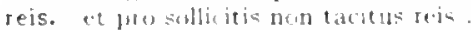

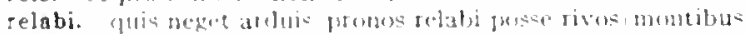

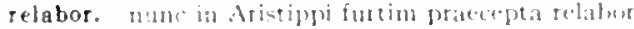

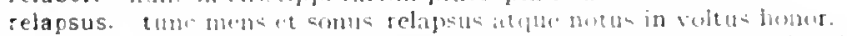

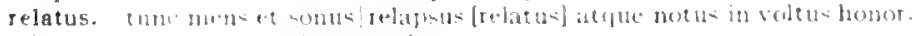

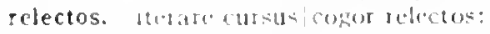

selegata. ambicionc rulegata to dicert posam.

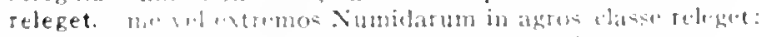

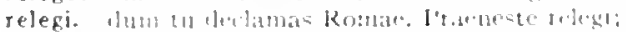

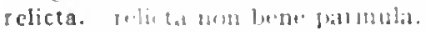

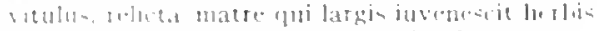

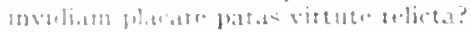

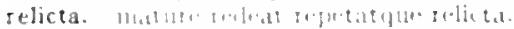

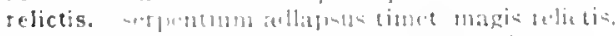

ielictis.

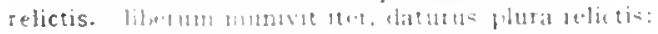

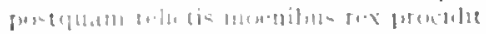

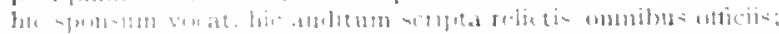

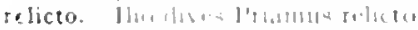

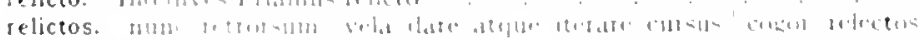

$$
\text { |ritis } 21,-\}
$$

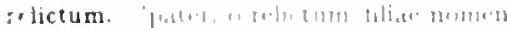

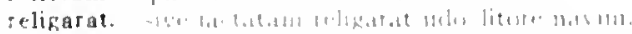

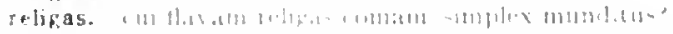

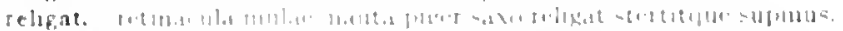

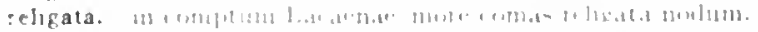

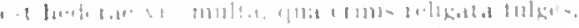

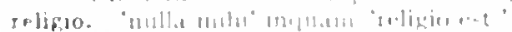

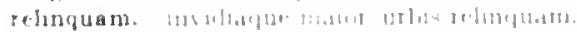

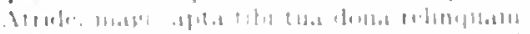

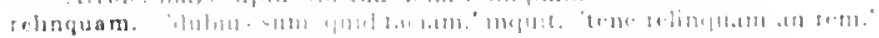

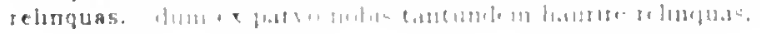

Carm.3.re.11

carmitot.2

Serm.3.3.123

sermetises

IEpist.1.1.3.3

Sirmt.3.118

Corm 3.513

Corm.1 12.37

Corm.1.1.1

(arm.1.35.11

Corm.2.12.12

Corm.2.18 3.9

(arm.3.1.5

Carm:3.21.20

(arm.3.20.1

(arm.t.3.8

Carm.t.12.8

sirm.1.3.130

Sorme1.10.12

vorm.2.2.45

Serm.2.3.190

1.pist.1.1.107

Lpist.1.2.8

List 1.10.3.3

Epist.2.1.24

Epist.2.1.101

Ars I'oit.i3

Ars I'vel...41

carm.3.34.25

(arm.3.29.1.t

Serm.1.10120

(iom.q.4. 2

Girm. 2.3 .18

(ism.3.4).20

Carmatsio

(arm.2.1.13

carm.tis

Carm.1.20!1

Epist.1.15

lepotat? 18

iar lepolit 17.18

conicurm.1.3.1.5

herm 1.11.6.t

Corm.3.11.48

Lepist:2.2

Cium 2.7.10

(iarm 1230

sirm.2.3.1.3

1.151 1.707

fipul is

Curm 2137

corm sale .4t

l.pul.t-1.3

l.pist.2? th

(iarm, 1 111 i.?

iar.ciom 1315

(iarm. i 23.3 ?

cirme 327

(ism.1.3.1

Sirn: \& 511

(

( arm +115

verm.1 1

(i)ren : 211 5

1 pest 1.: 13

iem $1.0,11$

Srm.1 152 
relinquendis. saepe ferenten|plura quidem tollenda relinquendis. relinquens. esset ador loliumque, dapis meliora relinquens.

"ut libet: haee porcis hodie comedenda relinques [relinquens]."

relinquent. iam pauca aratro iugera regiae $\mid$ moles relinquent.

relinquere. quodsi frigida curarum fomenta relinquerc posses, sublimis cupidusque et amata relinquere pernix.

relinqueret. quam si clientum longa negotia/diiudicata lite relinqueret relinques. 'ut libet: haec porcis hodie comedenda relinques.'

relinqui. sane murteta relinqui . . . vicus gemit.

occupet extremum scabies; mihi turpe relinqui est

relinquis. 'ut libet: haee porcis hodie comedenda relinques [relinquis].'

relinquit. nee turmas equitum relinquit

quac' desperat tractata nitescere posse, relinquit

relinquont. nec priores inpiae tectum dominae relinquont.

reliquerit. 'irigida si puerum quartana reliquerit.

reliqui. viro et regno, simul ista reliqui, quae vos arl cattum fertis

reliquit. nee Titvi iecur/reliquit ales.

apris reliquit et rapacibus lupis.

verecundus color reliquit ossa pelle amicta lurida,

quod cupide petiit. mature plena reliquit.

reluctantis. nunc in reluctantis dracones

rem. quan rem cumque ferox navibus aut equis, nriles te duce gesserit.

Romulae genti date remque prolemque et decus omme.

remque Romanam Latiumque felix . . . prorogat

ne te morer, audi, quo rem deducan.

ari cur atque parentis | praeclaram ingrata stringat malus ingluvie rem.

bonam deperdere faman.|rem patris oblimare malum est ubicumque.

piurima, quae invideant pure adparere tibi rem.

ob hane rem. ... minus hoc iucundus amicus $\mid$ sit mihi?

volgo recitare timentis ob hanc rem,

nequid!summa deperdat metuens aut ampliet ut rem.

magnuni documentum, ne patriam rem/perdere quis velit.

'dubius sum, quid faciam', inquit./'tene relinquam an rem."

tamquam ad rem attincat quidquam. .

si nule rem gerere insani est, contra bene sani:

aequam ' rem imperito

si neque maiorem feci ratione mala rem

"quid tibi vis, insane, et quam rem agis?"

conmittes rena omnem et vitam et cum corpore lamam.

'rem facias, rem.' si possis, recte.

si possis, recte. si non, quocunque modo, rem,'

utrum gaudeat an doleat, cupiat metuatne, quid ad rem,

nunc i, rem strenuos auge."

Celso gaudere et bene rem gerere Albinovano

post haec, ut valeat. quo pacto ren gerat et se.

"nempe pecus, rem. / lectos, argentum: tollas licet."

temptavit quoque rem si digne vertere posset

cum speramus eo rem venturam.

nec meus audet 'rem temptare pudor quam vires ferre recusent.

cui|rem di donarent, illi decedere pravam/stultitian;

qui variare cupit rem prodigialiter unam.

ren tibi Socraticae poterunt ostendere chartae.

verbaque provisam rem non invita sequentur.

rem poteris servare tuam.

remanete. et cubito remante presso.

remeare. si natura iuberet a certis annis aevom reneare peractum

Remi. ut inmerentis fluxit in terram Remi|sacer nepotibus cruor.

remige. non huc Argoo contendit remige pinus

remiges. sactosa duris exuere pellibus/laboriosi reniges vixei / volente

Circa nembra;

remigio. nonne vides, ut $\mid$ nudum remigio latus

remigium. remigium vitiosum thacensis Vlixei.

remis. sterilisve diu palus aptaque remis.

remis. Caesar ab Italia volantem remis adurgens,

remiscet. atque ita mentitur. sic veris falsa remiscet.

remisit. pressa lenafranae quod baca remisit olivae.

remissi. oderunt.. . sedatum celeres, agilem navomque remissi;

remisso, perfidum ridens Venus et remisso/filius arcu.

remittas. remittas/quaerere
Sirm.I.IO.5I

Sirm.2.0.89

var.lipist.1.7.I9

Carm.2.15.2

Epist.1.3.20

Ars Poet.105

Carm.3.5.5t

Epist.1.7.19

Lipist.1.15.5

Ars Pod.4iz

val. Epist.1.7.19

Carm.2.16.22

dirs Potel. 150

Carm.8.19

Serm.2.3.290

Epist.1.10.8

Carm.3.4.75

Epod.16.20

Epod.17.22

Epist.2.I.100

Carm.4.4. I

Carm.1.6.3

Carm.Sale.47

Carm.saec.6o

Serm.1.1.15

Serm.1.2.8

Serm.1.2.02

Serm.1.2.100

Serm. 3.91

Serm.1.4.23

Serm.1.4.32

Serm.1.4.110

Serm.I.9.4 I

Serm.2.2.27

Serm.2.3.74

Serm.2.3.189

Serm.2.to

coni.Serm.2.6.20

Serm.2.7.67

Epist.1.1.65

Epist.1.1.66

Epist.1.6.12

Epist.1.7.7I

Epist.1.8.1

Epist.1.8.13

Epist.I.I6.75

Epist.2.1.164

Epist.2.1.220

Epist.2.1.259

Epist.2.2.152

Ars Poet.29

Ars Poet.3io

Ars Poet.3 I 1

Ars Poct.329

Cirm.1.27.8

Serm.1.6.94

Iipod.7.19

IEpod.10.57

Epod.17.16

Carm.1.14.4

Epist.1.6.63

Ars Poct.65

Carm.1.37.17

Ars Pocl.15I

Sirm.2.4.69

lipist.1.18.90

Corm.3.27.67

Curm.2.1 1.3 


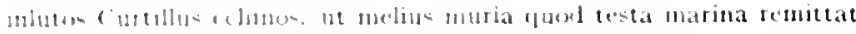

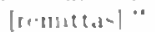

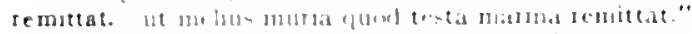

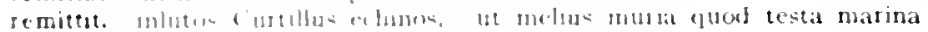
Ie.multent [rentittit] "

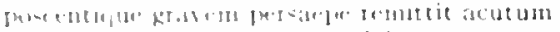

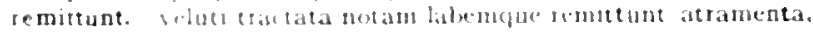

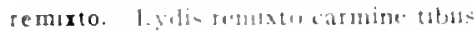

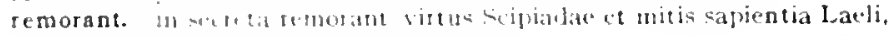

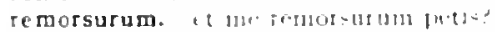

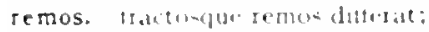

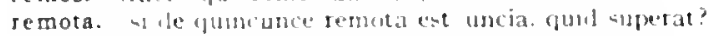

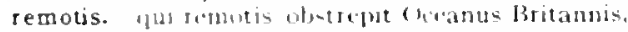

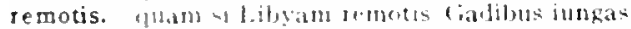

remotis. Bacclum in remotis armina supubu vibli docentem.

remotis. Surnique dath nimbis remotis. . venti

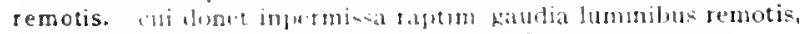

jam saget prosibet merris natura remotic.

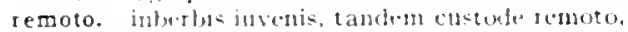

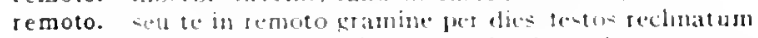

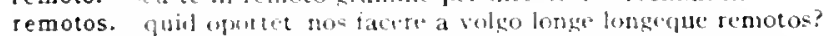

tuntes ut anderemotos.

remotus. Titbonucolfe remotus in aldas

pratartm concus equetrin cumman nummorum sitioque remotus ab ounui.

semovere. abnuere ct tabulac a te removere mementus.

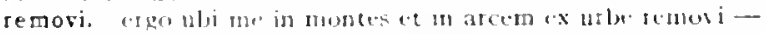

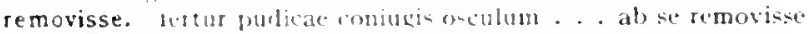

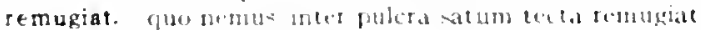

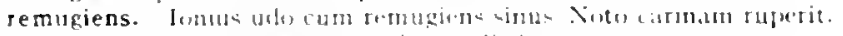

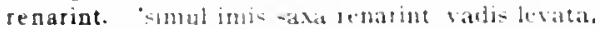

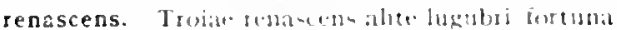

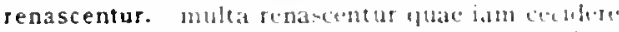

renati. me be lonthagorate lallant arcana romati

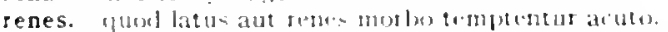

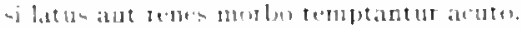

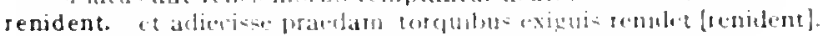

renidentis. Groum rombloncis latis."

senidet. ut pura nom tum romiclet loma mari

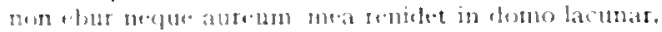

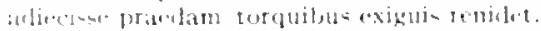

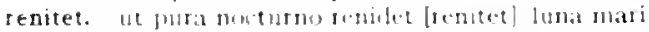

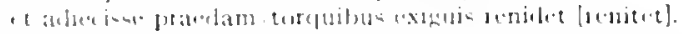

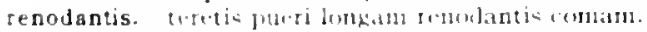

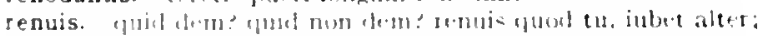

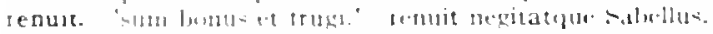

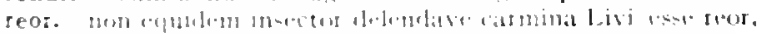

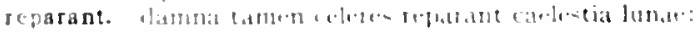

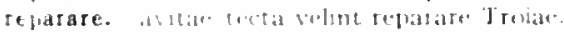

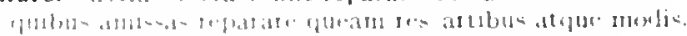

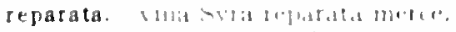

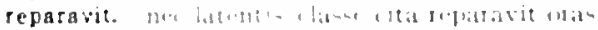

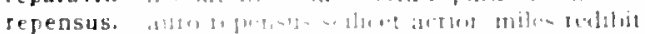

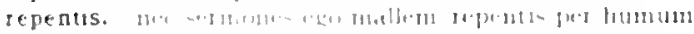

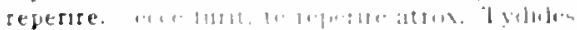

1.ethe 1111 -

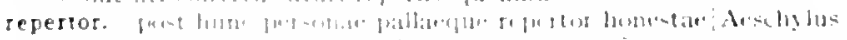

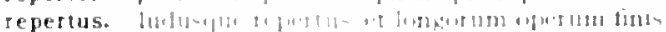

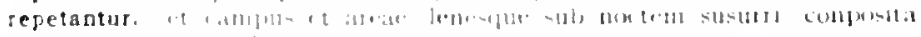

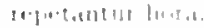

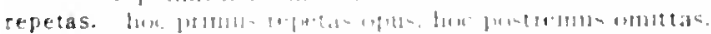

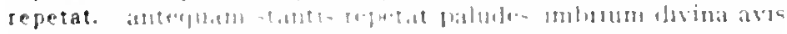

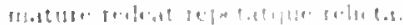

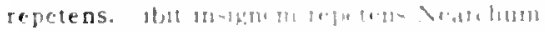

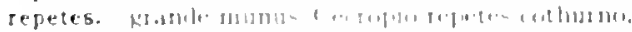

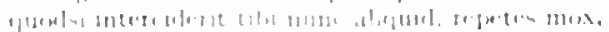

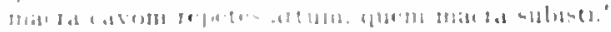

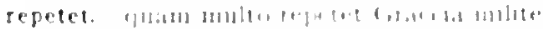

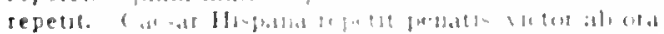

: ar.Serm.2. 4.53

serm.2.6.53

rar.sirn.2.8.53

Ars Pod 3.40

List 2.1235

Carms 15.3")

Serm.2.1.71

Epollo.4

Iipout lo.e

Ars Puel 327

Corm.14.47

Corm.2.11)

Carm.2.19.1

Carm-4.4

Carm.3.0.28

serm.2.7.7.

Ars liveldes

Carm.2.3.

Sirmido. 8

Setm.2.494

Carm.1.28.8

Ars linet. 384

Serm.2.5.52

Serm.2.(3.10

Carm.3.5.43

Carm.3.10.e

l.podicite

Lpod. I0.25

Carm.3.3.15

Ars Poef 70

Spoul. 15.21

Serm.2.3.113

Epret 1.0.2s

iar. Carm.3.0.12

Epodepes

Carm2.5.10

Corm 2.132

Corm.3.1.12

ior Carm.2.5.10

sar. Carm.3.1.12

Epod.11 2s

I.pist 2.2.83

1.pist.1.11.20

lepist.2.1.7o

(arm..ob 7.13

( iarm.3.3.ces)

Sirm.2.5.2

( arm.1.31.12

Carm.t.37.2.4

carm. 35.25

J.prot.2.1251

cirmel 1525

serm 1110

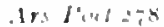

Ars linet lo5

(ijem.1 0211

lepistice as

(arm 325,0

Lposel-1);

(arm 32010

(iarm.21 12

serm. 2 :

A. $10.11,73$

carmet is

(arm.3 14.3 
hinc repetit, 'paucorum hominum et mentis bene sanae;

guod petiit spernit, repetit quod nuper omisit.

repetita. hace placuit semel, have deciens repetita placebit.

repetitum. si forte suas repetitum venerit olim grex avium plumas.

sepimus. milia tum pransi tria repimus

reponens. dissolve trigus ligna super foco'large reponens

reponere. inspice, si possum donata reponere latus.

repones. dissolve frigus ligna super focollarge reponems [repones]

reponet. languidus in cubitum iam se conviva repontet.

reponi. curat reponi deterioribus.

fabula, quae posci volt et spectanda reponi;

reponis. tu pias laetis animas reponis sedibus

honoratum si torte reponis Achillem.

reponit. ligna super foco large reponens [? reponit]

ignarum. . quibus assis/ languidus in cubitum iam se conviva reponet [reponit].

reportasti. nec Iugurthino parem|bello reportasti ducem . . . .

reportia. (licebit|ille repotia [reportia], natalisaliosve dierum|festos albatus celebrt t)

reporto. spen bonan certanque domum reporto . . . . . . .

reposci. fabula. quae posci [poni] volt et spectanda [spectata] reponi [reposci];

repositum. quando repositum Caecubum ad festas dapes.. . biban

repostum. quando repositum [repostum] Caccubum ad festas dapes... bibam

repotia. ille repotia, natalis aliosve dierum (iestos albatus celebret)

repraesentet. virtutemne repraesentet moresque Catonis?

reprehendere. nil sane fecit quod tu reprehendere possis:

unum siquis amicorum est ausus reprehendere versum;

reprehendet. vir bonus et prudens versus reprendet [reprehendet] inertis. reprehendi. tanto reprehendi iustius illis.

reprehendis. tu nihil in magno doctus reprehendis Homero?

reprehendit. vir bonus et prudens versus reprendet [reprehendit] inertis,

reprehendite. vos, o, Pompilius sanguis, carmen reprehendite.

reprendas. velut si egregio inspersos reprendas corpore naevos,

reprendere. ea cum reprendere coner. . . quar doctus Roseius egit:

reprendes. nec tua laudabis studia aut aliena reprendes,

reprendet. vir bonus et prudens versus teprendet inertis.

reprendi. quicquam reprendi, non quia crasse/conpositun

reprendit. vir bonus et prudens versus reprendet [reprendit] inertis,

reprensis. cum de se loguitur non ut maiore reprensis?

repressae. sed diu lateque victrices catervae / consilis iuvenis revictae [repressac] sensere.

repserat. per angustam tenuis volpecula simam / repserat in cumeram irumenti,

reptare. an tacitum silvas inter reptare salubris

repugnant. sensus noresque repugnant atque ipsa utilitas.

repulsae. Virtus repulsat nescia sordidae.

repulsam. exiguon censum turpenque repulsam. quanto devites

exiguom censum turpemque repulsam [laborem], quanto devites animi capitisque labore [repulsam]

repulsum. foribusque repulsum|perfundit gelirla.

requiem. sibi dum requirm, dum risus undique quaerit,

requies. neu morem in Salium sit requies pedum

requiro. ad mare cum veni, generosum et lone requiro,

rere. 'non isto vivimus illic, quo tu tere, nodo;

reris. an tu reris eum oceisa insanisse parente

rerum. mearum grande decus columenque rerum.

est animus tibi terumque prudens et secundia tempotibus dubisque rectus

custode rerum Caesare

stabilisque rerum terminus servet.

curam metunque Cacsaris rerum

tuo vitio rerume labores, nil reterte putas?

verit vilissima rerum lic aqua,

arreptaque manu "quid agis, dulcisime rerum?"

nun rerum dura negarit 'sersiculos natura magis tactos

corruptus vanis rermm, quia vencat auro rara avis

rerum inperis hominungue tot tantisque minor.
Sirm.1.Q.it

Epist.1.1.95

Ars 1 '0it.30,5

Epist.1.3 Is

Serm.1.5.25

Curm. I.1)

Epist.1.7.39

iar.Carm.I.Q.t)

Sirm.2.4.39

Curm.3-5.30

Ars Poet.igo

Curm.I.IU.I 7

Ars Puit.d 20

7 sar.Curm.1.9.0

i'ar.Serm.2.4.39

Epolo. 24

aur.serm.2 200

Carm.siet.7t

coni.tirs Poet.igo

Epod.g.1

Tur. Epodis.

Serm.2.2.

Epist.I.I9.I

Serm.2.3.138

Epist.z.I. 222

iar.Ars Poet.t.t.5

Sorm.2.180

Serm.1.10.52

z'ar.ders Peet. 145

Ars Ioet.202

Sirm.t.6.07

Epist.2.1.81

Epist.I.I 8.39

Ars livel.45

Epist.2.1.

war.elrs Poel. +45

Serm. 1.10 .55

iur.Carm.4.4.24

Epist.1.7.30

Epist.1.4

Serm.1.3.97

Carm.3.2.1 7

Epist.1.1.43

aur. Epist.r.1. it

Serm.2.7.90

Episl.1.7.79

Carm.1.36.12

Epist.1.15.18

Serm.1.9.49

Serm.2.3.134

Curm.2.17.4

Carm.4.9.35

Carm.tis.t

Carmatale 21)

Epod.9.37

Serm. I.3.76

Serm.1.5.88

Serm. I.g.t

Serm.I.I().57

Serm.2.2.25

Serm.2.7.75 


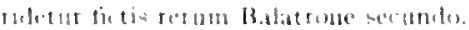

Serm.2.8.83

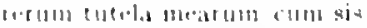

Jipist.1.1.103

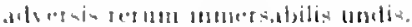

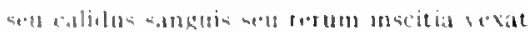

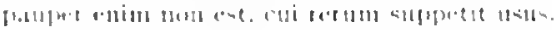

Epist.1.2.22

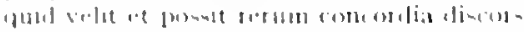

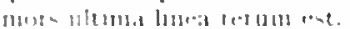

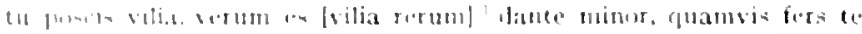

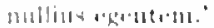

at)

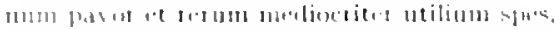

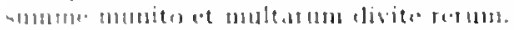

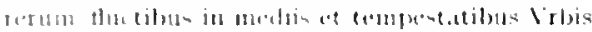

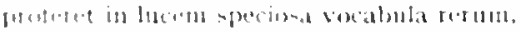

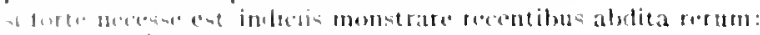

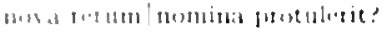

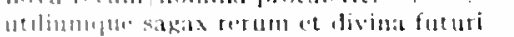

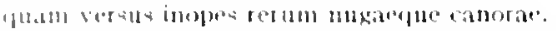

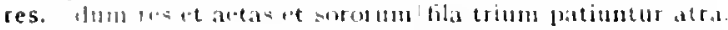

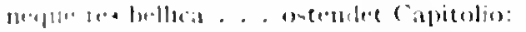

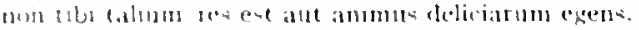

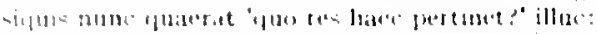

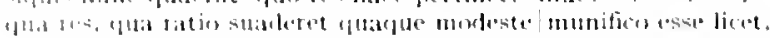

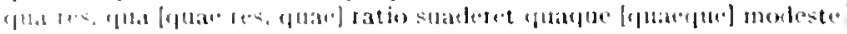

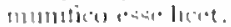

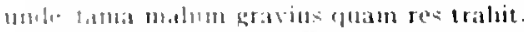

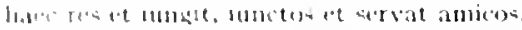

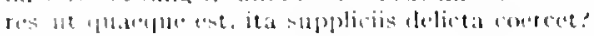

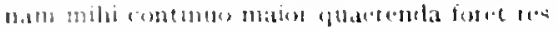

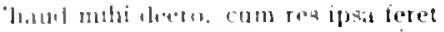

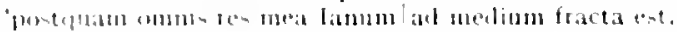

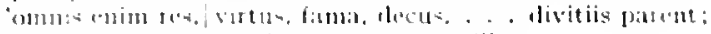

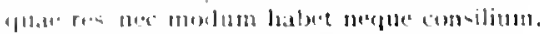

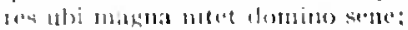

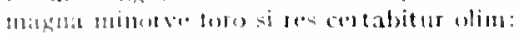

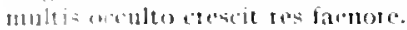

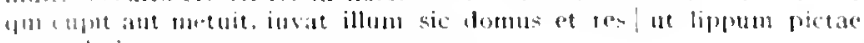
1.11milate.

nit almuati ptope tes ast una, Numbi.

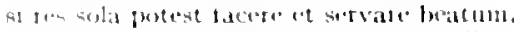

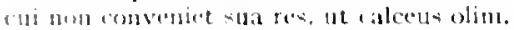

I11. tamen ixnores, guo sit Romana loceres:

IImlan sit lloratios an res.

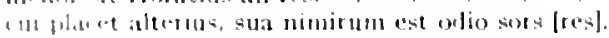

mmin . bistippum decuit color et status et res.

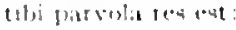

natm tua rou apitur, parjes cum proximus ardet.

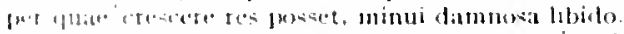

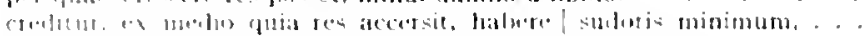

$$
\text { cisminnlial }
$$

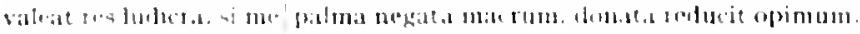

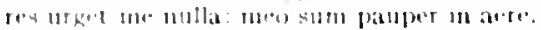

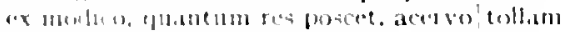

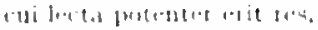

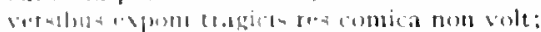

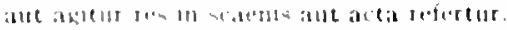

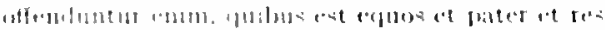

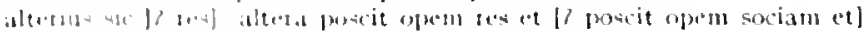

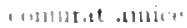

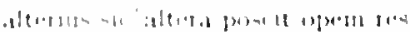

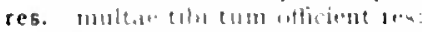

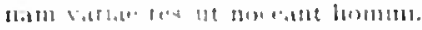

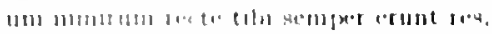

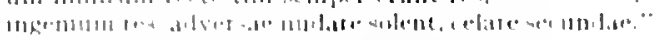

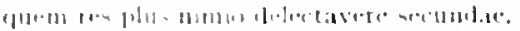

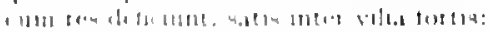

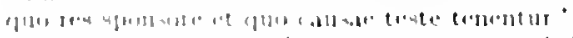

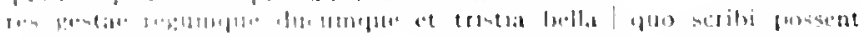

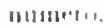


res. qui res hominum ac georum. . . temperat

(itrm.1.12.14

mox uhi publicas tes ordinaris.

cirm.2.1.1

cum dicas esse paris res/turta litrociniis

Sirm. 1.312

fortius et melius magnas plertumedue secal tes.

aude $\mid$ Cancaris imvicti res dicere.

utpote res tenuiv, tenui sermono peractas.'

qubus andicsa teparare quean res artibus atque numb.

"quid tibi vis [quid vis], insane, et quam tem lquas tes] acis?"

"quid tili vis, insane, et eftam tem agis [et quas res]?"

merulas poni et sine clane palumbis. | suavis tes,

et mili res. nom me tebus subiungere conor.

quis sibi tes gettas Augusti scribere sumit?

res gerere et captos ostendere civibus host is

secutus. . non reset agentia verba I ycamben

les ltalas armis tuteris, morilus ornes.

quam res conponere gostas termamque situs

in mefliat les non sects ac notas atuditom rapt

vel guod res omnis timide gedichequ' minist rat.

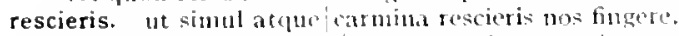

rescinditur. an male sarta|kratia nepuiguam coit et rescintitur

rescribe. tu quotus asse velis leseribe

rescribere. lictantis, qund tu numpuam rescribere posis.

debes hocetiam rescribere.

resecantem. cultello proprios purgantem [resecantem] hesiler unguis.

reseces. spatio brevi spem longan reseces.

resedit. nostrisque ductum soditionibus, bollum resedit:

residunt. iam iam residunt cruribus asperae pelles

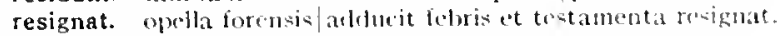

resigno. resigno quat dedit

hac ego si conpellor imagine, cuncta resigno

resolvent. tegue piacula nulla resolvent.

resolvit. nil agit cxemplum, lifom quod lite resolvit.

resonantis. quam domus Albuneae resomantis

resonare, tuque testudo resomate septem/calliob nemii.

resonarent. quo pacto alterna loquentes/ umbrae cum saganat pisonarint [resonarent] triste et acutum

resonaret. quo pacto alterna loquentes | umbrae cun sagana resonarint [rosonaret] triste et acutum

resonarint. umbrac cun Sagana resonarint tristo et acutum

resonat. modo summa/voce. morlo hac, tesonat quae choslis quat tuor ma. suave locus voci resonat conclusus.

resonet. undique magno!pulsa domus strepitu resonet.

citaret "io Bacchace" morbo smmma/ voce, morlo hac, wionat [resonet] guar chorelis quattuor ima.

resorbens. te rursus in bellum resorbens/unda

respicere. respicere isnoto discet pendentia tergo.'

respicere exemplar vitac normuntue iubedon doetum initatorem

respicientis. de te pendentis. te respicientis antici?

respicis. sive neglectum genus et nepotes/respicis, autor

non bavtiaden, exitium tual gentis, non Pylium Nestora respicia?

respondat. tibi ingens virtus atque animus cenis responsat [respondat] opinisis?

responde. 'hoc quoque, Teresia, practer narrata petenti' responde.

respondeat. "we prior officio quisfuam respondeat, urpe.'

respondebam. ut illi nil respond.bam.

respondere. casu tum respondere vadato/debebat.

ergo consulere et mox respondere licebit?"

seu civica iura|respontere para: .

ploravere suis non respondere favorem / speratum meriti.

clament perisse pudorem/cuncti pacme patres. ea cum reprendere coner [/ respondere conesis].

responderet. quid responderet? "maguo patre nata puella cost."

responderit. accipe quid contra haec iuvenis respmlerit aequos.

respondes. respondes, ut twos est mos./ pauca:

respondesne tun, dic, sodes, nomine?

respondet. sordidus atque anini quol parvi nolit haberi./responetet.

unde venis" et "quo tendis:" rogat et responflet.

ne gallina malum responet [respondec] dura palato.

dic. I ad cenam ventat.". . "brnigne"| responelet

Srm.1.10.15

Sim.2.tu

Sirm. 2.5.2

2ar.sien. $2,0.20$

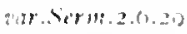

Sim.s.s.9.2

İ⿴囗十.1.10

1.pist.1.3.7

Ifpist.1.1\%3.3

Ixplat.10.25

Ifing.t.2

lipis a I $25 \mathrm{I}$

des lontis

Ars rist.17

Fivid.2.22\%

Ifpist 1-3.32

Ifpid.1.5.30

serm.2.3.

IPpist.1.3.30

otr. Epist. I. 51

(arm.t.11.7

Carm.3.3.31

(itm.2.20.0

Epist. I. To

(urm.3.20).5t

Jepis.1.7.3.t

('19m. I.28.3t

Sirm.2.3.103

(iam.1.7. 2

carm.3.12.3

war.sirm.1.8. 1

vor..serm.I.S.4

Serm. I.8. 11

Sorm. 1.3.8

Sipm. 1. 4 .7n

Sirm.1.2.120

2ar.serm.1.38

(ar)'.2.7.15

Sirm.2.3200

. 1rs liset.3I

lepit.1.1.105

(arm.1.2.3")

cirm.1.5.22

"itr.term.2.7.103

Serm.2.5.2

Sirm.2.0.2t

Sirm.1.0.1.1

Sirm.t.0.3"

sirm.2.3.102

Epint.1.3.2.1

topt.2.1.9

? zur. Epist.2.1.8!

Srrm.1.2.72

sirm.2.3.233

Sirm.1.0.00

lipist.1.10.31

Sirm. I-2.1 1

serm.1.0.03

gar. Sirm.2.4 18

l.pist. [.7.63 


\section{RESPONDIT}

\section{RET TVLIT}

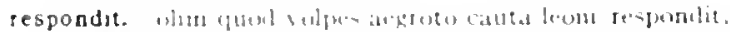

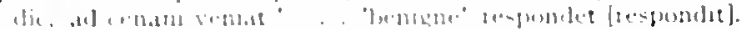

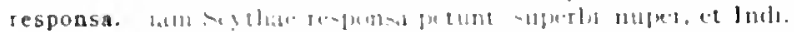

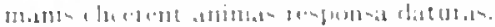

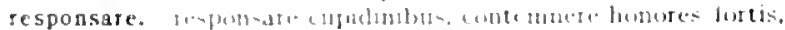

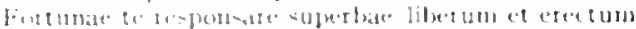

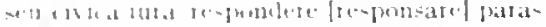

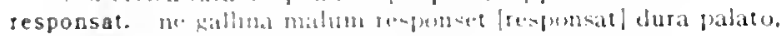

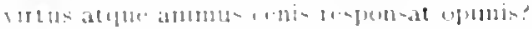

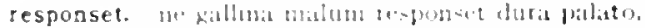

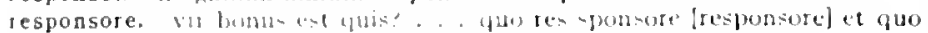

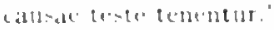

sesponsum. re:sutn-13m date.

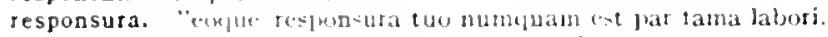

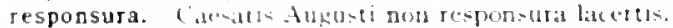

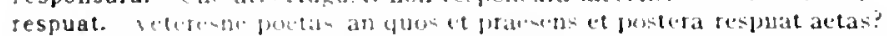

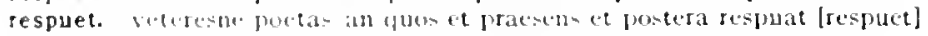
allet.l一:

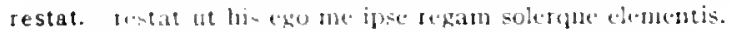

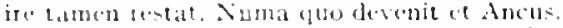

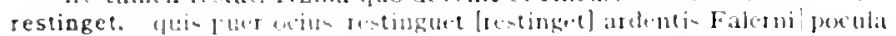

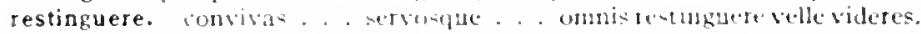

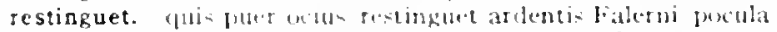

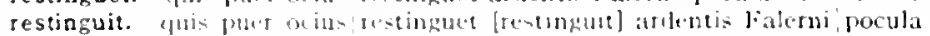

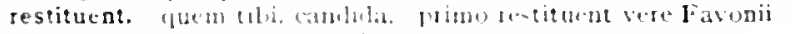

restituet. non te stotutuct bietas;

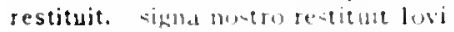

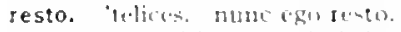

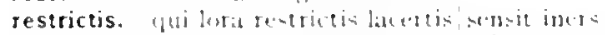

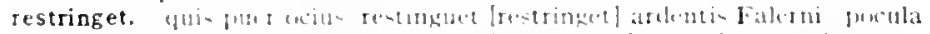

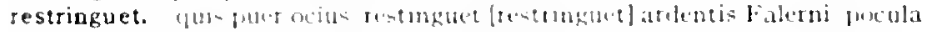

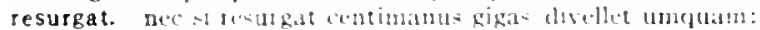

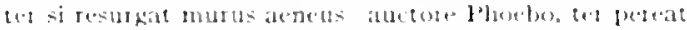

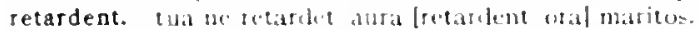

retardet. cua ne retardet aura masitos.

retegis. arcanumb iocoso comcilium rotegic l, saten.

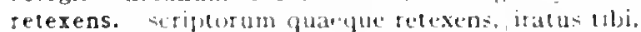

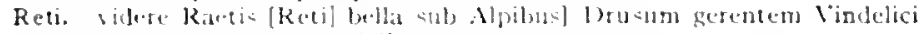
[arerentedu et Vindelici]

retia. ant amite levi rata tenclat retia

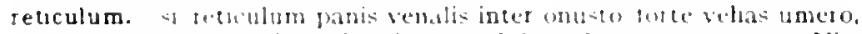

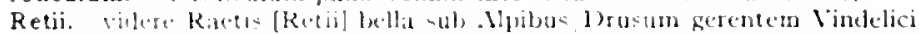
[erenteme cet lindelici]. .

retinacula. retinacula mulate natuda piger sano rolipat

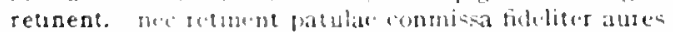

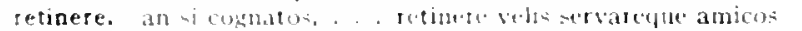

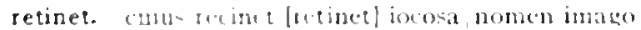

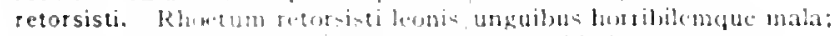

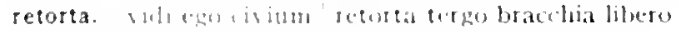

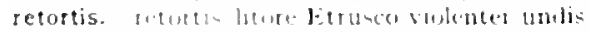

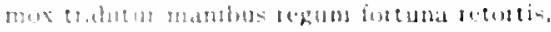

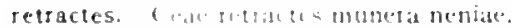

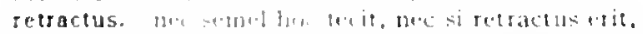

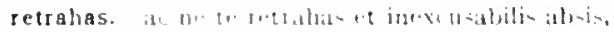

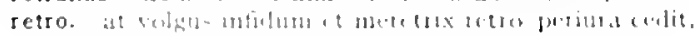

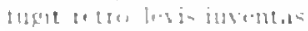

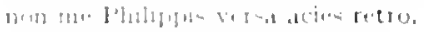

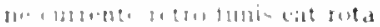

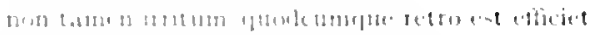

(1t)

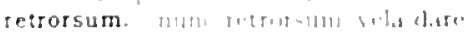

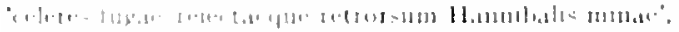

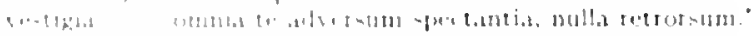

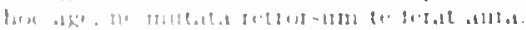

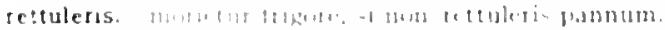

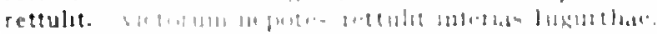

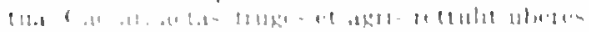

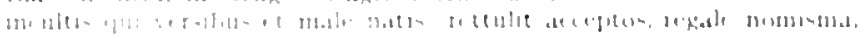

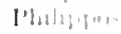

L.pist 1.1.74

:ar. I:pist 1.7 .63

Carm.suce.55

berm.1.X.20

Sorm.2.7.85

I:pist.1.1.88

Iar. Epist 1.3 .24

zar.Sorm.2. 18

Sirm.2.7.103

Sorm.2.t.18

Iar. Fist 1.10 .43

Itpod.7.14

Sirm.2.8.60

L pist.2.2.48

Esist.2.1.\$2

Ior. I.pist.2.1.42

Epistic1.27

Epist.1.6.27

idr. Curm.2.11.19

Serm.1.5.70

Curm.2.11.19

I'ar. Carm.2.11.19

Carm.3-7.2

Corm.4.7.24

Carm.1.15.6

Sirm.1.9.28

Carm.3.5.35

iar (arm.2.11.19

car Carm.211.19

Carm.2.17.14

Carm.3.3.65

cuni Corm.2.8.23

Carm 2.823

Curm.3.21.10

Serm.2.3.2

iar.carm+a 17

I. pod.2.3.3

Sirm. 1. 1.47

ar.Carm +4.17

Serm. 1.5 .18

Epist.1.18.70

Sorm.1.1.se

far.Carm.1.12.3

Cirm 2.10 .23

(arm.3.5.22

(istm.1.2.13

l.pist 2.1.101

(arm.2.1 is

lirs Jued.ges

L.p156.1.18.58

Curm.1.3.525

(ormitits

Cium.3.420

(arm.3.11\%10)

(a)m.3. 24.4)

I.pud. 17

(a)thl 3.3

(iorm a s 16

J.pest 1.175

Jipuld at as

Jpist $1: 32$

(ism.2.1.2s

( $1 \mathrm{rm}+4155$

J.pot2.13.15 
retusum. utinam nova|incurle ditingas retusum . . ferrun. reum. qualia vincent | Pythagoran Anytique reum doctumque Platona.' revehet. nec mater domum cacrula te revet.

revehi. non satis est Ithatan revehi

revellis. usque proximos' resellis agri terminos

reverti. quis neget arduis pronos telabi posse rivos/ nontibus to Tiberim reverti.

atque a Fabricio non tristem ponte reverti.

orabant hodie meminisses. Quinte, reverti.'

pinguis ut inde domum possim Phaeaxque reverti -

delere licebit.' quod non edideris; nescit vox missa reverti.

revexit. nec sateiles Orcil callidum Promethea/revexit auro captus;

revictae. consilis imvenis revictae

revinctae. sed diu lateque victrices caterval consilis iuvenis revictae [revinctae] sensere.

revinxit. nec satelles Orci callidum Promethea revexit [revinxit] auro captus:

revisens. ter ut quater 'anno revisens aequor Atlanticum inpune.

reviset. te, dulcis anice, reviset cum Zephyris.

revixit. nee satelles Orci callidum Promethea/revexit [revixit] auro captus; revocant. quo blandae iuvenum te revocant preces.

revocas. abeo, et revocas nono post mense

revocat. exclusit; revocat: redeam? non, si obsecret."

revocavit. emovitque culpas/ et veteres revocavit astis,

revolvimus. cum loca iam recitata revolvinus inrevocati;

rex. quis sub Arcto rex gelidae metuatur orae.

cui rex deorum regnum in avis vagas / permisit

postquam relictis moenibus rex procidit heu purvicacis ad pedes Achillei. et sutor bonus et solus formosus et est rex,

sapiens operis sic optimus omnis est opifex, solus sic rex."

dum tu quadrante lavatum|tex ibis

'etiam et rexlet quidquid volet.'

'nequis humasse velit Aiacem. Atrida, 'etas cur?" 'rex sum.'

at pueri ludentes 'rex eris' aiunt. 'si recte facies.'

sapiens... liber, honoratus, pulcer, rex denique regum,

mancupiis locuples eget aeris Cappadocum rex:

rexque paterque audisti coram, nec rerbo parcius absens:

equos ut me portet, alat rex., officium facio:

idem rex ille, poema/qui tam ridiculum tan care prodigus emit.

rex. o pater et rex/luppiter.

Rheni. diffingit Rheni luteum caput.

Rhenum. aut flumen Rhenum aut plovius describitur arcus;

rhetor. rhetor comes Heliodorus, Graecorum longe doctissimus;

trater erat Ronae consulti rhetor.

rhetoris. defendente vicem modo rhetoris atque poetae,

Rhodani. me peritus/discet Hiber Rhodanique potor.

Rhode. purote similem. Teleple, Vesperol tempestiva petit Rhode:

Rhodio. Rhodio quod Pitholeonti contigit?

Rhodon. laudabunt alii claram Rhodon aut Mytilenen

Rhodopen. pede harbaro lustratam Rhodopen,

Rhodos. incolumi Rhodos et Mytilene pulcra facit

Romae laudetur Samos et Chios et Rhodos absens.

Rhoetum. Rlwetum retorsiati leonis unguibus

Rhoetus. quid Rhoetus evolsisque truncis| Enceladus iaculator audax. . posetnt

rhombi. cum passeris atque ingustata mihi porrexerat ilia rhombi.

rhombi. grandes rhombi patinaeque / grande terunt una cum damno dedecus.

rhombos. quid? tunc rhombos minus aequor alebat?

rhombum. nun esuriens fasticlis omnia practer pavonem rlombumque?

rhombus. masisire rlonhus aut seari.

putet aper rhombusque recens.

tutus uat rhombus tutoque ciconia nido.

rictum. ergo non satis est fisu diducere rictum auditoris

ride. quirl pauper? ride: nutat cenacula. lectos,

rideant. senent. quod omnes rideant, adulterum

rideat. ne potum largins atequ| rirleat et pulset lasciva decentius aetas.

ridebit. ticlebit monitor non exanditus.

ridebo. male si mandata loqueris, aut dormitabo aut ridebo.
Carm.1.35.39

Serm.2.4.3

Epod.13.I0

Serm.2.5.4

Carm.2.18.24

Carm.1.29.1 2

sirm.2.3.30

Sirm.2.6.37

Epist.1.15.24

Ars Poel. 390

Curm.2.18.36

Carm.4.t.24

coni.Carm.4.4.24

Far.Carm.2.18.30

carm.I.31.I

Epist.1.7.12

i'ar.Carm.2.18.36

Carm.4.1.8

Serm.1.0.61

Serm.2.3.264

Carm.4.15.12

Epist.2.1.223

Carm.1.26.4

Carm.4.4.2

Epod. 7.13

Serm.I.3.125

Sirm.1.3.133

Serm.1.3.138

Sirm.2.3.97

Serm.2.3.188

Epist.1.I.50

Epist.1.1.107

Epist.1.0.39

Epist.1.7.37

Epist.1.17.20

Epist.2.1.237

Serm.2.1.+2

Serm.1.10.37

Ars Poti. 8

Serm. I.5.2

Epist.2.2.87

Serm.I.IO.I 2

Carm.2.20.20

Carm.3.19.27

Serm.1.10.22

Carm.1.7.I

Carm.3.25.12

Epist.I.I I.I 7

Epist.I.I [.2 I

Carm.2.19.23

Carm.3.4.55

Sirm.2.8.30

Serm.2.2.95

Sirm-2.2.48

Sirm,1.2. I 6

E.pod.2.50

Serm.2.2.42

Serm.2.2.49

Serm.1.10.7

Epist.I.I.9 I

Epod.5.57

Epist.2.2.216

Epist.1.20.14

Ars Poet. 105 


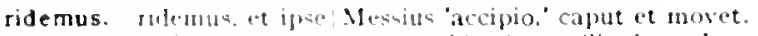
ridendus. Ho" mectet and extremunt ridendus et ilia ducat." .

Serm.1.5.57

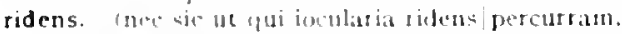

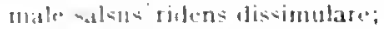

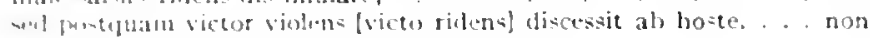
ireriusu elepulit ore.

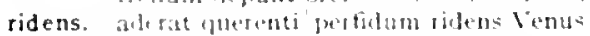

ridens. ire tu mavis, Erycinas ridens.

rident. sune simplices Symphae.

ghlont vicini glatbas et saka mosentesn / cum stervis.

ridenten. quamyuam rideneem dicere vesum quif vetat?

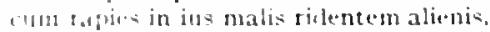

ridentem. dulce fielentem l.alagen amabe. dulco loutentem.

ridentes. insani inlentere pratemia setibate.

ridentibus. ut ridentibus alriclest, ita tlentibus adflent, humani voltus.

ridentur. ridentur mala qui conponunt carmina;

ridere. cum ticlete voles. Eppicuri de groge poreum.

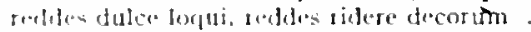

rideret. -i foret in terris. rideree l bemocritus.

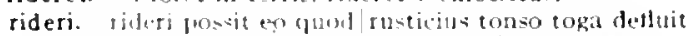

rides. 'fuid rides"' mutato nomine de te fabula narratur ril... Turboniw in armis|spiritum et incessum:

'puid tiden?"

ci curatus inuequali tonuore caspillos occurri. rides:

it toka climinlet injar. tirles:

insanire putas sollemnia me negue rides

ride." ast. iet losic aurbus jeta servas:

necurnes leanures portentague Thersala rides:

ridet. ifhe tortarum mihi prateter omnis angulus ridet,

rluet bue. inquam. Ienus ipsa,

rilletqut. si mortalis ultra' fas trepidat.

tidet atgrito lomus,

non rirlet sersus Euni gravitate minores.

videc sichetgue Pbilippls.

derimenta, fugas servorum, incemdia tide?.

ridetur. ridetur ab omni consentu;

dompluse ridetur fictis rerum Balatrone secundo.

-itharuelus ridetur, chorla qui semper obersat eadem:

Fipistiog

Sirm.1.1.23

sirm. 1.000

chil Epist.t 10.37

Curm.3.27.67

Cirm.1.2.33

Curm.2.8.13

bisist.1 1439

Sirm.1.1.24

Sirm.2.3.72

Cirm.1.22.23

serm.1.5.35

Irs Poetiot

Jisist.2 2.106

Lepist.1.1.

Epist.1.7.27

Epist.2.1.104

Sierm. 1.3.31)

Serm.1.1.60

Serm.2.3.310

Serm.2.5.3

Epist1.1.95

Epist 1.1.97

Epist.1.1.101

Epist.1.19.43

I.pist.2.2.209

Cirm.2.0.14

(ism. 2.8 .13

Corm.3.2931

Curm.tidin

Serm.1.10.54

Epist. I. 7.78

Pist.2.1.121

Serm.1.7.22

Sierm. 2.8 .83

irs $\operatorname{Pod} .35^{\circ}$

ridiculum. ridiculum acsi fortius ct melius magnas plerumque secat res.

ridiculum. irfers rex ille. joema, gui tam ridiculum tam care profigus emit. anlsetw, vethit.

ridiculus. qui tidiculus minus illo?

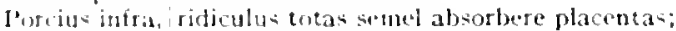

farturient montes, nasetur tidiculus mus.

rigat. gisa tuminlte rigat arva Xijus.

rigent. tam me prata rigent noc thvii strepunt hiberna nive turgidi.

inbirititi num minue netsi rigent

riget. "mo nunc Thressa ("hlox regit [riget].

rigida. nec rigula mollior aesculo

rigidi. melim - bethat. . . vivont et rigidi Getar.

rigides. fenterd regum|vel fabis vel cum rigidis aequata Salvinis.

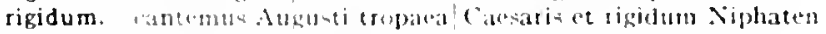

rigidus. sirtutia worate cu-toi rigitusque satelles:

rimam. Jut port angu-tan tenuis volpecula rimam/repserat

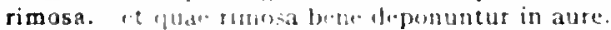

ringi. practulerin scripeor delirus inersque videri. . quam sapere et

$$
\text { anges }
$$

ripa. aretrat mat sabia tacienrsa ventis.

ripa. Sugua et smatra labatur nua love non probante u- xorius atunis.

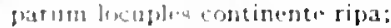

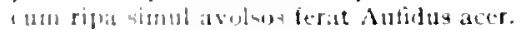

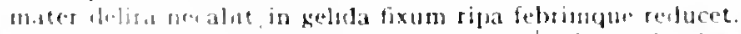

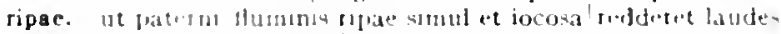

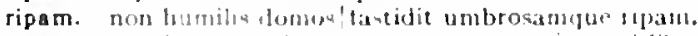

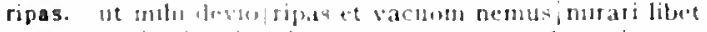

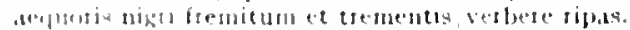

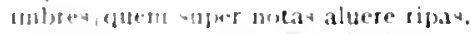

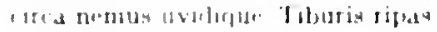

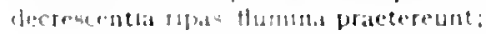

Sirm.1.10.14

Epist.2.1.235

Sorm.2.3.311

Sirm.2.8.24

Irs Poef. 130

Carm.3.3.45

Cirm. 12.3

Epote.17

iar Carm.3.0.9

(iorm.310.17

Cirm.3.24.1t

Lpist.2.1.25

Cirm 2.0.20

Epist.1.17

lepist 1.720

Serm. 2 (1. f')

Fist.2.2.128

Cirm.3.2924

curm. 1.219

(irm 218.22

icrm.1.1.58

firm.2.3.294

Cism.120\%

cism.3.1.23

Cirm.3 25.13

(iirm.327.24

Cism.t2.p

cirm. 231

(ism.4 73 
ripis. labuntur altis interin tipis aquae.

riseris. imultus ut tu tiscris Cotytia/volgata.

riserit. quandoque potentior|largi muneribus riscrit acmuli,

risero. ast ego vicissim tisero.

risi. ego si risi, quod ineptus | pastillos Rufillus olet, Gargonius hircum,"

risis. Jabuntur altis interint ripis [risis] aquac,

risissent. si non Actisium. . Iuppiter et Venus|risissent:

risisset. si non Acrisium . . I Iuppiter et Venus|risissent [risisset]: .

risisti. illa/redke, age, quae deinceps risisti."

risit. puerum minaci|voce dum terret, viduos pharetra|risit $A$ pollo. quin et Ixion Tityosque voltu/risit invito,

qui primus alma risit adorea.

risores. verum ita risores, it a commendare dicacis/comveniet satyros,

risu. anara lento temperet risu:

multo now sime risu

cum magno risuque iocoque videres.

ergo mon satis est risu diducere rictum/auditoris

"solventur risu tabulae. tu missus abibis."

statua taciturnims exit ples unque ct risu populum quatit:

quem bis terve bonmm cum risu milor;

risum. dummodo ismm lexcutint sibi non, non cuipuan parcet amico

Varius mappa conpescere rismm / vix poterat.

moveat cornicula risum/fus tivis nudata coloribus.

cognonen vertas in risum et fabula fas.

spectatum admissi sisum teneatis, anici?

ne spissate risum tollant impune corome:

risus. gratus puellice risus ab angulo

risus. o magnus post hac inimicis risus.

risus. solutos/qui captat risus honsinum fananque dicacis.

dein Gnatia Lynphis iratis exstructa dedit risusque iocosque. captator que tlabit risus Nasica Corano.'

sibi dun repujem, dum risus undique quacrit.

rite. dulce lenimen fmihicumque salve/rite vocanti.

quorum plaustra vagas rite trahunt donos.

sensere, quic! mens rite.

rite Latonac puerum canentes,

rite crescentem tace Noctilucan,

rite deos prius adprecati,

rite maturos aperire partus|lenis, Ilithyia. the me matres,

rite cliens Bacelii somno gundentis et umbra:

cetera iam simul isto cum vitio lugere [fuge ritel?

situ. cur invidentis postibus et novo/sublime situ moliar atium?

Herculis ritu norlo dictus,

cetera tluminis ritu leruntur.

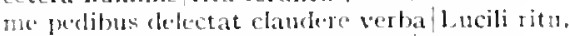

hace siquis tempestatis prope ritu| mobilia

et invmum ritu tlosent modonata vigentque.

rivali. quin sime rivali teque et tua solus amares.

rivis. udianobililus pomaria tivis.

labuntu altis interim ripis [rivis] aquae.

rivo. fons ctian rivo dare nonen idousus.

rivo. quid ollicuo laborat /ynupha fugax trepiclare rivo?

fisom. phistor unbras cun grege languido|rivomgue fessus quaerit

quan quat jur promu trepielat cum mutmure rivon?

cera brevis juvat et prope tivom sonums in herba;

rivos. purae rivos aquae silvaque ingerum/paucorum

ut te confestim liquidus lortmate tivos inamet.

addit opus pigno livos, si decidit imber.

me guotiens reficit gelidus Digentia rivos,

rivos. (quis aeget arluis, promos relabi posse rivos montibus

vinique fontem lactis et ubere'cantare rivos

rivos celeres morati:

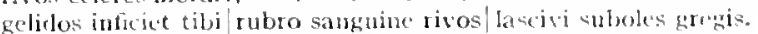

fastidire lacus ct rivos ausus apertos,

ego laudorusic amoni|rivos

rivus. ut te conbestim liguidus Fontume rivos [rivus] inauret,

rixa. Contaurea monet cum Lapiths rixa super meródebellata,

rixae. litinn ct Iisae cupidos protelvae;

abstineto' dist 'irarum calidacepe rixae.
Lipod.2 25

lepol.17.50

Carm.4.1.18

Epoil.15.2.4

Serm.1.4.0I

ine. lopd.2.25

Curm.3.10.7

conicarm.3.16.7

Serm.2.8.80

Carm.1.10.12

(itrm.3.11.22

(inm.4.4.41

Ars I'ott.225

Carm.2.16.27

(amm.4.13.27

Sirm.1.8.50

Serm.1.10.7

Sirm.2.1.80

Enist.2.2.8.4

irs 1'ut'.358

Sirm.1.4.3.1

Sorm.2.8.63

Epist. 1.3.10

Lifist.1.1.3.9

Ars I'oet.5

Ars Poct.381

Curm.1.9.22

Sirm.2.2.107

Sirm.1.4.83

Sirm.1.5.08

Sirm.2.5.57

Epist.1.7.79

Carm.1.32.10

(arm.3.2.10

("arm.4.4.25

Carm.4.0.37

(arm.4.6.38

(inm.1.15.28

Carm.Sace.13

lepist.2.2.78

"ar. Npist.2.2.200

(arm.3.1.4h

( $a$ rm-3.1.4.1

(a)m.3.20).3.1

Sirm.2.1.20

Sirm.2.3.2188

Ars Poetetoz

Ars biototit

Carm.1.7.1.1

var. L pol.2.25

lipisl.1.10.12

Carm.2.3.1 2

Carm.3.20.22

Epist.1.10.2I

Epist.1.14.35

Carm.3.16.29

L) pist.1.129

1.pist.1.14.29

Epist.t.18.104

Carm. f.20.11

Carm.2.10.1

Corm.3.15.14

(arm.3.13.7

Epist.1.3.1

Epist.1. I0.7

sar.lpist.1.12.9

(a)m.1. Is.8

(arm.3.14.26

(avm.3.27.70 


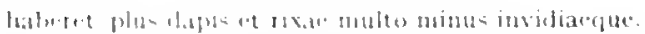

Epist.1.17.51

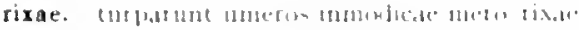

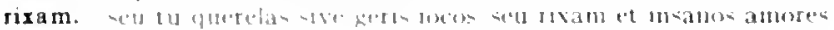

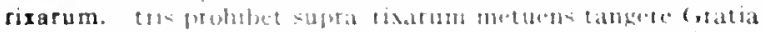

(ivm.1.1311

Carm 3.213

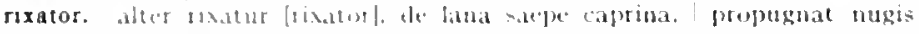
attidaters:

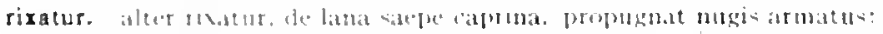

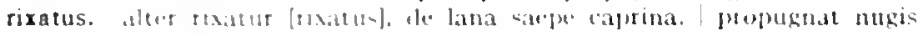
allus.stus:

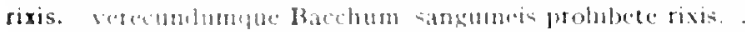

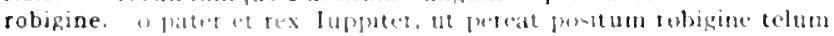

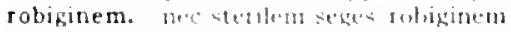

robogant. reeteque cultus pectora loborant:

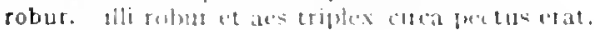

robur. timet. Catenas lartlus tet lablum robur?

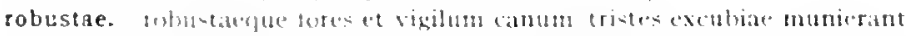

robustis. tunta wolunti= buctantur fumera plaustrin.

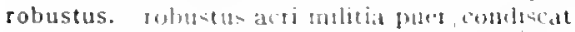

Ciarm, 3.19.1\%

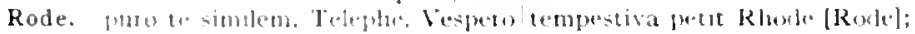

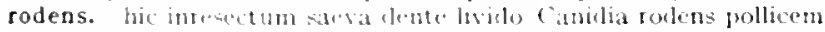

rodere. urbilia liatla rudere mavia.

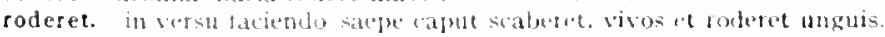

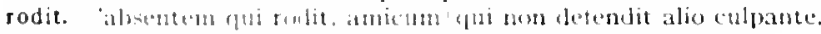

rodunt. quent rentane nmnes libertim patre natum,

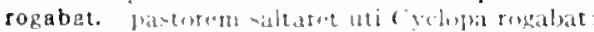

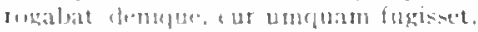

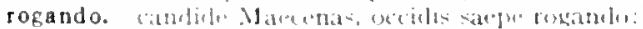

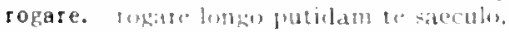

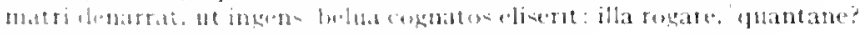

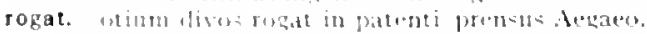

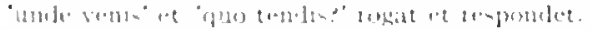

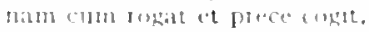

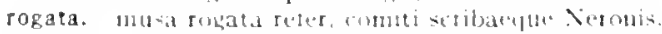

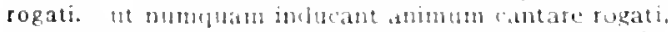

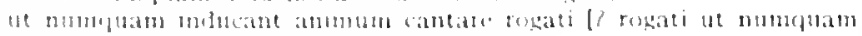

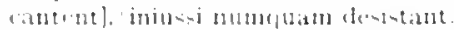

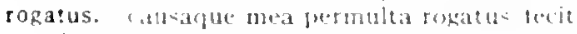

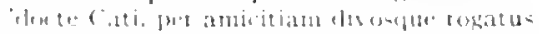

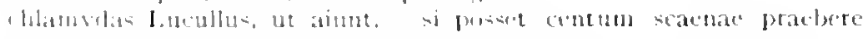
rog.ottes

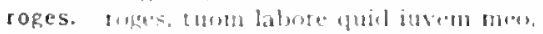

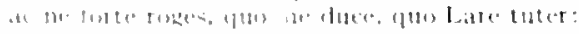

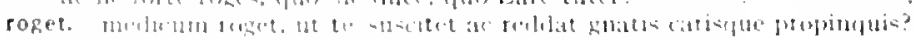

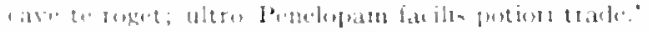

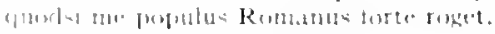

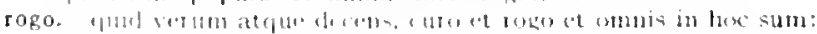

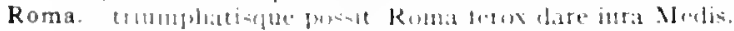

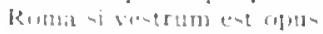

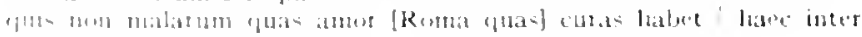

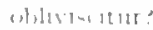

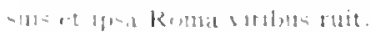

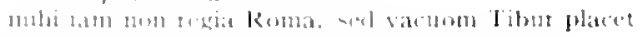

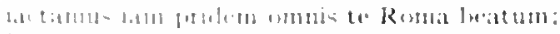

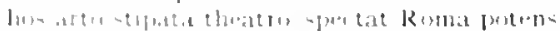

Roma. wathon inse et urbo Roma?

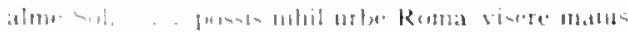

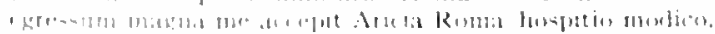

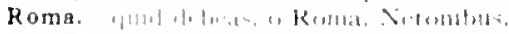

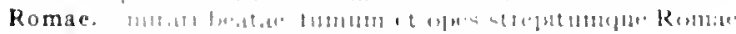

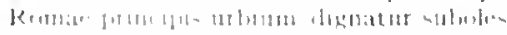

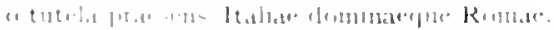

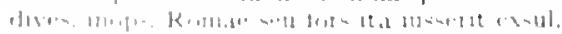

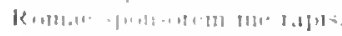

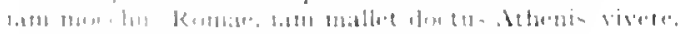

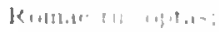

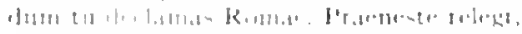

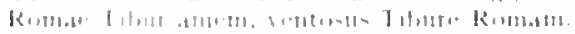

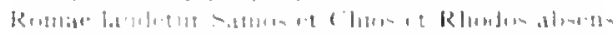

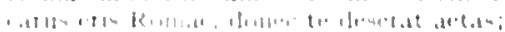

cons. Epist.1.18.15

lipist 1.1815

gar. L pist I IR. I 5

Ciarm. 1.27 .4

Serm 2.1 .13

Corm 3.237

Carm.4.4.34

Carm 1.30

Curm.2.1310

Carm.3.10.2

I.pist 2.2.74

Carm 322

:ar. Curm 31927

lipol.5.js

Jipist 1.14.4"

Sirm.1 10.75

Serm.1.4.81

sirm. 1.6. 16)

Serm. 1.5.113

Sirm.1.5.07

Ferdetis

I.pod.S.I

Sirm. 2.3 .310

(ism.2.16.1

Serm 1.0 .03

I.pist is 2

Ipistis 2

strm.1.3.2

I:ar.form.1.3 =

Sirmlatis

Serm.2. s

Epist.o.pla

lipod 1.5

IEpist.1.1.3

Serm.1.1.82

Sirm.2.5.75

Epist.1.7\%

lipistalat

Cism,3-3.4.4

(armbsace.37

(amilipul. 2-3i

lepoitivi, 2

l.post. 7.1 .1

Eptst.10.18

lepintane

(arm.35.12

(ingm Yianta I

serm.1.5.1

(iarmst 137

(itrm.3 20) 1 2

ciams 131.5

(arm + 1.t.

serm: 150

serm 2.0.2.3

Sirm. 27.13

serme.2.28

1.pes 1.2.2

1.pist.1 $\times 12$

f.pol 1,1121

I.P1. 1 216.1" 
Romae dulce diu fuit et sollemne reclusa mane domo vigilare.

Romae nutriri mihi contigit atque doceri,

praeter cetera me Romaene poemata censes'scribere posse

frater crat Romae consulti rhetor.

Romam. dum longus inter saeviat Ilion Romanque pontus.

sed puerum est ausus Romam portare docendum|artis.

Romae Tibur amem, sentosus Tibure Romam.

qui Capua Roman petit. imbre lutoque adspersus.

quandocumque trahunt invisa negotia Roman.

et formidatam Parthis te principe Romarn.

Romana. Romana pubes cresit quol mihi pareret legio Romana tribuno.

(si Romana fatigat militia ad=uetum graecari) .

parebit pravi docilis Romana iuventus. -

ne tamen ignores. quo sit Romana loco res:

Romana. Romana rigui clarior Ilia.'

Romana. quid Titius? Romana brevi venturus in ora.

Romanae. quod monstror digito praetereuntium| Romanae fidicen lyrae:

Romanam. remque Romanam Latiumque felix... semper prorogat

Romane. delicta maiorum inmeritus lues. Romane, hic niger est. hune tu, Rowane, caveto.'

Romani, si. . . Romani pensantur eadem 'seriptores trutina. Romani tollent equites perlitesque cachimmun.

Romani pueti longis rationibus assem | discunt in partis centum diducere

Romanis. Romanis sollemne viris opus, utile famae t' data Romanis venia est indigna poetis.

Romanis. circum- /snectemus vacuam Romanis vatibus aedem;

Romano. quo ne per vacuon Romano incurteret hostis.

Romano. tu cum proiectis insignibus, anulo equestri Romanoque habitu.

Romanos. sic est: acerba fata Romanos agunt

Romanus. non ut superbas invidiae Karthaginis|Romanus arces ureret. Romamus eheu. . fert vallum et arma miles

ede hominis nomen. simul et. Romanus an hospes." quodsi me populus Romanus forte roget.

Cafecilio Plautoque dabit Romanus ademptum Vergilio Variogue?

Romulae. opture Romulae/custos gentis.

Romulae. Romulae genti date remque prolemgue et decus omne.

Romuli. Romuli praescriptum et intonsi Catonis auspiciis si taciturnitas obstaret meritis invida Romuli?

Romulum. Romulum post hos prius an quictum| Pompili regnum memorem.

$$
\text { . . dubito. }
$$

Romulus. Romulus et Liber pater. ploravere suis non respondere farorem -peratum meriti=.

rore. qui rore puro Castaliac lavit crinis solutos. parvos coronantem marino' tore deos

roren. etiam stillabit amicis ex oculis rorem.

rores. qua parte debacchentur ignes. qua nelbulae pluvique rores.

sosa. mitte sectari, rosa quo locorum sera moretur.

rosa. quis multa gracilis te puer in rosa genfusus liquidis urget odoribus rosa camns odorati capillos

rosae. niminm brevis thores amoenae tirre iube rosae,

te. . non citharae lecent nec tios purpureus rosae

nunc et qui cohor est puniceae flore prior rosae

rosae. reu desint expulis rosae

sosarum. cum Hore. Maecunas, rosarum

rosas. parcentis ego dexteras odi: sparge roæas.

Roscia. Roscia, dic aodes, melior lex an puerorum est nenia,

Roscius. quat gravis tesopus, quae doctu Roscius egit:

Roscius. ante secumdam Roscius orabat silyi adesape ad Puteal cras."

roseam. Telephil cerricem rosan. cerea Trlephi laudas bracchia

rostrata, tot ora naviun gravi sostrata duri fundere

rostris. frigidua a tostris manat per compita rumor:

rota. me currente retro funis "at rota:

amphora cofpit institui: currente rota cur ufceus exit?

rotantes. sordidum flammar trepidant rotantes vertice fumbm

rotarum. si te pulvis strepituspue rotarum, si lardit caupma.

rotas. magna sonabit cornua quod vincatequ tubas [sotas]:

rotis. metaqu fervidis evitata rotis palnaque nobilis.
Epist.2.1.In3

Epist.2.2.4 I

Epist.2.2.65

Epist.2.2.87

Cirm.3.3.38

Sirm.1.6.70

Epist. I. 8 I2

I.pist.t.1I.II

Epist.I.I4.17

Epist.2.1.250

Carm.4.4.46

Serm.1.6.48

Serm.2.2.10

Sirm.2.2.52

Epist.1.12.25

Carm.3.9.8

Epist.1.3.9

Carm.4.3.23

(arm.nace.66

Carm.3.0.2

Serm.I.t. 85

Epist.2.1.29

Ars Poct. 13

Ars Poet.325

Epist.1.18.49

1rs Pot.264

Epist.2.2.94

Serm-2.I.37

Sirm.2.7.54

Epod.7.17

Epod.7.t

Epotio. I I

Serm.2.t.IO

Epist.1. I. 50

Irs Pod.5t

Carm.4.5.1

Cirm.Sactit

Corm.2.15.10

Carm.t.8.24

Carm, I. I 2.33

Epist.2.1.5

carm.3.4.0I

Carm.3.23.16

Ars loct. 430

carm.3.3.56

Carm.t.38.3

Carm.1.5.I

Carm.2.1I.It

Carm.2.3.14

Carm.3.15.15

Carm.10.t

Carm.1.30.15

Carm.3.20.3

Cizm.3.19.22

Epist.t.1.02

Esist.2.I.82

Serm.2.0.35

Carm.1.13.2

Epoit.t. 8

Sirm.2.6.50

Carm.3.10.10

Ars Potl.22

Corm.t.I I.II

Epister.7.7

conisirm. I 0.tA

Corm.t.t.5 


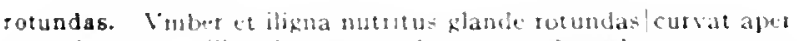
sotundentur. mille talenta tutundentur. totide-m altera.

potundioribus. martal. quare intundorbú, onusta bacis ambulet. ro:undis. wis. . ut slei me liotis et ut magis oblo entundis.

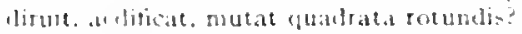

rotundo. Cisake dedit ore totumblo, Musal Jopui.

sotundum. animoglte sotumlum, percursine polum morituro.

rotundus. et in se ipso totus. teres atgue rutumes.

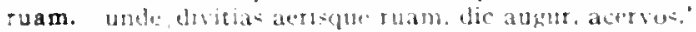

ruant. atile hos praeteres casus, aulaca rlsut si.

zubeam. ne rulueam pingui donatus munere

rubens. nexue unu luna rubens nitet voltu:

rubente. rubented fextera saltas iaculatus arios

rubentem. Lunangue rubentern, ne foret his testis.

ruber. olscanogue ruber porrecturab inguine palus.

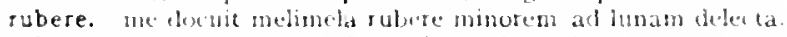

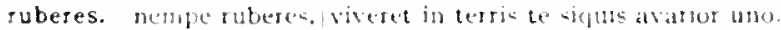

rubicunda. quid si rubicunda bengri, corna velses et fruna tetant.

Rubos. inde kubos desi perveninus.

rubra. sou rubra (anicula fincet intantis statuas.

zubrica. preclia rubrica picta ant tarbome

subro. "xamen Eos timendum partabus ( )eanogue subro.

rubso. Rebles inficiet tibl rubro sangune rivos

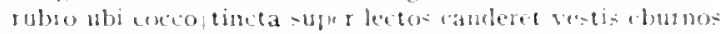

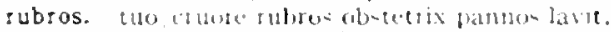

rubum. sell virlos rubum dimovere larertace.

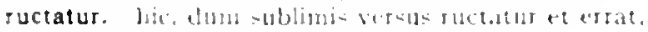

sude. prectatum atis et conatum iam rude

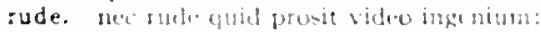

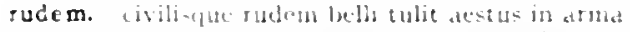

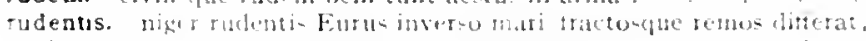

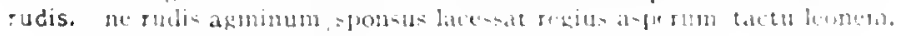

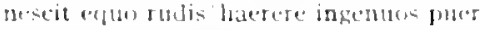

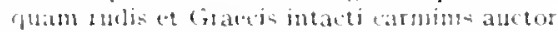

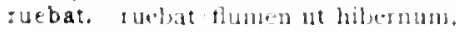

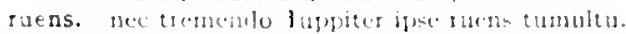

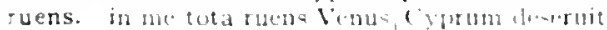

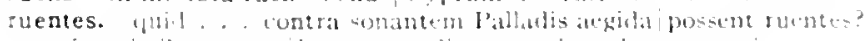

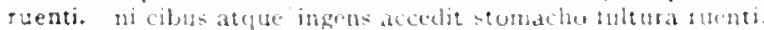

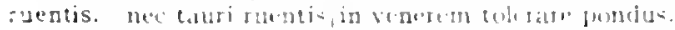

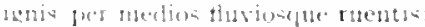

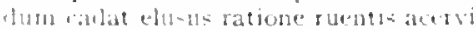

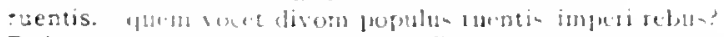

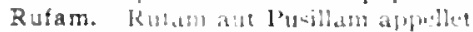

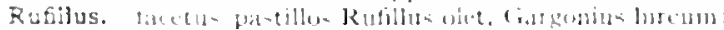

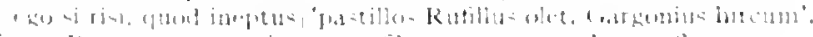

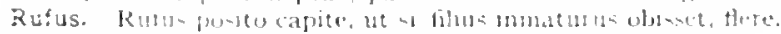

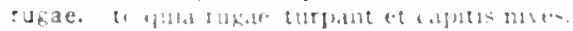

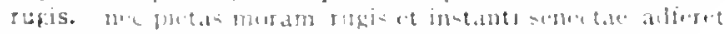

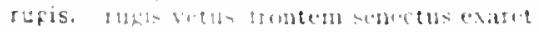

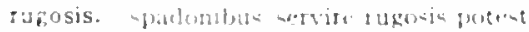

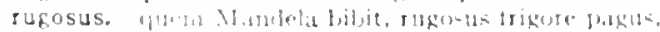

ruina. Hine da nom heri ruma

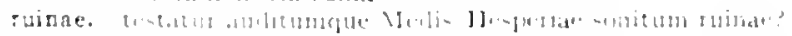

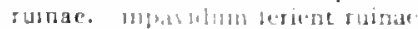

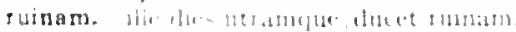

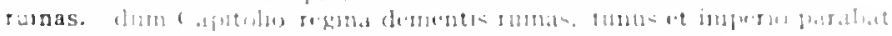

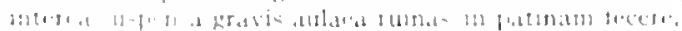

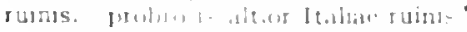

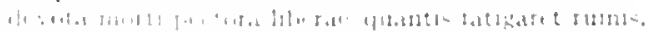

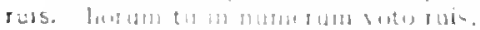

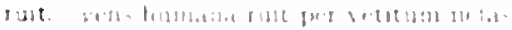

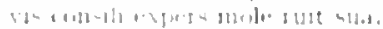

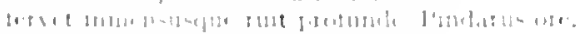

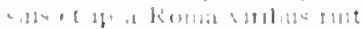

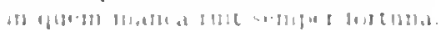

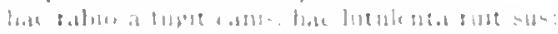

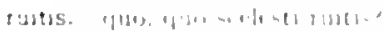

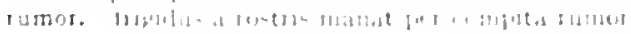

serm.2.4.40

l.pist.1.0.34

lipod.8.13

Serm.2.13

lipit.1.1.100

Ars Poet. 323

carm.1.28.5

form.2.7.80

serm.2.522

Sirm.2.8.71

H.pist.2.1.207

Corm.2.1t.10

Corm.1.2 2

Serm.1.8.35

Serm.1.8.5

serm.2.8.31

Jpist.2.2.150

J.pist.1.16.8

Serm.1.5.9.4

Acrm.2.5.30

Sirm.2.7.98

(iarm:1.3.5.32

Carm.3.13.7

serm.2.0.102

l.pod.1.51

Giorm.123.0

irs J'cet.p5?

lipist.1 \& 2

los l'sel 410

lipist 22.47

Spod 115.5

Carm.3.2.0

(a) 19.3 .2 .45 .4

serme 100in

sem. 7.20

carm.1.16.12

(arm I 11)

(crm:3.1.5s

srom 2.3154

(iormi.2.5.3

arm.2357

I. pest. 21.47

(ivm: 1.2.25

Crmas 210

herm.1.2.27

verm 1.112

armins $2 \mathrm{~s}$

(arm t 1, II

(ismi:2 1.4 .3

I. pond 3

Ifod dy t

I.fist.1.15 105

( $12 \mathrm{rm}+210.15$

(arm.2.132

( iorm 3.3

lism 2.17.9

(4)n: 1.3.7

crm 2 854

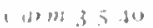

(iirm! 140

I pist 1 1641

(12r): I ;.20

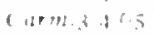

(a)ms =

I. Prul are

brin $2,: x 8$

l. plet $2: 35$

1 puld 7.1

seros a 20.50 
rumore. flagret rumore malo cum hic atque ille?"

quae vos ad caelum fertis rumore secundo.

rumpat. rumpit [rumpat] et serpens iter institutum.

rumpent. nor qui profundum Daruvium bibunt edicta rumpent Iulia,

rumpere. coniurata tuas rumpere nuptias

indigni fraternum rumpere foedus.

purior in vicis aqua tendit rumpere plumbum

amat spatiis obstantia rumpere claustra.

rumperet. sed dubius unde rumperel silentium.

rumperis. miserque rumperis th latras, magnorum maxime regum.

tumpi. malis terigine rumpi?

rumpit. runspit et serpens iter institutum,

iamque subando tenta cubilia tectaque rumpit.

ruont. guare templa ruont antiqua deum?

rupem. posset qui rupem et puttum vitare patentem.

rupere. unde tibi redicun certo subtemine Parcae/rupere.

I uperis. 'non. si te ruperis,' inquit, |'par eris.'

ruperit. Ionis udo cum remugiens sinus/ Toto carman ruperit.

rupes. 'hic fossa est ingens, hic rupes maxima: serva!'

rupes. sive te rupes et acuta leto saxa delectant,

rupes. ut rupes tluriosqut in campo obstare queratur;

rupibus. Bacchum in remotis carmina rupibus/vidi docenten,

Rupili. pruscripti Regis Rupili pus atque venenum

Rupili et Persi par pugnat.

rupis. qui male parentem in rupis protrusit asellum iratus:

supit. seu rupit teretes Marsus aper plagas.

rupit Iarbitam Timagenis aemula lingua.

ruptis. quat belua ruptis. cum semel effugit, redrlit

rura. mercator metuens otium et oppidi|laudat rura sui;

non rura, quae l.iris quieta mordet aqua

regnata petam Laconi rura Phalantho.

mili parva rura . . Parca non mendax dedit

per meos finis et aprica rura lenis incedas

tutus bos etenin rura perambulat.

nutrit rura Ceres alnaque Faustitas,

paterna rura bubus exercet suis

circum, me Satureiano vectari rura caballo,

rura suburbana irdictis comes ite Latinis.

tu mediastinus tacita prece rura petebas.

Gabiocque petunt et irigida rura.

rure. ille, datis vadibus qui rure extractus in Vrbem est

nec vereor, ne, dum futuo, vir rure recurat.

Vergilio adnuerunt gaudentes rure Camenae.

quinque dies tibi pollicitus me rure futuruin

novistine locum potioren rure beato?

rure togo riventem. tu clicis in Virbe beatum:

rure meo possum quidvis perferse patique;

interdum nugaris rure paterno.

ruris. copia. . benigno ruris honorum opulenta contu.

te pauper ambit sollicita prece ruris colonus.

urbis amatorem Fuscum salvere iubemus ruris amatores,

eqo laudo ruris amoeni rivos

mancerunt hodieque manent vestigia rutis.

rursum. in amore haec sunt mala, bellum. pax rursum:

rursus. te rursus in bellum resorbens

intermisa. Venus. diu turus bella moves?

ferisque rursus accupabitur soluni:

inquirant vitia ut tua rurcus et itli.

aequnn est pecatis venian poscentem redrete rursus.

perfundit gelicla, rur-us vocat:

rusus. quid virtuset quid sapientia possit,

pastague rursus ire foras plemo tendebat corpore frustra.

rus. uti ne solu= rusve peregre/ve/exirem,

uti ne solus ruave peregreve' [rusve aut peregre] exirn,

uti ne solus ruspe peregre vo [ne rus solucye peregre] exirem,

Romate rus optas:

rus. orus, quando ego te adspiciam

Rusonem. acerbu= odisti tet fugis ut Rusonem dubitor artis,

rustica. caelo supinas si tuleris manus nacente luna, rustica Phidyle.
S.rm.1.4.125

I.Pist. I. 10.0

tar. Carm: $3,27.5$

carm.15.22

Carm.1.15.7

Epist.I.3.35

Epist.1.10.20

Epist. I. If.9

Epod.5.85

Sirm.1.3.1.36

Serm.1.2.118

(arm-3.27.5

Lipod.12.12

Germ.2.2.104

Epist.2.2.135

Enod.13.10

Serm.2.3.319

Efod. 10.20

sirm.2.3.59

Carm.3.27.0I

Sirm.2.3.55

Carm.2.10.1

sim.1.7.

Sirmi.7.19

Epist.1.20.15

Carm-1.1.28

Epist.1.19.15

Serm.2.7.70

Cirm.1.I.t

Carm.1.3I.7

curm.2.6. I

Carm.2.11.37

Corm.3.1t.2

Carm.t.5.I

Curm.t5.18

Epod.2.3

Serm.1.t.50

Epist.1.7.76

Epist.I-ItIt

lipist.1.15.0

Sirm.1.1. I 1

Sirm.1.2.127

Sirm.t.10.45

I.pist.t.7.

Epist.1.10.1t

Epist.r.J.to

Rpist.1.15.17

Epist. I 8.00

Cirm.1.17.16

Curm.1.35.6

Epist.1.10.2

Epist.1.10.0

Epist.2. I I 00

Sirm.2.3.208

Carm.2.7.15

Carmet I.2

Lepod (1). Io

Tirm.1.3.28

Sirm.1375

Sirm.2.7.91

lipist.I. II

Lpist.1 - . 3, 30

Sirme1. [0]2

iar. Serm.1.192

conistrm.1.102

Serm.2.7.2.8

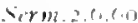

serm. 1.3 so

(arm.3.23.2 
rustica. versibut alternis opprobria rustica fudit

Epist.2.1 1.15

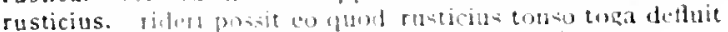

Serm.1.3.31

rusticorum. sell |untrcorumb habcula malitum|proles,

rustacus. i.an iam tuturus raticus.

th. comsultus modo. rubticus:

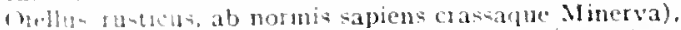

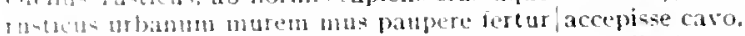

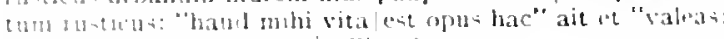

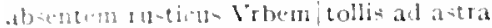

musticus essuectat, ijum detluate amnis:

(x) muthlo bie rusticns

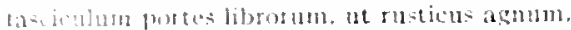

port bata ille catas. quantuntis tusticus.

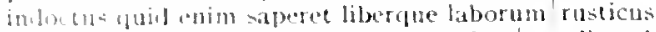

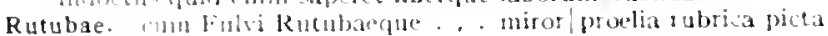

Carm.3.6.37

Epod. 2.68

Serm.1.1.17

Serm.2.2.3

Serm.2.6.80

Serm.2.6.115

Serm.2.7.25

Lipist.1.2.42

Epist.1.7.83

Fipist.1.13.13

Iipist.2.2.39

Ars Poel. 213

Serm.2.7.96

\section{$S$}

Sabaeae. mu ante devictis Sabae / regibus

Corm.1.29.3

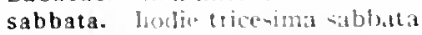

Sabella. Sarlla guod puesu cecinit divina nota anus urma:

Sabella. Sistolla pectus increpare camma

Sabellis. Sibullic lineta lizombun verse glacha misons ant hon pulas, vetus est ut tama. sabellis,

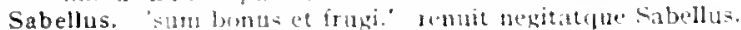

Sabina, Sabina qualis ane porusta solbus pernicis uxor Apuli.

Sabina. deprome quadrinum Sabina. . . merum riuk namrlae mo silva luphs in Sabina, . . fugit inerntem:

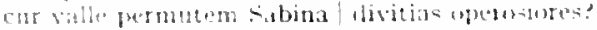

Sabinis. utis boatus unicia S̈abinis.

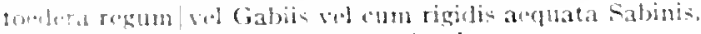

Sabino. "wecles opera agh" nona Sabino."

Sabinos. vetrin arduon tollor Sabinos.

Sabinum. vile potabis mode Sahinum canthats.

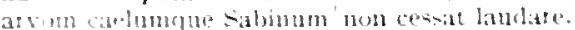

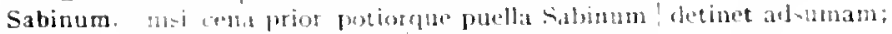
saccis. hungentis undlqu" saccis/indormis indian:

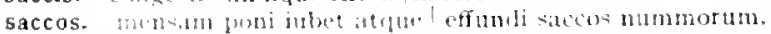

sacer. mu tablata sacer sentiva paties indicat

ut infongentin fluxit in tersam Remi|saces nopotibns ctuot.

1. inte-uatsilis iet sacer wato.".

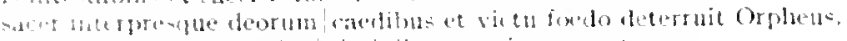

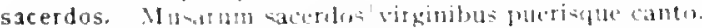

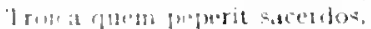

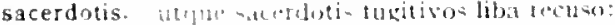

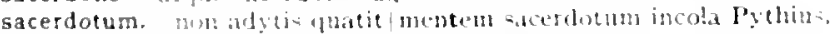

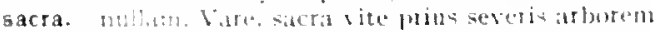

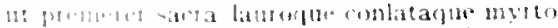

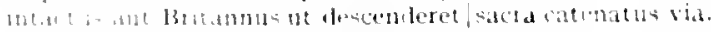

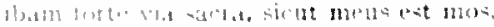

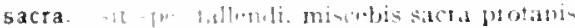

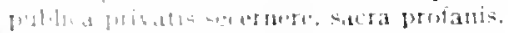

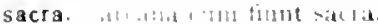

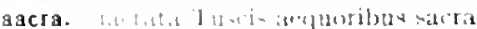

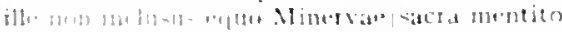

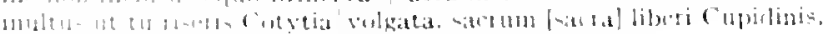

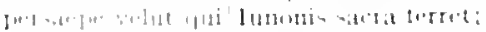

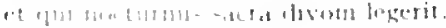

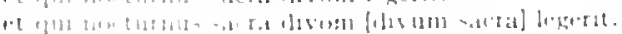

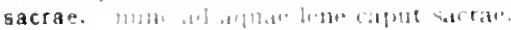

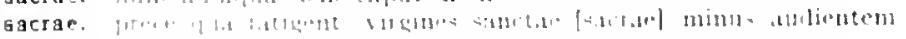

1.

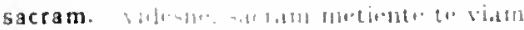

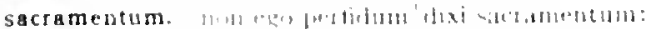

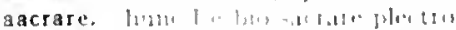

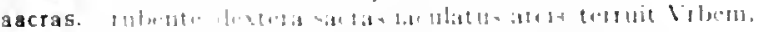

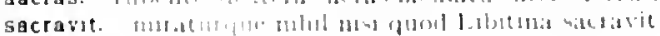

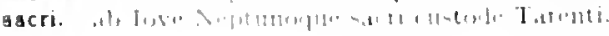

Serm.1.9.69

Sermil. 9.20

Spod.17.28

Cirm.3.6.3. 38

Sirm.2.1.30

Epist.1.10.49

Frod.2.11

Corm.1.9.7

Corm.1.22.9)

Carm.3.1...7

Cirm.2.I8.1.

Fpist.2.1.25

Sirm.2.7.118

Corm.3.4.22

(iorm.1.20. I

Epist.8.7.77

Fpist.1.5.27

Sermas.t.7o

Sirm.2.3.19

Carm.1.5.13

Fpod 7.20

Sirm.2.3.181

Ars loot.iul

Carm.3.1.3

Cism.3.3.32

Epist I Io

(arm.1.1ent)

Carm.18.1

(is)m $3 \ldots 18$

Ispold.7.8

Sirm.1 O.I

Lipist.1.11.54

Ars Pot 39:

Ispol.5.52

Cism.t 4.54

Cormed bold

tor Epod 17.57

sirm.1.3.11

Sirm.1.3117

sor ferm. 1.3 1

Cirm 1.122

asr Cisrm I 2.27

lopoditi

(iarm.2.15)

(iarm.1.26.1]

(iamla 2.3

I.pist.2 1.40

(intm. 1.282 
sacrilega. sacrilega manu produxit, arbos,

Citm.2.13.2

sacris. Canidia: parce vocibuc tanden sacri

I.pod. I.

sacris. nosque et profestis lucibus et sacris

sacris. tamquam parcere sacris cogeris

sacris. ut Attica virgo/cum sacris Cereris

sacris. prodeat iustis operata sacris

spectator functusque sacris et potus et exlex.

sacro. sacro Dianae celebi is die.

carent quia vate sacro.

sacro. utrumque sacro digna silentio' mirantur umbrae dicere.

et pugnata sacro bella sub Ilio:

date quae precamur tempore sacro.

dum flamma sine tura liquescere limine sacro|persuaclere cupit.

sacrum. per sacrum clivom merita decorus/fronde sacrum vetustis exstruat lignis focum

sacrum. qui Cereris sacrum/volgarit areanae, onne sacrum rapiente dextra.

sacrun liberi Cupidinis,

metuensque velut contingcre sacrum?

saecula. fecunda culpae saecula nuptias/primum inquinavere aere. dehinc ferro duravit saccula,

saeculo. saeculo festas referente luces rogare longo putidam te saeculo,

saeculum. ne rediret saeculum Pyrrhae nova monstra questae.

saepe. deterget nubila caelo saepe Notus neque parturit imbris o fortes peioraque passi| neeum saepe viri. neque iam livida gestat armis|bracchia saepe disco,

saepe trans finem iaculo nobilis expedito?

velox amoenum saepe Lucretilem/mutat Lycaco Faunus

o saepe mecum tempus in ultimum

cum quo morantem saepe diem merolfregi.

nec priores'inpiae tectum dominae relinquont, | saepe minati. saepe Diespiter/neglectus incesto addidit integrum.

et te saepe vocanti duram

narratur et prisci Catonis|saepe mero caluisse virtus.

candide Maecenas. occidis saepe rogando:

atque haec rara cadat dura inter saepe pericla.

ne si facies, ut saepe, decoralmolli fulta pede est, emptorem inducat

hiantem.

saepe velut qui currebat fugiens hostem.

habebat saepe ducentos.' saepe decem servos;

habebat saepe ducentos, saepe decen servos;

qualem me saepe libenter|obtulerim tibi, Maecenas.

in hora saepe ducentos.| ut magnum, versus dictabat

saepe tribus lectis videas cenare quaternos.

sic tenetos animos aliena opprobria saepe/absterrent vitiis.

multos saepe viros nullis naioribus ortos

qui stultus honores saepe dat indignis et famae servit ineptus.

fallacem eircum vespertinumque pererro| saepe forum,

cui saepe viator cessisset magna conpellans voce cuculum.

et sermone opus est modo tristi, saepe iocoso,

saepe furenten | plura quidem tollenda relinquendis.

in versu faciendo saepe caput scaberet.

saepe stilum vertas, iterum quae digna legi sint|scripturus.

saepe notatus'. cum tribus anellis.

saepe verecundum laudasti,

ubi saefe occultum visus decurrere piscis ad hamum.

ut proficiscentem docui te saepe diuque.

nota refert neretricis acumina, saepe catellam,

saepe perisceliden raptan sibi flentis.

alter rixatur, de lana saepe caprina.

dives amicus. ' saepe decen vitiis instructior.

quid de quoque viro et cui dicas, saepe videto.

ut mili saepe bilem, saepe iocum restri movere tumultus!

ut mili saepe bilen, saepe iocum restri movere tumultu=?

saepe etiam audacem fugat hoc terretque poetan.

nulta quidem nobis facimus mala saepe poetae.

agepius. saepius ventis agitatur ingens pinus .

saetosa. saetosa duris exuere pellibus.. membra;

Cism.4.15.25

Serm.1.1.7

Serm.2.8.14

Carm.3. [.4.6

Ars Poet.224

Corm.2.12.19

Carm.t.0.28

Citrm.2.13.29

Carm.3.19.4

Carm.Sitce.t

Serm.1.5.99

Curm.4.2.35

Iipod.2.43

Carm.3.2.26

Carm-3.3.52

Ipod.17.57

Serm.2.3.1 10

Carm.3.0.17

Epod.16.65

Carm.4.5.42

Epod.8. I

Carm.1.2.6

Carm.1.7.16

Carm.1.7.31

Carm.r.8.I I

Carm.1.8. 2

Carm.1.I7.I

Curm.2.7.I

Carm.2.7.6

Carm.2.8.20

Carm.3.2.29

Carm.3.7.31

Carm.3.21.12

IEpod.1 $\$ .5$

Serm.1.2.40

Sirm.1.2.S7

Sirm.1.3.9

Serm.1.3.I I

Sirm.1.3.I.

Serm.1.3.63

Sirm.1.4.9

Sirm.1.4.86

Sirm.1.4.I 28

Sirm.10.10

Serm.1.6.16

Serm.1.6.11t

Sirm.1.7.30

Sermilo.I 1

Serm.1.10.50

Sirm.1.10.7

Serm.1.10.72

Serm.2.7.8

Epist.1.7.37

Lipist.1.7.73

IEpist.1.13.1

Epist.1.17.55

Epist.1.17.56

Epist.1.18.15

Epist.1.18.25

Epist.1.18.68

Ispist.1.19.19

Epist.r.19.20

lipist.2.1.182

Epist.2.1.219

Curm.2.10.9

lipoil.17.15 


\section{SAETOSAM}

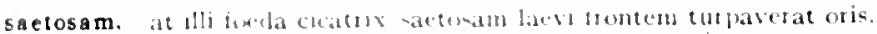
saeva. tulit et Comillum sat"ba fabperta- et avitus arto cum lase tundus.

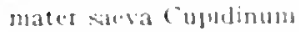

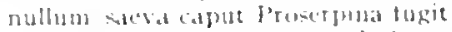

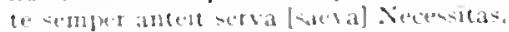

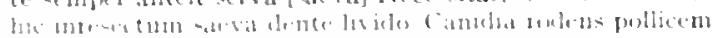

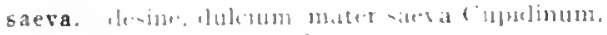

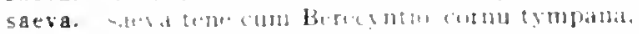

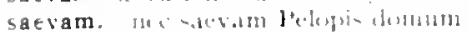

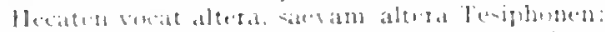

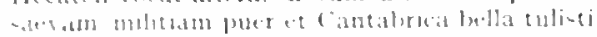

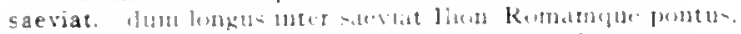

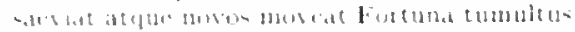

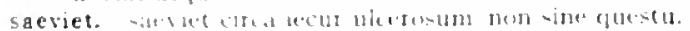

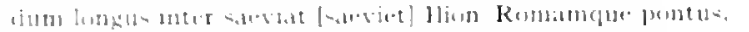

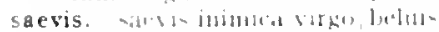

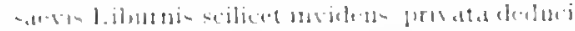

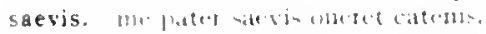

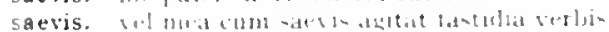

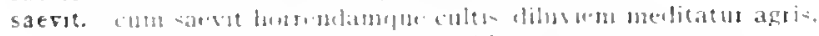

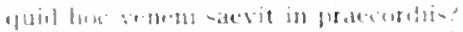

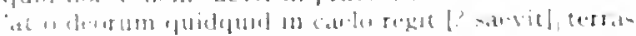

it patter atrline mevit.

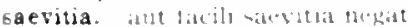

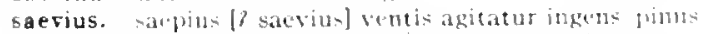

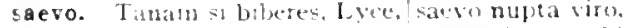

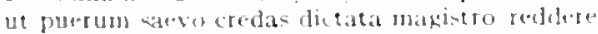

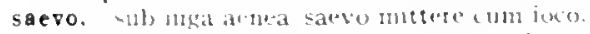

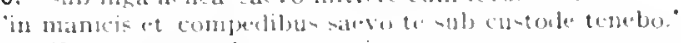

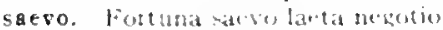

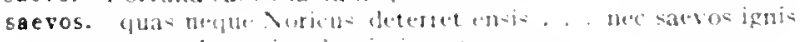

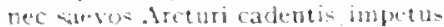

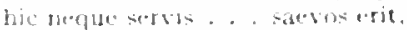

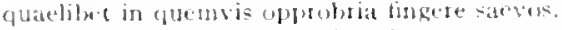

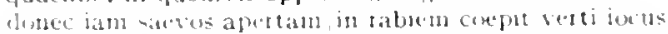

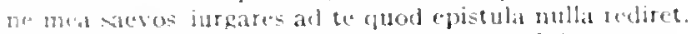

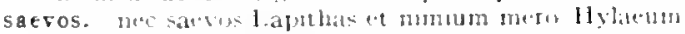

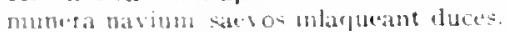

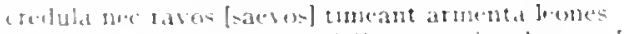

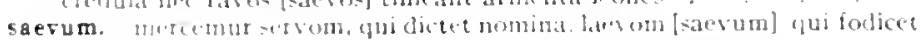
litition

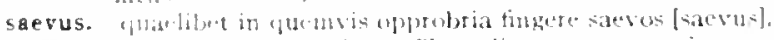

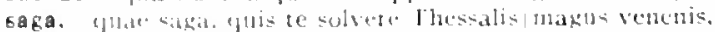

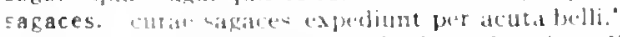

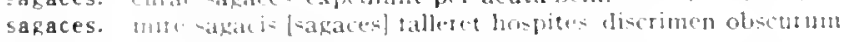

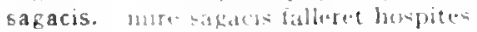

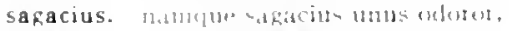

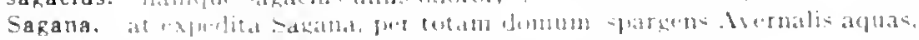

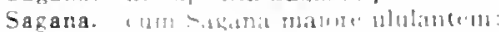

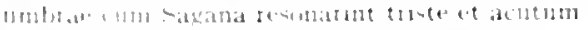

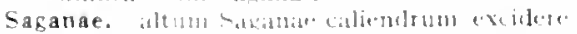

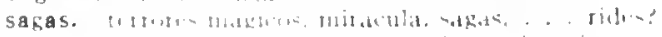

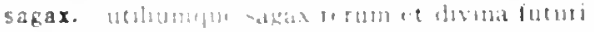

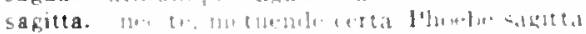

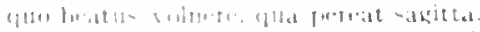

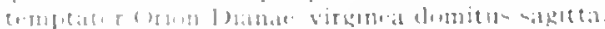

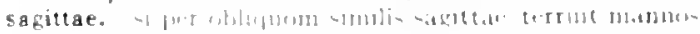

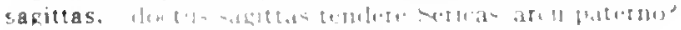

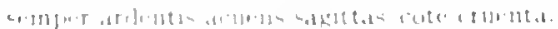

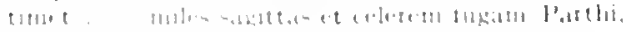

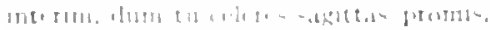

"umble sabtetil-

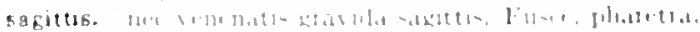

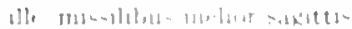

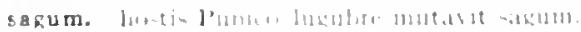

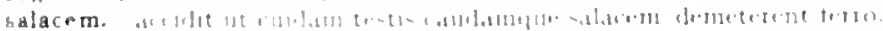

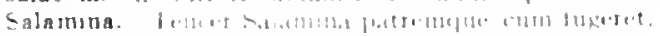

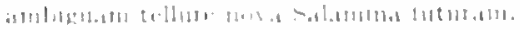

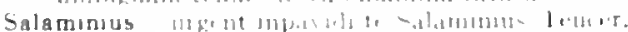

\section{SALAMINIVS}

Serm. 1.5.6.

Corm 1.12..83

Carm.10.J

Carm.1.28.20

iar. Carm! $3.5 \cdot 7$

I:pout.5.45

(arma is 5

(arm. 1. 14 13

cirm.t. is

Sirm 1.3 .3

Fist.1.1.5t

Carm. 3.37

viru: 2 2 124

( irm.1.25 is

unicarm 3.37

(arm.1.12.22

Carm 1.37.34

(arm.3.1:.55

Find 12.13

Curm.1.1.2-

J. ponj.3.5

$\therefore$ iar I. pond 5.1

Serm. 1.4 40

(itrm.2.12.2\%)

$r$ :at.Curm.2.100

Carm.310.2

List.1.18.13

Carm.1.3.3.12

lipist.1.14.77

Carm.3.20.10

Curm.1.1n.11

(arm.3.1.27

Sirm.z.2.

L pist.1.15.30

Jpist.2.1.1.8

Epist. 221

Carm.2125

(arm.3.10.1\%)

:ar. Jipod.te. 33

a ar. l.pist. 1. (1.50

vur Jipist 1.15.30

Carm. 1.27.21

Carm + +75

a ar. Curm.2.5.22

Carm.2.5.2

f.pod.I 2 .

Ifold 5.5

strm.1.ti 25

term. I 8 .

sorm.t.t..4

l. pist. $2=213 \mathrm{~s}$

Ars Juet 214

Cirm.1 12.2:

(arm.1 27.12

(urm.3 : 72

( arm.3 : 30

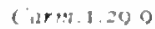

(iarm.2 15

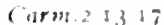

Carma

terin? 2,110

(iarm) 1.2=3

(arm 3.P. If

I pindi) 28

srrm!2:5

(ism 17.21

("irm) - 2u)

(iven $1+5.23$ 
sale. quod sale multolV́rbem defricuit.

cum sale panis|latranten stonachum bene leniet.

S.rm. I.10.3

piper album cum sale nigro|incretum .

nembra gruis sparsi sale multo non sine farre.

his lelectatur iambis, ille Bioneis sermonibus et sale nigro.

salebras. qui queritur salebras et acerbum frigus et imbris

salem. tectum| praebuit et parochi, quae debent. ligma salemque.

Salerni. quae sit hiems Veliae. quod caelum. Vala. Salerni.

sales. at vestri proavi Plautinos et numeros et laudavere sales.

Saliare. ian Saliare Numae carmen qui laudat

Saliaribus. nunc Saliaribus|ornare pulvinar deorum tempus erat dapibus. salias. nec meretrix tibicina cuius arl strepitum salias terae gravis;

salicto. in udolfudere cum vitulis salicto praegestientis.

saliente. farre pio et saliente mica.

saliere. inbres/quen [cun] super notas aluere [saliere] ripa:.

saliet. saliet. tundet pede terram.

saligno. ac mulae nautaeque caput lumbosque saligno|tiste dolat:

salinum. e"ui paternum/splendet in nensa tenui salinum

salis. 'sit uihi mensa tripes et concha salis puri

salis. ultra linites clientium| salis avarus?

Salium. neu morem in Salium sit requies pedum

in morem Salium ter quationt humum.

saliunt. aliena negotia centum per caput et circa saliunt latus.

Salius. etiam stillabit anicis|ex oculis rorem. saliet [Salius], tundet pede terram.

Sallusti. inimice lamnae Crispe Sallusti.

Sallustius. Sallustius in quas|non minus insanit quam qui moechatur.

salo. Neptunus alto tundit hibernus salo.

salsa. spargisque mola caput. inprobe, salsa.

salsa. ametque salsa levis hircus aequora."

salso. tum Praenestinus salso multoque fluenti

salsus. male salsus|ridens dissimulare:

saltamus. pinginus atque / psallimus et luctamur [? saltamus] Achivis doctius unctis.

saltaret. pastorem saltaret uti Cyclopa rogabat:

saltat. saltat Milonius, ut semel icto|accessit fervor capiti

saltem. saltem tenet hoc nos."

saltet. nee male necne Lepos saltet;

saltibus. quidve Calabris saltibus adiecti Lucani.

saltibus. cedes coenuptis saltibus et domo

saltus. saltusque Bantinos et arvom|pingue tenent humilis Forenti,

salubrem. ille lapes laudet mensae brevis. ille saluhrom|iustitiam

salubres. mutriant fetus et aquae salubres fet lovis anrae.

gravi nalvae salubres corpori

salubribus. nunc licet Esquiliis habitare salubribus

salubris. stellasque salubris appellat comites

ille salubu is aestates peraget

an tacitum silvas inter reptare salubris

saluere. imbres quem super notas aluere [saluere] ripas.

imbre quem [cum] super notas aluere [saluere] ripas.

salutandi. atque salutandi plures, ducendus et unuslet comes alter.

salutari. qui salutari levat arte fessos/corporis artus.

salutor. cur ego si nequeo igneroque. poeta salutor?

salvare. urbis amatoren Fuscun salvere [salvare] iubemus|ruris amatores,

salve. dulce lenimen tmiticumque salve rite vocanti. .

salvere. occupat et salvere iubet prior:

urbia amatorem Fuscum salveti iubemus'ruris amatores.

salvo. "est tibi mater, I cognati. quis te salvo est opus?"

salvom. non uxor salvom te volt, non filius;

tene rragis salvom populus velit an populum tu.

salvos. nt valvos regnet vivat que" beatus.

salvum. non uxor salvom te volt [alvum te vult]. won filius:

non uxor salvom te volt [te vult salyum], nou filius;

Samio. non aliter Samio dicunt arsisse Bathyllo

Samnites. lento Samnites ad hnuina prina ducllo.

Samos. quid concinna Samos, quid Croesi regia Sardis.

Romac laudecur Samos rt Chios et Rhodos abu'tls.

sanae. hine repetit. "paucorum lominum et nentic bene sanac:

sancimus. quam temere in nosmet legem sancimus inicuan.

Serm.2.2.17

Sirm.2.4.74

Sirm.2.8.87

Epist 2.2 .00

I.pist. 1.17 .53

Sirm.1.5.4t

Epist.I.I5.r

Ars Poet.27I

Epist.2.1.80

Carm.1.37.2

Lpist.1.14.26

Citrm.2.5.8

Carm.3.23.20

var.Carm.t.2.

Ars Poet. 430

Sirm.1.5.22

Cirm.2.10.14

Sirm.1.3.It

Carm.2.18.26

Carm.1.36.12

Carm 4.1.28

Sirm.2.6.34

coni.trs Poet. 430

Carm.2.2.3

Serm.1.2.4S

Epod.17.53

Sirm.2.3.200

Epod.16.34

Sirm.1.7.28

Serm. I.9\%5

? gar.lspist.2.1.33

Strm.1.5.63

Sirm.2.1.24

Sirm.1.8.44

Serm.2.0.72

Epist.2.2.178

Carm.2.3. 7

Carm.3.4.15

Ars Poct. 198

Carm.Sate.3

Epod.2.58

Sirm.I.8.14

Serm.1.7 24

Serm.2.4.21

Epist.14.4

yar.Curm.at.2.6

for.Carm. 4.2 .6

Sirm.t.6.101

Carm.Saec.03

Irs Poet.87

t'ar. Epist.1. IO. I

Cirm.1.32.15

Epist.1.7.60

Epist.t.10.t

Sirm. I-9.27

Sirm.1.1.84

Epist.1.10.27

lipist.1.2.10

2ur.sirm-1.1.84

z'ar.Sirm.1.1.S4

Epod.141)

Epi.t.2.2.9.8

Iepist.1.1 I.2

Epist.1.11.21

Sirm.1.0.4t

Serm.1.3.07 


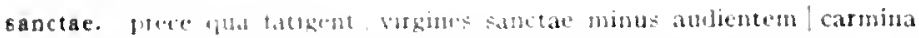
Vistasis?

sanctarum. imoutiat thi quid sanct.umb inacita begum:

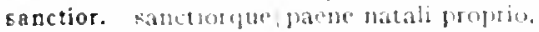

sancto. dat mithillege da itsto anctoyut videri.

sancto. matum rolutum pollicitas parma sancto concilio

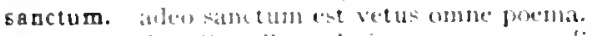

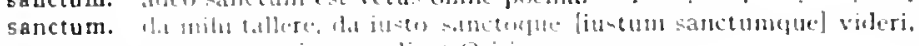

Eanctum. jut sathitutu iuratus dicat () sirin:

sane. nil same bect pluod tu reprehendere possis:

mom s.me stedere Mena, mitar secum tacitus.

sane multeta relimelu. . vichs gemit.

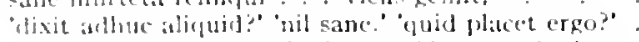

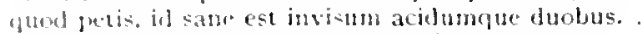

thersallat vides lmmane [hata] sanc] commoda.

bonuc sane vicinus, amabilis hospes.

quo sane populus mumerabilis, wtpote parvos,

equol non didici sant nescire hateri."

sanguine. cur olivom sanguine viperino cautius vitat.

fidibus iubl placare et vituli sanguise debitolcusendes Xumblac deos, quis mon l. atino sanguine pinguior | canpus

siculum mate Pocmo jurpurensu sangubue

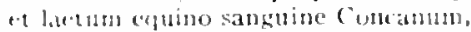

julecit aceltor satuguine l'unico

delides moticice tibi rubro sastume risoz

verris obliquom meditantic ictum sanguine donetll.

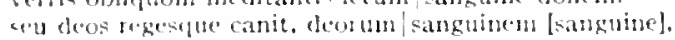

- t wirta turpis ora ranae sanguine

prudens placavi sanguinc divos."

cruentus sanguine fraterso.

sanguineis. verceumbunqu* Bacchum | sanguincis probibete rixis.

sanguinem. scu deos regestuc canit, cteorum, sanguincon.

sanguinis. parmine campls atgue Xeptums suger í fusum est latini sallguinis.

inpia perdemus devoti sanguinis actas

вanguis. num vanae redeat samguis imagini.

ego. pauperum|sarguis parentum.

regius sanglis dominacque tracti|basbarae paelex." "

clarus Anchisac Vinerisyue sanguis inpetret,

su calidus sangus seu rermm inscitia vexat

sanguis. vos, b, l’ompilius samguis, carmen repreluendite.

sani. si male ictu gevere insani est, contra bene sani:

sani. guturmulu abeant? sanj ut creta. an carbone gotati?

sanies. Plifhtus tiretel sandesque manet ore trilingui;

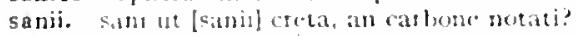

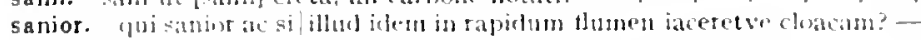
atedituante

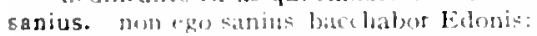

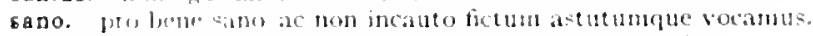

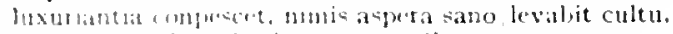

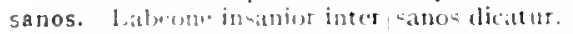

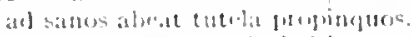

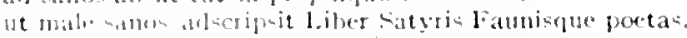

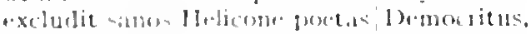

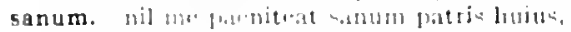

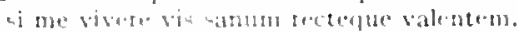

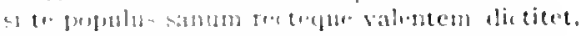

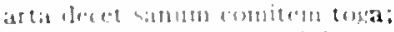

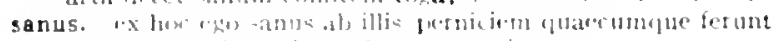

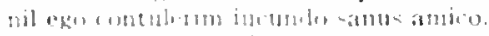

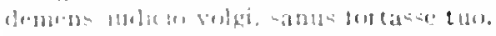

tin whilldu:

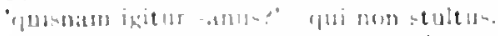

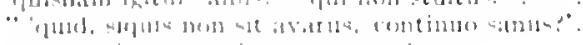

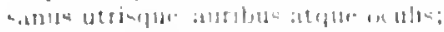

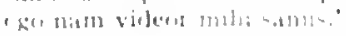

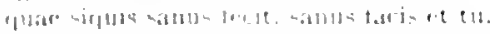

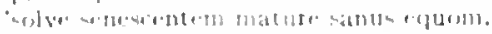

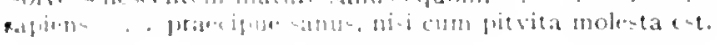

Carm 1.2 .27

sirm.2.1.81

Carm.4.11.17

Jisist.16.81

Carmit.5.

Jipist.2.1.54

idr.tist. 1.1\%.6 I

Epist.1.17.00

Sirm.2.3.1.35

Fipist.1.7.t,

IEpist.1.15.5

Iipist.2.1 206

Epist.2.2.0.4

coni.Ispist.2.2.70

Ispist.2.2.132

Ars J"ort.20t,

Ars Poot.ais

Carm.1.8.9

Corm.1.36.2

Carnt.2.1.20

Corm.2.12.3

Carm.3.4.3.1

Carm.3.6.34

Carm.3.1.3.7

Carm.3.22.8

iar.Carm.4.2.14

lipod.5.19

Serm.2.3.206

Sorm.2.5.10

Carm.1.27.

Carm.4.2.14

Ispod.7.4

Jpod.10.0

Corm.1.24.15

Carm.2.211.0

Carm.3.27.0.5

Carm.sarc. 50

1.pist.1.3.3.3

Ars Joot.202

Serm.2.3.74

sicm.2.32 20

Catm.3.11.10

ior.serm. 2.3.2.40

Scrmi.2.3.2.11

Sirm.2.3.275

(armi.2. 20)

Sirm.1.3.11

I.pist 2.2.122

Sirn.1.383

sirmi.2.3215

tipist.1.10. 3

irs lint 200

sirm.t.tio

I. pist.1.7.3

IApist 1.t0.2 I

I. pist 1 . 18.30

Serm 1.120

sorm. 15.1 .1

sirm. 1.0.0

Scrm 2.3.128

Sirm.2.3.158

Scrm. 2.3.1101)

Sirm.2.3.28.9

Scrm. 3.3112

serm.2.3.322

bipist.1.6

Eid I I gos 
si noles sanus, curres hydropicus;

sanxerunt. quas bis quinque viri sanxerunt.

sapere. dinidium facti, qui coepit, habet: sapere aude, /meipe.

qui sapere et fari possit quae sentiat

idem/vos sapere et solos aio bene vivere,

plus quam se sapere et virtutibus esse priorem/rolt

praetulerim scriptor delirus inersque videti. . . quam sapere et ringi?

nimirum sapere est abiect is utile nugis

scribendi recte sapere est et principium et fons.

saperet. indoctus quid enim saperet liberque laborum/rusticus

sapias. sapias, vina liques et spatio brevi|spen longan reseces.

nil parvom sapias et adhuc sublimia cures:

sapiat. loquacis, / si sapiat, vitet,

sapiens. sic tu sapiens finire memento/tristitiam vitaeque labores si dives. qui sapiens est,

sapiens crepidas sibi numquam | nec soleas fecit;

sutor tamen est sapiens.'

sapiens operis sic optimus omnis/est opifex,

'sapiens, vitatu quidque petitu/sit melius, causas reddet tibi;

Scipiadam ut sapiens Lucilius.'

Ofellus|rusticus, ab normis sapiens crassaque Minerva),

quali igitur victu sapiens utetur

in pace, ut sapiens, aptarit idonea bello?

'sapiensne?" 'etiam et rex |et quidquid volet.'

fecundae leporis sapiens sectabitur armos. .

neque ego, hercule, fur, ubi vasa/practereo sapiens argentea.

quisnan! igitur liber? sapiens, sibi qui imperiosus.

ni sapiens sic Nomentanus amicum tolleret:

sapiens uno ninor est Iove, dives, / liber.

insani sapiens nomen ferat, aequos iniqui,

vir bonus et sapiens dignis ait esse paratus

cum pateris sapiens emendatusque vocari.

vir bonus et sapiens audebit dicere:

sed tuos hic populus sapiens et justus in uno

Ennius, et sapiens et fortis et 'alter Homerus'.

sapiens. non usquam prorepit et illis utitur ante quaesitis patiens [sapiens],

sapiente, haec populos, haec magnos formula reges, |excepto sapiente, tenet. curantem quidquid dignum sapiente bonoque est? neve putes alium sapiente bonoque beatum

sapientem. iussit sapientem pascere barbam

sapienter. sapienter idem $\mid$ contrahes vento nimium secundo|turgida vela. . qui deorum $\mid$ muneribus sapienter uti

laetus sorte tua vives sapienter, Aristi,

sapientia. virtus Scipiadae et mitis sapientia Laeli.

virtus est vitium fugere et sapientia prima/stultitia caruisse.

rursus, quid virtus et quid sapientia possit.

quo te caclestis sapientia duceret, ires.

fuit haec sapientia quondam / publica privatis secernere. .

sapientiae. insanientis dum sapientiae/consultus erro. .

sapientiae. munitaeque adhibe vim sapientiae.

sapientior. nihilo ut sapientior ille/qui te deridet caudam trahat. ecce $\mid$ servos, non paulo sapientior

cum sis nihilo sapientior ex quo/plenior es,

sapientis. Telemachus, proles patientis [sapientis] Vlixei:

sapientium. tu sapientium / curas et arcanum jocoso / consilium retegis Lyaeo.

sapientius. alterum et huic varum et nibilo sapientius

sapientum. "haee mihi Stertinius, sapientum octavos, amicolarma dedit,

sapis. quamvis et voce paternalfingeris ad rectum et per te sapis,

sapit. et sapit et mecum facit et love iudicat aequo.

sapiunt. vesanum tetigisse timent fugiuntọue poetam/qui sapiunt;

saporem. non Siculae dapes/dulcem elaborabunt saporem. integrum perdunt lino vitiata saporem.

saporum. non prius exacta tenui ratione saporum.

Sappho. temperat Archilochi musan pede mascula Sappho.

Sappho. Acolis fidibus querentem Sappho

sarcina. si te forte meae gravis uret sarcina chartae,

sarculo. gaudentem patrios findere sarculo agros

Sardiniae. non opimae! Sardiniac segetes feracis.
Epist.1.2.3.4

Episi.2.1.24

Epist.1.2..40

Epist.I.4.9

Epist.I.15.45

Epist.I.18.27

Epist.2.2.128

Epist.2.2.1.4 I

Ars Poel.3og

Ars Poll.2I 2

Curm.I.IIO

Epist.1.12.15

Sirm.1.9.34

Carm.1.7.17

Serm.1.3.1 2.7

Sirm.1.3 127

Sirm.1.3.128

Sorm.1.3.132

Serm.1.t.I 5

Serm.2.1.17

Serm.2.2.3

Serm.2.2.03

Serm.2.2.III

Serm 2.3.97

Sirm.2.4.44

Serm.2.7.73

Serm.2.7.83

Serm.2.8.60

Epist.1.1.106

Epist.1.0.15

Epist.1.7.22

Epist.I.I0.30

Epist.I.16.73

Epist.2.1.18

Epist.2.1.50

rar.Sirm.1.1.38

Serm.2.3.46

Epist.1.4.5

Epist.1.10.20

Serm.2.3.35

Carm.2.10.22

Carm.4.9.48

Epist.r. 0.44

Sern.2.1.72

Epist.1.1.t1

Epist.1.2.I 7

Epist.1.3.27

Ars Poet. 396

Carm.1.3. 2

Carm.3.28.t

Serm.2.3.52

Scrm.2.3.265

Epist.2.2. 153

zar.Epist.1.7.40

Carm.3.21.1.

Serm.2.3.56

Sirm.2.3.296

Ars Foet. 367

Epist.2.1.68

Ars Poet. $45^{\circ}$

Carm.3.1.19

Serm.2.4.54

Sirm.2.4.30

Epist.1.I9.28

Carm.2.\$3.25

Epist.1.13.6

Carm.1.1.1t

Carm.1.31.t 


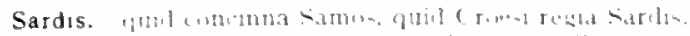

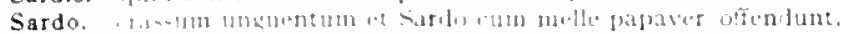

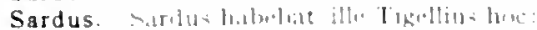

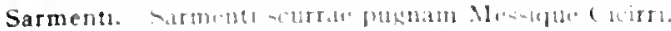

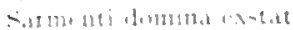

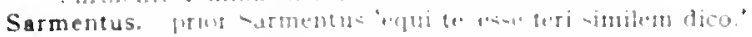

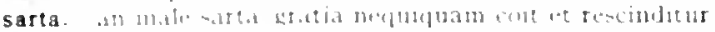

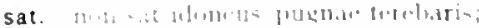

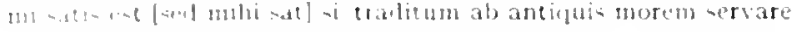
[1, $-1,111]$

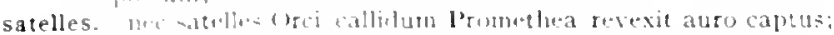

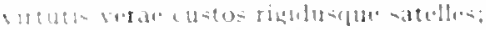

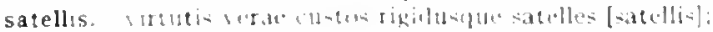

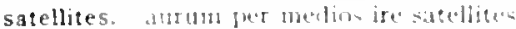

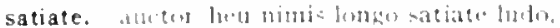

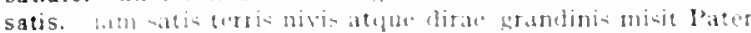

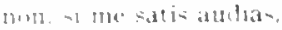

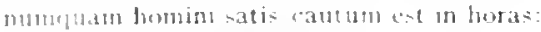

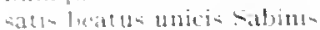

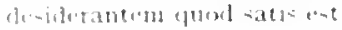

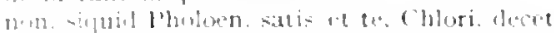

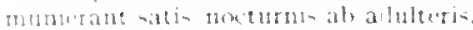

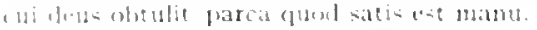

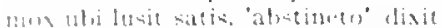

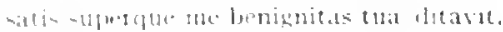

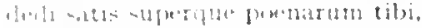

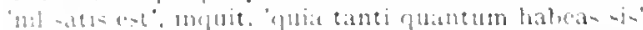

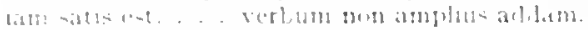

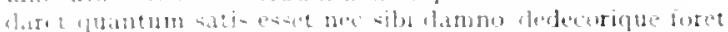

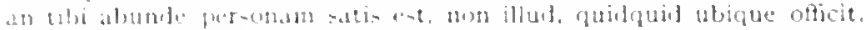
"ustarn"

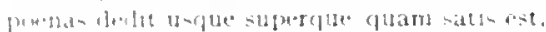

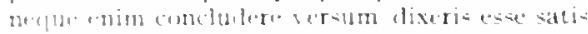

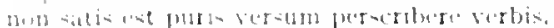

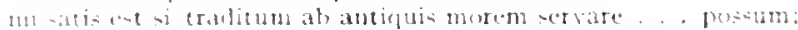

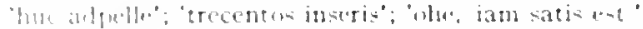

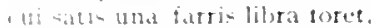

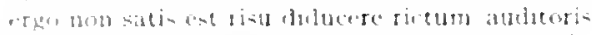

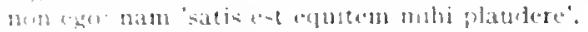

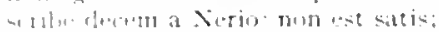

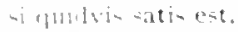

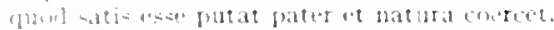

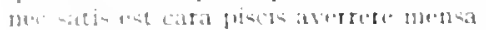

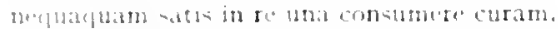

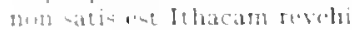

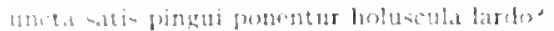

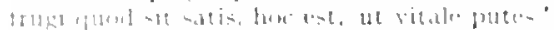

grod tot

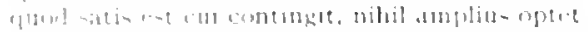

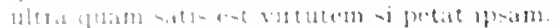

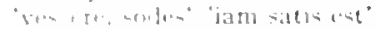

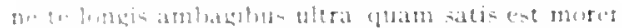

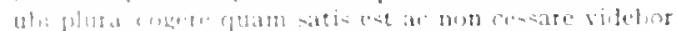

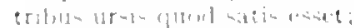

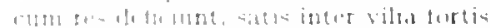

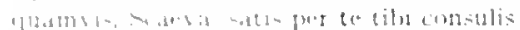

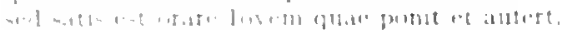

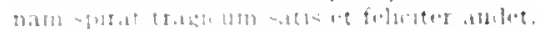

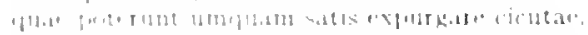

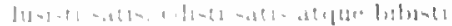

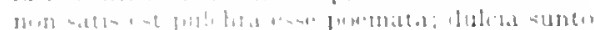

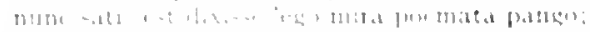

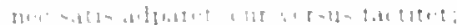

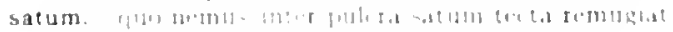

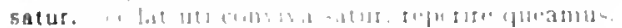

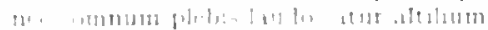

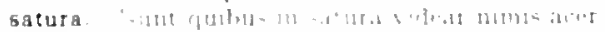

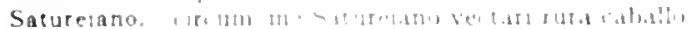

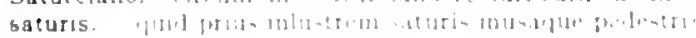

1.pist 1.11:2

Ars Peiti.3:5

Sirm 133

sirm.1.5.52

Siend s 5.55

Siermi 15 is

L fist 1.3 it

(i) 21120

ior.stm.8. 1 th

(arm:2.13 34

t.pi:d 1.1 1 ;

isr. I fist. I I. I

Carm.3.10.9

(arm.t $=37$

(iorm.1 2.1

Carm.1.13:5

(arm 2.13 .13

(iarm: 2 เ8. 14

Carm-3 35

(arm.3.15)

(iarm: $3 \cdot 14.3$

(arm. 3.14. I4

(arm.3.27)

fipol 1.31

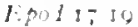

Sirm 1.1.12

Sirthe 1813

sirm.1.252

Sirm, 1.2.11

Sirml.210

arm $1: 11$

sirmat 15

Sirmation

Sirm.1.5.

Sirmis. 1.09

Somilo

Serm.1.10=0

Sirm 2.310

Serm.2.127

Serm. $2.31-6$

Sirm.2337

sirn $2.4: 4$

Sirm 25.1

Sirm. 21 it

sirm: = 3

lpot | il

fipll 1.2.40

bist intu

Frist t.7. 10

I. pirti $1-83$

I.put + 80.4 .

l. pist 1.153 .5

lipte 1.1530

Ppid a 17.

EProt IS at

I pist.z. Ifert

lipul $=253$

1.pist 2 23:

Ars Pintas

Arslint in

Ars lout dio

(iarm 3.100

Sicrm1118

Fostis 3

Sirm 211

Sorm a (1)

Serm 21:17 
Saturnalibus. at ipsis/Saturnalibus huc fugisti.

S.rm.2.3.5

Saturni, fulgens contremuit domus| Saturni veteris:

(a)m.2.12.9

Saturnius. sic horridus ille fletuxit numerus Saturnius

Saturno. Le lovis inpio tutela Saturno refulgens/eripuit

Saturso. antis humane pater atque custos, orte Saturno.

Satyris. wt male sanos adscripsit l,iber Satyis Fauniclue poetas.

intuserit Satyris paulum purlibunda protervis.

Satyris. Nympharumque leves cum Satyris chori

Satyrorum. auris capripedum Satyrorum acuta.

non... dominantia nomina solum! verbaque, Piones, Satyrorum scriptor aniabo

Satyros, mox etiam agrestis Satyros nulavit. ital commendare dicacis conveniet satyros.

Satyrum. qui nune Satyrum, nume agrestem Cyelopal moretut.

saucius. et malus celeri saucius Africo nec vir I'ieria paelice sancius

savio, manum puella savio opponat tuo,

saxa. Viticae cubantis levia promuere saxa. sive te rupes et acuta leto|saxa delectant, -imul imis saxa renarint vadis levata.

saxa, et perrumpere amat saxa potentius/ictu fulmineo: mon sexa nudis surdiora navitis| Negtunus alto tuntit hibernua salo. per mare pauperiem tugiens, per satia, per ignia): ego laurlu ruris amoeni|rivos et musco circumlita saxa nemusque. rilent vicini glaebas et saxa moventeru saxa movert sono testudinis

saxis. me diconte cavis inpositam ilicrm saxis, atque subimus inpositum saxis late candentibus Anxur. atrue subimus inpositum saxis late [late saxis] candentibus Anxur.

saxis. retluit saxis agitatus unor.

vos turlo vicatim hinc et hinc saxis petens

populum si caedere saxis/incipias

saxo. summam patrimoni insculpere saxo

saxo. deorum templa novo decorare saxo.

hic caxo, liquidis ille coloribus|sollers

retinacula mulae nauta piger saxo religat stertitque supinus. deicere de saxn civis aut tradere Caulmo?'

saxum. fiet aper, modo avis. modo saxum et, cum volet, arbor. saxum. optat supreno collocare Sisyphus in monte saxum;

scaberet. in wrsu faciendo'saepe caput scaberet.

scabiem. cum tu inter scabiem tantam el contagia luci

scabies. occupet extremum scalsies; mihi turpe relinqui est ut mala quem scabies aut morbus regius urget

scabrum. quem simul arlapexit scalorum intonsumque plilippus.

scaena. quin ubi se a volgo et scauma in secreta remorant actor cum stetit in scatna, concurrit dextera laevae.

scaenae, chlanydas. . si posset centum scaenat fraphere rogatus, siquicl incxpertum scaenae conmittis

scaenam. quem tulit ad scaenam ventoso Gioria curru. non tamen intus' ligna geri promes in scaenam

Enni in scaenam misos cum magno pondere versus

scaenis, aut agitur res in scaenis aut acta refertur.

Scaeva. quamvis Scaeva, satis per te tili consulis

Scaevae, Scavere vivacen crede nepoti matren:

scaevum. mercemut servom, qui dictet nomina, laesom [scaevun] qui forlicet latus

scalis. in scalis latuit metuens pendentis labenae' -

scalpe. nostri memorem sepulcrolscalpe querelam."

scalpere. scalpere tertam unguibus.. coeperunt;

scalpra, emat. . si scalpra et formas non sutur,

scalptum. olim nam quaererc anabam... quid sculptum [scalptum] infabre, quil fusum durius esset.

Scamandri. quan frigida parvi|findunt Scamandri flumina.

scamnum. cum faber, incertus samnum laceretne I'inpum,

scandens. neque ut superni villa canders [scandens\} Tusculi Circaea tangat muenia:

scanderet. cum parentis regua per arfuom colors gigantum scanderet inpia,

scandet. dum Capitolium scandet cum tacita virgine pontifex.

lifist.2.1.158

Corm.2.17.23

Carm.1.I2.50

Iepist.1.19.t

Ars l'oct.233

Carm.1, $1.3 \mathrm{a}$

(arm.2.10.4

Ars Poit.235

Ars Pixt.22 I

Ars Podt.zat

Epist.2.2.125

(itrm. I. $1+5$

(arm.3.10.15

fipot.3.21

Carm-1 I7.12

Carm.3.27.2

I. pod 10.25

Cirm 3. [0.10

Epoil. 7 - $5+$

Lipist.1.1.t6

Epist 1.10.7

Inist. I. 14.39

- Irs Poel.395

Cirm-3.1.315

Sirm.1.5.26

a'ar.Serm. 5.5 .26

Curm.1.12.29

Epod.5.97

Serm.2.3.128

Sorm.2.3.40

Corm.2.15.20

Carmals.7

Serm.t. 99

Serm. 1.6.39

S.rm.2.3.73

f.pod.1. 7.90

Sirm.t.10.7I

Epist r. 12.14

Ars loct.ti7

Ars $I^{2}(0, t .+53$

Epist. I . 7.00

Serm.2.1.T

Enist.2.1.205

Epist i b.ts

Ars loet.125

Inpist.2.1.17

Ars Port.183

Ars fort.200

Ars Poet. 79

Epist.1.17. I

Sirm.2.1.53

coni. Epist. r.6.50

Epist.2.2.15

Carm.3.11.52

Sirm.1.8.20

Sirm.2.3.100

trar.Serm.2.3.22

Expod.13.It

Srm. 1.8 .2

gar. I pod.1.2)

Carm.2.19.22

(a)m.3.30.9 


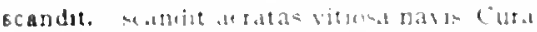

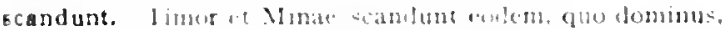

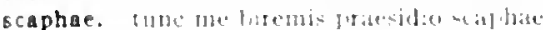

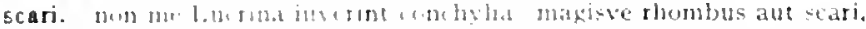

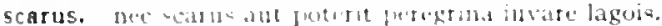

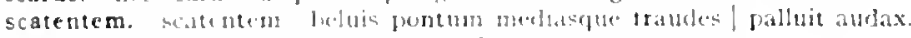

Scauros. Rekulum et scatures . . Tell sarm

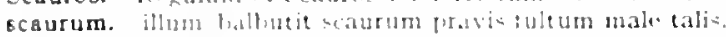

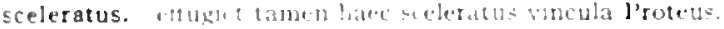

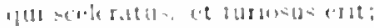

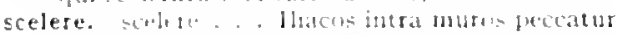

sceleris. integer vita scelerispue purbs

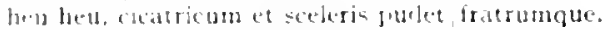

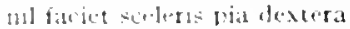

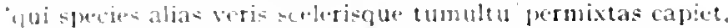

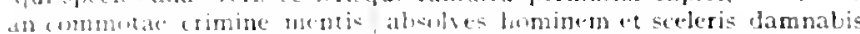

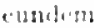

scelerum. monertam si bene parenited.

scelesta. crede non illam tibi de scelental plebe dilectam

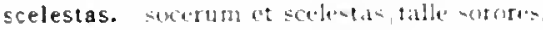

scelesti. guro, guo scolesti ruttis?

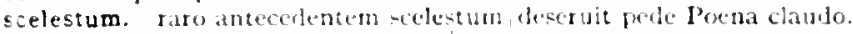

scelus. acciba fata komanos indulscelusque traternat necis.

scelus. cui dabie pat is scelus cxpiameli luppoter?

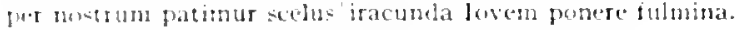

isteliatt 1, ide sechus atque notas virginum joenas

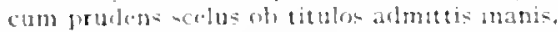

Scerani. "Scetani dismimilis -in."

sci. continta montes, ni [ori] dissocientur upaca valle,

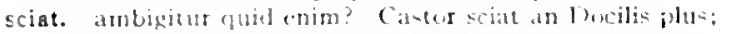

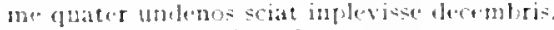

muabor, si scies [-iat] inter-, nowere mandacm veramgue beatus atmicum.

sciebat. atıui sciebat, quat" sbi barbaru tortor pararet:

sciens. urgent inpardi te Salaminius Tever, te sthemelds, sciensipugnae guanois non alius flectere equom scienc

sciens. dulcis derta morlos ett cithasate selerns.

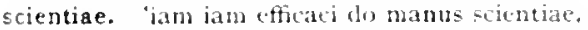

scientioris. G)lutus ambulat vemeficac semeris cambine.

sciet. mirabur, si ciet inter- nocere mesolacem verumque beatus andicum.

scilicet. saevis Liburnis scilice invidens pronta deduci

unda, scilicet cmmibus. . enavipanda.

aturo repersass sciliect acrior miles redibit:

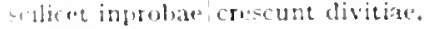

divite me scilicet artiun

cilinet chlitos pacriacque patrisque latini.

elliect mi aterjuos vistuti atque etus amicis.

robia silice illis maiorem natura molum dedit. he breve frombe:

-coliene at jolatus quos fert Aerippa feras tu.

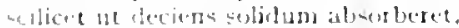

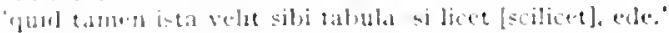

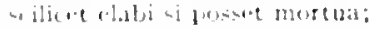

ut unum erilicet rerregii mastiale-th alticue silenti.

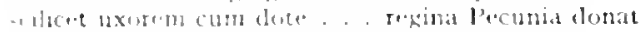

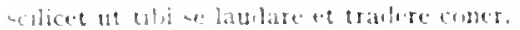

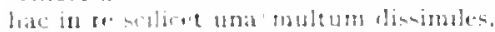

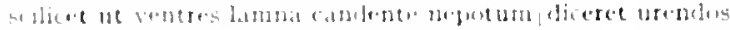

sollicet. 14 mon est milu prma fietes

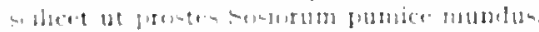

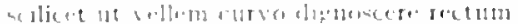

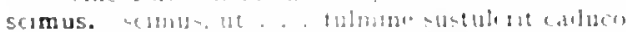

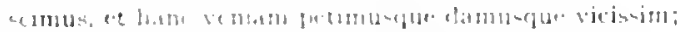

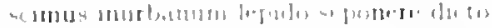

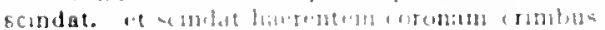

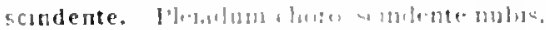

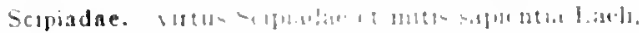

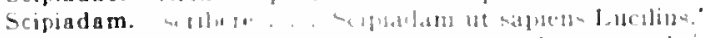

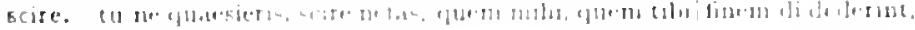

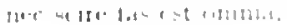

Carm.2.16.21

Carm.3.1.38

Carm.3 2912

E:por1.2.50

Serm.2.2 22

Carm.3.27.26

Carm.1.12.37

Sorm.1.3.

Sorm.2.3.71

Som.2.3221

Lipist.1.2.15

Carm.1.22.1

Carm.1.35.33

Sirm.2.1.54

Sim.2.3.208

Serm.2.3.270

Carn:-3.2.5.50

Carm.2.47

Curm.3.11.30

Epod.7.1

Carm.3.2.3I

Epod.7.18

Corm.1.2.29

Carm.1.3.39

Curm.3.11.25

Serm.2.3.212

Serm.1.4.112

ar. Epist.1.16.5

Epist.1.18.10

Epist.1.20.27

:ir.Ars Pod.424

Carm.3.5.79

Carm.1.15.24

Curm.3.7.25

Carm.3.9.10

Epod.17.1

Epod.5.72

Ars I'ont.424

Carm.1.37.30

Carm.2.14.9

Corm.3.5.25

Carm.3.24.02

Corm.4.8.5

Serm.1.10.27

Sirm.2.1.70

Sirm.2.2.3"

Sorm 2.3.185

Serm.2.32.49

a ar.Sorm.2.5.6

Serm.2.5.87

Serm.2.0.58

Epist.1.0.30

Fist.1 0.3

Espist.1.10.2

EPust.1.15.3e

Lisist.1.18.10

I.pitt.1.20.2

L.p.36.2.2.47

(arm 3.442

Ars liud 11

Ars linel 273

Corm.1.17.27

(arm.11.822

Sका $2.17=$

Serm.2 17

Corm.1.11.1

curm.4.22 
omnis /gestiet a furno redeuntis scire lacuque

Sirm. I.4.37

(nam te|scire, deos quoniam propius contingis, oportet), . . . Serm.2.0.52

iurantem me scire nihil mirantur . . . . . . . . . Sorm.2.0.57

quibus terrarun militet oris/Claudius Augusti privignus, scire laboro. . Epist.1.3.2

scire velis, mea cur ingratus opuscula lector/laudet ametque domi. - Epist.r.19.35

scire velim. chartis pretium quotus arroget annus.

illud, quod mecum ignorat, solus volt scire videri.

Epist.2.1.35

tamen iden scire volam.

sciret. 'si sciret regibus uti, | fastidiret holus, qui me notat.'
scis. quis scit [qui scis] an adiciant hodiernac crastina summac/tempora di

$$
\text { superi? }
$$

et propero quo scis."

scis. Lebedus quid sit: Gabiis desertior atque $\mid$ Fidenis vicus;

me constare nihi scis et discedere tristem

quem scis inmunem Cinarae placuisse rapaci,

quamvis, . . scis, |quo tandem pacto deceat maioribus uti.

scis, quo clamore coronae / proelia sustineas campestria; .

scis in breve te cogi, cum plenus languet amator.

et fortasse cupressum|scis simulare:

qui scis, an prudens huc se deiecerit

scit. quis scit an adiciant hodiernae crastina summae/tempora.

quam scit uterque, libens, censebo, exerceat artem.

scit Genius, natale comes qui temperat astrum.

reddere qui voces iam scit puer

ille profecto/reddere personae scit convenientia cuique. .

nec scit quantum Cascellius Aulus,

scitari. 'scitari libet ex ipso quodcumque refers:

scitius. pingimus atque | psallimus et luctamur Achivis doctius [scitius] unctis.

scobe. vilibus in scopis, in mappis, in scobe quantus/consistit sumptus?.

Scopas. quas aut Parrhasius protulit aut Scopas.

scopis. vilibus in scopis, in mappis, in scobe quantus/consistit sumptus?

scopulis. frustra: nam scopulis surdior Icari

scopulos. qui vidit ... infamis scopulos Acroceraunia?

Scorpios. seu Libra seu me Scorpios adspicit/formidolosus. .

scortator. scortator erit: cave te roget;

scorto. scorto postponet honestum ofticium.

scortum. quis devium scortum eliciet domo'Lyden?

scriba. scriba quod esset.|nilo deterius dominae ius esse:

plerumque recoctus/scriba ex quinqueviro corvom deludet hiantem

scribae. insani ridentes praemia scribae,

scribae. nusa rogata refer, comiti scribaeque Neronis. .

scribae. scribae . . te orabant lodie meminisses, Quinte. reverti.'

scribam. quisquis erit vitae scribam color.'

scribam. idcircone vager scribamque licenter?

scribare. scribare secundus|heres

scribat. siqui scribat uti nos/sermoni propiora.

scribe. scribe decen a Nerio: non est satis;

scribe tui gregis hunc et fortem crede bonumque.

scribendi. garrulus atque piger scribendi ferre laborem. scribendi recte: nam ut multum, nil moror. suspectum genus hoc scribendi.

aut si tantus amor scribendi te rapit.

calet uno scribendi studio:

scribendi recte sapere est et principium et fons.

scribens. munus et officium, til scribens ipse, docebo:

scribentes. verum gaudent scribentes et se venerantur

scribere. nihil me sicut antea iuvat' scribere versiculos rideamus uter plus scribere possit."

nam quis me scribere plures aut citius possit versus?

melius quod scribere possem.

attamen et iustum poteras et scribere fortem.

quis sibi res gestas Augu-ti scribere sumit?

scribere quod Cassi Parmensis opuscula vincat.

scribere te nobis. tibi nos adcredere par est.

ipse ego qui nulios me adfirmo scribere versus,

commorlus ultro arcessas et egere vetes et scribere cogas.

ni melius dormire putern quan scribere versus?

Epist.2.1.87

Epist.2.2.193

Epist.1.17.14

2ar.Carm.4.7.I 7

Serm.1.9.40

Epist.1.I1.7

Epist.1.14.16

Epist.1.14.33

Epist.1.17.1

Epist.r.I 8.53

Epist.1.20.7

Ars Poet.zo

Ars Pott.46z

Carm.4.7.17

Epist.I.I 4.44

Epist.2.2.187

Ars Poet. 58

Ars Poet.3 6

Ars Poct.37 I

Epist.1.7.60

iar.Epist.2.I.33

Serm.2.4.8I

Carm.4.8.0

Serm.2.4.8 I

Carm.3.7.2 I

Carm.I.3.20

Carm.2.I7.I 7

Serm.2.5.75

Epist.I.I8.34

Carm.2.II.2I

Sirm.1.5.66

Serm.2.5.56

Serm.1.5.35

Epist.1.8.2

Sirm.2.6.36

Sirm.2.1.00

Ars Poet. 265

Sirm.2.5.48

Serm. I.4.41

Sirm.2.3.69

Epist.1.9.13

Sirm.I.4.I 2

Sorm.I.4.I3

Serm.I.4.65

Sorm.2.I. Io

Epist.2.1.109

Ars Poet.zog

Ars Poet.306

Epist.2.2.107

Epod.I I. 2

Sirm.1.4. I6

Strm.1.9.23

Sirm.1.I0.47

Serm.2.1.16

Epist.1.3.7

Epist.1.4.3

Epist.1 15.25

Epist.2.1.III

Epist.2.1.228

Efist.2.2.54

Epist.2.2.66 


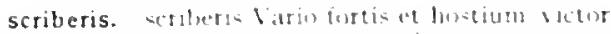

Carmidis

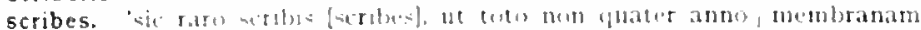
puikeats.

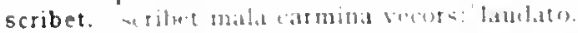

Fur Serm.231

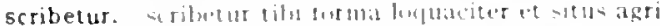

Torm.2.5.74

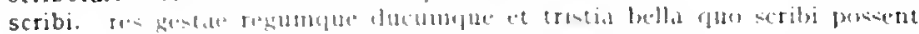

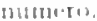

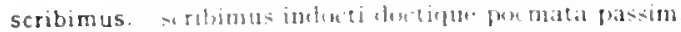

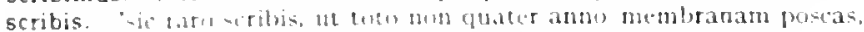

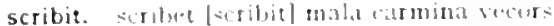

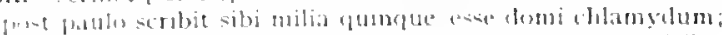

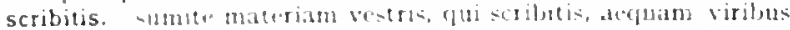

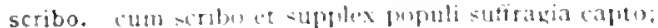

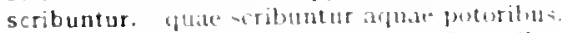

scrinia. ne mu ('rispini - trinda lippt conpilasse putes,

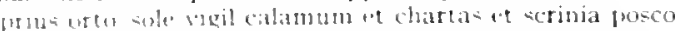

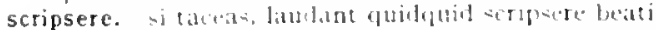

scripseris. sipuat amen slim stripseris.

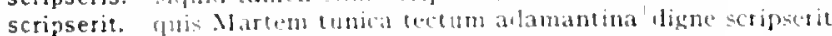

scripsisse, aume seripsisse ducentus ante cibum versus.

scripsit, his. ego puatsunc, olim quae scripsit luscilius.

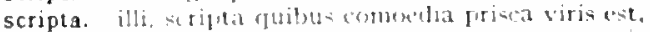

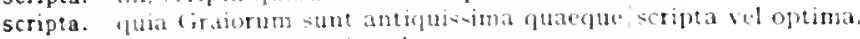

scripta. enm mea meame ecripta lickat

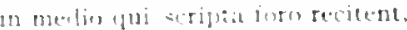

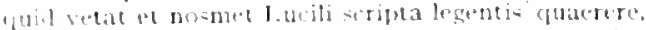

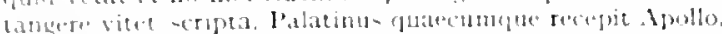

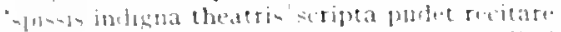

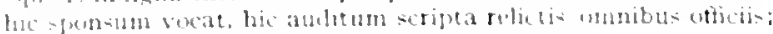

scripto, fote atte-ripte quat me tacitum iust.

scriptor. Fripter abhine annos centem gut decielit.

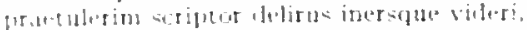

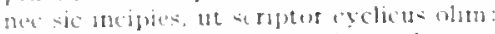

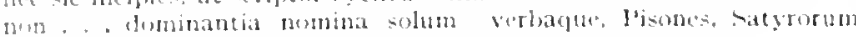
oripter amabo

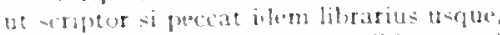

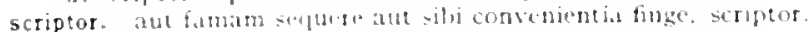

scriptore. what cum soriptere mere. deferat in vicum

scriptorem. Trutani belli stiptorem, Naxime lolli,

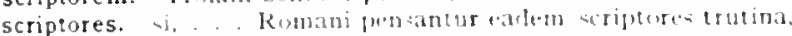

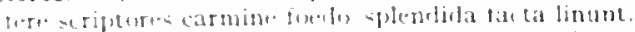

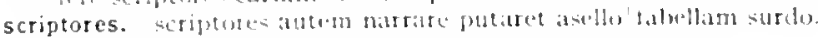

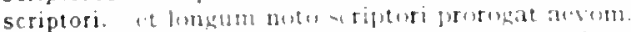

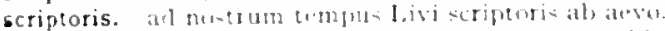

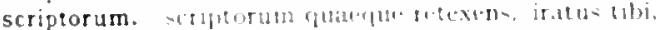

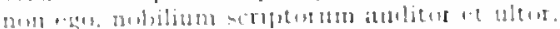

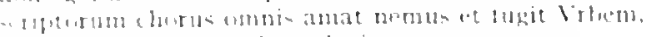

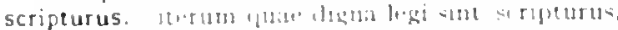

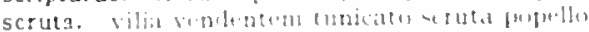

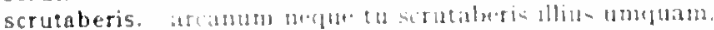

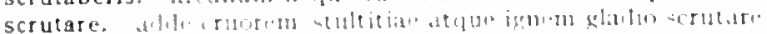

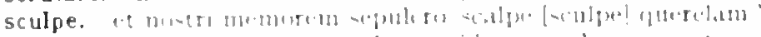

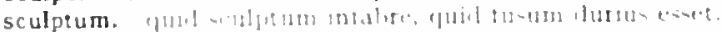

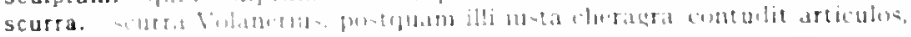

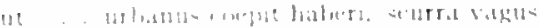

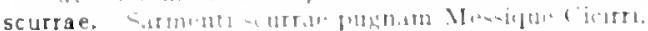

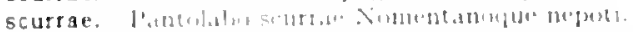

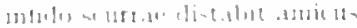

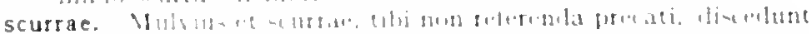

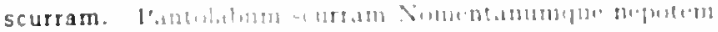

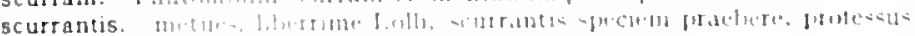
a allit 11 an

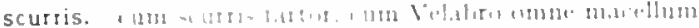

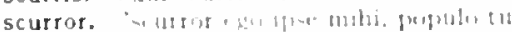

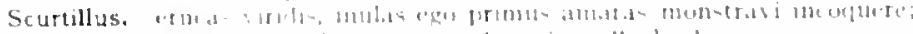

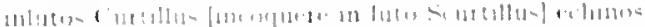

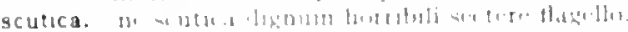

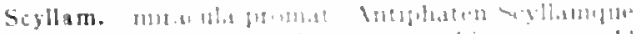

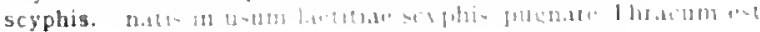

I:pist 1.1P.

Irs Pined - is

liptit.21.117

Sirm.2.3.1

iar Sirm.25 57

IEpist 1. 13

irs Prid 34

IEpist 2.2.103

I.post.1.10.3

Sirm.1 1120

1.pist.2.1.113

I. prot. 2.2.108

Ars Pote.38:

Cirm.t.1 t

Sirm.1.10.10

Sirm 1.57

Sirm.1.1011

Exist 2.120

Serm.1.423

Serm.1.45

Sirmidas se?

1.pist. 317

l.pist.1.10 . 2

1.pist.2.217

Sirm.1.123

lepist.2.1.3\%

1. pist.2.2 20

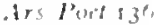

Ars linete.35

Ars loé3:3:

Ars Pues 320

1. pist.z.l zas

lipist. 1 = 1

lifist.21 311

fipist.2.1.23ts

lipiste 1100

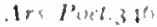

lpist.2.12

Sirm 2.32

l.pest.1.10.39

lipit.2.27;

Sirm] [1], ;

I ped 1 - e.5

1.pistie is 37

sirm 2327

:Is (arm 311.52

serm 2322

Sirm.zis 15

d.pont 1.1528

sirmis 552

Sirmes 611

lapist a 1 s

serm.2 $7.3 p$

Sipm $=122$

l.pold in :

sirm 2320

l.pist a 17.0

;ar..trm 2.8 :

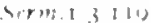

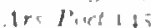

citront 127 ? 
scyphos. capaciores adier huc, pucr, scyphos

Scythae. te Dacus asper, te profugi Scythae... metuont .

Lipod.9.33

Carm. I-35.9

iam Scythae laxo meditantur arculcedere campis.

Carm.3.8.23

campestres melius Scythae. . . vivont

Carm.3.24.9

jam Scythe responsa petunt, superbi/nuper. et Indi.

Scythas. Venus/Cyprum desernit nec patitur scytuas... dicere

Scythen. quis Parthum pareat, quis gelidum scythen.

Scythes. Scythes, Hirpine Quinte, cogitet Hadria divisus obiecto, te profugus Serthes miratur.

Scythicum. et Scythicum inviolatus amnem.

(urm.Sacc.55

Curm.1.19.10

Carm.t.5.25

C'arm-2.I1.I

Carm.4.14.42

(itrm-3.4.36

se. Carm.1.2.17;2.10.20;3.5.33; 4.9.38; Sirm.1.1.21; 1.I.96; I.1.98; I.1.I99; 1.I.III; I.1.II7; Sim.1.2.18; I.2.22; 1.2.41; I.2.53; 1.2.130; 1.6.120; 1.10.9; 2.1.71; 2.2.75; 2.3.198; Serm.2.3.277; $2.3 .317 ; 2.3 .319 ; 2.4 .34 ; 2.4 .39 ; 2.7 .11 ; 2.7 .32 ; 2.7 .63 ; 2.7 .71 ;$ EPist.1.7.98; Epist.1.8.13; I.9.3; I.I4.13; I.10.04; 1.18.7; 1.18.27; 2.1.14; 2.1.214; 2.1.239; 2.1.201; Epist.2.2.107; 2.2.129; Ars Poet.402

se. Carm.3.5.43; Sorm.I.I.102; $1.10 .55 ; 2.1 .49 ; 2.2 .70 ; 2.3 .260 ; 2.7 .16 ; 2.7 .86 ;$ Epist.1.I.97; Epist.1.7.02; 2.1.245; Ars Poet.174i 175

secanda. tu secanda marmora locas sub ipsum funis

secandi. cotis, achtum reddere quae ferrum valet exsors ipsa secandi;

secantur. quo multae magnaeque secantur iudice lites,

secat. ridiculum acri, fortius et melius magnas plerumque secat res.

secer. luctantis acuto se secer ungui,

secernere. nec natura potest iusto secernere iniquom,

fuit baec sapientia quondam publica privatis secernere.

secernis. qui turpi secernis honestum| non patre praeclaro,

secernit. qua merlius liquor secernit Europen ab Afro,

secernunt. me gelidum nemus, Nympharumque leves cum Satyis chori secernunt populo.

secet. Myrtoum pavidus nauta secet mare.

secreta. stridere secreta divisos aure susurros.'

secreta. quin ubi se a volgo et scaena in secreta remorant

secreta petit loca, balnea vitat.

secreto. "certe nescio quid secreto velle loqui te aiebas mecun."

secretum. quid pure tranquillet. . secretum iter et tallentis semita vitae.

secrevit. I uppiter illa piae secrevit litora genti.

sectabitur. neque te quisquan stipator ineptuin praeter Crispinun sectabitur,

fecundae leporis sapiens sectabitur armos. .

sectamur. cervi. Iuporum praeda rapacium. 'sectamur ultro

sectantem. sectantem levia nervi deficiunt animique;

sectari. nitte sectari, roza quo locorum sera moretur.

quare, ne paeniteat te. / desint sectari matronas,

sectarier. quare, ne pacnitcat te. desine stetari matronas [matronas sectarier],

sectatur. nomina sectatur modo sumpta vest virili sub patribus duris tironum.

leporem verator ut aita in nive sectetur lsectaturl, positum sic tangere nolit"

sectatus. Leporem sectatus equove laseus ab indomito

sectere. no scutica dignum horribili sectert flagello.

sectetur. 'leporem renator ut alta in nive secturur.

sectis. sectic in iuvenes nuguibus acrium

sectis. hoc uli confusum sectis inferbuit herbis

secto. non hydra secto corpore firmior

sectum. prave sectum stomacheris ob unguc:m

sectus. tua sectuc orbis nomina ducet."

sectus llagellis hic triumviralibus

secuisse. autliet riris acuisate [secuisse] formm.

secunda. quorm piis secunda rate me datur 1 uga.

secunda. secunda ratem ocupare quikl moramm alite?

tutior at quanto metx in classe secunda.

non ut de sede secunda|cederet aut quarta sncialiter.

secundae. ingenim res, adversac nudare solent, celare scennalat." quem res plus nimio delectavere secunflat.

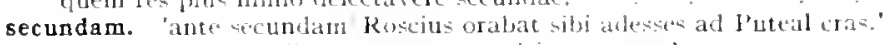

secundas. magnum atiugorem. proset qui ferto secundas, tum pensilis uta setudac et nux ormabat mensas partis minum tractare secumbla;

Carm.2.18.1 7

Ars Poet.305

Eptst.1.I6.42

Serm.1.10.15

Epist.i.i9.40

Sirm.I.3.II 3

Ars Poit.397

Sirm.1.0.63

Carm.3.3.47

Carm.I.I.32

Carm.I.I It

Serm.2.8.78

Sirm.2.I.7 I

Ars Poet. 298

Serm. I.Q.67

Epist.I.1 8.103

Lpod.16.03

Sirm.1.3.1 39

Serm.2.7.t

(arm.4.4.5 I

Ars Poel.ze

Carm.I.38.3

Sirm.1.2.78

iar.Serm. I. 2.78

Sirm.1.2.I6

sor. Sirm. I.2.100

Sim.2.2.0

Sirm.1.3.119

Serm.1.2.106)

carm.t.t.18

Serm.2.4.07

Camm.t.oI

Epist.r.I.IO4

(urm.3.27.75

Lpod.q. I I

cmicarm.1.2.21

Fipod.10.6e)

i. pudentr.23

Serm.1.2.47

drs poet.257

serm.28.4

I.pist. I. Iu. 3n

Serm.2.10.34

Sirm.1.0.40

Serm.2.2.I I I

d.pist.I.IS.I4 
secundi. Jexe pitce habuere bonar venteque secundi.

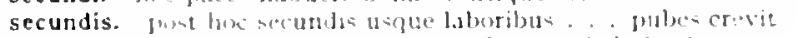

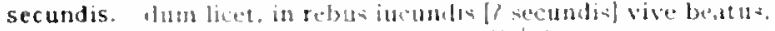

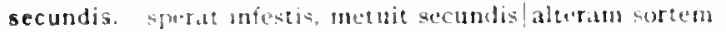

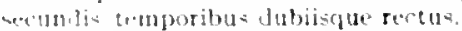

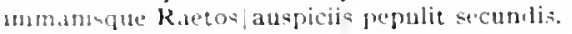

secundo. tu recundo Cacsire regrices.

contraher vento nimium secundolturgida vela

qual proma secundo cera velit versuli

rubeent tictis rerum Balatrone secundo.

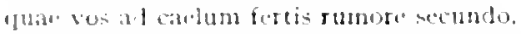

bivit siliguis det panese secundo:

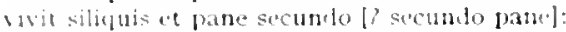

non alginut tumintis velis aquilone seeunito:

secundo. dum favet Nox et benus, i secundolomine

secundes. Brlli secundos redelidit ovitus

secundum. Hoc viget quidquant smble aut secondum

secundum. sed ut secundum veta l'arthorum sha / Vibs laec periret

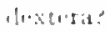

secundus. Cur diax, heros ah Achlle secundus, putescit.

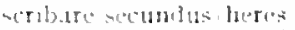

secures. Wic ponite lucida|funalia et vertis et farcus [rectis securesque] (3) pountis foribu= minaci:

securi. Ambonia securi dextrats obarmet.

at bunc libertat securj jivisit molinm,

securim. funtiticum securis [securim]/cervice tinguet:

securis. listur quo tara securic.

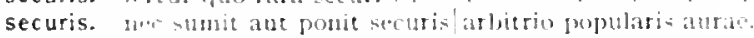

puntibum securis cervice tinguct:

manus potentis Medus Albanasque tinct securis.

securum. natmilue aleos didici securum agere aevom laudas securum holus

securus. "fubl liridaten terreat, unice/securus.

qualj jorfundat piscis securus olivo.

just hoc securus. carlat an recto stce fabuia talo.

ille forit pretium poenae securus. opinor.

secus. non socus in bonis ab insolenti temperatam lactitia.

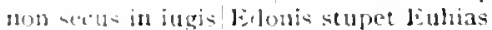

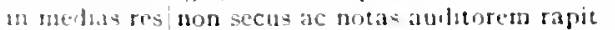

secuta. pute hac ab orno penduhum zom bene te secuta e- lidere collum.

secuti. Remtle secuti mazomomo pueri magno liscerpta ferentes/membra artuis

secutus. invertunt Alifanis vinaria tota | Vibidius Batiltoque secutis

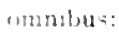

secutus. hine onmis pronlet Lucilias, hosce secutus numerua animosque secutus Archilochi.

Cistist.1.102

Corren.4.4.45

? inar. Sermiz.0.05

Carm.2.ro.13

Carm.4.9.35

Cormatato

Corm.1.12.5:

Cism.2.10.23

Sirm.2.5.53

Sirm.2.8.83

I:pist.1.109

Epist.2.1.123

P tur.lipist.2.1.123

Epist.2.2.201

Curm.311.50

Carm..t 14.38

Curm.1.12.18

Lipodi.9

Sorm.2.3.193

Serm.2.5.48

cunticarm-3.20.7

(arm.1. 1.20

Serm.1.1.09)

iar.Carm.3.23.12

Serm.1.7.27

carm.3.2.19

Carm.3.23.12

Curm.tosect.54

Sorm. 1.5.10I

Serm.2.7.30

Carm. I.2pses

S.rm.2.4.50

Epist.2.1.19

Fpist.2.17

Corm.2.3.2

Carm.3.258

Ars Iivel. I

Carm 327.50

STM.2.S.s.

Sermi2.8.40

Sirm. 1.0

litist.1.10.24

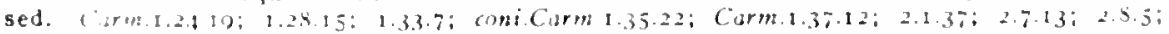

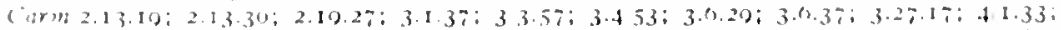

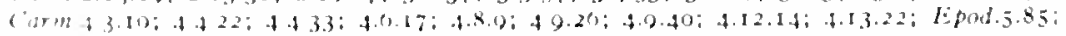

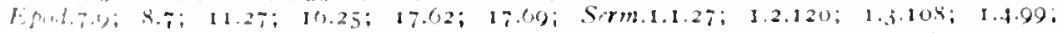

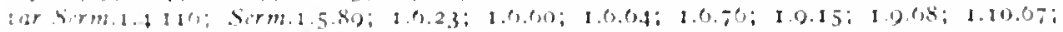

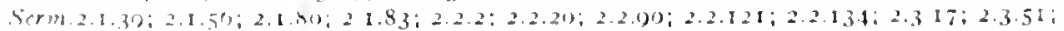

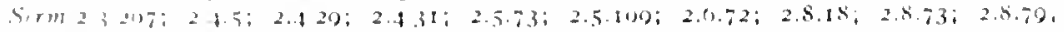

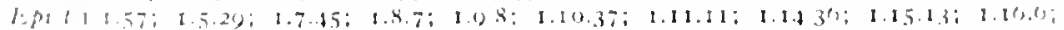

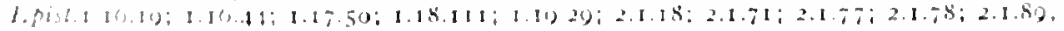

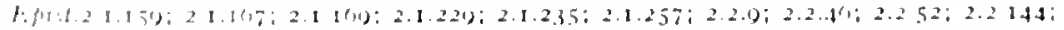

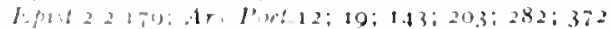

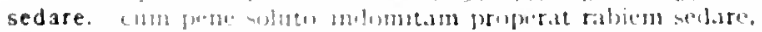

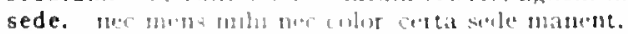

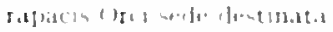

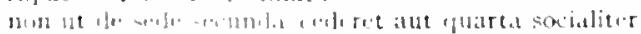

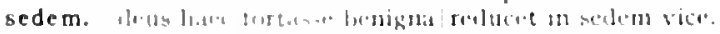

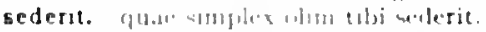

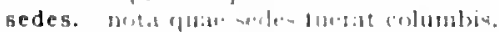

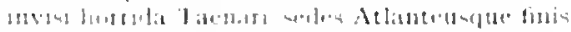

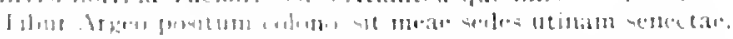

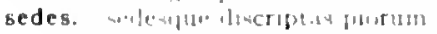

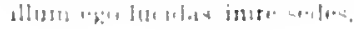

$\operatorname{liphit} 120$

Lisis : 18.00

(arm, 1, 1, (1, )

(i.rm.2.15.30

irs loct. 25

l. $p 01.135$

Serm.2.2.73

(.rm 1.2 .10

( arm.t.34 II

(arm 2.0 .0

(inrm.2.1323

(iarm 3339 
si priores Maeonius tenet|sedes Homerus.

sedet. post equiten sedet atra Cura.

sedilibusque magnus in primis eques/Othone contempto sedet.

'at Novius collega gradu post me sedet uno:

sedibus. tu pias laetis animas reponis/sedibus

sedilia. nondum spissa nimis complere sedilia flatu:

sedilious. sedilibusque magnus in primis eques/Othone contempto sedet.

sedit. aedit qui timuit, ne non succederet.

seditione. seditione. . . lliacos intra muros peccatur et extra.

seditionibus. nostrisque ductum seditionibus/bellum resedit; paene occupatam seditionibus|delevit Trbem

sedula. matrona potens an sedula nutrix.

sedulitas. officiosaque sedulitas et opella forensis adducit febris sedulitas autem stulte quem diligit urget.

sedulus. simplici myrto nihil adlabores|sedulus curo:

ubi sedulus hospes | paene macros arsit

odiumque libellis/sedulus inportes opera velzemente minister.

exanimat lentus spectator, sedulus intat:

seges. nee sterilen seges/robiginem

baec seges ingratos tulit et feret onmibus annis.

spein mentita seges, bos est enectus arando:

segetes. non opimae|Sardiniae segetes feracis.

cum segetes occat tibi mox frumenta daturus.

segetis. segetis certa files meae

segnes. quia tardius irent/propter onus segnes.

segnes. segnesque nodum solvere Gratiae

segni. neque pugno neque segni pede victus.

segnis. segnis ego, indignus qui tantum possideam:

segnius. segnius irritant animos demissa per aurem

selectis. (unum ex iudicibus selectis obiciebat)

sellis. honestoslfascibus et sellis nollem mihi sumere.

semel. quam virga semel horrida

et calcanda semel via leti.

nec vera virtus, cum semel excidit,

regina, sublimi tlagello|tange Chloen semel arrogantem.

quod fugiens semel bora vexit.

"io triumpbe"| non semel dicemus, io triumple"

quem... semel| nascentem placido lumine videris.

cum semel occideris

non semel llios/rexata;

quae semel notis condita fastis' inclusit rolucri= die.

quod senel dictum est

interminato cum semel fixae cibolintabuisent pupula..

nec semel oftensi cedet constantia formae.

et quodcumque semel chartis inleverit.

ut semel icto accessit fervor capiti

quae si semel uno' de sene gustarit tecum partita lucellum.

quae belua ruptis, / cum semel effugit, reddit se prava catenis?

ridiculus totas semel absorbere placentas;

quo semel est imbuta recens servabit odorem! testa diu.

qui semel adspexit, quantum dimissa petitis praestent.

cum semel accepit Solem furibundus acutum?

nee semel inrisus trisiis attollere curat/fracto crure planim.

et semel emissum volat inrevocabile verbum.

semel bic cessarit et. ut fit. In scalis latuit

haec animos aerugo et cura peculi|cum semel imbuerit,

haec placuit semel, haec deciens repetita placebit.

in mala derisum semel exceptumque sinistre.

nec semel hoc fecit, nec si retractus erit.

Semelae. Thebanaeque iubet me semelae puer

Semeleius, nee Semeleius|cum Marte confundet Thyoneus proelia

semesa. aridum et ore ferens acinum semesaque lardi frusta ledit.

semesos. semesos piscis tepidunque ligurrierit ius

semet. quas doceat quiris eque. atque senator semet prognato.

semina. pinguia nee siccis urantur semina glaebis.

semina. quid? cum Picenis excerpens semiua poni=| gauctea,

semis. redit uncia, quid fit?"| semis."

semita. quid pure tranguillet. . . secretum iter et fallentis semita ritae

semota. quae terris semota suisque temporibus deiuncta witet.
Carm.1.9.6

Cimm-3.1.40

Epod.4.16

Serm.1.6.40

Curm.I.Io.I8

Ars Pott.205

Epod.4. 5

Epist.1.17.37

Epist.I.2.I5

Carm.3.3.29

Curm.3.6.13

Ars Poct.1 I6

Epist.1.7.8

Enist.2.1.260

Carm.1.38.6

Sirm.1.5.7

Epist.1.13.5

Epist.2.1.17s

Carm.3.23.6

Epist.1.7.21

Epist.1.7.87

Carm.I.3I.4

lipist.2.2.16I

Curn.3.16.30

Sirm.2.3.102

Carm-3.21.22

Carm.3.52.9

S.rm.2.3.236

Ars Poet.180

Strm.I.4.123

Sirm.1.0.97

Cirm.1.24.16

Curm.1.28.16

Cirm.3.5.20

Carm.3.26.12

Curm.3.29.48

Carm.4.2.50

Carm-3.1

Comm.4.7.2I

Carm.t.9.18

Carm.1.13.14

Curm.Suec.26

Epol.5.39

I.pod.IS.I 5

Sermen.4.3"

Sim.2.1.24

Sirm.2.5.81

Sim.2.7.71

Sirm.2.3.24

Epist.1.2.69

Epist.1.7.96

Epist.1.10.17

Epist.1.17.58

Epist.I.I8.7 I

Enist.2.2.14

Ars I'oel.331

Ars Pot 365

Ars Pott.452

Ars Poet. 608

Carm.1.19.2

cirm.1.17.22

Sirmez.e.85

Serm. 1.3.8I

Sirmed.0.7s

I.pod.10.53

Serm.2.3.272

irs Poet.33

Esivit.18.103

Epist.2.1.2 I 


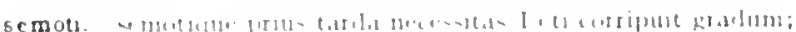

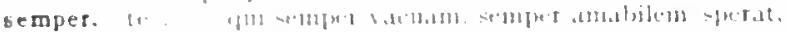

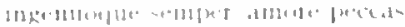

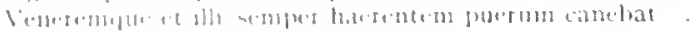

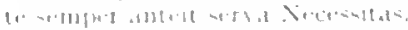

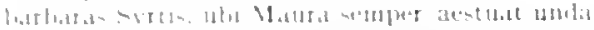

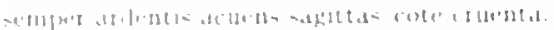

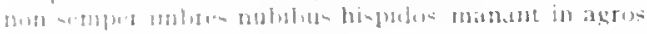

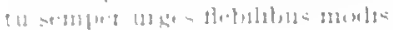

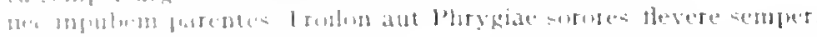

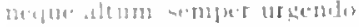

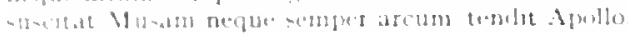

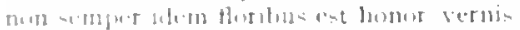

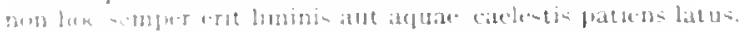

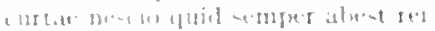

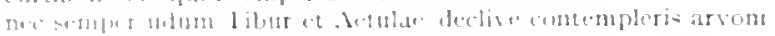

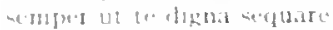

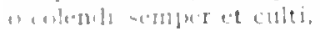

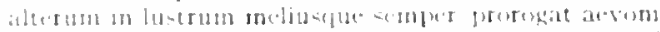

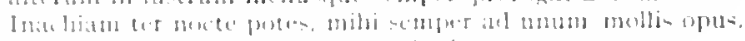

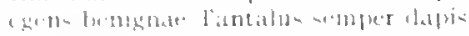

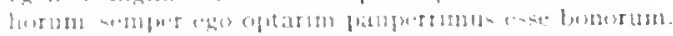

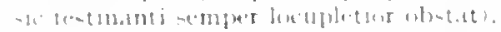

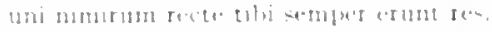

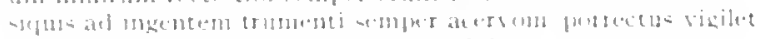

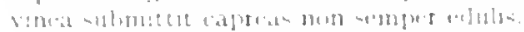

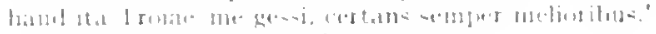

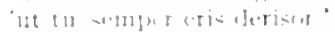

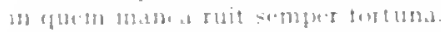

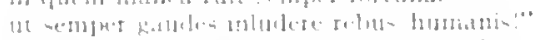

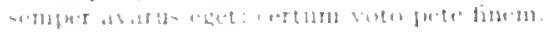

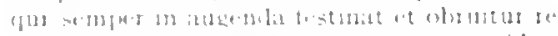

num to

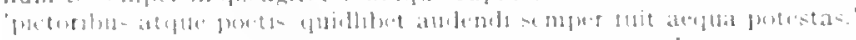

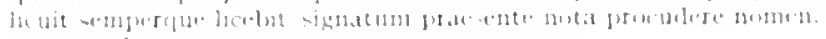

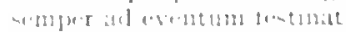

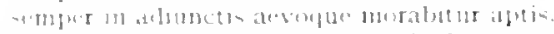

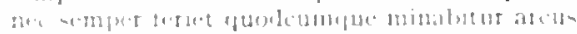

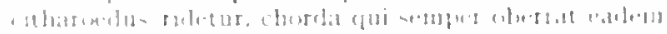

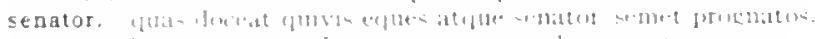

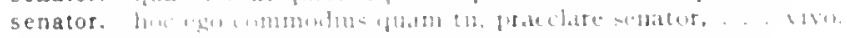

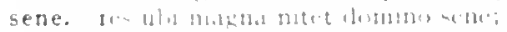

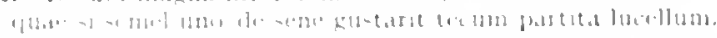

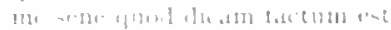

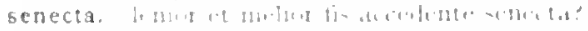

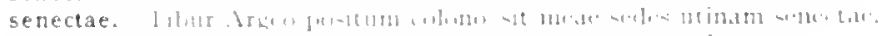

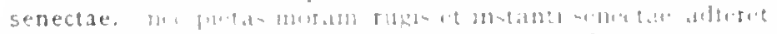

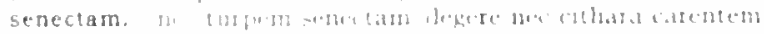

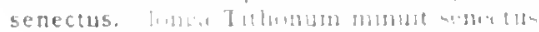

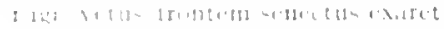

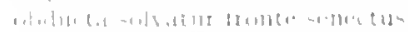

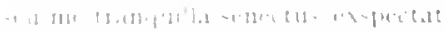

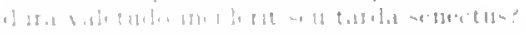

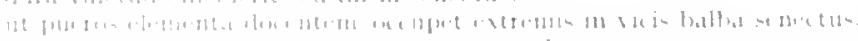

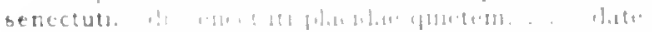

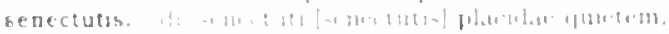

11.11,

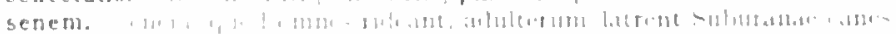

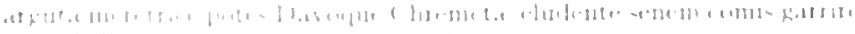

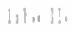

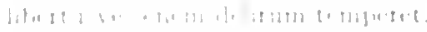

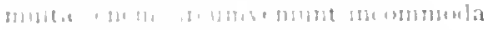

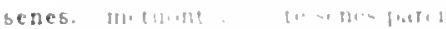

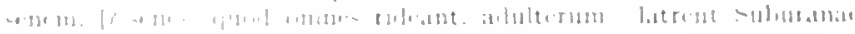

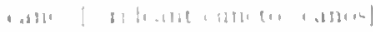

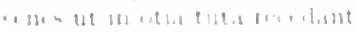

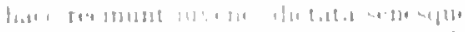

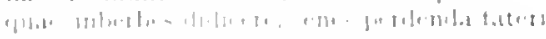

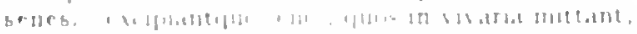

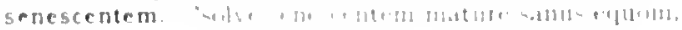

(ar $11.1 .3 \cdot 32$

Carme. 1.5 .10

(inm. 1.27 .10

(arm. 32.10

(ivm.1.35.17

(is)m 2.15.3

Cirm.2\$.5

(itrm 2.4) 1

( arm.2.0)

(iurm.20)17

(isrm 2.10 .2

Curm. $=10.19$

(i)m.2.11.0)

(iorm.3.110.10

(arm.3 24.44

(arm.3 20.6)

Carm + I 20

( armesiare. 3

Curmeside if

Epond.12.15

J. pod.1;.to

sirm 1.1 ;0

sirm I. I II 3

Serm. 2.2 |100)

Sirm.2.3111

Sirm 2.4. 4

Serm 25.10

serm.21.54

serm.2.7. As

siorlla a 4. Pa

lept $=50$

1.pist 1.10 ph

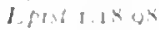

. Irs Inedelu

Ars Inot $5 x$

Irs lined 1.4

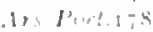

Ir I I . I B 30

der J lat ist

term $18, \overline{7}$

sirmel pelas

sirniza ; 12

$\rightarrow m: 54$

W $11:=5 \times 4$

18452211

(iorm a enter

( is $\mu^{2}=1: 3$

(ar)! $3: 10$

(itrm = 1is 3u

I pints

Epind 1,35

sinm 257

Drrma a a

l. PJal I and It

cerm tale fle

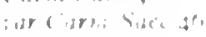

I in

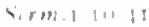

vere: 557

ard Jint (1)

( wrm 242

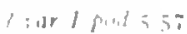

then 1313

$1711+155$

l.ful : at is

I.pin 1.1 ;.

lipri I I 


\section{SENESCIT}

senescit. inmoritur studis et anore senescit labenli.

senex. non ter aevo functus anabilem/plorat onnis . Intilochum sewar annos

siccus lantis mane senex nanibus currebat

maturusne senex an adhuc forente imenta|fervidus.

senex. dis inimice senex, custodis? ne tibi desit?

seni. et vicina seni non habilis Lyco.

senibus. il quot. . aeque neglectum pueris senibusque nuchit.

senile. parentis olin siquis inpia manu $\mid$ senile guttur fregerit,

seniles. ne forte seniles mantentur inveni partes.

senior. siunis forte coheredum senior male tussict.

seniorum. quamque poetarum seniorum turba;

centuriae seniorum agitant expertia irugis.

senis. pateat rehti descripta tabella/vita senis.

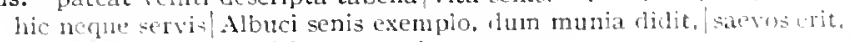
aufert Pacuvius docti faman senis,

senis. mollius ac siquis pedibus quil claudere senis.

serium. surge et inhmmae senium depone Camenae,

seros. cum senos redderet ictus/primus ad extremum silnilis sili:

sensere. sensere, quid mens rite,

sensi. tecum Philippos et celerem fugam|sensi

sersibus. mollis inertia cur tantam diffucrit inis foblivionem susins,

sensimus. postquam nihil esse pericli|sensimus.

sensit. qui lora restrictis lacertis ! sensit iners

proles Niobea magnae / vindicem linguae Tityosque rantor|senst .

quil ergo/ sensit, cum summam patrinoni insculpere saxo/horetes roluit?"

sensu. 'molestus / communi seusu plane caret' inquimus.

num sine sensu. | tempore num faciant alieno.

quo spectanda modo, quo sensis credis et ofe?

sensus. sensus moresque repugnant/atque ipsa utilitas,

sensus. donec verba, quibus voces sensusque notarent,

donec verba, quibus voces sensisque [sensus, vocesque.] notanent. nominante invenere;

sententia. 'macte rirtute esto' inruit scnicntia dia Catonis; est brevitate opus. ut currat sententia mea cum pugnat sententia secum. cur sit Aristippi potior sententia.

post etian incluza est roti sententia conjus; sortilegis non discrepuit sententia Deluhis.

sententia. mulla sit hac potior sententia: .

sententiarum. testis mearum centinanns gigas| sententiamm,

sentiant. hostimm uxores pueriçue catcos/sentiant motus

sentiat. qui sapere et fari possit quae sentiat .

sentiet. nue pestilenten sentiet Africun| iecunda vitis.

sentimus. nil cum procedere lintrem', sentinus,

sentire. haed loven aentire leosqut cunctos quid sentire putas, quid credis, anice, precari?

sentis. inclinare meridiem / sentis

unde datum sentis, lupus hic Tiberinus an alto $\mid$ captus liet:

aut quia nom sentis, quod clanas, rectius esses.

ecruiblan te post panlo ventura pericula scutis?

sentit. inulto diccre quol sentit permitto.'

lacus et mase sentit anorem | testinantis eri;

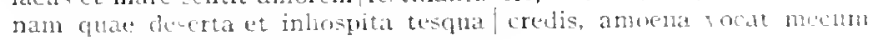
qui sentit,

opinor, 'loc sentit 'moriar.'

poscit opem churus el praesentia numina sentit,

vilicus ()rbi. . . te dominum sontit.

vicinas nubes ait et grave seneit aratrum.

sentiuat. contracta fisces aequod antint iactis in altum andiln

senum. mixia benmon ac invenum densentur funera.

captes antutua nhique| testamenta senum

separatis. tu separacis uvidus in iugis

seponere. scimus inurbanum lepilo sepmore dicto

sepositi. neque ille sepositi ciceris nec longate in irlit abcule.

septers. tuque teabulo resonare septem callida mervis.

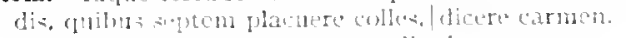

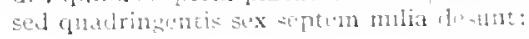

I.piti.1.7.5.

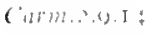

Sirm-2.3.2ti.

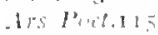

S.M.3.3. 123

(itrm.3.19.24

l.pist-1.1.24

libol. $3 .=$

lin loct. If

S.rm.2.3.107

Sermen.10.0\%

fis l'tet.3.1:

Sivm.3.3. 34

4.rm.2.2.

Iopist.2.1.5th

Sim.1.10.50

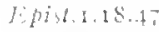

In Jint.25:

(immlates

(amm.?.7.

fipoldat. 2

Sim.3.3.58

(i)m

(c)m.t 4

‥m. 2.3.90

Serren 1 S.en

.5 $97 m .4 .4 .78$

L. pi.t. [.0.8

5.4.n.1.3.97

S.rml-1.Ins

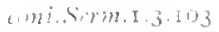

S.m. 1.2.32

Sintido.o

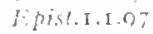

I:P:C.1.17.I?

the Poet 70

ins Poc!.2113

Prol.ipe.t7

(iarm.3기)

(am) $3 \cdot 27 \cdot 2 \cdot 2$

Hoist. I.4.9

(iarm.3.23.5

Serm.1.5.2I

(armated is

tepint I. IS.In

(itm.3.25ite

sem.2.2.31

Sirm.2.7.25

Epix!.1. is.t.

sirm.2.3.1013

LPist.1.1.84

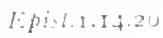

1.pist.1.10.7)

I.pi, 2. I. 1, ;

I.P $31.2 \geq .10$ -

.11. I's: tere

( ism, s.1.3.3

(1) (1) 2. 25.10)

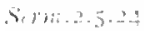

("4) 210.1

1,5 lout.27.

Cinmezes.s.

(

cinm siser:

$19061.15 \%$ 


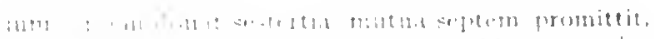

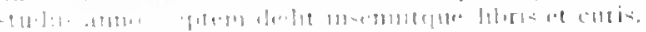

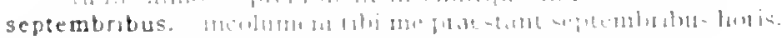

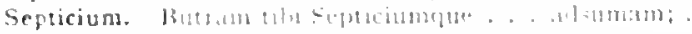

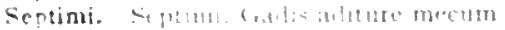

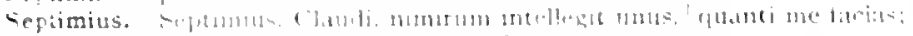

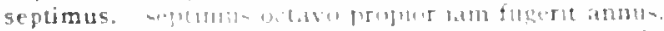

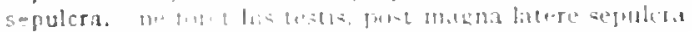

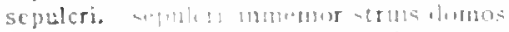

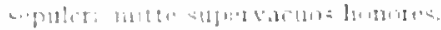

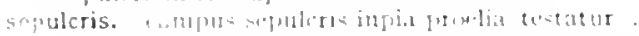

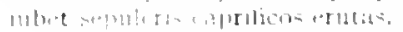

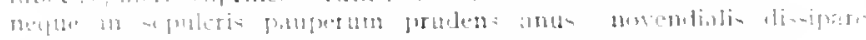

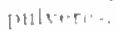

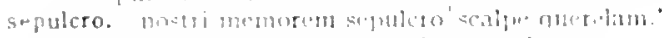

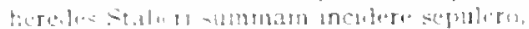

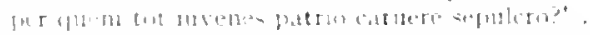

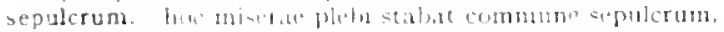

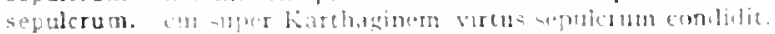

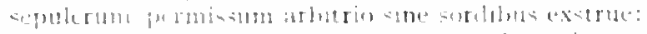

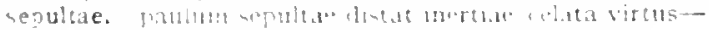

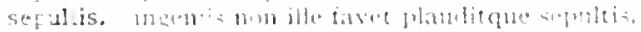

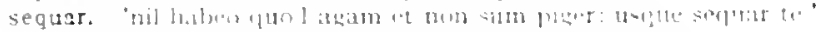

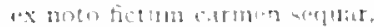

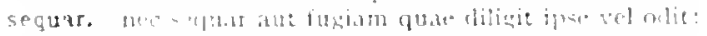

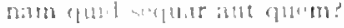

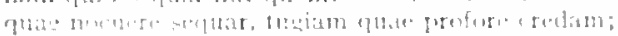

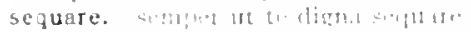

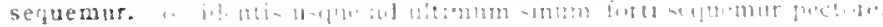

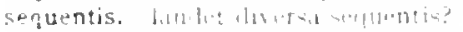

flit:

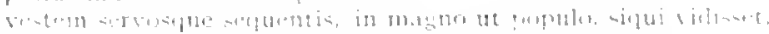

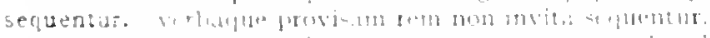

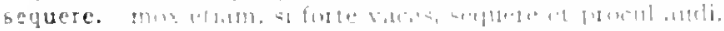

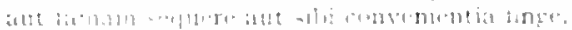

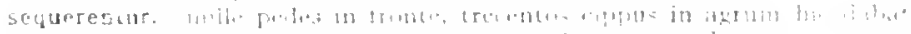

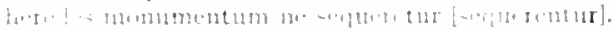

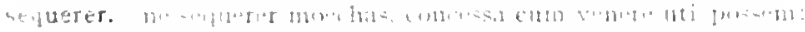

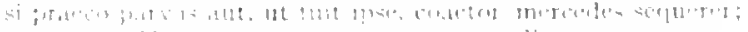

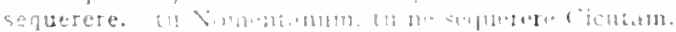

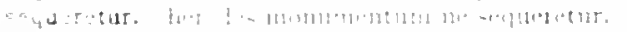

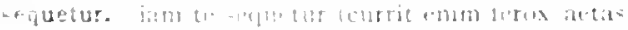

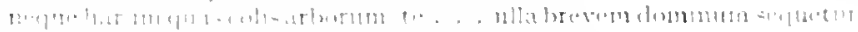

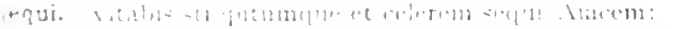

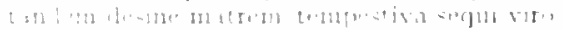

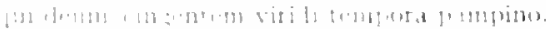

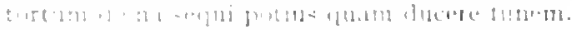

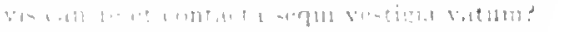

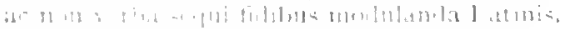

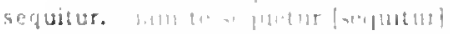

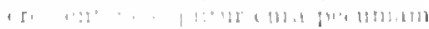

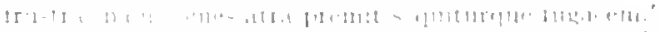

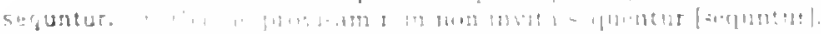

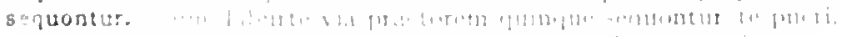

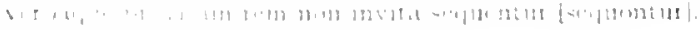

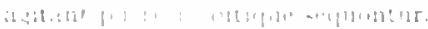

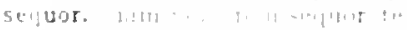

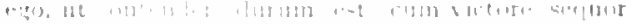

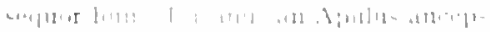

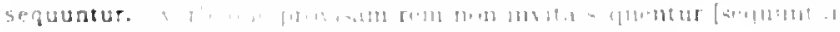

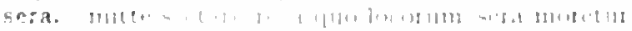

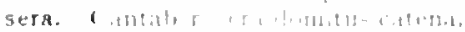

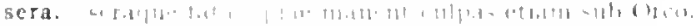

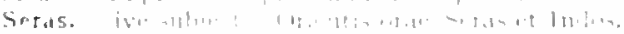

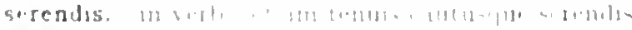

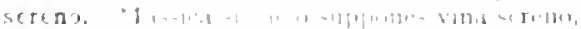

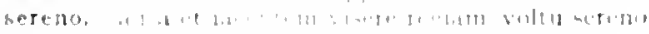

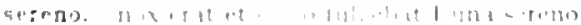

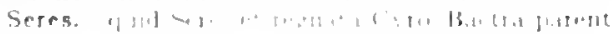

1.pist. I. . . So

T.pist.2.2., 2

Jepis! 1.10.10,

$1 . p+1+.5 .2 \%$

(15m.2.1,

1.jpl.10.1

virm 2.(1...9)

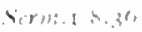

( Irm.z.1\% is

Carm, 2.211 23

( is ron.2.1.30

f. 3 ind.5.17

1.Pind.17.45

Cirm i 1 1.51

s.rin. $=3 . s !$

arem $23.30 \mathrm{sen}$

teren 1.2. Da

lapinla 2')

serm. 25.10 .1

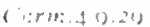

l.ping 2.1.s.s

vits. 10.1\%

Irs Pint.2 In

A.Pin.1.1.?

1.pid.1.1.71

I piv I.N II

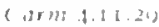

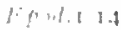

virm. 1 [.

sirm 1.R.1n

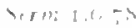

ir ring 31

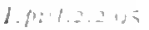

1, Hill :11

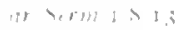

$\rightarrow r m 1: 11,3$

serm 1, ti, s?

$\therefore+11=3-175$

Vin', I S. Is

(.)rm.2.513

(a) its.2.5.9 2.1

Cirm 1 I I I

( iा 1 - 123.12

(itrm-3.25.19)

t. $2+1.1 .1014$

1. Pos ". nes

fopt $=213$

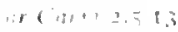

( i i) $m$; 11 1

Crn: : $=115$

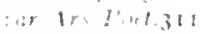

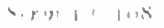

is lierial il:

ir linel tó

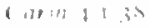

are: 1 is is

Serle? 131

alor itrs Jint zis

(int: 1 然

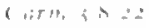

1 ifm i $11=4$

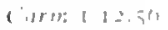

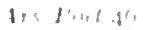

anen 2151

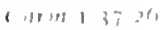

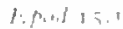

(ny) ; +4) 27 
non Seres inflique l'resic,

Cirm.4.15.23

seri. o seri stuliorum, quine putetis elifficile et minum.

seris. tristis matstum voltun verta deent. . . everum seria dictu.

Sirm.1.10.21

seria. sed tamen imoto quateranus seria ludo):

explicult vino contractae seria fronti:.

ita vertere seria ludo.

hae nume seria ducent

Sericas. doctus sagittas tendere Sericas/arcu paternu?

Sericos. inter sericos liacere pulvillos amant.

series. innumerabilis annorum stries fuga temponm.

tantum series inncturaque pollet.

serius. ommiun/versatur urna serius ocius sors exitura

sermo. nisi quod pede certolditert sermoni, sermo merus.

at sermo lingua concinnus utraque suavior.

(nec meus hic sermo ext. sed quat prateent ofellus.

sermo oritur, non de vilis domibusre alienis.

sermone. ut forte legentem iant tacitum inpellat quovis sermone:

et sermone opus eit modo tristi, saepe iocosis.

nil dignum sermone canas.

utpote res tenuis, tenui sermone peractas."

aestivam sermone benigno tendere notem.

si longo sermone norer tua tempora, Caesar.

ut alce'alterius sermone meros andiret honores.

tragicue plerumque, dolet sermone pedestri|Teleplus et Peleus.

migret in obscuras humili sermone tabernas

sermonem. cum lingua Catonis et Enni fermonem patriun ditaverit

sermones. desine pervicax / refere sermones deorum

locte sermones utrinsque linguae?

nec sermones ego mallem |repentis per humum.

sermoni. siqui scribat uti nos/sermoni propiora.

nisi quod pede certo differt sermoni. sermo merus.

sermonibus. alternis aptum sermonibus

sermonibus. quanquam Socraticis narlet sermonibus.

cresentem tumidis infia sermonibus utrem.

torçuet ab obscaenis iam nunc sermonbus aurem.

hic delo tatur inmbis. ille Bioneis surmonibus et sale nigro.

sermonis. locte sermones [sermonis] utriusque linguas? confilens tumilus, adeo sermonis amari.

sermonum. Albi, nostrorun sermonum andide iudrar, necium sermonum stet honos et gratia vivax.

serpens. rumpit et serpens iter institutum.

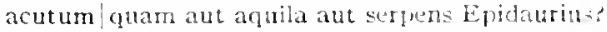

serpente. serpence fugit alite.

serpentes. non ut serpentes avibus geninentur, tigritu- ani.

serpentes fortis et asperas tractare serpentes. serpentes atque videres|iniernas errar cines

serpentibus. velut illis, Canidia adtasset, prior expentihus sfris."

serpentium. serpentium alipstus tinet

serpit. serpit humi tucus niminm timblucout procellap:

serum. serma sub lumina primat venire, contivan:

serus. serus in calum redeas

tamen, het serus, adulerol cultus putrere collines.

serus enim Graecis admovit acumina thatis

serva. te semper anteit serva Necessitas.

serva Brisots niseo colore movit Arbillem,

serva. "hic fossa est ingens. he rupes maximat serva!"

servabat. pulicum. . . Servasit [scrvalut ab omni non soluan incto. verum opprobrio quoque turpi

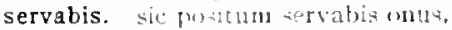

servabit, pulfoum. . . servath [servabit] ab onni mon solum facto, verum opgrobrio quaque turpi quo semel cit imbutat recena servabit odorem testa diu. .

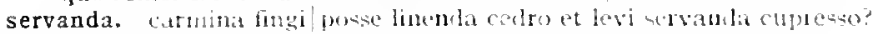

servantem. atria servantem fustico balle clientem.

servare, acquan menento rebus in ardutio sorvare montem. an si cognatos. . . retmere velis survareque anicos si|traditum ab antiquis moregr servare . . possmon; quae posit facre et servare beatun. si res soia potest fictere et servare bentum.

Ars Pot bion

Sirm.1.1.27

Sirm.2.2.125

Arstort. 226

A. 1 . $10.45 \mathrm{I}$

(crin.1.29.9

Fpul.8.15

carm. 3.30 .5

irs $7 t^{2} t .242$

Curm.2.3.26

Serm. T.4.48

Sirm.1.50.23

Sirm.2.2.2

serm.2.0.7 I

Sirm?.1.3.05

Sirm.t. IO.II

Serm.2.3.4

Sirm.2.4.9

lepist.1.5.I I

lipist.2.t.4

IfPist.2.2.88

drs Poet.95

1rs Poret. 229

Ars Pod.57

(ivm 3.3.7 I

carm.3.8.5

Ifint.2 I 250

Serm.1.4 42

Serm.1.4.45

Ar. I'oct.s I

(arme.3.21 Io

Serm.2.508

Esist.21.127

Epist.2.

ar.Corn 3 s. 5

Serm 1.7.7

1. +. ist. I.t I

Ars frutedo

Cism 3.27.5

S.rm.1.3.27

l.ped.3.14

- Irs Potitis

Carm.1.37.27

s.mol.8.34

srm.zos

Fon? I.20

(1) I I $0: 2.28$

5.9.9!. 2.7.33

(itrm.1.2.45

(a)m.I.I5. I0

Lipist.2. . [3 I

('t)m.1.35.17

Ciarm.2.t. 3

sirm.2.350

:ur.s rm. 1.6 .83

lipist.1.13.12

itr.stirn.1.6.83

Espist 1.200

Ars lote.332

f.Mest.1.5.3 I

(ivm.2.3.2

Surm.1.1.8is

Sierm. J.4.157

I.pistio. 0.2

l.pist.t.t.47 


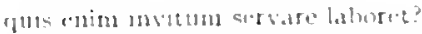

1.pist.1.20.10

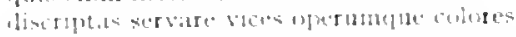

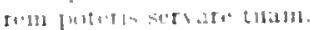

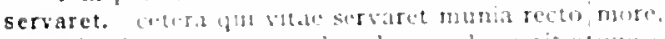

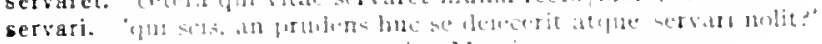

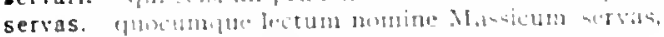

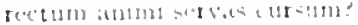

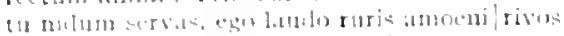

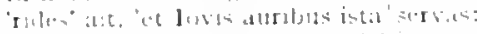

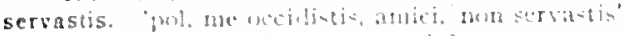

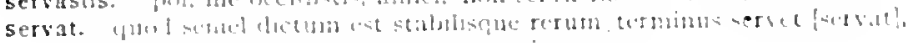

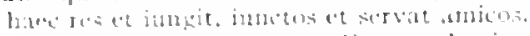

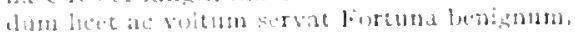

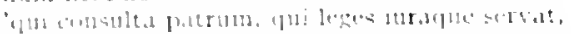

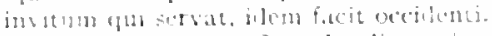

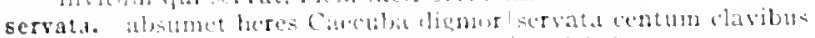

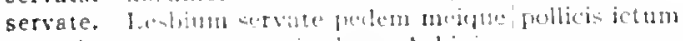

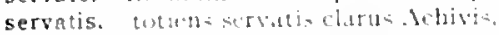

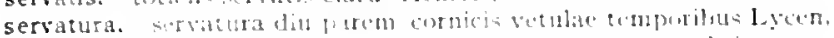

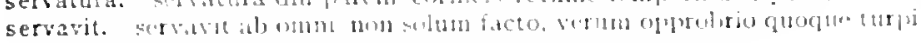

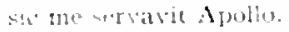

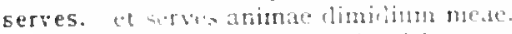

sersi s iturum calcearem in ultimos orbis Britanus

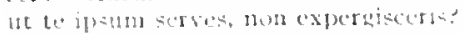

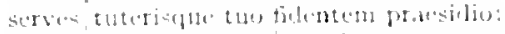

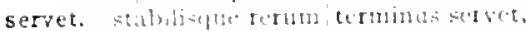

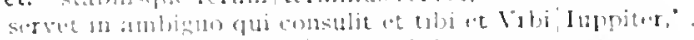

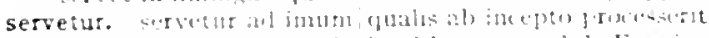

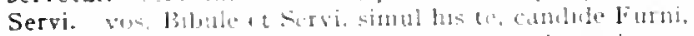

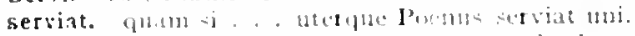

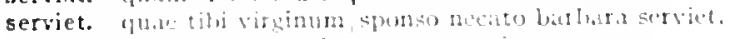

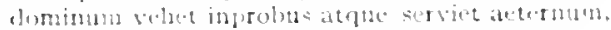

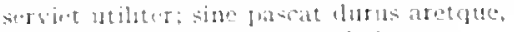

serrile. nit strile gulate murese hatwe?

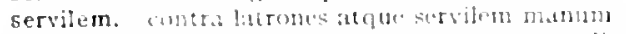

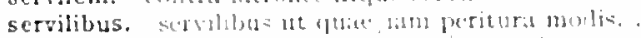

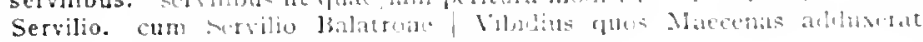
1 1!mbtian.

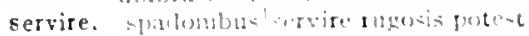

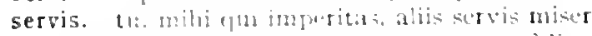

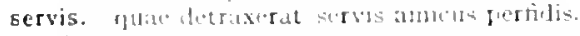

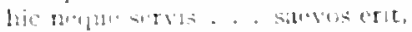

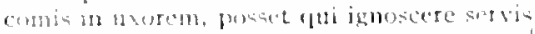

servis, diefent vicini gladsas t saxa mosentem/cum servis.

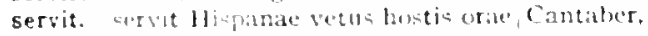
f.t.

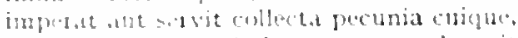

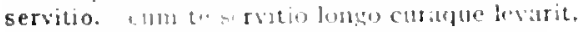

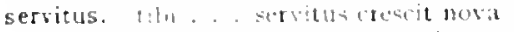

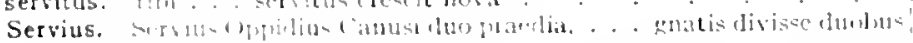
fititis

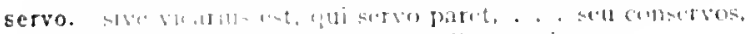

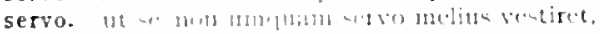

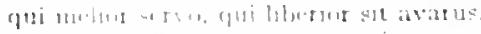

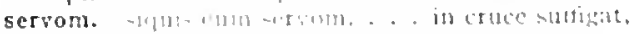

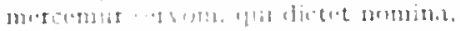

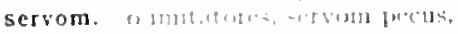

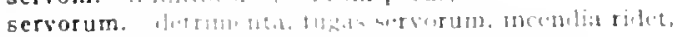

servos. 101

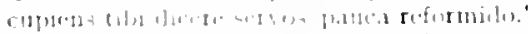

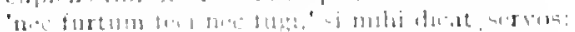

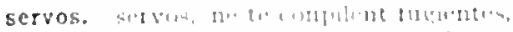

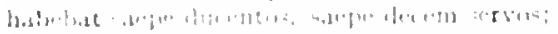

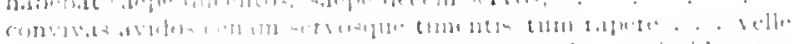

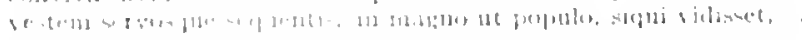

math

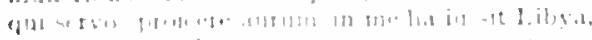

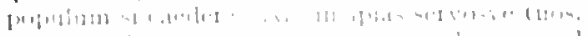

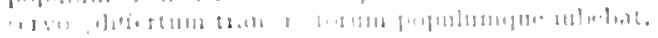

Irs Poet.80

Ars P(uis 20

1. pist.2.2.1.31

irs lostat"s

(a)m.3.21,

Sirm! $2,3 \cdot 31,1$

l.pist a.10.te

disivi.lo..t

List.2.2.1.1

intelurmistatenza

serm. I.3.54

1 pist.1.11.20

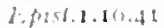

Ars loudat

(i)m.2.1.201)

Cimmo.s. 1.35

Serm.2.3.104

( ism:-1.3 21

Simmetesis

sim.1.0.8

ciarm.1.3.t

(in) 1.35 .21

I. Aid.1.2.3.3

lifist.t.8s.8us

carmstociza

fpist.t.11s.2b

Ars Juet. 120

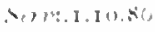

(a) (4).2.2.12

Gism:1.2uce

I pist 1.816 f1

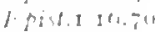

arm.2.7.14

l. pint. t.11)

Sirm.1.s.32

S. rmi.2.8.21

1. pulio.ti

sirm.2.7.s.

Jipollog 10

sirn.2.2.01

If pist.2.2.13.3

J.pist 1.4.40

corm.3.8.21

sermateren

1.pist.1.10.17

Crerme.5.90

(iorn 2 . 18

Se) m.2.3.168

Sirm. 2.7.79

Sirmelar

fipitid.1e.6.3

simplas so

lifest 1.0 .50

1. pist.10.10)

1. pivis.2.1.1.21

Sirm. 3235

seras?

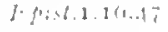

Sirme1.1.77

sermis 312

ximis.5.5

sipmet 4.75

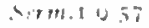

Serme 2.1011

Sirmiz 3120

1 pint t.1.54 
servos. quaeris, quando iterum paveas iterumque perire | possis, o totiens servos.

sese. hic mente laborem / sese ferre, . . aiunt.

et redit ad sese, pol, me occillistis, anici,

sesquipedalia. uterque/proicit ampullas et sesquipeda!ia vorba, .

sessor. in vacuo laetus sessor plausorque theatro,

sessuri. usque| sessuri, donec cantor 'vos plaudite' dicat:

sestertia. dun septem donat sestertia. mutua septem promittit.

accipit et bis dena super sestertia nummum.

Strm.2.7.70

Sirm 1.i.3 I

Epist.2.2.138

- irs liotion

Iistist.2.2.130

Atrs Poet. 55

I.pist. T. . 50

EPist.2.2.33

Sesti. o beate Sesti, | vitae summa brevis spem nos vetat incolare longam; Carm.I.4.I.4

seu. Carm.1.3.16; Epod.10.29; Serm.2.1.59; qur.Serm.2.5.24; Sim.2.0.20; Ars Poet.67

seu. Carm.Surc.16; Serm.2.1.38; $2.2 .8 .4 ; 2.3 .85 ; 2.6 .25 ; 2.7 .80$

seu. Carm.1.4.12; 1.12.53; 1.13.9; Epol.17.38; Sirm.2 2.118; 2.4.78; 2.5.50S; F.pist.2.1.194

seu. Corm.1.1.27; I.1.28; 1.7.19; 1.7.20; I.1 1.4 (bis); 1.2.3.5; 1.23.0; 2.3.5;2.3.0; 2.17 17 (bis); Carm.2 17.19; 3.4.3; 3.4.4; 3.4 2.2; $34.23 ; 34.24 ; 3.0 .30 ; 3.6 .31 ; 3.21 .2 ; 3.21 .3 ; 3.21 .4$;

Curm.3.24.57; 3.24.58; 4.2.10; 4.2.13; Stm.1.1.2 (bis); 2.1.57; 2.1.58; 2.2.11; 2.2.13; Sirm.2.2.8; $2.2 .88 ; 2.5 .39 ; 2.5 .40 ; 2.6 .09 ; 2.6 .70 ;$ Efist.t.3.23 (bis); 1 3.2.4; 1.3 .33 (bis); Epist.t.12.21 (bis); Ars Poct. 220 (bis)

seva. te semper anteit serva [seva] Necessitas.

severa. dona praesentis cape laetus horae (ac)/lingue severa.

severae. paulum severae nusa tragoediae/desit theatris:

severae matris ad arbitrium

severi. voltis severi me quoque sumere/partem Falerni?

severi. pueri patresque severiffonde comas vincti cenant

severis. nullan, Vare, sacra vite prius severis arborem

severis. form putealque Libonis nandabo siccis, adimam cantare severis"

severis. (sic etian fidibus voces crevere severis)

severo. donec suspecta severo'conticuit lyra.

severum. tristia maestum | voitum verba decent. . . severum seria dictu.

severus. nec severus| uncus abest

ubi haee severus te palam laudaveran.

parcus ob heredis curam niniumque severusladidet insano:

sevum. mercemur serrom, qui dictet nomina, laevom [kevum]|qui fodicet Jatus

sex. 'solventur risu [solventur bis sex] tabulae. tu nisstls abibis.' sed quadringentis sex septem milia desunt:

seztarius. panis ematur, holus, vini sextarius,

Sextilem. Sextilem totum mendax desideror

Sextili. facit quod ... per bruman Tiberis, Sextili mense caminus.

Fur.Carm. I.35.17

Curm.3.R.28

Carm.2.19

(a)m? 3 -39

Carm.1.27.9

Epist.z.1.109

Carm.I.IS.I

Epis?.1.19-9

Ars Pott.216

Epist.1.18.42

irs Ioet. 107

Carm.1.35.19

Epod.1 I. 19

Epist.1.5.13

Far. Epist.1.6.50

coni.Serm.2.1.86

Epist.1.1.57

Sirm.1.1.74

Epist.1.7.2

Epist.r.11.19

si. Corm.I.I.7; 1.1.9; I.I.32; 1.3.23; I.I3.I3; I.16.8; 1.24.13; 1.32.1;2.2.10; 2.5.21; 2.6.9; 2.8.1; Corm.2.8.3; 2.10.17; 2.14.5; 2.17.5;2.17.14; 3.3.5; 3.3.65; 3.5.17; 3.5.31; 3.5.5.3; 3.9.1 2 ; Carm.3.9.16; 3.9.17; 3.9.19; 3.10.1; 3.14.19; 3.14.23; 3.15.7; 3.16.5; 3.16.20; 3.10.38; Curm.3 I6.4I; 3.18.5; 3.2I.2I; 3.23.1; 3.23.3; 3.23.17; 3.24.5; $324.27 ; 3.24 .34 ; 3.24 .36 ;$ Carm.3.24.50; 3.27.0; 3.27.45; 3.27.5I; 3.29.3 I: 3.29.53; 3.29.57; 4.I.12:4.2.45; 4.3.20; Carm.4.3.24;4.8.21;4.8.23; 4.9.5; 4.9.0; 4.12.15;4.12.21; Corm.Sced.37;0.5; :ar.Epod.1.5;

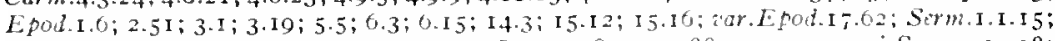
Serm.1.1.43; I.1.40; I.1.54; I.I.57; I.1.50; I.I.S7; I.1.SS; I.1.90; coni.Sirm.1.I.108; Sim.1.2.7; 1.2.23; 1.2.49; 1.2.65; 1.2.74; 1.2.84; 1.2.87; 1.2.90; 1.2.1 16; 1.2.120; Serm.I.3.5; 1.3.6; 1.3.44; I-3.71; 1.3.72; 1.3.80; 1.3.04 (bis); 1.3.112; I.3.123; I.3.124; Sirm.1.3.140; 1.4.3; 1.4.14; 1.4.41; 1.4.53; 1.4.55; 1.4.57; 1.4.00; 1.4.67; $14.91 ; 1.4 .93$; :ar.Serm.1.4 93; Serm 1.i.102; coni.Strm.1.4.102; Sorm.1.4.103; I.4.104; 1.4.1 16; I.4.140;

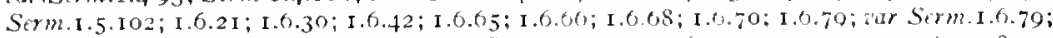
Serm.1.9.86; I.6.93; zar.Serm.1.0.90; Serm.1.0.105; 1.6.130; 1.7.I5; 1.7.10; 1.S.37; Serm.1.9.22; 1.9.34; 1.9.38 (bis); 1.9.47; I.9.57; I.10.24; I.10.34; 1.10.59; 1.10.68; Stm.I.I0.89; 2.I.6; 2.I.IO; 2.1.20; 2.I.31; 2.I.32; 2.I.49; 2.I.S2; 2.1.83 (bis); 2.I.84; Sim.2.2.8; 2.2.10; 2.2.51; 2.2.55; zar.Serm.2.3.I; Sem.2.3.10; 2.3.33; 2.3.41; 2.3.66;

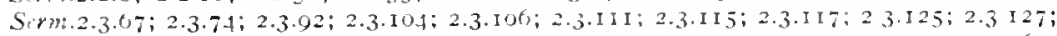
Sirm.2.3.128; 2.3.159; 2.3.2I4; 2.3.219; 2.3.24I; 2.3.240; 2.3.350; 2.3.259; 2.3.26.4; Serm.2.3.218; 2.3.270; 2.3.273; 2.3.290; zar.Serm.2.3.31\%; Serm.2.3.310; 2.3.322; 2.4.17; Sim.2.7.27; 2.4.49; 2.4.51; 2.4.52; 2.5.17; 2.5.24; 2.5.27; 2.5.31; idr.Serm.2.5.38; Sim.2.5.49; 2.5.61; 2.5.70; 2.5.81; 2.5.87; 2.5.0.3; 2.5.10.3; 2.5.100; 2.0.1); 2.e.8 (bis); Serm.2.0.10; 2.6.13; 2.6.31; 2.0.32; $2.6 .55 ; 2.6 .78 ; 2.7 .2 .72 .7 .29 ; 2.7 .35 ; 2.7 .42 ; 2.7 .98 ;$ Strm.2.7.102; 2.S.4; 2.8.21; 2.8.25; $2.8 .58 ; 2.8 .71 ; 28.72 ; 2.5 .90 ; 2.8 .92 ; 1$ Fist.1.1.32;

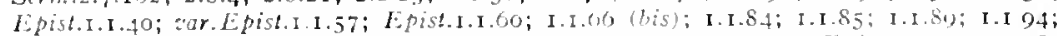
Epist.I.1.95; I.1.96; I.2.2.1; I.2.34; 1.2.35; 1.2.38; for.Epist.1.2.3S; LPist.1.2.50; 1.3.18; Epist.1.3.29 (bis); coni.1pist.1.3.30; Epist.1.5.1; 1.50; 1.5.12; 1.0.13; 1.0.10; 1.0.2S; Epist.1.6.30; 1.0.41; 1.6.47; 1.6.40; 1.0.56; 1.6.65; 1.0.67 1.6.0.8; 1.7.3; 1.7.1.3; 1.7.18: Lpist.1.7.32; 1.7.34; 1.7.30; I.7.70; 1.7.93; 1.8.3; 8.15; I.10.12; 1.I0.31; 1.10.43 (Tis); Epist.I.II.I5; I.II.25; I.I1.30; 1.I2.2; I.I2.5(his); I.12.7; I.I2.I2; I.12.22; I.13.3 (lir); 


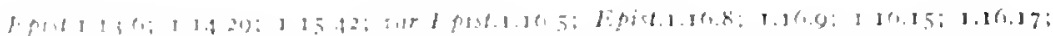

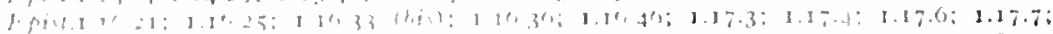

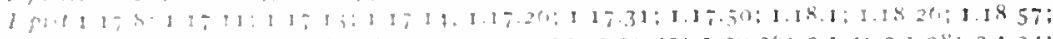

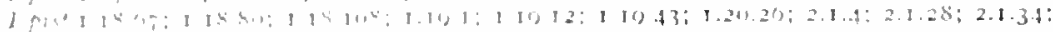

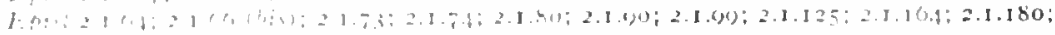

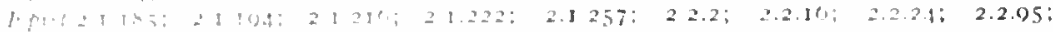

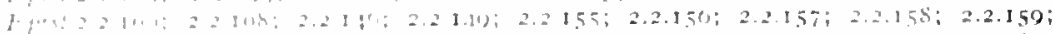

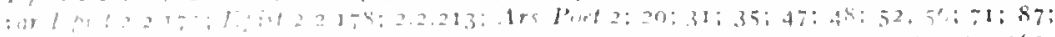

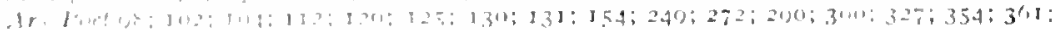

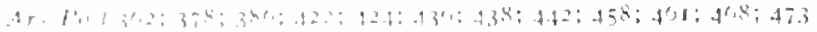

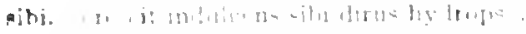

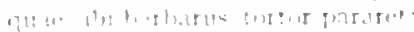

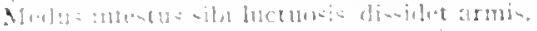

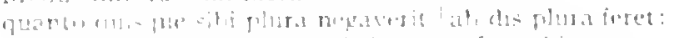

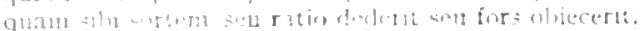

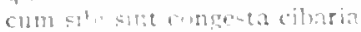

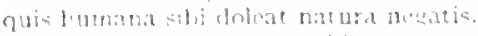

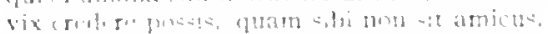

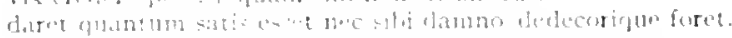

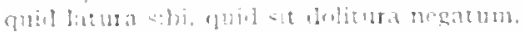

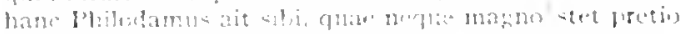

nil tuit anquan' ar inpar eipri.

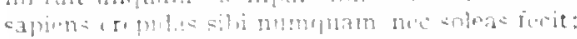

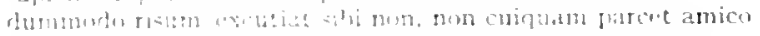

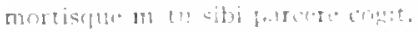

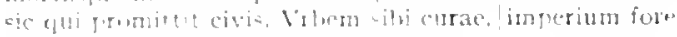

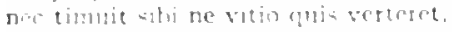

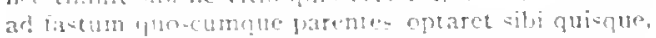

detervet -itis min?

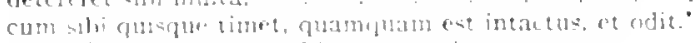

uterne arl catus dubos lidet aho certius?

ipa" sileretur sibi nequior:

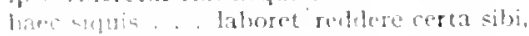

silsi tume furiosa vingetur

nes shli cenumb quivio temere arroget artem.

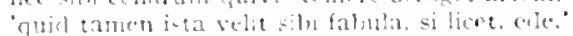

nil sibilegatum graner fintare suicigue.

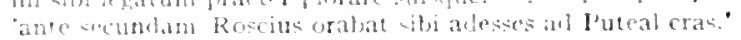

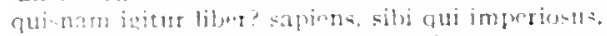

qued eibit pusenei non dentur pocula.

nil and

lum silit. dum socis reolitum parat.

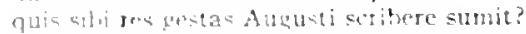

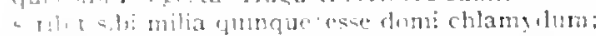

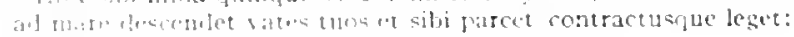

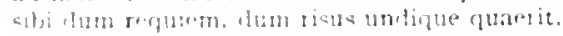

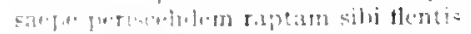

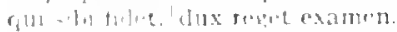

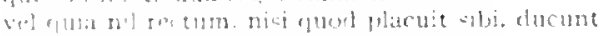

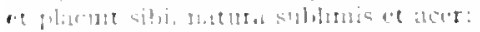

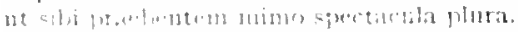

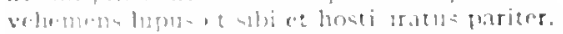

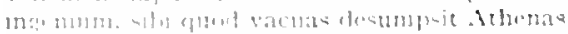

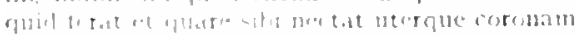

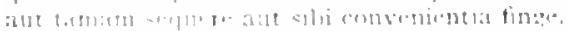

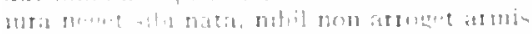

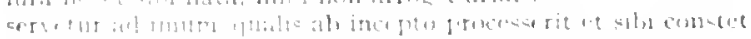

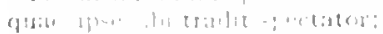

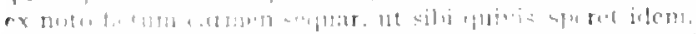

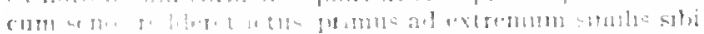

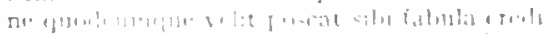

(arm: 2.2 .13

(')

(comis.s. 10

carm-3.10.2!

Sermer.r.1

Sitm:1.32

Serm:1.75

Sirm.1.2.20

Sormina.52

Srm.1.2.112

Sirmi.1.2 121

Serm.1.3 19

Serm: 1.3127

sirmidal 35

Simn-1.127

strmes a.34

Sirmentis

Sermistiofi

Sirm. I I Co

Serm.2.1.23

virm 2.108

Setme 304

Sitrm.2.3.270

Sirm.2.3.30.4

Sirm 2.435

sirmiz 2-5it

Sorm. 250

Sorm.2.16.35

Serm: 2. - . S 3

Sirntz.R.R2

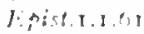

Fpist. 1 2 2 I

1.pist.1.3.7

Ifist.1.0.4.3

1. P:5t.1.7. I

1. A. 1.1 .7 .70

1. fidt 1.17.51

F. $1: 561.1022$

I:. 312.1 .3

L.P.s. 2.1.:45

firit.2.1.108

Fpent 2.2.28

T.P.S2.2. as

I pint $2.29^{\prime}$

- Irs lind I

Ars I've': 22

Ars lest.127

Ars Ind 182

des livende

in Int $=9$

ders louet 3.30

sermer 1 ien

cistre solos 5

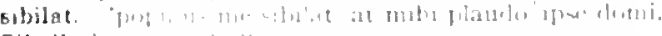

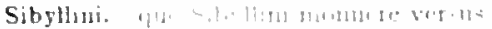

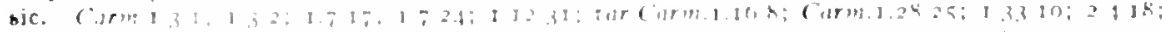

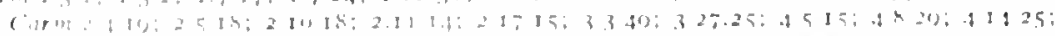

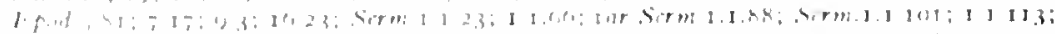

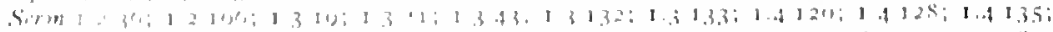

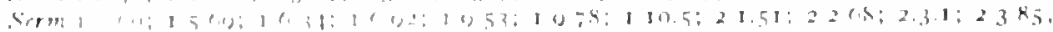

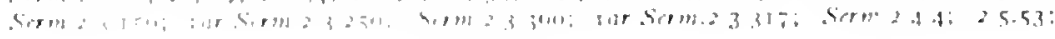




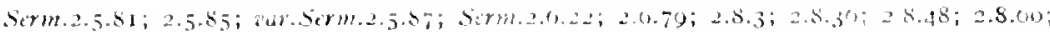

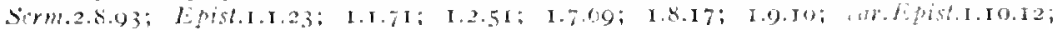

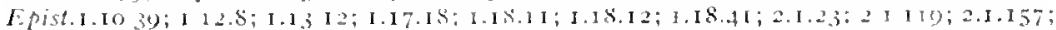

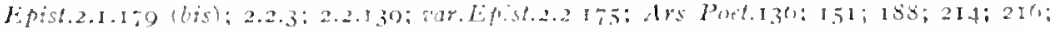

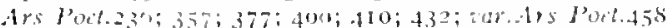

Sicana. nee Sicana lervita' virens in letna flamma:

$\operatorname{liphl.17\cdot 32}$

sicarius. quod moechus foret aut sicarius aut aliogui fumenis.

sieca. stetit unua paulumalsieca,

siceas. Tahuntque siceas machinae carinas

siccat. siecat inatepualis calices convila sthuns|legilus insonis.

siccatis. diftugiunt cadis/cum farece siecatis amici.

siccet. thistenta siccel uberi

sicci. dicinas integrolsicei mane dir.

siccis. ciccis omnia nam dura deus propesult

formm putealque Libonis mantabo siceis,

siccis. qui siceis oeulis monstrat natantial. . . vitlit

eauk sulurbano gui siceis crevit in agris|duleitr.

siccis. pinguia nee siccis urantur semina glaebis.

siccos. sole dies relerente sicco:;

siccus. siccus, inanis/sperne cibum vilem;

sicus lantis mane senex manibus currebat

accedes siceus ad unctun.

sictari. quare, ne paeniteat te, hesine sectari mutrond [matronas sictali],

sicui. pullum, mate parros sicui filins est. sicui vikeor non iustua, .

sicti praeterea validus male tilius in re praedara sublatus aletur.

Sicula. devota non extinxit arbor|nce Sicula Palinurus unda.

Siculae. te greges centun Sicularque eireum| mugiunt vaccae, non siculae dapes/duleem elaborabunt saporem.

Siculas. vel Eurus per siculas equitavit undas.

Siculi. Plautus ad exemplar Siculi properare Ejpicharmi. dicam sieulique poetae narrabo interitum.

Sicuil. invidia siculi non invenere tyranni|maius tormentum.

Siculis. Truetibus Agrippae siculis, quos colligis, Icci, si recte frutris.

Siculum. Siculum nare Poeno [urpuretum sanguine

sieut. nec sicjuid [? sicut] olim hisit Anaereon/delevit aetas;

nihil me sieut antea itwat serihere versiculos

sicut parvola, man exemplo est, mani formica laboris/onetrabit

ibam forte vid sacra, sicut melus ext mos.

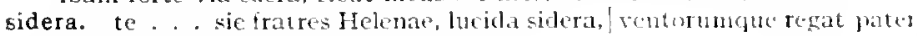
neque certa fulgent/sidera nattis.

sidera. sublimi feriam sitlera vertice.

culpante, nune torrentia agroa|sidera.

post insana Caprae sidera

quae sidera exeantata voce Thessala lunamque indo deriplit.

caelo iulgebat Luna sereno|inter minora sidera.

refixa caelo devocare sidera.

sidere. nec purpurarum sidtere clarior delenit usus

'quamquium sidere pulcrior/ille est.

siderum. siferum regina bicormis, auti, Luna, pullas. nec tantus umquan siderum insedit vapor

sidet. prituque cachun sidet inferits mari|tellure pouget supet

Sidonif. non huc sibuii torserunt cornua nantale,

Sidonio. gui sidloniu contendere rallidue nstrol nesed

sidus. Iulium sijus velut inter ignis/luna minores.

clarum Tyndaridae sidus

nec sidus atra nocte amitum adpareat,

"tu pudica, tu proba|perambulabis astra silus antrenum."

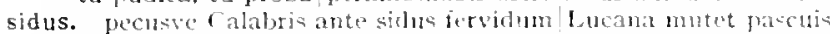
Canem illum, invisum agrievis sidus,

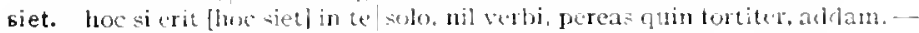
rigilla. orlisti clavis et grita sigilla pudico;

Tyrhenas sigila, talrellas. . . sunt qui non babeant,

signa. "xpmbt. . laller"et ioto taciturna noctis signa cum caclo signa ego l'unicis a thixa elehubric

lat siona feret militiat thas .

signa nostro restituit Iovi rerenta l'arthorum superbis postibuc interfue signa furpe anilitarial sol andspicit conopiums.

caclo ditun lore signa paralit:;

rrm.1.s.d

curm.3.15.23

(umi. 4.2

Sirm.2.6.68

(ivm. 1.35 .27

I. peld.2.t)

(ium.4.5.39

(inm.1.18.3

I. fist.1.10.0

('a) I. I.Is

S.rm?.2.4.15

L.P. P. 16.5.5

Cirm?.3.20.20

Sirm, 2.2.14

$\therefore$. $m$ m.2.3.28I

Jipist 1.17 .12

irt? . S

vicmit. $1.3 \cdot 4^{6}$

Sirm.2.3.180

Strm 2.5 .45

(a)m.3.4.28

(amm.2.16.33

carme.3.18

(imm.t.4.44

Jist 2.1 .58

lirs l'ollatis

latict.t.2.58

lepint i 12.1

cirmm.12.2

$\therefore$ antr.ciomol y.u

fipedel I. 1

Stm.1.I.32

Sirm. I.9.J

(arm i. 3.2

(ierm.s.16..4

(itrm.1.1.3r)

(ivm).3.1.32

(itrm-3.7.0)

l.poll.5.45

Jipula 5.2

l.pod.17.5

Cirm?-3.1.t2

(imm-3.0.21

carm.Satc.35

lipoll.3.15

leptes.50

I:poll. I0.50

Epist.t +10.26

('thm.I.I 2.47

Corm.1.8.3 I

lipel.10.0

Iporl.t. 7

l.poll.1.27

Sirm.1.7.20

2ut r. Sirm.2.3.11

Epist.1.20.3

ENoist.2.2.180

(

(itrm 3.5.14

(itrm.1.1.10

(irm.t. I 5.4

liperdo. 5

Sirm.1.5. I0 


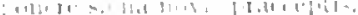

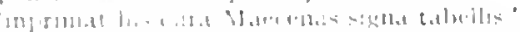

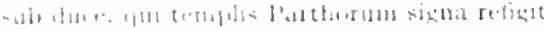

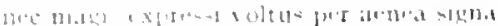

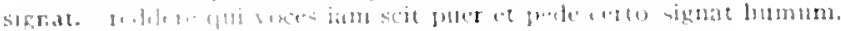

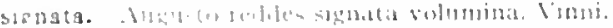

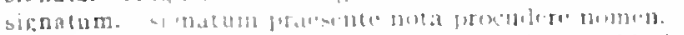

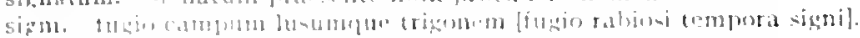

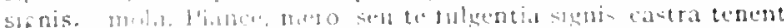

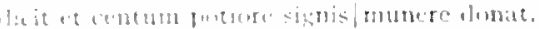

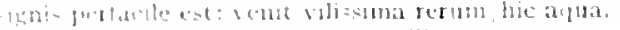

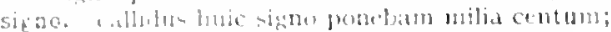

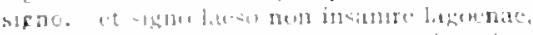

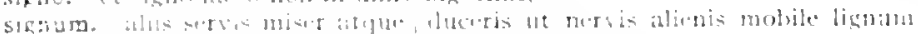
$[\rightarrow 1+13,[3]\})$

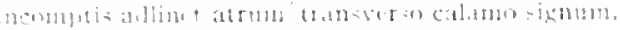

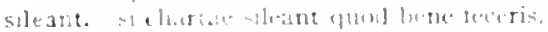

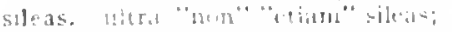

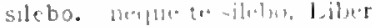

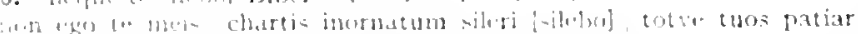

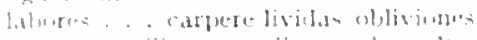

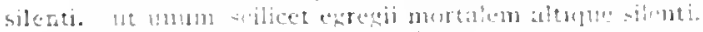

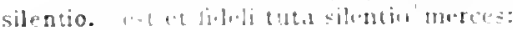

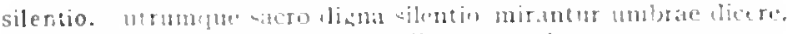

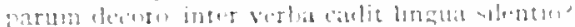

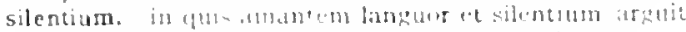

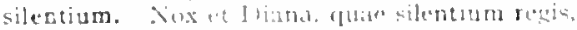

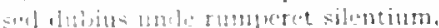

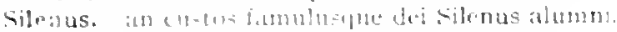

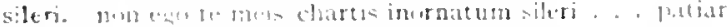

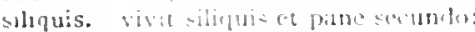

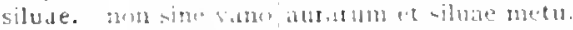

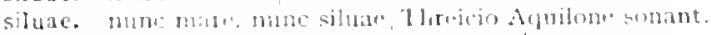

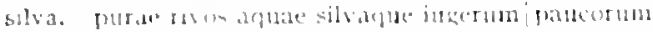

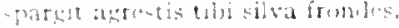

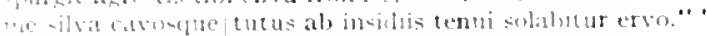

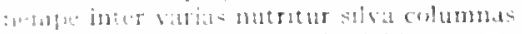

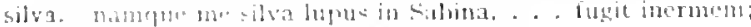

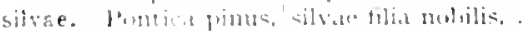

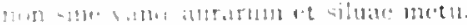

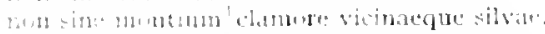

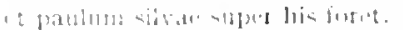

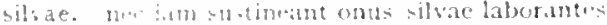

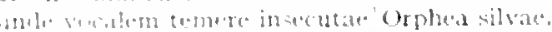

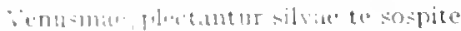

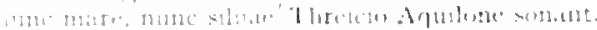

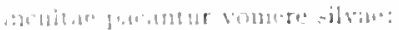

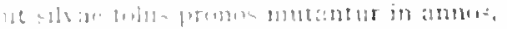

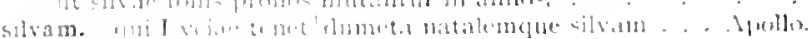

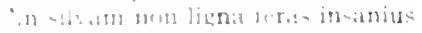

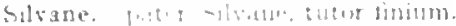

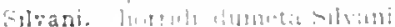

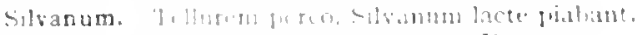

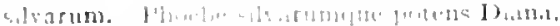

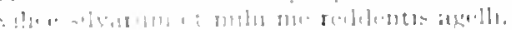

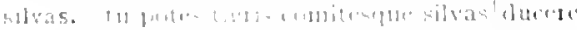

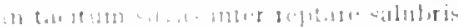

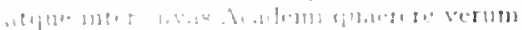

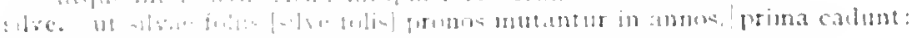

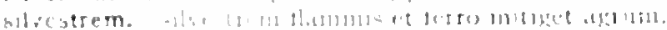

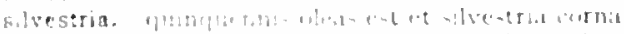

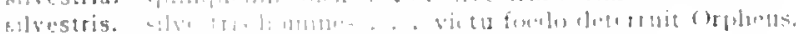

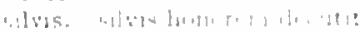

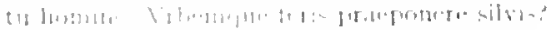

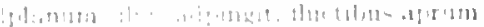

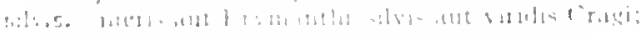

it andstibt an

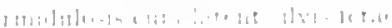

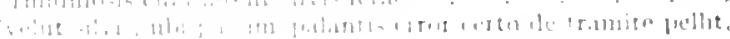

Sierm.2.9.2

Serm.2.1.35

$\int=p a s t .1 .18 .50$

J.pist.2.1.2.48

Irs l'ort. 159

I. Pist. I. I 3.2

-1rs Joet.59

$\because$ r.sirm, I (1, s 26

(ism.1.7.19

Carm.12.19

cierm.1.5.88

Sirm. 23.23

f.pist.2.2.131

compis.serm.2.7.82

Ars l'ret.it?

curm.1.8.21

Sirmi2.5.01

carm.1.12.2I

isr.corm.4.9.31

Sirm.2.4.58

(arm.3.2.25

Carm.2.13.20

(arm.t.1.36

jepoded 11.0

1. Pud 5.51

1. purt.

. 1r: Put 230

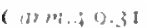

1. 196.2.1. 23

ctrm.23.

l. poul 1.3 .2

(itrmas 111.20

(armo.3.15.34

Sirm.2110

1. pist 1.10.22

(iirmi. 120

(arm.1.1. 12

(")

(arm.3.?) 39

chrm.2. 3

(cermm 10.3

corm.1.12s

(arm.1.28.27

1. pord 1.i. 2

fepol 1.2.45

irs linetero

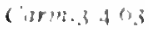

serm.t 10.34

l. $p_{1012} 22$

Cirm 320.23

1. pist 2.1.1.4.3

(itrms.riste.

I.prat is I

(isrm 3.11.13

I find 1.94

1 pid 2.2:15

air lor Ineselo

l. post a.s.seo

S.rot.2.25

Ars 1id 301

I poll is le

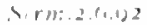

Ars libet 30

(arm 1.21.

l. foul z 20

1 poids 5 \&

virnt 2.34 
militat in sily- custulus.

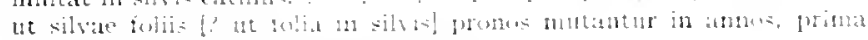
catunt:

silvis deduci caveant me indice bauni.

sim. comes minore sum [sin] futurus in mett,

non exo sin Capri neque: Sulei: cur metuas nue?

nuts. qua sim tibi, Maecenas, cunvictor,

simile. nec riget quidquam simile aut secundum.

'dum nequil sinale huic, esto ut libet."

simile. numquid ego ih inpruhens olim faciam simile:"

quin! simile isti|Graecus dristiplus?

similem. puro te similem. Telephe. Vesperoltompuativa patit Klumb:

'equi te esse feri similem dico.'

hinc cao bolgus errori similem cunctum insanire docubo.

similem. jlam curit amor Jothi latsivae sinilen ludure camban.

sinili. crera nequaquatn simili rationt modoque atestimat.

simili. latudantur simili prole puerperits.

magnis para mineris talee rectiurum sinili te.

similis. si per obliquom similis sagit tae tertuit manws:

cantat et adponit 'meus est anor huic similis:

ut sis tu simulis Caeli Birrique hatronum.

huic ego volpu errori sinilem cunctum [sinulis cuncta] insanise dorebo. stes capite obstipo, multum similis metuenti.

cum semos redderet ictus primus al extremum similis sibi:

similis. vitas hinnuleo me similis. Chloe.

similis. sinilisque meorum mille die versus deduci pose.

simillimus. venens et liquidus puroque similimus amni

simius. simius iste nil praeter Calvon et doctus cantare Catulim.

Simois. findunt scamandri Humima lubricus ct Sinois, .

Simone. Pythias, emuncto licrata Simone talentum.

simplex. plus aequo liber: simplex fortisque habeatur:

nec sic ut simplex Naevius unctan convivis praebelit aquan:

quantum simplex hilariaque nequti discrepet

simplex. cui tlavam religas comam, simplex munditis?

quae simplex olim tibi sederit.

tibia... tenuis simplexque foramine pauco

simplex. simplex dulei constat oliso.

denique sit quod vis. simplex dumtaxat et unmn.

simplices. rivent, simplices Xynphae.

simplici. simplici myto nibil adlabores sedulu= uro:

simplici. deiecit acer plus vice simplici;

simplicior. simplicior quis t't e:t.

simul. ut patermi Huminis ripae simut et iocosa redderet laude= memor|actae non alio rege pucrtial mutatacque simul togae. otium non dulce, ni lecum simul,

cum ripa simul avolsos ferat Aufidus acer.

Capitoque simul Fonteius, ad unguem lactus homo.

'wle hominis nonen, siniulet, Komanus an hospes."

simulque' uncta satis pingui ponentur holuscula lardo'

Porcius infra. ridiculus tota semel [amul] absorbere phacentä;

excepto quol non simul esses, cctera laetur.

cetera iam simuliato cum vitio iligere:

aut simul et iucunda et ilonfa ricere vitae.

simul. simuline vos. Bibule et servi,

vis. Bibulu et sury simul his te, condide Furna:

simul. quo simnl mears. nee rena vini sorticre tala

permitte disis cetera. qui simul strasere ventos

quorum simul aiba nutis stella refulsit.

sed tu sinul obligasti p'rhilum votis caput, contescis

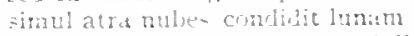

militia simul fessas collortes abdirlit oppidin.

simul uncers Tiberinis uneros lavit in undis,

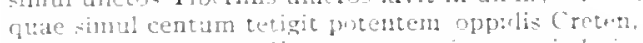

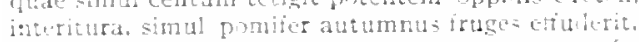

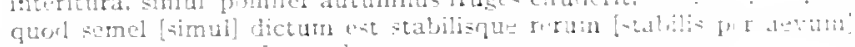

tormatus sorvet [servat].

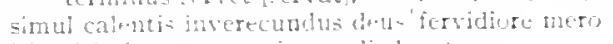

simul imis saxit renerint sadi= lesata.

quae, simul inversto contristat Aquarilo atsmum.

j:pist. $=1,7$

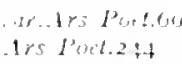

: $13 \%$. l-pent.1.17

Sirm.1.4.79

Sirm.t. (1).7:

(itm:1.12.1S

$\sin 2.3 .31$

Serm.1...t.1.37

S.m.m.2.3.95

Cirm?.3.19.26

Sirm.1.5.57

> 7 m.2.3. 3

("1rm.3.15.12

L.thit.z.1.20

Cism.4.5.23

s.rm.1.3.123

(tarm-3.27.0

s.rm12.107

Simmento

i ir.s.trm. 2-3.6/3

sirm.2.5.02

.195 Pert.254

(ivm).1.23.1

verm.2.1.3

1. 1).3.2.2.120

Sirm.h.10.I8

1. Pod.t.3.14

Ars loxt.238

Sirm. 1.3.52

Serno.2.2.08

1.pp:1.2.2.193

Corm.1.5.5

strm.2.2.73

- Ars l'vel.zos

Sirmizated

- irs lopt.23

(arm.2.8.

(ism. 1.38.5

(i)m.1.1.13

sermin. 1.3 .3

cirm. I.20.0

(

1. Pot. I. 8

Sermo1.t.5s

Sirm.1.5.32

Sirma.4.21"

sierm.20.153

itr. S.rm.2.8.24

leptut.10.50

J.pirt.2.2.205

Ars $100+334$

sirm.t.10.85

sirm. $10.8 \%$

cirm.147

('ism. I.0)

Girm.1.12.2\%

cirmi.2.5.5

(ismestine

(ism-3.1.37

ciarm.3.12.7

(i) 19.3 .27 .33

Coms: T.50

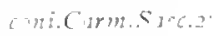

1.p.t.11.1.3

L.poldi. I . 5

Serm.1.34 


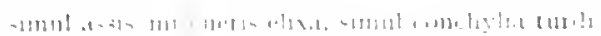

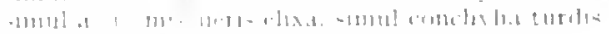

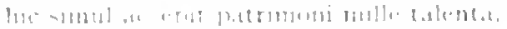

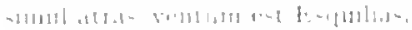

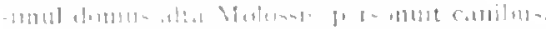

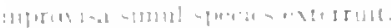

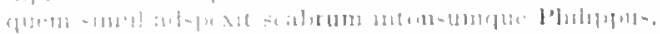

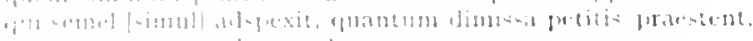

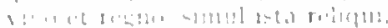

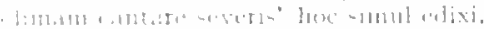

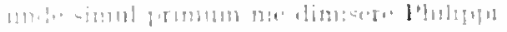

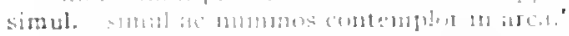

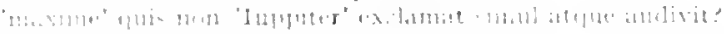

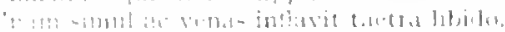

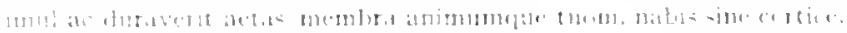

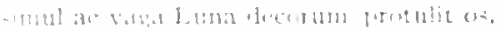

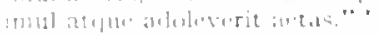

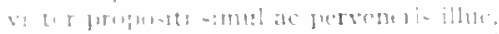

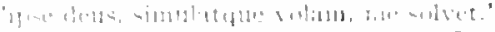

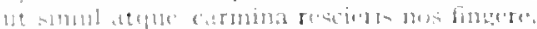

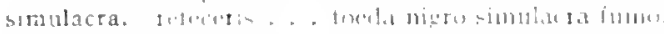

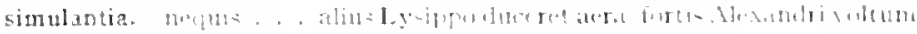
cilumlintin

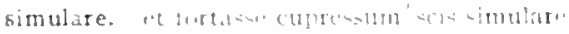

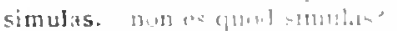

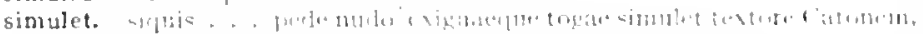

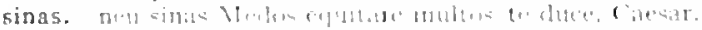

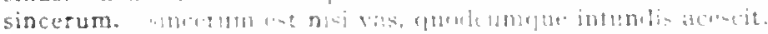

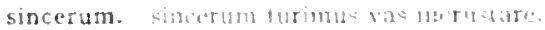

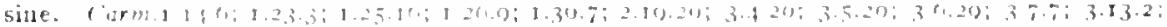

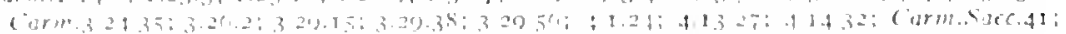

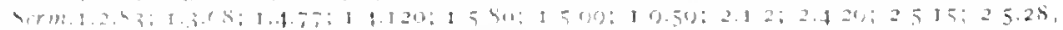

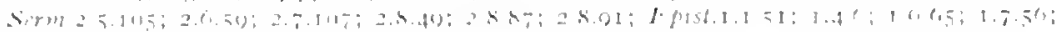

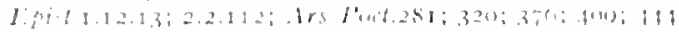

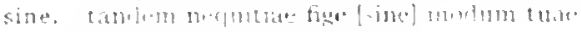

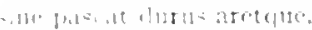

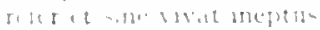

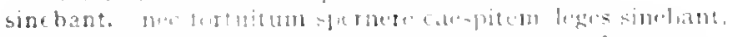

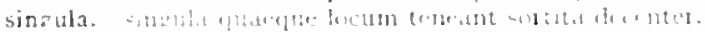

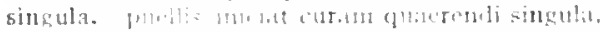

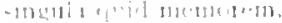

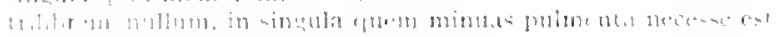

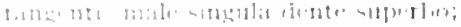

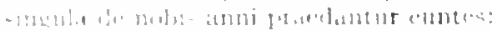

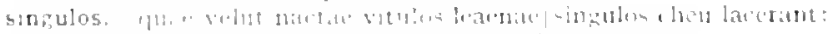

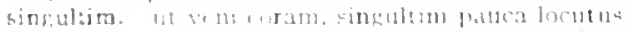

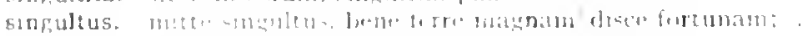

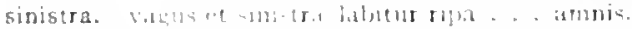

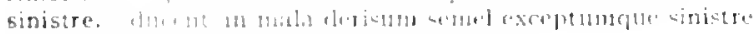

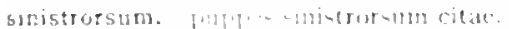

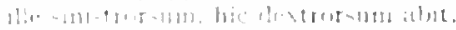

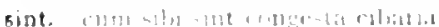

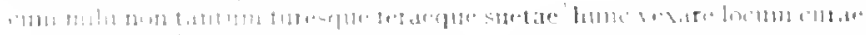
$111: \mid 1101\}$

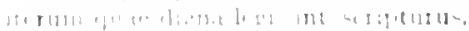

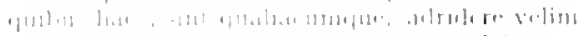

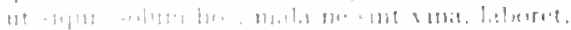

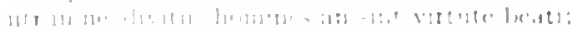

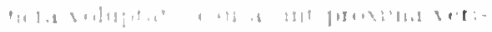

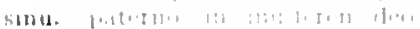

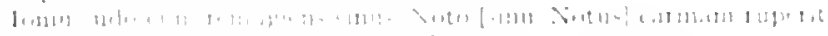

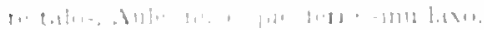

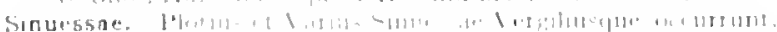

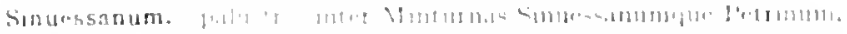

sanum. 1. …

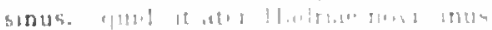

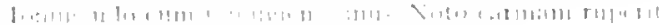

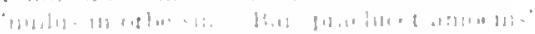

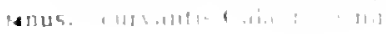

Sirm 22.73

Sirm. $32-7$

Sirm. 2.3.220

sirn.z.12.32

Serm.2.n, I I I

f.pict.1.11.11

Ipist. 1.7.80

ior lopiat.7.74

IP.N.1.10.S

Ifu.19.10

Dirm. 1.1 .7

virm.1.2.18

sirm 1.2 .33

sirm. i 1 1+1

hirm: 1 เ.. 1

sirm.1, $\$ 1$

I.pint.1.1.3.11

1. nistalde-

1:yint.2.2.2\%

( a)m 3.1...

I pive.1.29

itri l'riet.20

Sim.2.7.50

I pi:1.1.10.13

("ar)!. I . 2.5.

1 jict.1.25.1

sirme. I.3.5\%

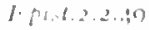


siqua. Spartacum iqua potuit vagantemfollere testa.

(imm? $3 \cdot 1.1 .10$ mentio siquar [siqua] de Capitolini furtis iniecta Petili|ke coran tuerit. difendils.

siquae. mentio siquaelde Capitolini furtis iniecta Petili|te coran fuerit. .

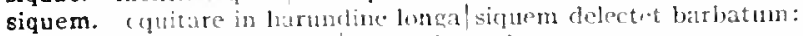

siqui. sirpi scribat uti nos/sermoni propiora.

ut siqui atsontet quo morbo Barrus.

vestem servosque sequentis, in magno nt populo, sigh vidised.

"non hercule miror." aiebat. "iqui comedunt bona.

siquid. non. siquid Pholorn, satisfet te. Chlori, decet:

nam sicuic! in Flacen viri est.

nec, siquikl houesti est, iact.t labetque palam.

nocturnet siquid crassi est tenuabiur aura.

qui, siquir forte lateret, indio monstráret hisito:

siquid, est animum. differs rurandi tempus in annum?

siguir! abest. Italis adiurlicat armis.

siquid. siquid loquar audiembn.

nec siquid olim lusit Anacreon/chlevit actus;

at siquid umquam tale concupiveris.

ignosent. siquid peccaro stultus, anici

ut siquid promitterte de me $\mid$ possum alud vere, promitto.

quod vitium procul afore chartislatque animo prims. ut siquid lanimo, prius ut. siquidl promittere de me/ possum aliud vere, promitto. siquid miri faciat natura.

mentior at siquirl.

grande matun Turius, siquis se iurlice certes.

siquid Stertiniıs veri crepat.

imbecillus, iners. siyuid ris, adde, popino.

siquid novisti rectius istis, / candilus inperti;

siquid mirabere, pones/invitus.

siquicl petet, intro'defer:

siquid ct nos. quod cures proprium fecisse. Jopuanur.

protinus ut moneam (siquil! monitoris eges).

quod superest aevi, siguid superesce volunt di;

hunc ego me. siquid componere curem. | non maris csse velin.

siquid inexpertum scaenae connittis .

nec, siquid fricti ciceris probat et uncis emptor,

siquid tamen olim|scripscris.

Quintilio siquie recitares. "corrige, soles, 'hoc' aiebat 'et joc."

siquis. siquis infamem mihi nume iuvencun/dedat irata.,

o deorum / siquis hacc audis.

parentis olim siquis inpia manu|senile guttur fregerit.

si quis atro dente me petiverit.

si quis deus 'en ego' dicat.|"ian faciam quorl voltis:

ut siguis aselum in campo doceat parentem curre frenis?

siquis nune quaerat "quo res haee pertinet?"

siquis eum servom. . . in rruce sutigat,

siquis crat lipnus describi, quor malus ac fur.

bene siquis/et vivat puris manibus,
restem s.rvosque sequentis, in magno ut populin, siqui [squis] ridissot, mollitu ac siquis pedibus quil claudere senis,

si mala condiderit in quem quis camina.

esto, siquis mala; sed bona siquis iudice condiderit hudatus Cmenare?

sinuin opprobriis dignum latraverit, integer ipen?

siquis munc mres suavis coliserit assos.

sipuis enat citharas, enptas conportet in unuts,

siguis ad ingentem frumenti soufer acersom/ porrectus vigilet

"' 'fuil. siquis non sit avarus, / cuntinuo sanu=""

siquis Sectica niticlam gestare anet asnan,

siquis gnatam promuta livovet anna.

baec siluis temprestatis prope ritu . . Laboret reblere certa sibi.

quar siguis sanus fecit, sanu facis ct tu.

nt. siguis solum lioc, mala ne sint vina, laboret,

siquis casu: jur rum egerit ciro.

siquis forte coberedum senior male tussiet,

siquis nam lautat Areli! sollicitas ignarus opes.

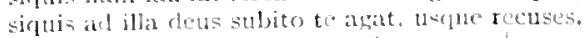

leporum avolsos, ut multo suavins, armos. "quan si coun lumbis quis edit.

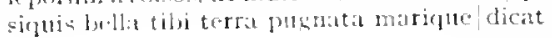

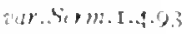

Sim:1. 1.03

$\sin m \cdot 2 \cdot 3.240$

Serm.1.4.4I

Sirm. I.

Sim.1.9.79

I.M.1.15.4=

(arm:3.15.7

Epod.15.I2

Sirm.1.2.84

Sirm.2.4.52

Sirm.2.8.25

Epist.s.3.35

l.pist.1. I k.57

(itrm.at.2.45

(cam.t.9.)

Fipularig

Sierm.1-3.140

Serm.1.t.102

coni.Serm.t.4.102

Serm. 1.5. 10 ?

Sirm.t.5.37

Sirm.2.1.49

S.rm.2.3.33

Sim-2.7.39

IEpist.1 P.67

L.pist.s.Jo.3 I

Iifist.1.2.22

Fpist.1.17.4

Jipint. I 8.07

Finter.tion

Airs Iod. 35

Irs I'vit. I25

- Irs Pot. 240

- Ars Poet.3so

Irs Iotet.438

(t)m.3.27.4.5

carm.3.27.5 I

Epert.3.I

I.potido.15

Sirm.IIIS

Sirm.1.I.90

S.rm.1.2.23

Sirm-1.3.80

Serm. I.4.3

Sirm.1.4.67

iar.Serm.1.6.70

Sirm.1.10.59

Serm.2.1.82

Sirm.2.1.83

Strm.2.1.84

Sirm.2.2.5I

Sirm.2.3.104

Sithe2.3.11 I

Sirm.2.3.2.59

Serm.2.3.214

Str. 3250

Sim.2.3.208

$\sin 2 \cdot 2 \cdot 3 \cdot 3=2$

Sirm. 2.4 .49

Sirm.2.5.49

Sim.2.5.10'

Sirmo.6.

Sirm.2.7.2.i

Sirm.2.8.00

Ispist.J.10.25 


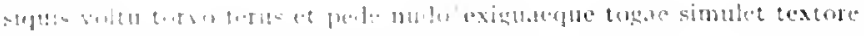

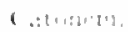

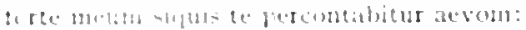

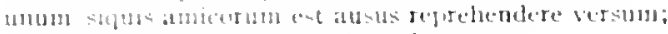

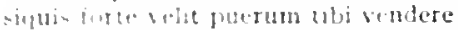

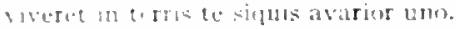

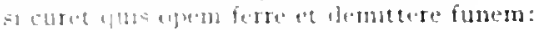

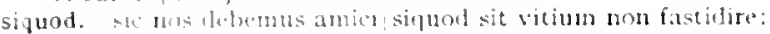

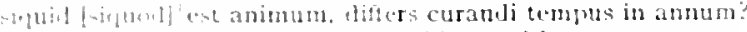

siquos. subue lowimenata thuctibus hiems all hoc vertat mare,

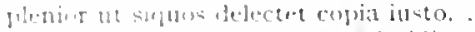

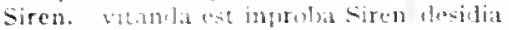

Sirenum. Sirtum boces et Circar pocula nosti;

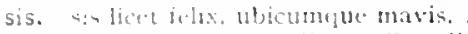

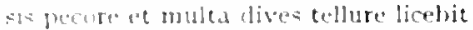

"nil satia ese." inquit. "quia tamti quantum habeas sis":

ut sis tu watlis Ceeli Burripue latronum.

"rentum ditusurulis sis."

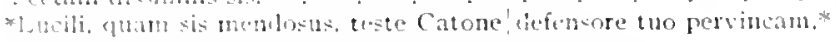

is guter, ut tio, vialis metue

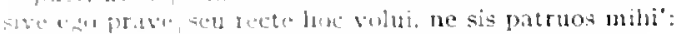

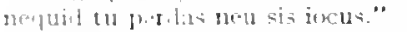

i. [uta] fugmunr ipse. persta atque obdura:

Thbo: sin commens atude istes capite obstipo.

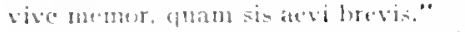

tu cutn sis quenl renet tortassis nequior.

serum tutelit mearum cum sis

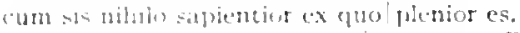

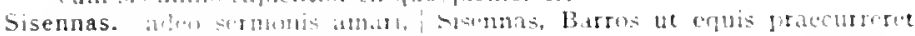
alisic

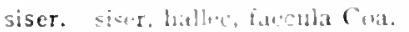

Sisyphus. Hammaturnue longe Misphua Arolides laboris.

eprat sufremo collocare Sisyphus in monte saxum;

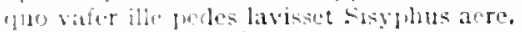

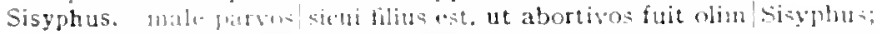

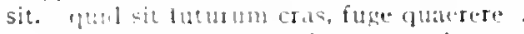

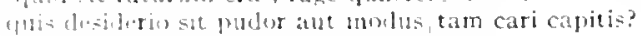

nen nuscum in Salium sit requies pedum

12. -it asuctlace tibi amor putori.

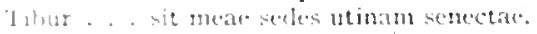

-if multr lasur maris et viarum| malitiaeque.

num, si trorentic [it reneds] puntquot eunt dies.

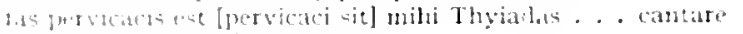

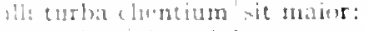

-14) (a)forr cit trabsbus

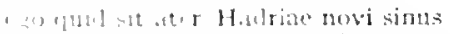

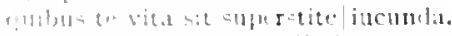

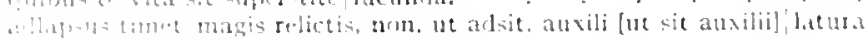

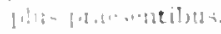

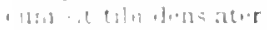

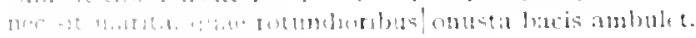

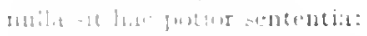

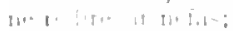

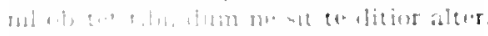

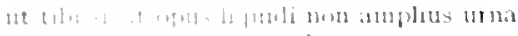

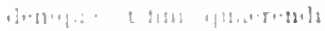

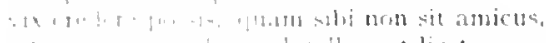

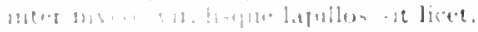

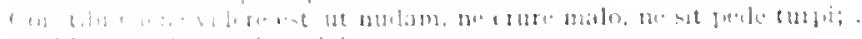

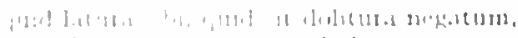

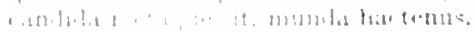

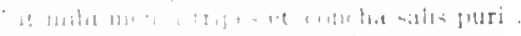

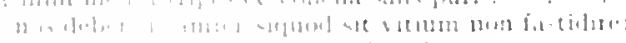

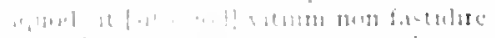

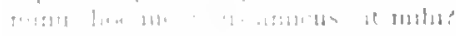

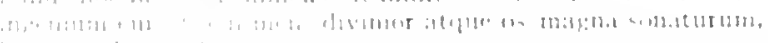

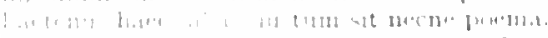

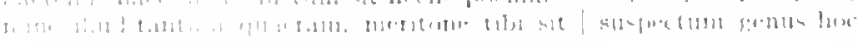
1.1, 11,11 .

J.Pist.1.10-12

Fis.1.1.20.20

Jipit.2.1.222

Jist.2.2.2

I.post.2.2.15:

- Irs linetiatid

Sirm. 1.3..4.

int. Epist.1.2.39

I.pod.2.5I

Sirmi1.1.57

Sirm.2.3.1.4

lipist.1.2.2.3

(1:4):3.27.13

IPAd.15.19

Sirm.1.1.12

sirm.1.4.(1)

Sermed.d 112

Serm.r.ro*1

Sicru. 2. 1.60

Serm.2.3.88

Sorm.2.5.37

:ur.Sirm.2.5.38

Sirm.2.5.01

Serm.2.1.07

sirm.2.7.40

J.pist. I. 104

E. Hist.2.2.153

Serm. 1.7.8

Sirm.2.6.0

(arm.21120

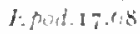

Sirm.2.3.21

sermis. 1.37

(arm.1.0.13

Coum. 2-4.1

(arind. 30.12

(itrm.2.1. I

(iarm.zepee

(ar:n-2.0.7

Far.Cum.2.1.5

conicarm.2.50?

(istin.3.1.14

(arm-3.2.28

(arm-3.27.IS

(a)illpold.5

ast.f.pest.1.2I

fasods.s.3

I:Astis. i.

I. joud.10.17

1. pind.11.21

Sitm.1.t.

Sirm.1.1.51

SัTm.1.1.02

sorm.1.2.20

Sirm.1.2.S1

virm.1.2.102

Sirm 1.2.112

Serm.1.2: 123

Setm.1 3 I3

sitm. 1.3.1.t.

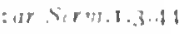

sirm.1.3 0.9

Sitm. 1.4 .3

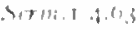

sirns ind 
sapiens. vitutu quilque petitu/sit melius, causas reddet tibi: an hoc inhonestum et inutile factu|necne sit adlubites, auxilio quac|sit nilii (nam multo plures sumus), neque quis me sit devinctior alter.

cum referre negas, quali sit quisque parente|natus, . quali? sit facie, sura quali, pede, dente, capillo: . quo patre sit natus, num ignota matre inhonestus, mon sollicitus milii quod cras'surgendum sit mane. librida quo pacto sit Persius ultus, an et cum dura tibi peragenda rei sit callsa Petilli? quae virtus et quanta, boni, sit vivere parvo primum nam inquiram, quid sit furere:

"'quit, siquis mon sit avarus, | continuo sanus?" "quartae sit partis V'lixes"|audieris "heres": ex parte tua seu fundi sive domus sit/emptor, ct quae sit natura boni summumque quid eius. frugi quod sit satis, hoc est. |ut vitale putes.' quod nusguam tibi sit potandum.

num sit quoque iracta lagoena, cui sit condicio dulcis sine pulvere palmac? quid sit pulcrum. quid turpe, quid utile, quid non, sit tibi curae quantae conveniat Mumatius. ne fidos inter anicos|sit qui dicta foras climinet, (indignum, quod sit peioribus ortus) lic tibi sit potins quam tu mirabilis illi. cuius fortunae, quo sit patre quove patrono.' scis, Lebedus quid sit: Gabiis desertior atque/Fidenis vicus; ne tamen ignores, quo sit Romana loco res: melior sit Horatius an res. quae sit hiens l'eliae, quod caelum, Vala, Salerni. cun sit obesolnil nuelius turdo.

sit spes fallendi, niscebis sacra profanis. qui melior servo, qui liberior sit ararus. cur sit Aristipni potior sententia.

scilicet, ut mon'sit mihi prima fides

sit mili. guod nune est, ctian minus.

sit bona ibrorum et provisae frugis in annum | copia ambigitur quotiens, uter utro sit prior. quantus sit bossenus edacibus in parasitis.

tamquam / sit proprium quicquan,

Ienique sit quod vis. simplex flumtaxat et unum. sit Medea ferox invictaque, flebilis Ino.

neve minor neu sit quinto proluctior actu| falula,

quo sit amore parens, quo frater amandus ct hospes. quod sit conscripti, quod iudicis officium.

ne forte purlori|sit tibi Musa lyrae sollers ct cantor Apollo. an sit amicitia clignus; non sit qui tollere curct. sit ius liceatque perire poet is:

Sithonia. Memphin carenten Sithonia nive.

Sithoniis. monet Sithoniis non Jevis Euhius,

siticulosae. nec tantus umquam siderum insedit vapor siticulosat Apuliae sitiens. 'Tantalus a labris sitiens fugientia captat thunina'-

sitim. nec sitim pellit, nisi causa morbiffugerit venis aclduxere sitim tempora, Versili: si tibi nulla sitin finiret copia lymphae,

sitis. num, tibi cum fancis urit sitis, aurea quacris/pocula? quem tenct argenti sitis inportuna fanesçu,

situ. regalique situ pyramidum altius.

situm. sic melius situm. |cum terril celat.

audis. . . (quo nemus i inter pulcra satum [situm] tecta remulat ventis

situs. scriluctur tibi forma loquaciter et situs agri. . nunc sius informis pronit iel reserta vetustias;

situs. quam res componcre gethas terrarmeque situs

give. Curm.1.412;1.6.10;1.12.55; 1.13.11; 1.15.25; 1.32.7:3.21.2;3.27.61;4.2.17; Cammisec.15;

Fphl.17.30; Serm.2.1.38; 2.2.8.3; 2.2.110; 2.3.87; 2.4.50; 2.5.11:2.5.119; 2.6.25; 2.7.70;

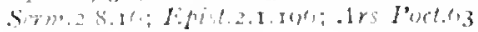

Sirm.1.t.1It)

Simin. 1.1 .125

Sirm.1.4.1.t2

Sirm.1.5.42

Sirm.1.6.7

Sirm.1.0.3.i

Sirm.1.0.3\%

Serm.1.0.120

Sirm.1.7.2

Sirm.1.10.20

Sirm.2.2.1

Sirm.2.3.41

Serm.2.3.150

Serm.2.5.10n

Sirm.2.5.105

Sirm.20.70

Sirm.2.7.3

Serm.2.7.32

S.m.2.8.8I

I.pist.i.1.5I

Iipist.1.2.3

If pist.1.3.30

Epist.1.5.25

Epist.a.6.22

Epist.1.0.23

Iipisi.t.7.54

IPpisi.r. I.7

l.pist.1.1 2.25

Epist.r.1.4.5

Epist.r.I5.:

Epist.1.15.42

lipist.1.16.5t

lipist.1.10.4.3

Epist.1.17.17

fipist.18.1

Eptit.1 $18.10 \%$

Epist.1.18.I00

Fifist.2.1.5.5

If pist 2.1.173

IPist.2.2.172

lrs Pott.23

Ars Toetitaz

- Irs Podirio

Ars loost.3 3

Ars Joct.31+

Ars Pretagro

Ars Poet.t.io

Ars Poetafen

Irs Peset.teles

(inn:3.20.10)

(itm:1.18.9

I. poul.3. Is

Sirmer.tes

Corm.2.2.14

Corm-12.13

Iifist.2.2.140

Sirm.1.2.114

Jipid.1.1\$.2.

(itrm.3.30..

(iarme.3.3.t.)

atr. Carm?3.11)"

I.pist.1.16..1

Eprot.2.118

lipist.2.1.252 


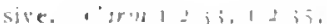
$1+121, \pm 1 \div 1,1,1$

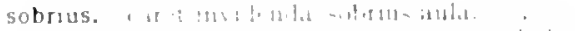

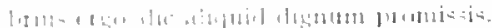

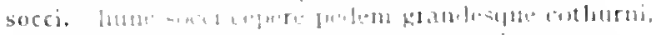

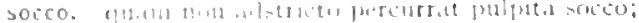

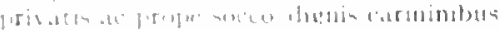

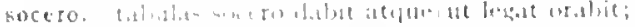

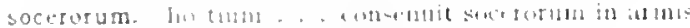

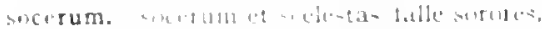

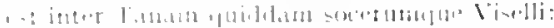

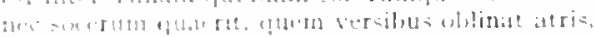

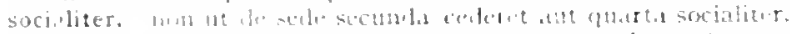

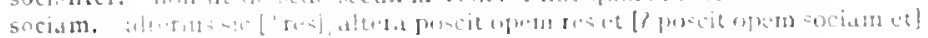

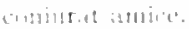

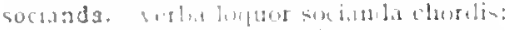

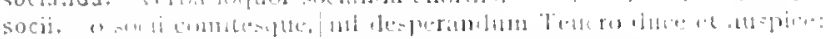

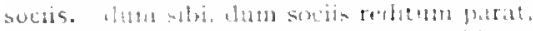

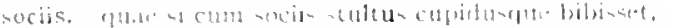

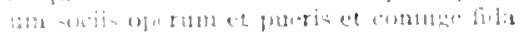

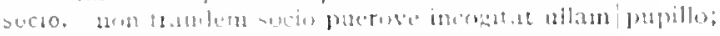

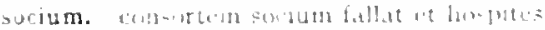

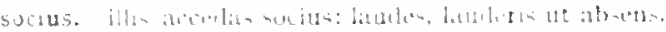

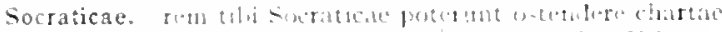

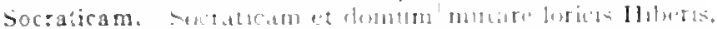

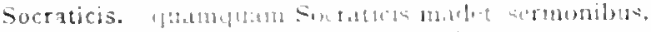

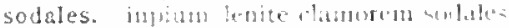

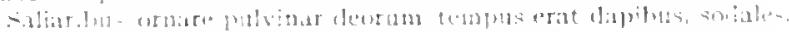

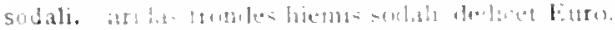

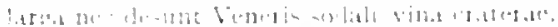

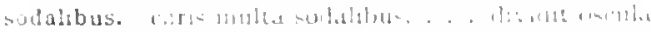

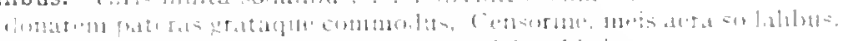

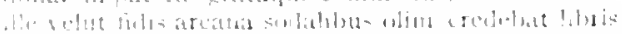

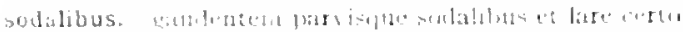

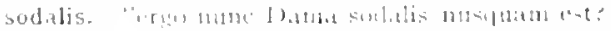

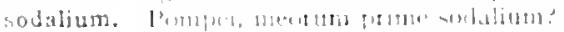

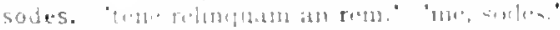

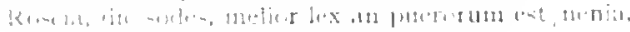

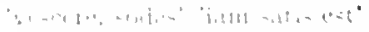

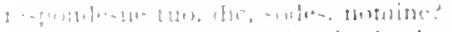

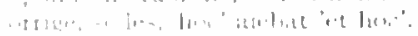

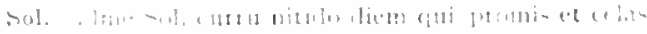

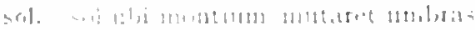

$.111+1, \mid 1,+1,110,411,1,-t$.

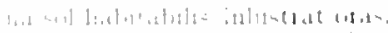

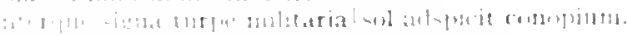

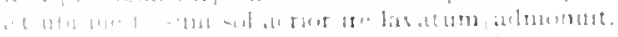

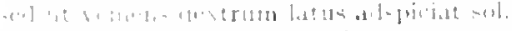

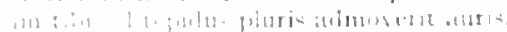

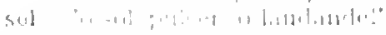

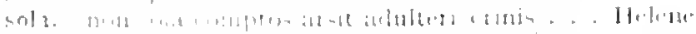

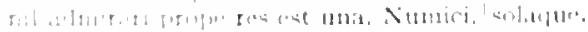

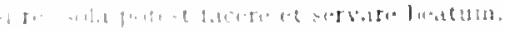

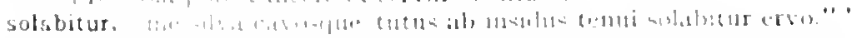

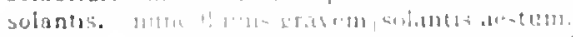

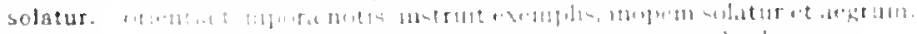

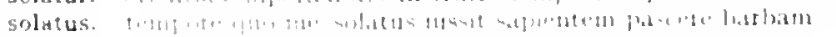

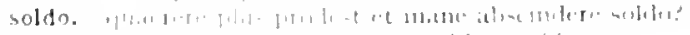

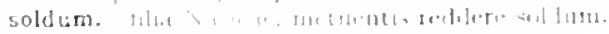

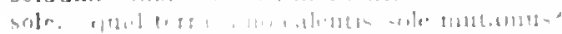

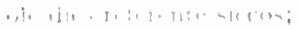

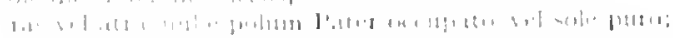

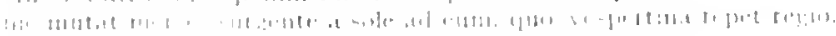

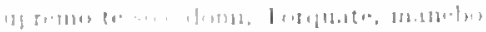

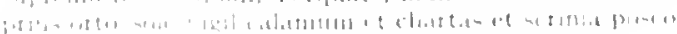

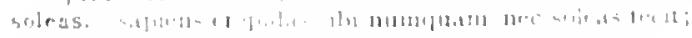

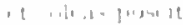

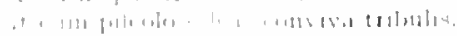

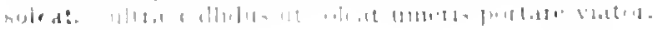

(1irm!.2.11).

sirn. 23.5

- Ars Jenetson

Jipit =1.17\%

in Jouter

sirnt. 5.60

(irren. 3.5.5

(a)ritis in

Sirgita.1 10.5

ispi 1.1 .10 .313

Irs / 1. 1.258

i iert. Ars Pind...11

cirws.10.9

(cirm. 1. 7.20

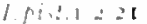

$10: 1,2 \geq+1$

f.lid...1.1.2

Jip:I $2 \pm: 22$

(itemlis at (1)

S rmas. 572

Arefores 10

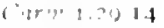

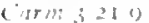

(is), $1=7=7$

Cirlst. 1.37:

c arm; $1=519$

( I.r

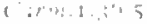

( w) w...

s.r.ti= $=1.34$

j xita 75

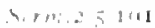

( n m $=7.5$

S.rmt is i

I. 101.100

$12 ! 187.15$

I f:1.1.11..\} $\mathbf{I}$

. 1rs / $10+6.60$

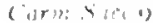

riarl \{.tedt

(ior) 15 in

( iaringl15

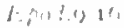

Nirn.1: $1: 5$

1 piel t tien

1 $61+1=10$

t ar nt... 2 .

( iarmas) 13

1. Pol. 1.1..'

1. Pigt : 1. $\$ 7$

Sell.20.11\%

(

1.pit: .1.131

ง.rm.2.3.55

$4 t r 1.12113$

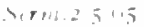

( arm: = 110.10

(aria

(1,roi is 2015

$\rightarrow r M 1, \quad 21)$

I.PI: 153

$141,6 \pm 113$

Sirit: 1828

प, 207

\& 51111315

merls 1 ;un 
Solem. comn semcl atecepit Solem furibundus acutum?

solem. ner rapilum fugiente soletwl.

solen Asine Brutum abledlat

huncine solem tam nigrum surrexe mili!

ante gravem quae legerit arbore solem.

bunc solem et stelias. . specteut:

solent. ut plerique solent, naso suspendis adumolignotis

ingenium res/adverate mulare solent, celare sccumdiu."

et neglecta solent incendia sume't vires.

soler. restat ut his ego me ips: regam solerque elenentia.

soles. gratior it dies et soles melius nitent.

soles. Htque soles. custos mihi maximus adsis.

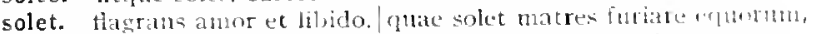
ut solet, in cor traiecto lateris miseri capitizse debure.

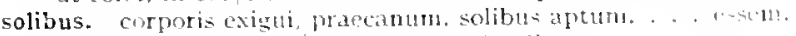

solibus. pernsta solibus pornicis uxur Ipuli,

quatque carent ventis tolibus gisa Quirini

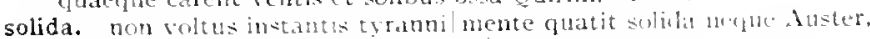

solido. franili quaterens illitere dontem/offendet solulo,

solido. nee partem solido denere de die spernit.

solidum. non voltu instantis tyrani|mente quatit solich ?? colinlum] scilicet ut deciens soliclum absorberet,

solio. redolicum Cyi solio Pliraten .

solis. cur apricumiloderit campum patiens pulveris atume solis. sub curru nimium propinqui solis in terra domibus negata: oscinem corvorn froce suacitalual solis ab urtu. ald or us'solis ab Hesperiocubili.

solis. inrat beue solis esse maritis.

num neque divitibus contingme gamplia solis

soliti. aversus soliti componere anicos.

nugari cum ilio et discincti lutrere. . . solit

luscinias soliti inpen*o prantere comptas.

solitis. quid prims dicam solicis parentis, laudibus.

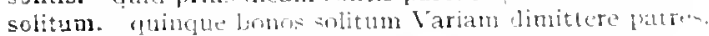

solitum. mon proture solitum leves.

solitus. populi contenuere voces sic solitus

nollem ontls haud unquan sulutus portare mol'stum.

testis putare diebns Campana solitus trulia

solium. attingit solium Iovis cot culestia temptat:

sollemne. Romani soltemne viris upus. utile fomate

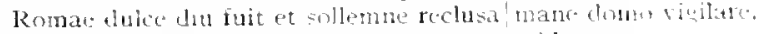

sollemnia. intiure futas collomnia mo neque riclus

sollennis. iurte ollombis mihi sancturque

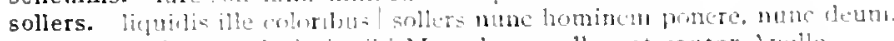

sollers. We lote purfori sit tibi Musa lyrae sollers ret cantor Aprollo.

sollicita. te panper anbit sollic ita prece, ruris coloman-

sollicitae. atqui sollicitar mumtius hospitae.

ducere sollicitise iucumla oblivia vitae?

sollicitam. sollicitan cxplicume frontem.

sollicitas. cantu tremulo puta ("upidineng lentum stlicitis.

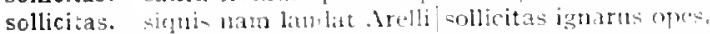

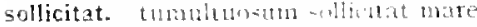

matial (o)

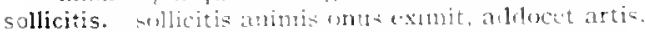

sollicitis. w prosllititis mon tacitus reje

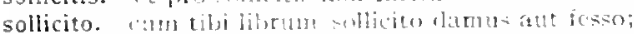

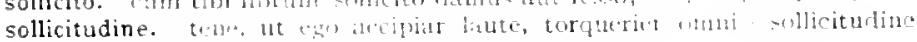
dintrictum,

sollicitudines. mataces alitur diffuginnt sulliwitulines.

sollicitudinibus. lewe diris frectrisa sollicitulinibus,

sollicitum. mupet solicitam quae mihi taedium.

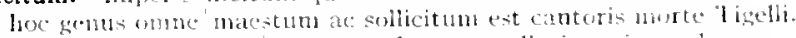

sollicitun. Follicitum ne flitior ant formae melioris meliat enlem.

sollicitus. Vrbi sulicitus time's.

men sollacitue mith quod cras/surgendum sit manc.

all moretrici-amore sollicitus plores:

solo. diratileque zole nives mereaturem abigunt?

solo. tlehis in solo leris angipurtu

hore si r rit in t: solo.
I.pist.1.80.17

(iom.20.12

herme. 1.7 .24

S.rm.1.0.72

s.m. 2..4.23

1.pist.1.3

Sermerts.5

virmasit

l.pist.1.18.85

lipist.1.1.27

( $12 \times+4.5 .8$

Serming. I 5

(4)

s.p.t. 2.3.28

I.pil.1.20.24

I:Pul.2.11

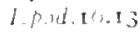

(arm 33.4

Sirm.2.1.58

(imm.1.1.20

? int corme.3-3.t

cern: $=3.240$

(arm.2.217

(iorm.s.s 4

(com: 1.22.22

( $1514.3=712$

(urm+1.5.16

intistr r 89

lipis.1.10

S. $M 7 \cdot 1.5 .29$

Sim.2 1.it

S.rय.2.3.2.45

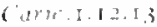

1.pint. I +4.3

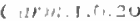

siris.1.110

Sirmes a go

sirn: 2.3144

1 pis' 1.IT.34

1.pul. $1.5 \$ 19$

1 pist 2.1 .103

l. fist.1.1.101

(ism. 11.17

(ivms.8.8

Are lint. 107

Cirm.1. $\$ 5.5$

(arme.3.70

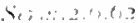

(isth) $;=0$. Ir)

(arm-tis

Sirm? 1.79

(arm.3.1,2)

Sirm.2.2.43

f:pt.t.1.5. Is

Citrm.t.1.1.t

l.pisi.2.1.221

Sirme.s.e.S

(arm.1.15?

I. pul. 310

(itrm.1.1. I

Sirm 1.2.3

s.ruts.2.7.5I

cirm? 3.20.20

serm.t.1.1 I9

sirm.2.3.253

(1)

('arm.1.25.111

sirm.2.3.43 


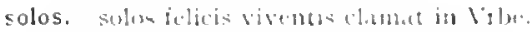

Sitm.1.1.12

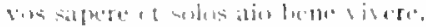

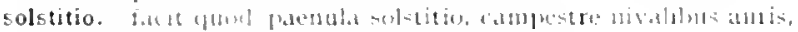

l.pist.1.15.45

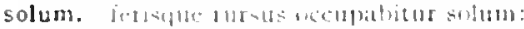

LPist.1.11.18

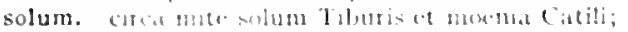

l. 0.1618 .10

mances

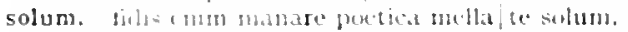

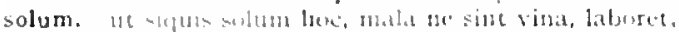

rm.1.18.2

Carm.2.7.12

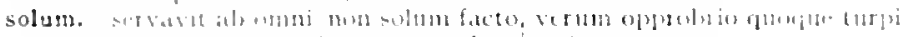

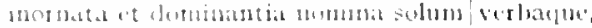

lipist.1.19.45

Sithi.2.1.49

Sirmos.osit

solus. mon pugnavit ingens finmemets stheneloste solus

is Juct.23it

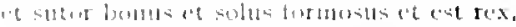

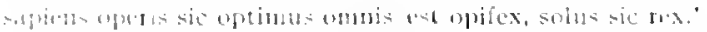

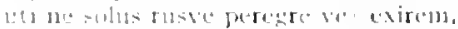

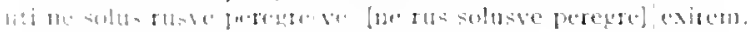

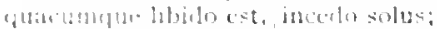

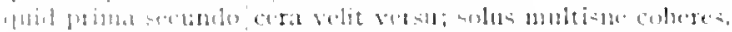

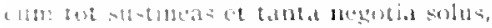

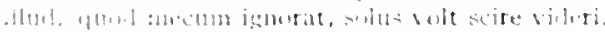

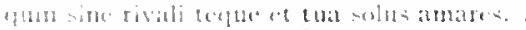

soluta. Meblat moluta natis eatt alite

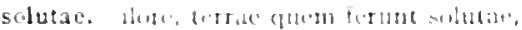

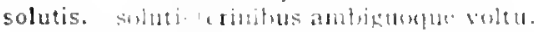

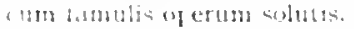

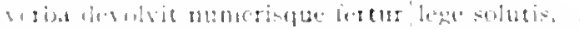

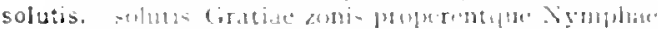

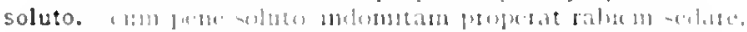

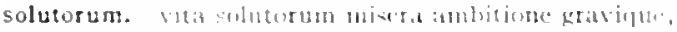

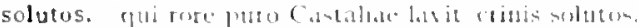

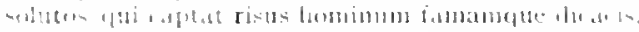

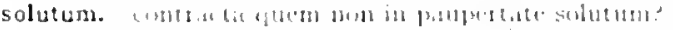

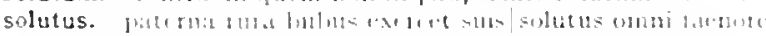

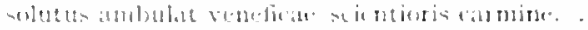

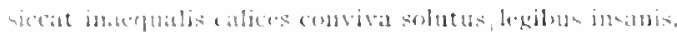

(iorm.40.20

ivimis.3.125

S.rmi.1.3.13.3

S.rmi.s.e.102

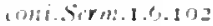

Serm.J.0.312

Sirm.25.5.t

Finst.2.1.1

l. pisl.2.1.87

lls livetiath

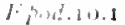

corme $\$$. 10

( arm. 2.5.23

(arm.3.17.10

(crmp.t.2.12

(irm. T.31).5

1.prol.13.s

Sirmito.120

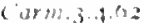

sorme 1.4.t.2

1 Sin. 1.5 .50

I.P.i.l. 2.4

Find 5.71

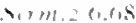

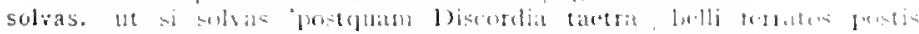

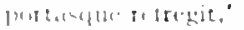

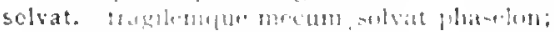

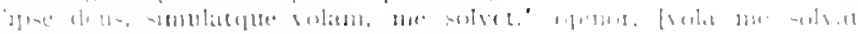
$[$ [ $111+1,1]$

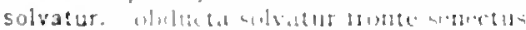

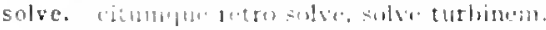

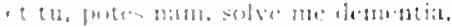

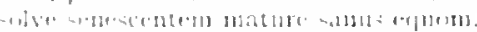

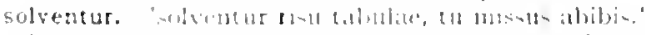

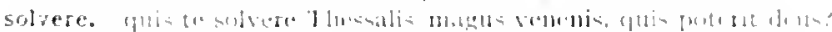

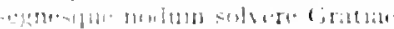

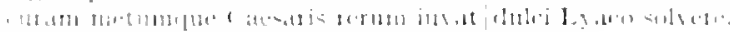

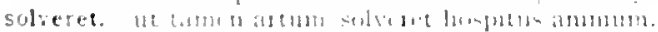

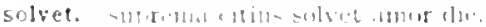

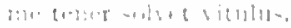

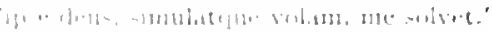

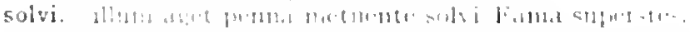

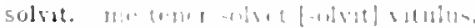

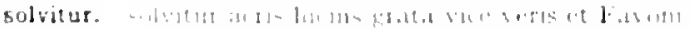

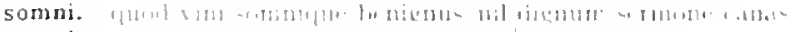

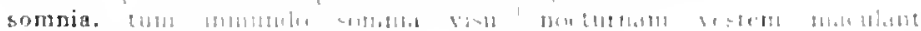

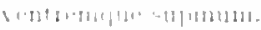

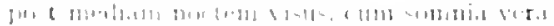

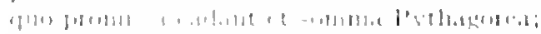

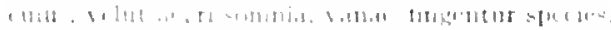

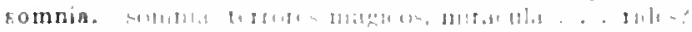

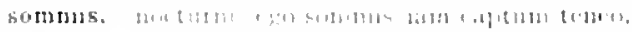

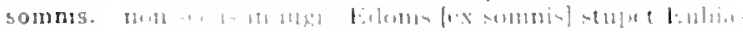

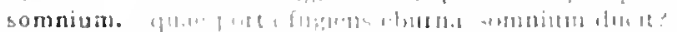

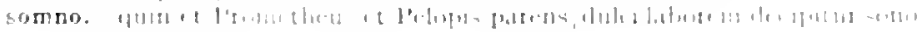
$[\cdot, 1] 1,1,1$,

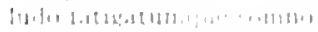

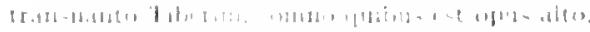

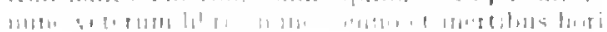

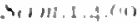

(ii) $3,3,2,20$

:ar.lipid.1.31..4

l.pili.13.5

1. 1.04 .17 .7

fopul $17 .+15$

1.p.t.1.1.1.

inm.z.I. Se

(arm.1.27.25

corm? 2122

tipilla is

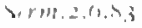

(iat):1.1.3.2.

(armet.2.5t

1.piv1.010.0

(a) $2.2-7$

our tormis 1 = :

cillm.s.4.

sirm $\therefore$ : is

$\therefore+m 1.5 \times 4$

mem.1.10.3

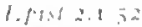

ir linel

1 pr. 2.:2018

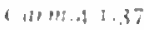

. . 1 1 1 illmi.3.25.9

(111) 3.27 .42

.urt arme 13 in

cinen $3: 11$

b. pk: 2.18

$\therefore, m: 4,1,3$ 
ian vino quaerens, iam somno fallere curam;

Sirm.2.7.114

rite cliens Bacchi somno gaudentis et umbra:

1.pist.2.2.78

comnos. nee tibi somnos adimunt amatque/ianua limen.

nec levis somnos timor aut cupido! sordidus aufert.

sommos quod invitet levis.

pavore somnos auferan.

pocula Lethaeos ut si ducentia somnos

mali culices ranaeque palustres | avertunt somnos;

est ubi divellat somnos ninus invida cura?

somnum. arida/pellente lascivos amores/canitie facilenqui sommum.

non avium citharaeque cantus / somnum reducent:

seu facilem, pia testa, somnum.

cui pulcrun fuit in medios dormire dies et / ad strepitun citharav cessatwu ducere curam [sonmum].

festus / lat venian somnumque dies; .

n'c somnum plebis laudo satur altilium

verum operi longo fas est obrepere somnun.

somnus. somnus agrestium / lenis virorum non humilis domos/fastirdit

ne longus tibi somnus unde|non times detur;

somnus tamen aufert $\mid$ intentum veneri:

cena brevis iuvat et prope rivom sommus in lierba;

si te grata quies et primam somnus in horanldelectat.

conabit. magna sonabit / cornua quod vincatque tubas:

sonant. nunc mare, nunc siluae/Threicio Aquilone sonant.

sonante. sonante mixtum tibiis carmen lyra,

Vrbem!eques sonante verberabit ungula,

montibus altis/levis crepante [? sonante] lympha desilit [? dissilit] pede.

sonantem. et te sonantem plenius aureo, .

longe sonanten natus ad Aufidum

sonantem. quid . . . contra sonantem Palladis aegida|possent ruentes?

conare. sive mendaci lyra|voles sonare:

bonari. seu poposceris/centum iuvencos sive mendaci lya foics snnar [sonari]:

sonat. displosa sonat quantum vesica, perpedi|diftissa rate ficts;

sonaturum. cui mens divinior atque os magna sonaturum,

conent. quae neque in aede sonent certantia iudice Tarpa

conitum. Hesperiae sonitum ruinae?

conitus. lituo tubae permixtus sonitus bellaque matribus detestata.

sono. dulci laborem decipitur sono

saxa novere sono testudinis

sonum. cum populus frequens'lactum theatris ter crepuit smmm;

donatura cycni, si libeat, somum.

nam quae pervincere voces levaluere sonum.

verba lyrae notura sonum conectere digner?

legitimumque sonum digitis callemus et aure.

nank neque chorda sonun reddit quem rolt manus ex wacto, .

sonus. tune mens et sonus/relapsus.

Sophocles. quid Sophocles et Thespis et Aeschylos utike ierrem;

sopor. ergo Quintilium perpetuos sopor/urget?

6opore. cum latent silvis ferac|dulci sopore languilac.

sopori. ubi dico citius curatil sopori|membra dedit.

Soracte. alt.t stet nise candidun! Soracti.

sorde. auriculas cutharac collecta sorde dolentis.

sordent. cunctant prae Campo et Tiherimo fumine sorlont?

cordes. si neque avaritiam neque sordes aut mala lustrit

sordescere. contrectatus ubi mabus sordescere volgi coperin.

sordet. protium aetas altera sorilet.'

sordibus. tutus caret obsoleti|sublibus tect:

o nec putruis obsoleta sordilous

mumbs trit, qua non offenclute sulibus

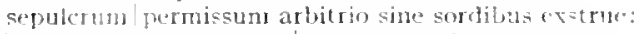

Bordida. ne sordida mappa'corruget maris,

cordidae. Virtus, repulsae neseir sordidac,

6ordidos. mon inflecoro pulvere surrliclos

ferens deosiet uxor et vir sorridosque natus.

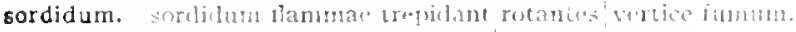

cordidus. indice te nen sorlin?s andet $\mid$ naturae vaque.

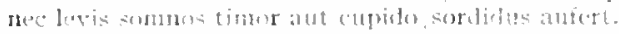

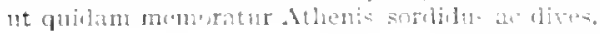

Corm.1.25.3

Corm.2.10.15

l.pod.2.28

Lifol.5.90

Lforl.14.3

Serm.1.5.15

Epist.1.10.18

Carm.2.I I.8

(a)m.3.1.2I

Carm.3.21.4

:ur.lipist.1.2.3:

Epist.1.5.10

Epist. $1.7-35$

Alts Poet.zon

Carm.3.1.2I

Carm.3.II.3o

Serm.1.5.83

Epist.1.1435

Epist 1.170

Sermit. 6.43

Epol.13.3

lipod.9.5

Epod.10.12

Iater.Epod.16.48

Carm.2.13.20

Carm.4.9.2

Corm.3.4.57

Lipod.17.po

acer. Iipod. 1 7...p"

Serm.1.8.40

Sirm.1.4.1-1

Sirm.1.10.38

Carm.2.1.32

Carm.1.1.2t

(arm.2.13.3k

.1rs / net-39s

(ism.2.17.2")

cirm.4.3.20

S.pist.].20t

Epist.2.2.84

Irs Poet.274

Ars I'ot'.3ts

Epol.17.17

lipel.2.1.18

(iir)" 1.24 .5

l. piol 5.50

.40m.2.2.80

corm. I.O.?

Jipist.1.2.53

Erivtertit

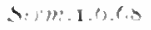

I. pist I . O. I I

JPhEI.ISIL

(urte.10.7

lipd.1. th

Sivm 2.2.5

tierm.?.5.105

Ixpit 1.5.2.

(iom.3.2.17

(iam 2.1.2.?

(arm.2.15.2s

(":?m?-4.11.5!

Carm.I.z-if

("arm.s.u.

s.m.1.9.1. 


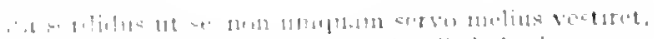

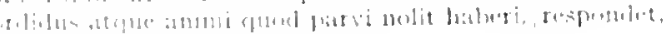

Serm.1.2.10

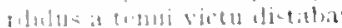

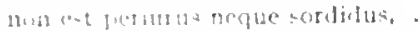

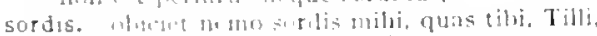

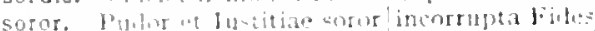

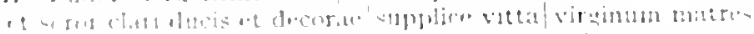

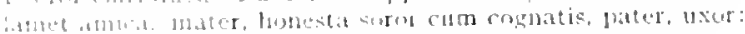

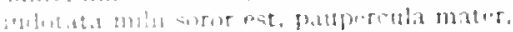

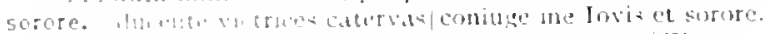

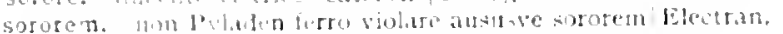

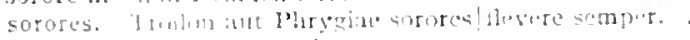

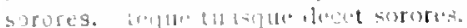

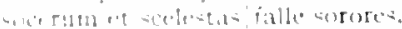

sororious. Tiratia'nulis innet.l sororilnas.

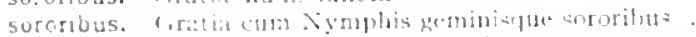

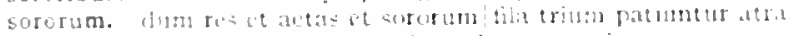

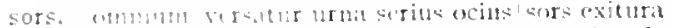

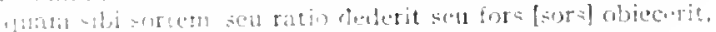

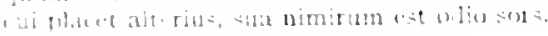

sorice fillut arte heitior.

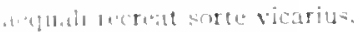

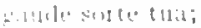

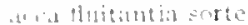

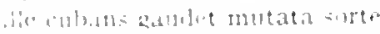

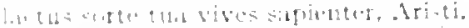

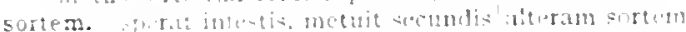

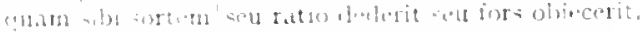
sortes. lint un per cormina serters

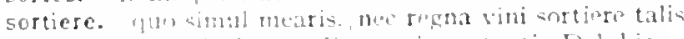

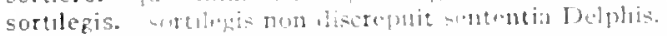

sortis. funt to wo sortis iubenom

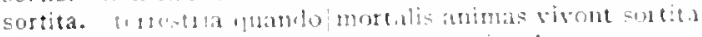

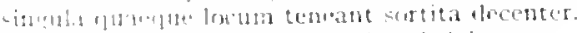

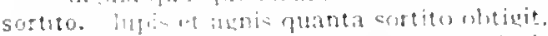

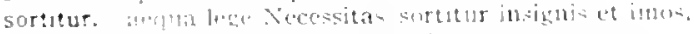

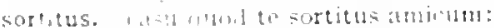

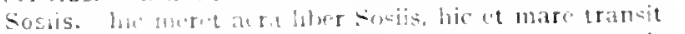

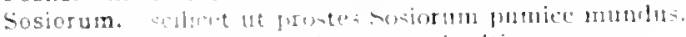

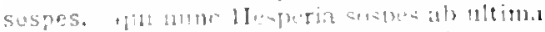

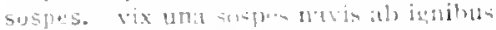

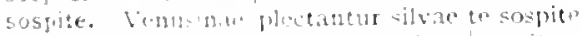

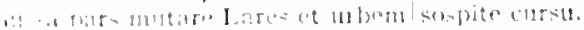

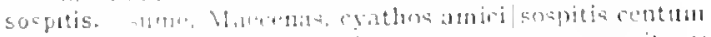

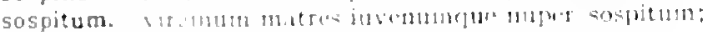

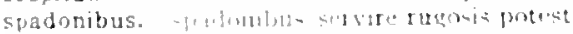

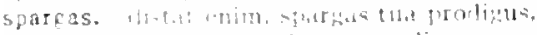

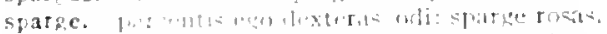

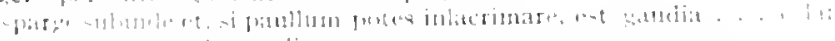

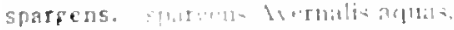

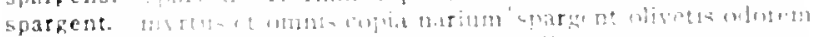

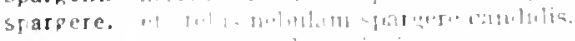

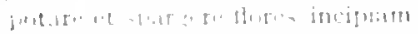

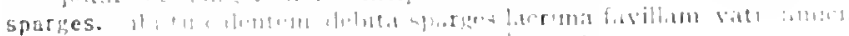

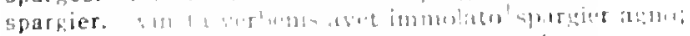

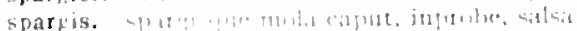

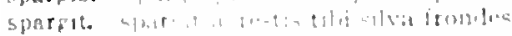

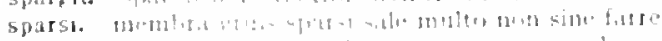

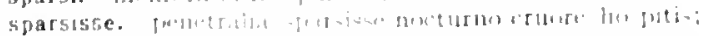

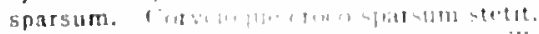

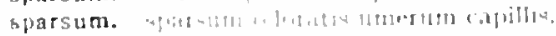

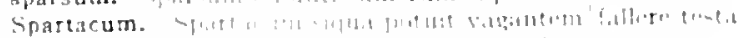

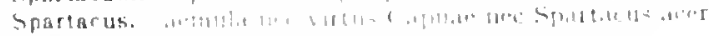

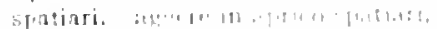

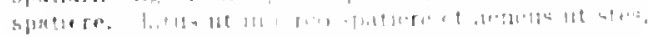

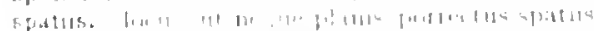

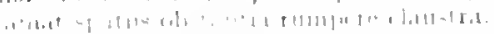

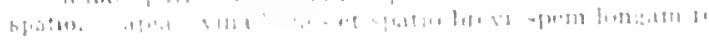

Strm.2.2.5.3

$\sin 2.3 .169$

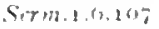

Cirmit.e.tes,

(ion $3.1+7$

Simmin.2.3.5.

$101+6.1 .17 \cdot .913$

Cism.3.3.3.4

Serm.2.3.1.39

tim.2.0.1",

(imm.1.2u.1 =

titrm 3.11. 10

(arm 3.11).17

Cirme 7.5

( is: $2 \cdot 3 \cdot 15$

(iarm 2.3 .27

i.1r.sirm.1.12

J.pist. I.1.1 I I

( isto.310.32

(itrm.3.2.1.10)

i.jerl.18.t5

$\therefore r m 23.2\left(1 r_{3}\right.$

Srm.2.1.110

B.pist.1.117.t4

Cirring. IU.1.

Sirm. I. I. 1

- tris linedon 3

(ism: 1.1.18

ir, $14+1.214$

( in) 1 I.2.

arm-2episi

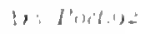

f. p.u.t.

Girm.1 15

S.rnit.1.5.3

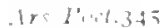

F) P1:21:2

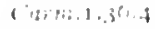

(i) 140.37 .3

('irm: 28.2 ;

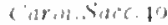

(irm-3 S.I.

(128m.3.18.10

I. pond.9.1.3

1.pis 220105

(i, ire 31022

sirm.2 5.113

1 pion' 5.20

airm: 215.7

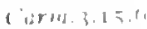

I. $141,1=1$ :

1 is

(arm: $11 \mathrm{~s}$

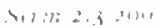

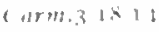

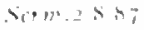

(4) 9.3 .2 .137

sermentis

ciurm-1.21) 1 !

ciarm 31910

pond 10.5

Sirvid \& 15

Sirm.2.3.1.5

ioll : ?

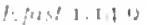

(artis ire

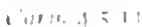


spatium. ianque tenebat/nox medium caeli spatium.

spe. si placeant spe/deterius nostra. .

quidquin! vidit melius peiusve sua spe,

quod cum spe divite manet $f$ in venas animumeque meum.

neu flutem dubiae spe pendulus horae."

corpus et ipsum animum spe finis dura ferentem

dilator, spe longus, iners avidusque futuri.

specie. specie, virtute, loco. relextremi primorum,

maxima pars vatum, pater et iuvenes patre digni. I decipimur specie reti.

speciem. netues, liberrime Lolli, scurrantis speciem inabere, professu amicum.

modestus occupat obscuri speciem, taciturnus acerli.

ludentis speciem dabit et torquebitur,

species. ducit te species, video: .

inprovisa simul species exteruit.

si fortunatum species et gratia pratstat.

species. euius, velut aegri somnia, vanae| fingentur specien,

species. 'qu species alias veris scolerisque turultu formatis captet,

speciosa. speciosa quaerol pascere tigris. interdum speciosa locis moratarue recte iabula

speciosa. proferet in lucem speciosa pocabula rerum,

ut speciosa delinc miracula promat,

speciosius. virilia quod speciosius arma non est qui tracter:

speciosum. introrsum turpem. speciosum pelte decora.

spectabant. albis intormem spectabant ossibus asrum;

spectacula. dant alios Furiae torvo spectacula Mari.

picta pandat spectacula cauda:

ut sibi pratentem mimo spectacula plura.

spectaculo. dapis, inemori spectaculo,

spectaculum. neque hoc parentes, heu misi superstitcs, cofugetit spectaculum,'

in ius acres concurrunt, magnum spectaculum utomue. .

spectarda, nec redeant iterum atque iterum spectanca theatris.

quo spectanda modo, quo sensu credis et ore?

iabula. quae posci volt et spectanda reponi:

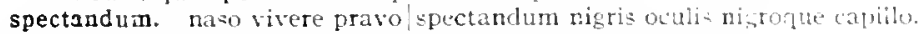
spectandus. spectandus in certamine 1 artio.

spectant. gaude quod spectant ocul te mille loquentem:

spectante. populo spectante referrelemptum mulus apmm?.

spectantia. nec redeant iterum atque iterum spectindal [-pectantia] theatris.

omnia te adversum spectantia, nulla retrorsum.'

spectentis. si curat cor spectantis tetigise querclla.

spectantur. tanto cum strepitu ludi spectantur

spectare. 'porvetum magno magnum spectare catino, velem'

Ceptumum procul ex terra spectare furentem.'

Vortumnum Ianumque. liber. spectare videris.

spectaret. Democritus. . . spectaret popuium ludis attentins insis.

spectasse. 'nullos his mallem ludos spectasse;

spectat. quisquis ingentis oculo inretortalspectat acervos.

vir bothus. omne forum quem spectat et omme tribunal.

hos arto stipata theatrolspectat Roma potens,

spectata. qualis aedituos habeat belli spectata domique/ virtus.

fabula, quae posci volt et spectanda [spectata] reponi;

spectata. nec releant it rum atque iterum spectanda [spectata] theatris.

spectate. ian virum †expertae, male nominatis [spectate ma]e ominati-] parcite rerbis.

spectator. exanimat lentus spectator, sedulus infat: quae ips" sibi tradit spectator:

spectator tunctusque sacris et potus et exlex.

spectatoris. quam spectatoris hastidia ferres superbi.

spectatum. spectatum admissi risum teneatis, amici?

spectatum. spectatum satis et donatum ian rude

spectaverat. ludos spectaverat, una|luserat in campo:

spectaverit. ludos spectaverat [spectiverit], una luserat [hus rit] in campo: spectent. sunt qui tormidine nulla/imbuti spectent:

gatude quol spectant [spectent] oculi te inille lorgenten;

spectes. 11 ypsea caedor illa, |quae mala sunt, spectes.
Sirm.2.6.10I

Sirm.1.10.80

Iisis.t.0.13

Pepist.1.15.10

Lepist.T. IS.110

LPist.2 I.I +1

Ars l'oet. 172

L.pist.2.2.203

.1rs lodt.25

Whint.1.IS.2

1.pit. 1. . \$.95

1.pist 2.2.124

Sirm.2.2.35

I. Aist.1. 1 I

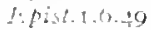

Ars tooks

S.rm.2.3.208

carm.3.27.5.5

- tres isot.319

Iipist.2.2.116

-1rs Poct.I4

EPSTI.I 8.52

tipista.10.4.

Sirm.1.8.10

Curm.1.28.17

Sirm.2.2.20

fipist.2.1.108

lipul. 3.34

Fipold.5.102

Sirt? I.7.21

Serin. I. 10.39

Epist. I.0.8

Ars lintigo

Lrs 1Poth 3

Cirm.n.1.17

l.pit.1.1.19

1.tist.1.0.00

:ar. Serro.1.10.39

E.pist.1.1.75

Ars Poul.ys

Epist.2.1.203

Sirn.2.230

Epist.I.II.IO

It fist.1.20.I

I.pist.2.1.197

Serm.2.8.79

Curm.2.2.24

Ifpist.I. I 5.57

Iipist.2.1.0I

Iepist.2.1.230

var.irs lodt.190

:sr.s.rm.1.10.39

roni.Curm.3.14.1 I

Fpist.2.1.178

Irs I'vet. 182

Are 104.224

lipist.2.1.2I5

Ars 1'oet.5

JPist.1.1.2

Sum.2.6.48

ter.s.rm.2.6. 88

lopist.1.6.5

E'tr.lepist.1 n. I

Serm.1.2.92 
ut propina spretes lacrimuan pocmata l'upi:

Epist.1.1.67

Carm.4.10.6

Cirm.3.25.2

speculo. dien heu'. quotiens te in speculo vuderis alterum.

Carm.1.4.15

spem. vitale summa brevis spesn nos retat incuhate longam:

Carm.1.11.7

spatio brevilspern longitu reseces.

tu spern reducis menuhus anxis

spern bonam certamque domum reguren

militabtur bellum in tuae sprem gratian.

aut spen deponas aut artem inlusus mnittas.

leniter on sprem adrepe ofticiosus. .

quae sjem|consiliumque morantur apendi naviter

Inter spem curanque, timores inter et iras

spen mentita seges, bos est enectus aranto:

tutus et intra|spem veniac cautus?

eperabitur. grata superveniet. quac non sperabitur hora.

operamus. cum speramusen rententuran.

speremus [speramus] carmina fingi poss linenda cedro

sperare. quidtibet inpotens, sperare fortumarue dulci, chria.

ultra| quam licet sperate nefas putando

speras. Hiscine versiculis speras tibi posse folore atque aestus curasqur" gravis e pectore pelli?

eperat. te.. qui semper vacuan, semper amabilem / sperat, mesius aurae fallucis.

sperat infestis. metuit secundis |alteram sortem

speratum. ploravere stiq nun respondere havorem! speratum meritin.

eperavit. speravit inagnac laulifore.

eperemus. spresentes carmina tingi|posec linenda certro

speres. non. . speres perpetuon dulcia batbare laedentem oceulat.

inmortilia ne aperes, monet annus

eperet. ex noto fucturn carmen secpur, ut sibi quivis speret idom.

eperaat. hoc amet, hoc spernat pronissi carminis aucter.

6perne. nec lukis anotes sperne puet neque tu churas.

o Venus resuld Condi Paphieque, sperne dibectam Cypron

siccus, inanis|:sperne cibum vilem:

fana cisem cansaque priorem eperne.

sperno voluptates: nocet cmpta dolore volupuas.

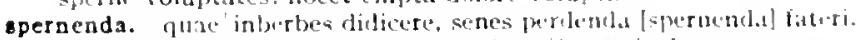

spernere. nec fortutum sperbore catespitem/leges sindbant.

mihi pas rata. . Farca nom mendatx declit et malignan, spormere valuas.

aurusn. . spermere fortior|quan cogere humanos in usus

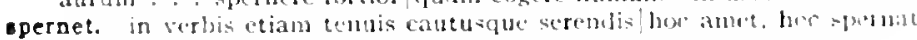
[sjuernet] promissi carminis auctor.

spernit. nece partem solido dernere de die spernit.

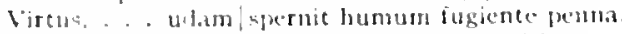

guod petit spernit. repetst efuod nuper ominit,

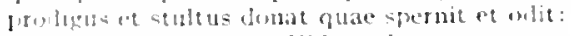

Spes. to pres et allow rara billes collet

spes. inu ne- yos animi crefula mutui

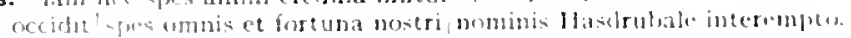

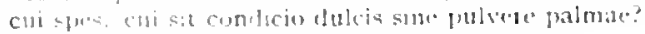

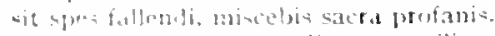

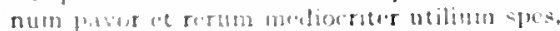

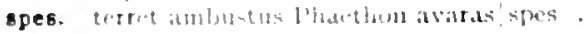

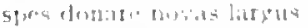

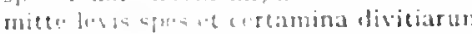

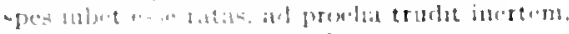

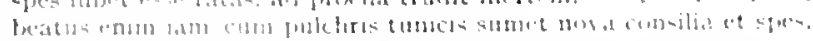

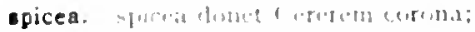

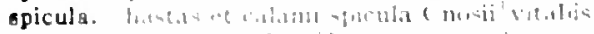

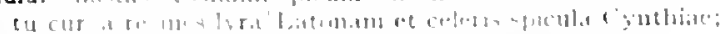

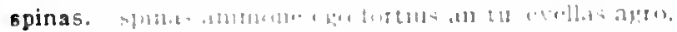

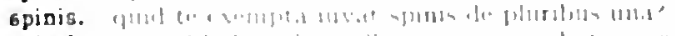

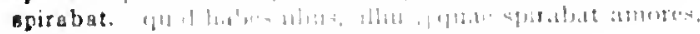

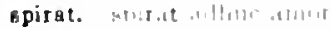

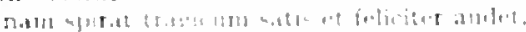

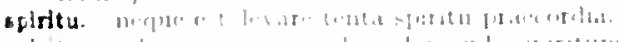

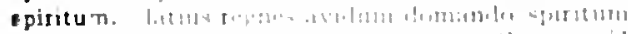

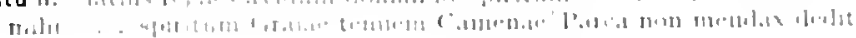

$\operatorname{corm}, 3,21,17$

Carm.Soec.74

If pod.t.24

Sirm.2.5.26

S.rm.2.5.47

Lepist.1. 1.23

lepist.1.4.12

Pepist.1.7.57

Irs l'oet. 267

Eipist.1.1.1.4

JPist.2.1.226

lar..1rs l'oet.331

Carm.1.37.1 I

(urm.4.11.30)

S.rn.1.2.109

Carm.1.5.11

Corm.2.10.13

IDpr.2.1.10

Serm.2.3.99

Ars Pod.331

Cirm.I.I3.1.

ciorm.t.7.7

irs loct.241

lirs Poct.45

Cirm. 1.9 .10

Cirm.t.30.2

Sirm.2.2.15

cirm.2.5.31

l.pist.t.2.55

conitipist.2.8.85

(urm.2.15.17

Cisme.2.10.40

(iurn.3.3.50

iner.trs Podets

Cirm.1.21

(iorm.3.2.2.4

Jipist 1.105

I.p.s6.1.7.20

Ciwne. 1.35.21

Curmed 1.30

Carmatitis

l. pist I 1,50

Epist.1.10.54

t.peste1 1899

carest 11.20

carm+12.19

Eptst.5.8

R.post.1.5.7

Jefistit th. 33

(iarmitises.30)

(i)rm.1.15

fiurm 3.25.12

J. post 1 i.:.

foptez 2212

cistm +8 130

cinrmago 0

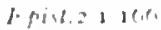

1 pid.1721

( Ir) 2.2 In

corm. $2 \times 3.38$ 
spiritum Phoelus, mihi l'hoehus artem / cambis nonenque dedit poetae.

rides Turbonis in armis|spiritum et incessum:

spiritus. me nec Chimaerae spiritus igneat/nec... gigas/ cliveliet

spiritus taeter saniesque manet /ore trilingui;

per quae spiritus et vita redit bonis/ post morten duciluse.

latere petitus imo spiritus.

quod acer spiritus ac vis/nec verbis nec rebus inest.

spiro. quod spiro et placeo, si placeo tuom est.

spissa. tum spissa ramis laurea ferviclos/excludet ictus.

spissa. spissa te nitidun coma.

spissa. nondum spissa nimis complere sedilia flatu;

spissae. et spissae nenorum conae

ne spissae risum tollant inpune coronae:

spissis. 'spissis indigna theatris/scripta pudet recitare

splendeat. inimice lamnae/Crispe Sallusti. nisi temperato splendeat usu. purpureus, late qui splendeat, unus et alter'adsuitur pannus,

splendentis. splendentis Pario marmore purius,

splendet. cui paternum|splendet in nensa tenui salinum iam nec lacaenae splendet adulterae fanosus liostes iandudum splendet focus et tibi inunda supellex.

splendida. iussit quod splendida bilis.

splendida. de te, splendide. Minos [te splendida Minos]/fecerit arbitria, fere scriptores carmine foedo splendida facta linunt.

splendide. de te, splendide, Minosffecerit arbitria.

splendide. periurum fuit in parentem|splendide mendax

salendidior. contemptae dominus splendidior rei.

splendidior. o fons Bandusiae splendidior vitro,

splendidius. rectius hoc te / splendidius multo est.

splendor. hunc capit argenti splendor; stupet Albius aere;

splendoris. quaecumque parum splendoris habebunt

sponda. extrema et in sponda cubet.

spondeos. spondeos stabiis in iura paterna recepit

spondere. possit /et spondere levi pro paupere

sponsae. Hebili sponsae iuvenemve raptum|plorat

nec sponsae laqueum famoso carmine nectit.

sponsi. sponsi Penelopae nebulones

sponso. quae tibi virginum|sponso necato barbara servict, .

sponsore, quo res sponsore et quo causae teste tenentur.'

sponsorem. Romae sponsorem me rapis.

sponsos. inpiae sponsos potuere duro perdere ferro.

sponsum. si|prodiderit conmissa fide sponsumve negarit?

sponsum. hic sponsum vocat, hic auditum scripta relictis/oinnibus officiis:

sponsus. ne rudis agminum |sponsus lacessat regius asperum|tactu leonem.

sponte. stellae sponte sua iussaene vagentur et errent.

spretus. qualis Lycanbae spretus infido gener

spurco. 'utne tegam spurco Damae latus?

squillas. adfertur squillas inter nurena natantis/in patina porrecta. .

squillis. tostis marcentem squillis recreabis et Arra|potoren coclea: .

stabant. illi, . . boc stabant, hoc sunt initanli;

stabat. hoc miserae plebi stabat commune sepulcrum.

cerea suppliciter stabat.

Staberi. heredes Staberi summam incidere sepulcro.

hoc Staberi prudentem animum vidisse.

stabilis. stabilisque rerum/terminus servet.

quod semel [simul] dictum est stabilisque reruin [stabilis per aevum] terminus servet [servat].

stabilis. spondeos stabilis in iura paterna recepit

stabit. sudus|in Tiberi stabit."

stabulis. ac neque iam stabulis gaudet pecus aut arator igui

stagna. undique latius/extenta visentur Lucrino|stagna lisu stans. ducentos, /ut magnum, versus dictabat stans pede in uno.

stante. urgeris turba circum te stante

stantem. aliquis cubito stantem prope tangens| inquict,

stantem. iniurioso ne perle proruas|stantem columnam

contra alius nullam nisi olenti in fornice stantem.

stantis. antequan stantis repetat paludes

stare. si|ant valeo stare aut novi civilia iura;

stas. stas animo et purum est vitio tibi, cum tumidum est cor"

Carm.1.6.29

Serm.2.3.3 II

(arm.2.17.13

Cirm.3.11.19

Carm.1.8.14

lipod.rito

Sirm.1.4.46

(iorm.4.3.24

(urm.2.15.9

(arm.3.19.25

Ars Poct.205

Carm.4.3.II

irs Poet.38 I

Epist.1.I9-4 I

Carm.2.2.4

dis Poet. Is

Carm.1.19.6

carm.2.16.14

ciarm.3.3.25

Epist.1.5.7

Serm.2.3.14I

var.Cerm.4.7.2 I

IEpist.2.1.237

coni.Carm 4.7.2I

Carm.3.11.35

Carm.3.16.25

Carm.3.13.1

Epist.1.17.20

Sirm.1.4.28

Epist.2.2.I I I

Epod.3.22

Ars Poet.256

Ars Poet.423

Corm.4.2.2 I

Epist.1.19.3 I

Epist.1.2.28

Carm.1.29.6

Epist.1 10.43

Serm.2.6.23

Curm.3.1I.3I

Sirm.1.3.95

Epist.2.2.67

Corm.3.2.10

Epist.1.12.17

Epod.t). 13

Sirm.2.5. 18

Sirm.2.8.42

Sirm. 2.458

Sorm.1.10.17

Sirm.1.8.10

Sirm.r.8.32

Sorm.2.3.84

Sirm.2.3.89

carm.Sact.26

coni.Carm.Sace 26

Ars 1'oet. 256

Sirmi.2.3.292

Curm.1.43

Carm.2.15.4

Serm. I 7.10

Serm.1.3.135

Serm.2.5.42

Carm.1.35. I 4

Scrm.1.2.30

(a)m.3279

Serm. 10.39

Serm.2.3.2 13 


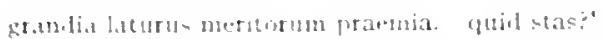

I.pist.2.2.38

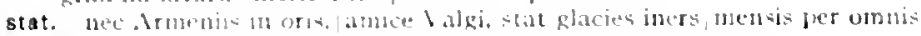

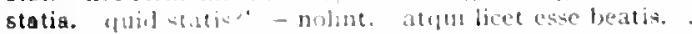

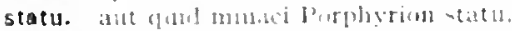

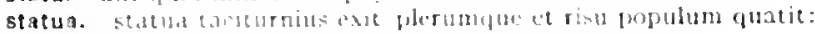

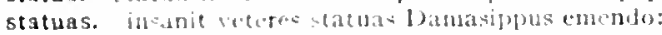

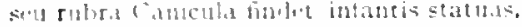

statuat. nome. cugld labuse statuat natura modum quem,

statuetur. puts quis tax ala rapillis! an cyathus statuetur unctis

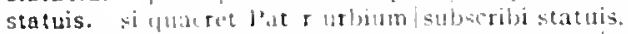

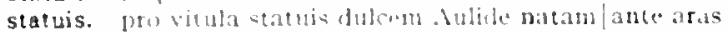

statuit. $1 \mathrm{~kg}$ ro qui statuit wron te.

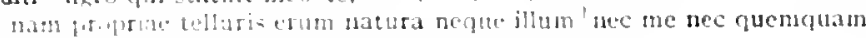
it.atuit:

status. 2u ciritatem quis decent statuslcuras ommis Arifiplum decuit colot et status et res,

stella. querum sifnul alba nautis|stebla refulsit. e. stcolla vosini jeonis

stellae. stollae spmbe sua iusache vagentur et crtent.

stellas. steblazque salubris, approllat comites

hunc solem et stollat . . stont chu formidine nullalimbuti spectent:

stellis. Joatate comugis adfitum|stelliu lonorem

stellis. et stellis :lobulath spargerse candidis.

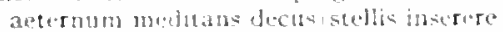

stercore. colotqu streure ducatha crocolliti

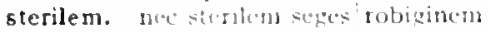

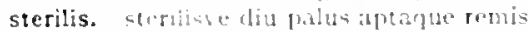

siernet. alyol bitus inutili demion tempestas ab Euro'sternct.

stertebat. netis veilabat al igsums mane. dien tortum stertubat.

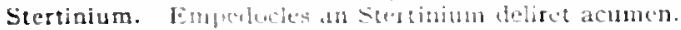

Stertinius. siquil stertinits sori crepat.

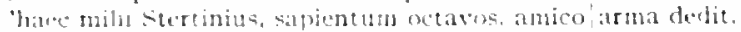

Stertinum. Eingedeles an Stortingm [Gertinuml dealiret acumen.

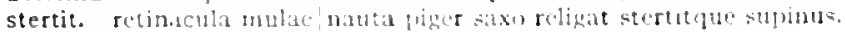
hasus dum tuxctu stertit. al asem perliderat:

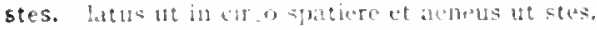

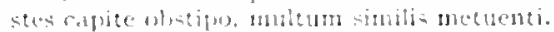

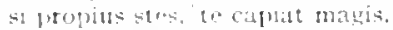

Stesichori. Stenichorive prober $C^{\circ}$ menae

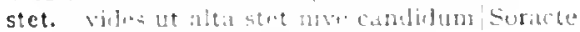

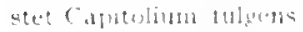

veluti stee forluterio dies.

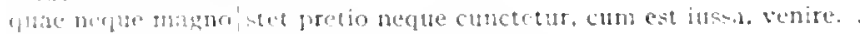

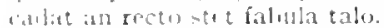

nethan wermotum stet homos et gratia visax.

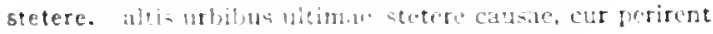

stetit. hum avilug stedit Volcanus.

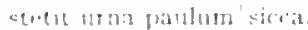

4]

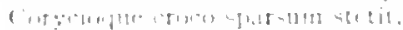

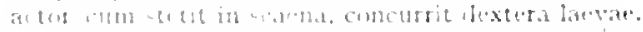

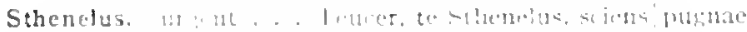

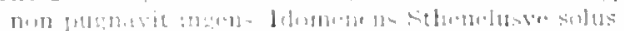

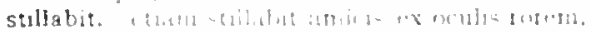

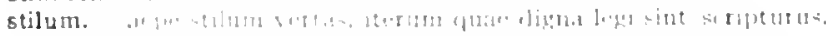

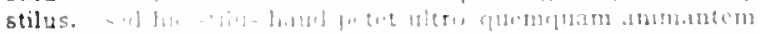

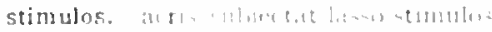

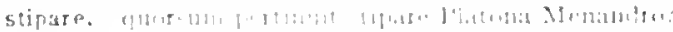

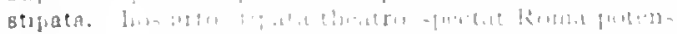

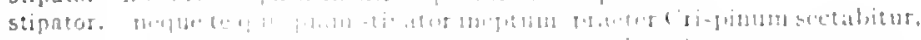

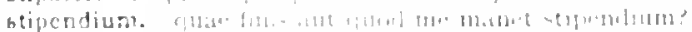

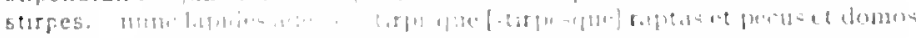

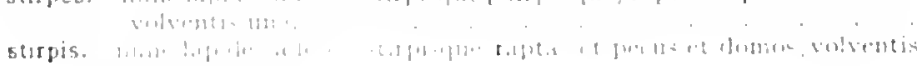

Segice.

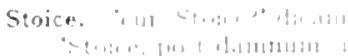

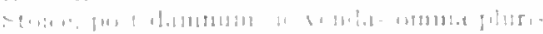

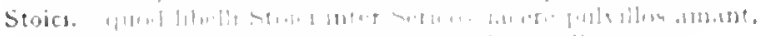

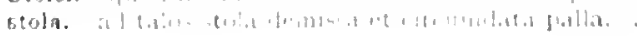

Cormi.2.9.5

Sermiti.10

Carm $3 \cdot 4 \cdot 54$

Jifist. 2.2 .83

$\operatorname{serm} 2.3 .6 .4$

Serm.2.5.40

Sirmit.2.IIt

Carm.1.20.S

Cirm.3.2\$.28

Serm.2.3.109

Corm.2.13.10

Serm.2.2.130

Carm.3.20.25

Epist.1.17.23

Carm.1.12.28

Carm.3.29.19

Lpist.1.12.17

Serm:-1.7.24

loist. 1.0 .3

Curm.2.19.14

Carm.3 15.0

Carm.3.25.6

IEpod.12.II

ciarn.3.23.6

Ars Joetens

Cirm:3.17.12

Sermis.3.18

Jipist.1.12.20

Sermi.2.3.33

Serm.2.3.206

anr.l.pit.1.12.20

Sirm.1.5.19

E)

Sirm.3.3.13.3

Serm.2.5.92

dirs l'oot. $30 \mathrm{I}$

cirmita. S

(arm: I.9.I

(corm.33.42

cirm.3 $2 \times 0$

Sirm.1.2.122

lisisi-2 1.170

Ars l'oetero

cirm.1.16.10

Carmi.3.4.58

(i)rtit-3.11-22

Sirm $=3.35$

sirmeses

LPist.2.1.20.5

(iom 1.15.2.

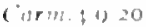

Lers Portedzo

Sirme1.11.72

Sirm: 2 - 1, (3)

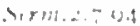

Sirm.2 i 1

I fitil $=1.11$

Sirm: J.3 B.3

1.puld. $7.3^{2}$

tar (arm.3 20.37

( iormit.3 $=0.37$

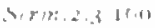

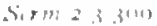

I. put? a t

Sirm.1.2.100 
stols. numquid ego a te / magno prognatum deposco consule cumum velatumque stola,

stolidi. indocti stolidique et depugnare parati.

etomacheris. prave sectum stomacheris ob unguem

stomachetur. quem si dissolvas, quivis stomachetur codem quo personatus pacto pater.

stomacho. insani leonis! vim stomacho adposuisse nostro.

stomachoque tumultum|lenta feret pitrita.

ni cibus at que/ingens accedit stomacho fultura ruenti.

lactuca innatat acri|post vinum stomacho; magna movet stomacho fastidia

stomachosus. laeva stomacliosus habena!dicet erues;

stomschum. graven Pelidac stomachum cedere nescii cun sale panis|latrantem stomachum hene lenict. mala copia quando/aegrum sollicitat stomachum. manum stonachumque teneto.

qualia lassum / pervellunt stomachum.

qui caput et stomachum supponere fontibus audent i Clusinis

stomachus. ieiunus raro stomacluus volgaria temit.

strabonem. strabonem appellat pactun pater.

stragula. cui stragula vestis. . . putrescat in arca:

stramentis. si et stramentis incubet unde-/octoginta anmos natus,

stratus. nunc viridi menbra sub arbuto stratus,

stravere. qui sinul|stravere ventos acquore fervido irae Thyesten exitio gravi!stravere

stravit. stravit humum sine clade victor.

ore trahit quodcumque potest atque addit acervo'quem struit [stravit], cum stravit ferro pecus,

strenua. prome reconditum, | Jyile, strenua Caecubum . strenua nos exercet inertia:

strenuos. quodsi cessas aut strenuos anteis. strenuos ct fortis causisque Plilippus agendis/clarus, nune $i$, rem strenuos auge.'

strepitu. audis, quo strepitu ianua, undique magno|pulsa domus strepitu resonet, tanto cum strepitu ludi spectantur

strepitum. vitabis strepitunque et celerem sequil Aiacem: audiat invidus|dementem strepitum Lycus mirari beatae/fumum et opes strepitumque Ronae. testudinis aureae dulcem quae strepitum. Pieri, tenperas. ad strepitum citharae cessatum ducere curam. nec meretrix tibicina cuius/ad strepitum salias terrac gravis;

streoitus. ingens/valvarum strepitus lectis excussit utrumque. si te pulvis strepitusque rotarum, | si laedit caupona.

strepitus. tu me inter strepitus nocturnos atque diurnos $v$ is canere popularis/vincentem strenitus et natum rebus agendis.

strepunt. perstringis auris, iam litui strepunt, nec fluvii strepurt hiberna nive turgidi.

stricti. siquirl fricti [stricti] ciceris probat et nucis emptor,

strictis. nos proelia virginum [sectis [strictis] in iusenes unguibus acrim cantamus,

strictis. bovemque/disiunctum curas et strictis frondius exples.

etridere. videres/stridere secreta divisos aure susurros.'

stridore. hinc apicen rapax [Fortuna cum stridore acuto| sustulit,

strigili. sub noctem qui puer uwam|furtiva mutat strixili:

etrigis. plumamque nocturnae strigis . . aduri

plumanque nocturnae strigis [strigis nocturnal . achuri .

stringat. avi cur atque parentis|pracclaram ingrata stringat malus ingluvi rem.

struam. tu protinus, unde $\mid$ divitias aerisque ruam [struam], dic augur, acervos:

struis. sepulcri|inmemor struis domo

etruit. addit acervolquen struic. quid studiosa cohors operum struit? hoc tilonte curo.

siudet. Pindarum quisquis studet aemulari,

fidibusne latinis Thebanos aptare modos sturlet auspice Musa. dum sturlet urbanus tenlitulue disertus haberi. . versus amat, hoc siudet numm; qui stuclet optatam cursu contingere metan,

Sim.1.2.7I

lipist.2.1.18:

ipist.1.1.104

Serm.t.4.55

Cam.10.Is)

Sormt2.2.75

serm.2.3.154

Sirmeztho

Serm 2.4.78

liptist.I.I5.I2

Carm.1.0.6

Sirm.2.2.IS

Sirn:2.2.43

Simm.2.7.44

Sirm.2.8.9

Epist.I.I 5.8

Sirm.2.2.38

Serm. I.3.4.4

Sirm.2.3.I Is

Serm.2.3.11\%

Corm.I.I.22

Camirgero

Carm.1.I6.IS

Carm.4.1.3.32

iar.Serm.1.I.35

Serm.2.3.202

Carm.3.28.3

Epist. I. I.28

Epist.1.2.70

Epist.1.7.40

E.pist.t.7.7 I

Corm.3.10.5

Serm.1.2.129

EPpist.2.1.203

Curm.1.15.18

Carmej.19.23

Carm.3.29.1 2

Corm.4.3.18

fifist.I.z.3

Epist.r. 4.20

Sirm.2.0.1 I2

EPis!. I. 7.7

Efist.2.2.79

Ars loet.82

(iorm.2.1.18

(wint. 12.3

qur.Ars Poth 240

coni.c amm.r.6.I8

Epist.1.14.28

Sim.2.8.78

Camm. 0.34 .15

Som.z.7.110

Iiprit.s.2n

aur. Lpod.5.20

Serm.1.2.8

conit.s.rut.2.5.22

Cum.218.19

STrite.1.35

J.pist.1.3.6

Corm.2.1

Epist. I.3.13

Epist.1.19.16

J.pist.2.1.120

Ars Ioet.412 


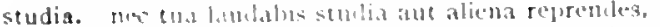

Epist I.18.39

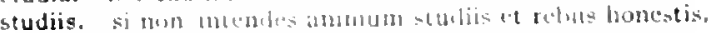

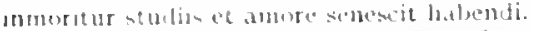

consenture stus studiis gut eredubest te hallor.

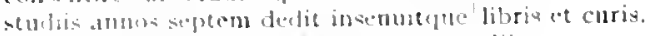

studis. mentes almerioribus formandate studies.

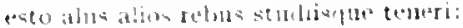

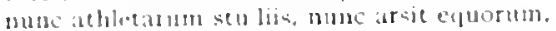

idem limens sturlis et menter receptat

converats studis actas animusque virilis quacrit opes

studio. nae stulio eitharat nee Musae dedicus ulli,

studio. "iactore sithles." inguit. "ent luc studio pravos facis." molliter auiforum studio fallene laborem.

nee setuclo nostri peeces

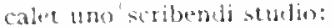

ut studio maiofe petant 1 lelicon.t virentern.

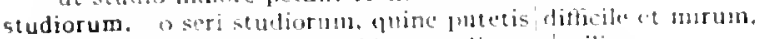
quot capitum vivent, fotidion stuljorum m milia:

studiosa. nuper in pratis studiosit florum nec tantum vemeris quantum seudiosa eulinae.

quid sturliogit chlors opertum struit? ho quoplue curo.

studium. nec studium sine diviti vena ne rude quil prosit video ingenium:

studium. tibi telat operosateque Minerrac sturlium aufert.

virum pone moras et studium lueri

hoc upus, boc sundium parvi preperemus et anpli.

stulte. He cures eat ruae stulto miruriset optas.

sedulitas ant?un stulte quem dilight nrget.

nimum patinto's utrumque. / ne dicams stule. mirati.

stulti. dum vitant stulti vita, in contraria currume.

insanis et tu stultuque propre ombes.

stultior. si me stuleior ipso'quingentis empto elrachusis reprenderis:

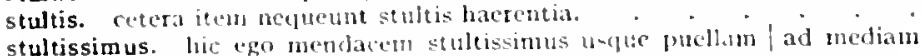
noctem exspecto:

stultitia. "quem mala stulticia et quemcumque inscitia verileaccum agit. ubi pra:a stultitia, hic summa est insania:

stultitia. caelum ipsum petimus stultitia.

stultitiance etret nihilum ofist abit an irat.

qua me stuhitia. quonam non est genus unum. /insanire putas?

virtus ost vitum fugere et sophuntia prima!stultitia caruisse.

stultitiae. "as gom

stultitiae. alde crisorem/stultitiae atque ignem gladio scrutare.

stultitiam. miace stultitiam consiliis brevem:

imeac (conterdere noli) | stultitian patiuntur opes:

cuil rem li donarent, illi decedere pravam istultitiam;

stultorum. stulcorum regun et populorum continet aestus. stultorume incurata purlor malus ulcera celat.

stultos. vincet conim stultos ratio insanire nepotes.

stultum. Sthlenum nathor (liccat concedere veria)

stultus. tultu at injobus hic anor est dignus due: notari.

ignoscent, sipgid peccaro stultue, anici

qui stultug lunores sacpe dat indignis

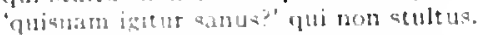

"quid avarua:" atuleus et inaanus.

ai sermeror atultus bihul hrown

gua* si $\mathrm{cmm}$ and

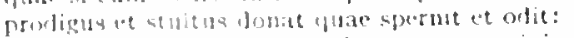

stultus utergth* lowm inmeritum calusatur inique:

stupeas. quis! matum, ubi ilis carmisibus stujens.

stupent. merted pu? precul-ae stument.

stupet. non se zua ut iugla Fonis atupet Eubias

bunc capit arenti plembor: stupet Abbius aces:

que atupt in tatulis a

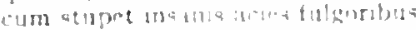

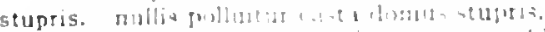

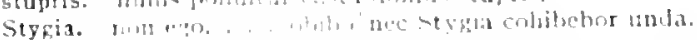

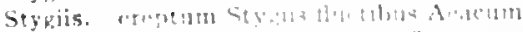

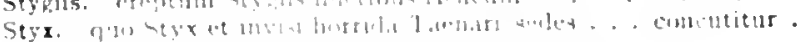

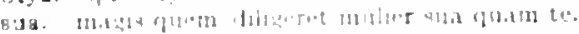

Epist.1.2.30

I.pist. I.7.85

Lipist.1.18.05

jipist.2.2.82

Carm.3.24.54

Lipist. I.1.81

Epist.2.1.95

Lifist.2.2.104

Ars Poet.106

Serm.2.3.105

Sermit.4.79

Serm.2.2.12

Episti.1.13.4

Epist.2.1.100

Epirk.2.1.218

Serm.1.10.21

Serm.2.1.27

Corm.3.27.29

Sirmi2.5.80

Fist.1.3.6

Ars loel 409

Carm.3.12.5

Carm.4.12.25

Eist.1.3.28

Iipist.1.1.47

List.2.1.260

Ars loel. 272

Serm.1.2.24

Sinm.2.3.32

som.2.7.42

S.rm. : 3.77

Sirm.1.5.82

Serm.2.3.4.3

Sirm.2.3.22I

Carm.1.3.38

Serm.2.3.210

Sorm.2.3.301

Epist.1.1.42

Sirm.2.3.54

Serm.2.3.270

Corm.t.12.27

Epist.1.18.29

Epist.2.2.153

Epist.1.2.8

lipist.1.10.24

Sirm.2-3.225

Sirm.2.3.305

Sierm.1.3.24

Sirm.1.3.140

Sormina.t 5

Scrm.2.3.158

Serm.2.3.159

Srrm.2.0.8

Ejist 1.2.24

Epost.t.7.20

Epest.1.1.1 12

Cismi.2.13.33

fipisd 7.10

Carm 3259

Sorm.1.4.28

Som.1.0.17

Serm.22.5

(i)

Cism.2.208

Carm.t 3.25

cirm.1.34 10

Epond.12.2.4 
cui non conveniet sua res, ut calceus olim.

Ifpist. I. 10.42

cui placet alterius. sua nimirun est onlio sors.

Lipist.1.14.1 I

quem sua culpa premet. decertus onitte tueri.

lipist.1. I 8.79

5us. vis consili expers mole ruit sua.

(arin. 34.65

sualVrus haec periret dextera?

quidquid vidit melius peiusve sua spe,

stellae sponte sua iussaene vagentur et errent,

Lipod.7.9

L.pist.1.0.13

coram rege suo [sta] de paupertate tacentes/plus poscente ferent:

вus. per obstantis catervas/explicuit sua victor arma. .

Susdela. ac bene nummatum decorat Suadela Venusque.

Lisision 2.17

iar. Epist.1.1 7.4 .3

Carm.4.9.4t

Epist.1.6.38

auadere. sic placet? an melius quis habet suadere?

suaderet. qua res, qua ratio suaderet quaque modeste| munifico esse licet.

suades. quid mi igitur suades? .

suadet. isne tibi melius suadet.

suae. at quanto meliora monet pugnantiaque istis|dives opis natura suae.

suam. suamque pulla ficus ornat arborem.

si peteret per amicitiam patris atque suam.

suas. si force suas repetitum venerit olim|grex avium plunas.

suaserit. infectum volet esse. dolor quod suaserit et mens.

suave. 'at suave est ex magno tollere acervo.'

auave. suave locus voci resonat conclusus.

suavior. 'at sermo lingua concinnus utraque|suavior.

susvis. siquis nunc mergos suavis edixerit assos.

merulas poni et sine clune palumbis.|suavis res.

susviter. 'suaviter. ut nunc est, inquam, 'et cupio onnia quae vis.' .

dic multa et pulcra minantem|vivere nec recte nec suaviter.

suavius. avolsos, ut multo suavius, armos, /quam si cum lumbis quis edit. .

suavius. bis me consolor victurum suavius

Ispod.16.23

Serm.1.2.50

Serm.1.1.10I

E.pist.I.1.65

Sirm.1.2.74

Ispod.16.46

Serm.1.3.5

Epist.1.3.18

Sipist.1 2.60

Serm.1.1.5 I

Serm.1.4.76

Serm.1.10.24

Serm.2.2.5I

Sirm.2.8.92

Serm.1.9.5

Epist.1.8.4

Sirm.2.8.89

Serm. I.6.I30

sub. Carm.1.8.1.7; I.9.I9; I.I8.13; 1.25.11; I.33.II; 2.18.18; Epod.2.44; 5.83; Serm.I.I.Io; Serm.2.I.9; 2.I.35; 2.2.33; 2.7.33; 2.7.66; 2.7.109; 2.8.43; Epist.1.16.22;2.2.34; 2.2 .169 ; Ars Poel.302

sub. Carm.I.I.2I；I.I.25; I.5.3; 1.17.22; I.22.21; I.26.3; I.32.I; I.38.7; 2.I.39; 2.3.2.3; 2.7.19; Carm.2.II.13; 3.2.5; 3.2.27; 3-5.9; 3.7.30; 3.11.29; 2ar.Carm.3.13.1I; Carm.3.19.4; Carm.3.20.1 2; 3.29.14; 4.1.4; 4.1.20; 4.4.17; 4.4.26; Epod.2.23; 9.3; Serm.1.2.17; I.3.34; Serm.1.9.74; 2.2.133; 2.7.48; Epist.1.2.25; 1.6.24; 1.10.32; I.13.12; 1.16.77; I.18.56; Epist.2.1.99; Ars Poe't.78; 363; 437

subacta. nondum subacta ferre iugun valet|cervice,

Carm.2.5.I

subacta. et cuncta terrarum subacta

aubando. iamque subando' tenta cubilia tectaque rumpit.

Carm.2.1.23

L.pot.I 2 . I I

aubducta. aut cistam effractam et subducta viatica plorat.

Epist.I.17.54

subductis. est qui|inguen ad obscaenum subductis usque;

subductum. post ignem aetheria domo|subductum macies

Serm.1.2.26

Carm.1.3.30

Eipist.2.I.I I

Carm 9.5 .40

subest. cum sol Oceano subest.

LPist.1.1.96

si forte subucula pexae/trita subest tunicae

nec vicina subest vinum praebere taberna|quae possit tibi

Epist.I.14.2.4

Carm:-3.4.8

Ars Pott.25 1

Ars Poet I 8 I

Serm.2.7.94

subiecta. quam quae sunt oculis subiecta fidelibus

Serm.2.6.47

subiectior. per totum hoc tempus subiectior in diem et horam / invidiae

noster.

subiectos. sive subiectos Orientis orae/Seras et lndos, .

Carm.I.I 2.55

Serm.1.92 I

subiit. cum gravius dorso subiit onus.

subimus. subimus inpositum saxis late candentibus Anxur.

Serm.1.5.25

subinde. sparge subinde et, si paullum potes inlacrimare, est gaudia... celare.

subinde|praeceptum auriculis hoc instillare memento:

Sirm.2.5.103

Epist.1.8.15

Epod.1.4

subire. paratus omne Caesaris periculun/subire,

ferula caedas meritum maiora subire/verhera

subisti. macra cavom repetes artum, quen macra subisti."

subit. hic onus horret, . . hic subit tot perfert.

subito. si vespertinus subito te oppresserit hospes.

cum subito ingens/valvarun strepitus lectis excussit utrumque.

aedibus ex magnis subito se conleret.

siquis ad illa deus subito te agat. usque recuses.

subiungere. et mili res, non me rebus subiungere conor.

sublata. agam per altas aure sublata nivis

sublatam. sublatam ex oculis quacrimus invicli.

Serm.1.3. 20

Estist.1.7.33

Epist.1.I 7.41

Serm.2.4.17

Sirm.2.0.II I

Serm.2.7.II

Serm 2.7.2.4

Sifist.1.1.19

Epod.6.7

Carm.3.24.32 


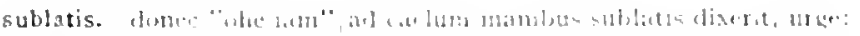

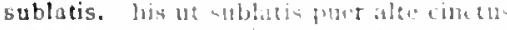

Sermin. 8.10

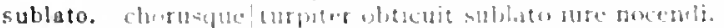

Irs loct. 28.9

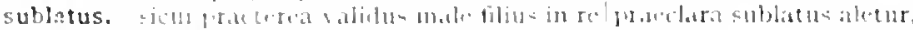

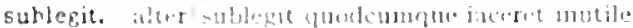

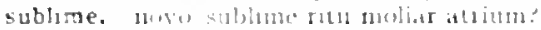

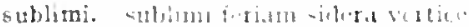

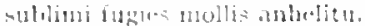

sublimi. suldimi thath thatge (bhom

sublimia. mil parrom sipias et allug sublimia cures:

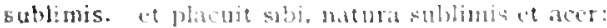

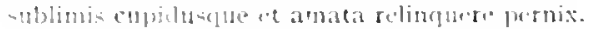

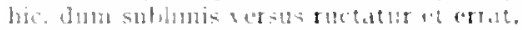

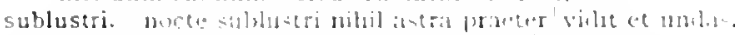

submisere. monetrumbe subniscre Culchilmains

submittit. vineal 4 thmittit capreas non semper edulis.

submotus. desinct inparibus certare submotas pulor." .

submovere. mariaglue bais olotropentis urges| subnovere litora.

submovet. informis hiemes reducit luppter, idem/submoset.

meque consularis submovet lictor marcos cumultus mentis

subolem. Miva. proulucas subolem

suboles. lateivi suboles gromia.

Romae principis urbina dignatur kuboles.

subrepere. Vrbis aventes moenia nocturmi subremer.

subruit. Eubruit amblos reges murabms;

animum quod laulia a burmm subruit ant reficit.

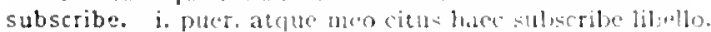

subscribi, si quatet l'ater ulbium sulicribi statuis.

subsequitur. Tlate subeguitur calchs Anot sui

subsidere. iuset uk ingis stobichere corvis.

substringe, atrem substringe lorpluar.

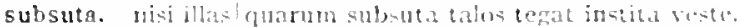

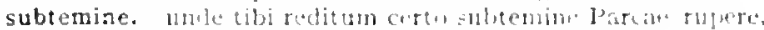

subtile. forvita quod subthe exsurdant vina piatun.

imbiom subtile viderdis artibng illu!

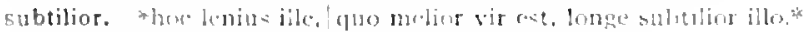

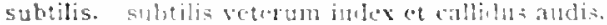

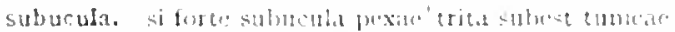

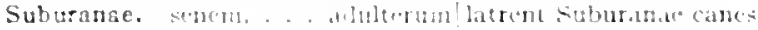

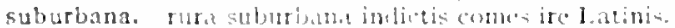

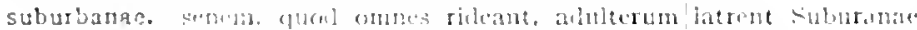
[omburtanad cands.

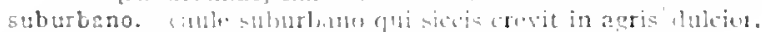

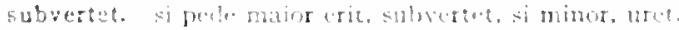

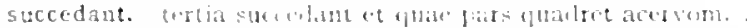

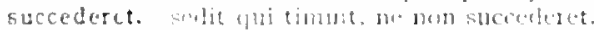

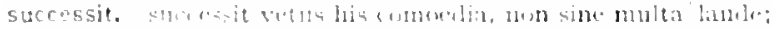

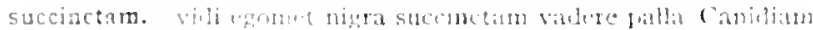

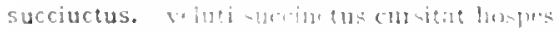

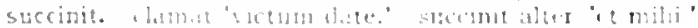

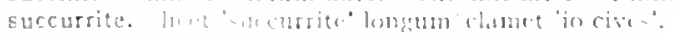

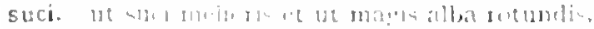

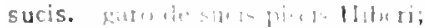

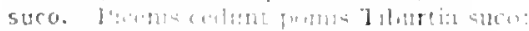

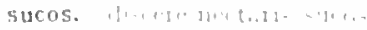

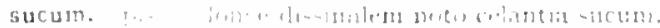

sucus. T.148.

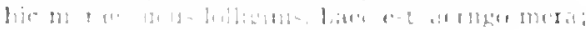

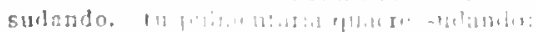

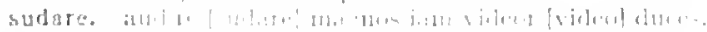

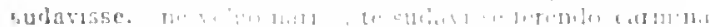

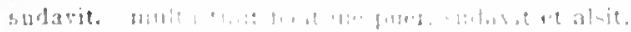

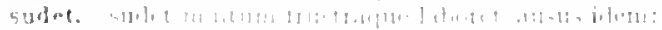

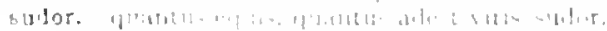

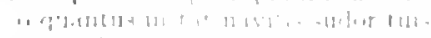

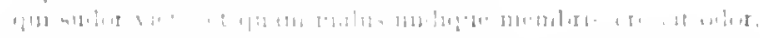

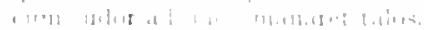

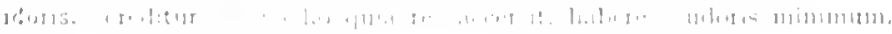

Sirm.2.5.4"

Sirmitis. 12

(iorm:3.1.4.

(arm.1.1.3"s

(urm:1.15.3.

Ciarm:-3.20.11

J.pist.1.12.8.5

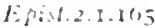

Ars Jinet res

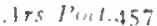

Carm.3.27.3:

Carmi-4 103

Sormand 23

J: pud II Is

Curm.2.1\$.21

Carm.2.10.17

Carm.2.10.10

Carm. Suec. 17

Carm.3.13.8

Carm.13.1.1

S.rm.2.1.100

Corm.3.1\%.14

Jpist.2.1.180

Sirm.1.10.02

Curm.3.24.28

Carm.1.IX.1.4

E. pod. 16.31

Serm.2.5.95

Sirm.1.2.20

I. Pod.13.15

Serme.8.3\%

List.2.1.2.12

Sirmes.10 *

Serme.7.811

lipist 1.103

I. pod.5.s.

Expte. $7.7^{n}$

Fide J podt.5.5s

Sirm.2.4.15

I. Pist.1.10.43

lisist.t. 1.35

fepist.1.17.37

Ars Finelest

Sirm.1.8.2.3

Sirm 2.6.107

I. pist 1.17.4.

Ars liviluso

Sint 2.13

Som $2+4$, th

Sirms.2.4 $=0$

Cormaso.3.35

Serm. $28=8$

(iil) 3. 3.

sem. \& 1 14m

firm, ?.ant

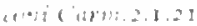

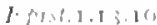

des litotio

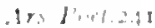

(it) 218 - 15.10

I. Pould (1) I I

Fond I 27

Simenger 
suetae. non tantum furesque ferafple suctae/ hune vexare locum curat - mnt suffigat. siquis enm servom, . . . in cruce sufigat.

suffians. mum tantum, suflans se, magni fuisset?

suffragia. non ego rentosae plebis sufiragia venor cum scribo et supplex populi suffragia enpto;

sui. illnn... parentis crediderim sui|fregisse cervicu

sui. mercator... otium et oppidi|laudat rural sui; oscula, quae Venus|quinta parte sui nectaris imbuit.

sui. saeva tene cum Berecsntiol cormu tympana, quae subsequitur caccus Amor sui. ille potens sui| linetusqua deget

suis. te suis matres metuont iuvencis, nil sibi legatum praeter plorare sui qute.

suis. iniecta monstris Terra dolet suis consentire suis studis qui crediderit te fautor. ploravere suis non respondere fivorem/speratum meritis.

suis. condit quisque diem collibus in suis

paterna rura bubus exercet suis ventis iturus non suis ut. . . instat equis auriga suos [inis] vincentibus, cur non ponderibus modulisque suis ratio utitur

suis, suis et ipsa Roma viribus ruit. .

suis. quae terris semota suisque temporibus defuncta videt.

Sulci. non ego sim Capri neque Sulci: eur metuas me?

sulcis. est ut viro vir latius ordinet arbusta sulcis,

Sulcius. Sulcius acer/ambulat et Caprius, rauci male cumque libellis.

sulcos. sulcos et rineta crepat nera, praeparat ulmos.

Sulgi. ut sis tu similis Caeli Birrique latronum, | non ego sim Capri neque Sulci [Sulgi]:

Sulgius. Sulcius [Sulgius] acer/ambulat et Caprius.

Sulpiciis. qui nunc Sulpiciis adeubat horreis,

sulpura. dictaque cessantem nervis edidere morbum | sulpura contenni ricus gennit.

sum. non sum qualis eram bonaelsub regno Cinarae.

comes minore sum futurus in metu.

ut sis ta similis Caeli Birrique latronum, non ego sim [sun] Capri neque Sulci:

nunc, quia sim [sum] tibi, Maecenas, convictor.

'nil habeo quod agam et non sum piger: usque sequar te.'

'dubius sum, quid taciam.' inquit.

sum paulo infirmior, unus multorum.

quidquid sum ego, quamvis infra Licili censum ingeniumque,

'rex sum.'

nee sum facturus s itio culpave minorem;

"non sum moecluss" ats.

tibi quid sum ego?

"liber liber sum." dic age.

quid verum atque decens, curo et rogo et omnis in hoc sum:

nimirum lac eso sum; nam tuta et parvola laudo.

'sum bonus et frugi.' renuit negitatque Sabellus.

res urget me rulla: meo sum pauper in acre.

sumas. distat, sunasne purlenter/an rapias.

sume. sume, Maecenas. cyathos anici| sospitis centum

sume supctbian! quaesitam neritis

tu cessas? agedum. sume hoc ptisanarium oryzae."

slune tibi decicns; .

'sume. cattelie': negat; si non des, optet.

grata sume monu neu dulcial differ in annmon.

sumere. voltis sereri me quoque sumere/fartem ialerii?

quam ex hoc fonticulo tantumfem sumere.'

sumere depositun clavom ferique tribnno?

honestos/fascibus et sellis nolbu mihi sumere.

ct neglectit solent incendia sumere vires.

sumeret. hic, unde vitan sumeret inscius, prom duch miseut.

sumes. quen virum aut heroa lyta vel acri! tibia sumis [sumes] celebrare, clios.

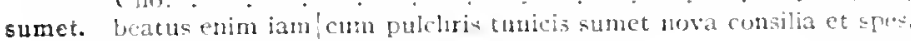
cum tabulis animum censoris sumet lotresti.

sumi. quib parvo sumi nogucunt, obonia captas.

Sirme1.8.17

Sirm. 3.52

Strm.2.3.317

lipist.1.10.37

fepist.2.2.10.3

Citrm.2.13.5

Cirm.1.1.I?

citm.1.13.16

Camblos.14

(ism-3.20.41

carm.2.8.2I

Siermas.jon

(iarm.34.3

Et:5t.I. I\$.6.5

lepist.2. I.O

(arm.t.5.2\%

Lepoll.2.3

Enod.o.3o

tur.Serm. I. I.IS5

Srm.1.3.78

Jipod.10.2

Fist.2.I.2I

Sum.t.t.7o

Carm.3.1.10

Som.1.4.05

Itpist.1.7.84

wer.Serm.1.4.70

sur. Siom. I.4.05

Carmot.t2.18

Epist.1.15.7

Carm.t.1.3

Fidul.t.

cer.serm.1.4. 70

zor.Serm.1.6.47

Sim.1.9.10

Sirm. I.9.40

Simn. 1.9.7 I

S.rm.2.1.74

Sirm.2.3.188

Sirm.2.t.

S:rm.2.7.72

Sirm.2.7.8o

Sirm.2.7.92

Lpist.I.I.I I

Epist.1 I 5.4 .4

Epist.1.10.49

Epist.2.2.12

Enish.1.17.41

(a)m-3.8.13

Cam.3.30.14

Serm.2.3. I.55

Sirme.23.237

Serm.2.3.250

lipist.1.11.23

(isme.1.27.0

Sirm.1.1.5'

Sermento.es

Sirmerofo7

Epistr. I8.85

(itrm.3.5.37

iar.Carm.I.I2.2

I.pist. 1.13 .33

lipist.2.2.IIn

Sirm+2.7. 


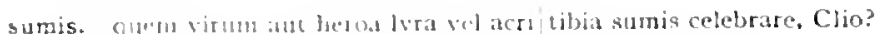

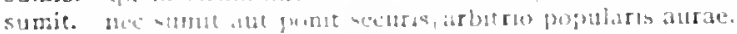

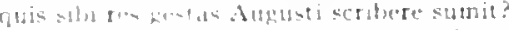

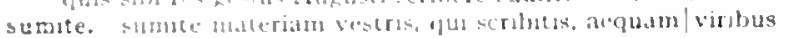

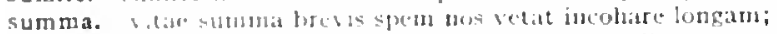

summa. Hergud sumba deperdat freduens aut adrplice ut dem.

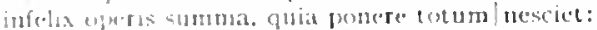

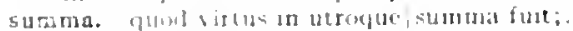

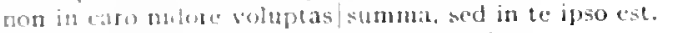

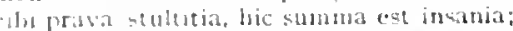

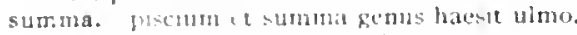

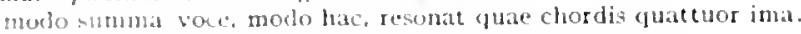

frgha dicte mali. sumnad dicemle ("amena.

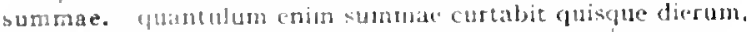

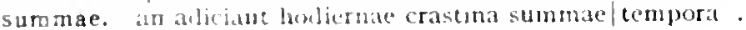

summam. Jucreles staberi summan incidere sepulcro. " - uth nitu patrimoni insculpere sixos

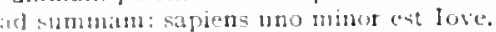

J3utam tobi Septiciumeste et nisi cena prior potiorque puella Sabinum detituet alsumam [ad summam];

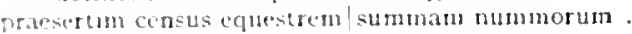

summe. sunme munico et multarum divite rerma.

sนmmi. summi materiem mali.

summis. si figtt adimantimos|sumnis verticibus dira Necessitas/clavos.

summis. valet inat sumbis/mutare. . deus

summo. shmmo carmane quae Cnidon fulgentisque temet Cyeladas.

-i paulum summo decescil, vergit ad jumm.

summos. kritutque sumbos fulgutid Inontis.

bummosses. dispream, ni sumbloses ofnnis."

summum. et roae sut natura boni summunque quid eits.

summum. stombun properabat lambere tectun.

ab ins and summurn totus moduli bipedalis.

: taituus al sumtumen fortunte.

summus. "sumbut ego et prope me Viscus Thurinus

mace lanus summus ab imo|prodocet.

sumpta. daloiturguc Jicestia sumpta pudenter.

numpta. nombla sectatur modo sumpta veste virili / sub patribus duris tir 0 ก1 4 แ1).

sumptis. lanturn de nedio sumptia accedit honoris.

sumptu. oppida publico'sumptu iubentes. . decorare

sumptum. "at in sc| pro qualestu sumptum facit hic."

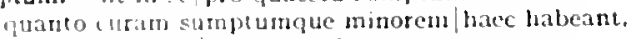

nequo sumpiuminuitus facias

sumptuasa. non sumptuosa blandior hostia.

sumptus. vilbus ig scopis. in mappis, in scobt quantusiconsistit sumptus?

sumptus. asitalex re prateri sumplus mibi credoret illos.

sumus. pulve et umbra sumus.

auxilin quan, sut mile (nam multo plures sumus).

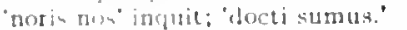

nos mulurus simus ot fruges consumere nati.
Carm.1.12.2

Carm.3.2.10

l:pist 1.3 .7

Ars l'od. 38

Corm.1.415

Sirm.1.4. 32

Ars J'ues.34

Sirm.1.7.15

Serm.2 2.20

Scrm.2.3221

Carm.1.29

Sirm.1.37

Epist.t.1.1

Sirm.2.3.124

C"arm.4.7.17

Sirm:.2.3.8.4

Sirm.2.3.00

lipist. a.100

I'ur. Ispist.1.5.28

Ars Joel. 384

lipist.2.2.31

Curm.3.24.49

Curm.3.2.4.

Carm.1.34.12

Carm.3.28.13

des l'oct.378

Curm.z.IO.II

Sirm.1.9.98

Sirm.2.0.76

Serm.1.5.74

Sirm:2.3.309

1:pist.2.1.32

Serm.2.8.20

E.pist.1.1.5.

. Irs I'oel.5I

Serm.1.2.10

Ars l'oet.243

Carm.2.15.19

Serirt.1.2.10

Sorm:-2.4.85

Lpist.2.2.195

Carm.3.23.18

Serit.2.1.82

Sorm. 1.80

Curm.4.7.16

Serm.1.4. 142

Scrmi.1.0.7

Lpist.1.2.27

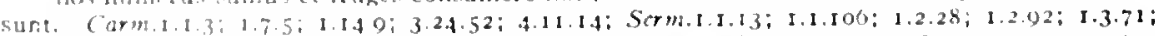

Sirm.1.1 $=1 ; 1 .+75 ; 1.7 .10 ; 1.8 .18 ; 1.10 .17 ;$ iur.Sirm.1.10.88; \$crm.2.1.1; 2.3.207;

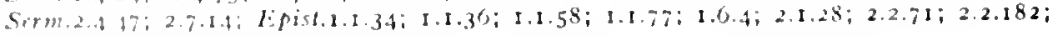

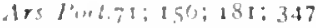

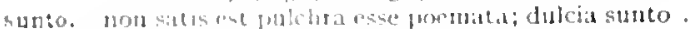

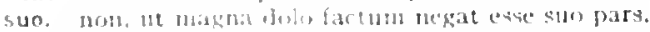

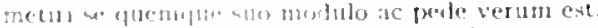

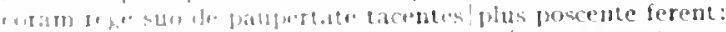

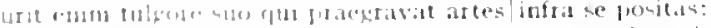

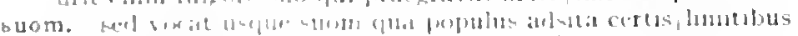

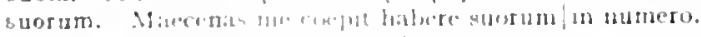

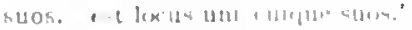

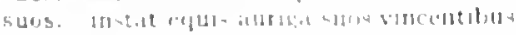

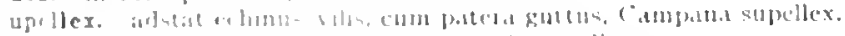

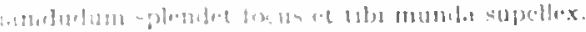

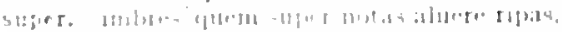

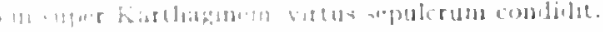

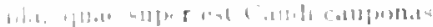

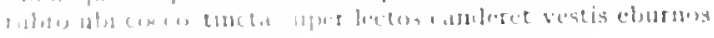

Ars liodiog

Serm.1.0.00

I:pist. I. 7.08

1.pist.1.17.43

I. pist 2.1 .13

I.post.22.170

Sirm.2.0.11

Sirm-1.052

Sirm.1 $\$ 115$

Sicrm.1.1, 118

fipdat 57

( itrm . 2.0

Iipend 25

Serm.1.5 51

Sorm. 2.0.103 
Nomentanus erat super ipsum, Porcius infra,

super. superiecto [super iacto] pavidae natarunt|aequore damnae. dissolve frigus ligna super focollarge reponens. aut super Pindo gelidove in Haemo?

Centaurea monet cum Lapithis rixa super mero destrictus ensis cui super inpia/cervice pendet. mitte civilis super Vrbe curas: super inpetrato| fortis Augusti reditu. prosperes decreta super iugandis|feminis priusque caelum sidet inferius mari|tellure porrecta super parumne campis atque Neptuno super/fusum est Latini sanguinis, et paulum silvae super his foret.

fuit intactis quoque cura|condicione super commua, quereris super hoc etiam. pallescet super his, etiam stillabit amicis|ex oculis rorem.

super. satis superque me benignitas tua/ditavit. dedi satis superque poenarum tibi. poenas dedit usque supcrque/quam satis est. adde super, dictis quod non levius valeat: accipit et bis dena super sestertia nummum.

superante. animaeque magnaelprodigum Paulum superante Poeno superantis. est mihi nonum superantis annum|plents Albani cadus. superare. hunc equis, illum superare pugnis/nobilem; . hunc atque hunc superare laboret vel cursu superare canem vel viribus aprum|possis.

superat. quod superat non est melius quo insumere possis? . si de quincunce remota est|uncia. quid superat?

superba. quibus superbam [superba] fugit ulta paelicem. superba. superba civium/potentiorum limina.

superbae. Fortunae te responsare superbaelliberum et erectum soperbae. fors et/debita iura vicesque superbae/te maneant ipsum: superbam. quibus superbam fugit ulta paelicem.

superbas. sliperbas invidae Karthaginis|Romanus arces ureret.

superbe. qui Fortunae te responsare superbae [superbe] / liberum et erectum praesens hortatur

superbi. quam spectatoris fastidia ferre superbi,

superbi. iam Scythae responsa petunt, superbi|nuper, et Indi.

superbiae. insperata tuae cum veniet pluma superbiae.

superbiam. ingratam V'eneri pone superbiam. sume superbiam $\{$ quaesitam meritis

superbis. derepta Parthorum superbis/postibus ut redeat miseris, abeat Fortuna superbis.

superbo. privata deduci superbo. / non humilis mulier, triumpho. tangentis male singula dente superbo;

superbo. mero|tinguet pavimentum superbo. quod ut superbo provoces ab inguine.

superbos. quin et Atridas duce te superbos . . . fefellit. an superbos| Tarquini fascis, dubito. superbos/vertere funeribus triumphos: non ego nuntios $\mid$ mittam superbos:

superbum. (ontra Laevinum. Valeri genus, unde Superbus [superbum] hic superbum/Tantalum atque Tantali|genus coercet, pluribus arlsuerit mentem corpusque superbum

Superbus. unde Superbus|Tarquinius regno pulsus fugit,

superbus. heres... mero|tinguet pavimentum superbo [superbus], licet superbus ambules pecunia. meo nunc/superbus incedis malo. in quem superbus ordinarat agmina|Mysorum .

supercilio. cuncta supercilio moventis. deme supercilio nutrem:

superesse. quod superest aevi, siquid superesse volunt ri; superessent. multique de magna superessent fercula cena,

superest. ut mihi vivam quod superest aevi.

superi. an adiciant hodiernae crastina summae/tempora di superi? carmine di superi placantur, carmine Manes.

superiecto. ct superiecto pavidae natarunt|aequnre damae.

superis. me docturum hederae praemia frontium/dis miscent superis. ope Pallabis| Tydiden superis parem? superis deorum|gratus et imis.
Serm.2.8.23

iar.Carm.1.2.:

Carm. I.9.5

Corm.1.12.6

Carm.1.18.8

Carm.3.1.17

Carm.3.8.I 7

Carm.4.2.12

Carm.Sacc.I8

Eppd.5.80

Epod.7.3

Sirm.2.6.3

Epist.2.I.152

Epist.2.2.24

- Irs Poct. 120

Epod.1.3I

Epoiti 7.19

Semr. 2.65

Serm.2.7.78

Epist.2.2.33

Curm.1.12.38

Carm.t. I I.

Curm.1.12.25

Sirm.1.1.112

Epist.I.1S.5I

Sum.2.2.102

Ars Pod.328

aur. Epod. 5.63

Epod.2.7

Epist.1.1.68

Curm.1.28.32

Epod.5.63

inod.7.5

star. Epist.1.1.tos

Epist.2. I.2I 5

Curm.sued.55

Corm.10.2

Carm.3.10.9

Curm.3.30.I4

Carm.4. 15.7

Ais $J^{2}$ oel.20I

Cirm.1.37.3I

Serm.2.6.87

Cern.2.14.27

Epod.s.19

Carmar.10.Is

Carm-1.12.34

Cirm.1.35.3

Carm+4.70

a ar.Surm.1.6.Iz

Curme.18.36

Sirm.2.2.109

Sirm.1.0.12

conicinm.2.Itz-

Epollts

Epod.15.18

Epol.17.o

Carm.3-1.8

I.pist. I. 18.94

Epist.1.18.108

Sirm.2.0.104

sipist.r. I 8.108

Firm.4.7.18

lipist.2.1.13

Carm.1.2.II

(arm.1.1.30

carms.o.10

Cormel.Iu.Io 


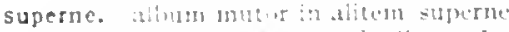

(1) $13: 2.20 .1$ t

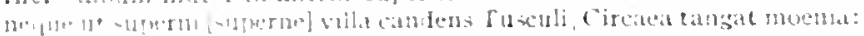

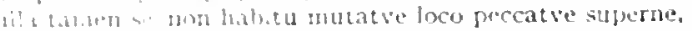

I'ar. J:POL. I. 20

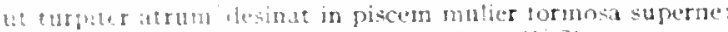

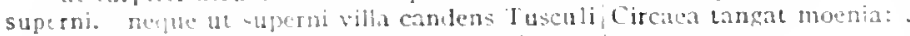

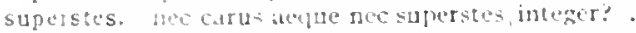

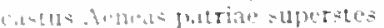

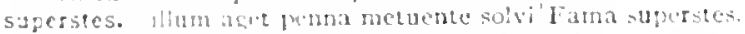

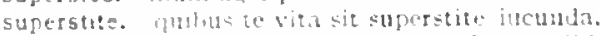

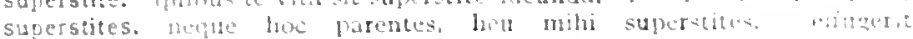

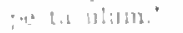

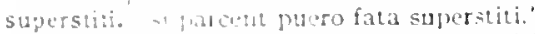

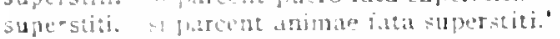

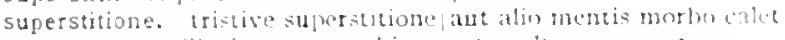

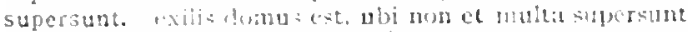

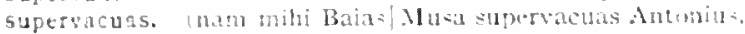

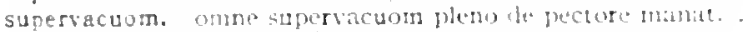

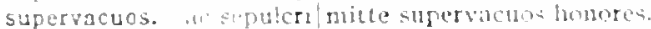

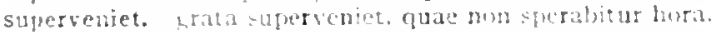

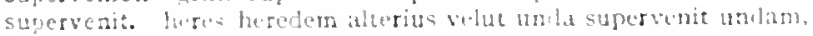

supinas. cieles supinas si luleras manus

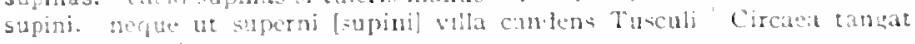
thutelin:

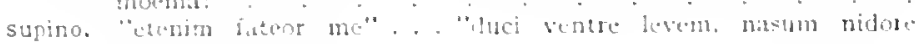

supinor. "* "

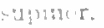

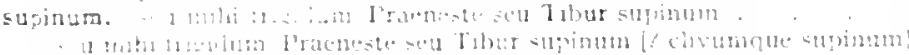

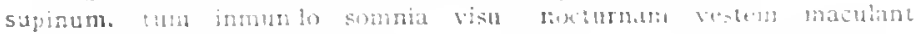
var.

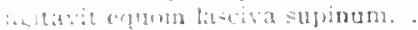

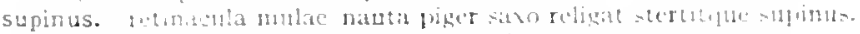

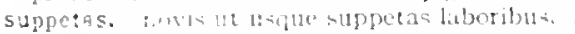

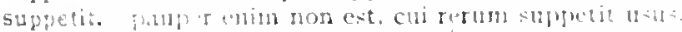

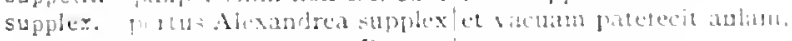

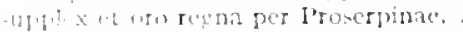

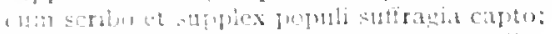

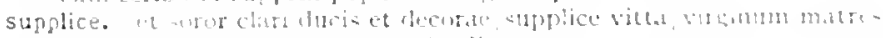

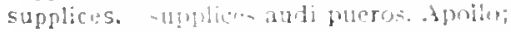

suprlicibus. miplicillut tuis parcas,

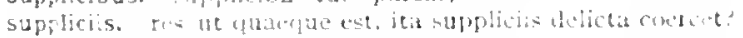

supplicio. ation eluplicio culparealutur.

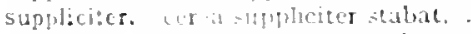

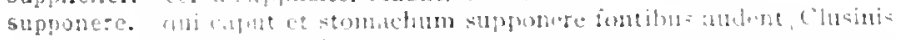

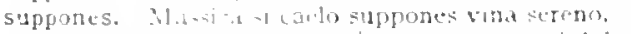

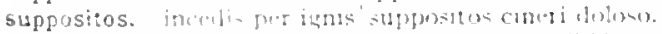

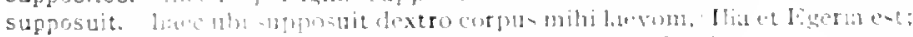

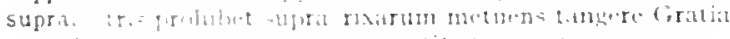

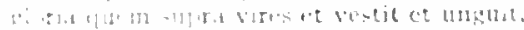

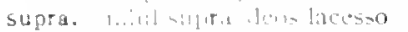

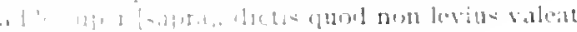

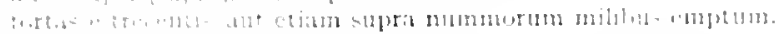

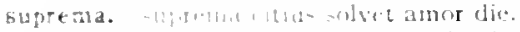

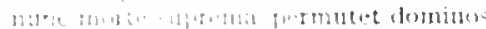

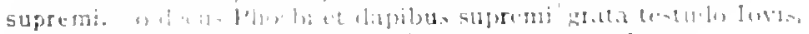

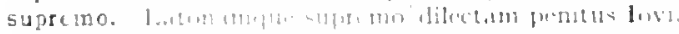

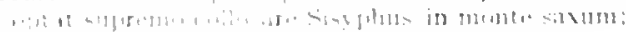

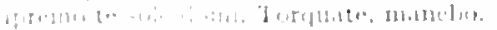

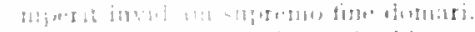

6upremums. Am

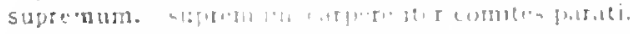

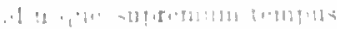

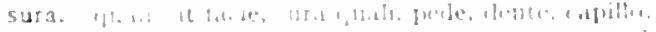

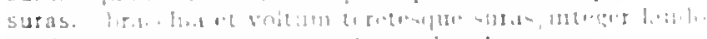

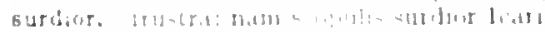

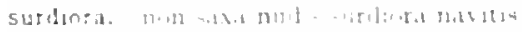

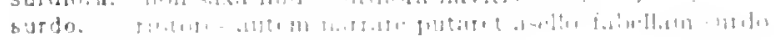

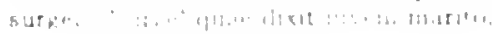

Serm 2.7 .09

Irs Jivetas

J: od 1.20

(iern. 2.17.7

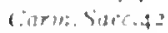

Tirrit. 28

I.Pi) I. 5

I. $p 0.6 .5 .1111$

(istri.3.1).10

(ism.3.0.12

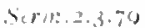

t.pit: :.6..5

A.pist. I. 15.3

1rs Jinet.3.37

(iorm. 2.24).2.:

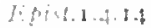

I. Pirt 2.2.17's

( i.t):.3.2.3.1

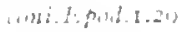

ar.s.rm.2. . . 39

S.rm: $2,3.35$

(iormes.ot =3

t:irc(itris.3..\$2.3

ㄱ.

5 r. 2.8.50

S.mi, $5,[1]$

$1+191 \%$

1. pot.1.12.4

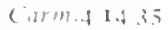

T:P 310.17 .2

1 1.11.2.2.103

Gurls 314.8

curmasion. is

curmita. 10

sron. 1.3.79

cirm-3.2+34

S.rin.1.6.3.

lipith. I.I 1 .R

Sermping.is

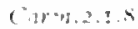

ง.MP1.1. 125

(16) 3.10 .15

t.pust.1.1.2.22

( irm 2.1S.1 1

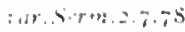

1. prist.2.2. 2115

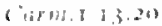

i.jut.e $=17.3$

carni-1 is: 13

("irm.1.21.3

I:Pend. Ii.c.s

s.pints 5

I. pine 112

for:1:13

(iob): 273

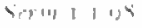

Sirm I 41,31

(intel. 2.21

cirth.t 7

$12,117.5 .6$

1 for $0.120(1)$

( w)ets 1137 
surge, ne hngus tibi somnus undefnon times dotur;

surge et inlumanae sestiun depone Camenae.

surgendum. non sollicitus mili quod cras|surgendum sit matse.

surgente. nec tibi respero|surgente decedunt amores

hie mutat merces surgente a sole ad eum, quol respertin. tepet resio.

surgeret. ac vencrata Ceres, ita culmo surgeret alto.

surget. recte est igitur, surgetque?

surgit. non sine conscio/surgit marito.

vegetus praescripta ad munia surgit.

sed vocat usque suom qua populus ahsita certis ?? \&uriti | linutibus viciua refugit iurgia;

surgunt. ut ingulent lominem, surgunt de nocte latrones: .

suris. fenur tumentibus/esile suris additum.

surpite. ('quiu tan magnum?' arklenc), 'unum me surpitu monti!

surpuerat. quae re surpuerat mul

Surrentina. Surrentina vafer qui misect faece Falerus risa,

Surrentum. Brundisium comes aut Surrentum ductus antonthm

surreze. huncine solem/tam nigrun surreze mihi! .

surripis. quare. . . periuras. surripis, aufers/undiqle?

nam de mille fabae modis cum surripis unum.

sus. yuan canis acer ubi lateat sus. .

vixi-set eanis inmunius vel aniea luto sus.

liac rabioss fugit canis, luac lutulenta ruit sus:

suscipe, i nune, argentam et narmor vetus aerafue et atis / susnice [suscine].

suscitabo. oscinem corvon prece suscitabolsolis ab ortu.

suscitat. quondam cithara tacentem suscitat Musan

suscies. lit te suscitet ac reddat gnatis carisque propinculis?

suspecta. nee metues protervon! suspecta Cyrum,

donec suspecta severoleonticuit lyra.

suspectos. ut quo quisque valet suspectos terreat

metuit foveata lupus accipiterque / suspectos laqums

suspecam. quaram, meritone tibi sit|suspectum senus hoc scribenti.

suspecius. calus enim metuit fovean inpus acciptcrque | suspectos [suspectus] laqueos

suspondens. Balatro suspemdens onuia naso

suspendis. ut plerique solent, naso suppendis aluno isnotos

suspendisse. urida|suspendisse potenti restimenta mats flow.

suspendit. suspendit picta voltum mentenulue tabeila.

suspensa. guantum exstant aqua/suspensa mento corpora;

interea supenua sravis allaed rumas in patinar fecer.

suspensi. lato suspensi loculos tabulamque lacerto.

'laevo suspensi loculos tabulangue lacerto.'

suspicari. Suge suzpicari|cuius oetavom trepidavit aftal chuflere lustrum. suspice. argentum et marmor vetus arague et artisistupice.

suspirare. suspirare Chloen et miseran tuis/dicens ighbus $11 \mathrm{i}$.

suspiret. adulta virgo|suapiret:

sustineant. noc jim sustineant onus|cilvae laborantes

sustineas. quo clamore coronal proclia sustineas campertia;

cum tot sustineas et tanta negotia solus.

sustinet. lapis albus poculd cum cyatho duo sustinct.

sustulerat. me truncus inlapsus cerebro|sustulerat,

sustulerit. fulmine sustulerit calluco.

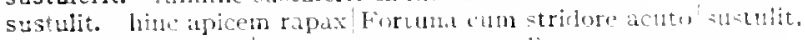

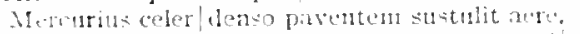

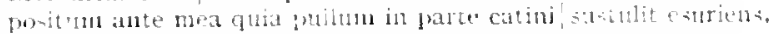

susurri. lenesque sub nocton slatiri

susurros. strulere secreta divisos alure susurros."

sutor. ct sutor bonus et solus formustls det est rex.

zitor tamen eit sapiens.'

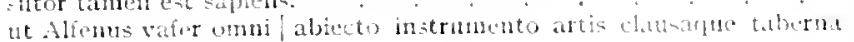
sutor trat:

emat. . si sculura et formas non sutor.

Sybarin. Sybarin cur properes amandi/perdere.

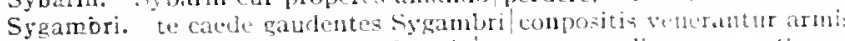

Sygambros. quandogue trahet ferceis\}per sicrum clivom . . Sygambus:

syllaba. syllaba lonsa brevi sublecta rocatur iambus.

Syllae. Villins in Faista Syllat gener. . . poenat dolit
C.rm.3.1 I.3S

Lisist.1.18.47

Sirm.1.1.120

(:irm.2.0.1 I

Serm:1.+.29

Sirm.2.2.121

Sirn.2.3.102

corme. 30.30

Serm.2.2.81

? tar. Epist.2.2.170

lipist.1.2.32

Lipute.so

S. $r \times 2.2 \cdot 3 \cdot 283$

Citrmatis.s? 20

5.rint.2.4. 55

Eipist.1.17.52

Simt. 1.0.73

Sicut.2.3.127

Epist.I.I 6.55

Ithod.12.6

Ltpist.1.2.26

Lisist.2.2.75

ios. Epist.1.6.18

Carm.3.27.11

Curm.2.10.19

Serm.1.1.83

Cerm.1.17.25

lipist.1. I 8.42

Sirm.2.1.50

IPISt. I. I0.5 r

Sermatity

tur.lisist. I.IS.5 I

Surti2.S.0.4

Sermi.1.0.5

Carm.1.5.15

Epist.2.1.07

Iipod.5.31)

S.rm.2.5.54

Sermesco.t4

Lisist.1.1.50

(a) 34.22

I‥85t.1.6.18

(arm.3.7.Ir)

C(trm.3.2.)

(avm.1.e.2

fipist.1.15.51

1.pist.2.1.1

Sirm.1.117

c'rom.2.17.28

C.sm.3.4.44

(izrot.1.37.15

(izrin.2.7.14

Sirpll.1.3.1)3

(i)m.1.9.19

Simi.2.8. 75

Sirm-1.3.125

Som. 1.3.128

Sir.t.1.3.132

S.mon.3.10ts

(armols.s.

(arm. 1.515

(a)m insoso

Ars Pot.35I

sirm.t.2.6. 
SYMPHONIA

symphonia. ne gratas inter mensas symphonia discors / et crassum unguentum . . oflendunt.

Syra. vina sigra roparatal nucerce.

Syri. (une. Syr. Damae aut 1)ronysi filius, audes.

Syriae. et volis pacisci ne Cyntac Tyraeque [Syrineque] merces/addant avaro duvithas narl:

Syrio. coronatus nututis/malobathro syrio capillos.

Syro. nugas hoc genus: "hora quota est?" Thraex est Gallina Syro par?"

Syrtis. sive per Sytis iter acstiosas.

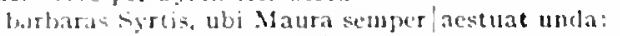

vism . . Ltora Bospori|Syrtisque Gaetulas canorus|ales .

exreifatis aut petit syres noto
TACITVS

Ars Poet. 37.4

Curm.1.31.12

Scrm.1.0.38

rar. Corm.3.29.60

Curm.2.7.8

Serm.2.0.44

Carm.1.22.5

Carm.2.6.3

Carm.2.20.15

Lpod.9.31

\section{$\mathrm{T}$}

tabella. It onmic|votiva pateat veluti descripta tabella|vita senis.

vol cum lisumaca corpers. insane. tabella.

surfundt focta voltum mentemque tabella.

tabellas. munera quid niti quidve tabellas/mittis 'infrimat his cura Maecenas signa tabellis [tabellas]."

Tyrthena sigilla, tabellas. . . sunt qui nou habcant.

tabellis. 'mprimat bis cura Matecenas signa tabellis.'

tabellis. aut pictis tamquam gaudere tabellis.

taberna. mulla tiberna meos habeat necue pila libellos, u०C vichla subest vinum ptaebere taberna'quac nosit tibi

taberna. onni abicoto instrunento areis clausaque tabernal/sutor erat:

tabernas. pallida Mors aequo pulsaf perde pauperum tabernas / regunque turtis.

nigice in obscuras humili sermone tabernas

tabescat. cabecat neque se majori panperiorun tubac conparet.

tabo. cum palla, tabo munus imbutum.

tabula. me tibulis sacet, votiva jarses indicat .

tabulae. isti tabulae fore librum! persinilem.

tabulae. "solvantur risu tabulae, tu missus abibis." nt lippom pictate tabulare, fomenta podagrum.

tabujan. layosusensi loculon tabulameque lacerto. "latevo su quenci loculog tabulanque lacerto."

tabulas. accipe, si sis.laccipian tibulas;

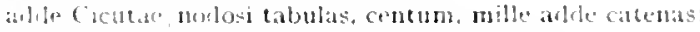
ialunere ct tabulas a te removere nemento.

talublas secoro diabit atcume ut logat orabit;

-10 fantor veterum, ut tabulas peccare vetancis,

tabuls. cum tabulis animum censogis sunet bonesti.

taceas. ci taceas, laulant qualquill scripsere beati.

tacenda. In vencum ald cenamest. dicenta tacenda locutne

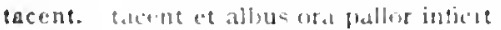

tacentem. ythomban cithara tatencem|stacital Musam

tacentes. hin de paupertalle bacentes| plus poscente ferent:

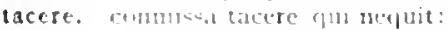

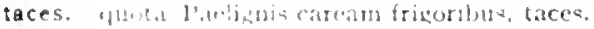

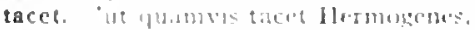

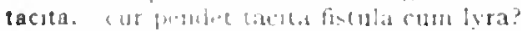

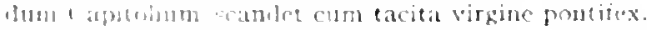

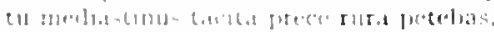

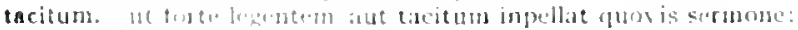

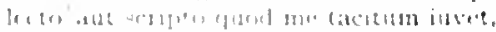

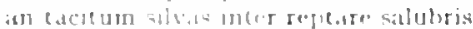

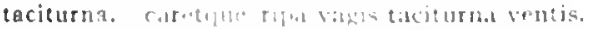

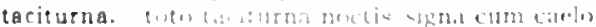

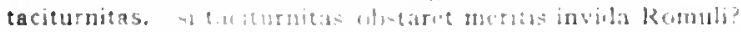

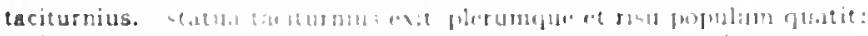

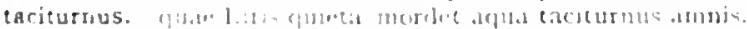

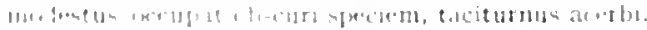

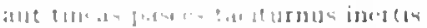

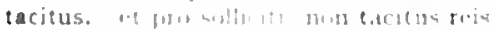

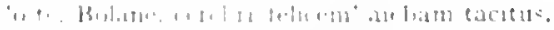

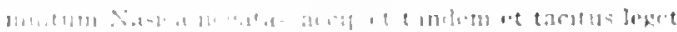

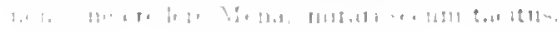

Serm.2.1.33

Sirm.2.7.95

Epist.2.1.97

Epod.1 2.2

1ur.Sorm.2.6.38

Epist.2.2.180

Sorm.2,6.38

Sirm.1.1.72

Sirm.1.4.7.

Espst.1.14.2.4

Serm:1.3.131

Curm.1.4.13

Ars l'uet 220

Sermat.11]

lipod.5.05

Curm:1.5.13

Ars Pueto

Serm.2.1.80

lipis!.1.2.52

Sirm.1.0.74

Epist.1.1.50

Sermid.t5

Sirm.2.3. 30

Serm.2.5.52

Serm.2.5.00

Epist.2.1.23

lipist.2.2.110

I.pret.2.2.108

l: fist.1.7.72

1. pol. 7.15

(ivn:2.10.18

1.pist.1.17.013

Sirmisis sit

(a)m.3.10 8

Sorm. 1.3120

Cimm.3.1020

(iarm.3.300

Jipher. 1.114

Serin 1.3.5.

Sirm.1.1.123

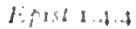

(arm 3.20 2.4

(cortis.s. 10

Cormis 8.23

l. purt 22.83

( al): 131.8

f pilt t.tsis 5

Ipid 1.20.12

(armid 1.3.

Sirs. 1012

sirn: $=5018$

7 1.:1 =1.2 
sed tacitus pasci si posset corvos,

Epist.I.I7.50

quocirca mecum loquor haec. tacitusque recordor: . . . . Epist.2.2.145

tacta. urges/iampridem non tacta ligonibus arva . . . . . . Epist.I.I4.27

tu me inter strepitus nocturnos atque diurnos | vis canere et contacta [non tacta] sequi vestigia vatum?

tactu. ne .. . sponsus lacessat regius asperum|tactu leonem.

tacuit. quid dixit aut quid tacuit?

taedas. ceu flamma per taedas

taedium. nuper sollicitum quae mihi taedium.

Taenari. quo Styx et invisi borrida Taenari|sedes.

taeter. spiritus taeter saniesque manet|ore trilingui;

taeterrima. nam fuit ante Helenam cunnus taeterrima belli $\mid$ causa,

taetra. "nam simul ac venas inflavit taetra libido.

ut si solvas "postquam Discordia taetra|belli ferratos postis portasque refregit,"

tale. at siquid umquam tale concupiveris,

nil oriturum alias, nil ortum tale fatentes.

talenta. mille talenta rotundentur, totidem altera,

talenta. hic simul accepit patrimoni mille talenta.

quinque talenta| poscit te mulier,

talentum. Pythias, emuncto lucrata Simone talentum.

tali. vetuit me tali voce Quirinus

talibus. me... dixi|talibus officiis prope mancum,

talis. quo simul mearis. | nec regna vinj sortiere talis

illum balbutit scaurum pravis fultum male talis.

talium. non tibi talium|res est aut animus deliciarum egens.

talo. cadat an recto stet fabula talo.

talos. nisi illas|quarum subsuta talos tegat instita veste,

ad talos stola demissa et circumdata palla.

cum sudor ad imos|manaret talos.

te talos, Aule, nucesque ferre sinu laxo. donare et ludere vidi;

qui pro se tolleret atque/mitteret in phimum talos.

"hic et / candidus et talos a vertice pulcher ad imos| fiet

coni.Epist.2.2.80

Carm.3.2.11

Epod.5.49

Carm. 4.4 .43

Carm.1.14.17

Carm.1.34.10

Carm.3.I I.I9

Serm.1.3.107

Sirm.1.2.33

Serm.1.4.60

Epod.3.I9

Epist.2.1.17

Epist.1.6.34

Serm.2.3.226

Serm.2.7.89

Ars Pott.238

Serm. I. 10.32

Epist.2.2.2I

Carm.1.4.I 8

Serm.1.3.48

Carm.t.8.9

Epist.2.1.176

Serm.1.2.29

Serm.1.2.99

Serm.1.9.I I

Serm.2.3.I7I

Serm:2.7.I7

Epist.2.2.4

tam. Carm.1.7.10; I.7.1I; 1.24.2; Serm.1.1.22; 1.3.20; 1.5.69; 1.9.73; I.10.2; 2.3.18; 2.3.283; conti.Serm.2.3.313; Serm.2.5.77 (bis); 2.5.102 (bis); zar.Serm.2.7.20; Serm.2.7.21; Epist.1.7.18; 2.1.90; 2.1 .238 (bis)

tamen. Carm.I.3.23; I.7.22; 1.I2.I9; I.I5.19; I.32.6; 1.36.6; 2.18.29; 3.5.50; 3.10.2; 3.16.37; Carm.3.24.03; 3.29.45; 4.7.I3; 4.II.I3; 4.13.2; Serm.1.1.27; I.3.128; I.3.I29; I.4.99; Serm.1.5.83; I.10.5; I.10.8; 2.1.75; 2.1.80;2.2.23;2.2.29; 2.2.82; 2.3.7I; zur.Serm.2.4.47; Serm.2.4.91; 2.5.16; 2.5.53; 2.5.6I; 2.6.82; 2.7.63; Epist.1.1.29; 1.6.27; 1.6.42; 1.7.23; Epist.I.I0.24; I.II.8; I.I 2.25; I.I4.8; I.I4.26; I.I5.3; I.I7.4; I.20.25; 2.I.II8; 2.I.I59; Epist.2.1.229; 2.2.19; 2.2.24; 2.2.I54; 2.2.192; coni.Epist.2.2.199; Epist.2.2.202; Ars Pott.77;93; 182;347;372;382;386

tamquam. tamquam parcere sactis|cogeris aut pictis tamquam gaudere tabellis. tamquam ad rem at ineat quidquan. . tamquam|sit proprium quicquam.

Tanain. extremum Tanain si biberes, Lyce, non Tanain prope flumen orti. est inter Tanain quiddam socerumque Viselli:

Tanais. Bactra parent Tanaisque discors.

tandem. tandem venias precamur ... augur Apollo; tandem desine matrem|tempestiva sequi viro. . desine mollium|tandem querellarum tandem nequitiae fige modum tuae dixitque tandem perfidus Hannibal: Canidia: parce vocibus tandem sacris . tandem fessus dormire viator/incipit. illa rogare, |quantane? num tantum [tandem], sufflans se. magna fuisset? 'o major tandem parcas, insane. minori.' multum Nasica negatas/accipict tandem et tacitus leget tandem urbanus ad hunc "quid te iuvat" inquit, "amice, tandem dormitum dimitcitur. quo tandem pacto deceat maioribus uti. inberbis iuvenis, tandem custode remoto.

tangas. contractum genibus tangas caput?

tangat. quicumque mundo terminus obstitit, / hunc tanget [tangat] armis. neque ut superni villa candens Tusculi|Circaea tangat moenia:

tange. sublimi flagello|tange Chloen semel arrogantem.

Serm.I.I.7I

Serm.I.I.72

Sirm,2.2.27

Epist.2.2.17I

Carm.3.1O.I

Carm.t.15.2.4

Sermil.1.105

Carm.3.29.28

Carm.1.2.30

Carm.1.23.1 I

Carm.2.9.1 8

Carm.3.15.2

Carm.4.4. 49

Epod.17.0

Serm.1.5.I7

iar.Serm.2.3.317

Serm.2.3.326

Serm.2.5.08

Serm.2.0.90

Epist.1.7.73

Epist.I.I7.2

Ars Pott. IoI

Serm.2.7.0I

var.Carm.3.3.5.t

Epod.r.30

Curm.3.20.I2 
tangenda. si tamen unpia"| non tangenda rates transiliunt vada.

tangens. aliquir cubito stanten prope tangena/inquviet.

Serm.2.5.42

langens. mente" the superni villa candens [tangens] Tusculi|Circaea tangat moetmat

tangentis. cupren-varia fastidia cena|vincere tangentis male singula dente superbo:

angere. cur thut thavom Tiberin tangere?

te thagrantis atrox hora Caniculaejnescit tangere.

tris prohibet stupa|rixarum metuens tangere Gratia

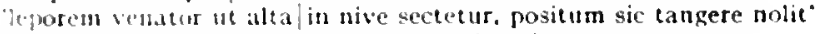

qu the conmoric (melius non tangete, clamo).

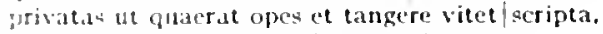

tanget. hunc tanget armus, visete gestiens.

tangi. Itrdit c $x$ ultein metuitque tangi

lango. hoc amitt et laudat "matronam nullam ego tango."

tanta. huic si mutonis verbis mala tanta vilentidiceret haec animus cum tot surtuneas et tinta negotia solus.

Tantsli. hic superbum|Tantalum atcue Tantali|genus coercet, .

Tantalum. lic mperbum! Tantalum atque Tantali|genus coercet.

Tantalus. egene benignate Tantalus semper dapis,

"rantalus a habrs sitien: fughentia captat/ dumina" -

tantam. mollis incrtia cur tantam diffuderit imis|nblivionem senobus. cum tu inter acabiem tantam et contagia lucti .

tants. (nam pudet tawti mali)

'nil satis e'st", inquit. "quia tanti quantum luabeas sis":

vertm nil tanti eat.

tantis. refum imperis lominumque tot tantisque minor.

tanto. cur, inprobe, carat non aliques patriae tanto emetiris acervo?

:anto cun strepitu ludi spectantur

'guil digntm tanto feret lic promissor liatu?

tanto. at qui tantuli eget [tanto leget] quanto est opus.

it: que, quanto perditior quisquce est. tanto acrius urget;

tanco dissimilem et tanto certare aninotem?

'major Jimidio. 'mun tanto?'

into repreluendi iustius illis.

tanto levilis miver ac prior ille

habet combedia tato olus oneris, quanto veratae minus:

yuod quanto flurd parasti. tanto plura cupis, nulline fatericr audes?

tantos. Fupolia. Archilochum. comites educere tantos?

tantuli. at qui tintuli eget quanto est opts.

tantulo. at qui tantuli eget [tantulo eget] quanto est opus.

tantum. muthtis tontum peribus numerisque.

sune illut l.sutum quatram, meritome thbi sit

mihi non tantum buresque feracoue suetac| hunc vexare locum curac sunt

-scerrit gublan notus mibi pomine tantum

-inus perlibu- quid clawdere senis, hoc antum contentus.

Rancum maledicit utrieque

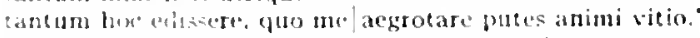

anto [tantum] disibuilom ct tanto certart" minorem?

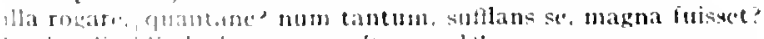

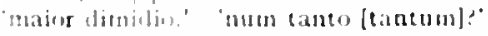

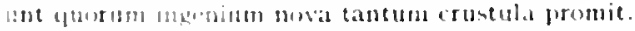

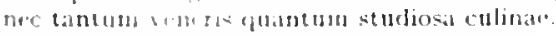

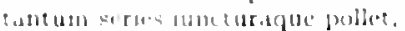

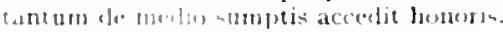

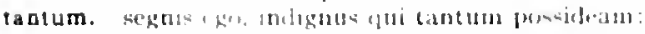

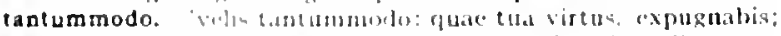

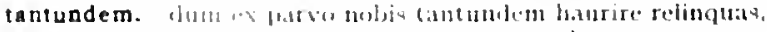

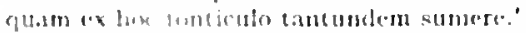

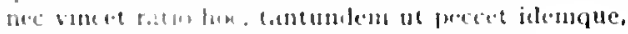

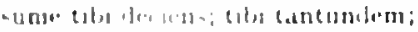

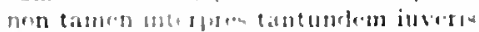

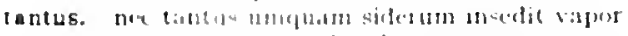

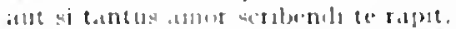

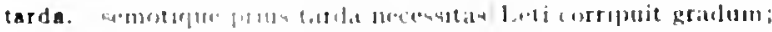

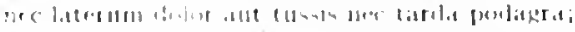

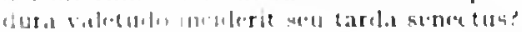

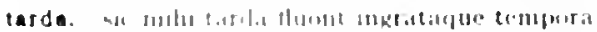

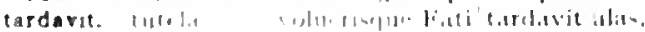

rar.Ispod.1.29

Serm.2.0.87

Carm.1.8.8

Carm.3.13.10

Carm.3.19.16

Serm.1.2.106

Serm.2.1.45

Fpist.1.3.16

Carm.3.3.54

Carm.3.11.10

Serm.1.2.54

Serm.1.2.68

Epist.2.1.1

Curm.2.18.37

Carm.2.18.37

ispod.17.66

Serm.1.1.68

lipod.14.1

Eppist.1.12.14

Ispod.11.7

Serm.1.1.02

Ars Poct.304

Serm. 2.7.76

Serm.2.2.105

Epist.2.1.203

Ars Poct. 138

:ur Serm.1.1.59

Serm.1.2.15

Serm.2.3.313

Serm.2.3.318

Sirm.2.48\%,

Serm.2.7.19

Jpist.2.1.100

Epist.2.2.148

Sorm.2.3.12

Serm.t.1.59

mor.Sern.1.1.50

Serm.1.4.

Sorm.1 4.04

Sirm.1.8.17

Serm.1.9.3

Serm.t. 10.60

Serm.2.3.140

Serm.2.3.306

sar.Serm.2.3.313

Serm.2.3.317

fur.Sorm 2.3 .318

Sorm.2.4.47

Sorm 2.5.80

Ars loet. 242

Ars Port 243

Serm. 2.3 .230

siorm.1 954

Sorm. I.I.52

Sorm.1.1.56

Sierm 1.3.115

Serm. 2.3.237

Sirm 2.4.91

lipod 315

Serm 2.1.10

6arm.1.3.32

Sermi.1 0.32

Sirm.2.288

l:pist:1.23

Corm 217 5 
tardi. quam frigida parvi [tardi] | findunt Scamandri flumina lubricus et Sinnois,

tardior. tardior ut paullo graviorque veniret ad auris,

tardiora. sed tardiora fata te votis manent:

tardis. minus est gravis Appia tardis.

luctandum in turba et facienda iniuria tardis.

tardius. hospes tardius adveniens vitiatum commodius . . consumeret. quia tardius irent $\mid$ propter onus segnes.

tardo. illi|'tardo' cognomen, 'pingui' damus.

tardum. nec tardum opperior nec praecedentibus insto.

tardus. utilium tardus provisor, prodigus aeris.

Tarenti. ab love Neptunoque sacri custode Tarenti.

Tarentino. "lana Tarentino violas imitata veneno."

Tarentum. pectinibus patulis iactat se molle Tarentum. sed vacuom Tibur placet aut inbelle Tarentum.

Tareatum. tendens Venafranos in agros/aut Lacedaemonium Tarentum. . nune mihi curtol ire licet nulo vel si libet usque Tarentum. dicas adductutr propius frondere Tarentum.

Tarpa. quae neque in aede sonent certant ia iudice Tarpa

Tarquini. an superbos/Tarquini lascis, dubito, an Catonis|nobile letum:

Tarquinius. unde Superbus|Tarquinius regno pulsus fugit,

Tartara. habentque/Tartara Panthoiden iterum Orco/demissum.

Tartaro. narrat paene datum Pelea Tartaro,

sauri. nec tauri ruentis|in venerem tolerare pondus.

lacerare ferro et | frangere enitar modo inultum amati | cornua monstri [tauri].

tauri. te decem tauri totidemque vaccae.

tauriformis. sic tauriformis volvitur Aufidus, .

tauris. tu frigus amabile|fessis vomere tauris|praebes

ignota tauris inligaturum iuga

tauris. non, si trecenis . . places inlacrimabilem| Plutona tauris,

Tauro. vina bibes iterum Tauro diffusa palustris|inter Minturnas

tauro. Europe niveurn doloso/credidit tauro latus

taurum. quae te Lesbia quaerenti taurum monstravit inertem,

taurus. cum tibi invisus laceranda reddet/cornua taurus.

viribus editior caedebat ut in grege taurus.

dente lupus, cornu taurus petit:

te. me [te] doctarum hederae praemia frontium/dis miscent superis. neve te nostris vitiis iniquom /ocior aura| tollat;

sic te diva potens Cypri,.. . regat

iam te premet nox fabulaeque Manes

quis multa gracilis te puer in rosa ... Pyrrha.

molli, Plance. mero, seu te fulgentia signis/castra tenent

dic per omnis hoc deos vere [te deos oro],

te canan. magni lovis et deorum|nuntium

te, boves olim nisi reddidisses. . voce dum terret,

neque te silebo. Liber

nec te, metuende certa|Phoebe sagita.

"navis, referent in mare te novilfuctus.

nrgent inpavidi te Salaminius! Teucer.

te Sthenelus, sciens/pugnat

rece furit, te reperire atrox. | Tydides

quis non te potius. Bacche pater. teque, decens V'enus?

non ego te, candide Bassareu.|invitum quatiam

atqui non ego te tigris ut aspera/Gaetulusve leo frangere persequor:

teque tuasque decet sorores. .

quae te cumque domat lenus.

yuae saga, quis te solvere Thessalis/magus venenis.

vix inligatum te tritormi/ Pegasus expediet Chimaera.

te maris et terrae numcroque carentis harenae / mensorem cohibent.

Archyta.

fors et/cebita iura vicesque superbae/ te maneant ipsum:

precibus non linquar inultis|teque piacula unlla resolvent.

vountis / cure te multo Glycerae decoram / transfer in aedent.

insignem tenui fronte Lycorida|Cyri torret [te torret] amor.

te pauper ambit sollicita prece/ruris colonus.

te dominam aequoris

te Dacus asper, te profugi Scythide

te semper anteit servi Nicessitas,

coni.Epod.13.13

Ars Poet.255

Ifpod.17.62

Serm.1.5.6

Sirm.2.6.28

Strm.2.2.9I

Sirm.2.3.101

Sirm.1.3.58

Epist.1.2.7I

Ars Poet.164

Carm.1.28.29

Epist.2.1.207

Sirm.2.4.34

Ejpist.1.7.45

Carm.3.5.56

Serm.1.6.105

Eipist.1.16.11

Serm.1.10.38

Carm.1.12.35

Serm.1.6.13

Carm.1.28.10

Carm.3.7.17

Carm.2.5.3

tar.Carm.3.27.43

Corm.4.2.53

Carm.4.14.25

Corm.3.13.11

Epod.3.I I

Carm.2.14.7

Epist.1.5.4

Carm.3.27.26

Epod.12.17

Carm.3.27.72

Serm.1.3.1 10

Serm.2.1.52

coni.Carm.1.1.29

Carm.1.2.47

Carm.1.3.I

Carm 1.4.16

Carm.1.5.I

Carm-1.7.19

zur.Carm.1.8.2

Carm.1.10.5

Carm.I 10.9

Carm.1.12.2I

Carm.1.12.23

Carm.1.14.1

Carm.1.15.23

Carm.1.15.24

Carm.1.15.27

Carm.1.18.6

Carm.1.18.11

Carm.1.23.9

Carm.1.26.12

Carm.1.27.14

Carm.1.27.21

Carm.1.27.23

Carm.1.28.1

Carm.1.28.33

Carm.1.28.34

Carm.1.30.3

sar.Carm.1.33.6

Carm.1.35.5

Carm.1.35.6

Carm.1.35.9

Carm. 1.35 .17 
te. Snes ct albo rara Fides culit / velata panno neque te ninistrum/dedecet myrtus su to in remoto gramine per dies/festos reclinatum bearis nescias an te genterum beati|Plyllidis thavae decorent parentes: ian te sequetur (currit enim ferox/aetas ille te necum locus et beatae postulant arces: quis te redonavit Quiritem te tus sus an bellum resorbens te stis matres metuont iurencis. to" sus matres metuont invencis, / te senes parci ilie et nefasto te posuit die... arbos,

agto qui statuit neo | te, triste lignum, te, caducum / in domini caput innerentis.

te sonantem plenius aureo. Alcaee.

te practer unvisas cupressos/ulla brevem dominum sequetur. . te greges centum Siculaeque circum $\mid$ mugiunt vaccae.

te bis Afro murice tinctae/vestiunt lanae: $n t^{\circ} \mathrm{d}$ is anicum est nec mihi te prius/obire. a, te mesc si partem animae rapit/maturior vis. te Jovis inpio|tutela Saturno refulgens/eripuit. te. vidit insons Cerberus aureo/cornu decorum hac te metenteth, Baccle pater. dis te minorem quod geris. imperas: et te saepe vocanti duram non te Jenclopen diffeilem procis|Tyrbenus genuit parens. o quamvis neque te nunera nec preces . curvat, nec te forian neque intra|claustra tenebo.

i pedes quo te rapiunt et aurae.

te Aagrantis atrox hora Caniculae nescit tangere, non, siquis l'holoen, sat is iet te, Chlori, decet: te lanae prope noblem/tonsae Luceriam. spisa te nitidum coma. puto te similem. Telephe, Vesperoltempestiva petit Rhode; non ille, . . te neglegit horridus:

post te neque iratos trenenti|regun apices

te liber e.t. producent lucernae,

te nilail ittinet/temptare multa caede bielentium teque nel lacvos vetet ire picus nec vaga cotnix. potes hac ab orno pendulum zona bene te secuta e- lidere collum. sive te rujes et acuta letolsaxa delectant.

age t. procellac $\mid$ crede veloci.

erife te" murie

aln. quo blandae jurenum te revocant preces.

Albancs pruje te lacus/ponet marmoream

nocturns ege somnis [ege te somniis] |ian captum teneo. ian volurem sequor te fer grasnina Martii|campi,

te fer autuas, dute. volubilis.

fteque. olum procedis. "Io trimphe" non senel dicemus.

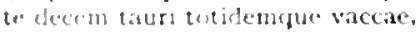

alters, te mencis adthibed deum

te multa prece, te prosequitur meto

non te factumbia, non te restituet pietas:

non ego to meis chartia imornattum sileri

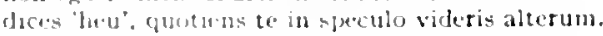

non ege to neis' inmuncm ineditor tinguere puculis.

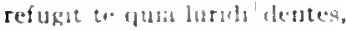

te quial rukse, turpant

te Cantaleer non inte domabilis . . miratur,

te profugus sigthes, matalur.

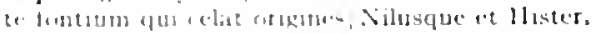

to rapidus Tigris. . . aturdit

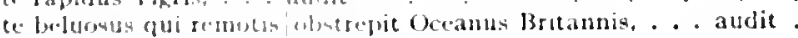

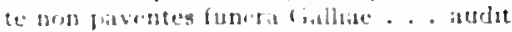

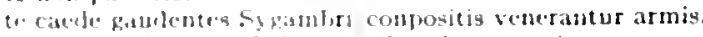

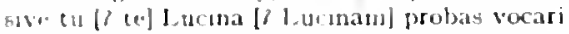

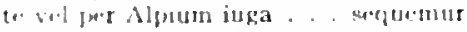

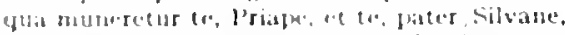

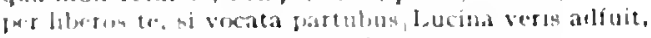

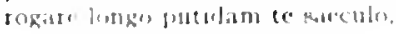

Carm.1.35.21

Carm.1.38.6

Carm.2.3.6

Carm.2.4.13

Carm.2.5.13

Carm.2.6.21

Corm.2.7.3

Carm.2.7.15

Carm.2.5.21

Carm.2.8.22

Corm.2.13.1

Corm.2.13.11

Carm.2.13.26

Carm.2.14.23

Carm.2.10.33

Carm.2.10.35

Carm.2.17.2

Carm.2.17.5

Carm.2.17.22

Carm.2.19.29

Carm.3.3.13

Carm.3.6.5

Carst.3.7.31

Carm.3.10.I I

Carm.3.10.13

Carm.3.11.43

Carm.3.11.49

Carm.3.13.9

Carm.3.15.8

Curm.3.15.13

Carm.3.19.25

Carm.3.19.20

(cirm.3.21.10

Carm.3.21.19

Carm.3.21.2I

Carm.3.23.13

Carm.3.27.15

Carm.3.27.59

Curm.3.27.61

Carm.3.27.02

Carm.3.29.5

Carm.4.1.8

Carmatiso

far.Carm.4.1.37

Carma.4.39

Carm.t 1.40

Carm.4.2.49

Carm.4 253

(arm..45.32

Carmat5.33

Carm.4.7.23

Carm.te.30

Cormetio.e

Curm.4.12.22

Carmiti3.10

Carmatiz.tI

Corm.4.14.4t

Cormat.1.42

carmot.t4.45

Corm.t4 40

Corm.4.1.47

cism. 14.49

Carm 1 1451

I vur ciarm.Saecis

I:pudel.ti

1. pood.2.2I

l: pend 5.5

IEpods.i 
quae te l lesbia quaerenti taurum monstravit inertem.

Epod.12.16

magis quem/diligeret mulier sua quam te. .

te manet Assaraci telius,

nec mater domum caerula te revehet. .

non feret adsiduas potiori te dare noctes

nec te Pythagorae fallant arcana renati

sed tardiora fata te votis manent:

ne te morer, audi.|quo rem deducam.

cum te neque fervidus aestus/demoveat lucro

quid invat inmensum te argenti pondus et auri

servos, / ne te conpilent fugientes.

aut alius casus lecto te adfixit.

ut te suscitet ac reddat gnatis carisque propinquis?

non uxor salrom te volt, non filius;

non uxor salvom te volt [te vult salvum], non filius;

avarum/cun veto te fieri.

quare, ne paeniteat te./desine sectari matronas,

si interricta petes, vallo circumdata (nam te/hoc facit insanum). . ad talos stola demissa et circumdata palla. [circumdata nam te]

'heus, tu'|quidam ait 'ignoras te.

denique te ipsum $\mid$ concute.

magnis parva mineris|falce recisurum simili te,

urgeris turba circum te stante

neque te quisquam stipator ineptum/praeter Crispinum sectabitur. velut tel Iudaei cogemus in hanc concedere turbam.

'equi te/esse feri similem dico.'

ita te quoque amicum.

casu quod te sortitus amicum:

nulla etenim mihi te fors obtulit;

cum Tiburte via praetorem quinque sequontur|te pieri,

"per magnos, Brute. deos te|oro, .

'o te. Bolane, cerebri|felicem'

'nil opus est te/circumagi:

'nil habeo quod agam et non sum piger: usque sequar te.' . .

'si bene me [te] novi, non Viscum pluris amicum,|non Varium facies:

'dubius sum, quid faciam', inquit, | tene relinquam an rem."

'certe nescio quid secreto velle loqui te/aiebas mecum.'

cum versus facias, te ipsum percontor,

ambitione relegata te dicere possum. | Pollio,

te. Messalla, tuo cum fratre,

simulque/ ros, Bibule et Servi, sinul his te, candide Furni, .

Demetri, teque. Tigelli, / discipularum inter iubeo plorare cathedras.

aut si tantus amor scribendi te rapit.

maiorum nequis amicus|frigore te feriat.'

sen te discus agit (pete cedentem aera disco) -

inparibus formis deceptum te petere esto:

ducit te species, video:

si te alio pravom detorseris.

te tibi iniquom let frustra mortis cupidum.

'di te, Damasippe, deaeque/ verum ob consilium donent tonsore. . et miror morbi purgatum te illius."

ne telfrustrere: insanis et tu stultique prope omnes,

pudor" inquit "te malus angit.

hoc te crede mado insanum.

nihilo ut sapientior ille qui te deridet caudam trahat.

Catienis mille ducentis| mater, te appello" clamantibus. .

insanum te omnes pueri clamentque puellae;

'deficient inopem venae te.

'postquam te talos, Aule, nuce que/ferre sinu laxo, donare et ludere vidi. vidi. te. Tiberi. numerare. cavis abscondere tristem.

gaudes, si cameram percusti forte, penes te es?

an, quodcumque facit Maecenas, te quoque verum est,

tanto dissimilem et tanto [tam te dissimilem quanto] certare ininorem? 'non, si te ruperis, inquit. ! 'par eris.' .

- 'teneas, Damasippe, tuis te' -

cum te sic tempore laevo/interpellarim;

si vespertinus subito te oppresserit hospes,

ten lapides varios lutulenta radere palma

quam te/contemptum cassa nuce pauperet; 
ne mantestun careitsis obsecuium nudet te.

Serm. 2.5.47 cave te Ioget; uttro Penelopam facilis potiori trade.

Sorm.2.5.75 cun te servitio longo curaque levarit.

dic. . . gaudenten numno te addicere.

si quod adest gratum iuvat (hac prece te oro):

te orabant hodic meminisses, Quinte reverti."

(nam te' scire, teos quoniam propius contingis, oportet).

o rus, unando ego te adspiciarn

tanden urhanus ad hune "quid te invat" inquit.

quorsum haec tim putida tendant.|furcifer?" 'all te, inquam."

siqus ard illa deus subito te agat, usque recuses.

ita te lehoem dicis

te coniund alina capit, neretriculis Ditron:

(11 [te] cum prodectiv insignibus, . . prodis ex iudice Dama.

quo te demisit peccati conscia erilis.

cum te formislet mulier neque credat amanti.

quinque talenta poscit to mulicr.

teque ipsun vilas fugitivos et crro.

ocus hine teini rapis.

ut Cisideni juvit te cena beati?

sive forkernum te magis adpositis delectat:

tene, ue egu acciviar laute, torquerier omni|sollicitudine districtum.

qua te|ter bute lecto poterunt recrate libello.

qui lortuna te responsare superbac / liberun et erectum praesens lostatur

omma te allersum spectanti.t, mulla retrorsum.

de te pendentis te respic ients anici?

cur jta credidesim. nist quid te detinet, atudi.

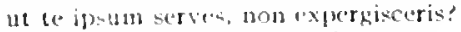

puer, nume te meliuribus offer.

quo ic adedestie sapientia duceret, ires.

quid nunc te dican facote an tegione Pedana?

cupremo te sole demi, Torghite, manem.

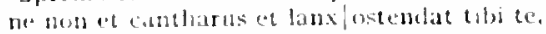

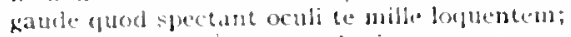

cum the dotum porticus agriplate, val te conspexerat Appi.

te, luleis antice, reviset cum Zephyris.

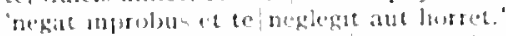

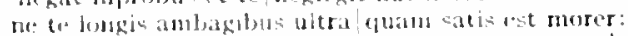

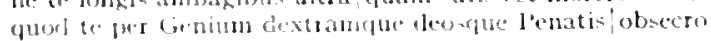

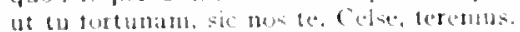

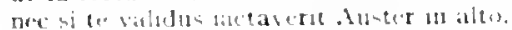

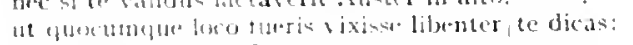

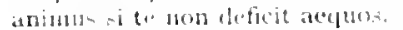

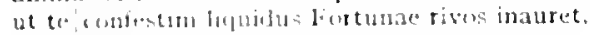

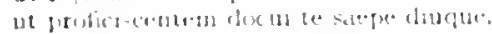

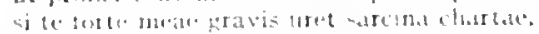

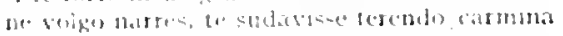

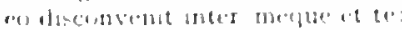

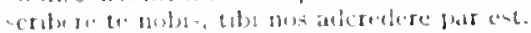

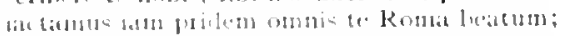

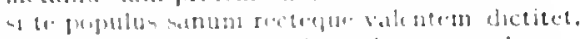

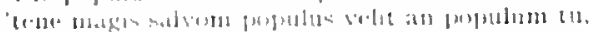

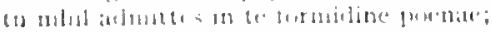

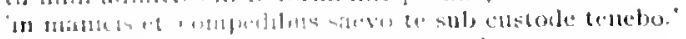

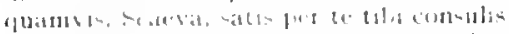

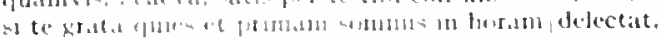

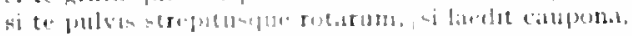

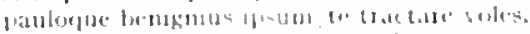

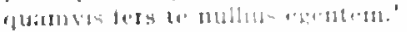

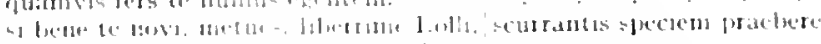

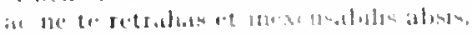

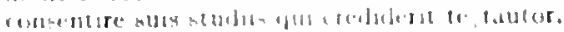

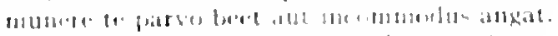

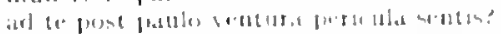

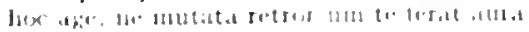

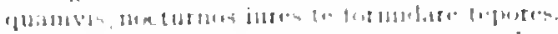

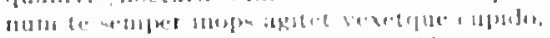

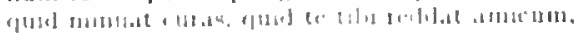

Serm.2.5.90

Serm.2.5.10)

Serm.2.0.13

Serm.2.0.3"

Serm.2.0.51

Srm.2.6.00

Serm.2.0.90

Serm.2.7.22

Sorm. 2.7.24

Sirm.2.7.31

Sirm.2.7.40

:ar.serm.2.7.53

Serm.2.7.00

Serm.2.7.45

Sorm.2.7.90

Sirm.2.7.1 3

Sorm.2.7.117

Sirm.2.8.I

Sirm.2.8.17

Serm.2.8.07

Epist.1.1.3"

lipist.1.tes

Epist.1.175

Epist.1.1.115

Epist.1.2.5

lipitt.1.2.3.3

Ispist. 2018

Fpist.1.3.27

lipetct.1.2

Lipist. 5.3

JPset.5.21

lepist.1.0.10

fepist 1.6.2"

lipist.1.7.12

repist a 7 e

Epist. 1.7.5:

Epist. 1.701

Epist.1.s.17

l.pist.1.11.1

lepist.1.11.25

fipist.1.11.31)

fist.1.12.s

L pist.1.13.1

L. prot.t.1.3.6

f. post.t.1.3. In

LPist.1.1.10

Jipist.1.15.25

l:pist.t. If is

Jepist.1.241.21

I.pist.1.10.27

Lisist.1.16.5.3

1.pist.1.10.75

Jipist.1.17.1

tepist.1.17.6

lipist.1.17.7

1.pist.1.17.12

lipse1.17.2:

LPest 1.18.1

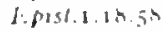

depist 1.tsits

Postel IR 75

d.pord.1.18.8.3

1.pish.1 I8.8K

I:pist.1.15.

Eposte1.18

Epost in 101 
fidis enin manare poetica mella/te solum, tibi pulcher.' quid volui?" dices, ubi quid te laeserit:

scislin breve te cogi. cum plenus languet amator.

carus eris Romae, donec te deserat aetas; .

hoc quoque te manet.

forte meum siquis te percontabitur aevom:

te nostris ducibus, te Grais anteferendo

des nummos, excepta nihil te si fuga laedat:

ne mea saevos|iugares ad te quod epistula nulla rediret.

¿i bone, quo virtus tua te vocat, i pede fausto.

si cupidum timidumque ninus te:

qui te pascit ager tuos est.

et vilicus Orbi, ... te dominum sentit.

quid te exempta iurat spinis de pluribus una? .

si propius stes. | te capiat magis.

quamvis et voce paterna/fingeris ad rectum et per te sapis,

numquam te fallent anini sub volpe latentes.

melius te posse negares|bis terque expertum frustra:

quin sine rivali teque et tua solus amares.

te.

neu sinas Medos equitare inultos/te duce, Caesar.
qui nunc te fruitur credulus aurea.

quam rem cumque ferox. . . miles te duce gesseric.

quin et Atridas duce te superbos . . . fefellit.

te minor laetum reget aequos orbem:

nil sine te mei|prosunt honores:

iudice te non sordidus auctor/naturae verique.

Venusinae plectantur silvae te sospite

neglegis inmeritis nocituram|postmodo te natis iraudem connittere?

fervidus tecum puer et solutis/Gratiae zonis properentque Nymphae et parum comis sine te Iuventas/Mercuriusque.

si quid vacui sub umbra|lusimus tecum,

tecum Philippos et celerem fugam / sensi

cum [te] populus frequens|laetum theatris ter crepuit sonun;

tecum vivere anem, tecum obean lubens.

Mercuri, nam te docilis magistro movit Amphion lapides canendo.

de te, splendide. Minos |fecerit arbitria,

semper ut te digna sequare

te copias, te consilium et tuos praebente divos.

quibus te vita sit superstite iucunda, .

otium !non dulce, ní tecun simul,

tecum milhi discordia est.

videsne. sacram metiente te viam

tecum sub alta - sic Iovi gratum - domo,

ubi haec severus te palam laudaveram,

plorem artis in te nil agentis exicus?"

nil obstet tibi, dum ne sit te ditior alter.

mutato nomine de te fabula narratur:

numquid ego a te magno prognatum deposco consule cunnum

privatusque magis vivam te rege beatus.

mentio siquae|de Capitolini furtis iniecta Petilli| te coram fuerit.

Maecenas. . nemo generosior est te

"est tibi nater. / cognati, quis te salvo est opus?"

'Maecenas quomodo tecum?'

neque te ut miretur turba labores.

non in caro nidore voluptas/summa, sed in te ipso est.

cur eget indignus quisquam te divite?

"cave faxis/te quicquam indignum.

hoc si erit in te solo,

hace a te non multum abludit imago.

nudus inopsque domun redean te vate,

abnuere et tabulas a te removere memento.

quae si semel uno de sene gustarit tecum partita lucellun.

non lioram tecum esse potes.

'heu, Fortuna, quis est crudelior in nos/te deus?

de te pendentis, te respicientis anjici?

sed vercor, ne cui de te plus quam tibi credas

Actia pugna te duce per pueros hostili more refertur:

et formidatam Parthis te principe Romant.

tecum sic agat hic et/candidus
Iipist.1.19.45

lipist.1.20.7

lepist. $1.20,8$

Epist. I.20.10

Epist.1.20.17

Epist.1.20.2\%

Epist.2.1.19

Epist.2.2.11

Epist.2.2.22

Lipist.2.2.37

Epist.2.2.15

IEpist.2.2.160

Lipist.2.2.162

Epist.2.2.212

Ars 1'oil.36z

Ars Poet.367

Ars Poet. 437

Ars Pot 130

Ars Poet.147

Carm.1.2.52

Corm.1.5.9

Curm.1.6.4

Curm.1.10.r,

Carm.1.12.57

Carm.1.26.9

Corm.1.28.14

Carm.1.28.2-

Carm.1.28.3

Carm.1.30.5

C'arm.r.30.7

Carm.r.32.2

Carm.2.7.9

Far.Carm.2.I7.25

Carm.3.9.24

Carm.3.1 I

Carmat.7.21

Carm.t. I I.2,

Corm.14.33

lepol.1.5

Epol.1.8

Epol.4.2

Epod.4.7

Epol.9.3

Epol.11.1y

Epod.17.8I

Sirm.1.1.40

Sirm.1.1.6y

Sirm.1.2.69

Serm.1.3.142

Serm.1.t.95

Sirm.1.0.2

Sirm.1.9.27

Serm, 1.9.43

Sirm.1.10.7.3

Serm.2.2.20

Sirm.2.2.103

Sirm.2.3.3n

Sirm.2.3.tI

Sirm.2.3.3?

Sirm.2.5.0

Serm.2.5.52

Sirm.2.5.82

Sirm.2.7.112

Sirm.2.8.02

Epist.1.1. Io5

Epist.1.Jo.10

Epist.1.18.62

Epist.2.1.25'

Epist.2.2.3 
i nunc et versus tecum meditare casoros.

viveret in serris te siquis avarior uno.

Teanum. cras ferramenta Teanum/tolletis. fabri.

Tecmessae. movic Aiacum . . forma captivae dominum Tecmessae.

tecta. curas laqueatit circum/tecta volantis.

tectaqu" l'enthej disiecta non leni ruina

avitac ecea velint reparare Troiat.

quo nemus inter pulcra saburn tecta remugiat.

iamclue subando tenca cubilia cectaque rumpit.

nosm simul ac renas intlat tactra // tecta] libido.

tecti. tutus caret obsoleti|sorlubus tecti.

tecta. hortus ubi etecto vicinus iugis aquae fons.

tecto. hic se praceiplem tecto dedit.

leos ul tristis ex alco cacli femittere tecto.

si vacuon sepido cepisset villula tecto.

licet sub papere tecto reges et regum vita praecurrere amicos.

tectum. nce tores inpiae tectun dominae relinquont.

proxima Campano ponti quae villula. tectum|praebuit.

sumamusu properabat lanbere tectum.

navos man. formm et vespertigus pete tectum.

tectum. quis Nartem tunica tectum adamantina/digne scripserit

tectus. me veluti custodiet ensis/vagina tectus:

tegam. 'uthe tegam spurco Damac latus?

tegat. nisi illis quarum subsuta talos tegat instita veste.

ithe tegat conmisa deosque precetur et oret.

Tegellus. -arilus habebat ille Tigelliu ( Tegellus) hoc:

tegentis. nil cernere possis/cetera. ni Catia est, demissa veste tegentis.

teges. conmussumque teges et vino tortus et ira.

Tegilli. hoc genus omne| macstum et sollicitum est cantoris morte Tigelli [Tegulli].

tegit. sunt qui nolint [nolunt] tetigisse nisi illas|quarum subsuta talos tegat [regit] instita veste.

Tegmessae. movit Aiacem Telamone natum | forma captivae dominum Tecnessic [Tegmessae].

Teia. "t fide Teia dices laborantis in uno/Penelopen vitreamque Circen; .

Teium. inacreonta Teium,

tela. primusve Teucer tela Cydonio/derexit arcu; .

in (u)(in) tela acusa torserat.

Telamone. movit Aiacem Telamone natum/forna captivae

telas. tibi telas opetosaeque $\mathrm{M}$ inervae studium aufert. .

Telegoni. Telegoni juga parricidae.

Telerachus. hand male Telemachus, proles patientis Vhixei:

Telephe. Juro te similem. Telephe, Vespero

Telephe. tum tua sne isfortunia laedent, Telephe vel Peleu;

Telephi. cum tu, Lydia. Telephi|cervicem roseam.

crea Irephil laudas bracchia.

Telephum. Telephum. . . . non tuae sortis iuvenem

Telephus. movit nepotem Telephus Nereium, tragicun plerumque, dolet sermone pedestri| Telephus et Peleus.

tellure. ambiguan tellure nova Salamina futuram.

inulta cescerat inpotens, tellure

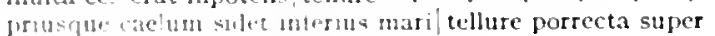

sis pecon et multa dives tellure licebit

tellure marique magnus erat,

militibur promicat Isupuetra / practia Cacsar an est ltala tellure daturus:

Tellurem. Tollurem porco. Sibunum lacte piabant.

Telluris. Jomitosque llerculea nanu|lelluris iuvenes. . . . telluris. nam proprial tellusic crum natura neque illum/nec me nec rimegnquam statult:

tel]us. noc [uba" tellus generat. leonntan atida nutrix.

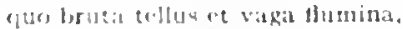

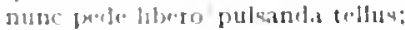

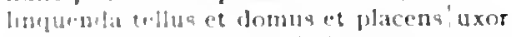

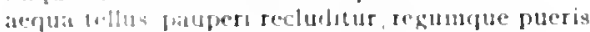

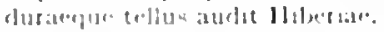

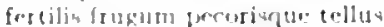

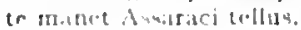

reldit ubi crerens coltus marata puotannis
Epist.2.2.76

Epist.2.2.157

Epist.1.1.86

Carm.2.4.6

Carm.2.10.12

Carm.2.19.14

Carm.3.3.60

Carm.3.10.8

Epod.12.1 2

P :ar.Serm.1.2.33

Carm.2.10.7

Serm.2.0.2

Serm.1.2.4 I

Serm.1.5.103

Serm.2.3.10

Epist.1.10.32

Carm.2.8.19

Serm.1.5.45

Serm.1.5.74

Epist.1.6.20

Carm.1.0.13

Serm 2.1 .41

Serm.2.5.I 8

Serm.1.2.29

Ars Poet.200

far. Sirm. I.3.4

Serm.1.2.95

Epist.1.18.38

tar.Serm.1.2.3

iar.Serm.1.2.29

var.Corm.2.4.6

Carm.1.17.18

Epod.14.10

Carm.t.9.I 7

Epod.17.10

Carm.2.4.5

Carm.3.12.4

Carm.3.29.8

Lipist.1.7.40

Carm.3.19.26

Ars l'oet.104

Carm.1.13.I

Carm.1.13.2

Carm.t.II.2I

Epod.17.s

. Irs Pocl. 96

Carm.7.7.29

Carm.2.1.27

Eprod.5.80

Enod.1 5.19

Sarm.2.5.03

Sorm.2.6.50

Jpist. 2.1 .143

Carm.2.12.7

Serm 2.2.120

Corm.1.22.15

Carm.1.34.9

Carm.1.37.2

Carm.2.1.21

Carm.2.18.32

Carm.4 1450

Carm.Sinecing

L.pod.13.13

Epost 10.43 
hos utinam inter heroas natum tellus me prima tulisset.

telo. condito mitis placidusque telo

telum. Iuppiter, ut pereat positum robigine telum

temere. unde vocalem temere insecutae/Orphea silvae.

cur non sub alta vel platano vel hac pinu iacentes sic temere

quam temere in nosmet legem sancimus iniquam.

'non ego' narrantem 'temere edi luce profesta

nec sibi cenarum quivis temere arroget artem.

vatis avarus $\mid$ non temere est animus;

non temere a me/quivis ferret idem.

iram colligit ac ponit temere et mutatur in horas.

temeti. das numnos, accipis uvam. | pullos, ova. cadum temeti:

temnens. illum| praeteritum temnens extremos inter euntem:-

temnit. ieiunus raro stomachus volgaria temnit.

Tempe. laudabunt alii ... Thessala Tempe;

vos Tempe totidem tollite laudibus

fastidit ... non Zephyris agitata Tempe.

temperant. mea nec Falernae / temperant vites neque Formiani | pocula colles.

iam veris comites, quae mare temperant.

temperante. utrumque rege temperante caelitum

temperare. possim crematos excitare mortuos | desiderique temperare pocula.

temperas. o testudinis aureae dulcem quae strepitum, Pieri, temperas,

temperat. Gallica nec lupatis|temperet [temperat] ora frenis?

qui mare ac terras varisque mundum $\mid$ temperat horis?

qui terram inertem. qui mare temperat|ventosum

matre carentibus|privignis mulier temperat innocens

adhuc sublimia cures: quae mare conpescant causae, quid temperet [temperat] annum.

temperat Archilochi musam pede mascula Sappho, .

temperat Alcaeus, sed rebus et ordine dispar.

scit Genius, natale comes qui temperat astrum,

temperatam. non secus in bonis/ab insolenti temperatam / laetitia. vim temperatam di quoque provehunt in maius;

temperato. inimice lamnae|Crispe Sallusti. nisi temperato|splendeat usu.

temperet. Gallica nec lupatis|temperet ora frenis?

animus ... amara lentol temperet risu:

quis aquam temperet ignibus.

libertusve senem delirum temperet.

quae mare conpescant causae, quid temperet annum,

temperiem. temperiem laudes.

tempestas. demissa tempestas ab Euro horrida tempestas caelum contraxit postera tempestas melior. via peior quo me cumque rapit tempestas, deferor lisopes. pernicies et tempestas barathrumque macelli.

Tempestatibus. immolabitur caper|et agna Tempestatibus

tempestatibus. rerum|fluctibus in medis et tempestatibus Vrbis

tempestatis. haec siquis tempestatis prope ritu|mobilia

tempestiva. tandem desine matrem/tempestiva sequi viro. puro te similem. Telephe, Vesperoltempestiva petit Rhode;

tempestivius. tempestivius in domum Pauli .. . comissabere Maximi,

tempestivom. et tempestivom pueris concedere ludum .

templa. quare/templa ruont antiqua deum?

templa. ire deiectum monumenta regis|templaque Vestae, deorum / templa novo decorare saxo.

donec templa refeceris

post ingentia facta deorum in templa recepti.

templis. disitum mensis et amica templis.

templis. sub duce, qui templis Parthorum signa refigit.

tempora. nec dabunt, quamvis redeant in aurum|tempora priscum. adduxere sitim tempora, Vergili: .

tempora quae spem/consiliumque morantur

dura sed emovere loco me tempora grato.

tempora. uda Lyaeo'tempora populea fertur vinxisse corona

clipeo Troiana refixo/tempora testatus

deum|cingentem viridi tempora pampino. .

nec vincire novis tempora thoribus.
S.rm.2.2.93

Carm.Saec.33

Serm.2.1.43

Carm.1.12.7

Carm.2.II.I 4

Serm.1.3.67

Sirm.2.2.156

Serm.2.4.35

Epist.2.1.120

Epist.2.2.13

Ars Poet. I00

Epist.2.2.163

Serm.I.I.IIo

Serm.2.2.38

Carm.1.7.4

Carm.I.2I.9

Carm.3.1.24

Carm.I.20.II

Carm.4.I2. I

Epod. 10.50

Epod.17.80

Carm.4.3.18

zar.Carm.1.8.7

Carm.1.12.16

Carm.3.4.45

Carm.3.24.18

z'ar.Epist.I.I2. I6

Epist.1.19.28

Epist. I. 19.29

Epist.2.2.187

Cirm.2.3.3

Carm.3.4.66

Carm.2.2.3

Carm.1.8.7

Carm.2.10.27

Carm.3.19.6

Serm.2.5.7 I

Epist.I.I2.16

Epist.1.16.8

Carm.3-I7.II

Epod.13.1

Sirm.1.5.96

Epist.I.1.15

Epist.I.15.3. I

Epol.10.24

Epist.2.2.85

Serm.2.3.268

Carm.1.23.1 2

Carm.3.19.27

Carm.1.1.9

Epist.2.2.1 42

Serm.2.2.104

Carm.1.2.10

Carm.2.15.20

Carm.3.0.2

Epist.2.1.6

Carm.3.11.6

Epist.1.18.56

Carm.4.2.40

Carm.q.I2.I 3

Epist.1.1.23

Epist.2.2.46

Carm.1.7.23

Carm.1.28.12

Carm.3.25.20

Carm.4.1.32 


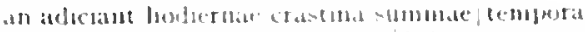

Carm.4.7.18

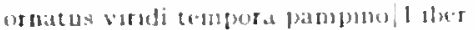

referunt jam tuld . . nec cari latpides temporat.

Carm.4.8.33

rempora si hastespue velis evolvete mundi.

"rlplas sifampora rerti modospue.

tugho canjum lusmaque trigonem [fugio rabiasi tempora signi].

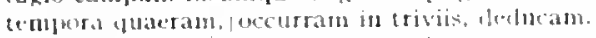

Jecedentat certis tempura monemtis. . spectant:

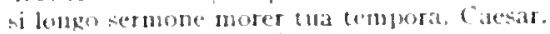

orientia tempors notis anserull camplis, inepent solatur at acgrum.

captase pow empora Troist"

tempore. soll maestus ommi compor varts

abate quale precamur jempore sáters.

adete comentens tempors vitat

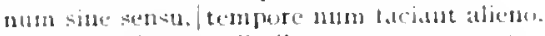

lune mul, capuare clitellas tempore poument.

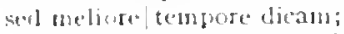

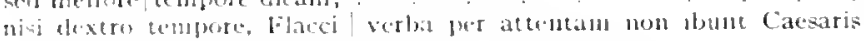
at158.111.

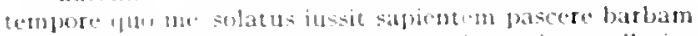

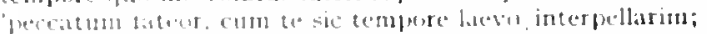

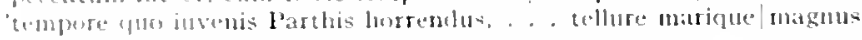
erit.

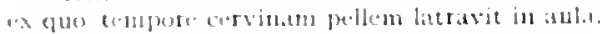

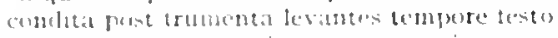

"xigues kn:

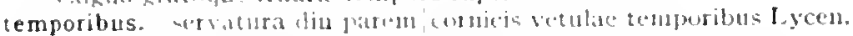

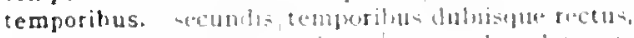

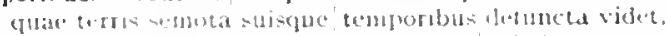

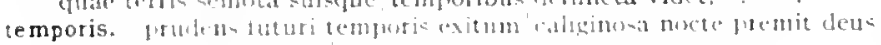

bataters exanjoris acti, se puern.

qua butger bilems sub serni tamposin horam.

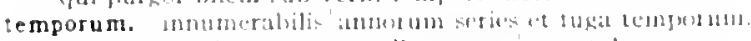

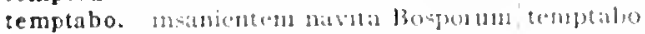

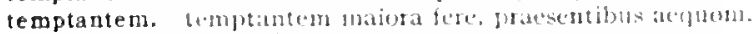

temptantur. negatic, quod latus at remes mosbo tomptentur [temptantur] atcuto.

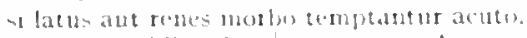

temptare. te mhil attinct temptare multa cobede bidnontium

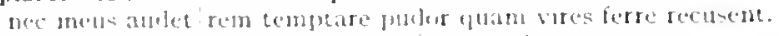

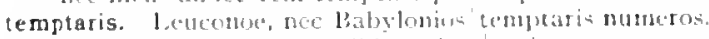

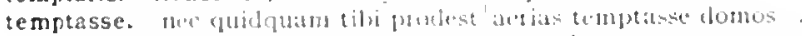

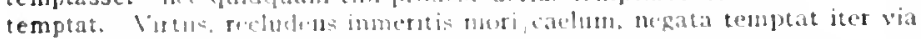
termuent millie viter motlis.

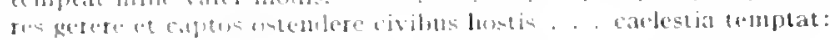

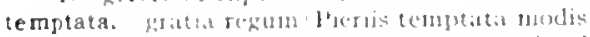

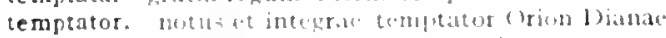

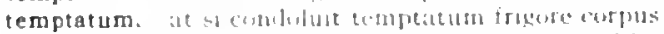

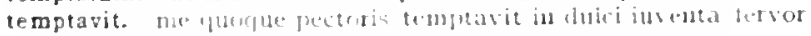

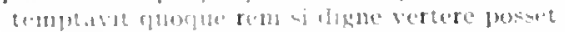

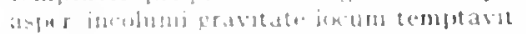

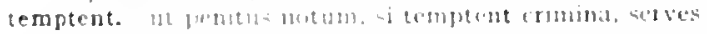

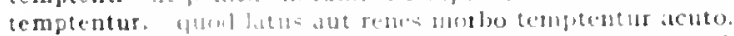

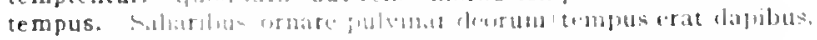

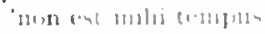

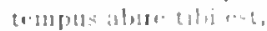

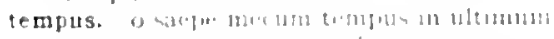

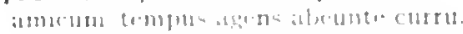

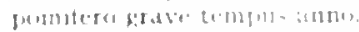

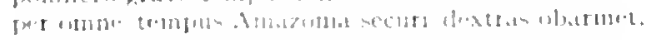

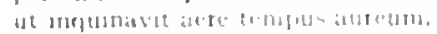

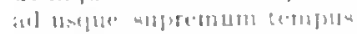

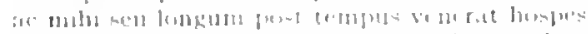

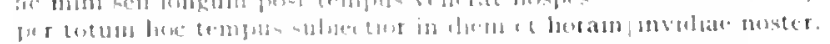

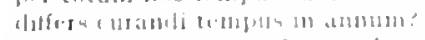

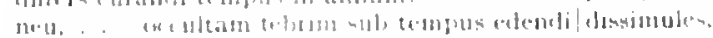

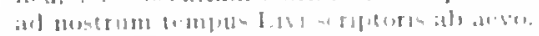

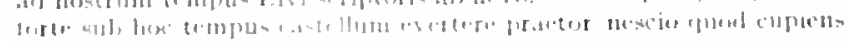

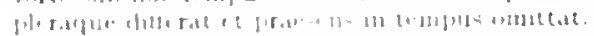

Carm.4.13.14

Serm.1.3.112

Serm.1.4.58

far. Sorm.1.0.1 20

Serm.1.0.58

Eisist.1.0.4

Epist.2.1.4

Lipist.2.1.130

Ars Pod.1.11

Corm.2.3.5

Carm.Saec.

Serm.1.1.118

Serm.1.4.78

Sorm.1.5.47

Sirm. 1.9.er

Serm.2.1.18

Sirm.2.3.3.1

Serm.2.4.4

Serm.2.5.1)

Epist.1.2.06,

Epist.2.1.190

Epist.2.2.19\$

Carmot.13.25

Carm.4.9.30

Epist.2.1.22

Carm.3.29.20

- Irs livel.173

- Irs Pod 302

(arm.3.30.5

ciom.3.1 31

Epist.1724

iar.Sermi.2.3.143

EFist.1.0.28

Curm.3.23.14

I.pist.2.1.259

curm.1.11.3

Cirm.1.28.5

Cinrm.3.2.22

Carm.3.7.12

Lpist.1.17.3.1

Ars liveligus

corm.3.t it

Serm. I. I.tio

(armt.1.10.23

Epist.2.1.Iet

- Irs lent 22

lipist. I 18 sin

Sorm.2.3.11.3

Curm.1.37.4

Sirm.2.4.1

Lpist 2.2.215

Carm.2.7.1

Carm.3.(1.4t)

Corm.3.2.3

Carm.ti 20

lopell ichad

sirm.1.1 ys

Serm.2.2118

Sirm.2.6.4?

1.) $1101,2,31)$

Eprst.1.10.22

1:pist.2.1.6.2

Ispist. 2. 2.3.1

tre lint 1 
tenacem. iustum et tenacem propositi virum tenaci. modo in tenaci gramine:

tendant. 'non dices hodie, quorsum haec tam putida tendant, tendebat, ire foras pleno tendebat corpore frustra.

tendens. tendens Venafranos in agros

tendentes. fratresque tendentes opaco/Pelion inposuisse Olympo.

tendere. nec Polyhymnia|Lesboum refugit tendere barbiton.

doctus sagittas tendere Sericas/arcu paterno?

ultra|legein tenclere opus;

inpune licebit aestivam sermone benigno tendere noctem.

tendimus. tendimus hine recta Beneventum,

tendis. cum tu . . . nutare loricis Hiberis, | pollicitus meliora, tendis? quid ultra tendis?

quo. Musa, tendis?

'unde venis' et "quo tendis?' rogat et respondet.

'quo tendis? non mihi Cumas|est iter aut Baias'

tendit. suseitat Musam neque semper arcum!tendit Apollo.

tendit. Antoni. quotiens in altos/nubium tractus:

aut amite levi rara tendit retia

'unde venis' et "quo tendis?" [tendit] rogat et respondet.

iratusque Philippi tendit ad aedis.

purior in vieis aqua tendit rumpere plumbun.

dum studet urbanus tenditque disertus haberi.

tendunt. tendunt cxtorquere poemata: quid faciam vis?

tene. saeva tene cum Berecyntio/cormu tympana.

teneam. quo teneam voltus mutanten Protea nodo?

teneant. singula quaeque locum teneant sortita decenter.

ut cito dicta' percipiant animi dociles teneantque fideles;

teneas. 'teneas, I )anasippe, tuis te' -

teneatis. spectatum admissi rismm teneatis, andici?

tenebat. iamque tenebat/nox medium caeli spatium.

tenebit. seu densa tencbit|Tiburis umbra tui.

tenebo. nee te ferian neque intra claustra tenebo.

iandudum vides; sed nil agis: usque tenebo;

"in manicia et/compedibus saevo te sub custode tenebo."

tenebris. pulcher fugatis ille dies Latio tenebris.

internis neque enim tenebris Diana pudicum|liberat Fippolytum

tenent, seu te fulgentia signis castra tenent

quicumque... arrom/pingue tenent humilis Forenti,

tenente. nee nori per vim metman tenente/Caesare terras.

Bruto pratore tenentelditum Asians.

tenentur. quo res sponiore et quo cansae tuste twentur."

teneo. ego somnis ian captum teneo.

teneor. mediocribus et quis/ignoscas vitis teneor;

'tam teneor dono, quam si dimitar onustus"

tener. si tener plenu cadit haedus anno

me tener solvet vitulus,

senera. fingit equom tenera docilem cervice magister

tenerae. venator tomerae coniugis inmemor.

teneraeque sucus defluat praedae.

tenerae. tenerae nimis|mentes asperioribu|formandae studis.

tenerae. Dianam tenerae dicite virgines.

teneram. hoc tentram facict.

tenerem. quo pacto cuncta tenerem.

teneret. scura ragus, non qui certum pratejeje tencret.

aut quid haberet, quod legeret tereretque [teneretque] viritin publicus usus?

teneri. esto aliis alins rebus studisque teneri:

iuvat inmemorata ferentem |ingenuis oculişue legi manibusque tencri.

teneris. aut nininm teneris iuvenentur versibus umquam

teneris. numen cun teneris virginibus twom|laudantes

tenero. incestos amoreslde tenero meditatur ungui.

tenero. in tenero gramine pinguium|custodes ovium

teneros. qui tencros caulis alieni fregerit lorti

sic teneros animos aliena opprobria saepe absterrent vitiis.

tenerum. nee magis huic. . . Cerinthe, tuo tenerum est fenur aut crus| rectius;

tenerum. quo simul mearis. . nee tenerum lycidan mirabere,

tenerum. os tenerum pueri halbumulue pocta figurat.
Carm.3.3.1

Lipod.2.24

Sirm.2.7.2 r

Epist.1.7.31

Carm.3.5.55

Carm.3.4.51

Carm.1.1.3.1

Carm.1.29.9

Serm.2.1.2

Epist.1.5.I I

Serm.1.5.7I

Corm.1.29.I'

Carm.2.18.32

Carm.3.3.70

Sirm. r.9.63

Epist.1.I5.II

Carm.2.10.20

Carm.4.2.26

Epod.2.33

iar.Serm.1.9.63

Epist. 1.7 .89

Epist.1.10.20

Epist.1.19.16

Epist.2.2.57

Corm.1.18.13

Epist.1.1.90

.1rs Poil.92

Ars Poct. 335

Sirm.2.3.324

Ars Poct.5

Serm.2.6.100

Curm.1.7.20

Curm.3.11.44

Sirm. I.g. 5

Epist.1.16.77

Carm.4.4.40

Carm.4.7.25

Corm.1.7.20

Carm.3.4.10

Carm-3.14.15

Sim.1.7.18

Epist.1.16.43

Carm.4.1.38

Sirm.1.4.I3I

Epist.1.7.IS

Carm.3.I8 5

Carm.4.2.54

Epist.1.2.64

Carm.1.1.20

Carm.3.27.54

Carm.3.24.52

Carm.I.2I.I

Serm.2.4.20

Sorm.2.4.8

Epist. I.15.28

z'ar. Epist.2.1.92

Epist.I.I.8I

Epist.I.I9.34

Ars Poet. $24^{\circ}$

Corm.4.1.26

Corm.3.6.24

Carm.4.12.9

Sirm.1.3.110

Serm.1.4.128

Serm.1.2.81

Carm.1.4.19

Epist.2.1.12\% 
tenes. o quae beatan diva tenes Cyprum

tenet. quos inrupta tenet copula

qui l yciac tenet/dumeta natalemque silvam fulgentisque enet Cucladis

si priores Maennius tenet sedes Honerus.

tenesque grata compede vincsum.

quatque Avontinum tence Algidumque.

anor l.ycisci me tenet;

sillen tenue hoe nos.'

hate populos, hac magnos formula reges. | excepto sapiente. tenet.

quern: conet argenti sitis injortuna famesque,

quen vero arripuit, tenet oceiditque legendo.

teneto. manum stomachumque teneto,

teasa. teqque, dum procedis. [tensa dum procedic, "io triumphe non semel dicemus.

tenta. iangue subando! tunta cubilia tectaque rumpit. refertque tenta grex amicus ubera

neque est / have tenta spiritu praecordia.

teatigine. malis tentigine rumpi?

tentus. pingui tentus omaso| Furius.

teauabitur. nocturna siquid crasci est tenuabitur aura .

tenuare. desine pervicax . . magna modis tenuare parvis.

tenuatum. seu recreare volet tenuatum corpus

tenuem. spiritum Graias qenuen Camenae

quamvis. Scaeva, satis per te tibi consulis et scis. / quo tandem [tenuem] pacto deceat maioribus uti,

tenuere. Jliaeque litua Etrusenm tenuere turmae. .

tenues. nos. Igrippa. neque haec dicre . . conamur, tenues grandia.

tenues. quem tenues decuere togae nitidique capilli.

tenui. sordidus a tenui victu distabat

utpote res tenuis, tenui sermone peractas."

praeconem. tenui censu, sine crimine, notum

tenui. insignem tenui fronte Lycorida

cui patcrmam/splendet in mensa tenui salinum

non usitata nec tenui ferar penna

non prius exacta tenui ratione saporum.

me libertino natum patre et in tenui re . . loqueris,

tenui. me silva cavosque tutus ab insidis tenui solabitur ervo." non adparere labores nostros et tenui deducta poemata filo;

tenuis. victus tenuis quae quantaque secum|adferat. in verbis ctiam tenuis cautusque serendis.

tenuis. utpote res tenuis, tenui sermone peractas." forte jer angustam tenuis volpecula rimam/repserat

libia. . tenuis simplexque foramine pauco

tenuisse. princeps annantem Naricae litoribus tenuisse Lirim.

tenuit. nutr tu f)ae temuit dives Achaemenes

tenus. nec poti. vefulan. faece tenus cadi.

est quadam prodire tenus, si non datur ultra.

tepeant. est ubi plus tepeant hiemes.

tepebunt. guo calct irventus' nune omnis et mox virgines tepebunt. tepefecit. ante... guan' in matris iugulo ferrum tepefecit acutum? tepet. surgente a sole ad eum, quo/vespertina tepet regio.

tepidas. ver ubi longurn tepidasque praebet|I uppiter brumas

tepido. si vacurn tepido cepisset viliula tecto.

tepidum. seme anq piscis tepidumqur ligurrierit ius.

tepidus. cum tibt sol tepidue pluris admoverit auris.

tepores. quamvis nocturnosiures te formidare tepores.

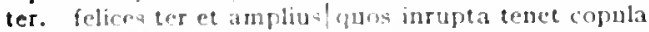

licelit iniecto ter pulvere curras.

quife ter "quacr anno revisens aequor Atlanticum/inpune.

at non trat arofufunctua. . . senex

trer anplum' Creryonen Ticyongue

cum pojulu frequens/lactum theatris ter crepuit sonum:

ter si requrgat nurua acneus.

ter perrat meis, "xcisna Argivis.

tur uxor/capta varum puerosgue ploret.

gatudet inviuan pepuliuse fossor|ter pede terram.

terurs ter cyouthos atconituy petet/vatea;

ter vocata aulis arlimiague leto. / diva triformin.
Carm.3.26.9

Carm.1.13.18

Carm.3.4.02

Carm.3.28.14

Corm.9. 5

Carm.411.23

Carm.Saciog

Epod.11.24

Sirm.1.6.44

Sorm.2.3.40

Epist.1.18.23

Ars Poet 475

Sorm.2.7.44

cons.Carm.4.2.49

Epod 12.12

Epod.10.50

Epod. 17.26

Serm.1.2.1'8

Serm.2.5.40

Serm.2.4.52

Carm.3.3.72

Scrm.2.2.84

Carm.2.10.38

coni. Epist.1.17.2

Carm.Sace.38

Carm.1.6.9

Epist.1.1.4.32

Sirm.2.2.53

Serm.2.4.9

Epist.1.7.56

Carm.1.33.5

Carm.2.10.1

Carm.20.1

Serm 2.430

LEpist.1.20.20

Sorm.26.117

Fipist.2.1.225

Serm.2.2.70

Ars loet.to

Serm.2.4.9

Epist.1.7.29

Ars loot.203

Carm-3.1.8

Carm.2.12.21

Carm-3.15.10

E.pist 1.1.32

Epist.1.10.15

Carm.1.4.20

Sirm.2.3.136

Serm.1.4.30

Carm.20.1\%

Serm.2.3.10

Sorm.1.3.8I

Fist.1.20.19

Epist. 18.93

Carm.1.13.17

Carm.1.28.3n

Carm.t.31.13

Corm.2.9.13

Corm.2.14.7

Carm.2.17.20

Corm.3.3.0.5

Carm.3.3.00

Carm.3.307

Corm.3.18.10

Carm.3.19.14

Carm 3.22.3 
in morem Salium ter quatient humum.
tteque, dum procedis, [terque, dum procedit] 'io triumphe'| non semel

Corm.4.1.28 dicemus,

ter die claro totiensque grata nocte frequentis.

sacram metiente te riam [cum bis trium [ter] ulnarum toga, .

longo die bis terque mutatae dapis

Inachiam ter nocte potes, mili semper ad unum/mollis opus.

Pollio regum | facta canit pede ter percusso;

ter uncti| transnanto Tiberim.

quem ter vindicta quaterque/inposita

ter pure lecto poterunt recreare libello.

quem bis terve bonum cum risu miror:

melius te posse negares $\mid$ bis terque expertum frustra:

delere iubebat |et male tornatos [ter natos] incudi reddere versus.

tercentum. mille cadis, nihil est, tercentum milibus,
Terenti. ut pater ille, Terenti|fabula quem miserum gnato vixisse fugato| inducit.

Terentino. 'lana Tarentino [Terentino] violas imitata veneno.'

Terentius. vincere Caecilius gravitate, Terentius arte.

tereret. quod legeret tereretque viritim publicus usus?

teres. et in se ipso totus, teres atque rotundus,

Teresia. "hoc quoque. Teresia, praeter narrata petenti|responde. teretes. seu rupit teretes Marsus aper plagas.

bracchia et voltum teretesque suras/integer laudo:

teretis. alius ardor aut puellae candidae $\mid$ aut teret is pueri

tergeminis. certat tergeminis tollere honoribus.

tergere. hoc potius quam gallina tergere palatum.

tergo. nec parcit inbellis iuventae | poplitibus timidove tergo.

tergo. retorta tergo bracchia libero

respicere ignoto discet pendentia tergo.'

tergo plector enim.

terit. et Appiam mannis terit

teritur, altera iam teritur bellis civilibus aetas,

termes. germinat et numquam fallentis termes olivae

Terminalibus. vel agna festis caesa Terminalibus

terminos. usque proximos|revellis agri terminos

terminum. ultra|terminum curis vagor expeditis,

terminus. quicumque mundo terminus obstitit,

stabilisque rerum|terminus servet.

terna. inmane est vitium dare milia terna macello

ternos. ternos ter cyathos attonitus petet/vates;

Terra. iniecta monstris Terra dolet suis

terra. sic melius situm, |cum tetra celat.

mutat terra vices et decrescentia ripas|flumina praetereunt;

meaeque terra cedet insolentiae.

animae qualis neque candidiores| terra tulit

terra. in terra domibus negata:

neque in terris [terra] morabor|longius

iam mari terraque manus potentis|M edus Albanasque timet securis, quod aut avarus ut Chremes terra premam.

terra marique victus hostis

furtim defossa timidum deponere terra?

quidquid sub terra est, in apricum proferet aetas,

Neptunum procul ex terra spectare furentem.' .

siquis bella tibi terra pugnata marique/dicat

receptus|terra Neptunus classis Aquilonibus arcet. .

terra. o mare et terra, ardeo.

terrae. te maris et terrae numeroque carent is harenae/mensotem cohibent, quicumque terrae munere vescimur

dominusque terraelfastidiosus:

quid censes munera terrae.

terrae. nec meretrix tibicina cuius|ad strepitum salias terrae gravis; .

terrae. flore, tertae quen ferunt solutae. .

terram. iunctaeque Nymphis Gratiae decentes/alterno terram quatiunt

qui mare ac terras [aut terram] varisque mundum/temperat hotis? qui terram inertem, qui mare temperat|ventosum

gaudet invisam pepulisse fossor|ter pede terram.

ut inmerentis fluxit in terram Remi|sacer nepotibus cruor.

coni.Carm.4.2.49

Carm.Saec. 23

var.Epod.4.8

Epod.5.33

Epod.12.15

Sirm.1.10.43

Serm.2.1.7

Serm.2.7.76

Epist.r.1.37

Ars Poct. 358

Ars Poct. 440

coni.Ars Poet.44 I

Serm.2.3.116

Serm.1.2.20

var.Epist.2.1.207

Epist.2.1.59

Epist.2.1.92

Serm.2.7.86

Sirm.2.5.I

Carm.1.1.28

Carm.2.4.2I

Epod.1 I.28

Carm.1.1.8

Serm.2.2.24

Carm.3.2.16

Carm.3.5.22

Serm.2.3.299

Serm.2.7.105

Epod.4.14

Epod. I0.I

Epod.16.45

Epod.2.59

Carm.2.18.24

Carm.1.22.11

Carm.3.3.53

Carm.Sace. 7

Serm.2.4.70

Carm.3.19.14

Carm.3.4.73

Carm.3.3.50

Carm.t.7.3

Epod.17.75

Serm.1.5.42

Carm.1.22.22

zar.Carm.2.20.3

Carm.Saec.53

Epod. I.33

Epod.9.27

Sirm.1.1.42

Inpist.1.0.24

Epist.r.1 I.10

Epist.r.16.25

Ars Poet.6.4

Epod.1\%30

Carm.1.28.I

Carm.2.14.10

Carm.3.1.36

List.1.0.5

Epist.1.1.\$.26

Carm.1.4.10

Carm.1.4.7

zar.Carm.1.12.15

Carm.3.4.45

Curm.3.18.16

Epod.7.19 
llle gravem thro terran qui sertit aratro.

Serm.1.1.28

calpere berram| unguibus . . coeperume;

saliet. turdet pede terram.

tetrarum. tertatum dominos cechit ad deos/hunc.

el cuncta certarum subicu

ille cerrarmm nibi praeter onnis angulus ridet.

quibus tersarum milited oris/Claudus

quam rea conponere geatas/terratumque situs

terras. nequicuam deus abscidic/ prueterns oceano dissociabilil terras.

qui nure ac terras varisque mundum/tenperat horis?

(juld terras alio calentis| sole mutamus?

nec nur pet vin metuan tenentc: Caesare teras.

tegit terrase humamun gemtls.

sive aquilo radic terras.

un freta vicinas inter currentia turris [terras]

dunz tertationinumque colunt genus.

terreat. quil Tirilaten terfeat, unice|securus.

ue quo quisqu" valet suspeccos terreat

terrent. quem neque pauperies neque mors neque vincula torrent. iquia me vestigia tertent.

tertenum. catmentis licet occupes'tertenum omne tuis et mare publicum: Pigasus terrenum equitum gravatua|Bellerophontem.

tertere. aufer me voltu hertere:

terres. an freta vicinas inter currentia turris [terres]

terresiria. terrestria quando mortalis animas vivont sortita

terret. Imurum minaci/voce dum erret, virluos pharetra|risit Apollo.

iam tulgor armorum fugacisiterred equos equitumque volth:

:"rret ambustus Photethon avarastspes

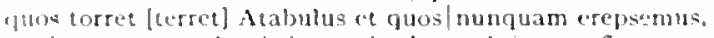

he infortumas voluctic in vertice harundo terret fixa

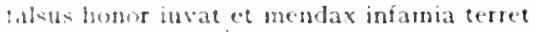

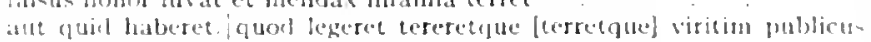

11:11:?

solepe cotam audacem fugat hoc terretgue poetam.

terris. ian satts tertis nivic atque dirae grandinis mieit pater nova febrium terfis incubuit cohor:

fuo molil maius meliusbe tertis fata demavere

i.tun nox inducere terris, umbras

on frela vicints inter currentia turris [tertis]

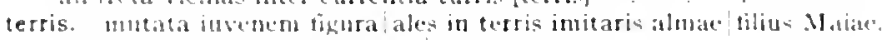

nullus argento colot ent inaris atbolito tertis.

me'pue in ("rris morabor longlus

atum frotepserunt primis animalia terris.

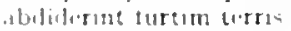

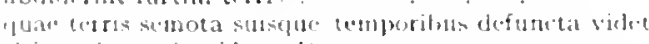

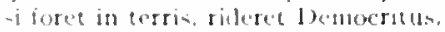

viseret in turris te siquis avarior uno.

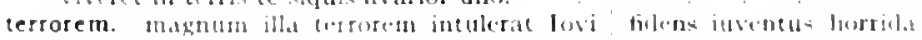
biscorlinis

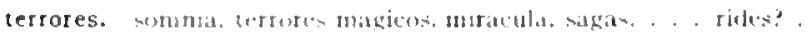

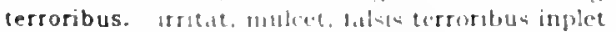

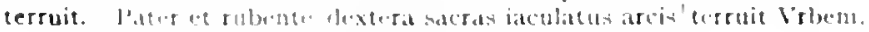

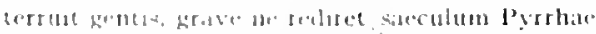

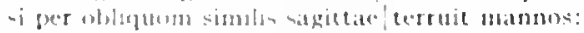

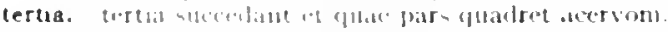

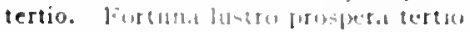

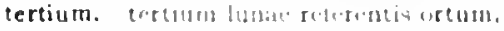

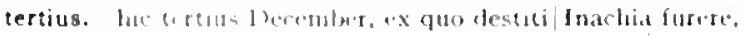

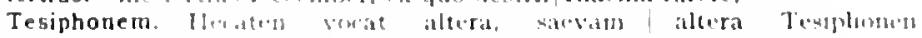

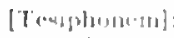

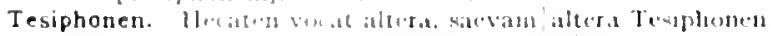

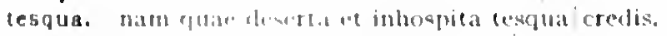

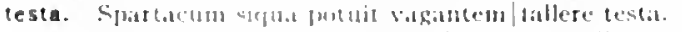

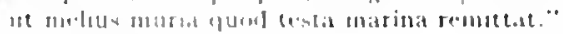

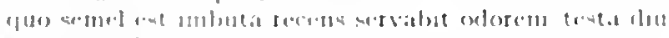

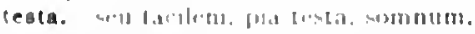

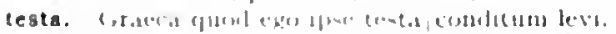

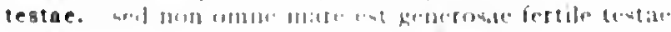

testamenta. capten asturu. ubriue ceutamenta semulu

Serm.1.8.20

Ars Poet.43u

Carm.1.1.0

Carm.2.1.23

Carm.2.0.13

Epist 1.3.1

LPist.2.1.252

Carm.1.3.23

Carm.1.12.15

Carm.2.10.18

Corm 3.14

Epod 5.2

SiTm.2.0.25

:ar. F pist.1.3.+

Epist.2.1.7

Corm. 1.2f 5

Sirm.2.1.50

SiTm.2.7.84

Sistid1.74

Corm.3.24.4

Carm.4.11.27

SeTm.2.7.44

tar. Epist.1.3.4

Serm.2.0.93

Carm.1.IO.II

Carm.2.1.20

Carm.4.11.25

tar.Serm.1.5.78

Serm. 1.8.7

Eist.1.16.39

int. Fipist.2.1.92

Lipit.2.1.182

Carm.1.2.1

Carm.1.3.31

Carm.1.37

Sirm.1-5.9

ror.tipist.1.3...

Carm.1.2.42

Carm.2.2.2

Carm.2.20.3

Sirm.1.3.0\%

Sirm. 1.83

1.pist.2.1.21

fepist 2.1.19.1

Epist.2.2.157

Carm.3.4.40

tepist.2.2 208

JPist.2.1.212

Carm 1.2.4

(urm.1.2.5

(ism-3.27.7

I.pist.1.0.35

Cirm.41.1-3\%

Carmat $25 \mathrm{~K}$

fepot 11.5

lar.Sorm. 1.8.3.

Serm.1.8 34

lipist.1.j.19

cirm.3.1.1.20

Serm 2853

f. fort 1.2.71

(ivir) 321.4

(itrm.1 20.2

Sirm.2.1.31

serm $2 . \$ 2.1$ 
opella forensis/adducit febris et testamenta resignat. testamento. anus inproba Thebis/ex testamento sic est elata: testamentum. qui testamentum tradet tibi cumque legendum. teatatur. campus sepulcris inpia proelia|testatur testatus. clipeo Troiana refixo|tempora testatus teste. *Lucili, quam sis mendosus, teste Catoneldefensore tuo pervincam,* quo res sponsore et quo causae teste tenentur.'

testis. testis mearum centimanus gigas|sententiarum. testis Metaurum flumen et Hasdrubal|devictus ne foret his testis, post magna latere sepulcra. ut non testis inultus

testis. accidit ut cuidam testis caudanque salacenidemeterent ferro. testudine. qui persaepe cava testudine flevit amoren

testudinis. o testudinis aureae/dulcem quae strepitum. Pieri. temperas. saxa movere sono testudinis.

testudo. dapibus supremi|grata testudo Iovis. tuque test udo resonare septem|callida nervis.

tetendit. aut anite levi rara tendit [tetendit] retia

teterrima. nam fuit ante Ilelenam cumns taeterrima [teterrima] belli) causa,

tetigere. minaces! turpe solum tetigere mento;

tetigisse. sunt qui nolint tetigisse nisi illas si eurat cor spectantis tetigisse querella. vesanum tetigisse timent fugiuntque poetam/qui sapiunt;

tetigit. recedentis trilingui|ore pedes tetigitque crura. inmunis aram si tetigit manus. quae simul centum tetigit potentem /oppidis Creten.

tetra. 'nam simul ac venas inflavit taetra [tetra] libido,

tetrarchas. modo reges atque tetrarchas. Jomnia magna loquens.

Teucer. Teucer Salamina patremque/cum fugeret. urgent inpavidi te Salaminius Teucer, te Stlenelus, sciens/pugnac primusve Teucer tela Cydoniolerexit arcu;

Teucri. Teucri|certus enim promisit Apollo

Teucro. nil desperandum Teucro duce et auspice: auspice: Teucri [auspice Teucro:! eertue cnin promisit Apollo ambiguan tellure nova Salamina futuran.

Teucro. procidit late posuitque collum in | pulere Teucro:

Teucrum. non ille aut Teucrum aut ipsun violavit l'lixin.'

texere. fronde nova puerum palumbes|tesere.

textam. alter Mileti textam cane peius et angui / vitahit chlanidem.

textis. claudensque textis cratibus lactum pecus

textore. siquis.. . pede nudolexignaeque togate simulet textore Catonem. thalamo. nequiquam thalamo gravis/hastas.. . vitabis

Thaliae, doctor argutae fidicen Thaliae

Thaliarche. deprome quadrinum Sabina, o "lowliatele" merum diota

theatra. sonum, referunt quem nostra theatra?

theatris. paulun severae nusa tragoediae/desit theatris: nec redeant iterum atque iterum spectanda theatris.

theatris. cum populus frequens/ laetum thatris ter cromit smum; spisis indigna theatris | scripta pudet recitar.

theatro. datus in theatro, cum tibi plausus,

hos arto stipata theatro/spectat Roma potens in sacuo lactus sessor plausorque theatro.

Thebse. monstrumve submisere Colchi|maius Echioniacro Thobac.

Thebanae. Thebanaeque iubet me Semelac putr dictu a ct Amphion. "Thebanae conditor urbis. | saxa mosere

Thebanos. fidibusne Latinis/Thebanos aptare mordos studet auspice Musa.

Thebarum. Pentheu'rector Theharum, quir me jerferre patique indignum coges?"

Thebas. vel Baceho "lhebas vel . Apolline Delplos insignis:

Thebis. anus inproba Thebis/ex testamento sic est elata:

nt magus, et nodo me Thelis, modo ponit Athronis.

Colchus an Assyrus. Thebis nutritus an . Mrgis.

Theonino. ruildente Tlunimo cum circumroditur.

thesauris. intactis opnlentior thesauris Arabum et disitis louliat.

thesauro. thesauro invento qui mercennarius agrum| illum ipsum morcatus aravit.

Theseus. nec lethaca valct Theseus abrumpere carol vincula perithon.

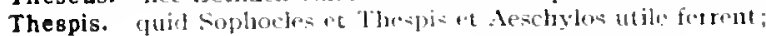

lipist.1.7.9

Serm.2.5.85

Serm.2.5.5t

Carm.2.1.31

Carm.1.28.12

Serm.1.10.*1

Epist. I. 16.43

Carm.3.4.69

Carm.4.4.38

Serm.1.8.36

Serm.r.8.44

Sirm.1.2.45

Epod.14.11

Curm.4.3.17

Ars Pocl.395

Carm.1.32.I 4

Carm.3.11.3

Ear.Epod.2.33

10r.Serm.1.3.107

Carm.2.7.1 2

Serm.1.2.28

Ars Poet.98

Ars l'oet. 455

Carm.2.19.32

Carm.3.23.17

Carm.3.27.33

var.Serm.1.2.33

Serm.1.3.1 2

Carm.1.7.21

Carm.1.15.24

Carm.4.9.17

Carm.1.7.27

(arm.1.7.27

zear.Cam.I.7.2\%

Carm.4.6.12

Sirm 2.3.204

Carm.3.4.13

lepist. I. 7.30

Inpol.2.45

Epist.1.19.13

Carm.1.15.16

Cirm.4.0.25

("armi.1.9.8

Fpist.2.1.20 I

(arm.2.1.10

Sierm.1.10.39

carm.2.17.26

ISpist.1.19.41

Carm.1.20.3

Epist.2.1.60

Epist.2.2.130

(arm.t.4.64

(arm.1.19.2

Irs Peet.394

Epist.1.3.13

E.pist.1.16.74

(iurm.1.7.3

Serm.2.5.84

I.pist.2.1.21.3

Irs Poet.i Is

Ifpist.1.18.82

(arm.3 2.1 .2

Sirm.26.11

(iarm.1.7.27

lipist.2.1.103 
dicieur et plaustris vexisse poemala Thespis.

Ars Poct. 276

Thessala. quat sidera excantata voce Thessala

Epoid. 5.45

Carm.1.7.4

Thessala. laudabunt alii ... Thessala Tempe:

Epist.2.2.200

nocturnos li"nures portentaque Thessala rides?

Carm.1.27.21

Corm.24.10

Carm.1.10.15

E.pod.13.12

Carm.1.8.14

Thetide. invicte, mortalis dea nate puer Thetide.

Thetidis. marinat filium dicune Thetidis sub lacrinosa Troiat|iuncra.

Carm.4.6.6 filius quanvis Theridis narinae

Thraca. Thracane vos Hebrusque nivali compede vinctus . . morantur?

Thrace. ocium bello furiosa Tbrace.

Thracen. Jlebrum prospiciens et nive candidan|Thracen

List. $2.3 \cdot 3$

Thracise. infellunt animae linea Tbraciae.

Thracio. Thracio bacchante nagis sub inter-[junia rento.

Thracis. Thracis et exitium Lycurgi.

Thracum. natis in usum lactitiae scyphis/pugnate Tirsacum est: quale poscet inpia/mollire l'hracurn pectora:

$\operatorname{Carm} \cdot 2.16 .5$

Carm.3.25.11

$\operatorname{Corm} .4 .12 .2$

Carm.1.25.11

Carm.2.19.10

Carm.1.27.2

Epod.5.14

Epist.1.10.13

Thraecam. ut nec frigidior Thraecam nec purior ambiat llebrus.

Thraer. תugas hoc genus: 'hora quota est?" "lhorax est Gallina Syso par?" ad immm Throex erit aut holitoris aget mercele cabalium.

Sirm.2.0.44

lipist.1.18.36

Threca. Thracane [Threcane] vos Jebrusque nivali compede vinctus . . morantur?

Threcibus. regibus [ [hrecibus] bic mos est, ubi cquos mercantur:

Threicia. Basun Threicia vincat anystice

Threicio. quid? si Threicio blandius Opheolanditam moderere arboribus tillem.

nunc mate, unc siluae | Threicio Aquilone sonant.

Thressa. 'me nunc Thressa Chloe reg't.

Thurini. Thurini Calais filius Ornyei.

Tburinus. summus ego et prope me Viscus Thurinus

Thyestae. frivatis ac prope socco/dignis carminibus narraricena Thyestac:

Thyesteas. misit Thyesteas preces:

Thyesten. Irate lhyesten exitio gravi|stravete

Thyiadas. fas pervicacis est mihi libyadas

Thyias. pulso Thyias uti concita tynpano.

thyma. tucum per nenus arbutos|quatsunt lateneis et thyma deviae.

kratia carpentis thyma per laborem|plurimum

quace curcumolitas agilis thyma?

Thyna. Ityma merce beatum.

thyni. plures anabunt thyni et cetaria crescent.

Thyous. navta Bosporum Poenus [Thynus] perhortescit

Thyoneus. no hednuteis cum Marte coniundet Thyoneus iproelia

thyrso. parce gravi metwende thytno.

Tiberi. nutu in "liberi stabit."

Tiberi. ti. luberi, numerare, cavis absomkere tristem.

Tiberim. silums flavom Iibrim retoreis... Ire deietun momumenta regitis

cur tamet Havon Tiberim tangere.

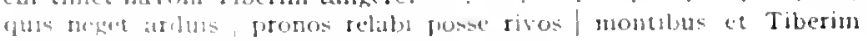
tovertis

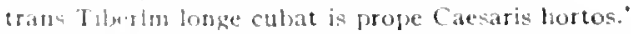

ter unete trangnato Taberim,

Tiherinis. smal muctos l ibernis umeros lavit in undis.

Tiberino. anctome brae Cimgo et liberno fumine sordent?

Tiberinus. lupus hic Tibermus an aleo, capeus buct?

Tiberis. vllatue, disvos quam Tiberis lave.

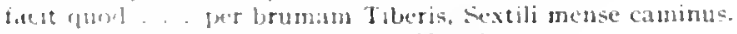

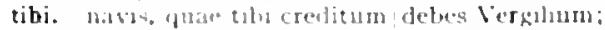

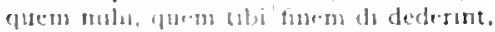

orte soburmen, thlo cura magni, caesiris fatis data:

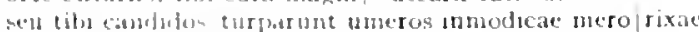

wess ebbs sunt integred henters.

lame tabi eogus mandme al plonum

dotus in theatro cum tulu platusus.

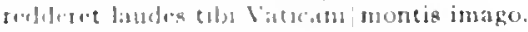

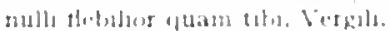

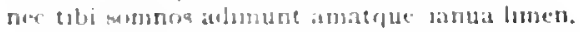

cun tibi llagrans amor et libulo.

tar. I.pist.J.3.3

coni.Serm.1.2.80

Curm.1.30.14

Corm.1.24.13

lipod. 1.3 .3

Carm.3.9.9

Carm.3.0.14

Sorm.2.8.20

Ars Pued or

Iipod. 5 sio

Carm.1.10.17

Corm.2.10.9

Corm.3.15.10

Curm.1.17.0

Cism.is 2.20

lifist.t.3.21

Curm.3.7.3

Sirm $2.5 \cdot 44$

conic isrm.2.13.15

(inm.1.17.23

(arm.2.19.8

Sirm.2.3.292

Sirm.2.3.173

Citm.1.2.13

(iarmas.s

Citm.1.29.12

Serm. 1. 0.38

Sorm.2.1.8

(c)

Epist.1.11.4

Sorm.2.2.3I

Cism.2.3.18

lipist.1.11.19

(iurm.1.3.5

Carm.1.I1.I

Curm.1.12.50

(arm.1.13.?

(irm.1.t4.9

curm.1.17.14

(iorm.t.20.4

Carm.1.20.7

Curm.1.24 10

Carm.1.25.3

Curm.1.25.13 
nec quidquan tibi prodest/aerias temptasse domos

multaque merces $\mid$ unde potest tibi defluat aequo|ab love

quae tibi virginum|sponso necato barbara servict,

cur tibi iunior|laesa praeniteat fide.

ne sit ancillae tibi amor pudori, | Xanthia Phocen:

crede non illan tibi de scelesta/plebe dilectam.

iam tibi lividos/distinguet autunnus racemos/purpureo varius colore.

illi quod tibi dempserit|adponet annus)

nec|parce cadis tibi destinatis.

ulla si iuris tibi peierati| poena.

adde quod pubes tibi crescit omnis,

nec tibi vespero|surgente decedunt amores

et mihi forsan tibi quod negarit/porriget hora.

tibi tollit hinnitum/apta quadrigis equa,

quem tibi, candida, | primo restituent vere Favonii

at tibi|ne vicinus Enipeus|plus iusto placeat

donec gratus eram tibi.

cessit inmanis tibi blandienti|ianitor aulae

ne longus tibi somnus unde non times detur;

tibi qualum Cythereae puer ales, tibi telas operosacque Minervac studium aufert.

gelidos inficiet tibi|rubro sanguine rivos

cum tibi nonae redeunt Decembres.

spargit agrestis tibi silva frondes,

grande certamen. tibi praeda cedat, | naior an illa.

cum tibi invisus laceranda reddet/cornua taurus.

tibi $\mid$ non ante verso lene merum cado.

ceteris nuaior, tibi miles inpar,

non tibi talium / res est aut aninus deliciarum egens.

est animus tibi|rerumque prudens

Idus tibi sunt agendae.

nec Coap referunt ian tibi purpurae

nam tibi quo die/portus Alexandrea . . patefecit .

maius infundam tibi|fastidienti poculnm

cum sit tibi dens ater

ore adlaborandum est tibi.

tibique pallor luteus

querebar alplorans tibi,

quid tıbi vis. mulier nigris dignissima barris?

cui properabantur? tibi nenpe.

unde tibi reditum certo subtemine ]'arcael rupere.

tibique Pactolus fluat

dedi satis superque poenarum tibi.

tibi hospitale pectus et purac manus.

nil obstet tibi. dum ne sit te ditior alter.

ut tibi si sit opus liquidi non amplius urna

nullo natura labore/quos tibi dat,

an tibi abunde! personam satis est, non illud, quidequid ubique officit evitare?

huic si mutonis rerbis. . diceret haec amimus 'quil vis tibi?

multae tibi tum officient res:

plurima, quae invideant pure adparere tibi rem.

Cois tibi paene videre est|ut mudam,

an tibi mavis / insidias fieri pretiumque avellier ante / quam mercem ostendi?

hiscine versiculis speras tibi posse dolores/atque aestus curasque gravis e pectore pelli?

num, tibi cum faucis urit sitis, aurea quaeris|pocula?

tument tibi cum inguina,

at tibi contralevenit, inquirant vitia ut tua rursus et illi.

at est bonus, ut melior vir $\mid$ non alius quisquam, at tibi annicus.

nuniqua tibi vitiorum inseverit olim|natura

qualem me saepe libenter|oltulerim tibi, Naecenas,

si tibi regnum permittant lomines.

vellunt tibi barbam | lascivi pueri,

dummodo risum|excutiat sibi [tibi] non, non cuiguam parcet amico

nune illud tantum quaeram, meritone tibi sit

hic tibi comis et urbanus liberque videtur.

lividus et mordax videor tibi?
Carm.1.28.4

Carm.1.28.25

Carm.1.29.5

Carm.1.33.3

Carm.2.4.1

Carm.2.4.I7

Carm.2.5.10

Carm.2.5.14

Carm.2.7.20

Carm.2.8.1

Carm.2.8.17

Carm.2.9.10

Carm.2.16.31

Carm.2.16.34

Carm.3.7.1

Carm.3.7.22

Carm.3.9.1

Carm.3.11.15

Carm.3.11.3k

Carm.3.12.4

Carm.3.13.6

Carm.3.18.10

Carm.3.18.1.

Carm.3.20.7

Carm.3.27.71

Carm.3.29.1

Carm.40.5

Carm.4.8.9

Carm.1.9.34

Carmal1.14

Carm.1.13.13

(arm.t.14.3.t

Epod.5.77

Epod.8.3

Epod.8.20

Epod.10.If

Epod.11.12

Epod.12.I

Epod.12.22

Epod.13.1 5

Epod.15.20

IFpod.17.19

Epod.17.49

Sirm.1.1.40

Serm.1.1.5.4

Serm.1.1.89

Sirm.1.2.59

Serm.1.2.69

Serm.1.2.97

Serm.1.2.100

Sirm.1.2.101

Serm.1.2.103

Sirm.1.2.109

Sirm.1.2.114

Sern.1.2.110

Serm.1.3.27

Strm.1.3.33

Sirm. J.3.35

Serm.1.3.6.t

Serm.1.3.123

Sirm.1.3.133

coni.Sorm.1.4.3

Sorm.1.t.64

Serm.1.4.90

Sorm.1.4.93 
- apjerss, viatu quidque putitu sit melius, causas redolet tibi;

Serm.1.4.116

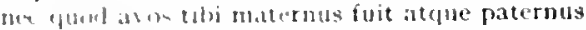
peratuades heme tibi rere,

gun tabl. lulli. aumere demsitum clavom fierique tribuno?

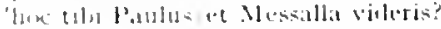

num, quat an tubi, Maceras, convictor,

magnum hike ego duco./quod placui tibi,

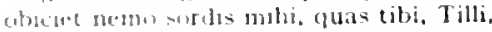

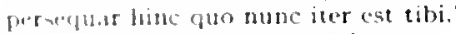

quementu volu vizere non tibi notum:

"et tibi matct. cognati, quis te salvo est opus?"

dora toba zeragenda rei sit causa Petilli?

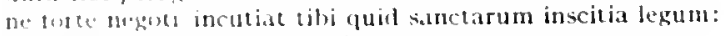

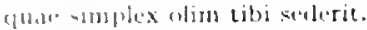

thos funluam accedec als istam. . . mollitiem,

(e. ubu miguone a frustra mortis cupidum,

uni mundrus recte libi somper erunt res.

uni mmisum recte tibi [tibi recte] semper erunt res. 0 naguus posthac ininicis rasus.

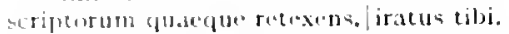

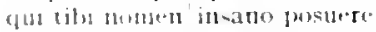

"tecipe equel numequan reddats mihi" si tibi dicam:

dis immle anex, custodis? ne tibi lesit?

di tibi dent tapta classem redducere Troia.

stas ammo et furtul est vitio tibi, cum tumbum est cor?"

sume tibj decens; tibi tanturdena tibi triplex.

qual-i incerculeriz tibi nunc aliquicl. repetes mox.

thr] sise aliutl privom dabitur tibi,

quescumgue fieret cultus tibi fundus honores

"ubs me virtus tua fecit amicum.

qui toldmentum tradet tibi cumque legentum.

ste thls l'neluge frugi lost :

iput thbl vis. magne, et yuam rem agis?"

cupsens tibi diereservos patua réformido.

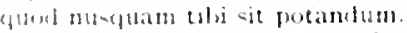

Mnhiu- et semrate, tibi mon referemda precalti, discedunt.

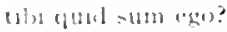

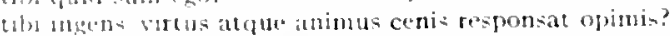

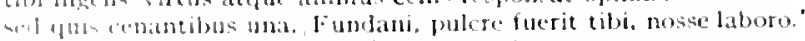

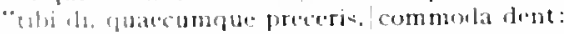

at atsumus tiln. sunt mores et lingua fidesque.

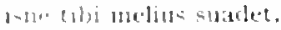

mon thb: parsm ingenium,

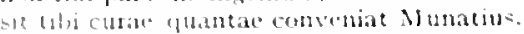

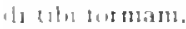

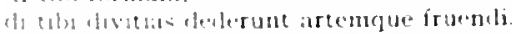

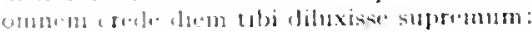

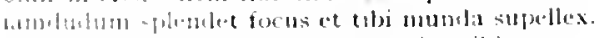

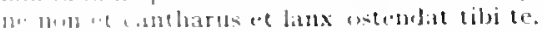

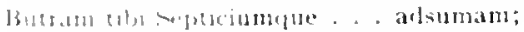

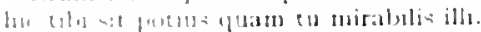

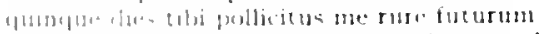

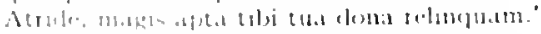

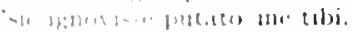

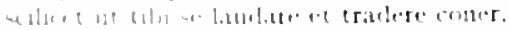

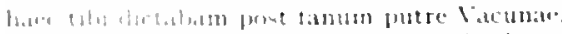

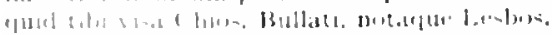

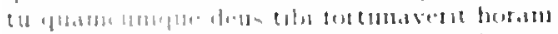

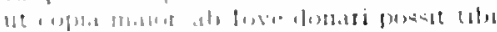

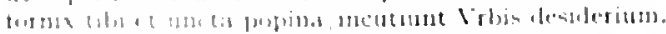

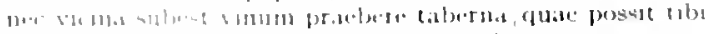

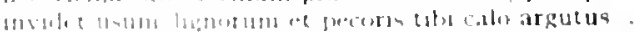

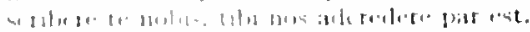

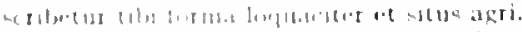

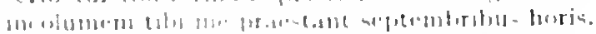

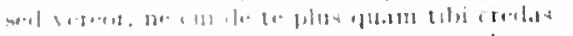

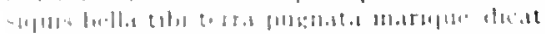

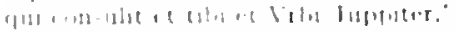

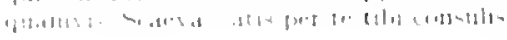

Serm.t.0.3

Serm.1.0.8

Serm.1.0.24

Serm.1.6.41

Sirm.1.6.47

Serm.1.0.03

Serm.1.0.107

Sim.1.9.10

Serm.1.0.17

Serm.1.9.20

Serm.1.10.20

Serm.2.1.8I

Serm.2.2.73

Serm.2.2.80

Serm.2.2.97

Serm.2.2.106

rar.Scrm.2.2.106

Serm.2.3.3

Serm.2.3.47

Sirm.2.3.00

Sirm.2.3.123

Sirm.2.3.191

Sirn.2.3.213

Sirm.2.3.237

Serm.2.4.6

Serm.2.5.11

Sirm.2.5.13

Serm.2.5.33

Sorm.2.5.5I

Serm.2.5.8I

Sitm.2.0.20

Sirm.2.7.1

Sirm. 2.7.32

Setm.2.7.3t

Sirm.2.7.80

Serm.2.7.102

Sorm.2.8.19

Sirm.2.8.75

Ifpist.1.1.58

Jifist.1.1.05

feptet 1.321

Epist.1.3.30

Epost.1.4.)

Epict.1.7

IEpist.1.1.13

IEpist.1.5.7

I.pors. 5.24

Loprot.5.20

l. pist a p.e.,

d.pold.7. I

Jipint. 1.7 .43

Ef pist 1.7 .70

lipist 103

Eprst.1.10.20

lipert I 11.1

Epist 111.22

f. pist I 12.3

f.pust 1.1.421

f. pust 1125

l.post t.1.4.42

I.P131 1.15.25

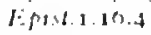

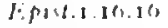

J:pell t.10.10

J:pisd 1.10.25

I pist 1.31, 28

J.Pul 17.1 
tibi parvola res est:

ne mox ineutiant aliena tibi peceata pudorem.

quir minuat curas, quid te tibi reddat anieum,

fidis enim manare poetica mella! te solum, tibi pulcher."

fuge quo descendere gest is: I non erit emisso reditus tibi.

cum tibi sol tepidus pluris admoverit auris.

praesenti tibi maturos largimur honores

cum tibi lihrum sollicito danıs aut fesso;

dilecti tibi Vergilius Variusque poetae.

siquis forte velit puerum tibi vendere.

nemo hoc mangonum faceret tibi;

prudens emisti vitiosum, dicta tibi est lex:

prudens emisti vitiosum, dicta tibi est lex [dieta tibi lex est]:

prudens emisti vitiosun, dicta tibi est lex [dicta est tibi lex]:

prudens emisti vitiosum, dicta tibi est lex [est dicta tibi lex]:

dixi me pigrum proficiscenti tibi.

expectata tibi non mittam carmina mendax.

si tibi nulla sitim finiret copia lymphae.

si volnus tibi monstrata radice vel lierba|non fieret levius.

cum segetes occat tibi mox frumenta daturus.

caret tibi pectus inani|ambitione?

tempus abire tibi est.

si vis me Here, dolendum est / primum ipsi tibi: .

aetatis cuiusque notandi sunt tibi nores.

rem tibi Soeraticae poterunt ostendere chartae.

hoe tibi rictum tolle memor.

id tibi iuclicium est, ea mens.

ne forte pudori|sit tibi Musa lyrae sollers et cantor Apollo.

nolito ad versus tibi factos ducere plenum|laetitiae;

tibia. tibia non, ut nunc, orichalco vincta tubaeque laemula.

tibia. quem virum aut heroa lyra vel acri|tibia sumis celebrare, Clio?

descende caelo et dic age tibia

lyraeque et Berecyntiae delectabere tibiae [tibia]|mixtis carminibus non sine fistula;

Iyraeque [yraque] et Berecyntiae [Berecyntia] / delectabere tibiae [tibia]| mixtis carminibus non sine fistula;

tibiae. neque in vias|sub cantu querulae despice tibiae

cur Berecrntiae / cessant flamina tibiae?

Berecyntiae / lelectabere tibiae $/$ mixtis carninibus

tibias. si neque tibias/Euterpe colsbet

tibicen. sic priscae motumque et luxurien addidit arti|tibicen qui Pythiz cantat|tibicen, didicit prius

tibicina. nec meretrix tibicina cuitus|ad strepitum salias terrae gravis:

tibicinibus. nune tibicinibus, nunc est gavisa tragoedis;

tibiis. Lydis remixto carmine tibiis sonante mixtum tibiis earmen lyra.

Tibur. Tibur Argeo positum colono Praeneste seu Tibur supinum seu liquidae placuere Baiae. sed vacuom Tibur placet aut inbelle Tarentum.

Tibur. nec semper udum Tibur et Aefulat declive entempleris arvom sed quat Tibur aquae fertile praetuont Romae Tibur amem, ventosus Tibure Romam.

Tibure. Romae Tibur amen, ventosus Tibure Romam. puerum tibi ventere natum. Tibure vel Gabiis

Tiburis. sea rensa tenebit| Tiburis unbra tui. circa mite solum Tiburis et moenia Catili; circa nemua uvidique|Tiburis ripas

Tiburni. et praeceps Anio ac Tiburni lucus

Tiburte. cun Tiburte via praetorem quinque sequontur/te pueri.

Tiburtia. Picenis cedunt pomis Tiburtia suco:

Tigelli. hoc genus omne maestum ac sollicitum est cantoris morte Tigelli.

Tigelli. quis manus insudet volgi lfermogenisque Tigelli,

quod ineptus|Fannius Hernogenis laedat conviva Tigelli?

Tigelli. Demetri, teque, Tigelli. Giscipularum inter iubeo plorare cathedras.

Tigellius. Sardu= habebat lille Tigellius hoc:

Tigellus. Sardus habebat ille Tigellius [Tigellus] hoc:

Tigilli. loc genus omne $\mid$ maestum ac sollicitum est cantoris mot te Tigelli [Tigilli].

Tigillius. Sirrdua habebat ille Tigellius [Tigillius] hoc:
Epist.1.18.20

Epist.1.18.77

Lipist.t.18.10

Epist.1.19.45

Epist. r 20.6

Epist.1.20.19

Epist.2.1.15

Lipist.2.1.220

Epist.2.1.247

Epist.2.2.2

Epist.2.2.13

lipist.2.2.18

q'ar. Epist.2.2.1 8

var.lepist.2.2.18

:ar. Epist.2.2.1 8

Epist.2.2.20

Epist.2.2.25

Epist.2.2.1.46

I.pist.2.2.1.49

Epist.2.2.10 $\mathrm{I}$

Epist.2.2.206

Lisist.2.2.215

Ars loet.103

Ars Pot.150

Ars Poet.3io

Ars Pot. 367

Ars Poct.386

Ars Poct.407

Ars Poit.p27

Ars Poct.202

Carm.J.12.2

Carm.3.4.1

tor.Carm.4.1.23

E'ar.Carm.4.T.23

Carm.3.7.30

Curm.3.19.19

Carm.4.1.23

Carm.I.I.32

dirs Pott. 25

Ars Pott.115

Eppist.1.14.25

f.pist.2.1.98

Carm.4.15.30

IEpod.9.5

Carm.2.0.5

Carm.3.4.23

Epist.1.7.45

Carm.3.29.6

Carm.4.3.10

lepist.1.8.1 2

Iipist.1.S.I 2

Epist.2.2.3

Carm.1.7.2I

Carm.I.IR.2

Carm.t.2.31

Carm.1.7.I3

Sirm.1.0.108

Sirm.2.70

Sorm.1.2.3

Sirm.1..172

Serm.1.10.80

Sirm.1.10.90

Serm.1.3.4

ear.Serm. [.3.+

2'ur.. Serm. I. 2.3

sar.Serm.1.3.4 
tignis. Aeschylus et modicis instravit pulpita tignis

Ars Poet.279

tignum. torquet nume lapidem, nune ingens machina tignum.

Epist.2.2.73

tigres. twat verere tigres indocili iugum collo trabentes.

Carm.3.3.14

tigres. dittus ub ho lenire tagres rabidosque leones:

Ars Poct.303

tigribus. non ul serperses avibus geminentur, tigribus agni.

Tigris. te rapidus Tigtis... atudit

Ars Poet.13

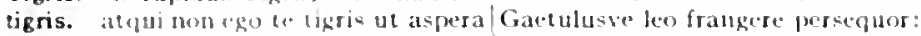

tigris. tu potes ther conitesque silvas/ducere

specionil quatero pascere tigris.

jubet us thris subsiflere cervis.

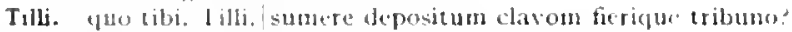
obici"t nemes serdis milii, quas tibi, Tilli.

Timagenis. Iupit larbutan Truagenis acmula lingua.

timeant. credula nec ravis timeant armenta leones

timebo. 'Ro cui tinubo./providus auspex,

timesda. tu. cum timenda voce complesti nemus.

tumendorum. regun timentorum in proprios greges,

timendos. hare clentes acuil timentos,

timendum. Examen lois timendum|partibus Oceanoque rubro.

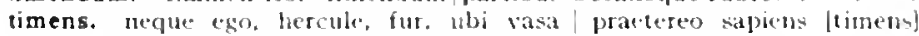
argenteas.

timent. vesanum tetigisse timent fugiunque poetam|qui sapiunt:

timent. dabis aegrotare timenti. Maecrnas, veniam.

tumentis. volge recilare timcutis ol hanc rem,

"est genus unum inultitian nililum metuchda timentis, .

umentis. convivis avidescenam servosque timentis, tum ragere. . velle et regat iratos et amet pacare timentis;

times. He longus tibi sommus umblen times dotur;

Vrbi solleritus times.

nec modica enore times helus onne pateth

umet. cur tume llavom Tiberim tangere?

neaper ulta, caleat binet aliunde lata,

vernarigute time , lucleret dectior.

peinsque leso thatintan timet.

manus potemtis| Modus Abanasque tumed securis.

avislserpentium arllapaus timet

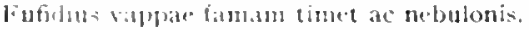

cum subi quinque timet, quamquan est intactua ct odit."

yui tumet his athersal,

תavem agere igharms mavis timet.

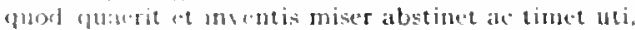

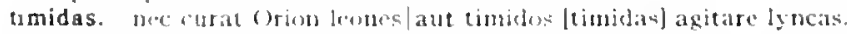

timide. vel quad res umnis timide gelideque ministrat.

(arm.4.14.46

Carm.1.23.1)

Carm.3.21.13

Carm.3.27.5\%

l:pod.10.31

Serm.1.0.24

Serms.1.0.107

fipist.1.19.15

Epod.10.33

Carm.3.27.7

L pod.op

(ism.3.1.5

Carm.3.20.10

(arm.1.3531

iar.sorm. 3.7 .73

Ars Pocl. 455

Ejot.1.7.4

Serm.1.4.23

Serm.2.3.54

Serm.1.5.75

Ars Poet. 197

Carm.3.11.39

Corm.3.29.20

List.1.5.2

Carm.t.8.8

Corm.2.13 I0

Corm.3.24 $5^{1)}$

Curm. 1950

Carm.Suer.5.t

Esod. 1.20

Serm.1.2.12

Serm.2.1.23

Jipist. 1.0 .9

Epist.2.114

Ars Poctilo

tar.Carm.2.13.40

dirs l'oditi

timidis. hic ubi neegritian fauteribus et simide nil aus paulum abstulerat,

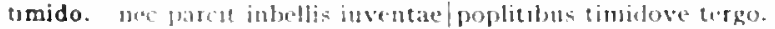

verbis. guare timide gurgure posent addere mentem:

tumidos. aut timulos agifare lyncas.

tumidum. furtur defossa timirlum teponere terrat

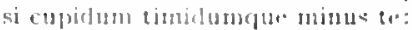

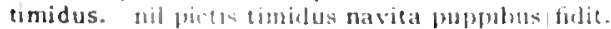

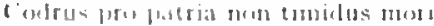

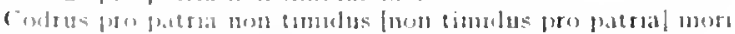

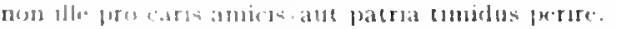

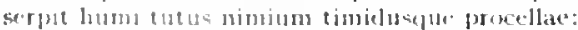

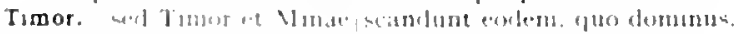

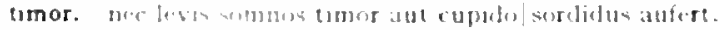

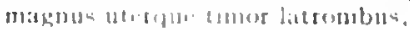

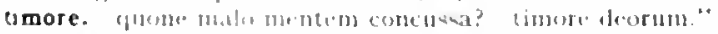

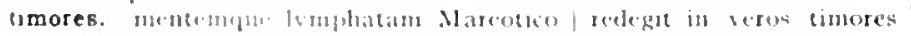

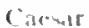

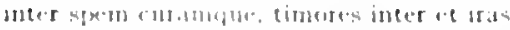

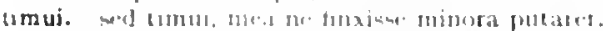

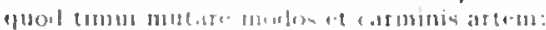

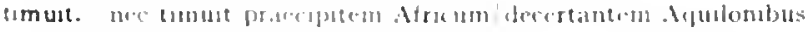

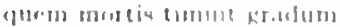

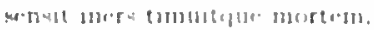

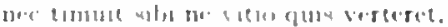

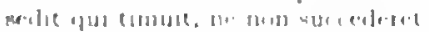

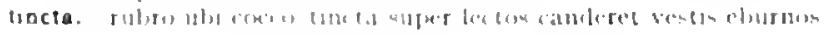

lipist.1.15.33

(itrm.3.2.16

Iisial.2.2.30

(arm. $2.13 \mathrm{gin}$

Serm.1.1.42

I:sest.2.2.150

(iom.1.1.1.1

(iarm.3.102

lar (arm.3. I1).

Corm.4952

Ars boel 28

(arm.31.32

curm.2.10.15

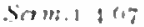

Sorm. 2.3 29.5

Corm.1.37.15

Lppote $1+12$

Epist t.es 8

EPost 11027

(iorm.1.312

(ism.1317

carm. 3536

Sirm I 4.85

1.putt 1.17 .37

form 2.1.10.3 
tincte. arma|noudum expiatis uncta [tincta] cruoribus.

tinctee. te bis Afro murice tinctate vestiunt lanae:

tinctos. argentum, vestis Gaetulo murice tinctas| sunt qui non habeant.

tinctus. nec tinctus viola pallor amantium

tinearum. stragula restis. | blattarum ac tinearum epulate.

tiness. aut tineas pasces taciturnus inertis

tinguere. non ego te meis/inmunem meditor tinguere pocmlis.

tinguet. mero|tinguet pavimentum superbo.

pontificum securis/cervice tinguet:

Tiridaten. quid Tiridaten terreat, unicelsecurus.

tironum. nomina sectatur modo smota veste virili sub patribus duris tironum.

tisanarium. agedum. sume hoc ptisanarium [tisanarium] oryzae.'

Tisiphonem. Hecaten vocat altera, saevam /altera Tesiphonen [Tisiphonetn]: Titanas. impios' Titanas imnanemque turbam 'fulmine sustulerit caduco

titerat. credo. quod ninium institerat [titerat] viventi.

Tithonum. longa Tithonum minuit senectus

Tithonus. Tithonusque remntus in auras.

titillet. praeterea ne vos titillet gloria.

Titius. quid Titius? Romana brevi venturus in ora.

titubes. vale, cave ne titubes mandataque frangas.

titulis. qui stupet in titulis et imaginibus.

titulos. per titulos memoresque fastos

cum prudens scelus ob titulos admittis inanis.

Tityi. incontinentis nec Tityi iecur

Tityon. Geryonen Tityonque tristi|conpescit unda,

Tityos. quin et Jxion Tityosque voltu/risit invito.

proles Niobea magnae Vindicem linguae Tityosque raptor sensit

toga. toga, quae defendere frigus| quamvis crassa qucat."

rideri possit eo quod|rusticius tonso toga defluit

si toga dissidet inpar.

arta decet sanum comitem toga;

dicitur Afrani toga convenisse Menandro.

toga. cum bis trium uharun toga.

togae. memor. . mutataeque simul togae.

anciliorum et nominis et togae / oblitus

siquis.. pede nudolexiguaeque togae simulet textore Catonem.

togae. quen tenues decuere togae nitidique capilli.

togam. audire atque togam iubeo conponere. .

togata. quid inter-lest in matrona, ancilla peccesne togata?

togatae. atque etiam melius persaepe togatae (est).

togatas. vel qui praetextas vel qui docuere togatas.

tolerabile. certis mediun et tolerabile rebus/recte concedi

tolerase. nec tauri ruentis|in veneren tolerare pondus.

'forten hoc animum tolerare iubebo;

tallam. ex modico, quantum res poscet, acervol tollam

tollant. ne spissae risum tollant inpune coronae:

tallas. 'ne'mpe pecus, rem. lectos, argentun: tollas licet.'

tollat. neve te nostris vitis iniquom / ocior aura|tollat;

talle. tolle cupidinem inmit is uva :

tolle periclum:| iam vaga prosiliet frenis natura remotis.

'at tu, quantum vis, tolle' 'benigne'

tolle querellas;

loc tibi dictun tolle memor.

tollenda. saepe ferentem/plura quidem tollenda relinquendis.

tollens. et tollens vacuom plus nimio Gloria verticem

tollent. Romani tollent equites peditesque cachinnum.

tollere. certat tergeminis tollere honoribus.

tollere seu ponere volt freta;

praesens vel imo tollere de gradu/mortale corpus

iure perhorruillate conspicuom tollere verticem.

caedis et rabiem tollere civicam.

'at suare est ex magno tollere acervo.'

"leporem venator ut altalin nive sectetur, positum sic tangere [tollere] nolit'.

enn servom. patinam qui tollere jussus

cum flueret lutulentus, erat quod tollere velles;

qui reges consueris tollere.

quem tollere raeda $\mid$ vellet iter faciens.
coni.Carm.2.1.5

(itrm.2.10.36

Epist.2.2.18 I

Carm.3.10.I\$

Serm.2.3.110

Sipist.1.20.12

Carm.t. 12.23

Citm.2.14.27

(arm.3.23.13

(itrm.1.26.5

Sirm.1.2.17

iur.serm.2 3.155

are.sirm. 1.8 .34

Carm.3.4.43

s'ar.t.erm.2.5.88

Carm.2.10.30

Carm.1.28.8

Sirm.2.3.179

Epist.1.3.9

Epist 1.13.10

Sirm.1.0.17

Carm.4.14.4

Sirm.2.3.212

Carm.3.4.77

Carm.2.14.8

Carm.3.11.21

Carm.4.6.2

Serm.1.3.1 4

Sirm.1.3.31

Epist.1.1.90

Ipist.1. 18.30

Epist.2.1.57

Epod.t.8

Carm.1.3p.9

Carm.3.5.10

Epist.1.19.13

Epist.1.1.32

Serm.2.3.77

Serm. I.2.63

Serm.1.2.82

Ars Poet. 288

Ars Poet. 368

Carm.2.5.4

Serm.2.5.20

Epist.2.2.19I

Ars Poot.38

Epist.1.16.70

Carm.1.2.49

Carm.2.5.9

Serm.2.7.73

Epist.1.7.16

Epist.1.12.3

irs Poet.zo8

Serm.1.10.51

Carm.1.18.15

ders loct.193

Carm.1.1.8

Carm.1.3.16

Carm.1.35.2

Carm.3.10.10

Carm.3.24.26

Sirm.1.1.51

:ar. Serm.1.2.10's

Serm.1.3.80

Sirm.1.t.1 I

Serm.1.7.34

Sirm.2.6.42 
non sit quat tollete curet.

tolleret. gul pro we tulletet istgue mitueret in phimum talos.

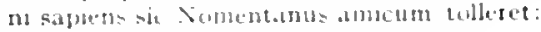

partemesed tullere.t (andms.

tolles. multatoun Lalle.s, ex inculin.

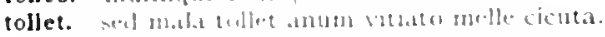

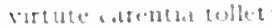

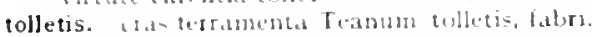

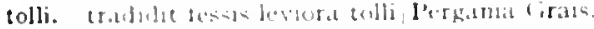

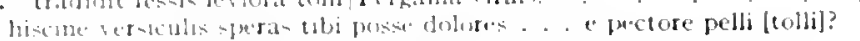

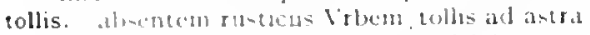

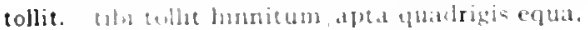

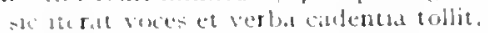
metalum tamen tet buem comedia tollit.

tollite. be lempe Lutidem toblite latudus

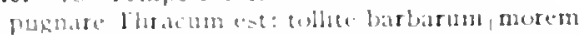
ves. yushus ar vartus, muliebrem tollite luctum.

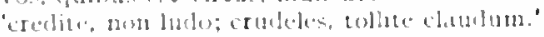

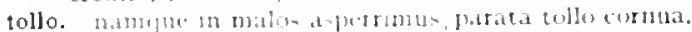

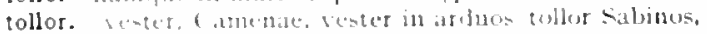

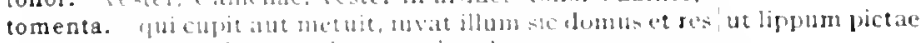

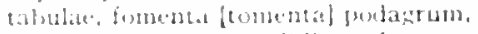

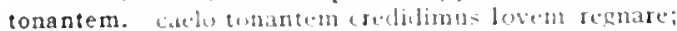

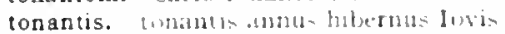

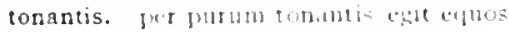

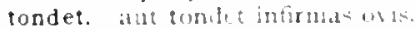

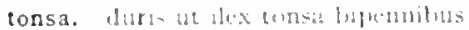

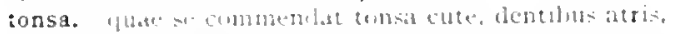

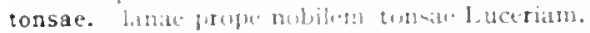

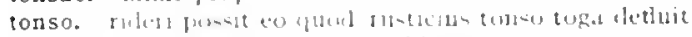

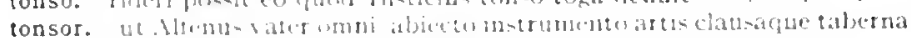

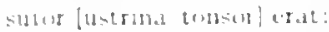

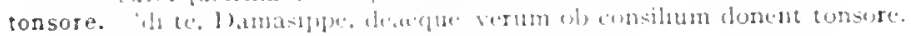

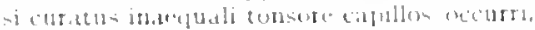

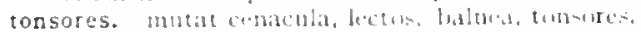

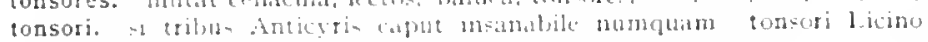
cummicerit.

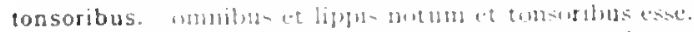

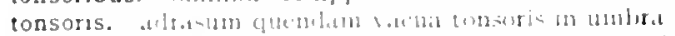

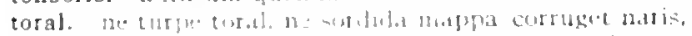

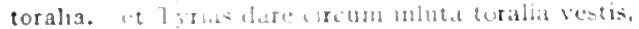

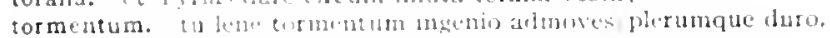

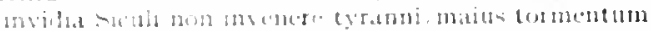

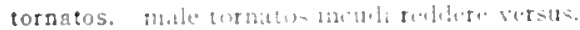

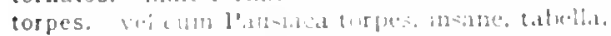

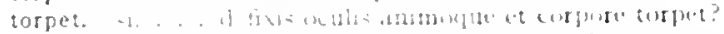

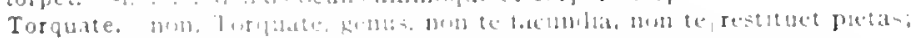

$$
\text { - }
$$

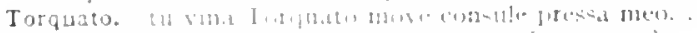

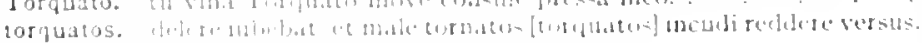

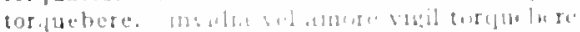

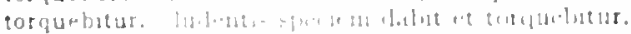

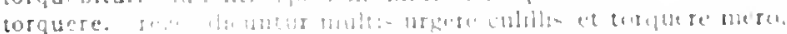

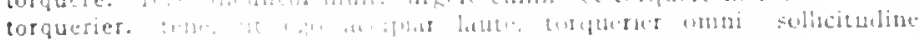
, $12+1,1131$.

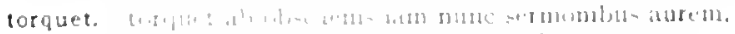

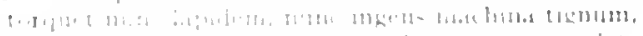

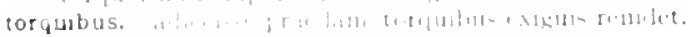

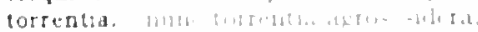

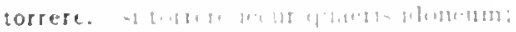

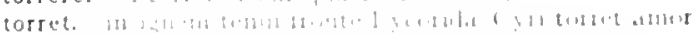

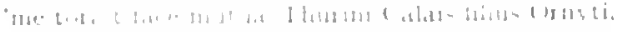

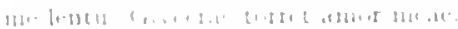

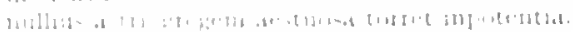

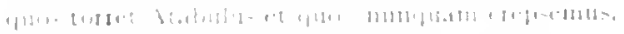

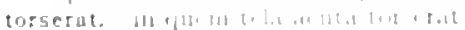

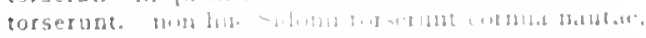

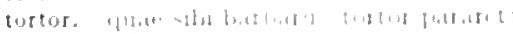

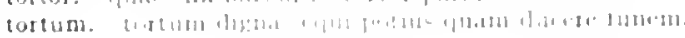

Ars Poct.quo

Sorm.2.7.16

Sorm.2.b.es

Epist.1.6.4.

Ars l'ocl. 183

Sorm.2.1.50

Lpist.2.2.123

Epist.1.1.87

Carm.2.4.1I

sur.Serm.1.2.110

Serm.2.7 29

Carm.2.10.34

Lpist.1.18.12

Ars loat 93

(arm.1.21.9)

Corm.1.27.2

lepod.10.39

Epist.1.170.t

Is puldo.12

Corm.3.4.22

cont.Lpist.1.2.52

Carm.3.5.1

fipod.2.20

Corm, 1.3. 7

I. pod.2.10

Carm.4.45:

Episterdat:

Curm-3.15.1.4

serm.1.3.31

tor.serm.1.3.132

Sirmizar 3

L.pist.1.1.4.

l.pist.1.1.2

. Irs lentsol

Sirmid.7.3

l. plust. I. - . 50

lepist. 1.5.22

Sirm.2.484

Corm.3.21.13

Epto1.2.59

Ars loctidit

Sirut.2.95

Lpistionat

(iarmat.7.23

Eptld $5 .$,

I.p.ued.3.c.

atr irs Int At

I.folt 1.2.35

I. pith $2=12.4$

Ars I'nt +35

Sitol 2atio

I.prats.2.1.27

I. 8.1 .22 .73

(arm is a.12

(itrots.3 131

(4) 194.12

(iam I.3.31

(armesul 18

(it)m.3.10) $=\mathrm{k}$

1 phedefente

Si, $1.5-8$

1. p.6.1.7.10

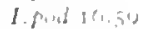

ciarmb.3.50

L.pon 1.111..8 
tortus. commissumque teges et vino tortus et ira.

Epist.1.18.38

torvo. dant alios Furiae torvo spectacula Mlarti,

Carm.1.25.17

torvo. quid? siquis voltu torvo ferus et pede nudo.

Epist.1.10.12

torvos. torvos humi posuise voltum,

tostis. tostis marcentem squillis recreabis et Afra|potorem coclea:

tot. totre tuos patiar laboresinpune. Lolli, carpere

tot ora naviun gravi|rostrata duci pondere

per quem tot iuvenes patrio caruere sepulcro?"

rerum imperis hominumque tot tantisque minor.

'qui possum tot?' ait;

cum tot sustincas et tanta negotia solus.

scribere posse inter tot curas totque labores?

tota. in me tota ruens Venus

dum ars exigitur, dum mula ligatur, / tota abit hora.

sed videt hunc omnis domus et vicinia tota introrsum turpen,

tota. flebit et insignis tota cantabitur Vibe.

tota. invertunt Allifanis Winaria tota/Vibidius Balatroque qui . . notaque [totaqu"] tatali portenta labore subegit,

totam. per totam domun|spargens Avernalis aquas.

totas. ridiculus totas semel absorbere placentas;

totidem. vos Tempe totiden tollite laudibus

te decen tauri totidemque vaccat,

ut cantus referatque ludos / ter die claro totiensque [totidemque] gratai nocte irequentis.

ducentos ante cibum versus, totidem cenatus;

quot capitum vivont, totiden studiorun | milia:

dixerit insanum qui ne, totidem audiet atque.

mille talenta rotundentur, totidem altera.

caedinur et totidem plagis consumimus hostem

totiens. ter die claro totiensque grata nocte frequentis.

totiens servatis clarus Achivis,

quacris, quando iterum paveas iterumque perire|possis, o totiens servos. ne populum extrema totiens exoret harena.

toto. sic raro subib. at toto mon quater anno/membranam poscas.

sic raro scribis, ut toto non [toto non ut] quater anno/ membranam poscas.

aestuat et vitae disconsenit ordine toto.

qui rel mense brevi vel toto est iunior anno."

toto. toto taciturua noctis/signa cum caelo

sed quia mente minus validus quam corpore toto

totum. cotum muneris hoe tui est.

totum. noctis vigilabat ad ipsum/mane, diem totum stertebat.

Sextilem totun mendax desideror.

tuisque auspicis totum confecta duella per orbem

totum. per totum hoc tenpus subiectior in diem et horam/invidiat noster. currere ber totum pavidi conclave

iniuste totum ducit venditque poena.

infelix opuris summa. quia ponere totum nescite:

totus. rescio quid meditans nugarum, totus in illis:

ab imo|ad summum totus moduli bijedalis.

et in se ipson totus, teres atque rotundus.

toxicum. velociusve miscuisse toxicum?

trabalis. clavos trabalis et cuneos manu|gestans aena.

trabe. ut trabe Cypria Myrtoum pridus nauta secet mare.

Abanos prope te lacus pont mamortam sub trabe citrea.

trabes. Hon trabes Hymettiat / premunt columnas.

trabibus. sub isden, sit trabilu-

tractant. quod nedicurun est|fromittunt medici, tractant fabrilia fabri:

tractare. fortis et asperais tratcile berpentes.

pauloque benignius ipsum/te tractare voles,

creals. . partis mimum tractar" secundas;

tractari. tractari mollius aetas imlecilla rolet:

ratione modoque tractari num vole.

tractas. periculosze plenum opus alcase, tractas

tractata. Veluti tractata motam labemulue renittunt atrancinte.

tractata. quae/ desperat tractata nitescere posse, relinquit

tractavit. guidquid usquam coneipicur nefits/tractavit. .

an malas, Canidia tractavit dapes: puer unctis eractavit calicen manibus.

Carm.3.5.4t

Serm.2.4.58

Carm.4.9.32

Epod.4.17

$\operatorname{Sirm} 2.3 .190$

Sirm.2.7.70

Eipist.1.6.t2

Epist.2.1.1

Eipist.2.2.00

Carm.1.19.9

Sirm.1.5.14

Lpist.1.se.t4

Sirm.2.1.40

S.rm.2.8.39

zur.l pist.2.1. I I

lipert.5.25

Sirm.2.8.24

Curm.1.21.9

Carm.1.2.53

sur.Carm..Sate. 23

Serm.1.10.01

Sirm.2.1.27

Sorm.2.3.298

Epist I. 1.34

Epist.2.2.97

Carmsatic 23

Sirm.2.3.194

Serm.2.7.70

Epish.1.1.0

Serm.2.3.1

conisirn.2.3.I

Epot.r. I.99

Epist.2.1.th

cirm.z.s. I0

Epist.1.8.?

Cam.t.3.2I

Sorm.1.3.Is

Epist.1.7.2

Iipist.2 1.254

Serm.2.0.47

S.rm.2.0.113

Epist.2.I.75

Ars I'Oet.3.t

Sirm.1.0.2

Sirm.2.3.300

Sirm.2.7.80

Sipod.17.01

Carm.1.35.18

Corm.1.1.13

Cirm.t.1.20

Carm.2.15.3

carm-3.2, 2 s

f.pist 2.1.110

( arm-1.37.27

Epist.1.17.12

lepist.1.IStit

Sirm.2.2.85

Serm.2.3.267

(it)m.2.1.7

Epost.2. I.2.35

Ars loet.1.50

Carm.2. 3.10

1:pol. 3.8

Sirm.2.70 
tractert. quate lacere upsu recuscul, pentus recte tractent alii. tractet. virulia quond speciosius arma non e-t qui tractet:

tractus. tractu+ ilter pluris lopores, user colucet aloros;

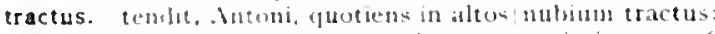

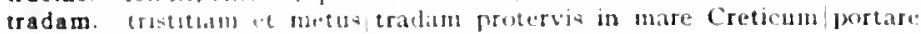
sectits.

trade. ultro lonelopam tacils potiori tade.

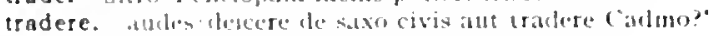

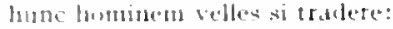

- ollicet ut cilai se dindare cet tradere comer.

tradet. gus tretistruntum tratet tibi exumpe legendum,

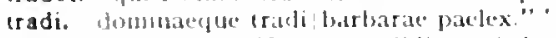

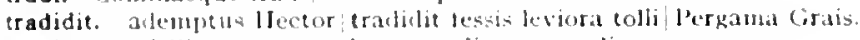

tradimus. Fallinur et quondam non diganm trablintus:

tradit. elise | apte shi tradit spectator;

traditum. tratlitum ab antiquis morem servare

traducere. qua ratione queas baducre lenter aevom.

tragica. ath tratsica desaevic et ampullatur in arte?

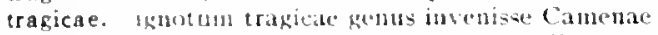

trafici. Bil comis tragici mutat Lucilats Ace?

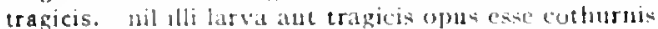

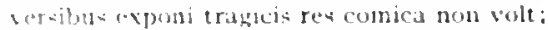

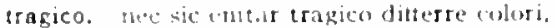

tragico. carmine qui tragico vilem certalsit ob hiroum,

tragicum. Haun ipurat triggicum sat is et felicuter audet.

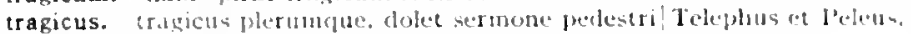

tragoedia. enutire lovis indigna tragoelia versus.

tragoediae. publum scverate musa tragoedice| deest theatris:

tragoedis. nunc cibcinibus, nunc est gavisa tragoedis: .

tragoedos. yui so crejebut miros audire tragocdos

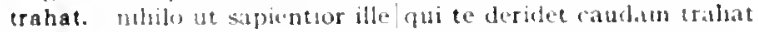

quifie al andertias, usus rectumne, trahat nos

trahentes. thu vexere tigres infocili iugum collo trahentes.

trahenti. Roguli disentientis condicionibus foedis et exemplo trallentis

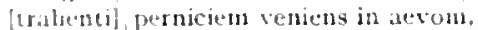

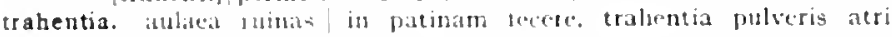
(1)artum

trahentis. Koguli. . exemplo trahentis/ perniciom veniens in aevom,

trahentis. villor hesus vomercm inversum boves/collo trahentis languido traheret. putstor cum trahiret per Ireta navibus/Idaeis lielemen.

traheretur. atuod ulua/perfectum traheretur.

trahet. flubloque trabet ferocis/per sacrum clivom... Sygambros;

trahis. yuo nuc, Bucche, rapis [trahis] tui, plenum?

trahit. 1naguj formica babotis, ore trabit quodcumatue potest

nule tatra malum graviug quan res trahil.

sect fulcernte trahit constrictos Gloria curru

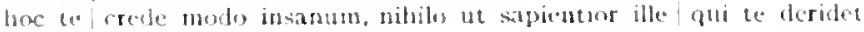
cumdaun traliat [tralitit.

and mo imperiosil erahic l'roserpina:

ceu bruma nisalem interiore diem gyro trabit.

trahitur mox trobitur manibus regum iortuna retortis.

trahunt. Trahuntule siceas machinde carima

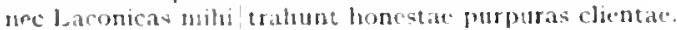

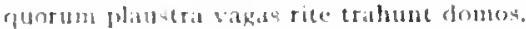

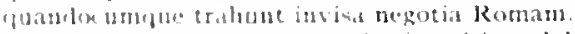

traiecto. in cort tratedo latersis miscri caspitiave dolore.

tramite. etrus enter de tramber pellit.

tranquilla. woll me trampulla sometus exepectat

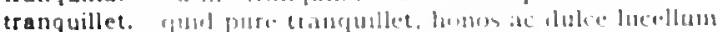

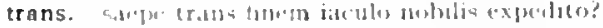

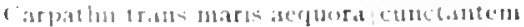

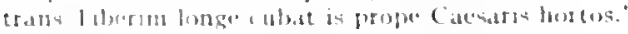

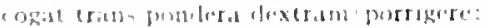

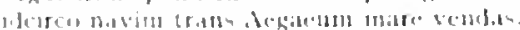

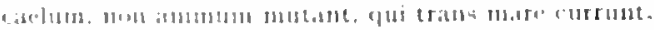

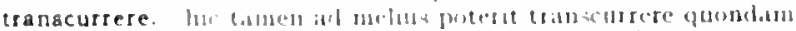

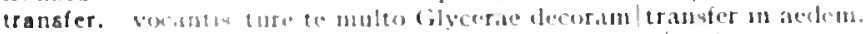

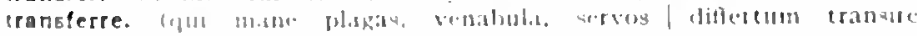

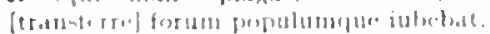

l:pist.2.5.209

Fipist 1.18 .53

Epist.1.15.22

(orm.4.2.27

Curm.1.20.2

Serm.2.5.7\%

Sirm.1.10.30

Serm.1.0.17

lipist.1.0.3

Sirm.2.5.51

Curm.3.2705

(iurm.2.4.11

lipist 1.18.78

tirs Poch.182

Serm.1.1117

lepist.1.18.97

Epist.1.3.11

trs 10ut.275

Sirm.1 10.53

Sirm.1.5.04

irs foutso

Irs lonet. 230

Irs Pod.220

lifit.2.1.100

les l'uet. 05

Irs loct.23I

(urm.2.1.9

lepist 2.1.08

f.pist.2.2.120

Serm.2-3.53

Serm.2.6.75

Corm 3.3.15

coniciorm.3.5.13

Serm.2.8.55

Curm.3.5.15

Fpod 2.01

Carm.1.15.1

Sirm 1.10 .70

Carm.4.2.34

ist. Corm.3.25.t

Sirm.1.1.34

Sirm 1.2.59

Sorm.1.0.2.3

1ur.. Sirm. 2.3.53

Sirm. 5.110

Sorm.2.0.20

IEpist.2.1.191

(arm.1.t.2

(ar) 2.18.8

Carm.3.24.10)

lipist.14.17

Sorm.2.3.20

virm.2.3.49

form.2.1.57

Jiptst.1.18.102

carm.18.12

(a)m.t. 50

Serm.t.0.1s

lopist 1.10.51

depest.1.10

J.pist 1.1127

Serm.2.282

(corm.1.30.1

:sr. lopst 1.6 .50 
transfuga. transfuga divitum partis linquere gestio, transiliat. ac ne quis modici transiliat munera Liberi, transiliunt. si tamen inpiae non tangenda rates transiliunt vala. transire. servos differtum transire forum populumque iubebat. transit. hic neret aera liber Sosiis, hic et mare transit translatos. Hen heu, tranklatos alio maerebis amores. iransmutat. transinutat incertos honores. transuanta. 'ter uncti|transnanto Tiberin. ttansverso. incomptis adlinet atrum|transverso calamo signum. transvolat. importunus enim transiolat aridas/quercus nam/transvolat in nedio posita et fugientia captat."

Trausius. "iure" inquit "Trausius istis/inrgatur verbis;

Travius. 'iure' inquit 'Trausius [Travius] istis'iurgatur verbis; traxerim. pocula Lethaeos ut si ducentia somnos arente tauce traxerim. traxit. traxitque vagus per pulpita vestem

Trebati. Trebati, quid faciam? praescribe." nisi quid tu, docte Trebati, dissentis.'

Treboni. 'deprensi non bella est fama Treboni'

trecenis. non. si trecenis quotquot eunt dies, ! anice, placts. . . tauris, trecentae. amatorem trecentae/Pirithoum colsibent catenae.

irecentis. non. si trecenis [trecentis] quotquot eunt dies, anice. places . . tauris.

Fortasise trecentis aut etiam supra nummorum milisus emptum

trecentos. 'huc adpelle'; 'trecentos inseris'; 'ohe, ian satis est.'

trecentos cippus in agrum lic dabat.

tremenda. Dardanas turris quateret tremendalcuspide pugnax -

tremendae. cecidit tremendae flamma Chimaerae,

tremendis. arcis|Alpibus inpositas tremendis/deiecit

tremendo. nec tremendo/ luppiter ipse ruens tumultu.

trementi. pauperi... neque iratos trementi|regun apicrs

trementi. ut haec trementi questus ore

irementis. acqunris nigri fremitum et trementis/verbere ripas.

insurgat Aquilo, quantus altis montibus|frangit trenentis ilices;

iremis. altercante ibidinibus tremis ossa pavore.

tremit. et corde et genibus tremit.

tremor. donec nuanibus tremor incidat unctis.

tremulo. et cantu tremulo pota Cupidinem/lentum sollicitas.

trepidant. sordidum flammae trepidant rotantes/vertice tumum.

trepidare. quid obliquo laborat|lympha fugax trepidare rivo?

inagisque lexanimes trepiclare.

irepidat. euhoe, recenti mens trepidat metu

ridetque, si mortalis ultra|fas trepidat.

quam quae per pronum trepidat cum nurmure rivom?

trepidavit. cuius octavon trepidavit actas/elaudere lustrun.

trepides. nec trepides in usum/poscentis aevi panca:

trepidet. quanto trepidet tumultu/pronus Orion.

irepidis. vitamque sub divo et trepirlis agat in rebus.

trepidum. Indus enim genuit trepidum certamen et iraus,

res. tres nihi convivae prope dissentire videntur

ires. thesauro [tres auro] invento qui mercennarius agrum | illum ipsum mercatus aravit,

tria. si plostra ducental concurrantque foro tria funcra,

tria. milia tum pransi tria repimus

tribuens. nec tamen hoc tribuens dederin quoque cetera:

tribuit. seu pluris hiemes seu tribuit luppiter ultimam.

tribulis. ut cum pileolo soleas conviva tribulis.

tribunal. vir bonus, omne forum quem spectat et omne tribunal.

tribuno. guo tibi. Tilli.|sumere depositum clavom fierique tribuno? quod mihi pareret legio Romana tribuno.

tribuno. hoc, hoc tribuno militum?"

tribus. divitiasque habeo tribus amplas regibus." tribus ursis quod satis esset;

tribus. tribus aut novem $\mid$ miscentur cyathis pocula commodis.

saepe tribus lect is vileas cenare quaternos.

cena ministratur pueris tribus

saepe notatus|cum tribus anellis,

tribus, si tribus Anticyris caput imamabile numguan / tonsori Licino conmiserit.

tribus. granmatica- ambire tribus et pulpita dignor:
Carm.3.16.23

Carm.1.18.7

Ciurm.1.3.24

lipist 1.0 .50

Ars Poct.3.45

lipod 15.23

Curm.3.29.5t

Sirm.2.I.8

Ars Podtat7

Carm.4.13.9

Sirm.1.2.108

Sirm.2.2.09

irst. Sorm.2.2.90

fipod. 4.4

Ars Pott.2 15

Sirm.2.1.4

Serm.2.1.78

Serm.1.4.1 It

Corm.2.IA.5

Carm.3.4.79

Fur. Carm.2.14.5

Epist.2.2.10.4

Serm.1.5.1 2

Sirm.1.8.1 2

Curm.t 0.7

Corm.4.2.15

Carm.4.14.12

Carm.I.I6.I I

Corm.3.21.19

Ispod.5. I 1

Carm.3.27.23

lipod.10.8

Sirm.2.7.57

Cttrm.1.23.8

Ispist.r.16.23

Cirm.4.13.5

Carm.4.11.11

Cirm.2.3.12

Serm.2.6.114

Carm.2.19.5

Carm.3.29.32

Epist.1.10.21

Carm.2.4.23

Carm.2.II.4

Carm.3.27.17

Carm.3.2.5

Epist.t.19.48

Epist.2.2.61

Tar. Sirm.2.6.1

Serm.1.6.43

Sorm.1.5.25

Sorm. I 10.5

Carm.r.1 4

Epist.1.13.15

Epist 1.16 .57

Serm. I.6.25

Serm.1.6.48

Fpod.4.20

Sirm.2.2.10I

Epist.1.15.35

Carm.3.19.11

Sermi.1.4.86

Serm.1.6.116

Serm.2.7.9

Ars l'oet.3oo

lipist.1.19.40 
tributim. atelus mmares populi aripust pupulunque trabutim,

Sirni.2.1.00

tributum. atpha primores popnli arripuit populumque tributin [eributum].

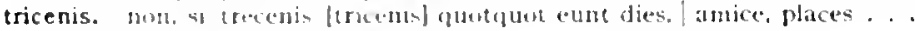
ใ.แ⿰纟:

tricesima. how tre tecima siblbat:

iur.Serm.2.1.00

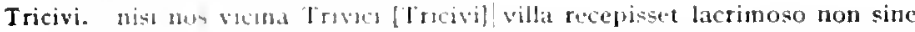
it)

iar.Carm 2.14 .5

Sermitiog(r)

sor.Serm.1.5.79

trienem. 4 le quancunce remota est, watia, quil superat? poteras dixisse."

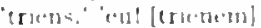

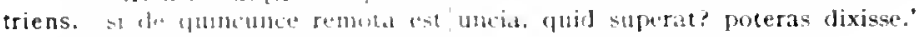
'trints:

triformi. va mbigatus te triformi legasus expediet Chinacra.

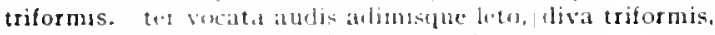

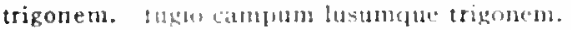

trilibrem. lathlas, msiant, trulderema mullum.

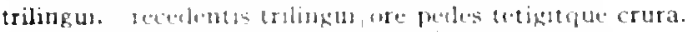

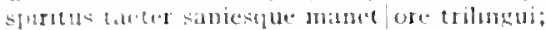

trima. fluate velut hat is engua trma campus

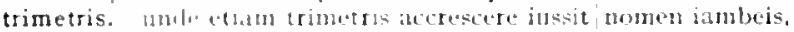

trimetris. hle et in . Ice nobihbus trimetris adparet rarus

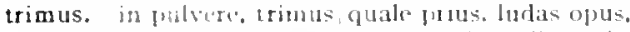

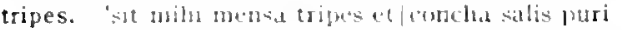

triplex. illi robut et ates triphex circá pectus erat.

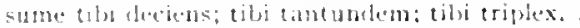

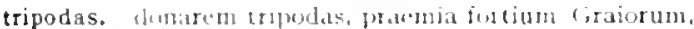

Triquetra. malthens formissa Iriquetra pratedia Cibesar in est Itala tellure liat tutu:

triremi. Heceollt inethat criromi

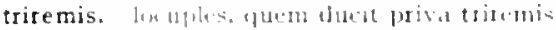

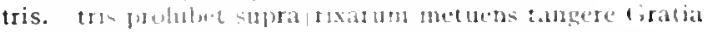

triste. nomplat math tatum mahi triste.

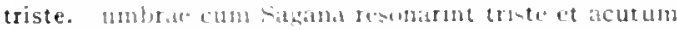
ath triste budental nuverat incestus:

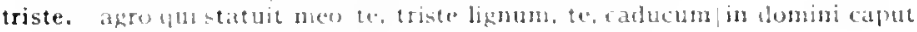

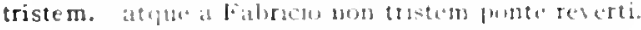

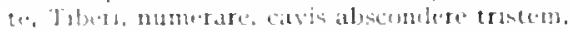

111. comatiate mblu kel- et ancedere tristem

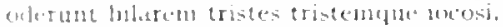

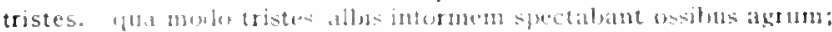

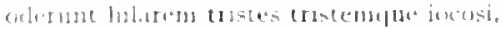

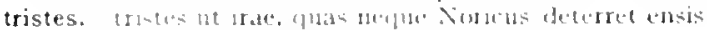

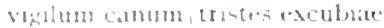

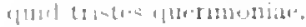

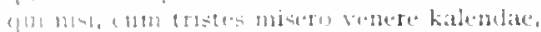

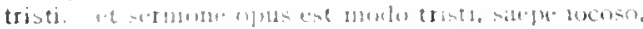

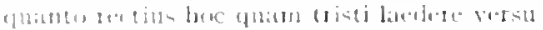

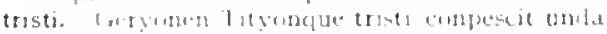

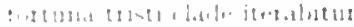

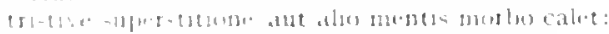

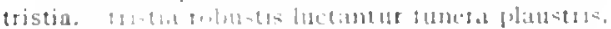

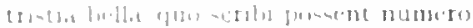

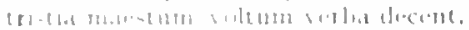

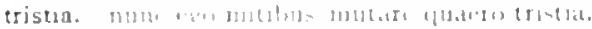

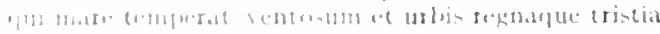

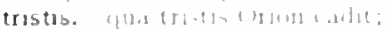

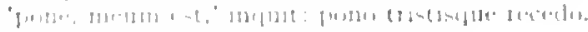

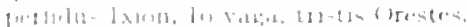

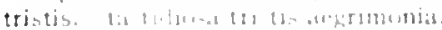

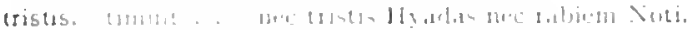

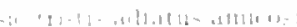

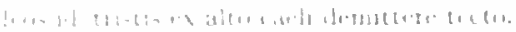

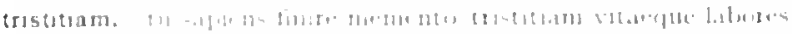

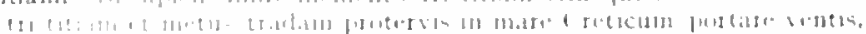

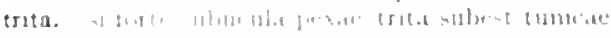

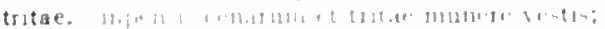

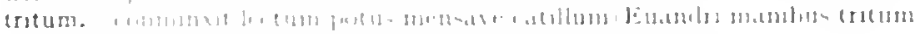
$+1 \cdot 1+\cdots, ?$

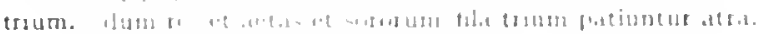

iur. Ars P'od.328

Ars Poot 328

Carm.1.27.23

Carm.3.22.4

Scrm.1.0.120

Serm.2.2.33

Carm.2.10.3 I

Carm.3.11.20

Carmi3.11.es

Ars l'oet. 252

Ars l'uet 250

Sirm.2.3.251

Serm.1.3.13

Carm.1.3.0

Serm.2.3.2.37

Carm.4.8.3

Serm.2.0.55

Carm.3.1.30

Lepist.1.1.0.3

Corm.3.10.15

sermi.1.4.20

Sirm.1.S...1

Ars Pentels I

Carm.2.1,3.11

Serm.2.3.313

Serm.2.3.173

Bepost.1.1.10

leptatisto

Sirmal.8 I5

lopistidising

Carm.111.0)

carm.3.34.3

carm-3.2.4-3.3

sirmaldist

Sirn.1.10.11

Sirm.2.1.21

Cirm.2.3. 8

carm.3.3.62

Sirm.2-3.70

IEpist.2.2.7.4

Ars Prut.7.3

Ars Indidus

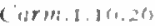

Carm.3..t pe

l. pont.tusus

1.pry.1.10.3.5

Ars lued 124

1.pontio $7.7,3$

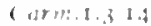

(itrm.1.7.2.8

termes 5.1103

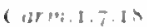

firm.t.zer

l.pord.1.1 us

d.post.1.11, 3s

Sirmit.3.1)1

(arm.2.3 36

conrtgend as 
triumphales. funus atque imagines/ducant triumphales tuom

triumphatis. triumphatisque possit Roma ferox dare iura Medis.

Triumphe. io Triumphe, tu moraris aureos $\mid$ currus io Triumphe, nec I ugurthino parem | bello reportasti ducem

triumphe. tteque. dum procedis. 'io triumplee' non semel dicemus, "io triumphe"

triumpho. Parthos Latio imminentis/egerit justo domitos triumpho privata deduci superbo. non humilis mulier, triumpho. cui laurus aeternos honores|Delmatico peperit triumpho. arsit Atrides medio in triumplıo virgine rapta, clari giganteo triumplio.

triumphos. hic magnos potius triumphos, /hic anes dici pater superbos/vertere funeribus triumphos:

triumphus. quos opimus| fallere et effugere est triumphus.

triumviralibus. 'sectns flagellis hic triumviralibus

triverit. milia frumenti tua triverit area centum:

Trivici. nisi nos vicina Trivici|villa recepisset

triviis. ne velut innati triviis ae paene forenses

triviis. occuram in trivis, deducam.

in trivis fixum cum se demittit ob assem.

nec semel inrisus triviis attollere curat/fracto erure planim.

Trivuci. nisi nos vicina Trivici [Trivuci]/villa recepisset lacrimoso non sine fumo.

Troas. male feriatos/ Troas et laetan Priami choreis/falleret aulam.

trochi. indoctusque pilae discive trochive quiescit.

trocho. Iudere doctior, / seu Graeco iubeas trocho, seu malis vetita legibus alea.

Troia. di tibi dent capta classem redducere Troia.

Troiae. filium dicunt Thetidis sub lacrimosa Troiat funera. avitae tecta velint reparare Troiae.

Troiae renascens alite lugubri|fortuna

Troiae prope victor altat| Pthius Achilles.

haud ita Troine/me gessi, certans semper melioribus.'

qui domitor Troiae multorum providus arbes/et mores hominum inspexit captae post tempora Troiae

Troiae. Thessalosque ignis et iniqua Troial castra fefellit.

Troiam. Troiamque et Anchisen et almae/progeniem Veneris canemus. cui per ardentem sine fraude Troiam

Troiana. quamvis clipeo Trobana retixo/tempora testatus

Troiani. Troiani belli scrintorem, Maxime Lolli.

Troianum. nee genino bellum Troianum orditur ab ovo;

Troica. invisun nepotem.| Troica quem peperit sacerdos.

Troico. digme scripserit aut pulvere Troico nigrum Merionen

Troilon. nec inpubem parentes/Troilon aut Phrygiae sorores/ Hevere semper.

tropaea. potius novalcantenus Augusti tropaea Causaris

truces. quid omnum/voltus in smum me truces?

ira truces inimicitias et funchre bellum.

truci. qui fragilem truci|conmisit pelago ratem, primus:

truci. neque excitatur classiso miles truci

trucidas. verum seu piscis seu porrum et caepe trucidas.

trucidet. ne pueros coram populo Medea trucidet

truculentior. ar est trucnlentior atque plus atquo liber:

trudit. trudit acris hinc et hine multa cane/apros.

ebrietas. - spes iuhet esse ratas. ad proelia trudit inertem.

truditur. truditar dies die

trulla. iests potare diebus Campana solitus trulla

truncis. truncis, lapsa cavis iterare metla; quid Rinotus evolsisque truncis

truncus. me truncus inlapsus crebro olim truncas cran ficulnas, inutile lignum,

trutina. hat lege in trutina fonetur cadem.

si. . . Romani prosantur eadem scriptores trutina,

Épod.8.12

Carm.3.3.43

Epod.9.21

I.pol.9.23

Carm.t.2.49

Carm.1.2.50

Carm.1.12.5t

Carm.1.37.32

Carm.2.1.10

Carm.2.4.7

Carm.3.1.7

Carm.1.2.49

Carm.1-35.4

Carm.4.4.52

Epod.4.I 1

Serm.1.1.45

Serm.1.5.79

Ars Poet.245

Serm.1.9.59

Ejtist.1.10.64

Epist.1.17.58

var.Serm.1.5.79

Carmt.0.15

Ars Poet.3so

Carm.3.24.57

Sirm.2.3.19I

Curm.1.8.14

Curm-3.3.60

Corm.3.3.t) I

Carm.4.0.3

Sirm.2.5.18

Epist.1.2.19

Ars Poet.1 I

Cirm.1.10.15

Curm.4.15.3I

Carm.Saecot 1

(arm.1.28.1 I

Epist.1.2.I

Ars Ioet.147

Carm.3.3.32

Carmito.14

Carm.2.9.10

Carm-2.9.19

Lpend.5.4

Epist.I.I9. 19

Carm.1.3.10

Epod.2.5

Epist.1.12.2I

Ars Pott.185

Sirm.1.3.5i

Epod.2.31

fipist. 15.17

Carm.2.18.15

Sirm.2.3.1.4t

Curm.2. ID.I I

Curm.3.4.55

Curm.2.17.27

sirm.1.8.1

Sirm.1.3.72

L.pist.2.1.30

tu. Carm.1.2.33;1.7.17; 1.9.10:1.10.17;1.11.1; 1.12.51;1.12.58;1.12.59;1.13.1;1.1\%15;1.15.29; Carm.1.20.10; 1.26.1 ; 1.28.23; $1.20 .13 ; 2.0 .22 ; 2.8 .5 ; 29.9 ; 2.12 .0 ; 2.12 .21 ; 2.18 .17$;

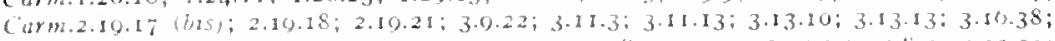
Corm.3.20.9; 3.21.2; 3.21.1.3; 3.21.14: 3.21.17; 3.25.11; 3.29.25; +3.1; 4.8.4; 4.11.21:

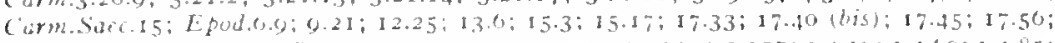
Sim.1.1.10;1.1.27; 1.1.86; 1.2.74; 1.3.19;1.3.21; 1.3.134; 1.3.137; 1.4.19;1.4.00; 1.4.85; 
Srm.1 1.38;1.0.110;1.0.49:1.0.(0);1.0.75;1.10.52;2.1.78;2.1.80;2 2.20; fror.Serm.2.3.13;

Scrm $2.332 ; 2.3 .7 ; 23.67 ; 2.3 .50: 23.128 ; 2.3 .132 ; 2.3 .134 ; 2 \cdot 3 \cdot 138: 2.3 .155: 2.3 .175$ (bis);

Serm:2 3177 (bis); 2.3.182; 2.3.185; 2.3.190: coni.Serm.2.3.234: Serm.2.3.235: 2.3.291;

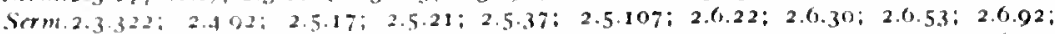

Serm.2.7.40:2.7.53; 2.7.75:2.7.81;2.7.305; F pist 1.2.2; 1.2.63:1.4.6; 1.5.30;1.0.23; 1.6.40:

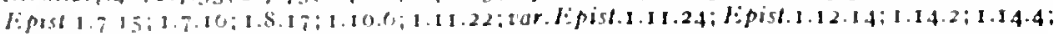

lepist I 1.4.10;1 1.41.4:1.1.425;1.14.41;1.16.17;1.16.27;1.16.32;1.16.53;1.17.19:1.17.21;

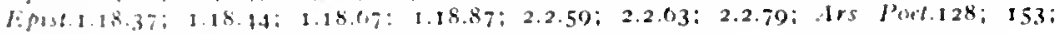

irs I

tua. that due retardeb intat mariess.

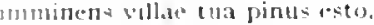

tua. Cacsar. actas fruges ct agris rettulu uberees

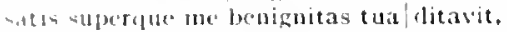

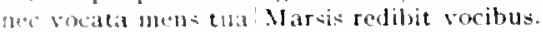

molia frumenti tha triverit area centum:

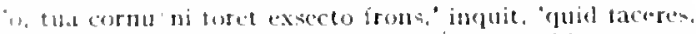

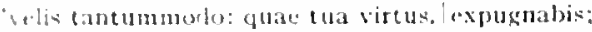

"แbi me vortus tua fecit asmicum.

nash tha res agitur, pirtes cun proximus ardet.

dum that navin in alto est.

mecpe parom earnen maicstas recipht tua

i bume. qua virtus twa te vocat, i pele fausto

tua cum this velos mored reni:

aratule sorte thas:

or manusegue tua latimus, Foromit, lyuphas:

ex parte tua seu fundi sive donus sit cmotor.

Juetus sorte thil vives sapienter, Aristi.

tua. (um tua me infortunia laedent.| Telephe vel Pelen;

tua. tua sectus orbis momina ducet."

cur tua plus laudes cumeris granaria nostris?

cum tuat perveleas oculis mala lipjous inunctis.

initurant vitia ut tua rursus et illi.

an tua dencrs rilibus in ludis dictari carmina malis?

"ui tua custodis, avidus iam haec auferet heres."

icride, magis aptátibi tua dona relinquam."

ne. tua lautabis studia aut aliena reprendes.

si longo sermone morer tua tempora. Caesar

it neque delecorant tua de se iudicia.

distat enim. spargas twa profligus.

quin sine rivili teque et tua solus anares.

tuae. Lactiaden, exitium tuae/gentis.

bate signat furet militiae tuac

nrat tuae sortis juvenem

multalitur bellum in twate spen gratiac.

tuae. non hoc pollicitus tuae.

crga birontis t"ut animus tuae/campos iusencar

halem noquitiac fige modum tuac:

?ucem redile tuat:- dux bone, patrias:

innperata tuace cuth venict pluma superbiat.

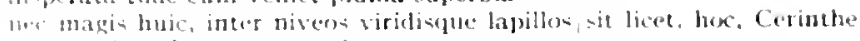
tan [thand thellerum e-s femur

tuae. that vexpre tugres indocili ingum|collo trahentes.

usule lorduace lymplace desilunt thae.

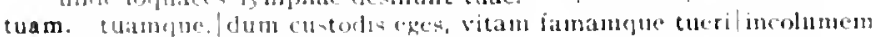
rent poleric servare tham.

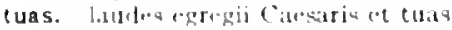

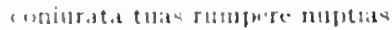

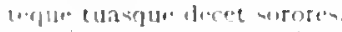

th.s', Auguate. virtutes in a.vorn . a acternet.

tubae. Letsos thbar. permixtus gomtut

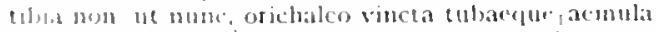

tubas. Maldma sonabil cotnuin quod vincalteuc tubas:

tuberibus. "f

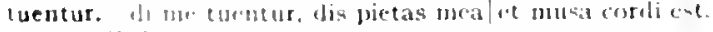

tuere. Ilithyll, turse matres.

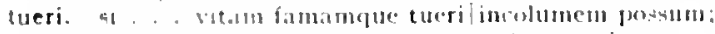

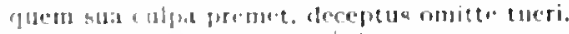

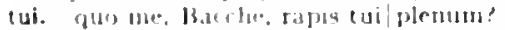

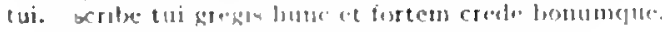

( $\operatorname{corm} .2 .8 .23$

Corm.3.22.5

Carm.1.15.4

Ligot.1.31

Fod.5.75

Sirm.1.1.45

Sirm.1.5.5\%

Sirm.1.9.54

Sirm.2.5.3.3

Jojst.1.8.8.4

Jpist.1.18.87

Epist.2.1.258

Epist.2.2.37

Carm.t.12.21

Epodials

Serm.1.5.2.4

Sirm.2.5.108

Fpist.1.10.44

Ars J'oet. 103

Carm.3.27.75

Simi.1.1.53

Srrm.1 3.25

Serm.1.3.28

Siem.1.10.74

Serm.2.3.15I

Epist.7.7.43

I:pist.1.18.39

Epist.2.1.t

Eist.2.1.245

Epist.2.2.195

les Pod.444

Carm.1.15.21

Carm.1.10

Carm +11.22

Epot.1.24

Corm.1.15.32

Corm.2.5.5

Carm.3.15.2

Carm.4.5.5

(idrm.tito.2

romi.sorm.1.2.s

Curm.3.3.13

(arm.3.13.10

Serm.1.4.117

Ars Port.329

Carm.toll

Corm.1.15.7

(iurm.1.26.12

corm.4.1.2

Cirm.1.1.23

ars Porl.202

Sirm.1.19..14

Sirm.1.373

(a)m.1.17.13

(iarm Sare 1 a

Sorm.1.18

Spite1.18 70

( arm 3.25. I

fisict.1.9 13 
tui. seu densa tenebit / Tiburis umbra tui

totum muneris hoc tui est,

tuis. supplicibus tuis|parcas,

pressa tuis balanus capillis

o quantus instat navitis sudor tuis

si ventri bene, si lateri est pedibusque tuis.

si prodesse tuis pauloque benignius ipsum|te tractare voles,

tuis. miseram tuis/dicens ignibus uri,

tuis capillus albus est odoribus.

tuis. cur me querelis exaninas tuis? tuis victus Venerisque gratae | vocibus

tuis. caementis licet occupes/terrenum onne tuis et mare publicum:

'teneas, Damasippe, tuis te' -

tuisque auspiciis totum confecta duella per orbem

tuleris. caelo supinas si tuleris manus

neque, | si chartae sileant quod bene feceris, | merceden tuleris.

tulerunt. mumera, quae multa dantis cum laude tulerunt

tuli. 'fortem hoc animum tolerare iubebo; ( et quondam maiora tulit [tuli].

tulisset. hos utinam inter heroas natum tellus me prima tulisset.

tulisti. saeram/militiam puer et Cantabrica bella tulisti|sub duce.

tulit. incomptis Curium capillis / utilem bello tulit et Camillum / saeva panpertas

unda fretis tulit aestuosis.

aetas parentum. peior avis, tulit | nos nequiores,

animae qualis neque canflidiores/terra tulit

et quondam maiora $t u l i\langle t\rangle$.

cadaver|unctum oleo largo nudis umeris tulit heres.

haec seges ingratos tulit et feret omnibus annis.

quem tulit ad scaenanı ventoso Gloria curru.

civilisque rudem belli tulit aestus in arma

et tulit eloquium insolitum facundia praeceps

omne tulit punctum, qui miscuit utile dulci

multa tulit fecitque puer, sudavit et alsit.

Tulli. ante potestatem Tulli atque ignobile regnum

Tulli. quo tibi, Tilli [Tulli],| sumere depositum clavom fierique tribuno? obiciet nemo sordis mihi, quas tibi, Tilli [Tulli],

Tullius. quo pius Aeneas, quo Tullus [Tullius] dives et Ancus,

Tullo. amphorae fumm bibere institutael consule Tullo.

Tullus. nos ubi decidinus/quo pius Aeneas, quo Tullus dives et Ancus. quo Tullus dives [dives 'Tullus] et Ancus,

tum. tunc [tum] nec mens mihi nec color/certa sede manent.

Caecubum et prelo domitam Caleno|tu [tum] bibes uvam:

cum violaria et inytus et omnis copia narium

tum spissa ramis laurea fervidos|excludet ictus.

cum [tum] populus frequens| laetum theatris ter crepuit sonum;

tu [tum] curva reeines lyra|Latonam et celeris spicula Cynthiae;

tunc [tum] ne... aura feret

tum meae. . . vocis accedet bona pars

nultae tibi tum officient res:

tum pueri nautic. pueris convicia nataelingerere

milia tum pransi tria repinus

convivas avidos cenam servosque timentis/tum rapere. . velle

tum inmundo somnia visu | nocturnam vestem maculant ventrenque supinum.

tum Praenestinus salso inultoque fluenti

casu tum respondere vadatol debebat.

quid? tunc [tum] rhombos minus aequor alebat?

tum pensilis ura secundas/et nux ornabat mensas

quid tum? venete frequentes.

caput abscissum demens cum portat Agaue!gnati infelicis, sibi unc

[tum] turiosa videtur?"

tum gener lioc faciet:

tum rusticus: "hand mihi vita|est opus hac" ait

tum Vibidius Balatroni| "nos nisi damnose bibinus, moricmur inulti,"

vertere pallor|tum parochi faciem

tum in lecto quoque videres

tum pectore aristo/vidimus et merulas poni

quid tum profeci. mecum facientia iura|si tamen attemptas?

tum tua me infortunia laedent.
Carm.1.7.21

Carm.4.3.2I

Carm.3.10.16

Carm.3.29.4

Epod.10.15

Epist.1.1 2.5

Epist.1.I7.I

Carm.3.7.10

Epod.17.23

Curm.2.17.1

Carm.4.6.21

Carm.3.24.4

Serm.2.3.324

Epist.2.1.253

Carm-3.23.1

Carm.4.8.22

Epist.2.1.240

var.Serm.2.5.21

Sorm.2.2.93

Epis'.1.18.55

Corm.I.12.42

Carm.2.7.16

Carm.3.6.40

Serm.1.5.42

Serm.2.5.2t

Serm.2.5.86

Epist.1.7.21

Epist.2.1.17

Epist 2.2.47

Ars Poel.2I 7

Ars Pod. 343

Ars Pod.41.3

Serm.1.6.9

zar.Serm.1.6.24

gar.Serm.1.6.107

7ar.Carm.4.7.15

Carm.3.8.1 2

Carm.4.7.15

Ear.Carm.4.7.15

\{ar.Carm.1.13.5

:ar.Curm.1.2o.Io

Carm.2.15.5

Carm.2.15.9

7ur.Carm.2.17.25

coni.Carm.3.28.1 I

zar.Carm.3.29.62

Carm.4.2.45

Serm.1.297

Sirm.1.5.I I

Serm.1.5.25

Sorm.1.5.70

Sirm.1.5.84

Serm.1.7.28

Sorm.1.9.36

tor.Serm.2.2.4s

Sirm.2.2.I2!

Sirm.2.3.230

:ur.Serm.2.3.301

Serm.2.5.60

Serm.2.0.115

Sirm.2.8.33

Serm.2.8.3r,

Serm.2.8.77

Serm.2.8.90

Epist.2.2.23

Ars loet.103 
tument. tument ubi cum inguina.

tumentes. "re rebe iratos et amet pacare timentis [tumences]:

Serm.1.2.110

tumentibus. emus tumenthbs exile suris aelditum.

rar.Ars loet.197

tumes. latulin inmerce tumis:

tumet. Aorvons aldwoli bile tumet iecur.

tumidas. 'funl regum tumialas contuderit mbias.

tumidi. cruh tunthlupe lavemut,

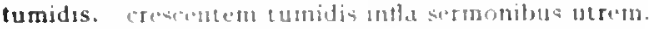

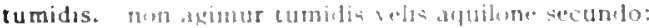

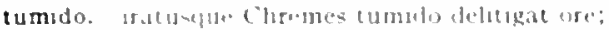

tumidum. Sek anmo "t purum est vallo tubi. cum tumidum est cor?"

tumidus. el11.t Lumulus rebat arva Nilus.

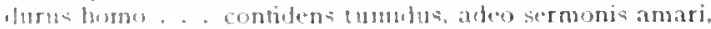

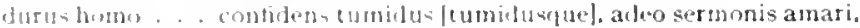

tumultu. nec tremonto luppiser iphe ruens cumultu.

nom sitles, ifuanto moveas periclo [tumultu], | l'yrrbe, Gaetulac catulos

leatstite:

quanto trepidet tomultu, prome orion.

mpor vistata lonenom tumultu| fanat

'qui species alias veris scelerisnu tumultus permixtas capiet.

tumultum. me tumultum nec mori ber vin metuam

scomachefue elsmulem lenta foret pitvita.

tumultuosum. tumultuosum sollicitat nare

tumultus. quat kta iert tumultus

tumultus. Ht mili salepe bilem, stepe jexum vestri movere tumultus?

eumultus. Hoque consulars submovet licer miseros tumuless mentis

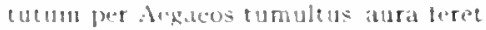

s.levat itgur movos moveat fortuna thmultus:

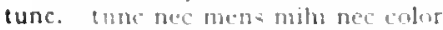

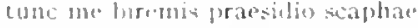

tunc morta cet snnus relapsus .

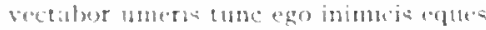

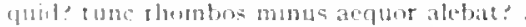

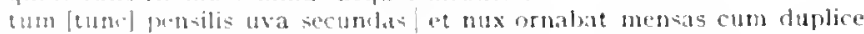
fict.

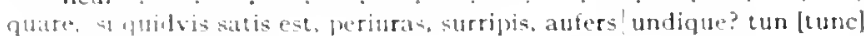
s.1 1111 ?

shbi tune turioa vilecur?"

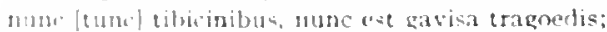

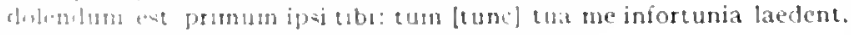

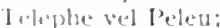

tundet. siliet, Lumlet pedie terram.

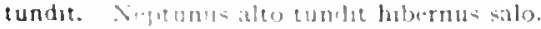

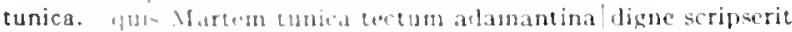

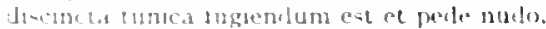

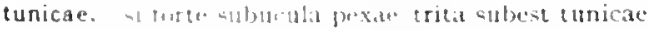

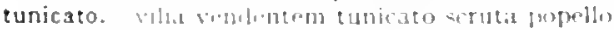

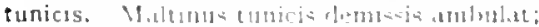

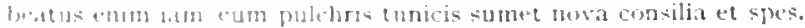

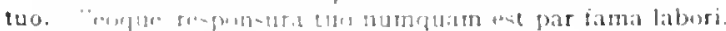

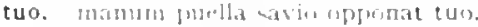

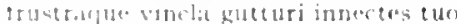

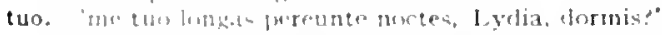

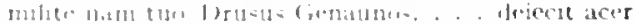

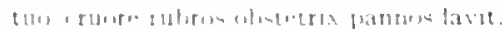

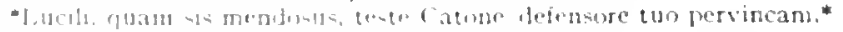

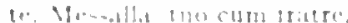

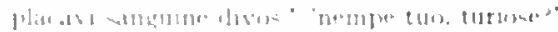

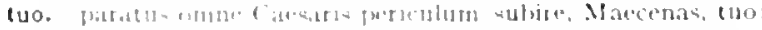

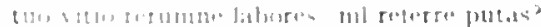

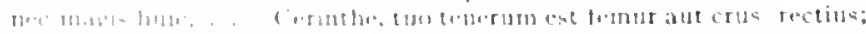

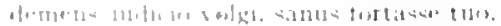

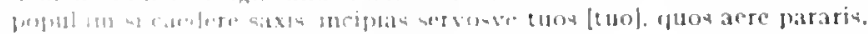

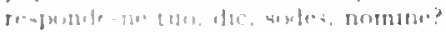

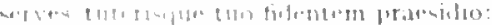

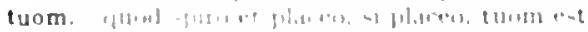

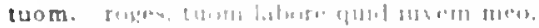

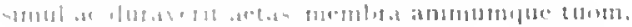

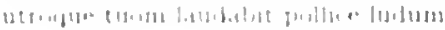

lipod.8.0

Fopist I.1.36

Carm.1.13.4

Carm.4.3.8

Epist.1.0.11

Sermi-2 5.08

l.pist 2.2201

Ars Joel.9.4

Sirm.2.3.213

Carm.3.3.48

Serm.1.7.7

iar.Serm.1.7.7

Carm.1.10.12

var.Carm.3.20. I

Corm.3.27.17

Corm.4.2.47

Serm.2.3.208

(itrm.3.1.14

Serm.2.2.75

Cism.3.1.26

Epod.5.3

Jistst.1.10.20

Corm.2.10.10

(i)rm.3.2063

serm.2.2 126

(arm.1.135

Curm.3.20.b2

fipold17. 17

Expol 17.79

Sorm.2.2.48

P121..Serm!.2.2.121

E'sr.5.rm.2.3.128

Sorm.2.3.304

I.etr.l.pist.2.1.98

seir..ters loed. 103

Ars Pines.1.30

lapold.1755

Cirm.tido.13

Sirm.1.2.1,32

lepistation

lipist 1.7.0.5

cirm.1.2.25

J. pist 1.18 .33

sirm 2.800

Epont 3.21

l.perd.17.72

Ciarmi.125.7

Ciurn.tide

lipod.17.50

Sorm 1.11). 2

Sorm.1 to.85

Strm 2.3.207

l:pind I...

Sirm 1270

serm.3.2.si

Serm 10.08

tur Serm: 2.3129

1. pest a per.31

l. pist 1.2א 81

( a) +32.4

I pist 15

cirren 1120

f. post t is.po 
tuom. pueri... numen cum teneris virginibus tuom|laudantes

Carm.4.1.26

Laribus tuom? miscet nunen,

funus atque imagines|ducant triumphales tuon

Carm.4.5.34

id crede tuon et vel nunc pete vel cras."

non ancilla tuon iecur ulceret ulla puerve.

iurandasque tuom per nurnen ponimus aras.

tuorum. operum hoc, milhi crede, tuorum est."

tuos. enim voltus ubi tuos|adfulsit populo.

tuosque venter Pactumeius et tuo / cruore rubros obstetrix pannos lavit. non tuos hoc capiet venter plus ac meus.

defendas, ut tuos est mos:

respondes, ut tuos est mos. | pauca:

ad mare descendet vates tuos

sed tuos bic populus sapiens et iustus in uno

eritque tuos nummorum milibus octo.

qui te pascit ager tuos est.

tuos. totve tuos patiar labores/inpune, Lolli, carpere

te consilium et tuos | praebente divos.

et tuolcruore rubros [? at tuos rubros] obstetrix pannos lavit, servosie tuos, quos acre pararis.

tura. hic/verbenas, pueri, ponite turaque

illic plurima naribus|duces tura

ciritas omnis dabimusque divis|tura benignis.

dum tlamma sine tura liquescere limine sacrol persuadere cupit.

turba. hunc. si mobilium turba Quiritium | certat tergeninis tollere homoribus,

illi turba clientium / sit maior:

quo clamor vocat et turba faventium.

quamque poetarm seniorum turba;

neque te ut miretur turba labores.

unguentarius ac Tusci turba inpia vici. . . mane domum veniant.

nam cetera turba, / nos, inquam, cenamus avis. .

turba. vos turba vicatim hinc et hinc saxis petens.

urgeris turba circum te stante

quemvis media erue turba:

extrabe turba|oppositis umeris;

luctandum in turba et facienda iniuria tardis.

turbae. neque se maiori pauperiorum|turbae conparet.

turbam. virgaque leven coerces/aurea turbam.

ut inpios. Titanas immanemque turbam fulmine sustulerit caduco

fugiens hic decidit acrem $\mid$ praedonum in turbam.

beluti te Iudaei cogenus in hanc concedere turbam.

ut praeco. ad merces turbam qui cogit emendas.

turbaret. turbaret thibernum mare

turbas. divosque mortalisque turmas [tutbas] imperio regit unus aequo.

turbatam. is neque lino turbatam haurit aquan

turbidum. qui vidit mare turgidum [turbidum] plenoque Bacchi pectore turbidum|lactatur.

turbidus. dux inquieti turbidus Hadriae.

turbine. fortur uti pulvis collectus turbine.

turbinem. citumque retro solve, solve turbinem.

Turbonis. corpore maiorem rides Turbonis in armis|spiritum et incessum:

turdis. aut amice levi rara tendit retia| turdis edacibus dolos

turdis. simul assis miscueris elixa, simul conchylia turdis.

turdo. cum sit obeso|nil nelius turdo.

turdos. lum turdos bersat in igni:

turdus. turdus sive aliud privom dabitur tibi.

ture. vocantis ture te multo Glycerae decoram transfer in aedem.

et ture et fidibus iuvat

si ture placaris et horna|iruge Laris

turgentis. quaecumque excepit turgentis verlera caudac/clunibus

turget. professus gramlia turget:

turgida. cui frons turgida cornibus/primis

turgida. contrahes vesto niunium secundolurgida vela.

turgidi. nee fuvii strepunt hiberna nive turgirli.

turgidum. qui virlit mare turgidum

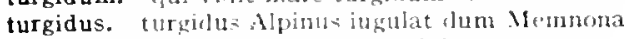

Turias. Cervius iratus lege's minitatur et urnam. . grande malum Turutrs [Turias].

Serm.2.3.232

Epist.1.18.72

Epist.2.1.16

Serm.1.7.35

Carm.t.5.0

Epod.17.50

Serm. I. I. 10

Serm. 1.4.95

Serm.1.6.60

Epist.1.7.II

Epist.2.1.18

Epist.2.2.5

Epist.2.2.160

Carm.4.9.32

Carm.4.1.4.33

7 iar.Epod.17.50

Sirm.2.3.129

Carm.r.19.14

Carm.4.1.22

carm.4.2.52

S.rm.1.5.99

Carm.1.1.7

Carm.3.1.13

Carm.3.24.46

Serm.1.10.67

Serm.1.I0.73

Sirm.2.3.228

Sirm.2.8.20

Epol.5.97

Scrm.1.3.135

Sirm.1.4.25

Sirm.2.5.94

Serm.2.0.28

Sirm.I.I.1 I

Curm.rio.19

Carm.3.4. 43

Sirm. I. 2.43

Sirm $1 .+143$

-1rs Poetitio

IEpod. 15.8

zar.Carm.3.4.47

Sirm. I. I.to

F'ar Carm 1.3.19

Carm.2.19.i)

Cirm.3.3.5

Sirmitis

lipod. 7.7

Sirm.2.3.310

Epot.2.34

Sirm.2.2.74

Epist.1. I 5.43

Serm.1.5.72

Serm.2.5.10

Curm.1.30.3

carm.t.3

Carm.3.23.3

Serm.2.7.49

Ars Pot.27

Carm.3.13.4

Carm.2.j0.21

Carm.1.12.4

Carm.1.3.10

Serm.1. I0.30

int. Serm.2.1.49 
turientis. quaceumute except turgentus [turientus] verbera caudae clumbus

turis. qual velint tures acera turis plena

Turius. mumatur. . grande malum Turims, suefuid se iudice certes.

turmae. barbarac postquan ceclete turmac

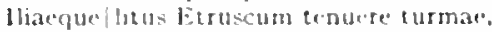

dum fugunt equitum turmae peditumeque catervae:

turmam. ut injus Titanas immanemelue tubam [turmand tuhuime sustulerit carduco

turmas. nec turmas equitum relinejuat

mortalisque curmas imperto regit unus aequo.

infuger hostium vexare turmas

turpsnt. te quia rugae turpant et captín nives.

turpsrunt. seu tibi candidos/turparunt umeros inmodicae mero|rixae

turpavera?. at illi foeda cicatrix sactosam laevi frontem turpaverat oris.

turpe. munacesturpe solum tetigere mento;

cum prosepserunt primin animalia tertis. mutum et turpe pecus,

gunl sit putcrum, quid turge, quid utile, quid non,

ne turpe toral, ne sordida mappa|corruget naris.

(xсcupet catremum scibles; mili turpe relingui est

turpe. vigilansne ploro turpe conmissum

interçue signa turpe militaria sol adspicit conopium

vel quia turge putant parere minoribus

turpem. introrsum turperd, speciosum pelle decora. .

surpem. necturpern seructam (logere nec cithara carentem.

aiguon censum iurpemque repulsam. quanto devites

sed turjem putat inscute metuitude laturan.

turpes. Juctunque turpes et (ุ)romoniat:

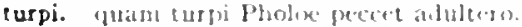

Costubi pastu videre ent ut nudam, ne cruse mabs, we st pede turpi:

a turpi meretricis anore ém recterreret:

iurpi. an eurpi clausus in area.

turpi. qui turpi sicernis honestum non patre pratelaro,

servatit ab sani non solam facto, verum opprebrio quogue eurpu

eripe turpi/colla iugo.

atu ignoratae premit arts crimine turpi.

turpia. anatorem quod amicate turpia decipiunt caecum vitia

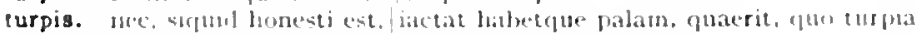
pelet.

turpios. Jente sigigro tieres vel uno turpior ungui.

turpis. milesne Crasia coniugo barbara|turpis maritus vixit

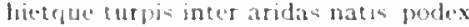

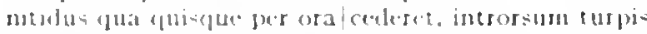

tuppe olestum caput obscurante larerna.

sub thombla nueretree fujece turpis et exeors.

rusticus urbane confusus. turpis lome-nets?

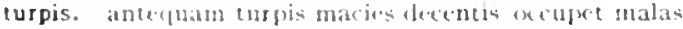

turpis. et uncta kurpin ova ranae alrguise

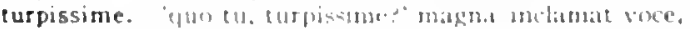

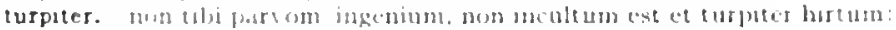

at eurgulet atrum desinat in piscem mutier formena superme:

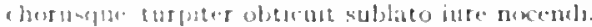

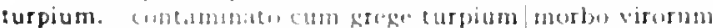

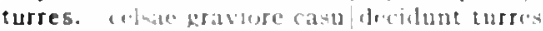

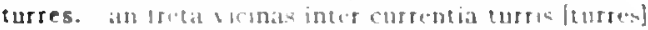

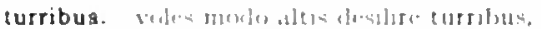

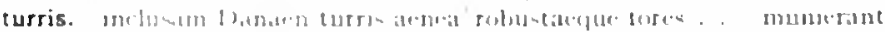

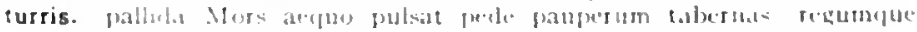
tursis

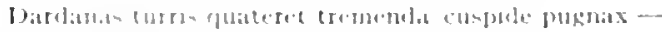

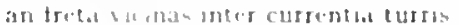

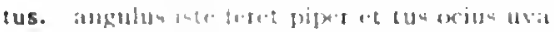

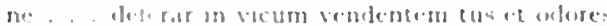

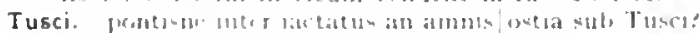

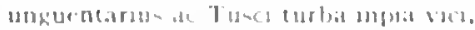

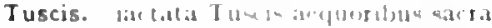

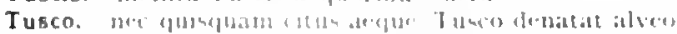

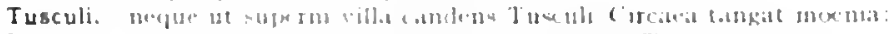

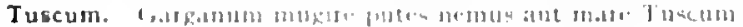

1.ar. Serm.2.7.40

Carm.3.8.2

Serm.2.1.40

C'arm.2.4.9

Carm.Saec. 38

I.pist.2.1.100

far. Carm. 3-4 43

Carm.2.10.22

Carm:3.4.47

Carm.4.14.23

Carm.t.13:12

Carm.1.13.10

Serm.1.5.c!

Carm.2.7.12

Serm.1.3.100

fisist.1.2.3

lipist.1.5.22

Ars Poct.417

Carm.3.27.30

Jipod.9. 15

Epist.2.1.84

I:pist.1.10.45

Carn.1.31.19

I:pest.1.1.43

Epist.2.1.167

Carm.2.2022

(arm.1.33.0

Serm.1.2.102

Serm. 1..4 111

Serm.2-7.59

Sorm.1.0.1.3

serm.1.1.84

Serm.2.7.01

- Its lued 202

Sorm.1.3.39

Sern:1.2.85

Carm.2.8.4

Carm 3.5 .6

1. pod 8.5

Sirm.2.1.05

Sorm.2.7.55

Esist 1.2 .25

- lers Jivel 213

Carm-s 27.53

l. poul 5.10

Serm.1 17.75

d.pst1.322

Ars I'orl.3

Ars linet.28s

(iarm.137.0)

(iarm.2.1011

iar 1.pas .1.3.4

Liped $1=70$

Ciam.3. 10.1

Cism $1 .+1.1$

(iarmato =

J.prst 1.3 .4

J.PIU.1 $1+23$

lipish.2.1.2(x)

Sorm $2+33$

Sirm 2328

(iarmid + 5.4

(nemb3 35

1. ponil. 10

fopt 2120 . 
tussiet. siquis|forte coheredum senior male tussiet.

tussis. nec laterum dolor aut tussis nec tarda podagra;

tuta. est et fideli tuta silentio/nerees:

tuta. senes ut in otia tuta recedant,

nimirum hic ego sum; nam tuta et parvola laudo.

tutae. quin, ex quo est habitus male tutae mentis Orestes.

tutela. te Iovis inpio tutela Saturno refulgens|eripuit

ad sanos abeat tutela propinquos.

rerum tutela mearum|cum sis

tutela. Deliae tutela deae,

o tutela praesens|Italiae dominaeque Romae.

tuter. ac ne forte roges, quo me duce, quo Lare tuter:

tuteris. serves/tuterisque tuo fidentem praesidio:

res Italas armis tuteris. moribus ornes,

tutetur. Plautus'quo pacto partis tutetur amantis ephebi.

tutior. iam Daedaleo notior [tutior] Icaro|visam gement is litora Bospori

tutior. tutior at quanto merx est in classe secunda.

tutis. quidquid habes, age, depone tutis auribus.

tuto. tutus erat rhombus tutoque ciconia nido.

tuto. ut tuto ab atris corpore viperis/dormiren

tutor. pater/silvane, tutor finium.

tutum. tutum per Aegaeos tumultusiaura feret

tutum. inpune tutum per nemus arbutos/quaerunt regnum et diadema tutum|deferens uni fore enim tutum iter et patens

tutus. tutus caret obsoleti|sordibus tecti.

tutus bos etenim rura perambulat.

cui male si palpere, recalcitrat undique tutus."

tutus ab infest is latronibus?

tutus erat rhombus tutoque ciconia nido,

me silva cavosque tutus ab insidiis tenui solahitur ervo."

serpit humi tutus nimiun tinidusque procellae:

tutus et intra|spem veniae cautus?

tuum. funus atque imagines|ducant triumphales tuom [tumin]

nee magis . . Cerinthe, tuo [tum tenerum est femur

nec magis.. Cerinthe, tuo tenerum est femur [? femur, Cerinthe, tuum]

Tydiden. ope Palladis|Tydiden superis parem?

Tydides. eece furit, te reperire atrox.|Tydides melior patre:

tympana. saeva tene cum Berecyntio|cornu tympana,

tympano. pulso Thyias uti concita tympano.

Tyndari. utcumque dulci. Tyndari, fistula

Tyndaridae. clarun Tyndaridae sidus

Tyadaridarum. at hune liberta securi divisit medium, fortissina Tyndaridarum.

Typhoeus. sed quid Typhoeus et validus Mimas

tyranni. matrona hellantis tyranni|prospiciens non voltus instantis tyranni.

tyranni. te... purpurei metuont tyranni.

invidia Siculi non invenere tyranni|maius tormentum.

tyrannos. regumque matres barbarorum et purpurei metuont tyranni [? purpureos tyrannos].

pugnas et exactos tyrannos/densum umeris hibit aure volgus.

tyrannus. sen tyrannus|Hesperiae Capricornus undae: . tenuisse Lirim, | late tyrannus - :

Tyrcaeus. post hos insignis Homerus / Tyrtaeusque [Tyrcaeusque] mares animos in $\mathrm{M}$ artia bella versibus exacuit;

Tyrceus. post hos insignis IIomerus | Tyrtaeusque [Tyrceusquel mares aninos in Martia bella! rersibus exacuit;

Tyriae. ne Cypriae Tyriaeque mercesladdant avaro divitias már:

Tyrias, et Tyrias dare circum inluta toralia vestis.

Tyriis. muricibus Tyris iteratae vellera lanae fui properabantur?

Tyrios. cum gemmis Tyrios mirare colores;

Tyrrhena, Tyrrhena regum progenits,

Tyrrhena. Tyrrhena sigilla, tabellas, . . sunt qui non habeant,

Tyrrhenum. quae nunc oppositis debilitat pumicibus mare/Tyrrlienum:

caementis licet occupes | terrenum [Tyrhenum] omne tuis et mare publicum [A pulicum]:

ne parva Tyrrhenum per aequor|vela darem.
Serm.2.5.107

Sirm.1.9.32

Carm.3.2.25

Sirm.1.1.31

Epist. I. I5.44

Sirm.2.3.137

Carm.2.17.23

Sirm.2.3.218

Efist.1.1.103

Carm.4.6.33

Carm.4.14.43

lipist.1.1.13

Epist.1.18.81

Epist.2.1.2

Epist.2.1.171

conicarm.2.20.13

Sirm. I 2.47

Carm.1.27.18

Sirm.2.2.49

Carm.3.2.17

lipod.2.22

Carm.3.29.63

Carm.1.17.5

Corm.2.2.25

Carm.3.10.7

Curm.z.10.6

Curm.4.5.17

Sorm.2.1.20

Sirm.2.1.42

Sirm.2.2.49

Sirm.2.0.11?

Ars Pott.28

Ars Poet.266

iar. Epod.8.12

sur.Serm.1.2.8 I

7 tar.Serm.1.2.8I

Carm.10.10

Carm.1.15.28

Carm.1.18.14

Carm.3.15.10

Carm.1.17.10

Carm.4.8.31

Sim.1.I.IO0

Carm.3-4.53

Corm.3.2.7

Curm.3.3.3

Curm.1.35.12

I.pist.1.2.58

8 iur.Carm.1.35.12

Carm.2.13.31

Carm.2.17.19

Corm.3.17.9

var. Ars Iod.to2

gar.Ars l'oet. $\$ 02$

Cirm.3.20.60

Sirm.2.4.84

Epod.12.21

lipist.1.6.18

Carm.3.20.I

Lipist.2.2.180

Carmbsists

far Carm.3.24.4

Carm. +5.3 


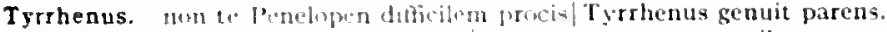

Tyrtaeus. punt hos insigmi- lomerns Tyrtaeusque . . versibus exacuit;

Tyrteus. most lins insignis lfomerns/Tyrtacusque [Tyrteusque] mares animos in Martia bella versibus exacuit:

Carm.3.10.12

Ars Poet.402

tysanarium. "Iscolum, sume hoc ptisanarium [tyanarium] oryzac [orize].'

\section{V'(vocal.)}

uber. questifue aliona capella gerat distentius uber.

ubera. mamma putres/equina quales ubera.

ubera. clatudenclue textis crotibus lactum [ecus/distenta siccet ubera répreque tenta grex amicus ubera

ubere. fulve matris ab ubere/iam lacte depulsum leonem

uberes. vinigue fontem lactis et uberes/cantare rivos.

uberes. Irteres agris rectulit uberes

ubi. pone ne pixtis ubi uulla campis, arbor aestiva recreatur aura,

barbaras sutic, ubi Maura semperlaestuat unda:

ubi non llymetto mella decedunt viridiqu certat|baca venafro. .

rer uhi Jongum tepidasque pracbet / lappiter brumas

ibi [ubi] tu calentem lebita sparges lacrina favillam/vatis anici.

quam cunis acer ubi lateat sus.

redit ubi ceresem tellus inarata quotannis

ubi auric invidia atcque vigent uli crimina:

ubi acris imvidia atque vigent uhi crimina:

ubi setuhts houpes pacne macros arsit

ubi passin palantis etror certo de tramite pellit.

ubi forst stultitia, hic simma est insania;

res ubi magma nitet domino sene:

hortus ubiet tecto ricinus ingis aquae fons

rubro ubi caceo tincta super loctos canderet vestis eburnos

exilis donluz as, ubj non et multa supersmet

est ubi plus tepeant himes, ubi gratior aura f leniat et rabiem Canis et nusinenta leonis.

ect ulgi divellat sommos minus invida cura?

interiun valgua rectum viclet, exst ubi peccat.

vertum ubi flura nitunt in carmine.

ubi. tund ubi fublicas res urdinaris.

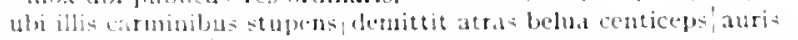

sol ulsi momesum motaret umbras

mex ubi lucit satis. "abstineto" / dixit

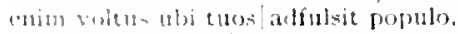

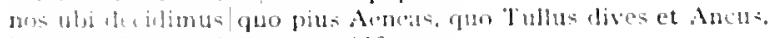

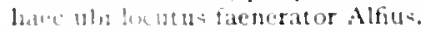

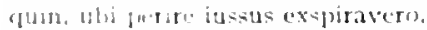

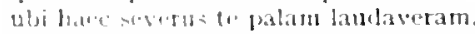

sub gsalli cantum consult or ubi ostia pulase.

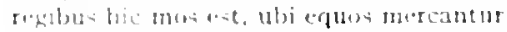

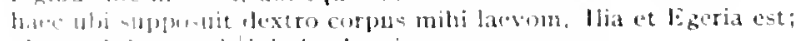

ubl puld Hatur oti, inlurlo chartis.

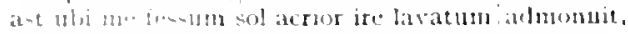

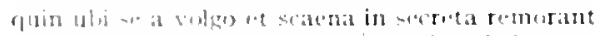

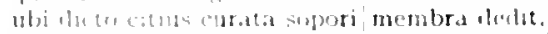

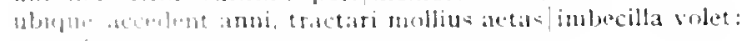

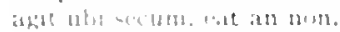

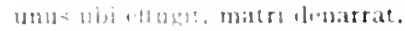

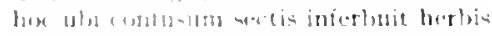

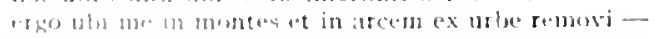

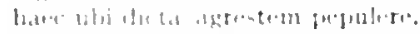

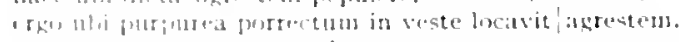

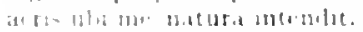

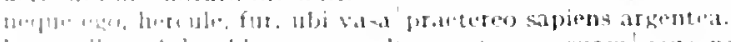

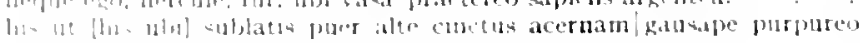

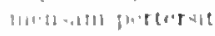

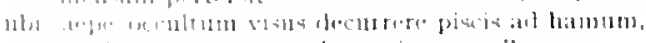

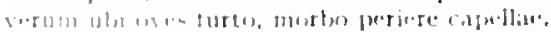

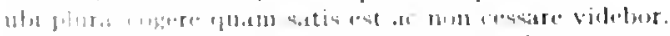

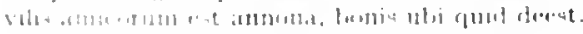

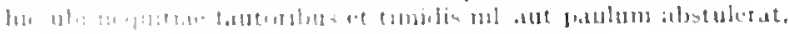

Serm.1.1.110

Ispod.8.8

Epod.2.46

Epod.10.5o

Carm.4.4.14

Carm.2.10.10

Carm.4.15.5

Carm.1.22.17

Curm.2.03

Curm.2.0.14

Carm.2.0.1 7

ar.Carm.2.6.22

Epod 12.0

I.pod.10.43

Sirm.1.3.00

Serm.1.3.01

Strm.1.5.7I

Sirm.2.3.48

Setm.2.3.220

Sirm.2.5.12

Serm.2.0.2

Sitm.2.0.102

List.1.1.45

Epist 1.10.13

Lipist.1.10.18

Lfist 2.1.13

Ars loct.35I

Corm.2.1.10

Carm.2.13.33

Carm.3.0.41

Corm.3 27.69

Cisrm.4.5.t)

Corm.4.7.14

fipol. 207

Epod 5.9

LPol.11.19

Sitm.1.1.10

Sirm.1.2.80

Sirm.1.2.125

Sirm.1.4.138

Sormitiol.125

Serm.2.1.71

Sirm.2.2.81

Sirm.2.2.84

Sirm.2.3.2!

Sirm.2 3.315

Serm.2.4.

Sirm.20.1es

Serm $2(1.07 \%$

sernizentopes

Serm.2.7...7

Sierm.2.7.72

Tat. Sitm 2.8.10

Epist. 1.7.7

lopitt.7.8.

Epist. I I U. 45

lopist 1.12.24

1. p.s. 1.15 .33 
ubi omne/verterat in fumum et cinerem.

Epist.1.15.38

verum ubi quid melius contingit et unctius,

quid volui?' dices, ubi quid te laeserit;

contrectatus ubi manibus sordescere volgi|coeperis,

I.pist.I. 5.40

Epist.1.20.7

Epist.r.20.1 I

ubi plenius aequo|laudat venalis qui volt extrudere merces: . . P . Pist.2.2.10
hic ubi cognatorum opibus curisque refectus!expulit elleboro morbum

ubicumque. sis licet felix, ubicunque mavis. .

bonam deperdere famam, rem patris oblimare malum est ubicumque. .

ubicumque locorum|vivitis, indigni fraternum rumpere foedus.

Carm.3.27.13

Serm.1.2.02

ubique. an tibi abunde/personam satis est, non illud, quidquid ubique officit, evitare?

captes astutus ubique / testamenta senum

ubivis. non ubivis coramve quibuslibet.

uda. argilla quidvis initaberis uda;

uda. uda mobilibus pomaria rivis.

uda. cum fugeret, tamen uda Lyaeo tempora populea fertur vinxisse corona

udam. coetusque volgaris et udam|spernit humum

udis. *qui multum puerum loris et funibus ussit [udis]|exoratus, *

udo. Ionius udo cum remugiens sinus| Joto carinam ruperit.

udo. sive iactatam religarat udo/litore navin.

nunc in udo|ludere cum vitulis salicto|praegestientis.

quis 11 do deproperare apio coronas|curatve myrto?

udos. udos cum folis ramos urente camino.

udum. nec semper udum Tibur et Aefulae/declive contempleris arvom

ucera. stultorum incurata pudor malus ulcera celat.

ulceret. mantica cui lumbos onere ulceret atque eques armos:

non ancilla tuom jecur ulceret ulla puerve.

ulcerosum. saeviet circa iecur ulcerosum/non sine questu.

Vlius. in me veniat mictum atque cacatum / Julius [Vlius] et fragilis Pediatia furque Voranus.

Vlixei. nec cursus duplicis per mare Vlixei laboriosa nec cohors Vlixei.

laboriosi remiges Vlixei.

remigium vitiosum Ithacensis V'lixei.

haud male Telentachus, proles patientis Vlixei:

Vlixen. inclitum Vlixen! et Nenelaum una mecum se occidere clamans." non ille aut Teucrum aut ipsum violavit Vlixen."

utile proposuit nobis exemplar V'lixen.

Vlixes. "quartae sit partis Vlixes"| audieris "heres":

Vlixi. remigium ritiosum Ithacensis Vlixei [Vlixi]. Telemachus, proles patientis Vlixei [Vlixi]:

Vlixis. remiginm vitiosum Ithacensis Vlixei [Vlixis],

Telemachus. proles patientis Vlixei [Vlixis]:

ulla. ulla si iuris ribi peierati|poena.

neque harum quas colis arborum . . ulla brevem dominum sequetur.

domus hac nec purior ulla est

neque ulla est | aut magno aut parvo leti fuga: .

non ancilla tuom jecur ulceret ulla puerve.

ullam. non fraudem socio puerove incogitat ullam|pupillo:

ulli. nee studio citharae nec Musae deditus ulli.

ullius. arcantm neque tu scrutaberis illius [ullius] umquam,

ullum. (cocto Chium sic convenit, ut non/hoc magis ullum aliud):

ullum. cui ... quando ullum inveniet parem?

ulmo. piscium et summa gerus haesit ulmo, opulentet ... pratis an amicta vitibus ulmo:

ulmos. platanusque caelebs evincet ulmos;

sulcos et vineta crepat mera, praeparat ulmos,

ulnarum. cum bis trium ulnarum toya.

ulta. male barbaras/regum est ulta libidines.

hoc delibutis ulta donis paelicem

quibus superbam fugit ulta paelicen,

ulti. quen nos sic fugimus ulti, .

ultima. ira fuit capitalis, ut ultima flivideret mors.

mors ultima linea rerum est.

principibus placuisse viris non ultima lats est.

ultima. qui numc lesperia sospes ab ultima columnas ultima recisas Africa

ultima. praeponens ultima primis.

ultimae. altis urbibus ultimae|stetere causae, cur perirent

Epist.1.3.34

Serm.1.2.60

Sirm.2-5.23

Serm.1.4.74

Epist.2.2.8

Cirm.t.7.I3

Carm.t.7.22

Carm.3.2.23

zar.Serm. I.Io.*5

Epod.10.19

Carm.t.32.7

Carm.2.5.7

Carm.2.7.23

Sirm.1.5.8 I

Curm.3.29.6

Ispist.1.10.24

Sirm.1.0.106

Epist.1.18.72

Carm.1.25.15

coni.Serm.1.8.39

Curm.i.6.7

Epod.10.60

Epod.17.16

Epist.1.0.03

Epist.1.7.40

Serm.2.3.197

Sorm.2.3.204

Epist I.2.18

Sirm.2.5.100

vitr. Epist.1.6.63

rar. Epist.1.7.40

iur. Ifist. I.0.03

sar. Epist.1.7.40

Carm.2.3.I

Carm.2.14.24

Sirm.10.49

Sirm.2.0.04

IEpist.1.18.72

Epist.2.1.122

Sirm.2.3.105

adr. Epist. I. I 8.37

Sirm.2.8.49

Carm.1.24.8

Curm.1.2.9

Epist.1.10.3

Carm.2.I5.5

Lpist.1.7.84

lipod.4.8

Carm.4.12.8

E pod.3.13

lipod.5.13

Sirm.2.8.93

Serm.1.7.13

Espist.1.10.79

l:pist.1.17.35

Carm.1.31.4

Cirm.2.18.4

Sirm.1.4.50

Cirm.I.1h.18 
ultimam. ueu pluris hemes seu tribuit Iuppiter ultimam,

Carm.1.11.4

ultimas. lutrende lase homen in thltinas/extentat oras.

ultimi. serves iturum Cacsirem in ultimos [ultimi]|orbis Britannos

coni Carm.1.35.29

ultimi. me. . Ultimi' noscent Geloni.

ultimos. Gerve iturum Caesarem in ultimos/orbis Jritanno

Carm.2.20.18

ultimum. val acribentis usque ad uleimum simuml forti sequenur pectere.

$\operatorname{Corm} 1.35 .29$

ultimum. osiege mecum tempus in ultumum

ultor. hilius Mabt, puticns vocari Caesaris ultor:

non eng, nobilium seriptorum auditor et ultor.

ultorem. lliote dum so" (ninitum) qu.rentiliactat ultorem.

ulera. Ot ul: r.t terminum curis vagot expeditis.

nihil wha nervos atque cutem morti concesserat atrae,

ultra limites clingtiuni salis avarus?

ridetulue, si mortais ultralfis trepidat.

quos ulera citrique nequit consistere rectum.

quod uitra jerfectums tratieretur.

ultralegent tendere opus:

ultra. neque ultra caeca timet aliunde fata.

anime quod ultra est oderit curart

quid ulta ctomelis?

hitra guan licet sperare nefas putando

ulera collidus ut soleat umeris portare viator.

rex cum." 'nil ultra guacto plebeius.'

ultr.i "non" "ttiam" sile"as;

est pubdan prodire tenus, si non datur ulta.

ulat quam satis 1.st virtus.m si fectat ipsam.

ne eto longis anbagibus ultra quam satis est morer:

nullum ulta wrbun aut optram insunebat inanem,

ultro. cervi. lugusum pracela rapacium, / sectamur ulto

beatua Fannius uleroldelatis capsis ot imagne,

pulcrior, ultro muneribus missis):

sed hic stilus haud petet ultro/quenquam animantem

'nec nume, cum me vocate ultro, accedan?

ulenl qui melierem andax voces in ius.

nlero Penclopan facilis potion trate."

uleril [ulero] "non" "ptiam" sileas;

ultos menctere velut neclior

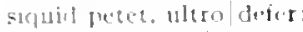

commonlua ultroiraseas et egere vetes et scribere cogas.

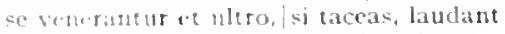

ultus. halirilia quon pacto cit Persiug ultus.

Vlubris. guod furets. bic est. est V'lubris.

ululantem. cmsn sitgana maine ululantem:

ulyis. num l.atutens malus est, ulvis "t harundine pinguis.

Vmber. Vinfor "e lipna rutritus glande rotundas curvit aper lances

umbilicum. arl umblicum adducere".

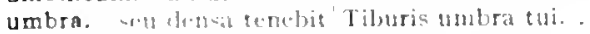

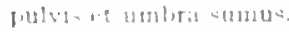

petimenu soluc umbra cursis ungubus.

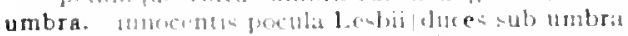

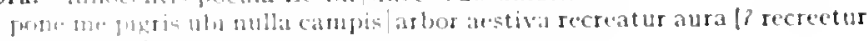
(18)

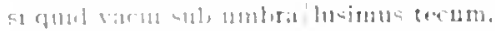

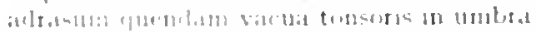

a

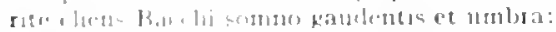

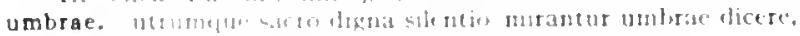

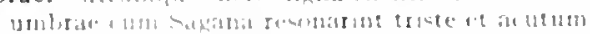

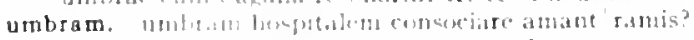

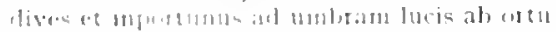

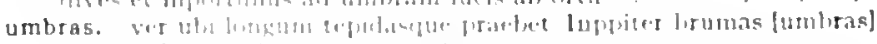

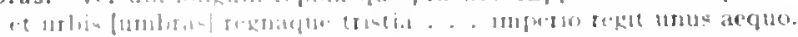

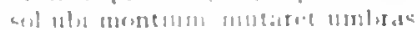

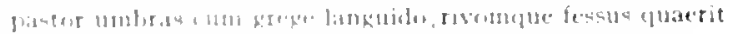

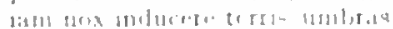

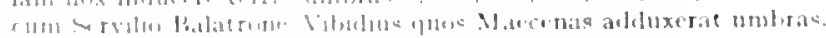

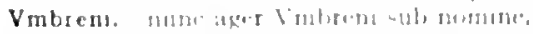

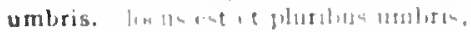

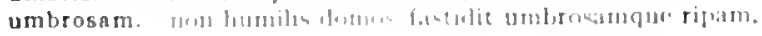

L pod 1.13

Curm.2.7.1

Carm.t.2.44

Fitist.1.19.39

Corm.1.2.18

Curm.1.22.10

Ciorm.1.28.12

Curm.2.18.24

Corm.3.29.3I

Serm-1.1 107

Sirm.1.1009

Serm.2.1. I

Curm.2.13.15

(arm!.2.10.25

Curm.2.18.32

Carm.t.1129

Sermit.5.80

Serm.2.3.188

Serm.2.5.90

Lpist.1.1.32

Epist.t.10

Epist 1.7.82

Ars Poet. 43

Carm.4.5I

Sotm.1.t21

Sirm.1.7.IT

Sirm.2.1.30

Sirm.2.3.262

Serm.2.5.28

Serm 2.5.75

rar Serm.2.5.90

Sirm.2.70

IFist 1.12 .22

Iipist.2.1.227

Lpist.2.2.107

Serm.1.7.2

Epist.1.1 + 30

s.tm.J.s.25

Serm.2.4.42

Sirm.2.+4n

F pod 14.8

carmet.21

(armation

Food 5.03

Carm.17.22

8:ar.Corm.1.22.18

(arm.1.32. I

Ifput 1.750

Tpist I. IT 10

lepist.2 2.78

Corm 21.3 .30

Sorm.1.8. 1

Curm.2.310

1 pist 2.2 .185

rese ( inrm 2.1 .18

enple cirm.3.4. 40

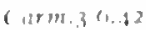

(iurm.32028

Sirm. 1.5.10

cirm.28.2

sirm.2 21.33

1. post 1.528

Cism 3123 
umbrosis. nunc et in umbrosis Fauno decet immolare lucis, umbrosis. aut in umbrosis Heliconis or is .

umeri. quid ferte recusent, | quid valeant umeri.

umeris. numquam umeris positurus arcum

et. quae nunc umeris involitant, deciderint comae.

umeris. densum umeris bibit aure volgus.

nec munus umeris efficacis Herculis|inarsit aestuosius.

vectabor umeris tunc ego inimicis eques

ultra|callidus ut soleat umeris portare viator.

cadaver/unctum oleo largo nudis umeris tulit heres.

extrahe turba oppositis umeris;

umero. non Chioris albo sic umero nitens

si reticulum panis venalis inter onusto|forte vehas umero,

umeros. nube candentis umeros amictus|augur A pollo;

tibi canfidos turparunt uneros inmodicae mero|rixae

per digitos umerosque plumae.

simul unctos Tiberinis umeros lavit in undis.

umerum. insignemque pharetra|fraternaque umerum lyra.

leni recreare vento/ sparsum odoratis umerum capillis.

umescit. seu quis capit acria fortis / pocula seu modicis uvescit [umescit]

umida. neque illi iam manet umida creta

Vmidius. ne facias quod/Vmmidius [Vmidius] quidam.

Vmmidius. ne facias quod|Vmmidius quidam.

umor. defluit saxis agitatus umor,

An umor et in genas/furtim labitur arguens.

umquam. ulla si iuris tibi peierati|poena, Barine, nocuisset umquam,

nec si resurgat centimanus gigasidivellet umquam: .

nec tantus umquam siderum insedit vapor

at siquid umquam tale concupiveris.

umquam nisi in dispar feris.

ut se|non umquam servo melius vestiret,

'nil fuerit mi' inquit 'cum uxoribus umquam alienis.'

rogabat | denique, cur umquam fugisset.

unius assis|non umquam pretio pluris licuisse.

nollem onus haud umquam solitus portare molestum.

nil mi officit.' inquam. [umquam]| 'ditior hic aut est quia doctior;

quos neque pulcer $\mid$ Hermogenes umquam legit .

credebat libris neque. si male cesserat, usquam [unquam]|decurrens alio haud umquam misera formidine privet?

in culpa est animus, qui se non effugit umquam.

qui metuens vivet, Jiber mihi non erit umquam.

arcanum neque tu scrutaberis illius umquam.

quae poterunt umquam satis expurgare cicutae.

aut nimium teneris iuvenentur versibus umquam

una. nunc lapides adesos / stirpisque raptas et pecus et domos | volventis una, quin corpus onustum/ hesternis vitis animum quoque praegravat una . grandes rhombi patinaeque grande ferunt una cum damno dedecus. et Menelaum una mecum se occidere clamans."

ludos spectaverat, una|luserat in campo:

sed quis cenantibus una. | Fundani, pulcre fuerit tihi.

unalcum scriptore meo... deferar in vicum .

una. sed omnis una manet nox.

vix una sospes navis ab ignibus

una de multis face nuptiali|digna

levis una mors est / virginum culpae.

cui satis una farris libra foret.

nil admirari prope res est una, Numici.

si virtus hoc una potest dare.

an venit in votum Attalicis ex urbibus una.

quid te exempta itrvat spinis de pluribus una?.

una. nequaquam satis in re una consumere curam.

hac in re scilicet unal multum dissimiles.

vel quia cuncta putas una virtute minora.

unam. nam de mille fabae modiis cum surripis unum [unam],

qui variare cupit rem prodigialiter unam.

uncia. si de quincunce remota e'st uncia, quid superat?

redit uncia, nuid fit?'|'semis.'

unco. dente si nigro fieres vel uno [unco]|turpior ungui.

uncta. fornix tibi et uncta popinalincutiunt V'rbis desiderium.

Carm.1.4.1 I

Carm.1.12.5

Ars Poe't.40

Carm.3.4.60

Carm.4.10.3

Carm.2.13.32

Epod.3.I 7

Ispod.17.74

Serm.1.5.90

Sirm.2.5.86

Serm.2.5.95

Carm.2.5.18

Serm.1.1.48

Carm.1.2.31

Carm.1.13.10

Carm.2.20.12

Carm-3.12.7

Carm.1.21.12

Carm.3.20.14

var.Sirm.2.6.70

Ispod.12.10

s'ar.Srm. I.1.95

Sorm_I.I.95

Carm.1.12.29

Carm.1.13.6

Carm.2.8.2

Curm.2.17.I5

Epod.3.15

Epod.3.19

Epod.7.12

Serm.1.I.97

Sirm.1.2.57

Sirm.1.5.68

Serm.1.0.14

Sirm.1.6.99

t'ar.Serm.1.9.50

Serm.1.10.I 8

zar.Serm.2.1.3 I

Serm.2.7.77

Epist.1.14.13

Epist.1.10.66

Epist.1.18.37

Epist.2.2.53

Ars Poet.246

Carm.3.29.38

Serm.2.2.78

Serm.2.2.96

Serm.2.3.198

Sorm.2.6.48

Serm.3.8.18

Epist.2.1.267

Carm.1.28.15

Carm.1.37.13

Carm.3.1 I.33

Carm.3.27.37

Serm.1.5.08

Epist.1.6.1

Epist.1.6.30

Epist.1.11.5

Epist.2.2.212

Sorm.2.4.48

Iepist.1.10.2

Epist.1.12.II

coni. Epist.1.16.55

Ars Pott.29

Ars Poet.328

Ars Poet.329

coni.Carm.2.8.3

Ipist.1.14.21 
uncta. uncta satis pingui ponentur lobluscula lardo?

uncta. arma nondum expintis uncta cruoribus.

el uncta turphe ora rante sanguime

unctam. We sic ut simplex Vacvius unctantconvisis pracbebit aquam:

uncti. lum lex" Assyrange nardolpotanus uncti?

"ter umeti trub manto Tiberin.

unctis. donte mandus tremor incikat unctis.

unctis. 1ubromit unctis omnium abilibus oblivione paelicum?

unctis. Puer guis a a ala capillis all cyathum statuetur unctis

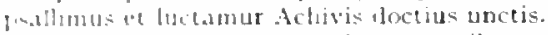

unctis. Wuef unctse tractarit calletm manbus.

unctius. verum ub quil melius comeingit et unctius.

uncto. 14 eanis a corio numaum abstertebitur uncto.

unctos. cimul unetos Therinis uncos lavit in undis.

unctum. dalas' unctum oleo largo nudis umeris tulit heres.

aecerles siccus a d unctur.

si vero t'st, unctum qui recte ponere possit

uncus. mex sobers uncu< abest liquiduntut plumbum:

unda. "t mimax, tqua sic voluere, pontolunda recumbit. birbiris syrtis, ubi Naura semper aestuat unda: unda fretis tulic aestuosis.

lectos lercelem alturius whe unila supervenit undam.

unda. Cryonen Titgunetue tristi compeste unda.

nee styegia colubelont undis.

mer Sicula balinuru- turtat.

gelialueum peluor unda per anediun frigus.

undae. tyrannus Hesperiate cubricormus undae:

undam. In res, horelem alteriss belut unda supervent undarn.

undas. Hock sublustri nhil andra fraeter vidit et undas.

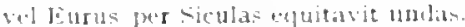

molomstas prope qualis umbas cxercet Auster

quxumque per umfas Notus socablt

unde. unde masum iuventus metu deorum eontinut?

minle r|llo s'ni?

qubbis ruos unse deductus get omneltempus

see! dubitus unde rumperet shlontium.

undw pretum he in me iacin?

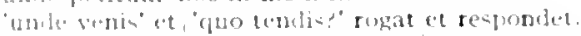

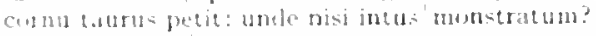

unde foutas atut qui partum?

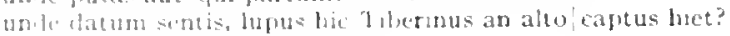

sold unde tatm bene me nosti?"

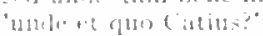

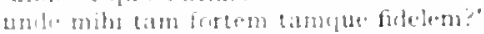

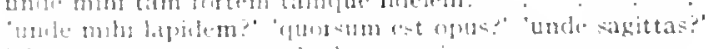

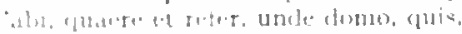

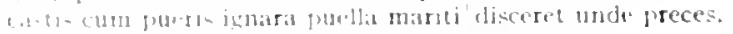

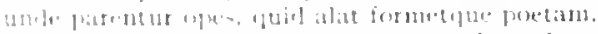

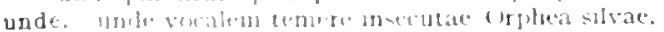

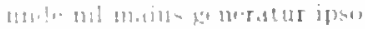

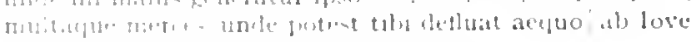

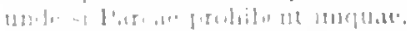

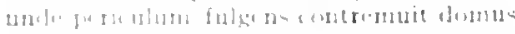

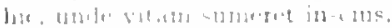

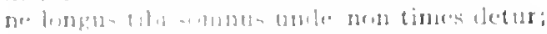

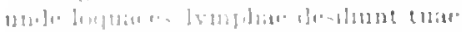

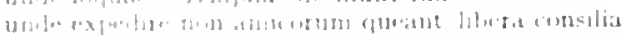

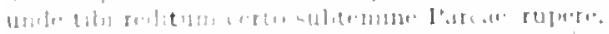

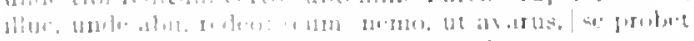

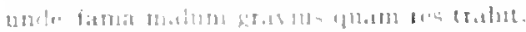

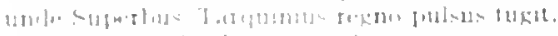

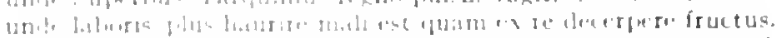

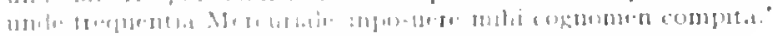

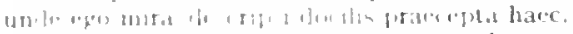

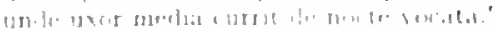

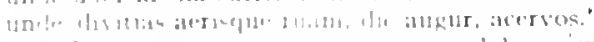

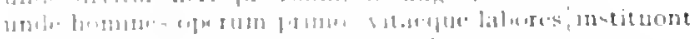

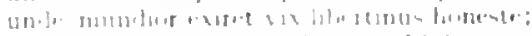

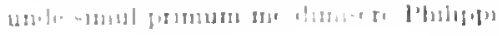

Sorm.2.0.64

Corm.2.1.5

Epod.5.19

Sirm.2.2.08

Carm.2.11.17

Sarmi2.1.7

E.pist.1.10.23

Epod.5.tes

Curm.1.29.8

LPist.2.1.33

Sitm.2.4.78

Epist.1.15.40

Sirm.2.5.83

Carm.3.12.7

Sitm.2.5.80

Lisist.1.17.12

Ars Port.122

Carm.1.35.20

Carm.1.12.32

Corm.2.0.4

Curm.2.7.10

Lipist.2.2.170

Curm.2.140

Curm.2.20.8

Cirm.3.+28

l.pist.1.15..

Carm.2.17.20

LPist.2.2.170

Carm.3.27.32

Carmatit4

Carm.14.20

C. poulde.21

(arm. 2.35 .30

Carm.3.27.37

Curm.t.19

F.pod.5.85

Sirm. I.4.70

Sorm. 1.0.1.2

Sirm.2.1.52

Serm.2.2.18

Sirm.2.2.31

Sorm.2.3.17

Serm.2..4. 1

Sorm.2.5.102

Serm.2.7.110

I.pste. 1.7.5.3

LPart. 2.1.133

- los loed 307

Corm.1.12.7

(i)m.1.12.17

(ium.1.28.28

(i)rmi.2. ().

(armit.12.7

carm.3.5.37

Cism.3.14.35

Cirm 3.13 .15

Lif foll a I $=5$

I.Pul. 1315

sitmitions

Sirm. 1.2.58

Sirm.1.6.12

Serm. 2.78

Sirm.2.3.25

Sirm. 2.3.3.3.3

Sirm.2.3.2.38

Sorm.2.5.2I

Sitm.: C.2 1

Sirn.2 201

Iffist.2.2.19 
unde pedem proferre pudor vetet ant operis lex.

irs Port.135

unde etiam trinetris accrescere iussit|nomen iambeis, . . . . Ars Poet.252

unde. mercedem aut nummos unde unde extricat.

unde. si et stramentis incubet unde-foctoginta annos natus,

Sirm.1.3.88

undenos. certus undenos deciens per annos/orbis. me quater undenos sciat inplevisse decembris,

Serm.2.3. I I 7

Carm.Saec.2 I

Epist.1.20.27

unde-octoginta. si et stramentis incubet unde-foctoginta annos nat us,

undique. undique decerptam fronti praeponere olivam;

Prometheus addere principi|limo coactus particulam undique/desectam coemptos undique nobilis/libros Panaeti

undique latius extenta visentur Lucrino/ stagna lacu

quam nalus undique membris/crescit odor.

congestis undique saccis/indormis inhians.

undique magno|pulsa domus strepitu resonet, .

rapit in ius; clamor utrimque, | undique concursus.

cui male si palpere, recalcitrat undique tutus.' .

delirus et amens| undique dicatur merito.

quare. . . periuras, surripis, aufers\}undique?

sibi dum requiem, dun risus undique quacrit,

varias inducere plunas. | undique collatis menbris

Sorm.2.3.117.118

Carm.1.7.7

Carm.1.10.14

Carm.1.29.13

Corm.2.15.2

Ifpod.1 2.7

Serm.1.1.70

Serm.1.2.1 28

Sirm.1.9.7s

Serm.2.1.20

Sorm.2.3.108

Serm.2.3-1 28

Epist.1.7.79

Ars Poit. 3

Carm.1.2.14

undis. retortis/litore Etrusco violenter und is me quoque devexi rapidus comes Orionis | Illyricis Notus obruit undis. sinul unctos Tiberinis umeros lavit in undis. neque vitam amittit in undis. nunc agilis fio et mersor civilibus undis, adversis rerum inmersabilis undis. naviget ac medis hiemet mercator in undis.

unguem. Capitoque simul Fonteius, ad unguem|factus homo. prave sectum stomacheris ob unguem praesectum decies non castigavit ad unguem.

Carm.1.28.22

Carm.3.1 2.7

Serm.I.I.60

Epist.1.1.10

Epist.1.2.22

EPist.1.16.71

Serm.1.5.32

Epist.I.I.TOA

Ars Pott.29.4

unguenta. huc rina et unguenta et nimium brevis|flores.. . ferre iube funde capacibus|unguenta de conchis.

unguentarius. unguentarius ac Tusci turba inpia vici. . . mane domum veniant.

unguentum. crassim unguentum et Sardo cum melle papaver foffendunt, . unguentum. i pete unguentum, puer, et coronas

unguere. unguere si caulis oleo meliore... coeperis

ungui. dente si nigro fieres vel uno|turpior ungui. .

incestos amores/de tenero meditatur ungui.

luctantis acuto ne secer ungui,

ungui. cur alter fratrum cessare et ludere et ungui praeferat

unguibus. sectis in iuvenes unguibus acrium

Rhoetum retorsisti leonis] unguibus horribilemque mala;

petamcue voltus umbra curvis unguibus.

unguibus et pugnis, dein fustibus atque ita porro|pugnabant armis

scalpere terram|unguibus

unguis. vivos et roderet unguis.

cultello proprios purgantem leniter unguis.

unguis lexprimet et mollis imitabitur aere capillos,

bona pars non unguis ponere curat, | non barbam,

unguit. gloria quem supra vires et vestit et unguit,

ungula. ut cum carceribus missos rapit ungula currus,

ungula. Vibent eques sonante verberabit ungula,

unguor. lectolaut scripto quod me tacitum iuvet, unguor olivo, .

uni. quam si... uterque Poenus|serviat uni.

diadema tutum' deferens uni proprianque laurum

uni nimirum recte tibi semper erunt res,

dissimulator opis propriae. mihi commodus uni.

uni. scilicet uni aequos virtuti atque eius amicis. ut nec pes nee caput uni reddatur formae.

uni. est locus uni|cuique suos."

unice. quid Tiridaten terreat, unicelsecuris.

unicis. satis beatus unicis Sabinis.

unico. unico gaudeas mulier marito

unius. consulque non unius anni,

unius assis non umquam pretio pluris licuisse.

uno. fide Teial dices laborantis in uno Penelopen vitreantue Circen;

Carm.2.3. 3

Carm.2.7.23

Serm.2.3.228

Ars Pot 375

Carm.3 14.17

Sirm.2.3.125

Corm.2.8.4

Carm.3.6.24

Epist.1.19.46

Epist.2.2.183

Carm.1.0.18

Carm.2.19.24

Epod.5.93

Serm.1.3.10I

Sirm.1.8.27

Sirm.1.10.7I

Epist.1.7.5 I

Ars I'oet.32

Ars Poit.297

Epist.I.I8.22

Sorm.1.1.II

Epod.16.I2

Serm.1.6.123

Carm.2.2.12

Curm.2.2.22

Serm.2.2.100

Epist.I.9.9

Sirm.2.1.70

Ars Potes

Serm. I.0.5 I

(arm.1.20.5

Carm.2.18.14

corm.3.1.4.5

Carm. $4.9 \cdot 30$

Sorm.1.0.13

Carm.1.17.19

Carm.2.8.3

dente si nigro fieres vel uno|turpior ungui,

Carm.2.11.10 
me Jibertina, nec uno'contenca, l'hryne macerat.

Epod.14.15

versuc lictabat stans pede in uno.

at Vurtus collega gradu post me sedet uno:

furte mbus locuples uno qualrante perisset.

quac s setnel urolde sene gustart tecum partita lucellum,

saprens uno minor est love, dives, liber.

iustu in unn te nostris ducibus, te Grais anteferendo

yus tejurlit manor uno mense vel antro.

suberet in tortis te siquis aviatior unn.

uno. verum hex ie amplectitur smo,

Villin in Fausta syllace gener, hoc miser uno nomine deceptus, poenas $1+0+1 ! t$

Caleet uno scribendi stuelio:

unquam. ms fuit unquam! sic inpar sibi.

crerlefbat hbris neque, si male cesserat, usquam [unquam], decurrens alio neque. si bene:

unum. sunt qubus unum opu* "st intactae Palladis urbem carmine pretpet110 colebrare

hoc wh medrocribua illis ex vitis unum;

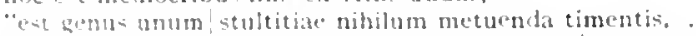

qual me stultitia, quoniam non est genus unum. insanire putas?

drongue sit quod vis, simplex dumbaxat et unum.

unum. qual omminm volus in unum me truces?

funum ex iuebibus selectis obiciebat"

"unum". (quid tam magnum?" ardens).

'unum me surquite morti!

ut unum scilicet egregii mortalem altique silents.

nam se mille tabae modis cum surripis unum. .

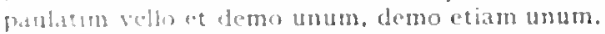

unum -1qua imicortam rst ausus reprobendete versum;

unum. Inacharn tor nocte potes, mihi semper ad unum mollis opus.

altus ac nos procinetis unum:

siquis emalt chtharas, emptas conportet in unum.

ver:us amat. hoc studiet unum:

unum. Li mon offenderet unum $/$ guemque poetarum limae labor et mona.

unum. naturae fess bumanae, mortalis in unm quodque caput,

unus. impertio regut unus aepuo.

namiplac sagacius unus odoror.

c qubus unus avet quavis aspergere cunctos|pracser eum qui praebet squam:

donte cerebrowis prosilit unus

Hacemilus ande comos alter.

sum pautin infronior, unus multorum.

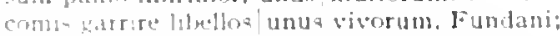

formos me rearier unus cum lucro noram:

unss utreque eror. sed varise inluest partibus:

$10014=11$, i effugit, matri denarrat.

st visler unus et alter insiratorem prarroso fugerit hamo.

umus ut e mult pojuln spectante referret emptum mulus aprum).

s.pumba. Clabli, nimirum intellogit unos./quanti me facias;

si viet-ra paulo concinnior wnus et alter.

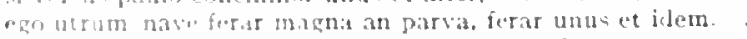

purpure: L, late qui splenteat, unua et alter adeutut pannus,

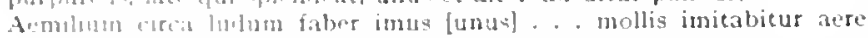
e.tphltio, molix operis cumma.

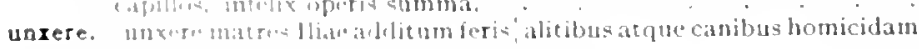

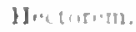

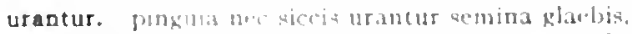

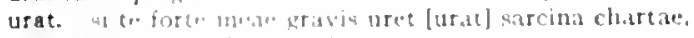

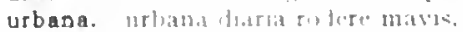

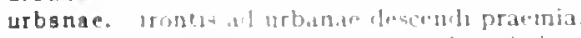

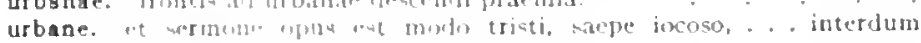
urb.un [urluane-1.

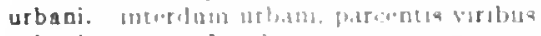

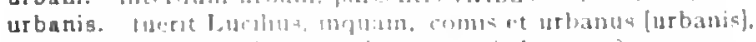

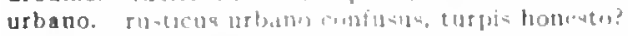

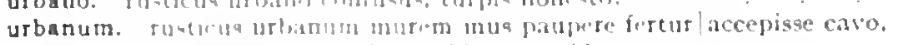

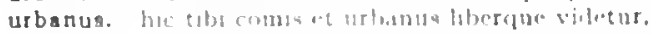

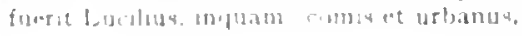

Serm.1.4.10

Serm.1.0.40

$S \sin 2.3 .93$

Serm.2.5.81

Lipist.1.1.106

lipist.2.1.18

Epist 2.1.40

Lpist.2.2.157

Serm.1.2.53

Serm.1.2.04

L.pist.2.1.108

Serm.1.3.18

Iar.Serm.2.1.31

Carm.1.7.5

Serm.1.4.140

Sirm.2.3.53

Serm.2.3.30I

Ars Plet. 23

lipod.5.4

Sorm.1.4.123

Sorm.2.3.282

Serm.2.3.283

Serm.2.0.57

Lpist.1 10.55

E.pist.2.1.40

Epist 2.1.221

F. Foul. I2.15

Serm.1.5.0

Sorm.2.3.10.1

Epist 2.1.120

Ars Podtizoo

Epist.2.2.188

Curm.3.4.48

Epod.12.4

Serm.1.4.87

Strm.1.5.21

Serm.1.0.101

Serm.1.0.7

Sem.1.10.42

Serm.2.3.2.4

Serm.2.3.50

Serm.2.3.315

S.rm.2.5.24

Epist.1.0.00

IEpist.1.0.1

lipist.2.1.7.1

Epist. 22200

irs Poes.15

2ar. Ars Poet. 32

Epoditi.t!

Lpod.10.55

rur.lipist 1.1.3.6

Epiet.1.14

Eprest 1.9.1

sar.Serm. 1.10 .13

Sern 1.10 .13

var.Serm.1.10.05

Ars loet 213

Som.2.1.80

Sorm.1400

Sorm.1.10.05 
tandem urbanus ad hunc "quid te iuvat" inquit. ut . . urbanus coepit haberi.|scurra vagus. dum studet urbanus tenditque disertus haberi.

Vrbe. mitte civilis super V'rbe curas: solos felicis viventis clamat in V'rbe. incolumis laetor quod vivit in V'rbe; flebit et insignis tota cantabitur Vrbe. bene erat non piscibus V'rbe petitis. rure ego viventem, tu dicis in V'rbe beatum:

urbe. incolumi love et urbe Roma? possis nilil urbe Roma|visere maius. in Mamurrarum lassi deinde urbe manenus. ergo ubi me in montes et in arcen ex urbe removi 'nullus in orbe [urbe] sinus Bais praelucet amocnis'

Vrbem. rubente/dextera sactas iaculatus arcis/terruit Virbem, piene vecupatam seditionibus/delevit Vrbem Dacus et Aethiops. per Vrbem . . fabula quanta fui.

Trbem leques sonante verberabit ungula. inpune ut Vibem nomine inpleris meo?

ille, datis vadibus qui rure extractus in V'rbem est. sic qui promittit civis. Vrbem sibi curae, |imperium fore at illae currere in Vrben.

garriret, vicos. Vrbem laudaret.

quod sale multo V'rbem defricuit.

vis tu homines lirbemque feris praeponere silvis?

absentem rusticus Vrbem|tollis ad astra

nunc Vrbem et ludos et balnea vilicus optas;

scriptorum chorus omnis amat nemus et fugit V'rbem.

urbem. intactae Palladis urbem/carmine perpetuo celebrare

iussa pars mutare Lares et urben|sospite cursu,

et sermone opus est modo tristi, saepe iocoso,... interdum urbani

[urbem].

postquan coepit agros extendere victor et urbis [urbem]| latior amplecti murus

urbes. urbesque gentesque et Latium ferox

urbes. iussa pars mutare Lares et urbem [urbes] / sospite cursu. multorum providus urbes et mores hominum inspexit scriptorum chorus omnis anat nemus et fugit Vrbem [urbes]. vicinas $n$ rbes alit et grave sentit aratrum. qui mores hominum multorum vidit et urbes."

Vrbi. V'rbi sollicitus times, ninatus Vrbi vincla. qui consulit et tibi et vrbi|Iuppiter.' . militiae quamquam piger et malus, utilis Vrbi.

urbibus. altis urbibus ultimae/stetere causae, cur perirent

urbibus. aut ille centum nobilen Cretam urbibus . an venit in votum Attalicis ex urbibus una,

Vrbis. concines lactosque dies et V'rbis|publicum ludum Vrbis aventes|moenia nocturni subrepere. fornix tibi et uncta popina|incutiunt Vrbis desiderium, me primis Vrbis belli placuisse domique. rerum |fluctibus in mediis et tempestatibus Vrbi

urbis. Amphion. Thebanae conditor urbis, / saxa movere urbis amatorem Fuscum salvere iubemus|ruris amatores,

urbis. invidiaque maior|urbis relinquam. .

qui mare temperat / ventosum et urbis regnaque tristia

dirus per urbis Afer ut Italas

pertulit Ausonias ad urbis.

volentem proclia me loqui victas et urbis.

et miseras inimicat urbis.

urbis|latior ansplecti murus.

urbium. diffidit urbium|portas vir Macedo si quacret Pater urbium/subscribi statuis, Romae principis urbium/dignatur suboleg

Vrbs. sua|Vrbs haec periret dextera?

urceus. amphora coepit /institui: currente rota cur urceus exit? .

urenda. neglectis urenda filix inmascitur agris.

urendos. ut ventres lamna candente nepotum / diceret urendos correctus Bestius.
Serm.2.6.00

Epist.1.15.27

Epist.1.19.16

Carm-3.8. I 7

Serm.1.I.I2

Serm.1.4.98

Serm.2.1.40

Serm.2.2.1 20

Epist.J.14.IO

Carm.3.5.12

Carm.Sacc. I I

Serm.1.5.37

Sirm.2.0.16

qur. Epist. I. I.83

(itrm.1.2.4

Carm.3.6.14

Epod.11.7

Epod.16. I I

Efod.17.59

Sirm.1.1.JI

Sirm.1.0.3.t

Sorm.1.8.t7

Sirm.1.9.13

Serm.1.JO.t

Sirm.2.0.92

Sirm.2.7.28

Epist.1.14.15

Epist.2.2.77

Curm.t.7.5

Curm.Suec.39

rar.Serm.1.10.13

iur.tirs Poet.208

Carm.1.35.10

var.Carmi.Saec. 39

Epist.1.2.19

i'or. Epist.2.2.77

Ars Poet.66

Ars Port.1.12

Carm-3.29.26

Epod.9.9

Epist.1.16.28

Epist.2.1.I 2.4

Carm.1.IG.18

Epotl.9.29

Epist.I.II-5

Carm.4.2.4I

Sorm.2.6.99

Epist.1.1.4.22

Epist.1.20.23

Epist.2.2.85

Ars Poet.39.1

Epist.1.10.I

Carm.2.20.5

Carm.3.4.40

Carm.4.42

Carm.4.4.56

Carm.t.15.2

Carm.4. 5.20

Ars Poet.208

Carm.3.16.13

Carm.3.24.27

Carm.4.3.13

Epoil.7.10

Ars Pott.22

Serm.1.3.37

Epist.I.I 5.37 
urens. nec sicana forvida/virens [urens] in Setma flamma:

var. Egod.17.33

urente. Hos am folis ramos urente camino.

urentes. navita Bospordm/ emptaho et urentis [urentes] hatenas/jitoris Asivrii vistor.

urentis. usentis havends litoris Assyrii viator.

urere. expest mollolus in pueris aue in puedlis urere. meum ine ur urere bilis.

ureset. mesiog forri pueros Achisis ureret flammis.

non ut superbos moldae Karthangis Romanus arces ureret,

ureris. Hretivipue minet:

"Haber pretiun, loris non uretis," ato.

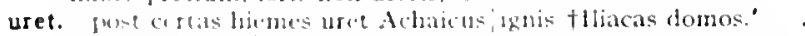

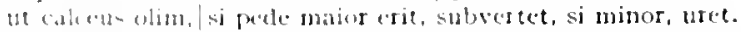

si to furte meate grive uret sirtrcind chartate.

urge. "dome "obe jam"|ad caelum manibus sublatis dixerit, urge:

ne print ufticio quspluan respondeat, urge."

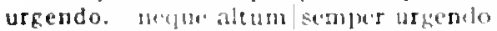

urgent. urgene ingavidi te Salaminius Teucer,

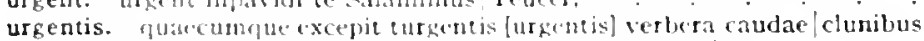

urgentur. mmas inlacrimabiles, urgentur ignotique longa|nocte.

urgere. anguctejule vagos piccis urgere catino.

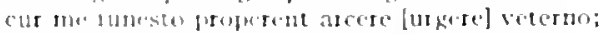

reges dicuntur mult is urgete culilis

urgeris. Hetris qurba circum te stante

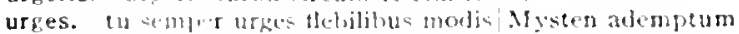

matratue Bais nbetrepentis urges submovere litora,

camen urgec iandorden non tacta ligonitus arva

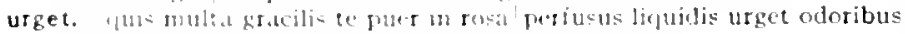

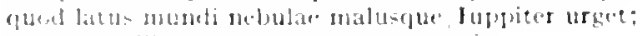

ren Cumpilium perpetuos sopor urget?

"whis burogn" priter urget atkens:

urgee diem nox at dies nesceds

atpue quanto perditior quisque est, tanto acrits urget;

has urget lupus, hac canis, atunt.

ue lectargicus he cum fit jugil et modicum urget."

wheter" inquit "tc malus angit [urget].

mprohus urget, iratis precibus:

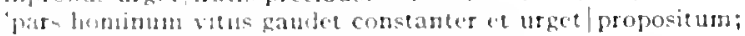

ureat inim dominus mentem mom lens

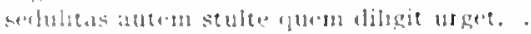

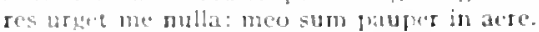

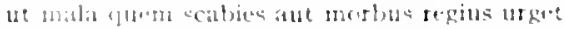

urgetur. Vhas memo sime nascicur; untimus ille ese qui misimis urgetur.

uri. min sou enistacens ignibus un.

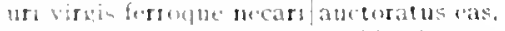

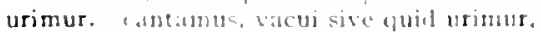

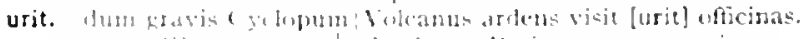

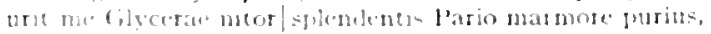

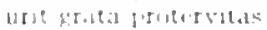

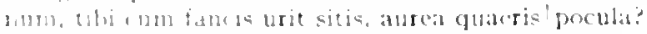

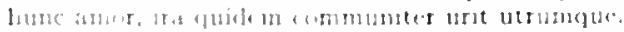

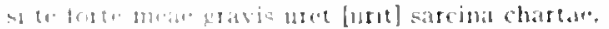

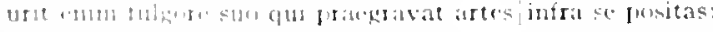

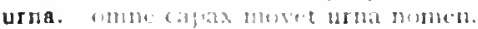

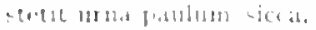

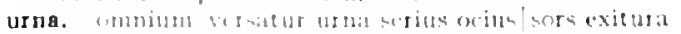

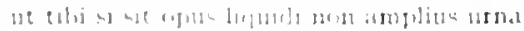

notre (

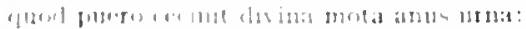

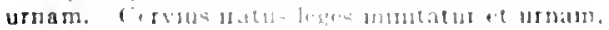

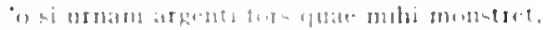

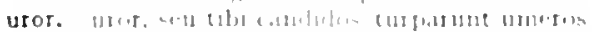

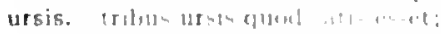

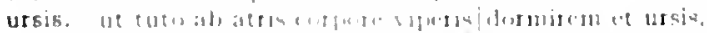

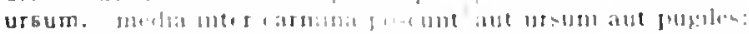

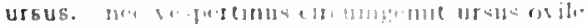

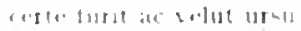

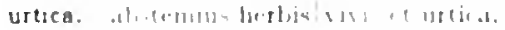

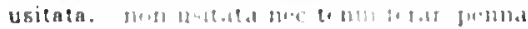

Sorm.1.5.81

Iar.Carm.3.+.31

Carm.3.4.31

Epod.11.4

Serm.1.9.86

Carm.1.19.19

Ejod.7.6

Fod.1.1.13

Fist 1.10.47

Carm.1.15-35

I.jist.1.10.43

Epist.1.13.6

Scrm.2.5.97

Sorm.2.0.2.4

Carm.2.10.2

Carm.1.15.23

vor.Sorm.2.7.49

Carm. 9.27

Sirm.2.4.77

sar.lepist.1.8.10

Ars locl. 434

Serm.1.3.135

Carm.2.0.0

Carm.2.18.20

Epist.1.20

Carmi.1.5.2

Carm.1.22.20

Carm.1.24."

Corm.3.27.57

1: pod.17.25

Sirm.1.2.15

Sitm.2.2.1.9

Sorm.2.3.30

tor.Sorm.2.3.39

Sirm.2.1.20

Serm.2.7.

Serm.2.7.93

Espist.2.1.200

Jipist.2.2.12

Ars I'oct..453

Sortr.1.3.19

Carm.3.7.1 1

Sirm.2.758

Corm.1.6.19

:ar.Corm.1.A.8

Corm.1.10.5

Cormino.

Sormi.1.2.114

1. fist 1.2.13

iar fopist 1.30

1. pist 2.1 .13

Cirm-3.1.11

Carm.3.1122

Cism.2.3.2\%

Sorm.1.5.

Serm.1.501

Serm! 1230

Sermiditi

Som $=4.10$

Cormition

Ifote.15.35

Com. 3.48

l.pit.2.1.15e

If podf Ires I

Irs Ped 172

1 fist I $12 \mathrm{~s}$

(arm.2 20 i 
usitatis. non usitatis, Vare, potionibus,

usquam. quilquid usquam concipitur nefas

non usquam prorepit et illis utitur ante/quaesitis patiens.

neque, si male cesserat, usquam/decurrens alio neque, si bene:

velut usquam/vinctus eas,

quodsi me noles usquam discedere.

neque fictolin peius voltu proponi cereus usquam

usque. defendit aestatem capellis|usque meis pluviosque ventos. aut mare Caspium | vexant inaequales procellae $\mid$ usque quid quonl usque proxinos|revellis agri terminos usque ego posteralcrescam laude recens,

post hoc secundis usque laboribus

vel occidentis usque ad ultimum sinum|forti sequemur pectore.

et inputata floret usque vinea.

novis ut usque suppetas laboribus.

ad usque/suprenum tempus

est quilinguen ad obscaenum subductis usque;

poenas dedit usque superque|quam satis est.

ab ovolusque ad mala citaret "io Bacchae"

at tu conclusas bircinis follibus auras, / usque laborantis, . . ut mavis, imitare

bic ego mendacem stultissimus usque puellan | ad mediam noctem exspecto;

via peior ad usque $\mid$ Bari moenia piscosi;

nunc mihi curtolire licet mulo vel si libet usque Tarentum, .

iamdudum video; sed nil agis: usque tenebo:

'nil habeo quod agam et non sum piger: usque sequar te.'

me/cum magnis vixisse invita fatebitur usque invidia

siquis ad illa deus subito te agat, usque recuses,

naturam expelles furca, tamen usque recurret

sed vocat usque suom qua populus adsita certis/limitibus

extremi primorum, extremis usque priores.

usque/sessuri, donec cantor 'vos plaudite' dicat:

ut scriptor si peceat idem librarius usque,

ussit. *qui multum puerum loris et Iunibus ussit exoratus,*

Vsticae. Vsticae cubantis|levia personuere saxa.

ustis. dux fugit ustis navibus

usto. cum Pallas usto vertit iram ab Ilio.

ustrina. ut Alfenus vafer onmi abiecto instrumento artis clausaque taberna sutor [ustrina tonsor] erat:

usu. inimice lamna|Crispe Sallusti, nisi temperato'splendeat usu.

usum. natis in usum laetitiae scyphis/pugnare Thracum est:

nec tregides in usum poscentis aevi pauca:

nescis quo valeat nummus, quem pracbeat usum?

Ofellum integris opibus novi non latius usum|quam nunc accisis.

sed cedet in usum nutc mihi, nunc alii.

invidet usum| lignorum et pecoris tibi calo argutus

usus. nee purpurarum sidere clarior delenit usus

pugnabant armis quae post fabricaverat usus.

quidve ad amicitias, usus rectumne, trahat nog

pauper enim non est, cui rerum suppetit usus.

qund legeret tireretque viritim publicus usus?

adsciscet nova. quae genitor produxerit usus.

quaedan. si credis consultis. mancipat usus:

sic quia perpetuos nulli datur usus

si volet usus. quem penes arbitrium est et ius et norma loquendi.

usus. natis in usum [usus] laetitiac scyphis|pugnare Thracum est:

quam cogere humanos in usus

usus. 'me Capitolinus convictore usus amicoquela puero est nemo desterius fortuna est usus.

ut. Carm.1.7.15;1.8.13;1.9.1; 1.14.3; 1.16.9:1.23.9:2.5.19:3.4.42:3.5.42;3.7.13:3.10.7:3.25.12; Carm.4.4.5; 4.5.9; 4.12.24; 4.14.29; Fpod.1.19; 1.33; rar.Epod.1.34; Efod.2.2; 4.9; Epol.5.9; 5.27; 5.83; 0.16; 9.7; 12.25; 13.11; I4.3: 17.77; Serm.1.1.23; 1.1.25; 1.1.46; Serm.1.1.54; 1.1.11; I.1.6.4; 1.1.90; 1.1.102; 1.1.108; 1.1.114; ? ior.Serm.1.1.119; Serm.1.2.38; 1.2.39; 1.2.55; 1.2.87; 1.2.102; 1.2.105;1.3.22; 7 ar.Serm.1.3.27; Serm.1.3.43; Sorm.1.3.46; 1.3.69; 1.3.79; 1.3.86; 1.3.89; 1.3.110; 1.3.11.4; 1.3.120; 1.3.130; 1.4.10; Setm.1.4.21; 1.4.00; 1.4.95; 1.4.102; 1.4.109 (bis); 1.4.126; 1.6.5; 1.0.0; 1.6.30; 1.0.49; Sorm.1.0.60; 1.6.79; I.6.86; 1.6.90; 1.7.16:1.7.27; 1.8.32; 1.8.42; 1.8.4.1; 1.0.5; 1.9.20; Serm.1.Q.42; I.10.t; 1.10.24; I.10.44; I.I0.55; 1.10.76; 2.1.17; 2.1.36; 2.1.50 (/75); 
Sorm.2.1.55; 2.2.1.8; 2.2.72; 2.2.76; 2.2.111; 2.3.28; 2.3.30; 2.3.31; 2.3.133; 2.3.215; Serm.2.3.2.1);2-3.255;2.3-315;2.1.13 (his);2.4.49;2.5.5;2.5.43(tor); 2.5.83;2.0.10; 2.0.15; Serm.2.0.57; i or Sorm.2.0.67; 2.7.79; Serm.2.7.82; 2.7.89; tar.Sorm.2.7.113; Sorm.2.8.1; Sorm.2 8.7; 2.8.13; 2.8.29; 2.8.30; 2.8.53; 2.8.58; 2.8.72; 2.8.84; 2.8.89; If ist.1.1.20; lipist 1.1.21; 1.1.71; 1.2.52; 1.3.12 (bis); 1.tr.Epist.1.6.31; Epist.1.0.40; 1.0.55; 1.6.57; lipist 1.7.10;1.7.71;1.7.49; 1.7.70;1.8.13;1.8.14 (bis); 1.8.17;1.10.10; 1.10.42; 1.11.1.4; l.p156.1.13.1; 1.13.13;1.13.14;1.13.15;1.16.33;1.17.3;1.17.18;1.17.40;1.18.3; 1.20.1.4; l.pist 2.1.3.t; 2.1.45; 2.1.5I; 2.1.172 (bis); 2.1.198; 2.1.213; 2.2.14; 2.2.30; 2.2.12.4; lesst 2.2.107; .Irs Porteco; 101; 136; 202; 232; 354; Iur.Ars Poct.355; Ars Poet.361; Ars Pod.374:419:431; 453

ut. I comicarm.1.12.31; Carm.4.427 Epod.3.9; 5.11; 7.19; 16.64; Scrm.1.5.15; 1.6.27; Serm.1.6.5\%; 1.0.13; 2.1.24; 2.2.128; 1dr.Sorm.2.4.9; coni.Serm.2.4.40; Serm.2.8.10; F. pist.1.7.72; 1.15.2\%; 1.19.3; 2.1.93

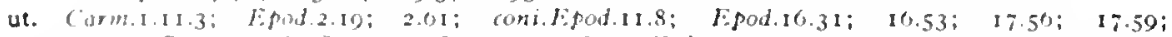
Fur. Sirm.1.1.88; Scrm.2.5.18;2.0.53; 2.8.62; Epist.1.18.10;1.18.17; 1.10.10

ut." Carm.1 1.13:1 15.4:1.20.5: 1.31.10:1.37.20; 1.37.27:3.1.9; 3.4.17:3.4.18;4.11.13;4.11.29: Carm 4.13.20; Carm.Sacc.22; Epod.1.25;1.29;7.5;7.7;7.9;8.19;10.3; 11.10; 17.27; 17.0.4; Sorm.1.1.1; 1.1.22; 1.1.20; 1.1.31; 1.1.57; 1.1.82; 1.1.96 (bis); 1.1.101; 1.1.117; 1.2.20; Sorm 1.2.45; iar.Sirm.1.2.49; Sirm.1.2.123;1.3.2; 1.3.28; 1.3.32; 1.3.51; 1.3.0.4; 1.3.115; Serm.1.3.120;1.4.13;1.4.32;1.4 100; 1.4.122; 1.5.33;1.5.90; Iat.Serm.1.0.31; Serm.1.0.70; Serm.1.7.8; 1.7.13; 1.8.28; 1.9.45; 1.10*0; 1.10.8; 1.10.3; 1.109;1.10.73; 2.1.32; 2.1.43; Sirm.2.1.80: 2.1.80; :ur.Serm.2.2.tz4; Sorm.2.3.1; 2.3.52; 2.3.54; 2.3.55; 2.392; 2.3 .122 ; Serm.2.3.1.45; 2.3.152; 2.3.183 (his); 2.3.1.55; 2.3.195; 2.3.205; 2.3.234; 2.3.240; 2.4.9.4; Serm.2.5.45; 2.5.53; 2.5.7\% 2.5.72; var.Sirm.2.5.87; Serm.2.0.5; 2.6.82; 2.7.4; 2.7.10; gor.Serm.2.7.0I; Serm.2.8.3; $28.48 ; 2.8 .67 ; 2.8 .69 ; 2.8 .94 ;$ Epist.1.1.27; 1.1.39; 1.1.67; F.pist.1.2.32; 1.2.33; 1.3.10; 1.5.25; 1.0.60;1.0.3; 1.11.24; 1.12.2; 1.12.8; 1.15.24; 1.15.30; 1.pist.1.10;1.10.12;1.17.20;1.18.13;1.18.48;1.18.67;1.18.80;1.18.107; 1.20.2; 1.20.17; I.pist.1.20 22; 1.20.25; 2.1.23; 2.1.05; 2.1.218; 2.1.220; 2.1.220; 2.2.44; 2.2.52; 2.2.71; IEpist 2 2.87; 2.2.80 (bis); 2 2.102; Ars Pont.3; 8; 12 (bis); 43; 144: 201; 237; 2.40; 255 ; Ars I'oel. $257: 335$

ut. Fopd.1.21; Sirm.1.409; Epist.1.2.10

ut. coni.lpist 2.2.109

utar. utar et "x modico, quantum res posect. acervo tollam

utare. an numquam utare piratis? -

utcumque. uecumigue fulct. Tyndarı. fistula

utcumpue mutato potentis, veste domos inimica linquis,

ibimus, ibinus, ' utcumque praecedes,

utcumgue mecum sos eritiq.

utcunique Aefocere nores.

utcumque fortis exsilis puerpera."

uter. videamua uter phoseribere possic."

uterne arl casus clubios fulut sibi certius?

uter rest insibior horum?

net adilis fueritue vestum prator,

viret uter frecuples sine gnatis.

peccat uter nostrum conce dignius?

tractus uter phris lejores, uter educet apros;

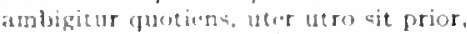

were. libertate decembri.l quando ata maintes voluerunt, utere: . his utere mecum.

utere Pompero Grosploct, siguid petet, ultroldefer:

uteris. vorifuc uteris per clisos fumina hamas.

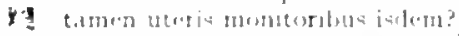

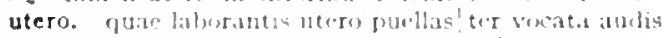

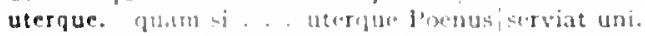

magnua uterque timot latronibus;

miqui miknu do ro bua uterpue legati.

velim memores at fus jotte thatus uterque/contulerit litis.

magnum spectacilium uto.tpur.

-e hame utinam Viacorum lisdace uerque.

guare per divos oroleda atergue Penatis

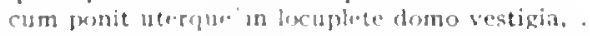

atultua uerorie lixum bmeritum calusitur inique:

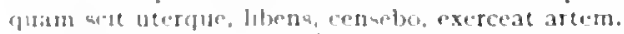

cubst hic in colbe Gurm. / hic extrmo in Aventino. visendus uterque:

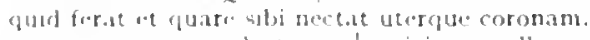

cum pauper et exald uterquelprocit ampullata.

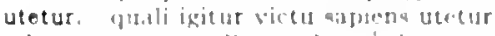

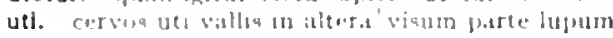

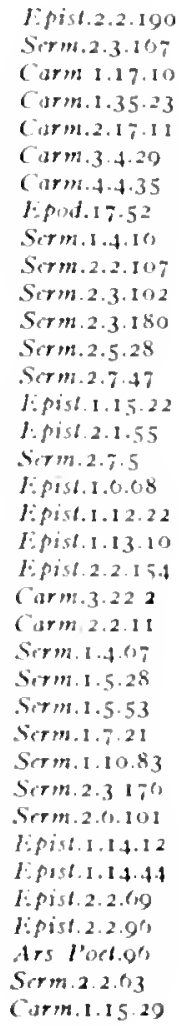


pulso Thyias uti concita tympano.

Carm.3.15.10

uti Graecia Castoris/et magni memor Herculis.

Carm.4.5.35

aut uti|petita ferro belua?"

uti|hitumen atris ignibus."

pocula Lethaeos ut si [Lethaeos uti] ducentia somos | arente fauce traxerim.

cedat uti conviva satur, reperire queamus.

fertur uti pulvis collectus turbine.

siqui scribat uti nos|sermoni propiora.

uti mos'vester ait,

convivatoris, uti ducis, ingenium .

si. Mimnermus uti censet. sine anore iocisque|nil est iucundum.

uti. adtapsus timet / magis [timet.| magis] relictis, non, ut adsit, [uti sit] auxili|latura plus praesentibus.

exsucta uti medulla et aridum ieeur

viverem uti contentus eo quod mi ipse parasset:

pastorem saltaret uti Cyclopa rogabat:

uti ne solus rusve peregre〈ve $\rangle$ exirem.

uti non/conpositum melius cum Bitho Bacchius.

ac venerata Ceres, ita [uti] culmo surgeret alto.

piscator uti, pomarius, auceps. . . mane domum veniant.

leniter in spem/adrepe officiosus, ut et [uti] scribare secundus|heres

cautus uti velet carum caput;

persuadet uti mercetur agellum.

uti mox |nulla fides damnis verisque doloribus adsit.

uti. populumque falsis/dedocet uti|vocibus,

qui deorum /muneribus sapienter uti

ne sequerer moechas, concessa cum venere uti|possem:

nescius uti|conpositis

si conportatis rebus bene cogitat uti. .

quo mihi fortunam. si non conceditur uti?

et properare loco et cessare et quaerere et uti. .

quia parvo nesciet uti.

quo tandem pacto deceat maioribus uti.

"si pranderet holus patienter. regibus uti|nollet Aristippus."

'si sciret regibus uti.| fastidiret holus, qui me notat."

ad haec ego naribus uti formido.

quod/quaerit et invent is miser abstinet ac timet uti,

Vticam, aut fugies Vticam atit vinctus mitteris llerdam.

utile. quid sit pulcrum, quid turpe, quid utile, quid non,

Romanis sollemne viris opus, utile famae

nimirum sapere est abiectis utile nugis

utile. utile proposuit nobis exemplar Vlixen,

quid Sophocles et Thespis et Aeschylos utile ferrent;

omne tulit punctum, qui miscuit utile dulci

utilem. inconptis Curium capillis utilem bello tulit

utili, quotiens bonus atque fidus iudex honestum praetulit utili.

utilis. infirmo capiti fluit utilis, utilis alvo.

militiae quamquam piger et malus, utilis Vrbi. .

adspirare et adesse choris erat utilis

utilitas. sensus moresque repugnant | atque ipsa utilitas,

utiliter. serviet utiliter; sine pascat durue aretque.

utilium. num pavor et rerum mediocriter utilium spes, utiliumque sagax rerum et divina futuri

utilium. utilium tardus provisor, prodigus aeris,

utinam. o utinam nova|incude diffingas retusum. . . ferrum.

sit meate sedes utinam senectae.

utinam inter errem $\mid$ nuda leones.

'longas o utinam, dux bone, ferias/praestes Hesperiael'

Fuscus et haee ntinam Viscorum laudet uterque.

Epod.5.9

Epod.5.8I

iar. Epod.1.4.3

Sirm.1.I.II9

Serm.1.4.31

Serm.1.4.41

Sirm.2.7.79

Serm.2.8.73

Epist.1.6.65

ior.Epod.1.2I

Epod.5.37

Serm.1.4.508

Serm.5.5.63

Serm.1.6.102

Sirm.1.7.19

iar.Serm.2.2.I 24

Sirm.2.3.227

coni.Serm.2.5.48

Serm.2.5.94

Epist.1.7.8 I

Epist.1.17.56

Carm.2.2.20

Carm.4.9.48

Serm.1.4.113

Serm.2.3.109

Epist.1.2.50

Epist.1.5.12

Epist.1.7.57

Epist.1.10.4I

Epist.1.17.2

Epist.1.17.13

Epist.I.17.14

Epist.1.19.45

Ars Poet. 170

Epist. 1.20.13

Epist.1.2.3

Epist. 1.18 .49

Epist.2.2.14I

Epist.r.2.1 8

Epist.2.1.163

Ars Poet.343

Carm.I.12.42

Carm.4.9.4I

Epist.I.I6. 4

Epist.2.1.124

Ars Poel.204

Serm.r.3.9s

Epist.1.16.70

Epist.J.18.99

Ars Poet. 218

Ars Poft.10.4

Carm.1.35.38

Carm.2.6.6

Curm.3.27.5I

Carm.4.5.37

Serm.1.10.83

Serm.2.2.92

utique. qualia vincent | Pythagoran Anytique [utique] reum doctumque Platona.'

utitur. illis utitur ante/quaesitis patiens. .

cur non|ponderibus modulisque suis ratio utitur

utor. utor permisso caudaeque pilos ut equinae/paulatim vello

utpote, utpote plures'culpari dignos.

utpote longum carpentes iter et factum corruptius imbri. utpote res tenuis, tenui sermone peractas.'

tar. Serm.2.4.3

Sorm.1.1.37

Sirm.1.3.78

Epist.2.1.45

Sirm.1.4.24

Sirm.1.5.94

Serm.2.4.9 
quo sane pupulus numerabilis. ut pote parvos.

utra. utra 19.1pis priscis et echiros aequora celent.

utraque. "al remo lingua concinnus utraque suavior.

I:pist.1.15.2.3

utramque. ille dise utramplue / luece rumim.

Serm.1.10.23

propondmatu letet non inconcinnus uttamque; .

Carm.2.17.8

Jpist.1.17.29

Serm.1.8.25

utrasque. [p]lur utrasque/fecerat horendas adspectu.

Serm.2.5.98

utrem. crescuter cunidis intla sermonibus utrem.

Serm.t.9.77

1. pist.1.18.9

SeTm.2.3.50

virtus est mediun vitiorum et utrmque reductum.

utrique. nлแq ntrique error. sed variis inludic partibus:

Serm.2.3.140

utrisque. ithe smistrorsum, hic dextrorsum abic, unus utrique [utrisque] error, sed waris inludit partubus: .

sints ntritume turibus atque veulis: .

utrius. utrius horum verba probes et facta, doce

utriusque. decte strmones utriusrue linguae? .

utro. ambigitur quotiens, uter utero sit prior.

utrobique. pavor est utrubique [utrobique] molestus. | inprovisa sinul species ixperruit.

utroque. quoil virtus in utroque|sunma fuit: .

Lucili ratu, nostrum melioris utroque. .

sive est naturae hoc sive artis, mirus utroque."

utruptu turn latudabit pollice ludum.

utrubique. pator est utrubique molestis.

utrum. quali gritur victu sapiens utetur et horum / utrum imitabitur? maior utrun populum frumenti copia pascat.

utrum. utrum kudeat an doleat.

(gi) utrum mate ferar magna an parva, ferar unus et idem.

utrum minserit in patrios cinetes in triste bidentil| moserit

utrumne. Horme iussi petsequemur otium

utrumne in pulvere, trimus quale prius, ludas opus.

utrumno: divitiis lomines an sint virtute beati;

utrumque. Htrumque nostrum increditibi molo consentit astrum; virtus lot menlium bitiorum et utrinque [utrumque] reductum.

utrumque. werumque sacro tigna silentio/mirantur umbrite dicere. bene siquis let vival puris manibua, contemnat utrumque.

po-tqu.nu whil inter utrumpue convenit

nam Vinuhintus arat fincm sub utrumque colonus,

Valvirtum serepitus lectis excussit utrumçue.

lunc amor, irat quilem communiter urat utrumque.

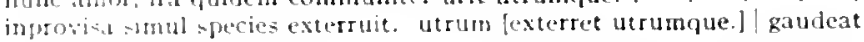
itil kelpat.

inposesen simul species extertuit. utrum lexternat utrumque.] gaudeat ins thisat.

carmini conpono, hic elegos: mirabile visu [nirabile utrumque] calelatumatue noven Dusis opus.

utrumque. Herumque verberes latws. Anster, memento fluctibus:

hertumple rog. tempetante ciblitum.

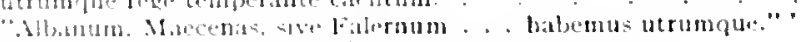

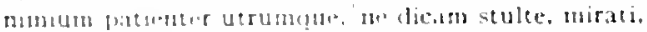

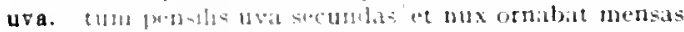

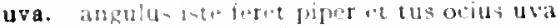

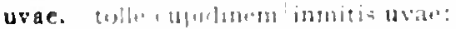

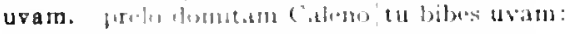

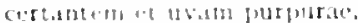

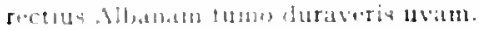

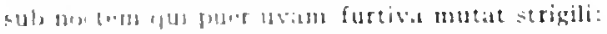

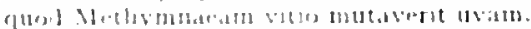

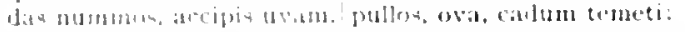

urescit.

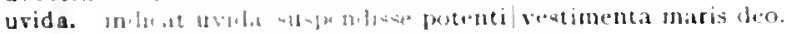

uvidi. Ir. a

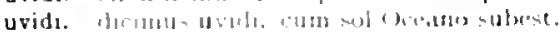

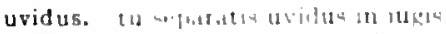

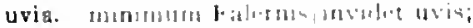

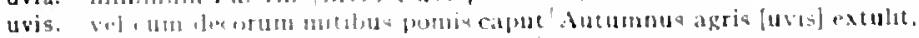

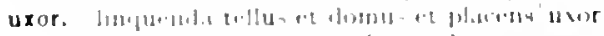

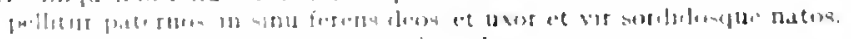

thes

:ar. Serm.2.3.50

S.rm.2.3.28.4

Epist.1.17.15

Curm.3.8.5

Epist.2.1.55

ior.Epist.1.6.10

Setm.1.7.1.4

Sitm.2.1.29

Sotm.2.4.7

Esist.1. I8.00

Epist. I.0.10

Serm.2.2.64

Epist.t.15.ta

Epistid.(1.1 t

Jisist.2.2.199

Ars l'oet.ato

E.pol.1.7

Sirm.2.3.25t

Sorm.2.0.73

Carm.2.17.21

far.lepist.1.18.9

Carm.2.13.29

Sath.t.4.0S

Serm.1.7.9

Sirm.2.1.35

Serm.2.0.112

E.pist.1.2.13

fur. Epist.1.0.1 I

noni. Epist.1.0.11

(o)ni.t.pist.2.2.91

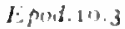

lipudite.5\%

Sirm.2 S.IT

Ars l'oet.27I

Sirm.2.2.12I

IEpest.1.1.23

Ciurm. 25.10

(iarm.1.20.10)

I.pid. 2.20

Serm $2.4 \div 2$

Sirm.2.7.100

Sirm 2 is 50

E.pist.2 2.102

Sirm.20\%0

(itrm.1.5.1.8

(iarm.8.2.3"

(arm+5.30

(itrm 2.10.18

Cirm 2.0.211

fur. lipod.2 18

(arm 21422

(a) 21828

(ism 13 by 
uxor invicti Iovis esse nescis.

perusta solibus/pernicis uxor Apuli,

non uxor salvom te volt, non filius;

clamet amica. | mater, honesta soror cum cognatis, pater, uxor unde uxor media currit de nocte vocata." -

quaeritur argentum puerisque beata ereandis/uxor.

uxor. uxor pauperis Ibyci.

uxore. abstinuit vin|uxore et gnato;

uxorem. filius uxorem grandi cum dote recuset.

cum laqueo uxorem interimis matremque veneno,

fortique marito|destinet uxorem:

seilicet uxorem cum dote . . regina Pecunia donat

comis in uxorem. posset qui ignoscere servis

uxores. olentis uxores mariti

hostium uxores puerique caecos/sentiant motus

uxores. non alienas|permolere uxores."

uxoribus, 'nil fuerit mi' inquit 'eum uxoribus nmquam alienis.'

Carm.3.27.73

Iipod.2.42

Sirm.1.1.84

Sirm.2.3.58

Sirm.2.3.238

Eipist.1.2.45

Carm.3.15.1

Sirm.2.3.203

Sirm.1.4.50

Strm.2.3.13 I

Sirm.2.3.217

Epist.1.6.36

Epist.2.2.133

Carm.1.17.7

Carm.3.27.21

Sirm.1.2.35

Sirm.1.2.57

uxorius. vagus et sinistra|labitur ripa Iove non probante u-/xorius amnis.

Carm.1.2.19.20

\section{$V$ (cons.)}

vacas. mox etiam, si forte vacas, sequere et procul audi.

vacat. festus in pratis vacat otiosolcum bove pagus,

mox etiam, si forte vacas [vacat], sequere et procul audi,

vaccae. te greges centum Siculaeque circum|mugiunt vaccae.

te decem tauri totidemque vaccae.

vacua. adrasum quendam vacua tonsoris in umbra

vacuam. te.. qui semper vacuam, semper amabilem|sperat.

et vacuam patefecit aulam.

circum- $\mid$ spectemus vacuam Romanis vatibus aedem;

vacuas. his verbis vacuas permulceat auris:

ingenium, sibi quod vacuas desumpsit Athenas

vacui. cantamus, vacui sive quid urimur.

si quid racui sub umbra|lusimus tecum.

racuis. quonian vacuis conmittere venis|nil nisi lene decet:

Vacunae. haec tibi dictabam post fanum putre Vacunae.

vacuo. sive operum vacuo gratus conviva per imbrem/ricinus.

vacuo. in vacuo laetus sessor plausorque theatro.

racuom. sed sacuom Tibur placet ant inbelle Tarentum.

vacuom. expertus vacuom Daedalus aera

et tollens vacuom plus nimio Gloria verticem

vacuom duellis| Ianum Quirini clausit

si vacuom tepido eepisset villula tecto.

vacuom. ut mihi devio ripas et vacuom nemus| nirari libet.

quo ne per vacuom Romano incurreret hostis,

ut . . . siquis casus puerum egerit Orco, in vacuom renias: .

libera per racuom posui vestigia princeps, .

vada. si tamen inpiae/non tangenda rates transilimt vada.

vadato. casu tum respondere vadato/debebat.

vade. oratus multa prece nitere, porro/vade;

vadere. vidi egonet nigra suecinctam vadere palla/Canidiam

vadet. quicllibet indutus celeberrima per loca vadet

vadibus. ille, rlatis vadibus qui rure extractus in V'rbem est.

vadis. 'sinul inis saxa renarint/radis levata,

vae. vae, meum fervens difficili bile tumet iecur.

vepallida [vae pallidal lecto|clesiliat mulier.

vaesania. ne vos ageret vesania [vaesania] discors.

vafer. temptat mille vafer modis.

ut Alfenus vafer omni | abiecto instrumento artis clausaque taberna | sutor erat:

quo vafer ille pedes lavisset Sisyphus acre.

Surrentina vafer qui miscet facce Falema, vina,

si vafer unus et alter' insidiatorem praeroso fugetit hamo.

vafri. illum aut nequities aut vafri inscitia iuris.

vaga. teque nee laevos vetet ire picus/nee vaga cornix.

nam raga per veterem dilapzo fiamma culinam/Volcano

vaga Luna decorum protulit os.

iam vaga prosiliet freni natura remotis.

Epist.2.2.95

Carm-3.I8. I I

*ar. Epist.2.2.95

Carm.2.10.34

Carm.4.2.53

Epist. I.7.50

Carm.1.5.10

Curm.4.14.36

Epist.2.2.9.4

Epist.1.1 6.26

Epist.2.2.81

Carm.1.0.19

Carm.1.32.1

Sirm.2.4.25

Epist. I. 10.49

Sirm.2 2.119

Epist.2.2.130

Epist.1.7.45

Carm.1.3.34

Carm.t.18.15

Carm.4.15.8

Sirm.2.3.10

Cirm.3.25.13

Sirm.2.1.37

Sirm.2.5.50

Epist.1.19.21

Carm.1.3.24

Serm.1.9.3

Epist.1.13.19

Sirm.1.8.23

Epist.1.17.28

Serm.I.I.I I

Epod. I0.20

Curm.1.133

var.Serm.I.2.I 29

itor.Serm.2.3.174

Carm.3.7.12

Serm. I.3.130

Sirm.2.3.2 I

Sirm.2.4.55

Serm.2.5.2!

Serm 2.2.13t

Curm.3.27.16

Serm. 1-5.73

Sirm.1.8.21

Sirm.2.7.7.4 
pettidus Ixion, lo vaga, eristis Orestes.

Ars Poet.124

vaga. guo brutia tellus et viga flumina.

Carm.1.34.9

ragacem. Spatucum siçua perut vagantem [vagacem] fallere testa.

tar. Curn.3.14.19

vagae. at tu. natuen. vagave ne parce thalignus harente . Particulan dare: Carm.1.28.23

ragans. Thracio batchante magk [vagans] sub inter-/lunia vento.

cont.Carm.1.25.11

vagantem. Sipartacum siquat potuit sagantent fallere testa. .

raganti. eturinem, recum csaganti [et vaganti] frena licentiae iniecit

Carm.3.14.10

vagas. guterum platustra vagas rite trahunt domos.

gar.Carm.4.15.10

Curm.3.24.10

chi rex deortum tegnum an avis vagas! permisit

Carm.4.4.2

vagentur. stellate sponce sua iussilene vapratur et errent,

vager. infitcula saget scrbamelue licenter?

vagina. me veluti custodiet encis/ sagina tectus:

ragis. catretgue tipa ragis taturna ventis.

rago. tesis vonere tauris pracbes et pecori bago.

rago. cencubatu pohibere vago, date jura maritis,

ragor. ulta terminun curis vagor expeditis,

at) (plattath haceo: post hane vagor

vagos. angurtoque vagos piscis urgere catino.

vagus, bagus et sinistra labitur ripa . a annis.

vapus 11 (erolles|enisus arees at tigit igneas.

nos manet ( heautus circum vagus:

-curra vagus, non qui certum praesepe teneret.

nercatortue vagus culeome vircntis agelli.

traxitgue vigus per pulpita vestem

Vala. quar sit hems Veliae, qunol caelum, Vala. Salerni.

ralde. oritus multa prece nitere, porrolsade: vale. [? valde, vale] cave ne tiules mandataflue trangas.

raldius. elud pesam videt ac novit mo valdius ipso. valulin ollectat populum melinsque moratur

rale. sed ne impriosi trahit l'roserpina: vive valeque."

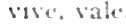

vale, calle ne qubles mandataque frangas.

valeant. quid forse recusent, quud valeant umeri.

valeas. in primis valuas bene:

"hatu mibr sita est opts hac" ait et "ralcas:

ntile buna viraeque et nembris, proesertim cum valeas

valeat. nuscis guo valeat numulus, fuem pracbeat usun?

aedre stuwer, dictis quod nen levins valeat:

extrmi necpuiel saleat per leve motari.

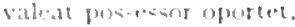

1) bit batere, ut valtak, quo pacto rom gerat et se.

valleist reos bistiera.

valent. F"11 dig, barbarae minus vemena Necleac valent.

non valent, comstere humanam vicem.

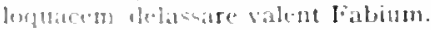

valentem. "u me vivese vis sinum recteque valentem.

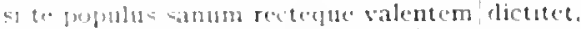

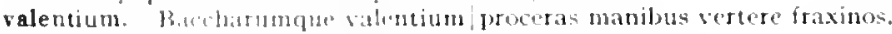

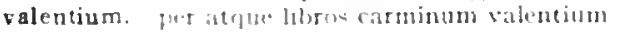

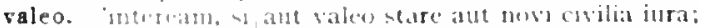

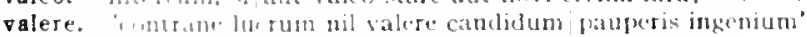

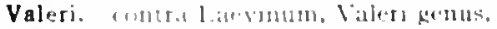

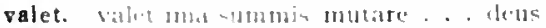

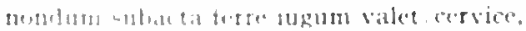

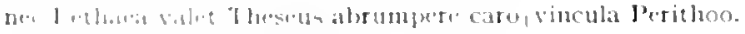

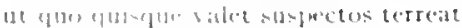

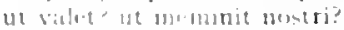

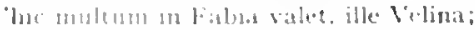

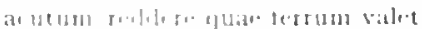

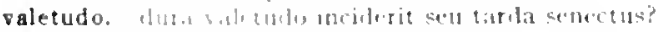

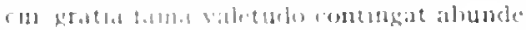

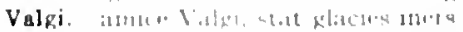

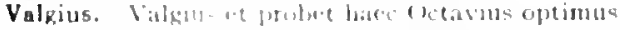

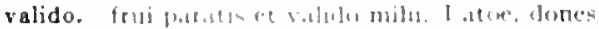

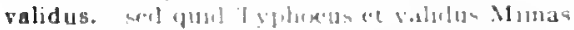

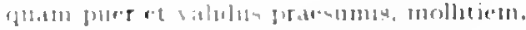

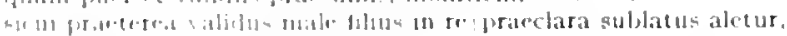

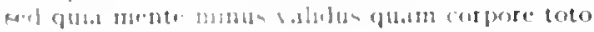

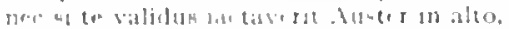

fipist.1.12.17

Ars Poct.265

Sirm.2.1.41

Carm.3.29.24

Carm.3.13.12

Ars Poct. 398

Carm.122.11

Serm.1.0.122

Sorm.2.4.77

Carm.1.2.18

Carm.3.3.9

L. pod 10.41

Jist.1.15.28

Ars Pod.117

Ars Poct.215

Epist.1.15.1

gar. Epist 1.13 .19

I.pist. 1.9.6

Ars Porl.32 I

Sorm.2.5.110

lipist. I. S.6.

Joful 1.13 .19

Ars Pot.jo

Serm.2.2.71

Sirm.21,1]0

Jiprot 1.1850

Sirm.1.1.73

Sirm.2.75

Sirm.2.7.87

1.pist.1.2.49

Fepist.1.8.13

1.pist.2.1.180

l: pold 502

I. pout. 5.87

Sirm.1.14

I.Pitt.1.7.3

lipist.1 If. 2 I

(it $y_{3.3 .25 .15}$

J.politit

Sirm. 0.30

Jipold11.11

Sirmal e. 12

(i)rm.1.3412

(i) irm.2.5.1

(i) 19.27

Sirm. 21.50

J.pist 1.3 .12

J. Pust 1.0.52

Ars Poot 305

sirm 2 $2 \mathrm{~s}$

Ifpet $1+10$

(itrmit2) 5

Sorm I 10.82

(

Ciurm. 3.5 .3

Serm. 2.287

Sorm. 2.545

lipouti.8.7

Jipt.1.11.15 
si validus, si laetus erit, si denique poscet;

valle, hic in reducta valle Caniculae/vitabis aestus

Epist.1.13.3

cur valle permutem Sabina/divitins operosiores?

aut in reducta valle nugientium /prospectat errantis greges

continui montes, ni dissocientur opaca|valle,

valles. valles et Vsticae cubantis/levia personuere saxa.

vallis. cervos uti vallis in alteral visum parte lupun

vallis. quorum / conspicitur nitidis fundata pecunia villis [rallis].

vallo. si interdicta petes, vallo circumdata

vallum. fest vallum et arma miles

valuerunt. quam neque finitimi valuerunt perdere Mlarsi

valuit. obiectos caveae valuit si frangere clatros,

valvarum. ingens|valvarum strepitus lectis excussit utrumque.

vana. vitiis carentem| Iudit imago|vana.

vana. migravit ab aure voluptas/omnis ad incertos oculos et gaudia vana.

vanae. num vanae redeat sanguis imagini,

vanae. quid leges sine moribus/vanae proficiunt,

cuius, velut aegri somnia, vanae/fingentur species. .

vanis. corruptus vanis rerum, quia veneat auso/rara avis

vano. non sine vanolaurarum et siluae metu. .

vanum. "nunc age, luxuriam et Nomentanum [nomen vanum] arripe mecum:

vapor. nec tantus umquam siderum insedit vapor .

vapores. quanvis|nocturnos iures te formidare tepores [vapores].

vaporet. laevom discedens curru fugiente vaporet.

vappa. absentem ut cantat amicam|multa prolutus vappa nauta

vappae. Fufidius rappae famam timet ac nebulonis,

vappam. non ego, avarum | cum veto te fieri, vappam iubeo ac nebulonem. potare . . Campana solitus trulla vappamque profestis.

vare. nullam, Vare, sacra vite prius severis arborem non usitatis, Vare, potionibus,

varia. cupiens varia fastidia cena|vincere

variae. utque lupi barbam variae cum dente colubrae

variae. nam variae res/ut noceant homini.

Variam. quinque bonos solitum Variam dimittere patres.

variare. qui variare cupit rem prodigialiter unam.

varias. nempe inter varias nutritur silva columnas

varias inducere plumas.|undique collatis membris

variis. qui mare ac terras variisque mundum|temperat horis?

nee variis obsita frondibus|sub divom rapiam.

unus utrique error, sed variis inludit partibus:

Varina. ulla si iuris tibi peierati|poena, Barine [Varina]. nocuisset umquam.

Varinae. ulla si iuris tibi peierati | poena, Barine [Varinae], nocuisset umquan,

Varine. ulla si iuris tibi peierati|poena. Barine [Varine], nocuisset umquam.

Vario. scriberis Vario fortis et hostium|victor

Caecilio Plautoque dabit Ronanus ademptum/Vergilio Varioque?

vario. poscentes vario multum diversa palato.

varios. jam tibi lividos / distinguet autumnus racemos / pirpureo varius [varios] colore.

ten lapides varios lutulenta radere palma.

Varium. non Viscum pluris amicum. | non Varium facies: : : *

varium. alterum et huic varum [vatium] et nihilo sapientius ignis | per medios fluviosque ruentis:

Varius. Plotius et Varius Simuessae Vergiliusque/occurrunt,

flentibus hinc Varius discedit maestus anjicis.

Vergilius, post hunc Varius dixere quid essem.

forte epos acer. / ut nemo. Varius ducit;

Plotius et Varius, Maecenas Vergiliusque. .

infra, / si menini. Varius:

Varius mappa conpescere risum / vix poterat.

dilecti tibi Vergilius lariusque poetae.

varius. tibi lividos/distinguet autumnus racenos|purputeo varius colore.

Varrone. experto frustra Vartone Atacino

Varros. adeo sermonis amari, / Sisennas, Barros [Varros] ut equis praecurreret albis.

Varrus. ut siqui aegrotet quo morbo Barrus [Vartus],

varum. alterum et huic varum et nihilo sapientius

varum. hune varum distortis cruribus.

Carm.1.IT.IT

Carm.3.1.47

I.pod.2.I I

Fist.1.16.6

Carm.I.IT.II

Carm.1.15.29

:ar. Epist.I.I 5.46

Sirm.I. 2.96

Epod.o.13

If pod.10.3

Ars Poet.473

Sirm.2.6.112

Cirm.3.27.4 I

Epist.2.1.188

Carmi. I.24.15

Corm.3.24.36

Ars Pot. 7

Sirm.2.2.25

Carm.1.23.3

Far.Sirm.2.3.224

Ipod.3.I5

gar. Epist.1.1 8.93

Epist.1.10.7

Sirm.1.5.10

Sirm.1.2.12

Sirm.r.I.IOA

Sirm.2.3.1.4

Corm.1.18.1

lipol.5.73

Sirm.2.6.80

Sirm.1.8.42

Serm.2.2.7I

Eisist.I.14.3

Ars Pot.29

Epist.1.10.22

Ars Poit.2

Carm.1.12.15

Carm.1.18.12

Sormi.2.3.5I

rar.Corm.2.8 =

ior Cam.2.8.2

iur.Corm.2.8.2

CarmeIn. I

-1 r.s Poct.5.5

Epist.2.2.02

conti.Carm.2.5.12

Sirm.2.4.83

Serm.1.9.23

*ur. Serm.2.3.56

Sirm.1.5..70

Sermt. 5.93

Sermoto. 0.55

Serm.1.10.44

Sirm.t.ro.81

Serm.2.8.21

Sirm.2.8.0 3

Epist.2.1.247

Carm.2.5.12

Serm.t. 10.pe

iur.Sirm.1.7.S

gar. Sirm. 1.6.30

Serm.2.3.50

Sirm.1.3.47 


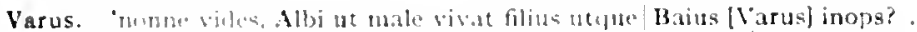

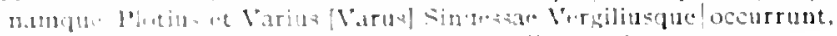

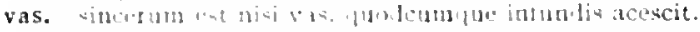

vas. shacerum burbus vá incrutare"

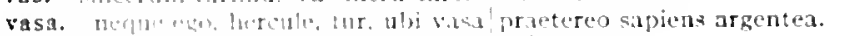

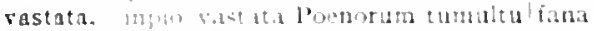

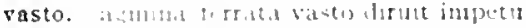

vate. carthe puid bite aatero

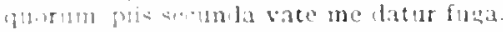

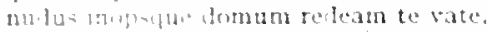

sasem. Rump fracipis urbium / dignatur suboles inter amabilis/vatum

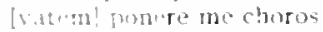

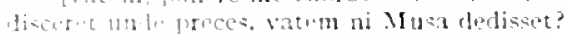

rates. qu: 1 indicatum poscit Apollinem rates?

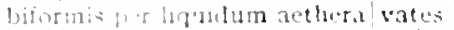

tornus uer ogthos attonitus petet! vates;

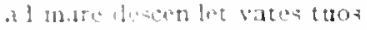

vati. Nemptz vati reldidere lumina:

vatibus. qumli mo lyricis satibus inseres.

vabu= al lere calcar.| ut studio mainre petunt Heliconat virentem.

sic tom ot nomen divinis vatibus atque/carminibus venit.

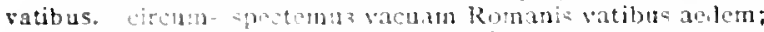

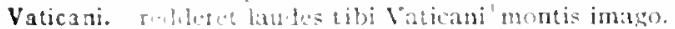

ratilum. fraplatum et laturn cham prunaeque vatillum.

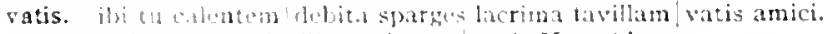

reldidi cormen lociliz modorum| watis Horati.'

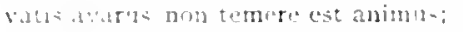

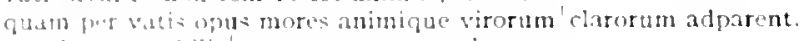

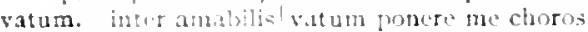

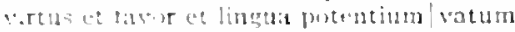

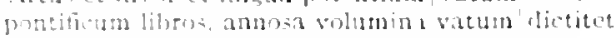

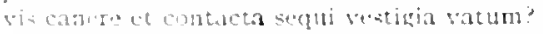

mulatulero, ut placem genus irrit.uhite visum,

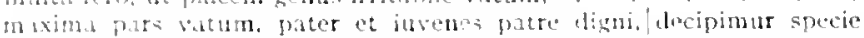

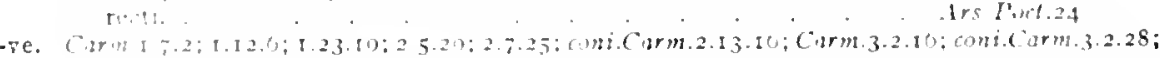

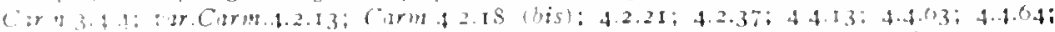

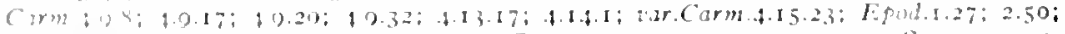

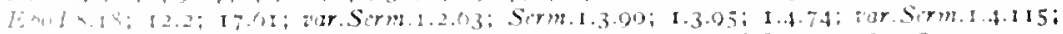

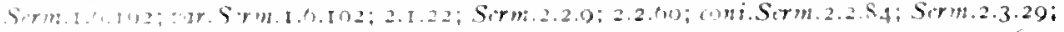

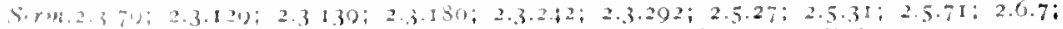

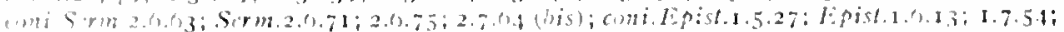

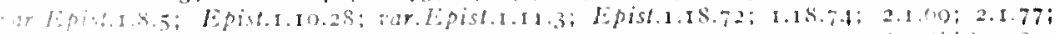

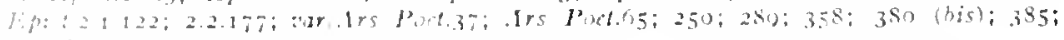

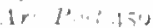

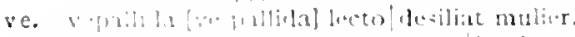

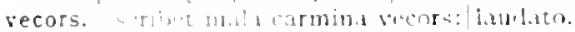

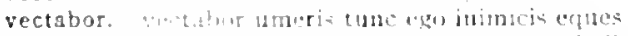

vectari. is z:m mo. Sataruano vect ari rara cabillo.

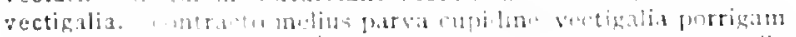

iar. Serm.1.2.120

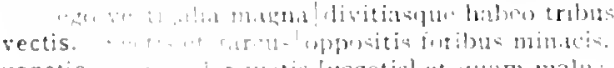

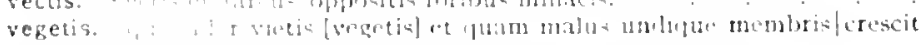

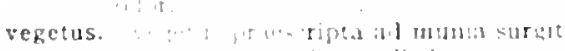

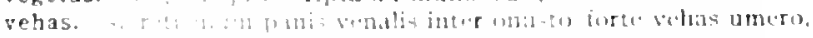

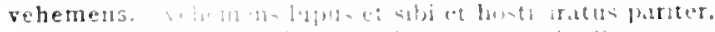

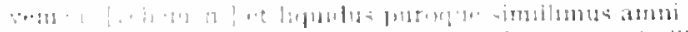

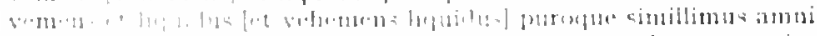

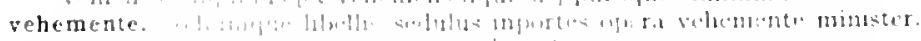

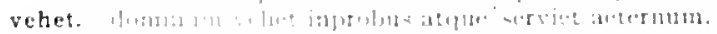

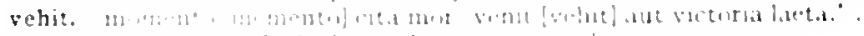

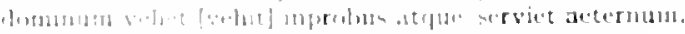

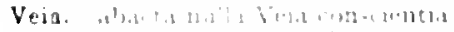

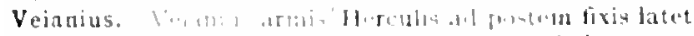

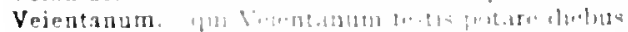

Sirm. 2.5 .7

lipol.17.7:

S.r.o.?. 1.0 .50

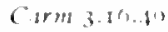

Sinn.2.2.100

(it) 326.7

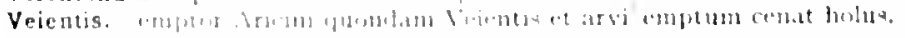

:ar lispond 127

Serm.2.28 1

Serm.t. 1 . : :

Existis.2 2s

ar. Esipel: 2120

ar lipist 2.2 .120

lopist $1: 5$

Esist 1 ine..90

int Siers 18

iur I:pint I 10.40

I. plu 520

lepiet a $1 . .1$

Serm.2.3.1:3

lipist 2.2.107

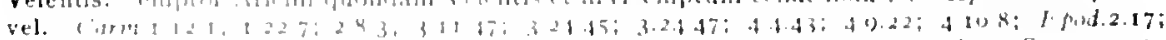

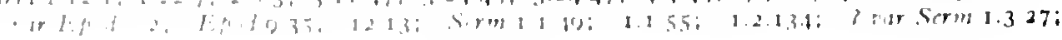


Serm.1.6.22; 1.6.105; 2.2.10; 2.7.63; 2.7.95; 2.8.29; Epist.1.1.72; 1 1.97; 1.2.26; 1.2.37; Epist.1.5.6; 1.5.15; 1.6.44; 1.17.16; 1.IS.14; 2.1.29; 2.1.40; zar.Epist.2.1.122; Epist.2.2.3; Epist.2.2.127; 2.2.1.19; 2.2.150; Ars Pot.10.4

vel. Corm.1.7.3 (bis); 1.35.2; 1.35.3; 2.11.13 (bis); 3.29.43; 3.29.45; Epod.1.11; 1.13; 2.59; 2.60: Sirm.2 3.2.32 (his); 2.8.37 (bis); Epist.1.12.10; 1.12.11; 1.16.58 (bis); I.I8.51 (bis); Eist.2.1.25 (bis); 2.1.4.t (bis); 2.1.S3; 2.1.8.4; Ars Pott.109; 171;28s (his)

vela. nunc retrorsum| vela dare contrahes vento nimim secundo|turgida vela. ne parva Ty'rhenum per aequor|vela darem. emat. . nautica vela|aversus mercaturis:

Velabro. cum scurris fartor, cum Velabro omne macellum velat. contra. quem duplici panno patientia velat.

velata. albo rara Fides colit velata panno

velatum. numquid ego a te magno prognatum deposco consule cunnum veiatumque stola,

velet. mone, si increbruit aura, /cautus uti velet carum caput;

Carm.1.3.4.4

(i) rm.2.10.24

Cirm.1.15..7

Sirm.2.3. 106

Sirm.2.3.229

Epist.1.17.25

Carm.1.35.22

Veliae. quac sit hiens Veliae, quod caelum. Vala, Salerui,

velim. nee, si plura velim, tu dare deneges.

Sarmenti scurrae pugnam Messique Cicirri./musa, velin memores quibus haec, sint qualiacumque,|adridere velim, doliturus, si placeant spe

nil audire velim, nil discere, quod levet aegrum;

scire velim. chartis pretium quotus arroget annus.

hunc ego me, siquid conponere curem. / non magis esse velim.

velimus. sunt delicta tamen, quibus ignovisse velimus:

Velina. hic multum in Fabia valet, ille Velina;

velint. ne... avitae/tecta velint reparare Troiae. quid velint tlores et acerra turis elementa velint ut discere prima;

velis. permutare velis crine Licymniae

an si cognatos.... retinere velis servareque amicos

tu si modo recte/dispensare velis.

tempora si fastoaque velis evolvere nundi.

'velis tantummodo: quae tua virtus, fexpugnabis;

posito pa*one velis quin | hoc potius quam gallina tergere palatum, tu quotus esse velis rescribe

scire velis, mea cur ingratus opuscula lector laudet ametque domi.

velis. non agimur tumidis velis aquilone secundo:

velit. ut neque longa/nec magis alba vit quam dat natura videri.

magnum documentum, ne patriam rem/perdere quis velit.' .

'nequis humasse velit Aiacem, Atrida, vetas cur?'

quid prima secundo cera velit versu; .

'quid tamen ista velit sibi fabula, si licet, ede.'

quid velit et possit rerum concordia discors.

tene magis salvom populus velit an populum tu.

ut sileacus iter monstrare velit.

siquis forte velit puerum tibi vendere

humano capiti cervicem pictor equinam /iungere si velit.

ne quodcumque velit poscat sibi fabula credi

velle. servosque. . omnis restinguere velle videres. 'certe nescio quid secreto velle loqui te/aiebas mecum.' .

vellem. vellom in amicitia sic crraremus

'porrectum magno magnum spectare catino 'vellem'

cum vellem mittere operto| ne capite in flumen.

tamen illic vivere vellem

scilicet ut rellem curvo dignoscere rectun.

vellera. nec pinguia Gallicis crescunt vellera pascuis:

muricibus Tyris iteratae vellera lanaelcui properabantur?

vellera. qui Siconio contendere callidus ostro/nescit Aquinatem potantia vellera fucum

vellere. vellere cocpilet pressare manu lentissima bracchia.

velles. cum theret lutulentus, erat quod tollere velles: .

hunc hominem velles si tradere:

si vellm" inquit "verum mihi ponere nomen.

vellet. at hic si. . vellet bonus atque benignusiessce,

quen tollere raeda'vellet iter faciens.

saxa movere sono testudinis et prece blanda / duecre: quo vellet.

vellicat. mer moveat cimex Pantilius aut cruciet quod|vellicet [? vellicat] absutem Demetrius

Sirm.1.2.7 I

Sirm.2.5.9.

Epist.1.15.1

carm.3.16.38

Serm.1.5.53

Sermilo. 89

Epist.I.S.S

E.pist.2.1.35

. irs Poet.36

Irs Poet.347

Epist.1.0.52

Carm.3.3.60

Carm.3.8.2

Sirm. I. 1.26

Cum.2.12.23

Sirm.1.1.89

Serm.1.2.75

Sim.1.3.1 12

Sirm.1.9.54

Sirm.2.2.23

Epist.1.5.30

Epist.1.19.35

Eipist.2.2.20I

Serm.1.2.124

Serm. I.t.1 I I

Serm.2.3.187

Serm.2.5.5.t

Sirin.2.5.61

Epist.1.12.19

Epist.r.10.27

T.pist.1.17.t

Ispist.2.2.2

Ars Poet.2

Ars loot.3.39

Sirm.1.5.70

Serm.1.9.67

Strm.I.3.4I

Sirm.2.2.40

Serm.2.3.37

Epist.1.11.8

Epist.2.2.44

Carm.3.16.36

IEpol.12.2 I

Epist.1.10.27

Serm. 1.0.0.3

Sirm.1...1. I

Serm.1.0.47

Epist.1.7.93

Serm.1.2.5 I

Serm 2.0..\$3

Irs 1'oct.39o

:4r.S.rm.1.10.79 
vellicet. quod vellicet absentem Demetrins

Sam.1.10.79

vellis. tu piscis hberno ex aequore ver is [vellis].

3ar.Serm.2.3.235

vello. caulatruc pilos ut equinae/ paulatin vello

Epist.2.1.4t

vellunt. velluse libi barban!l lascivi pueri.

veloci. age te procellate/crede velexi.

reloci. sulus multisne coheres, / veloci percurre oculo.

Serm.1.3.133

Carm.3.27.13

Serm.2.5.55

velocis. Breumsque velocis et arcis! Alpibus inpositas tremeotis

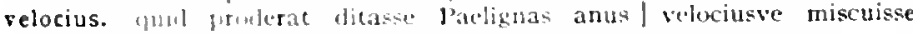
tosicum?

relorum. litae dum sin (nimium) querenti|iactat ultorem [velorum],

velox. vlix amornum saipe Lucrutilem!mutat Lycaeo Faunus

qual hemrat aut quos agor in specus. / velox mente nova?

cum tha velox metce seni:

dun peregre act animus sine corpote velox?

velox. seu pila velox!molliter aurterum studio fallente laborem. donec alterutrum velox Victoria fronde coronet.

velut. crescit occulto velut arbor aevolfama Marcellis; nicat inter ommis|Juliun sidus velut inter ignis/luna minores. atccipiter velut mollis columbas

qual volut latis equa trima campis|ludit

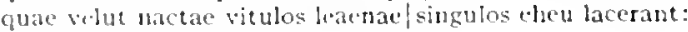

monte dewrens velut annis.

mordaci velut icta firrolpinus

polex bilut crudae bovis.

Phocatorum/volut profugit exsecrata ciritas

sacpe velut yuil currebat fugien hostem,

pegareger velut qui Iunonis sacra ferret:

velut si extegio inspersos reprendas corpore nacvos.

ille velut fulis arcana sodalibus olim/credelut libris

"velut silvis. ubi passim palantis error certo do tranite pellit.

hoc, veluti [velut in] virtute paratum. spetavit magnae laudi fore.

metuensque velut contingere sacrum?

velut usquan | vinctus eas.

ultro insetrete velut melior

protia rulifica fictal aut carbone velut si|re vera pugnest.

velut illis Caniclia adflasset, fretor setpentibus Afris."

sub mutrice puclla velut si luderet infans.

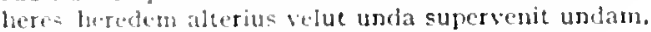

cuius, velut ateri somnia, vanae|fingentur species.

ne sclut innati trivis ac paene forenses

certe intit ac velut ursus,

veluti. veluci set voluctis dis,

aut eldm ipsa lasec dedectant, veluti Balbinum polypus Hagnae.

ac vint le Indaei cogemus in hanc concedere turban.

votiva pateat veluti descripta tabella/vita senis.

mo veluti custoliet ensis/ vakina tectus:

hoc, volue vireute paratum, | spetavit magnae laudi fote.

veluti succincture cursitat hospes.

belut pia mater plus quam se sapere. . volt

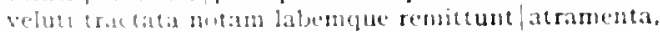

si veluti mesulis intentus decidit auceplin pusum

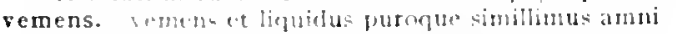

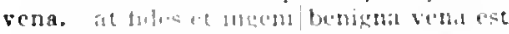

rena. nec tulnum - mo divite vena nee rude quid prosit video ingenium.

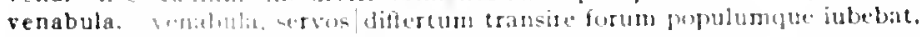

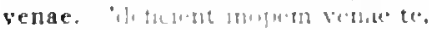

Venafranae, foren linafrante qued baca remist olivae.

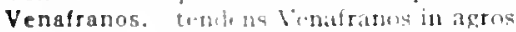

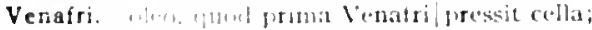

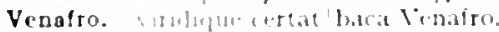

venale. (

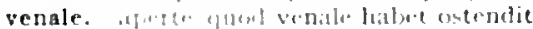

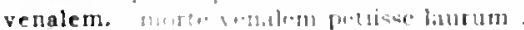

venalis. \& 3 .

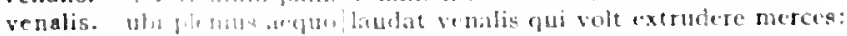

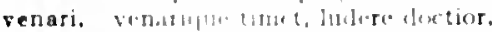

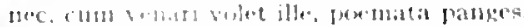

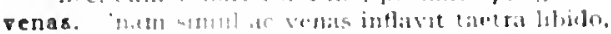

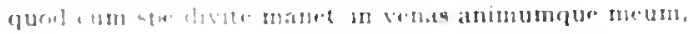

Lpod.17.61

gar.Carm.1.2.18

Corm.t.itis

Carm.3.25.3

(urm.4.12.22

Epist.1.12.13

Serm.2.2.II

Ejist.1.18.0.4

Carm.1.12..15

Carm.1.12.47

Corm.1.37.17

Carm.3.11.9

Carm.3.11.41

Carm. 1.2 .5

Corm.t.6.9

Epod.8.6

Lpod.16.18

Sorm.1.3.9

Sorm.1.3.10

Sam.1.0.00

Sitm.2.1.30

Sitm. $2 \cdot 3 \cdot 4^{8}$

fisr.Sirm.2.3.98

Sirm.2.3.110

Sirm.2.7.30

Sirmi.2.7.41

Sirm.2.7.08

Sorm.2.8.94

lipist.2.1.09

List.2.2.176

Ars Poct.7

Ars loct 245

Ars Poet.atz

Carm.3.28.6

Sirm.1.3.40

Sirmat.4.142

Sirm.2.1.33

Sorm.2.1.10

Sirm.2.308

Serm.2.0.107

Ifpist. I 18.20

Itist.2.1.235

Ars lint 458

lipist.2.2.120

Carm.2.18.11)

Ars Pevef alo

Lpist 11.58

Serm.2.3.153

Sorm.2..109

Corm.3.5.55

Som. 285

Carm.2tiel

Carm.2.107.8

Serm.1.2.st

Carm 3.1.2.2

Scrm 18.47

1 pestz= 21

(is rm.3245 5 (1

1 pist 18.40

Sormi.1.2.33

J.put 1520 
venaticus. venaticus, . . . militat in silvis catulus.

venator. manet sub Iove frigido/venator tenerae coniugis inmenor.

Epist.1.2.65

leporem citus|venator in campis nivalis

"leporem venator ut alta|in nive sectetur.

vendas. 'Stoice, post damnum sic vendas onnia pluris.

idcirco navim trans Aegaeum mare vendas.

vendentem. Volteium mane Philippus | vilia vendentem tunicato scruta popelloloccupat

ne... deferar in vicum vendentem tus et odores

vendere. vendere cum possis captivom, occidere noli:

siquis forte velit puerum tibi vendere.

venderet. exciperet dominus, cum venderet.

vendibilis. et fundus nec vendibilis nee pascere firmus'

vendit. qui praedia vendit.|nil servile gulae parens habet?

iniuste totum ducit venditque poema.

veneat. quia veneat auro/rara avis

veneficae. solutus ambulat venefieae/scientioris carmine.

venefici. et Esquilini pontifex renefici

venemur. piscemur, venemur, ut olin| Gargilius

venena. cur dira barbarae minus/venena Medeae valent,

renena maga non fas nefasque.

"hune neque dira venena nec hosticus auferet ensis.

venena. ille venena Colcha... tractavit,

venenat. non odio obscuro morsuque venenat:

venenatis. nee venenatis gravida sagittis.|Fusce, pharetra.

veneni. quid hoc veneni saevit in praecordiis?

venenis. quis te solvere Thessalis|magus venenis, quis poterit deus? cales renenis ofticina Colchicis.

quantum carminibus quae versant atque venenis

veneno. cum laqueo uxorem interimis matremque veneno,

'lana Tarentino violas imitata veneno.'

venenorum. Hiberia/mittit venenorum ferax,

venentur. quifirustis et pomis viduas venentur avaras.

venenum. ut atrum/corpore conbiberet venenum. .

proscripti Regis Rupili pus atque venenum

Canidia Albuci. quibus est inimica, venenum.

venerabilior. ante Lasem gustet venerabilior Lare dives.

venerandi. intra marmoreum venerandi limen anici,

venerantur. te caede gaudentes Sygambril conpositis venerantur armis. verum/gaudent scribentes et se venerantur

venerat. ac mihi seu longum post tempus venerat hospes

venerata. ac venerata Ceres, ita culmo surgeret alto.

venerati. nec, cum venari [? venerati] volet ille, poemata panges.

veneratione. nec, cum venari [? ne cum veneratione] volet ille, poemata panges.

veneratur. quaeque vos bubus veneratur albis

meminitque libentius illud | quod quis deridet quam quod probat et veneratur.

venere. qui nisi, cum tristes misero venere kalendae. ab his maioribus ortiład pugnam venere. quid tum? venere frequentes.

venere. ne sequerer moechas, concessa cum venere uti $\mid \dot{\text { possem: }}$ : abstinuit venere et vino;

Venerem. Liberum et Musas Veneremque . . canebat

venerem. nee tauri ruentis|in venerem tolerare pondus. et venerem et proelia destinat.

non ego: namque parabilem amo venerem facilemque. quos venerem incertam rapientis more ferarum eripuere iocos, venerem. convivia. ludum; .

Veneri. sic visum Veneri, cui placet inpares! formas atque animos sub iuga ingratam Veneri pone superbiam.

veneri. somnus tamen aufert lintentum veneri:

Veneris. nequiquam Veneris praesidio ferox.

larga nec desunt Veneris sodali| vina craterae.

laterom marinae qui Veneris latus/custodit.

tuis victus Venerisque gratae/ vocibus

o crudelis adhue et Veneris muneribus potens, .

qui dies mensem Veneris marinae|findit Aprilem.

almaelprogeniem Veneris canemus.

Carm.1.1.26

Carm.1.37.19

Serm.1.2.105

Sirm.2.3.300

Epist.I.11.16

Epist.x.7.65

Epist.2.1.269

Epist.1.16.69

Epist.2.2.2

S.rm.2.3.286

Epist.1.17.47

Serm.2.7.IIO

Epist.2.1.75

Serm.2.2.25

Epod.5.7I

Epod.1 7.58

Epist.1.0.57

Epod.5.62

Epod.5.87

Serm.I.9-3I

Carm.2.13.8

Epist.1.14.38

Carm.1.22.3

Epod.3.5

Carm.1.27.22

Epod.1 7.35

Sirm.1.8.19

Serm.2.3.13I

Epist.2.1.207

Epod.5.22

Epist.1.1.78

Carm.1.37.28

Sirm.1.7.I

Sirm.2.1.18

Serm.2.5.14

Epist.1.I 8.73

Carm.4.14.52

Epist.2.2.I07

Serm.2.2.1 18

Scrm.2.2.124

? ior.Episl.1.1 8.40

3 tar.Epist.1.1 8.40

Carm.Sate. 49

Epist.2.1.263

Serm.1.3.87

Serm.1.5.56

Serm.2.3.230

Serm.1.4.1I 3

Ars Poct. 414

Carm.1.32.9

Carm.2.5.4

Carm.3.13.5

Serm.1.2.119

Serm.1.3.109

Epist.2.2.56

Carm.1.33.Io

Carm.3.10.9

Serm.1.5.84

Carm.I.15.13

Carm.3.18.6

Carm.3.20.5

Carm.46.21

Carm.tio.I

Carm.t.II.Is

Carm.4.1 5.32 


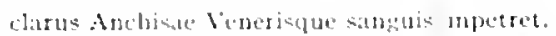

Carm.Suec.50

veneris. nec tantum vencrts quantua studios culinae.

Serm.2.5.80

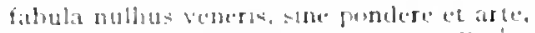

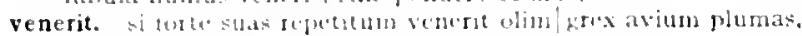

Ars I'och.320

veneror. si vencrur rultus nibil hurmm

lifist.1.3.18

veni. unde gue veni?

ut veni custur, singultim panca lincutus

Serm.2.4.8

Carm.3.27.37

at! mase com veru, generosum et lene requiro.

veni. collit tha velox metce buni:

venia. ct lint. Ronnanis venia eot indigna goetis.

Sirm.1.6.5t

Epist.1. 15.18

Corm.4.12.22

Ars I'tr't.204

venia. huc moli iuricicum renia dabis

ut scriptur stecat idem libritiug usque fquam is est monitus, venia carlet.

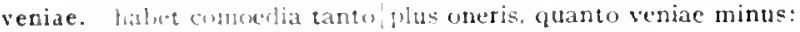

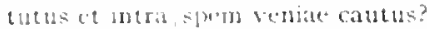

reniam. peratis vorian posecntem reddere rursus.

and les whiam bonus. cors.

fu-tus lat ventam sombunatue dies:

babis astotare timenti. / Marcenas, veniam.

vec venam antiquis sed! lonoremet praemia posci.

scimus. 1 lane veniam fetimusque damusque vicissim; .

Sirm.t.4.105

Ars $\log 1.355$

Epist.2.1.170

-1rs $\operatorname{lod} \$ .267$

Sirm.1.3.75

Sirm.2.4.5

Lisist.1.5.10

Epist.1.7.5

lipist.2.1 is

Ars loctil

veniant, in nue renst [renunt] netum atque cacatum|Iulius et fragilis Ineliatia furpue Voranus.

mlicit piecator uti, gromarius. . . Mane domum veniant.

venias. tambur veriat precambr . a agur Ajollo:

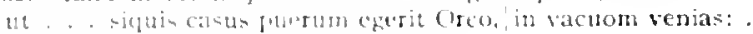

venist. multal juetertson veniat manus.

in ne senjat mictum atque catatum

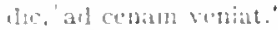

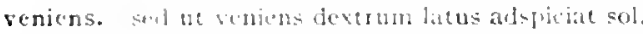

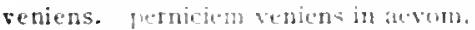

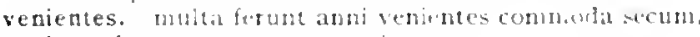

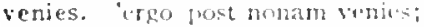

veniet. mactata viniel lenior hostia.

mefolata tuae cum veniet plumal superbiac

cui s concedere nolis, multa poretarum what [roniet] manus.

venimus. venimus al sumbum tortunae.

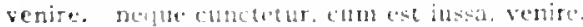

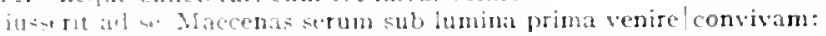

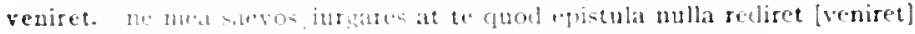

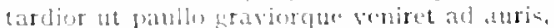

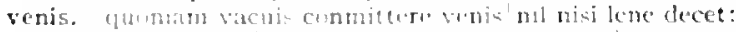

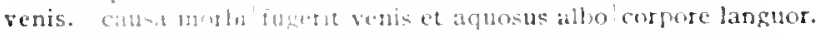

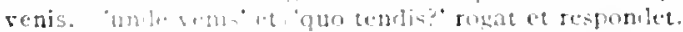

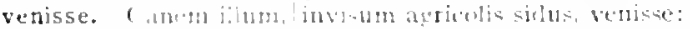

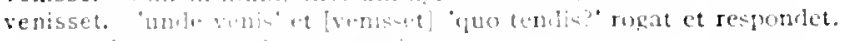

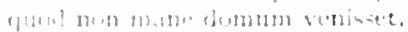

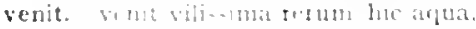

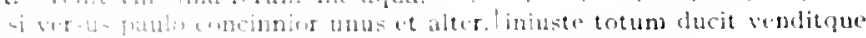

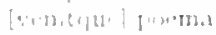

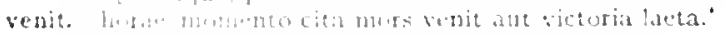

a

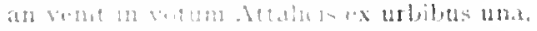

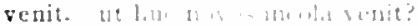

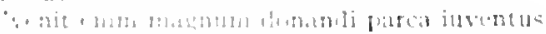

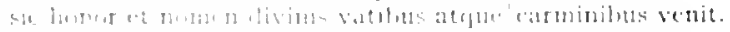

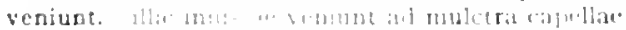

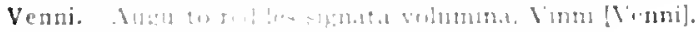

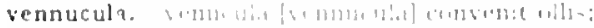

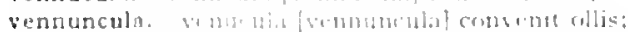

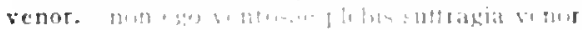

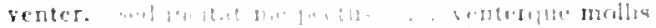

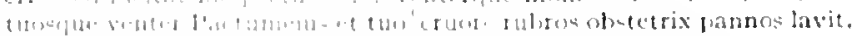

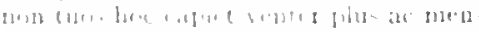

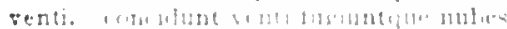

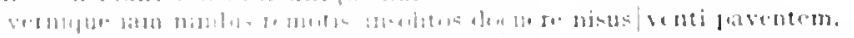

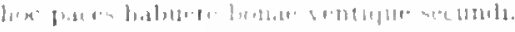

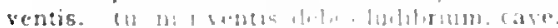

1ar.Sitm. I. $8,3^{8}$

Sirm.2.3230

Corm.1.2.3n

Serm.2.5.50

Sirm.1.4.14 I

Strm.1.8.38

Dist.1.7.t.

Epist.1.10.0

Cirm.3.5.14

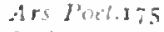

lopist.7.7.

Cirm.1.10 10

ciarmatald =

a ar.serm.1.4.1.4 I

1. pist 2.1 .32

Sirm.1.2.122

Sirn.2.7.33

iur.tigist.2.2.22

Ars l'olt.255

Sirm.2 4.25

(corm.2.2.15

Sorm.1.0.12

serm.1.7.2e

tar.sirmad.0 2

I.pist.t.7.0.8

Serm.1.5.88

iar. L.pist.2.1.75

Sorm.1.8

Sirnt.079

I.p.s.st 1.1.5

Sirm.2.2.128

Sirmaz.50

Ars l'net.quI

l:folled .90

iar. J tiat.1.13.2

iar.Sirm.2 \&-8

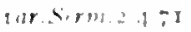

1 pust 10.37

1.ponts.

t:polition

Serm. 1 . 4to

Cinry: 12.30

(at) $4: 0$

1 thst $=1.102$

(iarm? 31.15

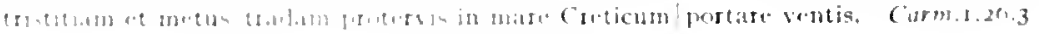


ut hace ingrata ventis dividat/fomenta

Lipod.1 I. It

Curm.1.5.7

Carm: 2.10 .9

saepius ventis agitatur ingens/pinus

quo nemus/inter pulcra satum tecta remugiat / vent is

Carm.3.10.7

caretque/ripa vagis taciturna ventis.

ventis iturus non suis

quaeque carent vent is et solibus ossa Quirini,

donec cinis' iniuriosis aridus vent is ferar.

vento. Thracio bacchante magis sub inter-lunia vento.

contrahes vento nimium secundo|turgicla vela.

leni recreare vento.

ventorum. te. . ventorumque regat pater

ventos. qui simul, stravere rentos aequore fervidoldcproliantis,

rapidos morantem|fluminum lapsus celeresque ventos.

ingrato celeres obruit otio'ventos

defendit aestatem capellis usque meis pluviosque ventos.

ventosae. non ego rentosae plebis suffragia venor

ventoso. quem tulit ad scaenam ventoso Gloria currts.

ventosum. qui mare temperat ventosum.

ventosus, Romae Tibur anrem, ventosus Tibure Romam.

ventre. quantum interpellet inani ventre dien durare.

"etenim fateor me" dixerit ille|"cluci ventre levem.

ventrem. non Afra avis descendat in ventrem meuns,

tum inmundo somnia visu / nocturnam vestem maculant ventrenque supinum.

quae prima iratum ventrem pacaverit esea.'

ventres. ut ventres lamna candente nepotum|diceret urendos

ventri. hic ego propter aquam, quod erat deterrima, ventri|indico bellum. si ventri bene, si lateri est pedibusque tuis.

quidquid quaesierat ventri donabat avaro.

ventris. obsequium ventris mihi perniciosius est cur?

ventum. seu mobilibus vepris inhorruit/ad ventun folis

ventum. laborant, 'cum ventum ad verum est:

ventum erat ad Vestae

simul atras/ventum est Esquilias.

ut ventum ad cenam est, dicenda tacenda locutus

ventura. ad te post paulo ventura pericula sentis?

venturam. cum speranus co rem venturam.

venturum. cun speramus eo rem venturam [item fore venturum]... commodus ultrolarcessas

venturus. huc venturus erat Naecenas optimus atque/Coceeius.

quid Titius? Romana brevi venturus in ora,

Romae Tibur amem. ventosus [venturus] Tibure Romam.

venucula. venucula convenit ollis; rectius Albanam funo duraveris uvam.

Venus. jan Cytherea choros ducit lenus imminente luna oscula, quac lenus quinta parte sui nectaris inbuit. in me tota ruens Venus|Cyprum deseruit.

quae te cunque domat Vents.

me meling cum petert Vinus.

quem lenue arbitrum/dice bibendi?

ridet hoc, inquam, lenus ipsa.

'quid si prisca redtit lenus

dum favet Sox et Venus.

eustodem pavidum I uppiter ot Venus risissent:

si larta aderit benus

alerat querenti porfidum ridens venus

ac ben. numnatum decont siarleda Ventreque.

Venus. quis non te potius, Bacehe pater, teque, decens Venus? o Venus regina Cnirli Paplique.

intermissa. Venus, diu!rursus bella moves?

venus. quo fugit venus, lietu,

quen damnosa venus, quen pracceps alea nudat.

ordints haec virtus erit et venus. aut ego fallor.

Venusinae. Venusina / plectantur silvae te sospite

Venusinus. nam Venusinus arat finenr sub utrumque colonus.

repallida. vepallirla iectoldesiliat mulies.

repres. quid si rubicunda benigni|corna repres et pruna ferant. .

vepris. nam seu mobilibus vepris inhorruit/arl ventum foliis

ver. ver ubi longum tepidasque praebet' I uppiter brumas

Carm.3.29.2.

lipod.16.1.3

EPod.1.7.3.4

Carm.t.25.12

Carm.zoso 23

Carm.3.20.13

Corm.1.3.3

Carm.1.0.10

(itrm.1 12.10

Carm.1.15.4

Corm.1.17.9

Lpist. I.19.37

Epist.2.1.17\%

Carm-3.4...to

Etpist.1.8.12

Sirm. i.0.128

Serm.2.7.39

Lepod.2.53

Sirm.1.5.85

S.rm.2.8.5

Epist.1.15.36

Serm. 1.5.7

Epist.1.12.5

Iipist.I. 5.32

Sirm.2.7.104

(t) ni.Carm. $1.23 . t$

Sirm 1.3 .97

Strm.1.9.35

Sirm.2.1.33

Lpist.1.572

lipist. I. 18.83

Epist.2.1.226

zur.Iipist.2.1.226

Sirm.1.5.27

L. 1 ist.1.39

iar.Jpist.1.8.12

Sirm.24.75

Carm.1.4.5

Carm.1.13.15

Carm.10.9

Ciarm.1.27.14

Corm.1.3.3.13

(arm.2.7.25

(arm.2.8. 13

Carm.3.9.17

(arm?.3.11.50

Carm.3.10.p

Curm.3.2121

Curm.3.27.07

Esist it 38

Corm.1.18.6

Carm.1.30. I

Cirmidi.1

Carm.13.17

Epist.1.18.21

Ars Port.q2

Corm.1.28.26

Serm.2.1.35

Serm.1.2.120

Fpist i. I0.9

conti.(arm.1.23.5

Carm.20.17 
trigurat mutesunt Lephyris. ver proterit aestas/interitura.

vera. nec vera virtus, cum semel excidit.

dum snit libertas dici mera veraque virtus.

Carm.3.5.29

Epist.1. 18.8

Serm.2.7.99

vera. velut sile vera pugnent.

vera. post medam noctem visus, cum somnia vera:

Serm.1.10.33

vera. ale prope vera: ineace (contendere noli)/stultitian patiuntur opes;

Epist.1.18.28

veraces. bosilue, veraces cecinisse Parcae.

Carm.Susec.25

Epist.1.1.17

verae. "urtutis verae custos rigidusque sacelles:

Epist.2.2.144

and perase numerosque modosque ediscere vitae.

veraliter. continuatque dapes nec non verniliter [veraliter] ipsis/fungitur ofticits,

verar. comluta cun verax aperit praecorlia Liber.

verba. Flacei'verba per atcentam non ibunt Catsaris aurem. sune sugblet voces, quilus hunc lenire dolorem/possis novia tictalue nuper habebunt verba fidem. trictia maestum voltum verba decent. verbulue proviam rem non invita sequentur.

verba. cur facunla parum decoro inter verba cadit lingua silentio? per anlacis nova dithyrambos verba devolvit verba loquor socianda chordis: in verba iurabas mea. an ut ignotum dare nobis, verba putas?" donec verbat, qubus voces sensusque notarent. muminaque invmere: partic intermiscere petit.i verba foris malis. me" pedibus riclectat clablere verlod verba facit leaso: quil? cum bulba foris annoso verba palato. nullid: alluctus iurare in verba magistri. nunc allibe puro pectore verba, puer. virtutem verba putas et lucum ligna: requirs. . . aluod verba manistret. utrus horum verba probes ce facta. doce sic iterat voces tet verba calentia tollit. secutus. . non res et agentia verba Lycamben. verbat lysac motura sonum conectere digner? audebit. . . verba movere loco. quamvis invita recedant ac non verba requi fidaus modulamda latinis. utergue proicit ampullas et sesquipedalia verba. non.. dominantia nomina solum / verbaque. Pisones. Satyrorum scripters antmabo

verbenas. hic verlenas, pueri, ponite turaque verbenis. ara castis| vincta verbenis

verbera. "xanimari metuentis patruae verbera linguae. ferula catelas meritum maiora subire/verbera quareumque excepit turgentis verbera caudac/ clunibus

verberabit. Vrbem eques sonante verberabit ungula, verberatae. non vorberatae grandine vinean verbere. aeguoris mgri fremitum et ementis/verbere ripas. verberes. Wtrumque serberes latus, Auster, memento verbi. nil verbi, jureas quin fortiter, aldam.-verbis. male nominatis parcite verbis. quol acer spiritus at vis mec verbis nee rebus inest. quod verbin granca latuis miscuit.

verbis. mulibua linire verbis mpias.

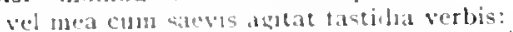

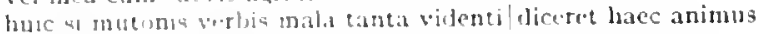

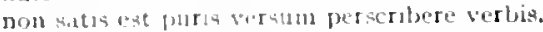

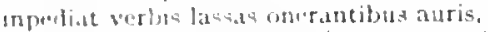

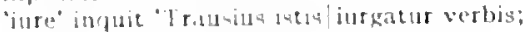
verbinglae decorts obrolvas vitum?"

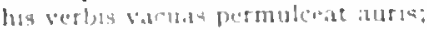

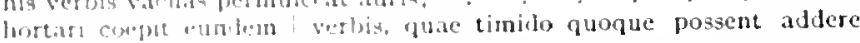
ine"rituris:

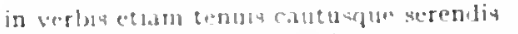

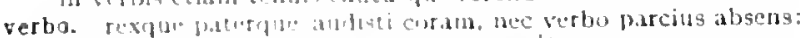

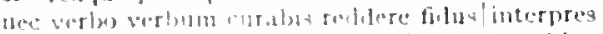

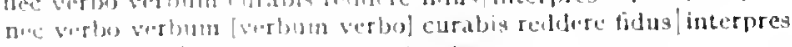

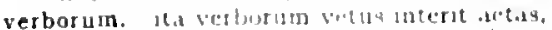

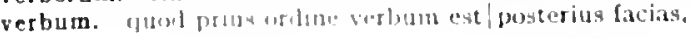

I'ur. Serm.2.6.108

Serm.1.4.89

Serm.2.1.19

Epist.1.1.34

Ars Poct.52

Ars Poit. 106

Ars Poet.3 II

Corm.1.1.36

Carm.4.2.11

Corm.49.4

Epod.15.4

Sirm.1.3 23

Serm.1.3.103

Serm.1,10.30

Sirm.2.1.28

Serm.2.3.231

Serm.2.3.274

Epist.1.1.14

Epist.1.2.08

Epist.1.0.31

List.1.15.20

Epist.1.17.16

Epist.1.15.12

Epist.1.10.25

Epist.2.2.86

Epist 2.2.113

Epist.2.2.143

Ars Poct.97

Ars Pot?.235

Carm.1.19.14

Curm.t.11.7

Carm.3.12.3

Sorm.1.3.12I

Serm.2.7.49

Ispod.10.12

Carm.3.1.29

Carm.327.24

Ispos.10.3

Som.2.3.42

Curm.3.1.1 2

Sorm.1.4.47

Serin.1.10.20

Epod.5.8.t

Epod.12.13

Serm.t.2.18

Sorm.1.4.54

Sorm.1.10.10

Sirm.2.2.100

Serm.2.7.41

E.pist.1.10.20

Epist.2.2.36 Ars Pocho

Epist.1.7.38

Ars Poes.133

sar.Ars lioet. 133

trs Puebes

Serm.t.4.58 
et senel enissum volat inrevocabile verbum. inter quae verbum emicuit si forte decorum

verbum. verbum non amplius addam.

ergolnon satis est puris versum perscribere verbis [verbum], notum si callida verbum/reddiderit iunctura novom. nee verbo verbum curabis reddere fidus/interpres nec verbo verbum [verbum verbo] curabis reddere fidusfinterpres mullum ultra verbum aut operam insumebat inanem.

vere. primo restituent vere Favonii

vere. dic per omnis/hoc deos vere,

hic clies vere mihi festus atras|exiget curas:

ut siquid promittere de me/possum aliud vere, pronito.

persuades hoc tibi vere, .

obiciet vere quisquam mihi.

si neque avaritiam neque sordes aut mala instra| obiciet vere quisquam [quisquam vere] mihi.

vere quod placet ut non|acriter elatrem.

vereare. insanos qui inter vereare insanus haberi.

verecundum. verecuntumque Bacthum|sanguineis prohibete rixis. saepe verecundum laudasti.

verecundus. verecundus color/reliquit ossa pelle anicta lurida, et frugi castusque verecundusque coibat.

vereor, nec vereor, ne, dum futuo, vir rure recurrat,

nam ut ferula caedas meritum maiora subire/verbera non vereor. sed vereor, ne cui de te plus quam tibi credas

Vergili. nulli flebilior quann tibi, Vergili. adduxere sitim tempora, Vergili:

Vergitio. Vergilio adnuerunt gaudentes rure Camenae.

Caecilio Plautoque dabit Romanus ademptum/Vergilio V'arioque?

Vergitium. navis, quae tibi creditum/debes Vergilium; .

Vergilius. Plotius et Varius Sinuessae Vergiliusque/occurrunt, lusum it Maecenas, dormitum ego Vergiliusque; optimus olim / Vergilius, post hunc Varius dixere quid essem. Plotius et Varius, Maecenas V'ergiliusque,

dilecti tibi Vergilius Variusque poetae,

vergit. si paulum summo decessit, vergit ad imum.

veri. iudice te non sordibus auctor/naturae verique. siquid Stertinius veri crepat. quemcunque inscitia veri|caecum agit.

qui species alias veris [veri] scelerisque tumultu i permixtas capiet. commotus habebitur.

veris. Solvitur acris hiens grata vice veris et Favoni seu mobilibus vepris [veris] inhorsut] ad ventum [adventus] foliis instar veris enim voltus ubi tuos.

ian veris comites, quae mare temperant.

veris, si vocata partubus|Lucina veris adfuit, uti moxinulla fides damnis verisque doloribus adsit.

veris. 'stultum me fateor (liceat concedere veris) ficta voluptatis causa sint proxima veris:

veris. "qui species alias veris scelerisque tumultu/permixtas capiet. atque ita mentitur, sic veris falsa remiscet.

Veritas, incorrupta Fides nudaque Veritas

veriti. nos maius veriti, postquam nihil esse pericli|sensimus, erigimui;

veritus. qui pauperiem veritus potiore metallis|libertate caret.

verna. si ancilla aut verna est praesto puer.

verna ministeriis ad nutus aptus erilis.

vernaliter. continuatque dapes nec non verniliter [vernaliter] ipsis|fungitur officis,

vernas. positosque vernas, ditis examen domus.

vernasque procaeis / pasco libatis dapibus.

verni. qui purgor bilem sub verni temporis horam.

verni. vernique iam nimbis remotis/in rolitos docuere nisus/venti paventem. verniliter. nec non verniliter ipsis/fungitur officis,

vernis, non semper idem floribus est honor/vernis

vernis. vernique [vernisque] iam nimbis remotis|insolitos docuere nisus| venti paventem.

vero. ego vero|oppono auriculam.

si vero est, unetum qui recte ponere possit

quem vero arripuit, tenet occiditque legendo.
Epist.1.18.7 I

Epist.2.1.73

Sirm.1.1.12 I

var.Serm.1.4.54

Ars Peit.t7

Ars Pott.1.33

i'ar.Ars Poet.133

Ars Poot $_{1+43}$

Corm.3.7.2

Cirm.1.8.2

Curm.3.I.1.13

Serm.1.1.103

Serm.1.p.8

S.rm. x.0.09

far.Serm.1.6.69

Epist.1.18.17

Serm.2.3.40

Curm.1.27.3

Epist.1.7.37

Fopol.17.21

Ars Pot.207

Sirm.1.2.127

Serm.1-3.I2I

Epist I.16.19

Carm.1.24.10

Curm.4.12.13

Sirm.1.I0.45

Ars loet. 55

Carm.1.3.0

Serm.1.5.40

Sirm.1.5.48

Sirm.1.0.55

Serm.1.10.81

Epist.2.1.247

Ars Poit. 378

Curm.1.2S.I5

Serm.2.3-33

Serm.2.3.43

var.Strm.2.3.208

Carm.I.4.I

var.Carm.1.23.5

Carm.4.5.6

Carm.4.12.I

Epol.5.6

IEpt.1.17.57

Sirm.2.3.305

Ars I'oct.33s

Sirm.2.3.208

Ars Poet.15I

Carm.1.24.7

Sirm.2.5.57

Epist.1.10.39

Strm.1.2.IT

Epist.2.2.0

Fir. Serm.2.6.108

Epod.2.15

Serm.2.6.06

Ars Poet.302

Carm.4.1.7

Sirm.2.6.108

Carm.2.I1.Io

rar.Carm-4.1.7

Serm.1.9.76

Ars Poet.122

Ars Poel.475 


\section{VERO}

VERSVS

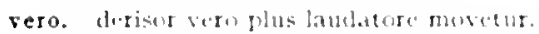

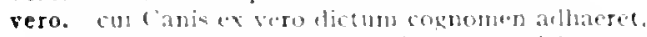

guasn yui non puterit vero dietinguese falsum.

reros. mentemque lymplatam Marentico / redegit in veros timores Catsint

verris. vertis ohliefum medientis ictum|sanguine donem.

verris. tu priscis buberno ex acquore verris.

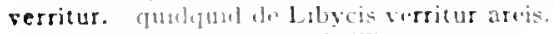

verrucis. ipmenent vertucis ilhus:

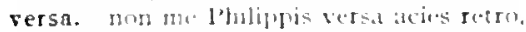

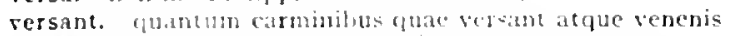

versare. Siblellis docta ligonibus persare glandas

rersat. ubi wolulus bosges pacne macros arsit dum turdos versat in igni: acris sublectat lesson stimules rersatedu mesantem.

rersate. Busace diu, quirl firre recusent, quid valeant umeri.

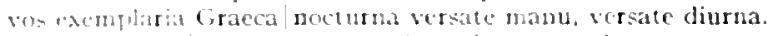

versatur. ombun| reseat ur urna serius ocins/sors exitura

rersemur. cum genus hoc ince vitale versetur [rersemur], ubi acris] inviklab atgue vigent ubi crimina:

versent. mili mon tantum.. Curke sunt aqqu hbori / quantum

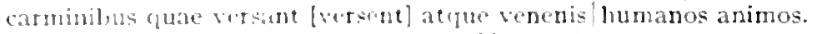

rersentus. It versentur adhuc intra persetralia bestae; .

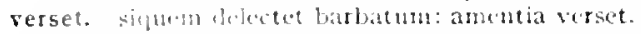

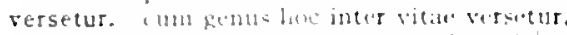

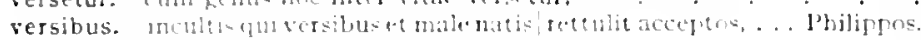

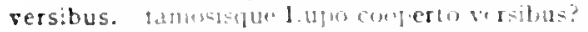

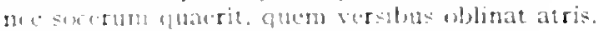

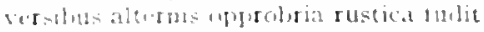

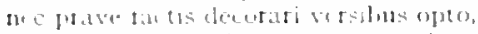

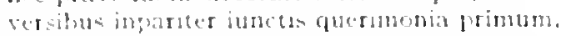

Westbus apmi trapicis a cos curica mon volt:

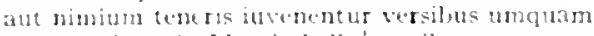

mates animes in Matia bulla vereibus exactut;

versiculis. hiscine versiculis speras uls josse dolores atque acstus

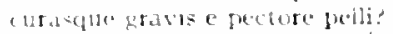

versiculos. mhil me sicut antea iuvat/scribere versiculos anore preussum kian.

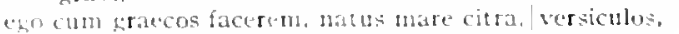
num ferum dura negarte versiculos natura magis factos.

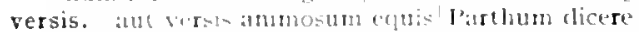

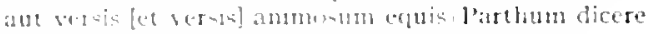

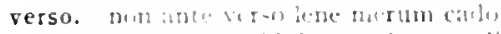

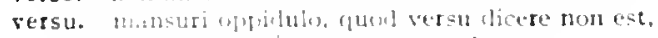

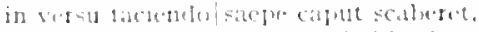

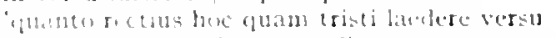

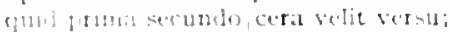

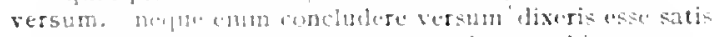

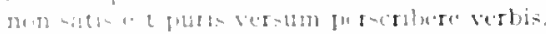

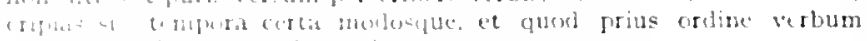

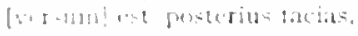

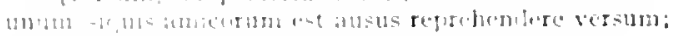

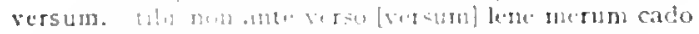

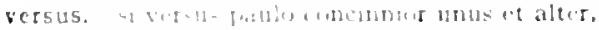

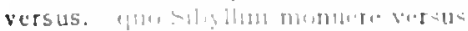

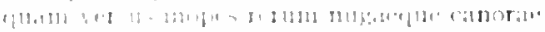

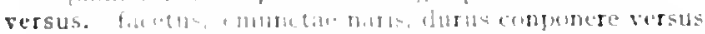

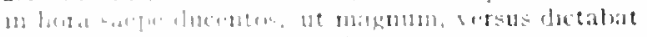

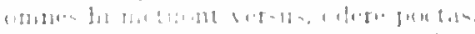

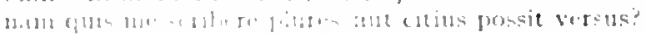

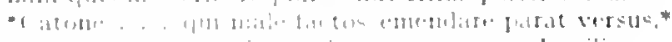

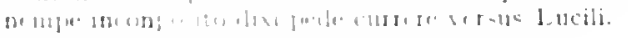

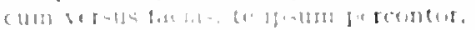

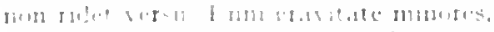

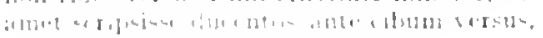

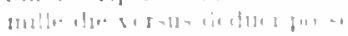

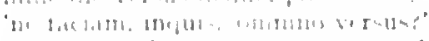

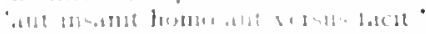

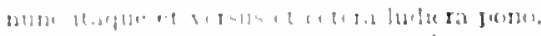

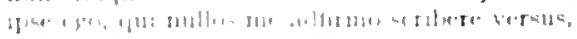

Ars Joct.433

Scrm.2.2.50

Epist.1.10.29

Carm.1.37.15

Carm.3.22.7

Serm.2.3.235

Corm.1 1.10

Sirm.1.3.74

Carm-3.4.21

Sermis.in

Carm.3.1.30

Sorm.1.5.72

Serm.2.7.94

Ars l'ort.39

Ars loet.219

Carm.2.3.2p

inr.Serm. I.3.ein

ar.Serm.1.8.19

Epist.2.2.1 I

Sirm.2.3.249

Serm.1.3.10

Epist.2.1.233

Serm.2.1.88

Litist.1.19.30

Jpist.2.1.146

ppist.2 I 200

Ars Itet.75

Ars leviso

Ars loct ath

Ars loxtedo3

Sorm.1.2.100

Epoditi.2

Sermitio 32

Serm 1.10 .58

Carm.1.10.1 I

iar Carm.1.10.11

Corm.3.20.2

Serm.1.5.87

Serm.1.10.70

Sirtil.2.1.21

Sitm.2.5.5.1

Sirm. 1.9

Sirmi.454

sar.sorm.1.458

Epist.2.1.222

ar. Curm-3.20.2

lepist 2.154

Cormsoses

Ars liet.322

Sorme 1.48

Sirm.1.t10

Sirmet:3i

Sirn. 10.24

Sitm.1.30.3

Sirm: 1 . 101

sirm 1.111.25

Sirmer.jes

sirmel 10it

Siches. 1 it

sill 216

Sorn.2.7.117

1 pist 1.10

1 p1.t.2 1.1 II 
versus amat, hoc studet unum;

Epist.2.1.120

paupertas inpulit audax|ut versus facerem.

Epist.2.2.52

ni melius dormire putem quan scribere versus?

i nunc et versus tecum meditare canoros.

effutire levis indigna tragoedia versus,

Enni! in scaenam missos cun magno pondere versus

qui nescit, versus tamen audet fingere.

nolito ad versus tibi factos ducere plenum / laetitiae;

male tornatos incudi reddere versus.

$v$ ir bonus et prudens versus reprendet inertis,

hic, dum sublimis versus ructatur et errat.

nec satis adparet, cur versus factitet;

vertas. saepe stilum vertas, iterum quae digna legi sint|scripturus,

cognomen vertas in risum et labula fias.

rertat. hiems ad boc vertat mare.

ut ora vertat huc et luc euntium a
saepe stilum vertas [? vertat]. iterum quae digna legi sint/scripturus.

vertatur. aut in avem Procne vertatur. Cadmus in anguem.

verte. quin huc inanis, si potes, vertis [verte] minas/et me remorsurum petis [pete]?

vertent. dulcia se in bilen vertent

verterat. ubi omne/verterat in fumun et cinerem.

vertere. praesens... superbos|vertere funeribus triumphos:

valentium proceras manibus vertere fraxinos.

vertere pailor/tum parochi iaciem

vertere nodun formidine fustis / ad bene dicendum delectandumque redacti.

temptavit quoque rem si digne vertere posset

ita vertere seria ludo.

si defendere delictum quam vertere malles.

verteret. nec timuit sibi ne vitio quis verteret.

ubi omne |verterat [verteret] in fumum et cinerem.

verterit. nutatus. Ligurine, in faciem verterit bispidam.

mutatus, Ligurine, [mutatus Ligurinum] in faciem verterit [verterit in facienl] hispidan,

verterunt. ad hunc frementis verterunt bis mille equos/Galli . . . verti. donec iam saevos ancrtam in rabiem coepit verti iocus
donec ian saevos apertan $\mid$ in rabiem coepit verti [verti coepit] iocus. vertice. sublini feriam sidera vertice.

sordilum flammae trepidant rotantes|vertice fumum. ast inportunas volucris it vertice harundo|terret fixa

"hic et candidus et talos a vertice pulcher ad imos|fiet

verticem. et tollens vacuon plus nimio Gloria verticem late conspicuom tollere verticem.

vertices. flumcn gentibus additum / rictis minores volvere vertices

verticibus. si figit adamantinos|summis verticibus dira Necessitas/clavos, rertis. guin huc inanis, si potes, vertis minas

vertit. ille sraven duro terram qui vertit aratro.

vertit. Ilins... mulier peregrina vertit|in pulverem, cum Pallas usto vertit iram ab llio

vertite. iran atque numen vertite.

Vertumnis. Vertumus. quotquot sunt, natus iniquis.

verum. verum pone moras et studium lucri

verum hoc se amplectitur uno.

verum est cun nimis, est cum neretricibus.

verum defugic, nasuta, trevi latcre ac pede longo est.

servavit ab omni non solum facto. verum opprobio quoque turpi

vermm nequeo rormire.'

verum hic inpransi mecum disquirite.

verun ambitinis et aurlax:

'verum ego, . . prutens plicavi sanguine divos.'

vino quinquenini, verum citra nare nato, / lum coquitur

verum esto alis aliog rebus studiisque teneri:

verum ubi oves furto, norbo pericres capellae.

verum seu piscis seu porrum it cacpe truciras.

verum nli quid melius contingit et unctius.

tu poscie vilia. verum es/rante minor.
verum equitis quoque an migravit ab aure roluptas/onnis

terun age et his, qui se lectori credere malunt.

Epist.2.2.54

Epist 2.2.70

Ars Pott.23I

Ars Poel.260

Ars Poct.382

Ars Poet.427

Ars Poet.41I

Ars Poct.445

Ars Pot. 457

Ars Poit. $77^{\circ}$

Serm.1.10.72

Epist 1.13.9

Epod.2.52

Epod.4.9

? iar. Serm.I.10.72

Ars Poetis 7

sar. Epod.6.3

Sorm.2.2.75

Epist.I.I5.4I

Carm.1.35.4

Carm.3.25.16

Sirm.2.8.35

Epist.2.1.154

Epist.2.1.164

Ars l'out.226

Ars Poet 142

Serm.t.6 55

qar.Epist. I. $15.7 \mathrm{I}$

Carm.4.10.5

iar.Corm.4.10.5

Epod.9. 7

Epist.2.I.I 49

zar.lepist.2.I.I 49

Corm.1.1.36

Carm.4.11.12

Serm.1.S.o

Epist.2.2.4

Carm.1.IS.15

Carm.3.16.19

Carm.2.9.22

Carm.3.24.6

Epod.0.3

Strm.1.1.28

Carm.3.3.20

I pod.10.13

Epol.5.54

Serm.2.7.14

Carm.4.12.25

Serm.1.2.53

Sorm.1.2.58

Serm.1.2.92

Serm.1.6.84

Sirm.2.1.7

Sirm.2.2.7

Sirm.2.3.105

Sirm.2.3.205

Sirm.2.3.47

Epist.1.1.80

Iipist.1.7.80

Epist.1.12.21

Ifpist.1.15.4o

lepist.1.17.2I

lipist.2.1.187

Epist.2.1.21 4 
VERVM

'verum |purae sunt plateac, nituil ut meditantibus obstet.'

verum / gudent scribentes et se venctantur

verum th. risores, ita commendare dicacis/conveniet Satyros.

verum nil tant cimt.

verum uhi phura nitent in carmine,

verum ofxeri longo fas est obrepere somnum.

serum. an. quadeumque facit Maecenas, te quoque verum est,

quu! verum itque decens. curo ct rogo et ornnis in hoc sum:

mectri se quemque suo mojulo ac pede verum est.

rerum. miralur, si sciet inter- nosece mendacem verumque beatus amicum.

verum. quamquam ridentem dicere verum/quid vetat?

laborant, cum ventum ad verum est:

male verum examinat omnis corruptus iudex.

"Ji ce, 1)amasippe. deacque verum ob consilium donent tonsore.

jusanis et tu stultique prope omnes. | siquid Stertinius veri [verum] ereipat.

si velles" inquit "verum mihi ponere nomen.

nil $G$ rosphus nisi verum orabit et acquom.

atque huter sibus Academi quaerere verum.

vesani. et stella vesani Leonis

vesania. extimui, ne vos ageret vesania discors.

vesanum. vesanum tetigisse timent fugiuntque poetan/qui sapiunt;

vescatur. ac potius folis parcus vescatur amaris;

rescere. "v"escere. sodes", "iam satis test"

resceris. mun vesceris ista, iquan laudas, pluma?.

vesci. mon quo more piris vesci Calaber iubet hospes

vescimur. quicumque terrae muncte rescimur

rescit. seu (luis capic acria fortis/pocula seu modicis uvescit [vescit] laetius.

vescor. quibus jpse meique ante Larem proprium vescor

Veselli. "st inter Tanain quidlam socerumque Viselli [Veselli]:

vesica. displosa sonat quantum resica.

Vespero. puro te similem. Telephe, Vesperoltempestivi petit Rhode;

vespero. nec tibi vespero|surgente decedunt amores

respertina. surgente a sole ad eum, quo/vespertina tepet regio,

respertinum. fallacem circum vespertinumque peretro|saepe forum.

respertinus. nec vespertinus circungenit ursus ovile

iallacem circum vespertinumque [vespertinusque] pererrolsaepe forum.

si vespertinus subito te oppresserit hospes.

navos mane forum et vespertinus pete tectum.

Vestae. ire deicctum monunenta regis/templaque Vestae.

togac/oblitus aternaeque bestae.

ventum crat ad lestac

eq versentur allhuc intra pencetalia lestae;

Vestam. prece qua fatigent, virgines sanctae minus audientem / carmina bistalm?

reste. utcumiue mutata potentis|reste domos inimica linquis.

n.mina sectatur mojo sumpta veste sirili|sub patribus duris tironum.

nisi illab|quarum subsuta talos tegat instita veste.

ntl cernere possis, ceteria, ni Catia cet, demissa veste tegentis.

r.ro ubi purpurea porrectum in vente locavit/agrestem. .

vestem. scindut hacrentun coronam/crinibus inmeritamque sustem. .

turn inmunlo somnia visu nocturnam vestem maculant ventremque supunum

vestem arvocrum sequ'ntis. in magno ut populo, siqui vidisset, huic sestem ut gnatas. praret ancillas, paret aurum, traxitgue varid per pulpita vestem

vester. vester, Camerac. vester in arduos/tollor Sabinos, uti mos/vester int.

restibus. aurum vertbids illitum/mirata

vestigia. "qua me ventigia terrent. manserunt hediergue mancont vestigia ruris.

restigis. ponit utrorque'in locuplete domo vestigia. nacuram expelleg iurea, tamen usque recurret et mala perrumpet furtim tatidua [vestigial victrix

lob.ra fret vacuon poat beatigia princepa.

vis canere et contar ta sequi vegtigi.i vatism?

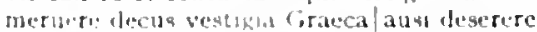

restimenta. uvida|suspenliswe potenti|vestmenta masis deo.
VESTIMENTA

Epist.2.2.70

Epist.2.2.106

Ars Poet.225

Ars Poet. 303

Ars Joct.35I

Ars Jod.360

Sirm.2.3.312

Epist.1.1.11

Epist.1.7.98

Ars Joct. 425

Serm.1.1.24

Sorm.1.3.97

Serm.2.2.8

Sim.2.3.17

Iar..Serm.2.3.33

Exist.1.7.93

Ëpist.1.1 2.23

Epist.2.2.45

Carm.3.29.19

Serm.2.3.174

Ars Poet. 455

Serm.2.3.114

Efist.1.7.15

Sirm.2.2.27

Epist.1.7.14

Curm.2.14.10

Iar.Serm.2.0.70

Sorm.zep.or

:or.Sorm 1.1.105

Sorm.1.8.40

Carm.3.19.26

Curm.2.9.10

Serm.1.4.30

Serm.1.0.113

Epod.10.5I

rar.Serm.1.6.113

Serm.2.1.17

Epist.1.0.20

Carm.1.2.10

Carm.3.5.11

Serm.1.9.35

Lisist.2.2.114

Corm.1.2.28

Carm.1.35.24

Serm.1.2.10

Serm.1.2.29

Serm.1.2.05

Sorm.2.0.100

Curm.1.17.28

Serm.1.5.85

Sorm.1.0.78

Serm.2.3.215

Ars Poct.215

Carm.3.4.21

Serm.2.7.80

Carm..t9.1.8

Fpista.1.74

Jpist.2.1.100

Serm.2.6.102

tar. Ipist.1.10.25

Epist.1.10.21

Epist.2.2.80

Ars l'ort.286

Carm.1.5.10 
Eutrapelus cuicumque nocere volebat / vestimenta dabat pretiosa: vestiret. ut se/non umquam servo melius vestiret,

vestis. cui stragula vestis.... putrescat in arca:

rubro ubi coccoltincta super lectos canderet vestis eburnos

vestis. inpensis cenarum et tritae munere vestis;

vestis. et Tyrias dare circum inluta toralia vestis,

argentum, vestis Gaetulo murice tinctas|sunt qui non babeant. vestit. gloria quem supra vires et vestit et unguit,

vestiunt. te bis Afro|murice tinctaelvestiunt lanae:

vestra. in |Persas atque Britannos| vestra motus aget prece.

vestri. ut mihi saepe|bilem, saepe iocum vestri movere tunultus!

at vestri proavi Plautinos et numeros et|laudavere sales,

vestris. vestris anicum fontibus et choris

vestris. sumite materian vestris, qui scribitis, aequam/viribus

vestrum. Roma si vestrum est opus

vestrum. pascitur in vestrum reditum votiva iuvenca.

vestrum. uter aedilis fueritve|vestrum praetor.

vetabat. sive vetabat, 'an hoc inhonestum et inutile factu / necne sit addubites.

vetabo. vetabo, qui Cereris sacrum/volgarit arcanae,

vetant. sed retant leges Jovis.

vetantis. sic fautor veterum, ut tabulas peccare vetantis,

vetas. "nequis humasse velit Aiacem. Atrida, vetas cur?"

vetat. vitae summa brevis spem nos retat incohare longam;

dum pudor inbellisque lyrae Musa potens vetat

teque nec laevos vetet [vetat] ire picus/nec vaga comix.

dignum laude virum Musa vetat mori.

deus, deus nam me vetat

quamquam ridentem dicere verum|quid vetat?

vetatque novis considere in hortis.

quid vetat et nosmet Lucili scripta legentis/quaerere,

veterem. emovit veterem mire novos.

veterem vetus hospes amicum.

veterem. nam vaga per veterem dilapso flamma culinam /Volcano

veteres. nec cupressi|nec veteres agitantur orni.

veteres. inter perfectos veteresque referri debet

veteresne poctas an quos et praesens et postera respuat aetas?

iste quidem vetures inter ponetur honeste.

si veteres ita miratur laudatque poetas,

veteres. et veteres revocavit artis,

in -anit veteres statuas Damasippus emendo:

veteri. sive gravis veteri craterae limus adhaesit.

veteris. fulgens contremuit domus|Saturni veteris:

reteris. est qui nec veteris pocula Mlassici . . spernit.

veteris non parcus aceti.

si positis intus Chii veterisque Falerni|mille cadis. .

reterno. cur me funesto properent arcere veterno;

veterum. intonsi Catonis auspicis veterumque norma.

nunc veterum libris, nunc somno et inertibus horis.

subtilis veterum iudex et callidus audis.

sic fautor veterum. ut tabulas peccare vetantis.

vetes. commodus ultro|arcessas et egere vetes et scribere cogas.

vetet. teque nec laevos vetet ire picus/nec vaga cornix.

unde pedem proferre pudor vetet aut operis lex.

vetita. seu malis vetita legibus alea,

vetitum. gens lumana ruit per vetitum nefas:

veto. avarum $\mid$ cum veto te fieri.

vetuit. vetuit me tali voce Quirinus.

edicto retuit, nequis se praeter Apelien| pingeret

vetula. te.. non citharae decent/nec flos purpureus rosal / nec poti. vetulam [vetula], iaece tenus cadi.

vetulae. servatura diu parem|cornicis vetulae temporibus Lycen.

vetulam. te lanae prope nobilem | tonsae Luceriam, non citharae decent . . vetulam,

vetuli. adnuimus pariter. vetuli notique columbi|tu nidum servas,

vetulis. vetuli notique columbi [vetulis notisque columbis]|tu nidum servis.

vetus. Servit II ispanae vetus hostis orae. veterem vetus hospes amicum.
Epist.1.18.32

Serm.1.1.97

Serm.2.3.118

Serm.2.6.103

Epist.1.19.38

Scrm.2.4.84

Epist.2.2.18 r

Epist.1.18.22

Carm.2.16.37

Carm.1.21.16

Epist.1.19.20

Ars P'ocl.270

Carm.3.4.25

Ars P'oct. 38

Carm.Sacc.37

Epist.1.3.36

Serm.2.3.181

Serm.I.4.I 24

Carm.3.2.26

Epod.1 7.09

Epist.2.I.23

Serm.2.3.187

Carm.1.1.15

Carm.1.6.10

var.Carm-3.27.15

Carm.4.8.28

Epod.14.6

Serm.1.1.25

Serm.1.8.7

Serm.1. 10.56

Sirm 2.3 .28

Serm.2.6.8 r

Serm.1.5.73

Carm.t.9.12

Fist.2.1 37

Epist.2.1.41

Epist.2.1.43

Epist.2.1.64

Carm.4.15.12

Serm.2.3.04

Serm.2.t.80

Carm.2.12.9

Carm.1.1.19

Sirm.2.2.62

Sirm.2.3.II5

Epist.1.8.10

Carm.2.15.I2

Sim.2.6.6I

Sirm.2.7.IOI

Epist.2.1.23

Epist.2.1.228

Carm.3.27.I 5

Ars Poet.135

Carm.3.24.58

Corm.1.3.20

Serm.I.I.IOH

Serm.1.10.32

lipist.2. I.239

var.Carm.3.15.16

Carm.1.13.25

Carm.3.15.16

Episl.I.I0.5

Ear. Fpist.I.I 0.5

Curm.3.8.21

Serm.2.0.8I 
'est veeus autue probus, centum qui perficit annos.'

Lpist.2.1.39

vetus. vetus abra multofinmat oflore'.

rugis retus irontem senectus exaret

niseus au luc pulsis. vetus est ut fama. Sabellis.

itat verbortum vetus interit aetas,

successit retus his comoedia. non sime multallaude;

Carm.3.18.7

Epod.8.3

$\operatorname{Sin} 1.2 .1 .36$

Ars P'ocs.oI

Ars Poet.28I

petus. anters shetum est vetus omne poema.

quod si tum Graecis nowlas invisa fuistet quam nobis, quid nunc esset vitu?

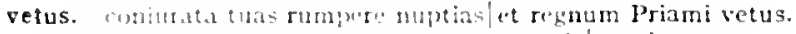

argentum te marmor vetus acraque et artis/suspice.

Lipist.2.1.54

Epist.2.1.01

Curm.1.15.8

Epist.1.1.17

vetustas. nunc satus informis premit et deserta vetustas;

retustis. sikrum betustis exirtat lignis focum

vetusto. Aeli betusto notilia ab lano-

vexant. aut mar. Caspium|vexant inacquales procellaejusque

mihi non tantum . . Curne sunt atque labori. | quantum carminibus quale versint [vexant] atque venenis/humanos animos.

vexare. ingugre li htium/vexare turmas

feraterue suetate bunc vexare locum

vexas. quid innurentis hospited vexas.

vexat. çunque talenta / poscit te mulier. vexat forbusque repulsum |

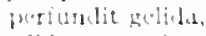

seu calilus sanguis seu rerum inscitia vexat

qui minus arkutos vexat furor iste poetas?

vexata. nut sinuel lliog vexata;

vexatur. all jucus folis parcus vescatur [vexatur] amaris;

vexere. tuat bxere tigres indocili ingmicollo tralientes.

vexet. Partho indocis/roxt eques metuendas hasta

duosi lliecordia bexet inertis

num te semprer inops agitet vexet que cupido.

verisse. Jicitur et plaustris vexisse pormata Thespis.

vexit. qund lugrens senel fora vexit.

ri. nunc vi, numc norte suprema, permutet dominos

via, et calcandal semel via leti.

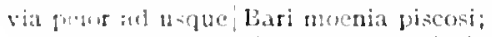

porticus lgriplate, via te conspexerit Appi,

quorum homintan regio el qualis via

mirabur, vtlue via si combersa lecebit.

Brumriciun Minuci melius vid ducat an Appi

dictir prormina sortes/et vitac nonstrita via est

via. mengiten lomplat iter via

ut reschlepit sacra catrnatus via.

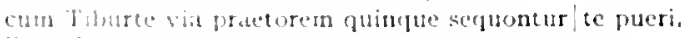

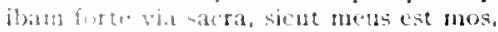

viae. lonmlicium longae hing chartaeque viaeque est.

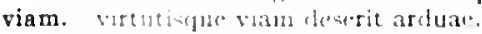

vilfo-m, bactan metionte te viam

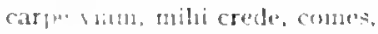

ire siam glta monatret eques;

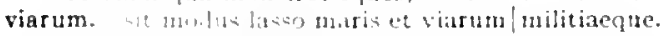

an $1, x+1+4$ tum tisudas orlio maris atque viarma?

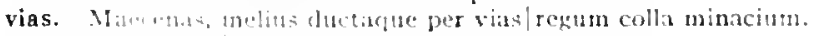

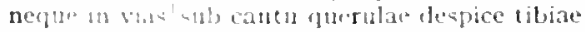

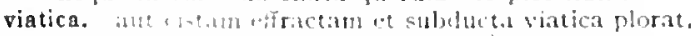

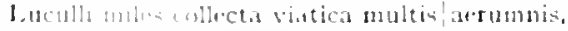

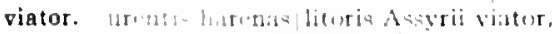

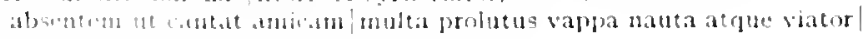
(1.21+1)

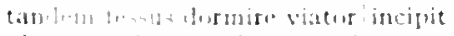

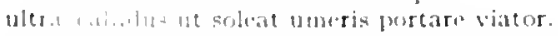

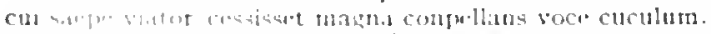

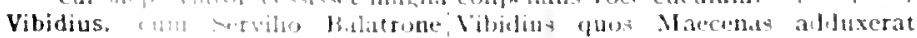
แani,

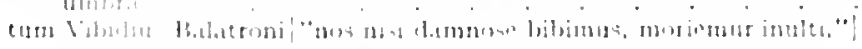

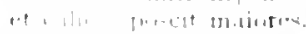

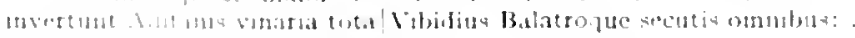

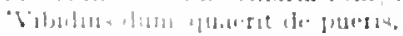

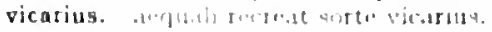

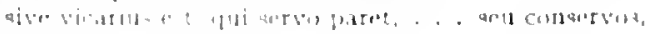

Epist.2.2.115

I.pod.2..13

Carm.3.17.1

Curm.2.9.3

¿ar.Serm.1.8.19

Carm.4.14.23

Sirm.1.8.1 8

Epolo. :

Sirm.2.7.00

Epist. I. 3.33

Epist.2.2.94)

Carm.1.9.19

itur.Serm.2.3.114

Carm.3.3.1.

Corm.3.2.t

Sermit.7.15

Etist.1.1S.0s

-1rs Putizas

Carm.3.20.45

Epist.2.2.173

Cirm.1.29.10

Sermis. 1.5.ges

List.1.0.2p)

IEpist.1.I 5.2

lipist.1.17.20

Epist 1.IS.20

Ars 1006..pos

Carm.3.2.22

Fpod.7.8

Sermiti.108

Serm.1.0.I

Serm.1.5.104

Carm.3.24.4!

1.pori.t. 7

Sirm 2.1.03

lipist.t.2.05

Corm.2.0.7

Epist.1.11.\%

Cirm.2.12.I!

Curm.3.7.20

Eprot.i.1.5.54

Epist.2.2.26

Cirm.3.4.32

Sirm.1.5.1\%

Serm.15.17

Sirm.1.5.00

Sorm.1.7.30

Sirn. 2.R.22

Sirm 2.5 .33

Serm.2.5.t1

Serm.2.8.80

Cormb.3.2.1 :4

S.r. 2.7.70 
vicatim. vosturba vicatim hinc et hinc saxis petens

vice. solvitur acris hiens grata vice veris et Favoni deiecit acer plus vice simplici;

delus hac fortasse benigna/reducet in seden vice.

infamis Helenae Castor offensus vice.

ergo fungar vice cotis.

ricem. noa valent/convertere humanam ricem.

infamis Helenae Castor offensus vice [ricem] fraterque nagni Castoris, inque vicen illorum patiar delicta libenter

defendente vicen modo rhetoris atque poetae.

vices. fors et debita iura vicesque superbae | te maneant ipsum: plerumque gratae divitibus vices

vices. non cantabimus invicem [in vices]|Neptunum et viridis Nereidum comas;

mutat terra vices et decrescentia ripas/Aumina praterent;

venena maga non fas nefasque, non valent convertere humanam [humanas] vicem [? vices].

discriptas servare vices opernmque colores

vici. unguentarius ac Tusci turba inpia vici.

vici. quid vici prosunt aut horrea?

ricina. et ricina seni non habilis Lyco.

nisi nos vicina Trivici|villa recepisset.

nec vicina subest vinum praebere taberna|quae possit tibi

vicina. Gra populus adsita certis/linitibus vicma refugit iurgia;

vicinae. non siue montium/clamore vicinaeque silvae.

vicinas. Cervius haec inter vicinus [vicinas] garrit anilis'ex re fabellas. an freta vicinas inter currentia turris

vicinas urbes alit et grave sentit aratrum,

vicini. onnes vicini oderunt, noti, pueri atque puellue

rident vicini glaebas et saxa noventem

ricinia. funus egregie factum laudet ricinia.

sed videt hunc omnis domus et vicinia totalintrorsum turpem. 'quaere peregrinum' vicinia rauca reclamat.

vicino. Cervius haec inter vicinus [vicino] garrit anilis/ex re fabellas.

vicinos. adite iratum patruom, vicinos.

Cervius haec inter vicinus [ricinos] garrit anilis ex re fabeilas.

vicinum. et onne ricinum oppidun. avidos vicinum funus ut aegros|exanimat

ricinus. ne vicinus Enipeus'plus iusto placeat sive nperum vacuo gratus conviva per inbrem/vicinas. hortus ubi et tecto vicinus iugis aquae ions Cervius haec inter vicinus garrit anilis/ex re fabellas. bonus sane vicinus, amabilis hospes.

vicis. purior in vicis aqua tendit rumpere phumbum ut pueros vementa docentem /occupet extremis in vicis balba senectus. ricissim. ast ego vicissim risero. scimus, et hanc venian petimusque damusque ricisim;

vicos. garriret, vicos, Vrbem laudaret.

victa. pietasule" dixit "victa furore.

rictas. volenten orolia me loqui/ victas et urbis

victi. fraterque magn Castoris, victi prece,

victima. victina nil miserantis Orci. .

crescit Albanis in herbis/rictima,

victima. dira detestatiol nulli expiatur victima.

victimas. rellere victimas/aedemque rotivam memento;

victis. Humen gethibus additum, victis

victo. sed pritquam victor viokens [victo ridena] discescit ab hoste. . . non iremum epulit ore.

victor. scriberis Tario fortis et hostium, victor

Cacsar llispana repetit penatia|rictor ab ora.

Troine prope victor athe Pthius Achilles,

sed patim captis [victor] gravis. . nescios tari puros Achivis

ureret thammis,

explicuit sua victor arma.

stravit humum sine clade victor,

barbarus heu cineres insistet victor

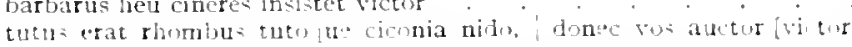
hement practeriu:

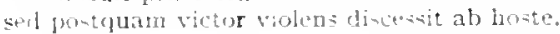

Epud.5.97

Curm.I.t.I

Carm.4.1 4.13

Epod.r3.s

Epod.17...2

Ars Poet.3nt

Epod.5.38

iar. Epod. I 7.12

Serm.I.3.I.4 I

Serm.I.IO.I 2

Corm.1.28.32

C'arm.3.29.13

qar.Carm.3.28.9

Ciarm...7.3

?:ur. ISPOd.5.88

Ars l'art.80

Serm.2.3.228

Epist.2.2.177

Corm.3.19.24

Serm.1.5.79

Epist.I.I4.24

Epist.2.2.17I

Curm.3.29.39

cor.Serm.2.6.77

Iipist. I. 3.4

Ars Puet.66

Sirm.1.I.85

Epist.1.14.39

Sirm.2.5.100

Epist.1.16.4.4

Iipist.1.17.62

iar.Serm.z.0.77

Serm.2.2.97

far. Serm.2.6.77

Esol.5.4t

Serm.I.t.126

Corm.3.7.23

Serm.2.2.120

Sirm.2.6.2

Sirm.2.6.77

Epist.2.2.132

Epist.t.10.20

Epist.1.20.ts

IP:Ad I 5.21

irs Pudeli

Srm.1.0.1.3

(arm-3.27.3')

Carm.t.15.2

lipol.17.43

Carm.2.3.24

(iarm.3.23.12

Sepod.5.00

(arme.17.30

(itr)it.2.1).22

conillipis?.I.I0.37

(itrm.ro.t

Cirm-3.14:

Curm..4. 3

\footnotetext{
:1) Carm. 1.0.17

(iorm.t9.4.4

Ciarm..4.1 $\$ 32$

lipol.te. I I

isr.tirm.2.2.50

i.pist. I. 0.37
} 
sed postquatn victor violens [violens victor] discessit ab hoste, victor propositi sinul ac perveneris illuc, postquam coepit agros extendere victor

victore. barbarac postquam cecidere turnae| Thessalo victore victore lasetus careate ut contendere durum (est / cum victore, sequor.

victorem. non equos inpiger/curru ducet Achaico/victorem nulta proruet integrum|cum laude victorem Gracejia capta ferum victorem cepit "e pugilem victorem et equon certamine primum

Victoria. Jonec alterutrum velox lictoria fronde coronet. victoria. hnat/monento cita mors venit aut victoria laeta.' victorum. victorum nepotes|rettulit inferias I ugurthae. quan Craia victorum manus.

victrices. diu lafeque victrices catervae

victrices. ducente victrices catervas/coniuge me lovis et sorore.

victricis. prima feres hederae victricis praemia.

victrix. et mala ferrumpet furtim fasticlia victrix.

victu. sordidus a tenui victu distabat quali igitur victu sapiens utetur cacribus et victu fordo deterruit Orpheus.

victum. tenetque grata compede vinctum [victum]. rictum. qui dicit, clamat 'victum date.'

victurum. lis ne consolot victurum suavius

victurus. his me consolor victurum [victurus] suavius victus. victus enus quae quantaqque secum arlierat. mundus victus non deficiente crumina?

victus. ne se jenuria victus opprimetet metucbat.

victus. nerpte pugno meglue segni pede victus. . tuis viceus Venerisque gratae/vocibus divom pater terta marique victus hostis

ricus. Gabis desertior atque Fidenis vicus; sulpura contemni vicus gemit.

vicum. ne... deferar in vicum vendentem tus et odores

videamus. videamus uter plus scribere possit.'

videar. "sunt quilus in satura videar nimis acer

rideas. cum tua pervideas [non videas] oculis mala lippus inunctis, sacpe tribu- hetis videas cemare quaternos. videas mutato in agello/cum pecote et gnatis

videatur. "uncinuns anicis postulat ut videatur; nimirum manuk paucis videatur.

videbor. ubt plura! cugere quan sutis est ac non cessare videbor. videndis. iurlicium subtile videndis artibus illud

videnti. Luic s nutonis verbis mala tantal videntildiceret hace aninus

videntis. Inus si mutumis verbis mala tantis videnti [videntis]' diceset haec

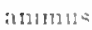

videntur. tras miht convivate prope disenture videntur

video. amlite [embre] magnos iam videor [virleo] duces.

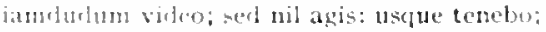

rucit the menes video:

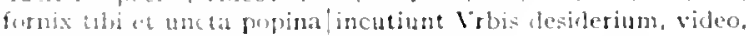
qui molior servo, quil liberior sit avarus. . . non video:

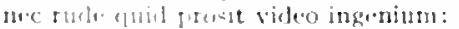

videor. andre malkas iam videor duces.

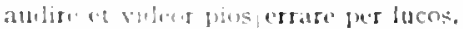

dividna et merelax videor tibi?

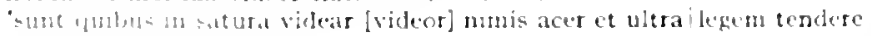
opils:

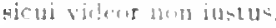

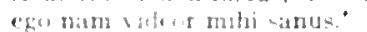

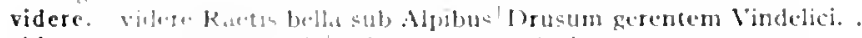

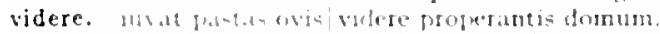

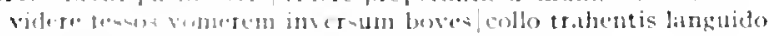

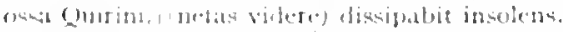

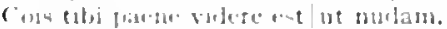

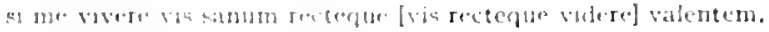

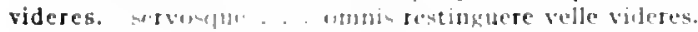

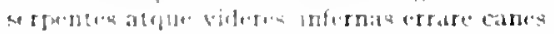

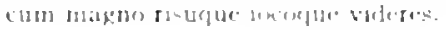

rar.Epist.1.10.37

Epist.1.13.II

Ars loet.208

Carm.2.4.10

L pod.9.2

Sorm.1.9.43

Carm.4.3.6

Carm.4.4.07

Epist.2.2.156

Ars 1'oet.84

Epist.1.18.0.4

Serm.1.1.8

Carm.2.1.27

Ispod.10.12

Carn.4.4.23

Carm.3.3.03

E.pist.1.3.25

lepist.1.10.25

Serm:2.2.53

Scrm.2.2.03

Ars $1400+392$

rar Corm.4.11.24

Lipist.1.:7.4s

Serm:1.0.130

ror.Serm. 1.0 .130

Serm.2.2.70

Epist.1.41

Sermil.1.gs

Carm.3.12.0

Carm.to.2I

Epod.q.2;

Lipt.1.1 18

Epist.1.15.7

Fpist.2.1.2po

Sorn:1 1.10

Sermi.2.1.1

ar.Sermi.1.3.25

Sirni.1.4. So

Sormit2.1:4

Sirnd-3.51

S.rn:23.120

Epist 810.40

1.pist.2.1.2.t2

Sornt 2.06

rur.term.8.2.68

l. p:st 2.2.2. I

comic (irm.2.1.2I

Sirm.1.0.15

Sirm.2.2.3.5

1 pist.1.1422

lepist 1 . 10.05

Ars loutho

Cism.2.1.2I

Carm-3.0.6

Sermid. 493

a ar.Serm.2.t.

Serm.2.3.150

Scrm.2 3.302

Cism-14.4.17

lifold.21:2

Epod.2.13

I. pold 10.14

Srrm.1 2.101

ger. Epist.1.7.3

Scrm.1 5.70

Serm 1.8.3.

Serm.1.8.50 


\section{VIDERES}

videres stridere secreta divisos aure susurros.' videretur. ipse videretur sibi nequior:

videri. cua notam duxit, niveus videri, / cetera fulvos.

vis formosa videri

quaeque carcnt ventis et solibus ossa Quirini, (nefas videre [rideri]) dissipabit insolens.

ut neque longa/nec magis alba velit quam dat natura videri.

da mihi fallere, da iusto sanctoque videri.

emendata videri pulchraque et exactis minimum distantia miror.

illud. fquod mecum ignorat, solus volt seire videri.

praetulerin scriptor delirus inersque virleri.

haec amat obscurum; volet haec sub luce videri.

videris. Melponene, senel nascentem placido lumine vicleris,

dices "hell", quotiens te in speculo videris alterum.

"hoc tibi Paulus/et Messalla videris? .

"durus", ait, 'Voltei, nimis attentusque videris lesse mihi.'

Vortumnum Ianumque, liber, spectare videris, .

vides. vides ut aita stet nive candidun Soracte

nonne vides, ut nudum renigio latus

Caecubum et prelo donitan Caleno tu bibes [rides] uvam:

non vides, quanto moveas periclo.

vides, quanto trepidet tumultu|pronus Orion.

videsne, sacram metiente te viam

nonne vides. Albi ut male vivat filus utque Baius inops?

avidos [vides] vicinum funus ut aegros exanimat mortisque metu sibi pareere congit.

vides, ut pallidus omnis' cena desurgat dubia? .

vides ut $\mid$ nudus inopsque domum redeam te vate.

"nonne vides". . . "ut patiens, ut amicis aptus, ut acer?"

vides, . . quanto devites animi capitisque labore

intervalla vides humane commoda.

videt. si Palatinas videt aequos aras

videt ridetque Philippus.

quid possim videt ae novit me valdius ipeo.

sed ridet hunc omnis domus et vicinia tota introrsum turpem,

quae terris semota suisque temporibus defuncta videt,

interdum volgta rectum videt, est ubi peceat.

non quivis vilet inmodulata poemata iudex

videto, quil de quoque viro et cui dicas, saepe videto.

videtur. hic tibi comis et urbanus liberque videtur.

sibi tunc turiosa videtur?"

ut . . diesque longa videtur opus debentibus,

Ennius, . . leviter curare ridetur, quo promissa cadant

ille per extentum funem mihi posse videtur|ire poeta.

vidi. Bacclum in remotis carmina rupibus/ ridi docentem.

arma militibus sine caede' dixit 'derepta vidi, vidi ego civium / retorta tergo bracchia

vidi egomet nigra succinctam radere palla Canidiam

postquam te talos, Aule, nucesque / ferre sinu laxo, donare et ludere vidi,

vidimus. vidimus llavom Tiberim retortis litore Etrusco violenter undis quam paene. . et iudicantem vidimus Aeacum vidimus et mermlas poni et sine clune palumbis.

vidisse. hoc staberi prudentem animum ridisse. voltum habitumque hominis, quem tu ridisse beatus

vidisset. vestem servosque sequentis, in magno ut populo, siqui vidisset. . vidit. qui vidit mare turgidum

te vidit insun Cerberus aureo cornu decorum

rocte sublustri nihil astra praeter/vidit et undas.

caprea. l.onem dente novo peritura vidit:

quidquid virit melius peiusve sua spe,

qui nores lominum multorum vidit et urbes.' .

viduantur. et folis viduantur orni:

viduas. qu' frustik et pomis viduas venentur avaras

viduas. et vitem viluas ducit ad arbores;

viduos. pucrum minaci roce dum terret, viduos pharetra!risit Apollo.

viduus, viduos [villuas] pharetra|risit Apollo.

vietis. qui suclor victis et quam malus undique membrisicrescit odor.

vigent, ubiacris, invilia atque vigent ubi crimina:

et iuvenum ritu florent modo nata vigentque.
VIGENT

Serm.2.8.77

Sirm.2.3.31

Carm.-2.2.59

Curm.4 13.3

zar.tipod.10.1t

Serm.1.2. I 24

Epist.1.10.61

Epist.2.1.71

Epist.2.1.87

Epist.2.2.120

Ars 101.313

Carm+3.2

Carm.tion

Serm.I.1).12

Epist.r.7.9 I

Epist.1.20.1

Carm.1.9.1

Carm.1.14.3

conicitm.1.20.10

Carm.3.20.1

Carm.3.27.17

Epoll.1.7

Serm.1.t. 109

zar.Serm. I. +1. 126

Serm.2.2.-7)

Strm.2.5.5

Serm.2.5.12

Epist.1.1.12

Epist.2.2.70

Carm.Saleto5

Epist.1.7.78

Epist.1.0.6

Epist.1.10.41

Epist.2.1.22

Epist.2.1.03

Ars Pot.263

Epist. I.ISts

Serm.1.4.90

Sirm.2.3.30.4

Epist.1.1.2I

Epist.2.1.51

Epist.2.1.210

Carm.2.19.2

Carm.3.5.21

Serm.1.8.23

Sirm.2.3.172

Carm.1.2.13

Carm.2.13.22

Sirm.2.8.91

Serm.2.3.80

Sorm.2.7.02

Sirmi.1.0.70

Carm.1.3.11)

(arm.2.10.29

Carm.3.27.32

Carmtitis,

Eipist.1.1.13

Ars Prot.I.92

Carm 2.9 .8

Epist.1.1.7s

Corm.4.5.30

Cirm.1.IO.1I

iar Carm.I.I.I I

Epol.12.7

Serm.1.3.1.1

drs Poet.t 2 
vigentis. magettorn: vagus cultom, virentu [vigentis] agelli. viget. nec viget pusdquam sumbe aut secundum.

ar. Ars Poel.117

vigil. insula vel atmore vigil totquebere.

It 14 uren solu vagil calamum et chartols tet scrinia posco.

Carm.1.12.18

Epist.1.2.37

Epist.2.1.113

Serm.2.3.152

Sirm.1.3.17

vigilabat. mxts vigilabat an ipsum/mane, diem totum stertebat.

vigilans. "iglansnt ploro|turpe conmissum

"t cortum tigilans "quartae sit partis Vlixes"|audictis "beres":

vigilant. ut agulent hominem, surgunt [vigilant] de nocte latrones:

vigilare, an vigulare metu cx.minem,

Ronate lufce diu fuit et solemne reclusa/mane domo vigilare.

vigiles. vigiles lucernas perier in lucem:

vigilet. siguis. . . porrectus vigilet cum longo fuste

vigilum. turtw anea . . ot vigilum canum/tristes excubiae

viginti. guattuor hinc rapinter viginti et milia raedis.

vigor. olun inventas et patrius vigor

viguj. J'Tsitrum vigui rege beatior.'

Romana vigui clarior llia.'

vile. vile potabis modicis Sabinum / cantharis.

vilem. 'utued. si conminuas, vilem redigatur ad assem."

siccus, inanis sperne cibum vilem;

si non circa vilem patulumque moraberis orbem

carnine qui tragico vilem certavit ob hircum,

viles. mituluc ct viles pelledt obstantia conchae

vili. contros qili portanda locabat in arca;

vilia. vilia vendentern tunicato scruta popello

cum res deficint, satis inter vilia fortis:

tu poscis vilia, kerum es dante minor.

vilibus. nam vilibus ovis| nigrisque est oleis bodic locus

vilibus. vilitus in ludis dictari carmina malis?

vilibus. vilibus in scopis, in mappis, in scobe quantus/consistit sumptus? vilice. bilice silvarum et mibi me reddentis agelli.

vilicus. nusc lthem ct ludos et balneá vilicus optas;

vlicus (rhi. . te dominum sentit.

vilior. "t dents eq virtus, nisi cum re, vilior alga est."

vilis. adstat chlums rilis, cum patera guttus,

vilis. vils anicorm est annona. Lonis ubi guid deest.

vilis. phathat comilbat omasi/vilis et agninae.

vilis. "vilis furogre" pitcer urget absens: .

vilis. buc frius angustis ejecta cadavera cellis / conservos vili [vilis] portambla locabist in arca:

reterti dibet an inter vilis atque novos?

vilissima. vont vitszima rerun hic alua.

vilius. vilus argentum est auro, virtuthus aurum.

villa. neofut ut superni villa candens Tusculi, Circacat tangat moenia:

hute nue ("incerei recipit plenissimal willa,

nat mos ventat Trivici villat recepiset.

villa. villathe, Havos quan Tiberis lavit.

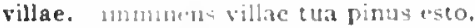

villis. Nmonttur, non de villis dombuswe alienis.

quorum com-picitur nition fundata pecunias villis.

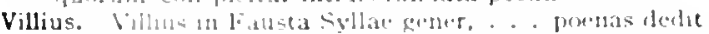

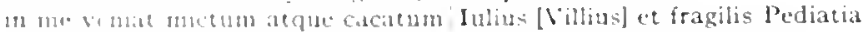

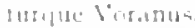

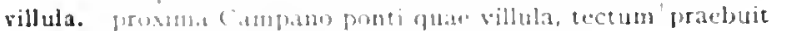

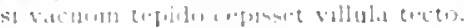

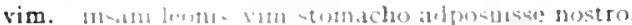

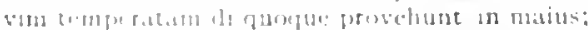

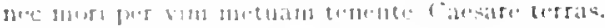

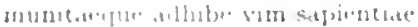

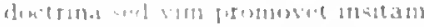

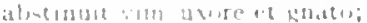

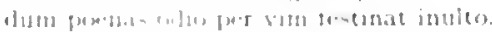

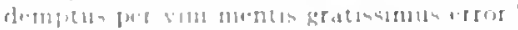

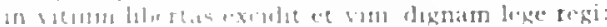

vin. 811120 (1)

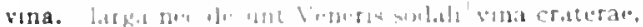

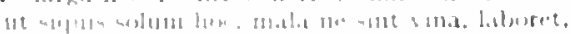

f०.

Corm.3.27.38

Serm.2.5.100

Far.Epist.1.2.32

Sirm.1.1.70

Epist.2.1.104

Corm.3.8.1.

Serm.2.3.112

Corm.3.16.2

Serm.1.5.86

Corm.\$. 4.5

Carm.3.9.4

Corm.3.9.8

Carm.1.20.I

Serm.1.1.43

Sirm.2.2.15

Ars Poct.132

Ars Poct.220

Serm.2.4.28

Sirm.1.8.9

Epist.1.7.05

Lpist.1.15.39

Epist.1.17.21

Sirm.2.2.45

Serm.1.10.75

Sirm.2.4.81

Epist.1.1.1

Epist.1.1.4. I5

I.pist.2.2.100

Serm.2.5.8

Serm.1.0.118

EPist.1.12.21

EPist.1.15.35

Corm. 327.57

zar.Sirm.1.8.0

List.2.1.38

Serm.1.5.88

Epist.1.1.52

I:pord. 1.29

Serm. I.5.50

Serm.1.5.80

Carn.2.3.18

corm.3.22.5

Serm.20.71

List.1.15..40

Sorm.1.2.04

coni.s.m. 5.8 .30

Sorm. 1.5.45

Serm.2.3.10

(idrm.1.17.16

Corm.3 a (it)

(a)m 3.1. 15

(arm.3.28.4

cism. \& 3.3

Serm.2 3.202

Epist 1.2.le

Epist 2.2.1.40

-irs lioet 282

Sicrm. I.1)(11)

(iorms 318.7

Serm.2.4.40

Serm.2.8.38 
vina. dissolve frigus ligna [vina] super foco|large reponens sapias, vina liques et spatio brevi quis post vina gravem militiam aut pauperiem crepat? exsiccet culillis/vina Syra reparata merce. . huc vina et unguenta et nimium brevis|thores... fure iube iuniores quaerit adulteros |inter mariti vina promere languidiora vina. hinc ad vina redit laetus nardo vina merebere. et horna dulci vina promens dolio adfer. . sesphos/et Clia vina aut Lesbia tu vina Torquato move consule pressa meo. Massica si caelo suppones vina sereno. Surrentina vafer qui miscet faece Falerna/vina. procedit fuscus Hydaspes|Caccuba vina ferens. vina bibes iterum Tauro diffusa palustris/inter Minturnas inter vina fugam Cinarae maerere protervae. (nam vina nihil moror illius orae.

vina fere dulces oluerunt mane Camenae. si meliora dies, ut vina, poemata reddit. et iuvenum curas et libera vina referre

vinaria. invertunt Allifanis vinaria tota/Vibidius Balatroque

vincam. deprendi miserum est : Fabıo vel iudice vincam.

vincant. qualia vincent [vincant] | Pythagoran Anytique reum doctunque Platonit."

vincas. formaque vincas Nirea,

vincat. neu multi Damalis meri|Bassum Threicia vincat amystide magna sonabit / cornua quod vincatque tubas: scribere quod Cassi Parmensis opuscula vincat .

vincent. qualia vincent|Pythagoran Anytique reum

vincentem. popularis/vincentem strepitus et natum rebus agendis.

vincentibus. instat equis auriga suos vincentibus.

vincere. gloriantis quamlibet mulierculam/vincere mollitia durus homo atque odio qui posset vincere Regem, cupiens varia fastidia cena|vincere dicitur ... vincere Caecilius gravitate. Terentius arte.

vincet. nec vincet ratio hoc, tantundem ut peccet idemque. vincet enim stultos ratio insanire nepotes. . si pucrilius his ratio esse evincet [esset vincet] amare adiuvat hoc quoque. sed vincit [vincet] longe prius ipsum | expugnare caput.

vinci. vincidolentem crevit in Herculem. et est qui vinci possit

vincire. nec vincire novis tempora floribus.

vincit. vincet [vincit] enim stultos ratio insanire nepotes. vincit longe prius ipsum|expugnare caput.

vincla. minatus Vrbi vincła, frustraque vincla gutturi innectes tuo excusare laborem et mercennaria vincla.

vincor. ergo negatum vincor ut credam miser,

vincta. ara castis /vincta verbenis tibia non, ut nunc, orichalco vincta tubaeque/aemula. vincti. fronde comas vincti cenant et carmina dictant. vinctum. tenetque grata|compede vinctum.

vinctus. velut usquam|vinctus eas. . Hebrusidue nirali compede vinctus aut fugies Vticam aut vinctus mitteris Ilerlam.

vincula. quem neque pauperies neque mors neque vincula terrent,

vincula. nec Lethaea valet Theseus abrumpere caro/ vincula Perithoo. dux fugit ustis navibus/minatus Vrbi vincla [vincula]. herbas atque incantata lacertis|vincula effugiet tamen haec sceleratus vincula Proteus.

vincunt. horrida callidi/vincunt aequora navitae, qualia vincent [vincunt] Pythagoran Anytique reum doctumquo Platona."

Vindelici. viclere Raetis bella sul, 1 pibus| Drusum gerentem Vindelici.

Vindelici didicere nuper. . durus, / vindemiator [vindemator] et
vindemator. tum Jraenestinus . . invictus.

2*ar.Curm.1.9.5

Carm.1.1ro

Carmis.18.5

Carm.1.3I.I 2

Curm.2.3.13

Curm.3.0.26

Curm.3.21.8

Carm.at.5.31

Carm.t.12.16

Lipod.2.47

Epod.9.34

lepod.13.6

Serm.2.4.5 I

Serm.2.4.56

Serm.2.8.15

Epist.1.5..1

Epist.1.7.28

Epist.1.15.16

Epist.1.19.5

Epist.2.1.3.4

Ars Poet.85

Sirm.2.8.39

Sirm.1.2.134

sur.Serm.2.4.2

Epol.15.22

Carm.1.36.1.4

Serm.1.0.74

IEpist.1.4.3

Serm.2.1.2

Ars Pot.82

Sermili.i 5

Epod.11.24

Serm.1.7.6

Serm:2.6.87

Epist.2.1.59

Sirm.1.3.115

Sirm.2.3.225

var.Serm.2.3.250

var.Serm 2.5.73

Carm.4.4.62

Serm.1.9.55

Carm. 1.32

itur..Serm.2.3.225

Sirm.2.5.73

Epoll.9.9

Epol. 7.72

Epist.1.7.67

Epol. 7.27

Carm.4.11.7

Ars Iodel.202

Epist.2.1.110

Carm.4.1 1.24

Serm.2.7.31

Epist.1.3.3

Fist.1 20.13

Sirm.2.7.8.1

(iarm... 7.28

gur. Ispol.9.9

Serm.1.8.50

Serm.2.3.7I

Citrm.3.24.41

E'tr. Serm.2.4.2

Cism.t.4.Is

curm.t. 18

q'ar.Serm. 1.7.30 
rindeniator. ijurus, vinderniat or et juvitus.

Serm. $1.7 \cdot 30$

vindex. voulex unate tramlis

Carm. 10.37

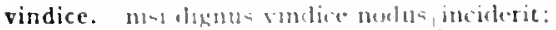

Ars Portion

vindicem. probes Ninbas magnale vindicem linguat Titgosque raptor $\rightarrow n \rightarrow 16$

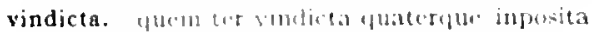

Carmete.2

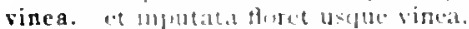

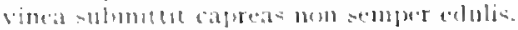

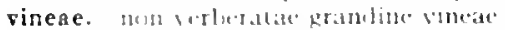

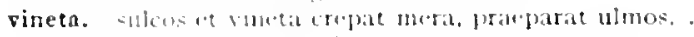

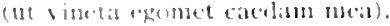

vini. guo smul mearts. nec regna vini sortiere talis

volupte fontem lactis et uheres/cantare rivos

Janfs cmatur, bolus. vini sextarius.

yumd vini sommique benignus

lanrlubus argutur vini vinosus Ionserus:

Vinni. Augusw redeles signata rolumina, Vimi.

vino. vino et lucemis Medus acinaces immane quantum discrepat:

rino. mune vinus prllite cura:;

meque ilule; mala vino lavere

illic omme inalum vino cantucute bevato

explicut vino contractat seria fromtis.

iam vime quacens, iam sommo fallere curam;

vmu quincluenui, verum etra mare nato. (dum coquitur.

conmisumughe leges et vime tortus et ind

fiabane, Horibu- to vino Genium memorem brevis acvi.

simeque diurno placari Genius festis inpune diebus,

abstmuit vemere et vino;

vinosa. ut vimo glomus turtiva florria lanat.

rinosus. vinusus, amator - nemo aleo terus ast. latulbus atgutur vini vinosus IJomerus:

vinum. ac nisi mutstum patreit defundere vigum

columbian limum [rinum] bene colligit ovo.

lactuca innatat acri post vinum stomacho:

nee vicial sulwit vinum pratele taberna quac posst tibi

Sirm.2.7.70

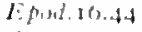

Sirm. 2.4 .43

Cism.3.1.20

isint.1.7.8.4

Epist.2.1.220

Carm.1.4.18

Curm.2.19.10

Sirm.1.1.74

Sirm.2.3.3

Lisis.1.10.6

Epist.1.13.2

Carm.1.27.5

Carm.1.7.31

Carm.3.12.2

Epoil.13.17

Sirm.2.2.125

Serm.2.7.114

Serm.2.8.47

Epist.1.18.38

Epist.2.1.14

Ars J'uet. 209

Ars Poet.t14

Epist.1.3.3.14

IEpist.1.1.38

Lipist.1.190

Sirm.2.2.58

ior.tirm.2.4.50

Sirm.2.teo

Epist.1.1.24

rinxere. undu [vindere] matres llage additum feris | alitibus... hombelani Ilectorem.

vinxisse. Hal lyan empora jojulea fetur vinxise comna

sur. Fond 17,11

Corm.1.7.23

Carm.3.10.1.1

viola ne: unctia vioba pallor amantium .

siolare. nom l'yloblen ferto violare aususwe sororem| Electran.

violaria. subistat et mytus et ommis copla narium

violas. "bona larentubs volas imitata reneno."

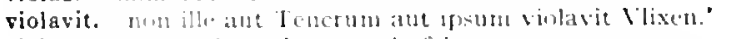

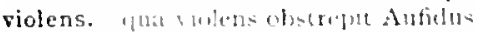

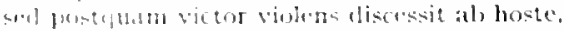

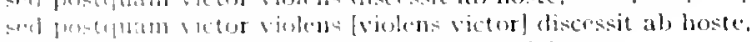

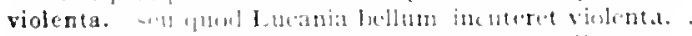

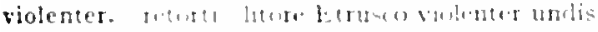

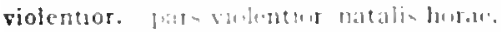

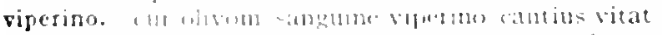

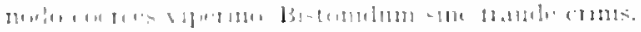

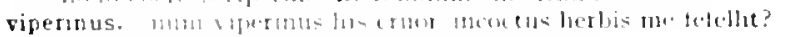

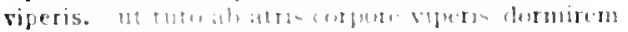

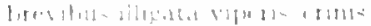

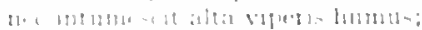

Sirn.2.3.139

(arm.2.15.5

Lipist.2.1.207

Serm.2.3.20.4

(arm.3.30.10)

lipist 1037

tor. t.piv1.1.10.37

Sirm 2.1.30

(cir)! 1.2.1.

(arme17.18

(arm.1 4.1$)$

(arm.210.19

Epotín.3.1

Cinm-3+1:

1.pul.5.15

1. peuldest

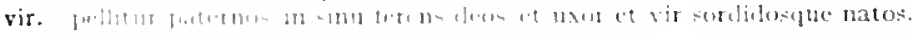

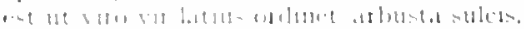

Cirm.t.is.2s

(itrm $3 \cdot 1.0$

Jie.

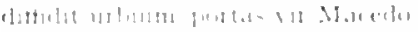

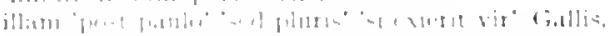

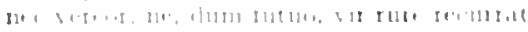

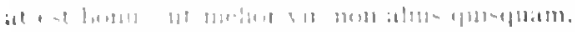

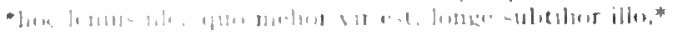

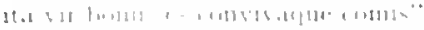

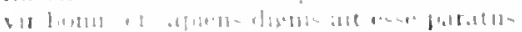

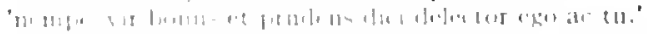

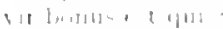

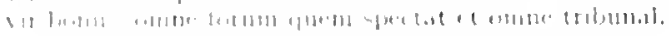

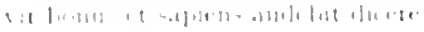

(isms.3 lol. Is

(i)m.3 10. I

sirm. 1.2.1 0

serm 1 2127

sirng.1.3 32

serm $1.10 * 4$

Sirm ! sis

180.617 .22

1.111.61 14).32

1.fus: 1.36...80

I PS: 116.57

1. M.s.1.10.7.3 
aut decus at pretium recte petit experiens vir.

Epistititi.42

vir bonus et prudens versus reprentet inertis.

virens. nec - lcama fervida virens in Aetna flamma;

virent. dumpue virent genualet decet.

virente. lited quot puless ledera virenti [virestel galdeat

virentem. ut studio majore petant Ilelicona virentem

vireati, lonec virenticanities alsest morosa.

virenti. laeta quod pubes hederat vitenti gatureat

virentis. virencis et doctae psallere Chiat maleris axubut in genis.

virentis. mercatorne vagus cultorne virentis agedli.

virentis. circit virentis est animus tuate campos invenca"

vires. pet g11a" Latinum nomen st Italac crevere vires

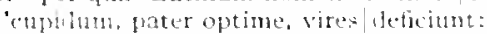

nec menc autet rem templare pudor quam vires fetre rectsent.

vires. gloria quem supra virs et vestit et unguit.

ot nerlecta solent incendia sumere vires.

virga. virgaque leven coerces|aurea turban, ţuam virga ecurel horrila

virgine. arsit Atrirles medio in trimmpho' virgine rapta.

dum Capitolium scanset cum tacita virgine prontiox.

virginea. interede' trmptator ()rion biama" virgimed chmitus sagita.

virgines. prece qua fatigent / virgines sanctac minus allientem / carmim Visiant?

quo xalet inventu= mus omnis et mox virgines tepelunt.

miserartue nuper virgines nuptac.

virgines. inter luclere vitgines

virgime lectas puerosque castos

virgines. bianam tenerat licite virginee.

virginibus. dare bracelia ludentem nitilis virsinibus

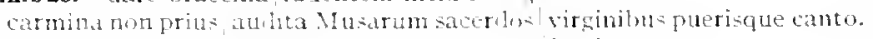

virginibus. numen cum teneris virginibus tuom lautantes.

rirginis. Acrisium virgins abditare custodem

virginum. nos convivia, nos prodia virginum . Contamus.

quae tibi virginum sponso necato barbara frritet,

scelus atque notas vitginum poenas

virginum metres iuvenumplue nuper'sospitum;

levis una mors est virginum etrlpae.

virginum primate puerique claris patribu= orti.

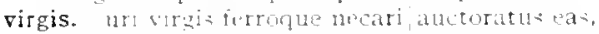

virgo. alluila virgo, suspirat:

motus loceri gaudet Ionicos matera virgo

splemblute mentax +t in omm vitgol molilis aevom.

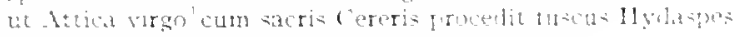

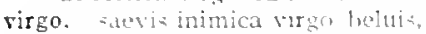

montim custos nemorumble, vign.

viri. motuenc alterius viri certo fonelere cartitas.

la-si strl, arlventum viri

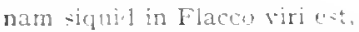

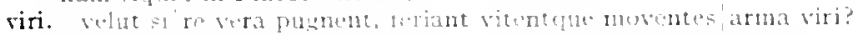
quas lis quinque riri maserumt,

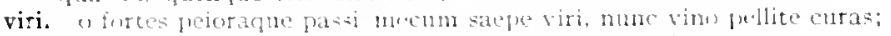

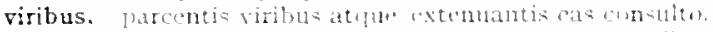

anmite materiam vestris, qui serblitis, dequan, viribus

viribus. suis et ipsa koma vinhas rait.

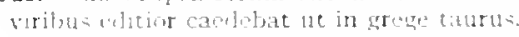

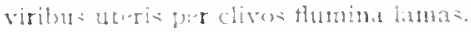

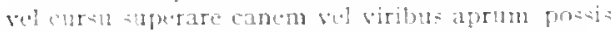

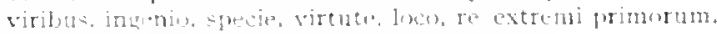

virides. atu vililu rubun limolete lacertas.

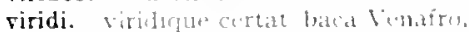

viridi. nume viridimembra suls arbutal stratne,

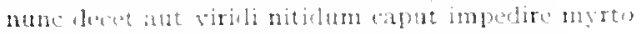

cingentern visili temporat pampino.

ornatus bridi temporia frampinus

viridis. nigrio ant Erymanth silvis aut virislis Cragi;

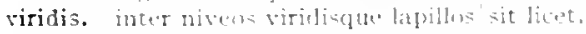

riridis. nec viridis metunt colubrat

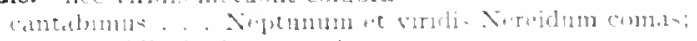

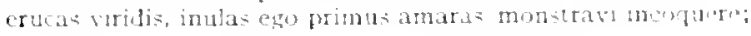

irs Pinet 195

lipudi:T.33

lipost. I 3 ;

"urderm.1.25.17

1.pint.2.1 218

(iarmacis.t7

cirm.1.25.17

curm.t.13.to

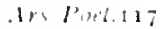

(iorm.2.5.5

Ciorm.t 15.1.4

sermt.2.1.12

t.pitit 1.25 ?

l.pist.1.18.22

lipist.1.15.85

curme.10.18

(iarme. 1.2.10

(armezs.t.

(

(a)m.3 $+: 2$

(iirm.1.2.27

(iirm. I +20

(urm.2.4.23

cism.3.15.5

Cirmbiben

(itrm. I.2I.I

(iorm.2.12.10)

(itr) 3.3 .1

(a) (a)

(

(a)m.1.17

(iarm. 1 .20.5

(ism. 3.11 2',

(is)m.3.

( $2 r m .3 .25 \cdot 3.3$

(iarmatest

Sirm. 235

Cism-3.2.s

(itrm.jo.22

Cimm.3.11.35

S.p.'. 2813

(itrm.1.12.22

Cirm 3.22 I

(it)m.32+32

J. phend $2+1$

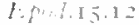

Sirnt2.5.500

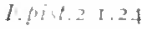

(it)m.1,-3I

Sirme.1, 11, I.3

Irs I" it 32

lipotione. I

Sirmbla 100

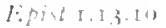

H.thet 1.18.5

Fits.2.2.3

(iiruld.230

(iormest. 15

(iirm.1.1.21

(iorm, [..t?

ciernis 3 25.20

(iarm, 98.33

(ierm. I.21.8

Sirm.1.2.s.)

(iorm 1.t7s

Cism.3.24.11)

s.rm.2. 
virile. actuis barces chorus afticiumque visile/defendat.

virilem. virilem/torvos humi posuisse voltum.

Carm!.3.5.43

viriles. neforte seniles | mandentur iuveni partes pueroque viriles:

Ars Pod. 177

virili. nonina ectatur modo sumpta veste virili| sub patribus duris tromum.

ririlis. virilia quod speciosius ar nalmonest qui tractet:

virilis. De virilis cultus in caedem et lycias proriperet catervas? actas anduscut virilis/quarerit opes et amicitias.

virilis. et llat mon virilis heiulatio

viriliter. qui pervent fecitne viriliter?

viris. heu heu, quantus equis, quantus adest viris!sudor,

illi. reripta quilus comodia prisca viris ent.

primeiplus flacuisse viris non ultima laus cost.

komanis solleme vitis opus, utile famae

riris. Idem inlere viris!omne nefas anino noventis.

tu spen reducis mentilus anxis/virisque

viris animumgue moresque |aureos educit

viris quid "nervet meas.

viritim. cuusl legreget tereretque viritim publicus usus?

virium. nam siquid in Flaceo vifi [ririunl est.

viro. tamelen alesime matren/tempestiva sequi viro. Tanain si biberes. Lyce, | saevo nupta viro. quod vito clemens misero peperci.

viro. est ue virovir latius ot dimet arbusta sulcis. quid de quogur viro et cui dicas, saepe videto.

virorum. contaminato cum grege turpium|notbo virorum .

Mescurialium custos virerum.

somnus agrestum lenis virorum

quindecim Diana preces viform, curat

atque alii. quorum comedia prica vironum est.

quan bet vatis ofus moses animigue virorum/clarorum adparent.

siros. decet qua fere non mollis viros? multos sacpe vros nullis maioribus ortos

Virtus. dissidens plebi numero latorum eximit virtus Virtus, repulére nescia sorlielac.

Virtus, reclulens inmeritis mori' caclum. neglecta redire Virius:audet

virtus. Felicta non bene parmula, fom fracta virtus. nec vera vituc. cum semel excilit. prisci Catonis|saepe nuto caluisse virtus. dos est magna parentium/virtus. est in refuis partum | virtus virtus et faves et lingua potentium/vatum paulum scpulew distat indrac' celata virtus cui super Karthaginem vistus sopulcrum condidit. acmula nec virtus Capuac uec Spartacus acer. vos, gulibus we virtus, muliebsom tollite luctum, inti errori nomen vigrue posuisset honestum. quod sugum in utroque stmma suit:

ivlis tantummolo: quite tua virtus lexplugnabis;

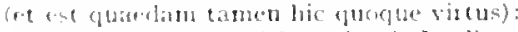

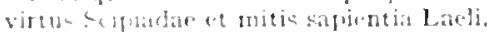

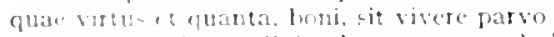

vifus, landa, decus, disina humangue fuld ris/divitis parent

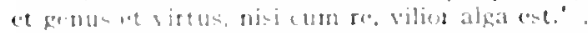

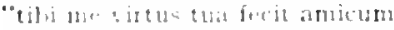

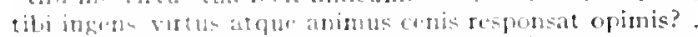

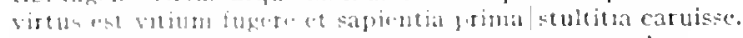

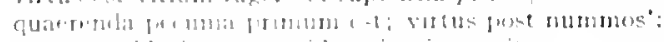

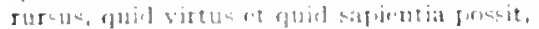

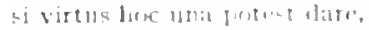

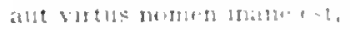

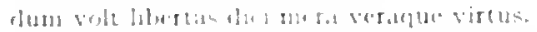

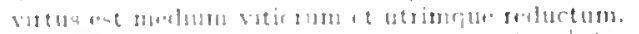

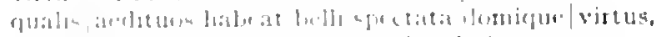

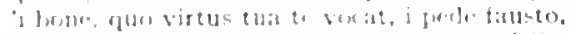

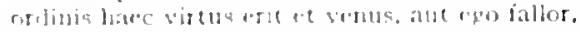

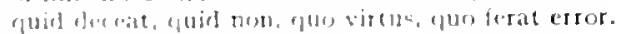

Serm.1 2.16

Epist.1.18.52

Carm.1.8.15

Ars Poet.166

Epod.10.17

Epist.1.17.38

Carm.1.15.9

Serm.1.10.16

Epist.1.17.35

Epist.1.18.49

Carm.3.4.67

Carm.3.21.18

Carm.4.2.22

Epod.8.2

Epist.2.1.92

tar. Fod. I 5.12

Curm.1.23.12

Carm.3.10.2

Corm.3.11.46

Carm-3.1.9

Epist.1.18.68

Carm.1.37.10

Curm.2.17.30

Corm.31.22

Carm.succio

Serm.1.4.2

I.pist.2.1.249

Epod.1.IO

Sormato.io

Carm.2.2.19

Carm.3.2.17

Carm.3.2.21

Corm.sulec. 58

Carm.2.7.11

Carm.3.5.20

Corm.3.21.12

Carm.3.2.1.22

Carm.4.4.3I

Carmis.8.20

Carmit. 0.30

Epod.0.26

Epolde.5

Epod.10.3?

Serm.1.3.42

Serm.1.74

Serm.1.9.54

Sorm,1.ro.8

Sorm.2.1.72

Serm.2.2.1

Sirm: 2.3 .95

Sirm.2.5. S

Sirm.2.5.33

Sorm.2.7.103

1:Pist.1.1.4 I

Lepist 1.1.5.4

I. pist.1.217

L.pist 1.0 .30

I.pist.1.17...1

Fist I. IS.

1. pist.1.18.0

Is pist $21.23 \mathrm{t}$

I. pist 2.2.37

Ars l'odt.p2

Ars l'iset. 308

Carm.329-55 
virtute functos more patrum duces . . canemus. . o dolitura mea multum virtute ieaera:

"macte/virtute esto" inquit sententia dia Catonis; invidian placare paras virtute relicta?

hoc, veluti virtute paratum, |speravit magnae laudi fore. utrumne/divitis homines an sint virtute beati; vel quia cuncta putas una virtute minora.

Claudi virtute Neronis|Armenius cecidit; quod numero plures, virtute et honore minores, virtute carentia tollet: virtute, loco, re extremi primorum. nec virtute foret clarisve potentius armis/quam lingua Latiun, actor causarum mediocris abest virtute diserti|Messaltae

virtutem. virtutem incolumem odinus. ultra quam satis est virtutem si petat ipsam. virtutem verba putas et/lucum ligna: virtutem doctrina paret naturane donet virtutemne repraesentet noresque Catonis? qui redit in fastos et virtutem aestimat annis

virtutes, tuas, /Auguste, virtutes in aevom . . aeternet, at nos virtutes ipsas invertinus levis haec insania quantas|virtutes habeat.

virtuti. scilicet uni aequos virtuti atque eius amicis.

virtutibus. ut, quantum generi demas, virtutibus addas;

virtutibus. vilius argentum est auro, virtutibus aurum. plus quam se sapere et virtutibus esse priorem/volt

virtutis. virtutisque viam deserit arduae. pudicum. |qui primus virtut is honos, virtutis verae custos rigidusque satelles; oderunt peccare boni virtutis amore: perdidit arma. locum virtutis deseruit.

virum. quem virum aut heroa lyra vel acri|tibia sumis celebrare, Clio? mors et fugacem persequitur virum iustum et tenacem propositi virum ter uxor/capta virum puerosque ploret.' o pueri et puellae iam virum texpertae, nec dotata regit virum|coniunx. dignum laude virum Musa vetat mori, icacio Musa beat. dic mili, Musa, virum. .

virus. grave virus munditiae pepulere;

vis. inprovisa leti/vis rapuit rapietque gentis. te nieae si partem animae rapit/maturior vis. vis consili expers mole ruit sua, sed non haec mihi vis, est hederae vis/multa, non furor $\mid$ civilis aut vis exiget otium, quae vis deorum est Manium. amica vis pastoribus, furome caecos an rapit vis acrior an culpa? quod acer spititus ac vis|nec verbis nec rebus inest.

vis. vis formosa videri quid tibi vis, mulier nigris dignissima barris? quid amplius vis? huic si nutonis verbis . . diceret hec animus "quid vis tibi? accipe, si vis. /accipian tahulas;

'suaviter, ut nunc est.' inquan, et cupio omnia quae vis." cum adsectaretur. 'numquid vis?' occupo. vin tu|curtis ludizeis opredure?" hoc age." quid vis?"

ut ne [visne] tegan spurco Damae latus? "quid tibi vis, insane, et quam rem agis?" dixeris: 'experiar'. 'si vis, potes,' addit et instat. vis tu homines libemque feris pracponere silvis? imbecillus, incrs, siquid vis, adde, popino. discere et andire et meliori creder: non vis: quacre fugam morbi. vis recte vivere (quis non?): si me vivere vis sanum rectcque valcntem, 'at tu. quantum vis, tolle" benigne" cui mustela procul "si vis' ait 'effugere istinc,

Carm.t. $\$ 5.29$

Liped. I5. II

$\operatorname{Sirm} \cdot 1.2 .32$

Sirm.2.3.13

Serm.2.3.08

Sim.2.0.74

lipist.1.12.11

Epist.1.12.26

Epist.2.1.183

Epist.2.2.123

Epist.2.2.203

Ars Iret.289

Ars Poet.370

Curm.3.24.31

Epist. Ito. Io

Epist.I.1.3I

Epist.1.18.100

Epist.1.10.14

Epist.2.1.48

Carm.4.1.4.3

Sorm.1.3.55

Epist.2.1.119

Sirm.2.1.70

Epist.1.20.22

Epist.1.1.52

Epist.1.18.27

Carm.3.24.4.4

Serm.1.0.'s

Episti1.17

IEpist.1.10.52

Epist.1.10.07

Carm.1.12.1

Carm.3.2.14

Curm-3.3.1

Curm.3.3.08

Carm-3.t4.1I

Cirm.3.2.4.19

Carm-4.8.28

Ars Juetiat

Lipist.2.1.158

Curm.2.13.20

Curm.2.17.t

Carm.3.4. 5

Curm-4.8

Curm...11.4

Carm.15.18

I.pol.5.94

Epod.co

Epod.7.13

Sormo1.40

Carm...1. 3.3

lipod.12.I

I.poli.17.30

Serm. 1.2.to

Serm.I.t.

Serm.1.0.5

Sermation

Sirm-1.1) 0

Serm.2.3.5.52

ar.Serm.2.5.18

Sirm.2020

Sirm.20.30)

Sirm.2 C.02

Sirm.2.7.30

J.pit I.I.ts

Epist.r. 29

Epist.1.7.3

Epist.1.7. It

Epist.1.7.32 


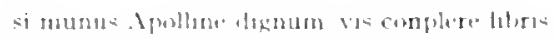

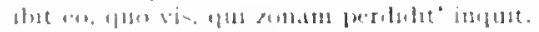

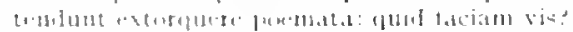

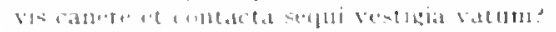

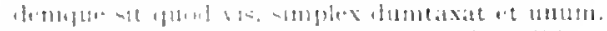

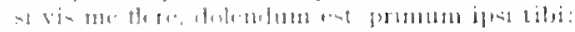

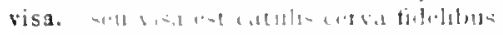

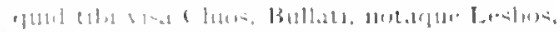

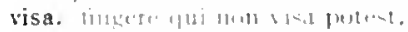

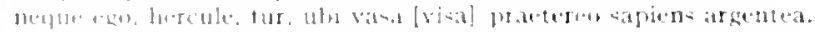

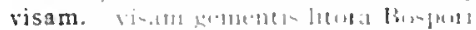

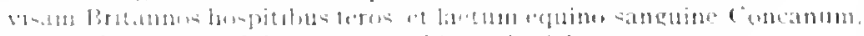

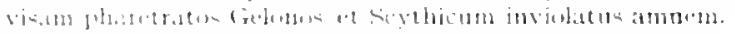

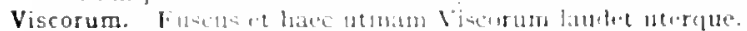

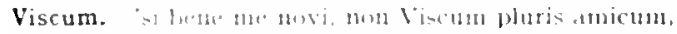

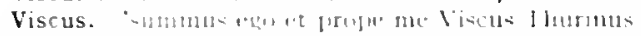

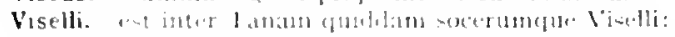

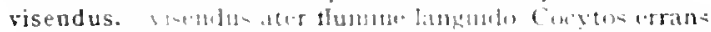

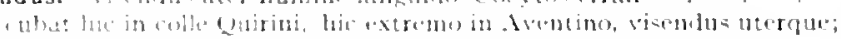

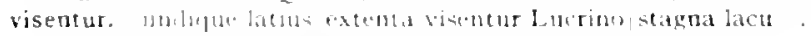

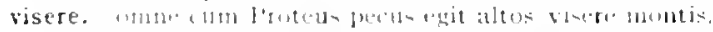

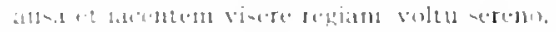

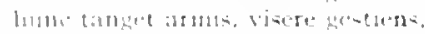

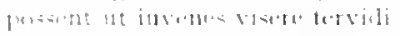

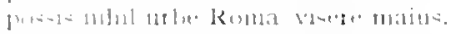

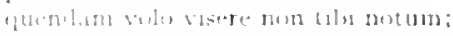

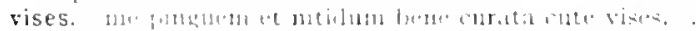

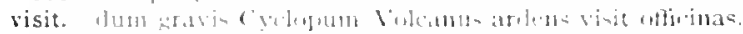

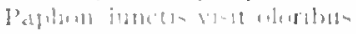

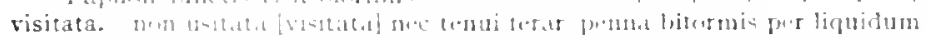
ine theras riat?

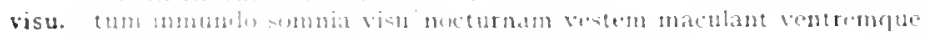
- $41 \cdot 1+14113$

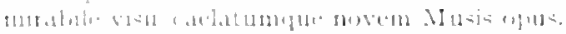

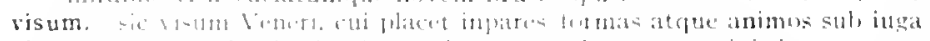

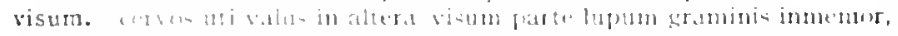

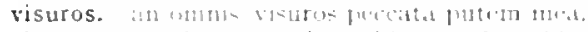

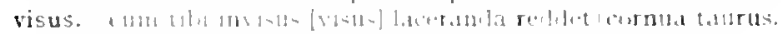

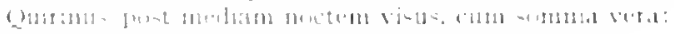

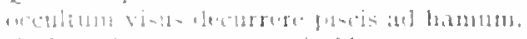

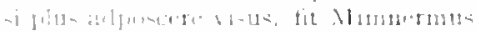

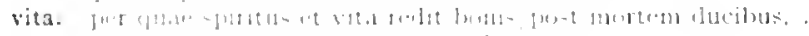

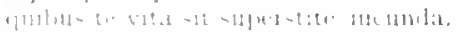

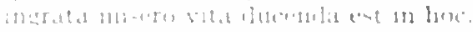

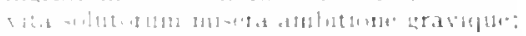

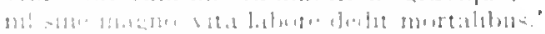

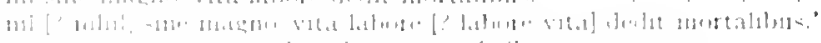

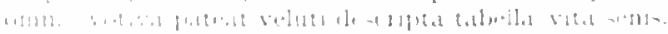

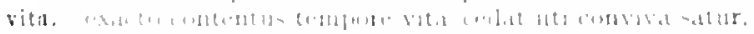

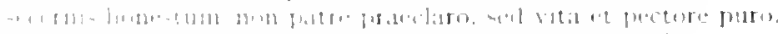

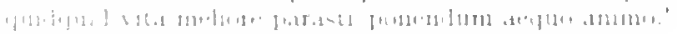

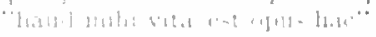

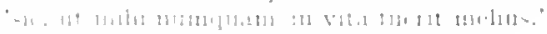

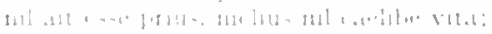

ro

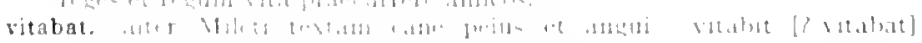

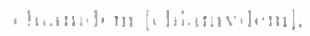

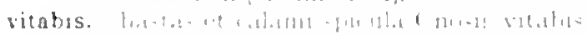

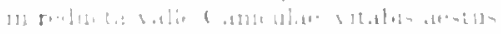

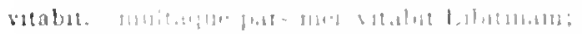

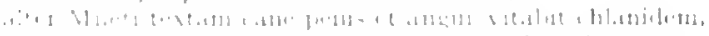

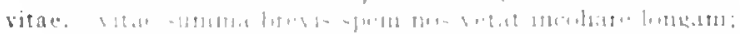

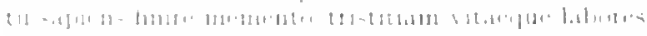

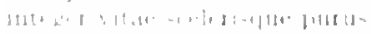

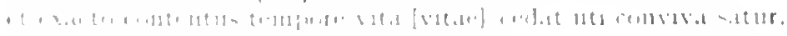

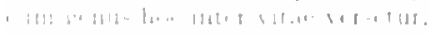

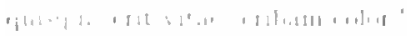

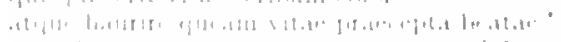

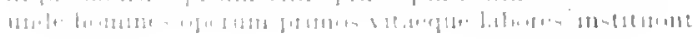

Esist.2.217

Esist 2.2 .411

ISpist 2.2 .57

Thest 2.2 s.o

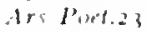

- Irsineticisz

(ionstid. 17

lisist : : 1. I

SirmeI-iki

sur..serm.2.7.72

(isrm? 2014 4

cism $3 \cdot 4 \cdot 3.3$

curm. $3+3.5$

Serm.1.10.83

Sirme1022

Sirm.2.8.20

Sirm.1.105

(iorm.2.1 17

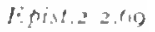

(iorm. 2.15.3

Curm.t 28

(isrm, t.37.25

ciem 3.3.5.6

Cirme. 13.20

cism Sistel 2

Sirmato:

lipial $1 .+15$

Cirmer 1.8

Citrm.3 24.15

curlic Carm 220.1

Sirmed.5.4.

l.pist.z.201

cirm.1.3.3.10

cigrn.1.1 15.30

Ar Pivel aches

atere ardi.3.27.75

Serni 1.10 .33

Fistid.7.74

Pifist 2. 2100

carmentit

lipuld.5

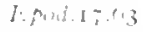

Sirm.1 1 $=0$

Sirmes.1) (nis)

ar Y r m 1.10,10

S rm: 131

sirntal 1:s

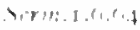

S.men $2: 5$

Serm zenis

Sirmen:

1.pive 1 \& 8 s

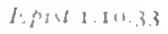

3 :ur lapid 1 17.31

carmel t5.14

Cerme 1 : : :

(itrm 3 in

tipatian

(arm $1: 15$

(iorm 1 ;

(arm 121

ior trem I J.1.8

Germ 1 ; 10 )

and = 1 (an)

$\therefore, 112+105$

Serm 240.21 
Huctre sollicitac iucunda oblivia vitae?

Sirm.2.6.62

acstuit of vitae discomvenit ordine toto.

mirabor. vitat via si conversa decebit.

quid pure tranquillet, . . . secretum iter et fallentis semita vition.

Epist. I. I.09

Epist.1.17.26

cetera qui vitae servaret inumia rectolmore.

sed verae numerosque modusque ediscere vitae.

Epist.r.18.103

Epist.2.2.13 I

lipist.2.2.1.t.t

Ars Poet.317

Ars I"0it.pou

vitae. quis scit an anlicint hodiernate crastina summac [vitas]|tempora di superi?

obsecro et obtestor, vitac me redde priori.'

utile famal vitacque et membris, pracsertim cum valeas

aut simul et iucunda et idoned licere vitae.

vitale. frugi quod sit satis, hoc est./ut vitale putes."

vitalis. 'o puer, ut sis/vitalis metuo

vitam. vitamque sub divo et trepidis agat|in rebus.

hic, unde ritam sumeret inscius, | pacen dueilo miscuit.

neque vitam amittit in undis.

tuanque, dum custodis eges, vitam famanque tueri|incolumen .

conmittes rem omnem et vitam et cum corpore famam.

ut fortunatam plene praestantia ritam;

det vitam, det opes; aequom mi animum ipse parabo.

vitanda. vitanda est inproba Siren/desidia

vitant. dum vitant stulti vitia, in contraria currunt.

ritantis. curvat aper lances carnem vitantis inertem:

vitare. posset qui rupem et puteum ritare patentem.

vitas. vitas linnuleo me sinrilis, Chloe.

teque ipsum vitas fugitivos et erro.

vitat. cur olivom / sanguine viperino/cautius vitat.

ritas [vitat] hinnulco me sinilis, Chloe,

forumque vitat et superba civium/potentiorum limina.

aut, dun vitat hunum. nubis et inauia captet.

secreta petit loca, balnea vitat.

vitatu. 'sapiens, vitatu quikque petitu/sit melius, causas reduet tibi;

ritaveris. nam frustra vitium vitaveris illud.

vitavi. vitavi denique culpan, / non laudem merui.

vitavit. alter lileti textam cane peius et angui|vitabit [vitavit] clilanidem.

vite. mullam, lare, sacra vite prius severis arborem neque me sub arta/vite bibenten.

vitellum. namque marem cohibent callosa vitellum.

vitellus. quatenus ima petit volvers aliena vitelus.

vitem. premant Calenam falce quibus derlit/fortuna vitem,

et vitem viduas ducit aul arborcs;

vitent. velut silte vera pughent, feriant vitentque moventes/arma viri?

vites. interfusa nitentis, vites aequora Cycladas.

mea nce Falernaltemperant vites neque Formiani|pocula colles.

nec Falerna [Falernae] vitis [vites] Achaemeniunque costum.

ultra|quam licet sperare mefas putando/distarem vites.

vitet. quid quisque ritet, num quam homini satis/cautum est

loquacis, / si sapiat, vitet.

privatas ut quaerat opes et tangere vitet/scripta.

vitia. anatorem quod annicae / turpia decipint caecum vitia

vitia. bellique catusas et vitia et molos

dum vitant stulti vitia, in contraria currunt.

"quis] tu? nullane habes viti.l?"

inculirant vitia ut tua rurstus et illi.

vitiantis. Vuber et ilima nutritus glande rotudas / curvat aper lances carnen vitantis [utiantis] ine rem:

vitiaret. quen hospes / tardius alveniens vitiatmin [vitiaret] commodius ruam! integrum cdax dominus comsmmeret.

vitiata. illa|integrum perdunt lian vitiata samorim.

vitiato. sel malia tollet arum vitiato melle cicutal.

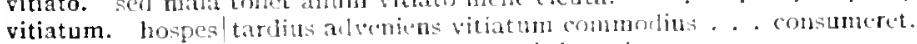

vitibus. opulentat . . Fratis an amictin vitubus uimo

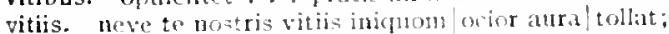

meeliocribus et quis/ignocas vitiiz teneor;

vitis. vitis carenten//udit inago/mana,

cur in amicorum vitiis tan cernis acutum

natı vitiis nemo sine nascitur;

intr.Cam.4.7.17

Épist.1.7.95

Epist.1.18.50

Ars Poet.334

Serm.2.7.4

Sirm.2.1.6I

Carnt.3.2.5

Carm.3.5.37

Serm.1.1.60

Serm.1.4. I 18

Sirm.2.7.67

Epist.I.II.I

Fpist.1.I8. I 2

Serm.2-3.14

Sirm.1.2.2.

Sirm.2.4.41

Epist.2.2.135

Carm.1.23.I

Serm.2.7.113

Carm.1.8.10

vur.Carm.1.23.I

lipod.2.7

Ars Pott.230

Ars Poct.298

Sirm.1.4.II 5

Sirm.2.2.54

Ars Poet.267

sar. Epist. โ.17.3 I

Carm.1.18.1

Carm.1.35.8

Serm.2.4.14

Serm.2.4.57

Carm.1.31.10

Carm.4.5.30

Sirm.2.7.99

Carm.I.I 420

Carm.1.20.I I

rar.Carm.3.1.1.1

Carm.4.11.31

Carm.2 13.13

Sirm.1.9.34

Epist.1.3.16

Sirm.1.3.39

Carm.2.1.2

Sirm.1.2.24

Sirm.t.3.20

Sirm.t.3.28

“'br.Serm.2 4.4

sar.Serm.2.2.9 I

Serm.2.4.5.4

Sirm.2.1.50

Sirm.2.2.0I

List.1.10.3

Carm.1.2.47

Serm.1..1.131

Carm.3.27.39

Sorm.1.3.26

Serm.1.3.08 
cum mea confrensat vitis bona.

Serm.1.3.70

sic tences anmos alicha opyobrid sacpe absterent vitiis.

hoe cst mentum robus illis/ex vitus unum;

atqui st vits medier rous ac mea paucis|menclosa est natura,

Serm.1.4.140

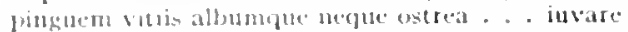

yun corpus onustum hesten vis vitis asimum quoque praegravat una.

"pars hominum vitis gatudet constanter

Serm.1.0.05

Serml.2.2.2I

Serm.2.2.78

quanto constantior istem, in vitis.

dues andeus, ! supe decen vitus instructior.

deciput extmplat vitis instabile:

vitio. nec tanuth siln ne vitio quis verterte

est huic diversum vitio vitium prope maius.

vitio. aulate pugnas vitio parentumpara inventus.

tuo vitio rerumne labores, a nil referse putas?

stis anima ef furutn est vitio tibi. cum turnidum est cor

Serm.2.7.6

Serm.2.7.19

Epist.1.18.25

Epist.1.19.17

Sirm.1.0.85

Lipist.1.18.5

Carm.1.2.23

Serm.1.2.76

Sirm.2.3.213

(140) the ategrotare putes animi vitio." .

mec smm liteturus vitio culpave minoren;

guod Methymatean vitio mutaverit uvam.

cetera iam simul istofcum vitio fugere?

proset tom census equestrem ! summan nummorum vitioque remotus

ab amni.

vitiorum. numclua tibi vitionm inseverit olim/natura.

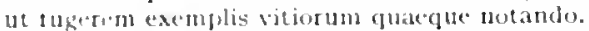

virths ese modium vitiorum tet utrimgue reductum.

vitiosa. Scandit actatas vitiosa navis/cira

cui si vitus libilo becrit au-picium.

vitiosiorem. mox liaturos|progenien intosiorem.

vitiosum. remiginum vitiosum bluacensis V'lixei,

vitiosum. inlusique pedes bitiosin torre tecusant $/$ corpus.

vitiosum. prudens emisti vitiosum, dieta tibi est hex:

vitiosus. Ham tuit hoc vitiosus:

vitis. nam seu mobilibus vepris [vitis] inhorruit|ad ventum folis

nee Foberma vitis Achaemeniunulue costum,

nec pestilantem sentiel Africum|fecumbititis

vitis. haud quia grando/conturlerit vitis .

vitium. (Tge) alut mlulta vitium propbeine"

vitium. omsjibus hoc vitum est cantoribus.

sic nos delremus andei|siquid sit vitiutu non fastitire:

stenique, quatenus excidi penstus vicium irate.

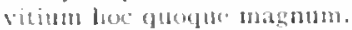

inmane ext vitum dare milia tema macelfo

tot hute dorersum vitio bitium prope mains,

vitium. qued vitium procul afore chartis|atgue auime prius.

man trungal vitum vitaveris illud,

credilu angens pangersem vitinu

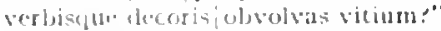

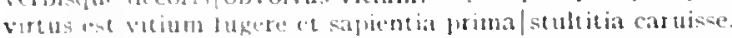

In vitust tortuna labier ateonat

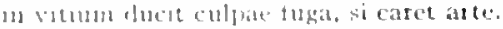

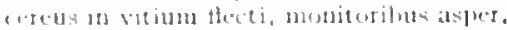

in butum hisertas excildt it vim

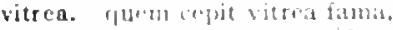

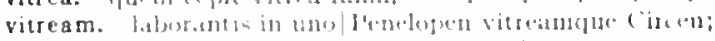

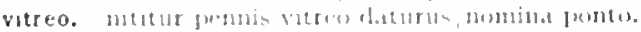

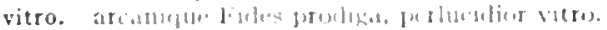

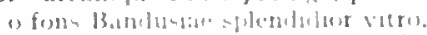

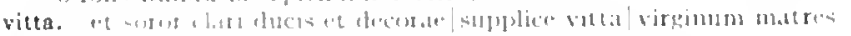

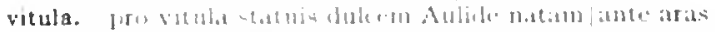

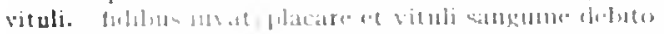

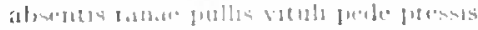

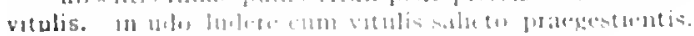

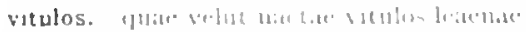

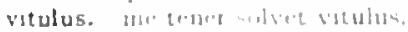

vivacem. S.

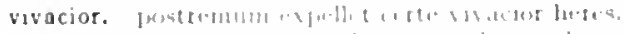

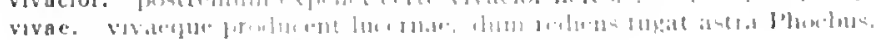

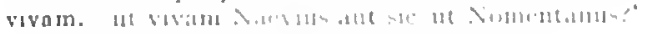

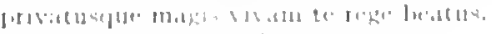

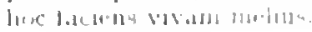

Serm.2.3.307

Sirm.2.0.7

Sirm.2.8.50

Epist.2.2.200

Ars Poct.384

Serm.1.3.35

Sirm.1.4.100

Epist.1.18.9

Carm.2.10.2I

Lpist.1.1.85

Carm.3.6.48

List.1.0.03

Sirm.2.7.108

Epist.2.2.18

Serm. 1.4.9

coni.Corm.1.23.5

Carm.3.1.44

Carm.3.23.6

Epist.1.8.5

lifod. 2.9

Sirm.1.3.I

Serm.1.3.44

Serm.1.3 76

Serm.2.2.69

Serm.2.4.76

Epist.1.18.5

Serm.1.4.101

Serm.2.2.5.4

Sirn.2.3.92

$\operatorname{ser} .2 .7 .42$

f.pist.1.I.4I

I. pist.2.I.0.4

Ars l'oel.3 I

Ars lodide 3

Ars I'Orl. 282

Sirm.2.3.222

Cirm.1.17.20

(iurm..4.2.3

Carm.1.18.10

( arm.3.1.3.1

carm.3.1.1.8

Sirm.2.3.100

(itrm.1.31.2

Sirm.2.3.31.1

(ivm.2.5.s

(arm.3.11.11

Ciurm.t2 28

Serm.2.1.5.3

Sirm 2.2.131

(jurm.3 2].23

Sirmt.t.101

Serm 1.31 .92

Sirm.1..4.135 
doctus eris vivan musto mersare Falerno:

ut mihi vivam/quod superest aevi,

vivaria. excipiantque senes. quos in vivaria mittant;

vivas. et nemor mostri. Galatea, vivas

"ut vivas igitur, vigila. hoc age." .

rivas in amore iocisque.

quid refert, vivas numerato nuper an olim?

vivas hine ducere voces.

vivat. quod et hume in annum $/$ vivat et phises.

ut newo, . . illa contentus vivat,

bene siquislet vivat puris manibus.

nonne vides. Albi ut male vivat filius utque/Baius inops?

ut salvos regnet vivatque beatus, / cogi preae negat.

morietur frigore, si non|rettuleris pannum. refer et sine vivat ineptus.

vivax. nedum sermonum stet honos et gratia vivax.

vivax. neu vivax apium nen breve lilium.

vive. sed me/imperiosa trahit Proserpina: vive valeque."

dum licet, in rebus incundis vive beatus,

vive memor, quan sis aevi brevis."

vive, vale.

vivendi. "haec est condicio vivendi" abebat.

qui recte vivendi prorogat loram,

qui recte vivendi [vivendi qui recte] prorogat horam./ rusticus expectat. dum defluat anmis;

vivent. quid referat intra|naturae finis viventi [vivent], iugera centum an | mille aret?

viventem. rure ego viventem. tu dicis in Trbe beatum:

viventi. quid referat intra/naturae finis viventi,

quod nimium institerat viventi.

viventis. solos felicis viventis clamat in Vrue.

quid referat intra / naturae finis viventi [viventis], iugera centum an nille aret?

vivere. tecum vivere amem, tecum ubeam lubens."

quae virtus et quanta. buni, sit vivere parso

"quid te iuvat" inquit. "anice, / priserupti nemoris patientem vivere dorso?

iam mallet doctus Athenis/vivere

si patriae volumus, si nobis vivere cari.

quaere fugam morbi. vis recte vivere (quis nom?): .

si me vivere vis sanum recteque valuntem,

dic multa et pulcra minantem/vivere nee recte nec suaviter.

vivere naturae si convenienter oportet

tamen illic vivere vellem

neque. . . volet in caupona vivere;

navibus atque quadrigis petimus be vivere.

vos sapere et solos aio bene vivere.

nulla placere diu nec vivere carmina possunt.

vivire si recte nescis. decede peritis.

non magis esat velim quan nato vivere pravolsfoctambu nigris oculis

viverem. cum me hortaretur, parce frugaliter atque vivioun uti contentus eo

viveret. numquid Pomponius istis/audiret luviora, pater si viveret? viveret in terris te siquis atvarior unu.

vives. rectius vives, Licini, neque altum semper urgtotho

laetus sorte cua vives sibientet. Aristi.

si...herbis vivis et urtica. sic vines jrotinus.

vivet. vivet extento Proculeius atso,

vivet uter locuples sine gnatis.

qui meturns vivet, liber milh nom erit umquan.

vividus. demist hostem virulus impetus.

vivimus. mon isto vivimus illic. |qubo tu rete, modo;

vivis. si ... abstemius herbic/vivia cet urtica,

tu rece vivis, gi curas esse quod audis.

vivit. vivet [rivit] extento Pruchloits aevo,

parcins hic vivit: irugi dieatur;

probus quis|nobiseum vist, multum demissus homo:

incolumis lactor quod vivit in Vrlse;

si bere qui cenat bene vivit. .

si bene qui cenat bene vivit [7 rivit bent], incet, eanus/quo ducit gula:
Serm.2.1.19

EDist.1.18.107

lipist.1.1.79

(arm.3.27.14

Sirm.2.3. 152

Lipist.1.0.6ito

Lisist.2.2.100

Ars Iott.318

Carm.1.32.3

Serm.1.1.3

Serm.1.4.68

Sermis.a.100

lipist.1.2.10

Ispist.1. 7.32

Ars l'odton

(irm.1.30.10

Serm.2-5.110

Serm.2.6.0\%

Sirm.2.6.97

lipist.1.0.67

Serm.2.8.t)5

lipist. 1.2..1 I

:'ar. Epist.1.2.,1

i'(6r.Sirm.1.1.50

Epist.r. Ifo

Sirm.I.1.50

Sorm.2.5.88

Sirm.1.1.12

comi.sirm.1.1.50

Carm.3.0.24

Serm.2.2.I

Serm.2.4.9I

Serm.2.7.1.

Lpist.1.3.29

lipist.1.0.20

Jpist.1.7.3

Epist.1.8. 1

lipist.1.10.12

lipist.r.t1.8

Lpist.1.11.12

Epist.1.11.20

Epivi.1. 5.45

IEpist.1.10.2

latist 2.2.213

irs loet. 3

Serm.t.4.108

Sirmo. 1 ... 5.53

l.pist.2.2.157

(iarm, 2.10.1

Lipist. T.10.94

Epist, I. I 2.8

(arm.2.2.5

Sirm.2.5.2S

Epist.1.10.00

(arm.4.4.10

Sirm 1.9.18

lepist.1.12.8

Jipist.I.ISt.17

sur. (urm.2.2.5

Sirm. I.3.49

Sirm 1.3.57

Sirm. I...

Eipistal.e.5's

atr. Epist. 1.0.5" 
vivit siliquis et jane secunlo:

Epist.2.1.123

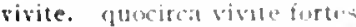

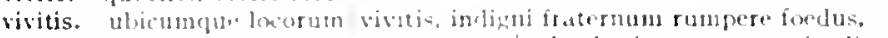

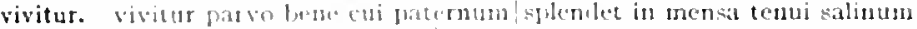

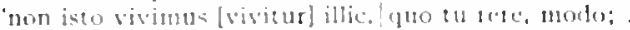

Sermi.2.2.135

fisist.1.3.35

Carm.2.16.13

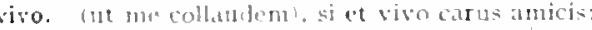

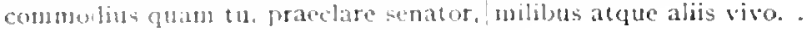
vivo et rogno, sinul ista reliqui.

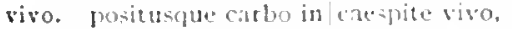
"men viso?" "ut vivas ighter, vigilat. huc athe"

vivom. hic vivom milhi ciatspitum,

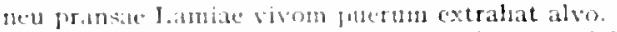

vivont. camplestes melius sethac. . vivont et rigidi Getae,

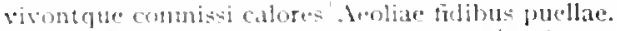
quot cajnem vivont, tutilem stuliorm milia: turrestria quantolmortalis animas vivone sortita

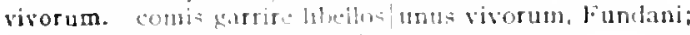
vivos, vivos ct tolleret unguic.

vix. sine funibus|vix durar. earinat possint vix inligatum te triformi Pegasus experliet Chimatera. wix una sospes natris ab ignilsus vix credure posis. quam sibi non sit amicus. tuarta vix dernum exponimur hora. "magnum narras, vix crolibile. vix tamen eripiam. posito pavone velis uncle mundior exiret vix lifrertinus honeste; Varius mappa conpesecre risum / vix poterat.

vixere, vixere fortes ante Agamemnona multi;

vixeris. seu matstus omni tempore vixeris

vixi. vixi pulllis muper idoneus.

cui licet in them | dixisse "vixi:

est auctor quis denique corum. / vixi cum quilus?

vixisse. in le fit, ut raro, qui se vixisse beatum|dicat

Terent fabula quem miserum gnato vixised fugatolinducit. .

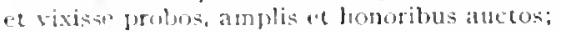

me / cum ntagnis vixisa invita fatebitur ustue | invidia

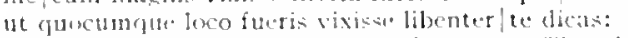

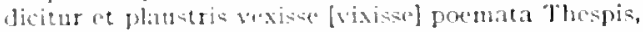

Iur.Serm.1.9..\$8

Sirm.r.6. 70

Sirm.1.0.111

Jist. I.10.8

Carm.3.8.4

Sorm.2.3.152

Corm.1.59.13

Ars l'oel. 340

Carm.3.24.11

Carm.q.9.1 1

Sirm.2.1.27

Sirm.2.6.94

Sirm.1.10. $\$ 2$

Sirm.1.10.71

Carm.1.14.7

Carm.1.27.23

Curm.1.37.13

Sirm.1.2.19

Sirm.1.5.23

Sirm.1.9.52

Sorm.2.2.23

Sirm.2.7.12

Sorm.2.8.04

Carm.4.9.25

Carm.2.3.5

Curm.3.26.1

Carm.3.29.43

Serm.1.4.S1

Scrm.1.1117

Sirm.1.2.21

Sirm.1.0.11

Srm.2.1.76

fipist.1.11.24

"ar..trs J'oel.276

I.pist.1.2.26

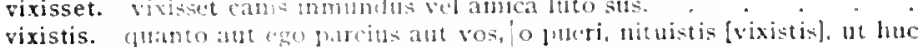
novers incolit serit?

vixit. Inileca. Craci coninge barlara'turpis maritus vixit

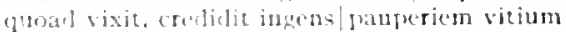

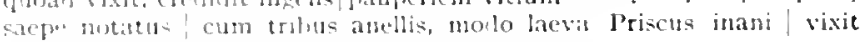
imargualis,

nec rixt male, gut natus morimsque fefollit.

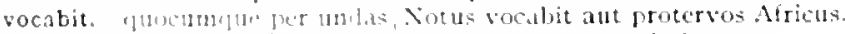

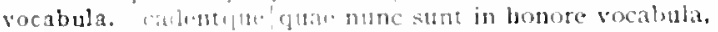

rocabula. "x met inpents cognita rocabula rebus?

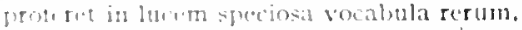

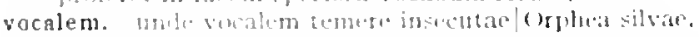

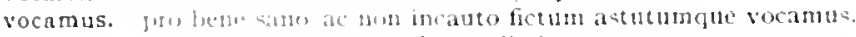

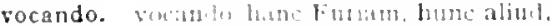

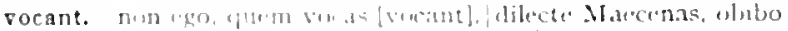

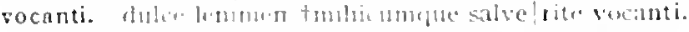

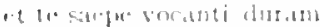

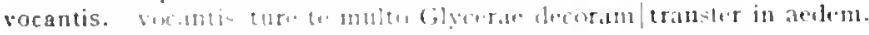

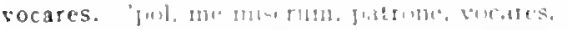

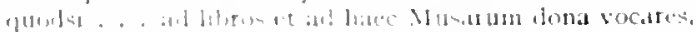

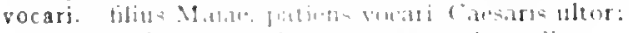

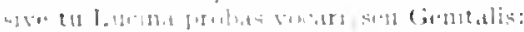

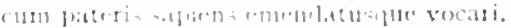

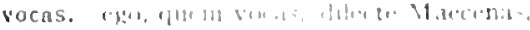

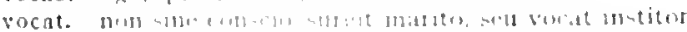

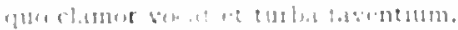

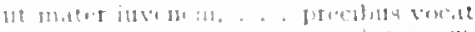

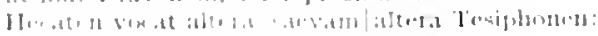

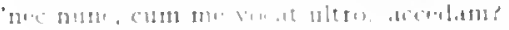

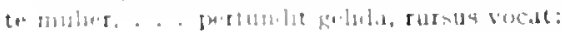

:'ar.Serm.2.2.128

(arm.3.5.0

Sirm.2.3.91

Sirm.2.7.10

fist.1.17.10

Ifpoldo.to2

Ars luetiti

Serm.2.3.280

Jist.2.2.110

Cirm.1.12.7

Sirm.1.3.12

Serm.2-3.1.

contichrm.2.20.6

Cisrm.1.32.16

Carm.3.7.3I

Carm.1.30.2

fist. 1.7 .92

Spist.2.1.2.13

(armi.1.2.4.3

cismessise 1 :

1: post. 1 1 1 . 30

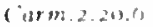

Carm.3.30)

(is) 32.40

(iarm.t.5.13

Sirm. 1.833

Serni.2.3.26]

Sicrm.2.7.91 
amoena vocat mecum qui sentit.

i bone, quo virtus tua te vocat, i pede fausto.

Epist.1.14.20

hic sponsum vecat, hic auditum scripta relictis/omnibus officis;

lipist.2.2.37

serl vocat usque suom qua populus adsita certis/limitibus

vocata. ter vocata audis adimisque leto, /diva triformis,

si vocata partubus|Lucina reris adfuit.

n'e vocata mens tua|Marsis redibit vocibus.

unde uxor media currit de nocte vocata.' -

vocatis. hoc moriens pueris dixsic rocatislad lcetum:

vocatur. syllaba longa brevi subiecta vocatur ianbus.

vocatus. vocatus atque non vocatus audit.

si nusquan es forte vocatus arl cenan.

vocaveris. non possidentem multa veaveris/recte beatum;

voce. roce formasti catus et decorae more palaestrae.

puerum minacilvoce dum terret, viduos phatetra|risit Apollo.

seu voce nunc mavis acuta

modos, amanula roce quos redlas:

quae sidera excantata voce Thessala

tu. cum timenda voce complesti nemus,

modo summa| roce, modo hac, resonat quae chordis quattuor ima.

cessisset magna conpellans voce cuculum.

"quo tu. turpissine?" magna| inclamat voce.

vetuit me tali voce Quirinus.

postquam est inpransi correptus voce magistri?

quamvis et voce paterna tingeris ad rectum

rocem. cui hiquidam pater/vocem cum cithara dedit.

interdum tamen et vocem comoedia tollit.

roces. non di, quos iterum pressa voces malo.

voces. sunt verba et voces, quibus hunc lenire dolorm 'possis

nam quae pervincere voces evaluere sonum.

(sic etiam fidibus voces crevert severis)

roces. roces andit adhuc integer.

populi contemmere voces/sic solitus

donec verba, quitus roces semsusque notarent.

doner verba, qubus voces sensusque [sensus, vocesque,] notarent, nominague invenere;

hormerim voces Furiarum et facta duarum.

Sirenum roces ot Circale pocula nosti;

sic iterat voes et werba cadentia tollit.

reddere qui vores iam scit puer

visas hine ducere voces.

vocet. guem vocet divom populus ruentis imperi tebus?

nec nuac, cum me vocat [rocet] ultro, accedam?

ultrolqui meliorem audax rocet in ius.

voci. suave locus voci resonat conclusus.

vocibus. Canifia: parce vocibu-tanden sacria

vocibus. populumque falsis, detocet uti, rocibus.

tuis victus Vencrisque gratae, vocibu"

nec rocata men- tua Marsis redibit vocibus.

pololderipere lunam vocibus possim meis,

vocis. tum meae. . . . vocis accedet bona pars

vola. 'ipse deus, simulatque volan, me solvet [rola me soluat].' .

volam. 'inse dens, simulatque volam, me solvet.'

tamen idemiscire volam.

Volanerius. scurra Volantius, postguani illi iusta cheragra i contudit articulos,

rolantem. Catsar ab Italia volantem remis adurgens.

volantis. curas laqueata circun tectu volantis.

rolat. quan loeus circum volat et cupido;

et semel misum volat insevocabile verbum.

volate. Etrusca praeter vo volatc limra.

Volcano. vaga per veterem dihapon flamma culinam Volcano

Volcanus. dum gravis Cyclopmu| Voleanus ardene visit offeinas.

hinc avislus stertit Volcanus.

volebat. Eutrapelus cuicumque nocte volebat? restimenta dabat pretiosa:

volens. mihi belphical lauro cinge welens, Melpontente, comdm.

volent. et quocumiute volent anmum auditoris agunto.

volente. saetosi furig exuere pellibu; . . volente Circa nembra;

volentem. volintem procha me loqui

Epist.2.2.67

I.pist.2.2.1;0

Carm.3.22.3

Fipod.5.5

Epod.5.75

Sirm.2.3.238

Sirm.2.3.170

Ars l'oet.25I

Carm.2.18.40

Sirm.2.7.29

Carmat9.45

Curm.1.10.3

Carmirio.II

Carm.3.4.3

Curm.4.11.35

Jipol. 5.45

Epod.6.9

Sirm.1.3.8

Sirm.1.7.31

Sirm.1.9.76

Sirm.1.10.32

Sirm.2.3.257

Ars l'ot. 360

Carm.I.24.4

Ars Potio3

Carm.1.14.10

IEpist.1.1.34

Fpist.2.1.200

Ars lothen

Carm-3.7.22

Sirnilit.es

. Serm 1.3.103

comisirm. [-3.103

Sirm.1.8.45

Epest. 1.23

Lpist.1.18.12

Ars Poit. 58

Ars Petelis

Curm.1.2.25

ior.serm.2.3.262

Sirm-2.5.20

Sim. I.4.7)

Is poll. $1 ;$.

(amm.2.2I

Corm + 1.22

lipod.5.7e

Ifpol.17.75

Carm.2.4t)

iwr. Epist. I. If.7s

I.P. $1.10,78$

1.pist.2.2.103

Sirm.2.7.15

Curm.1.37.16

(itrm.2.10.12

Corm.1.2.34

I. Pist.I.18.7I

1 pert.19.40

Serm.1.5.7.8

Corm.t.98

firm.3.4.50

J.pist. I. I8.3 I

(arm.3.30.10

ders loit 500

I:perd.17.17

Carmat5.I 
voles. quen criminosis cumque voles modum/pones iambis.

sive mendaci lyra|voles somare:

voles nodo altis desilire turribus,

cum rudere voleg. lipicuri de grege porcun.

si professe tuis paulonue benignius ipsum/te tractare voles. .

tu seu donaris seu quil donare voles cui.

volet. o quisquis rolet inpias/cacdis et rabiem tollere civicam. pluribus hisce. . antri|si volet:

seu Jecreare volct tenuatum corpus

tractari mollius aetas|imbecilla volet:

fiet aper. nodo avis, modo saxum et, cum volct, arbor.

'etiam et sex et quidquill volet.'

intectum volet esec, dolor quod suaserit et mens.

erpietalue curule|cui volet inportunus ebur."

neque. . . volet in caupona vivere;

qui dedit hoc hodie, cras si volet auferet.

nec, cum venari volet ille, poemata panges.

si volet usus. |quem penes arbitrium est et ius et norma loquendi. . ne quodeumque relit [rolet] noscat sibi fabula credi

baec auat obscurun; volet hace sub luce videri.

volgaria. ieiutus raro stomachus volgaria temnit. .

rolgaris. coetusque volgaris ut udam|spernit lumum

volgarit. qui Cuteris sacrum volgatit arcanac.

volgata. inultus ut tu riseris Cotytia: volgata,

volgatas. non ante volgatils per artis

rolgavi. huncego, non alio dictun prius ore, Latinus/volgavi fidicen;

volgi. quis manus iusudet volgi Jermogenisque Tigelli,

demens/iudicio volgi, sanus fortasse tuo.

contrectatus ubi manibus sordescere volgi|coeperis.

sive clephaus albus volgi converteret ora;

volgo. volgo recitare tinentis ob lane rem.

ne volgo narres. te sudavisse ferendo|carmina.

volgo. quil oportet nos facere a volgo longe longeque remotos? . quin ubi se a volgo et scaena in secreta remorant

volgus. at volgus inficlun et meretrix rebro/periura cedit,

densum umeris bibit aure volgus.

interdum volgus rectum videt, est ubi peccat. .

volgus. Parca non mendax dedit et malignum|spernere volgus. .

orli protanum rolgus et arceo.

huic ego volguslerrori similem cunctum insanire docebo.

hoc quonue volfus Chrsippus ponit fecunda in gente Meneni. -

volitant. pacatum volitant per mare navitac;

volnera. aut labentis equo describit volnera Parthi."

volnere. quo beatus/ volnere, qua pereat sagita.

volnus. si volous tibi monstrata ralice vel hetba|uon fieret levius.

volnus. volnus nil malum levantia,

volo. guemlan volo visere non tibi notum;

volpe. numprim to fallens animi sub volpe latentes.

volpecula. fonte ixer angustan teruis volpecula rimam/repserat.

volpes. al itgro rava decurens lupa lanuvino|fetaque volpes;

actuta ingernom volpes imitata loonem? -

olin quod volpes aregroto cauta leoni|respondit.

volt. tollere seth innere volt fretai;

non wares salvan te volb, mon filius:

ration molnctun| tractari non volt.

dum volt libertar lici mera veraque vistus.

dives amicua. . virtutibue ene griorem / volt

iflut, guod nuectom igunat, solus velt scire videri.

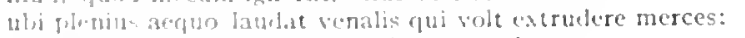

versbue exponi tribpicia res condica mon rolt:

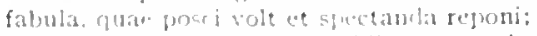

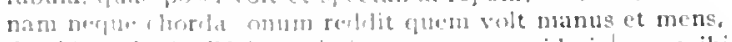

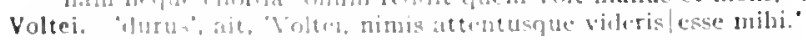

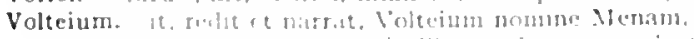

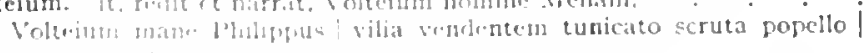

$$
\text { recidget: }
$$

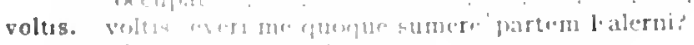

"iats fan lam quot veltic

procerlete red" qui mune hia non voltis.

Carm.1.16.2

Epod.17.40

Epod.17.70

Epist.1.4.16

Epist.1.17.12

Ars Poct.426

Corm.3.24.25

Scrm 1.3 .72

Serm.2.2.84

Serm.2.2.80

Serm.2.3.73

Scrm.2.3.98

Epist.1.2.00

Epist.1.0.54

Epist.1.11.12

EPist.1.10.33

Epist.1.18.40

Ars Poet.71

l'ur.Ars l'oct.339

Ars l'ort.303

Sorm.2.2.38

Carm.3.2.23

Carm.3.2.27

Epod.17.57

Corm.4.9.3

Epist.1.19-33

Serm.1.4.72

Sirm.1.6.08

Epist.1.20.II

Epist.2.1.196

Scrm.1.4.23

Epist.1.13.16

Sermidu. Is

Serm.2.1.71

Carm.1.35.25

Carm.2.13.32

Epist.2.1.03

Carm.2.16.40

Carm.3.I.I

Sorm.2.3.02

Sorm.2.3.286

Carm.4.5.19

Sorm.2.1.15

Corm.1.27.12

Epist.2.2.149

Epod.11.17

Serm.1.9.17

Ars Poot.437

Epist.1.7.29

Corm.3.27.4

Sorm.2.3.180

Eist.1.1.73

Carm.1.3.10

Sorm.1.1.s4

Sorm.2.3.207

Efist.1.18.8

Epist.1.18.28

Epist.2.1.87

lifist.2.2.11

Ars Poctso

dis Poct.joo

Ars Joit 3.48

Ifpist.7.7.9

IEfist.].7.55

Epist 1.7.6.

Carm.127.9

Serm.1.10

Serm.1.2.38 
voltu. ausa et iacentem visere regiam/voltu sereno,

solutis|crinibus ambiguoque voltu.

neque uno luna rubens nitet / roltu:

quin et Ixion Tityosque voltu/risit invito.

reiecit alto doma nocentium / voltu,

aufer/me voltu terrere;

siquis voltu torvo ferus et pede nudo.

neque fictolin peius voltu proponi cereus usquam

voltu mutabilis, albus et ater.

voltum. bracchia et roltum teretesque suras|integer laudo:

virilem |torvos humi posuisse voltum. .

qui selvoltum ferre negat Noviorum posse minoris.

adde /roltum habitumque hominis.

est /gaudia prodentem voltum celare.

dum licet ac voltum servat Fortuna benignum.

suspendit picta voltum mentemque tabella,

nequis... alius Lysippo duceret aera | fortis Alexandri simulantia.

tristia maestum fvoltum verba decent, . . Fonde nova puerum
Volture. ne fabulosae volture in Apulo... fronde

$$
\text { palumbes/texere. }
$$

voltus. acer et Marsi peditis eruentum/voltus in hostem;

et voltus nimium lubricus adspici.

non voltus instantis tyranni.

enim voltus ubi tuos adfulsit populo.

atqui voltus erat multa et praeclara minantis.

voltus. quid omnium/voltus in unum me truces? nec magis expressi voltus per aenea signa ut ridentibus adrident, ita flentibus adflent/humani voltus.

voltus. terret equos equitumque voltus. petamque voltus umbra curvis unguibus. notus in voltus honor. quo teneam voltus mutantem Protea nodo?

volubilis. sequor .. te per aquas, dure, volubilis. labitur et labetur in omne volubilis aevom.

volucrem. per purum tonantis/egit equos volucremque currum. jam volucrem sequor te

volucris. ast inportunas volucris in vertice harundo/terret fixa

volucris. veluti stet volucris dies. quae semel. . . inclusit volucris dies.

volucris. volucrisque Fati|tardavit alas.

voluere. et minax, tquia sic voluere, ponto/unda recumbit.

voluerunr. libertate decembri.|quando ita maiores voluerunt, utere:

volui. 'sive ego prave|seu recte hoc volui, ne sis patruos mihi': 'quid miser egi? quid volui?' dices.

voluit. the voluit dicere lucidum fulgentis oculos cum summam patrimoni insculpere saxolheredes voluit?"

volumina. Augusto reddes signata rolumina, Vinni. pontificum libros, annosa volutnina vatum/dictitet

volumus. si patriae volumus, si nobis vivere cari.

volunt. quod superest aevi, siquid superesse volunt di; .

non satis est pulchra esse poemata; dulcia sunto/et quocumque volent

[volunt] animum auditoris agunto.

aut prodesse volunt aut delectare poetae

voluntas. cessat voluntas? non alia bibam! mercede.

voluptas. Cessat voluntas [roluptas]?

utque illis multo corrupta dolore voluptas.

non in caro nidore voluptas/summa, sce in te ipso est.

sperne voluptates: nocet empta dolore voluptas.

cui potior patria fuit interdicta voluptas.

verum equitis quoque iam migravit ab aure voluptas|onnis

"cui sic extorta voluptas et demptus jer vim

voluptates. sperne voluptates: nocet empta dolore voluptas.

roluptatis. fieta voluftatis causa sint froxima veris:

volva. nil melius turrlo, nil volva pulchrius ampla."

volvens. quatenus ima petit volvens aliena vitellus.

volventis. nunc lapides adesos / stirpiscue raptas et pecus et domos volventis una.

volvere. fumen gentibus additum/victis minores volverevertices

Carm.1.37.26

Corm.2.5.24

Carm.2.II.II

Carm.3.1I.2 I

Carm.4.9.43

Scrm.2.7.44

Epist.1.19.12

Epist.2.1.265

Epist.2.2.180

Carm.2.4.21

Carm.3.5.4.4

Serm.1.6.I 21

Sirm.2.4.92

Serm.2.5-I04

Epist.1.1I.20

Epist.2.1.97

Epist.2.I.241

Ars Poet. Io6

Carm.3.4.9

Curm.r.2.40

Carm.I.19.8

Carm.3.3.3

Carm.4.5.6

Serm.2.3.9

Epod.5.4

Epist.2.1.248

Ars Poet.Ioz

Corm.2.1.20

Epod.5.93

Epod.17.18

Epist.I.1.90

Corm.4.I.40

Epist.1.2.43

Corm.1.34.8

Corm.4.1.38

Serm.1.8.6

Carm.3.28.6

Carm.4.13.16

Carm.2.17.24

Carm.I.I2.3I

Serm.2.7.5

Serm.2.3.88

Epist.I.20.7

Carm.2.12.14

Sirm.2-3.91

Epist.1.13.2

Epist.2.1.26

Epist.1.3.29

Epist.1.18.108

sar.Ars Poet. I0o

Ars Poct.333

Carm.1.27.13

vor.Corm.1.27.13

Sirm.1.2.39

Serm.2.2.19

Epist. I. 2.55

Epist.1.0.04

Epist.2.I.I87

l.pist.2.2.139

Lipist.1.2.55

Ars Pott. 338

Epist.1.15.43

Serm.2.4.57

Carm.2.9.22 
prosperam frugum coleromatu" pronos/volvere mensis.

Carm.4. 40

volvitur. ste taltrotemis volvitur hutdus.

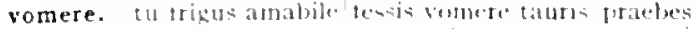

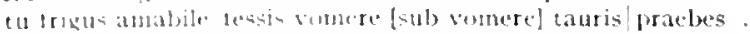

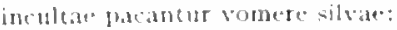

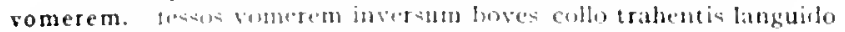
Voranus. Lulins et tragilia Pediatia lurplac Voramus.

Vortumnum. Viotmmum lantmequ*, liber, spectate videris.

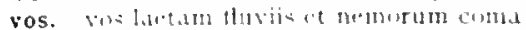

var lompe totidem tollite latulibus

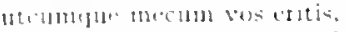

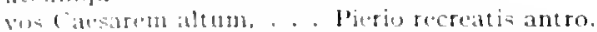

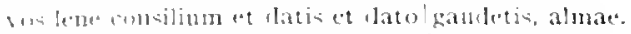

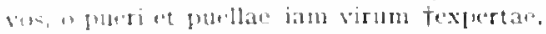

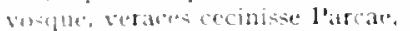

Voe, quibus eat birtus, woulielirom tollite lactum,

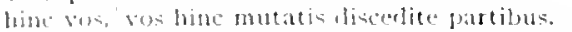

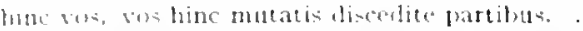

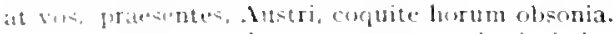

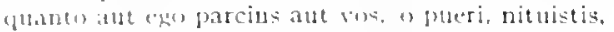

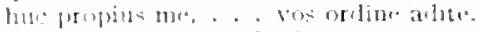

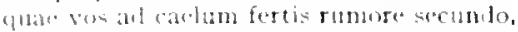

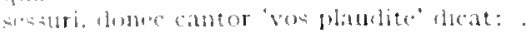

ver expmplatia fratea mucturail versate manu, verate diutma.

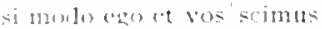

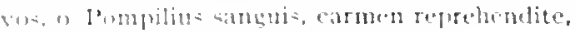

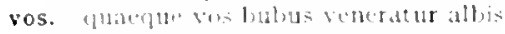

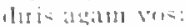

vos tubla vatin hinc et binc saxis pentens contunelet

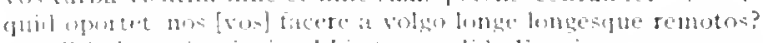

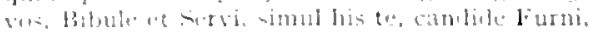

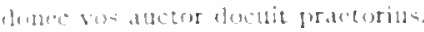

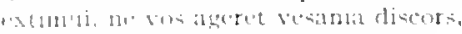

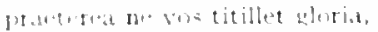

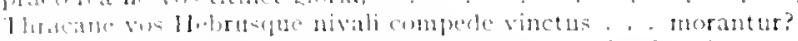

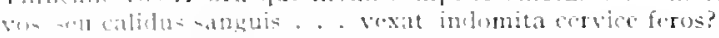

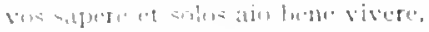

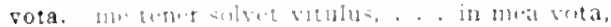

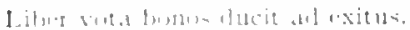

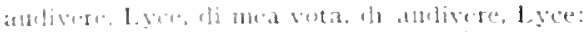

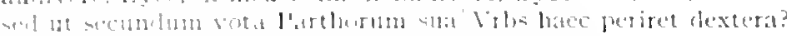

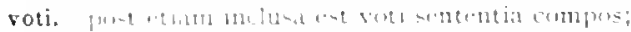

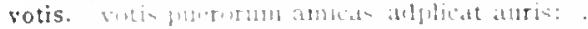

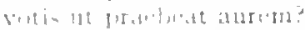

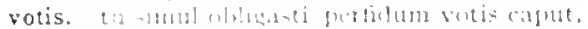

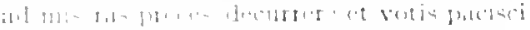

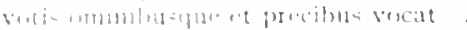

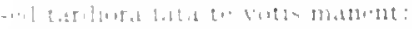

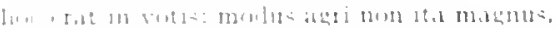

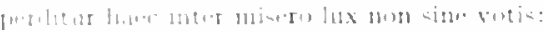

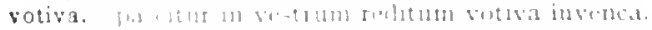

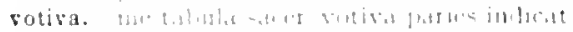

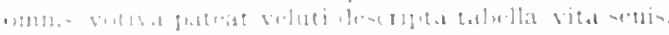

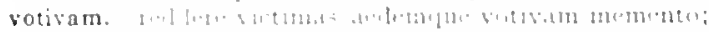

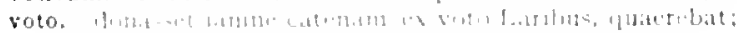

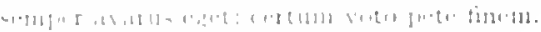

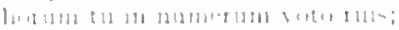

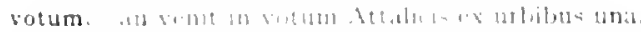

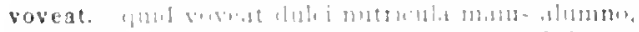

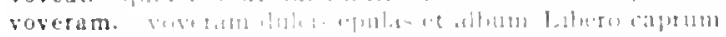

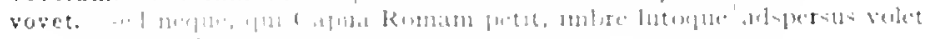

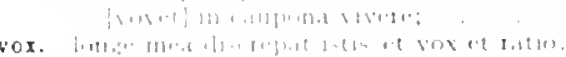

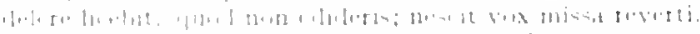

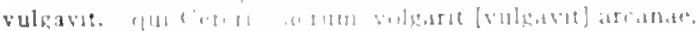

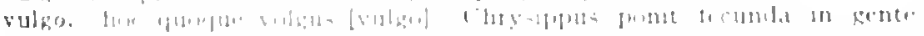

$$
\text { \10.11 } 11 \text { - }
$$

Cirm.4.14.25

Carm.3.13.11

iur. Carm.3.13.11

Epist.1.2.45

I:Prol.2.03

Serm 1.8.39

Ejist 1.20.1

Cism? I 21.5

Carm.1.21.9

Carm.3.+29

Carm.3.937

Cirm $3++1$

Carm.31.9.10

Curm.liec 25

LEPS.11.30

Sirm.1.1.17

Serm 1 1.18

$\operatorname{sen} 2.2 \ldots 10$

Sirm.2.2.127

Sorm 2-3.81

Esistido. I0

Ars Modit 55

Ars Iont.2es

Ars lisid.272

- Irs Pued.201

Carmesaec 19

Jopt 5.80

I. pod 5.07

contis.sim.1.6.18

Serma I. 10.Ses

Serm.2.2.50

Serm.2.3.174

Sirm.2.3.179

S.sit. 1.3 .3

Lipit 13.32

Г.p11.1.15.45

Cicrma 2. 20

Carm.t. 34

Corm 1.3.1

lipul $=0$

Ars lont:o

Carmsisenti

Sirm 1.1.22

(urm 2.s.er

(atrit.3.20.50

("is rin 1513

find 17 ing

Sirm.21.1

Sirm 2.4.50

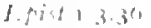

Carm 1.5 1.4

s $\operatorname{rm} 2 \cdot 1 \cdot 3.3$

Cism, 217.31

sirm t. 5 ine

I. piot. 2.56

J.P.t. 1.1.1.1

f. pist 1.11.5

f. pisti... S

Corm 3 st

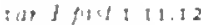

Sirm [ $(10) 3$

Ir t1., 1310

Har ( CH:m 3.2.27

ior vien.2.3.280

:is $5 . \mathrm{rm} \cdot 2 \cdot 3.12$ 
hoc guoque volgus [rulgum] | Chrysippes ponit iecunda in gente Mentni. - . . . . . . . . . .

vulgus. huic ego volgus [rulgus]/errori simile m cunctum insinire docebo.

hoc quoque volgus [rulgus] / Chrysippus ponit fecunda in gente Neneni. -

vulpecula. moveat cormicula [? vulpecula] risum furtivis nutata colorilus.

per angustam tenuis volpecula [rolpocula] riman|reperat in cumeram irtamenti,

vult. non wxor salvom te volt [te vult salvint, non filins; . . . . not uxor salvom te volt [salvum te vult], non filins;
um, huic ego volgus [rultum] errori similem cunctum insanire docebo.

rultum, huic ego volgus [rultum]|errori sinilem cunctum insanire docebo.
si paullum potes inlacrimare, est graudia protenten voltum [rultmil celare.

vultus. huic tgo volgus [vultus], errori similem enctum insanire docebo. .

F'ar. Serm.2.3.2\$1

:ar.serm.2.3.1.2

sur. Serm.2.3.286

litur lisist. I.3.19

isr. Epist.1.7.29

5 or.thrm.1.].8.

s'tor. Serm.5.1.84

thr.serm.2.3.1.2

Fir. Serm.2.5.104

iar.serm.2.3.02

\section{N}

Xanthia. ne sit ancillae tibi anor pudori, Xanthia Phoceu: . . . Camm.2.2

Xantho. Phoube, qui Xantho lavis ame crinis, . . . . . . Carm.4.0.20

\section{Z}

Zephyris. non Zephỵris agitata Tempe.

frigora mitescunt Zephyris,

te, dulcis anice, reviset cum Zephyris.

Cirm.3.1.24

Zethi. gratia sic iratrum geminorum, Amphionis

Zmyrna. Zmyrna quid et Colophon, maiora minorane fama?

Eist.1.18.43

zona. potes hac ab orno pendulum zona bene te secuta c-liflere collum.

zonam. ibit en, quo vis, qui zonam perdidit' inquit.

lisist.1.11.3

zonam. solutis Gratiae zonis properentque Nymphae

Carm.3.27.50

Efist.2.2.40

Cirm.1.30.6 






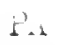

5444

$\mathrm{C} 6$

1916
Cooper, Lane (eu.)

i concordance to the wirks of Itorace

PLEASE DO NOT REMOVE CARDS OR SLIPS FROM THIS POCKEI UNIVERSITY OF TORONTO LIBRARY 


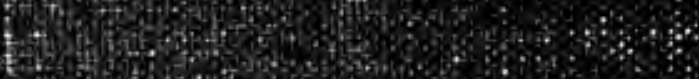

(15)

(1).

\begin{tabular}{|l}
\hline \\
0
\end{tabular}

(19)

H Q 0 \%

3.

\%

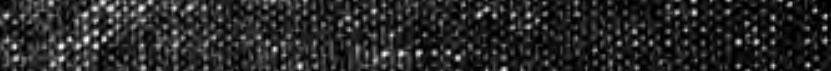
68 (3) (3) 6.

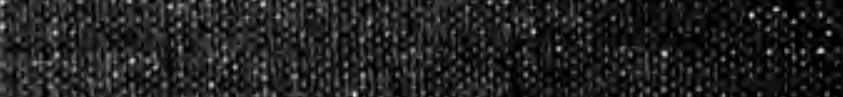

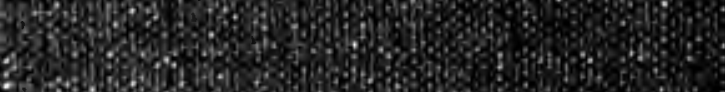

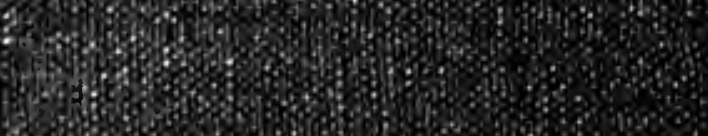
(6) 18. 6. $\alpha+\alpha+\infty$ 